UNITED STATES DEPARTMENT OF THE INTERIOR

Harold L. Ickes, Secretary

GEOLOGICAL SURVEY

W. C. Mendenhall, Director

Water-Supply Paper 867

\title{
HURRICANE FLOODS OF SEPTEMBER 1938
}

\author{
CARL G. PAULSEN \\ Acting Chief Hydraulic Enging :
}

B. L. BIGWOOD, A. W. HARFNGTQA O. W. HARTWELL, and H. B. KNINLSON

District Engineers

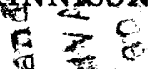

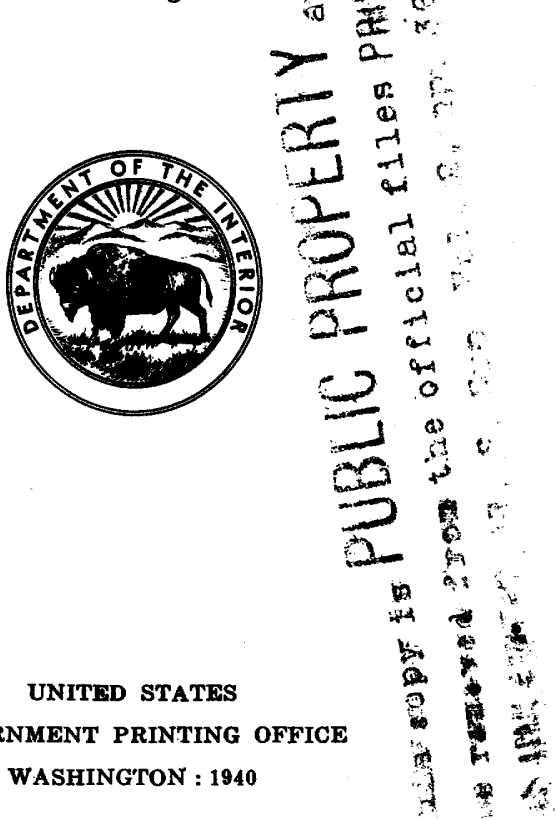



Abstract ${ }_{\text {Introduction }}: \cdots$

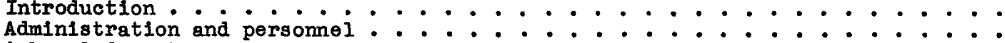
Acknowledgments

General features of the storms

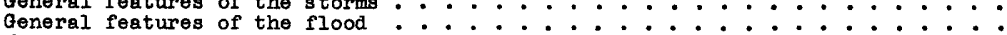
Meteorologic and hydrolog 10 conditions
Antecedent conditions

Precipitation

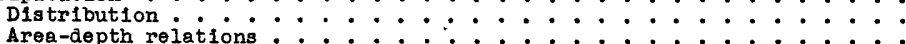

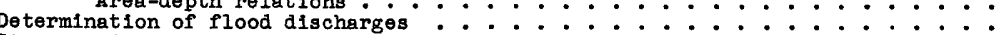

Stages and discharges at stream-gaging stations $: \ldots: \therefore: \ldots$

Explanation of data

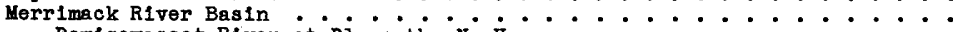

Pemlgewaset River at Piymouth, N. H. : : : : : : : :

Pemigewasset River at Bristol, N. H. : : : : : : : : :

Pemigewasset River at Franklin, N. H.

MerrImack RIver at Franklin Junction, N. H. .............

Merrimack RIver at Garvins Falls, N. H.

Merrimack River near Goffs Falls, below Manchester, ․ B. : : : :

Merrimack River below Concord River, at Lowell, Kass. . . . . . . . .

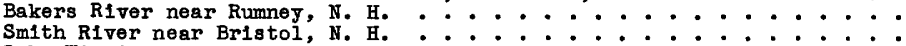

Lake WInfpesauke at The Weirs, N.

WInnipesaukeo River at T1Iton, N. H.

Contoocook River at Penacook, N. H.

North Branch of Contoocook River near Antrim, N. H. (i936 revision): : ll

Blackwater River near Webster, N. H.

Blackwater RIver near Webster, N. H. (1936 revision) : $: \ldots 120$

Suncook River at North Chlchester, N, H. ............. 121

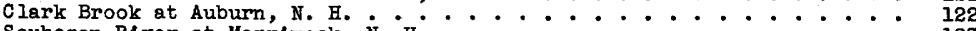

Souhegan RIver at Merrimack, N. H. Hass.

Nashua R1ver at East Pepperell, Mass. . . . . . . . . . 125

Wachusett Reservoir on South Branch of Nashua River at Clinton, Mass. - 126

South Branch of Nashua River at Clinton, Mass. . . . . ..... 126

Concord River below River Meadow Brook, at Loweil, Mass. : : : : 127

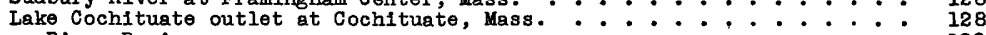

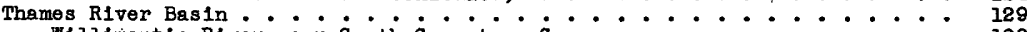

Willmantic River near South coventry, com. : : : : : : 128

Shetucket River near Willimantic, Conn. $: \cdots$

Hop River near Columbla, Conn.

Quinebaug River at Quinebaug, Conn. : : : : $: \therefore: \therefore: \vdots: \vdots 133$

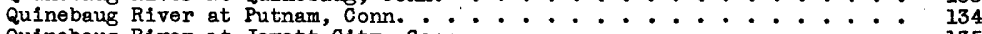

Quinebaug River at Jewett City, Conn. : : : : : : : : 135

Five Mile River at Killingly, Conn. : : : : : : : $: 136$

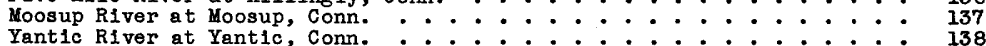

Connecticut River Basin

First and Second Connecticut Lakes near Pittsburg, स. H. : : : 139

Connecticut River at First Connecticut Lake, near Pittsburg, i. . $_{0}^{*}:$ : $_{140}$

Connecticut River at North Stratford, N. H. . . . . . . . . 141

Connect icut River near Dalton, N. H. . . . : . : . 142

Fifteenmile Falls Reservolr near Bamet, vt $: \vdots: \vdots: \vdots::_{0}: 143$

Connecticut River at outlet of Fiftenmile Fails Reservolr near

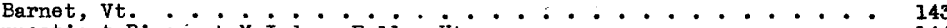

Connecticut River at Mcindoes Falis, vt.: $: \therefore: \therefore: \therefore: \therefore 4$

Connecticut River at South Newbury, vt. : : . : . : . . . . 145

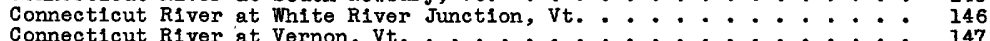

Connectlcut River at Vernon, vt.

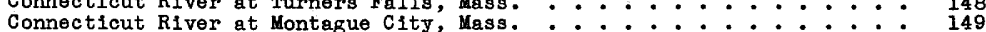

Connecticut River at Holyoke, Mass. . . . . . . . . . . 150

Connecticut River at Springfield, Mass.

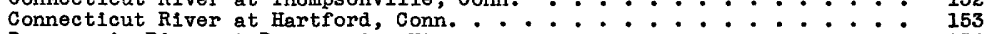

Passumpsic River at Passumpsic, vt. : : : : : : : : 154

Moose River at St. Johnsbury, vt. . : . : . : . : . 155

Ammonoosuc River near Bath, N. H. : : : : : : : : : $:$ is6

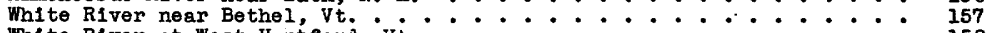

White River at West Hartford, vt. . . . . . . . . . . . . . 158

Mascoma River reservolrs above Mascoma, N. H. . . . . . . . . 159

Mascoma River at Mascoma, N. H. . . . . . . . . . . . 160

Ottauquechee River at North Hartland, vt. $:: \therefore: 161$

Sugar River at Wost Claremont, N. H.

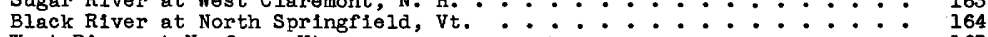

West River at Newfane, vt. . . . . . . . . . . 165

Ashuelot River near Gilsum, N. H. $: \therefore \therefore: \therefore \therefore: \therefore: \therefore: \therefore: 166$

Ashuelot River at Hinsdale, N. H. . : : : : : : : : 167 
Stages and discharges at stream-gaging stations--Continued Connecticut River Basin--Continued

South Branch of Ashuelot River at Webb, near Marlboro, H. H. . . . . . 169

Miliers River near Winchendon, Mass. . . . . . . . . . . . . . . . . 170

Miliers River at Erving, Mass.

Sip Pond Brook near Winchendon, Kass.

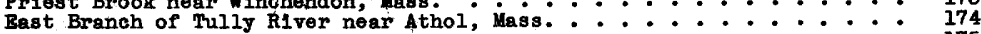

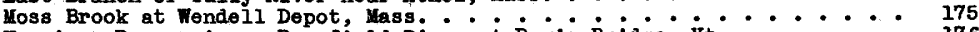

Harriman Reservoir on Deerfield River at Davis Bridge, vt.: : : 176

Deerfleld River at outlet of Harriman Reservoir, at Davis Bridge, vt. .176

Somerset Reservoir on East Branch of Deerfield ifier near somerset, vi... 178

East Branch of Deerfleld River at outlet of Somerset Reservolr near Somerset, vt.

Ware River at Cold Brook, Mass. . . . . .

Ware River at Gibbs Crositng, Mess

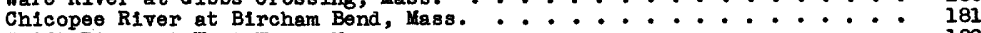

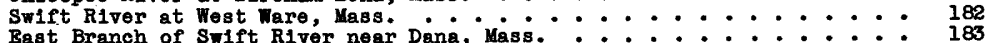

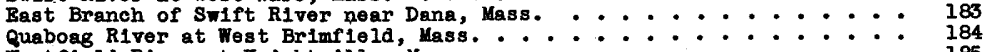

Vestfleld River at Rnightville, Mass. . . : . : . . . . . . . . . . . 185

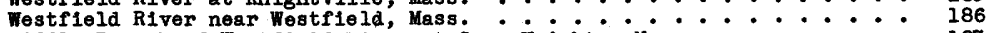

Middie Branch of Westfleld River at Goss Heights, Mass. . . . . . . . . 187

West Branch of Westfield River at Huntington, lass. ${ }_{\text {Borden Brook and Cobble Mountain Reservoirs in Westeleld ittie River }}$

Basin near Westfield, Mass. at out iet óbile Mountain Reservoir, near

Testfleld Littlo River at outlet of Cobble Mountain Reservoir, near

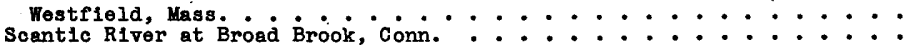

Farmington River near New Boston, . Mass.

189

190

Fermington River at Riverton, Conn. . . . . . . . . . . . . . . . 192

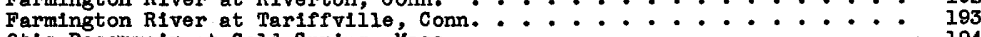

otis Reservolr at Cola Spring, Mass. . . . . . . . . . . . . . . . . . . 194

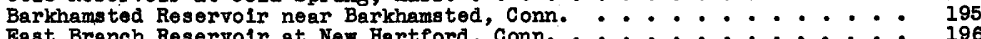

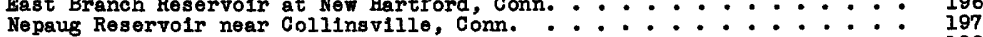

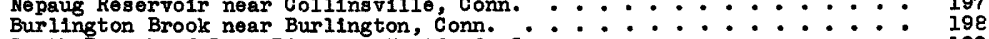

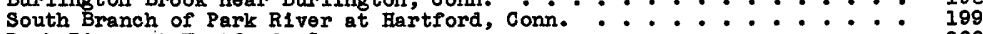

Park RIver at Hartford, Conn. . . . . . . . . . . . . . . 200

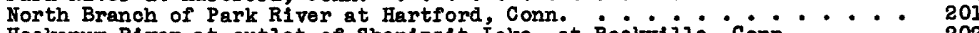

Hockanum River at outlet of Shenipsit Lake, at Rockvilie, Conn. : . : 202

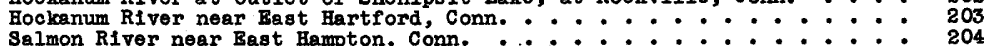

Salmon River near East Hampton, Conn.

West Branch of Eightmile River near North Lyme, Conn. : : : : : : : : : 206

Quinnipac River Basin ..... . . . . . . . . . . . . . . . . 207

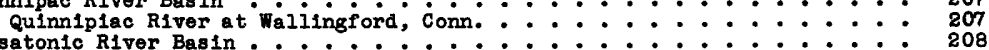

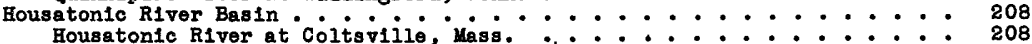

Housatonic River near Great Barrington, Mass. . . . . . . . . . . . . 209

Housatonic River at Falls V1liage, Conn. . . . . . . . . . . . . . . . 210

zoar Lake at Stevenson, Conn. . . . . . . . . . . . . . . . . . 211

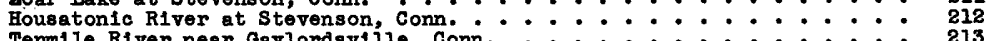

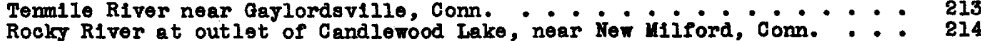

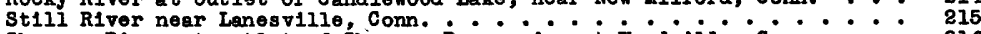

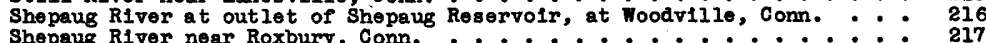

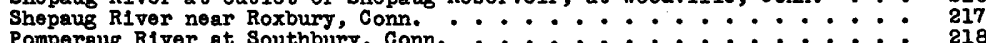

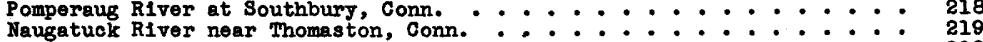

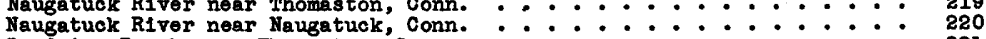

Leadmine Brook near Thomaston, Conn. . * . . . . . . . . . . . . 221

Branch of Naugatuck River at outlet of Wiswam Reservoir, near

Thomaston, Conn. . . . . . . . . . . . . . . . . . . 222

Saugatuck River Basin : . . . . . . . . . . . . . . . . . . . . . . 223

Saugatuck River near Westport, Conn. . . . . . . . . . . . . . . . . . 223

Streams on Long Island

M111 Keck Creek at Kill Neck, K. Y.

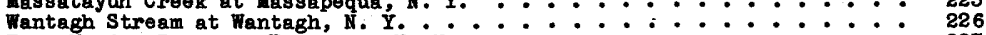

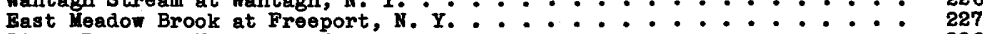

Pines Brook at Malverne, N. Y. . . . . . . . . . . . . . . . . . . 228

Hudson River Besin in

Fudaon RIver near Nevcomb, N. Y.

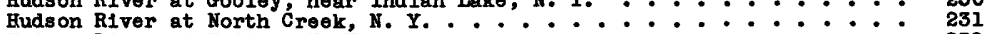

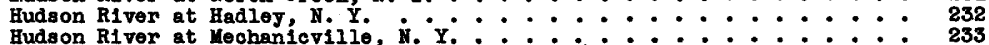

Cedar River below Chain Lakes, near Indian Lake, N. Y. : : : : : : : : :

Indian Lake Reservolr near Indian Lake, H. Y. . . . . . . . . . . . . . 235

Indian River near Indian Iake, N. Y. . . . . . . . . . . . . . . . . . 236

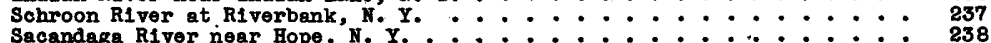

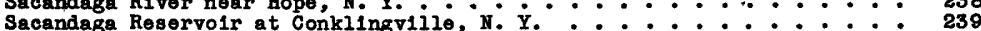

Sacandaga River at Conklingvilie, J. Y. : . : : : : : : : : : : : : : : 240

Batten Kill at Arlington, Vt. . . . . . . . . . . . . . . . . . . 241

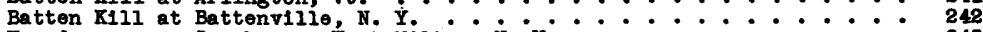

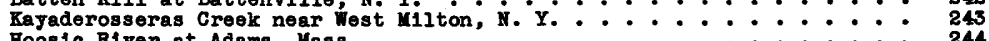

Hoos1c River at Adams, Mess. - . - . . . . . . . . . . . . . . . 244

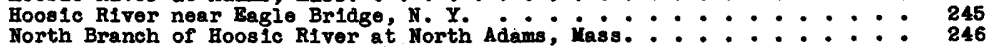


Stages and discharges at stream-gaging stations--Continued Hudson River Besin--Contimued

Walloomsac River near North Bennington, vt. . . . . . . 247

Black River Canal (flowing south) near Boonvilie, N. $\dot{Y}_{*}^{*}::_{:}:{ }^{*} 48$

Delta Reservo1r at Delta Dam, near Rome, N. Y. . . . . . . . . 248

Mohamk RIver below Dolta Dam, near Rome, N. Y. . . . . . . . . . 249

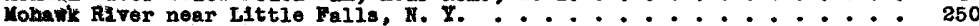

Mohatk RIVor at Cohoos, H. Y.

Hinckley Resertrolr at Hinckley, H. ${ }^{*}: \cdots$

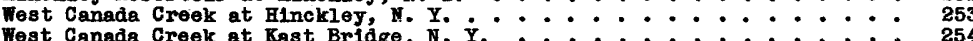

Bast Canad Creek at Dolgevilie, N. Y. . : : : : : : : 255

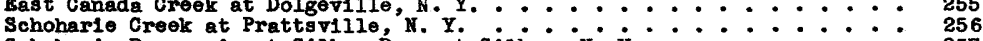

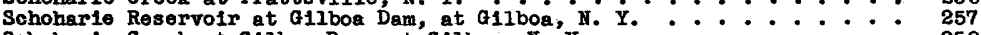

Schoharle Greek at G11boa Dam, t Gllboa, 1. Y. .......... 258

Schoharle Greek at Middleburg, N. Y. . . . . . . . . . . . . 259

Poesten K111 near Troy, H. Y. ..................... . 260

Kinderhook Creek at Rossman, X. Y.

Esopus Creek at Coldbrook, $1 . X$. .

Ashokan Reservolr near Kingston, I. Y. . . .............. 264

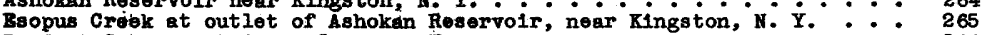

Rondout Croek near Lowes Comers, H. Y. . . . . . . . . . . 266

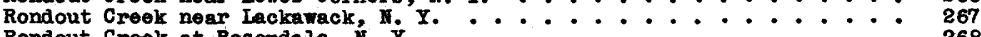

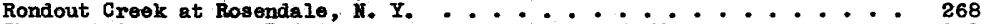

Ches tmut Creok above Red Brook, at Grahamsvilile, N. Y. . . . . . 269

Wallkill River near Untonville, N. Y. . . . . . . . . 270

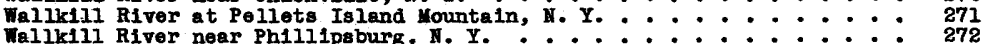

Walikili RIVer et Gardiner, H. Y! . . . ........... 273

Pochuck Greek at Newport, near Pine Islend, N. Y. . . . . . 274

Quaker Creok at Florida, K. Y. . . . . . . 275

Wappinger Creek near Wappinger Fails, $\mathrm{r} . \mathrm{Y}$.

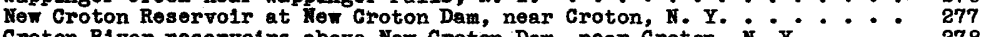

Croton River reservoirs above New Croton Dam, near Croton, N. Y. . . . . 278

Croton River at Hew Croton Dam, near Croton, H. Y. . . . . . . . . 279

Groton River at' Quaker' BrIdge, near Groton, K. Y. . . . . . . . 280

Hackensack River Basin

Oradell Reservolr at Oredell, N. J. J: : : : : : : : : : : : ${ }_{282}$

Woodeliff Lake at Hilladale, N. J.

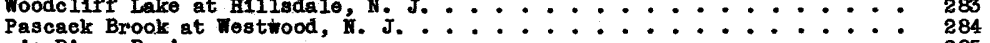

Passalc R1ver Basin

Pessalc River near Chatham, N. J, . . . : : : : : 286

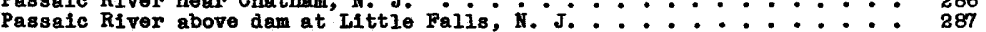

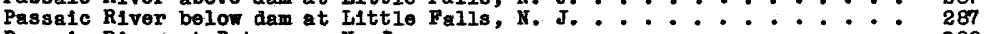

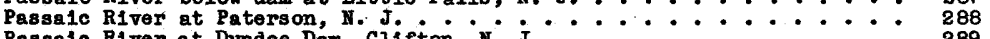

Passalc River at Dundeo Dam, Clifton, N. J. . . . . . . . . . 289

Rockaway RIver at Dóver, K. J. . . . . . . . . . . 290

Rockaway River above reservolr at Boonton, i. J. . . . . . . . 291

Boonton Reservolir at Boonton, N. J.

Beaver Brook at outlet of Splitrock Pond, N. J. ........... 294

Wh1ppany River at Morristown, N.J.

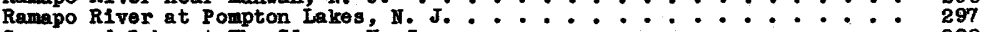

Greonmood Lake at The Glons, ir. J. . . . . . . . . . . . 298

Manaque RIver at Monks, K. J. . . . . . . . . . . . . . . . 299

Wanaque Reservolr at Wanaque, N. J. .............. 300

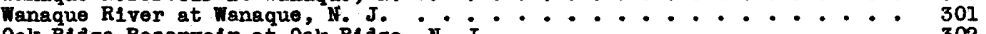

Oak Ridge Reservolr at oak R1dge, N. J. . . . . . . . . 302

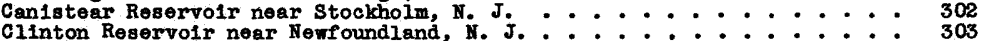

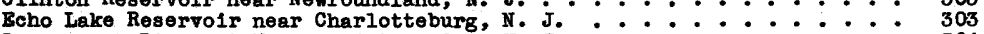

Pequannock River at Macopin intake dam, N. J. : $:: \therefore: \therefore: \therefore$

Saddle R1ver at Lod1,.K. J. . . . . . : : : : : 305

Ellzaboth River Basin

Ellzabeth River at Élizabeth, N. J. : . . . . . . . . 306

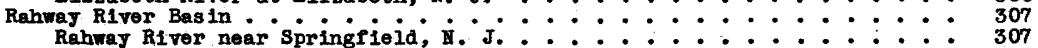

Rahway River near Springfield, H. J.: : : : : : : : : : : : ${ }_{308}$

Raritan River Bas in

South Branch of Raritan River noar High Briage, N. J. . . . . . . . . 309

South Branch of Raritan River at Stanton, N. J. . . . . . . 310

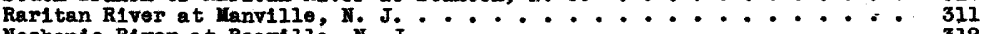

Neshanic River at Reavilio, N. J.

North Branch of Raritan River near Far Hilis, J. J. $::_{:}::_{:}: 3_{14}$

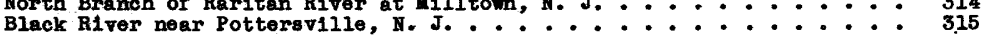

Lake Carnegie at Princeton, $\mathrm{N}$ J.

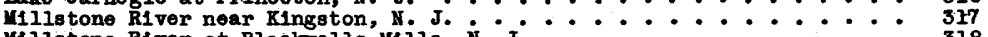

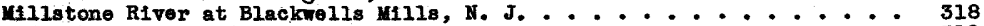

Groen Brook at Plalnfield, N. J. . . . . . : : 319

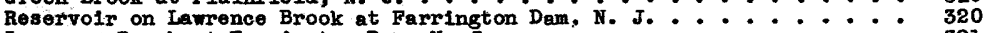

Lawrence Brook at Farrington Dam, N. J.

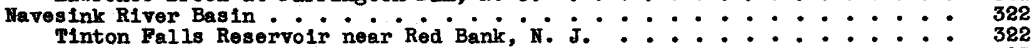

Swlminling R17er near Red Bank, N. J. ? : : : : : : : : 323

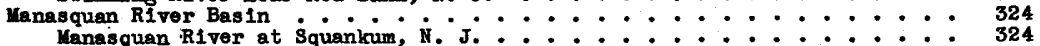


Stages and discharges at stream-gaging stations--Continued

Toms River Basin

River near Toms River, N. J.

Great Bgo River at Foisomi

Delaware River Basin .

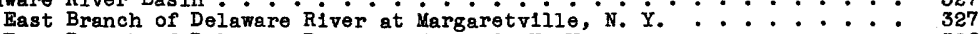

East Branch of Delaware River at Harvard, N. Y. . . . . . . . . . . 328

Bast Branch of Delaware River at Fishs Eddy, N. Y. . . . . . . . . . . 329

Deleware River at Port Jervis, N. Y. . . . . . . . . . . . . . . . . 330

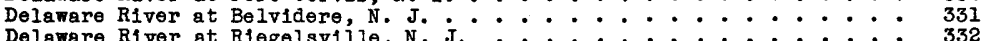

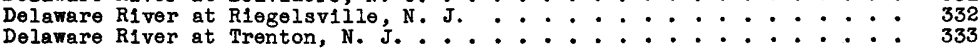

Mill Brook at Arena, N. Y. . . : . . . . . . .

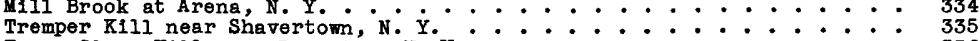

Terry Clove Kill near Pepacton, N. Y. . . . . . . . . . . . . . . . 336

Beaver Kill at Craigie Clair, N. Y. . . . . . . . . . . . . . . . . . . . 337

Beaver Kill at Cooks Falls, N. Y. . . . . . . . . . . . . . . . 338

Willowemoc Creek near IIVIngston Manor, N. Y. . . . . . . . . . . . . 339

Little Beaver Kill near Livingston Manor, N. Y. . . . . . . . . . . . 340

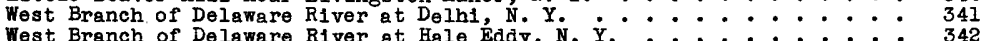

Little Delaware River near Delhi, N. Y. . . . . . . . . . . . . . . 343

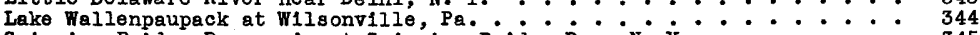

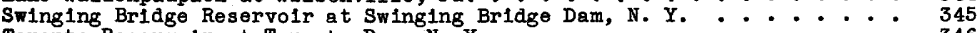

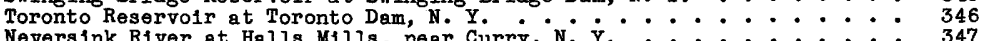

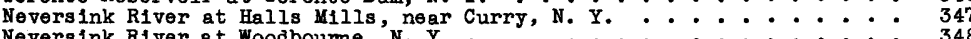

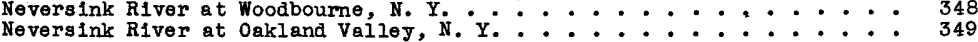

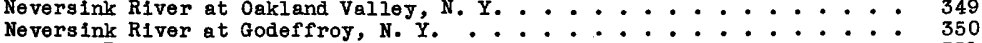

Susquehanna River Basin

Susquehanna River at Colliersvilie,

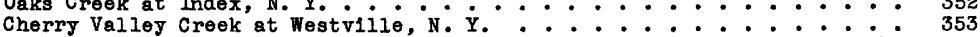

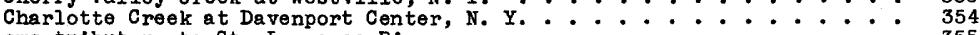

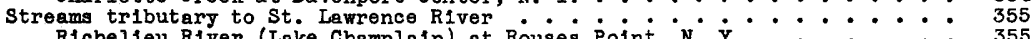

Richelieu River (Lake Champlain) at Rouses Point,

Lake Champlain at Burlington, vt. . . . . . . . . . . . . . . . 355

Saranac River at Saranac, N. Y. . . . . . . . . . . . . . . . . 356

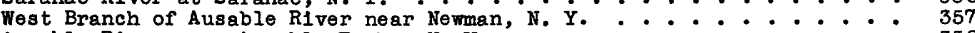

Ausable River near Ausable Forks, N. Y. . . . . . . . . . . . . . . . 358

Black Brook at Black Brook, N. Y. . . . . . . . . . . . . . . . 359

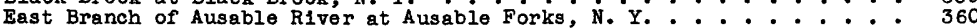

Bouquet River at Willsboro, N. Y. . . . . . . . . . . . . . . . . 361

Lake George at Rogers Rock, N. Y. . . . . . . . . . . . . . . . . . . . 362

Poultney River below Falr Haven, vt. . . . . . . . . . . . . . . . . 363

Otter Creek at Center Rutland, Vt. . . . . . . . . . . . . . . . . . 364

Otter Creek at Middlebury, vt. . . . . . . . . . . . . . . . . . . 365

Winooski River at Montpelfer, vt. . . . . . . . . . . . . . . . . . . 366

Winooski River near Essex Junction, vt. . . . . . . . . . . . . . . 367

East Barre Detention Reservolr on Ja1l Branch at East Barre, Vt. . . : 368

Jall Branch at East Barre, Vt. . . . . . . . . . . . . . . . . . 369

Wrightsvilie Detention Reservoir on North Branch of Winooski River

at Wrightsville, Vt. : . - . * . . . . . . . 370

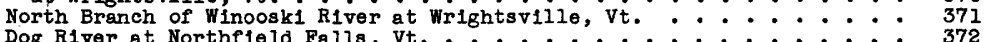

Dog River at Northfield Falls, Vt. . . . . . . . . . . . . . . .

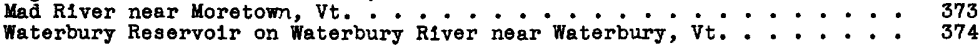

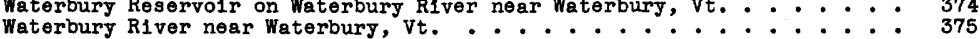

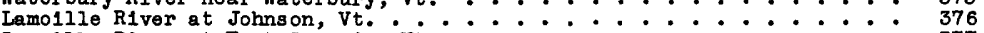

Iamolile River at East Georgia, Vt. . . . . . . . . . . . . . . . . . . 377

Missisquo1 River near North Troy, Vt. . . . . . . . . . . . . . . 378

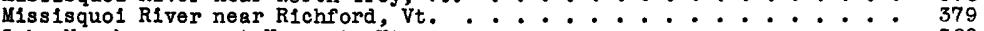

Lake Memphremegog at Newport, vt. . . . . . . . . . . . . . . . . . 380

Sumary of flood dlscharges . . . . . . . . . . . . . . . . . . . . . . 381

$\cdot \cdot \cdot \cdot \cdot \cdot \cdot \cdot \cdot \cdot \cdot \cdot \cdot \cdot \cdot \cdot \cdot \cdot \cdot \cdot \cdot \cdot \cdot \cdot \cdot \cdot 412$

Scope and utility .... . . . . . . . . . . . . . . . . . . . . . . 412

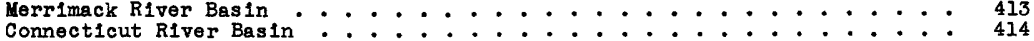

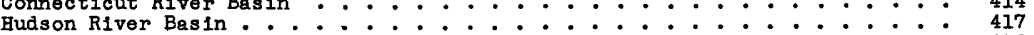

Eastern New Jersey basins . . . . . . . . . . . . . . . . . . . . . . 418

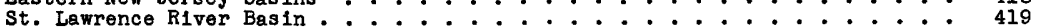

RaInfall and mun-off studies:. . . . . . . . . . . . . . . . . . . . . . . 420

Methods of analysis . . . . . . . . . . . . . . . . . . . . . . . 420

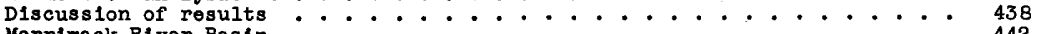

Merrimack River Basin ... . . . . . . . . . . . . . . . . . . . . . 442

Thames River Basin . . . . . . . . . . . . . . . . . . . . . . . . 445

Connecticut River Basin .... . . . . . . . . . . . . . . . . . . . . 448

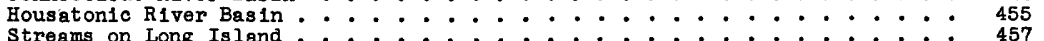

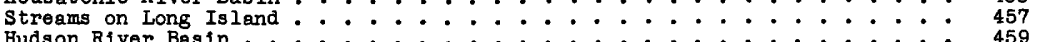

Eastern New Jersey basins

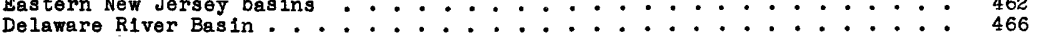

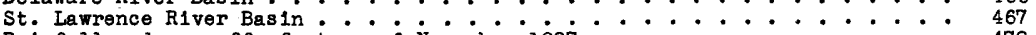

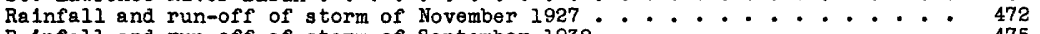

Rainfall and run-off of storm of September 1932 . . . . . . . . . . . . 475

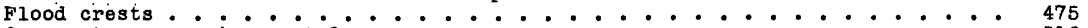

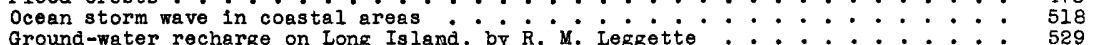

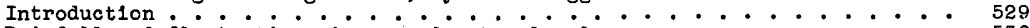

Rainfall and fluctuations in ground-water levels . . . . . . . . . . . . . 530

Soll-molsture conditions... . . . . . . . . . . . . . . . . 546 
Ground-water recharge on Long Island--Continued Increase in ground-water storage

Direct run-off .

Sumary ........................................ 551

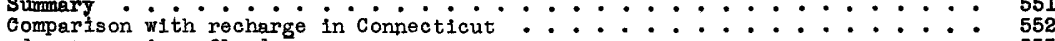

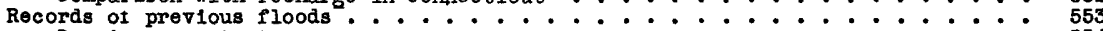

Previous great storms . . . . . . . . . . . . . . . . . . . . . . . . 554

Index .......................................55r

\section{ILLUSTRATIONS}

Plate 1. Map of North Atlantic States showing location of principal drainage basins, precipitation stations, and isohyetals of total precipitation, in inches, September 17-21, 1938 . . . . . . . . . . In pocket

2. Storm wreckage in Rhode Island: A, Waterfront district of Newport, R. I.; B, Shore wreckage at Weekapaugh, R. I. . . . . . . . . . . 22

3. Hurricane damage in Massachusetts: A, Shade trees in metropolitan Boston, Mass.; B, Harvard forest near Petersham, Mass. . . .

4. A, Rallroad yards and residential area of Concord, N. H., floodod by Merrimack River; B, View of East Hartford, Conn. : . . . . . . . . 38

5. A, Flooded water front at Albany, N. Y.; B, Scene at West spring-

6. A, old covered bridge on roed between Hoosic Falis, $\dot{N}$. $\dot{Y}$, and Bennington, Vt.; B, Scene at bridge near Watervilie, Mass....... . 38

7. Wash-outs on raliroed and highway right-of-ways: A, Scene on Mohawk Trail (D. S. Highway 2) near Fiorida, Mass., along Cold River; $B$, Scene on the New York, New Haven Hartford Railroad at Putnam.

8. Flood damage in Massachusetts: A, Debris in hyaroelectric plant at Wendell, Mass.; B, Street undermined in Adams, Mass........... .38

9. House in Ware, Mass., before and after destructión by fiood: : : : : 38

10. Flood passing over dam on Housatonlc River at Stevenson, Conn. . . . . 86

11. Map showing location of flood determinations in the drainage basins in the area covered by this report . . . . - . . . . . . In pocket

12. A, Scene on Quinebaug River at Southbridge, Kass.; $B$, Scene on Millers River at Winchendon, Mass. . . . . . . . . . . . . . . 454

13. Wash-outs on Millers River: A, Approach to Boston Maine Railroad bridge destroyed by flood at Wendell, Mass.; B, V1ew on Boston

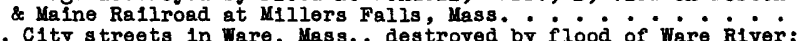

14. A, City streets in Ware, lass., destroyed by flood of Ware River;

15. A, Wapplnger Creek at Wapplnger Falls, N. Y., at height of flood; B, West Branch of Ausable River at Ausable Forks, N. Y. . . * . . . 454

16. Map showing he1ght of ocean-storm wave from Cape Cod, Kass., to

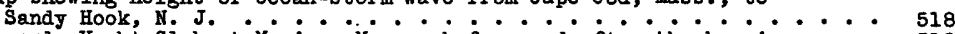

17. Beverly Yacht Club at Marlan, Mass, before and after the hurricane . . 518

18. Damage by storm wave on Connecticut coast: A, Plers and boats at New London; B, Sumer homes and cottages at Hawks Negt. . . .

19. Water front at Watch Hill, Westerly, R. I., before and after the hurricano $\dot{0}$ icitation

20. Graphs showing precipltation at Mineola, N. Y., stream flow at
Hassatavun Creek, and water levels in observation wells on Lons Massatayun Creek, and water levels in observation wells on Long

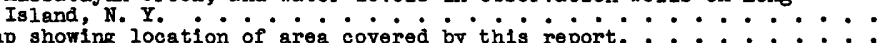

Figure 1. Map showing location of area covered by this report......... .

2. Isohyetal map of the North Atlantic states showing the totai preclpitation, in Inches, September 12-16, 1938...........

3. Isohyetal map of the North Atlant1c States showing the total precipitation, in inches, September $17-21$, 1938 .

4. Isohyetal map of the North Atlantic States showing the total pre-

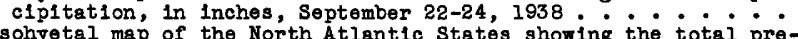

5. Isohyetal map of the North Atlantic States showing the total prec1pitation, in inches, for 24 hours ending at 6 p.m., September 19, 1938 map of the North Atlantic states shoving the total precipitation, in inches, for 24 hours ending at 6 p.m., September 20,1938 . : * :

7. Isohyetal map of the North Atlantic States showing the total preclpitation, in inches, for 24 hours onding at 6 p.m.s september

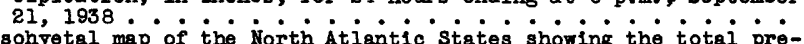
cipitation, in inches, 5 to 11 p.m. September 17,1938 .

9. Isohyetal map of the North Atlantic States showing the totai precipitation, in inches, $11 \mathrm{am}$. to $5 \mathrm{p.m}$. September 18, 1938 . c1pitation, in inches, 5 to 11 p.m., September 18,1938 ...

11. Isohyetal map of the North Atlantic States showing the total preclpitation, in inches, 11 p.m., September 18, to 5 a.m., Septem-

12. Isohyetal map of the North Atiantic states showing the totai precipitation, in inches, 5 to 11 a.m., September 19,1938 .

13. Isohyetal map of the North Atlantic States showing the total precipltation, in inches, 11 a.m., to 5 p.m., September 19 , 1938
sohyetal map of the North Atlentic states showing the total pre-

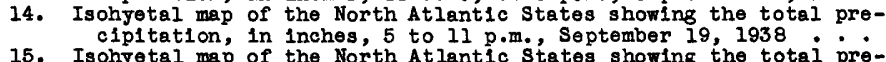
olpitation, in inches, 11 p.m., September 19, to 5 a.m., September 20, 1938 ..... . . . . . . . . . . . . ......... 
Figure 16. Isohyetal map of the North Atlantic Stetes showing the total precipitation, in inches, 5 to 11 a.m., September 20,1938 .

17. Isohyetal map of the North Atlantic states showing the total pre-

18. Isohyetal map of the North Atlantic States showing the total precipitation, in inches, 5 to 11 p.m., September 20, 1938 .....

19. Isohyetal mep of the North Atlantic states showing the totai precipitation, in inches, 11 p.m., September 20, to 5 a.m., September 21, 1938 ..........................

20. Isohyetal map of the North Atisntic States showing the totel precipitation, in inches, 5 to 11 a.m., September 21,1938 . . . . .

21. Isohyetal map of the North Atlantic States showing the total precipitation, in inches, 11 a.m. to 5 p.m., September 21, 1938 ...

22. Isohyetal map of the North Atlantic states showing the total precipitation, in inches, 5 to 11 p.m., September 21, 1938 ......

23. Cumilative monthly soli moisture, Festfield River Basin above Knightvillo, Masa., 1927, 1932, 1938. . . . . . . . . .

24. Hourly precipitation, in inches, at various precipitation stations.

25. Hourly precipitation, in inches, at various precipitation stations.

26. Daily precipitation at various precipitation stations, August 1 to

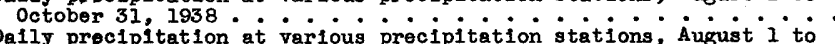
October 31, 1938 . . . . . . . . . . . . . . . . . .

28. Graphs of mean dally discharges at various stream-gaging stations

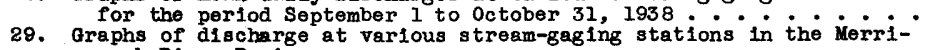

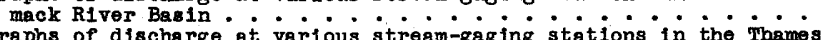

30. Graphs of discharge at various stream-gaging stations in the Thames River Basin - alscharge at various stream-gaging stations on the con-

31. Graphs of discharge at various stream-gaging stations on the Connecticut RIver :

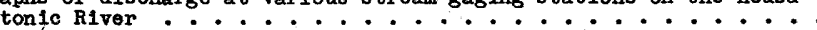

33. Graphs of alscharge at various stream-gaging stations in the Hudson

34. Graphs of discharge at various stream-gaging stations in the Mohawk

35. Graphs of discharge at various stream-gaging stations in the

Passaic River Basin
36. Graphs of discharge at various stream-gaging stations in the
Raritan River Basin

37. Graphs of discharge at various stream-gaging stations in the

38. Graphs of discharge at various stream-gaging stations on the Neversink River a is irious stream-gaging stations in the

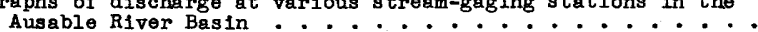

40. Graphs of discharge at various stream-gaging stations on streams

41. Chart showing flood discharges, in second-feet per square mile,
for numerous drainage areas as given in tablo $10 . .$. . .

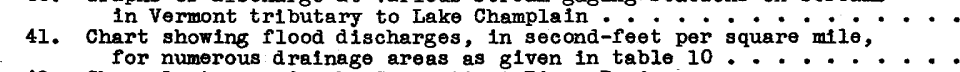

42. Channel storage in the connecticut River Basin 4ethod of analyses used in determining the direct run-off associated with the rains of. September $12-16$ and $17-21,1938$. .

44. Chart showing relation of total precipitation and retention, sept. 17-2I, 1938 , to indicated infiltration indices.

45. Map showing generalized values of infiltration index, in inches

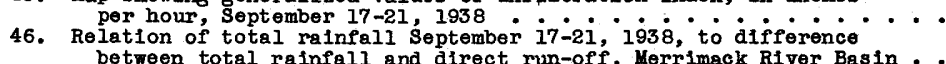
between total rainfall and direct run-off, Merrimack River Basin .

47. Relation of total rainfall september 17-21, 1938, to difference between total rainfall and direct run-off, Thames River Basin

48. Relation of total rainfall September 17-21, 1938, to difference between total rainfall and direct run-off, Connecticut River Basin.

49. Analyses of rainfall and mun-off, in basin of Burlingtion Brook,

near Burlington, Conn.
50. Relation of total rainfail september $17-2 i, 1938$, to difference
between total rainfall and direct mun-off, Housatonic River Basin . between total rainfall and direct mun-off, Housatonic River Basin
drograph of discharge, Pines Brook at Malverne, $N$. $Y$., and graph of hourly rainfall at Mineola, N. Y between total rainfall and direct mun-off, Hudson River Basin

53. Analyses of rainfall and run-off, in basin of Neshanic River at Reaville, N. J. between total rainfall and direct run-off, St. Lawrence River Basin . . . . . . . . . . .

55. Analyses of rainfali and run-off, in basin of Dog River at North-

56. Study of water levels at The Battery, New York, N. $\dot{Y}$, September 21 , 1938 of the western part of Long Island showing iocation of observation wells, stream-gaging stations, and raingages tation and average ground-water level on Long Is land, N. Y.

59. Graphs showing relation of barometrlc pressure to water levels in three artesian wells on Long Island during the hurricane

60. Graphs showing pumpage from the Lloyd sand at Long Beach, N. Y., water level in a well ending in the Lloyd sand, and atmospheric
pressure at Jamaica, N. Y. . . . . . . . . . . . . . . . . . .

61. Graphs showing precipitation at Mineoia and stream fiow of Massatayun Creek, Long Island, during three storms in $1938 . . .$. . 
Table 1. Meteorologic data of the hurricane . . . . . . . . . . . . . . Page

2. Monthly total precipltation and departure from normal, in inches,

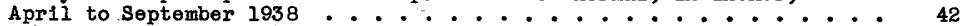

3. Monthly mean temperature and departure from normal, in degreos Fahrenhe1t, April to September 1938 . . . . . 43

4. Dally procipitation, in inchos, september $12-22,1938^{\circ}::_{0}: \therefore{ }_{46}$

5. Supplemental records of da11y precipitation, in inches, september $12-22,1938 \ldots \ldots \ldots$

6. Precipltation, in inches, for period ending at indicated time,

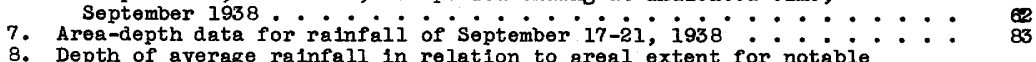

8. Depth of average rainfall in relation to areal extent for notable . . . 84

9. Depth of average rainfail, in inches, for indicated area and period: : 85

11. Summary of flood discharges storage, in millions of cuble foet, in reservoirs in the $\quad 382$ Fudson RIver Basin.................................. 418

12. Summary of storage, in millions of cubic feet, in reservolrs in the

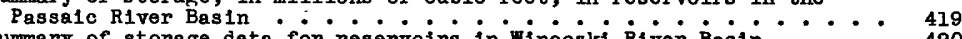

13. Summary of storage data for reservoirs in winooski River Basin : : 420

14. Precipitation and associated run-off of floods of september $1938: \vdots: 424$

15. Rate and duration of precipitation September 17-21, based on hourly

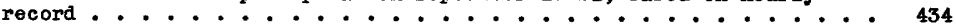

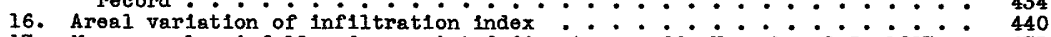

17. Mean areal rainfall and assoclated direct run-off, November $2-5$, i $927^{\circ}: 473$

18. Mean areal rainfall and associated direct run-off, September 16-17, 1932 . . . . . . . . . . . . . . 474

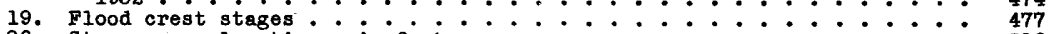

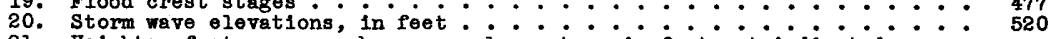

21. Heights of storm wave above mean low water, in foet, at indicated time, September 21, 22, 1938 . . . . . 525

22. Dally precipltation, in inches, during three storms in $1938^{\circ}$ at four stations on western Long Is land . . . . . . . . . 532

23. Water levels in observation wells on Long Islend, $\dot{N}^{*} \dot{Y}^{*}$; in feet, with reference to mean sea level, 1938 ............... 533

24. Summary of observation well data and approximate rise of water table on Long Island, N. Y., following storms in June, July, and September, 1938 . . . . 538

25. Average prectpltation on Long Island during 4 weoks preceding esch

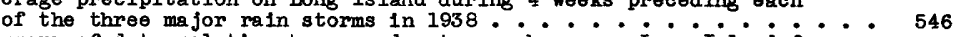

26. Summary of data relating to ground-water recharge on Long is land for

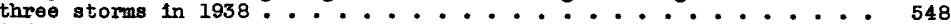

27. Rainfall, direct run-of, and retention, in inches, resulting from three storms in 1938 on the south shore of Long Island....... 551 

During the brief interval of 6 hours on September 21, 1938, a West Indian hurricane passed over Long Island and New England. The hurricane as it struck New England was the climax of a 4-day period of rainfall which in itself was of outstanding amount and character and which produced river stages that inundated and damaged nearly everything on the river flood plains. When measured by the appalling loss of life and property by the combined forces of the hurricane winds and the associated ocean storm waves and river floods, these events constituted the greatest catastrophe in New England since its settlement by the white man.

Although the river floods were generally contemporary with the hurricane, their magnitude was a result of the rainfall which began with light showers during the afternoon of September 17 and which continued with but little interruption and with generally increasing intensity unt1l late afternoon of September 21, when it ended abruptly with the passing of the hurricane. Total precipitation exceeded 17 inches locally and averaged 11.5 inches over an area of 10,000 square miles in the central storm area.

The peak stages in many places on the smaller streams in the central storm area greatly exceeded those previously recorded during the outstanding storms of November 1927 and March 1936. Although all streams in the area were above flood stage, the upper Contoocook River in New Hampshire, the western tributaries of the Thames River, the tributaries of the Connecticut River below White River Junction, the upper Housatonic River and many of its tributaries, the tributaries of the Hudson River from the east, and the Raritan River in New Jersey reached flood stages that exceeded any previously recorded.

Rates of discharge of 400 to 500 second-feet per square mile were measured for areas as large as 100 square miles on the smaller tributaries to the Connecticut River in southern Vermont, in the Westfield and Deerfleld River Basins, and in the drainage basin of the Chicopee River in central Massachusetts. On these streams many dams and bridges failed, buildings were swept away, and debris was deposited on overflowed lands.

Volumes of direct run-off produced by the storm rainfall of september 17-21 reached as high as 9 and 10 inches in the central storm area, an amount rarely exceeded in the northeastern United States during single storms not assoclated with snow. The volume of direct run-off was equivalent to 3.7 inches over the Merrimack River Basin and 4.05 inches over the Connecticut River Basin. The absorption of rainfali indicated by the infiltration index ranged from 0.02 inch per hour in central Vermont and New Hampshire to 0.26 inch and more per hour on Long Island. A marked tendency was disclosed for the infiltration index to be greater in the relatively flat coastal areas than in the steep mountainous areas. The general average was 0.10 inch per hour.

A1l along the coast between New York City and Cape Cod recordbreaking ocean levels were recorded. Maximum storm-wave helghts were measured in Rhode Island where several heights exceeded 17 feet above mean high water.

The extraordinary amount of rainfall during the period september 1721 was instrumental in producing an exceptionaliy high water table on Long Island. In this region where the 4-day rainfali was 11 inches it was computed that the recharge was approximately 7.2 inches. In less permeable and steeper reglons on the mainland, the recharge was considerably less, being estimated as generelly between 0.5 and 3.0 inches.

This report presents records of stage and discharge for the period including the flood at about 240 stream-gaging stations, records of $s$ torage in many reservolrs, a summary of peak discharges with comparative data for other floods at about 530 measurement points, and tables showing crest stages along an aggregate length of stream channel for 1,450 miles, records of dally observations of precipitation during the period september 12-21 at about 745 places, and records of more frequent observations of precipitation at about 110 places of measurement, records of ocean-wave helght at about 230 locations along the coast, and records of water level in 31 observation wells on Long Island.

The report also includes basic information in regard to the hurricane and general weather conditions assoclated with floods, analyses of rainfall and run-off, discussions of storage and ground-water recharge, and many other data pertinent to the floods. 


\section{INTRODUCTION}

A hurricane, an ocean storm wave, and floods combined their forces of violence in September 1938 to produce destruction of Iife and property In the North Atlantic States probably exceeding that of any previous single natural disaster in the history of the nation. A tropical hurricane moving northward off the Atlantic Coast suddenly stmuck inland from the ocean on the afternoon of September 21 and crossed Long Island and the coast of Connecticut and Rhode Island, where gales and ocean Inundation caused almost unimaginable damage along the thickly populated shores. Had not many summer residents returned to their homes soon after Labor Day, the loss of lives would have been more appaling. The hurricane continued northward with almost unabated force through Connecticut and Massachusetts, and then gradually diminishing, crossed the Green Mountains in central Vermont, and passed Into Canada near Lake Champlain. It left behind a ravaged countryside extending scores of miles eastward from its central path.

New England had been experiencing heavy rainfall on September 18, 19, and 20, and streams were bank full when the rain associated with the hurricane brought the total rainfall during a 4-day period to a maximum of about 17 inches in certain limited aress and to an average of more than 11.5 inches over an area of 10,000 square miles.

Thus the great storm wave that swept inland along the shores of Connecticut and Rhode Island coincident with the passing of the hurricane on the afternoon of September 21 was followed by a wave of floods in all the stream channels on the timbered slopes of the New England hills and in the larger rivers, inundating, destroying, or damaging all within the flood plains. Generally by the evening of September 23 the flood waters had passed into the Atlantic Ocean.

The rates of flood discharge resulting from the heavy precipitation were so much in excess of the capacities of the unobstructed parts of the natural channels that hundreds of bridges were seriously damaged or destroyed. Major damages were inflicted upon many cities and town, and upon railroads, highways, mills, dams, and other improvements which for convenience and largely of necessity had been constructed within, on, or over natural channels of flow.

It was variously estimated that about 500 or more lives were lost, mainly along the coastal areas where the hurricane and inundation by the record ocean wave were coincident, and estimates fix the direct property 
loss and damage in the area as a whole at close to one-third of a billion dollars.

In each of the following primary drainage basins the flood discharges of many of the tributaries closely approached or exceeded--some of them by large amounts--any records of floods previously known in those areas:

$\begin{array}{ll}\text { Merrimack River } & \text { Huds on River } \\ \text { Thames River } & \text { Passaic River } \\ \text { Connecticut River } & \text { Raritan River } \\ \text { Housatonic River } & \text { Lake Champlain }\end{array}$

The large area included within these primary drainage basins and the nearby lesser basins or parts of basins that were affected by the floods are shown on figure 1 .

The floods of September 1938 coming so shortly after the wide-spread floods of March 1936 and only 11 years after the New England flood of November 1927 have not only impressed upon the inhabitants of the affected regions the magnitude of the problem of controlling and confining the flood waters but have also indicated a prevalling frequency of occurrence that may have an important bearling on the economics of flood control. Each local, State, or Federal organization engaged in formulating plans for protective measures requires sound and adequate basic information relating to the stages, discharges, and other characteristics of all outstanding floods that have affected their particular areas.

The United States Geological Survey operating through several local district offices maintains as a part of the regular nation-wide streamgaging program about 300 river-measurement stations within the area affected by the floods of September 1938. These stations have been maintained by the Geological Survey largely in cooperation with States and municipalities and generally for periods beginning several years prior to the september floods. By this program the Survey has obtained systematic records of stages and rates and volumes of flow of the streams covering the range from drought to extraordinary floods.

Immediately after the floods of September 1938, action was taken to collect and compile all available basic meteorologic and hydrologic data from official and private sources, and surveys were begun to determine the maximum discharge of streams throughout the flooded area. For the furtherance/of this work $\$ 24,000$ of the funds allotted at the beginning of the fiscli year to the Geological Survey by the Federal Emergency Administration of Public Works in accordance with the National Industrial Recovery Act of 1933 for "surveys of floods and droughts" was used to 
4

HURRICANE FLOODS OF SEPTEMBER 1938

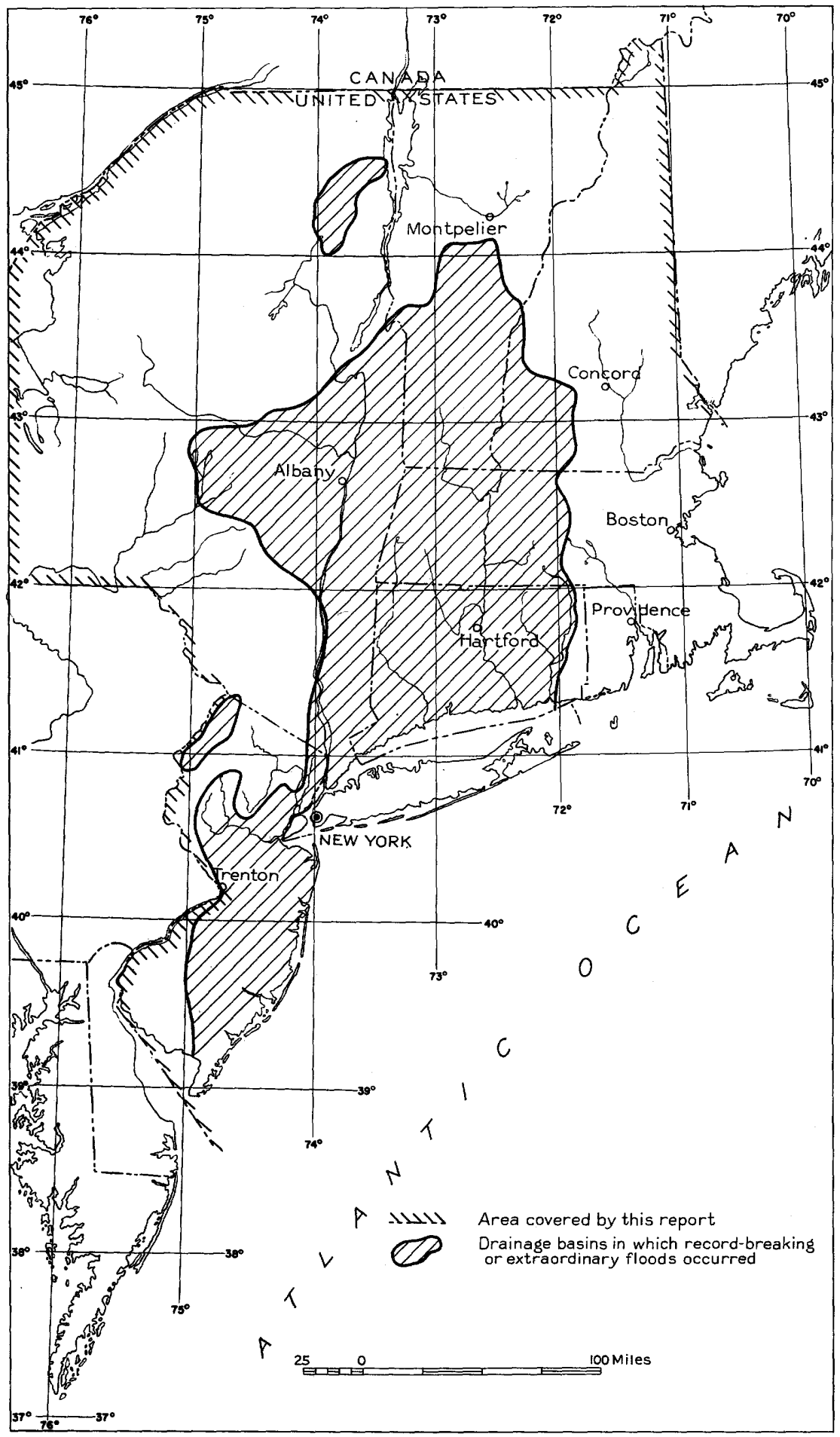

Figure 1. --Map showing location of area cover id by this report. 
supplement regular and cooperative funds. Prompt inauguration of fleld work made it possible to obtain pertinent evidence of flood stages and profiles before the area was snow-covered and before evidences of the flood were obliterated by processes of reconstruction which were undertaken promptly in every city, town, and hamlet.

This report contains all the basic information relating to stages

- and discharges collected at the regular river-measurement stations, the results of flood-flow determinations made at points where regular gaging stations were not being maintained, all basic meteorologic and hydrologic Information, and the results of analyses of rainfall, run-off and channel storage.

\section{ADMINISTRATION AND PERSONNEL}

The field and office work incident to the preparation of this report were performed by the water-resources branch of the Geological Survey under the general administrative direction of $\mathrm{N}$. C. Grover, chief hydraulic engineer, up to the time of his retirement from the Government service on January 31, 1939, then under C. G. Paulsen, acting chief hydraulic engineer, unt1l October 17, 1939, and G. L. Parker, chief hydrauIic engineer thereafter, the major part of the work being performed during Mr. Paulsen's incumbency. The actual field work and collection and tabulation of the basic information for stages and discharges were done by the district engineers and their staffs in the division of surface water, C. G. Paulsen, chief. The district engineers primarily responsible for the collection and preparation of this information were B. L. Bigwood, Hartford, Conn.; A. W. Harrington, Albany, N. Y.; 0. W. Hartwell, Trenton, N. J.; and H. B. Kinnison, Boston, Mass. The section entitled "Groundwater recharge on Long Island" was prepared by R. M. Leggette, geologist, of the division of ground water, under the direction of 0 . E. Meinzer, chief. The compilation of maximum ocean storm-wave heights associated with the hurricane was prepared by B. L. Bigwood, district engineer, Hartford, Conn.

The information on rainfall and other climatological features and the analyses of rainfall and run-off relations and storage were prepared by W. B. Langbein, assistant engineer, division of water utilization, under the direction of R. W. Davenport, chlef. The coordination of the collection of data and a major part of the preparation of material for publication were directed by Hollister Johnson, hydraulic engineer, temporarily assigned to the division of water utilization, through the 
technical and clerical staff and other facilities of the office of H. B. Kinnison, district engineer, Boston, Mass. W. G. Hoyt, consulting engineer, conservation branch, reviewed the report and assisted in the final phases of preparation. The report was finslly reviewed and assembled for publication in the division of water utilization in Washington, D. $C$. Many other members of the staff of the Geological survey made valuable contributions to this work. The permanent fleld and office staff were assisted by temporary employees appointed by the Secretary of the Interior under the provisions of the National Industrial Recovery Act.

\section{ACKNOWLEDGMENTS}

The Geological Survey, acting through its district field offices, cooperated with State and municipal agencies in the several districts. Acknowledgment is made to these cooperating agencies for participation in the systematic collection of the records of river alscharge that form the broad base for the specific flood information and in the maintenance of fleld organizations in which engineers trained for investigation of this kind were available for the special studies related to the collection of the field data and the preparation of the report.

Information appearing in this report has been obtained from many sources, including individuals, corporations, and local, State and Federal governmental organizations. Financial cooperation in connection with the regular river-measurement program of the Geological Survey in the areas covered by this report has been recelved from the following agencies: In Connecticut, the State Water Commission, the City of New Britain Board of Water Commissioners, and the City of Hartford Flood Investigation and Improvement Commission; in Massachusetts, the Department of Public Works, the Department of Public Health, the Metropolitan District Water Supply Commission, and the Metropolitan District Comission; in New Hampshire, the State Water Resources Board; in New Jersey, the State Water Pollcy Commission, the North Jersey District Water Supply Commission, and the Delaware River Joint Toll Bridge Commission; in New York, the State Water Power and Control Commission, the State Department of Public Works, the State Department of Conservation, the Board of the Hudson River Regulating District, the New York City Board of Water Supply, the City of Albany Department of Water and Water Supply, the County of Nassau Department of Public Works, and the Village of Ossining Board of Water Commissioners; and in Vermont, the State through its Executive Department. 
Federal agencles to whom acknowledgments are made for services rendered or data furnished include the Weather Bureau; the Corps of Engineers and the Air Corps of the United States Army; the Soll Conservation Service; the Emergency Administration of Public Works, and the Works Progress Administration.

Special assistance in collecting data and furnishing records was also rendered by the Connecticut State Water Commission, the Massachusetts Department of Public Health, the Massachusetts Geodetic Survey, the New Hampshire Water Resources Board, the Rhode Island Department of Public Works, the City of Pawtucket, the Springfield Board of Water Commissioners, the Water Bureau of the Hartford Metropolitan District, the Connecticut Light \&c Power Co., Connecticut Power Co., the Hartford Electric Light Co., the city of Waterbury, Conn., Bureau of Engineering, the Collins Co. of Connecticut, the Rockville, Conn., Water \& Aqueduct Co., School of Engineering at Yale University, the Belding-Hemingway Co. of Connecticut, the New England Power Co., the New England Power Association, the Proprietors of Locks and Canals on the Merrimack River, the Essex Co., the Holyoke Water Power Co., the Turners Falls Power \& Blectric Co., Mascoma River Improvement Co., the New Hampshire Public Service Co., Worcester Electric Light Co., New York City Department of Water Supply, Gas \& Electricity, System Properties, West V1rginia Pulp \& Paper Co., New York * Pennsylvania Co., Assoclated Gas S Electric System, Oswego River Watershed Co., New York Power \& Light Corporation, Central Hudson Gas \& Electric Corporation, Indian River Co., Streever Constmuction Co., Blandy Paper Co., Rockland Iight \& Power Co., Charles H. Tenney Co., Dutchess Bleachery, Inc., Rensselaer Polytechnic Institute, the Society for Establishing Useful Manufactures, Hackensack Fater Co., Jersey Central Power \& Light Co., Monmouth Consolidated Water Co., Morris Canal \& BankIng Co. and Taylor-Wharton Iron \& Steel Co. In New York the following municipalities also gave assistance: Schenectady, Kingston, and Ilion; In New Jersey, the municipalities of Atlantic City, Jersey City, Morriston, Newark, New Brunswick, and Princeton. So far as practicable, acknowledgments for individual contributions of information are given at appropriate places in the report.

$2279070-40-2$ 
GENERAL FEATURES OF THE STORMS

Although the time of occurrence of the major floods on the New England streams during September 1938 was coincident with the tropical hurricane that swept northward across New England on September 21, it appears that the magnitude of the floods may have been determined in part by meteorological conditions not intimately associated with the tropical disturbances. It was not until September 16 that the hurricane had been definitely charted as a fully developed hurricane some 1,200 miles east of the south Atlantic cosst traveling in the usual course at the moderate speed of about 20 miles an hour. Prior to that time a continental disturbance centered over northern Maine on the afternoon of September 12 and was the cause of appreciable rainfall in the New England area. At the same time a low-pressure area centered over Nebraska moved along the regular paths eastward across the Ohio and St. Lawrence Valleys and by the afternoon of September 15 was over eastern Quebec. These disturbances brought 1 to 4 inches of rain to New England and eastern New York (see flg. 2) during the period september 12 to 16 which in this report has been designated as the time of the first storm. The greatest recorded precipitation on any calendar day was between 1.5 and 2 inches. There was no appreciable flood run-off from the rainfall of the first storm, but a considerable part of the absorptive capacity of the ground had been utilized at the beginning of the second or major storm period with the result that the magnitude and intensity of the flood run-off were correspondingly increased during the subsequent major storm.

The jor storm period began with light showers during the afternoon of September 17 after which, on September 18, there ensued a steady accumulation of precipitation generally increasing in intensity. The period closed abruptly with the passing of the hurricane during the afternoon and evening of September 21. (See fig. 3.) The precipitation on September 17, 18, and 19 seems to have been indirectly assoclated with a rather severe continental disturbance that was situated over Lake Michigan and Lake Superior and with the inflow of polar air from the high-pressure area that centered over Newfoundland. The precipitation during the latter part of this period is shown in flgure 4. The weather maps for the mornings of September 18 and 19 show a well-defined front situated slightly to the east but parallel to the belt of maximum rainfall shown in figure 5 . The weather map for the morning of September 20 showed material alterations; the continental low-pressure area had diminished in depth and had moved 


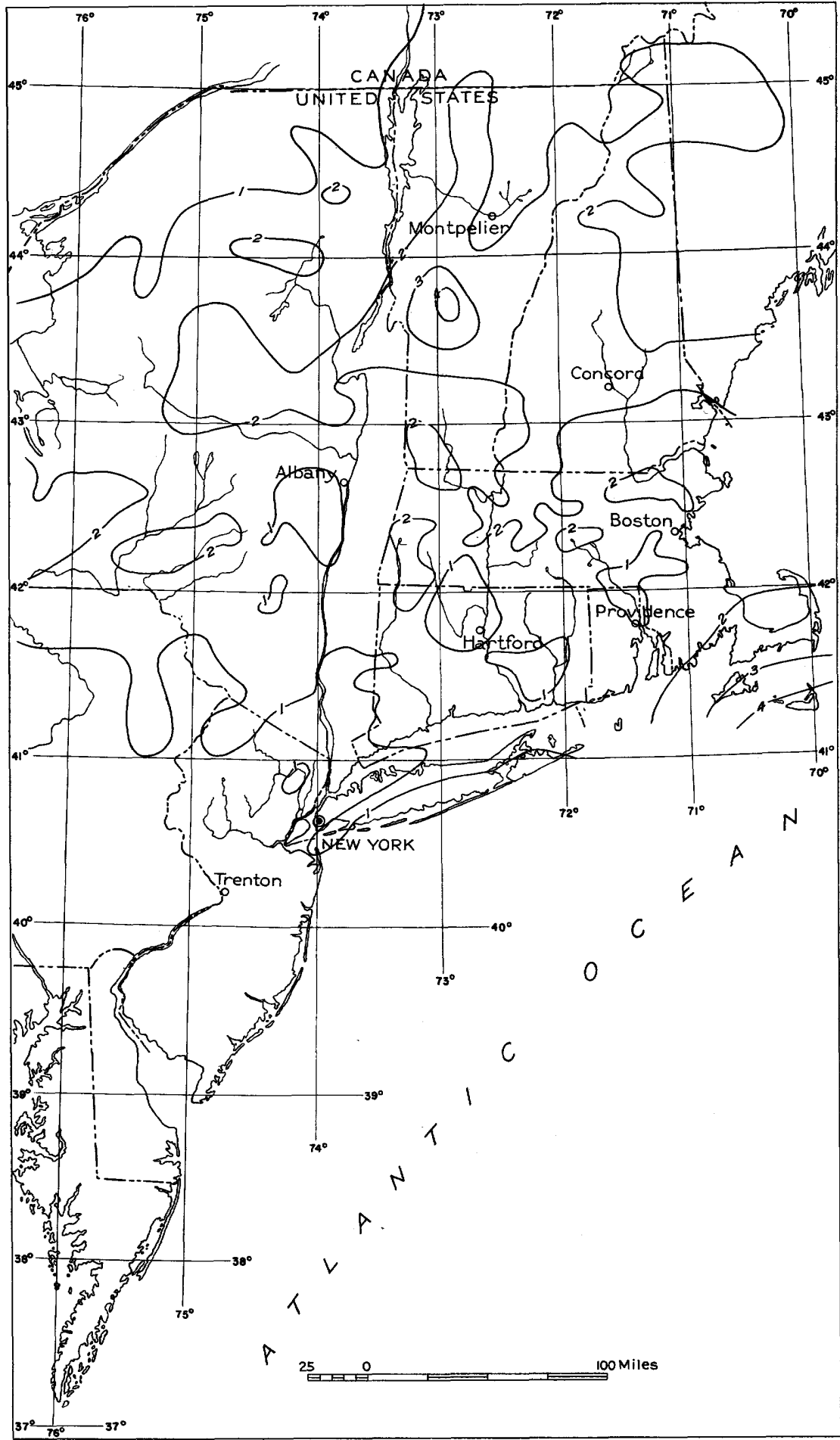

Figure 2.- Isohyetal map of the North Atlantic States showing the total precipitation, in inches, September 12-16, 1938. 


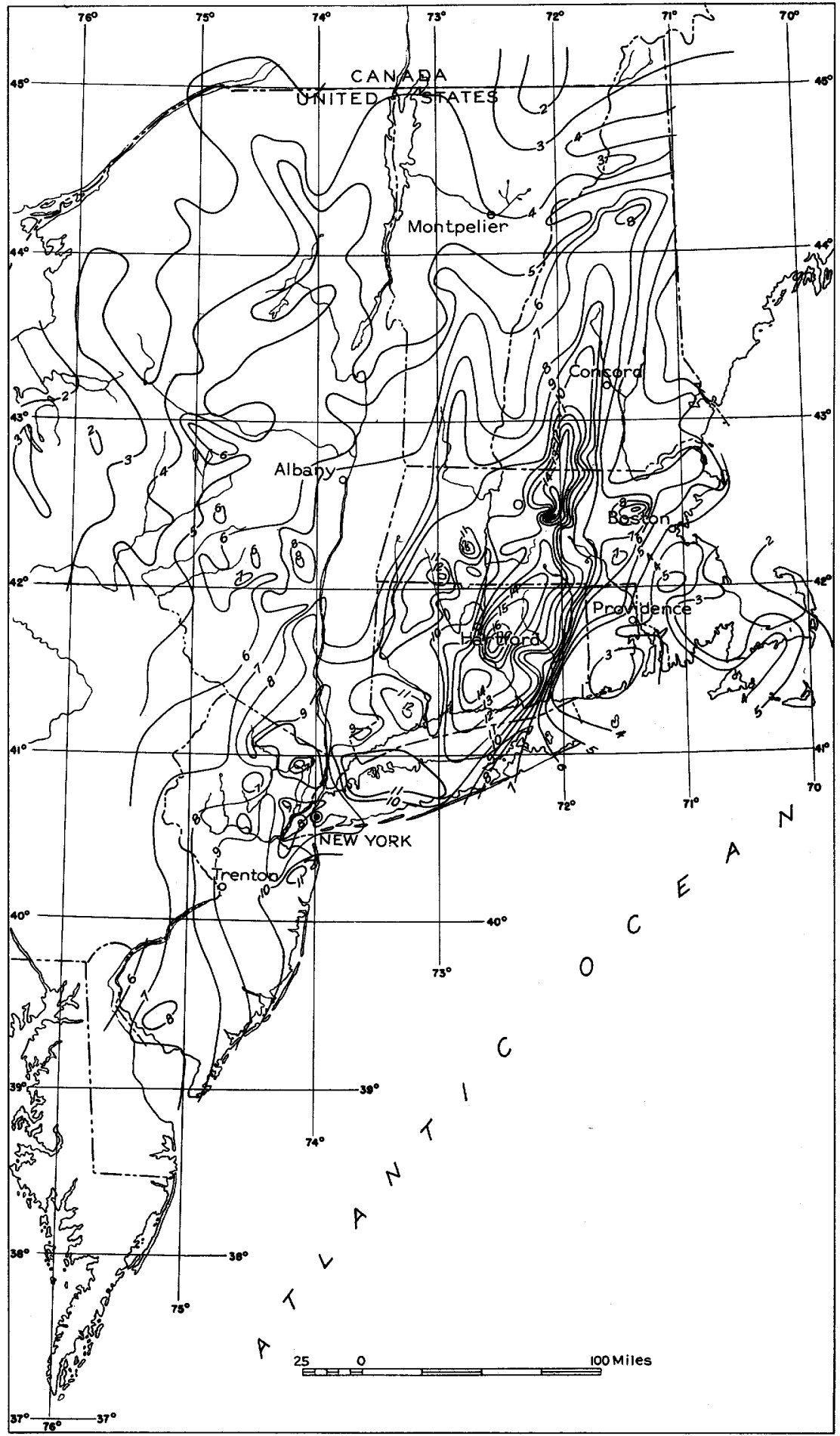




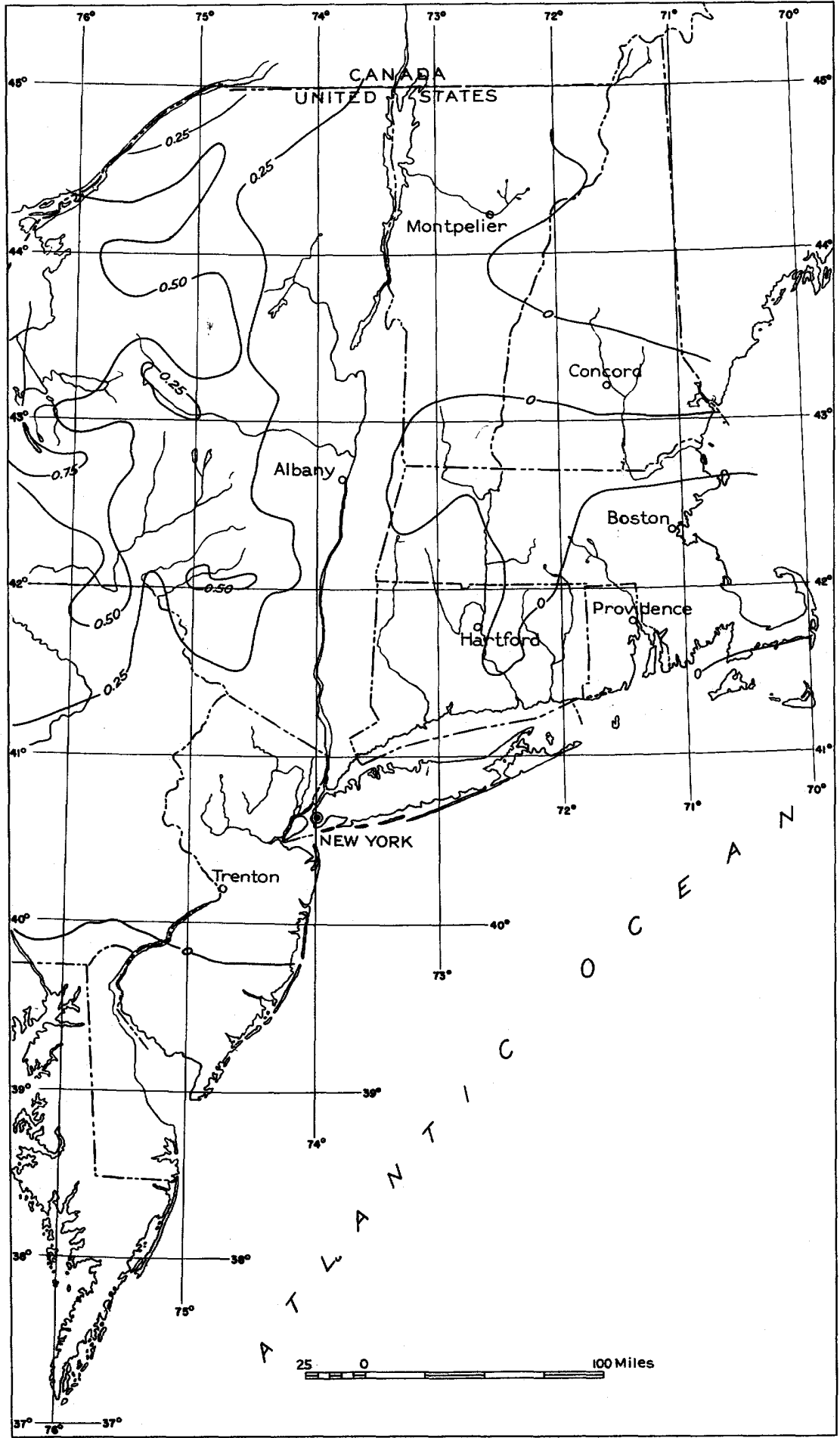

Figure 4.--Isohyetal map of the North Atlant1c States showing the total precipitation, in Inches, September 22-24, 1938. 


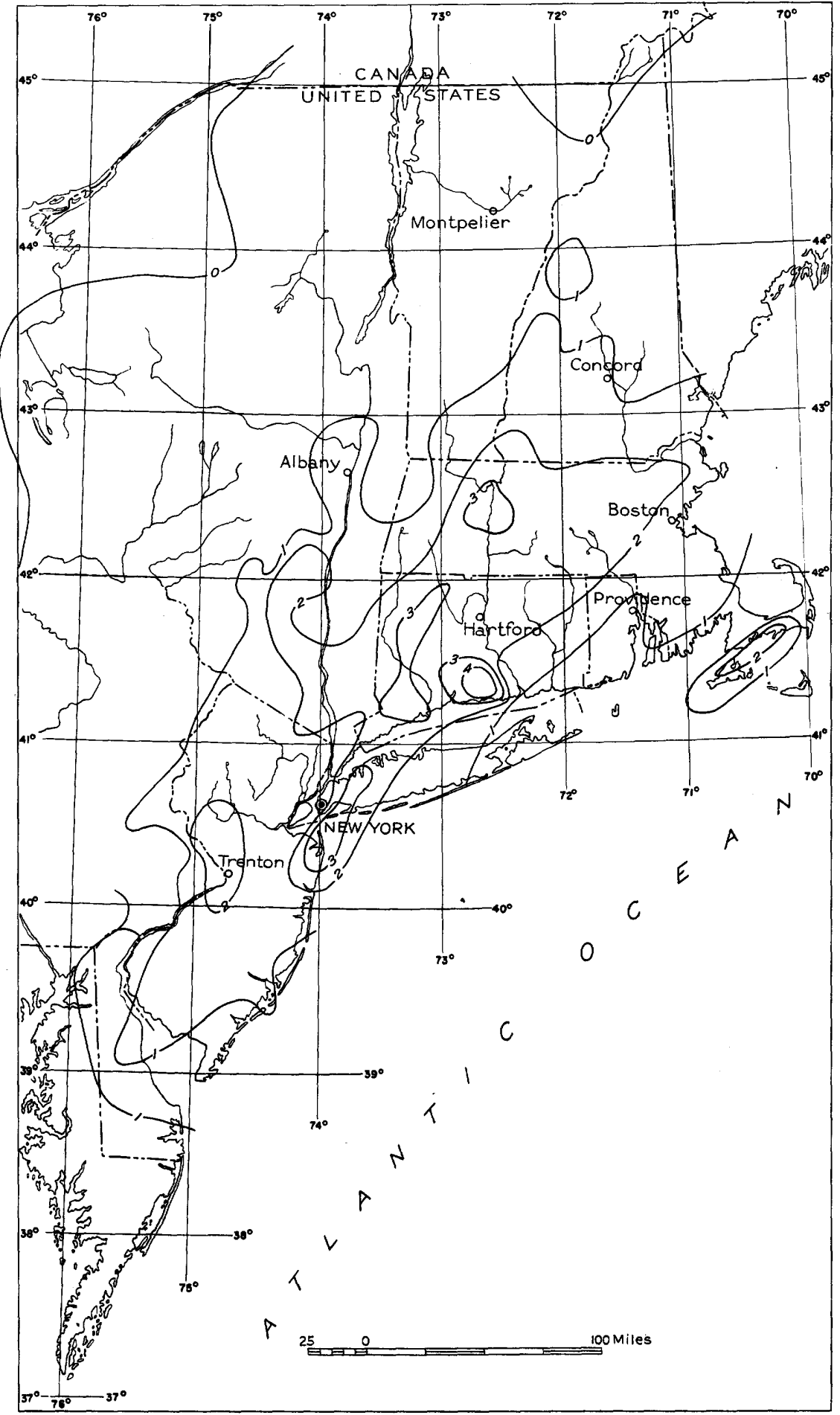

F1gure 5.--Isohjetal map of the North Atlantic States showing the total precipltation, in inches, for 24 hours ending at 6 p.m. . September 19, 1938 . 
to the northeast over Quebec. It was succeeded by a high-pressure area. An associated trough of low pressure had developed to the east of the coast extending from North Carolina into central New Ergland. This trough was then situated between one high-pressure area over the eastern Great Plains and a second over Newfoundland and the north Atlantic Ocean. Into the trough so formed molst tropical air moved northward and aloft, causing coplous rainfall over New England (see fig. 6). Meanwhile the hurricane disturbance was progressing rapidly northward along the Atlantic coast between the nearly stationary high-pressure areas. On the morning of september 21 the low-pressure areas had united and a deep trough of low barometric pressure remained over the coastal area from Cape Hatteras northward and over New England and eastern New York, along the center of which the hurricane was rapidly advancing northward. This sequence of meteorologic conditions produced torrential rains that continued through the afternoon of the 2lst, generally culminating in high intensity rates and abruptly terminating with the passing of the central low-pressure area or hurricane. The rainfall during the 24-hour period ending on the afternoon of the 2lst is shown in figure 7; the central path of the hurricane is also shown. The isohyetal maps, figures 6 and 7 , for the rains of September 20 and 21 , and especially plate 1 (in pocket) showing the isohyetals for the full storm period, disclose a sharply defined front In the east, particularly in Connecticut; on the west the front was not so closely defined. Direct run-off was accumulating in all streams on September 19 and 20 and into their well-filled channels came the heavy mun-off resulting from the intensive storm precipitation on the 21 st.

At 10:30 a.m., September 18, the Weather Bureau forecast center at Jacksonville, Fla., 1ssued the following warning:

The tropical disturbance, probably of full hurricane intensity, is centered at 7 a.m. E.S.T. In appróximately latitude $22^{\circ} 30^{\prime}$ north and longltude $62^{\circ}$ west, apparently moving west or west-northwestward about 15 to 20 miles per hour. Caution is advised all vessels in path of this dangerous $\mathrm{s}$ torm.

This warning was followed by 16 bulletins, each giving the location of the hurricane center, its speed, and probable course. Table 1 shows meteorologic data concerning the hurricane for each of a number of places, Ilsted northward from Cape Hatteras, N. C., to Burlington, Vt.

At about 7:30 a.m. on September 21 the storm center was off Cape Hatteras where, as a result of the prevaling barometric conditions previously described, it departed from the usual storm track that projects to the northeast over the Atlantic Ocean, and drove slightly east of 


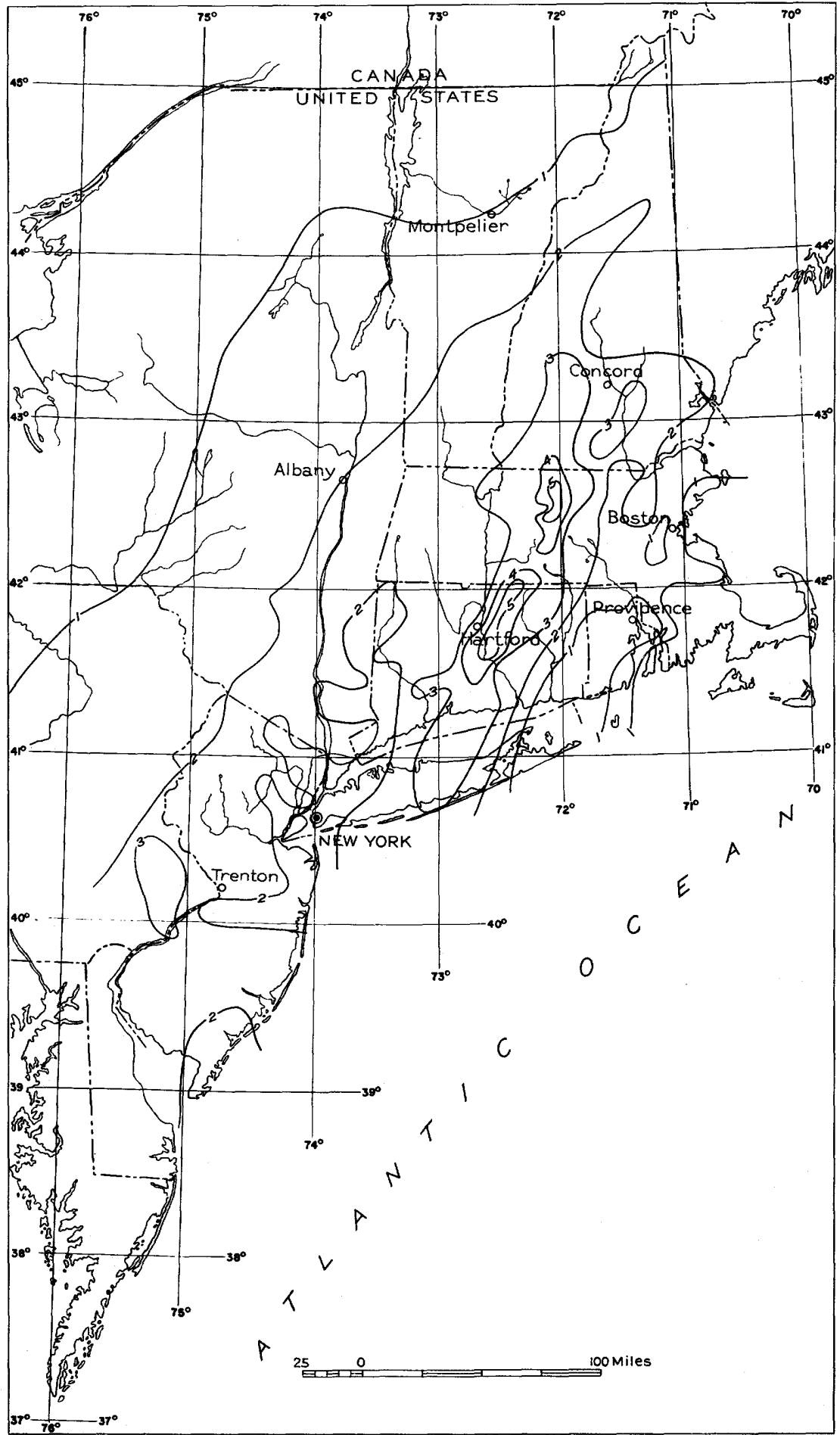

F1gure 6.--Isohyetal map of the North Atlantic States showing the total precipitation, in Inches, for 24 hours ending at $6 \mathrm{p} . \mathrm{m}$., September 20, 1938. 


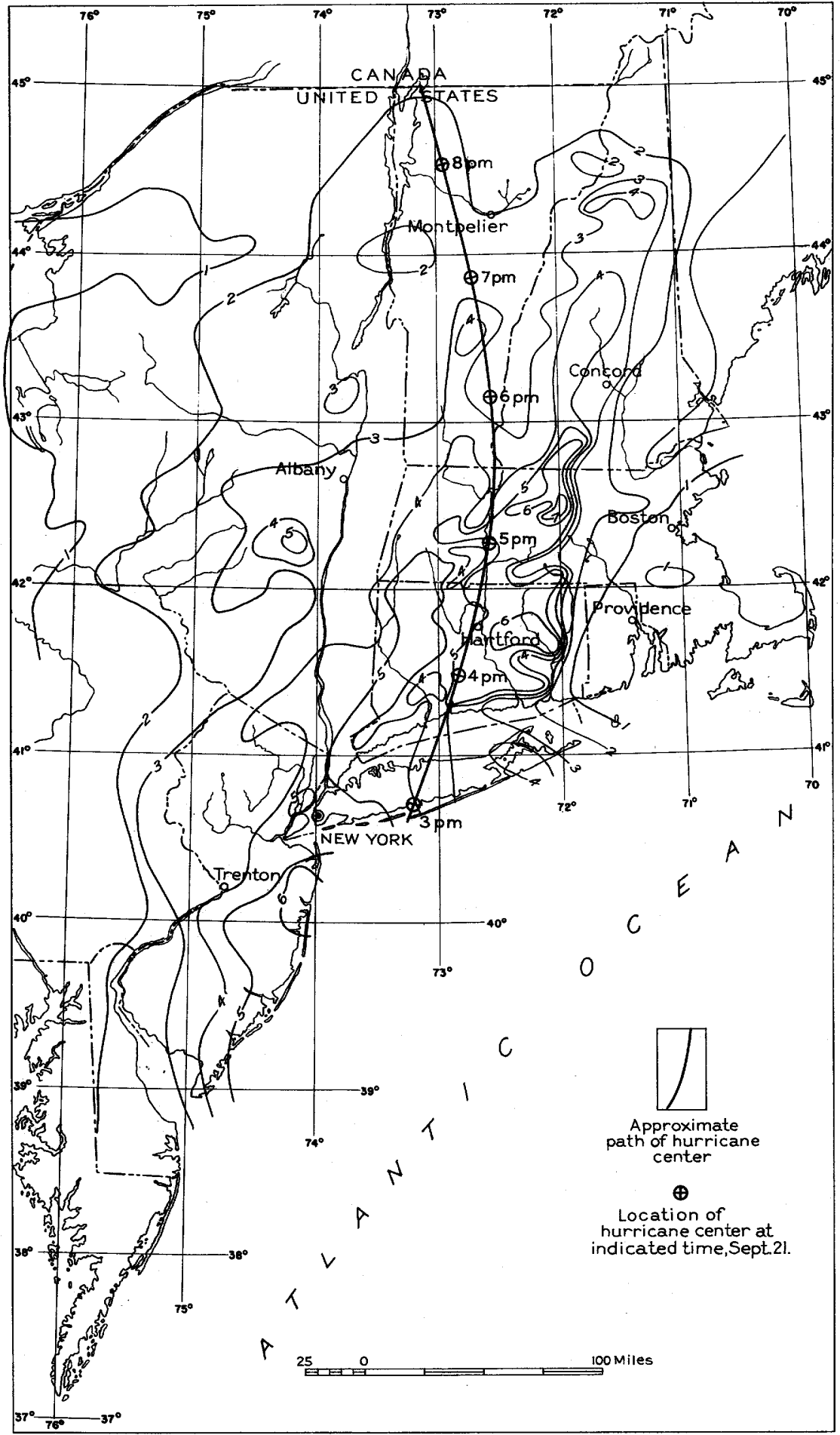

Figure 7.--Isohyetal map of the North Atlantic States showing the total precipitation, in Inches, for 24 hours ending at $6 \mathrm{p.m}$., September 21, 1938 . 
Table 1.--Meteorologic data of the hurricane

\begin{tabular}{|c|c|c|c|c|c|c|c|}
\hline \multirow{3}{*}{ Location } & \multicolumn{2}{|c|}{ Barometer } & \multicolumn{2}{|l|}{ Wind } & \multirow{2}{*}{\multicolumn{3}{|c|}{$\begin{array}{c}\text { Precipitation accompanying } \\
\text { mintmum pressure } \\
\text { (Inches) }\end{array}$}} \\
\hline & \multirow{2}{*}{$\begin{array}{l}\text { Min1mum } \\
\text { pressure } \\
\text { (1nches) }\end{array}$} & \multirow{2}{*}{$\begin{array}{l}\text { T1me } \\
\text { Sept. } \\
21\end{array}$} & \multirow{2}{*}{$\begin{array}{c}\text { Maximum } \\
\text { (miles } \\
\text { per } \\
\text { hour) }\end{array}$} & \multirow{2}{*}{$\begin{array}{l}\text { D1- } \\
\text { rec- } \\
\text { tion }\end{array}$} & & & \\
\hline & & & & & $\begin{array}{c}\text { Hour } \\
\text { before }\end{array}$ & $\begin{array}{c}\text { Hour } \\
\text { of }\end{array}$ & $\begin{array}{l}\text { Hour } \\
\text { after }\end{array}$ \\
\hline Cape Hatterss, N. C. & 29.30 & $7: 30 \mathrm{a.m}$. & 50 & NW. & - & - & - \\
\hline Atlantic Clty, N. J. & 28.99 & $1: 10 \mathrm{p.m}$. & 61 & พ. & 0.59 & 0.59 & 0.15 \\
\hline Sandy Hook, N. J. & 28.71 & $2: 00 \mathrm{p.m}$. & 56 & N. & a. 73 & .61 & .31 \\
\hline $\begin{array}{l}\text { Floyd Bennett Airport, } \\
\text { N. Y. b/ }\end{array}$ & 28.61 & 2:51 p.m. & - & - & .62 & .40 & .18 \\
\hline Babylon, N. Y. c/ & 28.00 & 3:00 p.m. & - & - & .26 & .34 & .11 \\
\hline New York, N. Y. & 28.72 & $2: 43$ p.m. & 70 & NW. & a. 88 & .05 & .01 \\
\hline Mitchell Fleld, N. Y.c/ & 28.58 & $2: 30 \mathrm{p} . \mathrm{m}$. & 52 & $\mathrm{NE}$. & .26 & .34 & .11 \\
\hline Garden C1ty, N. Y. d/ & 28.31 & 2:15 p.m. & - & - & .40 & a. 60 & .02 \\
\hline Mineola, N. Y. & 28.50 & $3: 00 \mathrm{p} \cdot \mathrm{m}$. & - & - & .40 & a. 60 & .02 \\
\hline Patchogue, N. Y. & 28.20 & - & - & - & - & - & - \\
\hline Water Mill, N. Y. & 28.44 & 3-4 p.m. & - & - & - & - & - \\
\hline Bridgehampton, N. Y. & 28.69 & 3:00 p.m. & - & - & - & - & - \\
\hline Setauket, N. Y. & 28.02 & $3: 14$ p.m. & - & - & - & - & - \\
\hline Block Island, R. I. & 28.66 & $3: 15$ p.m. & 82 & SE. & .15 & a. 74 & .10 \\
\hline New Haven, Conn. & 28.11 & $3: 50$ p.m. & 38 & NE. & a. 63 & .31 & $\operatorname{Tr}$ \\
\hline Hartford, Conn. & 28.04 & $4: 17$ p.m. & 46 & NE. & .26 & a. 75 & .16 \\
\hline Kingston, N. Y. & 28.06 & $4: 30$ p.m. & - & - & .44 & .21 & 0 \\
\hline Worcester, Mass. & 28.68 & $5: 00 \mathrm{p.m}$. & - & - & .28 & .10 & .02 \\
\hline Blue H1ll, Mass. & 29.01 & $5: 16 \mathrm{p} . \mathrm{m}$. & e121 & s. & .05 & 0 & $\operatorname{Tr}$ \\
\hline Boston, Mass. & 29.05 & $5: 30 \mathrm{p}: \mathrm{m}$. & 73 & s. & .06 & $\operatorname{Tr}$ & $\mathrm{Tr}$ \\
\hline Amherst, Mass. & 28.41 & $5: 06 \mathrm{p.m}$. & 58 & - & .39 & .60 & .10 \\
\hline Concord, N. H. & 28.91 & $5: 45$ p.m. & 56 & SE. & .05 & .01 & $\operatorname{Tr}$ \\
\hline Hanover, N. H. & 28.70 & $6: 20 \mathrm{p} . \mathrm{m}$. & 46 & SE. & .17 & .17 & .01 \\
\hline Northfield, vt. & 28.77 & $7: 30$ p.m. & 47 & s. & a. .58 & .40 & .01 \\
\hline Whiteface Mountain,N.Y. & $\mathbf{f 2 4 . 3 5}$ & $7: 30$ p.m. & - & - & - & - & - \\
\hline Burlington, vt. & 28.68 & $8: 00$ p.m. & 47 & s. & a.51 & .19 & .04 \\
\hline
\end{tabular}

a Laximum hourly rate for day.

b Precipitation based on record at Brooklyn, N. Y.

c Precipitation based on record at Freeport, N. Y.

d Precipitation based on record at Kineola, $\mathrm{H}$. I.

- For periods shorter than 5 minutes, 173 to 183 miles an hour.

f Hot reduced to sea level; altitude' 4,872 feet. 
north over Long Island and thence over central. New England. The storm center reached the latitude of Atlantic City, N. J., at 1:10 p.m., September 21, when 1t was moving almost northward at about 56 miles an hour. One hour. and 5 minutes later it was east of Sandy Hook, indicating an average speed of $78 \mathrm{miles}$ an hour. About half an hour later the center reached the south Iong Island coast between Jones Beach and Saltaire. At Brentwood, $1 /$ near the central part of Long Island, an observer reported that the "eje" of the storm required 50 minutes in passing, during which interval there were 11ght drizzles of rain from no determinable direction. The clouds broke for two or three 5-minute intervals, and the air was very calm. At Setauket, on Iong Island Sound north of Brentwood, the Weather Bureau observer reported that the barometer fell rapidiy with the approach of the hurricane from 29.37 inches at $1: 30 \mathrm{p} \cdot \mathrm{m}$. to a $10 \mathrm{w}$ of 28.02 inches at $3: 14 \mathrm{p.m}$. He further reported that the calm of the center of the storm, which lasted about 20 minutes, was followed by a terrific gale from the west and northwest. During the first half of the storm the wind was mainly due east.

The Weather Bureau reported as follows: $\frac{2}{4}$

The storm crossed central Long Island near Brentwood, moving nearly northward, and passed slightly to the west of New Haven at $3: 50$ p.m.; Hartford was passed, also slightly to the west, at $4: 17$ p.m. and thence paralleling the Connecticut River, passing Amherst at $5.05 \mathrm{p.m}$. Thereafter its tract curved more and more northwestward, and the center passed Hanover, N. H., at 6:20 p.m.; Northf101d, Vt., at 7:30 p.m., and Burlington at $8 \mathrm{p.m}$. The storm's forward advance was then retarding rapidly, and the center was diminishing in its depth of gradient. During the night it passed into western Quebec with diminished force and movement.

On the basis or the time of travel of the storm center from New Haven, Conn., to Burlington, Vt., the storm crossed New England at about 55 miles an hour. Also according to the Weather Bureau:

There has never been a storm of such high speed migration since precision instrumental observations have been possible, nor has one maintained Its Intensity of gradient and such high speed in combination.

Minimum barometric pressure recorded by the Weather Bureau in the hurricane path in southern New England was 28.04 inches at Hartford, Conn., the lowest ever recorded by the Weather Bureau in this area. The hurricane winds, revolving in a counter-clockwise direction about the center were augmented in their velocity on the east side by the northward movement of the storm, thus producing the extremely destructive wind forces that swept the eastern sector of the storm area. (See pl. 2.) On the west side the

I/ Kimball, J. H., The history and developments of the Long Island hurricane of September 2i, 1938: report in manuscript form prepared for Power Group, New York Sec., Am. Inst. Elec. Eng., Dec. 6, 1938.

2/ U. S. Dept. Ágr., Weather Bur., Cilmatological Data, vol. 25, no. 10, New England sec., p. 53, Sept. 1938. 
forward velocity opposed the circulating velocities, and consequently the resultant winds were less devastating on that side. The effect of the passing hurricane in producing the storm wave from the ocean is described in another section of this report. The wind seriously dameged buildings and broke off or uprooted trees in all parts of the area treversed by the hurricane and over a wide zone farther east. (See pl. 3.) Wind damage did not extend far west of the path. In addition to a large number of newspaper accounts, several articles 3 , which supplement those mentioned in other parts of this report, describe the hurricane in further detail, with appropriate reference to lts damaging effects.

As shown in table 6 on page 62, the maximum hourly precipitation for the day was recorded at many localities elther during the hour of lowest barometric pressure or during the preceding hour.. In general, there was almost complete cessation of rain by the second hour after the passing of the storm center except for an area in northern New York where light rains continued for several days. (See fig. 4.)

The major storm period as mentioned previausly essentially embraced the rain that fell between the afternoon of September 17 and the evening of September 21. The rain during the 24 hours preceding $6 \mathrm{p.m}$., September 18, was relatively light and produced but littlo direct run-off. The precipitation during each of the following 3 days (shown on figs. 5 to 7 previously alluded to and derived by methods explained in the section on meteorologic and hydrologic conditions) was appreciable and was localized over nearly the same area and along nearly the same axis. Figures 8 to 22 show the precipitation during 6-hour intervals through the storm period as determined by the Corps of Engineers, United states Army, in cooperation with the Weather Bureau.

During the 24 hours ending at 6 p.m., September 19, it rained from 1 to 4 inches and more along the front mentioned previously over an area that extended through New Jersey, southeastern New York, western Long Island, Connecticut, Massachusetts, and into the southerm part of New Hampshire and Vermont. The area that received more than 3 inches of rain was confined to central Massachusetts, eastern Connecticut, and

3/ Brooks, C. F., Hurricanes into New England; Meteorology of the storm of September 21, 1938: Geog. Rev., vol. 29, pp. 119-127, January 1939. Tannehill, I.R., Hurricane of September 16 to 22, 1938: Monthiy Weather Rev., vol. 66, no. 9, pp. 286-8, Sept. 1938. Knox. J. C., Cyclone storm of September 21, 1938: report in manuscript form prepared for Department of Public Health, Commonwerlth of Hassachusetts. Pierce, C. H., The meteorological history of the New England hurricane of September 21, 1938: Monthly Weather Rev., vol. 67, no. 8, pp. 237-85, Aug. 1939. 


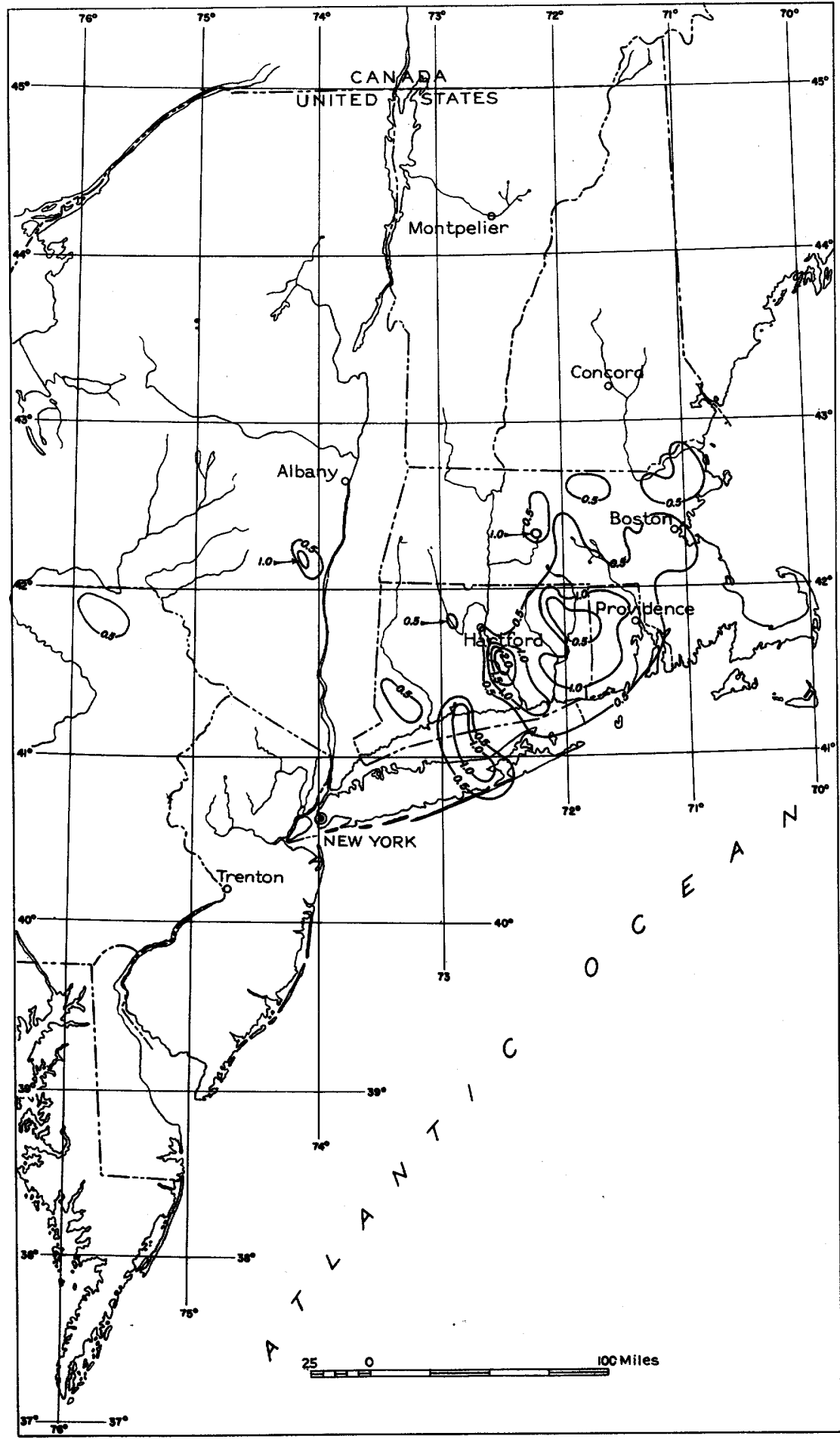

Figure 8.--Isohyetal map of the North Atlantic States showing the totel precipitation, in inchos, 5 to 11 p.m., September 17, 1938. 


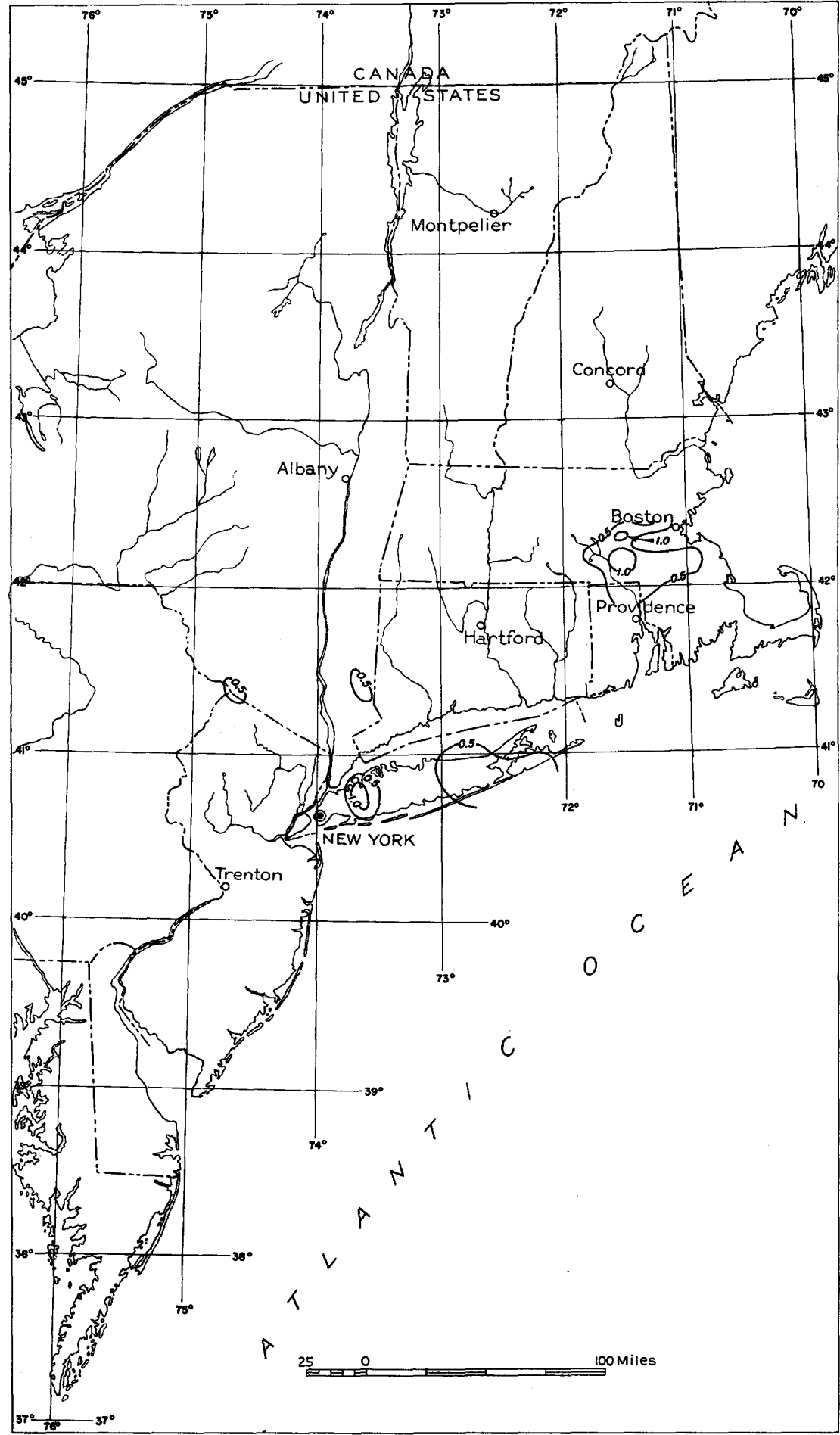




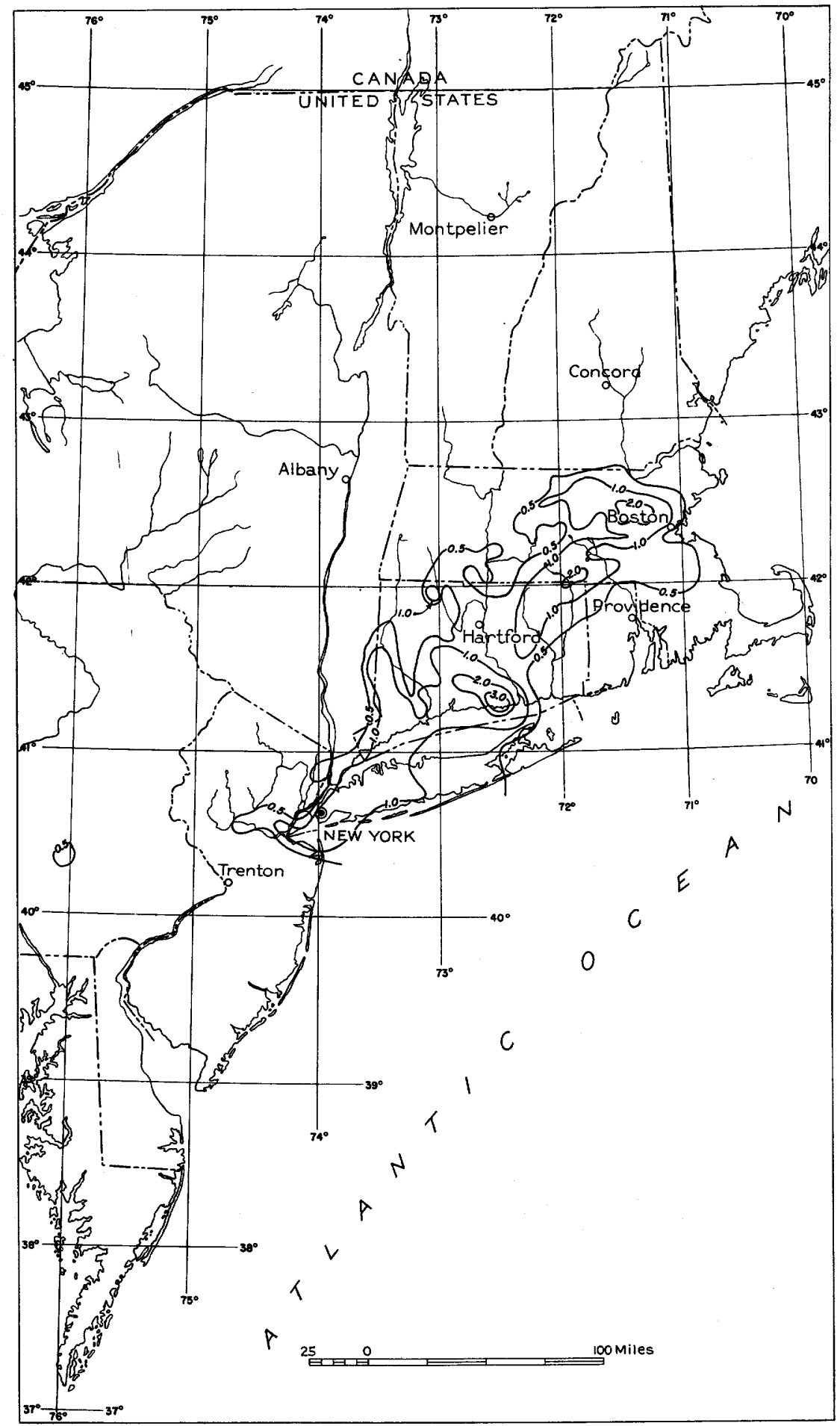

Figure 10.--Isohyetal map of the North Atlantic States showing the total precipitation, in inches, 5 to 11 p.m., September 18, 1938. 
22

HURRICANE FLOODS OF SEPTEMBER 1938

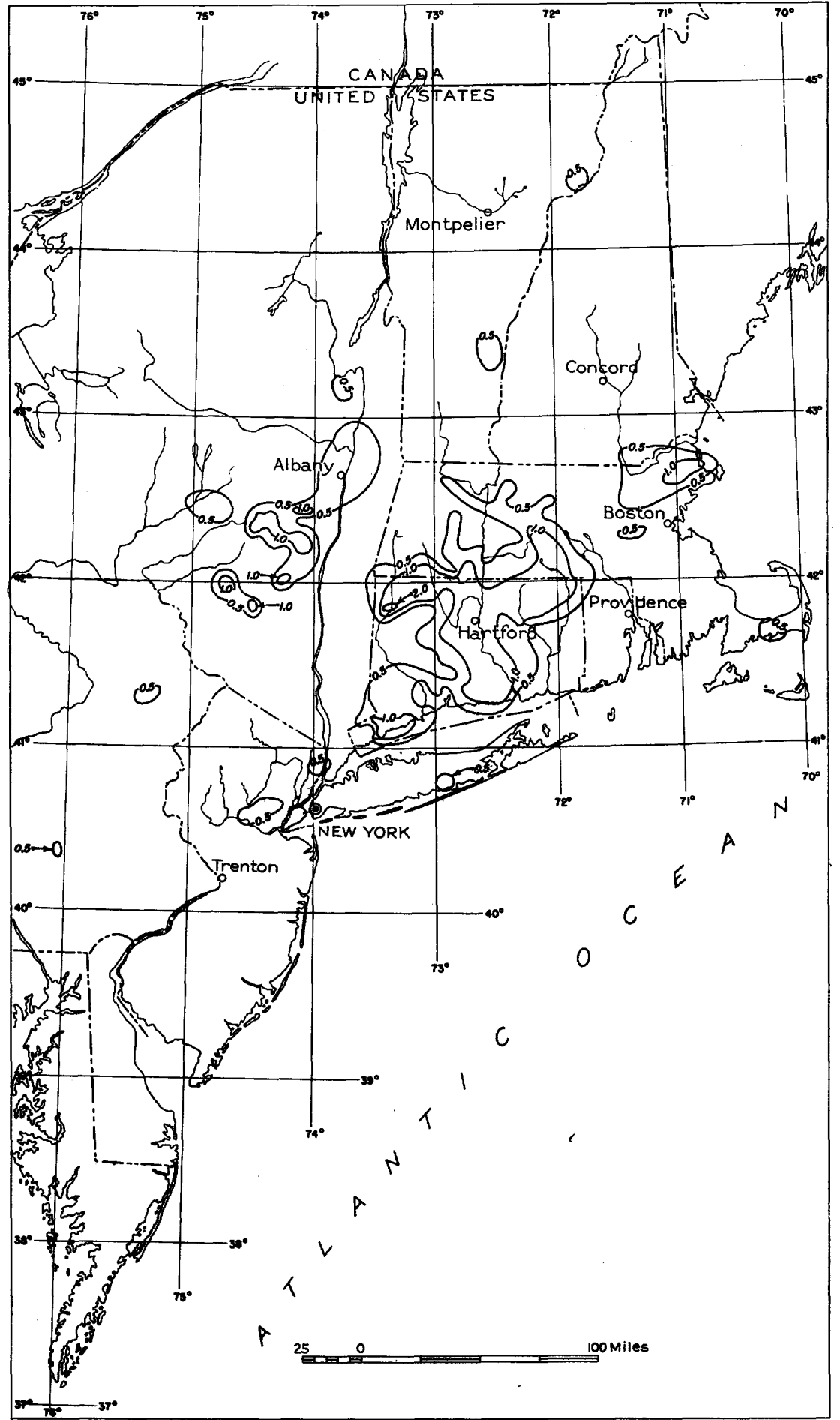

Figure 11.--Isohyetal map of the North Atlantic States showing the total precipitation, 


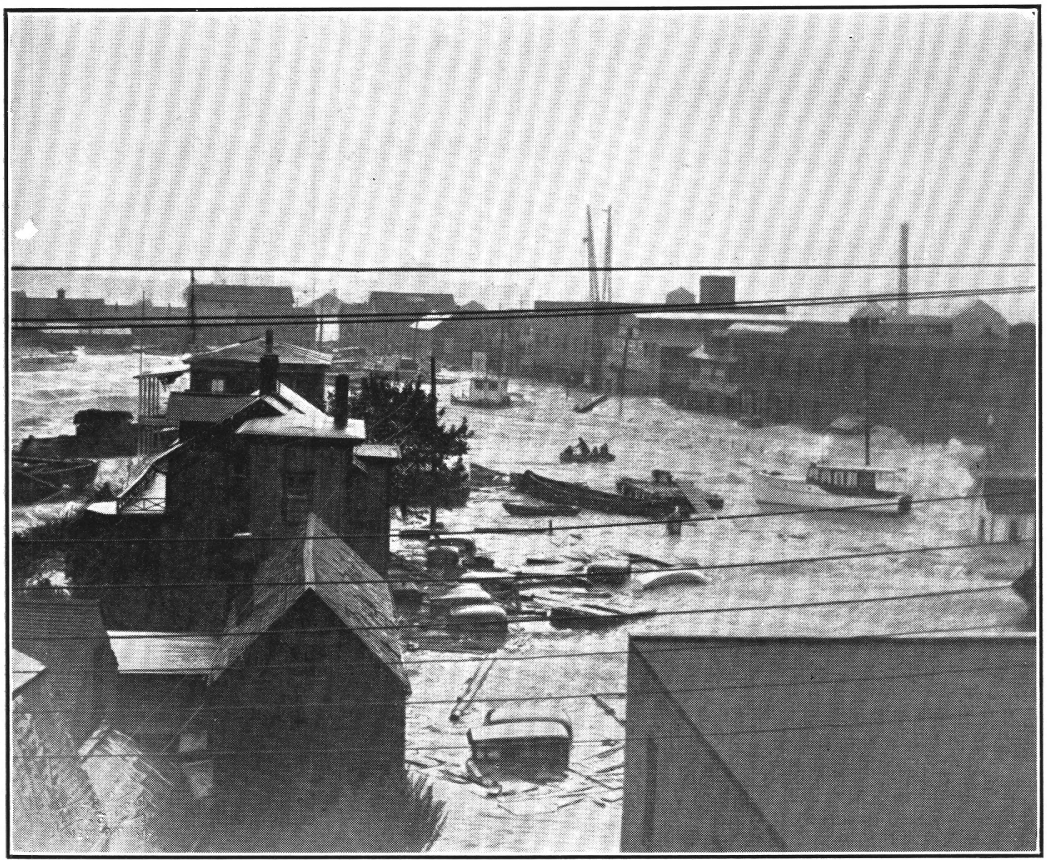

A. WATER FRONT DISTRICT OF NEWPORT, R. I.

Wreckage and small boats being tossed among submerged automobiles and buildings at the height of the storm. Photograph by Christy Petropoulos.

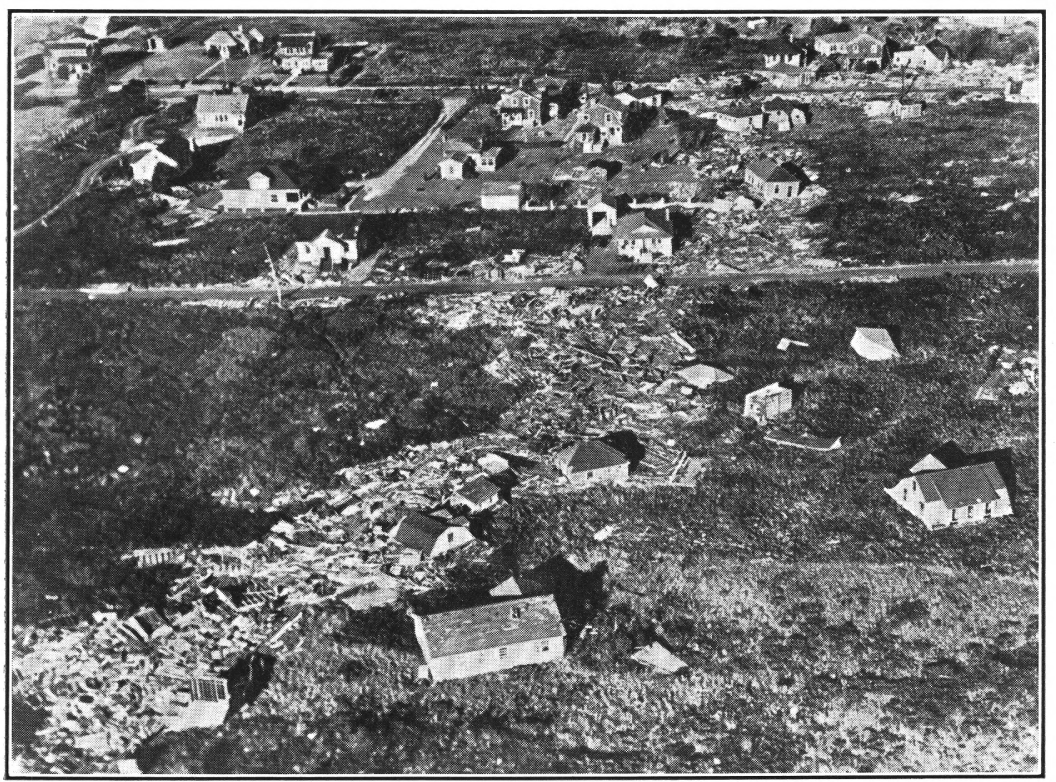

B. SHORE WRECKAGE AT WEEKAPAUGH, R. I.

STORM WRECKAGE IN RHODE ISLAND. 


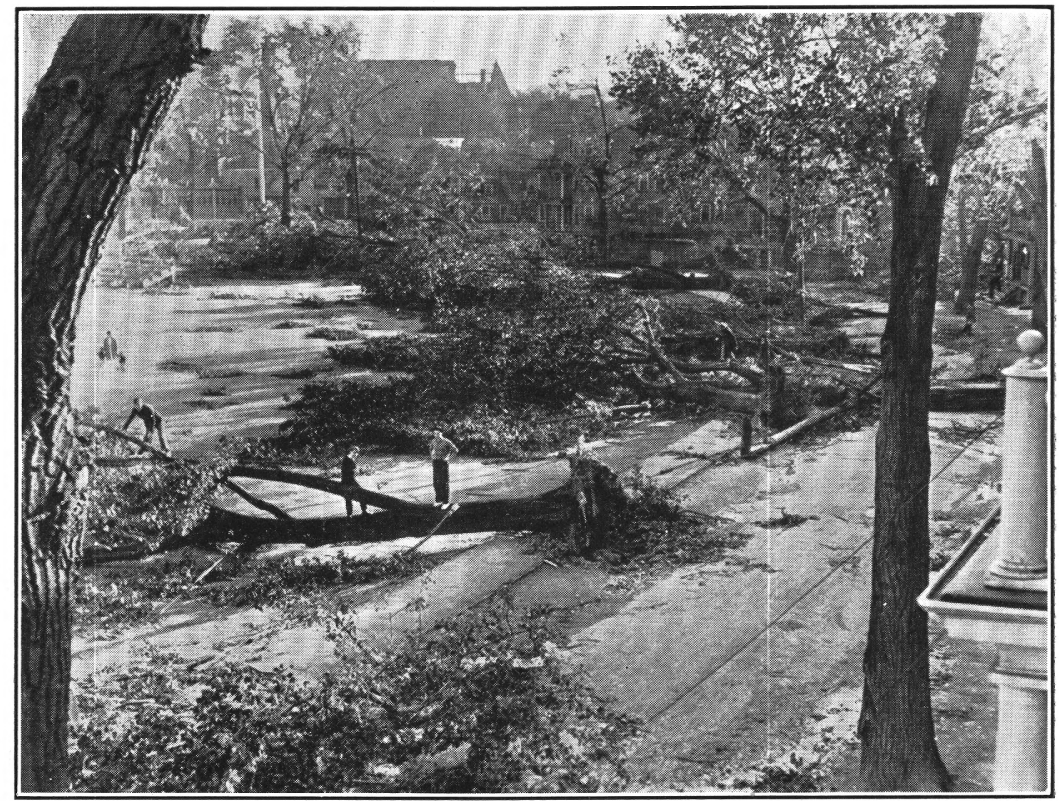

A. SHADE TREES IN METROPOLITAN BOSTON, MASS.

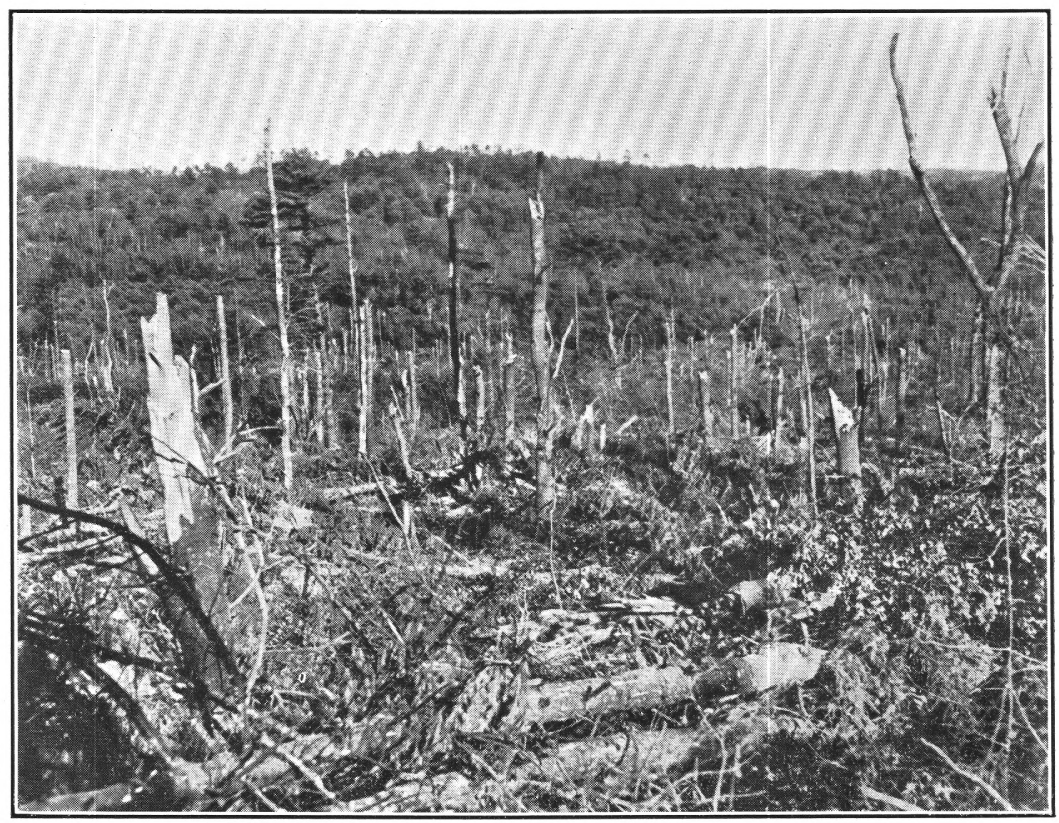

B. HARYARD FOREST NEAR PETERSHAM, MASS.

HURRICANE DAMAGE IN MASSACHUSETTS.

Photographs by Boston Herald Traveler. 


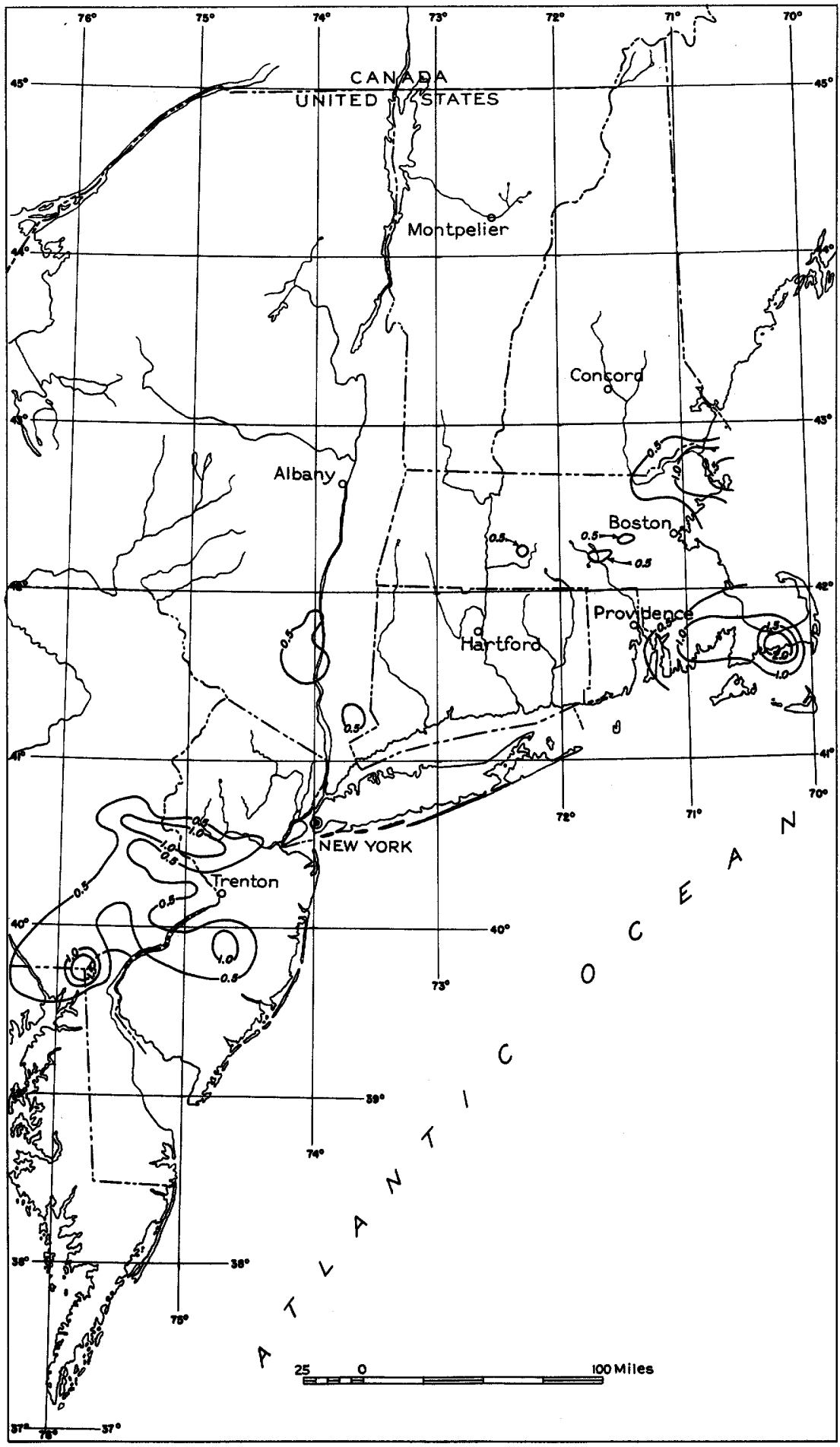

Figure 12.--Isohretal map of the North Atlant1c Statea showing the total precipitation, in inches, 5 to 11 a.m., September 19, 1938.

$22 \pi 90 \overline{\mathrm{i}} \mathrm{O}-40-3$ 


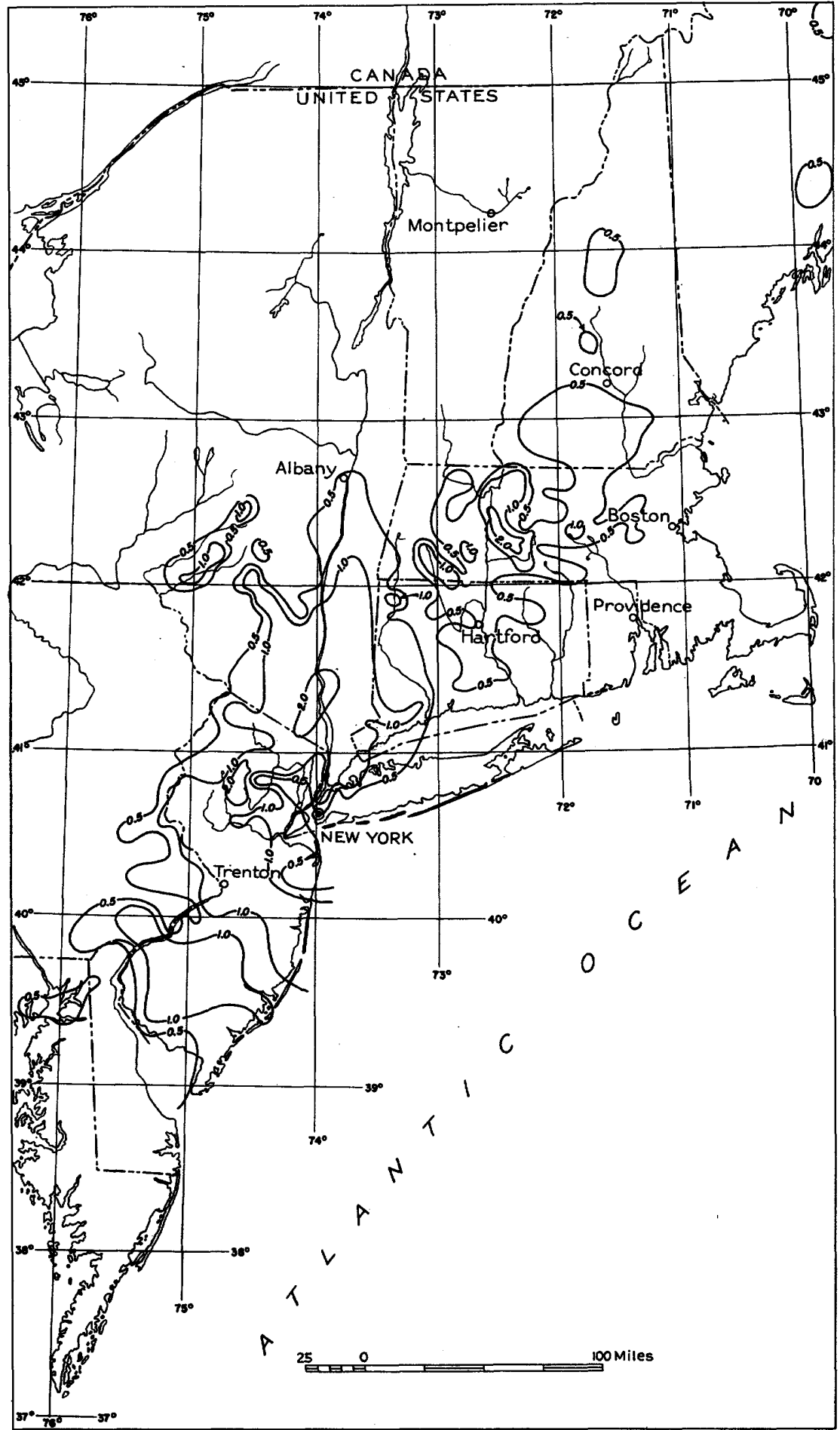

Figure 13.--Isohyetel map of the North Atlantic States showing the total precipitation, in incher, $11 \mathrm{a} \cdot \mathrm{m}$. to $5 \mathrm{p} . \mathrm{m}$. , September 10, 1938. 


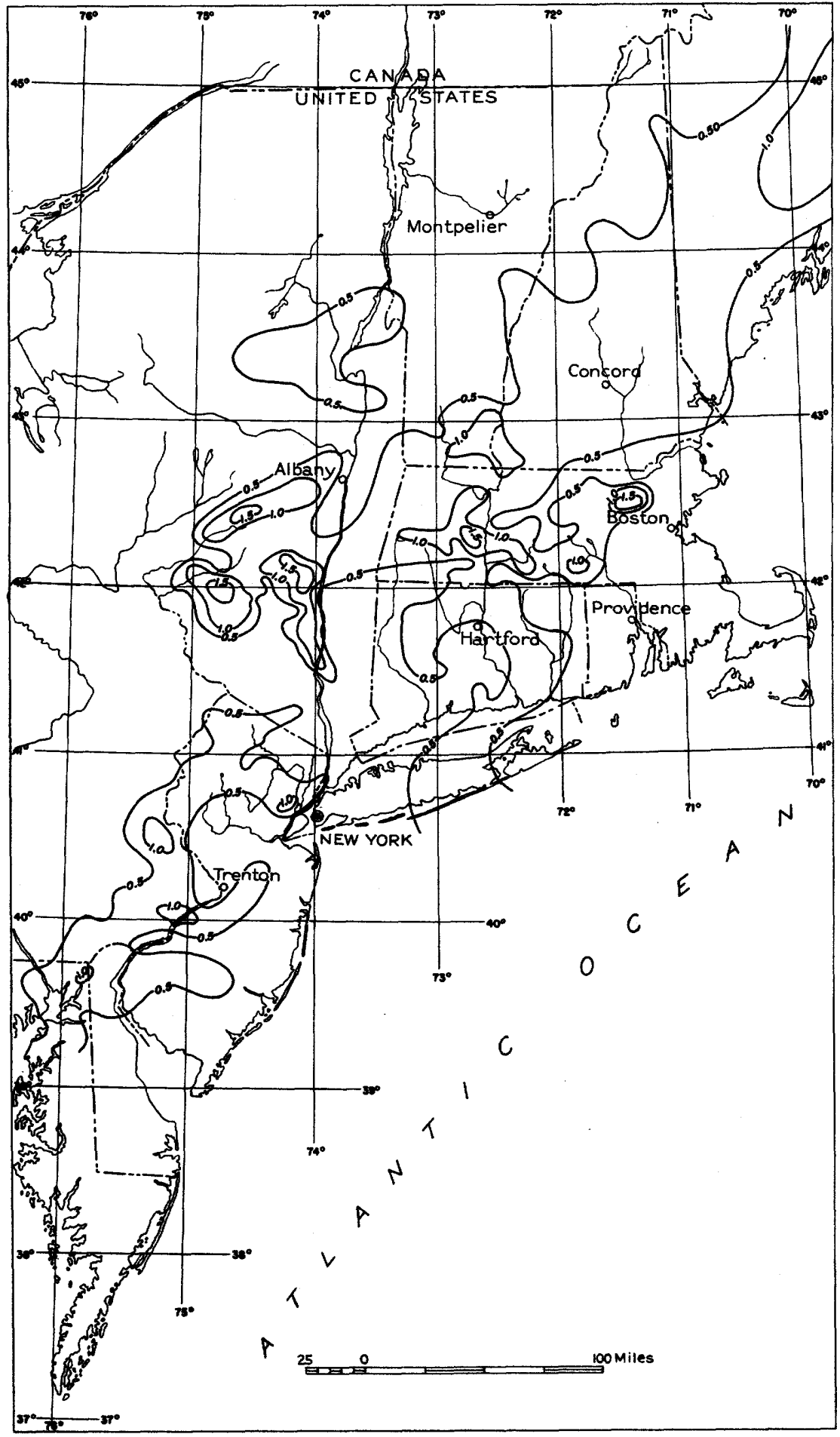

F1gure 14.--Isohyetal map of the Worth Atlant1c states showing the total precipltation, in Inches, 5 to 11 p.m., Septesubor 19, 1938. 


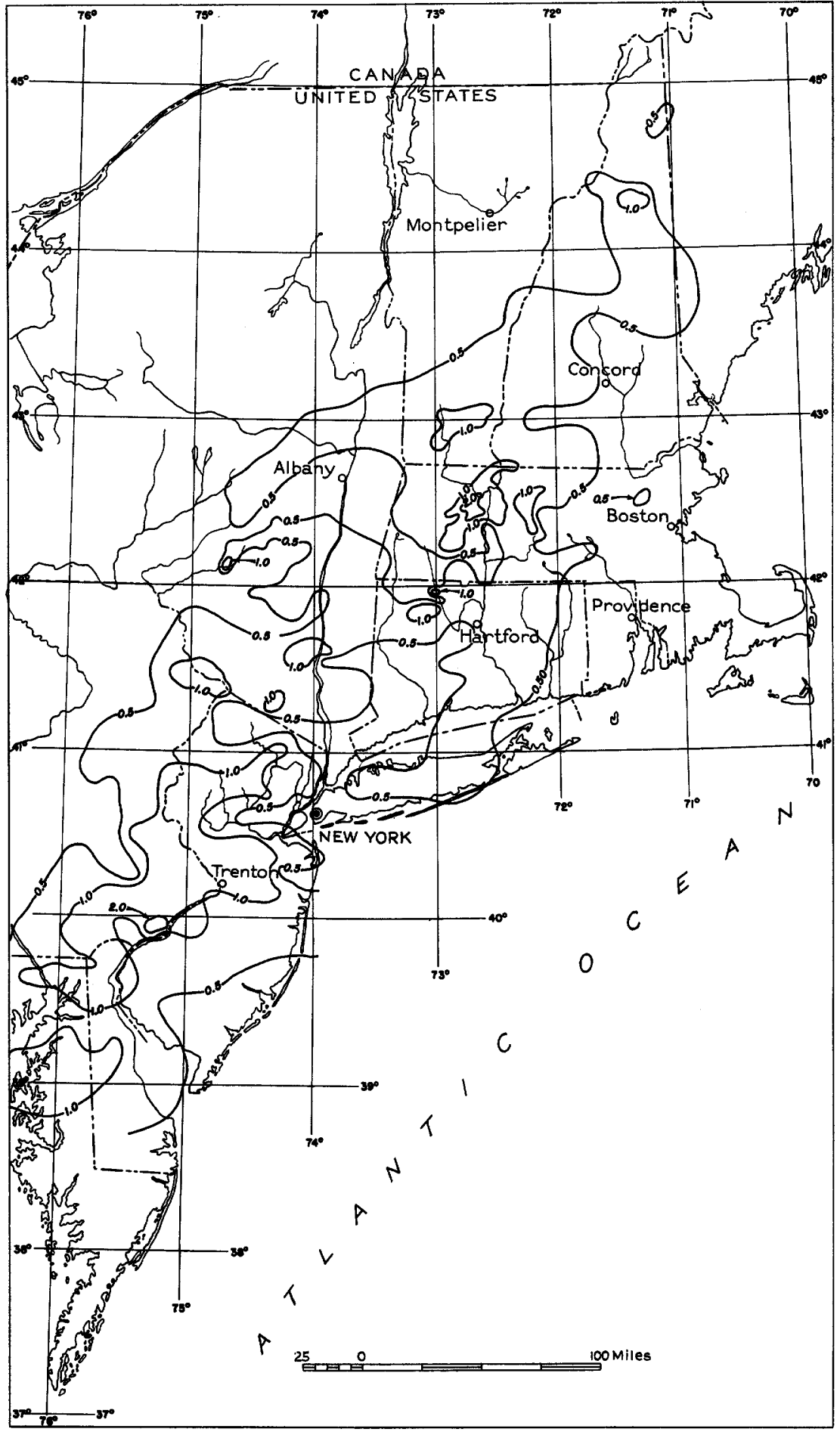

Figure 15.--Isohyetal map of the Horth Atlantic States showing the total precipitation, in Inches, 11 p.m., September 19, to 5 a.m., September 20, 1938. 


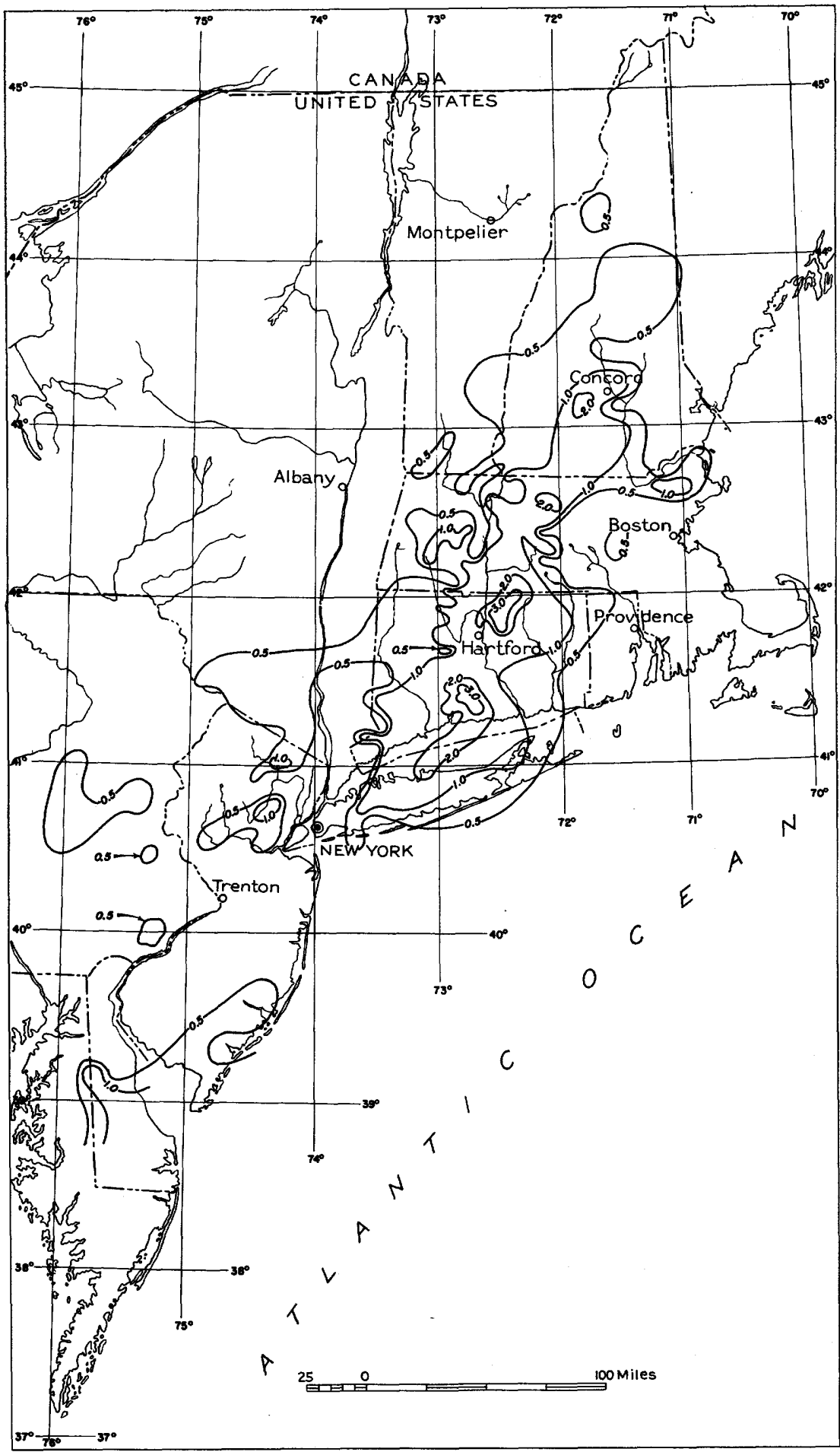

F1gure 16.--Isohyetal map of the North Atlantic States showing the total precipitation, in inches, 5 to 11 a.m., September 20, 1938. 


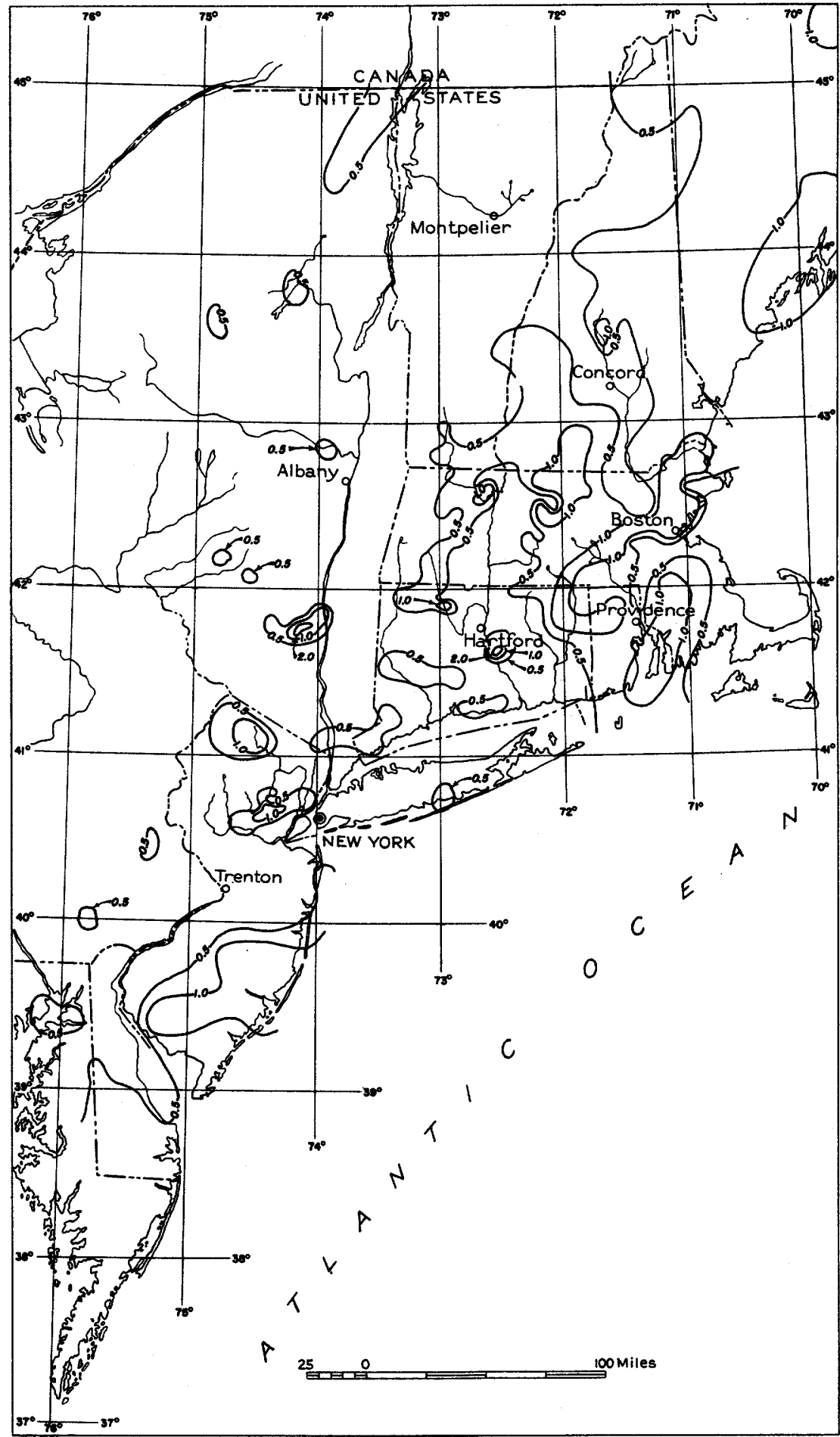

Figure 17.--Isohyetal map of the North Atlantic States showing the total precipitation, in inches, 11 a.m. to 5 p.m., September 20, 1938. 
GENERAL FEATURES OF THE STORMS

29

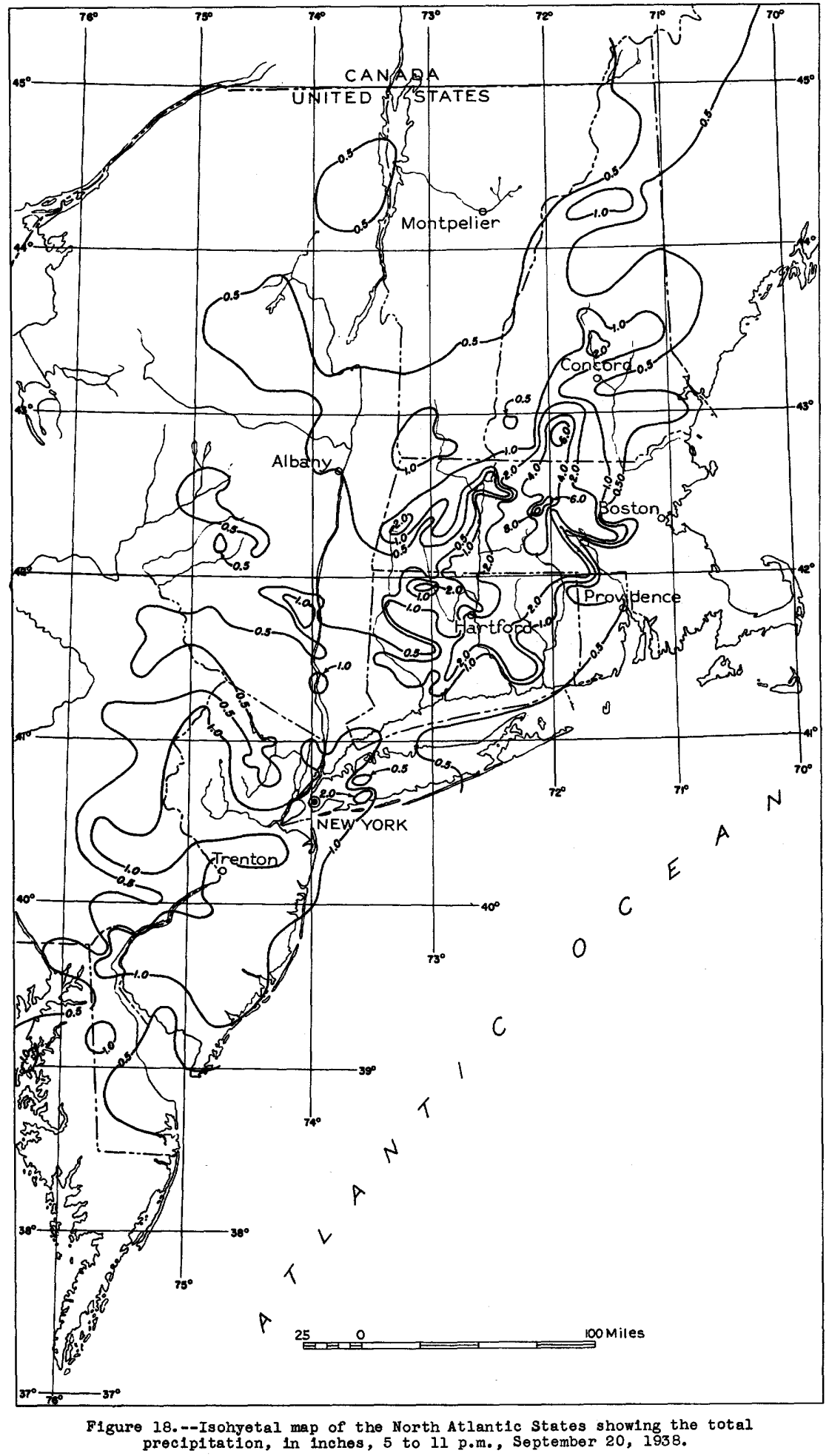


30

HURRICANE FLOODS OF SEPTEMBER 1938

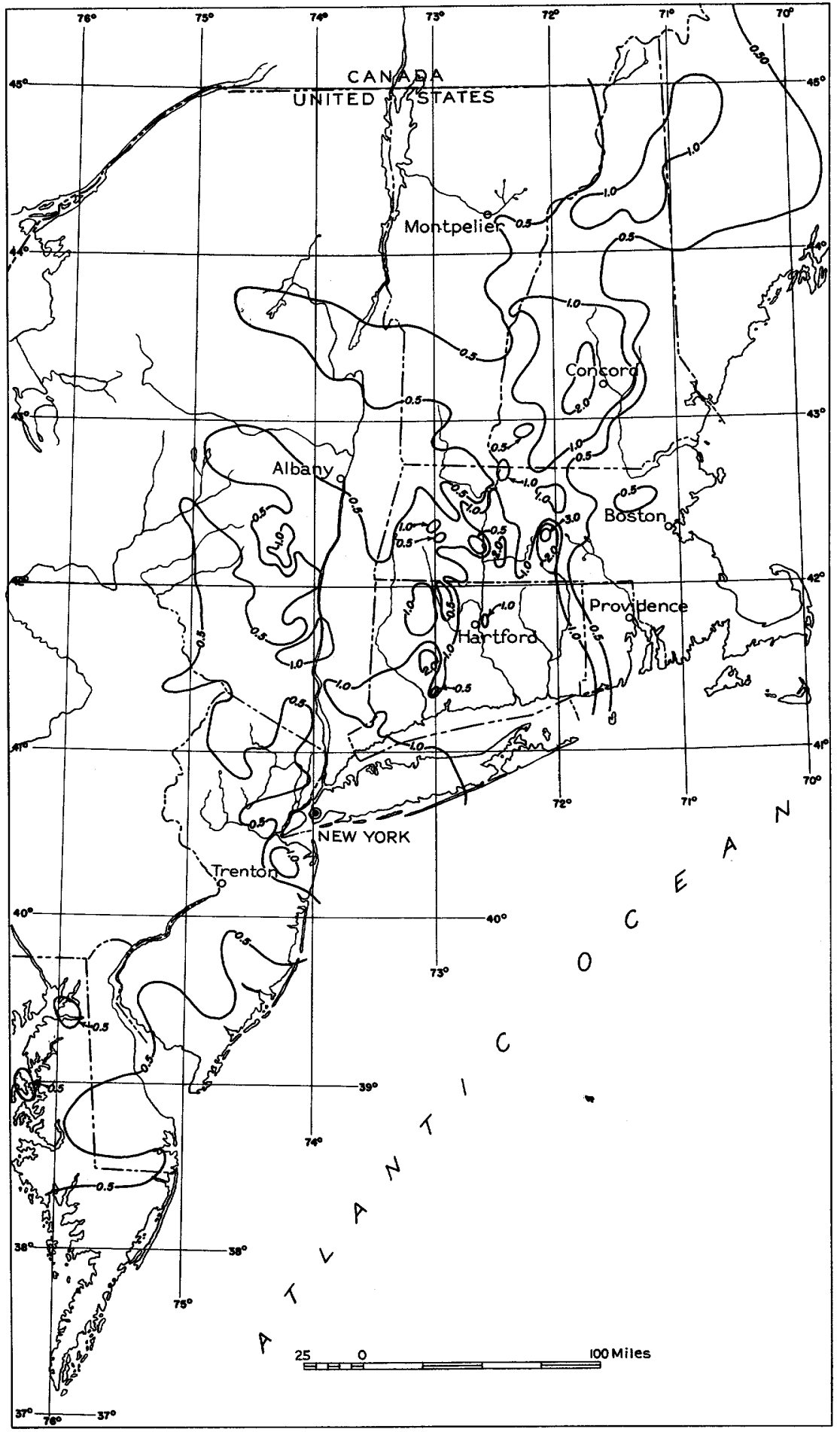
Figure 19.--Isohyetal map of the North Atlantic States showing the total precipitation,
in Inches, 11 pom., September 20, to 5 am., September 21, 1938. 


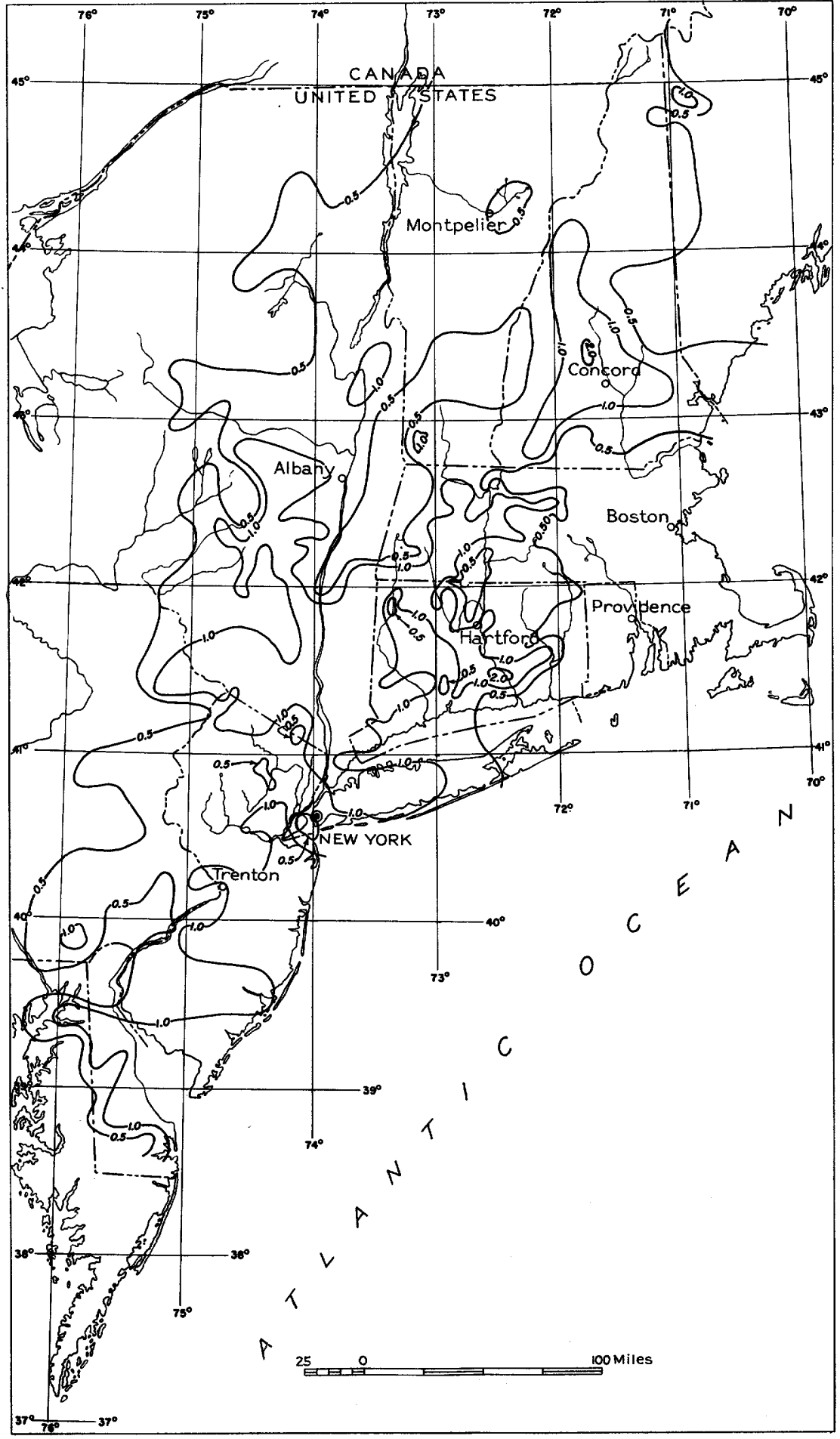

Figure 20.--Isohyetal map of the North Atlantic States showing the total precipitation, in inches, 5 to 11 a.m., September $21,1938$. 
32

HURRICANE FLOODS OF SEPTEMBER 1938

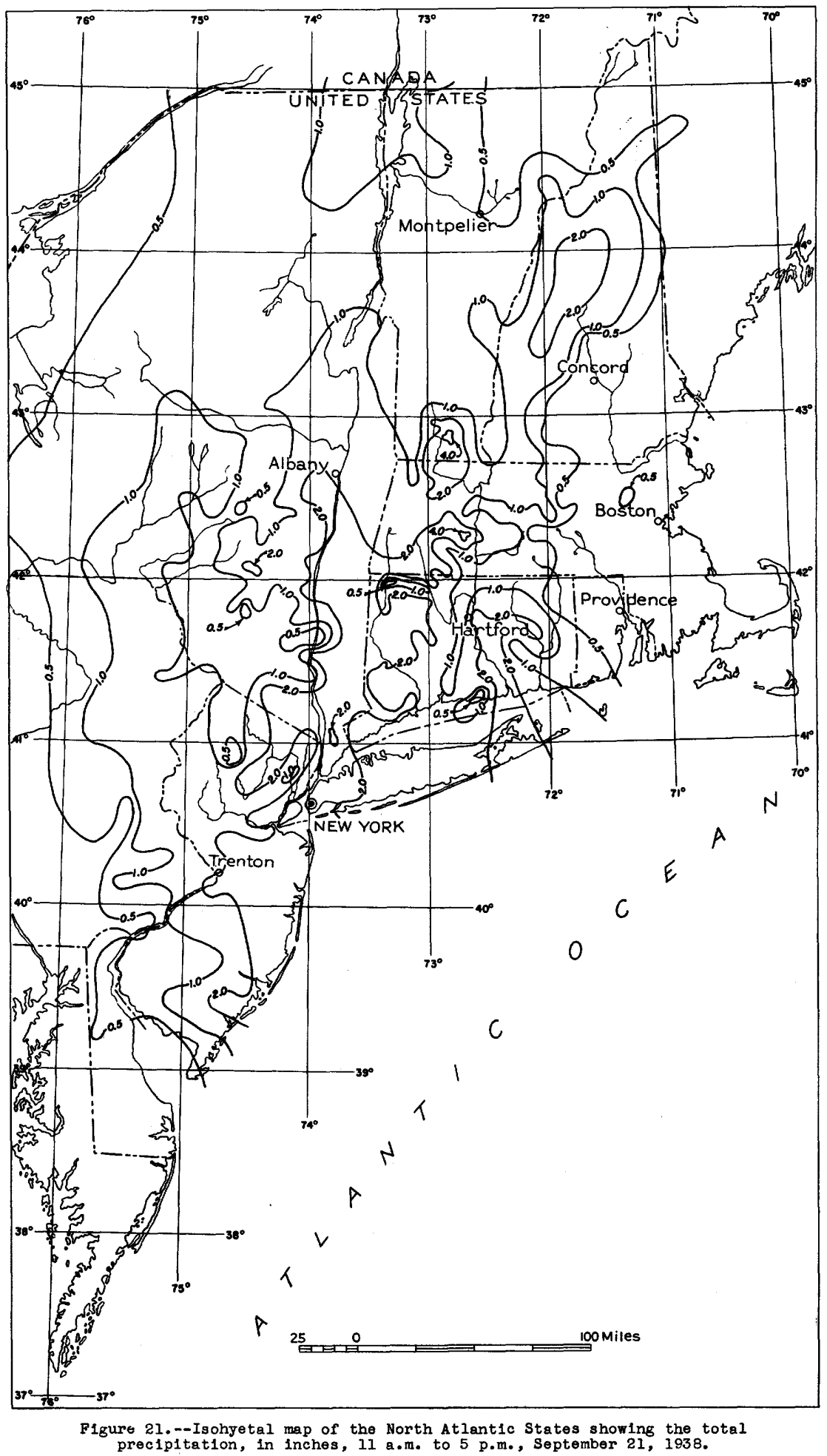


GENERAL FEATURES OF THE STORMS

33

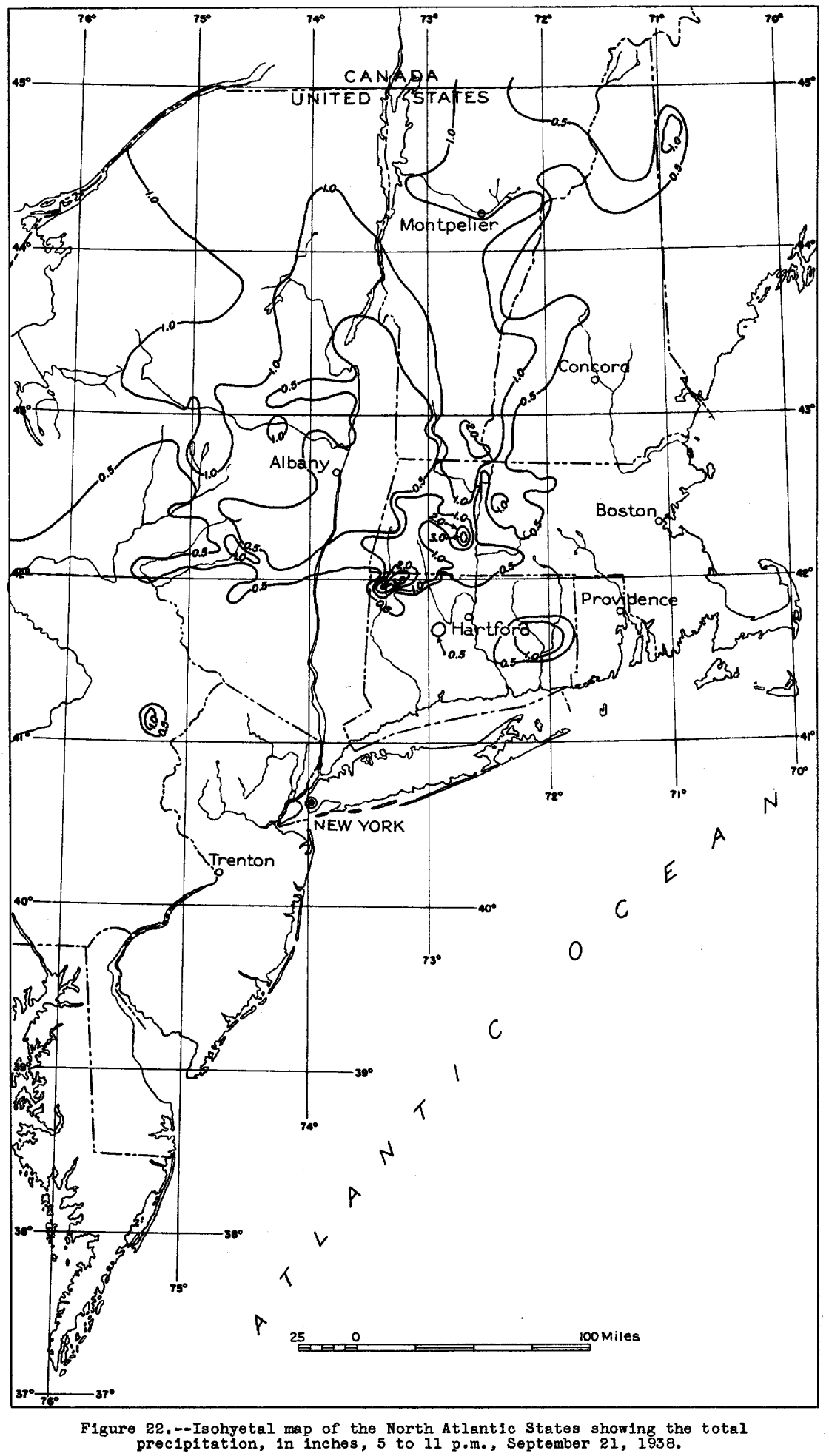


the eastern part of Long Island, and the relatively small area in which there was 4 inches and more was confined to the coast along Long Island Sound east of New Haven. Precipitation was generally less than 1 inch over the northern parts of New York, Vermont, and New Hampshire.

Precipitation continued during the 24-hour period ending at 6 p.m., September 20, at rates somewhat exceeding those of the previous 24 hourg. As shown in figure 6 the precipitation was general over most of the area but exceeded 3 inches in a long belt extending from central Long Island to central New Hampshire and covering part of the lower Connecticut Valley and much of the divide between the Connecticut and Merrimack Rivers. Preclpitation exceeded 6 inches in central Connect1cut and Massachusetts and ranged from one-half to 2 inches in central and northern New York and in the northern parts of New Hampshire and Vermont.

An appreciable portion of the precipitation during the 24 hours endIng at 6 p.m., September 21, was associated with the passing of the hurricane and in general exceeded the amounts recorded during the preceding 24-hour periods.

Kimball $4 /$ states that $" 3$ inches is probably a fair estimate of the rain due solely to the hurricane". Areas in which the total precipitation during the 24-hour period ending at 6 p.m., September 21, exceeded 4 inches include eastern New Jersey, southeastern New York Including Long Island, most of Connecticut and all of central Massachusetts.

In a very considerable part of Connecticut and central Massachusetts, the total storm precipitation of September 17 to 21 exceeded 16 inches, and maxima of more than 17 inches were recorded in central Massachusetts and Connecticut. At Barre, Mass., 11.83 inches was recorded during the 24-hour period ending at $8 \mathrm{a} . \mathrm{m}$. on the morning of september 21, a 24-hour maximum for the storm at any point where observations are ava1lable.

\section{GENERAL FEATURES OF THE FLOOD}

Only rarely are large areas subjected to such ravages of nature as were New England, eastern New York, and the New Jersey coast from about noon, September 21, when the tropical hurricane turned inland, until the midnight hours of September 23, when the crests of the floods of the Merrimack, Connecticut, and other coastal rivers had swept dow their channels into the Atlantic 0cean. From the time the hurricane and ocean storm wave struck the coast during the afternoon of September 21 with such disastrous

4/ Kimball, J. H., op. cit. 
results along the shores of Long Island, Connecticut, and Rhode Island unt1l the flood run-off from the timbered slopes of the Berkahire, White, Green, Adirondack, and Catsk1ll Mountains had Inundated all the flood plains of the lower valleys, the north Atlant1c States were experiencing a great catastrophe. In New England it was the greatest catastrophe since settlement by the white man.

Although the nearly continuous rain of Sunday, Monday, and Muesday, September 18-20, had so greatly exceeded the capac1ty of the so1l to absorb and retain water that all rivers on Nednesday morning, September 21 , were at bank-full stage, the run-off was being taken care of in an orderly manner. Quite sizeable floods were in sight, but had there been no further rain, little if any damage would have resulted. Advancing northward, however, was the hurricane storm, and the intensity of the torrential rains accompanying it were far in excess of the retentive ability of the basins. In an incredibly short time all tributary strean channels were called upon to carry volumes of water far in excess of their normal capacities. Highways, rallways, bridges, mills, and dams largely occupying or encroaching on channels that had not been called upon to carry unusual flood flows for long periods of time were either damaged or washed away. Damage was confined chlefly to the natural stream channels and their flood plains. Most rura] homesteads are located above the flood plain, and damage to them was generally small. Villages, tows, and clties, however, which for convenience or necessity have been bullt In the velleys, suffered damage from submergence. (See pl. 4.) In many places the high water brought debris onto the flood plains, but generally most of the movement of debris was confined to the natural tributary channels and to the main channels below the confluence of the tributary streams. There was in general little widespread deposition of silt on the overflowed flood plain.

There were variations in the pheses of the floods determined in part by the direction of the storm movement and the size and storage capacitios of the several dralnage basins. In many headwater areas in the Thames and Connecticut River Basins in Connecticut and central Massachusetts, peak stages were reached during the morning of september 21 and were incident to the intense rainfall of the preceding evening. However, during the evening of september 21, peak stages were occurring in most of the headwater streams throughout western New Bngland and eastern New York and by the morning of the 22d flood crests were moving down the major streams. 
With the destruction of bridges by the flood and the obstruction of highways by timber blow dow by the hurricane, auto and raliway transportation in the area was seriously srippled. Warnings and forecasts were is sued as soon as the seriousness of the flood situation became apparent, and as a result many low-lying areas in major induetrial centers were evacuated, and through herolc measures barricades were erected which did much to restrain the flood waters, as show in plate 5. Areas that had suffered from the floods of November 1927 and March 1936 were again inundated by the floods of September 1938. In many areas, especially in central Messachusetts and Connecticut, the destruction wrought on structures and developments that have been in place since the early days of settlement gives mute evidence of the magnitude of the floods. (Seo pls. 6, 7, 8, and 9,) Many excellent textual and pictorlal records of the floods and hurricane have been prepared and published, some of which are listed below. Doubtless there are many more of equal interest and value.

New England hurricane, a factual, pictorial record, written and complled by members of the Federal Vriters Project of the Forks Progress Administration in the Hew Ingland States, 220 pp., 1938.

Boston \& Maine Rallroad Rmployees Magazine, vol. 10, no. 5, 40 pp., fall issue (flood and hurricane souvenir edition).

The devastation and restoration of Ner England's vital Iffe-line, $48 \mathrm{pp} .$, Now York, Hew Haven \& Hartford Railroad.

Hal1, C. I., The 1938 murricane and 1ts effect on Long Is land beachprotection structures: Civil Eng., vol. 9, no. 3, pp. 169-172, larch 1939.

Freak winds, New Hampshire 1938, 48 pp., Manchester, N. H., Iew A. Cumings Co., September 1938.

The great hurricane and tidal wave, Rhode Island, September 21, 1938, 128 pp., Providence (R.I.) Journai Co., 1938.

Hurricane and flood, New England's greatest disaster, 66 pp., published for the New England Historlcal Events Committes, Sulte i229, 30 Rockefeller Plaza, New York City, 1938.

Standish, Myles E., Hurricane views, Norwich, Conn., Bulletin Co., 84 pp., 1938.

Photo story of what happened to Athol and Orange, Kass., 16 pp.., Athol, Yass., Hames Studio, 1938.

Floods and hurricane ravage Ner England: Telephone topics, vol. 32, no. 5, pp. 2-30, New England Telephone Telegraph Co., October 1938.

The Merrimack River Basin marked the northeasterly extent of the area of serious floods. Tributaries of the Merrimack River from the east were generally only in minor flood; the tributaries from the west had floods approaching those of Karch 1936 in severity, except in the upper Contoocook River Basin, where the 1936 floods were exceeded. The flood on the 
main river at Lowell, Mass., was about the magnitude of that of April 1852, was 51,900 second-feet less than the flood of March 1936 and was probably the second largest during the period of record, which extends back almost 100 jears. Damages were relatively the greatest in the area of heaviest precipitation in the upper Contoocook River Basin, where . many dams were breached, bridges destroyed, and bulldings swept away.

In the coestal basins from the Merrimeck River to the Thames River the floods were light and damages were generally small.

Streams in the Thames River Basin, with the exception of the lower Quinebaug River and its easterm tributaries, attained very extraordinary stages and flows.

According to data listed in table 10 presented in the section "Summary of flood discharges", gaging stations on the Willimantic, Natchaug, Hop, and shetucket Rivers had peak discharges about twice as great as those of March 1936, the previous maximum flood of record. Stations on the Yantic River, the Quinebaug River at Quinebaug, Conn., and at Putnam, Conn., attained stages from 2 to 3 feet higher and discharge rates from 20 to 85 percent higher than previously recorded maxima. The lower Quinebaug River, at Jewett City, Conn., peaked at a stage 2.3 feet lower than 1ts record of 1936 and at the crest discharged at a rate 21 percent less; this condition developed from the absence of heavy rains on the east side of its basin, as previously described, and the resultant comparatively low contribution from eastern tributaries such as Five Mile and Moosup Rivers.

The Connecticut River in Massachusetts and Connecticut was visited by its second largest kmown flood in a perlod of more than 300 years. This flood was exceeded only by that of March 1936. At Hartford, Conn., the Connecticut River reached a stage of 35.42 feet on September 23, which was only 2.2 feet lower than that reached on March 21, 1936, and it surpassed by 5.6 feet the flood of May 1, 1854, the third highest known flood since settlement. The heary precipitation over the lower connecticut Valley did not carry through to its upper reaches. In Vermont and New Hampshire the stages and discharges on the main river were generally less than those recorded in November 1927 and March 1936. In southern Vermont and New Hampshire the floods on the headwaters of streams tributary to the Connecticut River approached or exceeded in magnitude those previously recorded. In Massachusetts and Connecticut the tributary streams, however, showed no conformity to past historical occurrences and, almost 
wthout exception, discharges were greater than those previously recorded. Reference to table 10 on page 382 discloses that stations on the Millers, Deerfield, Ware, Quaboag, Westfield, and Farmington Rivers reached peak rates of discharge of $1 \frac{1}{2}$ to 2 or more times the previous maxima recorded during about 25 years of continuous observation. River-measurement stations on Scantic and Hockanum Rivers recorded peak alscharges of more than three times those previously recorded. Rates of discharge of 400 to 500 second-feet per square mile were measured for drainage areas as large as 100 square miles. Damage and losses from flood were great, especially in the drainage basins of the Millers, Ware, Swift, Quaboag, West, Williams, Deerfield, Westfield, and Farmington Rivers. On these tributary streams dams falled, bridges were destroyed, buildings were swept away, and debris was deposited on flooded lands adjacent to the normal stream channel. The hurricane, in passing up the Connecticut Valley, flattened many tobacco sheds, wrecked bulldings and churches, and uprooted, blew down, and snapped off many millions of board feet of timber, which presented a major salvage problem and created a very serious fire hazard. Cities, towns, comminities, farms, transportation lines, and improvements adjacent to the large rivers suffered damage and loss from inundation.

The Quinnipiac River, somewhat west of the area of heaviest precipitation, peaked at Wallingford, Conn., at a flow rate about 60 percent greater than that of March 1936 and attained a crest stage about 1.3 feet higher.

The Housatonic River Basin, particularly the lower portion, did not receive as heavy average precipitation as most other basins in Connecticut. The concentration of rainfall was sufficient, however, to cause record-breaking stages and flows on most of the streams in the basin. At Falls Village, Conn., on the main Housatonic River, where a 26-year record of flow has been collected, the 1938 flood had a maximum discharge 37 percent higher than the previous record flow of March 1936, and the peak stage was 3.3 feet higher. Dowstream at Stevenson, Conn., on the main river, the 1938 peak was 2 feet lower than that of March 1936, which was augmented by a breaking 1ce jam, and the highest flow in 1938 wes 14 percent lower than in 1936. Among the tributaries, Tenmile, Still, Shepaug, Pomeraug, and Naugatuck R1vers reached discharges that exceeded the previous maxima by 12 to 46 percent. 


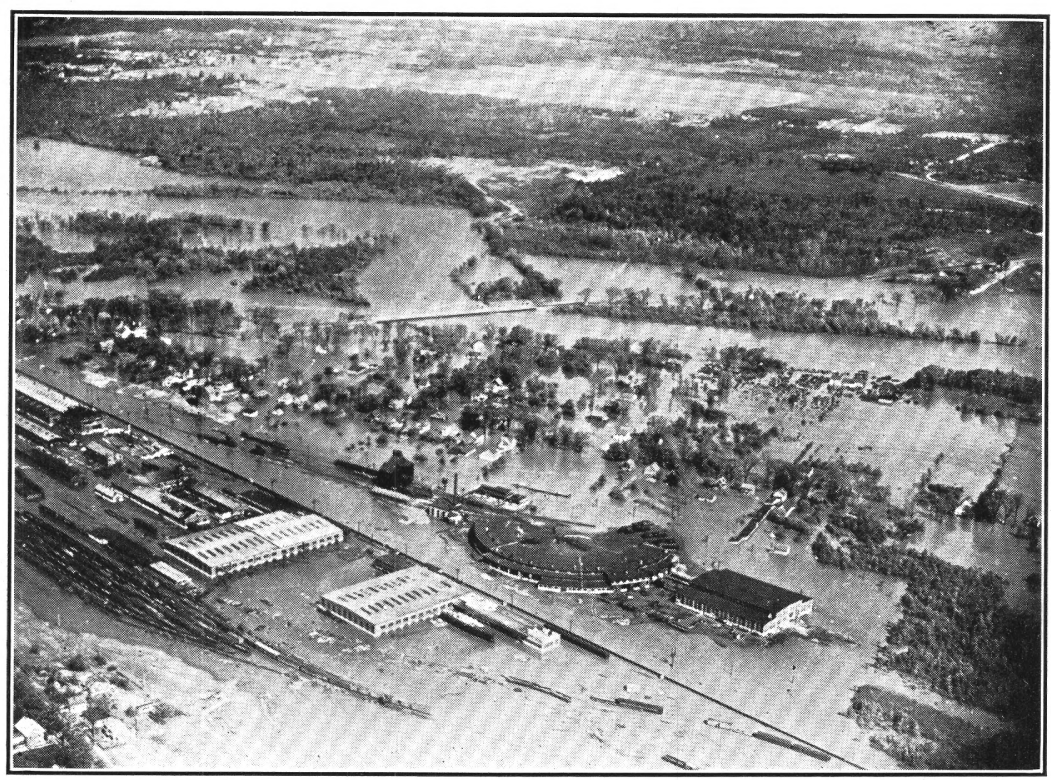

A. RAILROAD YARDS AND RESIDENTIAL AREA OF CONCORD, N. H., FLOODED BY MERRIMACK RIVER.

Photograph by Corps of Engineers, U. S. Army.

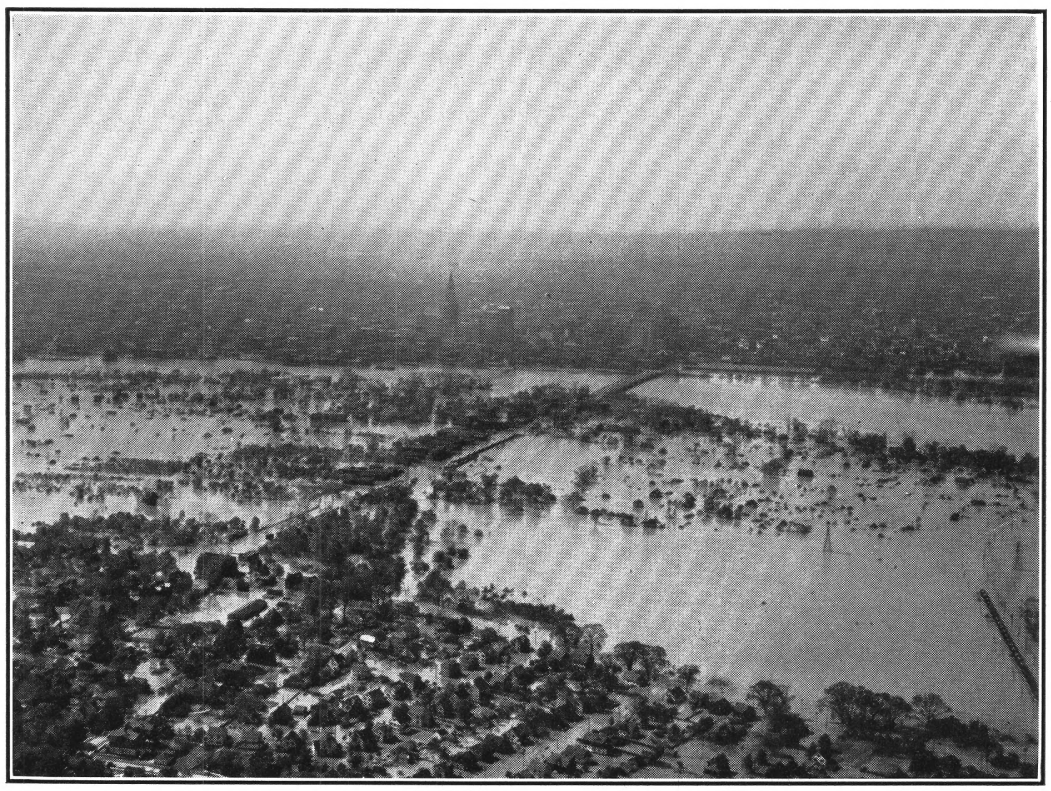

B. VIEW OF EAST HARTFORD, CONN.

Shows the large section flooded by Connecticut River. Photograph by 118th Photo Section, Air Corps, Connecticut National Guard. 


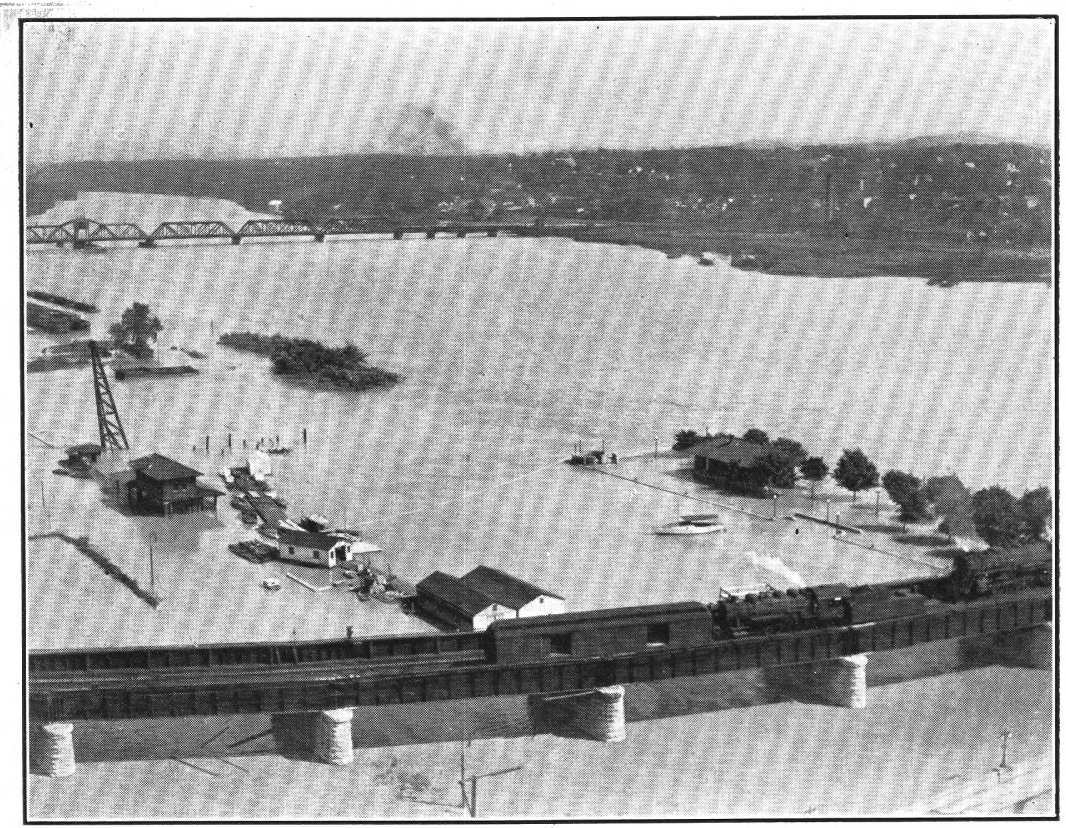

A. FLOODED WATER FRONT AT ALBANY, N. Y.

Courtesy of Knickerbocker News, Albany, N. Y.

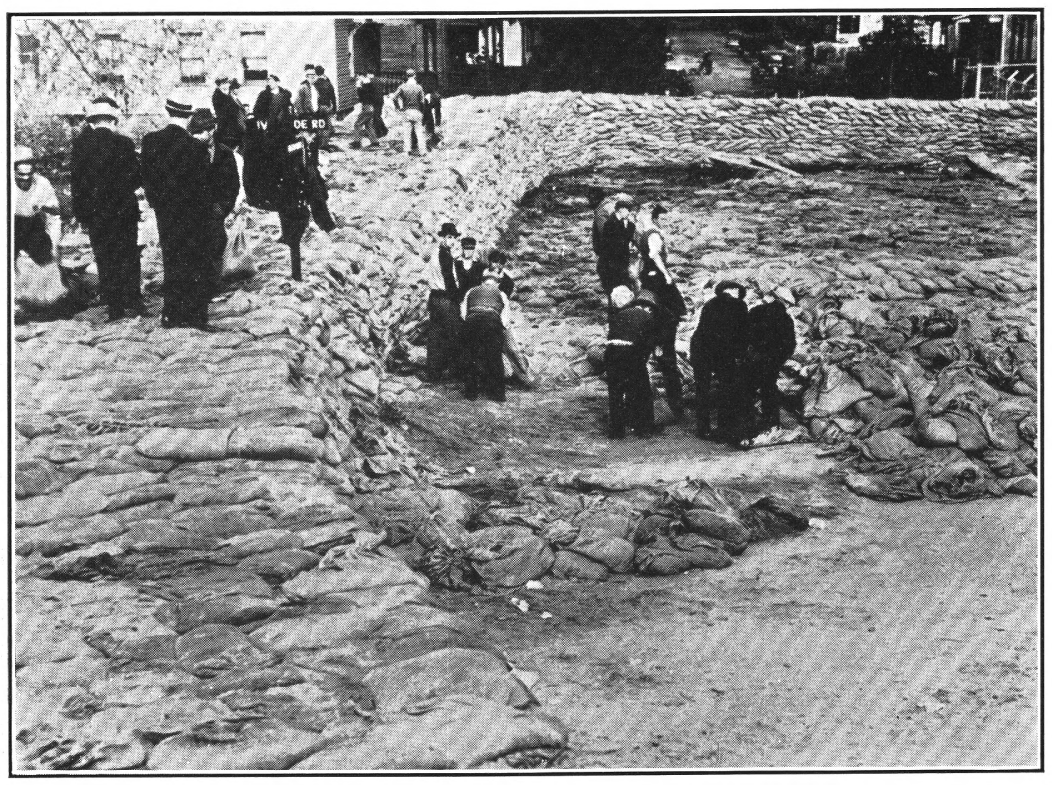

B. SCENE AT WEST SPRINGFIELD, MASS.

Sandbag embankment illustrates effectiveness of adequate flood-warning and flood-fighting organization. 


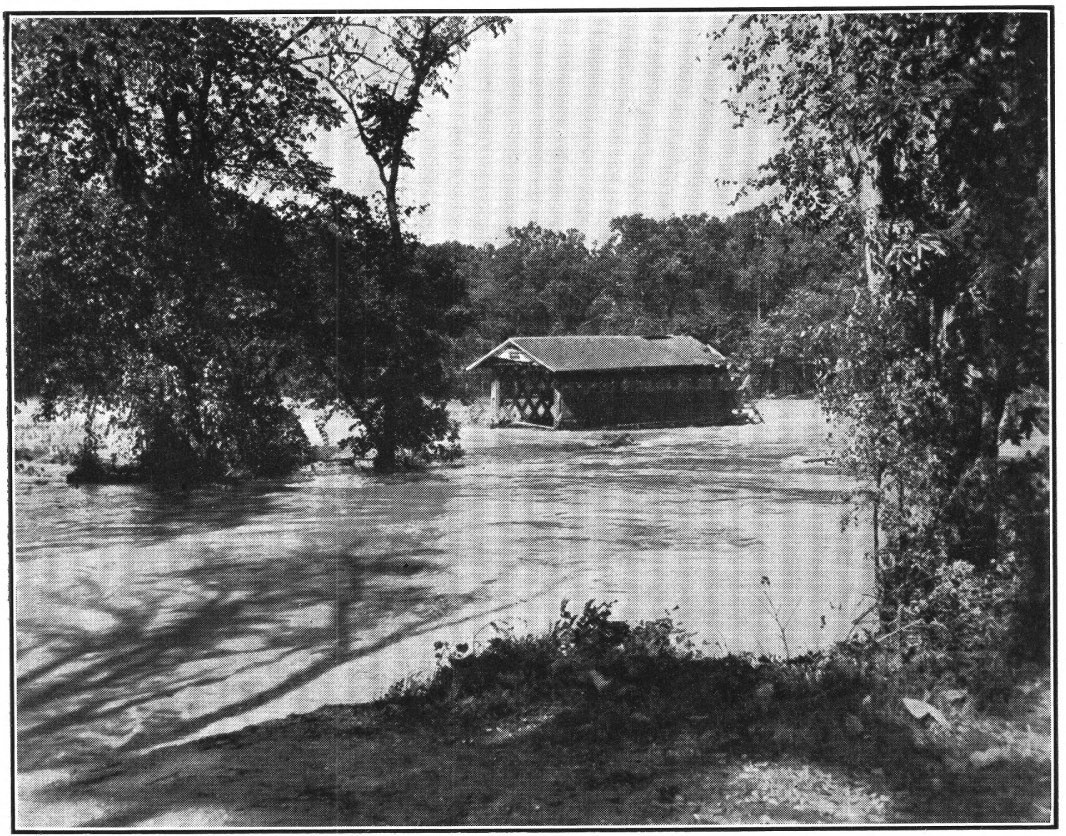

A. OLD COVERED BRIDGE ON ROAD BETWEEN HOOSIC FALLS, N. Y., AND BENNINGTON, VT.

This bridge was washed from original site and carried downstream until becoming lodged as shown in photograph. Courtesy of Knickerbocker News, Albany, N. Y.

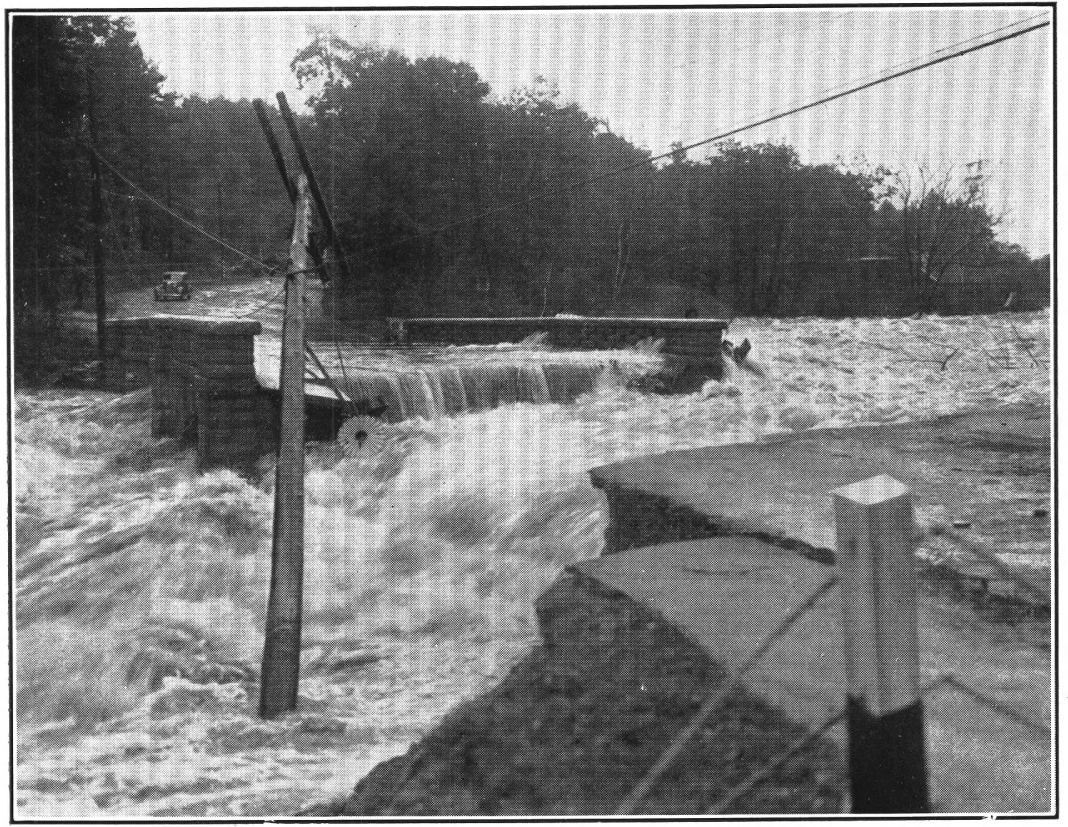

B. SCENE AT BRIDGE NEAR WATERVILLE, MASS.

Courtesy of International News Photo. 


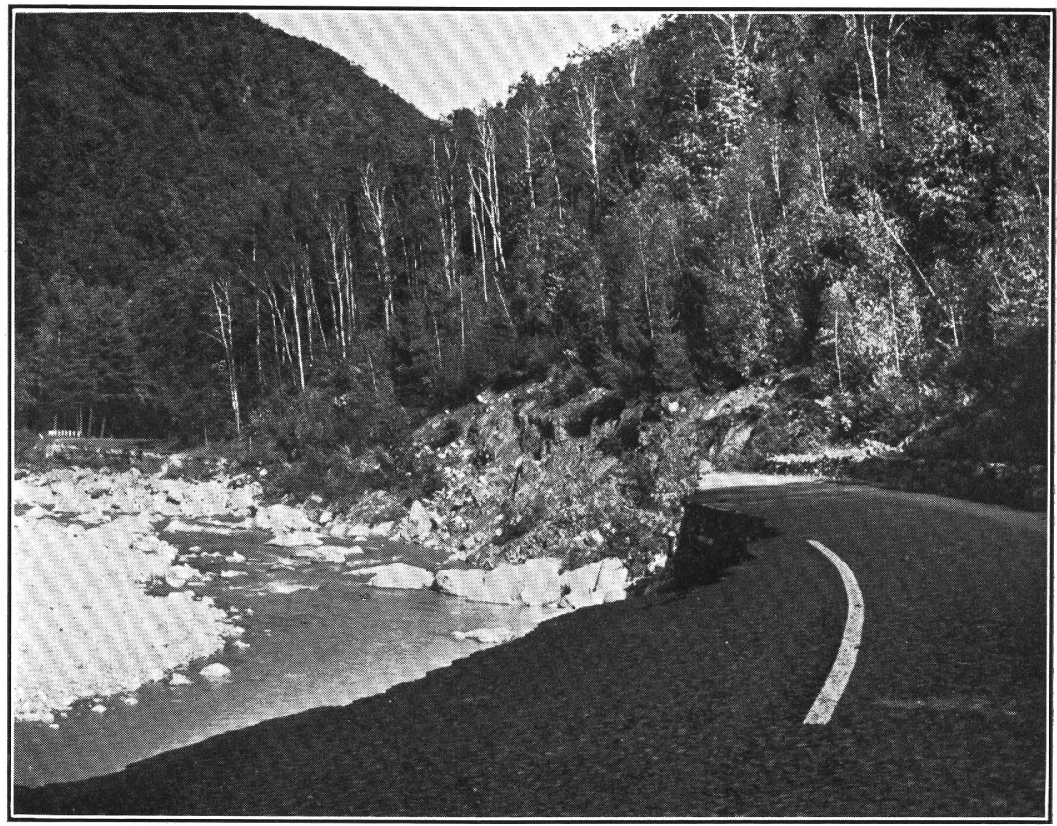

A. SCENE ON MOHAWK TRAIL (U. S. HIGHWAY 2) NEAR FLORIDA, MASS., ALONG COLD RIVER.

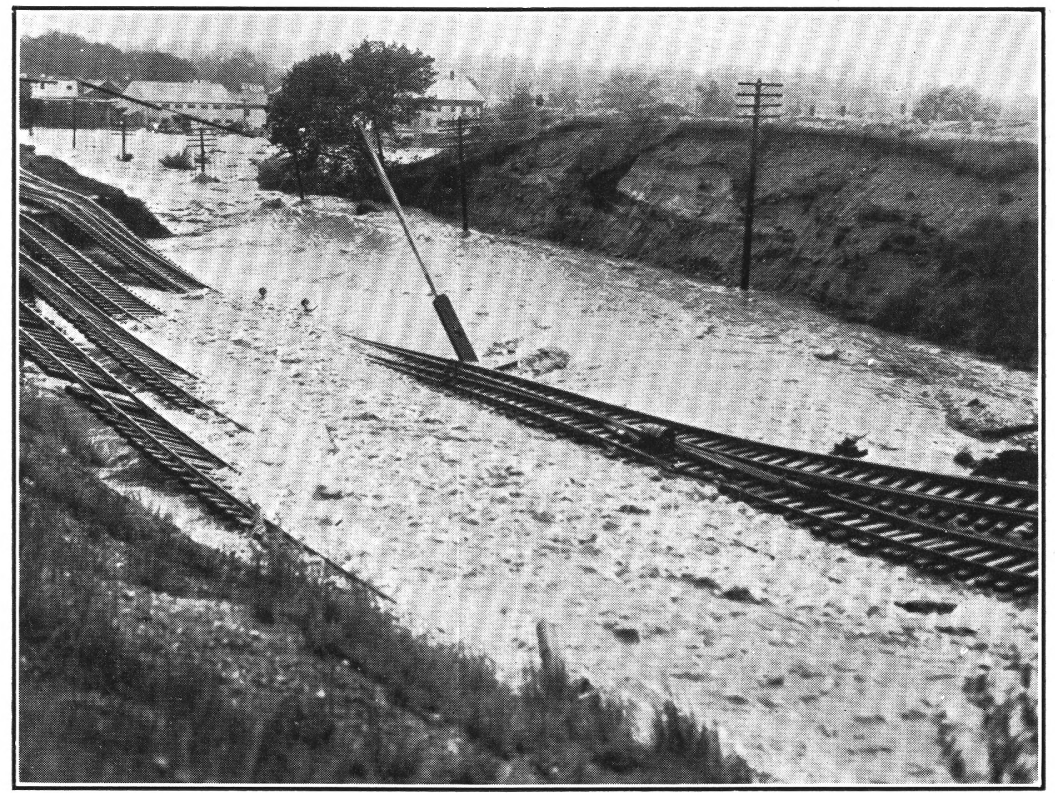

B. SCENE ON THE NEW YORK, NEW HAVEN \& HARTFORD RAILROAD AT PUTNAM, CONN. Courtesy of Worcester Telegram.

WASH-OUTS ON RAILROAD AND HIGHWAY RIGHT-OF-WAYS. 


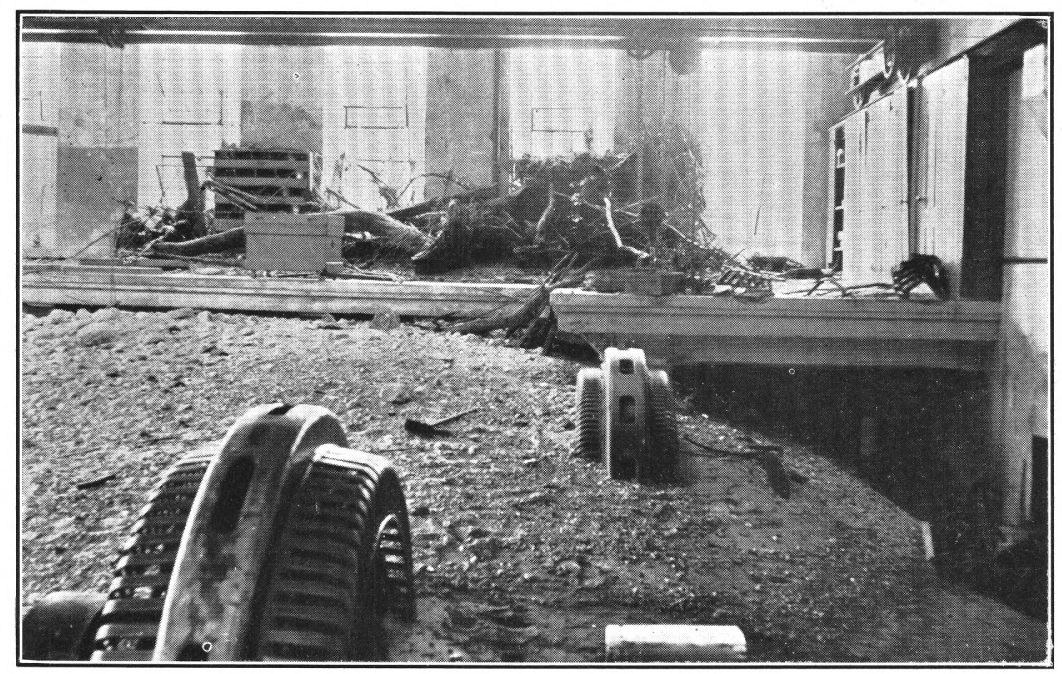

A. DEBRIS IN HYDROELECTRIC PLANT AT WENDELL, MASS.

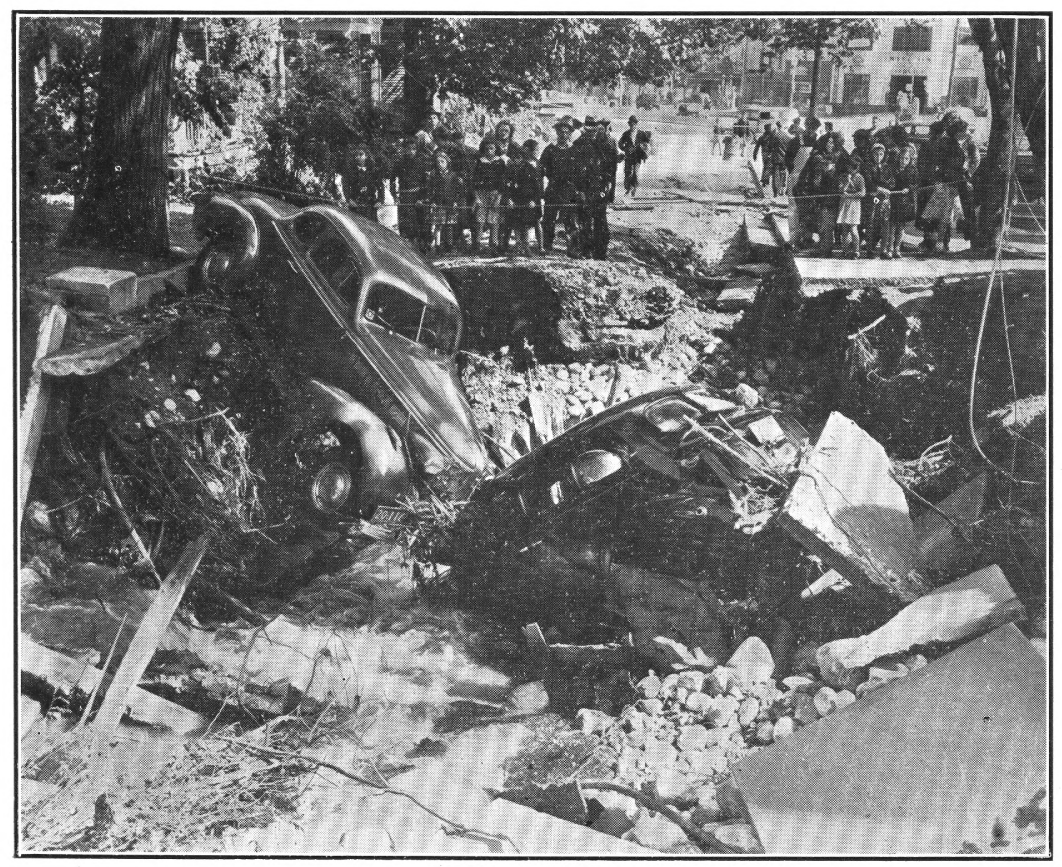

B. STREET UNDERMINED IN ADAMS, MASS.

FLOOD DAMAGE IN MASSACHUSETTS. 


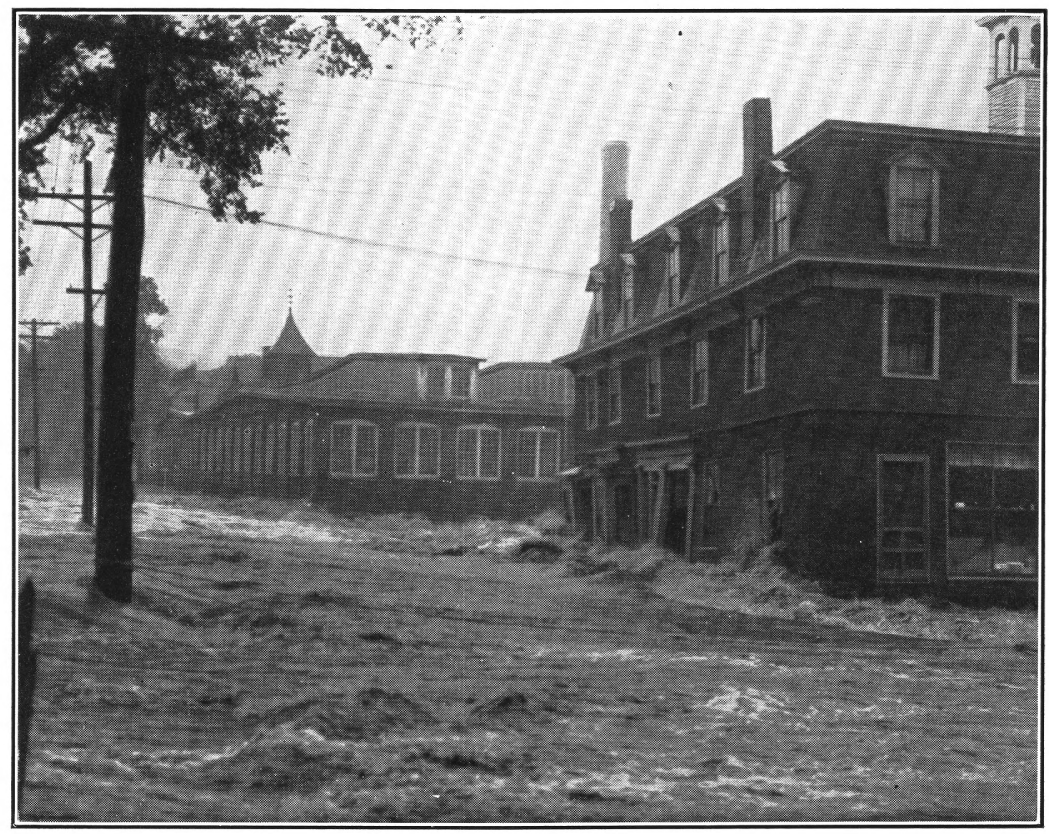

A.

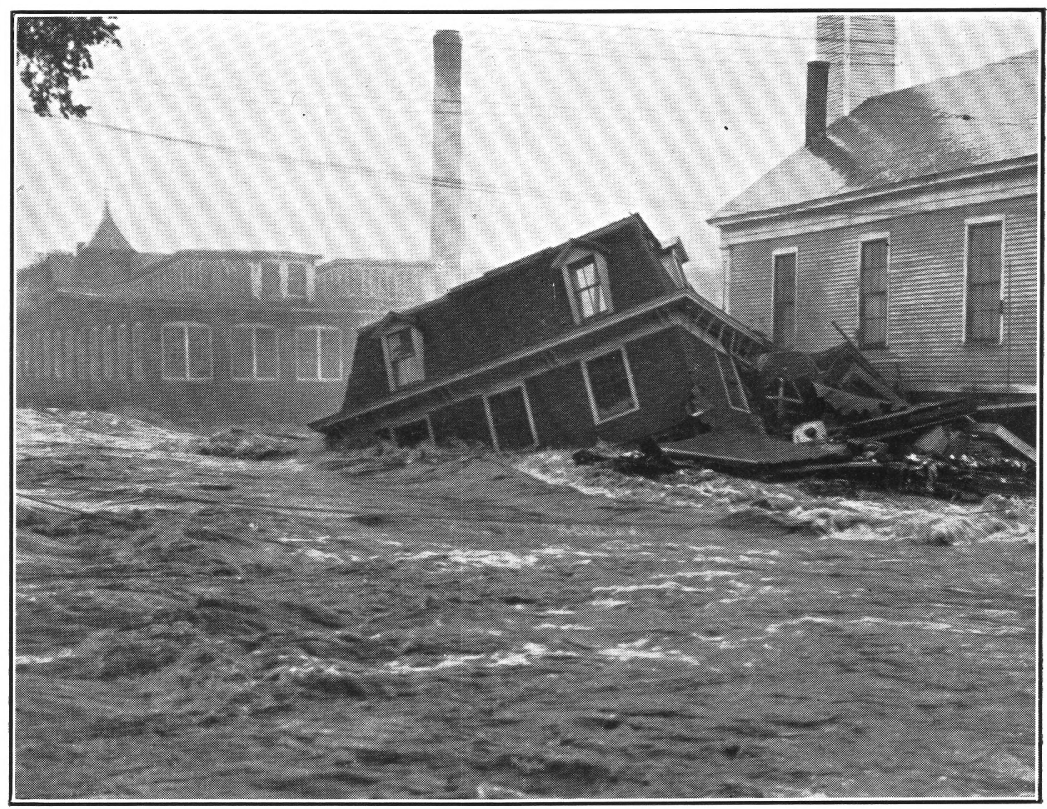

B.

HOUSE IN WARE, MASS., BEFORE AND AFTER DESTRUCTION BY FLOOD. 
The Saugatuck River near Westport evidently did not recelve a proportionately large amount of precipitation in the 1938 flood and therefore crested at a stage 1 foot below its 1936 record, with a peak flow rate of 17 percent less.

In the Hudson River Basin the stages and discharges were high but generalif well below those previously recorded. However, in the dralnage basins of the Hoosic River, Kinderhook Creek, Fappinger Creek, Poesten K111, and streams tributary to the Hudson River from the east, stages and discharges were by far the highest of record. It was reported by valatie Mills, Valatie, N. Y., that the water was 4 fe日t higher than ever before over the dam at the outlet of Kinderhook Lake at Niverville, N. Y. J. T. Lampman \& Co., Oleverack, $M$. $Y$., reported that the water was higher than ever seen before by anjone now living there and probably higher than the great flood of 1869. The Ancram Paper M1lls, Ancram, N. Y., reported that the water in the Roeliff Jansen Kill rose to the highest level in the memory of the oldest inhobitants. Unharvested crops of fruit and grain were ruined, with serious losses to farmers. Harvey 0. Schermerhorn, Commissioner of Canals and Waterways, stated that the flood in the Mohawk Valley during the navigation season was the biggest in 20 years, and between scotia and Cranesville the flood was the worst ever seen in the navigation season. Traffic on the Barge Canal was at a standstill for several days. At Albany, N. Y., water was about 4 feet deep on the West Shore Railroad trecks on the lower level at the station.

In New Jersey the most serlous floods occurred in the Raritan River Basin and on some of the small coastal streams, where stages and discharges were generally greater than previously known. These floods coming so soon after the floods of July 1938 and March 1936 have made the people of New Jersey, especially in the central part of the state, increasingly floodconsclous and have demonstrated the advisability of limiting encroachments on the flood channels and of having the flood plains clear for the passage of flood waters.

In New York in the Delaware and Susquehanna River Basins, the floods were severe only in the headwater areas in the easterly part of the basins where stages and discharges were greater than recently known.

Streams tributary to the St. Lawrence River generally had moderate floods except in the Ausable River Basin on the west side of Lake Champlain, where stages and discharges of the Ausable River at Ausable Forks, N. Y., were the greatest since 1910. Many of the small tributaries $2279070-10-4$ 
draining the west slope of the Green Mountains in Vermont had high flood flows that caused considerable damage.

With the passing of the hurricane, fair weather returned and the flooded rivers rapidly receded. Immediately the vast job of clean-up, repair, and restoration began. In the most devastated areas seemingly every able-bodied citizen had a part in the job of restoration. State, Federal, and local governments immediately organized their forces to open the debris-choked or flood-damaged arteries of transportation, to relleve the infured and homeless, and to perform the somber tasks of accounting for the known dead and searching for the missing. Private organizations, particularly the public utilities companies, faced a vast job of untangling trees, poles, and wire in connection with the restoration of telephone, telegraph, and electric lighting and power facilities. The railroads were serlously damaged by flood, wind, and the coastal storm wave. Homes, factories, stores, churches, mills, schools and colleges, cemeteries, summer homes and cottages, wharves and docks, warehouses, dams, some water supplies, ships and other navigation equipment, and all other man-made structures and facilities, felt in greater or lesser degree the destructiveness of the combined flood waters and hurricane winds. The task of restoration after all this devastation was gigantic, and only through the whole-hearted cooperation of every citizen, every agency of government, and every private organization, and the remarkable resourcefulness of all, was the job accomplished, and accomplished in large proportion within a seomingly impossibly short time.

Lessons have been learned, and social and economic problems and problems of control and protection have arisen as a result of the disaster. The lessons mast not soon be forgotten, and the problems ought to be studied and analyzed and solutions diligently sought. Steps have already been taken toward these ends, and it seems evident that the extraordinary experiences of this disaster will provide the basis for sound measures of forewarning, control, and protection that will operate to reduce substantially the attendant social and economic crippling should any similar catastrophe strike in the future. 
As an aid to the many engineers and hydrologists who are engaged on problems relating to the control of flood run-off and the alleviation of damage therefrom, a special effort has been made to collect and combine in this report all basic information relating to the meteorologic and hydrologic conditions pertinent to the storm and floods of September 1938. These conditions bear principally upon the 4 days of rainfall between September 17 and 21 in the area covered by this flood and the antecedent conditions that affected the rainfall and run-off relations.

\section{Antecedent cond1tions}

To an important extent the foundation of a flood event may be laid during the period that precedes 1t. This is especially apparent in winter or spring, when the extent and depth of snow accumulated through the preceding months or the presence of frost in the ground become of transcending importance as factors in the production of floods. During other seasons the preceding perlod affects chiefly the capacity of the soil and vegetation for retaining water and includes as a principal factor the degree to which such capacity has been ut1lized by the antecedent rains. The rate at which such retained or intercepted water is dissipated through the action of evaporation and transpiration, thus making available storage space for additional water, is largely a function of the temperature. In the humid East the ground reservoir is most drawn upon by these agencies and hence is most nearly in a state of depletion at a time nearly contemporaneous with the season of highest temperatures. Horton $5 /$ shows that normally the maximum infiltration capacity usually occurs during August. Likewise Hoyt 6 Indicates that the maximum soll-moisture deficiency generally occurs in August.

The factors that determine climate may, in their seemingly erratic varlations from normal, result in corresponding variations in the retentive capacity of the soll. Therefore, a study of the changes in soil molsture and its relative state at the beginning of the storm rains as determined by the rainfall and temperature during the period preceding a flood event is informative of the background of the flood and furnishes a basis for possible studies and forecast of run-off from storm rainfall. Tables 2 and 3 give the total precipitation and the mean

5/ Horton, R. E., Determination of infiltration capacity for large drainage basins: Am. Geophys. Union Trans., p. 384, 1937.

67 Hoyt, W. G., Studies of rainfall and run-off in the United

States: U. S. Geol'. Survey Water-Supply Paper 772, p. 253, 1936. 
Table 2.-Monthly total precipitation and departure from normal, in inches, April to September 1938

\begin{tabular}{|c|c|c|c|c|c|c|c|c|c|c|c|c|}
\hline \multirow[b]{2}{*}{ State } & \multicolumn{2}{|c|}{ April } & \multicolumn{2}{|c|}{ May } & \multicolumn{2}{|c|}{ June } & \multicolumn{2}{|c|}{ July } & \multicolumn{2}{|c|}{ August } & \multicolumn{2}{|c|}{ September 1-16 } \\
\hline & Total & $\begin{array}{c}\text { Depar- } \\
\text { tare }\end{array}$ & Total & $\begin{array}{c}\text { Depar- } \\
\text { ture }\end{array}$ & Total & $\begin{array}{c}\text { Depar- } \\
\text { ture }\end{array}$ & Total & $\begin{array}{c}\text { Depar- } \\
\text { ture }\end{array}$ & Total & $\begin{array}{c}\text { Depar- } \\
\text { ture }\end{array}$ & Total & $\begin{array}{c}\text { Depar- } \\
\text { ture }\end{array}$ \\
\hline New Hampshire & 2.61 & -0.42 & 3.10 & -0.02 & 4.00 & +0.45 & 7.24 & +3.56 & 3.64 & +0.05 & 2.80 & +0.94 \\
\hline Vermont & 2.73 & -.11 & 2.94 & -.21 & 3.32 & -.30 & 6.84 & +3.07 & 4.15 & +.55 & 2.86 & +1.02 \\
\hline Massachusetts & 3.04 & -.52 & 3.92 & +.62 & 7.39 & +3.89 & 8.97 & +5.45 & 3.21 & -.54 & 2.44 & +.53 \\
\hline Rhode Island & 3.12 & -.73 & 4.63 & +1.21 & 7.18 & +4.10 & 4.40 & +1.33 & 3.38 & -.31 & 2.05 & +.23 \\
\hline Connecticut & 3.17 & -.52 & 4.05 & +.41 & 6.92 & +3.44 & 9.57 & +5.61 & 4.20 & +.03 & 1.90 & -.17 \\
\hline Eastern New York & 2.73 & -.46 & 3.13 & -.30 & 3.97 & +.10 & 5.49 & +1.74 & 4.68 & +.61 & 2.51 & +.01 \\
\hline New Jersey & 2.82 & -.79 & 3.52 & -.22 & 7.79 & +4.08 & 8.84 & +4.05 & 3.09 & -1.66 & 1.02 & -1.06 \\
\hline
\end{tabular}


Table 3.--Monthly mean teraperature and departure Prom normal, in degrees Fahrenhelt, April to September 1938

\begin{tabular}{|c|c|c|c|c|c|c|c|c|c|c|c|c|}
\hline \multirow{2}{*}{ State } & \multicolumn{2}{|c|}{ April } & \multicolumn{2}{|c|}{ May } & \multicolumn{2}{|c|}{ June } & \multicolumn{2}{|c|}{ July } & \multicolumn{2}{|c|}{ August } & \multicolumn{2}{|c|}{ Septeraber $1-16$} \\
\hline & Mean & $\begin{array}{c}\text { Depar- } \\
\text { ture }\end{array}$ & Lean & $\begin{array}{c}\text { Depar- } \\
\text { ture }\end{array}$ & Moan & $\begin{array}{c}\text { Depar- } \\
\text { ture }\end{array}$ & Mean & $\begin{array}{c}\text { Deper- } \\
\text { ture }\end{array}$ & Mean & $\begin{array}{c}\text { Depar- } \\
\text { tare }\end{array}$ & Mean & $\begin{array}{c}\text { Depar- } \\
\text { ture }\end{array}$ \\
\hline New Hampshire & 44.7 & +2.7 & 52.5 & -1.5 & 65.0 & +2.0 & 68.5 & +0.5 & 68.4 & +3.0 & 55.0 & -2.7 \\
\hline Vermont & 44.8 & +3.2 & 52.8 & -1.1 & 64.9 & +1.9 & 68.3 & +.6 & 68.5 & +3.3 & 56.0 & -1.5 \\
\hline Inssachusetts & 48.3 & +3.1 & 55.0 & -1.4 & 66.1 & +1.0 & 71.0 & +.7 & $7 E .1$ & +3.7 & 62.6 & +.2 \\
\hline Rhode Island & 47.5 & +2.0 & 54.6 & -1.2 & 64.3 & -.3 & 71.0 & +.9 & 72.4 & +3.3 & 60.4 & +3.5 \\
\hline Connecticut & 49.9 & +3.3 & 55.8 & -1.7 & 66.6 & +.5 & 71.7 & +1.0 & 72.4 & +3.4 & 62.1 & -.1 \\
\hline Eastern Hew York & 47.6 & +3.5 & 54.8 & -.9 & 65.5 & +1.1 & 70.6 & +1.3 & 70.9 & +3.4 & 58.6 & -.9 \\
\hline New Jersey & 53.0 & +3.3 & 59.2 & -1.2 & 67.2 & -1.6 & 74.7 & +1.0 & 75.4 & +3.6 & 65.2 & -.4 \\
\hline
\end{tabular}


temperature, respectively, with departures from normal, by months for the period April to September 16, for the affected areas. Precipitation during the months shown in table 2 was such that there was an accumulated surplus of precipitation above normel at the beginning of the september storm. The deficiency of precipitation during April was more than overcome during Jiune and July; August remained about normal, and the first 16 days of Suptember were generally above normal, except in New Jersey, where there was a 1-inch deficiency, and in Connecticut, where the precipitation was only slightly below normal. Temperatures during the months shown in table 3 were generally above normal.

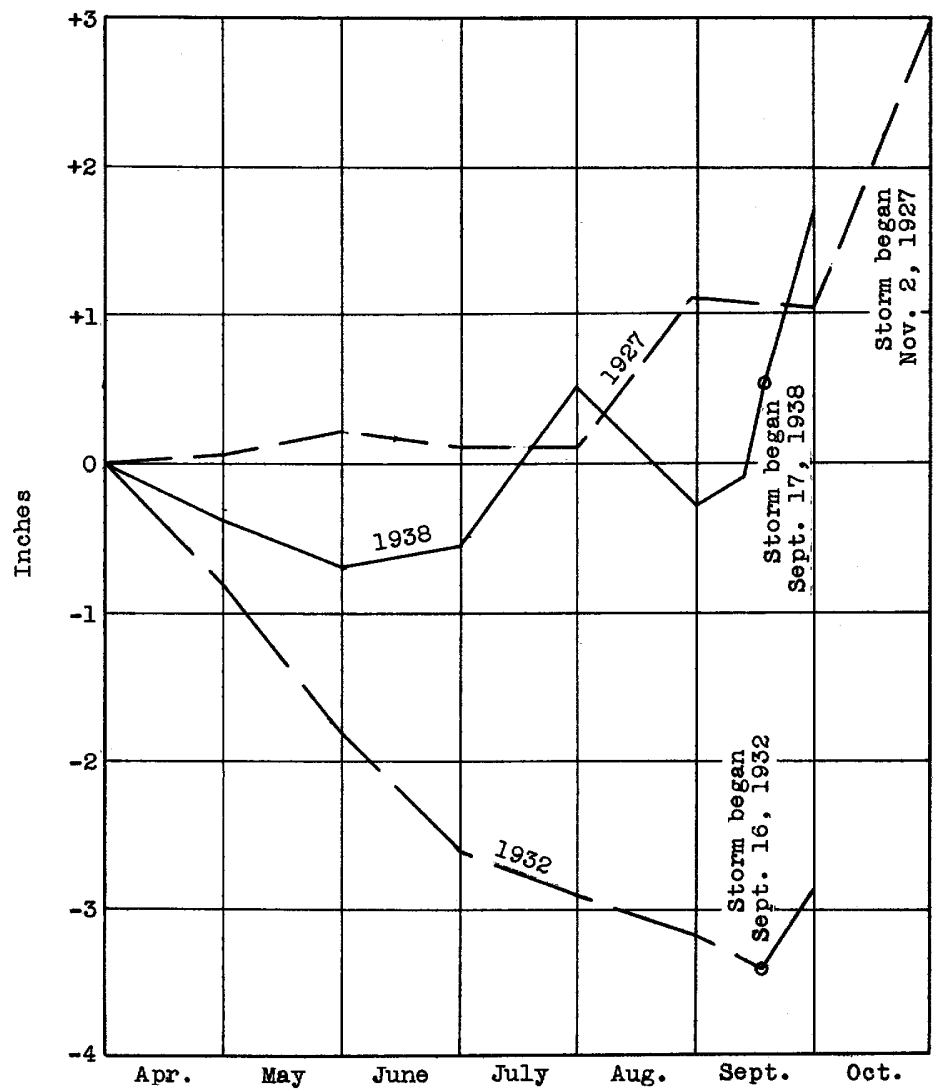

Figure 23.--Cumulatipe monthly soil molsture, Festfield River Basin above Knightville, Mass., 1927, 1932, 1938.

The amount of antecedent precipitation and the temperature are of direct interest insofar as they affect the soll moisture, which may be taken as a measure of the rain-absorbing capacity of the ground. Figure 23 shows a study of the cumulative soll molsture of the Westfield River Basin beginning on April 1 as computed by methods outlined in Water-Supply 
Paper 772, using precipitation, temperature, and stream-flow data for the non-winter seasons of 1927, 1932, and 1938. Each of these years was marked by outstanding storms and wide departure from normal conditions. It may be observed on this figure that the soll molsture during the flood years 1927 and 1938 tended toward stablilty throughout the summer season, the normal tendency toward depletion being absent. The graph for 1938 shows a sharp increase in soll molsture due to rainfall of september 1 to 16 immediately preceding the flood. The trend of soll moisture during the drought year of 1932 was consistentiy downward. The outstanding storm of September 1932 brought 7.8 inches of rain in 1 day over 6,000 square miles, virtually all of which was absorbed. The significance of the marked departures from normal is readily apparent.

\section{Precipitation}

Precipitation records collected at about 750 stations have been accumulated and used for the construction of the isohyetal maps presented herein and for the study of the relation between rainfall and run-off. These records have been furnished by numerous governmental agencies, public utility power companies, and many individuals whose cooperation is hereby acknowledged.

In some places the catch of rain on September 21 was lost owing to displacement of the rain gage by the hurricane winds. In some of these places estimates of the catch were made by the agency that furnished the record. The records were essentially of three kinds, viz., those in which only one or two readings of the gage were made each day; those in which more than two readings of the gage were made each day (readings were at 2-hour intervals at some places during the heavier parts of the storm); and those in which automatic recording gages were used. A few gages in New York were read twice a day, In the morning and in the evening. In table 4 both sets of readings are published for these gages.

The daily precipitation at all stations from september 12 to 22 inclusive, is reported in tables 4 and 5 , with appropriate footnotes ind cating the time of measurement and the source of the record. All records were furmished by the Weather Bureau unless otherwise noted. The records at the gages at which more than two readings a day were made are also listed in table 6 which shows the available readings together with the hourly precipitation amounts at the automatic recording gages. All records in the latter table have been adjusted to eastern standard time whenever it was definitely known that the records were kept on daylight 
Table 4.--Daily precipitation, in inches, September 12-22, 1938 (Measured in the afternoon except as noted)

\begin{tabular}{|c|c|c|c|c|c|c|c|c|c|c|c|c|c|}
\hline $\begin{array}{c}\text { No. } \\
\text { on } \\
\text { pl.1 }\end{array}$ & Station & 12 & 13 & 14 & 15 & 16 & 17 & 18 & 19 & 20 & 21 & 22 & $\begin{array}{l}\text { Total, } \\
\text { storm } \\
17-22\end{array}$ \\
\hline & $\begin{array}{l}\text { Merrinack River Bagin } \\
\text { New Hampshire: }\end{array}$ & & & & & & . & & & & & & \\
\hline $\begin{array}{l}1 \\
2 \\
3 \\
4 \\
5\end{array}$ & $\begin{array}{l}\text { Allenstow a/ } \\
\text { Bradford }+ \\
\text { Bristol (Ayers Is.) + b/ } \\
\text { Concord } \\
\text { Eastman Falls }+\end{array}$ & $\begin{array}{l}- \\
- \\
\overline{1} \\
\mathbf{H}\end{array}$ & $\begin{array}{l}1.64 \\
1.32 \\
1.24 \\
.41 \\
\dot{M}\end{array}$ & $\begin{array}{l}- \\
\overline{0.03} \\
\bar{y}\end{array}$ & $\begin{array}{r}0.63 \\
.74 \\
.58 \\
.75 \\
.65\end{array}$ & $\begin{array}{l}0.11 \\
.42 \\
.29 \\
- \\
.26\end{array}$ & $\begin{array}{l}- \\
- \\
- \\
0.23 \\
-\end{array}$ & $\begin{array}{r}0.27 \\
.24 \\
.10 \\
.09 \\
.17\end{array}$ & $\begin{array}{r}0.47 \\
.32 \\
.19 \\
1.45 \\
.32\end{array}$ & $\begin{array}{l}3.11 \\
1.67 \\
1.49 \\
2.74 \\
1.61\end{array}$ & $\begin{array}{l}1.35 \\
3.82 \\
4.48 \\
2.79 \\
5.22\end{array}$ & $\begin{array}{l}0.13 \\
3.38 \\
3.26 \\
- \\
1.44\end{array}$ & $\begin{array}{l}5.33 \\
9.43 \\
9.52 \\
7.30 \\
0.76\end{array}$ \\
\hline $\begin{array}{r}6 \\
7 \\
8 \\
9 \\
10\end{array}$ & $\begin{array}{l}\text { Franklin } \\
\text { Franklin Falls }+ \text { a/ } \\
\text { Garvins Falls }+ \text { b/ } \\
\text { Gilmanton lron Works a/ } \\
\text { Greenville }+\end{array}$ & $\begin{array}{l}- \\
- \\
-\end{array}$ & $\begin{array}{r}1.32 \\
1.35 \\
1.28 \\
1.22 \\
.75\end{array}$ & $\begin{array}{l}- \\
- \\
.07 \\
-\end{array}$ & $\begin{array}{l}.90 \\
.58 \\
.41 \\
.75 \\
.59\end{array}$ & $\begin{array}{l}- \\
.22 \\
.41 \\
- \\
.20\end{array}$ & $\begin{array}{l}- \\
- \\
- \\
- \\
.01\end{array}$ & $\begin{array}{l}.20 \\
.15 \\
.25 \\
.25 \\
.48\end{array}$ & $\begin{array}{r}1.12 \\
.56 \\
.53 \\
.70 \\
1.05\end{array}$ & $\begin{array}{l}1.70 \\
1.95 \\
1.46 \\
1.75 \\
1.44\end{array}$ & $\begin{array}{r}5.80 \\
5.50 \\
2.95 \\
.10 \\
5.32\end{array}$ & $\begin{array}{r}.07 \\
1.77 \\
.57 \\
- \\
1.07\end{array}$ & $\begin{array}{l}8.89 \\
9.93 \\
5.76 \\
2.80 \\
9.36\end{array}$ \\
\hline $\begin{array}{l}11 \\
12 \\
13 \\
14 \\
15\end{array}$ & $\begin{array}{l}\text { Greggs Falls }+b / \\
\text { H1llsboro } t \\
\text { Jackman Falls Dax }+b / \\
\text { Jeremy Hill }+ \\
\text { Laconia } t\end{array}$ & $\begin{array}{l}- \\
- \\
- \\
-\end{array}$ & $\begin{array}{r}.91 \\
1.17 \\
.86 \\
.88 \\
1.63\end{array}$ & $\begin{array}{l}.06 \\
\mathrm{Tr} . \\
.03 \\
- \\
.03\end{array}$ & $\begin{array}{l}.32 \\
.67 \\
.64 \\
.57 \\
.66\end{array}$ & $\begin{array}{l}.38 \\
.90 \\
.62 \\
.13 \\
.03\end{array}$ & $\begin{array}{l}- \\
- \\
- \\
\text { Tr. }\end{array}$ & $\begin{array}{l}.35 \\
.24 \\
.20 \\
.58 \\
-\end{array}$ & $\begin{array}{r}.63 \\
.45 \\
.44 \\
1.42 \\
.20\end{array}$ & $\begin{array}{r}1.26 \\
2.66 \\
2.70 \\
1.29 \\
.73\end{array}$ & $\begin{array}{l}3.42 \\
5.61 \\
4.85 \\
1.55 \\
1.92\end{array}$ & $\begin{array}{c}.80 \\
1.75 \\
2.39 \\
M \\
1.69\end{array}$ & $\begin{array}{c}6.56 \\
10.71 \\
10.58 \\
4.84+ \\
4.54\end{array}$ \\
\hline $\begin{array}{l}16 \\
17 \\
18 \\
19 \\
20\end{array}$ & $\begin{array}{l}\text { Lakeport }+ \\
\text { Lakeport } \\
\text { Lincoln }+\mathrm{c} / \\
\text { Manchester }+\mathrm{b} / \\
\text { Nashua }+t\end{array}$ & $\begin{array}{l}\overline{\text { Tr. }} \\
\overline{-} \\
. \\
.87\end{array}$ & $\begin{array}{r}.98 \\
.97 \\
1.49 \\
.93 \\
.05\end{array}$ & $\begin{array}{l}.04 \\
\mathrm{Tr} . \\
- \\
.02 \\
.07\end{array}$ & $\begin{array}{l}.72 \\
.66 \\
.92 \\
.19 \\
.66\end{array}$ & $\begin{array}{l}.26 \\
.28 \\
.18 \\
.54 \\
-\end{array}$ & $\begin{array}{l}- \\
- \\
- \\
. \\
.37\end{array}$ & $\begin{array}{r}.17 \\
.15 \\
.10 \\
.38 \\
1.04\end{array}$ & $\begin{array}{r}.40 \\
.86 \\
.08 \\
.67 \\
1.45\end{array}$ & $\begin{array}{l}1.52 \\
1.42 \\
1.32 \\
2.66 \\
2.45\end{array}$ & $\begin{array}{r}4.41 \\
4.23 \\
2.62 \\
2.53 \\
.18\end{array}$ & $\begin{array}{r}.95 \\
.56 \\
z .36 \\
.19 \\
-\end{array}$ & $\begin{array}{l}7.45 \\
6.72 \\
7.48 \\
6.48 \\
5.48\end{array}$ \\
\hline $\begin{array}{l}21 \\
22 \\
23 \\
24 \\
25\end{array}$ & $\begin{array}{l}\text { New Durham }+ \\
\text { New Durham }+ \\
\text { Peterboro *-*** d/ } \\
\text { Plymouth }+ \text { b/ } \\
\text { Plymouth }\end{array}$ & $\begin{array}{l}- \\
- \\
- \\
-\end{array}$ & $\begin{array}{r}1.24 \\
1.15 \\
.75 \\
1.40 \\
1.30\end{array}$ & $\begin{array}{l}.02 \\
- \\
- \\
- \\
-\end{array}$ & $\begin{array}{r}.50 \\
.81 \\
.62 \\
1.04 \\
1.15\end{array}$ & $\begin{array}{l}.21 \\
- \\
- \\
\text { Tr. }\end{array}$ & $\begin{array}{l}- \\
\overline{-} \\
- \\
-\end{array}$ & $\begin{array}{r}.18 \\
.12 \\
2.5 \\
- \\
.19\end{array}$ & $\begin{array}{l}.42 \\
.42 \\
3.0 \\
.80 \\
.89\end{array}$ & $\begin{array}{l}1.52 \\
1.70 \\
* \\
1.20 \\
1.88\end{array}$ & $\begin{array}{l}2.05 \\
1.82 \\
9.5 \\
3.60 \\
4.45\end{array}$ & $\begin{array}{r}.38 \\
.32 \\
- \\
3.65 \\
.07\end{array}$ & $\begin{array}{c}4.55 \\
4.38 \\
15.0 \\
8.75 \\
7.48\end{array}$ \\
\hline $\begin{array}{l}26 \\
27 \\
28 \\
29 \\
30\end{array}$ & $\begin{array}{l}\text { South Denbury a } \\
\text { Suncook Pond a } \\
\text { Tebster *k-k a } \\
\text { West Rumney } a \\
\text { West Wilton } a\end{array}$ & $\begin{array}{l}- \\
- \\
- \\
-\end{array}$ & $\begin{array}{r}1.59 \\
1.60 \\
1.85 \\
1.58 \\
.18\end{array}$ & $\begin{array}{l}- \\
- \\
- \\
-\end{array}$ & $\begin{array}{l}.93 \\
.95 \\
- \\
1.17 \\
.81\end{array}$ & $\begin{array}{c}- \\
.35 \\
1.22 \\
- \\
.35\end{array}$ & $\begin{array}{l}- \\
. \\
.28 \\
-\end{array}$ & $\begin{array}{l}.13 \\
.25 \\
* \\
- \\
.61\end{array}$ & $\begin{array}{l}.67 \\
.25 \\
* \\
1.91 \\
1.12\end{array}$ & $\begin{array}{l}2.08 \\
2.30 \\
2.56 \\
2.44 \\
2.68\end{array}$ & $\begin{array}{l}4.41 \\
2.10 \\
6.85 \\
2.40 \\
6.12\end{array}$ & $\begin{array}{r}.52 \\
- \\
1.70 \\
.30 \\
.62\end{array}$ & $\begin{array}{r}7.81 \\
5.00 \\
11.89 \\
7.05 \\
11.15\end{array}$ \\
\hline 31 & $\begin{array}{l}\text { Wolfboro Falls } \\
\text { Massachusetts: }\end{array}$ & - & .86 & - & .72 & .08 & - & .07 & .63 & 2.17 & 1.09 & - & 3.96 \\
\hline $\begin{array}{l}32 \\
33 \\
34 \\
85 \\
36\end{array}$ & $\begin{array}{l}\text { Ashby } * * \text { e/ } \\
\text { Ashland } * * * * \pm / \\
\text { Boylston } * * * * f / \\
\text { Clinton }++1 / \\
\text { Concord }\end{array}$ & $\begin{array}{l}1.34 \\
- \\
- \\
-\end{array}$ & $\begin{array}{r}- \\
.85 \\
.94 \\
1.01 \\
1.06\end{array}$ & $\begin{array}{l}.36 \\
- \\
- \\
-\end{array}$ & $\begin{array}{l}.14 \\
.50 \\
.81 \\
.76 \\
.47\end{array}$ & $\begin{array}{l}- \\
- \\
- \\
.02\end{array}$ & $\begin{array}{l}.56 \\
* \\
* \\
.31\end{array}$ & $\begin{array}{l}1.12 \\
.75 \\
* \\
* \\
1.30\end{array}$ & $\begin{array}{l}3.09 \\
2.67 \\
* \\
* \\
3.66\end{array}$ & $\begin{array}{l}5.60 \\
1.19 \\
* \\
* \\
2.43\end{array}$ & $\begin{array}{l}1.65 \\
2.02 \\
7.35 \\
7.80 \\
2.47\end{array}$ & $\begin{array}{l}\overline{T r} . \\
\overline{-} \\
\overline{-}\end{array}$ & $\begin{array}{r}12.02 \\
6.63 \\
7.33 \\
7.30 \\
10.17\end{array}$ \\
\hline $\begin{array}{l}37 \\
38 \\
39 \\
40 \\
41\end{array}$ & $\begin{array}{l}\text { Cordavilie }+f / \\
\text { East Pepperell }+t e / \\
\text { Fitchburg } \\
\text { Framingham } * * * * f / \\
\text { Gates Pond }+t e \text { f }\end{array}$ & $\begin{array}{l}-\overline{1.03} \\
1.03 \\
- \\
1.02\end{array}$ & $\begin{array}{l}.93 \\
.15 \\
- \\
.90 \\
.05\end{array}$ & $\begin{array}{l}- \\
.23 \\
- \\
.18\end{array}$ & $\begin{array}{l}.52 \\
.17 \\
.50 \\
.63 \\
.61\end{array}$ & $\begin{array}{l}- \\
. \\
.12 \\
-\end{array}$ & $\begin{array}{l}* \\
.53 \\
.41 \\
. \\
.94\end{array}$ & $\begin{array}{l}* \\
1.28 \\
1.19 \\
.81 \\
2.54\end{array}$ & $\begin{array}{l}* \\
1.43 \\
2.81 \\
3.26 \\
1.58\end{array}$ & $\begin{array}{l}* \\
2.71 \\
3.42 \\
1.18 \\
2.38\end{array}$ & $\begin{array}{l}* \\
.64 \\
.80 \\
2.51 \\
.85\end{array}$ & $\begin{array}{l}6.71 \\
- \\
- \\
.02 \\
-\end{array}$ & $\begin{array}{l}6.71 \\
6.59 \\
8.64 \\
7.71 \\
7.79\end{array}$ \\
\hline $\begin{array}{l}42 \\
43 \\
44 \\
45 \\
46\end{array}$ & 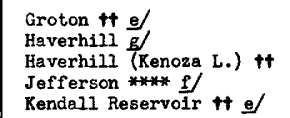 & $\begin{array}{c}1.52 \\
- \\
.97 \\
1.44\end{array}$ & $\begin{array}{r}- \\
.97 \\
.03 \\
1.26 \\
\mathrm{Tr} .\end{array}$ & $\begin{array}{l}.64 \\
- \\
.02 \\
.47\end{array}$ & $\begin{array}{l}.09 \\
.45 \\
.73 \\
.51 \\
.12\end{array}$ & $\begin{array}{l}- \\
.30 \\
\overline{T r} .\end{array}$ & $\begin{array}{l}.44 \\
-.85 \\
. \\
.40\end{array}$ & $\begin{array}{l}1.46 \\
1.25 \\
1.94 \\
* \\
1.68\end{array}$ & $\begin{array}{l}1.10 \\
1.59 \\
.98 \\
* \\
2.25\end{array}$ & $\begin{array}{l}2.33 \\
1.75 \\
1.55 \\
* \\
\mathbf{z} .50\end{array}$ & $\begin{array}{r}.47 \\
.40 \\
.06 \\
10.12 \\
1.06\end{array}$ & $\begin{array}{l}- \\
.03 \\
- \\
-\end{array}$ & $\begin{array}{r}5.80 \\
5.02 \\
5.38 \\
10.12 \\
8.89\end{array}$ \\
\hline $\begin{array}{l}47 \\
48 \\
49 \\
50 \\
51\end{array}$ & $\begin{array}{l}\text { Lake Cocht tuate }+f / \\
\text { Lawrence } \\
\text { Littleton }+t, e / \\
\text { Lowell t+ b/ } \\
\text { Lowell (Paitucket Dam) t+ }\end{array}$ & $\begin{array}{l}- \\
- \\
1.14 \\
1.83 \\
1.84\end{array}$ & $\begin{array}{l}.83 \\
1.23 \\
.03 \\
- \\
-\end{array}$ & $\begin{array}{l}.16 \\
- \\
.26 \\
.09 \\
-\end{array}$ & $\begin{array}{l}.04 \\
.76 \\
.66 \\
.99 \\
.98\end{array}$ & $\begin{array}{l}.49 \\
- \\
- \\
-\end{array}$ & $\begin{array}{l}- \\
* \\
.69 \\
.91 \\
.00\end{array}$ & $\begin{array}{l}.72 \\
* \\
1.63 \\
2.08 \\
2.08\end{array}$ & $\begin{array}{l}2.62 \\
* \\
1.08 \\
1.08 \\
1.41\end{array}$ & $\begin{array}{l}1.26 \\
5.12 \\
2.92 \\
1.95 \\
1.88\end{array}$ & $\begin{array}{r}1.47 \\
.69 \\
.86 \\
.21 \\
\mathrm{Tr}\end{array}$ & $\begin{array}{l}.20 \\
- \\
- \\
-\end{array}$ & $\begin{array}{l}6.27 \\
5.82 \\
6.68 \\
6.23 \\
6.17\end{array}$ \\
\hline $\begin{array}{l}52 \\
53 \\
54 \\
55 \\
56\end{array}$ & 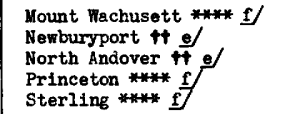 & $\begin{array}{l}- \\
.87 \\
- \\
-\end{array}$ & $\begin{array}{c}1.20 \\
.03 \\
- \\
1.15 \\
1.03\end{array}$ & $\begin{array}{l}- \\
.05 \\
1.62 \\
- \\
-\end{array}$ & $\begin{array}{l}.88 \\
.68 \\
- \\
.75 \\
.53\end{array}$ & $\begin{array}{l}- \\
- \\
.04 \\
- \\
-\end{array}$ & $\begin{array}{l}* \\
1.06 \\
.57 \\
* \\
*\end{array}$ & $\begin{array}{l}* \\
1.98 \\
- \\
* \\
*\end{array}$ & $\begin{array}{l}* \\
.38 \\
.86 \\
* \\
*\end{array}$ & $\begin{array}{c}\text { * } \\
2.63 \\
3.24 \\
* \\
*\end{array}$ & $\begin{array}{r}\text { * } \\
.03 \\
.98 \\
8.92 \\
8.67\end{array}$ & $\begin{array}{c}9.33 \\
- \\
- \\
- \\
-\end{array}$ & $\begin{array}{l}9.88 \\
6.08 \\
5.65 \\
8.92 \\
8.67\end{array}$ \\
\hline 57 & Sudbury Dam t+ $\underline{f} /$ & - & .94 & - & .50 & - & .62 & 3.09 & 1.12 & 2.20 & .26 & - & 7.29 \\
\hline
\end{tabular}

* Includea in following measurement.

* Measured at midnight.

*** Measured at irregular times.

+ Heasured in morning of day inácated.

t+ Measured in morning after day indicated.

u Record missing.

a Corps of Engineers, U. S. Arky.

b Public Service Co. of Nem Hempshire.

c U. S. Geological Survey.

d Charles L. Thittle.

Mssachusetts Depertment of Public Health.

$f$ Metropolitan District Comission.

g City Fngineer, Haverhill, Mass.

h Proprietors of the Locks and Canals on Merrimack RIver. 
Table 4.--Daily precipitation, in inches, September 12-22, 1938--Continued (Measured in the afternoon except as noted)

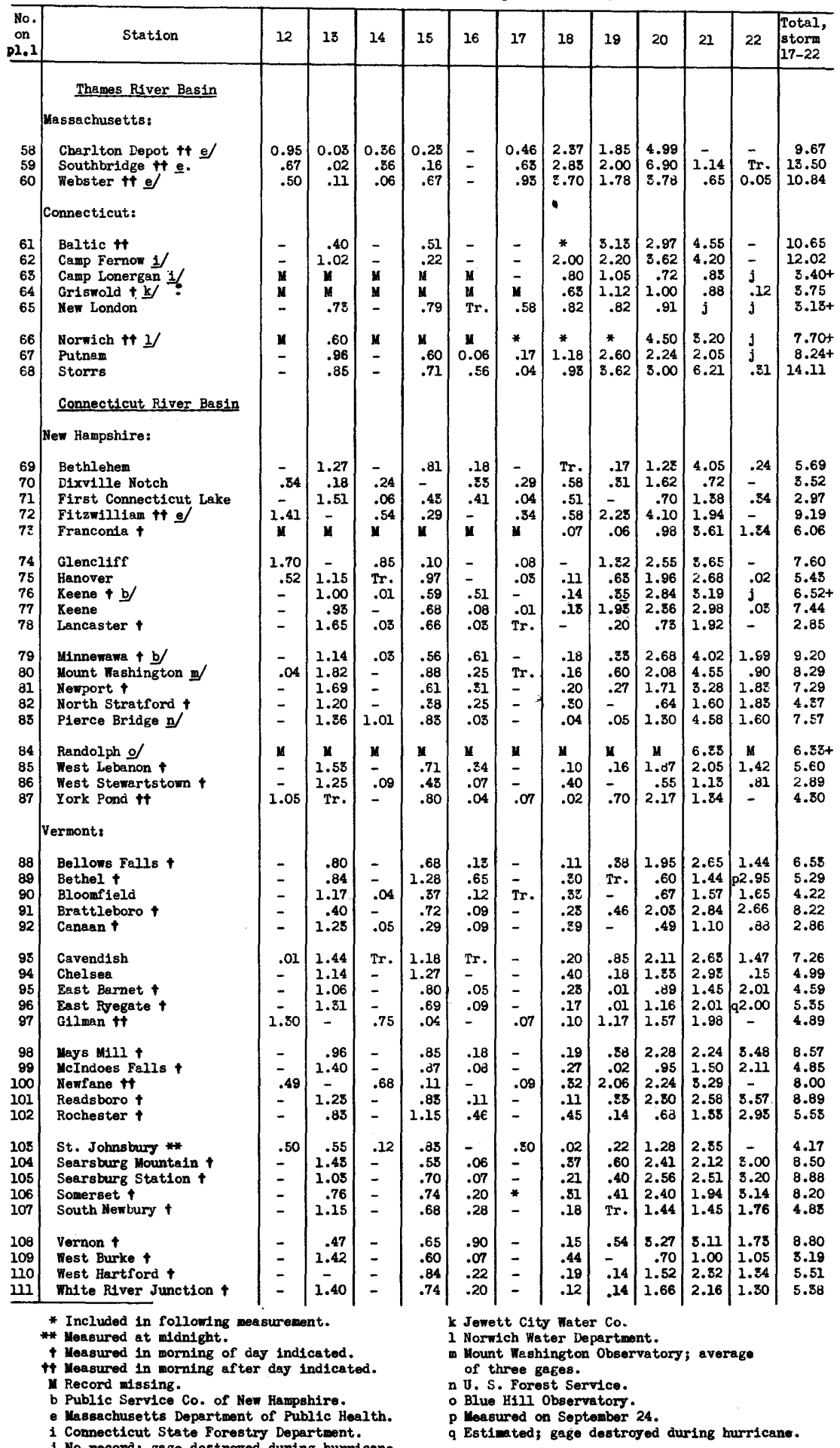

j No record; gage destroyed during hurricane. 
Table 4.--Da11y precipitation, in inches, September 12-22, 1938--Continued (Measured in the afternoon except as noted)

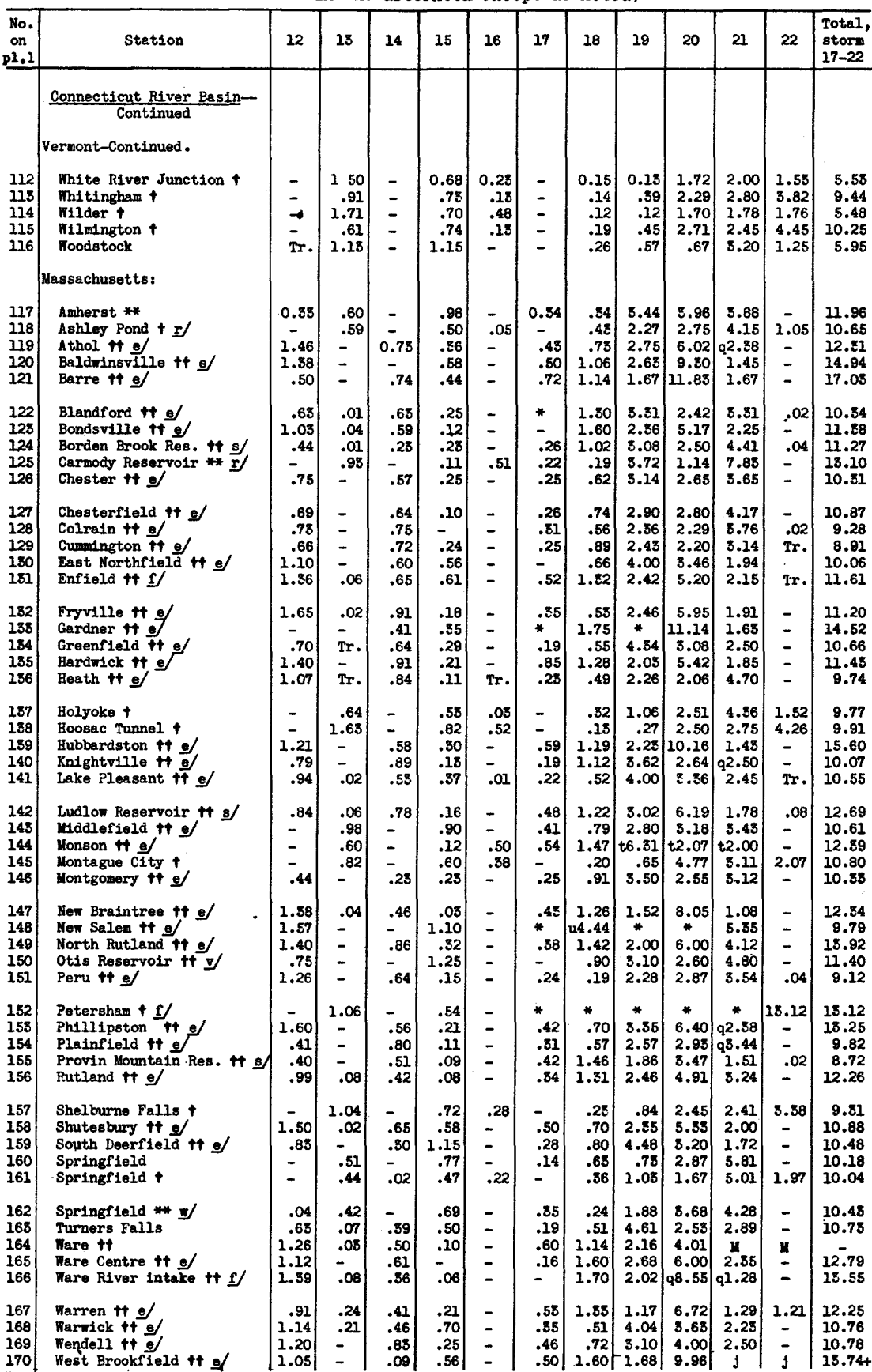

* Included in following measurement.

* Meesured at midnight.

Heasured in worning of day 1ndicated.

t Yeasured in morning after day indicated.

- Massachusetts Department of Public Health.

f Uotropolitan District Conmission.

j No record gage destroyed during murricane.

q Estinated; gage destroyed during hurricane.

C1ty of Holyoke, Hater Department.

- Springrield mater Norks.

t Totel catch correct; distribution estimated.

u Messured 1:30 p.m., Septenber 19.

v Collins Co., Collinsville, Com.

- City of Springfield, Department of Streets and Engineering. 
Table 4.--Daily precipitation, In Inches, September 12-22, 1938--Continued (Measured in the afternoon except as noted)

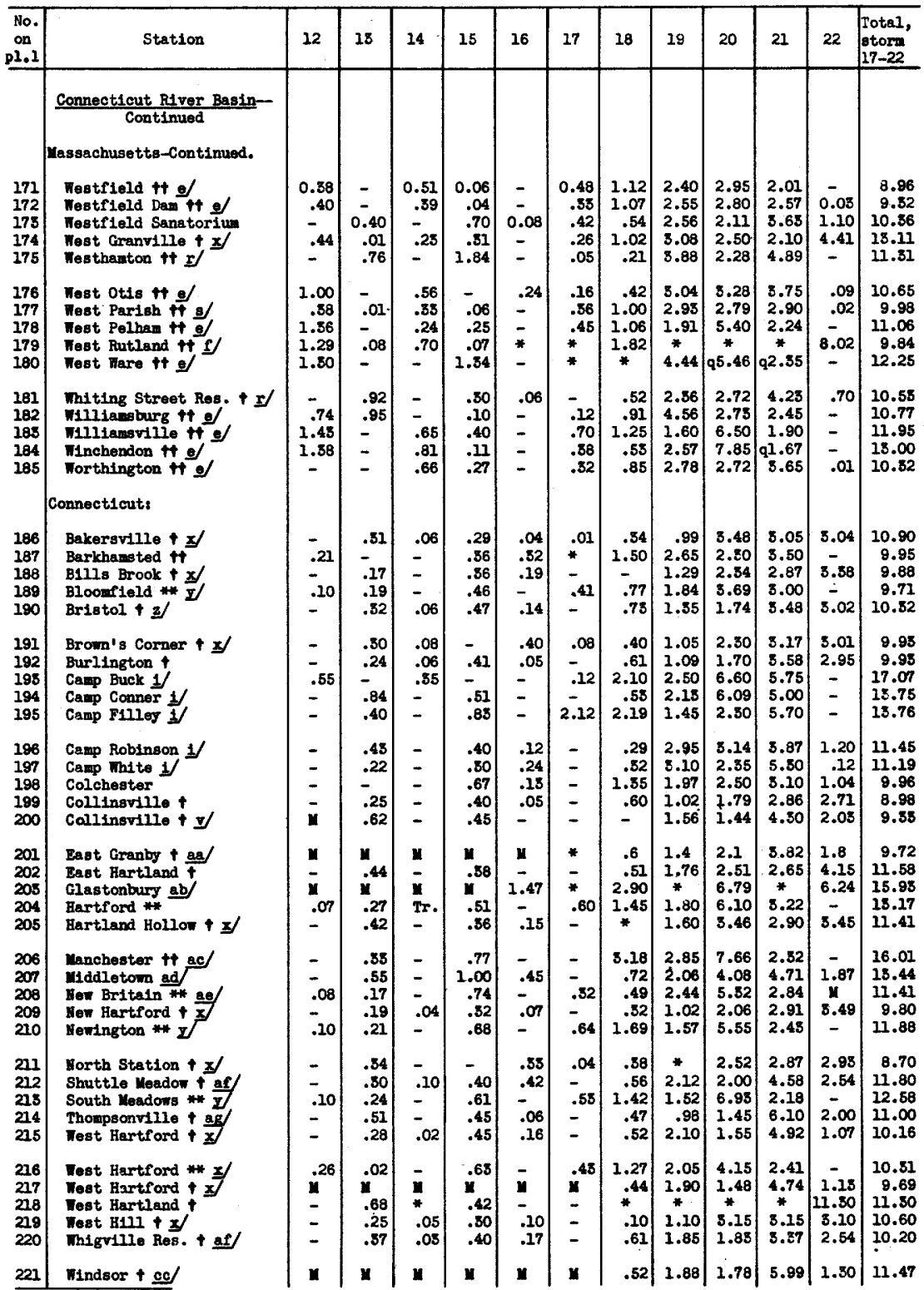

* Included in following measurement.

* Vessured at midnight.

t Measured in morning of day indicated.

t+ Measured in morning after day indicated.

it Record missing.

- Messachusetts Departnent of Public Health.

$f$ Hetropolitan District Comission.

1 Comnecticut State Forestry Departient.

q Estipated; gage destroyed during hurricane.

r c1ty of Holyoke, Nater Department.

B Springfield Nater Vorks.

$\checkmark$ Collins Co., Collinsville, Corm.

$x$ Hartford Metropolitan Nater Bureau.

y Hartford Flood Invest1gation and Improvenent Comission or City Engineer, Hartford, Conn.

2 Bristol Nater Co., Bristol, Conn.

a Hartford Electric Hight Co.

ab F. H. Parker, Manchester, Conn.

ac Manchester Water Co., Nanchester, Conn.

ad C1ty of Hiddletom; moasured at noon.

ae CIty Engineer, New Britain, Conn. Ho record

after 7 p.e., Sept. 21 ; pen blew off chart.

Weather for Sept. 22 roported clear.

af Mer Britain Water Co., Hew Britain, Conn.

ag Connecticut Iight a Power Co.

cc Connecticut Agricultural Experimont stat1on: 
Table 4.--Daily precipitation, in inches, September 12-22, 1938--Continued (Messured in the afternoon except as noted)

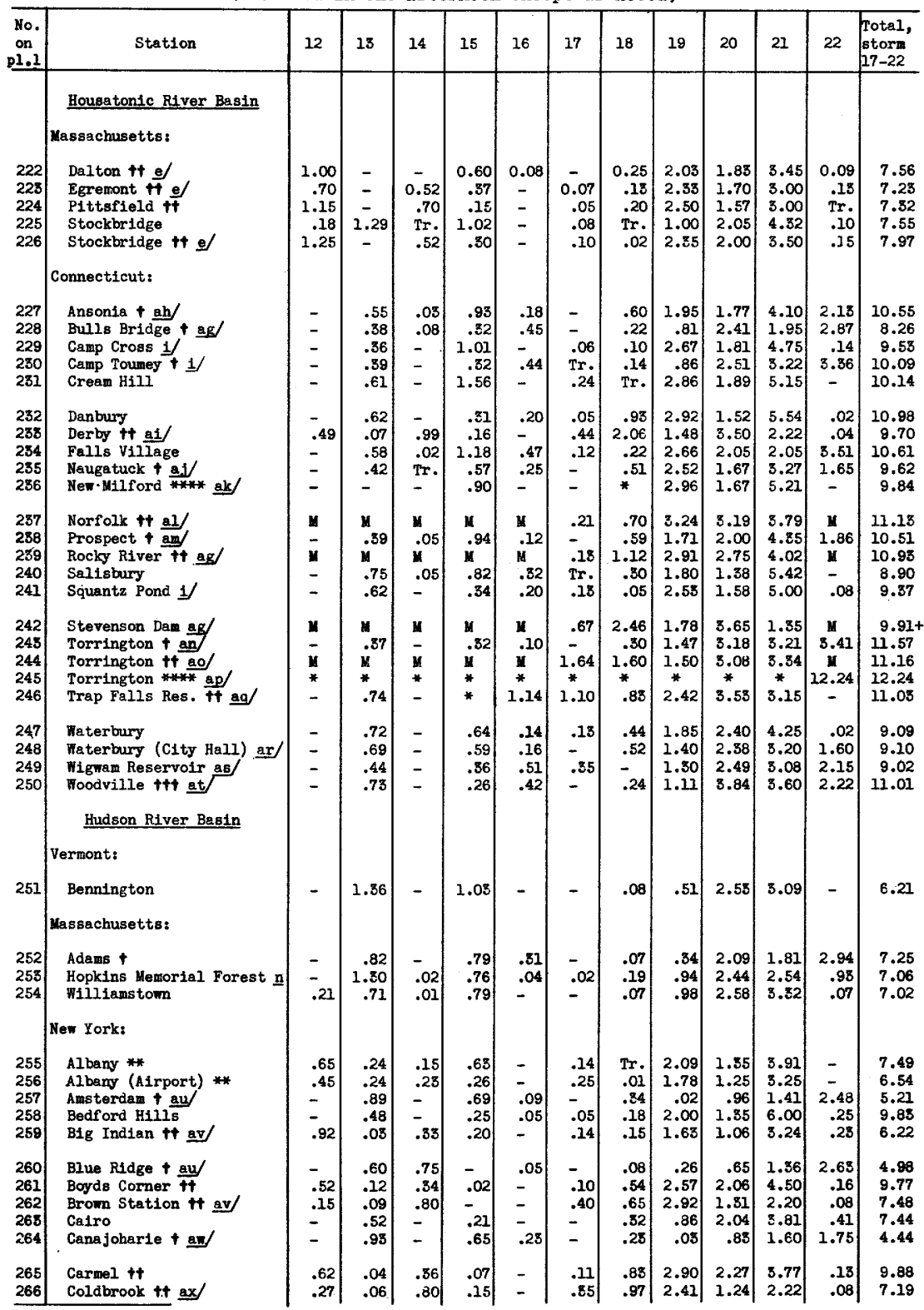

* Included in following messurement.

al Edward C. Childs.

an New Haven Fater Co., New Haven, Conn. an Torrington Register.

ao General S. H. Tadhams.

ap Torrington Water Co., Torrington, Conn. aq Bridgeport Hydraulic Co.

ar City of Waterbury; measured at noon.

as Naterbury Fater Co., Naterbury, Conn.;

measured at noon.

at City of Waterbury, Burean of Engineering.

au New York Power \& Light Corporation.

av Hew York City, Department Water Supply, Ges, and Electricity.

aw New York State Department of Public Forks.

ax Hew York C1ty Board of Water Supply. 
Table 4.--Da1ly precipitation, in inches, September 12-22, 1938--Continued (Messured in the afternoon except as noted)

\begin{tabular}{|c|c|c|c|c|c|c|c|c|c|c|c|c|c|}
\hline $\begin{array}{l}\text { No. } \\
\text { on } \\
\text { pl.1 }\end{array}$ & Station & 12 & 13 & 14 & 15 & 16 & 17 & 1B & 19 & 20 & 21 & 22 & $\begin{array}{l}\text { Total, } \\
\text { atorm } \\
17-22\end{array}$ \\
\hline & $\begin{array}{l}\frac{\text { Hudson River Basin- }}{\text { Continued }} \\
\text { New York-Continued. }\end{array}$ & & & & & & & & & & & & \\
\hline $\begin{array}{l}267 \\
268 \\
269 \\
270 \\
271\end{array}$ & $\begin{array}{l}\text { Conklingvilie t+ ay } \\
\text { Conklingville }+\frac{a u}{} \\
\text { Croton Lake t+ av/ } \\
\text { Delta }+\frac{a v}{\text { Dolgevilile }}\end{array}$ & $\begin{array}{l}0.62 \\
- \\
.46 \\
- \\
.82\end{array}$ & $\begin{array}{c}- \\
0.56 \\
.01 \\
.85 \\
-\end{array}$ & $\begin{array}{l}1.08 \\
- \\
.25 \\
- \\
-\end{array}$ & $\begin{array}{r}0.42 \\
1.02 \\
.15 \\
.55 \\
1.37\end{array}$ & $\begin{array}{l}-.48 \\
- \\
.06 \\
.86\end{array}$ & $\begin{array}{c}0.17 \\
- \\
.11 \\
- \\
-\end{array}$ & $\begin{array}{r}- \\
0.17 \\
1.00 \\
.11 \\
.36\end{array}$ & $\begin{array}{r}0.18 \\
.15 \\
2.26 \\
.07 \\
.05\end{array}$ & $\begin{array}{r}1.09 \\
.99 \\
2.11 \\
.06 \\
.71\end{array}$ & $\begin{array}{r}3.84 \\
1.70 \\
3.68 \\
.36 \\
1.40\end{array}$ & $\begin{array}{r}- \\
1.98 \\
.07 \\
1.85 \\
1.25\end{array}$ & $\begin{array}{l}5.28 \\
4.99 \\
9.16 \\
2.45 \\
3.77\end{array}$ \\
\hline $\begin{array}{l}272 \\
273 \\
274 \\
275 \\
276\end{array}$ & $\begin{array}{l}\text { East Jewett }+t \text { av } \\
\text { Edgewood }+t a v / \\
\text { Elka Park }+t a v / \\
\text { Ephratah }+a y / \\
\text { Frankfort }+a v /\end{array}$ & $\begin{array}{l}.76 \\
.65 \\
.69 \\
- \\
-\end{array}$ & $\begin{array}{l}- \\
- \\
.01 \\
.92 \\
.05\end{array}$ & $\begin{array}{l}.26 \\
.40 \\
.64 \\
- \\
-\end{array}$ & $\begin{array}{l}.14 \\
.12 \\
.79 \\
.95\end{array}$ & $\begin{array}{l}.01 \\
- \\
. \\
.31 \\
.38\end{array}$ & $\begin{array}{l}.23 \\
.25 \\
.46 \\
- \\
-\end{array}$ & $\begin{array}{r}.58 \\
.73 \\
1.43 \\
.22 \\
.15\end{array}$ & $\begin{array}{r}1.48 \\
1.86 \\
2.25 \\
.01 \\
.02\end{array}$ & $\begin{array}{r}1.60 \\
1.45 \\
1.59 \\
.91 \\
.26\end{array}$ & $\begin{array}{r}4.39 \\
3.30 \\
3.28 \\
1.24 \\
.82\end{array}$ & $\begin{array}{r}.11 \\
.30 \\
.30 \\
2.06 \\
3.10\end{array}$ & $\begin{array}{l}8.29 \\
7.59 \\
9.01 \\
4.44 \\
4.35\end{array}$ \\
\hline $\begin{array}{l}277 \\
278 \\
279 \\
280 \\
281\end{array}$ & $\begin{array}{l}\text { Glenhain }+ \\
\text { Glens Falls }+ \text { ay } \\
\text { Gloversville } \\
\text { Grahamsville }++ \text { ax } \\
\text { Grand Gorge t+ av }\end{array}$ & $\begin{array}{l}- \\
.28 \\
.24 \\
.68\end{array}$ & $\begin{array}{l}.46 \\
.61 \\
.40 \\
- \\
-\end{array}$ & $\begin{array}{l}\mathrm{Tr} \\
- \\
.08 \\
.95 \\
.26\end{array}$ & $\begin{array}{r}.81 \\
.63 \\
1.15 \\
-.28\end{array}$ & $\begin{array}{l}.05 \\
.17 \\
- \\
- \\
-\end{array}$ & $\begin{array}{l}- \\
- \\
.20 \\
.22 \\
.27\end{array}$ & $\begin{array}{l}.10 \\
.16 \\
.08 \\
.23 \\
.08\end{array}$ & $\begin{array}{r}.27 \\
.18 \\
.58 \\
2.10 \\
1.25\end{array}$ & $\begin{array}{r}3.99 \\
.89 \\
1.11 \\
1.32 \\
1.29\end{array}$ & $\begin{array}{l}1.56 \\
1.32 \\
2.83 \\
1.40 \\
3.40\end{array}$ & $\begin{array}{r}3.63 \\
1.87 \\
.18 \\
.25 \\
.24\end{array}$ & $\begin{array}{l}9.55 \\
4.42 \\
5.08 \\
5.27 \\
6.27\end{array}$ \\
\hline $\begin{array}{l}282 \\
283 \\
284 \\
285 \\
286\end{array}$ & $\begin{array}{l}\text { Greenfield Center } \\
\text { High Falls } \\
\text { Hinckley t an/ } \\
\text { Hoffaeister } \\
\text { Honk Falls }\end{array}$ & $\begin{array}{l}.25 \\
.08 \\
- \\
\mathrm{Tr} . \\
.03\end{array}$ & $\begin{array}{r}.25 \\
.20 \\
1.52 \\
1.38 \\
.28\end{array}$ & $\begin{array}{l}- \\
.01 \\
- \\
.13\end{array}$ & $\begin{array}{r}1.65 \\
.85 \\
.90 \\
.75 \\
.75\end{array}$ & $\begin{array}{l}- \\
- \\
.10 \\
.21 \\
-\end{array}$ & $\begin{array}{l}.15 \\
.27 \\
- \\
- \\
.24\end{array}$ & $\begin{array}{l}.20 \\
.07 \\
.20 \\
.20 \\
.04\end{array}$ & $\begin{array}{r}.80 \\
.65 \\
.07 \\
.07 \\
2.20\end{array}$ & $\begin{array}{r}1.55 \\
2.75 \\
.25 \\
.89 \\
1.48\end{array}$ & $\begin{array}{r}3.50 \\
2.68 \\
.68 \\
1.28 \\
2.56\end{array}$ & $\begin{array}{l}- \\
- \\
2.48 \\
2.25 \\
-\end{array}$ & $\begin{array}{l}6.20 \\
6.37 \\
8.56 \\
4.69 \\
6.52\end{array}$ \\
\hline $\begin{array}{l}287 \\
288 \\
289 \\
290 \\
291\end{array}$ & 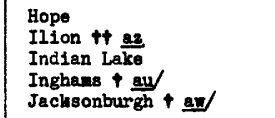 & $\begin{array}{l}- \\
- \\
-\end{array}$ & $\begin{array}{l}.67 \\
.87 \\
.47 \\
.80 \\
.80\end{array}$ & $\begin{array}{l}- \\
.98 \\
- \\
-\end{array}$ & $\begin{array}{r}1.15 \\
.16 \\
1.04 \\
1.15 \\
1.03\end{array}$ & $\begin{array}{l}.15 \\
- \\
.10 \\
.88 \\
.26\end{array}$ & $\begin{array}{l}- \\
.88 \\
- \\
-\end{array}$ & $\begin{array}{r}.27 \\
1.00 \\
.21 \\
.37 \\
.35\end{array}$ & $\begin{array}{l}.15 \\
.22 \\
.17 \\
.02 \\
.16\end{array}$ & $\begin{array}{l}.84 \\
.90 \\
.43 \\
.71 \\
.47\end{array}$ & $\begin{array}{l}1.72 \\
8.19 \\
1.99 \\
1.39 \\
1.26\end{array}$ & $\begin{array}{l}2.13 \\
2.40 \\
2.40 \\
2.58 \\
2.35\end{array}$ & $\begin{array}{l}5.09 \\
6.19 \\
5.20 \\
5.07 \\
4.59\end{array}$ \\
\hline $\begin{array}{l}292 \\
293 \\
294 \\
295 \\
296\end{array}$ & $\begin{array}{l}\text { Johnsonville ay } \\
\text { Kingston } \\
\text { Kingston } \\
\text { Lackarack + }+\mathrm{ax} / \\
\text { Lake Hill +t av/ }\end{array}$ & $\begin{array}{l}- \\
.35 \\
.02 \\
.40 \\
.47\end{array}$ & $\begin{array}{l}.85 \\
. \\
.24 \\
.02\end{array}$ & $\begin{array}{r}- \\
.75 \\
.04 \\
1.12 \\
.62\end{array}$ & $\begin{array}{l}.59 \\
.18 \\
.76 \\
. \\
.13\end{array}$ & $\begin{array}{l}.53 \\
.02 \\
- \\
-\end{array}$ & $\begin{array}{l}- \\
- \\
.22 \\
.82 \\
.42\end{array}$ & $\begin{array}{r}.25 \\
.25 \\
.51 \\
1.20 \\
.90\end{array}$ & $\begin{array}{r}.35 \\
.65 \\
2.41 \\
1.32 \\
2.65\end{array}$ & $\begin{array}{l}1.49 \\
8.20 \\
2.01 \\
1.15 \\
1.27\end{array}$ & $\begin{array}{l}1.17 \\
1.56 \\
2.98 \\
2.18 \\
2.22\end{array}$ & $\begin{array}{c}2.79 \\
2.10 \\
- \\
.28 \\
.24\end{array}$ & $\begin{array}{l}6.01 \\
7.75 \\
8.14 \\
6.17 \\
7.46\end{array}$ \\
\hline $\begin{array}{l}297 \\
298 \\
299 \\
800 \\
301\end{array}$ & $\begin{array}{l}\text { Lexington +t } \frac{\mathrm{av}}{\mathrm{No}} \\
\text { Little Falls } 1 \\
\text { Little Falle No. } 2+ \\
\text { Janor Kill tt av/ } \\
\text { Mechanicville } t\end{array}$ & $\begin{array}{l}.66 \\
.28 \\
. \\
.96\end{array}$ & $\begin{array}{l}- \\
.48 \\
.87 \\
. \\
.85\end{array}$ & $\begin{array}{l}.81 \\
.03 \\
- \\
.10 \\
-\end{array}$ & $\begin{array}{r}.25 \\
1.21 \\
1.10 \\
.42 \\
.70\end{array}$ & $\begin{array}{l}.01 \\
- \\
.40 \\
. \\
.32\end{array}$ & $\begin{array}{l}.16 \\
.21 \\
. \\
.25 \\
-\end{array}$ & $\begin{array}{l}.11 \\
.09 \\
.54 \\
.10 \\
.21\end{array}$ & $\begin{array}{r}1.42 \\
.45 \\
.01 \\
1.14 \\
.61\end{array}$ & $\begin{array}{r}1.33 \\
1.05 \\
.75 \\
1.85 \\
1.24\end{array}$ & $\begin{array}{l}3.55 \\
1.85 \\
1.38 \\
2.77 \\
1.88\end{array}$ & $\begin{array}{r}.16 \\
1.65 \\
2.85 \\
.29 \\
2.55\end{array}$ & $\begin{array}{l}6.57 \\
5.30 \\
5.31 \\
5.57 \\
5.99\end{array}$ \\
\hline $\begin{array}{l}802 \\
808 \\
804 \\
305 \\
306\end{array}$ & $\begin{array}{l}\text { Mohonk Lake } \\
\text { Morgans Mills ay/ } \\
\text { Mount McGregor } \\
\text { Newcomb }+ \text { ay/ } \\
\text { North Creek + au/ }\end{array}$ & $\begin{array}{l}- \\
.32 \\
- \\
-\end{array}$ & $\begin{array}{r}.18 \\
.86 \\
.59 \\
1.74 \\
.40\end{array}$ & $\begin{array}{l}- \\
- \\
-\end{array}$ & $\begin{array}{r}.85 \\
1.87 \\
1.30 \\
.74 \\
.71\end{array}$ & $\begin{array}{l}- \\
- \\
- \\
.14\end{array}$ & $\begin{array}{l}.10 \\
.19 \\
\mathrm{Tr} \\
- \\
-\end{array}$ & $\begin{array}{l}.26 \\
.11 \\
.30 \\
-.16\end{array}$ & $\begin{array}{l}1.72 \\
.51 \\
.25 \\
- \\
.11\end{array}$ & $\begin{array}{r}3.75 \\
1.19 \\
1.48 \\
.80 \\
.78\end{array}$ & $\begin{array}{l}8.80 \\
2.56 \\
5.01 \\
1.66 \\
1.50\end{array}$ & $\begin{array}{r}- \\
.59 \\
.78 \\
1.65 \\
2.22\end{array}$ & $\begin{array}{l}8.68 \\
5.15 \\
5.82 \\
4.09 \\
4.72\end{array}$ \\
\hline $\begin{array}{l}807 \\
308 \\
309 \\
310 \\
311\end{array}$ & $\begin{array}{l}\text { North Settlement t+ av/ } \\
\text { Morthvillet } \\
\text { Oak Hill +t ax } \\
\text { Pecks Pond +au } \\
\text { Peekanoose +t ax }\end{array}$ & $\begin{array}{l}.80 \\
.64 \\
. \\
.17\end{array}$ & $\begin{array}{l}.01 \\
.62 \\
- \\
.73 \\
-\end{array}$ & $\begin{array}{l}.22 \\
- \\
25 \\
-.82\end{array}$ & $\begin{array}{l}. \\
.98 \\
.02 \\
.96 \\
-\end{array}$ & $\begin{array}{l}.01 \\
.80 \\
. \\
. \\
-\end{array}$ & $\begin{array}{l}.15 \\
. \\
.85 \\
.48\end{array}$ & $\begin{array}{l}.20 \\
.28 \\
.18 \\
. .75\end{array}$ & $\begin{array}{r}1.59 \\
.14 \\
1.46 \\
.85 \\
8.10\end{array}$ & $\begin{array}{l}1.85 \\
1.86 \\
1.66 \\
1.10 \\
1.30\end{array}$ & $\begin{array}{l}4.18 \\
1.58 \\
2.78 \\
1.50 \\
2.30\end{array}$ & $\begin{array}{r}.88 \\
2.00 \\
.07 \\
2.12 \\
.10\end{array}$ & $\begin{array}{l}7.17 \\
5.86 \\
6.88 \\
5.05 \\
7.95\end{array}$ \\
\hline $\begin{array}{l}312 \\
813 \\
814 \\
315 \\
316\end{array}$ & $\begin{array}{l}\text { Phoentcia +t } \frac{a v /}{a v /} \\
\text { Pine Hill t+ } \\
\text { Poughkeepsie } \\
\text { Prattsville }+t \text { av } \\
\text { Preston Hollow t+ ax }\end{array}$ & $\begin{array}{l}.45 \\
.78 \\
\mathrm{Tr} . \\
.57 \\
.51\end{array}$ & $\begin{array}{l}- \\
- \\
.25 \\
-\end{array}$ & $\begin{array}{l}.36 \\
.24 \\
- \\
.24 \\
.20\end{array}$ & $\begin{array}{l}.12 \\
-. \\
.90 \\
.06 \\
.10\end{array}$ & $\begin{array}{l}- \\
\overline{-} \\
\overline{-}\end{array}$ & $\begin{array}{l}.8 I \\
.18 \\
.20 \\
.84 \\
.25\end{array}$ & $\begin{array}{l}.52 \\
.17 \\
.11 \\
.11 \\
.10\end{array}$ & $\begin{array}{l}1.75 \\
1.89 \\
1.84 \\
1.28 \\
1.40\end{array}$ & $\begin{array}{l}1.08 \\
1.10 \\
1.97 \\
1.24 \\
1.42\end{array}$ & $\begin{array}{l}2.50 \\
8.11 \\
3.37 \\
5.65 \\
2.80\end{array}$ & $\begin{array}{l}.18 \\
.12 \\
.50 \\
.17 \\
.10\end{array}$ & $\begin{array}{l}5.96 \\
5.90 \\
7.49 \\
6.62 \\
5.97\end{array}$ \\
\hline $\begin{array}{l}317 \\
318 \\
319 \\
820 \\
821\end{array}$ & $\begin{array}{l}\text { Rifton ** } \\
\text { Suliebury } \\
\text { Schaghticoke }+\frac{\mathrm{au}}{} \\
\text { Schenectady } \\
\text { Schroon Lake }+\end{array}$ & $\begin{array}{l}.08 \\
.41 \\
- \\
.24 \\
-\end{array}$ & $\begin{array}{l}.20 \\
.61 \\
.90 \\
.42 \\
.68\end{array}$ & $\begin{array}{l}.01 \\
- \\
- \\
.20 \\
\mathrm{Tr}\end{array}$ & $\begin{array}{r}.80 \\
1.85 \\
.64 \\
.92 \\
.76\end{array}$ & $\begin{array}{l}- \\
.44 \\
.10\end{array}$ & $\begin{array}{l}.29 \\
.84 \\
- \\
.28 \\
\mathrm{Tr}\end{array}$ & $\begin{array}{l}.07 \\
- \\
.20 \\
. \\
.12\end{array}$ & $\begin{array}{r}5.00 \\
.66 \\
.55 \\
.70 \\
-\end{array}$ & $\begin{array}{r}2.50 \\
1.10 \\
1.48 \\
1.81 \\
.80\end{array}$ & $\begin{array}{l}3.80 \\
2.28 \\
1.47 \\
2.86 \\
1.60\end{array}$ & $\begin{array}{l}- \\
.94 \\
2.75 \\
2.68\end{array}$ & $\begin{array}{l}9.68 \\
5.82 \\
6.88 \\
5.18 \\
5.20\end{array}$ \\
\hline $\begin{array}{l}322 \\
323 \\
324 \\
325 \\
826\end{array}$ & $\begin{array}{l}\text { Schuylerville *** ay } \\
\text { Scotia t+ ay/ } \\
\text { Sharon Springs No. } 1 \\
\text { Sharon Spring No. } 2 \\
\text { Slide Hountain } t \text { av }\end{array}$ & $\begin{array}{l}.35 \\
-.14 \\
.11 \\
.51\end{array}$ & $\begin{array}{l}.80 \\
.69 \\
.40 \\
.44 \\
.\end{array}$ & $\begin{array}{l}.17 \\
- \\
.04 \\
.05 \\
.64\end{array}$ & $\begin{array}{l}.70 \\
.85 \\
.82 \\
.84 \\
.16\end{array}$ & $\begin{array}{l}- \\
- \\
-\end{array}$ & $\begin{array}{l}.57 \\
.41 \\
.10 \\
.08 \\
.18\end{array}$ & $\begin{array}{l}.08 \\
.08 \\
.12 \\
.10 \\
.42\end{array}$ & $\begin{array}{r}1.88 \\
1.80 \\
.20 \\
.86 \\
.60\end{array}$ & $\begin{array}{r}2.10 \\
1.90 \\
1.14 \\
.70 \\
1.04\end{array}$ & $\begin{array}{l}2.11 \\
1.90 \\
3.75 \\
2.80 \\
3.58\end{array}$ & $\begin{array}{l}.02 \\
.11 \\
.50 \\
.42 \\
.45\end{array}$ & $\begin{array}{l}6.01 \\
5.59 \\
5.81 \\
4.47 \\
5.77\end{array}$ \\
\hline
\end{tabular}

* Messured at aldnight.

* Heasured at II P.i.

- Measured in mornisg of dey Indicated.

t+ Heasured in morning after day Indicated. tt+ Measured at 11 a.m.

au Hew York Power \& Light Corporation.

av Iew York C1ty, Department Vater Supply,

aw New York State Departwent of Public Forks.

$\mathrm{ax}$ Hew York City Board of Water Supply.

y bueson River Regulating Distritct.

as CIty Engineer, Ilion, $\mathrm{M}$. I.

be City Engineer, Kingston, M. I.

bb CIty of Schenectedy.

Cas, and mectricity. 
Table 4.--Daily precipitation, In Inches, September 12-22, 1938--Continued (Measured in the afternoon except as noted)

\begin{tabular}{|c|c|c|c|c|c|c|c|c|c|c|c|c|c|}
\hline $\begin{array}{l}\text { No. } \\
\text { on } \\
\text { pl.1 }\end{array}$ & Station & 12 & 13 & 14 & 15 & 16 & 17 & 18 & 19 & 20 & 21 & 22 & $\begin{array}{l}\text { Total, } \\
\text { storn } \\
17-22\end{array}$ \\
\hline & $\begin{array}{l}\frac{\text { Hudson River Basin-- }}{\text { Continued }} \\
\text { New York--Continued. }\end{array}$ & & & & & & & & & & & & \\
\hline $\begin{array}{l}327 \\
328 \\
329 \\
850 \\
831\end{array}$ & $\begin{array}{l}\text { Southeast Reservolr }+ \\
\text { Speculator }+ \text { ouy } \\
\text { Spier Falls } \\
\text { Sprite Creek }+ \text { ay } \\
\text { Stewart's Landing }+ \text { au }\end{array}$ & $\begin{array}{l}0.51 \\
1.08 \\
.02 \\
- \\
-\end{array}$ & $\begin{array}{r}0.02 \\
- \\
.88 \\
.87 \\
1.10\end{array}$ & $\begin{array}{r}0.26 \\
.62 \\
- \\
- \\
-\end{array}$ & $\begin{array}{l}0.18 \\
- \\
.98 \\
1.14 \\
1.30\end{array}$ & $\begin{array}{l}- \\
0.08 \\
- \\
.29 \\
.28\end{array}$ & $\begin{array}{l}0.21 \\
- \\
.05 \\
- \\
-\end{array}$ & $\begin{array}{r}1.84 \\
.16 \\
.19 \\
.41 \\
.49\end{array}$ & $\begin{array}{r}2.49 \\
.28 \\
.38 \\
.09 \\
.19\end{array}$ & $\begin{array}{r}2.44 \\
.60 \\
1.42 \\
.68 \\
.71\end{array}$ & $\begin{array}{l}5.64 \\
1.80 \\
3.10 \\
1.49 \\
1.68\end{array}$ & $\begin{array}{r}0.07 \\
2.00 \\
.62 \\
2.56 \\
2.75\end{array}$ & $\begin{array}{r}10.12 \\
4.84 \\
5.76 \\
5.25 \\
.5 .82\end{array}$ \\
\hline $\begin{array}{l}332 \\
355 \\
334 \\
335 \\
336\end{array}$ & $\begin{array}{l}\text { Sundown }+\mathrm{ax} \\
\text { Tannersville }+\mathrm{av} / \\
\text { Trenton Falls t+ } \\
\text { Tribes Hill }+ \\
\text { Utica }+\end{array}$ & $\begin{array}{l}.40 \\
.58 \\
1.19 \\
- \\
-\end{array}$ & $\begin{array}{l}- \\
- \\
. \\
.79 \\
.64\end{array}$ & $\begin{array}{l}.32 \\
.35 \\
.81 \\
- \\
-\end{array}$ & $\begin{array}{r}- \\
.18 \\
.11 \\
1.09 \\
.82\end{array}$ & $\begin{array}{l}- \\
- \\
- \\
.03 \\
.58\end{array}$ & $\begin{array}{l}.57 \\
.25 \\
.20 \\
- \\
-\end{array}$ & $\begin{array}{l}.90 \\
.78 \\
.21 \\
.32 \\
.18\end{array}$ & $\begin{array}{r}2.18 \\
1.98 \\
.24 \\
- \\
.08\end{array}$ & $\begin{array}{r}1.17 \\
1.42 \\
.62 \\
1.20 \\
.22\end{array}$ & $\begin{array}{r}1.89 \\
5.66 \\
2.79 \\
1.80 \\
.73\end{array}$ & $\begin{array}{r}- \\
.18 \\
.45 \\
2.60 \\
3.02\end{array}$ & $\begin{array}{l}6.71 \\
8.07 \\
4.06 \\
5.42 \\
4.18\end{array}$ \\
\hline $\begin{array}{l}\mathbf{3 8 7} \\
\mathbf{5 5 8} \\
\mathbf{3 8 9} \\
\mathbf{3 4 0} \\
\mathbf{3 4 1}\end{array}$ & $\begin{array}{l}\text { Voorbearlile be/ } \\
\text { Walden } \\
\text { Fappingers Falls } \\
\text { Farrensburg }+ \text { aud } \\
\text { Warwick }\end{array}$ & $\begin{array}{l}.45 \\
.08 \\
- \\
- \\
-\end{array}$ & $\begin{array}{l}.28 \\
.81 \\
.82 \\
.80 \\
.51\end{array}$ & $\begin{array}{l}.03 \\
\overline{T r} . \\
-\end{array}$ & $\begin{array}{l}.21 \\
.98 \\
.64 \\
.95 \\
.71\end{array}$ & $\begin{array}{l}- \\
- \\
.40 \\
-\end{array}$ & $\begin{array}{l}.22 \\
.17 \\
.07 \\
- \\
.15\end{array}$ & $\begin{array}{l}- \\
.07 \\
.03 \\
.20 \\
.12\end{array}$ & $\begin{array}{r}1.85 \\
2.30 \\
1.98 \\
.25 \\
1.15\end{array}$ & $\begin{array}{l}1.46 \\
2.52 \\
2.16 \\
1.10 \\
2.78\end{array}$ & $\begin{array}{l}4.02 \\
5.85 \\
4.18 \\
1.70 \\
4.75\end{array}$ & $\begin{array}{c}- \\
- \\
.07 \\
2.80 \\
.07\end{array}$ & $\begin{array}{l}7.65 \\
8.41 \\
8.49 \\
6.05 \\
8.97\end{array}$ \\
\hline $\begin{array}{l}342 \\
348 \\
344 \\
345 \\
346\end{array}$ & 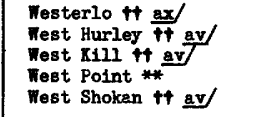 & $\begin{array}{l}.75 \\
.41 \\
.91 \\
.03 \\
.22\end{array}$ & $\begin{array}{l}- \\
- \\
.47 \\
-\end{array}$ & $\begin{array}{l}.32 \\
.70 \\
.44 \\
- \\
.87\end{array}$ & $\begin{array}{l}.10 \\
.02 \\
.17 \\
.49 \\
-\end{array}$ & $\begin{array}{l}- \\
- \\
.02 \\
-\end{array}$ & $\begin{array}{l}.80 \\
.85 \\
.16 \\
.03 \\
.49\end{array}$ & $\begin{array}{r}.25 \\
.60 \\
.18 \\
.21 \\
1.03\end{array}$ & $\begin{array}{l}1.59 \\
3.35 \\
1.41 \\
2.79 \\
2.05\end{array}$ & $\begin{array}{l}1.45 \\
1.28 \\
1.25 \\
1.95 \\
1.22\end{array}$ & $\begin{array}{l}8.30 \\
1.98 \\
5.57 \\
3.95 \\
2.00\end{array}$ & $\begin{array}{l}.12 \\
.14 \\
.81 \\
-.28\end{array}$ & $\begin{array}{l}6.89 \\
7.56 \\
6.30 \\
8.98 \\
6.79\end{array}$ \\
\hline 347 & $\begin{array}{l}\text { Windhem tt av/ } \\
\frac{\text { Hackensack, Passeic, and }}{\text { Raritan River Bagins }} \\
\text { New York: }\end{array}$ & .76 & - & .81 & .11 & .01 & .25 & .15 & 1.27 & 1.48 & 4.07 & .27 & 7.22 \\
\hline $\begin{array}{l}348 \\
\mathbf{3 4 9}\end{array}$ & $\begin{array}{l}\text { Palisedes Park *** a/ } \\
\text { Southfield ** a/ } \\
\text { New Jersey: }\end{array}$ & $\overline{-}$ & $\begin{array}{l}.89 \\
.30\end{array}$ & - & $\begin{array}{l}.44 \\
.48\end{array}$ & .07 & $\begin{array}{l}.10 \\
.19\end{array}$ & $\begin{array}{l}.07 \\
.06\end{array}$ & $\begin{array}{l}2.47 \\
2.80\end{array}$ & $\begin{array}{l}2.36 \\
2.10\end{array}$ & $\begin{array}{l}8.94 \\
4.28\end{array}$ & $\overline{-}$ & $\begin{array}{l}8.94 \\
9.48\end{array}$ \\
\hline $\begin{array}{l}\mathbf{8 5 0} \\
\mathbf{5} 51 \\
\mathbf{3 5 2} \\
\mathbf{3 5 5} \\
\mathbf{3 5 4}\end{array}$ & 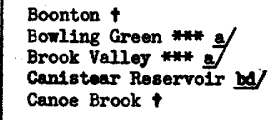 & $\begin{array}{l}- \\
- \\
-\end{array}$ & $\begin{array}{l}.01 \\
.06 \\
.08 \\
.20 \\
.12\end{array}$ & $\begin{array}{l}.04 \\
- \\
- \\
-\end{array}$ & $\begin{array}{l}.29 \\
.55 \\
.24 \\
- \\
.11\end{array}$ & $\begin{array}{l}\text { Tr. } \\
.01 \\
- \\
.50 \\
.02\end{array}$ & $\begin{array}{l}- \\
.10 \\
.11 \\
-\end{array}$ & $\begin{array}{l}.10 \\
- \\
.05 \\
.50 \\
.15\end{array}$ & $\begin{array}{r}.15 \\
2.24 \\
2.40 \\
1.20 \\
.20\end{array}$ & $\begin{array}{l}3.88 \\
2.00 \\
2.57 \\
2.90 \\
5.95\end{array}$ & $\begin{array}{l}1.21 \\
8.88 \\
8.41 \\
4.60 \\
1.82\end{array}$ & $\begin{array}{c}2.84 \\
.06 \\
- \\
.10 \\
2.97\end{array}$ & $\begin{array}{l}7.68 \\
8.22 \\
8.54 \\
9.80 \\
9.09\end{array}$ \\
\hline $\begin{array}{l}\mathbf{8 5 5} \\
\mathbf{5 5 6} \\
\mathbf{5 5 7} \\
\mathbf{3 5 8} \\
\mathbf{5 5 9}\end{array}$ & $\begin{array}{l}\text { Cedar Grove Res. }+\mathrm{bd} \\
\text { Charlotteburg ba/ } \\
\text { Chatham }+ \\
\text { Dover } \\
\text { Flenington }\end{array}$ & $\begin{array}{l}- \\
\bar{z} \\
\bar{z}\end{array}$ & $\begin{array}{l}.25 \\
.02 \\
.05 \\
.10 \\
.40\end{array}$ & $\begin{array}{l}.02 \\
- \\
.11 \\
.02 \\
\mathrm{Tr}\end{array}$ & $\begin{array}{l}.43 \\
.60 \\
.16 \\
.28 \\
.08\end{array}$ & $\begin{array}{l}.77 \\
.03 \\
.02 \\
- \\
-\end{array}$ & $\begin{array}{l}-.18 \\
.18 \\
.82 \\
.14\end{array}$ & $\begin{array}{l}.15 \\
.10 \\
.18 \\
.14 \\
.08\end{array}$ & $\begin{array}{r}.35 \\
.58 \\
.24 \\
4.50 \\
2.68\end{array}$ & $\begin{array}{r}2.86 \\
2.36 \\
4.48 \\
.56 \\
2.34\end{array}$ & $\begin{array}{l}1.84 \\
\$ .51 \\
1.42 \\
2.20 \\
. .66\end{array}$ & $\begin{array}{c}3.09 \\
.28 \\
5.41 \\
.08 \\
-\end{array}$ & $\begin{array}{l}8.29 \\
7.01 \\
9.78 \\
7.78 \\
8.90\end{array}$ \\
\hline $\begin{array}{l}860 \\
561 \\
362 \\
565 \\
864\end{array}$ & $\begin{array}{l}\text { Freehold } \\
\text { Freehold No. R-1 ** be/ } \\
\text { Freehold Ho: R-2 ** be/ } \\
\text { Freehold No: R-3 * } \mathrm{be} / \\
\text { Freehold No: R-4 ** be/ }\end{array}$ & $\begin{array}{l}\overline{\mathbf{u}} \\
\mathbf{u} \\
\mathbf{u}\end{array}$ & $\begin{array}{c}.15 \\
u \\
u\end{array}$ & $\begin{array}{l}\bar{u} \\
\mathbf{u} \\
\mathbf{u}\end{array}$ & $\begin{array}{l}\dot{4} \\
\dot{u} \\
\dot{u}\end{array}$ & $\begin{array}{l}\overline{\mathbf{u}} \\
\mathbf{u} \\
\mathbf{u}\end{array}$ & $\begin{array}{l}.19 \\
.15 \\
.15 \\
.10 \\
.17\end{array}$ & $\begin{array}{l}.28 \\
.52 \\
.38 \\
.41 \\
.52\end{array}$ & $\begin{array}{r}1.38 \\
1.05 \\
.75 \\
.78 \\
1.08\end{array}$ & $\begin{array}{l}.80 \\
1.89 \\
2.28 \\
2.11 \\
1.95\end{array}$ & $\begin{array}{l}8.68 \\
5.00 \\
6.01 \\
4.19 \\
4.56\end{array}$ & $\begin{array}{l}- \\
\overline{-} \\
-\end{array}$ & $\begin{array}{l}8.45 \\
8.61 \\
7.57 \\
7.58 \\
6.26\end{array}$ \\
\hline $\begin{array}{l}365 \\
566 \\
367 \\
568 \\
369\end{array}$ & $\begin{array}{l}\text { Freehold No: R-5 ** be/ } \\
\text { Freehold No. R-6 ** be/ } \\
\text { Freehold No. R-7 ** be/ } \\
\text { Greenwood Lake }+ \text { bf } \\
\text { Hightstomn }\end{array}$ & $\begin{array}{l}\mathbf{y} \\
\mathbf{u} \\
.14 \\
-\end{array}$ & $\begin{array}{l}u \\
\mathbf{u} \\
\mathbf{u} \\
-26\end{array}$ & $\begin{array}{l}M \\
M \\
.45 \\
-\end{array}$ & $\begin{array}{l}u \\
u \\
.04 \\
.40\end{array}$ & $\begin{array}{l}\mathbf{u} \\
\mathbf{u} \\
\mathbf{u} \\
. \\
.22\end{array}$ & $\begin{array}{l}.15 \\
.07 \\
.12 \\
.18 \\
.22\end{array}$ & $\begin{array}{l}.48 \\
.24 \\
.19 \\
.20 \\
.10\end{array}$ & $\begin{array}{r}.99 \\
.83 \\
.82 \\
5.11 \\
1.73\end{array}$ & $\begin{array}{l}1.98 \\
2.49 \\
2.42 \\
1.21 \\
2.92\end{array}$ & $\begin{array}{l}4.86 \\
4.79 \\
4.74 \\
2.85 \\
4.85\end{array}$ & $\begin{array}{l}- \\
\overline{-} \\
.07\end{array}$ & $\begin{array}{l}8.46 \\
8.48 \\
8.29 \\
7.60 \\
9.32\end{array}$ \\
\hline $\begin{array}{l}570 \\
571 \\
572 \\
575 \\
874\end{array}$ & $\begin{array}{l}\text { Little ralls } \\
\text { Long Valley } \\
\text { Wacopin Intake } \uparrow \mathrm{ba} \\
\text { Wahwah * o/ } \\
\text { Willington *** a }\end{array}$ & $\begin{array}{l}- \\
- \\
-\end{array}$ & $\begin{array}{l}.09 \\
.12 \\
.08 \\
. \\
.12\end{array}$ & $\begin{array}{l}.01 \\
- \\
- \\
-\end{array}$ & $\begin{array}{l}.29 \\
.58 \\
.86 \\
.25 \\
-\end{array}$ & $\begin{array}{l}.52 \\
- \\
-\end{array}$ & $\begin{array}{l}- \\
.05 \\
.12 \\
.02\end{array}$ & $\begin{array}{l}.18 \\
.18 \\
.21 \\
.07 \\
.18\end{array}$ & $\begin{array}{r}.28 \\
1.05 \\
.34 \\
2.75 \\
2.59\end{array}$ & $\begin{array}{l}2.86 \\
2.40 \\
4.00 \\
2.10 \\
2.25\end{array}$ & $\begin{array}{l}1.68 \\
5.80 \\
1.15 \\
5.02 \\
5.89\end{array}$ & $\begin{array}{r}2.58 \\
.05 \\
2.72 \\
- \\
-\end{array}$ & $\begin{array}{l}7.55 \\
7.48 \\
8.42 \\
8.06 \\
8.86\end{array}$ \\
\hline $\begin{array}{l}375 \\
576 \\
577 \\
378 \\
579\end{array}$ & $\begin{array}{l}\text { Milton }+\mathrm{bg} / \\
\text { Morristom ** bh/ } \\
\text { Morristom Res. } \\
\text { New Brunswick } \\
\text { New Milford ** }\end{array}$ & $\begin{array}{l}\overline{-} \\
\overline{-} \\
\overline{-}\end{array}$ & $\begin{array}{l}.05 \\
- \\
.14 \\
.12 \\
.05\end{array}$ & $\begin{array}{l}- \\
- \\
- \\
-\end{array}$ & $\begin{array}{l}.54 \\
.21 \\
.16 \\
.07 \\
.76\end{array}$ & $\begin{array}{l}.07 \\
- \\
.12 \\
-\end{array}$ & $\begin{array}{l}- \\
.08 \\
.28 \\
.25 \\
.09\end{array}$ & $\begin{array}{l}.24 \\
.02 \\
.08 \\
.10 \\
.22\end{array}$ & $\begin{array}{r}.24 \\
2.10 \\
.75 \\
1.82 \\
1.13\end{array}$ & $\begin{array}{l}4.56 \\
1.82 \\
2.84 \\
2.18 \\
1.98\end{array}$ & $\begin{array}{l}1.04 \\
2.20 \\
3.70 \\
4.81 \\
5.61\end{array}$ & $\begin{array}{c}8.56 \\
- \\
.05 \\
- \\
-\end{array}$ & $\begin{array}{l}9.54 \\
6.17 \\
7.15 \\
9.16 \\
7.01\end{array}$ \\
\hline
\end{tabular}

** Measured at midinight.

*** Measured at 11 p.m.

+ Measured in norning of day Indicated.

tt Measured in morning after day indicated.

4 Record visaing.

a Corpe of Engineers, J. S. Arw.

au Hew York Power \& Light Corporation.

av New York C1ty, Deperteont Water Supply.

Gas, and Electricity.

ax New York CIty Board of Mater Supply.

be Robert $\mathbf{s}$. Horton.

be C1ty of Ilowark, N. J., Department of Public Affatre.

bo 0.8 . Departeent of Acriculture, Soil Conservetion Service.

bf North Jersey Dietiriet Weter Supply Conission.

og Departaent of Publlo Iorke, Jersey C1ty, H. J.

bh Town Englnier, Norribtown, H. J. 
Table 4.--Da1ly precipitation, in Inches, September. 12-22, 1938--Continued (Measured in the efternoon except as noted)

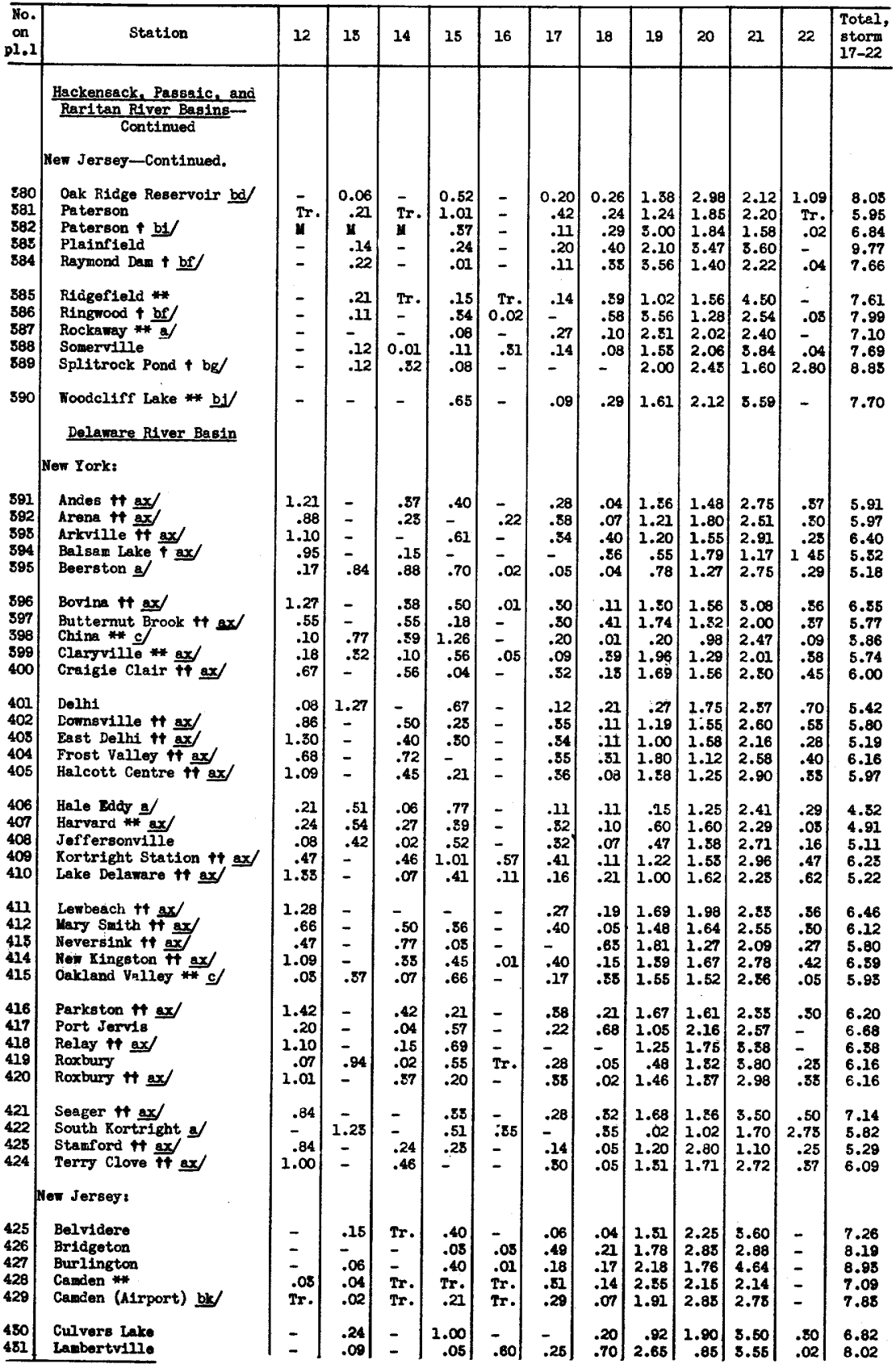

* Measured at midntght.

+ Measured in norning of day indicated.

t+ leasured in morning after day indicated.

If Record missing.

a Corps of Engineors, 0. S. Arm .

c D. S. Geologtcel Surveg.

ax Hew York City Board of Water Supply.

bd City of Newark, N. J., Eepartinent of Public Affairs. bf North Jersey District Water Supply Comedselon. bg Depertment of Public Works, Jersey C1ty, M. J bi Soc1ety for the Establishnent of Jeeful Vanufactures.

bj Hackensack water Co., Weehawken, A. J.

bk Meesured at 1,50 a.... and credited to preceding day. 
Table 4.--Daily precipitation, in inches, September 12-22, 1938--Continued (Messured in the afternoon except as noted)

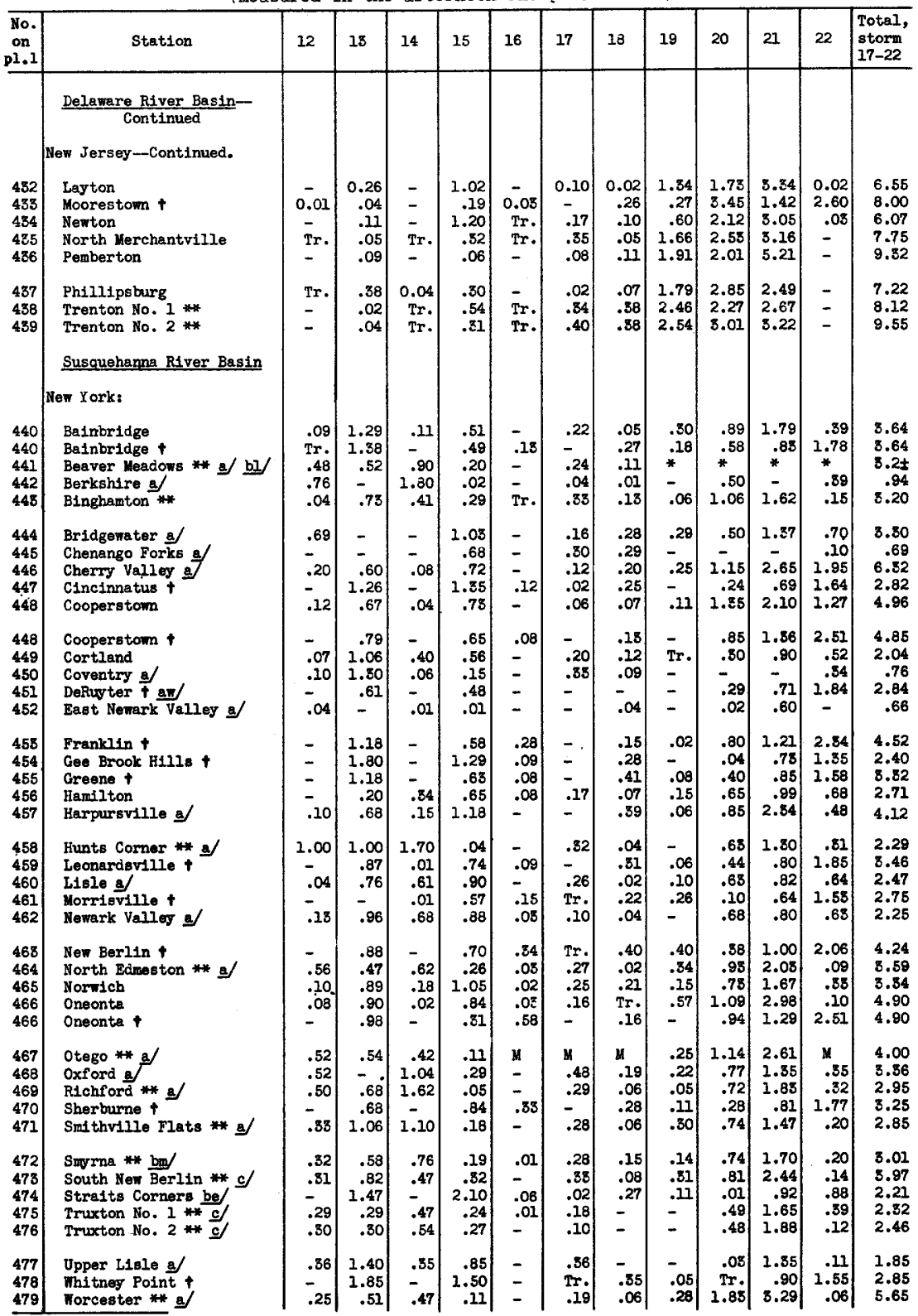

* Included in following measurement. * Heasured at midnight.

+ Measured in morning of day indicated.

- Corps of Engineers, U. S. ATry.

c U. S. Geological Survey. an New York State Department of Public Works.

be 0 . S. Departwent of Agriculture, Soll Conservation Service.

bl $\mathbf{3 . 0 0}$ Inches eseasured Sept. 26.

ba Chenango Experimental Forest. 
Table 4.--Daily precipitation, in inches, September 12-22, 1938--Continued (Measured in the aftermoon except as noted)

\begin{tabular}{|c|c|c|c|c|c|c|c|c|c|c|c|c|c|}
\hline $\begin{array}{l}\text { No. } \\
\text { on } \\
\text { pl.1 }\end{array}$ & Station & 12 & 18 & 14 & 3.5 & 16 & 17 & 18 & 19 & 20 & 21 & 22 & $\begin{array}{l}\text { Total, } \\
\text { storm } \\
17-22\end{array}$ \\
\hline & $\begin{array}{l}\text { St. Lamrence River Basin } \\
\text { Vermont: }\end{array}$ & & & & & & & & & & & & \\
\hline $\begin{array}{l}480 \\
481 \\
482 \\
483 \\
484\end{array}$ & $\begin{array}{l}\text { Barre }+ \text { bn } \\
\text { Burlington } \\
\text { Cornwall } \\
\text { Craftsbury Common } \\
\text { Enosburg Falls }\end{array}$ & $\begin{array}{l}- \\
0.69 \\
- \\
.10 \\
\mathrm{Tr} .\end{array}$ & $\begin{array}{r}1.05 \\
.46 \\
1.65 \\
.95 \\
1.93\end{array}$ & $\begin{array}{l}0.01 \\
.13 \\
- \\
\overline{T r} .\end{array}$ & $\begin{array}{r}0.73 \\
.11 \\
.72 \\
.67 \\
.24\end{array}$ & $\begin{array}{l}0.07 \\
\operatorname{Tr} . \\
- \\
\operatorname{Tr} . \\
-\end{array}$ & $\begin{array}{l}- \\
0.04 \\
- \\
.03 \\
.08\end{array}$ & $\begin{array}{l}\text { * } \\
\text { Tr. } \\
- \\
0.07 \\
.09\end{array}$ & $\begin{array}{r}0.52 \\
.38 \\
.20 \\
.12 \\
.12\end{array}$ & $\begin{array}{r}0.52 \\
.83 \\
1.08 \\
.87 \\
.55\end{array}$ & $\begin{array}{l}1.26 \\
2.85 \\
1.88 \\
1.60 \\
1.89\end{array}$ & $\begin{array}{l}1.94 \\
- \\
1.12 \\
.30 \\
.88\end{array}$ & $\begin{array}{l}4.24 \\
4.10 \\
4.28 \\
2.99 \\
3.61\end{array}$ \\
\hline $\begin{array}{l}485 \\
486 \\
487 \\
488 \\
489\end{array}$ & $\begin{array}{l}\text { Essex }+\frac{b n}{} \\
\text { Marshfield }+\frac{b_{n}}{\text { Middlesex }}+\underline{b n} \\
\text { Montpelier }+\frac{b_{n}}{\text { Newport }} \\
\text { N }\end{array}$ & $\begin{array}{l}- \\
\overline{-} \\
\overline{\mathrm{Tr}}\end{array}$ & $\begin{array}{r}1.28 \\
1.02 \\
.98 \\
.88 \\
1.00\end{array}$ & $\begin{array}{l}- \\
- \\
.02 \\
-\end{array}$ & $\begin{array}{l}.24 \\
.66 \\
.78 \\
.66 \\
.60\end{array}$ & $\begin{array}{l}.02 \\
.13 \\
.39 \\
.05 \\
-\end{array}$ & $\begin{array}{l}- \\
- \\
- \\
.01\end{array}$ & $\begin{array}{l}.04 \\
.45 \\
.07 \\
.25 \\
.10\end{array}$ & $\begin{array}{l}.45 \\
. \\
.16 \\
.04 \\
\mathrm{Tr} .\end{array}$ & $\begin{array}{l}.27 \\
.56 \\
.61 \\
.56 \\
.57\end{array}$ & $\begin{array}{l}1.20 \\
1.03 \\
1.07 \\
1.05 \\
1.19\end{array}$ & $\begin{array}{l}2.80 \\
1.48 \\
2.20 \\
1.47 \\
-\end{array}$ & $\begin{array}{l}4.76 \\
5.52 \\
4.11 \\
3.57 \\
1.87\end{array}$ \\
\hline $\begin{array}{l}490 \\
491 \\
492\end{array}$ & $\begin{array}{l}\text { Northfield ** } \\
\text { Rutiand } \\
\text { Waterbury Dam * a/ } \\
\text { New York: }\end{array}$ & $\begin{array}{l}.54 \\
.16 \\
.78\end{array}$ & $\begin{array}{r}.61 \\
2.37 \\
.39\end{array}$ & $\begin{array}{l}.25 \\
- \\
.25\end{array}$ & $\begin{array}{r}.47 \\
1.08 \\
.66\end{array}$ & $\begin{array}{l}- \\
-\end{array}$ & $\begin{array}{l}.20 \\
- \\
.15\end{array}$ & $\begin{array}{l}.03 \\
.25 \\
-\end{array}$ & $\begin{array}{l}.51 \\
.82 \\
.47\end{array}$ & $\begin{array}{r}.90 \\
1.00 \\
.69\end{array}$ & $\begin{array}{l}2.85 \\
2.09 \\
3.12\end{array}$ & $\begin{array}{l}-.84 \\
-\end{array}$ & $\begin{array}{l}4.59 \\
4.50 \\
4.48\end{array}$ \\
\hline $\begin{array}{l}493 \\
494 \\
495 \\
496 \\
497\end{array}$ & $\begin{array}{l}\text { Alexandria Bay } \\
\text { Ashley } \\
\text { Ausable Forks t+ bo } \\
\text { Baldwinsville }+ \text { aw' } \\
\text { Beaver Falls }+\end{array}$ & $\begin{array}{l}.08 \\
- \\
.77 \\
-\end{array}$ & $\begin{array}{c}.28 \\
1.41 \\
- \\
.50 \\
.67\end{array}$ & $\begin{array}{l}.02 \\
. \\
.37 \\
-\end{array}$ & $\begin{array}{l}.30 \\
.68 \\
- \\
.98 \\
.17\end{array}$ & $\begin{array}{l}- \\
.37 \\
- \\
.03 \\
.01\end{array}$ & $\begin{array}{l}- \\
\overline{-} \\
-\end{array}$ & $\begin{array}{l}- \\
- \\
.08 \\
-\end{array}$ & $\begin{array}{l}- \\
.42 \\
- \\
.06\end{array}$ & $\begin{array}{r}.04 \\
1.10 \\
.49 \\
.08 \\
.20\end{array}$ & $\begin{array}{r}2.55 \\
2.05 \\
1.47 \\
.16 \\
.58\end{array}$ & $\begin{array}{l}.40 \\
1.28 \\
2.85 \\
1.45 \\
1.87\end{array}$ & $\begin{array}{l}2.79 \\
4.80 \\
4.91 \\
1.77 \\
2.71\end{array}$ \\
\hline $\begin{array}{l}498 \\
499 \\
500 \\
501 \\
502\end{array}$ & $\begin{array}{l}\text { B1g Moose } \\
\text { Blooningdale }+ \\
\text { Boonvilie }+ \\
\text { Bonaparte } \\
\text { Brewerton }+ \text { and }\end{array}$ & $\begin{array}{l}- \\
\overline{-} \\
\overline{-}\end{array}$ & $\begin{array}{r}.80 \\
.86 \\
1.01 \\
.62 \\
.27\end{array}$ & $\begin{array}{l}- \\
- \\
.24 \\
-\end{array}$ & $\begin{array}{l}.73 \\
.12 \\
.95 \\
- \\
.88\end{array}$ & $\begin{array}{l}- \\
\mathrm{Tr} \\
.02 \\
-\end{array}$ & $\begin{array}{l}.15 \\
\mathrm{Tr} . \\
- \\
. \\
.12\end{array}$ & $\begin{array}{l}-\overline{T r} . \\
.21 \\
- \\
.08\end{array}$ & $\begin{array}{l}- \\
.10 \\
.18 \\
- \\
-\end{array}$ & $\begin{array}{l}.87 \\
.12 \\
.06 \\
- \\
-\end{array}$ & $\begin{array}{r}1.75 \\
1.00 \\
.52 \\
.45 \\
.28\end{array}$ & $\begin{array}{l}.52 \\
2.10 \\
1.88 \\
2.04 \\
1.88\end{array}$ & $\begin{array}{l}3.09 \\
3.32 \\
2.75 \\
2.49 \\
1.74\end{array}$ \\
\hline $\begin{array}{l}508 \\
504 \\
505 \\
506 \\
507\end{array}$ & $\begin{array}{l}\text { Cadyville }+\mathrm{bp} / \\
\text { Canastota }+\mathrm{bg} / \\
\text { Canton ** } \\
\text { Chasm Falls ** } \\
\text { Chazy }\end{array}$ & $\begin{array}{r}. \\
.66 \\
.45 \\
.50 \\
1.10\end{array}$ & $\begin{array}{l}.70 \\
-.11 \\
.25 \\
-\end{array}$ & $\begin{array}{l}- \\
.57 \\
.08 \\
.05 \\
.12\end{array}$ & $\begin{array}{l}.22 \\
.06 \\
.10 \\
.15 \\
-\end{array}$ & $\begin{array}{l}.01 \\
\mathrm{Tr} \\
\mathrm{Tr} . \\
.08 \\
-\end{array}$ & $\begin{array}{l}-.27 \\
\mathrm{Tr} . \\
. \\
.10\end{array}$ & $\begin{array}{l}.04 \\
- \\
- \\
-\end{array}$ & $\begin{array}{l}.18 \\
.05 \\
.14 \\
.05 \\
.12\end{array}$ & $\begin{array}{l}.26 \\
.48 \\
.13 \\
.50 \\
.93\end{array}$ & $\begin{array}{l}1.51 \\
1.69 \\
2.44 \\
2.97 \\
1.97\end{array}$ & $\begin{array}{r}2.16 \\
.21 \\
.27 \\
.05 \\
1.09\end{array}$ & $\begin{array}{l}4.10 \\
2.49 \\
2.71 \\
8.52 \\
4.21\end{array}$ \\
\hline $\begin{array}{l}508 \\
509 \\
510 \\
511 \\
512\end{array}$ & $\begin{array}{l}\text { Cleveland }+ \text { and } \\
\text { Colton }+ \\
\text { Copenhagen } \\
\text { Dannemora } \\
\text { Eagle Falls }+\end{array}$ & $\begin{array}{l}- \\
- \\
.30 \\
-\end{array}$ & $\begin{array}{r}.46 \\
.70 \\
.60 \\
.60 \\
1.06\end{array}$ & $\begin{array}{l}- \\
\overline{-} \\
\bar{z}\end{array}$ & $\begin{array}{l}.85 \\
.10 \\
.19 \\
.80 \\
.17\end{array}$ & $\begin{array}{l}.11 \\
.10 \\
- \\
.06 \\
.09\end{array}$ & $\begin{array}{l}\overline{\mathrm{T}} \mathrm{r} . \\
\overline{\mathrm{T}} \mathbf{} \\
\overline{\mathrm{T}} .\end{array}$ & $\begin{array}{l}.18 \\
.02 \\
- \\
.08 \\
.10\end{array}$ & $\begin{array}{l}- \\
\mathrm{Tr} . \\
- \\
.02 \\
.12\end{array}$ & $\begin{array}{l}.02 \\
.12 \\
- \\
.49 \\
.07\end{array}$ & $\begin{array}{r}.45 \\
.50 \\
1.00 \\
1.90 \\
.68\end{array}$ & $\begin{array}{l}1.75 \\
2.15 \\
2.20 \\
1.50 \\
2.40\end{array}$ & $\begin{array}{l}2.40 \\
2.79 \\
3.20 \\
8.99 \\
8.82\end{array}$ \\
\hline $\begin{array}{l}518 \\
514 \\
515 \\
516 \\
517\end{array}$ & $\begin{array}{l}\text { Forestport }+ \text { ay } \\
\text { Fulton } \$ \text { ay } \\
\text { Gabrielo } \\
\text { Gouverneur } \\
\text { Herring }+\end{array}$ & $\begin{array}{l}- \\
- \\
.02 \\
-\end{array}$ & $\begin{array}{r}.97 \\
.58 \\
.84 \\
.48 \\
1.43\end{array}$ & $\begin{array}{l}- \\
- \\
\overline{T r} . \\
.01\end{array}$ & $\begin{array}{l}.76 \\
.78 \\
.02 \\
.09 \\
.07\end{array}$ & $\begin{array}{l}.20 \\
.09 \\
- \\
\text { Tr. } \\
.08\end{array}$ & $\begin{array}{l}- \\
- \\
.26 \\
-\end{array}$ & $\begin{array}{l}.11 \\
.08 \\
.86 \\
. \\
.01\end{array}$ & $\begin{array}{l}.08 \\
- \\
.06 \\
.08 \\
-\end{array}$ & $\begin{array}{r}.06 \\
.08 \\
1.20 \\
.19 \\
.11\end{array}$ & $\begin{array}{r}.62 \\
.07 \\
1.80 \\
.48 \\
.22\end{array}$ & $\begin{array}{l}2.44 \\
1.56 \\
1.90 \\
1.88 \\
2.48\end{array}$ & $\begin{array}{l}5.26 \\
1.69 \\
5.58 \\
2.58 \\
2.82\end{array}$ \\
\hline $\begin{array}{l}518 \\
518 \\
520 \\
521 \\
522\end{array}$ & 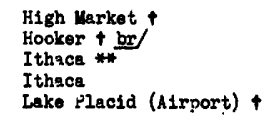 & $\begin{array}{l}- \\
.79 \\
- \\
-\end{array}$ & $\begin{array}{l}1.10 \\
1.20 \\
1.01 \\
1.85 \\
1.13\end{array}$ & $\begin{array}{l}- \\
\overline{1.25} \\
.01 \\
\mathrm{Tr} .\end{array}$ & $\begin{array}{r}.77 \\
.50 \\
.06 \\
1.15 \\
.27\end{array}$ & $\begin{array}{l}.04 \\
.03 \\
.14 \\
.16 \\
.01\end{array}$ & $\begin{array}{l}- \\
.23 \\
.01 \\
\mathrm{Tr} .\end{array}$ & $\begin{array}{l}.15 \\
= \\
\mathrm{Tr} \\
.21 \\
.19\end{array}$ & $\begin{array}{l}.08 \\
- \\
.08 \\
.11\end{array}$ & $\begin{array}{l}.02 \\
.20 \\
.50 \\
.13 \\
.27\end{array}$ & $\begin{array}{r}.55 \\
.80 \\
1.48 \\
.48 \\
1.64\end{array}$ & $\begin{array}{r}1.70 \\
1.80 \\
.27 \\
1.22 \\
3.40\end{array}$ & $\begin{array}{l}2.50 \\
2.80 \\
2.19 \\
2.05 \\
5.61\end{array}$ \\
\hline $\begin{array}{l}525 \\
524 \\
525 \\
526 \\
527\end{array}$ & $\begin{array}{l}\text { Lake Placld Club tt } \\
\text { Lawrencevillo } \\
\text { Locke t ba/ } \\
\text { Lowrille t } \\
\text { Lyons Falls + br }\end{array}$ & $\begin{array}{l}1.08 \\
.14 \\
= \\
\mathrm{Tr} \\
-\end{array}$ & $\begin{array}{r}- \\
.50 \\
1.25 \\
.54 \\
.79\end{array}$ & $\begin{array}{l}.29 \\
- \\
\text { Tr. } \\
-\end{array}$ & $\begin{array}{l}.12 \\
.09 \\
.95 \\
.89 \\
.55\end{array}$ & $\begin{array}{l}- \\
-.20 \\
.02 \\
.08\end{array}$ & $\begin{array}{l}.14 \\
\mathrm{Tr} \\
\overline{\mathrm{T}} \mathrm{r} . \\
-\end{array}$ & $\begin{array}{l}.09 \\
- \\
.21 \\
.05 \\
.25\end{array}$ & $\begin{array}{l}.25 \\
.08 \\
\mathrm{Tr} \\
\mathrm{Tr} \\
.37\end{array}$ & $\begin{array}{r}1.45 \\
.21 \\
.40 \\
.05 \\
.62\end{array}$ & $\begin{array}{r}2.95 \\
1.47 \\
1.20 \\
.62 \\
1.40\end{array}$ & $\begin{array}{r}.04 \\
1.78 \\
2.58 \\
1.86 \\
.12\end{array}$ & $\begin{array}{l}4.88 \\
5.49 \\
8.34 \\
2.56 \\
2.76\end{array}$ \\
\hline $\begin{array}{l}528 \\
529 \\
580 \\
581 \\
552\end{array}$ & $\begin{array}{l}\text { MoKeever } 4 \\
\text { Yew London }+ \text { ag } \\
\text { Morth Lake } \\
\text { Nubia } \mathrm{y} \\
\text { Ogdensburg }\end{array}$ & $\begin{array}{l}- \\
-. \\
.86 \\
.10 \\
.16\end{array}$ & $\begin{array}{r}1.88 \\
.51 \\
1.00 \\
-.14\end{array}$ & $\begin{array}{l}- \\
- \\
.50\end{array}$ & $\begin{array}{l}.76 \\
.78 \\
.87 \\
.47 \\
.47\end{array}$ & $\begin{array}{l}.07 \\
.29 \\
- \\
.08 \\
-\end{array}$ & $\begin{array}{l}.01 \\
- \\
.13 \\
.22 \\
\mathrm{Tr} .\end{array}$ & $\begin{array}{l}.10 \\
.48 \\
.07 \\
-\end{array}$ & $\begin{array}{l}.02 \\
.08 \\
.12 \\
.04 \\
-\end{array}$ & $\begin{array}{l}.11 \\
.07 \\
.78 \\
.62 \\
.28\end{array}$ & $\begin{array}{r}.58 \\
.59 \\
2.15 \\
.77 \\
.60\end{array}$ & $\begin{array}{l}2.50 \\
2.51 \\
1.60 \\
\therefore .66 \\
1.50\end{array}$ & $\begin{array}{l}8.32 \\
8.81 \\
4.79 \\
2.38 \\
2.88\end{array}$ \\
\hline $\begin{array}{l}583 \\
534 \\
585 \\
686 \\
587\end{array}$ & $\begin{array}{l}\text { Oswego ** } \\
\text { Peru } \\
\text { Port Henry *** auy } \\
\text { Raquette Lake }+ \\
\text { Sabatt1s }\end{array}$ & $\begin{array}{l}.87 \\
.09 \\
- \\
- \\
-\end{array}$ & $\begin{array}{r}77.8 \\
.62 \\
.90 \\
.75 \\
1.79\end{array}$ & $\begin{array}{l}.58 \\
-.48 \\
.10 \\
\mathrm{Tr} .\end{array}$ & $\begin{array}{l}.04 \\
.10 \\
.04 \\
.48 \\
.18\end{array}$ & $\begin{array}{l}.01 \\
- \\
. \\
.15 \\
.11\end{array}$ & $\begin{array}{l}\mathrm{Tr} . \\
.06 \\
- \\
.12 \\
\mathrm{Tr} .\end{array}$ & $\begin{array}{l}- \\
= \\
- \\
.02\end{array}$ & $\begin{array}{l}.07 \\
- \\
.14 \\
.06 \\
.11\end{array}$ & $\begin{array}{l}.05 \\
.70 \\
.46 \\
.80 \\
.11\end{array}$ & $\begin{array}{r}1.15 \\
2.54 \\
1.88 \\
1.14 \\
.87\end{array}$ & $\begin{array}{l}.88 \\
1.05 \\
2.72 \\
2.12 \\
2.01\end{array}$ & $\begin{array}{l}1.27 \\
4.85 \\
4.70 \\
8.62 \\
8.12\end{array}$ \\
\hline
\end{tabular}

* Inclucied in folloning measurement.

* Messured at midnight.

* Measured at 11 p.m.

*** Measured at 1rregular times.

Measured in morning of day indicated.

t+ Heasured in morning after day indicsted.

a Corps of Engineers, U. S. Aruy. 
Table 4.--Da1ly precipitation, in inches, September 12-22, 1938--Continued (Measured in the afternoon except as noted)

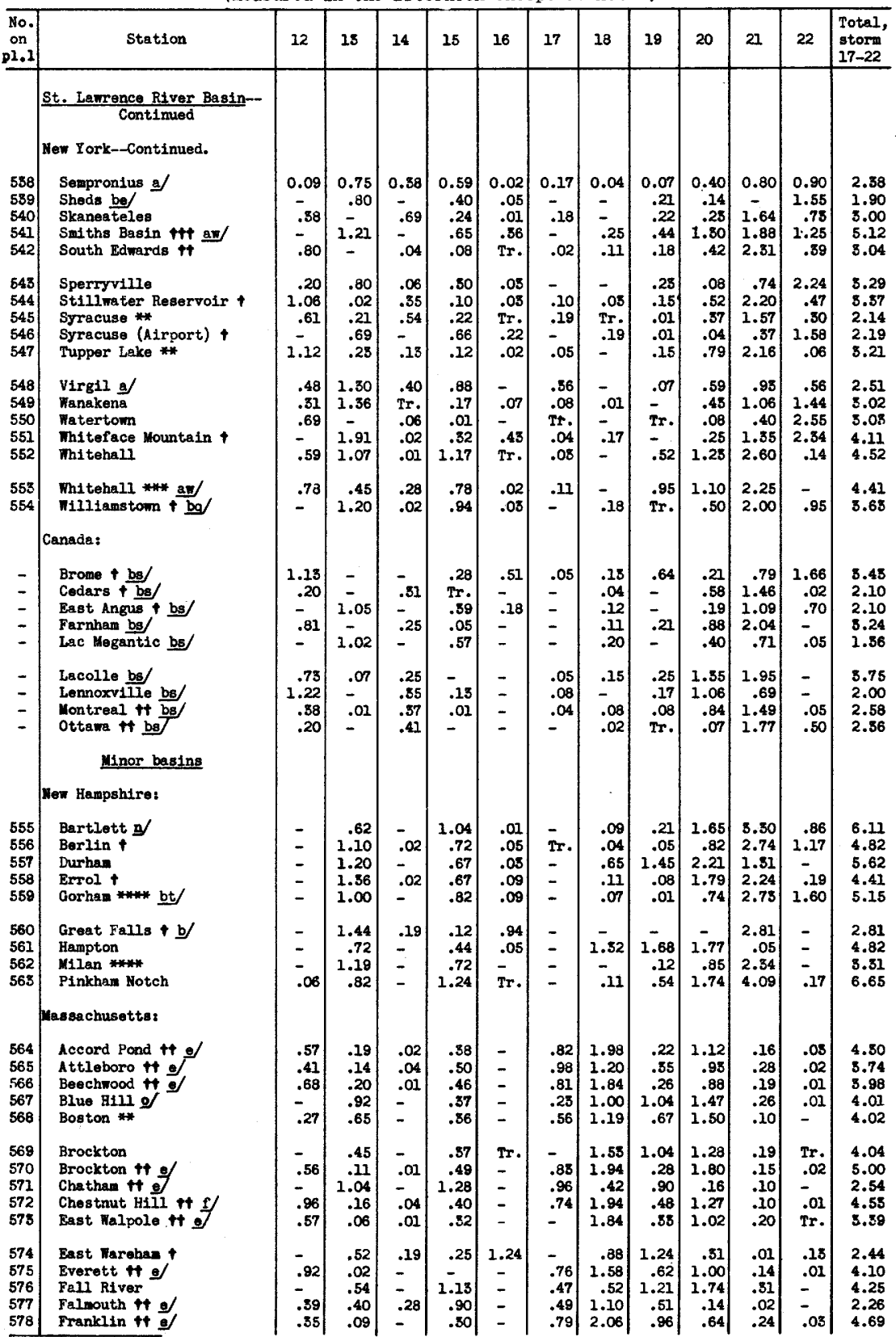

* Heasured at wdintght.

* Meagured at 11 p.

$f$ Metropolitan District Comalssion.

n U. S. Forest Service.

- Blue Hill Observatory.

a. Jew York State Depertment of Public Forks .

Heasured in noming of day indicated.

be $J . S$. Departient of Agriculture, Soll Conservation Service.

t Heasured in norning after dey indicated. itt Messurad at 11 a.e.

a Corps of Engineers, U. S. Arr.

b Public Service Co. of Ien Hanpehire.

bq Oswego River Watershed Corporation.

bs Meteorological Service of Canada.

- Massachusetts Depertment of Public Health. bt Onion Water Power Co., Lewiston, Maine. 
Table 4.--Da1ly precipitation, in inches, September 12-22, 1938--Continued (Measured in the afternoon except as noted)

\begin{tabular}{|c|c|c|c|c|c|c|c|c|c|c|c|c|c|}
\hline $\begin{array}{l}\text { No. } \\
\text { on } \\
\text { pl.1 }\end{array}$ & Station & 12 & 13 & 14 & 15 & 16 & 17 & 18 & 19 & 20 & 21 & 22 & $\begin{array}{l}\text { Total, } \\
\text { storn } \\
17-22\end{array}$ \\
\hline & $\begin{array}{l}\text { Hinor basins-Continued } \\
\text { Hassachusetts-Continued. }\end{array}$ & & & & & & & & & & & & \\
\hline $\begin{array}{l}579 \\
580 \\
581 \\
582 \\
583\end{array}$ & $\begin{array}{l}\text { Gloucester } \\
\text { Greenbush }+\theta / \\
\text { Hyamis } \\
\text { Ipswich }+\theta \text { of } \\
\text { Jamaica Plain }+ \text { e/ }\end{array}$ & $\begin{array}{l}- \\
0.55 \\
- \\
1.42 \\
1.06\end{array}$ & $\begin{array}{r}1.49 \\
.16 \\
.80 \\
.06 \\
.05\end{array}$ & $\begin{array}{l}- \\
0.03 \\
- \\
.06 \\
.04\end{array}$ & $\begin{array}{r}0.28 \\
.34 \\
.54 \\
.32 \\
.42\end{array}$ & $\begin{array}{l}- \\
\overline{0.75} \\
\overline{T r}\end{array}$ & $\begin{array}{r}0.21 \\
.58 \\
- \\
.64 \\
.54\end{array}$ & $\begin{array}{r}1.78 \\
1.26 \\
.93 \\
3.20 \\
1.50\end{array}$ & $\begin{array}{r}2.76 \\
.65 \\
2.93 \\
.76 \\
.47\end{array}$ & $\begin{array}{r}1.20 \\
.42 \\
.40 \\
1.65 \\
1.15\end{array}$ & $\begin{array}{r}0.02 \\
.05 \\
.25 \\
9.05 \\
.12\end{array}$ & $\begin{array}{l}- \\
- \\
0.02 \\
\operatorname{Tr} \\
\mathrm{Tr}\end{array}$ & $\begin{array}{l}5.97 \\
2.96 \\
4.53 \\
6.30 \\
3.78\end{array}$ \\
\hline $\begin{array}{l}\mathbf{5 8 4} \\
\mathbf{5 8 5} \\
\mathbf{5 8 6} \\
\mathbf{5 8 7} \\
\mathbf{5 8 8}\end{array}$ & $\begin{array}{l}\text { Lakeville tt } e / \\
\text { Lynn tt } e / \\
\text { Manchester t+ e/ } \\
\text { Mansfield tt ef } \\
\text { Marston's MAlls }\end{array}$ & $\begin{array}{l}.42 \\
1.08 \\
1.21 \\
.50 \\
-\end{array}$ & $\begin{array}{r}.25 \\
.13 \\
.25 \\
.10 \\
1.10\end{array}$ & $\begin{array}{l}.16 \\
.06 \\
.04 \\
.04 \\
.10\end{array}$ & $\begin{array}{l}.93 \\
.25 \\
.26 \\
.51 \\
.25\end{array}$ & $\begin{array}{l}- \\
.75 \\
- \\
.95\end{array}$ & $\begin{array}{l}.55 \\
. \\
.98 \\
.70 \\
-\end{array}$ & $\begin{array}{l}1.14 \\
1.72 \\
1.78 \\
2.01 \\
.80\end{array}$ & $\begin{array}{r}.54 \\
1.00 \\
.30 \\
.17 \\
.80\end{array}$ & $\begin{array}{l}.48 \\
1.80 \\
1.98 \\
1.64 \\
1.80\end{array}$ & $\begin{array}{l}.11 \\
.02 \\
.04 \\
.19 \\
.30\end{array}$ & $\begin{array}{l}.15 \\
.07 \\
.01 \\
.03 \\
-\end{array}$ & $\begin{array}{l}2.82 \\
4.04 \\
5.08 \\
4.71 \\
5.20\end{array}$ \\
\hline $\begin{array}{l}589 \\
590 \\
591 \\
592 \\
595\end{array}$ & $\begin{array}{l}\text { Middleboro }+t e / \\
\text { Middleton }+t \\
\text { Milford } t+e / \\
\text { Millbury }+ \\
\text { Millis } t+e /\end{array}$ & $\begin{array}{l}.49 \\
1.50 \\
.50 \\
- \\
.57\end{array}$ & $\begin{array}{l}.22 \\
.03 \\
.09 \\
.66 \\
.08\end{array}$ & $\begin{array}{l}.12 \\
.07 \\
.05 \\
.03 \\
-\end{array}$ & $\begin{array}{r}1.12 \\
.38 \\
.49 \\
.53 \\
.17\end{array}$ & $\begin{array}{l}- \\
- \\
- \\
.25 \\
-\end{array}$ & $\begin{array}{l}.54 \\
.80 \\
.63 \\
- \\
1.01\end{array}$ & $\begin{array}{r}1.04 \\
3.20 \\
3.18 \\
.82 \\
2.05\end{array}$ & $\begin{array}{r}.55 \\
.88 \\
1.53 \\
3.70 \\
1.00\end{array}$ & $\begin{array}{r}.84 \\
2.21 \\
1.49 \\
2.31 \\
.66\end{array}$ & $\begin{array}{r}.11 \\
.11 \\
.35 \\
2.19 \\
.16\end{array}$ & $\begin{array}{l}.09 \\
\mathrm{Tr} . \\
\overline{q .15} \\
-\end{array}$ & $\begin{array}{l}2.58 \\
6.70 \\
7.18 \\
9.17 \\
4.88\end{array}$ \\
\hline $\begin{array}{l}594 \\
595 \\
596 \\
597 \\
598\end{array}$ & 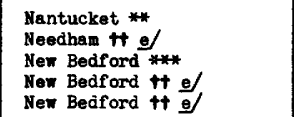 & $\begin{array}{l}- \\
.73 \\
- \\
.38 \\
.44\end{array}$ & $\begin{array}{l}.79 \\
.09 \\
.63 \\
.29 \\
.20\end{array}$ & $\begin{array}{l}- \\
.02 \\
- \\
.14 \\
.10\end{array}$ & $\begin{array}{l}4.05 \\
- \\
.95 \\
1.17 \\
1.33\end{array}$ & $\begin{array}{l}\text { Tr. } \\
- \\
- \\
-\end{array}$ & $\begin{array}{l}.06 \\
.97 \\
.18 \\
.68 \\
.70\end{array}$ & $\begin{array}{l}2.19 \\
2.14 \\
1.04 \\
1.13 \\
1.28\end{array}$ & $\begin{array}{r}.05 \\
1.20 \\
.65 \\
.53 \\
.98\end{array}$ & $\begin{array}{l}- \\
.55 \\
.37 \\
.31 \\
.08\end{array}$ & $\begin{array}{l}.04 \\
.13 \\
- \\
.08 \\
9.06\end{array}$ & $\begin{array}{l}- \\
- \\
.06 \\
.09 \\
9.08\end{array}$ & $\begin{array}{l}2.34 \\
4.99 \\
2.19 \\
2.78 \\
3.05\end{array}$ \\
\hline $\begin{array}{l}599 \\
600 \\
601 \\
602 \\
605\end{array}$ & 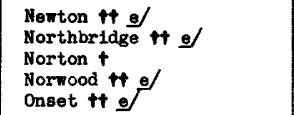 & $\begin{array}{l}.91 \\
.48 \\
- \\
.80 \\
.45\end{array}$ & $\begin{array}{l}.20 \\
- \\
.60 \\
.10 \\
.28\end{array}$ & $\begin{array}{l}.03 \\
.25 \\
.18 \\
.02 \\
.32\end{array}$ & $\begin{array}{r}.39 \\
.41 \\
.03 \\
.30 \\
1.39\end{array}$ & $\begin{array}{l}- \\
.47 \\
- \\
-\end{array}$ & $\begin{array}{l}.64 \\
.75 \\
- \\
.71 \\
.98\end{array}$ & $\begin{array}{l}2.30 \\
2.45 \\
1.28 \\
1.29 \\
1.38\end{array}$ & $\begin{array}{r}.61 \\
1.54 \\
2.00 \\
.35 \\
.34\end{array}$ & $\begin{array}{r}1.10 \\
1.42 \\
.41 \\
1.13 \\
\mathrm{Tr} .\end{array}$ & $\begin{array}{r}.12 \\
q .50 \\
1.58 \\
.16 \\
.09\end{array}$ & $\begin{array}{l}.01 \\
- \\
.10 \\
.01 \\
.03\end{array}$ & $\begin{array}{l}4.77 \\
6.66 \\
5.32 \\
3.64 \\
2.74\end{array}$ \\
\hline $\begin{array}{l}604 \\
605 \\
606 \\
607 \\
608\end{array}$ & $\begin{array}{l}\text { Peabody tt } e / \\
\text { Pembroke } t+e / \\
\text { Plymouth } \\
\text { Plymouth tt } \theta / \\
\text { Provincetom }\end{array}$ & $\begin{array}{l}1.14 \\
.53 \\
- \\
.33 \\
-\end{array}$ & $\begin{array}{l}.08 \\
.14 \\
.71 \\
.18 \\
.69\end{array}$ & $\begin{array}{l}.05 \\
.04 \\
- \\
.10 \\
-\end{array}$ & $\begin{array}{r}.29 \\
.68 \\
1.25 \\
.98 \\
.95\end{array}$ & $\begin{array}{l}- \\
- \\
- \\
- \\
.13\end{array}$ & $\begin{array}{l}.72 \\
.80 \\
.10 \\
.58 \\
.\end{array}$ & $\begin{array}{r}1.69 \\
1.11 \\
1.16 \\
1.03 \\
.20\end{array}$ & $\begin{array}{r}.83 \\
.70 \\
1.10 \\
1.08 \\
.12\end{array}$ & $\begin{array}{r}1.21 \\
.25 \\
.56 \\
.01 \\
.40\end{array}$ & $\begin{array}{l}.07 \\
.10 \\
.08 \\
\mathrm{Tr} \\
.35\end{array}$ & $\begin{array}{l}\mathrm{Tr} \\
.02 \\
- \\
.04 \\
-\end{array}$ & $\begin{array}{l}4.52 \\
2.96 \\
3.00 \\
2.70 \\
1.07\end{array}$ \\
\hline $\begin{array}{l}609 \\
610 \\
611 \\
612 \\
613\end{array}$ & $\begin{array}{l}\text { Rockport } \\
\text { Salem tt } e / \\
\text { South Carver } \\
\text { Spot Pond tt } f / \\
\text { State Farm tt e/ }\end{array}$ & $\begin{array}{c}- \\
1.18 \\
- \\
1.04 \\
.45\end{array}$ & $\begin{array}{r}1.29 \\
.15 \\
.58 \\
.20 \\
.10\end{array}$ & $\begin{array}{l}- \\
.04 \\
.11 \\
.02 \\
.07\end{array}$ & $\begin{array}{l}.29 \\
.33 \\
.12 \\
.40 \\
.74\end{array}$ & $\begin{array}{l}- \\
.96 \\
- \\
-\end{array}$ & $\begin{array}{l}- \\
.79 \\
- \\
.57 \\
*\end{array}$ & $\begin{array}{r}1.30 \\
1.95 \\
.64 \\
1.96 \\
2.07\end{array}$ & $\begin{array}{r}1.32 \\
.89 \\
1.13 \\
.64 \\
.71\end{array}$ & $\begin{array}{r}.93 \\
1.47 \\
.77 \\
1.88 \\
1.10\end{array}$ & $\begin{array}{l}.15 \\
.02 \\
.01 \\
.05 \\
.08\end{array}$ & $\begin{array}{l}- \\
\mathrm{Tr} \\
.07 \\
.01 \\
-\end{array}$ & $\begin{array}{l}3.70 \\
4.62 \\
2.62 \\
5.10 \\
3.96\end{array}$ \\
\hline $\begin{array}{l}614 \\
615 \\
616 \\
617 \\
618\end{array}$ & $\begin{array}{l}\text { Swampscott } \\
\text { Taunton }+t \theta / \\
\text { Tisbury tt } \theta \\
\text { Uxbridge, }+t e / \\
\text { Waltham }+t \theta\end{array}$ & $\begin{array}{l}- \\
.62 \\
\overline{T r} \\
.98\end{array}$ & $\begin{array}{r}1.05 \\
.20 \\
.50 \\
.37 \\
-\end{array}$ & $\begin{array}{l}- \\
.06 \\
.40 \\
-.15\end{array}$ & $\begin{array}{r}.30 \\
.54 \\
2.15 \\
.38 \\
.45\end{array}$ & $\begin{array}{l}- \\
- \\
-\end{array}$ & $\begin{array}{r}.23 \\
1.04 \\
.55 \\
.46 \\
.67\end{array}$ & $\begin{array}{l}.92 \\
1.89 \\
1.50 \\
1.60 \\
2.10\end{array}$ & $\begin{array}{r}1.21 \\
.22 \\
2.05 \\
2.36 \\
1.02\end{array}$ & $\begin{array}{c}1.52 \\
.91 \\
- \\
1.77 \\
.62\end{array}$ & $\begin{array}{l}.19 \\
.15 \\
.25 \\
.49 \\
.22\end{array}$ & $\begin{array}{l}\mathrm{Tr} . \\
\mathrm{Tr} . \\
- \\
.02 \\
.01\end{array}$ & $\begin{array}{l}4.07 \\
3.71 \\
4.35 \\
6.68 \\
4.65\end{array}$ \\
\hline $\begin{array}{l}619 \\
620 \\
621 \\
622 \\
623\end{array}$ & 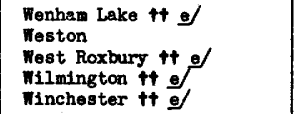 & $\begin{array}{c}1.20 \\
- \\
.92 \\
1.52 \\
1.15\end{array}$ & $\begin{array}{r}.40 \\
1.05 \\
.11 \\
.02 \\
.07\end{array}$ & $\begin{array}{l}.08 \\
\text { Tr. } \\
.02 \\
.07 \\
.03\end{array}$ & $\begin{array}{l}.31 \\
.55 \\
.37 \\
.59 \\
-\end{array}$ & $\begin{array}{l}- \\
- \\
-\end{array}$ & $\begin{array}{l}.46 \\
- \\
.82 \\
.65 \\
.74\end{array}$ & $\begin{array}{l}1.92 \\
1.43 \\
1.68 \\
3.14 \\
2.32\end{array}$ & $\begin{array}{r}.71 \\
2.34 \\
.50 \\
.70 \\
.65\end{array}$ & $\begin{array}{r}1.47 \\
2.02 \\
1.03 \\
.95 \\
1.95\end{array}$ & $\begin{array}{l}.02 \\
.25 \\
.10 \\
.19 \\
.15\end{array}$ & $\begin{array}{l}- \\
- \\
.01 \\
.01 \\
\mathrm{Tr} .\end{array}$ & $\begin{array}{l}4.58 \\
6.04 \\
4.13 \\
5.63 \\
5.81\end{array}$ \\
\hline $\begin{array}{l}624 \\
625 \\
626\end{array}$ & $\begin{array}{l}\text { Wollaston tt } e / \\
\text { Norcester buy } \\
\text { Wrentham t+ } \theta /\end{array}$ & $\begin{array}{l}.96 \\
\mathrm{Tr} . \\
.50\end{array}$ & $\begin{array}{r}.11 \\
1.25\end{array}$ & $\begin{array}{l}\text { Tr. } \\
-11\end{array}$ & $\begin{array}{l}.31 \\
.68 \\
.40\end{array}$ & $\begin{array}{l}- \\
\text { Tr. }\end{array}$ & $\begin{array}{l}* \\
.20 \\
.75\end{array}$ & $\begin{array}{r}2.64 \\
.58 \\
1.72\end{array}$ & $\begin{array}{r}.20 \\
2.45 \\
.50\end{array}$ & $\begin{array}{r}.76 \\
1.70 \\
.23\end{array}$ & $\begin{array}{r}.13 \\
3.44 \\
.25\end{array}$ & $\begin{array}{l}.02 \\
.02 \\
=\end{array}$ & $\begin{array}{l}3.73 \\
8.89 \\
8.25\end{array}$ \\
\hline & Rhode Island: & & & & & & & & & & & & \\
\hline $\begin{array}{l}627 \\
628 \\
629 \\
630 \\
631\end{array}$ & $\begin{array}{l}\text { Block Island ** } \\
\text { Diamond Hill Res. **** by } \\
\text { Greenville } \\
\text { Kingston } \\
\text { North Sifthfield }+ \text { bef }\end{array}$ & $\begin{array}{l}\vec{u} \\
- \\
-\end{array}$ & $\begin{array}{l}.74 \\
.70 \\
.56 \\
.40\end{array}$ & $\begin{array}{l}\bar{u} \\
\overline{-} \\
\bar{z}\end{array}$ & $\begin{array}{l}1.16 \\
\text { H } \\
.87 \\
1.32 \\
-\end{array}$ & $\begin{array}{l}\bar{u} \\
.01 \\
. \\
.30\end{array}$ & $\begin{array}{l}.44 \\
* \\
.01 \\
.07 \\
-\end{array}$ & $\begin{array}{c}.42 \\
* \\
1.98 \\
.93 \\
.85\end{array}$ & $\begin{array}{r}.37 \\
* \\
1.10 \\
.53 \\
2.15\end{array}$ & $\begin{array}{l}1.25 \\
* \\
1.88 \\
1.08 \\
2.00\end{array}$ & $\begin{array}{r}1.00 \\
4.00 \\
.62 \\
.18 \\
.86\end{array}$ & $\begin{array}{l}\bar{x} \\
.04 \\
.01 \\
-\end{array}$ & $\begin{array}{l}3.46 \\
4.00 \\
5.63 \\
2.80 \\
5.36\end{array}$ \\
\hline $\begin{array}{l}632 \\
635 \\
634 \\
635 \\
636\end{array}$ & $\begin{array}{l}\text { Pawtucket *** by/ } \\
\text { Pawtucket *** by/ } \\
\text { Portsmouth } \\
\text { Providence ** } \\
\text { Slocum }\end{array}$ & $\begin{array}{l}\boldsymbol{u} \\
\boldsymbol{u} \\
\overline{\mathbf{T}} \mathbf{r} . \\
-\end{array}$ & $\begin{array}{l}M \\
M \\
.55 \\
.39 \\
.47\end{array}$ & $\begin{array}{l}\text { u. } \\
\text { Tr. } \\
\text { Tr. }\end{array}$ & $\begin{array}{l}u \\
\mathbf{u} \\
.87 \\
.42 \\
1.10\end{array}$ & $\begin{array}{l}\mathbf{u} \\
\mathrm{Tr} \\
- \\
-\end{array}$ & $\begin{array}{l}* \\
* \\
.16 \\
.64 \\
.12\end{array}$ & $\begin{array}{l}* \\
* \\
.80 \\
.75 \\
.79\end{array}$ & $\begin{array}{l}* \\
* \\
1.05 \\
.49 \\
.45\end{array}$ & $\begin{array}{c}* \\
* \\
.90 \\
1.04 \\
1.13\end{array}$ & $\begin{array}{r}8.10 \\
5.88 \\
.50 \\
.17 \\
9.16\end{array}$ & $\begin{array}{l}\mathbf{M} \\
\mathbf{M} \\
- \\
- \\
-\end{array}$ & $\begin{array}{l}5.10 \\
7.38 \\
5.41 \\
5.09 \\
2.65\end{array}$ \\
\hline $\begin{array}{l}637 \\
688\end{array}$ & $\begin{array}{l}\text { Wood River Junction } \\
\text { Foonsocket }+\mathrm{bx} /\end{array}$ & .54 & .54 & - & $\begin{array}{l}.96 \\
.29\end{array}$ & - & - & ${ }^{*} .80$ & $\begin{array}{l}1.95 \\
1.76\end{array}$ & $\begin{array}{r}.50 \\
1.54\end{array}$ & $\begin{array}{l}.27 \\
.05\end{array}$ & $\overline{-}$ & $\begin{array}{l}2.72 \\
5.05\end{array}$ \\
\hline
\end{tabular}

* Included in following neasurement.

* Heasured at midnight.

** Measured at 11 p. .

*** Measured at Irregular times.

- Measured in morning of dey inalcated.

tt Heasured in morning after day indicated.

4 Record alssing.
- Massachusetts Department of Public Health.

$f$ Metropolitan District Commission.

q Estinated; gage destroyed during hurricane.

bu Winter Hill Meteorological Observatory.

bv City Engineer, Pawtucket, R. I.

bo Foonsocket, R. I. Fater Departuent.

bx Noonsocket, R. I., Sewage Norks. 
Table 4.--Da11y precipitation, in Inches, September 12-22, 1938--Continued (Measured in the aftermoon except as noted)

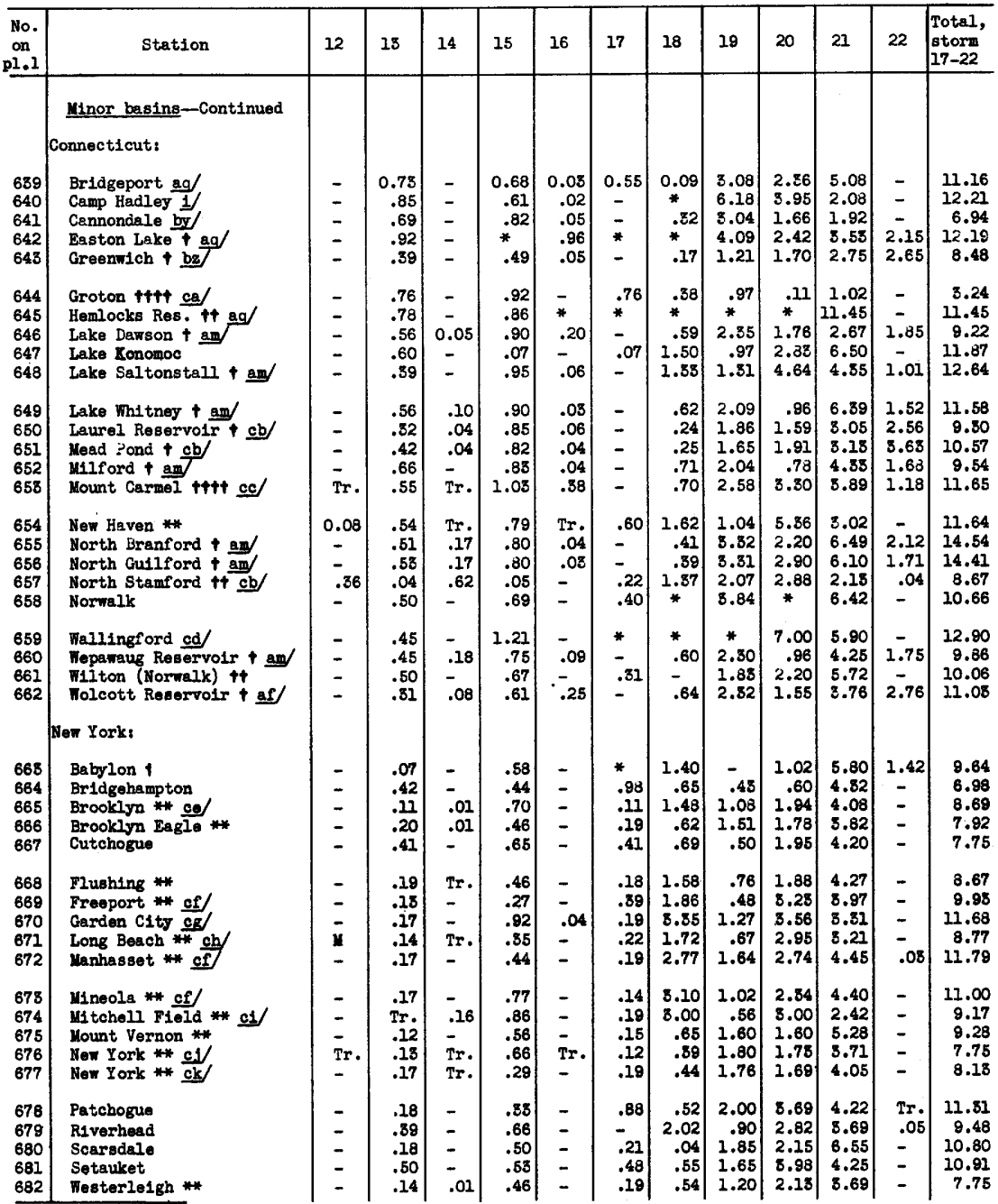

* Inciuded in following measurement.

* Measured at midintght.

+ Mesenred in morning of day indicated.

t Heasured in morning after day incicated. t+t+ Measured at noon.

M Record missing.

1 Connecticut State Forestry Department.

of Now Britain Fater Co., Men Britain, Conn.

am New Haven Water Co., New Haven, Conn'.

aq Bridgeport Hydraulic Co.

by D. Henry Miller, Cannondale, Conn.

be Greenwich, Conn., Water Co.

ce Feter and Electric Department, Groton, Conn. cb Stemford, Conn., Water Co.

cc Connecticut Agricultural Bxperimental Station. cd Fallingford, Conn., Hater Lepartment.

ce Gravesend-Ave. $V_{\mathbf{j}}$ C1ty of Hen York, Depertment of Sewers.

of Massau County Departiment of Public WorkB, Hydrologicel Bureau.

cB Oliver H. Fest, Garden City, N. Y.

ch C1ty of Long Beach, N. Y.

ci U. S. Army, A1r Corps.

cf Battery Place.

ok Central Park. 
Table 4.--Da1ly precipitation, in inches, September 12-22, 1938--Continued (Measured in the afternoon except as noted)

\begin{tabular}{|c|c|c|c|c|c|c|c|c|c|c|c|c|c|}
\hline $\begin{array}{l}\text { No. } \\
\text { on } \\
\text { pl.1 }\end{array}$ & Station & 12 & 13 & 14 & 15 & 16 & 17 & 18 & 19 & 20 & 21 & 22 & $\begin{array}{l}\text { Total, } \\
\text { storm } \\
17-22\end{array}$ \\
\hline & $\begin{array}{l}\text { Minor basins--Continued } \\
\text { New Jersey: }\end{array}$ & & & & & & & & & & & & \\
\hline $\begin{array}{l}683 \\
684 \\
685 \\
686 \\
687\end{array}$ & $\begin{array}{l}\text { Atlantic City ** } \\
\text { Belleplain } \\
\text { Clayton } \\
\text { Colts Neck No. R-8** be/ } \\
\text { Elizabeth }\end{array}$ & $\overline{-}$ & $\begin{array}{c}\mathrm{Tr} . \\
- \\
0.06 \\
\mathbf{y} \\
.09\end{array}$ & $\begin{array}{l}0.07 \\
\overline{-} \\
\bar{M} \\
\mathrm{Tr} .\end{array}$ & $\begin{array}{l}0.08 \\
.05 \\
.05 \\
.13\end{array}$ & $\begin{array}{l}\overline{-} \\
\bar{u} \\
0.20\end{array}$ & $\begin{array}{c}0.79 \\
.15 \\
- \\
.11 \\
.05\end{array}$ & $\begin{array}{r}0.22 \\
.22 \\
.22 \\
2.22 \\
.10\end{array}$ & $\begin{array}{r}1.81 \\
.82 \\
1.80 \\
1.22 \\
1.52\end{array}$ & $\begin{array}{l}3.22 \\
1.77 \\
2.23 \\
2.69 \\
1.65\end{array}$ & $\begin{array}{l}4.50 \\
4.32 \\
z .10 \\
4.76 \\
4.96\end{array}$ & $\begin{array}{l}- \\
0.04 \\
- \\
\overline{T r} .\end{array}$ & $\begin{array}{r}10.04 \\
7.32 \\
7.35 \\
11.00 \\
8.29\end{array}$ \\
\hline $\begin{array}{l}688 \\
689 \\
690 \\
691 \\
692\end{array}$ & $\begin{array}{l}\text { Elizabethport *** } \mathrm{cl} / \\
\text { Hammonton } \\
\text { Indian } \mathrm{K1Ils} \\
\text { Irvington } * * \mathrm{cl} \\
\text { Jersey City }\end{array}$ & $\begin{array}{l}- \\
- \\
0.08 \\
\mathrm{Tr} .\end{array}$ & $\begin{array}{l}.10 \\
- \\
.09 \\
.17\end{array}$ & $\begin{array}{l}- \\
\overline{\mathrm{Tr}} . \\
\overline{-}\end{array}$ & $\begin{array}{l}.15 \\
.08 \\
.01 \\
.24 \\
.24\end{array}$ & $\begin{array}{l}- \\
.11 \\
\operatorname{Tr} . \\
. \\
.18\end{array}$ & $\begin{array}{l}.09 \\
- \\
.20 \\
.06 \\
.02\end{array}$ & $\begin{array}{l}.23 \\
.05 \\
.10 \\
.23 \\
.84\end{array}$ & $\begin{array}{l}.92 \\
1.80 \\
1.63 \\
* \\
.42\end{array}$ & $\begin{array}{l}1.80 \\
3.00 \\
2.37 \\
* \\
2.12\end{array}$ & $\begin{array}{l}4.84 \\
2.88 \\
4.26 \\
6.17 \\
5.16\end{array}$ & $\begin{array}{l}- \\
- \\
- \\
.03\end{array}$ & $\begin{array}{l}7.38 \\
7.73 \\
8.56 \\
6.46 \\
8.10\end{array}$ \\
\hline $\begin{array}{l}693 \\
694 \\
695 \\
696 \\
697\end{array}$ & $\begin{array}{l}\text { Lakewood } \\
\text { Long Branch ** } \\
\text { Marlboro ** be/ } \frac{\mathrm{cm} /}{\mathrm{cn} /} \\
\text { Marlboro ** } \mathrm{be} / \mathrm{co} / \\
\text { Marlboro * be/ }\end{array}$ & $\begin{array}{l}- \\
\overline{\mathbf{M}} \\
\mathbf{M} \\
\mathbf{M}\end{array}$ & $\begin{array}{l}.17 \\
.24 \\
\dot{M} \\
\dot{u}\end{array}$ & $\dot{\mathbf{u}}_{\dot{\mathbf{u}}}^{-0 z}$ & $\begin{array}{l}.05 \\
.02 \\
u \\
M \\
M\end{array}$ & $\begin{array}{l}\text { Tr. } \\
\operatorname{Tr} . \\
\text { M } \\
\text { M } \\
\text { H }\end{array}$ & $\begin{array}{l}.17 \\
.16 \\
.13 \\
.13 \\
.12\end{array}$ & $\begin{array}{r}.12 \\
2.91 \\
.74 \\
.73 \\
.76\end{array}$ & $\begin{array}{r}1.90 \\
.37 \\
1.13 \\
1.10 \\
1.13\end{array}$ & $\begin{array}{l}1.75 \\
2.88 \\
2.00 \\
1.92 \\
2.07\end{array}$ & $\begin{array}{l}6.35 \\
4.54 \\
4.86 \\
4.75 \\
4.85\end{array}$ & $\begin{array}{l}- \\
- \\
- \\
-\end{array}$ & $\begin{array}{r}10.29 \\
10.86 \\
8.86 \\
8.63 \\
8.93\end{array}$ \\
\hline $\begin{array}{l}698 \\
699 \\
700 \\
701 \\
702\end{array}$ & $\begin{array}{l}\text { Newark ** cp/ } \\
\text { Northfleld } \\
\text { Pleasantville + } \\
\text { Runyon } \\
\text { Sandy Hook ** }\end{array}$ & $\begin{array}{l}\mathbf{M} \\
- \\
- \\
-\end{array}$ & $\begin{array}{l}\mathrm{M} \\
\mathrm{Tr} . \\
.01 \\
.15 \\
.17\end{array}$ & $\begin{array}{l}\mathrm{u} \\
- \\
\mathrm{Tr} . \\
. \\
.02\end{array}$ & $\begin{array}{l}.4 \\
.04 \\
.06 \\
.16 \\
.89\end{array}$ & $\begin{array}{l}\text { H } \\
- \\
- \\
.29 \\
\mathrm{Tr} .\end{array}$ & $\begin{array}{l}.20 \\
.28 \\
- \\
.11 \\
.13\end{array}$ & $\begin{array}{r}.30 \\
.20 \\
.88 \\
.25 \\
2.56\end{array}$ & $\begin{array}{r}1.89 \\
.84 \\
.29 \\
1.21 \\
.72\end{array}$ & $\begin{array}{l}2.10 \\
1.66 \\
1.24 \\
1.41 \\
2.24\end{array}$ & $\begin{array}{l}3.98 \\
5.92 \\
3.89 \\
4.90 \\
3.85\end{array}$ & $\begin{array}{l}- \\
2.85 \\
- \\
-\end{array}$ & $\begin{array}{l}8.47 \\
8.90 \\
8.65 \\
7.88 \\
9.51\end{array}$ \\
\hline 703 & Tuckerton & - & .04 & - & .02 & .01 & .83 & .41 & .92 & 2.96 & 5.16 & - & 9.78 \\
\hline
\end{tabular}

* Included in following measurement.

* Measured at midnight.

** Measured at 11 p.m.

+ Measured in morning of day indicated.

U Record missing.

be U. S. Department of Agriculture, Soll Conservation Service. cl Joint Meeting Maintenance.

cm Instrumental area.

cn Plot No. 1.

co Plot No. 24.

cp Kresge Department Store, Williem Wiener, Meteorologist. 
Table 5.--Supplemental records of daily precipitation, in inches, September $12-22,1938$

(Measured in the afternoon except as noted)

\begin{tabular}{|c|c|c|c|c|c|c|c|c|c|c|c|c|c|}
\hline $\begin{array}{l}\text { No. } \\
\text { on } \\
\text { pl.1 }\end{array}$ & Station & 12 & 13 & 14 & 15 & 16 & I7 & 18 & 19 & 20 & $2 \lambda$ & 22 & $\begin{array}{l}\text { Total, } \\
\text { story } \\
17-22\end{array}$ \\
\hline & $\begin{array}{l}\text { Herrimack Fiver Basin } \\
\text { Wew Hampshire: }\end{array}$ & - & & & & & & & & & & & \\
\hline 704 & $\begin{array}{l}\text { Milford }+\underline{a} \\
\text { Thames River Brsin } \\
\text { Connecticut: }\end{array}$ & - & 0.73 & Tr. & 0.49 & 0.20 & $\mathrm{Tr}$. & 0.31 & 0.90 & 2.06 & 3.10 & 0.33 & 6.70 \\
\hline 705 & $\begin{array}{l}\text { No. Grosvenordale t+ b/ } \\
\text { Connecticut River Basin } \\
\text { New Hampshire: }\end{array}$ & - & .65 & - & .61 & - & 0.87 & 3.83 & 2.37 & 8.29 & .44 & - & 10.80 \\
\hline $\begin{array}{l}706 \\
707 \\
708 \\
709 \\
710\end{array}$ & $\begin{array}{l}\text { Claremont }+c / \\
\text { Franconia d } \\
\text { Marlow } d / \\
\text { North Granthem d/ } \\
\text { Twin Mountain d] }\end{array}$ & $\begin{array}{c}- \\
- \\
0.10 \\
- \\
-\end{array}$ & $\begin{array}{l}1.87 \\
1.30 \\
1.20 \\
1.80 \\
1.28\end{array}$ & $\begin{array}{l}- \\
- \\
- \\
-\end{array}$ & $\begin{array}{l}.75 \\
.58 \\
.95 \\
.98 \\
.22\end{array}$ & $\begin{array}{l}.44 \\
- \\
- \\
.08\end{array}$ & $\begin{array}{l}- \\
\overline{-} \\
\overline{-}\end{array}$ & $\begin{array}{l}.07 \\
.06 \\
.20 \\
.15 \\
.02\end{array}$ & $\begin{array}{l}- \\
- \\
1.20 \\
1.38 \\
.12\end{array}$ & $\begin{array}{l}2.27 \\
1.41 \\
2.95 \\
2.85 \\
1.56\end{array}$ & $\begin{array}{l}2.27 \\
2.35 \\
3.40 \\
2.00 \\
3.05\end{array}$ & $\begin{array}{l}2.19 \\
.65 \\
- \\
1.10 \\
1.20\end{array}$ & $\begin{array}{l}6.80 \\
4.47 \\
7.75 \\
7.48 \\
6.01\end{array}$ \\
\hline 711 & $\begin{array}{l}\text { West Cansan } \mathrm{d} / \\
\text { Verinont: }\end{array}$ & .57 & 1.43 & - & .69 & .10 & .10 & .20 & .90 & 1.90 & 8.44 & .10 & 6.64 \\
\hline $\begin{array}{l}712 \\
713 \\
714 \\
715 \\
716\end{array}$ & $\begin{array}{l}\text { East Haven d/ } \\
\text { Gellup Hills d/ } \\
\text { North Tunbridge d/ } \\
\text { Plymouth d/ } \\
\text { Ricker MIIls d/ }\end{array}$ & $\begin{array}{l}\mathrm{Tr} \\
.10 \\
.26 \\
.42 \\
-\end{array}$ & $\begin{array}{l}1.6 \\
1.69 \\
.78 \\
1.20 \\
1.25\end{array}$ & $\begin{array}{c}- \\
0.01 \\
-\end{array}$ & $\begin{array}{l}.59 \\
.70 \\
1.74 \\
1.39 \\
1.08\end{array}$ & $\begin{array}{l}- \\
.40 \\
- \\
-\end{array}$ & $\begin{array}{l}- \\
- \\
.02 \\
\mathrm{Tr} .\end{array}$ & $\begin{array}{l}.59 \\
.26 \\
.87 \\
.47 \\
.36\end{array}$ & $\begin{array}{l}\operatorname{Tr} \\
.10 \\
.31 \\
.55 \\
.06\end{array}$ & $\begin{array}{l}1.16 \\
1.96 \\
1.80 \\
2.09 \\
1.15\end{array}$ & $\begin{array}{l}2.84 \\
1.62 \\
2.84 \\
4.40 \\
2.42\end{array}$ & $\begin{array}{l}- \\
- \\
-\end{array}$ & $\begin{array}{l}4.09 \\
8.94 \\
4.84 \\
7.51 \\
3.97\end{array}$ \\
\hline $\begin{array}{l}717 \\
718\end{array}$ & $\begin{array}{l}\text { Wheelock } d / \\
\text { windsor }+g \\
\text { Hudson R1ver Basin } \\
\text { New York: }\end{array}$ & - & $\begin{array}{l}1.41 \\
1.35\end{array}$ & $\begin{array}{l}.57 \\
-\end{array}$ & .90 & - & - & $\begin{array}{l}.35 \\
.15\end{array}$ & $\begin{array}{l}.10 \\
.20\end{array}$ & $\begin{array}{r}.86 \\
1.95\end{array}$ & $\begin{array}{l}2.38 \\
2.40\end{array}$ & 2.10 & $\begin{array}{l}3.69 \\
6.80\end{array}$ \\
\hline $\begin{array}{l}719 \\
720 \\
721 \\
722 \\
723\end{array}$ & $\begin{array}{l}\text { Amawalk }+t f / \\
\text { Cross River }+t f / \\
\text { Croton Falls }+t f / \\
\text { Bast Branch }+t f / \\
\text { Mechanicville }+g /\end{array}$ & $\begin{array}{l}.78 \\
.77 \\
.63 \\
.54 \\
\mathrm{u}\end{array}$ & $\begin{array}{l}.01 \\
.01 \\
.03 \\
.02 \\
\text { u. }\end{array}$ & $\begin{array}{l}.32 \\
.30 \\
.31 \\
.42 \\
\dot{H}\end{array}$ & $\begin{array}{l}.23 \\
.19 \\
.17 \\
.12 \\
\mathrm{H}\end{array}$ & $\begin{array}{l}- \\
- \\
\bar{M}\end{array}$ & $\begin{array}{l}.33 \\
.18 \\
.20 \\
.13 \\
\dot{x}^{.13}\end{array}$ & $\begin{array}{r}1.10 \\
.82 \\
1.29 \\
1.13 \\
.24\end{array}$ & $\begin{array}{r}2.48 \\
2.65 \\
2.60 \\
2.38 \\
.61\end{array}$ & $\begin{array}{l}2.30 \\
2.76 \\
3.10 \\
2.46 \\
1.21\end{array}$ & $\begin{array}{l}3.56 \\
4.18 \\
4.40 \\
4.28 \\
1.46\end{array}$ & $\begin{array}{r}.10 \\
.08 \\
.11 \\
.13 \\
2.96\end{array}$ & $\begin{array}{r}9.77 \\
10.59 \\
11.59 \\
10.38 \\
6.48\end{array}$ \\
\hline $\begin{array}{l}724 \\
725 \\
726\end{array}$ & $\begin{array}{l}\text { Spler Fells } t g / \\
\text { Titicus tt } f / g / \\
\text { White Pond tt } g / \\
\text { St. Lamrence River Bagin } \\
\text { Vermont: }\end{array}$ & $\begin{array}{l}x \\
.61 \\
.66\end{array}$ & $\begin{array}{l}M \\
.01 \\
.03\end{array}$ & $\begin{array}{l}\mathrm{K} \\
.30 \\
.38\end{array}$ & $\begin{array}{l}M \\
.28 \\
.15\end{array}$ & $\begin{array}{l}\mathbf{u} \\
- \\
-\end{array}$ & $\begin{array}{l}\mathrm{H} \\
.20 \\
.08\end{array}$ & $\begin{array}{l}.28 \\
.88 \\
.35\end{array}$ & $\begin{array}{l}.25 \\
2.44 \\
2.74\end{array}$ & $\begin{array}{r}.97 \\
2.55 \\
2.22\end{array}$ & $\begin{array}{l}1.82 \\
3.71 \\
4.74\end{array}$ & $\begin{array}{r}2.20 \\
.08 \\
.18\end{array}$ & $\begin{array}{r}5.47 \\
9.78 \\
10.18\end{array}$ \\
\hline $\begin{array}{l}727 \\
728 \\
729 \\
730 \\
731\end{array}$ & 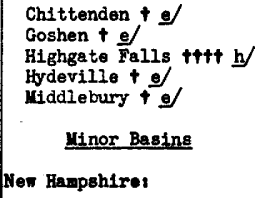 & $\begin{array}{l}- \\
\bar{y} \\
-\end{array}$ & $\begin{array}{c}2.35 \\
2.21 \\
u \\
1.76 \\
1.93\end{array}$ & $\begin{array}{l}- \\
\overline{-} \\
.79 \\
.04\end{array}$ & $\begin{array}{l}1.70 \\
.78 \\
-.52\end{array}$ & $\begin{array}{l}1.30 \\
.62 \\
.66 \\
.10\end{array}$ & $\begin{array}{l}\overline{-} \\
\bar{u} \\
-\end{array}$ & $\begin{array}{l}- \\
.09 \\
- \\
.04\end{array}$ & $\begin{array}{l}.12 \\
.28 \\
.2 \\
.28 \\
.18\end{array}$ & $\begin{array}{l}.79 \\
.79 \\
.4 \\
.74 \\
.58\end{array}$ & $\begin{array}{l}1.38 \\
1.20 \\
1.8 \\
1.42 \\
1.40\end{array}$ & $\begin{array}{l}2.75 \\
8.96 \\
1.9 \\
2.55 \\
1.89\end{array}$ & $\begin{array}{l}5.04 \\
6.82 \\
4.5 \\
4.99 \\
4.09\end{array}$ \\
\hline 732 & $\begin{array}{l}\text { Dxeter }+t 1 / \\
\text { Massachusetts }\end{array}$ & .5 & * & * & .5 & - & * & * & 2.25 & * & 2.0 & - & 4.25 \\
\hline $\begin{array}{l}735 \\
734 \\
735 \\
736\end{array}$ & 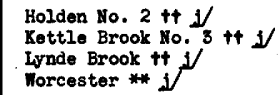 & $\begin{array}{r}1.38 \\
1.57 \\
1.21 \\
.18\end{array}$ & $\begin{array}{l}.02 \\
- \\
.78\end{array}$ & $\begin{array}{l}.43 \\
.66 \\
.46 \\
-\end{array}$ & $\begin{array}{l}.28 \\
.01 \\
.21 \\
.69\end{array}$ & $\begin{array}{l}- \\
- \\
-\end{array}$ & $\begin{array}{l}.46 \\
.40 \\
.56 \\
.78\end{array}$ & $\begin{array}{l}1.95 \\
1.69 \\
2.31 \\
1.07\end{array}$ & $\begin{array}{l}1.49 \\
2.01 \\
1.34 \\
3.18\end{array}$ & $\begin{array}{l}5.47 \\
4.08 \\
5.52 \\
2.02\end{array}$ & $\begin{array}{r}.56 \\
1.04 \\
.66 \\
1.98\end{array}$ & $\begin{array}{l}- \\
- \\
-\end{array}$ & $\begin{array}{l}7.91 \\
9.22 \\
8.89 \\
9.05\end{array}$ \\
\hline
\end{tabular}

* Included in following measurement.

c Claremont Nater Forks.

* Measured at mínight.

d Corps of Engineers, U. S. Aruy.

- Central Vermont Public Service Corporation.

Measured in morning of day indicated.

t+ Measured in morning after day indicated.

t+t Measured at noon.

u Record missing.

a Town of Milford.

b Grosvenordale Co.

Mentrict ty.

g Hew York Power \& Light Corporation.

$h$ Village of Swanton.

1 Bxeter Water Works.

J City Vater Department, Worcester, Mass. 
Table 5.--Supplemental records of daily precipitation, in inches, September 12-22, 1938--Continued

(Heasured in the aftermoon except as noted)

\begin{tabular}{|c|c|c|c|c|c|c|c|c|c|c|c|c|c|}
\hline $\begin{array}{l}\text { No. } \\
\text { on } \\
\text { pl.1 }\end{array}$ & Station & 12 & 13 & 14 & 15 & 16 & 17 & 18 & 19 & 20 & 21 & 22 & $\begin{array}{l}\text { Total, } \\
\text { storm } \\
17-22\end{array}$ \\
\hline & $\begin{array}{l}\text { Minor Besins-Contimued } \\
\text { Rhode Island: }\end{array}$ & & & & & & & & & & & & \\
\hline $\begin{array}{l}737 \\
738 \\
739 \\
740 \\
741\end{array}$ & 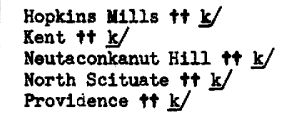 & $\begin{array}{r}0.78 \\
.87 \\
.27 \\
.46 \\
-\end{array}$ & $\begin{array}{r}0.07 \\
.05 \\
.16 \\
.29 \\
.48\end{array}$ & $\begin{array}{r}0.29 \\
.08 \\
.10 \\
.06 \\
-\end{array}$ & $\begin{array}{r}0.04 \\
.60 \\
.52 \\
.43 \\
.57\end{array}$ & $\begin{array}{l}- \\
- \\
-\end{array}$ & $\begin{array}{r}0.78 \\
.72 \\
.84 \\
.85 \\
-\end{array}$ & $\begin{array}{l}1.84 \\
1.02 \\
1.10 \\
1.65 \\
*\end{array}$ & $\begin{array}{r}1.82 \\
.50 \\
.40 \\
1.53 \\
2.02\end{array}$ & $\begin{array}{r}0.93 \\
.62 \\
.46 \\
.39 \\
.70\end{array}$ & $\begin{array}{c}0.47 \\
.54 \\
\text { n } \\
.38 \\
.51\end{array}$ & $\begin{array}{r}0.07 \\
.05 \\
.03 \\
.03 \\
-\end{array}$ & $\begin{array}{l}5.34 \\
3.40 \\
2.80+ \\
4.80 \\
3.25\end{array}$ \\
\hline $\begin{array}{l}742 \\
743 \\
744 \\
745\end{array}$ & $\begin{array}{l}\text { Rocky Hill t+ } \mathrm{k} / \\
\text { Nerren }+\mathrm{o} \\
\text { Westcott }+\mathrm{k} / \\
\text { Westerly of }\end{array}$ & $\begin{array}{l}.54 \\
. \\
.46 \\
-\end{array}$ & $\begin{array}{l}.17 \\
* \\
.18 \\
.60\end{array}$ & $\begin{array}{l}.11 \\
* \\
.06\end{array}$ & $\begin{array}{r}.17 \\
1.14 \\
.40 \\
1.30\end{array}$ & - & $\begin{array}{l}.79 \\
- \\
.78 \\
-\end{array}$ & $\begin{array}{r}2.12 \\
.94 \\
1.55 \\
-\end{array}$ & $\begin{array}{r}1.50 \\
.73 \\
1.60 \\
2.15\end{array}$ & $\begin{array}{r}.65 \\
2.25 \\
.40 \\
.95\end{array}$ & $\begin{array}{c}n .44 \\
.26 \\
.39 \\
-\end{array}$ & $\begin{array}{l}.04 \\
-.04 \\
-\end{array}$ & $\begin{array}{l}5.50 \\
4.18 \\
4.72 \\
8.10\end{array}$ \\
\hline
\end{tabular}

* Included in following measurement.

mo record; gage destroyed during hurricane.

$\uparrow$ Measured in morning of dey indicated.

n Estimated on September 21.

+ Measured in morning after day indicated.

- Bristol County Nater Co.

$k$ Department of Public Forks, Providence, R. I. P Board of Fater Comissioners. 
Table 6.-Preolpitation, in inches, for period ending at indicated time, September 1938

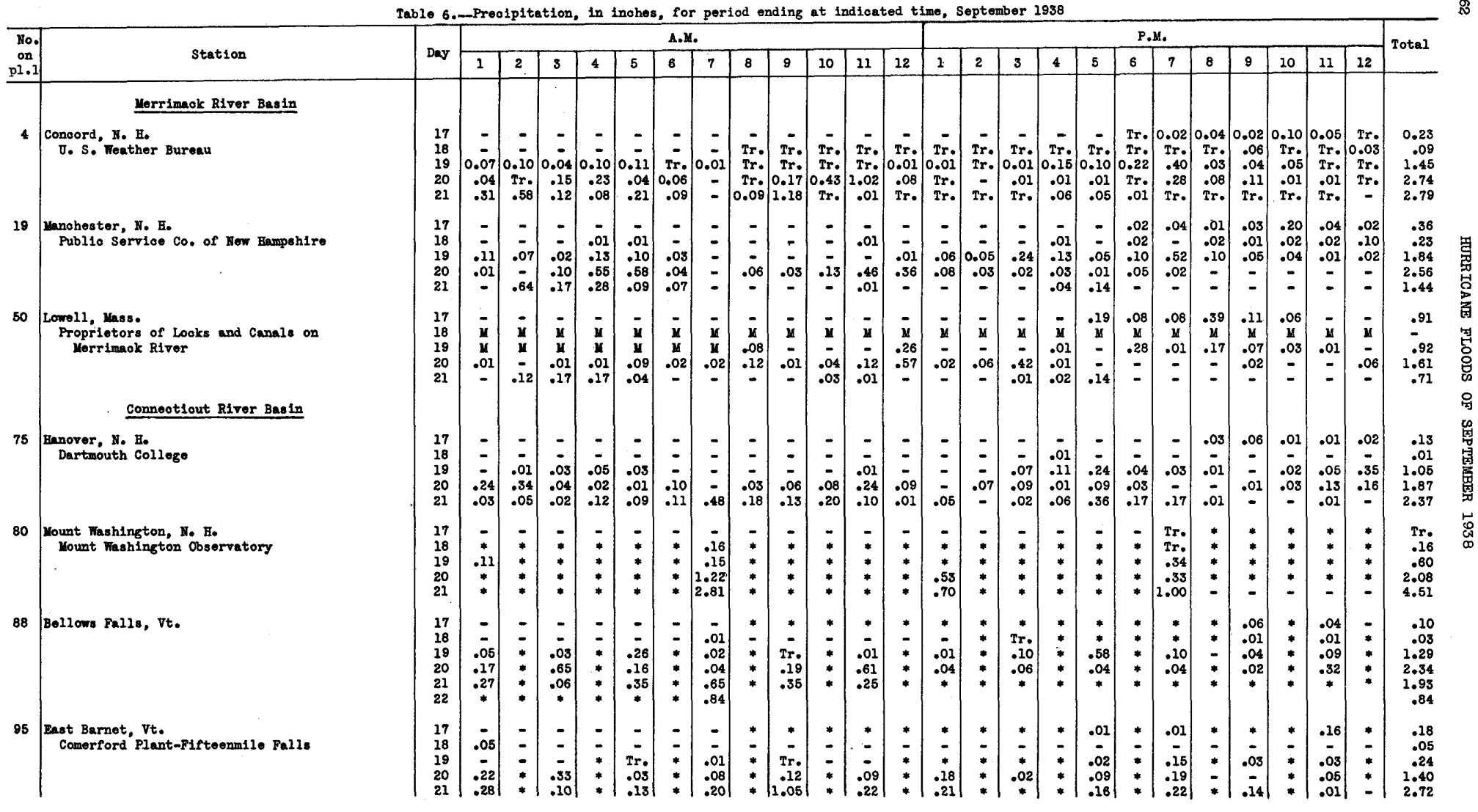


Table 6.-Preolpitation, in inohes, for poriod ending at indioated time, Septenber 1938--Continued

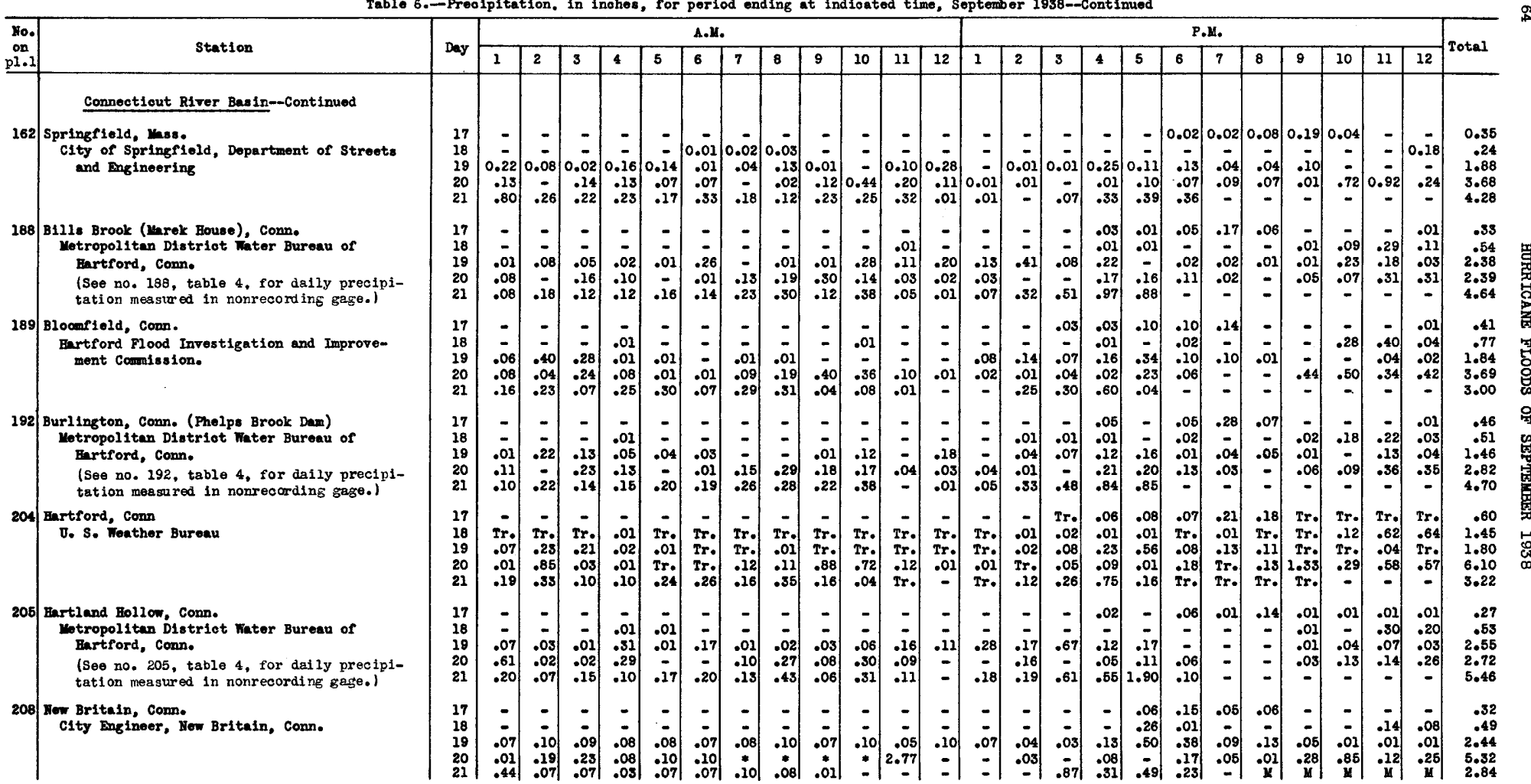


210| Mowington, Conn

artford Flood Investication and Improve-

ment Cormission.

213 South Moadows, conn

city Engineer, Bartford, Comn.

17 Wost Bartford, Conn. (filtration plant)

Yotropolitan District Mater Burean of

Eartford, Conn.

See no. 217, table 4, for daily precipitation measured in nonrecording gage.

218 West Burtford, Conn.

artford Flood Investigation and

Housatonio River Basin

60 Woodv1lle, Conn.

City of Waterbury, Bureau of Ingineering

Hudson River Basin

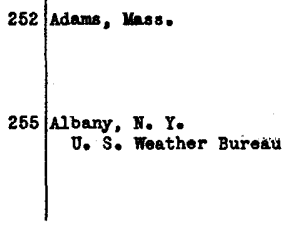

* Inoluded in following measurement.

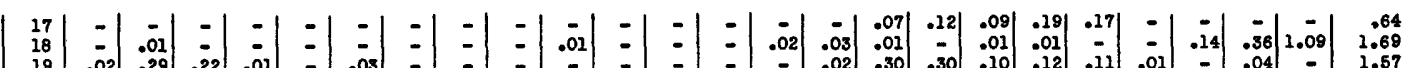

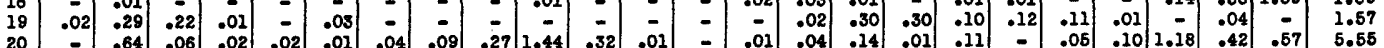

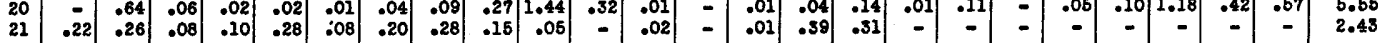

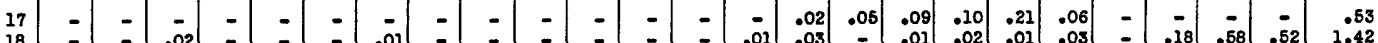

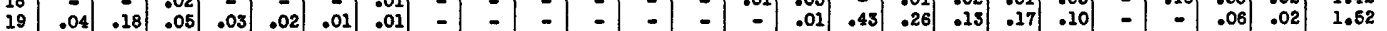

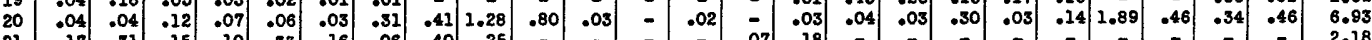

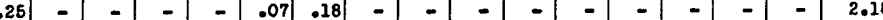

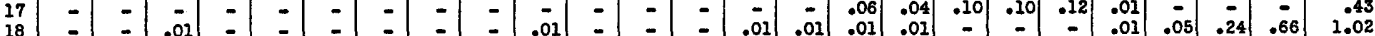

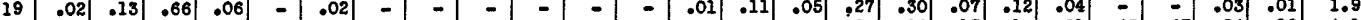

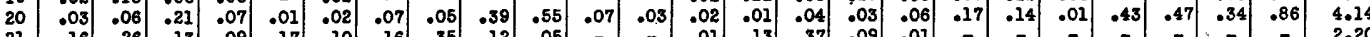

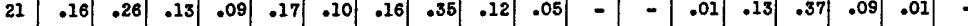

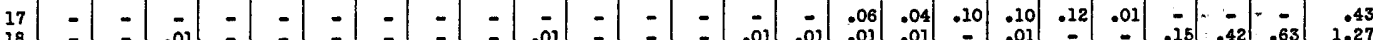

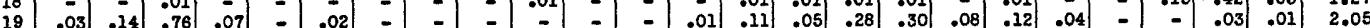

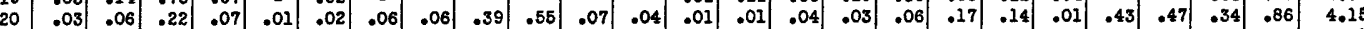

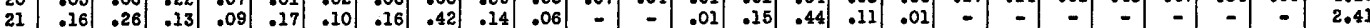

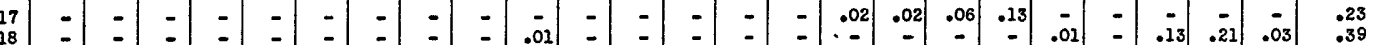

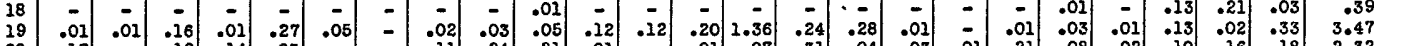

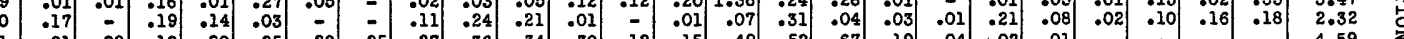

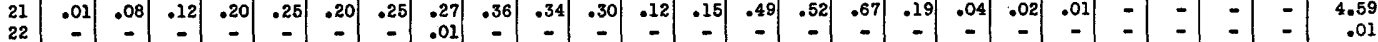

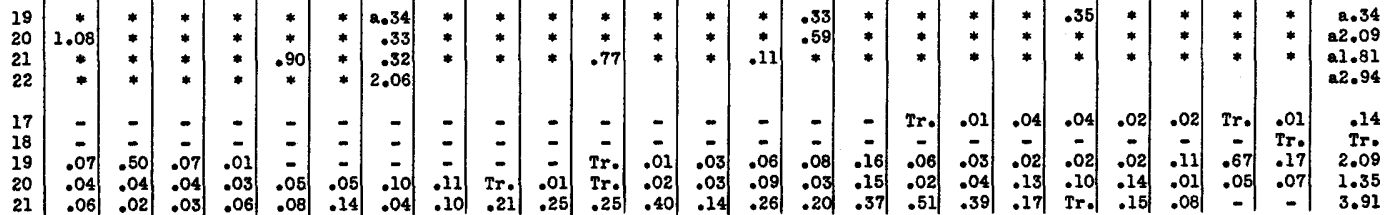

u Rooord missing. 


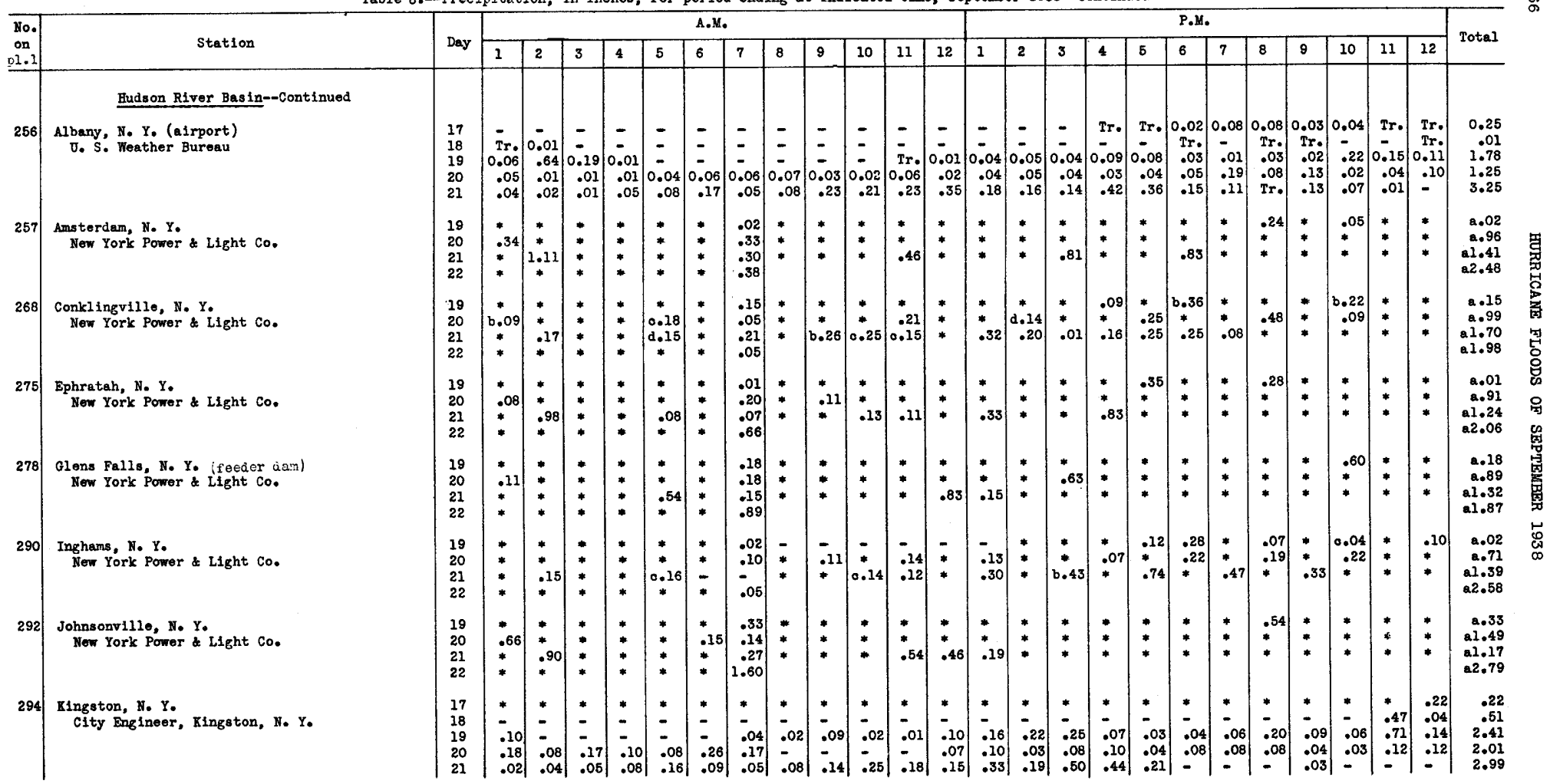




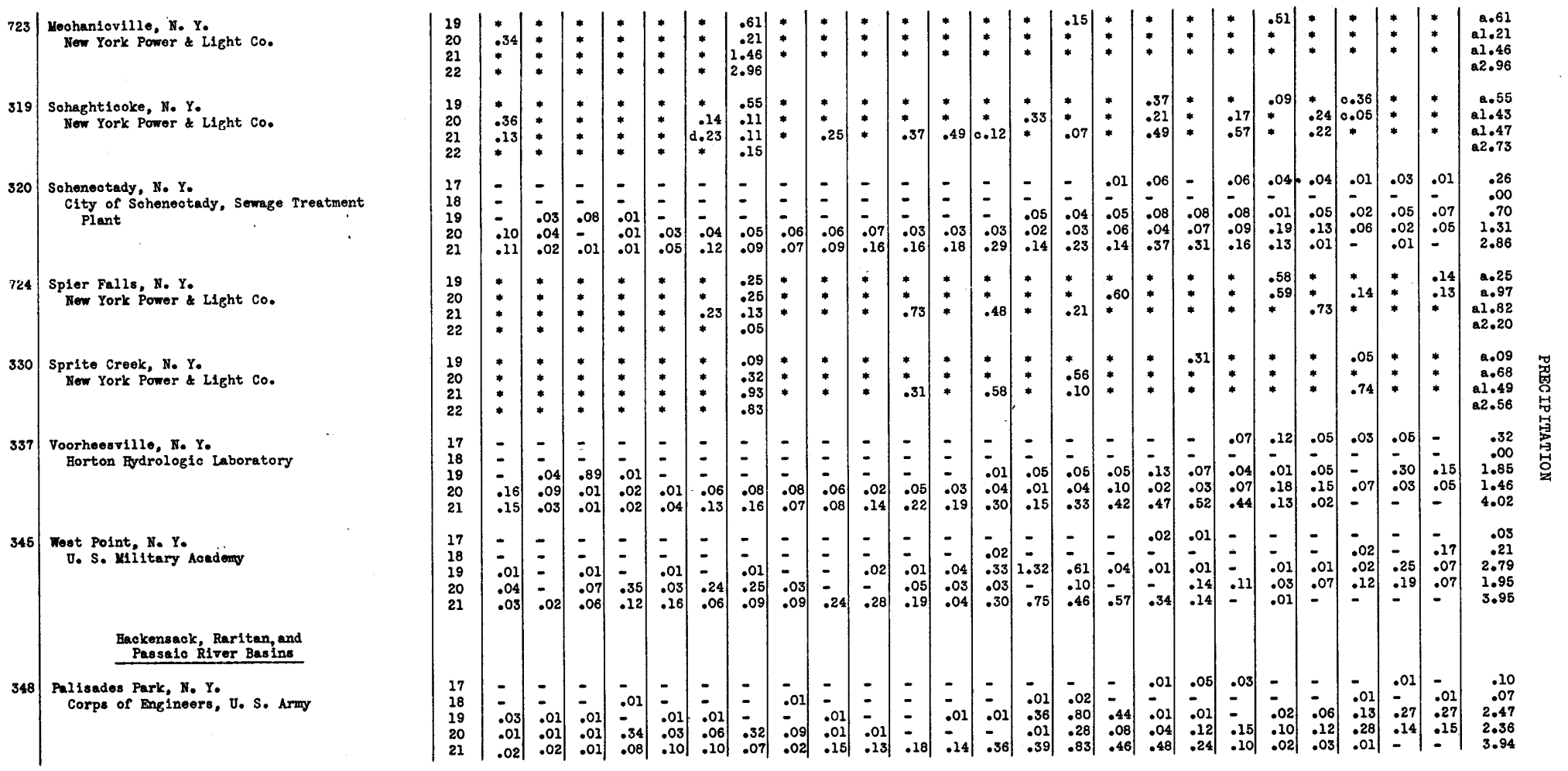

- Included in following measurement.

b Gage read 15 minutes after imicated time.
c Grege read 30 minutes after indicated time. 
Table 6.-Precipitation, in inohes, for period onding at indioated time, September 1938--Continued

\begin{tabular}{|c|c|c|c|c|c|c|c|c|c|c|c|c|c|c|c|c|c|c|c|c|c|c|c|c|c|c|c|}
\hline \multirow{2}{*}{$\begin{array}{r}\text { No } \\
\text { on } \\
\text { pl.1 }\end{array}$} & \multirow{2}{*}{ Station } & \multirow{2}{*}{ Day } & \multicolumn{12}{|c|}{ A.X. } & \multicolumn{12}{|c|}{ P.M. } & \multirow{2}{*}{ Total } \\
\hline & & & 1 & 2 & 3 & 4 & 5 & 6 & 7 & 8 & 9 & 10 & 11 & 12 & 1 & 2 & 3 & 4 & 5 & 6 & 7 & 8 & 9 & 10 & 11 & 12 & \\
\hline \multirow[b]{2}{*}{349} & $\begin{array}{l}\text { Haokensack, Raritan and } \\
\text { Passaio River Basins--Continued }\end{array}$ & & & & & & & & & & & & & & & & & & & & & & & & & & \\
\hline & $\begin{array}{l}\text { Southrield, No Y. } \\
\text { Corps of Enginoers, U. S. Aruy }\end{array}$ & $\begin{array}{l}17 \\
18 \\
19 \\
20 \\
21\end{array}$ & $\mid \begin{array}{c}0.01 \\
- \\
- \\
.10 \\
.05\end{array}$ & $\mid \begin{array}{c}0.01 \\
-.15 \\
.10 \\
-\end{array}$ & $\left|\begin{array}{c}0.01 \\
- \\
.20 \\
.10 \\
.05\end{array}\right|$ & $\left|\begin{array}{c}0.01 \\
- \\
- \\
.10 \\
.05\end{array}\right|$ & $\left|\begin{array}{c}- \\
- \\
0.15 \\
.10\end{array}\right|$ & $\mid \begin{array}{l}- \\
- \\
0.05 \\
.15 \\
.10\end{array}$ & $\mid \begin{array}{c}- \\
- \\
- \\
0.30 \\
.10\end{array}$ & $\begin{array}{l}\bar{z} \\
\overline{-} \\
0.05 \\
.05\end{array}$ & $\begin{array}{l}- \\
- \\
- \\
0.15\end{array}$ & $\mid \begin{array}{c}- \\
- \\
- \\
- \\
0.25\end{array}$ & $\mid \begin{array}{c}- \\
- \\
0.03 \\
.15\end{array}$ & $\left|\begin{array}{c}- \\
- \\
- \\
0.04 \\
.38\end{array}\right|$ & $\begin{array}{l}- \\
\overline{-} \\
0.03 \\
.32\end{array}$ & $\begin{array}{c}- \\
- \\
1.30 \\
.05 \\
.70\end{array}$ & $\mid \begin{array}{c}0.04 \\
-.10 \\
.10 \\
.15 \\
.60\end{array}$ & $\mid \begin{array}{c}0.04 \\
-.10 \\
.09 \\
.00\end{array}$ & $\mid \begin{array}{c}0.02 \\
- \\
- \\
.04 \\
.20\end{array}$ & $\left|\begin{array}{c}0.02 \\
- \\
- \\
.12 \\
.13\end{array}\right|$ & $\left|\begin{array}{c}0.02 \\
.01 \\
.02 \\
.08 \\
.02\end{array}\right|$ & $\mid \begin{array}{c}0.02 \\
.01 \\
.03 \\
.07 \\
.03\end{array}$ & $\begin{array}{c}- \\
0.01 \\
- \\
.15 \\
-\end{array}$ & $\begin{array}{c}0 . \\
0.01 \\
.05 \\
.08 \\
-\end{array}$ & $\begin{array}{c}- \\
0.01 \\
.50 \\
.10 \\
-\end{array}$ & $\begin{array}{c}- \\
0.01 \\
.20 \\
.07 \\
-\end{array}$ & $\begin{array}{r}0.20 \\
.06 \\
2.70 \\
2.15 \\
4.33\end{array}$ \\
\hline \multirow[t]{3}{*}{351} & $\begin{array}{l}\text { Bowling Green, N. J. } \\
\text { Corps of Engineers, U. S. Army }\end{array}$ & $\begin{array}{l}17 \\
18\end{array}$ & 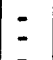 & $=$ & - & - & $=$ & - & - & $=$ & $=$ & $=$ & $=$ & $=$ & $=$ & $\overline{-}$ & $=$ & $\because 04$ & $\because 05$ & $\because 01$ & 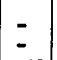 & $=$ & $=$ & $=$ & $=$ & $=$ & $\begin{array}{l}.10 \\
.00\end{array}$ \\
\hline & & $\begin{array}{l}19 \\
20\end{array}$ & .10 & -11 & $\begin{array}{l}.02 \\
.20\end{array}$ & .01 & .02 & $\begin{array}{l}.02 \\
.09\end{array}$ & .02 & $\begin{array}{l}.03 \\
.47\end{array}$ & $\begin{array}{l}.01 \\
.04\end{array}$ & $\begin{array}{l}.02 \\
.01\end{array}$ & $\begin{array}{l}.10 \\
.01\end{array}$ & $\begin{array}{l}.06 \\
.02\end{array}$ & .25 & $\because 44$ & $\begin{array}{l}.14 \\
.02\end{array}$ & .14 & -11 & $\begin{array}{l}.02 \\
.01\end{array}$ & $\begin{array}{l}.01 \\
.03\end{array}$ & $\begin{array}{l}.01 \\
.02\end{array}$ & $\begin{array}{l}.17 \\
.04\end{array}$ & $\begin{array}{l}.39 \\
.04\end{array}$ & $\begin{array}{l}.15 \\
.01\end{array}$ & .10 & $\begin{array}{l}2.24 \\
2.00\end{array}$ \\
\hline & & 21 & - & .01 & .05 & .08 & .13 & .09 & .03 & .01 & .05 & .05 & .10 & .14 & .20 & .55 & .71 & .54 & .51 & .50 & .12 & - & .01 & - & - & - & 3.88 \\
\hline \multirow[t]{3}{*}{352} & $\begin{array}{l}\text { Brook Valley, N. J. } \\
\text { Corps of Engineers, U. S. Army }\end{array}$ & $\begin{array}{l}17 \\
18\end{array}$ & $=$ & $=$ & - & $\overline{T r}_{\mathbf{p}}$ & $\overline{\mathrm{Tr}}$ & $\overline{\operatorname{Tr}}$ & $\overline{\mathbf{T r}}$. & $\overline{\mathrm{Tr}}$ & $\overline{\text { Tr. }}$ & $\overline{T r}$. & $\overline{\mathrm{Tr}}$ & $\overline{T r}$. & $\overline{T r}$. & .03 & .05 & $\because 03$ & -01 & $\because 01$ & $\because 01$ & .01 & $=$ & $=$ & $=$ & $\overline{-}$ & .05 \\
\hline & & $\begin{array}{l}19 \\
20\end{array}$ &.-20 & $\begin{array}{l}.05 \\
.05\end{array}$ & $\begin{array}{l}.22 \\
.10\end{array}$ & .01 & .01 & .01 & .80 & .01 & .02 & .02 & .01 & .01 & .02 & $\begin{array}{l}.50 \\
.02\end{array}$ & $\begin{array}{l}.65 \\
.03\end{array}$ & .05 & $\begin{array}{l}.03 \\
.05\end{array}$ & .02 & .01 & $\begin{array}{l}.01 \\
.05\end{array}$ & .02 & $\begin{array}{l}.02 \\
.13\end{array}$ & .39 & .35 & $\begin{array}{l}2.40 \\
2.57\end{array}$ \\
\hline & & 21 & .03 & - & .02 & .03 & .15 & .12 & .05 & .03 & .05 & .22 & .08 & .10 & .20 & .45 & .75 & .60 & .30 & .18 & .05 & - & - & - & - & - & 3.41 \\
\hline \multirow[t]{4}{*}{362} & $\begin{array}{l}\text { Froehold, N. J. } \\
\text { J. S. Department of Agriculture, Soil }\end{array}$ & $\begin{array}{l}17 \\
18\end{array}$ & $=$ & 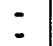 & $=$ & $=$ & $:$ & ! & - & $=$ & 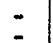 & $=$ & -.04 & - & .06 & 01 & .08 & - & - & - & - & - & - & - & - & - & .15 \\
\hline & Conservation Service, gage R-2 & 19 & - & - & - & - & - & - & - & $\overline{-}$ & $\overline{-}$ & - & $\because$ & $\because 0<$ & .03 & .46 & .04 & $=$ & $\overline{-}$ & .02 & $\because 10$ & $\begin{array}{l}.14 \\
.03\end{array}$ & .02 & $\begin{array}{l}.02 \\
.02\end{array}$ & .12 & .01 & .38 \\
\hline & & 20 & .01 & .01 & .03 & - & .01 & .48 & .03 & - & .04 & .03 & .02 & - & - & 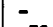 & .05 & .22 & .07 & .14 & .12 & .54 & .30 & .13 & .05 & - & 2.28 \\
\hline & & 21 & .01 & .02 & .20 & $\cdot 22$ & .17 & .11 & .09 & .06 & .31 & .11 & .13 & .43 & .86 & .72 & .29 & .24 & .04 & - & - & - & - & - & - & - & 4.02 \\
\hline \multirow[t]{4}{*}{373} & $\begin{array}{l}\text { Wahwat, N. Jo } \\
\text { Corps of Engineers, U. s, Army }\end{array}$ & $\begin{array}{l}17 \\
18\end{array}$ & - & $=$ & $\overline{-}$ & - & $\overline{-}$ & $\overline{-}$ & $\overline{-}$ & 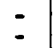 & $\because$ & - & - & - & $\overline{-}$ & .03 & $\because 05$ & .03 & $\because 02$ & $0^{.02}$ & $\Xi$ & $=$ & .01 & .01 & .01 &. & $\begin{array}{l}.12 \\
.07\end{array}$ \\
\hline & & 19 & .01 & .04 & - & - & - & - & - & - & - & - & - & .20 & .30 & 1.50 & .10 & .06 & .02 & .02 & - & .01 & .01 & .34 & .05 & .010 & 2.75 \\
\hline & & 20 & - & - & .27 & .13 & .05 & $\bullet 35$ & .25 & - & - & - & .04 & .01 & - & - & .20 & .05 & .15 & .05 & .05 & .10 & .15 & .10 & .10 & .05 & 2.10 \\
\hline & & 21 & - & - & .05 & .15 & .05 & .05 & .05 & .05 & .20 & .10 & .20 & .30 & .40 & .60 & .35 & .35 & .05 & .05 & - & - & - & .02 & - & - & 3.02 \\
\hline \multirow[t]{4}{*}{374} & $\begin{array}{l}\text { Millington, N. J. } \\
\text { corps of Engineers, U. S. Army }\end{array}$ & 17 & $\overline{-}$ & $\overline{-}$ & - & - & - & - & - & - & - & - & - & - & - & - & - & - & - & - & - & .01 & $\mathbf{T r}$ & $\mathrm{Tr}$ & $\mathrm{Tr}$. & .01 & .02 \\
\hline & Corps or engineers, U. S. Army & $\begin{array}{l}18 \\
19\end{array}$ & $\overline{-}$ & .03 & 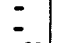 & 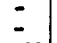 & -01 & $=01$ & .01 & $\begin{array}{l}.01 \\
.01\end{array}$ & .01 & .01 & $\begin{array}{l}- \\
.02\end{array}$ & .02 & $\begin{array}{l}.05 \\
.55\end{array}$ & 1.05 & $\overline{.20}$ & .05 & 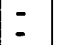 & $\overline{-}$ & $=$ & & $\begin{array}{l}.02 \\
.05\end{array}$ & $\begin{array}{l}.02 \\
.30\end{array}$ & .10 & $\begin{array}{l}.01 \\
.18\end{array}$ & $\begin{array}{r}.13 \\
2.59\end{array}$ \\
\hline & & 20 & .02 & .10 & .20 & .08 & .42 & .53 & .05 & .02 & .01 & - & - & .01 & .01 & .01 & - & - & .09 & .07 & .10 & .25 & .10 & .13 & .02 & .01 & 2.23 \\
\hline & & 21 & $\cdot 01$ & .01 & .04 & $\cdot 11$ & .04 & .06 & .02 & .06 & .07 & .30 & .17 & .20 & .60 & .60 & .40 & .40 & .25 & .03 & - & .01 & - & .01 & - & - & 3.39 \\
\hline \multirow[t]{4}{*}{378} & Morristom, N. J. & 17 & $=$ & $\overline{-}$ & $=$ & $\overline{-}$ & $\overline{-}$ & - & E & $\overline{-}$ & $\overline{-}$ & 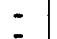 & $\overline{-}$ & $\overline{-}$ & $=$ & - & .01 & $\overline{-}$ & .01 & .01 & $\overline{-}$ & $=$ & - & - & - & - & .03 \\
\hline & & 19 & - & & - & - & - & - & & $\overline{-}$ & $=$ & .02 & .02 & $\overline{-}$ & .48 & 1.00 & .12 & .04 & .04 & $\overline{\mathrm{Tr}}$. & Tr. & $\overline{\mathrm{Tr}}$. & $\mathrm{Tr}$. & .03 & .03 & .32 & $\begin{array}{r}.02 \\
2.10\end{array}$ \\
\hline & & 20 & .04 & .03 & .02 & .03 & .03 & .03 & .03 & .71 & .05 & .05 & .03 & .03 & .02 & .02 & .03 & .03 & .03 & .08 & .05 & .1i & .15 & .09 & .00 & .02 & 1.82 \\
\hline & & 21 & & & & & & .08 & .05 & & & .17 & .18 & .10 & .27 & .40 & $.70 \mid$ & .12 & Tr. 1 & Tr. & Tr. & Tr.l & $\mathrm{Tr}_{\mathrm{r}}$ & -1 & - & - & 2.20 \\
\hline
\end{tabular}



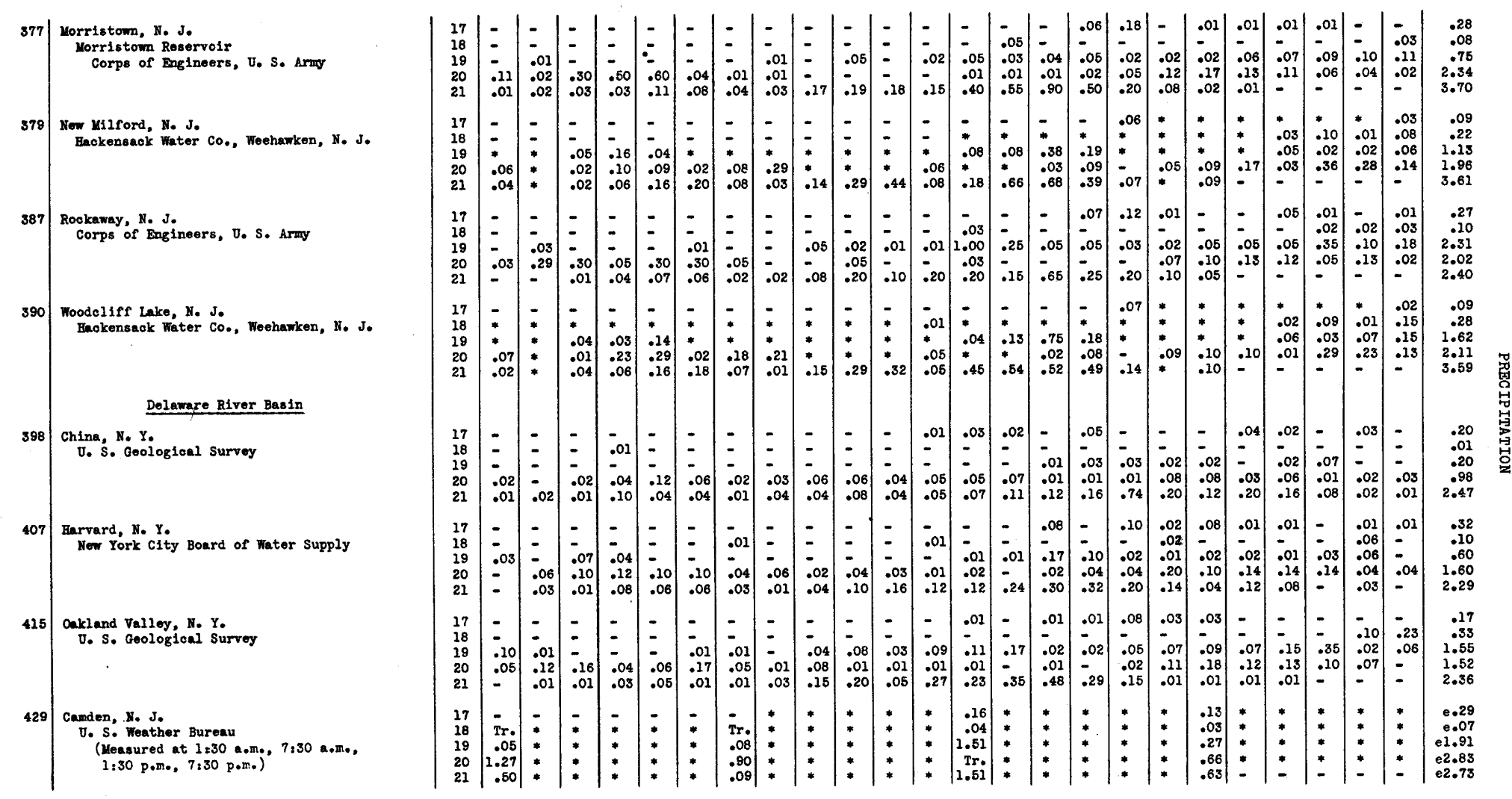

* Included in following measurement.

e Total for 24 hours preceding 1:30 a.me of following day. 


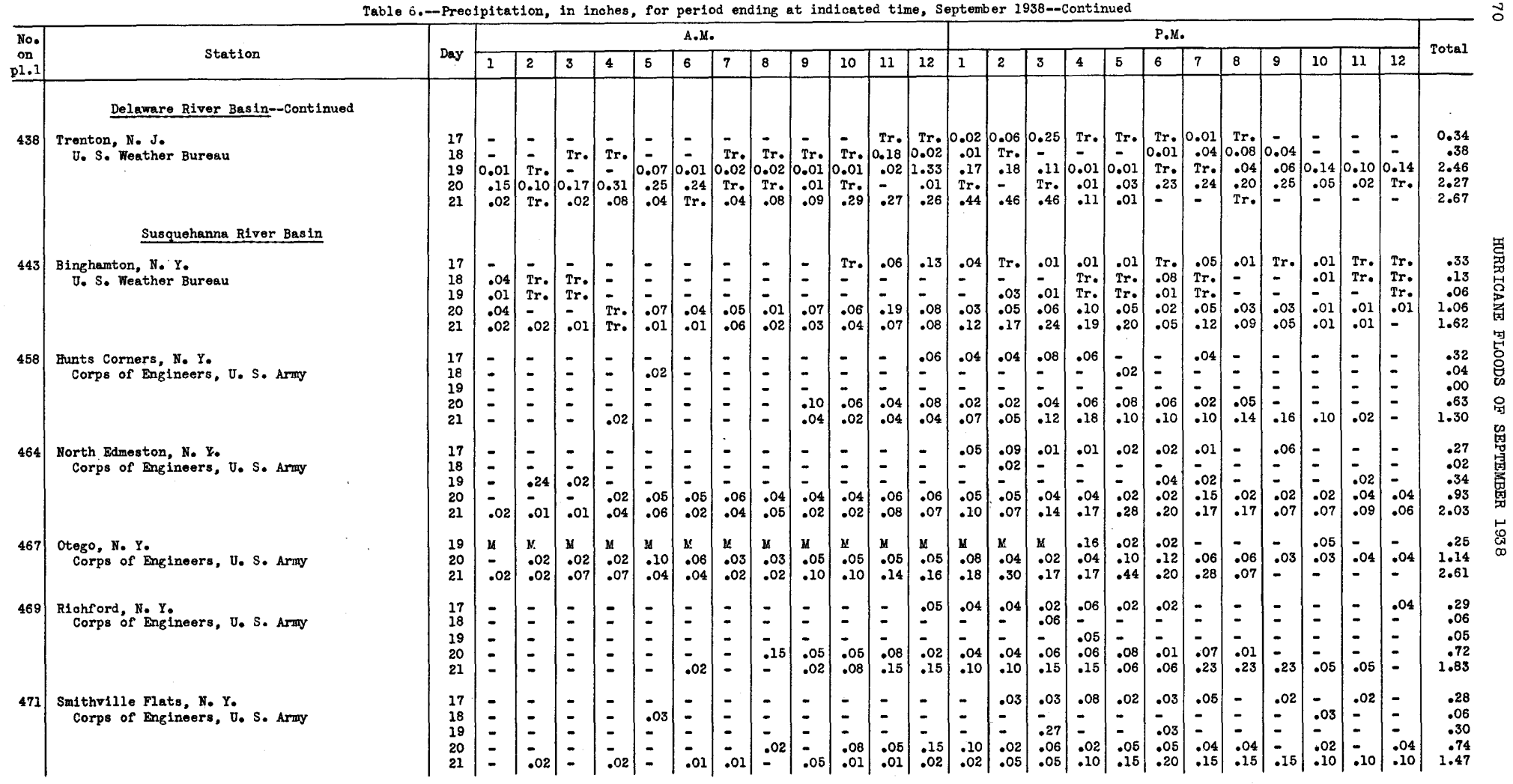


Susquehanna River Basin--Continued
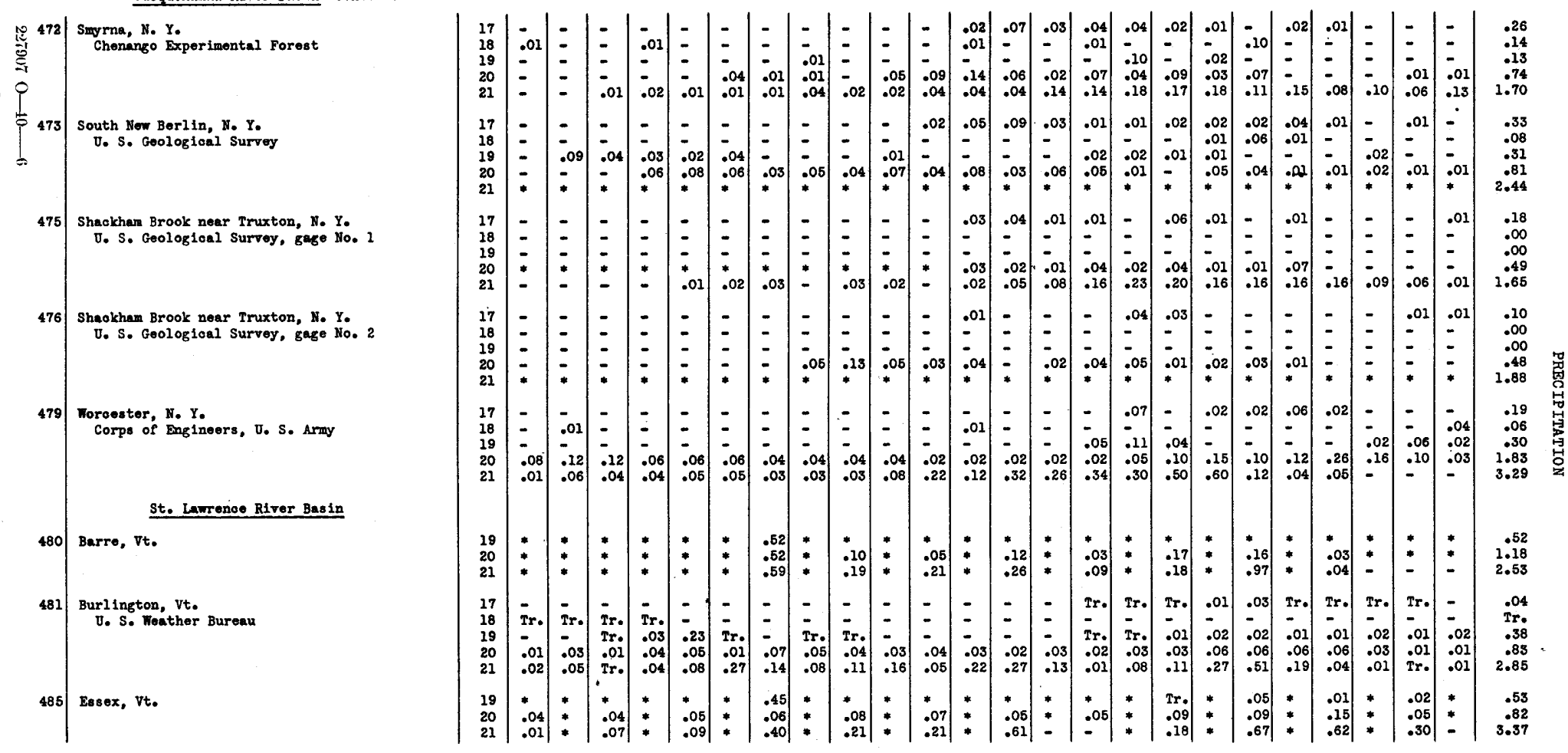

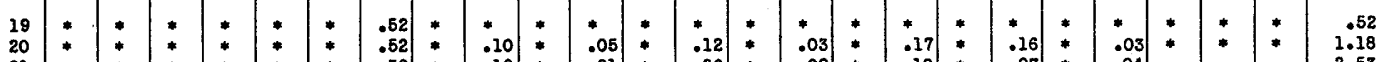

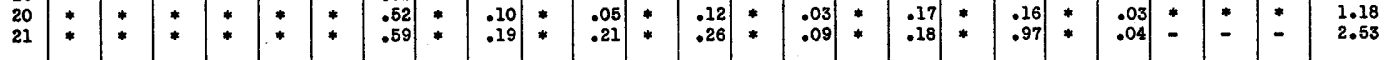

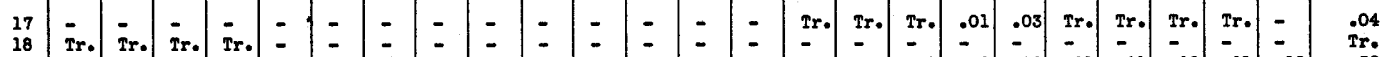

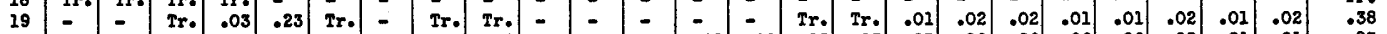

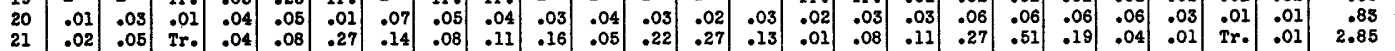

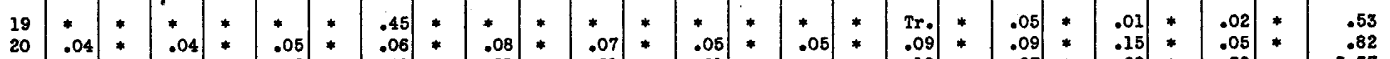

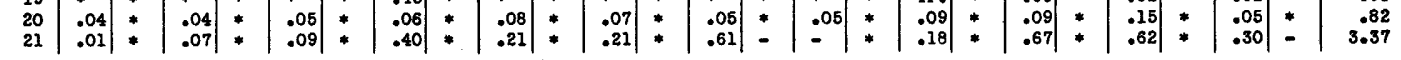
* Inoluded in following measurement. $\quad$ U Record missing. 
Table 6.-Precipitation, in inohes, for period ending at indicated timo, Soptember 1938--Continued

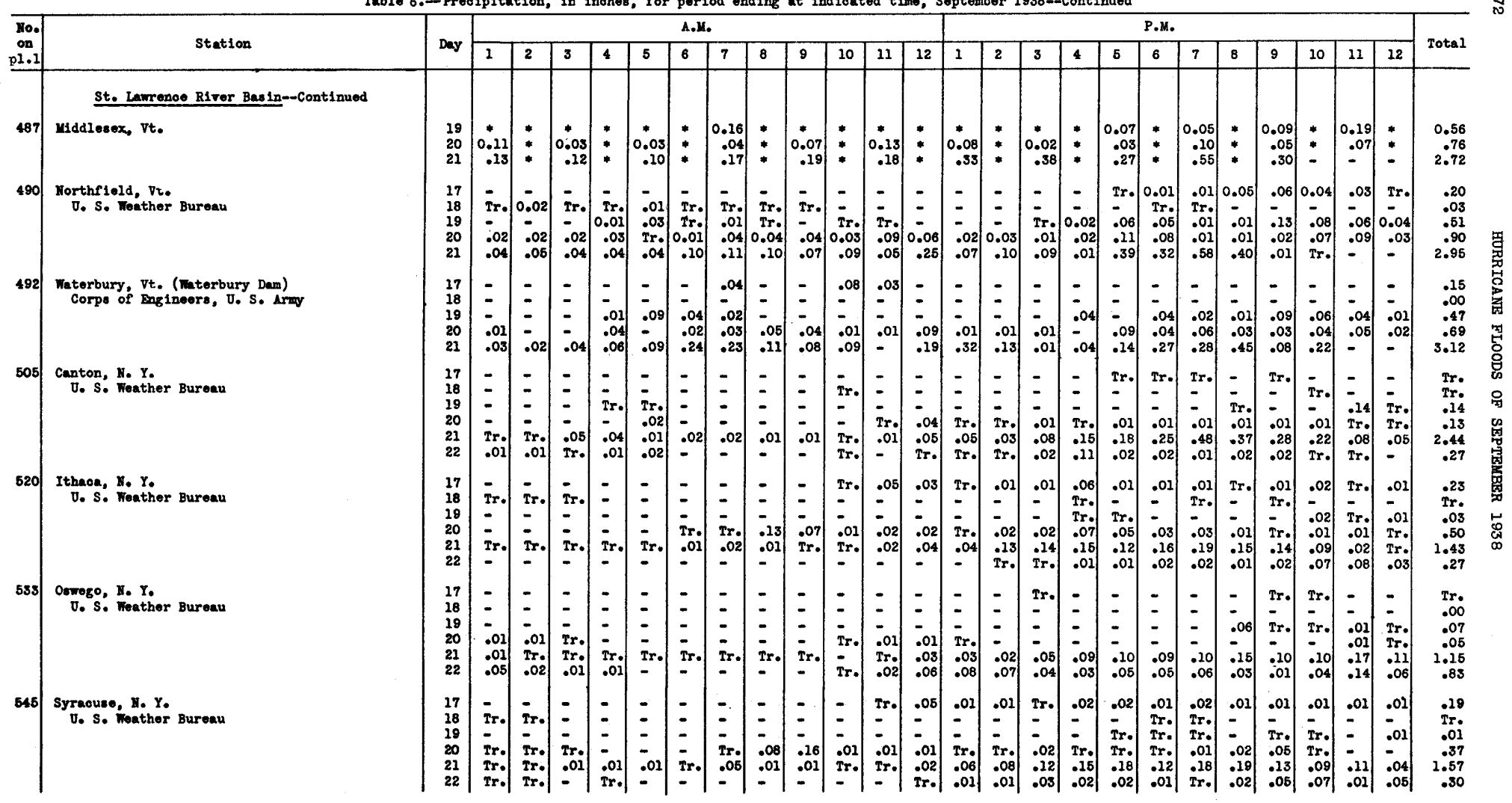




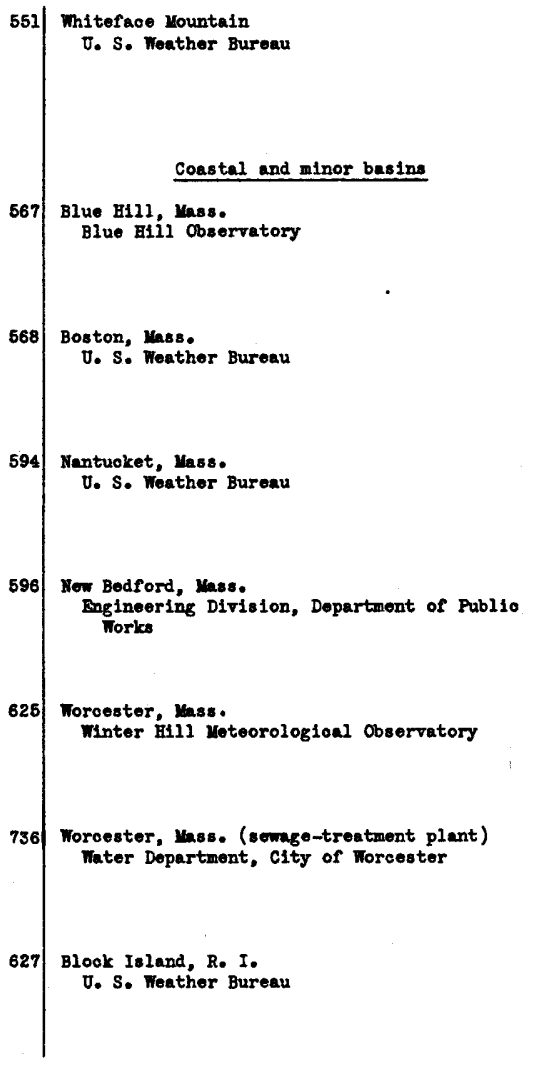

* Included in following measurement.

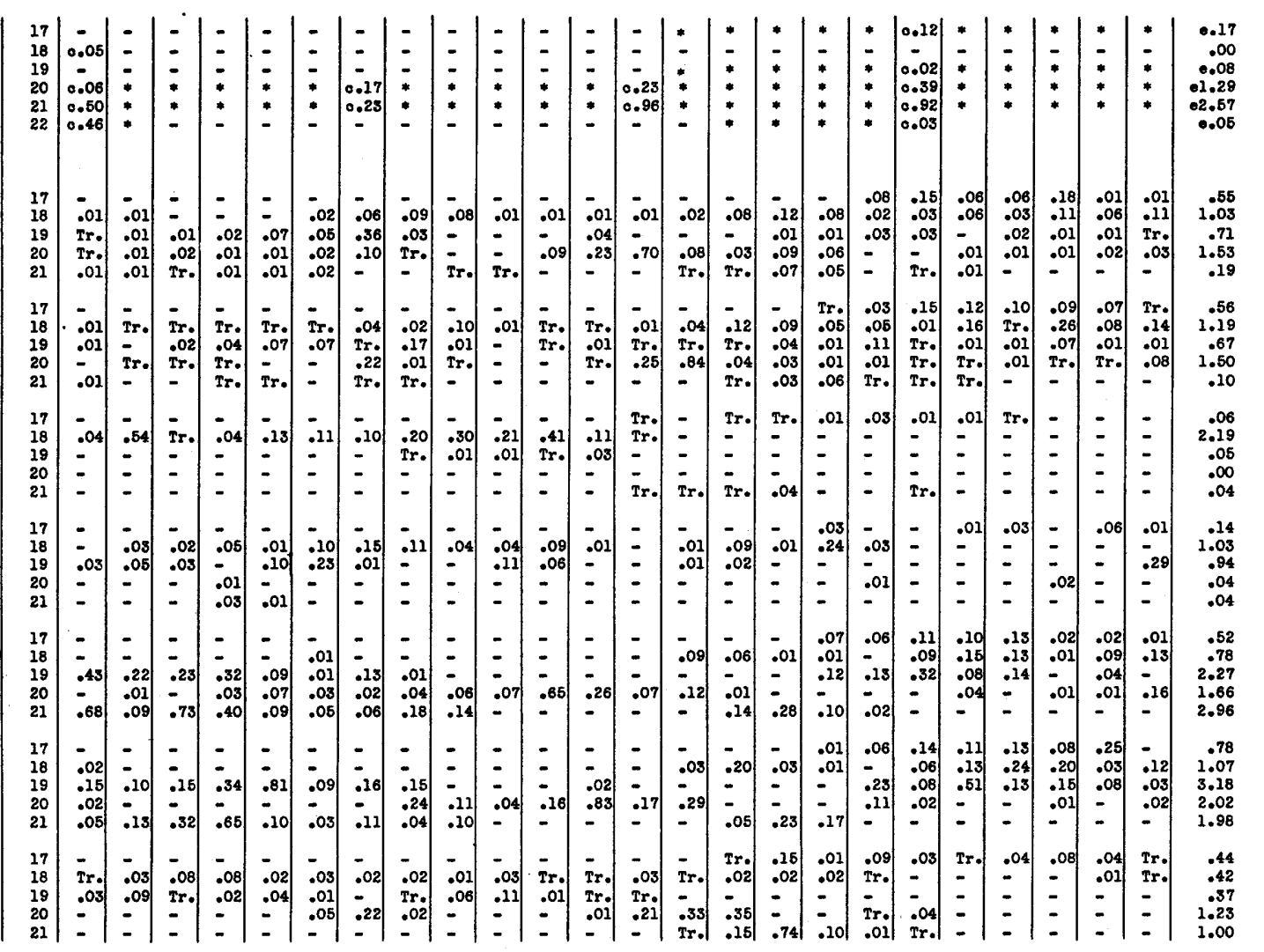

- Gage read 30 minutes after indicated time.

- Total for 24 hours precoding l:30 a.mo of following day. 


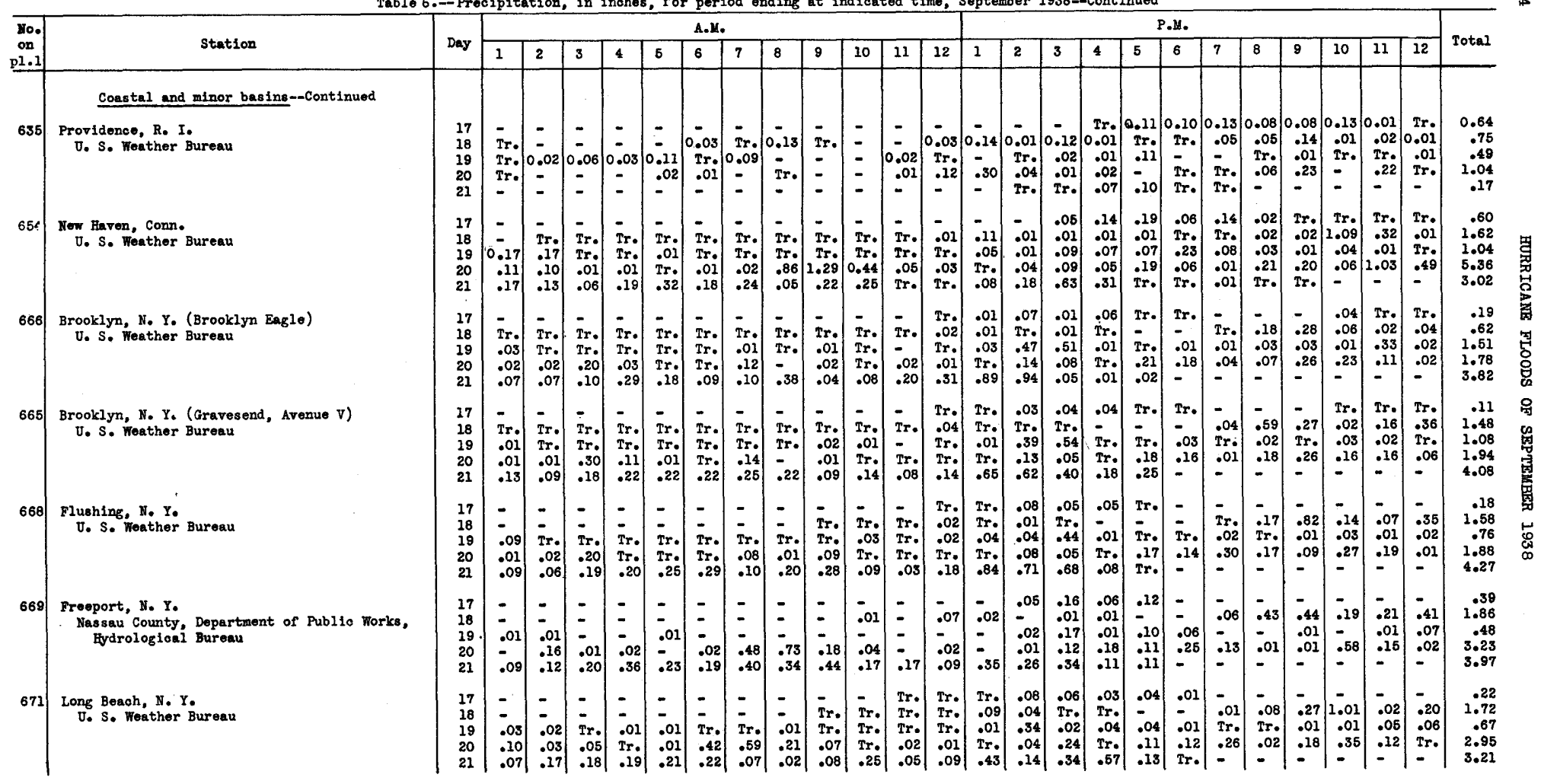



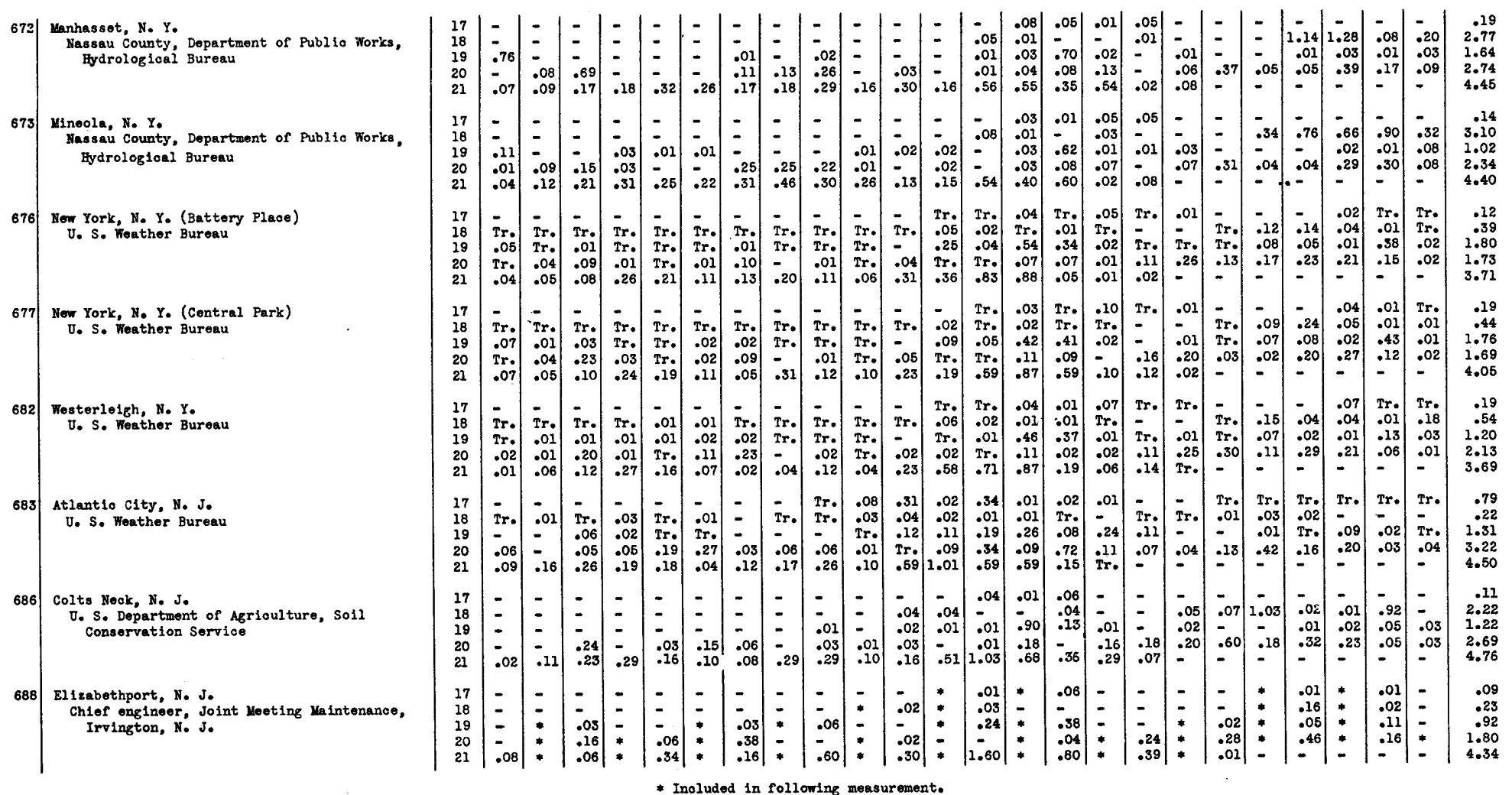


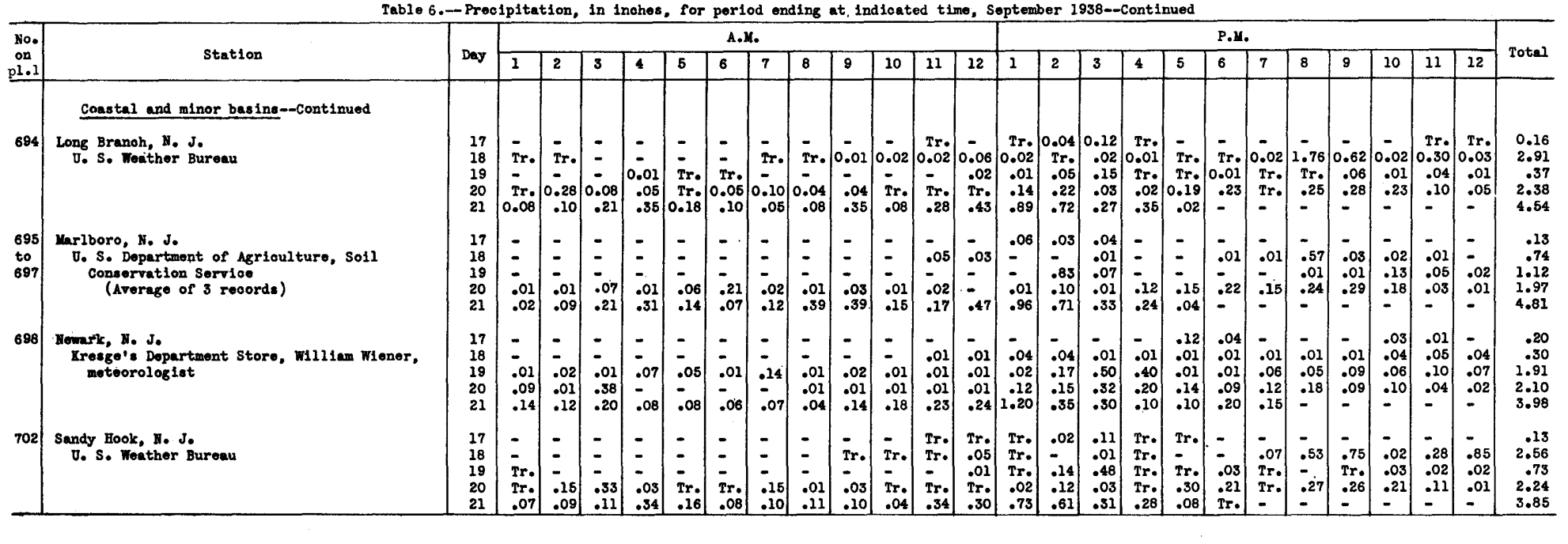


saving time. Some confusion was introduced by the change from daylight saving time to eastern standard time. The change would normally have been made on September 25 but the Governors of Massachusetts, Rhode Island, and Connecticut deferred the change to 0ctober 2 . It is not known to what extent their orders were observed. Some rain-gage charts were placed in the recording instrument according to daylight saving time and removed according to eastern standard time. Moreover, for a few records it was difficult to ascertain the standard of time that was used, so no adjustment was made, thus leaving some uncertainty with respect to time for such records.

The last column of tables 4 and 5 lists the total storm precipitation during the period between noon of September 17 and midnight of September 21, which embraces the major storm. There was generally no rain on September 16 or during the morning of September 17, and except in northern New York the storm ended before midnight of September 21, after which there were no further rains unt1l some light rains occurred in northern and western New York on the afternoon of September 22. Figures 24 and 25 show the hourly distribution of precipitation at several selected places in the area. The observations listed in table 6 were generally read and recorded at one of four different times during the day as Indicated. After inspection of the hourly rainfall records, the following rules were adopted for combining the several daily readings so as to include the total rainfall during the interval from noon September 17 to midnight september 21 and to exclude as closely as possible both the antecedent and subsequent rainfall:

1. For gages read in the aftermoon, the precipitation records for september $17,18,19,20,21$, and 22 were added.

2. For gages read at midnight, the records for september $17,18,19,20$, and 21 were totaled.

3. For gages read in the morning and recorded as of the day read, the records for september 18, 19, 20, 21, and 22 were combined.

4. For gages read in the morning and recorded as of the preceding day, the record for september $17,18,19,20$, and 21 were combined.

Figures 26 and 27 show daily precipitation at various representative precipitation stations from August 1 to October 31, 1938, in tha area covered by this report. 


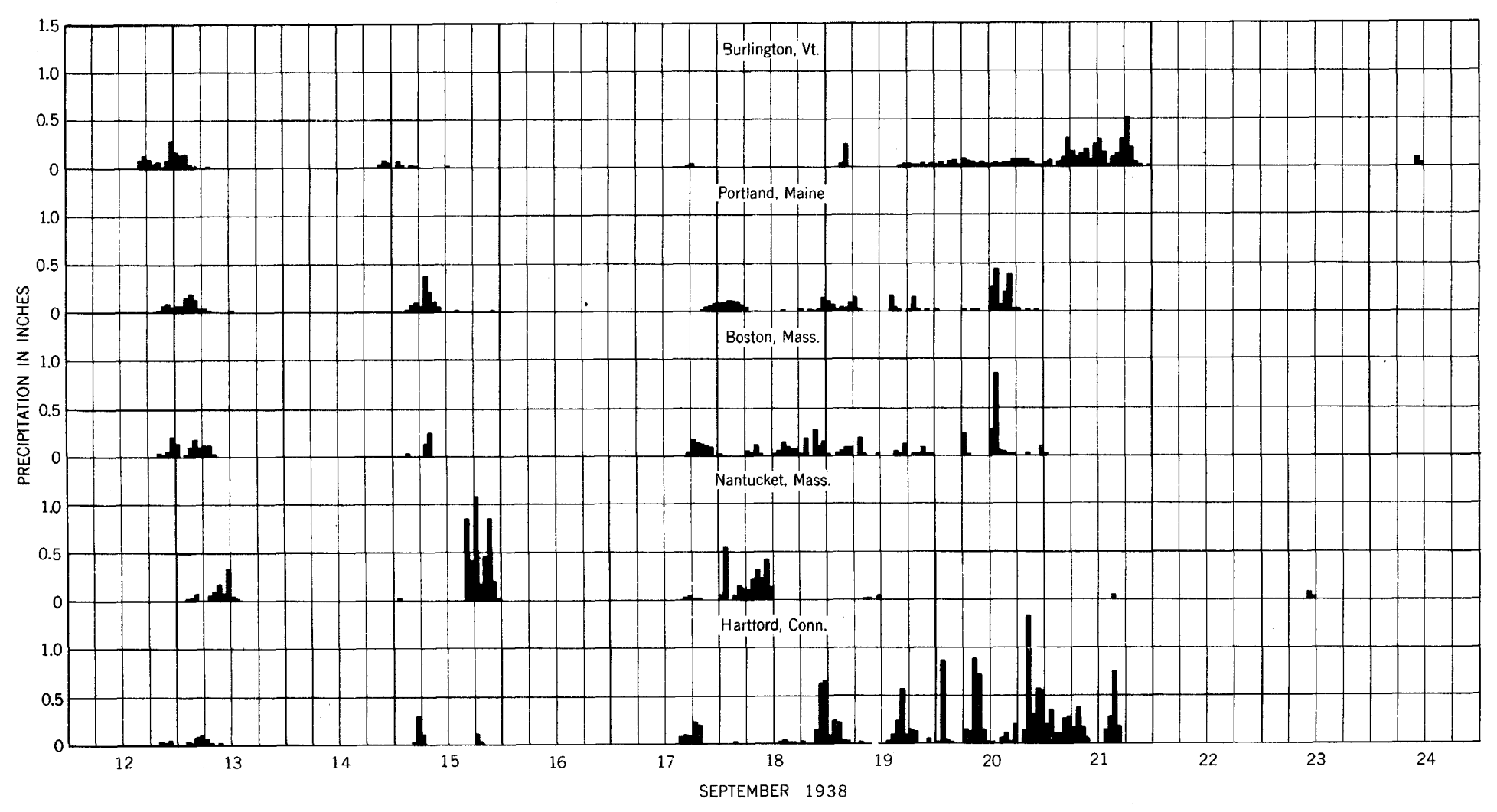

Figure 24.--Hourly precipitation, in inches, at various precipitation stations. 


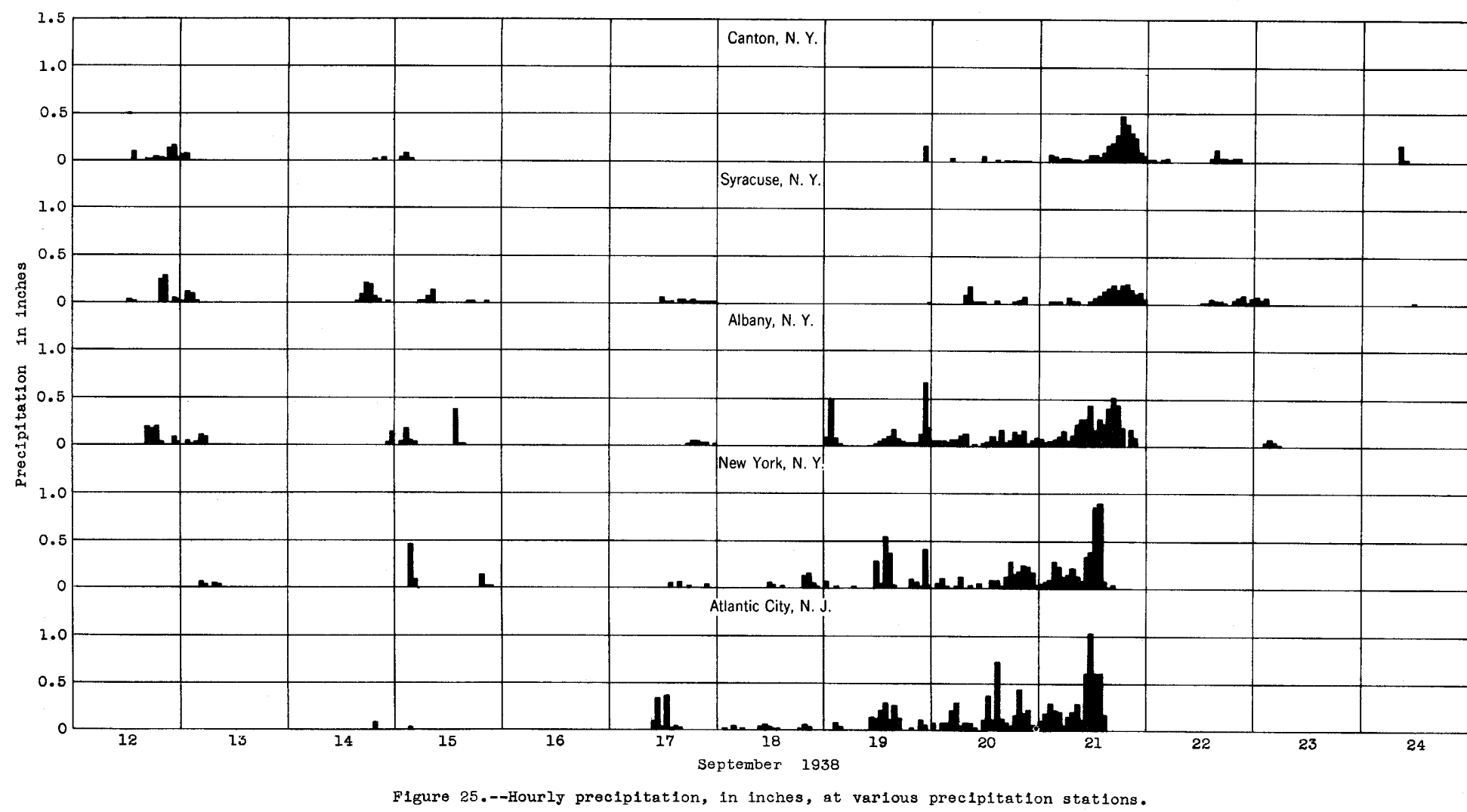




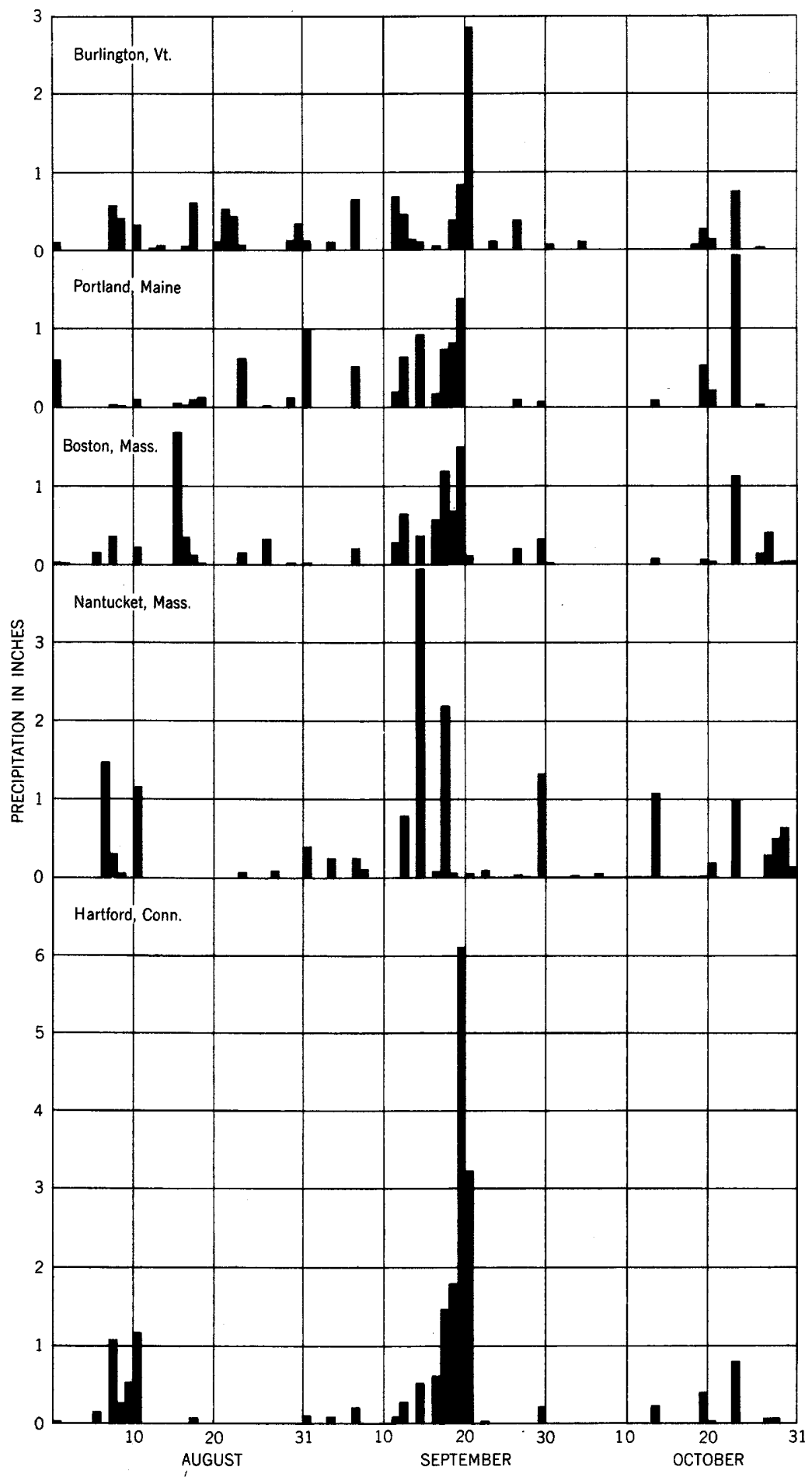

Figure 26.--Daily precipitation at various precipitation stations August 1 to October 31 , 1938 . 


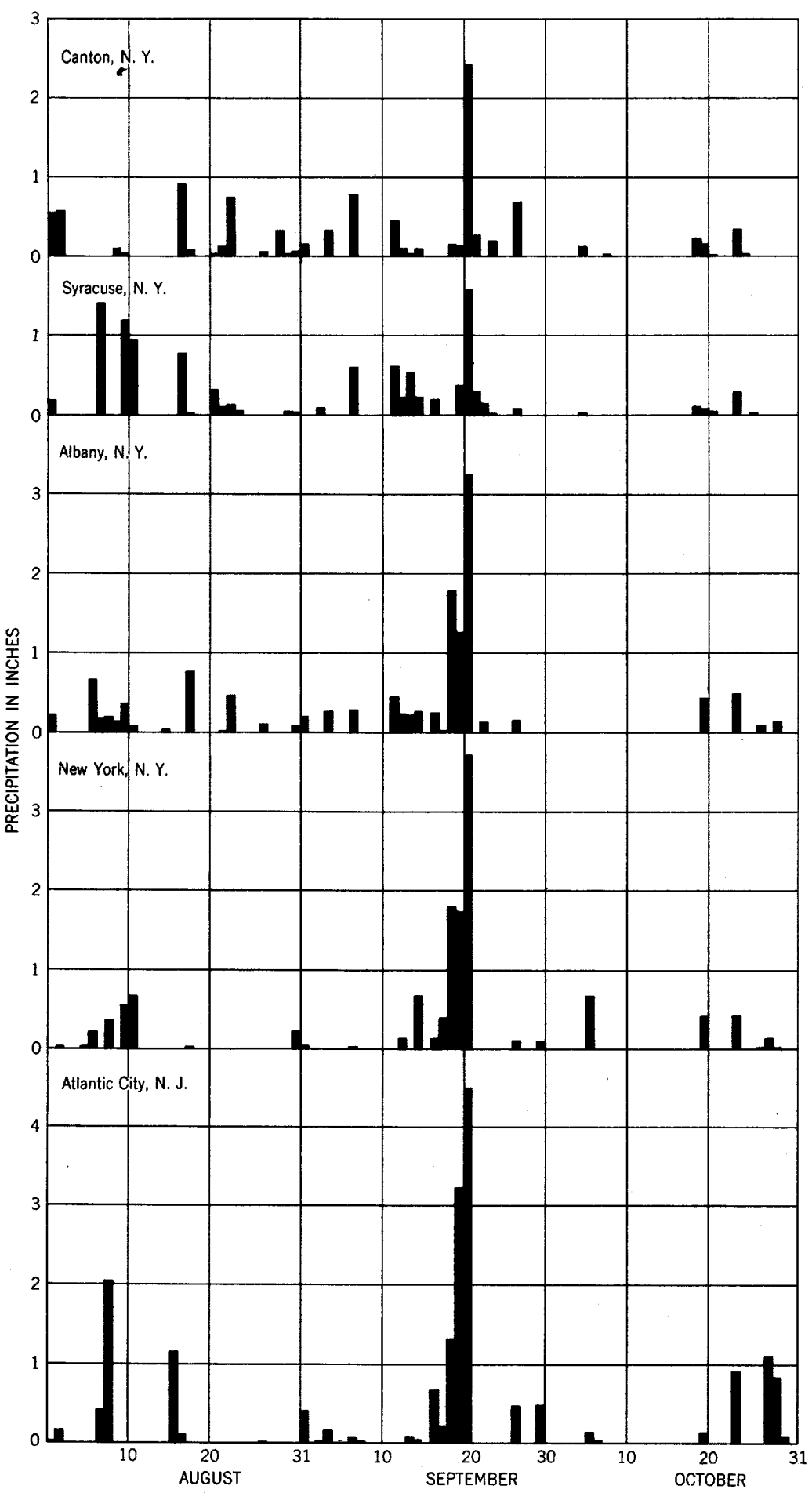

Higure 27.--Da1ly precipitation at various precipitation stations August 1 to October $31,1938$. 


\section{Distribution}

Figure 2 on page 9 presents an isohjetal map for the antecedent perlod September 12-16. Measurable precipitation fell everywhere over the area shown on the map, and the rainfall reached a maximum of more than 4 inches in west-central Vermont and at Nantucket, Mass. Over the greater part of the area the rainfall was between $I$ and 2 inches, somewhat irregularly distributed, and most of the rain fell during the 24hour periods ending on the evenings of september 12 and 15, respectively, although there were other scattered light rains.

The total precipitation during the period September 17-21, based on data listed in tables 4 and 5 , is show in figure 3 and plate 1 . The ridge of maximum precipitation may be observed to occupy a well defined position across New England from Long Island Sound to New Hampshire in an axial direction about N. $20^{\circ} \mathrm{E}$. The recorded maximum precipitation along this ridge exceeded 17 inches at one station in Connecticut and one in Massachusetts. Inspection of figures 5, 6, and 7, showing precipitation for three 24-hour periods respectively between September 18 and 21 as previousiy described indicates that the storm remained fairly fixed in position during the entire period. The steeper precipitation gradient on the easterly side of the ridge of maximum precipitation as shown on plate 1 seems to indicate that the easterly storm front was more sharply defined than the westerly.

Figures 5, 6, and 7 show the precipitation during each of the 24-hour periods ending at 6 p.m., September 19, 20, and 2l. These maps were prepared by (1) plotting the measured catch at those stations where the reading was reported to have been made in the aftermoon, generally between 5 and 7 p.m., (2) plotting the 6 p.m. to 6 p.m. catch at recording raingage stations, and (3) plotting the computed 6 p.m. to 6 p.m. catch at those stations read in the morning. The $6 \mathrm{p} . \mathrm{m}$. to $6 \mathrm{p} . \mathrm{m}$. catch at the latter stations was computed on the basis of the distribution of rainfall at nearby recording rein gages. These maps show the distribution of preclpitation during the storm period and are discussed, together with other meteorologic charecteristics of the storm in the preceding section of this report.

The Weather Bureau and the Corps of Engineers, United States Army, have prepared a series of maps to show the precipitation for 6-hour intervals during the storm. These maps are included in this report as $\mathrm{fig}-$ ures 8 to 22 on pages 19 to 33 . The precipitation from 11 a.m. to 5 p.m., September 17, and from 11 p.m., september 17, to 11 a.m., September 18, 
was limited in area and was generally less than 0.50 inch, and maps showing it are therefore not included. These maps are included to make possible a more detalled study of the morphology of the storm or correlation of rainfall and run-off.

Additional light rain fell in the western and northern parts of New York between September 22 and 24 as a result of a shallow low-pressure area that developed on September 22 after the hurricane had passed northward. On the morning of September 23 this area centered over the New YorkVermont line and induced rainfall on its westerm side as shown in figure 4.

\section{Area-depth relations}

The area within the various isohyetal lines shown on plate 1 (in pocket) and on figures $3,5,6$, and 7 have been planimetered and the results have been used to compute the mean areal rainfall within each of the Indicated isonyetal IInes. Table 7 gives the results of such computations for selected 1sohyetals.

\begin{tabular}{|c|c|c|}
\hline $\begin{array}{c}\text { Isohyetal } \\
\text { (rainfall, in inches) }\end{array}$ & $\begin{array}{l}\text { Area } \\
\text { (square mlles) }\end{array}$ & $\begin{array}{l}\text { Rainfall } \\
\text { (mean depth, in inchos) }\end{array}$ \\
\hline \multicolumn{3}{|c|}{ Noon Sept. 17 to 12 p.m. Sept. 21} \\
\hline 16 & 100 & 16.8 \\
\hline 14 & 835 & 15.0 \\
\hline 12 & 2,670 & 13.6 \\
\hline 10 & 9,020 & 11.7 \\
\hline 8 & 20,300 & 10.2 \\
\hline 6 & 36,000 & 8.85 \\
\hline 4 & 58,600 & 7.35 \\
\hline \multicolumn{3}{|c|}{ 24-hour per1od ending 6 p.m. Sept. 19} \\
\hline 4 & 135 & 4.50 \\
\hline 3 & 2,010 & 3.55 \\
\hline 2 & 12,580 & 2.65 \\
\hline \multicolumn{3}{|c|}{ 24-hour period ending $6 \mathrm{p.m}$. Sept. 20} \\
\hline 4 & 990 & 4.75 \\
\hline 3 & 5,450 & 3.75 \\
\hline 2 & 27,200 & 2.75 \\
\hline \multicolumn{3}{|c|}{ 24-hour perlod ending 6 p.m. Sept. 21} \\
\hline 6 & 1,020 & 6.55 \\
\hline 4 & 16,000 & 5.02 \\
\hline 2 & 52,400 & 3.55 \\
\hline
\end{tabular}


Comparison of these results with those of previous storms in the region as reported by the Miaml Conservancy District (see table 8 ) indicate that in respect to depth of rainfall and area covered the 4-day storm of September 17-21, 1938, has not been surpassed by any storm of like duration of which there is record.

Table 8.--Depth of average rainfall in relation to areal extent for notable storms

\begin{tabular}{|c|c|c|c|c|c|c|c|c|}
\hline \multirow{2}{*}{ Date of storm } & \multirow{2}{*}{$\begin{array}{c}\text { Center } \\
\text { of } \\
\text { storm }\end{array}$} & \multicolumn{6}{|c|}{$\begin{array}{l}\text { Average rainfall, in inches, over } \\
\text { indicated area, in square miles }\end{array}$} & \multirow{2}{*}{$\begin{array}{l}\text { Dura- } \\
\text { tion } \\
\text { (days) }\end{array}$} \\
\hline & & 1 & 500 & 1,000 & 2,000 & 4,000 & 6,000 & \\
\hline 1869 oct. $3-4$ a & Conn. & 12.4 & 10.4 & 9.7 & 8.9 & 8.1 & 7.8 & 2 \\
\hline 1897 July $12-14$ a/ & do & 10.3 & 9.5 & 9.1 & 8.5 & 7.5 & 6.9 & 2 \\
\hline 1903 0ct. $8-9$ a & N. J. & 15.0 & 11.9 & 10.9 & 9.9 & 9.0 & 8.4 & 2 \\
\hline 1919 July 19-23 a/ & do & 12.8 & 10.7 & 9.7 & 8.5 & 7.5 & 7.0 & 5 \\
\hline 1919 Aug. 13-17 a/ & do & 10.2 & 9.9 & 9.6 & 9.2 & 8.4 & 7.7 & 5 \\
\hline 1927 Nov. $3-4$ a/ & Vt. & 9.4 & 9.1 & 8.9 & 8.6 & 8.1 & 7.7 & 2 \\
\hline 1932 Sept. $16-17$ b/ & R. I. & 12.2 & 11.2 & 10.4 & 9.4 & 8.3 & 7.8 & 1 \\
\hline 1936 Mar. 9-13 & $\begin{array}{l}\text { New } \\
\text { England }\end{array}$ & 9.2 & 7.9 & 7.3 & 6.6 & 5.9 & 5.45 & 4 \\
\hline 1936 Mar. $16-19$ & do & 9.0 & 8.0 & 7.7 & 7.4 & 7.0 & 6.8 & 3 \\
\hline 1938 Sept. 17-21 & do & 18.0 & 15.5 & 14.8 & 14.0 & 13.0 & 12.3 & 4 \\
\hline
\end{tabular}

a Data given in Storm rainfall of eastern United States, part 5 , Tech. Repts. Miami Conservancy District, p. 278, 1936

b Based on duta of Geo. V. Wite, Great storm of September 16 and 17, 1932: New England Water Works Assoc. Jour., vol. 47, no. 2, pp. $164-183,1933$.

That the storm remained localized in position during the 3 days of heaviest rainfall, september 19,20 , and 21 , is 11 lustrated by table 9 , which shows the average rainfall, in inches, over the indicated areas durIng each of the 3 days, their sum over areas of corresponding magnitude, and for comparison, the average rainfall during the storm of september 17-21, also over areas of corresponding magnitude.

It should be noted that the depths of rainfall during each of the selected storm periods, listed in colums 2 to 5 , represent the average over the areas of maximum rainfall indicated in colum 1. These areas of maximum rainfall were not necessarily in the same geographical position during each of the perlods tabulated. The extent to which the figures in column 5 agree with those in column 6 indicates the degree of geographical coincldence of areas of maximum rainfall during the selected storm periods. 
Although the total of the three separate 1-day rainfall amounts on an areal basis omits the Iight rainfall between the afternoon of Septembe 17 and September 18, which reached a maximum of more than 2 inches but averaged only about 0.7 inch over the entire area, table 9 nevertheless emphasizes the fact that the areas of heaviest rainfall during each of the 3 days were nearly colncident.

Table 9.--Depth of average rainfall, in 1nches, for indicated area and period

\begin{tabular}{|c|c|c|c|c|c|}
\hline \multirow{2}{*}{$\begin{array}{c}\text { Area } \\
\text { (square } \\
\text { miles) }\end{array}$} & \multicolumn{3}{|c|}{ 24-hour period ending 6 p.m. } & \multirow{2}{*}{$\begin{array}{l}\text { Sum of } \\
\text { Columm } 2 \\
\text { to } \\
\text { Column } 4\end{array}$} & \multirow{2}{*}{$\begin{array}{c}\text { Storm } \\
\text { of } \\
\text { Sept. } 17-21\end{array}$} \\
\hline & Sept. 19 & Sept. 20 & Sept. 21 & & \\
\hline I & 2 & 3 & 4 & 5 & 6 \\
\hline 1 & 4.9 & 6.3 & 8.5 & 19.7 & 18.0 \\
\hline 500 & 4.05 & 5.15 & 6.8 & 16.0 & 15.5 \\
\hline 1,000 & 3.8 & 4.8 & 6.55 & 15.15 & 14.8 \\
\hline 2,000 & 3.55 & 4.4 & 6.2 & 14.15 & 14.0 \\
\hline 4,000 & 3.2 & 3.95 & 5.9 & 13.05 & 13.0 \\
\hline 6,000 & 3.0 & 3.7 & 5.75 & 12.45 & 12.3 \\
\hline 10,000 & 2.75 & 3.4 & 5.45 & 11.6 & 11.5 \\
\hline
\end{tabular}

\section{DETERMINATION OF FLOOD DISCHARGES}

The general methods employed by the Geological Survey in the determination of maximum flood discharges at regular river-measurement stations and at locations where regular river-measurement stations are not maintained have been described in detall in several recent watersupply papers relating to floods, and repetition of the description in this volumn is deemed unnecessary.

At the regular river-measurement stations operations consist principally of the determination of a stage-discharge relation from which, under normal conditions, and from a known stage the discharge can be determined. At other places or for stages in excess of those defined by the stage-discharge relation, determinations of maximum flow have been based chiefly on (1) computation of flow over dams such as that shown on plate 10, (2) computation of flow from slope-area observations and (3) computation of flow through contracted openings. Examples and general information in regard to the use of these methods with special references to the conditions experienced by the Geological Survey in ap plying them to various severe floods are given in Water-Supply Papers $773-\mathrm{E}, 796-\mathrm{G}, 798,800$, and 816 . 


\section{STAGES AND DISCHARGES AT STREAM-GAGING STATIONS}

One of the foremost purposes of this report is the publication of useful detailed information regarding the stages and discharges of streams during the floods of September 1938 that will not be avallable in the summarized records of river discharge published annually in the watersupply papers of the Geological Survey. The justification for making available such detalled information rests upon the recognized need for records of flood behavior that w1ll show not only the mean dally discharge and the maximum rates of discharge during a flood as usually published for a gaging station but also the stages and rates of discharge at frequent times throughout the flood period and will make possible a definition of conditions of stage and discharge at all stations in a basin at a given time during the progress of the flood. This detail is essential for intensive and comprehensive studies of the characteristics of floods and promotes the formulation of appropriate plans for flood protection and control. It furnishes basic information for studying the behavior of flood crests, including the incldence of crests from different tributaries of a stream, the progress of flood orests throughout a river system, and other features useful in deriving the elements necessary for forecasting flood helghts and for appraising the characteristics of different basins in the shedding of flood waters. It furnishes basic information for the consideration of the feasibility of detention reservoirs, channel improvement, forest management, so1l treatment, flood forecasting, and other messures with respect to their merits for amellorating damage and losses caused by floods. Moreover, in view of the exceptional record-setting character of the floods of september 1938, it 1s important that full and authentic information concerning them be ava11able for reference and guldance in connection with future urban and industrial development, with highway and bridge construction, and especialif with the design of hydraulic structures in their relation to flood channels of streams.

In general, records of gaging stations published in this roport relate to streams on which floods occurred or which are situated adjacent to the margins of the flooded reglons and so serve to define the areal extent of the floods. 


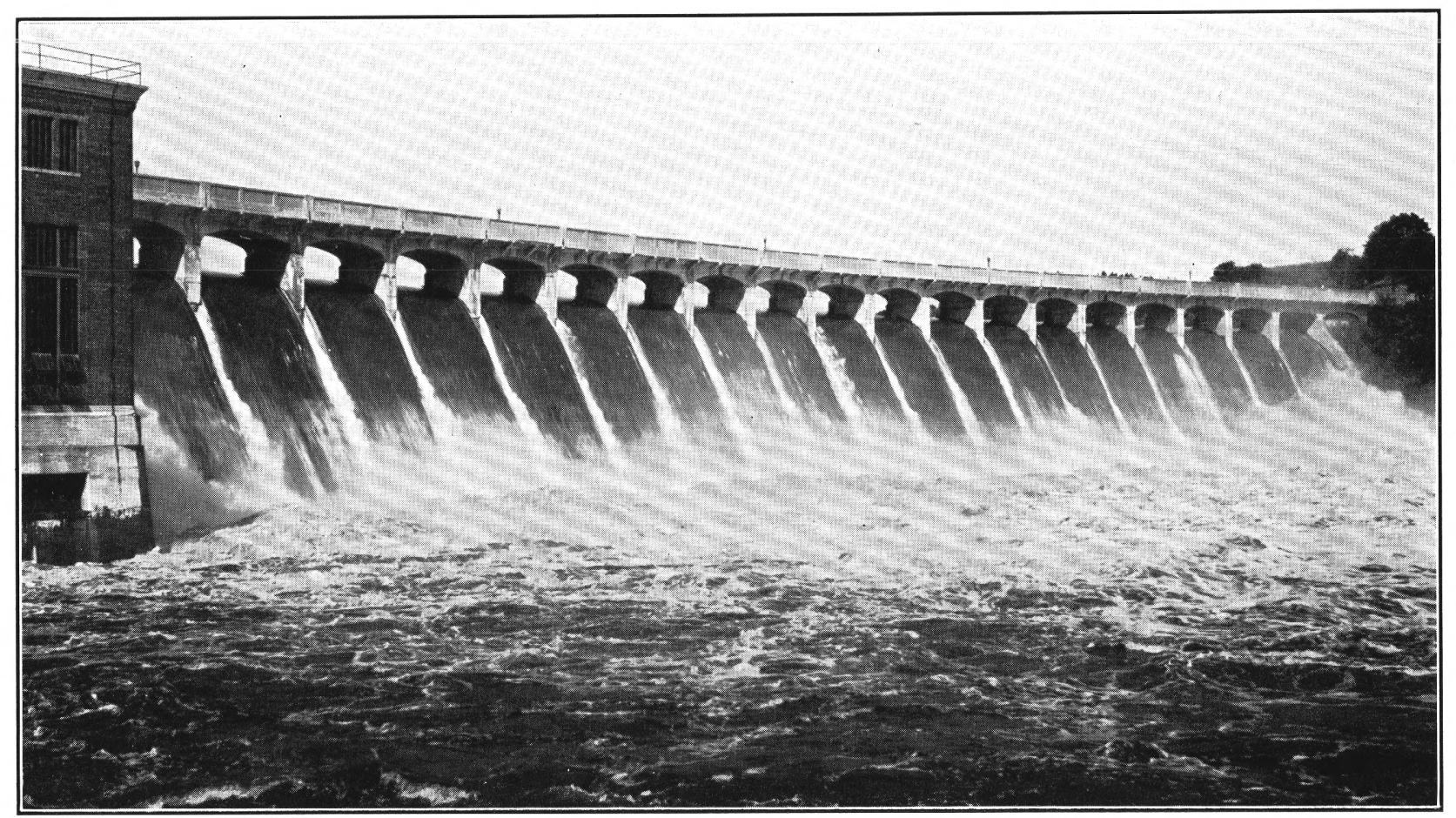

FLOOD PASSING OVER DAM ON HOUSATONIC RIVER AT STEVENSON, CONN. Courtesy of Connecticut Light \& Power Co. 


\section{Explanation of data}

The basic data systematically collected at stream-gaging stations consist of records of stage, measurements of discharge, and general information useful in determining the dally flow from the records of gage helghts and discharge measurements. The records of stage are obtained either by perlodic direct readings on a nonrecording gage or by a waterstage recorder which provides a continuous graph of stage. Measurements of discharge are generally made by a current meter, the methods of use of which are outlined in standard textbooks. Occasionaliy determination of extraordinary peak flows must be made by auxillary methods referred to in the preceding section of this report. A typical stream-gaging station is usualiy equipped with a water-stage recorder and cableway and a suspended car from which discharge measurements are made. Rating tables showing the discharges for indicated stages are prepared from the results of discharge measurements. At some river stations other or auxiliary devices are used in the determination of discharge, such as artificial controls, turbines, venturi meters, and gates, so calibrated as to indicate rates of discharge.

The data presented in the following tables comprise, in general, for each stream-gaging station a description of the station, a table showIng the dally discharges throughout the 2-month perlod september and October 1938, and a table showing the stage and discharge at the indicated time during the period of major flood flow, generally september 18 to 29 inclusive, which is sufficiently detalled to permit the delineation of reasonably accurate graphs of the instantaneous stage and discharge for the flood period. The data are intended to be reasonably complete and explicit with respect to essential information, although they are presented in concise form.

The description of the station gives information concerning the type, location, and datum of the gage, the area of the drainage basin, and the record of gage heights. The information regaraing gage heights describes the method of determining the stage during the flood and is of special techical significance, because the flood conditions at some localities prevented the use of the usual method of obtaining records of stage and discharge. A statement regarding the stage-discharge relation explains briefly the methods used in the definition of the rating curve over the ranges of stage occurring in the floods of September 1938 as well as of the previous maximm flood of record and gives information on conditions that affected the stage-discharge relation. The description $2279070-40-7$ 
also includes information with respect to other auxiliary methods used in obtaining the discharge, such as by flow through turbines or gates, or by venturi meters. The maximum stage and discharge at the gaging station are given for the floods of September 1938 and for the indicated period of record prior thereto, also at some stations for floods antedating such perlod of record. Miscellaneous notes and comments essential or helpful to an understanding of the record are included as remarks.

The table of mean daily discharge presents the data generally for September and October, which cover not only the period of the flood but also a time of sufficlent length before and after the peak to show the relation of the flood discharges to the prevalent discharges of the late summer, thus giving a general perspective of the stream-flow conditions prior to, throughout, and subsequent to the flood rise. The table shows the mean monthly discharge for the 2 months and the volume of run-off expressed in depth in inches over the drainage area, adjusted for diversions and artificial storage when appropriate and if the information needed therefor was available. Figure 28 shows hydrographs of mean dally discharge at 10 selected stream-gaging stations for this 2-month period.

The tables showing stage and discharge at indicated times are designed to present the rise and recession of the flood in detail. In general each table begins on september 18, well before the beginning of the major flood rise, and continues through september 29, when the flood had largely passed out of the river systems. Generally, unless otherwise explained, standard time is used. This table is accompanied by supplemental records of stage and discharge when necessary to afford an adequate record for the given river-measurement station. Hydrographs of discharge showing characteristics of the flood peaks and conditions of stream flow during the flood period are shown for stream-gaging stations in the Merrimack, Thames, Connecticut, Housatonic, Hudson, Passaic, Raritan, Upper Delaware, Neversink, and Ausable River Basins in figures 29 to 39 inclusive, and on streams in Vermont tributary to Lake Champlain in figure 40.

The stages at the indicated times were obtained from the records of continuous water-stage recorders, so far as such records were avaliable. For stations at which the records of stage were intermittent, consisting of a few gage readings a day, or for which the records were broken because of some fallure in the recording system, stage graphs have been 


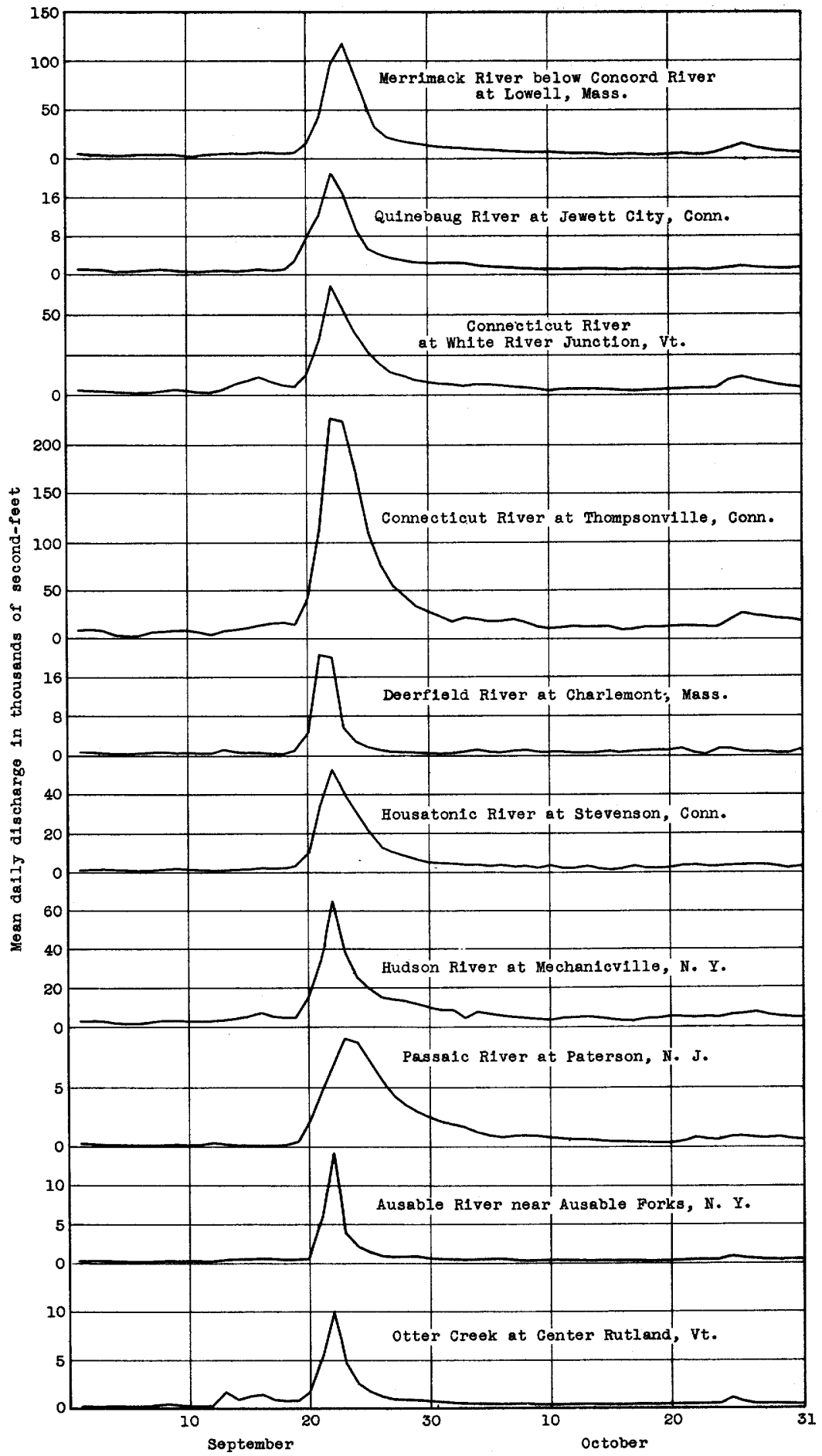

Figure 28. - - Fraphs of mean daily discharges at verious stream-gazing stations for the period September 1 to October 31, 1938. 


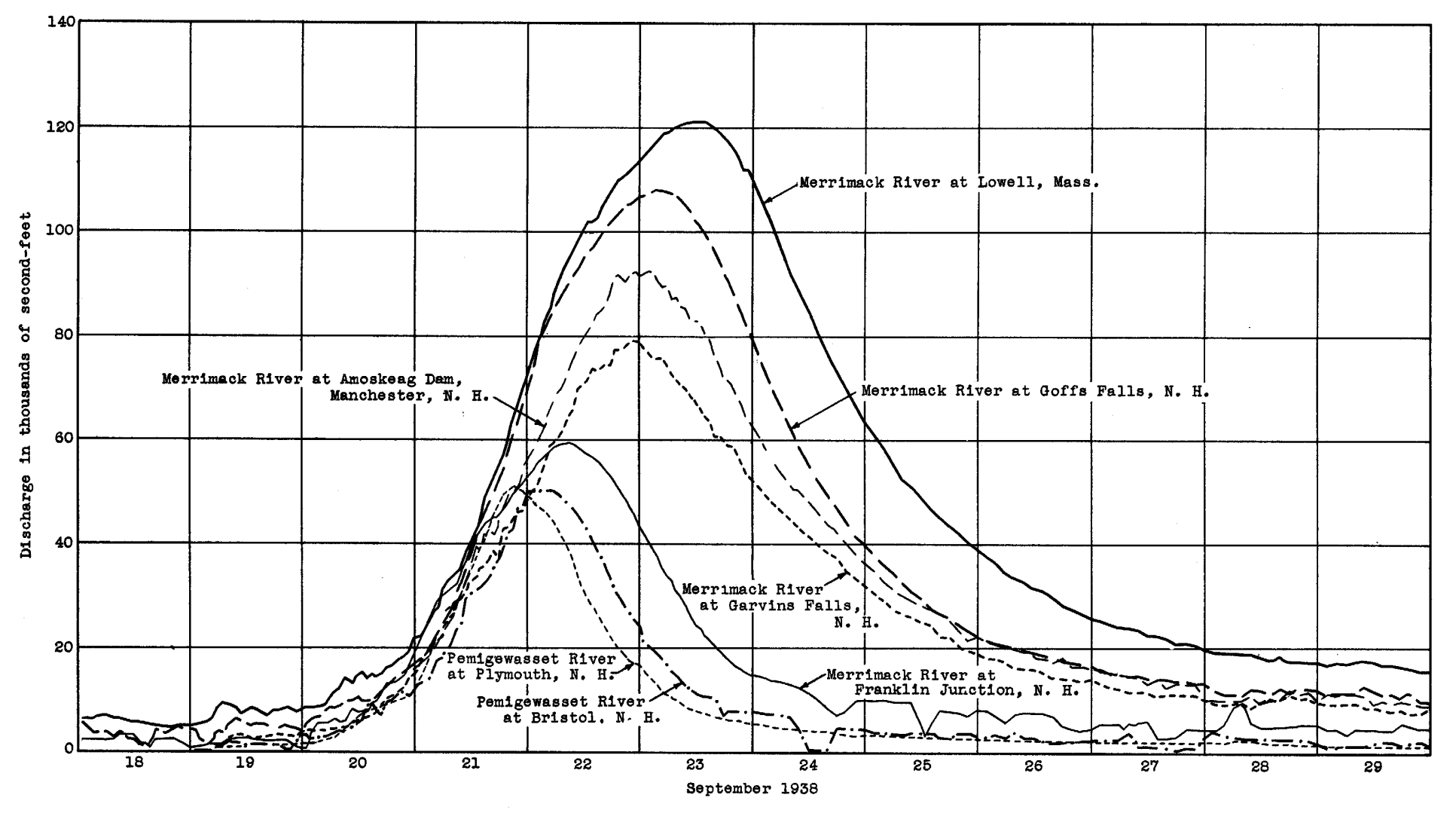

Figure 29.--Graphs of discharge at various stream-gaging stations in the Merrimack River Basin. 


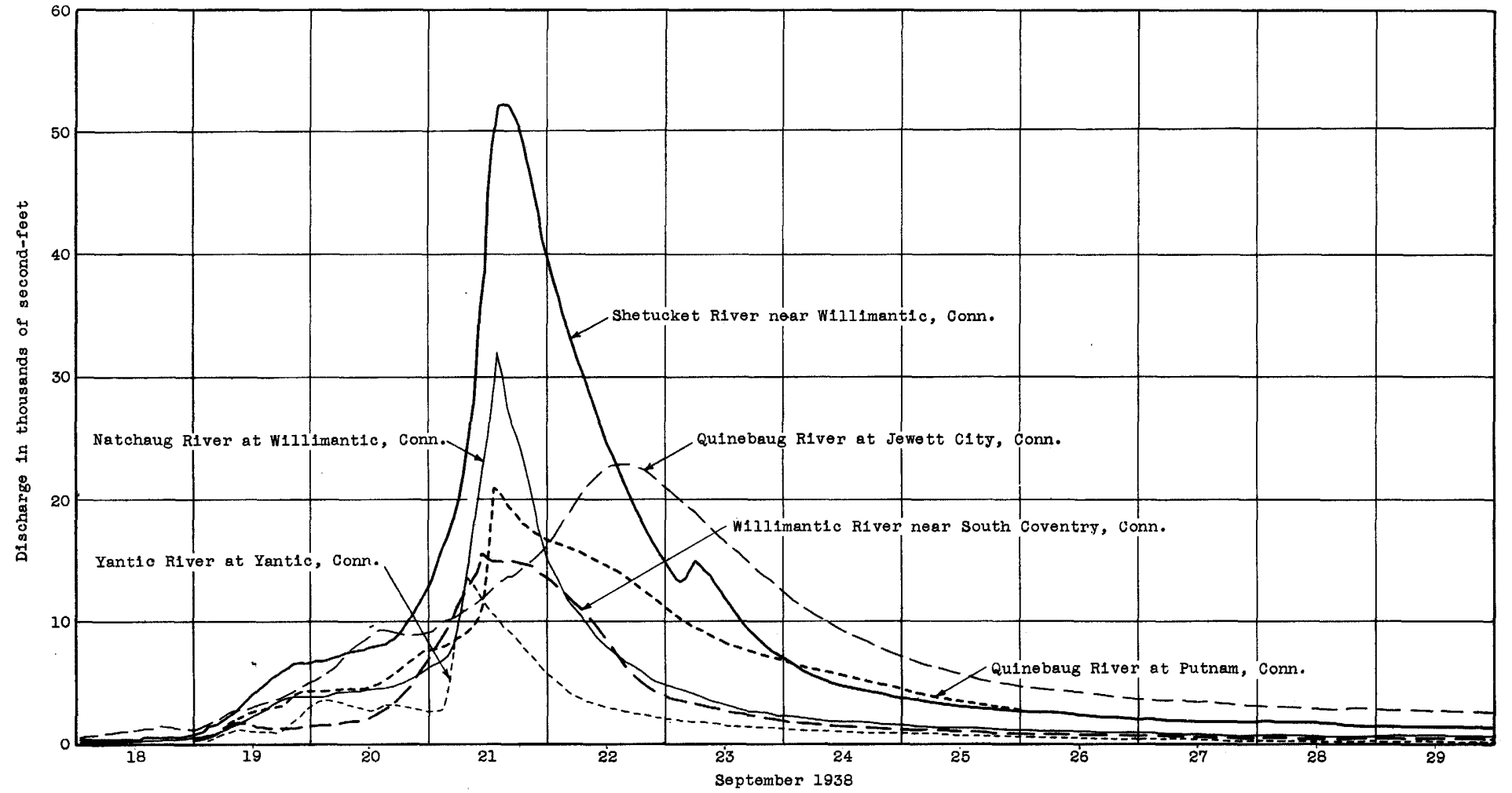




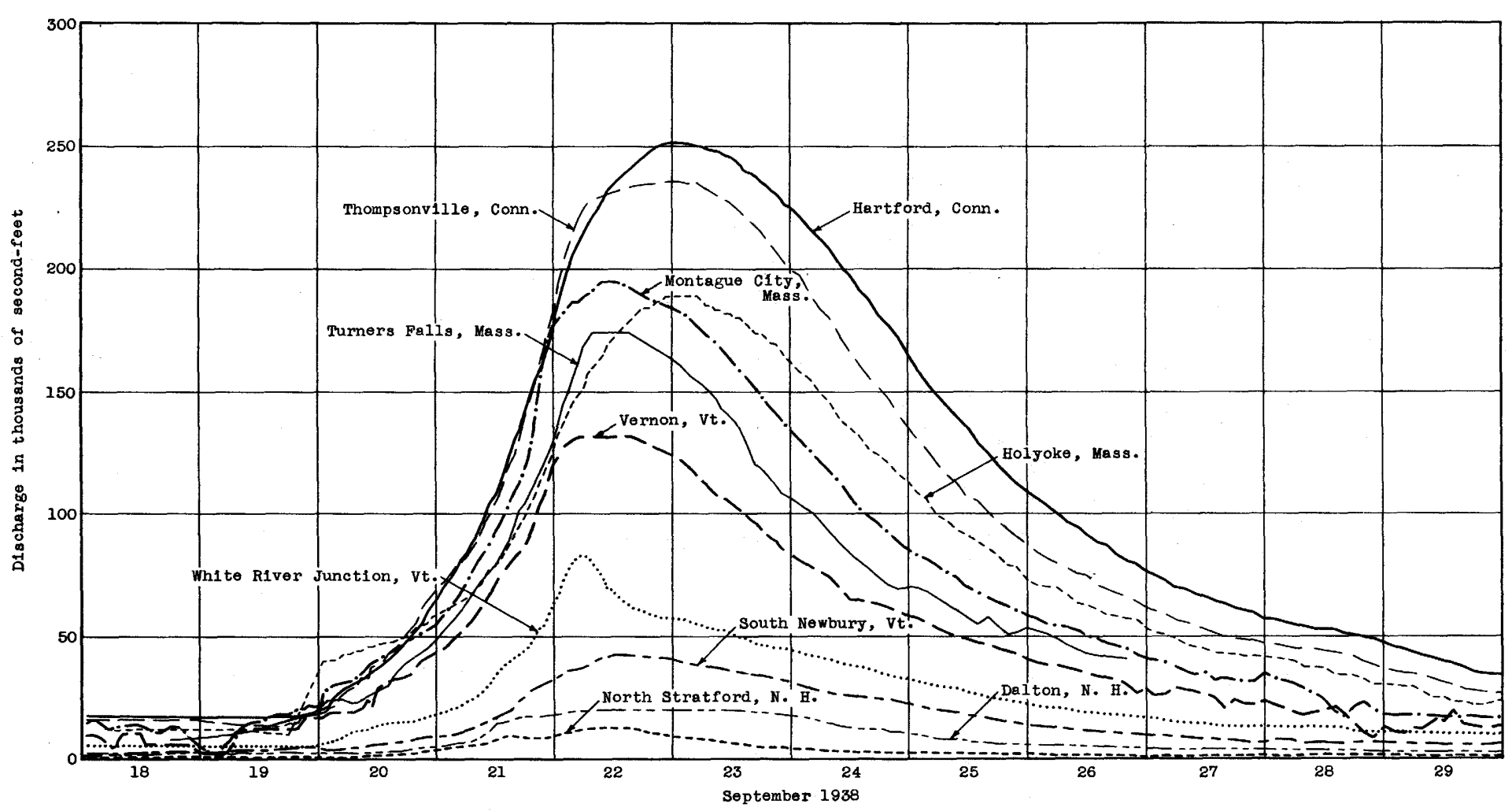

Figure 31.--Graphs of discharge at various stream-gaging stations on the Connecticut River. 


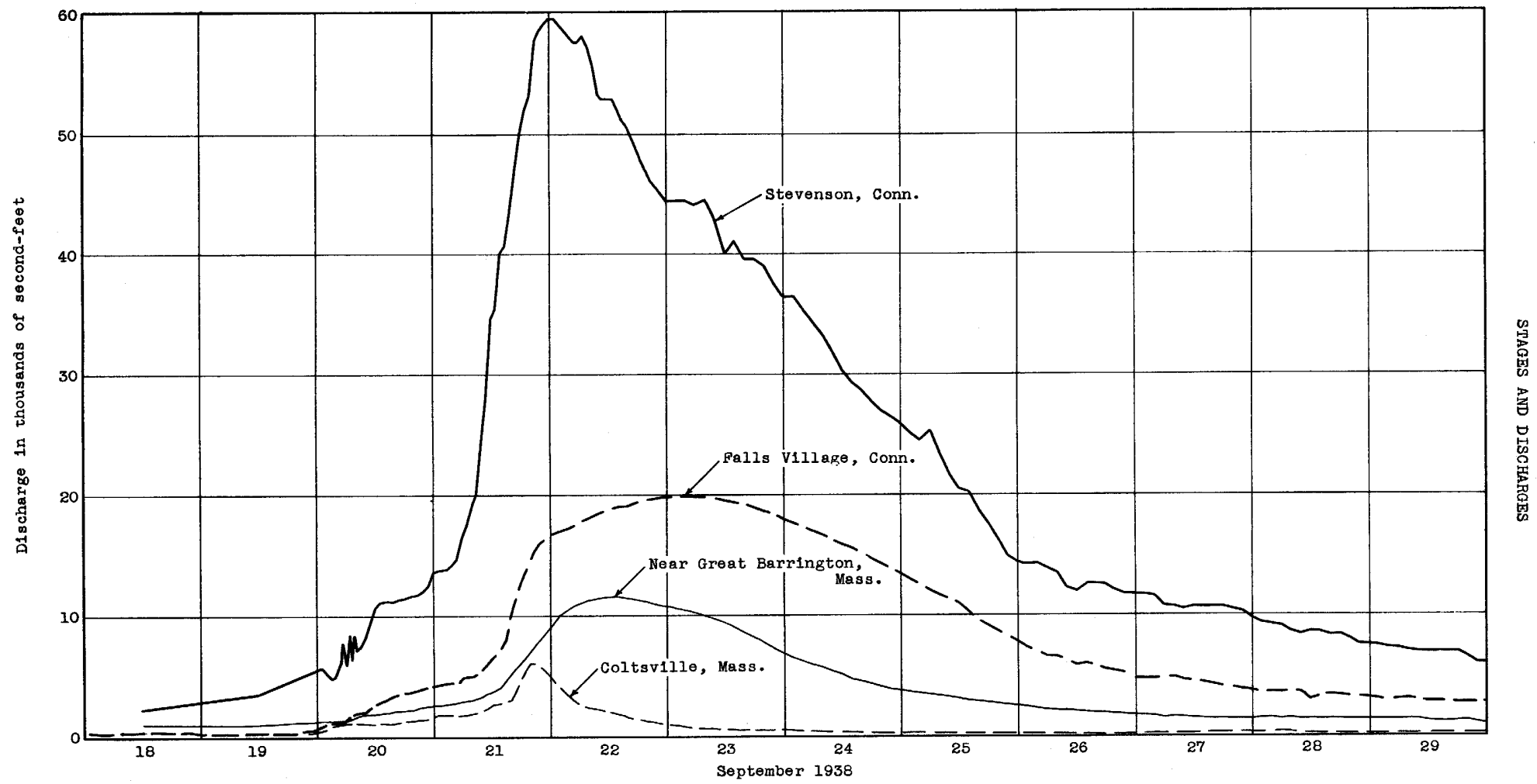

Figure 32.--Graphs of discharge at various stream-gaging stations on the Housatonic River. 


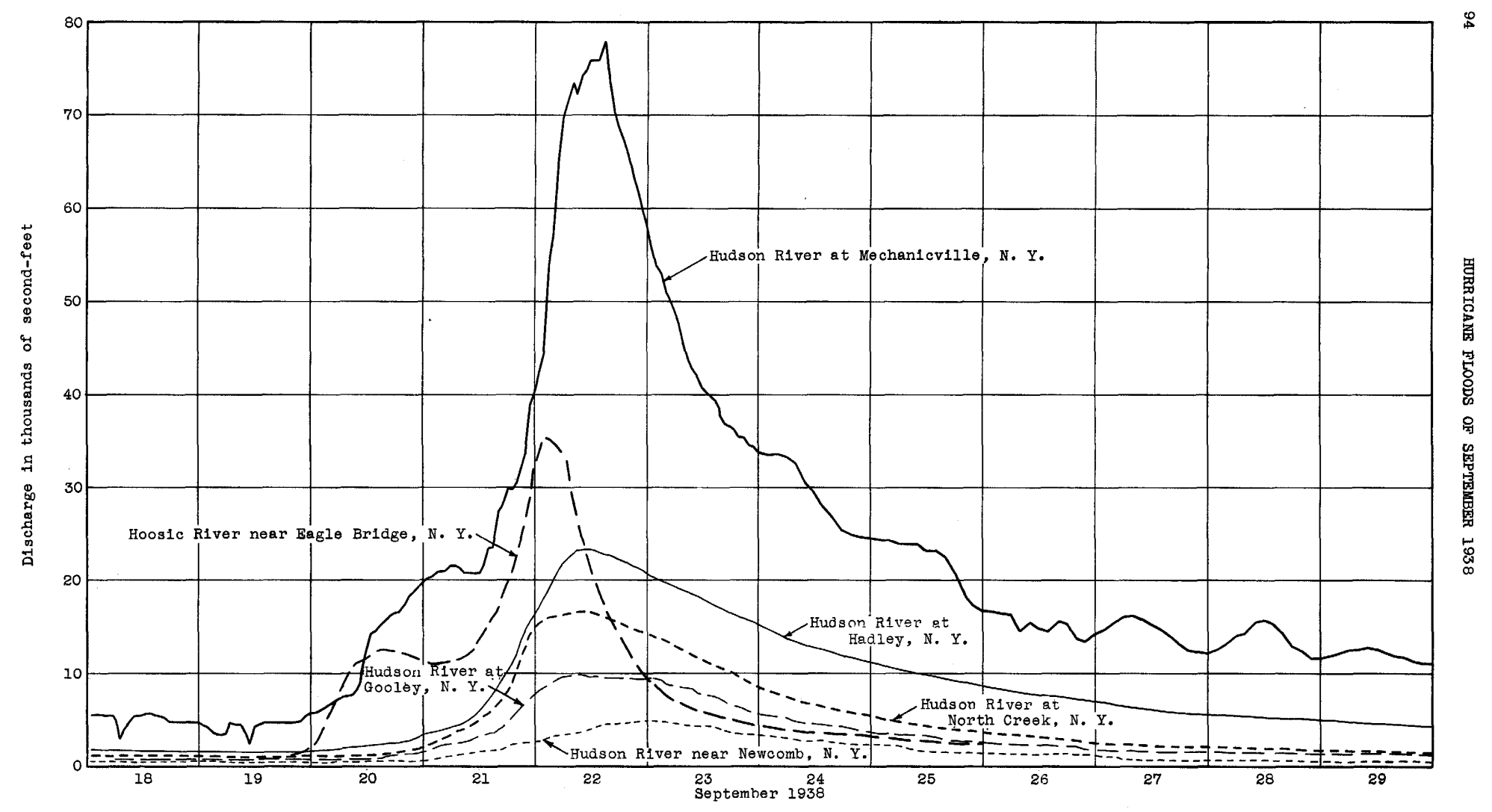

Figure 33.--Graphs of discharge at various stream-gaging stations in the Hudson River Besin. 


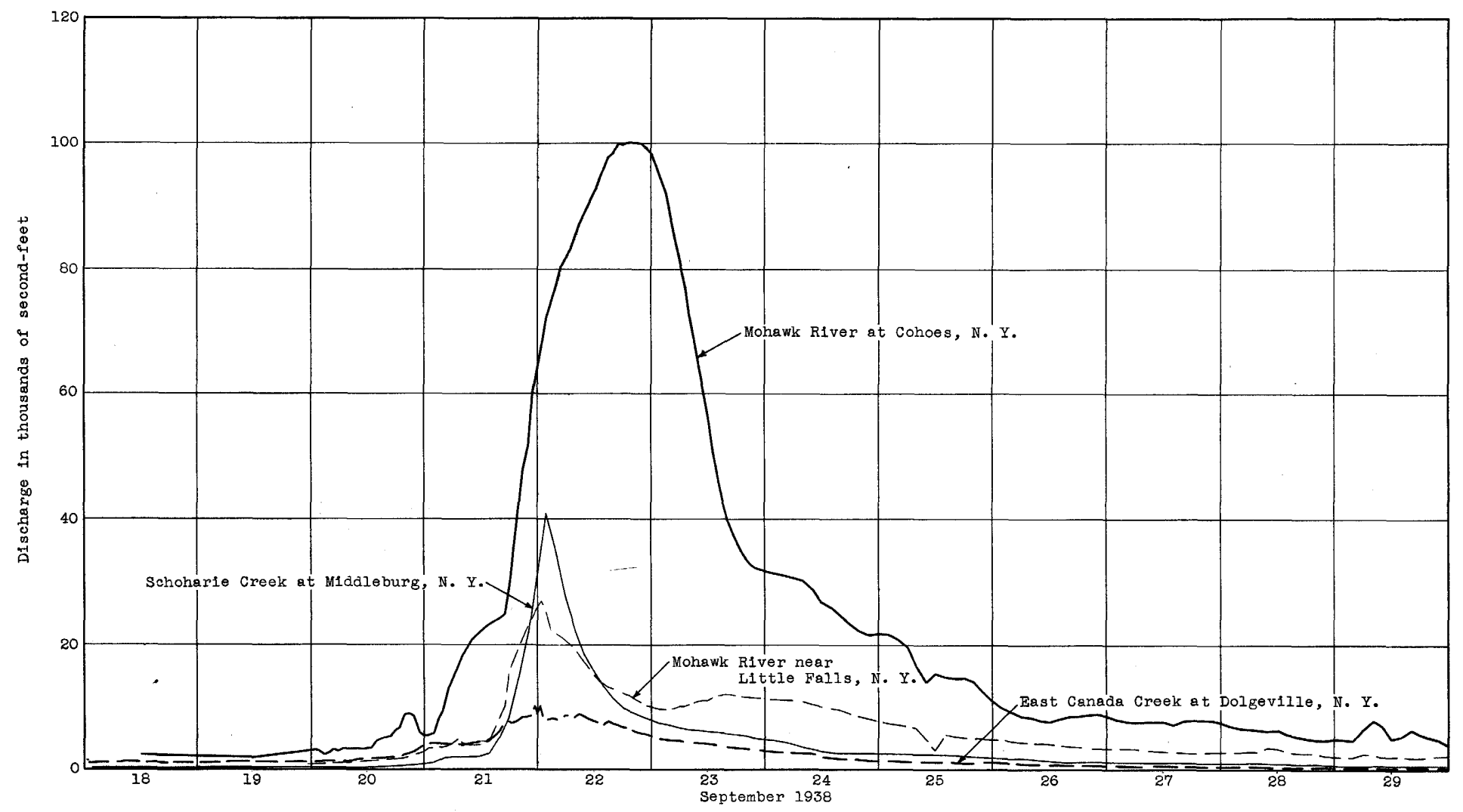

Figure 34.--Graphs of discharge at various stream-gaging stations in the Mohawk River Basin. 


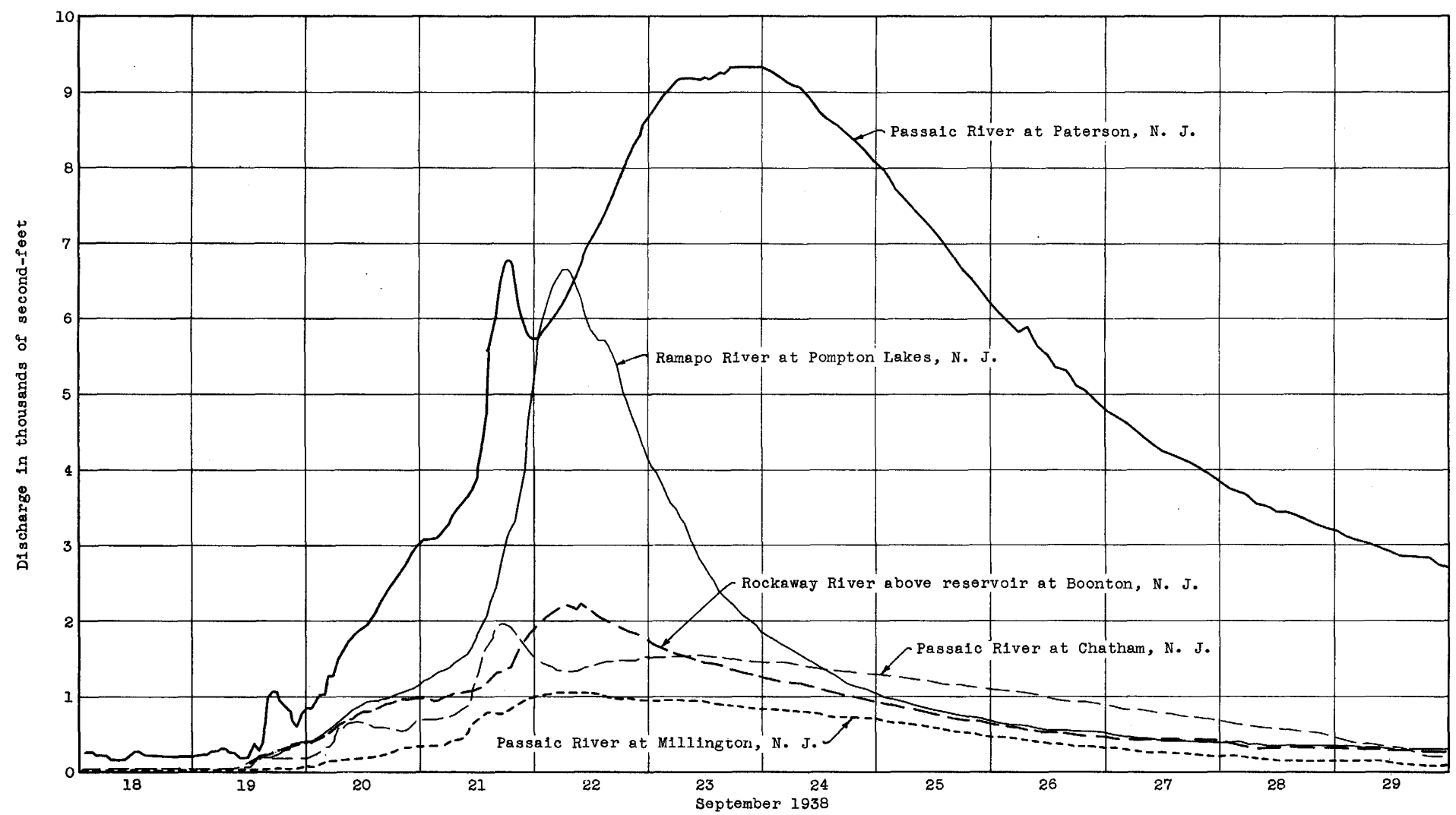

Figure 35.--Graphs of discharge at various stream-gaging stations in the Passaic River Basin. 


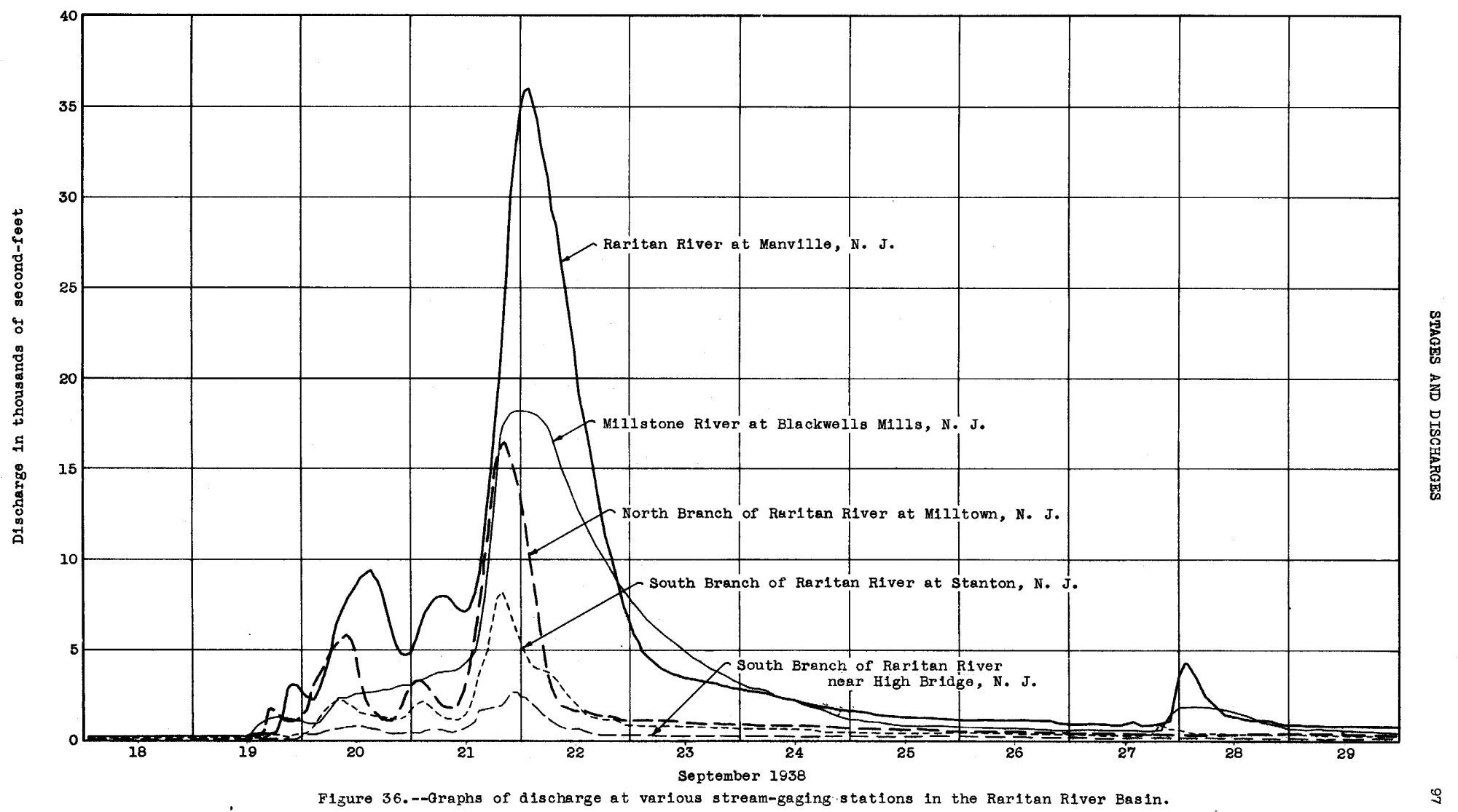




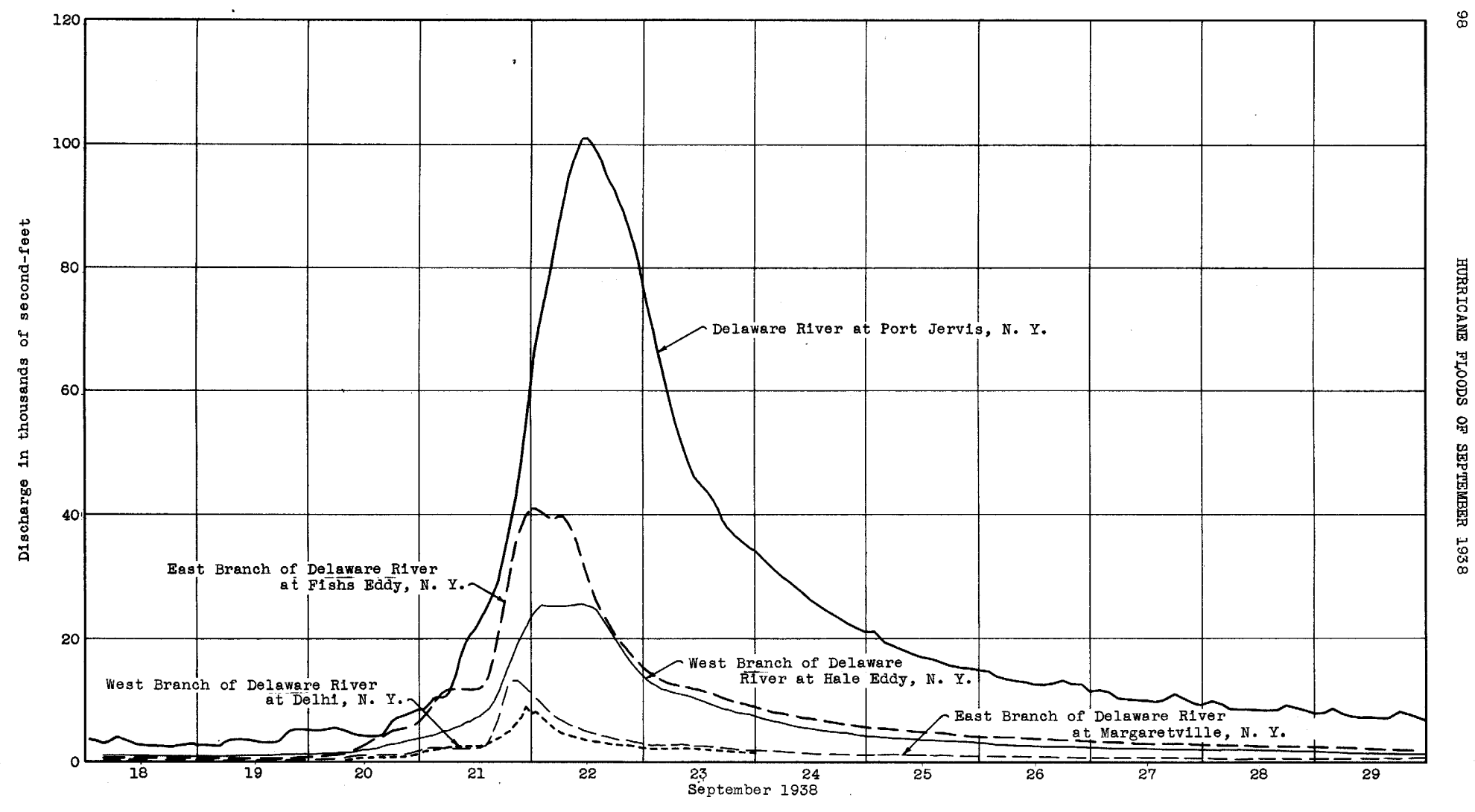

Figure 37.--Graphs of discharge at various stream-gaging stations in the Delaware River Basin. 


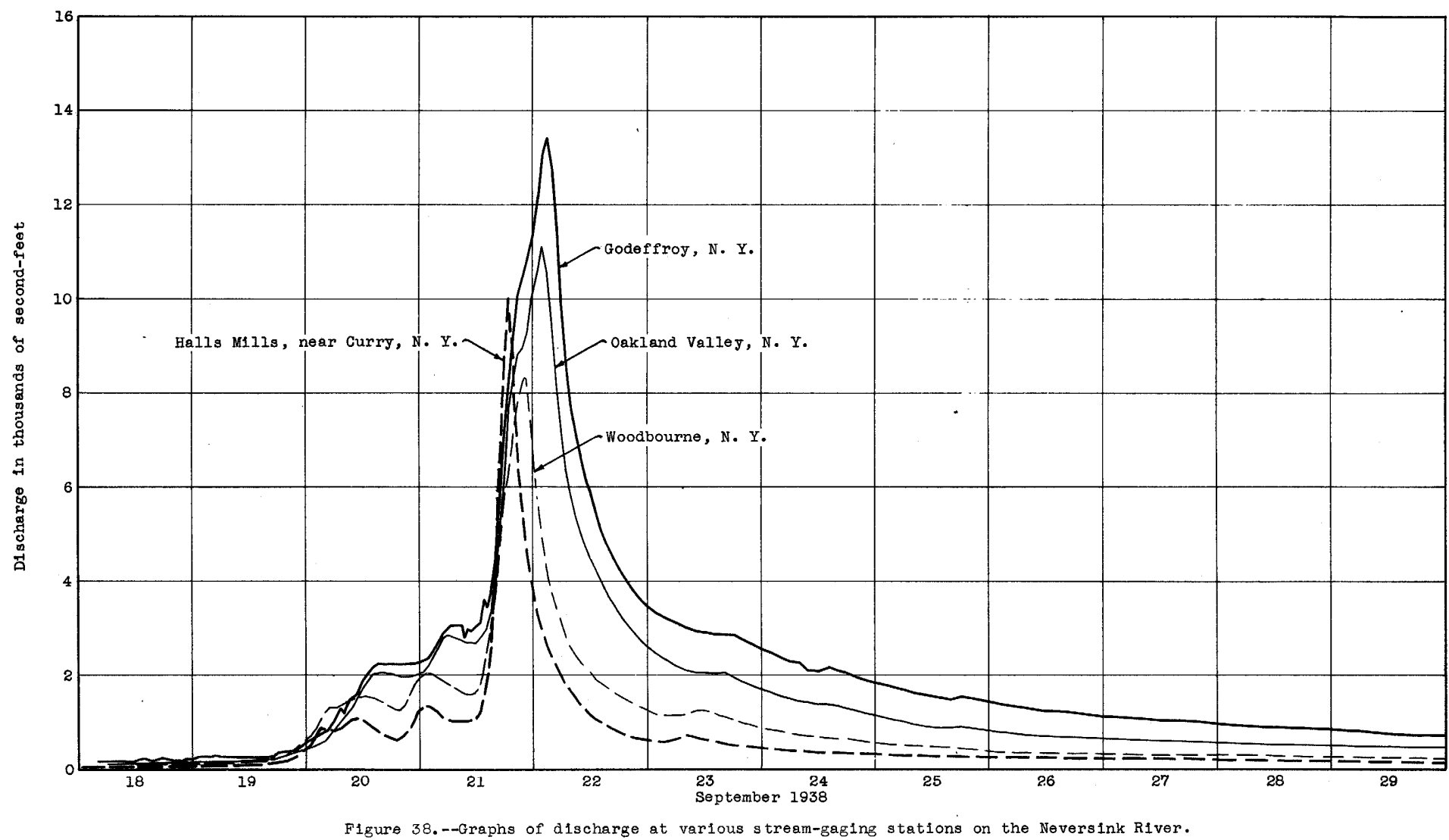




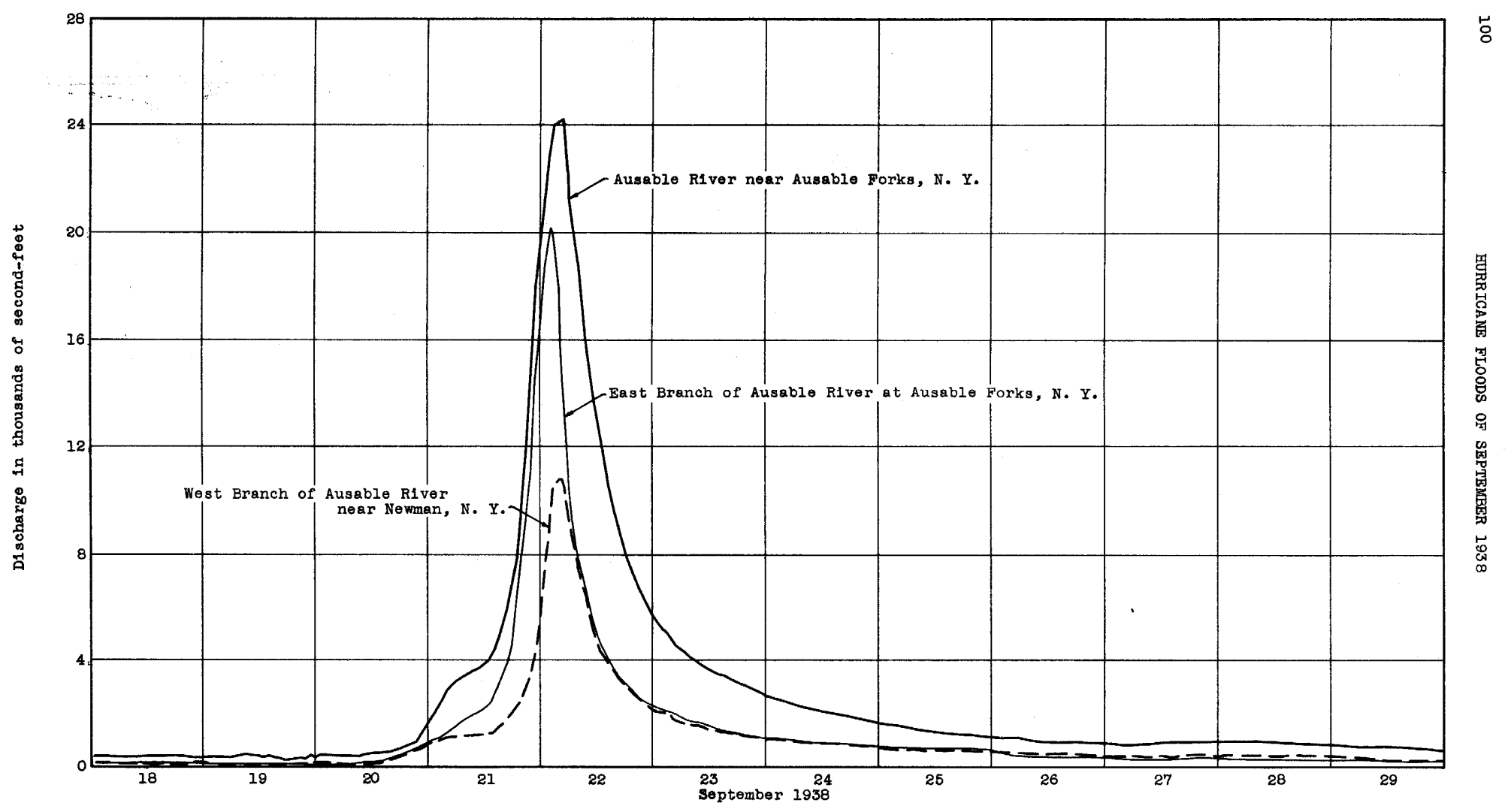

Figure 39.--Graphs of discharge at various stream-gaging stations in the Ausable River Basin. 


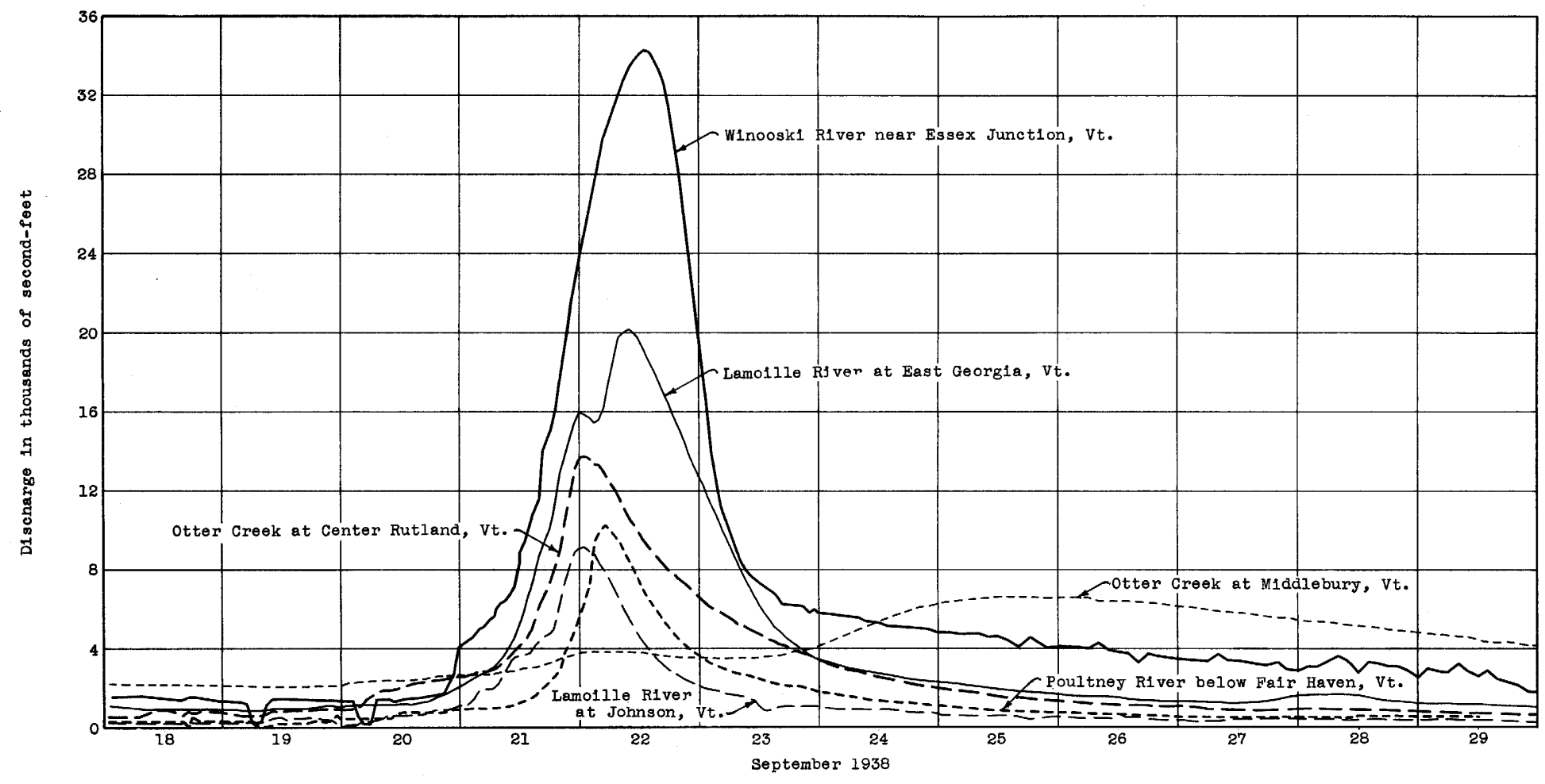

Figure 40.--Graphs of discharge at varlous stream-gaging stations on streams in Vermont tributary to Lake Champlain. 
developed on the basis of the available information, and the stages at indicated times have been obtained from those graphs.

The discharge at indicated times is related in general to the corresponding stage in accordance with a stable stage-discharge relation, as previously discussed, but where the normal stage-discharge relation was affected by backwater or other abnormal conditions, these factors were taken into consideration in the derermination of discharge. In accordance with the usual Geological Survey practice, discharge is generally shown to three significant figures.

On certain streams affected by diversions or by storage in reservoirs above the place of measurement the usual form is varied as necessary for presentation of records of dissharge. On such streams the records of observed discharge are adjusted for diversions and gain or loss in storage as explained in the description accompanying the tables. The records of observed and adjusted discharges at the gage are published in the tables with appropriate reference to the source of the data on diversions and gain or loss in storage used in arriving at the adjusted discharges. The following tables present, for several reservolrs, records of stages and storage content through the flood period in a form similar to the data for the stream-gaging stations. These records are or special value in showing the influence of storage reservolrs on flood flows, in relation both to the appraisal of their effect on flood flows and to the extending of information on the natural characteristics of drainage basins in the shedaing of flood waters. However, it should be understood that adjustment for the effect of artificial storage has generally been made in the following tables only to a moderate extent and only for stations situated within such distance below storage reservoirs as to make the adjustment readily determinable. For many stations the determination and application of complete adjustments would involve analyses and studies beyond the scope of the present report. The descriptive and tabular matter relating to the records is intended to define clearly the status of the modifications and adjustments introduced by storage. Further consideration of storage reservoirs as a factor influencing the September floods is presented elsewhere in this report.

The records are presented in the order regularly used by the Geological Survey in its water-supply papers. The major drainage basins are treated from north to south in order of their discharge into the Atlantic Ocean except the St. Lawrence River Basin, which follows the other basins. 
In each of the mafor drainage basins gaging stations on the main streams are treated first, In downstream order, and then stations on tributaries in similar order beginning with the uppermost. The table of contents presents the stations in the order in which they appear herein; the Index presents them alphabetically by stream and place names.

The maximum discharges at these atream-gaging stations and at other places on these streams, with other related information, are listed in table 10 on pages 382 to 410. The stations are identified on plate 11 (In pocket) by means of the index numbers shown in the first column of the table.

Reference should be made to the water-supply papers of the Geological Survey for other available published records of flow of the streams discussed in this report. The records of flow published here are based on all the information available at this time. Accelerated erosion and deposition in the river channels due to the floods has changed the stagedischarge relation at some stream-gaging stations, particularly at medium and Iow discharges, and all these changes may not have been fully defined In the period avaliable for observations since the floods.

Since the publication of Water-Supply Paper 798, "The floods of Harch 1936, Part 1, New England Rivers", further Information indicates that some records of discharge previously published should be revised. Insofar as practicable, such revisions have been included in this volume with the records for September 1938. Any additional revisions found necessary in the light of future information will be published in subsequent water-supply papers.

$2279070-10 \longleftarrow 8$ 
Pemigewasset River at Plymouth, N. H.

Location. - Water-stage recorder, lat. $43^{\circ} 45^{\prime} 35^{\prime \prime}$, long. $71^{\circ} 41^{\prime} 10^{n}$, just below bridge in Plymouth, Grafton County, and a third of a mile below mouth of Bakers River.

Drainage area.- 622 square miles.

Gage-helght record. - Water-stage recorder graph.

Stage-discharge relation. - Defined by current-meter measurements below $32,5,00$ secondfeet; extended to peak stage on basis of determinations of flood flow over dam.

Discharges adjusted for rate of change of stage during period 11 a.m. Sept. 20 to

11 p.m. Sept. 23. Shifting-control method used for period oct. 24-3i.

Maxima.- September 1938: Maximum d1scharge, 50,900 second-feet 9 p.m. Sept. 21 (gage

helght, 23.00 feet); maximum gage height, 23.62 feet 12 p.m. Sept. 21.

1903 to August 1938: Discharge, 65,400 second-feet Mar. 19, 1936 (gage

helght, 29.0 feet, from floodmarks).

Remarks.- Flood run-off not materially affected by artificlal or natural storage.

Mean dally discherge, in second-feet, 1938

\begin{tabular}{|c|c|c|c|c|c|c|c|c|c|c|c|}
\hline Day & Sept. & Oct. & Day & Sept. & Oct. & Day & Sept. & Oct. & Day & Sept. & Oct. \\
\hline $\begin{array}{l}1 \\
2 \\
3 \\
4 \\
5 \\
6 \\
7 \\
8\end{array}$ & $\begin{array}{l}464 \\
736 \\
460 \\
399 \\
350 \\
335 \\
328 \\
460 \\
\end{array}$ & $\begin{array}{r}1,270 \\
1,150 \\
1,020 \\
940 \\
890 \\
830 \\
790 \\
740 \\
\end{array}$ & $\begin{array}{r}9 \\
10 \\
11 \\
12 \\
13 \\
14 \\
15 \\
16\end{array}$ & $\begin{array}{r}416 \\
342 \\
328 \\
298 \\
1,230 \\
1,250 \\
1,900 \\
2,360\end{array}$ & $\begin{array}{l}710 \\
700 \\
672 \\
672 \\
645 \\
627 \\
627 \\
609\end{array}$ & $\begin{array}{l}17 \\
18 \\
19 \\
20 \\
21 \\
22 \\
23 \\
24\end{array}$ & $\begin{array}{r}1,360 \\
1,040 \\
1,010 \\
6,090 \\
34,800 \\
33,200 \\
8,920 \\
4,280\end{array}$ & $\begin{array}{r}582 \\
573 \\
564 \\
555 \\
800 \\
990 \\
800 \\
1,100\end{array}$ & $\begin{array}{l}25 \\
26 \\
27 \\
28 \\
29 \\
30 \\
31\end{array}$ & $\begin{array}{l}2,910 \\
2,240 \\
1,900 \\
1,960 \\
1,620 \\
1,400\end{array}$ & $\begin{array}{r}5,040 \\
2,300 \\
1,660 \\
1,390 \\
1,200 \\
1,080 \\
980\end{array}$ \\
\hline $\begin{array}{l}\text { Mean } \\
\text { Run- }\end{array}$ & $\begin{array}{l}\text { nthly } \\
, \text { in }\end{array}$ & Lschar & , Ir & $\begin{array}{c}\text { second- } \\
.\end{array}$ & at. & $\dot{0} \cdot$ & $\because \cdot \dot{ }$ & $\begin{array}{lll}\cdot & \bullet & \cdot \\
\cdot & . & \bullet\end{array}$ & $\dot{0}$ & $\begin{array}{r}3,813 \\
6.84\end{array}$ & $\begin{array}{r}1,049 \\
1.94\end{array}$ \\
\hline
\end{tabular}

Gage height, in feet, and discharge, in second-feet, at indlcated time, 1938

\begin{tabular}{|c|c|c|c|c|c|c|c|c|c|c|c|c|}
\hline \multirow{2}{*}{$\begin{array}{l}\xi \\
3 \\
0 \\
\end{array}$} & Feet & Sec.ft. & Feet & Sec.ft. & Feet & Sec.ft. & Feet & Sec.ft. & Feet & Sec.ft. & Feet & Sec.ft. \\
\hline & \multicolumn{2}{|c|}{ September 18} & \multicolumn{2}{|c|}{ September 19} & \multicolumn{2}{|c|}{ September 20} & \multicolumn{2}{|c|}{ September 21} & \multicolumn{2}{|c|}{ September 22} & \multicolumn{2}{|c|}{ September 23} \\
\hline $\begin{array}{l}1 \\
2 \\
3 \\
4 \\
5 \\
6\end{array}$ & $\begin{array}{c}- \\
1.69 \\
- \\
1.68 \\
- \\
1.68\end{array}$ & $\begin{array}{l}1, \overline{110} \\
1, \overline{100} \\
1, \overline{100}\end{array}$ & $\begin{array}{c}- \\
1.54 \\
- \\
1.56 \\
- \\
1.57\end{array}$ & $\begin{array}{l}\overline{931} \\
\overline{954} \\
\overline{9} \\
965\end{array}$ & $\begin{array}{l}1.90 \\
2.02 \\
2.22 \\
2.36 \\
2.55 \\
2.74\end{array}$ & $\begin{array}{l}1,360 \\
1,520 \\
1,780 \\
1,960 \\
2,200 \\
2,450\end{array}$ & \begin{tabular}{|r|}
9.42 \\
10.00 \\
10.98 \\
11.95 \\
13.00 \\
13.80
\end{tabular} & $\begin{array}{l}13,300 \\
14,900 \\
17,800 \\
20,400 \\
23,400 \\
25,600\end{array}$ & \begin{tabular}{|l|}
23.61 \\
23.52 \\
23.38 \\
23.25 \\
23.02 \\
22.76
\end{tabular} & $\begin{array}{l}48,500 \\
47,500 \\
46,900 \\
46,300 \\
45,000 \\
43,700\end{array}$ & \begin{tabular}{|r|}
11.60 \\
11.05 \\
10.40 \\
10.00 \\
9.40 \\
8.93
\end{tabular} & $\begin{array}{l}15,500 \\
14,500 \\
13,400 \\
12,600 \\
11,600 \\
10,900\end{array}$ \\
\hline $\begin{array}{r}7 \\
8 \\
9 \\
10 \\
11 \\
\mathrm{~N}\end{array}$ & $\begin{array}{c}- \\
1.68 \\
- \\
1.67 \\
- \\
1.64\end{array}$ & $\begin{array}{l}1, \overline{100} \\
\overline{-} \\
1, \overline{0} 00 \\
1, \overline{050}\end{array}$ & $\begin{array}{c}- \\
1.57 \\
- \\
1.57 \\
- \\
1.57\end{array}$ & $\begin{array}{l}\overline{965} \\
\overline{965} \\
\overline{965}\end{array}$ & $\begin{array}{l}3.00 \\
3.45 \\
4.10 \\
4.72 \\
5.30 \\
5.80\end{array}$ & $\begin{array}{l}2,790 \\
3,380 \\
4,260 \\
5,130 \\
5,990 \\
6,740\end{array}$ & $\begin{array}{l}14.50 \\
15.05 \\
15.60 \\
16.10 \\
16.62 \\
17.20\end{array}$ & $\begin{array}{l}27,000 \\
28,400 \\
29,700 \\
31,100 \\
32,800 \\
34,800\end{array}$ & $\begin{array}{l}22.40 \\
22.00 \\
21.50 \\
21.00 \\
20.30 \\
19.65\end{array}$ & $\begin{array}{l}42,100 \\
40,300 \\
38,600 \\
36,400 \\
34,000 \\
32,800\end{array}$ & $\begin{array}{l}8.50 \\
8.10 \\
7.73 \\
7.40 \\
7.13 \\
6.88\end{array}$ & $\begin{array}{r}10,300 \\
9,710 \\
9,150 \\
8,660 \\
8,250 \\
7,890\end{array}$ \\
\hline $\begin{array}{l}1 \\
2 \\
3 \\
4 \\
5 \\
6\end{array}$ & $\begin{array}{c}- \\
1.61 \\
- \\
1.60 \\
- \\
1.59\end{array}$ & $\begin{array}{c}1, \overline{010} \\
\overline{-} \\
1,000 \\
\overline{9}\end{array}$ & $\begin{array}{c}\overline{-} \\
\overline{1.58} \\
\overline{1.60} \\
\overline{1.66}\end{array}$ & $\begin{array}{c}\overline{977} \\
\overline{-} \\
1,000 \\
1, \overline{0} \\
1,0\end{array}$ & $\begin{array}{l}6.20 \\
6.45 \\
6.68 \\
6.88 \\
7.10 \\
7.35\end{array}$ & $\begin{array}{l}7,310 \\
7,650 \\
7,990 \\
8,300 \\
8,660 \\
9,060\end{array}$ & $\begin{array}{l}17.80 \\
18.45 \\
19.10 \\
19.70 \\
20.50 \\
21.20\end{array}$ & $\begin{array}{l}36,800 \\
39,000 \\
40,700 \\
43,100 \\
46,000 \\
47,700\end{array}$ & $\begin{array}{l}19.05 \\
18.40 \\
17.82 \\
17.20 \\
16.60 \\
16.00\end{array}$ & $\begin{array}{l}31,200 \\
29,500 \\
28,100 \\
26,500 \\
25,000 \\
23,500\end{array}$ & $\begin{array}{l}6.68 \\
6.45 \\
6.30 \\
6.15 \\
6.00 \\
5.85\end{array}$ & $\begin{array}{l}7, \\
7, \\
7, \\
6, \\
6, \\
6,\end{array}$ \\
\hline \multirow[t]{2}{*}{$\begin{array}{r}7 \\
8 \\
9 \\
10 \\
11 \\
M\end{array}$} & $\begin{array}{c}- \\
1.58 \\
- \\
1.56 \\
- \\
1.55\end{array}$ & $\begin{array}{l}- \\
977 \\
\overline{954} \\
\overline{942}\end{array}$ & $\begin{array}{c}- \\
1.68 \\
- \\
1.71 \\
-7.79\end{array}$ & $\begin{array}{c}1, \overline{100} \\
\overline{1} \\
1, \overline{130} \\
\overline{1, \overline{2} 30}\end{array}$ & $\begin{array}{l}7.60 \\
7.78 \\
7.98 \\
8.22 \\
8.52 \\
8.85\end{array}$ & $\begin{array}{r}9,440 \\
9,710 \\
10,100 \\
10,600 \\
11,200 \\
11,900\end{array}$ & $\begin{array}{l}21.90 \\
22.50 \\
23.00 \\
23.35 \\
23.55 \\
23.62\end{array}$ & $\begin{array}{l}49,400 \\
50,500 \\
50,900 \\
50,600 \\
50,000 \\
49,200\end{array}$ & $\begin{array}{l}15.40 \\
14.80 \\
14.15 \\
13.55 \\
12.90 \\
12.25\end{array}$ & $\begin{array}{l}22,200 \\
20,600 \\
19,600 \\
18,500 \\
17,500 \\
16,500\end{array}$ & $\begin{array}{l}5.73 \\
5.63 \\
5.50 \\
5.40 \\
5.30 \\
5.20\end{array}$ & $\begin{array}{l}6,170 \\
6,020 \\
5,830 \\
5,690 \\
5,540 \\
5,400\end{array}$ \\
\hline & \multicolumn{2}{|c|}{ September 24} & \multicolumn{2}{|c|}{ September 25} & \multicolumn{2}{|c|}{ September 26} & \multicolumn{2}{|c|}{ September 27} & \multicolumn{2}{|c|}{ September 28} & \multicolumn{2}{|c|}{ September 29} \\
\hline $\begin{array}{l}2 \\
4 \\
6\end{array}$ & $\begin{array}{l}5.03 \\
4.88 \\
4.74\end{array}$ & $\begin{array}{l}5,140 \\
4,930 \\
4,740\end{array}$ & $\begin{array}{l}3.75 \\
3.66 \\
3.60\end{array}$ & $\begin{array}{l}3,350 \\
3,220 \\
3,140\end{array}$ & $\begin{array}{l}3.08 \\
3.02 \\
2.99\end{array}$ & $\begin{array}{l}2,450 \\
2,380 \\
2,340\end{array}$ & $\begin{array}{l}2.75 \\
2.71 \\
2.69\end{array}$ & $\begin{array}{l}2,020 \\
1,970 \\
1,950\end{array}$ & $\begin{array}{l}2.70 \\
2.72 \\
2.75\end{array}$ & $\begin{array}{l}1,960 \\
1,990 \\
2,020\end{array}$ & $\begin{array}{l}2.54 \\
2.52 \\
2.50\end{array}$ & \\
\hline $\begin{array}{r}8 \\
10 \\
N\end{array}$ & $\begin{array}{l}4.59 \\
4.48 \\
4.37\end{array}$ & $\begin{array}{l}4,530 \\
4,370 \\
4,220\end{array}$ & $\begin{array}{l}3.53 \\
3.45 \\
3.40\end{array}$ & $\begin{array}{l}3,040 \\
2,940 \\
2,870\end{array}$ & $\begin{array}{l}2.95 \\
2.91 \\
2.89\end{array}$ & $\begin{array}{l}2, \\
2, \\
2,\end{array}$ & & $\begin{array}{l}1,920 \\
1,900 \\
1,870\end{array}$ & $\begin{array}{l}2.78 \\
2.77 \\
2.75\end{array}$ & $\begin{array}{l}2, \\
2, \\
2,\end{array}$ & $\begin{array}{l}2.46 \\
2.44 \\
2.43\end{array}$ & $\begin{array}{l}350 \\
330 \\
520\end{array}$ \\
\hline $\begin{array}{r}2 \\
4 \\
6 \\
8 \\
10 \\
M\end{array}$ & $\begin{array}{l}4.28 \\
4.18 \\
4.05 \\
3.97 \\
3.88 \\
3.80\end{array}$ & $\begin{array}{l}4,090 \\
3,950 \\
3,770 \\
3,660 \\
3,530 \\
3,420\end{array}$ & $\begin{array}{l}3.33 \\
3.29 \\
3.26 \\
3.22 \\
3.17 \\
3.12\end{array}$ & $\begin{array}{l}2,780 \\
2,730 \\
2,690 \\
2,640 \\
2,570 \\
2,510 \\
\end{array}$ & $\begin{array}{l}2.87 \\
2.84 \\
2.81 \\
2.84 \\
2.83 \\
2.79\end{array}$ & $\begin{array}{l}2,180 \\
2,140 \\
2,100 \\
2,140 \\
2,130 \\
2,080\end{array}$ & $\begin{array}{l}2.61 \\
2.59 \\
2.59 \\
2.59 \\
2.62 \\
2.68\end{array}$ & $\begin{array}{l}1,840 \\
1,820 \\
1,820 \\
1,820 \\
1,860 \\
1,930\end{array}$ & $\begin{array}{l}2.72 \\
2.70 \\
2.67 \\
2.63 \\
2.61 \\
2.58\end{array}$ & $\begin{array}{l}1,990 \\
1,960 \\
1,920 \\
1,870 \\
1,840 \\
1,800\end{array}$ & $\begin{array}{l}2.42 \\
2.40 \\
2.38 \\
2.36 \\
2.34 \\
2.32\end{array}$ & $\begin{array}{l}1,600 \\
1,580 \\
1,560 \\
1,530 \\
1,510 \\
1,480\end{array}$ \\
\hline
\end{tabular}


Pemigewasset River at Bristol, N. H.

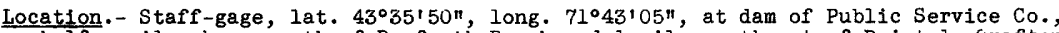
half a mile above mouth of Danforth Brook and 1 mile northeast of Bristol, Grafton County.

Drainage area.- 746 square miles.

Gege-height record.- Gage-helght graph constructed from hourly observed gage readings. Gage helghts given to tenths.

Stage-discharge relation.- Affected by flashboards on dam prior to 10 a.m. Sept. 21 and after $4 \mathrm{p.m}$. Sept. 23. Discharge ascertained from flow over dam and through wheels and gates.

Maxima.- September 1938: Discharge, 49,700 second-feet 5 a.m. Sept. 22 (gage height, 11.8 feet).

Maximum discharge known, 71,400 second-feet Mar, 19, 1936

Remarks.- Flood run-off affected by storage in Squam Lake. Records furnished by Public Service Co. of New hampshire.

Mean daily discharge, in second-feet, 1938

\begin{tabular}{|c|c|c|c|c|c|c|c|c|c|c|c|}
\hline Day & Sept. & Oct. & Day & Sept. & Oct. & Day & Sept. & oct. & Day & Sept. & Oct. \\
\hline $\begin{array}{l}1 \\
2 \\
3 \\
4 \\
5 \\
6 \\
7 \\
8\end{array}$ & $\begin{array}{l}488 \\
451 \\
519 \\
461 \\
417 \\
322 \\
367 \\
593\end{array}$ & $\begin{array}{r}1,590 \\
1,360 \\
1,200 \\
1,080 \\
1,070 \\
964 \\
957 \\
886\end{array}$ & $\begin{array}{r}9 \\
10 \\
11 \\
12 \\
13 \\
14 \\
15 \\
16\end{array}$ & $\begin{array}{r}448 \\
437 \\
292 \\
341 \\
1,100 \\
1,420 \\
1,750 \\
2,470\end{array}$ & $\begin{array}{r}934 \\
794 \\
842 \\
1,300 \\
786 \\
717 \\
737 \\
832\end{array}$ & $\begin{array}{l}17 \\
18 \\
19 \\
20 \\
21 \\
22 \\
23 \\
24\end{array}$ & $\begin{array}{r}1,460 \\
1,350 \\
1,150 \\
6,340 \\
29,400 \\
40,900 \\
12,600 \\
4,340\end{array}$ & $\begin{array}{r}636 \\
641 \\
667 \\
677 \\
962 \\
1,100 \\
798 \\
1,280 \\
\end{array}$ & $\begin{array}{l}25 \\
26 \\
27 \\
28 \\
29 \\
30 \\
31\end{array}$ & $\begin{array}{l}3,580 \\
2,940 \\
1,870 \\
2,900 \\
1,840 \\
1,580\end{array}$ & $\begin{array}{l}4,270 \\
2,740 \\
1,730 \\
1,480 \\
1,220 \\
1,160 \\
1,040\end{array}$ \\
\hline $\begin{array}{l}\text { Mean } \\
\text { Run- }\end{array}$ & in & & : in & . . & $\cdot \cdot \cdot$ & . $\cdot$ : & 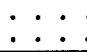 & $\cdot \dot{*} \cdot$ & : & $\begin{array}{r}4,148 \\
6.20 \\
\end{array}$ & $\begin{array}{r}1,176 \\
1.82 \\
\end{array}$ \\
\hline
\end{tabular}

Gage height, in feet, and discharge, in second-feet, at indicated t1me, 1938

\begin{tabular}{|c|c|c|c|c|c|c|c|c|c|c|c|c|}
\hline \multirow{2}{*}{$\begin{array}{l}5 \\
3 \\
0\end{array}$} & Feet & Sec.ft. & Feet & Sec.ft. & Feet & Sec.ft. & Feet & Sec.ft. & Feet & Sec.ft. & Feet & Sec.ft. \\
\hline & \multicolumn{2}{|c|}{ September 18} & \multicolumn{2}{|c|}{ September 19} & \multicolumn{2}{|c|}{ September 20} & \multicolumn{2}{|c|}{ September 21} & \multicolumn{2}{|c|}{ September 22} & \multicolumn{2}{|c|}{ September 23} \\
\hline $\begin{array}{l}1 \\
2 \\
3 \\
4 \\
5 \\
6\end{array}$ & $\begin{array}{l}8.3 \\
8.3 \\
8.2 \\
8.2 \\
8.1 \\
8.0\end{array}$ & $\begin{array}{l}1,830 \\
1,830 \\
1,760 \\
1,760 \\
1,700 \\
1,910\end{array}$ & $\begin{array}{l}7.9 \\
8.0 \\
8.0 \\
8.1 \\
8.1 \\
8.1\end{array}$ & $\begin{array}{r}639 \\
575 \\
575 \\
603 \\
797 \\
1,340\end{array}$ & $\begin{array}{l}7.5 \\
7.3 \\
7.2 \\
7.0 \\
7.0 \\
6.9\end{array}$ & $\begin{array}{l}3,150 \\
2,840 \\
2,740 \\
2,760 \\
2,870 \\
3,090\end{array}$ & $\begin{array}{l}5.5 \\
5.8 \\
6.0 \\
6.0 \\
5.9 \\
6.0\end{array}$ & $\begin{array}{l}12,600 \\
13,300 \\
13,800 \\
16,000 \\
17,400 \\
18,000\end{array}$ & $\begin{array}{l}11.8 \\
11.8 \\
11.8 \\
11.8 \\
11.8 \\
11.8\end{array}$ & $\begin{array}{l}49,600 \\
49,600 \\
49,600 \\
49,600 \\
49,700 \\
49,600\end{array}$ & $\begin{array}{l}6.5 \\
6.2 \\
6.0 \\
5.8 \\
5.6 \\
5.3\end{array}$ & $\begin{array}{l}21,600 \\
20,400 \\
19,500 \\
18,600 \\
17,800 \\
16,500\end{array}$ \\
\hline $\begin{array}{r}7 \\
8 \\
9 \\
10 \\
11 \\
\mathrm{~N}\end{array}$ & $\begin{array}{l}8.0 \\
7.9 \\
7.9 \\
7.8 \\
7.8 \\
7.7\end{array}$ & $\begin{array}{l}1,510 \\
1,630 \\
1,610 \\
1,540 \\
1,550 \\
1,570\end{array}$ & $\begin{array}{l}8.0 \\
7.9 \\
7.8 \\
7.6 \\
7.5 \\
7.5\end{array}$ & $\begin{array}{r}1,870 \\
2,180 \\
1,970 \\
1,810 \\
1,540 \\
891\end{array}$ & $\begin{array}{l}6.8 \\
6.7 \\
6.6 \\
6.6 \\
6.6 \\
6.6\end{array}$ & $\begin{array}{l}3,620 \\
3 ; 990 \\
3,770 \\
3,840 \\
5,030 \\
5,440\end{array}$ & $\begin{array}{l}6.3 \\
6.7 \\
7.3 \\
7.5 \\
7.8 \\
8.1\end{array}$ & $\begin{array}{l}19,500 \\
21,200 \\
23,700 \\
25,300 \\
29,200 \\
30,500\end{array}$ & $\begin{array}{l}11.7 \\
11.6 \\
11.4 \\
11.2 \\
11.0 \\
10.8\end{array}$ & $\begin{array}{l}49,100 \\
48,400 \\
47,400 \\
46,100 \\
45,000 \\
44,000\end{array}$ & $\begin{array}{l}5.0 \\
4.8 \\
4.5 \\
4.3 \\
4.1 \\
3.9\end{array}$ & $\begin{array}{l}15,300 \\
14,600 \\
13,500 \\
12,700 \\
12,000 \\
11,300\end{array}$ \\
\hline $\begin{array}{l}1 \\
2 \\
3 \\
4 \\
5 \\
6\end{array}$ & $\begin{array}{l}7.7 \\
7.6 \\
7.6 \\
7.6 \\
7.5 \\
7.5\end{array}$ & $\begin{array}{l}1,590 \\
1,700 \\
1,220 \\
1,430 \\
1,390 \\
1,160\end{array}$ & $\begin{array}{l}7.5 \\
7.6 \\
7.6 \\
7.6 \\
7.6 \\
7.6\end{array}$ & $\begin{array}{r}1,240 \\
1,280 \\
1,100 \\
956 \\
1,320 \\
1,160\end{array}$ & $\begin{array}{l}6.5 \\
6.1 \\
5.8 \\
5.7 \\
5.8 \\
5.7\end{array}$ & $\begin{array}{l}6,110 \\
9,080 \\
9,340 \\
7,700 \\
6,980 \\
9,380\end{array}$ & $\begin{array}{r}8.3 \\
8.5 \\
8.7 \\
9.1 \\
9.6 \\
10.0\end{array}$ & $\begin{array}{l}31,700 \\
32,800 \\
33,800 \\
35,900 \\
37,800 \\
39,500\end{array}$ & $\begin{array}{r}10.5 \\
10.2 \\
9.9 \\
9.6 \\
9.2 \\
8.8\end{array}$ & $\begin{array}{l}42,300 \\
40,700 \\
38,900 \\
37,400 \\
35,200 \\
33,000\end{array}$ & $\begin{array}{l}3.7 \\
3.6 \\
3.5 \\
3.5 \\
3.6 \\
3.8\end{array}$ & $\begin{array}{r}10,800 \\
10,400 \\
10,110 \\
10,080 \\
8,360 \\
6,660\end{array}$ \\
\hline \multirow[t]{2}{*}{$\begin{array}{r}7 \\
8 \\
9 \\
10 \\
11 \\
M \\
\end{array}$} & $\begin{array}{l}7.5 \\
7.5 \\
7.6 \\
7.7 \\
7.7 \\
7.8\end{array}$ & $\begin{array}{l}897 \\
750 \\
569 \\
274 \\
240 \\
316\end{array}$ & $\begin{array}{l}7.6 \\
7.7 \\
7.7 \\
7.8 \\
7.9 \\
7.8\end{array}$ & $\begin{array}{r}1,010 \\
740 \\
512 \\
438 \\
1,390 \\
3,100\end{array}$ & $\begin{array}{l}5.5 \\
5.0 \\
4.8 \\
4.6 \\
4.6 \\
5.0\end{array}$ & $\begin{array}{r}9,800 \\
10,900 \\
11,500 \\
10,600 \\
10,500 \\
11,400\end{array}$ & $\begin{array}{l}10.3 \\
10.5 \\
10.8 \\
11.3 \\
11.5 \\
11.7\end{array}$ & $\begin{array}{l}41,200 \\
42,200 \\
44,000 \\
46,800 \\
48,000 \\
49,100\end{array}$ & $\begin{array}{l}8.4 \\
8.1 \\
7.8 \\
7.6 \\
7.3 \\
7.0\end{array}$ & $\begin{array}{r}500 \\
500 \\
500 \\
500 \\
100\end{array}$ & $\begin{array}{l}4.1 \\
4.2 \\
4.3 \\
4.3 \\
4.3 \\
4.3\end{array}$ & $\begin{array}{l}7,150 \\
7,300 \\
7,450 \\
7,270 \\
7,370 \\
7,340 \\
\end{array}$ \\
\hline & \multicolumn{2}{|c|}{ September 24} & \multicolumn{2}{|c|}{ September 25} & \multicolumn{2}{|c|}{ September 26} & \multicolumn{2}{|c|}{ September 27} & \multicolumn{2}{|c|}{ September 28} & \multicolumn{2}{|c|}{ September 29} \\
\hline $\begin{array}{r}2 \\
4 \\
6 \\
8 \\
10 \\
N\end{array}$ & $\begin{array}{l}4.1 \\
4.0 \\
3.9 \\
3.6 \\
3.9 \\
5.3\end{array}$ & $\begin{array}{r}7,050 \\
6,900 \\
6,870 \\
6,450 \\
4,560 \\
416\end{array}$ & $\begin{array}{l}7.6 \\
7.5 \\
7.4 \\
7.5 \\
7.5 \\
7.5\end{array}$ & $\begin{array}{l}3,830 \\
3,670 \\
3,600 \\
3,350 \\
3,720 \\
3,690\end{array}$ & $\begin{array}{l}7.2 \\
7.2 \\
7.0 \\
7.0 \\
6.8 \\
6.6\end{array}$ & $\begin{array}{l}3,180 \\
3,350 \\
3,200 \\
3,830 \\
3,240 \\
3,220\end{array}$ & $\begin{array}{l}6.9 \\
6.9 \\
7.0 \\
6.9 \\
7.0 \\
7.2\end{array}$ & $\begin{array}{l}2,490 \\
2,520 \\
2,515 \\
3,940 \\
1,332 \\
1,333\end{array}$ & $\begin{array}{l}8.4 \\
8.2 \\
8.0 \\
7.9 \\
7.8 \\
7.8\end{array}$ & $\begin{array}{l}3,910 \\
3,660 \\
3,540 \\
2,740 \\
2,730 \\
2,620\end{array}$ & $\begin{array}{l}7.5 \\
7.7 \\
7.9 \\
8.0 \\
8.1 \\
8.1\end{array}$ & $\begin{array}{l}1,500 \\
1,630 \\
1,710 \\
1,600 \\
1,660 \\
2,120\end{array}$ \\
\hline $\begin{array}{r}2 \\
4 \\
6 \\
8 \\
10 \\
M\end{array}$ & $\begin{array}{l}6.3 \\
7.5 \\
7.8 \\
7.7 \\
7.7 \\
7.7\end{array}$ & $\begin{array}{r}461 \\
770 \\
4,350 \\
4,280 \\
4,190 \\
4,120\end{array}$ & $\begin{array}{l}7.5 \\
7.5 \\
7.6 \\
7.5 \\
7.4 \\
7.3\end{array}$ & $\begin{array}{l}3,700 \\
3,030 \\
3,150 \\
3,810 \\
3,680 \\
3,370\end{array}$ & $\begin{array}{l}6.6 \\
6.7 \\
6.9 \\
6.9 \\
6.9 \\
6.9\end{array}$ & $\begin{array}{l}2,440 \\
2,090 \\
2,120 \\
2,840 \\
2,660 \\
2,760\end{array}$ & $\begin{array}{l}7.4 \\
7.6 \\
8.0 \\
8.2 \\
8.4 \\
8.5\end{array}$ & $\begin{array}{r}1,390 \\
1,260 \\
443 \\
1,310 \\
1,230 \\
2,650\end{array}$ & $\begin{array}{l}7.7 \\
7.6 \\
7.5 \\
7.5 \\
7.4 \\
7.4\end{array}$ & $\begin{array}{l}2,640 \\
2,610 \\
2,620 \\
2,690 \\
2,710\end{array}$ & $\begin{array}{l}8.1 \\
8.0 \\
8.1 \\
8.0 \\
7.9 \\
8.0\end{array}$ & $\begin{array}{l}2,180 \\
2,100 \\
1,720 \\
2,123 \\
2,124 \\
1,280\end{array}$ \\
\hline
\end{tabular}


Location.- Staff gage, lat. $43^{\circ} 26^{\prime} 50^{\prime}$, long. $71^{\circ} 39^{\prime} 35^{\prime \prime}$, at dam of Public Service Co., in Franklin, Merrimack County, $0.9 \mathrm{mile}$ above confluence with Winnipesaukee River. Drainage area.- 1,000 square milés.

Gage-height record.- Graph constructed from hourly observed gage readings. Gage heights given to tenths.

Stage-discharge relation.- Affected by flashboards on dam prior to 5 a.m. Sept. 21 and after $10 \mathrm{a} . \mathrm{m}$. Sept. 25. Discharge ascertained from flow over dam and through wheels and gates.

Maxima.- September 1938: Discharge, 54,400 second-feet 4 to 9 a.m. Sept. 22 (gage height, 11.4 feet).

Remarks.- Flood run-off affected by storage in Squam and Newfound Lakes. Records furnished by Public Service Co. of New Hampshire.

Mean dally discharge, in second-feet, 1938

\begin{tabular}{|c|c|c|c|c|c|c|c|c|c|c|c|}
\hline Day & Sept. & Oct. & Day & Sept. & Oct. & Day & Sept. & 0 ct. & Day & Sept. & oct. \\
\hline $\begin{array}{l}1 \\
2 \\
3 \\
4 \\
5 \\
6 \\
7 \\
8\end{array}$ & $\begin{array}{l}726 \\
850 \\
669 \\
576 \\
457 \\
430 \\
617 \\
731\end{array}$ & $\begin{array}{r}1,530 \\
1,730 \\
1,560 \\
1,410 \\
1,180 \\
1,400 \\
1,180 \\
969\end{array}$ & $\begin{array}{r}9 \\
10 \\
11 \\
12 \\
13 \\
14 \\
15 \\
16\end{array}$ & $\begin{array}{r}822 \\
209 \\
435 \\
675 \\
1,010 \\
1,530 \\
2,040 \\
3,590\end{array}$ & $\begin{array}{r}887 \\
1,250 \\
1,260 \\
891 \\
1,450 \\
1,320 \\
1,270 \\
780\end{array}$ & $\begin{array}{l}17 \\
18 \\
19 \\
20 \\
21 \\
22 \\
23 \\
24\end{array}$ & $\begin{array}{r}1,580 \\
1,650 \\
1,370 \\
6,940 \\
32,200 \\
49,100 \\
18,900 \\
7,320\end{array}$ & $\begin{array}{r}1,180 \\
869 \\
868 \\
863 \\
981 \\
1,130 \\
1,500 \\
2,210 \\
\end{array}$ & $\begin{array}{l}25 \\
26 \\
27 \\
28 \\
29 \\
30 \\
31\end{array}$ & $\begin{array}{l}5,440 \\
4,570 \\
3,180 \\
3,770 \\
2,840 \\
2,370\end{array}$ & $\begin{array}{l}6,450 \\
2,640 \\
2,520 \\
1,800 \\
1,140 \\
1,790 \\
1,420\end{array}$ \\
\hline $\begin{array}{l}\text { Mean } \\
\text { Run- }\end{array}$ & in & & & - . - & . & $: \dot{ }$ & 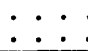 & $\begin{array}{l}\cdot \cdot \cdot \\
\cdot \dot{ }\end{array}$ & . : & $\begin{array}{r}5,220 \\
5.82\end{array}$ & $\begin{array}{r}1,530 \\
1.76\end{array}$ \\
\hline
\end{tabular}

Gage height, in feet, and discharge, in second-feet, at indicated time, 1938

\begin{tabular}{|c|c|c|c|c|c|c|c|c|c|c|c|c|}
\hline \multirow{2}{*}{$\begin{array}{l}3 \\
\text { 量 } \\
\text { 足 }\end{array}$} & Feet & Sec.ft. & Feet & Sec.ft. & Feet & Sec.ft. & Feet & Sec.ft. & Feet & Sec.ft. & Feet & Sec.ft. \\
\hline & \multicolumn{2}{|c|}{ September 18} & \multicolumn{2}{|c|}{ September 19} & \multicolumn{2}{|c|}{ September 20} & \multicolumn{2}{|c|}{ September 21} & \multicolumn{2}{|c|}{ September 22} & \multicolumn{2}{|c|}{ September 23} \\
\hline $\begin{array}{l}1 \\
2 \\
3 \\
4 \\
5 \\
6\end{array}$ & $\begin{array}{l}5.9 \\
5.8 \\
5.8 \\
5.8 \\
6.0 \\
6.1\end{array}$ & $\begin{array}{l}1,720 \\
1,710 \\
1,710 \\
1,710 \\
1,720 \\
1,730\end{array}$ & $\begin{array}{l}6.0 \\
6.0 \\
5.9 \\
5.8 \\
5.7 \\
5.7\end{array}$ & $\begin{array}{r}884 \\
884 \\
881 \\
1,290 \\
1,160 \\
430\end{array}$ & $\begin{array}{l}6.2 \\
6.4 \\
6.4 \\
6.4 \\
6.2 \\
6.1\end{array}$ & $\begin{array}{r}467 \\
2,710 \\
3,180 \\
4,470 \\
4,490 \\
4,610\end{array}$ & $\begin{array}{l}5.9 \\
6.5 \\
6.9 \\
7.0 \\
6.9 \\
6.4\end{array}$ & $\begin{array}{l}16,500 \\
18,800 \\
20,400 \\
20,900 \\
20,600 \\
23,200\end{array}$ & $\begin{array}{l}10.8 \\
11.0 \\
11.3 \\
11.4 \\
11.4 \\
11.4\end{array}$ & $\begin{array}{l}50,000 \\
51,400 \\
53,600 \\
54,400 \\
54,400 \\
54,400\end{array}$ & $\begin{array}{l}8.0 \\
7.7 \\
7.5 \\
7.2 \\
6.8 \\
6.5\end{array}$ & $\begin{array}{l}32,200 \\
30,600 \\
29,400 \\
27,800 \\
25,900 \\
24,200\end{array}$ \\
\hline $\begin{array}{r}7 \\
8 \\
9 \\
10 \\
11 \\
\mathrm{~N}\end{array}$ & $\begin{array}{l}6.1 \\
6.1 \\
6.0 \\
5.9 \\
5.7 \\
5.5\end{array}$ & $\begin{array}{l}1,730 \\
1,910 \\
2,760 \\
2,750 \\
2,730 \\
2,560\end{array}$ & $\begin{array}{l}5.7 \\
5.8 \\
5.9 \\
6.0 \\
6.0 \\
6.0\end{array}$ & $\begin{array}{r}830 \\
1,380 \\
1,590 \\
1,830 \\
2,220 \\
2,230\end{array}$ & $\begin{array}{l}5.8 \\
5.6 \\
5.6 \\
5.6 \\
5.3 \\
5.1\end{array}$ & $\begin{array}{l}5,370 \\
4,700 \\
4,760 \\
4,700 \\
6,080 \\
6,140\end{array}$ & $\begin{array}{l}6 . \\
6 . \\
6 . \\
7 . \\
7 . \\
8 .\end{array}$ & $\begin{array}{l}24,1 \\
24,0 \\
26,2 \\
28,2 \\
31,2 \\
34,3\end{array}$ & $\begin{array}{l}11.4 \\
11.4 \\
11.4 \\
11.3 \\
11.3 \\
11.2\end{array}$ & $\begin{array}{l}400 \\
400 \\
400 \\
600 \\
600 \\
800\end{array}$ & $\begin{array}{l}5.4 \\
5.1 \\
5.8 \\
5.5 \\
5.7 \\
5.6\end{array}$ & $\begin{array}{l}23,900 \\
22,500 \\
21,100 \\
19,900 \\
18,400 \\
17,000\end{array}$ \\
\hline $\begin{array}{l}1 \\
2 \\
3 \\
4 \\
5 \\
6\end{array}$ & $\begin{array}{l}5.6 \\
5.7 \\
5.9 \\
6.0 \\
6.0 \\
6.0\end{array}$ & $\begin{array}{r}1,560 \\
830 \\
820 \\
1,100 \\
1,610 \\
1,640\end{array}$ & $\begin{array}{l}5.9 \\
5.8 \\
5.7 \\
5.7 \\
5.7 \\
5.7\end{array}$ & $\begin{array}{l}2,230 \\
1,880 \\
1,640 \\
1,640 \\
1,700 \\
1,640\end{array}$ & $\begin{array}{l}4.9 \\
5.1 \\
5.7 \\
6.2 \\
6.2 \\
5.5\end{array}$ & $\begin{array}{r}6,780 \\
5,810 \\
6,320 \\
7,690 \\
10,100 \\
11,400\end{array}$ & $\begin{array}{l}8.4 \\
8.6 \\
8.7 \\
8.8 \\
9.0 \\
9.2\end{array}$ & $\begin{array}{l}36, \\
37, \\
37, \\
38, \\
39, \\
39,\end{array}$ & $\begin{array}{l}11.2 \\
11.0 \\
11.0 \\
10.6 \\
10.3 \\
10.0\end{array}$ & $\begin{array}{l}52, \\
51, \\
51, \\
48, \\
46, \\
44,\end{array}$ & $\begin{array}{l}5.4 \\
5.3 \\
5.1 \\
5.2 \\
5.2 \\
5.2\end{array}$ & $\begin{array}{l}16, \\
15, \\
15, \\
13, \\
13, \\
12,\end{array}$ \\
\hline \multirow[t]{2}{*}{$\begin{array}{r}7 \\
8 \\
9 \\
10 \\
11 \\
\end{array}$} & $\begin{array}{l}6.0 \\
6.0 \\
5.9 \\
5.8 \\
5.9 \\
6.0\end{array}$ & $\begin{array}{r}1,640 \\
1,690 \\
1,630 \\
1,120 \\
425 \\
74 \\
\end{array}$ & $\begin{array}{l}5.7 \\
5.7 \\
5.7 \\
5.7 \\
5.7 \\
5.9\end{array}$ & $\begin{array}{r}1,590 \\
1,590 \\
1,640 \\
1,320 \\
400 \\
0 \\
\end{array}$ & $\begin{array}{l}5.2 \\
5.2 \\
5.4 \\
5.8 \\
5.7 \\
5.6\end{array}$ & $\begin{array}{l}11,500 \\
11,600 \\
11,900 \\
12,700 \\
11,500 \\
15,300 \\
\end{array}$ & $\begin{array}{r}9.5 \\
9.7 \\
10.0 \\
10.3 \\
10.6 \\
10.7\end{array}$ & $\begin{array}{l}41,400 \\
43,100 \\
44,700 \\
46,700 \\
48,600 \\
49,400\end{array}$ & $\begin{array}{l}9.8 \\
9.6 \\
9.2 \\
8.9 \\
8.6 \\
8.4\end{array}$ & $\begin{array}{l}43,500 \\
42,400 \\
39,400 \\
37,600 \\
35,800 \\
34,600\end{array}$ & $\begin{array}{l}4.9 \\
4.7 \\
4.7 \\
4.6 \\
4.6 \\
4.6 \\
\end{array}$ & $\begin{array}{r}11,400 \\
10,500 \\
10,500 \\
10,100 \\
9,890 \\
10,100 \\
\end{array}$ \\
\hline & \multicolumn{2}{|c|}{ September 24} & \multicolumn{2}{|c|}{ September 25} & \multicolumn{2}{|c|}{ September 26} & \multicolumn{2}{|c|}{ September 27} & \multicolumn{2}{|c|}{ September 28} & \multicolumn{2}{|c|}{ September 29} \\
\hline $\begin{array}{r}2 \\
4 \\
6 \\
8 \\
10 \\
N\end{array}$ & $\begin{array}{l}4.6 \\
4.5 \\
4.5 \\
4.3 \\
4.2 \\
3.9\end{array}$ & $\begin{array}{r}10,100 \\
9,550 \\
9,550 \\
9,100 \\
8,780 \\
7,820\end{array}$ & $\begin{array}{l}3.7 \\
3.8 \\
3.8 \\
3.6 \\
3.3 \\
4.8\end{array}$ & $\begin{array}{l}6,970 \\
7,280 \\
7,280 \\
6,670 \\
6,330 \\
2,210\end{array}$ & $\begin{array}{l}6.0 \\
5.8 \\
5.9 \\
6.1 \\
6.1 \\
6.0\end{array}$ & $\begin{array}{l}5,310 \\
5,060 \\
3,700 \\
5,390 \\
5,580 \\
5,560\end{array}$ & $\begin{array}{l}5.8 \\
5.7 \\
5.6 \\
5.6 \\
5.7\end{array}$ & $\begin{array}{l}4,290 \\
4,310 \\
4,260 \\
4,100 \\
4,230 \\
3,970\end{array}$ & $\begin{array}{l}5.9 \\
6.0 \\
6.3 \\
5.4 \\
5.5 \\
5.6\end{array}$ & $\begin{array}{l}2,631 \\
2,633 \\
5,050 \\
6,470 \\
3,950 \\
3,218\end{array}$ & $\begin{array}{l}.0 \\
.8 \\
.0 \\
.1 \\
.0\end{array}$ & \\
\hline $\begin{array}{r}2 \\
4 \\
6 \\
8 \\
10 \\
M\end{array}$ & $\begin{array}{l}3.1 \\
2.6 \\
2.3 \\
2.8 \\
3.2 \\
3.7\end{array}$ & $\begin{array}{l}5,490 \\
4,220 \\
3,520 \\
5,050 \\
6,100 \\
6,970\end{array}$ & $\begin{array}{l}5.9 \\
5.9 \\
5.7 \\
5.7 \\
6.0 \\
6.0\end{array}$ & $\begin{array}{l}2,100 \\
5,370 \\
5,320 \\
4,780 \\
4,810\end{array}$ & $\begin{array}{l}5.8 \\
5.5 \\
5.4 \\
5.5 \\
5.8 \\
6.0\end{array}$ & $\begin{array}{l}5,510 \\
4,880 \\
3,110 \\
3,120 \\
3,080 \\
3,680\end{array}$ & $\begin{array}{l}5.5 \\
6.0 \\
6.1 \\
6.0 \\
6.0 \\
5.9\end{array}$ & $\begin{array}{l}1,480 \\
1,515 \\
1,525 \\
2,643 \\
2,638 \\
2,630\end{array}$ & $\begin{array}{l}5.8 \\
6.0 \\
6.1 \\
6.1 \\
6.1 \\
6.0\end{array}$ & $\begin{array}{l}3,221 \\
3,230 \\
3,840 \\
3,990 \\
3,780 \\
3,790\end{array}$ & $\begin{array}{l}6.0 \\
6.1 \\
6.0 \\
5.8 \\
5.9\end{array}$ & $\begin{array}{l}2,700 \\
2,650 \\
3,690 \\
3,140 \\
2,640 \\
2,430\end{array}$ \\
\hline
\end{tabular}


Merrimack RIver at Franklin Junction, N. H.

Location.- Water-stage recorder, lat. $43^{\circ} 25^{\prime} 2^{\prime \prime}$, long. $71^{\circ} 39^{\prime} l^{\prime \prime}$, at railroad bridge 1 mile below confluence of Pemigewasset and Winnipesaukee Rivers, at Franklin Junction, Merrimack County. Zero of gage is 250.4 feet above mean sea level.

Drainage area.- 1,507 square miles.

Gage-neight record.- Water-stage recorder graph except for period 4:30 a.m. to 1 p.m. Sept. 22, when it was based on flood marks and shape of recorded graph.

Stage-discharge reiation.- Defined by current-meter measurements below 30,000 secondfeet; extended to peak stage on basis of velocity-area study at control section, verifled by determinations of flood flow over dam and by slope-area method.

Maxima.- September 1938: Discharge, 59,200 second-feet 9 a.m. Sept. 22 (gage height, 29.5 feet, from flood marks).

1903 to August 1938: Discharge, 83,000 second-feet Mar. 19, 1936 (gage helght, 36.4 feet, from flood marks).

Remarks.- Flood mun-off affected by storage in Winnipesaukee, Squam, Newfound and other lakes. For information on storage see record for Lake Winnipesaukee at The Weirs, N. H.

Mean daily discharge, in second-feet, 1938

\begin{tabular}{|c|c|c|c|c|c|c|c|c|c|c|c|}
\hline Day & Sept. & Oct. & Day & Sept. & oct. & Day & Sept. & oct. & Day & Sept. & Oct. \\
\hline $\begin{array}{l}1 \\
2 \\
3 \\
4 \\
5 \\
6 \\
7 \\
8\end{array}$ & $\begin{array}{r}1,350 \\
1,470 \\
1,220 \\
1,050 \\
1,020 \\
940 \\
1,210 \\
1,330\end{array}$ & $\begin{array}{l}3,120 \\
3,020 \\
2,950 \\
2,820 \\
1,770 \\
2,740 \\
2,660 \\
2,370\end{array}$ & $\begin{array}{r}9 \\
10 \\
11 \\
12 \\
13 \\
14 \\
15 \\
16\end{array}$ & $\begin{array}{r}1,420 \\
820 \\
970 \\
1,220 \\
1,670 \\
2,360 \\
2,470 \\
4,630\end{array}$ & $\begin{array}{l}1,740 \\
2,030 \\
2,040 \\
1,640 \\
2,120 \\
2,080 \\
1,860 \\
1,120\end{array}$ & $\begin{array}{l}17 \\
18 \\
19 \\
20 \\
21 \\
22 \\
23 \\
24\end{array}$ & $\begin{array}{r}2,340 \\
2,280 \\
2,170 \\
8,600 \\
37,500 \\
54,800 \\
26,500 \\
11,200\end{array}$ & $\begin{array}{l}2,200 \\
1,710 \\
1,620 \\
1,670 \\
1,960 \\
2,010 \\
2,170 \\
3,240\end{array}$ & $\begin{array}{l}25 \\
26 \\
27 \\
28 \\
29 \\
30 \\
31\end{array}$ & $\begin{array}{l}100 \\
520 \\
670 \\
780 \\
650 \\
040\end{array}$ & $\begin{array}{l}7,820 \\
3,890 \\
3,620 \\
3,020 \\
2,680 \\
2,740 \\
2,330\end{array}$ \\
\hline & & & 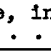 & & - . & & $\dot{0} \cdot \dot{ }$ & . $\bullet$ & $\dot{.} \cdot$ & $\begin{array}{r}6,810 \\
5.04 \\
\end{array}$ & $\begin{array}{r}2,541 \\
1.95 \\
\end{array}$ \\
\hline
\end{tabular}

Gage height, in feet, and discharge, in second-feet, at indicated time, 1938

\begin{tabular}{|c|c|c|c|c|c|c|c|c|c|c|c|c|}
\hline \multirow{2}{*}{$\begin{array}{l}\text { \& } \\
\text { ? } \\
\text { 东 }\end{array}$} & Feet & Sec.ft. & Feet & Sec.ft. & Feet & sec.ft. & Feet & Sec.ft. & Feet & Sec.ft. & Feet & Sec.ft. \\
\hline & \multicolumn{2}{|c|}{ September 18} & \multicolumn{2}{|c|}{ September 19} & \multicolumn{2}{|c|}{ September 20} & \multicolumn{2}{|c|}{ September 21} & \multicolumn{2}{|c|}{ September 22} & \multicolumn{2}{|c|}{ Sept ember 23} \\
\hline $\begin{array}{l}1 \\
2 \\
3 \\
4 \\
5 \\
6\end{array}$ & $\begin{array}{l}5.75 \\
5.75 \\
5.75 \\
5.76 \\
5.77 \\
5.78\end{array}$ & $\begin{array}{l}2,280 \\
2,280 \\
2,280 \\
2,290 \\
2,300 \\
2,320\end{array}$ & $\begin{array}{l}4.82 \\
5.00 \\
5.01 \\
5.39 \\
5.40 \\
4.67\end{array}$ & $\begin{array}{l}1,330 \\
1,470 \\
1,480 \\
1,850 \\
1,860 \\
1,210\end{array}$ & $\begin{array}{l}4.43 \\
6.50 \\
7.50 \\
7.73 \\
7.80 \\
7.88\end{array}$ & $\begin{array}{l}1,020 \\
3,320 \\
4,910 \\
5,320 \\
5,450 \\
5,590\end{array}$ & $\begin{array}{l}15.10 \\
16.00 \\
16.80 \\
17.35 \\
18.30 \\
18.85\end{array}$ & $\begin{array}{l}20,800 \\
22,900 \\
24,800 \\
26,200 \\
28,600 \\
30,000\end{array}$ & $\begin{array}{l}27.70 \\
28.10 \\
28.40 \\
28.70 \\
29.00 \\
29.20\end{array}$ & $\begin{array}{l}54,000 \\
55,200 \\
56,100 \\
56,900 \\
57,800 \\
58,400\end{array}$ & $\begin{array}{l}23.35 \\
22.80 \\
22.20 \\
21.65 \\
21.00 \\
20.40\end{array}$ & $\begin{array}{l}42,000 \\
40,500 \\
38,800 \\
37,400 \\
35,600 \\
34,000\end{array}$ \\
\hline $\begin{array}{r}7 \\
8 \\
9 \\
10 \\
11 \\
\frac{N}{N}\end{array}$ & $\begin{array}{l}5.78 \\
5.79 \\
6.45 \\
6.47 \\
6.46 \\
6.40\end{array}$ & $\begin{array}{l}2,320 \\
2,330 \\
3,240 \\
3,280 \\
3,260 \\
3,170\end{array}$ & $\begin{array}{l}5.10 \\
5.70 \\
5.79 \\
6.00 \\
6.20 \\
6.22\end{array}$ & $\begin{array}{l}1,560 \\
2,220 \\
2,330 \\
2,600 \\
2,880 \\
2,910\end{array}$ & $\begin{array}{l}8.34 \\
8.05 \\
8.03 \\
8.07 \\
9.22 \\
8.98\end{array}$ & $\begin{array}{l}6,480 \\
5,900 \\
5,870 \\
5,940 \\
8,240 \\
7,760\end{array}$ & $\begin{array}{l}19.05 \\
19.25 \\
19.65 \\
20.30 \\
21.20 \\
22.20\end{array}$ & $\begin{array}{l}30,600 \\
31,100 \\
32,100 \\
33,800 \\
36,100 \\
38,800\end{array}$ & $\begin{array}{l}29.40 \\
29.47 \\
29.50 \\
29.46 \\
29.30 \\
29.10\end{array}$ & $\begin{array}{l}59,000 \\
59,170 \\
59,200 \\
59,160 \\
58,700 \\
58,100\end{array}$ & $\begin{array}{l}19.80 \\
19.25 \\
18.65 \\
18.10 \\
17.25 \\
16.75\end{array}$ & $\begin{array}{l}32,500 \\
31,000 \\
29,500 \\
28,100 \\
25,900 \\
24,700\end{array}$ \\
\hline $\begin{array}{l}1 \\
2 \\
3 \\
4 \\
5 \\
6\end{array}$ & $\begin{array}{l}5.88 \\
5.25 \\
5.14 \\
5.13 \\
5.63 \\
5.77\end{array}$ & $\begin{array}{l}2,440 \\
1,700 \\
1,600 \\
1,590 \\
2,140 \\
2,300\end{array}$ & $\begin{array}{l}6.25 \\
6.00 \\
5.89 \\
5.91 \\
5.96 \\
5.97\end{array}$ & $\begin{array}{l}2,950 \\
2,600 \\
2,460 \\
2,480 \\
2,550 \\
2,560\end{array}$ & $\begin{array}{r}9.40 \\
9.10 \\
8.95 \\
9.90 \\
10.55 \\
11.50\end{array}$ & $\begin{array}{r}8,600 \\
8,000 \\
7,700 \\
9,600 \\
10,900 \\
13,000\end{array}$ & $\begin{array}{l}23.00 \\
23.50 \\
24.00 \\
24.25 \\
24.50 \\
24.70\end{array}$ & $\begin{array}{l}41,000 \\
42,400 \\
43,700 \\
44,400 \\
45,000 \\
45,600\end{array}$ & $\begin{array}{l}28.85 \\
28.70 \\
28.40 \\
28.10 \\
27.70 \\
27.30\end{array}$ & $\begin{array}{l}57,400 \\
56,900 \\
56,100 \\
55,200 \\
54,000 \\
52,900\end{array}$ & $\begin{array}{l}16.35 \\
15.90 \\
15.55 \\
14.90 \\
14.55 \\
14.00\end{array}$ & $\begin{array}{l}23,800 \\
22,700 \\
21,900 \\
20,400 \\
19,600 \\
18,400\end{array}$ \\
\hline \multirow[t]{2}{*}{$\begin{array}{r}7 \\
8 \\
9 \\
10 \\
11 \\
11\end{array}$} & $\begin{array}{l}5.77 \\
5.77 \\
5.77 \\
5.40 \\
4.75 \\
4.30\end{array}$ & $\begin{array}{r}2,300 \\
2,300 \\
2,300 \\
1,860 \\
1,270 \\
925\end{array}$ & $\begin{array}{l}6.00 \\
6.03 \\
6.04 \\
5.75 \\
5.08 \\
4.65\end{array}$ & $\begin{array}{l}2,600 \\
2,640 \\
2,660 \\
2,280 \\
1,540 \\
1,190\end{array}$ & $\begin{array}{l}11.62 \\
11.70 \\
11.95 \\
12.45 \\
13.40 \\
14.20\end{array}$ & $\begin{array}{l}13,200 \\
13,400 \\
13,900 \\
15,000 \\
17,100 \\
18,800\end{array}$ & $\begin{array}{l}25.10 \\
25.55 \\
26.00 \\
26.40 \\
26.80 \\
27.25\end{array}$ & $\begin{array}{l}46,700 \\
48,000 \\
49,200 \\
50,300 \\
51,400 \\
52,800\end{array}$ & $\begin{array}{l}26.80 \\
26.30 \\
25.75 \\
25.15 \\
24.55 \\
23.95\end{array}$ & $\begin{array}{l}400 \\
000 \\
500 \\
800 \\
200 \\
600\end{array}$ & $\begin{array}{l}.65 \\
.20 \\
.90 \\
.70 \\
.50 \\
.42\end{array}$ & $\begin{array}{l}17,600 \\
16,600 \\
16,000 \\
15,500 \\
15,100 \\
14,900\end{array}$ \\
\hline & \multicolumn{2}{|c|}{ September 24} & \multicolumn{2}{|c|}{ September 25} & \multicolumn{2}{|c|}{ September 26} & \multicolumn{2}{|c|}{ September 27} & \multicolumn{2}{|c|}{ September 28 . } & \multicolumn{2}{|c|}{ September 29} \\
\hline $\begin{array}{r}2 \\
4 \\
6 \\
8 \\
10 \\
N\end{array}$ & $\begin{array}{l}12.25 \\
12.00 \\
11.75 \\
11.50 \\
11.30 \\
10.80\end{array}$ & $\begin{array}{l}14,600 \\
14,000 \\
13,500 \\
13,000 \\
12,500 \\
11,500\end{array}$ & $\begin{array}{r}10.03 \\
10.10 \\
10.07 \\
10.00 \\
9.87 \\
7.55\end{array}$ & $\begin{array}{r}9,860 \\
10,000 \\
9,950 \\
9,800 \\
9,540 \\
5,000\end{array}$ & $\begin{array}{l}9.11 \\
8.63 \\
8.00 \\
8.67 \\
8.85 \\
8.83\end{array}$ & $\begin{array}{l}8,020 \\
7,060 \\
5,810 \\
7,140 \\
7,500 \\
7,460\end{array}$ & $\begin{array}{l}7.94 \\
7.90 \\
7.86 \\
7.85 \\
7.95 \\
7.90\end{array}$ & $\begin{array}{l}\mathbf{5}, 700 \\
\mathbf{5}, 630 \\
\mathbf{5}, 560 \\
\mathbf{5}, 540 \\
\mathbf{5}, 720 \\
\mathbf{5}, 630\end{array}$ & $\begin{array}{l}7.12 \\
7.64 \\
9.35 \\
9.76 \\
7.90 \\
7.52\end{array}$ & $\begin{array}{l}4,280 \\
5,160 \\
8,500 \\
9,320 \\
5,630 \\
4,950\end{array}$ & $\begin{array}{l}7.45 \\
7.42 \\
6.78 \\
7.20 \\
7.27 \\
7.25\end{array}$ & $\begin{array}{l}4,820 \\
4,770 \\
3,740 \\
4,410 \\
4,520 \\
4,490\end{array}$ \\
\hline $\begin{array}{r}2 \\
4 \\
6 \\
8 \\
10 \\
M\end{array}$ & $\begin{array}{r}10.10 \\
9.25 \\
8.70 \\
9.10 \\
9.82 \\
10.05\end{array}$ & $\begin{array}{r}10,000 \\
8,300 \\
7,000 \\
8,000 \\
9,440 \\
9,900\end{array}$ & $\begin{array}{l}7.60 \\
9.00 \\
9.05 \\
8.75 \\
8.65 \\
9.13\end{array}$ & $\begin{array}{l}5,090 \\
7,800 \\
7,900 \\
7,300 \\
7,100 \\
8,060\end{array}$ & $\begin{array}{l}8.83 \\
8.60 \\
7.56 \\
7.45 \\
7.28 \\
7.43\end{array}$ & $\begin{array}{l}7,460 \\
7,000 \\
5,020 \\
4,820 \\
4,540 \\
4,790\end{array}$ & $\begin{array}{l}6.44 \\
6.30 \\
6.47 \\
7.14 \\
7.12 \\
7.10\end{array}$ & $\begin{array}{l}3,220 \\
3,020 \\
3,270 \\
4,310 \\
4,280\end{array}$ & $\begin{array}{l}7.54 \\
7.55 \\
7.80 \\
7.87 \\
7.87\end{array}$ & $\begin{array}{l}4,980 \\
5,000 \\
5,450 \\
5,580 \\
5,580\end{array}$ & $\begin{array}{l}7.28 \\
7.28 \\
7.83 \\
7.55 \\
7.22 \\
7.22\end{array}$ & $\begin{array}{l}4,540 \\
4,540 \\
5,500 \\
5,000 \\
4,440 \\
4,440\end{array}$ \\
\hline
\end{tabular}

Supplemental records.- Sept. 25, 1 p.m., $6.14 \mathrm{ft} ., 2,800$ sec.-ft. Sept. 27,

7 a.m., 7.42 ft., 4,770 sec.-ft. (éfects of reguletion). 
Merrimack River at Garvins Falls, N. H.

Location.- Staff-gage, lat. $43^{\circ} 10^{\prime} 00^{n}$, Iong. $71^{\circ} 30^{\prime} 35^{\prime \prime}$, at dam of Public Service Co., $0.8 \mathrm{mile}$ below mouth of Turkey River, and $43 / 4$ miles below upper highway bridge at Concord, Merrimack County.

Drainage area.- 2,427 square miles.

Gage-helght record.- Gage-height graph constructed from hourly observed gage readings. Gage heights given to half tenths

Stage-discharge relation.- Affected by flashboards prior to 8 a.m. Sept. 20 . Discharge ascertained from flow over dam and through wheels and gates.

Maxima.- September 1938: Discharge, 86,900 second-feet 11 p.m. Sept. 22 (gage height, 11.75 feet).

Maximum discharge known, 122,000 second-feet Mar. 20, 1936.

Remarks.- Flood run-off affected by artificial and natural storage in winnipesaukee, Squam, Newfound, and other lakes. For information on storage see record for Lake Winnipesaukee at The Weirs, N. H. Records furnished by Public Service Co. of New Hampshire.

Mean daily discharge, in second-feet, 1938

\begin{tabular}{|c|c|c|c|c|c|c|c|c|c|c|c|}
\hline Day & Sept. & Oct. & Day & Sept. & Oct. & Day & Sept. & Oct. & Day & Sept. & Oet. \\
\hline $\begin{array}{l}1 \\
2 \\
3 \\
4 \\
5 \\
6 \\
7 \\
8\end{array}$ & $\begin{array}{r}1,610 \\
1,320 \\
1,400 \\
1,300 \\
1,650 \\
813 \\
1,110 \\
1,570\end{array}$ & $\begin{array}{l}6,120 \\
5,460 \\
4,790 \\
4,300 \\
4,310 \\
3,980 \\
3,840 \\
3,650\end{array}$ & $\begin{array}{r}9 \\
10 \\
11 \\
12 \\
13 \\
14 \\
15 \\
16\end{array}$ & $\begin{array}{r}1,620 \\
1,280 \\
989 \\
1,160 \\
1,620 \\
2,560 \\
2,820 \\
4,560\end{array}$ & $\begin{array}{l}3,460 \\
2,330 \\
3,200 \\
2,920 \\
2,720 \\
2,870 \\
2,790 \\
2,390\end{array}$ & $\begin{array}{l}17 \\
18 \\
19 \\
20 \\
21 \\
22 \\
23 \\
24\end{array}$ & $\begin{array}{r}3,580 \\
2,950 \\
2,950 \\
7,410 \\
33,200 \\
73,300 \\
72,700 \\
44,200\end{array}$ & $\begin{array}{l}2,630 \\
2,600 \\
2,240 \\
2,340 \\
2,570 \\
3,040 \\
3,020 \\
3,300\end{array}$ & $\begin{array}{l}25 \\
26 \\
27 \\
28 \\
29 \\
30 \\
31\end{array}$ & $\begin{array}{r}26,000 \\
16,700 \\
12,400 \\
10,600 \\
9,170 \\
7,420\end{array}$ & $\begin{array}{l}8,810 \\
8,220 \\
6,500 \\
5,300 \\
4,800 \\
4,390 \\
3,890\end{array}$ \\
\hline Run & In & & , 1 & & t. . & $\dot{.}:$ & 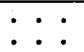 & $\cdot . \cdot \dot{0}$ & $\dot{.}$ & $\begin{array}{r}11,670 \\
5.37\end{array}$ & $\begin{array}{r}3,961 \\
1.88\end{array}$ \\
\hline
\end{tabular}

Gage height, in feet, and discharge, in second-feet, at indicated time, 1938

\begin{tabular}{|c|c|c|c|c|c|c|c|c|c|c|c|c|}
\hline \multirow{2}{*}{ 名 } & Féet & Sec.ft. & Feet & Sec.ft. & Feet & Sec.ft. & Feet & Sec.ft. & Feet & Sec.ft. & Feet & Sec.ft. \\
\hline & \multicolumn{2}{|c|}{ September 18} & \multicolumn{2}{|c|}{ September 19} & \multicolumn{2}{|c|}{ September 20} & \multicolumn{2}{|c|}{ September 21} & \multicolumn{2}{|c|}{ September 22} & \multicolumn{2}{|c|}{ September 23} \\
\hline $\begin{array}{l}1 \\
2 \\
3 \\
4 \\
5 \\
6\end{array}$ & $\begin{array}{l}1.7 \\
1.6 \\
1.4 \\
1.5 \\
1.6 \\
1.7\end{array}$ & $\begin{array}{l}2,620 \\
3,020 \\
3,440 \\
3,350 \\
3,320 \\
2,690\end{array}$ & $\begin{array}{l}2.8 \\
2.8 \\
2.9 \\
2.9 \\
2.9 \\
2.9\end{array}$ & $\begin{array}{l}2,540 \\
2,540 \\
2,510 \\
2,510 \\
2,550 \\
2,510\end{array}$ & $\begin{array}{r}1.1 \\
1.0 \\
.9 \\
.9 \\
.9 \\
.9\end{array}$ & $\begin{array}{l}4,150 \\
4,170 \\
4,040 \\
4,100 \\
4,080 \\
4,150\end{array}$ & $\begin{array}{l}4.0 \\
4.2 \\
4.4 \\
4.6 \\
4.7 \\
4.9\end{array}$ & $\begin{array}{l}17,700 \\
19,100 \\
20,400 \\
21,800 \\
22,600 \\
24,600\end{array}$ & $\begin{array}{l}8.7 \\
8.8 \\
9.05 \\
9.3 \\
9.6 \\
9.7\end{array}$ & $\begin{array}{l}53,500 \\
54,400 \\
56,900 \\
59,500 \\
62,500 \\
63,600\end{array}$ & $\begin{array}{l}11.6 \\
11.55 \\
11.5 \\
11.5 \\
11.5 \\
11.3\end{array}$ & $\begin{array}{l}85,100 \\
84,400 \\
83,800 \\
83,800 \\
83,800 \\
81,400\end{array}$ \\
\hline $\begin{array}{r}7 \\
8 \\
9 \\
10 \\
11 \\
11\end{array}$ & $\begin{array}{l}2.3 \\
2.4 \\
2.1 \\
1.95 \\
2.3 \\
2.2\end{array}$ & $\begin{array}{l}2,430 \\
2,480 \\
3,250 \\
3,540 \\
3,060 \\
2,610\end{array}$ & $\begin{array}{l}2.8 \\
2.8 \\
2.5 \\
2.2 \\
1.9 \\
2.25\end{array}$ & $\begin{array}{l}2,610 \\
2,680 \\
3,230 \\
3,520 \\
3,590 \\
2,460\end{array}$ & $\begin{array}{r}.8 \\
.7 \\
.5 \\
.7 \\
.7 \\
1.4\end{array}$ & $\begin{array}{l}4,350 \\
4,690 \\
4,560 \\
4,950 \\
5,540 \\
6,130\end{array}$ & $\begin{array}{l}4.9 \\
5.1 \\
5.4 \\
5.6 \\
5.8 \\
6.1\end{array}$ & $\begin{array}{l}26,600 \\
27,000 \\
29,400 \\
30,200 \\
31,600 \\
33,900\end{array}$ & $\begin{array}{r}9.9 \\
10.1 \\
10.3 \\
10.5 \\
10.8 \\
10.9\end{array}$ & $\begin{array}{l}65,800 \\
68,100 \\
70,300 \\
72,500 \\
75,800 \\
76,900\end{array}$ & $\begin{array}{l}11.1 \\
11.0 \\
10.9 \\
10.8 \\
10.7 \\
10.6\end{array}$ & $\begin{array}{l}79,100 \\
78,000 \\
76,900 \\
75,800 \\
74,600 \\
73,500\end{array}$ \\
\hline $\begin{array}{l}1 \\
2 \\
3 \\
4 \\
5 \\
6\end{array}$ & $\begin{array}{l}2.5 \\
2.5 \\
2.5 \\
2.6 \\
2.65 \\
2.65\end{array}$ & $\begin{array}{l}2,680 \\
2,640 \\
2,620 \\
2,730 \\
2,610 \\
2,980\end{array}$ & $\begin{array}{l}2.2 \\
2.1 \\
2.1 \\
2.1 \\
1.85 \\
1.6\end{array}$ & $\begin{array}{l}2,620 \\
2,620 \\
2,640 \\
2,680 \\
3,200 \\
3,500\end{array}$ & $\begin{array}{l}1.4 \\
1.55 \\
1.7 \\
1.9 \\
2.5 \\
2.7\end{array}$ & $\begin{array}{r}6,580 \\
7,070 \\
7,200 \\
8,060 \\
9,400 \\
10,300\end{array}$ & $\begin{array}{l}6.1 \\
6.3 \\
6.4 \\
6.55 \\
6.75 \\
7.0\end{array}$ & $\begin{array}{l}34,000 \\
35,700 \\
36,500 \\
37,800 \\
39,600 \\
38,700\end{array}$ & $\begin{array}{l}11.0 \\
11.2 \\
11.2 \\
11.25 \\
11.3 \\
11.3\end{array}$ & $\begin{array}{l}78,100 \\
80,300 \\
80,200 \\
80,800 \\
81,500 \\
81,500\end{array}$ & $\begin{array}{c}10.5 \\
10.3 \\
10.2 \\
10.0 \\
9.9 \\
9.85\end{array}$ & $\begin{array}{l}72,300 \\
70,100 \\
69,000 \\
66,800 \\
65,700 \\
65,100\end{array}$ \\
\hline \multirow[t]{2}{*}{$\begin{array}{r}7 \\
8 \\
9 \\
10 \\
11 \\
11\end{array}$} & $\begin{array}{l}2.5 \\
2.4 \\
2.3 \\
2.6 \\
2.7 \\
2.7 \\
\end{array}$ & $\begin{array}{l}3,530 \\
3,520 \\
3,550 \\
2,850 \\
2,610 \\
2,600\end{array}$ & $\begin{array}{l}1.5 \\
1.5 \\
1.5 \\
1.5 \\
1.6 \\
1.3\end{array}$ & $\begin{array}{l}3,060 \\
3,530 \\
3,500 \\
3,430 \\
3,380 \\
4,080\end{array}$ & $\begin{array}{l}2.8 \\
3.0 \\
3.1 \\
3.3 \\
3.6 \\
3.8\end{array}$ & $\begin{array}{l}10,900 \\
12,000 \\
12,500 \\
13,500 \\
15,100 \\
16,400\end{array}$ & $\begin{array}{l}7.75 \\
7.9 \\
8.0 \\
8.2 \\
8.3 \\
8.5\end{array}$ & $\begin{array}{l}45,400 \\
45,700 \\
46,800 \\
48,700 \\
49,600 \\
51,400\end{array}$ & $\begin{array}{l}11.6 \\
11.6 \\
11.65 \\
11.7 \\
11.75 \\
11.7\end{array}$ & $\begin{array}{l}85,100 \\
85,100 \\
85,700 \\
86,200 \\
86,900 \\
86,300\end{array}$ & $\begin{array}{l}9.7 \\
9.7 \\
9.4 \\
9.2 \\
9.1 \\
9.0\end{array}$ & $\begin{array}{l}63,500 \\
63,500 \\
60,400 \\
58,400 \\
57,400 \\
56,400\end{array}$ \\
\hline & \multicolumn{2}{|c|}{ September 24} & \multicolumn{2}{|c|}{ September 25} & \multicolumn{2}{|c|}{ September 26} & \multicolumn{2}{|c|}{ September 27} & \multicolumn{2}{|c|}{ September 2B } & \multicolumn{2}{|c|}{ September 29} \\
\hline $\begin{array}{r}2 \\
4 \\
6 \\
8 \\
10 \\
N\end{array}$ & $\begin{array}{l}8.7 \\
8.5 \\
8.3 \\
8.1 \\
7.9 \\
7.7\end{array}$ & $\begin{array}{l}53,600 \\
51,500 \\
49,600 \\
47,700 \\
45,900 \\
44,000\end{array}$ & $\begin{array}{l}6.25 \\
6.1 \\
5.85 \\
5.8 \\
5.7 \\
5.6\end{array}$ & $\begin{array}{l}31,500 \\
30,200 \\
28,300 \\
27,900 \\
27,200 \\
26,400\end{array}$ & $\begin{array}{l}4.4 \\
4.4 \\
4.3 \\
4.0 \\
3.9 \\
3.9\end{array}$ & $\begin{array}{l}19,000 \\
19,100 \\
18,400 \\
17,000 \\
16,800 \\
16,800\end{array}$ & $\begin{array}{l}3.5 \\
3.4 \\
3.35 \\
3.10 \\
3.1 \\
3.1\end{array}$ & $\begin{array}{l}14,100 \\
13,400 \\
13,200 \\
12,400 \\
12,300 \\
12,300\end{array}$ & $\begin{array}{l}2.9 \\
2.8 \\
2.8 \\
2.6 \\
2.5 \\
2.7\end{array}$ & $\begin{array}{r}10,300 \\
9,910 \\
9,950 \\
9,920 \\
9,480 \\
10,400\end{array}$ & $\begin{array}{l}2.9 \\
2.9 \\
2.9 \\
2.6 \\
2.5 \\
2.5\end{array}$ & $\begin{array}{r}10,100 \\
10,000 \\
10,000 \\
9,920 \\
9,490 \\
9,480\end{array}$ \\
\hline $\begin{array}{r}2 \\
4 \\
6 \\
8 \\
10 \\
M\end{array}$ & $\begin{array}{l}7.5 \\
7.3 \\
7.15 \\
6.8 \\
6.7 \\
6.5\end{array}$ & $\begin{array}{l}42,200 \\
40,400 \\
39,000 \\
36,000 \\
35,100 \\
33,500\end{array}$ & $\begin{array}{l}5.5 \\
5.05 \\
4.95 \\
4.8 \\
4.6 \\
4.5\end{array}$ & $\begin{array}{l}25,600 \\
23,000 \\
22,900 \\
21,800 \\
20,500 \\
19,800\end{array}$ & $\begin{array}{l}3.8 \\
3.7 \\
3.65 \\
3.6 \\
3.55 \\
3.6\end{array}$ & $\begin{array}{l}16,100 \\
15,500 \\
15,200 \\
15,000 \\
14,600 \\
14,700\end{array}$ & $\begin{array}{l}3.0 \\
3.0 \\
3.2 \\
3.2 \\
3.1 \\
3.1\end{array}$ & $\begin{array}{l}11,800 \\
11,800 \\
12,000 \\
12,000 \\
11,300 \\
10,800\end{array}$ & $\begin{array}{l}2.9 \\
2.85 \\
3.0 \\
2.85 \\
2.9 \\
2.8\end{array}$ & $\begin{array}{l}11,300 \\
11,200 \\
11,600 \\
10,900 \\
11,100 \\
10,600\end{array}$ & $\begin{array}{l}2.4 \\
2.3 \\
2.3 \\
2.2 \\
2.2 \\
2.3\end{array}$ & $\begin{array}{l}8,980 \\
8,510 \\
8,290 \\
7,920 \\
7,880 \\
8,230\end{array}$ \\
\hline
\end{tabular}


Location.- Staff gage, 1at. $43^{\circ} 00^{\prime} 10^{n}$, long. $71^{\circ} 28^{\prime} 10^{n}$, at Amoskeag Dam in Manchester, Hillsborough County, 2 miles above'Piscataquog River and $9 \frac{1}{2}$ miles below Sumcook River.

Drainage area.- 2,854 square miles.

Gage-helght record. - Graph constructed from hourly gage readings.

Stage-discharge relation. - Affected by flashboards on dam. Discharge ascertained from flow over dam and through wheels and gates.

Maxima.- September 1938: Discharge 97,600 second-feet 2 a.m. Sept. 23 (gage he1ght, 13.7 feet).

1924 to August 1938: Discharge, 144,000 second-feet Mar. 20, 1936 (gage helght, 17.1 feet).

Remarks.- Flood mun-off affected by storage in Winn1pesaukee, Squam, Newfound, and other lakes. For information on storage see record for Lake Winnipesaukee at The Weirs,

N. H. Basic data furnished by Public Service Co. of New Hampshire.

Mean dally discharge, in second-feet, 1938

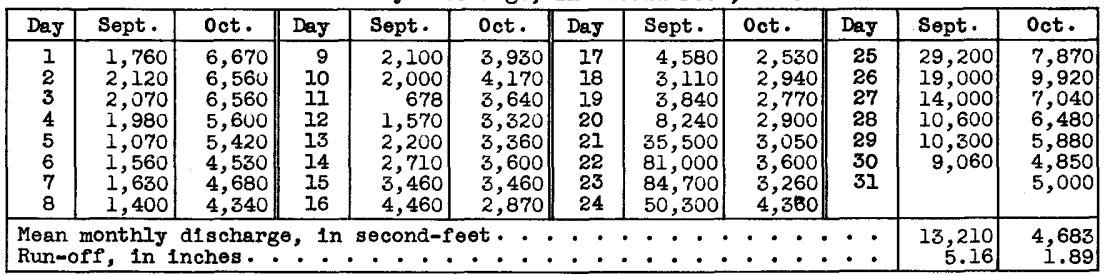

Gage height, In feet, and discharge, in second-feet, at indicated time, 1938

\begin{tabular}{|c|c|c|c|c|c|c|c|c|c|c|c|c|}
\hline \multirow{2}{*}{$\begin{array}{l}3 \\
3 \\
0 \\
0\end{array}$} & Feet & Sec.ft. & Feet & Sec.ft. & Feet & Sec.ft. & Feet & Sec.ft. & Feet & Sec.ft. & Feet & Sec.ft. \\
\hline & \multicolumn{2}{|c|}{ September 18} & \multicolumn{2}{|c|}{ September 19} & \multicolumn{2}{|c|}{ September 20} & \multicolumn{2}{|c|}{ September 21} & \multicolumn{2}{|c|}{ September 22} & \multicolumn{2}{|c|}{ September 23} \\
\hline $\begin{array}{l}1 \\
2 \\
3 \\
4 \\
5 \\
6\end{array}$ & $\begin{array}{l}2.9 \\
2.9 \\
2.95 \\
2.95 \\
3 . \\
3 .\end{array}$ & $\begin{array}{l}3,430 \\
3,220 \\
3,100 \\
3,280 \\
3,380 \\
3,030\end{array}$ & \begin{tabular}{|l|}
4.2 \\
4.4 \\
4.5 \\
4.4 \\
4.4 \\
4.4 \\
\end{tabular} & $\begin{array}{r}910 \\
1,360 \\
2,670 \\
3,300 \\
2,760 \\
4,090\end{array}$ & $\begin{array}{l}3.4 \\
3.4 \\
3.35 \\
3.2 \\
3.1 \\
2.8\end{array}$ & $\begin{array}{l}4,760 \\
5,000 \\
5,400 \\
5,860 \\
6,200 \\
6,260\end{array}$ & \begin{tabular}{|l|}
4.6 \\
4.8 \\
5.0 \\
5.2 \\
5.4 \\
5.5
\end{tabular} & $\begin{array}{l}16,700 \\
17,700 \\
18,400 \\
19,400 \\
21,400 \\
22,500\end{array}$ & $\begin{array}{l}10.1 \\
10.3 \\
10.4 \\
10.6 \\
10.85 \\
11.15\end{array}$ & $\begin{array}{l}60,000 \\
61,600 \\
63,300 \\
65,400 \\
68,100 \\
70,800\end{array}$ & \begin{tabular}{l|}
13.6 \\
13.7 \\
13.65 \\
13.55 \\
13.45 \\
13.35
\end{tabular} & $\begin{array}{l}96,900 \\
97,600 \\
96,600 \\
95,200 \\
94,200 \\
93,400\end{array}$ \\
\hline $\begin{array}{r}7 \\
8 \\
9 \\
10 \\
11 \\
\text { N }\end{array}$ & $\begin{array}{l}3.05 \\
3 . \\
3.1 \\
3.25 \\
3.4 \\
3.8\end{array}$ & $\begin{array}{r}3,440 \\
3,320 \\
2,200 \\
2,260 \\
2,320 \\
440\end{array}$ & $\begin{array}{l}4.4 \\
4.2 \\
3.9 \\
3.9 \\
3.8 \\
3.7\end{array}$ & $\begin{array}{l}4,880 \\
4,780 \\
4,780 \\
4,500 \\
4,820 \\
4,040\end{array}$ & $\begin{array}{l}2.6 \\
2.3 \\
1.8 \\
1.6 \\
1.4 \\
1.7\end{array}$ & $\begin{array}{l}6,300 \\
6,720 \\
7,430 \\
7,430 \\
6,090 \\
6,580\end{array}$ & $\begin{array}{l}5.6 \\
5.9 \\
6.9 \\
6.9 \\
7.2 \\
7.6\end{array}$ & $\begin{array}{l}24,200 \\
26,000 \\
29,000 \\
31,200 \\
34,800 \\
37,900\end{array}$ & $\begin{array}{l}11.2 \\
11.4 \\
11.6 \\
11.8 \\
12.1 \\
12.3\end{array}$ & $\begin{array}{l}71,900 \\
73,900 \\
76,400 \\
78,800 \\
81,100 \\
82,800\end{array}$ & $\begin{array}{l}13.2 \\
13.2 \\
13.1 \\
12.9 \\
12.75 \\
12.75\end{array}$ & $\begin{array}{l}91,500 \\
91,700 \\
90,200 \\
89,300 \\
87,400 \\
86,900\end{array}$ \\
\hline $\begin{array}{l}1 \\
2 \\
3 \\
4 \\
5 \\
6\end{array}$ & $\begin{array}{l}4.2 \\
4.25 \\
4.25 \\
4.1 \\
4.15 \\
4.15\end{array}$ & $\begin{array}{l}1,600 \\
2,800 \\
3,150 \\
3,150 \\
3,150 \\
3,270\end{array}$ & $\begin{array}{l}3.6 \\
3.5 \\
3.4 \\
3.55 \\
3.3 \\
3.2\end{array}$ & $\begin{array}{l}4,330 \\
4,100 \\
4,100 \\
4,100 \\
4,050 \\
4,050\end{array}$ & $\begin{array}{l}1.8 \\
2.1 \\
2.3 \\
2.7 \\
2.95 \\
3.05\end{array}$ & $\begin{array}{l}6,780 \\
6,990 \\
8,120 \\
8,340 \\
9,430 \\
9,190\end{array}$ & $\begin{array}{l}7.7 \\
7.75 \\
8.0 \\
8.1 \\
8.45 \\
8.6\end{array}$ & $\begin{array}{l}40,600 \\
40,400 \\
42,800 \\
43,700 \\
43,600 \\
45,400\end{array}$ & $\begin{array}{l}12.5 \\
12.6 \\
12.8 \\
12.85 \\
13.15 \\
13.3\end{array}$ & $\begin{array}{l}84,700 \\
86,100 \\
87,800 \\
88,600 \\
90,800 \\
93,300\end{array}$ & $\begin{array}{l}12.8 \\
12.5 \\
12.5 \\
12.2 \\
12.0 \\
11.7\end{array}$ & $\begin{array}{l}86,700 \\
84,500 \\
83,000 \\
80,100 \\
77,500 \\
75,300\end{array}$ \\
\hline \multirow[t]{2}{*}{$\begin{array}{r}7 \\
8 \\
8 \\
10 \\
11 \\
M\end{array}$} & $\begin{array}{l}4.2 \\
4.15 \\
4.15 \\
4.1 \\
4.1 \\
3.9\end{array}$ & $\begin{array}{l}3,770 \\
4,250 \\
4,250 \\
4,250 \\
4,190 \\
1,880\end{array}$ & $\begin{array}{l}3.2 \\
3.3 \\
3.35 \\
3.5 \\
3.6 \\
3.5\end{array}$ & $\begin{array}{l}4,050 \\
4,050 \\
4,240 \\
3,880 \\
4,920 \\
4,760\end{array}$ & $\begin{array}{l}3.25 \\
3.5 \\
3.75 \\
4 . \\
4.2 \\
4.4\end{array}$ & $\begin{array}{l}10,900 \\
11,800 \\
13,400 \\
14,100 \\
14,500 \\
15,700\end{array}$ & $\begin{array}{l}8.9 \\
9.2 \\
9.3 \\
9.4 \\
9.7 \\
9.9\end{array}$ & $\begin{array}{l}48,400 \\
51,300 \\
51,800 \\
52,700 \\
56,200 \\
57,900\end{array}$ & $\begin{array}{l}13.35 \\
13.35 \\
13.4 \\
13.6 \\
13.7 \\
13.6\end{array}$ & $\begin{array}{l}96,100 \\
96,200 \\
94,700 \\
96,400 \\
96,900 \\
96,300\end{array}$ & $\begin{array}{l}11.6 \\
11.5 \\
11.3 \\
11.2 \\
10.9 \\
10.7\end{array}$ & $\begin{array}{l}74,100 \\
72,900 \\
71,000 \\
69,500 \\
66,800 \\
65,500\end{array}$ \\
\hline & \multicolumn{2}{|c|}{ September 24} & \multicolumn{2}{|c|}{ September 25} & \multicolumn{2}{|c|}{ September 26} & \multicolumn{2}{|c|}{ September 27} & \multicolumn{2}{|c|}{ September 28} & \multicolumn{2}{|c|}{ September 29} \\
\hline $\begin{array}{r}2 \\
4 \\
6 \\
8 \\
10 \\
N\end{array}$ & $\begin{array}{r}10.4 \\
10.0 \\
9.7 \\
9.4 \\
9.1 \\
8.9\end{array}$ & $\begin{array}{l}62,700 \\
58,900 \\
55,800 \\
54,100 \\
51,900 \\
49,700\end{array}$ & $\begin{array}{l}7.3 \\
7.2 \\
6.9 \\
6.75 \\
6.6 \\
6.5\end{array}$ & $\begin{array}{l}35,200 \\
33,900 \\
32,600 \\
31,300 \\
30,100 \\
29,100\end{array}$ & $\begin{array}{l}5.45 \\
5.4 \\
5.25 \\
4.9 \\
4.85 \\
4.8\end{array}$ & $\begin{array}{l}22,000 \\
21,300 \\
20,400 \\
19,700 \\
19,500 \\
18,600\end{array}$ & $\begin{array}{l}4.6 \\
4.5 \\
4.35 \\
4.2 \\
4.0 \\
4.0\end{array}$ & $\begin{array}{l}16,100 \\
15,000 \\
15,000 \\
14,900 \\
14,100 \\
13,100\end{array}$ & $\begin{array}{l}3.8 \\
3.8 \\
3.65 \\
3.6 \\
3.5 \\
3.5\end{array}$ & $\begin{array}{r}10,200 \\
10,100 \\
10,200 \\
10,100 \\
10,800 \\
9,460\end{array}$ & $\begin{array}{l}4.2 \\
4.15 \\
4.1 \\
3.9 \\
3.7 \\
3.85\end{array}$ & $\begin{array}{r}11,200 \\
11,000 \\
11,200 \\
11,500 \\
10,900 \\
9,440\end{array}$ \\
\hline $\begin{array}{r}2 \\
4 \\
6 \\
8 \\
10 \\
M\end{array}$ & $\begin{array}{l}8.7 \\
8.5 \\
8.3 \\
7.95 \\
7.85 \\
7.6\end{array}$ & $\begin{array}{l}47,500 \\
45,400 \\
44,300 \\
41,700 \\
39,700 \\
37,700\end{array}$ & $\begin{array}{l}6.45 \\
6.2 \\
6.0 \\
5.8 \\
5.65 \\
5.55\end{array}$ & $\begin{array}{l}27,900 \\
26,900 \\
26,400 \\
24,100 \\
22,400 \\
22,800\end{array}$ & $\begin{array}{l}4.65 \\
4.6 \\
4.6 \\
4.6 \\
4.6 \\
4.6\end{array}$ & $\begin{array}{l}18,400 \\
17,400 \\
18,200 \\
16,700 \\
16,600 \\
16,200\end{array}$ & $\begin{array}{l}3.95 \\
3.85 \\
3.9 \\
3.95 \\
3.9 \\
3.8\end{array}$ & $\begin{array}{l}14,100 \\
12,500 \\
13,500 \\
13,200 \\
13,300 \\
10,400\end{array}$ & $\begin{array}{l}3.65 \\
3.8 \\
3.95 \\
4.1 \\
4.2\end{array}$ & $\begin{array}{l}10,300 \\
10,300 \\
12,000 \\
11,400 \\
11,800 \\
10,300\end{array}$ & $\begin{array}{l}3.95 \\
3.9 \\
3.5 \\
3.6 \\
3.65 \\
3.75\end{array}$ & $\begin{array}{r}10,200 \\
9,710 \\
9,840 \\
9,680 \\
9,360 \\
9,010\end{array}$ \\
\hline
\end{tabular}


Location.- Water-stage recorder, lat. $42^{\circ} 56^{\prime} 55^{\prime \prime}$, long. $71^{\circ} 27^{\prime} 45^{\prime \prime}, 0.8$ mile below mouth

of Bowman Brook, 1.3 miles north of Goffs Falls, Hillsboro County, and 2.3 miles below mouth of Piscataquog River.

Drainage area.- 3,092 square miles.

Gage-height record.- Water-stage recorder graph.

Stage-discharge relation.- Defined by current-meter measurements below 51,000 second feet; extended to peak stage on basis of determinations of flood flow over dam.

Maxima.- September 1938: Discharge, 102,500 second-feet 4 a.m. Sept. 23 (gage height, 25.87 feet).

November 1936 to August 1938: Discharge, 35,500 second-feet May 16, 1937

(gage height, 11.52 feet)

Maximum discharge known, 150,000 second-feet Mar. 20, 1936 (gage height, 35.19 feet).

Remarks.- Flood run-off affected by storage ir. Winnipesaukee, Squam, Newfound, and other

lakes. For information on storage see record for Lake Winnipesaukee at The Weirs, N. H.

Mean dally discharge, in second-feet, 1938

\begin{tabular}{|c|c|c|c|c|c|c|c|c|c|c|c|}
\hline Day & Sept. & Oct. & Dey & Sept. & Oct. & Day & Sept. & Oct. & Day & Sept. & Oct. \\
\hline $\begin{array}{l}1 \\
2 \\
3 \\
4 \\
5 \\
6 \\
7 \\
8\end{array}$ & $\begin{array}{r}2,050 \\
3,410 \\
2,620 \\
1,540 \\
580 \\
2,060 \\
2,040 \\
1,430\end{array}$ & $\begin{array}{l}7,950 \\
6,850 \\
7,020 \\
6,000 \\
5,950 \\
5,310 \\
5,370 \\
4,870\end{array}$ & $\begin{array}{r}9 \\
10 \\
11 \\
12 \\
13 \\
14 \\
15 \\
16\end{array}$ & $\begin{array}{l}2,260 \\
2,670 \\
1,040 \\
1,500 \\
2,640 \\
2,910 \\
4,040 \\
5,310\end{array}$ & $\begin{array}{l}4,530 \\
4,880 \\
3,290 \\
3,850 \\
4,300 \\
3,830 \\
3,920 \\
3,650\end{array}$ & $\begin{array}{l}17 \\
18 \\
19 \\
20 \\
21 \\
22 \\
23 \\
24 \\
\end{array}$ & $\begin{array}{r}5,840 \\
3,740 \\
4,730 \\
9,890 \\
38,600 \\
89,200 \\
94,800 \\
56,200 \\
\end{array}$ & $\begin{array}{l}2,820 \\
3,520 \\
2,850 \\
3,740 \\
3,090 \\
4,370 \\
3,970 \\
5,320\end{array}$ & $\begin{array}{l}25 \\
26 \\
27 \\
28 \\
29 \\
30 \\
31\end{array}$ & $\begin{array}{r}29,500 \\
18,400 \\
13,900 \\
11,500 \\
10,900 \\
9,590\end{array}$ & $\begin{array}{r}9,540 \\
11,400 \\
8,130 \\
6,930 \\
6,350 \\
5,280 \\
5,470\end{array}$ \\
\hline $\begin{array}{l}\text { Mean } \\
\text { Run- }\end{array}$ & $\begin{array}{l}\text { onthly } \\
\text { e, in } 1\end{array}$ & $\begin{array}{l}\text { scharg } \\
\text { hes. }\end{array}$ & , Ir & $\begin{array}{l}\text { econd-f } \\
\text {. }\end{array}$ & t. . & & 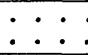 & $\begin{array}{l}. \\
.\end{array}$ & $\dot{.}$ & $\begin{array}{r}14,500 \\
5.23\end{array}$ & $\begin{array}{r}5,302 \\
1.97\end{array}$ \\
\hline
\end{tabular}

Gage height, in feet, and discharge, in second-feet, at indicated time, 1938

\begin{tabular}{|c|c|c|c|c|c|c|c|c|c|c|c|c|}
\hline \multirow{2}{*}{$\begin{array}{l}8 \\
3 \\
0 \\
\end{array}$} & Feet & Sec.ft. & Feet & Sec.ft. & Feet & Sec.ft. & Feet & Sec.ft. & Feet & Sec.ft. & Feet & Sec.ft. \\
\hline & \multicolumn{2}{|c|}{ September 18} & \multicolumn{2}{|c|}{ September 19} & \multicolumn{2}{|c|}{ September 20} & \multicolumn{2}{|c|}{ September 21} & \multicolumn{2}{|c|}{ September 22} & \multicolumn{2}{|c|}{ Sept ember 23} \\
\hline $\begin{array}{l}7 \\
2 \\
3 \\
4 \\
5 \\
6\end{array}$ & $\begin{array}{l}5.30 \\
4.98 \\
4.60 \\
4.44 \\
4.45 \\
4.49\end{array}$ & $\begin{array}{l}6,150 \\
5,140 \\
4,100 \\
3,710 \\
3,730 \\
3,830\end{array}$ & $\begin{array}{l}4.60 \\
4.12 \\
3.64 \\
3.42 \\
4.10 \\
4.57\end{array}$ & $\begin{array}{l}4,100 \\
2,990 \\
2,110 \\
1,770 \\
2,950 \\
4,020\end{array}$ & \begin{tabular}{|l|}
5.10 \\
5.35 \\
5.36 \\
5.41 \\
5.78 \\
5.95
\end{tabular} & \begin{tabular}{|l|}
5,500 \\
6,320 \\
6,350 \\
6,420 \\
7,840 \\
8,460
\end{tabular} & $\begin{array}{l}8.00 \\
8.20 \\
8.55 \\
8.80 \\
9.12 \\
9.43\end{array}$ & $\begin{array}{l}17,000 \\
17,900 \\
19,500 \\
20,700 \\
22,200 \\
23,700\end{array}$ & $\begin{array}{l}19.30 \\
20.00 \\
20.60 \\
21.05 \\
21.45 \\
21.75\end{array}$ & \begin{tabular}{|l|}
71,000 \\
74,400 \\
77,300 \\
79,400 \\
81,400 \\
82,800
\end{tabular} & \begin{tabular}{|l|}
25.75 \\
25.80 \\
25.85 \\
25.87 \\
25.85 \\
25.80
\end{tabular} & $\begin{array}{l}102,000 \\
102,200 \\
102,400 \\
102,500 \\
102,400 \\
102,200\end{array}$ \\
\hline $\begin{array}{r}7 \\
8 \\
9 \\
10 \\
11 \\
N\end{array}$ & $\begin{array}{l}4.40 \\
4.32 \\
4.52 \\
4.33 \\
4.08 \\
3.97\end{array}$ & $\begin{array}{l}3,610 \\
3,430 \\
3,900 \\
3,450 \\
2,910 \\
2,690\end{array}$ & $\begin{array}{l}4.43 \\
4.93 \\
5.23 \\
5.38 \\
5.25 \\
5.20\end{array}$ & $\begin{array}{l}3,680 \\
5,000 \\
5,920 \\
6,420 \\
5,980 \\
5,820\end{array}$ & $\begin{array}{l}5 . \\
5 . \\
6 . \\
6 . \\
6 . \\
6 .\end{array}$ & $\begin{array}{r}8,460 \\
8,580 \\
9,020 \\
9,550 \\
9,590 \\
10,200\end{array}$ & $\begin{array}{r}9.80 \\
10.20 \\
10.70 \\
11.10 \\
11.75 \\
12.35\end{array}$ & $\begin{array}{l}25,400 \\
27,400 \\
29,800 \\
31,700 \\
34,800 \\
37,700\end{array}$ & $\begin{array}{l}22.05 \\
22.35 \\
22.65 \\
22.90 \\
23.15 \\
23.40\end{array}$ & $\begin{array}{l}84,200 \\
85,700 \\
87,100 \\
88,300 \\
89,500 \\
90,700\end{array}$ & $\begin{array}{l}70 \\
60 \\
45 \\
25 \\
05 \\
80\end{array}$ & $\begin{array}{r}101,800 \\
101,300 \\
100,500 \\
99,600 \\
98,600 \\
97,400\end{array}$ \\
\hline $\begin{array}{l}1 \\
2 \\
3 \\
4 \\
5 \\
6\end{array}$ & $\begin{array}{l}3.80 \\
3.32 \\
3.07 \\
4.05 \\
4.60 \\
4.58\end{array}$ & $\begin{array}{l}2,380 \\
1,620 \\
1,280 \\
2,850 \\
4,100 \\
4,050\end{array}$ & $\begin{array}{l}5.08 \\
5.12 \\
5.12 \\
5.13 \\
5.06 \\
4.92\end{array}$ & $\begin{array}{l}5,440 \\
5,560 \\
5,560 \\
5,600 \\
5,380 \\
4,960\end{array}$ & $\begin{array}{l}6.21 \\
6.18 \\
6.24 \\
6.38 \\
6.58 \\
6.80\end{array}$ & $\begin{array}{r}9,440 \\
9,320 \\
9,550 \\
10,100 \\
10,900 \\
11,800\end{array}$ & $\begin{array}{l}13.05 \\
13.65 \\
14.10 \\
14.50 \\
14.95 \\
15.30\end{array}$ & $\begin{array}{l}41,000 \\
43,900 \\
46,100 \\
48,000 \\
50,200 \\
51,800\end{array}$ & $\begin{array}{l}23.65 \\
23.80 \\
24.05 \\
24.30 \\
24.50 \\
24.70\end{array}$ & $\begin{array}{l}91,900 \\
92,600 \\
93,800 \\
95,000 \\
96,000 \\
97,000\end{array}$ & & $\begin{array}{l}96,200 \\
94,800 \\
93,400 \\
92,200 \\
90,200 \\
88,800\end{array}$ \\
\hline \multirow[t]{2}{*}{$\begin{array}{r}7 \\
8 \\
9 \\
10 \\
11 \\
\mathrm{M} \\
\end{array}$} & $\begin{array}{l}4.44 \\
4.55 \\
4.76 \\
4.81 \\
4.78 \\
4.75\end{array}$ & $\begin{array}{l}3,710 \\
3,980 \\
4,520 \\
4,660 \\
4,580 \\
4,500\end{array}$ & $\begin{array}{l}4.85 \\
5.03 \\
5.06 \\
4.98 \\
4.92 \\
4.86\end{array}$ & $\begin{array}{l}4,770 \\
5,290 \\
5,380 \\
5,140 \\
4,970 \\
4,800\end{array}$ & $\begin{array}{l}6.98 \\
7.15 \\
7.32 \\
7.45 \\
7.62 \\
7.80\end{array}$ & $\begin{array}{l}12,500 \\
13,200 \\
14,000 \\
14,500 \\
15,300 \\
16,100\end{array}$ & $\begin{array}{l}15 . \\
16 . \\
16 . \\
17 . \\
17 . \\
18 .\end{array}$ & $\begin{array}{l}54,200 \\
56,900 \\
59,300 \\
61,700 \\
64,300 \\
67,700\end{array}$ & $\begin{array}{l}24 \\
25 \\
25 \\
25 \\
25 \\
25\end{array}$ & $\begin{array}{r}97 \\
98 \\
99 \\
100 \\
101 \\
101\end{array}$ & & $\begin{array}{l}, 100 \\
, 200 \\
300 \\
400 \\
400 \\
, 500\end{array}$ \\
\hline & \multicolumn{2}{|c|}{ September 24} & \multicolumn{2}{|c|}{ September 25} & \multicolumn{2}{|c|}{ September 26} & \multicolumn{2}{|c|}{ September 27} & \multicolumn{2}{|c|}{ September 28} & \multicolumn{2}{|c|}{ September 29} \\
\hline $\begin{array}{r}2 \\
4 \\
6 \\
8 \\
10 \\
\mathrm{~N}\end{array}$ & $\begin{array}{l}19.80 \\
18.90 \\
18.10 \\
17.40 \\
16.70 \\
15.90\end{array}$ & $\begin{array}{l}73,400 \\
69,100 \\
65,300 \\
61,900 \\
58,600 \\
54,700\end{array}$ & \begin{tabular}{|l|}
12.30 \\
11.90 \\
11.60 \\
11.20 \\
10.80 \\
10.50
\end{tabular} & $\begin{array}{l}37,400 \\
35,500 \\
34,100 \\
32,200 \\
30,200 \\
28,800\end{array}$ & $\begin{array}{l}8.83 \\
8.70 \\
8.58 \\
8.54 \\
8.37 \\
8.30\end{array}$ & $\begin{array}{l}20,800 \\
20,200 \\
19,700 \\
19,500 \\
18,700 \\
18,400\end{array}$ & $\begin{array}{l}7.57 \\
7.46 \\
7.40 \\
7.32 \\
7.35 \\
7.31\end{array}$ & $\begin{array}{l}15,100 \\
14,600 \\
14,300 \\
14,000 \\
14,100 \\
13,900\end{array}$ & $\begin{array}{l}6.74 \\
6.65 \\
6.61 \\
6.54 \\
6.78 \\
6.74\end{array}$ & $\begin{array}{l}11,500 \\
11,200 \\
11,000 \\
10,700 \\
11,700 \\
11,500\end{array}$ & 6.65 & $\begin{array}{l}11,200 \\
11,120 \\
10,180 \\
11,200 \\
12,100 \\
11,600\end{array}$ \\
\hline $\begin{array}{r}2 \\
4 \\
6 \\
8 \\
10 \\
M\end{array}$ & $\begin{array}{l}15.30 \\
14.70 \\
14.25 \\
13.65 \\
13.10 \\
12.80\end{array}$ & $\begin{array}{l}51,800 \\
49,000 \\
46,800 \\
43,900 \\
41,300 \\
39,800\end{array}$ & $\begin{array}{r}10.10 \\
9.90 \\
9.77 \\
9.52 \\
9.24 \\
9.00\end{array}$ & $\begin{array}{l}26,900 \\
25,900 \\
25,300 \\
24,100 \\
22,800 \\
21,600\end{array}$ & $\begin{array}{l}8.22 \\
8.12 \\
8.00 \\
7.88 \\
7.83 \\
7.70\end{array}$ & $\begin{array}{l}18,000 \\
17,600 \\
17,000 \\
16,400 \\
16,200 \\
15,600\end{array}$ & $\begin{array}{l}7.25 \\
7.25 \\
7.13 \\
7.09 \\
7.00 \\
7.03\end{array}$ & $\begin{array}{l}13,700 \\
13,700 \\
13,100 \\
13,000 \\
12,600 \\
12,700\end{array}$ & $\begin{array}{l}6.70 \\
6.80 \\
6.70 \\
6.86 \\
6.82 \\
6.80\end{array}$ & $\begin{array}{l}11,400 \\
11,800 \\
11,400 \\
12,000 \\
11,840 \\
11,760\end{array}$ & $\begin{array}{l}6.55 \\
6.58 \\
6.48 \\
6.60 \\
6.26 \\
6.22\end{array}$ & $\begin{array}{l}100 \\
100 \\
00 \\
00 \\
30 \\
80\end{array}$ \\
\hline
\end{tabular}




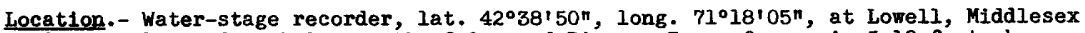
County, 1,100 feet below mouth of Concord River. Zero of gage is 5.18 feet above mean sea level.

Dralnage area.- 4,635 square miles; 210 square miles affected by storage and large diversions on parts of Nashua and Sudbury Rivers and Lake Cochituate Basins.

Gape-helght record. - Water-stage recorder graph.

Stage-discharge relation.- Defined by current-meter measurements.

Maxima.- September 1938: Discharge, 121,100 second-feet 11 to 12 a.m. Sept. 23 (gage height, 60.57 feet).

1848 to August 1938: Discharge, 173,000 second-feet Mar. 20, 1936 (gage height, 68.4 feet).

Remarks.- Flood run-off affected by storage in Winnipesaukee, Squam, Newfound, and other lakes and by diversions and storage above Wachusett Dam on South Branch of Nashua

River ( 117 square miles); at and above Framingham Reservoir No. 1 on Sudbury River (75.2 square miles) and above Lake Cochituate (17.4 square miles). For information on storage and diversion see records for Lake Winnipesaukee at The Weirs, N. H., Wachusett Reservoir on South Branch of iNashua River at Clinton, Mass., Sudbury River at Framingham Center, Mass, and for Lake Cochituate outlet at Cochituate, Mass.

Mean daily discharge, in second-feet, 1938

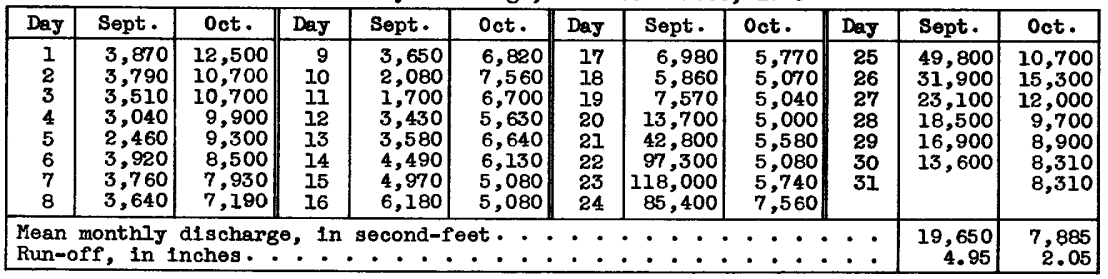

Gage helght, in feet, and discharge, in second-feet, at indicated time, 1938

\begin{tabular}{|c|c|c|c|c|c|c|c|c|c|c|c|c|}
\hline \multirow{2}{*}{$\begin{array}{l}3 \\
3 \\
\text { 起 }\end{array}$} & Feet & $1-0<0=0$ & Feet & c.ft. & & c.ft. & & Sec.ft. & Feot & Sec.ft. & & 000.16 \\
\hline & \multicolumn{2}{|c|}{ September 18} & \multicolumn{2}{|c|}{ September 19} & \multicolumn{2}{|c|}{ September 20} & \multicolumn{2}{|c|}{ September 21} & \multicolumn{2}{|c|}{ September 22} & \multicolumn{2}{|c|}{ September 23} \\
\hline & $\begin{array}{l}43.87 \\
43.87 \\
43.90 \\
43.96 \\
44.00 \\
44.00\end{array}$ & $\begin{array}{l}0,480 \\
0,480 \\
0,590 \\
, 810 \\
0,960 \\
0,960\end{array}$ & $\begin{array}{l}43 \\
43 \\
43 \\
43 \\
43 \\
44\end{array}$ & $\begin{array}{l}5,220 \\
5,340 \\
5,580 \\
6,060 \\
6,340 \\
8,340\end{array}$ & & $\begin{array}{l}10 \\
30 \\
20 \\
10 \\
50 \\
00\end{array}$ & & & & & & $\begin{array}{l}00 \\
00 \\
00 \\
00 \\
00\end{array}$ \\
\hline & $\begin{array}{l}43.97 \\
43.91 \\
43.85 \\
43.80 \\
43.74 \\
43.69\end{array}$ & $\begin{array}{l}6, \\
6, \\
6, \\
6, \\
6, \\
5,\end{array}$ & & $\begin{array}{l}20 \\
80 \\
80 \\
60 \\
60 \\
40\end{array}$ & & & & & & & & \\
\hline & $\begin{array}{l}43.65 \\
43.61 \\
43.60 \\
43.56 \\
43.46 \\
43.39\end{array}$ & $\begin{array}{l}0 \\
0 \\
0 \\
0 \\
0 \\
0\end{array}$ & $\begin{array}{l}44.3 \\
44.3 \\
44.2 \\
44.3 \\
44 . \\
44.2\end{array}$ & & & & & & & & & \\
\hline \multirow[t]{2}{*}{$\begin{array}{r}7 \\
8 \\
9 \\
10 \\
11 \\
M\end{array}$} & $\begin{array}{l}43 . \\
43 . \\
43 . \\
43 . \\
43 .\end{array}$ & $\begin{array}{l}4, \\
4, \\
4, \\
4, \\
4, \\
5,\end{array}$ & & $\begin{array}{l}8, \\
8, \\
8, \\
8 \\
7\end{array}$ & & $\begin{array}{c}50 \\
50 \\
50 \\
50 \\
50\end{array}$ & & & & & & \\
\hline & \multicolumn{2}{|c|}{ September 24} & \multicolumn{2}{|c|}{ September 25} & \multicolumn{2}{|c|}{ September 26} & \multicolumn{2}{|c|}{ September 27} & \multicolumn{2}{|c|}{ September 28} & \multicolumn{2}{|c|}{ September. 29} \\
\hline & & & & & & & & & & & & \\
\hline & $\begin{array}{l}55 \\
55 \\
55 \\
54 \\
54 \\
53\end{array}$ & $\begin{array}{l}8 \\
7 \\
7 \\
6 \\
6\end{array}$ & & $\begin{array}{l}46 \\
45 \\
43 \\
42 \\
40\end{array}$ & & & & $\begin{array}{l}22,700 \\
22,100 \\
21,500 \\
21,480 \\
21,100\end{array}$ & & & & \\
\hline
\end{tabular}


Location. - Water-stage recorder, lat. $43^{\circ} 47^{\prime} 45^{\prime \prime}$, long. $71^{\circ} 50^{\prime} 45^{\prime \prime}, 0.3$ mile above

mouth of Halls Brook and $13 / 4$ miles southwest of Rumney, Grefton County. Drainge areg. - 143 square miles.

Gage-helght record. - Water-stage recorder graph.

Stage-discharge relation.- Defined by current-meter measurements below 2,980 second-feet; extended to peak stage on basis of determinations of flood flow by slope-area method.

Mexima.- September 1938: Discharge, 15,900 second-feet 3 p.m. Sept. 21 (gage he1ght, 13.03 feet)

(gage height, 14.49 feet).

17. 4 Maximum discharge know

Remarks.- Flood mun-off not materially affected by artiflcial or natural storage.

Mean dally discharge, in second-feet, 1938

\begin{tabular}{|c|c|c|c|c|c|c|c|c|c|c|c|}
\hline Day & Sept. & Oct. & Day & Sept. & Oct. & Day & Sept. & oct. & Day & Sept. & Oct. \\
\hline $\begin{array}{l}1 \\
2 \\
3 \\
4 \\
5 \\
6 \\
7 \\
8\end{array}$ & $\begin{array}{l}62 \\
66 \\
53 \\
48 \\
44 \\
40 \\
43 \\
60\end{array}$ & $\begin{array}{l}326 \\
202 \\
180 \\
162 \\
144 \\
134 \\
121 \\
115\end{array}$ & $\begin{array}{l}9 \\
10 \\
11 \\
12 \\
13 \\
14 \\
15 \\
16\end{array}$ & $\begin{array}{r}55 \\
46 \\
38 \\
35 \\
378 \\
242 \\
433 \\
469\end{array}$ & $\begin{array}{r}111 \\
105 \\
102 \\
97 \\
94 \\
92 \\
86 \\
83\end{array}$ & $\begin{array}{l}17 \\
18 \\
19 \\
20 \\
21 \\
22 \\
23 \\
24\end{array}$ & $\begin{array}{r}254 \\
189 \\
186 \\
2,030 \\
9,790 \\
5,560 \\
1,330 \\
788\end{array}$ & $\begin{array}{r}72 \\
78 \\
76 \\
78 \\
228 \\
191 \\
140 \\
401\end{array}$ & $\begin{array}{l}25 \\
26 \\
27 \\
28 \\
29 \\
30 \\
31\end{array}$ & $\begin{array}{l}546 \\
405 \\
343 \\
400 \\
306 \\
254\end{array}$ & $\begin{array}{l}874 \\
433 \\
314 \\
254 \\
218 \\
191 \\
165\end{array}$ \\
\hline $\begin{array}{l}\text { Mean } \\
\text { Run- }\end{array}$ & $\begin{array}{l}\text { nthly } \\
, \text { in }\end{array}$ & & , ir & - . & t. & $\dot{0}$ & . $\cdot$. & : : & : & $\begin{array}{r}816 \\
6.37\end{array}$ & $\begin{array}{r}186 \\
2.14\end{array}$ \\
\hline
\end{tabular}

Gage helght, in feet, and discharge, in second-feet, at indicated time, 1938

\begin{tabular}{|c|c|c|c|c|c|c|c|c|c|c|c|c|c|c|}
\hline \multirow{2}{*}{ 里 } & Feet & Sec & ft. & Feet & Sec & .ft. & Feet & sec.ft. & Feet & Sec.ft. & Feet & Sec.ft. & Feet & Sec.ft. \\
\hline & \multicolumn{3}{|c|}{ September 18} & \multicolumn{3}{|c|}{ September 19} & \multicolumn{2}{|c|}{ September 20} & \multicolumn{2}{|c|}{ September 21} & \multicolumn{2}{|c|}{ September 22} & \multicolumn{2}{|c|}{ September 23} \\
\hline $\begin{array}{l}1 \\
2 \\
3 \\
4 \\
5 \\
6\end{array}$ & $\begin{array}{l}3.10 \\
3.09 \\
3.08 \\
3.07 \\
3.07 \\
3.06\end{array}$ & & $\begin{array}{l}210 \\
206 \\
202 \\
199 \\
199 \\
195\end{array}$ & $\begin{array}{l}3.00 \\
3.00 \\
3.00 \\
3.00 \\
2.99 \\
2.99\end{array}$ & & $\begin{array}{l}172 \\
172 \\
172 \\
172 \\
168 \\
168\end{array}$ & $\begin{array}{l}3.52 \\
3.70 \\
3.89 \\
4.15 \\
4.35 \\
4.63\end{array}$ & $\begin{array}{r}393 \\
485 \\
594 \\
758 \\
895 \\
1,100\end{array}$ & $\begin{array}{l}7.03 \\
7.21 \\
7.46 \\
7.71 \\
7.90 \\
8.03\end{array}$ & $\begin{array}{l}3,900 \\
4,180 \\
4,580 \\
5,010 \\
5,350 \\
5,580\end{array}$ & $\begin{array}{r}11.57 \\
11.41 \\
11.10 \\
10.65 \\
10.04 \\
9.54\end{array}$ & $\begin{array}{r}12,600 \\
12,300 \\
11,700 \\
10,700 \\
9,480 \\
8,480\end{array}$ & $\begin{array}{l}5.38 \\
5.33 \\
5.28 \\
5.21 \\
5.16 \\
5.10\end{array}$ & $\begin{array}{l}1,810 \\
1,750 \\
1,700 \\
1,630 \\
1,580 \\
1,520\end{array}$ \\
\hline $\begin{array}{r}7 \\
8 \\
9 \\
10 \\
11 \\
N\end{array}$ & $\begin{array}{l}3.06 \\
3.06 \\
3.05 \\
3.05 \\
3.04 \\
3.04\end{array}$ & & $\begin{array}{l}195 \\
195 \\
191 \\
191 \\
187 \\
187\end{array}$ & $\begin{array}{l}2.99 \\
2.99 \\
2.99 \\
2.99 \\
2.99 \\
2.99\end{array}$ & & $\begin{array}{l}168 \\
168 \\
168 \\
168 \\
168 \\
168\end{array}$ & $\begin{array}{l}5.05 \\
5.38 \\
5.58 \\
5.63 \\
5.62 \\
5.57\end{array}$ & $\begin{array}{l}1,470 \\
1,810 \\
2,030 \\
2,090 \\
2,070 \\
2,020\end{array}$ & $\begin{array}{r}8.06 \\
8.11 \\
8.64 \\
9.27 \\
10.10 \\
10.80\end{array}$ & $\begin{array}{r}5,640 \\
5,730 \\
6,730 \\
7,940 \\
9,600 \\
11,000\end{array}$ & $\begin{array}{l}8.92 \\
8.42 \\
7.98 \\
7.60 \\
7.32 \\
7.05\end{array}$ & $\begin{array}{l}7,260 \\
6,310 \\
5,490 \\
4,820 \\
4,350 \\
3,920\end{array}$ & $\begin{array}{l}5.05 \\
5.00 \\
4.97 \\
4.92 \\
4.89 \\
4.84\end{array}$ & $\begin{array}{l}1,470 \\
1,420 \\
1,390 \\
1,350 \\
1,320 \\
1,280\end{array}$ \\
\hline $\begin{array}{l}1 \\
2 \\
3 \\
4 \\
5 \\
6\end{array}$ & $\begin{array}{l}3.04 \\
3.04 \\
3.03 \\
3.03 \\
3.03 \\
3.02\end{array}$ & & $\begin{array}{l}187 \\
187 \\
183 \\
183 \\
183 \\
180\end{array}$ & $\begin{array}{l}2.99 \\
2.99 \\
2.99 \\
2.99 \\
3.00 \\
3.02\end{array}$ & & $\begin{array}{l}168 \\
168 \\
168 \\
168 \\
172 \\
180\end{array}$ & $\begin{array}{l}5.61 \\
5.72 \\
5.91 \\
6.12 \\
6.27 \\
6.33\end{array}$ & $\begin{array}{l}2,060 \\
2,190 \\
2,420 \\
2,670 \\
2,850 \\
2,930\end{array}$ & $\begin{array}{l}11.61 \\
12.50 \\
13.03 \\
13.01 \\
12.80 \\
12.39\end{array}$ & $\begin{array}{l}12,700 \\
14,700 \\
15,900 \\
15,800 \\
15,300 \\
14,400\end{array}$ & $\begin{array}{l}6.81 \\
6.60 \\
6.40 \\
6.25 \\
6.10 \\
6.00\end{array}$ & $\begin{array}{l}3,560 \\
3,270 \\
3,010 \\
2,830 \\
2,650 \\
2,530\end{array}$ & $\begin{array}{l}4.80 \\
4.77 \\
4.72 \\
4.69 \\
4.66 \\
4.63\end{array}$ & $\begin{array}{l}1,240 \\
1,220 \\
1,180 \\
1,150 \\
1,130 \\
1,100\end{array}$ \\
\hline $\begin{array}{r}7 \\
8 \\
9 \\
10 \\
11 \\
M\end{array}$ & $\begin{array}{l}3.02 \\
3.02 \\
3.01 \\
3.01 \\
3.01 \\
3.00\end{array}$ & & $\begin{array}{l}180 \\
180 \\
176 \\
176 \\
176 \\
172\end{array}$ & $\begin{array}{l}3.06 \\
3.10 \\
3.15 \\
3.19 \\
3.27 \\
3.37\end{array}$ & & $\begin{array}{l}195 \\
210 \\
230 \\
246 \\
279 \\
323\end{array}$ & $\begin{array}{l}6.35 \\
6.37 \\
6.46 \\
6.61 \\
6.79 \\
6.91\end{array}$ & $\begin{array}{l}2,950 \\
2,970 \\
3,090 \\
3,280 \\
3,540 \\
3,720\end{array}$ & $\begin{array}{l}11.96 \\
11.60 \\
11.31 \\
11.30 \\
11.40 \\
11.53\end{array}$ & $\begin{array}{l}13,500 \\
12,700 \\
12,100 \\
12,100 \\
12,300 \\
12,600\end{array}$ & $\begin{array}{l}5.88 \\
5.77 \\
5.70 \\
5.62 \\
5.54 \\
5.45\end{array}$ & $\begin{array}{l}2,390 \\
2,250 \\
2,170 \\
2,070 \\
1,980 \\
1,880\end{array}$ & $\begin{array}{l}4.60 \\
4.57 \\
4.53 \\
4.50 \\
4.48 \\
4.45\end{array}$ & $\begin{array}{r}1,080 \\
1,060 \\
1,020 \\
1,000 \\
986 \\
965\end{array}$ \\
\hline & \multicolumn{3}{|c|}{ September } & \multicolumn{3}{|c|}{ September 25} & \multicolumn{2}{|c|}{ September 26} & \multicolumn{2}{|c|}{ September 27} & \multicolumn{2}{|c|}{ September 28} & \multicolumn{2}{|c|}{ September 29} \\
\hline $\begin{array}{r}2 \\
4 \\
6 \\
8 \\
10 \\
N\end{array}$ & $\begin{array}{l}4.40 \\
4.35 \\
4.30 \\
4.27 \\
4.22 \\
4.18\end{array}$ & & $\begin{array}{l}930 \\
895 \\
860 \\
839 \\
804 \\
777\end{array}$ & $\begin{array}{l}3.95 \\
3.92 \\
3.89 \\
3.86 \\
3.83 \\
3.80\end{array}$ & & $\begin{array}{l}630 \\
612 \\
594 \\
576 \\
558 \\
540\end{array}$ & $\begin{array}{l}3.62 \\
3.61 \\
3.59 \\
3.58 \\
3.56 \\
3.55\end{array}$ & $\begin{array}{l}443 \\
438 \\
428 \\
423 \\
413 \\
408\end{array}$ & \begin{tabular}{|l|}
3.43 \\
3.42 \\
3.41 \\
3.40 \\
3.39 \\
3.38
\end{tabular} & $\begin{array}{l}350 \\
345 \\
341 \\
336 \\
332 \\
327\end{array}$ & $\begin{array}{l}3.60 \\
3.61 \\
3.60 \\
3.59 \\
3.58 \\
3.55\end{array}$ & $\begin{array}{l}433 \\
438 \\
433 \\
428 \\
423 \\
408\end{array}$ & $\begin{array}{l}3.40 \\
3.38 \\
3.37 \\
3.36 \\
3.34 \\
3.32\end{array}$ & $\begin{array}{l}336 \\
327 \\
323 \\
318 \\
310 \\
301\end{array}$ \\
\hline $\begin{array}{r}2 \\
4 \\
6 \\
8 \\
10 \\
M\end{array}$ & $\begin{array}{l}4.15 \\
4.11 \\
4.08 \\
4.03 \\
4.01 \\
3.98\end{array}$ & & $\begin{array}{l}758 \\
782 \\
712 \\
680 \\
666 \\
648\end{array}$ & $\begin{array}{l}3.78 \\
3.75 \\
3.72 \\
3.70 \\
3.67 \\
3.66\end{array}$ & & $\begin{array}{l}529 \\
512 \\
496 \\
485 \\
469 \\
464\end{array}$ & $\begin{array}{l}3.52 \\
3.51 \\
3.50 \\
3.48 \\
3.46 \\
3.44\end{array}$ & $\begin{array}{l}393 \\
388 \\
383 \\
374 \\
364 \\
355\end{array}$ & $\begin{array}{l}3.37 \\
3.37 \\
3.40 \\
3.43 \\
3.47 \\
3.55\end{array}$ & $\begin{array}{l}323 \\
323 \\
336 \\
350 \\
370 \\
408\end{array}$ & $\begin{array}{l}3.52 \\
3.50 \\
3.48 \\
3.46 \\
3.44 \\
3.42\end{array}$ & $\begin{array}{l}393 \\
383 \\
362 \\
364 \\
355 \\
345\end{array}$ & $\begin{array}{l}3.31 \\
3.30 \\
3.30 \\
3.29 \\
3.28 \\
3.26\end{array}$ & $\begin{array}{l}296 \\
292 \\
292 \\
288 \\
284 \\
275\end{array}$ \\
\hline
\end{tabular}


Locat1on. - Fater-stage recorder, lat. $43^{\circ} 34^{\prime} 00^{\prime \prime}$, long. $71^{\circ} 44^{\prime} 50^{\prime \prime}$, in Hill township, Ierrimack County, $13 / 4$ miles southmest of Bristol, Grafton County. Zero of gage is 449.85 feet above mean sea level.

Dralnage area.- 85.8 square miles.

Gage-helght record. - Vater-stage recorder graph.

Stage-discharge relation. - Defined by current-meter measurements below 1,560 secondleet; extended to peak stage on basis of determinations of flood flow by siope-area method and through contracted opening at gaging station.

Maxima. - September 1938: Discharge, 5,070 second-feet 5 a.m. Sept. 22 (gage helght, 10.77 feet)

1918 to August 1938: D1scharge, 8,100 second-feet Mar. 19, 1936 (gage he1ght, 16.09 feet, from floodmarks), by contracted-opening method.

Remarks.- Plood run-off not materially affected by artificlal storage.

Mean dajly discharge, in second-feet, 1938

\begin{tabular}{|c|c|c|c|c|c|c|c|c|c|c|c|}
\hline Day & Sept. & oct. & Day & Sept. & Oct. & Day & Sept. & oct. & Day & Sept. & Oct. \\
\hline $\begin{array}{l}1 \\
2 \\
3 \\
4 \\
5 \\
6 \\
7 \\
8\end{array}$ & $\begin{array}{l}28 \\
25 \\
24 \\
22 \\
19 \\
20 \\
20 \\
24\end{array}$ & $\begin{array}{r}141 \\
126 \\
115 \\
106 \\
99 \\
91 \\
86 \\
84\end{array}$ & $\begin{array}{r}9 \\
10 \\
11 \\
12 \\
13 \\
14 \\
15 \\
16\end{array}$ & $\begin{array}{r}26 \\
22 \\
20 \\
18 \\
90 \\
128 \\
139 \\
170\end{array}$ & $\begin{array}{l}84 \\
75 \\
73 \\
69 \\
76 \\
78 \\
72 \\
68\end{array}$ & $\begin{array}{l}17 \\
18 \\
19 \\
20 \\
21 \\
22 \\
23 \\
24\end{array}$ & $\begin{array}{r}114 \\
88 \\
108 \\
566 \\
3,390 \\
4,470 \\
1,780 \\
785\end{array}$ & $\begin{array}{r}66 \\
64 \\
62 \\
62 \\
99 \\
134 \\
130 \\
169\end{array}$ & $\begin{array}{l}25 \\
26 \\
27 \\
28 \\
29 \\
30 \\
31\end{array}$ & $\begin{array}{l}483 \\
317 \\
253 \\
222 \\
191 \\
160 \\
-\end{array}$ & $\begin{array}{l}318 \\
257 \\
191 \\
158 \\
141 \\
131 \\
156\end{array}$ \\
\hline $\begin{array}{l}\text { Mean } \\
\text { Run- }\end{array}$ & nthly & 8 & , 1 & $\cdot \cdot \cdot$ & $\dot{.}$ & $: \dot{ }$ & $: \cdot \dot{0}$ & $: \dot{*}$ & $\dot{0}$ & $\begin{array}{r}457 \\
5.95\end{array}$ & $\begin{array}{r}116 \\
1.56\end{array}$ \\
\hline
\end{tabular}

Gage helght, in feet, and discharge, In second-feet, at Indicated time, 1938

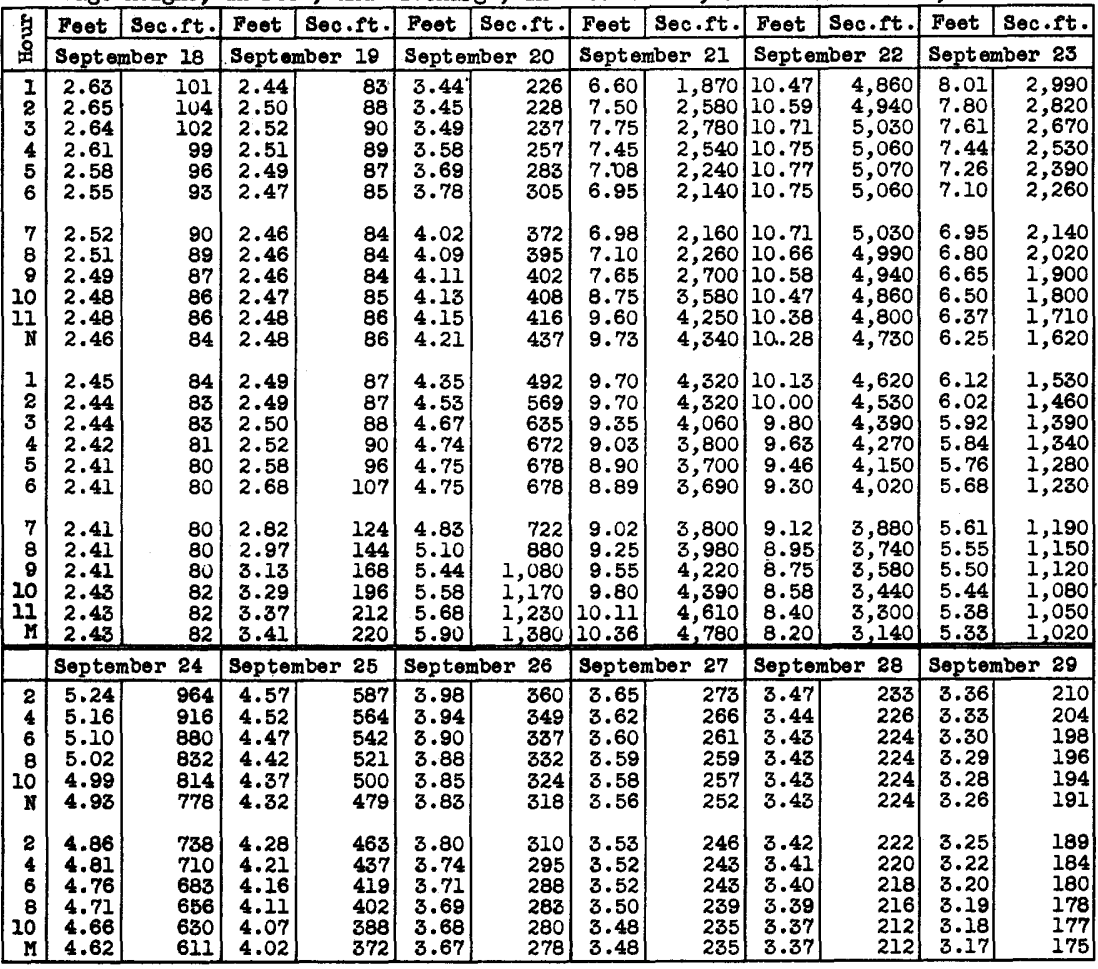


Lake Winnipesaukee at The Weirs, N. H.

Location. - Water-stage recorder, lat. $43^{\circ} 36^{\prime} 20^{\prime \prime}$, long. $71^{\circ} 27^{\prime} 25^{\prime \prime}$, about 800 feet above nignway bridge at The Weirs, Belknap County, Zero of gage is 500.00 feet above mean sea level.

Drainage area.- 363 square miles (above Lakeport).

Gage-height record.- Water-stage recorder graph. Gage heights given in table adjusted for effects of wind and seiches.

Maxima.- September 1938: Gage height, 4.08 feet at 6:20 p.m. Sept. 21 (effect of hurricane).

Remarks.- Affected by storage in Wentworth and Mirror Lakes. Records of stage and contents are for Lake Winnipesaukee only (capacity, 7,190,000,000 cubic feet).

Gain or loss in storage, in millions of cubic feet, 1938

\begin{tabular}{|c|c|c|c|c|c|c|c|c|c|c|c|}
\hline Day & Sept. & oct. & Day & Sept. & oct. & Day & Sept. & oct. & Day & Sept. & oct. \\
\hline $\begin{array}{l}1 \\
2 \\
3 \\
4 \\
5 \\
6 \\
7 \\
8\end{array}$ & $\begin{array}{r}-79 \\
-58 \\
-40 \\
-98 \\
-98 \\
-39 \\
0 \\
-59\end{array}$ & $\begin{array}{l}-98 \\
-20 \\
-59 \\
-78 \\
-59 \\
-20 \\
-78 \\
-39\end{array}$ & $\begin{array}{r}9 \\
10 \\
11 \\
12 \\
13 \\
14 \\
15 \\
16\end{array}$ & $\begin{array}{r}-78 \\
-59 \\
-39 \\
+20 \\
+58 \\
0 \\
+20 \\
-39\end{array}$ & $\begin{array}{r}-137 \\
-20 \\
-39 \\
-39 \\
-40 \\
-39 \\
-19 \\
-40\end{array}$ & $\begin{array}{l}17 \\
18 \\
19 \\
20 \\
21 \\
22 \\
23 \\
24\end{array}$ & $\begin{array}{r}+19 \\
0 \\
+118 \\
+490 \\
+490 \\
+78 \\
+20 \\
-39\end{array}$ & $\begin{array}{r}-39 \\
-39 \\
-78 \\
0 \\
0 \\
-40 \\
-39 \\
+157\end{array}$ & $\begin{array}{l}25 \\
26 \\
27 \\
28 \\
29 \\
30 \\
31\end{array}$ & $\begin{array}{r}+19 \\
-19 \\
0 \\
-39 \\
0 \\
-98\end{array}$ & $\begin{array}{r}+20 \\
0 \\
0 \\
-20 \\
-39 \\
-39 \\
-98\end{array}$ \\
\hline $\begin{array}{l}\text { Gain } \\
\text { Gain }\end{array}$ & $\begin{array}{l}\text { or loss } \\
\text { or loss }\end{array}$ & $\begin{array}{l}\text { stor } \\
\text { stor }\end{array}$ & $\begin{array}{l}e, 1 \\
\text { e, } 1\end{array}$ & $\begin{array}{l}\text { millio } \\
\text { equiva }\end{array}$ & $\begin{array}{l}\text { of cu } \\
\text { at mea }\end{array}$ & $f$ & $\dot{e e t}$ & : : : & & $\begin{array}{l}+451 \\
+174\end{array}$ & $\begin{array}{r}-1,078 \\
-402\end{array}$ \\
\hline
\end{tabular}

Gage height, in feet, and contents, in millions of cubic feet, at indicated time, 1938

\begin{tabular}{|c|c|c|c|c|c|c|c|c|c|c|}
\hline \multirow[t]{2}{*}{ Hour } & $\begin{array}{c}\text { Gage } \\
\text { helght }\end{array}$ & Contents & $\begin{array}{c}\text { Gage } \\
\text { height }\end{array}$ & Contents & $\begin{array}{c}\text { Gage } \\
\text { neight }\end{array}$ & Contents & $\begin{array}{c}\text { Gage } \\
\text { helght }\end{array}$ & Contents & $\begin{array}{c}\text { Gage } \\
\text { helght }\end{array}$ & Contents \\
\hline & \multicolumn{2}{|c|}{ September 11} & \multicolumn{2}{|c|}{ September 12} & \multicolumn{2}{|c|}{ September 13} & \multicolumn{2}{|c|}{ September 14} & \multicolumn{2}{|c|}{ September 15} \\
\hline \multirow[t]{2}{*}{$\begin{array}{l}6 \\
\mathrm{~N} \\
6 \\
\mathrm{M} \\
\end{array}$} & $\begin{array}{l}3.12 \\
3.12 \\
3.11 \\
3.10 \\
\end{array}$ & $\begin{array}{r}5,135 \\
5,135 \\
5,116 \\
5,096 \\
\end{array}$ & $\begin{array}{l}3.10 \\
3.10 \\
3.10 \\
3.11 \\
\end{array}$ & $\begin{array}{l}5,096 \\
5,096 \\
5,096 \\
5,116 \\
\end{array}$ & $\begin{array}{l}3.15 \\
3.14 \\
3.14 \\
3.14\end{array}$ & \begin{tabular}{|l|}
5,194 \\
5,174 \\
5,174 \\
5,174 \\
\end{tabular} & $\begin{array}{l}3.14 \\
3.14 \\
3.14 \\
3.14 \\
\end{array}$ & $\begin{array}{r}5,174 \\
5,174 \\
5,174 \\
5,174 \\
\end{array}$ & $\begin{array}{l}3.17 \\
3.18 \\
3.17 \\
3.15\end{array}$ & $\begin{array}{l}5,233 \\
5,253 \\
5,233 \\
5,194 \\
\end{array}$ \\
\hline & \multicolumn{2}{|c|}{ September 16} & \multicolumn{2}{|c|}{ September 17} & \multicolumn{2}{|c|}{ September 18} & \multicolumn{2}{|c|}{ September 19} & \multicolumn{2}{|c|}{ September 20} \\
\hline \multirow[t]{2}{*}{$\begin{array}{l}6 \\
N \\
6 \\
M \\
\end{array}$} & $\begin{array}{l}3.14 \\
3.13 \\
3.13 \\
3.13\end{array}$ & \begin{tabular}{|}
5,174 \\
5,155 \\
5,155 \\
5,155 \\
\end{tabular} & $\begin{array}{l}3.14 \\
3.15 \\
3.14 \\
3.14 \\
\end{array}$ & $\begin{array}{r}5,174 \\
5,194 \\
5,174 \\
5,174\end{array}$ & $\begin{array}{l}3.13 \\
3.13 \\
3.12 \\
3.14\end{array}$ & $\begin{array}{r}5,155 \\
5,155 \\
5,135 \\
5,174\end{array}$ & $\begin{array}{l}3.13 \\
3.13 \\
3.17 \\
3.20\end{array}$ & $\begin{array}{l}5,155 \\
5,155 \\
5,233 \\
5,292\end{array}$ & $\begin{array}{l}3.21 \\
3.35 \\
3.37 \\
3.45\end{array}$ & $\begin{array}{l}5,312 \\
5,586 \\
5,625 \\
5,782\end{array}$ \\
\hline & \multicolumn{2}{|c|}{ September 21} & \multicolumn{2}{|c|}{ September 22} & \multicolumn{2}{|c|}{ September 23} & \multicolumn{2}{|c|}{ September 24} & \multicolumn{2}{|c|}{ September 25} \\
\hline \multirow[t]{2}{*}{$\begin{array}{l}6 \\
N \\
6 \\
M \\
\end{array}$} & $\begin{array}{l}3.57 \\
3.65 \\
3.70 \\
3.70\end{array}$ & $\begin{array}{l}6,017 \\
6,174 \\
6,272 \\
6,272 \\
\end{array}$ & $\begin{array}{l}3.70 \\
3.71 \\
3.72 \\
3.74 \\
\end{array}$ & $\begin{array}{l}6,272 \\
6,292 \\
6,311 \\
6,350\end{array}$ & $\begin{array}{l}3.75 \\
3.75 \\
3.75 \\
3.75\end{array}$ & $\begin{array}{l}6,370 \\
6,370 \\
6,370 \\
6,370\end{array}$ & $\begin{array}{l}3.75 \\
3.73 \\
3.74 \\
3.73\end{array}$ & $\begin{array}{l}6,370 \\
6,331 \\
6,350 \\
6,331\end{array}$ & $\begin{array}{l}3.74 \\
3.72 \\
3.72 \\
3.74\end{array}$ & $\begin{array}{l}6,350 \\
6,311 \\
6,311 \\
6,350\end{array}$ \\
\hline & \multicolumn{2}{|c|}{ September 26} & \multicolumn{2}{|c|}{ September 27} & \multicolumn{2}{|c|}{ September 28} & \multicolumn{2}{|c|}{ September 29} & \multicolumn{2}{|c|}{ September 30} \\
\hline \multirow[t]{2}{*}{$\begin{array}{l}6 \\
N \\
6 \\
M \\
\end{array}$} & $\begin{array}{l}3.74 \\
3.74 \\
3.74 \\
3.73 \\
\end{array}$ & $\begin{array}{l}6,350 \\
6,350 \\
6,350 \\
6,331\end{array}$ & $\begin{array}{l}3.73 \\
3.73 \\
3.74 \\
3.73\end{array}$ & \begin{tabular}{|l|}
6,331 \\
6,331 \\
6,350 \\
6,331 \\
\end{tabular} & $\begin{array}{l}3.72 \\
3.72 \\
3.72 \\
3.71\end{array}$ & \begin{tabular}{|l|}
6,311 \\
6,311 \\
6,311 \\
6,292 \\
\end{tabular} & $\begin{array}{l}3.70 \\
3.70 \\
3.69 \\
3.71\end{array}$ & $\begin{array}{l}6,272 \\
6,272 \\
6,252 \\
6,292\end{array}$ & $\begin{array}{l}3.70 \\
3.70 \\
3.68 \\
3.66\end{array}$ & $\begin{array}{l}6,272 \\
6,272 \\
6,233 \\
6,194\end{array}$ \\
\hline & \multicolumn{2}{|c|}{ October 1} & \multicolumn{2}{|c|}{ October 2} & \multicolumn{2}{|c|}{ October 3} & \multicolumn{2}{|c|}{ October 4} & \multicolumn{2}{|c|}{ October 5} \\
\hline \multirow[t]{2}{*}{$\begin{array}{l}6 \\
N \\
6 \\
M \\
\end{array}$} & $\begin{array}{l}3.64 \\
3.63 \\
3.62 \\
3.61 \\
\end{array}$ & $\begin{array}{l}6,154 \\
6,135 \\
6,115 \\
6,096 \\
\end{array}$ & $\begin{array}{l}3.60 \\
3.60 \\
3.60 \\
3.60\end{array}$ & $\begin{array}{l}6,076 \\
6,076 \\
6,076 \\
6,076 \\
\end{array}$ & $\begin{array}{l}3.59 \\
3.59 \\
3.58 \\
3.57\end{array}$ & $\begin{array}{l}6,056 \\
6,056 \\
6,037 \\
6,017 \\
\end{array}$ & $\begin{array}{l}3.55 \\
3.55 \\
3.55 \\
3.53 \\
\end{array}$ & \begin{tabular}{|l}
5,978 \\
5,978 \\
5,978 \\
5,939 \\
\end{tabular} & $\begin{array}{l}3.52 \\
3.53 \\
3.50 \\
3.50\end{array}$ & \begin{tabular}{|l}
5,919 \\
5,939 \\
5,880 \\
5,880 \\
\end{tabular} \\
\hline & \multicolumn{2}{|c|}{ October 6} & \multicolumn{2}{|c|}{ October 7} & \multicolumn{2}{|c|}{ October 8} & \multicolumn{2}{|c|}{ October 9} & \multicolumn{2}{|c|}{ October 10} \\
\hline $\begin{array}{l}6 \\
\mathrm{~N} \\
6 \\
\mathrm{M} \\
\end{array}$ & $\begin{array}{l}3.50 \\
3.51 \\
3.50 \\
3.49\end{array}$ & \begin{tabular}{|r|}
5,880 \\
5,900 \\
5,880 \\
5,860 \\
\end{tabular} & $\begin{array}{l}3.48 \\
3.46 \\
3.45 \\
3.45\end{array}$ & \begin{tabular}{|l|}
5,841 \\
5,802 \\
5,782 \\
5,782 \\
\end{tabular} & $\begin{array}{l}3.44 \\
3.44 \\
3.44 \\
3.43\end{array}$ & $\begin{array}{l}5,762 \\
5,762 \\
5,762 \\
5,743\end{array}$ & $\begin{array}{l}3.41 \\
3.39 \\
3.37 \\
3.36\end{array}$ & $\begin{array}{l}5,704 \\
5,664 \\
5,625 \\
5,606\end{array}$ & $\begin{array}{l}3.35 \\
3.34 \\
3.35 \\
3.35\end{array}$ & $\begin{array}{r}5,586 \\
5,566 \\
5,586 \\
5,586\end{array}$ \\
\hline & Octob & eer 11 & Octob & ser 12 & Octor & er 13 & Octob & ber 14 & octob & er 15 \\
\hline $\begin{array}{l}6 \\
N \\
6 \\
M\end{array}$ & $\begin{array}{l}3.35 \\
3.34 \\
3.34 \\
3.33\end{array}$ & $\begin{array}{l}5,586 \\
5,566 \\
5,566 \\
5,547\end{array}$ & $\begin{array}{l}3.33 \\
3.32 \\
3.32 \\
3.31\end{array}$ & $\begin{array}{l}5,547 \\
5,527 \\
5,527 \\
5,508\end{array}$ & $\begin{array}{l}3.30 \\
3.30 \\
3.30 \\
3.29\end{array}$ & $\begin{array}{l}5,488 \\
5,488 \\
5,488 \\
5,468\end{array}$ & $\begin{array}{l}3.29 \\
3.28 \\
3.28 \\
3.27\end{array}$ & $\begin{array}{l}5,468 \\
5,449 \\
5,449 \\
5,429\end{array}$ & $\begin{array}{l}3.26 \\
3.26 \\
3.26 \\
3.26\end{array}$ & $\begin{array}{l}5,410 \\
5,410 \\
5,410 \\
5,410\end{array}$ \\
\hline
\end{tabular}


Location.- Water-stage recorder, lat. $43^{\circ} 26^{\prime} 30^{\prime \prime}$, long. $71^{\circ} 35^{\prime} 15^{n}, 0.3$ mile above mouth of Packer Brook in Tilton, Belknap County.

Drainage area. - 471 square miles.

Gare-height record.- Water-stage recorder graph.

Stage-discharge relation.- Defined by current-meter measurements below 2,100 secondfeet; extended to peak stage on basis of determination of flood flow over dam.

Maxtma.- September 1938: Discharge, 3,810 second-feet 6:15 p.m. Sept. 21 (gage height, 7.90 feet).

January 1937 to August 1938: Discharge, 3,120 second-feet May 17, 1937 (gage he1ght, 7.27 feet).

Remarks.- Flood mun-off affected by storage in Mirror, Winnipesaukee, Wentworth, and Winnisquam Lakes. For information on storage see record for Lake Winnipesaukee at The Weirs, N. H.

Mean datly discharge, in second-feet, 1938

\begin{tabular}{|c|c|c|c|c|c|c|c|c|c|c|c|}
\hline Day & Sept. & Oct. & Day & Sept. & Oot. & Day & Sept. & Oot. & Day & Sept. & Oct. \\
\hline $\begin{array}{l}1 \\
2 \\
3 \\
4 \\
5 \\
6 \\
7 \\
8\end{array}$ & $\begin{array}{l}470 \\
470 \\
430 \\
390 \\
390 \\
445 \\
475 \\
475\end{array}$ & $\begin{array}{r}1,000 \\
805 \\
835 \\
898 \\
865 \\
898 \\
965 \\
1,000 \\
\end{array}$ & $\begin{array}{l}9 \\
10 \\
11 \\
12 \\
13 \\
14 \\
15 \\
16\end{array}$ & $\begin{array}{l}440 \\
395 \\
380 \\
390 \\
530 \\
646 \\
691 \\
805\end{array}$ & $\begin{array}{l}588 \\
545 \\
590 \\
525 \\
560 \\
570 \\
241 \\
242\end{array}$ & $\begin{array}{l}17 \\
18 \\
19 \\
20 \\
21 \\
22 \\
23 \\
24\end{array}$ & $\begin{array}{r}697 \\
570 \\
671 \\
1,110 \\
3,230 \\
3,130 \\
2,550 \\
2,000\end{array}$ & $\begin{array}{l}835 \\
605 \\
590 \\
595 \\
805 \\
835 \\
805 \\
898\end{array}$ & $\begin{array}{l}25 \\
26 \\
27 \\
28 \\
29 \\
30 \\
31\end{array}$ & $\begin{array}{r}1,570 \\
1,220 \\
970 \\
973 \\
1,060 \\
1,040\end{array}$ & $\begin{array}{r}1,180 \\
898 \\
835 \\
965 \\
865 \\
727 \\
691\end{array}$ \\
\hline $\begin{array}{l}\text { Mean } \\
\text { Run- }\end{array}$ & $\begin{array}{l}\text { nthly } \\
\mathrm{f} \text {, in }\end{array}$ & $\pi$ & $\begin{array}{l}1 \\
\therefore\end{array}$ & $\begin{array}{c}\text { second- } \\
.\end{array}$ & et. . & $\dot{0} \cdot \dot{ }$ & 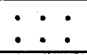 & $\dot{0} \cdot \dot{ }$ & $\dot{0} \cdot$ & $\begin{array}{r}954 \\
2.26 \\
\end{array}$ & $\begin{array}{r}750 \\
1.83 \\
\end{array}$ \\
\hline
\end{tabular}

Gage height, in feet, and discharge, in second-feet, at indicated time, 1938

\begin{tabular}{|c|c|c|c|c|c|c|c|c|c|c|c|c|}
\hline \multirow{2}{*}{$\begin{array}{l}\mathbf{y} \\
3 \\
\text { 号 }\end{array}$} & Feet & Sec.ft. & Feet & Sec.ft. & Fout & Sec.ft. & Feet & Sec.ft. & Feot & Sec.ft. & Feet & Sec.ft. \\
\hline & \multicolumn{2}{|c|}{ September 18} & \multicolumn{2}{|c|}{ September 19} & \multicolumn{2}{|c|}{ September 20} & \multicolumn{2}{|c|}{ September 21} & \multicolumn{2}{|c|}{ September 22} & \multicolumn{2}{|c|}{ September 23} \\
\hline $\begin{array}{l}7 \\
2 \\
3 \\
4 \\
5 \\
6\end{array}$ & $\begin{array}{l}4.22 \\
4.21 \\
4.20 \\
4.20 \\
4.20 \\
4.19\end{array}$ & $\begin{array}{l}\mathbf{5 9 0} \\
\mathbf{5 8 5} \\
\mathbf{5 8 0} \\
\mathbf{5 8 0} \\
\mathbf{5 8 0} \\
\mathbf{5 7 5}\end{array}$ & $\begin{array}{l}4.16 \\
4.16 \\
4.16 \\
4.16 \\
4.17 \\
4.17\end{array}$ & $\begin{array}{l}560 \\
560 \\
560 \\
560 \\
565 \\
565\end{array}$ & $\begin{array}{l}4.50 \\
4.50 \\
4.50 \\
4.52 \\
4.53 \\
4.53\end{array}$ & $\begin{array}{l}745 \\
745 \\
745 \\
757 \\
763 \\
763\end{array}$ & $\begin{array}{l}7.14 \\
6.85 \\
6.82 \\
6.89 \\
7.01 \\
7.06\end{array}$ & $\begin{array}{l}2,970 \\
2,670 \\
2,640 \\
2,710 \\
2,830 \\
2,890\end{array}$ & $\begin{array}{l}7.51 \\
7.50 \\
7.48 \\
7.45 \\
7.43 \\
7.41\end{array}$ & $\begin{array}{l}3,380 \\
3,370 \\
3,350 \\
3,320 \\
3,290 \\
3,270\end{array}$ & $\begin{array}{l}7.03 \\
7.01 \\
6.98 \\
6.95 \\
6.92 \\
6.88\end{array}$ & $\begin{array}{l}2,850 \\
2,830 \\
2,800 \\
2,770 \\
2,740 \\
2,700\end{array}$ \\
\hline $\begin{array}{r}7 \\
8 \\
9 \\
10 \\
11 \\
1\end{array}$ & $\begin{array}{l}4.18 \\
4.18 \\
4.18 \\
4.18 \\
4.18 \\
4.17\end{array}$ & $\begin{array}{l}570 \\
570 \\
570 \\
570 \\
570 \\
565\end{array}$ & $\begin{array}{l}4.18 \\
4.21 \\
4.25 \\
4.29 \\
4.33 \\
4.37\end{array}$ & $\begin{array}{l}570 \\
585 \\
605 \\
625 \\
646 \\
668\end{array}$ & $\begin{array}{l}4.53 \\
4.55 \\
4.61 \\
4.71 \\
4.91 \\
5.04\end{array}$ & $\begin{array}{r}763 \\
775 \\
811 \\
872 \\
1,010 \\
1,100\end{array}$ & $\begin{array}{l}7.13 \\
7.18 \\
7.23 \\
7.49 \\
7.48 \\
7.57\end{array}$ & $\begin{array}{l}2,960 \\
3,020 \\
3,070 \\
3,360 \\
3,350 \\
3,450\end{array}$ & $\begin{array}{l}39 \\
36 \\
33 \\
30 \\
26 \\
25\end{array}$ & $\begin{array}{l}3,250 \\
3,220 \\
3,180 \\
3,150 \\
3,110 \\
3,100\end{array}$ & $\begin{array}{l}86 \\
83 \\
81 \\
78 \\
76 \\
73\end{array}$ & $\begin{array}{l}2,680 \\
2,650 \\
2,630 \\
2,600 \\
2,580 \\
2,550\end{array}$ \\
\hline $\begin{array}{l}1 \\
2 \\
3 \\
4 \\
5 \\
6\end{array}$ & $\begin{array}{l}4.17 \\
4.17 \\
4.17 \\
4.17 \\
4.17 \\
4.16\end{array}$ & $\begin{array}{l}565 \\
565 \\
565 \\
565 \\
565 \\
560\end{array}$ & $\begin{array}{l}4.41 \\
4.44 \\
4.47 \\
4.51 \\
4.68 \\
4.62\end{array}$ & $\begin{array}{l}691 \\
709 \\
727 \\
751 \\
853 \\
817\end{array}$ & $\begin{array}{l}5.07 \\
5.10 \\
5.15 \\
5.19 \\
5.31 \\
5.80\end{array}$ & $\begin{array}{l}1,120 \\
1,140 \\
1,180 \\
1,200 \\
1,290 \\
1,280\end{array}$ & $\begin{array}{l}7.57 \\
7.63 \\
7.66 \\
7.71 \\
7.73 \\
7.86\end{array}$ & $\begin{array}{l}3,450 \\
3,510 \\
3,550 \\
3,600 \\
3,620 \\
3,770\end{array}$ & $\begin{array}{l}7.24 \\
7.22 \\
7.22 \\
7.21 \\
7.20 \\
7.18\end{array}$ & $\begin{array}{l}3,080 \\
3,060 \\
3,060 \\
3,050 \\
3,040 \\
\mathbf{3}, 020\end{array}$ & $\begin{array}{l}6.70 \\
6.67 \\
6.64 \\
6.61 \\
6.59 \\
6.57\end{array}$ & $\begin{array}{l}2,520 \\
2,490 \\
2,460 \\
2,430 \\
2,410 \\
2,390\end{array}$ \\
\hline \multirow[t]{2}{*}{$\begin{array}{r}7 \\
8 \\
9 \\
10 \\
11 \\
1\end{array}$} & $\begin{array}{l}4.16 \\
4.16 \\
4.16 \\
4.16 \\
4.16 \\
4.16\end{array}$ & $\begin{array}{l}560 \\
560 \\
560 \\
560 \\
560 \\
560\end{array}$ & $\begin{array}{l}4.58 \\
4.55 \\
4.54 \\
4.52 \\
4.51 \\
4.50\end{array}$ & $\begin{array}{l}793 \\
775 \\
769 \\
757 \\
751 \\
745\end{array}$ & $\begin{array}{l}5.45 \\
5.62 \\
5.88 \\
5.89 \\
5.92 \\
6.15\end{array}$ & $\begin{array}{l}1,400 \\
1,540 \\
1,740 \\
1,750 \\
1,780 \\
1,980\end{array}$ & $\begin{array}{l}7.68 \\
7.60 \\
7.58 \\
7.56 \\
7.54 \\
7.53\end{array}$ & $\begin{array}{l}3,570 \\
3,480 \\
3,460 \\
3,440 \\
3,410 \\
3,400\end{array}$ & $\begin{array}{l}7.16 \\
7.15 \\
7.12 \\
7.10 \\
7.08 \\
7.06\end{array}$ & $\begin{array}{l}3,000 \\
2,980 \\
2,950 \\
2,930 \\
2,910 \\
2,890\end{array}$ & & $\begin{array}{l}2,360 \\
2,340 \\
2,320 \\
2,300 \\
2,280 \\
2,260\end{array}$ \\
\hline & \multicolumn{2}{|c|}{ September 24} & \multicolumn{2}{|c|}{ September 25} & \multicolumn{2}{|c|}{ September 26} & \multicolumn{2}{|c|}{ September 27} & \multicolumn{2}{|c|}{ September $\mathbf{2 8}$} & \multicolumn{2}{|c|}{ September 29} \\
\hline $\begin{array}{r}2 \\
4 \\
6 \\
8 \\
10 \\
y\end{array}$ & $\begin{array}{l}6.40 \\
6.36 \\
6.32 \\
6.27 \\
6.20 \\
6.14\end{array}$ & $\begin{array}{l}2,220 \\
2,180 \\
2,140 \\
2,090 \\
2,030 \\
1,980\end{array}$ & \begin{tabular}{|l|}
5.88 \\
5.85 \\
5.82 \\
5.78 \\
5.71 \\
5.64
\end{tabular} & $\begin{array}{l}1,740 \\
1,720 \\
1,700 \\
1,660 \\
1,610 \\
1,550\end{array}$ & $\begin{array}{l}5.41 \\
5.39 \\
5.37 \\
5.35 \\
5.31 \\
5.23\end{array}$ & $\begin{array}{l}1,370 \\
1,350 \\
1,340 \\
1,320 \\
1,290 \\
1,230\end{array}$ & & $\begin{array}{r}, 010 \\
993 \\
986 \\
972 \\
958 \\
951\end{array}$ & & $\begin{array}{r}951 \\
944 \\
944 \\
944 \\
944 \\
944\end{array}$ & & $\begin{array}{l}1,050 \\
1,050 \\
1,060 \\
1,060 \\
1,060 \\
1,060\end{array}$ \\
\hline $\begin{array}{r}2 \\
4 \\
6 \\
8 \\
10 \\
11\end{array}$ & $\begin{array}{l}6.10 \\
6.05 \\
6.01 \\
5.97 \\
5.93 \\
5.91\end{array}$ & $\begin{array}{l}1,940 \\
1,900 \\
1,860 \\
1,820 \\
1,790 \\
1,770\end{array}$ & $\begin{array}{l}5.58 \\
5.55 \\
5.51 \\
5.48 \\
5.45 \\
5.43\end{array}$ & $\begin{array}{l}1,500 \\
1,480 \\
1,450 \\
1,420 \\
1,400 \\
1,380\end{array}$ & $\begin{array}{l}5.15 \\
5.09 \\
5.04 \\
5.00 \\
4.97\end{array}$ & $\begin{array}{l}1,180 \\
1,130 \\
1,100 \\
1,070 \\
1,050 \\
1,030\end{array}$ & $\begin{array}{l}4 . \\
4 . \\
4 . \\
4 . \\
4 .\end{array}$ & $\begin{array}{l}951 \\
951 \\
958 \\
958 \\
958\end{array}$ & $\begin{array}{l}4.85 \\
4.88 \\
4.90 \\
4.93 \\
4.95 \\
4.96\end{array}$ & $\begin{array}{l}965 \\
986 \\
, 000 \\
020 \\
085\end{array}$ & & $\begin{array}{l}1, \\
1, \\
1, \\
1, \\
1, \\
1,\end{array}$ \\
\hline
\end{tabular}

Supplemental records.- Sept. $21,6: 15$ p...., 7.90 ft., 3,810 sec,-ft. 


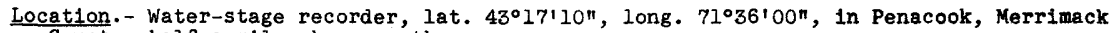
County, half a mile above mouth.

Drainage area.- 766 square miles.

Gage-helght record.- Water-stage recorder graph except for periods 0ct. 4-24 and 29-31, when graph was based on one staff-gage reading daily and shape of stage-graphs at nearby stations.

Stege-discharge relation.- Defined by current-meter measurements below 39,900 secondfeet; extended to peak stage on basis of velocity-area studies.

Maxima.- September 1938: Discharge, 42,400 second-feet 3 a.m. Sept. 23 (gage helght, 13.34 feet). 14.26 feet).

1928 to August 1938: Discharge, 46,800 second-feet Mar. 20, 1936 (gage he1ght,

Remarks.- Flood run-off affected slightly by artificial storage.

Mean dally discharge, in second-feet, 1938

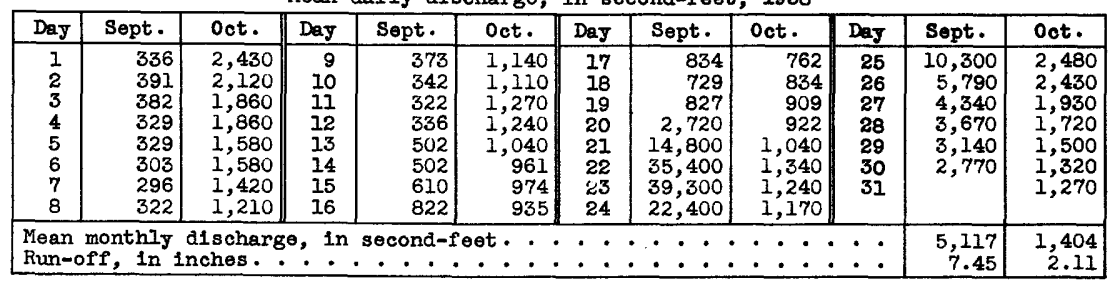

Gage height, in feet, and discharge, in second-feet, at indicated time, 1938

\begin{tabular}{|c|c|c|c|c|c|c|c|c|c|c|c|c|}
\hline \multirow{2}{*}{$\begin{array}{l}3 \\
\text { 号 } \\
\end{array}$} & Feet & Sec.ft. & Feet & Sec.ft. & Feot & Sec.ft. & Feet & Sec.ft. & Feet & Sec.ft. & Feet & Sec.ft. \\
\hline & \multicolumn{2}{|c|}{ September 18} & \multicolumn{2}{|c|}{ September 19} & \multicolumn{2}{|c|}{ September 20} & \multicolumn{2}{|c|}{ September 21} & \multicolumn{2}{|c|}{ September 22} & \multicolumn{2}{|c|}{ September 23} \\
\hline $\begin{array}{l}1 \\
2 \\
3 \\
4 \\
5 \\
6\end{array}$ & $\begin{array}{l}2.52 \\
2.52 \\
2.51 \\
2.50 \\
2.50 \\
2.50\end{array}$ & $\begin{array}{l}774 \\
774 \\
762 \\
750 \\
750 \\
750\end{array}$ & $\begin{array}{l}2.47 \\
2.48 \\
2.48 \\
2.48 \\
2.48 \\
2.48\end{array}$ & $\begin{array}{l}717 \\
728 \\
728 \\
728 \\
728 \\
728\end{array}$ & $\begin{array}{l}2.80 \\
2.83 \\
2.89 \\
2.97 \\
3.05 \\
3.13\end{array}$ & $\begin{array}{l}1,140 \\
1,180 \\
1,270 \\
1,380 \\
1,500 \\
1,620\end{array}$ & $\begin{array}{l}5.03 \\
5.33 \\
5.51 \\
5.73 \\
5.84 \\
6.02\end{array}$ & $\begin{array}{l}5,950 \\
6,880 \\
7,470 \\
8,250 \\
8,650 \\
9,340\end{array}$ & $\begin{array}{r}9.88 \\
10.10 \\
10.30 \\
10.50 \\
10.75 \\
10.98\end{array}$ & $\begin{array}{l}26,400 \\
27,400 \\
28,400 \\
29,300 \\
30,500 \\
31,500\end{array}$ & $\begin{array}{l}13.31 \\
13.33 \\
13.34 \\
13.33 \\
13.30 \\
13.26\end{array}$ & $\begin{array}{l}42,200 \\
42,300 \\
42,400 \\
42,300 \\
42,200 \\
42,000\end{array}$ \\
\hline $\begin{array}{r}7 \\
8 \\
9 \\
10 \\
11 \\
11\end{array}$ & $\begin{array}{l}2.50 \\
2.49 \\
2.49 \\
2.48 \\
2.47 \\
2.47\end{array}$ & $\begin{array}{l}750 \\
739 \\
739 \\
728 \\
717 \\
717\end{array}$ & $\begin{array}{l}2.50 \\
2.50 \\
2.50 \\
2.51 \\
2.51 \\
2.52\end{array}$ & $\begin{array}{l}720 \\
750 \\
750 \\
762 \\
762 \\
774\end{array}$ & $\begin{array}{l}3.21 \\
3.30 \\
3.33 \\
3.41 \\
3.51 \\
3.69\end{array}$ & $\begin{array}{l}1,740 \\
1,880 \\
1,930 \\
2,060 \\
2,230 \\
2,550\end{array}$ & $\begin{array}{l}6.27 \\
6.50 \\
6.62 \\
6.83 \\
7.14 \\
7.20\end{array}$ & $\begin{array}{l}10,400 \\
11,300 \\
11,800 \\
12,600 \\
14,000 \\
14,300\end{array}$ & $\begin{array}{l}11.15 \\
11.22 \\
11.40 \\
11.60 \\
11.70 \\
12.00\end{array}$ & $\begin{array}{l}32,200 \\
32,600 \\
33,400 \\
34,400 \\
34,800 \\
36,200\end{array}$ & $\begin{array}{l}13.20 \\
13.13 \\
13.09 \\
13.01 \\
12.94 \\
12.85\end{array}$ & $\begin{array}{l}41,700 \\
41,400 \\
41,200 \\
40,800 \\
40,500 \\
40,100\end{array}$ \\
\hline $\begin{array}{l}1 \\
2 \\
3 \\
4 \\
5 \\
6\end{array}$ & $\begin{array}{l}2.47 \\
2.46 \\
2.46 \\
2.46 \\
2.47 \\
2.47\end{array}$ & $\begin{array}{l}717 \\
706 \\
706 \\
706 \\
717 \\
717\end{array}$ & $\begin{array}{l}2.53 \\
2.53 \\
2.54 \\
2.56 \\
2.61 \\
2.62\end{array}$ & $\begin{array}{l}786 \\
786 \\
798 \\
822 \\
883 \\
896\end{array}$ & $\begin{array}{l}3.78 \\
3.88 \\
3.94 \\
4.03 \\
4.10 \\
4.20\end{array}$ & $\begin{array}{l}2,730 \\
2,950 \\
3,080 \\
3,290 \\
3,460 \\
3,710\end{array}$ & $\begin{array}{l}7.40 \\
7.60 \\
7.80 \\
8.01 \\
8.21 \\
8.38\end{array}$ & $\begin{array}{l}15,100 \\
16,000 \\
16,900 \\
17,800 \\
18,700 \\
19,600\end{array}$ & $\begin{array}{l}12.19 \\
12.32 \\
12.50 \\
12.63 \\
12.78 \\
12.88\end{array}$ & $\begin{array}{l}37,000 \\
37,700 \\
38,500 \\
39,100 \\
39,800 \\
40,200\end{array}$ & $\begin{array}{l}12.77 \\
12.68 \\
12.57 \\
12.50 \\
12.35 \\
12.20\end{array}$ & $\begin{array}{l}39,800 \\
39,300 \\
38,800 \\
38,500 \\
37,800 \\
37,100\end{array}$ \\
\hline \multirow[t]{2}{*}{$\begin{array}{r}7 \\
8 \\
9 \\
10 \\
11 \\
11\end{array}$} & $\begin{array}{l}2.46 \\
2.46 \\
2.46 \\
2.46 \\
2.46 \\
2.47\end{array}$ & $\begin{array}{l}706 \\
706 \\
706 \\
706 \\
706 \\
717\end{array}$ & $\begin{array}{l}2.68 \\
2.69 \\
2.71 \\
2.72 \\
2.74 \\
2.77 ?\end{array}$ & $\begin{array}{r}974 \\
987 \\
1,010 \\
1,030 \\
1,060 \\
1,100\end{array}$ & $\begin{array}{l}4.28 \\
4.44 \\
4.50 \\
4.60 \\
4.69 \\
4.80\end{array}$ & $\begin{array}{l}3,920 \\
4,330 \\
4,490 \\
4,760 \\
5,000 \\
5,300\end{array}$ & $\begin{array}{l}8.62 \\
9.07 \\
9.19 \\
9.33 \\
9.51 \\
9.70\end{array}$ & $\begin{array}{l}20,700 \\
22,700 \\
23,200 \\
23,900 \\
24,800 \\
25,600\end{array}$ & $\begin{array}{l}13.00 \\
13.08 \\
13.13 \\
13.19 \\
13.25 \\
13.28\end{array}$ & $\begin{array}{l}40,800 \\
41,100 \\
41,400 \\
41,600 \\
42,000 \\
42,100\end{array}$ & $\begin{array}{l}12.08 \\
11.90 \\
11.73 \\
11.57 \\
11.38 \\
11.20\end{array}$ & $\begin{array}{l}36,500 \\
35,700 \\
35,000 \\
34,200 \\
33,300 \\
32,500\end{array}$ \\
\hline & \multicolumn{2}{|c|}{ September 24} & \multicolumn{2}{|c|}{ September 25} & \multicolumn{2}{|c|}{ September 26} & \multicolumn{2}{|c|}{ September 27} & \multicolumn{2}{|c|}{ September 28} & \multicolumn{2}{|c|}{ September 29} \\
\hline $\begin{array}{r}2 \\
4 \\
6 \\
8 \\
10 \\
\mathrm{~N}\end{array}$ & $\begin{array}{r}10.83 \\
10.40 \\
9.92 \\
9.50 \\
9.15 \\
8.81\end{array}$ & $\begin{array}{l}30,800 \\
28,800 \\
26,600 \\
24,700 \\
23,000 \\
21,500\end{array}$ & $\begin{array}{l}7.07 \\
6.87 \\
6.67 \\
6.47 \\
6.29 \\
6.10\end{array}$ & $\begin{array}{r}13,700 \\
12,800 \\
12,000 \\
11,200 \\
10,500 \\
9,660\end{array}$ & & $\begin{array}{l}6,840 \\
6,560 \\
6,310 \\
6,070 \\
5,860 \\
5,690\end{array}$ & & $\begin{array}{l}4,760 \\
4,650 \\
4,520 \\
4,460 \\
4,390 \\
4,310\end{array}$ & & & & $\begin{array}{l}3,320 \\
3,290 \\
3,240 \\
3,220 \\
3,200 \\
3,130\end{array}$ \\
\hline $\begin{array}{r}2 \\
4 \\
6 \\
8 \\
10 \\
M\end{array}$ & $\begin{array}{l}8.53 \\
8.24 \\
8.00 \\
7.76 \\
7.51 \\
7.28\end{array}$ & $\begin{array}{l}20,200 \\
18,900 \\
17,800 \\
16,800 \\
15,600 \\
14,700\end{array}$ & $\begin{array}{l}6.05 \\
5.92 \\
5.78 \\
5.66 \\
5.54 \\
5.42\end{array}$ & $\begin{array}{l}9,460 \\
8,960 \\
8,430 \\
8,000 \\
7,580 \\
7,170\end{array}$ & $\begin{array}{l}4.88 \\
4.82 \\
4.77 \\
4.71 \\
4.68 \\
4.63\end{array}$ & $\begin{array}{l}5,520 \\
5,360 \\
5,220 \\
5,060 \\
4,980 \\
4,840\end{array}$ & $\begin{array}{l}4.40 \\
4.38 \\
4.36 \\
4.33 \\
4.31 \\
4.30\end{array}$ & $\begin{array}{l}4,230 \\
4,180 \\
4,130 \\
4,050 \\
4,000 \\
3,970\end{array}$ & $\begin{array}{l}4.16 \\
4.14 \\
4.12 \\
4.11 \\
4.09 \\
4.07\end{array}$ & $\begin{array}{l}3,610 \\
3,560 \\
3,510 \\
3,480 \\
3,440 \\
3,390\end{array}$ & $\begin{array}{l}3.95 \\
3.93 \\
3.92 \\
3.90 \\
3.89 \\
3.87\end{array}$ & $\begin{array}{l}3,100 \\
3,060 \\
3,040 \\
2,990 \\
2,970 \\
2,920\end{array}$ \\
\hline
\end{tabular}




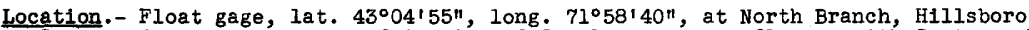
County, 4 miles northwest of Antrim and 6 miles above confluence with Contoocook RIver. Zero of gage is 882.38 feet above mean sea level.

Drainage area.- 54.8 square miles.

Gage-height record.- Graph based on two gage readings dally and flood marks.

Stage-discharge relation.- Defined by current-meter measurements below 1,590 secondfeet; extended to peak stage on besis of slope-area determinations of flood flow.

Maxima.- September 1938: Discharge, 3,850 second-feet 7 a.m. Sept. 22 (gage he1ght, 8.40 feet, from flood marks).

1924 to August 1938: Discharge, 4,680 second-feet (revised) Mar. 19, 1936 (gage helght, 9.30 feet, from flood marks).

Remarks.- Flood run-off slightly affected by artificial.and natural storage.

Mean dally discharge, in second-feet, 3938

\begin{tabular}{|c|c|r||r|r|r||r|r|r|r|r|r|}
\hline Day & Sept. & 0ct. & Day & Sept. & 0ct. & Day & Sept. & 0ct. & Day & Sept. & Oct. \\
\hline 1 & 14 & 131 & 9 & 9.8 & 49 & 17 & 70 & 33 & 25 & 550 & 156 \\
2 & 17 & 115 & 10 & 9.8 & 48 & 18 & 67 & 32 & 26 & 387 & 182 \\
3 & 16 & 94 & 11 & 9.2 & 43 & 19 & 105 & 32 & 27 & 286 & 176 \\
4 & 14 & 79 & 12 & 8.0 & 40 & 20 & 473 & 32 & 28 & 235 & 156 \\
5 & 12 & 71 & 13 & 12 & 38 & 21 & 2,960 & 40 & 29 & 188 & 134 \\
6 & 10 & 66 & 14 & 16 & 37 & 22 & 3,480 & 52 & 30 & 159 & 118 \\
7 & 9.8 & 59 & 15 & 27 & 36 & 23 & 2,190 & 51 & 31 & & 103 \\
8 & 11 & 54 & 16 & 58 & 34 & 24 & 987 & 75 & & \\
\hline
\end{tabular}

Gage helght, in feet, and discharge, in second-feet, at indicated time, 1938

\begin{tabular}{|c|c|c|c|c|c|c|c|c|c|c|c|c|}
\hline \multirow{2}{*}{ 里 } & Feet & Sec.ft. & Feet & Sec.ft. & Feet & Sec.ft. & Feet & Sec.ft. & Feet & Sec.ft. & Feot & Sec.ft. \\
\hline & \multicolumn{2}{|c|}{ Sept ember 18} & \multicolumn{2}{|c|}{ September 19} & \multicolumn{2}{|c|}{ September 20} & \multicolumn{2}{|c|}{ September 21} & \multicolumn{2}{|c|}{ September 22} & \multicolumn{2}{|c|}{ September 23} \\
\hline $\begin{array}{l}1 \\
2 \\
3 \\
4 \\
5 \\
6\end{array}$ & \begin{tabular}{l|}
1.56 \\
1.56 \\
1.56 \\
1.56 \\
1.56 \\
1.56
\end{tabular} & \begin{tabular}{|l|}
67 \\
67 \\
67 \\
67 \\
67 \\
67 \\
\end{tabular} & $\begin{array}{l}1.56 \\
1.56 \\
1.56 \\
1.57 \\
1.57 \\
1.59\end{array}$ & \begin{tabular}{|l|}
67 \\
67 \\
67 \\
68 \\
68 \\
70
\end{tabular} & $\begin{array}{l}2.59 \\
2.65 \\
2.72 \\
2.79 \\
2.87 \\
2.96 \\
\end{array}$ & \begin{tabular}{|l|}
213 \\
226 \\
242 \\
258 \\
277 \\
300
\end{tabular} & \begin{tabular}{|l|}
5.54 \\
5.82 \\
6.14 \\
6.49 \\
6.79 \\
7.12
\end{tabular} & $\begin{array}{l}1,460 \\
1,660 \\
1,910 \\
2,190 \\
2,430 \\
2,700\end{array}$ & $\begin{array}{l}7.82 \\
7.93 \\
8.07 \\
8.22 \\
8.33 \\
8.38\end{array}$ & $\begin{array}{l}3,330 \\
3,430 \\
3,550 \\
3,690 \\
3,790 \\
3,830\end{array}$ & $\begin{array}{l}7.25 \\
7.18 \\
7.10 \\
7.05 \\
6.98 \\
6.91\end{array}$ & $\begin{array}{l}2,820 \\
2,750 \\
2,680 \\
2,640 \\
2,580 \\
2,530\end{array}$ \\
\hline $\begin{array}{r}7 \\
8 \\
9 \\
10 \\
11 \\
N\end{array}$ & $\begin{array}{l}1.56 \\
1.56 \\
1.56 \\
1.56 \\
1.56 \\
1.56\end{array}$ & $\begin{array}{l}67 \\
67 \\
67 \\
67 \\
67 \\
67\end{array}$ & $\begin{array}{l}1.60 \\
1.65 \\
1.67 \\
1.71 \\
1.76 \\
1.80\end{array}$ & $\begin{array}{l}71 \\
76 \\
78 \\
82 \\
88 \\
92\end{array}$ & $\begin{array}{l}3.05 \\
3.12 \\
3.18 \\
3.24 \\
3.28 \\
3.31\end{array}$ & $\begin{array}{l}323 \\
342 \\
358 \\
375 \\
386 \\
395\end{array}$ & $\begin{array}{l}7.38 \\
7.59 \\
7.76 \\
7.88 \\
7.98 \\
8.02\end{array}$ & $\begin{array}{l}2,930 \\
3,120 \\
3,270 \\
3,380 \\
3,470 \\
3,510\end{array}$ & $\begin{array}{l}8.40 \\
8.39 \\
8.37 \\
8.33 \\
8.27 \\
8.21\end{array}$ & $\begin{array}{l}3,850 \\
3,840 \\
3,820 \\
3,790 \\
3,730 \\
3,680\end{array}$ & $\begin{array}{l}6.85 \\
6.78 \\
6.71 \\
6.64 \\
6.58 \\
6.50\end{array}$ & $\begin{array}{l}2,480 \\
2,420 \\
2,370 \\
2,310 \\
2,260 \\
2,200\end{array}$ \\
\hline $\begin{array}{l}1 \\
2 \\
3 \\
4 \\
5 \\
6\end{array}$ & $\begin{array}{l}1.56 \\
1.56 \\
1.56 \\
1.56 \\
1.56 \\
1.56\end{array}$ & $\begin{array}{l}67 \\
67 \\
67 \\
67 \\
67 \\
67\end{array}$ & $\begin{array}{l}1.86 \\
1.90 \\
1.94 \\
1.99 \\
2.04 \\
2.10\end{array}$ & $\begin{array}{r}99 \\
103 \\
108 \\
114 \\
120 \\
128\end{array}$ & $\begin{array}{l}3.36 \\
3.40 \\
3.48 \\
3.58 \\
3.72 \\
3.87\end{array}$ & $\begin{array}{l}409 \\
420 \\
444 \\
474 \\
519 \\
571\end{array}$ & $\begin{array}{l}8.04 \\
8.03 \\
8.01 \\
7.98 \\
7.91 \\
7.83\end{array}$ & $\begin{array}{l}3,530 \\
3,520 \\
3,500 \\
3,470 \\
3,410 \\
3,340\end{array}$ & $\begin{array}{l}8.16 \\
8.08 \\
8.00 \\
7.95 \\
7.87 \\
7.78\end{array}$ & $\begin{array}{l}3,630 \\
3,560 \\
3,490 \\
3,440 \\
3,370 \\
3,290\end{array}$ & $\begin{array}{l}6.44 \\
6.36 \\
6.28 \\
6.20 \\
6.14 \\
6.06\end{array}$ & $\begin{array}{l}2,150 \\
2,090 \\
2,020 \\
1,960 \\
1,910 \\
1,850\end{array}$ \\
\hline \multirow[t]{2}{*}{$\begin{array}{r}7 \\
8 \\
9 \\
10 \\
21 \\
M\end{array}$} & $\begin{array}{l}1.56 \\
1.56 \\
1.56 \\
1.56 \\
1.56 \\
1.56\end{array}$ & $\begin{array}{l}67 \\
67 \\
67 \\
67 \\
67 \\
67 \\
\end{array}$ & $\begin{array}{l}2.20 \\
2.25 \\
2.31 \\
2.39 \\
2.46 \\
2.52\end{array}$ & $\begin{array}{l}143 \\
151 \\
161 \\
174 \\
187 \\
199\end{array}$ & $\begin{array}{l}4.01 \\
4.18 \\
4.41 \\
4.68 \\
4.98 \\
5.25\end{array}$ & $\begin{array}{r}624 \\
692 \\
784 \\
910 \\
1,070 \\
1,260 \\
\end{array}$ & $\begin{array}{l}7.75 \\
7.67 \\
7.62 \\
7.62 \\
7.67 \\
7.74\end{array}$ & $\begin{array}{l}3,260 \\
3,190 \\
3,150 \\
3,150 \\
3,190 \\
3,260\end{array}$ & $\begin{array}{l}7.70 \\
7.62 \\
7.54 \\
7.45 \\
7.38 \\
7.31 \\
\end{array}$ & $\begin{array}{l}3,220 \\
3,150 \\
3,080 \\
3,000 \\
2,930 \\
2,870\end{array}$ & $\begin{array}{l}6.00 \\
5.90 \\
5.82 \\
5.74 \\
5.66 \\
5.57\end{array}$ & $\begin{array}{l}1,800 \\
1,720 \\
1,660 \\
1,600 \\
1,540 \\
1,480\end{array}$ \\
\hline & \multicolumn{2}{|c|}{ September 24} & \multicolumn{2}{|c|}{ September 25} & \multicolumn{2}{|c|}{ September 26} & \multicolumn{2}{|c|}{ September 27} & \multicolumn{2}{|c|}{ September 2B } & \multicolumn{2}{|c|}{ September 29} \\
\hline $\begin{array}{r}2 \\
4 \\
6 \\
8 \\
10 \\
N\end{array}$ & $\begin{array}{l}5.40 \\
5.25 \\
5.09 \\
4.95 \\
4.84 \\
4.72\end{array}$ & $\begin{array}{r}1,360 \\
1,260 \\
1,140 \\
1,050 \\
990 \\
930\end{array}$ & \begin{tabular}{|l|}
4.10 \\
4.02 \\
3.95 \\
3.88 \\
3.81 \\
3.78 \\
\end{tabular} & $\begin{array}{r}660 \\
628 \\
601 \\
575 \\
550 \\
539\end{array}$ & \begin{tabular}{|l|}
3.48 \\
3.44 \\
3.40 \\
3.36 \\
3.32 \\
3.28 \\
\end{tabular} & \begin{tabular}{|l|}
444 \\
432 \\
420 \\
409 \\
398 \\
386
\end{tabular} & \begin{tabular}{|l|}
3.02 \\
2.99 \\
2.97 \\
2.94 \\
2.91 \\
2.89
\end{tabular} & $\begin{array}{l}315 \\
307 \\
302 \\
294 \\
287 \\
282\end{array}$ & $\begin{array}{l}2.78 \\
2.77 \\
2.75 \\
2.72 \\
2.70 \\
2.69\end{array}$ & $\begin{array}{l}255 \\
253 \\
248 \\
242 \\
237 \\
235\end{array}$ & $\begin{array}{l}2.56 \\
2.54 \\
2.51 \\
2.50 \\
2.48 \\
2.46\end{array}$ & $\begin{array}{l}20 \\
19 \\
19 \\
19 \\
18\end{array}$ \\
\hline $\begin{array}{r}2 \\
4 \\
6 \\
8 \\
10 \\
M\end{array}$ & $\begin{array}{l}4.62 \\
4.53 \\
4.45 \\
4.37 \\
4.29 \\
4.19\end{array}$ & $\begin{array}{l}880 \\
838 \\
802 \\
768 \\
736 \\
696 \\
\end{array}$ & $\begin{array}{l}3.73 \\
3.68 \\
3.64 \\
3.61 \\
3.57 \\
3.52\end{array}$ & $\begin{array}{l}522 \\
506 \\
493 \\
483 \\
471 \\
456\end{array}$ & $\begin{array}{l}3.24 \\
3.20 \\
3.16 \\
3.1 .3 \\
3.09 \\
3.05\end{array}$ & $\begin{array}{l}375 \\
364 \\
353 \\
344 \\
333 \\
323 \\
\end{array}$ & $\begin{array}{l}2.88 \\
2.86 \\
2.84 \\
2.82 \\
2.81 \\
2.80\end{array}$ & $\begin{array}{l}279 \\
274 \\
270 \\
265 \\
262 \\
260\end{array}$ & $\begin{array}{l}2.68 \\
2.66 \\
2.64 \\
2.62 \\
2.60 \\
2.58 \\
\end{array}$ & $\begin{array}{l}233 \\
228 \\
224 \\
219 \\
215 \\
211 \\
\end{array}$ & $\begin{array}{l}2.45 \\
2.42 \\
2.41 \\
2.40 \\
2.38 \\
2.36 \\
\end{array}$ & $\begin{array}{l}186 \\
180 \\
178 \\
176 \\
173 \\
169 \\
\end{array}$ \\
\hline
\end{tabular}


North Branch of Contoocook River near Antrim, N. H. (revision of 1936 records) 의

Location.- Float gage, lat. $43^{\circ} 04^{\prime} 55^{\prime \prime}$, long. $71^{\circ} 58^{\prime} 40^{n}$, at North Branch, Hillsboro County, 4 miles northwest of Antrim and 6 miles above confluence with Contoocook River. Zero of gage is 882.38 feet above mean sea level.

Drainage area.- 54.8 square miles.

Gage-helght record. - Graph based on two gage' readings daily and floodmarks. Gage helghts given to half tenths between 1.30 and 3 . I0 feet; hundredths below and tenths above these limits.

Stage-discharge relation.- Affected by ice Feb. 1 to Mar. 13. Defined by currentmeter measurements below 1,590 second-feet; extended to peak stage on basis of slopearea determinations of flood flows.

Mexima.- 1936: Discharge, 4,680 second-feet (revised) 2 to 4 p.m. Mar. 19 (gage helght, 9.30 feet, from floodmarks).

1924-1935: Discharge, 2,370 second-feet Apr. 19, 1933 (gage helght, 6.55

Remarks.- Flood run-off slightly affected by artificial and natural storage. Revised discharges for perlod Mar. 18-20 based on current-meter measurements and determina-

tions of flood flows by slope-area method and other information not available in 1936.

Mean discharge, in second-feet, 1936

\begin{tabular}{|c|c|c|c|c|c|c|c|c|c|c|c|}
\hline Day & Feb. & Mar. & Apr. & Day & Feb. & Mar. & Apr. & Day & Feb. & Mar. & Apr. \\
\hline $\begin{array}{r}1 \\
2 \\
3 \\
4 \\
5 \\
6 \\
7 \\
8 \\
9 \\
10\end{array}$ & $\begin{array}{l}40 \\
38 \\
36 \\
36 \\
36 \\
34 \\
33 \\
31 \\
29 \\
30\end{array}$ & $\begin{array}{l}31 \\
30 \\
30 \\
30 \\
32 \\
30 \\
30 \\
28 \\
27 \\
28\end{array}$ & $\begin{array}{l}395 \\
369 \\
344 \\
319 \\
272 \\
344 \\
452 \\
553 \\
485 \\
395\end{array}$ & $\begin{array}{l}11 \\
12 \\
13 \\
14 \\
15 \\
16 \\
17 \\
18 \\
19 \\
20\end{array}$ & $\begin{array}{l}30 \\
28 \\
28 \\
30 \\
32 \\
35 \\
35 \\
41 \\
47 \\
47\end{array}$ & $\begin{array}{r}43 \\
400 \\
1,100 \\
1,300 \\
1,070 \\
723 \\
613 \\
1,490 \\
4,270 \\
3,020\end{array}$ & $\begin{array}{l}319 \\
319 \\
319 \\
295 \\
261 \\
272 \\
272 \\
250 \\
229 \\
200\end{array}$ & $\begin{array}{l}21 \\
22 \\
23 \\
24 \\
25 \\
26 \\
27 \\
28 \\
29 \\
30 \\
31\end{array}$ & $\begin{array}{l}46 \\
43 \\
40 \\
38 \\
32 \\
35 \\
32 \\
35 \\
32\end{array}$ & $\begin{array}{r}1,750 \\
1,870 \\
1,440 \\
856 \\
696 \\
610 \\
610 \\
732 \\
665 \\
560 \\
475\end{array}$ & $\begin{array}{r}180 \\
162 \\
144 \\
128 \\
113 \\
100 \\
90 \\
84 \\
79 \\
74\end{array}$ \\
\hline \multicolumn{9}{|c|}{ 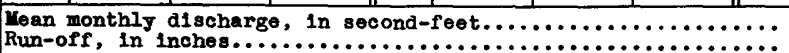 } & $\begin{array}{l}35.5 \\
0.70\end{array}$ & $\begin{array}{r}793 \\
16.72\end{array}$ & $\begin{array}{r}261 \\
5.31\end{array}$ \\
\hline
\end{tabular}

Gage-height, in feet, and discharge, in second-feet, at indicated time, 1936

\begin{tabular}{|c|c|c|c|c|c|c|c|c|c|c|c|c|}
\hline \multirow{2}{*}{ 点 } & Feet & sec.ft. & Feet & Sec.ft. & Feet & Sec.ft. & Feet & Sec.ft. & Feet & Sec.ft. & Feet & Sec.et. \\
\hline & \multicolumn{2}{|c|}{ Harch 8} & \multicolumn{2}{|c|}{ March 9} & \multicolumn{2}{|c|}{ Merch 10} & \multicolumn{2}{|c|}{ March 11} & \multicolumn{2}{|c|}{ March 12} & \multicolumn{2}{|c|}{ March 13} \\
\hline $\begin{array}{r}2 \\
4 \\
6 \\
8 \\
10 \\
1 \\
2 \\
4 \\
6 \\
8 \\
10 \\
4\end{array}$ & $\begin{array}{l}= \\
= \\
= \\
- \\
= \\
= \\
= \\
= \\
= \\
=\end{array}$ & $\begin{array}{l}= \\
= \\
= \\
= \\
= \\
= \\
= \\
= \\
=\end{array}$ & $\begin{array}{c}- \\
- \\
- \\
- \\
=1.55 \\
- \\
\overline{-} \\
\overline{-} \\
-\end{array}$ & $\begin{array}{l}= \\
= \\
= \\
= \\
= \\
= \\
= \\
= \\
=\end{array}$ & $\begin{array}{l}- \\
- \\
= \\
= \\
= \\
= \\
- \\
- \\
- \\
= \\
-\end{array}$ & $\begin{array}{c}= \\
- \\
\overline{-} \\
\overline{-} \\
* \\
\overline{-} \\
- \\
\overline{-} \\
= \\
-\end{array}$ & $\begin{array}{c}1.6 \\
- \\
- \\
1.7 \\
- \\
1.75 \\
- \\
1.8 \\
-\overline{1.95} \\
2.3\end{array}$ & $\begin{array}{c}- \\
- \\
- \\
- \\
=43 \\
- \\
= \\
= \\
- \\
-\end{array}$ & $\begin{array}{l}2.55 \\
8.85 \\
3.2 \\
3.6 \\
4.0 \\
4.3 \\
4.5 \\
4.8 \\
4.9 \\
5.1 \\
5.2 \\
5.2\end{array}$ & $\begin{array}{l}- \\
\overline{-} \\
\overline{-} \\
\overline{4} \\
= \\
- \\
= \\
= \\
=\end{array}$ & $\begin{array}{l}5.3 \\
5.3 \\
5.3 \\
5.3 \\
5.3 \\
5.3 \\
5.3 \\
5.3 \\
5.2 \\
5.2 \\
5.2 \\
5.2\end{array}$ & $\begin{array}{c}= \\
= \\
= \\
= \\
* 1,100 \\
= \\
= \\
= \\
= \\
=\end{array}$ \\
\hline & \multicolumn{2}{|c|}{ Tarch 14} & \multicolumn{2}{|c|}{ March 15} & \multicolumn{2}{|c|}{ Maroh 16} & \multicolumn{2}{|c|}{ March 17} & \multicolumn{2}{|c|}{ Harch 18} & \multicolumn{2}{|c|}{ Maroh 19} \\
\hline \multirow[t]{2}{*}{$\begin{array}{r}2 \\
4 \\
6 \\
8 \\
10 \\
1 \\
2 \\
4 \\
6 \\
8 \\
10 \\
4\end{array}$} & $\begin{array}{l}5.2 \\
5.2 \\
5.2 \\
5.3 \\
5.3 \\
5.3 \\
5.4 \\
5.4 \\
5.4 \\
5.4 \\
5.4 \\
5.3\end{array}$ & $\begin{array}{l}1,210 \\
1,210 \\
1,210 \\
1,280 \\
1,280 \\
1,280 \\
1,360 \\
1,360 \\
1,360 \\
1,360 \\
1,360 \\
1,280\end{array}$ & $\begin{array}{l}5.3 \\
5.3 \\
5.2 \\
5.1 \\
5.0 \\
5.0 \\
4.9 \\
4.9 \\
4.8 \\
4.8 \\
4.7 \\
4.6 \\
\end{array}$ & $\begin{array}{r}1,280 \\
1,280 \\
1,280 \\
1,140 \\
1,080 \\
1,080 \\
1,020 \\
1,020 \\
964 \\
964 \\
908 \\
854\end{array}$ & $\begin{array}{l}4.2 \\
4.2 \\
4.1 \\
4.1\end{array}$ & \begin{tabular}{|l}
854 \\
804 \\
804 \\
758 \\
758 \\
714 \\
714 \\
670 \\
670 \\
670 \\
630 \\
630 \\
\end{tabular} & $\begin{array}{l}4.1 \\
4.1 \\
4.0 \\
4.0 \\
4.0 \\
4.0 \\
4.0 \\
4.0 \\
4.1 \\
4.1 \\
4.1 \\
4.2\end{array}$ & \begin{tabular}{|l|}
630 \\
630 \\
590 \\
590 \\
590 \\
590 \\
590 \\
590 \\
630 \\
630 \\
630 \\
670 \\
\end{tabular} & $\begin{array}{l}4.2 \\
4.3 \\
4.3 \\
4.5 \\
4.7 \\
5.0 \\
5.3 \\
5.8 \\
6.3 \\
6.8 \\
7.2 \\
7.6 \\
\end{array}$ & $\begin{array}{r}670 \\
714 \\
714 \\
804 \\
908 \\
1,080 \\
1,280 \\
1,680 \\
2,040 \\
2,440 \\
2,770 \\
3,130 \\
\end{array}$ & $\begin{array}{l}8.0 \\
8.3 \\
8.6 \\
8.8 \\
9.0 \\
9.2 \\
9.3 \\
9.3 \\
9.3 \\
9.2 \\
9.1 \\
8.9 \\
\end{array}$ & $\begin{array}{l}3,490 \\
3,760 \\
4,030 \\
4,210 \\
4,390 \\
4,580 \\
4,680 \\
4,680 \\
4,680 \\
4,580 \\
4,480 \\
4,300 \\
\end{array}$ \\
\hline & \multicolumn{2}{|c|}{ March 20} & \multicolumn{2}{|c|}{$\operatorname{March} 21$} & \multicolumn{2}{|c|}{ March 22} & \multicolumn{2}{|c|}{ March 23} & \multicolumn{2}{|c|}{ Yarch 24} & \multicolumn{2}{|c|}{ March 25} \\
\hline $\begin{array}{r}2 \\
4 \\
6 \\
8 \\
10 \\
4 \\
2 \\
4 \\
6 \\
8 \\
10 \\
4\end{array}$ & $\begin{array}{l}8.6 \\
8.4 \\
8.2 \\
7.9 \\
7.6 \\
7.4 \\
7.2 \\
7.0 \\
6.8 \\
6.5 \\
6.3 \\
6.2\end{array}$ & $\begin{array}{l}4,030 \\
3,650 \\
3,670 \\
3,400 \\
3,130 \\
2,950 \\
2,770 \\
2,600 \\
2,440 \\
2,200 \\
2,040 \\
1,960\end{array}$ & $\begin{array}{l}5.9 \\
5.8 \\
5.7 \\
5.7 \\
5.8 \\
5.8 \\
5.9 \\
5.9 \\
6.0 \\
6.0 \\
6.0 \\
6.1\end{array}$ & $\begin{array}{l}1,760 \\
1,680 \\
1,600 \\
1,600 \\
1,680 \\
1,680 \\
1,760 \\
1,760 \\
1,840 \\
1,840 \\
1,840 \\
1,920\end{array}$ & $\begin{array}{l}6.1 \\
6.1 \\
6.1 \\
6.1 \\
6.1 \\
6.1 \\
6.0 \\
6.0 \\
6.0 \\
6.0 \\
5.9 \\
5.9\end{array}$ & $\begin{array}{l}1,920 \\
1,920 \\
1,920 \\
1,920 \\
1,920 \\
1,920 \\
1,840 \\
1,840 \\
1,840 \\
1,840 \\
1,760 \\
1,760\end{array}$ & $\begin{array}{l}5.8 \\
5.8 \\
5.7 \\
5.6 \\
5.6 \\
5.5 \\
5.5 \\
5.4 \\
5.4 \\
5.3 \\
5.2 \\
5.1\end{array}$ & $\begin{array}{l}1,680 \\
1,680 \\
1,600 \\
1,520 \\
1,520 \\
1,440 \\
1,440 \\
1,360 \\
1,360 \\
1,280 \\
1,210 \\
1,140\end{array}$ & $\begin{array}{l}5.0 \\
4.9 \\
4.8 \\
4.7 \\
4.6 \\
4.6 \\
4.5 \\
4.4 \\
4.4 \\
4.4 \\
4.4\end{array}$ & $\begin{array}{r}1,080 \\
1,020 \\
964 \\
908 \\
854 \\
854 \\
804 \\
758 \\
758 \\
758 \\
758 \\
758 \\
\end{array}$ & $\begin{array}{l}4.4 \\
4.3 \\
4.3 \\
4.3 \\
4.3 \\
4.3 \\
4.2 \\
4.2 \\
4.2 \\
4.2 \\
4.2 \\
4.2\end{array}$ & $\begin{array}{l}758 \\
714 \\
714 \\
714 \\
714 \\
714 \\
670 \\
670 \\
670 \\
670 \\
670 \\
670\end{array}$ \\
\hline
\end{tabular}

a This record supersedes that publiched in Geol. Survey Water-Supply Paper 798,

* Vlean for daj. 
Location.- Water-stage recorder, lat. $43^{\circ} 17^{\prime} 50^{\prime \prime}$, long. $71^{\circ} 41^{\prime} 40^{\prime \prime}, 0.2$ mile west of Ding 1 t Corner, $2 \frac{1}{2}$ miles southeast of Webster, Merrimack County, and $6 \frac{1}{2}$ miles above mouth of river.

Drainage area.- 129 square miles.

Gage-height record.- Water-stage recorder graph.

Stage-discharge relation.- Defined by current-meter measurements below 6,680 secondfeet; extended to peak stage on basis of determinations of flood flow by slope-area and critical depth methods.

Maxima.- September 1938: Discharge, 6,880 second-feet 6 p.m. Sept. 22 (gage height, 10.47 feet).

1918 to August 1938: D1scharge, 11,000 second-feet (revised) Mar. 19, 1936 (gage height, 11.78 feet).

Remarks.- Flood run-off not materially affected by artificial or natural storage.

Mean dally discharge, in second-feet, 1938

\begin{tabular}{|c|r|r||r|r|r||r|r|r||r|r|r|}
\hline Dey & Sept. & 0ct. & Day & Sept. & Oct. & Day & Sept. & 0ct. & Day & Sept. & Oct. \\
\hline 1 & 53 & 289 & 9 & 50 & 166 & 17 & 202 & 122 & 25 & 1,200 & 306 \\
2 & 53 & 260 & 10 & 49 & 157 & 18 & 174 & 122 & 26 & 781 & 372 \\
3 & 47 & 238 & 11 & 50 & 151 & 19 & 161 & 125 & 27 & 568 & 340 \\
4 & 45 & 221 & 12 & 51 & 146 & 20 & 417 & 126 & 28 & 448 & 260 \\
5 & 47 & 210 & 13 & 70 & 144 & 21 & 2,510 & 148 & 29 & 379 & 217 \\
6 & 43 & 202 & 14 & 124 & 139 & 22 & 6,090 & 177 & 30 & 328 & 191 \\
7 & 41 & 189 & 15 & 166 & 131 & 23 & 4,720 & 179 & 31 & & 169 \\
8 & 47 & 177 & 16 & 179 & 125 & 24 & 2,210 & 185 & & & \\
\hline
\end{tabular}

Gage height, in feet, and discharge, in second-feet, at indicated time, 1938

\begin{tabular}{|c|c|c|c|c|c|c|c|c|c|c|c|c|}
\hline \multirow{2}{*}{$\begin{array}{l}5 \\
0 \\
0 \\
0\end{array}$} & eot & Sec.ft. & Feet & Sec.ft. & Feot & Sec.ft. & Feet & Sec.ft. & Feet & Sec.ft. & Feot & Sec.ft. \\
\hline & \multicolumn{2}{|c|}{ September 18} & \multicolumn{2}{|c|}{ September 19} & \multicolumn{2}{|c|}{ September 20} & \multicolumn{2}{|c|}{ September $2 I$} & \multicolumn{2}{|c|}{ September 22} & \multicolumn{2}{|c|}{ September 23} \\
\hline $\begin{array}{l}1 \\
2 \\
3 \\
4 \\
5 \\
6\end{array}$ & $\begin{array}{l}3.32 \\
3.31 \\
3.30 \\
3.29 \\
3.28 \\
3.27\end{array}$ & & $\begin{array}{l}3.12 \\
3.12 \\
3.12 \\
3.10 \\
3.10 \\
3.10\end{array}$ & $\begin{array}{l}157 \\
157 \\
157 \\
153 \\
153 \\
153\end{array}$ & & & $\begin{array}{l}6.16 \\
6.26 \\
6.20 \\
6.08 \\
6.01 \\
6.01\end{array}$ & & & & $\begin{array}{r}10.20 \\
10.13 \\
10.03 \\
9.94 \\
9.85 \\
9.75\end{array}$ & $\begin{array}{l}6,340 \\
6,210 \\
6,040\end{array}$ \\
\hline $\begin{array}{r}7 \\
8 \\
9 \\
10 \\
11 \\
N\end{array}$ & & $\begin{array}{l}183 \\
179 \\
179 \\
177 \\
175 \\
171\end{array}$ & & $\begin{array}{l}151 \\
150 \\
150 \\
148 \\
148 \\
148\end{array}$ & & $\begin{array}{l}278 \\
292 \\
306 \\
320 \\
349 \\
389\end{array}$ & & $\begin{array}{l}500 \\
600 \\
40 \\
60 \\
60 \\
10\end{array}$ & & & & \\
\hline $\begin{array}{l}1 \\
2 \\
3 \\
4 \\
5 \\
6\end{array}$ & $\begin{array}{l}3.19 \\
3.18 \\
3.18 \\
3.17 \\
3.17 \\
3.16\end{array}$ & $\begin{array}{l}169 \\
167 \\
167 \\
166 \\
166 \\
164\end{array}$ & $\begin{array}{l}3.06 \\
3.06 \\
3.06 \\
3.08 \\
3.16 \\
3.19\end{array}$ & $\begin{array}{l}146 \\
146 \\
146 \\
150 \\
164 \\
169\end{array}$ & & $\begin{array}{l}413 \\
434 \\
449 \\
453 \\
453 \\
464\end{array}$ & $\begin{array}{l}7.38 \\
7.48 \\
7.59 \\
7.73 \\
7.88 \\
8.05\end{array}$ & $\begin{array}{l}2,580 \\
2,680 \\
2,790 \\
2,940 \\
3,110 \\
3,300\end{array}$ & & & & \\
\hline \multirow[t]{2}{*}{$\begin{array}{r}7 \\
8 \\
9 \\
10 \\
11 \\
M\end{array}$} & $\begin{array}{l}3.15 \\
3.14 \\
3.14 \\
3.14 \\
3.13 \\
3.12\end{array}$ & $\begin{array}{l}162 \\
160 \\
160 \\
160 \\
158 \\
157\end{array}$ & $\begin{array}{l}3.25 \\
3.27 \\
3.28 \\
3.29 \\
3.30 \\
3.31 \\
\end{array}$ & $\begin{array}{l}181 \\
185 \\
187 \\
189 \\
191 \\
193\end{array}$ & & $\begin{array}{r}495 \\
544 \\
632 \\
779 \\
919 \\
1,200 \\
\end{array}$ & $\begin{array}{l}8.18 \\
8.29 \\
8.42 \\
8.57 \\
8.70 \\
8.80\end{array}$ & & & & & \\
\hline & \multicolumn{2}{|c|}{ September 24} & \multicolumn{2}{|c|}{ September 25} & \multicolumn{2}{|c|}{ September 26} & \multicolumn{2}{|c|}{ September 27} & \multicolumn{2}{|c|}{ September 28 . } & \multicolumn{2}{|c|}{ September 29} \\
\hline $\begin{array}{r}2 \\
4 \\
6 \\
8 \\
10 \\
N\end{array}$ & & & & & & & & $\begin{array}{l}641 \\
623 \\
609 \\
591 \\
574 \\
561\end{array}$ & & & & \\
\hline $\begin{array}{r}2 \\
4 \\
6 \\
8 \\
10 \\
M\end{array}$ & $\begin{array}{l}6.7 \\
6.6 \\
6.5 \\
6.4 \\
6.3 \\
6.18\end{array}$ & $\begin{array}{l}2,0 \\
1,9 \\
1,8 \\
1,7 \\
1,6 \\
1,5\end{array}$ & $\begin{array}{l}5.53 \\
5.46 \\
5.40 \\
5.34 \\
5.28 \\
5.23\end{array}$ & $\begin{array}{l}967 \\
937\end{array}$ & $\begin{array}{l}4.90 \\
4.85 \\
4.82 \\
4.78 \\
4.75 \\
4.71\end{array}$ & $\begin{array}{l}753 \\
728 \\
713 \\
693 \\
679 \\
660\end{array}$ & $\begin{array}{l}4.45 \\
4.42 \\
4.38 \\
4.36 \\
4.33\end{array}$ & $\begin{array}{l}548 \\
544 \\
531 \\
515 \\
507 \\
495\end{array}$ & $\begin{array}{l}4.17 \\
4.15 \\
4.13 \\
4.12 \\
4.10\end{array}$ & $\begin{array}{l}420 \\
416 \\
409\end{array}$ & & $\begin{array}{l}372 \\
369 \\
365\end{array}$ \\
\hline
\end{tabular}

$227007 \mathrm{O}-40-0$. 
Blackwater River near Webster, N. H. (revision of 1936 records) a/

Location. - Water-stage recorder, lat. $43^{\circ} 17^{\prime} 50^{n}$, long. $71^{\circ} 41 ' 40^{\prime \prime}, 0.2$ mile west of Dingit Comer, $2 \frac{1}{2}$ miles southeast of Webster, and $6 \frac{1}{2}$ miles above mouth of river. Drainage area. - 129 square miles.

Gage-helght record. - Water-stage recorder graph except for period 1 a.m. Mar. 13 to $112 . \mathrm{m}$. Mar. 24, record for which was based on floodmarks and shape of stage grephs at nearby stations. Gage heights given to half tenths between 5.10 and 8.40 feet; hundredths below and tenths above these limits.

Stage-discharge relation.- Affected by 1ce Feb. 1 to Mar. 10. Defined by currentmeter megsurements below 6,680 second-feet; extended to peak stage on basis of determinations of flood flow by slope-area and critical-depth methods.

Maxima.- 1936: Discharge, 11,000 second-feet (revised) 8 p.m. Har. 19 (gage hefght, 11.78 feet, from floodmarks).

1918-1935: Discharge, 2,920 second-feet Apr. 14, 1934 (gage he1ght, 16.31 feet, former site and datum near Contoocook).

Remarks. - Flood run-off not materially affected by artificlal or natural storage. Kevised discharge for perlod Mar. 12 to Apr. 19 based on current-meter measurements and determinations of flood flow by siope-area and critical-depth methods and other information not avallable in 1936.

- Mean daily discharge, in second-feet, 1936

\begin{tabular}{|r|r|r|r||r|r|r|r||r|r|r|r|}
\hline Day & Feb. & Mar. & Apr. & Day & Feb. & Mar. & Apr. & Day & Feb. & Mar. & Apr. \\
\hline 1 & 100 & 84 & 753 & 11 & 80 & 114 & 703 & 21 & 84 & 2,430 & 406 \\
2 & 98 & 84 & 663 & 12 & 79 & 372 & 703 & 22 & 84 & 2,520 & 375 \\
3 & 95 & 84 & 655 & 13 & 79 & 1,790 & 753 & 23 & 82 & 2,610 & 354 \\
4 & 95 & 85 & 655 & 14 & 80 & 3,190 & 703 & 24 & 81 & 1,910 & 315 \\
5 & 97 & 88 & 632 & 15 & 80 & 1,790 & 609 & 25 & 80 & 1,460 & 289 \\
6 & 96 & 90 & 718 & 16 & 76 & 1,270 & 565 & 26 & 82 & 1,300 & 272 \\
7 & 93 & 90 & 1,200 & 17 & 82 & 1,220 & 587 & 27 & 84 & 1,240 & 254 \\
8 & 88 & 90 & 1,440 & 18 & 85 & 1,740 & 632 & 28 & 84 & 1,170 & 241 \\
9 & 85 & 92 & 1,070 & 19 & 84 & 8,030 & 540 & 29 & 84 & 1,170 & 232 \\
10 & 82 & 98 & 805 & 20 & 83 & 5,090 & 462 & 30 & & 1,040 & 230 \\
& & &
\end{tabular}

Gage height, in feet, and discharge, in second-feet, at indicated time, 1936

\begin{tabular}{|c|c|c|c|c|c|c|c|c|c|c|c|c|}
\hline \multirow{2}{*}{ 韋 } & Feet & ec.ft. & Feet & ec.ft. & Feet & iec.ft. & Feet & ec.ft. & Feet & ec.ft. & Feet & Sec.ft. \\
\hline & \multicolumn{2}{|c|}{ March 8} & \multicolumn{2}{|c|}{$\operatorname{March} 9$} & \multicolumn{2}{|c|}{ March 10} & \multicolumn{2}{|c|}{ March 11} & \multicolumn{2}{|c|}{ March 12} & \multicolumn{2}{|c|}{ March 13} \\
\hline 2 & - & - & - & - & - & - & - & - & 2.99 & 143 & 4.93 & 769 \\
\hline 4 & - & - & - & & - & & - & 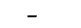 & & & & 822 \\
\hline 6 & - & - & - & - & - & & 2.77 & - & & 184 & & 919 \\
\hline 8 & - & & - & - & - & - & - & & & 11 & & 1,040 \\
\hline 10 & - & & - & & - & - & - & & & 267 & & 1,240 \\
\hline$N$ & $* 2.68$ & $* 90$ & $* 2.71$ & $* 92$ & $* 2.76$ & $* 98$ & $* 2.79$ & *114 & & 348 & & 1,440 \\
\hline 2 & - & - & - & - & - & - & - & - & & 422 & & 1,810 \\
\hline 4 & - & - & - & - & - & - & 2.83 & - & & & & 2,100 \\
\hline 6 & - & - & - & - & - & - & - & - & & 52 & & 2,550 \\
\hline 8 & - & - & - & - & - & - & 2.86 & - & & 605 & & \\
\hline \multirow{3}{*}{$\begin{array}{r}10 \\
M\end{array}$} & - & - & - & - & - & - & - & - & & 655 & & 3,410 \\
\hline & - & - & - & - & - & - & 2.85 & - & 4.83 & 718 & & 3,710 \\
\hline & \multicolumn{2}{|c|}{ March 14} & \multicolumn{2}{|c|}{ March 15} & \multicolumn{2}{|c|}{ March 16} & \multicolumn{2}{|c|}{ March 17} & \multicolumn{2}{|c|}{ March 18} & \multicolumn{2}{|c|}{ March 19} \\
\hline 2 & 8.4 & 3,710 & 6.95 & 2,180 & 5.9 & 1,370 & 5.65 & 1,200 & 5.8 & 1,300 & 8.4 & 3,710 \\
\hline 4 & 8.5 & & & & & & 5.65 & & & & & 4,480 \\
\hline 6 & 8.4 & & 6.7 & & 5.8 & & 5.65 & & & & & 5,360 \\
\hline 8 & 8.35 & & 6 & & & & 5.65 & & & & & 6,340 \\
\hline 10 & 8.2 & & 6.55 & & 5. & & 5.65 & & & & & 7,890 \\
\hline $\mathrm{N}$ & 8.0 & & 6.4 & 1,7 & 5.7 & & 5.65 & & & & & 9,430 \\
\hline 2 & 7.85 & & 6.35 & & & & 5.7 & & & & & 10,600 \\
\hline 4 & 7.7 & & 5 & & & & 5.7 & & & & & 10 \\
\hline 6 & 7 & & 2 & 1 & & & 5.7 & & & & & \\
\hline 8 & & & & & & & 5.7 & & & & & \\
\hline \multirow{3}{*}{$\begin{array}{r}10 \\
M \\
\end{array}$} & 7.2 & 0 & 6.05 & & 5.6 & & 5.75 & & & & & 10,200 \\
\hline & 7.05 & & 5.95 & 1,4 & 5.65 & 1,200 & 5.75 & 1,270 & 7.8 & 3,020 & 11.3 & 9,080 \\
\hline & \multicolumn{2}{|c|}{ March 20} & \multicolumn{2}{|c|}{ March 21} & \multicolumn{2}{|c|}{ March 22} & \multicolumn{2}{|c|}{ March 23} & \multicolumn{2}{|c|}{ March 24} & \multicolumn{2}{|c|}{ March 25} \\
\hline 2 & 10.9 & 7,890 & 7.85 & 3,080 & 6.45 & 1,770 & 7.8 & 3,020 & 6.95 & 2,180 & 6.2 & 1,580 \\
\hline 4 & & & & & & & 7.6 & & & & & \\
\hline 6 & & & 7.6 & & & & 7.5 & & & & & \\
\hline 8 & & & & & & & 7.45 & & & & & \\
\hline 10 & & & 7. & & & & 7.4 & & & & & \\
\hline $\mathbf{N}$ & & & 7.2 & & 6 & & 7.4 & & 6.65 & & 6.0 & 1,44 \\
\hline 2 & & & & & & & & & & & & \\
\hline 4 & 8 & & 6.85 & & & & 7.2 & & & & & \\
\hline 6 & 8 & & 6.7 & & & & 7.2 & & & & & 1,400 \\
\hline 8 & & & & & & & 7.15 & & & & & 1,370 \\
\hline 10 & & & 6.6 & & & & 7.05 & & & & & 1,370 \\
\hline M & & & & & & & & & & & & 1,3 \\
\hline
\end{tabular}

a This record supersedes that published in Geol. Survey Water-Supply Paper 798, p. 161 .

* Mean for day. 
Suncook PHes at Horth Chichester, N. H.

Location. - Water-stage recorder and concrete control, lat. $43^{\circ} 15^{\prime} 45^{\prime \prime}, 10 n g .71^{\circ} 22^{\prime} 10^{\prime \prime}$, at North Chichester, Merrimack County, 3.1 miles above mouth of Little Suncook River. Zero of gage is 329.35 feet above mean sea level (general adjustment of 1912 ). Drainage area.- 157 square miles.

Gage-neight record.- Water-stage recorder graph.

Stage-discharge relation.- Defined by current-meter measurements below 4,780 secondfeet; extended to peak stage on basis of average discharge determined by slope-area and contracted-opening metnods.

Maxima.- September 1938: Discharge, 2,110 second-feet 10 a.m. Sept. 21 (gage height, 8.96 feet) 1918 to August 1938: Discharge, 12,900 second-feet Mar. 19, 1936 (gage he1ght, 15.27 feet).

Remarks.- Flood flow not materially affected by artificial or natural storage.

Mean delly discharge, in second-feet, 1938

\begin{tabular}{|c|c|c|c|c|c|c|c|c|c|c|c|}
\hline Day & Sept. & Oct. & Day & Sept. & Oct. & Day & Sept. & Oct. & Day & Sept. & Oct. \\
\hline $\begin{array}{l}1 \\
2 \\
3 \\
4 \\
5 \\
6 \\
7 \\
8\end{array}$ & $\begin{array}{l}51 \\
50 \\
43 \\
37 \\
34 \\
36 \\
56 \\
60\end{array}$ & $\begin{array}{l}144 \\
155 \\
253 \\
264 \\
253 \\
261 \\
255 \\
137\end{array}$ & $\begin{array}{r}9 \\
10 \\
11 \\
12 \\
13 \\
14 \\
15 \\
16\end{array}$ & $\begin{array}{r}50 \\
55 \\
44 \\
48 \\
114 \\
121 \\
132 \\
165\end{array}$ & $\begin{array}{r}105 \\
228 \\
248 \\
245 \\
258 \\
242 \\
123 \\
38\end{array}$ & $\begin{array}{l}17 \\
18 \\
19 \\
20 \\
21 \\
22 \\
23 \\
24\end{array}$ & $\begin{array}{r}116 \\
110 \\
169 \\
991 \\
1,880 \\
1,520 \\
1,020 \\
555\end{array}$ & $\begin{array}{r}170 \\
254 \\
260 \\
246 \\
275 \\
136 \\
51 \\
233\end{array}$ & $\begin{array}{l}25 \\
26 \\
27 \\
28 \\
29 \\
30 \\
31\end{array}$ & $\begin{array}{l}401 \\
338 \\
298 \\
304 \\
287 \\
285\end{array}$ & $\begin{array}{l}577 \\
367 \\
279 \\
274 \\
133 \\
103 \\
195\end{array}$ \\
\hline $\begin{array}{l}\text { Mean } \\
\text { Run- }\end{array}$ & $\begin{array}{l}\text { onthly } \\
f \text {, in }\end{array}$ & $\begin{array}{l}\text { Lschare } \\
\text { shes. }\end{array}$ & : 1 & $\begin{array}{c}\text { second- } \\
. \text {. }\end{array}$ & et. & $\dot{\cdot} \cdot \dot{ }$ & . $: \dot{ }$ & . : & $\dot{.} \dot{ }$ & $\begin{array}{r}312 \\
2.22\end{array}$ & $\begin{array}{r}218 \\
1.60 \\
\end{array}$ \\
\hline
\end{tabular}

Gage height, in feet, and discharge, in second-feet, at indicated time, 1938

\begin{tabular}{|c|c|c|c|c|c|c|c|c|c|c|c|c|c|c|c|}
\hline \multirow{2}{*}{ 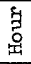 } & Feet & Sec & .ft. & Feet & Sec & . ft. & Feet & Sec & . ft. & Feet & Sec.ft. & Feet & Sec.ft. & Feet & Sec.ft. \\
\hline & \multicolumn{3}{|c|}{ September 18} & \multicolumn{3}{|c|}{ September 19} & \multicolumn{3}{|c|}{ September 20} & \multicolumn{2}{|c|}{ September 21} & \multicolumn{2}{|c|}{ September 22} & \multicolumn{2}{|c|}{ September 23} \\
\hline $\begin{array}{l}1 \\
2 \\
3 \\
4 \\
5 \\
6\end{array}$ & $\begin{array}{l}3.35 \\
3.36 \\
3.37 \\
3.38 \\
3.39 \\
3.39\end{array}$ & & $\begin{array}{l}103 \\
105 \\
107 \\
110 \\
112 \\
112\end{array}$ & $\begin{array}{l}3.38 \\
3.39 \\
3.40 \\
3.41 \\
3.43 \\
3.44\end{array}$ & & $\begin{array}{l}110 \\
112 \\
114 \\
116 \\
121 \\
124\end{array}$ & $\begin{array}{l}4.14 \\
4.31 \\
4.33 \\
4.33 \\
4.34 \\
4.42\end{array}$ & & $\begin{array}{l}356 \\
433 \\
442 \\
442 \\
447 \\
487\end{array}$ & $\begin{array}{l}7.75 \\
7.73 \\
7.84 \\
8.02 \\
8.22 \\
8.38\end{array}$ & $\begin{array}{l}1,520 \\
1,520 \\
1,550 \\
1,620 \\
1,710 \\
1,790\end{array}$ & \begin{tabular}{|l|}
8.39 \\
8.32 \\
8.28 \\
8.21 \\
8.11 \\
8.10
\end{tabular} & $\begin{array}{l}1,800 \\
1,760 \\
1,740 \\
1,700 \\
1,680 \\
1,660\end{array}$ & $\begin{array}{l}6.51 \\
6.46 \\
6.39 \\
6.30 \\
6.21 \\
6.13\end{array}$ & $\begin{array}{l}1,210 \\
1,200 \\
1,180 \\
1,160 \\
1,140 \\
1,120\end{array}$ \\
\hline $\begin{array}{r}7 \\
8 \\
9 \\
10 \\
11 \\
\text { N }\end{array}$ & $\begin{array}{l}3.40 \\
3.40 \\
3.40 \\
3.40 \\
3.40 \\
3.40\end{array}$ & & $\begin{array}{l}114 \\
114 \\
114 \\
114 \\
114 \\
114\end{array}$ & $\begin{array}{l}3.47 \\
3.49 \\
3.50 \\
3.51 \\
3.55 \\
3.58\end{array}$ & & $\begin{array}{l}131 \\
136 \\
138 \\
141 \\
152 \\
160\end{array}$ & $\begin{array}{l}4.51 \\
4.67 \\
4.92 \\
4.91 \\
5.00 \\
5.21\end{array}$ & & $\begin{array}{l}535 \\
627 \\
756 \\
751 \\
790 \\
870\end{array}$ & $\begin{array}{l}8.51 \\
8.68 \\
8.91 \\
8.96 \\
8.95 \\
8.94\end{array}$ & $\begin{array}{l}1,860 \\
1,940 \\
2,080 \\
2,110 \\
2,100 \\
2,090\end{array}$ & $\begin{array}{l}8.04 \\
8.08 \\
7.91 \\
7.85 \\
7.81 \\
7.74\end{array}$ & $\begin{array}{l}1,630 \\
1,650 \\
1,580 \\
1,560 \\
1,540 \\
1,520\end{array}$ & $\begin{array}{l}6.05 \\
6.08 \\
6.01 \\
5.92 \\
5.85 \\
5.76\end{array}$ & $\begin{array}{l}1,110 \\
1,110 \\
1,100 \\
1,080 \\
1,060 \\
1,040\end{array}$ \\
\hline $\begin{array}{l}1 \\
2 \\
3 \\
4 \\
5 \\
6\end{array}$ & $\begin{array}{l}3.40 \\
3.37 \\
3.37 \\
3.37 \\
3.35 \\
3.37\end{array}$ & & $\begin{array}{l}114 \\
107 \\
107 \\
107 \\
103 \\
107\end{array}$ & $\begin{array}{l}3.61 \\
3.62 \\
3.62 \\
3.62 \\
3.63 \\
3.67\end{array}$ & & $\begin{array}{l}168 \\
171 \\
171 \\
171 \\
174 \\
185\end{array}$ & $\begin{array}{l}5.61 \\
6.17 \\
6.97 \\
7.40 \\
7.64 \\
7.81\end{array}$ & & $\begin{array}{l}997 \\
, 130 \\
, 310 \\
, 420 \\
490 \\
, 540\end{array}$ & $\begin{array}{l}8.91 \\
8.87 \\
8.81 \\
8.76 \\
8.72 \\
8.71\end{array}$ & $\begin{array}{l}2,080 \\
2,050 \\
2,020 \\
1,990 \\
1,970 \\
1,960\end{array}$ & $\begin{array}{l}7.66 \\
7.59 \\
7.50 \\
7.41 \\
7.32 \\
7.23\end{array}$ & $\begin{array}{l}1,500 \\
1,480 \\
1,450 \\
1,420 \\
1,400 \\
1,380\end{array}$ & $\begin{array}{l}5.67 \\
5.59 \\
5.52 \\
5.46 \\
5.38 \\
5.32\end{array}$ & $\begin{array}{r}1,010 \\
991 \\
971 \\
953 \\
927 \\
908\end{array}$ \\
\hline \multirow[t]{2}{*}{$\begin{array}{r}7 \\
8 \\
9 \\
10 \\
11 \\
M\end{array}$} & $\begin{array}{l}3.40 \\
3.39 \\
3.38 \\
3.38 \\
3.38 \\
3.38\end{array}$ & & $\begin{array}{l}114 \\
112 \\
110 \\
110 \\
110 \\
110\end{array}$ & $\begin{array}{l}3.71 \\
3.77 \\
3.83 \\
3.93 \\
4.03 \\
4.10\end{array}$ & & $\begin{array}{l}197 \\
216 \\
236 \\
271 \\
309 \\
338\end{array}$ & $\begin{array}{l}7.95 \\
8.01 \\
8.02 \\
7.99 \\
7.93 \\
7.86\end{array}$ & & $\begin{array}{l}, 590 \\
, 610 \\
, 620 \\
, 610 \\
580 \\
560\end{array}$ & $\begin{array}{l}8.71 \\
8.70 \\
8.65 \\
8.49 \\
8.45 \\
8.42\end{array}$ & $\begin{array}{l}1,960 \\
1,960 \\
1,930 \\
1,840 \\
1,820 \\
1,810\end{array}$ & $\begin{array}{l}7.13 \\
7.04 \\
6.93 \\
6.84 \\
6.77 \\
6.60\end{array}$ & $\begin{array}{l}1,350 \\
1,330 \\
1,300 \\
1,280 \\
1,260 \\
1,230\end{array}$ & $\begin{array}{l}5.24 \\
5.19 \\
5.11 \\
5.07 \\
5.02 \\
4.89\end{array}$ & $\begin{array}{l}880 \\
862 \\
833 \\
817 \\
798 \\
742\end{array}$ \\
\hline & \multicolumn{2}{|c|}{ September } & 24 & \multicolumn{2}{|c|}{ September } & 25 & \multicolumn{2}{|c|}{ September } & 26 & \multicolumn{2}{|c|}{ September 27} & \multicolumn{2}{|c|}{ September 28} & \multicolumn{2}{|c|}{ September 29} \\
\hline $\begin{array}{r}2 \\
4 \\
6 \\
8 \\
10 \\
N\end{array}$ & $\begin{array}{l}4.86 \\
4.85 \\
4.79 \\
4.64 \\
4.63 \\
4.68\end{array}$ & & $\begin{array}{l}728 \\
723 \\
694 \\
609 \\
603 \\
632\end{array}$ & $\begin{array}{l}4.35 \\
4.31 \\
4.30 \\
4.29 \\
4.26 \\
4.24\end{array}$ & & $\begin{array}{l}452 \\
433 \\
428 \\
423 \\
410 \\
400\end{array}$ & \begin{tabular}{|l|}
4.11 \\
4.10 \\
4.08 \\
4.06 \\
4.30 \\
4.17
\end{tabular} & & $\begin{array}{l}342 \\
338 \\
330 \\
322 \\
428 \\
369\end{array}$ & $\begin{array}{l}3.81 \\
3.78 \\
3.78 \\
3.87 \\
4.06 \\
4.07\end{array}$ & \begin{tabular}{|l|}
229 \\
220 \\
220 \\
250 \\
322 \\
326
\end{tabular} & $\begin{array}{l}3.90 \\
3.87 \\
3.85 \\
3.86 \\
4.08 \\
4.10\end{array}$ & \begin{tabular}{|l|}
260 \\
250 \\
243 \\
246 \\
330 \\
338 \\
\end{tabular} & $\begin{array}{l}3.83 \\
3.77 \\
3.82 \\
3.87 \\
4.08 \\
4.07\end{array}$ & $\begin{array}{l}236 \\
216 \\
233 \\
250 \\
330 \\
326\end{array}$ \\
\hline $\begin{array}{r}2 \\
4 \\
6 \\
8 \\
10 \\
M\end{array}$ & $\begin{array}{l}4.67 \\
4.20 \\
3.63 \\
4.28 \\
4.38 \\
4.38\end{array}$ & & $\begin{array}{l}627 \\
382 \\
174 \\
419 \\
467 \\
467\end{array}$ & $\begin{array}{l}4.22 \\
4.19 \\
4.18 \\
4.16 \\
4.14 \\
4.12\end{array}$ & & $\begin{array}{l}392 \\
378 \\
373 \\
364 \\
356 \\
347\end{array}$ & $\begin{array}{l}4.09 \\
4.06 \\
4.05 \\
4.03 \\
4.04 \\
4.03\end{array}$ & & $\begin{array}{l}334 \\
322 \\
318 \\
309 \\
313 \\
309\end{array}$ & $\begin{array}{l}4.07 \\
4.09 \\
4.11 \\
4.10 \\
4.11 \\
4.10\end{array}$ & $\begin{array}{l}326 \\
334 \\
342 \\
338 \\
342 \\
338\end{array}$ & $\begin{array}{l}4.10 \\
4.10 \\
4.08 \\
4.04 \\
4.09 \\
4.05\end{array}$ & $\begin{array}{l}338 \\
338 \\
330 \\
313 \\
334 \\
318\end{array}$ & $\begin{array}{l}4.03 \\
4.03 \\
4.03 \\
4.03 \\
4.03 \\
4.03\end{array}$ & $\begin{array}{l}309 \\
309 \\
309 \\
309 \\
309 \\
309\end{array}$ \\
\hline
\end{tabular}




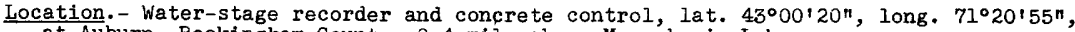
at Auburn, Rockingham County, 0.4 mile above Massabesic Lake.

prainage area.- 27.7 square miles.

Gage-height record.- Water-stage recorder graph.

Stage-discharge relation.- Defined by current-meter measurements.

Maxima.- September 1938: Discharge, 218 second-feet noon to 5 p.m. Sept. 21 (gage height, 1.75 feet).

January to August 1938: Discharge, 290 second-feet July 30, 1938 (gage

height, 1.94 feet)

Remarks.- Run-off affected by natural storage.

Mean da1ly discharge, in second-feet, 1938

\begin{tabular}{|c|c|c|c|c|c|c|c|c|c|c|c|}
\hline Day & Sept. & Oct. & Day & Sept. & Oct. & Day & Sept. & Oct. & Day & Sept. & Oct. \\
\hline $\begin{array}{l}1 \\
2 \\
3 \\
4 \\
5 \\
6 \\
7 \\
8\end{array}$ & $\begin{array}{l}19 \\
18 \\
17 \\
14 \\
14 \\
14 \\
17 \\
17\end{array}$ & $\begin{array}{l}81 \\
75 \\
73 \\
70 \\
62 \\
60 \\
57 \\
53\end{array}$ & $\begin{array}{r}9 \\
10 \\
11 \\
12 \\
13 \\
14 \\
15 \\
16\end{array}$ & $\begin{array}{l}16 \\
13 \\
12 \\
14 \\
16 \\
23 \\
24 \\
32\end{array}$ & $\begin{array}{l}46 \\
44 \\
38 \\
33 \\
32 \\
31 \\
27 \\
20\end{array}$ & $\begin{array}{l}17 \\
18 \\
19 \\
20 \\
21 \\
22 \\
23 \\
24\end{array}$ & $\begin{array}{r}32 \\
29 \\
35 \\
98 \\
205 \\
199 \\
169 \\
150\end{array}$ & $\begin{array}{l}27 \\
27 \\
28 \\
27 \\
32 \\
36 \\
27 \\
30\end{array}$ & $\begin{array}{l}25 \\
26 \\
27 \\
28 \\
29 \\
30 \\
31\end{array}$ & $\begin{array}{r}124 \\
112 \\
108 \\
100 \\
91 \\
85\end{array}$ & $\begin{array}{l}56 \\
72 \\
80 \\
70 \\
59 \\
40 \\
42\end{array}$ \\
\hline $\begin{array}{l}\text { Mean } \\
\text { Run- }\end{array}$ & $\begin{array}{l}\text { onthly } \\
f, \ln 1\end{array}$ & $\begin{array}{l}\text { schar } \\
\text { hes. }\end{array}$ & 1 & $\begin{array}{l}\text { lecond- } \\
\text {. }\end{array}$ & et. & & $\dot{0} \cdot \dot{ }$ & $: \dot{ }$ & : & $\begin{array}{l}60.6 \\
2.44\end{array}$ & $\begin{array}{l}46.9 \\
1.95\end{array}$ \\
\hline
\end{tabular}

Gage he1ght, in feet, and discharge, in second-feet, at indicated time, 1938

\begin{tabular}{|c|c|c|c|c|c|c|c|c|c|c|c|c|c|c|c|c|}
\hline \multirow{2}{*}{$\begin{array}{l}9 \\
9 \\
0 \\
1\end{array}$} & Feet & Sec.ft. & Feet & Sec.ft. & Feet & \multicolumn{2}{|c|}{ Sec.ft. } & Feot & \multicolumn{2}{|c|}{ Sec.ft. } & Feet & \multicolumn{2}{|c|}{ sec.ft. } & Feet & \multicolumn{2}{|c|}{ Sec.ft. } \\
\hline & \multicolumn{2}{|c|}{ September 18} & \multicolumn{2}{|c|}{ September 19} & \multicolumn{3}{|c|}{ September 20} & \multicolumn{3}{|c|}{ September 21} & \multicolumn{3}{|c|}{ September 22} & \multicolumn{3}{|c|}{ September 23} \\
\hline $\begin{array}{l}1 \\
2 \\
3 \\
4 \\
5 \\
6\end{array}$ & $\begin{array}{l}0.80 \\
.80 \\
.80 \\
.80 \\
.79 \\
.79\end{array}$ & $\begin{array}{l}30 \\
30 \\
30 \\
30 \\
29 \\
29\end{array}$ & $\begin{array}{r}0.79 \\
.79 \\
.79 \\
.80 \\
.81 \\
.82\end{array}$ & $\begin{array}{l}29 \\
29 \\
29 \\
30 \\
31 \\
32\end{array}$ & $\begin{array}{l}0.99 \\
1.01 \\
1.03 \\
1.04 \\
1.08 \\
1.09\end{array}$ & & $\begin{array}{l}49 \\
52 \\
55 \\
56 \\
61 \\
63\end{array}$ & $\begin{array}{l}1.60 \\
1.63 \\
1.64 \\
1.66 \\
1.67 \\
1.68\end{array}$ & & $\begin{array}{l}172 \\
181 \\
184 \\
189 \\
192 \\
195\end{array}$ & $\begin{array}{l}1.74 \\
1.74 \\
1.74 \\
1.73 \\
1.73 \\
1.72\end{array}$ & & $\begin{array}{l}215 \\
215 \\
215 \\
211 \\
211 \\
208\end{array}$ & $\begin{array}{l}1.63 \\
1.63 \\
1.62 \\
1.62 \\
1.61 \\
1.60\end{array}$ & & $\begin{array}{l}181 \\
181 \\
178 \\
178 \\
175 \\
172\end{array}$ \\
\hline $\begin{array}{r}7 \\
8 \\
9 \\
10 \\
11 \\
N\end{array}$ & $\begin{array}{l}.79 \\
.79 \\
.79 \\
.78 \\
.78 \\
.78\end{array}$ & $\begin{array}{l}29 \\
29 \\
29 \\
28 \\
28 \\
28\end{array}$ & $\begin{array}{l}.82 \\
.82 \\
.82 \\
.82 \\
.82 \\
.82\end{array}$ & $\begin{array}{l}32 \\
32 \\
32 \\
32 \\
32 \\
32\end{array}$ & $\begin{array}{l}1.11 \\
1.14 \\
1.16 \\
1.18 \\
1.25 \\
1.29\end{array}$ & & $\begin{array}{l}66 \\
70 \\
73 \\
76 \\
89 \\
96\end{array}$ & $\begin{array}{l}1.69 \\
1.70 \\
1.71 \\
1.72 \\
1.73 \\
1.75\end{array}$ & & $\begin{array}{l}198 \\
201 \\
204 \\
208 \\
211 \\
218\end{array}$ & $\begin{array}{l}1.72 \\
1.71 \\
1.71 \\
1.70 \\
1.70 \\
1.70\end{array}$ & & $\begin{array}{l}208 \\
204 \\
204 \\
201 \\
201 \\
201\end{array}$ & $\begin{array}{l}1.60 \\
1.60 \\
1.60 \\
1.60 \\
1.60 \\
1.59\end{array}$ & & $\begin{array}{l}172 \\
172 \\
172 \\
172 \\
172 \\
169\end{array}$ \\
\hline $\begin{array}{l}1 \\
2 \\
3 \\
4 \\
5 \\
6\end{array}$ & $\begin{array}{l}.78 \\
.78 \\
.78 \\
.78 \\
.78 \\
.78\end{array}$ & $\begin{array}{l}28 \\
28 \\
28 \\
28 \\
28 \\
28\end{array}$ & $\begin{array}{l}.82 \\
.82 \\
.83 \\
.84 \\
.85 \\
.87\end{array}$ & $\begin{array}{l}32 \\
32 \\
33 \\
34 \\
35 \\
37\end{array}$ & $\begin{array}{l}1.30 \\
1.33 \\
1.36 \\
1.38 \\
1.42 \\
1.46\end{array}$ & & $\begin{array}{r}98 \\
105 \\
111 \\
116 \\
125 \\
135\end{array}$ & $\begin{array}{l}1.75 \\
1.75 \\
1.75 \\
1.75 \\
1.75 \\
1.74\end{array}$ & & $\begin{array}{l}218 \\
218 \\
218 \\
218 \\
218 \\
215\end{array}$ & $\begin{array}{l}1.69 \\
1.68 \\
1.68 \\
1.67 \\
1.66 \\
1.66\end{array}$ & & $\begin{array}{l}198 \\
195 \\
195 \\
192 \\
189 \\
189\end{array}$ & $\begin{array}{l}1.59 \\
1.58 \\
1.58 \\
1.57 \\
1.56 \\
1.56\end{array}$ & & $\begin{array}{l}169 \\
167 \\
167 \\
164 \\
161 \\
161\end{array}$ \\
\hline \multirow[t]{2}{*}{$\begin{array}{r}7 \\
8 \\
9 \\
10 \\
11 \\
M\end{array}$} & $\begin{array}{l}.78 \\
.78 \\
.78 \\
.78 \\
.78 \\
.78 \\
\end{array}$ & $\begin{array}{l}28 \\
28 \\
28 \\
28 \\
28 \\
28\end{array}$ & $\begin{array}{l}.90 \\
.94 \\
.94 \\
.95 \\
.97 \\
.98 \\
\end{array}$ & $\begin{array}{l}40 \\
44 \\
44 \\
45 \\
47 \\
48\end{array}$ & $\begin{array}{l}1.48 \\
1.50 \\
1.52 \\
1.54 \\
1.56 \\
1.57\end{array}$ & & $\begin{array}{l}140 \\
145 \\
150 \\
156 \\
161 \\
164\end{array}$ & $\begin{array}{l}1.74 \\
1.74 \\
1.74 \\
1.74 \\
1.74 \\
1.74\end{array}$ & & $\begin{array}{l}215 \\
215 \\
215 \\
215 \\
215 \\
215\end{array}$ & $\begin{array}{l}1.65 \\
1.65 \\
1.65 \\
1.64 \\
1.64 \\
1.64\end{array}$ & & $\begin{array}{l}186 \\
186 \\
186 \\
184 \\
184 \\
184\end{array}$ & $\begin{array}{l}1.56 \\
1.55 \\
1.55 \\
1.55 \\
1.55 \\
1.55\end{array}$ & & $\begin{array}{l}161 \\
158 \\
158 \\
158 \\
158 \\
158\end{array}$ \\
\hline & \multicolumn{2}{|c|}{ September 24} & \multicolumn{2}{|c|}{ September 25} & \multicolumn{3}{|c|}{ September 26} & \multicolumn{3}{|c|}{ September 27} & \multicolumn{3}{|c|}{ September 28} & \multicolumn{3}{|c|}{ September 29} \\
\hline $\begin{array}{r}2 \\
4 \\
6 \\
8 \\
10 \\
N\end{array}$ & $\begin{array}{l}1.55 \\
1.54 \\
1.54 \\
1.53 \\
1.53 \\
1.52\end{array}$ & $\begin{array}{l}158 \\
156 \\
156 \\
153 \\
153 \\
150\end{array}$ & $\begin{array}{l}1.46 \\
1.45 \\
1.44 \\
1.43 \\
1.41 \\
1.40\end{array}$ & $\begin{array}{l}135 \\
132 \\
130 \\
128 \\
122 \\
120\end{array}$ & $\begin{array}{l}1.38 \\
1.38 \\
1.37 \\
1.36 \\
1.36 \\
1.37\end{array}$ & & $\begin{array}{l}116 \\
116 \\
113 \\
111 \\
111 \\
113\end{array}$ & $\begin{array}{l}1.34 \\
1.35 \\
1.35 \\
1.35 \\
1.35 \\
1.36\end{array}$ & & $\begin{array}{l}107 \\
109 \\
109 \\
109 \\
109 \\
111\end{array}$ & $\begin{array}{l}1.32 \\
1.32 \\
1.32 \\
1.31 \\
1.31 \\
1.32\end{array}$ & & $\begin{array}{l}102 \\
102 \\
102 \\
100 \\
100 \\
102\end{array}$ & $\begin{array}{l}1.27 \\
1.27 \\
1.27 \\
1.27 \\
1.26 \\
1.28\end{array}$ & & $\begin{array}{l}92 \\
92 \\
92 \\
92 \\
91 \\
94\end{array}$ \\
\hline $\begin{array}{r}2 \\
4 \\
6 \\
8 \\
10 \\
M \\
\end{array}$ & $\begin{array}{l}1.51 \\
1.50 \\
1.50 \\
1.50 \\
1.49 \\
1.48\end{array}$ & $\begin{array}{l}148 \\
145 \\
145 \\
145 \\
142 \\
140 \\
\end{array}$ & $\begin{array}{l}1.40 \\
1.39 \\
1.39 \\
1.39 \\
1.38 \\
1.38\end{array}$ & $\begin{array}{l}120 \\
118 \\
118 \\
118 \\
116 \\
116\end{array}$ & $\begin{array}{l}1.36 \\
1.36 \\
1.36 \\
1.35 \\
1.34 \\
1.34\end{array}$ & & $\begin{array}{l}111 \\
111 \\
111 \\
109 \\
107 \\
107\end{array}$ & $\begin{array}{l}1.36 \\
1.35 \\
1.35 \\
1.33 \\
1.32 \\
1.32\end{array}$ & & $\begin{array}{l}111 \\
109 \\
109 \\
105 \\
102 \\
102\end{array}$ & $\begin{array}{l}1.32 \\
1.30 \\
1.30 \\
1.29 \\
1.28 \\
1.28\end{array}$ & & $\begin{array}{r}102 \\
98 \\
98 \\
96 \\
94 \\
94\end{array}$ & $\begin{array}{l}1.27 \\
1.26 \\
1.26 \\
1.25 \\
1.24 \\
1.23\end{array}$ & & $\begin{array}{l}92 \\
91 \\
91 \\
89 \\
87 \\
85\end{array}$ \\
\hline
\end{tabular}


Souhegan River at Merrimack, N. H.

Location.- Water-stage recorder, lat. $42^{\circ} 51^{\prime} 25^{\prime \prime}$, long. $71^{\circ} 30^{\prime} 30^{\prime \prime}$, at head of Atherton Falls at Merrimack, Hillsboro County, $l \frac{1}{2}$ miles above confluence with Merrimack River. Zero of gage is 160.58 feet above mean sea level.

Drainage area.- 171 square miles.

Gage-height record.- Water-stage recorder graph.

Stage-discharge relation.- Defined by current-meter measurements below 7,200 secondfeet; extended to peak stage on basis of determinations of flood flow over dam, verified by velocity-area study at measuring section.

Maxima.- September 1938: Discharge, 10,800 second-feet 11:45 p.m. Sept. 2l (gage height, 12.78 feet). ig09 to August 1938: Discharge, 16,900 second-feet Mar. 19, 1936 (gage height, 16.2 feet)

Remarks.- Flood run-off not materially affected by artificial or natural storage.

Mean daily discharge, in second-feet, 1938

\begin{tabular}{|c|c|c|c|c|c|c|c|c|c|c|c|}
\hline Day & Sept. & Oct. & Day & Sept. & $0 \mathrm{ct}$. & Day & Sept. & oct. & Day & Sept. & Oct. \\
\hline $\begin{array}{l}1 \\
2 \\
3 \\
4 \\
5 \\
6 \\
7 \\
8\end{array}$ & $\begin{array}{r}102 \\
113 \\
98 \\
81 \\
72 \\
68 \\
62 \\
84\end{array}$ & $\begin{array}{l}332 \\
308 \\
296 \\
273 \\
238 \\
235 \\
229 \\
222\end{array}$ & $\begin{array}{l}9 \\
10 \\
11 \\
12 \\
13 \\
14 \\
15 \\
16\end{array}$ & $\begin{array}{r}92 \\
84 \\
65 \\
66 \\
70 \\
100 \\
113 \\
199\end{array}$ & $\begin{array}{l}169 \\
197 \\
205 \\
191 \\
175 \\
172 \\
169 \\
152\end{array}$ & $\begin{array}{l}17 \\
18 \\
19 \\
20 \\
21 \\
22 \\
23 \\
24\end{array}$ & $\begin{array}{r}169 \\
130 \\
314 \\
1,260 \\
5,780 \\
7,770 \\
2,440 \\
1,290\end{array}$ & $\begin{array}{l}172 \\
180 \\
159 \\
146 \\
205 \\
262 \\
222 \\
240\end{array}$ & $\begin{array}{l}25 \\
26 \\
27 \\
28 \\
29 \\
30 \\
31\end{array}$ & $\begin{array}{l}881 \\
675 \\
534 \\
472 \\
417 \\
364\end{array}$ & $\begin{array}{l}690 \\
505 \\
356 \\
308 \\
292 \\
277 \\
251\end{array}$ \\
\hline $\begin{array}{l}\text { Mean } \\
\text { Run- }\end{array}$ & $\begin{array}{l}\text { onthily } \\
\mathrm{f}, \text { in } 1\end{array}$ & hes. & , ir & $\begin{array}{c}\sec o n a \\
.\end{array}$ & et. . & $\dot{0}$ & : $\cdot$. & $\dot{0} \cdot \dot{ }$ & $\dot{0}$ & $\begin{array}{r}799 \\
5.21 \\
\end{array}$ & $\begin{array}{r}253 \\
1.71\end{array}$ \\
\hline
\end{tabular}

Gage height, in feet, and discharge, in second-feet, at indicated time, 1938

\begin{tabular}{|c|c|c|c|c|c|c|c|c|c|c|c|c|}
\hline \multirow{2}{*}{ 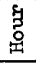 } & Feet & Sec.ft. & Feet & Sec.ft. & Feot & Sec.ft. & Feet & Sec.ft. & Feet & Sec.ft. & Feet & Sec.ft. \\
\hline & \multicolumn{2}{|c|}{ September 18} & \multicolumn{2}{|c|}{ September 19} & \multicolumn{2}{|c|}{ September 20} & \multicolumn{2}{|c|}{ September 21} & \multicolumn{2}{|c|}{ September 22} & \multicolumn{2}{|c|}{ September 23} \\
\hline $\begin{array}{l}1 \\
2 \\
3 \\
4 \\
5 \\
6\end{array}$ & $\begin{array}{l}2.78 \\
2.78 \\
2.77 \\
2.77 \\
2.76 \\
2.75\end{array}$ & $\begin{array}{l}134 \\
134 \\
132 \\
132 \\
129 \\
127\end{array}$ & $\begin{array}{l}2.84 \\
2.87 \\
2.91 \\
2.94 \\
2.98 \\
3.02\end{array}$ & \begin{tabular}{|l|}
149 \\
156 \\
167 \\
175 \\
186 \\
197 \\
\end{tabular} & $\begin{array}{l}4.03 \\
4.05 \\
4.09 \\
4.17 \\
4.31 \\
4.46\end{array}$ & $\begin{array}{l}615 \\
625 \\
645 \\
685 \\
760 \\
846\end{array}$ & $\begin{array}{l}6.51 \\
6.63 \\
6.73 \\
6.88 \\
7.03 \\
7.19\end{array}$ & $\begin{array}{l}2,300 \\
2,400 \\
2,490 \\
2,630 \\
2,780 \\
2,940\end{array}$ & \begin{tabular}{|l|}
12.74 \\
12.69 \\
12.60 \\
12.57 \\
12.30 \\
12.12
\end{tabular} & $\begin{array}{r}10,700 \\
10,600 \\
10,400 \\
10,400 \\
9,960 \\
9,690\end{array}$ & $\begin{array}{l}7.94 \\
7.76 \\
7.58 \\
7.41 \\
7.27 \\
7.11\end{array}$ & $\begin{array}{l}3,800 \\
3,580 \\
3,370 \\
3,180 \\
3,030 \\
2,860\end{array}$ \\
\hline $\begin{array}{r}7 \\
8 \\
9 \\
10 \\
11 \\
11\end{array}$ & $\begin{array}{l}2.74 \\
2.73 \\
2.73 \\
2.73 \\
2.73 \\
2.72\end{array}$ & $\begin{array}{l}125 \\
122 \\
122 \\
122 \\
122 \\
120\end{array}$ & $\begin{array}{l}3.06 \\
3.09 \\
3.11 \\
3.13 \\
3.15 \\
3.19\end{array}$ & $\begin{array}{l}208 \\
216 \\
222 \\
229 \\
235 \\
248\end{array}$ & $\begin{array}{l}4.61 \\
4.71 \\
4.78 \\
4.85 \\
4.93 \\
5.05\end{array}$ & $\begin{array}{r}936 \\
1,000 \\
1,050 \\
1,090 \\
1,140 \\
1,220\end{array}$ & $\begin{array}{l}7.40 \\
7.64 \\
7.93 \\
8.21 \\
8.53 \\
8.88\end{array}$ & $\begin{array}{l}3,170 \\
3,440 \\
3,790 \\
4,130 \\
4,550 \\
5,000\end{array}$ & $\begin{array}{l}12.00 \\
11.82 \\
11.59 \\
11.41 \\
11.18 \\
10.96\end{array}$ & $\begin{array}{l}9,510 \\
9,240 \\
8,900 \\
8,620 \\
8,280 \\
7,950\end{array}$ & $\begin{array}{l}6.99 \\
6.87 \\
6.76 \\
6.65 \\
6.55 \\
6.47\end{array}$ & $\begin{array}{l}2,740 \\
2,620 \\
2,510 \\
2,420 \\
2,330 \\
2,270\end{array}$ \\
\hline $\begin{array}{l}1 \\
2 \\
3 \\
4 \\
5 \\
6\end{array}$ & $\begin{array}{l}2.72 \\
2.72 \\
2.72 \\
2.73 \\
2.75 \\
2.77\end{array}$ & $\begin{array}{l}120 \\
120 \\
120 \\
122 \\
127 \\
132\end{array}$ & $\begin{array}{l}3.24 \\
3.31 \\
3.38 \\
3.45 \\
3.54 \\
3.65\end{array}$ & $\begin{array}{l}266 \\
292 \\
320 \\
348 \\
385 \\
432\end{array}$ & $\begin{array}{l}5.15 \\
5.24 \\
5.33 \\
5.42 \\
5.51 \\
5.62\end{array}$ & $\begin{array}{l}1,290 \\
1,350 \\
1,410 \\
1,470 \\
1,540 \\
1,610\end{array}$ & $\begin{array}{r}9.21 \\
9.63 \\
10.05 \\
10.60 \\
11.00 \\
11.57\end{array}$ & $\begin{array}{l}5,450 \\
6,040 \\
6,630 \\
7,410 \\
8,010 \\
8,860\end{array}$ & $\begin{array}{r}10.73 \\
10.52 \\
10.28 \\
10.01 \\
9.77 \\
9.52\end{array}$ & $\begin{array}{l}7,600 \\
7,290 \\
6,950 \\
6,570 \\
6,240 \\
5,890\end{array}$ & $\begin{array}{l}6.38 \\
6.31 \\
6.21 \\
6.16 \\
6.08 \\
6.01\end{array}$ & $\begin{array}{l}2,190 \\
2,140 \\
2,060 \\
2,020 \\
1,950 \\
1,900\end{array}$ \\
\hline $\begin{array}{r}7 \\
8 \\
9 \\
10 \\
11 \\
M\end{array}$ & $\begin{array}{l}2.81 \\
2.83 \\
2.82 \\
2.82 \\
2.82 \\
2.81\end{array}$ & $\begin{array}{l}142 \\
146 \\
144 \\
144 \\
144 \\
142\end{array}$ & $\begin{array}{l}3.78 \\
3.87 \\
3.92 \\
3.95 \\
3.97 \\
4.00\end{array}$ & $\begin{array}{l}491 \\
535 \\
560 \\
575 \\
585 \\
600\end{array}$ & $\begin{array}{l}5.76 \\
5.92 \\
6.05 \\
6.19 \\
6.30 \\
6.42 \\
\end{array}$ & $\begin{array}{l}1,710 \\
1,830 \\
1,930 \\
2,040 \\
2,130 \\
2,230\end{array}$ & $\begin{array}{l}11.82 \\
12.18 \\
12.40 \\
12.61 \\
12.70 \\
12.75\end{array}$ & $\begin{array}{r}9,240 \\
9,780 \\
10,100 \\
10,400 \\
10,600 \\
10,700\end{array}$ & $\begin{array}{l}9.27 \\
9.00 \\
8.77 \\
8.54 \\
8.34 \\
8.12 \\
\end{array}$ & $\begin{array}{l}5,540 \\
5,160 \\
4,860 \\
4,560 \\
4,300 \\
4,020 \\
\end{array}$ & $\begin{array}{l}5.95 \\
5.89 \\
5.81 \\
5.76 \\
5.69 \\
5.63 \\
\end{array}$ & $\begin{array}{l}1,850 \\
1,800 \\
1,750 \\
1,710 \\
1,660 \\
1,620 \\
\end{array}$ \\
\hline & \multicolumn{2}{|c|}{ September 24} & \multicolumn{2}{|c|}{ September 25} & \multicolumn{2}{|c|}{ September 26} & \multicolumn{2}{|c|}{ September 27} & \multicolumn{2}{|c|}{ September 28} & \multicolumn{2}{|c|}{ September 29} \\
\hline $\begin{array}{r}2 \\
4 \\
6 \\
8 \\
10 \\
\mathrm{~N}\end{array}$ & $\begin{array}{l}5.51 \\
5.41 \\
5.33 \\
5.25 \\
5.18 \\
5.12\end{array}$ & \begin{tabular}{|l}
1,540 \\
1,470 \\
1,410 \\
1,360 \\
1,310 \\
1,270
\end{tabular} & $\begin{array}{l}4.73 \\
4.67 \\
4.61 \\
4.57 \\
4.54 \\
4.50\end{array}$ & \begin{tabular}{|r|}
, 010 \\
976 \\
936 \\
912 \\
894 \\
870 \\
\end{tabular} & $\begin{array}{l}4.26 \\
4.23 \\
4.21 \\
4.18 \\
4.15 \\
4.12\end{array}$ & $\begin{array}{l}733 \\
716 \\
706 \\
690 \\
675 \\
660\end{array}$ & $\begin{array}{l}3.98 \\
3.95 \\
3.91 \\
3.88 \\
3.83 \\
3.83\end{array}$ & $\begin{array}{l}590 \\
575 \\
555 \\
540 \\
515 \\
515\end{array}$ & $\begin{array}{l}3.81 \\
3.78 \\
3.74 \\
3.72 \\
3.70 \\
3.70\end{array}$ & $\begin{array}{l}505 \\
491 \\
473 \\
464 \\
455 \\
455\end{array}$ & $\begin{array}{l}3.71 \\
3.68 \\
3.62 \\
3.60 \\
3.58 \\
3.57\end{array}$ & $\begin{array}{l}460 \\
446 \\
419 \\
410 \\
402 \\
397\end{array}$ \\
\hline $\begin{array}{r}2 \\
4 \\
6 \\
8 \\
10 \\
M\end{array}$ & $\begin{array}{l}5.06 \\
5.00 \\
4.94 \\
4.89 \\
4.83 \\
4.79\end{array}$ & $\begin{array}{l}1,230 \\
1,190 \\
1,150 \\
1,120 \\
1,080 \\
1,050\end{array}$ & $\begin{array}{l}4.47 \\
4.46 \\
4.39 \\
4.37 \\
4.33 \\
4.30\end{array}$ & $\begin{array}{l}852 \\
846 \\
804 \\
794 \\
772 \\
755\end{array}$ & $\begin{array}{l}4.11 \\
4.10 \\
4.09 \\
4.09 \\
4.09 \\
4.01\end{array}$ & $\begin{array}{l}655 \\
650 \\
645 \\
645 \\
645 \\
605\end{array}$ & $\begin{array}{l}3.88 \\
3.89 \\
3.82 \\
3.79 \\
3.76 \\
3.77\end{array}$ & $\begin{array}{l}540 \\
545 \\
510 \\
496 \\
482 \\
486\end{array}$ & $\begin{array}{l}3.73 \\
3.75 \\
3.74 \\
3.73 \\
3.71 \\
3.71\end{array}$ & $\begin{array}{l}468 \\
478 \\
473 \\
468 \\
460 \\
460\end{array}$ & $\begin{array}{l}3.60 \\
3.62 \\
3.62 \\
3.61 \\
3.55 \\
3.52\end{array}$ & $\begin{array}{l}410 \\
419 \\
419 \\
414 \\
389 \\
376\end{array}$ \\
\hline
\end{tabular}

Supplemental records.- Sept. 21 , $11: 45$ p.m., 12.78 ft., 10,800 sec.-ft. 
Location. - Water-stage recorder, lat. $42^{\circ} 30^{\prime} 10^{\prime \prime}$, long. $71^{\circ} 43^{\prime} 20^{\prime \prime}$, 1.3 miles above mouth of Wekepeke Brook, $2 \frac{1}{2}$ miles southeast of Leominster, Worcester County, and 6.1 miles above confluence with South Branch of Nashua River. Zero of gage is 270.04 feet above mean sea level (general adjustment of 1929).

Drainage area.- 107 square miles.

Gage-helght record. - Water-stage recorder graph except for periods Sept. 1 to 9 a.m. Sept. 8 and 1 a.m. Oct. 3 to $9 \mathrm{a} . \mathrm{m}$. Oct. 4 , record for which was based on shape of stage graphs at nearby stations.

Stage-discharge relation.- Defined by current-meter measurements belov 3 , 800 secondfeet; extended to peak stage on basis of determinations of flood flow over dam and by alope-area method.

Maxima.- September 1938: Discharge, 10,300 second-feet 3 p.m. Sept. 21 (gage height, 14.57 feet).

September 1935 to August 1938: Discharge, 16,300 second-feet 8 p.m. Mar. 18, 1936 (gage helght, 20.53 feet, from flood marks), by computation of flood flow over dam.

Remarks.- Flood mun-off affected by some artiflcial storage.

Mean daily discharge, in second-feet, 1938

\begin{tabular}{|c|c|c|c|c|c|c|c|c|c|c|c|}
\hline Day & Sept. & oct. & Day & Sept. & Oct. & Day & Sept. & Oct. & Day & Sept. & Oct. \\
\hline $\begin{array}{l}1 \\
2 \\
3 \\
4 \\
5 \\
6 \\
7 \\
8\end{array}$ & $\begin{array}{r}130 \\
150 \\
120 \\
100 \\
110 \\
90 \\
75 \\
87\end{array}$ & $\begin{array}{l}242 \\
227 \\
220 \\
220 \\
212 \\
220 \\
190 \\
173 \\
\end{array}$ & $\begin{array}{r}9 \\
10 \\
11 \\
12 \\
13 \\
14 \\
15 \\
16 \\
\end{array}$ & $\begin{array}{r}91 \\
69 \\
51 \\
66 \\
195 \\
132 \\
170 \\
154\end{array}$ & $\begin{array}{l}204 \\
172 \\
111 \\
125 \\
132 \\
132 \\
121 \\
108\end{array}$ & $\begin{array}{l}17 \\
18 \\
19 \\
20 \\
21 \\
22 \\
23 \\
24\end{array}$ & $\begin{array}{r}100 \\
125 \\
546 \\
1,690 \\
6,040 \\
3,120 \\
1,310 \\
793\end{array}$ & $\begin{array}{l}145 \\
125 \\
119 \\
139 \\
242 \\
212 \\
140 \\
316\end{array}$ & $\begin{array}{l}25 \\
26 \\
27 \\
28 \\
29 \\
30 \\
31\end{array}$ & $\begin{array}{l}591 \\
415 \\
360 \\
370 \\
321 \\
282\end{array}$ & $\begin{array}{l}416 \\
282 \\
227 \\
234 \\
190 \\
167 \\
197\end{array}$ \\
\hline $\begin{array}{l}\text { Mean } \\
\text { Run- }\end{array}$ & $\begin{array}{l}\text { onthly } \\
f, \text { in }\end{array}$ & $\begin{array}{l}\text { scharg } \\
\text { hes. }\end{array}$ & , in & $\begin{array}{c}\text { second-f } \\
\text { - }\end{array}$ & et. & & . : : & . : & $\dot{.}$ & $\begin{array}{r}595 \\
6.20\end{array}$ & $\begin{array}{r}192 \\
2.06\end{array}$ \\
\hline
\end{tabular}

Gage height, in feet, and discharge, in second-feet, at indicated time, 1938

\begin{tabular}{|c|c|c|c|c|c|c|c|c|c|c|c|c|}
\hline \multirow{2}{*}{$\begin{array}{l}5 \\
3 \\
\text { 孚 }\end{array}$} & Feet & Sec.ft. & Feet & Sec.ft. & Feet & Sec.ft. & Feet & Sec.ft. & Feet & Sec.ft. & Feet & Sec.ft. \\
\hline & \multicolumn{2}{|c|}{ September 18} & \multicolumn{2}{|c|}{ September 19} & \multicolumn{2}{|c|}{ September 20} & \multicolumn{2}{|c|}{ September 21} & \multicolumn{2}{|c|}{ September 22} & \multicolumn{2}{|c|}{ September 23} \\
\hline $\begin{array}{l}1 \\
2 \\
3 \\
4 \\
5 \\
6\end{array}$ & $\begin{array}{l}2.22 \\
2.23 \\
2.26 \\
2.26 \\
2.25 \\
2.24\end{array}$ & $\begin{array}{l}114 \\
115 \\
119 \\
119 \\
118 \\
117\end{array}$ & $\begin{array}{l}2.47 \\
2.60 \\
2.78 \\
3.09 \\
3.55 \\
4.03\end{array}$ & $\begin{array}{l}149 \\
167 \\
194 \\
240 \\
316 \\
403\end{array}$ & $\begin{array}{l}6.61 \\
6.70 \\
6.75 \\
6.85 \\
4.33 \\
8.05\end{array}$ & $\begin{array}{r}978 \\
1,000 \\
1,010 \\
1,040 \\
1,160 \\
1,360\end{array}$ & $\begin{array}{r}9.90 \\
10.10 \\
10.47 \\
10.92 \\
11.30 \\
11.62\end{array}$ & $\begin{array}{l}1,930 \\
2,000 \\
2,260 \\
2,590 \\
2,890 \\
3,200\end{array}$ & $\begin{array}{l}12.02 \\
11.79 \\
11.60 \\
11.40 \\
11.25 \\
11.05\end{array}$ & $\begin{array}{l}5,300 \\
4,940 \\
4,660 \\
4,370 \\
4,160 \\
3,880\end{array}$ & $\begin{array}{l}8.74 \\
8.65 \\
8.54 \\
8.48 \\
8.37 \\
8.29\end{array}$ & $\begin{array}{l}1,690 \\
1,640 \\
1,590 \\
1,560 \\
1,510 \\
1,480\end{array}$ \\
\hline $\begin{array}{r}7 \\
8 \\
9 \\
10 \\
11 \\
N\end{array}$ & $\begin{array}{l}2.24 \\
2.26 \\
2.27 \\
2.28 \\
2.32 \\
2.33\end{array}$ & $\begin{array}{l}117 \\
119 \\
121 \\
122 \\
128 \\
129\end{array}$ & $\begin{array}{l}4.50 \\
4.70 \\
4.76 \\
4.80 \\
5.06 \\
5.09\end{array}$ & $\begin{array}{l}492 \\
534 \\
547 \\
555 \\
610 \\
616\end{array}$ & $\begin{array}{l}8.46 \\
8.63 \\
8.69 \\
8.72 \\
8.83 \\
9.10\end{array}$ & $\begin{array}{l}1,490 \\
1,540 \\
1,560 \\
1,570 \\
1,600 \\
1,680\end{array}$ & $\begin{array}{l}12.03 \\
12.35 \\
12.65 \\
12.95 \\
13.30 \\
13.68\end{array}$ & $\begin{array}{l}3,700 \\
4,300 \\
4,800 \\
5,400 \\
6,400 \\
7,200\end{array}$ & $\begin{array}{l}10.93 \\
10.80 \\
10.59 \\
10.47 \\
10.41 \\
10.31\end{array}$ & $\begin{array}{l}3,730 \\
3,560 \\
3,300 \\
3,150 \\
3,080 \\
2,970\end{array}$ & $\begin{array}{l}8.21 \\
8.15 \\
8.13 \\
7.99 \\
7.95 \\
7.86\end{array}$ & $\begin{array}{l}1,440 \\
1,420 \\
1,410 \\
1,360 \\
1,340 \\
1,310\end{array}$ \\
\hline $\begin{array}{l}1 \\
2 \\
3 \\
4 \\
5 \\
6\end{array}$ & $\begin{array}{l}2.33 \\
2.34 \\
2.34 \\
2.34 \\
2.34 \\
2.33\end{array}$ & $\begin{array}{l}129 \\
131 \\
131 \\
131 \\
131 \\
129\end{array}$ & $\begin{array}{l}5.04 \\
5.11 \\
5.27 \\
5.32 \\
5.33 \\
5.21\end{array}$ & $\begin{array}{l}605 \\
620 \\
654 \\
665 \\
667 \\
641\end{array}$ & $\begin{array}{r}9.53 \\
9.89 \\
10.17 \\
10.30 \\
10.39 \\
10.47\end{array}$ & $\begin{array}{l}1,810 \\
1,930 \\
2,050 \\
2,140 \\
2,200 \\
2,260\end{array}$ & $\begin{array}{l}14.14 \\
14.42 \\
14.57 \\
14.50 \\
14.21 \\
14.05\end{array}$ & $\begin{array}{r}8,600 \\
9,600 \\
10,300 \\
10,200 \\
9,480 \\
9,130\end{array}$ & $\begin{array}{r}10.05 \\
9.96 \\
9.80 \\
9.67 \\
9.53 \\
9.42\end{array}$ & $\begin{array}{l}2,700 \\
2,610 \\
2,470 \\
2,360 \\
2,240 \\
2,160\end{array}$ & $\begin{array}{l}7.75 \\
7.60 \\
7.52 \\
7.43 \\
7.31 \\
7.15\end{array}$ & $\begin{array}{l}1,280 \\
1,230 \\
1,210 \\
1,180 \\
1,150 \\
1,110\end{array}$ \\
\hline \multirow[t]{2}{*}{$\begin{array}{r}7 \\
8 \\
9 \\
10 \\
11 \\
11\end{array}$} & $\begin{array}{l}2.32 \\
2.32 \\
2.33 \\
2.33 \\
2.34 \\
2.40\end{array}$ & $\begin{array}{l}128 \\
128 \\
129 \\
129 \\
131 \\
139\end{array}$ & $\begin{array}{l}5.18 \\
5.44 \\
5.90 \\
6.14 \\
6.31 \\
6.46\end{array}$ & $\begin{array}{l}635 \\
692 \\
800 \\
860 \\
902 \\
940\end{array}$ & $\begin{array}{r}10.46 \\
10.41 \\
10.31 \\
10.22 \\
10.07 \\
9.90\end{array}$ & $\begin{array}{l}2,250 \\
2,220 \\
2,150 \\
2,080 \\
1,990 \\
1,930\end{array}$ & $\begin{array}{l}13.75 \\
13.49 \\
13.20 \\
12.98 \\
12.68 \\
12.26\end{array}$ & $\begin{array}{l}8,480 \\
7,950 \\
7,370 \\
6,950 \\
6,400 \\
5,690\end{array}$ & $\begin{array}{l}9.29 \\
9.17 \\
9.08 \\
9.00 \\
8.92 \\
8.82\end{array}$ & $\begin{array}{l}2,050 \\
1,970 \\
1,910 \\
1,850 \\
1,800 \\
1,740\end{array}$ & $\begin{array}{l}6.97 \\
6.85 \\
6.75 \\
6.63 \\
6.56 \\
6.52\end{array}$ & $\begin{array}{r}1,070 \\
1,040 \\
1,010 \\
982 \\
965 \\
955\end{array}$ \\
\hline & \multicolumn{2}{|c|}{ September 24} & \multicolumn{2}{|c|}{ September 2} & \multicolumn{2}{|c|}{ September 26} & \multicolumn{2}{|c|}{ September 27} & \multicolumn{2}{|c|}{ September 28} & \multicolumn{2}{|c|}{ September 29} \\
\hline $\begin{array}{r}2 \\
4 \\
6 \\
8 \\
10 \\
\mathrm{~N}\end{array}$ & $\begin{array}{l}6.40 \\
6.26 \\
6.14 \\
6.10 \\
6.00 \\
5.89\end{array}$ & $\begin{array}{l}925 \\
890 \\
860 \\
850 \\
825 \\
798\end{array}$ & $\begin{array}{l}5.27 \\
5.22 \\
5.17 \\
5.14 \\
5.00 \\
4.96\end{array}$ & $\begin{array}{l}654 \\
643 \\
633 \\
626 \\
597 \\
589\end{array}$ & $\begin{array}{l}4.31 \\
4.24 \\
4.20 \\
4.20 \\
4.38 \\
4.30\end{array}$ & $\begin{array}{l}456 \\
443 \\
435 \\
435 \\
469 \\
454\end{array}$ & $\begin{array}{l}3.68 \\
3.77 \\
3.84 \\
3.89 \\
4.13 \\
4.02\end{array}$ & $\begin{array}{l}339 \\
354 \\
367 \\
376 \\
422 \\
401\end{array}$ & $\begin{array}{l}3.73 \\
3.84 \\
3.85 \\
3.96 \\
4.05 \\
4.11\end{array}$ & $\begin{array}{l}347 \\
367 \\
368 \\
389 \\
414 \\
418\end{array}$ & $\begin{array}{l}3.52 \\
3.57 \\
3.60 \\
3.64 \\
3.78 \\
3.83\end{array}$ & $\begin{array}{l}311 \\
320 \\
325 \\
332 \\
356 \\
365\end{array}$ \\
\hline $\begin{array}{r}2 \\
4 \\
6 \\
8 \\
10 \\
M\end{array}$ & $\begin{array}{l}5.72 \\
5.65 \\
5.47 \\
5.42 \\
5.38 \\
5.32\end{array}$ & $\begin{array}{l}757 \\
740 \\
699 \\
688 \\
678 \\
665\end{array}$ & $\begin{array}{l}5.02 \\
4.96 \\
4.84 \\
4.73 \\
4.52 \\
4.38\end{array}$ & $\begin{array}{l}601 \\
589 \\
563 \\
540 \\
496 \\
469\end{array}$ & $\begin{array}{l}4.35 \\
4.13 \\
3.88 \\
3.80 \\
3.31 \\
3.57\end{array}$ & $\begin{array}{l}464 \\
422 \\
374 \\
359 \\
276 \\
320\end{array}$ & $\begin{array}{l}3.94 \\
3.93 \\
3.73 \\
3.57 \\
3.50 \\
3.57\end{array}$ & $\begin{array}{l}386 \\
384 \\
347 \\
320 \\
308 \\
320\end{array}$ & $\begin{array}{l}3.90 \\
3.96 \\
3.87 \\
3.66 \\
3.67 \\
3.58\end{array}$ & $\begin{array}{l}378 \\
389 \\
372 \\
335 \\
337 \\
322\end{array}$ & $\begin{array}{l}3.60 \\
3.65 \\
3.52 \\
3.37 \\
3.35 \\
3.33\end{array}$ & $\begin{array}{l}325 \\
334 \\
311 \\
286 \\
282 \\
279\end{array}$ \\
\hline
\end{tabular}


Nashua River at East Pepperell, Mass.

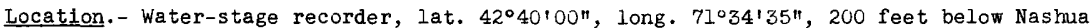
River Paper Co. power plant in town of East Pepperell, Middlesex County. Zero of gage is 169.04 feet above mean sea level (general adjustment of 1929).

Drainage area.- 433 square miles; 117 square miles above Wachusett Dam affected by storage and diversions.

Gage-heigh- record.- Water-stage recorder graph.

Stage-discharge relation.- Defined by current-meter measurements below 11,800 secondfeet; extended to peak stage on basis of velocity-area study at control section.

Maxima.- September 1938: Discharge, 10,200 second-feet 8 to 10 a.m. Sept. 23 (gage helight, 14.08 feet).

ótober 1935 to August 1938: Discharge, 20,900 second-feet Mar. 20, 1936 (gage height, 19.1 feet, from flood marks).

Remarks.- Flood run-off considerably affected by artificial storage and diversions on 117 square miles on South Branch of Nashua River; slightly affected by artif1cial and natural storage on other parts. For information on storage and diversion see record for South Branch of Nashua River at Clinton, Mass.

Mean daily discharge, in second-feet, 1938

\begin{tabular}{|c|c|c|c|c|c|c|c|c|c|c|c|}
\hline Day & Sept. & oct. & Day & Sept. & oct. & Day & Sept. & oct. & Day & Sept. & Oct. \\
\hline $\begin{array}{l}1 \\
2 \\
3 \\
4 \\
5 \\
6 \\
7 \\
8\end{array}$ & $\begin{array}{c}540 \\
5 C 3 \\
371 \\
56 \\
8.4 \\
232 \\
232 \\
225\end{array}$ & $\begin{array}{r}1,120 \\
1,070 \\
836 \\
811 \\
761 \\
761 \\
861 \\
836\end{array}$ & $\begin{array}{r}9 \\
10 \\
11 \\
12 \\
13 \\
14 \\
15 \\
16\end{array}$ & $\begin{array}{l}234 \\
235 \\
124 \\
180 \\
349 \\
349 \\
503 \\
503\end{array}$ & $\begin{array}{r}219 \\
553 \\
836 \\
780 \\
570 \\
711 \\
324 \\
9.7\end{array}$ & $\begin{array}{l}17 \\
18 \\
19 \\
20 \\
21 \\
22 \\
23 \\
24\end{array}$ & $\begin{array}{r}631 \\
173 \\
554 \\
1,700 \\
3,740 \\
6,390 \\
9,790 \\
7,440\end{array}$ & $\begin{array}{r}598 \\
736 \\
582 \\
436 \\
561 \\
536 \\
54 \\
764\end{array}$ & $\begin{array}{l}25 \\
26 \\
27 \\
28 \\
29 \\
30 \\
31\end{array}$ & $\begin{array}{l}4,830 \\
3,310 \\
2,400 \\
1,850 \\
1,520 \\
1,150\end{array}$ & $\begin{array}{r}1,020 \\
1,230 \\
1,150 \\
1,100 \\
1,100 \\
354 \\
1,000\end{array}$ \\
\hline $\begin{array}{l}\text { Mean } \\
\text { Run- }\end{array}$ & $\begin{array}{l}n \ln l y \\
\text {, in }\end{array}$ & hes. & . & - & et. & & $: . \dot{ }$ & : : : & & $\begin{array}{r}1,671 \\
4.31\end{array}$ & $\begin{array}{r}719 \\
1.91\end{array}$ \\
\hline
\end{tabular}

Gage height, in feet, and discharge, in second-feet, at indicated time, 1938

\begin{tabular}{|c|c|c|c|c|c|c|c|c|c|c|c|c|}
\hline \multirow{2}{*}{$\begin{array}{l}9 \\
9 \\
9 \\
0\end{array}$} & Feet & Sec.ft. & Feet & Sec.ft. & Feet & Sec.ft. & Feet & Sec.ft. & Feet & Sec.ft. & Feet & Sec.ft. \\
\hline & \multicolumn{2}{|c|}{ September 18} & \multicolumn{2}{|c|}{ September 19} & \multicolumn{2}{|c|}{ Septomber 20} & \multicolumn{2}{|c|}{ September 21} & \multicolumn{2}{|c|}{ September 22} & \multicolumn{2}{|c|}{ September 23} \\
\hline $\begin{array}{l}1 \\
2 \\
3 \\
4 \\
5 \\
6\end{array}$ & $\begin{array}{r}2.26 \\
2.26 \\
2.25 \\
2.25 \\
2.25 \\
.80\end{array}$ & $\begin{array}{l}674 \\
674 \\
670 \\
670 \\
670 \\
193\end{array}$ & $\begin{array}{r}-0.05 \\
-\quad .05 \\
-\quad .05 \\
-\quad .04 \\
.80 \\
2.26\end{array}$ & $\begin{array}{r}10 \\
10 \\
10 \\
11 \\
193 \\
674\end{array}$ & $\begin{array}{l}2.47 \\
2.59 \\
2.74 \\
2.92 \\
3.10 \\
3.27\end{array}$ & $\begin{array}{r}759 \\
810 \\
874 \\
954 \\
1,040 \\
1,120\end{array}$ & $\begin{array}{l}6.23 \\
6.39 \\
6.50 \\
6.60 \\
6.79 \\
6.93\end{array}$ & $\begin{array}{l}2,860 \\
2,960 \\
3,040 \\
3,110 \\
3,240 \\
3,340\end{array}$ & $\begin{array}{l}8.49 \\
8.58 \\
8.70 \\
8.80 \\
8.92 \\
9.15\end{array}$ & $\begin{array}{l}4,460 \\
4,530 \\
4,630 \\
4,710 \\
4,810 \\
4,990\end{array}$ & $\begin{array}{l}13.61 \\
13.75 \\
13.85 \\
13.94 \\
14.03 \\
14.05\end{array}$ & $\begin{array}{r}9,470 \\
9,670 \\
9,810 \\
9,940 \\
10,100 \\
10,100\end{array}$ \\
\hline $\begin{array}{r}7 \\
8 \\
9 \\
10 \\
11 \\
-N\end{array}$ & $\begin{array}{r}.50 \\
-.06 \\
-.06 \\
-.06 \\
-.06 \\
-.06\end{array}$ & $\begin{array}{r}118 \\
9.2 \\
9.2 \\
9.2 \\
9.2 \\
9.2\end{array}$ & $\begin{array}{l}2.29 \\
2.32 \\
2.32 \\
2.32 \\
2.32 \\
2.32\end{array}$ & $\begin{array}{l}686 \\
698 \\
698 \\
698 \\
698 \\
698\end{array}$ & $\begin{array}{l}3.42 \\
3.55 \\
3.71 \\
3.83 \\
4.07 \\
4.35\end{array}$ & $\begin{array}{l}1,190 \\
1,260 \\
1,340 \\
1,400 \\
1,530 \\
1,690\end{array}$ & $\begin{array}{l}7.5 \\
7.2 \\
7.2 \\
7.2 \\
7.5 \\
7.5\end{array}$ & $\begin{array}{l}3,450 \\
3,540 \\
3,530 \\
3,600 \\
3,690 \\
3,750\end{array}$ & $\begin{array}{r}9.43 \\
9.56 \\
9.68 \\
9.88 \\
10.04 \\
10.25\end{array}$ & $\begin{array}{l}5,130 \\
5,320 \\
5,410 \\
5,590 \\
5,740 \\
5,920\end{array}$ & $\begin{array}{l}14.07 \\
14.08 \\
14.08 \\
14.08 \\
14.07 \\
14.06\end{array}$ & $\begin{array}{l}10,100 \\
10,200 \\
10,200 \\
10,200 \\
10,100 \\
10,100\end{array}$ \\
\hline $\begin{array}{l}1 \\
2 \\
3 \\
4 \\
5 \\
6\end{array}$ & $\begin{array}{l}-.06 \\
-.06 \\
-.06 \\
-.06 \\
-.06 \\
-.06\end{array}$ & $\begin{array}{l}9.2 \\
9.2 \\
9.2 \\
9.2 \\
9.2 \\
9.2\end{array}$ & $\begin{array}{l}2.33 \\
2.33 \\
2.33 \\
2.34 \\
2.35 \\
2.35\end{array}$ & $\begin{array}{l}702 \\
702 \\
702 \\
706 \\
710 \\
710\end{array}$ & $\begin{array}{r}4.53 \\
4.70 \\
4.89 \\
5.04 \\
5.23 \\
5.37\end{array}$ & $\begin{array}{l}1,800 \\
1,900 \\
2,010 \\
2,100 \\
2,220 \\
2,300\end{array}$ & $\begin{array}{l}7.63 \\
7.73 \\
7.83 \\
7.94 \\
8.20 \\
8.50\end{array}$ & $\begin{array}{l}3,830 \\
3,900 \\
3,970 \\
4,050 \\
4,230 \\
4,470\end{array}$ & $\begin{array}{l}10.54 \\
10.70 \\
11.12 \\
11.35 \\
11.60 \\
12.68\end{array}$ & $\begin{array}{l}6,190 \\
6,330 \\
6,710 \\
6,920 \\
7,160 \\
8,320\end{array}$ & $\begin{array}{l}14.03 \\
13.95 \\
13.98 \\
13.85 \\
13.79 \\
13.73\end{array}$ & $\begin{array}{r}10,100 \\
9,960 \\
9,980 \\
9,810 \\
9,730 \\
9,640\end{array}$ \\
\hline \multirow[t]{2}{*}{$\begin{array}{r}7 \\
8 \\
9 \\
10 \\
11 \\
M\end{array}$} & $\begin{array}{l}-.06 \\
-.06 \\
-.06 \\
-.06 \\
-.06 \\
-.06\end{array}$ & $\begin{array}{l}9.2 \\
9.2 \\
9.2 \\
9.2 \\
9.2 \\
9.2\end{array}$ & $\begin{array}{l}2.36 \\
2.37 \\
2.38 \\
2.38 \\
2.39 \\
2.40\end{array}$ & $\begin{array}{l}714 \\
718 \\
722 \\
722 \\
726 \\
730\end{array}$ & $\begin{array}{l}5.51 \\
5.65 \\
5.78 \\
5.90 \\
6.02 \\
6.12\end{array}$ & $\begin{array}{l}2,390 \\
2,480 \\
2,570 \\
2,640 \\
2,720 \\
2,790\end{array}$ & $\begin{array}{l}8.40 \\
8.27 \\
8.24 \\
8.28 \\
8.33 \\
8.41\end{array}$ & $\begin{array}{l}4,390 \\
4,290 \\
4,260 \\
4,290 \\
4,330 \\
4,400\end{array}$ & $\begin{array}{l}12.78 \\
12.84 \\
12.97 \\
13.15 \\
13.35 \\
13.48\end{array}$ & $\begin{array}{l}8,440 \\
8,510 \\
8,660 \\
8,880 \\
9,140 \\
9,300\end{array}$ & $\begin{array}{l}13.67 \\
13.55 \\
13.48 \\
13.40 \\
13.32 \\
13.20\end{array}$ & $\begin{array}{l}9,560 \\
9,400 \\
9,300 \\
9,200 \\
9,100 \\
8,940\end{array}$ \\
\hline & \multicolumn{2}{|c|}{ Septernber 24} & \multicolumn{2}{|c|}{ September 25} & \multicolumn{2}{|c|}{ September 26} & \multicolumn{2}{|c|}{ September 27} & \multicolumn{2}{|c|}{ September 28} & \multicolumn{2}{|c|}{ September 29} \\
\hline $\begin{array}{r}2 \\
4 \\
6 \\
8 \\
10 \\
N\end{array}$ & $\begin{array}{l}13.00 \\
12.78 \\
12.52 \\
12.35 \\
12.12 \\
11.92\end{array}$ & $\begin{array}{l}8,700 \\
8,440 \\
8,130 \\
7,940 \\
7,690 \\
7,480\end{array}$ & $\begin{array}{r}10.09 \\
9.83 \\
9.58 \\
9.35 \\
9.10 \\
8.83\end{array}$ & $\begin{array}{l}5,780 \\
5,550 \\
5,330 \\
5,150 \\
4,950 \\
4,730\end{array}$ & $\begin{array}{l}7.57 \\
7.42 \\
7.27 \\
7.20 \\
7.05 \\
6.88\end{array}$ & $\begin{array}{l}3,790 \\
3,680 \\
3,580 \\
3,530 \\
3,420 \\
3,310\end{array}$ & $\begin{array}{l}6.02 \\
5.92 \\
5.81 \\
5.72 \\
5.63 \\
5.54\end{array}$ & $\begin{array}{l}2,720 \\
2,650 \\
2,590 \\
2,530 \\
2,470 \\
2,410\end{array}$ & $\begin{array}{l}4.92 \\
4.86 \\
4.80 \\
4.73 \\
4.67 \\
4.60\end{array}$ & $\begin{array}{l}2,030 \\
2,000 \\
1,960 \\
1,920 \\
1,880 \\
1,840\end{array}$ & \begin{tabular}{|l|}
4.25 \\
4.21 \\
4.18 \\
4.13 \\
3.52 \\
4.15
\end{tabular} & $\begin{array}{l}1,640 \\
1,620 \\
1,600 \\
1,580 \\
1,240 \\
1,590\end{array}$ \\
\hline $\begin{array}{r}2 \\
4 \\
6 \\
8 \\
10 \\
M\end{array}$ & $\begin{array}{l}11.65 \\
11.35 \\
11.06 \\
10.83 \\
10.58 \\
10.35\end{array}$ & $\begin{array}{l}7,210 \\
6,920 \\
6,650 \\
6,450 \\
6,220 \\
6,020\end{array}$ & $\begin{array}{l}8.60 \\
8.42 \\
8.27 \\
8.12 \\
7.95 \\
7.77\end{array}$ & $\begin{array}{l}4,550 \\
4,410 \\
4,290 \\
4,170 \\
4,060 \\
3,930\end{array}$ & $\begin{array}{l}6.72 \\
6.61 \\
6.46 \\
6.33 \\
6.23 \\
6.12\end{array}$ & $\begin{array}{l}3,190 \\
3,120 \\
3,010 \\
2,920 \\
2,860 \\
2,790\end{array}$ & $\begin{array}{l}5.40 \\
5.29 \\
5.22 \\
5.12 \\
5.05 \\
4.99\end{array}$ & $\begin{array}{l}2,320 \\
2,250 \\
2,210 \\
2,150 \\
2,110 \\
2,070\end{array}$ & $\begin{array}{l}4.53 \\
4.49 \\
4.42 \\
4.38 \\
4.34 \\
4.28\end{array}$ & $\begin{array}{l}1,800 \\
1,770 \\
1,730 \\
1,700 \\
1,680 \\
1,650\end{array}$ & $\begin{array}{l}4.10 \\
4.00 \\
3.96 \\
3.92 \\
3.88 \\
3.83\end{array}$ & $\begin{array}{l}1,560 \\
1,500 \\
1,470 \\
1,450 \\
1,430 \\
1,410\end{array}$ \\
\hline
\end{tabular}

ft., 1,260 sec. $-\mathrm{ft}$. 
Wachusett Reservoir on South Branch of Nashua River at Clinton, Mass.

Location. - Lat. $42^{\circ} 24^{\prime} 15^{\prime \prime}$, long. $71^{\circ} 41^{\prime} 25^{\prime \prime}$, at Wachusett Dam, 1 mile south of Clinton, Worcester County.

Drainage area.- Total above Wachusett Dam, 117 square miles since July 1937; practi-

cally all flow from 9.43 square miles of Pine H1ll Reservoir drainage aree diver-

ted from basin for Worcester water supply.

Remarks.- Records furnished by water division of the Metropolitan District Commission.

Gain or loss in storage, in millions of cubic feet, 1938

\begin{tabular}{|c|c|c|c|c|c|c|c|c|c|c|c|}
\hline Day & Sept. & oct. & Day & Sept. & oct. & Day & Sept. & oct. & Day & Sept. & oct. \\
\hline $\begin{array}{l}1 \\
2 \\
3 \\
4 \\
5 \\
6 \\
7 \\
8\end{array}$ & $\begin{array}{c}-16.3 \\
-16.3 \\
-10.8 \\
0 \\
0 \\
-18.1 \\
-16.2 \\
-19.8\end{array}$ & $\begin{array}{c}+1.8 \\
0 \\
-14.4 \\
-14.4 \\
-18.0 \\
-18.0 \\
-16.2 \\
-3.6\end{array}$ & $\begin{array}{l}9 \\
10 \\
11 \\
12 \\
13 \\
14 \\
15 \\
16\end{array}$ & $\begin{array}{r}-21.6 \\
-9.0 \\
0 \\
-7.2 \\
-10.8 \\
-10.8 \\
-1.8 \\
-12.6\end{array}$ & $\begin{array}{r}-3.6 \\
-19.8 \\
-19.7 \\
0 \\
-17.9 \\
-10.7 \\
-5.4 \\
+1.8\end{array}$ & $\begin{array}{l}17 \\
18 \\
19 \\
20 \\
21 \\
22 \\
23 \\
24\end{array}$ & $\begin{array}{r}+1.8 \\
+45.0 \\
+37.8 \\
+202.8 \\
+142.4 \\
-71.3 \\
-74.7 \\
-54.5\end{array}$ & $\begin{array}{r}-14.3 \\
-16.1 \\
-17.9 \\
-10.7 \\
-12.5 \\
-7.1 \\
+7.1 \\
+7.2\end{array}$ & $\begin{array}{l}25 \\
26 \\
27 \\
28 \\
29 \\
30 \\
31\end{array}$ & $\begin{array}{r}-32.6 \\
-38.0 \\
-21.7 \\
-12.6 \\
-12.6 \\
-3.6\end{array}$ & $\begin{array}{r}-16.1 \\
-16.1 \\
-14.3 \\
-8.9 \\
-16.0 \\
-14.2 \\
-28.4\end{array}$ \\
\hline $\begin{array}{l}\text { Gain } \\
\text { Gain }\end{array}$ & $\begin{array}{l}\text { or loss } \\
\text { or loss }\end{array}$ & $\begin{array}{l}\text { sto } \\
\text { sto }\end{array}$ & & $\begin{array}{l}\text { mill1 } \\
\text { equiv }\end{array}$ & $\begin{array}{l}\text { of } c \\
\text { t me }\end{array}$ & se & i-feet. & : : & $:$ & $\begin{array}{l}-63.1 \\
-24.3\end{array}$ & $\begin{array}{r}-336.4 \\
-126\end{array}$ \\
\hline
\end{tabular}

South Branch of Nashua River at Clinton, Mass.

Location.- Lat. $42^{\circ} 24^{\prime} 1^{\prime \prime}$, long. $71^{\circ} 41^{\prime} 25^{\prime \prime}$, at Wachusett Dam, 1 mile south of Clinton, Worcester County.

Drainage area.- Total above Wachusett Dam, 117 square miles since July 1937; pract1cally all flow from 9.43 square miles of Pine Hill Reservolr drainage area diverted from basin for Worcester water supply.

Discharge.- Observed discharge from 117 square miles is the outflow from Wachusett Reservoir into South Branch of Nashua River and is the combined flow over spillway and tnrough Venturi meter.

Adjusted discharge is the run-off from 108 square miles and is the observed discharge adjusted for diversions into the basin from Ware River, diversions from the basin through Pine stone River Basin for Worcester water supply, diversions from the basin through Wachusett Aqueduct for Boston water supply, and for storage in Wacnusett Reservolr.

Remarks.- For information on storage see record for Wachusett Reservoir on South Branch of the Nashua River at Clinton, Mass. Records furnished by water division of tne Metropolitan District Commission.

Mean daily discharge, in second-feet, 1938

\begin{tabular}{|c|c|c|c|c|c|c|c|c|c|}
\hline \multirow[t]{2}{*}{ Day } & \multicolumn{2}{|c|}{ September } & \multicolumn{2}{|c|}{ October } & \multirow{2}{*}{ Day } & \multicolumn{2}{|c|}{ September } & \multicolumn{2}{|c|}{ October } \\
\hline & Observed & Adjusted & Observed & Adjusted & & Observed & Ad justed & Observed & Adjusted \\
\hline $\begin{array}{l}1 \\
2 \\
3 \\
4 \\
5\end{array}$ & $\begin{array}{c}12 \\
10 \\
9.4 \\
10 \\
8.8\end{array}$ & $\begin{array}{c}55 \\
54 \\
1.2 \\
10 \\
8.8\end{array}$ & $\begin{array}{l}283 \\
289 \\
219 \\
190 \\
177\end{array}$ & $\begin{array}{l}279 \\
265 \\
233 \\
205 \\
153\end{array}$ & $\begin{array}{l}16 \\
17 \\
18 \\
19 \\
20\end{array}$ & $\begin{array}{l}4.3 \\
4.2 \\
4.2 \\
4.3 \\
64\end{array}$ & $\begin{array}{r}111 \\
140 \\
524 \\
694 \\
2,650\end{array}$ & $\begin{array}{l}77 \\
61 \\
81 \\
96 \\
80\end{array}$ & $\begin{array}{r}85 \\
111 \\
110 \\
105 \\
173\end{array}$ \\
\hline $\begin{array}{r}6 \\
7 \\
8 \\
9 \\
10\end{array}$ & $\begin{array}{l}8.2 \\
7.3 \\
5.4 \\
3.9 \\
3.9\end{array}$ & $\begin{array}{l}53 \\
71 \\
30 \\
6.8 \\
15\end{array}$ & $\begin{array}{l}159 \\
125 \\
147 \\
142 \\
114\end{array}$ & $\begin{array}{r}135 \\
123 \\
91 \\
86 \\
124\end{array}$ & $\begin{array}{l}21 \\
22 \\
23 \\
24 \\
25\end{array}$ & $\begin{array}{l}2,690 \\
3,620 \\
2,450 \\
1,650 \\
1,160\end{array}$ & $\begin{array}{r}4,150 \\
2,330 \\
1,430 \\
1,010 \\
795\end{array}$ & $\begin{array}{r}103 \\
97 \\
96 \\
155 \\
281\end{array}$ & $\begin{array}{l}172 \\
112 \\
164 \\
450 \\
293\end{array}$ \\
\hline $\begin{array}{l}11 \\
12 \\
13 \\
14 \\
15\end{array}$ & $\begin{array}{l}3.9 \\
4.2 \\
4.2 \\
4.3 \\
4.3\end{array}$ & $\begin{array}{l}3.9 \\
173 \\
130 \\
131 \\
235\end{array}$ & $\begin{array}{r}145 \\
99 \\
80 \\
86 \\
75\end{array}$ & $\begin{array}{r}155 \\
86 \\
112 \\
200 \\
115\end{array}$ & $\begin{array}{l}26 \\
27 \\
28 \\
29 \\
30 \\
31\end{array}$ & $\begin{array}{l}781 \\
533 \\
414 \\
321 \\
272\end{array}$ & $\begin{array}{l}579 \\
480 \\
415 \\
320 \\
379\end{array}$ & $\begin{array}{l}254 \\
215 \\
189 \\
368 \\
348 \\
288\end{array}$ & $\begin{array}{l}262 \\
257 \\
294 \\
272 \\
163 \\
171\end{array}$ \\
\hline $\begin{array}{l}\text { Me } \\
\text { Ru }\end{array}$ & $\begin{array}{l}\text { daily } \\
\text { cf, in }\end{array}$ & $\begin{array}{l}\text { harge, } \\
\text { hes.". }\end{array}$ &.$\cdot$ & et : : & & $\begin{array}{r}469 \\
-\quad 4\end{array}$ & $\begin{array}{r}566 \\
5.87\end{array}$ & $\begin{array}{r}165 \\
-\end{array}$ & $\begin{array}{r}179 \\
1.91\end{array}$ \\
\hline
\end{tabular}


Location.- Water-stage recorder, lat. $42^{\circ} 38^{\prime} 15^{\prime \prime}$, long. $71^{\circ} 18^{\prime} 10^{n}$, at Lowell, M1ddlesex County, 300 feet below Rogers Street Bridge, 0.3 mile below River Meadow Brook, and $0.8 \mathrm{mile}$ above mouth. Zero of gage is 67.41 feet above mean sea level (general adjustment of 1929).

Drainage area.- 405 square miles; 93 square miles affected by storage and diversion in Sudbury River and Lake Cochituate Basins.

Stage-discharge relatíon.- Defined by current-meter measurements.

Moxima:- September 1938: Discharge, 3,210 second-feet 2 p.m. Sept. 24 (gage height, 7.74 feet).

December 1936 to August 1938: Discharge, 3,790 second-feet July 29, 1938 (gage height, 8.11 feet).

Remarks.- Flood mu-off affected by natural storage in swamps and by storage and diversion in Sudbury River and Lake Cochituate Basins. For information on storage and diversion see records for Sudbury River at Framingham Center, Mass., and Lake Cochituate outlet at Cocht tuate, Mass.

Mean daily discharge, in second-feet, 1938

\begin{tabular}{|c|r|r||r|r|r||r|r|r||r|r|r|}
\hline Day & Sept. & 0ct. & Day & Sept. & 0ct. & Day & Sept. & 0ct. & Day & Sept. & 0ct. \\
\hline 1 & 421 & 1,760 & 9 & 251 & 878 & 17 & 416 & 581 & 25 & 3,040 & 574 \\
2 & 416 & 1,600 & 10 & 228 & 846 & 18 & 506 & 544 & 26 & 2,890 & 634 \\
3 & 370 & 1,490 & 11 & 183 & 788 & 19 & 890 & 515 & 27 & 2,690 & 669 \\
4 & 340 & 1,390 & 12 & 276 & 732 & 20 & 1,460 & 481 & 28 & 2,430 & 676 \\
5 & 292 & 1,300 & 13 & 320 & 711 & 21 & 2,160 & 476 & 29 & 2,180 & 648 \\
6 & 312 & 1,150 & 14 & 338 & 669 & 22 & 2,650 & 426 & 30 & 1,930 & 648 \\
7 & 298 & 1,050 & 15 & 389 & 607 & 23 & 3,000 & 437 & 31 & & 669 \\
8 & 278 & 958 & 16 & 426 & 574 & 24 & 3,150 & 498 & & \\
\hline
\end{tabular}

Gage helght, in feet, and discharge, in second-feet, at indicated time, 1938

\begin{tabular}{|c|c|c|c|c|c|c|c|c|c|c|c|c|}
\hline \multirow{2}{*}{$\begin{array}{l}\text { 点 } \\
\text { 号 } \\
\end{array}$} & eet & Sec.ft. & Feet & Sec.ft. & Feet & Sec.ft. & Feet & Sec.ft. & Feet & Sec.ft. & Feet & Sec.ft. \\
\hline & \multicolumn{2}{|c|}{ September 18} & \multicolumn{2}{|c|}{ September 19} & \multicolumn{2}{|c|}{ September 20} & \multicolumn{2}{|c|}{ September 21} & \multicolumn{2}{|c|}{ September 22} & \multicolumn{2}{|c|}{ September 23} \\
\hline $\begin{array}{l}1 \\
2 \\
3 \\
4 \\
5 \\
6\end{array}$ & & & & & & & & & & & & \\
\hline $\begin{array}{r}7 \\
8 \\
9 \\
10 \\
7\end{array}$ & & & & & & & & & & & & 3 \\
\hline $\begin{array}{l}1 \\
2 \\
3 \\
4 \\
5 \\
6\end{array}$ & & & & $\begin{array}{r}934 \\
934 \\
934 \\
1,010 \\
966 \\
998\end{array}$ & & & & & & & & \\
\hline \multirow[t]{2}{*}{$\begin{array}{r}7 \\
8 \\
9 \\
10 \\
11 \\
M \\
\end{array}$} & $\begin{array}{l}5.15 \\
5.16 \\
5.20 \\
5.23 \\
5.26 \\
5.28 \\
\end{array}$ & $\begin{array}{l}526 \\
532 \\
555 \\
574 \\
594 \\
607 \\
\end{array}$ & $\begin{array}{l}6 \\
9 \\
3 \\
5\end{array}$ & & & & & & & & & \\
\hline & \multicolumn{2}{|c|}{ September 24} & \multicolumn{2}{|c|}{ September 25} & \multicolumn{2}{|c|}{ September 26} & \multicolumn{2}{|c|}{ September 27} & \multicolumn{2}{|c|}{ September 28} & \multicolumn{2}{|c|}{ September 29} \\
\hline $\begin{array}{l}2 \\
4 \\
6\end{array}$ & & & & $\begin{array}{l}3,110 \\
3,100 \\
3,080 \\
3,100 \\
3,050 \\
3,050\end{array}$ & & & & $\begin{array}{l}2,770 \\
2,760 \\
2,730 \\
2,720 \\
2,730 \\
2,700\end{array}$ & & & & \\
\hline $\begin{array}{r}2 \\
4 \\
6 \\
8 \\
10\end{array}$ & $\begin{array}{l}7.74 \\
7.75 \\
7.67 \\
7.69 \\
7.68 \\
7.67\end{array}$ & $\begin{array}{l}3,210 \\
3,160 \\
3,110 \\
3,140 \\
3,120 \\
3,110\end{array}$ & $\begin{array}{l}7.61 \\
7.59 \\
7.58 \\
7.58 \\
7.57 \\
7.55 \\
\end{array}$ & & $\begin{array}{l}7.50 \\
7.48 \\
7.45 \\
7.46 \\
7.44 \\
7.41 \\
\end{array}$ & & $\begin{array}{l}7.35 \\
7.33 \\
7.30 \\
7.28 \\
7.25 \\
7.24 \\
\end{array}$ & $\begin{array}{c}700 \\
570 \\
530 \\
500 \\
560 \\
550\end{array}$ & $\begin{array}{l}7.12 \\
7.10 \\
7.09 \\
7.07 \\
7.04\end{array}$ & & & \\
\hline
\end{tabular}


Location. - Lat. $42^{\circ} 17^{\prime} 30^{\prime \prime}$, long. $71^{\circ} 26^{\prime} 40^{\prime \prime}$, at dam of Framingham Reservoir No. 1, half a mile above outlet of Farm Pond and three-quarters of a mile southwest of Framingham Center, Middlesex County.

Drainage area.- 75.2 square miles (includes Farm Pond).

Stage-discharge relation.-- Observed discharge is combined flow over dam and through venturi meter and is the run-off from 75.2 square miles into the sudbury River.

Remarks.- Mean monthly discharge adjusted for storage and for diversions into reservolr from Wachusett Reservoir on South Branch of Nashua River at Clinton, Mass., and diversions from reservoir for Boston water supply. Records furnished by water division of the Metropolitan District Commission.

Mean daily discharge, in second-feet, 1938

\begin{tabular}{|c|c|c|c|c|c|c|c|c|c|c|c|}
\hline Day & Sept. & oct. & Day & Sept. & oct. & Day & Sept. & oct. & Day & Sept. & oct. \\
\hline $\begin{array}{l}1 \\
2 \\
3 \\
4 \\
5 \\
6 \\
7 \\
8\end{array}$ & $\begin{array}{l}43 \\
38 \\
35 \\
31 \\
28 \\
26 \\
30 \\
56\end{array}$ & $\begin{array}{r}345 \\
170 \\
97 \\
90 \\
86 \\
84 \\
82 \\
77\end{array}$ & $\begin{array}{r}99 \\
10 \\
11 \\
12 \\
13 \\
14 \\
15 \\
16\end{array}$ & $\begin{array}{l}69 \\
68 \\
64 \\
62 \\
61 \\
56 \\
57 \\
53\end{array}$ & $\begin{array}{l}77 \\
76 \\
73 \\
73 \\
73 \\
73 \\
75 \\
71\end{array}$ & $\begin{array}{l}17 \\
18 \\
19 \\
20 \\
21 \\
22 \\
23 \\
24\end{array}$ & $\begin{array}{r}51 \\
80 \\
172 \\
711 \\
1,120 \\
877 \\
660 \\
355\end{array}$ & $\begin{array}{l}66 \\
65 \\
62 \\
62 \\
62 \\
61 \\
62 \\
68\end{array}$ & $\begin{array}{l}25 \\
26 \\
27 \\
28 \\
29 \\
30 \\
31\end{array}$ & $\begin{array}{l}248 \\
210 \\
188 \\
169 \\
157 \\
299\end{array}$ & 67 \\
\hline an- & monthly & tare & & & & & 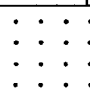 & $: \therefore:$ & $\dot{ }$ & $\begin{array}{r}202 \\
+73.2 \\
265 \\
3.93\end{array}$ & $\begin{array}{r}85.1 \\
-66.3 \\
111 \\
1.71\end{array}$ \\
\hline
\end{tabular}

Lake Cochituate outlet at Cochituate, Mass.

Location.- Lat. $42^{\circ} 18^{\prime} 45^{\mathrm{n}}$, long. $71^{\circ} 23^{\prime} 15^{\mathrm{n}}$, at outlet three-elghths of a mile north of Cochituate railroad station, Middlesex County, and $1 \frac{1}{4}$ miles above confluence with Sudbury River.

Drainage area.- 17.40 square miles since January 1937.

Stage-discharge relation.- Observed discharge is combined flow over dam and through ventur1 meter and is the run-off from 17.4 square miles into the Sudbury River.

Remarks.- Mean monthly discharge adjusted for storage and diversions into and from Lake Cochituate. Records furnished by water division of the Metropolitan District Commission.

Mean daily discharge, in second-feet, 1938

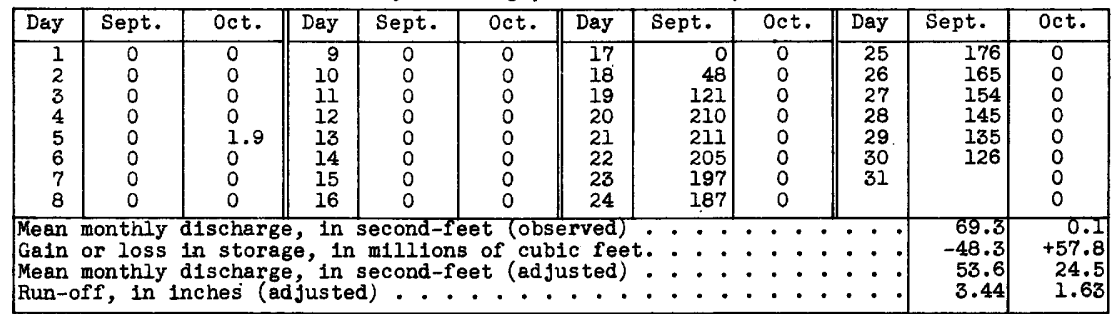


Wilifmant1c River near South Coventry, Conn.

Location. - Water-stage recorder, lat. $41^{\circ} 45^{\prime} 00^{\prime \prime}$, long. $72^{\circ} 16^{\prime} 00^{n}$, 700 feet above highway bridge, 2 miles southeast of South Coventry, Tolland County, and $2 \frac{1}{2}$ miles above mouth of Hop River. Zero of gage is 239.05 feet above mean sea level general adjustment of 1929 ).

Drainage area.- 121 square miles.

Sept. 21 , record for which was based on high-water mark, existing record, and study of distribution of water released by failure of dam upstream.

Stage-discharge relation. - Defined by current-meter measurements to 3,510 second-feet; extended to peak stage on basis of determination of flood flow over spillway of dam 3 miles upstream in March 1936 and September 1938 and study of theoretical shape of rating curve for contracted-opening control.

Maxima.- September 1938: Discharge resulting from breaking of dam upatream, 15,500 second-feet $11 \mathrm{a} . \mathrm{m}$. Sept. 21 (gage helght, 18.08 feet, from floodmark). 1931 to August 1938: D1scharge, 7,880 second-feet Mar. 12, 1936 (gage height, 12.19 feet

Remarks. - Flood run-off affected by storage in several ponds and reservo1rs.

Mean daily discharge, in second-feet, 1938

\begin{tabular}{|c|c|c|c|c|c|c|c|c|c|c|c|}
\hline Day & Sept. & oct. & Day & Sept. & oct. & Day & Sept. & oct. & Day & Sept. & Oct. \\
\hline $\begin{array}{l}1 \\
2 \\
3 \\
4 \\
5 \\
6 \\
7 \\
8\end{array}$ & $\begin{array}{r}170 \\
164 \\
160 \\
32 \\
15 \\
117 \\
99 \\
83\end{array}$ & $\begin{array}{l}480 \\
414 \\
389 \\
348 \\
323 \\
299 \\
285 \\
269\end{array}$ & $\begin{array}{r}9 \\
10 \\
11 \\
12 \\
13 \\
14 \\
15 \\
16\end{array}$ & $\begin{array}{r}81 \\
104 \\
41 \\
118 \\
136 \\
125 \\
160 \\
202\end{array}$ & $\begin{array}{l}251 \\
257 \\
251 \\
253 \\
239 \\
240 \\
228 \\
228\end{array}$ & $\begin{array}{l}17 \\
18 \\
19 \\
20 \\
21 \\
22 \\
23 \\
24\end{array}$ & $\begin{array}{r}176 \\
79 \\
1,230 \\
2,830 \\
12,900 \\
8,410 \\
2,750 \\
1,440\end{array}$ & $\begin{array}{l}234 \\
221 \\
218 \\
218 \\
246 \\
238 \\
211 \\
248\end{array}$ & $\begin{array}{l}25 \\
26 \\
27 \\
28 \\
29 \\
30 \\
31\end{array}$ & $\begin{array}{l}915 \\
680 \\
583 \\
535 \\
474 \\
478\end{array}$ & $\begin{array}{l}412 \\
343 \\
269 \\
238 \\
224 \\
207 \\
207\end{array}$ \\
\hline $\begin{array}{l}\text { Mean } \\
\text { Run- }\end{array}$ & $\begin{array}{l}\text { nthly } \\
\text {, in }\end{array}$ & 98 . & & & & & $\dot{*} \cdot \dot{\cdot}$ & $: \dot{*}$ & $\dot{0}$ & $\begin{array}{l}1,176 \\
10.84\end{array}$ & $\begin{array}{r}274 \\
2.61\end{array}$ \\
\hline
\end{tabular}

Gage height, in feet, and discharge, in second-feet, at indicated time, 1938

\begin{tabular}{|c|c|c|c|c|c|c|c|c|c|c|c|c|}
\hline \multirow{2}{*}{$\begin{array}{l}4 \\
8 \\
0 \\
\end{array}$} & Feet & Sec.ft. & Feet & Sec.ft. & Feet & sec.ft. & Feet & Sec.ft. & Beet & Sec.ft. & Feet & Sec.ft. \\
\hline & \multicolumn{2}{|c|}{ September 18} & \multicolumn{2}{|c|}{ September 19} & \multicolumn{2}{|c|}{ September 20} & \multicolumn{2}{|c|}{ September 21} & \multicolumn{2}{|c|}{ September 22} & \multicolumn{2}{|c|}{ September 23} \\
\hline $\begin{array}{l}1 \\
2 \\
3 \\
4 \\
5 \\
6\end{array}$ & $\begin{array}{l}3.23 \\
3.10 \\
2.91 \\
2.55 \\
2.31 \\
2.19\end{array}$ & \begin{tabular}{|r|}
170 \\
145 \\
112 \\
59 \\
34 \\
25
\end{tabular} & $\begin{array}{l}4.10 \\
4.71 \\
5.34 \\
5.72 \\
6.16 \\
6.74\end{array}$ & $\begin{array}{r}370 \\
533 \\
722 \\
836 \\
971 \\
1,210\end{array}$ & $\begin{array}{l}7.24 \\
7.27 \\
7.23 \\
7.27 \\
7.38 \\
7.52\end{array}$ & $\begin{array}{l}1,470 \\
1,490 \\
1,470 \\
1,490 \\
1,560 \\
1,640\end{array}$ & $\begin{array}{l}11.94 \\
12.30 \\
12.69 \\
13.12 \\
13.63 \\
14.46\end{array}$ & $\begin{array}{r}7,330 \\
8,080 \\
8,780 \\
9,490 \\
10,200 \\
11,200\end{array}$ & $\begin{array}{l}16.11 \\
15.85 \\
15.57 \\
15.24 \\
14.92 \\
14.56\end{array}$ & $\begin{array}{l}13,100 \\
12,800 \\
12,500 \\
12,100 \\
11,700 \\
11,300\end{array}$ & $\begin{array}{l}9.79 \\
9.70 \\
9.60 \\
9.53 \\
9.45 \\
9.35\end{array}$ & $\begin{array}{l}3,710 \\
3,600 \\
3,480 \\
3,400 \\
3,300 \\
3,180\end{array}$ \\
\hline $\begin{array}{r}7 \\
8 \\
9 \\
10 \\
11 \\
\text { N }\end{array}$ & $\begin{array}{l}2.12 \\
2.10 \\
2.10 \\
2.16 \\
2.20 \\
2.21\end{array}$ & $\begin{array}{l}21 \\
20 \\
20 \\
24 \\
26 \\
27\end{array}$ & $\begin{array}{l}7.22 \\
7.47 \\
7.54 \\
7.53 \\
7.43 \\
7.31\end{array}$ & $\begin{array}{l}1,460 \\
1,610 \\
1,660 \\
1,650 \\
1,590 \\
1,520\end{array}$ & $\begin{array}{l}7.64 \\
7.71 \\
7.73 \\
7.77 \\
7.88 \\
8.17\end{array}$ & $\begin{array}{l}1,730 \\
1,780 \\
1,790 \\
1,820 \\
1,900 \\
2,120\end{array}$ & $\begin{array}{l}15.17 \\
15.78 \\
16.35 \\
16.75 \\
18.08 \\
17.81\end{array}$ & $\begin{array}{l}12,000 \\
12,700 \\
13,400 \\
13,900 \\
15,500 \\
15,200\end{array}$ & $\begin{array}{l}14.22 \\
13.86 \\
13.51 \\
13.14 \\
12.83 \\
12.52\end{array}$ & $\begin{array}{r}10,900 \\
10,500 \\
10,000 \\
9,520 \\
9,030 \\
8,480\end{array}$ & $\begin{array}{l}9.28 \\
9.19 \\
9.13 \\
9.05 \\
8.99 \\
8.91\end{array}$ & $\begin{array}{l}3,110 \\
3,010 \\
2,940 \\
2,860 \\
2,790 \\
2,710\end{array}$ \\
\hline $\begin{array}{l}1 \\
2 \\
3 \\
4 \\
5 \\
6\end{array}$ & $\begin{array}{l}2.24 \\
2.22 \\
2.22 \\
2.19 \\
2.21 \\
2.31\end{array}$ & $\begin{array}{l}29 \\
27 \\
27 \\
25 \\
27 \\
34\end{array}$ & $\begin{array}{l}7.18 \\
7.07 \\
6.96 \\
6.85 \\
6.81 \\
6.78\end{array}$ & $\begin{array}{l}1,440 \\
1,380 \\
1,320 \\
1,260 \\
1,240 \\
1,230\end{array}$ & $\begin{array}{l}8.48 \\
8.71 \\
8.93 \\
9.15 \\
9.43 \\
9.74\end{array}$ & $\begin{array}{l}2,370 \\
2,580 \\
2,790 \\
3,020 \\
3,320 \\
3,690\end{array}$ & $\begin{array}{l}17.62 \\
17.59 \\
17.61 \\
17.60 \\
17.55 \\
17.50\end{array}$ & $\begin{array}{l}14,900 \\
14,900 \\
14,900 \\
14,900 \\
14,900 \\
14,800\end{array}$ & $\begin{array}{l}12.21 \\
11.92 \\
11.63 \\
11.36 \\
11.11 \\
10.86\end{array}$ & $\begin{array}{l}7,900 \\
7,280 \\
6,680 \\
6,170 \\
5,720 \\
5,300\end{array}$ & $\begin{array}{l}8.84 \\
8.74 \\
8.67 \\
8.61 \\
8.54 \\
8.45\end{array}$ & $\begin{array}{l}2,640 \\
2,540 \\
2,470 \\
2,410 \\
2,340 \\
2,260\end{array}$ \\
\hline $\begin{array}{r}7 \\
8 \\
9 \\
10 \\
11 \\
M\end{array}$ & $\begin{array}{l}2.42 \\
2.92 \\
2.91 \\
3.57 \\
3.70 \\
3.97\end{array}$ & $\begin{array}{r}44 \\
113 \\
112 \\
241 \\
271 \\
338 \\
\end{array}$ & $\begin{array}{l}6.79 \\
6.84 \\
6.96 \\
7.06 \\
7.13 \\
7.21\end{array}$ & $\begin{array}{l}1,240 \\
1,260 \\
1,320 \\
1,370 \\
1,410 \\
1,460\end{array}$ & $\begin{array}{l}10.07 \\
10.36 \\
10.75 \\
11.14 \\
11.44 \\
11.71\end{array}$ & $\begin{array}{l}4,100 \\
4,500 \\
5,120 \\
5,770 \\
6,310 \\
6,840\end{array}$ & $\begin{array}{l}17.42 \\
17.31 \\
17.22 \\
16.93 \\
16.63 \\
16.38\end{array}$ & $\begin{array}{l}14,700 \\
14,600 \\
14,500 \\
14,100 \\
13,800 \\
13,500\end{array}$ & $\begin{array}{r}10.65 \\
10.46 \\
10.30 \\
10.13 \\
10.01 \\
9.90\end{array}$ & $\begin{array}{l}4,960 \\
4,660 \\
4,420 \\
4,180 \\
4,010 \\
3,860\end{array}$ & $\begin{array}{l}8.37 \\
8.31 \\
8.24 \\
8.16 \\
8.10 \\
8.05 \\
\end{array}$ & $\begin{array}{r}2,180 \\
2,130 \\
2,070 \\
1,990 \\
1,940 \\
1,900\end{array}$ \\
\hline & \multicolumn{2}{|c|}{ September 24} & \multicolumn{2}{|c|}{ September 25} & \multicolumn{2}{|c|}{ September 26} & \multicolumn{2}{|c|}{ September 27} & \multicolumn{2}{|c|}{ September 28} & \multicolumn{2}{|c|}{ September 29} \\
\hline $\begin{array}{r}2 \\
4 \\
6 \\
8 \\
10 \\
\text { N }\end{array}$ & $\begin{array}{l}7.91 \\
7.79 \\
7.69 \\
7.61 \\
7.55 \\
7.43\end{array}$ & $\begin{array}{l}1,790 \\
1,690 \\
1,610 \\
1,560 \\
1,520 \\
1,430\end{array}$ & $\begin{array}{l}6.79 \\
6.72 \\
6.65 \\
6.55 \\
6.51 \\
6.45\end{array}$ & $\begin{array}{r}1,060 \\
1,030 \\
995 \\
950 \\
934 \\
910\end{array}$ & $\begin{array}{l}6.02 \\
5.98 \\
5.94 \\
5.90 \\
5.85 \\
5.82\end{array}$ & $\begin{array}{l}747 \\
733 \\
719 \\
705 \\
688 \\
677\end{array}$ & $\begin{array}{l}5.58 \\
5.56 \\
5.55 \\
5.54 \\
5.50 \\
5.49\end{array}$ & $\begin{array}{l}599 \\
593 \\
590 \\
587 \\
575 \\
572\end{array}$ & $\begin{array}{l}5.53 \\
5.54 \\
5.48 \\
5.41 \\
5.33 \\
5.28\end{array}$ & $\begin{array}{l}584 \\
587 \\
569 \\
548 \\
524 \\
509\end{array}$ & $\begin{array}{l}5.24 \\
5.22 \\
5.16 \\
5.13 \\
5.10 \\
5.10\end{array}$ & $\begin{array}{l}497 \\
491 \\
475 \\
468 \\
460 \\
460\end{array}$ \\
\hline $\begin{array}{r}2 \\
4 \\
6 \\
8 \\
10 \\
1\end{array}$ & $\begin{array}{l}7.31 \\
7.21 \\
7.13 \\
7.04 \\
6.95 \\
6.86\end{array}$ & $\begin{array}{l}1,360 \\
1,300 \\
1,250 \\
1,190 \\
1,140 \\
1,100\end{array}$ & $\begin{array}{l}6.37 \\
6.33 \\
6.25 \\
6.19 \\
6.14 \\
6.08\end{array}$ & $\begin{array}{l}878 \\
862 \\
830 \\
806 \\
789 \\
768\end{array}$ & $\begin{array}{l}5.74 \\
5.76 \\
5.72 \\
5.68 \\
5.66 \\
5.61\end{array}$ & $\begin{array}{l}649 \\
656 \\
642 \\
629 \\
623 \\
608\end{array}$ & $\begin{array}{l}5.52 \\
5.54 \\
5.50 \\
5.50 \\
5.51 \\
5.47\end{array}$ & $\begin{array}{l}581 \\
587 \\
575 \\
575 \\
578 \\
566\end{array}$ & $\begin{array}{l}5.31 \\
5.32 \\
5.28 \\
5.27 \\
5.30 \\
5.26\end{array}$ & $\begin{array}{l}518 \\
521 \\
509 \\
506 \\
515 \\
503\end{array}$ & $\begin{array}{l}5.13 \\
5.16 \\
5.14 \\
5.13 \\
5.17 \\
5.11\end{array}$ & $\begin{array}{l}468 \\
475 \\
470 \\
468 \\
478 \\
462\end{array}$ \\
\hline
\end{tabular}


Location. - Water-stage recorder, lat. $41^{\circ} 41 ' 58^{\prime \prime}$, long. $72^{\circ} 10^{\prime} 53^{\prime \prime}$, at Bingham Br1dge, 1 mile below confluence of Wilimantic and Natchaug Rivers and $1 \frac{1}{2}$ miles below Willimantic, Windham County. Zero of gage is 131.40 feet above mean sea level (general ad jus tment of 1929).

Drainage area.- 401 square miles.

Gage-he1ght record.- Water-stage recorder graph except for period 6 a.m. Sept. 21 to 5 p.m. Sept. 23, record for which was based on partial gage-helght record, floodmarks, information from local residents, and correlation with flood-routing study for gaging stations on three main headwater streams.

Stage-discharge relation. - Defined by current-meter measurements below 10,900 secondfeet; extended logarithmically to peak stage on basis of computation of flood flow of March 1936, and of September 1938 over spillway of dams 5 and 9 miles downstream, correlated with combined flow at gring stations on three main headwater streams.

Maxima. - September 1938: D1scharge, 52,200 second-feet 2-3 p.m. Sept. 21 (gage helght, 27. 6 feet, from floodmarks)

1904-5, 1933 to August 1938: Discharge, 23,900 second-feet Mar. 12, 1936 (gage he1ght, 18.\$5 feet, from floodmarks).

Remarks. - Flood run-off affected by storage in numerous ponds and reservoirs and by fallure of dams upstream.

Mean dally discharge, in second-feet, 1938

\begin{tabular}{|c|c|c|c|c|c|c|c|c|c|c|c|}
\hline Day & Sept. & oct. & Day & Sept. & Oct. & Day & Sept. & Oct. & Day & Sept. & Oct. \\
\hline $\begin{array}{l}1 \\
2 \\
3 \\
4 \\
5 \\
6 \\
7 \\
8\end{array}$ & $\begin{array}{l}270 \\
300 \\
267 \\
206 \\
139 \\
237 \\
238 \\
217\end{array}$ & $\begin{array}{r}1,600 \\
1,380 \\
1,190 \\
1,080 \\
956 \\
896 \\
914 \\
878\end{array}$ & $\begin{array}{l}9 \\
10 \\
11 \\
12 \\
13 \\
14 \\
15 \\
16\end{array}$ & $\begin{array}{l}206 \\
117 \\
172 \\
212 \\
249 \\
341 \\
386 \\
620\end{array}$ & $\begin{array}{l}832 \\
810 \\
728 \\
690 \\
665 \\
670 \\
665 \\
645\end{array}$ & $\begin{array}{l}17 \\
18 \\
19 \\
20 \\
21 \\
22 \\
23 \\
24\end{array}$ & $\begin{array}{r}489 \\
553 \\
3,950 \\
8,420 \\
35,500 \\
25,500 \\
11,400 \\
4,960\end{array}$ & $\begin{array}{l}635 \\
605 \\
580 \\
575 \\
625 \\
665 \\
585 \\
645\end{array}$ & $\begin{array}{l}25 \\
26 \\
27 \\
28 \\
29 \\
30 \\
31\end{array}$ & $\begin{array}{l}3,190 \\
2,400 \\
1,910 \\
1,700 \\
1,520 \\
1,460\end{array}$ & $\begin{array}{r}1,150 \\
1,100 \\
890 \\
783 \\
766 \\
734 \\
665\end{array}$ \\
\hline $\begin{array}{l}\text { Mean } \\
\text { Run- }\end{array}$ & $\begin{array}{l}\text { onthly } \\
\text { e, in }\end{array}$ & achere & 1 & Acond & et. . & : & 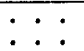 & . : . & : & $\begin{array}{r}3,571 \\
9.94\end{array}$ & $\begin{array}{r}825 \\
2.38\end{array}$ \\
\hline
\end{tabular}

Gage helght, in feet, and discharge, In second-feet, at indicated time, I938

\begin{tabular}{|c|c|c|c|c|c|c|c|c|c|c|c|c|}
\hline \multirow{2}{*}{$\begin{array}{l}8 \\
0 \\
0\end{array}$} & Feet & Sec.ft. & Feet & Sec.ft. & Feet & Sec.ft. & Feet & Sec.ft. & Feet & Sec.ft. & Feet & Sec.ft. \\
\hline & \multicolumn{2}{|c|}{ September 18} & \multicolumn{2}{|c|}{ September 19} & \multicolumn{2}{|c|}{ September 20} & \multicolumn{2}{|c|}{ September 21} & \multicolumn{2}{|c|}{ Septembèr 22} & \multicolumn{2}{|c|}{ September 23} \\
\hline $\begin{array}{l}1 \\
2 \\
3 \\
4 \\
5 \\
6\end{array}$ & $\begin{array}{l}3.25 \\
3.25 \\
3.26 \\
3.27 \\
3.28 \\
3.25\end{array}$ & $\begin{array}{l}498 \\
498 \\
502 \\
506 \\
511 \\
498\end{array}$ & $\begin{array}{l}4.01 \\
4.20 \\
4.72 \\
4.92 \\
5.06 \\
5.50\end{array}$ & $\begin{array}{r}886 \\
1,000 \\
1,350 \\
1,500 \\
1,610 \\
1,960\end{array}$ & $\begin{array}{r}9.73 \\
9.78 \\
9.86 \\
9.92 \\
10.02 \\
10.12\end{array}$ & $\begin{array}{l}6,760 \\
6,830 \\
6,940 \\
7,030 \\
7,170 \\
7,310\end{array}$ & \begin{tabular}{|l|}
13.94 \\
14.53 \\
15.00 \\
15.51 \\
16.1 \\
16.8
\end{tabular} & $\begin{array}{l}13,800 \\
15,000 \\
16,000 \\
17,000 \\
18,300 \\
19,900\end{array}$ & $\begin{array}{l}23.3 \\
22.85 \\
22.4 \\
21.95 \\
21.6 \\
21.15\end{array}$ & $\begin{array}{l}38,000 \\
36,600 \\
35,200 \\
33,800 \\
32,800 \\
31,400\end{array}$ & $\begin{array}{l}14.05 \\
13.75 \\
13.65 \\
13.8 \\
14.15 \\
14.5\end{array}$ & $\begin{array}{l}14,100 \\
13,500 \\
13,300 \\
13,600 \\
14,300 \\
15,000\end{array}$ \\
\hline $\begin{array}{r}7 \\
8 \\
9 \\
10 \\
11 \\
\text { N }\end{array}$ & $\begin{array}{l}3.23 \\
3.21 \\
3.22 \\
3.24 \\
3.31 \\
3.09\end{array}$ & $\begin{array}{l}488 \\
480 \\
484 \\
493 \\
524 \\
426\end{array}$ & $\begin{array}{l}5.74 \\
6.17 \\
6.55 \\
6.93 \\
7.26 \\
7.66\end{array}$ & $\begin{array}{l}2,180 \\
2,560 \\
2,940 \\
3,320 \\
3,680 \\
4,120\end{array}$ & $\begin{array}{l}10.22 \\
10.29 \\
10.31 \\
10.37 \\
10.44 \\
10.57\end{array}$ & $\begin{array}{l}7,450 \\
7,550 \\
7,570 \\
7,660 \\
7,760 \\
7,960\end{array}$ & $\begin{array}{l}17.6 \\
18.6 \\
19.85 \\
21.85 \\
23.45 \\
25.5\end{array}$ & $\begin{array}{l}21,900 \\
24,500 \\
27,800 \\
33,600 \\
38,400 \\
45,100\end{array}$ & $\begin{array}{l}20.8 \\
20.35 \\
19.95 \\
19.5 \\
19.1 \\
18.7\end{array}$ & $\begin{array}{l}30,400 \\
29,200 \\
28,100 \\
26,800 \\
25,800 \\
24,700\end{array}$ & $\begin{array}{l}14.3 \\
14.1 \\
13.85 \\
13.55 \\
13.25 \\
12.95\end{array}$ & $\begin{array}{l}14,600 \\
14,200 \\
13,700 \\
13,100 \\
12,500 \\
11,900\end{array}$ \\
\hline $\begin{array}{l}1 \\
2 \\
3 \\
4 \\
5 \\
6\end{array}$ & $\begin{array}{l}2.99 \\
3.39 \\
3.54 \\
3.44 \\
3.47 \\
3.50\end{array}$ & $\begin{array}{l}381 \\
560 \\
630 \\
583 \\
596 \\
610\end{array}$ & $\begin{array}{l}7.93 \\
8.23 \\
8.48 \\
8.76 \\
8.92 \\
9.19\end{array}$ & $\begin{array}{l}4,450 \\
4,810 \\
5,120 \\
5,490 \\
5,700 \\
6,050\end{array}$ & $\begin{array}{l}10.60 \\
10.65 \\
10.72 \\
10.84 \\
11.00 \\
11.21\end{array}$ & $\begin{array}{l}8,000 \\
8,080 \\
8,180 \\
8,360 \\
8,600 \\
8,940\end{array}$ & $\begin{array}{l}26.8 \\
27.6 \\
27.6 \\
27.55 \\
27.35 \\
27.1\end{array}$ & $\begin{array}{l}49,500 \\
52,200 \\
52,200 \\
52,100 \\
51,400 \\
50,500\end{array}$ & $\begin{array}{l}18.3 \\
17.95 \\
17.6 \\
17.2 \\
16.8 \\
16.45\end{array}$ & $\begin{array}{l}23,700 \\
22,800 \\
21,900 \\
20,900 \\
19,900 \\
19,100\end{array}$ & $\begin{array}{l}12.6 \\
12.3 \\
12.0 \\
11.7 \\
11.46 \\
11.20\end{array}$ & $\begin{array}{l}11, \\
10, \\
10, \\
9, \\
9, \\
8,\end{array}$ \\
\hline \multirow[t]{2}{*}{$\begin{array}{r}7 \\
8 \\
9 \\
10 \\
11 \\
M \\
\end{array}$} & $\begin{array}{l}3.51 \\
3.53 \\
3.55 \\
3.61 \\
3.85 \\
3.89\end{array}$ & $\begin{array}{l}615 \\
625 \\
635 \\
665 \\
790 \\
814\end{array}$ & $\begin{array}{l}9.33 \\
9.50 \\
9.56 \\
9.58 \\
9.63 \\
9.67\end{array}$ & $\begin{array}{l}6,230 \\
6,450 \\
6,530 \\
6,550 \\
6,620 \\
6,680\end{array}$ & $\begin{array}{l}11.52 \\
11.89 \\
12.31 \\
12.71 \\
13.10 \\
13.58\end{array}$ & $\begin{array}{r}9,430 \\
10,000 \\
10,800 \\
11,500 \\
12,200 \\
13,100\end{array}$ & $\begin{array}{l}26.75 \\
26.2 \\
25.55 \\
25.0 \\
24.3 \\
23.8\end{array}$ & $\begin{array}{l}49,400 \\
47,500 \\
45,300 \\
43,400 \\
41,200 \\
39,600\end{array}$ & $\begin{array}{l}16.05 \\
15.7 \\
15.3 \\
15.0 \\
14.65 \\
14.35\end{array}$ & $\begin{array}{l}18,200 \\
17,500 \\
16,600 \\
16,000 \\
15,300 \\
14,700\end{array}$ & $\begin{array}{r}10.99 \\
10.76 \\
10.52 \\
10.33 \\
10.12 \\
9.92\end{array}$ & $\begin{array}{l}8,580 \\
8,220 \\
7,840 \\
7,560 \\
7,240 \\
6,940\end{array}$ \\
\hline & \multicolumn{2}{|c|}{ September 24} & \multicolumn{2}{|c|}{ September 25} & \multicolumn{2}{|c|}{ September 26} & \multicolumn{2}{|c|}{ September 27} & \multicolumn{2}{|c|}{ September 28} & \multicolumn{2}{|c|}{ September 29} \\
\hline $\begin{array}{r}2 \\
4 \\
6 \\
8 \\
10 \\
N\end{array}$ & $\begin{array}{l}9.57 \\
9.23 \\
8.98 \\
8.72 \\
8.51 \\
8.32\end{array}$ & $\begin{array}{l}6,430 \\
5,950 \\
5,600 \\
5,270 \\
4,990 \\
4,750\end{array}$ & $\begin{array}{l}7.40 \\
7.29 \\
7.19 \\
7.09 \\
7.00 \\
6.91\end{array}$ & $\begin{array}{l}3,670 \\
3,550 \\
3,440 \\
3,330 \\
3,230 \\
3,140\end{array}$ & $\begin{array}{l}6.44 \\
6.37 \\
6.31 \\
6.26 \\
6.20 \\
6.13\end{array}$ & $\begin{array}{l}2,670 \\
2,600 \\
2,550 \\
2,500 \\
2,450 \\
2,390\end{array}$ & $\begin{array}{l}5.79 \\
5.73 \\
5.69 \\
5.65 \\
5.60 \\
5.56\end{array}$ & $\begin{array}{l}2,080 \\
2,030 \\
2,000 \\
1,970 \\
1,930 \\
1,900\end{array}$ & \begin{tabular}{|l|}
5.46 \\
5.45 \\
5.43 \\
5.41 \\
5.40 \\
5.32
\end{tabular} & $\begin{array}{l}1,820 \\
1,810 \\
1,790 \\
1,780 \\
1,770 \\
1,710\end{array}$ & $\begin{array}{l}5.16 \\
5.14 \\
5.17 \\
5.13 \\
5.11 \\
5.07\end{array}$ & $\begin{array}{l}1,580 \\
1,560 \\
1,590 \\
1,550 \\
1,540 \\
1,510\end{array}$ \\
\hline $\begin{array}{r}2 \\
4 \\
6 \\
8 \\
10 \\
M\end{array}$ & $\begin{array}{l}8.18 \\
8.01 \\
7.90 \\
7.75 \\
7.61 \\
7.50\end{array}$ & $\begin{array}{l}4,580 \\
4,370 \\
4,240 \\
4,060 \\
3,900 \\
3,780\end{array}$ & $\begin{array}{l}6.84 \\
6.78 \\
6.69 \\
6.62 \\
6.57 \\
6.50\end{array}$ & $\begin{array}{l}3,070 \\
3,010 \\
2,920 \\
2,850 \\
2,800 \\
2,730\end{array}$ & $\begin{array}{l}6.09 \\
6.00 \\
5.97 \\
5.93 \\
5.89 \\
5.83\end{array}$ & $\begin{array}{l}2,350 \\
2,270 \\
2,240 \\
2,210 \\
2,170 \\
2,120\end{array}$ & $\begin{array}{l}5.51 \\
5.42 \\
5.43 \\
5.44 \\
5.46 \\
5.46\end{array}$ & $\begin{array}{l}1,860 \\
1,790 \\
1,790 \\
1,800 \\
1,820 \\
1,820\end{array}$ & $\begin{array}{l}5.28 \\
5.27 \\
5.13 \\
5.13 \\
5.14 \\
5.15\end{array}$ & $\begin{array}{l}1,670 \\
1,670 \\
1,550 \\
1,550 \\
1,560 \\
1,570\end{array}$ & $\begin{array}{l}5.04 \\
5.02 \\
5.01 \\
5.01 \\
5.00 \\
4.99\end{array}$ & $\begin{array}{l}1,490 \\
1,470 \\
1,470 \\
1,470 \\
1,460 \\
1,450\end{array}$ \\
\hline
\end{tabular}


Location. - Water-stage recorder, lat. $41^{\circ} 43^{\prime} 25^{\prime \prime}$, long. $72^{\circ} 18^{\prime} 05^{\prime \prime}, 1,000$ feet below abandoned mill and dam, a quarter of a mile below Hop River depot, 2 miles north of Columbla, Tolland County, and $3 \frac{1}{2} \mathrm{miles}$ above confluence of Hop and Willimantic Rivers. Zero of gage is 249.25 feet above mean sea level (general adjustment of 1929).

Drainage area.- 76.2 square miles.

Gage-he1ght record. - Water-stage recorder graph except for period 5:30 a.m. Sept. 21 to noon Sept. 24, record for which was based on high-water marks, existing record, one inspection, and study of distribution of water released by failure of dam upstream.

Stage-discharge relation.- Defined by current-meter measurements to 2,880 secondfeet; extended to peak stage on basis of determination of flood flow over spillway of dam a quarter of a mile upstream.

Maxima.- September 1938: Discharge, 6,450 second-feet 4 p.m. Sept. 21 (gage height, 16.25 feet, from floodmarks).

1932 to August 1938: Discharge, 3,300 second-feet Mar. 12, 1936 (gage

helght, 13.85 feet, from floodmarks).

Remarks.- Flood run-off affected by storage in two reservoirs.

Mean dally discharge, in second-feet, 1938

\begin{tabular}{|c|r|r||r|r|r|r|r|r|r|r|r|}
\hline Day & Sept. & Oct. & Day & Sept. & 0ct. & Day & Sept. & 0ct. & Day & Sept. & Oct. \\
\hline 1 & 38 & 264 & 9 & 32 & 188 & 17 & 63 & 115 & 25 & 622 & 242 \\
2 & 32 & 224 & 10 & 27 & 151 & 18 & 78 & 110 & 26 & 444 & 181 \\
3 & 24 & 199 & 11 & 21 & 140 & 19 & 712 & 108 & 27 & 331 & 156 \\
4 & 31 & 183 & 12 & 32 & 127 & 20 & 1,900 & 108 & 28 & 298 & 144 \\
5 & 31 & 170 & 13 & 29 & 123 & 21 & 4,930 & 126 & 29 & 257 & 152 \\
6 & 36 & 165 & 14 & 41 & 119 & 22 & 3,500 & 129 & 30 & 242 & 143 \\
7 & 29 & 207 & 15 & 52 & 119 & 23 & 3,180 & 120 & 31 & & 131 \\
8 & 28 & 199 & 16 & 85 & 117 & 24 & 1,050 & 135 & & & \\
\hline
\end{tabular}

Gage helght, in feet, and discharge, in second-feet, at indicated time, 1938

\begin{tabular}{|c|c|c|c|c|c|c|c|c|c|c|c|c|}
\hline & Feet & Sec.ft. & eot & Sec.ft. & Feet & Sec.ft. & Feet & ec.ft. & Feet & Sec.ft. & oet & Sec.ft. \\
\hline & \multicolumn{2}{|c|}{ September 18} & \multicolumn{2}{|c|}{ September 19} & \multicolumn{2}{|c|}{ September 20} & \multicolumn{2}{|c|}{ September 21} & \multicolumn{2}{|c|}{ September 22} & \multicolumn{2}{|c|}{ September 23} \\
\hline & $\begin{array}{l}3.13 \\
3.12 \\
3.17 \\
3.25 \\
3.31 \\
3.39\end{array}$ & $\begin{array}{l}47 \\
47 \\
51 \\
57 \\
62 \\
69\end{array}$ & $\begin{array}{l}4.15 \\
4.32 \\
4.63 \\
5.24 \\
5.91 \\
6.25\end{array}$ & \begin{tabular}{l|}
168 \\
199 \\
261 \\
384 \\
538 \\
622
\end{tabular} & $\begin{array}{l}7.26 \\
7.28 \\
7.34 \\
7.44 \\
7.53 \\
7.63\end{array}$ & $\begin{array}{l}875 \\
880 \\
895 \\
920 \\
944 \\
974\end{array}$ & & $\begin{array}{l}3,150 \\
3,170 \\
3,200 \\
3,260 \\
3,420 \\
3,680\end{array}$ & $\begin{array}{l}14.90 \\
14.70 \\
14.45 \\
14.30 \\
14.10 \\
13.90\end{array}$ & & & \\
\hline & $\begin{array}{l}3.42 \\
3.46 \\
3.48 \\
3.49 \\
3.50 \\
3.50\end{array}$ & $\begin{array}{l}72 \\
76 \\
78 \\
79 \\
80 \\
80\end{array}$ & $\begin{array}{l}6.52 \\
6.75 \\
6.93 \\
7.09 \\
7.20 \\
7.30\end{array}$ & $\begin{array}{l}690 \\
748 \\
792 \\
832 \\
860 \\
885\end{array}$ & $\begin{array}{l}7.75 \\
7.87 \\
8.01 \\
8.23 \\
8.60 \\
9.00\end{array}$ & $\begin{array}{l}1,010 \\
1,050 \\
1,090 \\
1,150 \\
1,270 \\
1,410\end{array}$ & $\begin{array}{l}14.35 \\
14.75 \\
15.05 \\
15.30 \\
15.50 \\
15.75\end{array}$ & & & & & \\
\hline & $\begin{array}{l}3.50 \\
3.54 \\
3.54 \\
3.55 \\
3.57 \\
3.59\end{array}$ & $\begin{array}{l}80 \\
84 \\
84 \\
86 \\
88 \\
90\end{array}$ & $\begin{array}{l}7.39 \\
7.30 \\
7.37 \\
7.30 \\
7.22 \\
7.17\end{array}$ & $\begin{array}{l}908 \\
885 \\
902 \\
885 \\
865 \\
852\end{array}$ & $\begin{array}{r}9.40 \\
9.98 \\
11.41 \\
12.75 \\
13.13 \\
13.22\end{array}$ & $\begin{array}{l}1,550 \\
1,770 \\
2,380 \\
3,050 \\
3,240 \\
3,290\end{array}$ & $\begin{array}{l}15.90 \\
16.05 \\
16.20 \\
16.25 \\
16.20 \\
16.15\end{array}$ & & & & & \\
\hline & $\begin{array}{l}3.60 \\
3.61 \\
3.63 \\
3.65 \\
3.74 \\
3.90 \\
\end{array}$ & $\begin{array}{r}91 \\
92 \\
95 \\
97 \\
108 \\
129 \\
\end{array}$ & $\begin{array}{l}7.14 \\
7.17 \\
7.21 \\
7.25 \\
7.26 \\
7.25 \\
\end{array}$ & $\begin{array}{l}845 \\
852 \\
862 \\
872 \\
875 \\
872 \\
\end{array}$ & $\begin{array}{l}13.15 \\
13.06 \\
13.03 \\
12.96 \\
12.93 \\
12.91 \\
\end{array}$ & $\begin{array}{r}3,250 \\
3,210 \\
3,200 \\
3,160 \\
3,140 \\
3,140 \\
\end{array}$ & $\begin{array}{l}16.10 \\
15.95 \\
15.80 \\
15.60 \\
15.40 \\
15.15 \\
\end{array}$ & & & & & $\begin{array}{l}2,120 \\
2,040 \\
1,960 \\
1,880 \\
1,780 \\
1,700 \\
\end{array}$ \\
\hline & \multicolumn{2}{|c|}{ September 24} & \multicolumn{2}{|c|}{ September 25} & \multicolumn{2}{|c|}{ September 26} & \multicolumn{2}{|c|}{ September 27} & \multicolumn{2}{|c|}{ Septermber 28} & \multicolumn{2}{|c|}{ September 29} \\
\hline & $\begin{array}{l}9.30 \\
8.90 \\
8.50 \\
8.25 \\
7.95 \\
7.75\end{array}$ & $\begin{array}{r}1,500 \\
1,350 \\
1,210 \\
1,120 \\
1,020 \\
955\end{array}$ & & $\begin{array}{l}714 \\
689 \\
668 \\
652 \\
631 \\
616\end{array}$ & & $\begin{array}{l}507 \\
497 \\
485 \\
471 \\
443\end{array}$ & & & & \begin{tabular}{|l|}
314 \\
312 \\
310 \\
307 \\
303 \\
300
\end{tabular} & & $\begin{array}{l}264 \\
264 \\
260 \\
256\end{array}$ \\
\hline & $\begin{array}{l}7.59 \\
7.48 \\
7.32 \\
7.22 \\
7.12 \\
7.03\end{array}$ & $\begin{array}{l}907 \\
868 \\
826 \\
796 \\
768 \\
742\end{array}$ & $\begin{array}{l}6.50 \\
6.44 \\
6.39 \\
6.33 \\
6.27 \\
6.21\end{array}$ & $\begin{array}{l}600 \\
584 \\
572 \\
557 \\
543 \\
528\end{array}$ & $\begin{array}{l}5.72 \\
5.65 \\
5.60 \\
5.53 \\
5.49 \\
5.44\end{array}$ & $\begin{array}{l}416 \\
402 \\
392 \\
378 \\
370 \\
360 \\
\end{array}$ & $\begin{array}{l}5.25 \\
5.24 \\
5.23 \\
5.22 \\
5.21 \\
5.21\end{array}$ & $\begin{array}{l}323 \\
321 \\
319 \\
318 \\
316 \\
316\end{array}$ & $\begin{array}{l}5.11 \\
5.07 \\
5.04 \\
5.02 \\
5.00 \\
4.98\end{array}$ & $\begin{array}{l}298 \\
291 \\
285 \\
282 \\
278 \\
274\end{array}$ & & $\begin{array}{l}251 \\
247 \\
246 \\
242 \\
240\end{array}$ \\
\hline
\end{tabular}


Natchaug River at Willimantic, Conn.

Location. - Water-stage recorder, lat. $41^{\circ} 43^{\prime} 14^{\prime \prime}$, long. $72^{\circ} 11^{\prime} 53^{\prime \prime}$, 200 foet below New York, New Haven \& Hartford Rallroad bridge and 1 mile northeast of Willimantic, Windham County. Zero of gage is 150.31 feet above mean sea level (general adjustment of 1929 ).

Dralnage area. - 169 square miles.

Gage-height record. - Water-stage recorder graph except for period 11:00 a.m. to 7:00 p.m. Sept. 21, record for which was based on high-water mark and existing record. Stage-discharge relation. - Defined by current-meter measurements to 6;530 second-feet; extended to peak stage on basis of determinations of flood flow over spillway of dam 2 miles upstream in March 1936 and September 1938.

Maxima. - September 1938: Discharge, resulting from breaking of dam upstream, 32,000 second-feet 2 p.m., Sept. 21 (gage helght, 16.39 feet, from floodmarks). 1930 to August 1938: Discharge, resulting from breaking of dam upstream, 14,200 second-feet Mar. 18, 1936 (gage he1ght, 13.57 feet).

Remarks.- Flood mun-off affected by storage in several small ponds. Small diversions for water supply of Willimantic pumped from reservoir 2 miles upstream. Mean monthly diversions: September, 1.56 second-feet; October, 1.77 second-feet.

Mean daily discharge, in second-feet, 1938

\begin{tabular}{|c|c|c|c|c|c|c|c|c|c|c|c|}
\hline Day & Sept. & Oct. & Day & Sept. & Oct. & Day & Sept. & Oct. & Day & Sept. & oct. \\
\hline $\begin{array}{l}1 \\
2 \\
3 \\
4 \\
5 \\
6 \\
7 \\
8\end{array}$ & $\begin{array}{r}102 \\
94 \\
87 \\
73 \\
73 \\
68 \\
62 \\
66\end{array}$ & $\begin{array}{l}691 \\
596 \\
498 \\
434 \\
362 \\
354 \\
350 \\
323\end{array}$ & $\begin{array}{r}9 \\
10 \\
11 \\
12 \\
13 \\
14 \\
15 \\
16\end{array}$ & $\begin{array}{r}64 \\
62 \\
54 \\
38 \\
75 \\
155 \\
166 \\
295\end{array}$ & $\begin{array}{l}311 \\
296 \\
278 \\
257 \\
247 \\
257 \\
271 \\
257\end{array}$ & $\begin{array}{l}17 \\
18 \\
19 \\
20 \\
21 \\
22 \\
23 \\
24\end{array}$ & $\begin{array}{r}198 \\
297 \\
2,230 \\
4,570 \\
18,200 \\
8,570 \\
3,310 \\
1,810\end{array}$ & $\begin{array}{l}240 \\
234 \\
228 \\
218 \\
237 \\
237 \\
215 \\
237\end{array}$ & $\begin{array}{l}25 \\
26 \\
27 \\
28 \\
29 \\
30 \\
31\end{array}$ & $\begin{array}{r}1,280 \\
983 \\
782 \\
685 \\
641 \\
601\end{array}$ & $\begin{array}{l}426 \\
410 \\
350 \\
315 \\
323 \\
327 \\
285\end{array}$ \\
\hline \multicolumn{6}{|c|}{ Mean monthly discharge, in second-feet. } & $\dot{.}$ & $\begin{array}{l}\cdot . \\
.\end{array}$ & $\begin{array}{l}\cdot \\
.\end{array}$ & $\begin{array}{l}. \\
.\end{array}$ & $\begin{array}{l}1,523 \\
10.05\end{array}$ & $\begin{array}{r}325 \\
2.21\end{array}$ \\
\hline
\end{tabular}

Gage helght, in feet, and discharge, in second-feet, at indicated time, 1938

\begin{tabular}{|c|c|c|c|c|c|c|c|c|c|c|c|c|}
\hline \multirow{2}{*}{ 哠 } & Feot & Sec.ft. & Feet & Sec.ft. & Feet & Sec.ft. & Feet & Sec.ft. & Feet & Sec.ft. & Feet & Sec.ft \\
\hline & \multicolumn{2}{|c|}{ September 18} & \multicolumn{2}{|c|}{ September 19} & \multicolumn{2}{|c|}{ September 20} & \multicolumn{2}{|c|}{ September 21} & \multicolumn{2}{|c|}{ September 22} & \multicolumn{2}{|c|}{ September 23} \\
\hline $\begin{array}{l}1 \\
2 \\
3 \\
4 \\
5 \\
6\end{array}$ & $\begin{array}{l}2.08 \\
2.13 \\
2.17 \\
2.20 \\
2.22 \\
2.25\end{array}$ & $\begin{array}{l}173 \\
184 \\
193 \\
200 \\
205 \\
212\end{array}$ & $\begin{array}{l}3.31 \\
3.50 \\
3.81 \\
4.00 \\
4.14 \\
4.41\end{array}$ & $\begin{array}{r}538 \\
610 \\
734 \\
820 \\
883 \\
1,020\end{array}$ & $\begin{array}{l}9.07 \\
9.14 \\
9.20 \\
9.28 \\
9.37 \\
9.45\end{array}$ & $\begin{array}{l}3,870 \\
3,920 \\
3,970 \\
4,030 \\
4,110 \\
4,170\end{array}$ & $\begin{array}{l}11.30 \\
11.40 \\
11.52 \\
11.70 \\
12.01 \\
12.46\end{array}$ & $\begin{array}{l}6,400 \\
6,600 \\
6,850 \\
7,300 \\
8,130 \\
9,560\end{array}$ & $\begin{array}{l}13.56 \\
13.37 \\
13.20 \\
13.02 \\
12.88 \\
12.73\end{array}$ & $\begin{array}{l}14,200 \\
13,300 \\
12,600 \\
11,700 \\
11,200 \\
10,600\end{array}$ & & $\begin{array}{l}4,710 \\
4,540 \\
4,410 \\
4,240 \\
4,090 \\
3,920\end{array}$ \\
\hline $\begin{array}{r}7 \\
8 \\
9 \\
10\end{array}$ & $\begin{array}{l}2.29 \\
2.32 \\
2.40 \\
2.51 \\
2.52 \\
2.52\end{array}$ & $\begin{array}{l}222 \\
230 \\
251 \\
281 \\
284 \\
284\end{array}$ & $\begin{array}{l}4.75 \\
5.16 \\
5.52 \\
5.84 \\
6.24 \\
6.64\end{array}$ & $\begin{array}{l}1,180 \\
1,390 \\
1,570 \\
1,730 \\
1,930 \\
2,170\end{array}$ & $\begin{array}{l}54 \\
50 \\
53 \\
55 \\
74 \\
30\end{array}$ & $\begin{array}{l}240 \\
290 \\
310 \\
330 \\
410 \\
460\end{array}$ & & $\begin{array}{l}11 \\
14 \\
17 \\
19 \\
22 \\
25\end{array}$ & $\begin{array}{l}67 \\
51 \\
35 \\
20 \\
07 \\
91\end{array}$ & $\begin{array}{r}10,300 \\
9,740 \\
9,180 \\
8,700 \\
8,310 \\
7,830\end{array}$ & & $\begin{array}{l}3 \\
3 \\
3 \\
3\end{array}$ \\
\hline $\begin{array}{l}1 \\
2 \\
3 \\
4 \\
5 \\
6\end{array}$ & $\begin{array}{l}2.56 \\
2.65 \\
2.70 \\
2.72 \\
2.76 \\
2.80\end{array}$ & $\begin{array}{l}295 \\
320 \\
335 \\
341 \\
353 \\
365\end{array}$ & $\begin{array}{l}7.04 \\
7.45 \\
7.84 \\
8.22 \\
8.44 \\
8.66\end{array}$ & $\begin{array}{l}110 \\
560 \\
330 \\
190 \\
560 \\
540\end{array}$ & $\begin{array}{r}9.8 \\
9.8 \\
9.8 \\
9 . \\
10 . \\
10 .\end{array}$ & $\begin{array}{l}470 \\
500 \\
540 \\
580 \\
720 \\
830\end{array}$ & $\begin{array}{l}5.95 \\
6.39 \\
6.12 \\
5.74 \\
5.54 \\
5.40\end{array}$ & $\begin{array}{l}29,000 \\
32,000 \\
30,100 \\
27,500 \\
26,100 \\
25,100\end{array}$ & $\begin{array}{l}.77 \\
.65 \\
.52 \\
.40 \\
.30 \\
.16\end{array}$ & $\begin{array}{l}7,480 \\
7,180 \\
6,850 \\
6,600 \\
6,400 \\
6,120\end{array}$ & & $\begin{array}{l}3, \\
2, \\
2, \\
2, \\
2, \\
2,\end{array}$ \\
\hline \multirow[t]{2}{*}{$\begin{array}{r}7 \\
8 \\
9 \\
10 \\
11 \\
M\end{array}$} & $\begin{array}{l}2.85 \\
2.89 \\
2.91 \\
2.99 \\
3.12 \\
3.22\end{array}$ & $\begin{array}{l}380 \\
392 \\
398 \\
426 \\
472 \\
507 \\
\end{array}$ & $\begin{array}{l}8.83 \\
8.93 \\
8.96 \\
8.95 \\
8.98 \\
9.03 \\
\end{array}$ & $\begin{array}{l}70 \\
50 \\
80 \\
70 \\
90 \\
30 \\
\end{array}$ & $\begin{array}{l}10 \\
10 \\
10 \\
10 \\
11 \\
11\end{array}$ & $\begin{array}{l}4,950 \\
5,140 \\
5,400 \\
5,660 \\
5,850 \\
6,180\end{array}$ & & $\begin{array}{l}23, \\
22, \\
19, \\
18, \\
16, \\
15,\end{array}$ & & & $\begin{array}{l}64 \\
54 \\
45 \\
37 \\
29 \\
21 \\
\end{array}$ & $\begin{array}{l}2,560 \\
2,490 \\
2,430 \\
2,380 \\
2,320 \\
2,270\end{array}$ \\
\hline & \multicolumn{2}{|c|}{ September 24} & \multicolumn{2}{|c|}{ September 25} & \multicolumn{2}{|c|}{ September 26} & \multicolumn{2}{|c|}{ September 27} & \multicolumn{2}{|c|}{ September 28} & \multicolumn{2}{|c|}{ September 29} \\
\hline $\begin{array}{r}2 \\
4 \\
6 \\
8 \\
10 \\
N\end{array}$ & $\begin{array}{l}7.04 \\
6.90 \\
6.76 \\
6.64 \\
6.50 \\
6.37\end{array}$ & $\begin{array}{l}2,160 \\
2,070 \\
1,990 \\
1,910 \\
1,830 \\
1,750\end{array}$ & & $\begin{array}{l}1,450 \\
1,410 \\
1,370 \\
1,330 \\
1,270 \\
1,260\end{array}$ & & $\begin{array}{r}1,100 \\
1,070 \\
1,050 \\
1,020 \\
1,000 \\
970\end{array}$ & & & & & & \\
\hline $\begin{array}{r}2 \\
4 \\
6 \\
8 \\
10\end{array}$ & $\begin{array}{l}6.32 \\
6.21 \\
6.14 \\
6.05 \\
5.96 \\
5.88\end{array}$ & $\begin{array}{l}1,720 \\
1,660 \\
1,620 \\
1,580 \\
1,530 \\
1,490\end{array}$ & $\begin{array}{l}5 . \\
5 . \\
5 . \\
5 . \\
5 . \\
5 .\end{array}$ & $\begin{array}{l}1, \\
1, \\
1, \\
1, \\
1, \\
1,\end{array}$ & $\begin{array}{l}4.82 \\
4.73 \\
4.73 \\
4.72 \\
4.69 \\
4.66\end{array}$ & $\begin{array}{l}960 \\
915 \\
915 \\
910 \\
895 \\
880\end{array}$ & & & & & & $\begin{array}{l}628 \\
624 \\
624 \\
614 \\
610\end{array}$ \\
\hline
\end{tabular}


Location.- Water-stage recorder, lat. $42^{\circ} 01^{\prime} 20^{\prime \prime}$, long. $71^{\circ} 57^{\prime} 15^{\prime \prime}$, at Quinebaug, Winaham county, 500 feet above highway bridge, a quarter of a mile beilow MassachusettsConnecticut state line, and 7 miles above confluence with French River.

Drainage area.- 157 square miles.

Gage-helght record.- Water-stage recorder graph except for one hour during very sharp peak.

Stage-discharge relation.- Defined by current-meter measurements to 2,000 second-fe日t; extended to peak stage on basis of computations of 1936 and 1938 peak flows at bridge 500 feet downstream, and determination of peak flow during 1936 flood at dom a quarter of a mile upstream. Shortly after peak of 1938 flood, a deep bypass was scoured around right end of bridge whlch created a shifting. stage-discharge relation down to about 9.0 feet, where flow through bypass ceased; stage-discharge relation for this period based on studies of amount of water bypassed and verified by hydrographic comparison with records for station at Putnam, Conn.

Maxima.- September 1938: Discharge, 14,100 second-feet 10:30 a.m. Sept. 21 (gage height, 16.21 feet; from high-water mark).

1931 to August 1938: Discharge, 10,500 second-feet (rev1sed) 8:30 p.r. Mar. 18, 1936 (gage helght, 13.44 feet).

Remarks.- Flood mun-off doubtless affected by storage in several lakes and ponds.

Mean daily discharge, in second-feet, 1938

\begin{tabular}{|c|r|r||r|r|r||r|r|r||r|r|r|}
\hline Day & Sept. & 0ct. & Day & Sept. & Oct. & Day & Sept. & Oct. & Day & Sept. & Oct. \\
\hline 1 & 215 & 660 & 9 & 194 & 300 & 17 & 198 & 198 & 25 & 1,590 & 357 \\
2 & 201 & 594 & 10 & 204 & 287 & 18 & 243 & 226 & 26 & 1,140 & 331 \\
3 & 149 & 480 & 11 & 137 & 269 & 19 & 968 & 202 & 27 & 907 & 320 \\
4 & 114 & 436 & 12 & 99 & 244 & 20 & 2,020 & 174 & 28 & 819 & 322 \\
5 & 124 & 410 & 13 & 229 & 230 & 21 & 9,620 & 220 & 29 & 707 & 271 \\
6 & 130 & 375 & 14 & 204 & 202 & 22 & 9,010 & 208 & 30 & 649 & 244 \\
7 & 194 & 365 & 15 & 236 & 186 & 23 & 5,500 & 195 & 31 & - & 254 \\
8 & 197 & 338 & 16 & 244 & 198 & 24 & 2,630 & 268 & & \\
\hline
\end{tabular}

Gage height, in feet, and discharge, in second-feet, at indicated time, 1938

\begin{tabular}{|c|c|c|c|c|c|c|c|c|c|c|c|c|}
\hline \multirow{2}{*}{$\begin{array}{l}\dot{9} \\
\text { 号 }\end{array}$} & Feet & Sec.ft. & Feet & Sec.ft. & Feet & Sec.ft. & Feet & Sec.ft. & Feet & Sec.ft. & Feet & Sec.ft. \\
\hline & \multicolumn{2}{|c|}{ September 18} & \multicolumn{2}{|c|}{ September 19} & \multicolumn{2}{|c|}{ September 20} & \multicolumn{2}{|c|}{ September 21} & \multicolumn{2}{|c|}{ September 22} & \multicolumn{2}{|c|}{ September 23} \\
\hline $\begin{array}{l}1 \\
2 \\
3 \\
4 \\
5 \\
6\end{array}$ & $\begin{array}{l}2.70 \\
2.73 \\
2.74 \\
2.74 \\
2.74 \\
2.75\end{array}$ & $\begin{array}{l}204 \\
215 \\
218 \\
218 \\
218 \\
222\end{array}$ & $\begin{array}{l}3.04 \\
3.07 \\
3.23 \\
3.56 \\
3.91 \\
4.27\end{array}$ & $\begin{array}{l}337 \\
349 \\
418 \\
580 \\
770 \\
982\end{array}$ & $\begin{array}{l}4.67 \\
4.69 \\
4.67 \\
4.70 \\
4.70 \\
4.70\end{array}$ & $\begin{array}{l}1,250 \\
1,260 \\
1,250 \\
1,270 \\
1,270 \\
1,270\end{array}$ & $\begin{array}{l}6.70 \\
6.72 \\
6.82 \\
7.30 \\
8.10 \\
9.20\end{array}$ & $\begin{array}{l}2,940 \\
2,960 \\
3,060 \\
3,570 \\
4,500 \\
5,590\end{array}$ & $\begin{array}{l}12.76 \\
12.77 \\
12.75 \\
12.66 \\
12.55 \\
12.41\end{array}$ & $\begin{array}{r}10,500 \\
10,400 \\
10,200 \\
10,100 \\
10,000 \\
9,760\end{array}$ & $\begin{array}{r}10.40 \\
10.25 \\
10.07 \\
9.95 \\
9.80 \\
9.65\end{array}$ & $\begin{array}{l}7,270 \\
7,180 \\
7,020 \\
6,940 \\
6,860 \\
6,690\end{array}$ \\
\hline $\begin{array}{r}7 \\
8 \\
9 \\
10 \\
11 \\
\mathrm{~N}\end{array}$ & $\begin{array}{l}2.84 \\
2.83 \\
2.85 \\
2.88 \\
2.86 \\
2.89\end{array}$ & $\begin{array}{l}256 \\
252 \\
260 \\
271 \\
263 \\
275\end{array}$ & $\begin{array}{l}4.51 \\
4.60 \\
4.70 \\
4.70 \\
4.62 \\
4.51\end{array}$ & $\begin{array}{l}1,140 \\
1,200 \\
1,270 \\
1,270 \\
1,210 \\
1,140\end{array}$ & $\begin{array}{l}4.80 \\
4.91 \\
5.13 \\
5.30 \\
5.26 \\
5.40\end{array}$ & $\begin{array}{l}1,340 \\
1,420 \\
1,570 \\
1,700 \\
1,670 \\
1,780\end{array}$ & $\begin{array}{l}10.40 \\
12.30 \\
14.40 \\
16.00 \\
14.75 \\
14.25\end{array}$ & $\begin{array}{r}6,830 \\
8,250 \\
11,800 \\
13,800 \\
14,100 \\
14,000\end{array}$ & $\begin{array}{l}12.32 \\
12.26 \\
12.16 \\
12.07 \\
11.96 \\
11.84\end{array}$ & $\begin{array}{l}9,460 \\
9,520 \\
9,400 \\
9,280 \\
9,160 \\
9,040\end{array}$ & $\begin{array}{l}9.50 \\
9.38 \\
9.21 \\
9.10 \\
8.97 \\
8.85\end{array}$ & $\begin{array}{l}6,510 \\
6,400 \\
6,130 \\
5,990 \\
5,710 \\
5,500\end{array}$ \\
\hline $\begin{array}{l}1 \\
2 \\
3 \\
4 \\
5 \\
6\end{array}$ & $\begin{array}{l}2.85 \\
2.90 \\
2.83 \\
2.85 \\
2.87 \\
2.86\end{array}$ & $\begin{array}{l}260 \\
279 \\
252 \\
260 \\
267 \\
263\end{array}$ & $\begin{array}{l}4.40 \\
4.32 \\
4.31 \\
4.30 \\
4.30 \\
4.30\end{array}$ & $\begin{array}{l}1,060 \\
1,010 \\
1,010 \\
1,000 \\
1,000 \\
1,000\end{array}$ & $\begin{array}{l}5.73 \\
6.03 \\
6.13 \\
6.16 \\
6.32 \\
6.50\end{array}$ & $\begin{array}{l}2,040 \\
2,3-0 \\
2,400 \\
2,420 \\
2,570 \\
2,740\end{array}$ & $\begin{array}{l}14.00 \\
13.67 \\
13.4 .6 \\
13.27 \\
13.05 \\
13.07\end{array}$ & $\begin{array}{l}13,700 \\
13,300 \\
12,900 \\
12,600 \\
12,300 \\
11,900\end{array}$ & $\begin{array}{l}11.76 \\
11.68 \\
11.60 \\
11.56 \\
11.46 \\
11.35\end{array}$ & $\begin{array}{l}8,820 \\
8,710 \\
8,600 \\
8,490 \\
8,380 \\
8,270\end{array}$ & $\begin{array}{l}8.63 \\
8.52 \\
8.40 \\
8.30 \\
8.10 \\
7.98\end{array}$ & $\begin{array}{l}5,190 \\
5,050 \\
4,890 \\
4,760 \\
4,500 \\
4,360\end{array}$ \\
\hline \multirow[t]{2}{*}{$\begin{array}{r}7 \\
8 \\
9 \\
10 \\
11 \\
M\end{array}$} & $\begin{array}{l}2.87 \\
2.88 \\
2.90 \\
2.92 \\
2.91 \\
2.93\end{array}$ & $\begin{array}{l}267 \\
271 \\
279 \\
287 \\
283 \\
291\end{array}$ & $\begin{array}{l}4.25 \\
4.20 \\
4.30 \\
4.45 \\
4.55 \\
4.63\end{array}$ & $\begin{array}{r}970 \\
940 \\
1,000 \\
1,100 \\
1,160 \\
1,220\end{array}$ & $\begin{array}{l}6.80 \\
6.71 \\
6.71 \\
6.67 \\
6.63 \\
6.62\end{array}$ & $\begin{array}{l}3,040 \\
2,950 \\
2,950 \\
2,910 \\
2,870 \\
2,860\end{array}$ & $\begin{array}{l}13.06 \\
13.05 \\
12.97 \\
12.92 \\
12.76 \\
12.70\end{array}$ & $\begin{array}{l}11,500 \\
11,200 \\
11,100 \\
11,000 \\
10,700 \\
10,600\end{array}$ & $\begin{array}{l}11.24 \\
11.11 \\
10.98 \\
10.86 \\
10.74 \\
10.55\end{array}$ & $\begin{array}{l}8,060 \\
7,960 \\
7,860 \\
7,760 \\
7,560 \\
7,460\end{array}$ & $\begin{array}{l}7.84 \\
7.73 \\
7.60 \\
7.50 \\
7.39 \\
7.21\end{array}$ & $\begin{array}{l}4,190 \\
4,060 \\
3,900 \\
3,790 \\
3,670 \\
3,470\end{array}$ \\
\hline & \multicolumn{2}{|c|}{ September 24} & \multicolumn{2}{|c|}{ September 25} & \multicolumn{2}{|c|}{ September 26} & \multicolumn{2}{|c|}{ September 27} & \multicolumn{2}{|c|}{ September 28} & \multicolumn{2}{|c|}{ September 29} \\
\hline $\begin{array}{r}2 \\
4 \\
6 \\
8 \\
10 \\
\text { N }\end{array}$ & $\begin{array}{l}7.04 \\
6.91 \\
6.78 \\
6.68 \\
6.47 \\
6.31\end{array}$ & $\begin{array}{l}3,280 \\
3,150 \\
3,020 \\
2,920 \\
2,710 \\
2,560\end{array}$ & $\begin{array}{l}5.51 \\
5.45 \\
5.39 \\
5.30 \\
5.20 \\
5.13\end{array}$ & $\begin{array}{l}1,870 \\
1,820 \\
1,770 \\
1,700 \\
1,620 \\
1,560\end{array}$ & $\begin{array}{l}4.75 \\
4.70 \\
4.67 \\
4.65 \\
4.57 \\
4.57\end{array}$ & $\begin{array}{l}1,280 \\
1,240 \\
1,220 \\
1,200 \\
1,150 \\
1,150\end{array}$ & $\begin{array}{l}4.31 \\
4.30 \\
4.27 \\
4.24 \\
4.22 \\
4.20\end{array}$ & $\begin{array}{l}972 \\
965 \\
946 \\
926 \\
913 \\
900\end{array}$ & $\begin{array}{l}4.17 \\
4.15 \\
4.13 \\
4.11 \\
4.11 \\
4.03\end{array}$ & $\begin{array}{l}880 \\
868 \\
854 \\
842 \\
842 \\
793\end{array}$ & $\begin{array}{l}3.96 \\
3.93 \\
3.92 \\
3.92 \\
3.94 \\
3.91\end{array}$ & $\begin{array}{l}751 \\
733 \\
727 \\
727 \\
739 \\
721\end{array}$ \\
\hline $\begin{array}{r}2 \\
4 \\
6 \\
8 \\
10 \\
M\end{array}$ & $\begin{array}{l}6.19 \\
6.08 \\
5.94 \\
5.80 \\
5.74 \\
5.63\end{array}$ & $\begin{array}{l}2,450 \\
2,350 \\
2,230 \\
2,100 \\
2,050 \\
1,960\end{array}$ & $\begin{array}{l}5.09 \\
5.03 \\
4.93 \\
4.90 \\
4.84 \\
4.79\end{array}$ & $\begin{array}{l}1,530 \\
1,480 \\
1,400 \\
1,380 \\
1,340 \\
1,300\end{array}$ & $\begin{array}{l}4.50 \\
4.48 \\
4.41 \\
4.41 \\
4.36 \\
4.33\end{array}$ & $\begin{array}{r}1,100 \\
1,090 \\
1,040 \\
1,040 \\
1,000 \\
984\end{array}$ & $\begin{array}{l}4.18 \\
4.16 \\
4.12 \\
4.09 \\
4.19 \\
4.18\end{array}$ & $\begin{array}{l}887 \\
874 \\
848 \\
829 \\
894 \\
887\end{array}$ & $\begin{array}{l}4.03 \\
4.05 \\
4.00 \\
4.00 \\
4.00 \\
3.99\end{array}$ & $\begin{array}{l}793 \\
805 \\
775 \\
775 \\
775 \\
769\end{array}$ & $\begin{array}{l}3.87 \\
3.85 \\
3.81 \\
3.80 \\
3.80 \\
3.80\end{array}$ & $\begin{array}{l}698 \\
688 \\
666 \\
660 \\
660 \\
660\end{array}$ \\
\hline
\end{tabular}

Supplemental records.- Sept. $20,6: 20$ p.m., 6.87 ft., 3,110 sec.-ft.; Sept. 21, $10: 30$ a.m., $16.21 \mathrm{ft} ., 14,100$ sec.-ft. 
Quinebaug River at Putnam, Conn.

Location. - Water-stage recorder, lat. $41^{\circ} 54^{\prime} 30^{\prime \prime}$, long. $71^{\circ} 54^{\prime} 30^{\prime \prime}$, at Putnam, Windham County, 600 feet below mouth of Muddy Brook and 3 miles below junction of Quinebaug and French Rivers.

Drainage area.- 331 square miles.

Gage-helght record. - Water-stage recorder graph except for period 1 p.m. Sept. 21 to 4 p.m. Sept. 24, record for whlch was based on floodmarks, partial gage-helght eraph at Belding-Hemingway Co. dam at Putnam, and records at Putnam Water Co. dam on Muddy Brook.

Stage-discharge relation.- Defined by current-meter measurements below 2,880 secondfeet; extended to peak stage on basis of determination of flood flow at dam $1 \mathrm{mile}$ upstream, combined with inflow from Muddy Brook determined by flow over spiliway at dam 2 miles above its mouth.

Maxima. - September 1938: D1scharge, 20,900 second-feet 1:30 p.m. Sept. 21 (gage helght, 19.45 feet, from floodmarks). 1929 to August 1938: Discharge, 17,200 second-feet Mar. 19, 1936 (gage height, 17.28 feet, f rom floodmarks).

Remarks.- Flood run-off affected by storage in several ponds and reservolrs and by fallure of dams eupstream. City of Putnam diverts about 1,000,000 gallons per day from Muddy Brook for municipal water supply.

Mean daily discharge, in second-feet, 1938

\begin{tabular}{|c|c|c|c|c|c|c|c|c|c|c|c|}
\hline Day & Sept. & oct. & Day & Sept. & Oct. & Day & Sept. & Oct. & Day & Sept. & Oct. \\
\hline $\begin{array}{l}1 \\
2 \\
3 \\
4 \\
5 \\
6 \\
7 \\
8\end{array}$ & $\begin{array}{l}380 \\
478 \\
306 \\
167 \\
289 \\
398 \\
324 \\
242\end{array}$ & $\begin{array}{r}1,380 \\
1,260 \\
1,140 \\
1,020 \\
980 \\
852 \\
834 \\
820\end{array}$ & $\begin{array}{r}9 \\
10 \\
11 \\
12 \\
13 \\
14 \\
15 \\
16\end{array}$ & $\begin{array}{l}360 \\
330 \\
242 \\
258 \\
322 \\
396 \\
430 \\
418\end{array}$ & $\begin{array}{l}712 \\
676 \\
656 \\
640 \\
616 \\
584 \\
580 \\
493\end{array}$ & $\begin{array}{l}17 \\
18 \\
19 \\
20 \\
21 \\
22 \\
23 \\
24\end{array}$ & $\begin{array}{r}407 \\
513 \\
2,450 \\
5,170 \\
13,800 \\
14,300 \\
8,490 \\
5,560\end{array}$ & $\begin{array}{l}610 \\
596 \\
604 \\
542 \\
554 \\
556 \\
501 \\
613\end{array}$ & $\begin{array}{l}25 \\
26 \\
27 \\
28 \\
29 \\
30 \\
31\end{array}$ & $\begin{array}{c}3,430 \\
2,370 \\
1,880 \\
1,690 \\
1,510 \\
1,380 \\
-\end{array}$ & $\begin{array}{l}850 \\
870 \\
743 \\
836 \\
714 \\
696 \\
741\end{array}$ \\
\hline $\begin{array}{l}\text { Niean } \\
\text { Run- }\end{array}$ & $\begin{array}{l}\text { nthly } \\
\text {, in }\end{array}$ & $\theta \mathrm{s}$. & , Ir & & & $\dot{.}$ & $\cdot \dot{*} \cdot$ & $\dot{0}: \dot{ }$ & $\dot{0}$ & $\begin{array}{r}2,276 \\
7.68\end{array}$ & $\begin{array}{r}751 \\
2.62\end{array}$ \\
\hline
\end{tabular}

Gage helght, in feet, and discharge, in second-feet, at indicated time, 1938

\begin{tabular}{|c|c|c|c|c|c|c|c|c|c|c|c|c|}
\hline \multirow{2}{*}{$\begin{array}{l}3 \\
3 \\
0 \\
0 \\
\end{array}$} & Feet & Sec.ft. & Feet & Sec.ft. & Feet & Sec.ft. & Feet & Sec.ft. & Feet & Sec.ft. & Feet & Sec.ft. \\
\hline & \multicolumn{2}{|c|}{ September 18} & \multicolumn{2}{|c|}{ September 19} & \multicolumn{2}{|c|}{ September 20} & \multicolumn{2}{|c|}{ September 21} & \multicolumn{2}{|c|}{ September 22} & \multicolumn{2}{|c|}{ September 23} \\
\hline $\begin{array}{l}1 \\
2 \\
3 \\
4 \\
5 \\
6\end{array}$ & $\begin{array}{l}3.76 \\
3.75 \\
3.74 \\
3.56 \\
3.32 \\
2.70\end{array}$ & $\begin{array}{l}584 \\
580 \\
576 \\
506 \\
422 \\
238\end{array}$ & $\begin{array}{l}4.46 \\
4.50 \\
4.64 \\
4.76 \\
4.73 \\
5.11\end{array}$ & $\begin{array}{r}892 \\
910 \\
980 \\
1,040 \\
1,020 \\
1,220\end{array}$ & $\begin{array}{l}9.04 \\
9.05 \\
9.06 \\
9.07 \\
9.08 \\
9.16\end{array}$ & $\begin{array}{l}4,250 \\
4,260 \\
4,280 \\
4,290 \\
4,300 \\
4,390\end{array}$ & $\begin{array}{l}11.83 \\
11.92 \\
12.02 \\
12.16 \\
12.30 \\
12.49\end{array}$ & $\begin{array}{l}7,650 \\
7,770 \\
7,900 \\
8,090 \\
8,290 \\
8,560\end{array}$ & $\begin{array}{l}17.25 \\
17.15 \\
17.05 \\
17.00 \\
12.90 \\
16.85\end{array}$ & $\begin{array}{l}16,500 \\
16,300 \\
16,200 \\
16,100 \\
15,900 \\
15,800\end{array}$ & $\begin{array}{l}14.15 \\
13.95 \\
13.80 \\
13.60 \\
13.50 \\
13.30\end{array}$ & $\begin{array}{r}10,800 \\
10,500 \\
10,200 \\
9,900 \\
9,740 \\
9,420\end{array}$ \\
\hline $\begin{array}{r}7 \\
8 \\
9 \\
10 \\
11 \\
\mathrm{~N}\end{array}$ & $\begin{array}{l}2.86 \\
3.14 \\
2.96 \\
2.50 \\
2.50 \\
2.35\end{array}$ & $\begin{array}{l}283 \\
367 \\
313 \\
185 \\
185 \\
148\end{array}$ & $\begin{array}{l}5.98 \\
6.24 \\
6.50 \\
6.80 \\
7.07 \\
7.29\end{array}$ & $\begin{array}{l}1,730 \\
1,890 \\
2,070 \\
2,280 \\
2,470 \\
2,620\end{array}$ & $\begin{array}{l}9.14 \\
9.11 \\
9.10 \\
9.10 \\
9.17 \\
9.26\end{array}$ & $\begin{array}{l}4,360 \\
4,330 \\
4,320 \\
4,320 \\
4,400 \\
4,500\end{array}$ & $\begin{array}{l}12.68 \\
12.91 \\
13.10 \\
13.60 \\
14.50 \\
16.50\end{array}$ & $\begin{array}{r}8,820 \\
9,140 \\
9,410 \\
10,200 \\
11,600 \\
15,100\end{array}$ & $\begin{array}{l}16.75 \\
16.65 \\
16.55 \\
16.45 \\
16.35 \\
16.25\end{array}$ & $\begin{array}{l}15,600 \\
15,400 \\
15,200 \\
15,000 \\
14,800 \\
14,600\end{array}$ & $\begin{array}{l}13.20 \\
13.05 \\
12.90 \\
12.80 \\
12.65 \\
12.50\end{array}$ & $\begin{array}{l}9,260 \\
9,000 \\
8,800 \\
8,650 \\
8,420 \\
8,200\end{array}$ \\
\hline $\begin{array}{l}1 \\
2 \\
3 \\
4 \\
5 \\
6\end{array}$ & $\begin{array}{l}2.36 \\
3.11 \\
3.81 \\
3.78 \\
3.80 \\
3.89\end{array}$ & $\begin{array}{l}151 \\
358 \\
604 \\
592 \\
600 \\
636\end{array}$ & $\begin{array}{l}7.44 \\
7.53 \\
7.62 \\
7.70 \\
7.89 \\
7.86\end{array}$ & $\begin{array}{l}2,740 \\
2,810 \\
2,890 \\
2,950 \\
3.120 \\
3,090\end{array}$ & $\begin{array}{r}9.47 \\
9.64 \\
9.88 \\
10.05 \\
10.30 \\
10.51\end{array}$ & $\begin{array}{l}4,730 \\
4,920 \\
5,210 \\
5,410 \\
5,710 \\
5,960\end{array}$ & $\begin{array}{l}19.30 \\
19.35 \\
19.10 \\
18.80 \\
18.50 \\
18.20\end{array}$ & $\begin{array}{l}20,600 \\
20,700 \\
20,200 \\
19,600 \\
19,000 \\
18,400\end{array}$ & $\begin{array}{l}16.10 \\
15.95 \\
15.85 \\
15.70 \\
15.55 \\
15.40\end{array}$ & $\begin{array}{l}14,400 \\
14,100 \\
13,900 \\
13,600 \\
13,300 \\
13,000\end{array}$ & $\begin{array}{l}12.40 \\
12.30 \\
12.20 \\
12.15 \\
12.05 \\
11.95\end{array}$ & $\begin{array}{l}8,060 \\
7,920 \\
7,780 \\
7,710 \\
7,570 \\
7,430\end{array}$ \\
\hline \multirow[t]{2}{*}{$\begin{array}{r}7 \\
8 \\
9 \\
10 \\
11 \\
1\end{array}$} & $\begin{array}{l}4.26 \\
4.36 \\
4.36 \\
4.37 \\
4.49 \\
4.46\end{array}$ & $\begin{array}{l}802 \\
847 \\
847 \\
852 \\
906 \\
892\end{array}$ & $\begin{array}{l}8.05 \\
8.60 \\
8.84 \\
8.96 \\
9.08 \\
9.11\end{array}$ & $\begin{array}{l}3,260 \\
3,800 \\
4,040 \\
4,170 \\
4,300 \\
4,330\end{array}$ & $\begin{array}{l}10.75 \\
11.00 \\
11.27 \\
11.47 \\
11.62 \\
11.73\end{array}$ & $\begin{array}{l}6,250 \\
6,570 \\
6,920 \\
7,180 \\
7,380 \\
7,520 \\
\end{array}$ & $\begin{array}{l}18.00 \\
17.85 \\
17.70 \\
17.55 \\
17.45 \\
17.35\end{array}$ & $\begin{array}{l}18,000 \\
17,700 \\
17,400 \\
17,100 \\
16,900 \\
16,700 \\
\end{array}$ & $\begin{array}{l}15.20 \\
15.05 \\
14.85 \\
14.70 \\
14.50 \\
14.30\end{array}$ & $\begin{array}{l}12,700 \\
12,400 \\
12,000 \\
11,800 \\
11,400 \\
11,100\end{array}$ & $\begin{array}{l}11.85 \\
11.80 \\
11.70 \\
11.60 \\
11.50 \\
11.40\end{array}$ & $\begin{array}{l}7,290 \\
7,220 \\
7,080 \\
6,950 \\
6,820 \\
6,690 \\
\end{array}$ \\
\hline & \multicolumn{2}{|c|}{ September 24} & \multicolumn{2}{|c|}{ September 25} & \multicolumn{2}{|c|}{ September 26} & \multicolumn{2}{|c|}{ September 27} & \multicolumn{2}{|c|}{ September 28} & \multicolumn{2}{|c|}{ September 29} \\
\hline $\begin{array}{r}2 \\
4 \\
6 \\
8 \\
10 \\
\text { N }\end{array}$ & $\begin{array}{l}11.25 \\
11.10 \\
10.95 \\
10.80 \\
10.65 \\
10.50\end{array}$ & $\begin{array}{l}6,500 \\
6,300 \\
6,110 \\
5,930 \\
5,750 \\
5,570\end{array}$ & $\begin{array}{l}9.22 \\
9.03 \\
8.88 \\
8.74 \\
8.58 \\
8.43\end{array}$ & $\begin{array}{l}4,160 \\
3,970 \\
3,820 \\
3,680 \\
3,530 \\
3,400\end{array}$ & $\begin{array}{l}7.57 \\
7.49 \\
7.42 \\
7.38 \\
7.26 \\
7.20\end{array}$ & $\begin{array}{l}2,660 \\
2,590 \\
2,540 \\
2,500 \\
2,410 \\
2,360\end{array}$ & $\begin{array}{l}6.70 \\
6.64 \\
6.60 \\
6.57 \\
6.56 \\
6.53\end{array}$ & $\begin{array}{l}2,000 \\
1,960 \\
1,930 \\
1,910 \\
1,900 \\
1,880\end{array}$ & $\begin{array}{l}6.26 \\
6.27 \\
6.28 \\
6.29 \\
6.30 \\
6.27\end{array}$ & $\begin{array}{l}1,710 \\
1,710 \\
1,720 \\
1,720 \\
1,730 \\
1,710\end{array}$ & $\begin{array}{l}6.00 \\
5.98 \\
5.96 \\
5.95 \\
5.94\end{array}$ & $\begin{array}{l}1,550 \\
1,540 \\
1,530 \\
1,520 \\
1,510 \\
1,510\end{array}$ \\
\hline $\begin{array}{r}2 \\
4 \\
6 \\
8 \\
10 \\
M\end{array}$ & $\begin{array}{r}10.35 \\
10.23 \\
9.99 \\
9.83 \\
9.60 \\
9.40\end{array}$ & $\begin{array}{l}5,390 \\
5,250 \\
4,990 \\
4,810 \\
4,560 \\
4,340\end{array}$ & $\begin{array}{l}8.28 \\
8.16 \\
7.99 \\
7.79 \\
7.73 \\
7.66 \\
\end{array}$ & $\begin{array}{l}3,260 \\
3,150 \\
3,000 \\
2,830 \\
2,780 \\
2,730\end{array}$ & $\begin{array}{l}7.16 \\
7.08 \\
7.00 \\
6.85 \\
6.80 \\
6.76\end{array}$ & $\begin{array}{l}2,330 \\
2,270 \\
2,210 \\
2,100 \\
2,070 \\
2,040\end{array}$ & $\begin{array}{l}6.53 \\
6.50 \\
6.45 \\
6.40 \\
6.34 \\
6.30\end{array}$ & $\begin{array}{l}1,880 \\
1,860 \\
1,820 \\
1,790 \\
1,750 \\
1,730\end{array}$ & $\begin{array}{l}6.27 \\
6.25 \\
6.19 \\
6.14 \\
6.12 \\
6.06\end{array}$ & $\begin{array}{l}1,710 \\
1,700 \\
1,660 \\
1,630 \\
1,620 \\
1,590\end{array}$ & $\begin{array}{l}5.95 \\
5.96 \\
5.93 \\
5.84 \\
5.80 \\
5.76\end{array}$ & $\begin{array}{l}1,520 \\
1,530 \\
1,510 \\
1,450 \\
1,430 \\
1,410\end{array}$ \\
\hline
\end{tabular}

Supplemental Records.- Sept. 2l, l:30 p.m., 19.45 ft., 20,900 sec.-ft. 
Location. - Water-stage recorder, lat. $41^{\circ} 35^{\prime} 55^{\prime \prime}$, long. $71^{\circ} 59^{\prime} 05^{\prime \prime}$, at Jewett C1ty, New London county, 1,000 feet below railroad bridge and 570 feet below outlet of canal from Slater Milis (mouth of Pachaug River).

Drainage area.- 711 square miles.

Gage-helght record. - Water-stage recorder graph except for period 11:30 p.m. Sept. 21 to 4 p.m. Sept. 25, record for which was based on floodmark, existing record, and operation record at dam of Connecticut Light B Power Co. 6 miles downstream.

Stage-discharge relation. - Defined by current-meter measurements to 15,000 secondfeet; extended to peak stage on basis of flood determinations of March 1936 , and verified by hourly computations of flow at dam 6 miles downstream during flood of September 1938 .

Maxima.- September 1938: Discharge, 22,800 second-feet 2-5 p.m. Sept. 22 (gage helght, 21.7 feet, from floodmark).

1918 to August 1938: Discharge, 29,200 second-feet Mar. 19, 1936 (gage helght, 24.0 feet, from floodmarks).

Remarks.- Flood run-off affected by unregulated storage in numerous ponds and reservolrs.

Mean deily discharge, in second-feet, 1938

\begin{tabular}{|c|r|r||r|r|r||r|r|r||r|r|r|}
\hline Day & Sept. & 0ct. & Day & Sept. & Oct. & Day & Sept. & Oct. & Day & Sept. & Oct. \\
\hline 1 & 844 & 2,450 & 9 & 706 & 1,270 & 17 & 642 & 1,140 & 25 & 5,790 & 1,820 \\
2 & 868 & 2,130 & 10 & 644 & 1,360 & 18 & 1,000 & 1,190 & 26 & 4,150 & 1,880 \\
3 & 777 & 2,170 & 11 & 467 & 1,300 & 19 & 2,990 & 1,100 & 27 & 3,390 & 1,680 \\
4 & 522 & 1,930 & 12 & 721 & 1,190 & 20 & 7,940 & 1,100 & 28 & 2,930 & 1,520 \\
5 & 464 & 1,830 & 13 & 730 & 1,170 & 21 & 12,400 & 1,040 & 29 & 2,690 & 1,440 \\
6 & 672 & 1,700 & 14 & 740 & 1,130 & 22 & 21,000 & 926 & 30 & 2,480 & 1,330 \\
7 & 857 & 1,550 & 15 & 866 & 968 & 23 & 16,600 & 852 & 31 & \\
8 & 814 & 1,360 & 16 & 968 & 932 & 24 & 9,410 & 1,190 & 1,480 \\
\hline
\end{tabular}

Gage helght, In feet, and discharge, In second-feet, at indlcated time, 1938

\begin{tabular}{|c|c|c|c|c|c|c|c|c|c|c|c|c|}
\hline \multirow{2}{*}{ 名 } & Feet & Sec.ft. & Feet & Sec.ft. & Feet & Sec.ft. & Feet & Sec.ft. & Feet & Sec.ft. & Feet & Sec.ft. \\
\hline & \multicolumn{2}{|c|}{ September 18} & \multicolumn{2}{|c|}{ September 19} & \multicolumn{2}{|c|}{ September 20} & \multicolumn{2}{|c|}{ September 21} & \multicolumn{2}{|c|}{ September 22} & \multicolumn{2}{|c|}{ September 23} \\
\hline $\begin{array}{l}1 \\
2 \\
3 \\
4 \\
5 \\
6\end{array}$ & $\begin{array}{l}5.30 \\
5.37 \\
5.52 \\
5.66 \\
5.76 \\
5.82\end{array}$ & $\begin{array}{l}522 \\
552 \\
619 \\
682 \\
730 \\
760\end{array}$ & $\begin{array}{l}6.72 \\
6.91 \\
7.13 \\
7.34 \\
7.57 \\
7.97\end{array}$ & $\begin{array}{l}1,270 \\
1,390 \\
1,540 \\
1,690 \\
1,850 \\
2,170\end{array}$ & $\begin{array}{l}11.30 \\
11.50 \\
11.70 \\
11.88 \\
12.13 \\
12.56\end{array}$ & $\begin{array}{l}5,310 \\
5,530 \\
5,770 \\
5,990 \\
6,290 \\
6,840\end{array}$ & $\begin{array}{l}14.34 \\
14.56 \\
14.73 \\
14.83 \\
15.00 \\
15.19\end{array}$ & $\begin{array}{r}9,310 \\
9,640 \\
9,900 \\
10,000 \\
10,300 \\
10,600\end{array}$ & $\begin{array}{l}18.85 \\
19.2 \\
19.5 \\
19.8 \\
20.1 \\
20.4\end{array}$ & $\begin{array}{l}16,800 \\
17,500 \\
18,000 \\
18,600 \\
19,200 \\
19,800\end{array}$ & $\begin{array}{l}20.75 \\
20.6 \\
20.45 \\
20.3 \\
20.1 \\
19.9\end{array}$ & $\begin{array}{l}20,600 \\
20,200 \\
19,900 \\
19,600 \\
19,200 \\
18,800\end{array}$ \\
\hline $\begin{array}{r}7 \\
8 \\
9 \\
10 \\
11 \\
1\end{array}$ & $\begin{array}{l}5.90 \\
5.97 \\
6.04 \\
6.13 \\
6.16 \\
6.21\end{array}$ & $\begin{array}{l}800 \\
838 \\
877 \\
926 \\
943 \\
970\end{array}$ & $\begin{array}{l}8.31 \\
8.49 \\
8.51 \\
8.68 \\
8.80 \\
8.89\end{array}$ & $\begin{array}{l}2,440 \\
2,580 \\
2,600 \\
2,730 \\
2,840 \\
2,920\end{array}$ & $\begin{array}{l}12.87 \\
13.13 \\
13.34 \\
13.54 \\
13.75 \\
13.97\end{array}$ & $\begin{array}{l}7,240 \\
7,580 \\
7,880 \\
8,760 \\
8,450 \\
8,760\end{array}$ & $\begin{array}{l}15.32 \\
15.47 \\
15.63 \\
15.86 \\
16.06 \\
16.26\end{array}$ & $\begin{array}{l}10,800 \\
11,100 \\
11,300 \\
11,700 \\
12,000 \\
12,300\end{array}$ & $\begin{array}{l}20.7 \\
20.95 \\
21.15 \\
21.3 \\
21.45 \\
21.6\end{array}$ & $\begin{array}{l}20,400 \\
21,000 \\
21,400 \\
21,800 \\
22,200 \\
22,500\end{array}$ & $\begin{array}{l}19.7 \\
19.5 \\
19.3 \\
19.1 \\
18.9 \\
18.7\end{array}$ & $\begin{array}{l}18,400 \\
18,000 \\
17,700 \\
17,300 \\
16,900 \\
16,600\end{array}$ \\
\hline $\begin{array}{l}1 \\
2 \\
3 \\
4 \\
5 \\
6\end{array}$ & $\begin{array}{l}6.50 \\
6.63 \\
6.64 \\
6.59 \\
6.96 \\
6.93\end{array}$ & $\begin{array}{l}1,140 \\
1,220 \\
1,220 \\
1,190 \\
1,420 \\
1,400\end{array}$ & $\begin{array}{l}9.14 \\
9.24 \\
9.29 \\
9.51 \\
9.65 \\
9.77\end{array}$ & $\begin{array}{l}3,150 \\
3,240 \\
3,370 \\
3,480 \\
3,600 \\
3,710\end{array}$ & $\begin{array}{l}14.18 \\
14.27 \\
14.29 \\
14.28 \\
14.22 \\
14.17\end{array}$ & $\begin{array}{l}9,070 \\
9,200 \\
9,240 \\
9,220 \\
9,130 \\
9,060\end{array}$ & $\begin{array}{l}16.48 \\
16.72 \\
16.90 \\
16.98 \\
17.00 \\
17.27\end{array}$ & $\begin{array}{l}12,700 \\
13,100 \\
13,400 \\
13,600 \\
13,600 \\
14,100\end{array}$ & $\begin{array}{l}21.65 \\
21.7 \\
21.7 \\
21.7 \\
21.7 \\
21.65\end{array}$ & $\begin{array}{l}22,600 \\
22,800 \\
22,800 \\
22,800 \\
22,800 \\
22,600\end{array}$ & $\begin{array}{l}18.5 \\
18.3 \\
18.1 \\
17.9 \\
17.7 \\
17.5\end{array}$ & $\begin{array}{l}16,200 \\
15,800 \\
15,500 \\
15,100 \\
14,800 \\
14,400\end{array}$ \\
\hline \multirow[t]{2}{*}{$\begin{array}{r}7 \\
8 \\
9 \\
10 \\
11 \\
11 \\
\end{array}$} & $\begin{array}{l}6.85 \\
6.75 \\
6.69 \\
6.67 \\
6.67 \\
6.71 \\
\end{array}$ & $\begin{array}{l}1,350 \\
1,290 \\
1,250 \\
1,240 \\
1,240 \\
1,270\end{array}$ & $\begin{array}{l}10.00 \\
10.28 \\
10.43 \\
10.64 \\
10.89 \\
11.11\end{array}$ & $\begin{array}{l}3,930 \\
4,210 \\
4,360 \\
4,580 \\
4,860 \\
5,100\end{array}$ & $\begin{array}{l}14.13 \\
14.11 \\
14.04 \\
14.04 \\
14.13 \\
14.23\end{array}$ & $\begin{array}{l}9,000 \\
8,960 \\
8,860 \\
8,860 \\
9,000 \\
9,140\end{array}$ & $\begin{array}{l}17.48 \\
17.65 \\
17.82 \\
18.00 \\
18.27 \\
18.5\end{array}$ & $\begin{array}{l}14,400 \\
14,700 \\
15,000 \\
15,300 \\
15,800 \\
16,200\end{array}$ & $\begin{array}{l}21.6 \\
21.5 \\
21.35 \\
21.2 \\
21.05 \\
20.9\end{array}$ & $\begin{array}{l}22,500 \\
22,300 \\
21,900 \\
21,600 \\
21,200 \\
20,900\end{array}$ & $\begin{array}{l}17.3 \\
17.1 \\
16.9 \\
16.7 \\
16.5 \\
16.3\end{array}$ & $\begin{array}{l}14,100 \\
13,800 \\
13,400 \\
13,100 \\
12,800 \\
12,400\end{array}$ \\
\hline & \multicolumn{2}{|c|}{ September 24} & \multicolumn{2}{|c|}{ September 25} & \multicolumn{2}{|c|}{ September 26} & \multicolumn{2}{|c|}{ September 27} & \multicolumn{2}{|c|}{ September 28} & \multicolumn{2}{|c|}{ September 29} \\
\hline $\begin{array}{r}2 \\
4 \\
6 \\
8 \\
10 \\
N\end{array}$ & $\begin{array}{l}15.9 \\
15.55 \\
15.20 \\
14.9 \\
14.6 \\
14.3\end{array}$ & $\begin{array}{r}11,700 \\
11,200 \\
10,600 \\
10,200 \\
9,700 \\
9,250\end{array}$ & $\begin{array}{l}12.6 \\
12.4 \\
12.2 \\
12.0 \\
11.8 \\
11.65\end{array}$ & $\begin{array}{l}6,890 \\
6,630 \\
6,370 \\
6,130 \\
5,890 \\
5,710\end{array}$ & $\begin{array}{l}10.67 \\
10.57 \\
10.46 \\
10.38 \\
10.31 \\
10.23\end{array}$ & $\begin{array}{l}4,620 \\
4,510 \\
4,390 \\
4,310 \\
4,240 \\
4,160\end{array}$ & & & $\begin{array}{l}9.07 \\
9.04 \\
8.98 \\
8.98 \\
8.92 \\
8.86\end{array}$ & $\begin{array}{l}3,080 \\
3,060 \\
3,000 \\
3,000 \\
2,950 \\
2,890\end{array}$ & $\begin{array}{l}8.76 \\
8.74 \\
8.71 \\
8.72 \\
8.71 \\
8.65\end{array}$ & $\begin{array}{l}2,800 \\
2,790 \\
2,760 \\
2,770 \\
2,760 \\
2,710\end{array}$ \\
\hline $\begin{array}{r}2 \\
4 \\
6 \\
8 \\
10\end{array}$ & $\begin{array}{l}14.0 \\
13.75 \\
13.5 \\
13.25 \\
13.0 \\
12.8\end{array}$ & $\begin{array}{l}8,800 \\
8,450 \\
8,100 \\
7,750 \\
7,410 \\
7,150\end{array}$ & $\begin{array}{l}11.5 \\
11.32 \\
11.19 \\
11.04 \\
10.89 \\
10.77\end{array}$ & $\begin{array}{l}5,530 \\
5,330 \\
5,190 \\
5,020 \\
4,860 \\
4,730\end{array}$ & $\begin{array}{r}10.14 \\
10.07 \\
9.91 \\
9.84 \\
9.76 \\
9.69\end{array}$ & $\begin{array}{l}4,070 \\
4,000 \\
3,840 \\
3,780 \\
3,700 \\
3,640\end{array}$ & $\begin{array}{l}9.41 \\
9.32 \\
9.20 \\
9.17 \\
9.13 \\
9.10\end{array}$ & $\begin{array}{l}3,390 \\
3,310 \\
3,200 \\
3,170 \\
3,140 \\
3,110\end{array}$ & $\begin{array}{l}8.83 \\
8.71 \\
8.79 \\
8.83 \\
8.82 \\
8.79\end{array}$ & $\begin{array}{l}2,870 \\
2,760 \\
2,830 \\
2,870 \\
2,860 \\
2,830\end{array}$ & $\begin{array}{l}8.65 \\
8.54 \\
8.45 \\
8.46 \\
8.41 \\
8.45\end{array}$ & $\begin{array}{l}10 \\
20 \\
50 \\
60 \\
20 \\
50\end{array}$ \\
\hline
\end{tabular}

227907 O $-40-10$ 
Location.- Water-stage recorder, lat. $41^{\circ} 50^{\prime} 10^{\prime \prime}$, Iong. $71^{\circ} 53^{\prime} 09^{\prime \prime}$, beside northwest abutment of New York, New Haven \& Hartford Railroad bridge five-eighths of a mile south of Killingly, Windham County, and 2.7 miles above confluence with Guinebaug River.

Drainage area.- 58.2 square miles.

Gage-height record. - Water-stage recorder graph.

Stage-discharge relation.- Defined by current-meter measurements to 1,540 second-feet; extended logarithmically to maximum flood stage.

Maxima.- September 1938: Discharge, 1,060 second-feet 11:20 p.m. Sept. 21 (gage height, 5.22 feet).

November 1937 to August 1938: Discharge, 2,480 second-feet 2 p.m. July 24 , 1938 (gage he1ght, 8.52 feet).

Remarks.- Flood run-off affected by storage in ponds and reservoirs.

Mean daily discharge, in second-feet, 1938

\begin{tabular}{|c|c|c|c|c|c|c|c|c|c|c|c|}
\hline Day & Sept. & oct. & Day & Sept. & Oct. & Day & Sept. & Oct. & Day & Sept. & oct. \\
\hline $\begin{array}{l}1 \\
2 \\
3 \\
4 \\
5 \\
6 \\
7 \\
8\end{array}$ & $\begin{array}{l}77 \\
78 \\
53 \\
66 \\
56 \\
75 \\
76 \\
81\end{array}$ & $\begin{array}{l}186 \\
172 \\
161 \\
150 \\
142 \\
134 \\
127 \\
118\end{array}$ & $\begin{array}{r}9 \\
10 \\
11 \\
12 \\
13 \\
14 \\
15 \\
16\end{array}$ & $\begin{array}{l}78 \\
58 \\
58 \\
70 \\
78 \\
81 \\
90 \\
93\end{array}$ & $\begin{array}{l}116 \\
115 \\
109 \\
109 \\
107 \\
104 \\
102 \\
100\end{array}$ & $\begin{array}{l}17 \\
18 \\
19 \\
20 \\
21 \\
22 \\
23 \\
24\end{array}$ & $\begin{array}{r}56 \\
96 \\
256 \\
490 \\
797 \\
1,010 \\
839 \\
584\end{array}$ & $\begin{array}{r}116 \\
99 \\
96 \\
106 \\
103 \\
74 \\
78 \\
111\end{array}$ & $\begin{array}{l}25 \\
26 \\
27 \\
28 \\
29 \\
30 \\
31\end{array}$ & $\begin{array}{l}382 \\
305 \\
255 \\
215 \\
183 \\
179\end{array}$ & $\begin{array}{l}151 \\
159 \\
140 \\
136 \\
122 \\
123 \\
131\end{array}$ \\
\hline $\begin{array}{l}\text { Mean } \\
\text { Run- }\end{array}$ & $\begin{array}{l}\text { onthly } \\
f, \text { in } 1\end{array}$ & hes. & , 1 & $\begin{array}{l}\text { econd- } \\
\text {. } . \text {. }\end{array}$ & $\dot{.}$ & $\dot{0}$ & . : & 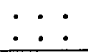 & . $\dot{ }$ & $\begin{array}{r}227 \\
4.35 \\
\end{array}$ & $\begin{array}{r}122 \\
2.42 \\
\end{array}$ \\
\hline
\end{tabular}

Gage helght, in feet, and discharge, in second-feet, at indicated time, 1938

\begin{tabular}{|c|c|c|c|c|c|c|c|c|c|c|c|c|}
\hline \multirow{2}{*}{$\begin{array}{l}3 \\
3 \\
00\end{array}$} & Feet & Sec.ft. & Feet & Sec.ft. & Feet & Sec.ft. & Feet & Sec.ft. & Feet & Sec.ft. & Feet & Sec.ft \\
\hline & \multicolumn{2}{|c|}{ September 18} & \multicolumn{2}{|c|}{ September 19} & \multicolumn{2}{|c|}{ September 20} & \multicolumn{2}{|c|}{ September 21} & \multicolumn{2}{|c|}{ September 22} & \multicolumn{2}{|c|}{ September 23} \\
\hline $\begin{array}{l}1 \\
2 \\
3 \\
4 \\
5 \\
6\end{array}$ & $\begin{array}{l}1.48 \\
1.42 \\
1.44 \\
1.47 \\
1.46 \\
1.45\end{array}$ & $\begin{array}{l}87 \\
79 \\
82 \\
86 \\
84 \\
83\end{array}$ & $\begin{array}{l}1.89 \\
1.94 \\
2.03 \\
2.12 \\
2.20 \\
2.28\end{array}$ & $\begin{array}{l}152 \\
161 \\
177 \\
194 \\
209 \\
225\end{array}$ & $\begin{array}{l}3.04 \\
3.13 \\
3.20 \\
3.22 \\
3.22 \\
3.21\end{array}$ & $\begin{array}{l}396 \\
418 \\
436 \\
441 \\
441 \\
439\end{array}$ & $\begin{array}{l}3.71 \\
3.75 \\
3.81 \\
3.88 \\
3.97 \\
4.08\end{array}$ & \begin{tabular}{|l|}
575 \\
586 \\
604 \\
324 \\
351 \\
684
\end{tabular} & $\begin{array}{l}5.19 \\
5.18 \\
5.17 \\
5.16 \\
5.16 \\
5.16\end{array}$ & $\begin{array}{l}1,050 \\
1,040 \\
1,040 \\
1,040 \\
1,040 \\
1,040\end{array}$ & $\begin{array}{l}4.95 \\
4.92 \\
4.89 \\
4.86 \\
4.83 \\
4.80\end{array}$ & $\begin{array}{l}962 \\
952 \\
942 \\
931 \\
920 \\
910\end{array}$ \\
\hline $\begin{array}{r}7 \\
8 \\
9 \\
10 \\
11 \\
\text { N }\end{array}$ & $\begin{array}{l}1.42 \\
1.38 \\
1.36 \\
1.43 \\
1.44 \\
1.45\end{array}$ & $\begin{array}{l}79 \\
73 \\
71 \\
80 \\
82 \\
83\end{array}$ & $\begin{array}{l}2.38 \\
2.48 \\
2.62 \\
2.64 \\
2.59 \\
2.55\end{array}$ & $\begin{array}{l}246 \\
268 \\
298 \\
303 \\
292 \\
283\end{array}$ & $\begin{array}{l}3.27 \\
3.30 \\
3.37 \\
3.40 \\
3.42 \\
3.43\end{array}$ & $\begin{array}{l}4 . j 4 \\
462 \\
481 \\
489 \\
494 \\
497\end{array}$ & $\begin{array}{l}4.22 \\
4.32 \\
4.44 \\
4.44 \\
4.40 \\
4.37\end{array}$ & $\begin{array}{l}726 \\
756 \\
792 \\
792 \\
780 \\
771\end{array}$ & $\begin{array}{l}5.11 \\
5.01 \\
4.96 \\
4.99 \\
5.02 \\
5.04\end{array}$ & $\begin{array}{r}1,020 \\
984 \\
966 \\
976 \\
987 \\
994\end{array}$ & $\begin{array}{l}4.76 \\
4.73 \\
4.70 \\
4.66 \\
4.62 \\
4.58\end{array}$ & $\begin{array}{l}896 \\
886 \\
875 \\
861 \\
847 \\
834\end{array}$ \\
\hline $\begin{array}{l}1 \\
2 \\
3 \\
4 \\
5 \\
6\end{array}$ & $\begin{array}{l}1.47 \\
1.53 \\
1.61 \\
1.63 \\
1.62 \\
1.65\end{array}$ & $\begin{array}{r}86 \\
94 \\
107 \\
110 \\
108 \\
113\end{array}$ & $\begin{array}{l}2.50 \\
2.48 \\
2.47 \\
2.43 \\
2.37 \\
2.42\end{array}$ & $\begin{array}{l}272 \\
268 \\
265 \\
257 \\
244 \\
254\end{array}$ & $\begin{array}{l}3.45 \\
3.48 \\
3.50 \\
3.51 \\
3.50 \\
3.51\end{array}$ & $\begin{array}{l}502 \\
511 \\
516 \\
519 \\
516 \\
519\end{array}$ & $\begin{array}{l}4.34 \\
4.31 \\
4.29 \\
4.64 \\
4.66 \\
4.72\end{array}$ & $\begin{array}{l}762 \\
753 \\
747 \\
854 \\
861 \\
882\end{array}$ & $\begin{array}{l}5.05 \\
5.06 \\
5.07 \\
5.07 \\
5.06 \\
5.06\end{array}$ & $\begin{array}{r}998 \\
1,000 \\
1,000 \\
1,000 \\
1,000 \\
1,000\end{array}$ & $\begin{array}{l}4.54 \\
4.50 \\
4.47 \\
4.43 \\
4.40 \\
4.36\end{array}$ & $\begin{array}{l}822 \\
810 \\
801 \\
789 \\
780 \\
768\end{array}$ \\
\hline \multirow[t]{2}{*}{$\begin{array}{r}7 \\
8 \\
9 \\
10 \\
11 \\
\end{array}$} & $\begin{array}{l}1.68 \\
1.67 \\
1.67 \\
1.68 \\
1.76 \\
1.82 \\
\end{array}$ & $\begin{array}{l}118 \\
116 \\
116 \\
118 \\
131 \\
140\end{array}$ & $\begin{array}{l}2.48 \\
2.57 \\
2.65 \\
2.74 \\
2.84 \\
2.94 \\
\end{array}$ & $\begin{array}{l}268 \\
287 \\
305 \\
325 \\
348 \\
372\end{array}$ & $\begin{array}{l}3.58 \\
3.60 \\
3.61 \\
3.65 \\
3.66 \\
3.69\end{array}$ & $\begin{array}{l}538 \\
544 \\
547 \\
558 \\
561 \\
569\end{array}$ & $\begin{array}{l}4.92 \\
5.12 \\
5.18 \\
5.20 \\
5.21 \\
5.20\end{array}$ & $\begin{array}{r}952 \\
1,020 \\
1,040 \\
1,050 \\
1,050 \\
1,050\end{array}$ & $\begin{array}{l}5.05 \\
5.04 \\
5.03 \\
5.01 \\
4.99 \\
4.97\end{array}$ & $\begin{array}{l}998 \\
994 \\
990 \\
984 \\
976 \\
970\end{array}$ & $\begin{array}{l}4.33 \\
4.30 \\
4.27 \\
4.24 \\
4.21 \\
4.18\end{array}$ & $\begin{array}{l}759 \\
750 \\
741 \\
732 \\
723 \\
714\end{array}$ \\
\hline & \multicolumn{2}{|c|}{ September 24} & \multicolumn{2}{|c|}{ September 25} & \multicolumn{2}{|c|}{ September 26} & \multicolumn{2}{|c|}{ September 27} & \multicolumn{2}{|c|}{ September 28} & \multicolumn{2}{|c|}{ September 29} \\
\hline $\begin{array}{r}2 \\
4 \\
6 \\
8 \\
10 \\
N\end{array}$ & $\begin{array}{l}4.11 \\
4.04 \\
3.97 \\
3.90 \\
3.83 \\
3.75\end{array}$ & $\begin{array}{l}693 \\
672 \\
651 \\
630 \\
610 \\
586\end{array}$ & $\begin{array}{l}3.21 \\
3.15 \\
3.09 \\
3.04 \\
3.00 \\
2.97\end{array}$ & $\begin{array}{l}439 \\
424 \\
408 \\
396 \\
386 \\
379\end{array}$ & $\begin{array}{l}2.77 \\
2.74 \\
2.72 \\
2.69 \\
2.67 \\
2.65\end{array}$ & $\begin{array}{l}332 \\
325 \\
321 \\
314 \\
309 \\
305\end{array}$ & $\begin{array}{l}2.50 \\
2.48 \\
2.46 \\
2.45 \\
2.43 \\
2.42\end{array}$ & $\begin{array}{l}272 \\
268 \\
263 \\
261 \\
257 \\
254\end{array}$ & $\begin{array}{l}2.31 \\
2.29 \\
2.28 \\
2.27 \\
2.25 \\
2.24\end{array}$ & $\begin{array}{l}231 \\
227 \\
225 \\
223 \\
219 \\
217\end{array}$ & $\begin{array}{c}2 . \\
2.15 \\
- \\
2.14 \\
- \\
2.12\end{array}$ & $\begin{array}{l}- \\
-200 \\
-198 \\
-\quad 194\end{array}$ \\
\hline $\begin{array}{r}2 \\
4 \\
6 \\
8 \\
10 \\
M\end{array}$ & $\begin{array}{l}3.67 \\
3.58 \\
3.51 \\
3.42 \\
3.33 \\
3.27\end{array}$ & $\begin{array}{l}564 \\
538 \\
519 \\
494 \\
470 \\
454\end{array}$ & $\begin{array}{l}2.93 \\
2.84 \\
2.84 \\
2.83 \\
2.81 \\
2.78\end{array}$ & $\begin{array}{l}369 \\
348 \\
348 \\
346 \\
341 \\
334\end{array}$ & $\begin{array}{l}2.63 \\
2.60 \\
2.58 \\
2.56 \\
2.54 \\
2.52\end{array}$ & $\begin{array}{l}301 \\
294 \\
290 \\
285 \\
281 \\
276\end{array}$ & $\begin{array}{l}2.41 \\
2.45 \\
2.35 \\
2.34 \\
2.34 \\
2.33\end{array}$ & $\begin{array}{l}252 \\
261 \\
240 \\
237 \\
237 \\
235\end{array}$ & $\begin{array}{l}2.23 \\
2.10 \\
2.17 \\
2.19 \\
2.18 \\
2.17\end{array}$ & $\begin{array}{l}215 \\
190 \\
203 \\
207 \\
205 \\
203\end{array}$ & $\begin{array}{c}- \\
2.10 \\
- \\
1.78 \\
- \\
1.91\end{array}$ & $\begin{array}{r}- \\
-190 \\
-134 \\
-\quad 156\end{array}$ \\
\hline
\end{tabular}

Supplemental records.- Sept. $21,11: 20$ p.m., $5.22 \mathrm{ft} ., 1,060$ sec.-ft. 
Moosup River at Moosup, Gonn.

Location.- Water-stage recorder, lat. $41^{\circ} 42^{\prime} 40^{\prime \prime}$, long. $71^{\circ} 53^{\prime} 15^{\prime \prime}$, at outlet of ta11race from Aldrich Bros, mill, 100 feet above New York, New Haven Hartford Ra11road bridge at Moosup, Windham County, and $3 \frac{1}{2}$ miles above confluence with Quinebaug River.

Drainage area.- $83.5^{\prime}$ square miles.

Gage-he1ght record. - Water-stage recorder graph.

Stage-discharge relation.- Defined by current-meter messurements below 850 secondreet; extended to peak stage on basis of two determinations of flood flow over dam a quarter of a mile upstream.

Maxima:- September 1938: D1scharge, 686 second-feet 7 a.m. Sept. 21 (gage height, 3.74 feet).

1932 to August 1938: Maximum discharge, 4,100 second-feet (natural) July 24, 1938 (gage height, 8.20 feet); maximum stage, 8.35 feet Mar. 12, 1936, resulted from sharp short rise of unknown origin.

Remarks.- Diumal fluctuation caused by regulation at mills upstream.

Mean dally discharge, in second-feet, 1938

\begin{tabular}{|c|c|c||c|c|c||c|c|c||c|c|c|}
\hline Day & Sept. & 0ct. & Day & Sept. & 0ct. & Day. & Sept. & 0ct. & Day & Sept. & Oct. \\
\hline 1 & 72 & 136 & 9 & 66 & 76 & 17 & 41 & 106 & 25 & 212 & 280 \\
2 & 71 & 139 & 10 & 14 & 113 & 18 & 131 & 86 & 26 & 183 & 254 \\
3 & 83 & 153 & 11 & 27 & 90 & 19 & 379 & 79 & 27 & 146 & 213 \\
4 & 29 & 121 & 12 & 75 & 83 & 20 & 540 & 80 & 28 & 139 & 170 \\
5 & 9.2 & 122 & 13 & 72 & 83 & 21 & 586 & 78 & 29 & 133 & 182 \\
6 & 78 & 116 & 14 & 74 & 85 & 22 & 478 & 46 & 30 & 128 & 205 \\
7 & 72 & 103 & 15 & 84 & 57 & 23 & 379 & 91 & 31 & & 203 \\
8 & 68 & 45 & 16 & 76 & 72 & 24 & 276 & 124 & & & \\
\hline
\end{tabular}

Gage helght, in feet, and discharge, in second-feet, at indicated time, 1938

\begin{tabular}{|c|c|c|c|c|c|c|c|c|c|c|c|c|}
\hline \multirow{2}{*}{$\begin{array}{l}5 \\
\text { 量 } \\
\end{array}$} & Feet & Sec.ft. & Feet & Sec.ft. & Feet & Sec.ft. & Feet & Sec.ft. & Feet & Sec.ft. & Feet & Sec.ft. \\
\hline & \multicolumn{2}{|c|}{ September 18} & \multicolumn{2}{|c|}{ September 19} & \multicolumn{2}{|c|}{ September 20} & \multicolumn{2}{|c|}{ September 21} & \multicolumn{2}{|c|}{ September 22} & \multicolumn{2}{|c|}{ September 23} \\
\hline $\begin{array}{l}1 \\
2 \\
3 \\
4 \\
5 \\
6\end{array}$ & $\begin{array}{l}1.63 \\
1.65 \\
1.68 \\
1.74 \\
1.75 \\
1.78\end{array}$ & $\begin{array}{l}73 \\
76 \\
80 \\
90 \\
92 \\
97\end{array}$ & $\begin{array}{l}2.33 \\
2.50 \\
2.53 \\
2.62 \\
2.67 \\
2.78\end{array}$ & $\begin{array}{l}222 \\
270 \\
279 \\
306 \\
321 \\
354\end{array}$ & $\begin{array}{l}3.29 \\
3.19 \\
3.16 \\
3.20 \\
3.22 \\
3.27\end{array}$ & $\begin{array}{l}516 \\
482 \\
471 \\
485 \\
492 \\
510\end{array}$ & $\begin{array}{l}3.55 \\
3.60 \\
3.71 \\
3.54 \\
3.57 \\
3.60\end{array}$ & & & & & \begin{tabular}{|l|}
420 \\
417 \\
414 \\
393 \\
393 \\
408
\end{tabular} \\
\hline $\begin{array}{r}7 \\
8 \\
9 \\
10 \\
11 \\
\text { N }\end{array}$ & $\begin{array}{l}1.80 \\
1.83 \\
1.86 \\
1.87 \\
1.87 \\
1.90\end{array}$ & $\begin{array}{l}100 \\
106 \\
111 \\
113 \\
113 \\
119\end{array}$ & $\begin{array}{l}3.08 \\
2.98 \\
2.97 \\
2.97 \\
2.96 \\
2.95\end{array}$ & $\begin{array}{l}444 \\
414 \\
411 \\
411 \\
408 \\
405\end{array}$ & $\begin{array}{l}3.45 \\
3.35 \\
3.33 \\
3.32 \\
3.28 \\
3.35\end{array}$ & $\begin{array}{l}572 \\
538 \\
530 \\
527 \\
513 \\
538\end{array}$ & $\begin{array}{l}3.74 \\
3.65 \\
3.62 \\
3.60 \\
3.59 \\
3.58\end{array}$ & & & & & $\begin{array}{l}471 \\
417 \\
411 \\
396 \\
339 \\
429\end{array}$ \\
\hline $\begin{array}{l}1 \\
2 \\
3 \\
4 \\
5 \\
6\end{array}$ & $\begin{array}{l}2.08 \\
2.01 \\
2.01 \\
2.04 \\
2.09 \\
2.10\end{array}$ & $\begin{array}{l}158 \\
142 \\
142 \\
149 \\
161 \\
163\end{array}$ & $\begin{array}{l}2.93 \\
2.90 \\
2.89 \\
2.83 \\
2.84 \\
2.84\end{array}$ & $\begin{array}{l}399 \\
390 \\
387 \\
369 \\
372 \\
372\end{array}$ & $\begin{array}{l}3.37 \\
3.40 \\
3.41 \\
3.38 \\
3.41 \\
3.42\end{array}$ & $\begin{array}{l}544 \\
555 \\
558 \\
548 \\
558 \\
562\end{array}$ & $\begin{array}{l}3.56 \\
3.48 \\
3.50 \\
3.40 \\
3.25 \\
3.26\end{array}$ & $\begin{array}{l}614 \\
583 \\
590 \\
555 \\
502 \\
506\end{array}$ & & & & $\begin{array}{l}387 \\
384 \\
369 \\
318 \\
357 \\
354\end{array}$ \\
\hline \multirow[t]{2}{*}{$\begin{array}{r}7 \\
8 \\
9 \\
10 \\
17 \\
M \\
\end{array}$} & $\begin{array}{l}2.13 \\
2.14 \\
2.18 \\
2.23 \\
2.27 \\
2.30\end{array}$ & $\begin{array}{l}170 \\
173 \\
183 \\
196 \\
206 \\
214\end{array}$ & $\begin{array}{l}2.85 \\
2.97 \\
3.11 \\
3.18 \\
3.22 \\
3.26\end{array}$ & $\begin{array}{l}375 \\
411 \\
454 \\
478 \\
492 \\
506\end{array}$ & $\begin{array}{l}3.43 \\
3.44 \\
3.47 \\
3.50 \\
3.51 \\
3.53\end{array}$ & $\begin{array}{l}566 \\
569 \\
580 \\
590 \\
594 \\
602\end{array}$ & $\begin{array}{l}3.27 \\
3.28 \\
3.29 \\
3.30 \\
3.30 \\
3.29\end{array}$ & $\begin{array}{l}510 \\
513 \\
516 \\
520 \\
520 \\
516\end{array}$ & $\begin{array}{l}3.10 \\
3.08 \\
3.07 \\
3.06 \\
3.04 \\
3.02\end{array}$ & & & $\begin{array}{l}348 \\
333 \\
330 \\
324 \\
321 \\
312\end{array}$ \\
\hline & \multicolumn{2}{|c|}{ September 24} & \multicolumn{2}{|c|}{ September 25} & \multicolumn{2}{|c|}{ September 26} & \multicolumn{2}{|c|}{ September 27} & \multicolumn{2}{|c|}{ September 28} & \multicolumn{2}{|c|}{ September 29} \\
\hline \begin{tabular}{|r|}
2 \\
4 \\
6 \\
8 \\
10 \\
$N$
\end{tabular} & \begin{tabular}{|l|}
2.63 \\
2.62 \\
2.61 \\
2.59 \\
2.56 \\
2.42
\end{tabular} & $\begin{array}{l}309 \\
306 \\
303 \\
297 \\
288 \\
247\end{array}$ & $\begin{array}{l}2.42 \\
2.42 \\
2.31 \\
2.30 \\
2.29 \\
2.28\end{array}$ & $\begin{array}{l}217 \\
214 \\
211 \\
209\end{array}$ & $\begin{array}{l}= \\
= \\
= \\
2.10\end{array}$ & $\begin{array}{l}= \\
= \\
\bar{E} 183\end{array}$ & $\begin{array}{l}\overline{-} \\
\overline{-} \\
\overline{2} .02\end{array}$ & $\begin{array}{l}\overline{-} \\
\overline{-} \\
\overline{1}\end{array}$ & $\begin{array}{l} \pm \\
\pm \\
\pm \\
\pm .00\end{array}$ & $\begin{array}{l}= \\
= \\
= \\
=139\end{array}$ & $\begin{array}{l}- \\
- \\
- \\
- \\
* 1.96\end{array}$ & $\begin{array}{l}- \\
\overline{-} \\
- \\
\overline{-} \\
=133\end{array}$ \\
\hline $\begin{array}{r}2 \\
4 \\
6 \\
8 \\
10 \\
\mathrm{M}\end{array}$ & $\begin{array}{l}2.45 \\
2.47 \\
2.47 \\
2.44 \\
2.43 \\
2.40\end{array}$ & $\begin{array}{l}256 \\
261 \\
261 \\
253 \\
250 \\
241\end{array}$ & $\begin{array}{l}2.31 \\
2.23 \\
2.23 \\
2.22 \\
2.20 \\
2.19\end{array}$ & $\begin{array}{l}190 \\
196 \\
193 \\
188 \\
186\end{array}$ & $\begin{array}{l}\overline{-} \\
\overline{-}\end{array}$ & $\begin{array}{l}\overline{-} \\
\overline{-} \\
\overline{-}\end{array}$ & $\begin{array}{l}\overline{-} \\
\overline{-} \\
\overline{-}\end{array}$ & $\begin{array}{l}E \\
\bar{E} \\
\bar{E}\end{array}$ & $\begin{array}{l}\overline{-} \\
\overline{-} \\
\overline{-}\end{array}$ & $\begin{array}{l}\bar{z} \\
\bar{z}\end{array}$ & $\begin{array}{l}= \\
= \\
=\end{array}$ & $\begin{array}{l}\overline{-} \\
\bar{E} \\
\overline{-}\end{array}$ \\
\hline
\end{tabular}

* Hean for the dey. 
Location.- Water-stage recorder, lat. $41^{\circ} 33^{\prime} 35^{\prime \prime}$, long. $72^{\circ} 07^{\prime} 20^{\prime \prime}$, 700 feet below stonearch highway bridge at Yantic, New Iondon County, and 1 mile below Susquetongcut Brook.

Dralnage area.- 88.6 square miles.

Gage-helght record. - Water-stage recorder graph except for periods 7 a.m. Sept. 21 to 5 p.m. Sept. 25, when graph was based on existing record and comparison with graphs of nearby stations, and 0ct. 19-31, when dally discharge was determined by hydrographic comparison with records of nearby stations.

Stage-discharge relation.- Defined by current-meter measurements below 4,520 secondfeet; extended to peak stage on basis of determinations of 1936 and 1938 flood flows over spillway of dam $2 \frac{1}{2}$ miles upstream and determination of 1938 flood flow over splilway of dam 3 miles downstream.

Mexima.- September 1938: Discharge, 13,500 second-feet 8 a.m. Sept. 21 (gage height, 14.66 feet, observed from floodmark).

1930 to August 1938: D1scharge, 6,980 second-feet July 24, 1938 (gage he1ght, 11.12 feet, adjusted for intake draw-down).

Remarks.- Flood run-orf affected by storage in a few lakes and ponds.

Mean daily discharge, in second-feet, 1938

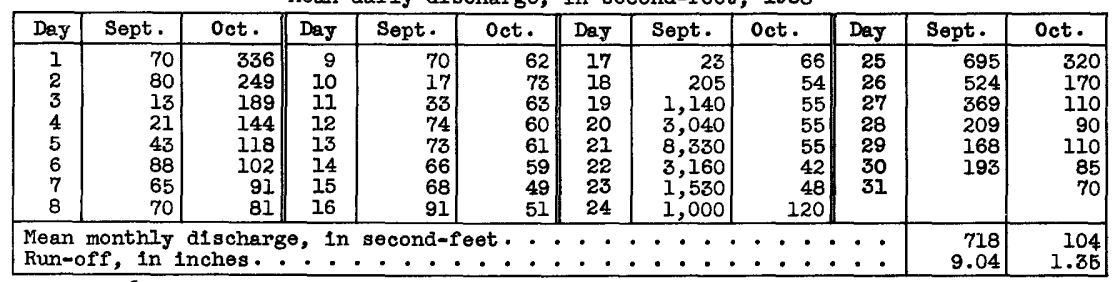

Gage helght, in feet, and discharge, in second-feet, at indicated time, 1938

\begin{tabular}{|c|c|c|c|c|c|c|c|c|c|c|c|c|}
\hline \multirow{2}{*}{ 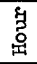 } & Feet & Sec.ft. & Feet & Sec.ft. & Feet & Sec.ft. & Feet & Sec.ft. & Feet & Sec.ft. & Feet & Sec.ft. \\
\hline & \multicolumn{2}{|c|}{ September 18} & \multicolumn{2}{|c|}{ September 19} & \multicolumn{2}{|c|}{ September 20} & \multicolumn{2}{|c|}{ September 21} & \multicolumn{2}{|c|}{ September 22} & \multicolumn{2}{|c|}{ September 23} \\
\hline $\begin{array}{l}1 \\
2 \\
3 \\
4 \\
5 \\
6\end{array}$ & $\begin{array}{l}1.73 \\
1.91 \\
2.02 \\
2.09 \\
2.15 \\
2.19\end{array}$ & $\begin{array}{r}84 \\
106 \\
122 \\
132 \\
142 \\
148\end{array}$ & $\begin{array}{l}3.69 \\
3.73 \\
3.87 \\
4.06 \\
4.31 \\
4.57\end{array}$ & $\begin{array}{l}497 \\
509 \\
551 \\
616 \\
704 \\
798\end{array}$ & $\begin{array}{l}8.49 \\
8.71 \\
8.80 \\
8.74 \\
8.64 \\
8.48\end{array}$ & $\begin{array}{l}3,300 \\
3,500 \\
3,590 \\
3,530 \\
3,440 \\
3,290\end{array}$ & $\begin{array}{r}7.59 \\
7.63 \\
7.95 \\
9.60 \\
11.75 \\
13.3\end{array}$ & $\begin{array}{r}2,550 \\
2,580 \\
2,840 \\
4,460 \\
7,580 \\
10,400\end{array}$ & $\begin{array}{l}11.15 \\
10.9 \\
10.7 \\
10.45 \\
10.25 \\
10.1\end{array}$ & $\begin{array}{l}5,290 \\
4,890 \\
4,590 \\
4,240 \\
3,980 \\
3,780\end{array}$ & $\begin{array}{l}8.25 \\
8.2 \\
8.1 \\
8.05 \\
8.0 \\
7.95\end{array}$ & \\
\hline $\begin{array}{r}7 \\
8 \\
9 \\
10 \\
11 \\
N\end{array}$ & $\begin{array}{l}2.20 \\
2.21 \\
2.22 \\
2.22 \\
2.20 \\
2.19\end{array}$ & $\begin{array}{l}150 \\
152 \\
153 \\
153 \\
150 \\
148\end{array}$ & $\begin{array}{l}4.87 \\
5.14 \\
5.29 \\
5.26 \\
5.15 \\
5.02\end{array}$ & $\begin{array}{r}918 \\
1,040 \\
1,120 \\
1,100 \\
1,040 \\
984\end{array}$ & $\begin{array}{l}8.37 \\
8.28 \\
8.16 \\
8.01 \\
7.91 \\
7.81\end{array}$ & $\begin{array}{l}3,190 \\
3,110 \\
3,010 \\
2,890 \\
2,810 \\
2,730\end{array}$ & $\begin{array}{l}14.3 \\
14.66 \\
14.45 \\
14.2 \\
13.9 \\
13.6\end{array}$ & $\begin{array}{l}12,600 \\
13,500 \\
13,000 \\
12,400 \\
11,600 \\
11,000\end{array}$ & $\begin{array}{l}9.95 \\
9.8 \\
9.65 \\
9.55 \\
9.4 \\
9.3\end{array}$ & $\begin{array}{l}3,600 \\
3,420 \\
3,260 \\
3,140 \\
2,980 \\
2,880\end{array}$ & $\begin{array}{l}7.9 \\
7.85 \\
7.8 \\
7.75 \\
7.7 \\
7.65\end{array}$ & \\
\hline $\begin{array}{l}1 \\
2 \\
3 \\
4 \\
5 \\
6\end{array}$ & $\begin{array}{l}2.35 \\
2.40 \\
2.46 \\
2.51 \\
2.59 \\
2.70\end{array}$ & $\begin{array}{l}176 \\
185 \\
196 \\
206 \\
222 \\
245\end{array}$ & $\begin{array}{l}4.75 \\
5.03 \\
5.04 \\
4.98 \\
4.80 \\
5.00\end{array}$ & $\begin{array}{l}870 \\
988 \\
993 \\
966 \\
890 \\
975\end{array}$ & $\begin{array}{l}7.87 \\
8.00 \\
8.10 \\
8.19 \\
8.20 \\
8.18\end{array}$ & $\begin{array}{l}2,770 \\
2,880 \\
2,960 \\
3,030 \\
3,040 \\
3,020\end{array}$ & $\begin{array}{l}13.35 \\
13.1 \\
12.85 \\
13.1 \\
13.0 \\
12.75\end{array}$ & $\begin{array}{r}10,500 \\
10,000 \\
9,520 \\
9,130 \\
8,900 \\
8,330\end{array}$ & $\begin{array}{l}9.2 \\
9.1 \\
9.0 \\
8.9 \\
8.85 \\
8.75\end{array}$ & $\begin{array}{l}2,780 \\
2,680 \\
2,580 \\
2,490 \\
2,440 \\
2,360\end{array}$ & $\begin{array}{l}7.6 \\
7.6 \\
7.55 \\
7.5 \\
7.45 \\
7.4\end{array}$ & $\begin{array}{l}1,460 \\
1,460 \\
1,430 \\
1,400 \\
1,370 \\
1,340\end{array}$ \\
\hline \multirow[t]{2}{*}{$\begin{array}{r}7 \\
8 \\
9 \\
10 \\
11 \\
1\end{array}$} & $\begin{array}{l}2.86 \\
2.98 \\
3.20 \\
3.29 \\
3.47 \\
3.66 \\
\end{array}$ & $\begin{array}{l}281 \\
310 \\
365 \\
388 \\
432 \\
488 \\
\end{array}$ & $\begin{array}{l}5.65 \\
6.30 \\
6.85 \\
7.33 \\
7.85 \\
8.20\end{array}$ & $\begin{array}{l}1,300 \\
1,660 \\
2,020 \\
2,350 \\
2,760 \\
3,040\end{array}$ & $\begin{array}{l}8.12 \\
8.02 \\
7.90 \\
7.81 \\
7.69 \\
7.63\end{array}$ & $\begin{array}{l}2,980 \\
2,900 \\
2,800 \\
2,730 \\
2,630 \\
2,580\end{array}$ & $\begin{array}{l}12.55 \\
12.3 \\
12.1 \\
11.9 \\
11.6 \\
11.4\end{array}$ & $\begin{array}{l}7,900 \\
7,380 \\
6,990 \\
6,610 \\
6,060 \\
5,710 \\
\end{array}$ & $\begin{array}{l}8.65 \\
8.6 \\
8.5 \\
8.4 \\
8.35 \\
8.3\end{array}$ & $\begin{array}{l}2,260 \\
2,220 \\
2,130 \\
2,050 \\
2,010 \\
1,970\end{array}$ & $\begin{array}{l}7.35 \\
7.35 \\
7.3 \\
7.25 \\
7.2 \\
7.2\end{array}$ & $\begin{array}{l}1,310 \\
1,310 \\
1,280 \\
1,250 \\
1,220 \\
1,220\end{array}$ \\
\hline & \multicolumn{2}{|c|}{ September 24} & \multicolumn{2}{|c|}{ September 25} & \multicolumn{2}{|c|}{ September 26} & \multicolumn{2}{|c|}{ September 27} & \multicolumn{2}{|c|}{ September 28} & \multicolumn{2}{|c|}{ September 29} \\
\hline $\begin{array}{r}2 \\
4 \\
6 \\
8 \\
10 \\
N\end{array}$ & $\begin{array}{l}7.1 \\
7.0 \\
6.95 \\
6.9 \\
6.85 \\
6.8\end{array}$ & $\begin{array}{l}1,160 \\
1,110 \\
1,080 \\
1,060 \\
1,040 \\
1,010\end{array}$ & $\begin{array}{l}6.35 \\
6.3 \\
6.25 \\
6.2 \\
6.35 \\
6.1\end{array}$ & $\begin{array}{l}810 \\
790 \\
770 \\
750 \\
810 \\
710\end{array}$ & $\begin{array}{l}5.74 \\
5.70 \\
5.68 \\
5.82 \\
5.85 \\
5.48\end{array}$ & $\begin{array}{l}579 \\
565 \\
558 \\
607 \\
618 \\
494\end{array}$ & $\begin{array}{l}5.35 \\
5.33 \\
5.30 \\
5.57 \\
5.46 \\
5.20\end{array}$ & $\begin{array}{l}455 \\
449 \\
440 \\
521 \\
488 \\
415\end{array}$ & & $\begin{array}{l}224 \\
221 \\
217 \\
316 \\
320 \\
216\end{array}$ & $\begin{array}{l}3.97 \\
3.97 \\
3.97 \\
4.50 \\
4.51 \\
3.96\end{array}$ & $\begin{array}{l}172 \\
172 \\
172 \\
260 \\
262 \\
170\end{array}$ \\
\hline $\begin{array}{r}2 \\
4 \\
6 \\
8 \\
10 \\
M\end{array}$ & $\begin{array}{l}6.7 \\
6.65 \\
6.6 \\
6.5 \\
6.45 \\
6.4 \\
\end{array}$ & $\begin{array}{l}965 \\
942 \\
920 \\
875 \\
852 \\
830\end{array}$ & $\begin{array}{l}5.85 \\
5.75 \\
5.76 \\
5.80 \\
5.80 \\
5.77\end{array}$ & $\begin{array}{l}618 \\
582 \\
586 \\
600 \\
600 \\
590\end{array}$ & $\begin{array}{l}5.62 \\
5.45 \\
5.23 \\
5.33 \\
5.37 \\
5.37\end{array}$ & $\begin{array}{l}537 \\
485 \\
422 \\
449 \\
461 \\
461\end{array}$ & $\begin{array}{l}5.10 \\
4.80 \\
4.11 \\
4.17 \\
4.26 \\
4.30\end{array}$ & $\begin{array}{l}390 \\
320 \\
193 \\
202 \\
217 \\
224\end{array}$ & $\begin{array}{l}4.36 \\
4.17 \\
3.38 \\
3.63 \\
3.85 \\
3.94\end{array}$ & $\begin{array}{r}235 \\
202 \\
98 \\
127 \\
155 \\
168\end{array}$ & $\begin{array}{l}4.11 \\
3.90 \\
3.23 \\
3.48 \\
3.64 \\
3\end{array}$ & $\begin{array}{r}193 \\
162 \\
83 \\
109 \\
128 \\
139\end{array}$ \\
\hline
\end{tabular}

Supplemental records.- Sept. 26, 7 a.m., $5.66 \mathrm{ft} ., 551$ sec.-ft. Sept. 28,

$12: 30$ p.m., 4.10 ft., 191 sec.-ft. Sept. 29, $12: 30$ p.m., 3.76 ft., 148 sec. ft. 
First and Second Connecticut Lakes near Pittsburg, N. H.

Location.- At Second Connecticut Lake at Idlewilde, Coos County, about 12 miles northeast of Pittsburg and at First Connecticut Lake about 6 miles northeast of Pittsburg, Coos County.

Drainage area.- $83.0^{\circ}$ square miles, above outlet of First Connecticut Lake.

Remarks.- Total capacity, 3,840,000,000 cubic feet. Basic data furnished by connecticut River Power Co.

Gain or loss in storage, in millions of cubic feet, 1938

\begin{tabular}{|c|c|c|c|c|c|c|c|c|c|c|c|}
\hline Day & Sept. & oct. & Day & Sept. & oct. & Day & Sept. & oct. & Day & Sept. & oct. \\
\hline $\begin{array}{l}1 \\
2 \\
3 \\
4 \\
5 \\
6 \\
7 \\
8\end{array}$ & $\begin{array}{l}-5.3 \\
+1.2 \\
-6.1 \\
-8.3 \\
-6.7 \\
+2.9 \\
+4.4 \\
+2.2\end{array}$ & $\begin{array}{r}-36.3 \\
-32.0 \\
-34.6 \\
-15.9 \\
+2.2 \\
-6.4 \\
-32.9 \\
-33.2\end{array}$ & $\begin{array}{l}9 \\
10 \\
11 \\
12 \\
13 \\
14 \\
15 \\
16\end{array}$ & $\begin{array}{r}+5.3 \\
+1.0 \\
-0.3 \\
+12.1 \\
+14.7 \\
+16.2 \\
+19.8 \\
+14.9\end{array}$ & $\begin{array}{l}-32.0 \\
-32.4 \\
-33.3 \\
-32.9 \\
-39.9 \\
-55.6 \\
-57.3 \\
-53.3\end{array}$ & $\begin{array}{l}17 \\
18 \\
19 \\
20 \\
21 \\
22 \\
23 \\
24\end{array}$ & $\begin{array}{r}-4.7 \\
0 \\
-6.8 \\
+37.2 \\
+7.8 \\
-5.2 \\
0 \\
-18.8\end{array}$ & $\begin{array}{l}-51.8 \\
-50.5 \\
-53.3 \\
-52.2 \\
-47.4 \\
-48.7 \\
-47.4 \\
-30.8\end{array}$ & $\begin{array}{l}25 \\
26 \\
27 \\
28 \\
29 \\
30 \\
31\end{array}$ & $\begin{array}{r}-29.5 \\
-28.4 \\
-6.4 \\
-32.3 \\
-34.1 \\
-35.0\end{array}$ & $\begin{array}{r}+6.5 \\
-2.3 \\
-6.3 \\
-8.6 \\
-10.5 \\
-10.1 \\
-6.3\end{array}$ \\
\hline $\begin{array}{l}\text { Gain } \\
\text { Gain }\end{array}$ & $\begin{array}{l}\text { or loss } \\
\text { or loss }\end{array}$ & $\begin{array}{l}\text { In stor } \\
\text { In stor }\end{array}$ & e, & $\begin{array}{l}\text { millic } \\
\text { equive }\end{array}$ & $\begin{array}{l}\text { of cub } \\
\text { at mear }\end{array}$ & c $f$ & t-feet. & $\cdot: \cdot \cdot$ & : : : & $\begin{array}{r}-88.2 \\
-35\end{array}$ & $\begin{array}{r}-945.5 \\
-353\end{array}$ \\
\hline
\end{tabular}


Connecticut River at First Connecticut Lake, near P1ttaburg, N. H.

Location. - Water-stage recorder, lat. $45^{\circ} 05^{\prime} 15^{\prime \prime}$, long. $71^{\circ} 17^{\prime} 35^{\prime \prime}$, a quarter of a mile below dam at First Connecticut Lake and 6 miles northeast of Pittsburg, Coos County. Drainage area.- 83.0 square miles.

Gage-helght record. - Water-stage recorder graph except for per1od Sept. 1 to Sept. 13, record for which was based on relationship with stage and gate openings at First Connecticut Lake.

Stage-discharge relation.- Defined by current-meter measurements below 1,620 secondfeet.

Maxima.- September 1938: Discharge observed, 2,000 second-feet 8 p.m. Sept. 21 (gage height, 4.09 feet); mean delly discharge, adjusted for storage, 1,440 second-feet Sept. 21 .

1917 to August 1938: Maximum discharge observed, 1,810 second-feet May 27, 1930 (gage helght, 4.02 feet); maximum gage helght, 6.35 feet May 5 , 1925 (caused by backwater during logging operations).

Remarks.- Flood run-off almost completely stored in First and second connecticut Lakes (total of $3,840,000,000$ cub1c feet of atorage capacity). Mean daily and monthly discharges djusted for storage in First and Second Connecticut Lakes. For information on storage see record for First and Second Connecticut Lakes near P1ttsburg, N. H. Basic data on storage in First and Second Connecticut Lakes furnished by New England Power Co.

\begin{tabular}{|c|c|c|c|c|c|c|c|c|c|}
\hline \multirow{2}{*}{ Day } & \multicolumn{2}{|c|}{ September. } & \multicolumn{2}{|c|}{ October } & \multirow{2}{*}{ Day } & \multicolumn{2}{|c|}{ September } & \multicolumn{2}{|c|}{ October } \\
\hline & Observed & Adjusted & Observed & Adjusted & & Observed & Adjusted & Observed & Adjusted \\
\hline $\begin{array}{l}1 \\
2 \\
3 \\
4 \\
5\end{array}$ & $\begin{array}{l}196 \\
196 \\
196 \\
196 \\
196\end{array}$ & $\begin{array}{l}135 \\
210 \\
125 \\
100 \\
118\end{array}$ & $\begin{array}{l}580 \\
580 \\
580 \\
334 \\
113\end{array}$ & $\begin{array}{l}160 \\
210 \\
180 \\
150 \\
138\end{array}$ & $\begin{array}{l}16 \\
17 \\
18 \\
19 \\
20\end{array}$ & $\begin{array}{l}196 \\
322 \\
361 \\
442 \\
570\end{array}$ & $\begin{array}{r}368 \\
268 \\
361 \\
363 \\
1,000\end{array}$ & $\begin{array}{l}749 \\
749 \\
749 \\
749 \\
749\end{array}$ & $\begin{array}{l}132 \\
150 \\
165 \\
132 \\
145\end{array}$ \\
\hline $\begin{array}{r}6 \\
7 \\
8 \\
9 \\
10\end{array}$ & $\begin{array}{r}152 \\
79 \\
79 \\
79 \\
79\end{array}$ & $\begin{array}{r}185 \\
130 \\
105 \\
140 \\
91\end{array}$ & $\begin{array}{l}160 \\
475 \\
475 \\
475 \\
475\end{array}$ & $\begin{array}{r}86 \\
94 \\
91 \\
105 \\
100\end{array}$ & $\begin{array}{l}21 \\
22 \\
23 \\
24 \\
25\end{array}$ & $\begin{array}{r}1,350 \\
1,240 \\
509 \\
489 \\
570\end{array}$ & $\begin{array}{r}1,440 \\
1,180 \\
509 \\
271 \\
229\end{array}$ & $\begin{array}{l}749 \\
749 \\
749 \\
627 \\
250\end{array}$ & $\begin{array}{l}200 \\
185 \\
200 \\
270 \\
325\end{array}$ \\
\hline $\begin{array}{l}11 \\
12 \\
13 \\
14 \\
15\end{array}$ & $\begin{array}{r}79 \\
62 \\
148 \\
200 \\
196\end{array}$ & $\begin{array}{r}76 \\
202 \\
318 \\
388 \\
425\end{array}$ & $\begin{array}{l}475 \\
475 \\
564 \\
738 \\
749\end{array}$ & $\begin{array}{r}90 \\
94 \\
102 \\
94 \\
86\end{array}$ & $\begin{array}{l}26 \\
27 \\
28 \\
29 \\
30 \\
31\end{array}$ & $\begin{array}{l}549 \\
286 \\
574 \\
580 \\
580\end{array}$ & $\begin{array}{l}220 \\
212 \\
200 \\
185 \\
175\end{array}$ & $\begin{array}{l}250 \\
250 \\
250 \\
250 \\
250 \\
250\end{array}$ & $\begin{array}{l}223 \\
177 \\
150 \\
128 \\
133 \\
177\end{array}$ \\
\hline $\begin{array}{l}\mathrm{Me} \\
\mathrm{Ru}\end{array}$ & $\begin{array}{l}\text { monthly } \\
\text { off, in }\end{array}$ & $\begin{array}{l}\text { 1scharge } \\
\text { ches.. }\end{array}$ & $\begin{array}{c}\text { In secon } \\
.\end{array}$ & $\begin{array}{l}\text { feet. } \\
.\end{array}$ & $\therefore$ & -358 & $\begin{array}{r}324 \\
4.35\end{array}$ & $\begin{array}{r}504 \\
-\quad 5\end{array}$ & $\begin{array}{r}151 \\
2.10\end{array}$ \\
\hline
\end{tabular}

Gage height, in feet, and discharge, in second-feet, at incicated time, 1938

\begin{tabular}{|c|c|c|c|c|c|c|c|c|c|c|c|c|}
\hline \multirow{2}{*}{ 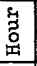 } & Feet & Sec.ft. & Feet & Sec.ft. & Feet & Sec.ft. & Feet & Sec.ft. & Feet & Sec.ft. & Feet & Sec.ft. \\
\hline & \multicolumn{2}{|c|}{ September 18} & \multicolumn{2}{|c|}{ September 19} & \multicolumn{2}{|c|}{ September 20} & \multicolumn{2}{|c|}{ September 21} & \multicolumn{2}{|c|}{ September 22} & \multicolumn{2}{|c|}{ September 23} \\
\hline \begin{tabular}{r|}
2 \\
4 \\
6 \\
8 \\
10 \\
$\mathbf{N}$
\end{tabular} & $\begin{array}{l}2.91 \\
2.91 \\
2.91 \\
2.91 \\
2.59 \\
2.59\end{array}$ & $\begin{array}{l}482 \\
482 \\
482 \\
482 \\
295 \\
295\end{array}$ & $\begin{array}{l}2.59 \\
2.59 \\
2.59 \\
2.59 \\
2.75 \\
2.75\end{array}$ & \begin{tabular}{|l|}
295 \\
295 \\
295 \\
295 \\
382 \\
382
\end{tabular} & $\begin{array}{l}3.02 \\
3.02 \\
3.02 \\
3.02 \\
3.02 \\
3.02\end{array}$ & \begin{tabular}{|l|}
570 \\
570 \\
570 \\
570 \\
570 \\
570 \\
\end{tabular} & $\begin{array}{l}3.02 \\
3.02 \\
3.23 \\
3.42 \\
3.60 \\
3.70\end{array}$ & \begin{tabular}{r|}
570 \\
570 \\
798 \\
1,040 \\
1,290 \\
1,430
\end{tabular} & $\begin{array}{l}3.97 \\
3.98 \\
3.85 \\
3.84 \\
3.76 \\
3.56\end{array}$ & $\begin{array}{l}1,820 \\
1,840 \\
1,640 \\
1,630 \\
1,510 \\
1,230\end{array}$ & $\begin{array}{l}2.98 \\
2.98 \\
2.98 \\
2.98 \\
2.98 \\
2.98\end{array}$ & \begin{tabular}{|}
535 \\
535 \\
535 \\
535 \\
535 \\
535
\end{tabular} \\
\hline \multirow[t]{2}{*}{$\begin{array}{r}2 \\
4 \\
6 \\
8 \\
10 \\
M\end{array}$} & $\begin{array}{l}2.59 \\
2.59 \\
2.59 \\
2.59 \\
2.59 \\
2.59\end{array}$ & $\begin{array}{l}295 \\
295 \\
295 \\
295 \\
295 \\
295\end{array}$ & $\begin{array}{l}3.02 \\
3.02 \\
3.02 \\
3.02 \\
3.02 \\
3.02\end{array}$ & $\begin{array}{l}570 \\
570 \\
570 \\
570 \\
570 \\
570\end{array}$ & $\begin{array}{l}3.02 \\
3.02 \\
3.02 \\
3.02 \\
3.02 \\
3.02\end{array}$ & $\begin{array}{l}570 \\
570 \\
570 \\
570 \\
570 \\
570\end{array}$ & $\begin{array}{l}3.76 \\
3.94 \\
4.05 \\
4.09 \\
4.01 \\
3.97\end{array}$ & $\begin{array}{l}1,510 \\
1,780 \\
1,940 \\
2,000 \\
1,880 \\
1,820\end{array}$ & $\begin{array}{l}3.56 \\
3.34 \\
3.34 \\
2.98 \\
2.98 \\
2.98\end{array}$ & $\begin{array}{r}1,230 \\
935 \\
935 \\
535 \\
535 \\
535\end{array}$ & $\begin{array}{l}2.90 \\
2.90 \\
2.90 \\
2.90 \\
2.90 \\
2.90\end{array}$ & $\begin{array}{l}475 \\
475 \\
475 \\
475 \\
475 \\
475\end{array}$ \\
\hline & \multicolumn{2}{|c|}{ September 24} & \multicolumn{2}{|c|}{ September 25} & \multicolumn{2}{|c|}{ September 26} & \multicolumn{2}{|c|}{ September 27} & \multicolumn{2}{|c|}{ September 28} & \multicolumn{2}{|c|}{ September 29} \\
\hline $\begin{array}{r}2 \\
4 \\
6 \\
8 \\
10 \\
N\end{array}$ & $\begin{array}{l}2.90 \\
2.90 \\
2.90 \\
2.80 \\
2.80 \\
2.80\end{array}$ & \begin{tabular}{|l|}
475 \\
475 \\
475 \\
410 \\
410 \\
410
\end{tabular} & $\begin{array}{l}3.02 \\
3.02 \\
3.02 \\
3.02 \\
3.02 \\
3.02\end{array}$ & \begin{tabular}{|l|}
570 \\
570 \\
570 \\
570 \\
570 \\
570
\end{tabular} & $\begin{array}{l}3.02 \\
3.02 \\
3.02 \\
3.02 \\
3.02 \\
3.02\end{array}$ & \begin{tabular}{|l|}
570 \\
570 \\
570 \\
570 \\
570 \\
570
\end{tabular} & $\begin{array}{l}1.91 \\
1.91 \\
1.91 \\
1.91 \\
1.91 \\
3.01\end{array}$ & \begin{tabular}{|r|}
54 \\
54 \\
54 \\
54 \\
54 \\
560
\end{tabular} & $\begin{array}{l}3.01 \\
3.01 \\
3.01 \\
3.03 \\
3.03 \\
3.03\end{array}$ & \begin{tabular}{|l|}
560 \\
560 \\
560 \\
580 \\
580 \\
580
\end{tabular} & $\begin{array}{l}3.03 \\
3.03 \\
3.03 \\
3.03 \\
3.03 \\
3.03\end{array}$ & $\begin{array}{r}580 \\
580 \\
580 \\
580 \\
580 \\
580\end{array}$ \\
\hline $\begin{array}{r}2 \\
4 \\
6 \\
8 \\
10 \\
M\end{array}$ & $\begin{array}{l}2.80 \\
3.02 \\
3.02 \\
3.02 \\
3.02 \\
3.02\end{array}$ & $\begin{array}{l}410 \\
570 \\
570 \\
570 \\
570 \\
570\end{array}$ & $\begin{array}{l}3.02 \\
3.02 \\
3.02 \\
3.02 \\
3.02 \\
3.02\end{array}$ & $\begin{array}{l}570 \\
570 \\
570 \\
570 \\
570 \\
570\end{array}$ & $\begin{array}{l}3.02 \\
3.02 \\
3.02 \\
3.02 \\
3.02 \\
1.92\end{array}$ & $\begin{array}{r}570 \\
570 \\
570 \\
570 \\
570 \\
56\end{array}$ & $\begin{array}{l}1.02 \\
3.01 \\
3.01 \\
3.01 \\
3.01 \\
3.01\end{array}$ & $\begin{array}{r}56 \\
560 \\
560 \\
560 \\
560 \\
560\end{array}$ & $\begin{array}{l}3.03 \\
3.03 \\
3.03 \\
3.03 \\
3.03 \\
3.03\end{array}$ & $\begin{array}{l}580 \\
580 \\
580 \\
580 \\
580 \\
580\end{array}$ & $\begin{array}{l}3.03 \\
3.03 \\
3.03 \\
3.03 \\
3.03 \\
3.03\end{array}$ & $\begin{array}{l}580 \\
580 \\
580 \\
580 \\
580 \\
580\end{array}$ \\
\hline
\end{tabular}


Location.- Water-stage recorder, lat. $44^{\circ} 44^{\prime} 55^{\prime \prime}$, long. $71^{\circ} 371^{\prime 5}$ ", in North Stratford, Coos County, 400 feet below mouth of Nulhegan River. Zero of gage is 880.00 feet above mean sea level.

Drainage area.- 796 square miles.

Gage-helght record.- Water-stage recorder graph.

tage-discharge relation.- Defined by current-meter measurements below 14,400 secondfeet; extended to peak stage by study of flow characteristics at control section.

Max1ma.- September 1938: Discharge, 12,800 second-feet 10:45 a.m. Sept. 22 (gage height, 9.81 feet).

1930 to August 1938: Discharge, 28,400 second-feet Mar. 19, 1936 (gage height, 14.64 feet).

Remarks. - Flood flow affected by a total of $3,840,000,000$ cublc feet of storage capacity in First and Second Connecticut Lakes. For information on storage see record for First and Second Connecticut Lakes near Pittsurg, N. $H$.

Mean dafly discharge, in second-feet, 1938

\begin{tabular}{|c|r|r||r|r|r||r|r|r||r|r|r|}
\hline Day & Sept. & 0ct. & Day & Sept. & 0ct. & Day & Sept. & 0ct. & Day & Sept. & Oct. \\
\hline 1 & 782 & 1,530 & 9 & 692 & 1,030 & 17 & 1,660 & 1,130 & 25 & 2,900 & 2,840 \\
2 & 1,860 & 1,500 & 10 & 519 & 1,070 & 18 & 1,870 & 1,120 & 26 & 2,390 & 2,220 \\
3 & 1,190 & 1,460 & 11 & 495 & 1,010 & 19 & 1,810 & 1,120 & 27 & 1,930 & 1,600 \\
4 & 895 & 1,340 & 12 & 468 & 992 & 20 & 2,790 & 1,160 & 28 & 1,980 & 1,300 \\
5 & 912 & 1,050 & 13 & 1,770 & 965 & 21 & 8,870 & 1,520 & 29 & 1,860 & 1,160 \\
6 & 852 & 894 & 14 & 2,760 & 1,040 & 22 & 11,900 & 1,660 & 30 & 1,660 & 1,030 \\
7 & 720 & 947 & 15 & 2,140 & 1,110 & 23 & 7,140 & 1,460 & 31 & & 1,000 \\
8 & 727 & 1,130 & 16 & 2,370 & 1,110 & 24 & 3,640 & 1,490 & & & \\
\hline
\end{tabular}

Gage helght, in feet, and discharge, in second-feet, at indicated time, 1938

\begin{tabular}{|c|c|c|c|c|c|c|c|c|c|c|c|c|}
\hline \multirow{2}{*}{$\begin{array}{l}5 \\
3 \\
0 \\
4\end{array}$} & Feet & Sec.ft. & eet & Sec.ft. & Feet & Sec.ft. & Feet & Sec.ft. & Feet & Sec.ft. & Feet & Sec.ft. \\
\hline & \multicolumn{2}{|c|}{ September 18} & \multicolumn{2}{|c|}{ September 19} & \multicolumn{2}{|c|}{ September 20} & \multicolumn{2}{|c|}{ September 21} & \multicolumn{2}{|c|}{ September 22} & \multicolumn{2}{|c|}{ September 23} \\
\hline $\begin{array}{l}1 \\
2 \\
3 \\
4 \\
5 \\
6\end{array}$ & & $\begin{array}{l}1,520 \\
1,520 \\
1,530 \\
1,540 \\
1,530 \\
1,540\end{array}$ & & & & & & & & & & \\
\hline $\begin{array}{l}7 \\
8 \\
9 \\
0\end{array}$ & & $\begin{array}{l}1,660 \\
1,690 \\
1,700 \\
1,790 \\
1,820 \\
1,920\end{array}$ & & & & & & & & & & \\
\hline $\begin{array}{l}1 \\
2 \\
3 \\
4 \\
5 \\
6\end{array}$ & $\begin{array}{l}4.8 \\
4.8 \\
4.9 \\
4.9 \\
4.9 \\
4.9\end{array}$ & $\begin{array}{l}1,970 \\
2,060 \\
2,100 \\
2,100 \\
2,160 \\
2,180\end{array}$ & $\begin{array}{l}4.72 \\
4.67 \\
4.65 \\
4.63 \\
4.60 \\
4.59\end{array}$ & $\begin{array}{l}1,820 \\
1,750 \\
1,720 \\
1,700 \\
1,660 \\
1,650\end{array}$ & $\begin{array}{l}.50 \\
.57 \\
.63 \\
.71 \\
.73 \\
.80\end{array}$ & $\begin{array}{l}000 \\
110 \\
210 \\
340 \\
370 \\
500\end{array}$ & & & & & $\begin{array}{l}7.07 \\
6.97\end{array}$ & \\
\hline \multirow[t]{2}{*}{$\begin{array}{r}7 \\
8 \\
9 \\
10 \\
11 \\
M\end{array}$} & $\begin{array}{l}4.98 \\
4.97 \\
4.95 \\
4.96 \\
4.96 \\
4.95\end{array}$ & & $\begin{array}{l}.57 \\
.55 \\
.53 \\
.52 \\
.51\end{array}$ & $\begin{array}{l}1,580 \\
1,560 \\
1,550 \\
1,550\end{array}$ & $\begin{array}{r}.85 \\
.92 \\
.01 \\
.10 \\
.20 \\
.30 \\
\end{array}$ & & & & & & & \\
\hline & \multicolumn{2}{|c|}{ September 24} & \multicolumn{2}{|c|}{ September 25} & \multicolumn{2}{|c|}{ September 26} & \multicolumn{2}{|c|}{ September 27} & \multicolumn{2}{|c|}{ September 28} & \multicolumn{2}{|c|}{ September 29} \\
\hline \begin{tabular}{r|}
2 \\
4 \\
6 \\
8 \\
10 \\
$\mathrm{~N}$
\end{tabular} & & $\begin{array}{l}4,380 \\
4,170 \\
3,970 \\
3,810 \\
3,660 \\
3,520\end{array}$ & & & & & & & & & & \\
\hline $\begin{array}{r}2 \\
4 \\
6 \\
8 \\
10\end{array}$ & $\begin{array}{l}5.7 \\
5.6 \\
5.6 \\
5.6 \\
5.5 \\
5.5\end{array}$ & $\begin{array}{l}3,4 \\
3, \\
3, \\
3, \\
3, \\
3,\end{array}$ & $\begin{array}{l}5.4 \\
5.4 \\
5.3 \\
5.3 \\
5.3 \\
5.2\end{array}$ & & $\begin{array}{l}5 . \\
5 . \\
5 . \\
5 . \\
4 . \\
4 .\end{array}$ & & $\begin{array}{l}4 . \\
4 . \\
4 . \\
4 . \\
4 . \\
4 .\end{array}$ & 1, & $\begin{array}{l}4.91 \\
4.92 \\
4.90 \\
4.88 \\
4.86\end{array}$ & & & \\
\hline
\end{tabular}

Supplemental records.- Sept. 22, 10:45 a.m., $9.81 \mathrm{ft.,12,800} \mathrm{sec.-ft.}$ 
Location.- Water-stage recorder, lat. $44^{\circ} 24^{\prime} 35^{\prime \prime}$, long. $71^{\circ} 43^{\prime} 05^{\prime \prime}$, 800 feet below dam and $1 \frac{1}{4}$ miles below Dalton, Coos County. Zero of gage is 800.00 feet above mean sea level.

Drainage area.- 1,538 square miles.

Gage-height record. - Water-stage recorder graph.

Stage-discharge relation.- Defined by current-meter measurements below 44,000 secondfeet.

Max1ma:- September 1938: Discharge, 19,600 second-feet 7 a.m. Sept. 22 (gage height, 17.5 feet).

1927 to August 1938: Discharge, 48,300 second-feet Mar. 20, 1936 (gage height, 25.6 feet).

Remarks.- Flood run-off affected by a total of 4,030,000,000 cubic feet of storage capacity in First and Second Connecticut Lakes and small reservoirs. For information on storage (total capacity, 3,840,000,000 cubic feet) see record for First and Second Connecticut Lakes near Pittsburg, N. H.

Mean daily discharge, in second-feet, 1938

\begin{tabular}{|c|c|c|c|c|c|c|c|c|c|c|c|}
\hline Day & Sept. & Oct. & Day & Sept. & Oct. & Day & Sept. & Oct. & Day & Sept. & Oct. \\
\hline $\begin{array}{l}1 \\
2 \\
3 \\
4 \\
5 \\
6 \\
7 \\
8\end{array}$ & $\begin{array}{l}1,220 \\
1,730 \\
2,240 \\
1,330 \\
1,140 \\
1,490 \\
1,630 \\
1,310\end{array}$ & $\begin{array}{l}2,830 \\
2,530 \\
2,910 \\
2,590 \\
2,410 \\
2,080 \\
1,680 \\
1,830\end{array}$ & $\begin{array}{r}9 \\
10 \\
11 \\
12 \\
13 \\
14 \\
15 \\
16\end{array}$ & $\begin{array}{r}1,260 \\
1,310 \\
900 \\
750 \\
1,650 \\
3,450 \\
3,950 \\
4,250\end{array}$ & $\begin{array}{l}1,780 \\
1,930 \\
1,880 \\
1,730 \\
1,780 \\
1,830 \\
1,440 \\
1,260\end{array}$ & $\begin{array}{l}17 \\
18 \\
19 \\
20 \\
21 \\
22 \\
23 \\
24\end{array}$ & $\begin{array}{r}3,800 \\
2,720 \\
2,960 \\
3,550 \\
12,200 \\
19,100 \\
18,700 \\
13,900\end{array}$ & $\begin{array}{l}1,670 \\
1,780 \\
1,780 \\
1,540 \\
1,880 \\
2,530 \\
2,300 \\
2,530\end{array}$ & $\begin{array}{l}25 \\
26 \\
27 \\
28 \\
29 \\
30 \\
31\end{array}$ & $\begin{array}{l}8,030 \\
5,820 \\
4,560 \\
3,910 \\
3,660 \\
3,270\end{array}$ & $\begin{array}{l}4,360 \\
5,180 \\
3,800 \\
3,010 \\
2,530 \\
1,980 \\
2,190\end{array}$ \\
\hline $\begin{array}{l}\text { Mean } \\
\text { Run- }\end{array}$ & in & & 1 & & t: & . & $\cdot \dot{*} \cdot$ & $\dot{*} \cdot \dot{ }$ & $: \dot{ }$ & $\begin{array}{r}4,526 \\
3.28\end{array}$ & $\begin{array}{r}2,308 \\
1.73\end{array}$ \\
\hline
\end{tabular}

Gage height, in feet, and discharge, in second-feet, at indicated time, 1938

\begin{tabular}{|c|c|c|c|c|c|c|c|c|c|c|c|c|}
\hline \multirow{2}{*}{$\begin{array}{l}9 \\
3 \\
0 \\
0\end{array}$} & Feet & Sec.ft. & Feet & Sec,ft, & Feet & Sec.ft. & Feet & Sec.ft. & Feet & Sec.ft. & Feet & Sec.ft. \\
\hline & \multicolumn{2}{|c|}{ September 18} & \multicolumn{2}{|c|}{ September 19} & \multicolumn{2}{|c|}{ September 20} & \multicolumn{2}{|c|}{ September 21} & \multicolumn{2}{|c|}{ September 22} & \multicolumn{2}{|c|}{ September 23} \\
\hline $\begin{array}{l}1 \\
2 \\
3 \\
4 \\
5 \\
6\end{array}$ & $\begin{array}{l}9.98 \\
9.97 \\
9.93 \\
9.90 \\
9.89 \\
9.87\end{array}$ & $\begin{array}{l}3,240 \\
3,230 \\
3,180 \\
3,140 \\
3,130 \\
3,100\end{array}$ & $\begin{array}{l}9.59 \\
9.60 \\
9.60 \\
9.61 \\
9.62 \\
9.63\end{array}$ & $\begin{array}{l}2,760 \\
2,770 \\
2,770 \\
2,780 \\
2,790 \\
2,810\end{array}$ & $\begin{array}{l}9.76 \\
9.76 \\
9.77 \\
9.80 \\
9.81 \\
9.33\end{array}$ & $\begin{array}{l}2,960 \\
2,960 \\
2,970 \\
3,010 \\
3,020 \\
2,450\end{array}$ & $\begin{array}{l}11.49 \\
11.68 \\
11.88 \\
12.07 \\
12.24 \\
12.45\end{array}$ & $\begin{array}{l}5,480 \\
5,800 \\
6,140 \\
6,490 \\
6,800 \\
7,200\end{array}$ & $\begin{array}{l}17.01 \\
17.05 \\
17.16 \\
17.26 \\
17.30 \\
17.39\end{array}$ & $\begin{array}{l}18,100 \\
18,200 \\
18,500 \\
18,800 \\
19,000 \\
19,200\end{array}$ & $\begin{array}{l}17.40 \\
17.38 \\
17.39 \\
17.39 \\
17.40 \\
17.40\end{array}$ & $\begin{array}{l}19,260 \\
19,200 \\
19,230 \\
19,230 \\
19,260 \\
19,260\end{array}$ \\
\hline $\begin{array}{r}7 \\
8 \\
9 \\
10 \\
11 \\
\mathrm{~N}\end{array}$ & $\begin{array}{l}8.85 \\
8.78 \\
8.97 \\
9.28 \\
9.38 \\
9.39\end{array}$ & $\begin{array}{l}1,930 \\
1,860 \\
2,050 \\
2,390 \\
2,510 \\
2,520\end{array}$ & $\begin{array}{l}9.86 \\
9.88 \\
9.88 \\
9.86 \\
9.85 \\
9.25\end{array}$ & $\begin{array}{l}3,090 \\
3,110 \\
3,110 \\
3,090 \\
3,080 \\
2,360\end{array}$ & $\begin{array}{r}9.54 \\
9.99 \\
10.00 \\
10.01 \\
10.04 \\
10.09\end{array}$ & $\begin{array}{l}2,700 \\
3,260 \\
3,270 \\
3,280 \\
3,320 \\
3,390\end{array}$ & $\begin{array}{l}12.70 \\
12.92 \\
13.65 \\
14.02 \\
14.73 \\
16.05\end{array}$ & $\begin{array}{r}7,700 \\
8,140 \\
9,600 \\
10,300 \\
11,000 \\
15,300\end{array}$ & $\begin{array}{l}17.50 \\
17.49 \\
17.49 \\
17.49 \\
17.49 \\
17.48\end{array}$ & $\begin{array}{l}19,600 \\
19,530 \\
19,530 \\
19,530 \\
19,530 \\
19,500\end{array}$ & $\begin{array}{l}17.38 \\
17.40 \\
17.38 \\
17.35 \\
17.35 \\
17.31\end{array}$ & $\begin{array}{l}19,200 \\
19,260 \\
19,200 \\
19,100 \\
19,100 \\
19,000\end{array}$ \\
\hline $\begin{array}{l}1 \\
2 \\
3 \\
4 \\
5 \\
6\end{array}$ & $\begin{array}{l}9.29 \\
9.30 \\
9.68 \\
9.67 \\
9.64 \\
9.62\end{array}$ & $\begin{array}{l}2,400 \\
2,410 \\
2,870 \\
2,850 \\
2,820 \\
2,790\end{array}$ & $\begin{array}{l}9.45 \\
9.94 \\
9.98 \\
9.93 \\
9.90 \\
9.89\end{array}$ & $\begin{array}{l}2,590 \\
3,190 \\
3,240 \\
3,180 \\
3,140 \\
3,130\end{array}$ & $\begin{array}{l}10.18 \\
10.21 \\
10.02 \\
10.14 \\
10.45 \\
10.60\end{array}$ & $\begin{array}{l}500 \\
540 \\
300 \\
450 \\
380 \\
100\end{array}$ & $\begin{array}{l}16.03 \\
16.18 \\
16.24 \\
16.32 \\
16.45 \\
16.53\end{array}$ & $\begin{array}{l}15,280 \\
15,700 \\
15,900 \\
16,100 \\
16,500 \\
16,700\end{array}$ & $\begin{array}{l}17.46 \\
17.43 \\
17.42 \\
17.40 \\
17.40 \\
17.40\end{array}$ & $\begin{array}{l}19,400 \\
19,350 \\
19,300 \\
19,260 \\
19,260 \\
19,260\end{array}$ & $\begin{array}{l}17.30 \\
17.25 \\
17.20 \\
17.19 \\
17.14 \\
17.10\end{array}$ & $\begin{array}{l}18,960 \\
18,800 \\
18,700 \\
18,600 \\
18,500 \\
18,400\end{array}$ \\
\hline \multirow[t]{2}{*}{$\begin{array}{r}7 \\
8 \\
9 \\
10 \\
17 \\
M \\
\end{array}$} & $\begin{array}{l}9.60 \\
9.60 \\
9.59 \\
9.59 \\
9.59 \\
9.59 \\
\end{array}$ & $\begin{array}{l}2,770 \\
2,770 \\
2,760 \\
2,760 \\
2,760 \\
2,760\end{array}$ & $\begin{array}{l}9.87 \\
9.85 \\
9.84 \\
9.81 \\
9.78 \\
9.77 \\
\end{array}$ & $\begin{array}{l}3,100 \\
3,080 \\
3,060 \\
3,020 \\
2,990 \\
2,970\end{array}$ & $\begin{array}{l}10.68 \\
10.77 \\
10.88 \\
11.00 \\
11.14 \\
11.30\end{array}$ & $\begin{array}{l}4,220 \\
4,360 \\
4,520 \\
4,700 \\
4,920 \\
5,180\end{array}$ & $\begin{array}{l}16.62 \\
16.50 \\
16.60 \\
16.68 \\
16.80 \\
16.85\end{array}$ & $\begin{array}{l}16,900 \\
16,600 \\
16,900 \\
17,100 \\
17,500 \\
17,600\end{array}$ & $\begin{array}{l}17.40 \\
17.40 \\
17.40 \\
17.40 \\
17.40 \\
17.40\end{array}$ & $\begin{array}{l}19,260 \\
19,260 \\
19,260 \\
19,260 \\
19,260 \\
19,260\end{array}$ & $\begin{array}{l}17.05 \\
16.98 \\
16.91 \\
16.86 \\
16.80 \\
16.73\end{array}$ & $\begin{array}{l}18,200 \\
18,000 \\
17,800 \\
17,600 \\
17,500 \\
17,200\end{array}$ \\
\hline & \multicolumn{2}{|c|}{ September 24} & \multicolumn{2}{|c|}{ September 25} & \multicolumn{2}{|c|}{ September 26} & \multicolumn{2}{|c|}{ September 27} & \multicolumn{2}{|c|}{ September 28} & \multicolumn{2}{|c|}{ September 29} \\
\hline $\begin{array}{r}2 \\
4 \\
6 \\
8 \\
10 \\
N\end{array}$ & $\begin{array}{l}16.58 \\
16.38 \\
16.18 \\
15.97 \\
15.77 \\
15.48\end{array}$ & $\begin{array}{l}16,800 \\
16,300 \\
15,700 \\
15,100 \\
14,600 \\
13,900\end{array}$ & $\begin{array}{l}13.86 \\
13.55 \\
13.28 \\
13.05 \\
12.92 \\
12.75\end{array}$ & $\begin{array}{r}10,000 \\
9,400 \\
8,860 \\
8,400 \\
8,140 \\
7,800\end{array}$ & $\begin{array}{l}11.96 \\
11.90 \\
11.81 \\
12.01 \\
11.87 \\
11.78\end{array}$ & $\begin{array}{l}6,290 \\
6,180 \\
6,020 \\
6,380 \\
6,130 \\
5,970\end{array}$ & $\begin{array}{l}11.16 \\
11.10 \\
11.03 \\
10.99 \\
10.93 \\
10.91\end{array}$ & $\begin{array}{l}4,960 \\
4,866 \\
4,750 \\
4,680 \\
4,600 \\
4,560\end{array}$ & $\begin{array}{l}10.62 \\
10.59 \\
10.55 \\
10.52 \\
10.49 \\
10.45\end{array}$ & $\begin{array}{l}4,130 \\
4,080 \\
4,020 \\
3,980 \\
3,940 \\
3,880\end{array}$ & $\begin{array}{l}10.35 \\
10.35 \\
10.35 \\
10.34 \\
10.33 \\
10.33\end{array}$ & $\begin{array}{l}3,730 \\
3,730 \\
3,730 \\
3,720 \\
3,700 \\
3,700\end{array}$ \\
\hline $\begin{array}{r}2 \\
4 \\
6 \\
8 \\
10 \\
M\end{array}$ & $\begin{array}{l}15.24 \\
15.00 \\
14.82 \\
14.60 \\
14.35 \\
14.10\end{array}$ & $\begin{array}{l}13,300 \\
12,700 \\
12,200 \\
10,700 \\
11,100 \\
10,500\end{array}$ & $\begin{array}{l}12.61 \\
12.47 \\
12.35 \\
12.25 \\
12.16 \\
12.05\end{array}$ & $\begin{array}{l}7, \\
7, \\
7, \\
6, \\
6, \\
6,\end{array}$ & $\begin{array}{l}11.63 \\
11.53 \\
11.44 \\
11.36 \\
11.29 \\
11.23\end{array}$ & $\begin{array}{l}5,710 \\
5,550 \\
5,400 \\
5,280 \\
5,160 \\
5,070\end{array}$ & $\begin{array}{l}10.83 \\
10.79 \\
10.75 \\
10.73 \\
10.68 \\
10.65\end{array}$ & $\begin{array}{l}4,440 \\
4,380 \\
4,320 \\
4,300 \\
4,220 \\
4,180\end{array}$ & $\begin{array}{l}10.42 \\
10.41 \\
10.39 \\
10.37 \\
10.36 \\
10.36\end{array}$ & $\begin{array}{l}3,830 \\
3,820 \\
3,790 \\
3,760 \\
3,740 \\
3,740\end{array}$ & $\begin{array}{l}10.31 \\
10.29 \\
10.25 \\
10.23 \\
10.20 \\
10.17\end{array}$ & $\begin{array}{l}670 \\
650 \\
600 \\
570 \\
530 \\
490\end{array}$ \\
\hline
\end{tabular}


Fifteenmile Falls Reservoir near Barnet, Vt.

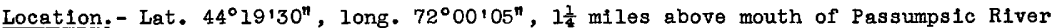
and $4 \frac{1}{2}$ miles east of Barnet, Caledonia county.

Drainage area.- 1,650 square miles.

Remarks.- Infliow affected by a total of 4,030,000,000 cublc feet of storage capacity In First and Second Connecticut Lakes and small reservoirs. For information on storage (total capacity, 3,840,000,000 cubic feet) see record for First and Second Connecticut Lakes near Pittsburg, N. H. Basic data furnished by Connecticut River Power Company.

Gain or loss in storage, in millions of cubic feet, 1938

\begin{tabular}{|c|c|c|c|c|c|c|c|c|c|c|c|}
\hline Day & Sept. & oct. & Day & Sept. & oct. & Day & Sept. & oct. & Day & Sept. & oct. \\
\hline $\begin{array}{l}1 \\
2 \\
3 \\
4 \\
5 \\
6 \\
7 \\
8\end{array}$ & $\begin{array}{r}-45.8 \\
+20.6 \\
+110.3 \\
+96.7 \\
+49.5 \\
-22.6 \\
-9.1 \\
-13.5\end{array}$ & $\begin{array}{r}-22.2 \\
+81.0 \\
-9.1 \\
-18.1 \\
-49.3 \\
-74.6 \\
-72.7 \\
+120.8\end{array}$ & $\begin{array}{r}9 \\
10 \\
11 \\
12 \\
13 \\
14 \\
15 \\
16\end{array}$ & $\begin{array}{r}-35.5 \\
+32.4 \\
+77.1 \\
-90.5 \\
-109.2 \\
-38.4 \\
-66.8 \\
+33.2\end{array}$ & $\begin{array}{r}+116.8 \\
-27.4 \\
-9.1 \\
-4.5 \\
-53.7 \\
-26.5 \\
0 \\
+102.8\end{array}$ & $\begin{array}{l}17 \\
18 \\
19 \\
20 \\
21 \\
22 \\
23 \\
24\end{array}$ & $\begin{array}{r}+185.7 \\
+76.8 \\
-36.5 \\
-97.8 \\
+115.8 \\
0 \\
0 \\
0\end{array}$ & $\begin{array}{r}-58.6 \\
-17.8 \\
-26.6 \\
-30.7 \\
+8.7 \\
+35.1 \\
+71.6 \\
-18.1\end{array}$ & $\begin{array}{l}25 \\
26 \\
27 \\
28 \\
29 \\
30 \\
31\end{array}$ & $\begin{array}{l}-64.7 \\
-91.8 \\
-38.5 \\
+68.8 \\
+43.8 \\
+35.6\end{array}$ & $\begin{array}{r}-18.0 \\
-56.7 \\
-13.1 \\
-123.9 \\
+71.9 \\
+167.6 \\
-58.4\end{array}$ \\
\hline $\begin{array}{l}\text { Gain } \\
\text { Gain }\end{array}$ & & & & & & & & & & $\begin{array}{r}+185.6 \\
+72\end{array}$ & $\begin{array}{r}-12.8 \\
-5\end{array}$ \\
\hline
\end{tabular}

Connecticut River at outlet of Fifteenmile Falls Reservolr near Barnet, vt.

Location.- Water-stage recorder, lat. 44.19'30", long. $72^{\circ} 00^{\prime} 05^{\prime \prime}$, at Frank D. Comerford Hydro-Electric plant at outlet of Fif teenmile Falls Reservoir, $1 \frac{1}{4}$ miles above mouth of Passumpsic River and $4 \frac{1}{2}$ miles east of Barnet, Caledonia County.

Drainage area.- 1,650 square miles.

Stage-discharge relation.- Discharge computed from flow over dam and through wheels and gates.

Maxima.- September 1938: Discharge, about 28,000 second-feet, adjusted for storage in Fifteenmile Falls Reservoir, Sept. 22.

Remarks.- Flood run-off affected by a total of 5,210,000,000 cubic feet of storage capacity in First and Second Connecticut Lakes, and Fif teenmile Falls and small reservoirs. For information on storage (total capacity, 5,020,000,000 cubic feet) see records for First and Second Connecticut Lakes near Pittsburg, N. H., and Fifteenmile Falls Reservoir near Barnet, $V t$. Mean daily and monthly discharges adjusted for storage in Fifteenmile Falls Reservoir. Basic data furnished by Connecticut River Power Company.

Mean daily discharge, in second-feet, 1938

\begin{tabular}{|c|c|c|c|c|c|c|c|c|c|}
\hline \multirow[t]{2}{*}{ Day } & \multicolumn{2}{|c|}{ September } & \multicolumn{2}{|c|}{ October } & \multirow[t]{2}{*}{ Day } & \multicolumn{2}{|c|}{ September } & \multicolumn{2}{|c|}{ October } \\
\hline & Observed & Adjusted & Observed & Adjusted & & Observed & Adjusted & Observed & Adjusted \\
\hline $\begin{array}{l}1 \\
2 \\
3 \\
4 \\
5\end{array}$ & $\begin{array}{r}1,380 \\
1,060 \\
654 \\
283 \\
300\end{array}$ & $\begin{array}{r}849 \\
1,300 \\
1,930 \\
1,400 \\
873\end{array}$ & $\begin{array}{l}2,620 \\
1,510 \\
2,520 \\
2,520 \\
2,700\end{array}$ & $\begin{array}{l}2,370 \\
2,450 \\
2,420 \\
2,310 \\
2,130\end{array}$ & $\begin{array}{l}16 \\
17 \\
18 \\
19 \\
20\end{array}$ & $\begin{array}{l}3,410 \\
1,420 \\
1,610 \\
3,000 \\
4,850\end{array}$ & $\begin{array}{l}3,790 \\
3,560 \\
2,500 \\
2,580 \\
3,720\end{array}$ & $\begin{array}{r}0 \\
1,960 \\
1,830 \\
1,910 \\
1,790\end{array}$ & $\begin{array}{l}1,190 \\
1,280 \\
1,630 \\
1,600 \\
1,440\end{array}$ \\
\hline $\begin{array}{r}6 \\
7 \\
8 \\
9 \\
10\end{array}$ & $\begin{array}{r}1,370 \\
1,540 \\
1,170 \\
1,460 \\
641\end{array}$ & $\begin{array}{l}1,110 \\
1,430 \\
1,010 \\
1,050 \\
1,020\end{array}$ & $\begin{array}{r}2,730 \\
2,340 \\
183 \\
296 \\
1,840\end{array}$ & $\begin{array}{l}1,870 \\
1,500 \\
1,580 \\
1,650 \\
1,520\end{array}$ & $\begin{array}{l}21 \\
22 \\
23 \\
24 \\
25\end{array}$ & $\begin{array}{r}12,400 \\
20,000 \\
19,000 \\
15,000 \\
8,450\end{array}$ & $\begin{array}{r}13,700 \\
20,000 \\
19,000 \\
15,000 \\
7,700\end{array}$ & $\begin{array}{l}1,530 \\
1,830 \\
1,310 \\
2,770 \\
4,360\end{array}$ & $\begin{array}{l}1,630 \\
2,240 \\
2,140 \\
2,560 \\
4,150\end{array}$ \\
\hline $\begin{array}{l}11 \\
12 \\
13 \\
14 \\
15\end{array}$ & $\begin{array}{r}12 \\
1,550 \\
2,630 \\
3,340 \\
4,600\end{array}$ & $\begin{array}{r}904 \\
503 \\
1,360 \\
2,900 \\
3,820\end{array}$ & $\begin{array}{l}1,780 \\
1,480 \\
2,110 \\
1,880 \\
1,360\end{array}$ & $\begin{array}{l}1,670 \\
1,430 \\
1,490 \\
1,580 \\
1,360\end{array}$ & $\begin{array}{l}26 \\
27 \\
28 \\
29 \\
30 \\
31\end{array}$ & $\begin{array}{l}6,160 \\
4,440 \\
2,580 \\
2,410 \\
2,400\end{array}$ & $\begin{array}{l}5,100 \\
3,990 \\
3,380 \\
2,920 \\
2,810\end{array}$ & $\begin{array}{r}5,740 \\
3,900 \\
4,310 \\
1,620 \\
41 \\
2,580\end{array}$ & $\begin{array}{l}5,090 \\
3,740 \\
2,880 \\
2,450 \\
1,980 \\
1,900\end{array}$ \\
\hline $\begin{array}{l}\mathrm{Me} \\
\mathrm{Ru}\end{array}$ & $\begin{array}{l}\text { onthly } \\
f \text {, in }\end{array}$ & $\begin{array}{l}\text { scharge } \\
\text { hes. }\end{array}$ & . . . & . . . . & & 4,305 & $\begin{array}{r}4,377 \\
2.96\end{array}$ & 2,108 & $\begin{array}{r}2,104 \\
1.48\end{array}$ \\
\hline
\end{tabular}


Location. - Water-stage recorder, lat. $44^{\circ} 15^{\prime} 40^{\prime \prime}$, long. $72^{\circ} 03^{\prime} 35^{\prime \prime}$, at Connect1cut River hydroelectric plant just east of McIndoes Falls, Caledonia County.

Drainage area.- 2,200 square miles.

Stage-discharge relation.- Discharge computed from flow over dam and through whels

Maxima.- September 1938: Discharge, about 33,000 second-feet, adjusted for changes in McIndoes Pond, Sept. 22.

Remarks. - Flood run-off affected by a total of 5,390,000,000 cublc feet of storage capacity in First and Second Connecticut Lakes, Fifteenmile Falls, and small reservoirs. For information on storage (total capacity, 5,020,000,000 cublc feet) see records for First and Second Connecticut Lakes near Pittsburg, N. H., Fifteenmile Falls Reservolr near Barnet, vt. Mean daily and monthly discharges adjusted for McIndoes plant pondage operations.

Mean daily discharge, in second-feet, 1938

\begin{tabular}{|c|c|c|c|c|c|c|c|c|c|}
\hline \multirow[t]{2}{*}{ Day } & \multicolumn{2}{|c|}{ September } & \multicolumn{2}{|c|}{ October } & \multirow{2}{*}{ Day } & \multicolumn{2}{|c|}{ September } & \multicolumn{2}{|c|}{ October } \\
\hline & Observed & Adjusted & Observed & Adjusted & & Observed & Adjusted & Observed & Adjusted \\
\hline $\begin{array}{l}1 \\
2 \\
3 \\
4 \\
5\end{array}$ & $\begin{array}{r}1,520 \\
1,780 \\
1,240 \\
392 \\
993\end{array}$ & $\begin{array}{r}1,770 \\
1,500 \\
993 \\
586 \\
730\end{array}$ & $\begin{array}{l}3,810 \\
1,800 \\
3,520 \\
3,080 \\
3,340\end{array}$ & $\begin{array}{l}3,760 \\
2,190 \\
3,360 \\
3,240 \\
3,480\end{array}$ & $\begin{array}{l}16 \\
17 \\
18 \\
19 \\
20\end{array}$ & $\begin{array}{l}5,060 \\
2,630 \\
2,380 \\
4,230 \\
5,800\end{array}$ & $\begin{array}{l}4,880 \\
2,350 \\
2,520 \\
3,930 \\
6,430\end{array}$ & $\begin{array}{l}1,050 \\
1,630 \\
2,000 \\
2,280 \\
2,340\end{array}$ & $\begin{array}{r}473 \\
2,550 \\
2,340 \\
2,330 \\
2,320\end{array}$ \\
\hline $\begin{array}{r}6 \\
7 \\
8 \\
9 \\
10\end{array}$ & $\begin{array}{l}1,300 \\
1,700 \\
1,850 \\
1,720 \\
1,050\end{array}$ & $\begin{array}{r}1,810 \\
1,830 \\
1,570 \\
1,840 \\
971\end{array}$ & $\begin{array}{r}3,210 \\
2,680 \\
1,540 \\
630 \\
2,260\end{array}$ & $\begin{array}{r}3,530 \\
3,040 \\
775 \\
822 \\
2,660\end{array}$ & $\begin{array}{l}21 \\
22 \\
23 \\
24 \\
25\end{array}$ & $\begin{array}{l}19,600 \\
30,400 \\
24,600 \\
19,700 \\
11,500\end{array}$ & $\begin{array}{l}19,300 \\
30,400 \\
24,600 \\
19,700 \\
11,100\end{array}$ & $\begin{array}{l}2,310 \\
2,970 \\
2,260 \\
3,550 \\
6,470\end{array}$ & $\begin{array}{l}2,260 \\
2,680 \\
2,010 \\
3,600 \\
6,610\end{array}$ \\
\hline $\begin{array}{l}11 \\
12 \\
13 \\
14 \\
15\end{array}$ & $\begin{array}{r}476 \\
1,410 \\
3,640 \\
4,690 \\
5,740\end{array}$ & $\begin{array}{r}229 \\
1,890 \\
3,740 \\
4,490 \\
5,900\end{array}$ & $\begin{array}{l}2,490 \\
2,480 \\
2,450 \\
2,440 \\
2,120\end{array}$ & $\begin{array}{l}2,280 \\
2,230 \\
2,650 \\
2,490 \\
1,870\end{array}$ & $\begin{array}{l}26 \\
27 \\
28 \\
29 \\
30 \\
31\end{array}$ & $\begin{array}{r}10,100 \\
6,910 \\
4,830 \\
4,050 \\
4,010\end{array}$ & $\begin{array}{r}10,100 \\
7,030 \\
4,360 \\
4,090 \\
3,550\end{array}$ & $\begin{array}{r}7,400 \\
5,550 \\
4,060 \\
3,480 \\
802 \\
2,280\end{array}$ & $\begin{array}{r}7,550 \\
4,920 \\
5,190 \\
2,310 \\
762 \\
3,210\end{array}$ \\
\hline $\begin{array}{l}\text { Mer } \\
\text { Rur }\end{array}$ & $\begin{array}{l}\text { monthly } \\
\text { off, in } 1\end{array}$ & $\begin{array}{l}\text { 1scharge } \\
\text { ches. }\end{array}$ & in second & -feet: & & 6,177 & $\begin{array}{r}6,142 \\
3.11\end{array}$ & 2,848 & $\begin{array}{r}2,886 \\
1.51\end{array}$ \\
\hline
\end{tabular}


Location. - Water-stage recorder, lat. $44^{\circ} 02^{\prime} 45^{\prime \prime}$, long. $72^{\circ} 04130^{\prime \prime}$, below bridge at South Newbury, Orange County, 4 miles above mouth of Waits River. Zero of gage is 374.90 feet above mean sea level.

Drainage area. - 2,825 square miles.

Gage-helght record.- Water-stage recorder graph except for periods 11 p.m. Sept. 21 to 11 p.m. Sept. 23 and 6 a.m. Oct. 12 to oct. 31, record for wh1ch wes besed on floodmarks, two chain-gage readings daily, and shape of graphs at nearby stations. Stage-discharge relation. - Defined by current-meter measurements below 49,100 secondfeet; extended to peak stage on besis of drainage area comparison of instantaneous and total yleld of flood at other gaging stations on the Connecticut River.

Maxima.- September 1938: Discharge, 43,700 second-feet 3 p.m. Sept. 22 (gage height, 28.60 feet).

1918 to August 1938: Discharge, 77,800 second-feet Mar. 19, 20, 1936 (gage he1ght, 38.6 feet).

Remarks.- Flood run-off affected by a total of 5,390,000,000 cubic feet of storage capacity in First and Second Connecticut Lakes, and Fifteenmile Falls, and small reservolrs. For information on storage (total capacity, 5,020,000,000 cuble feet) see records for First and Second Connecticut Lakes, Fifteenmile Falis Reservolr near Barnet, vt.

Mean daily discharge, in second-feet, 1938

\begin{tabular}{|c|r|r||r|r|r||r|r|r||r|r|r|}
\hline Day & Sept. & 0ct. & Day & Sept. & 0ct. & Day & Sept. & 0ct. & Day & Sept. & Oct. \\
\hline 1 & 2,030 & 5,140 & 9 & 2,070 & 1,830 & 17 & 4,150 & 1,830 & 25 & 18,200 & 8,040 \\
2 & 2,070 & 3,490 & 10 & 1,870 & 1,990 & 18 & 3,120 & 2,230 & 26 & 12,400 & 9,290 \\
3 & 2,070 & 4,100 & 11 & 814 & 2,960 & 19 & 4,080 & 2,630 & 27 & 8,600 & 7,920 \\
4 & 1,000 & 3,960 & 12 & 1,000 & 3,140 & 20 & 6,620 & 2,630 & 28 & 7,620 & 5,800 \\
5 & 867 & 4,060 & 13 & 3,050 & 3,050 & 21 & 18,600 & 2,960 & 29 & 5,670 & 4,810 \\
6 & 1,360 & 3,960 & 14 & 5,140 & 2,960 & 22 & 40,500 & 3,140 & 30 & 5,140 & 3,120 \\
7 & 1,790 & 3,680 & 15 & 6,240 & 2,790 & 23 & 35,700 & 3,410 & 31 & & 1,790 \\
8 & 2,310 & 2,790 & 16 & 7,440 & 2,310 & 24 & 27,000 & 3,420 & & & \\
\hline
\end{tabular}

Gage helght, in feet, and discharge, in second-feet, at indicated time, 1938

\begin{tabular}{|c|c|c|c|c|c|c|c|c|c|c|c|c|}
\hline \multirow{2}{*}{$\begin{array}{l}9 \\
0 \\
0\end{array}$} & ent & Sec.ft. & Peet & Sec.ft. & Feet & Sec.ft. & Feet & -2000 & Feet & Sec.ft. & Feet & 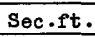 \\
\hline & \multicolumn{2}{|c|}{ September 18} & \multicolumn{2}{|c|}{ September 19} & \multicolumn{2}{|c|}{ Septerber 20} & \multicolumn{2}{|c|}{ September 21} & \multicolumn{2}{|c|}{ September 22} & \multicolumn{2}{|c|}{ September 23} \\
\hline $\begin{array}{l}7 \\
2 \\
3 \\
4 \\
5 \\
6\end{array}$ & $\begin{array}{l}4.42 \\
4.46 \\
4.48 \\
4.49 \\
4.50 \\
4.50\end{array}$ & & & $\begin{array}{l}2,800 \\
2,890 \\
2,990 \\
3,080 \\
3,170\end{array}$ & & $\begin{array}{l}4,880 \\
4,860 \\
4,860 \\
4,860 \\
4,890 \\
4,940\end{array}$ & & & & & & $\begin{array}{l}39,900 \\
39,600 \\
39,100 \\
38,600\end{array}$ \\
\hline $\begin{array}{l}7 \\
8 \\
9\end{array}$ & $\begin{array}{l}4.4 \\
4.4 \\
4.3 \\
4.2 \\
4.1 \\
4.0\end{array}$ & & $\begin{array}{l}4.2 \\
4.3 \\
4.4 \\
4.5 \\
4.8 \\
5.0\end{array}$ & & & & & & & & & \\
\hline $\begin{array}{l}1 \\
2 \\
3 \\
4 \\
5\end{array}$ & $\begin{array}{l}3.82 \\
3.70 \\
3.60 \\
3.53 \\
3.50 \\
3.47\end{array}$ & & $\begin{array}{l}5.3 \\
5.5 \\
5.7 \\
5.8 \\
5.8 \\
5.8\end{array}$ & & & & & & & & & \\
\hline \multirow[t]{2}{*}{$\begin{array}{r}7 \\
8 \\
9 \\
10 \\
11 \\
M\end{array}$} & $\begin{array}{l}3.46 \\
3.45 \\
3.44 \\
3.43 \\
3.44 \\
3.51 \\
\end{array}$ & & $\begin{array}{l}5.95 \\
5.90 \\
5.87 \\
5.83 \\
5.80 \\
5.78\end{array}$ & & & & & & & & & \\
\hline & \multicolumn{2}{|c|}{ September 24} & \multicolumn{2}{|c|}{ September 25} & \multicolumn{2}{|c|}{ September 26} & \multicolumn{2}{|c|}{ September 27} & \multicolumn{2}{|c|}{ September 28} & \multicolumn{2}{|c|}{ September 29} \\
\hline $\begin{array}{r}2 \\
4 \\
6 \\
8 \\
10 \\
N\end{array}$ & & & & & & & & & & & & \\
\hline $\begin{array}{r}2 \\
4 \\
6 \\
8 \\
10\end{array}$ & & $\begin{array}{l}26 \\
25 \\
24 \\
24 \\
23 \\
22\end{array}$ & & & & $\begin{array}{c}00 \\
00 \\
00 \\
00 \\
00 \\
00\end{array}$ & & $\begin{array}{l}8, \\
7, \\
7, \\
7, \\
7,\end{array}$ & & & & \\
\hline
\end{tabular}


Location. - Water-stage recorder, lat. $43^{\circ} 38^{\prime} 50^{\prime \prime}$, long. $72^{\circ} 18^{\prime} 45^{\prime \prime}$, below ra1lroad bridge at White River Junction, Windsor County, just below mouth of White River. Zero of gage is 321.59 feet above mean sea level.

Drainage area.- 4,068 square miles.

Gage-helght record. - Water-stage recorder graph except for perlods 3 p.m. Sept. 19 to 2 p.m. Sept. 27 and Oct. 28 to 31 , when graph was based on floodmarks and two cha1ngage readings dally.

Stage-discharge relation.- Defined by current-meter measurements below 70,100 secondfeet; extended to peak stage by velocity-area study near control section.

Maxima. - September 1938: Discharge, 82,400 second-feet 5 to 6 a.m. Sept. 22 (gage helght, 26.7 feet, from floodmarks at chain-gage site).

1911 to August 1938: Discharge, 136,000 second-feet Nov. 4, 1927 (gage height, 35.0 feet, from floodmarks at water-stgge recorder site).

Remarks. - Flood mun-off affected by a total of 5,550,000,000 cubic feet of storage capecity in First and Second Connecticut Lakes and Fifteenmile Falls, and small reservolrs. For information on storage (total capacity, 5,020,000,000 cubic feet) see records for First and Second Connecticut Lakes near Pittsburg, N. H., and for Fif-

teenmile Falls Reservolr near Barnet, Vt.

Mean dally discharge, in second-feet, 1938

\begin{tabular}{|c|c|c||r|r|r||r|r|r||r|r|r|}
\hline Day & Sept. & 0ct. & Day & Sept. & Oct. & Dey & Sept. & Oct. & Day & Sept. & Oct. \\
\hline 1 & 3,450 & 8,320 & 9 & 3,120 & 4,260 & 17 & 8,090 & 3,200 & 25 & 27,300 & 10,200 \\
2 & 2,960 & 7,400 & 10 & 2,810 & 3,040 & 18 & 5,970 & 3,200 & 26 & 19,400 & 11,900 \\
3 & 2,880 & 5,840 & 11 & 2,180 & 3,450 & 19 & 5,710 & 3,540 & 27 & 14,500 & 10,600 \\
4 & 2,590 & 6,720 & 12 & 1,600 & 4,560 & 20 & 12,900 & 3,980 & 28 & 12,500 & 8,600 \\
5 & 1,930 & 6,280 & 13 & 3,020 & 4,560 & 21 & 35,200 & 4,560 & 29 & 10,400 & 7,100 \\
6 & 1,650 & 6,280 & 14 & 6,280 & 4,460 & 22 & 68,500 & 4,970 & 30 & 8,830 & 5,670 \\
7 & 2,120 & 5,840 & 15 & 8,750 & 4,360 & 23 & 51,100 & 5,080 & 31 & \\
8 & 2,880 & 5,290 & 16 & 11,300 & 4,080 & 24 & 38,200 & 5,180 & & 3,830 \\
\hline
\end{tabular}

Gage height, in feet, and discharge, in second-feet, at indlcated time, 1938

\begin{tabular}{|c|c|c|c|c|c|c|c|c|c|c|c|c|}
\hline \multirow{2}{*}{$\begin{array}{l}5 \\
3 \\
\text { 寻 } \\
\end{array}$} & Feet & Sec.ft. & Feet & Sec.ft. & Feet & Sec.ft. & Feet & Sec.ft. & Feet & Sec.ft. & Feet & Sec.ft. \\
\hline & \multicolumn{2}{|c|}{ September 18} & \multicolumn{2}{|c|}{ September 19} & \multicolumn{2}{|c|}{ September 20} & \multicolumn{2}{|c|}{ September 21} & \multicolumn{2}{|c|}{ September 22} & \multicolumn{2}{|c|}{ September 23} \\
\hline $\begin{array}{l}1 \\
2 \\
3 \\
4 \\
5 \\
6\end{array}$ & $\begin{array}{l}7.38 \\
7.33 \\
7.30 \\
7.27 \\
7.26 \\
7.25\end{array}$ & $\begin{array}{l}6,240 \\
6,130 \\
6,060 \\
5,990 \\
5,970 \\
5,950\end{array}$ & $\begin{array}{l}7.15 \\
7.10 \\
7.06 \\
7.04 \\
7.00 \\
6.98\end{array}$ & $\begin{array}{l}5,730 \\
5,620 \\
5,530 \\
5,490 \\
5,400 \\
5,360\end{array}$ & $\begin{array}{l}8.02 \\
8.18 \\
8.30 \\
8.50 \\
8.85 \\
9.16\end{array}$ & $\begin{array}{r}7,650 \\
8,050 \\
8,350 \\
8,850 \\
9,720 \\
10,500\end{array}$ & $\begin{array}{l}12.00 \\
12.22 \\
12.50 \\
12.75 \\
13.03 \\
13.30\end{array}$ & $\begin{array}{l}18,800 \\
19,500 \\
20,300 \\
21,100 \\
22,100 \\
23,000\end{array}$ & $\begin{array}{l}23.90 \\
24.80 \\
25.50 \\
26.30 \\
26.70 \\
26.70\end{array}$ & $\begin{array}{l}67,800 \\
72,500 \\
76,100 \\
80,300 \\
82,400 \\
82,400\end{array}$ & $\begin{array}{l}21.75 \\
21.70 \\
21.62 \\
21.55 \\
21.45 \\
21.35\end{array}$ & $\begin{array}{l}56,900 \\
56,700 \\
56,300 \\
55,900 \\
55,500 \\
55,000\end{array}$ \\
\hline $\begin{array}{r}7 \\
8 \\
9 \\
10 \\
11 \\
\mathrm{~N}\end{array}$ & $\begin{array}{l}7.24 \\
7.23 \\
7.20 \\
7.19 \\
7.19 \\
7.20\end{array}$ & $\begin{array}{l}5,930 \\
5,910 \\
5,840 \\
5,820 \\
5,820 \\
5,840\end{array}$ & $\begin{array}{l}6.97 \\
6.96 \\
6.95 \\
6.95 \\
6.95 \\
6.95\end{array}$ & $\begin{array}{l}5,330 \\
5,310 \\
5,290 \\
5,290 \\
5,290 \\
5,290\end{array}$ & $\begin{array}{r}9.40 \\
9.50 \\
9.62 \\
9.74 \\
10.00 \\
10.18\end{array}$ & $\begin{array}{l}11,100 \\
11,400 \\
11,700 \\
12,000 \\
12,800 \\
13,300\end{array}$ & $\begin{array}{l}13.60 \\
13.95 \\
14.35 \\
15.00 \\
15.85 \\
16.45\end{array}$ & $\begin{array}{l}24,000 \\
25,300 \\
26,700 \\
29,000 \\
31,900 \\
34,000\end{array}$ & $\begin{array}{l}26.60 \\
26.10 \\
25.60 \\
25.00 \\
24.50 \\
24.10\end{array}$ & $\begin{array}{l}81,800 \\
79,200 \\
76,600 \\
73,500 \\
70,900 \\
68,800\end{array}$ & $\begin{array}{l}21.20 \\
21.08 \\
20.91 \\
20.80 \\
20.76 \\
20.52\end{array}$ & $\begin{array}{l}54,300 \\
53,700 \\
52,900 \\
52,400 \\
52,200 \\
51,100\end{array}$ \\
\hline $\begin{array}{l}1 \\
2 \\
3 \\
4 \\
5 \\
6\end{array}$ & $\begin{array}{l}7.22 \\
7.25 \\
7.27 \\
7.28 \\
7.28 \\
7.28\end{array}$ & $\begin{array}{l}5,880 \\
5,950 \\
5,990 \\
6,020 \\
6,020 \\
6,020\end{array}$ & $\begin{array}{l}6.96 \\
6.97 \\
7.00 \\
7.05 \\
7.12 \\
7.28\end{array}$ & $\begin{array}{l}5,310 \\
5,320 \\
5,360 \\
5,420 \\
5,500 \\
5,850\end{array}$ & $\begin{array}{l}10.34 \\
10.50 \\
10.78 \\
10.80 \\
10.83 \\
10.88\end{array}$ & $\begin{array}{l}13,800 \\
14,300 \\
15,100 \\
15,200 \\
15,300 \\
15,400\end{array}$ & $\begin{array}{l}17.00 \\
17.70 \\
18.10 \\
18.40 \\
18.70 \\
19.00\end{array}$ & $\begin{array}{l}36,100 \\
38,900 \\
40,500 \\
41,800 \\
43,000 \\
44,300\end{array}$ & $\begin{array}{l}23.65 \\
23.30 \\
23.00 \\
22.78 \\
22.60 \\
22.45\end{array}$ & $\begin{array}{l}66,400 \\
64,700 \\
63,100 \\
62,000 \\
61,100 \\
60,400\end{array}$ & $\begin{array}{l}20.40 \\
20.25 \\
20.10 \\
19.98 \\
19.85 \\
19.74\end{array}$ & $\begin{array}{l}50,500 \\
49,800 \\
49,200 \\
48,600 \\
48,000 \\
47,600\end{array}$ \\
\hline \multirow[t]{2}{*}{$\begin{array}{r}7 \\
8 \\
9 \\
10 \\
11 \\
M \\
\end{array}$} & $\begin{array}{l}7.28 \\
7.27 \\
7.27 \\
7.26 \\
7.23 \\
7.19 \\
\end{array}$ & $\begin{array}{l}6,020 \\
5,990 \\
5,990 \\
5,970 \\
5,910 \\
5,820 \\
\end{array}$ & $\begin{array}{l}7.40 \\
7.50 \\
7.58 \\
7.67 \\
7.77 \\
7.90 \\
\end{array}$ & $\begin{array}{l}6,110 \\
6,350 \\
6,550 \\
6,780 \\
7,020 \\
7,350\end{array}$ & $\begin{array}{l}10.94 \\
11.05 \\
11.20 \\
11.40 \\
11.60 \\
11.80\end{array}$ & $\begin{array}{l}15,600 \\
16,000 \\
16,400 \\
17,000 \\
17,600 \\
18,200\end{array}$ & $\begin{array}{l}19.50 \\
20.15 \\
20.90 \\
21.70 \\
22.20 \\
23.20\end{array}$ & $\begin{array}{l}46,500 \\
49,400 \\
52,800 \\
56,700 \\
59,100 \\
64,100\end{array}$ & $\begin{array}{l}22.33 \\
22.21 \\
22.10 \\
22.00 \\
21.90 \\
21.82\end{array}$ & $\begin{array}{l}59,800 \\
59,200 \\
58,600 \\
58,100 \\
57,600 \\
57,200\end{array}$ & $\begin{array}{l}19.60 \\
19.50 \\
19.35 \\
19.25 \\
19.12 \\
19.00\end{array}$ & $\begin{array}{l}46,900 \\
46,500 \\
45,800 \\
45,400 \\
44,800 \\
44,300\end{array}$ \\
\hline & \multicolumn{2}{|c|}{ September 24} & \multicolumn{2}{|c|}{ September 25} & \multicolumn{2}{|c|}{ September 26} & \multicolumn{2}{|c|}{ September 27} & \multicolumn{2}{|c|}{ September 28} & \multicolumn{2}{|c|}{ September 29} \\
\hline $\begin{array}{r}2 \\
4 \\
6 \\
8 \\
10 \\
N\end{array}$ & $\begin{array}{l}18.75 \\
18.52 \\
18.28 \\
18.00 \\
17.72 \\
17.50\end{array}$ & $\begin{array}{l}43,200 \\
42,300 \\
41,300 \\
40,100 \\
39,000 \\
38,100\end{array}$ & $\begin{array}{l}15.75 \\
15.52 \\
15.30 \\
15.02 \\
14.80 \\
14.60\end{array}$ & $\begin{array}{l}31,600 \\
30,800 \\
30,000 \\
29,000 \\
28,200 \\
27,600\end{array}$ & \begin{tabular}{|l|}
12.90 \\
12.73 \\
12.60 \\
12.42 \\
12.28 \\
12.15
\end{tabular} & $\begin{array}{l}21,600 \\
21,000 \\
20,600 \\
20,100 \\
19,600 \\
19,200\end{array}$ & \begin{tabular}{l|}
11.20 \\
11.04 \\
10.92 \\
10.80 \\
10.66 \\
10.52
\end{tabular} & $\begin{array}{l}16,400 \\
15,900 \\
15,600 \\
15,200 \\
14,800 \\
14,400\end{array}$ & $\begin{array}{r}10.04 \\
10.04 \\
10.03 \\
10.00 \\
9.96 \\
9.90\end{array}$ & $\begin{array}{l}12,900 \\
12,900 \\
12,890 \\
12,870 \\
12,840 \\
12,800\end{array}$ & $\begin{array}{l}9.50 \\
9.45 \\
9.40 \\
9.30 \\
9.20 \\
9.10\end{array}$ & $\begin{array}{l}11,600 \\
11,400 \\
11,300 \\
11,000 \\
10,800 \\
10,500\end{array}$ \\
\hline $\begin{array}{r}2 \\
4 \\
6 \\
8 \\
10 \\
M \\
\end{array}$ & $\begin{array}{l}17.25 \\
17.00 \\
16.75 \\
16.50 \\
16.28 \\
16.00\end{array}$ & $\begin{array}{l}37,100 \\
36,100 \\
35,200 \\
34,200 \\
33,400 \\
32,400\end{array}$ & $\begin{array}{l}14.30 \\
14.00 \\
13.75 \\
13.50 \\
13.30 \\
13.10\end{array}$ & $\begin{array}{l}26,500 \\
25,400 \\
24,600 \\
23,700 \\
23,000 \\
22,300\end{array}$ & $\begin{array}{l}12.05 \\
11.90 \\
11.80 \\
11.62 \\
11.48 \\
11.32\end{array}$ & $\begin{array}{l}19,000 \\
18,500 \\
18,200 \\
17,700 \\
17,200 \\
16,800\end{array}$ & $\begin{array}{l}10.40 \\
10.20 \\
10.15 \\
10.10 \\
10.05 \\
10.04\end{array}$ & $\begin{array}{l}14,000 \\
13,400 \\
13,200 \\
13,100 \\
13,000 \\
12,900\end{array}$ & $\begin{array}{l}9.80 \\
9.70 \\
9.65 \\
9.60 \\
9.55 \\
9.50\end{array}$ & $\begin{array}{l}12,500 \\
12,200 \\
12,000 \\
11,900 \\
11,700 \\
11,600\end{array}$ & $\begin{array}{l}8.92 \\
8.80 \\
8.70 \\
8.65 \\
8.60 \\
8.56\end{array}$ & $\begin{array}{l}9,980 \\
9,640 \\
9,370 \\
9,240 \\
9,100 \\
8,990\end{array}$ \\
\hline
\end{tabular}


Location. - Water-stage recorder, lat. $42^{\circ} 46^{\prime} 10^{n}$, long. $72^{\circ} 30^{\prime} 50^{\prime \prime}$, just below dam at Vernon, Windham County, and 2 miles above mouth of Ashuelot River.

Drainage area.- 6,240 square miles.

Gage-helght record:- Water-stage recorder graph. Gage helghts are for tallwater gage. Stage-d1scharge relation. - Defined by current-meter measurements below 68,900 secondfeet; extended to peak stage by study of flow characteristics at control section.

Maxima.- September 1938: Discharge, 132,500 second-feet 5 a.m. to 9 a.m. Sept. 22 (gage height, 120.7 feet).

Maximum discharge known, 176,000 second-feet Mar. 19, 20, 1936 (gage helght, 128.8 feet).

Bemarka. - Flood run-off affected by a total storage capacity of $8,360,000,000$ cubic feet. For information on storage (total capacity, 7,130,000,000 cubic feet) see records for First and Second Connecticut Lakes near P1ttsburg, N. H., Fifteenmilo

Falls Reservolr near Bamet, Vt., Mascoma River reservoirs above Máscoma, N. H., and Lake Sunapee, at Sumapee, N. H. Records computed from basic data furnished by Connect1cut R1ver Power Co.

Mean daily discharge, in second-feet, 1938

\begin{tabular}{|c|c|c|c|c|c|c|c|c|c|c|c|}
\hline Day & Sept. & Oct. & Day & Sept. & oct. & Day & Sept. & Oct. & Day & Sept. & Oct. \\
\hline $\begin{array}{l}1 \\
2 \\
3 \\
4 \\
5 \\
6 \\
7 \\
8\end{array}$ & $\begin{array}{r}5,660 \\
4,870 \\
1,920 \\
574 \\
231 \\
2,780 \\
4,620 \\
3,760 \\
\end{array}$ & $\begin{array}{r}8,780 \\
13,000 \\
10,900 \\
9,220 \\
9,240 \\
11,600 \\
12,200 \\
5,310\end{array}$ & $\begin{array}{l}9 \\
10 \\
11 \\
12 \\
13 \\
14 \\
15 \\
16\end{array}$ & $\begin{array}{r}5,870 \\
2,140 \\
328 \\
3,160 \\
5,680 \\
6,700 \\
5,350 \\
13,400\end{array}$ & $\begin{array}{l}3,320 \\
6,460 \\
6,630 \\
5,400 \\
7,520 \\
7,850 \\
5,870 \\
3,160\end{array}$ & $\begin{array}{l}17 \\
18 \\
19 \\
20 \\
21 \\
22 \\
23 \\
24\end{array}$ & $\begin{array}{r}14,200 \\
7,660 \\
10,900 \\
28,700 \\
73,800 \\
130,000 \\
104,000 \\
69,900\end{array}$ & $\begin{array}{l}6,230 \\
5,970 \\
6,140 \\
6,210 \\
5,820 \\
6,930 \\
4,760 \\
9,080\end{array}$ & $\begin{array}{l}25 \\
26 \\
27 \\
28 \\
29 \\
30 \\
31\end{array}$ & $\begin{array}{l}50,400 \\
35,500 \\
26,200 \\
18,100 \\
14,600 \\
12,400\end{array}$ & $\begin{array}{r}16,100 \\
16,300 \\
16,000 \\
14,400 \\
14,000 \\
7,860 \\
7,970\end{array}$ \\
\hline & & & & & & & . . . & & $\therefore$ & $\begin{array}{r}22,110 \\
3.95 \\
\end{array}$ & 8,7 \\
\hline
\end{tabular}

Gage helght, in feet, and discharge, in second-feet, at indicated time, 1938

\begin{tabular}{|c|c|c|c|c|c|c|c|c|c|c|c|c|}
\hline \multirow{2}{*}{$\begin{array}{l}8 \\
3 \\
\text { 오 } \\
\end{array}$} & eet & Sec.ft. & Feet & Sec.ft & Feet & Sec.ft & Feet & Sec.ft & Feot & Sec.ft. & Feet & 1.00020 \\
\hline & \multicolumn{2}{|c|}{ September 18} & \multicolumn{2}{|c|}{ September 19} & \multicolumn{2}{|c|}{ September 20} & \multicolumn{2}{|c|}{ September 21} & \multicolumn{2}{|c|}{ September 22} & \multicolumn{2}{|c|}{ September 23} \\
\hline $\begin{array}{l}1 \\
2 \\
3 \\
4 \\
5 \\
6\end{array}$ & & & & $\begin{array}{l}2,110 \\
2,110 \\
2,110 \\
1,970 \\
6,770 \\
8,030\end{array}$ & & & $\begin{array}{l}100.7 \\
101.1 \\
101.8 \\
102.1 \\
102.5 \\
103.0\end{array}$ & & & & & \\
\hline $\begin{array}{l}7 \\
8\end{array}$ & & $\begin{array}{l}6, \\
10, \\
11, \\
11, \\
11, \\
11,\end{array}$ & & & & & & & & & & \\
\hline $\begin{array}{l}\frac{1}{2} \\
3 \\
4 \\
5\end{array}$ & $\begin{array}{l}89.1 \\
89.1 \\
89.1 \\
89.1 \\
89.1\end{array}$ & & & & & & & & & & & \\
\hline \multirow[t]{2}{*}{$\begin{array}{r}7 \\
8 \\
9 \\
10 \\
11 \\
M\end{array}$} & $\begin{array}{l}89.1 \\
89.1 \\
89.1 \\
89.0 \\
88.2 \\
87.2\end{array}$ & & $\begin{array}{l}91.5 \\
92.0 \\
92.9 \\
93.0 \\
93.1 \\
93.1\end{array}$ & & & & & & & & & \\
\hline & \multicolumn{2}{|c|}{ September 24} & \multicolumn{2}{|c|}{ September 25} & \multicolumn{2}{|c|}{ September 26} & \multicolumn{2}{|c|}{ September 27} & \multicolumn{2}{|c|}{ September 28} & \multicolumn{2}{|c|}{ September 29} \\
\hline $\begin{array}{r}2 \\
4 \\
6 \\
8 \\
10 \\
N\end{array}$ & & & & & & & & & & & & \\
\hline $\begin{array}{r}2 \\
4 \\
6 \\
8 \\
10\end{array}$ & & & $\begin{array}{r}101 \\
101 \\
100 \\
100 \\
100 \\
99\end{array}$ & & $\begin{array}{l}97 \\
97 \\
97 \\
97 \\
96 \\
96\end{array}$ & & $\begin{array}{l}95 \\
95 \\
94\end{array}$ & & & & & \\
\hline
\end{tabular}


Location. - Hater-stage recorder, lat. $42^{\circ} 36^{\prime} 40^{\prime \prime}$, long. $72^{\circ} 33^{\prime} 20^{\prime \prime}$, at dam of Turners Falls Power Electric Co., Turners Falls, Franklin County, just above mouth of Falls River.

Drainage area. - 7,138 square miles.

Gage-helght record. - Water-stage recorder graph. Stage affected by flashboards prior to 6 p.m. Sept. 21 and subsequent to $10 \mathrm{a} . \mathrm{m}$. Sept.28. Crest of dam is at gage helght, 3.00 feet.

Discharge.- Determined from flow over dam, through canal and flood gates.

Maxima.- September 1938: Discharge, 174,000 second-feet 8 a.m. to 3 p.m. Sept. 22 (gage height, 14.5 feet).

1915 to August 1938: 210,000 second-feet Mar. 19, 20, 1936 (gage height, 16.7 feet).

Remarks. - Flood run-off affected by a total storage capacity of $8,360,000,000$ cubic feet. For information on storage (total capacity, 7,130,000,000 cublc feet) see records for First and Second Connecticut Lakes near P1ttsburg, N. H., Fifteenmile Falls Reservoir near Barnet, Vt., Mascoma River reservoirs above Mascoma, N. H., and Lake Sunapee, at Sunapee, N. H. Records computed from basic data furnished by Turners Falls Power \& Electric $\mathrm{Co}_{0}$

Mean discherge, in second-feet, 1958 a/

\begin{tabular}{|c|c|c|c|c|c|c|c|c|c|c|c|}
\hline Day & Sept. & 0 ct. & Day & Sept. & oct. & Day & Sept. & Oct. & Day & Sept. & Oct. \\
\hline $\begin{array}{l}1 \\
2 \\
3 \\
4 \\
5 \\
6 \\
7 \\
8\end{array}$ & $\begin{array}{r}6,340 \\
5,420 \\
2,460 \\
900 \\
636 \\
4,520 \\
3,200 \\
6,010\end{array}$ & $\begin{array}{r}11,400 \\
13,700 \\
12,400 \\
11,000 \\
11,300 \\
13,700 \\
12,100 \\
7,400\end{array}$ & $\begin{array}{r}9 \\
10 \\
11 \\
12 \\
13 \\
14 \\
15 \\
16\end{array}$ & $\begin{array}{r}5,320 \\
2,190 \\
1,260 \\
4,190 \\
6,080 \\
8,420 \\
11,600 \\
13,800\end{array}$ & $\begin{array}{l}4,560 \\
6,580 \\
8,710 \\
6,260 \\
9,320 \\
8,420 \\
5,350 \\
4,360\end{array}$ & $\begin{array}{l}17 \\
18 \\
19 \\
20 \\
21 \\
22 \\
23 \\
24\end{array}$ & $\begin{array}{r}14,200 \\
8,880 \\
17,000 \\
40,000 \\
108,000 \\
168,000 \\
123,000 \\
77,900\end{array}$ & $\begin{array}{r}7,240 \\
6,060 \\
7,730 \\
7,280 \\
7,900 \\
7,860 \\
6,590 \\
12,800\end{array}$ & $\begin{array}{l}25 \\
26 \\
27 \\
28 \\
29 \\
30 \\
31\end{array}$ & $\begin{array}{l}56,400 \\
43,200 \\
34,100 \\
26,500 \\
18,200 \\
13,200\end{array}$ & $\begin{array}{r}18,900 \\
19,200 \\
19,100 \\
15,800 \\
14,800 \\
9,410 \\
9,000\end{array}$ \\
\hline $\begin{array}{l}\text { Mean } \\
\text { Run- }\end{array}$ & $+h 7$ & & in & . . . & et. & & . . . & . : . & : & $\begin{array}{r}27,700 \\
4.33\end{array}$ & $\begin{array}{r}10,200 \\
1.65\end{array}$ \\
\hline
\end{tabular}

a) For 24 hours ending at 6 a.m. following day indicated.

Gage height, in feet, and discharge, in second-feet, at indicated time, 1938

\begin{tabular}{|c|c|c|c|c|c|c|c|c|c|c|c|c|}
\hline \multirow{2}{*}{$\begin{array}{l}5 \\
3 \\
0 \\
0\end{array}$} & Feet & Sec.ft. & Feet & Sec.ft. & Feet & Sec.ft. & Feet & Sec:ft. & Feet & Sec.ft. & Feet & Sec.ft. \\
\hline & \multicolumn{2}{|c|}{ September 18} & \multicolumn{2}{|c|}{ September 19} & \multicolumn{2}{|c|}{ September 20} & \multicolumn{2}{|c|}{ September 21} & \multicolumn{2}{|c|}{ September 22} & \multicolumn{2}{|c|}{ September 23} \\
\hline $\begin{array}{l}1 \\
2 \\
3 \\
4 \\
5 \\
6\end{array}$ & $\begin{array}{l}- \\
- \\
- \\
- \\
-\end{array}$ & $\begin{array}{l}- \\
- \\
- \\
- \\
- \\
-\end{array}$ & $\begin{array}{l}- \\
- \\
- \\
- \\
-\end{array}$ & $\begin{array}{l}- \\
- \\
- \\
- \\
- \\
-\end{array}$ & $\begin{array}{l}7.2 \\
7.0 \\
7.0 \\
7.0 \\
7.0 \\
6.8\end{array}$ & $\begin{array}{l}23,000 \\
24,000 \\
24,800 \\
25,400 \\
25,900 \\
25,000\end{array}$ & $\begin{array}{l}9.9 \\
9.8 \\
9.8 \\
9.8 \\
9.9 \\
9.9\end{array}$ & $\begin{array}{l}51,000 \\
54,000 \\
56,500 \\
58,700 \\
61,000 \\
63,600\end{array}$ & $\begin{array}{l}12.8 \\
13.2 \\
13.4 \\
13.8 \\
14.0 \\
14.2\end{array}$ & $\begin{array}{l}138,000 \\
146,000 \\
150,000 \\
157,000 \\
161,000 \\
168,000\end{array}$ & $\begin{array}{l}14.0 \\
13.9 \\
13.8 \\
13.6 \\
13.6 \\
13.4\end{array}$ & $\begin{array}{l}164,000 \\
162,000 \\
160,000 \\
157,000 \\
155,000 \\
154,000\end{array}$ \\
\hline $\begin{array}{r}7 \\
8 \\
9 \\
10 \\
11 \\
\text { N }\end{array}$ & $\begin{array}{l}- \\
- \\
- \\
- \\
-\end{array}$ & $\begin{array}{l}- \\
- \\
- \\
- \\
-\end{array}$ & $\begin{array}{l}- \\
- \\
- \\
- \\
\overline{6} .5\end{array}$ & $\begin{array}{c}\overline{-} \\
\mathrm{b} 11,100 \\
\overline{-} \\
13,200\end{array}$ & $\begin{array}{l}6.8 \\
7.2 \\
7.4 \\
7.4 \\
7.3 \\
7.3\end{array}$ & $\begin{array}{l}23,800 \\
24,300 \\
25,400 \\
26,500 \\
27,300 \\
28,500\end{array}$ & $\begin{array}{l}9.9 \\
9.8 \\
9.8 \\
9.8 \\
9.8 \\
9.9\end{array}$ & $\begin{array}{l}67,000 \\
69,500 \\
72,000 \\
74,500 \\
77,000 \\
80,200\end{array}$ & $\begin{array}{l}14.4 \\
14.5 \\
14.5 \\
14.5 \\
14.5 \\
14.5\end{array}$ & $\begin{array}{l}172,000 \\
174,000 \\
174,000 \\
174,000 \\
174,000 \\
174,000\end{array}$ & $\begin{array}{l}13.4 \\
13.2 \\
13.1 \\
13.0 \\
12.8 \\
12.8\end{array}$ & $\begin{array}{l}152,000 \\
149,000 \\
147,000 \\
144,000 \\
142,000 \\
141,000\end{array}$ \\
\hline $\begin{array}{l}1 \\
2 \\
3 \\
4 \\
5 \\
6\end{array}$ & $\begin{array}{l}- \\
- \\
- \\
-\end{array}$ & $\begin{array}{l}- \\
- \\
- \\
- \\
- \\
c 8,880\end{array}$ & $\begin{array}{l}6.4 \\
6.4 \\
6.2 \\
6.2 \\
6.4 \\
6.5\end{array}$ & $\begin{array}{l}13,800 \\
14,300 \\
15,000 \\
15,300 \\
15,800 \\
16,200\end{array}$ & $\begin{array}{l}7.4 \\
7.8 \\
8.0 \\
8.0 \\
8.1 \\
8.2\end{array}$ & $\begin{array}{l}30,200 \\
31,800 \\
34,400 \\
36,500 \\
38,200 \\
40,200\end{array}$ & $\begin{array}{r}9.9 \\
10.0 \\
10.1 \\
10.3 \\
10.5 \\
10.7\end{array}$ & $\begin{array}{r}83,800 \\
87,000 \\
92,500 \\
95,800 \\
100,000 \\
104,000\end{array}$ & $\begin{array}{l}14.5 \\
14.5 \\
14.5 \\
14.4 \\
14.4 \\
14.4\end{array}$ & $\begin{array}{l}174,000 \\
174,000 \\
174,000 \\
173,000 \\
172,000 \\
171,000\end{array}$ & $\begin{array}{l}12.6 \\
12.4 \\
12.0 \\
11.8 \\
11.6 \\
11.6\end{array}$ & $\begin{array}{l}138,000 \\
134,000 \\
129,000 \\
125,000 \\
122,000 \\
120,000\end{array}$ \\
\hline \multirow[t]{2}{*}{$\begin{array}{r}7 \\
8 \\
9 \\
10 \\
11 \\
1 \\
\end{array}$} & $\begin{array}{l}\overline{-} \\
= \\
- \\
- \\
-\end{array}$ & $\begin{array}{l}- \\
- \\
- \\
- \\
-\end{array}$ & $\begin{array}{l}6.7 \\
6.9 \\
7.0 \\
7.0 \\
7.0 \\
7.2\end{array}$ & $\begin{array}{l}16,700 \\
17,100 \\
17,600 \\
18,200 \\
18,700 \\
20,500\end{array}$ & $\begin{array}{l}8.3 \\
8.5 \\
8.7 \\
9.0 \\
9.3 \\
9.7\end{array}$ & $\begin{array}{l}41,300 \\
42,300 \\
43,000 \\
44,200 \\
47,000 \\
49,600\end{array}$ & $\begin{array}{l}11.0 \\
11.2 \\
11.5 \\
11.8 \\
12.1 \\
12.4\end{array}$ & $\begin{array}{l}108,000 \\
111,000 \\
116,000 \\
121,000 \\
126,000 \\
131,000\end{array}$ & $\begin{array}{l}14.4 \\
14.2 \\
14.2 \\
14.2 \\
14.1 \\
14.0\end{array}$ & $\begin{array}{l}170,000 \\
169,000 \\
168,000 \\
167,000 \\
166,000 \\
165,000\end{array}$ & $\begin{array}{l}11.4 \\
11.3 \\
11.1 \\
10.9 \\
10.8 \\
10.8\end{array}$ & $\begin{array}{l}118,000 \\
116,000 \\
112,000 \\
110,000 \\
109,000 \\
108,000\end{array}$ \\
\hline & \multicolumn{2}{|c|}{ September 24} & \multicolumn{2}{|c|}{ September 25} & \multicolumn{2}{|c|}{ September 26} & \multicolumn{2}{|c|}{ September 27} & \multicolumn{2}{|c|}{ September 28} & \multicolumn{2}{|c|}{ September 29} \\
\hline $\begin{array}{r}2 \\
4 \\
6 \\
8 \\
10 \\
\mathrm{~N}\end{array}$ & $\begin{array}{r}10.6 \\
10.4 \\
10.2 \\
9.9 \\
9.6 \\
9.4\end{array}$ & $\begin{array}{r}104,000 \\
102,000 \\
97,500 \\
93,000 \\
88,300 \\
84,600\end{array}$ & $\begin{array}{l}8.6 \\
8.6 \\
8.4 \\
8.2 \\
8.0 \\
8.2\end{array}$ & $\begin{array}{l}70,000 \\
68,200 \\
66,200 \\
63,900 \\
61,600 \\
58,900\end{array}$ & $\begin{array}{l}8.4 \\
8.4 \\
8.4 \\
7.7 \\
7.4 \\
7.2\end{array}$ & $\begin{array}{l}53,000 \\
52,000 \\
50,000 \\
48,300 \\
45,800 \\
44,800\end{array}$ & $\begin{array}{l}7.3 \\
7.2 \\
7.0 \\
6.4 \\
6.0 \\
6.0\end{array}$ & $\begin{array}{l}40,800 \\
40,000 \\
38,000 \\
36,800 \\
35,400 \\
35,000\end{array}$ & $\begin{array}{l}4.4 \\
4.2 \\
3.4 \\
3.2 \\
3.2 \\
3.2\end{array}$ & $\begin{array}{l}33,600 \\
32,700 \\
31,500 \\
30,200 \\
27,500 \\
26,000\end{array}$ & $\begin{array}{l}- \\
- \\
- \\
-\end{array}$ & $\begin{array}{l}- \\
- \\
- \\
-\end{array}$ \\
\hline $\begin{array}{r}2 \\
4 \\
6 \\
8 \\
10 \\
M\end{array}$ & $\begin{array}{l}9.0 \\
8.8 \\
8.6 \\
8.3 \\
8.3 \\
8.8\end{array}$ & $\begin{array}{l}81,000 \\
78,000 \\
74,800 \\
72,000 \\
70,500 \\
72,000\end{array}$ & $\begin{array}{l}8.0 \\
8.2 \\
8.0 \\
8.0 \\
8.1 \\
8.2\end{array}$ & $\begin{array}{l}56,600 \\
58,900 \\
55,000 \\
51,700 \\
52,800 \\
54,000\end{array}$ & $\begin{array}{l}7.2 \\
7.1 \\
7.3 \\
7.2 \\
7.2 \\
7.2\end{array}$ & $\begin{array}{l}44,300 \\
43,800 \\
43,400 \\
42,000 \\
40,600 \\
40,200\end{array}$ & $\begin{array}{l}6.0 \\
5.8 \\
5.9 \\
5.8 \\
5.6 \\
5.0\end{array}$ & $\begin{array}{l}35,600 \\
33,800 \\
33,000 \\
32,300 \\
32,000 \\
34,000\end{array}$ & $\begin{array}{l}3.6 \\
5.0 \\
6.6 \\
6.9 \\
6.6 \\
6.6\end{array}$ & $\begin{array}{l}21,600 \\
18,100 \\
22,500 \\
24,700 \\
21,600 \\
19,800\end{array}$ & $\begin{array}{l}- \\
- \\
- \\
-\end{array}$ & $\begin{array}{c}- \\
\text { d } 18,200 \\
- \\
- \\
-\end{array}$ \\
\hline
\end{tabular}

b Mean for 6-hour period 6 a.m. to noon.

c Mean for 24 hours ending at $6 \mathrm{a} \cdot \mathrm{m}$. Sept. 19.

d Mean for 24 hours ending at $6 \mathrm{a} . \mathrm{m}$. Sept. 30 . 
Location.- Water-ztage recorder, lat. $42^{\circ} 34^{\prime} 45^{\prime \prime}$, long. $72^{\circ} 344^{\prime} 20^{\prime \prime}$, in Montague City, Franki in County 600 feet below mouth of Deerfield River. Zero of gage is 99.87 feet above mean sea level (general adjustment of 1929).

Drainage area. - 7,840 square miles.

Gage-he1ght record. - Water-stage recorder graph except for per1od 2 a.m. Sept. 22 to I a.m. Sept. 23, record for which was based on floodmarks, two wire-weight gage readings dally, and shape of stage graphs at nearby stations.

Stege-discharge relation.- Defined by current-meter measurements below 151,000 secondfeet; extended to peak stage by study of flow characteristics at high water control section.

Maxima.- September 1938: Discharge, 195,000 second-feet 11:30 a.m. Sept. 22 (gage helght, 44.74 feet, from floodmarks).

1904 to August 1938: D1scharge, 236,000 second-feet Mar. 19, 1936 (gage height, 49.2 feet, from floodmarks).

Remarks.- Flood run-off affected by a total storage capacity of 16,140,000,000 cubic feet. For information on storage (total capacity, 14,860,000,000 cubic feet) seo records for First and Second Connect1cut Lekes near Pittsburg, N. H., Fifteenmile Falls Reservoir near Barnet, Vt., Mascoma River reservolrs above Mascoma, N. H., Lake Sunapee at Sunapee, N. H., Somerset Reservolr on East Branch of Deerfield River near Somerset, Vt., and Harriman Reservolr on Deerfield River at Davis Bridge, Vt.

Mean dally discharge, in second-feet, 1938

\begin{tabular}{|c|c|c|c|c|c|c|c|c|c|c|c|}
\hline Day & ept. & Oct. & Day & Sept. & Oct. & Day & Sept. & oct. & Day & Sept. & Oct. \\
\hline $\begin{array}{l}1 \\
2 \\
3 \\
4 \\
5 \\
6 \\
7 \\
8\end{array}$ & $\begin{array}{l}7,380 \\
7,790 \\
3,600 \\
2,080 \\
1,360 \\
5,870 \\
4,610 \\
7,500\end{array}$ & $\begin{array}{l}13,600 \\
16,000 \\
17,600 \\
14,400 \\
13,600 \\
14,400 \\
16,800 \\
11,300\end{array}$ & $\begin{array}{r}9 \\
10 \\
11 \\
12 \\
13 \\
14 \\
15 \\
16\end{array}$ & $\begin{array}{r}7,140 \\
3,330 \\
2,100 \\
5,460 \\
7,470 \\
10,700 \\
12,300 \\
14,700\end{array}$ & $\begin{array}{r}7,980 \\
8,600 \\
11,400 \\
8,940 \\
10,700 \\
11,800 \\
7,670 \\
7,250\end{array}$ & $\begin{array}{l}17 \\
18 \\
19 \\
20 \\
21 \\
22 \\
23 \\
24\end{array}$ & \begin{tabular}{|r|}
15,900 \\
13,500 \\
13,400 \\
39,200 \\
101,000 \\
189,000 \\
163,000 \\
109,000
\end{tabular} & $\begin{array}{r}9,540 \\
8,680 \\
9,700 \\
10,600 \\
10,000 \\
10,200 \\
10,200 \\
12,000\end{array}$ & $\begin{array}{l}25 \\
26 \\
27 \\
28 \\
29 \\
30 \\
31\end{array}$ & & $\begin{array}{l}20,600 \\
21,800 \\
21,500 \\
19,400 \\
17,600 \\
14,900 \\
11,500\end{array}$ \\
\hline & & & & & & . . & 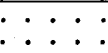 & & & $\begin{array}{r}32,660 \\
4.65\end{array}$ & $\begin{array}{r}12,910 \\
1.90\end{array}$ \\
\hline
\end{tabular}

Gage helght, in feet, and discharge, in second-feet, at indicated time, 1938

\begin{tabular}{|c|c|c|c|c|c|c|c|c|c|c|c|c|}
\hline \multirow{2}{*}{$\begin{array}{l}4 \\
\text { 总 } \\
\text { 足 }\end{array}$} & Feet & Sec.ft. & Feet & Sec.ft. & Feot & Sec.ft. & Feet & Sec.ft. & Feet & Sec.ft. & Foet & Sec.ft. \\
\hline & \multicolumn{2}{|c|}{ September I8 } & \multicolumn{2}{|c|}{ September 19} & \multicolumn{2}{|c|}{ September 20} & \multicolumn{2}{|c|}{ September 21} & \multicolumn{2}{|c|}{ September 22} & \multicolumn{2}{|c|}{ September 23} \\
\hline $\begin{array}{l}1 \\
2 \\
3 \\
4 \\
5 \\
6\end{array}$ & $\begin{array}{l}11.95 \\
12.39 \\
12.41 \\
11.92 \\
11.50 \\
11.30\end{array}$ & $\begin{array}{l}15,200 \\
16,470 \\
16,500 \\
15,200 \\
14,100 \\
13,600\end{array}$ & $\begin{array}{l}8.25 \\
7.30 \\
6.65 \\
6.20 \\
5.83 \\
7.00\end{array}$ & $\begin{array}{l}6,130 \\
4,200 \\
3,020 \\
2,300 \\
1,780 \\
3,640\end{array}$ & \begin{tabular}{|l}
15.20 \\
15.77 \\
16.01 \\
16.20 \\
16.90 \\
17.37
\end{tabular} & $\begin{array}{l}25,100 \\
26,900 \\
27,700 \\
28,400 \\
30,700 \\
32,300\end{array}$ & \begin{tabular}{|l|}
24.20 \\
24.76 \\
25.24 \\
25.81 \\
26.45 \\
27.05
\end{tabular} & \begin{tabular}{|l}
59,200 \\
61,700 \\
63,900 \\
66,400 \\
69,400 \\
72,200
\end{tabular} & \begin{tabular}{|l|}
42.90 \\
43.22 \\
43.48 \\
43.70 \\
43.90 \\
44.10
\end{tabular} & $\begin{array}{l}180,000 \\
183,000 \\
185,000 \\
187,000 \\
188,000 \\
190,000\end{array}$ & \begin{tabular}{|l|}
43.25 \\
43.12 \\
42.98 \\
42.75 \\
42.55 \\
42.34
\end{tabular} & $\begin{array}{l}183,000 \\
182,000 \\
181,000 \\
179,000 \\
178,000 \\
175,000\end{array}$ \\
\hline $\begin{array}{r}7 \\
8 \\
9 \\
10 \\
11 \\
\text { N }\end{array}$ & $\begin{array}{l}11.43 \\
11.52 \\
11.54 \\
11.56 \\
11.55 \\
11.53\end{array}$ & $\begin{array}{l}13, \\
14, \\
14, \\
14, \\
14, \\
14,\end{array}$ & $\begin{array}{r}9.30 \\
10.70 \\
11.40 \\
11.71 \\
11.95 \\
12.00\end{array}$ & $\begin{array}{r}8,580 \\
12,000 \\
13,800 \\
14,600 \\
15,200 \\
15,400\end{array}$ & & & & & & & & $\begin{array}{l}174,000 \\
172,000 \\
171,000 \\
169,000 \\
167,000 \\
164,000\end{array}$ \\
\hline $\begin{array}{l}1 \\
2 \\
3 \\
4 \\
5 \\
6\end{array}$ & $\begin{array}{l}11.10 \\
10.56 \\
10.38 \\
10.59 \\
10.85 \\
11.25\end{array}$ & $\begin{array}{l}13,100 \\
11,700 \\
11,200 \\
11,800 \\
12,400 \\
13,400\end{array}$ & $\begin{array}{l}12.20 \\
12.42 \\
12.62 \\
12.82 \\
13.00 \\
13.10\end{array}$ & $\begin{array}{l}15,900 \\
16,600 \\
17,100 \\
17,700 \\
18,200 \\
18,500\end{array}$ & $\begin{array}{l}19.25 \\
19.75 \\
20.30 \\
20.95 \\
21.40 \\
21.65\end{array}$ & & $\left|\begin{array}{l}31.50 \\
32.10 \\
32.80 \\
33.50 \\
34.30 \\
35.06\end{array}\right|$ & $\begin{array}{r}97,000 \\
101,000 \\
105,000 \\
110,000 \\
115,000 \\
121,000\end{array}$ & & & & $\begin{array}{l}162,000 \\
160,000 \\
158,000 \\
155,000 \\
152,000 \\
150,000\end{array}$ \\
\hline \multirow[t]{2}{*}{$\begin{array}{r}7 \\
8 \\
9 \\
10 \\
11 \\
M \\
\end{array}$} & $\begin{array}{r}11.38 \\
11.44 \\
11.40 \\
10.60 \\
9.85 \\
9.38 \\
\end{array}$ & $\begin{array}{r}13,800 \\
13,900 \\
13,800 \\
11,800 \\
9,890 \\
8,770 \\
\end{array}$ & $\begin{array}{l}13.22 \\
13.45 \\
13.75 \\
14.10 \\
14.10 \\
14.20 \\
\end{array}$ & $\begin{array}{l}18, \\
19, \\
20, \\
21, \\
21, \\
21,\end{array}$ & & & & $\begin{array}{l}126,000 \\
136,000 \\
151,000 \\
164,000 \\
172,000 \\
177,000\end{array}$ & & & & \\
\hline & \multicolumn{2}{|c|}{ September 24} & \multicolumn{2}{|c|}{ September 25} & \multicolumn{2}{|c|}{ September 26} & \multicolumn{2}{|c|}{ September 27} & \multicolumn{2}{|c|}{ September 28} & \multicolumn{2}{|c|}{ September 29} \\
\hline $\begin{array}{r}2 \\
4 \\
6 \\
8 \\
10 \\
\text { N }\end{array}$ & $\begin{array}{l}36.58 \\
35.92 \\
35.30 \\
34.70 \\
34.05 \\
33.38\end{array}$ & & & & \begin{tabular}{|l|}
23.95 \\
23.64 \\
23.36 \\
23.32 \\
22.97 \\
22.31
\end{tabular} & & & & & & & $\begin{array}{l}22,400 \\
20,200 \\
17,900 \\
19,800 \\
19,500 \\
19,700\end{array}$ \\
\hline $\begin{array}{r}2 \\
4 \\
6 \\
8 \\
10 \\
M \\
\end{array}$ & $\begin{array}{l}32.64 \\
31.98 \\
31.38 \\
30.90 \\
30.20 \\
29.72\end{array}$ & $\begin{array}{r}104,000 \\
100,000 \\
96,300 \\
93,400 \\
89,200 \\
86,500 \\
\end{array}$ & $\begin{array}{l}26.40 \\
26.03 \\
25.65 \\
25.19 \\
24.95 \\
24.42 \\
\end{array}$ & $\begin{array}{l}69,200 \\
67,400 \\
65,800 \\
63,100 \\
62,600 \\
60,200\end{array}$ & \begin{tabular}{|l|}
22.07 \\
21.70 \\
21.32 \\
21.05 \\
20.68 \\
20.23
\end{tabular} & & $\begin{array}{l}18.93 \\
18.70 \\
18.38 \\
18.39 \\
18.16 \\
18.22 \\
\end{array}$ & $\begin{array}{l}37,920 \\
37,100 \\
35,900 \\
36,000 \\
35,100 \\
35,300 \\
\end{array}$ & $\begin{array}{l}15.90 \\
14.60 \\
14.25 \\
15.60 \\
15.55 \\
15.00\end{array}$ & & & $\begin{array}{l}22,000 \\
22,100 \\
21,300 \\
22,500 \\
21,000\end{array}$ \\
\hline
\end{tabular}

Supplemental records.- Sept. $22,11: 30$ a.m., $44.74 \mathrm{ft} ., 195,000$ sec.-ft. 
Location. - Water-stage recorder, lat. $42^{\circ} 12^{\prime} 50^{\prime \prime}$, long. $72^{\circ} 36^{\prime} 10^{n}$, above dam of Holyoke Water Power Co., in Holyoke, Hampden County.

Drainage area. - 8,284 square miles.

Gage-he1ght record. - Water-stage recorder graph. Stage affected by flashboards on dam prior to 1 a.m. Sept. 20.

Discharge. - Determined by adding flow over dam to flow in the canals of Holyoke Power Co.

Maxima.- September 1938: Discharge, 189,000 second-feet 11 p.m. Sept. 22 to 5 a.m. Sept. 23 (gage height, 14.9 feet).

1860 to August 1938: Discharge, 244,000 second-feet Mar. 19, 20, 1936 (gage helght, 16.8 feet).

Remarks.- Flood run-off affected by a total storage capacity of 16,540,000,000. cubic feet. For Information on storage (total capacity 14,860,000,000 cublc feet) see records for First and Second Connecticut Lakes near Pittsburg, N. H., Fifteenmile Falls Reservolr near Barnet, Vt., Mascoma River reservoirs above Mascome, N. H., Lake Sunapee at Sunapee, N. H., Somerset Reservolr on East Branch of Deerfleld River near Somerset, Vt., and Harriman Reservolr on Deerfleld River at Davis Bridge, Vt. Records computed from basic data furnished by Holyoke Water Power Co.

Mean discharge, in second-feet, 1938 a/

\begin{tabular}{|c|c|c|c|c|c|c|c|c|c|c|c|}
\hline Day & Sept. & oct. & Day & Sept. & Oct. & Day & Sept. & Oct. & Day & Sept. & Oct. \\
\hline $\begin{array}{l}1 \\
2 \\
3 \\
4 \\
5 \\
6 \\
7 \\
8\end{array}$ & $\begin{array}{l}6,520 \\
7,290 \\
3,710 \\
2,050 \\
1,770 \\
4,440 \\
4,800 \\
4,720\end{array}$ & $\begin{array}{l}15,400 \\
15,100 \\
17,700 \\
14,400 \\
12,600 \\
14,000 \\
16,400 \\
12,300\end{array}$ & $\begin{array}{r}9 \\
10 \\
11 \\
12 \\
13 \\
14 \\
15 \\
16\end{array}$ & $\begin{array}{r}6,620 \\
3,900 \\
1,650 \\
4,730 \\
5,780 \\
8,370 \\
10,300 \\
11,500\end{array}$ & $\begin{array}{r}8,090 \\
8,960 \\
13,100 \\
14,200 \\
8,030 \\
9,460 \\
6,990 \\
5,740\end{array}$ & $\begin{array}{l}17 \\
18 \\
19 \\
20 \\
21 \\
22 \\
23 \\
24\end{array}$ & $\begin{array}{r}14,000 \\
12,300 \\
10,400 \\
52,200 \\
103,000 \\
179,000 \\
171,000 \\
124,000\end{array}$ & $\begin{array}{l}8,240 \\
8,110 \\
7,910 \\
8,370 \\
8,160 \\
8,520 \\
8,410\end{array}$ & $\begin{array}{l}25 \\
26 \\
27 \\
28 \\
29 \\
30 \\
31\end{array}$ & $\begin{array}{l}82,900 \\
57,800 \\
43,400 \\
33,900 \\
23,700 \\
21,300\end{array}$ & $\begin{array}{l}14,700 \\
17,800 \\
17,700 \\
14,000 \\
16,100 \\
12,600 \\
10,300\end{array}$ \\
\hline & & & & & & & & & & $\begin{array}{r}33,880 \\
4.56\end{array}$ & $\begin{array}{r}11,710 \\
1.63\end{array}$ \\
\hline
\end{tabular}

a For 24 hours ending at 6 a.m. following day indicated.

Gage helght, In feet, and discharge, in second-feet, at indicated time, 1938

\begin{tabular}{|c|c|c|c|c|c|c|c|c|c|c|c|c|}
\hline \multirow{2}{*}{$\begin{array}{l}3 \\
0 \\
0\end{array}$} & 'eot & Sec.ft. & Feet & Sec.ft. & Feet & Sec.ft. & Feet & Sec.ft. & Feet & Sec.ft. & Feet & Sec.ft. \\
\hline & \multicolumn{2}{|c|}{ September 18} & \multicolumn{2}{|c|}{ September 19} & \multicolumn{2}{|c|}{ September 20} & \multicolumn{2}{|c|}{ September 21} & \multicolumn{2}{|c|}{ September 22} & \multicolumn{2}{|c|}{ September 23} \\
\hline $\begin{array}{l}3 \\
4 \\
5 \\
6\end{array}$ & $\begin{array}{l}- \\
- \\
z \\
-\end{array}$ & $\begin{array}{l}= \\
z \\
z\end{array}$ & $\begin{array}{l}\bar{z} \\
\bar{z} \\
z\end{array}$ & $\begin{array}{l}- \\
- \\
- \\
-\end{array}$ & $\begin{array}{l}4.6 \\
4.7 \\
4.7 \\
4.7 \\
4.8 \\
4.8\end{array}$ & & $\begin{array}{l}6.2 \\
6.3 \\
6.4 \\
6.6 \\
6.7 \\
6.9\end{array}$ & & & & & \\
\hline 7 & $\begin{array}{l}- \\
- \\
- \\
-\end{array}$ & $\begin{array}{l}z \\
\bar{z} \\
\bar{z} \\
\bar{y}\end{array}$ & $\begin{array}{l}- \\
\overline{-} \\
\overline{-} \\
\overline{-}\end{array}$ & $\begin{array}{l}\bar{z} \\
\overline{-} \\
\overline{-} \\
\overline{-}\end{array}$ & & & & & & & & \\
\hline $\begin{array}{l}1 \\
2 \\
3 \\
4\end{array}$ & $\begin{array}{l}\bar{z} \\
\bar{z} \\
\bar{z}\end{array}$ & $\begin{array}{c}- \\
- \\
- \\
- \\
- \\
* 12,300\end{array}$ & $\begin{array}{l}- \\
\overline{-} \\
\overline{-} \\
\overline{-}\end{array}$ & $\begin{array}{c}- \\
- \\
- \\
- \\
* 10,400\end{array}$ & $\begin{array}{l}5.1 \\
5.2 \\
5.2 \\
5.3 \\
5.4 \\
5.5\end{array}$ & & $\begin{array}{l}8.2 \\
8.4 \\
8.6 \\
8.9 \\
9.1 \\
9.3\end{array}$ & & & & & \\
\hline \multirow[t]{2}{*}{$\begin{array}{r}7 \\
8 \\
9 \\
10 \\
11 \\
M \\
\end{array}$} & $\begin{array}{l}\bar{z} \\
\bar{z} \\
\overline{-} \\
-\end{array}$ & $\begin{array}{l}\bar{z} \\
\bar{z} \\
\overline{-}\end{array}$ & $\begin{array}{l}- \\
\overline{-} \\
\overline{-} \\
\overline{-}\end{array}$ & $\begin{array}{l}\overline{-} \\
\bar{z} \\
\bar{z} \\
\overline{-}\end{array}$ & $\begin{array}{l}5.6 \\
5.7 \\
5.8 \\
5.9 \\
6.0 \\
6.1\end{array}$ & & $\begin{array}{r}9.6 \\
9.9 \\
10.3 \\
10.5 \\
10.8 \\
11.2\end{array}$ & & $\begin{array}{l}14.6 \\
14.7 \\
14.8 \\
14.8 \\
14.9 \\
14.9\end{array}$ & & $\begin{array}{l}13.9 \\
13.8 \\
13.8 \\
13.7 \\
13.8 \\
13.4\end{array}$ & \\
\hline & \multicolumn{2}{|c|}{ September 24} & \multicolumn{2}{|c|}{ September 25} & \multicolumn{2}{|c|}{ September 26} & \multicolumn{2}{|c|}{ September 27} & \multicolumn{2}{|c|}{ September 28} & \multicolumn{2}{|c|}{ September 29} \\
\hline $\begin{array}{r}2 \\
4 \\
6 \\
8 \\
10 \\
N\end{array}$ & $\begin{array}{l}13.2 \\
13.0 \\
12.6 \\
12.4 \\
12.0 \\
11.8\end{array}$ & & $\begin{array}{r}10.1 \\
9.9 \\
9.5 \\
9.4 \\
9.1\end{array}$ & $\begin{array}{r}108,000 \\
105,000 \\
98,900 \\
97,400 \\
92,900\end{array}$ & $\begin{array}{l}7.5 \\
7.4 \\
7.2 \\
6.9 \\
6.7 \\
6.6\end{array}$ & & $\begin{array}{l}5.7 \\
5.6 \\
5.4 \\
5.2 \\
5.1 \\
5.0\end{array}$ & & $\begin{array}{l}4.7 \\
4.6 \\
4.6 \\
4.4 \\
4.4 \\
4.4\end{array}$ & & $\begin{array}{l}3.7 \\
3.6 \\
3.5 \\
3.2\end{array}$ & \\
\hline $\begin{array}{r}2 \\
4 \\
6 \\
8 \\
10\end{array}$ & $\begin{array}{l}11.6 \\
11.2 \\
11.1 \\
10.9 \\
10.6 \\
10.4\end{array}$ & $\begin{array}{l}132,0 \\
126,0 \\
124,0 \\
121,0 \\
116,0 \\
113,0\end{array}$ & $\begin{array}{l}8.8 \\
8.6 \\
8.4 \\
8.1 \\
8.0 \\
7.7\end{array}$ & $\begin{array}{l}85,800 \\
83,000 \\
78,800 \\
77,400 \\
73,500\end{array}$ & $\begin{array}{l}6.4 \\
6.3 \\
6.1 \\
6.0 \\
5.9 \\
5.8\end{array}$ & & $\begin{array}{l}4.9 \\
4.9 \\
4.9 \\
4.8 \\
4.8 \\
4.8\end{array}$ & & $\begin{array}{l}4.2 \\
4.1 \\
4.1 \\
3.9 \\
3.7 \\
3.7\end{array}$ & & $\begin{array}{l}2.8 \\
2.8 \\
2.7 \\
2.7 \\
2.8 \\
2.9\end{array}$ & \\
\hline
\end{tabular}

* Mean for 24 hours ending at $6 \mathrm{a.m}$. following day ind1cated. 
Connecticut River at Springfield, Mass.

Location. - Water-stage recorder, lat. $42^{\circ} 06^{\circ} 00^{n}$, long. $72^{\circ} 35^{\prime} 50^{n}$, at Memorial Bridge,

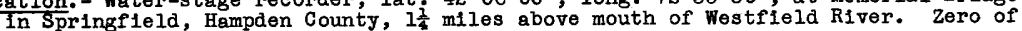
gage is 37.30 feet above mean sea level.

Drainage area.- 9,587 square miles including Westfleld River Basin.

Gage-helght recora. - Water-stage recorder graph.

Stege-discharge relation.- Developed from rating curve at Thompsonville, Conn.; adjusted for discharge from intervening drainage area.

Maxima. - September 1938: Discharge, 235,000 second-feet 10 p.m. Sept. 22 to 1 a.m. Sept. 23 (gage height, 25.75 feet).

1801 to August 1938: D1scharge, 281,000 second-feet Mar. 19, 20, 1936 (gage height, 28.60 feet).

Remarks.- Flood run-off affected by a total storage capac1ty of 19,940,000,000 cub1c feet. For information on storage (total capacity, 18,260,000,000 cublc feet) see records for First and Second Connecticut Lakes near Pittsburg, N. B., Fifteenmile Folls Reservoir near Barnet, Vt., Mescoma River reservolrs above Mascoma, N. H., Lake Sumapee at Sunapee, N. H., Somerset Reservolr on Bast Branch of Deerfield River near Somerset, vt., Harriman Reservolr on Deerfleld River at Davis Bridge, Vt., and Borden Brook and Cobble Mountain Reservolrs in Westfleld Little River Basin near Westfleld, Mass. Records computed from basic data furnished by the U. S. Weather Bureau. D1s. charge record includes flow of Westfield River.

Mean dally discharge, in secondafeet, 1938

\begin{tabular}{|c|c|c|c|c|c|c|c|c|c|c|c|}
\hline Day & Sept. & Oct. & Day & Sept. & Oct. & Day & Sept. & oct. & Day & Sept. & Oct. \\
\hline $\begin{array}{l}1 \\
2 \\
3 \\
4 \\
5 \\
6 \\
7 \\
8\end{array}$ & $\begin{array}{l}8,100 \\
8,500 \\
7,050 \\
3,450 \\
3,070 \\
3,700 \\
5,500 \\
7,000\end{array}$ & $\begin{array}{l}22,000 \\
17,800 \\
21,000 \\
19,400 \\
17,800 \\
16,800 \\
18,400 \\
17,300\end{array}$ & $\begin{array}{r}9 \\
10 \\
11 \\
12 \\
13 \\
14 \\
15 \\
16\end{array}$ & $\begin{array}{r}7,750 \\
7,500 \\
4,080 \\
4,920 \\
7,050 \\
8,620 \\
11,000 \\
13,200\end{array}$ & $\begin{array}{r}12,700 \\
11,200 \\
11,700 \\
13,200 \\
12,200 \\
12,200 \\
12,700 \\
9,750\end{array}$ & $\begin{array}{l}17 \\
18 \\
19 \\
20 \\
21 \\
22 \\
23 \\
24\end{array}$ & $\begin{array}{r}14,700 \\
15,000 \\
14,400 \\
39,900 \\
109,000 \\
225,000 \\
223,000 \\
169,000\end{array}$ & $\begin{array}{l}10,700 \\
11,700 \\
11,700 \\
11,700 \\
12,400 \\
12,700 \\
12,200 \\
13,200\end{array}$ & $\begin{array}{l}25 \\
26 \\
27 \\
28 \\
29 \\
30 \\
31\end{array}$ & $\begin{array}{r}109,000 \\
75,200 \\
54,200 \\
43,400 \\
31,500 \\
26,200\end{array}$ & $\begin{array}{l}19,900 \\
24,100 \\
23,400 \\
22,000 \\
20,400 \\
18,900 \\
15,800\end{array}$ \\
\hline & & & & & . & : & $\cdot: \cdot \dot{0}$ & . : & $: \dot{ }$ & $\begin{array}{r}42,000 \\
4.89\end{array}$ & $\begin{array}{r}15,710 \\
1.89\end{array}$ \\
\hline
\end{tabular}

Gage helght, in feet, and discharge, in second-fe日t, at indicated time, 1938

\begin{tabular}{|c|c|c|c|c|c|c|c|c|c|c|c|c|}
\hline \multirow{2}{*}{ 多 } & Feet & Sec.ft. & Feet & Sec.ft. & Feet & Sec.ft. & Feet & Sec.ft. & Feet & Sec.ft. & Feet & Sec.ft. \\
\hline & \multicolumn{2}{|c|}{ September 18} & \multicolumn{2}{|c|}{ September 19} & \multicolumn{2}{|c|}{ September 20} & \multicolumn{2}{|c|}{ September 21} & \multicolumn{2}{|c|}{ September 22} & \multicolumn{2}{|c|}{ September 23} \\
\hline $\begin{array}{l}1 \\
2 \\
3 \\
4 \\
5 \\
6\end{array}$ & $\begin{array}{l}4.70 \\
4.70 \\
4.70 \\
4.70 \\
4.70 \\
4.70\end{array}$ & $\begin{array}{l}15,200 \\
15,200 \\
15,200 \\
15,200 \\
15,200 \\
15,200\end{array}$ & $\begin{array}{l}4.50 \\
4.49 \\
4.49 \\
4.50 \\
4.48 \\
4.48\end{array}$ & $\begin{array}{l}14,200 \\
14,150 \\
14,150 \\
14,200 \\
14,100 \\
14,100\end{array}$ & $\begin{array}{l}5.75 \\
6.00 \\
6.25 \\
6.50 \\
6.70 \\
6.90\end{array}$ & $\begin{array}{l}20,700 \\
22,000 \\
23,800 \\
25,500 \\
26,900 \\
28,300\end{array}$ & $\begin{array}{l}12.1 \\
12.3 \\
12.6 \\
12.85 \\
13.2 \\
13.5\end{array}$ & $\begin{array}{l}66,800 \\
68,400 \\
70,800 \\
72,800 \\
75,600 \\
78,000\end{array}$ & $\begin{array}{l}23.2 \\
23.7 \\
24.1 \\
24.5 \\
24.8 \\
25.0\end{array}$ & $\begin{array}{l}195,000 \\
202,000 \\
209,000 \\
215,000 \\
220,000 \\
223,000\end{array}$ & $\begin{array}{l}25.75 \\
25.70 \\
25.70 \\
25.65 \\
25.60 \\
25.55\end{array}$ & $\begin{array}{l}235,000 \\
234,200 \\
234,200 \\
233,400 \\
232,600 \\
231,800\end{array}$ \\
\hline $\begin{array}{r}7 \\
8 \\
9 \\
10 \\
11 \\
N\end{array}$ & $\begin{array}{l}4.70 \\
4.70 \\
4.70 \\
4.70 \\
4.70 \\
4.70\end{array}$ & $\begin{array}{l}15,200 \\
15,200 \\
15,200 \\
15,200 \\
15,200 \\
15,200\end{array}$ & $\begin{array}{l}4.50 \\
4.50 \\
4.50 \\
4.48 \\
4.47 \\
4.40\end{array}$ & $\begin{array}{l}14,200 \\
14,200 \\
14,200 \\
14,100 \\
14,000 \\
13,700\end{array}$ & $\begin{array}{l}7.20 \\
7.50 \\
7.85 \\
8.03 \\
8.30 \\
8.52\end{array}$ & $\begin{array}{l}30,400 \\
32,500 \\
35,000 \\
36,200 \\
38,100 \\
39,600\end{array}$ & $\begin{array}{l}14.0 \\
14.35 \\
14.7 \\
15.2 \\
15.6 \\
16.0\end{array}$ & $\begin{array}{r}82,000 \\
85,200 \\
88,300 \\
93,000 \\
97,000 \\
101,000\end{array}$ & $\begin{array}{l}25.2 \\
25.25 \\
25.30 \\
25.35 \\
25.40 \\
25.45\end{array}$ & $\begin{array}{l}226,000 \\
227,000 \\
227,800 \\
228,600 \\
229,400 \\
230,200\end{array}$ & $\begin{array}{l}25.55 \\
25.45 \\
25.40 \\
25.35 \\
25.25 \\
25.15\end{array}$ & $\begin{array}{l}231,800 \\
230,200 \\
229,400 \\
228,600 \\
227,000 \\
225,000\end{array}$ \\
\hline $\begin{array}{l}1 \\
2 \\
3 \\
4 \\
5 \\
6\end{array}$ & $\begin{array}{l}4.70 \\
4.70 \\
4.68 \\
4.67 \\
4.65 \\
4.64\end{array}$ & $\begin{array}{l}15,200 \\
15,200 \\
15,100 \\
15,050 \\
14,950 \\
14,900\end{array}$ & $\begin{array}{l}4.32 \\
4.30 \\
4.31 \\
4.32 \\
4.37 \\
4.40\end{array}$ & $\begin{array}{l}13,300 \\
13,200 \\
13,250 \\
13,300 \\
13,550 \\
13,700\end{array}$ & $\begin{array}{r}8.80 \\
9.00 \\
9.30 \\
9.60 \\
9.80 \\
10.10\end{array}$ & $\begin{array}{l}41,600 \\
43,000 \\
45,100 \\
47,200 \\
48,600 \\
50,800\end{array}$ & $\begin{array}{l}16.45 \\
16.9 \\
17.4 \\
18.0 \\
18.5 \\
19.0\end{array}$ & $\begin{array}{l}106,000 \\
111,000 \\
117,000 \\
124,000 \\
130,000 \\
136,000\end{array}$ & $\begin{array}{l}25.5 \\
25.55 \\
25.6 \\
25.6 \\
25.6 \\
25.6\end{array}$ & $\begin{array}{l}231,000 \\
231,800 \\
232,600 \\
232,600 \\
232,600 \\
232,600\end{array}$ & $\begin{array}{l}.05 \\
.00 \\
.90 \\
.80 \\
.65 \\
.55\end{array}$ & $\begin{array}{l}224 \\
223 \\
221 \\
224 \\
217 \\
216\end{array}$ \\
\hline \multirow[t]{2}{*}{$\begin{array}{r}7 \\
8 \\
9 \\
10 \\
11 \\
M\end{array}$} & & $\begin{array}{l}14,850 \\
14,700 \\
14,450 \\
14,400 \\
14,800 \\
14,250\end{array}$ & $\begin{array}{l}4.50 \\
4.60 \\
4.80 \\
5.00 \\
5.22 \\
5.50\end{array}$ & $\begin{array}{l}14,200 \\
14,700 \\
15,800 \\
16,800 \\
17,900 \\
19,400\end{array}$ & $\begin{array}{l}10.22 \\
10.40 \\
10.70 \\
11.05 \\
11.50 \\
11.80\end{array}$ & $\begin{array}{l}51,800 \\
53,200 \\
55,600 \\
58,400 \\
62,000 \\
64,400\end{array}$ & $\begin{array}{l}19.3 \\
20.0 \\
20.4 \\
21.1 \\
21.7 \\
27.6\end{array}$ & $\begin{array}{l}140,000 \\
149,000 \\
155,000 \\
164,000 \\
173,000 \\
186,000\end{array}$ & $\begin{array}{l}25.65 \\
25.70 \\
25.70 \\
25.75 \\
25.75 \\
25.75\end{array}$ & $\begin{array}{l}233,400 \\
234,200 \\
234,200 \\
235,000 \\
235,000 \\
235,000\end{array}$ & $\begin{array}{l}4.35 \\
4.20 \\
4.10 \\
3.95 \\
3.80 \\
3.60\end{array}$ & $\begin{array}{l}213,000 \\
210,000 \\
209,000 \\
206,000 \\
204,000 \\
201,000\end{array}$ \\
\hline & \multicolumn{2}{|c|}{ September 24} & \multicolumn{2}{|c|}{ September 25} & \multicolumn{2}{|c|}{ September 26} & \multicolumn{2}{|c|}{ September 27} & \multicolumn{2}{|c|}{ September 28} & \multicolumn{2}{|c|}{ September 29} \\
\hline $\begin{array}{r}2 \\
4 \\
6 \\
8 \\
10 \\
N\end{array}$ & $\begin{array}{l}23.30 \\
22.90 \\
22.55 \\
22.2 \\
21.8 \\
21.4\end{array}$ & $\begin{array}{l}196,000 \\
190,000 \\
185,000 \\
180,000 \\
174,000 \\
169,000\end{array}$ & $\begin{array}{l}18.60 \\
18.2 \\
17.7 \\
17.3 \\
16.9 \\
16.6\end{array}$ & $\begin{array}{l}131,000 \\
126,000 \\
120,000 \\
116,000 \\
111,000 \\
108,000\end{array}$ & $\begin{array}{l}14.6 \\
14.25 \\
13.95 \\
13.55 \\
13.3 \\
13.1\end{array}$ & $\begin{array}{l}87,400 \\
84,200 \\
81,600 \\
78,400 \\
76,400 \\
74,800\end{array}$ & $\begin{array}{l}11.5 \\
11.3 \\
11.0 \\
10.8 \\
10.65 \\
10.5\end{array}$ & $\begin{array}{l}62,000 \\
60,400 \\
58,000 \\
56,400 \\
55,200 \\
54,000\end{array}$ & $\begin{array}{l}9.52 \\
9.45 \\
9.35 \\
9.27 \\
9.20 \\
9.15\end{array}$ & $\begin{array}{l}46,600 \\
46,200 \\
45,400 \\
14,900 \\
44,400 \\
44,000\end{array}$ & & $\begin{array}{l}36,100 \\
35,200 \\
34,200 \\
33,600 \\
32,500 \\
31,400\end{array}$ \\
\hline $\begin{array}{r}2 \\
4 \\
6 \\
8 \\
10 \\
M\end{array}$ & $\begin{array}{l}21.0 \\
20.6 \\
20.2 \\
19.8 \\
19.4 \\
19.0\end{array}$ & $\begin{array}{l}163,000 \\
157,000 \\
152,000 \\
146,000 \\
141,000 \\
136,000\end{array}$ & $\begin{array}{l}16.2 \\
15.9 \\
15.65 \\
15.35 \\
15.2\end{array}$ & $\begin{array}{r}103,000 \\
100,000 \\
97,500 \\
94,500 \\
93,000\end{array}$ & $\begin{array}{l}12.8 \\
12.6 \\
12.35 \\
12.1 \\
11.85 \\
11.7\end{array}$ & $\begin{array}{l}72,400 \\
70,800 \\
68,800 \\
66,800 \\
64,800 \\
63,600\end{array}$ & $\begin{array}{r}10.3 \\
10.1 \\
9.95 \\
9.82 \\
9.66\end{array}$ & $\begin{array}{l}52,400 \\
50,800 \\
49,600 \\
48,700 \\
47,800 \\
47,200\end{array}$ & $\begin{array}{l}9.08 \\
8.97 \\
8.80 \\
8.63 \\
8.40 \\
8.20\end{array}$ & $\begin{array}{l}43,600 \\
42,800 \\
41,600 \\
40,400 \\
38,800\end{array}$ & $\begin{array}{l}7.18 \\
7.00 \\
6.91 \\
6.85 \\
6.77\end{array}$ & $\begin{array}{l}30,300 \\
29,000 \\
28,400 \\
28,000 \\
27,400 \\
27,100\end{array}$ \\
\hline
\end{tabular}

$2279070-40-11$ 
Location. - Water-stage recorder, lat. $41^{\circ} 59^{\prime} 20^{n}$, long. $72^{\circ} 36^{\prime} 15^{\prime \prime}$, in pool above Enfield Dam, 1 mile below Thompsonvilie, Hartford County. Zero of gage 1s 38.48 feet above mean sea level.

Drainage area.- 9,637 square miles.

Gage-helght record. - Water-stage recorder graph except for period 1 a.m. Sept. 22 to 2 a.m. Sept. 24, record for which was based on floodmarks and shape of stage graphs at nearby stations.

Stage-discharge relation.- Defined by current-meter measurements.

Maxlma:- September 1938: D1scharge, 236,000 second-feet 11 p.m. sept. 22 to 2 a.m. sept. 23 (gage helght, 14.40 feet, from floodmarks).

1928 to August 1938: Discharge, 282,000 second-feet Mar. 20, 1936 (gage helght, 16.6 feet, from floodmarks).

Remarks.- Flood rum-off affected by a total storage capacity of 19,940,000,000 cubic feet. For information on storage (total capacity, 18,260,000,000 cubic feet) see records for First and Second Connecticut Lakes near Pittsburg, N. H., Fifteenmile Falls Reservolr near Barnet, Vt., Mascoma River reservolrs above Mascoma, N. H. Lake Sunapee at Sunapee, N. H., Somerset Reservoir on East Branch of Deerfleld River near Somerset, Vt., Harriman Reservolr on Deerfield River at Davis Bridge, Vt., and Borden Brook and Cobble Mountain Reservoirs in Westfield Little River Basin near Westfield, Mass.

Mesin dally discharge, in second-feet, 1938

\begin{tabular}{|c|c|c|c|c|c|c|c|c|c|c|c|}
\hline Day & Sept. & oct. & Day & Sept. & Oct. & Day & Sept. & oct. & Day & Sept. & Oct. \\
\hline $\begin{array}{l}1 \\
2 \\
3 \\
4 \\
5 \\
6 \\
7 \\
8\end{array}$ & $\begin{array}{l}8,310 \\
8,840 \\
7,550 \\
3,510 \\
3,150 \\
3,720 \\
6,020 \\
7,220 \\
\end{array}$ & $\begin{array}{l}23,000 \\
18,300 \\
22,200 \\
20,200 \\
18,300 \\
17,700 \\
19,500 \\
18,300\end{array}$ & $\begin{array}{r}9 \\
10 \\
11 \\
12 \\
13 \\
14 \\
15 \\
16\end{array}$ & $\begin{array}{r}7,980 \\
7,960 \\
5,920 \\
4,930 \\
6,620 \\
8,700 \\
10,900 \\
14,000\end{array}$ & $\begin{array}{r}13,500 \\
11,500 \\
11,900 \\
13,700 \\
12,500 \\
12,500 \\
13,200 \\
9,800\end{array}$ & $\begin{array}{l}17 \\
18 \\
19 \\
20 \\
21 \\
22 \\
23 \\
24\end{array}$ & $\begin{array}{r}15,800 \\
16,400 \\
14,700 \\
41,200 \\
112,000 \\
226,000 \\
224,000 \\
169,000\end{array}$ & $\begin{array}{l}11,100 \\
12,300 \\
11,900 \\
12,300 \\
13,500 \\
13,500 \\
12,800 \\
13,400\end{array}$ & $\begin{array}{l}25 \\
26 \\
27 \\
28 \\
29 \\
30 \\
31\end{array}$ & $\begin{array}{r}110,000 \\
75,100 \\
55,200 \\
44,900 \\
33,200 \\
28,200\end{array}$ & $\begin{array}{l}20,700 \\
26,000 \\
25,200 \\
23,700 \\
21,500 \\
20,200 \\
16,600\end{array}$ \\
\hline $\begin{array}{l}\text { Mean } \\
\text { Run- }\end{array}$ & , in & I a hano & & onond & et. & - & 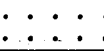 & $\begin{array}{ll}\cdot & \bullet \\
& \bullet\end{array}$ & . : & $\begin{array}{r}42,700 \\
4.94\end{array}$ & $\begin{array}{r}16,480 \\
1.97\end{array}$ \\
\hline
\end{tabular}

Gage helght, in feet, and discharge, in second-feet, at indicated t1me, 1938

\begin{tabular}{|c|c|c|c|c|c|c|c|c|c|c|c|c|}
\hline \multirow{2}{*}{$\begin{array}{l}9 \\
0 \\
0 \\
0\end{array}$} & Feet & Sec.ft. & Feet & Sec.ft. & Feet & Sec.ft. & Feet & Sec.ft. & Feet & Sec.ft. & Feet & sec.ft. \\
\hline & \multicolumn{2}{|c|}{ September 18} & \multicolumn{2}{|c|}{ September 19} & \multicolumn{2}{|c|}{ September 20} & \multicolumn{2}{|c|}{ September 21} & \multicolumn{2}{|c|}{ September 22} & \multicolumn{2}{|c|}{ September 23} \\
\hline $\begin{array}{l}1 \\
2 \\
3 \\
4 \\
5 \\
6\end{array}$ & $\begin{array}{l}2.42 \\
2.42 \\
2.41 \\
2.41 \\
2.41 \\
2.41\end{array}$ & $\begin{array}{l}16,600 \\
16,600 \\
16,500 \\
16,500 \\
16,500 \\
16,500\end{array}$ & $\begin{array}{l}2.33 \\
2.33 \\
2.32 \\
2.32 \\
2.32 \\
2.20\end{array}$ & $\begin{array}{l}15,600 \\
15,600 \\
15,500 \\
15,500 \\
15,500 \\
14,200\end{array}$ & $\begin{array}{l}2.71 \\
2.86 \\
2.97 \\
3.06 \\
3.16 \\
3.25\end{array}$ & $\begin{array}{l}20,000 \\
22,000 \\
23,600 \\
25,000 \\
26,600 \\
28,000\end{array}$ & $\begin{array}{l}5.75 \\
5.82 \\
5.96 \\
6.10 \\
6.19 \\
6.32\end{array}$ & $\begin{array}{l}72,100 \\
73,500 \\
76,100 \\
78,600 \\
80,300 \\
82,800\end{array}$ & $\begin{array}{l}12.30 \\
12.75 \\
13.05 \\
13.35 \\
13.62 \\
13.80\end{array}$ & $\begin{array}{l}194,000 \\
203,000 \\
209,000 \\
215,000 \\
220,000 \\
224,000\end{array}$ & \begin{tabular}{|l|}
14.40 \\
14.40 \\
14.39 \\
14.37 \\
14.35 \\
14.30
\end{tabular} & $\begin{array}{l}236,000 \\
236,000 \\
235,800 \\
235,400 \\
235,000 \\
234,000\end{array}$ \\
\hline $\begin{array}{r}7 \\
8 \\
9 \\
10 \\
11 \\
\frac{N}{N}\end{array}$ & $\begin{array}{l}2.41 \\
2.41 \\
2.44 \\
2.44 \\
2.43 \\
2.43\end{array}$ & $\begin{array}{l}16,500 \\
16,500 \\
16,800 \\
16,900 \\
16,700 \\
16,700\end{array}$ & $\begin{array}{l}2.21 \\
2.22 \\
2.22 \\
2.23 \\
2.22 \\
2.19\end{array}$ & $\begin{array}{l}14,300 \\
14,400 \\
14,400 \\
14,500 \\
14,400 \\
14,100\end{array}$ & $\begin{array}{l}3.34 \\
3.44 \\
3.64 \\
3.86 \\
3.92 \\
3.99\end{array}$ & $\begin{array}{l}29,500 \\
31,200 \\
34,600 \\
38,300 \\
39,200 \\
40,500\end{array}$ & $\begin{array}{l}6.48 \\
6.66 \\
6.87 \\
7.09 \\
7.28 \\
7.50\end{array}$ & $\begin{array}{r}85,700 \\
89,000 \\
92,900 \\
97,000 \\
100,500 \\
105,000\end{array}$ & $\begin{array}{l}3.93 \\
4.00 \\
4.05 \\
4.09 \\
4.13 \\
4.15\end{array}$ & $\begin{array}{l}227,000 \\
228,000 \\
229,000 \\
230,000 \\
230,600 \\
231,000\end{array}$ & $\begin{array}{l}14.26 \\
14.22 \\
14.16 \\
14.10 \\
14.04 \\
13.96\end{array}$ & $\begin{array}{l}233,000 \\
232,000 \\
231,000 \\
230,000 \\
229,000 \\
227,000\end{array}$ \\
\hline $\begin{array}{l}1 \\
2 \\
3 \\
4 \\
5 \\
6\end{array}$ & $\begin{array}{l}2.43 \\
2.43 \\
2.42 \\
2.41 \\
2.40 \\
2.39\end{array}$ & $\begin{array}{l}16,700 \\
16,700 \\
16,600 \\
16,500 \\
16,400 \\
16,200\end{array}$ & $\begin{array}{l}2.17 \\
2.13 \\
2.12 \\
2.12 \\
2.15 \\
2.17\end{array}$ & $\begin{array}{l}13,900 \\
13,400 \\
13,300 \\
13,300 \\
13,600 \\
13,900\end{array}$ & $\begin{array}{l}4.09 \\
4.18 \\
4.27 \\
4.36 \\
4.48 \\
4.62\end{array}$ & $\begin{array}{l}42,300 \\
43,900 \\
45,600 \\
47,200 \\
49,300 \\
51,900\end{array}$ & $\begin{array}{l}7.72 \\
7.97 \\
8.31 \\
8.58 \\
8.87 \\
9.32\end{array}$ & $\begin{array}{l}108,400 \\
113,000 \\
119,000 \\
125,000 \\
130,000 \\
138,000\end{array}$ & $\begin{array}{l}14.19 \\
14.24 \\
14.27 \\
14.30 \\
14.33 \\
14.33\end{array}$ & $\begin{array}{l}231,800 \\
232,800 \\
233,400 \\
234,000 \\
234,600 \\
234,600\end{array}$ & $\begin{array}{l}13.88 \\
13.80 \\
13.72 \\
13.60 \\
13.50 \\
13.40\end{array}$ & $\begin{array}{l}226,000 \\
224,000 \\
222,000 \\
220,000 \\
218,000 \\
216,000\end{array}$ \\
\hline \multirow[t]{2}{*}{$\begin{array}{r}7 \\
8 \\
9 \\
10 \\
11 \\
M\end{array}$} & $\begin{array}{l}2.38 \\
2.37 \\
2.36 \\
2.35 \\
2.34 \\
2.33\end{array}$ & $\begin{array}{l}16,100 \\
16,000 \\
16,000 \\
15,900 \\
15,700 \\
15,600 \\
\end{array}$ & $\begin{array}{l}2.19 \\
2.24 \\
2.28 \\
2.36 \\
2.47 \\
2.60 \\
\end{array}$ & $\begin{array}{l}14,100 \\
14,600 \\
15,100 \\
16,000 \\
17,200 \\
18,700\end{array}$ & $\begin{array}{l}4.76 \\
4.84 \\
5.20 \\
5.39 \\
5.37 \\
5.63 \\
\end{array}$ & $\begin{array}{l}54,400 \\
55,800 \\
62,400 \\
65,900 \\
67,400 \\
70,400\end{array}$ & $\begin{array}{r}9.57 \\
9.92 \\
10.23 \\
10.68 \\
11.20 \\
11.71\end{array}$ & $\begin{array}{l}143,000 \\
149,000 \\
155,000 \\
164,000 \\
173,000 \\
183,000\end{array}$ & $\begin{array}{l}14.34 \\
14.35 \\
14.36 \\
14.38 \\
14.40 \\
14.40\end{array}$ & $\begin{array}{l}234,800 \\
235,000 \\
235,200 \\
235,600 \\
236,000 \\
236,000\end{array}$ & $\begin{array}{l}13.27 \\
13.14 \\
13.00 \\
12.92 \\
12.80 \\
12.67\end{array}$ & $\begin{array}{l}213,000 \\
211,000 \\
208,000 \\
206,000 \\
204,000 \\
201,000\end{array}$ \\
\hline & \multicolumn{2}{|c|}{ September 24} & \multicolumn{2}{|c|}{ September 25} & \multicolumn{2}{|c|}{ September 26} & \multicolumn{2}{|c|}{ September 27} & \multicolumn{2}{|c|}{ September 28} & \multicolumn{2}{|c|}{ September 29} \\
\hline $\begin{array}{r}2 \\
4 \\
6 \\
8 \\
10 \\
N\end{array}$ & $\begin{array}{l}12.43 \\
12.17 \\
11.87 \\
11.58 \\
11.27 \\
10.97\end{array}$ & $\begin{array}{l}197,000 \\
191,000 \\
185,000 \\
181,000 \\
174,000 \\
168,000\end{array}$ & $\begin{array}{l}8.94 \\
8.65 \\
8.39 \\
8.14 \\
7.88 \\
7.68\end{array}$ & $\begin{array}{l}131,000 \\
126,000 \\
121,000 \\
117,000 \\
112,000 \\
108,000\end{array}$ & $\begin{array}{l}6.48 \\
6.36 \\
6.24 \\
6.11 \\
6.00 \\
5.90\end{array}$ & & $\begin{array}{l}5.18 \\
5.09 \\
5.02 \\
4.94 \\
4.88 \\
4.81\end{array}$ & \begin{tabular}{|l|}
61,700 \\
60,000 \\
58,700 \\
57,200 \\
56,100 \\
54,900
\end{tabular} & & \begin{tabular}{|l|}
48,000 \\
47,300 \\
46,800 \\
46,400 \\
46,100 \\
45,500
\end{tabular} & $\begin{array}{l}3.85 \\
3.79 \\
3.74 \\
3.71 \\
3.66 \\
3.60\end{array}$ & $\begin{array}{l}37,800 \\
36,700 \\
35,900 \\
35,400 \\
34,500 \\
33,500\end{array}$ \\
\hline $\begin{array}{r}2 \\
4 \\
6 \\
8 \\
10 \\
M\end{array}$ & $\begin{array}{r}10.67 \\
10.38 \\
10.09 \\
9.83 \\
9.48 \\
9.21\end{array}$ & $\begin{array}{l}163, \\
158, \\
153, \\
148, \\
142, \\
136,\end{array}$ & $\begin{array}{l}7.48 \\
7.30 \\
7.12 \\
6.96 \\
6.79 \\
6.63\end{array}$ & $\begin{array}{r}105, \\
101, \\
97, \\
94, \\
91, \\
88,\end{array}$ & $\begin{array}{l}77 \\
65 \\
57 \\
47 \\
37 \\
28\end{array}$ & $\begin{array}{l}72, \\
70, \\
68, \\
67, \\
65, \\
63,\end{array}$ & $\begin{array}{l}73 \\
68 \\
62 \\
58 \\
53 \\
48\end{array}$ & $\begin{array}{l}53,400 \\
52,500 \\
51,500 \\
50,700 \\
49,800 \\
48,900\end{array}$ & $\begin{array}{l}26 \\
21 \\
16 \\
09 \\
01 \\
92\end{array}$ & $\begin{array}{l}45 \\
44, \\
43 \\
41 \\
40 \\
38,\end{array}$ & $\begin{array}{l}50 \\
14 \\
38 \\
37 \\
35 \\
32\end{array}$ & $\begin{array}{l}31,8 \\
30,8 \\
29,8 \\
29,6 \\
29,2 \\
28,7\end{array}$ \\
\hline
\end{tabular}


Location. - Water-gtage recorder, lat. $41^{\circ} 46^{\prime} 10^{\prime \prime}$, long. $72^{\circ} 40^{\prime} 00^{n}$, at Memorial Bridge in Hartford, Hartford County, three-quarters of a mile above Park River and $1 \frac{1}{2}$ miles above mouth of Hockanum River. Zero of gage is 0.55 foot below mean sea level. Drainage area.- 10,480 square miles.

Gage-helght record. - Water-stage recorder graph.

Stage-discharge relation.- Discharge is the measured discharge for Connecticut River at Thompsonville, Farmingt on River at Tariffville, and Scantic River at Broad Brook

(98.4 percent of the drainage area) plus computed inflow from ungaged area; adjusted for gain or loss in valley storage between points of measured discharge and Hartford gage.

Maxima.- September 1938: Maximum discharge, 251,000 second-feet 12 p.m. Sept. 22 to 4 a.m. Sept. 23 ; maximum gage height, 35.42 feet at 4 p.m. Sept. 23.

1639 to August 1938: Maximum discharge, 313,000 second-feet Mar. 20, 1936 (augmented by breaching of Hartford dikes); maximum gage helght, 37.6 feet Mar. 21, 1936.

Remarks. - Gage-height record furnished by U. S. Weather Bureau. Flood run-off affected by a total storage capacity of $20,940,000,000$ cublc feet. For information on storage (total capacity, 19,260,000,000 cubic feet) see records for First and Second Connecticut Lakes near Pittsburg, N. H., Fifteenmile Falls Reservoir near Barnet, Vt., Hascoma R1ver reservoirs above Mascoma, N. H., Lake Sunapee at Sunapee, N. H., Somerset Reservoir on East Branch of Deerfleld River near Somerset, vt. Harriman Reservoir on Deerfield River at Davis Bridge, Vt., Borden Brook and Cobble Kountain Reservofrs in Westfield Little River Basin near Westfield, Mass., Otis Reservolr at Cold Spring, Mass., Barkhamsted Reservoir near Barkhamsted, Conn., East Branch Reservoir at New Hartiord, Conn, and Nepaug Reservolr near Collinsville, Conn.

Mean daily discharge, in second-feet, 1938

\begin{tabular}{|c|c|c|c|c|c|c|c|c|c|c|c|}
\hline Day & Sept. & Oct. & Day & Sept. & Oct. & Day & Sept. & oct. & Day & Sept. & Oet. \\
\hline $\begin{array}{l}1 \\
2 \\
3 \\
4 \\
5 \\
6 \\
7 \\
8\end{array}$ & $\begin{array}{l}9,110 \\
9,660 \\
8,190 \\
3,960 \\
3,600 \\
4,280 \\
6,800 \\
8,050\end{array}$ & $\begin{array}{l}26,900 \\
21,600 \\
24,000 \\
22,700 \\
21,100 \\
20,000 \\
21,300 \\
20,600\end{array}$ & $\begin{array}{r}9 \\
10 \\
11 \\
12 \\
13 \\
14 \\
15 \\
16\end{array}$ & $\begin{array}{r}8,800 \\
8,610 \\
6,380 \\
5,460 \\
7,440 \\
9,600 \\
11,900 \\
15,100\end{array}$ & $\begin{array}{l}15,500 \\
13,000 \\
13,600 \\
15,400 \\
14,400 \\
13,900 \\
14,600 \\
11,300\end{array}$ & $\begin{array}{l}17 \\
18 \\
19 \\
20 \\
21 \\
22 \\
23 \\
24\end{array}$ & $\begin{array}{r}16,700 \\
17,500 \\
17,000 \\
39,300 \\
113,000 \\
228,000 \\
242,000 \\
197,000\end{array}$ & $\begin{array}{l}13,500 \\
13,200 \\
13,600 \\
15,200 \\
15,500 \\
14,300 \\
14,700\end{array}$ & $\begin{array}{l}25 \\
26 \\
27 \\
28 \\
29 \\
30 \\
31\end{array}$ & & $\begin{array}{l}22,600 \\
28,000 \\
27,300 \\
25,800 \\
23,500 \\
22,000 \\
18,300\end{array}$ \\
\hline & & & & & & - & & . . & & $\begin{array}{r}47,190 \\
5.02 \\
\end{array}$ & $\begin{array}{r}18,370 \\
2.02 \\
\end{array}$ \\
\hline
\end{tabular}

Gage helght, in feet, and discharge, in second-feet, at indicated time, 1938

\begin{tabular}{|c|c|c|c|c|c|c|c|c|c|c|c|c|}
\hline \multirow{2}{*}{ 孚 } & & Sec.ft. & eet & Sec.ft & eet & Note. & Feet & Sec.ft & Feet & sec.ft. & Feet & \\
\hline & \multicolumn{2}{|c|}{ Sept ember 18} & \multicolumn{2}{|c|}{ September 19} & \multicolumn{2}{|c|}{ September 20} & \multicolumn{2}{|c|}{ September 21} & \multicolumn{2}{|c|}{ September 22} & \multicolumn{2}{|c|}{ September 23} \\
\hline $\begin{array}{l}1 \\
2 \\
3 \\
4 \\
5 \\
6\end{array}$ & & & & & & & & & & & & 251,000 \\
\hline $\begin{array}{l}7 \\
8\end{array}$ & & & & & & & & & & & & \\
\hline $\begin{array}{l}1 \\
2 \\
3 \\
4 \\
5 \\
6\end{array}$ & & & $\begin{array}{l}5.29 \\
5.27 \\
5.32 \\
5.30 \\
5.30\end{array}$ & & & & & & & & & \\
\hline \multirow[t]{2}{*}{$\begin{array}{r}7 \\
8 \\
9 \\
10 \\
11 \\
11 \\
\end{array}$} & & & $\begin{array}{l}5.51 \\
5.68 \\
5.82 \\
5.93 \\
6.04\end{array}$ & & & & & & & & & \\
\hline & \multicolumn{2}{|c|}{ September 24} & \multicolumn{2}{|c|}{ September 25} & \multicolumn{2}{|c|}{ September 26} & \multicolumn{2}{|c|}{ September 27} & \multicolumn{2}{|c|}{ September 28} & \multicolumn{2}{|c|}{ September 29} \\
\hline $\begin{array}{r}2 \\
4 \\
6 \\
8 \\
10 \\
N\end{array}$ & & & & & & & & & & & & \\
\hline $\begin{array}{r}2 \\
4 \\
6 \\
8 \\
10\end{array}$ & & & & & & & & & & & & \\
\hline
\end{tabular}


Location.- Water-stage recorder, lat. 44'21', long. $72^{\circ} 01^{\prime}, 1$ mile below dam at Passumpsic, Caledonia County.

Drainage area.- 423 square miles.

Gage-neight record.- Water-stage recorder graph except for period 0ct. 26-31, when graph was based on twice daily gage readings.

Stage-discharge relation.- Defined by current-meter measurements below 9 , 180 secondfeet; extended to peak stage on basis of determinations of flood flor $s$ over dam.

Maxima.- September 1938: Discharge, 7,710 second-feet 1 a.m. Sept. 22 (gage helght, 12.23 feet).

1928 to August 1938: Discharge, 16,000 second-feet Mar. 18, 1936 (gage hetght, 21.23 feet).

Remarks.- Flood run-off slightly affected by storage.

Mean dally discharge, in second-feet, 1938

\begin{tabular}{|c|c|c|c|c|c|c|c|c|c|c|c|}
\hline Day & Sept. & Oct. & Day & Sept. & Oct. & Day & Sept. & Oct. & Day & Sept. & Oct. \\
\hline $\begin{array}{l}1 \\
2 \\
3 \\
4 \\
5 \\
6 \\
7 \\
8\end{array}$ & $\begin{array}{l}175 \\
300 \\
214 \\
196 \\
256 \\
238 \\
155 \\
233\end{array}$ & $\begin{array}{l}556 \\
516 \\
490 \\
472 \\
417 \\
413 \\
390 \\
387\end{array}$ & $\begin{array}{l}9 \\
10 \\
11 \\
12 \\
13 \\
14 \\
15 \\
16\end{array}$ & $\begin{array}{r}250 \\
165 \\
120 \\
165 \\
812 \\
1,030 \\
870 \\
1,140\end{array}$ & $\begin{array}{l}361 \\
388 \\
349 \\
328 \\
330 \\
323 \\
326 \\
268\end{array}$ & $\begin{array}{l}17 \\
18 \\
19 \\
20 \\
21 \\
22 \\
23 \\
24\end{array}$ & $\begin{array}{r}688 \\
649 \\
622 \\
1,120 \\
4,670 \\
6,140 \\
3,000 \\
1,690\end{array}$ & $\begin{array}{l}324 \\
295 \\
281 \\
304 \\
574 \\
604 \\
420 \\
540\end{array}$ & $\begin{array}{l}25 \\
26 \\
27 \\
28 \\
29 \\
30 \\
31\end{array}$ & $\begin{array}{r}1,220 \\
872 \\
778 \\
810 \\
690 \\
595\end{array}$ & $\begin{array}{r}1,680 \\
1,340 \\
600 \\
640 \\
500 \\
530 \\
480\end{array}$ \\
\hline $\begin{array}{l}\text { Mean } \\
\text { Run- }\end{array}$ & , in & & . 1 & & . & $: \dot{ }$ & 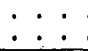 & $\therefore \dot{.}$ & $\dot{.}$ & $\begin{array}{r}995 \\
2.62\end{array}$ & $\begin{array}{r}498 \\
1.36\end{array}$ \\
\hline
\end{tabular}

Gage height, in feet, and discharge, in second-feet, at indlcated time, 1938

\begin{tabular}{|c|c|c|c|c|c|c|c|c|c|c|c|c|c|}
\hline \multirow{2}{*}{$\begin{array}{l}\xi \\
7 \\
0 \\
\end{array}$} & Feet & Sec.ft. & Feet & Sec.ft. & Feet & Sec.ft. & Feet & Sec.ft. & Feet & Sec.ft. & Feet & \multicolumn{2}{|c|}{ Sec.ft. } \\
\hline & \multicolumn{2}{|c|}{ September 18 . } & \multicolumn{2}{|c|}{ September 19} & \multicolumn{2}{|c|}{ September 20} & \multicolumn{2}{|c|}{ September 21} & \multicolumn{2}{|c|}{ September 22} & \multicolumn{3}{|c|}{ September 23} \\
\hline $\begin{array}{l}1 \\
2 \\
3 \\
4 \\
5 \\
6\end{array}$ & $\begin{array}{l}2.93 \\
2.90 \\
2.94 \\
2.92 \\
2.93 \\
2.97\end{array}$ & $\begin{array}{l}485 \\
467 \\
491 \\
479 \\
485 \\
509\end{array}$ & $\begin{array}{l}3.25 \\
3.23 \\
3.21 \\
3.21 \\
3.20 \\
3.20\end{array}$ & $\begin{array}{l}686 \\
673 \\
660 \\
660 \\
653 \\
653\end{array}$ & $\begin{array}{l}2.89 \\
2.76 \\
2.77 \\
2.90 \\
3.00 \\
3.10\end{array}$ & $\begin{array}{l}461 \\
390 \\
395 \\
467 \\
527 \\
589\end{array}$ & $\begin{array}{l}5.40 \\
5.52 \\
5.60 \\
5.69 \\
5.88 \\
6.17\end{array}$ & $\begin{array}{l}2,180 \\
2,260 \\
2,320 \\
2,380 \\
2,520 \\
2,720\end{array}$ & $\begin{array}{l}12.23 \\
12.20 \\
12.05 \\
11.84 \\
11.61 \\
11.40\end{array}$ & $\begin{array}{l}7,710 \\
7,680 \\
7,540 \\
7,360 \\
7,150 \\
6,960\end{array}$ & $\begin{array}{l}8.11 \\
7.90 \\
7.72 \\
7.57 \\
7.41 \\
7.25\end{array}$ & & $\begin{array}{l}, 220 \\
, 050 \\
, 910 \\
790 \\
660 \\
, 530\end{array}$ \\
\hline $\begin{array}{r}7 \\
8 \\
9 \\
10 \\
11 \\
N\end{array}$ & $\begin{array}{l}3.03 \\
3.12 \\
3.21 \\
3.24 \\
3.28 \\
3.31\end{array}$ & $\begin{array}{l}546 \\
602 \\
660 \\
680 \\
707 \\
727\end{array}$ & $\begin{array}{l}3.19 \\
3.18 \\
3.18 \\
3.20 \\
3.33 \\
3.37\end{array}$ & $\begin{array}{l}647 \\
640 \\
640 \\
653 \\
740 \\
767\end{array}$ & $\begin{array}{l}3.21 \\
3.30 \\
3.43 \\
3.59 \\
3.98 \\
4.01\end{array}$ & $\begin{array}{r}660 \\
720 \\
807 \\
915 \\
1,190 \\
1,210\end{array}$ & $\begin{array}{l}6.40 \\
6.70 \\
6.80 \\
7.05 \\
7.75 \\
8.21\end{array}$ & $\begin{array}{l}2,880 \\
3,090 \\
3,170 \\
3,370 \\
3,930 \\
4,300\end{array}$ & $\begin{array}{l}11.20 \\
11.05 \\
10.90 \\
10.79 \\
10.63 \\
10.48\end{array}$ & $\begin{array}{l}6,780 \\
6,640 \\
6,510 \\
6,410 \\
6,270 \\
6,130\end{array}$ & $\begin{array}{l}7.10 \\
6.96 \\
6.82 \\
6.71 \\
6.50 \\
5.83\end{array}$ & & $\begin{array}{l}410 \\
300 \\
190 \\
100 \\
950 \\
480\end{array}$ \\
\hline $\begin{array}{l}1 \\
2 \\
3 \\
4 \\
5 \\
6\end{array}$ & $\begin{array}{l}3.30 \\
3.29 \\
3.40 \\
3.26 \\
3.27 \\
3.31\end{array}$ & $\begin{array}{l}720 \\
713 \\
787 \\
693 \\
700 \\
727\end{array}$ & $\begin{array}{l}3.23 \\
3.19 \\
3.00 \\
2.91 \\
3.14 \\
3.09\end{array}$ & $\begin{array}{l}673 \\
647 \\
527 \\
473 \\
615 \\
583\end{array}$ & $\begin{array}{l}4.00 \\
4.06 \\
4.01 \\
4.21 \\
4.48 \\
4.49\end{array}$ & $\begin{array}{l}1,200 \\
1,240 \\
1,210 \\
1,350 \\
1,536 \\
1,543\end{array}$ & $\begin{array}{r}9.00 \\
10.05 \\
10.65 \\
11.00 \\
11.11 \\
11.10\end{array}$ & $\begin{array}{l}4,930 \\
5,770 \\
6,280 \\
6,600 \\
6,700 \\
6,690\end{array}$ & $\begin{array}{r}10.30 \\
10.12 \\
9.98 \\
9.79 \\
9.61 \\
9.44\end{array}$ & $\begin{array}{l}5,970 \\
5,830 \\
5,710 \\
5,560 \\
5,420 \\
5,280\end{array}$ & $\begin{array}{l}6.10 \\
6.17 \\
6.11 \\
5.93 \\
5.93 \\
5.89\end{array}$ & & $\begin{array}{l}, 670 \\
, 720 \\
, 680 \\
, 550 \\
, 550 \\
, 520\end{array}$ \\
\hline \multirow[t]{2}{*}{$\begin{array}{r}7 \\
8 \\
9 \\
10 \\
11 \\
M \\
\end{array}$} & $\begin{array}{l}3.34 \\
3.35 \\
3.35 \\
3.41 \\
3.32 \\
3.29\end{array}$ & $\begin{array}{l}747 \\
754 \\
754 \\
794 \\
733 \\
713 \\
\end{array}$ & $\begin{array}{l}3.03 \\
3.01 \\
3.08 \\
3.04 \\
2.96 \\
3.05 \\
\end{array}$ & $\begin{array}{l}546 \\
533 \\
577 \\
552 \\
503 \\
558\end{array}$ & $\begin{array}{l}4.68 \\
4.80 \\
4.94 \\
5.03 \\
5.20 \\
5.26 \\
\end{array}$ & $\begin{array}{l}1,680 \\
1,760 \\
1,860 \\
1,920 \\
2,040 \\
2,080\end{array}$ & $\begin{array}{l}11.03 \\
11.10 \\
11.40 \\
11.72 \\
12.00 \\
12.13\end{array}$ & $\begin{array}{l}6,630 \\
6,690 \\
6,960 \\
7,250 \\
7,500 \\
7,620\end{array}$ & $\begin{array}{l}9.29 \\
9.11 \\
8.95 \\
8.73 \\
8.53 \\
8.32 \\
\end{array}$ & $\begin{array}{l}5,160 \\
5,020 \\
4,890 \\
4,710 \\
4,550 \\
4,390\end{array}$ & $\begin{array}{l}5.74 \\
5.65 \\
5.55 \\
5.54 \\
5.44 \\
5.30\end{array}$ & & $\begin{array}{l}, 420 \\
, 360 \\
, 285 \\
, 278 \\
, 210 \\
, 110 \\
\end{array}$ \\
\hline & \multicolumn{2}{|c|}{ September 24} & \multicolumn{2}{|c|}{ September 25} & \multicolumn{2}{|c|}{ September 26} & \multicolumn{2}{|c|}{ September 27} & \multicolumn{2}{|c|}{ September 28} & \multicolumn{3}{|c|}{ September 29} \\
\hline $\begin{array}{r}2 \\
4 \\
6 \\
6 \\
10 \\
N\end{array}$ & $\begin{array}{l}5.13 \\
4.98 \\
4.90 \\
4.80 \\
4.75 \\
4.71\end{array}$ & $\begin{array}{l}1,990 \\
1,890 \\
1,830 \\
1,760 \\
1,720 \\
1,700\end{array}$ & $\begin{array}{l}4.03 \\
4.18 \\
4.12 \\
4.10 \\
4.10 \\
4.17\end{array}$ & $\begin{array}{l}1,220 \\
1,330 \\
1,280 \\
1,270 \\
1,270 \\
1,320\end{array}$ & $\begin{array}{l}3.72 \\
3.63 \\
3.61 \\
3.61 \\
3.38 \\
3.31\end{array}$ & \begin{tabular}{|r|}
1,000 \\
943 \\
929 \\
929 \\
774 \\
727 \\
\end{tabular} & $\begin{array}{l}3.22 \\
3.38 \\
3.37 \\
3.33 \\
3.58 \\
3.50\end{array}$ & $\begin{array}{l}666 \\
774 \\
767 \\
740 \\
908 \\
854\end{array}$ & $\begin{array}{l}3.35 \\
3.41 \\
3.41 \\
3.40 \\
3.62 \\
3.57\end{array}$ & \begin{tabular}{|l|}
754 \\
794 \\
794 \\
787 \\
936 \\
902 \\
\end{tabular} & $\begin{array}{l}3.07 \\
3.30 \\
3.26 \\
3.24 \\
3.48 \\
3.33\end{array}$ & & $\begin{array}{l}570 \\
720 \\
693 \\
680 \\
841 \\
740\end{array}$ \\
\hline $\begin{array}{r}2 \\
4 \\
6 \\
8 \\
10 \\
M\end{array}$ & $\begin{array}{l}4.61 \\
4.44 \\
4.36 \\
4.36 \\
4.47 \\
4.35\end{array}$ & $\begin{array}{l}1,630 \\
1,510 \\
1,450 \\
1,450 \\
1,530 \\
1,440\end{array}$ & $\begin{array}{l}3.94 \\
3.93 \\
3.90 \\
3.87 \\
3.88 \\
3.77\end{array}$ & $\begin{array}{l}1,160 \\
1,150 \\
1,130 \\
1,110 \\
1,120 \\
1,040\end{array}$ & $\begin{array}{l}3.51 \\
3.50 \\
3.71 \\
3.61 \\
3.10 \\
3.46\end{array}$ & $\begin{array}{l}861 \\
854 \\
998 \\
929 \\
589 \\
827\end{array}$ & $\begin{array}{l}3.68 \\
3.20 \\
3.32 \\
3.30 \\
3.48 \\
3.10\end{array}$ & $\begin{array}{l}977 \\
653 \\
733 \\
720 \\
841 \\
589\end{array}$ & $\begin{array}{l}3.50 \\
3.44 \\
3.40 \\
3.48 \\
3.54 \\
3.05\end{array}$ & $\begin{array}{l}854 \\
814 \\
787 \\
841 \\
881 \\
558\end{array}$ & $\begin{array}{l}3.25 \\
3.25 \\
3.22 \\
3.31 \\
3.30 \\
3.03\end{array}$ & & $\begin{array}{l}686 \\
686 \\
666 \\
727 \\
720 \\
546\end{array}$ \\
\hline
\end{tabular}


Moose River at St. Johnsbury, Vt.

Location.- Water-stage recorder, lat. $44^{\circ} 25^{\prime} 20^{\prime \prime}$, long. $71^{\circ} 59^{\prime} 55^{n}$, half a mile above mouth of river in St. Johnsbury, Caledonia County.

Drainage area.- 126 square miles.

Gage-helght record.- Water-stage recorder graph.

Stage-discharge relation.- Defined by current-meter measurements below 2,430 secondfeet; extended to peak stage by determination of flood flow over dam.

Maxima.- September 1938: Discharge, 2,030 second-feet 3:15 p.m. Sept. 21 (gage height, 4.25 feet).

1928 to August 1938: Discharge observed, 5,220 second-feet Apr. 30, 1929

(gage height, 8.09 feet, former site and datum)

Remarks.- Flood run-off affected by some artificial and natural storage.

Meen delly discharge, in second-feet, 1938

\begin{tabular}{|c|r|r||r|r|r||r|r|r||r|r|r|}
\hline Dey & Sept. & 0ct. & Day & Sept. & 0ct. & Day & Sept. & 0ct. & Day & Sept. & Oct. \\
\hline 1 & 36 & 151 & 9 & 60 & 91 & 17 & 246 & 67 & 25 & 432 & 581 \\
2 & 45 & 138 & 10 & 42 & 86 & 18 & 201 & 63 & 26 & 293 \\
3 & 45 & 125 & 11 & 31 & 82 & 19 & 187 & 63 & 27 & 245 & 293 \\
4 & 40 & 117 & 12 & 34 & 79 & 20 & 417 & 78 & 28 & 234 & 212 \\
5 & 51 & 109 & 13 & 282 & 76 & 21 & 1,220 & 187 & 29 & 201 & 174 \\
6 & 45 & 106 & 14 & 344 & 73 & 22 & 1,490 & 201 & 30 & 169 & 153 \\
7 & 38 & 102 & 15 & 310 & 72 & 23 & 1,150 & 129 & 31 & \\
8 & 49 & 94 & 16 & 384 & 69 & 24 & 736 & 188 & 135 \\
\hline
\end{tabular}

Gage helght, in feet, and discharge, in second-feet, at indicated time, 1938

\begin{tabular}{|c|c|c|c|c|c|c|c|c|c|c|c|c|c|}
\hline \multirow{2}{*}{ 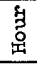 } & Feet & Sec.ft. & Feet & \multicolumn{2}{|c|}{ Sec.ft. } & Feet & Sec.ft. & Feet & Sec.ft. & Feet & Sec.ft. & Feet & sec.ft. \\
\hline & \multicolumn{2}{|c|}{ September 18} & \multicolumn{3}{|c|}{ September 19} & \multicolumn{2}{|c|}{ September 20} & \multicolumn{2}{|c|}{ September 21} & \multicolumn{2}{|c|}{ September 22} & \multicolumn{2}{|c|}{ Sept ember 23} \\
\hline $\begin{array}{l}1 \\
2 \\
3 \\
4 \\
5 \\
6\end{array}$ & $\begin{array}{l}3.06 \\
3.06 \\
3.07 \\
3.08 \\
3.08 \\
3.09\end{array}$ & $\begin{array}{l}197 \\
197 \\
200 \\
203 \\
203 \\
206\end{array}$ & $\begin{array}{l}3.11 \\
3.11 \\
3.10 \\
3.09 \\
3.08 \\
3.08\end{array}$ & & $\begin{array}{l}212 \\
212 \\
209 \\
206 \\
203 \\
203\end{array}$ & $\begin{array}{l}3.01 \\
3.06 \\
3.14 \\
3.20 \\
3.33 \\
3.41\end{array}$ & $\begin{array}{l}182 \\
197 \\
221 \\
240 \\
287 \\
319\end{array}$ & $\begin{array}{l}3.84 \\
3.86 \\
3.86 \\
3.89 \\
3.89 \\
3.90\end{array}$ & $\begin{array}{l}632 \\
654 \\
654 \\
687 \\
687 \\
698\end{array}$ & $\begin{array}{l}4.08 \\
4.10 \\
4.09 \\
4.09 \\
4.06 \\
4.07\end{array}$ & $\begin{array}{l}1,290 \\
1,360 \\
1,320 \\
1,320 \\
1,220 \\
1,260\end{array}$ & $\begin{array}{l}4.11 \\
4.10 \\
4.06 \\
4.05 \\
4.04 \\
4.05\end{array}$ & $\begin{array}{l}1,400 \\
1,360 \\
1,220 \\
1,180 \\
1,150 \\
1,180\end{array}$ \\
\hline $\begin{array}{r}7 \\
8 \\
9 \\
10 \\
11 \\
N\end{array}$ & $\begin{array}{l}3.09 \\
3.09 \\
3.08 \\
3.08 \\
3.06 \\
3.05\end{array}$ & $\begin{array}{l}206 \\
206 \\
203 \\
203 \\
197 \\
194\end{array}$ & $\begin{array}{l}3.06 \\
3.05 \\
3.04 \\
3.04 \\
3.03 \\
3.01\end{array}$ & & $\begin{array}{l}197 \\
194 \\
191 \\
191 \\
188 \\
182\end{array}$ & $\begin{array}{l}3.47 \\
3.51 \\
3.53 \\
3.54 \\
3.55 \\
3.56\end{array}$ & $\begin{array}{l}346 \\
366 \\
378 \\
384 \\
390 \\
397\end{array}$ & $\begin{array}{l}3.92 \\
3.95 \\
4.06 \\
4.11 \\
4.11 \\
4.13\end{array}$ & $\begin{array}{r}724 \\
764 \\
1,080 \\
1,400 \\
1,400 \\
1,490\end{array}$ & $\begin{array}{l}4.10 \\
4.12 \\
4.12 \\
4.15 \\
4.16 \\
4.16\end{array}$ & $\begin{array}{l}1,360 \\
1,450 \\
1,450 \\
1,580 \\
1,620 \\
1,620\end{array}$ & $\begin{array}{l}4.06 \\
4.09 \\
4.09 \\
4.08 \\
4.07 \\
4.05\end{array}$ & $\begin{array}{l}1,220 \\
1,320 \\
1,320 \\
1,290 \\
1,260 \\
1,180\end{array}$ \\
\hline $\begin{array}{l}1 \\
2 \\
3 \\
4 \\
5 \\
6\end{array}$ & $\begin{array}{l}3.05 \\
3.04 \\
3.03 \\
3.04 \\
3.04 \\
3.06\end{array}$ & $\begin{array}{l}194 \\
191 \\
188 \\
191 \\
191 \\
197\end{array}$ & $\begin{array}{l}2.99 \\
2.99 \\
2.97 \\
2.98 \\
2.98 \\
2.98\end{array}$ & & $\begin{array}{l}176 \\
176 \\
171 \\
174 \\
174 \\
174\end{array}$ & $\begin{array}{l}3.59 \\
3.62 \\
3.67 \\
3.73 \\
3.75 \\
3.77\end{array}$ & $\begin{array}{l}415 \\
436 \\
475 \\
525 \\
543 \\
561\end{array}$ & $\begin{array}{l}4.17 \\
4.17 \\
4.24 \\
4.23 \\
4.22 \\
4.17\end{array}$ & $\begin{array}{l}1,670 \\
1,670 \\
1,980 \\
1,940 \\
1,890 \\
1,670\end{array}$ & $\begin{array}{l}4.16 \\
4.16 \\
4.17 \\
4.18 \\
4.16 \\
4.15\end{array}$ & $\begin{array}{l}1,620 \\
1,620 \\
1,670 \\
1,710 \\
1,620 \\
1,580\end{array}$ & $\begin{array}{l}4.02 \\
4.01 \\
4.01 \\
4.01 \\
4.02 \\
4.01\end{array}$ & $\begin{array}{l}1,080 \\
1,040 \\
1,040 \\
1,040 \\
1,080 \\
1,040\end{array}$ \\
\hline \multirow[t]{2}{*}{$\begin{array}{r}7 \\
8 \\
9 \\
10 \\
17 \\
M\end{array}$} & $\begin{array}{l}3.08 \\
3.09 \\
3.10 \\
3.11 \\
3.11 \\
3.11\end{array}$ & $\begin{array}{l}203 \\
206 \\
209 \\
212 \\
212 \\
212\end{array}$ & $\begin{array}{l}2.97 \\
2.96 \\
2.97 \\
2.98 \\
2.99 \\
2.99\end{array}$ & & $\begin{array}{l}171 \\
169 \\
171 \\
174 \\
176 \\
176\end{array}$ & $\begin{array}{l}3.80 \\
3.80 \\
3.80 \\
3.81 \\
3.81 \\
3.82\end{array}$ & $\begin{array}{l}588 \\
588 \\
588 \\
599 \\
599 \\
610\end{array}$ & $\begin{array}{l}4.14 \\
4.09 \\
4.09 \\
4.04 \\
4.10 \\
4.09\end{array}$ & $\begin{array}{l}1,540 \\
1,320 \\
1,320 \\
1,150 \\
1,360 \\
1,320\end{array}$ & $\begin{array}{l}4.14 \\
4.14 \\
4.14 \\
4.14 \\
4.13 \\
4.11\end{array}$ & $\begin{array}{l}1,540 \\
1,540 \\
1,540 \\
1,540 \\
1,490 \\
1,400\end{array}$ & $\begin{array}{l}4.01 \\
4.01 \\
4.01 \\
4.00 \\
3.98 \\
3.96\end{array}$ & $\begin{array}{r}1,040 \\
1,040 \\
1,040 \\
1,010 \\
968 \\
926\end{array}$ \\
\hline & \multicolumn{2}{|c|}{ September 24} & \multicolumn{2}{|c|}{ September 2} & 25 & \multicolumn{2}{|c|}{ September 26} & \multicolumn{2}{|c|}{ September 27} & \multicolumn{2}{|c|}{ September 28} & \multicolumn{2}{|c|}{ September 29} \\
\hline $\begin{array}{r}2 \\
4 \\
6 \\
8 \\
10 \\
N\end{array}$ & $\begin{array}{l}3.95 \\
3.93 \\
3.91 \\
3.90 \\
3.87 \\
3.85\end{array}$ & $\begin{array}{l}905 \\
863 \\
821 \\
800 \\
755 \\
725\end{array}$ & $\begin{array}{l}3.70 \\
3.67 \\
3.64 \\
3.61 \\
3.59 \\
3.57\end{array}$ & & $\begin{array}{l}535 \\
508 \\
481 \\
454 \\
438 \\
424\end{array}$ & $\begin{array}{l}3.42 \\
3.40 \\
3.38 \\
3.37 \\
3.36 \\
3.34\end{array}$ & $\begin{array}{l}331 \\
320 \\
311 \\
306 \\
302 \\
293\end{array}$ & $\begin{array}{l}3.24 \\
3.23 \\
3.22 \\
3.21 \\
3.20 \\
3.19\end{array}$ & $\begin{array}{l}254 \\
250 \\
247 \\
244 \\
240 \\
237\end{array}$ & $\begin{array}{l}3.20 \\
3.19 \\
3.19 \\
3.19 \\
3.19 \\
3.19\end{array}$ & $\begin{array}{l}240 \\
237 \\
237 \\
237 \\
237 \\
237\end{array}$ & $\begin{array}{l}3.13 \\
3.12 \\
3.11 \\
3.09 \\
3.08 \\
3.08\end{array}$ & $\begin{array}{l}218 \\
215 \\
212 \\
206 \\
203 \\
203\end{array}$ \\
\hline $\begin{array}{r}2 \\
4 \\
6 \\
8 \\
10 \\
M\end{array}$ & $\begin{array}{l}3.83 \\
3.81 \\
3.79 \\
3.78 \\
3.75 \\
3.73\end{array}$ & $\begin{array}{l}695 \\
665 \\
638 \\
627 \\
592 \\
570\end{array}$ & $\begin{array}{l}3.55 \\
3.52 \\
3.50 \\
3.48 \\
3.46 \\
3.44\end{array}$ & & $\begin{array}{l}410 \\
389 \\
375 \\
364 \\
353 \\
342\end{array}$ & $\begin{array}{l}3.33 \\
3.30 \\
3.28 \\
3.27 \\
3.26 \\
3.25\end{array}$ & $\begin{array}{l}288 \\
275 \\
268 \\
264 \\
261 \\
258\end{array}$ & $\begin{array}{l}3.19 \\
3.21 \\
3.22 \\
3.21 \\
3.21 \\
3.21\end{array}$ & $\begin{array}{l}237 \\
244 \\
247 \\
244 \\
244 \\
244\end{array}$ & $\begin{array}{l}3.19 \\
3.18 \\
3.17 \\
3.16 \\
3.15 \\
3.14\end{array}$ & $\begin{array}{l}237 \\
234 \\
231 \\
228 \\
224 \\
221\end{array}$ & $\begin{array}{l}3.06 \\
3.05 \\
3.04 \\
3.08 \\
3.01 \\
3.00\end{array}$ & $\begin{array}{l}197 \\
194 \\
191 \\
188 \\
182 \\
179\end{array}$ \\
\hline
\end{tabular}

Supplemental records.- Sept. $21,3: 15$ p.m., $4.25 \mathrm{ft} ., 2,030$ sec. $-\mathrm{ft}$. 


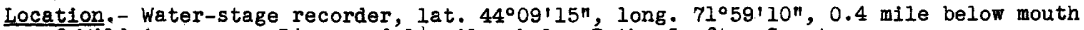
of WIId Ammonoosuc River and $1 \frac{1}{2}$ miles below Bath, Grafton County.

Drainage area.- 393 square miles.

Gage-helght record.- Water-stage recorder graph except for period Sept. 1 to 4 p.m. Sept. 14, record for which. was based on 3 tage graphs at nearby stations.

Stage-discharge relation.- Defined by current-meter measurements below 12,800 secondfeet; extended to perk stage by velocity-area study at measuring section.

Maxima.- September 1938: Discharge, 26,800 second-feet 6 p.m. Sept. 2l (gage height, 15.07 feet)

1935 to August 1938: D1scharge, 27,900 second-feet Mar. 18, 1936 (gage helght, 15.40 feet).

Remarks.- Flood run-off not materially affected by artificial or natural storage.

Mean daily discharge, in second-feet, 1938

\begin{tabular}{|c|c|c|c|c|c|c|c|c|c|c|c|}
\hline Day & Sept. & Oct. & Day & Sept. & Oct. & Day & Sept. & $0 \mathrm{ct}$. & Day & Sopt. & Oct. \\
\hline $\begin{array}{l}1 \\
2 \\
3 \\
4 \\
5 \\
6 \\
7 \\
8\end{array}$ & $\begin{array}{l}470 \\
370 \\
280 \\
270 \\
260 \\
250 \\
260 \\
310 \\
\end{array}$ & $\begin{array}{l}637 \\
575 \\
536 \\
531 \\
469 \\
407 \\
394 \\
380 \\
\end{array}$ & $\begin{array}{r}9 \\
10 \\
11 \\
12 \\
13 \\
14 \\
15 \\
16\end{array}$ & $\begin{array}{l}270 \\
240 \\
230 \\
220 \\
630 \\
450 \\
778 \\
932\end{array}$ & $\begin{array}{l}349 \\
358 \\
319 \\
311 \\
303 \\
292 \\
272 \\
258\end{array}$ & $\begin{array}{l}17 \\
18 \\
19 \\
20 \\
21 \\
22 \\
23 \\
24\end{array}$ & $\begin{array}{r}536 \\
400 \\
367 \\
1,770 \\
16,300 \\
13,000 \\
3,280 \\
1,960\end{array}$ & $\begin{array}{l}245 \\
245 \\
232 \\
239 \\
512 \\
542 \\
383 \\
669\end{array}$ & $\begin{array}{l}25 \\
26 \\
27 \\
28 \\
29 \\
30 \\
31\end{array}$ & $\begin{array}{r}1,550 \\
1,190 \\
999 \\
1,040 \\
849 \\
714\end{array}$ & $\begin{array}{r}2,550 \\
1,220 \\
828 \\
654 \\
547 \\
494 \\
444\end{array}$ \\
\hline $\begin{array}{l}\text { Mean } \\
\text { Run- }\end{array}$ & $\begin{array}{l}\text { nthly } \\
\text {, in }\end{array}$ & & , 1 &.$\cdot$ & at. : & $: \dot{ }$ & $: \dot{*}$ & $\begin{array}{l}\cdot \\
.\end{array}$ & $\dot{0}$ & $\begin{array}{r}1,672 \\
4.74 \\
\end{array}$ & $\begin{array}{r}522 \\
1.53 \\
\end{array}$ \\
\hline
\end{tabular}

Gage helght, in feet, and discharge, in second-feet, at indicated time, 1938

\begin{tabular}{|c|c|c|c|c|c|c|c|c|c|c|c|c|}
\hline \multirow{2}{*}{$\begin{array}{l}9 \\
0 \\
0\end{array}$} & Feet & Sec.ft. & Feot & Sec.ft. & Feet & Sec.ft. & Feet & Bec.ft. & Feet & Sec.ft. & Feet & Sec.ft \\
\hline & \multicolumn{2}{|c|}{ September 18} & \multicolumn{2}{|c|}{ September 19} & \multicolumn{2}{|c|}{ September 20} & \multicolumn{2}{|c|}{ September 21} & \multicolumn{2}{|c|}{ September 22} & \multicolumn{2}{|c|}{ September 23} \\
\hline $\begin{array}{l}7 \\
2 \\
3 \\
4 \\
5 \\
6\end{array}$ & $\begin{array}{l}2.90 \\
2.89 \\
2.80 \\
2.80 \\
2.83 \\
2.84\end{array}$ & $\begin{array}{l}444 \\
439 \\
398 \\
398 \\
412 \\
416\end{array}$ & $\begin{array}{l}2.75 \\
2.71 \\
2.67 \\
2.62 \\
2.67 \\
2.69\end{array}$ & \begin{tabular}{|l|}
376 \\
358 \\
340 \\
319 \\
340 \\
349
\end{tabular} & $\begin{array}{l}2.80 \\
2.84 \\
2.88 \\
2.93 \\
3.20 \\
3.42\end{array}$ & $\begin{array}{l}398 \\
416 \\
435 \\
459 \\
603 \\
733\end{array}$ & $\begin{array}{l}6.88 \\
7.24 \\
7.70 \\
8.01 \\
8.26 \\
8.50\end{array}$ & $\begin{array}{l}4,210 \\
4,780 \\
5,600 \\
6,220 \\
6,730 \\
7,260\end{array}$ & $\begin{array}{l}13.90 \\
13.90 \\
13.80 \\
13.57 \\
13.23 \\
12.85\end{array}$ & $\begin{array}{l}22,800 \\
22,800 \\
22,500 \\
21,800 \\
20,700 \\
19,400\end{array}$ & $\begin{array}{l}7.11 \\
6.99 \\
6.88 \\
6.78 \\
6.68 \\
6.59\end{array}$ & $\begin{array}{l}4,580 \\
4,380 \\
4,210 \\
4,050 \\
3,910 \\
3,790\end{array}$ \\
\hline $\begin{array}{r}7 \\
8 \\
9 \\
10 \\
11 \\
N\end{array}$ & $\begin{array}{l}2.84 \\
2.84 \\
2.83 \\
2.88 \\
2.87 \\
2.80\end{array}$ & $\begin{array}{l}416 \\
416 \\
412 \\
435 \\
430 \\
398\end{array}$ & $\begin{array}{l}2.69 \\
2.70 \\
2.79 \\
2.79 \\
2.76 \\
2.72\end{array}$ & $\begin{array}{l}349 \\
353 \\
394 \\
394 \\
380 \\
362\end{array}$ & $\begin{array}{l}3.62 \\
4.00 \\
4.25 \\
4.37 \\
4.40 \\
4.45\end{array}$ & $\begin{array}{r}861 \\
1,120 \\
1,300 \\
1,390 \\
1,410 \\
1,450\end{array}$ & $\begin{array}{r}.8 .80 \\
9.17 \\
9.68 \\
10.40 \\
11.60 \\
12.70\end{array}$ & $\begin{array}{r}7,920 \\
8,770 \\
10,000 \\
12,000 \\
15,600 \\
19,000\end{array}$ & $\begin{array}{l}12.50 \\
12.05 \\
11.58 \\
11.10 \\
10.68 \\
10.25\end{array}$ & $\begin{array}{l}18,400 \\
17,000 \\
15,500 \\
14,100 \\
12,800 \\
11,500\end{array}$ & $\begin{array}{l}6.52 \\
6.42 \\
6.35 \\
6.29 \\
6.19 \\
5.99\end{array}$ & $\begin{array}{l}3,690 \\
3,550 \\
3,450 \\
3,370 \\
3,250 \\
3,010\end{array}$ \\
\hline $\begin{array}{l}1 \\
2 \\
3 \\
4 \\
5\end{array}$ & $\begin{array}{l}2.78 \\
2.78 \\
2.77 \\
2.70 \\
2.70 \\
2.78\end{array}$ & $\begin{array}{l}389 \\
389 \\
384 \\
353 \\
353 \\
389\end{array}$ & $\begin{array}{l}2.72 \\
2.70 \\
2.67 \\
2.66 \\
2.70 \\
2.79\end{array}$ & $\begin{array}{l}362 \\
353 \\
340 \\
336 \\
353 \\
394\end{array}$ & $\begin{array}{l}4.63 \\
4.95 \\
5.18 \\
5.35 \\
5.58 \\
5.80\end{array}$ & $\begin{array}{l}1,590 \\
1,860 \\
2,080 \\
2,250 \\
2,520 \\
2,780\end{array}$ & $\begin{array}{l}13.60 \\
13.98 \\
14.22 \\
14.60 \\
14.92 \\
15.07\end{array}$ & $\begin{array}{l}21,900 \\
23,100 \\
23,900 \\
25,200 \\
26,300 \\
26,800\end{array}$ & $\begin{array}{l}9.85 \\
9.49 \\
9.15 \\
8.85 \\
8.55 \\
8.28\end{array}$ & $\begin{array}{r}10,400 \\
9,540 \\
8,720 \\
8,030 \\
7,370 \\
6,780\end{array}$ & $\begin{array}{l}6.00 \\
5.98 \\
5.90 \\
5.82 \\
5.80 \\
5.74\end{array}$ & $\begin{array}{l}3,020 \\
3,000 \\
2,900 \\
2,800 \\
2,780 \\
2,710\end{array}$ \\
\hline \multirow[t]{2}{*}{$\begin{array}{r}7 \\
8 \\
9 \\
10 \\
11 \\
11 \\
\end{array}$} & $\begin{array}{l}2.79 \\
2.73 \\
2.72 \\
2.79 \\
2.79 \\
2.82\end{array}$ & $\begin{array}{l}394 \\
366 \\
362 \\
394 \\
394 \\
407\end{array}$ & $\begin{array}{l}2.81 \\
2.80 \\
2.78 \\
2.78 \\
2.78 \\
2.78\end{array}$ & $\begin{array}{l}408 \\
398 \\
389 \\
389 \\
389 \\
389\end{array}$ & $\begin{array}{l}6.00 \\
6.10 \\
6.19 \\
6.38 \\
6.57 \\
6.69\end{array}$ & $\begin{array}{l}3,020 \\
3,140 \\
3,250 \\
3,490 \\
3,760 \\
3,930\end{array}$ & $\begin{array}{l}14.91 \\
14.77 \\
14.35 \\
14.10 \\
13.91 \\
13.84\end{array}$ & $\begin{array}{l}26,200 \\
25,700 \\
24,400 \\
23,500 \\
22,800 \\
22,600\end{array}$ & $\begin{array}{l}8.05 \\
7.87 \\
7.68 \\
7.52 \\
7.37 \\
7.23\end{array}$ & $\begin{array}{l}6,300 \\
5,940 \\
5,560 \\
5,280 \\
5,010 \\
4,770\end{array}$ & $\begin{array}{l}5.70 \\
5.61 \\
5.59 \\
5.55 \\
5.50 \\
5.43\end{array}$ & $\begin{array}{l}2,660 \\
2,550 \\
2,530 \\
2,480 \\
2,420 \\
2,340\end{array}$ \\
\hline & \multicolumn{2}{|c|}{ September 24} & \multicolumn{2}{|c|}{ September 25} & \multicolumn{2}{|c|}{ September 26} & \multicolumn{2}{|c|}{ September 27} & \multicolumn{2}{|c|}{ September 28} & \multicolumn{2}{|c|}{ September 29} \\
\hline $\begin{array}{r}2 \\
4 \\
6 \\
8 \\
10 \\
N\end{array}$ & $\begin{array}{l}5.36 \\
5.27 \\
5.20 \\
5.14 \\
5.07 \\
5.00\end{array}$ & $\begin{array}{l}2,260 \\
2,170 \\
2,100 \\
2,040 \\
1,970 \\
1,900\end{array}$ & $\begin{array}{l}4.80 \\
4.77 \\
4.73 \\
4.66 \\
4.64 \\
4.58\end{array}$ & $\begin{array}{l}1,730 \\
1,710 \\
1,670 \\
1,620 \\
1,600 \\
1,550\end{array}$ & $\begin{array}{l}4.25 \\
4.21 \\
4.19 \\
4.17 \\
4.12 \\
4.10\end{array}$ & $\begin{array}{l}1,300 \\
1,270 \\
1,250 \\
1,240 \\
1,200 \\
1,190\end{array}$ & $\begin{array}{l}3.87 \\
3.86 \\
3.83 \\
3.80 \\
3.80 \\
3.77\end{array}$ & $\begin{array}{r}1,030 \\
1,020 \\
1,000 \\
982 \\
982 \\
962\end{array}$ & $\begin{array}{l}3.93 \\
3.97 \\
3.97 \\
3.96 \\
3.95 \\
3.92\end{array}$ & $\begin{array}{l}1,070 \\
1,100 \\
1,100 \\
1,090 \\
1,080 \\
1,060\end{array}$ & $\begin{array}{l}3.69 \\
3.68 \\
3.65 \\
3.63 \\
3.62 \\
3.59\end{array}$ & $\begin{array}{l}908 \\
902 \\
882 \\
868 \\
861 \\
842\end{array}$ \\
\hline $\begin{array}{r}2 \\
4 \\
6 \\
8 \\
10 \\
M\end{array}$ & $\begin{array}{l}4.95 \\
4.90 \\
4.88 \\
4.87 \\
4.84 \\
4.81\end{array}$ & $\begin{array}{l}1,860 \\
1,810 \\
1,794 \\
1,786 \\
1,760 \\
1,740\end{array}$ & $\begin{array}{l}4.54 \\
4.49 \\
4.44 \\
4.40 \\
4.34 \\
4.30\end{array}$ & $\begin{array}{l}1,520 \\
1,480 \\
1,440 \\
1,410 \\
1,360 \\
1,330\end{array}$ & $\begin{array}{l}4.08 \\
4.02 \\
4.00 \\
3.98 \\
3.93 \\
3.90\end{array}$ & $\begin{array}{l}1,180 \\
1,130 \\
1,120 \\
1,110 \\
1,070 \\
1,050\end{array}$ & $\begin{array}{l}3.78 \\
3.79 \\
3.80 \\
3.84 \\
3.87 \\
3.90\end{array}$ & $\begin{array}{r}969 \\
975 \\
982 \\
1,010 \\
1,030 \\
1,050\end{array}$ & $\begin{array}{l}3.90 \\
3.88 \\
3.83 \\
3.81 \\
3.76 \\
3.72\end{array}$ & $\begin{array}{r}1,050 \\
1,040 \\
1,000 \\
989 \\
955 \\
928\end{array}$ & $\begin{array}{l}3.58 \\
3.57 \\
3.58 \\
3.60 \\
3.43 \\
3.44\end{array}$ & $\begin{array}{l}835 \\
828 \\
835 \\
848 \\
739 \\
745\end{array}$ \\
\hline
\end{tabular}


White River near Bethel, Vt.

Location. - Water-stage recorder, lat. $43^{\circ} 48^{\prime} 45^{n}$, long. $72^{\circ} 39^{\prime} 25^{n}$, a third of a mile above mouth of Locust Creek and $13 / 4$ miles southwest of Bethel, Windsor County. Drainage area.- 241 square miles.

Gage-helght record.- Water-stage recorder graph.

Stage-discharge relation.- Defined by current-meter measurements below 5,090 secondfeet; extended to peak stage on basis of determinations of flood flows over dam and by slope-area method.

Maxima.- September 1938: D1scharge, 32,20n. second-feet, midnight Sept. 21 (gage height, 9.46 feet)

1931 to August 1938: Maximum discharge, 16,100 second-feet, Mar. 18, 1936

(gage helght, 6.72 feet); maximum gage height, 8.32 feet Mar. 27, 1934 (affected by 1ce).

Remarks.- Flood mun-off not materially affected by artificial or natural storage.

Mear dally discharge, in second-feet, 1938

\begin{tabular}{|c|r|r||r|r|r||r|r|r|r|r|r|}
\hline Day & Sept. & \multicolumn{1}{|c|}{ 0ct. } & Day & \multicolumn{1}{|c|}{ Sept. } & Oct. & Day & Sept. & 0ct. & Day & Sept. & 0ct. \\
\hline 1 & 230 & 485 & 9 & 230 & 286 & 17 & 778 & 206 & 25 & 1,090 & 675 \\
2 & 215 & 437 & 10 & 190 & 270 & 18 & 773 & 198 & 26 & 836 & 580 \\
3 & 185 & 404 & 11 & 168 & 260 & 19 & 733 & 188 & 27 & 714 & 485 \\
4 & 232 & 379 & 12 & 160 & 250 & 20 & 2,020 & 184 & 28 & 754 & 360 \\
5 & 205 & 355 & 13 & 723 & 240 & 21 & 9,190 & 224 & 29 & 609 & 265 \\
6 & 172 & 331 & 14 & 455 & 230 & 22 & 9,250 & 276 & 30 & 535 & 250 \\
7 & 175 & 303 & 15 & 1,780 & 220 & 23 & 2,360 & 255 & 31 & & 235 \\
8 & 382 & 292 & 16 & 1,200 & 211 & 24 & 1,530 & 269 & & & \\
\hline
\end{tabular}

Gage height, in feet, and discharge, in second-feet, at indicated time, 1938

\begin{tabular}{|c|c|c|c|c|c|c|c|c|c|c|c|c|}
\hline \multirow{2}{*}{ 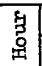 } & eot & Sec.ft. & reot & Sect.ft. & Feot & sec.ft. & Feet & Sec.ft. & Feet & Sec.ft. & Feot & Sec.ft. \\
\hline & \multicolumn{2}{|c|}{ September 18} & \multicolumn{2}{|c|}{ September 19} & \multicolumn{2}{|c|}{ September 20} & \multicolumn{2}{|c|}{ September 21} & \multicolumn{2}{|c|}{ September 22} & \multicolumn{2}{|c|}{ September 23} \\
\hline 1 & $\begin{array}{l}1.54 \\
1.59 \\
1.64 \\
1.69 \\
1.70\end{array}$ & $\begin{array}{l}678 \\
696 \\
741 \\
788 \\
836 \\
845\end{array}$ & $\begin{array}{l}1.5 \\
1.5 \\
1.5 \\
1.5 \\
1.5\end{array}$ & $\begin{array}{l}687 \\
678 \\
669 \\
669 \\
660 \\
660\end{array}$ & $\begin{array}{l}1.77 \\
1.84 \\
1.95 \\
2.15 \\
2.37 \\
2.53\end{array}$ & $\begin{array}{r}912 \\
980 \\
1,100 \\
1,330 \\
1,620 \\
1,860\end{array}$ & & & & & & \\
\hline 7 & $\begin{array}{l}1.71 \\
1.71 \\
1.70 \\
1.69 \\
1.68 \\
1.68\end{array}$ & $\begin{array}{l}854 \\
854 \\
845 \\
836 \\
826 \\
826\end{array}$ & $\begin{array}{l}1.50 \\
1.50 \\
1.50 \\
1.53 \\
1.56 \\
1.59\end{array}$ & $\begin{array}{l}660 \\
660 \\
660 \\
687 \\
714 \\
741\end{array}$ & $\begin{array}{l}2.59 \\
2.60 \\
2.59 \\
2.58 \\
2.58 \\
2.59\end{array}$ & $\begin{array}{l}1,940 \\
1,960 \\
1,940 \\
1,930 \\
1,930 \\
1,940\end{array}$ & 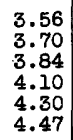 & & $\begin{array}{l}0 \\
9 \\
3 \\
9 \\
4 \\
6\end{array}$ & & & \\
\hline $\begin{array}{l}1 \\
2\end{array}$ & $\begin{array}{l}1.66 \\
1.64 \\
1.62 \\
1.62 \\
1.60 \\
1.60\end{array}$ & $\begin{array}{l}807 \\
788 \\
769 \\
769 \\
750 \\
750\end{array}$ & $\begin{array}{l}1.61 \\
1.62 \\
1.63 \\
1.64 \\
1.64 \\
1.64\end{array}$ & $\begin{array}{l}760 \\
769 \\
778 \\
788 \\
788 \\
788\end{array}$ & $\begin{array}{l}2.63 \\
2.68 \\
2.73 \\
2.77 \\
2.86 \\
2.92\end{array}$ & $\begin{array}{l}2,010 \\
2,090 \\
2,170 \\
2,230 \\
2,380 \\
2,480\end{array}$ & $\begin{array}{l}4.70 \\
4.89 \\
5.04 \\
5.17 \\
5.38 \\
5.65\end{array}$ & $\begin{array}{r}6,750 \\
7,370 \\
7,880 \\
8,340 \\
9,120 \\
10,190\end{array}$ & & & & \\
\hline \multirow[t]{2}{*}{$\begin{array}{r}7 \\
8 \\
9 \\
10 \\
11 \\
M\end{array}$} & $\begin{array}{l}1.58 \\
1.58 \\
1.57 \\
1.56 \\
1.55 \\
1.54\end{array}$ & $\begin{array}{l}732 \\
732 \\
723 \\
714 \\
705 \\
696 \\
\end{array}$ & $\begin{array}{l}1.64 \\
1.64 \\
1.64 \\
1.66 \\
1.68 \\
1.70\end{array}$ & $\begin{array}{l}788 \\
788 \\
788 \\
807 \\
826 \\
845\end{array}$ & $\begin{array}{l}2.99 \\
3.04 \\
3.06 \\
3.10 \\
3.14 \\
3.19\end{array}$ & $\begin{array}{l}2,600 \\
2,690 \\
2,730 \\
2,800 \\
2,870 \\
2,960\end{array}$ & $\begin{array}{l}.08 \\
.14 \\
.09 \\
.29 \\
.03 \\
.46\end{array}$ & & $\begin{array}{l}3.51 \\
3.44 \\
3.32 \\
3.27 \\
3.22\end{array}$ & & & \\
\hline & \multicolumn{2}{|c|}{ September 24} & \multicolumn{2}{|c|}{ September 25} & \multicolumn{2}{|c|}{ September 26} & \multicolumn{2}{|c|}{ September 27} & \multicolumn{2}{|c|}{ September 28} & \multicolumn{2}{|c|}{ September 29} \\
\hline 2 & $\begin{array}{l}2.37 \\
2.32 \\
2.28 \\
2.25 \\
2.22 \\
2.19\end{array}$ & & $\begin{array}{l}1.97 \\
1.93 \\
1.90 \\
1.87 \\
1.84 \\
1.82\end{array}$ & $\begin{array}{l}1,250 \\
1,210\end{array}$ & $\begin{array}{l}1.67 \\
1.64 \\
1.63 \\
1.61 \\
1.59 \\
1.58\end{array}$ & & $\begin{array}{l}1.47 \\
1.46 \\
1.44 \\
1.43 \\
1.42 \\
1.41\end{array}$ & $\begin{array}{l}734 \\
726 \\
709 \\
700\end{array}$ & $\begin{array}{l}1.59 \\
1.58 \\
1.55 \\
1.53 \\
1.50 \\
1.49\end{array}$ & & & 651 \\
\hline 1 & $\begin{array}{l}2.16 \\
2.12 \\
2.09 \\
2.05 \\
2.02 \\
1.99\end{array}$ & $\begin{array}{l}1,49 \\
1,44 \\
1,40 \\
1,35 \\
1,31 \\
1,28\end{array}$ & $\begin{array}{l}1.80 \\
1.77 \\
1.75 \\
1.73 \\
1.70 \\
1.68\end{array}$ & $\begin{array}{l}1,060 \\
1,030 \\
1,000\end{array}$ & $\begin{array}{l}1 . \\
1 . \\
1 . \\
1 .\end{array}$ & & $\begin{array}{l}1.41 \\
1.41 \\
1.45 \\
1.50 \\
1.57\end{array}$ & $\begin{array}{l}684 \\
684 \\
718 \\
760 \\
823\end{array}$ & $\begin{array}{l}1.5 \\
1.5 \\
1.5 \\
1.2 \\
1.2\end{array}$ & 658 & $\begin{array}{l}1.01 \\
1.30 \\
1.28 \\
1.27 \\
1.26 \\
1.26\end{array}$ & $\begin{array}{l}95 \\
80\end{array}$ \\
\hline
\end{tabular}


Location. - Water-stage recorder, lat. $43^{\circ} 42^{\prime} 45^{\prime \prime}$, long. $72^{\circ} 25^{\prime} 10^{\prime \prime}$, 500 feet above highway bridge at West Hartford, Windsor County, and 7 miles above mouth of river. Zero of gage is 374.22 feet above mean sea level.

Drainage area.- 690 square miles.

Gage-helght record.- Water-stage recorder graph.

Stage-discharge relation.- Defined by current-meter measurements below 12,800 secondfeet, extended to peak stage on basis of determination of flood flow by slope-area method.

Maxima.- September 1938: Discharge, 47,600 second-feet 3:30 a.m. Sept. 22 (gage height, 19.26 feet).

1915 to August 1938: Discharge, 120,000 second-feet Nov. 4, 1927 (gage height, 29.3 feet, from flood marks).

Remarks.- Flood run-off not materially affected by artificial or natural storage.

Mean dafly discharge, in second-feet, 1938

\begin{tabular}{|c|c|c|c|c|c|c|c|c|c|c|c|}
\hline Day & Sept. & oct. & Day & Sept. & Oct. & Day & Sept. & Oct. & Day & Sept. & Oct. \\
\hline $\begin{array}{l}1 \\
2 \\
3 \\
4 \\
5 \\
6 \\
7 \\
8\end{array}$ & $\begin{array}{l}505 \\
495 \\
435 \\
435 \\
500 \\
388 \\
370 \\
629\end{array}$ & $\begin{array}{r}1,450 \\
1,360 \\
1,220 \\
1,140 \\
1,060 \\
952 \\
924 \\
896\end{array}$ & $\begin{array}{r}9 \\
10 \\
11 \\
12 \\
13 \\
14 \\
15 \\
16\end{array}$ & $\begin{array}{r}536 \\
416 \\
380 \\
352 \\
1,030 \\
1,000 \\
2,340 \\
3,060\end{array}$ & $\begin{array}{l}840 \\
805 \\
758 \\
740 \\
704 \\
668 \\
650 \\
632\end{array}$ & $\begin{array}{l}17 \\
18 \\
19 \\
20 \\
21 \\
22 \\
23 \\
24\end{array}$ & $\begin{array}{r}1,550 \\
1,540 \\
1,480 \\
3,850 \\
12,900 \\
25,100 \\
6,300 \\
4,180\end{array}$ & $\begin{array}{l}608 \\
580 \\
550 \\
565 \\
770 \\
784 \\
644 \\
906\end{array}$ & $\begin{array}{l}25 \\
26 \\
27 \\
28 \\
29 \\
30 \\
31\end{array}$ & $\begin{array}{l}3,120 \\
2,480 \\
2,190 \\
2,240 \\
1,830 \\
1,600\end{array}$ & $\begin{array}{r}1,700 \\
1,140 \\
931 \\
826 \\
752 \\
698 \\
668\end{array}$ \\
\hline $\begin{array}{l}\text { Mean } \\
\text { Run- }\end{array}$ & $\begin{array}{c}\operatorname{th} l y \\
\text { in }\end{array}$ & & & & & & $\begin{array}{l}\cdot \cdot \cdot \\
.\end{array}$ & $\because \cdot \dot{*}$ & : & $\begin{array}{r}2,774 \\
4.48\end{array}$ & $\begin{array}{r}869 \\
1.45\end{array}$ \\
\hline
\end{tabular}

Gage height, in feet, and discharge, in second-feet, at indicated time, 1938

\begin{tabular}{|c|c|c|c|c|c|c|c|c|c|c|c|c|}
\hline \multirow{2}{*}{$\begin{array}{r}8 \\
3 \\
0 \\
0\end{array}$} & Feet & Sec.ft. & Feet & Sec.ft. & Feet & Sec.ft. & Feet & Sec.ft. & Feet & Sec.ft. & Feet & Sec.ft. \\
\hline & \multicolumn{2}{|c|}{ September 18} & \multicolumn{2}{|c|}{ September 19} & \multicolumn{2}{|c|}{ September 20} & \multicolumn{2}{|c|}{ September 21} & \multicolumn{2}{|c|}{ September 22} & \multicolumn{2}{|c|}{ September 23} \\
\hline $\begin{array}{l}1 \\
2 \\
3 \\
4 \\
5 \\
6\end{array}$ & $\begin{array}{l}5.05 \\
5.05 \\
5.06 \\
5.07 \\
5.08 \\
5.10\end{array}$ & $\begin{array}{l}1,355 \\
1,355 \\
1,364 \\
1,370 \\
1,380 \\
1,400\end{array}$ & $\begin{array}{l}5.24 \\
5.22 \\
5.20 \\
5.18 \\
5.17 \\
5.16\end{array}$ & $\begin{array}{l}1,540 \\
1,520 \\
1,500 \\
1,480 \\
1,470 \\
1,460\end{array}$ & $\begin{array}{l}5.46 \\
5.62 \\
5.85 \\
5.91 \\
6.00 \\
6.10\end{array}$ & $\begin{array}{l}1,770 \\
1,940 \\
2,210 \\
2,280 \\
2,390 \\
2,520\end{array}$ & $\begin{array}{l}8.66 \\
8.73 \\
8.80 \\
8.90 \\
9.03 \\
9.11\end{array}$ & $\begin{array}{l}6,740 \\
6,880 \\
7,020 \\
7,220 \\
7,490 \\
7,660\end{array}$ & $\begin{array}{l}18.32 \\
19.05 \\
19.24 \\
19.25 \\
19.09 \\
18.60\end{array}$ & $\begin{array}{l}41,900 \\
46,300 \\
47,400 \\
47,500 \\
46,500 \\
43,600\end{array}$ & $\begin{array}{l}9.35 \\
9.23 \\
9.12 \\
9.01 \\
8.92 \\
8.81\end{array}$ & $\begin{array}{l}8,190 \\
7,930 \\
7,680 \\
7,440 \\
7,260 \\
7,040\end{array}$ \\
\hline $\begin{array}{r}7 \\
8 \\
9 \\
10 \\
11 \\
N\end{array}$ & $\begin{array}{l}5.11 \\
5.13 \\
5.18 \\
5.23 \\
5.30 \\
5.35\end{array}$ & $\begin{array}{l}1,410 \\
1,430 \\
1,480 \\
1,530 \\
1,600 \\
1,650\end{array}$ & $\begin{array}{l}5.14 \\
5.13 \\
5.12 \\
5.11 \\
5.10 \\
5.10\end{array}$ & $\begin{array}{l}1,440 \\
1,430 \\
1,420 \\
1,410 \\
1,400 \\
1,400\end{array}$ & $\begin{array}{l}6.20 \\
6.32 \\
6.51 \\
6.79 \\
7.08 \\
7.26\end{array}$ & $\begin{array}{l}2,650 \\
2,810 \\
3,070 \\
3,480 \\
3,940 \\
4,230\end{array}$ & $\begin{array}{r}9.20 \\
9.37 \\
9.59 \\
9.81 \\
10.08 \\
10.40\end{array}$ & $\begin{array}{r}7,860 \\
8,230 \\
8,720 \\
9,240 \\
9,890 \\
10,700\end{array}$ & $\begin{array}{l}17.80 \\
16.88 \\
15.92 \\
15.01 \\
14.17 \\
13.40\end{array}$ & $\begin{array}{l}39,000 \\
34,400 \\
29,700 \\
26,000 \\
22,900 \\
20,000\end{array}$ & $\begin{array}{l}8.72 \\
8.64 \\
8.56 \\
8.50 \\
8.41 \\
8.34\end{array}$ & $\begin{array}{l}6,860 \\
6,700 \\
6,540 \\
6,430 \\
6,260 \\
6,130\end{array}$ \\
\hline $\begin{array}{l}1 \\
2 \\
3 \\
4 \\
5 \\
6\end{array}$ & $\begin{array}{l}5.39 \\
5.40 \\
5.41 \\
5.40 \\
5.39 \\
5.38\end{array}$ & $\begin{array}{l}1,690 \\
1,700 \\
1,710 \\
1,700 \\
1,690 \\
1,680\end{array}$ & $\begin{array}{l}5.10 \\
5.09 \\
5.09 \\
5.10 \\
5.12 \\
5.16\end{array}$ & $\begin{array}{l}1,400 \\
1,390 \\
1,390 \\
1,400 \\
1,420 \\
1,460\end{array}$ & $\begin{array}{l}7.36 \\
7.39 \\
7.43 \\
7.46 \\
7.49 \\
7.60\end{array}$ & $\begin{array}{l}4,390 \\
4,440 \\
4,510 \\
4,560 \\
4,610 \\
4,800\end{array}$ & $\begin{array}{l}10.71 \\
10.96 \\
11.29 \\
11.61 \\
11.90 \\
12.29\end{array}$ & $\begin{array}{l}11,500 \\
12,300 \\
13,200 \\
14,100 \\
15,000 \\
16,200\end{array}$ & $\begin{array}{l}12.73 \\
12.16 \\
11.70 \\
11.32 \\
10.99 \\
10.73\end{array}$ & $\begin{array}{l}17,700 \\
15,800 \\
14,400 \\
13,300 \\
12,300 \\
11,600\end{array}$ & $\begin{array}{l}8.28 \\
8.21 \\
8.14 \\
8.07 \\
8.02 \\
7.96\end{array}$ & $\begin{array}{l}010 \\
880 \\
750 \\
630 \\
540 \\
430\end{array}$ \\
\hline \multirow[t]{2}{*}{$\begin{array}{r}7 \\
8 \\
9 \\
10 \\
11 \\
\end{array}$} & $\begin{array}{l}5.36 \\
5.34 \\
5.32 \\
5.30 \\
5.28 \\
5.26\end{array}$ & $\begin{array}{l}1,660 \\
1,640 \\
1,620 \\
1,600 \\
1,580 \\
1,560\end{array}$ & $\begin{array}{l}5.21 \\
5.26 \\
5.29 \\
5.32 \\
5.34 \\
5.38\end{array}$ & $\begin{array}{l}1,510 \\
1,560 \\
1,590 \\
1,620 \\
1,640 \\
1,680\end{array}$ & $\begin{array}{l}7.77 \\
7.88 \\
8.02 \\
8.15 \\
8.31 \\
8.51\end{array}$ & $\begin{array}{l}5,090 \\
5,280 \\
5,540 \\
5,770 \\
6,070 \\
6,450\end{array}$ & $\begin{array}{l}12.57 \\
12.90 \\
13.69 \\
14.47 \\
15.40 \\
17.00\end{array}$ & $\begin{array}{l}17,100 \\
18,300 \\
21,100 \\
24,000 \\
27,600 \\
35,000\end{array}$ & $\begin{array}{r}10.47 \\
10.24 \\
10.08 \\
9.90 \\
9.73 \\
9.59\end{array}$ & $\begin{array}{r}10,900 \\
10,300 \\
9,890 \\
9,460 \\
9,050 \\
8,720 \\
\end{array}$ & $\begin{array}{l}7.89 \\
7.84 \\
7.80 \\
7.74 \\
7.69 \\
7.65 \\
\end{array}$ & $\begin{array}{l}5,300 \\
5,210 \\
5,140 \\
5,040 \\
4,940 \\
4,880\end{array}$ \\
\hline & \multicolumn{2}{|c|}{ September 24} & \multicolumn{2}{|c|}{ September 25} & \multicolumn{2}{|c|}{ September 26} & \multicolumn{2}{|c|}{ September 27} & \multicolumn{2}{|c|}{ September 28} & \multicolumn{2}{|c|}{ September 29} \\
\hline $\begin{array}{r}2 \\
4 \\
6 \\
8 \\
10 \\
N\end{array}$ & $\begin{array}{l}7.56 \\
7.47 \\
7.41 \\
7.34 \\
7.27 \\
7.22\end{array}$ & $\begin{array}{l}4,730 \\
4,580 \\
4,480 \\
4,360 \\
4,240 \\
4,160\end{array}$ & $\begin{array}{l}6.78 \\
6.73 \\
6.66 \\
6.61 \\
6.57 \\
6.54\end{array}$ & $\begin{array}{l}3,470 \\
3,400 \\
3,290 \\
3,220 \\
3,160 \\
3,120\end{array}$ & $\begin{array}{l}6.21 \\
6.17 \\
6.14 \\
6.11 \\
6.09 \\
6.07\end{array}$ & $\begin{array}{l}2,660 \\
2,610 \\
2,570 \\
2,530 \\
2,510 \\
2,480\end{array}$ & $\begin{array}{l}5.86 \\
5.83 \\
5.81 \\
5.79 \\
5.78 \\
5.77\end{array}$ & $\begin{array}{l}2,220 \\
2,190 \\
2,160 \\
2,140 \\
2,130 \\
2,110\end{array}$ & $\begin{array}{l}6.05 \\
6.06 \\
6.03 \\
5.98 \\
5.90 \\
5.85\end{array}$ & $\begin{array}{l}2,460 \\
2,470 \\
2,430 \\
2,370 \\
2,270 \\
2,210\end{array}$ & \begin{tabular}{|l|}
5.62 \\
5.60 \\
5.58 \\
5.56 \\
5.54 \\
5.52
\end{tabular} & $\begin{array}{l}1,940 \\
1,920 \\
1,900 \\
1,880 \\
1,850 \\
1,830\end{array}$ \\
\hline $\begin{array}{r}2 \\
4 \\
6 \\
8 \\
10 \\
M\end{array}$ & $\begin{array}{l}7.16 \\
7.09 \\
7.04 \\
6.98 \\
6.91 \\
6.84\end{array}$ & $\begin{array}{l}4,070 \\
3,950 \\
3,870 \\
3,780 \\
3,670 \\
3,560\end{array}$ & $\begin{array}{l}6.49 \\
6.45 \\
6.40 \\
6.35 \\
6.31 \\
6.27\end{array}$ & $\begin{array}{l}3,050 \\
2,990 \\
2,920 \\
2,850 \\
2,790\end{array}$ & $\begin{array}{l}6.05 \\
6.02 \\
5.99 \\
5.97 \\
5.93 \\
5.89\end{array}$ & $\begin{array}{l}2,460 \\
2,420 \\
2,380 \\
2,350 \\
2,310 \\
2,260\end{array}$ & $\begin{array}{l}5.76 \\
5.78 \\
5.83 \\
5.87 \\
5.99 \\
6.03\end{array}$ & $\begin{array}{l}2,100 \\
2,130 \\
2,190 \\
2,230 \\
2,380 \\
2,430\end{array}$ & $\begin{array}{l}5.81 \\
5.77 \\
5.75 \\
5.72 \\
5.68 \\
5.65\end{array}$ & $\begin{array}{l}2,160 \\
2,110 \\
2,090 \\
2,050 \\
2,010 \\
1,980\end{array}$ & $\begin{array}{l}5.51 \\
5.48 \\
5.47 \\
5.43 \\
5.42 \\
5.40\end{array}$ & $\begin{array}{l}320 \\
790 \\
780 \\
730 \\
720 \\
700 \\
\end{array}$ \\
\hline
\end{tabular}

Supplemental records.- Sept. $22,3: 30 \mathrm{a} . \mathrm{m} ., 19.26 \mathrm{ft} ., 47,600 \mathrm{sec} . \mathrm{ft}$. 
Mascoma River reservolrs above Mascoma, N. H.

Location.- Mascoma and Crystal Lakes and Goose and Grafton Ponds on or tributary to Mascoma River above Mascoma, Grafton County, have a combined storage capac1ty of about $1,250,000,000$ cublc feet, which is used to regula te the flow of the Mascoma R1 ver.

Drainage area.- 153 square mlles above Mascoma Lake dam.

Storage.- Dally gain or loss in storage, in millions of cuble feet, is the net change in contents in the reservolrs.

Remarks.- Records computed from bas1c data furnished by Mascoma River Improvement Co.

Gain or loss in storage, in millions of cuble feet, 1938

\begin{tabular}{|c|c|c|c|c|c|c|c|c|c|c|c|}
\hline Day & Sept. & Oct. & Day & Sept. & 0ct. & Day & Sept. & oct. & Day & Sept. & Oct. \\
\hline $\begin{array}{l}1 \\
2 \\
3 \\
4 \\
5 \\
6 \\
7 \\
8\end{array}$ & $\begin{array}{l}-6.2 \\
-5.8 \\
-6.9 \\
-7.0 \\
-6.8 \\
-6.3 \\
-7.0 \\
-6.3\end{array}$ & $\begin{array}{l}-7.3 \\
-6.0 \\
-5.5 \\
-1.0 \\
-2.8 \\
-3.6 \\
-3.9 \\
-3.6\end{array}$ & $\begin{array}{l}9 \\
10 \\
11 \\
12 \\
13 \\
14 \\
15 \\
16\end{array}$ & $\begin{array}{r}-5.2 \\
-5.8 \\
-6.4 \\
+6.1 \\
+22.8 \\
+23.7 \\
+25.8 \\
+37.3\end{array}$ & $\begin{array}{l}-2.2 \\
-1.7 \\
-3.8 \\
-5.2 \\
-5.3 \\
-5.4 \\
-9.9 \\
-4.4\end{array}$ & $\begin{array}{l}17 \\
18 \\
19 \\
20 \\
21 \\
22 \\
23 \\
24\end{array}$ & $\begin{array}{r}+10.8 \\
+14.7 \\
+62.4 \\
+137.3 \\
+216.3 \\
+83.9 \\
-113.5 \\
-112.3\end{array}$ & $\begin{array}{r}-7.4 \\
-8.1 \\
-8.1 \\
-8.3 \\
+10.0 \\
0 \\
+4.4 \\
+20.4\end{array}$ & $\begin{array}{l}25 \\
26 \\
27 \\
28 \\
29 \\
30 \\
31\end{array}$ & $\begin{array}{r}-57.5 \\
-25.1 \\
-5.9 \\
-1.4 \\
-5.6 \\
-7.9\end{array}$ & $\begin{array}{r}+36.8 \\
+14.7 \\
+1.9 \\
-2.2 \\
-6.5 \\
-5.4 \\
-2.4\end{array}$ \\
\hline $\begin{array}{l}\text { Gair } \\
\text { Gair }\end{array}$ & $\begin{array}{l}\text { or loss } \\
\text { or loss }\end{array}$ & $\begin{array}{l}\text { stor } \\
\text { stor }\end{array}$ & & equi & $\begin{array}{l}\text { of cu } \\
\text { nt mea }\end{array}$ & $f$ & - feet & : $: \dot{ }$ & $:$ : & $\begin{array}{r}+242.2 \\
+94\end{array}$ & $\begin{array}{r}-31.8 \\
-12\end{array}$ \\
\hline
\end{tabular}

$2279070-40-11$ 
Mascoma River at Mascome, N. H.

Location. - Water-stage recorder, lat. $43^{\circ} 39^{1} 00^{\prime \prime}$, long. $72^{\circ} 11^{\prime} 05^{\prime \prime}$, in Mascoma, Grafton county, 250 feet below railroad bridge and 1,500 feet below outlet of Mascoma Lake. Drainage area.- 153 square miles.

Gage-helght record.- Water-stage recorder graph except for perlod Sept. 1 to 4 p.m. Sept. 19, record for which was based on Mascoma Lake gate openings and gage heights. Stage-discharge relation.- Rating curve defined by current-meter measurements below 2,450 second-feet; $\theta x t e n d e d$ to peak stage by determinations of flood flows over dams.

Mexima.- September 1938: Discharge, 4,400 second-feet 8 p.m. Sept. 22 (gage height, 6.85 feet). 1923 to August 1938: Discharge, 5, 840 second-feet Mar. 19, 1936 (gage height,
7.50 feet).

Remarks.- Flood run off considerably affected by storage in Mascoma and Crystal Lakes and Goose and Grafton Ponds, total capacity, 1,250,000,000 cublc feet. For information on storage see record for Mascoma River reservolrs. Mean da1ly and monthly discharges adjusted for storage.

Mean daily discharge, in second-feet, 1938

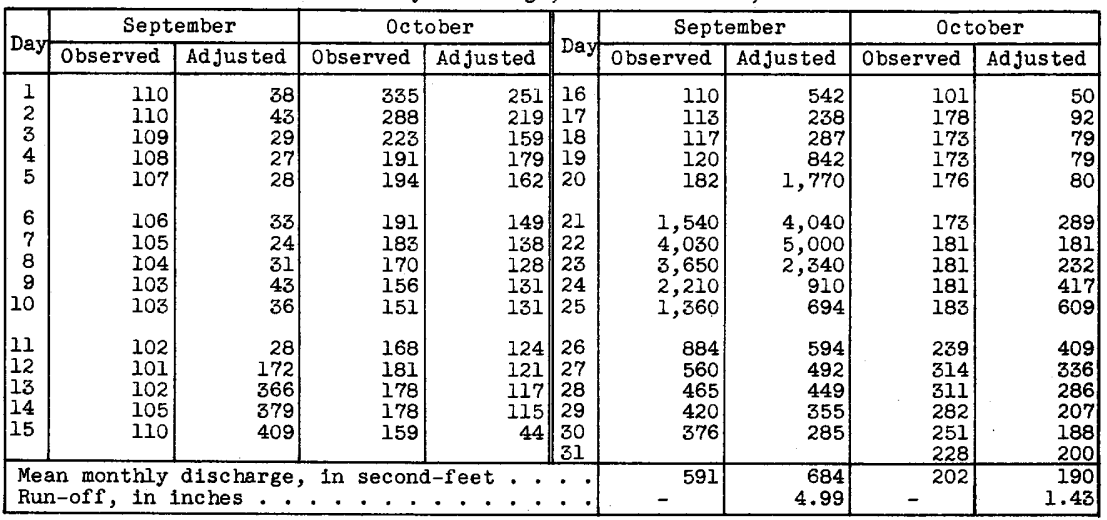

Gage height, in feet, and discharge, in second-feet, at indicated time, 1938

\begin{tabular}{|c|c|c|c|c|c|c|c|c|c|c|c|c|}
\hline \multirow{2}{*}{ हี } & Feet & Sec.Ft. & Feet & Sec.Ft. & Feet & Sec.Ft. & Feet & ec.Ft. & Feet & sec.Ft. & Feet & Sec.Ft. \\
\hline & \multicolumn{2}{|c|}{ September 18} & \multicolumn{2}{|c|}{ September 19} & \multicolumn{2}{|c|}{ September 20} & \multicolumn{2}{|c|}{ September 21} & \multicolumn{2}{|c|}{ September 22} & \multicolumn{2}{|c|}{ September 23} \\
\hline $\begin{array}{r}2 \\
4 \\
6 \\
8 \\
10 \\
\text { N }\end{array}$ & $\begin{array}{l}2.30 \\
2.30 \\
2.30 \\
2.30 \\
2.31 \\
2.31\end{array}$ & $\begin{array}{l}116 \\
116 \\
116 \\
116 \\
118 \\
118\end{array}$ & $\begin{array}{l}2.31 \\
2.31 \\
2.32 \\
2.32 \\
2.32 \\
2.32\end{array}$ & $\begin{array}{l}118 \\
118 \\
121 \\
121 \\
121 \\
121\end{array}$ & $\begin{array}{l}2.32 \\
2.32 \\
2.32 \\
2.32 \\
2.32 \\
2.32\end{array}$ & $\begin{array}{l}121 \\
121 \\
121 \\
121 \\
121 \\
121\end{array}$ & $\begin{array}{l}3.55 \\
3.72 \\
3.87 \\
4.02 \\
4.25 \\
4.67\end{array}$ & $\begin{array}{r}584 \\
682 \\
776 \\
879 \\
1,050 \\
1,410\end{array}$ & $\begin{array}{l}6.30 \\
6.45 \\
6.55 \\
6.70 \\
6.63 \\
6.69\end{array}$ & $\begin{array}{l}3,440 \\
3,680 \\
3,860 \\
4,120 \\
3,990 \\
4,100\end{array}$ & $\begin{array}{l}6.78 \\
6.74 \\
6.67 \\
6.59 \\
6.51 \\
6.44\end{array}$ & $\begin{array}{l}4,260 \\
4,190 \\
4,070 \\
3,920 \\
3,790 \\
3,670\end{array}$ \\
\hline \multirow[t]{2}{*}{$\begin{array}{r}2 \\
4 \\
6 \\
8 \\
10 \\
M\end{array}$} & $\begin{array}{l}2.31 \\
2.31 \\
2.31 \\
2.31 \\
2.31 \\
2.31\end{array}$ & $\begin{array}{l}118 \\
118 \\
118 \\
118 \\
118 \\
118\end{array}$ & $\begin{array}{l}2.32 \\
2.32 \\
2.32 \\
2.32 \\
2.32 \\
2.32\end{array}$ & $\begin{array}{l}121 \\
121 \\
121 \\
121 \\
121 \\
121\end{array}$ & $\begin{array}{l}2.32 \\
2.34 \\
2.37 \\
2.90 \\
3.34 \\
3.44\end{array}$ & $\begin{array}{l}121 \\
125 \\
132 \\
289 \\
476 \\
526 \\
\end{array}$ & $\begin{array}{l}4.90 \\
5.14 \\
5.50 \\
5.69 \\
6.05 \\
6.09\end{array}$ & $\begin{array}{l}1,630 \\
1,880 \\
2,300 \\
2,550 \\
3,060 \\
3,120\end{array}$ & $\begin{array}{l}6.74 \\
6.76 \\
6.79 \\
6.85 \\
6.77 \\
6.81\end{array}$ & $\begin{array}{l}4,190 \\
4,230 \\
4,280 \\
4,400 \\
4,250 \\
4,320\end{array}$ & $\begin{array}{l}6.35 \\
6.26 \\
6.18 \\
6.10 \\
6.01 \\
5.93\end{array}$ & $\begin{array}{l}3,520 \\
3,380 \\
3,250 \\
3,130 \\
3,000 \\
2,880\end{array}$ \\
\hline & \multicolumn{2}{|c|}{ September 24} & \multicolumn{2}{|c|}{ September 25} & \multicolumn{2}{|c|}{ September 26} & \multicolumn{2}{|c|}{ September 27} & \multicolumn{2}{|c|}{ September 28} & \multicolumn{2}{|c|}{ September 29} \\
\hline $\begin{array}{r}2 \\
4 \\
6 \\
8 \\
10 \\
\mathrm{~N}\end{array}$ & $\begin{array}{l}5.84 \\
5.75 \\
5.68 \\
5.59 \\
5.49 \\
5.37\end{array}$ & $\begin{array}{l}2,760 \\
2,630 \\
2,530 \\
2,420 \\
2,290 \\
2,140\end{array}$ & $\begin{array}{l}4.88 \\
4.82 \\
4.75 \\
4.70 \\
4.64 \\
4.59\end{array}$ & $\begin{array}{l}1,610 \\
1,550 \\
1,480 \\
1,440 \\
1,380 \\
1,340\end{array}$ & $\begin{array}{l}4.30 \\
4.25 \\
4.22 \\
4.17 \\
4.13 \\
4.08\end{array}$ & $\begin{array}{r}1,090 \\
1,050 \\
1,030 \\
988 \\
958 \\
921\end{array}$ & $\begin{array}{l}3.67 \\
3.65 \\
3.63 \\
3.62 \\
3.59 \\
3.31\end{array}$ & $\begin{array}{l}655 \\
645 \\
635 \\
630 \\
615 \\
484\end{array}$ & $\begin{array}{l}3.29 \\
3.29 \\
3.29 \\
3.28 \\
3.27 \\
3.26\end{array}$ & $\begin{array}{l}476 \\
476 \\
476 \\
472 \\
468 \\
464\end{array}$ & $\begin{array}{l}3.19 \\
3.19 \\
3.18 \\
3.17 \\
3.16 \\
3.15\end{array}$ & $\begin{array}{l}436 \\
436 \\
432 \\
428 \\
424 \\
420\end{array}$ \\
\hline $\begin{array}{r}2 \\
4 \\
6 \\
8 \\
10 \\
M\end{array}$ & $\begin{array}{l}5.29 \\
5.22 \\
5.15 \\
5.07 \\
4.98 \\
4.92\end{array}$ & $\begin{array}{l}2,050 \\
1,970 \\
1,900 \\
1,810 \\
1,710 \\
1,650\end{array}$ & $\begin{array}{l}4.57 \\
4.51 \\
4.47 \\
4.43 \\
4.38 \\
4.34\end{array}$ & $\begin{array}{l}1,320 \\
1,260 \\
1,230 \\
1,200 \\
1,150 \\
1,120\end{array}$ & $\begin{array}{l}4.04 \\
3.77 \\
3.75 \\
3.74 \\
3.72 \\
3.70\end{array}$ & $\begin{array}{l}893 \\
712 \\
700 \\
694 \\
682 \\
670\end{array}$ & $\begin{array}{l}3.32 \\
3.33 \\
3.34 \\
3.34 \\
3.33 \\
3.31\end{array}$ & $\begin{array}{l}489 \\
494 \\
498 \\
498 \\
494 \\
484\end{array}$ & $\begin{array}{l}3.25 \\
3.25 \\
3.24 \\
3.23 \\
3.23 \\
3.22\end{array}$ & $\begin{array}{l}460 \\
460 \\
456 \\
452 \\
452 \\
448\end{array}$ & $\begin{array}{l}3.14 \\
3.13 \\
3.13 \\
3.12 \\
3.10 \\
3.09\end{array}$ & $\begin{array}{l}416 \\
412 \\
412 \\
408 \\
400 \\
396\end{array}$ \\
\hline
\end{tabular}

Supplemental records.- Sept. 20,7 p.m., 2.38 ft., 134 sec.-ft.; 9 p.m., 3.27 ft., 442 sec.-ft. Sept. 21,3 a.m., 3.62 ft., 624 sec.-ft.; 9 a.m., 4.10 ft., 935 sec.-ft.; 11 a.m., 4.40 ft., 1,170 sec.-ft.; 1 p.m., 4.80 ft., 1,530 sec.-ft.; 3 p.m., 5.00 ft., 1,730 sec.-ft.; 5 p.m., 5.22 ft., 1,970 sec.-ft.; 7 p.m., 5.58 ft., 2,400 sec.-ft.

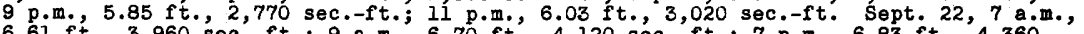
6.61 ft., 3,960 sec.-ft.; 9 a.m., 6.70 ft., 4,120 sec.-ft.; 7 p.m., 6.83 ft., 4,360 sec.-ft.; 9 p.m., 6.83 ft., 4,360 sec.-ft. Sept. 23,5 p.m., 6.23 ft., 3,330 sec.-ft. 
Location.- Water-stage recorder, lat. $43^{\circ} 36^{\prime} 05^{\prime \prime}$, long. $72^{\circ} 21^{\prime} 20^{\prime \prime}$, at highway bridge In North Hartland, Windsor County, 1 mile above mouth.

Drajnage area.- 221 square miles.

Gage-helght record.- Water-stage recorder graph.

Stage-discharge relation.- Defined by current-meter measurements below 5,380 secondfeet; extended to peak stage of November 1927 on basis of determinations of flood flows over dams.

Maxima.- September 1938: Discharge, 24,400 second-feet 11:45 p.m. Sept, 21 (gage helght, 17.68 feet).

1930 to August 1938: Discharge, 19,200 second-feet Mar. 18, 1936 (gage height, 15.58 feet)

(known, 30,400 second-feet November 1927 (gage helght,

Remarks.- Flood run-off not materially affected by artificial or natural storage.

Mean dally discharge, in second-feet, 1938

\begin{tabular}{|c|c|c|c|c|c|c|c|c|c|c|c|}
\hline Day & Sept. & Oct. & Day & Sept. & oct. & Day & Sept. & oct. & Day & Sept. & oct. \\
\hline $\begin{array}{l}1 \\
2 \\
3 \\
4 \\
5 \\
6 \\
7 \\
8\end{array}$ & $\begin{array}{l}159 \\
174 \\
132 \\
126 \\
128 \\
143 \\
116 \\
137\end{array}$ & $\begin{array}{l}520 \\
480 \\
443 \\
400 \\
383 \\
350 \\
327 \\
290\end{array}$ & $\begin{array}{r}9 \\
10 \\
11 \\
12 \\
13 \\
14 \\
15 \\
16\end{array}$ & $\begin{array}{r}150 \\
126 \\
99 \\
143 \\
313 \\
312 \\
552 \\
686\end{array}$ & $\begin{array}{l}294 \\
297 \\
270 \\
263 \\
250 \\
244 \\
214 \\
228\end{array}$ & $\begin{array}{l}17 \\
18 \\
19 \\
20 \\
21 \\
22 \\
23 \\
24\end{array}$ & $\begin{array}{r}400 \\
399 \\
440 \\
2,180 \\
7,550 \\
7,860 \\
2,270 \\
1,450\end{array}$ & $\begin{array}{l}234 \\
205 \\
208 \\
208 \\
301 \\
270 \\
222 \\
455\end{array}$ & $\begin{array}{l}25 \\
26 \\
27 \\
28 \\
29 \\
30 \\
31\end{array}$ & $\begin{array}{r}1,110 \\
910 \\
807 \\
806 \\
660 \\
571 \\
-\quad\end{array}$ & $\begin{array}{l}703 \\
438 \\
362 \\
319 \\
270 \\
266 \\
283\end{array}$ \\
\hline $\begin{array}{l}\text { Mean } \\
\text { Run- }\end{array}$ & $\begin{array}{l}\text { nthly } \\
, \text { in }\end{array}$ & $\begin{array}{l}\text { Lschar } \\
\text { hes. }\end{array}$ & $: 1$ & gennd- & et. : & . : & $\begin{array}{ll}\cdot & \cdot \\
. & -\end{array}$ & $\begin{array}{lll}\cdot & \cdot & \cdot \\
\cdot & \bullet & \end{array}$ & . : & $\begin{array}{r}1,030 \\
5.20\end{array}$ & $\begin{array}{r}322 \\
1.68\end{array}$ \\
\hline
\end{tabular}

Gage helght, in feet, and discharge, In second-feet, at indicated time, 1938

\begin{tabular}{|c|c|c|c|c|c|c|c|c|c|c|c|c|}
\hline \multirow{2}{*}{$\begin{array}{l}\text { s } \\
\text { 定 }\end{array}$} & Feet & Sec.ft. & Feet & Sec.ft. & Feot & Sec.ft. & Feet & Sec.ft. & Feet & Sec.ft. & Feet & Sec.ft. \\
\hline & \multicolumn{2}{|c|}{ September 18} & \multicolumn{2}{|c|}{ September 19} & \multicolumn{2}{|c|}{ September 20} & \multicolumn{2}{|c|}{ September 21} & \multicolumn{2}{|c|}{ September 22} & \multicolumn{2}{|c|}{ September 23} \\
\hline $\begin{array}{l}1 \\
2 \\
3 \\
4 \\
5 \\
6\end{array}$ & $\begin{array}{l}3.15 \\
3.12 \\
3.13 \\
3.17 \\
3.20 \\
3.22\end{array}$ & $\begin{array}{l}316 \\
304 \\
308 \\
323 \\
334 \\
342\end{array}$ & $\begin{array}{l}3.38 \\
3.37 \\
3.36 \\
3.35 \\
3.35 \\
3.41\end{array}$ & $\begin{array}{l}408 \\
404 \\
400 \\
396 \\
396 \\
421\end{array}$ & $\begin{array}{l}3.83 \\
3.97 \\
4.19 \\
4.43 \\
4.75 \\
5.10\end{array}$ & $\begin{array}{r}632 \\
708 \\
839 \\
991 \\
1,220 \\
1,520\end{array}$ & $\begin{array}{l}6.84 \\
6.81 \\
6.88 \\
7.10 \\
7.13 \\
7.13\end{array}$ & $\begin{array}{l}3,760 \\
3,720 \\
3,820 \\
4,120 \\
4,160 \\
4,160\end{array}$ & $\begin{array}{l}16.55 \\
14.80 \\
13.25 \\
12.20 \\
11.40 \\
10.70\end{array}$ & $\begin{array}{r}21,700 \\
17,800 \\
14,600 \\
12,600 \\
11,100 \\
9,800\end{array}$ & \begin{tabular}{|l|}
6.25 \\
6.20 \\
6.13 \\
6.10 \\
6.03 \\
5.98
\end{tabular} & $\begin{array}{l}2,970 \\
2,900 \\
2,800 \\
2,760 \\
2,670 \\
2,610\end{array}$ \\
\hline $\begin{array}{r}7 \\
8 \\
9 \\
10 \\
11 \\
\text { N }\end{array}$ & $\begin{array}{l}3.26 \\
3.31 \\
3.36 \\
3.42 \\
3.46 \\
3.48\end{array}$ & $\begin{array}{l}358 \\
378 \\
400 \\
426 \\
443 \\
451\end{array}$ & $\begin{array}{l}3.42 \\
3.43 \\
3.43 \\
3.41 \\
3.39 \\
3.37\end{array}$ & $\begin{array}{l}426 \\
430 \\
430 \\
421 \\
413 \\
404\end{array}$ & $\begin{array}{l}5.53 \\
5.78 \\
5.80 \\
5.74 \\
5.73 \\
5.73\end{array}$ & $\begin{array}{l}2,000 \\
2,330 \\
2,360 \\
2,270 \\
2,260 \\
2,260\end{array}$ & $\begin{array}{l}7.20 \\
7.36 \\
7.63 \\
7.98 \\
8.40 \\
8.67\end{array}$ & $\begin{array}{l}4,250 \\
4,460 \\
4,830 \\
5,320 \\
5,970 \\
6,400\end{array}$ & $\begin{array}{r}10.10 \\
9.62 \\
9.20 \\
8.85 \\
8.50 \\
8.22\end{array}$ & $\begin{array}{l}8,770 \\
7,950 \\
7,250 \\
6,690 \\
6,130 \\
5,680\end{array}$ & $\begin{array}{l}5.94 \\
5.89 \\
5.83 \\
5.78 \\
5.73 \\
5.69\end{array}$ & $\begin{array}{l}2,550 \\
2,480 \\
2,400 \\
2,330 \\
2,260 \\
2,210\end{array}$ \\
\hline $\begin{array}{l}1 \\
2 \\
3 \\
4 \\
5 \\
6\end{array}$ & $\begin{array}{l}3.49 \\
3.49 \\
3.48 \\
3.47 \\
3.46 \\
3.44\end{array}$ & $\begin{array}{l}456 \\
456 \\
451 \\
447 \\
443 \\
434\end{array}$ & $\begin{array}{l}3.36 \\
3.37 \\
3.41 \\
3.42 \\
3.44 \\
3.53\end{array}$ & $\begin{array}{l}400 \\
404 \\
421 \\
426 \\
434 \\
475\end{array}$ & $\begin{array}{l}5.80 \\
5.89 \\
5.93 \\
5.97 \\
5.98 \\
6.03\end{array}$ & $\begin{array}{l}2,360 \\
2,480 \\
2,540 \\
2,590 \\
2,610 \\
2,670\end{array}$ & $\begin{array}{l}8.78 \\
8.80 \\
9.20 \\
9.45 \\
9.60 \\
9.80\end{array}$ & $\begin{array}{l}6,580 \\
6,610 \\
7,250 \\
7,660 \\
7,920 \\
8,260\end{array}$ & $\begin{array}{l}8.00 \\
7.72 \\
7.52 \\
7.32 \\
7.17 \\
7.00\end{array}$ & $\begin{array}{l}5,350 \\
4,960 \\
4,690 \\
4,410 \\
4,210 \\
3,980\end{array}$ & $\begin{array}{l}5.65 \\
5.61 \\
5.55 \\
5.52 \\
5.50 \\
5.47\end{array}$ & $\begin{array}{l}2,160 \\
2,100 \\
2,020 \\
1,990 \\
1,960 \\
1,920\end{array}$ \\
\hline \multirow[t]{2}{*}{$\begin{array}{r}7 \\
8 \\
9 \\
10 \\
11 \\
11\end{array}$} & $\begin{array}{l}3.43 \\
3.43 \\
3.42 \\
3.41 \\
3.40 \\
3.39\end{array}$ & $\begin{array}{l}430 \\
430 \\
426 \\
421 \\
417 \\
413\end{array}$ & $\begin{array}{l}3.56 \\
3.59 \\
3.56 \\
3.64 \\
3.68 \\
3.73\end{array}$ & $\begin{array}{l}490 \\
505 \\
490 \\
530 \\
550 \\
576\end{array}$ & $\begin{array}{l}6.11 \\
6.20 \\
6.28 \\
6.47 \\
6.70 \\
6.88\end{array}$ & $\begin{array}{l}2,770 \\
2,900 \\
3,010 \\
3,260 \\
3,580 \\
3,820\end{array}$ & $\begin{array}{l}10.10 \\
10.60 \\
11.60 \\
13.90 \\
16.80 \\
17.64\end{array}$ & $\begin{array}{r}8,770 \\
9,620 \\
11,400 \\
15,900 \\
22,300 \\
24,300\end{array}$ & $\begin{array}{l}6.88 \\
6.71 \\
6.62 \\
6.48 \\
6.43 \\
6.31\end{array}$ & $\begin{array}{l}3,820 \\
3,590 \\
3,470 \\
3,280 \\
3,210 \\
3,050\end{array}$ & $\begin{array}{l}5.43 \\
5.40 \\
5.36 \\
5.32 \\
5.29 \\
5.27\end{array}$ & $\begin{array}{l}1,880 \\
1,840 \\
1,800 \\
1,750 \\
1,720 \\
1,700\end{array}$ \\
\hline & \multicolumn{2}{|c|}{ September 24} & \multicolumn{2}{|c|}{ September 25} & \multicolumn{2}{|c|}{ September 26} & \multicolumn{2}{|c|}{ September 27} & \multicolumn{2}{|c|}{ September 28} & \multicolumn{2}{|c|}{ September 29} \\
\hline $\begin{array}{r}2 \\
4 \\
6 \\
8 \\
10 \\
N\end{array}$ & $\begin{array}{l}5.21 \\
5.13 \\
5.13 \\
5.09 \\
5.05 \\
5.01\end{array}$ & $\begin{array}{l}1,630 \\
1,550 \\
1,550 \\
1,510 \\
1,480 \\
1,440\end{array}$ & \begin{tabular}{|l|}
4.73 \\
4.71 \\
4.68 \\
4.67 \\
4.65 \\
4.62 \\
\end{tabular} & $\begin{array}{l}1,200 \\
1,190 \\
1,170 \\
1,160 \\
1,140 \\
1,120\end{array}$ & $\begin{array}{l}4.39 \\
4.37 \\
4.35 \\
4.41 \\
4.33 \\
4.31\end{array}$ & $\begin{array}{r}964 \\
950 \\
938 \\
977 \\
924 \\
912\end{array}$ & \begin{tabular}{|l|}
4.13 \\
4.13 \\
4.08 \\
4.14 \\
4.12 \\
4.12
\end{tabular} & $\begin{array}{l}803 \\
803 \\
773 \\
809 \\
797 \\
797\end{array}$ & $\begin{array}{l}4.28 \\
4.25 \\
4.18 \\
4.21 \\
4.15 \\
4.13\end{array}$ & $\begin{array}{l}893 \\
875 \\
833 \\
851 \\
815 \\
803\end{array}$ & $\begin{array}{l}3.96 \\
3.93 \\
3.88 \\
3.93 \\
3.93 \\
3.89\end{array}$ & $\begin{array}{l}703 \\
686 \\
659 \\
686 \\
686 \\
664\end{array}$ \\
\hline $\begin{array}{r}2 \\
4 \\
6 \\
8 \\
10 \\
11\end{array}$ & $\begin{array}{l}4.99 \\
4.94 \\
4.92 \\
4.86 \\
4.83 \\
4.77\end{array}$ & $\begin{array}{l}1,420 \\
1,380 \\
1,360 \\
1,310 \\
1,280 \\
1,240\end{array}$ & $\begin{array}{l}4.59 \\
4.55 \\
4.51 \\
4.47 \\
4.45 \\
4.42\end{array}$ & $\begin{array}{l}1,100 \\
1,080 \\
1,050 \\
1,020 \\
1,000\end{array}$ & $\begin{array}{l}4.30 \\
4.27 \\
4.25 \\
4.23 \\
4.18 \\
4.13\end{array}$ & $\begin{array}{l}905 \\
887 \\
875 \\
863 \\
833 \\
803\end{array}$ & $\begin{array}{l}4.12 \\
4.12 \\
4.13 \\
4.14 \\
4.21 \\
4.26\end{array}$ & $\begin{array}{l}797 \\
797 \\
803 \\
809 \\
851 \\
881\end{array}$ & $\begin{array}{l}4.13 \\
4.09 \\
4.05 \\
4.03 \\
4.01 \\
3.98\end{array}$ & $\begin{array}{l}803 \\
779 \\
755 \\
743 \\
731 \\
714\end{array}$ & $\begin{array}{l}3.87 \\
3.86 \\
3.83 \\
3.82 \\
3.80\end{array}$ & $\begin{array}{l}654 \\
648 \\
632 \\
626 \\
615 \\
604\end{array}$ \\
\hline
\end{tabular}

Supplemental records.- Sept. $21,11: 45$ p.m., 17.68 ft., 24,400 sec.-ft. 
Location.- Staff gage, lat. $43^{\circ} 23^{\prime} 10^{\prime \prime}$, long. $72^{\circ} 04^{\prime} 55^{\prime \prime}$, at outlet of Sunapee Lake, in Sunapee, Sullivan County.

Drainage area.- 45.5 square miles.

Gage-height record.- Graph based on weekly gage readings except during flood period, when gage was read daily.

Remarks.- Total storage capacity of sunapee Lake is $862,000,000$ cubic feet.

Gage height, in feet, and contents, in millions of cubic feet, 1938

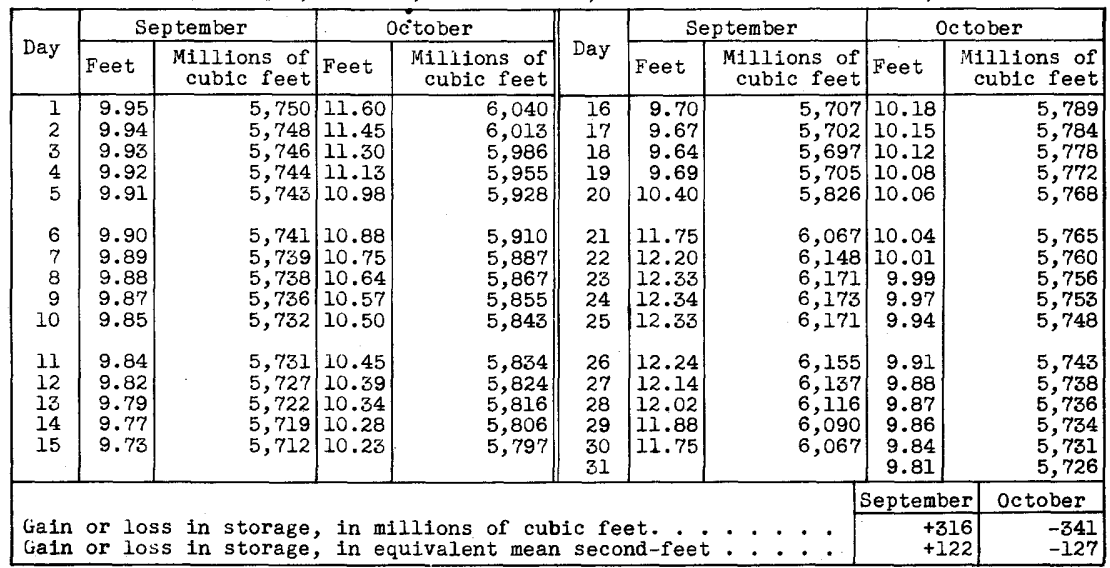


Sugar River at West Claremont, N. H.

Location.- Water-stage recorder, lat. $43^{\circ} 25^{\prime} 1^{\prime \prime}$, long. $72^{\circ} 21^{\prime} 45^{\prime \prime}$, below Redwater Brook at West Claremont, Sullivan County.

Drainage area.- 269 square miles.

Gage-height record.- Water-stage recorder graph.

Stage-discharge relation.- Defined by current-meter measurements below 3,940 secondfeet, extended to peak stage on the basis of determinations of flood flows over dam.

Maxima.- September 1938: Discharge, 13,100 second-feet 8:30 p.m. Sept. 2l (gage height, 10.49 feet).

1928 to August 1938: Maximum discharge, 14,000 second-feet Mar. 19, 1936

(gage height, 10.92 feet); maximum gage neight, 11.80 feet Mar. 12, 1938 (ice jam).

Remarks.- Flood run-off affected by storage in Sunapee Lake, total capacity 862,000,000 cubic feet. For information on storage see record for Sunapee Lake at Sunapee, N. H.

Mean dally discharge, in second-feet, 1938

\begin{tabular}{|c|c|c|c|c|c|c|c|c|c|c|c|}
\hline Day & Sept. & 0 ct. & Day & Sept. & oct. & Day & Sept. & Oct. & Day & Sept. & Oct. \\
\hline $\begin{array}{l}1 \\
2 \\
3 \\
4 \\
5 \\
6 \\
7 \\
8\end{array}$ & $\begin{array}{l}129 \\
135 \\
132 \\
123 \\
113 \\
101 \\
101 \\
126\end{array}$ & $\begin{array}{l}784 \\
732 \\
686 \\
642 \\
624 \\
594 \\
600 \\
534\end{array}$ & $\begin{array}{r}9 \\
10 \\
11 \\
12 \\
13 \\
14 \\
15 \\
16\end{array}$ & $\begin{array}{r}135 \\
110 \\
104 \\
96 \\
358 \\
471 \\
488 \\
770\end{array}$ & $\begin{array}{l}476 \\
417 \\
427 \\
427 \\
319 \\
280 \\
284 \\
276\end{array}$ & $\begin{array}{l}17 \\
18 \\
19 \\
20 \\
21 \\
22 \\
23 \\
24\end{array}$ & $\begin{array}{r}523 \\
389 \\
369 \\
3,000 \\
8,650 \\
8,720 \\
3,660 \\
2,290\end{array}$ & $\begin{array}{l}271 \\
263 \\
250 \\
271 \\
456 \\
391 \\
315 \\
569\end{array}$ & $\begin{array}{l}25 \\
26 \\
27 \\
28 \\
29 \\
30 \\
31\end{array}$ & $\begin{array}{r}1,610 \\
1,310 \\
1,110 \\
1,120 \\
973 \\
855\end{array}$ & $\begin{array}{r}1,250 \\
751 \\
600 \\
517 \\
444 \\
391 \\
375\end{array}$ \\
\hline $\begin{array}{l}\text { Mear } \\
\text { Run- }\end{array}$ & $\begin{array}{l}\text { onthly } \\
f, \text { in } 1\end{array}$ & $\begin{array}{l}\text { schar } \\
\text { hes. }\end{array}$ & $\begin{array}{l}3 \\
.1 \\
\end{array}$ & $\begin{array}{c}\text { second- } \\
.\end{array}$ & et. . & . $\dot{.}$ & $\begin{array}{l}\cdot \\
.\end{array}$ & $\begin{array}{ll}\cdot & \bullet \\
. & \bullet\end{array}$ & . & $\begin{array}{r}1,269 \\
5.27\end{array}$ & $\begin{array}{r}491 \\
2.11 \\
\end{array}$ \\
\hline
\end{tabular}

Gage helght, in feet, and discharge, in second-feet, at indlcated time, 1938

\begin{tabular}{|c|c|c|c|c|c|c|c|c|c|c|c|c|}
\hline \multirow{2}{*}{$\begin{array}{r}8 \\
\text { ? } \\
\text { 号 } \\
\end{array}$} & Feet & Sec.ft. & Feet & Sec.ft. & Feet & Sec.ft. & Feet & Sec.ft. & Feet & Sec.ft. & Feet & Sec.ft. \\
\hline & \multicolumn{2}{|c|}{ September 18} & \multicolumn{2}{|c|}{ September 19} & \multicolumn{2}{|c|}{ September 20} & \multicolumn{2}{|c|}{ September 21} & \multicolumn{2}{|c|}{ September 22} & \multicolumn{2}{|c|}{ September 23} \\
\hline $\begin{array}{l}1 \\
2 \\
3 \\
4 \\
5 \\
6\end{array}$ & $\begin{array}{l}2.17 \\
2.18 \\
2.18 \\
2.18 \\
2.18 \\
2.18\end{array}$ & $\begin{array}{l}411 \\
417 \\
417 \\
417 \\
417 \\
417\end{array}$ & $\begin{array}{l}1.97 \\
1.95 \\
1.94 \\
1.93 \\
1.93 \\
1.94\end{array}$ & $\begin{array}{l}315 \\
306 \\
302 \\
297 \\
297 \\
302\end{array}$ & $\begin{array}{r}2.94 \\
3.11 \\
-3.50 \\
3.90 \\
4.20 \\
4.40\end{array}$ & $\begin{array}{r}881 \\
997 \\
1,310 \\
1,700 \\
2,020 \\
2,250\end{array}$ & $\begin{array}{l}6.40 \\
6.52 \\
6.60 \\
6.68 \\
6.70 \\
6.72\end{array}$ & $\begin{array}{l}5,000 \\
5,190 \\
5,330 \\
5,470 \\
5,500 \\
5,530\end{array}$ & $\begin{array}{l}9.94 \\
9.82 \\
9.77 \\
9.74 \\
9.68 \\
9.63\end{array}$ & $\begin{array}{l}11,900 \\
11,540 \\
11,450 \\
11,400 \\
11,300 \\
11,200\end{array}$ & $\begin{array}{l}6.31 \\
6.22 \\
6.12 \\
6.02 \\
5.93 \\
5.84\end{array}$ & $\begin{array}{l}4,860 \\
4,710 \\
4,560 \\
4,410 \\
4,280 \\
4,140\end{array}$ \\
\hline $\begin{array}{r}7 \\
8 \\
9 \\
10 \\
11 \\
N\end{array}$ & $\begin{array}{l}2.18 \\
2.18 \\
2.18 \\
2.18 \\
2.17 \\
2.17\end{array}$ & $\begin{array}{l}417 \\
417 \\
417 \\
417 \\
411 \\
411\end{array}$ & $\begin{array}{l}1.95 \\
1.96 \\
1.98 \\
1.98 \\
2.00 \\
2.00\end{array}$ & $\begin{array}{l}306 \\
310 \\
319 \\
319 \\
328 \\
328\end{array}$ & $\begin{array}{l}4.53 \\
4.60 \\
4.63 \\
4.68 \\
4.77 \\
4.91\end{array}$ & $\begin{array}{l}2,410 \\
2,490 \\
2,530 \\
2,590 \\
2,690 \\
2,860\end{array}$ & $\begin{array}{l}6.85 \\
7.08 \\
7.60 \\
8.07 \\
8.48 \\
8.67\end{array}$ & $\begin{array}{l}5,760 \\
6,150 \\
7,070 \\
7,970 \\
8,790 \\
9,180\end{array}$ & $\begin{array}{l}9.52 \\
9.30 \\
9.13 \\
8.95 \\
8.62 \\
8.44\end{array}$ & $\begin{array}{r}10,900 \\
10,500 \\
10,200 \\
9,760 \\
9,070 \\
8,710\end{array}$ & $\begin{array}{l}5.77 \\
5.69 \\
5.60 \\
5.53 \\
5.47 \\
5.40\end{array}$ & $\begin{array}{l}4,040 \\
3,920 \\
3,790 \\
3,690 \\
3,610 \\
3,510\end{array}$ \\
\hline $\begin{array}{l}1 \\
2 \\
3 \\
4 \\
5 \\
6\end{array}$ & $\begin{array}{l}2.16 \\
2.15 \\
2.12 \\
2.11 \\
2.10 \\
2.08\end{array}$ & $\begin{array}{l}406 \\
401 \\
385 \\
380 \\
375 \\
366\end{array}$ & $\begin{array}{l}2.01 \\
2.02 \\
2.03 \\
2.04 \\
2.05 \\
2.08\end{array}$ & $\begin{array}{l}333 \\
337 \\
342 \\
347 \\
352 \\
366\end{array}$ & $\begin{array}{l}5.11 \\
5.38 \\
5.59 \\
5.70 \\
5.74 \\
5.78\end{array}$ & $\begin{array}{l}3,120 \\
3,470 \\
3,780 \\
3,930 \\
3,990 \\
4,050\end{array}$ & $\begin{array}{l}8.81 \\
8.85 \\
8.80 \\
8.90 \\
8.95 \\
9.13\end{array}$ & $\begin{array}{r}9,470 \\
9,560 \\
9,450 \\
9,660 \\
9,760 \\
10,200\end{array}$ & $\begin{array}{l}8.25 \\
8.10 \\
7.90 \\
7.70 \\
7.46 \\
7.24\end{array}$ & $\begin{array}{l}8,330 \\
8,030 \\
7,640 \\
7,260 \\
6,820 \\
6,420\end{array}$ & $\begin{array}{l}5.34 \\
5.29 \\
5.23 \\
5.19 \\
5.14 \\
5.10\end{array}$ & $\begin{array}{l}3,430 \\
3,360 \\
3,280 \\
3,230 \\
3,160 \\
3,110\end{array}$ \\
\hline \multirow[t]{2}{*}{$\begin{array}{r}7 \\
8 \\
9 \\
10 \\
11 \\
M\end{array}$} & $\begin{array}{l}2.05 \\
2.02 \\
2.00 \\
2.00 \\
1.99 \\
1.98\end{array}$ & $\begin{array}{l}352 \\
337 \\
328 \\
328 \\
324 \\
319\end{array}$ & $\begin{array}{l}2.10 \\
2.15 \\
2.30 \\
2.48 \\
2.60 \\
2.78\end{array}$ & $\begin{array}{l}375 \\
401 \\
482 \\
588 \\
660 \\
777\end{array}$ & $\begin{array}{l}5.87 \\
5.93 \\
6.00 \\
6.12 \\
6.23 \\
6.31\end{array}$ & $\begin{array}{l}4,180 \\
4,280 \\
4,380 \\
4,560 \\
4,730 \\
4,860\end{array}$ & $\begin{array}{l}10.12 \\
10.48 \\
10.48 \\
10.43 \\
10.32 \\
10.07\end{array}$ & $\begin{array}{l}12,200 \\
13,100 \\
13,100 \\
13,000 \\
12,700 \\
12,200\end{array}$ & $\begin{array}{l}7.09 \\
6.92 \\
6.80 \\
6.67 \\
6.53 \\
6.41\end{array}$ & $\begin{array}{l}6,160 \\
5,870 \\
5,670 \\
5,450 \\
5,210 \\
5,020\end{array}$ & $\begin{array}{l}5.06 \\
5.01 \\
4.98 \\
4.94 \\
4.90 \\
4.86\end{array}$ & $\begin{array}{l}3,060 \\
2,990 \\
2,950 \\
2,900 \\
2,850 \\
2,800\end{array}$ \\
\hline & \multicolumn{2}{|c|}{ September 24} & \multicolumn{2}{|c|}{ September 25} & \multicolumn{2}{|c|}{ September 26} & \multicolumn{2}{|c|}{ September 27 } & \multicolumn{2}{|c|}{ September 28} & \multicolumn{2}{|c|}{ September 29} \\
\hline $\begin{array}{r}2 \\
4 \\
6 \\
8 \\
10 \\
N\end{array}$ & \begin{tabular}{|l|}
4.78 \\
4.70 \\
4.62 \\
4.55 \\
4.48 \\
4.41
\end{tabular} & $\begin{array}{l}2,710 \\
2,610 \\
2,510 \\
2,430 \\
2,350 \\
2,260\end{array}$ & $\begin{array}{l}4.03 \\
3.99 \\
3.93 \\
3.88 \\
3.85 \\
3.88\end{array}$ & $\begin{array}{l}1,830 \\
1,790 \\
1,730 \\
1,680 \\
1,650 \\
1,680\end{array}$ & $\begin{array}{l}3.62 \\
3.61 \\
3.58 \\
3.55 \\
3.51 \\
3.50\end{array}$ & $\begin{array}{l}1,420 \\
1,410 \\
1,380 \\
1,360 \\
1,320 \\
1,310\end{array}$ & $\begin{array}{l}3.34 \\
3.31 \\
3.30 \\
3.28 \\
3.25 \\
3.23\end{array}$ & $\begin{array}{l}1,170 \\
1,150 \\
1,140 \\
1,120 \\
1,100 \\
1,084\end{array}$ & $\begin{array}{l}3.35 \\
3.39 \\
3.38 \\
3.35 \\
3.31 \\
3.27\end{array}$ & $\begin{array}{l}1,180 \\
1,210 \\
1,200 \\
1,180 \\
1,150 \\
1,120\end{array}$ & $\begin{array}{l}3.14 \\
3.12 \\
3.12 \\
3.11 \\
3.10 \\
3.09\end{array}$ & $\begin{array}{r}1,020 \\
1,000 \\
1,000 \\
997 \\
990 \\
983\end{array}$ \\
\hline $\begin{array}{r}2 \\
4 \\
6 \\
8 \\
10 \\
M\end{array}$ & $\begin{array}{l}4.34 \\
4.28 \\
4.23 \\
4.20 \\
4.14 \\
4.09\end{array}$ & $\begin{array}{l}2,180 \\
2,110 \\
2,050 \\
2,020 \\
1,950 \\
1,900\end{array}$ & $\begin{array}{l}3.82 \\
3.63 \\
3.59 \\
3.61 \\
3.62 \\
3.62\end{array}$ & $\begin{array}{l}1,620 \\
1,430 \\
1,390 \\
1,410 \\
1,420 \\
1,420\end{array}$ & $\begin{array}{l}3.49 \\
3.46 \\
3.43 \\
3.41 \\
3.39 \\
3.37\end{array}$ & $\begin{array}{l}1,300 \\
1,270 \\
1,250 \\
1,230 \\
1,210 \\
1,200\end{array}$ & $\begin{array}{l}3.22 \\
3.21 \\
3.21 \\
3.23 \\
3.27 \\
3.31\end{array}$ & $\begin{array}{l}1,076 \\
1,070 \\
1,070 \\
1,080 \\
1,120 \\
1,150\end{array}$ & $\begin{array}{l}3.25 \\
3.22 \\
3.20 \\
3.19 \\
3.18 \\
3.16\end{array}$ & $\begin{array}{l}1,100 \\
1,080 \\
1,060 \\
1,053 \\
1,046 \\
1,030\end{array}$ & $\begin{array}{l}3.07 \\
3.05 \\
3.03 \\
3.01 \\
3.00 \\
2.99\end{array}$ & $\begin{array}{l}969 \\
955 \\
941 \\
927 \\
920 \\
914\end{array}$ \\
\hline
\end{tabular}

Supplemental records.- Sept. $21,8: 30$ p.m., 10.49 ft., 13,100 sec.-ft. 
Location.- Water-stage recorder, lat. $43^{\circ} 20^{\prime} 00^{\prime \prime}$, long. $72^{\circ} 30^{\prime} 5^{\prime \prime}$, in North Springfleld, Windsor County, 1,300 feet above Great Brook.

Drainage area.- 158 square miles.

Gage-height record. - Water-stage recorder graph.

Stage-discharge relation.- Defined by current-meter measurements below 2,330 second-feet; extended to peak stage on besis of determinations of flood flows over dams. For 1936 defined by current-meter measurements below 4,600 second-feet; extended to peak stage on basis of determination of flood flow over dam.

Maxima.- September 1938: Discharge, 15,500 second-feet 12:30 a.m. Sept. 22 (gage height, 17.68 feet)

1930 to August 1938: Discharge, 14,700 second-feet Mar. 18, 1936 (gage height, 26.41 feet)

Remarks.- Flood run-off not materially affected by artificial storage or natural pondage.

Mean dally discharge, in second-feet, 1938

\begin{tabular}{|c|c|c|c|c|c|c|c|c|c|c|c|}
\hline Day & Sept. & oct. & Day & Sept. & Oct. & Day & Sept. & Oct. & Day & Sept. & Oct. \\
\hline $\begin{array}{l}1 \\
2 \\
3 \\
4 \\
5 \\
6 \\
7 \\
8\end{array}$ & $\begin{array}{r}94 \\
106 \\
89 \\
50 \\
83 \\
68 \\
97 \\
113\end{array}$ & $\begin{array}{l}280 \\
264 \\
234 \\
220 \\
203 \\
190 \\
182 \\
157\end{array}$ & $\begin{array}{r}9 \\
10 \\
11 \\
12 \\
13 \\
14 \\
15 \\
16\end{array}$ & $\begin{array}{r}87 \\
93 \\
73 \\
68 \\
351 \\
235 \\
515 \\
586\end{array}$ & $\begin{array}{l}160 \\
145 \\
122 \\
137 \\
135 \\
128 \\
119 \\
106\end{array}$ & $\begin{array}{l}17 \\
18 \\
19 \\
20 \\
21 \\
22 \\
23 \\
24\end{array}$ & $\begin{array}{r}348 \\
308 \\
431 \\
2,980 \\
7,350 \\
6,660 \\
1,810 \\
1,050\end{array}$ & $\begin{array}{r}96 \\
108 \\
127 \\
112 \\
219 \\
170 \\
119 \\
448\end{array}$ & $\begin{array}{l}25 \\
26 \\
27 \\
28 \\
29 \\
30 \\
31\end{array}$ & $\begin{array}{l}733 \\
561 \\
484 \\
364 \\
265 \\
270\end{array}$ & $\begin{array}{l}668 \\
349 \\
300 \\
231 \\
189 \\
192 \\
189\end{array}$ \\
\hline $\begin{array}{l}\text { Mean } \\
\text { Run- }\end{array}$ & $\begin{array}{l}\text { nthly } \\
\text { in } 1\end{array}$ & & , ir & - . & t. & . : & : $\cdot$ : & $\begin{array}{ll}\cdot & \bullet \\
- & \bullet \\
\end{array}$ & - $\dot{ }$ & $\begin{array}{r}877 \\
6.19 \\
\end{array}$ & $\begin{array}{r}203 \\
1.48 \\
\end{array}$ \\
\hline
\end{tabular}

Gage height, in feet, and discharge, in second-feet, at indicated time, 1938

\begin{tabular}{|c|c|c|c|c|c|c|c|c|c|c|c|c|}
\hline \multirow{2}{*}{ 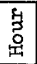 } & Feet & Sec.ft. & Feet & Sec.ft. & Feet & Sec.ft. & Feet & Sec.ft. & Feet & Sec.ft. & Feet & Sec.ft. \\
\hline & \multicolumn{2}{|c|}{ September 18} & \multicolumn{2}{|c|}{ September 19} & \multicolumn{2}{|c|}{ September 20} & \multicolumn{2}{|c|}{ September 21} & \multicolumn{2}{|c|}{ September 22} & \multicolumn{2}{|c|}{ September 23} \\
\hline $\begin{array}{l}1 \\
2 \\
3 \\
4 \\
5 \\
6\end{array}$ & $\begin{array}{l}3.52 \\
3.52 \\
3.52 \\
3.52 \\
3.52 \\
3.52\end{array}$ & $\begin{array}{l}302 \\
302 \\
302 \\
302 \\
302 \\
302\end{array}$ & $\begin{array}{l}3.55 \\
3.55 \\
3.55 \\
3.55 \\
3.55 \\
3.55\end{array}$ & $\begin{array}{l}312 \\
312 \\
312 \\
312 \\
312 \\
312\end{array}$ & $\begin{array}{l}5.05 \\
5.65 \\
6.05 \\
6.55 \\
7.15 \\
7.48\end{array}$ & $\begin{array}{l}1,030 \\
1,400 \\
1,690 \\
2,090 \\
2,580 \\
2,880\end{array}$ & $\begin{array}{l}9.12 \\
9.28 \\
9.45 \\
9.77 \\
9.83 \\
9.85\end{array}$ & $\begin{array}{l}4,470 \\
4,630 \\
4,800 \\
5,120 \\
5,180 \\
5,200\end{array}$ & $\begin{array}{l}17.20 \\
16.30 \\
15.40 \\
14.20 \\
13.30 \\
12.50\end{array}$ & $\begin{array}{r}14,720 \\
13,350 \\
12,010 \\
10,360 \\
9,190 \\
8,200\end{array}$ & $\begin{array}{l}7.30 \\
7.12 \\
7.00 \\
6.85 \\
6.72 \\
6.60\end{array}$ & $\begin{array}{l}2,720 \\
2,560 \\
2,450 \\
2,330 \\
2,230 \\
2,130\end{array}$ \\
\hline $\begin{array}{r}7 \\
8 \\
9 \\
10 \\
11 \\
N\end{array}$ & $\begin{array}{l}3.51 \\
3.51 \\
3.51 \\
3.51 \\
3.52 \\
3.53\end{array}$ & $\begin{array}{l}298 \\
298 \\
298 \\
298 \\
302 \\
306\end{array}$ & $\begin{array}{l}3.55 \\
3.56 \\
3.56 \\
3.57 \\
3.57 \\
3.55\end{array}$ & $\begin{array}{l}312 \\
316 \\
316 \\
320 \\
320 \\
312\end{array}$ & $\begin{array}{l}7.72 \\
7.82 \\
7.78 \\
7.64 \\
7.56 \\
7.59\end{array}$ & $\begin{array}{l}3,100 \\
3,190 \\
3,150 \\
3,030 \\
2,950 \\
2,980\end{array}$ & $\begin{array}{r}9.95 \\
10.20 \\
10.54 \\
10.83 \\
11.04 \\
11.35\end{array}$ & $\begin{array}{l}5,300 \\
5,570 \\
5,940 \\
6,260 \\
6,490 \\
6,840\end{array}$ & $\begin{array}{l}11.85 \\
11.50 \\
11.15 \\
10.85 \\
10.55 \\
10.23\end{array}$ & $\begin{array}{l}7,420 \\
7,000 \\
6,620 \\
6,280 \\
5,960 \\
5,600\end{array}$ & $\begin{array}{l}6.49 \\
6.38 \\
6.28 \\
6.16 \\
6.14 \\
6.04\end{array}$ & $\begin{array}{l}2,040 \\
1,950 \\
1,870 \\
1,780 \\
1,760 \\
1,680\end{array}$ \\
\hline $\begin{array}{l}1 \\
2 \\
3 \\
4 \\
5 \\
6\end{array}$ & $\begin{array}{l}3.54 \\
3.54 \\
3.55 \\
3.56 \\
3.56 \\
3.56\end{array}$ & $\begin{array}{l}309 \\
309 \\
312 \\
316 \\
316 \\
316\end{array}$ & $\begin{array}{l}3.61 \\
3.74 \\
3.83 \\
3.92 \\
3.99 \\
4.05\end{array}$ & $\begin{array}{l}334 \\
381 \\
417 \\
453 \\
481 \\
508\end{array}$ & $\begin{array}{l}7.73 \\
7.85 \\
7.92 \\
7.91 \\
7.98 \\
7.95\end{array}$ & $\begin{array}{l}3,110 \\
3,220 \\
3,280 \\
3,270 \\
3,330 \\
3,300\end{array}$ & $\begin{array}{l}11.65 \\
11.92 \\
12.20 \\
12.40 \\
12.60 \\
12.65\end{array}$ & $\begin{array}{l}7,180 \\
7,500 \\
7,840 \\
8,080 \\
8,320 \\
8,380\end{array}$ & $\begin{array}{l}9.94 \\
9.62 \\
9.39 \\
9.10 \\
8.82 \\
8.60\end{array}$ & $\begin{array}{l}5,290 \\
4,970 \\
4,740 \\
4,450 \\
4,170 \\
3,950\end{array}$ & $\begin{array}{l}5.98 \\
5.90 \\
5.86 \\
5.80 \\
5.75 \\
5.70\end{array}$ & $\begin{array}{l}1,640 \\
1,580 \\
1,550 \\
1,510 \\
1,480 \\
1,440\end{array}$ \\
\hline \multirow[t]{2}{*}{$\begin{array}{r}7 \\
8 \\
9 \\
10 \\
11 .\end{array}$} & $\begin{array}{l}3.57 \\
3.57 \\
3.57 \\
3.56 \\
3.56 \\
3.55\end{array}$ & $\begin{array}{l}320 \\
320 \\
320 \\
316 \\
316 \\
312\end{array}$ & $\begin{array}{l}4.15 \\
4.27 \\
4.40 \\
4.52 \\
4.67 \\
4.84\end{array}$ & $\begin{array}{l}552 \\
610 \\
675 \\
736 \\
818 \\
912\end{array}$ & $\begin{array}{l}8.04 \\
8.28 \\
8.50 \\
8.86 \\
8.94 \\
9.00\end{array}$ & $\begin{array}{l}3,390 \\
3,630 \\
3,850 \\
4,210 \\
4,290 \\
4,350\end{array}$ & $\begin{array}{l}12.64 \\
13.15 \\
14.20 \\
15.60 \\
16.50 \\
17.25\end{array}$ & $\begin{array}{r}8,370 \\
9,000 \\
10,360 \\
12,300 \\
13,650 \\
14,800\end{array}$ & $\begin{array}{l}8.37 \\
8.15 \\
7.95 \\
7.78 \\
7.60 \\
7.46\end{array}$ & $\begin{array}{l}3,720 \\
3,500 \\
3,300 \\
3,150 \\
2,990 \\
2,860 \\
\end{array}$ & $\begin{array}{l}5.56 \\
5.59 \\
5.57 \\
5.50 \\
5.47 \\
5.44\end{array}$ & $\begin{array}{l}1,340 \\
1,360 \\
1,350 \\
1,300 \\
1,280 \\
1,260\end{array}$ \\
\hline & \multicolumn{2}{|c|}{ September 24} & \multicolumn{2}{|c|}{ September 25} & \multicolumn{2}{|c|}{ September 26} & \multicolumn{2}{|c|}{ September 27} & \multicolumn{2}{|c|}{ September 28} & \multicolumn{2}{|c|}{ September 29} \\
\hline $\begin{array}{r}2 \\
4 \\
6 \\
8 \\
10 \\
\mathrm{~N}\end{array}$ & $\begin{array}{l}5.36 \\
5.28 \\
5.22 \\
5.17 \\
5.13 \\
5.07\end{array}$ & $\begin{array}{l}1,220 \\
1,170 \\
1,130 \\
1,100 \\
1,080 \\
1,040\end{array}$ & $\begin{array}{l}4.70 \\
4.66 \\
4.62 \\
4.58 \\
4.53 \\
4.50\end{array}$ & $\begin{array}{l}835 \\
813 \\
791 \\
769 \\
742 \\
725\end{array}$ & $\begin{array}{l}4.26 \\
4.24 \\
4.22 \\
4.20 \\
4.18 \\
4.22\end{array}$ & $\begin{array}{l}605 \\
595 \\
585 \\
575 \\
566 \\
585\end{array}$ & $\begin{array}{l}4.02 \\
3.99 \\
3.98 \\
3.98 \\
3.97 \\
3.98\end{array}$ & $\begin{array}{l}494 \\
481 \\
477 \\
477 \\
473 \\
477\end{array}$ & $\begin{array}{l}3.91 \\
3.90 \\
3.82 \\
3.55 \\
3.40 \\
3.80\end{array}$ & $\begin{array}{l}449 \\
445 \\
417 \\
326 \\
279 \\
410\end{array}$ & $\begin{array}{l}3.52 \\
3.51 \\
3.34 \\
3.30 \\
3.29 \\
3.18\end{array}$ & $\begin{array}{l}316 \\
313 \\
261 \\
249 \\
246 \\
216\end{array}$ \\
\hline $\begin{array}{r}2 \\
4 \\
6 \\
8 \\
10 \\
M\end{array}$ & $\begin{array}{l}5.03 \\
4.97 \\
4.88 \\
4.85 \\
4.80 \\
4.75\end{array}$ & $\begin{array}{r}1,020 \\
984 \\
934 \\
918 \\
890 \\
862\end{array}$ & $\begin{array}{l}4.48 \\
4.45 \\
4.40 \\
4.38 \\
4.30 \\
4.29\end{array}$ & $\begin{array}{l}715 \\
700 \\
675 \\
665 \\
625 \\
620\end{array}$ & $\begin{array}{l}4.12 \\
4.05 \\
4.09 \\
4.20 \\
4.06 \\
4.04\end{array}$ & $\begin{array}{l}539 \\
508 \\
526 \\
575 \\
512 \\
503\end{array}$ & $\begin{array}{l}3.98 \\
4.04 \\
4.03 \\
4.03 \\
3.96 \\
3.92\end{array}$ & $\begin{array}{l}477 \\
503 \\
498 \\
498 \\
469 \\
453\end{array}$ & $\begin{array}{l}3.78 \\
3.60 \\
3.58 \\
3.57 \\
3.39 \\
3.30\end{array}$ & $\begin{array}{l}403 \\
342 \\
336 \\
332 \\
276 \\
249\end{array}$ & $\begin{array}{l}3.42 \\
3.42 \\
3.40 \\
3.37 \\
3.20 \\
3.20\end{array}$ & $\begin{array}{l}285 \\
285 \\
279 \\
270 \\
221 \\
221\end{array}$ \\
\hline
\end{tabular}

Supplemental records.- Sept. $22,12: 30 \mathrm{a.m.,} 17.68 \mathrm{ft.,} 15,500$ sec.-ft. 
West River at Newfane, Vt.

Location. - Water-stage recorder, lat. $42^{\circ} 59^{\prime} 45^{\prime \prime}$, long. $72^{\circ} 38^{\prime} 20^{\prime \prime}$, 600 feet below highway bridge and $1 \mathrm{mile}$ northeast of Newfane, Windham County. (Revised).

Drainage area.- 308 square miles.

Gage-helght record.- Water-stage recorder graph except for perlods Sept. 1, 9 p.m. sept. 2I to $1: 30$ a.m. Sept. $22,5: 30$ a.m. Sept. 22 to 3 p.m. Sept. 24, and 0ct. 20$24,28-31$, records for which were based on two chain gage readings dally, floodmarks, and shape of stage graphs at nearby stations.

Stage-discharge relation.- Defined by current-meter measurements below 8,770 secondfeet; extended to peak atage on basis of determinations of flood flows by contractedopening and slope-area methods.

Maxime.- September 1938: Discharge, 52,300 second-feet 11 p.m. Sept. 21 (gage height, 22. 81 feot, from floodmarks).

1919 to August 1938: Discharge, 45,000 second-feet Nov. 3, 1927 (gage he1ght, 23.0 feet, floodmarks at chain-gage site at highway bridge upstream), from logarithmic extension of rating curve. (The revised discharge 53,100 second-feet, published in Water-Supply Papers 781, 798, and 801 , is now belleved to be in error.)

Remarks.- Flood run-off not materially affected by artificlal or natural storage.

Mean daily discharge, in second-fert, 1938

\begin{tabular}{|c|c|c|c|c|c|c|c|c|c|c|c|}
\hline Day & Sept. & Oct. & Day & Sept. & Oct. & Day & Sept. & Oct. & Day & Sept. & Oct. \\
\hline $\begin{array}{l}1 \\
2 \\
3 \\
4 \\
5 \\
6 \\
7 \\
8\end{array}$ & $\begin{array}{r}79 \\
106 \\
93 \\
76 \\
72 \\
76 \\
67 \\
127\end{array}$ & $\begin{array}{l}716 \\
660 \\
612 \\
580 \\
566 \\
538 \\
517 \\
496\end{array}$ & $\begin{array}{r}9 \\
10 \\
11 \\
12 \\
13 \\
14 \\
15 \\
16\end{array}$ & $\begin{array}{r}144 \\
95 \\
79 \\
72 \\
167 \\
333 \\
624 \\
860\end{array}$ & $\begin{array}{r}482 \\
482 \\
475 \\
454 \\
447 \\
440 \\
434 \\
427\end{array}$ & $\begin{array}{l}17 \\
18 \\
19 \\
20 \\
21 \\
22 \\
23 \\
24\end{array}$ & $\begin{array}{r}384 \\
322 \\
609 \\
5,830 \\
17,200 \\
13,500 \\
3,250 \\
1,680\end{array}$ & $\begin{array}{l}427 \\
427 \\
414 \\
205 \\
352 \\
423 \\
275 \\
730\end{array}$ & $\begin{array}{l}25 \\
26 \\
27 \\
28 \\
29 \\
30 \\
31\end{array}$ & $\begin{array}{r}1,050 \\
759 \\
638 \\
762 \\
519 \\
423\end{array}$ & $\begin{array}{r}1,640 \\
735 \\
228 \\
347 \\
347 \\
328 \\
292\end{array}$ \\
\hline $\begin{array}{l}\text { Mean } \\
\text { Run-c }\end{array}$ & $\begin{array}{l}\text { nthly } \\
\text { in } 1\end{array}$ & 108 . & Ir & gecond- & t. & : : & . $\cdot \dot{ }$ & : : & : $:$ & $\begin{array}{r}1,667 \\
6.04\end{array}$ & $\begin{array}{r}500 \\
1.87 \\
\end{array}$ \\
\hline
\end{tabular}

Gage height, in feet, and discharge, in second-feet, at indicated time, 1938

\begin{tabular}{|c|c|c|c|c|c|c|c|c|c|c|c|c|}
\hline \multirow{2}{*}{$\begin{array}{l}\text { 乌ุ } \\
\text { 总 }\end{array}$} & Feet & Sec.ft. & Feet & Sec.ft. & Feet & Sec.ft. & Feet & Sec.ft. & Feet & Sec.ft. & Feet & Sec.ft. \\
\hline & \multicolumn{2}{|c|}{ September 18} & \multicolumn{2}{|c|}{ September 19} & \multicolumn{2}{|c|}{ September 20} & \multicolumn{2}{|c|}{ September 21} & \multicolumn{2}{|c|}{ September 22} & \multicolumn{2}{|c|}{ September 23} \\
\hline $\begin{array}{l}1 \\
2 \\
3 \\
4 \\
5 \\
6\end{array}$ & $\begin{array}{l}4.74 \\
4.74 \\
4.74 \\
4.74 \\
4.73 \\
4.72\end{array}$ & $\begin{array}{l}290 \\
290 \\
290 \\
290 \\
285 \\
280\end{array}$ & $\begin{array}{l}4.90 \\
4.89 \\
4.88 \\
4.89 \\
4.88 \\
4.88\end{array}$ & $\begin{array}{r}375 \\
370 \\
364 \\
370 \\
364 \\
364\end{array}$ & $\begin{array}{l}6.33 \\
6.53 \\
6.85 \\
7.35 \\
8.07 \\
8.51\end{array}$ & $\begin{array}{l}1,750 \\
2,020 \\
2,480 \\
3,300 \\
4,580 \\
5,450\end{array}$ & $\begin{array}{r}9.80 \\
9.95 \\
10.02 \\
10.01 \\
10.00 \\
10.00\end{array}$ & $\begin{array}{l}8,340 \\
8,700 \\
8,870 \\
8,840 \\
8,820 \\
8,820\end{array}$ & $\begin{array}{l}20.00 \\
18.00 \\
16.20 \\
14.55 \\
13.10 \\
12.20\end{array}$ & $\begin{array}{l}41,700 \\
34,100 \\
26,600 \\
21,900 \\
17,200 \\
14,600\end{array}$ & $\begin{array}{l}8.28 \\
8.20 \\
8.09 \\
8.00 \\
7.95 \\
7.83\end{array}$ & $\begin{array}{l}4,740 \\
4,570 \\
4,340 \\
4,150 \\
4,040 \\
3,800\end{array}$ \\
\hline $\begin{array}{r}7 \\
8 \\
9 \\
10 \\
11 \\
N\end{array}$ & $\begin{array}{l}4.70 \\
4.70 \\
4.70 \\
4.70 \\
4.71 \\
4.73\end{array}$ & $\begin{array}{l}270 \\
270 \\
270 \\
270 \\
275 \\
285\end{array}$ & $\begin{array}{l}4.88 \\
4.88 \\
4.89 \\
4.90 \\
4.93 \\
4.96\end{array}$ & $\begin{array}{l}364 \\
364 \\
370 \\
375 \\
394 \\
414\end{array}$ & $\begin{array}{l}8.72 \\
8.83 \\
8.90 \\
8.95 \\
8.97 \\
8.98\end{array}$ & $\begin{array}{l}5,890 \\
6,130 \\
6,280 \\
6,390 \\
6,450 \\
6,460\end{array}$ & $\begin{array}{l}10.01 \\
10.15 \\
10.25 \\
10.42 \\
10.62 \\
11.00\end{array}$ & $\begin{array}{r}8,840 \\
9,200 \\
9,440 \\
9,870 \\
10,400 \\
11,400\end{array}$ & $\begin{array}{l}11.70 \\
11.35 \\
11.00 \\
10.70 \\
10.40 \\
10.20\end{array}$ & $\begin{array}{r}13,200 \\
12,300 \\
11,400 \\
10,600 \\
9,810 \\
9,290\end{array}$ & $\begin{array}{l}7.79 \\
7.70 \\
7.62 \\
7.59 \\
7.51 \\
7.45\end{array}$ & $\begin{array}{l}3,720 \\
3,540 \\
3,380 \\
3,320 \\
3,170 \\
3,060\end{array}$ \\
\hline $\begin{array}{l}1 \\
2 \\
3 \\
4 \\
5 \\
6\end{array}$ & $\begin{array}{l}4.75 \\
4.78 \\
4.82 \\
4.86 \\
4.90 \\
4.92\end{array}$ & $\begin{array}{l}295 \\
310 \\
331 \\
353 \\
375 \\
388\end{array}$ & $\begin{array}{l}5.01 \\
5.09 \\
5.23 \\
5.35 \\
5.45 \\
5.52\end{array}$ & $\begin{array}{l}447 \\
503 \\
604 \\
700 \\
785 \\
848\end{array}$ & $\begin{array}{l}9.03 \\
9.10 \\
9.12 \\
9.10 \\
9.08 \\
9.08\end{array}$ & $\begin{array}{l}6,570 \\
6 ; 720 \\
6,760 \\
6,720 \\
6,680 \\
6,680\end{array}$ & $\begin{array}{l}11.43 \\
11.80 \\
12.10 \\
12.25 \\
12.28 \\
12.43\end{array}$ & $\begin{array}{l}12,500 \\
13,500 \\
14,300 \\
14,700 \\
14,800 \\
15,300\end{array}$ & $\begin{array}{r}10.00 \\
9.80 \\
9.60 \\
9.45 \\
9.20 \\
9.15\end{array}$ & $\begin{array}{l}8,790 \\
8,290 \\
7,790 \\
7,420 \\
6,940 \\
6,700\end{array}$ & $\begin{array}{l}7.40 \\
7.38 \\
7.32 \\
7.25 \\
7.21 \\
7.20\end{array}$ & $\begin{array}{l}2,960 \\
2,920 \\
2,820 \\
2,690 \\
2,620 \\
2,600\end{array}$ \\
\hline $\begin{array}{r}7 \\
8 \\
9 \\
10 \\
11 \\
M\end{array}$ & $\begin{array}{l}4.93 \\
4.93 \\
4.93 \\
4.93 \\
4.92 \\
4.91\end{array}$ & $\begin{array}{l}394 \\
394 \\
394 \\
394 \\
388 \\
382\end{array}$ & $\begin{array}{l}5.56 \\
5.62 \\
5.69 \\
5.80 \\
5.99 \\
6.16\end{array}$ & $\begin{array}{r}884 \\
940 \\
1,010 \\
1,120 \\
1,330 \\
1,530\end{array}$ & $\begin{array}{l}9.13 \\
9.37 \\
9.63 \\
9.65 \\
9.62 \\
9.60\end{array}$ & $\begin{array}{l}6,790 \\
7,330 \\
7,930 \\
7,980 \\
7,910 \\
7,860\end{array}$ & $\begin{array}{l}13.20 \\
16.20 \\
19.60 \\
22.40 \\
22.81 \\
21.80\end{array}$ & $\begin{array}{l}17,600 \\
27,600 \\
40,200 \\
50,800 \\
52,300 \\
48,500\end{array}$ & $\begin{array}{l}8.99 \\
8.83 \\
8.72 \\
8.60 \\
8.50 \\
8.40\end{array}$ & $\begin{array}{l}6,330 \\
5,960 \\
5,710 \\
5,440 \\
5,220 \\
5,000\end{array}$ & $\begin{array}{l}7.15 \\
7.11 \\
7.06 \\
7.02 \\
7.00 \\
6.98\end{array}$ & $\begin{array}{l}2,520 \\
2,450 \\
2,360 \\
2,290 \\
2,260 \\
2,230\end{array}$ \\
\hline & \multicolumn{2}{|c|}{ September 24} & \multicolumn{2}{|c|}{ September 25 } & \multicolumn{2}{|c|}{ September 26} & \multicolumn{2}{|c|}{ September 27} & \multicolumn{2}{|c|}{ September 28} & \multicolumn{2}{|c|}{ September 29} \\
\hline $\begin{array}{r}2 \\
4 \\
6 \\
8 \\
10 \\
N\end{array}$ & $\begin{array}{l}6.89 \\
6.82 \\
6.78 \\
6.71 \\
6.65 \\
6.60\end{array}$ & $\begin{array}{l}2,080 \\
1,970 \\
1,910 \\
1,800 \\
1,720 \\
1,640\end{array}$ & $\begin{array}{l}6.32 \\
6.27 \\
6.23 \\
6.20 \\
6.17 \\
6.14\end{array}$ & $\begin{array}{l}1,260 \\
1,190 \\
1,150 \\
1,110 \\
1,080 \\
1,040\end{array}$ & $\begin{array}{l}5.99 \\
5.96 \\
5.93 \\
5.92 \\
5.89 \\
5.87\end{array}$ & $\begin{array}{l}875 \\
845 \\
815 \\
805 \\
776 \\
756\end{array}$ & $\begin{array}{l}5.74 \\
5.73 \\
5.70 \\
5.68 \\
5.67 \\
5.67\end{array}$ & \begin{tabular}{|l}
636 \\
627 \\
600 \\
584 \\
576 \\
576
\end{tabular} & $\begin{array}{l}5.95 \\
5.96 \\
5.96 \\
5.95 \\
5.93 \\
5.90\end{array}$ & $\begin{array}{l}835 \\
845 \\
845 \\
835 \\
815 \\
785\end{array}$ & $\begin{array}{l}5.69 \\
5.66 \\
5.64 \\
5.63 \\
5.60 \\
5.58\end{array}$ & \begin{tabular}{|l}
592 \\
568 \\
552 \\
544 \\
520 \\
506
\end{tabular} \\
\hline $\begin{array}{r}2 \\
4 \\
6 \\
8 \\
10 \\
11\end{array}$ & $\begin{array}{l}6.57 \\
6.53 \\
6.45 \\
6.42 \\
6.40 \\
6.35\end{array}$ & $\begin{array}{l}1,600 \\
1,540 \\
1,430 \\
1,390 \\
1,360 \\
1,300\end{array}$ & $\begin{array}{l}6.11 \\
6.08 \\
6.05 \\
6.02 \\
6.00 \\
6.00\end{array}$ & $\begin{array}{r}1,010 \\
973 \\
940 \\
907 \\
885 \\
885\end{array}$ & $\begin{array}{l}5.85 \\
5.82 \\
5.79 \\
5.77 \\
5.78 \\
5.77\end{array}$ & $\begin{array}{l}738 \\
709 \\
681 \\
663 \\
672 \\
663\end{array}$ & $\begin{array}{l}5.67 \\
5.72 \\
5.78 \\
5.80 \\
5.87 \\
5.93\end{array}$ & $\begin{array}{l}576 \\
618 \\
672 \\
690 \\
756 \\
815\end{array}$ & $\begin{array}{l}5.86 \\
5.84 \\
5.81 \\
5.77 \\
5.74 \\
5.71\end{array}$ & $\begin{array}{l}747 \\
728 \\
700 \\
663 \\
636 \\
609\end{array}$ & $\begin{array}{l}5.57 \\
5.57 \\
5.55 \\
5.53 \\
5.51 \\
5.50\end{array}$ & $\begin{array}{l}500 \\
500 \\
486 \\
472 \\
459 \\
452\end{array}$ \\
\hline
\end{tabular}


Location.- Water-stage recorder, lat. $43^{\circ} 02^{\prime} 20^{\prime \prime}$, long. $72^{\circ} 16^{\prime} 15^{\prime \prime}$, at stone-arch bridge just off Keene-Newport roed, 0.7 mile below Gilsum, Cheshire County.

Drainage area.- 71.1 square miles.

Gage-helght record. - Water-stage recorder graph.

Stage-discharge relation.- Defined by current-meter measurements below 1,990 secondfeet; extended to peak stage on basis of determinations of flood flows by slopearea and surface-float methods.

Maxima.- September 1938: Discharge, 5,220 second-feet 6 p.m. Sept. 21 (gage he1ght, 11.24 foet)

1922 to August 1938: Discharge, 4,400 second-feet Mar. 18, 19, 1936 (gage helght, 12.80 feet).

Remarks.- Flood run-off affected by some artificial and natural storage.

Mean dally discharge, in second-feet, 1938

\begin{tabular}{|c|r|r||r|r|r||r|r|r||r|r|r|}
\hline Day & Sept. & 0ct. & Day & Sept. & 0ct. & Day & Sept. & 0ct. & Day & Sept. & 0ct. \\
\hline 1 & 49 & 145 & 9 & 31 & 37 & 17 & 96 & 16 & 25 & 441 & 362 \\
2 & 39 & 124 & 10 & 24 & 29 & 18 & 66 & 16 & 26 & 301 & 313 \\
3 & 32 & 100 & 11 & 14 & 36 & 19 & 130 & 17 & 27 & 243 & 231 \\
4 & 25 & 86 & 12 & 8 & 25 & 20 & 971 & 21 & 28 & 238 \\
182 \\
5 & 30 & 75 & 13 & 62 & 29 & 21 & 4,140 & 65 & 29 & 209 & 145 \\
6 & 16 & 65 & 14 & 81 & 25 & 22 & 3,500 & 74 & 30 & 176 & 116 \\
7 & 22 & 41 & 15 & 93 & 27 & 23 & 1,520 & 60 & 31 & 97 \\
8 & 32 & 36 & 16 & 136 & 19 & 24 & 709 & 128 & & \\
\hline
\end{tabular}

Gage height, In feet, and discharge, In second-feet, at Indicated time, 1938

\begin{tabular}{|c|c|c|c|c|c|c|c|c|c|c|c|c|}
\hline \multirow{2}{*}{$\begin{array}{l}9 \\
9 \\
0 \\
\end{array}$} & Feet & Sec.ft. & Feet & Sec.ft. & Feet & \multirow{2}{*}{$\begin{array}{l}\text { Sec . ft. } \\
\text { nber } 20\end{array}$} & Feet & \multirow{2}{*}{$\frac{\text { Sec.ft. }}{\text { nber } 21}$} & Feet & Sec.ft. & Feet & Sec.ft. \\
\hline & \multicolumn{2}{|c|}{ September 18} & \multicolumn{2}{|c|}{ September 19} & September 20 & & September 21 & & \multicolumn{2}{|c|}{ September 22} & \multicolumn{2}{|c|}{ September 23} \\
\hline $\begin{array}{l}1 \\
2 \\
3 \\
4 \\
5 \\
6\end{array}$ & $\begin{array}{l}2.19 \\
2.15 \\
2.12 \\
2.09 \\
2.07 \\
2.07\end{array}$ & $\begin{array}{l}76 \\
73 \\
71 \\
68 \\
67 \\
67\end{array}$ & $\begin{array}{l}1.90 \\
1.90 \\
1.90 \\
1.91 \\
1.91 \\
1.92\end{array}$ & $\begin{array}{r}53 \\
53 \\
53 \\
54 \\
54 \\
55\end{array}$ & $\begin{array}{l}3.60 \\
4.20 \\
4.48 \\
4.55 \\
4.63 \\
4.83\end{array}$ & $\begin{array}{l}306 \\
452 \\
525 \\
544 \\
567 \\
627\end{array}$ & $\begin{array}{l}7.25 \\
7.45 \\
7.60 \\
7.90 \\
8.40 \\
9.30\end{array}$ & $\begin{array}{l}1,640 \\
1,840 \\
2,020 \\
2,300 \\
2,750 \\
3,590\end{array}$ & $\begin{array}{r}10.50 \\
10.15 \\
9.90 \\
9.85 \\
9.85 \\
9.90\end{array}$ & $\begin{array}{l}4,550 \\
4,270 \\
4,070 \\
4,030 \\
4,030 \\
4,070\end{array}$ & $\begin{array}{l}7.60 \\
7.50 \\
7.25 \\
7.00 \\
6.90 \\
6.70\end{array}$ & $\begin{array}{l}2,330 \\
2,270 \\
2,120 \\
1,970 \\
1,910 \\
1,790\end{array}$ \\
\hline $\begin{array}{r}7 \\
8 \\
9 \\
10 \\
11 \\
\mathrm{~N}\end{array}$ & $\begin{array}{l}2.06 \\
2.06 \\
2.07 \\
2.07 \\
2.08 \\
2.08\end{array}$ & $\begin{array}{l}66 \\
66 \\
67 \\
67 \\
68 \\
68\end{array}$ & $\begin{array}{l}1.95 \\
2.00 \\
2.05 \\
2.07 \\
2.12 \\
2.15\end{array}$ & $\begin{array}{l}57 \\
61 \\
65 \\
67 \\
71 \\
73\end{array}$ & $\begin{array}{l}4.85 \\
4.86 \\
5.04 \\
5.60 \\
5.80 \\
6.20\end{array}$ & $\begin{array}{r}633 \\
636 \\
693 \\
890 \\
966 \\
1,120\end{array}$ & $\begin{array}{l}10.55 \\
10.76 \\
10.95 \\
10.85 \\
11.00 \\
10.80\end{array}$ & $\begin{array}{l}4,600 \\
4,780 \\
4,960 \\
4,860 \\
5,000 \\
4,820\end{array}$ & $\begin{array}{l}9.80 \\
9.50 \\
9.00 \\
9.30 \\
9.10 \\
9.20\end{array}$ & $\begin{array}{l}3,990 \\
3,750 \\
3,350 \\
3,590 \\
3,430 \\
3,510\end{array}$ & $\begin{array}{l}6.40 \\
6.35 \\
6.30 \\
6.15 \\
6.05 \\
5.90\end{array}$ & $\begin{array}{l}1,630 \\
1,600 \\
1,580 \\
1,500 \\
1,460 \\
1,380\end{array}$ \\
\hline $\begin{array}{l}1 \\
2 \\
3 \\
4 \\
5 \\
6\end{array}$ & $\begin{array}{l}2.10 \\
2.11 \\
2.11 \\
2.10 \\
2.08 \\
2.05\end{array}$ & $\begin{array}{l}69 \\
70 \\
70 \\
69 \\
68 \\
65\end{array}$ & $\begin{array}{l}2.18 \\
2.23 \\
2.28 \\
2.60 \\
3.20 \\
3.35\end{array}$ & $\begin{array}{r}75 \\
80 \\
84 \\
119 \\
215 \\
248\end{array}$ & $\begin{array}{l}6.35 \\
6.37 \\
6.37 \\
6.43 \\
6.52 \\
6.65\end{array}$ & $\begin{array}{l}1,180 \\
1,190 \\
1,190 \\
1,210 \\
1,250 \\
1,300\end{array}$ & $\begin{array}{l}10.75 \\
10.70 \\
10.65 \\
10.60 \\
10.70 \\
11.24\end{array}$ & $\begin{array}{l}4,780 \\
4,730 \\
4,680 \\
4,640 \\
4,730 \\
5,220\end{array}$ & $\begin{array}{l}9.10 \\
9.00 \\
8.90 \\
8.85 \\
8.75 \\
8.60\end{array}$ & $\begin{array}{l}3,430 \\
3,350 \\
3,270 \\
3,230 \\
3,150 \\
3,030\end{array}$ & $\begin{array}{l}5.90 \\
5.85 \\
5.70 \\
5.60 \\
5.60 \\
5.50\end{array}$ & $\begin{array}{l}1,380 \\
1,360 \\
1,280 \\
1,230 \\
1,230 \\
1,180\end{array}$ \\
\hline \multirow[t]{2}{*}{$\begin{array}{r}7 \\
8 \\
9 \\
10 \\
11 \\
M\end{array}$} & $\begin{array}{l}2.03 \\
2.00 \\
1.97 \\
1.95 \\
1.93 \\
1.90\end{array}$ & $\begin{array}{l}63 \\
61 \\
59 \\
57 \\
55 \\
53 \\
\end{array}$ & $\begin{array}{l}3.44 \\
3.48 \\
3.50 \\
3.52 \\
3.54 \\
3.55\end{array}$ & $\begin{array}{l}268 \\
277 \\
282 \\
287 \\
292 \\
294\end{array}$ & $\begin{array}{l}6.75 \\
6.90 \\
7.00 \\
7.05 \\
7.10 \\
7.20 \\
\end{array}$ & $\begin{array}{l}1,340 \\
1,400 \\
1,440 \\
1,460 \\
1,480 \\
1,530\end{array}$ & $\begin{array}{l}11.00 \\
10.85 \\
10.80 \\
10.75 \\
10.70 \\
10.70\end{array}$ & $\begin{array}{l}5,000 \\
4,860 \\
4,820 \\
4,780 \\
4,730 \\
4,730 \\
\end{array}$ & $\begin{array}{l}8.55 \\
8.55 \\
8.45 \\
8.25 \\
8.10 \\
7.90\end{array}$ & $\begin{array}{l}3,000 \\
3,000 \\
2,920 \\
2,780 \\
2,680 \\
2,540\end{array}$ & $\begin{array}{l}5.40 \\
5.35 \\
5.30 \\
5.30 \\
5.30 \\
5.20\end{array}$ & $\begin{array}{l}1,140 \\
1,120 \\
1,100 \\
1,100 \\
1,100 \\
1,060\end{array}$ \\
\hline & \multicolumn{2}{|c|}{ September 24} & \multicolumn{2}{|c|}{ September 25} & \multicolumn{2}{|c|}{ September 26} & \multicolumn{2}{|c|}{ September 27} & \multicolumn{2}{|c|}{ September 28} & \multicolumn{2}{|c|}{ September 29} \\
\hline $\begin{array}{r}2 \\
4 \\
6 \\
8 \\
10 \\
N\end{array}$ & $\begin{array}{l}5.00 \\
4.85 \\
4.40 \\
4.25 \\
4.25 \\
4.20\end{array}$ & $\begin{array}{l}980 \\
920 \\
740 \\
680 \\
680 \\
660\end{array}$ & $\begin{array}{l}3.86 \\
3.80 \\
3.70 \\
3.67 \\
3.55 \\
3.52\end{array}$ & $\begin{array}{l}541 \\
520 \\
490 \\
481 \\
445 \\
436\end{array}$ & $\begin{array}{l}3.15 \\
3.10 \\
3.10 \\
3.09 \\
3.08 \\
3.05\end{array}$ & $\begin{array}{l}333 \\
320 \\
320 \\
318 \\
315 \\
308\end{array}$ & $\begin{array}{l}2.83 \\
2.80 \\
2.74 \\
2.72 \\
2.70 \\
2.69\end{array}$ & $\begin{array}{l}257 \\
250 \\
237 \\
233 \\
229 \\
227\end{array}$ & $\begin{array}{l}2.78 \\
2.78 \\
2.77 \\
2.75 \\
2.75 \\
2.75\end{array}$ & $\begin{array}{l}246 \\
246 \\
244 \\
239 \\
239 \\
239\end{array}$ & $\begin{array}{l}2.69 \\
2.68 \\
2.65 \\
2.64 \\
2.62 \\
2.60\end{array}$ & $\begin{array}{l}227 \\
225 \\
219 \\
217 \\
213 \\
209\end{array}$ \\
\hline $\begin{array}{r}2 \\
4 \\
6 \\
8 \\
10 \\
1\end{array}$ & $\begin{array}{l}4.20 \\
4.12 \\
4.03 \\
4.00 \\
3.92 \\
3.90\end{array}$ & $\begin{array}{l}660 \\
632 \\
600 \\
590 \\
562 \\
555\end{array}$ & $\begin{array}{l}3.48 \\
3.40 \\
3.35 \\
3.30 \\
3.21 \\
3.18\end{array}$ & $\begin{array}{l}424 \\
401 \\
387 \\
373 \\
349 \\
341\end{array}$ & $\begin{array}{l}3.00 \\
2.98 \\
2.93 \\
2.88 \\
2.88 \\
2.86\end{array}$ & $\begin{array}{l}295 \\
290 \\
279 \\
268 \\
268 \\
263\end{array}$ & $\begin{array}{l}2.69 \\
2.82 \\
2.81 \\
2.81 \\
2.79 \\
2.78\end{array}$ & $\begin{array}{l}227 \\
254 \\
252 \\
252 \\
248 \\
245\end{array}$ & $\begin{array}{l}2.75 \\
2.74 \\
2.72 \\
2.71 \\
2.70 \\
2.70\end{array}$ & $\begin{array}{l}239 \\
237 \\
233 \\
231 \\
229 \\
229\end{array}$ & $\begin{array}{l}2.58 \\
2.55 \\
2.53 \\
2.52 \\
2.50 \\
2.49\end{array}$ & $\begin{array}{l}205 \\
200 \\
196 \\
194 \\
190 \\
188\end{array}$ \\
\hline
\end{tabular}


Location. - Water-stage recorder, lat. $42^{\circ} 47^{\prime} 05^{\prime \prime}$, long. $72^{\circ} 29^{\prime} 10^{\prime \prime}$, above highway bridge In HInsdale, cheshire County, a quarter of a mile below dam and $1 \frac{1}{4}$ miles above mouth of river.

Drainage area.- 420 square miles.

Gage-helght record. - Water-stage recorder graph except for periods 9 p.m. Sept. 6 to $10 \mathrm{a.m}$. Sept. 21 and midnight Sept. 21 to $6 \mathrm{p.m}$. Sept. 23, record for which was based on floodmarks and two gage readings daily.

Stage-discharge relation.- Defined by current-meter measurements below 11,200 secondfeet; extended to peak stage on basis of determinations of flood flow over dam.

Maxima. - September 1938: Discharge, 16,200 second-feet 12 p.m. Sept. 22 (gage height, 11.37 feet).

1907 to August 1938: Max1mum discharge observed, 18,000 second-feet Mar. 29, 1920 (gage helght, 9.98 feet, former site, same datum). Maximum gage helght, 20.2 feet Mar. 19, 1936 (backwater from Connecticut River).

Remarks.- Flood run-off affected by artiflcial storage and natural pondage.

Mean dally discharge, in second-feet, 1938

\begin{tabular}{|c|r|r||r|r|r||r|r|r|r|r|r|}
\hline Day & Sept. & 0ct. & Day & Sept. & Oct. & Day & Sept. & Oct. & Day & Sept. & 0ct. \\
\hline 1 & 196 & 938 & 9 & 247 & 471 & 17 & 624 & 345 & 25 & 6,680 & 1,470 \\
2 & 199 & 818 & 10 & 238 & 460 & 18 & 439 & 392 & 26 & 2,710 & 1,670 \\
3 & 229 & 744 & 11 & 153 & 471 & 19 & 620 & 388 & 27 & 1,750 & 1,320 \\
4 & 215 & 662 & 12 & 147 & 498 & 20 & 3,580 & 388 & 28 & 1,440 & 1,010 \\
5 & 178 & 630 & 13 & 158 & 466 & 21 & 8,520 & 512 & 29 & 1,270 & 856 \\
6 & 144 & 618 & 14 & 333 & 420 & 22 & 14,200 & 676 & 30 & 1,070 & 662 \\
7 & 156 & 582 & 15 & 378 & 425 & 23 & 14,300 & 493 & 31 & & 570 \\
8 & 178 & 526 & 16 & 663 & 333 & 24 & 10,800 & 549 & & & \\
\hline
\end{tabular}

Gage height, in feet, and discharge, in second-feet, at indicated time, 1938

\begin{tabular}{|c|c|c|c|c|c|c|c|c|c|c|c|c|}
\hline \multirow{2}{*}{$\begin{array}{l}\text { 里 } \\
\text { 号 } \\
\end{array}$} & Feet & Sec.ft. & Feet & Sec.ft. & Feet & Sec.ft. & Feet & Sec.ft. & Feet & Sec.ft. & Feet & Sec.ft. \\
\hline & \multicolumn{2}{|c|}{ September 18} & \multicolumn{2}{|c|}{ September 19} & \multicolumn{2}{|c|}{ September 20} & \multicolumn{2}{|c|}{ September 21} & \multicolumn{2}{|c|}{ September 22} & \multicolumn{2}{|c|}{ September 23} \\
\hline 1 & - & - & - & - & - & - & - & - & - & - & - & - \\
\hline $\begin{array}{l}2 \\
3\end{array}$ & & & $\overline{4.75}$ & *435 & 5.50 & ${ }^{-}$ & 768 & *6. 830 & - & * $12-000$ & - & $* 16,000$ \\
\hline 4 & 4.14 & *430 & 4.15 & *435 & 5.50 & *1,550 & 7.68 & ${ }^{* 6,830}$ & 9.50 & $\begin{array}{c}* 12,000 \\
-\end{array}$ & $\stackrel{11.30}{-}$ & $\stackrel{210,000}{-}$ \\
\hline 5 & - & - & - & - & - & - & - & - & - & - & - & - \\
\hline 6 & - & - & - & - & - & - & - & - & - & - & - & - \\
\hline 7 & - & - & - & - & - & - & - & - & - & - & - & - \\
\hline 8 & - & - & - & & - & - & - & - & - & - & - & - \\
\hline 9 & 4.15 & *435 & 4.22 & $* 471$ & 6.19 & $* 2,530$ & 7.83 & $* 7,370$ & 10.40 & $* 14,200$ & 10.85 & $* 15,200$ \\
\hline 10 & - & - & - & - & - & - & - & - & - & - & - & \\
\hline$\frac{11}{N}$ & - & - & - & - & - & - & - & - & - & - & - & - \\
\hline N & - & - & - & - & - & - & - & - & - & - & - & - \\
\hline 1 & - & - & - & - & - & - & - & - & - & - & - & - \\
\hline 2 & - & - & - & & - & - & - & - & - & - & - & - \\
\hline 3 & 4.18 & $* 450$ & 4.48 & $* 618$ & 6.94 & $* 4,320$ & 8.40 & $* 9,200$ & 10.65 & * 14,800 & 10.00 & $* 13,200$ \\
\hline$\frac{4}{5}$ & $\overline{-}$ & $\overline{-}$ & $\overline{-}$ & $\overline{-}$ & $\overline{-}$ & $\overline{-}$ & $\overline{-}$ & $\bar{z}$ & $\bar{z}$ & $=$ & $\overline{-}$ & $\overline{-}$ \\
\hline 6 & - & 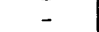 & - & - & - & - & - & - & - & - & - & - \\
\hline 7 & - & & - & & & & - & - & _- & - & - & - \\
\hline 8 & - & & - & & - & - & - & - & - & - & - & - \\
\hline 9 & 4.16 & *440 & 4.94 & *956 & 7.42 & $* 5,910$ & 9.02 & $* 10,700$ & 11.20 & $* 15,800$ & 9.80 & $* 12,700$ \\
\hline 10 & - & & - & & & & - & & & & & \\
\hline 2 & - & - & - & - & & - & - & - & - & - & - & - \\
\hline \multirow[t]{2}{*}{$\mathbf{M}$} & - & - & - & -- & - & - & - & - & - & - & - & $=$ \\
\hline & \multicolumn{2}{|c|}{ September 24} & \multicolumn{2}{|c|}{ September 25} & \multicolumn{2}{|c|}{ September 26} & \multicolumn{2}{|c|}{ September 27} & \multicolumn{2}{|c|}{ September 28} & \multicolumn{2}{|c|}{ September 29} \\
\hline $\begin{array}{r}2 \\
4 \\
6 \\
8 \\
10 \\
\text { N }\end{array}$ & $\begin{array}{l}9.44 \\
9.17 \\
9.17 \\
9.10 \\
9.09 \\
9.20\end{array}$ & $\begin{array}{l}11,800 \\
11,100 \\
11,100 \\
11,000 \\
10,900 \\
11,200\end{array}$ & $\begin{array}{l}8.30 \\
8.20 \\
8.06 \\
7.88 \\
7.77 \\
7.66\end{array}$ & $\begin{array}{l}8,900 \\
8,600 \\
8,180 \\
7,560 \\
7,150 \\
6,760\end{array}$ & $\begin{array}{l}6.69 \\
6.57 \\
6.47 \\
6.38 \\
6.29 \\
6.20\end{array}$ & $\begin{array}{l}3,620 \\
3,330 \\
3,090 \\
2,900 \\
2,720 \\
2,550\end{array}$ & $\begin{array}{l}5.81 \\
5.79 \\
5.76 \\
5.71 \\
5.69 \\
5.66\end{array}$ & $\begin{array}{l}1,940 \\
1,920 \\
1,880 \\
1,810 \\
1,790 \\
1,750\end{array}$ & $\begin{array}{l}5.48 \\
5.47 \\
5.45 \\
5.43 \\
5.41 \\
5.40\end{array}$ & $\begin{array}{l}1,530 \\
1,510 \\
1,490 \\
1,470 \\
1,440 \\
1,430\end{array}$ & $\begin{array}{l}5.34 \\
5.33 \\
5.31 \\
5.29 \\
5.28 \\
5.26\end{array}$ & $\begin{array}{l}1,360 \\
1,350 \\
1,320 \\
1,300 \\
1,290 \\
1,270\end{array}$ \\
\hline $\begin{array}{r}2 \\
4 \\
6 \\
8 \\
10 \\
M \\
\end{array}$ & $\begin{array}{l}9.09 \\
8.91 \\
8.76 \\
8.66 \\
8.61 \\
8.53 \\
\end{array}$ & $\begin{array}{r}10,900 \\
10,500 \\
20,100 \\
9,850 \\
9,720 \\
9,520 \\
\end{array}$ & $\begin{array}{l}7.49 \\
7.36 \\
7.21 \\
7.10 \\
6.96 \\
6.81\end{array}$ & $\begin{array}{l}6,160 \\
5,700 \\
5,180 \\
4,820 \\
4,380 \\
3,950 \\
\end{array}$ & $\begin{array}{l}6.14 \\
6.08 \\
6.02 \\
5.98 \\
5.92 \\
5.87\end{array}$ & $\begin{array}{l}2,450 \\
2,350 \\
2,250 \\
2,190 \\
2,100 \\
2,030\end{array}$ & $\begin{array}{l}5.61 \\
5.59 \\
5.57 \\
5.54 \\
5.51 \\
5.49\end{array}$ & $\begin{array}{l}1,680 \\
1,660 \\
1,630 \\
1,600 \\
1,560 \\
1,540\end{array}$ & $\begin{array}{l}5.39 \\
5.38 \\
5.38 \\
5.37 \\
5.36 \\
5.35 \\
\end{array}$ & $\begin{array}{l}1,420 \\
1,410 \\
1,410 \\
1,390 \\
1,380 \\
1,370 \\
\end{array}$ & $\begin{array}{l}5.24 \\
5.22 \\
5.21 \\
5.20 \\
5.18 \\
5.19 \\
\end{array}$ & $\begin{array}{l}1,240 \\
1,220 \\
1,210 \\
1,200 \\
1,180 \\
1,190\end{array}$ \\
\hline
\end{tabular}

Supplemental records.- Sept. $22,12: 00$ p.m., 11.37 ft., 16,200 sec.-ft. Sept. 23, 12:00 p.m., $9.69 \mathrm{ft} ., 12,400 \mathrm{sec}$. $\mathrm{ft}$.

* Mean for 6-hour period ending 3 hours after indicated time. 
Location. - Fater-stage recorder, lat. $42^{\circ} 57^{\prime} 55^{\prime \prime}$, long. $72^{\circ} 14^{\prime} 00^{\prime \prime}$, at bridge near State

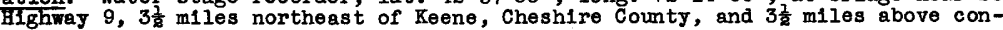
fluence with Minewawa Brook.

Drainage area.- 41.8 square miles.

Gage-helght record. - Water-stage recorder graph except for period 0ct. 17-21, record for which was based on shape of stage graphs at nearby stations.

Stage-discharge relation.- Defined by current-meter measurements below 1 , 230 secondfeet; extended to peak stage on basis of determinations of flood flow by float measurements and by slope-area and contracted-opening methods.

Maxima.- September 1938: Discharge, 6,130 second-feet 1 p.m. Sept. 21 (gage helght, 7.93 feet).

1923 to August 1938: Maximm d1scharge, 3,580 second-feet Mar. 18, 1936

(gage helght, 7.10 feet); maximum gage height, 7.77 feet Mar. 12,1936 (1ce jam). Remarks.- Flood run-off not affected by artificial or natural storage.

Mean deily discharge, in second-feet, 1938

\begin{tabular}{|c|r|r||r|r|r||r|r|r||r|r|r|}
\hline Day & Sept. & 0ct. & Day & Sept. & 0ct. & Day & Sept. & Oct. & Day & Sept. & Oct. \\
\hline 1 & 30 & 103 & 9 & 18 & 44 & 17 & 60 & 30 & 25 & 296 & 239 \\
2 & 23 & 88 & 10 & 15 & 40 & 18 & 51 & 30 & 26 & 226 & 140 \\
3 & 18 & 79 & 11 & 14 & 38 & 19 & 183 & 32 & 27 & 184 & 96 \\
4 & 17 & 70 & 12 & 14 & 36 & 20 & 1,010 & 30 & 28 & 182 & 79 \\
5 & 15 & 59 & 13 & 62 & 34 & 21 & 4,040 & 60 & 29 & 147 & 67 \\
6 & 14 & 54 & 14 & 32 & 34 & 22 & 2,190 & 50 & 30 & 118 \\
7 & 19 & 50 & 15 & 90 & 33 & 23 & 645 & 42 & 31 & - & 60 \\
8 & 27 & 46 & 16 & 85 & 31 & 24 & 407 & 119 & 54 \\
\hline
\end{tabular}

Gage helght, in feet, and discharge, in second-feet, at indicated time, 1938

\begin{tabular}{|c|c|c|c|c|c|c|c|c|c|c|c|c|c|}
\hline \multirow{2}{*}{ 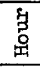 } & Feet & Sec.ft. & Feet & Sec.ft. & Feet & \multirow{2}{*}{$\frac{\text { Sec.ft. }}{\text { nber } 20}$} & Feet & Sec.ft. & Feet & Sec.ft. & Feet & \multicolumn{2}{|c|}{ Sec.ft. } \\
\hline & \multicolumn{2}{|c|}{ September 18} & \multicolumn{2}{|c|}{ September 19} & September 20 & & \multicolumn{2}{|c|}{ September 21} & \multicolumn{2}{|c|}{ September 22} & \multicolumn{3}{|c|}{ September 23} \\
\hline $\begin{array}{l}1 \\
2 \\
3 \\
4 \\
5 \\
6\end{array}$ & $\begin{array}{l}3.15 \\
3.15 \\
3.15 \\
3.15 \\
3.15 \\
3.15\end{array}$ & $\begin{array}{r}54 \\
54 \\
54 \\
54 \\
54 \\
54\end{array}$ & $\begin{array}{l}3.09 \\
3.10 \\
3.10 \\
3.13 \\
3.15 \\
3.16\end{array}$ & $\begin{array}{l}46 \\
47 \\
47 \\
51 \\
54 \\
55\end{array}$ & $\begin{array}{l}4.25 \\
4.26 \\
4.40 \\
4.55 \\
4.73 \\
4.74\end{array}$ & $\begin{array}{l}480 \\
485 \\
562 \\
647 \\
757 \\
763\end{array}$ & $\begin{array}{l}5.79 \\
5.81 \\
6.03 \\
6.18 \\
6.28 \\
6.52\end{array}$ & $\begin{array}{l}1,750 \\
1,770 \\
2,060 \\
2,270 \\
2,420 \\
2,820\end{array}$ & $\begin{array}{l}7.05 \\
7.00 \\
6.80 \\
6.83 \\
6.78 \\
6.67\end{array}$ & $\begin{array}{l}3,850 \\
3,740 \\
3,340 \\
3,400 \\
3,300 \\
3,090\end{array}$ & $\begin{array}{l}4.93 \\
4.85 \\
4.81 \\
4.76 \\
4.74 \\
4.70\end{array}$ & & $\begin{array}{l}898 \\
839 \\
810 \\
777 \\
763 \\
737\end{array}$ \\
\hline $\begin{array}{r}7 \\
8 \\
9 \\
10 \\
11 \\
-1\end{array}$ & $\begin{array}{l}3.15 \\
3.15 \\
3.14 \\
3.14 \\
3.13 \\
3.13\end{array}$ & $\begin{array}{l}54 \\
54 \\
52 \\
52 \\
51 \\
51\end{array}$ & $\begin{array}{l}3.18 \\
3.20 \\
3.22 \\
3.23 \\
3.24 \\
3.25\end{array}$ & $\begin{array}{l}57 \\
60 \\
63 \\
65 \\
67 \\
68\end{array}$ & $\begin{array}{l}4.70 \\
4.65 \\
4.70 \\
4.81 \\
4.98 \\
5.42\end{array}$ & $\begin{array}{r}737 \\
706 \\
737 \\
810 \\
935 \\
1,330\end{array}$ & $\begin{array}{l}7.10 \\
7.55 \\
7.03 \\
6.67 \\
7.17 \\
7.47\end{array}$ & $\begin{array}{l}3,960 \\
5,040 \\
3,810 \\
3,090 \\
4,110 \\
4,820\end{array}$ & $\begin{array}{l}6.57 \\
6.40 \\
6.33 \\
6.22 \\
6.09 \\
6.01\end{array}$ & $\begin{array}{l}2,910 \\
2,610 \\
2,500 \\
2,330 \\
2,140 \\
2,030\end{array}$ & $\begin{array}{l}4.65 \\
4.62 \\
4.57 \\
4.55 \\
4.52 \\
4.48\end{array}$ & & $\begin{array}{l}706 \\
688 \\
659 \\
647 \\
630 \\
607\end{array}$ \\
\hline $\begin{array}{l}1 \\
2 \\
3 \\
4 \\
5 \\
6\end{array}$ & $\begin{array}{l}3.13 \\
3.12 \\
3.11 \\
3.11 \\
3.11 \\
3.12\end{array}$ & $\begin{array}{l}51 \\
50 \\
48 \\
48 \\
48 \\
50\end{array}$ & $\begin{array}{l}3.26 \\
3.28 \\
3.31 \\
3.43 \\
3.75 \\
4.05\end{array}$ & $\begin{array}{r}70 \\
74 \\
79 \\
106 \\
224 \\
374\end{array}$ & $\begin{array}{l}5.58 \\
5.56 \\
5.48 \\
5.40 \\
5.33 \\
5.33\end{array}$ & $\begin{array}{l}1,500 \\
1,480 \\
1,390 \\
1,310 \\
1,240 \\
1,240\end{array}$ & $\begin{array}{l}7.93 \\
7.85 \\
7.65 \\
7.53 \\
7.44 \\
7.60\end{array}$ & $\begin{array}{l}6,130 \\
5,890 \\
5,310 \\
4,980 \\
4,750 \\
5,170\end{array}$ & $\begin{array}{l}5.90 \\
5.79 \\
5.68 \\
5.57 \\
5.48 \\
5.38\end{array}$ & $\begin{array}{l}1,880 \\
1,750 \\
1,620 \\
1,490 \\
1,390 \\
1,290\end{array}$ & $\begin{array}{l}4.46 \\
4.43 \\
4.42 \\
4.40 \\
4.39 \\
4.37\end{array}$ & & $\begin{array}{l}596 \\
579 \\
573 \\
562 \\
556 \\
546\end{array}$ \\
\hline \multirow[t]{2}{*}{$\begin{array}{r}7 \\
8 \\
9 \\
10 \\
11 \\
M \\
\end{array}$} & $\begin{array}{l}3.11 \\
3.10 \\
3.10 \\
3.09 \\
3.09 \\
3.08 \\
\end{array}$ & $\begin{array}{l}48 \\
47 \\
47 \\
46 \\
46 \\
45 \\
\end{array}$ & $\begin{array}{l}4.27 \\
4.30 \\
4.33 \\
4.31 \\
4.27 \\
4.26 \\
\end{array}$ & $\begin{array}{l}491 \\
507 \\
524 \\
512 \\
491 \\
485\end{array}$ & $\begin{array}{l}5.32 \\
5.32 \\
5.23 \\
5.21 \\
5.43 \\
5.63\end{array}$ & $\begin{array}{l}1,230 \\
1,230 \\
1,140 \\
1,130 \\
1,340 \\
1,560\end{array}$ & $\begin{array}{l}7.65 \\
7.50 \\
7.50 \\
7.37 \\
7.27 \\
7.13 \\
\end{array}$ & $\begin{array}{l}5,310 \\
4,900 \\
4,900 \\
4,580 \\
4,340 \\
4,030\end{array}$ & $\begin{array}{l}5.31 \\
5.24 \\
5.14 \\
5.08 \\
5.01 \\
5.00\end{array}$ & $\begin{array}{r}1,220 \\
1,150 \\
1,060 \\
1,010 \\
958 \\
950\end{array}$ & $\begin{array}{l}4.36 \\
4.34 \\
4.31 \\
4.29 \\
4.28 \\
4.27 \\
\end{array}$ & & $\begin{array}{l}540 \\
529 \\
512 \\
502 \\
496 \\
491 \\
\end{array}$ \\
\hline & \multicolumn{2}{|c|}{ September 24} & \multicolumn{2}{|c|}{ September 25} & \multicolumn{2}{|c|}{ September 26} & \multicolumn{2}{|c|}{ September 27} & \multicolumn{2}{|c|}{ September 28} & \multicolumn{3}{|c|}{ September 29} \\
\hline $\begin{array}{r}2 \\
4 \\
6 \\
8 \\
10 \\
N\end{array}$ & $\begin{array}{l}4.25 \\
4.21 \\
4.18 \\
4.15 \\
4.13 \\
4.11\end{array}$ & $\begin{array}{l}480 \\
458 \\
442 \\
426 \\
416 \\
405\end{array}$ & $\begin{array}{l}3.97 \\
3.95 \\
3.94 \\
3.93 \\
3.92 \\
3.90\end{array}$ & $\begin{array}{l}333 \\
322 \\
317 \\
312 \\
307 \\
297\end{array}$ & $\begin{array}{l}3.81 \\
3.80 \\
3.79 \\
3.78 \\
3.76 \\
3.75\end{array}$ & $\begin{array}{l}253 \\
248 \\
243 \\
239 \\
229 \\
224\end{array}$ & $\begin{array}{l}3.68 \\
3.67 \\
3.66 \\
3.66 \\
3.65 \\
3.64\end{array}$ & $\begin{array}{l}192 \\
188 \\
183 \\
183 \\
179 \\
175\end{array}$ & $\begin{array}{l}3.68 \\
3.68 \\
3.67 \\
3.66 \\
3.66 \\
3.66\end{array}$ & $\begin{array}{l}192 \\
182 \\
188 \\
183 \\
183 \\
183\end{array}$ & $\begin{array}{l}3.61 \\
3.61 \\
3.60 \\
3.59 \\
3.58 \\
3.57\end{array}$ & & $\begin{array}{l}161 \\
161 \\
157 \\
154 \\
150 \\
147\end{array}$ \\
\hline $\begin{array}{r}2 \\
4 \\
6 \\
8 \\
10 \\
1\end{array}$ & $\begin{array}{l}4.08 \\
4.06 \\
4.04 \\
4.02 \\
4.00 \\
3.98\end{array}$ & $\begin{array}{l}390 \\
379 \\
369 \\
358 \\
348 \\
338\end{array}$ & $\begin{array}{l}3.88 \\
3.87 \\
3.85 \\
3.84 \\
3.83 \\
3.82\end{array}$ & $\begin{array}{l}287 \\
282 \\
272 \\
268 \\
263 \\
258\end{array}$ & $\begin{array}{l}3.74 \\
3.73 \\
3.72 \\
3.71 \\
3.70 \\
3.69\end{array}$ & $\begin{array}{l}220 \\
215 \\
210 \\
206 \\
201 \\
197\end{array}$ & $\begin{array}{l}3.64 \\
3.64 \\
3.65 \\
3.67 \\
3.68 \\
3.68\end{array}$ & $\begin{array}{l}175 \\
175 \\
179 \\
188 \\
192 \\
192\end{array}$ & $\begin{array}{l}3.65 \\
3.65 \\
3.64 \\
3.64 \\
3.63 \\
3.62\end{array}$ & $\begin{array}{l}179 \\
179 \\
175 \\
175 \\
170 \\
166\end{array}$ & $\begin{array}{l}3.56 \\
3.55 \\
3.54 \\
3.53 \\
3.52 \\
3.51\end{array}$ & & $\begin{array}{l}143 \\
140 \\
137 \\
133 \\
130 \\
126\end{array}$ \\
\hline
\end{tabular}


Location.- Water-stage recorder, lat. $42^{\circ} 52^{\prime} 20^{\prime \prime}$, long. $72^{\circ} 12^{\prime} 55^{\prime \prime}$, at bridge a quarter of a mile from Webb railroad station and about $2 \frac{1}{2}$ miles south of Marlboro, Cheshire County.

Drainage area. - 36.6 square miles.

Gage-he1ght record. - Water-s tage recorder graph.

Stage-discharge relation.- Defined by current-meter measurements below 3,280 second-feet; extended to peak stage on basis of determinations of flood flow by slope-area and contracted-opening methods.

Maxima.- September 1938: Discharge, 5,960 second-feet 10:15 a.m. Sept. 21 (gage height, 7.89 feet).

1920 to August 1938: Maximum discharge, 3,880 second-feet Mar. 18, 1936 (gage

height, 7.55 feet); maximum gage height, 9.70 feet Mar. 12,1936 (ice jam).

Remarks.- Flood run-off affected by artificial and natural storage.

Mean daily discharge, in second-feet, 1938

\begin{tabular}{|c|c|r||r|r|r||r|r|r||r|r|r|}
\hline Day & Sept. & 0ct. & Day & Sept. & 0ct. & Day & Sept. & 0ct. & Day & Sept. & 0ct. \\
\hline 1 & 18 & 85 & 9 & 20 & 35 & 17 & 45 & 29 & 25 & 185 & 208 \\
2 & 27 & 60 & 10 & 11 & 44 & 18 & 37 & 37 & 26 & 151 & 127 \\
3 & 25 & 73 & 11 & 7.9 & 53 & 19 & 197 & 38 & 27 & 134 & 91 \\
4 & 3.0 & 62 & 12 & 14 & 51 & 20 & 1,070 & 41 & 28 & 132 & 81 \\
5 & 7.0 & 56 & 13 & 41 & 47 & 21 & 3,070 & 108 & 29 & 113 & 53 \\
6 & 7.6 & 72 & 14 & 41 & 44 & 22 & 1,190 & 68 & 30 & 105 & 40 \\
7 & 13 & 70 & 15 & 45 & 44 & 23 & 454 & 36 & 31 & & 46 \\
8 & 28 & 54 & 16 & 105 & 29 & 24 & 262 & 111 & & & \\
\hline
\end{tabular}

Gage height, In leet, and discharge, in second-feet, at indicated time, 1938

\begin{tabular}{|c|c|c|c|c|c|c|c|c|c|c|c|c|}
\hline \multirow{2}{*}{ 年 } & Feet & Sec.ft. & Feet & Sec.ft. & Feet & Sec.ft. & Feet & Sec.ft. & Feet & Sec.ft. & Feet & Sec.ft. \\
\hline & \multicolumn{2}{|c|}{ September 18} & \multicolumn{2}{|c|}{ September 19} & \multicolumn{2}{|c|}{ September 20} & \multicolumn{2}{|c|}{ September 21} & \multicolumn{2}{|c|}{ September 22} & \multicolumn{2}{|c|}{ September 23} \\
\hline $\begin{array}{l}1 \\
2 \\
3 \\
4 \\
5 \\
6\end{array}$ & $\begin{array}{l}1.83 \\
2.65 \\
2.67 \\
2.68 \\
2.68 \\
2.68\end{array}$ & $\begin{array}{l}5.6 \\
30 \\
30 \\
30 \\
30 \\
30\end{array}$ & $\begin{array}{l}1.87 \\
1.87 \\
2.83 \\
2.87 \\
2.91 \\
2.98\end{array}$ & $\begin{array}{l}6.6 \\
6.6 \\
35 \\
37 \\
38 \\
41\end{array}$ & & $\begin{array}{l}695 \\
695 \\
718 \\
766 \\
843 \\
888\end{array}$ & $\begin{array}{l}6.30 \\
6.43 \\
6.56 \\
6.66 \\
6.78 \\
6.88\end{array}$ & & & & & $\begin{array}{l}616 \\
588 \\
562 \\
543 \\
530 \\
512\end{array}$ \\
\hline $\begin{array}{r}7 \\
8 \\
9 \\
10\end{array}$ & $\begin{array}{l}2.68 \\
2.68 \\
3.77 \\
3.76 \\
2.92 \\
2.42\end{array}$ & $\begin{array}{r}30 \\
30 \\
106 \\
105 \\
39 \\
23\end{array}$ & & $\begin{array}{r}45 \\
118 \\
112 \\
110 \\
34 \\
18\end{array}$ & & $\begin{array}{r}915 \\
944 \\
953 \\
1,010 \\
1,130 \\
1,270\end{array}$ & & & & & & $\begin{array}{l}500 \\
488 \\
476 \\
470 \\
454 \\
443\end{array}$ \\
\hline $\begin{array}{l}1 \\
2 \\
3 \\
4 \\
5 \\
6\end{array}$ & $\begin{array}{l}2.06 \\
1.91 \\
1.84 \\
1.82 \\
2.73 \\
2.48\end{array}$ & $\begin{array}{c}12 \\
7.7 \\
5.8 \\
5.3 \\
32 \\
33\end{array}$ & $\begin{array}{l}3.90 \\
3.84 \\
3.84 \\
3.91 \\
4.30 \\
4.56\end{array}$ & $\begin{array}{l}126 \\
116 \\
116 \\
128 \\
212 \\
307\end{array}$ & $\begin{array}{l}5.93 \\
5.99 \\
5.99 \\
5.97 \\
5.94 \\
5.91\end{array}$ & $\begin{array}{l}1,380 \\
1,460 \\
1,460 \\
1,430 \\
1,390 \\
1,350\end{array}$ & $\begin{array}{l}7.36 \\
7.24 \\
6.88 \\
6.84 \\
6.79 \\
6.71\end{array}$ & & $\begin{array}{l}5.57 \\
5.52 \\
5.48 \\
5.44 \\
5.40 \\
5.37\end{array}$ & $\begin{array}{l}982 \\
934 \\
897 \\
861 \\
825 \\
800\end{array}$ & & $\begin{array}{l}432 \\
416 \\
406 \\
402 \\
392 \\
382\end{array}$ \\
\hline \multirow[t]{2}{*}{$\begin{array}{r}7 \\
8 \\
9 \\
10 \\
11 \\
M \\
\end{array}$} & $\begin{array}{l}3.28 \\
3.78 \\
3.62 \\
2.50 \\
2.10 \\
1.93\end{array}$ & $\begin{array}{r}59 \\
107 \\
88 \\
25 \\
13 \\
8.2 \\
\end{array}$ & $\begin{array}{l}4.70 \\
4.87 \\
5.12 \\
5.20 \\
5.22 \\
5.23 \\
\end{array}$ & $\begin{array}{l}368 \\
454 \\
609 \\
665 \\
680 \\
688 \\
\end{array}$ & $\begin{array}{l}5.87 \\
5.82 \\
5.47 \\
5.75 \\
5.93 \\
6.14\end{array}$ & $\begin{array}{l}1,300 \\
1,240 \\
1,190 \\
1,160 \\
1,380 \\
1,670 \\
\end{array}$ & $\begin{array}{l}.76 \\
.70 \\
.69 \\
.69 \\
.64 \\
.54 \\
\end{array}$ & & & $\begin{array}{l}766 \\
740 \\
718 \\
695 \\
672 \\
637 \\
\end{array}$ & & $\begin{array}{l}378 \\
368 \\
359 \\
354\end{array}$ \\
\hline & \multicolumn{2}{|c|}{ September 24} & \multicolumn{2}{|c|}{ September 25} & \multicolumn{2}{|c|}{ September 26} & \multicolumn{2}{|c|}{ September 27} & \multicolumn{2}{|c|}{ September 28} & \multicolumn{2}{|c|}{ September 29} \\
\hline $\begin{array}{r}2 \\
4 \\
6 \\
8 \\
10 \\
N\end{array}$ & & $\begin{array}{l}323 \\
303 \\
291 \\
275 \\
272 \\
256\end{array}$ & & $\begin{array}{l}207 \\
202 \\
196 \\
194 \\
189 \\
186\end{array}$ & & $\begin{array}{l}150 \\
155\end{array}$ & & $\begin{array}{l}143 \\
140 \\
134 \\
133 \\
129 \\
129\end{array}$ & & & & $\begin{array}{l}121 \\
121 \\
120\end{array}$ \\
\hline $\begin{array}{r}2 \\
4 \\
6 \\
8 \\
10 \\
M \\
\end{array}$ & $\begin{array}{l}4.40 \\
4.37 \\
4.35 \\
4.33 \\
4.32 \\
4.30 \\
\end{array}$ & $\begin{array}{l}245 \\
235 \\
228 \\
222 \\
219 \\
212 \\
\end{array}$ & $\begin{array}{l}4.18 \\
4.16 \\
4.15 \\
4.12 \\
4.11 \\
4.00\end{array}$ & $\begin{array}{l}181 \\
177 \\
174 \\
168 \\
165 \\
143\end{array}$ & $\begin{array}{l}4.07 \\
4.02 \\
4.02 \\
4.01 \\
4.01 \\
4.00\end{array}$ & $\begin{array}{l}157 \\
147 \\
147 \\
145 \\
145 \\
143\end{array}$ & $\begin{array}{l}3.93 \\
3.92 \\
3.92 \\
3.96 \\
3.99\end{array}$ & $\begin{array}{l}129 \\
131 \\
129 \\
129 \\
136 \\
141\end{array}$ & & $\begin{array}{l}120 \\
121 \\
121\end{array}$ & & $\begin{array}{r}90 \\
104 \\
106 \\
107\end{array}$ \\
\hline
\end{tabular}

Supplemental records.- Sept. 21, 10:15 a.m., $7.89 \mathrm{ft.,} 5,960$ sec.-ft. 


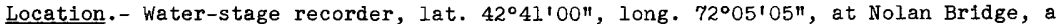
third of a mile below mouth of Sip Pond Brook and 2 miles west of Winchendon, Worcester County. Zero of gage is 826.66 feet above mean sea level (general adjustment of 1929).

Drainage area.- 83.8 miles.

Gage-height record. - Water-stage recorder graph except for periods 1 a.m. Sept. 21 to 7 a.m. Sept. 23 and 8 a.m. Sept. 25 to 4 p.m. Sept. 28, when it was based on flood marks, occasional gage readings, and shape of stage graphs at nearby stations.

Stage-discharge relation.- Defined by current-meter measurements below 2,870 secondfeet; extended to peak stage on basis of determination of flood flow over dam adjusted for intermediate inflow.

Maxima.- September 1938: Discharge, 8,500 second-feet 2 a.m. Sept. 22 (gage height, 21.55 feet, from floodmarks).

1916 to August 1938: Discharge, 5,530 second-feet Mar. 19, 1936 (gage helght, 18.3 feet, from floodmarks).

Remarks.- Flood mun-off affected by artificial and natural storage.

Mean dajly discharge, in second-feet, 1938

\begin{tabular}{|c|c|c|c|c|c|c|c|c|c|c|c|}
\hline Day & Sept. & $0 \mathrm{ct}$. & Day & Sept. & oct. & Day & Sept. & $0 \mathrm{ct}$. & Day & Sept. & Oct. \\
\hline $\begin{array}{l}1 \\
2 \\
3 \\
4 \\
5 \\
6 \\
7 \\
8\end{array}$ & $\begin{array}{r}87 \\
93 \\
43 \\
20 \\
13 \\
59 \\
73 \\
103\end{array}$ & $\begin{array}{r}291 \\
273 \\
195 \\
214 \\
197 \\
178 \\
169 \\
83\end{array}$ & $\begin{array}{r}9 \\
10 \\
11 \\
12 \\
13 \\
14 \\
15 \\
16\end{array}$ & $\begin{array}{r}97 \\
45 \\
16 \\
56 \\
124 \\
140 \\
156 \\
159\end{array}$ & $\begin{array}{r}74 \\
110 \\
49 \\
88 \\
29 \\
22 \\
24 \\
22\end{array}$ & $\begin{array}{l}17 \\
18 \\
19 \\
20 \\
21 \\
22 \\
23 \\
24\end{array}$ & $\begin{array}{r}52 \\
109 \\
229 \\
1,250 \\
5,670 \\
6,130 \\
2,730 \\
1,540 \\
\end{array}$ & $\begin{array}{r}47 \\
93 \\
101 \\
79 \\
113 \\
104 \\
104 \\
153\end{array}$ & $\begin{array}{l}25 \\
26 \\
27 \\
28 \\
29 \\
30 \\
31\end{array}$ & $\begin{array}{r}1,040 \\
773 \\
590 \\
447 \\
383 \\
333\end{array}$ & $\begin{array}{l}330 \\
289 \\
283 \\
200 \\
206 \\
197 \\
161\end{array}$ \\
\hline $\begin{array}{l}\text { Mean } \\
\text { Run- }\end{array}$ & $\begin{array}{l}\text { nthly } \\
\text {, in }\end{array}$ & schar & , in & $\begin{array}{c}\text { second- } \\
\text {. } \text {. }\end{array}$ & $\dot{.}$ & $\therefore$ & $\cdot \vec{\cdot} \cdot \overrightarrow{.}$ & $\therefore$ & $\dot{.}$ & $\begin{array}{r}752 \\
10.01\end{array}$ & $\begin{array}{r}144 \\
1.98\end{array}$ \\
\hline
\end{tabular}

Gage height, in feet, and discharge, in second-feet, at indicated time, 1938

\begin{tabular}{|c|c|c|c|c|c|c|c|c|c|c|c|c|c|c|}
\hline \multirow{2}{*}{ 皇 } & Feet & Sec.ft. & Feet & Sec.ft. & Feet & \multicolumn{2}{|c|}{ Sec.ft. } & Feet & Sec.ft. & Feet & \multirow{2}{*}{$\frac{\text { Sec.ft. }}{\text { aber } 22}$} & Feet & \multicolumn{2}{|c|}{ Sec.ft. } \\
\hline & \multicolumn{2}{|c|}{ September 18} & \multicolumn{2}{|c|}{ September 19} & \multicolumn{3}{|c|}{ September 20} & \multicolumn{2}{|c|}{ September 21} & September 22 & & \multicolumn{3}{|c|}{ September 23} \\
\hline $\begin{array}{l}1 \\
2 \\
3 \\
4 \\
5 \\
6\end{array}$ & $\begin{array}{l}3.98 \\
3.98 \\
3.98 \\
3.98 \\
3.98 \\
3.98\end{array}$ & $\begin{array}{l}35 \\
35 \\
35 \\
35 \\
35 \\
35\end{array}$ & $\begin{array}{l}4.61 \\
4.61 \\
4.62 \\
4.54 \\
4.93 \\
4.80\end{array}$ & $\begin{array}{l}164 \\
164 \\
168 \\
142 \\
282 \\
242\end{array}$ & $\begin{array}{l}5.28 \\
5.63 \\
6.01 \\
6.42 \\
6.52 \\
6.65\end{array}$ & & $\begin{array}{l}358 \\
413 \\
494 \\
597 \\
624 \\
660\end{array}$ & $\begin{array}{l}13.10 \\
13.50 \\
13.90 \\
14.30 \\
14.60 \\
14.97\end{array}$ & $\begin{array}{l}3,320 \\
3,520 \\
3,740 \\
4,000 \\
4,120 \\
4,320\end{array}$ & $\begin{array}{l}21.48 \\
21.55 \\
21.49 \\
21.20 \\
20.90 \\
20.50\end{array}$ & $\begin{array}{l}8,460 \\
8,500 \\
8,460 \\
8,260 \\
8,050 \\
7,770\end{array}$ & $\begin{array}{l}13.60 \\
13.40 \\
13.20 \\
13.00 \\
12.85 \\
12.70\end{array}$ & \multicolumn{2}{|c|}{$\begin{array}{l}3,570 \\
3,470 \\
3,370 \\
3,270 \\
3,200 \\
3,120\end{array}$} \\
\hline $\begin{array}{r}7 \\
8 \\
9 \\
10 \\
11 \\
\mathrm{~N}\end{array}$ & $\begin{array}{l}3.98 \\
3.98 \\
4.28 \\
4.58 \\
4.59 \\
4.59\end{array}$ & $\begin{array}{r}35 \\
35 \\
83 \\
154 \\
157 \\
157\end{array}$ & $\begin{array}{l}4.69 \\
4.70 \\
4.73 \\
4.62 \\
4.81 \\
4.86\end{array}$ & $\begin{array}{l}194 \\
198 \\
211 \\
168 \\
245 \\
261\end{array}$ & $\begin{array}{l}7.00 \\
7.45 \\
8.00 \\
8.50 \\
8.60 \\
8.55\end{array}$ & $\begin{array}{l}1, \\
1, \\
1, \\
1,\end{array}$ & $\begin{array}{r}760 \\
902 \\
, 095 \\
, 270 \\
, 310 \\
, 290\end{array}$ & $\begin{array}{l}15.30 \\
15.70 \\
16.00 \\
16.40 \\
16.75 \\
17.10\end{array}$ & $\begin{array}{l}4,500 \\
4,730 \\
4,910 \\
5,150 \\
5,360 \\
5,570\end{array}$ & $\begin{array}{l}20.20 \\
19.80 \\
19.40 \\
19.00 \\
18.50 \\
18.00\end{array}$ & $\begin{array}{l}7,560 \\
7,300 \\
7,040 \\
6,780 \\
6,460 \\
6,130\end{array}$ & $\begin{array}{l}12.50 \\
12.38 \\
12.20 \\
12.02 \\
11.90 \\
11.75\end{array}$ & \multicolumn{2}{|c|}{$\begin{array}{l}3,020 \\
2,960 \\
2,870 \\
2,780 \\
2,720 \\
2,660\end{array}$} \\
\hline $\begin{array}{l}1 \\
2 \\
3 \\
4 \\
5 \\
6\end{array}$ & $\begin{array}{l}4.59 \\
4.59 \\
4.58 \\
4.58 \\
4.58 \\
4.58\end{array}$ & $\begin{array}{l}157 \\
157 \\
154 \\
154 \\
154 \\
154\end{array}$ & $\begin{array}{l}4.87 \\
4.86 \\
4.67 \\
4.90 \\
4.98 \\
5.01\end{array}$ & $\begin{array}{l}264 \\
261 \\
187 \\
274 \\
295 \\
302\end{array}$ & $\begin{array}{l}8.50 \\
8.43 \\
8.40 \\
8.42 \\
8.50 \\
8.70\end{array}$ & & $\begin{array}{l}270 \\
, 250 \\
, 235 \\
, 240 \\
, 270 \\
, 350\end{array}$ & $\begin{array}{l}17.50 \\
17.85 \\
18.20 \\
18.65 \\
19.10 \\
19.40\end{array}$ & $\begin{array}{l}5,810 \\
6,030 \\
6,260 \\
6,550 \\
6,840 \\
7,040\end{array}$ & $\begin{array}{l}17.30 \\
16.70 \\
16.35 \\
16.00 \\
15.60 \\
15.30\end{array}$ & $\begin{array}{l}5,690 \\
5,330 \\
5,120 \\
4,910 \\
4,670 \\
4,500\end{array}$ & $\begin{array}{l}11.60 \\
11.50 \\
11.40 \\
11.25 \\
11.15 \\
11.05\end{array}$ & \multicolumn{2}{|c|}{$\begin{array}{l}2,590 \\
2,540 \\
2,500 \\
2,430 \\
2,390 \\
2,340\end{array}$} \\
\hline \multirow[t]{2}{*}{$\begin{array}{r}7 \\
8 \\
9 \\
10 \\
11 \\
M\end{array}$} & $\begin{array}{l}4.58 \\
4.58 \\
4.57 \\
4.57 \\
4.58 \\
4.61\end{array}$ & $\begin{array}{l}154 \\
154 \\
151 \\
151 \\
154 \\
164 \\
\end{array}$ & $\begin{array}{l}5.03 \\
4.93 \\
4.76 \\
4.73 \\
4.77 \\
4.98\end{array}$ & $\begin{array}{l}307 \\
282 \\
224 \\
211 \\
229 \\
295\end{array}$ & $\begin{array}{r}9.10 \\
9.80 \\
10.60 \\
11.50 \\
12.25 \\
12.70\end{array}$ & & $\begin{array}{l}, 510 \\
, 790 \\
, 140 \\
, 540 \\
900\end{array}$ & $\begin{array}{l}19.75 \\
20.10 \\
20.45 \\
20.70 \\
21.10 \\
21.30\end{array}$ & $\begin{array}{l}7,270 \\
7,500 \\
7,740 \\
7,910 \\
8,190 \\
8,330 \\
\end{array}$ & $\begin{array}{l}14.95 \\
14.65 \\
14.40 \\
14.20 \\
14.00 \\
13.80\end{array}$ & $\begin{array}{l}4,310 \\
4,150 \\
4,010 \\
3,900 \\
3,790 \\
3,680\end{array}$ & $\begin{array}{l}10.90 \\
10.80 \\
10.65 \\
10.55 \\
10.40 \\
10.30\end{array}$ & & $\begin{array}{l}280 \\
, 230 \\
, 160 \\
, 120 \\
, 050 \\
000 \\
\end{array}$ \\
\hline & \multicolumn{2}{|c|}{ September 24} & \multicolumn{2}{|c|}{ September 25} & \multicolumn{3}{|c|}{ September 26} & \multicolumn{2}{|c|}{ September 27} & \multicolumn{2}{|c|}{ September 28} & \multicolumn{3}{|c|}{ September 29} \\
\hline $\begin{array}{r}2 \\
4 \\
6 \\
8 \\
10 \\
N\end{array}$ & $\begin{array}{r}10.08 \\
9.90 \\
9.70 \\
9.50 \\
9.30 \\
9.10\end{array}$ & $\begin{array}{l}1,910 \\
1,830 \\
1,750 \\
1,670 \\
1,590 \\
1,510\end{array}$ & & $\begin{array}{l}1,170 \\
1,150 \\
1,120 \\
1,090 \\
1,060 \\
1,020\end{array}$ & $\begin{array}{l}7.40 \\
7.30 \\
7.22 \\
7.15 \\
7.08 \\
7.00\end{array}$ & & $\begin{array}{l}885 \\
850 \\
826 \\
805 \\
784 \\
760\end{array}$ & $\begin{array}{l}6.65 \\
6.60 \\
6.56 \\
6.50 \\
6.44 \\
6.40\end{array}$ & $\begin{array}{l}660 \\
646 \\
635 \\
618 \\
602 \\
592\end{array}$ & $\begin{array}{l}6.01 \\
6.00 \\
5.97 \\
5.92 \\
5.85 \\
5.80\end{array}$ & $\begin{array}{l}494 \\
492 \\
485 \\
473 \\
457 \\
446\end{array}$ & & & $\begin{array}{l}391 \\
398 \\
400 \\
398 \\
362 \\
362\end{array}$ \\
\hline $\begin{array}{r}2 \\
4 \\
6 \\
8 \\
10 \\
M\end{array}$ & $\begin{array}{l}8.95 \\
8.60 \\
8.65 \\
8.55 \\
8.45 \\
8.35\end{array}$ & $\begin{array}{l}1,450 \\
1,310 \\
1,330 \\
1,290 \\
1,250 \\
1,220\end{array}$ & $\begin{array}{l}7.75 \\
7.68 \\
7.62 \\
7.57 \\
7.50 \\
7.45\end{array}$ & $\begin{array}{r}1,010 \\
983 \\
962 \\
944 \\
920 \\
902\end{array}$ & $\begin{array}{l}6.95 \\
6.90 \\
6.85 \\
6.80 \\
6.75 \\
6.70\end{array}$ & & $\begin{array}{l}745 \\
730 \\
716 \\
702 \\
688 \\
674\end{array}$ & $\begin{array}{l}6.35 \\
6.30 \\
6.23 \\
6.15 \\
6.10 \\
6.05\end{array}$ & $\begin{array}{l}579 \\
566 \\
548 \\
528 \\
516 \\
504\end{array}$ & $\begin{array}{l}5.74 \\
5.66 \\
5.63 \\
5.60 \\
5.52 \\
5.45\end{array}$ & $\begin{array}{l}434 \\
419 \\
413 \\
408 \\
395 \\
385\end{array}$ & $\begin{array}{l}5.30 \\
5.75 \\
5.40 \\
5.32 \\
5.32 \\
5.32\end{array}$ & & $\begin{array}{l}362 \\
436 \\
378 \\
365 \\
365 \\
365\end{array}$ \\
\hline
\end{tabular}


Millers River at Erving, Mass.

Location. - Water-stage recorder, lat. $42^{\circ} 35^{\prime} 55^{\prime \prime}$, long. $72^{\circ} 24^{\prime} 15^{\prime \prime}$, a quarter of a mile below dam at Erving, Franklin County, 8 miles above mouth, and below all important tributaries. Zero of gage is 438.26 feet above mean sea level (general adjustment of 1929).

Drainage area.- 370 square miles.

Gage-height record. - Water-stage recorder graph for period Sept. 1 to 10 a.m. Sept. 21. No gage-height record from 10 a.m. Sept. 21 to 7 a.m. Sept. 27. Graph for Sept. 27 to 0ct. 31 based on two staff-gage readings daily and shape of stage-graphs at nearby stations.

Stage-discharge relation.- Defined by current-meter measurements below 7,960 secondfeet; extended to peak stage on basis of determinations of flood flows over dam and by contracted-opening and slope-area methods.

Maxima.- September 1938: Discharge, 29,000 second-feet 8 a.m. Sept. 22 (gage height, 13.37 feet, from flood marks)

1914 to August 1938: Discharge, 19,700 second-feet Mar. 19, 1936 (gage height, 10.86 feet, from flood marks)

Remarks.- Flood run-off affected slightly by artificial and natural storage. Discharge for period Sept. 21-26 computed on basis of hydrographic comparison with nearby stations.

Mean dally discharge, in second-feet, 1938

\begin{tabular}{|c|c|c|c|c|c|c|c|c|c|c|c|}
\hline Day & Sept. & Oct. & Day & Sept. & $0 \mathrm{ct}$. & Day & Sept. & oct. & Day & Sept. & Oct. \\
\hline $\begin{array}{l}1 \\
2 \\
3 \\
4 \\
5 \\
6 \\
7 \\
8\end{array}$ & $\begin{array}{l}263 \\
250 \\
222 \\
268 \\
153 \\
194 \\
196 \\
249 \\
\end{array}$ & $\begin{array}{r}1,340 \\
1,040 \\
931 \\
980 \\
966 \\
864 \\
803 \\
664 \\
\end{array}$ & $\begin{array}{l}9 \\
10 \\
11 \\
12 \\
13 \\
14 \\
15 \\
16\end{array}$ & $\begin{array}{r}411 \\
202 \\
76 \\
177 \\
388 \\
484 \\
593 \\
655\end{array}$ & $\begin{array}{l}595 \\
534 \\
534 \\
556 \\
552 \\
538 \\
484 \\
447\end{array}$ & $\begin{array}{l}17 \\
18 \\
19 \\
20 \\
21 \\
22 \\
23 \\
24\end{array}$ & $\begin{array}{r}559 \\
385 \\
1,190 \\
5,280 \\
17,000 \\
22,000 \\
14,000 \\
8,000\end{array}$ & $\begin{array}{l}411 \\
423 \\
451 \\
529 \\
642 \\
632 \\
620 \\
720\end{array}$ & $\begin{array}{l}25 \\
26 \\
27 \\
28 \\
29 \\
30 \\
31\end{array}$ & $\begin{array}{l}5,000 \\
3,800 \\
2,980 \\
2,450 \\
1,960 \\
1,530\end{array}$ & $\begin{array}{r}1,270 \\
973 \\
743 \\
749 \\
698 \\
664 \\
642\end{array}$ \\
\hline $\begin{array}{l}\text { Mean } \\
\text { Run- }\end{array}$ & $\begin{array}{l}\text { nthly } \\
\text {, in }\end{array}$ & es. & . & Dond & өt. & & . : & $\begin{array}{lll}\cdot & \cdot & . \\
. & . & \end{array}$ & 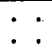 & $\begin{array}{r}3,031 \\
9.14\end{array}$ & $\begin{array}{r}710 \\
2.21\end{array}$ \\
\hline
\end{tabular}

Gage height, in feet, and discharge, in second-feet, at indicated time, 1938

\begin{tabular}{|c|c|c|c|c|c|c|c|c|c|c|c|c|}
\hline \multirow{2}{*}{$\begin{array}{l}5 \\
0 \\
0 \\
\text { 出 }\end{array}$} & Feet & Sec.ft. & Feet & Sec.it. & Feet & Sec.ft. & Feet & sec.ft. & Feet & Sec.ft. & Feet & Sec.ft. \\
\hline & \multicolumn{2}{|c|}{ September 18} & \multicolumn{2}{|c|}{ September 19} & \multicolumn{2}{|c|}{ September 20} & \multicolumn{2}{|c|}{ September 21} & \multicolumn{2}{|c|}{ September 22} & \multicolumn{2}{|c|}{ September 23} \\
\hline $\begin{array}{l}1 \\
2 \\
3 \\
4 \\
5 \\
6\end{array}$ & $\begin{array}{l}2.08 \\
2.08 \\
2.08 \\
2.09 \\
2.09 \\
2.09\end{array}$ & $\begin{array}{l}329 \\
329 \\
329 \\
332 \\
332 \\
332\end{array}$ & $\begin{array}{l}2.32 \\
2.34 \\
2.54 \\
2.61 \\
2.62 \\
3.08\end{array}$ & $\begin{array}{l}425 \\
435 \\
537 \\
576 \\
581 \\
866\end{array}$ & $\begin{array}{l}4.35 \\
4.56 \\
4.70 \\
4.78 \\
4.75 \\
4.73\end{array}$ & $\begin{array}{l}2,360 \\
2,720 \\
2,980 \\
3,140 \\
3,080 \\
3,040\end{array}$ & $\begin{array}{l}7.00 \\
7.15 \\
7.50 \\
7.67 \\
8.14 \\
8.17\end{array}$ & $\begin{array}{r}8,730 \\
9,140 \\
10,100 \\
10,600 \\
11,800 \\
11,900\end{array}$ & $\begin{array}{l}- \\
- \\
- \\
- \\
-\end{array}$ & $\begin{array}{l}- \\
- \\
- \\
- \\
-\end{array}$ & $\begin{array}{l}- \\
- \\
- \\
- \\
-\end{array}$ & $\begin{array}{l}- \\
- \\
- \\
- \\
-\end{array}$ \\
\hline $\begin{array}{r}7 \\
8 \\
9 \\
10 \\
11 \\
N\end{array}$ & $\begin{array}{l}2.09 \\
2.08 \\
2.08 \\
2.08 \\
2.08 \\
2.08\end{array}$ & $\begin{array}{l}332 \\
329 \\
329 \\
329 \\
329 \\
329\end{array}$ & $\begin{array}{l}3.18 \\
3.20 \\
3.19 \\
3.18 \\
3.20 \\
3.22\end{array}$ & $\begin{array}{l}944 \\
960 \\
952 \\
944 \\
960 \\
978\end{array}$ & $\begin{array}{l}4.73 \\
5.05 \\
5.47 \\
5.60 \\
5.70 \\
6.06\end{array}$ & $\begin{array}{l}3,040 \\
3,720 \\
4,760 \\
5,090 \\
5,350 \\
6,290\end{array}$ & $\begin{array}{l}8.21 \\
8.48 \\
8.65 \\
8.88 \\
- \\
-\end{array}$ & $\begin{array}{l}12,000 \\
12,800 \\
13,200 \\
13,900 \\
- \\
-\end{array}$ & $\begin{array}{l}- \\
- \\
- \\
-\end{array}$ & $\begin{array}{c}- \\
- \\
- \\
- \\
- \\
022,000\end{array}$ & $\begin{array}{l}- \\
- \\
- \\
- \\
-\end{array}$ & $\begin{array}{c}- \\
- \\
- \\
- \\
- \\
0.14,000\end{array}$ \\
\hline $\begin{array}{l}1 \\
2 \\
3 \\
4 \\
5 \\
6\end{array}$ & $\begin{array}{l}2.08 \\
2.08 \\
2.15 \\
2.43 \\
2.47 \\
2.55\end{array}$ & $\begin{array}{l}329 \\
329 \\
354 \\
480 \\
500 \\
542\end{array}$ & $\begin{array}{l}3.25 \\
3.41 \\
3.74 \\
3.82 \\
3.78 \\
3.71\end{array}$ & $\begin{array}{l}1,000 \\
1,160 \\
1,510 \\
1,610 \\
1,560 \\
1,470\end{array}$ & $\begin{array}{l}6.00 \\
6.18 \\
6.16 \\
6.15 \\
6.15 \\
6.15\end{array}$ & $\begin{array}{l}6,130 \\
6,600 \\
6,550 \\
6,520 \\
6,520 \\
6,520\end{array}$ & $\begin{array}{l}- \\
- \\
- \\
-\end{array}$ & $\begin{array}{c}- \\
- \\
- \\
- \\
b 21,200\end{array}$ & $\begin{array}{l}- \\
\overline{-} \\
\overline{-} \\
-\end{array}$ & $\begin{array}{l}- \\
- \\
- \\
- \\
-\end{array}$ & $\begin{array}{l}- \\
- \\
- \\
- \\
-\end{array}$ & $\begin{array}{l}- \\
- \\
- \\
- \\
-\end{array}$ \\
\hline \multirow[t]{2}{*}{$\begin{array}{r}7 \\
8 \\
9 \\
10 \\
11 \\
M\end{array}$} & $\begin{array}{l}2.56 \\
2.56 \\
2.50 \\
2.25 \\
2.22 \\
2.28\end{array}$ & $\begin{array}{l}548 \\
548 \\
515 \\
394 \\
381 \\
406\end{array}$ & $\begin{array}{l}3.86 \\
4.24 \\
4.14 \\
4.13 \\
4.11 \\
4.23\end{array}$ & $\begin{array}{l}1,660 \\
2,190 \\
2,040 \\
2,020 \\
2,000 \\
2,180\end{array}$ & $\begin{array}{l}6.15 \\
6.16 \\
6.47 \\
6.78 \\
6.84 \\
6.90\end{array}$ & $\begin{array}{l}6,520 \\
6,550 \\
7,350 \\
8,160 \\
8,310 \\
8,470\end{array}$ & $\begin{array}{l}- \\
- \\
- \\
- \\
-\end{array}$ & $\begin{array}{l}- \\
- \\
- \\
- \\
-\end{array}$ & $\begin{array}{l}- \\
- \\
- \\
- \\
-\end{array}$ & $\begin{array}{l}- \\
- \\
- \\
- \\
-\end{array}$ & $\begin{array}{l}- \\
- \\
- \\
- \\
-\end{array}$ & $\begin{array}{l}- \\
\overline{-} \\
- \\
-\end{array}$ \\
\hline & \multicolumn{2}{|c|}{ September 24} & \multicolumn{2}{|c|}{ September 25} & \multicolumn{2}{|c|}{ September 26} & \multicolumn{2}{|c|}{ September 27} & \multicolumn{2}{|c|}{ September 28} & \multicolumn{2}{|c|}{ September 29} \\
\hline $\begin{array}{r}2 \\
4 \\
6 \\
8 \\
10 \\
\mathrm{~N}\end{array}$ & $\begin{array}{l}- \\
- \\
- \\
- \\
-\end{array}$ & $\begin{array}{c}- \\
- \\
- \\
- \\
- \\
28,000\end{array}$ & $\begin{array}{l}- \\
- \\
- \\
- \\
-\end{array}$ & $\begin{array}{c}- \\
- \\
- \\
- \\
- \\
25,000\end{array}$ & $\begin{array}{l}- \\
\overline{-} \\
\overline{-} \\
\overline{-}\end{array}$ & $\begin{array}{c}- \\
- \\
- \\
- \\
- \\
\mathrm{a} 3,800\end{array}$ & $\begin{array}{l}5.03 \\
5.01 \\
5.00 \\
4.98 \\
4.91 \\
4.84\end{array}$ & $\begin{array}{l}3,300 \\
3,270 \\
3,250 \\
3,220 \\
3,120 \\
3,030\end{array}$ & $\begin{array}{l}4.54 \\
4.54 \\
4.53 \\
4.52 \\
4.48 \\
4.44\end{array}$ & $\begin{array}{l}2,610 \\
2,610 \\
2,590 \\
2,580 \\
2,530 \\
2,480\end{array}$ & $\begin{array}{l}4.14 \\
4.12 \\
4.11 \\
4.10 \\
4.07 \\
4.04\end{array}$ & $\begin{array}{l}2,120 \\
2,090 \\
2,080 \\
2,070 \\
2,030 \\
2,000\end{array}$ \\
\hline $\begin{array}{r}2 \\
4 \\
6 \\
8 \\
10 \\
M\end{array}$ & $\begin{array}{l}- \\
- \\
- \\
- \\
-\end{array}$ & $\begin{array}{l}- \\
\overline{-} \\
\overline{-} \\
\overline{-} \\
\bar{z}\end{array}$ & $\begin{array}{l}- \\
- \\
- \\
- \\
-\end{array}$ & $\begin{array}{l}- \\
- \\
- \\
- \\
-\end{array}$ & $\begin{array}{l}- \\
- \\
- \\
- \\
- \\
5.05\end{array}$ & $\begin{array}{l}- \\
- \\
- \\
- \\
- \\
3,330\end{array}$ & $\begin{array}{l}4.75 \\
4.65 \\
4.60 \\
4.57 \\
4.55 \\
4.54\end{array}$ & $\begin{array}{l}2,900 \\
2,760 \\
2,690 \\
2,650 \\
2,620 \\
2,610\end{array}$ & $\begin{array}{l}4.41 \\
4.37 \\
4.30 \\
4.25 \\
4.21 \\
4.18\end{array}$ & $\begin{array}{l}2,440 \\
2,390 \\
2,310 \\
2,250 \\
2,200 \\
2,170\end{array}$ & $\begin{array}{l}4.01 \\
3.97 \\
3.91 \\
3.85 \\
3.78 \\
3.71\end{array}$ & $\begin{array}{l}1,960 \\
1,920 \\
1,860 \\
1,800 \\
1,730 \\
1,660\end{array}$ \\
\hline
\end{tabular}

\footnotetext{
Mean for the day.
}

b Mean for 14 hours. 
Sip Pond Brook near Winchendon, Mass.

Location. - Water-stage recorder, lat. $42^{\circ} 42^{\prime} 45^{\prime \prime}$, long. $72^{\circ} 05^{\prime} 10^{\prime \prime}$, a quarter of a mile below Massachusetts-New Hampshire State line, li miles below outlet of Sip Pond, and 3 miles northwest of Winchendon, Worcester County.

Drainage area.- 19.0 square miles.

Gage-helght record. - Water-stage recorder graph.

stage-discharge relation. - Defined by current-meter measurements below 1,170 second-

reet; extended to peak stage on basis of study of critical depth at control section. Maxima.- September 1938: Discharge, 2,630 second-feet 10 a.m. Sept. 21 (gage height, 13.72 feet).

1916 to August 1938: Discharge, 1,430 second-feet Mar. 18, 19, 1936 (gage helght, 12.40 feet).

Remarks.- Flood run-off affected by storage in Pearly and Sip Ponds.

Mean dafly, discharge, in second-feet, 1938

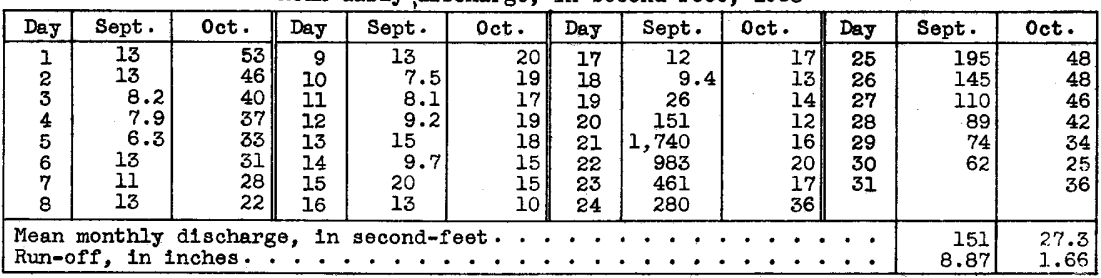

Gage helght, in feet, and discharge, in second-feet, at indicated time, 1938

\begin{tabular}{|c|c|c|c|c|c|c|c|c|c|c|c|c|}
\hline \multirow{2}{*}{$\begin{array}{l}\xi \\
0 \\
8 \\
\end{array}$} & Feet & Sec.ft. & Feet & Sec.ft. & Fevt & Sec.ft. & Feet & Sec.ft. & Feet & Sec.ft. & Feet & Sec.ft. \\
\hline & \multicolumn{2}{|c|}{ September 18} & \multicolumn{2}{|c|}{ September 19} & \multicolumn{2}{|c|}{ September 20} & \multicolumn{2}{|c|}{ September 21} & \multicolumn{2}{|c|}{ September 22} & \multicolumn{2}{|c|}{ September 23} \\
\hline $\begin{array}{l}1 \\
2 \\
3 \\
4 \\
5 \\
6\end{array}$ & $\begin{array}{l}5.39 \\
5.40 \\
5.40 \\
5.41 \\
5.41 \\
5.41\end{array}$ & $\begin{array}{l}7.9 \\
8.1 \\
8.1 \\
8.3 \\
8.3 \\
8.3\end{array}$ & $\begin{array}{l}5.50 \\
5.55 \\
5.58 \\
5.60 \\
5.62 \\
5.64\end{array}$ & $\begin{array}{l}10 \\
12 \\
13 \\
13 \\
14 \\
14\end{array}$ & $\begin{array}{l}6.20 \\
6.22 \\
6.34 \\
6.44 \\
6.49 \\
6.52\end{array}$ & \begin{tabular}{|l}
35 \\
36 \\
42 \\
47 \\
50 \\
51
\end{tabular} & $\begin{array}{l}10.36 \\
10.68 \\
10.97 \\
11.21 \\
11.40 \\
11.72\end{array}$ & $\begin{array}{r}558 \\
658 \\
760 \\
854 \\
935 \\
1,090\end{array}$ & $\begin{array}{l}12.40 \\
12.31 \\
12.20 \\
12.10 \\
12.00 \\
11.90\end{array}$ & $\begin{array}{l}1,470 \\
1,420 \\
1,350 \\
1,290 \\
1,240 \\
1,180\end{array}$ & $\begin{array}{l}10.50 \\
10.44 \\
10.38 \\
10.33 \\
10.27 \\
10.23\end{array}$ & $\begin{array}{l}600 \\
582 \\
564 \\
549 \\
532 \\
522\end{array}$ \\
\hline $\begin{array}{r}7 \\
8 \\
9 \\
10 \\
11 \\
N\end{array}$ & $\begin{array}{l}5.40 \\
5.40 \\
5.39 \\
5.58 \\
5.65 \\
5.54\end{array}$ & $\begin{array}{l}8.1 \\
8.1 \\
7.9 \\
13 \\
15 \\
12\end{array}$ & $\begin{array}{l}5.68 \\
5.93 \\
6.09 \\
6.13 \\
6.17 \\
6.21\end{array}$ & $\begin{array}{l}16 \\
24 \\
31 \\
32 \\
34 \\
36\end{array}$ & $\begin{array}{l}6.55 \\
6.62 \\
6.77 \\
6.97 \\
7.18 \\
7.40\end{array}$ & $\begin{array}{r}52 \\
56 \\
65 \\
78 \\
93 \\
109\end{array}$ & $\begin{array}{l}12.05 \\
12.70 \\
13.66 \\
13.72 \\
13.71 \\
13.68\end{array}$ & $\begin{array}{l}1,260 \\
1,680 \\
2,570 \\
2,630 \\
2,620 \\
2,590\end{array}$ & $\begin{array}{l}11.80 \\
11.72 \\
11.64 \\
11.55 \\
11.49 \\
11.42\end{array}$ & $\begin{array}{r}1,130 \\
1,090 \\
1,050 \\
1,000 \\
975 \\
944\end{array}$ & $\begin{array}{r}10.18 \\
10.12 \\
10.08 \\
10.04 \\
9.98 \\
9.94\end{array}$ & $\begin{array}{l}510 \\
495 \\
485 \\
476 \\
462 \\
453\end{array}$ \\
\hline $\begin{array}{l}1 \\
2 \\
3 \\
4 \\
5 \\
6\end{array}$ & $\begin{array}{l}5.46 \\
5.42 \\
5.41 \\
5.41 \\
5.43 \\
5.46\end{array}$ & $\begin{array}{l}9.5 \\
8.6 \\
8.3 \\
8.3 \\
8.8 \\
9.5\end{array}$ & $\begin{array}{l}6.14 \\
6.06 \\
6.04 \\
6.04 \\
6.07 \\
6.14\end{array}$ & $\begin{array}{l}33 \\
29 \\
29 \\
29 \\
30 \\
33\end{array}$ & $\begin{array}{l}7.60 \\
7.90 \\
8.18 \\
8.37 \\
8.57 \\
8.73\end{array}$ & $\begin{array}{l}125 \\
152 \\
178 \\
197 \\
218 \\
238\end{array}$ & $\begin{array}{l}13.62 \\
13.53 \\
13.44 \\
13.33 \\
13.22 \\
13.13\end{array}$ & $\begin{array}{l}2,520 \\
2,420 \\
2,330 \\
2,220 \\
2,120 \\
2,040\end{array}$ & $\begin{array}{l}11.34 \\
11.25 \\
11.16 \\
11.10 \\
11.03 \\
10.96\end{array}$ & $\begin{array}{l}908 \\
870 \\
834 \\
810 \\
782 \\
756\end{array}$ & $\begin{array}{l}9.90 \\
9.85 \\
9.80 \\
9.76 \\
9.72 \\
9.67\end{array}$ & $\begin{array}{l}444 \\
432 \\
421 \\
412 \\
403 \\
392\end{array}$ \\
\hline \multirow[t]{2}{*}{$\begin{array}{r}7 \\
8 \\
9 \\
10 \\
11 \\
M \\
\end{array}$} & $\begin{array}{l}5.48 \\
5.50 \\
5.50 \\
5.50 \\
5.49 \\
5.48 \\
\end{array}$ & $\begin{array}{l}10 \\
10 \\
10 \\
10 \\
10 \\
10\end{array}$ & $\begin{array}{l}6.17 \\
6.18 \\
6.18 \\
6.17 \\
6.16 \\
6.18\end{array}$ & $\begin{array}{l}34 \\
34 \\
34 \\
34 \\
33 \\
34\end{array}$ & $\begin{array}{r}8.85 \\
8.99 \\
9.10 \\
9.35 \\
9.68 \\
10.02 \\
\end{array}$ & $\begin{array}{l}253 \\
273 \\
290 \\
331 \\
394 \\
472\end{array}$ & $\begin{array}{l}13.04 \\
12.96 \\
12.82 \\
12.74 \\
12.61 \\
12.52\end{array}$ & $\begin{array}{l}1,960 \\
1,890 \\
1,780 \\
1,710 \\
1,620 \\
1,550\end{array}$ & $\begin{array}{l}10.90 \\
10.82 \\
10.75 \\
10.68 \\
10.62 \\
10.56\end{array}$ & $\begin{array}{l}735 \\
707 \\
682 \\
658 \\
637 \\
618\end{array}$ & $\begin{array}{l}9.63 \\
9.59 \\
9.54 \\
9.50 \\
9.47 \\
9.44\end{array}$ & $\begin{array}{l}384 \\
376 \\
366 \\
358 \\
353 \\
347\end{array}$ \\
\hline & \multicolumn{2}{|c|}{ September 24} & \multicolumn{2}{|c|}{ September 25} & \multicolumn{2}{|c|}{ September 26} & \multicolumn{2}{|c|}{ September 27} & \multicolumn{2}{|c|}{ September 28} & \multicolumn{2}{|c|}{ September 29} \\
\hline $\begin{array}{r}2 \\
4 \\
6 \\
8 \\
10 \\
N\end{array}$ & $\begin{array}{l}9.35 \\
9.28 \\
9.22 \\
9.15 \\
9.08 \\
9.02\end{array}$ & $\begin{array}{l}331 \\
319 \\
309 \\
298 \\
287 \\
277\end{array}$ & $\begin{array}{l}8.60 \\
8.54 \\
8.50 \\
8.44 \\
8.38 \\
8.34\end{array}$ & $\begin{array}{l}222 \\
215 \\
210 \\
204 \\
198 \\
194\end{array}$ & $\begin{array}{l}8.03 \\
7.98 \\
7.94 \\
7.90 \\
7.85 \\
7.82\end{array}$ & $\begin{array}{l}164 \\
159 \\
156 \\
152 \\
148 \\
145\end{array}$ & $\begin{array}{l}7.56 \\
7.52 \\
7.50 \\
7.47 \\
7.44 \\
7.41\end{array}$ & $\begin{array}{l}122 \\
119 \\
117 \\
115 \\
112 \\
110\end{array}$ & $\begin{array}{l}7.24 \\
7.22 \\
7.20 \\
7.17 \\
7.15 \\
7.14\end{array}$ & $\begin{array}{l}97 \\
95 \\
94 \\
92 \\
90 \\
90\end{array}$ & $\begin{array}{l}6.99 \\
6.97 \\
6.95 \\
6.94 \\
6.93 \\
6.92\end{array}$ & $\begin{array}{l}79 \\
78 \\
76 \\
76 \\
75 \\
74\end{array}$ \\
\hline $\begin{array}{r}2 \\
4 \\
6 \\
8 \\
10 \\
M\end{array}$ & $\begin{array}{l}8.95 \\
8.88 \\
8.82 \\
8.77 \\
8.72 \\
8.66\end{array}$ & $\begin{array}{l}267 \\
257 \\
249 \\
242 \\
236 \\
229\end{array}$ & $\begin{array}{l}8.29 \\
8.25 \\
8.20 \\
8.15 \\
8.10 \\
8.07\end{array}$ & $\begin{array}{l}189 \\
185 \\
180 \\
175 \\
170 \\
167\end{array}$ & $\begin{array}{l}7.78 \\
7.72 \\
7.69 \\
7.66 \\
7.62 \\
7.59\end{array}$ & $\begin{array}{l}141 \\
137 \\
133 \\
130 \\
127 \\
124\end{array}$ & $\begin{array}{l}7.38 \\
7.35 \\
7.33 \\
7.30 \\
7.27 \\
7.25\end{array}$ & $\begin{array}{r}107 \\
105 \\
103 \\
101 \\
99 \\
98\end{array}$ & $\begin{array}{l}7.13 \\
7.09 \\
7.07 \\
7.04 \\
7.02 \\
7.00\end{array}$ & $\begin{array}{l}89 \\
86 \\
85 \\
83 \\
81 \\
80\end{array}$ & $\begin{array}{l}6.90 \\
6.88 \\
6.86 \\
6.83 \\
6.81 \\
6.79\end{array}$ & $\begin{array}{l}73 \\
72 \\
71 \\
69 \\
68 \\
66\end{array}$ \\
\hline
\end{tabular}


Priest Brook near Winchendon, Mass.

Location.- Water-stage recorder, lat. $42^{\circ} 40^{\prime} 55^{\prime \prime}$, long. $72^{\circ} 06^{\prime} 55^{n}$, 100 feet below highway bridge, 3 miles above confluence mith Miliers River, and $3 t^{2}$ miles west of Winchendon, Worcester County. Zero of gage is 849.67 feet above mean sea level (general adjustment of 1929 ):

Drainage area.- 18.8 square miles.

Gage-helght record.- Water-stage recorder graph.

Stage-discharge relation.- Affected by backwater from tree on control 4 p.m. Sept. 21 to 5 p.m. Oct. 8. Defined by current-meter measurements below 230 second-feet; extended to peak stage on basis of determinations of flood flows by contractedopening method.

Maxima:- September 1938: Discharge, 3,000 second-feet noon Sept. 21 (gage height, 9.90 feet).

1816 to August 1938: Discharge, 1,840 second-feet Mar. 18, 1936 (gage helght, 8.4 feet, from floodmarks).

Remarks.- Flood mun-off not materially affected by storago.

Mean daily discharge, in second-feet, 1938

\begin{tabular}{|c|c|c|c|c|c|c|c|c|c|c|c|}
\hline Day & Sept. & oct. & Day & Sept. & Oct. & Day & Sept. & Oct. & Day & Sept. & Oct. \\
\hline $\begin{array}{l}1 \\
2 \\
3 \\
4 \\
5 \\
6 \\
7 \\
8\end{array}$ & $\begin{array}{l}6.6 \\
6.3 \\
5.5 \\
5.8 \\
5.0 \\
4.7 \\
5.2 \\
7.2\end{array}$ & $\begin{array}{l}41 \\
36 \\
33 \\
27 \\
24 \\
25 \\
23 \\
19\end{array}$ & $\begin{array}{r}9 \\
10 \\
11 \\
12 \\
13 \\
14 \\
15 \\
16\end{array}$ & $\begin{array}{l}5.2 \\
4.4 \\
3.9 \\
5.0 \\
20 \\
16 \\
18 \\
31\end{array}$ & $\begin{array}{l}17 \\
16 \\
17 \\
15 \\
15 \\
24 \\
28 \\
19\end{array}$ & $\begin{array}{l}17 \\
18 \\
19 \\
20 \\
21 \\
22 \\
23 \\
24\end{array}$ & $\begin{array}{r}20 \\
14 \\
29 \\
412 \\
2,280 \\
1,200 \\
473 \\
245\end{array}$ & $\begin{array}{l}13 \\
20 \\
19 \\
12 \\
29 \\
34 \\
21 \\
25\end{array}$ & $\begin{array}{l}25 \\
26 \\
27 \\
28 \\
29 \\
30 \\
31\end{array}$ & $\begin{array}{r}154 \\
109 \\
83 \\
68 \\
56 \\
45\end{array}$ & $\begin{array}{l}58 \\
50 \\
44 \\
42 \\
35 \\
30 \\
27\end{array}$ \\
\hline $\begin{array}{l}\text { Mean } \\
\text { Run- }\end{array}$ & nthly & es. & , 1 . & . . . & $\dot{.}$ & & : : & $\dot{0}$ & . $:$ & $\begin{array}{r}178 \\
10.68\end{array}$ & $\begin{array}{l}27.0 \\
1.67\end{array}$ \\
\hline
\end{tabular}

Gage height, in feet, and discharge, in second-feet, at Indicated time, 1938

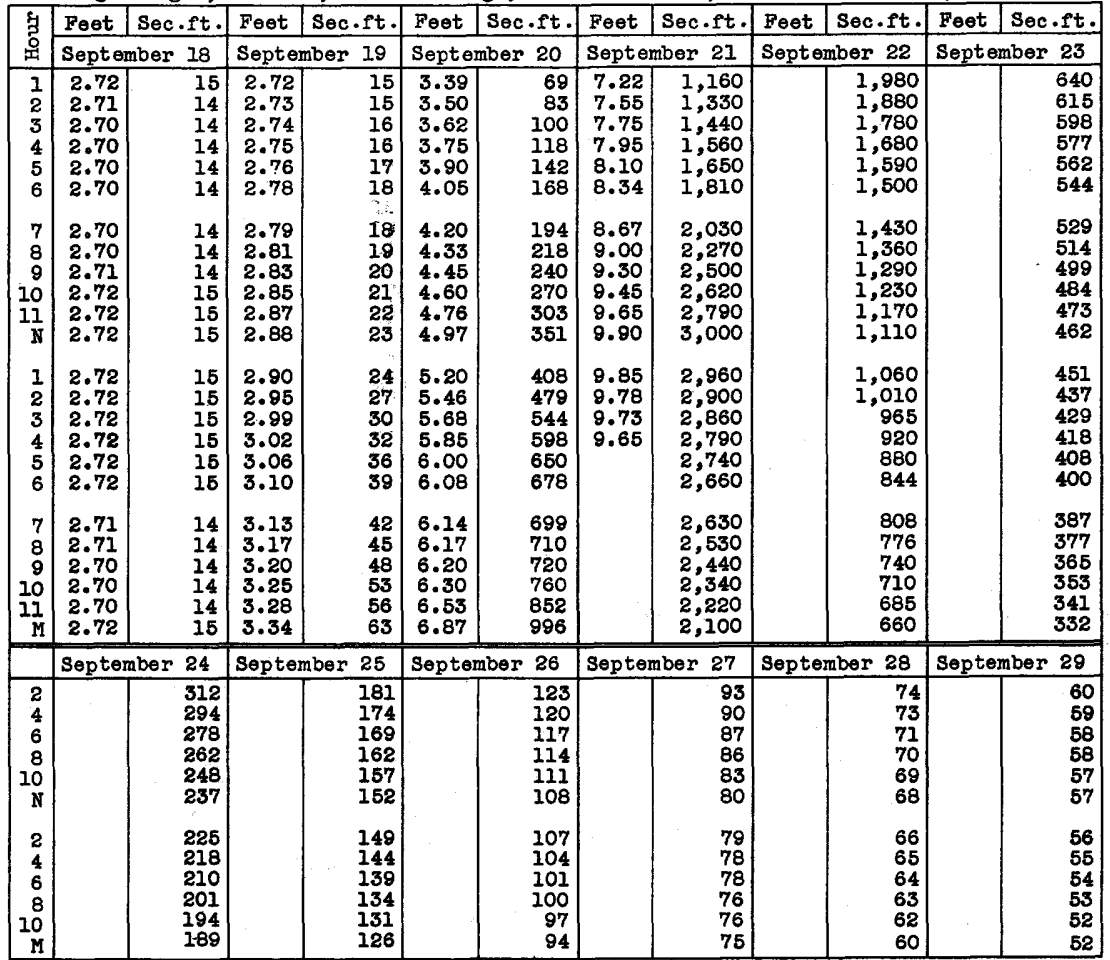


East Branch of Tully River near Athol, Mass.

Location.- Staff gage, lat. $42^{\circ} 38^{\prime} 35^{\prime \prime}$, long. $72^{\circ} 13^{\prime} 20^{\prime \prime}$, at highway bridge half a mile below mouth of Lawrence Brook and $3 \frac{1}{2}$ miles north of Athol, Worcester County. Zero of gage is 628.11 feet above mean sea level.

Dralnage area.- 49.9 square miles.

Gage-helght record. - Graph based on two gage readings dally and shape of stage graphs for nearby streams except during period Sept. 20-27, when graph was based on more frequent gage readings and flood marks.

Stage-discharge relation.- Defined by current-meter meesurements below 1,540 secondfeet; extended to peak stage on basis of determinations of flood flow over dam and by contracted-opening method.

Maxima.- September 1938: D1scharge, 5,140 second-feet 4 p.m. Sept. 21 (gage helght, 8.60 feet, from flood marks)

1916 to August 1938: Discharge, 3,700 second-feet Mar. 18, 19, 1936 (gage height, 6.50 feet)

Remarks.- Flood run-off not materlally affected by artificial or natural storage.

Mean dally discharge, in second-feet, 1938

\begin{tabular}{|c|c|c|c|c|c|c|c|c|c|c|c|}
\hline Day & Sept . & oct. & Day & Sept. & Oct. & Day & Sept. & oct. & Day & Sept. & Oct. \\
\hline $\begin{array}{l}1 \\
2 \\
3 \\
4 \\
5 \\
6 \\
7 \\
8\end{array}$ & $\begin{array}{l}16 \\
18 \\
16 \\
14 \\
12 \\
11 \\
11 \\
17\end{array}$ & $\begin{array}{r}131 \\
112 \\
106 \\
99 \\
88 \\
81 \\
74 \\
69\end{array}$ & $\begin{array}{r}9 \\
10 \\
11 \\
12 \\
13 \\
14 \\
15 \\
16\end{array}$ & $\begin{array}{l}17 \\
16 \\
14 \\
13 \\
48 \\
74 \\
75 \\
94\end{array}$ & $\begin{array}{l}67 \\
62 \\
56 \\
54 \\
51 \\
51 \\
55 \\
51\end{array}$ & $\begin{array}{l}17 \\
18 \\
19 \\
20 \\
21 \\
22 \\
23 \\
24\end{array}$ & $\begin{array}{r}83 \\
80 \\
107 \\
625 \\
3,650 \\
2,820 \\
1,330 \\
770\end{array}$ & $\begin{array}{l}48 \\
46 \\
43 \\
44 \\
72 \\
96 \\
86 \\
86\end{array}$ & $\begin{array}{l}25 \\
26 \\
27 \\
28 \\
29 \\
30 \\
31\end{array}$ & $\begin{array}{l}493 \\
359 \\
277 \\
224 \\
186 \\
164\end{array}$ & $\begin{array}{r}142 \\
152 \\
131 \\
112 \\
99 \\
81 \\
68\end{array}$ \\
\hline $\begin{array}{l}\text { Mean } \\
\text { Run- }\end{array}$ & $\begin{array}{l}\text { nthly } \\
\text {, in }\end{array}$ & schar & 1 & and & et. : & & : : : & $\dot{0}$ & $\dot{0}$ & $\begin{array}{r}388 \\
8.68\end{array}$ & $\begin{array}{l}81.1 \\
1.88\end{array}$ \\
\hline
\end{tabular}

Gage height, in feet, and discharge, in second-feet, at indicated time, 1938

\begin{tabular}{|c|c|c|c|c|c|c|c|c|c|c|c|c|}
\hline \multirow{2}{*}{ ใุ } & Feet & Sec.ft. & Feet & Sec.ft. & Feet & \multirow{2}{*}{$\frac{\text { Sec.ft. }}{\text { nber } 20}$} & Feet & Sec.ft. & Feet & Sec.ft. & Feet & Sec.ft. \\
\hline & \multicolumn{2}{|c|}{ September 18} & \multicolumn{2}{|c|}{ September 19} & September 20 & & \multicolumn{2}{|c|}{ September 21} & \multicolumn{2}{|c|}{ September 22} & \multicolumn{2}{|c|}{ September 23} \\
\hline $\begin{array}{l}7 \\
2 \\
3 \\
4 \\
5 \\
6\end{array}$ & $\begin{array}{l}1.65 \\
1.65 \\
1.65 \\
1.65 \\
1.65 \\
1.65\end{array}$ & $\begin{array}{l}78 \\
78 \\
78 \\
78 \\
78 \\
78\end{array}$ & $\begin{array}{l}1.70 \\
1.70 \\
1.70 \\
1.71 \\
1.71 \\
1.71\end{array}$ & \begin{tabular}{|l|}
83 \\
83 \\
83 \\
84 \\
84 \\
84
\end{tabular} & $\begin{array}{l}2.36 \\
2.42 \\
2.50 \\
2.58 \\
2.65 \\
2.72\end{array}$ & $\begin{array}{l}193 \\
206 \\
224 \\
243 \\
261 \\
280\end{array}$ & $\begin{array}{l}5.14 \\
5.30 \\
5.47 \\
5.65 \\
5.87 \\
6.08\end{array}$ & $\begin{array}{l}1,680 \\
1,810 \\
1,950 \\
2,100 \\
2,300 \\
2,490\end{array}$ & $\begin{array}{l}7.42 \\
7.30 \\
7.20 \\
7.10 \\
7.00 \\
6.88\end{array}$ & $\begin{array}{l}3,820 \\
3,700 \\
3,600 \\
3,500 \\
3,400 \\
3,280\end{array}$ & $\begin{array}{l}5.27 \\
5.20 \\
5.12 \\
5.05 \\
4.98 \\
4.92\end{array}$ & $\begin{array}{l}1,790 \\
1,730 \\
1,670 \\
1,610 \\
1,550 \\
1,510\end{array}$ \\
\hline $\begin{array}{r}7 \\
8 \\
9 \\
10 \\
11 \\
\mathrm{~N}\end{array}$ & $\begin{array}{l}1.65 \\
1.65 \\
1.65 \\
1.66 \\
1.66 \\
1.66\end{array}$ & $\begin{array}{l}78 \\
78 \\
78 \\
79 \\
79 \\
79\end{array}$ & $\begin{array}{l}1.72 \\
1.72 \\
1.73 \\
1.75 \\
1.79 \\
1.79\end{array}$ & $\begin{array}{l}85 \\
85 \\
87 \\
89 \\
94 \\
94\end{array}$ & $\begin{array}{l}2.80 \\
2.88 \\
2.98 \\
3.08 \\
3.19 \\
3.30\end{array}$ & $\begin{array}{l}302 \\
328 \\
362 \\
400 \\
446 \\
495\end{array}$ & $\begin{array}{l}6.30 \\
6.50 \\
6.82 \\
7.15 \\
7.50 \\
7.85\end{array}$ & $\begin{array}{l}2,700 \\
2,900 \\
3,220 \\
3,550 \\
3,910 \\
4,290\end{array}$ & $\begin{array}{l}6.79 \\
6.70 \\
6.62 \\
6.54 \\
6.46 \\
6.38\end{array}$ & $\begin{array}{l}3,190 \\
3,100 \\
3,020 \\
2,940 \\
2,860 \\
2,780\end{array}$ & $\begin{array}{l}4.86 \\
4.80 \\
4.75 \\
4.70 \\
4.66 \\
4.63\end{array}$ & $\begin{array}{l}1,460 \\
1,410 \\
1,370 \\
1,330 \\
1,300 \\
1,280\end{array}$ \\
\hline $\begin{array}{l}1 \\
2 \\
3 \\
4 \\
5 \\
6\end{array}$ & $\begin{array}{l}1.66 \\
1.67 \\
1.67 \\
1.67 \\
1.68 \\
1.68\end{array}$ & $\begin{array}{l}79 \\
80 \\
80 \\
80 \\
81 \\
81\end{array}$ & $\begin{array}{l}1.82 \\
1.84 \\
1.87 \\
1.91 \\
1.96 \\
2.00\end{array}$ & $\begin{array}{r}98 \\
101 \\
105 \\
111 \\
119 \\
125\end{array}$ & $\begin{array}{l}3.43 \\
3.57 \\
3.69 \\
3.82 \\
3.98 \\
4.10\end{array}$ & $\begin{array}{l}558 \\
625 \\
685 \\
752 \\
848 \\
920\end{array}$ & $\begin{array}{l}8.15 \\
8.35 \\
8.55 \\
8.60 \\
8.55 \\
8.45\end{array}$ & $\begin{array}{l}4,620 \\
4,840 \\
5,080 \\
5,140 \\
5,080 \\
4,960\end{array}$ & $\begin{array}{l}6.30 \\
6.22 \\
6.16 \\
6.10 \\
6.00 \\
5.90\end{array}$ & $\begin{array}{l}2,700 \\
2,620 \\
2,560 \\
2,510 \\
2,420 \\
2,330\end{array}$ & $\begin{array}{l}4.60 \\
4.56 \\
4.53 \\
4.50 \\
4.47 \\
4.44\end{array}$ & $\begin{array}{l}1,260 \\
1,230 \\
1,210 \\
1,190 \\
1,170 \\
1,150\end{array}$ \\
\hline \multirow[t]{2}{*}{$\begin{array}{r}7 \\
8 \\
9 \\
10 \\
11 \\
M\end{array}$} & $\begin{array}{l}1.68 \\
1.69 \\
1.69 \\
1.69 \\
1.69 \\
1.69 \\
\end{array}$ & $\begin{array}{l}81 \\
82 \\
82 \\
82 \\
82 \\
82\end{array}$ & $\begin{array}{l}2.04 \\
2.08 \\
2.13 \\
2.18 \\
2.24 \\
2.30\end{array}$ & $\begin{array}{l}132 \\
139 \\
147 \\
156 \\
168 \\
180\end{array}$ & $\begin{array}{l}4.22 \\
4.35 \\
4.51 \\
4.67 \\
4.82 \\
4.98\end{array}$ & $\begin{array}{r}994 \\
1,080 \\
1,200 \\
1,310 \\
1,430 \\
1,550\end{array}$ & $\begin{array}{l}8.28 \\
8.12 \\
7.97 \\
7.82 \\
7.68 \\
7.54\end{array}$ & $\begin{array}{l}4,770 \\
4,590 \\
4,430 \\
4,260 \\
4,110 \\
3,950\end{array}$ & $\begin{array}{l}5.81 \\
5.72 \\
5.62 \\
5.52 \\
5.43 \\
5.35\end{array}$ & $\begin{array}{l}2,250 \\
2,170 \\
2,080 \\
1,990 \\
1,910 \\
1,850\end{array}$ & $\begin{array}{r}4.40 \\
4.36 \\
4.33 \\
4.30 \\
4.27 \\
4.23 \\
\end{array}$ & $\begin{array}{l}1,120 \\
1,090 \\
1,070 \\
1,050 \\
1,030 \\
1,000\end{array}$ \\
\hline & \multicolumn{2}{|c|}{ September 24} & \multicolumn{2}{|c|}{ September 25} & \multicolumn{2}{|c|}{ September 26} & \multicolumn{2}{|c|}{ September 27} & \multicolumn{2}{|c|}{ September 28} & \multicolumn{2}{|c|}{ September 29} \\
\hline $\begin{array}{r}2 \\
4 \\
6 \\
8 \\
10 \\
\text { N }\end{array}$ & $\begin{array}{l}4.17 \\
4.10 \\
4.04 \\
3.98 \\
3.90 \\
3.83\end{array}$ & \begin{tabular}{|r|}
962 \\
920 \\
884 \\
848 \\
800 \\
758
\end{tabular} & $\begin{array}{l}3.46 \\
3.42 \\
3.40 \\
3.36 \\
3.32 \\
3.29\end{array}$ & \begin{tabular}{|l|}
570 \\
550 \\
540 \\
520 \\
500 \\
486
\end{tabular} & $\begin{array}{l}3.10 \\
3.08 \\
3.06 \\
3.04 \\
3.02 \\
2.99\end{array}$ & $\begin{array}{l}400 \\
392 \\
384 \\
376 \\
368 \\
357\end{array}$ & $\begin{array}{l}2.85 \\
2.83 \\
2.81 \\
2.80 \\
2.78 \\
2.76\end{array}$ & $\begin{array}{l}308 \\
301 \\
294 \\
290 \\
283 \\
276\end{array}$ & $\begin{array}{l}2.66 \\
2.65 \\
2.64 \\
2.62 \\
2.61 \\
2.60\end{array}$ & $\begin{array}{l}243 \\
240 \\
237 \\
231 \\
228 \\
225\end{array}$ & $\begin{array}{l}2.50 \\
2.48 \\
2.47 \\
2.47 \\
2.46 \\
2.45\end{array}$ & $\begin{array}{l}200 \\
195 \\
193 \\
193 \\
190 \\
188\end{array}$ \\
\hline $\begin{array}{r}2 \\
4 \\
6 \\
8 \\
10 \\
M\end{array}$ & $\begin{array}{l}3.75 \\
3.68 \\
3.62 \\
3.58 \\
3.52 \\
3.50\end{array}$ & $\begin{array}{l}715 \\
680 \\
650 \\
630 \\
600 \\
590\end{array}$ & $\begin{array}{l}3.26 \\
3.24 \\
3.22 \\
3.18 \\
3.16 \\
3.13\end{array}$ & $\begin{array}{l}472 \\
463 \\
454 \\
436 \\
427 \\
414\end{array}$ & $\begin{array}{l}2.97 \\
2.94 \\
2.92 \\
2.90 \\
2.88 \\
2.87\end{array}$ & $\begin{array}{l}350 \\
339 \\
332 \\
325 \\
318 \\
315\end{array}$ & $\begin{array}{l}2.74 \\
2.72 \\
2.70 \\
2.69 \\
2.68 \\
2.67\end{array}$ & $\begin{array}{l}269 \\
262 \\
255 \\
252 \\
249 \\
246\end{array}$ & $\begin{array}{l}2.58 \\
2.56 \\
2.55 \\
2.54 \\
2.53 \\
2.52\end{array}$ & $\begin{array}{l}220 \\
215 \\
212 \\
210 \\
208 \\
205\end{array}$ & $\begin{array}{l}2.43 \\
2.42 \\
2.40 \\
2.39 \\
2.38 \\
2.38\end{array}$ & $\begin{array}{l}183 \\
180 \\
175 \\
173 \\
170 \\
170\end{array}$ \\
\hline
\end{tabular}


Moss Brook at Wendell Depot, Mass.

Location.- Staff gage, lat. $42^{\circ} 36^{\prime} 05^{n}$, long. $72^{\circ} 21^{\prime} 35^{n}$, a quarter of a mile above confluence with Miliers River and a quarter of a mile north of Wendell Depot, Franklin County. Zero of gage is 508.88 feet above mean sea level.

Drainage area.- 12.2 square miles.

Gage-helght record.- Graph based on two gage readings daily and shape of stage graphs at nearby stations except for perjod $7 \mathrm{p} . \mathrm{m}$. Sept. 20 to $9: 30 \mathrm{a} . \mathrm{m}$. Sept. 22, record for which was besed on floodmarks and shape of stage graphs at nearby stations.

Stage-discharge relation. - Defined by current-meter measurements below 138 secondfeet; extended to peak stage on basis of three slope-area determinations of flood flow.

Maxima.- September 1938: D1scharge, 1,070 second-feet 5 p.m. Sept. 21 (gage helght, 5.62 feet, from floodmarks).

1916 to August 1938: D1scharge, 1,540 second-feet (revised) Mar. 19, 1936

(gage height, 6.30 feet, from floodmarks).

Remarks. - Flood run-off not materially affected by artificial or natural storage.

Mean daily discharge, in second-feet, 1938

\begin{tabular}{|c|c|c|c|c|c|c|c|c|c|c|c|}
\hline Day & Sept. & Oct. & Day & Sept. & Oct. & Day & Sept. & Oct. & Day & Sept. & oct. \\
\hline $\begin{array}{l}1 \\
2 \\
3 \\
4 \\
5 \\
6 \\
7 \\
8\end{array}$ & $\begin{array}{r}3.9 \\
3.8 \\
3.5 \\
3.2 \\
2.9 \\
2.8 \\
9.6 \\
14\end{array}$ & $\begin{array}{l}32 \\
21 \\
23 \\
25 \\
21 \\
20 \\
21 \\
17\end{array}$ & $\begin{array}{r}9 \\
10 \\
11 \\
12 \\
13 \\
14 \\
15 \\
16\end{array}$ & $\begin{array}{l}13 \\
11 \\
8.3 \\
7.2 \\
15 \\
12 \\
13 \\
17\end{array}$ & $\begin{array}{l}14.5 \\
13 \\
15 \\
13 \\
12 \\
12 \\
12 \\
12\end{array}$ & $\begin{array}{l}17 \\
18 \\
19 \\
20 \\
21 \\
22 \\
23 \\
24\end{array}$ & $\begin{array}{r}16 \\
15 \\
40 \\
283 \\
660 \\
334 \\
152 \\
92\end{array}$ & $\begin{array}{c}11 \\
10 \\
9.9 \\
10 \\
21 \\
23 \\
18 \\
26\end{array}$ & $\begin{array}{l}25 \\
26 \\
27 \\
28 \\
29 \\
30 \\
31\end{array}$ & $\begin{array}{l}55 \\
42 \\
37 \\
41 \\
40 \\
37\end{array}$ & $\begin{array}{l}68 \\
51 \\
33 \\
24 \\
21 \\
18 \\
18\end{array}$ \\
\hline $\begin{array}{l}\text { Mean } \\
\text { Run- }\end{array}$ & $\begin{array}{l}\text { onthiy } \\
f, \text { in } 1\end{array}$ & $\begin{array}{l}\text { schar } \\
\text { hes. }\end{array}$ & , 1 & $\begin{array}{l}\text { econd- } \\
.\end{array}$ & et. . &. & $\begin{array}{ll}\cdot & \cdot \\
. & \cdot\end{array}$ & $\begin{array}{lll}\cdot & \bullet & \bullet \\
. & - & -\end{array}$ & $: \dot{ }$ & $\begin{array}{l}66.1 \\
6.05\end{array}$ & $\begin{array}{l}20.8 \\
1.96\end{array}$ \\
\hline
\end{tabular}

Gage height, in feet, and discharge, in second-feet, at indicated time, 1938

\begin{tabular}{|c|c|c|c|c|c|c|c|c|c|c|c|c|}
\hline \multirow{2}{*}{$\begin{array}{l}9 \\
\text { g } \\
\text { 出 }\end{array}$} & Feet & Sec.ft. & Feet & Sec.ft. & Feet & Sec.ft. & Feet & Sec.ft. & Feet & Sec.ft. & Feet & Sec.ft. \\
\hline & \multicolumn{2}{|c|}{ September 18} & \multicolumn{2}{|c|}{ September 19} & \multicolumn{2}{|c|}{ September 20} & \multicolumn{2}{|c|}{ September 21} & \multicolumn{2}{|c|}{ September 22} & \multicolumn{2}{|c|}{ September 23} \\
\hline $\begin{array}{l}1 \\
2 \\
3 \\
4 \\
5 \\
6\end{array}$ & $\begin{array}{l}1.72 \\
1.72 \\
1.71 \\
1.70 \\
1.70 \\
1.70\end{array}$ & $\begin{array}{l}15 \\
15 \\
15 \\
14 \\
14 \\
14\end{array}$ & $\begin{array}{l}1.76 \\
1.76 \\
1.77 \\
1.78 \\
1.78 \\
1.79\end{array}$ & $\begin{array}{l}17 \\
17 \\
17 \\
18 \\
18 \\
18\end{array}$ & $\begin{array}{l}2.95 \\
3.05 \\
3.14 \\
3.22 \\
3.30 \\
3.40\end{array}$ & $\begin{array}{l}126 \\
141 \\
156 \\
170 \\
185 \\
205\end{array}$ & $\begin{array}{l}4.18 \\
4.21 \\
4.25 \\
4.31 \\
4.36 \\
4.42\end{array}$ & $\begin{array}{l}414 \\
424 \\
438 \\
459 \\
476 \\
497\end{array}$ & $\begin{array}{l}4.42 \\
4.35 \\
4.28 \\
4.21 \\
4.18 \\
4.12\end{array}$ & $\begin{array}{l}497 \\
472 \\
448 \\
424 \\
414 \\
396\end{array}$ & $\begin{array}{l}3.39 \\
3.36 \\
3.33 \\
3.30 \\
3.25 \\
3.21\end{array}$ & $\begin{array}{l}203 \\
197 \\
191 \\
185 \\
176 \\
168\end{array}$ \\
\hline $\begin{array}{r}7 \\
8 \\
9 \\
10 \\
11 \\
\frac{N}{N}\end{array}$ & $\begin{array}{l}1.69 \\
1.68 \\
1.67 \\
1.67 \\
1.67 \\
1.68\end{array}$ & $\begin{array}{l}14 \\
14 \\
13 \\
13 \\
13 \\
14\end{array}$ & $\begin{array}{l}1.80 \\
1.81 \\
1.82 \\
1.86 \\
1.91 \\
1.97\end{array}$ & $\begin{array}{l}18 \\
19 \\
19 \\
21 \\
24 \\
27\end{array}$ & $\begin{array}{l}3.50 \\
3.60 \\
3.68 \\
3.72 \\
3.77 \\
3.82\end{array}$ & $\begin{array}{l}225 \\
250 \\
270 \\
280 \\
293 \\
306\end{array}$ & $\begin{array}{l}4.50 \\
4.56 \\
4.62 \\
4.73 \\
4.84 \\
4.95\end{array}$ & $\begin{array}{l}525 \\
546 \\
568 \\
612 \\
658 \\
708\end{array}$ & $\begin{array}{l}4.08 \\
4.04 \\
4.01 \\
3.96 \\
3.92 \\
3.88\end{array}$ & $\begin{array}{l}384 \\
372 \\
363 \\
348 \\
336 \\
324\end{array}$ & $\begin{array}{l}3.18 \\
3.15 \\
3.11 \\
3.09 \\
3.07 \\
3.06\end{array}$ & $\begin{array}{l}163 \\
158 \\
151 \\
147 \\
144 \\
143\end{array}$ \\
\hline $\begin{array}{l}1 \\
2 \\
3 \\
4 \\
5 \\
6\end{array}$ & $\begin{array}{l}1.68 \\
1.69 \\
1.69 \\
1.70 \\
1.71 \\
1.72\end{array}$ & $\begin{array}{l}14 \\
14 \\
14 \\
14 \\
15 \\
15\end{array}$ & $\begin{array}{l}2.02 \\
2.09 \\
2.14 \\
2.21 \\
2.26 \\
2.33\end{array}$ & $\begin{array}{l}30 \\
35 \\
39 \\
44 \\
48 \\
54\end{array}$ & $\begin{array}{l}3.86 \\
3.90 \\
3.92 \\
3.95 \\
3.97 \\
4.00\end{array}$ & $\begin{array}{l}318 \\
330 \\
336 \\
345 \\
351 \\
360\end{array}$ & $\begin{array}{l}5.10 \\
5.25 \\
5.38 \\
5.55 \\
5.62 \\
5.48\end{array}$ & $\begin{array}{r}780 \\
858 \\
929 \\
1,030 \\
1,070 \\
988\end{array}$ & $\begin{array}{l}3.85 \\
3.80 \\
3.75 \\
3.71 \\
3.68 \\
3.62\end{array}$ & $\begin{array}{l}315 \\
300 \\
288 \\
278 \\
270 \\
255\end{array}$ & $\begin{array}{l}3.05 \\
3.03 \\
3.02 \\
3.01 \\
3.00 \\
3.00\end{array}$ & $\begin{array}{l}141 \\
138 \\
136 \\
135 \\
133 \\
133\end{array}$ \\
\hline \multirow[t]{2}{*}{$\begin{array}{r}7 \\
8 \\
9 \\
10 \\
11 \\
M \\
\end{array}$} & $\begin{array}{l}1.72 \\
1.73 \\
1.73 \\
1.74 \\
1.75 \\
1.75\end{array}$ & $\begin{array}{l}15 \\
16 \\
16 \\
16 \\
16 \\
16\end{array}$ & $\begin{array}{l}2.41 \\
2.51 \\
2.60 \\
2.70 \\
2.76 \\
2.87 \\
\end{array}$ & $\begin{array}{r}61 \\
70 \\
79 \\
91 \\
99 \\
114\end{array}$ & $\begin{array}{l}4.02 \\
4.03 \\
4.05 \\
4.08 \\
4.11 \\
4.15\end{array}$ & $\begin{array}{l}366 \\
369 \\
375 \\
384 \\
393 \\
405\end{array}$ & $\begin{array}{l}5.20 \\
5.00 \\
4.85 \\
4.70 \\
4.60 \\
4.50\end{array}$ & $\begin{array}{l}830 \\
730 \\
662 \\
600 \\
560 \\
525\end{array}$ & $\begin{array}{l}3.60 \\
3.57 \\
3.53 \\
3.50 \\
3.48 \\
3.42\end{array}$ & $\begin{array}{l}250 \\
242 \\
232 \\
225 \\
221 \\
209\end{array}$ & $\begin{array}{l}2.99 \\
2.98 \\
2.97 \\
2.96 \\
2.94 \\
2.93\end{array}$ & $\begin{array}{l}132 \\
130 \\
128 \\
127 \\
124 \\
122\end{array}$ \\
\hline & \multicolumn{2}{|c|}{ September 24} & \multicolumn{2}{|c|}{ September 25} & \multicolumn{2}{|c|}{ Septeraber 26} & \multicolumn{2}{|c|}{ September 27} & \multicolumn{2}{|c|}{ September 28} & \multicolumn{2}{|c|}{ September 29} \\
\hline $\begin{array}{r}2 \\
4 \\
6 \\
8 \\
10 \\
N\end{array}$ & $\begin{array}{l}2.90 \\
2.87 \\
2.84 \\
2.81 \\
2.76 \\
2.70\end{array}$ & $\begin{array}{r}118 \\
114 \\
110 \\
105 \\
99 \\
91\end{array}$ & $\begin{array}{r}2.45 \\
2.43 \\
-2.41 \\
2.40 \\
2.37 \\
2.34\end{array}$ & $\begin{array}{l}64 \\
63 \\
61 \\
60 \\
57 \\
55\end{array}$ & $\begin{array}{l}2.24 \\
2.23 \\
2.23 \\
2.22 \\
2.22 \\
2.21\end{array}$ & $\begin{array}{l}46 \\
45 \\
45 \\
45 \\
45 \\
44\end{array}$ & $\begin{array}{l}2.12 \\
2.11 \\
2.11 \\
2.11 \\
2.12 \\
2.12\end{array}$ & $\begin{array}{l}37 \\
37 \\
37 \\
37 \\
37 \\
37\end{array}$ & $\begin{array}{l}2.12 \\
2.12 \\
2.13 \\
2.13 \\
2.14 \\
2.16\end{array}$ & $\begin{array}{l}37 \\
37 \\
38 \\
38 \\
39 \\
40\end{array}$ & $\begin{array}{l}2.21 \\
2.19 \\
2.18 \\
2.16 \\
2.15 \\
2.14\end{array}$ & $\begin{array}{l}44 \\
42 \\
42 \\
40 \\
40 \\
39\end{array}$ \\
\hline $\begin{array}{r}2 \\
4 \\
6 \\
8 \\
10 \\
11\end{array}$ & $\begin{array}{l}2.66 \\
2.60 \\
2.55 \\
2.51 \\
2.49 \\
2.46\end{array}$ & $\begin{array}{l}86 \\
79 \\
74 \\
70 \\
68 \\
65 \\
\end{array}$ & $\begin{array}{l}2.31 \\
2.28 \\
2.26 \\
2.26 \\
2.25 \\
2.25\end{array}$ & $\begin{array}{l}52 \\
49 \\
48 \\
48 \\
47 \\
47 \\
\end{array}$ & $\begin{array}{l}2.19 \\
2.16 \\
2.14 \\
2.13 \\
2.12 \\
2.12 \\
\end{array}$ & $\begin{array}{l}42 \\
40 \\
39 \\
38 \\
37 \\
37\end{array}$ & $\begin{array}{l}2.11 \\
2.10 \\
2.10 \\
2.10 \\
2.11 \\
2.12 \\
\end{array}$ & $\begin{array}{l}37 \\
36 \\
36 \\
36 \\
37 \\
37\end{array}$ & $\begin{array}{l}2.19 \\
2.21 \\
2.22 \\
2.21 \\
2.21 \\
2.21 \\
\end{array}$ & $\begin{array}{l}42 \\
44 \\
45 \\
44 \\
44 \\
44\end{array}$ & $\begin{array}{l}2.13 \\
2.13 \\
2.13 \\
2.13 \\
2.13 \\
2.12\end{array}$ & $\begin{array}{l}38 \\
38 \\
38 \\
38 \\
38 \\
37\end{array}$ \\
\hline
\end{tabular}


Harriman Reservoir on Deerfield River at Davis Bridge, Vt.

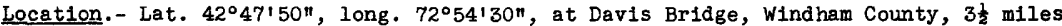
above mouth of West Branch of Deerfield River.

Drainage area.- 184 square miles; 30 square miles affected by storage in Somerset Reservoir on East Branch of Deerfield River near Somerset, $V t$.

Remarks.- Storage capacity, 5,050,000,000 cubic feet. Basic data furnished by New

England Power Co.

Gain or loss in storage, in millions of cubic feet, 1938

\begin{tabular}{|c|c|c|c|c|c|c|c|c|c|c|c|}
\hline Day & Sept. & oct. & Day & Sept. & oct. & Day & Sept. & oct. & Day & Sept. & oct. \\
\hline $\begin{array}{l}1 \\
2 \\
3 \\
4 \\
5 \\
6 \\
7 \\
8\end{array}$ & $\begin{array}{l}-57.96 \\
-69.59 \\
-20.57 \\
-12.17 \\
-12.16 \\
-70.48 \\
-60.11 \\
-15.02\end{array}$ & $\begin{array}{r}+17.89 \\
-8.95 \\
-35.77 \\
-35.78 \\
-35.42 \\
-44.37 \\
-43.64 \\
-35.06\end{array}$ & $\begin{array}{l}9 \\
10 \\
11 . \\
12 \\
13 \\
14 \\
15 \\
16\end{array}$ & $\begin{array}{r}-44.37 \\
-15.02 \\
0 \\
-51.52 \\
-21.83 \\
-30.05 \\
+22.54 \\
+7.51\end{array}$ & $\begin{array}{l}-42.94 \\
-33.99 \\
-33.99 \\
-26.47 \\
-35.06 \\
-51.88 \\
-41.86 \\
-16.46\end{array}$ & $\begin{array}{l}17 \\
18 \\
19 \\
20 \\
21 \\
22 \\
23 \\
24\end{array}$ & $\begin{array}{c}0 \\
+14.67 \\
+88.37 \\
+464.39 \\
+750.61 \\
-55.10 \\
-127.36 \\
-17.89\end{array}$ & $\begin{array}{c}-41.85 \\
-74.78 \\
-49.73 \\
-32.91 \\
-16.11 \\
-8.22 \\
0 \\
+16.10\end{array}$ & $\begin{array}{l}25 \\
26 \\
27 \\
28 \\
29 \\
30 \\
31\end{array}$ & $\begin{array}{r}-9.31 \\
-17.88 \\
0 \\
-8.95 \\
-8.94 \\
-17.89\end{array}$ & $\begin{array}{c}+82.64 \\
+8.23 \\
0 \\
-16.81 \\
0 \\
0 \\
-24.69\end{array}$ \\
\hline $\begin{array}{l}\text { Gain } \\
\text { Gain }\end{array}$ & $\begin{array}{l}\text { or loss } \\
\text { or loss }\end{array}$ & stor & , & 4711 & of $c$ & & $t \cdot \cdot$ & . . . & - . & $\begin{array}{r}+603.92 \\
+232\end{array}$ & $\begin{array}{r}-661.88 \\
-247\end{array}$ \\
\hline
\end{tabular}

Deerfield River at outlet of Harriman Reservoir, at Davis Bridge, vt.

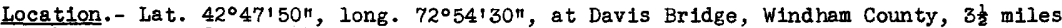
above mouth of West Branch of Deerfield'River.

Drainage area.- 184 square:miles; 30 square miles affected by storage in somerset Reservoir.

Stage-discharge relation. - Discharge determined from flow through wheels and over dam. Maxima.- September 1938: Discharge, about 44,400 second-feet, adjusted for storage In Harriman Reservoir, Sept. 21.

Remarks.- Flood mun-off affected by storage in Harriman and Somerset Reservolrs (total capacity, 7,750,000,000 cubic feet). Mean dally discharges adjusted for gain or loss in storage in Harriman Reservoir only. Mean monthly discharges adjusted for storage in Somerset and Harriman Reservoirs. For information on storage see record for Somerset Reservoir on East Branch of Deerfield River near Somerset, vt., and Harriman Reservoir on Deerfield River at Davis Bridge, Vt. Basic data furnished by New England Power Co.

Mean daily discharge, in second-feet, 1938

\begin{tabular}{|c|c|c|c|c|c|c|c|c|c|c|}
\hline \multirow[t]{2}{*}{ Day } & \multicolumn{2}{|c|}{ September } & \multicolumn{3}{|c|}{ October } & \multirow[t]{2}{*}{ Day } & \multicolumn{2}{|c|}{ September } & \multicolumn{2}{|c|}{ October } \\
\hline & Observed & Adjusted & Observed & Adju & isted & & Observed & AdJusted & Observed & Adjusted \\
\hline $\begin{array}{l}1 \\
2 \\
3 \\
4 \\
5\end{array}$ & $\begin{array}{l}718 \\
856 \\
296 \\
198 \\
R 58\end{array}$ & $\begin{array}{r}47 \\
51 \\
58 \\
57 \\
117\end{array}$ & $\begin{array}{l}145 \\
252 \\
765 \\
734 \\
910\end{array}$ & & $\begin{array}{l}352 \\
148 \\
351 \\
320 \\
500\end{array}$ & $\begin{array}{l}16 \\
17 \\
18 \\
19 \\
20\end{array}$ & $\begin{array}{r}465 \\
47 \\
0 \\
318 \\
11\end{array}$ & $\begin{array}{r}552 \\
47 \\
170 \\
1,340 \\
5,380\end{array}$ & $\begin{array}{r}468 \\
834 \\
1,160 \\
805 \\
861\end{array}$ & $\begin{array}{l}277 \\
350 \\
294 \\
229 \\
480\end{array}$ \\
\hline $\begin{array}{r}6 \\
7 \\
8 \\
9 \\
10\end{array}$ & $\begin{array}{r}951 \\
1,024 \\
656 \\
667 \\
347\end{array}$ & $\begin{array}{l}135 \\
328 \\
482 \\
153 \\
173\end{array}$ & $\begin{array}{l}894 \\
841 \\
678 \\
567 \\
841\end{array}$ & & $\begin{array}{r}380 \\
336 \\
272 \\
70 \\
448\end{array}$ & $\begin{array}{l}21 \\
22 \\
23 \\
24 \\
25\end{array}$ & $\begin{array}{r}3,797 \\
10,768 \\
3,542 \\
1,827 \\
1,258\end{array}$ & $\begin{array}{r}12,500 \\
10,100 \\
2,070 \\
1,620 \\
1,150\end{array}$ & $\begin{array}{l}637 \\
334 \\
209 \\
695 \\
160\end{array}$ & $\begin{array}{r}451 \\
239 \\
209 \\
881 \\
1,120\end{array}$ \\
\hline $\begin{array}{l}11 \\
12 \\
13 \\
14 \\
15\end{array}$ & $\begin{array}{l}278 \\
949 \\
620 \\
440 \\
317\end{array}$ & $\begin{array}{r}278 \\
353 \\
367 \\
92 \\
578\end{array}$ & $\begin{array}{l}572 \\
644 \\
729 \\
783 \\
949\end{array}$ & & $\begin{array}{l}179 \\
338 \\
323 \\
183 \\
465\end{array}$ & $\begin{array}{l}26 \\
27 \\
28 \\
29 \\
30 \\
31\end{array}$ & $\begin{array}{l}945 \\
745 \\
838 \\
600 \\
552\end{array}$ & $\begin{array}{l}738 \\
745 \\
734 \\
497 \\
345\end{array}$ & $\begin{array}{l}301 \\
475 \\
751 \\
258 \\
245 \\
840\end{array}$ & $\begin{array}{l}396 \\
475 \\
556 \\
258 \\
245 \\
554\end{array}$ \\
\hline \multicolumn{2}{|c|}{$\begin{array}{l}\text { Mean } \\
\text { Run- }\end{array}$} & $\begin{array}{l}\text { Ischarge, } \\
\text { ches. }\end{array}$ & $\begin{array}{c}\text { In second } \\
.\end{array}$ & feet & & & $\begin{array}{r}1,143 \\
6.93\end{array}$ & $\begin{array}{r}21,375 \\
28.33\end{array}$ & $\begin{array}{r}624 \\
3.91\end{array}$ & $\begin{array}{r}a 377 \\
82.36\end{array}$ \\
\hline $\begin{array}{l}\text { Mee } \\
\text { Rur }\end{array}$ & $\begin{array}{l}\text { monthly } \\
\text { off, in }\end{array}$ & $\begin{array}{l}\text { ischarge, } \\
\text { ches.? }\end{array}$ & in secon & feet & : & & $\dot{.}$ & • & $\begin{array}{r}\text { September } \\
\mathrm{b} 1,496 \\
\mathrm{~b} 9.07\end{array}$ & $\begin{array}{r}\text { October } \\
\text { b257 } \\
\text { bl. } 61\end{array}$ \\
\hline
\end{tabular}

a Adjusted for storage in Harriman Reservolr only

b Adjusted for storage in Somerset and Harriman Reservoirs. 
Deerfleld River at Charlemont, Mass.

Location. - Water-stage recorder, lat. $42^{\circ} 37^{\prime} 30^{\prime \prime}$, long. $72^{\circ} 51^{\prime} 20^{\prime \prime}$, 1 mile below Charlemont, Franklin County. Zero of gage is 517.36 feet above mean sea level (general adjustment of 1929).

Drainage area.- 362 square miles; 184 square miles affected by storage in Somerset and Harriman Reservoirs.

Gage-he1ght record.- Water-stage recorder graph except for period 10 a.m. Sept. 27 to 1 p.m. Oct. 1, when there was no record.

Stage-discharge relation.- Defined by current-meter measurements below 9,950 secondfeet; exterided to peak stage on basis of determinations of flood flow by slope-area and contracted-opening methods.

Maxima.- September 1938: Discharge, 56, z00 second-feet 6:45 p.m. Sept. 21 (gage height, 20.17 feet, from flood marks).

1913 to August 1938: Discharge, 38,200 second-feet July 8, 1915 (gage he1ght, 15.7 , feet)

Remarks. - Discharge for period Sept. 27 to Oct. 1 computed on basis of power-plant records. Flood run-off affected by a total of 7,750,000,000 cub1c feet of storage capacity in Somerset and Harriman Reservoirs. For information on storage see records for Somerset Reservoir on East Branch of Deerfield River near Somerset, Vt., and for harriman Reservoir on Deerfield River at Davis Bridge, Vt.

Mean dally discharge, in second-feet, 1938

\begin{tabular}{|c|c|c|c|c|c|c|c|c|c|c|c|}
\hline Day & Sept. & Oct. & Day & Sept. & Oct. & Day & Sept. & Oct. & Day & Sept. & Oct. \\
\hline $\begin{array}{l}1 \\
2 \\
3 \\
4 \\
5 \\
6 \\
7 \\
8 \\
\end{array}$ & $\begin{array}{l}782 \\
814 \\
582 \\
398 \\
556 \\
806 \\
766 \\
886 \\
\end{array}$ & $\begin{array}{r}445 \\
582 \\
998 \\
1,110 \\
934 \\
914 \\
1,090 \\
1,090 \\
\end{array}$ & $\begin{array}{r}9 \\
10 \\
11 \\
12 \\
13 \\
14 \\
15 \\
16\end{array}$ & $\begin{array}{r}774 \\
734 \\
539 \\
800 \\
1,120 \\
862 \\
721 \\
749 \\
\end{array}$ & $\begin{array}{l}924 \\
888 \\
952 \\
536 \\
798 \\
766 \\
984 \\
654 \\
\end{array}$ & $\begin{array}{l}17 \\
18 \\
19 \\
20 \\
21 \\
22 \\
23 \\
24\end{array}$ & $\begin{array}{r}276 \\
247 \\
1,060 \\
4,710 \\
20,600 \\
19,800 \\
5,450 \\
2,430 \\
\end{array}$ & $\begin{array}{r}966 \\
1,030 \\
1,040 \\
1,050 \\
1,160 \\
806 \\
246 \\
1,140 \\
\end{array}$ & $\begin{array}{l}25 \\
26 \\
27 \\
28 \\
29 \\
30 \\
31\end{array}$ & $\begin{array}{r}1,180 \\
1,140 \\
920 \\
880 \\
800 \\
730\end{array}$ & $\begin{array}{r}1,230 \\
656 \\
690 \\
844 \\
404 \\
572 \\
1,080\end{array}$ \\
\hline & & & & & & • & • • & $\cdot \cdot \cdot$ & - & $\begin{array}{r}2,404 \\
7.41\end{array}$ & $\begin{array}{r}857 \\
2.73\end{array}$ \\
\hline
\end{tabular}

Gage height, in feet, and discharge, in second-feet, at indicated time, 1938

\begin{tabular}{|c|c|c|c|c|c|c|c|c|c|c|c|c|}
\hline \multirow{2}{*}{ 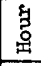 } & eet & ec.ft. & Feet & Sec.ft. & Feet & Sec.ft. & Feet & Sec.ft. & Feet & Sec.ft. & Feet & 3ec.ft \\
\hline & \multicolumn{2}{|c|}{ September 18} & \multicolumn{2}{|c|}{ September 19} & \multicolumn{2}{|c|}{ September 20} & \multicolumn{2}{|c|}{ September 21} & \multicolumn{2}{|c|}{ Sept ember 22} & \multicolumn{2}{|c|}{ September 23} \\
\hline $\begin{array}{l}1 \\
2 \\
3 \\
4 \\
5 \\
6\end{array}$ & $\begin{array}{l}2.70 \\
2.49 \\
2.32 \\
2.17 \\
2.07 \\
1.98\end{array}$ & $\begin{array}{l}635 \\
488 \\
384 \\
303 \\
254 \\
214\end{array}$ & $\begin{array}{l}3.01 \\
2.94 \\
2.94 \\
2.83 \\
2.70 \\
2.60\end{array}$ & $\begin{array}{l}87.9 \\
822 \\
822 \\
734 \\
635 \\
565\end{array}$ & $\begin{array}{l}4.20 \\
4.57 \\
5.48 \\
5.66 \\
5.66 \\
5.49\end{array}$ & & $\begin{array}{l}7.03 \\
7.06 \\
7.04 \\
6.96 \\
6.91 \\
6.90\end{array}$ & $\begin{array}{l}8,390 \\
8,470 \\
8,410 \\
8,210 \\
8,080 \\
8,050\end{array}$ & & & $\begin{array}{l}6.87 \\
6.71 \\
6.50 \\
6.42 \\
6.31 \\
6.19\end{array}$ & \\
\hline $\begin{array}{r}7 \\
8 \\
9 \\
10\end{array}$ & $\begin{array}{l}1.93 \\
1.88 \\
1.84 \\
1.83 \\
1.82 \\
1.81\end{array}$ & $\begin{array}{l}193 \\
172 \\
157 \\
153 \\
150 \\
146\end{array}$ & $\begin{array}{l}2.47 \\
2.33 \\
2.23 \\
2.15 \\
2.10 \\
3.22\end{array}$ & $\begin{array}{r}476 \\
389 \\
334 \\
293 \\
268 \\
1,070\end{array}$ & $\begin{array}{l}5.30 \\
5.14 \\
5.01 \\
4.98 \\
4.95 \\
5.10\end{array}$ & & $\begin{array}{l}7.03 \\
7.46 \\
8.20 \\
8.75 \\
9.00 \\
9.40\end{array}$ & $\begin{array}{r}8,390 \\
9,530 \\
11,600 \\
13,200 \\
13,900 \\
15,200\end{array}$ & & & $\begin{array}{l}5.99 \\
5.97 \\
5.91 \\
6.19 \\
5.92\end{array}$ & \\
\hline $\begin{array}{l}1 \\
2 \\
3 \\
4 \\
5 \\
6\end{array}$ & $\begin{array}{l}1.80 \\
1.80 \\
1.80 \\
1.80 \\
1.80 \\
1.80\end{array}$ & $\begin{array}{l}142 \\
142 \\
142 \\
142 \\
142 \\
142\end{array}$ & $\begin{array}{l}3.25 \\
3.26 \\
3.32 \\
3.40 \\
3.53 \\
3.68\end{array}$ & $\begin{array}{l}1,100 \\
1,110 \\
1,170 \\
1,250 \\
1,390 \\
1,550\end{array}$ & $\begin{array}{l}5.90 \\
5.37 \\
5.12 \\
4.99 \\
5.21 \\
6.06\end{array}$ & & $\begin{array}{r}9.07 \\
9.07 \\
9.03 \\
9.65 \\
13.10 \\
19.00\end{array}$ & & & & $\begin{array}{l}5.81 \\
5.71 \\
5.58 \\
5.50 \\
5.47 \\
5.46\end{array}$ & $\begin{array}{l}5 \\
4 \\
4 \\
4 \\
4\end{array}$ \\
\hline \multirow[t]{2}{*}{$\begin{array}{r}7 \\
8 \\
9 \\
10 \\
11 \\
M\end{array}$} & $\begin{array}{l}1.80 \\
1.79 \\
1.78 \\
1.78 \\
2.25 \\
3.14\end{array}$ & $\begin{array}{l}142 \\
139 \\
135 \\
135 \\
345 \\
996\end{array}$ & $\begin{array}{l}3.82 \\
3.93 \\
3.97 \\
3.93 \\
3.89 \\
3.93 \\
\end{array}$ & $\begin{array}{l}1,700 \\
1,840 \\
1,880 \\
1,840 \\
1,790 \\
1,840\end{array}$ & $\begin{array}{l}6.30 \\
6.35 \\
6.39 \\
6.81 \\
7.06 \\
7.10\end{array}$ & $\begin{array}{l}6,520 \\
6,640 \\
6,740 \\
7,820 \\
8,470 \\
8,570\end{array}$ & $\begin{array}{l}20.10 \\
17.50 \\
16.15 \\
15.35 \\
15.02 \\
15.02\end{array}$ & $\begin{array}{l}56,000 \\
45,400 \\
40,000 \\
36,800 \\
35,500 \\
35,500\end{array}$ & $\begin{array}{l}8.13 \\
7.89 \\
7.73 \\
7.55 \\
7.29 \\
7.06\end{array}$ & $\begin{array}{r}11,400 \\
10,800 \\
10,300 \\
9,780 \\
9,070 \\
8,470\end{array}$ & $\begin{array}{l}5.11 \\
5.25 \\
5.33 \\
5.33 \\
5.19 \\
4.77\end{array}$ & \\
\hline & \multicolumn{2}{|c|}{ September 24} & \multicolumn{2}{|c|}{ September 25} & \multicolumn{2}{|c|}{ September 26} & \multicolumn{2}{|c|}{ September 27} & \multicolumn{2}{|c|}{ September 28} & \multicolumn{2}{|c|}{ September 29} \\
\hline $\begin{array}{r}2 \\
4 \\
6 \\
8 \\
10 \\
\text { N }\end{array}$ & & & $\begin{array}{l}3.87 \\
3.55 \\
3.54 \\
3.42 \\
3.60 \\
3.72\end{array}$ & $\begin{array}{l}1,760 \\
1,410 \\
1,400 \\
1,270 \\
1,460 \\
1,590\end{array}$ & $\begin{array}{l}3.06 \\
3.03 \\
3.03 \\
3.05 \\
3.30 \\
3.45\end{array}$ & $\begin{array}{r}924 \\
897 \\
897 \\
915 \\
1,150 \\
1,3.00\end{array}$ & $\begin{array}{l}2.95 \\
2.84 \\
2.75 \\
2.47 \\
-\end{array}$ & $\begin{array}{r}830 \\
742 \\
672 \\
476 \\
-\quad\end{array}$ & $\begin{array}{l}\overline{-} \\
\overline{-} \\
\overline{-}\end{array}$ & $\begin{array}{l}= \\
= \\
\bar{z} \\
\end{array}$ & $\begin{array}{l}\overline{-} \\
\bar{z} \\
\bar{z}\end{array}$ & $\begin{array}{l}- \\
\overline{-} \\
\bar{*}\end{array}$ \\
\hline $\begin{array}{r}2 \\
4 \\
6 \\
8 \\
10\end{array}$ & & $\begin{array}{l}2, \\
1, \\
1, \\
2, \\
2, \\
1,\end{array}$ & $\begin{array}{l}3.13 \\
2.85 \\
2.67 \\
2.84 \\
2.70 \\
3.28\end{array}$ & $\begin{array}{r}987 \\
750 \\
614 \\
742 \\
635 \\
1,130\end{array}$ & $\begin{array}{l}3.46 \\
3.44 \\
3.43 \\
3.43 \\
3.43 \\
3.43\end{array}$ & $\begin{array}{l}1,310 \\
1,290 \\
1,280 \\
1,280 \\
1,280 \\
1,280\end{array}$ & $\begin{array}{l}\overline{-} \\
\bar{z} \\
\bar{z}\end{array}$ & $\begin{array}{l}\text { * } \\
= \\
= \\
=\end{array}$ & $\begin{array}{l}\overline{-} \\
\bar{z} \\
\bar{z} \\
\overline{-}\end{array}$ & $\begin{array}{l}\bar{z} \\
\bar{z} \\
\bar{z} \\
\bar{z}\end{array}$ & $\begin{array}{l}\overline{-} \\
\bar{z} \\
\bar{z} \\
\overline{-}\end{array}$ & $\begin{array}{l}\bar{z} \\
\bar{z} \\
\bar{z}\end{array}$ \\
\hline
\end{tabular}

Supplemental records.- Sept. $21,6: 45$ p.m., 20.17 ft., 56,300 sec. - ft. 
Somerset Reservoir on East Branch of Deerfield River near Somerset, Vt.

Location.- Lat. $42^{\circ} 58^{\prime} 2^{\prime \prime}$, long. $72^{\circ} 57^{\prime} 00^{\prime \prime}, 2 \frac{1}{2}$ miles northeast of Somerset, Windham County.

Drainage area. - 30 square miles.

Remarks.- Storage capacity, 2,700,000,000 cubic feet. Basic data furnished by New Eng-

land Power Co.

Gain or loss in storage, in millions of cubic feet, 1938

\begin{tabular}{|r|c|c||c|c|c||r|r|r||r|r|r|}
\hline Day & Sept. & oct. & Day & Sept. & oct. & Day & Sept. & 0ct. & Day & Sept. & 0ct. \\
\hline 1 & -3.31 & -7.03 & 9 & -11.88 & -10.33 & 17 & +3.29 & -20.13 & 25 & 0 & +19.98 \\
2 & -3.31 & 0 & 10 & -12.50 & -19.24 & 18 & +3.29 & -18.73 & 26 & -14.12 & 0 \\
3 & +1.32 & -16.10 & 11 & -11.83 & -16.43 & 19 & +26.41 & -15.99 & 27 & -3.52 & -6.66 \\
4 & +1.99 & -15.38 & 12 & -16.37 & -17.05 & 20 & +96.84 & -13.30 & 28 & +7.04 & -6.66 \\
5 & 0 & -17.40 & 13 & +9.84 & -19.71 & 21 & +188.64 & +3.32 & 29 & -7.04 & -9.98 \\
6 & -13.24 & -19.43 & 14 & +6.53 & -14.90 & 22 & +70.26 & 0 & 30 & -14.07 & -11.28 \\
7 & -3.30 & -16.61 & 15 & +6.57 & -15.54 & 23 & -3.53 & -6.64 & 31 & -8.61 \\
8 & 0 & -13.79 & 16 & +6.57 & -16.84 & 24 & 0 & +9.96 & & \\
\hline
\end{tabular}

East Branch of Deerfleld River at outlet of Somerset Reservoir, near Somerset, $\nabla t$.

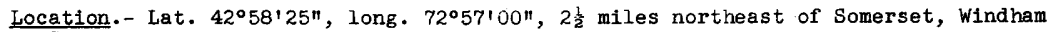
County.

Drainage area.- 30.0 square miles.

Stage-discharge relation.- Discharge determined from flow through gates.

Maxima.- September 1938: Discharge, about 7,500 second-feet, adjusted for storage in Somerset Reservoir, Sept. 21.

Remarks.- Flood run-off almost completely stored in Somerset Reservolr (capacity,

$2,700,000,000$ cubic feet). Mean daily and monthly discharges adjusted for gain or loss in storage. For information on storage see record for Somerset Reservolr on

East Branch of Deerfield River near Somerset, Vt. Basic data furmished by New Bngland Power Co.

Mean daily discharge, in second-feet, 1938

\begin{tabular}{|c|c|c|c|c|c|c|c|c|c|}
\hline \multirow{2}{*}{ Day } & \multicolumn{2}{|c|}{ September } & \multicolumn{2}{|c|}{ October } & \multirow{2}{*}{ Day } & \multicolumn{2}{|c|}{ September } & \multicolumn{2}{|c|}{ October } \\
\hline & Observed & Adjusted & Observed & Adjusted & & Observed & Adjusted & Observed & Adjusted \\
\hline $\begin{array}{l}1 \\
2 \\
3 \\
4 \\
5\end{array}$ & $\begin{array}{r}71 \\
46 \\
0 \\
0 \\
25\end{array}$ & $\begin{array}{r}33 \\
8 \\
15 \\
23 \\
25\end{array}$ & $\begin{array}{r}92 \\
17 \\
200 \\
200 \\
215\end{array}$ & $\begin{array}{l}11 \\
17 \\
14 \\
22 \\
14\end{array}$ & $\begin{array}{l}16 \\
17 \\
18 \\
19 \\
20\end{array}$ & $\begin{array}{r}0 \\
0 \\
12 \\
23 \\
0\end{array}$ & $\begin{array}{r}76 \\
38 \\
50 \\
329 \\
1,120\end{array}$ & $\begin{array}{l}215 \\
250 \\
235 \\
200 \\
188\end{array}$ & $\begin{array}{l}20 \\
17 \\
18 \\
15 \\
34\end{array}$ \\
\hline $\begin{array}{r}6 \\
7 \\
8 \\
9 \\
10\end{array}$ & $\begin{array}{r}167 \\
117 \\
58 \\
152 \\
150\end{array}$ & $\begin{array}{r}14 \\
79 \\
58 \\
15 \\
5\end{array}$ & $\begin{array}{l}235 \\
200 \\
167 \\
125 \\
235\end{array}$ & $\begin{array}{r}10 \\
8 \\
7 \\
6 \\
12\end{array}$ & $\begin{array}{l}21 \\
22 \\
23 \\
24 \\
25\end{array}$ & $\begin{array}{r}164 \\
669 \\
219 \\
86 \\
100\end{array}$ & $\begin{array}{r}2,340 \\
1,480 \\
178 \\
86 \\
100\end{array}$ & $\begin{array}{r}0 \\
19 \\
95 \\
64 \\
0\end{array}$ & $\begin{array}{r}38 \\
19 \\
18 \\
179 \\
231\end{array}$ \\
\hline $\begin{array}{l}11 \\
12 \\
13 \\
14 \\
15\end{array}$ & $\begin{array}{r}150 \\
204 \\
0 \\
33 \\
54\end{array}$ & $\begin{array}{r}13 \\
15 \\
114 \\
109 \\
130\end{array}$ & $\begin{array}{l}200 \\
206 \\
238 \\
200 \\
200\end{array}$ & $\begin{array}{r}10 \\
9 \\
10 \\
28 \\
20\end{array}$ & $\begin{array}{l}26 \\
27 \\
28 \\
29 \\
30 \\
31\end{array}$ & $\begin{array}{r}185 \\
119 \\
23 \\
168 \\
200\end{array}$ & $\begin{array}{r}22 \\
78 \\
105 \\
86 \\
37\end{array}$ & $\begin{array}{l}65 \\
148 \\
150 \\
150 \\
165 \\
200\end{array}$ & $\begin{array}{r}65 \\
71 \\
73 \\
34 \\
34 \\
100\end{array}$ \\
\hline $\begin{array}{l}\text { Me } \\
\text { Rum }\end{array}$ & $\begin{array}{l}\text { monthly } \\
\text { off, in }\end{array}$ & $\begin{array}{l}\text { 1scharge } \\
\text { ches.? }\end{array}$ & in secon & feet: : & & $-^{107}$ & $\begin{array}{r}226 \\
8.40\end{array}$ & $\begin{array}{r}157 \\
-\quad\end{array}$ & $\begin{array}{l}37.5 \\
1.44\end{array}$ \\
\hline
\end{tabular}


Location.- Water-stage recorder, lat. $42^{\circ} 23^{\prime} 30^{\prime \prime}$, long. $72^{\circ} 03^{\prime} 40^{\prime \prime}$, just above dam at Ware River intake works $0.8 \mathrm{mile}$ west of Cold Brook, Worcester County. Zero of gage $1 \mathrm{~s} 5.65$ feet below mean sea level.

Drainăge area.- 96.8 square milès.

Gage-height record.- Water-stage recorder graph. Add 600 to published figures to convert to Boston City datum.

Stage-discharge relation.- Discharge ascertained from flow over dam, through venturi meter, and sluices.

Maxima.- September 1938: Discharge, 14,000 second-feet 10:15 a.m. Sept. 21 (gage helght, 64.28 feet).

ig28 to August 1938: 5,990 second-feet Mar. 19, 1936 (gage helght, 61.35 feet).

Remarks.- Flood run-off not materially affected by storage. No diversions for Boston water supply. Records computed from basic data furnished by Metropolitan District Water Supply Commission.

Mean daily discharge, in second-feet, 1938

\begin{tabular}{|c|c|c|c|c|c|c|c|c|c|c|c|}
\hline Day & Sept. & Oct. & Dey & Sept. & Oct. & Day & Sept. & oct. & Dey & Sept. & Oet. \\
\hline $\begin{array}{l}1 \\
2 \\
3 \\
4 \\
5 \\
6 \\
7 \\
8 \\
\end{array}$ & $\begin{array}{l}65 \\
61 \\
51 \\
47 \\
45 \\
41 \\
40 \\
52\end{array}$ & $\begin{array}{l}397 \\
371 \\
317 \\
297 \\
274 \\
260 \\
251 \\
228\end{array}$ & $\begin{array}{r}9 \\
10 \\
11 \\
12 \\
13 \\
14 \\
15 \\
16\end{array}$ & $\begin{array}{r}50 \\
44 \\
40 \\
37 \\
99 \\
125 \\
125 \\
159 \\
\end{array}$ & $\begin{array}{l}221 \\
214 \\
206 \\
202 \\
200 \\
192 \\
188 \\
187\end{array}$ & $\begin{array}{l}17 \\
18 \\
19 \\
20 \\
21 \\
22 \\
23 \\
24\end{array}$ & $\begin{array}{r}132 \\
137 \\
305 \\
1,010 \\
8,740 \\
5,820 \\
3,160 \\
1,880\end{array}$ & $\begin{array}{l}183 \\
175 \\
167 \\
162 \\
228 \\
258 \\
218 \\
220\end{array}$ & $\begin{array}{l}25 \\
26 \\
27 \\
28 \\
29 \\
30 \\
31\end{array}$ & $\begin{array}{r}1,310 \\
960 \\
733 \\
597 \\
498 \\
439\end{array}$ & $\begin{array}{l}345 \\
355 \\
296 \\
279 \\
277 \\
248 \\
218\end{array}$ \\
\hline $\begin{array}{l}\text { Mean } \\
\text { Run- }\end{array}$ & $\begin{array}{l}\text { onthly } \\
f \text {, in }\end{array}$ & schare & ?, 1 & econd- & et. & $\begin{array}{l}\cdot \\
\end{array}$ & . $\cdot \dot{\cdot}$ & . : & : & $\begin{array}{r}893 \\
10.30 \\
\end{array}$ & $\begin{array}{r}246 \\
2.93\end{array}$ \\
\hline
\end{tabular}

Gage helght, in feet, and discharge, in second-feet, at indicated time, 1938

\begin{tabular}{|c|c|c|c|c|c|c|c|c|c|c|c|c|}
\hline \multirow{2}{*}{ 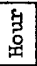 } & Feet & Sec.ft. & Feet & Sec.ft. & Feet & Sec.ft. & Feet & Sec.ft. & Feet & Sec.ft. & Feet & Sec.ft. \\
\hline & \multicolumn{2}{|c|}{ September 18} & \multicolumn{2}{|c|}{ September 19} & \multicolumn{2}{|c|}{ September 20} & \multicolumn{2}{|c|}{ September 21} & \multicolumn{2}{|c|}{ September 22} & \multicolumn{2}{|c|}{ September 23} \\
\hline $\begin{array}{l}7 \\
2 \\
3 \\
4 \\
5 \\
6\end{array}$ & $\begin{array}{l}57.39 \\
57.39 \\
57.40 \\
57.40 \\
57.41 \\
57.41\end{array}$ & $\begin{array}{l}125 \\
125 \\
130 \\
130 \\
135 \\
135\end{array}$ & $\begin{array}{l}57.45 \\
57.48 \\
57.50 \\
57.53 \\
57.55 \\
57.58\end{array}$ & $\begin{array}{l}155 \\
171 \\
182 \\
198 \\
210 \\
227\end{array}$ & $\begin{array}{l}57.96 \\
57.98 \\
58.00 \\
58.02 \\
58.04 \\
58.05\end{array}$ & $\begin{array}{l}503 \\
518 \\
534 \\
551 \\
571 \\
582\end{array}$ & $\begin{array}{l}59.64 \\
60.00 \\
60.40 \\
60.84 \\
61.32 \\
61.87\end{array}$ & $\begin{array}{l}2,750 \\
3,350 \\
4,060 \\
4,900 \\
5,850 \\
7,100\end{array}$ & $\begin{array}{l}62.12 \\
62.07 \\
61.97 \\
61.86 \\
61.78 \\
61.68\end{array}$ & $\begin{array}{l}7,700 \\
7,560 \\
7,300 \\
7,050 \\
6,850 \\
6,600\end{array}$ & $\begin{array}{l}60.38 \\
60.31 \\
60.26 \\
60.22 \\
60.16 \\
60.11\end{array}$ & $\begin{array}{l}4,020 \\
3,880 \\
3,800 \\
3,720 \\
3,620 \\
3,530\end{array}$ \\
\hline $\begin{array}{r}7 \\
8 \\
9 \\
10 \\
1.1 \\
N\end{array}$ & $\begin{array}{l}57.41 \\
57.42 \\
57.42 \\
57.42 \\
57.42 \\
57.42\end{array}$ & $\begin{array}{l}135 \\
140 \\
140 \\
140 \\
140 \\
140\end{array}$ & $\begin{array}{l}57.60 \\
57.63 \\
57.65 \\
57.66 \\
57.67 \\
57.68\end{array}$ & $\begin{array}{l}240 \\
259 \\
273 \\
280 \\
287 \\
295\end{array}$ & $\begin{array}{l}58.07 \\
58.08 \\
58.10 \\
58.13 \\
58.20 \\
58.30\end{array}$ & $\begin{array}{l}603 \\
614 \\
635 \\
667 \\
742 \\
850\end{array}$ & $\begin{array}{l}62.46 \\
63.10 \\
63.80 \\
64.14 \\
64.10 \\
63.81\end{array}$ & $\begin{array}{r}8,600 \\
10,300 \\
12,400 \\
13,600 \\
13,400 \\
12,400\end{array}$ & $\begin{array}{l}61.61 \\
61.52 \\
61.43 \\
61.36 \\
61.30 \\
61.27\end{array}$ & $\begin{array}{l}6,480 \\
6,270 \\
6,100 \\
5,900 \\
5,800 \\
5,730\end{array}$ & $\begin{array}{l}60.08 \\
60.04 \\
59.99 \\
59.94 \\
59.90 \\
59.85\end{array}$ & $\begin{array}{l}3,480 \\
3,430 \\
3,330 \\
3,250 \\
3,160 \\
3,100\end{array}$ \\
\hline $\begin{array}{l}1 \\
2 \\
3 \\
4 \\
5 \\
6\end{array}$ & $\begin{array}{l}57.42 \\
57.42 \\
57.42 \\
57.42 \\
57.42 \\
57.42\end{array}$ & $\begin{array}{l}140 \\
140 \\
140 \\
140 \\
140 \\
140\end{array}$ & $\begin{array}{l}57.70 \\
57.71 \\
57.72 \\
57.74 \\
57.76 \\
57.80\end{array}$ & $\begin{array}{l}309 \\
317 \\
325 \\
339 \\
354 \\
383\end{array}$ & $\begin{array}{l}58.37 \\
58.43 \\
58.49 \\
58.54 \\
58.62 \\
58.72\end{array}$ & $\begin{array}{r}928 \\
996 \\
1,070 \\
1,130 \\
1,240 \\
1,380\end{array}$ & $\begin{array}{l}63.62 \\
63.45 \\
63.22 \\
63.12 \\
62.80 \\
62.64\end{array}$ & $\begin{array}{r}11,800 \\
11,300 \\
10,600 \\
10,400 \\
9,500 \\
9,000\end{array}$ & $\begin{array}{l}61.24 \\
61.22 \\
61.05 \\
60.99 \\
60.92 \\
60.86\end{array}$ & $\begin{array}{l}5,690 \\
5,620 \\
5,300 \\
5,150 \\
5,000 \\
4,900\end{array}$ & $\begin{array}{l}59.81 \\
59.78 \\
59.74 \\
59.71 \\
59.67 \\
59.64\end{array}$ & $\begin{array}{l}3,020 \\
2,980 \\
2,940 \\
2,860 \\
2,800 \\
2,750\end{array}$ \\
\hline \multirow[t]{2}{*}{$\begin{array}{r}7 \\
8 \\
9 \\
10 \\
11 \\
M \\
\end{array}$} & $\begin{array}{l}57.42 \\
57.42 \\
57.42 \\
57.42 \\
57.42 \\
57.43\end{array}$ & $\begin{array}{l}140 \\
140 \\
140 \\
140 \\
140 \\
145\end{array}$ & $\begin{array}{l}57.84 \\
57.86 \\
57.88 \\
57.89 \\
57.92 \\
57.94\end{array}$ & $\begin{array}{l}413 \\
428 \\
443 \\
450 \\
473 \\
488\end{array}$ & $\begin{array}{l}58.80 \\
58.87 \\
58.95 \\
59.12 \\
59.28 \\
59.47\end{array}$ & $\begin{array}{l}1,430 \\
1,520 \\
1,640 \\
1,860 \\
2,100 \\
2,500\end{array}$ & $\begin{array}{l}62.61 \\
62.57 \\
62.53 \\
62.45 \\
62.35 \\
62.27\end{array}$ & $\begin{array}{l}8,900 \\
8,800 \\
8,740 \\
8,500 \\
8,250 \\
8,000\end{array}$ & $\begin{array}{l}60.79 \\
60.72 \\
60.64 \\
60.58 \\
60.51 \\
60.44\end{array}$ & $\begin{array}{l}4,760 \\
4,630 \\
4,500 \\
4,380 \\
4,250 \\
4,150\end{array}$ & $\begin{array}{l}59.61 \\
59.57 \\
59.54 \\
59.51 \\
59.47 \\
59.44\end{array}$ & $\begin{array}{l}2,700 \\
2,650 \\
2,600 \\
2,550 \\
2,480 \\
2,400\end{array}$ \\
\hline & \multicolumn{2}{|c|}{ September 24} & \multicolumn{2}{|c|}{ September 25} & \multicolumn{2}{|c|}{ September 26} & \multicolumn{2}{|c|}{ September 27 } & \multicolumn{2}{|c|}{ September 28} & \multicolumn{2}{|c|}{ September 29} \\
\hline $\begin{array}{r}2 \\
4 \\
6 \\
8 \\
10 \\
N\end{array}$ & $\begin{array}{l}59.38 \\
59.33 \\
59.27 \\
59.22 \\
59.16 \\
59.11\end{array}$ & $\begin{array}{l}2,280 \\
2,200 \\
2,100 \\
2,020 \\
1,900 \\
1,820\end{array}$ & $\begin{array}{l}58.84 \\
58.81 \\
58.77 \\
58.73 \\
58.70 \\
58.67\end{array}$ & $\begin{array}{l}1,480 \\
1,430 \\
1,410 \\
1,390 \\
1,350 \\
1,310\end{array}$ & $\begin{array}{l}58.50 \\
58.48 \\
58.46 \\
58.44 \\
58.42 \\
58.40\end{array}$ & $\begin{array}{r}1,080 \\
1,060 \\
1,030 \\
1,010 \\
984 \\
961\end{array}$ & $\begin{array}{l}58.26 \\
58.24 \\
58.23 \\
58.22 \\
58.20 \\
58.19\end{array}$ & $\begin{array}{l}807 \\
785 \\
774 \\
763 \\
742 \\
731\end{array}$ & \begin{tabular}{|l|}
58.12 \\
58.11 \\
58.10 \\
58.09 \\
58.07 \\
58.06
\end{tabular} & $\begin{array}{l}657 \\
646 \\
635 \\
625 \\
603 \\
592\end{array}$ & $\begin{array}{l}58.00 \\
57.99 \\
57.98 \\
57.97 \\
57.96 \\
57.95\end{array}$ & $\begin{array}{l}\mathbf{5 3 4} \\
\mathbf{5 2 6} \\
518 \\
510 \\
503 \\
496\end{array}$ \\
\hline $\begin{array}{r}2 \\
4 \\
6 \\
8 \\
10 \\
M\end{array}$ & $\begin{array}{l}59.06 \\
59.02 \\
58.98 \\
58.94 \\
58.90 \\
58.87\end{array}$ & $\begin{array}{l}1,770 \\
1,720 \\
1,670 \\
1,600 \\
1,550 \\
1,520\end{array}$ & $\begin{array}{l}58.64 \\
58.62 \\
58.59 \\
58.57 \\
58.55 \\
58.53\end{array}$ & $\begin{array}{l}1,260 \\
1,240 \\
1,190 \\
1,170 \\
1,140 \\
1,120\end{array}$ & $\begin{array}{l}58.38 \\
58.35 \\
58.33 \\
58.31 \\
58.29 \\
58.27\end{array}$ & $\begin{array}{l}939 \\
905 \\
882 \\
860 \\
840 \\
818\end{array}$ & $\begin{array}{l}58.17 \\
58.16 \\
58.15 \\
58.14 \\
58.14 \\
58.13\end{array}$ & $\begin{array}{l}710 \\
700 \\
689 \\
678 \\
678 \\
667\end{array}$ & $\begin{array}{l}58.05 \\
58.04 \\
58.03 \\
58.02 \\
58.01 \\
58.00\end{array}$ & $\begin{array}{l}582 \\
571 \\
561 \\
551 \\
543\end{array}$ & $\begin{array}{l}57.94 \\
57.94 \\
57.98 \\
57.92 \\
57.91 \\
57.90\end{array}$ & $\begin{array}{l}488 \\
488 \\
480 \\
473 \\
465 \\
458\end{array}$ \\
\hline
\end{tabular}

Supplemental records.- Sept. $21,10: 15$ a.m., $64.28 \mathrm{ft} ., 14,000$ sec. $-\mathrm{ft}$. 
Location. - Water-stage recorder, lat. $42^{\circ} 14^{\prime} 05^{\prime \prime}$, long. $72^{\circ} 16^{\prime} 45^{\prime \prime}$, half a mile above Gibbs Crossing, Hampshire County, $1 \frac{1}{4}$ miles above mouth of Beaver Brook, and $2 \frac{1}{2}$ miles southwest of Ware. Zero of gage is 379.79 feet above mean sea level (general adjustment of 1929 ).

Drainage area.- 199 square miles.

Gage-helght record.- Water-stage recorder graph except for period 10 a.m. Sept. 21 to 2 p.m. Sept. 28 when there was no record.

Stage-discharge relation.- Defined by current-meter measurements below 9,220 secondfeet; extended to peak stage on basis of determinations of flood flow by islope-area method.

Maxima.- September 1938; Discharge, 22,700 second-feet noon Sept. 21 (gage height, 18.2 feet, from flood marks).

1912 to August 1938: Discharge, 11,200 second-feet Mar. 19, 1936 (gage helght, 12.04 feet).

Remarks.- Discharge for period of missing record computed on basis of peak discharge, current-meter discharge measurement Sept. 26 , and records for Ware River at cold Brook, Mass. Flood run-off affected silghtly by natural storage.

Mean da1ly discharge, in second-feet, 1938

\begin{tabular}{|c|c|c|c|c|c|c|c|c|c|c|c|}
\hline Day & Sept. & Oct. & Day & Sept. & Oct. & Day & Sept. & Oct. & Day & Sept. & oct. \\
\hline $\begin{array}{l}1 \\
2 \\
3 \\
4 \\
5 \\
6 \\
7 \\
8\end{array}$ & $\begin{array}{r}167 \\
132 \\
82 \\
82 \\
63 \\
169 \\
127 \\
169\end{array}$ & $\begin{array}{l}670 \\
614 \\
531 \\
551 \\
497 \\
482 \\
451 \\
420\end{array}$ & $\begin{array}{l}9 \\
10 \\
11 \\
12 \\
13 \\
14 \\
15 \\
16\end{array}$ & $\begin{array}{r}125 \\
113 \\
63 \\
122 \\
144 \\
240 \\
304 \\
382\end{array}$ & $\begin{array}{l}405 \\
405 \\
391 \\
363 \\
356 \\
349 \\
377 \\
420\end{array}$ & $\begin{array}{l}17 \\
18 \\
19 \\
20 \\
21 \\
22 \\
23 \\
24\end{array}$ & $\begin{array}{r}290 \\
328 \\
718 \\
3,180 \\
16,700 \\
10,700 \\
6,000 \\
3,100\end{array}$ & $\begin{array}{l}443 \\
384 \\
291 \\
310 \\
538 \\
608 \\
538 \\
551\end{array}$ & $\begin{array}{l}25 \\
26 \\
27 \\
28 \\
29 \\
30 \\
31\end{array}$ & $\begin{array}{r}2,140 \\
1,550 \\
1,300 \\
1,070 \\
880 \\
778\end{array}$ & $\begin{array}{l}766 \\
697 \\
620 \\
577 \\
531 \\
510 \\
474\end{array}$ \\
\hline $\begin{array}{l}\text { Mean } \\
\text { Run- }\end{array}$ & $\begin{array}{l}\text { onthly } \\
f \text {, in }\end{array}$ & hes. & , & o thate & : & $\cdot$ & 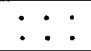 & $\dot{0}$ & $: \dot{ }$ & $\begin{array}{r}1,707 \\
9.57\end{array}$ & $\begin{array}{r}488 \\
2.83\end{array}$ \\
\hline
\end{tabular}

'Gage height, in feet, and discharge, In second-feet, at indicated time, 1938

\begin{tabular}{|c|c|c|c|c|c|c|c|c|c|c|c|c|}
\hline \multirow{2}{*}{ 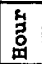 } & Feet & Sec.ft. & Feet & Sec.ft. & Feet & Sec.ft. & Feet & Sec.ft. & Feet & Sec.ft. & Feet & Sec.ft. \\
\hline & \multicolumn{2}{|c|}{ September 18} & \multicolumn{2}{|c|}{ September 19} & \multicolumn{2}{|c|}{ September 20} & \multicolumn{2}{|c|}{ September 21} & \multicolumn{2}{|c|}{ September 22} & \multicolumn{2}{|c|}{ September 23} \\
\hline $\begin{array}{l}1 \\
2 \\
3 \\
4 \\
5 \\
6\end{array}$ & $\begin{array}{l}2.57 \\
2.57 \\
2.57 \\
2.58 \\
2.59 \\
2.60\end{array}$ & $\begin{array}{l}274 \\
274 \\
274 \\
280 \\
285 \\
290\end{array}$ & $\begin{array}{l}2.76 \\
2.78 \\
2.80 \\
2.82 \\
2.87 \\
2.88\end{array}$ & $\begin{array}{l}392 \\
406 \\
420 \\
438 \\
483 \\
492\end{array}$ & $\begin{array}{l}3.58 \\
3.57 \\
3.68 \\
3.74 \\
3.85 \\
4.09\end{array}$ & $\begin{array}{l}1,140 \\
1,130 \\
1,210 \\
1,250 \\
1,320 \\
1,490\end{array}$ & $\begin{array}{r}9.80 \\
10.30 \\
10.85 \\
11.35 \\
12.00 \\
12.75\end{array}$ & $\begin{array}{r}7,450 \\
8,160 \\
8,980 \\
9,760 \\
10,800 \\
12,100\end{array}$ & $\begin{array}{l}- \\
- \\
- \\
- \\
- \\
-\end{array}$ & $\begin{array}{l}- \\
- \\
- \\
- \\
- \\
-\end{array}$ & $\begin{array}{l}- \\
- \\
- \\
- \\
-\end{array}$ & $\begin{array}{l}- \\
- \\
- \\
- \\
- \\
-\end{array}$ \\
\hline $\begin{array}{r}7 \\
8 \\
9 \\
10 \\
11 \\
\text { N }\end{array}$ & $\begin{array}{l}2.62 \\
2.64 \\
2.65 \\
2.66 \\
2.67 \\
2.67\end{array}$ & $\begin{array}{l}302 \\
314 \\
320 \\
326 \\
332 \\
332\end{array}$ & $\begin{array}{l}2.92 \\
3.06 \\
3.09 \\
3.08 \\
3.08 \\
3.07\end{array}$ & $\begin{array}{l}530 \\
676 \\
709 \\
698 \\
698 \\
687\end{array}$ & $\begin{array}{l}4.18 \\
4.32 \\
4.54 \\
4.90 \\
5.50 \\
6.15\end{array}$ & $\begin{array}{l}1,560 \\
1,650 \\
1,780 \\
2,000 \\
2,480 \\
3,090\end{array}$ & $\begin{array}{l}13.80 \\
15.00 \\
15.90 \\
16.80 \\
17.75 \\
18.2\end{array}$ & $\begin{array}{l}13,900 \\
16,200 \\
18,000 \\
19,800 \\
21,800 \\
22,700\end{array}$ & $\begin{array}{l}- \\
- \\
- \\
-\end{array}$ & $\begin{array}{c}- \\
- \\
- \\
- \\
\overline{-} \\
010,700\end{array}$ & $\begin{array}{l}- \\
- \\
- \\
- \\
-\end{array}$ & $\begin{array}{c}- \\
\overline{-} \\
\overline{-} \\
\mathbf{2 6 , 0 0 0}\end{array}$ \\
\hline $\begin{array}{l}1 \\
2 \\
3 \\
4 \\
5 \\
6\end{array}$ & $\begin{array}{l}2.68 \\
2.69 \\
2.69 \\
2.69 \\
2.71 \\
2.71\end{array}$ & $\begin{array}{l}338 \\
344 \\
344 \\
344 \\
357 \\
357\end{array}$ & $\begin{array}{l}3.06 \\
3.11 \\
3.14 \\
3.16 \\
3.18 \\
3.25\end{array}$ & $\begin{array}{l}676 \\
730 \\
760 \\
780 \\
800 \\
865\end{array}$ & $\begin{array}{l}6.55 \\
6.85 \\
7.12 \\
7.32 \\
7.44 \\
7.63\end{array}$ & $\begin{array}{l}3,490 \\
3,800 \\
4,080 \\
4,300 \\
4,460 \\
4,700\end{array}$ & $\begin{array}{l}- \\
- \\
- \\
-\end{array}$ & $\begin{array}{c}- \\
- \\
- \\
- \\
- \\
\mathrm{b} 19,900\end{array}$ & $\begin{array}{l}- \\
- \\
- \\
- \\
-\end{array}$ & $\begin{array}{l}- \\
- \\
- \\
- \\
-\end{array}$ & $\begin{array}{l}- \\
- \\
- \\
-\end{array}$ & $\begin{array}{l}- \\
- \\
- \\
-\end{array}$ \\
\hline \multirow[t]{2}{*}{$\begin{array}{r}7 \\
8 \\
9 \\
10 \\
11 \\
M\end{array}$} & $\begin{array}{l}2.72 \\
2.72 \\
2.72 \\
2.75 \\
2.73 . \\
2.73\end{array}$ & $\begin{array}{l}364 \\
364 \\
364 \\
385 \\
371 \\
371\end{array}$ & $\begin{array}{l}3.31 \\
3.40 \\
3.47 \\
3.54 \\
3.58 \\
3.62\end{array}$ & $\begin{array}{r}919 \\
1,000 \\
1,060 \\
1,110 \\
1,140 \\
1,160\end{array}$ & $\begin{array}{l}7.79 \\
7.95 \\
8.23 \\
8.55 \\
8.95 \\
9.40\end{array}$ & $\begin{array}{l}4,880 \\
5,060 \\
5,420 \\
5,780 \\
6,300 \\
6,890\end{array}$ & $\begin{array}{l}- \\
- \\
- \\
- \\
-\end{array}$ & $\begin{array}{l}- \\
- \\
- \\
- \\
-\end{array}$ & $\begin{array}{l}- \\
- \\
- \\
- \\
-\end{array}$ & $\begin{array}{l}- \\
- \\
- \\
- \\
-\end{array}$ & $\begin{array}{l}- \\
- \\
- \\
- \\
-\end{array}$ & $\begin{array}{l}- \\
- \\
- \\
-\end{array}$ \\
\hline & \multicolumn{2}{|c|}{ September 24} & \multicolumn{2}{|c|}{ September 25} & \multicolumn{2}{|c|}{ September 26} & \multicolumn{2}{|c|}{ September 27} & \multicolumn{2}{|c|}{ September 28} & \multicolumn{2}{|c|}{ September 29} \\
\hline $\begin{array}{r}2 \\
4 \\
6 \\
8 \\
10 \\
11\end{array}$ & $\begin{array}{l}- \\
- \\
- \\
- \\
-\end{array}$ & $\begin{array}{c}- \\
\overline{-} \\
\overline{-} \\
\mathrm{a} 3,100\end{array}$ & $\begin{array}{l}- \\
- \\
- \\
-\end{array}$ & $\begin{array}{c}- \\
- \\
- \\
- \\
- \\
\text { a2,140 }\end{array}$ & $\begin{array}{l}- \\
\overline{-} \\
- \\
-\end{array}$ & $\begin{array}{l}- \\
- \\
- \\
- \\
- \\
01,550\end{array}$ & $\begin{array}{l}- \\
- \\
- \\
- \\
-\end{array}$ & $\begin{array}{c}- \\
- \\
\overline{-} \\
- \\
- \\
\text { a1, } 300\end{array}$ & $\begin{array}{l}- \\
- \\
- \\
-\end{array}$ & $\begin{array}{c}- \\
\text { bl, } 160 \\
- \\
- \\
-\end{array}$ & $\begin{array}{l}3.56 \\
3.52 \\
3.49 \\
3.46 \\
3.43 \\
3.42\end{array}$ & $\begin{array}{l}946 \\
922 \\
904 \\
886 \\
868 \\
862\end{array}$ \\
\hline $\begin{array}{r}2 \\
4 \\
6 \\
8 \\
10 \\
1\end{array}$ & $\begin{array}{l}- \\
- \\
- \\
-\end{array}$ & $\begin{array}{l}- \\
- \\
- \\
-\end{array}$ & $\begin{array}{l}- \\
- \\
- \\
-\end{array}$ & $\begin{array}{l}- \\
- \\
- \\
-\end{array}$ & $\begin{array}{l}- \\
- \\
- \\
-\end{array}$ & $\begin{array}{l}- \\
\overline{-} \\
\overline{-} \\
-\end{array}$ & $\begin{array}{l}- \\
- \\
- \\
-\end{array}$ & $\begin{array}{l}- \\
\overline{-} \\
\overline{-}\end{array}$ & $\begin{array}{l}3.68 \\
3.65 \\
3.57 \\
3.58 \\
3.59 \\
3.58\end{array}$ & $\begin{array}{r}1,030 \\
1,000 \\
952 \\
958 \\
964 \\
958\end{array}$ & $\begin{array}{l}3.45 \\
3.45 \\
3.35 \\
3.35 \\
3.37 \\
3.37\end{array}$ & $\begin{array}{l}880 \\
880 \\
820 \\
820 \\
832 \\
832\end{array}$ \\
\hline
\end{tabular}

Mean for the day.

b Mean for 12-hour period. 
Chicopee River at Bircham Bend, Mass.

Location.- Lat. $42^{\circ} 09^{\prime} 30^{\prime \prime}$, long. $72^{\circ} 32^{\prime} 30^{\prime \prime}$, at dam at B1rcham Bend, Hampden County, three-quarters of a mile below Higher Brook and $5 \frac{1}{2}$ miles above mouth.

Drainage area.- 703 square miles.

Gage-he1ght record. - None (station destroyed by flood).

Max1ma.- September 1938: Discharge, about 45,200 second-feet Sept. 21. 1928 to August 1938: Discharge, 20,400 second-feet Mar. 19, 1936 (gage height, 9.87 feet)

Remarks.- Flood run-off affected by storage above Quabbin Dam and by natural storage.

Discharge computed on basis of measured flow at Quaboag River at West Brimfleld, Mass., Ware River at Gibbs Crossing, Mass., and Swift River at West Ware, Mass.

(76.4 percent of drainage area).

Mean daily discharge, in second-feet, 1938

\begin{tabular}{|c|r|r||r|r|r||r|r|r||r|r|r|}
\hline Day & Sept. & 0ct. & Day & Sept. & 0ct. & Day & Sept. & Oct. & Day & Sept. & Oct. \\
\hline 1 & 620 & 3,810 & 9 & 494 & 1,740 & 17 & 1,110 & 1,395 & 25 & 10,500 & 2,160 \\
2 & 562 & 3,460 & 10 & 470 & 1,620 & 18 & 1,190 & 1,280 & 26 & 8,060 & 2,120 \\
3 & 459 & 3,140 & 11 & 397 & 1,530 & 19 & 2,060 & 1,120 & 27 & 6,590 & 1,950 \\
4 & 457 & 2,920 & 12 & 465 & 1,420 & 20 & 7,610 & 1,130 & 28 & 5,650 & 1,850 \\
5 & 413 & 2,670 & 13 & 611 & 1,360 & 21 & 37,000 & 1,570 & 29 & 4,890 & 1,740 \\
6 & 540 & 2,480 & 14 & 937 & 1,340 & 22 & 30,400 & 1,680 & 30 & 4,340 & 1,660 \\
7 & 463 & 2,270 & 15 & 1,020 & 1,370 & 23 & 20,900 & 1,580 & 31 & & 1,530 \\
8 & 540 & 1,960 & 16 & 1,260 & 1,400 & 24 & 14,200 & 1,660 & & & \\
\hline
\end{tabular}




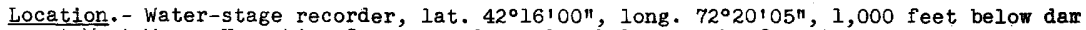
at West Ware, Hampshire County, and 3 miles below mouth of West Branch of Swift River. Zero of gage is 365.18 feet above mean sea level.

Drainage area.- 188 square miles (revised).

Gage-height record.- Water-stage recorder graph.

Stage-discharge relation.- Defined by current-meter measurements below 6,600 secondfeet; extended to maximum flood stage.

Maxima.- September 1938: Discharge, 5,540 second-feet 11 a.m. Sept. 22 (gage height, 13.74 feet)

1910 to August 1938: Discharge, 7,590 second-feet Mar. 19, 1936 (gage height, 15.00 feet).

Remarks.- Flood run-off affected by some artificial and natural storage.

Mean daily discharge, in second-feet, 1938

\begin{tabular}{|c|c|c|c|c|c|c|c|c|c|c|c|}
\hline Day & Sept. & $0 \mathrm{ct}$. & Day & Sept: & Oct. & Day & Sept. & Oct. & Day & Sept. & Oct. \\
\hline $\begin{array}{l}1 \\
2 \\
3 \\
4 \\
5 \\
6 \\
7 \\
8\end{array}$ & $\begin{array}{l}168 \\
166 \\
153 \\
151 \\
149 \\
140 \\
132 \\
149\end{array}$ & $\begin{array}{r}1,160 \\
1,080 \\
1,010 \\
946 \\
886 \\
822 \\
739 \\
588\end{array}$ & $\begin{array}{l}9 \\
10 \\
11 \\
12 \\
13 \\
14 \\
15 \\
16\end{array}$ & $\begin{array}{l}149 \\
144 \\
142 \\
138 \\
200 \\
250 \\
258 \\
311\end{array}$ & $\begin{array}{l}475 \\
423 \\
391 \\
368 \\
351 \\
354 \\
365 \\
362\end{array}$ & $\begin{array}{l}17 \\
18 \\
19 \\
20 \\
21 \\
22 \\
23 \\
24\end{array}$ & $\begin{array}{r}299 \\
314 \\
436 \\
1,130 \\
3,740 \\
5,440 \\
4,710 \\
3,730\end{array}$ & $\begin{array}{l}354 \\
343 \\
326 \\
317 \\
388 \\
411 \\
414 \\
438\end{array}$ & $\begin{array}{l}25 \\
26 \\
27 \\
28 \\
29 \\
30 \\
31\end{array}$ & $\begin{array}{l}2,770 \\
2,110 \\
1,690 \\
1,490 \\
1,370 \\
1,250\end{array}$ & $\begin{array}{l}550 \\
589 \\
544 \\
508 \\
472 \\
443 \\
397\end{array}$ \\
\hline $\begin{array}{l}\text { Mean } \\
\text { Run- }\end{array}$ & nthly & s. & & - & $\dot{\bullet}$ & & . $\cdot \dot{0}$ & : : : & : & $\begin{array}{r}1,109 \\
6.58\end{array}$ & $\begin{array}{r}542 \\
3.32\end{array}$ \\
\hline
\end{tabular}

Gage height, In feet, and discharge, in second-feet, at indicated time, 1938

\begin{tabular}{|c|c|c|c|c|c|c|c|c|c|c|c|c|}
\hline \multirow{2}{*}{$\begin{array}{r}5 \\
7 \\
0 \\
1 \\
\end{array}$} & Feet & Sec.ft. & Feet & Sec.ft. & Feet & Sec.ft. & Feet & Sec.ft. & Feet & Sec.ft. & Feet & Sec.ft. \\
\hline & \multicolumn{2}{|c|}{ September 18} & \multicolumn{2}{|c|}{ September 19} & \multicolumn{2}{|c|}{ September 20} & \multicolumn{2}{|c|}{ September 21} & \multicolumn{2}{|c|}{ September 22} & \multicolumn{2}{|c|}{ September 23} \\
\hline $\begin{array}{l}1 \\
2 \\
3 \\
4 \\
5 \\
6\end{array}$ & $\begin{array}{l}3.39 \\
3.40 \\
3.40 \\
3.40 \\
3.41 \\
3.41\end{array}$ & $\begin{array}{l}302 \\
305 \\
305 \\
305 \\
308 \\
308\end{array}$ & $\begin{array}{l}3.49 \\
3.52 \\
3.53 \\
3.56 \\
3.60 \\
3.63\end{array}$ & $\begin{array}{l}332 \\
341 \\
344 \\
353 \\
365 \\
374\end{array}$ & $\begin{array}{l}4.45 \\
4.49 \\
4.59 \\
4.76 \\
4.86 \\
4.98\end{array}$ & $\begin{array}{l}636 \\
650 \\
684 \\
741 \\
775 \\
816\end{array}$ & $\begin{array}{l}7.53 \\
7.83 \\
8.16 \\
8.51 \\
8.87 \\
9.22\end{array}$ & $\begin{array}{l}1,770 \\
1,890 \\
2,040 \\
2,200 \\
2,380 \\
2,570\end{array}$ & \begin{tabular}{l|}
13.42 \\
13.47 \\
13.49 \\
13.56 \\
13.62 \\
13.65
\end{tabular} & $\begin{array}{l}5,370 \\
5,400 \\
5,410 \\
5,440 \\
5,470 \\
5,490\end{array}$ & \begin{tabular}{|l|}
13.33 \\
13.28 \\
13.22 \\
13.16 \\
13.12 \\
13.07
\end{tabular} & $\begin{array}{l}5,170 \\
5,120 \\
5,070 \\
5,010 \\
4,980 \\
4,930\end{array}$ \\
\hline $\begin{array}{r}7 \\
8 \\
9 \\
10 \\
11 \\
\mathrm{~N}\end{array}$ & $\begin{array}{l}3.41 \\
3.41 \\
3.42 \\
3.43 \\
3.43 \\
3.43\end{array}$ & $\begin{array}{l}308 \\
308 \\
311 \\
314 \\
314 \\
314\end{array}$ & $\begin{array}{l}3.66 \\
3.69 \\
3.72 \\
3.73 \\
3.75 \\
3.80\end{array}$ & $\begin{array}{l}383 \\
392 \\
401 \\
404 \\
410 \\
426\end{array}$ & $\begin{array}{l}5.05 \\
5.14 \\
5.27 \\
5.48 \\
5.82 \\
6.05\end{array}$ & $\begin{array}{r}840 \\
871 \\
915 \\
988 \\
1,110 \\
1,190\end{array}$ & $\begin{array}{r}9.57 \\
10.01 \\
10.38 \\
10.70 \\
11.03 \\
11.28\end{array}$ & $\begin{array}{l}2,780 \\
3,050 \\
3,280 \\
3,500 \\
3,740 \\
3,940\end{array}$ & $\begin{array}{l}13.67 \\
13.69 \\
13.71 \\
13.72 \\
13.74 \\
13.72\end{array}$ & $\begin{array}{l}5,500 \\
5,510 \\
5,520 \\
5,520 \\
5,540 \\
5,520\end{array}$ & $\begin{array}{l}02 \\
98 \\
93 \\
89 \\
85 \\
81\end{array}$ & $\begin{array}{l}4,890 \\
4,850 \\
4,810 \\
4,770 \\
4,740 \\
4,700\end{array}$ \\
\hline $\begin{array}{l}1 \\
2 \\
3 \\
4 \\
5 \\
6\end{array}$ & $\begin{array}{l}3.43 \\
3.43 \\
3.44 \\
3.44 \\
3.45 \\
3.45\end{array}$ & $\begin{array}{l}314 \\
314 \\
317 \\
317 \\
320 \\
320\end{array}$ & $\begin{array}{l}3.83 \\
3.84 \\
3.86 \\
3.87 \\
3.90 \\
4.02\end{array}$ & $\begin{array}{l}435 \\
438 \\
445 \\
448 \\
457 \\
495\end{array}$ & $\begin{array}{l}6.21 \\
6.38 \\
6.50 \\
6.60 \\
6.65 \\
6.69\end{array}$ & $\begin{array}{l}1,250 \\
1,310 \\
1,360 \\
1,400 \\
1,420 \\
1,440\end{array}$ & $\begin{array}{l}11.46 \\
11.63 \\
11.82 \\
12.04 \\
12.24 \\
12.64\end{array}$ & $\begin{array}{l}4,090 \\
4,240 \\
4,410 \\
4,610 \\
4,780 \\
4,980\end{array}$ & $\begin{array}{l}13.72 \\
13.72 \\
13.72 \\
13.69 \\
13.66 \\
13.64\end{array}$ & $\begin{array}{l}5,520 \\
5,520 \\
5,520 \\
5,490 \\
5,460 \\
5,450\end{array}$ & $\begin{array}{l}12.77 \\
12.72 \\
12.66 \\
12.63 \\
12.58 \\
12.52\end{array}$ & $\begin{array}{l}4,670 \\
4,630 \\
4,580 \\
4,550 \\
4,510 \\
4,470\end{array}$ \\
\hline \multirow[t]{2}{*}{$\begin{array}{r}7 \\
8 \\
9 \\
10 \\
11 \\
\mathrm{M} \\
\end{array}$} & $\begin{array}{l}3.45 \\
3.46 \\
3.46 \\
3.46 \\
3.46 \\
3.47\end{array}$ & $\begin{array}{l}320 \\
323 \\
323 \\
323 \\
323 \\
326 \\
\end{array}$ & $\begin{array}{l}4.06 \\
4.12 \\
4.20 \\
4.27 \\
4.33 \\
4.40\end{array}$ & $\begin{array}{l}508 \\
527 \\
553 \\
576 \\
596 \\
619\end{array}$ & $\begin{array}{l}6.71 \\
6.77 \\
6.82 \\
6.90 \\
7.06 \\
7.28\end{array}$ & $\begin{array}{l}1,440 \\
1,470 \\
1,490 \\
1,520 \\
1,580 \\
1,670\end{array}$ & $\begin{array}{l}12.80 \\
12.96 \\
13.16 \\
13.25 \\
13.33 \\
13.38\end{array}$ & $\begin{array}{l}5, \\
5 \\
5 \\
5 \\
5 \\
5,\end{array}$ & $\begin{array}{l}13.61 \\
13.57 \\
13.52 \\
13.48 \\
13.43 \\
13.38\end{array}$ & $\begin{array}{l}120 \\
380 \\
340 \\
300 \\
260 \\
210\end{array}$ & $\begin{array}{l}12.47 \\
12.43 \\
12.38 \\
12.34 \\
12.28 \\
12.24\end{array}$ & $\begin{array}{l}30 \\
90 \\
50 \\
21 \\
70 \\
40\end{array}$ \\
\hline & \multicolumn{2}{|c|}{ September 24} & \multicolumn{2}{|c|}{ September 25} & \multicolumn{2}{|c|}{ September 26} & \multicolumn{2}{|c|}{ September 27} & \multicolumn{2}{|c|}{ September 28} & \multicolumn{2}{|c|}{ September 29} \\
\hline $\begin{array}{r}2 \\
4 \\
6 \\
8 \\
10 \\
\mathrm{~N}\end{array}$ & $\begin{array}{l}12.14 \\
12.03 \\
11.92 \\
11.81 \\
11.69 \\
11.57\end{array}$ & $\begin{array}{l}4,160 \\
4,070 \\
3,990 \\
3,910 \\
3,820 \\
3,740\end{array}$ & $\begin{array}{l}10.65 \\
10.53 \\
10.39 \\
10.27 \\
10.13 \\
10.01\end{array}$ & $\begin{array}{l}3,120 \\
3,050 \\
2,960 \\
2,890 \\
2,810 \\
2,740\end{array}$ & \begin{tabular}{|l|}
9.26 \\
9.17 \\
9.08 \\
8.98 \\
8.86 \\
8.75 \\
\end{tabular} & $\begin{array}{l}2,340 \\
2,300 \\
2,250 \\
2,200 \\
2,140 \\
2,080\end{array}$ & \begin{tabular}{|l|}
8.11 \\
8.03 \\
7.96 \\
7.88 \\
7.80 \\
7.72
\end{tabular} & $\begin{array}{l}1,820 \\
1,790 \\
1,760 \\
1,730 \\
1,700 \\
1,670\end{array}$ & $\begin{array}{l}7.44 \\
7.39 \\
7.34 \\
7.30 \\
7.26 \\
7.22\end{array}$ & $\begin{array}{l}1,560 \\
1,540 \\
1,520 \\
1,510 \\
1,500 \\
1,480\end{array}$ & $\begin{array}{l}7.04 \\
7.01 \\
6.99 \\
6.95 \\
6.93 \\
6.90\end{array}$ & $\begin{array}{l}1,420 \\
1,410 \\
1,400 \\
1,390 \\
1,380 \\
1,370\end{array}$ \\
\hline $\begin{array}{r}2 \\
4 \\
6 \\
8 \\
10 \\
M \\
\end{array}$ & $\begin{array}{l}11.44 \\
11.32 \\
11.18 \\
11.05 \\
10.91 \\
10.78 \\
\end{array}$ & $\begin{array}{l}3,650 \\
3,560 \\
3.470 \\
3,380 \\
3,280 \\
3,200 \\
\end{array}$ & $\begin{array}{l}9.93 \\
9.81 \\
9.70 \\
9.58 \\
9.48 \\
9.37\end{array}$ & $\begin{array}{l}2,690 \\
2,620 \\
2,560 \\
2,500 \\
2,450 \\
2,400 \\
\end{array}$ & $\begin{array}{l}8.67 \\
8.58 \\
8.49 \\
8.41 \\
8.30 \\
8.21\end{array}$ & $\begin{array}{l}2,050 \\
2,010 \\
1,980 \\
1,940 \\
1,900 \\
1,860\end{array}$ & $\begin{array}{l}7.65 \\
7.58 \\
7.64 \\
7.58 \\
7.53 \\
7.49\end{array}$ & $\begin{array}{l}1,640 \\
1,610 \\
1,640 \\
1,610 \\
1,590 \\
1,570\end{array}$ & $\begin{array}{l}7.19 \\
7.16 \\
7.13 \\
7.11 \\
7.09 \\
7.07\end{array}$ & $\begin{array}{l}1,470 \\
1,460 \\
1,450 \\
1,440 \\
1,440 \\
1,430\end{array}$ & $\begin{array}{l}6.88 \\
6.85 \\
6.82 \\
6.79 \\
6.75 \\
6.73\end{array}$ & $\begin{array}{l}60 \\
350 \\
340 \\
530 \\
320 \\
310\end{array}$ \\
\hline
\end{tabular}


East Branch of Swift River near Dana, Mass.

Lecation.- Water-stage recorder, lat. $42^{\circ} 23^{\prime} 35^{\prime \prime}$, long. $72^{\circ} 14^{\prime} 25^{\prime \prime}$, 0.6 mile below outlet of Pottapaug Pond, 2.1 miles south of Dana, Worcester County. Zero of gage is 504.70 feet above mean sea level (general adjustment of 1929).

Dralnage area.- 43.7 square miles.

Gage-he1ght record.- Water-stage recorder graph.

Stage-discharge relation.- Defined by current-meter measurements below 282 second-feet; extended to peak stage on basis of determinations of flood flow by slope-area and contracted-opening methods.

Maxima.- September 1938: Discharge, 6,780 second-feet 12:45 p.m. Sept. 2l (gage he1ght, 15.05 feet).

1937 to August 1938: Discharge, 900 second-feet Jan. 26, 1938 (gage he1ght, 7.95 feet).

Remarks.- Flood run-off affected slightly by natural storage.

Mean daily discharge, in second-feet, 1938

\begin{tabular}{|c|c|c|c|c|c|c|c|c|c|c|c|}
\hline Day & Sept. & Oct. & Dey & Sept. & Oct. & Day & Sept. & Oct. & Day & Sept. & Oct. \\
\hline $\begin{array}{l}1 \\
2 \\
3 \\
4 \\
5 \\
6 \\
7 \\
8\end{array}$ & $\begin{array}{l}21 \\
22 \\
20 \\
18 \\
17 \\
15 \\
14 \\
21\end{array}$ & $\begin{array}{r}142 \\
128 \\
120 \\
110 \\
100 \\
93 \\
87 \\
82\end{array}$ & $\begin{array}{r}9 \\
10 \\
11 \\
12 \\
13 \\
14 \\
15 \\
16\end{array}$ & $\begin{array}{l}25 \\
22 \\
19 \\
17 \\
34 \\
60 \\
58 \\
75\end{array}$ & $\begin{array}{l}81 \\
76 \\
70 \\
66 \\
63 \\
62 \\
68 \\
72\end{array}$ & $\begin{array}{l}17 \\
18 \\
19 \\
20 \\
21 \\
22 \\
23 \\
24\end{array}$ & $\begin{array}{r}70 \\
68 \\
120 \\
720 \\
4,690 \\
2,750 \\
927 \\
503\end{array}$ & $\begin{array}{r}70 \\
63 \\
56 \\
55 \\
91 \\
124 \\
106 \\
100\end{array}$ & $\begin{array}{l}25 \\
26 \\
27 \\
28 \\
29 \\
30 \\
31\end{array}$ & $\begin{array}{l}350 \\
267 \\
220 \\
205 \\
186 \\
159\end{array}$ & $\begin{array}{r}162 \\
169 \\
138 \\
115 \\
98 \\
87 \\
76\end{array}$ \\
\hline $\begin{array}{l}\text { Mean } \\
\text { Run- }\end{array}$ & $\begin{array}{l}\text { onthly } \\
\text { e, in }\end{array}$ & $\begin{array}{l}\text { schare } \\
\text { hes. }\end{array}$ & , in & $\begin{array}{c}\text { second- } \\
. \text {. }\end{array}$ & et. . & . & $\begin{array}{l}\cdot \cdot \cdot \\
.\end{array}$ & . : & : & $\begin{array}{r}390 \\
9.95\end{array}$ & $\begin{array}{l}94.5 \\
2.49\end{array}$ \\
\hline
\end{tabular}

Gage height, in feet, and discharge, in second-feet, at indicated time, 1938

\begin{tabular}{|c|c|c|c|c|c|c|c|c|c|c|c|c|c|}
\hline \multirow{2}{*}{$\begin{array}{l}3 \\
\text { 寽 }\end{array}$} & Feet & Sec.ft. & Feet & \multicolumn{2}{|c|}{ Sec.ft. } & Feet & Sec .ft. & Feet & Sec.ft. & Feet & sec. It. & Feet & sec.tt. \\
\hline & \multicolumn{2}{|c|}{ September 18} & \multicolumn{3}{|c|}{ September 19} & \multicolumn{2}{|c|}{ September 20} & \multicolumn{2}{|c|}{ September 21} & \multicolumn{2}{|c|}{ September 22} & \multicolumn{2}{|c|}{ September 23} \\
\hline $\begin{array}{l}1 \\
2 \\
3 \\
4 \\
5 \\
6\end{array}$ & $\begin{array}{l}4.77 \\
4.77 \\
4.77 \\
4.77 \\
4.77 \\
4.77\end{array}$ & $\begin{array}{l}64 \\
64 \\
64 \\
64 \\
64 \\
64\end{array}$ & $\begin{array}{l}4.91 \\
4.92 \\
4.93 \\
4.95 \\
4.97 \\
4.98\end{array}$ & & $\begin{array}{l}77 \\
78 \\
80 \\
81 \\
84 \\
85\end{array}$ & $\begin{array}{l}5.90 \\
5.96 \\
6.08 \\
6.15 \\
6.22 \\
6.29\end{array}$ & $\begin{array}{l}225 \\
237 \\
263 \\
278 \\
296 \\
310\end{array}$ & $\begin{array}{l}10.09 \\
10.50 \\
11.00 \\
11.47 \\
11.90 \\
12.25\end{array}$ & $\begin{array}{l}2,030 \\
2,300 \\
2,650 \\
3,030 \\
3,370 \\
3,680\end{array}$ & $\begin{array}{l}13.04 \\
12.90 \\
12.74 \\
12.50 \\
12.32 \\
12.11\end{array}$ & $\begin{array}{l}4,390 \\
4,260 \\
4,120 \\
3,900 \\
3,740 \\
3,550\end{array}$ & $\begin{array}{l}8.92 \\
8.80 \\
8.68 \\
8.58 \\
8.48 \\
8.37\end{array}$ & $\begin{array}{l}1,350 \\
1,290 \\
1,230 \\
1,180 \\
1,130 \\
1,080\end{array}$ \\
\hline $\begin{array}{r}7 \\
8 \\
9 \\
10 \\
11 \\
\mathrm{~N}\end{array}$ & $\begin{array}{l}4.78 \\
4.79 \\
4.80 \\
4.80 \\
4.81 \\
4.82\end{array}$ & $\begin{array}{l}65 \\
66 \\
67 \\
67 \\
68 \\
69\end{array}$ & $\begin{array}{l}5.02 \\
5.04 \\
5.06 \\
5.08 \\
5.13 \\
5.17\end{array}$ & & $\begin{array}{r}88 \\
91 \\
94 \\
96 \\
103 \\
108\end{array}$ & $\begin{array}{l}6.36 \\
6.46 \\
6.55 \\
6.68 \\
6.80 \\
6.92\end{array}$ & $\begin{array}{l}335 \\
360 \\
390 \\
428 \\
465 \\
515\end{array}$ & $\begin{array}{l}12.66 \\
13.06 \\
13.32 \\
14.36 \\
14.87 \\
14.98\end{array}$ & $\begin{array}{l}4,040 \\
4,410 \\
4,680 \\
5,890 \\
6,550 \\
6,690\end{array}$ & $\begin{array}{l}11.92 \\
11.69 \\
11.50 \\
11.31 \\
11.13 \\
10.93\end{array}$ & $\begin{array}{l}3,390 \\
3,200 \\
3,050 \\
2,900 \\
2,750 \\
2,600\end{array}$ & $\begin{array}{l}8.29 \\
8.19 \\
8.11 \\
8.04 \\
7.99 \\
7.91\end{array}$ & $\begin{array}{r}1,050 \\
1,000 \\
964 \\
936 \\
916 \\
884\end{array}$ \\
\hline $\begin{array}{l}1 \\
2 \\
3 \\
4 \\
5 \\
6\end{array}$ & $\begin{array}{l}4.82 \\
4.83 \\
4.83 \\
4.84 \\
4.84 \\
4.85\end{array}$ & $\begin{array}{l}69 \\
69 \\
69 \\
70 \\
70 \\
71\end{array}$ & $\begin{array}{l}5.21 \\
5.25 \\
5.30 \\
5.34 \\
5.39 \\
5.50\end{array}$ & & $\begin{array}{l}113 \\
118 \\
125 \\
130 \\
137 \\
155\end{array}$ & $\begin{array}{l}7.10 \\
7.30 \\
7.55 \\
7.87 \\
8.20 \\
8.50\end{array}$ & $\begin{array}{r}570 \\
655 \\
742 \\
868 \\
1,000 \\
1,140\end{array}$ & $\begin{array}{l}15.04 \\
14.89 \\
14.67 \\
14.25 \\
14.14 \\
13.81\end{array}$ & $\begin{array}{l}6,770 \\
6,580 \\
6,290 \\
5,760 \\
5,630 \\
5,230\end{array}$ & $\begin{array}{r}10.74 \\
10.56 \\
10.38 \\
10.20 \\
10.04 \\
9.90\end{array}$ & $\begin{array}{l}2,470 \\
2,340 \\
2,220 \\
2,100 \\
2,000 \\
1,910\end{array}$ & $\begin{array}{l}7.83 \\
7.80 \\
7.70 \\
7.67 \\
7.59 \\
7.53\end{array}$ & $\begin{array}{l}852 \\
840 \\
800 \\
788 \\
756 \\
736\end{array}$ \\
\hline \multirow[t]{2}{*}{$\begin{array}{r}7 \\
8 \\
9 \\
10 \\
11 \\
11\end{array}$} & $\begin{array}{l}4.85 \\
4.85 \\
4.85 \\
4.86 \\
4.87 \\
4.88\end{array}$ & $\begin{array}{l}71 \\
71 \\
71 \\
72 \\
73 \\
74\end{array}$ & $\begin{array}{l}5.54 \\
5.57 \\
5.63 \\
5.69 \\
5.75 \\
5.83\end{array}$ & & $\begin{array}{l}160 \\
168 \\
177 \\
188 \\
197 \\
212\end{array}$ & $\begin{array}{l}8.73 \\
8.94 \\
9.07 \\
9.22 \\
9.43 \\
9.74\end{array}$ & $\begin{array}{l}1,260 \\
1,360 \\
1,430 \\
1,510 \\
1,630 \\
1,810\end{array}$ & $\begin{array}{l}13.61 \\
13.47 \\
13.37 \\
13.27 \\
13.22 \\
13.13\end{array}$ & $\begin{array}{l}5,000 \\
4,850 \\
4,740 \\
4,630 \\
4,570 \\
4,480\end{array}$ & $\begin{array}{l}9.72 \\
9.57 \\
9.42 \\
9.30 \\
9.17 \\
9.03\end{array}$ & $\begin{array}{l}1,800 \\
1,710 \\
1,620 \\
1,560 \\
1,480 \\
1,410\end{array}$ & $\begin{array}{l}7.49 \\
7.43 \\
7.41 \\
7.34 \\
7.32 \\
7.25\end{array}$ & $\begin{array}{l}722 \\
700 \\
694 \\
669 \\
662 \\
638\end{array}$ \\
\hline & \multicolumn{2}{|c|}{ September 24} & \multicolumn{2}{|c|}{ September } & 25 & \multicolumn{2}{|c|}{ September 26} & \multicolumn{2}{|c|}{ September 27} & \multicolumn{2}{|c|}{ September 28} & \multicolumn{2}{|c|}{ September 29} \\
\hline $\begin{array}{r}2 \\
4 \\
6 \\
8 \\
10 \\
N\end{array}$ & $\begin{array}{l}7.17 \\
7.10 \\
7.02 \\
6.93 \\
6.87 \\
6.81\end{array}$ & $\begin{array}{l}610 \\
585 \\
557 \\
529 \\
511 \\
493\end{array}$ & $\begin{array}{l}6.47 \\
6.43 \\
6.39 \\
6.36 \\
6.32 \\
6.29\end{array}$ & & $\begin{array}{l}395 \\
385 \\
374 \\
367 \\
357 \\
350\end{array}$ & $\begin{array}{l}6.07 \\
6.04 \\
6.01 \\
5.98 \\
5.96 \\
5.94\end{array}$ & $\begin{array}{l}295 \\
288 \\
281 \\
275 \\
271 \\
266\end{array}$ & $\begin{array}{l}5.79 \\
5.77 \\
5.75 \\
5.73 \\
5.71 \\
5.69\end{array}$ & $\begin{array}{l}236 \\
232 \\
228 \\
224 \\
220 \\
216\end{array}$ & $\begin{array}{l}5.65 \\
5.65 \\
5.64 \\
5.64 \\
5.64 \\
5.63\end{array}$ & $\begin{array}{l}208 \\
208 \\
207 \\
207 \\
207 \\
205\end{array}$ & $\begin{array}{l}5.58 \\
5.57 \\
5.57 \\
5.55 \\
5.54 \\
5.53\end{array}$ & $\begin{array}{l}195 \\
193 \\
193 \\
190 \\
188 \\
186\end{array}$ \\
\hline $\begin{array}{r}2 \\
4 \\
6 \\
8 \\
10 \\
1\end{array}$ & $\begin{array}{l}6.75 \\
6.70 \\
6.65 \\
6.60 \\
6.56 \\
6.52\end{array}$ & $\begin{array}{l}475 \\
460 \\
446 \\
431 \\
420 \\
409\end{array}$ & $\begin{array}{l}6.25 \\
6.22 \\
6.18 \\
6.15 \\
6.12 \\
6.09\end{array}$ & & $\begin{array}{l}340 \\
332 \\
322 \\
314 \\
307 \\
300\end{array}$ & $\begin{array}{l}5.92 \\
5.89 \\
5.87 \\
5.85 \\
5.83 \\
5.81\end{array}$ & $\begin{array}{l}262 \\
256 \\
252 \\
248 \\
244 \\
240\end{array}$ & $\begin{array}{l}5.67 \\
5.66 \\
5.67 \\
5.67 \\
5.66 \\
5.65\end{array}$ & $\begin{array}{l}212 \\
210 \\
212 \\
212 \\
210 \\
208\end{array}$ & $\begin{array}{l}5.63 \\
5.62 \\
5.62 \\
5.61 \\
5.60 \\
5.60\end{array}$ & $\begin{array}{l}205 \\
203 \\
203 \\
201 \\
199 \\
199\end{array}$ & $\begin{array}{l}5.52 \\
5.51 \\
5.49 \\
5.48 \\
5.47 \\
5.46\end{array}$ & $\begin{array}{l}184 \\
182 \\
178 \\
176 \\
175 \\
173\end{array}$ \\
\hline
\end{tabular}

$2279070-40-13$ 
Quaboag River at West Brimfleld, Mass.

Location. - Water-stage recorder, lat. $42^{\circ} 10^{\prime} 30^{\prime \prime}$, long. $72^{\circ} 15^{\prime} 50^{n}$, at highray bridge at West Brimfield, Hampden County, a third of a mile above mouth of Blodgett Mill Brook. Zero of gage is 377.36 feet above mean sea level (general adjustment of 1929).

Drainage area.- 151 square miles.

Gege-height record.- Water-stage recorder graph except for period 1 a.m. Sept. 9 to 10 a.m. Sept. 25 .

Stage-discharge relation.- Defined by current-meter measurements below 3,140 secondfeet; extended to peak stage on basis of determinations of flood flow by slope-area method.

Maxima.- September 1938: Discharge, 8,470 second-feet 7 p.m. Sept. 21 (gage height, 11.8 feet, from floodmark).

1909 to August 1938: Maximum d1scharge, 3,620 second-feet Mar. 18, 1936 (gage helght, 8.62 feet); maximum gage height, 8.75 feet Mar. 12,1936 (ice jam).

Remarks.- Discharge for perlod of missing record based on power plant records, peak stage and discharge, and study of recession graphs for the station. Flood runoff affected by natural storage.

Mean daily discharge, in second-feet, 1938

\begin{tabular}{|r|r|r|r|r|r||r|r|r||r|r|r|}
\hline Day & Sept. & 0ct. & Day & Sept. & Oct. & Day & Sept. & Oct. & Day & Sept. & Oct. \\
\hline 1 & 138 & 1,160 & 9 & 103 & 463 & 17 & 255 & 268 & 25 & 3,120 & 337 \\
2 & 131 & 1,030 & 10 & 102 & 415 & 18 & 270 & 252 & 26 & 2,510 & 332 \\
3 & 115 & 930 & 11 & 98 & 388 & 19 & 420 & 236 & 27 & 2,080 & 328 \\
4 & 115 & 800 & 12 & 95 & 351 & 20 & 1,500 & 232 & 28 & 1,800 & 328 \\
5 & 103 & 716 & 13 & 122 & 332 & 21 & 7,800 & 276 & 29 & 1,540 & 328 \\
6 & 103 & 638 & 14 & 225 & 319 & 22 & 7,040 & 264 & 30 & 1,350 & 314 \\
7 & 94 & 579 & 15 & 220 & 306 & 23 & 5,260 & 252 & 31 & \\
8 & 94 & 514 & 16 & 265 & 289 & 24 & 4,000 & 280 & & 297 \\
\hline
\end{tabular}

Gage height, In feet, and discharge, in second-feet, at indlcated time, 1938

\begin{tabular}{|c|c|c|c|c|c|c|c|c|c|c|c|c|}
\hline \multirow{2}{*}{ 尔 } & Feet & Sec.ft. & Feet & Sec.ft. & Feet & Sec.ft. & Feet & sec.ft. & Feet & Sec.ft. & Feet & Sec.ft. \\
\hline & \multicolumn{2}{|c|}{ September 18} & \multicolumn{2}{|c|}{ September 19} & \multicolumn{2}{|c|}{ September 20} & \multicolumn{2}{|c|}{ September 21} & \multicolumn{2}{|c|}{ September 22} & \multicolumn{2}{|c|}{ September 23} \\
\hline 1 & - & - & - & - & - & - & - & - & - & $\ldots$ & - & - \\
\hline 2 & - & - & - & - & - & - & - & - & - & - & - & - \\
\hline 3 & - & - & - & - & - & - & - & - & - & - & - & - \\
\hline 4 & - & - & - & - & - & - & - & - & - & 7,750 & - & 5,760 \\
\hline 5 & - & - & - & - & - & - & - & - & - & - & - & - \\
\hline 6 & - & - & - & - & - & - & - & - & - & - & - & - \\
\hline 7 & - & - & - & - & - & - & - & - & - & - & - & - \\
\hline 8 & - & - & - & - & - & - & - & - & - & 7,350 & - & 5,500 \\
\hline 9 & - & - & - & - & - & - & - & - & - & - & - & - \\
\hline 10 & - & - & - & - & - & - & - & - & - & - & - & - \\
\hline 11 & - & & - & & - & - & - & - & - & - & - & - \\
\hline $\mathbf{N}$ & - & $\star 270$ & - & $* 420$ & - & $* 1,500$ & - & $* 7,800$ & - & 7,000 & - & 5,240 \\
\hline 1 & - & - & - & - & - & - & - & - & - & - & - & - \\
\hline 2 & - & - & - & - & - & - & - & - & - & - & - & - \\
\hline 3 & - & - & - & - & - & - & - & - & - & - & - & - \\
\hline 4 & - & - & - & - & - & - & - & - & - & 6,670 & - & 4,990 \\
\hline 5 & - & - & - & - & - & - & - & - & - & - & - & - \\
\hline 6 & $\rightarrow$ & - & - & - & - & - & - & - & - & - & - & - \\
\hline \multirow{7}{*}{$\begin{array}{r}7 \\
8 \\
9 \\
10 \\
11 \\
\end{array}$} & - & - & - & - & - & - & - & 8,470 & - & - & - & - \\
\hline & - & - & - & - & - & - & - & 8,340 & - & 6,350 & - & 4,760 \\
\hline & - & - & - & - & - & - & - & - & - & - & - & - \\
\hline & - & - & - & - & - & - & - & - & - & - & - & - \\
\hline & - & - & - & - & - & - & - & - & - & - & - & - \\
\hline & - & - & - & - & - & - & - & 8,160 & - & 6,050 & - & 4,560 \\
\hline & \multicolumn{2}{|c|}{ September 24} & \multicolumn{2}{|c|}{ September 25} & \multicolumn{2}{|c|}{ September 26} & \multicolumn{2}{|c|}{ September 27} & \multicolumn{2}{|c|}{ September 28} & \multicolumn{2}{|c|}{ September 29} \\
\hline $\begin{array}{r}2 \\
4 \\
6 \\
8 \\
10 \\
N\end{array}$ & $\begin{array}{l}- \\
- \\
- \\
- \\
-\end{array}$ & $\begin{array}{c}4,360 \\
\overline{4,170} \\
\overline{3,980}\end{array}$ & $\begin{array}{c}- \\
- \\
- \\
- \\
- \\
7.38\end{array}$ & $\begin{array}{c}- \\
3,360 \\
- \\
3,240 \\
- \\
3,130\end{array}$ & $\begin{array}{l}6.96 \\
6.91 \\
6.85 \\
6.80 \\
6.75 \\
6.70\end{array}$ & $\begin{array}{l}2,730 \\
2,690 \\
2,640 \\
2,590 \\
2,550 \\
2,510\end{array}$ & $\begin{array}{l}6.35 \\
6.31 \\
6.26 \\
6.22 \\
6.17 \\
6.13\end{array}$ & $\begin{array}{l}2,230 \\
2,200 \\
2,160 \\
2,130 \\
2,090 \\
2,050\end{array}$ & $\begin{array}{l}5.98 \\
5.94 \\
5.91 \\
5.87 \\
5.84 \\
5.80\end{array}$ & $\begin{array}{l}1,930 \\
1,900 \\
1,880 \\
1,850 \\
1,830 \\
1,800\end{array}$ & $\begin{array}{l}5.57 \\
5.54 \\
5.51 \\
5.48 \\
5.45 \\
5.43\end{array}$ & $\begin{array}{l}1,640 \\
1,620 \\
1,600 \\
1,580 \\
1,560 \\
1,540\end{array}$ \\
\hline $\begin{array}{r}2 \\
4 \\
6 \\
8 \\
10 \\
M\end{array}$ & $\begin{array}{l}- \\
- \\
- \\
- \\
-\end{array}$ & $\begin{array}{c}- \\
3,810 \\
- \\
3,650 \\
- \\
3,500\end{array}$ & $\begin{array}{l}7.32 \\
7.26 \\
7.18 \\
7.12 \\
7.06 \\
7.01\end{array}$ & $\begin{array}{l}3,070 \\
3,010 \\
2,930 \\
2,880 \\
2,820 \\
2,780\end{array}$ & $\begin{array}{l}6.64 \\
6.59 \\
6.54 \\
6.49 \\
6.45 \\
6.41\end{array}$ & $\begin{array}{l}2,460 \\
2,420 \\
2,380 \\
2,340 \\
2,310 \\
2,280\end{array}$ & $\begin{array}{l}6.10 \\
6.06 \\
6.08 \\
6.08 \\
6.04 \\
6.00\end{array}$ & $\begin{array}{l}2,030 \\
2,000 \\
2,010 \\
2,010 \\
1,980 \\
1,950\end{array}$ & $\begin{array}{l}5.77 \\
5.72 \\
5.68 \\
5.65 \\
5.63 \\
5.61\end{array}$ & $\begin{array}{l}1,780 \\
1,740 \\
1,720 \\
1,700 \\
1,680 \\
1,670\end{array}$ & $\begin{array}{l}5.39 \\
5.37 \\
5.34 \\
5.31 \\
5.29 \\
5.27\end{array}$ & $\begin{array}{l}1,510 \\
1,500 \\
1,480 \\
1,460 \\
1,440 \\
1,430\end{array}$ \\
\hline
\end{tabular}

Supplemental records.- Sept. 27, 5 p.m., 6.04 ft., 1,980 sec.-ft.; 7 p.m., 6.09

ft., 2,020 sec. - ft.

* Mean for the day. 
Westfield River at Knightville, Mass.

Location.- Water-stage recorder, lat. $42^{\circ} 17^{\prime} 25^{n}$, long. $72^{\circ} 51^{\prime} 45^{n}$, at Knightv1lle, Hampshire county, three-quarters of a mile above'mouth of Pond Brook and 2.7 miles above mouth of Middle Branch of Westfield River. Zero of gage is 471.82 feet above mean sea level (general adjustment of 1929).

Drainage area.- 162 square miles.

Gage-height record.- Water-stage recorder graph except for period Sept. 16-29, for which there is no record.

Stage-discharge relation.- Defined by current-meter measurements below 3,630 second-feet; extended to peak stage on basis of determinations of flood flows by slope-area method.

Maxima.- September 1938: Discharge, 37,900 second-feet about 9 p.m. Sept. 21 (gage helght, 29.58 feet, from flood marks).

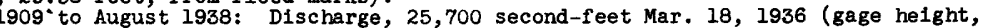
24.07 feet, from flood marks).

Remarks.- Intake pipe partially clogged Sept. 30 to Oct. 16. Discharge for period Sept. 16 to oct. 16 computed on basis of flood marks, occasional staff-gage readings, and hydrographic comparison with records for other stations in the Westfield River Basin. Flood run-off not materially affected by storage.

Mean dally discharge, in second-feet, 1938

\begin{tabular}{|c|c|c|c|c|c|c|c|c|c|c|c|}
\hline Day & Sept. & oct. & Day & Sept. & Oct. & Day & Sept. & Oct. & Day & Sept. & Oct. \\
\hline $\begin{array}{l}1 \\
2 \\
3 \\
4 \\
5 \\
6 \\
7 \\
8\end{array}$ & $\begin{array}{l}64 \\
82 \\
59 \\
60 \\
55 \\
49 \\
49 \\
71\end{array}$ & $\begin{array}{l}340 \\
320 \\
300 \\
270 \\
250 \\
240 \\
220 \\
200\end{array}$ & $\begin{array}{r}9 \\
10 \\
11 \\
12 \\
13 \\
14 \\
15 \\
16\end{array}$ & $\begin{array}{r}75 \\
56 \\
48 \\
46 \\
146 \\
156 \\
167 \\
200 \\
\end{array}$ & $\begin{array}{l}190 \\
180 \\
190 \\
200 \\
190 \\
160 \\
140 \\
140\end{array}$ & $\begin{array}{l}17 \\
18 \\
19 \\
20 \\
21 \\
22 \\
23 \\
24\end{array}$ & $\begin{array}{r}120 \\
110 \\
1,200 \\
3,000 \\
8,000 \\
9,000 \\
3,000 \\
1,000\end{array}$ & $\begin{array}{l}136 \\
123 \\
115 \\
120 \\
344 \\
232 \\
161 \\
403\end{array}$ & $\begin{array}{l}25 \\
26 \\
27 \\
28 \\
29 \\
30 \\
31\end{array}$ & $\begin{array}{l}700 \\
500 \\
380 \\
440 \\
400 \\
360\end{array}$ & $\begin{array}{l}800 \\
390 \\
268 \\
225 \\
252 \\
244 \\
199\end{array}$ \\
\hline $\begin{array}{l}\text { Mean } \\
\text { Run- }\end{array}$ & & & 11 & & $\dot{0} \cdot \dot{ }$ &.$\quad$. & $\bullet \cdot \dot{\bullet}$ & 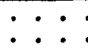 & : & $\begin{array}{r}986 \\
6.80 \\
\end{array}$ & $\begin{array}{r}243 \\
1.73\end{array}$ \\
\hline
\end{tabular}


Westfield River near Westfield, Mass.

Location.- Water-stage recorder, lat. $42^{\circ} 06^{\prime} 2^{\prime \prime}$, long. $72^{\circ} 42^{\prime} 05^{\prime \prime}$, 1 mile below mouth of Great Brook and 3 miles east of Westfield, Hampden County. Zero of gage is 98.25 feet above mean sea level (general adjustment of 1929).

Drainage area.- 497 square miles.

Gage-he1ght record. - Water-stage recorder graph except for period 11 p.m. Sept. 21 to $3 \mathrm{a} \cdot \mathrm{m}$. Sept. 22, when graph was based on flood marks and shape of water-stage recorder graph, and for periods Sept. 26 to oct. 5, 0ct. 7, 11 to 31 , when there was no record.

Stage-discharge relation.- Defined by current-meter measurements below 17,600 secondfeet; extended to peak stage on basis of determinations of flood flow over dam.

Maxima.- September 1938: Discharge, 55,500 second-feet 12 p.m. Sept. 21 to 1 a.m. Sept. 22 (gage height, 29.40 feet, f'rom flood marks). 27.20 feet).

1914 to August 1938: D1scharge, 48,200 second-feet Mar. 18, 1936 (gage height,

Remarks.- Flood run-off affected by some artificial and natural storage; slightly affected by diversions. Discharge for periods of no record computed on basis of records for other stations in Westfield River Basin and from limits of stage indicated on water-stage recorder chart.

Mean daily discharge, in second-feet, 1938

\begin{tabular}{|c|c|c|c|c|c|c|c|c|c|c|c|}
\hline Day & Sept. & Oct. & Day & Sept. & Oct. & Day & Sept. & oct. & Day & Sept. & Oct. \\
\hline $\begin{array}{l}1 \\
2 \\
3 \\
4 \\
5 \\
6 \\
7 \\
8\end{array}$ & $\begin{array}{l}543 \\
470 \\
378 \\
206 \\
202 \\
468 \\
647 \\
505\end{array}$ & $\begin{array}{l}880 \\
810 \\
760 \\
730 \\
700 \\
690 \\
650 \\
600\end{array}$ & $\begin{array}{r}9 \\
10 \\
11 \\
12 \\
13 \\
14 \\
15 \\
16\end{array}$ & $\begin{array}{l}372 \\
434 \\
188 \\
354 \\
573 \\
590 \\
658 \\
760\end{array}$ & $\begin{array}{l}570 \\
605 \\
630 \\
660 \\
620 \\
540 \\
500 \\
500\end{array}$ & $\begin{array}{l}17 \\
18 \\
19 \\
20 \\
21 \\
22 \\
23 \\
24\end{array}$ & $\begin{array}{r}455 \\
413 \\
1,700 \\
8,790 \\
22,900 \\
26,100 \\
6,680 \\
3,890\end{array}$ & $\begin{array}{r}500 \\
490 \\
470 \\
500 \\
1,100 \\
800 \\
600 \\
1,300\end{array}$ & $\begin{array}{l}25 \\
26 \\
27 \\
28 \\
29 \\
30 \\
31\end{array}$ & $\begin{array}{r}2,290 \\
1,810 \\
1,640 \\
1,780 \\
1,360 \\
990\end{array}$ & $\begin{array}{r}2,000 \\
1,300 \\
900 \\
650 \\
800 \\
770 \\
600\end{array}$ \\
\hline $\begin{array}{l}\text { Mean } \\
\text { Run- }\end{array}$ & $\begin{array}{l}\text { onthly } \\
\mathrm{e} \text {, in }\end{array}$ & $\begin{array}{l}\text { schar } \\
\text { hes. }\end{array}$ & ? 11 & . . . & өt. : & $\dot{0}$ & : $:$ & : : & $: \dot{ }$ & $\begin{array}{r}2,938 \\
6.59\end{array}$ & $\begin{array}{r}749 \\
1.74\end{array}$ \\
\hline
\end{tabular}

Gage height, In feet, and discharge, in second-feet, at indicated time, 1938

\begin{tabular}{|c|c|c|c|c|c|c|c|c|c|c|c|c|}
\hline \multirow{2}{*}{$\begin{array}{l}9 \\
3 \\
0\end{array}$} & Feet & Sec.ft. & Feet & Sec.ft. & Feet & sec.ft. & Feet & Sec.ft. & Feet & Sec.ft. & Feet & Sec.ft. \\
\hline & \multicolumn{2}{|c|}{ September 18} & \multicolumn{2}{|c|}{ September 19} & \multicolumn{2}{|c|}{ September 20} & \multicolumn{2}{|c|}{ September 21} & \multicolumn{2}{|c|}{ September 22} & \multicolumn{2}{|c|}{ September 23} \\
\hline $\begin{array}{l}1 \\
2 \\
3 \\
4 \\
5 \\
6\end{array}$ & $\begin{array}{l}4.11 \\
4.09 \\
4.07 \\
4.10 \\
4.14 \\
4.17\end{array}$ & $\begin{array}{l}435 \\
426 \\
416 \\
430 \\
450 \\
465\end{array}$ & $\begin{array}{l}3.82 \\
3.85 \\
3.87 \\
4.00 \\
4.12 \\
4.27\end{array}$ & $\begin{array}{l}306 \\
318 \\
327 \\
385 \\
440 \\
515\end{array}$ & $\begin{array}{r}10.41 \\
10.20 \\
9.87 \\
9.74 \\
9.80 \\
10.06\end{array}$ & $\begin{array}{l}7,120 \\
6,800 \\
6,300 \\
6,110 \\
6,200 \\
6,590\end{array}$ & $\begin{array}{l}12.24 \\
12.70 \\
13.15 \\
13.60 \\
14.05 \\
14.42\end{array}$ & $\begin{array}{l}10,100 \\
10,900 \\
11,700 \\
12,500 \\
13,300 \\
14,000\end{array}$ & $\begin{array}{l}29.40 \\
29.15 \\
28.40 \\
27.40 \\
26.30 \\
25.02\end{array}$ & $\begin{array}{l}55,500 \\
54,700 \\
52,200 \\
48,900 \\
45,400 \\
41,300\end{array}$ & $\begin{array}{l}11.50 \\
11.30 \\
11.12 \\
10.95 \\
10.80 \\
10.63\end{array}$ & $\begin{array}{l}8,850 \\
8,530 \\
8,240 \\
7,970 \\
7,730 \\
7,460\end{array}$ \\
\hline $\begin{array}{r}7 \\
8 \\
9 \\
10 \\
11 \\
\mathbb{N}\end{array}$ & $\begin{array}{l}4.27 \\
4.39 \\
4.38 \\
4.28 \\
4.17 \\
4.11\end{array}$ & $\begin{array}{l}515 \\
575 \\
570 \\
520 \\
465 \\
435\end{array}$ & $\begin{array}{l}4.37 \\
4.40 \\
4.43 \\
4.60 \\
4.85 \\
5.02\end{array}$ & $\begin{array}{l}565 \\
580 \\
595 \\
690 \\
840 \\
942\end{array}$ & $\begin{array}{l}10.55 \\
11.25 \\
11.72 \\
11.99 \\
12.01 \\
11.99\end{array}$ & $\begin{array}{l}7,330 \\
8,450 \\
9,220 \\
9,680 \\
9,720 \\
9,680\end{array}$ & $\begin{array}{l}14.63 \\
14.84 \\
15.05 \\
15.50 \\
15.95 \\
16.90\end{array}$ & $\begin{array}{l}14,500 \\
14,900 \\
15,300 \\
16,200 \\
17,200 \\
19,300\end{array}$ & $\begin{array}{l}23.60 \\
22.10 \\
20.30 \\
18.95 \\
17.75 \\
16.70\end{array}$ & $\begin{array}{l}36,900 \\
32,500 \\
27,500 \\
24,000 \\
21,200 \\
18,800\end{array}$ & $\begin{array}{l}10.48 \\
10.35 \\
10.22 \\
10.10 \\
10.06 \\
10.15\end{array}$ & $\begin{array}{l}7, \\
7, \\
6, \\
6, \\
6, \\
6,\end{array}$ \\
\hline $\begin{array}{l}1 \\
2 \\
3 \\
4 \\
5 \\
6\end{array}$ & $\begin{array}{l}4.07 \\
4.02 \\
4.00 \\
3.99 \\
3.97 \\
3.93\end{array}$ & $\begin{array}{l}416 \\
394 \\
385 \\
380 \\
372 \\
354\end{array}$ & $\begin{array}{l}5.08 \\
5.06 \\
5.11 \\
5.33 \\
5.48 \\
5.80\end{array}$ & $\begin{array}{r}978 \\
966 \\
1,000 \\
1,150 \\
1,260 \\
1,500\end{array}$ & $\begin{array}{l}12.10 \\
12.34 \\
12.49 \\
12.52 \\
12.52 \\
12.44\end{array}$ & $\begin{array}{r}9,870 \\
10,300 \\
10,500 \\
10,600 \\
10,600 \\
10,400\end{array}$ & $\begin{array}{l}17.66 \\
18.34 \\
18.80 \\
19.08 \\
19.20 \\
19.65\end{array}$ & $\begin{array}{l}21,000 \\
22,500 \\
23,600 \\
24,300 \\
24,600 \\
25,800\end{array}$ & $\begin{array}{l}15.80 \\
15.15 \\
14.55 \\
14.00 \\
13.55 \\
13.15\end{array}$ & $\begin{array}{l}16,900 \\
15,500 \\
14,300 \\
13,200 \\
12,400 \\
11,700\end{array}$ & $\begin{array}{r}10.15 \\
9.90 \\
9.80 \\
9.70 \\
9.60 \\
9.51\end{array}$ & $\begin{array}{l}6,720 \\
6,350 \\
6,200 \\
6,050 \\
5,910 \\
5,780\end{array}$ \\
\hline \multirow[t]{2}{*}{$\begin{array}{r}7 \\
8 \\
9 \\
10 \\
11 \\
11 \\
\end{array}$} & $\begin{array}{l}3.89 \\
3.85 \\
3.83 \\
3.79 \\
3.79 \\
3.79\end{array}$ & $\begin{array}{l}336 \\
318 \\
310 \\
293 \\
293 \\
293\end{array}$ & $\begin{array}{r}6.50 \\
7.60 \\
8.80 \\
9.80 \\
10.41 \\
10.52 \\
\end{array}$ & $\begin{array}{l}2,140 \\
3,360 \\
4,830 \\
6,200 \\
7,120 \\
7,280\end{array}$ & $\begin{array}{l}12.25 \\
12.00 \\
11.73 \\
11.64 \\
11.63 \\
11.83\end{array}$ & $\begin{array}{r}10,100 \\
9,700 \\
9,240 \\
9,090 \\
9,070 \\
\mathbf{9 , 4 1 0}\end{array}$ & $\begin{array}{l}20.95 \\
22.75 \\
25.10 \\
26.85 \\
28.40 \\
29.40\end{array}$ & $\begin{array}{l}29,300 \\
34,400 \\
41,500 \\
47,100 \\
52,200 \\
55,500\end{array}$ & $\begin{array}{l}12.85 \\
12.55 \\
12.25 \\
12.01 \\
11.85 \\
11.65\end{array}$ & $\begin{array}{r}11,100 \\
10,600 \\
10,100 \\
9,720 \\
9,440 \\
9,100\end{array}$ & $\begin{array}{l}9.42 \\
9.30 \\
9.17 \\
9.06 \\
8.94 \\
8.82\end{array}$ & \\
\hline & \multicolumn{2}{|c|}{ September 24} & \multicolumn{2}{|c|}{ September 25} & \multicolumn{2}{|c|}{ September 26} & \multicolumn{2}{|c|}{ September 27} & \multicolumn{2}{|c|}{ September 28} & \multicolumn{2}{|c|}{ September 29} \\
\hline $\begin{array}{r}2 \\
4 \\
6 \\
8 \\
10 \\
N\end{array}$ & $\begin{array}{l}8.61 \\
8.47 \\
8.36 \\
8.25 \\
8.15 \\
8.06\end{array}$ & $\begin{array}{l}4,580 \\
4,400 \\
4,270 \\
4,140 \\
4,020 \\
3,910\end{array}$ & $\begin{array}{l}6.97 \\
6.88 \\
6.79 \\
6.73 \\
6.63 \\
6.62\end{array}$ & $\begin{array}{l}2,630 \\
2,530 \\
2,430 \\
2,370 \\
2,270 \\
2,260\end{array}$ & $\begin{array}{l}6.18 \\
6.10 \\
5.99 \\
5.92 \\
5.88 \\
5.86\end{array}$ & $\begin{array}{l}1,830 \\
1,760 \\
1,660 \\
1,600 \\
1,560 \\
1,550\end{array}$ & $\begin{array}{l}6.30 \\
6.16 \\
6.04 \\
5.96 \\
5.90 \\
5.87\end{array}$ & $\begin{array}{l}1,940 \\
1,810 \\
1,710 \\
1,630 \\
1,580 \\
1,560\end{array}$ & $\begin{array}{l}5.97 \\
6.06 \\
6.18 \\
6.28 \\
6.30 \\
6.28\end{array}$ & $\begin{array}{l}1,640 \\
1,720 \\
1,830 \\
1,920 \\
1,940 \\
1,920\end{array}$ & $\begin{array}{l}5.89 \\
5.83 \\
5.78 \\
5.72 \\
5.65 \\
5.60\end{array}$ & $\begin{array}{l}1,570 \\
1,520 \\
1,480 \\
1,440 \\
1,380 \\
1,340\end{array}$ \\
\hline $\begin{array}{r}2 \\
4 \\
6 \\
8 \\
10 \\
1\end{array}$ & $\begin{array}{l}8.03 \\
8.00 \\
7.87 \\
7.55 \\
7.25 \\
7.06\end{array}$ & $\begin{array}{l}3,880 \\
3,840 \\
3,680 \\
3,300 \\
2,940 \\
2,730\end{array}$ & $\begin{array}{l}6.59 \\
6.56 \\
6.49 \\
6.41 \\
6.38 \\
6.27\end{array}$ & $\begin{array}{l}2,230 \\
2,200 \\
2,130 \\
2,050 \\
2,020 \\
1,904\end{array}$ & $\begin{array}{l}5.93 \\
6.17 \\
6.46 \\
6.52 \\
6.48 \\
6.40\end{array}$ & $\begin{array}{l}1,610 \\
1,820 \\
2,100 \\
2,160 \\
2,120 \\
2,040\end{array}$ & $\begin{array}{l}5.86 \\
5.83 \\
5.82 \\
5.81 \\
5.83 \\
5.89\end{array}$ & $\begin{array}{l}1,550 \\
1,520 \\
1,520 \\
1,510 \\
1,520 \\
1,570\end{array}$ & $\begin{array}{l}6.22 \\
6.17 \\
6.11 \\
6.03 \\
5.98 \\
5.93\end{array}$ & $\begin{array}{l}1,870 \\
1,820 \\
1,770 \\
1,700 \\
1,650 \\
1,610\end{array}$ & $\begin{array}{l}5.57 \\
5.50 \\
5.47 \\
5.40 \\
5.34 \\
5.28\end{array}$ & $\begin{array}{l}20 \\
70 \\
50 \\
00 \\
60 \\
20\end{array}$ \\
\hline
\end{tabular}


Location.- Water-stage recorder, lat. $42^{\circ} 15^{\prime} 30^{\prime \prime}$, Long. $72^{\circ} 52^{\prime} 25^{n}$, at highway bridge in Goss Heights, Hampshire County, half a mile above mouth. Zero of gage is 400.30 feet above mean sea level (general adjustment of 1929).

Drainege area.- 52.6 square miles.

Gage-helght record.- Water-stage recorder graph.

Stage-discharge relation.- Defined by current-meter measurements below 2,110 second-feet; extended to peak stage on besis of determinations of flood flow by contracted-opening and slope-area methods.

Maximg.- September 1938: Discharge, 19,900 second-feet 6:30 p.m. Sept. 21 (gage helght, 10.61 feet)

1910 to August 1938: Maximum discharge, 8,400 second-feet Mar. 18, 1936; maximum gage height, 13.87 feet Mar. 12, 1936 (1ce fam).

Remarks.- Flood run-off not materially affected by artificial or natural storage.

Mean daily discharge, in second-feet, 1938

\begin{tabular}{|c|c|c|c|c|c|c|c|c|c|c|c|}
\hline Day & Sept. & Oet. & Day & Sept. & Oct. & Day & Sept. & oct. & Day & Sept. & Oct. \\
\hline $\begin{array}{l}1 \\
2 \\
3 \\
4 \\
5 \\
6 \\
7 \\
8\end{array}$ & $\begin{array}{l}16 \\
16 \\
13 \\
13 \\
12 \\
12 \\
11 \\
18\end{array}$ & $\begin{array}{l}81 \\
67 \\
59 \\
53 \\
47 \\
44 \\
40 \\
40\end{array}$ & $\begin{array}{r}9 \\
10 \\
11 \\
12 \\
13 \\
14 \\
15 \\
16\end{array}$ & $\begin{array}{l}16 \\
12 \\
11 \\
10 \\
32 \\
32 \\
50 \\
61\end{array}$ & $\begin{array}{l}36 \\
36 \\
40 \\
42 \\
40 \\
34 \\
28 \\
28\end{array}$ & $\begin{array}{l}17 \\
18 \\
19 \\
20 \\
21 \\
22 \\
23 \\
24\end{array}$ & $\begin{array}{r}31 \\
32 \\
454 \\
1,380 \\
4,720 \\
1,220 \\
475 \\
300\end{array}$ & $\begin{array}{r}26 \\
24 \\
22 \\
24 \\
101 \\
59 \\
44 \\
164\end{array}$ & $\begin{array}{l}25 \\
26 \\
27 \\
28 \\
29 \\
30 \\
31\end{array}$ & $\begin{array}{r}208 \\
155 \\
147 \\
180 \\
123 \\
91\end{array}$ & $\begin{array}{r}248 \\
118 \\
75 \\
59 \\
80 \\
73 \\
53\end{array}$ \\
\hline $\begin{array}{l}\text { Mean } \\
\text { Run- }\end{array}$ & $\begin{array}{l}\text { onthly } \\
f \text {, in }\end{array}$ & $\begin{array}{l}\text { schar } \\
\text { hes. }\end{array}$ & 9, Ir & $\begin{array}{c}3 e \operatorname{cond}-1 \\
\text {. }\end{array}$ & et. : & : : & 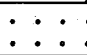 & 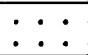 & $:$ : & $\begin{array}{r}328 \\
6.96\end{array}$ & $\begin{array}{l}60.8 \\
1.34\end{array}$ \\
\hline
\end{tabular}

Gage height, in feet, and discherge, In second-feet, at indicated time, 1938

\begin{tabular}{|c|c|c|c|c|c|c|c|c|c|c|c|c|c|}
\hline \multirow{2}{*}{ 皃 } & Feet & Sec.ft. & Feet & Sec.ft. & Feet & Sec.ft. & Feet & Sec.ft. & Feet & Sec.ft. & Feet & Sec & .ft. \\
\hline & \multicolumn{2}{|c|}{ September 18} & \multicolumn{2}{|c|}{ September 19} & \multicolumn{2}{|c|}{ September 20} & \multicolumn{2}{|c|}{ September 21} & \multicolumn{2}{|c|}{ September 22} & \multicolumn{3}{|c|}{ September 23} \\
\hline $\begin{array}{l}1 \\
2 \\
3 \\
4 \\
5 \\
6\end{array}$ & $\begin{array}{l}2.36 \\
2.36 \\
2.36 \\
2.36 \\
2.36 \\
2.37\end{array}$ & $\begin{array}{l}29 \\
29 \\
29 \\
29 \\
29 \\
30\end{array}$ & $\begin{array}{l}2.45 \\
2.47 \\
2.48 \\
2.52 \\
2.57 \\
2.62\end{array}$ & $\begin{array}{l}44 \\
47 \\
49 \\
59 \\
73 \\
88\end{array}$ & $\begin{array}{l}4.08 \\
4.13 \\
4.52 \\
5.18 \\
5.26 \\
5.18\end{array}$ & $\begin{array}{r}788 \\
818 \\
1,060 \\
1,520 \\
1,590 \\
1,520\end{array}$ & $\begin{array}{l}5.92 \\
5.95 \\
6.09 \\
6.10 \\
6.00 \\
5.95\end{array}$ & $\begin{array}{l}2,190 \\
2,220 \\
2,370 \\
2,380 \\
2,270 \\
2,220\end{array}$ & $\begin{array}{l}6.20 \\
5.91 \\
5.68 \\
5.48 \\
5.28 \\
5.13\end{array}$ & $\begin{array}{l}2,500 \\
2,180 \\
1,950 \\
1,770 \\
1,600 \\
1,480\end{array}$ & $\begin{array}{l}3.78 \\
3.75 \\
3.72 \\
3.70 \\
3.67 \\
3.65\end{array}$ & & $\begin{array}{l}609 \\
592 \\
576 \\
565 \\
548 \\
538\end{array}$ \\
\hline $\begin{array}{r}7 \\
8 \\
9 \\
10 \\
11 \\
\text { N }\end{array}$ & $\begin{array}{l}2.37 \\
2.38 \\
2.38 \\
2.38 \\
2.39 \\
2.39\end{array}$ & $\begin{array}{l}30 \\
31 \\
31 \\
31 \\
33 \\
33\end{array}$ & $\begin{array}{l}2.64 \\
2.64 \\
2.66 \\
2.66 \\
2.74 \\
2.78\end{array}$ & $\begin{array}{r}95 \\
95 \\
101 \\
101 \\
129 \\
143\end{array}$ & $\begin{array}{l}5.11 \\
5.03 \\
4.91 \\
4.84 \\
4.87 \\
5.01\end{array}$ & $\begin{array}{l}1,470 \\
1,410 \\
1,330 \\
1,280 \\
1,300 \\
1,400\end{array}$ & $\begin{array}{l}6.00 \\
6.33 \\
6.80 \\
7.23 \\
7.34 \\
7.21\end{array}$ & $\begin{array}{l}2,270 \\
2,670 \\
3,430 \\
4,280 \\
4,520 \\
4,230\end{array}$ & $\begin{array}{l}4.99 \\
4.88 \\
4.77 \\
4.66 \\
4.56 \\
4.48\end{array}$ & $\begin{array}{l}1,380 \\
1,310 \\
1,230 \\
1,150 \\
1,090 \\
1,040\end{array}$ & $\begin{array}{l}3.63 \\
3.60 \\
3.58 \\
3.56 \\
3.54 \\
3.52\end{array}$ & & $\begin{array}{l}526 \\
510 \\
499 \\
488 \\
477 \\
466\end{array}$ \\
\hline $\begin{array}{l}1 \\
2 \\
3 \\
4 \\
5 \\
6\end{array}$ & $\begin{array}{l}2.39 \\
2.40 \\
2.40 \\
2.40 \\
2.40 \\
2.40\end{array}$ & $\begin{array}{l}33 \\
34 \\
34 \\
34 \\
34 \\
34\end{array}$ & $\begin{array}{l}2.82 \\
2.87 \\
3.02 \\
3.18 \\
3.91 \\
5.08\end{array}$ & $\begin{array}{r}157 \\
174 \\
233 \\
301 \\
686 \\
1,450\end{array}$ & $\begin{array}{l}5.34 \\
5.36 \\
5.19 \\
4.98 \\
4.79 \\
4.68\end{array}$ & $\begin{array}{l}1,650 \\
1,670 \\
1,530 \\
1,380 \\
1,240 \\
1,170\end{array}$ & $\begin{array}{l}7.11 \\
6.91 \\
6.17 \\
6.85 \\
8.12 \\
9.80\end{array}$ & $\begin{array}{r}4,020 \\
3,630 \\
2,460 \\
3,520 \\
6,560 \\
14,100\end{array}$ & $\begin{array}{l}4.41 \\
4.33 \\
4.26 \\
4.19 \\
4.13 \\
4.07\end{array}$ & $\begin{array}{l}992 \\
940 \\
896 \\
854 \\
818 \\
782\end{array}$ & $\begin{array}{l}3.50 \\
3.49 \\
3.47 \\
3.45 \\
3.43 \\
3.41\end{array}$ & & $\begin{array}{l}455 \\
450 \\
440 \\
430 \\
420 \\
410\end{array}$ \\
\hline \multirow[t]{2}{*}{$\begin{array}{r}7 \\
8 \\
9 \\
10 \\
11 \\
M\end{array}$} & $\begin{array}{l}2.40 \\
2.40 \\
2.40 \\
2.40 \\
2.42 \\
2.44\end{array}$ & $\begin{array}{l}34 \\
34 \\
34 \\
34 \\
38 \\
42\end{array}$ & $\begin{array}{l}5.40 \\
5.11 \\
4.80 \\
4.54 \\
4.32 \\
4.13\end{array}$ & $\begin{array}{r}1,700 \\
1,470 \\
1,250 \\
1,080 \\
933 \\
818\end{array}$ & $\begin{array}{l}4.74 \\
4.94 \\
4.96 \\
5.14 \\
5.79 \\
5.94\end{array}$ & $\begin{array}{l}1,210 \\
1,350 \\
1,360 \\
1,490 \\
2,060 \\
2,210\end{array}$ & $\begin{array}{r}10.25 \\
8.86 \\
8.10 \\
7.49 \\
6.93 \\
6.51\end{array}$ & $\begin{array}{r}17,100 \\
9,190 \\
6,500 \\
4,880 \\
3,670 \\
2,940\end{array}$ & $\begin{array}{l}4.02 \\
3.97 \\
3.93 \\
3.89 \\
3.83 \\
3.81\end{array}$ & $\begin{array}{l}752 \\
722 \\
698 \\
674 \\
638 \\
626\end{array}$ & $\begin{array}{l}3.39 \\
3.37 \\
3.35 \\
3.34 \\
3.32 \\
3.30\end{array}$ & & $\begin{array}{l}400 \\
390 \\
380 \\
375 \\
365 \\
355\end{array}$ \\
\hline & \multicolumn{2}{|c|}{ September 24} & \multicolumn{2}{|c|}{ September 25} & \multicolumn{2}{|c|}{ September 26} & \multicolumn{2}{|c|}{ September 27} & \multicolumn{2}{|c|}{ September 28} & \multicolumn{3}{|c|}{ September 29} \\
\hline $\begin{array}{r}2 \\
4 \\
6 \\
8 \\
10 \\
N\end{array}$ & $\begin{array}{l}3.29 \\
3.26 \\
3.24 \\
3.22 \\
3.20 \\
3.18\end{array}$ & $\begin{array}{l}350 \\
337 \\
328 \\
319 \\
310 \\
301\end{array}$ & $\begin{array}{l}3.03 \\
3.01 \\
3.00 \\
2.99 \\
2.97 \\
2.96\end{array}$ & $\begin{array}{r}237 \\
\therefore 229 \\
225 \\
221 \\
213 \\
209\end{array}$ & $\begin{array}{l}2.85 \\
2.84 \\
2.84 \\
2.83 \\
2.83 \\
2.82\end{array}$ & $\begin{array}{l}168 \\
164 \\
164 \\
160 \\
160 \\
157\end{array}$ & \begin{tabular}{l|}
2.76 \\
2.76 \\
2.75 \\
2.75 \\
2.75 \\
2.75
\end{tabular} & $\begin{array}{l}136 \\
136 \\
132 \\
132 \\
132 \\
132\end{array}$ & $\begin{array}{l}3.00 \\
2.97 \\
2.94 \\
2.91 \\
2.89 \\
2.87\end{array}$ & \begin{tabular}{|l|}
225 \\
213 \\
201 \\
189 \\
182 \\
174
\end{tabular} & $\begin{array}{l}2.77 \\
2.76 \\
2.75 \\
2.75 \\
2.74 \\
2.73\end{array}$ & & $\begin{array}{l}140 \\
136 \\
132 \\
132 \\
129 \\
126\end{array}$ \\
\hline $\begin{array}{r}2 \\
4 \\
6 \\
8 \\
10 \\
M\end{array}$ & $\begin{array}{l}3.16 \\
3.14 \\
3.11 \\
3.08 \\
3.06 \\
3.04\end{array}$ & $\begin{array}{l}292 \\
283 \\
270 \\
257 \\
249 \\
241\end{array}$ & $\begin{array}{l}2.95 \\
2.93 \\
2.91 \\
2.89 \\
2.88 \\
2.86\end{array}$ & $\begin{array}{l}205 \\
197 \\
189 \\
182 \\
178 \\
171\end{array}$ & $\begin{array}{l}2.81 \\
2.80 \\
2.79 \\
2.78 \\
2.77 \\
2.76\end{array}$ & $\begin{array}{l}154 \\
150 \\
146 \\
143 \\
140 \\
136\end{array}$ & $\begin{array}{l}2.75 \\
2.75 \\
2.80 \\
2.89 \\
2.84 \\
2.95\end{array}$ & $\begin{array}{l}132 \\
132 \\
150 \\
182 \\
201 \\
205\end{array}$ & $\begin{array}{l}2.86 \\
2.84 \\
2.82 \\
2.81 \\
2.80 \\
2.78\end{array}$ & $\begin{array}{l}171 \\
164 \\
157 \\
154 \\
150 \\
143\end{array}$ & $\begin{array}{l}2.72 \\
2.70 \\
2.69 \\
2.68 \\
2.67\end{array}$ & & $\begin{array}{l}122 \\
115 \\
112 \\
108 \\
105 \\
101\end{array}$ \\
\hline
\end{tabular}

Supplemental records.- Sept. $21,6: 30$ p.m., 10.61 ft., 19,900 sec.-ft. 
West Branch of Westfield River at Huntington, Hass.

Location.- Lat. $42^{\circ} 14{ }^{\prime 20}$, long. $72^{\circ} 53^{\prime} 40^{\prime \prime}$, In Huntington, Hampshire County, 0.4 mile below Roaring Brook and $l_{2}$ miles above confluence with Westfield River.

Drainage area.- 93.7 square miles.

Gage-helght record.- None (gaging station destroyed during flood).

Stage-discharge relation. - Déffined by current-meter measurements below 1,930 secondfeet and extended to peak stage on basis of determinations of flood flow over dam and by slope-area method; used to obtain maximum discharge only.

Maxima.- September 1938; Discharge, 21,800 second-feet about 7 p.m. Sept. 21 (gage helght, 15.5 feet, from floodmarks).

12.95 feet).

Remarke.- Flood mun-off not materially affected by storage. Discharge estimated by hydrographic comparison with other stations in Westfleld River Basin.

Mean daily discharge, in second-feet, 1938

\begin{tabular}{|c|r|r||r|r|r|r|r|r|r|r|r|}
\hline Day & Sept. & Oct. & Day & Sept. & Oct. & Day & Sept. & Oct. & Day & Sept. & Oct. \\
\hline 1 & 30 & 190 & 9 & 35 & 100 & 17 & 60 & 60 & 25 & 390 & 450 \\
2 & 40 & 180 & 10 & 25 & 95 & 18 & 60 & 55 & 26 & 280 & 220 \\
3 & 30 & 160 & 11 & 25 & 100 & 19 & 760 & 50 & 27 & 240 & 140 \\
4 & 30 & 150 & 12 & 20 & 110 & 20 & 2,100 & 55 & 28 & 290 & 120 \\
5 & 25 & 140 & 13 & 70 & 100 & 21 & 6,500 & 190 & 29 & 230 & 140 \\
6 & 25 & 130 & 14 & 75 & 80 & 22 & 3,700 & 120 & 30 & 210 & 130 \\
7 & 25 & 120 & 15 & 90 & 65 & 23 & 1,300 & 85 & 31 & & 110 \\
8 & 35 & 110 & 16 & 110 & 65 & 24 & 560 & 260 & & & \\
\hline
\end{tabular}


Borden Brook and Cobble Mountain Reservoirs in

Westfield Little River Basin near Westfield, Mass.

Iocation.- At Borden Brook Reservolr on Borden Brook about half a mile above Cobble Mountain Reservoir and about 10 miles west of Westfield, Hampden County, and at Cobble Hountain Reservoir on Westfield Little River at Cobble Mountain, about $6 \frac{1}{2}$ miles west of Westfield.

Draingge area.- 45.8 square miles above Cobble Mountain Dam.

Reznarks.- Total storage capecity is 3,$380 ; 000,000$ cubic feet. Gain or loss in storage is the net gain or loss in both reservoirs. Basic data furnished by Board of Water Combissioners, Springfleld, Mass.

Gain or loss in storage, in millions of cublc feet, 1938

\begin{tabular}{|c|c|c|c|c|c|c|c|c|c|c|c|}
\hline Day & Sept. & oct. & Day & Sept. & Oct. & Day & Sept. & oct. & Day & Sept. & oct. \\
\hline $\begin{array}{l}1 \\
2 \\
3 \\
4 \\
5 \\
6 \\
7 \\
8\end{array}$ & $\begin{array}{r}-20.99 \\
-11.50 \\
0 \\
+.94 \\
+.88 \\
-34.60 \\
-53.49 \\
-1.92\end{array}$ & $\begin{array}{l}+2.01 \\
+1.34 \\
+2.27 \\
0 \\
+.94 \\
0 \\
0.40\end{array}$ & $\begin{array}{r}9 \\
10 \\
11 \\
12 \\
13 \\
14 \\
15 \\
16\end{array}$ & $\begin{array}{r}-12.23 \\
+1.00 \\
+.99 \\
-33.90 \\
-22.41 \\
-5.88 \\
-23.66 \\
+.67\end{array}$ & $\begin{array}{r}+1.34 \\
0 \\
-18.04 \\
-6.82 \\
-9.36 \\
-2.67 \\
+.94 \\
+.94\end{array}$ & $\begin{array}{l}17 \\
18 \\
19 \\
20 \\
21 \\
22 \\
23 \\
24\end{array}$ & $\begin{array}{r}+0.67 \\
+10.70 \\
+93.32 \\
+131.67 \\
+234.88 \\
-126.59 \\
-81.01 \\
-19.38\end{array}$ & $\begin{array}{r}-2.01 \\
-42.64 \\
-45.18 \\
-41.04 \\
-28.47 \\
+3.21 \\
+5.48 \\
+12.70\end{array}$ & $\begin{array}{l}25 \\
26 \\
27 \\
28 \\
29 \\
30 \\
31\end{array}$ & $\begin{array}{l}-0.67 \\
-6.15 \\
-4.81 \\
-3.74 \\
+3.34 \\
+3.21\end{array}$ & $\begin{array}{r}+6.42 \\
+5.35 \\
+.94 \\
+5.48 \\
+5.48 \\
+3.21 \\
+2.27\end{array}$ \\
\hline $\begin{array}{l}\text { Gain } \\
\text { Gain }\end{array}$ & $\begin{array}{l}r \text { loss } \\
\text { loss }\end{array}$ & $\begin{array}{l}\text { sto } \\
\text { sto }\end{array}$ & & & of & & fee & $: \vdots$ & $: \dot{ }$ & $\begin{array}{r}+19.34 \\
+8\end{array}$ & $\begin{array}{r}-136.31 \\
-51.1\end{array}$ \\
\hline
\end{tabular}

Westfield Little River at outlet of Cobble Mountain Reservo1r, near Westfleld, Mass.

Location. - Lat. $42^{\circ} 07^{\prime} 2^{n}$, long. $72^{\circ} 53^{\prime} 05^{\prime \prime}$, at Cobble Mountain Dam, 1t miles below confluence of Pebble and Borden Brooks and $6 \frac{1}{2}$ miles west of Westfleld, Hampden County. Draingge area.- 45.8 square miles.

Stage-discharge relation.- Observed discharge is combined flow through power plant and over dam.

Maxima.- September 1938: Mean dally discharge adjusted for storage, 4,760 second-feet Sept. 21 .

1905 to August 1938: Discharge, 6,100 second-feet Nov. 3, 1927, at s1te $13 / 4$ miles downstream.

Remarks.- Flood run-off affected by storage in Borden Brook and Cobble Mountain Reservoirs (total capacity, 3,380,000,000 cublc feet). Daily and monthly discharges adjusted for storage in both reservoirs. Basic data furnished by Board of Water Commissioners, Springfield, Mass.

Mean da1ly discharge, in second-feet, 1938

\begin{tabular}{|c|c|c|c|c|c|c|c|c|c|}
\hline \multirow{2}{*}{ Day } & \multicolumn{2}{|c|}{ September } & \multicolumn{2}{|c|}{ October } & \multirow{2}{*}{ Day } & \multicolumn{2}{|c|}{ September } & \multicolumn{2}{|c|}{ October } \\
\hline & Observed & Adjusted & Observed & Adjusted & & Observed & Adjusted & Observed & Adjusted \\
\hline $\begin{array}{l}1 \\
2 \\
3 \\
4 \\
5\end{array}$ & $\begin{array}{r}268 \\
162 \\
12 \\
0 \\
0\end{array}$ & $\begin{array}{l}25 \\
29 \\
12 \\
11 \\
10\end{array}$ & $\begin{array}{r}24 \\
20 \\
0 \\
16 \\
20\end{array}$ & $\begin{array}{l}47 \\
35 \\
26 \\
16 \\
30\end{array}$ & $\begin{array}{l}16 \\
17 \\
18 \\
19 \\
20\end{array}$ & $\begin{array}{r}16 \\
20 \\
0 \\
17 \\
212\end{array}$ & $\begin{array}{r}24 \\
28 \\
124 \\
1,100 \\
1,740\end{array}$ & $\begin{array}{r}0 \\
39 \\
506 \\
542 \\
562\end{array}$ & $\begin{array}{l}11 \\
15 \\
12 \\
19 \\
87\end{array}$ \\
\hline $\begin{array}{r}6 \\
7 \\
8 \\
9 \\
10\end{array}$ & $\begin{array}{r}410 \\
628 \\
34 \\
153 \\
0\end{array}$ & $\begin{array}{r}10 \\
9 \\
12 \\
12 \\
12\end{array}$ & $\begin{array}{r}21 \\
20 \\
16 \\
0 \\
20\end{array}$ & $\begin{array}{l}21 \\
16 \\
16 \\
15 \\
20\end{array}$ & $\begin{array}{l}21 \\
22 \\
23 \\
24 \\
25\end{array}$ & $\begin{array}{r}2,040 \\
1,930 \\
1,150 \\
399 \\
107\end{array}$ & $\begin{array}{r}4,760 \\
469 \\
212 \\
175 \\
99\end{array}$ & $\begin{array}{r}425 \\
0 \\
0 \\
73 \\
0\end{array}$ & $\begin{array}{r}95 \\
37 \\
63 \\
220 \\
74\end{array}$ \\
\hline $\begin{array}{l}11 \\
12 \\
13 \\
14 \\
15\end{array}$ & $\begin{array}{r}0 \\
405 \\
273 \\
91 \\
328\end{array}$ & $\begin{array}{l}11 \\
13 \\
14 \\
23 \\
54\end{array}$ & $\begin{array}{r}246 \\
121 \\
144 \\
50 \\
0\end{array}$ & $\begin{array}{l}37 \\
42 \\
36 \\
19 \\
11\end{array}$ & $\begin{array}{l}26 \\
27 \\
28 \\
29 \\
30 \\
31\end{array}$ & $\begin{array}{r}148 \\
128 \\
112 \\
16 \\
13\end{array}$ & $\begin{array}{l}76 \\
73 \\
69 \\
55 \\
50\end{array}$ & $\begin{array}{r}15 \\
14 \\
14 \\
0 \\
0 \\
25\end{array}$ & $\begin{array}{l}77 \\
25 \\
77 \\
63 \\
37 \\
51\end{array}$ \\
\hline $\begin{array}{l}\mathrm{Me} \\
\mathrm{Ru}\end{array}$ & $\begin{array}{l}\text { monthly } \\
\text { off, in }\end{array}$ & $\begin{array}{l}\text { ischarge } \\
\text { ches. }\end{array}$ & In secon & feet & & $\begin{array}{r}302 \\
-\quad 3\end{array}$ & $\begin{array}{r}310 \\
7.55\end{array}$ & $\begin{array}{l}94.6 \\
-\quad\end{array}$ & $\begin{array}{l}43.5 \\
1.10\end{array}$ \\
\hline
\end{tabular}


Scantic River at Broad Brook, Conn.

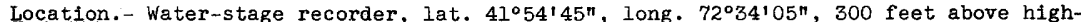
way bridge, I mile southwest of Broad Brook, Hartford County, half a mile below confluence with Broad Brook, and $5 \frac{1}{2}$ miles above mouth.

Drainage area.- 98.4 square miles.

Gage-height record.- Water-stage recorder graph except for period 9 a.m. Sept. 21 to noon Sept. 27, when it was based on flood marks, two inspections, shape of recession computed by summation of previous smaller floods, and computation of storage released by fallure of dam upstream, and for period Oct. 17-3l, when it was based on records for station on Willimantic River near South Coventry.

Stage-discharge relation.- Defined by current-meter measurements below 725 second-feet; extended to peak stage on basis of determinations of flood flow at dams 7 and 9 miles upstream, study of storage released by failure of dam, and estimate of intervening area run-off based upon determination of flood flow at dam on Broad Brook at Broad Brook, Conn.

Maxima.- September 1938: Discharge, 7,360 second-feet 2:30 p.m. Sept. 21 (gage height, 16.08 feet, from floodmark resulting from breaking of dam upstream). 1928 to August 1938: Maximum discharge, 1,820 second-feet (revised) 1 a.m. Mar. 13, 1936 (gage height, 10.17 feet); maximum gage height, 12.31 feet 3-4 p.m. Mar. 21, 1936 (backwater from Connecticut River).

Remarks.- Flood run-off affected by storage in one reservoir and several small ponds.

Mean daily discharge, in second-feet, 1938

\begin{tabular}{|c|c|c|c|c|c|c|c|c|c|c|c|}
\hline Day & Sept. & Oct. & Day & Sept. & $0 \mathrm{ct}$. & Day & Sept. & 0ct. & Day & Sept. & Oct. \\
\hline $\begin{array}{l}1 \\
2 \\
3 \\
4 \\
5 \\
6 \\
7 \\
8\end{array}$ & $\begin{array}{l}74 \\
82 \\
60 \\
46 \\
60 \\
81 \\
80 \\
84\end{array}$ & $\begin{array}{l}372 \\
350 \\
326 \\
295 \\
283 \\
264 \\
249 \\
246\end{array}$ & $\begin{array}{r}9 \\
10 \\
11 \\
12 \\
13 \\
14 \\
15 \\
16\end{array}$ & $\begin{array}{r}74 \\
52 \\
41 \\
52 \\
77 \\
76 \\
86 \\
100\end{array}$ & $\begin{array}{l}240 \\
240 \\
225 \\
222 \\
212 \\
207 \\
205 \\
207\end{array}$ & $\begin{array}{l}17 \\
18 \\
19 \\
20 \\
21 \\
22 \\
23 \\
24\end{array}$ & $\begin{array}{r}86 \\
119 \\
367 \\
1,580 \\
5,090 \\
3,740 \\
2,080 \\
1,230\end{array}$ & $\begin{array}{l}220 \\
200 \\
200 \\
200 \\
220 \\
200 \\
150 \\
180\end{array}$ & $\begin{array}{l}25 \\
26 \\
27 \\
28 \\
29 \\
30 \\
31\end{array}$ & $\begin{array}{l}798 \\
601 \\
491 \\
436 \\
409 \\
388\end{array}$ & $\begin{array}{l}300 \\
280 \\
240 \\
220 \\
200 \\
200 \\
190\end{array}$ \\
\hline $\begin{array}{l}\text { Mean } \\
\text { Run- }\end{array}$ & $\begin{array}{l}\text { onth } \mathrm{y} \\
\text {, in } 1\end{array}$ & 8. & , 1 & econd- & t. : & $\dot{0}$ & 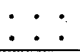 & 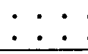 & . : & $\begin{array}{r}618 \\
7.01 \\
\end{array}$ & $\begin{array}{r}237 \\
2.78 \\
\end{array}$ \\
\hline
\end{tabular}

Gage height, in feet, and discharge, in second-feet, at indicated time, 1938

\begin{tabular}{|c|c|c|c|c|c|c|c|c|c|c|c|c|c|}
\hline \multirow{2}{*}{$\begin{array}{l}\text { \& } \\
\text { О् } \\
\text { 足 }\end{array}$} & Feet & Sec.ft. & Feet & Sec.ft. & Feet & Sec.ft. & Feet & Sec.ft. & Feet & Sec.ft. & Feet & Sec & . ft. \\
\hline & \multicolumn{2}{|c|}{ September 18} & \multicolumn{2}{|c|}{ September 19} & \multicolumn{2}{|c|}{ September 20} & \multicolumn{2}{|c|}{ September 21} & \multicolumn{2}{|c|}{ September 22} & \multicolumn{3}{|c|}{ September 23} \\
\hline $\begin{array}{l}1 \\
2 \\
3 \\
4 \\
5 \\
6\end{array}$ & $\begin{array}{l}- \\
1.20 \\
- \\
1.22 \\
- \\
1.23\end{array}$ & $\begin{array}{l}-111 \\
- \\
114 \\
- \\
116\end{array}$ & $\begin{array}{l}1.60 \\
1.70 \\
2.00 \\
2.30 \\
2.50 \\
2.69\end{array}$ & $\begin{array}{l}172 \\
185 \\
221 \\
250 \\
270 \\
289\end{array}$ & $\begin{array}{l}4.45 \\
5.65 \\
5.92 \\
6.05 \\
6.08 \\
6.07\end{array}$ & \begin{tabular}{|l}
539 \\
742 \\
791 \\
814 \\
819 \\
818
\end{tabular} & $\begin{array}{l}12.59 \\
12.70 \\
12.88 \\
13.09 \\
13.25 \\
13.33\end{array}$ & $\begin{array}{l}3,250 \\
3,350 \\
3,510 \\
3,710 \\
3,870 \\
3,950\end{array}$ & $\begin{array}{c}14.0 \\
- \\
13.8 \\
- \\
13.65\end{array}$ & $\begin{array}{c}- \\
4,670 \\
- \\
4,450 \\
\overline{4,280}\end{array}$ & $\begin{array}{c}- \\
- \\
- \\
11.65 \\
- \\
-\end{array}$ & 2 & 480 \\
\hline $\begin{array}{r}7 \\
8 \\
9 \\
10 \\
17 \\
11\end{array}$ & $\begin{array}{l}- \\
1.23 \\
- \\
1.23 \\
- \\
1.23\end{array}$ & $\begin{array}{r}-116 \\
-\quad 116 \\
-\quad 116\end{array}$ & $\begin{array}{l}2.93 \\
3.07 \\
3.10 \\
3.14 \\
3.18 \\
3.23\end{array}$ & $\begin{array}{l}315 \\
331 \\
335 \\
340 \\
345 \\
352\end{array}$ & $\begin{array}{l}6.20 \\
7.05 \\
7.95 \\
8.65 \\
9.05 \\
9.38\end{array}$ & $\begin{array}{r}841 \\
1,000 \\
1,180 \\
1,340 \\
1,440 \\
1,540\end{array}$ & $\begin{array}{l}13.42 \\
13.59 \\
13.7 \\
13.9 \\
14.1 \\
14.7\end{array}$ & $\begin{array}{l}4,040 \\
4,220 \\
4,340 \\
4,560 \\
4,780 \\
5,490\end{array}$ & $\begin{array}{c}- \\
13.5 \\
- \\
13.3 \\
- \\
13.1\end{array}$ & $\begin{array}{c}- \\
4,120 \\
- \\
3,920 \\
- \\
3,720\end{array}$ & $\begin{array}{c}- \\
11.3 \\
- \\
- \\
11.0\end{array}$ & 2, & $\begin{array}{l}240 \\
060\end{array}$ \\
\hline $\begin{array}{l}1 \\
2 \\
3 \\
4 \\
5 \\
6\end{array}$ & $\begin{array}{l}\overline{1.23} \\
- \\
\overline{1.24} \\
\overline{1.26}\end{array}$ & $\begin{array}{r}-116 \\
-\quad 117 \\
-\quad 121\end{array}$ & $\begin{array}{l}3.27 \\
3.30 \\
3.34 \\
3.60 \\
4.05 \\
4.20\end{array}$ & $\begin{array}{l}358 \\
362 \\
368 \\
406 \\
475 \\
499\end{array}$ & $\begin{array}{r}9.70 \\
10.09 \\
10.40 \\
10.59 \\
10.70 \\
10.79\end{array}$ & $\begin{array}{l}1,640 \\
1,790 \\
1,910 \\
1,990 \\
2,030 \\
2,080\end{array}$ & $\begin{array}{l}15.8 \\
16.05 \\
16.05 \\
15.8 \\
15.6 \\
15.35\end{array}$ & $\begin{array}{l}6,970 \\
7,320 \\
7,320 \\
6,970 \\
6,690 \\
6,340\end{array}$ & $\begin{array}{c}- \\
12.9 \\
\overline{-} \\
12.7 \\
\overline{-} \\
12.5\end{array}$ & $\begin{array}{c}- \\
3,530 \\
- \\
3,350 \\
- \\
3,170\end{array}$ & $\begin{array}{c}- \\
- \\
- \\
10.65 \\
- \\
-\end{array}$ & 1 & 880 \\
\hline \multirow[t]{2}{*}{$\begin{array}{r}7 \\
8 \\
9 \\
10 \\
11 \\
M\end{array}$} & $\begin{array}{l}- \\
1.27 \\
- \\
1.29 \\
1.36 \\
1.57\end{array}$ & $\begin{array}{r}-122 \\
- \\
125 \\
137 \\
168\end{array}$ & $\begin{array}{l}4.35 \\
4.42 \\
4.40 \\
4.25 \\
4.22 \\
4.22\end{array}$ & $\begin{array}{l}523 \\
534 \\
531 \\
507 \\
502 \\
502\end{array}$ & $\begin{array}{l}10.87 \\
11.20 \\
11.72 \\
12.01 \\
12.30 \\
12.48\end{array}$ & $\begin{array}{l}2,120 \\
2,280 \\
2,580 \\
2,790 \\
3,010 \\
3,150\end{array}$ & $\begin{array}{l}15.1 \\
14.85 \\
14.65 \\
14.45 \\
14.3 \\
14.15\end{array}$ & $\begin{array}{l}5,990 \\
5,670 \\
5,430 \\
5,190 \\
5,010 \\
4,840\end{array}$ & $\begin{array}{c}- \\
12.35 \\
- \\
12.15 \\
- \\
11.95\end{array}$ & $\begin{array}{c}- \\
3,040 \\
- \\
2,870 \\
- \\
2,710\end{array}$ & $\begin{array}{c}10.3 \\
- \\
- \\
- \\
10.0\end{array}$ & \multicolumn{2}{|c|}{$\begin{array}{l}1,700 \\
- \\
- \\
1,570\end{array}$} \\
\hline & Septe & ber 24 & Septer & iber 25 & Septer & ber 26 & Septer & ber 27 & Septe & aber 28 & Septen & aber & 29 \\
\hline $\begin{array}{r}2 \\
4 \\
6 \\
8 \\
10 \\
\text { N }\end{array}$ & $\begin{array}{c}- \\
- \\
9.5 \\
- \\
- \\
9.05\end{array}$ & $\begin{array}{l}- \\
\overline{1}, 370 \\
- \\
- \\
1,220\end{array}$ & $\begin{array}{l}- \\
\overline{7} .8 \\
\overline{-} \\
\overline{7} .4\end{array}$ & $\begin{array}{l}- \\
- \\
-860 \\
- \\
-785\end{array}$ & $\begin{array}{c}- \\
- \\
6.3 \\
- \\
- \\
6.0\end{array}$ & $\begin{array}{l}- \\
- \\
-639 \\
- \\
600\end{array}$ & $\begin{array}{l}5.4 \\
5.35 \\
5.3 \\
5.35 \\
5.25 \\
5.2\end{array}$ & $\begin{array}{l}522 \\
516 \\
509 \\
516 \\
502 \\
496\end{array}$ & $\begin{array}{l}4.87 \\
4.83 \\
4.80 \\
4.88 \\
4.80 \\
4.72\end{array}$ & $\begin{array}{l}454 \\
450 \\
446 \\
456 \\
446 \\
436\end{array}$ & $\begin{array}{l}4.47 \\
4.50 \\
4.50 \\
4.62 \\
4.58 \\
4.52\end{array}$ & & $\begin{array}{l}406 \\
410 \\
410 \\
424 \\
420 \\
412\end{array}$ \\
\hline $\begin{array}{r}2 \\
4 \\
6 \\
8 \\
10 \\
M\end{array}$ & $\begin{array}{c}\overline{-} \\
\overline{8.6} \\
- \\
\overline{8.2}\end{array}$ & $\begin{array}{l}\overline{-} \\
1,080 \\
- \\
-960\end{array}$ & $\begin{array}{l}- \\
\overline{7} .0 \\
\overline{6} \\
\overline{6} .6\end{array}$ & $\begin{array}{l}- \\
- \\
-730 \\
- \\
678\end{array}$ & $\begin{array}{c}- \\
- \\
5.7 \\
- \\
\overline{5.45}\end{array}$ & $\begin{array}{l}- \\
- \\
-561 \\
- \\
528\end{array}$ & $\begin{array}{l}5.11 \\
5.06 \\
4.94 \\
4.88 \\
4.88 \\
4.88\end{array}$ & $\begin{array}{l}484 \\
478 \\
463 \\
456 \\
456 \\
456\end{array}$ & $\begin{array}{l}4.67 \\
4.62 \\
4.59 \\
4.58 \\
4.56 \\
4.42\end{array}$ & $\begin{array}{l}430 \\
424 \\
421 \\
420 \\
417 \\
400\end{array}$ & $\begin{array}{l}4.49 \\
4.47 \\
4.47 \\
4.47 \\
4.47 \\
4.33\end{array}$ & & $\begin{array}{l}409 \\
406 \\
406 \\
406 \\
406 \\
390\end{array}$ \\
\hline
\end{tabular}

Supplemental records.- Sept. $21,2: 30$ p.m., 16.08 ft., 7,360 sec.-ft. 


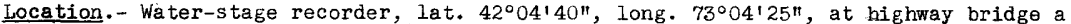
quarter of a mile below Clam River and 1 mile south of New Boston, Berkshire County. Zero of gage is 758.21 feet above mean sea level (general adjustment of 1929 ). Drainage area.- 92.0 square miles.

Gage-height record.- Water-stage recorder graph except for period sept. 10 to 12 , for which there is no record.

Stage-dischange relation.- Defined by current-meter measurements below 1,380 secondfeet; extended to peak stage on basis of determinations of flood flows by contracted-opening and slope-area methods.

Maxima.- September 1938: Discharge, 18,500 second-feet 6 p.m. Sept. 21 (gage helght, 12.94 feet).

1913 to August 1938: Maximum discharge, 9,080 second-feet Mar. 18, 1936 (gage height, 10.65 feet); maximum gage height, 11.20 feet Mar. 12, 1936 (1ce Jam). Remarks.- Discharge for period Sept. 10 to 12 computed on basis of discharge from 0 tis Reservoir and records for nearby stations. Flood run-off affected by storage in otis Reservoir, total storage capacity, 780,000,000 cubic feet. For information on storage see record for Otis Reservoir at Cold Spring, Mass.

Mean daily discharge, in second-feet, 1938

\begin{tabular}{|c|c|c|c|c|c|c|c|c|c|c|c|}
\hline Day & Sept. & $0 \mathrm{ct}$. & Day & Sept. & oct. & Dey & Sept. & Oct. & Day & Sept. & Oct. \\
\hline $\begin{array}{l}1 \\
2 \\
3 \\
4 \\
5 \\
6 \\
7 \\
8\end{array}$ & $\begin{array}{r}169 \\
44 \\
36 \\
52 \\
164 \\
184 \\
218 \\
196\end{array}$ & $\begin{array}{r}218 \\
167 \\
172 \\
223 \\
201 \\
119 \\
109 \\
97\end{array}$ & $\begin{array}{r}9 \\
10 \\
11 \\
12 \\
13 \\
14 \\
15 \\
16\end{array}$ & $\begin{array}{r}52 \\
90 \\
210 \\
255 \\
240 \\
232 \\
289 \\
142\end{array}$ & $\begin{array}{r}86 \\
79 \\
75 \\
74 \\
60 \\
54 \\
89 \\
184\end{array}$ & $\begin{array}{l}17 \\
18 \\
19 \\
20 \\
21 \\
22 \\
23 \\
24\end{array}$ & $\begin{array}{r}126 \\
257 \\
1,020 \\
2,050 \\
6,680 \\
3,120 \\
1,180 \\
610\end{array}$ & $\begin{array}{l}178 \\
180 \\
189 \\
175 \\
175 \\
150 \\
210 \\
331\end{array}$ & $\begin{array}{l}25 \\
26 \\
27 \\
28 \\
29 \\
30 \\
31\end{array}$ & $\begin{array}{l}380 \\
285 \\
246 \\
271 \\
270 \\
241 \\
-\end{array}$ & $\begin{array}{l}350 \\
243 \\
201 \\
130 \\
148 \\
228 \\
210\end{array}$ \\
\hline $\begin{array}{l}\text { Mean } \\
\text { Run- }\end{array}$ & $\begin{array}{l}\text { onthly } \\
f \text {, in . }\end{array}$ & $\begin{array}{l}\text { schar } \\
\text { hes. }\end{array}$ & ? & $\begin{array}{c}\text { second- } \\
. \text {. }\end{array}$ & et. & . & 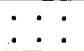 & . : & $\dot{.}$ & $\begin{array}{r}644 \\
7.81\end{array}$ & $\begin{array}{r}165 \\
2.06\end{array}$ \\
\hline
\end{tabular}

Gage height, In feet, and discharge, in second-feet, at indicated time, 1938

\begin{tabular}{|c|c|c|c|c|c|c|c|c|c|c|c|c|c|}
\hline \multirow{2}{*}{$\begin{array}{r}5 \\
3 \\
0 \\
0 \\
0\end{array}$} & Feet & Sec & . ft. & Feet & Sec.ft. & Feet & Sec.ft. & Feet & Sec.ft. & Feet & Sec.ft. & Feet & Sec.ft. \\
\hline & \multicolumn{3}{|c|}{ September } & \multicolumn{2}{|c|}{ September 19} & \multicolumn{2}{|c|}{ September 20} & \multicolumn{2}{|c|}{ September 21} & \multicolumn{2}{|c|}{ September 22} & \multicolumn{2}{|c|}{ September 23} \\
\hline $\begin{array}{l}1 \\
2 \\
3 \\
4 \\
5 \\
6\end{array}$ & $\begin{array}{l}4.17 \\
4.18 \\
4.18 \\
4.18 \\
4.18 \\
4.18\end{array}$ & & $\begin{array}{l}256 \\
259 \\
259 \\
259 \\
259 \\
259\end{array}$ & $\begin{array}{l}4.25 \\
4.29 \\
4.40 \\
4.43 \\
4.46 \\
4.50\end{array}$ & $\begin{array}{l}280 \\
292 \\
325 \\
336 \\
346 \\
360\end{array}$ & $\begin{array}{l}6.22 \\
6.57 \\
6.87 \\
6.82 \\
6.80 \\
6.68\end{array}$ & $\begin{array}{l}1,420 \\
1,750 \\
2,070 \\
2,010 \\
1,990 \\
1,860\end{array}$ & $\begin{array}{l}7.42 \\
7.49 \\
7.50 \\
7.43 \\
7.43 \\
7.52\end{array}$ & $\begin{array}{l}2,780 \\
2,880 \\
2,890 \\
2,790 \\
2,790 \\
2,920\end{array}$ & $\begin{array}{l}9.34 \\
8.98 \\
8.70 \\
8.40 \\
8.18 \\
8.02\end{array}$ & $\begin{array}{l}6,300 \\
5,480 \\
4,900 \\
4,320 \\
3,930 \\
3,670\end{array}$ & $\begin{array}{l}6.46 \\
6.39 \\
6.33 \\
6.28 \\
6.22 \\
6.18\end{array}$ & $\begin{array}{l}1,640 \\
1,570 \\
1,520 \\
1,470 \\
1,420 \\
1,380\end{array}$ \\
\hline $\begin{array}{r}7 \\
8 \\
9 \\
10 \\
11 \\
1\end{array}$ & $\begin{array}{l}4.18 \\
4.18 \\
4.18 \\
4.18 \\
4.18 \\
4.18\end{array}$ & & $\begin{array}{l}259 \\
259 \\
259 \\
259 \\
259 \\
259\end{array}$ & $\begin{array}{l}4.53 \\
4.55 \\
4.56 \\
4.56 \\
4.57 \\
4.64\end{array}$ & $\begin{array}{l}370 \\
378 \\
381 \\
381 \\
384 \\
411\end{array}$ & $\begin{array}{l}6.77 \\
6.65 \\
6.53 \\
6.50 \\
6.70 \\
6.95\end{array}$ & $\begin{array}{l}1,960 \\
1,830 \\
1,710 \\
1,680 \\
1,880 \\
2,160\end{array}$ & $\begin{array}{l}7.75 \\
7.99 \\
8.21 \\
8.27 \\
8.47 \\
8.89\end{array}$ & $\begin{array}{l}3,260 \\
3,620 \\
3,980 \\
4,090 \\
4,450 \\
5,280\end{array}$ & $\begin{array}{l}7.90 \\
7.77 \\
7.66 \\
7.55 \\
7.44 \\
7.35\end{array}$ & $\begin{array}{l}3,480 \\
3,280 \\
3,120 \\
2,960 \\
2,810 \\
2,680\end{array}$ & $\begin{array}{l}6.13 \\
6.08 \\
6.04 \\
5.99 \\
5.95 \\
5.90\end{array}$ & $\begin{array}{l}1,340 \\
1,290 \\
1,260 \\
1,220 \\
1,190 \\
1,160\end{array}$ \\
\hline $\begin{array}{l}1 \\
2 \\
3 \\
4 \\
5 \\
6\end{array}$ & $\begin{array}{l}4.18 \\
4.17 \\
4.17 \\
4.16 \\
4.16 \\
4.16\end{array}$ & & $\begin{array}{l}259 \\
256 \\
256 \\
253 \\
253 \\
253\end{array}$ & $\begin{array}{l}4.76 \\
5.10 \\
5.82 \\
6.92 \\
7.50 \\
7.50\end{array}$ & $\begin{array}{r}459 \\
620 \\
1,090 \\
2,120 \\
2,890 \\
2,890\end{array}$ & $\begin{array}{l}7.00 \\
6.87 \\
6.75 \\
6.68 \\
6.76 \\
7.00\end{array}$ & $\begin{array}{l}2,220 \\
2,070 \\
1,940 \\
1,860 \\
1,950 \\
2,220\end{array}$ & $\begin{array}{r}8.83 \\
8.76 \\
8.78 \\
9.24 \\
10.40 \\
12.94\end{array}$ & $\begin{array}{r}5,160 \\
5,020 \\
5,060 \\
6,060 \\
9,080 \\
18,500\end{array}$ & $\begin{array}{l}7.27 \\
7.18 \\
7.11 \\
7.04 \\
6.97 \\
6.91\end{array}$ & $\begin{array}{l}2,570 \\
2,450 \\
2,360 \\
2,270 \\
2,180 \\
2,110\end{array}$ & $\begin{array}{l}5.86 \\
5.81 \\
5.77 \\
5.72 \\
5.67 \\
5.63\end{array}$ & $\begin{array}{r}1,120 \\
1,090 \\
1,060 \\
1,020 \\
990 \\
964\end{array}$ \\
\hline \multirow[t]{2}{*}{$\begin{array}{r}7 \\
8 \\
9 \\
10 \\
11 \\
1 \\
\end{array}$} & $\begin{array}{l}4.16 \\
4.16 \\
4.14 \\
4.16 \\
4.19 \\
4.22\end{array}$ & & $\begin{array}{l}253 \\
253 \\
247 \\
253 \\
262 \\
271\end{array}$ & $\begin{array}{l}7.17 \\
6.85 \\
6.64 \\
6.42 \\
6.28 \\
6.21\end{array}$ & $\begin{array}{l}2,440 \\
2,040 \\
1,820 \\
1,600 \\
1,470 \\
1,410\end{array}$ & $\begin{array}{l}7.04 \\
6.96 \\
7.17 \\
7.40 \\
7.44 \\
7.40\end{array}$ & $\begin{array}{l}2,270 \\
2,170 \\
2,440 \\
2,750 \\
2,810 \\
2,750 \\
\end{array}$ & $\begin{array}{r}12.45 \\
12.20 \\
11.45 \\
11.04 \\
10.46 \\
9.84\end{array}$ & $\begin{array}{r}16,400 \\
15,400 \\
12,500 \\
11,100 \\
9,260 \\
7,540 \\
\end{array}$ & $\begin{array}{l}6.84 \\
6.78 \\
6.71 \\
6.64 \\
6.58 \\
6.53\end{array}$ & $\begin{array}{l}2,030 \\
1,970 \\
1,890 \\
1,820 \\
1,760 \\
1,710\end{array}$ & $\begin{array}{l}5.58 \\
5.56 \\
5.52 \\
5.49 \\
5.45 \\
5.41\end{array}$ & $\begin{array}{l}932 \\
919 \\
893 \\
874 \\
850 \\
826\end{array}$ \\
\hline & \multicolumn{2}{|c|}{ September } & 24 & \multicolumn{2}{|c|}{ September 25} & \multicolumn{2}{|c|}{ September 26} & \multicolumn{2}{|c|}{ September 27} & \multicolumn{2}{|c|}{ September 28} & \multicolumn{2}{|c|}{ September 29} \\
\hline $\begin{array}{r}2 \\
4 \\
6 \\
8 \\
10 \\
N\end{array}$ & $\begin{array}{l}5.34 \\
5.26 \\
5.19 \\
5.14 \\
5.08 \\
5.01\end{array}$ & & $\begin{array}{l}784 \\
738 \\
700 . \\
672 \\
640 \\
605\end{array}$ & $\begin{array}{l}4.62 \\
4.58 \\
4.54 \\
4.50 \\
4.48 \\
4.45\end{array}$ & \begin{tabular}{|l|}
437 \\
423 \\
410 \\
396 \\
389 \\
380
\end{tabular} & \begin{tabular}{|l}
4.25 \\
4.23 \\
4.21 \\
4.19 \\
4.17 \\
4.15
\end{tabular} & $\begin{array}{l}316 \\
310 \\
304 \\
298 \\
293 \\
287\end{array}$ & $\begin{array}{l}4.01 \\
4.00 \\
3.99 \\
3.98 \\
3.97 \\
3.96\end{array}$ & $\begin{array}{l}249 \\
246 \\
243 \\
241 \\
238 \\
236\end{array}$ & $\begin{array}{l}4.12 \\
4.12 \\
4.11 \\
4.10 \\
4.09 \\
4.08\end{array}$ & $\begin{array}{r}279 \\
279 \\
276 \\
273 \\
270 \\
268\end{array}$ & $\begin{array}{l}4.15 \\
4.13 \\
4.12 \\
4.11 \\
4.10 \\
4.10\end{array}$ & $\begin{array}{l}287 \\
281 \\
279 \\
276 \\
273 \\
273\end{array}$ \\
\hline $\begin{array}{r}2 \\
4 \\
6 \\
8 \\
10 \\
M\end{array}$ & $\begin{array}{l}4.92 \\
4.85 \\
4.80 \\
4.75 \\
4.71 \\
4.67\end{array}$ & & $\begin{array}{l}560 \\
528 \\
505 \\
485 \\
469 \\
454\end{array}$ & $\begin{array}{l}4.42 \\
4.38 \\
4.35 \\
4.31 \\
4.28 \\
4.26\end{array}$ & $\begin{array}{l}370 \\
357 \\
347 \\
334 \\
325 \\
319\end{array}$ & $\begin{array}{l}4.12 \\
4.09 \\
4.07 \\
4.05 \\
4.03 \\
4.02\end{array}$ & $\begin{array}{l}279 \\
270 \\
265 \\
260 \\
254 \\
251\end{array}$ & $\begin{array}{l}3.94 \\
3.93 \\
3.97 \\
4.04 \\
4.14 \\
4.14\end{array}$ & $\begin{array}{l}230 \\
228 \\
238 \\
257 \\
284 \\
284\end{array}$ & $\begin{array}{l}4.06 \\
4.03 \\
4.01 \\
4.11 \\
4.15 \\
4.14\end{array}$ & $\begin{array}{l}262 \\
254 \\
249 \\
276 \\
287 \\
284\end{array}$ & $\begin{array}{l}4.08 \\
4.06 \\
4.05 \\
4.04 \\
4.03 \\
4.02\end{array}$ & $\begin{array}{l}268 \\
262 \\
260 \\
257 \\
254 \\
251\end{array}$ \\
\hline
\end{tabular}


Location.- Water-stage recorder, lat. 41057'15", long. $73^{\circ} 00^{\prime} 45^{\prime \prime}$, a quarter of a mile below mouth of Still River, 1 mile below Riverton, Iitchfield County, and 4 miles northeast of Winsted.

Drainage area.- 216 square miles.

Gage-height record. - Water-stage recorder graph except for period 5:20 to $9 \mathrm{p} . \mathrm{m}$. Sept. 21 , record for which was based on floodmark and avallable record.

Stage-discharge relation.- Defined by current-meter measurements below 5,670 secondfeet; extended to peak stage on basis of velocity-area study; roughly verified by comparison with other records on Farmington River.

Maxima.- September 1938: Discharge, 37,100 second-feet 6:30 p.m. Sept. 21 (gage height, 17.95 feet, from floodmark).

1929 to August 1938: Discharge, 19,900 second-feet Mar. 18, 1936 (gage height, 13.42 feet).

Remarks.- Flood run-off affected by artificial storage. For information on storage see record for Otis Reservoir at Cold Spring, Mass.

Mean daily discharge, in second-feet, 1938

\begin{tabular}{|c|r|r||r|r|r|r|r|r|r|r|r|}
\hline Day & Sept. & 0ct. & Day & Sept. & Oct. & Day & Sept. & Oct. & Day & Sept. & 0ct. \\
\hline 1 & 249 & 473 & 9 & 136 & 218 & 17 & 208 & 314 & 25 & 1,080 & 882 \\
2 & 136 & 381 & 10 & 96 & 224 & 18 & 354 & 308 & 26 & 814 & 584 \\
3 & 101 & 364 & 11 & 212 & 214 & 19 & 1,820 & 320 & 27 & 650 & 484 \\
4 & 62 & 432 & 12 & 256 & 211 & 20 & 4,530 & 331 & 28 & 634 & 371 \\
5 & 169 & 411 & 13 & 328 & 198 & 21 & 15,100 & 556 & 29 & 590 & 337 \\
6 & 238 & 310 & 14 & 328 & 181 & 22 & 7,860 & 388 & 30 & 531 & 424 \\
7 & 283 & 278 & 15 & 410 & 184 & 23 & 2,870 & 416 & 31 & & 428 \\
8 & 302 & 253 & 16 & 328 & 303 & 24 & 1,640 & 669 & & & \\
\hline
\end{tabular}

Gage helght, in feet, and discharge, in second-feet, at indicated time, 1938

\begin{tabular}{|c|c|c|c|c|c|c|c|c|c|c|c|c|}
\hline \multirow{2}{*}{$\begin{array}{l}3 \\
0 \\
0\end{array}$} & Feot & Sec.ft. & Feet & Sec.ft. & Feet & Sec.ft. & Feet & sec.ft. & Feet & Sec.ft. & Feet & Sec.ft. \\
\hline & \multicolumn{2}{|c|}{ September 18} & \multicolumn{2}{|c|}{ September 19} & \multicolumn{2}{|c|}{ September 20} & \multicolumn{2}{|c|}{ September 21} & \multicolumn{2}{|c|}{ September 22} & \multicolumn{2}{|c|}{ September 23} \\
\hline $\begin{array}{l}1 \\
2 \\
3 \\
4 \\
5 \\
6\end{array}$ & $\begin{array}{l}- \\
- \\
- \\
- \\
-\end{array}$ & $\begin{array}{l}- \\
- \\
- \\
- \\
- \\
-\end{array}$ & $\begin{array}{l}2.38 \\
2.21 \\
2.22 \\
2.28 \\
2.34 \\
2.44\end{array}$ & $\begin{array}{l}439 \\
369 \\
373 \\
397 \\
422 \\
467\end{array}$ & $\begin{array}{l}5.56 \\
5.57 \\
5.75 \\
6.18 \\
6.39 \\
6.48\end{array}$ & $\begin{array}{l}3,220 \\
3,230 \\
3,480 \\
4,110 \\
4,420 \\
4,560\end{array}$ & $\begin{array}{l}7.45 \\
7.57 \\
7.69 \\
7.69 \\
7.67 \\
7.79\end{array}$ & $\begin{array}{l}6,160 \\
6,370 \\
6,580 \\
6,580 \\
6,550 \\
6,760\end{array}$ & $\begin{array}{r}11.64 \\
10.97 \\
10.54 \\
9.98 \\
9.61 \\
9.26\end{array}$ & $\begin{array}{r}15,300 \\
13,600 \\
12,600 \\
11,300 \\
10,400 \\
9,650\end{array}$ & $\begin{array}{c}- \\
5.98 \\
- \\
5.79 \\
- \\
5.62\end{array}$ & $\begin{array}{l}- \\
3,810 \\
- \\
3,540 \\
3,300\end{array}$ \\
\hline $\begin{array}{r}7 \\
8 \\
9 \\
10 \\
11 \\
N\end{array}$ & $\begin{array}{c}- \\
- \\
- \\
- \\
* 2.17\end{array}$ & $\begin{array}{l}= \\
= \\
z \\
* 354\end{array}$ & $\begin{array}{l}2.55 \\
2.80 \\
3.06 \\
3.12 \\
3.14 \\
3.15\end{array}$ & $\begin{array}{l}520 \\
650 \\
809 \\
848 \\
861 \\
868\end{array}$ & $\begin{array}{l}6.54 \\
6.47 \\
6.37 \\
6.33 \\
6.42 \\
6.64\end{array}$ & $\begin{array}{l}4,650 \\
4,540 \\
4,400 \\
4,340 \\
4,470 \\
4,810\end{array}$ & $\begin{array}{r}8.08 \\
8.62 \\
9.20 \\
9.64 \\
9.98 \\
10.38\end{array}$ & $\begin{array}{r}7,290 \\
8,330 \\
9,520 \\
10,500 \\
11,300 \\
12,200\end{array}$ & $\begin{array}{l}8.95 \\
8.67 \\
8.44 \\
8.25 \\
8.03 \\
7.82\end{array}$ & $\begin{array}{l}9,000 \\
8,430 \\
7,980 \\
7,620 \\
7,200 \\
6,820\end{array}$ & $\begin{array}{c}- \\
5.49 \\
- \\
5.35 \\
- \\
5.21\end{array}$ & $\begin{array}{l}\overline{3,130} \\
\overline{2,950} \\
\overline{2,780}\end{array}$ \\
\hline $\begin{array}{l}1 \\
2 \\
3 \\
4 \\
5 \\
6\end{array}$ & $\begin{array}{l}- \\
- \\
- \\
-\end{array}$ & $\begin{array}{l}\bar{z} \\
\bar{z} \\
\bar{z} \\
\bar{z}\end{array}$ & $\begin{array}{l}3.14 \\
3.25 \\
3.58 \\
4.04 \\
5.60 \\
6.74\end{array}$ & $\begin{array}{r}861 \\
935 \\
1,170 \\
1,580 \\
3,270 \\
4,970\end{array}$ & $\begin{array}{l}6.84 \\
6.86 \\
6.70 \\
6.52 \\
6.41 \\
6.38\end{array}$ & $\begin{array}{l}5,130 \\
5,170 \\
4,910 \\
4,620 \\
4,460 \\
4,410\end{array}$ & $\begin{array}{l}10.63 \\
10.59 \\
10.90 \\
12.13 \\
14.80 \\
17.3\end{array}$ & $\begin{array}{l}12,800 \\
12,700 \\
13,400 \\
16,600 \\
24,700 \\
34,200\end{array}$ & $\begin{array}{l}7.64 \\
7.48 \\
7.32 \\
7.18 \\
7.03 \\
6.89\end{array}$ & $\begin{array}{l}6,490 \\
6,210 \\
5,930 \\
5,700 \\
5,440 \\
5,210\end{array}$ & $\begin{array}{c}- \\
5.09 \\
- \\
4.96 \\
- \\
4.84\end{array}$ & $\begin{array}{l}2,640 \\
- \\
2,500 \\
- \\
2,360\end{array}$ \\
\hline \multirow[t]{2}{*}{$\begin{array}{r}7 \\
8 \\
9 \\
10 \\
11 \\
M \\
\end{array}$} & $\begin{array}{c}- \\
\overline{-} \\
\overline{-} \\
2.44\end{array}$ & $\begin{array}{l}- \\
- \\
- \\
467\end{array}$ & $\begin{array}{l}7.04 \\
6.65 \\
6.27 \\
6.00 \\
5.78 \\
5.61\end{array}$ & $\begin{array}{l}5,460 \\
4,830 \\
4,240 \\
3,840 \\
3,520 \\
3,280\end{array}$ & $\begin{array}{l}6.56 \\
6.63 \\
6.64 \\
6.81 \\
7.16 \\
7.34 \\
\end{array}$ & $\begin{array}{l}4,690 \\
4,800 \\
4,810 \\
5,090 \\
5,660 \\
5,970\end{array}$ & $\begin{array}{l}17.9 \\
16.7 \\
15.20 \\
14.07 \\
13.21 \\
12.27\end{array}$ & $\begin{array}{l}36,900 \\
31,700 \\
26,100 \\
22,400 \\
19,700 \\
17,000\end{array}$ & $\begin{array}{l}6.76 \\
6.64 \\
6.51 \\
6.40 \\
6.28 \\
6.18\end{array}$ & $\begin{array}{l}5,010 \\
4,810 \\
4,610 \\
4,440 \\
4,260 \\
4,110\end{array}$ & $\begin{array}{c}- \\
4.73 \\
- \\
4.63 \\
- \\
4.54\end{array}$ & $\begin{array}{l}2,240 \\
- \\
2,140 \\
- \\
2,050\end{array}$ \\
\hline & \multicolumn{2}{|c|}{ September 24} & \multicolumn{2}{|c|}{ September 25} & \multicolumn{2}{|c|}{ September 26} & \multicolumn{2}{|c|}{ September 27} & \multicolumn{2}{|c|}{ September 28} & \multicolumn{2}{|c|}{ September 29} \\
\hline 2 & - & - & & - & & - & - & - & - & - & - & - \\
\hline 4 & 4.37 & 1,880 & 3.63 & 1,210 & 3.18 & 887 & - & - & - & - & - & - \\
\hline O & 4.24 & $\overline{1,760}$ & 3.54 & $\overline{1,140}$ & 3.13 & & $\overline{-}$ & - & $\overline{-}$ & $\overline{-}$ & - & $\overline{-}$ \\
\hline 10 & & & & & & & - & & & & & \\
\hline $\mathbf{N}$ & 4.11 & 1,640 & 3.44 & 1,070 & 3.09 & 828 & $\# 2.80$ & $* 650$ & $* 2.77$ & $* 634$ & *2.69 & *590 \\
\hline 2 & - & - & - & - & - & & - & - & - & - & - & - \\
\hline 4 & 3.96 & 1,500 & 3.37 & 1,020 & 3.03 & 790 & - & - & - & - & - & - \\
\hline & 3.83 & $\overline{1,390}$ & 3.28 & -956 & 2.93 & & - & & - & - & $\overline{-}$ & $\overline{-}$ \\
\hline 10 & - & & 0.20 & & 2.00 & & $\overline{-}$ & $\overline{-}$ & - & 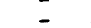 & $\overline{-}$ & 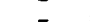 \\
\hline M & 3.72 & 1,290 & 3.22 & 914 & 2.86 & 686 & - & - & - & & - & - \\
\hline
\end{tabular}

Supplemental records.- Sept. $20,1: 30$ p.m., $6.88 \mathrm{ft} ., 5,200$ sec.-ft. Sept. 21 , $6: 30$ p.m., $17.95 \mathrm{ft} ., 37,100$ sec. $-\mathrm{ft}$.

* Mean for the day. 
Location.- Water-stage recorder, lat. $41^{\circ} 54^{\prime} 35^{\prime \prime}$, long. $72^{\circ} 45^{\prime} 40^{\prime \prime}$, at Tariffville, Hartford County, half a mile above Hartford Electric Light Co.'s plant, three-quarters of a mile below Salmon Brook, and 12 miles above mouth.

Drainage area.- 578 square miles.

Gage-he1ght record.- Water-stage recorder graph except for period 9 a.m. Sept. 10 to 4 p.m. Sept. 26. Gage-height graph determined from power plant data for period midnight sept. 18 to 3 p.m. Sept. 26.

Stage-discharge relation.- Varies with number of generators operating at power plant. Base rating curves developed for one and two generators operating at full capacity and for flow over splliway of dam with no generators operating. These ratings are correlated by stage relationship curves and are basically defined by discharge measurements and computations of flow over dam. Stage-graph adjusted for periods when generators running at less than full capacity. One-generator rating used Sept. 1-10; spillmay rating, Sept. 18-25; and two-generator rating, Sept. 26 to 0 ct. 31.

Maxima.- September 1938: Discharge, 29,900 second-feet 3-4 p.m. Sept. 22 (gage height, 14.0 feet, from floodmarks).

1928 to August 1938: 'D1scharge, 26,900 second-feet (revised) Mar. 19, 1936 (gage helght, 13.4 feet).

Remarks.- Discharge during period of faulty gage-helght record based on operation records of Hartford Electric Ilght Co.'s power plant, half a mile below. Flood runoff affected by artificial storage in reservoirs on main and tributary streams. For information on storage see records for Otis Reservoir at Cold Spring, Mass. Barkhamstead Reservoir near Barkhamstead, Conn., East Branch Reservoir at New Hartford, Conn., and Nepaüg Reservolr near Collinsville, Conn.

Mean daily discharge, in second-feet, 1938

\begin{tabular}{|c|c|c|c|c|c|c|c|c|c|c|c|}
\hline Day & Sept. & Oct. & Day & Sept. & Oct. & Day & Sept. & Oct. & Day & Sept. & Oct. \\
\hline $\begin{array}{l}1 \\
2 \\
3 \\
4 \\
5 \\
6 \\
7 \\
8\end{array}$ & $\begin{array}{l}566 \\
584 \\
462 \\
326 \\
300 \\
346 \\
532 \\
588\end{array}$ & $\begin{array}{l}2,000 \\
1,850 \\
1,630 \\
1,440 \\
1,660 \\
1,610 \\
1,500 \\
1,400\end{array}$ & $\begin{array}{r}9 \\
10 \\
11 \\
12 \\
13 \\
14 \\
15 \\
16\end{array}$ & $\begin{array}{l}602 \\
470 \\
340 \\
370 \\
580 \\
650 \\
710 \\
790\end{array}$ & $\begin{array}{r}823 \\
836 \\
1,280 \\
1,300 \\
1,280 \\
1,060 \\
846 \\
780\end{array}$ & $\begin{array}{l}17 \\
18 \\
19 \\
20 \\
21 \\
22 \\
23 \\
24\end{array}$ & $\begin{array}{r}650 \\
580 \\
1,110 \\
3,960 \\
8,210 \\
24,500 \\
16,500 \\
7,790\end{array}$ & $\begin{array}{r}832 \\
846 \\
839 \\
852 \\
1,240 \\
1,360 \\
976 \\
998\end{array}$ & $\begin{array}{l}25 \\
26 \\
27 \\
28 \\
29 \\
30 \\
31\end{array}$ & $\begin{array}{l}3,880 \\
2,440 \\
2,440 \\
2,310 \\
2,080 \\
1,980\end{array}$ & $\begin{array}{r}2,030 \\
1,750 \\
1,360 \\
1,280 \\
1,210 \\
1,010 \\
862\end{array}$ \\
\hline \multicolumn{6}{|c|}{$\begin{array}{l}\text { Mean monthly discharge, } \\
\text { Run-off, in inches. }\end{array}$} & . & $\cdot \cdot \cdot \cdot$ & $: \div:$ & $: \dot{ }$ & $\begin{array}{r}2,888 \\
5.58\end{array}$ & $\begin{array}{r}1,250 \\
2.49\end{array}$ \\
\hline
\end{tabular}

Gage height, In feet, and discharge, in second-feet, at indicated time, 1938

\begin{tabular}{|c|c|c|c|c|c|c|c|c|c|c|c|c|}
\hline \multirow{2}{*}{ 丞 } & Feet & Sec.ft. & Feet & Sec.ft. & Feet & Sec.ft. & Feet & Sec.ft. & Feet & Sec.ft. & Feet & Sec.ft. \\
\hline & \multicolumn{2}{|c|}{ September 18} & \multicolumn{2}{|c|}{ Septomber 19} & \multicolumn{2}{|c|}{ September 20} & \multicolumn{2}{|c|}{ September 21} & \multicolumn{2}{|c|}{ September 22} & \multicolumn{2}{|c|}{ September 23} \\
\hline 1 & - & - & - & - & - & - & - & - & - & 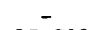 & $-2+a$ & 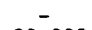 \\
\hline$\overline{2}$ & - & - & 2.65 & 590 & 4.7 & 2,440 & 7.1 & 6,190 & 10.65 & 15,200 & 12.4 & 22,200 \\
\hline 3 & - & - & & & - & & - & - & - & - & & \\
\hline 4 & - & - & 2.8 & 680 & 5.2 & 3,070 & 7.4 & 6,790 & 11.3 & 17,600 & 12.0 & 20,400 \\
\hline 5 & - & - & - & & - & - & - & - & - & חח & & \\
\hline 6 & - & - & 2.95 & 785 & 5.45 & 3,420 & 7.3 & 6,590 & 12.0 & 20,400 & 11.7 & 19,200 \\
\hline 7 & - & - & - & & - & & - & - & - & - & - & - \\
\hline 8 & - & - & 3.05 & 855 & 5.6 & 3,640 & 7.3 & 6,590 & 12.65 & 23,300 & 11.4 & 18,000 \\
\hline 9 & - & - & - & & - & - & - & - & - & - & - & - \\
\hline 10 & - & - & 3.15 & 930 & 5.7 & 3,790 & 7.65 & 7,300 & 13.25 & 26,200 & 11.15 & 17,000 \\
\hline 11 & *2. & $\overline{-}$ & - & - & 5 & - & - & - & - & - & 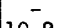 & 10 10 \\
\hline N & $* 2.63$ & $\star 580$ & 3.3 & 1,050 & 5.75 & 3,860 & 7.8 & 7,620 & 13.75 & 28,600 & 10.9 & 16,000 \\
\hline 1 & - & - & - & - & - & - & - & - & - & - & - & - \\
\hline $\overrightarrow{2}$ & - & - & 3.4 & 1,130 & 5.85 & 4,020 & 8.15 & 8,380 & 13.95 & 29,600 & 10.65 & 15,200 \\
\hline 3 & - & - & - & & - & - & - & - & - & - & - & - \\
\hline 4 & - & - & 3.55 & 1,250 & 6.15 & 4,490 & 8.5 & 9,150 & 14.0 & 29,900 & 10.4 & 14,300 \\
\hline $\begin{array}{l}5 \\
6\end{array}$ & - & - & $\overline{3.75}$ & 1,420 & 6.35 & 4,820 & 8.7 & 9,610 & 13.9 & 29,400 & 10.1 & $13 \overline{, 400}$ \\
\hline & & & & & & & & & & & & \\
\hline 7 & - & - & - & - & - & - & - & - & - & - & - & - \\
\hline 8 & - & - & 3.95 & 1,600 & 6.4 & 4,910 & 8.85 & 9,960 & 13.7 & 28,400 & 9.9 & 12,800 \\
\hline 9 & - & - & - & - & - & - & - & - & - & a & - & - \\
\hline 10 & - & & 4.15 & 1,800 & 6.6 & 5,260 & 9.3 & 11,000 & 13.4 & 26,900 & 9.65 & 12,000 \\
\hline 11 & - & & - & - & - & $5-620$ & - & $13^{-}$ & $32^{-}$ & $24^{-}$ & $9^{-}$ & $11^{-} 300$ \\
\hline & & & & & & $0,0<0$ & \multirow{2}{*}{\multicolumn{2}{|c|}{ September 27}} & \multirow{2}{*}{\multicolumn{2}{|c|}{ September 28}} & \multirow{2}{*}{\multicolumn{2}{|c|}{ September 29}} \\
\hline & \multicolumn{2}{|c|}{ September 24} & \multicolumn{2}{|c|}{ September 25} & \multicolumn{2}{|c|}{ September 26} & & & & & & \\
\hline 2 & 9.05 & 10,400 & 6.45 & 5,000 & & 2,440 & - & 500 & - & - & - & - \\
\hline $\begin{array}{l}4 \\
6\end{array}$ & $\begin{array}{l}8.75 \\
8.45\end{array}$ & $\begin{array}{l}9,720 \\
9,040\end{array}$ & $\begin{array}{l}6.35 \\
6.2\end{array}$ & $\begin{array}{l}4,820 \\
4,570\end{array}$ & & $\begin{array}{l}2,330 \\
2,330\end{array}$ & $\begin{array}{c}4.15 \\
-\end{array}$ & 2,500 & $\begin{array}{c}4.05 \\
-\end{array}$ & & $\begin{array}{c}3.89 \\
-\end{array}$ & 2,22 \\
\hline 8 & $\begin{array}{l}8.2 \\
7.95\end{array}$ & $\begin{array}{l}8,490 \\
7,940\end{array}$ & 6.05 & $\begin{array}{l}4,330 \\
4,30\end{array}$ & 4.15 & 2,500 & 4.26 & 2,620 & $\begin{array}{c}4.12 \\
-\end{array}$ & 2,460 & 3.93 & 2,260 \\
\hline N & & & 5.8 & 3,940 & 4.2 & 2,550 & 4.26 & 2,620 & 4.12 & 2,460 & 3.88 & 2,210 \\
\hline 2 & 7.6 & 7,200 & 5.7 & 3,790 & 4.2 & 2,550 & - & - & - & - & - & - \\
\hline 4 & 7.45 & 6,890 & 5.5 & 3,490 & 4.15 & 2,500 & 4.07 & 2,410 & 3.96 & 2,290 & 3.64 & 1,970 \\
\hline $\begin{array}{l}6 \\
8\end{array}$ & $\begin{array}{l}7.3 \\
7.0\end{array}$ & $\begin{array}{l}6,590 \\
6,000\end{array}$ & $\begin{array}{l}5.25 \\
5.05\end{array}$ & $\begin{array}{l}3,140 \\
2,880\end{array}$ & $\begin{array}{l}4.1 \\
4.0\end{array}$ & $\begin{array}{l}2,440 \\
2,330\end{array}$ & $\overline{3.89}$ & 2,220 & 3.80 & 2,130 & 3.52 & 1,860 \\
\hline 10 & & & 4.9 & 2,680 & 4.0 & 2,330 & - & - & - & - & - & - \\
\hline M & 6.55 & 5,170 & 4.8 & 2,560 & & 2,330 & 3.91 & 2,240 & 3.74 & 2,070 & 3.52 & 1,860 \\
\hline
\end{tabular}

* Mean for the day based upon power plant data. 


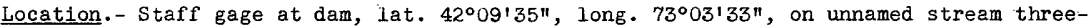
quarters of a mile above confluence with Farmington River and 1 mile northeast of Cold Spring, Hampden County

Drainage area.- 17.2 square miles.

Gage-height record.- One gage reading daily, usually at 7 a.m. Gage height at midnight from graph based on gage-height readings, and correlated with study of gate operation and weather records.

Stage-discharge relation.- Observed discharge computed from records of gate openings and slight flow over spillway.

Remarks.- Mean deily and monthly discharges adjusted for gain or loss in storage in otis Reservoir. No adjustments for evaporation from reservoir surface. Records based on data furnished by the Collins Co., Collinsville, Conn.

Mean discharge, in second-feet, and gain or loss in storage, in equivalent mean second-feet, 1938

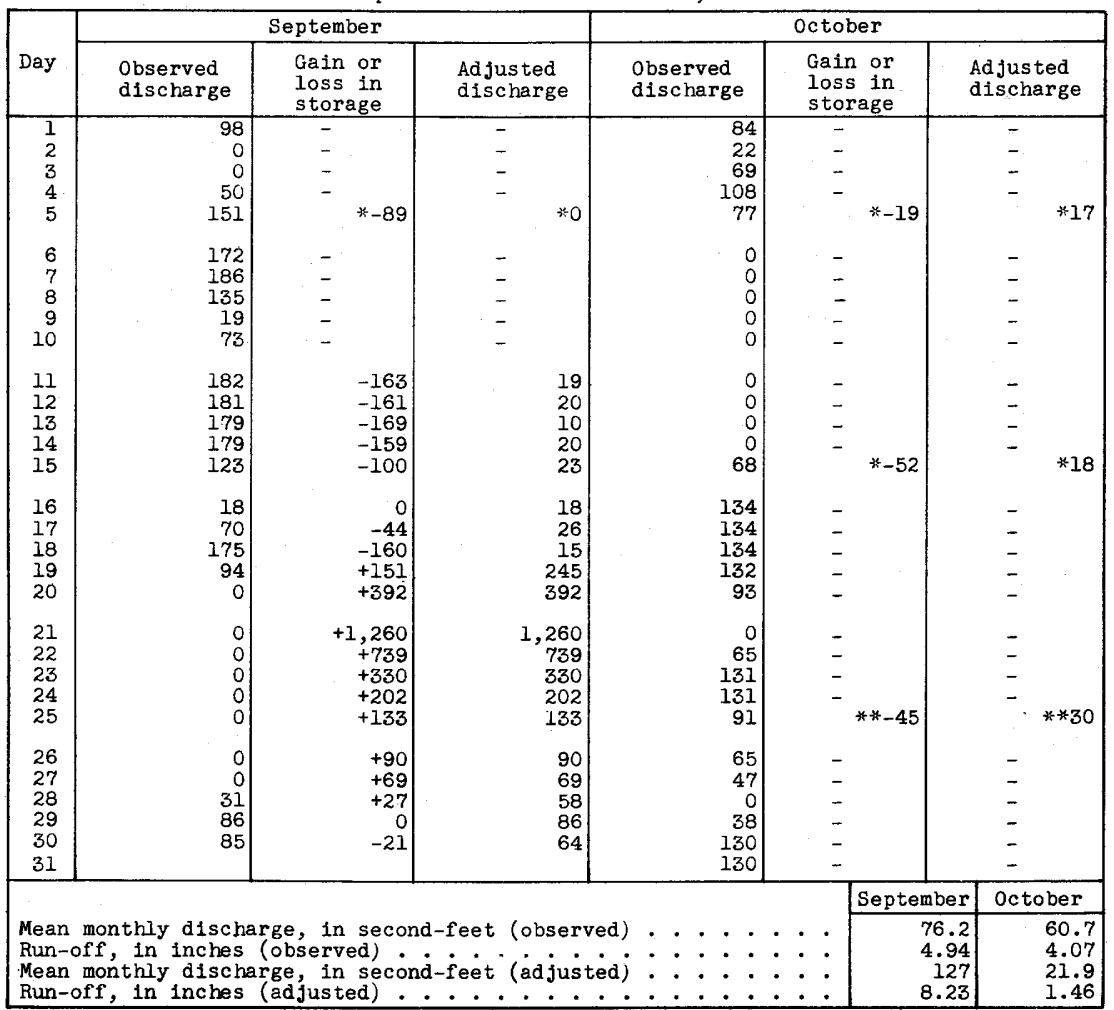

* Mean for 10-day period. * Mean for 1l-day period. 
Barkhamsted Reservoir near Barkhamsted, Conn.

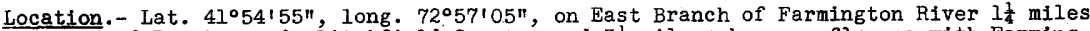
south of Barkhamsted, Litchfield County, and $3 \frac{1}{2}$ miles above confluence with Farmington River.

Dralnage area. - 50.5 square miles.

Remarks.- Elevations of reservoir surface are for 8 a.m. Gain or loss in $s$ torage is for 24-hour period prior to $8 \mathrm{a} . \mathrm{m}$. Data furnished by Water Bureau of the Metropolitan District Commission, Hartford, Conn.

Elevation, in feet, and gain or loss in storage, in millions of gallons, 1938

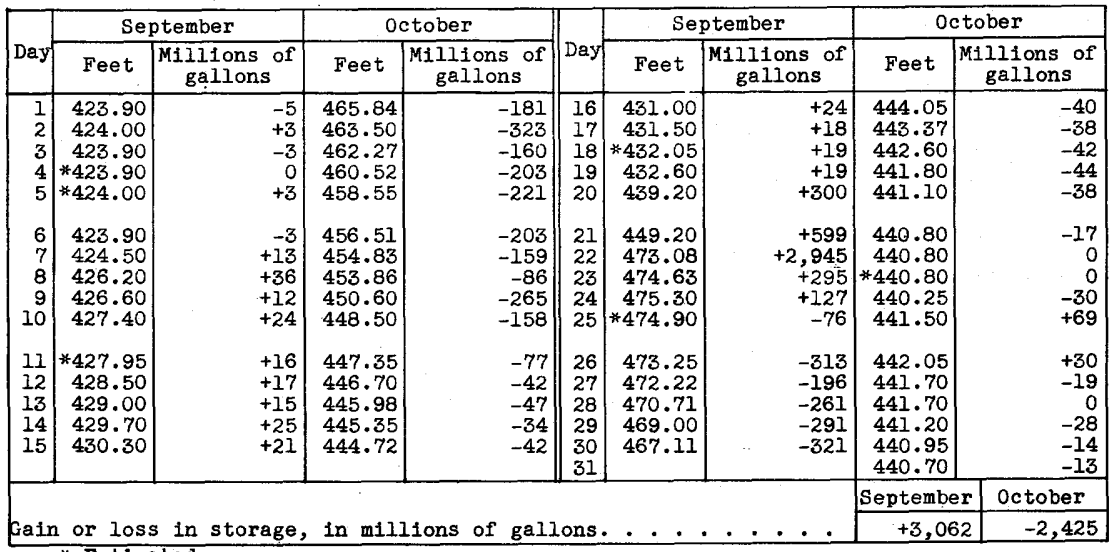

* Estimated. 
East Branch Reservoir at New Hartford, Conn.

Location.- Lat. $41^{\circ} 52^{\prime} 5^{\prime \prime}$, long. $72^{\circ} 57^{\prime} 2^{\prime \prime}$, on East Branch of Farmington River I mile east of New Hartford, Hartford County, and $1 \frac{1}{4}$ miles above confluence with Farmington River.

Drainage area.- 61.2 square miles.

Remarks.- Elevations of reservoir surface are for 8 a.m. Elevation of crest of spillway, 422.5 feet. Gain or loss in storage is for 24 -hour pertod previous to 8 a.m.

Data furnished by Water Bureau of the Metropolitan District Commission, Hartford, Conn.

Elevation, in feet, and gain or loss in storage, in millions of gallons, 1938

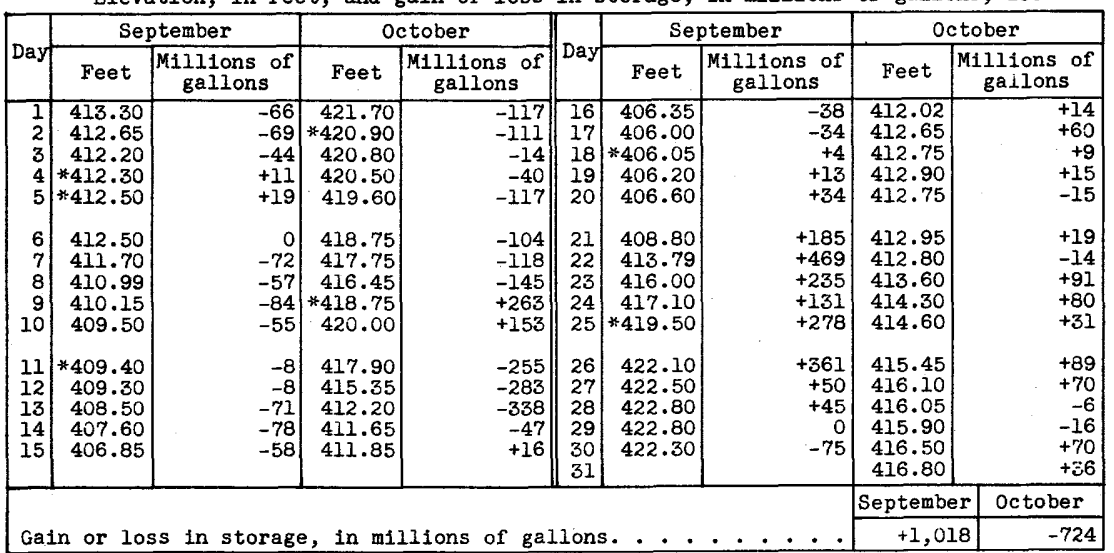

* istimated. 
Nepaug Reservoir near Collinsville, Conn.

Location.- Lat. $41^{\circ} 49^{\prime} 40^{\prime \prime}$, long. $72^{\circ} 56^{\prime} 05^{n}$, on Nepaug River three-quarters of a mile above confluence with Farmington River and $1 \frac{1}{2}$ miles northwest of Collinsville, Hartford County.

Drainage area.- 32.0 square miles.

Remarks.- Elevations of reservoir surface are for 8 a.m. Elevation of crest of spillway, 485.0 feet. Gain or loss in storage is for 24-hour period prior to 8 a.m. Diversions for Hartford water supply are for calendar day. Data furnished by Water Bureau of the Metropolitan District Commission, Hartford, Conn.

Elevation, in feet, gain or loss in storage, in millions of gallons, and diversions, in millions of gallons, 1938

\begin{tabular}{|c|c|c|c|c|c|c|c|c|}
\hline \multirow[b]{2}{*}{ Day } & \multicolumn{3}{|c|}{ September } & \multicolumn{5}{|c|}{ October } \\
\hline & Elevation & $\begin{array}{l}\text { Gain or } \\
\text { loss in } \\
\text { storage }\end{array}$ & Diversion & Elevation & $\begin{array}{l}\text { Gain } \\
\text { loss } \\
\text { stora }\end{array}$ & $\begin{array}{l}\text { or } \\
\text { in } \\
\text { age }\end{array}$ & $\mathrm{Di}$ & version \\
\hline $\begin{array}{l}1 \\
2 \\
3 \\
4 \\
5\end{array}$ & $\begin{array}{l}484.36 \\
484.29 \\
484.24 \\
484.18 \\
484.08\end{array}$ & $\begin{array}{r}-8.2 \\
-19.2 \\
-13.7 \\
-16.4 \\
-27.4\end{array}$ & $\begin{array}{l}25.0 \\
25.0 \\
25.0 \\
25.0 \\
25.0\end{array}$ & $\begin{array}{l}484.54 \\
484.56 \\
484.56 \\
484.57 \\
484.57\end{array}$ & & $\begin{array}{r}+8.2 \\
+5.5 \\
0 \\
+2.7 \\
0\end{array}$ & & $\begin{array}{l}25.0 \\
25.0 \\
25.0 \\
25.0 \\
25.0\end{array}$ \\
\hline $\begin{array}{r}6 \\
7 \\
8 \\
9 \\
10\end{array}$ & $\begin{array}{l}484.03 \\
483.98 \\
483.91 \\
483.85 \\
483.78\end{array}$ & $\begin{array}{l}-13.7 \\
-13.7 \\
-19.1 \\
-16.4 \\
-19.1\end{array}$ & $\begin{array}{l}25.0 \\
25.0 \\
25.0 \\
25.0 \\
25.0\end{array}$ & $\begin{array}{l}484.57 \\
484.57 \\
484.57 \\
484.56 \\
484.55\end{array}$ & & $\begin{array}{r}0 \\
0 \\
0 \\
-2.7 \\
-2.7\end{array}$ & & $\begin{array}{l}25.0 \\
25.0 \\
25.0 \\
25.0 \\
25.0\end{array}$ \\
\hline $\begin{array}{l}11 \\
12 \\
13 \\
14 \\
15\end{array}$ & $\begin{array}{l}483 \cdot 69 \\
483 \cdot 64 \\
483 \cdot 58 \\
483 \cdot 52 \\
483.51\end{array}$ & $\begin{array}{r}-24.5 \\
-13.6 \\
-16.3 \\
-16.3 \\
-2.7\end{array}$ & $\begin{array}{l}25.0 \\
25.6 \\
28.0 \\
27.3 \\
25.0\end{array}$ & $\begin{array}{l}484.53 \\
484.52 \\
484.51 \\
484.53 \\
484.53\end{array}$ & & $\begin{array}{r}-5.5 \\
-2.7 \\
-2.7 \\
+5.5 \\
0\end{array}$ & & $\begin{array}{l}25.0 \\
25.0 \\
25.0 \\
25.0 \\
25.0\end{array}$ \\
\hline $\begin{array}{l}16 \\
17 \\
18 \\
19 \\
20\end{array}$ & $\begin{array}{l}483.48 \\
483.41 \\
483.39 \\
483.48 \\
483.98\end{array}$ & $\begin{array}{r}-8.2 \\
-19.0 \\
-5.4 \\
+24.4 \\
+136.3\end{array}$ & $\begin{array}{l}25.0 \\
25.0 \\
25.0 \\
26.6 \\
28.0\end{array}$ & $\begin{array}{l}484.54 \\
484.54 \\
484.52 \\
484.50 \\
484.48\end{array}$ & & $\begin{array}{r}+2.7 \\
0 \\
-5.5 \\
-5.5 \\
-5.5\end{array}$ & & $\begin{array}{l}25.0 \\
25.0 \\
25.0 \\
25.0 \\
25.0\end{array}$ \\
\hline $\begin{array}{l}21 \\
22 \\
23 \\
24 \\
25\end{array}$ & $\begin{array}{l}485 \cdot 40 \\
486.92 \\
485.74 \\
485.35 \\
485.10\end{array}$ & $\begin{array}{r}+391.1 \\
+425.3 \\
-330.8 \\
-108.5 \\
-69.3\end{array}$ & $\begin{array}{r}16.3 \\
0 \\
9.4 \\
25.0 \\
25.0\end{array}$ & $\begin{array}{l}484.62 \\
484.79 \\
484.77 \\
484.90 \\
484.84\end{array}$ & & $\begin{array}{r}+38.5 \\
+46.8 \\
-5.5 \\
+35.8 \\
-16.5\end{array}$ & & $\begin{array}{l}25.0 \\
25.0 \\
25.0 \\
25.0 \\
25.0\end{array}$ \\
\hline \multirow[t]{2}{*}{$\begin{array}{l}26 \\
27 \\
28 \\
29 \\
30 \\
31\end{array}$} & $\begin{array}{l}484.95 \\
484 \cdot 74 \\
484.50 \\
484.46 \\
484.51\end{array}$ & $\begin{array}{l}-41.5 \\
-57.9 \\
-66.0 \\
-11.0 \\
+13.7\end{array}$ & $\begin{array}{l}25.0 \\
25.0 \\
25.0 \\
25.0 \\
25.0\end{array}$ & $\begin{array}{l}484.68 \\
484.42 \\
484.14 \\
483.87 \\
483.78 \\
483.81\end{array}$ & & $\begin{array}{r}-44.1 \\
-71.5 \\
-76.8 \\
-73.8 \\
-24.6 \\
+8.2\end{array}$ & & $\begin{array}{l}25.0 \\
25.0 \\
25.0 \\
25.0 \\
25.0 \\
25.0\end{array}$ \\
\hline & & & & & & \multicolumn{2}{|c|}{ September } & October \\
\hline $\begin{array}{l}\text { Gain } \\
\text { Dive }\end{array}$ & $\begin{array}{l}\text { or loss in sto } \\
\text { sion in milito }\end{array}$ & $\begin{array}{l}\text { age, in mill } \\
\text { is of gallons }\end{array}$ & $\begin{array}{l}\text { ons of gallor } \\
. .\end{array}$ & .....+ & 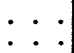 & \multicolumn{2}{|c|}{\begin{tabular}{|l|}
+32.9 \\
711.2
\end{tabular}} & $\begin{array}{r}-191.7 \\
775.0\end{array}$ \\
\hline
\end{tabular}


Burlington Brook near Burlington, Conn.

Location.- Water-stage recorder and artificial control, lat. $41^{\circ} 4^{\prime} 7^{\prime} 0^{\prime \prime}, 10 n g .72^{\circ} 57^{\prime} 55^{\prime \prime}$, It miles north of Burlington, Hartford County, $2 \frac{1}{2}$ miles above mouth, and $3 \mathrm{miles}$ southwest of Collinsville.

Drainage area.- 4.1 square miles.

Gage-helght record.- Water-stage recorder graph.

Stage-discharge relation.- Artificial control consists of a sharp-edged orifice 1 foot square and a sharp-crested rectangular welr 12 feet long with end contrections 5 feet high. Crest of weir is at gage height of 1.02 feet, 1.02 feet above bottom edge of orifice. Reting curve developed from formula and coefficients and checked by currentmeter measurements below 321 second-feet.

Maxima.- September 1938: Discharge, 645 second-feet 6:30 p.m. Sept. 21 (gage helght, 7.24 feet).

1931 to August 1938: D1scharge, 503 second-feet Mar. 12, 1936 (gage height, 6.58 feet).

Remarks.- Flood run-off not affected by artificlal storege.

Mean dally alscharge, in second-feet, 1938

\begin{tabular}{|c|c|c|c|c|c|c|c|c|c|c|c|}
\hline Day & Sept. & Oct. & Day & Sept. & Oct. & Day & Sept. & Oct. & Day & Sept. & Oct. \\
\hline $\begin{array}{l}1 \\
2 \\
3 \\
4 \\
5 \\
6 \\
7 \\
8\end{array}$ & $\begin{array}{l}2.90 \\
2.46 \\
2.33 \\
2.33 \\
2.13 \\
2.05 \\
2.31 \\
2.62\end{array}$ & $\begin{array}{l}6.85 \\
6.30 \\
6.03 \\
5.77 \\
5.52 \\
5.52 \\
5.26 \\
5.26\end{array}$ & $\begin{array}{r}9 \\
10 \\
11 \\
12 \\
13 \\
14 \\
15 \\
16\end{array}$ & $\begin{array}{l}2.21 \\
2.13 \\
2.09 \\
2.09 \\
2.67 \\
2.29 \\
3.16 \\
2.93\end{array}$ & $\begin{array}{l}5.02 \\
5.02 \\
4.78 \\
4.78 \\
4.78 \\
6.30 \\
5.52 \\
4.78\end{array}$ & $\begin{array}{l}17 \\
18 \\
19 \\
20 \\
21 \\
22 \\
23 \\
24\end{array}$ & $\begin{array}{c}2.77 \\
4.44 \\
22.2 \\
44.1 \\
219 \\
61.8 \\
21.1 \\
15.0\end{array}$ & $\begin{array}{c}4.55 \\
4.55 \\
4.55 \\
4.78 \\
15.1 \\
7.41 \\
6.03 \\
15.3\end{array}$ & $\begin{array}{l}25 \\
26 \\
27 \\
28 \\
29 \\
30 \\
31\end{array}$ & $\begin{array}{c}11.6 \\
10.0 \\
9.08 \\
8.33 \\
7.59 \\
7.41\end{array}$ & $\begin{array}{c}16.6 \\
8.63 \\
7.41 \\
6.57 \\
8.32 \\
7.13 \\
6.30\end{array}$ \\
\hline $\begin{array}{l}\text { Yean } \\
\text { Run- }\end{array}$ & $\begin{array}{l}\text { nthly } \\
\text {, in } 1\end{array}$ & & In & econd- & et. . & . & 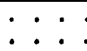 & . : & $\dot{*}$ & $\begin{array}{r}16.1 \\
4.38\end{array}$ & $\begin{array}{l}6.80 \\
1.91\end{array}$ \\
\hline
\end{tabular}

Gage height, In feet, and discharge, in second-feet, at indicated time, 1938

\begin{tabular}{|c|c|c|c|c|c|c|c|c|c|c|c|c|}
\hline \multirow{2}{*}{$\begin{array}{l}8 \\
\text { 党 } \\
\text { 足 }\end{array}$} & Feet & Sec.et. & Feet & Sec.ft. & Feet & Sec.ft. & Feet & Sec.ft. & Feet & Sec.ft. & Feet & Sec.ft. \\
\hline & \multicolumn{2}{|c|}{ September 18} & \multicolumn{2}{|c|}{ September 19} & \multicolumn{2}{|c|}{ September 20} & \multicolumn{2}{|c|}{ September 21} & \multicolumn{2}{|c|}{ September 22} & \multicolumn{2}{|c|}{ September 23} \\
\hline $\begin{array}{l}1 \\
2 \\
3 \\
4 \\
5 \\
6\end{array}$ & $\begin{array}{l}1.16 \\
1.15 \\
1.14 \\
1.12 \\
1.11 \\
1.11\end{array}$ & $\begin{array}{l}6.03 \\
5.77 \\
5.52 \\
5.02 \\
4.78 \\
4.78\end{array}$ & $\begin{array}{l}1.16 \\
1.24 \\
1.32 \\
1.37 \\
1.42 \\
1.48\end{array}$ & $\begin{array}{c}6.03 \\
8.32 \\
11.0 \\
12.8 \\
14.7 \\
17.2\end{array}$ & $\begin{array}{l}1.83 \\
1.78 \\
1.74 \\
1.73 \\
1.72 \\
1.71\end{array}$ & $\begin{array}{l}34.3 \\
31.6 \\
29.5 \\
29.0 \\
28.5 \\
27.9\end{array}$ & $\begin{array}{l}2.31 \\
2.29 \\
2.39 \\
2.68 \\
2.96 \\
3.11\end{array}$ & $\begin{array}{r}64 \\
62 \\
69 \\
90 \\
111 \\
124\end{array}$ & $\begin{array}{l}3.37 \\
3.12 \\
2.93 \\
2.77 \\
2.61 \\
2.51\end{array}$ & $\begin{array}{r}145 \\
125 \\
109 \\
97 \\
85 \\
77\end{array}$ & $\begin{array}{l}1.67 \\
1.66 \\
1.64 \\
1.63 \\
1.62 \\
1.61\end{array}$ & $\begin{array}{l}26.0 \\
25.5 \\
24.5 \\
24.0 \\
23.5 \\
23.0\end{array}$ \\
\hline $\begin{array}{r}7 \\
8 \\
9 \\
10 \\
11 \\
\mathrm{~N}\end{array}$ & $\begin{array}{l}1.10 \\
1.09 \\
1.09 \\
1.08 \\
1.08 \\
1.08\end{array}$ & $\begin{array}{l}4.55 \\
4.33 \\
4.33 \\
4.13 \\
4.13 \\
4.13\end{array}$ & $\begin{array}{l}1.51 \\
1.53 \\
1.54 \\
1.53 \\
1.52 \\
1.53\end{array}$ & $\begin{array}{l}18.5 \\
19.4 \\
19.8 \\
19.4 \\
18.9 \\
19.4\end{array}$ & $\begin{array}{l}1.72 \\
1.74 \\
1.76 \\
1.78 \\
1.82 \\
1.89\end{array}$ & $\begin{array}{l}28.5 \\
29.5 \\
30.6 \\
31.6 \\
33.7 \\
37.6\end{array}$ & $\begin{array}{l}3.19 \\
3.26 \\
3.41 \\
3.73 \\
4.00 \\
4.17\end{array}$ & $\begin{array}{l}130 \\
136 \\
149 \\
177 \\
202 \\
218\end{array}$ & $\begin{array}{l}2.40 \\
2.32 \\
2.25 \\
2.18 \\
2.15 \\
2.08\end{array}$ & $\begin{array}{l}70 \\
64 \\
60 \\
55 \\
52 \\
48.8\end{array}$ & $\begin{array}{l}1.60 \\
1.59 \\
1.58 \\
1.57 \\
1.57 \\
1.56\end{array}$ & $\begin{array}{l}22.5 \\
22.1 \\
21.6 \\
21.2 \\
21.2 \\
20.7\end{array}$ \\
\hline $\begin{array}{l}1 \\
2 \\
3 \\
4 \\
5 \\
6\end{array}$ & $\begin{array}{l}1.08 \\
1.07 \\
1.07 \\
1.07 \\
1.07 \\
1.07\end{array}$ & $\begin{array}{l}4.13 \\
3.93 \\
3.93 \\
3.93 \\
3.93 \\
3.93\end{array}$ & $\begin{array}{l}1.54 \\
1.57 \\
1.61 \\
1.66 \\
1.72 \\
1.76\end{array}$ & $\begin{array}{l}19.8 \\
21.2 \\
23.0 \\
25.5 \\
28.5 \\
30.6\end{array}$ & $\begin{array}{l}1.97 \\
2.13 \\
2.26 \\
2.31 \\
2.29 \\
2.27\end{array}$ & $\begin{array}{l}42.2 \\
52 \\
60 \\
64 \\
62 \\
61\end{array}$ & $\begin{array}{l}4.21 \\
4.09 \\
3.91 \\
3.85 \\
5.35 \\
7.01\end{array}$ & $\begin{array}{l}222 \\
211 \\
194 \\
188 \\
340 \\
590\end{array}$ & $\begin{array}{l}2.04 \\
1.99 \\
1.95 \\
1.92 \\
1.88 \\
1.85\end{array}$ & $\begin{array}{l}46.4 \\
43.4 \\
41.0 \\
39.3 \\
37.0 \\
35.4\end{array}$ & $\begin{array}{l}1.56 \\
1.55 \\
1.54 \\
1.53 \\
1.53 \\
1.52\end{array}$ & $\begin{array}{l}20.7 \\
20.3 \\
19.8 \\
19.4 \\
19.4 \\
18.9\end{array}$ \\
\hline \multirow[t]{2}{*}{$\begin{array}{r}7 \\
8 \\
9 \\
10 \\
11 \\
M\end{array}$} & $\begin{array}{l}1.07 \\
1.07 \\
1.07 \\
1.07 \\
1.09 \\
1.12\end{array}$ & $\begin{array}{l}3.93 \\
3.93 \\
3.93 \\
3.93 \\
4.33 \\
5.02\end{array}$ & $\begin{array}{l}1.80 \\
1.84 \\
1.87 \\
1.90 \\
1.87 \\
1.86\end{array}$ & $\begin{array}{l}32.6 \\
34.8 \\
36.5 \\
38.1 \\
36.5 \\
35.9\end{array}$ & $\begin{array}{l}2.23 \\
2.20 \\
2.21 \\
2.27 \\
2.30 \\
2.32\end{array}$ & $\begin{array}{l}58 \\
56 \\
57 \\
61 \\
63 \\
64\end{array}$ & $\begin{array}{l}7.00 \\
6.20 \\
5.30 \\
4.60 \\
4.09 \\
3.70\end{array}$ & $\begin{array}{l}588 \\
438 \\
334 \\
261 \\
211 \\
174\end{array}$ & $\begin{array}{l}1.81 \\
1.78 \\
1.76 \\
1.74 \\
1.71 \\
1.69\end{array}$ & $\begin{array}{l}33.2 \\
31.6 \\
30.6 \\
29.5 \\
27.9 \\
26.9\end{array}$ & $\begin{array}{l}1.51 \\
1.50 \\
1.50 \\
1.49 \\
1.48 \\
1.48\end{array}$ & $\begin{array}{l}18.5 \\
18.0 \\
18.0 \\
17.6 \\
17.2 \\
17.2\end{array}$ \\
\hline & \multicolumn{2}{|c|}{ September 24} & \multicolumn{2}{|c|}{ September 25} & \multicolumn{2}{|c|}{ September 26} & \multicolumn{2}{|c|}{ September 27} & \multicolumn{2}{|c|}{ September 28} & \multicolumn{2}{|c|}{ September 29} \\
\hline $\begin{array}{r}2 \\
4 \\
6 \\
8 \\
10 \\
N\end{array}$ & $\begin{array}{l}1.47 \\
1.46 \\
1.45 \\
1.45 \\
1.44 \\
1.43\end{array}$ & $\begin{array}{l}16.8 \\
16.4 \\
16.0 \\
16.0 \\
15.6 \\
15.1\end{array}$ & $\begin{array}{l}1.36 \\
1.36 \\
1.35 \\
1.35 \\
1.35 \\
1.34\end{array}$ & $\begin{array}{l}12.4 \\
12.4 \\
12.1 \\
12.1 \\
12.1 \\
11.7\end{array}$ & $\begin{array}{l}1.30 \\
1.30 \\
1.30 \\
1.30 \\
1.30 \\
1.30\end{array}$ & $\begin{array}{l}10.3 \\
10.3 \\
10.3 \\
10.3 \\
10.3 \\
10.3\end{array}$ & $\begin{array}{l}1.27 \\
1.27 \\
1.27 \\
1.27 \\
1.27 \\
1.27\end{array}$ & $\begin{array}{l}9.27 \\
9.27 \\
9.27 \\
9.27 \\
9.27 \\
9.27\end{array}$ & $\begin{array}{l}1.25 \\
1.25 \\
1.25 \\
1.25 \\
1.25 \\
1.24\end{array}$ & $\begin{array}{l}8.63 \\
8.63 \\
8.63 \\
8.63 \\
8.63 \\
8.32\end{array}$ & $\begin{array}{l}1.22 \\
1.22 \\
1.22 \\
1.22 \\
1.22 \\
1.22\end{array}$ & $\begin{array}{l}7.71 \\
7.71 \\
7.71 \\
7.71 \\
7.71 \\
7.71\end{array}$ \\
\hline $\begin{array}{r}2 \\
4 \\
6 \\
8 \\
10 \\
M\end{array}$ & $\begin{array}{l}1.42 \\
1.41 \\
1.39 \\
1.38 \\
1.37 \\
1.37\end{array}$ & $\begin{array}{l}14.7 \\
14.3 \\
13.6 \\
13.2 \\
12.8 \\
12.8\end{array}$ & $\begin{array}{l}1.33 \\
1.33 \\
1.32 \\
1.31 \\
1.30 \\
1.30\end{array}$ & $\begin{array}{l}11.4 \\
11.4 \\
11.0 \\
10.6 \\
10.3 \\
10.3\end{array}$ & $\begin{array}{l}1.30 \\
1.29 \\
1.28 \\
1.27 \\
1.27 \\
1.27\end{array}$ & $\begin{array}{r}10.3 \\
9.93 \\
9.60 \\
9.27 \\
9.27 \\
9.27\end{array}$ & $\begin{array}{l}1.27 \\
1.27 \\
1.25 \\
1.25 \\
1.25 \\
1.25\end{array}$ & $\begin{array}{l}9.27 \\
9.27 \\
8.63 \\
8.63 \\
8.63 \\
8.63\end{array}$ & $\begin{array}{l}1.24 \\
1.24 \\
1.23 \\
1.23 \\
1.22 \\
1.22\end{array}$ & $\begin{array}{l}8.32 \\
8.32 \\
8.00 \\
8.00 \\
7.71 \\
7.71\end{array}$ & $\begin{array}{l}1.22 \\
1.22 \\
1.21 \\
1.21 \\
1.20 \\
1.20\end{array}$ & $\begin{array}{l}7.71 \\
7.71 \\
7.41 \\
7.41 \\
7.13 \\
7.13\end{array}$ \\
\hline
\end{tabular}

Supplemental records:- Sept. $21,12: 40$ p.m., 4.22 ft., 223 sec.-ft.; 3:50 p.m., 3.78

ft., 182 sec.-ft.; $6: 30$ p.m., 7.24 ft., 645 sec.-ft. 


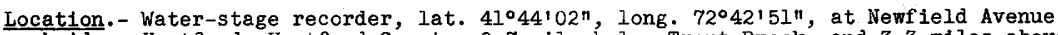
bridge, Hartford, Hartford County, 0.7 mile below Trout Brook and 3.3 miles above junction with North Branch of Park River. Zero of gage is 31.07 feet above mean sea level (general adjustment of 1929).

Drainage area.- 40.6 square miles.

Gage-height record.- Water-stage recorder graph; adjusted for varlable intake drawdown 6 a.m. Sept. 21 to 8 a.m. Sept. 22 .

Stage-discharge relation.- Seriously affected by rate of change of stage above gage height 5 feet. Base rating for no change in stage prior to 7 .m. Sept. 22 defined by current-meter measurements corrected for changing stage below 1,100 second-feet; extended to peak stage on basis of comparison with flow of North Branch of Park River and Park River. Base rating subsequent to 11 p.m. Sept. 22 defined by current-meter measurements corrected for changing stage. Transition rating used 7 to 11 p.m. Sept. 22. Above gage height 5 feet, rather poorly defined rating curves developed for different rates of change of stage on besis of results of several varylng-stage measurements. Correction applied for backwater from unkmown source sept. 1-18 and 0ct. 26-31.

Maxima.- September 1938: Discharge, 3,600 second-feet 10 p.n. Sept. 21 (adjusted gage height, 13.6 feet).

1936 to August 1938: Discharge, 2,860 second-feet Jan. 25, 1938 (adjusted gage helght, 12.15 feet). Flood of Mar. 12, 1936, reached a stage of 12.1 feet as determined from floodmarks by Hartford city engineers (discharge not determined). Remarks.- Flood rur-off not appreciably affected by artificial storage.

Mean da1ly discharge, in second-feet, 1938

\begin{tabular}{|c|c|c|c|c|c|c|c|c|c|c|c|}
\hline Day & Sept. & Oct. & Day & Sept. & Oct. & Day & Sept. & Oct. & Day & Sept. & Oct. \\
\hline $\begin{array}{l}1 \\
2 \\
3 \\
4 \\
5 \\
6 \\
7 \\
8\end{array}$ & $\begin{array}{l}26 \\
24 \\
22 \\
22 \\
23 \\
28 \\
26 \\
27\end{array}$ & $\begin{array}{l}71 \\
58 \\
58 \\
53 \\
53 \\
50 \\
46 \\
43\end{array}$ & $\begin{array}{r}9 \\
10 \\
11 \\
12 \\
13 \\
14 \\
15 \\
16\end{array}$ & $\begin{array}{l}24 \\
23 \\
23 \\
24 \\
30 \\
30 \\
42 \\
33\end{array}$ & $\begin{array}{l}43 \\
44 \\
44 \\
41 \\
40 \\
47 \\
58 \\
42\end{array}$ & $\begin{array}{l}17 \\
18 \\
19 \\
20 \\
21 \\
22 \\
23 \\
24\end{array}$ & $\begin{array}{r}32 \\
41 \\
306 \\
871 \\
3,080 \\
2,060 \\
519 \\
288\end{array}$ & $\begin{array}{l}43 \\
40 \\
37 \\
37 \\
60 \\
45 \\
38 \\
63\end{array}$ & $\begin{array}{l}25 \\
26 \\
27 \\
28 \\
29 \\
30 \\
31\end{array}$ & $\begin{array}{r}176 \\
128 \\
109 \\
86 \\
74 \\
70\end{array}$ & $\begin{array}{l}89 \\
65 \\
61 \\
59 \\
60 \\
56 \\
53\end{array}$ \\
\hline $\begin{array}{l}\text { Mean } \\
\text { Run- }\end{array}$ & $\begin{array}{l}\text { in } \\
\text { in }\end{array}$ & & $1 r$ & - . & t. & . & $\dot{0} \cdot \dot{ }$ & •. $\cdot \dot{ }$ & $: \dot{ }$ & $\begin{array}{r}276 \\
7.59 \\
\end{array}$ & $\begin{array}{l}51.5 \\
1.46 \\
\end{array}$ \\
\hline
\end{tabular}

Gage helght, in feet, and discharge, in second-feet, at indicated time, 1938

\begin{tabular}{|c|c|c|c|c|c|c|c|c|c|c|c|c|}
\hline \multirow{2}{*}{$\begin{array}{l}8 \\
0 \\
0 \\
\end{array}$} & Peet & Sec.ft. & Feet & Sec.ft. & Feet & Sec.ft. & Feet & Sec.ft. & Feet & Sec.ft. & Feet & Sec.ft. \\
\hline & \multicolumn{2}{|c|}{ September 18} & \multicolumn{2}{|c|}{ September 19} & \multicolumn{2}{|c|}{ September 20} & \multicolumn{2}{|c|}{ September 21} & \multicolumn{2}{|c|}{ Sept ember 22} & \multicolumn{2}{|c|}{ September 23} \\
\hline $\begin{array}{l}1 \\
2 \\
3 \\
4 \\
5 \\
6\end{array}$ & $\begin{array}{l}2.98 \\
2.80 \\
2.66 \\
2.52 \\
2.42 \\
2.35\end{array}$ & & $\begin{array}{l}3.40 \\
3.85 \\
4.13 \\
4.45 \\
4.76 \\
5.04\end{array}$ & $\begin{array}{l}122 \\
162 \\
188 \\
220 \\
251 \\
280\end{array}$ & $\begin{array}{l}6.47 \\
6.59 \\
6.71 \\
6.76 \\
6.79 \\
6.78\end{array}$ & \begin{tabular}{|l}
470 \\
525 \\
490 \\
500 \\
475 \\
470
\end{tabular} & $\begin{array}{r}9.55 \\
10.03 \\
10.51 \\
11.05 \\
11.48 \\
11.85\end{array}$ & $\begin{array}{l}1,760 \\
2,000 \\
2,210 \\
2,450 \\
2,620 \\
2,760\end{array}$ & $\begin{array}{l}13.4 \\
13.25 \\
13.1 \\
12.9 \\
12.65 \\
12.4\end{array}$ & $\begin{array}{l}3,490 \\
3,410 \\
3,330 \\
3,230 \\
3,090 \\
2,950\end{array}$ & $\begin{array}{l}7.44 \\
7.31 \\
7.16 \\
7.05 \\
6.95 \\
6.86\end{array}$ & $\begin{array}{r}765 \\
690 \\
685 \\
640 \\
600 \\
595\end{array}$ \\
\hline $\begin{array}{r}7 \\
8 \\
9 \\
10 \\
11 \\
\text { N }\end{array}$ & $\begin{array}{l}2.30 \\
2.27 \\
2.25 \\
2.23 \\
2.21 \\
2.20\end{array}$ & & $\begin{array}{l}5.23 \\
5.40 \\
5.55 \\
5.68 \\
5.75 \\
5.79\end{array}$ & $\begin{array}{l}310 \\
330 \\
350 \\
360 \\
355 \\
345\end{array}$ & $\begin{array}{l}6.77 \\
6.76 \\
6.80 \\
7.01 \\
7.24 \\
7.50\end{array}$ & $\begin{array}{l}470 \\
465 \\
575 \\
665 \\
765 \\
855\end{array}$ & $\begin{array}{l}12.15 \\
12.4 \\
12.7 \\
12.95 \\
13.2 \\
13.35\end{array}$ & $\begin{array}{l}2,920 \\
3,030 \\
3,170 \\
3,290 \\
3,420 \\
3,470\end{array}$ & $\begin{array}{l}12.15 \\
11.85 \\
11.60 \\
11.31 \\
11.02 \\
10.72\end{array}$ & $\begin{array}{l}2,810 \\
2,650 \\
2,500 \\
2,330 \\
2,160 \\
1,990\end{array}$ & $\begin{array}{l}6.78 \\
6.72 \\
6.65 \\
6.60 \\
6.55 \\
6.51\end{array}$ & $\begin{array}{l}590 \\
555 \\
540 \\
520 \\
505 \\
490\end{array}$ \\
\hline $\begin{array}{l}1 \\
2 \\
3 \\
4 \\
5 \\
6\end{array}$ & $\begin{array}{l}2.20 \\
2.19 \\
2.19 \\
2.19 \\
2.18 \\
2.17\end{array}$ & & $\begin{array}{l}5.77 \\
5.70 \\
5.60 \\
5.49 \\
5.45 \\
5.57\end{array}$ & $\begin{array}{l}305 \\
260 \\
260 \\
260 \\
320 \\
355\end{array}$ & $\begin{array}{l}7.73 \\
7.98 \\
8.22 \\
8.49 \\
8.68 \\
8.77\end{array}$ & $\begin{array}{r}935 \\
1,030 \\
1,130 \\
1,210 \\
1,260 \\
1,280\end{array}$ & $\begin{array}{l}13.4 \\
13.35 \\
13.3 \\
13.25 \\
13.25 \\
13.3\end{array}$ & $\begin{array}{l}3,490 \\
3,460 \\
3,440 \\
3,420 \\
3,420 \\
3,440\end{array}$ & $\begin{array}{r}10.43 \\
10.13 \\
9.84 \\
9.56 \\
9.29 \\
9.01\end{array}$ & $\begin{array}{l}1,850 \\
1,680 \\
1,520 \\
1,350 \\
1,260 \\
1,100\end{array}$ & $\begin{array}{l}6.46 \\
6.42 \\
6.39 \\
6.34 \\
6.31 \\
6.27\end{array}$ & $\begin{array}{l}475 \\
465 \\
460 \\
450 \\
435 \\
425\end{array}$ \\
\hline \multirow[t]{2}{*}{$\begin{array}{r}7 \\
8 \\
9 \\
10 \\
11 \\
M\end{array}$} & $\begin{array}{l}2.17 \\
2.17 \\
2.18 \\
2.20 \\
2.25 \\
2.96\end{array}$ & & $\begin{array}{l}5.77 \\
5.91 \\
6.03 \\
6.16 \\
6.27 \\
6.38\end{array}$ & $\begin{array}{l}380 \\
385 \\
415 \\
420 \\
435 \\
450\end{array}$ & $\begin{array}{l}8.82 \\
8.80 \\
8.73 \\
8.84 \\
8.97 \\
9.23\end{array}$ & $\begin{array}{l}1,240 \\
1,190 \\
1,200 \\
1,310 \\
1,380 \\
1,580\end{array}$ & $\begin{array}{l}13.35 \\
13.45 \\
13.5 \\
13.6 \\
13.55 \\
13.5\end{array}$ & $\begin{array}{l}3,470 \\
3,520 \\
3,550 \\
3,600 \\
3,570 \\
3,540\end{array}$ & $\begin{array}{l}8.74 \\
8.50 \\
8.25 \\
8.02 \\
7.82 \\
7.62\end{array}$ & $\begin{array}{r}1,020 \\
945 \\
860 \\
860 \\
810 \\
780\end{array}$ & $\begin{array}{l}6.23 \\
6.20 \\
6.15 \\
6.11 \\
6.07 \\
6.02\end{array}$ & $\begin{array}{l}420 \\
410 \\
400 \\
385 \\
375 \\
365\end{array}$ \\
\hline & \multicolumn{2}{|c|}{ September 24} & \multicolumn{2}{|c|}{ September 25} & \multicolumn{2}{|c|}{ September 26} & \multicolumn{2}{|c|}{ September 27} & \multicolumn{2}{|c|}{ September 28} & \multicolumn{2}{|c|}{ September 29} \\
\hline $\begin{array}{r}2 \\
4 \\
6 \\
8 \\
10 \\
\mathbb{N}\end{array}$ & $\begin{array}{l}5.92 \\
5.82 \\
5.72 \\
5.60 \\
5.46 \\
5.31\end{array}$ & $\begin{array}{l}350 \\
335 \\
320 \\
310 \\
295 \\
280\end{array}$ & $\begin{array}{c}- \\
4.30 \\
- \\
4.09 \\
\overline{3.94}\end{array}$ & $\begin{array}{r}-205 \\
-\quad 184 \\
-170\end{array}$ & $\begin{array}{l}- \\
\overline{3.52} \\
- \\
\overline{3.47}\end{array}$ & $\begin{array}{l}- \\
- \\
- \\
- \\
- \\
132\end{array}$ & $\begin{array}{c}- \\
- \\
3.29 \\
- \\
- \\
3.27\end{array}$ & $\begin{array}{l}- \\
- \\
- \\
- \\
-113\end{array}$ & $\begin{array}{c}- \\
- \\
2.95 \\
- \\
\overline{2.91}\end{array}$ & $\begin{array}{l}- \\
- \\
- \\
- \\
-88\end{array}$ & $\begin{array}{c}- \\
- \\
2.80 \\
- \\
\overline{2.78}\end{array}$ & $\begin{array}{l}- \\
-77 \\
-76 \\
-7\end{array}$ \\
\hline $\begin{array}{r}2 \\
4 \\
6 \\
8 \\
10 \\
M\end{array}$ & $\begin{array}{l}5.17 \\
5.03 \\
4.91 \\
4.79 \\
4.66 \\
4.53\end{array}$ & $\begin{array}{l}270 \\
260 \\
250 \\
245 \\
240 \\
230\end{array}$ & $\begin{array}{l}- \\
3.85 \\
- \\
3.75 \\
- \\
3.63\end{array}$ & $\begin{array}{r}-162 \\
- \\
152 \\
-\quad 142\end{array}$ & $\begin{array}{c}- \\
\overline{3.42} \\
\overline{-} \\
\overline{3.32}\end{array}$ & $\begin{array}{l}- \\
- \\
- \\
- \\
124\end{array}$ & $\begin{array}{l}- \\
\overline{3.22} \\
- \\
\overline{3.03}\end{array}$ & \begin{tabular}{l}
- \\
- \\
-108 \\
- \\
\multicolumn{1}{c}{93}
\end{tabular} & $\begin{array}{c}- \\
- \\
2.91 \\
- \\
\overline{2.83}\end{array}$ & 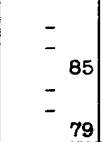 & $\begin{array}{c}- \\
\overline{2} \\
\overline{2.76} \\
\overline{-} \\
\overline{2.60}\end{array}$ & $\begin{array}{l}- \\
-74 \\
- \\
-63\end{array}$ \\
\hline
\end{tabular}

Supplemental records.- Sept. 18, 11:30 p.m., 2.35 ft., 48 sec.-ft. 
Park River at Hartford, Conn.

Location. - Water-stage recorder above spillway of timber dam, lat. $47^{\circ} 45^{\prime} 36^{\prime \prime}$, $10 n g$. $72^{\circ} 41^{\top} 2^{n}$, at plate girder footbridge on Riverside street, Hartford, Hartford County, 1,300 feet below junction of North and South Branches of Park River and $2.3 \mathrm{miles}$ above mouth. Zero of gage is 27.13 feet above mean sea level (general adjustment of 1929).

Drainage area.- 74.0 square miles.

Gage-helght record.- Water-stage recorder graph.

Stage-discharge relation.- Prior to Sept. 22 , defined by current-meter measurements. iransition curve used 1 to 6 a.m. Sept. 22. From 6 a.m. Sept. 22 until holes openod in dam on sept. 26, defined by current-meter measurements below 3,700 second-feet; extended to peak stage on basis of previous rating curve. Fran sept. 26 until another hole opened in dam on Oct. 10, defined by current-meter measurements. Subsequent to oct. 10, defined by comparison with flow at atations on North and South Branches of Park River. Backwater from Connecticut River 11 a.m. Sept. 22 to 11 a.m. Sept. 25.

Maxima.- September 1938: Discharge, 5,320 second-feet 3:15 p.m. Sept. 21 (gage he1ght, 8.93 feet); probably a result of concentration of local inflow during hurricane rain; normal maximum, at a slightly lower stage, occurred at 11:30 p.m.

1936 to August 1938: D1 s charge, 5,650 second-feet Jan. 25, 1838 (gage he1ght, 9.16 feet). Flood of Mar. 12, 1936, resched a sage of 9.0 feet a determined from floodmarks by Hartford clty engineers (discharge, 5,400 second-feet). Backwater from Connecticut River on Mar. 21, 1936, caused a stage of 10.7 feet as determined from floodmarks.

Remarks.- Flood run-off probably not appreciably affected by artificial storage.

Mean daily discharge, in second-feet, 1938

\begin{tabular}{|c|c|c|c|c|c|c|c|c|c|c|c|}
\hline Day & Sept. & Oct. & Day & Sept. & Oct. & Day & Sept. & oct. & Day & Sept. & Oct. \\
\hline $\begin{array}{l}1 \\
2 \\
3 \\
4 \\
5 \\
6 \\
7 \\
8 \\
\end{array}$ & $\begin{array}{l}34 \\
28 \\
28 \\
23 \\
23 \\
28 \\
26 \\
32 \\
\end{array}$ & $\begin{array}{r}107 \\
88 \\
83 \\
78 \\
76 \\
72 \\
63 \\
58 \\
\end{array}$ & $\begin{array}{r}9 \\
10 \\
11 \\
12 \\
13 \\
14 \\
15 \\
16 \\
\end{array}$ & $\begin{array}{l}26 \\
26 \\
23 \\
26 \\
37 \\
37 \\
59 \\
44 \\
\end{array}$ & $\begin{array}{l}56 \\
56 \\
57 \\
56 \\
56 \\
63 \\
75 \\
63 \\
\end{array}$ & $\begin{array}{l}17 \\
18 \\
19 \\
20 \\
21 \\
22 \\
23 \\
24 \\
\end{array}$ & $\begin{array}{r}44 \\
77 \\
469 \\
1,490 \\
4,620 \\
3,010 \\
780 \\
376 \\
\end{array}$ & $\begin{array}{l}61 \\
61 \\
57 \\
61 \\
97 \\
79 \\
63 \\
94 \\
\end{array}$ & $\begin{array}{l}25 \\
26 \\
27 \\
28 \\
29 \\
30 \\
31\end{array}$ & $\begin{array}{r}241 \\
178 \\
148 \\
119 \\
104 \\
94\end{array}$ & $\begin{array}{r}184 \\
103 \\
91 \\
85 \\
87 \\
83 \\
79\end{array}$ \\
\hline $\begin{array}{l}\text { Mean } \\
\text { Run- } \\
\end{array}$ & $\begin{array}{l}\text { onthly } \\
, \text { in }\end{array}$ & $\begin{array}{l}\text { schar } \\
\text { hes. }\end{array}$ & $\begin{array}{l}1 \\
: \\
\end{array}$ & $\begin{array}{l}\text { second- } \\
. \\
\end{array}$ & $\begin{array}{l}\text { et . : } \\
\\
\end{array}$ & $\dot{0}:$ & $: \dot{0}$ & $\dot{0} \cdot \dot{ }$ & $\dot{0}:$ & $\begin{array}{r}408 \\
6.15 \\
\end{array}$ & $\begin{array}{l}77.2 \\
1.20 \\
\end{array}$ \\
\hline
\end{tabular}

Gage helght, In feet, and discharge, in second-feet, at indicated time, 1938

\begin{tabular}{|c|c|c|c|c|c|c|c|c|c|c|c|c|}
\hline \multirow{2}{*}{ 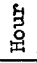 } & Feet & Sec.ft. & Feet & Sec.ft. & Feet & Sec.ft. & Feet & Sec.ft. & Feet & Sec.ft. & Feet & Sec.ft. \\
\hline & \multicolumn{2}{|c|}{ September 18} & \multicolumn{2}{|c|}{ September 19} & \multicolumn{2}{|c|}{ September 20} & \multicolumn{2}{|c|}{ September 21} & \multicolumn{2}{|c|}{ September 22} & \multicolumn{2}{|c|}{ September 23} \\
\hline $\begin{array}{l}1 \\
2 \\
3 \\
4 \\
5 \\
6\end{array}$ & $\begin{array}{l}2.66 \\
2.68 \\
2.67 \\
2.66 \\
2.63 \\
2.60\end{array}$ & $\begin{array}{l}84 \\
90 \\
87 \\
84 \\
76 \\
67\end{array}$ & $\begin{array}{l}3.15 \\
3.28 \\
3.32 \\
3.31 \\
3.31 \\
3.33\end{array}$ & $\begin{array}{l}261 \\
317 \\
335 \\
331 \\
331 \\
340\end{array}$ & $\begin{array}{l}3.98 \\
4.31 \\
4.26 \\
4.30 \\
4.33 \\
4.35\end{array}$ & $\begin{array}{l}678 \\
876 \\
846 \\
870 \\
888 \\
900\end{array}$ & $\begin{array}{l}6.65 \\
6.92 \\
7.06 \\
7.29 \\
7.71 \\
7.94\end{array}$ & $\begin{array}{l}2,790 \\
3,060 \\
3,210 \\
3,460 \\
3,920 \\
4,170\end{array}$ & $\begin{array}{l}8.79 \\
8.71 \\
8.61 \\
8.49 \\
8.37 \\
8.21\end{array}$ & $\begin{array}{l}5,100 \\
4,930 \\
4,710 \\
4,470 \\
4,230 \\
3,940\end{array}$ & $\begin{array}{l}6.71 \\
- \\
6.84 \\
- \\
7.00\end{array}$ & $\begin{array}{c}- \\
1,130 \\
- \\
1,010 \\
-922\end{array}$ \\
\hline $\begin{array}{r}7 \\
8 \\
9 \\
10 \\
11 \\
\text { N }\end{array}$ & $\begin{array}{l}2.58 \\
2.56 \\
2.55 \\
2.54 \\
2.53 \\
2.53\end{array}$ & $\begin{array}{l}62 \\
57 \\
54 \\
51 \\
49 \\
49\end{array}$ & $\begin{array}{l}3.36 \\
3.39 \\
3.43 \\
3.47 \\
3.50 \\
3.53\end{array}$ & $\begin{array}{l}354 \\
367 \\
386 \\
406 \\
420 \\
435\end{array}$ & $\begin{array}{l}4.38 \\
4.41 \\
5.02 \\
5.16 \\
5.10 \\
5.16\end{array}$ & $\begin{array}{r}918 \\
937 \\
1,360 \\
1,470 \\
1,420 \\
1,470\end{array}$ & $\begin{array}{l}8.19 \\
8.46 \\
8.61 \\
8.68 \\
8.74 \\
8.77\end{array}$ & $\begin{array}{l}4,450 \\
4,750 \\
4,930 \\
5,020 \\
5,090 \\
5,120\end{array}$ & $\begin{array}{l}8.04 \\
7.86 \\
7.70 \\
7.53 \\
7.38 \\
7.23\end{array}$ & $\begin{array}{l}3,640 \\
3,460 \\
3,320 \\
3,170 \\
3,000 \\
2,820\end{array}$ & $\begin{array}{c}- \\
7.14 \\
- \\
7.27 \\
\overline{7.37}\end{array}$ & $\begin{array}{r}- \\
-740 \\
-785 \\
-735\end{array}$ \\
\hline $\begin{array}{l}1 \\
2 \\
3 \\
4 \\
5 \\
6\end{array}$ & $\begin{array}{l}2.53 \\
2.53 \\
2.53 \\
2.53 \\
2.53 \\
2.53\end{array}$ & $\begin{array}{l}49 \\
49 \\
49 \\
49 \\
49 \\
49\end{array}$ & $\begin{array}{l}3.55 \\
3.56 \\
3.58 \\
3.80 \\
3.95 \\
3.89\end{array}$ & $\begin{array}{l}445 \\
450 \\
460 \\
575 \\
660 \\
624\end{array}$ & $\begin{array}{l}5.24 \\
5.33 \\
5.45 \\
5.57 \\
5.62 \\
5.75\end{array}$ & $\begin{array}{l}1,530 \\
1,600 \\
1,700 \\
1,800 \\
1,840 \\
1,940\end{array}$ & $\begin{array}{l}8.73 \\
8.75 \\
8.91 \\
8.77 \\
8.81 \\
8.79\end{array}$ & $\begin{array}{l}5,080 \\
5,100 \\
5,290 \\
5,120 \\
5,170 \\
5,150\end{array}$ & $\begin{array}{l}7.09 \\
6.96 \\
6.84 \\
6.73 \\
6.65 \\
6.58\end{array}$ & $\begin{array}{l}2,690 \\
2,560 \\
2,390 \\
2,270 \\
2,150 \\
1,990\end{array}$ & $\begin{array}{l}\overline{7.44} \\
\overline{7} \\
\overline{7.50} \\
\overline{7.51}\end{array}$ & $\begin{array}{r}-685 \\
-635 \\
-610\end{array}$ \\
\hline \multirow[t]{2}{*}{$\begin{array}{r}7 \\
8 \\
9 \\
10 \\
11 \\
\end{array}$} & $\begin{array}{l}2.53 \\
2.53 \\
2.53 \\
2.58 \\
3.25 \\
3.23 \\
\end{array}$ & $\begin{array}{r}49 \\
49 \\
49 \\
62 \\
304 \\
295 \\
\end{array}$ & $\begin{array}{l}3.92 \\
3.93 \\
3.92 \\
3.93 \\
3.94 \\
3.96 \\
\end{array}$ & $\begin{array}{l}642 \\
648 \\
642 \\
648 \\
654 \\
666 \\
\end{array}$ & $\begin{array}{l}5.75 \\
5.80 \\
6.26 \\
6.13 \\
6.36 \\
6.54\end{array}$ & $\begin{array}{l}1,940 \\
1,990 \\
2,400 \\
2,290 \\
2,500 \\
2,680\end{array}$ & $\begin{array}{l}8.79 \\
8.78 \\
8.82 \\
8.85 \\
8.88 \\
8.84\end{array}$ & $\begin{array}{l}5,150 \\
5,140 \\
5,180 \\
5,220 \\
5,260 \\
5,210\end{array}$ & $\begin{array}{l}6.53 \\
6.51 \\
6.50 \\
6.51 \\
6.54 \\
6.59\end{array}$ & $\begin{array}{l}1,870 \\
1,760 \\
1,650 \\
1,510 \\
1,400 \\
1,310\end{array}$ & $\begin{array}{c}- \\
7.49 \\
- \\
7.45 \\
- \\
7.38\end{array}$ & $\begin{array}{r}-560 \\
-\quad 535 \\
-\quad 512 \\
\end{array}$ \\
\hline & \multicolumn{2}{|c|}{ September 24} & \multicolumn{2}{|c|}{ September 25} & \multicolumn{2}{|c|}{ September 26} & \multicolumn{2}{|c|}{ September 27} & \multicolumn{2}{|c|}{ September 28} & \multicolumn{2}{|c|}{ September 29} \\
\hline $\begin{array}{r}2 \\
4 \\
6 \\
8 \\
10 \\
N\end{array}$ & $\begin{array}{l}7.13 \\
- \\
6.76 \\
- \\
6.24\end{array}$ & $\begin{array}{r}-445 \\
- \\
-400 \\
-355\end{array}$ & $\begin{array}{c}- \\
3.54 \\
- \\
3.19 \\
- \\
3.10\end{array}$ & $\begin{array}{r}-275 \\
- \\
256 \\
- \\
236\end{array}$ & $\begin{array}{c}- \\
2.98 \\
- \\
2.95 \\
- \\
2.86\end{array}$ & $\begin{array}{r}-192 \\
- \\
-181 \\
-174\end{array}$ & $\begin{array}{c}- \\
2.73 \\
- \\
2.72 \\
- \\
2.71\end{array}$ & $\begin{array}{r}-152 \\
- \\
-150 \\
-147\end{array}$ & $\begin{array}{c}- \\
- \\
2.62 \\
- \\
- \\
2.59\end{array}$ & $\begin{array}{l}- \\
-123 \\
- \\
-116\end{array}$ & $\begin{array}{c}- \\
- \\
2.54 \\
- \\
- \\
2.53\end{array}$ & $\begin{array}{l}- \\
-105 \\
- \\
- \\
103\end{array}$ \\
\hline $\begin{array}{r}2 \\
4 \\
6 \\
8 \\
10 \\
M\end{array}$ & $\begin{array}{l}- \\
5.63 \\
- \\
4.95 \\
- \\
4.25\end{array}$ & $\begin{array}{r}-335 \\
- \\
315 \\
- \\
295\end{array}$ & $\begin{array}{c}- \\
3.06 \\
- \\
3.03 \\
- \\
3.01\end{array}$ & $\begin{array}{r}-221 \\
-210 \\
- \\
203\end{array}$ & $\begin{array}{l}- \\
2.79 \\
- \\
2.78 \\
- \\
2.76\end{array}$ & $\begin{array}{c}- \\
-170 \\
166 \\
- \\
161\end{array}$ & $\begin{array}{c}- \\
2.71 \\
- \\
2.70 \\
\overline{2.66}\end{array}$ & $\begin{array}{l}- \\
-147 \\
-144 \\
- \\
134\end{array}$ & $\begin{array}{c}- \\
\overline{2.58} \\
- \\
\overline{2.57}\end{array}$ & $\begin{array}{l}- \\
-114 \\
- \\
111\end{array}$ & $\begin{array}{c}- \\
\overline{2.53} \\
- \\
\overline{2.50}\end{array}$ & $\begin{array}{l}- \\
- \\
- \\
- \\
-963\end{array}$ \\
\hline
\end{tabular}

Supplemental records. - Sept. $18,11: 30 \mathrm{p}, \mathrm{m}, 3.44 \mathrm{ft}, 391 \mathrm{sec}, \mathrm{ft}$. Sept. 19 , $3: 30$ p.m., $3.60 \mathrm{ft.}, 470 \mathrm{sec} . \mathrm{ft} . ; 4: 30$ p.m., $4.09 \mathrm{ft} ., 744 \mathrm{sec} . \mathrm{ft}$. Sept. 20, $1: 30 \mathrm{a} . \mathrm{m} .$, 4.42 ft., 944 sec.-ft.; 10:30 p.m., 6.il ft., 2,270 sec.-ft. Sept. 2l, $2: 15$ p.m., 8.87 ft., 5,240 sec.-ft.; 3:15 p.m., 8.93 ft., 5,320 sec.-ft.; 4:30 p.m., 8.83 ft., 5,200 sec. $-f t_{.} ; 11: 30$ p.m., $8.88 \mathrm{ft.}, 5,260$ sec.-ft. 
Location.- Water-stage recorder and masonry control, lat. 41 ${ }^{\circ} 7^{\prime} 03^{\prime \prime}$, long. $72^{\circ} 42^{\prime} 31^{\prime \prime}$, 60 feet below stone arch bridge on Albany Avenue, Hartford, Hartford County, and 3 miles above junction with South Branch of Park River. Zero of gage is 34.20 feet above mean sea level (general adjustment of 1929).

Drainage area.- 25.3 square miles.

Gage-height record.- Water-stage recorder graph.

Stage-discharge relation.- Defined by current-meter measurements below 800 second-feet; extended logarithmically to peak stages; verified by area-velocity studies.

Maxima.- September 1938: Discharge, 1,350 second-feet 10 p.m. Sept. 21 (gage height, 10.07 feet).

1936 to August 1938: Discharge, 1,640 second-feet Jan. 25, 1938 (effective gage height, 11.6 feet).

Flood of Mar. 12, 1936, reached a stage of 11.2 feet as determined from floodmarks by Hartford city engineers (discharge, probably 1,520 second-feet).

Remarks.- Flood run-off probably not appreciabiy affected by artificial storage.

Mean daily discharge, in second-feet, 1938

\begin{tabular}{|c|r|r||r|r|r||r|r|r|r|r|r|}
\hline Day & Sept. & Oct. & Day & Sept. & 0ct. & Day & Sept. & Oct. & Day & Sept. & 0ct. \\
\hline 1 & 5.0 & 31 & 9 & 4.0 & 13 & 17 & 6.6 & 14 & 25 & 48 & 78 \\
2 & 4.9 & 24 & 10 & 3.4 & 12 & 18 & 12 & 13 & 26 & 36 & 36 \\
3 & 4.2 & 20 & 11 & 3.3 & 12 & 19 & 145 & 14 & 27 & 31 & 25 \\
4 & 4.2 & 18 & 12 & 3.3 & 12 & 20 & 465 & 13 & 28 & 28 & 20 \\
5 & 4.0 & 16 & 13 & 4.4 & 12 & 21 & 1,210 & 38 & 29 & 24 & 21 \\
6 & 3.5 & 16 & 14 & 5.1 & 13 & 22 & 792 & 26 & 30 & 24 & 20 \\
7 & 3.6 & 14 & 15 & 7.0 & 18 & 23 & 187 & 19 & 31 & & 16 \\
8 & 4.3 & 14 & 16 & 9.1 & 16 & 24 & 80 & 34 & & & \\
\hline
\end{tabular}

Gage height, in feet, and discharge, in second-feet, at indicated time, 1938

\begin{tabular}{|c|c|c|c|c|c|c|c|c|c|c|c|c|c|}
\hline \multirow{2}{*}{$\begin{array}{l}3 \\
3 \\
\text { 足 }\end{array}$} & Feet & Sec.ft. & Feet & Sec.ft. & Feet & Sec.ft. & Feet & Sec.ft. & Feet & Sec.ft. & Feet & Sec & .ft. \\
\hline & \multicolumn{2}{|c|}{ September 18} & \multicolumn{2}{|c|}{ September 19} & \multicolumn{2}{|c|}{ September 20} & \multicolumn{2}{|c|}{ September 21} & \multicolumn{2}{|c|}{ September 22} & \multicolumn{3}{|c|}{ September 23} \\
\hline $\begin{array}{l}1 \\
2 \\
3 \\
4 \\
5 \\
6\end{array}$ & $\begin{array}{c}- \\
1.54 \\
- \\
1.54 \\
- \\
1.55\end{array}$ & $\begin{array}{r}- \\
-8.2 \\
-8.2 \\
-8.5 \\
8.5\end{array}$ & $\begin{array}{l}2.10 \\
2.11 \\
2.10 \\
2.33 \\
2.41 \\
2.43\end{array}$ & $\begin{array}{l}39 \\
40 \\
39 \\
66 \\
79 \\
82\end{array}$ & $\begin{array}{l}3.14 \\
3.17 \\
3.20 \\
3.24 \\
3.26 \\
3.28\end{array}$ & $\begin{array}{l}264 \\
274 \\
285 \\
299 \\
306 \\
313\end{array}$ & $\begin{array}{l}7.05 \\
7.50 \\
7.92 \\
8.32 \\
8.71 \\
9.03\end{array}$ & $\begin{array}{r}842 \\
910 \\
983 \\
1,050 \\
1,110 \\
1,170\end{array}$ & $\begin{array}{l}9.77 \\
9.54 \\
9.25 \\
8.95 \\
8.63 \\
8.31\end{array}$ & $\begin{array}{l}1,300 \\
1,260 \\
1,210 \\
1,160 \\
1,100 \\
1,050\end{array}$ & $\begin{array}{l}3.41 \\
3.30 \\
3.21 \\
3.12 \\
3.06 \\
3.02\end{array}$ & & $\begin{array}{l}358 \\
320 \\
288 \\
257 \\
237 \\
224\end{array}$ \\
\hline $\begin{array}{r}7 \\
8 \\
9 \\
10 \\
11 \\
\mathrm{~N}\end{array}$ & $\begin{array}{c}- \\
1.58 \\
- \\
1.62 \\
- \\
1.66\end{array}$ & $\begin{array}{l}-9.4 \\
\overline{11} \\
\overline{12}\end{array}$ & $\begin{array}{l}2.50 \\
2.57 \\
2.62 \\
2.66 \\
2.69 \\
2.70\end{array}$ & $\begin{array}{r}94 \\
107 \\
117 \\
126 \\
133 \\
135\end{array}$ & $\begin{array}{l}3.31 \\
3.33 \\
3.60 \\
4.14 \\
4.45 \\
4.68\end{array}$ & $\begin{array}{l}324 \\
330 \\
395 \\
454 \\
490 \\
517\end{array}$ & $\begin{array}{l}9.21 \\
9.39 \\
9.55 \\
9.60 \\
9.63 \\
9.60\end{array}$ & $\begin{array}{l}1,200 \\
1,230 \\
1,260 \\
1,270 \\
1,270 \\
1,270\end{array}$ & $\begin{array}{l}7.99 \\
7.67 \\
7.37 \\
7.06 \\
6.74 \\
6.41\end{array}$ & $\begin{array}{l}994 \\
940 \\
890 \\
844 \\
796 \\
751\end{array}$ & $\begin{array}{l}2.96 \\
2.92 \\
2.89 \\
2.86 \\
2.83 \\
2.81\end{array}$ & & $\begin{array}{l}205 \\
193 \\
184 \\
176 \\
168 \\
163\end{array}$ \\
\hline $\begin{array}{l}1 \\
2 \\
3 \\
4 \\
5 \\
6\end{array}$ & $\begin{array}{c}- \\
1.68 \\
- \\
1.67 \\
- \\
1.65\end{array}$ & $\begin{array}{l}\overline{13} \\
\overline{13} \\
\overline{12}\end{array}$ & $\begin{array}{l}2.71 \\
2.71 \\
2.71 \\
2.71 \\
3.01 \\
3.03\end{array}$ & $\begin{array}{l}138 \\
138 \\
138 \\
138 \\
220 \\
227\end{array}$ & $\begin{array}{l}4.89 \\
5.01 \\
5.08 \\
5.14 \\
5.15 \\
5.16\end{array}$ & $\begin{array}{l}539 \\
556 \\
563 \\
571 \\
572 \\
574\end{array}$ & $\begin{array}{l}9.54 \\
9.42 \\
9.34 \\
9.60 \\
9.83 \\
9.87\end{array}$ & $\begin{array}{l}1,260 \\
1,240 \\
1,220 \\
1,270 \\
1,310 \\
1,320\end{array}$ & $\begin{array}{l}6.11 \\
5.80 \\
5.51 \\
5.22 \\
4.93 \\
4.68\end{array}$ & $\begin{array}{l}706 \\
665 \\
622 \\
583 \\
544 \\
517\end{array}$ & $\begin{array}{l}2.79 \\
2.76 \\
2.74 \\
2.72 \\
2.70 \\
2.69\end{array}$ & & $\begin{array}{l}158 \\
150 \\
145 \\
140 \\
135 \\
133\end{array}$ \\
\hline \multirow[t]{2}{*}{$\begin{array}{r}7 \\
8 \\
9 \\
10 \\
11 \\
M\end{array}$} & $\begin{array}{c}- \\
1.63 \\
- \\
1.62 \\
1.83 \\
2.14\end{array}$ & $\begin{array}{l}\overrightarrow{11} \\
\overrightarrow{11} \\
21 \\
43\end{array}$ & $\begin{array}{l}3.04 \\
3.07 \\
3.12 \\
3.14 \\
3.15 \\
3.15\end{array}$ & $\begin{array}{l}230 \\
240 \\
257 \\
264 \\
268 \\
268\end{array}$ & $\begin{array}{l}5.11 \\
5.02 \\
5.20 \\
5.55 \\
5.90 \\
6.56\end{array}$ & $\begin{array}{l}566 \\
557 \\
580 \\
628 \\
680 \\
769\end{array}$ & $\begin{array}{r}9.91 \\
9.97 \\
10.03 \\
10.07 \\
10.05 \\
9.95\end{array}$ & $\begin{array}{l}1,320 \\
1,330 \\
1,340 \\
1,350 \\
1,350 \\
1,330\end{array}$ & $\begin{array}{l}4.44 \\
4.23 \\
4.03 \\
3.83 \\
3.69 \\
3.54\end{array}$ & $\begin{array}{l}489 \\
463 \\
443 \\
418 \\
404 \\
386\end{array}$ & $\begin{array}{l}2.67 \\
2.65 \\
2.63 \\
2.61 \\
2.60 \\
2.59\end{array}$ & & $\begin{array}{l}128 \\
124 \\
120 \\
115 \\
113 \\
111\end{array}$ \\
\hline & \multicolumn{2}{|c|}{ September 24} & \multicolumn{2}{|c|}{ September 25} & \multicolumn{2}{|c|}{ September 26} & \multicolumn{2}{|c|}{ September 27} & \multicolumn{2}{|c|}{ September 28} & \multicolumn{3}{|c|}{ September 29} \\
\hline $\begin{array}{r}2 \\
4 \\
6 \\
8 \\
10 \\
N\end{array}$ & $\begin{array}{l}2.55 \\
2.51 \\
2.49 \\
2.45 \\
2.42 \\
2.40\end{array}$ & $\begin{array}{r}104 \\
96 \\
92 \\
86 \\
80 \\
77\end{array}$ & $\begin{array}{c}\overline{-} \\
2.23 \\
- \\
2.20 \\
- \\
2.18\end{array}$ & 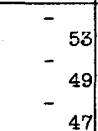 & $\begin{array}{c}- \\
- \\
2.08 \\
- \\
- \\
2.05\end{array}$ & $\begin{array}{l}- \\
- \\
\\
- \\
- \\
-36\end{array}$ & $\begin{array}{c}- \\
- \\
- \\
- \\
- \\
* 1.99\end{array}$ & $\begin{array}{l}- \\
- \\
- \\
- \\
- \\
* 31\end{array}$ & $\begin{array}{c}- \\
- \\
- \\
- \\
- \\
* 1.95\end{array}$ & $\begin{array}{l}- \\
- \\
- \\
- \\
- \\
* 28\end{array}$ & $\begin{array}{c}- \\
- \\
- \\
- \\
- \\
* 1.89\end{array}$ & & $\begin{array}{l}- \\
- \\
- \\
- \\
* 24\end{array}$ \\
\hline $\begin{array}{r}2 \\
4 \\
6 \\
8 \\
10 \\
M\end{array}$ & $\begin{array}{l}2.38 \\
2.35 \\
2.33 \\
2.31 \\
2.29 \\
2.27\end{array}$ & $\begin{array}{l}74 \\
70 \\
66 \\
64 \\
61 \\
58\end{array}$ & $\begin{array}{c}- \\
2.16 \\
- \\
2.13 \\
- \\
2.11\end{array}$ & $\begin{array}{r}-45 \\
-\quad 42 \\
-\quad 40\end{array}$ & $\begin{array}{c}- \\
- \\
2.04 \\
- \\
- \\
2.02\end{array}$ & $\begin{array}{l}- \\
- \\
-35 \\
- \\
-33\end{array}$ & $\begin{array}{l}- \\
- \\
- \\
- \\
-\end{array}$ & $\begin{array}{l}- \\
- \\
- \\
- \\
-\end{array}$ & $\begin{array}{l}- \\
- \\
- \\
- \\
-\end{array}$ & $\begin{array}{l}- \\
- \\
- \\
- \\
-\end{array}$ & $\begin{array}{l}- \\
- \\
- \\
- \\
-\end{array}$ & & $\begin{array}{l}- \\
- \\
- \\
-\end{array}$ \\
\hline
\end{tabular}

Supplemental records.- Sept. $18,10: 45$ p.m., $1.65 \mathrm{ft} ., 12 \mathrm{sec.-ft.;} \mathrm{11:30} \mathrm{p.m.,} 2.27$ ft., 58 sec.-ft. Sept. 19, 3:15 a.m., 2.29 ft., 61 sec.ft. Sept. 20, 8:30 p.m., 5.00 ft., 555 sec.-ft. Sept. $21,3: 30$ p.m., $9.31 \mathrm{ft} ., 1,220$ sec.-ft.

* Mean for the day. 
Hockanum River at outlet of Sheripsit Lake, at Rockville, Conn.

Location.- Staff gage at dam, lat. $41^{\circ} 52^{1} 06^{n}$, long. $72^{\circ} 25^{\prime} 56^{\pi}$, three-quarters of a mile east of Rockvilie, Tolland County.

Drainage area.- 16.5 square miles.

Gage-height record.- One reservoir gage reading dally in morning, except sundays. Additional hourly readings taken at times during high floods. Gage height at midnight determined from graph constructed from gage-helght readings.

Stage-discharge relation.- Observed discharge computed from flow over spillway and through pumps, venturi meter, wheel, and gate.

Maxima.- September 1938: Unadjusted discharge, 1,500 second-feet 5:30 p.m. Sept. 21 (head on dam, 4.23 feet, from floodmarks).

Previous maximum stage of record occurred on Feb. 14, 1886, when a head of 1.6 feet was reached on the same dam.

Remarks.- Mean daily and monthly discharges adjusted for gain or loss in storage in Shenipsit Lake. No adjustments for evaporation from lake surface. Basic data furnished by Rockville Water \& Aqueduct Co.

Mean discharge, in second-feet, and gain or loss in storage, in equivalent mean' second-feet, 1938

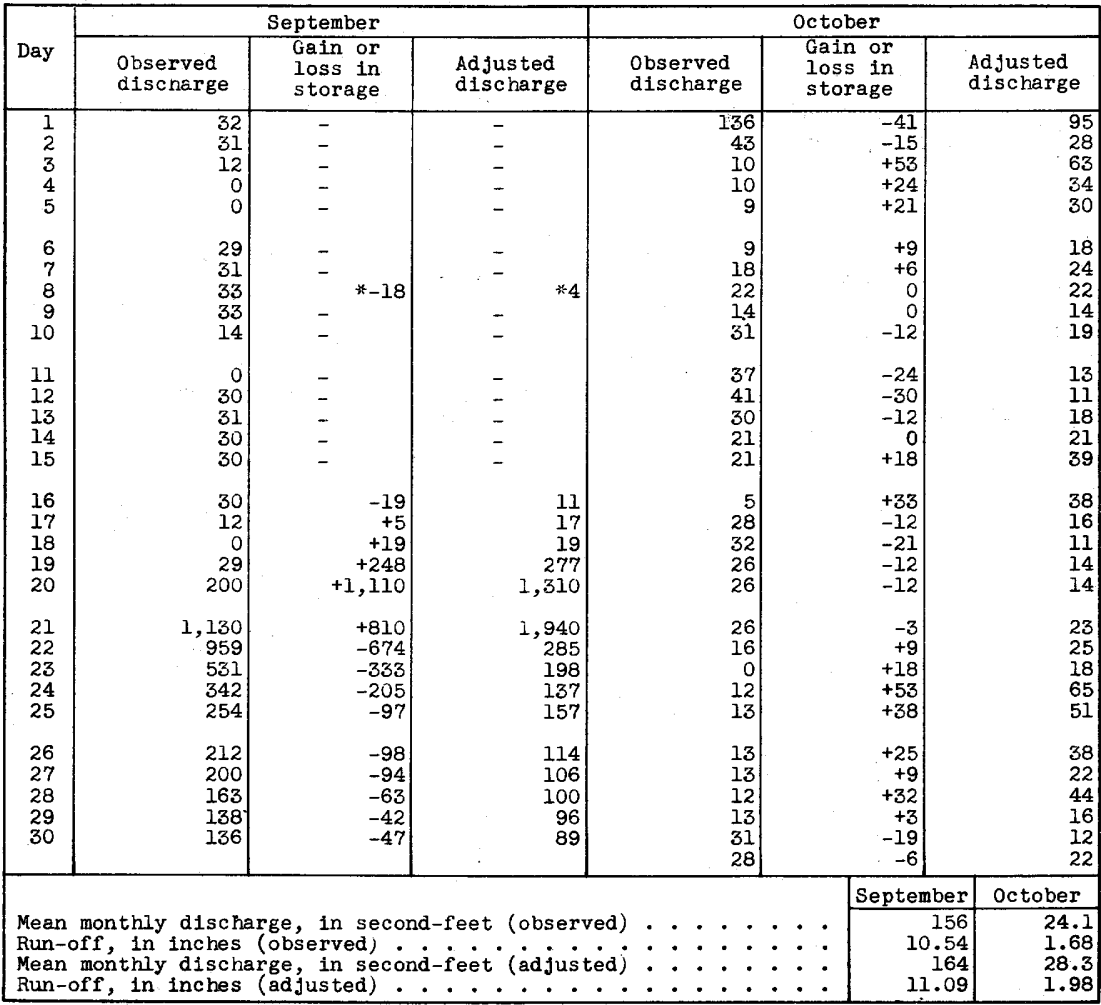

* Mean for 15-day period. 
Location.- Water-stage recorder, lat. $41^{\circ} 46^{\prime} 5^{\prime \prime}$, long. $72^{\circ} 35^{\prime} 20^{\prime \prime}$, at Case \&arshall

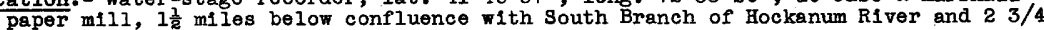
miles east of East Hartford, Hartford County.

Dralnage area.- 74.5 square miles.

Gage-helght record. - Water-stage recorder graph except for perlods 9 a.m. to 5 p.m. Sept. 2l and 9 p.m. Sept. 21 to 2 a.m. Sept. 22 , records for which were based on two floodmarks; 3 p.m. Sept. 22 to $12 \mathrm{p.m}$. Sept. 25 (Intake partlally plugged), record for which was based on shape of graph as recorded and one inspection; and Sept. 26 to Oct. 3l (intake plugged), when discharge was computed on basis of record for stations on Scantic River at Broad Brook and Willimantic River near South Coventry. Stage-discharge relation.- Defined by current-meter measurements below 2,100 secondfeet for rating used prior to peak of Sept. 21 and below 600 second-feet for rating used theresfter; extended to peak stages on basis of two determinations of flow over Case \& Marshall mill dam just above gage and one determination of flow over dam 1 mile below gage.

Maxima.- September 1938: Discharge, 5,160 second-feet 2 p.m. Sept. 21 (gage height, 13.78 fe日t, from floodmark).

1919-21, 1928 to August 1938: Discharge, 2,140 second-feet Jan. 25, 1938 (gage height, 8.79 feet).

Remarks.- Run-off affected by storage and diversions. For information on storage see record for Hockanum River at outlet of Shenlpsit Lake at Rockville, Conn. Distribution of run-off also affected by fallure of dams upstream.

Mean dally discharge, in second-feet, 1938

\begin{tabular}{|c|c|c|c|c|c|c|c|c|c|c|c|}
\hline Day & Sept. & Oct. & Day & Sept. & oct. & Day & Sept. & Oct. & Day & Sept. & Oet. \\
\hline $\begin{array}{l}1 \\
2 \\
3 \\
4 \\
5 \\
6 \\
7 \\
8\end{array}$ & $\begin{array}{r}85 \\
116 \\
78 \\
46 \\
33 \\
42 \\
58 \\
81\end{array}$ & $\begin{array}{l}280 \\
260 \\
240 \\
220 \\
220 \\
220 \\
200 \\
160\end{array}$ & $\begin{array}{r}9 \\
10 \\
11 \\
12 \\
13 \\
14 \\
15 \\
16\end{array}$ & $\begin{array}{r}111 \\
62 \\
40 \\
45 \\
73 \\
76 \\
120 \\
123\end{array}$ & $\begin{array}{l}150 \\
190 \\
180 \\
180 \\
170 \\
170 \\
130 \\
110\end{array}$ & $\begin{array}{l}17 \\
18 \\
19 \\
20 \\
21 \\
22 \\
23 \\
24\end{array}$ & $\begin{array}{r}70 \\
50 \\
377 \\
1,840 \\
4,300 \\
3,150 \\
1,420 \\
791\end{array}$ & $\begin{array}{r}190 \\
190 \\
180 \\
180 \\
170 \\
90 \\
80 \\
200\end{array}$ & $\begin{array}{l}25 \\
26 \\
27 \\
28 \\
29 \\
30 \\
31\end{array}$ & $\begin{array}{l}567 \\
460 \\
380 \\
340 \\
320 \\
300\end{array}$ & $\begin{array}{r}260 \\
220 \\
190 \\
160 \\
100 \\
60 \\
158\end{array}$ \\
\hline $\begin{array}{l}\text { Mean } \\
\text { Run- }\end{array}$ & , inthiy & char & , ir & - . & . . & : $:$ & $\cdot: \cdot \dot{ }$ & . . & - $\cdot$ & $\begin{array}{r}518 \\
7.75\end{array}$ & $\begin{array}{r}178 \\
2.76\end{array}$ \\
\hline
\end{tabular}

Gage helght, in feet, and discharge, in second-feet, at indicated time, 1938

\begin{tabular}{|c|c|c|c|c|c|c|c|c|c|c|c|c|}
\hline \multirow{2}{*}{$\begin{array}{l}\text { 多 } \\
\text { 号 }\end{array}$} & Feet & Sec.ft. & Fe日t & Sec.ft. & Feet & sec.ft. & Feet & Sec.ft. & Feet & Sec.ft. & Feet & Sec.ft. \\
\hline & \multicolumn{2}{|c|}{ September 18} & \multicolumn{2}{|c|}{ September 19} & \multicolumn{2}{|c|}{ September 20} & \multicolumn{2}{|c|}{ September 21} & \multicolumn{2}{|c|}{ September 22} & \multicolumn{2}{|c|}{ September 23} \\
\hline $\begin{array}{l}1 \\
2 \\
3 \\
4 \\
5 \\
6\end{array}$ & $\begin{array}{c}- \\
1.46 \\
- \\
1.44 \\
- \\
1.43\end{array}$ & $\begin{array}{r}-52 \\
-\quad 51 \\
-\quad 50\end{array}$ & $\begin{array}{l}1.91 \\
2.01 \\
2.28 \\
2.63 \\
2.84 \\
3.04\end{array}$ & $\begin{array}{r}97 \\
109 \\
142 \\
192 \\
224 \\
256\end{array}$ & $\begin{array}{l}3.93 \\
3.78 \\
3.70 \\
3.61 \\
3.67 \\
3.80\end{array}$ & $\begin{array}{l}426 \\
396 \\
380 \\
362 \\
374 \\
400\end{array}$ & $\begin{array}{l}10.78 \\
10.82 \\
10.99 \\
11.20 \\
11.49 \\
11.75\end{array}$ & $\begin{array}{l}3,150 \\
3,180 \\
3,270 \\
3,380 \\
3,540 \\
3,690\end{array}$ & $\begin{array}{l}13.42 \\
13.18 \\
12.93 \\
12.67 \\
12.41 \\
12.13\end{array}$ & $\begin{array}{l}4,840 \\
4,640 \\
4,440 \\
4,240 \\
4,030 \\
3,800\end{array}$ & $\begin{array}{l}9.5 \\
9.4 \\
9.25 \\
9.15 \\
9.05 \\
8.95\end{array}$ & $\begin{array}{l}1,940 \\
1,880 \\
1,800 \\
1,760 \\
1,700 \\
1,660\end{array}$ \\
\hline $\begin{array}{r}7 \\
8 \\
9 \\
10 \\
11 \\
N\end{array}$ & $\begin{array}{c}\overline{1.43} \\
\overline{1.42} \\
\overline{1.41}\end{array}$ & $\begin{array}{r}-50 \\
-\quad 49 \\
-\quad 48\end{array}$ & $\begin{array}{l}3.50 \\
3.73 \\
3.91 \\
4.10 \\
4.24 \\
4.33\end{array}$ & $\begin{array}{l}340 \\
386 \\
422 \\
462 \\
494 \\
515\end{array}$ & $\begin{array}{l}4.19 \\
4.32 \\
4.77 \\
5.50 \\
6.49 \\
7.74\end{array}$ & $\begin{array}{r}482 \\
513 \\
621 \\
810 \\
1,150 \\
1,660\end{array}$ & $\begin{array}{l}12.02 \\
12.29 \\
12.58 \\
12.88 \\
13.13 \\
13.42\end{array}$ & $\begin{array}{l}3,850 \\
4,030 \\
4,240 \\
4,450 \\
4,640 \\
4,880\end{array}$ & $\begin{array}{l}11.92 \\
11.71 \\
11.49 \\
11.30 \\
11.14 \\
11.00\end{array}$ & $\begin{array}{l}3,640 \\
3,470 \\
3,290 \\
3,140 \\
3,030 \\
2,930\end{array}$ & $\begin{array}{l}8.85 \\
8.75 \\
8.65 \\
8.55 \\
8.45 \\
8.35\end{array}$ & $\begin{array}{l}1,600 \\
1,560 \\
1,500 \\
1,460 \\
1,420 \\
1,380\end{array}$ \\
\hline $\begin{array}{l}1 \\
2 \\
3 \\
4 \\
5 \\
6\end{array}$ & $\begin{array}{c}\overline{1.40} \\
\overline{1.41} \\
\overline{1 .} \\
\overline{1.43}\end{array}$ & $\begin{array}{r}-47 \\
-\quad 48 \\
-\quad 50\end{array}$ & $\begin{array}{l}4.37 \\
4.36 \\
4.31 \\
4.22 \\
4.02 \\
4.01\end{array}$ & $\begin{array}{l}525 \\
522 \\
510 \\
489 \\
444 \\
442\end{array}$ & $\begin{array}{r}8.90 \\
9.79 \\
10.66 \\
11.40 \\
11.71 \\
11.68\end{array}$ & $\begin{array}{l}2,190 \\
2,640 \\
3,090 \\
3,500 \\
3,670 \\
3,650\end{array}$ & $\begin{array}{l}13.70 \\
13.78 \\
13.71 \\
13.50 \\
13.20 \\
12.91\end{array}$ & $\begin{array}{l}5,100 \\
5,160 \\
5,110 \\
4,940 \\
4,700 \\
4,470\end{array}$ & $\begin{array}{l}10.83 \\
10.71 \\
10.58 \\
10.45 \\
10.35 \\
10.25\end{array}$ & $\begin{array}{l}2,810 \\
2,730 \\
2,640 \\
2,540 \\
2,480 \\
2,400\end{array}$ & $\begin{array}{l}8.25 \\
8.15 \\
8.05 \\
8.0 \\
7.9 \\
7.8\end{array}$ & $\begin{array}{l}1,340 \\
1,300 \\
1,260 \\
1,240 \\
1,210 \\
1,180\end{array}$ \\
\hline \multirow[t]{2}{*}{$\begin{array}{r}7 \\
8 \\
9 \\
10 \\
11 \\
M\end{array}$} & $\begin{array}{l}1.44 \\
- \\
1.45 \\
1.48 \\
1.59\end{array}$ & $\begin{array}{r}-51 \\
-\quad 52 \\
54 \\
64\end{array}$ & $\begin{array}{l}4.01 \\
4.01 \\
4.02 \\
4.02 \\
4.02 \\
4.03\end{array}$ & $\begin{array}{l}442 \\
442 \\
444 \\
444 \\
444 \\
447\end{array}$ & $\begin{array}{l}11.44 \\
11.09 \\
10.76 \\
10.70 \\
10.60 \\
10.62\end{array}$ & $\begin{array}{l}3,520 \\
3,320 \\
3,140 \\
3,110 \\
3,060 \\
3,070\end{array}$ & $\begin{array}{l}12.90 \\
12.91 \\
13.05 \\
13.33 \\
13.52 \\
13.57\end{array}$ & $\begin{array}{l}4,460 \\
4,470 \\
4,580 \\
4,800 \\
4,960 \\
5,000\end{array}$ & $\begin{array}{c}10.15 \\
10.0 \\
9.9 \\
9.8 \\
9.7 \\
9.6\end{array}$ & $\begin{array}{l}2,340 \\
2,240 \\
2,180 \\
2,120 \\
2,060 \\
2,000\end{array}$ & $\begin{array}{l}7.7 \\
7.6 \\
7.55 \\
7.45 \\
7.35 \\
7.3\end{array}$ & $\begin{array}{l}1,140 \\
1,100 \\
1,090 \\
1,060 \\
1,020 \\
1,010\end{array}$ \\
\hline & \multicolumn{2}{|c|}{ September 24} & \multicolumn{2}{|c|}{ September 25} & \multicolumn{2}{|c|}{ September 26} & \multicolumn{2}{|c|}{ September 27} & \multicolumn{2}{|c|}{ September 28} & \multicolumn{2}{|c|}{ September 29} \\
\hline $\begin{array}{r}2 \\
4 \\
6 \\
8 \\
10 \\
N\end{array}$ & $\begin{array}{l}7.15 \\
7.0 \\
6.85 \\
6.7 \\
6.6 \\
6.45\end{array}$ & $\begin{array}{l}965 \\
920 \\
878 \\
836 \\
810 \\
7771\end{array}$ & $\begin{array}{c}- \\
5.8 \\
- \\
5.65 \\
- \\
5.55\end{array}$ & $\begin{array}{c}-616 \\
-583 \\
-562\end{array}$ & $\begin{array}{c}- \\
- \\
- \\
- \\
- \\
* 5.0\end{array}$ & $\begin{array}{l}- \\
- \\
- \\
- \\
- \\
* 460\end{array}$ & $\begin{array}{c}- \\
- \\
- \\
- \\
- \\
* 4.6\end{array}$ & $\begin{array}{l}- \\
- \\
- \\
- \\
- \\
* 380\end{array}$ & $\begin{array}{c}- \\
- \\
- \\
- \\
- \\
* 4,4\end{array}$ & $\begin{array}{l}- \\
- \\
- \\
- \\
- \\
* 340\end{array}$ & $\begin{array}{c}- \\
- \\
- \\
- \\
- \\
* 4.2\end{array}$ & $\begin{array}{l}- \\
- \\
- \\
- \\
* 320\end{array}$ \\
\hline $\begin{array}{r}2 \\
4 \\
6 \\
8 \\
10 \\
M\end{array}$ & $\begin{array}{l}6.35 \\
6.25 \\
6.15 \\
6.05 \\
6.0 \\
5.9\end{array}$ & $\begin{array}{l}745 \\
720 \\
696 \\
672 \\
660 \\
638\end{array}$ & $\begin{array}{c}- \\
5.45 \\
- \\
5.35 \\
- \\
5.30\end{array}$ & $\begin{array}{c}-542 \\
-522 \\
-512\end{array}$ & $\begin{array}{l}- \\
- \\
- \\
- \\
-\end{array}$ & $\begin{array}{l}- \\
- \\
- \\
-\end{array}$ & $\begin{array}{l}- \\
- \\
- \\
- \\
-\end{array}$ & $\begin{array}{l}- \\
- \\
- \\
- \\
-\end{array}$ & $\begin{array}{l}- \\
- \\
- \\
-\end{array}$ & $\begin{array}{l}- \\
- \\
- \\
- \\
-\end{array}$ & $\begin{array}{l}- \\
- \\
- \\
-\end{array}$ & $\begin{array}{l}- \\
- \\
- \\
- \\
-\end{array}$ \\
\hline
\end{tabular}

Supplemental records.- Sept. 20, 5:30 p.m., 11.74 ft., 3,680 sec.-ft. Sept. 21,

11:30 p.m., 13.58 ft., 5, 000 sec.-ft.

* Mean for the day. 
Location.- Water-stage recorder, lat. $41^{\circ} 33^{\prime} 14^{\prime \prime}$, long. $72^{\circ} 2^{\prime} 7^{\prime} 0^{\prime \prime}$, at Comstock Bridge, on Hartford-Middlesex County IIne, $3 \frac{1}{2}$ miles southeast of East Hampton, Middlesex County.

Drainage area.- 105 square miles.

Gage-height record.- Water-stage recorder graph.

Stage-discharge relation. - Defined by current-meter measurements below 1,450 secondfeet; extended to peak stage on basis of determination of peak flow over spillway of dam half a mile upstream.

Maxima.- September 1938: Discharge 12,400 second-feet 8 a.m. Sept. 21 (gage height, 10.96 feet).

1905-6, 1928 to August 1938: Discharge, 6,250 second-feet Mar. 12, 1936

(gage height, 6.98 feet, ice jam).

Remarks.- Flood run-off not materialiy affected by storage.

Mean daily discharge, in second-feet, 1938

\begin{tabular}{|c|c|c|c|c|c|c|c|c|c|c|c|}
\hline Day & Sept. & Oct. & Day & Sept. & Oct. & Day & Sept. & oct. & Day & Sept. & Oct. \\
\hline $\begin{array}{l}1 \\
2 \\
3 \\
4 \\
5 \\
6 \\
7 \\
8\end{array}$ & $\begin{array}{l}73 \\
67 \\
64 \\
60 \\
57 \\
52 \\
52 \\
71\end{array}$ & $\begin{array}{l}500 \\
408 \\
349 \\
312 \\
292 \\
264 \\
250 \\
236\end{array}$ & $\begin{array}{r}9 \\
10 \\
11 \\
12 \\
13 \\
14 \\
15 \\
16\end{array}$ & $\begin{array}{r}60 \\
52 \\
48 \\
46 \\
84 \\
84 \\
158 \\
205\end{array}$ & $\begin{array}{l}225 \\
215 \\
205 \\
205 \\
202 \\
199 \\
199 \\
195\end{array}$ & $\begin{array}{l}17 \\
18 \\
19 \\
20 \\
21 \\
22 \\
23 \\
24\end{array}$ & $\begin{array}{r}142 \\
310 \\
2,080 \\
4,280 \\
8,720 \\
2,990 \\
1,320 \\
911\end{array}$ & $\begin{array}{l}186 \\
179 \\
176 \\
173 \\
195 \\
192 \\
173 \\
309\end{array}$ & $\begin{array}{l}25 \\
26 \\
27 \\
28 \\
29 \\
30 \\
31\end{array}$ & $\begin{array}{l}697 \\
571 \\
495 \\
434 \\
392 \\
442\end{array}$ & $\begin{array}{l}450 \\
331 \\
253 \\
222 \\
232 \\
215 \\
189\end{array}$ \\
\hline $\begin{array}{l}\text { Mean } \\
\text { Run- }\end{array}$ & $\begin{array}{l}n \ln 7 \mathrm{y} \\
\text { in }\end{array}$ & & & . . & $\dot{.}$ & . & . : & $\dot{*} \cdot$ & . & $\begin{array}{r}834 \\
8.86\end{array}$ & $\begin{array}{r}249 \\
2.73\end{array}$ \\
\hline
\end{tabular}

Gage helght, In feet, and discharge, in second-feet, at indicated time, 1938

\begin{tabular}{|c|c|c|c|c|c|c|c|c|c|c|c|c|}
\hline \multirow{2}{*}{ 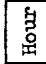 } & Feet & Sec.ft. & Feet & Sec.ft. & Feet & Sec.ft. & Feet & Sec.ft. & Feet & Sec.ft. & Feet & Sec.ft. \\
\hline & \multicolumn{2}{|c|}{ September 18} & \multicolumn{2}{|c|}{ September 19} & \multicolumn{2}{|c|}{ September 20} & \multicolumn{2}{|c|}{ September 21} & \multicolumn{2}{|c|}{ September 22} & \multicolumn{2}{|c|}{ September 23} \\
\hline $\begin{array}{l}1 \\
2 \\
3 \\
4 \\
5 \\
6\end{array}$ & $\begin{array}{l}1.34 \\
1.34 \\
1.34 \\
1.33 \\
1.32 \\
1.32\end{array}$ & $\begin{array}{l}198 \\
198 \\
198 \\
194 \\
191 \\
191\end{array}$ & $\begin{array}{l}2.54 \\
2.75 \\
3.24 \\
3.70 \\
3.99 \\
4.21\end{array}$ & $\begin{array}{r}835 \\
1,000 \\
1,440 \\
1,900 \\
2,250 \\
2,510\end{array}$ & $\begin{array}{l}4.60 \\
4.68 \\
4.71 \\
4.73 \\
4.72 \\
4.69\end{array}$ & $\begin{array}{l}3,040 \\
3,150 \\
3,190 \\
3,220 \\
3,210 \\
3,170\end{array}$ & $\begin{array}{l}6.58 \\
6.79 \\
7.12 \\
7.72 \\
8.82 \\
9.30\end{array}$ & $\begin{array}{r}6,460 \\
6,880 \\
7,560 \\
8,880 \\
9,940 \\
11,000\end{array}$ & $\begin{array}{l}7.24 \\
6.92 \\
6.60 \\
6.40 \\
6.20 \\
6.02\end{array}$ & $\begin{array}{l}5,380 \\
4,910 \\
4,460 \\
4 ; 200 \\
3,940 \\
3,710\end{array}$ & $\begin{array}{l}4.12 \\
4.07 \\
4.02 \\
3.98 \\
3.94 \\
3.90\end{array}$ & $\begin{array}{l}1,660 \\
1,610 \\
1,570 \\
1,530 \\
1,500 \\
1,470\end{array}$ \\
\hline $\begin{array}{r}7 \\
8 \\
9 \\
10 \\
11 \\
N\end{array}$ & $\begin{array}{l}1.31 \\
1.31 \\
1.31 \\
1.30 \\
1.30 \\
1.30\end{array}$ & $\begin{array}{l}188 \\
188 \\
188 \\
184 \\
184 \\
184\end{array}$ & $\begin{array}{l}4.22 \\
4.20 \\
4.13 \\
4.04 \\
3.97 \\
3.89\end{array}$ & $\begin{array}{l}2,520 \\
2,500 \\
2,420 \\
2,310 \\
2,220 \\
2,130\end{array}$ & $\begin{array}{l}4.67 \\
4.65 \\
4.64 \\
4.74 \\
5.03 \\
5.60\end{array}$ & $\begin{array}{l}3,140 \\
3,110 \\
3,100 \\
3,240 \\
3,670 \\
4,600\end{array}$ & $\begin{array}{r}10.16 \\
10.96 \\
10.76 \\
10.58 \\
10.16 \\
9.72\end{array}$ & $\begin{array}{r}11,900 \\
12,400 \\
11,900 \\
11,500 \\
10,600 \\
9,740\end{array}$ & $\begin{array}{l}5.83 \\
5.71 \\
5.52 \\
5.42 \\
5.22 \\
5.13\end{array}$ & $\begin{array}{l}3,470 \\
3,320 \\
3,090 \\
2,970 \\
2,750 \\
2,650\end{array}$ & $\begin{array}{l}3.86 \\
3.83 \\
3.80 \\
3.75 \\
3.72 \\
3.70\end{array}$ & $\begin{array}{l}1,440 \\
1,410 \\
1,390 \\
1,350 \\
1,330 \\
1,310\end{array}$ \\
\hline $\begin{array}{l}1 \\
2 \\
3 \\
4 \\
5 \\
6\end{array}$ & $\begin{array}{l}1.41 \\
1.56 \\
1.81 \\
1.97 \\
2.02 \\
1.99\end{array}$ & $\begin{array}{l}223 \\
282 \\
395 \\
475 \\
501 \\
485\end{array}$ & $\begin{array}{l}3.80 \\
3.72 \\
3.60 \\
3.52 \\
3.62 \\
3.73\end{array}$ & $\begin{array}{l}2,020 \\
1,920 \\
1,800 \\
1,720 \\
1,820 \\
1,940\end{array}$ & $\begin{array}{l}6.09 \\
6.37 \\
6.30 \\
6.22 \\
6.02 \\
5.87\end{array}$ & $\begin{array}{l}5,480 \\
6,040 \\
5,900 \\
5,740 \\
5,360 \\
5,090\end{array}$ & $\begin{array}{l}9.16 \\
8.61 \\
8.21 \\
8.62 \\
8.89 \\
9.03\end{array}$ & $\begin{array}{l}8,620 \\
7,600 \\
6,940 \\
7,620 \\
8,100 \\
8,360\end{array}$ & $\begin{array}{l}5.02 \\
4.91 \\
4.81 \\
4.73 \\
4.64 \\
4.55\end{array}$ & $\begin{array}{l}2,530 \\
2,410 \\
2,310 \\
2,230 \\
2,140 \\
2,050\end{array}$ & $\begin{array}{l}3.65 \\
3.62 \\
3.60 \\
3.56 \\
3.52 \\
3.50\end{array}$ & $\begin{array}{l}1,270 \\
1,250 \\
1,230 \\
1,200 \\
1,170 \\
1,160\end{array}$ \\
\hline \multirow[t]{2}{*}{$\begin{array}{r}7 \\
8 \\
9 \\
10 \\
11 \\
M\end{array}$} & $\begin{array}{l}1.95 \\
1.93 \\
1.92 \\
1.93 \\
2.05 \\
2.33\end{array}$ & $\begin{array}{l}465 \\
455 \\
450 \\
455 \\
518 \\
690\end{array}$ & $\begin{array}{l}3.92 \\
4.13 \\
4.30 \\
4.40 \\
4.45 \\
4.50\end{array}$ & $\begin{array}{l}2,160 \\
2,420 \\
2,620 \\
2,760 \\
2,830 \\
2,900\end{array}$ & $\begin{array}{l}5.85 \\
5.85 \\
5.82 \\
5.79 \\
5.86 \\
6.20\end{array}$ & $\begin{array}{l}5,050 \\
5,050 \\
5,000 \\
\mathbf{4}, 940 \\
\mathbf{5}, 070 \\
5,700\end{array}$ & $\begin{array}{l}8.89 \\
8.79 \\
8.52 \\
8.38 \\
8.02 \\
7.64\end{array}$ & $\begin{array}{l}8,100 \\
7,920 \\
7,440 \\
7,210 \\
6,630 \\
6,020\end{array}$ & $\begin{array}{l}4.48 \\
4.42 \\
4.35 \\
4.29 \\
4.22 \\
4.18\end{array}$ & $\begin{array}{l}1,980 \\
1,930 \\
1,860 \\
1,810 \\
1,750 \\
1,710\end{array}$ & $\begin{array}{l}3.46 \\
3.43 \\
3.42 \\
3.40 \\
3.37 \\
3.34\end{array}$ & $\begin{array}{l}1,130 \\
1,110 \\
1,100 \\
1,090 \\
1,070 \\
1,050\end{array}$ \\
\hline & \multicolumn{2}{|c|}{ September 24} & \multicolumn{2}{|c|}{ September 25} & \multicolumn{2}{|c|}{ September 26} & \multicolumn{2}{|c|}{ September 27} & \multicolumn{2}{|c|}{ September 28} & \multicolumn{2}{|c|}{ September 29} \\
\hline $\begin{array}{r}2 \\
4 \\
6 \\
8 \\
10 \\
\text { N }\end{array}$ & $\begin{array}{l}3.32 \\
3.29 \\
3.24 \\
3.22 \\
3.18 \\
3.13\end{array}$ & $\begin{array}{r}1,030 \\
1,010 \\
978 \\
964 \\
936 \\
901\end{array}$ & $\begin{array}{l}2.92 \\
2.89 \\
2.87 \\
2.84 \\
2.82 \\
2.79\end{array}$ & $\begin{array}{l}772 \\
754 \\
742 \\
724 \\
712 \\
694\end{array}$ & $\begin{array}{c}- \\
2.63 \\
- \\
2.60 \\
- \\
2.58\end{array}$ & $\begin{array}{r}-602 \\
- \\
-585 \\
-574\end{array}$ & $\begin{array}{c}- \\
2.47 \\
- \\
2.45 \\
- \\
2.43\end{array}$ & $\begin{array}{r}-515 \\
- \\
-505 \\
- \\
495\end{array}$ & $\begin{array}{c}- \\
- \\
2.34 \\
- \\
\overline{2} \\
2.31\end{array}$ & $\begin{array}{l}- \\
- \\
-450 \\
- \\
435\end{array}$ & $\begin{array}{c}- \\
- \\
2.24 \\
- \\
- \\
2.22\end{array}$ & $\begin{array}{l}- \\
- \\
- \\
- \\
394\end{array}$ \\
\hline $\begin{array}{r}2 \\
4 \\
6 \\
8 \\
10 \\
M\end{array}$ & $\begin{array}{l}3.11 \\
3.06 \\
3.02 \\
3.00 \\
2.97 \\
2.94\end{array}$ & $\begin{array}{l}887 \\
856 \\
832 \\
820 \\
802 \\
784\end{array}$ & $\begin{array}{l}2.77 \\
2.74 \\
2.72 \\
2.70 \\
2.68 \\
2.65\end{array}$ & $\begin{array}{l}682 \\
664 \\
652 \\
640 \\
629 \\
612\end{array}$ & $\begin{array}{c}- \\
2.54 \\
- \\
2.52 \\
- \\
2.50\end{array}$ & $\begin{array}{r}-552 \\
-541 \\
-530\end{array}$ & $\begin{array}{c}\overline{2 .} \\
\overline{-} \\
2.39 \\
\overline{2.36}\end{array}$ & $\begin{array}{r}- \\
-485 \\
-475 \\
-460\end{array}$ & $\begin{array}{c}- \\
- \\
2.27 \\
- \\
- \\
2.25\end{array}$ & $\begin{array}{l}- \\
- \\
-416 \\
- \\
408\end{array}$ & $\begin{array}{c}- \\
- \\
2.19 \\
- \\
- \\
2.18\end{array}$ & $\begin{array}{l}- \\
- \\
- \\
- \\
376\end{array}$ \\
\hline
\end{tabular}


Bast Branch of Elghtmile River near North Iyme, Conn.

Location.- Water-stage recorder, lat. $41^{\circ} 25^{\prime} 40^{\prime \prime}$, long. $72^{\circ} 20^{\prime} 05^{\prime \prime}$, at highway bridge, $0.4 \mathrm{mile}$ above confluence wi th West Branch of Eightmile River, and $1.1 \mathrm{miles}$ north of North Lyme, New London County, Conn.

Drainage area.- 22.0 square miles.

Gage-helght record. - Water-stage recorder graph.

Stage-discharge relation.- Defined by current-meter measurements below 300 second-

feet; extended to pear stage on basis of study of flow at control section. A constriction of the channel immediately above the gage changed conditions of flow and caused flow to occur at the gage at stages probably less than critical depth for discharges greater than about 1,000 second-feet. Excessive velocities, probably greater than critical, caused sufficient scour to produce the change in stagedischarge relation which was assumed to have been completed at the time of peak stage.

Maxima.- September 1938: D1scharge, 2,950 second-feet I p.m. Sept. 21 (gage helght, 7.00 feet, affected by constriction of channel above gage).

September 1937 to Auguat 1938: Discharge, 1,010 second-feet Nov. 29, 1937 (gage helght, 5.25 feet).

Remarks.- Flood run-off affected by storage in a few small ponds.

Mean daily discharge, in second-feet, 1938

\begin{tabular}{|c|c|c||c|c|c||r|r|r|r|r|r|}
\hline Day & Sept. & 0ct. & Day & Sept. & 0ct. & Day & Sept. & 0ct. & Day & Sept. & 0ct. \\
\hline 1 & 17 & 109 & 9 & 14 & 51 & 17 & 25 & 40 & 25 & 171 & 108 \\
2 & 12 & 97 & 10 & 12 & 48 & 18 & 58 & 37 & 26 & 136 & 96 \\
3 & 5.6 & 82 & 11 & 10 & 46 & 19 & 219 & 36 & 27 & 115 & 66 \\
4 & 13 & 72 & 12 & 10 & 45 & 20 & 721 & 36 & 28 & 106 & 54 \\
5 & 13 & 66 & 13 & 15 & 43 & 21 & 1,480 & 38 & 29 & 95 & 64 \\
6 & 12 & 62 & 14 & 19 & 45 & 22 & 750 & 38 & 30 & 93 & 70 \\
7 & 12 & 58 & 15 & 26 & 46 & 23 & 359 & 35 & 31 & - & 58 \\
8 & 16 & 53 & 16 & 34 & 42 & 24 & 230 & 43 & & & \\
\hline
\end{tabular}

Gage helght, in feet, and discharge, In second-feet, at indicated time, 1938

\begin{tabular}{|c|c|c|c|c|c|c|c|c|c|c|c|c|}
\hline \multirow[b]{2}{*}{ 象 } & Feet & Sec.ft. & Feot & Sec.ft. & Foet & Sec.ft. & Feet & Sec.ft. & Feot & Sec.ft. & Feet & Sec.ft. \\
\hline & \multicolumn{2}{|c|}{ Septëmber 18} & \multicolumn{2}{|c|}{ September 19} & \multicolumn{2}{|c|}{ September 20} & \multicolumn{2}{|c|}{ September 21} & \multicolumn{2}{|c|}{ September 22} & \multicolumn{2}{|c|}{ September 23} \\
\hline $\begin{array}{l}4 \\
5\end{array}$ & $\begin{array}{l}1.16 \\
1.19 \\
1.21 \\
1.23 \\
1.24 \\
1.25\end{array}$ & $\begin{array}{l}41 \\
43 \\
45 \\
47 \\
48 \\
48\end{array}$ & $\begin{array}{l}1.64 \\
1.72 \\
1.81 \\
1.88 \\
1.94 \\
1.98\end{array}$ & $\begin{array}{r}90 \\
100 \\
111 \\
121 \\
130 \\
135\end{array}$ & $\begin{array}{l}3.83 \\
3.91 \\
4.01 \\
4.09 \\
4.25 \\
4.40\end{array}$ & $\begin{array}{l}559 \\
583 \\
613 \\
637 \\
685 \\
730\end{array}$ & $\begin{array}{l}4.10 \\
4.22 \\
4.51 \\
4.73 \\
4.96 \\
5.19\end{array}$ & $\begin{array}{l}640 \\
676 \\
763 \\
830 \\
911 \\
992\end{array}$ & $\begin{array}{l}3.95 \\
4.02 \\
4.00 \\
3.56 \\
4.50 \\
4.35\end{array}$ & $\begin{array}{r}1,130 \\
1,150 \\
1,150 \\
990 \\
910 \\
850\end{array}$ & $\begin{array}{c}- \\
3.26 \\
- \\
3.19 \\
\overline{3.10}\end{array}$ & $\begin{array}{c}\overline{463} \\
\overline{4} \\
\overline{415}\end{array}$ \\
\hline 7 & $\begin{array}{l}1.26 \\
1.26 \\
1.26 \\
1.27 \\
1.27 \\
1.30\end{array}$ & $\begin{array}{l}49 \\
49 \\
49 \\
50 \\
50 \\
53\end{array}$ & $\begin{array}{l}2.01 \\
2.04 \\
2.06 \\
2.12 \\
2.16 \\
2.20\end{array}$ & $\begin{array}{l}140 \\
144 \\
147 \\
156 \\
163 \\
169\end{array}$ & $\begin{array}{l}4.51 \\
4.57 \\
4.59 \\
4.62 \\
4.63 \\
4.66\end{array}$ & $\begin{array}{l}763 \\
781 \\
787 \\
796 \\
799 \\
808\end{array}$ & $\begin{array}{l}5.43 \\
5.35 \\
5.40 \\
5.77 \\
6.30 \\
6.70\end{array}$ & $\begin{array}{l}1,080 \\
1,250 \\
1,500 \\
1,750 \\
2,200 \\
2,750\end{array}$ & $\begin{array}{l}4.28 \\
4.19 \\
4.15 \\
4.07 \\
3.97 \\
3.91\end{array}$ & $\begin{array}{l}822 \\
786 \\
770 \\
740 \\
704 \\
684\end{array}$ & $\begin{array}{c}- \\
3.00 \\
- \\
2.94 \\
- \\
2.89\end{array}$ & $\begin{array}{l}3 \overline{85} \\
\overline{367} \\
\overline{352}\end{array}$ \\
\hline 1 & $\begin{array}{l}1.33 \\
1.35 \\
1.37 \\
1.39 \\
1.43 \\
1.46\end{array}$ & $\begin{array}{l}56 \\
58 \\
60 \\
62 \\
66 \\
70\end{array}$ & $\begin{array}{l}2.24 \\
2.28 \\
2.32 \\
2.45 \\
2.52 \\
2.69\end{array}$ & $\begin{array}{l}176 \\
183 \\
190 \\
213 \\
226 \\
259\end{array}$ & $\begin{array}{l}4.65 \\
4.61 \\
4.58 \\
4.54 \\
4.50 \\
4.46\end{array}$ & $\begin{array}{l}805 \\
792 \\
784 \\
772 \\
760 \\
748\end{array}$ & $\begin{array}{l}7.00 \\
6.76 \\
6.42 \\
5.74 \\
4.50 \\
4.50\end{array}$ & $\begin{array}{l}2,950 \\
2,900 \\
2,600 \\
2,150 \\
1,430 \\
1,430\end{array}$ & $\begin{array}{l}3.88 \\
3.83 \\
3.78 \\
3.74 \\
3.70 \\
3.65\end{array}$ & $\begin{array}{l}673 \\
656 \\
638 \\
624 \\
610 \\
592\end{array}$ & $\begin{array}{c}- \\
2.81 \\
- \\
2.73 \\
- \\
2.68\end{array}$ & $\begin{array}{l}3 \overline{3} 2 \\
\overline{312} \\
\overline{300}\end{array}$ \\
\hline \multirow[t]{2}{*}{$\begin{array}{r}7 \\
8 \\
9 \\
10 \\
11 \\
M\end{array}$} & $\begin{array}{l}1.49 \\
1.52 \\
1.54 \\
1.57 \\
1.60 \\
1.62\end{array}$ & $\begin{array}{l}73 \\
76 \\
78 \\
82 \\
85 \\
87 \\
\end{array}$ & $\begin{array}{l}2.82 \\
3.16 \\
3.44 \\
3.58 \\
3.68 \\
3.74\end{array}$ & $\begin{array}{l}286 \\
365 \\
442 \\
484 \\
514 \\
532\end{array}$ & $\begin{array}{l}4.41 \\
4.36 \\
4.32 \\
4.25 \\
4.19 \\
4.13\end{array}$ & $\begin{array}{l}733 \\
718 \\
706 \\
685 \\
667 \\
649\end{array}$ & $\begin{array}{l}4.02 \\
4.12 \\
4.16 \\
4.14 \\
4.02 \\
3.90\end{array}$ & $\begin{array}{l}1,150 \\
1,210 \\
1,250 \\
1,230 \\
1,150 \\
1,110\end{array}$ & $\begin{array}{l}3.61 \\
3.56 \\
3.51 \\
3.48 \\
3.42 \\
3.36\end{array}$ & $\begin{array}{l}578 \\
561 \\
544 \\
533 \\
512 \\
493\end{array}$ & $\begin{array}{c}- \\
2.62 \\
- \\
2.58 \\
\overline{2.54}\end{array}$ & $\begin{array}{l}- \\
285 \\
2 \overline{7} \\
\overline{268}\end{array}$ \\
\hline & \multicolumn{2}{|c|}{ September 24} & \multicolumn{2}{|c|}{ September 25} & \multicolumn{2}{|c|}{ September 26} & \multicolumn{2}{|c|}{ September 27} & \multicolumn{2}{|c|}{ September 28} & \multicolumn{2}{|c|}{ September 29} \\
\hline 2 & $\begin{array}{c}\overline{2.48} \\
\overline{2.42} \\
\overline{2.34}\end{array}$ & $\begin{array}{c}256 \\
244 \\
2 \overline{-}\end{array}$ & $\begin{array}{c}- \\
2.12 \\
- \\
2.06 \\
- \\
2.02\end{array}$ & $\begin{array}{c}187 \\
- \\
176 \\
169\end{array}$ & $\begin{array}{c}- \\
1.85\end{array}$ & $\begin{array}{c}- \\
\overline{142} \\
\overline{135} \\
\overline{3}\end{array}$ & $\begin{array}{c}- \\
\overline{1.68} \\
- \\
- \\
1.64\end{array}$ & $\overline{-}$ & $\begin{array}{c}- \\
\overline{1.61} \\
\overline{-} \\
\overline{1.58}\end{array}$ & $\begin{array}{c}- \\
109 \\
- \\
106\end{array}$ & $\begin{array}{c}- \\
\overline{1.51} \\
\overline{-} \\
1.49\end{array}$ & $\begin{array}{l}\overline{-} \\
\overline{97} \\
\overline{9} \\
\overline{95}\end{array}$ \\
\hline & $\begin{array}{c}- \\
2.26 \\
- \\
2.22 \\
- \\
2.17\end{array}$ & $\begin{array}{l}\overrightarrow{212} \\
\overrightarrow{205} \\
\overrightarrow{196}\end{array}$ & $\begin{array}{c}- \\
1.98 \\
- \\
1.94 \\
- \\
1.90\end{array}$ & $\begin{array}{l}1 \overline{63} \\
\overline{156} \\
\overline{150}\end{array}$ & $\begin{array}{c}1.75 \\
- \\
- \\
1.72\end{array}$ & $\begin{array}{c}\overline{128} \\
\overline{-} \\
\overline{124}\end{array}$ & $\begin{array}{c}- \\
\overline{1.62} \\
\overline{-} \\
\overline{1.62}\end{array}$ & $\begin{array}{c}\overline{-} \\
\overline{111} \\
\overline{111}\end{array}$ & $\begin{array}{c}- \\
\overline{1.55} \\
- \\
\overline{1.53}\end{array}$ & $\overline{-}$ & $\begin{array}{c}\overline{-} \\
\overline{1.46} \\
\overline{1.44}\end{array}$ & $\begin{array}{l}- \\
\overline{92} \\
\overline{89}\end{array}$ \\
\hline
\end{tabular}

Supplemental records.- Sept. $21,8: 15 \mathrm{a.m.,} 5.28 \mathrm{ft}$; $1: 10 \mathrm{p.m} ., 6.67 \mathrm{ft}$. 
West Branch of Eightmile River near North Lyme, Conn.

Location.- Staff gage, lat. $41^{\circ} 25^{\prime} 55^{\prime \prime}$, long. $72^{\circ} 20110^{\prime \prime}$, at highway bridge 300 feet above confluence with East Branch of Eightmile River, 1룰 miles north of North Lyme, New London County, and $5 \frac{2}{2}$ miles above confluence with Connecticut River. Drainage area.- 19.2 square miles.

Gage-helght record.- Graph based on one or two gage readings da11y.

Stage-discharge relation.- Defined by current-meter measurements below 225 secondfeet; extended to peak stage on basis of determination of flood flow through bridge half a mile upstream and study of run-off for station on East Branch of Eightmile River near North Lyme.

Maxima.- September 1938: Discharge, 1,810 second-feet 10 to 11 a.m. Sept. 2l (gage helght, 8.2 feet, from floodmarks).

September 1937 to August 1938: Discharge, 1,020 second-feet Nov. 29, 1937 (gage helght, 6.8 feet, from floodmarks).

Remarks.- Flood run-off not affected by artificial storage. Shaw Lake (Lake Hayward) controls headwater run-off to some extent.

Mean daily discharge, in second-feet, 1938

\begin{tabular}{|c|c|c|c|c|c|c|c|c|c|c|c|}
\hline Dey & Sept. & oct. & Day & Sept. & Oct. & Day & Sept. & Oct. & Day & Sept. & oct. \\
\hline $\begin{array}{l}1 \\
2 \\
3 \\
4 \\
5 \\
6 \\
7 \\
8\end{array}$ & $\begin{array}{c}17 \\
15 \\
13 \\
12 \\
11 \\
8.8 \\
9.2 \\
13\end{array}$ & $\begin{array}{r}120 \\
89 \\
76 \\
68 \\
62 \\
58 \\
54 \\
50 \\
\end{array}$ & $\begin{array}{r}9 \\
10 \\
11 \\
12 \\
13 \\
14 \\
15 \\
16\end{array}$ & $\begin{array}{c}10 \\
8.8 \\
7.5 \\
6.7 \\
11 \\
12 \\
19 \\
23 \\
\end{array}$ & $\begin{array}{l}48 \\
46 \\
44 \\
44 \\
43 \\
44 \\
44 \\
41\end{array}$ & $\begin{array}{l}17 \\
18 \\
19 \\
20 \\
21 \\
22 \\
23 \\
24\end{array}$ & $\begin{array}{r}18 \\
68 \\
245 \\
557 \\
1,310 \\
726 \\
332 \\
226 \\
\end{array}$ & $\begin{array}{l}39 \\
37 \\
36 \\
37 \\
42 \\
37 \\
35 \\
56 \\
\end{array}$ & $\begin{array}{l}25 \\
26 \\
27 \\
28 \\
29 \\
30 \\
31\end{array}$ & $\begin{array}{c}176 \\
146 \\
117 \\
100 \\
87 \\
106 \\
-\end{array}$ & $\begin{array}{r}124 \\
67 \\
54 \\
51 \\
76 \\
57 \\
47\end{array}$ \\
\hline $\begin{array}{l}\text { Mean } \\
\text { Run-c }\end{array}$ & $\begin{array}{l}\text { onthly } \\
\mathrm{f}, \text { in }\end{array}$ & $\begin{array}{l}\text { scha } \\
\text { hes. }\end{array}$ & , in & $\begin{array}{l}\text { second } \\
-\quad . \quad\end{array}$ & et. . & $\begin{array}{l}\cdot \\
\cdot \\
\end{array}$ & ..$<$ & $: \dot{0}$ & . & $\begin{array}{r}147 \\
8.55 \\
\end{array}$ & $\begin{array}{l}55.7 \\
3.34\end{array}$ \\
\hline
\end{tabular}

Gage height, in feet, and discharge, in second-feet, at indicated time, 1938

\begin{tabular}{|c|c|c|c|c|c|c|c|c|c|c|c|c|}
\hline \multirow{2}{*}{$\begin{array}{r}5 \\
3 \\
0 \\
9 \\
\end{array}$} & Feet & Sec.ft. & Feet & Sec.ft. & Feet & Sec.ft. & Feet & Sec.ft. & Feet & Sec.ft. & Feet & Sec.ft. \\
\hline & \multicolumn{2}{|c|}{ September 18} & \multicolumn{2}{|c|}{ September 19} & \multicolumn{2}{|c|}{ September 20} & \multicolumn{2}{|c|}{ September 21} & \multicolumn{2}{|c|}{ September 22} & \multicolumn{2}{|c|}{ September 23} \\
\hline 1 & -- & $-\infty$ & -- & -- & -- & -- & 5.2 & 495 & -- & -- & -- & $-\infty$ \\
\hline 2 & $z-$ & - & -- & -- & -- & -- & 5.25 & 508 & 6.85 & $I, 040$ & -- & -- \\
\hline 3 & 1.55 & 40 & 2.9 & 165 & 5.3 & 520 & 5.4 & 545 & -- & $-\infty$ & 4.75 & 400 \\
\hline 4 & -- & -- & -- & -- & -- & -- & 5.8 & 655 & 6.7 & 980 & -- & -- \\
\hline 5 & -- & -- & -- & $-\infty$ & $=$ & $=$ & 6.4 & 860 & -- & $\cdots$ & -- & -- \\
\hline 6 & 1.6 & 45 & 3.2 & 190 & 5.6 & 595 & 7.0 & 1,110 & 6.5 & 900 & 4.6 & 373 \\
\hline 7 & -- & - & -- & -- & -- & -- & 7.6 & 1,430 & - & -- & -- & -- \\
\hline 8 & -- & -- & -- & -- & -- & -- & 7.9 & 1,610 & 6.3 & 820 & -- & $-\infty$ \\
\hline 9 & 1.6 & 45 & 3.35 & 204 & 5.7 & 625 & 8.1 & 1,740 & -- & -- & 4.45 & 348 \\
\hline 10 & -- & -- & -- & -- & - & -- & 8.2 & 1,810 & 6.1 & 750 & - & -- \\
\hline$\frac{11}{N}$ & --7 & $-\overline{55}$ & $\overline{3.5}$ & $\overline{219}$ & $\overline{5.65}$ & $\overline{610}$ & $\begin{array}{l}8.2 \\
8.15\end{array}$ & 1,810 & $=-$ & $\overline{685}$ & - & $\overline{324}$ \\
\hline & & & & 219 & 0.00 & 010 & 8.10 & 1,780 & & 685 & 4.3 & 324 \\
\hline 1 & - & -- & -- & -- & -- & -- & -- & -- & -- & -- & - & -- \\
\hline 2 & $=-$ & $-\bar{c}$ & $=-$ & -- & $=-$ & $=-$ & 8.05 & 1,700 & 5.75 & 640 & -- & -- \\
\hline 3 & 1.8 & 66 & 3.75 & 248 & 5.55 & 582 & - & $=-$ & -- & $=$ & 4.15 & 302 \\
\hline 4 & -- & -- & $-\infty$ & $\infty$ & -- & -- & 7.85 & 1,580 & 5.55 & 582 & -- & -- \\
\hline 5 & - & $-\overline{0}$ & - & - & $=-$ & - & $=$ & - & $=$ & $=-$ & - & $=$ \\
\hline 6 & 2.0 & 89 & 4.05 & 287 & 5.4 & 545 & 7.65 & 1,460 & 5.4 & 545 & 4.05 & 287 \\
\hline 7 & -- & -- & -- & -- & -- & -- & -- & -- & -- & -- & -- & $-\infty$ \\
\hline 8 & -- & - & - & $=-8$ & $=-$ & $=-$ & 7.5 & 1,370 & 5.25 & 508 & -- & - \\
\hline 9 & 2.3 & 119 & 4.5 & 356 & 5.25 & 508 & - & - & $=$ & -- & 3.95 & 274 \\
\hline 10 & -- & - & -- & -- & $\cdots$ & -- & 7.25 & 1,240 & 5.1 & 470 & -- & - \\
\hline$\frac{11}{M}$ & $\overline{2.6}$ & $\overline{141}$ & 4.95 & $\overline{440}$ & $\overline{5}$ & $\overline{495}$ & $\overline{7} 05$ & 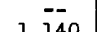 & - & - & $=$ & $=-$ \\
\hline & & & & & $=0.2$ & 490 & 1.00 & 1,140 & 4.95 & 440 & 3.85 & 260 \\
\hline & \multicolumn{2}{|c|}{ September 24} & \multicolumn{2}{|c|}{ September 25} & \multicolumn{2}{|c|}{ September 26} & \multicolumn{2}{|c|}{ September 27} & \multicolumn{2}{|c|}{ September 28} & \multicolumn{2}{|c|}{ September 29} \\
\hline 2 & -- & - & -- & -- & -- & -- & - & -- & -- & $-\infty$ & $-\infty$ & $-\infty$ \\
\hline 4 & $=-$ & -- & $=-$ & -- & -- & -- & -- & -- & $-\infty$ & -- & -- & -- \\
\hline 6 & 3.7 & 242 & 3.15 & 184 & 2.9 & 254 & -- & -- & $-\infty$ & -- & $-\infty$ & -- \\
\hline 8 & -- & -- & -- & -- & $=-$ & -- & 2.7 & 120 & 2.6 & 102 & 2.5 & 86 \\
\hline 10 & - & $-\overline{0}$ & - & $-\pi$ & $-\overline{0}$ & $\pi$ & -- & -- & -- & -- & -- & -- \\
\hline N & 3.55 & 224 & 3.05 & 174 & 2.85 & 146 & -- & -- & -- & -- & -- & -- \\
\hline 2 & -- & -- & -- & -- & -- & -- & -- & -- & -- & -- & -- & -- \\
\hline 4 & $=-$ & $\overline{-}$ & -- & $=-$ & -- & -- & 2.65 & 111 & 2.55 & 94 & 2.5 & 86 \\
\hline 6 & 3.4 & 209 & 3.0 & 168 & 2.8 & 138 & -- & -- & -- & -- & -- & - \\
\hline 8 & -- & - & -- & - & - & -- & -- & -- & -- & - & - & -- \\
\hline 10 & - & - & -- & $-\overline{-}$ & - & - & - & -- & -- & -- & $-\infty$ & -- \\
\hline $\mathbf{M}$ & 3.25 & 194 & 2.95 & 161 & 2.75 & 129 & 2.65 & 111 & 2.55 & 94 & 2.5 & 86 \\
\hline
\end{tabular}




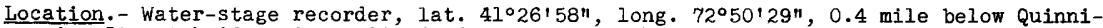
piac street bridge, in Wallingford, New Haven County, 2 miles above Worton Brook. Drainage area.- 109 square miles.

Gage-height record.- Water-stage recorder graph.

Stage-discharge relation.- Defined by current-meter measurements below 1,360 second-feet; extended to peak stage on basis of determination of flood flow over dam 1 mile upstream.

Maxima.- September 1938: Discharge, 5,230 second-feet 9 p.m. Sept. 21 (gage height, 9.55 feet)

1930 to August 1938: Discharge, 3,240 second-feet (revised) Mar. 12, 1936 (gage height, 8.2 feet)

Remarks.- Flood run-off affected by storage and regulation in several small ponds.

Mean daily discharge, in second-feet, 1938

\begin{tabular}{|c|c|c|c|c|c|c|c|c|c|c|c|}
\hline Day & Sept. & $0 \mathrm{ct}$. & Day & Sept. & Oct. & Dey & Sept. & Oct. & Day & Sept. & Oct. \\
\hline $\begin{array}{l}1 \\
2 \\
3 \\
4 \\
5 \\
6 \\
7 \\
8\end{array}$ & $\begin{array}{l}164 \\
145 \\
131 \\
128 \\
125 \\
131 \\
150 \\
150\end{array}$ & $\begin{array}{l}421 \\
391 \\
363 \\
340 \\
318 \\
304 \\
296 \\
282\end{array}$ & $\begin{array}{r}9 \\
10 \\
11 \\
12 \\
13 \\
14 \\
15 \\
16\end{array}$ & $\begin{array}{l}139 \\
120 \\
114 \\
120 \\
142 \\
147 \\
187 \\
187\end{array}$ & $\begin{array}{l}267 \\
249 \\
238 \\
218 \\
243 \\
224 \\
240 \\
224\end{array}$ & $\begin{array}{l}17 \\
18 \\
19 \\
20 \\
21 \\
22 \\
23 \\
24\end{array}$ & $\begin{array}{r}174 \\
194 \\
387 \\
1,560 \\
4,400 \\
3,990 \\
2,030 \\
1,080\end{array}$ & $\begin{array}{l}210 \\
198 \\
221 \\
212 \\
204 \\
218 \\
190 \\
212\end{array}$ & $\begin{array}{l}25 \\
26 \\
27 \\
28 \\
29 \\
30 \\
31\end{array}$ & $\begin{array}{l}721 \\
578 \\
510 \\
470 \\
434 \\
430\end{array}$ & $\begin{array}{l}315 \\
290 \\
226 \\
201 \\
224 \\
218 \\
193\end{array}$ \\
\hline $\begin{array}{l}\text { Mean } \\
\text { Run- }\end{array}$ & $\begin{array}{l}\text { nthly } \\
\text {, in }\end{array}$ & schar & 1 & $\begin{array}{c}\text { second- } \\
\cdot \text {. }\end{array}$ & et. : &. & $\begin{array}{ll}\cdot & \cdot \\
. & \cdot\end{array}$ & 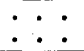 & : : & $\begin{array}{r}641 \\
6.56\end{array}$ & $\begin{array}{r}256 \\
2.71\end{array}$ \\
\hline
\end{tabular}

Gage height, in feet, and discharge, in.second-feet, at indicated time, 1938

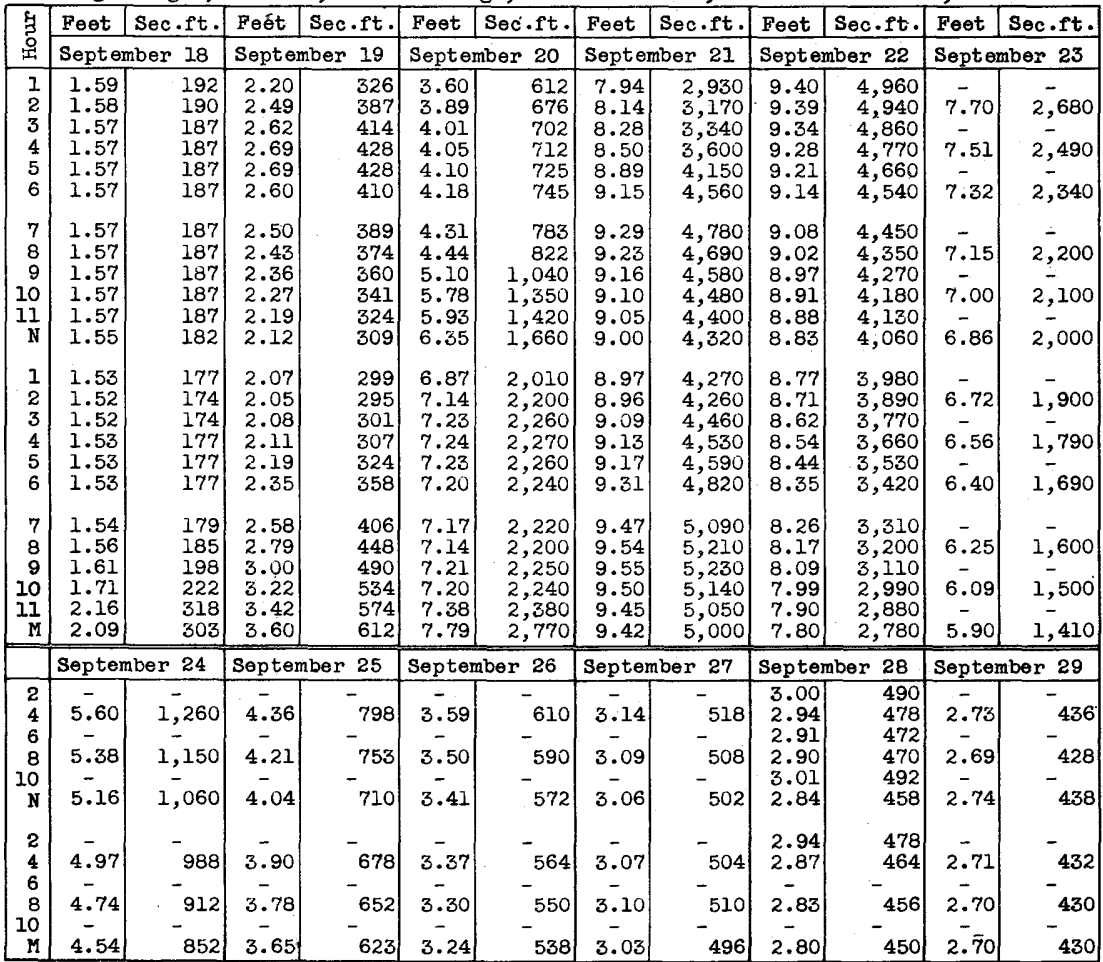

Supplemental records.- Sept. 28, 1 p.m., 2.82 ft., 454 sec.-ft. 
Location.- Water-stage recorder, Iat. $42^{\circ} 28^{\prime} 10^{\prime \prime}$, long. $73^{\circ} 11^{\prime} 50^{\prime \prime}$, In Coltsville, Berkshire County, I mile above mouth of Unkamet Brook and 2 miles northeast of city of Pittsfield.

Drainage area.- 57.1 square miles.

Gage-helght record.- Water-stage recorder graph.

Stage-discharge relation.- Defined by current-meter measurements below 2,260 secondfeet; extended to peak stage on basis of determination of flood flow over dam.

Maxima.- September 1938: Discharge, 6,400 second-feet 8:30 p.m. Sept. 21 (gage height, 10.80 feet).

1936 to August 1938: Discharge, 6,000 second-feet (revised) Mar. 18, 1936 (gage height, 10.14 feet).

Remarks. - Flood run-off not materially affected by artificial or natural storage.

Mean dally discharge, in second-feet, 1938

\begin{tabular}{|c|c|c|c|c|c|c|c|c|c|c|c|}
\hline Day & Sept. & 0 ct. & Day & Sept. & Oct. & Day & Sept. & Oct. & Day & Sept. & oct. \\
\hline $\begin{array}{l}1 \\
2 \\
3 \\
4 \\
5 \\
6 \\
7 \\
8\end{array}$ & $\begin{array}{l}72 \\
75 \\
34 \\
32 \\
42 \\
54 \\
41 \\
56\end{array}$ & $\begin{array}{r}99 \\
103 \\
114 \\
91 \\
98 \\
98 \\
91 \\
58\end{array}$ & $\begin{array}{r}9 \\
10 \\
11 \\
12 \\
13 \\
14 \\
15 \\
16\end{array}$ & $\begin{array}{r}40 \\
33 \\
30 \\
49 \\
153 \\
115 \\
142 \\
146\end{array}$ & $\begin{array}{l}67 \\
91 \\
67 \\
94 \\
91 \\
84 \\
70 \\
51\end{array}$ & $\begin{array}{l}17 \\
18 \\
19 \\
20 \\
21 \\
22 \\
23 \\
24\end{array}$ & $\begin{array}{r}72 \\
66 \\
157 \\
1,080 \\
3,110 \\
2,200 \\
565 \\
312\end{array}$ & $\begin{array}{r}69 \\
100 \\
60 \\
77 \\
116 \\
87 \\
82 \\
131\end{array}$ & $\begin{array}{l}25 \\
26 \\
27 \\
28 \\
29 \\
30 \\
31\end{array}$ & $\begin{array}{l}242 \\
210 \\
210 \\
200 \\
121 \\
108\end{array}$ & $\begin{array}{r}182 \\
119 \\
99 \\
95 \\
112 \\
107 \\
105\end{array}$ \\
\hline $\begin{array}{l}\text { Mean } \\
\text { Run- }\end{array}$ & $\begin{array}{l}\text { onthly } \\
\mathrm{f}, \text { in }\end{array}$ & $\begin{array}{l}\text { schar } \\
\text { ues. }\end{array}$ & , 1 & - . . & . & $\dot{.}$ & 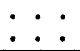 & $\begin{array}{lll}\cdot & \bullet & \bullet \\
\bullet & \bullet & \bullet\end{array}$ & . $\cdot$ & $\begin{array}{r}326 \\
6.37\end{array}$ & $\begin{array}{r}94 \\
1.90 \\
\end{array}$ \\
\hline
\end{tabular}

Gage height, in feet, and discharge, in second-feet, at indicated time, 1938

\begin{tabular}{|c|c|c|c|c|c|c|c|c|c|c|c|c|c|c|}
\hline \multirow{2}{*}{ 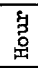 } & Feet & Sec.ft. & Feet & \multicolumn{2}{|c|}{ Sec.ft. } & Feet & Sec.ft. & Feet & Sec.ft. & Feet & Sec.ft. & Feet & \multicolumn{2}{|c|}{ Sec.ft. } \\
\hline & \multicolumn{2}{|c|}{ Sept ember 18} & \multicolumn{3}{|c|}{ September 19} & \multicolumn{2}{|c|}{ September 20} & \multicolumn{2}{|c|}{ September 21} & \multicolumn{2}{|c|}{ September 22} & \multicolumn{3}{|c|}{ September 23} \\
\hline $\begin{array}{l}1 \\
2 \\
3 \\
4 \\
5 \\
6\end{array}$ & $\begin{array}{l}2.87 \\
2.86 \\
2.85 \\
2.85 \\
2.85 \\
2.75\end{array}$ & $\begin{array}{l}69 \\
68 \\
67 \\
67 \\
67 \\
57\end{array}$ & $\begin{array}{l}2.85 \\
2.87 \\
2.85 \\
2.87 \\
2.88 \\
3.15\end{array}$ & & $\begin{array}{r}67 \\
69 \\
67 \\
69 \\
70 \\
104\end{array}$ & $\begin{array}{l}5.00 \\
5.52 \\
5.93 \\
6.07 \\
6.06 \\
6.05\end{array}$ & $\begin{array}{r}580 \\
789 \\
975 \\
1,040 \\
1,040 \\
1,040\end{array}$ & $\begin{array}{l}7.10 \\
7.15 \\
7.17 \\
7.18 \\
7.17 \\
7.21\end{array}$ & $\begin{array}{l}1,660 \\
1,700 \\
1,710 \\
1,720 \\
1,710 \\
1,740\end{array}$ & $\begin{array}{l}9.75 \\
9.45 \\
9.16 \\
8.84 \\
8.56 \\
8.38\end{array}$ & $\begin{array}{l}4,460 \\
4,020 \\
3,620 \\
3,220 \\
2,900 \\
2,700\end{array}$ & $\begin{array}{l}5.78 \\
5.66 \\
5.55 \\
5.45 \\
5.31 \\
5.15\end{array}$ & & $\begin{array}{l}906 \\
852 \\
802 \\
760 \\
704 \\
640\end{array}$ \\
\hline $\begin{array}{r}7 \\
8 \\
9 \\
10 \\
11 \\
N\end{array}$ & $\begin{array}{l}2.63 \\
2.70 \\
2.77 \\
2.81 \\
2.83 \\
2.84\end{array}$ & $\begin{array}{l}46 \\
52 \\
59 \\
63 \\
65 \\
66\end{array}$ & $\begin{array}{l}3.40 \\
3.45 \\
3.25 \\
3.29 \\
3.27 \\
3.20\end{array}$ & & $\begin{array}{l}146 \\
156 \\
120 \\
126 \\
123 \\
112\end{array}$ & $\begin{array}{l}6.17 \\
6.05 \\
5.95 \\
5.94 \\
5.96 \\
6.06\end{array}$ & $\begin{array}{r}1,100 \\
1,035 \\
985 \\
980 \\
990 \\
1,040\end{array}$ & $\begin{array}{l}7.28 \\
7.41 \\
7.53 \\
7.74 \\
7.98 \\
8.15\end{array}$ & $\begin{array}{l}1,790 \\
1,880 \\
1,960 \\
2,130 \\
2,330 \\
2,480\end{array}$ & $\begin{array}{l}8.18 \\
8.03 \\
7.93 \\
7.78 \\
7.65 \\
7.50\end{array}$ & $\begin{array}{l}2,510 \\
2,380 \\
2,290 \\
2,160 \\
2,060 \\
1,940\end{array}$ & $\begin{array}{l}5.11 \\
5.03 \\
4.98 \\
4.92 \\
4.87 \\
4.82\end{array}$ & & $\begin{array}{l}624 \\
592 \\
573 \\
552 \\
535 \\
519\end{array}$ \\
\hline $\begin{array}{l}1 \\
2 \\
3 \\
4 \\
5 \\
6\end{array}$ & $\begin{array}{l}2.83 \\
2.84 \\
2.85 \\
2.85 \\
2.85 \\
2.85\end{array}$ & $\begin{array}{l}65 \\
66 \\
67 \\
67 \\
67 \\
67\end{array}$ & $\begin{array}{l}3.27 \\
3.15 \\
3.24 \\
3.38 \\
3.28 \\
3.28\end{array}$ & & $\begin{array}{l}123 \\
104 \\
118 \\
142 \\
125 \\
125\end{array}$ & $\begin{array}{l}6.10 \\
6.08 \\
6.07 \\
6.08 \\
6.14 \\
6.25\end{array}$ & $\begin{array}{l}1,060 \\
1,050 \\
1,040 \\
1,050 \\
1,080 \\
1,138\end{array}$ & $\begin{array}{l}8.38 \\
8.45 \\
8.55 \\
8.70 \\
9.25 \\
9.90\end{array}$ & $\begin{array}{l}2,710 \\
2,780 \\
2,880 \\
3,050 \\
3,740 \\
4,700\end{array}$ & $\begin{array}{l}7.39 \\
7.25 \\
7.08 \\
6.90 \\
6.81 \\
6.70\end{array}$ & $\begin{array}{l}1,860 \\
1,760 \\
1,650 \\
1,520 \\
1,470 \\
1,400\end{array}$ & $\begin{array}{l}4.77 \\
4.72 \\
4.60 \\
4.35 \\
4.57 \\
4.58\end{array}$ & & $\begin{array}{l}501 \\
486 \\
448 \\
372 \\
439 \\
442\end{array}$ \\
\hline \multirow[t]{2}{*}{$\begin{array}{r}7 \\
8 \\
9 \\
10 \\
11 \\
M\end{array}$} & $\begin{array}{l}2.85 \\
2.85 \\
2.84 \\
3.06 \\
2.86 \\
2.85\end{array}$ & $\begin{array}{l}67 \\
67 \\
66 \\
92 \\
68 \\
67\end{array}$ & $\begin{array}{l}3.47 \\
3.83 \\
4.23 \\
4.35 \\
4.43 \\
4.85\end{array}$ & & $\begin{array}{l}160 \\
238 \\
338 \\
372 \\
396 \\
528\end{array}$ & $\begin{array}{l}6.40 \\
6.52 \\
6.63 \\
6.75 \\
6.85 \\
6.95\end{array}$ & $\begin{array}{l}1,220 \\
1,290 \\
1,360 \\
1,430 \\
1,490 \\
1,560\end{array}$ & $\begin{array}{l}10.35 \\
10.60 \\
10.63 \\
10.53 \\
10.35 \\
10.06\end{array}$ & $\begin{array}{l}5,470 \\
5,960 \\
6,030 \\
5,820 \\
5,470 \\
4,960\end{array}$ & $\begin{array}{l}6.55 \\
6.43 \\
6.30 \\
6.18 \\
6.05 \\
5.90\end{array}$ & $\begin{array}{r}1,310 \\
1,240 \\
1,160 \\
1,100 \\
1,040 \\
960\end{array}$ & $\begin{array}{l}4.57 \\
4.55 \\
4.53 \\
4.51 \\
4.49 \\
4.48\end{array}$ & & $\begin{array}{l}439 \\
432 \\
426 \\
420 \\
414 \\
411\end{array}$ \\
\hline & \multicolumn{2}{|c|}{ September 24} & \multicolumn{3}{|c|}{ September 25} & \multicolumn{2}{|c|}{ September 26} & \multicolumn{2}{|c|}{ September 27} & \multicolumn{2}{|c|}{ September 28} & \multicolumn{3}{|c|}{ September 29} \\
\hline $\begin{array}{r}2 \\
4 \\
6 \\
3 \\
10 \\
N\end{array}$ & $\begin{array}{l}4.44 \\
4.42 \\
4.38 \\
4.29 \\
4.33 \\
4.06\end{array}$ & $\begin{array}{l}399 \\
393 \\
381 \\
355 \\
367 \\
293\end{array}$ & $\begin{array}{l}3.92 \\
3.92 \\
3.90 \\
3.89 \\
3.87 \\
3.85\end{array}$ & & $\begin{array}{l}259 \\
259 \\
254 \\
252 \\
247 \\
242\end{array}$ & $\begin{array}{l}3.74 \\
3.72 \\
3.80 \\
3.83 \\
3.68 \\
3.79\end{array}$ & $\begin{array}{l}218 \\
213 \\
231 \\
238 \\
205 \\
229\end{array}$ & $\begin{array}{l}3.55 \\
3.53 \\
3.52 \\
3.53 \\
3.48 \\
3.65\end{array}$ & $\begin{array}{l}176 \\
172 \\
170 \\
172 \\
162 \\
198 \\
\end{array}$ & $\begin{array}{l}3.92 \\
3.94 \\
3.94 \\
3.93 \\
3.72 \\
3.58\end{array}$ & $\begin{array}{l}259 \\
264 \\
264 \\
261 \\
213 \\
183\end{array}$ & $\begin{array}{l}3.32 \\
3.33 \\
3.34 \\
3.33 \\
3.32 \\
3.33\end{array}$ & & $\begin{array}{l}132 \\
133 \\
135 \\
133 \\
132 \\
133\end{array}$ \\
\hline $\begin{array}{r}2 \\
4 \\
6 \\
8 \\
10 \\
M\end{array}$ & $\begin{array}{l}3.95 \\
3.83 \\
3.84 \\
3.87 \\
3.80 \\
3.91\end{array}$ & $\begin{array}{l}266 \\
238 \\
240 \\
247 \\
231 \\
256\end{array}$ & $\begin{array}{l}3.83 \\
3.82 \\
3.79 \\
3.77 \\
3.80 \\
3.74\end{array}$ & & $\begin{array}{l}238 \\
236 \\
229 \\
224 \\
231 \\
218\end{array}$ & $\begin{array}{l}3.68 \\
3.68 \\
3.64 \\
3.62 \\
3.60 \\
3.58\end{array}$ & $\begin{array}{l}205 \\
205 \\
196 \\
191 \\
187 \\
183\end{array}$ & $\begin{array}{l}3.70 \\
3.86 \\
3.91 \\
3.96 \\
3.93 \\
3.96\end{array}$ & $\begin{array}{l}209 \\
245 \\
256 \\
268 \\
261 \\
268\end{array}$ & $\begin{array}{l}3.49 \\
3.44 \\
3.44 \\
3.39 \\
3.32 \\
3.37\end{array}$ & $\begin{array}{l}164 \\
154 \\
154 \\
144 \\
132 \\
141\end{array}$ & $\begin{array}{l}3.32 \\
3.08 \\
3.05 \\
3.15 \\
3.18 \\
3.20\end{array}$ & & $\begin{array}{r}132 \\
94 \\
90 \\
104 \\
109 \\
112\end{array}$ \\
\hline
\end{tabular}

Supplemental records.- Sept. $21,8: 30$ p.m., 10.80 ft., 6,400 sec.-ft. 
Location. - Water-stage recorder, lat. $42^{\circ} 13^{\prime} 45^{\prime \prime}$, long. $73^{\circ} 21^{\prime} 3^{\prime \prime}$, just above highway bridge at Van Deusenville, Just above mouth of Wiliiams River and 2 miles north of Great Barrington, Berksinire County. Zero of gage is 683.04 feet above mean sea level (general adjustment of 1929).

Drainage area.- 280 square miles.

Gage-height record.- Water-stage recorder graph.

Stage-discharge relation.- Defined by current-meter measurements below 6,120 secondfeet; extended to peak stage on basis of determinations of flood flow by contracted-opening method and by flow over dam.

Maxima.- September 1938: Discharge, 11,520 second-feet 2 p.m. Sept. 22 (gage height, 11.72 feet).

1913 to August 1938: D1scharge, 8,990 second-feet Mar. 19, 1936 (gage height, 10.60 feet

Remarks.- Flood run-off affected by some artificial and natural storage.

Mean daily discharge, in second-feet, 1938

\begin{tabular}{|c|c|c|c|c|c|c|c|c|c|c|c|}
\hline Day & Sept. & oct. & Dey & Sept. & Oct. & Day & Sept. & Oct. & Day & Sept. & Oct. \\
\hline $\begin{array}{l}1 \\
2 \\
3 \\
4 \\
5 \\
6 \\
7 \\
8\end{array}$ & $\begin{array}{r}332 \\
237 \\
292 \\
89 \\
82 \\
281 \\
304 \\
304\end{array}$ & $\begin{array}{l}885 \\
718 \\
635 \\
640 \\
568 \\
536 \\
522 \\
532\end{array}$ & $\begin{array}{r}9 \\
10 \\
11 \\
12 \\
13 \\
14 \\
15 \\
16\end{array}$ & $\begin{array}{l}341 \\
262 \\
181 \\
130 \\
260 \\
480 \\
517 \\
663\end{array}$ & \begin{tabular}{l|}
254 \\
334 \\
428 \\
416 \\
408 \\
432 \\
488 \\
283
\end{tabular} & $\begin{array}{l}17 \\
18 \\
19 \\
20 \\
21 \\
22 \\
23 \\
24\end{array}$ & $\begin{array}{r}541 \\
323 \\
228 \\
1,800 \\
4,530 \\
11,000 \\
9,160 \\
5,180\end{array}$ & $\begin{array}{l}250 \\
373 \\
358 \\
366 \\
472 \\
568 \\
464 \\
304\end{array}$ & $\begin{array}{l}25 \\
26 \\
27 \\
28 \\
29 \\
30 \\
31\end{array}$ & $\begin{array}{l}3,130 \\
2,130 \\
1,600 \\
1,410 \\
1,230 \\
1,000\end{array}$ & $\begin{array}{l}745 \\
745 \\
690 \\
610 \\
492 \\
456 \\
274\end{array}$ \\
\hline $\begin{array}{l}\text { Mean } \\
\text { Run- }\end{array}$ & $\begin{array}{l}\text { onthly } \\
f \text {, in } 1\end{array}$ & $\begin{array}{l}\text { schar } \\
\text { hes. }\end{array}$ & $\begin{array}{l}\text { I } 1 \\
. \text {. }\end{array}$ & econd- & et. & . : & $\begin{array}{ll}\cdot & \cdot \\
. & \bullet\end{array}$ & $\begin{array}{ll}\cdot & \cdot \\
. & \bullet\end{array}$ & $\dot{0}$ & $\begin{array}{r}1,601 \\
6.38\end{array}$ & $\begin{array}{r}492 \\
2.03 \\
\end{array}$ \\
\hline
\end{tabular}

Gage helght, In feet, and discharge, in second-feet, at indicated time, 1938

\begin{tabular}{|c|c|c|c|c|c|c|c|c|c|c|c|c|}
\hline \multirow{2}{*}{ 尔 } & Feet & Sec.ft. & Feet & Sec.ft. & Feot & Sec.ft. & Feet & Sec.ft. & Feet & Sec.ft. & Feet & Sec.ft. \\
\hline & \multicolumn{2}{|c|}{ September 18} & \multicolumn{2}{|c|}{ September 19} & \multicolumn{2}{|c|}{ September 20} & \multicolumn{2}{|c|}{ September 21} & \multicolumn{2}{|c|}{ September 22} & \multicolumn{2}{|c|}{ September 23} \\
\hline $\begin{array}{l}1 \\
2 \\
3 \\
4 \\
5 \\
6\end{array}$ & $\begin{array}{l}2.77 \\
2.57 \\
2.41 \\
2.31 \\
2.26 \\
2.43\end{array}$ & $\begin{array}{l}314 \\
229 \\
173 \\
142 \\
129 \\
180\end{array}$ & $\begin{array}{l}2.43 \\
2.33 \\
2.23 \\
2.18 \\
2.14 \\
2.30\end{array}$ & $\begin{array}{l}180 \\
148 \\
121 \\
109 \\
101 \\
139\end{array}$ & $\begin{array}{l}3.75 \\
3.93 \\
4.07 \\
4.18 \\
4.35 \\
4.55\end{array}$ & $\begin{array}{r}855 \\
970 \\
1,060 \\
1,130 \\
1,240 \\
1,380\end{array}$ & $\begin{array}{l}6.15 \\
6.23 \\
6.28 \\
6.34 \\
6.41 \\
6.51\end{array}$ & $\begin{array}{l}2,580 \\
2,640 \\
2,680 \\
2,730 \\
2,790 \\
2,870\end{array}$ & $\begin{array}{l}11.02 \\
11.20 \\
11.31 \\
11.38 \\
11.47 \\
11.53\end{array}$ & $\begin{array}{r}9,410 \\
9,950 \\
10,800 \\
10,500 \\
10,800 \\
10,900\end{array}$ & $\begin{array}{l}11.44 \\
11.41 \\
11.38 \\
11.36 \\
11.33 \\
11.28\end{array}$ & $\begin{array}{l}10,700 \\
10,600 \\
10,500 \\
10,400 \\
10,300 \\
10,200\end{array}$ \\
\hline $\begin{array}{r}7 \\
8 \\
9 \\
10 \\
11 \\
\mathrm{~N}\end{array}$ & $\begin{array}{l}2.67 \\
2.76 \\
2.74 \\
2.78 \\
2.85 \\
2.86\end{array}$ & $\begin{array}{l}269 \\
309 \\
300 \\
318 \\
351 \\
356\end{array}$ & $\begin{array}{l}2.35 \\
2.30 \\
2.46 \\
2.45 \\
2.44 \\
2.43\end{array}$ & $\begin{array}{l}154 \\
139 \\
190 \\
186 \\
183 \\
180\end{array}$ & $\begin{array}{l}4.85 \\
5.05 \\
5.09 \\
5.13 \\
5.18 \\
5.21\end{array}$ & $\begin{array}{l}1,600 \\
1,750 \\
1,780 \\
1,810 \\
1,840 \\
1,880\end{array}$ & $\begin{array}{l}6.62 \\
6.79 \\
6.87 \\
6.99 \\
7.21 \\
7.42\end{array}$ & $\begin{array}{l}2,960 \\
3,110 \\
3,190 \\
3,310 \\
3,530 \\
3,700\end{array}$ & $\begin{array}{l}11.57 \\
11.61 \\
11.64 \\
11.69 \\
11.69 \\
11.70\end{array}$ & $\begin{array}{l}11,100 \\
11,200 \\
11,300 \\
11,390 \\
11,420 \\
11,450\end{array}$ & $\begin{array}{l}11.25 \\
11.21 \\
11.16 \\
11.12 \\
11.07 \\
11.01\end{array}$ & $\begin{array}{r}10,100 \\
9,980 \\
9,830 \\
9,710 \\
9,560 \\
9,380\end{array}$ \\
\hline $\begin{array}{l}1 \\
2 \\
3 \\
4 \\
5 \\
6\end{array}$ & $\begin{array}{l}3.02 \\
3.17 \\
3.12 \\
3.00 \\
2.89 \\
2.86\end{array}$ & $\begin{array}{l}435 \\
514 \\
486 \\
425 \\
370 \\
356\end{array}$ & $\begin{array}{l}2.42 \\
2.39 \\
2.33 \\
2.59 \\
2.38 \\
2.39\end{array}$ & $\begin{array}{l}177 \\
167 \\
148 \\
167 \\
164 \\
167\end{array}$ & $\begin{array}{l}5.28 \\
5.35 \\
5.43 \\
5.55 \\
5.59 \\
5.67\end{array}$ & $\begin{array}{l}1,920 \\
1,970 \\
2,030 \\
2,120 \\
2,150 \\
2,210\end{array}$ & $\begin{array}{l}7.67 \\
7.92 \\
8.42 \\
8.73 \\
9.05 \\
9.33\end{array}$ & $\begin{array}{l}3,920 \\
4,130 \\
4,750 \\
5,170 \\
5,630 \\
6,010\end{array}$ & $\begin{array}{l}11.71 \\
11.72 \\
11.71 \\
11.69 \\
11.67 \\
11.65\end{array}$ & $\begin{array}{l}11,480 \\
11,520 \\
11,480 \\
11,420 \\
11,400 \\
11,300\end{array}$ & $\begin{array}{l}10.95 \\
10.90 \\
10.83 \\
10.75 \\
10.66 \\
10.59\end{array}$ & $\begin{array}{l}9,200 \\
9,050 \\
8,840 \\
8,600 \\
8,350 \\
8,180\end{array}$ \\
\hline \multirow[t]{2}{*}{$\begin{array}{r}7 \\
8 \\
9 \\
10 \\
11 \\
M\end{array}$} & $\begin{array}{l}2.82 \\
2.84 \\
2.88 \\
2.91 \\
2.78 \\
2.58\end{array}$ & $\begin{array}{l}357 \\
346 \\
365 \\
380 \\
318 \\
233\end{array}$ & $\begin{array}{l}2.51 \\
2.75 \\
3.01 \\
3.22 \\
3.40 \\
3.48\end{array}$ & $\begin{array}{l}207 \\
304 \\
430 \\
541 \\
645 \\
693\end{array}$ & $\begin{array}{l}5.75 \\
5.85 \\
5.94 \\
5.95 \\
5.98 \\
6.06\end{array}$ & $\begin{array}{l}2,270 \\
2,350 \\
2,415 \\
2,425 \\
2,440 \\
2,510\end{array}$ & $\begin{array}{r}9.65 \\
10.00 \\
10.22 \\
10.45 \\
10.65 \\
10.86\end{array}$ & $\begin{array}{l}6,470 \\
7,080 \\
7,460 \\
7,960 \\
8,400 \\
8,960\end{array}$ & $\begin{array}{l}11.62 \\
11.58 \\
11.55 \\
11.51 \\
11.48 \\
11.46\end{array}$ & $\begin{array}{l}11,210 \\
11,100 \\
11,000 \\
10,900 \\
10,800 \\
10,700\end{array}$ & $\begin{array}{l}10.50 \\
10.43 \\
10.33 \\
10.24 \\
10.14 \\
10.06\end{array}$ & $\begin{array}{l}7,950 \\
7,780 \\
7,520 \\
7,300 \\
7,080 \\
6,920\end{array}$ \\
\hline & \multicolumn{2}{|c|}{ September 24} & \multicolumn{2}{|c|}{ September 25} & \multicolumn{2}{|c|}{ September 26} & \multicolumn{2}{|c|}{ September 27} & \multicolumn{2}{|c|}{ September 28} & \multicolumn{2}{|c|}{ September 29} \\
\hline $\begin{array}{r}2 \\
4 \\
6 \\
8 \\
10 \\
\mathrm{~N}\end{array}$ & $\begin{array}{l}9.86 \\
9.70 \\
9.55 \\
9.39 \\
9.22 \\
9.06\end{array}$ & $\begin{array}{l}6,520 \\
6,200 \\
5,920 \\
5,680 \\
5,430 \\
5,190\end{array}$ & $\begin{array}{l}7.99 \\
7.86 \\
7.76 \\
7.65 \\
7.56 \\
7.44\end{array}$ & $\begin{array}{l}3,710 \\
3,570 \\
3,460 \\
3,340 \\
3,240 \\
3,120\end{array}$ & $\begin{array}{l}6.70 \\
6.62 \\
6.53 \\
6.56 \\
6.43 \\
6.35\end{array}$ & $\begin{array}{l}2,430 \\
2,360 \\
2,280 \\
2,300 \\
2,190 \\
2,120\end{array}$ & $\begin{array}{l}5.85 \\
5.82 \\
5.79 \\
5.82 \\
5.71 \\
5.67\end{array}$ & $\begin{array}{l}1,720 \\
1,700 \\
1,670 \\
1,700 \\
1,610 \\
1,580\end{array}$ & $\begin{array}{l}5.64 \\
5.53 \\
5.50 \\
5.59 \\
5.48 \\
5.45\end{array}$ & $\begin{array}{l}1,550 \\
1,460 \\
1,440 \\
1,510 \\
1,430 \\
1,400\end{array}$ & $\begin{array}{l}5.28 \\
5.31 \\
5.30 \\
5.38 \\
5.25 \\
5.17\end{array}$ & $\begin{array}{l}1,290 \\
1,310 \\
1,300 \\
1,360 \\
1,260 \\
1,210\end{array}$ \\
\hline $\begin{array}{r}2 \\
4 \\
6 \\
8 \\
10 \\
M\end{array}$ & $\begin{array}{l}8.76 \\
8.67 \\
8.53 \\
8.37 \\
8.21 \\
8.09\end{array}$ & $\begin{array}{l}4,740 \\
4,600 \\
4,400 \\
4,180 \\
3,970 \\
3,830\end{array}$ & $\begin{array}{l}7.30 \\
7.19 \\
7.11 \\
7.03 \\
6.91 \\
6.80\end{array}$ & $\begin{array}{l}2,980 \\
2,870 \\
2,800 \\
2,730 \\
2,620 \\
2,520\end{array}$ & $\begin{array}{l}6.30 \\
6.18 \\
6.10 \\
6.09 \\
5.96 \\
5.86\end{array}$ & $\begin{array}{l}2,080 \\
1,980 \\
1,920 \\
1,910 \\
1,810 \\
1,730\end{array}$ & $\begin{array}{l}5.64 \\
5.60 \\
5.64 \\
5.58 \\
5.58 \\
5.46\end{array}$ & $\begin{array}{l}1,550 \\
1,520 \\
1,550 \\
1,500 \\
1,500 \\
1,410\end{array}$ & $\begin{array}{l}5.42 \\
5.41 \\
5.36 \\
5.36 \\
5.31 \\
5.23\end{array}$ & $\begin{array}{l}1,380 \\
1,380 \\
1,340 \\
1,340 \\
1,310 \\
1,250\end{array}$ & $\begin{array}{l}5.21 \\
5.14 \\
5.13 \\
5.13 \\
5.03 \\
4.89\end{array}$ & $\begin{array}{l}1,240 \\
1,190 \\
1,180 \\
1,180 \\
1,120 \\
1,030\end{array}$ \\
\hline
\end{tabular}


Housatonic River at Falls Village, Conn.

Location.- Water-stage recorder, lat. 41057'15", long. $73^{\circ} 22^{\prime} 05^{\prime \prime}$, at Falls Village, Litchfield County, half a mile below power plant of Connecticut Power Co. Zero of gage is 522.41 feet above mean sea level (general adjustment of 1929).

Drainage area.- 632 square miles.

Gage-height record.- Water-stage recorder graph except for periods 11 p.m. Sept. 21 to $10 \mathrm{a} . \mathrm{m}$. Sept. 24 , when recorder failed to function properly, and $0 \mathrm{ct.} 8,9$, 1131, when intake pipe was plugged.

Stage-discharge relation.- Defined by current-meter measurements below 14, 100 secondfeet; extended logarithmically to peak stage.

Maxlma.- September 1938: Discharge, 19,900 second-feet 2 to 6 a.m. Sept. 23 (gage height, 20.7 feet, from floodmark).

1912 to August 1938: Discharge, 14,500 second-feet Mar. 20, 1936 (gage height, 17.41 feet).

Remarks.- Gage-height graph during period of faulty recording and discharge during period of plugged intake determined from operation records of Connecticut Power Co. power plant half a mile upstream. Flood run-off affected by some artificial and natural storage. The following figures of daily discharge supersede those published in Water-Supply Paper 798, page 267:

$\begin{array}{lcccc}\text { March } 1936 & 8 & 9 & 10 & 11 \\ \text { Discharge, in second-feet } & 800 & 750 & 900 & 1,900\end{array}$

Mean dally discharge, in second-feet, 1938

\begin{tabular}{|c|c|c|c|c|c|c|c|c|c|c|c|}
\hline Dey & Sept. & Oct. & Day & Sept. & Oct. & Day & Sept. & Oct. & Day & Sept. & Oct. \\
\hline $\begin{array}{l}1 \\
2 \\
3 \\
4 \\
5 \\
6 \\
7 \\
8\end{array}$ & $\begin{array}{l}630 \\
594 \\
532 \\
444 \\
316 \\
305 \\
343 \\
498\end{array}$ & $\begin{array}{l}2,110 \\
1,860 \\
1,680 \\
1,440 \\
1,320 \\
1,170 \\
1,150 \\
1,080\end{array}$ & $\begin{array}{r}9 \\
10 \\
11 \\
12 \\
13 \\
14 \\
15 \\
16\end{array}$ & $\begin{array}{r}694 \\
634 \\
270 \\
276 \\
367 \\
696 \\
860 \\
1,150\end{array}$ & $\begin{array}{l}970 \\
682 \\
820 \\
840 \\
850 \\
740 \\
800 \\
750\end{array}$ & $\begin{array}{l}17 \\
18 \\
19 \\
20 \\
21 \\
22 \\
23 \\
24\end{array}$ & $\begin{array}{r}1,100 \\
892 \\
900 \\
2,600 \\
8,420 \\
18,500 \\
19,300 \\
15,800\end{array}$ & $\begin{array}{r}600 \\
620 \\
720 \\
710 \\
920 \\
1,030 \\
1,010 \\
930\end{array}$ & $\begin{array}{l}25 \\
26 \\
27 \\
28 \\
29 \\
30 \\
31\end{array}$ & $\begin{array}{r}10,700 \\
6,200 \\
4,450 \\
3,440 \\
2,910 \\
2,460\end{array}$ & $\begin{array}{r}1,230 \\
1,540 \\
1,330 \\
1,180 \\
1,010 \\
910 \\
830\end{array}$ \\
\hline $\begin{array}{l}\text { Mean } \\
\text { Run- }\end{array}$ & $\begin{array}{l}\text { onthly } \\
\mathrm{f} \text {, in }\end{array}$ & & 1 & cond & t. & $\dot{.}$ & $\begin{array}{l}\cdot \cdot \\
\end{array}$ & $\begin{array}{lll} & \bullet & \bullet \\
. & \bullet & \bullet \\
\end{array}$ & • & $\begin{array}{r}3,543 \\
6.26 \\
\end{array}$ & $\begin{array}{r}1,059 \\
1.94 \\
\end{array}$ \\
\hline
\end{tabular}

Gage helght, in feet, and discharge, in second-feet, at indicated time, 1938

\begin{tabular}{|c|c|c|c|c|c|c|c|c|c|c|c|c|}
\hline \multirow{2}{*}{ 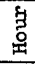 } & Feet & Sec.ft. & Feet & Sec.ft. & Feet & Sec.ft. & Feet & Sec.ft. & Feet & Sec.ft. & Feet & Sec.ft. \\
\hline & \multicolumn{2}{|c|}{ September 18} & \multicolumn{2}{|c|}{ September 19} & \multicolumn{2}{|c|}{ September 20} & \multicolumn{2}{|c|}{ September 21} & \multicolumn{2}{|c|}{ September 22} & \multicolumn{2}{|c|}{ September 23} \\
\hline $\begin{array}{l}1 \\
2 \\
3 \\
4 \\
5 \\
6\end{array}$ & $\begin{array}{l}3.35 \\
3.15 \\
3.05 \\
2.68 \\
2.44 \\
2.16\end{array}$ & $\begin{array}{l}- \\
- \\
- \\
- \\
- \\
-\end{array}$ & $\begin{array}{l}2.68 \\
2.42 \\
2.10 \\
1.78 \\
1.73 \\
1.02\end{array}$ & $\begin{array}{l}- \\
- \\
- \\
- \\
-\end{array}$ & $\begin{array}{l}3.94 \\
3.95 \\
3.95 \\
3.95 \\
3.95 \\
3.96\end{array}$ & $\begin{array}{l}1,350 \\
1,360 \\
1,360 \\
1,360 \\
1,360 \\
1,370\end{array}$ & $\begin{array}{l}8.28 \\
8.39 \\
8.50 \\
8.59 \\
8.67 \\
9.00\end{array}$ & $\begin{array}{l}4,220 \\
4,310 \\
4,400 \\
4,470 \\
4,540 \\
4,800\end{array}$ & $\begin{array}{c}19.0 \\
- \\
19.25 \\
- \\
19.5\end{array}$ & $\begin{array}{c}17,000 \\
- \\
17,300 \\
- \\
17,800\end{array}$ & $\begin{array}{c}- \\
20.7 \\
- \\
20.7 \\
- \\
20.7\end{array}$ & $\begin{array}{c}19,900 \\
- \\
19,900 \\
- \\
19,900\end{array}$ \\
\hline $\begin{array}{r}7 \\
8 \\
9 \\
10 \\
11 \\
N\end{array}$ & $\begin{array}{l}2.07 \\
2.05 \\
2.95 \\
3.36 \\
3.47 \\
3.53\end{array}$ & $\begin{array}{l}- \\
- \\
- \\
- \\
* 892\end{array}$ & $\begin{array}{l}2.65 \\
3.04 \\
3.13 \\
3.15 \\
3.26 \\
1.64\end{array}$ & $\begin{array}{l}- \\
- \\
- \\
- \\
- \\
* 900\end{array}$ & $\begin{array}{l}4.60 \\
4.85 \\
4.95 \\
4.99 \\
5.60 \\
6.10\end{array}$ & $\begin{array}{l}1,750 \\
1,900 \\
1,960 \\
1,980 \\
2,350 \\
2,670\end{array}$ & $\begin{array}{r}9.13 \\
9.30 \\
9.54 \\
9.80 \\
10.40 \\
10.80\end{array}$ & $\begin{array}{l}4,900 \\
5,040 \\
5,240 \\
5,470 \\
6,010 \\
6,370\end{array}$ & $\begin{array}{c}- \\
19.7 \\
- \\
19.9 \\
- \\
20.05\end{array}$ & $\begin{array}{c}- \\
18,100 \\
- \\
18,500 \\
- \\
18,700\end{array}$ & $\begin{array}{c}- \\
20.65 \\
- \\
20.6 \\
- \\
20.5\end{array}$ & $\begin{array}{c}- \\
19,800 \\
- \\
19,700 \\
- \\
19,500\end{array}$ \\
\hline $\begin{array}{l}1 \\
2 \\
3 \\
4 \\
5 \\
6\end{array}$ & $\begin{array}{l}3.55 \\
3.00 \\
2.76 \\
2.69 \\
2.66 \\
2.65\end{array}$ & $\begin{array}{l}- \\
- \\
- \\
- \\
-\end{array}$ & $\begin{array}{l}2.55 \\
2.75 \\
2.90 \\
3.33 \\
3.54 \\
3.60\end{array}$ & $\begin{array}{l}- \\
- \\
- \\
- \\
-\end{array}$ & $\begin{array}{l}6.45 \\
6.65 \\
6.87 \\
7.11 \\
7.25 \\
7.37\end{array}$ & $\begin{array}{l}2,920 \\
3,060 \\
3,210 \\
3,380 \\
3,480 \\
3,560\end{array}$ & $\begin{array}{l}11.25 \\
11.75 \\
12.40 \\
14.15 \\
15.30 \\
16.15\end{array}$ & $\begin{array}{r}6,820 \\
7,320 \\
8,010 \\
10,000 \\
11,500 \\
12,600\end{array}$ & $\begin{array}{c}20.2 \\
- \\
20.35 \\
- \\
20.45\end{array}$ & $\begin{array}{c}19,000 \\
- \\
19,200 \\
- \\
19,400\end{array}$ & $\begin{array}{c}- \\
20.4 \\
- \\
20.3 \\
- \\
20.15\end{array}$ & $\begin{array}{c}- \\
19,300 \\
- \\
19,200 \\
- \\
18,900\end{array}$ \\
\hline \multirow[t]{2}{*}{$\begin{array}{r}7 \\
8 \\
9 \\
10 \\
11 \\
M\end{array}$} & $\begin{array}{l}3.35 \\
3.45 \\
3.49 \\
3.50 \\
3.14 \\
2.80\end{array}$ & $\begin{array}{l}- \\
- \\
- \\
- \\
-\end{array}$ & $\begin{array}{l}3.62 \\
4.01 \\
4.21 \\
4.26 \\
3.93 \\
3.89\end{array}$ & $\begin{array}{l}- \\
- \\
- \\
- \\
-\end{array}$ & $\begin{array}{l}7.49 \\
7.71 \\
7.85 \\
7.94 \\
8.03 \\
8.17\end{array}$ & $\begin{array}{l}3,640 \\
3,800 \\
3,900 \\
3,960 \\
4,020 \\
4,140\end{array}$ & $\begin{array}{l}3.80 \\
7.45 \\
3.00 \\
3.40 \\
3.6 \\
3.8 \\
\end{array}$ & $\begin{array}{l}13,600 \\
14,500 \\
15,400 \\
16,000 \\
16,300 \\
16,600\end{array}$ & $\begin{array}{c}- \\
20.55 \\
- \\
20.6 \\
- \\
20.65\end{array}$ & $\begin{array}{c}- \\
19,600 \\
- \\
19,700 \\
- \\
19,800\end{array}$ & $\begin{array}{c}- \\
20.0 \\
- \\
19.85 \\
- \\
19.65\end{array}$ & $\begin{array}{c}18,600 \\
- \\
18,400 \\
- \\
17,900\end{array}$ \\
\hline & \multicolumn{2}{|c|}{ September 24} & \multicolumn{2}{|c|}{ September 25} & \multicolumn{2}{|c|}{ September 26} & \multicolumn{2}{|c|}{ September 27} & \multicolumn{2}{|c|}{ September 28} & \multicolumn{2}{|c|}{ September 29} \\
\hline $\begin{array}{r}2 \\
4 \\
6 \\
8 \\
10 \\
N\end{array}$ & $\begin{array}{l}19.45 \\
19.2 \\
19.0 \\
18.75 \\
18.55 \\
18.35\end{array}$ & $\begin{array}{l}17,700 \\
17,300 \\
17,000 \\
16,600 \\
16,200 \\
15,900\end{array}$ & $\begin{array}{l}16.41 \\
16.08 \\
15.75 \\
15.45 \\
15.21 \\
14.82\end{array}$ & $\begin{array}{l}13,000 \\
12,600 \\
12,100 \\
11,700 \\
11,400 \\
10,900\end{array}$ & $\begin{array}{l}11.77 \\
11.44 \\
11.10 \\
11.10 \\
10.77 \\
10.30\end{array}$ & $\begin{array}{l}7,340 \\
7,010 \\
6,670 \\
6,670 \\
6,340 \\
5,920\end{array}$ & $\begin{array}{l}8.99 \\
8.97 \\
9.02 \\
9.05 \\
8.77 \\
8.66\end{array}$ & $\begin{array}{l}4,790 \\
4,780 \\
4,820 \\
4,840 \\
4,620 \\
4,530\end{array}$ & $\begin{array}{l}7.43 \\
7.42 \\
7.44 \\
7.62 \\
7.53 \\
6.75\end{array}$ & $\begin{array}{l}3,600 \\
3,590 \\
3,610 \\
3,730 \\
3,670 \\
3,120\end{array}$ & $\begin{array}{l}6.72 \\
6.43 \\
6.67 \\
6.64 \\
6.53 \\
6.45\end{array}$ & $\begin{array}{l}3,100 \\
2,900 \\
3,070 \\
3,050 \\
2,970 \\
2,920\end{array}$ \\
\hline $\begin{array}{r}2 \\
4 \\
6 \\
8 \\
10 \\
M\end{array}$ & $\begin{array}{l}18.15 \\
17.88 \\
17.63 \\
17.32 \\
17.01 \\
16.75\end{array}$ & $\begin{array}{l}15,600 \\
15,200 \\
14,800 \\
14,300 \\
13,900 \\
13,500\end{array}$ & $\begin{array}{l}14.34 \\
13.80 \\
13.45 \\
13.10 \\
12.65 \\
12.20\end{array}$ & $\begin{array}{r}10,200 \\
9,600 \\
9,180 \\
8,780 \\
8,280 \\
7,790\end{array}$ & $\begin{array}{r}10.45 \\
10.15 \\
9.90 \\
9.77 \\
9.61 \\
9.00\end{array}$ & $\begin{array}{l}6,060 \\
5,780 \\
5,560 \\
5,440 \\
5,300 \\
4,800\end{array}$ & $\begin{array}{l}8.44 \\
8.29 \\
8.15 \\
8.02 \\
7.90 \\
7.65\end{array}$ & $\begin{array}{l}4,350 \\
4,230 \\
4,120 \\
4,020 \\
3,930 \\
3,760\end{array}$ & $\begin{array}{l}6.94 \\
7.05 \\
7.03 \\
6.92 \\
6.86 \\
6.80\end{array}$ & $\begin{array}{l}3,260 \\
3,340 \\
3,320 \\
3,240 \\
3,200 \\
3,160\end{array}$ & $\begin{array}{l}6.40 \\
6.32 \\
6.26 \\
6.23 \\
6.18 \\
6.12\end{array}$ & $\begin{array}{l}2,880 \\
2,820 \\
2,780 \\
2,760 \\
2,730 \\
2,680\end{array}$ \\
\hline
\end{tabular}

Supplemental records.- Sept. 27,5 a.m., 8.92 ft., 4,740 sec.-ft.; 7 a.m., 9.20 ft., 4,960 sec.-ft. Sept. 28, 11 a.m., 7.42 ft., 3,590 sec.-ft.; l. p.m., 6.80.ft., 3,160 sec. $-\mathrm{ft}$.

* Mean for the day. 
Zoar Lake at Stevenson, Conn.

Location.- Staff gage, lat. $41^{\circ} 22^{\prime} 55^{\prime \prime}$, long. $73^{\circ} 10^{\prime} 5^{\prime \prime}$, at Stevenson dam of Connecticut Light \& Power Co. at Stevenson, Fairfield County, Conn.

Drainage area.- 1,544 square miles.

Remarks.- Gain or loss in storage in equivalent mean second-feet computed from elevations of lake at midnight as furnished by Connecticut Light \& Power Co., Waterbury, Conn.

Gain or Loss in storage, in equivalent mean second-feet, 1938

\begin{tabular}{|c|c|c|c|c|c|c|c|c|c|c|c|}
\hline Day & Sept. & Oct. & Day & Sept. & Oct. & Day & Sept. & Oct: & Day & Sept. & Oct. \\
\hline $\begin{array}{l}1 \\
2 \\
3 \\
4 \\
5 \\
6 \\
7 \\
8\end{array}$ & $\begin{array}{r}+261 \\
+104 \\
-157 \\
-104 \\
+104 \\
-209 \\
+104 \\
-209\end{array}$ & $\begin{array}{l}-150 \\
-250 \\
-392 \\
-290 \\
+682 \\
-777 \\
+531 \\
-388\end{array}$ & $\begin{array}{r}9 \\
10 \\
11 \\
12 \\
13 \\
14 \\
15 \\
16\end{array}$ & $\begin{array}{r}-256 \\
-102 \\
+515 \\
+157 \\
-52 \\
-209 \\
+104 \\
-361\end{array}$ & $\begin{array}{r}+388 \\
-484 \\
-143 \\
+480 \\
-763 \\
+1,060 \\
+1,270 \\
+261\end{array}$ & $\begin{array}{l}17 \\
18 \\
19 \\
20 \\
21 \\
22 \\
23 \\
24\end{array}$ & $\begin{array}{r}+675 \\
-365 \\
+524 \\
+1,070 \\
+2,530 \\
-1,310 \\
-781 \\
-657\end{array}$ & $\begin{array}{r}-418 \\
-309 \\
+257 \\
+52 \\
+157 \\
-363 \\
+51 \\
+156\end{array}$ & $\begin{array}{l}25 \\
26 \\
27 \\
28 \\
29 \\
30 \\
31\end{array}$ & $\begin{array}{r}-804 \\
0 \\
-316 \\
-261 \\
-258 \\
-358\end{array}$ & $\begin{array}{r}+209 \\
-157 \\
-208 \\
0 \\
-307 \\
+987 \\
-263\end{array}$ \\
\hline Gain & loss & store & se & quival & $t$ mean & $\sec 0$ & feet & . & - & -20.7 & +28.4 \\
\hline
\end{tabular}


Location. - Water-stage recorder, lat. $41^{\circ} 23^{\prime} 05^{\prime \prime}$, Iong. $73^{\circ} 09^{\prime} 5^{\prime \prime}$, in New Haven County, a quarter of a mile below dam of Connecticut Iight \& Power Co. at Stevenson, Fairfleld County. Zero of gage is 24.98 feet above mean sea level (general adjustment of 1929).

Drainage area.- 1,545 square miles.

Gage-helght record.- Water-stage recorder graph except for period 8 a.m. Sept. $2 C$ to noon 0ct. 13. For the periods $8 \mathrm{a} . \mathrm{m}$. Sept. 20 to Sept. 30 , and midnight to noon oct. 13, graph was determined by gage-height relationship, from tailrace gage readIngs at stevenson dam, a quarter of a mile upstream. Gage-height graph not determined for period 0ct. 1-12; discharge based on power plant operation records. Intake pipe not functioning properly Sept. 7-12; discharge based upon power plant operation records.

Stage-discharge relation.- Defined by current-meter measurements below 35,000 secondfeet; extended to peak stage on basis of determinations of peak flow at Stevenson. dam and power plant, over spillway at Derby dam, and by slope-area method at gaging station.

Maxima.- September 1938: Discharge, 59,500 second-feet midnight Sept. 21 to 1 a.m. Sept. 22 (gage height, 21.5 feet, from high-water marks). 1928 to August 1938: Discharge, 69,500 second-feet Mar. 12, 1936 (gage height, 23.5 feet, from high-water marks).

Remarks.- Run-off affected by storage. For information on storage see records for Zoar Lake at Stevenson, Conn., Rocky River at outlet of Candlewood Lake, near New. Milford, Conn., and Shepaug River at outlet of Shepaug Reservolr, at Woodvilie, Conn.

Mean deily discharge, in second-feet, 1938

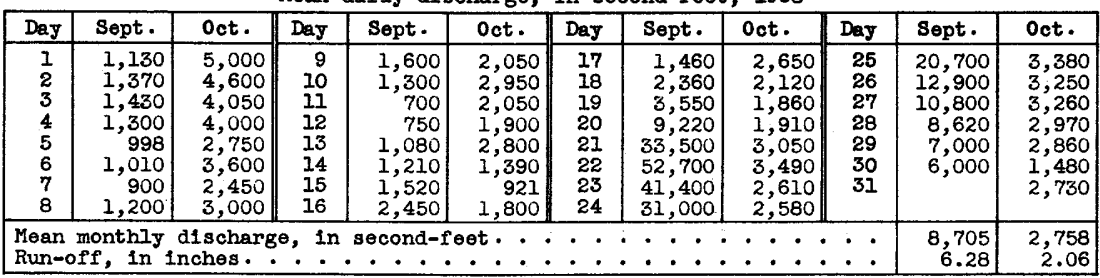

Gage helght, in feet, and discharge, in second-feet, at indlcated time, 1938

\begin{tabular}{|c|c|c|c|c|c|c|c|c|c|c|c|c|}
\hline \multirow{2}{*}{$\begin{array}{l}3 \\
3 \\
0 \\
0\end{array}$} & Feet & Sec.ft. & Feet & Sec.ft. & Feet & Sec.ft. & Feet & Sec.ft. & Feet & Sec.ft. & Feet & Sec.et. \\
\hline & \multicolumn{2}{|c|}{ September 18} & \multicolumn{2}{|c|}{ September 19} & \multicolumn{2}{|c|}{ September 20} & \multicolumn{2}{|c|}{ Sept ember 21} & \multicolumn{2}{|c|}{ September 22} & \multicolumn{2}{|c|}{ September 23} \\
\hline $\begin{array}{l}1 \\
2 \\
3 \\
4 \\
5 \\
6\end{array}$ & $\begin{array}{r}4.49 \\
4.03 \\
1.40 \\
.88 \\
.80 \\
.78\end{array}$ & $\begin{array}{l}- \\
- \\
- \\
- \\
-\end{array}$ & $\begin{array}{r}0.89 \\
.80 \\
.78 \\
.78 \\
.78 \\
.78\end{array}$ & $\begin{array}{l}- \\
- \\
- \\
-\end{array}$ & $\begin{array}{l}7.40 \\
7.17 \\
6.93 \\
6.99 \\
7.73 \\
7.63\end{array}$ & $\begin{array}{l}5,630 \\
5,250 \\
4,870 \\
4,960 \\
6,190 \\
6,020\end{array}$ & $\begin{array}{l}11.25 \\
11.3 \\
11.35 \\
11.5 \\
11.65 \\
12.2\end{array}$ & $\begin{array}{l}13,700 \\
13,800 \\
13,900 \\
14,300 \\
14,800 \\
16,500\end{array}$ & $\begin{array}{l}21.5 \\
21 \cdot 4 \\
21.3 \\
21.2 \\
21.1 \\
21.1\end{array}$ & $\begin{array}{l}59,500 \\
59,000 \\
58,500 \\
58,000 \\
57,500 \\
57,500\end{array}$ & $\begin{array}{c}18.5 \\
- \\
18.5 \\
\overline{-} \\
18.4\end{array}$ & $\begin{array}{c}- \\
44,500 \\
- \\
44,500 \\
\overline{-} \\
44,000\end{array}$ \\
\hline $\begin{array}{r}7 \\
8 \\
9 \\
10 \\
11 \\
\mathbb{N}\end{array}$ & $\begin{array}{l}4.93 \\
6.77 \\
6.26 \\
6.12 \\
6.44 \\
6.90\end{array}$ & $\begin{array}{c}- \\
- \\
- \\
- \\
* 2,360\end{array}$ & $\begin{array}{l}6.63 \\
7.33 \\
7.33 \\
7.33 \\
7.33 \\
1.65\end{array}$ & $\begin{array}{c}- \\
- \\
- \\
- \\
- \\
* 3,550\end{array}$ & $\begin{array}{l}8.84 \\
8.2 \\
8.35 \\
8.8 \\
9.5 \\
10.0\end{array}$ & $\begin{array}{r}8,280 \\
7,050 \\
7,340 \\
8,200 \\
9,600 \\
10,700\end{array}$ & $\begin{array}{l}12.5 \\
12.9 \\
13.2 \\
14.2 \\
15.0 \\
16.5\end{array}$ & $\begin{array}{l}17,600 \\
19,000 \\
20,100 \\
24,200 \\
27,800 \\
34,600\end{array}$ & $\begin{array}{l}21.2 \\
21.0 \\
20.6 \\
20.2 \\
20.15 \\
20.15\end{array}$ & $\begin{array}{l}58,000 \\
57,000 \\
55,000 \\
53,000 \\
52,800 \\
52,800\end{array}$ & $\begin{array}{c}- \\
18.5 \\
- \\
18.15 \\
- \\
17.6\end{array}$ & $\begin{array}{c}- \\
44,500 \\
42,800 \\
40,000\end{array}$ \\
\hline $\begin{array}{l}1 \\
2 \\
3 \\
4 \\
5 \\
6\end{array}$ & $\begin{array}{l}5.83 \\
4.86 \\
4.63 \\
4.80 \\
5.70 \\
5.91\end{array}$ & $\begin{array}{l}\ddot{-} \\
- \\
\bar{z} \\
= \\
\bar{z}\end{array}$ & $\begin{array}{l}6.45 \\
6.55 \\
6.55 \\
6.85 \\
7.36 \\
7.36\end{array}$ & $\begin{array}{l}- \\
- \\
- \\
- \\
-\end{array}$ & $\begin{array}{l}10.15 \\
10.2 \\
10.25 \\
10.25 \\
10.3 \\
10.35\end{array}$ & $\begin{array}{l}11,000 \\
11,100 \\
11,200 \\
11 ; 200 \\
11,400 \\
11,500\end{array}$ & $\begin{array}{l}16.7 \\
17.6 \\
17.75 \\
18.3 \\
19.0 \\
19.6\end{array}$ & $\begin{array}{l}35,500 \\
40,000 \\
40,800 \\
43,500 \\
47,000 \\
50,000\end{array}$ & $\begin{array}{l}20.15 \\
20.0 \\
19.8 \\
19.7 \\
19.5 \\
19.3\end{array}$ & $\begin{array}{l}52,800 \\
52,000 \\
51,000 \\
50,500 \\
49,500 \\
48,500\end{array}$ & $\begin{array}{c}17.8 \\
- \\
17.5 \\
- \\
17.5\end{array}$ & $\begin{array}{c}41,000 \\
39,500 \\
39,500\end{array}$ \\
\hline \multirow[t]{2}{*}{$\begin{array}{r}7 \\
8 \\
9 \\
10 \\
11 \\
\frac{M}{1} \\
\end{array}$} & $\begin{array}{l}6.45 \\
5.46 \\
6.03 \\
4.51 \\
3.55 \\
1.53\end{array}$ & $\begin{array}{l}- \\
- \\
- \\
- \\
- \\
-\end{array}$ & $\begin{array}{l}7.35 \\
7: 33 \\
7.33 \\
7.33 \\
7.34 \\
7.38\end{array}$ & $\begin{array}{l}- \\
\overline{-} \\
\overline{-} \\
- \\
-\end{array}$ & $\begin{array}{l}10.4 \\
10.45 \\
10.5 \\
10.6 \\
10.75 \\
11.2\end{array}$ & $\begin{array}{l}11,600 \\
11,700 \\
11,800 \\
12,000 \\
12,400 \\
13,600\end{array}$ & $\begin{array}{l}20.0 \\
20.2 \\
21.1 \\
21.3 \\
21.4 \\
21.5\end{array}$ & $\begin{array}{l}52,000 \\
53,000 \\
57,500 \\
58,500 \\
59,000 \\
59,500\end{array}$ & $\begin{array}{l}19.1 \\
18.95 \\
18.8 \\
18.7 \\
18.6 \\
18.5\end{array}$ & $\begin{array}{l}47,500 \\
46,800 \\
46,000 \\
45,500 \\
45,000 \\
44,500\end{array}$ & $\begin{array}{c}17.4 \\
- \\
17.1 \\
- \\
16.9\end{array}$ & $\begin{array}{c}39,000 \\
37,500 \\
36,500\end{array}$ \\
\hline & \multicolumn{2}{|c|}{ September 24} & \multicolumn{2}{|c|}{ September 25} & \multicolumn{2}{|c|}{ September 26} & \multicolumn{2}{|c|}{ September 27} & \multicolumn{2}{|c|}{ September 28} & \multicolumn{2}{|c|}{ September 29} \\
\hline $\begin{array}{r}2 \\
4 \\
6 \\
8 \\
10 \\
N\end{array}$ & $\begin{array}{l}16.9 \\
16.65 \\
16.45 \\
16.2 \\
15.9 \\
15.55\end{array}$ & $\begin{array}{l}36,500 \\
35,200 \\
34,300 \\
33,200 \\
31,800 \\
30,300\end{array}$ & $\begin{array}{l}14.4 \\
14.3 \\
14.45 \\
14.0 \\
13.6 \\
13.3\end{array}$ & $\begin{array}{l}25,100 \\
24,600 \\
25,300 \\
23,300 \\
21,700 \\
20,500\end{array}$ & \begin{tabular}{|l|}
11.5 \\
11.5 \\
11.4 \\
11.2 \\
10.65 \\
10.6
\end{tabular} & $\begin{array}{l}14,300 \\
14,300 \\
14,000 \\
13,600 \\
12,200 \\
12,000\end{array}$ & $\begin{array}{c}10.5 \\
10.4 \\
10.05 \\
10.0 \\
9.9 \\
10.0\end{array}$ & $\begin{array}{l}11,800 \\
11,600 \\
10,800 \\
10,700 \\
10,500 \\
10,700\end{array}$ & $\begin{array}{l}9.4 \\
9.35 \\
9.3 \\
9.05 \\
8.9 \\
9.0\end{array}$ & $\begin{array}{l}9,400 \\
9,300 \\
9,200 \\
8,700 \\
8,400 \\
8,600\end{array}$ & $\begin{array}{l}8.45 \\
8.3 \\
8.3 \\
8.25 \\
8.2 \\
8.2\end{array}$ & $\begin{array}{l}7,520 \\
7,240 \\
7,240 \\
7,140 \\
7,050 \\
7,050\end{array}$ \\
\hline $\begin{array}{r}2 \\
4 \\
6 \\
8 \\
10 \\
M \\
\end{array}$ & $\begin{array}{l}15.3 \\
15.2 \\
15.0 \\
14.8 \\
14.7 \\
14.6\end{array}$ & $\begin{array}{l}29,200 \\
28,700 \\
27,800 \\
26,900 \\
26,400 \\
26,000\end{array}$ & $\begin{array}{l}13.2 \\
12.8 \\
12.5 \\
12.1 \\
11.7 \\
11.55\end{array}$ & $\begin{array}{l}20,100 \\
18,600 \\
17,600 \\
16,200 \\
14,900 \\
14,400\end{array}$ & $\begin{array}{l}10.8 \\
10.8 \\
10.8 \\
10.6 \\
10.55 \\
10.5\end{array}$ & $\begin{array}{l}12,600 \\
12,600 \\
12,600 \\
12,000 \\
11,900 \\
11,800\end{array}$ & $\begin{array}{c}10.0 \\
10.0 \\
10.0 \\
9.9 \\
9.8 \\
9.55\end{array}$ & $\begin{array}{r}10,700 \\
10,700 \\
10,700 \\
10,500 \\
10,300 \\
9,710\end{array}$ & $\begin{array}{l}9.0 \\
8.9 \\
8.9 \\
8.75 \\
8.55 \\
8.5\end{array}$ & $\begin{array}{l}8,600 \\
8,400 \\
8,400 \\
8,100 \\
7,720 \\
7,620\end{array}$ & $\begin{array}{l}8.2 \\
8.2 \\
8.2 \\
8.0 \\
7.7 \\
7.6\end{array}$ & $\begin{array}{l}7,050 \\
7,050 \\
7,050 \\
6,680 \\
6,140 \\
5,970\end{array}$ \\
\hline
\end{tabular}

Supplemental records.- Sept. $18,5: 30$ p.m., 7.01 ft. Sept. 20, 5:30 a.m., 8.50 ft.,

7,620 sec.-ft.; 7:15 a.m., 7.84 ft., 6,390 sec.-ft.; 7:30 a.m., 8.83 ft., 8,260 sec.-ft.

* Mean for the day. 
Tenmile River near Gaylordsville, Conn.

Location.- Fater-stage recorder, lat. $41^{\circ} 39^{\prime} 35^{n}$, long. $73^{\circ} 31^{\prime} 45^{\prime \prime}$, I mile above Connecticut-New York State Ine, $1 \frac{1}{\mathrm{c}}$ miles above confluence with Housatonic River, and $2 \frac{1}{8}$ miles northwest of Gaylordsville, Litchfield County.

Drainage area.- 204 square miles.

Gage-he1ght record. - Fater-stage recorder graph except for period Sept. 13 to $4: 10 \mathrm{p} . \mathrm{m}$. Sept. 21 (pen not touching chart), record for which was based on hydrographic com-

parison with Wappinger Creek near' Wappinger Falls, N. Y., Shepaug River near Roxbury, Conn., Pomperaug River at Southbury, Conn., and study of climatological data.

Stage-discharge relation. - Defined by current-meter measurements below 9,650 secondreet; extended to perk stage.

Maxima.- September 1938: Discharge, 12,500 second-feet 4 to 5 a.m. Sept. 22 (gage he1ght, 12.77 feot).

11.61 peet).

1929 to August 1938: D1scharge, 10,200 second-feet Mar. 12, 1936 (gage he1ght,

Remarks.- Flood mun-off may be slightly affected by storage in several small ponds.

Mean dally discharge, in second-feet, 1938

\begin{tabular}{|c|r|r||r|r|r|r|r|r|r|r|r|}
\hline Day & Sept. & Oct. & Day & Sept. & Oct. & Day & Sept. & Oct. & Day & Sept. & Oct. \\
\hline 1 & 168 & 588 & 9 & 128 & 282 & 17 & 150 & 200 & 25 & 1,920 & 366 \\
2 & 165 & 522 & 10 & 111 & 267 & 18 & 130 & 193 & 26 & 1,380 & 291 \\
3 & 150 & 464 & 17 & 104 & 253 & 19 & 272 & 188 & 27 & 1,090 & 250 \\
4 & 144 & 427 & 12 & 102 & 236 & 20 & 1,660 & 188 & 28 & 899 & 228 \\
5 & 136 & 388 & 13 & 130 & 225 & 21 & 4,790 & 343 & 29 & 758 & 225 \\
6 & 122 & 349 & 14 & 130 & 210 & 22 & 9,380 & 301 & 30 & 656 & 217 \\
7 & 120 & 323 & 15 & 140 & 205 & 23 & 4,320 & 244 & 31 & & 200 \\
8 & 144 & 301 & 16 & 220 & 205 & 24 & 2,850 & 258 & & & \\
\hline
\end{tabular}

Gage helght, in feet, and discharge, in second-feet, at indicated time, 1938

\begin{tabular}{|c|c|c|c|c|c|c|c|c|c|c|c|c|}
\hline \multirow{2}{*}{ 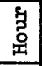 } & Feet & Sec.ft. & Feet & Sec.ft. & Feet & Sec.ft. & Feet & Sec.ft. & Feet & Sec.ft. & Feot & Sec.ft. \\
\hline & \multicolumn{2}{|c|}{ September 18} & \multicolumn{2}{|c|}{ September 19} & \multicolumn{2}{|c|}{ September 20} & \multicolumn{2}{|c|}{ September 21} & \multicolumn{2}{|c|}{ September 22} & \multicolumn{2}{|c|}{ September 23} \\
\hline 1 & - & - & - & - & - & - & - & - & 12.18 & 11,300 & 8.56 & 5,360 \\
\hline$\overline{2}$ & - & - & 1.6 & 140 & 3.65 & 885 & 5.95 & 2,500 & & 11,800 & 8.44 & 5,200 \\
\hline 3 & - & - & - & - & - & 140 & 505 & -500 & 63 & 200 & 8.34 & 5,070 \\
\hline $\begin{array}{l}4 \\
5\end{array}$ & - & $\overline{-}$ & 1.6 & 140 & 4.1 & 1,140 & 5.95 & 2,500 & $\begin{array}{l}12.77 \\
12.77\end{array}$ & $\begin{array}{l}12,500 \\
12,500\end{array}$ & $\begin{array}{l}8.25 \\
8.16\end{array}$ & $\begin{array}{l}4,960 \\
4,840\end{array}$ \\
\hline 6 & - & - & 1.6 & 140 & 4.45 & 1,350 & 6.05 & 2,600 & 12.70 & 12,300 & 8.09 & 4,760 \\
\hline 7 & - & - & - & - & - & - & - & - & 12.60 & 12,100 & 8.02 & 4,670 \\
\hline 8 & - & - & 1.65 & 150 & 4.5 & 1,380 & 6.25 & 2,780 & & 700 & 7.94 & \\
\hline 9 & - & - & - & - & - & - & - & & 12.17 & 200 & 7.87 & 4,490 \\
\hline 10 & - & - & 1.7 & 161 & 4.65 & 1,480 & 6.55 & 3,060 & 11.91 & 10,700 & 7.80 & 4,410 \\
\hline 12 & $* \overline{-55}$ & *130 & -8 & - & 48 & -590 & 60 & 54 & 11.63 & $\begin{array}{r}10,200 \\
9,680\end{array}$ & 7.74 & $\begin{array}{l}4,340 \\
4,270\end{array}$ \\
\hline & 1.00 & & 1.0 & & 4.0 & 1,090 & 0.0 & $0,4 \pm 0$ & 11.00 & & & $4,2<10$ \\
\hline 1 & - & - & - & - & - & - & - & - & 11.05 & 9,140 & 7.61 & 4,180 \\
\hline 2 & - & - & 1.95 & 220 & 5.0 & 1,780 & 7.45 & 4,000 & 10.76 & 640 & 7.55 & 4,120 \\
\hline 3 & - & - & - & & -0 & - & - & - & 10.50 & 200 & 7.48 & 4,040 \\
\hline 4 & - & - & 2.15 & 276 & 5.25 & 1,920 & 8.45 & 5,220 & 10.22 & 7,750 & 7.41 & 3,96 \\
\hline $\begin{array}{l}5 \\
6\end{array}$ & - & $\overline{-}$ & $\overline{2.45}$ & 374 & 5.5 & 2,120 & $\begin{array}{l}9.05 \\
9.26\end{array}$ & $\begin{array}{l}6,010 \\
6,300\end{array}$ & $\begin{array}{l}9.96 \\
9.77\end{array}$ & $\begin{array}{l}7,340 \\
7,060\end{array}$ & $\begin{array}{l}7.35 \\
7.28\end{array}$ & 3,820 \\
\hline \multirow{7}{*}{$\begin{array}{r}7 \\
8 \\
9 \\
10 \\
11 \\
\mathbf{M}\end{array}$} & - & - & - & - & - & - & 9.65 & 6,880 & 9.45 & 6,580 & 7.21 & 3,74 \\
\hline & - & - & 2.8 & 502 & 5.7 & 2,280 & 10.37 & 7,990 & 9.25 & 290 & 7.15 & \\
\hline & - & - & & & - & & 11.20 & 9,410 & 9.11 & 6,090 & 7.10 & 3,620 \\
\hline & - & - & 3.0 & 580 & 5.85 & 2,420 & 11.66 & 10,300 & 8.96 & & 7.05 & 3,56 \\
\hline & - & & $3 ?$ & & - & & 11.86 & 10,600 & 8.80 & 5,670 & 7.00 & 3,51 \\
\hline & $1.5 b$ & 130 & 3.2 & 665 & 5.95 & 2,500 & 12.01 & 10,900 & 8.67 & 500 & 6.95 & 3,460 \\
\hline & \multicolumn{2}{|c|}{ September 24} & \multicolumn{2}{|c|}{ September 25} & \multicolumn{2}{|c|}{ September 26} & \multicolumn{2}{|c|}{ September 27} & \multicolumn{2}{|c|}{ September 28} & \multicolumn{2}{|c|}{ September 29} \\
\hline 2 & & & - & & & - & - & & - & - & - & - \\
\hline 4 & 6.73 & 3,240 & 5.54 & 2,150 & 4.70 & 1,520 & 4.14 & 1,160 & 3.79 & 5 & 3.48 & \\
\hline $\begin{array}{l}6 \\
8\end{array}$ & 6.52 & $\overline{3,030}$ & 5.39 & $\overline{2,030}$ & $\overline{4.59}$ & $\overline{1,4}$ & 4.07 & 1,120 & 3.73 & -925 & 3.43 & 775 \\
\hline 10 & & & & & & & - & & - & & -7 & \\
\hline H & 6.32 & 2,840 & 5.24 & 1,910 & 4.49 & 1,370 & 4.00 & 1,080 & 3.68 & 900 & 3.39 & \\
\hline 2 & - & & - & - & - & - & - & - & - & - & - & - \\
\hline 4 & 6.12 & 2,660 & 5.09 & 1,790 & 4.39 & 1,310 & 3.95 & 1,050 & 3.62 & 870 & 3.36 & 740 \\
\hline 8 & 5.91 & $\overline{2,470}$ & 4.94 & 1,690 & 4.30 & 1,260 & 3.90 & 1,020 & 3.56 & 840 & 3.32 & 720 \\
\hline $\begin{array}{r}10 \\
\text { II }\end{array}$ & 5.72 & $\overline{2}, 300$ & 4.82 & -600 & 4.22 & 1,210 & 3.85 & -990 & -52 & ${ }_{820}$ & $\overline{3.28}$ & - \\
\hline & & & & & & & & & & & & \\
\hline
\end{tabular}

* Mean for the day. 
Rocky River at outlet of Candlewood Lake, near New Milford, Conn.

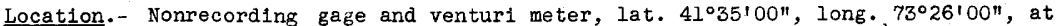
Rocky River hydroelectric plant of Connecticut Light \& Power Co., it miles northwest of New Milford, Litchfield County.

Drainage area.- 40.4 square miles.

Gage-height record.- Usually one lake-gage reading daily at about 8 a.m. Gage height at midnight determined from graph constructed from gage readings.

Stage-discharge relation. - Observed discharge computed from flow through venturi meters. Remarks.- Power plant is of pumped-storage type. Candlewood Lake stores both normal run-off of Rocky River and water pumped from Housatonic River, into which tailrace of plant discharges. No water was pumped from Housatonic River into lake during period Sept. 1 to oct. 3l. Daily and monthly discharges adjusted for gain or loss in Candlewood Lake. No corrections for evaporation from reservoir surface, which is about 8 square miles; negative adjusted discharge values indicate that evaporation from the reservolr surface at times exceeds the volume of inflow. Record based on data furmished by connecticut Light \& Power co.

Mean discharge, in second-feet, and gain or loss in storage, in equivalent mean second-feet, 1938

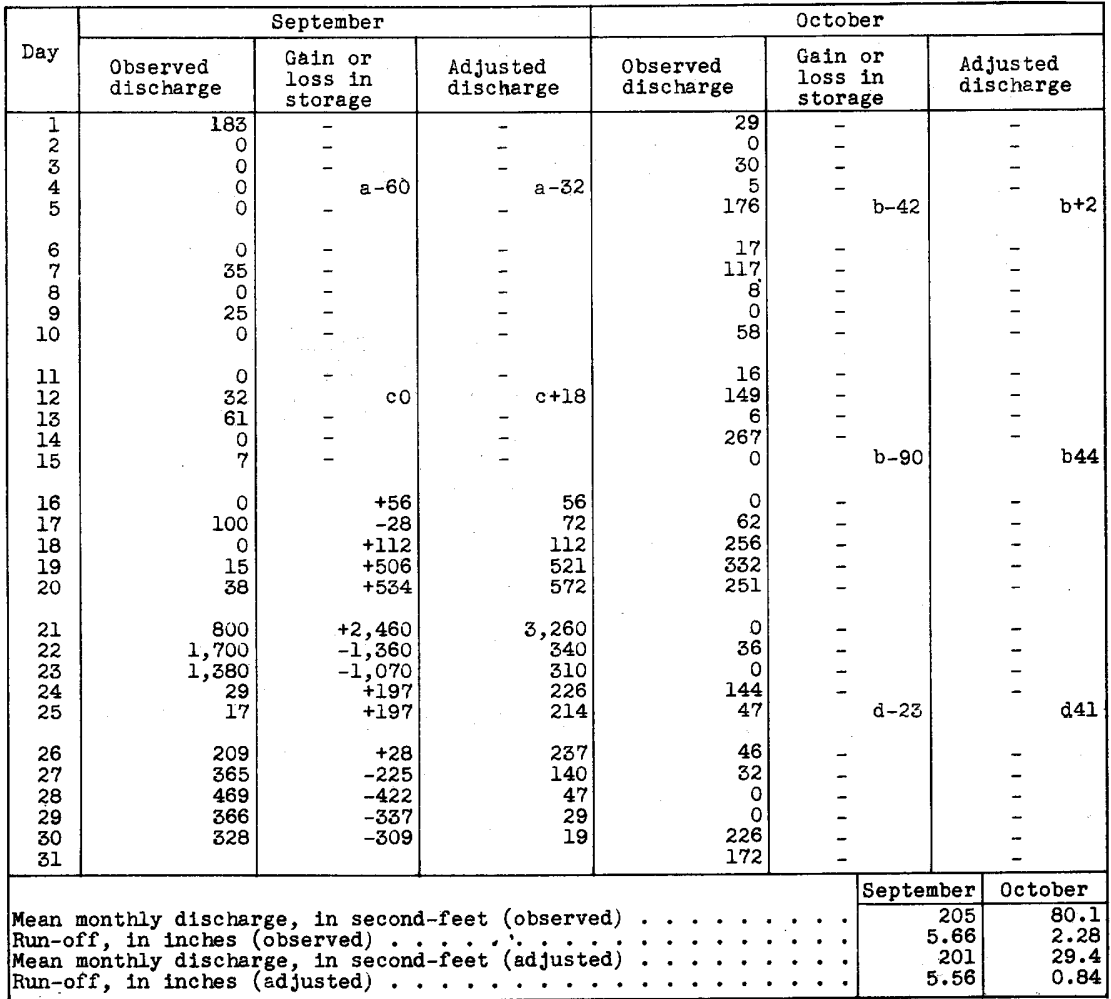
a Mean for 8-day period.
b Mean for 10-day period.
c Mean for 7-day period.
d Mean for 11-day period. 
Still River near Lanesville, Conn.

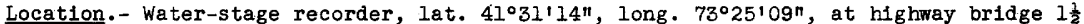
miles south of Lanesville, Litchfield County, 2 miles above mouth, and $4 \mathrm{miles}$ south of New Milford. Zero of gage is 213.05 feet above mean sea level (general adjustment of 1929).

Drainage area.- 68.5 square miles.

Gage-helght record. - Water-stage recorder graph.

Stage-discharge relation.- Defined by current-meter measurements below 1,890 secondfeet; extended logarithmically to peak stage.

Maxima.- September 1938: Discharge, 4,410 second-feet 8 a.m. Sept. 22 (gage he1ght, 10.88 feet).

1931 to August 1938: Discharge, 3,930 second-feet (revised) Mar. 12, 1936 (gage helght, 10.58 feet).

Remarks.- Flood run-off not appreciably affected by storage or regulation.

Mean daily discharge, in second-feet, 1938

\begin{tabular}{|c|c|c|c|c|c|c|c|c|c|c|c|}
\hline Day & Sept. & Oct. & Day & Sept. & Oct. & Day & Sept. & oot. & Day & Sept. & Oct. \\
\hline $\begin{array}{l}1 \\
2 \\
3 \\
4 \\
5 \\
6 \\
7 \\
8\end{array}$ & $\begin{array}{l}65 \\
68 \\
56 \\
52 \\
46 \\
43 \\
46 \\
62\end{array}$ & $\begin{array}{l}212 \\
191 \\
167 \\
153 \\
142 \\
135 \\
133 \\
127\end{array}$ & $\begin{array}{r}9 \\
10 \\
11 \\
12 \\
13 \\
14 \\
15 \\
16\end{array}$ & $\begin{array}{l}60 \\
50 \\
45 \\
42 \\
53 \\
72 \\
68 \\
85\end{array}$ & $\begin{array}{r}119 \\
113 \\
109 \\
106 \\
103 \\
99 \\
99 \\
95\end{array}$ & $\begin{array}{l}17 \\
18 \\
19 \\
20 \\
21 \\
22 \\
23 \\
24\end{array}$ & $\begin{array}{r}70 \\
62 \\
169 \\
572 \\
1,440 \\
3,460 \\
1,350 \\
879\end{array}$ & $\begin{array}{r}90 \\
92 \\
90 \\
91 \\
154 \\
154 \\
123 \\
116\end{array}$ & $\begin{array}{l}25 \\
26 \\
27 \\
28 \\
29 \\
30 \\
31\end{array}$ & $\begin{array}{l}671 \\
528 \\
408 \\
314 \\
274 \\
232\end{array}$ & $\begin{array}{r}170 \\
158 \\
123 \\
108 \\
109 \\
105 \\
94\end{array}$ \\
\hline $\begin{array}{l}\text { Mean } \\
\text { Run- }\end{array}$ & $\begin{array}{l}\text { onthly } \\
f, \text { in } 1\end{array}$ & hes. & ? is & $\begin{array}{c}\text { second- } \\
. \quad .\end{array}$ & • & • & • & $: \dot{0}$ & $\dot{0}$ & $\begin{array}{r}378 \\
6.16 \\
\end{array}$ & $\begin{array}{r}125 \\
2.10 \\
\end{array}$ \\
\hline
\end{tabular}

Gage helght, in feet, and discharge, in second-feet, at indicated time, 1938

\begin{tabular}{|c|c|c|c|c|c|c|c|c|c|c|c|c|}
\hline \multirow{2}{*}{$\begin{array}{r} \\
3 \\
3 \\
\text { 孚 } \\
\end{array}$} & Feet & Sec.ft. & Feet & Sec.ft. & Feet & Sec.ft. & Fevt & Sec.ft. & Feet & Sec.et. & Feet & Sec.ft. \\
\hline & \multicolumn{2}{|c|}{ September 18} & \multicolumn{2}{|c|}{ September 19} & \multicolumn{2}{|c|}{ September 20} & \multicolumn{2}{|c|}{ September 21} & \multicolumn{2}{|c|}{ September 22} & \multicolumn{2}{|c|}{ September 23} \\
\hline $\begin{array}{l}1 \\
2 \\
3 \\
4 \\
5 \\
6\end{array}$ & $\begin{array}{c}\overline{-} \\
2.06 \\
- \\
2.01 \\
- \\
1.99\end{array}$ & $\begin{array}{r}-63 \\
-60 \\
-60\end{array}$ & $\begin{array}{l}2.20 \\
2.35 \\
2.40 \\
2.45 \\
2.53 \\
2.59\end{array}$ & $\begin{array}{l}74 \\
78 \\
80 \\
83 \\
88 \\
90\end{array}$ & $\begin{array}{l}5.67 \\
5.77 \\
5.87 \\
5.96 \\
6.04 \\
6.11\end{array}$ & $\begin{array}{l}360 \\
376 \\
394 \\
410 \\
425 \\
438\end{array}$ & $\begin{array}{l}7.46 \\
7.48 \\
7.50 \\
7.52 \\
7.55 \\
7.60\end{array}$ & $\begin{array}{l}834 \\
842 \\
850 \\
860 \\
875 \\
900\end{array}$ & $\begin{array}{l}10.19 \\
10.38 \\
10.52 \\
10.66 \\
10.76 \\
10.83\end{array}$ & $\begin{array}{l}3,330 \\
3,610 \\
3,830 \\
4,060 \\
4,220 \\
4,330\end{array}$ & $\begin{array}{l}8.96 \\
8.87 \\
8.79 \\
8.70 \\
8.62 \\
8.58\end{array}$ & $\begin{array}{l}1,870 \\
1,790 \\
1,720 \\
1,640 \\
1,580 \\
1,540\end{array}$ \\
\hline $\begin{array}{r}7 \\
8 \\
9 \\
10 \\
11 \\
11\end{array}$ & $\begin{array}{l}\overline{1.99} \\
\overline{2.01} \\
\overline{2.02}\end{array}$ & $\begin{array}{r}-60 \\
-60 \\
-\quad 60 \\
61\end{array}$ & $\begin{array}{l}2.63 \\
2.70 \\
2.81 \\
2.92 \\
3.05 \\
3.20\end{array}$ & $\begin{array}{r}93 \\
97 \\
104 \\
109 \\
117 \\
126\end{array}$ & $\begin{array}{l}6.20 \\
6.30 \\
6.40 \\
6.49 \\
6.56 \\
6.63\end{array}$ & $\begin{array}{l}456 \\
476 \\
497 \\
517 \\
532 \\
548\end{array}$ & $\begin{array}{l}7.64 \\
7.70 \\
7.80 \\
7.86 \\
7.98 \\
8.07\end{array}$ & $\begin{array}{r}920 \\
950 \\
1,000 \\
1,040 \\
1,110 \\
1,160\end{array}$ & $\begin{array}{l}10.87 \\
10.88 \\
10.87 \\
10.81 \\
10.74 \\
10.64\end{array}$ & $\begin{array}{l}390 \\
410 \\
390 \\
300 \\
180 \\
020\end{array}$ & $\begin{array}{l}8.51 \\
8.46 \\
8.40 \\
8.35 \\
8.30 \\
8.25\end{array}$ & $\begin{array}{l}1,490 \\
1,450 \\
1,400 \\
1,360 \\
1,320 \\
1,280\end{array}$ \\
\hline $\begin{array}{l}7 \\
2 \\
3 \\
4 \\
5 \\
6\end{array}$ & $\begin{array}{c}2.03 \\
- \\
2.03 \\
- \\
2.03\end{array}$ & $\begin{array}{r}-62 \\
-\quad 62 \\
-\quad 62\end{array}$ & $\begin{array}{l}3.39 \\
3.66 \\
4.05 \\
4.40 \\
4.69 \\
4.86\end{array}$ & $\begin{array}{l}138 \\
157 \\
188 \\
218 \\
244 \\
261\end{array}$ & $\begin{array}{l}6.73 \\
6.82 \\
6.91 \\
7.00 \\
7.09 \\
7.16\end{array}$ & $\begin{array}{l}572 \\
596 \\
624 \\
655 \\
686 \\
714\end{array}$ & $\begin{array}{l}8.15 \\
8.23 \\
8.39 \\
8.61 \\
8.86 \\
9.03\end{array}$ & $\begin{array}{l}1,220 \\
1,270 \\
1,390 \\
1,570 \\
1,780 \\
1,940\end{array}$ & $\begin{array}{r}10.51 \\
10.39 \\
10.25 \\
10.09 \\
9.96 \\
9.80\end{array}$ & $\begin{array}{l}3,820 \\
3,620 \\
3,410 \\
3,190 \\
3,000 \\
2,780\end{array}$ & $\begin{array}{l}8.21 \\
8.18 \\
8.12 \\
8.10 \\
8.06 \\
8.01\end{array}$ & $\begin{array}{l}1,260 \\
1,240 \\
1,190 \\
1,180 \\
1,160 \\
1,130\end{array}$ \\
\hline \multirow[t]{2}{*}{$\begin{array}{r}7 \\
8 \\
9 \\
10 \\
11 \\
11\end{array}$} & $\begin{array}{c}- \\
2.04 \\
- \\
2.10 \\
- \\
2.21\end{array}$ & $\begin{array}{r}-62 \\
-\quad 65 \\
-\quad 70 \\
\end{array}$ & $\begin{array}{l}5.00 \\
5.10 \\
5.20 \\
5.30 \\
5.40 \\
5.54\end{array}$ & $\begin{array}{l}276 \\
287 \\
299 \\
311 \\
323 \\
341\end{array}$ & $\begin{array}{l}7.22 \\
7.27 \\
7.31 \\
7.36 \\
7.41 \\
7.44 \\
\end{array}$ & $\begin{array}{l}738 \\
758 \\
774 \\
794 \\
814 \\
826 \\
\end{array}$ & $\begin{array}{r}9.19 \\
9.32 \\
9.47 \\
9.62 \\
9.80 \\
10.00\end{array}$ & $\begin{array}{l}2,100 \\
2,230 \\
2,400 \\
2,560 \\
2,780 \\
3,060\end{array}$ & $\begin{array}{l}9.66 \\
9.51 \\
9.39 \\
9.26 \\
9.14 \\
9.03\end{array}$ & $\begin{array}{l}2,610 \\
2,440 \\
2,310 \\
2,170 \\
2,050 \\
1,940\end{array}$ & $\begin{array}{l}7.99 \\
7.96 \\
7.92 \\
7.90 \\
7.86 \\
7.84\end{array}$ & $\begin{array}{l}1,110 \\
1,100 \\
1,070 \\
1,060 \\
1,040 \\
1,020\end{array}$ \\
\hline & \multicolumn{2}{|c|}{ September 24} & \multicolumn{2}{|c|}{ September 25} & \multicolumn{2}{|c|}{ September 26} & \multicolumn{2}{|c|}{ September 27} & \multicolumn{2}{|c|}{ September 28} & \multicolumn{2}{|c|}{ September 29} \\
\hline $\begin{array}{r}2 \\
4 \\
6 \\
8 \\
10 \\
N\end{array}$ & $\begin{array}{l}7.79 \\
7.71 \\
7.69 \\
7.63 \\
7.59 \\
7.55\end{array}$ & $\begin{array}{l}995 \\
955 \\
945 \\
915 \\
895 \\
875\end{array}$ & $\begin{array}{l}7.20 \\
- \\
7.10 \\
- \\
7.03\end{array}$ & $\begin{array}{r}-730 \\
- \\
690 \\
-666\end{array}$ & $\begin{array}{c}- \\
- \\
6.68 \\
- \\
\overline{6.54}\end{array}$ & $\begin{array}{l}- \\
- \\
- \\
- \\
-526\end{array}$ & $\begin{array}{c}- \\
\overline{6.11} \\
\overline{-} \\
\overline{5.96}\end{array}$ & $\begin{array}{l}- \\
- \\
-438 \\
- \\
410\end{array}$ & $\begin{array}{c}- \\
\overline{5.43} \\
\overline{-} \\
\overline{5.31}\end{array}$ & $\begin{array}{l}- \\
- \\
-327 \\
- \\
312\end{array}$ & $\begin{array}{c}\overline{-} \\
\overline{5.07} \\
\overline{-} \\
\overline{4.99}\end{array}$ & $\begin{array}{l}- \\
- \\
-284 \\
- \\
275\end{array}$ \\
\hline $\begin{array}{r}2 \\
4 \\
6 \\
8 \\
10 \\
M\end{array}$ & $\begin{array}{l}7.50 \\
7.46 \\
7.40 \\
7.37 \\
7.32 \\
7.29\end{array}$ & $\begin{array}{l}850 \\
834 \\
810 \\
798 \\
778 \\
766\end{array}$ & $\begin{array}{c}- \\
6.96 \\
- \\
6.90 \\
- \\
6.80\end{array}$ & $\begin{array}{r}-641 \\
- \\
620 \\
-590\end{array}$ & $\begin{array}{l}- \\
\overline{6.40} \\
- \\
\overline{6.25}\end{array}$ & $\begin{array}{l}- \\
- \\
- \\
- \\
-467\end{array}$ & $\begin{array}{l}- \\
- \\
5.77 \\
- \\
\overline{5.60}\end{array}$ & $\begin{array}{l}- \\
- \\
- \\
- \\
-346\end{array}$ & $\begin{array}{l}- \\
\overline{5.20} \\
- \\
\overline{5.12}\end{array}$ & $\begin{array}{l}- \\
- \\
- \\
- \\
289\end{array}$ & $\begin{array}{l}\overline{-} \\
\overline{4.89} \\
\overline{-} \\
\overline{4.79}\end{array}$ & $\begin{array}{l}- \\
-264 \\
- \\
-254\end{array}$ \\
\hline
\end{tabular}

$2270070-10-15$ 
Shepaug River at outlet of Shepaug Reservoir, at Woodville, Conn.

Location.- Nonrecording gages at dam at outlet of Shepaug Reservoir, $12 t .41^{\circ} 43^{\prime} 16 "$, long. $73^{\circ} 17^{\prime} 40^{\prime \prime}$, I mile north of Woodville, Litchfield County, and 3 miles above confluence of Shepaug and Bantam Rivers.

Drainage area.- 38.0 square miles.

Gage-height record.- One reservoir gage reading daily at noon; additional readings during periods of rapid change in stage; gage height at midnight determined from graph constructed from gage-height readings.

Stage-discharge relation.- Observed discharges computed from flow through gates and over weir and spillway at times when reservoir gage was read. During period of rapid change in discharge, mean daily discharge computed from graph constructed from determinations of instantaneous discharges.

Maxima.- September 1938: Discharge, 6,000 second-reet 7 p.m. Sept. 21. 1935 to August 1938: Discharge, 4,070 second-feet Mar. 12, 1936.

Remarks.- Mean daily and monthly discharges adjusted for gain or loss in storage in Shepaug Reservoir and diversion to Naugatuck River drainage through Morris Reservoir. No corrections for evaporation from reservoir surface. Minimum flow of 2.35 second-feet maintalned at all times below reservoir. Basic data furnished by Bureau of Engineering, C1ty of Waterbury.

Mean discharge, in second-feet, and gain or loss in storage, in equivalent mean second-feet, 1938

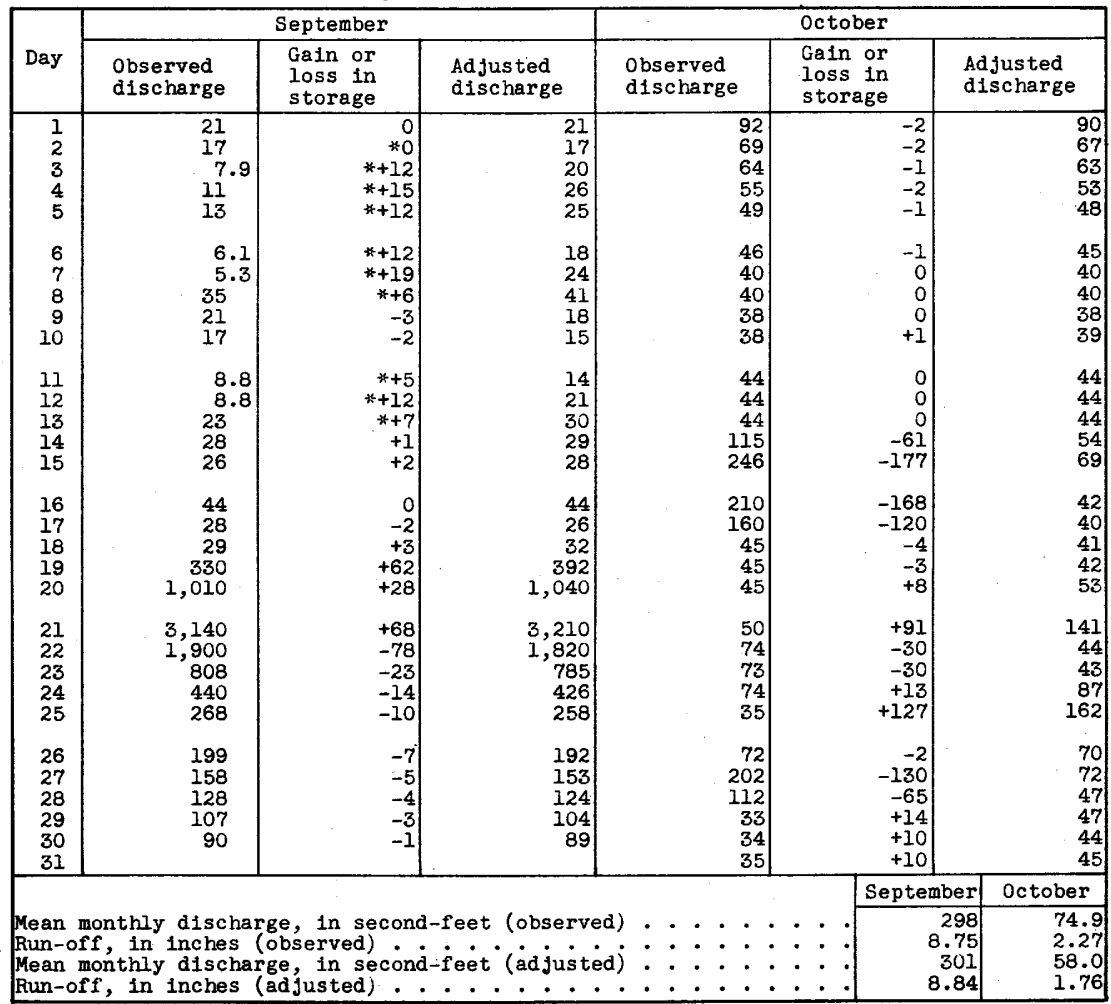

* Includes diversion for city of Wateriury water supply. 
Shepaug River near Roxbury, Conn.

Location.- Water-stage recorder, lat. 4132'53", long. $73^{\circ} 19^{\prime} 51 "$, at highway bridge 0.7 mile below Roxbury station and $1 \frac{1}{4}$ miles southwest of Roxbury, Litchfield County Zero of gage is 282.07 feet above mean sea level (general adjustment of 1929).

Drainage area.- 133 square miles.

Gage-he1ght record.- Water-stage recorder graph except for period 9 a.m. Sept. 21 to 2 p.m. Sept. 22 (bead on float wire caught), when it was based on shape of previous similar stage graphs and floodmark.

Stage-discharge relation.- Defined by current-meter measurements below 3,320 secondfeet; extended logarithmically to peak discharge, partly on basis of determination of flow over spiliway at dam at Roxbury Station.

Maxima.- September 1938: Discharge, 10,500 second-feet 7 p.m. Sept. 21 (gage height, 12.8 feet, from floodmark)

10.771930 to August 1938: Discharge, 7,000 second-feet Mar. 12, 1936 (gage height,

Remarks.-Flood mun-off affected by storage in Shepaug Reservoir and in Bantam Lake (drainage area at outlet, 33.2 square miles). For information on storage see record for shepaug Reservoir at Woodville, Conn.

Mean deily discharge, in second-feet, 1938

\begin{tabular}{|c|c|c|c|c|c|c|c|c|c|c|c|}
\hline Day & Sept. & oct. & Day & Sept. & Oct. & Day & Sept. & Oct. & Day & Sept. & Oct. \\
\hline $\begin{array}{l}1 \\
2 \\
3 \\
4 \\
5 \\
6 \\
7 \\
8\end{array}$ & $\begin{array}{l}99 \\
90 \\
71 \\
68 \\
66 \\
60 \\
54 \\
82\end{array}$ & $\begin{array}{l}446 \\
378 \\
337 \\
301 \\
278 \\
250 \\
229 \\
215\end{array}$ & $\begin{array}{r}9 \\
10 \\
11 \\
12 \\
13 \\
14 \\
15 \\
16\end{array}$ & $\begin{array}{r}73 \\
61 \\
55 \\
48 \\
69 \\
77 \\
82 \\
117\end{array}$ & $\begin{array}{l}194 \\
180 \\
174 \\
168 \\
165 \\
171 \\
333 \\
321\end{array}$ & $\begin{array}{l}17 \\
18 \\
19 \\
20 \\
21 \\
22 \\
23 \\
24\end{array}$ & $\begin{array}{r}86 \\
86 \\
768 \\
2,080 \\
6,390 \\
4,580 \\
2,590 \\
1,850\end{array}$ & $\begin{array}{l}301 \\
142 \\
123 \\
138 \\
339 \\
240 \\
215 \\
310\end{array}$ & $\begin{array}{l}25 \\
26 \\
27 \\
28 \\
29 \\
30 \\
31\end{array}$ & $\begin{array}{r}1,330 \\
1,020 \\
833 \\
655 \\
585 \\
505\end{array}$ & $\begin{array}{l}292 \\
183 \\
353 \\
304 \\
201 \\
177 \\
165\end{array}$ \\
\hline $\begin{array}{l}\text { Mean } \\
\text { Run- }\end{array}$ & $\begin{array}{l}\text { inthly } \\
\text { in }\end{array}$ & nes. & , In & $\begin{array}{c}\text { second- } \\
\text { - }\end{array}$ & et. . &.$:$ & 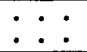 & $\cdot \dot{0} \cdot$ & $: \dot{ }$ & $\begin{array}{r}819 \\
6.87 \\
\end{array}$ & $\begin{array}{r}246 \\
2.13 \\
\end{array}$ \\
\hline
\end{tabular}

Gage helght, in feet, and discharge, in second-feet, at indicated time, I938

\begin{tabular}{|c|c|c|c|c|c|c|c|c|c|c|c|c|}
\hline \multirow{2}{*}{$\begin{array}{l}9 \\
8 \\
8\end{array}$} & Feet & Sec.ft. & Feot & Sec.ft. & Feet & Sec.ft. & Feet & Sec.ft. & Feet & Sec.et. & Feet & Sec.ft. \\
\hline & \multicolumn{2}{|c|}{ September 18} & \multicolumn{2}{|c|}{ September 19} & \multicolumn{2}{|c|}{ September 20} & \multicolumn{2}{|c|}{ September 21} & \multicolumn{2}{|c|}{ September 22} & \multicolumn{2}{|c|}{ September 23} \\
\hline $\begin{array}{l}7 \\
2 \\
3 \\
4 \\
5 \\
6\end{array}$ & $\begin{array}{l}2.25 \\
2.26 \\
2.25 \\
2.21 \\
2.20 \\
2.18\end{array}$ & \begin{tabular}{|l|}
92 \\
95 \\
92 \\
84 \\
82 \\
78
\end{tabular} & $\begin{array}{l}2.33 \\
2.35 \\
2.36 \\
2.40 \\
2.41 \\
2.41\end{array}$ & $\begin{array}{l}110 \\
115 \\
117 \\
127 \\
130 \\
130\end{array}$ & $\begin{array}{l}5.45 \\
5.41 \\
5.67 \\
5.92 \\
5.91 \\
5.93\end{array}$ & $\begin{array}{l}1,660 \\
1,630 \\
1,810 \\
2,000 \\
1,990 \\
2,000\end{array}$ & $\begin{array}{l}6.45 \\
6.72 \\
6.90 \\
6.87 \\
6.84 \\
6.92\end{array}$ & $\begin{array}{l}2,420 \\
2,650 \\
2,810 \\
2,780 \\
2,760 \\
2,830\end{array}$ & $\begin{array}{c}10.95 \\
10.55 \\
10.05 \\
9.75 \\
9.4 \\
9.15\end{array}$ & $\begin{array}{l}7,750 \\
7,190 \\
6,500 \\
6,100 \\
5,670 \\
5,370\end{array}$ & $\begin{array}{c}- \\
6.84 \\
- \\
6.74 \\
- \\
6.64\end{array}$ & $\begin{array}{c}- \\
2,960 \\
- \\
2,870 \\
- \\
2,780\end{array}$ \\
\hline $\begin{array}{r}7 \\
8 \\
9 \\
10 \\
11 \\
\mathbf{N}\end{array}$ & $\begin{array}{l}2.16 \\
2.28 \\
2.35 \\
2.31 \\
2.30 \\
2.29\end{array}$ & $\begin{array}{r}75 \\
99 \\
115 \\
105 \\
103 \\
101\end{array}$ & $\begin{array}{l}2.62 \\
2.70 \\
2.87 \\
2.98 \\
2.99 \\
2.94\end{array}$ & $\begin{array}{l}187 \\
211 \\
268 \\
309 \\
312 \\
294\end{array}$ & $\begin{array}{l}6.03 \\
5.97 \\
5.87 \\
5.81 \\
5.81 \\
6.03\end{array}$ & $\begin{array}{l}2,080 \\
2,040 \\
1,960 \\
1,910 \\
1,910 \\
2,080\end{array}$ & $\begin{array}{c}7.17 \\
7.54 \\
7.95 \\
8.5 \\
9.15 \\
10.05\end{array}$ & $\begin{array}{l}3,050 \\
3,410 \\
3,840 \\
4,450 \\
5,240 \\
6,470\end{array}$ & $\begin{array}{l}8.95 \\
8.7 \\
8.45 \\
8.25 \\
8.1 \\
7.95\end{array}$ & $\begin{array}{l}5,140 \\
4,860 \\
4,590 \\
4,360 \\
4,200 \\
4,040\end{array}$ & $\begin{array}{c}- \\
6.56 \\
- \\
6.52 \\
- \\
6.44\end{array}$ & $\begin{array}{c}2,700 \\
- \\
2,670 \\
2,600\end{array}$ \\
\hline $\begin{array}{l}1 \\
2 \\
3 \\
4 \\
5 \\
6\end{array}$ & $\begin{array}{l}2.26 \\
2.23 \\
2.20 \\
2.18 \\
2.16 \\
2.15\end{array}$ & $\begin{array}{l}95 \\
88 \\
82 \\
78 \\
75 \\
73\end{array}$ & $\begin{array}{l}2.97 \\
3.11 \\
3.55 \\
4.72 \\
5.66 \\
5.89\end{array}$ & $\begin{array}{r}305 \\
359 \\
548 \\
1,160 \\
1,800 \\
1,970\end{array}$ & $\begin{array}{l}6.34 \\
6.34 \\
6.20 \\
6.04 \\
6.02 \\
6.17\end{array}$ & $\begin{array}{l}2,330 \\
2,330 \\
2,220 \\
2,090 \\
2,080 \\
2,200\end{array}$ & $\begin{array}{l}10.7 \\
11.35 \\
12.2 \\
12.55 \\
12.6 \\
12.75\end{array}$ & $\begin{array}{r}7,380 \\
8,320 \\
9,600 \\
10,100 \\
10,200 \\
10,400\end{array}$ & $\begin{array}{l}7.85 \\
7.75 \\
7.65 \\
7.54 \\
7.48 \\
7.40\end{array}$ & $\begin{array}{l}3,920 \\
3,820 \\
3,720 \\
3,610 \\
3,550 \\
3,470\end{array}$ & $\begin{array}{c}\overline{6.34} \\
- \\
6.25 \\
\overline{-} \\
6.15\end{array}$ & $\begin{array}{c}- \\
2,520 \\
- \\
2,450 \\
- \\
2,370\end{array}$ \\
\hline \multirow[t]{2}{*}{$\begin{array}{r}7 \\
8 \\
9 \\
10 \\
11 \\
11\end{array}$} & $\begin{array}{l}2.13 \\
2.12 \\
2.11 \\
2.11 \\
2.18 \\
2.30\end{array}$ & $\begin{array}{r}69 \\
68 \\
66 \\
66 \\
78 \\
103\end{array}$ & $\begin{array}{l}5.91 \\
5.68 \\
5.53 \\
5.63 \\
5.61 \\
5.55 \\
\end{array}$ & $\begin{array}{l}1,990 \\
1,820 \\
1,710 \\
1,780 \\
1,770 \\
1,720\end{array}$ & $\begin{array}{l}6.24 \\
6.17 \\
6.23 \\
6.42 \\
6.43 \\
6.37 \\
\end{array}$ & $\begin{array}{l}2,250 \\
2,200 \\
2,240 \\
2,400 \\
2,400 \\
2,360\end{array}$ & $\begin{array}{l}12.8 \\
12.65 \\
12.45 \\
12.15 \\
11.75 \\
11.4\end{array}$ & $\begin{array}{r}10,500 \\
10,300 \\
9,980 \\
9,520 \\
8,920 \\
8,400 \\
\end{array}$ & $\begin{array}{l}7.33 \\
7.24 \\
7.15 \\
7.10 \\
7.04 \\
6.96\end{array}$ & $\begin{array}{l}3,400 \\
3,320 \\
3,240 \\
3,190 \\
3,140 \\
3,060\end{array}$ & $\begin{array}{c}- \\
6.05 \\
- \\
5.99 \\
- \\
5.92\end{array}$ & $\begin{array}{c}2,290 \\
- \\
2,240 \\
- \\
2,190\end{array}$ \\
\hline & \multicolumn{2}{|c|}{ September 24} & \multicolumn{2}{|c|}{ September 25} & \multicolumn{2}{|c|}{ September 26} & \multicolumn{2}{|c|}{ September 27} & \multicolumn{2}{|c|}{ September 28} & \multicolumn{2}{|c|}{ September 29} \\
\hline $\begin{array}{r}2 \\
4 \\
6 \\
8 \\
10 \\
\text { N }\end{array}$ & $\begin{array}{l}5.84 \\
5.76 \\
5.70 \\
5.63 \\
5.53 \\
5.49\end{array}$ & $\begin{array}{l}2,120 \\
2,060 \\
2,010 \\
1,950 \\
1,880 \\
1,850\end{array}$ & $\begin{array}{c}- \\
4.93 \\
\overline{4.84} \\
\overline{4.73}\end{array}$ & $\begin{array}{c}- \\
1,460 \\
1,400 \\
1,320\end{array}$ & $\begin{array}{c}- \\
- \\
4.35 \\
- \\
\overline{-}\end{array}$ & $\begin{array}{l}- \\
- \\
1,090 \\
- \\
1,030\end{array}$ & $\begin{array}{c}- \\
\overline{-} \\
3.99 \\
- \\
\overline{3.91}\end{array}$ & $\begin{array}{l}- \\
- \\
-874 \\
- \\
-826\end{array}$ & $\begin{array}{c}- \\
- \\
3.74 \\
- \\
- \\
3.70\end{array}$ & $\begin{array}{l}- \\
705\end{array}$ & $\begin{array}{c}- \\
- \\
3.51 \\
- \\
- \\
3.48\end{array}$ & $\begin{array}{l}- \\
- \\
- \\
- \\
5905\end{array}$ \\
\hline $\begin{array}{r}2 \\
4 \\
6 \\
8 \\
10 \\
M\end{array}$ & $\begin{array}{l}5.42 \\
5.34 \\
5.27 \\
5.22 \\
5.13 \\
5.05\end{array}$ & $\begin{array}{l}1,810 \\
1,750 \\
1,700 \\
1,660 \\
1,600 \\
1,540\end{array}$ & $\begin{array}{c}- \\
4.62 \\
- \\
4.52 \\
\overline{4.44}\end{array}$ & $\begin{array}{c}\overline{1,250} \\
\overline{1,190} \\
\overline{1,140}\end{array}$ & $\begin{array}{l}- \\
\overline{4.13} \\
\overline{-} \\
\overline{4.03}\end{array}$ & $\begin{array}{l}- \\
- \\
-958 \\
- \\
898\end{array}$ & $\begin{array}{c}- \\
\overline{3.87} \\
\overline{-} \\
\overline{3.80}\end{array}$ & $\begin{array}{l}- \\
- \\
-802 \\
- \\
760\end{array}$ & $\begin{array}{c}- \\
- \\
3.61 \\
- \\
- \\
3.55\end{array}$ & $\begin{array}{l}- \\
- \\
- \\
- \\
6256\end{array}$ & $\begin{array}{c}- \\
\overline{3.42} \\
- \\
\overline{3.39}\end{array}$ & $\begin{array}{l}- \\
-560 \\
- \\
- \\
545\end{array}$ \\
\hline
\end{tabular}




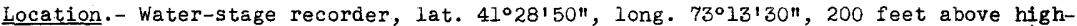
way bridge, three-quarters of a mile west of Southbury, New Haven County, and $5 \frac{1}{2}$ miles above mouth. Zero of gage is 165.64 feet above mean sea level (general adjustment of 1929).

Drainage area.- 75.3 square miles.

Gage-helght record. - Water-stage recorder graph except for period 9 p.m. Sept. 21 to 5 p.m. Sept. 22 (float against recorder table), when it was based on shape of $s$ tage graphs of previous peaks, floodmark, and one inspection.

Stage-discharge relation.- Defined by current-meter measurements below 1,170 secondfeet; extended to peak stage on basis of 1936 and 1938 peak flow determinations at dam 2 miles downstream, adjusted for run-off from intervening area.

Maxima.- September 1938: Discharge, 7,420 second-feet 9 p.m. Sept. 21 (gage height, 16.00 feet, from floodmark).

1932 to August 1938: Discharge, 5,990 second-feet (revised) Mar. 12, 1936

(gage height, 14.13 feet, from floodmark), and 5,980 second-feet Jan. 25, 1938

(gage height, 14.12 feet, from floodmark).

Remarks.- Flood run-off not affected by artificial storage.

Mean dally scharge, in second-feet, 1938

\begin{tabular}{|c|c|c|c|c|c|c|c|c|c|c|c|}
\hline Day & Sept. & Oct. & Dey & Sept. & oct. & Day & Sept. & oct. & Day & Sept. & Oct. \\
\hline $\begin{array}{l}1 \\
2 \\
3 \\
4 \\
5 \\
6 \\
7 \\
8\end{array}$ & $\begin{array}{l}68 \\
59 \\
52 \\
50 \\
48 \\
44 \\
45 \\
63\end{array}$ & $\begin{array}{l}186 \\
165 \\
147 \\
139 \\
129 \\
121 \\
116 \\
110\end{array}$ & $\begin{array}{l}9 \\
10 \\
11 \\
12 \\
13 \\
14 \\
15 \\
16\end{array}$ & $\begin{array}{l}48 \\
43 \\
40 \\
39 \\
59 \\
58 \\
70 \\
95\end{array}$ & $\begin{array}{r}102 \\
98 \\
94 \\
89 \\
86 \\
88 \\
86 \\
80\end{array}$ & $\begin{array}{l}17 \\
18 \\
19 \\
20 \\
21 \\
22 \\
23 \\
24\end{array}$ & $\begin{array}{r}62 \\
73 \\
257 \\
777 \\
2,670 \\
1,630 \\
707 \\
487\end{array}$ & $\begin{array}{r}76 \\
73 \\
72 \\
73 \\
198 \\
118 \\
100 \\
174\end{array}$ & $\begin{array}{l}25 \\
26 \\
27 \\
28 \\
29 \\
30 \\
31\end{array}$ & $\begin{array}{l}366 \\
300 \\
265 \\
238 \\
208 \\
196\end{array}$ & $\begin{array}{r}206 \\
132 \\
112 \\
101 \\
126 \\
104 \\
94\end{array}$ \\
\hline $\begin{array}{l}\text { Mean } \\
\text { Run- }\end{array}$ & $\begin{array}{l}\text { onthly } \\
f \text {, in }\end{array}$ & $\begin{array}{l}\text { schar } \\
\text { hes. }\end{array}$ & , $1 r$ & . & et. : & $\dot{.}$ & : : & : : & & $\begin{array}{r}304 \\
4.51\end{array}$ & $\begin{array}{r}116 \\
1.78\end{array}$ \\
\hline
\end{tabular}

Gage helght, in feet, and discharge, in second-feet, at indicated time, I938

\begin{tabular}{|c|c|c|c|c|c|c|c|c|c|c|c|c|}
\hline \multirow{2}{*}{ 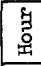 } & Feet & Sec.ft. & Feet & Sec.ft. & Feet & Sec.ft. & Feet & Sec.ft. & Feet & Sec.ft. & Feet & Sec.ft. \\
\hline & \multicolumn{2}{|c|}{ September 18} & \multicolumn{2}{|c|}{ Sept ember 19} & \multicolumn{2}{|c|}{ September 20} & \multicolumn{2}{|c|}{ September 21} & \multicolumn{2}{|c|}{ September 22} & \multicolumn{2}{|c|}{ September 23} \\
\hline $\begin{array}{l}1 \\
2 \\
3 \\
4 \\
5 \\
6\end{array}$ & $\begin{array}{c}- \\
3.26 \\
- \\
3.28 \\
- \\
3.30\end{array}$ & $\begin{array}{r}-67 \\
-\quad 69 \\
-\quad 72\end{array}$ & $\begin{array}{c}- \\
3.50 \\
- \\
3.60 \\
- \\
3.72\end{array}$ & $\begin{array}{l}-101 \\
- \\
-116 \\
135\end{array}$ & $\begin{array}{l}5.41 \\
5.19 \\
5.08 \\
5.03 \\
5.03 \\
5.11\end{array}$ & $\begin{array}{l}604 \\
516 \\
476 \\
459 \\
459 \\
487\end{array}$ & $\begin{array}{l}6.31 \\
6.35 \\
6.40 \\
6.45 \\
6.54 \\
6.65\end{array}$ & $\begin{array}{l}1,000 \\
1,020 \\
1,050 \\
1,080 \\
1,120 \\
1,180\end{array}$ & \begin{tabular}{|l}
10.3 \\
9.5 \\
8.95 \\
8.6 \\
8.3 \\
8.05
\end{tabular} & $\begin{array}{l}3,300 \\
2,800 \\
2,470 \\
2,260 \\
2,080 \\
1,930\end{array}$ & $\begin{array}{c}- \\
5.91 \\
- \\
5.84 \\
- \\
5.78\end{array}$ & $\begin{array}{r}-824 \\
-793 \\
-766 \\
766\end{array}$ \\
\hline $\begin{array}{r}7 \\
8 \\
9 \\
10 \\
11 \\
N\end{array}$ & $\begin{array}{l}- \\
3.32 \\
- \\
3.34 \\
- \\
3.34\end{array}$ & $\begin{array}{l}-75 \\
-\quad 78 \\
-\quad 78\end{array}$ & $\begin{array}{c}- \\
3.90 \\
- \\
4.11 \\
- \\
4.26\end{array}$ & $\begin{array}{r}-167 \\
- \\
209 \\
-243\end{array}$ & $\begin{array}{l}5.26 \\
5.41 \\
5.56 \\
5.69 \\
5.80 \\
5.90\end{array}$ & $\begin{array}{l}544 \\
604 \\
667 \\
726 \\
775 \\
820\end{array}$ & $\begin{array}{l}6.79 \\
6.91 \\
7.05 \\
7.21 \\
7.38 \\
7.54\end{array}$ & $\begin{array}{l}1,240 \\
1,300 \\
1,380 \\
1,470 \\
1,560 \\
1,650\end{array}$ & $\begin{array}{l}7.85 \\
7.7 \\
7.55 \\
7.4 \\
7.3 \\
7.15\end{array}$ & $\begin{array}{l}1,820 \\
1,740 \\
1,650 \\
1,570 \\
1,520 \\
1,430\end{array}$ & $\begin{array}{c}- \\
5.72 \\
- \\
5.69 \\
- \\
5.66\end{array}$ & $\begin{array}{r}-739 \\
-726 \\
-726 \\
712\end{array}$ \\
\hline $\begin{array}{l}1 \\
2 \\
3 \\
4 \\
5 \\
6\end{array}$ & $\begin{array}{c}- \\
3.35 \\
- \\
3.33 \\
- \\
3.31\end{array}$ & $\begin{array}{r}-79 \\
-\quad 76 \\
-\quad 73\end{array}$ & $\begin{array}{c}- \\
4.29 \\
- \\
4.31 \\
- \\
4.55\end{array}$ & $\begin{array}{r}- \\
- \\
-250 \\
- \\
314\end{array}$ & $\begin{array}{l}5.94 \\
5.99 \\
6.08 \\
6.19 \\
6.30 \\
6.40\end{array}$ & $\begin{array}{r}838 \\
860 \\
901 \\
950 \\
1,000 \\
1,050\end{array}$ & $\begin{array}{r}7.75 \\
7.99 \\
8.24 \\
9.20 \\
12.32 \\
12.52\end{array}$ & $\begin{array}{l}1,760 \\
1,890 \\
2,040 \\
2,620 \\
4,680 \\
4,820\end{array}$ & $\begin{array}{l}7.05 \\
6.95 \\
6.80 \\
6.69 \\
6.58 \\
6.46\end{array}$ & $\begin{array}{l}1,380 \\
1,320 \\
1,250 \\
1,200 \\
1,140 \\
1,080\end{array}$ & $\begin{array}{c}- \\
5.62 \\
- \\
5.57 \\
- \\
5.50\end{array}$ & $\begin{array}{r}-694 \\
-672 \\
-670\end{array}$ \\
\hline \multirow[t]{2}{*}{$\begin{array}{r}7 \\
8 \\
9 \\
10 \\
11 \\
M\end{array}$} & $\begin{array}{c}- \\
3.30 \\
- \\
3.29 \\
- \\
3.34\end{array}$ & $\begin{array}{r}-72 \\
-\quad 71 \\
-\quad 78\end{array}$ & $\begin{array}{c}- \\
4.90 \\
- \\
5.24 \\
- \\
5.42\end{array}$ & $\begin{array}{r}-416 \\
- \\
536 \\
-\quad 608\end{array}$ & $\begin{array}{l}6.45 \\
6.39 \\
6.28 \\
6.28 \\
6.29 \\
6.30\end{array}$ & $\begin{array}{r}1,080 \\
1,040 \\
991 \\
991 \\
996 \\
1,000\end{array}$ & $\begin{array}{l}12.49 \\
13.60 \\
16.00 \\
14.0 \\
12.6 \\
11.6\end{array}$ & $\begin{array}{l}4,800 \\
5,590 \\
7,420 \\
5,890 \\
4,880 \\
4,180\end{array}$ & $\begin{array}{l}6.36 \\
6.27 \\
6.19 \\
6.12 \\
6.06 \\
6.00\end{array}$ & $\begin{array}{r}1,030 \\
986 \\
950 \\
919 \\
892 \\
865\end{array}$ & $\begin{array}{c}- \\
5.43 \\
- \\
5.37 \\
- \\
5.31\end{array}$ & $\begin{array}{c}-612 \\
-\quad 588 \\
-\quad 564\end{array}$ \\
\hline & \multicolumn{2}{|c|}{ September 24} & \multicolumn{2}{|c|}{ September 25} & \multicolumn{2}{|c|}{ September 26} & \multicolumn{2}{|c|}{ September 27} & \multicolumn{2}{|c|}{ September 28} & \multicolumn{2}{|c|}{ September 29} \\
\hline $\begin{array}{r}2 \\
4 \\
6 \\
8 \\
10 \\
N\end{array}$ & $\begin{array}{c}- \\
5.23 \\
- \\
5.27 \\
- \\
5.11\end{array}$ & $\begin{array}{r}-532 \\
-\quad 509 \\
-\quad 487\end{array}$ & $\begin{array}{c}- \\
4.82 \\
- \\
4.79 \\
- \\
4.74\end{array}$ & $\begin{array}{c}-391 \\
- \\
382 \\
- \\
367\end{array}$ & $\begin{array}{l}\overline{-} \\
\overline{4.52} \\
\overline{-} \\
\overline{4} .50\end{array}$ & $\begin{array}{l}- \\
- \\
-306 \\
- \\
301\end{array}$ & $\begin{array}{c}- \\
- \\
4.37 \\
- \\
- \\
4.36\end{array}$ & $\begin{array}{l}- \\
- \\
269 \\
- \\
266\end{array}$ & $\begin{array}{c}- \\
- \\
4.28 \\
- \\
- \\
4.25\end{array}$ & $\begin{array}{l}- \\
- \\
247 \\
- \\
-240\end{array}$ & $\begin{array}{c}- \\
- \\
4.12 \\
- \\
- \\
4.11\end{array}$ & $\begin{array}{l}- \\
- \\
211 \\
- \\
209\end{array}$ \\
\hline $\begin{array}{r}2 \\
4 \\
6 \\
8 \\
10 \\
M\end{array}$ & $\begin{array}{c}- \\
5.06 \\
- \\
4.97 \\
- \\
4.88\end{array}$ & $\begin{array}{r}- \\
-469 \\
439 \\
-\quad 410\end{array}$ & $\begin{array}{c}- \\
4.70 \\
- \\
4.63 \\
- \\
4.58\end{array}$ & $\begin{array}{c}- \\
-355 \\
-335 \\
- \\
322\end{array}$ & $\begin{array}{c}- \\
\overline{4} \\
-47 \\
- \\
4.39\end{array}$ & $\begin{array}{l}- \\
- \\
- \\
- \\
274\end{array}$ & $\begin{array}{c}- \\
\overline{4.34} \\
- \\
\overline{4.29}\end{array}$ & $\begin{array}{l}- \\
- \\
-262 \\
- \\
250\end{array}$ & $\begin{array}{l}- \\
\overline{4.20} \\
- \\
\overline{4.15}\end{array}$ & $\begin{array}{l}- \\
- \\
- \\
- \\
218\end{array}$ & $\begin{array}{c}- \\
\overline{4} \\
\overline{-} \\
\overline{4.09}\end{array}$ & $\begin{array}{l}- \\
- \\
- \\
- \\
199\end{array}$ \\
\hline
\end{tabular}


Location.- Water-stage recorder, lat. $41^{\circ} 42^{\prime} 11^{\prime \prime}$, long. $73^{\circ} 03^{\prime} 56^{\prime \prime}$, at highway bridge half a mile above confluence with Leadmine Brook and 2 miles north of Thomaston, Litchfield County. Zoro of gage is 389.44 feet above mean sea level (general adjus tment of 1929).

Drainage area.- 71.9 square miles.

Gage-helght record.- Water-stage recorder graph.

Stage-discharge relation.- Defined by current-meter measurements below 5,980 secondfeet; extended logarithnically to peak stage.

Maxima.- September 1938: Discharge, 9,970 second-feet 9:40 p.m. Sept. 21 (gage height, 11.89 feet).

1930 to August 1938: Discharge, 6,830 second-feet Jan. 25, 1938 (gage height, 9.57 feet)

Remarks.- Flood run-off only slightly affected by storage in small ponds and reservoirs.

Mean daily discharge, in second-feet, 1938

\begin{tabular}{|c|c|c|c|c|c|c|c|c|c|c|c|}
\hline Day & Sept. & Oct. & Day & Sept. & Oct. & Day & Sept. & oct. & Day & Sept. & oct. \\
\hline $\begin{array}{l}1 \\
2 \\
3 \\
4 \\
5 \\
6 \\
7 \\
8\end{array}$ & $\begin{array}{l}42 \\
35 \\
30 \\
33 \\
32 \\
31 \\
31 \\
37\end{array}$ & $\begin{array}{r}148 \\
130 \\
122 \\
113 \\
107 \\
102 \\
96 \\
95\end{array}$ & $\begin{array}{r}9 \\
10 \\
11 \\
12 \\
13 \\
14 \\
15 \\
16\end{array}$ & $\begin{array}{l}30 \\
26 \\
26 \\
29 \\
39 \\
35 \\
39 \\
45\end{array}$ & $\begin{array}{l}91 \\
84 \\
82 \\
79 \\
76 \\
77 \\
76 \\
71\end{array}$ & $\begin{array}{l}17 \\
18 \\
19 \\
20 \\
21 \\
22 \\
23 \\
24\end{array}$ & $\begin{array}{r}34 \\
44 \\
464 \\
1,590 \\
5,290 \\
2,280 \\
684 \\
457\end{array}$ & $\begin{array}{r}71 \\
70 \\
68 \\
76 \\
262 \\
141 \\
105 \\
237\end{array}$ & $\begin{array}{l}25 \\
26 \\
27 \\
28 \\
29 \\
30 \\
31\end{array}$ & $\begin{array}{l}315 \\
253 \\
214 \\
190 \\
168 \\
152\end{array}$ & $\begin{array}{l}279 \\
167 \\
135 \\
118 \\
124 \\
111 \\
100\end{array}$ \\
\hline & & & & & & : & $\therefore \dot{0}$ & $\because \vdots$ & $\therefore$ & $\begin{array}{r}422 \\
6.55 \\
\end{array}$ & $\begin{array}{r}117 \\
1.88\end{array}$ \\
\hline
\end{tabular}

Gage height, in feet, and discharge, in second-feet, at indicated time, 1938

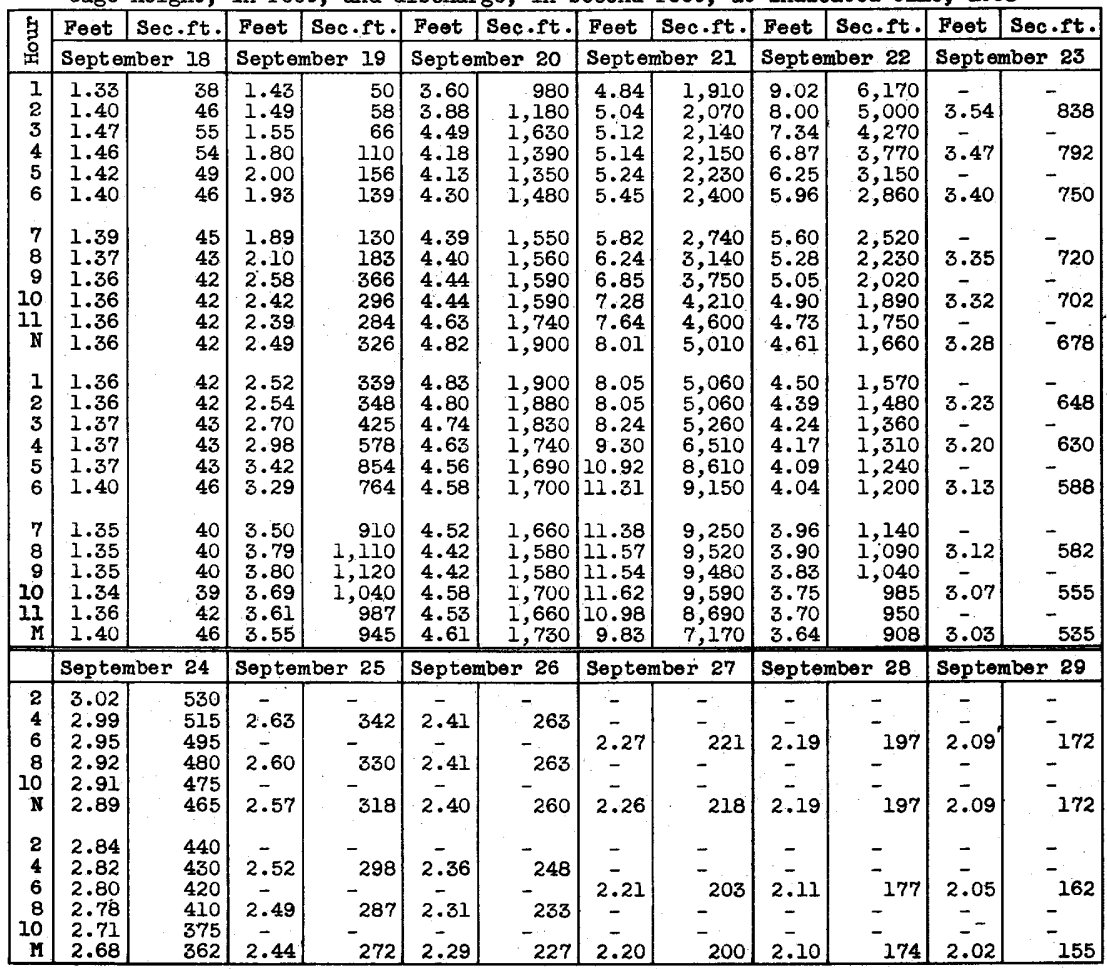

Supplemental records.- Sept. $21,9: 20$ p.m., 11.29 ft., 9,130 sec.-ft.; 9:40 p.m., $11.89 \mathrm{ft} ., 9,970$ sec. $-\mathrm{ft}$. 
Naugatuck River near Naugatuck, Conn.

Location.- Water-stage recorder, lat. $41^{\circ} 28^{\prime} 15^{n}$, long. $73^{\circ} 03^{\prime} 10^{n}$, a fifth of a mile above Beacon H1ll Brook, 1.3 miles below Naugatuck, New Haven County, and 12 miles above mouth. Zero of gage is 155.17 feet above mean sea level (general adjustment of 1929).

Drainage area.- 246 square miles.

Gage-height record.- Water-stage recorder graph.

Stage-discharge relation.- Defined by current-meter measurements below 4,650 secondfeet; extended logarithmically to peak stage on basis of comparison with records for stations on Leadmine Brook near Thomaston and Naugatuck River near Thomaston.

Maxime.- September 1938: Discharge, 17,000 second-feet 10 p.m. Sept. 2l (gage height, 12.40 feet).

1918-24: 1928 to August 1938: Gage height, 12.08 feet Apr. 7, 1924 (d1scharge uncertain; previously published flgure probably too $10 \mathrm{w}$ ).

Flood of November 1927 reached a stage of about 14 feet (discharge, probably 18,300 second-feet).

Remarks.- Run-off affected by storage in Wigwam and Morris Reservolrs and by storage in and diversion from Shepaug Reservolr. For information on storage and diversions seo records for Shepaug River at outlet of Shepaug Reservolr at Woodville, Conn., and for Branch of Naugatuck River at outlet of Wlgwam Reservolr near Thomaston, Conn.

Mean dally discharge, in second-feet, 1938

\begin{tabular}{|c|c|c|c|c|c|c|c|c|c|c|c|}
\hline Day & Sept. & oct. & Day & Sept. & 0 ct. & Day & Sept. & oct. & Day & Sept. & Oct. \\
\hline $\begin{array}{l}1 \\
2 \\
3 \\
4 \\
5 \\
6 \\
7 \\
8\end{array}$ & $\begin{array}{l}173 \\
162 \\
138 \\
130 \\
126 \\
123 \\
136 \\
143\end{array}$ & $\begin{array}{l}620 \\
530 \\
490 \\
451 \\
423 \\
404 \\
396 \\
347\end{array}$ & $\begin{array}{r}9 \\
10 \\
11 \\
12 \\
13 \\
14 \\
15 \\
16\end{array}$ & $\begin{array}{l}133 \\
116 \\
102 \\
111 \\
171 \\
151 \\
215 \\
215\end{array}$ & $\begin{array}{l}339 \\
330 \\
314 \\
305 \\
293 \\
305 \\
289 \\
273\end{array}$ & $\begin{array}{l}17 \\
18 \\
19 \\
20 \\
21 \\
22 \\
23 \\
24\end{array}$ & $\begin{array}{r}178 \\
240 \\
1,160 \\
3,550 \\
9,900 \\
6,040 \\
2,280 \\
1,620\end{array}$ & $\begin{array}{l}285 \\
258 \\
254 \\
254 \\
616 \\
465 \\
352 \\
536\end{array}$ & $\begin{array}{l}25 \\
26 \\
27 \\
28 \\
29 \\
30 \\
31\end{array}$ & $\begin{array}{c}1,220 \\
1,000 \\
865 \\
773 \\
672 \\
644 \\
-\end{array}$ & $\begin{array}{l}922 \\
565 \\
446 \\
386 \\
446 \\
432 \\
396\end{array}$ \\
\hline $\begin{array}{l}\text { Mean } \\
\text { Run- }\end{array}$ & $\begin{array}{l}\text { inthly } \\
\text { in }\end{array}$ & $\begin{array}{l}\text { schar } \\
\text { hes. }\end{array}$ & : ir & gecond- & et. : & : : & $\cdot \dot{\cdot} \cdot \dot{ }$ & : : : & $\because:$ & $\begin{array}{r}1,083 \\
4.91\end{array}$ & $\begin{array}{r}410 \\
1.92\end{array}$ \\
\hline
\end{tabular}

Gage helght, in feet, and discharge, in second-feet, at indicated time, 1938

\begin{tabular}{|c|c|c|c|c|c|c|c|c|c|c|c|c|}
\hline \multirow{2}{*}{$\begin{array}{l}9 \\
7 \\
0\end{array}$} & Feet & Sec.ft. & Feet & Sec.ft. & Feet & Sec.ft. & Feet & Sec.ft. & Beet & Sec.ft. & Feet & Sec.ft. \\
\hline & \multicolumn{2}{|c|}{ September 18} & \multicolumn{2}{|c|}{ September 19} & \multicolumn{2}{|c|}{ September 20} & \multicolumn{2}{|c|}{ September 21} & \multicolumn{2}{|c|}{ September 22} & \multicolumn{2}{|c|}{ September 23} \\
\hline $\begin{array}{l}1 \\
2 \\
3 \\
4 \\
5 \\
6\end{array}$ & $\begin{array}{l}1.13 \\
1.12 \\
1.11 \\
1.11 \\
1.11 \\
1.11\end{array}$ & $\begin{array}{l}242 \\
238 \\
234 \\
234 \\
234 \\
234\end{array}$ & $\begin{array}{l}2.43 \\
2.43 \\
2.66 \\
3.23 \\
3.10 \\
2.82\end{array}$ & $\begin{array}{r}873 \\
873 \\
1,010 \\
1,440 \\
1,340 \\
1,120\end{array}$ & $\begin{array}{l}4.44 \\
4.09 \\
4.04 \\
4.02 \\
3.97 \\
4.04\end{array}$ & $\begin{array}{l}2,620 \\
2,250 \\
2,200 \\
2,180 \\
2,130 \\
2,200\end{array}$ & $\begin{array}{l}5.97 \\
6.00 \\
6.14 \\
6.31 \\
6.61 \\
6.94\end{array}$ & $\begin{array}{l}4,700 \\
4,750 \\
4,960 \\
5,220 \\
5,680 \\
6,200\end{array}$ & $\begin{array}{r}11.08 \\
10.47 \\
9.73 \\
8.99 \\
8.23 \\
7.64\end{array}$ & $\begin{array}{r}13,900 \\
12,500 \\
11,100 \\
9,680 \\
8,340 \\
7,340\end{array}$ & \begin{tabular}{|l|}
4.41 \\
4.33 \\
4.29 \\
4.22 \\
4.17 \\
4.12
\end{tabular} & $\begin{array}{l}2,760 \\
2,670 \\
2,630 \\
2,560 \\
2,510 \\
2,460\end{array}$ \\
\hline $\begin{array}{r}7 \\
8 \\
9 \\
10 \\
11 \\
\text { N }\end{array}$ & $\begin{array}{l}1.11 \\
1.11 \\
1.11 \\
1.12 \\
1.15 \\
1.12\end{array}$ & $\begin{array}{l}234 \\
234 \\
234 \\
238 \\
248 \\
238\end{array}$ & $\begin{array}{l}2.62 \\
2.52 \\
2.47 \\
2.47 \\
2.47 \\
2.47\end{array}$ & $\begin{array}{l}988 \\
927 \\
897 \\
897 \\
897 \\
897\end{array}$ & $\begin{array}{l}4.57 \\
4.85 \\
5.10 \\
5.33 \\
5.43 \\
5.40\end{array}$ & $\begin{array}{l}2,770 \\
3,120 \\
3,440 \\
3,760 \\
3,900 \\
3,860\end{array}$ & $\begin{array}{l}7.09 \\
7.44 \\
7.77 \\
8.24 \\
8.73 \\
8.96\end{array}$ & $\begin{array}{l}6,440 \\
7,000 \\
7,560 \\
8,360 \\
9,210 \\
9,630\end{array}$ & $\begin{array}{l}7.24 \\
6.92 \\
6.61 \\
6.36 \\
6.14 \\
5.93\end{array}$ & $\begin{array}{l}6,680 \\
6,170 \\
5,680 \\
5,290 \\
4,960 \\
4,650\end{array}$ & $\begin{array}{l}4.09 \\
4.02 \\
4.01 \\
4.00 \\
3.93 \\
3.91\end{array}$ & $\begin{array}{l}2,430 \\
2,360 \\
2,350 \\
2,340 \\
2,270 \\
2,250\end{array}$ \\
\hline $\begin{array}{l}1 \\
2 \\
3 \\
4 \\
5 \\
6\end{array}$ & $\begin{array}{l}1.11 \\
1.10 \\
1.10 \\
1.10 \\
1.10 \\
1.08\end{array}$ & $\begin{array}{l}234 \\
231 \\
231 \\
231 \\
231 \\
225\end{array}$ & $\begin{array}{l}2.47 \\
2.42 \\
2.41 \\
2.55 \\
2.74 \\
3.09\end{array}$ & $\begin{array}{r}897 \\
867 \\
861 \\
945 \\
1,070 \\
1,330\end{array}$ & $\begin{array}{l}5.43 \\
5.53 \\
5.63 \\
5.72 \\
5.86 \\
5.84\end{array}$ & $\begin{array}{l}3,900 \\
4,040 \\
4,200 \\
4,330 \\
4,540 \\
4,510\end{array}$ & $\begin{array}{r}9.14 \\
9.34 \\
9.64 \\
10.05 \\
10.47 \\
10.67\end{array}$ & $\begin{array}{r}9,950 \\
10,300 \\
10,900 \\
11,700 \\
12,500 \\
13,000\end{array}$ & $\begin{array}{l}5.77 \\
5.62 \\
5.46 \\
5.33 \\
5.19 \\
5.08\end{array}$ & $\begin{array}{l}4,430 \\
4,220 \\
4,010 \\
3,840 \\
3,660 \\
3,530\end{array}$ & $\begin{array}{l}3.89 \\
3.83 \\
3.82 \\
3.78 \\
3.73 \\
3.71\end{array}$ & $\begin{array}{l}2,230 \\
2,170 \\
2,160 \\
2,120 \\
2,080 \\
2,060\end{array}$ \\
\hline \multirow[t]{2}{*}{$\begin{array}{r}7 \\
8 \\
9 \\
10 \\
11 \\
M\end{array}$} & $\begin{array}{r}1.07 \\
1.04 \\
.99 \\
.97 \\
1.41 \\
1.54\end{array}$ & $\begin{array}{l}221 \\
212 \\
196 \\
190 \\
350 \\
405\end{array}$ & $\begin{array}{l}3.04 \\
3.22 \\
3.62 \\
3.78 \\
3.82 \\
4.24\end{array}$ & $\begin{array}{l}1,290 \\
1,440 \\
1,790 \\
1,940 \\
1,980 \\
2,400\end{array}$ & $\begin{array}{l}5.80 \\
5.74 \\
5.72 \\
5.64 \\
5.63 \\
5.84\end{array}$ & $\begin{array}{l}4,450 \\
4,360 \\
4,330 \\
4,210 \\
4,200 \\
4,510\end{array}$ & $\begin{array}{l}11.38 \\
11.99 \\
12.27 \\
12.40 \\
11.98 \\
11.80\end{array}$ & $\begin{array}{l}14,500 \\
16,000 \\
16,600 \\
17,000 \\
16,000 \\
15,500\end{array}$ & $\begin{array}{l}4.96 \\
4.86 \\
4.75 \\
4.65 \\
4.57 \\
4.49\end{array}$ & $\begin{array}{l}3,380 \\
3,260 \\
3,140 \\
3,020 \\
2,940 \\
2,850\end{array}$ & $\begin{array}{l}3.75 \\
3.72 \\
3.67 \\
3.54 \\
3.52 \\
3.50\end{array}$ & $\begin{array}{l}2,100 \\
2,070 \\
2,020 \\
1,910 \\
1,890 \\
1,870\end{array}$ \\
\hline & \multicolumn{2}{|c|}{ September 24} & \multicolumn{2}{|c|}{ September 25} & \multicolumn{2}{|c|}{ September 26} & \multicolumn{2}{|c|}{ September 27} & \multicolumn{2}{|c|}{ September 28} & \multicolumn{2}{|c|}{ September 29} \\
\hline $\begin{array}{r}2 \\
4 \\
6 \\
8 \\
10\end{array}$ & $\begin{array}{l}3.42 \\
3.39 \\
3.34 \\
3.31 \\
3.26 \\
3.22\end{array}$ & $\begin{array}{l}1,800 \\
1,770 \\
1,730 \\
1,700 \\
1,660 \\
1,630\end{array}$ & $\begin{array}{c}- \\
2.82 \\
- \\
2.78 \\
- \\
2.72\end{array}$ & $\begin{array}{c}1, \overline{310} \\
\overline{1,} \\
1, \overline{270} \\
1, \overline{230}\end{array}$ & $\begin{array}{c}\overline{2.46} \\
\overline{2.45} \\
\overline{2.42}\end{array}$ & $\begin{array}{l}1, \overline{0} 40 \\
\overline{0} \\
1, \overline{0} 0 \\
1, \overline{0} 10\end{array}$ & $\begin{array}{c}\overline{-} \\
2.21 \\
\overline{-} \\
2.21\end{array}$ & $\begin{array}{c}- \\
\overline{-} \\
876 \\
- \\
8 \overline{6}\end{array}$ & $\begin{array}{c}\overline{-} \\
\overline{2.08} \\
\overline{-} \\
\overline{2.11}\end{array}$ & $\begin{array}{c}- \\
\overline{792} \\
- \\
\overline{812}\end{array}$ & $\begin{array}{l}- \\
- \\
1.89 \\
- \\
1.92\end{array}$ & $\begin{array}{c}- \\
\overline{674} \\
- \\
\overline{692}\end{array}$ \\
\hline $\begin{array}{r}2 \\
4 \\
6 \\
8 \\
10 \\
M\end{array}$ & $\begin{array}{l}3.18 \\
3.12 \\
3.09 \\
3.02 \\
2.97 \\
2.94\end{array}$ & $\begin{array}{l}1,590 \\
1,550 \\
1,520 \\
1,470 \\
1,430 \\
1,400\end{array}$ & $\begin{array}{l}2 . \\
2.66 \\
2.55 \\
- \\
2.51\end{array}$ & $\begin{array}{c}1, \overline{180} \\
1, \overline{100} \\
1, \overline{0} \\
1,00\end{array}$ & $\begin{array}{c}- \\
2.39 \\
- \\
2.31 \\
- \\
2.27\end{array}$ & $\begin{array}{l}\overline{994} \\
\overline{942} \\
\overline{916}\end{array}$ & $\begin{array}{c}- \\
2.16 \\
- \\
2.11\end{array}$ & $\begin{array}{c}- \\
\overline{844} \\
\overline{-} \\
\overline{812}\end{array}$ & $\begin{array}{l}- \\
1.99 \\
- \\
1.93\end{array}$ & $\begin{array}{c}- \\
7 \overline{34} \\
\overline{-} \\
\overline{698}\end{array}$ & $\begin{array}{c}- \\
\overline{1.87} \\
- \\
1.81\end{array}$ & $\begin{array}{c}\overline{-} \\
6 \overline{62} \\
\overline{-} \\
\overline{626}\end{array}$ \\
\hline
\end{tabular}

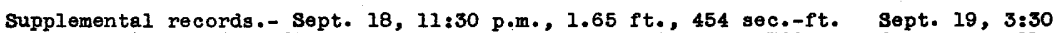
a.m., 2.61 ft. 982 sec.-ft. Sept. $20,12: 20$ a.m. $4.56 \mathrm{ft.,} 2,760$ sec.-ft. Sept. 21 , 8:30́p.m., 11.90 ft., 15,800 sec.-ft.; $9: 30$ p.m., 12.08 ft., 16,200 sec.-ft. 
Location.- Water-stage recorder, lat. $41^{\circ} 42^{\prime} 10^{\prime \prime}$, long. $73^{\circ} 03 \cdot 36^{\prime \prime}$, at highway bridge half a mile above mouth and $2 \frac{1}{4}$ miles northeast of Thomaton, Litchfield county. Dralnage area.- 24.0 square miles.

Gage-helght record. - Water-stage recorder graph.

Stage-discharge-relation.- Defined by current-meter measurements below 380 second-feet; extended logarithicaliy to peak stages on basis of mu-off comparison with records for stations on Naugatuck River near Thomaston and Naugatuck.

Maxima.- September 1938: D1 scharge, 3,050 second-feet 6:30 p.m. Sept. 21 (gage height, 11.14 feet).

1930 to August 1938: Discharge, about 2,800 second-feet Sept. 17, 1934 (gage height, 11.2 feet, from floodmarks).

Remarks. Flood run-off probably slightly affected by storage in a few small ponds.

Mean daily discharge, in second-feet, 1938

\begin{tabular}{|c|c|c|c|c|c|c|c|c|c|c|c|}
\hline Day & Sept. & 0ct. & Day & Sept. & Oct. & Day & Sept. & Oct. & Day & Sept. & Oct. \\
\hline $\begin{array}{l}1 \\
2 \\
3 \\
4 \\
5 \\
6 \\
7 \\
8\end{array}$ & $\begin{array}{c}12 \\
10 \\
7.9 \\
7.6 \\
7.3 \\
6.3 \\
6.1 \\
9.7\end{array}$ & $\begin{array}{l}41 \\
38 \\
34 \\
33 \\
31 \\
29 \\
27 \\
25\end{array}$ & $\begin{array}{r}9 \\
10 \\
11 \\
12 \\
13 \\
14 \\
15 \\
16\end{array}$ & $\begin{array}{c}7.9 \\
6.8 \\
6.5 \\
6.3 \\
10 \\
9.0 \\
12 \\
15\end{array}$ & $\begin{array}{l}24 \\
23 \\
22 \\
22 \\
22 \\
22 \\
23 \\
22\end{array}$ & $\begin{array}{l}17 \\
18 \\
19 \\
20 \\
21 \\
22 \\
23 \\
24\end{array}$ & $\begin{array}{r}11 \\
18 \\
131 \\
389 \\
1,370 \\
550 \\
224 \\
143\end{array}$ & $\begin{array}{r}20 \\
19 \\
19 \\
23 \\
105 \\
46 \\
33 \\
78\end{array}$ & $\begin{array}{l}25 \\
26 \\
27 \\
28 \\
29 \\
30 \\
31\end{array}$ & $\begin{array}{c}105 \\
82 \\
71 \\
62 \\
52 \\
43 \\
-\end{array}$ & $\begin{array}{l}91 \\
49 \\
40 \\
34 \\
39 \\
35 \\
30\end{array}$ \\
\hline $\begin{array}{l}\text { Mean } \\
\text { Run- }\end{array}$ & nthly & $\begin{array}{l}\text { schare } \\
\text { hes. }\end{array}$ & , 11 & and-1 & et. & . : & 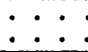 & 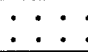 & $\dot{0} \cdot \dot{ }$ & $\begin{array}{r}113 \\
5.26\end{array}$ & $\begin{array}{l}35.5 \\
1.71\end{array}$ \\
\hline
\end{tabular}

Gage helght, In feet, and discharge, in second-feet, at indicated time, 1938

\begin{tabular}{|c|c|c|c|c|c|c|c|c|c|c|c|c|}
\hline \multirow{2}{*}{$\begin{array}{l}4 \\
3 \\
5 \\
5 \\
\end{array}$} & Foet & Sec.ft. & Feet & Sec.ft. & Feet & Sec.ft. & Feet & Sec.ft. & Feet & Sec.ft. & Feet & Sec.ft. \\
\hline & \multicolumn{2}{|c|}{ September 18} & \multicolumn{2}{|c|}{ September 19} & \multicolumn{2}{|c|}{ September 20} & \multicolumn{2}{|c|}{ September 21} & \multicolumn{2}{|c|}{ September 22} & \multicolumn{2}{|c|}{ September 23} \\
\hline $\begin{array}{l}1 \\
2 \\
3 \\
4 \\
5 \\
6\end{array}$ & $\begin{array}{c}\overline{2.60} \\
\overline{2} \\
2.63 \\
\overline{2.63}\end{array}$ & $\begin{array}{r}1 \overline{7} \\
18 \\
18\end{array}$ & $\begin{array}{l}2.79 \\
2.91 \\
3.09 \\
3.20 \\
3.30 \\
3.34\end{array}$ & \begin{tabular}{|l}
26 \\
33 \\
46 \\
56 \\
66 \\
70
\end{tabular} & $\begin{array}{l}4.12 \\
4.10 \\
4.46 \\
4.63 \\
4.63 \\
4.84\end{array}$ & $\begin{array}{l}178 \\
174 \\
244 \\
282 \\
282 \\
335\end{array}$ & $\begin{array}{l}5.28 \\
5.45 \\
5.50 \\
5.61 \\
5.80 \\
6.01\end{array}$ & $\begin{array}{l}464 \\
518 \\
535 \\
574 \\
640 \\
714\end{array}$ & $\begin{array}{l}6.83 \\
6.56 \\
6.31 \\
6.12 \\
6.00 \\
5.87\end{array}$ & $\begin{array}{r}1,030 \\
924 \\
824 \\
752 \\
710 \\
664\end{array}$ & $\begin{array}{c}\overline{4.68} \\
\overline{4} \\
4.61 \\
\overline{4.58}\end{array}$ & $\begin{array}{c}284 \\
\overline{265} \\
257\end{array}$ \\
\hline $\begin{array}{r}7 \\
8 \\
9 \\
10 \\
11 \\
N\end{array}$ & $\begin{array}{l}-\overline{2.63} \\
- \\
2.63 \\
- \\
2.63\end{array}$ & $\begin{array}{l}1 \overline{8} \\
1 \overline{8} \\
1 \overline{8}\end{array}$ & $\begin{array}{l}3.38 \\
3.39 \\
3.36 \\
3.35 \\
3.35 \\
3.42\end{array}$ & $\begin{array}{l}74 \\
75 \\
72 \\
71 \\
71 \\
78\end{array}$ & $\begin{array}{l}4.90 \\
4.96 \\
5.08 \\
5.20 \\
5.30 \\
5.39\end{array}$ & $\begin{array}{l}350 \\
368 \\
404 \\
440 \\
470 \\
497\end{array}$ & $\begin{array}{l}6.26 \\
6.50 \\
6.70 \\
7.30 \\
7.60 \\
7.70\end{array}$ & $\begin{array}{r}804 \\
900 \\
980 \\
1,220 \\
1,340 \\
1,380\end{array}$ & $\begin{array}{l}5.75 \\
5.66 \\
5.55 \\
5.50 \\
5.44 \\
5.39\end{array}$ & $\begin{array}{l}622 \\
591 \\
552 \\
535 \\
514 \\
497\end{array}$ & $\begin{array}{l}\overline{4.52} \\
\overline{4.48} \\
\overline{4.43}\end{array}$ & $\begin{array}{l}\overline{241} \\
\overline{231} \\
\overline{218}\end{array}$ \\
\hline $\begin{array}{l}1 \\
2 \\
3 \\
4 \\
5 \\
6\end{array}$ & $\begin{array}{c}- \\
2.62 \\
- \\
2.61 \\
- \\
\overline{2.61}\end{array}$ & $\begin{array}{r}\overline{18} \\
\overline{17} \\
1 \overline{7}\end{array}$ & $\begin{array}{l}3.59 \\
3.87 \\
4.00 \\
4.19 \\
4.41 \\
4.47\end{array}$ & $\begin{array}{r}98 \\
136 \\
157 \\
190 \\
233 \\
246\end{array}$ & $\begin{array}{l}5.40 \\
5.39 \\
5.35 \\
5.29 \\
5.29 \\
5.30\end{array}$ & $\begin{array}{l}500 \\
497 \\
485 \\
467 \\
467 \\
470\end{array}$ & $\begin{array}{r}7.40 \\
7.20 \\
7.44 \\
7.90 \\
9.55 \\
10.70\end{array}$ & $\begin{array}{l}1,260 \\
1,180 \\
1,280 \\
1,480 \\
2,240 \\
2,820\end{array}$ & $\begin{array}{l}5.30 \\
5.23 \\
5.19 \\
5.11 \\
5.06 \\
5.00\end{array}$ & $\begin{array}{l}470 \\
449 \\
437 \\
413 \\
398 \\
380\end{array}$ & $\begin{array}{l}\overline{-} \\
\overline{4} 40 \\
\overline{4.35} \\
\overline{4.30}\end{array}$ & $\begin{array}{c}2 \overrightarrow{11} \\
\overrightarrow{200} \\
\overline{18}\end{array}$ \\
\hline \multirow[t]{2}{*}{$\begin{array}{r}7 \\
8 \\
9 \\
10 \\
11 \\
M\end{array}$} & $\begin{array}{c}- \\
2.60 \\
- \\
2.60 \\
\overline{2.73}\end{array}$ & $\begin{array}{r}1 \overline{7} \\
\overline{17} \\
\overline{2}\end{array}$ & $\begin{array}{l}4.55 \\
4.58 \\
4.51 \\
4.40 \\
4.30 \\
4.20\end{array}$ & $\begin{array}{l}264 \\
270 \\
254 \\
231 \\
211 \\
192\end{array}$ & $\begin{array}{l}5.26 \\
5.19 \\
5.11 \\
5.10 \\
5.08 \\
5.10\end{array}$ & $\begin{array}{l}458 \\
437 \\
413 \\
410 \\
404 \\
410\end{array}$ & $\begin{array}{r}10.76 \\
10.70 \\
9.66 \\
8.60 \\
7.79 \\
7.26\end{array}$ & $\begin{array}{l}2,850 \\
2,820 \\
2,300 \\
1,790 \\
1,430 \\
1,200\end{array}$ & $\begin{array}{l}4.95 \\
4.90 \\
4.85 \\
4.80 \\
4.78 \\
4.73\end{array}$ & $\begin{array}{l}365 \\
350 \\
335 \\
320 \\
314 \\
299\end{array}$ & $\begin{array}{l}\overline{4.28} \\
- \\
4.23 \\
- \\
4.20\end{array}$ & $\begin{array}{c}\overline{184} \\
\overline{173} \\
\overline{167}\end{array}$ \\
\hline & \multicolumn{2}{|c|}{ September 24} & \multicolumn{2}{|c|}{ September 25} & \multicolumn{2}{|c|}{ September 26} & \multicolumn{2}{|c|}{ September 27} & \multicolumn{2}{|c|}{ September 28} & \multicolumn{2}{|c|}{ September 29} \\
\hline $\begin{array}{r}2 \\
4 \\
6 \\
8 \\
10 \\
N\end{array}$ & $\begin{array}{l}- \\
4.17 \\
- \\
4.11 \\
- \\
4.09\end{array}$ & $\begin{array}{c}\overline{161} \\
\overline{149} \\
145\end{array}$ & $\begin{array}{l}- \\
\overline{3.90} \\
\overline{-} \\
3.86\end{array}$ & $\begin{array}{c}\overline{-} \\
\overline{122} \\
\overline{-} \\
\overline{106}\end{array}$ & $\begin{array}{l}- \\
\overline{3.72} \\
- \\
\overline{3.70}\end{array}$ & $\begin{array}{r}\overline{-} \\
\overline{6} \\
\overline{-} \\
\overline{3}\end{array}$ & $\begin{array}{l}- \\
\overline{3.62} \\
\overline{-} \\
\overline{3.60}\end{array}$ & $\begin{array}{r}- \\
\overline{73} \\
- \\
70\end{array}$ & $\begin{array}{l}- \\
\overline{3.56} \\
- \\
\overline{3.53}\end{array}$ & $\begin{array}{l}\overline{-} \\
6 \overline{6} \\
\overline{-} \\
\overline{2}\end{array}$ & $\begin{array}{l}- \\
\overline{3.48} \\
\overline{-} \\
\overline{3.42}\end{array}$ & $\begin{array}{r}- \\
57 \\
- \\
51\end{array}$ \\
\hline $\begin{array}{r}2 \\
4 \\
6 \\
8 \\
10 \\
M\end{array}$ & $\begin{array}{l}\overline{4.02} \\
\overline{3.98} \\
\overline{3.94}\end{array}$ & $\begin{array}{l}\overline{133} \\
\overline{126} \\
\overline{119}\end{array}$ & $\begin{array}{l}- \\
\overline{3.79} \\
- \\
\overline{3.75}\end{array}$ & $\begin{array}{l}\overline{-} \\
\overline{96} \\
\overline{90}\end{array}$ & $\begin{array}{l}- \\
\overline{3.66} \\
- \\
\overline{3.63}\end{array}$ & $\begin{array}{r}\overline{-} \\
\overline{78} \\
\overline{74}\end{array}$ & $\begin{array}{l}- \\
\overline{3.59} \\
- \\
\overline{3.58}\end{array}$ & $\begin{array}{r}\overline{-} \\
\overline{-} \\
6 \overline{8}\end{array}$ & $\begin{array}{l}- \\
\overline{3.50} \\
\overline{3.49}\end{array}$ & $\begin{array}{l}\overline{-} \\
5 \overline{8}\end{array}$ & $\begin{array}{l}- \\
\overline{3.40} \\
\overline{3.35}\end{array}$ & $\begin{array}{l}\overline{-} \\
\overline{4} \\
\overline{-} \\
\overline{4}\end{array}$ \\
\hline
\end{tabular}

Supplemental records.- Sept. $21,3: 40$ p.m., 7.99 ft., 1,520 sec.-ft.; 3:50 p.m., 7.67 ft., 1,370 sec.-ft.; $4: 50$ p.m., 9.79 ft., 2,360 sec.-ft.; $5: 10$ p.m., 10.50 ft., 2,720 sec.-ft.; 6:20 p.m., 10.75 ft., 2,840 sec.-ft.; 6:30 p.m., 11.14 ft., 3,050 sec.-ft.; $6: 40 \mathrm{p} . \mathrm{m} \cdot, 10.76 \mathrm{ft} ., 2,850 \mathrm{sec} .-\mathrm{ft}$. 
Branch of Naugatuck River at outlet of Wigwam Reservoir, near Thomaston, Conn.

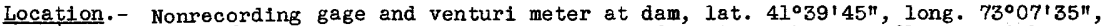
$2 \frac{1}{2}$ miles west of Thomaston, Litchfield County, and 3 miles above confluence with Naugatuck River.

Drainage area.- 18.0 square miles.

Gage-height record.- Three reservoir gage readings daily; gage height at midnight determined from graph constructed from gage-height readings.

Stage-discharge relation.- Observed discharge computed from flow over spillways and through venturi meter.

Maxima.- September 1938: Discharge observed, 3,610 second-feet 6 p.m. Sept. 21. Remariss.- Mean daily and monthly discharges adjusted for gain or loss in storage in Wigwam and Morris Reservoirs and for diversions from Shepaug River drainage basin to Morris Reservolr. No corrections for evaporation from reservoir surfaces. Basic data furnished by Bureau of Engineering, City of Waterbury.

Mean discharge, in second-feet, and gain or loss in storage, in equivalént mean second-feet, 1938

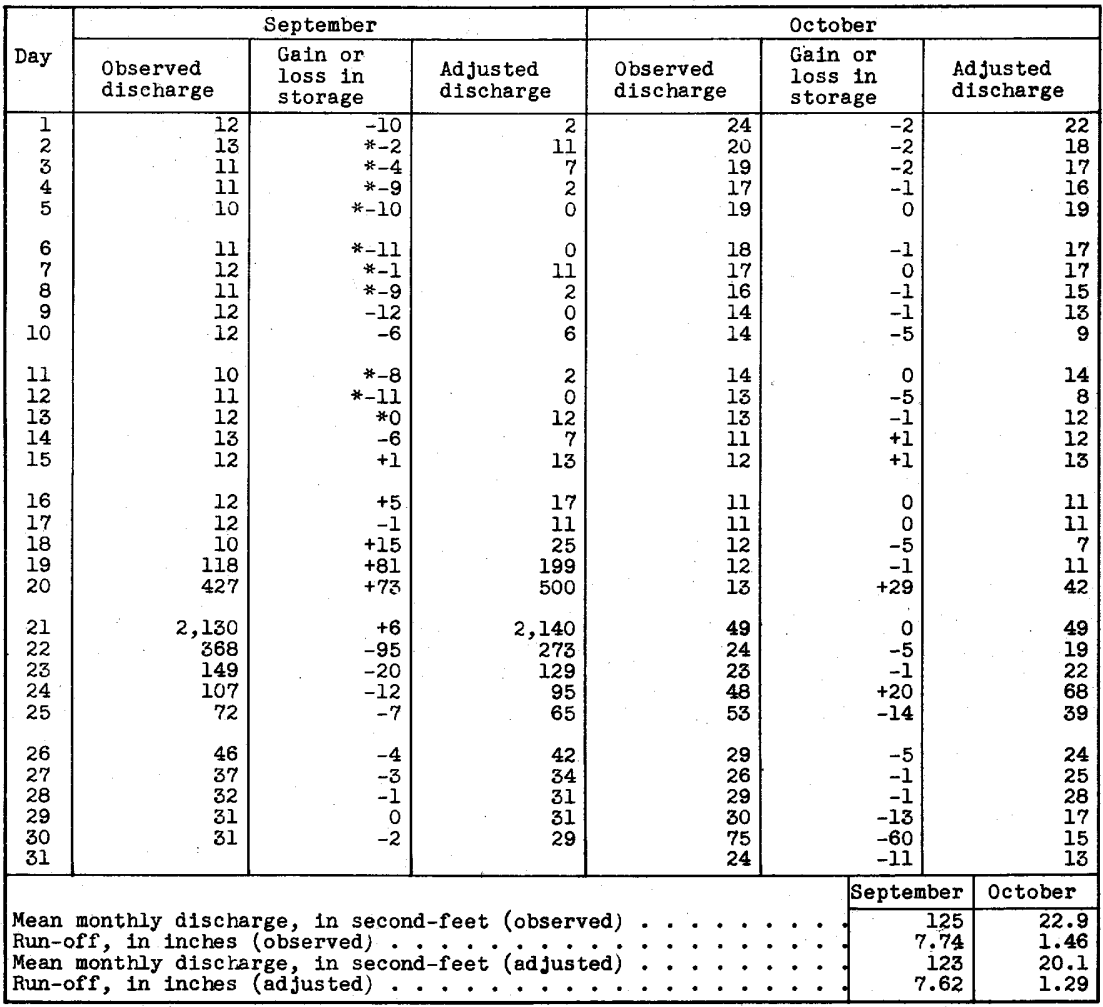

* Includes diversion from Shepaug Reservolr. 
Saugatuck River near Westport, Conn.

Location.- Water-stage recorder, lat. $41^{\circ} 10^{\prime} 15^{\prime \prime}$, long. $73^{\circ} 22^{\prime} 00^{n}$, on old Ford Road, or Clintón Ave., 400 feet below confluence with West Branch of saugafuck RIver, 600 feet below dam of Dorr Co.g. and 2 miles north of Westport, Falrfield County.

Drainage area.- 77.5 square miles.

Gage-height record. - Water-stage recorder graph.

Stage-discharge relati on.- Defined by current-meter measurements below 1,700 second-feot; extended logarithmicaliy to 3,000 second-feet with a straight-1ine extension above 3,000 second-feet on basis of determination of peak flow at dam 600 feet upstream.

Maxima.-- September 1938: Discharge, 4,420 second-feet at midnight Sept. 21 (gage helght, 10.28 feot).

1932 to August 1938: Discharge, 5,310 second-feet Mar. 12, 1936 (gage helght, 11.30 poot).

Remarks.- Brldgeport Hydraulic Co. diverts the flow from 17 square miles of the Aspetuck River drainage basin. Water for diversion is stored in Aspetuck Reservoir and diverted by canal 1nto Hemlocks Reservolr (M1ll River Basin), from which it is released for water supply. Dally and monthly discharge not adjusted for diversions. Run-off computations are based on total drainage area above station.

Mean dally discharge, in second-feet, 1938

\begin{tabular}{|c|c|c|c|c|c|c|c|c|c|c|c|}
\hline Day & Sept. & Oct. & Day & Sept. & Oct. & Day & Sept. & oct. & Day & Sept. & oct. \\
\hline $\begin{array}{l}1 \\
2 \\
3 \\
4 \\
5 \\
6 \\
7 \\
8\end{array}$ & $\begin{array}{l}38 \\
39 \\
33 \\
32 \\
30 \\
28 \\
27 \\
35\end{array}$ & $\begin{array}{l}282 \\
331 \\
197 \\
166 \\
153 \\
144 \\
166 \\
135\end{array}$ & $\begin{array}{r}9 \\
10 \\
11 \\
12 \\
13 \\
14 \\
15 \\
16\end{array}$ & $\begin{array}{l}33 \\
29 \\
27 \\
25 \\
33 \\
46 \\
66 \\
70\end{array}$ & $\begin{array}{r}129 \\
113 \\
100 \\
94 \\
94 \\
92 \\
94 \\
92\end{array}$ & $\begin{array}{l}17 \\
18 \\
19 \\
20 \\
21 \\
22 \\
23 \\
24\end{array}$ & $\begin{array}{r}51 \\
73 \\
448 \\
766 \\
2,680 \\
2,780 \\
1,220 \\
754\end{array}$ & $\begin{array}{r}89 \\
82 \\
79 \\
79 \\
144 \\
129 \\
109 \\
201\end{array}$ & $\begin{array}{l}25 \\
26 \\
27 \\
28 \\
29 \\
30 \\
31\end{array}$ & $\begin{array}{c}542 \\
417 \\
354 \\
416 \\
329 \\
293 \\
-\end{array}$ & $\begin{array}{r}302 \\
197 \\
148 \\
129 \\
127 \\
111 \\
98\end{array}$ \\
\hline & & & & & & . & $\because: \dot{ }$ & $\because:$ & • & $\begin{array}{r}390 \\
5.61\end{array}$ & $\begin{array}{r}142 \\
2.11\end{array}$ \\
\hline
\end{tabular}

Gage height, in feet, and discharge, in second-feet, at indicated time, 1938

\begin{tabular}{|c|c|c|c|c|c|c|c|c|c|c|c|c|}
\hline \multirow{2}{*}{$\begin{array}{l}8 \\
8 \\
0 \\
0\end{array}$} & eet & Sec.ft. & Feet & Sec.ft. & Feet & Sec.ft. & Feet. & Sec.ft. & Feot & Sec.ft. & Feet & Sec.ft. \\
\hline & \multicolumn{2}{|c|}{ September 18} & \multicolumn{2}{|c|}{ September 19} & \multicolumn{2}{|c|}{ September 20} & \multicolumn{2}{|c|}{ September 2] } & \multicolumn{2}{|c|}{ September 22} & \multicolumn{2}{|c|}{ September 23} \\
\hline $\begin{array}{l}1 \\
2 \\
3 \\
4 \\
5 \\
6\end{array}$ & $\begin{array}{l}2.75 \\
2.77 \\
2.78 \\
2.78 \\
2.78 \\
2.78\end{array}$ & \begin{tabular}{|c|}
63 \\
66 \\
67 \\
67 \\
67 \\
67
\end{tabular} & $\begin{array}{l}4.09 \\
4.35 \\
4.44 \\
4.50 \\
4.57 \\
4.58\end{array}$ & $\begin{array}{l}366 \\
450 \\
481 \\
503 \\
529 \\
\end{array}$ & & $\begin{array}{l}592 \\
604 \\
612 \\
612 \\
612 \\
612\end{array}$ & & & & & $\begin{array}{c}- \\
6.65 \\
- \\
6.50 \\
- \\
6.36\end{array}$ & $\begin{array}{l}1, \overline{5} 70 \\
\overline{-} \\
1,480 \\
1, \overline{400}\end{array}$ \\
\hline $\begin{array}{r}7 \\
8 \\
9 \\
10 \\
11 \\
N\end{array}$ & $\begin{array}{l}2.78 \\
2.78 \\
2.78 \\
2.78 \\
2.78 \\
2.77\end{array}$ & $\begin{array}{l}67 \\
67 \\
67 \\
67 \\
67 \\
66\end{array}$ & $\begin{array}{l}46 \\
41 \\
38\end{array}$ & $\begin{array}{l}507 \\
489 \\
471 \\
460 \\
440\end{array}$ & & $\begin{array}{l}620 \\
628 \\
660 \\
688 \\
724 \\
758\end{array}$ & & & $\begin{array}{l}90 \\
70 \\
54 \\
39 \\
21 \\
08\end{array}$ & & $\begin{array}{c}- \\
6.23 \\
-- \\
6.11 \\
- \\
6.00\end{array}$ & $\begin{array}{l}1, \overline{3} 20 \\
1, \overline{2} \\
-\overline{1} \\
1,180\end{array}$ \\
\hline $\begin{array}{l}1 \\
2 \\
3 \\
4 \\
5 \\
6\end{array}$ & $\begin{array}{l}2.77 \\
2.76 \\
2.75 \\
2.75 \\
2.74 \\
2.74\end{array}$ & $\begin{array}{l}66 \\
64 \\
63 \\
63 \\
62 \\
62\end{array}$ & $\begin{array}{l}4.22 \\
4.19 \\
4.14 \\
4.14 \\
4.15 \\
4.20\end{array}$ & $\begin{array}{l}407 \\
397 \\
381 \\
381 \\
384 \\
400\end{array}$ & & $\begin{array}{l}785 \\
798 \\
798 \\
821 \\
852 \\
888\end{array}$ & $\begin{array}{l}8 . \\
8 . \\
8 . \\
9 .\end{array}$ & & & & $\begin{array}{c}- \\
5.90 \\
5.80 \\
- \\
5.70\end{array}$ & $\begin{array}{c}1, \overline{120} \\
\overline{-} \\
1,070 \\
1, \overline{020}\end{array}$ \\
\hline \multirow[t]{2}{*}{$\begin{array}{r}7 \\
8 \\
9 \\
10 \\
11 \\
M\end{array}$} & $\begin{array}{l}2.74 \\
2.73 \\
2.73 \\
2.89 \\
3.29 \\
3.72\end{array}$ & $\begin{array}{r}62 \\
60 \\
60 \\
84 \\
157 \\
260 \\
\end{array}$ & $\begin{array}{l}4.25 \\
4.31 \\
4.39 \\
4.45 \\
4.55 \\
4.66\end{array}$ & $\begin{array}{l}416 \\
436 \\
464 \\
485 \\
522 \\
564\end{array}$ & $\begin{array}{l}5.51 \\
5.58 \\
5.61 \\
5.65 \\
5.73 \\
5.87\end{array}$ & $\begin{array}{r}925 \\
960 \\
975 \\
995 \\
1,040 \\
1,100\end{array}$ & $\begin{array}{r}9.86 \\
9.96 \\
9.99 \\
10.11 \\
10.23 \\
10.28\end{array}$ & & & & $\begin{array}{l}- \\
5.62 \\
- \\
5.55 \\
- \\
5.48\end{array}$ & $\begin{array}{l}\overline{980} \\
\overline{9} \\
\overline{9} 11\end{array}$ \\
\hline & \multicolumn{2}{|c|}{ September 24} & \multicolumn{2}{|c|}{ September 25} & \multicolumn{2}{|c|}{ September 26} & \multicolumn{2}{|c|}{ September 27} & \multicolumn{2}{|c|}{ September 28} & \multicolumn{2}{|c|}{ September 29} \\
\hline 2 & & & & & & & & & & & & - \\
\hline & & & & 59 & & 450 & & $35 ?$ & & & & 354 \\
\hline & 5.22 & $\overline{7} \overline{94}$ & 4,67 & 568 & 4.30 & 433 & .03 & 348 & 432 & 440 & 4.00 & 339 \\
\hline 10 & 5.12 & 749 & $\frac{-60}{4.60}$ & $5 \overline{540}$ & 4.25 & $4 \overline{16}$ & 4.01 & 342 & 4.30 & $\overline{43}$ & 3.97 & 330 \\
\hline 2 & & & & & & & & & - & & & \\
\hline & & 704 & 4.52 & 510 & & 400 & & & & 410 & & 313 \\
\hline & & & - & & & & & & & & & \\
\hline & & 664 & 4.46 & 489 & & 384 & & & 4.18 & 394 & & 304 \\
\hline 70 & 4.82 & $6 \overline{28}$ & 4.40 & 467 & 4.10 & $3 \overline{69}$ & 4.20 & 400 & 4.11 & $3 \overline{72}$ & 3.84 & $2 \overline{9}$ \\
\hline
\end{tabular}


Mill Neck Creek at Mill Neck, N. Y

Location.- Water-stage recorder and concrete control, lat. $40^{\circ} 53^{\prime} 15^{n}$, 1ong. $73^{\circ} 33^{\prime} 5^{\prime \prime}$, at Beaver Dam and highway bridge on Feeks Lane (Ciiff Road) in viliage of Mill Neck, Nassau County. Zero of gage is 6.55 feet above mean sea level (general adjustment of 1912).

Drainage area.- About 10 square miles.

Gage-helght record.- Water-stage recorder graph. Graph adjusted for tidal effect for period 7 p.m. Sept. 21 to noon Sept. 23.

Stage-discharge relation.- Defined by current-meter measurements below 84 second-feet. Affected by tide $7 \mathrm{p.m}$. Sept. 21 to noon Sept. 23.

Maxima.- September 1938: Maximum discharge, 86 second-feet 4:45 p.m. Sept. 21 (gage helght, $1.38 \mathrm{feet}$ ); maximum gage height, 4.85 feet (backwater from tide) 8 p.m. Sept. 2li.

January 1937 to August 1938: Discharge, 48.8 second-feet Sept. 13, 1937 (gage height, 0.96 foot)

Remarks.- Records good. Flood run-off probably affected by natural storage in swampy, flat areas and sandy soil.

Mean daily discharge, in second-feet, 1938

\begin{tabular}{|c|c|c|c|c|c|c|c|c|c|c|c|}
\hline Day & Sept. & Oct. & Day & Sept. & Oct. & Day & Sept. & Oct. & Day & Sept. & Oct. \\
\hline $\begin{array}{l}1 \\
2 \\
3 \\
4 \\
5 \\
6 \\
7 \\
8\end{array}$ & $\begin{array}{l}8.5 \\
7.3 \\
6.7 \\
6.5 \\
6.1 \\
5.9 \\
6.3 \\
6.3\end{array}$ & $\begin{array}{r}9.8 \\
8.8 \\
8.0 \\
7.9 \\
7.9 \\
8.8 \\
10.2 \\
9.2\end{array}$ & $\begin{array}{r}9 \\
10 \\
11 \\
12 \\
13 \\
14 \\
15 \\
16\end{array}$ & $\begin{array}{l}5.9 \\
6.1 \\
6.1 \\
6.3 \\
6.7 \\
6.7 \\
9.1 \\
8.1\end{array}$ & $\begin{array}{l}9.0 \\
9.0 \\
9.0 \\
8.8 \\
8.6 \\
8.4 \\
8.4 \\
8.4\end{array}$ & $\begin{array}{l}17 \\
18 \\
19 \\
20 \\
21 \\
22 \\
23 \\
24\end{array}$ & $\begin{array}{l}7.6 \\
11.8 \\
40 \\
33 \\
58 \\
35 \\
19.8 \\
13.6\end{array}$ & $\begin{array}{r}8.2 \\
8.0 \\
8.0 \\
8.3 \\
10.4 \\
9.2 \\
8.8 \\
10.2\end{array}$ & $\begin{array}{l}25 \\
26 \\
27 \\
28 \\
29 \\
30 \\
31\end{array}$ & $\begin{array}{r}10.8 \\
10.0 \\
9.6 \\
9.2 \\
9.0 \\
9.6\end{array}$ & $\begin{array}{r}10.8 \\
9.2 \\
8.6 \\
8.4 \\
8.8 \\
8.4 \\
8.4\end{array}$ \\
\hline $\begin{array}{l}\text { Mean } \\
\text { Run-c }\end{array}$ & $\begin{array}{l}\text { nthly } \\
\text { in }\end{array}$ & schar & , In & - . . & . & . $\cdot$ & $\begin{array}{l} \\
\end{array} \cdot$ & $\begin{array}{l} \\
\end{array}$ & . : & $\begin{array}{c}12.85 \\
-\end{array}$ & $\begin{array}{l}8.84 \\
-\quad \\
\end{array}$ \\
\hline
\end{tabular}

Gage helght, In feet, and discharge, in second-feet, at indicated time, 1938

\begin{tabular}{|c|c|c|c|c|c|c|c|c|c|c|c|c|}
\hline \multirow{2}{*}{$\begin{array}{l}5 \\
\text { 身 } \\
\text { 足 }\end{array}$} & Feet & Sec.ft. & Feet & Sec.ft. & Feet & Sec.ft. & Feet & Sec.ft. & Feet & Sec.ft. & Feet & Sec.ft. \\
\hline & \multicolumn{2}{|c|}{ September 18} & \multicolumn{2}{|c|}{ September 19} & \multicolumn{2}{|c|}{ September 20} & \multicolumn{2}{|c|}{ September 21} & \multicolumn{2}{|c|}{ September 22} & \multicolumn{2}{|c|}{ September 23} \\
\hline $\begin{array}{l}1 \\
2 \\
3 \\
4 \\
5 \\
6\end{array}$ & $\begin{array}{r}0.315 \\
.315 \\
.315 \\
.310 \\
.310 \\
.310\end{array}$ & $\begin{array}{l}8.33 \\
8.33 \\
8.33 \\
8.12 \\
8.12 \\
8.12\end{array}$ & $\begin{array}{r}1.00 \\
1.02 \\
1.01 \\
.99 \\
.96 \\
.93\end{array}$ & $\begin{array}{l}52 \\
54 \\
53 \\
51 \\
48.8 \\
46.4\end{array}$ & $\begin{array}{r}0.72 \\
.72 \\
.74 \\
.74 \\
.74 \\
.73\end{array}$ & $\begin{array}{l}30.4 \\
30.4 \\
31.8 \\
31.8 \\
31.8 \\
31.1\end{array}$ & $\begin{array}{r}0.83 \\
.83 \\
.83 \\
.84 \\
.87 \\
.91\end{array}$ & $\begin{array}{l}38.4 \\
38.4 \\
38.4 \\
39.2 \\
41.6 \\
44.8\end{array}$ & $\begin{array}{l}1.59 \\
1.49 \\
1.41 \\
1.33 \\
1.26 \\
1.20\end{array}$ & $\begin{array}{l}48.8 \\
47.2 \\
44.8 \\
43.2 \\
41.6 \\
40.0\end{array}$ & $\begin{array}{r}0.67 \\
.66 \\
.64 \\
.63 \\
.62 \\
.61\end{array}$ & $\begin{array}{l}24.5 \\
23.9 \\
23.3 \\
22.7 \\
22.7 \\
22.1\end{array}$ \\
\hline $\begin{array}{r}7 \\
8 \\
9 \\
10 \\
11 \\
N\end{array}$ & $\begin{array}{l}.310 \\
.310 \\
.310 \\
.305 \\
.310 \\
.310\end{array}$ & $\begin{array}{l}8.12 \\
8.12 \\
8.12 \\
7.92 \\
8.12 \\
8.12\end{array}$ & $\begin{array}{l}.90 \\
.87 \\
.84 \\
.81 \\
.80 \\
.79\end{array}$ & $\begin{array}{l}44.0 \\
41.6 \\
39.2 \\
36.8 \\
36.0 \\
35.3\end{array}$ & $\begin{array}{l}.72 \\
.73 \\
.76 \\
.78 \\
.78 \\
.78\end{array}$ & $\begin{array}{l}30.4 \\
31.1 \\
33.2 \\
34.6 \\
34.6 \\
34.6\end{array}$ & $\begin{array}{l}.95 \\
.99 \\
1.01 \\
1.08 \\
1.12 \\
1.12\end{array}$ & $\begin{array}{l}48.0 \\
51 \\
53 \\
59 \\
62 \\
62\end{array}$ & $\begin{array}{r}1.14 \\
1.09 \\
1.05 \\
1.01 \\
.97 \\
.94\end{array}$ & $\begin{array}{l}38.4 \\
37.6 \\
36.0 \\
35.3 \\
33.9 \\
33.2\end{array}$ & $\begin{array}{l}.60 \\
.60 \\
.59 \\
.58 \\
.57 \\
.56\end{array}$ & $\begin{array}{l}21.5 \\
21.5 \\
20.9 \\
20.3 \\
19.7 \\
19.7\end{array}$ \\
\hline $\begin{array}{l}1 \\
2 \\
3 \\
4 \\
5 \\
6\end{array}$ & $\begin{array}{l}.310 \\
.315 \\
.315 \\
.315 \\
.315 \\
.315\end{array}$ & $\begin{array}{l}8.12 \\
8.33 \\
8.33 \\
8.33 \\
8.33 \\
8.33\end{array}$ & $\begin{array}{l}.78 \\
.76 \\
.79 \\
.81 \\
.81 \\
.81\end{array}$ & $\begin{array}{l}34.6 \\
33.2 \\
35.3 \\
36.8 \\
36.8 \\
36.8\end{array}$ & $\begin{array}{l}.78 \\
.76 \\
.76 \\
.76 \\
.76 \\
.75\end{array}$ & $\begin{array}{l}34.6 \\
33.2 \\
33.2 \\
33.2 \\
33.2 \\
32.5\end{array}$ & $\begin{array}{l}1.13 \\
1.19 \\
1.25 \\
1.35 \\
1.36 \\
1.32\end{array}$ & $\begin{array}{l}63 \\
69 \\
74 \\
83 \\
84 \\
80\end{array}$ & $\begin{array}{l}.91 \\
.88 \\
.85 \\
.83 \\
.80 \\
.78\end{array}$ & $\begin{array}{l}32.5 \\
31.8 \\
31.1 \\
29.7 \\
29.0 \\
28.3\end{array}$ & $\begin{array}{l}- \\
.535 \\
- \\
.525 \\
- \\
.510\end{array}$ & $\begin{array}{l}\overline{18.8} \\
\overline{18.2} \\
\overline{17} .3\end{array}$ \\
\hline \multirow[t]{2}{*}{$\begin{array}{r}7 \\
8 \\
9 \\
10 \\
11 \\
M \\
\end{array}$} & $\begin{array}{l}.315 \\
.340 \\
.530 \\
.75 \\
.87 \\
.91 \\
\end{array}$ & $\begin{array}{r}8.33 \\
9.40 \\
18.6 \\
32.5 \\
41.6 \\
44.8 \\
\end{array}$ & $\begin{array}{l}.80 \\
.79 \\
.77 \\
.76 \\
.74 \\
.73 \\
\end{array}$ & $\begin{array}{l}36.0 \\
35.3 \\
33.9 \\
33.2 \\
31.8 \\
31.1\end{array}$ & $\begin{array}{l}.77 \\
.77 \\
.77 \\
.77 \\
.81 \\
.83\end{array}$ & $\begin{array}{l}33.9 \\
33.9 \\
33.9 \\
33.9 \\
36.8 \\
38.4\end{array}$ & $\begin{array}{l}1.32 \\
4.85 \\
3.10 \\
2.20 \\
1.87 \\
1.71\end{array}$ & $\begin{array}{l}77 \\
70 \\
64 \\
58 \\
54 \\
51\end{array}$ & $\begin{array}{l}.76 \\
.74 \\
.73 \\
.71 \\
.70 \\
.68 \\
\end{array}$ & $\begin{array}{l}27.6 \\
26.9 \\
26.3 \\
26.3 \\
25.7 \\
25.1\end{array}$ & $\begin{array}{l}- \\
.500 \\
\overline{490} \\
. \\
.480 \\
\end{array}$ & $\begin{array}{l}\overline{16.7} \\
\overline{16} .1 \\
\overline{15} .6\end{array}$ \\
\hline & \multicolumn{2}{|c|}{ September 24} & \multicolumn{2}{|c|}{ September 25} & \multicolumn{2}{|c|}{ September 26} & \multicolumn{2}{|c|}{ September 27} & \multicolumn{2}{|c|}{ September 28} & \multicolumn{2}{|c|}{ September 29} \\
\hline $\begin{array}{r}2 \\
4 \\
6 \\
8 \\
10 \\
\text { N }\end{array}$ & $\begin{array}{c}\overline{-} \\
0.460 \\
\overline{4} \\
.40 \\
\overline{4} \\
.40\end{array}$ & $\begin{array}{l}\overline{14.6} \\
\overline{13} .6 \\
\overline{13} .6\end{array}$ & $\begin{array}{c}\overline{-} \\
0.390 \\
\overline{3} \\
.380 \\
\overline{3} \\
.385\end{array}$ & $\begin{array}{l}\overline{11.2} \\
\overline{10} \\
\overline{10} \\
10.9\end{array}$ & $\begin{array}{c}\overline{-} \\
0 . \overline{3} 70 \\
\overline{3} 70 \\
\overline{3} \\
.365\end{array}$ & $\begin{array}{l}\overline{10.2} \\
\overline{10} \\
\overline{10} \\
10.0\end{array}$ & $\begin{array}{c}\overline{-} \\
0.360 \\
\overline{3} \\
.360 \\
\overline{3} 60\end{array}$ & $\begin{array}{l}\overline{9} .84 \\
\overline{9} .84 \\
\overline{9} .84\end{array}$ & $\begin{array}{c}\overline{-} \\
0.345 \\
\overline{3} \\
.345 \\
\overline{3} 45\end{array}$ & $\begin{array}{l}\overline{9} .23 \\
\overline{9} .23 \\
\overline{9} .23\end{array}$ & $\begin{array}{c}\bar{z} \\
0 . \overline{340} \\
\overline{3} 40 \\
\overline{3} 40\end{array}$ & $\begin{array}{l}\overline{9} .03 \\
\overline{9} .03 \\
\overline{9} .03\end{array}$ \\
\hline $\begin{array}{r}2 \\
4 \\
6 \\
8 \\
10 \\
\mathrm{M}\end{array}$ & $\begin{array}{l}. \overline{430} \\
\overline{415} \\
. \overline{400} \\
.\end{array}$ & $\begin{array}{l}\overline{13} .1 \\
\overline{12} .4 \\
\overline{11} .6\end{array}$ & $\begin{array}{c}. \\
.380 \\
- \\
.380 \\
- \\
.370 \\
\end{array}$ & $\begin{array}{l}\overline{10.7} \\
\overline{10} \\
\overline{10} \\
10.2\end{array}$ & $\begin{array}{l}. \overline{3} 65 \\
\overline{3} 65 \\
- \\
.365\end{array}$ & $\begin{array}{l}\overline{10.0} \\
\overline{10} \\
\overline{10} \\
10.0\end{array}$ & $\begin{array}{l}. \\
.360 \\
\overline{3} \\
.350 \\
\overline{3} \\
.350\end{array}$ & $\begin{array}{l}\overline{9} .84 \\
\overline{9} .43 \\
\overline{9} .43\end{array}$ & $\begin{array}{l}\overline{3} \\
.345 \\
\overline{3} 45 \\
\overline{3} \\
.30 \\
\end{array}$ & $\begin{array}{l}\overrightarrow{9} .23 \\
\overline{9} .23 \\
\overline{9} .03\end{array}$ & $\begin{array}{c}. \\
.340 \\
\overline{3} \\
. \\
\overline{3} 35 \\
.\end{array}$ & $\begin{array}{l}\overline{9} .03 \\
\overline{8} .83 \\
\overline{8} .63\end{array}$ \\
\hline
\end{tabular}

Supplemental records.- Sept. 18, 7:55 p.m., 0.315 ft., 8.33 sec.-ft. Sept. 19, $2: 45$ p.m., 0.76 ft., 33.2 sec.-ft. Sept. $21,4: 45$ p.m., 1.38 ft., 86 sec.-ft. 
Location.- Water-stage recorder and concrete V-notch control, lat. $40^{\circ} 41^{\prime} 20^{\prime \prime}, 10 n g$. 73'27'20", 350 feet west of Lake Shore Drive at Garfield Street, Massapequa,

Nassau County, and 3,000 feet above Clark Avenue bridge and head of Massapequa

Pond of the Brooklyn water-supply system. Zero of gage is 19.314 feet above

mean sea level (general adjustment of 1912).

Drainage area.- About 37 square miles.

Gage-height record. - Water-stage recorder graph.

Stage-discharge relation.- Defined by current-meter measurements below 87 second-feet. Maxima.- September 1938: Discharge, 90 second-feet $3: 20$ p.m. Sept. 21 (gege he1ght, 1.37 feet).

December 1936 to August 1938: Discharge, 64 second-feet Nov. 28, 1937 (gage he1ght, 1.18 feet).

Remarks.- Records good. Flood run-off probably affected by natural storage in swampy, flat areas and sandy soll.

Mean dally discharge, in second-feet, 1938

\begin{tabular}{|c|r|r||r|r|r|r|r|r||r|r|r|}
\hline Day & Sept. & \multicolumn{1}{|c|}{ Oct. } & Day & Sept. & Oct. & Day & Sept. & Oct. & Day & Sept. & Oct. \\
\hline 1 & 10.8 & 23.2 & 9 & 8.8 & 18.0 & 17 & 10.4 & 15.2 & 25 & 27.5 & 16.4 \\
2 & 10.4 & 21.0 & 10 & 8.6 & 17.4 & 18 & 11.2 & 14.8 & 26 & 25.5 & 15.2 \\
3 & 10.0 & 20.2 & 11 & 8.8 & 16.8 & 19 & 13.6 & 14.6 & 27 & 24.8 & 14.8 \\
4 & 9.9 & 19.6 & 12 & 8.8 & 16.4 & 20 & 29.5 & 14.6 & 28 & 24.8 & 14.4 \\
5 & 9.7 & 19.4 & 13 & 9.2 & 16.2 & 21 & 69 & 15.0 & 29 & 23.2 & 14.4 \\
6 & 9.2 & 20.2 & 14 & 8.8 & 16.0 & 22 & 48 & 14.2 & 30 & 24.0 & 14.0 \\
7 & 9.2 & 20.2 & 15 & 9.9 & 15.6 & 23 & 36.5 & 14.0 & 31 & \\
8 & 9.0 & 18.8 & 16 & 9.2 & 15.4 & 24 & 31 & 17.0 & & \\
\hline
\end{tabular}

Gage helght, in feet, and discharge, in second-feet, at indicated time, 1938

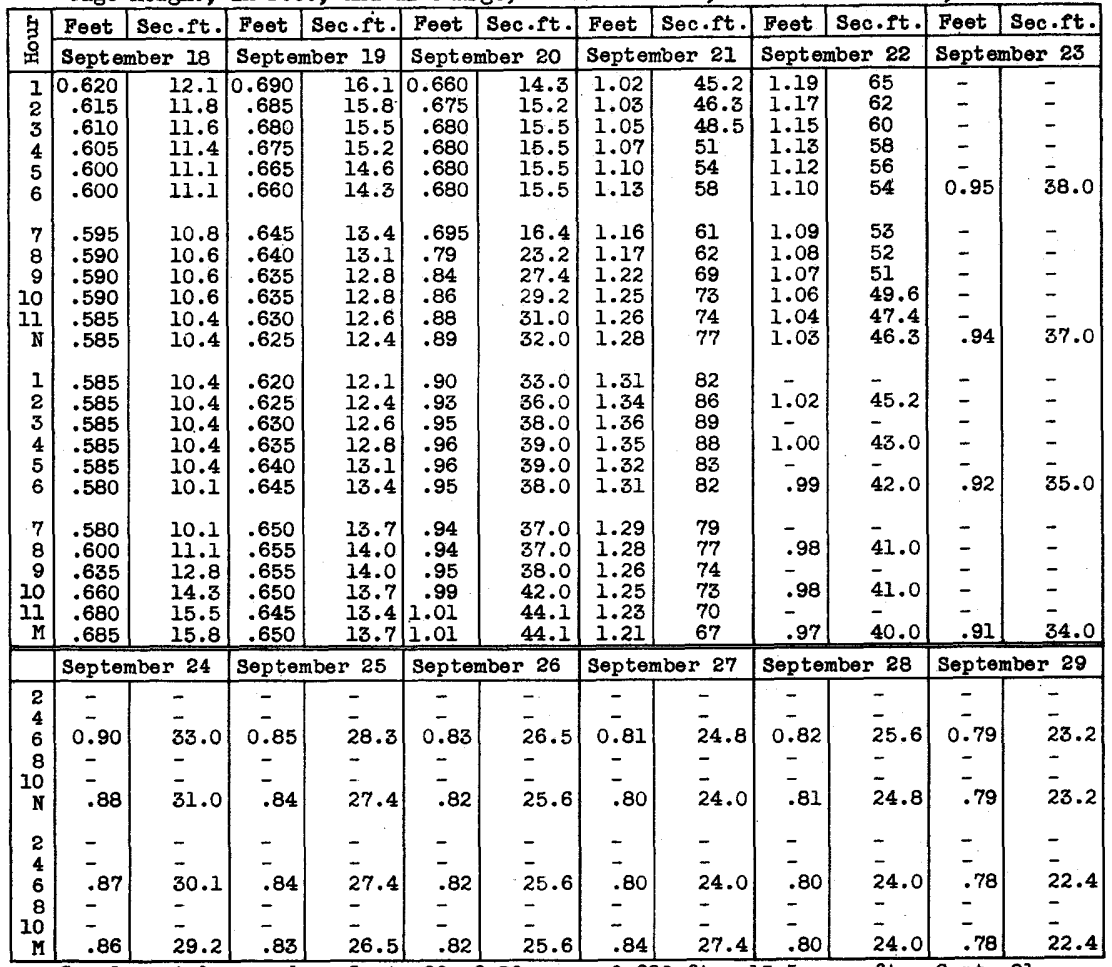

Supplemental records.- Sept. $20,6: 30 \mathrm{a.m.,} 0.680 \mathrm{ft.,} 15.5 \mathrm{sec} .-\mathrm{ft}$. Sept. 21

$3: 20 \mathrm{p.m.,} 1.37 \mathrm{ft} ., 90 \mathrm{sec} .-\mathrm{ft}$. 
Location. - Water-stage recorder and concrete V-notch control, lat. $40^{\circ} 40^{1} 40^{\prime \prime}$, long. $73^{\circ} 30^{i} 45^{n}$, on right bank, just above Reservoir No. 2 of Brooklyn water supply at

Wantagh, N. Y., and half a mile north of Sunrise Highway, on Wantagh Spur of Jones Beach Parkway, on northwest edge of village of Wantagh, Nassau County.

Dreinage area.- About 17 square miles.

Gage-helght record. - Water-stage recorder graph.

Stage-discharge relation.- Defined by current-meter measurements below 58 second-feet. Maxima.- September 1938: Discharge, 74 second-feet 9:20 a.m. Sept. 2l (gage height, 1.29 feet).

September 1937 to August 1938: Discharge, 55 second-feet Nov. 28, 1937 (gage height, 1.15 feet).

Remarks.- Records good. Flood run-off probably affected by natural storage in swampy, flat areas and sandy soil.

Mean daily drscharge, in second-feet, 1938

\begin{tabular}{|c|c|c|c|c|c|c|c|c|c|c|c|}
\hline Day & Sept. & oct. & Day & Sept. & oct. & Day & Sept. & Oct. & Day & Sept. & Oct. \\
\hline $\begin{array}{l}1 \\
2 \\
3 \\
4 \\
5 \\
6 \\
7 \\
8\end{array}$ & $\begin{array}{l}6.5 \\
6.2 \\
6.3 \\
6.2 \\
6.0 \\
5.7 \\
5.7 \\
5.6\end{array}$ & $\begin{array}{l}13.0 \\
11.2 \\
10.8 \\
10.6 \\
10.0 \\
11.2 \\
11.8 \\
10.6\end{array}$ & $\begin{array}{r}9 \\
10 \\
11 \\
12 \\
13 \\
14 \\
15 \\
16\end{array}$ & $\begin{array}{l}5.6 \\
5.4 \\
5.4 \\
5.5 \\
5.8 \\
5.7 \\
7.1 \\
6.7\end{array}$ & $\begin{array}{l}9.9 \\
9.5 \\
9.2 \\
9.2 \\
9.2 \\
9.6 \\
9.0 \\
8.6\end{array}$ & $\begin{array}{l}17 \\
18 \\
19 \\
20 \\
21 \\
22 \\
23 \\
24\end{array}$ & $\begin{array}{r}7.0 \\
8.5 \\
11.6 \\
25.0 \\
49.5 \\
27.5 \\
20.2 \\
17.0\end{array}$ & $\begin{array}{l}8.4 \\
8.4 \\
8.6 \\
8.7 \\
9.6 \\
8.6 \\
8.4 \\
9.8\end{array}$ & $\begin{array}{l}25 \\
26 \\
27 \\
28 \\
29 \\
30 \\
31\end{array}$ & $\begin{array}{l}15.0 \\
14.0 \\
13.6 \\
13.2 \\
12.4 \\
13.6\end{array}$ & $\begin{array}{l}9.7 \\
8.6 \\
8.4 \\
8.4 \\
8.0 \\
7.8 \\
7.6\end{array}$ \\
\hline $\begin{array}{l}\text { Mean } \\
\text { Run=c }\end{array}$ & $\begin{array}{l}\text { onthly } \\
f, \text { in } 1\end{array}$ & scharg & in & . . & et. . & . & 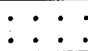 & $\begin{array}{ll}\cdot & \bullet \\
. & \bullet\end{array}$ & $\dot{0}:$ & 11.45 & $\begin{array}{l}9.43 \\
-\end{array}$ \\
\hline
\end{tabular}

Gage height, in feet, and discharge, in second-feet, at indicated time, 1938

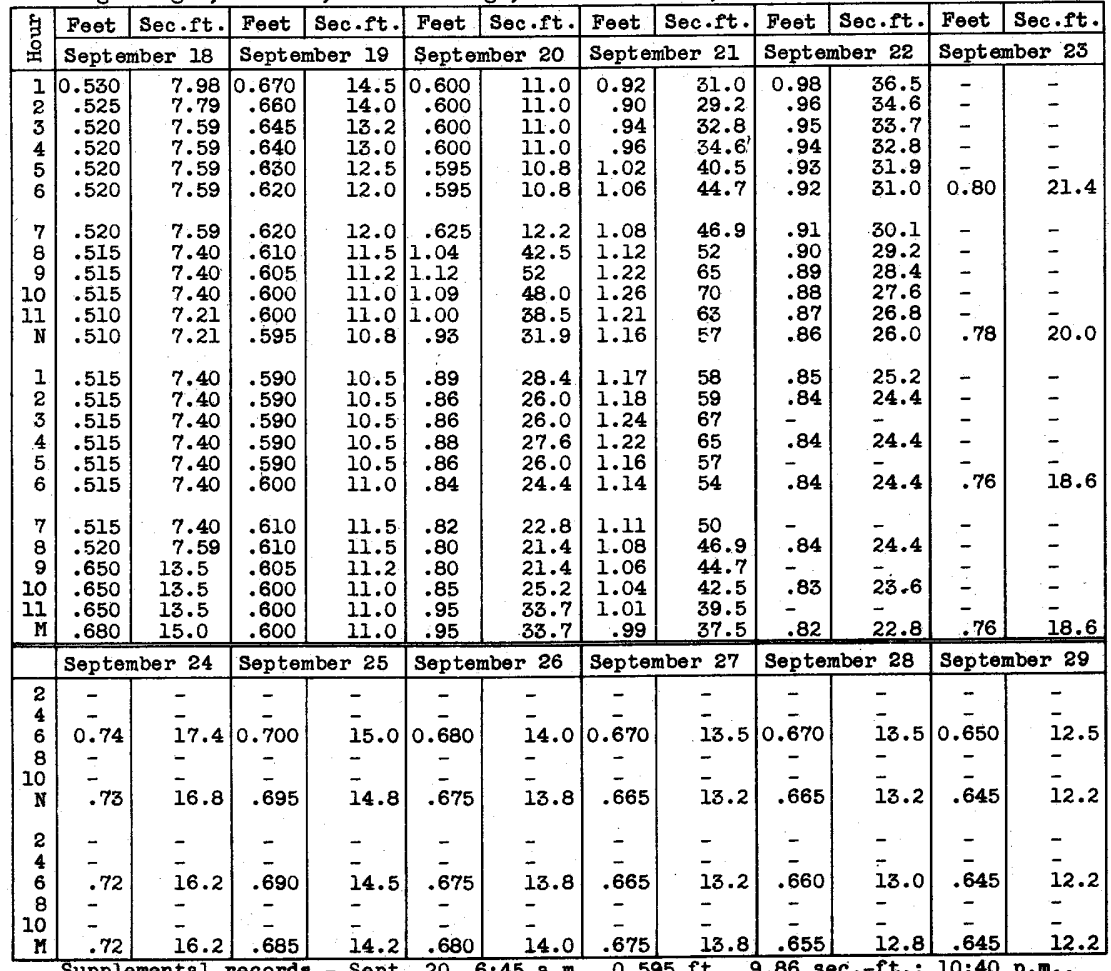

Supplemental records.- Sept. 20, 6:45 a.m., 0.595 ft., 9.86 sec.-ft.; 10:40 p.m., $0.79 \mathrm{ft} ., 20.7$ sec.-ft. Sept. $21,8: 30$ a.m., $1.10 \mathrm{ft.}, 49.2$ sec.-ft.; 9:20 a.m., $1.29 \mathrm{ft} ., 74 \mathrm{sec} . \mathrm{ft}$. 
East Meadow Brook at Freeport, N. Y.

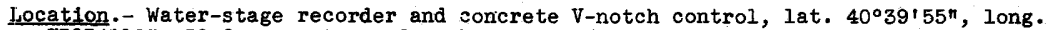
$73^{\circ} 34^{\prime} 10^{\prime \prime}, 50$ feet upstream from bridge on Hempstead-Babylon Turnplke, on north boundary of village of Freeport, Nassau County, and 300 feet west of East Meadow Brook Parkway. Zero of gage is 10.922 feet above mean sea level (general adjustment of 1912).

Drainage area.- About 31 square miles.

Gage-helght record. - Water-stage recorder graph.

Stage-discharge relation.- Defined by current-meter measurements below 140 secondfeet.

Maxima.- September 1938: Discharge, 149 second-feet 3 p.m. Sept. 21 (gage height, 1.76 feet).

January 1937 to August 1938: Discharge, 92 second-feet July 20, 1938 (gage height, 1.13 feet).

Remarks.- Records good. Flood run-off probebly affected by natural storage in swampy, flat areas and sandy soll.

Mean daily discharge, in second-feet, 1938

\begin{tabular}{|c|c|c||r|r|r||r|r|r|r|r|r|}
\hline Day & Sept. & Oct. & Day & Sept. & Oct. & Day & Sept. & Oct. & Day & Sept. & Oct. \\
\hline 1 & 16.4 & 31 & 9 & 13.6 & 23.8 & 17 & 15.4 & 20.4 & 25 & 33.5 & 24.2 \\
2 & 15.4 & 28 & 10 & 13.6 & 23.8 & 18 & 19.6 & 20.4 & 26 & 32.5 & 21.4 \\
3 & 14.6 & 27.5 & 11 & 13.6 & 22.8 & 19 & 51 & 20.0 & 27 & 31.5 & 20.8 \\
4 & 14.4 & 27 & 12 & 13.6 & 22.8 & 20 & 57 & 20.4 & 28 & 31.5 & 20.0 \\
5 & 14.0 & 26.5 & 13 & 14.0 & 22.2 & 21 & 121 & 23.8 & 29 & 29.5 & 19.0 \\
6 & 14.0 & 28 & 14 & 14.0 & 21.4 & 22 & 63 & 20.4 & 30 & 31 & 18.6 \\
7 & 14.2 & 30.5 & 15 & 18.6 & 21.0 & 23 & 40 & 20.4 & 31 & & 18.6 \\
8 & 14.0 & 26.5 & 16 & 16.4 & 20.4 & 24 & 36 & 23.6 & & & \\
\hline
\end{tabular}

Gage height, in feet, and discharge, in second-feet, at indicated time, 1938

\begin{tabular}{|c|c|c|c|c|c|c|c|c|c|c|c|c|}
\hline \multirow{2}{*}{$\begin{array}{l}\text { 先 } \\
\text { 胥 } \\
\end{array}$} & Feot & Sec.ft. & Feet & Sec.ft. & Foet & Sec.ft. & Feet & Sec.ft. & Beet & Sec.te. & Feet & Sec.ft. \\
\hline & \multicolumn{2}{|c|}{ September 18} & \multicolumn{2}{|c|}{ September 19} & \multicolumn{2}{|c|}{ September 20} & \multicolumn{2}{|c|}{ September 21} & \multicolumn{2}{|c|}{ September 22} & \multicolumn{2}{|c|}{ September 23} \\
\hline $\begin{array}{l}1 \\
2 \\
3 \\
4 \\
5 \\
6\end{array}$ & $\begin{array}{l}0.480 \\
.475 \\
.475 \\
.470 \\
.470 \\
.470\end{array}$ & $\begin{array}{l}17.1 \\
16.8 \\
16.8 \\
16.4 \\
16.4 \\
16.4\end{array}$ & $\begin{array}{r}0.81 \\
.80 \\
.81 \\
.83 \\
.90 \\
.96\end{array}$ & $\begin{array}{l}52 \\
51 \\
52 \\
54 \\
64 \\
71\end{array}$ & $\begin{array}{r}0.66 \\
.68 \\
.68 \\
.68 \\
.67 \\
.66\end{array}$ & $\begin{array}{l}34.2 \\
36.4 \\
36.4 \\
36.4 \\
35.3 \\
34.2\end{array}$ & $\begin{array}{l}1.03 \\
1.01 \\
1.02 \\
1.06 \\
1.15 \\
1.23\end{array}$ & $\begin{array}{r}80 \\
78 \\
79 \\
84 \\
94 \\
103\end{array}$ & $\begin{array}{r}1.25 \\
1.17 \\
1.11 \\
1.05 \\
1.00 \\
.96\end{array}$ & $\begin{array}{r}105 \\
96 \\
90 \\
82 \\
76 \\
72\end{array}$ & $\begin{array}{c}- \\
- \\
- \\
- \\
- \\
0.71\end{array}$ & $\begin{array}{l}\overline{-} \\
\overline{-} \\
\overline{4} \\
\overline{41.7}\end{array}$ \\
\hline $\begin{array}{r}7 \\
8 \\
9 \\
10 \\
11 \\
\mathrm{~N}\end{array}$ & $\begin{array}{l}.465 \\
.465 \\
.465 \\
.460 \\
.460 \\
.460\end{array}$ & $\begin{array}{l}16.0 \\
16.0 \\
16.0 \\
15.7 \\
15.7 \\
15.7\end{array}$ & $\begin{array}{r}1.02 \\
1.01 \\
.97 \\
.91 \\
.86 \\
.82\end{array}$ & $\begin{array}{l}79 \\
78 \\
73 \\
65 \\
58 \\
53\end{array}$ & $\begin{array}{l}.69 \\
.85 \\
.92 \\
.94 \\
.91 \\
.89\end{array}$ & $\begin{array}{l}37.6 \\
57 \\
66 \\
69 \\
65 \\
62\end{array}$ & $\begin{array}{l}1.34 \\
1.44 \\
1.55 \\
1.64 \\
1.66 \\
1.62\end{array}$ & $\begin{array}{l}114 \\
123 \\
132 \\
140 \\
141 \\
138\end{array}$ & $\begin{array}{l}.93 \\
.90 \\
.88 \\
.86 \\
.84 \\
.82\end{array}$ & $\begin{array}{l}68 \\
64 \\
62 \\
60 \\
57 \\
55\end{array}$ & $\begin{array}{l}\overline{-} \\
\overline{-} \\
- \\
- \\
.70\end{array}$ & $\begin{array}{l}\bar{z} \\
\overline{-} \\
\overline{40.5}\end{array}$ \\
\hline $\begin{array}{l}1 \\
2 \\
3 \\
4 \\
5 \\
6\end{array}$ & $\begin{array}{l}.460 \\
.460 \\
.460 \\
.460 \\
.460 \\
.460\end{array}$ & $\begin{array}{l}15.7 \\
15.7 \\
15.7 \\
15.7 \\
15.7 \\
15.7\end{array}$ & $\begin{array}{l}.78 \\
.76 \\
.74 \\
.72 \\
.71 \\
.70\end{array}$ & $\begin{array}{l}48.4 \\
46.0 \\
43.6 \\
41.2 \\
40.0 \\
38.8\end{array}$ & $\begin{array}{l}.88 \\
.86 \\
.86 \\
.88 \\
.91 \\
.92\end{array}$ & $\begin{array}{l}61 \\
58 \\
58 \\
61 \\
65 \\
66\end{array}$ & $\begin{array}{l}1.65 \\
1.67 \\
1.76 \\
1.69 \\
1.66 \\
1.66\end{array}$ & $\begin{array}{l}140 \\
142 \\
149 \\
144 \\
141 \\
141\end{array}$ & $\begin{array}{l}- \\
.80 \\
.78 \\
.78 \\
.77\end{array}$ & $\begin{array}{l}\overline{52} \\
\overline{50} \\
\overline{48.9}\end{array}$ & $\begin{array}{l}\bar{~} \\
\overline{-} \\
\overline{-} \\
-68\end{array}$ & $\begin{array}{l}\bar{z} \\
\bar{z} \\
\overline{3} 8.3\end{array}$ \\
\hline \multirow[t]{2}{*}{\begin{tabular}{r|}
7 \\
8 \\
9 \\
10 \\
11 \\
1 \\
\end{tabular}} & $\begin{array}{l}.460 \\
.480 \\
.64 \\
.70 \\
.74 \\
.79 \\
\end{array}$ & $\begin{array}{l}15.7 \\
17.1 \\
32.0 \\
38.8 \\
43.6 \\
49.6 \\
\end{array}$ & $\begin{array}{l}.69 \\
.68 \\
.66 \\
.66 \\
.66 \\
\end{array}$ & $\begin{array}{l}37.6 \\
36.4 \\
34.2 \\
34.2 \\
34.2 \\
34.2\end{array}$ & $\begin{array}{r}.94 \\
.93 \\
.91 \\
.99 \\
1.04 \\
1.06 \\
\end{array}$ & $\begin{array}{l}69 \\
68 \\
65 \\
75 \\
81 \\
84 \\
\end{array}$ & $\begin{array}{l}1.62 \\
1.56 \\
1.48 \\
1.41 \\
1.35 \\
1.30 \\
\end{array}$ & $\begin{array}{l}138 \\
133 \\
127 \\
120 \\
115 \\
110 \\
\end{array}$ & $\begin{array}{l}- \\
.76 \\
.75 \\
.74 \\
\end{array}$ & $\begin{array}{l}\overline{47.7} \\
\overline{46.5} \\
\overline{45.3}\end{array}$ & $\begin{array}{l}- \\
- \\
- \\
- \\
.67 \\
\end{array}$ & $\begin{array}{l}- \\
- \\
- \\
\overline{3} 7.2\end{array}$ \\
\hline & \multicolumn{2}{|c|}{ September 24} & \multicolumn{2}{|c|}{ September 25} & \multicolumn{2}{|c|}{ September 26} & \multicolumn{2}{|c|}{ September 27} & \multicolumn{2}{|c|}{ September 28} & \multicolumn{2}{|c|}{ September 29} \\
\hline 2 & - & - & - & - & - & - & - & - & - & - & - & - \\
\hline 4 & & & & $\bar{z}$ & - & - & & & - & - & - & \\
\hline 6 & 0.66 & 36.1 & 0.64 & 33.9 & 0.63 & 32.8 & 0.62 & 31.7 & 0.63 & 32.8 & 0.61 & 30.6 \\
\hline & - & - & - & - & - & - & - & - & - & - & - & - \\
\hline $\begin{array}{r}10 \\
\text { N }\end{array}$ & .66 & $\overline{36.1}$ & .64 & $\overline{3} 3.9$ & .63 & $\overline{32.8}$ & .62 & $\overline{31.7}$ & .62 & $\overline{3} 1.7$ & .60 & $\overline{29.6}$ \\
\hline 2 & - & - & - & - & - & - & - & - & - & - & - & - \\
\hline 4 & & & & & & & & & - & & & \\
\hline 6 & .65 & 3.0 & .63 & 32.8 & .62 & 31.7 & .62 & 31.7 & .61 & 30.6 & .60 & 29.6 \\
\hline & - & & & & & & & & & & - & \\
\hline $\mathrm{M}$ & .64 & 33.9 & .63 & 32.8 & .62 & 31.7 & .63 & 32.8 & .61 & 30.6 & .60 & 29.6 \\
\hline
\end{tabular}

Supplemental records.- Sept. 18, 7:30 p.m., $0.46 \mathrm{ft.}, 15.7$ sec.-ft.; 8:30 p.m., 0.63 ft., 30.9 sec.-ft.; 11:30 p.m., 0.79 ft., 49.6 sec.-ft. Sept. 19, 7:30 a.m., $1.03 \mathrm{ft}$., 80 sec.-ft. Sept. $20,8: 30$ p.m., $0.94 \mathrm{ft} ., 69$ sec.-ft. Sept. 21,3 p.m., $1.76 \mathrm{ft}$., 149 sec.-ft.; 4:30 p.m., 1.66 ft., i 41 sec.-ft. 
Pines Brook at Malverne, N. Y.

Location. - Water-stage recorder and concrete V-notch control, lat. $40^{\circ} 40^{\prime} 0^{\prime \prime}$, long. $73^{\circ} 39^{\prime} 30^{n}, 100$ feet below Lakeview Avenue Bridge and south line of village of Malverne, Nassau County, and 150 feet below outlet of Pines Pond. Zero of gage is 9.424 feet above mean sea level (general adjustment of 1912).

Drainage area.- About 10 square miles.

Gage-helght record. - Water-stage recorder graph.

Stage-discharge relation.- Defined by current-meter measurements below 39.4 secondfeet.

Maxima.- September 1938: Discharge, 74 second-feet 4:50 p.m. Sept. 21 (gage helght, 2.06 feet).

December 1936 to August 1938: Discharge, 36.7 second-feet July 24, 1938 (gage height, 1.78 feet).

Remarks.- Records good. Flood run-off probably affected by natural storage in swampy flat areas and sandy soll. Flow regulated by storage in Pines Pond.

Mean daily discharge, In second-feet, 1938

\begin{tabular}{|c|r|r||r|r|r||r|r|r|r|r|r|}
\hline Day & Sept. & \multicolumn{1}{|c|}{ Oct. } & Day & Sept. & Oct. & Day & \multicolumn{1}{|c|}{ Sept. } & 0ct. & Day & Sept. & \multicolumn{1}{c|}{ Oct. } \\
\hline 1 & 6.4 & 13.6 & 9 & 6.0 & 10.8 & 17 & 6.2 & 10.0 & 25 & 13.4 & 10.2 \\
2 & 6.4 & 13.2 & 10 & 5.9 & 10.6 & 18 & 7.1 & 9.8 & 26 & 13.2 & 9.4 \\
3 & 6.4 & 12.8 & 11 & 5.9 & 10.6 & 19 & 24.2 & 9.6 & 27 & 13.2 & 9.2 \\
4 & 6.4 & 12.4 & 12 & 5.9 & 10.6 & 20 & 19.4 & 9.9 & 28 & 13.2 & 9.1 \\
5 & 6.4 & 12.0 & 13 & 5.9 & 10.4 & 21 & 48.5 & 11.4 & 29 & 12.8 & 8.8 \\
6 & 6.3 & 13.0 & 14 & 5.8 & 11.6 & 22 & 25 & 9.7 & 30 & 13.8 & 8.6 \\
7 & 6.3 & 13.2 & 15 & 6.2 & 10.0 & 23 & 14.8 & 9.4 & 31 & & 8.4 \\
8 & 6.2 & 11.2 & 16 & 6.3 & 10.0 & 24 & 14.0 & 10.2 & & & \\
\hline
\end{tabular}

Gage height, in feet, and discharge, in second-feet, at indicated time, 1938

\begin{tabular}{|c|c|c|c|c|c|c|c|c|c|c|c|c|}
\hline \multirow{2}{*}{$\begin{array}{l}6 \\
\text { 营 } \\
\text { 总 }\end{array}$} & Feet & Sec.ft. & Feet & Sec.ft. & Feet & Sec.ft. & Feet & Sec.ft. & Feet & Sec.It. & Feet & Sec.ft. \\
\hline & \multicolumn{2}{|c|}{ September 18} & \multicolumn{2}{|c|}{ September 19} & \multicolumn{2}{|c|}{ September 20} & \multicolumn{2}{|c|}{ September 21} & \multicolumn{2}{|c|}{ September 22} & \multicolumn{2}{|c|}{ September 23} \\
\hline $\begin{array}{l} \\
2 \\
3 \\
4 \\
5 \\
6\end{array}$ & $\begin{array}{l}1.210 \\
1.210 \\
1.210 \\
1.210 \\
1.210 \\
1.210\end{array}$ & $\begin{array}{l}6.20 \\
6.20 \\
6.20 \\
6.20 \\
6.20 \\
6.20\end{array}$ & $\begin{array}{l}1.43 \\
1.51 \\
1.58 \\
1.63 \\
1.69 \\
1.74\end{array}$ & $\begin{array}{l}12.8 \\
16.5 \\
20.3 \\
23.6 \\
28.2 \\
32.7\end{array}$ & $\begin{array}{l}1.53 \\
1.54 \\
1.55 \\
1.54 \\
1.52 \\
1.50\end{array}$ & \begin{tabular}{|l|}
17.5 \\
18.0 \\
18.5 \\
18.0 \\
17.0 \\
16.0
\end{tabular} & $\begin{array}{l}1.64 \\
1.65 \\
1.65 \\
1.70 \\
1.72 \\
1.74\end{array}$ & $\begin{array}{l}24.3 \\
25.0 \\
25.0 \\
29.1 \\
30.9 \\
32.7\end{array}$ & $\begin{array}{l}1.91 \\
1.88 \\
1.85 \\
1.81 \\
1.76 \\
1.72\end{array}$ & $\begin{array}{l}51 \\
48.1 \\
44.5 \\
39.9 \\
34.7 \\
30.9\end{array}$ & $\begin{array}{c}- \\
- \\
- \\
- \\
- \\
1.48\end{array}$ & $\begin{array}{l}\overline{-} \\
\overline{-} \\
- \\
\overline{15} .0\end{array}$ \\
\hline $\begin{array}{r}7 \\
8 \\
9 \\
10 \\
11 \\
\frac{1}{11}\end{array}$ & $\begin{array}{l}1.210 \\
1.210 \\
1.210 \\
1.210 \\
1.210 \\
1.210\end{array}$ & $\begin{array}{l}6.20 \\
6.20 \\
6.20 \\
6.20 \\
6.20 \\
6.20\end{array}$ & $\begin{array}{l}1.78 \\
1.79 \\
1.78 \\
1.76 \\
1.72 \\
1.67\end{array}$ & $\begin{array}{l}36.7 \\
37.7 \\
36.7 \\
34.7 \\
30.9 \\
26.6\end{array}$ & $\begin{array}{l}1.52 \\
1.55 \\
1.55 \\
1.54 \\
1.54 \\
1.54\end{array}$ & $\begin{array}{l}17.0 \\
18.5 \\
18.5 \\
18.0 \\
18.0 \\
18.0\end{array}$ & $\begin{array}{l}1.78 \\
1.80 \\
1.81 \\
1.90 \\
1.86 \\
1.87\end{array}$ & $\begin{array}{l}36.7 \\
38.8 \\
39.9 \\
50 \\
45.7 \\
46.7\end{array}$ & $\begin{array}{l}1.69 \\
1.66 \\
1.63 \\
1.60 \\
1.58 \\
1.56\end{array}$ & $\begin{array}{l}28.2 \\
25.8 \\
23.6 \\
21.5 \\
20.3 \\
19.1\end{array}$ & $\begin{array}{l}\bar{z} \\
\bar{z} \\
\bar{z} \\
\overline{1.48}\end{array}$ & $\begin{array}{l}\overline{-} \\
- \\
- \\
\overline{15.0}\end{array}$ \\
\hline $\begin{array}{l}1 \\
2 \\
3 \\
4 \\
5 \\
6\end{array}$ & $\begin{array}{l}1.210 \\
1.210 \\
1.210 \\
1.210 \\
1.210 \\
1.210\end{array}$ & $\begin{array}{l}6.20 \\
6.20 \\
6.20 \\
6.20 \\
6.20 \\
6.20\end{array}$ & $\begin{array}{l}1.62 \\
1.59 \\
1.65 \\
1.61 \\
1.61 \\
1.60\end{array}$ & $\begin{array}{l}22.9 \\
20.9 \\
25.0 \\
22.2 \\
22.2 \\
21.5\end{array}$ & $\begin{array}{l}1.54 \\
1.53 \\
1.54 \\
1.54 \\
1.56 \\
1.58\end{array}$ & $\begin{array}{l}18.0 \\
17.5 \\
18.0 \\
18.0 \\
19.1 \\
20.3\end{array}$ & $\begin{array}{l}1.94 \\
1.96 \\
1.99 \\
2.02 \\
2.04 \\
2.02\end{array}$ & $\begin{array}{l}56 \\
59 \\
63 \\
67 \\
70 \\
67\end{array}$ & $\begin{array}{c}- \\
1.54 \\
- \\
1.52 \\
- \\
1.51\end{array}$ & $\begin{array}{l}\overline{18.0} \\
\overline{17} \\
\overline{17} .0 \\
16.5\end{array}$ & $\begin{array}{c}\bar{z} \\
\bar{z} \\
\bar{z} \\
1.47\end{array}$ & $\begin{array}{l}\bar{z} \\
\bar{z} \\
\overline{14} .6\end{array}$ \\
\hline $\begin{array}{r}7 \\
8 \\
9 \\
10 \\
11 \\
M\end{array}$ & $\begin{array}{l}1.220 \\
1.260 \\
1.59 \\
1.270 \\
1.260 \\
1.300\end{array}$ & $\begin{array}{c}6.40 \\
7.26 \\
20.9 \\
7.49 \\
7.26 \\
8.24 \\
\end{array}$ & $\begin{array}{l}1.56 \\
1.54 \\
1.52 \\
1.52 \\
1.52 \\
1.53\end{array}$ & $\begin{array}{l}19.1 \\
18.0 \\
17.0 \\
17.0 \\
17.0 \\
17.5\end{array}$ & $\begin{array}{l}1.63 \\
1.60 \\
1.61 \\
1.67 \\
1.64 \\
1.63\end{array}$ & $\begin{array}{l}23.6 \\
21.5 \\
22.2 \\
26.6 \\
24.3 \\
23.6\end{array}$ & $\begin{array}{l}2.00 \\
1.98 \\
1.96 \\
1.94 \\
1.93 \\
1.92\end{array}$ & $\begin{array}{l}64 \\
61 \\
59 \\
56 \\
55 \\
53 \\
\end{array}$ & $\begin{array}{c}- \\
1.50 \\
- \\
1.50 \\
- \\
1.49\end{array}$ & $\begin{array}{l}\overline{16} \\
\overline{16.0} \\
\overline{1} 6.0 \\
15.5\end{array}$ & $\begin{array}{l}- \\
- \\
- \\
- \\
- \\
1.46 \\
\end{array}$ & $\begin{array}{l}\overline{-} \\
\overline{-} \\
\overline{1} \\
\overline{1} \\
\end{array}$ \\
\hline & \multicolumn{2}{|c|}{ September 24} & \multicolumn{2}{|c|}{ September 25} & \multicolumn{2}{|c|}{ September 26} & \multicolumn{2}{|c|}{ September 27} & \multicolumn{2}{|c|}{ September 28} & \multicolumn{2}{|c|}{ September 29} \\
\hline 2 & - & - & - & - & - & - & - & - & - & - & - & - \\
\hline 4 & ר) & - & - & - & - & $-7=0$ & - & & - & $-7 x$ & - & \\
\hline $\begin{array}{l}6 \\
8\end{array}$ & 1.46 & 14.2 & 1.45 & 13.7 & 1.44 & 13.2 & 1.44 & 13.2 & 1.45 & 13.7 & 1.43 & 12.8 \\
\hline 10 & - & - & - & - & - & - & - & & & & - & \\
\hline $\mathrm{N}$ & 1.45 & 13.7 & 1.44 & 13.2 & 1.44 & 13.2 & 1.44 & 23.2 & 1.44 & 13.2 & 1.48 & 12.8 \\
\hline 2 & - & - & - & - & - & - & - & - & - & - & - & - \\
\hline 4 & - & - & - & - & - & - & - & - & - & - & & \\
\hline 6 & 1.46 & 14.2 & 1.44 & 13.2 & 1.44 & 13.2 & 1.44 & 13.2 & 1.44 & 13.2 & 1.43 & 12.8 \\
\hline 8 & - & - & - & & - & - & - & - & - & & - & - \\
\hline $\begin{array}{r}10 \\
M\end{array}$ & 1.45 & $\overline{13} .7$ & $\overline{1.44}$ & $\overline{13} .2$ & $\overline{1.44}$ & $\overline{13} .2$ & 1.44 & $\overline{13} .2$ & 1.43 & $\overline{12} .8$ & 1.43 & 12.8 \\
\hline
\end{tabular}

Supplemental records.- Sept. 18, 8:35 p.m., $1.65 \mathrm{ft} ., 25.0$ sec.-ft.; 9:10 p.m., $1.68 \mathrm{ft} .27 .4$ sec.-ft. Sept. $19,2: 30$ p.m., $1.77 \mathrm{ft} ., 35.7$ sec.-ft. Sept. 20 , $2: 20$ a.m., $1.59 \mathrm{ft} ., 20.9$ sec.-ft.; $9: 50$ p.m., $1.71 \mathrm{ft} ., 30.0$ sec.-ft. Sept. 21 , $9: 45$ a.m., $1.98 \mathrm{ft} ., 61$ sec.-ft.; $12: 30$ p.m., $1.98 \mathrm{ft} ., 61$ sec.-ft.; $4: 50$ p.m., $2.06 \mathrm{ft} ., 74 \mathrm{sec} .-\mathrm{ft}$. 
Location.- Water-stage recorder, lat. $43^{\circ} 58^{\prime}$ 100 n, long. $74^{\circ} 07^{\prime} 55^{\prime \prime}$, Just above highway bridge, half a mile below outlet of Harris Lake, and 2 miles east of Newcomb, Essex County. Prior to Aug. 5, 1931, staff gage 125 feet downstream (present datum but different control).

Drainage area.- 192 square miles.

Gage-height record.- Water-stage recorder graph.

Stage-discharge relation.- Defined by current-meter measurements below 5,840 secondfeet; extended logarithmically to peak stage of March 1936 flood.

Maxima.- September 1938: Discharge, 4,970 second-feet $11 \mathrm{p.m}$. Sept. 22 (gage height, 8.98 feet).

August 1931 to August 1938: Discharge, 5,760 second-feet Mar. 20, 1936 (gage height, 9.69 feet).

September 1925 to July 1931: Discharge, 6,250 second-feet Apr. 9, 1928 (gage helght, 8.0 feet, former site and present datum) from rating defined by current-

meter measurements below 4,680 second-feet; extended logarithmically to peak stage.

Remarks.- Slight regulation by small storage reservoirs.

Mean dally discharge, in second-feet, 1938

\begin{tabular}{|c|r|r||r|r|r||r|r|r||r|r|r|}
\hline Dey & Sept. & 0ct. & Day & Sept. & Oct. & Day & Sept. & Oct. & Day & Sept. & Oct. \\
\hline 1 & 161 & 448 & 9 & 139 & 190 & 17 & 644 & 131 & 25 & 1,870 & 310 \\
2 & 143 & 390 & 10 & 125 & 178 & 18 & 555 & 127 & 26 & 1,280 & 364 \\
3 & 123 & 339 & 11 & 113 & 166 & 19 & 492 & 122 & 27 & 936 & 309 \\
4 & 113 & 299 & 12 & 105 & 159 & 20 & 539 & 120 & 28 & 769 & 271 \\
5 & 102 & 271 & 13 & 221 & 152 & 21 & 1,600 & 123 & 29 & 637 & 240 \\
6 & 92 & 246 & 14 & 386 & 145 & 22 & 4,000 & 125 & 30 & 528 & 215 \\
7 & 92 & 220 & 15 & 482 & 141 & 23 & 4,260 & 122 & 31 & & 193 \\
8 & 133 & 201 & 16 & 692 & 137 & 24 & 2,810 & 140 & & & \\
\hline
\end{tabular}

Gage helght, in feet, and discharge, in second-feet, at indicated time, 1938

\begin{tabular}{|c|c|c|c|c|c|c|c|c|c|c|c|c|}
\hline \multirow{2}{*}{$\begin{array}{r}5 \\
3 \\
0 \\
0\end{array}$} & Feot & Sec.ft. & Feet & Sec.ft. & Foet & Sec.ft. & Feet & Sec.ft. & Feet & Sec.ft. & Feet & Sec.ft. \\
\hline & \multicolumn{2}{|c|}{ Sept ember 18} & \multicolumn{2}{|c|}{ September 19} & \multicolumn{2}{|c|}{ September 20} & \multicolumn{2}{|c|}{ September 21} & \multicolumn{2}{|c|}{ September 22} & \multicolumn{2}{|c|}{ September 23} \\
\hline $\begin{array}{l}1 \\
2 \\
3 \\
4 \\
5 \\
6\end{array}$ & $\begin{array}{l}3.53 \\
3.52 \\
3.51 \\
3.50 \\
3.49 \\
3.48\end{array}$ & $\begin{array}{l}594 \\
589 \\
584 \\
580 \\
576 \\
572\end{array}$ & $\begin{array}{l}3.34 \\
3.34 \\
3.33 \\
3.32 \\
3.32 \\
3.31\end{array}$ & \begin{tabular}{|l|}
516 \\
516 \\
512 \\
508 \\
508 \\
504
\end{tabular} & $\begin{array}{l}3.24 \\
3.24 \\
3.24 \\
3.24 \\
3.25 \\
3.25\end{array}$ & \begin{tabular}{|l|}
476 \\
476 \\
476 \\
476 \\
480 \\
480
\end{tabular} & $\begin{array}{l}4.00 \\
4.09 \\
4.19 \\
4.30 \\
4.40 \\
4.50\end{array}$ & $\begin{array}{r}815 \\
864 \\
924 \\
990 \\
1,050 \\
1,110\end{array}$ & $\begin{array}{l}6.75 \\
6.87 \\
7.00 \\
7.13 \\
7.24 \\
7.35\end{array}$ & $\begin{array}{l}2,780 \\
2,890 \\
3,010 \\
3,130 \\
3,230 \\
3,320\end{array}$ & $\begin{array}{l}8.95 \\
8.92 \\
8.88 \\
8.84 \\
8.79 \\
8.74\end{array}$ & $\begin{array}{l}4,940 \\
4,900 \\
4,860 \\
4,810 \\
4,760 \\
4,700\end{array}$ \\
\hline $\begin{array}{r}7 \\
8 \\
9 \\
10 \\
11 \\
\mathrm{~N}\end{array}$ & $\begin{array}{l}3.47 \\
3.47 \\
3.46 \\
3.45 \\
3.44 \\
3.43\end{array}$ & $\begin{array}{l}568 \\
568 \\
564 \\
560 \\
556 \\
552\end{array}$ & $\begin{array}{l}3.31 \\
3.30 \\
3.29 \\
3.28 \\
3.28 \\
3.27\end{array}$ & $\begin{array}{l}504 \\
500 \\
496 \\
492 \\
492 \\
488\end{array}$ & $\begin{array}{l}3.2 \\
3.2 \\
3.2 \\
3.2 \\
3.2 \\
3.3\end{array}$ & $\begin{array}{l}480 \\
484 \\
488 \\
492 \\
496 \\
504\end{array}$ & $\begin{array}{l}4.60 \\
4.70 \\
4.79 \\
4.88 \\
5.02 \\
5.12\end{array}$ & $\begin{array}{l}1,170 \\
1,240 \\
1,300 \\
1,370 \\
1,460 \\
1,530\end{array}$ & $\begin{array}{l}7.47 \\
7.58 \\
7.71 \\
7.84 \\
7.97 \\
8.11\end{array}$ & & $\begin{array}{l}8.67 \\
8.61 \\
8.54 \\
8.48 \\
8.41 \\
8.34\end{array}$ & \\
\hline $\begin{array}{l}1 \\
2 \\
3 \\
4 \\
5 \\
6\end{array}$ & $\begin{array}{l}3.42 \\
3.42 \\
3.41 \\
3.40 \\
3.39 \\
3.39\end{array}$ & $\begin{array}{l}548 \\
548 \\
544 \\
540 \\
536 \\
536\end{array}$ & $\begin{array}{l}3.27 \\
3.26 \\
3.26 \\
3.25 \\
3.25 \\
3.25\end{array}$ & $\begin{array}{l}488 \\
484 \\
484 \\
480 \\
480 \\
480\end{array}$ & $\begin{array}{l}3.33 \\
3.35 \\
3.37 \\
3.40 \\
3.44 \\
3.48\end{array}$ & $\begin{array}{l}512 \\
520 \\
528 \\
540 \\
556 \\
572\end{array}$ & $\begin{array}{l}5.24 \\
5.34 \\
5.46 \\
5.57 \\
5.70 \\
5.82\end{array}$ & $\begin{array}{l}1,620 \\
1,690 \\
1,770 \\
1,850 \\
1,940 \\
2,040\end{array}$ & $\begin{array}{l}8.24 \\
8.37 \\
8.48 \\
8.59 \\
8.69 \\
8.78\end{array}$ & & $\begin{array}{l}8.26 \\
8.18 \\
8.12 \\
8.04 \\
7.97 \\
7.90\end{array}$ & $\begin{array}{l}4,210 \\
4,130 \\
4,070 \\
3,990 \\
3,920 \\
3,850\end{array}$ \\
\hline \multirow[t]{2}{*}{$\begin{array}{r}7 \\
8 \\
9 \\
10 \\
11 \\
M \\
\end{array}$} & $\begin{array}{l}3.38 \\
3.38 \\
3.37 \\
3.36 \\
3.35 \\
3.35 \\
\end{array}$ & $\begin{array}{l}532 \\
532 \\
528 \\
524 \\
520 \\
520 \\
\end{array}$ & $\begin{array}{l}3.24 \\
3.24 \\
3.24 \\
3.24 \\
3.24 \\
3.24 \\
\end{array}$ & $\begin{array}{l}476 \\
476 \\
476 \\
476 \\
476 \\
476 \\
\end{array}$ & $\begin{array}{l}3.54 \\
3.59 \\
3.65 \\
3.73 \\
3.82 \\
3.90 \\
\end{array}$ & $\begin{array}{l}598 \\
620 \\
648 \\
684 \\
725 \\
765 \\
\end{array}$ & $\begin{array}{l}5.97 \\
6.12 \\
6.25 \\
6.37 \\
6.50 \\
6.62 \\
\end{array}$ & $\begin{array}{l}2,160 \\
2,280 \\
2,380 \\
2,480 \\
2,580 \\
2,680 \\
\end{array}$ & $\begin{array}{l}8.84 \\
8.89 \\
8.94 \\
8.96 \\
8.98 \\
8.96\end{array}$ & & $\begin{array}{l}7.83 \\
7.75 \\
7.68 \\
7.61 \\
7.54 \\
7.48 \\
\end{array}$ & $\begin{array}{l}3,780 \\
3,700 \\
3,630 \\
3,560 \\
3,500 \\
3,440 \\
\end{array}$ \\
\hline & \multicolumn{2}{|c|}{ September 24} & \multicolumn{2}{|c|}{ September 25} & \multicolumn{2}{|c|}{ September 26} & \multicolumn{2}{|c|}{ September 27} & \multicolumn{2}{|c|}{ September 28} & \multicolumn{2}{|c|}{ September 29} \\
\hline $\begin{array}{r}2 \\
4 \\
6 \\
8 \\
10 \\
\text { N }\end{array}$ & $\begin{array}{l}7.34 \\
7.21 \\
7.09 \\
6.97 \\
6.84 \\
6.74\end{array}$ & $\begin{array}{l}3,320 \\
3,200 \\
3,090 \\
2,980 \\
2,870 \\
2,780\end{array}$ & $\begin{array}{l}6.02 \\
5.92 \\
5.83 \\
5.75 \\
5.66 \\
5.57\end{array}$ & $\begin{array}{l}2,200 \\
2,120 \\
2,040 \\
1,980 \\
1,910 \\
1,850\end{array}$ & & $\begin{array}{l}1,480 \\
1,440 \\
1,390 \\
1,340 \\
1,310 \\
1,270\end{array}$ & $\begin{array}{l}4.38 \\
4.34 \\
4.29 \\
4.25 \\
4.20 \\
4.20\end{array}$ & $\begin{array}{r}1,040 \\
1,010 \\
984 \\
960 \\
930 \\
930\end{array}$ & & $\begin{array}{l}832 \\
815 \\
805 \\
795 \\
785 \\
770\end{array}$ & $\begin{array}{l}3.74 \\
3.72 \\
3.69 \\
3.67 \\
3.65 \\
3.62\end{array}$ & $\begin{array}{l}688 \\
679 \\
666 \\
656 \\
648 \\
634\end{array}$ \\
\hline $\begin{array}{r}2 \\
4 \\
6 \\
8 \\
10 \\
M \\
\end{array}$ & $\begin{array}{l}6.62 \\
6.52 \\
6.42 \\
6.32 \\
6.22 \\
6.12 \\
\end{array}$ & $\begin{array}{l}2,680 \\
2,600 \\
2,520 \\
2,440 \\
2,360 \\
2,280 \\
\end{array}$ & $\begin{array}{l}5.49 \\
5.41 \\
5.33 \\
5.26 \\
5.18 \\
5.12\end{array}$ & $\begin{array}{l}1,790 \\
1,740 \\
1,680 \\
1,630 \\
1,580 \\
1,530\end{array}$ & $\begin{array}{l}4.68 \\
4.63 \\
4.58 \\
4.53 \\
4.48 \\
4.43 \\
\end{array}$ & $\begin{array}{l}1,230 \\
1,190 \\
1,160 \\
1,130 \\
1,100 \\
1,070\end{array}$ & $\begin{array}{l}4.18 \\
4.15 \\
4.12 \\
4.09 \\
4.07 \\
4.05\end{array}$ & $\begin{array}{l}918 \\
900 \\
882 \\
864 \\
854 \\
842 \\
\end{array}$ & $\begin{array}{l}3.88 \\
3.86 \\
3.84 \\
3.81 \\
3.78 \\
3.76\end{array}$ & $\begin{array}{l}755 \\
745 \\
735 \\
720 \\
706 \\
697 \\
\end{array}$ & $\begin{array}{l}3.60 \\
3.58 \\
3.56 \\
3.54 \\
3.52 \\
3.49 \\
\end{array}$ & $\begin{array}{l}625 \\
616 \\
607 \\
598 \\
589 \\
576 \\
\end{array}$ \\
\hline
\end{tabular}


Location.- Water-stage recorder, lat. $43^{\circ} 49^{\prime} 55^{\prime \prime}$, long. $74^{\circ} 11^{\prime} 45^{n}$, half a mile above Gooley, Essex County, 1 mile above mouth of Indian River, and 5 miles northeast of Indian Lake viliage, Hamilton County.

Drainage area.- 419 square miles.

Gage-helght record. - Water-stage recorder graph.

Stage-discharge relation.- Defined by current-meter measurements below 9,180 secondfeet; extended logarithmicaliv to peak stage.

Mexima.- September 1938: Discharge, 9,980 second-feet 10 a.m. Sept. 22 (gage he1ght, 8.46 feet).

August 1916 to August 1938: Discharge, 13,900 second-feet Apr. 12, 1922 (gage height, 10.0 feet).

Remarks.- slight regulation by small storage reservolrs.

Mean dafly discharge, in second-feet, 1938

\begin{tabular}{|c|c|c|c|c|c|c|c|c|c|c|c|}
\hline Day & Sept. & Oct. & Day & Sept. & Oct. & Day & Sept. & Oot. & Day & Sept. & Oct. \\
\hline $\begin{array}{l}1 \\
2 \\
3 \\
4 \\
5 \\
6 \\
7 \\
8 \\
\end{array}$ & $\begin{array}{l}256 \\
229 \\
212 \\
195 \\
178 \\
162 \\
166 \\
229 \\
\end{array}$ & $\begin{array}{l}882 \\
777 \\
690 \\
609 \\
553 \\
493 \\
448 \\
417\end{array}$ & $\begin{array}{r}9 \\
10 \\
11 \\
12 \\
13 \\
14 \\
15 \\
16 \\
\end{array}$ & $\begin{array}{r}242 \\
220 \\
195 \\
182 \\
374 \\
506 \\
728 \\
1,030 \\
\end{array}$ & $\begin{array}{l}387 \\
364 \\
342 \\
314 \\
299 \\
285 \\
275 \\
270 \\
\end{array}$ & $\begin{array}{l}17 \\
18 \\
19 \\
20 \\
21 \\
22 \\
23 \\
24\end{array}$ & $\begin{array}{r}977 \\
841 \\
827 \\
1,010 \\
3,720 \\
9,430 \\
7,680 \\
4,620\end{array}$ & $\begin{array}{l}256 \\
247 \\
238 \\
234 \\
260 \\
275 \\
275 \\
350\end{array}$ & $\begin{array}{l}25 \\
26 \\
27 \\
28 \\
29 \\
30 \\
31\end{array}$ & $\begin{array}{l}3,130 \\
2,260 \\
1,800 \\
1,580 \\
1,310 \\
1,030\end{array}$ & $\begin{array}{l}713 \\
769 \\
645 \\
574 \\
500 \\
448 \\
411\end{array}$ \\
\hline $\begin{array}{l}\text { Mean } \\
\text { Run }-c\end{array}$ & nthly & char & : 1 & denond- & t. & . $:$ & 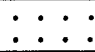 & $\begin{array}{lll}\cdot & - & - \\
. & . & -\end{array}$ & $: \dot{ }$ & $\begin{array}{r}1,511 \\
4.03\end{array}$ & $\begin{array}{r}489 \\
1.21 \\
\end{array}$ \\
\hline
\end{tabular}

Gage he1ght, in feet, and discharge, in second-feet, at indicated time, 1938

\begin{tabular}{|c|c|c|c|c|c|c|c|c|c|c|c|c|}
\hline \multirow{2}{*}{ 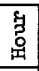 } & Feet & Sec.ft. & Feet & Sec.ft. & Feet & Sec.ft. & Feet & Sec.et. & Feot & sec.ft. & Feet & sec.ft. \\
\hline & \multicolumn{2}{|c|}{ September 18} & \multicolumn{2}{|c|}{ September 19} & \multicolumn{2}{|c|}{ September 20} & \multicolumn{2}{|c|}{ September 21} & \multicolumn{2}{|c|}{ September 22} & \multicolumn{2}{|c|}{ September 23} \\
\hline $\begin{array}{l}1 \\
2 \\
3 \\
4 \\
5 \\
6\end{array}$ & $\begin{array}{c}- \\
- \\
- \\
- \\
- \\
2.90\end{array}$ & $\begin{array}{l}- \\
- \\
- \\
- \\
865\end{array}$ & $\begin{array}{c}- \\
- \\
- \\
2.79 \\
- \\
-\end{array}$ & $\begin{array}{l}- \\
- \\
- \\
-777 \\
-\end{array}$ & $\begin{array}{l}2 . \\
2.89 \\
2.90 \\
2.90\end{array}$ & $\begin{array}{c}-857 \\
- \\
865 \\
-865\end{array}$ & $\begin{array}{l}3.81 \\
3.94 \\
4.06 \\
4.17 \\
4.27 \\
4.38\end{array}$ & $\begin{array}{l}1,740 \\
1,880 \\
2,020 \\
2,140 \\
2,260 \\
2,400\end{array}$ & $\begin{array}{l}7.66 \\
7.81 \\
7.95 \\
8.09 \\
8.20 \\
8.29\end{array}$ & $\begin{array}{l}8,120 \\
8,450 \\
8,780 \\
9,100 \\
9,360 \\
9,580\end{array}$ & $\begin{array}{l}8.19 \\
8.13 \\
8.06 \\
8.00 \\
7.92 \\
7.87\end{array}$ & $\begin{array}{l}9,340 \\
9,190 \\
9,030 \\
8,890 \\
8,710 \\
8,590\end{array}$ \\
\hline $\begin{array}{r}7 \\
8 \\
9 \\
10 \\
11 \\
N\end{array}$ & $\begin{array}{c}- \\
- \\
- \\
- \\
- \\
2.88\end{array}$ & $\begin{array}{l}- \\
- \\
- \\
- \\
849\end{array}$ & $\begin{array}{c}- \\
2.83 \\
- \\
- \\
- \\
2.88\end{array}$ & $\begin{array}{l}- \\
-809 \\
- \\
- \\
849\end{array}$ & $\begin{array}{c}- \\
2.91 \\
- \\
2.93 \\
- \\
2.95\end{array}$ & $\begin{array}{r}-874 \\
-\quad 890 \\
-\quad 908\end{array}$ & $\begin{array}{l}4.50 \\
4.60 \\
4.70 \\
4.79 \\
4.88 \\
4.96\end{array}$ & $\begin{array}{l}2,560 \\
2,690 \\
2,830 \\
2,960 \\
3,080 \\
3,190\end{array}$ & $\begin{array}{l}8.36 \\
8.40 \\
8.44 \\
8.46 \\
8.43 \\
8.41\end{array}$ & $\begin{array}{l}9,740 \\
9,840 \\
9,940 \\
9,980 \\
9,910 \\
9,860\end{array}$ & $\begin{array}{l}7.81 \\
7.73 \\
7.69 \\
7.63 \\
7.59 \\
7.53\end{array}$ & $\begin{array}{l}8,450 \\
8,280 \\
8,190 \\
8,060 \\
7,970 \\
7,840\end{array}$ \\
\hline $\begin{array}{l}1 \\
2 \\
3 \\
4 \\
5 \\
6\end{array}$ & $\begin{array}{l}- \\
- \\
- \\
- \\
- \\
2.83\end{array}$ & $\begin{array}{l}- \\
- \\
- \\
- \\
809\end{array}$ & $\begin{array}{c}- \\
- \\
- \\
2.88 \\
- \\
-\end{array}$ & $\begin{array}{l}- \\
- \\
- \\
849 \\
-\end{array}$ & $\begin{array}{l}- \\
3.00 \\
- \\
3.07 \\
\overline{3.13}\end{array}$ & $\begin{array}{c}- \\
- \\
\overline{1,050} \\
\overline{1,010} \\
1,070\end{array}$ & $\begin{array}{l}5.05 \\
5.17 \\
5.29 \\
5.48 \\
5.67 \\
5.89\end{array}$ & $\begin{array}{l}3,320 \\
3,500 \\
3,680 \\
3,990 \\
4,290 \\
4,660\end{array}$ & $\begin{array}{l}8.39 \\
8.36 \\
8.33 \\
8.30 \\
8.28 \\
8.26\end{array}$ & $\begin{array}{l}9,820 \\
9,740 \\
9,670 \\
9,600 \\
9,550 \\
9,500\end{array}$ & $\begin{array}{l}7.48 \\
7.41 \\
7.33 \\
7.24 \\
7.11 \\
6.98\end{array}$ & $\begin{array}{l}30 \\
80 \\
10 \\
20 \\
50 \\
90\end{array}$ \\
\hline \multirow[t]{2}{*}{$\begin{array}{r}7 \\
8 \\
9 \\
10 \\
11 \\
11\end{array}$} & $\begin{array}{c}- \\
- \\
- \\
- \\
- \\
2.80\end{array}$ & $\begin{array}{l}- \\
- \\
- \\
- \\
785\end{array}$ & $\begin{array}{l}- \\
2.89 \\
- \\
- \\
- \\
2.89\end{array}$ & $\begin{array}{l}- \\
-857 \\
- \\
- \\
857\end{array}$ & $\begin{array}{c}\overline{5.28} \\
\overline{3.46} \\
\overline{3.69}\end{array}$ & $\begin{array}{c}- \\
1,200 \\
- \\
1,380 \\
- \\
1,610\end{array}$ & $\begin{array}{l}6.16 \\
6.49 \\
6.80 \\
7.08 \\
7.30 \\
7.50\end{array}$ & $\begin{array}{l}5,140 \\
5,740 \\
6,330 \\
6,890 \\
7,350 \\
7,770\end{array}$ & $\begin{array}{l}8.25 \\
8.25 \\
8.23 \\
8.22 \\
8.21 \\
8.20\end{array}$ & $\begin{array}{l}9,480 \\
9,480 \\
9,430 \\
9,410 \\
9,380 \\
9,360\end{array}$ & $\begin{array}{l}6.88 \\
6.78 \\
6.68 \\
6.60 \\
6.52 \\
6.46\end{array}$ & $\begin{array}{l}490 \\
290 \\
100 \\
950 \\
300 \\
380\end{array}$ \\
\hline & \multicolumn{2}{|c|}{ September 24} & \multicolumn{2}{|c|}{ September 25} & \multicolumn{2}{|c|}{ September 26} & \multicolumn{2}{|c|}{ September 27} & \multicolumn{2}{|c|}{ September 28} & \multicolumn{2}{|c|}{ September 29} \\
\hline $\begin{array}{r}2 \\
4 \\
6 \\
8 \\
10 \\
1\end{array}$ & $\begin{array}{l}6.33 \\
6.22 \\
6.12 \\
6.01 \\
5.92 \\
5.83\end{array}$ & $\begin{array}{l}5,440 \\
5,250 \\
5,070 \\
4,870 \\
4,710 \\
4,560\end{array}$ & $\begin{array}{l}5.25 \\
5.18 \\
5.10 \\
5.02 \\
4.95 \\
4.90\end{array}$ & $\begin{array}{l}3,620 \\
3,520 \\
3,400 \\
3,280 \\
3,180 \\
3,110\end{array}$ & $\begin{array}{l}4.50 \\
4.44 \\
4.40 \\
4.33 \\
4.30 \\
4.25\end{array}$ & $\begin{array}{l}2,560 \\
2,480 \\
2,430 \\
2,340 \\
2,300 \\
2,240\end{array}$ & $\begin{array}{l}3.98 \\
3.93 \\
3.91 \\
3.87 \\
3.84 \\
3.84\end{array}$ & $\begin{array}{l}1,930 \\
1,870 \\
1,850 \\
1,810 \\
1,770 \\
1,770\end{array}$ & $\begin{array}{l}3.75 \\
3.74 \\
3.72 \\
3.70 \\
3.69 \\
3.66\end{array}$ & $\begin{array}{l}1,690 \\
1,660 \\
1,640 \\
1,620 \\
1,610 \\
1,580\end{array}$ & $\begin{array}{l}3.49 \\
3.46 \\
3.44 \\
3.43 \\
3.41 \\
3.39\end{array}$ & $\begin{array}{r}1,410 \\
1,380 \\
1,360 \\
1,350 \\
1,380\end{array}$ \\
\hline $\begin{array}{r}2 \\
4 \\
6 \\
8 \\
10 \\
M\end{array}$ & $\begin{array}{l}5.75 \\
5.67 \\
5.59 \\
5.50 \\
5.41 \\
5.33\end{array}$ & $\begin{array}{l}4,420 \\
4,290 \\
4,160 \\
4,020 \\
3,880 \\
3,750\end{array}$ & $\begin{array}{l}4.83 \\
4.77 \\
4.71 \\
4.66 \\
4.61 \\
4.57\end{array}$ & $\begin{array}{l}3,010 \\
2,930 \\
2,840 \\
2,770 \\
2,700 \\
2,650\end{array}$ & $\begin{array}{l}4.21 \\
4.18 \\
4.12 \\
4.09 \\
4.04 \\
4.00\end{array}$ & $\begin{array}{l}2,190 \\
2,160 \\
2,080 \\
2,050 \\
1,990 \\
1,950\end{array}$ & $\begin{array}{l}3.83 \\
3.82 \\
3.82 \\
3.81 \\
3.80 \\
3.78\end{array}$ & $\begin{array}{l}1,760 \\
1,750 \\
1,750 \\
1,740 \\
1,730 \\
1,710\end{array}$ & $\begin{array}{l}3.64 \\
3.62 \\
3.61 \\
3.59 \\
3.53 \\
3.51\end{array}$ & $\begin{array}{l}1, \\
1, \\
1, \\
1, \\
1, \\
1,\end{array}$ & $\begin{array}{l}3.36 \\
3.34 \\
3.33 \\
3.32 \\
3.30 \\
3.25\end{array}$ & $\begin{array}{l}1, \\
1, \\
1, \\
1, \\
1, \\
1,\end{array}$ \\
\hline
\end{tabular}


Location.- Water-stage recorder, lat. $43^{\circ} 42^{\prime} 0^{n}$, long. $73^{\circ} 59^{\prime} 00^{n}$, just above highway bridge in North Creek, Warren County, 500 feet above mouth of North Creek.

Drainage area.- 792 square miles; 131 square miles affected by storage in Indian Lake Reservolr.

Gage-helght record.- Water-stage recorder graph.

Stage-discharge relation.- Rating curve for 1938 defined by current-meter measurements below 20,600 second-feet. Rating curve for 1913 defined by current-meter measurements below 11,400 second-feet.

Maxima.- September 1938: D1scharge, 16,700 second-feet 10 a.m. Sept. 22 (gage beight, 9.42 feet).

September 1907 to August 1938: Discharge observed, 27,400 second-feet Mar. 27, 1913 (gage height, 11.5 feet, chain gage at present site and datum).

Remarks.- Discharge not adjusted for storage in Indian Lake Reservoir and other small reservoirs. For information on storage see record for Indian Lake Reservolr near Indian Lake, N. Y.

Mean dally discharge, in second-feet, 1938

\begin{tabular}{|c|c|c|c|c|c|c|c|c|c|c|c|}
\hline Day & Sept. & Oct. & Day & Sept. & Oct. & Day & Sept. & Oct. & Day. & Sept. & Oct. \\
\hline $\begin{array}{l}1 \\
2 \\
3 \\
4 \\
5 \\
6 \\
7 \\
8\end{array}$ & $\begin{array}{l}662 \\
655 \\
610 \\
575 \\
547 \\
534 \\
720 \\
904\end{array}$ & $\begin{array}{r}1,130 \\
993 \\
879 \\
805 \\
733 \\
670 \\
618 \\
575\end{array}$ & $\begin{array}{r}9 \\
10 \\
11 \\
12 \\
13 \\
14 \\
15 \\
16\end{array}$ & $\begin{array}{r}939 \\
896 \\
862 \\
845 \\
948 \\
1,210 \\
1,470 \\
1,400\end{array}$ & $\begin{array}{r}875 \\
1,060 \\
693 \\
554 \\
488 \\
475 \\
636 \\
749\end{array}$ & $\begin{array}{l}17 \\
18 \\
19 \\
20 \\
21 \\
22 \\
23 \\
24\end{array}$ & $\begin{array}{r}1,280 \\
1,100 \\
1,020 \\
1,320 \\
6,170 \\
15,800 \\
11,500 \\
6,7.40\end{array}$ & $\begin{array}{l}733 \\
593 \\
599 \\
678 \\
693 \\
717 \\
717 \\
871\end{array}$ & $\begin{array}{l}25 \\
26 \\
27 \\
28 \\
29 \\
30 \\
31\end{array}$ & $\begin{array}{l}4,480 \\
3,170 \\
2,260 \\
2,010 \\
1,670 \\
1,360\end{array}$ & $\begin{array}{r}1,290 \\
1,330 \\
1,090 \\
930 \\
837 \\
975 \\
966\end{array}$ \\
\hline & & & & & & & & & $\therefore$ & $\begin{array}{r}2,455 \\
3.46\end{array}$ & $\begin{array}{r}805 \\
1.18\end{array}$ \\
\hline
\end{tabular}

Gage he1ght, in feet, and discharge, in second-feet, at indicated time, 1938

\begin{tabular}{|c|c|c|c|c|c|c|c|c|c|c|c|c|}
\hline \multirow{2}{*}{$\begin{array}{l}\xi_{3} \\
\text { 总 } \\
\end{array}$} & Feot & Sec.ft. & Feot & Sec.ft. & Feet & Sec.ft. & Feet & Sec.ft. & Feet & Sec.ft. & Feot & Sec.ft. \\
\hline & \multicolumn{2}{|c|}{ September 18} & \multicolumn{2}{|c|}{ September 19} & \multicolumn{2}{|c|}{ September 20} & \multicolumn{2}{|c|}{ September 21} & \multicolumn{2}{|c|}{ September 22} & \multicolumn{2}{|c|}{ September 23} \\
\hline $\begin{array}{l}1 \\
2 \\
3 \\
4 \\
5 \\
6\end{array}$ & $\begin{array}{l}3.54 \\
3.54 \\
3.53 \\
3.53 \\
3.52 \\
3.51\end{array}$ & $\begin{array}{l}1,160 \\
1,160 \\
1,150 \\
1,150 \\
1,140 \\
1,130\end{array}$ & $\begin{array}{l}3.40 \\
3.40 \\
3.40 \\
3.40 \\
3.39 \\
3.39\end{array}$ & $\begin{array}{l}1,020 \\
1,020 \\
1,020 \\
1,020 \\
1,010 \\
1,010\end{array}$ & \begin{tabular}{|l|}
3.46 \\
3.47 \\
3.48 \\
3.49 \\
3.50 \\
3.50
\end{tabular} & $\begin{array}{l}1,080 \\
1,090 \\
1,100 \\
1,110 \\
1,120 \\
1,120\end{array}$ & $\begin{array}{l}4.40 \\
4.52 \\
4.67 \\
4.80 \\
4.94 \\
5.08\end{array}$ & $\begin{array}{l}2,260 \\
2,440 \\
2,680 \\
2,900 \\
3,150 \\
3,410\end{array}$ & $\begin{array}{l}9.12 \\
9.20 \\
9.25 \\
9.26 \\
9.29 \\
9.33\end{array}$ & $\begin{array}{l}15,400 \\
15,700 \\
16,000 \\
16,000 \\
16,100 \\
13,300\end{array}$ & $\begin{array}{l}8.80 \\
8.76 \\
8.70 \\
8.65 \\
8.59 \\
8.51\end{array}$ & $\begin{array}{l}14,100 \\
13,900 \\
13,700 \\
13,500 \\
13,300 \\
12,900\end{array}$ \\
\hline $\begin{array}{r}7 \\
8 \\
9 \\
10 \\
11 \\
\mathbb{N}\end{array}$ & $\begin{array}{l}3.51 \\
3.50 \\
3.50 \\
3.50 \\
\mathbf{3} .50 \\
\mathbf{3 . 4 9}\end{array}$ & $\begin{array}{l}1,130 \\
1,120 \\
1,120 \\
1,120 \\
1,120 \\
1,110\end{array}$ & $\begin{array}{l}3.39 \\
3.39 \\
3.38 \\
3.37 \\
3.37 \\
3.37\end{array}$ & $\begin{array}{r}1,010 \\
1,010 \\
1,000 \\
993 \\
993 \\
993\end{array}$ & $\begin{array}{l}3.50 \\
3.52 \\
3.53 \\
3.54 \\
3.56 \\
3.59\end{array}$ & $\begin{array}{l}1,1 \\
1,1 \\
1,1 \\
1,1 \\
1,1 \\
1,2\end{array}$ & $\begin{array}{l}5.28 \\
5.34 \\
5.44 \\
5.57 \\
5.70 \\
5.86\end{array}$ & $\begin{array}{l}3,810 \\
3,930 \\
4,130 \\
4,400 \\
4,670 \\
5,030\end{array}$ & & & & $\begin{array}{l}12,700 \\
12,400 \\
12,200 \\
11,900 \\
11,700 \\
11,500\end{array}$ \\
\hline $\begin{array}{l}1 \\
2 \\
3 \\
4 \\
5 \\
6\end{array}$ & $\begin{array}{l}3.48 \\
3.47 \\
3.47 \\
3.46 \\
3.45 \\
3.45\end{array}$ & $\begin{array}{l}1,100 \\
1,090 \\
1,090 \\
1,080 \\
1,070 \\
1,070\end{array}$ & $\begin{array}{l}3.38 \\
3.40 \\
3.41 \\
3.42 \\
3.43 \\
3.44\end{array}$ & $\begin{array}{l}1,000 \\
1,020 \\
1,030 \\
1,040 \\
1,050 \\
1,060\end{array}$ & $\begin{array}{l}3.61 \\
3.62 \\
3.65 \\
3.68 \\
3.74 \\
3.78\end{array}$ & $\begin{array}{l}1,240 \\
1,250 \\
1,290 \\
1,330 \\
1,400 \\
1,450\end{array}$ & $\begin{array}{l}6.01 \\
6.18 \\
6.35 \\
6.51 \\
6.72 \\
7.00\end{array}$ & $\begin{array}{l}5,370 \\
5,790 \\
6,220 \\
6,640 \\
7,210 \\
8,000\end{array}$ & $\begin{array}{l}9.36 \\
9.31 \\
9.27 \\
9.21 \\
9.18 \\
9.12\end{array}$ & & & $\begin{array}{l}11,000 \\
10,900 \\
10,600 \\
10,400 \\
10,200\end{array}$ \\
\hline \multirow[t]{2}{*}{$\begin{array}{r}7 \\
8 \\
9 \\
10 \\
11 \\
1 \\
\end{array}$} & $\begin{array}{l}3.45 \\
3.44 \\
3.43 \\
3.42 \\
3.41 \\
3.40 \\
\end{array}$ & $\begin{array}{l}1,070 \\
1,060 \\
1,050 \\
1,040 \\
1,030 \\
1,020\end{array}$ & $\begin{array}{l}3.44 \\
3.45 \\
3.46 \\
3.46 \\
3.46 \\
3.46\end{array}$ & $\begin{array}{l}1,060 \\
1,070 \\
1,080 \\
1,080 \\
1,080 \\
1,080\end{array}$ & $\begin{array}{l}3.81 \\
3.89 \\
3.96 \\
4.04 \\
4.18 \\
4.28\end{array}$ & $\begin{array}{l}1,480 \\
1,580 \\
1,670 \\
1,770 \\
1,950 \\
2,090\end{array}$ & $\begin{array}{l}7.29 \\
7.70 \\
8.13 \\
8.53 \\
8.82 \\
9.00\end{array}$ & $\begin{array}{r}8,870 \\
10,100 \\
11,600 \\
13,000 \\
14,200 \\
14,900\end{array}$ & $\begin{array}{l}9.07 \\
9.03 \\
8.98 \\
8.95 \\
8.90 \\
8.84\end{array}$ & & $\begin{array}{l}7.62 \\
7.52 \\
7.42 \\
7.32 \\
7.24 \\
7.17\end{array}$ & \\
\hline & \multicolumn{2}{|c|}{ September 24} & \multicolumn{2}{|c|}{ September 25} & \multicolumn{2}{|c|}{ September 26} & \multicolumn{2}{|c|}{ September 27} & \multicolumn{2}{|c|}{ September 28} & \multicolumn{2}{|c|}{ September 29} \\
\hline $\begin{array}{r}2 \\
4 \\
6 \\
8 \\
10 \\
11\end{array}$ & $\begin{array}{l}7.03 \\
6.92 \\
6.81 \\
6.70 \\
6.61 \\
6.52\end{array}$ & $\begin{array}{l}8,090 \\
7,770 \\
7,460 \\
7,750 \\
6,910\end{array}$ & $\begin{array}{l}5.93 \\
5.86 \\
5.78 \\
5.78 \\
5.66 \\
5.59\end{array}$ & $\begin{array}{l}5,190 \\
5,030 \\
4,850 \\
4,740 \\
4,590 \\
4,440\end{array}$ & $\begin{array}{l}5.18 \\
5.14 \\
5.10 \\
5.05 \\
5.00 \\
4.96\end{array}$ & $\begin{array}{l}3,610 \\
3,530 \\
3,450 \\
3,360 \\
3,260 \\
3,190\end{array}$ & \begin{tabular}{|l|}
4.54 \\
4.49 \\
4.46 \\
4.42 \\
4.39 \\
4.39 \\
\end{tabular} & $\begin{array}{l}2,470 \\
2,400 \\
2,350 \\
2,290 \\
2,250 \\
2,250\end{array}$ & \begin{tabular}{|}
4.30 \\
4.28 \\
4.27 \\
4.26 \\
4.24 \\
4.22
\end{tabular} & $\begin{array}{l}2,120 \\
2,090 \\
2,080 \\
2,060 \\
2,040 \\
2,010\end{array}$ & & \\
\hline $\begin{array}{r}2 \\
4 \\
6 \\
8 \\
10 \\
11\end{array}$ & $\begin{array}{l}6.43 \\
6.35 \\
6.27 \\
6.18 \\
6.10 \\
6.01\end{array}$ & $\begin{array}{l}0 \\
0 \\
0\end{array}$ & $\begin{array}{l}5.52 \\
5.46 \\
5.40 \\
5.34 \\
5.29 \\
5.28\end{array}$ & $\begin{array}{l}4,290 \\
4,170 \\
4,050 \\
3,930 \\
3,830 \\
3,710\end{array}$ & $\begin{array}{l}4.91 \\
4.87 \\
4.82 \\
4.78 \\
4.68 \\
4.60\end{array}$ & & $\begin{array}{l}4.37 \\
4.35 \\
4.34 \\
4.34 \\
4.32 \\
4.30 \\
\end{array}$ & $\begin{array}{l}2,200 \\
2,190 \\
2,180 \\
2,180 \\
2,150 \\
2,120\end{array}$ & $\begin{array}{l}4.20 \\
4.19 \\
4.17 \\
4.15 \\
4.13 \\
4.11\end{array}$ & $\begin{array}{l}1,980 \\
1,970 \\
1,940 \\
1,920 \\
1,890\end{array}$ & $\begin{array}{l}3.94 \\
3.91 \\
3.89 \\
3.89 \\
3.88 \\
3.86\end{array}$ & \\
\hline
\end{tabular}

$2279070-40-16$ 
Hudson River at Hadley, N. Y.

Location.- Water-stage recorder, lat. $43^{\circ} 19^{\prime} 10^{\prime \prime}$, long. $73^{\circ} 50^{\prime} 40^{\prime \prime}$, at Hadey, Saratoga County, a quarter of a mile above mouth of sacandaga River and 400 feet below mouth of Lake Luzerne outlet.

Drainage area.- 1,664 square miles; 131 square miles affected by storage in Indian Lake Reservolr.

Gage-helght record. - Water-stage recorder graph.

Stage-discharge relation.- Defined by current-meter measurements below 27,200 secondfeet.

Maxima.- September 1938: D1scharge, 23,200 second-feet 11 a.m. Sept. 22 (gage height, 12.96 foet)

July 1921 to August 1938: Discharge, 41,200 second-feet Mar. 18, 1936 (gage helght, 19.59 feet).

Remarks.- Flood discharge materlally affected by storage in Indian Lake Reservolr and other small reservolis. For information on storage see records for Indian Lake

Reservolr near Indian Lake, N. Y.

Mean dafly discharge, in second-feet, 1938 a

\begin{tabular}{|c|c|c|c|c|c|c|c|c|c|c|c|}
\hline Day & Sept. & oct. & Day & Sept. & Oct. & Day & Sept. & oct. & Day & Sept. & Oct. \\
\hline $\begin{array}{l}1 \\
2 \\
3 \\
4 \\
5 \\
6 \\
7 \\
8\end{array}$ & $\begin{array}{r}1,020 \\
1,000 \\
963 \\
914 \\
865 \\
824 \\
810 \\
1,100 \\
\end{array}$ & $\begin{array}{l}3,510 \\
3,080 \\
2,740 \\
2,470 \\
2,240 \\
2,010 \\
1,840 \\
1,690\end{array}$ & $\begin{array}{r}9 \\
10 \\
11 \\
12 \\
13 \\
14 \\
15 \\
16\end{array}$ & $\begin{array}{l}1,180 \\
1,200 \\
1,150 \\
1,130 \\
1,220 \\
1,300 \\
1,870 \\
2,130\end{array}$ & $\begin{array}{l}1,570 \\
2,100 \\
1,760 \\
1,460 \\
1,320 \\
1,220 \\
1,170 \\
1,360\end{array}$ & $\begin{array}{l}17 \\
18 \\
19 \\
20 \\
21 \\
22 \\
23 \\
24\end{array}$ & $\begin{array}{r}1,890 \\
1,730 \\
1,600 \\
2,190 \\
6,870 \\
21,400 \\
18,300 \\
13,200\end{array}$ & $\begin{array}{l}1,400 \\
1,330 \\
1,120 \\
1,200 \\
1,220 \\
1,260 \\
1,220 \\
1,370\end{array}$ & $\begin{array}{l}25 \\
26 \\
27 \\
28 \\
29 \\
30 \\
31\end{array}$ & $\begin{array}{l}9,970 \\
7,830 \\
6,240 \\
5,370 \\
4,710 \\
4,060\end{array}$ & $\begin{array}{l}2,210 \\
2,390 \\
2,240 \\
1,980 \\
1,790 \\
1,710 \\
1,820\end{array}$ \\
\hline $\begin{array}{l}\text { Mean } \\
\text { Run }-c\end{array}$ & $\mathrm{nth} l \mathrm{y}$ & - & : 1 & $\begin{array}{c}\text { second- } \\
\text {. }\end{array}$ & et. & . : & . . . & $\begin{array}{lll}. & . & . \\
. & . & \end{array}$ & $:$ : & $\begin{array}{r}4,135 \\
2.77\end{array}$ & $\begin{array}{r}1,800 \\
1.24\end{array}$ \\
\hline
\end{tabular}

a For 24-hour perlod ending at $11 \mathrm{p} . \mathrm{m}$.

Gage height, In feet, and aischarge, in second-feet, at indicated t1me, 1938

\begin{tabular}{|c|c|c|c|c|c|c|c|c|c|c|c|c|}
\hline \multirow{2}{*}{ 毠 } & Feet & Sec.ft. & Feet & Sec.ft. & Feet & Sec.ft. & Feet & Sec.ft. & Feet & Sec.ft. & Feet & Sec.ft. \\
\hline & \multicolumn{2}{|c|}{ September 18} & \multicolumn{2}{|c|}{ September 19} & \multicolumn{2}{|c|}{ September 20} & \multicolumn{2}{|c|}{ Sept ember 21} & \multicolumn{2}{|c|}{ September 22} & \multicolumn{2}{|c|}{ September 23} \\
\hline $\begin{array}{l}1 \\
2 \\
3 \\
4 \\
5 \\
6\end{array}$ & $\begin{array}{l}3.35 \\
3.34 \\
3.32 \\
3.31 \\
3.30 \\
3.30\end{array}$ & $\begin{array}{l}1,800 \\
1,790 \\
1,770 \\
1,760 \\
1,750 \\
1,750\end{array}$ & $\begin{array}{l}3.18 \\
3.17 \\
3.17 \\
3.17 \\
3.17 \\
3.17\end{array}$ & $\begin{array}{l}1,630 \\
1,620 \\
1,620 \\
1,620 \\
1,620 \\
1,620\end{array}$ & $\begin{array}{l}3.29 \\
3.30 \\
3.31 \\
3.33 \\
3.39 \\
3.42\end{array}$ & $\begin{array}{l}1,740 \\
1,750 \\
1,760 \\
1,780 \\
1,850 \\
1,880\end{array}$ & $\begin{array}{l}4.59 \\
4.65 \\
4.72 \\
4.79 \\
4.85 \\
4.91\end{array}$ & $\begin{array}{l}3,520 \\
3,620 \\
3,740 \\
3,860 \\
3,970 \\
4,080\end{array}$ & $\begin{array}{l}10.59 \\
10.93 \\
11.33 \\
11.73 \\
12.10 \\
12.43\end{array}$ & $\begin{array}{l}17,200 \\
18,000 \\
19,000 \\
20,000 \\
21,000 \\
21,800\end{array}$ & $\begin{array}{l}11.93 \\
11.83 \\
11.74 \\
11.66 \\
11.57 \\
11.48\end{array}$ & $\begin{array}{l}20,500 \\
20,300 \\
20,000 \\
19,800 \\
19,600 \\
19,400\end{array}$ \\
\hline $\begin{array}{r}7 \\
8 \\
9 \\
10 \\
11 \\
N\end{array}$ & $\begin{array}{l}3.30 \\
3.30 \\
3.30 \\
3.29 \\
3.29 \\
3.29\end{array}$ & $\begin{array}{l}1,750 \\
1,750 \\
1,750 \\
1,740 \\
1,740 \\
1,740\end{array}$ & $\begin{array}{l}16 \\
15 \\
14 \\
14 \\
13 \\
12\end{array}$ & $\begin{array}{l}1,610 \\
1,600 \\
1,590 \\
1,590 \\
1,580 \\
1,570\end{array}$ & $\begin{array}{l}3.48 \\
3.51 \\
3.56 \\
3.60 \\
3.63 \\
3.67\end{array}$ & $\begin{array}{l}1,950 \\
1,980 \\
2,040 \\
2,090 \\
2,130 \\
2,170\end{array}$ & $\begin{array}{l}5.00 \\
5.10 \\
5.23 \\
5.39 \\
5.59 \\
5.81\end{array}$ & $\begin{array}{l}4,240 \\
4,420 \\
4,660 \\
4,960 \\
5,350 \\
5,790\end{array}$ & $\begin{array}{l}12.64 \\
12.81 \\
12.91 \\
12.95 \\
12.96 \\
12.95\end{array}$ & $\begin{array}{l}22,400 \\
22,800 \\
23,100 \\
23,200 \\
23,200 \\
23,200\end{array}$ & $\begin{array}{l}11.40 \\
11.33 \\
11.24 \\
11.16 \\
11.06 \\
10.96\end{array}$ & $\begin{array}{l}19,200 \\
19,000 \\
18,800 \\
18,600 \\
18,400 \\
18,100\end{array}$ \\
\hline $\begin{array}{l}1 \\
2 \\
3 \\
4 \\
5 \\
6\end{array}$ & $\begin{array}{l}3.29 \\
3.28 \\
3.27 \\
3.26 \\
3.24 \\
3.22\end{array}$ & $\begin{array}{l}1,740 \\
1,730 \\
1,720 \\
1,710 \\
1,690 \\
1,670\end{array}$ & $\begin{array}{l}3.1 \\
3.1 \\
3.1 \\
3.1 \\
3.1 \\
3.1\end{array}$ & $\begin{array}{l}1,560 \\
1,560 \\
1,560 \\
1,560 \\
1,560 \\
1,560\end{array}$ & $\begin{array}{l}3.70 \\
3.74 \\
3.80 \\
3.85 \\
3.90 \\
3.93\end{array}$ & $\begin{array}{l}2,210 \\
2,260 \\
2,340 \\
2,400 \\
2,470 \\
2,510\end{array}$ & $\begin{array}{l}6.08 \\
6.39 \\
6.71 \\
7.04 \\
7.37 \\
7.72\end{array}$ & $\begin{array}{r}6,350 \\
7,000 \\
7,700 \\
8,450 \\
9,210 \\
10,000\end{array}$ & $\begin{array}{l}12.91 \\
12.88 \\
12.84 \\
12.77 \\
12.69 \\
12.62\end{array}$ & $\begin{array}{l}23,100 \\
23,000 \\
22,900 \\
22,700 \\
22,500 \\
22,300\end{array}$ & $\begin{array}{l}10.86 \\
10.75 \\
10.65 \\
10.55 \\
10.45 \\
10.37\end{array}$ & $\begin{array}{l}17,800 \\
17,600 \\
17,300 \\
17,100 \\
16,800 \\
16,600\end{array}$ \\
\hline \multirow[t]{2}{*}{$\begin{array}{r}7 \\
8 \\
9 \\
10 \\
11 \\
M\end{array}$} & $\begin{array}{l}3.21 \\
3.20 \\
3.20 \\
3.20 \\
3.19 \\
3.19\end{array}$ & $\begin{array}{l}1,660 \\
1,650 \\
1,650 \\
1,650 \\
1,640 \\
1,640\end{array}$ & $\begin{array}{l}3.13 \\
3.14 \\
3.16 \\
3.19 \\
3.20 \\
3.23\end{array}$ & $\begin{array}{l}1,580 \\
1,590 \\
1,610 \\
1,640 \\
1,650 \\
1,680\end{array}$ & $\begin{array}{l}4 . \\
4 . \\
4 . \\
4 . \\
4 . \\
4 .\end{array}$ & $\begin{array}{l}510 \\
570 \\
300 \\
60 \\
80 \\
570\end{array}$ & $\begin{array}{r}8 . \\
8 . \\
9 . \\
9 . \\
9 . \\
10 .\end{array}$ & $\begin{array}{l}10, \\
12, \\
13, \\
14, \\
15, \\
16,\end{array}$ & $\begin{array}{l}12.54 \\
12.44 \\
12.35 \\
12.25 \\
12.15 \\
12.04\end{array}$ & $\begin{array}{l}22,100 \\
21,800 \\
21,600 \\
21,400 \\
21,100 \\
20,800\end{array}$ & $\begin{array}{r}10.27 \\
10.18 \\
10.12 \\
10.06 \\
9.97 \\
9.89\end{array}$ & $\begin{array}{l}16, \\
16, \\
16, \\
15 \\
15 \\
15\end{array}$ \\
\hline & \multicolumn{2}{|c|}{ September 24} & \multicolumn{2}{|c|}{ September 25} & \multicolumn{2}{|c|}{ September 26} & \multicolumn{2}{|c|}{ September 27} & \multicolumn{2}{|c|}{ September 28} & \multicolumn{2}{|c|}{ September 29} \\
\hline $\begin{array}{r}2 \\
4 \\
6 \\
8 \\
10 \\
\mathrm{~N}\end{array}$ & $\begin{array}{l}9.69 \\
9.48 \\
9.29 \\
9.14 \\
9.00 \\
8.89\end{array}$ & $\begin{array}{l}14,900 \\
14,400 \\
13,900 \\
13,600 \\
13,200 \\
12,900\end{array}$ & $\begin{array}{l}8.10 \\
8.01 \\
7.92 \\
7.83 \\
7.73 \\
7.65\end{array}$ & $\begin{array}{r}11,000 \\
10,700 \\
10,500 \\
10,300 \\
10,100 \\
9,880\end{array}$ & $\begin{array}{l}7.09 \\
7.01 \\
6.94 \\
6.88 \\
6.80 \\
6.76\end{array}$ & & $\begin{array}{l}6.36 \\
6.29 \\
6.21 \\
6.12 \\
6.03 \\
5.98\end{array}$ & $\begin{array}{l}6,940 \\
6,790 \\
6,620 \\
6,430 \\
6,240 \\
6,140\end{array}$ & \begin{tabular}{|l|}
5.71 \\
5.69 \\
5.68 \\
5.64 \\
5.61 \\
5.59
\end{tabular} & & $\begin{array}{l}5.40 \\
5.38 \\
5.35 \\
5.32 \\
5.30 \\
5.27\end{array}$ & \\
\hline $\begin{array}{r}2 \\
4 \\
6 \\
8 \\
10 \\
M \\
\end{array}$ & $\begin{array}{l}8.77 \\
8.65 \\
8.51 \\
8.41 \\
8.30 \\
8.20\end{array}$ & $\begin{array}{l}12,600 \\
12,300 \\
12,000 \\
11,700 \\
11,400 \\
11,200\end{array}$ & $\begin{array}{l}7.57 \\
7.49 \\
7.40 \\
7.31 \\
7.24 \\
7.17\end{array}$ & $\begin{array}{l}9,690 \\
9,500 \\
9,280 \\
9,070 \\
8,910 \\
8,750\end{array}$ & $\begin{array}{l}6.70 \\
6.64 \\
6.60 \\
6.53 \\
6.48 \\
6.41\end{array}$ & $\begin{array}{l}7, \\
7, \\
7, \\
7, \\
7, \\
7,\end{array}$ & $\begin{array}{l}5.93 \\
5.90 \\
5.86 \\
5.81 \\
5.79 \\
5.75\end{array}$ & $\begin{array}{l}30 \\
70 \\
390 \\
90 \\
50 \\
70\end{array}$ & $\begin{array}{l}5.57 \\
5.54 \\
5.52 \\
5.50 \\
5.47 \\
5.43\end{array}$ & $\begin{array}{l}510 \\
250 \\
210 \\
70 \\
10 \\
40\end{array}$ & $\begin{array}{l}5.23 \\
5.20 \\
5.17 \\
5.13 \\
5.10 \\
5.07\end{array}$ & $\begin{array}{l}, 660 \\
, 600 \\
, 550 \\
, 470 \\
k, 420 \\
k, 370\end{array}$ \\
\hline
\end{tabular}


Hudson River at Mechanicville, N. Y.

Location. - Water-stage recorder, lat. $42^{\circ} 54^{\prime} 45^{n}$, long. $73^{\circ} 40^{\prime} 45^{\prime \prime}$, at dam of West Virginia Pulp and Paper Co., in Mechanicville, Saratoga County. Crest of dam at elevation 70.91 feet (West Virginia Pulp and Paper Co. datum).

Drainage area.- 4,500 square miles; 1,175 square miles affected by storage in Sacandaga and Indian Lake Reservoirs.

Gage-height record.- Water-stage recorder graph used in computing flow over dam and through wheels. Gage heights are heads on crest of dam.

Stage-discharge relation.- Discharge computed from flow over spillway and through wheels. Thirty-inch flashboards on crest of spillway prior to $2 \mathrm{p} . \mathrm{m}$. Sept. 22 . Between 2 and 3 p.m. Sept. 22 flashboards belleved to have failed progressively until about five percent remained, as found after the flood. Flashboards were not replaced during September 1938.

Maxima.- September 1938: Discharge, 78,000 second-feet 3 p.m. Sept. 22 (gage height, 9.04 feet).

1887 to August 1938: Discharge, 120,000 second-feet Mar. 28, 1913.

Remarks.- For information on storage see record for Sacandaga Reservoir at Conklingvilie and Indian Lake Reservolr near Indian Lake. Slight additional regulation from other small reservolrs. No adjustment is made for diversion through Glen Falls feeder into Champlain Canal. Daily discharges are for 24-hour period ending at 7 a.m. of following day. Discharges at indicated time do not inciude flow (about 50 second-feet) through lock of Champlain canal. Records of gage heights and discharge over spillway and through wheels furnished by West Virginia Pulp and Paper Co. Daylight Saving Time used to 7 a.m. Sept. 25.

Mean dally discharge, in second-feet, 1938

\begin{tabular}{|c|c|c||c|c|c|c|c|c||c|c|c|}
\hline Day & Sept. & 0ct. & Day & Sept. & Oct. & Day & Sept. & 0ct. & Dey & Sept. & 0ct. \\
\hline 1 & 3,120 & 9,240 & 9 & 3,450 & 5,070 & 17 & 5,400 & 3,680 & 25 & 19,700 & 6,350 \\
2 & 3,530 & 9,210 & 10 & 3,270 & 4,080 & 18 & 4,950 & 5,090 & 26 & 15,500 & 6,880 \\
3 & 3,230 & 5,770 & 11 & 3,040 & 5,670 & 19 & 5,050 & 4,990 & 27 & 14,000 & 7,560 \\
4 & 2,360 & 7,630 & 12 & 3,500 & 5,550 & 20 & 16,200 & 5,280 & 28 & 13,700 & 6,040 \\
5 & 1,630 & 7,180 & 13 & 3,940 & 5,730 & 21 & 34,200 & 5,620 & 29 & 11,900 & 5,580 \\
6 & 2,070 & 6,350 & 14 & 4,700 & 5,290 & 22 & 65,600 & 5,050 & 30 & 10,900 & 5,290 \\
7 & 3,110 & 5,830 & 15 & 5,650 & 4,190 & 23 & 37,800 & 5,500 & 31 & & 4,610 \\
8 & 3,280 & 5,280 & 16 & 6,160 & 3,890 & 24 & 27,500 & 4,970 & & & \\
\hline
\end{tabular}

Gage helght, in feet, and discharge, in second-feet, at indicated time, 1938

\begin{tabular}{|c|c|c|c|c|c|c|c|c|c|c|c|c|}
\hline \multirow{2}{*}{ 承 } & eet & Sec.ft. & Feet & Sec.ft. & reot & Sec.ft. & Feet & Sec.ft. & Feet & Sec.It. & Feet & Sec.ft. \\
\hline & \multicolumn{2}{|c|}{ September 18} & \multicolumn{2}{|c|}{ September 19} & \multicolumn{2}{|c|}{ September 20} & \multicolumn{2}{|c|}{ September 21} & \multicolumn{2}{|c|}{ September 22} & \multicolumn{2}{|c|}{ September 23} \\
\hline $\begin{array}{l}1 \\
2 \\
3 \\
4 \\
5 \\
6\end{array}$ & & & & & & & & & & & & $\begin{array}{l}55,000 \\
54,000\end{array}$ \\
\hline $\begin{array}{r}7 \\
8 \\
9 \\
10\end{array}$ & $\begin{array}{l}3.8 \\
4.0 \\
4.1 \\
4.1 \\
4.1\end{array}$ & & & & & $\begin{array}{r}7,460 \\
7,610 \\
7,770 \\
8,100 \\
10,200 \\
12,600\end{array}$ & & & & & & \\
\hline $\begin{array}{l}1 \\
2 \\
3 \\
4 \\
5 \\
6\end{array}$ & $\begin{array}{l}4.2 \\
4.2 \\
4.1 \\
4.1 \\
4.0 \\
4.0\end{array}$ & & $\begin{array}{l}2.7 \\
2.6 \\
2.5 \\
2.5 \\
2.5\end{array}$ & & & & & & & & & \\
\hline \multirow[t]{2}{*}{$\begin{array}{r}7 \\
8 \\
9 \\
10 \\
11 \\
M\end{array}$} & $\begin{array}{l}4.00 \\
4.00 \\
4.00 \\
4.00 \\
4.00 \\
4.00\end{array}$ & & & & & & & & & & & \\
\hline & \multicolumn{2}{|c|}{ September 24} & \multicolumn{2}{|c|}{ September 25} & \multicolumn{2}{|c|}{ September 26} & \multicolumn{2}{|c|}{ September 27} & \multicolumn{2}{|c|}{ September 28} & \multicolumn{2}{|c|}{ September 29} \\
\hline $\begin{array}{r}2 \\
4 \\
6 \\
8 \\
10 \\
\text { N }\end{array}$ & $\begin{array}{l}4.96 \\
4.96 \\
4.92 \\
4.75 \\
4.58 \\
4.46\end{array}$ & & & & & & & & & & & \\
\hline $\begin{array}{r}2 \\
4 \\
6 \\
8 \\
10 \\
\end{array}$ & $\begin{array}{l}4.29 \\
4.13 \\
3.96 \\
3.87 \\
3.83 \\
3.83\end{array}$ & & & & & $\begin{array}{l}14 \\
15 \\
15 \\
13 \\
13\end{array}$ & & & & & & \\
\hline
\end{tabular}




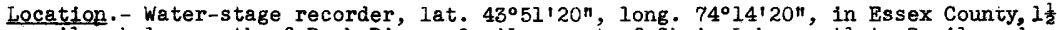
miles below mouth of Rock River, 2 miles east of Chain Lakes outlet, 3 miles above the mouth, and $5 \frac{1}{2}$ miles northeast of Indian Lake village, Hamilton County.

Drainage area.- 160 square miles.

Gage-height record. - Water-stage recorder graph.

Stage-discharge relation.- Defined by current-meter measurements below 2,460 secondfeet; extended logarithmically to peak stage.

Max1ma.- September 1938: Discharge, 4,800 second-feet 7 a.m. Sept. 22 (gage height, 10.45 feet).

October 1930 to August 1938: D1scharge, 6,050 second-feet 0ct. 7, 1932 (gage helght, 11.80 feet).

Remarks.- Flow slightly regulated by storage for log-driving operations.

Mean dafly dilscharge, in second-feet, 1938

\begin{tabular}{|c|r|r||r|r|r||r|r|r||r|r|r|}
\hline Day & Sept. & 0ct. & Day & Sept. & Oct. & Day & Sept. & Oct. & Day & Sept. & 0ct. \\
\hline 1 & 68 & 243 & 9 & 65 & 122 & 17 & 182 & 77 & 25 & 752 & 287 \\
2 & 60 & 213 & 10 & 59 & 117 & 18 & 165 & 80 & 26 & 656 & 225 \\
3 & 62 & 195 & 11 & 53 & 114 & 19 & 250 & 79 & 27 & 572 & 191 \\
4 & 58 & 177 & 12 & 51 & 102 & 20 & 367 & 78 & 28 & 527 & 170 \\
5 & 51 & 165 & 13 & 84 & 88 & 21 & 1,710 & 96 & 29 & 419 & 155 \\
6 & 50 & 151 & 14 & 98 & 83 & 22 & 4,160 & 110 & 30 & 289 \\
7 & 57 & 140 & 15 & 174 & 83 & 23 & 2,150 & 102 & 31 & \\
8 & 83 & 129 & 16 & 223 & 85 & 24 & 996 & 139 & & \\
8
\end{tabular}

Gage helght, in feet, and discharge, in second-feet, at indicated time, 1938

\begin{tabular}{|c|c|c|c|c|c|c|c|c|c|c|c|c|}
\hline \multirow{2}{*}{$\begin{array}{l}\text { 莦 } \\
\text { 号 }\end{array}$} & Feet & Sec.ft. & Feet & Sec.ft. & Feet & Sec.ft. & Feet & Sec.ft. & Feot & Sec.et. & Feet & Sec.ft. \\
\hline & \multicolumn{2}{|c|}{ September 18} & \multicolumn{2}{|c|}{ September 19} & \multicolumn{2}{|c|}{ Sept ember 20} & \multicolumn{2}{|c|}{ September 21} & \multicolumn{2}{|c|}{ September 22} & \multicolumn{2}{|c|}{ September 23} \\
\hline $\begin{array}{l}1 \\
2 \\
3 \\
4 \\
5 \\
6\end{array}$ & $\begin{array}{l}2.35 \\
2.34 \\
2.33 \\
2.33 \\
2.33 \\
2.33\end{array}$ & $\begin{array}{l}174 \\
172 \\
170 \\
170 \\
170 \\
170\end{array}$ & $\begin{array}{l}2.41 \\
2.45 \\
2.50 \\
2.55 \\
2.60 \\
2.67\end{array}$ & $\begin{array}{l}184 \\
191 \\
200 \\
210 \\
219 \\
233 \\
\end{array}$ & $\begin{array}{l}2.89 \\
2.90 \\
2.91 \\
2.92 \\
2.93 \\
2.93\end{array}$ & $\begin{array}{l}280 \\
282 \\
284 \\
287 \\
289 \\
289\end{array}$ & $\begin{array}{l}4.52 \\
4.67 \\
4.82 \\
5.00 \\
5.19 \\
5.32\end{array}$ & $\begin{array}{r}788 \\
848 \\
908 \\
980 \\
1,060 \\
1,130\end{array}$ & $\begin{array}{r}9.33 \\
9.63 \\
9.88 \\
10.12 \\
10.27 \\
10.39\end{array}$ & $\begin{array}{l}3,860 \\
4,100 \\
4,300 \\
4,510 \\
4,640 \\
4,750\end{array}$ & $\begin{array}{l}8.42 \\
8.24 \\
8.06 \\
7.91 \\
7.79 \\
7.70\end{array}$ & $\begin{array}{l}3,140 \\
2,990 \\
2,850 \\
2,750 \\
2,660 \\
2,600\end{array}$ \\
\hline $\begin{array}{r}7 \\
8 \\
9 \\
10 \\
11 \\
\mathrm{~N}\end{array}$ & $\begin{array}{l}2.33 \\
2.33 \\
2.33 \\
2.33 \\
2.32 \\
2.31\end{array}$ & $\begin{array}{l}170 \\
170 \\
170 \\
170 \\
168 \\
167\end{array}$ & $\begin{array}{l}2.72 \\
2.76 \\
2.77 \\
2.80 \\
2.81 \\
2.82\end{array}$ & $\begin{array}{l}243 \\
252 \\
254 \\
260 \\
262 \\
264\end{array}$ & $\begin{array}{l}2.93 \\
2.93 \\
2.94 \\
2.95 \\
2.97 \\
3.01\end{array}$ & $\begin{array}{l}289 \\
289 \\
291 \\
294 \\
298 \\
307\end{array}$ & $\begin{array}{l}5.42 \\
5.49 \\
5.54 \\
5.59 \\
5.63 \\
5.68\end{array}$ & $\begin{array}{l}1,180 \\
1,210 \\
1,240 \\
1,260 \\
1,280 \\
1,310\end{array}$ & $\begin{array}{l}10.45 \\
10.43 \\
10.38 \\
10.27 \\
10.16 \\
10.03\end{array}$ & $\begin{array}{l}4,800 \\
4,790 \\
4,740 \\
4,640 \\
4,540 \\
4,430\end{array}$ & $\begin{array}{l}7.62 \\
7.54 \\
7.49 \\
7.43 \\
7.38 \\
7.32\end{array}$ & $\begin{array}{l}2,540 \\
2,490 \\
2,450 \\
2,410 \\
2,380 \\
2,330\end{array}$ \\
\hline $\begin{array}{l}1 \\
2 \\
3 \\
4 \\
5 \\
6\end{array}$ & $\begin{array}{l}2.29 \\
2.28 \\
2.27 \\
2.26 \\
2.26 \\
2.26\end{array}$ & $\begin{array}{l}163 \\
162 \\
160 \\
158 \\
158 \\
158\end{array}$ & $\begin{array}{l}2.83 \\
2.83 \\
2.84 \\
2.85 \\
2.86 \\
2.87\end{array}$ & $\begin{array}{l}267 \\
267 \\
269 \\
271 \\
273 \\
275\end{array}$ & $\begin{array}{l}3.05 \\
3.09 \\
3.16 \\
3.21 \\
3.28 \\
3.38\end{array}$ & $\begin{array}{l}317 \\
327 \\
345 \\
358 \\
377 \\
404\end{array}$ & $\begin{array}{l}5.82 \\
6.07 \\
6.34 \\
6.59 \\
6.87 \\
7.23\end{array}$ & $\begin{array}{l}1,390 \\
1,540 \\
1,700 \\
1,850 \\
2,020 \\
2,270\end{array}$ & $\begin{array}{l}9.89 \\
9.77 \\
9.64 \\
9.51 \\
9.40 \\
9.28\end{array}$ & $\begin{array}{l}4,310 \\
4,220 \\
4,110 \\
4,010 \\
3,920 \\
3,820\end{array}$ & $\begin{array}{l}7.20 \\
6.99 \\
6.73 \\
6.47 \\
6.22 \\
6.02\end{array}$ & $\begin{array}{l}2,250 \\
2,100 \\
1,940 \\
1,780 \\
1,630 \\
1,510\end{array}$ \\
\hline \multirow[t]{2}{*}{$\begin{array}{r}7 \\
8 \\
9 \\
10 \\
11 \\
\mathbf{M} \\
\end{array}$} & $\begin{array}{l}2.26 \\
2.26 \\
2.26 \\
2.27 \\
2.31 \\
2.36\end{array}$ & $\begin{array}{l}158 \\
158 \\
158 \\
160 \\
167 \\
175 \\
\end{array}$ & $\begin{array}{l}2.87 \\
2.88 \\
2.88 \\
2.88 \\
2.88 \\
2.88\end{array}$ & $\begin{array}{l}275 \\
278 \\
278 \\
278 \\
278 \\
278 \\
\end{array}$ & $\begin{array}{l}3.50 \\
3.63 \\
3.77 \\
3.99 \\
4.19 \\
4.37\end{array}$ & $\begin{array}{l}440 \\
479 \\
521 \\
596 \\
666 \\
730 \\
\end{array}$ & $\begin{array}{l}7.61 \\
7.93 \\
8.22 \\
8.51 \\
8.77 \\
9.05\end{array}$ & $\begin{array}{l}2,540 \\
2,760 \\
2,980 \\
3,210 \\
3,420 \\
3,640 \\
\end{array}$ & $\begin{array}{l}9.17 \\
9.06 \\
8.97 \\
8.87 \\
8.75 \\
8.61\end{array}$ & $\begin{array}{l}3,740 \\
3,650 \\
3,580 \\
3,500 \\
3,400 \\
3,290 \\
\end{array}$ & $\begin{array}{l}5.86 \\
5.75 \\
5.65 \\
5.57 \\
5.51 \\
5.46 \\
\end{array}$ & $\begin{array}{l}1,420 \\
1,350 \\
1,300 \\
1,260 \\
1,220 \\
1,200\end{array}$ \\
\hline & \multicolumn{2}{|c|}{ September 24} & \multicolumn{2}{|c|}{ September } & \multicolumn{2}{|c|}{ September 26} & \multicolumn{2}{|c|}{ September 27} & \multicolumn{2}{|c|}{ September 28} & \multicolumn{2}{|c|}{ September 29} \\
\hline $\begin{array}{r}2 \\
4 \\
6 \\
8 \\
10 \\
\text { N }\end{array}$ & $\begin{array}{l}5.37 \\
5.28 \\
5.20 \\
5.13 \\
5.07 \\
5.00\end{array}$ & $\begin{array}{r}1,160 \\
1,110 \\
1,070 \\
1,040 \\
1,010 \\
980\end{array}$ & $\begin{array}{l}4.63 \\
4.57 \\
4.51 \\
4.47 \\
4.43 \\
4.39\end{array}$ & \begin{tabular}{|l|}
832 \\
808 \\
784 \\
768 \\
752 \\
736 \\
\end{tabular} & $\begin{array}{l}4.32 \\
4.28 \\
4.25 \\
4.22 \\
4.19 \\
4.16\end{array}$ & $\begin{array}{l}712 \\
698 \\
688 \\
677 \\
666 \\
656\end{array}$ & $\begin{array}{l}3.97 \\
3.95 \\
3.91 \\
3.89 \\
3.88 \\
3.89\end{array}$ & $\begin{array}{l}590 \\
582 \\
568 \\
562 \\
558 \\
562\end{array}$ & $\begin{array}{l}3.81 \\
3.89 \\
3.87 \\
3.85 \\
3.83 \\
3.81\end{array}$ & $\begin{array}{r}568 \\
562 \\
554 \\
548 \\
540 \\
534\end{array}$ & $\begin{array}{l}3.54 \\
3.52 \\
3.50 \\
3.47 \\
3.46 \\
3.45\end{array}$ & $\begin{array}{l}452 \\
446 \\
440 \\
481 \\
428 \\
425\end{array}$ \\
\hline $\begin{array}{r}2 \\
4 \\
6 \\
8 \\
10 \\
11\end{array}$ & $\begin{array}{l}4.94 \\
4.88 \\
4.83 \\
4.77 \\
4.71 \\
4.67\end{array}$ & $\begin{array}{l}956 \\
932 \\
912 \\
888 \\
864 \\
848\end{array}$ & $\begin{array}{l}4.35 \\
4.31 \\
4.29 \\
4.32 \\
4.33 \\
4.34\end{array}$ & $\begin{array}{l}722 \\
708 \\
702 \\
712 \\
716 \\
719\end{array}$ & $\begin{array}{l}4.13 \\
4.11 \\
4.08 \\
4.05 \\
4.02 \\
3.99\end{array}$ & $\begin{array}{l}646 \\
638 \\
628 \\
618 \\
607 \\
596\end{array}$ & $\begin{array}{l}3.89 \\
3.91 \\
3.93 \\
3.93 \\
3.93 \\
3.93\end{array}$ & $\begin{array}{l}562 \\
568 \\
576 \\
576 \\
576 \\
576\end{array}$ & $\begin{array}{l}3.80 \\
3.78 \\
3.75 \\
3.67 \\
3.60 \\
3.55\end{array}$ & $\begin{array}{l}530 \\
524 \\
515 \\
491 \\
470 \\
455\end{array}$ & $\begin{array}{l}3.43 \\
3.43 \\
3.42 \\
3.37 \\
3.28 \\
3.20\end{array}$ & $\begin{array}{l}419 \\
419 \\
416 \\
402 \\
377 \\
355\end{array}$ \\
\hline
\end{tabular}


Indian Lake Reservoir near Indian Lake, N. $\mathrm{Y}$.

Location.- Staff gage, lat. $43^{\circ} 45^{\prime} 2^{\prime \prime}$, long. $74^{\circ} 16^{\prime} 35^{\prime \prime}$, at Indian Lake Dam, 2 miles south of Indian Lake viliage, Hamilton County. Zero of gage is $1,617.95$ feet above mean sea level.

Drainage area.- 131 square miles.

Gage-height record.- Gage read to tenths daily about 8 a.m.

Maxima.- September 1938 to October 1938: Maximum gage height observed, 24.6 feet oct. 13-14.

1900 to August 1938: Maximum gage height observed, 38.8 feet Mar. $28,1913$.

Remarks. - Flow from reservoir regulated by operation of sluice gates. Usable storage capacity, about 4,700,000,000 cubic feet. Because of wave action, gage readings and corresponding contents may be approximate.

Gage height, in feet, and contents, in millions of cuble feet, 1938

\begin{tabular}{|c|c|c|c|c|c|c|c|c|c|c|}
\hline \multirow[b]{2}{*}{ Day } & \multicolumn{2}{|r|}{ September } & \multicolumn{2}{|r|}{ october } & \multirow[b]{2}{*}{ Day } & \multicolumn{2}{|c|}{ September } & \multicolumn{3}{|c|}{ October } \\
\hline & Feet & $\begin{array}{l}\text { Millions of } \\
\text { cublc feet }\end{array}$ & Feet & $\begin{array}{l}\text { Millions of } \\
\text { cubic feet }\end{array}$ & & Feet & $\begin{array}{l}\text { Millions of } \\
\text { cubic feet }\end{array}$ & Feet & & $\begin{array}{l}\text { llions of } \\
\text { abic feet }\end{array}$ \\
\hline $\begin{array}{l}1 \\
2 \\
3 \\
4 \\
5\end{array}$ & $\begin{array}{l}21.7 \\
21.6 \\
21.4 \\
21.3 \\
21.1\end{array}$ & $\begin{array}{l}2,671 \\
2,655 \\
2,624 \\
2,608 \\
2,576\end{array}$ & $\begin{array}{l}24.2 \\
24.2 \\
24.3 \\
24.3 \\
24.3\end{array}$ & $\begin{array}{l}3,075 \\
3,075 \\
3,091 \\
3,091 \\
3,091\end{array}$ & $\begin{array}{l}16 \\
17 \\
18 \\
19 \\
20\end{array}$ & $\begin{array}{l}18.8 \\
18.8 \\
18.9 \\
19.0 \\
19.1\end{array}$ & $\begin{array}{l}2,218 \\
2,218 \\
2,234 \\
2,249 \\
2,264\end{array}$ & $\begin{array}{l}24.4 \\
24.3 \\
24.2 \\
24.1 \\
24.0\end{array}$ & & $\begin{array}{l}3,108 \\
3,091 \\
3,075 \\
3,058 \\
3,042\end{array}$ \\
\hline $\begin{array}{r}6 \\
7 \\
8 \\
9 \\
10\end{array}$ & $\begin{array}{l}21.0 \\
20.8 \\
20.4 \\
20.1 \\
19.8\end{array}$ & $\begin{array}{l}2,560 \\
2,529 \\
2,466 \\
2,419 \\
2,372\end{array}$ & $\begin{array}{l}24.4 \\
24.4 \\
24.5 \\
24.5 \\
24.5\end{array}$ & $\begin{array}{l}3,108 \\
3,108 \\
3,124 \\
3,124 \\
3,124\end{array}$ & $\begin{array}{l}21 \\
22 \\
23 \\
24 \\
25\end{array}$ & $\begin{array}{l}19.7 \\
21.5 \\
22.5 \\
23.1 \\
23.5\end{array}$ & $\begin{array}{l}2,357 \\
2,639 \\
2,800 \\
2,896 \\
2,961\end{array}$ & $\begin{array}{l}23.9 \\
23.7 \\
23.6 \\
23.5 \\
23.7\end{array}$ & & $\begin{array}{l}3,026 \\
2,993 \\
2,977 \\
2,961 \\
2,993\end{array}$ \\
\hline $\begin{array}{l}11 \\
12 \\
13 \\
14 \\
15\end{array}$ & $\begin{array}{l}19.5 \\
19.2 \\
19.0 \\
18.8 \\
18.6\end{array}$ & $\begin{array}{l}2,326 \\
2,280 \\
2,249 \\
2,218 \\
2,188\end{array}$ & $\begin{array}{l}24.5 \\
24.5 \\
24.6 \\
24.6 \\
24.5\end{array}$ & $\begin{array}{l}3,124 \\
3,124 \\
3,140 \\
3,140 \\
3,124\end{array}$ & $\begin{array}{l}26 \\
27 \\
28 \\
29 \\
30 \\
31\end{array}$ & $\begin{array}{l}23.7 \\
23.8 \\
23.9 \\
24.0 \\
24.1\end{array}$ & $\begin{array}{l}2,993 \\
3,010 \\
3,026 \\
3,042 \\
3,058\end{array}$ & $\begin{array}{l}23.8 \\
23.9 \\
24.0 \\
24.1 \\
24.0 \\
23.9\end{array}$ & & $\begin{array}{l}3,010 \\
3,026 \\
3,042 \\
3,058 \\
3,042 \\
3,026\end{array}$ \\
\hline & & & & & & & & eptem & & October \\
\hline (1) & & 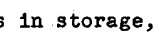 & & & & & & & & -20.5 \\
\hline
\end{tabular}

a Computed from contents corresponding to gage height interpolated for midnight of last day of month. 
Location. - Water-stage recorder, lat. $45^{\circ} 45^{\prime} 30^{\prime}$, long. $74^{\circ} 16^{\prime} 05^{n}$, three-quarters of a mile below Indian Lake Dam and 2 miles south of Indian Lake village, Hamilton County.

Drainage_area.- 132 square miles; 131 square miles affected by storage in Indian Lake Reservoir.

Gage-height record.- Water-stage recorder graph.

Stage-discharge relation.- Defined by current-meter measurements below 1,630 secondfeet.

Maxima.- September 1938: Discharge during flood period, 58 second-feot 8:30 p. m. sept. 21 (gage he1ght, 0.97 foot).

1912-14, 1915 to August 1938. Discharge, about 3,460 second-feet Mar. 28, 1913 (gage height, 7.8 feet).

Remarks.- For Information on storage see record for Indian Lake Reservoir near Indian Lake, N. Y. Mean montinly discharge adjusted for storage.

Mean daily discharge, in second-feet, 1938

\begin{tabular}{|c|c|c|c|c|c|c|c|c|c|c|c|}
\hline Day & Sept. & oct. & Day & Sept. & Oct. & Day & Sept. & oct. & Day & Sept. & $.0 \mathrm{ct}$ \\
\hline $\begin{array}{l}1 \\
2 \\
3 \\
4 \\
5 \\
6 \\
7 \\
8\end{array}$ & $\begin{array}{l}302 \\
299 \\
299 \\
296 \\
296 \\
428 \\
628 \\
624\end{array}$ & $\begin{array}{l}2.1 \\
2.1 \\
2.1 \\
2.1 \\
2.1 \\
2.1 \\
2.1 \\
2.1\end{array}$ & $\begin{array}{l}9 \\
10 \\
11 \\
12 \\
13 \\
14 \\
15 \\
16\end{array}$ & $\begin{array}{r}608 \\
596 \\
588 \\
584 \\
580 \\
576 \\
219 \\
2.3\end{array}$ & $\begin{array}{r}2.1 \\
2.1 \\
2.1 \\
2.1 \\
2.1 \\
123 \\
326 \\
323\end{array}$ & $\begin{array}{l}17 \\
18 \\
19 \\
20 \\
21 \\
22 \\
23 \\
24\end{array}$ & $\begin{array}{c}1.8 \\
1.6 \\
1.6 \\
4.5 \\
22 \\
11 \\
4.1 \\
2.8\end{array}$ & $\begin{array}{l}267 \\
156 \\
311 \\
308 \\
305 \\
305 \\
305 \\
189\end{array}$ & $\begin{array}{l}25 \\
26 \\
27 \\
28 \\
29 \\
30 \\
31\end{array}$ & $\begin{array}{l}2.4 \\
2.1 \\
2.1 \\
2.6 \\
2.3 \\
2.1\end{array}$ & $\begin{array}{r}3.6 \\
2.3 \\
1.9 \\
1.8 \\
176 \\
305 \\
305\end{array}$ \\
\hline $\begin{array}{l}\text { Mean } \\
\text { Mean } \\
\text { Run- }\end{array}$ & $\begin{array}{l}\text { monthly } \\
\text { monthly } \\
\text { ff, in }\end{array}$ & $\begin{array}{l}\text { dischar } \\
\text { dischar } \\
\text { nches }\end{array}$ & $\begin{array}{l}\text { ir } \\
\text { ir } \\
\text { just }\end{array}$ & $\begin{array}{l}\text { second- } \\
\text { second-1 } \\
\text { d) . . }\end{array}$ & $\begin{array}{l}\text { eet } \text { ob } \\
\text { eet ad } \\
\text {. }\end{array}$ & $\begin{array}{c}\text { arved) } \\
\text { asted) } \\
.\end{array}$ & 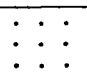 & 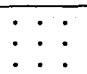 & $\dot{:}: \dot{ }$ & $\begin{array}{r}233 \\
385 \\
3.26\end{array}$ & $\begin{array}{r}121 \\
100 \\
0.87\end{array}$ \\
\hline
\end{tabular}

Gage height, in feet, and discharge, in second-feet, at indicated time, 1938

\begin{tabular}{|c|c|c|c|c|c|c|c|c|c|c|c|c|}
\hline \multirow{2}{*}{ 苟 } & \multicolumn{2}{|c|}{ September 18} & \multicolumn{2}{|c|}{ September 19} & \multicolumn{2}{|c|}{ September 20} & \multicolumn{2}{|c|}{ September 21} & \multicolumn{2}{|c|}{ September 22} & \multicolumn{2}{|c|}{ September 23} \\
\hline & Feet & Sec.-ft & Feet & Sec.-ft & Feet & Sec. $-f t$ & F'eet & Sec.-ft. & Feet & Sec.-ft & Feet & Sec.-ft. \\
\hline $\begin{array}{r}2 \\
4 \\
6 \\
8 \\
10 \\
\mathrm{~N}\end{array}$ & $\begin{array}{l}- \\
- \\
0.18 \\
- \\
- \\
.18\end{array}$ & $\begin{array}{l}- \\
- \\
- \\
- \\
1.6\end{array}$ & $\begin{array}{l}- \\
- \\
0.18 \\
- \\
- \\
.18\end{array}$ & $\begin{array}{l}- \\
- \\
-1.6 \\
- \\
1.6\end{array}$ & $\begin{array}{r}0.20 \\
.21 \\
.22 \\
.23 \\
.24 \\
.25\end{array}$ & $\begin{array}{l}1.9 \\
2.1 \\
2.3 \\
2.4 \\
2.6 \\
2.8\end{array}$ & $\begin{array}{r}0.55 \\
.53 \\
.49 \\
.45 \\
.45 \\
.45\end{array}$ & $\begin{array}{l}16.5 \\
15.1 \\
12.5 \\
10.4 \\
10.4 \\
10.4\end{array}$ & $\begin{array}{r}0.64 \\
.56 \\
.50 \\
.46 \\
.43 \\
.40\end{array}$ & $\begin{array}{r}23.2 \\
17.2 \\
13.0 \\
10.9 \\
9.3 \\
7.7\end{array}$ & $\begin{array}{l}- \\
- \\
0.31 \\
- \\
- \\
.30\end{array}$ & $\begin{array}{l}- \\
-4.5 \\
- \\
-4.1\end{array}$ \\
\hline $\begin{array}{r}2 \\
4 \\
6 \\
8 \\
10 \\
M\end{array}$ & $\begin{array}{l}- \\
- \\
.18 \\
- \\
.18\end{array}$ & $\begin{array}{l}- \\
- \\
-1.6 \\
- \\
1.6\end{array}$ & $\begin{array}{l}- \\
- \\
.18 \\
- \\
. \\
.20\end{array}$ & $\begin{array}{l}- \\
-1.6 \\
- \\
1.9\end{array}$ & $\begin{array}{l}.28 \\
.31 \\
.35 \\
.39 \\
.45 \\
.53\end{array}$ & $\begin{array}{r}3.6 \\
4.5 \\
5.9 \\
7.3 \\
10.3 \\
15.1\end{array}$ & $\begin{array}{l}.50 \\
.61 \\
.71 \\
.94 \\
.91 \\
.75\end{array}$ & $\begin{array}{l}13.0 \\
20.8 \\
29.0 \\
54 \\
50 \\
33.0\end{array}$ & $\begin{array}{l}.38 \\
.36 \\
.35 \\
.34 \\
.33 \\
.32\end{array}$ & $\begin{array}{l}7.0 \\
6.3 \\
5.9 \\
5.5 \\
5.2 \\
4.8\end{array}$ & $\begin{array}{l}- \\
- \\
.29 \\
- \\
.28\end{array}$ & $\begin{array}{l}- \\
- \\
-3.8 \\
- \\
3.6\end{array}$ \\
\hline
\end{tabular}

Supplemental records.- Sept. $21,8: 30$ p.m., 0.97 foot, 58 second-feet. 
Location.- Water-stage recorder, lat. $43^{\circ} 36^{\prime} 40^{\prime \prime}$, long. $73^{\circ} 44^{\prime} 10^{\prime \prime}$, at highway bridge at Riverbank, Warren County, 9 miles below Schroon Lake Reservoir.

Drainage area.- 527 square miles.

Gage-height record.- Water-stage recorder graph.

Stage-discharge relation.- For 1938 defined by current-meter measurements below 3,820

second-feet. For 1936 defined by current-meter measurements below 11,200 secondfeet.

Maxima:- September 1938: D1scharge, 3,850 second-feet 1 a.m. Sept. 24 (gage he1ght, 7.44 feet).

September 1907 to August 1938: Discharge, 12,100 second-feet Mar. 21, 1936 (gage height, 12.18 feet, from flood marks).

Remarks.- Discharge affected by storage in Schroon Lake, Brant Lake, and other small lakes and reservoirs.

Mean daily discharge, in second-feet, 1938

\begin{tabular}{|c|c|c|c|c|c|c|c|c|c|c|c|}
\hline Day & Sept. & Oct. & Dey & Sept. & Oet. & Day & Sept. & Oct. & Day & Sept. & Oct. \\
\hline $\begin{array}{l}1 \\
2 \\
3 \\
4 \\
5 \\
6 \\
7 \\
8\end{array}$ & $\begin{array}{l}242 \\
232 \\
229 \\
217 \\
207 \\
189 \\
184 \\
198 \\
\end{array}$ & $\begin{array}{r}1,660 \\
1,480 \\
1,310 \\
1,170 \\
1,060 \\
974 \\
860 \\
781 \\
\end{array}$ & $\begin{array}{r}9 \\
10 \\
11 \\
12 \\
13 \\
14 \\
15 \\
16 \\
\end{array}$ & $\begin{array}{l}189 \\
175 \\
166 \\
172 \\
166 \\
169 \\
214 \\
269 \\
\end{array}$ & $\begin{array}{l}723 \\
661 \\
607 \\
576 \\
537 \\
508 \\
480 \\
457 \\
\end{array}$ & $\begin{array}{l}17 \\
18 \\
19 \\
20 \\
21 \\
22 \\
23 \\
24\end{array}$ & $\begin{array}{r}286 \\
301 \\
319 \\
432 \\
1,050 \\
2,560 \\
3,680 \\
3,760 \\
\end{array}$ & $\begin{array}{l}431 \\
418 \\
381 \\
373 \\
377 \\
365 \\
346 \\
449\end{array}$ & $\begin{array}{l}25 \\
26 \\
27 \\
28 \\
29 \\
30 \\
31\end{array}$ & $\begin{array}{l}3,490 \\
3,090 \\
2,710 \\
2,380 \\
2,100 \\
1,850\end{array}$ & $\begin{array}{l}607 \\
672 \\
661 \\
644 \\
613 \\
592 \\
551\end{array}$ \\
\hline $\begin{array}{l}\text { Mean } \\
\text { Run- }\end{array}$ & $\begin{array}{l}\text { nthly } \\
\text { in }\end{array}$ & gahar &. & - . & et. & $\dot{.}$ & $\begin{array}{l}\cdot \cdot \dot{ } \\
\cdot\end{array}$ & 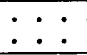 & $\dot{0}$ & $\begin{array}{r}1,041 \\
2.21\end{array}$ & $\begin{array}{r}688 \\
1.51 \\
\end{array}$ \\
\hline
\end{tabular}

Gage helght, in feet, and discharge, In second-feet, at indicated time, 1938

\begin{tabular}{|c|c|c|c|c|c|c|c|c|c|c|c|c|}
\hline \multirow{2}{*}{ 尔 } & Feet & Sec.ft. & Feet & Sec.st. & Feet & Sec.ft. & Feet & Sec.ft. & Feet & Sec.ft. & Feet & Sec.ft. \\
\hline & \multicolumn{2}{|c|}{ September 18} & \multicolumn{2}{|c|}{ September 19} & \multicolumn{2}{|c|}{ September 20} & \multicolumn{2}{|c|}{ September 21} & \multicolumn{2}{|c|}{ September 22 } & \multicolumn{2}{|c|}{ September 23} \\
\hline $\begin{array}{l}1 \\
2 \\
3 \\
4 \\
5 \\
6\end{array}$ & $\begin{array}{l}1.98 \\
1.99 \\
1.99 \\
2.00 \\
2.00 \\
2.00\end{array}$ & $\begin{array}{l}290 \\
294 \\
294 \\
297 \\
297 \\
297\end{array}$ & $\begin{array}{l}2.03 \\
2.03 \\
2.03 \\
2.04 \\
2.04 \\
2.04\end{array}$ & $\begin{array}{l}308 \\
308 \\
308 \\
312 \\
312 \\
312\end{array}$ & $\begin{array}{l}2.15 \\
2.16 \\
2.17 \\
2.18 \\
2.19 \\
2.20\end{array}$ & \begin{tabular}{|l|}
354 \\
357 \\
361 \\
365 \\
369 \\
373
\end{tabular} & $\begin{array}{l}2.66 \\
2.69 \\
2.71 \\
2.73 \\
2.77 \\
2.80\end{array}$ & $\begin{array}{l}582 \\
597 \\
607 \\
618 \\
639 \\
655\end{array}$ & $\begin{array}{l}4.46 \\
4.51 \\
4.57 \\
4.65 \\
4.75 \\
4.87\end{array}$ & $\begin{array}{l}1,760 \\
1,800 \\
1,840 \\
1,900 \\
1,960 \\
2,050\end{array}$ & $\begin{array}{l}6.83 \\
6.84 \\
6.86 \\
6.93 \\
6.99 \\
7.05\end{array}$ & $\begin{array}{l}3,420 \\
3,430 \\
3,440 \\
3,490 \\
3,530 \\
3,580\end{array}$ \\
\hline $\begin{array}{r}7 \\
8 \\
9 \\
10 \\
11 \\
N\end{array}$ & $\begin{array}{l}2.01 \\
2.01 \\
2.01 \\
2.01 \\
2.01 \\
2.02\end{array}$ & $\begin{array}{l}301 \\
301 \\
301 \\
301 \\
301 \\
304\end{array}$ & $\begin{array}{l}2.04 \\
2.04 \\
2.04 \\
2.04 \\
2.05 \\
2.05\end{array}$ & $\begin{array}{l}312 \\
312 \\
312 \\
312 \\
316 \\
316\end{array}$ & $\begin{array}{l}2.22 \\
2.23 \\
2.24 \\
2.26 \\
2.28 \\
2.29\end{array}$ & $\begin{array}{l}381 \\
385 \\
389 \\
398 \\
406 \\
410\end{array}$ & $\begin{array}{l}2.84 \\
2.88 \\
2.94 \\
3.00 \\
3.09 \\
3.19\end{array}$ & $\begin{array}{l}677 \\
700 \\
734 \\
769 \\
823 \\
885\end{array}$ & $\begin{array}{l}4.98 \\
5.09 \\
5.21 \\
5.32 \\
5.46 \\
5.58\end{array}$ & $\begin{array}{l}2,130 \\
2,200 \\
2,290 \\
2,360 \\
2,460 \\
2,550\end{array}$ & & $\begin{array}{l}3,610 \\
3,620 \\
3,640 \\
3,670 \\
3,690 \\
3,730\end{array}$ \\
\hline $\begin{array}{l}1 \\
2 \\
3 \\
4 \\
5 \\
6\end{array}$ & $\begin{array}{l}2.02 \\
2.02 \\
2.02 \\
2.02 \\
2.03 \\
2.03\end{array}$ & $\begin{array}{l}304 \\
304 \\
304 \\
304 \\
308 \\
308\end{array}$ & $\begin{array}{l}2.05 \\
2.05 \\
2.05 \\
2.06 \\
2.06 \\
2.08\end{array}$ & $\begin{array}{l}316 \\
316 \\
316 \\
319 \\
319 \\
327\end{array}$ & $\begin{array}{l}2.31 \\
2.33 \\
2.34 \\
2.37 \\
2.40 \\
2.43\end{array}$ & $\begin{array}{l}418 \\
427 \\
431 \\
444 \\
457 \\
471\end{array}$ & $\begin{array}{l}3.29 \\
3.40 \\
3.51 \\
3.64 \\
3.79 \\
3.93\end{array}$ & $\begin{array}{r}949 \\
1,020 \\
1,100 \\
1,190 \\
1,290 \\
1,390\end{array}$ & $\begin{array}{l}5.68 \\
5.79 \\
5.88 \\
6.00 \\
6.13 \\
6.19\end{array}$ & $\begin{array}{l}2,620 \\
2,690 \\
2,760 \\
2,840 \\
2,930 \\
2,970\end{array}$ & $\begin{array}{l}7.31 \\
7.34 \\
7.36 \\
7.38 \\
7.39 \\
7.40\end{array}$ & $\begin{array}{l}3,760 \\
3,780 \\
3,790 \\
3,810 \\
3,810 \\
3,820\end{array}$ \\
\hline \multirow[t]{2}{*}{$\begin{array}{r}7 \\
8 \\
9 \\
10 \\
11 \\
M \\
\end{array}$} & $\begin{array}{l}2.03 \\
2.03 \\
2.03 \\
2.03 \\
2.03 \\
2.02\end{array}$ & $\begin{array}{l}308 \\
308 \\
308 \\
308 \\
308 \\
304\end{array}$ & $\begin{array}{l}2.09 \\
2.10 \\
2.11 \\
2.12 \\
2.13 \\
2.14 \\
\end{array}$ & $\begin{array}{l}330 \\
334 \\
338 \\
342 \\
346 \\
350\end{array}$ & $\begin{array}{l}2.47 \\
2.51 \\
2.54 \\
2.57 \\
2.60 \\
2.64\end{array}$ & $\begin{array}{l}489 \\
508 \\
522 \\
537 \\
551 \\
571\end{array}$ & $\begin{array}{l}4.10 \\
4.27 \\
4.38 \\
4.40 \\
4.42 \\
4.44\end{array}$ & $\begin{array}{l}1,510 \\
1,630 \\
1,710 \\
1,720 \\
1,730 \\
1,750\end{array}$ & $\begin{array}{l}6.30 \\
6.41 \\
6.49 \\
6.58 \\
6.65 \\
6.74\end{array}$ & $\begin{array}{l}3,050 \\
3,130 \\
3,180 \\
3,250 \\
3,300 \\
3,360\end{array}$ & $\begin{array}{l}7.40 \\
7.40 \\
7.40 \\
7.41 \\
7.43 \\
7.44\end{array}$ & $\begin{array}{l}3,820 \\
3,820 \\
3,820 \\
3,830 \\
3,840 \\
3,850\end{array}$ \\
\hline & \multicolumn{2}{|c|}{ September 24} & \multicolumn{2}{|c|}{ September 25} & \multicolumn{2}{|c|}{ September 26} & \multicolumn{2}{|c|}{ September 27} & \multicolumn{2}{|c|}{ September 28} & \multicolumn{2}{|c|}{ September 29} \\
\hline $\begin{array}{r}2 \\
4 \\
6 \\
8 \\
10 \\
\mathrm{~N}\end{array}$ & $\begin{array}{l}7.42 \\
7.40 \\
7.39 \\
7.38 \\
7.36 \\
7.34\end{array}$ & $\begin{array}{l}3,830 \\
3,820 \\
3,810 \\
3,810 \\
3,790 \\
3,780\end{array}$ & $\begin{array}{l}7.14 \\
7.10 \\
7.06 \\
7.02 \\
6.97 \\
6.93\end{array}$ & $\begin{array}{l}3,640 \\
3,610 \\
3,580 \\
3,550 \\
3,520 \\
3,490\end{array}$ & $\begin{array}{l}6.61 \\
6.56 \\
6.51 \\
6.46 \\
6.41 \\
6.37\end{array}$ & $\begin{array}{l}3,270 \\
3,230 \\
3,200 \\
3,160 \\
3,130 \\
3,100\end{array}$ & \begin{tabular}{|l|}
6.04 \\
5.99 \\
5.94 \\
5.90 \\
5.84 \\
5.80
\end{tabular} & $\begin{array}{l}2,870 \\
2,830 \\
2,800 \\
2,770 \\
2,730 \\
2,700\end{array}$ & $\begin{array}{l}5.52 \\
5.48 \\
5.45 \\
5.41 \\
5.37 \\
5.33\end{array}$ & $\begin{array}{l}2,500 \\
2,480 \\
2,460 \\
2,430 \\
2,400 \\
2,370\end{array}$ & $\begin{array}{l}5.09 \\
5.06 \\
5.03 \\
5.00 \\
4.97 \\
4.94\end{array}$ & $\begin{array}{l}2,200 \\
2,180 \\
2,160 \\
2,140 \\
2,120 \\
2,100\end{array}$ \\
\hline $\begin{array}{r}2 \\
4 \\
6 \\
8 \\
10 \\
M \\
\end{array}$ & $\begin{array}{l}7.32 \\
7.30 \\
7.27 \\
7.23 \\
7.21 \\
7.17 \\
\end{array}$ & $\begin{array}{l}3,760 \\
3,750 \\
3,730 \\
3,700 \\
3,690 \\
3,660\end{array}$ & $\begin{array}{l}6.89 \\
6.85 \\
6.81 \\
6.75 \\
6.71 \\
6.66\end{array}$ & $\begin{array}{l}3,460 \\
3,440 \\
3,410 \\
3,360 \\
3,340 \\
3,300\end{array}$ & $\begin{array}{l}6.32 \\
6.25 \\
6.20 \\
6.16 \\
6.12 \\
6.08\end{array}$ & $\begin{array}{l}3,060 \\
3,020 \\
2,980 \\
2,950 \\
2,920 \\
2,900\end{array}$ & $\begin{array}{l}5.75 \\
5.72 \\
5.68 \\
5.64 \\
5.60 \\
5.56\end{array}$ & $\begin{array}{l}2,660 \\
2,640 \\
2,620 \\
2,590 \\
2,560 \\
2,530\end{array}$ & $\begin{array}{l}5.30 \\
5.26 \\
5.23 \\
5.19 \\
5.16 \\
5.13\end{array}$ & $\begin{array}{l}2,350 \\
2,320 \\
2,300 \\
2,270 \\
2,250 \\
2,230\end{array}$ & $\begin{array}{l}4.90 \\
4.87 \\
4.86 \\
4.83 \\
4.80 \\
4.76\end{array}$ & $\begin{array}{l}2,070 \\
2,050 \\
2,040 \\
2,020 \\
2,000 \\
1,970\end{array}$ \\
\hline
\end{tabular}

Supplemental records.- Sept..24, 1 a.m., $7.44 \mathrm{ft.,} 3,850$ sec.-ft. 


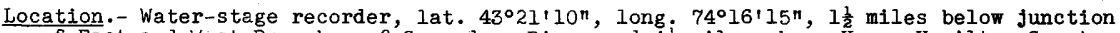
of East and West Branches of Sacandaga River' and $4 \frac{i}{2}$ miles above Hope, Hamilton County. Drainage area.- 491 square miles.

Gage-height record. - Water-stage recorder graph.

Stage-discharge relation. - For 1938 defined by current-meter measurements below 15,000 second-feet; extended logarithmically to peak stage. For 1913 defined by currentmeter measurements below 8,440 second-feet; extended logarithmically as a tangent to peak stage.

Maxima:- September 1938: Discharge, 16,200 second-feet 1 a.m. Sept. 22 (gage height, 8.04 feet)

September 1911 to August 1938: Discharge, 32,000 second-feet Mar. 27, 1913 (gage height, 11.0 feet, from floodmarks at former staff gage, present datum).

Remarks.- Flood discharge not affected by artificial storage or diversions. Occasional diurnal fluctuation due to operation of small dams.

Mean daily discharge, in second-feet, 1938

\begin{tabular}{|c|c|c|c|c|c|c|c|c|c|c|c|}
\hline Day & Sept. & oct. & Day & Sept. & 0ct. & Day & Sept. & Oct. & Day & Sept. & Oct. \\
\hline $\begin{array}{l}1 \\
2 \\
3 \\
4 \\
5 \\
6 \\
7 \\
8\end{array}$ & $\begin{array}{r}102 \\
99 \\
94 \\
87 \\
76 \\
73 \\
82 \\
115\end{array}$ & $\begin{array}{l}890 \\
784 \\
703 \\
634 \\
577 \\
522 \\
472 \\
437\end{array}$ & $\begin{array}{r}9 \\
10 \\
11 \\
12 \\
13 \\
14 \\
15 \\
16\end{array}$ & $\begin{array}{r}102 \\
92 \\
89 \\
99 \\
144 \\
150 \\
501 \\
694\end{array}$ & $\begin{array}{l}411 \\
392 \\
367 \\
350 \\
332 \\
321 \\
315 \\
300\end{array}$ & $\begin{array}{l}17 \\
18 \\
19 \\
20 \\
21 \\
22 \\
23 \\
24 \\
\end{array}$ & $\begin{array}{r}464 \\
444 \\
464 \\
1,240 \\
7,530 \\
11,100 \\
5,920 \\
3,860 \\
\end{array}$ & $\begin{array}{l}284 \\
273 \\
264 \\
254 \\
259 \\
259 \\
250 \\
593\end{array}$ & $\begin{array}{l}25 \\
26 \\
27 \\
28 \\
29 \\
30 \\
31\end{array}$ & $\begin{array}{l}2,670 \\
2,000 \\
1,620 \\
1,470 \\
1,210 \\
1,040\end{array}$ & $\begin{array}{r}1,500 \\
1,150 \\
940 \\
804 \\
685 \\
592 \\
522\end{array}$ \\
\hline $\begin{array}{l}\text { Mean } \\
\text { Run- }\end{array}$ & $\begin{array}{l}\text { nthly } \\
e \text {, in } 1\end{array}$ & $\begin{array}{l}\text { schar } \\
\text { hes. }\end{array}$ & 1n & . . . & . &. & $\begin{array}{lll}\cdot & \bullet & \bullet \\
. & \cdot & \bullet\end{array}$ & $\begin{array}{lll}\cdot & \bullet & . \\
. & . & .\end{array}$ & $: \dot{ }$ & $\begin{array}{r}1,451 \\
3.30\end{array}$ & $\begin{array}{r}530 \\
1.24\end{array}$ \\
\hline
\end{tabular}

Gage height, in feet, and discharge, in second-feet, at indicated time, 1938

\begin{tabular}{|c|c|c|c|c|c|c|c|c|c|c|c|c|}
\hline \multirow{2}{*}{$\begin{array}{l}9 \\
3 \\
0 \\
0\end{array}$} & Feet & Sec.ft. & Feet & Sec.ft. & Feet & Sec.ft. & Feet & Sec.ft. & Feet & Sec.ft. & Feet & Sec.ft. \\
\hline & \multicolumn{2}{|c|}{ September 18} & \multicolumn{2}{|c|}{ September 19} & \multicolumn{2}{|c|}{ September 20} & \multicolumn{2}{|c|}{ September 21} & \multicolumn{2}{|c|}{ September $2 \dot{2}$} & \multicolumn{2}{|c|}{ September 23} \\
\hline $\begin{array}{l}1 \\
2 \\
3 \\
4 \\
5 \\
6\end{array}$ & $\begin{array}{l}2.28 \\
2.28 \\
2.28 \\
2.29 \\
2.29 \\
2.29\end{array}$ & $\begin{array}{l}437 \\
437 \\
437 \\
444 \\
444 \\
444\end{array}$ & $\begin{array}{l}2.27 \\
2.27 \\
2.27 \\
2.26 \\
2.26 \\
2.26\end{array}$ & $\begin{array}{l}430 \\
430 \\
430 \\
426 \\
426 \\
426\end{array}$ & $\begin{array}{l}2.46 \\
2.48 \\
2.51 \\
2.53 \\
2.57 \\
2.60\end{array}$ & $\begin{array}{l}569 \\
584 \\
608 \\
626 \\
660 \\
685\end{array}$ & $\begin{array}{l}4.80 \\
4.97 \\
5.10 \\
5.20 \\
5.24 \\
5.27\end{array}$ & $\begin{array}{l}4,130 \\
4,530 \\
4,850 \\
5,110 \\
5,220 \\
5,300\end{array}$ & $\begin{array}{l}8.04 \\
8.00 \\
7.91 \\
7.81 \\
7.68 \\
7.52\end{array}$ & $\begin{array}{l}16,200 \\
16,000 \\
15,550 \\
15,050 \\
14,400 \\
13,600\end{array}$ & \begin{tabular}{|l|}
5.84 \\
5.81 \\
5.77 \\
5.74 \\
5.70 \\
5.68
\end{tabular} & $\begin{array}{l}6,980 \\
6,890 \\
6,770 \\
6,670 \\
6,550 \\
6,490\end{array}$ \\
\hline $\begin{array}{r}7 \\
8 \\
9 \\
10 \\
11 \\
\mathrm{~N}\end{array}$ & $\begin{array}{l}2.30 \\
2.30 \\
2.30 \\
2.30 \\
2.30 \\
2.30\end{array}$ & $\begin{array}{l}450 \\
450 \\
450 \\
450 \\
450 \\
450\end{array}$ & $\begin{array}{l}2.26 \\
2.27 \\
2.29 \\
2.29 \\
2.30 \\
2.30\end{array}$ & $\begin{array}{l}426 \\
430 \\
444 \\
444 \\
450 \\
450\end{array}$ & $\begin{array}{l}2.62 \\
2.66 \\
2.70 \\
2.75 \\
2.81 \\
2.88\end{array}$ & $\begin{array}{l}703 \\
739 \\
775 \\
822 \\
880 \\
950\end{array}$ & $\begin{array}{l}5.29 \\
5.28 \\
5.24 \\
5.22 \\
5.21 \\
5.24\end{array}$ & $\begin{array}{l}5,350 \\
5,330 \\
5,220 \\
5,160 \\
5,140 \\
5,220\end{array}$ & $\begin{array}{l}7.38 \\
7.25 \\
7.12 \\
7.01 \\
6.90 \\
6.80\end{array}$ & $\begin{array}{l}12,900 \\
12,250 \\
11,680 \\
11,240 \\
10,800 \\
10,400\end{array}$ & $\begin{array}{l}5.64 \\
5.62 \\
5.59 \\
5.56 \\
5.52 \\
5.50\end{array}$ & $\begin{array}{l}6,370 \\
6,310 \\
6,220 \\
6,130 \\
6,010 \\
5,950\end{array}$ \\
\hline $\begin{array}{l}1 \\
2 \\
3 \\
4 \\
5 \\
6\end{array}$ & $\begin{array}{l}2.30 \\
2.30 \\
2.30 \\
2.30 \\
2.30 \\
2.29\end{array}$ & $\begin{array}{l}450 \\
450 \\
450 \\
450 \\
450 \\
444\end{array}$ & $\begin{array}{l}2.31 \\
2.32 \\
2.33 \\
2.34 \\
2.35 \\
2.36\end{array}$ & $\begin{array}{l}457 \\
464 \\
472 \\
479 \\
486 \\
493\end{array}$ & $\begin{array}{l}2.94 \\
3.05 \\
3.11 \\
3.22 \\
3.32 \\
3.42\end{array}$ & $\begin{array}{l}1,010 \\
1,140 \\
1,200 \\
1,330 \\
1,460 \\
1,590\end{array}$ & $\begin{array}{l}5.32 \\
5.44 \\
5.67 \\
5.90 \\
6.16 \\
6.51\end{array}$ & $\begin{array}{l}5,440 \\
5,780 \\
6,460 \\
7,170 \\
8,020 \\
9,240\end{array}$ & $\begin{array}{l}6.70 \\
6.60 \\
6.50 \\
6.41 \\
6.32 \\
6.25\end{array}$ & $\begin{array}{r}10,000 \\
9,600 \\
9,200 \\
8,880 \\
8,570 \\
8,330\end{array}$ & $\begin{array}{l}5.46 \\
5.42 \\
5.39 \\
5.36 \\
5.32 \\
5.29\end{array}$ & $\begin{array}{l}5,830 \\
5,720 \\
5,630 \\
5,550 \\
5,440 \\
5,350\end{array}$ \\
\hline \multirow[t]{2}{*}{$\begin{array}{r}7 \\
8 \\
9 \\
10 \\
11 \\
M \\
\end{array}$} & $\begin{array}{l}2.29 \\
2.29 \\
2.29 \\
2.28 \\
2.27 \\
2.27\end{array}$ & $\begin{array}{l}444 \\
444 \\
444 \\
437 \\
430 \\
430\end{array}$ & $\begin{array}{l}2.38 \\
2.39 \\
2.40 \\
2.40 \\
2.40 \\
2.42\end{array}$ & $\begin{array}{l}508 \\
515 \\
522 \\
522 \\
522 \\
538\end{array}$ & $\begin{array}{l}3.54 \\
3.67 \\
3.81 \\
4.01 \\
4.26 \\
4.54\end{array}$ & $\begin{array}{l}1,760 \\
1,960 \\
2,180 \\
2,530 \\
2,990 \\
3,550\end{array}$ & $\begin{array}{l}6.92 \\
7.32 \\
7.65 \\
7.82 \\
7.91 \\
8.00\end{array}$ & $\begin{array}{l}10,880 \\
12,600 \\
14,250 \\
15,100 \\
15,550 \\
16,000\end{array}$ & $\begin{array}{l}6.20 \\
6.12 \\
6.07 \\
6.01 \\
5.94 \\
5.90\end{array}$ & $\begin{array}{l}8,160 \\
7,890 \\
7,720 \\
7,520 \\
7,300 \\
7,170\end{array}$ & $\begin{array}{l}5.24 \\
5.21 \\
5.18 \\
5.13 \\
5.11 \\
5.06\end{array}$ & $\begin{array}{l}5,220 \\
5,140 \\
5,060 \\
4,930 \\
4,880 \\
4,750\end{array}$ \\
\hline & \multicolumn{2}{|c|}{ September 24} & \multicolumn{2}{|c|}{ September 25} & \multicolumn{2}{|c|}{ September 26} & \multicolumn{2}{|c|}{ September 27} & \multicolumn{2}{|c|}{ September 28} & \multicolumn{2}{|c|}{ September 29} \\
\hline $\begin{array}{r}2 \\
4 \\
6 \\
8 \\
10 \\
\mathrm{~N}\end{array}$ & $\begin{array}{l}4.98 \\
4.90 \\
4.85 \\
4.79 \\
4.72 \\
4.67\end{array}$ & $\begin{array}{l}4,550 \\
4,360 \\
4,240 \\
4,110 \\
3,950 \\
3,830\end{array}$ & $\begin{array}{l}4.29 \\
4.24 \\
4.20 \\
4.16 \\
4.11 \\
4.09\end{array}$ & $\begin{array}{l}3,050 \\
2,960 \\
2,880 \\
2,800 \\
2,710 \\
2,670\end{array}$ & $\begin{array}{l}3.83 \\
3.80 \\
3.77 \\
3.73 \\
3.71 \\
3.69\end{array}$ & $\begin{array}{l}2,210 \\
2,160 \\
2,110 \\
2,050 \\
2,020 \\
1,980\end{array}$ & $\begin{array}{l}3.51 \\
3.50 \\
3.48 \\
3.44 \\
3.42 \\
3.43\end{array}$ & $\begin{array}{l}1,720 \\
1,700 \\
1,670 \\
1,620 \\
1,590 \\
1,600\end{array}$ & $\begin{array}{l}3.40 \\
3.40 \\
3.39 \\
3.37 \\
3.35 \\
3.32\end{array}$ & & $\begin{array}{l}3.20 \\
3.19 \\
3.17 \\
3.14 \\
3.12 \\
3.11\end{array}$ & $\begin{array}{l}1,310 \\
1,300 \\
1,270 \\
1,240 \\
1,210 \\
1,200\end{array}$ \\
\hline $\begin{array}{r}2 \\
4 \\
6 \\
8 \\
10 \\
M\end{array}$ & $\begin{array}{l}4.60 \\
4.55 \\
4.50 \\
4.44 \\
4.39 \\
4.33\end{array}$ & $\begin{array}{l}3,680 \\
3,580 \\
3,470 \\
3,350 \\
3,250 \\
3,130\end{array}$ & $\begin{array}{l}4.04 \\
4.00 \\
3.98 \\
3.94 \\
3.90 \\
3.87\end{array}$ & $\begin{array}{l}2,580 \\
2,510 \\
2,470 \\
2,400 \\
2,330 \\
2,280\end{array}$ & $\begin{array}{l}3.66 \\
3.63 \\
3.60 \\
3.59 \\
3.57 \\
3.54\end{array}$ & $\begin{array}{l}1,940 \\
1,900 \\
1,850 \\
1,840 \\
1,800 \\
1,760\end{array}$ & $\begin{array}{l}3.41 \\
3.40 \\
3.40 \\
3.40 \\
3.40 \\
3.40\end{array}$ & $\begin{array}{l}1, \\
1, \\
1, \\
1, \\
1, \\
1,\end{array}$ & $\begin{array}{l}3.30 \\
3.29 \\
3.28 \\
3.26 \\
3.23 \\
3.21\end{array}$ & $\begin{array}{l}1,430 \\
1,420 \\
1,410 \\
1,380 \\
1,350 \\
1,320\end{array}$ & $\begin{array}{l}3.10 \\
3.09 \\
3.08 \\
3.06 \\
3.04 \\
3.02\end{array}$ & $\begin{array}{l}1,190 \\
1,180 \\
1,170 \\
1,150 \\
1,120 \\
1,100\end{array}$ \\
\hline
\end{tabular}


Sacandaga Reservoir at Conklingville, N. Y.

Location.- Water-stage recorder, lat. $43^{\circ} 18^{\prime} 55^{\prime \prime}$, long. $73^{\circ} 55^{\prime} 35^{\prime \prime}$, 800 feet above right end of Conklingville Dam at Conklingville, Saratoga County. Gage readings are elevations above mean sea level (general adjustment of 1912).

Drainage area.- 1,044 square miles.

Gage-height record.- Hourly printing water-stage recorder.

Maxima.-September 1938: Elevation, 759.30 feet 8 p.m. Sept. 25 (contents, 24,890,000,000 cubic feet).

January 1930 to August 1938: Elevation, 769.34 feet July 11, 1935 (contents, $35,800,000,000$ cubic feet).

Remarks. - Flow of Sacandaga River regulatea at Conklingville by this reservoir. Capac1ty of reservoir at elevation of spillway crest ( 771 feet) is $37,720,000,000$ cubic feet. Available capacity (above 735 feet) is $33,120,000,000$ cubic feet. Area of water surface at elevation of spillway crest is 41.7 square miles. Records furnished by Board of Hudson River Regulating District.

Mean daily elevation, in feet, and contents, in millions of cubic feet, 1938 a

\begin{tabular}{|c|c|c|c|c|c|c|c|c|c|}
\hline \multirow{2}{*}{ Day } & \multicolumn{2}{|c|}{ September } & \multicolumn{2}{|r|}{ October } & \multirow[b]{2}{*}{ Day } & \multicolumn{2}{|c|}{ September } & \multicolumn{2}{|r|}{ October } \\
\hline & Feet & $\begin{array}{r}\text { Millions of } \\
\text { cubic feet }\end{array}$ & Feet & $\begin{array}{r}\text { Millions of } \\
\text { cubic feet }\end{array}$ & & Feet & $\begin{array}{r}\text { Millions of } \\
\text { cubic feet }\end{array}$ & Feet & $\begin{array}{l}\text { Millions of } \\
\text { cubic feet }\end{array}$ \\
\hline $\begin{array}{l}1 \\
2 \\
3 \\
4 \\
5\end{array}$ & $\begin{array}{l}756.48 \\
756.27 \\
756.09 \\
756.07 \\
756.01\end{array}$ & $\begin{array}{l}22,060 \\
21,850 \\
21,670 \\
21,650 \\
21,590\end{array}$ & $\begin{array}{l}758.57 \\
758.45 \\
758.42 \\
758.27 \\
758.09\end{array}$ & $\begin{array}{l}24,150 \\
24,020 \\
23,990 \\
23,840 \\
23,660\end{array}$ & $\begin{array}{l}16 \\
17 \\
18 \\
19 \\
20\end{array}$ & $\begin{array}{l}754.55 \\
754.44 \\
754.41 \\
754.41 \\
754.51\end{array}$ & $\begin{array}{l}20,180 \\
20,070 \\
20,040 \\
20,040 \\
20,140\end{array}$ & $\begin{array}{l}756.44 \\
756.37 \\
756.15 \\
756.00 \\
755.78\end{array}$ & $\begin{array}{l}22,020 \\
21,950 \\
21,730 \\
21,580 \\
21,370\end{array}$ \\
\hline $\begin{array}{r}6 \\
7 \\
8 \\
9 \\
10\end{array}$ & $\begin{array}{l}755.89 \\
755.69 \\
755.51 \\
755.33 \\
755.16\end{array}$ & $\begin{array}{l}21,470 \\
21,280 \\
21,100 \\
20,930 \\
20,770\end{array}$ & $\left|\begin{array}{l}757.87 \\
757.75 \\
757.63 \\
757.55 \\
757.49\end{array}\right|$ & $\begin{array}{l}23,440 \\
23,320 \\
23,200 \\
23,120 \\
23,060\end{array}$ & $\begin{array}{l}21 \\
22 \\
23 \\
24 \\
25\end{array}$ & $\begin{array}{l}755.20 \\
757.32 \\
758.34 \\
758.76 \\
759.01\end{array} \mid$ & $\begin{array}{l}20,800 \\
22,890 \\
23,910 \\
24,340 \\
24,590\end{array}$ & $\begin{array}{l}755.55 \\
755.29 \\
755.19 \\
755.18 \\
755.19\end{array}$ & $\begin{array}{l}21,140 \\
20,890 \\
20,790 \\
20,780 \\
20,790\end{array}$ \\
\hline $\begin{array}{l}11 \\
12 \\
13 \\
14 \\
15\end{array}$ & $\begin{array}{l}755.07 \\
754.98 \\
754.85 \\
754.66 \\
754.63\end{array}$ & $\begin{array}{l}20,680 \\
20,590 \\
20,470 \\
20,280 \\
20,250\end{array}$ & $\begin{array}{l}757.33 \\
757.16 \\
756.96 \\
756.74 \\
756.54\end{array}$ & $\begin{array}{l}22,900 \\
22,730 \\
22,530 \\
22,310 \\
22,110\end{array}$ & $\begin{array}{l}26 \\
27 \\
28 \\
29 \\
30 \\
31\end{array}$ & $\left|\begin{array}{l}759.17 \\
759.11 \\
759.03 \\
758.86 \\
758.71\end{array}\right|$ & $\begin{array}{l}24,760 \\
24,690 \\
24,610 \\
24,440 \\
24,290\end{array}$ & $\begin{array}{l}755.08 \\
754.99 \\
754.83 \\
754.75 \\
754.65 \\
754.70\end{array}$ & $\begin{array}{l}20,690 \\
20,600 \\
20,450 \\
20,370 \\
20,270 \\
20,320\end{array}$ \\
\hline & & & & & & & & $\frac{\text { Septembe }}{+80}$ & $\frac{\text { October }}{-1,475}$ \\
\hline
\end{tabular}

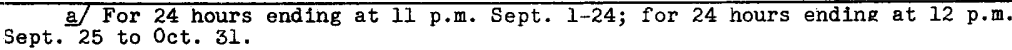


Location.- Water-stage recorder, lat. $43^{\circ} 18^{\prime} 40^{\prime \prime}$, long. $73^{\circ} 54^{\prime} 50^{\prime \prime}$, about half a mile be-

low Conklingville, Saratoga County, and about 5 miles above mouth.

Drainage area.- 1,044 square miles.

Gage-helght record.- Water-stage recorder graph.

Stage-discharge relation.- Defined by current-meter measurements below 7,480 secondfeet.

Maxima.- September 1938: Discharge, 5,040 second-feet 9 a.m. Sept. 23 (gage height, 6.12 feet)

October 1932 to August 1938: Discharge, 7,800 second-feet May 16, 1937 (gage height, 7.20 feet).

Remarks.- For information of storage see record for Sacandaga Reservoir at Conkling-

ville, N. Y. Records furnished by Board of Hudson River Regulating District.

Daylight Saving Time Sept. 1-24; Eastern Standard Time Sept. 25 to 0ct. 31.

Mean daily discharge, in second-feet, 1938

\begin{tabular}{|c|c|c|c|c|c|c|c|c|c|c|c|}
\hline Day & Sept. & Oct. & Day & Sept. & oct. & Day & Sept. & oct. & Day & Sept. & oct. \\
\hline $\begin{array}{l}1 \\
2 \\
3 \\
4 \\
5 \\
6 \\
7 \\
8\end{array}$ & $\begin{array}{r}2,110 \\
2,150 \\
2,140 \\
14 \\
13 \\
2,120 \\
2,150 \\
2,150\end{array}$ & $\begin{array}{r}3,220 \\
17 \\
2,830 \\
2,820 \\
2,410 \\
2,400 \\
2,400 \\
2,410\end{array}$ & $\begin{array}{l}9 \\
10 \\
11 \\
12 \\
13 \\
14 \\
15 \\
16\end{array}$ & $\begin{array}{r}2,130 \\
2,140 \\
14 \\
2,140 \\
2,130 \\
2,150 \\
2,140 \\
2,170\end{array}$ & $\begin{array}{r}16 \\
2,410 \\
2,400 \\
2,640 \\
2,800 \\
2,810 \\
2,790 \\
15\end{array}$ & $\begin{array}{l}17 \\
18 \\
19 \\
20 \\
21 \\
22 \\
23 \\
24\end{array}$ & $\begin{array}{r}2,140 \\
14 \\
2,150 \\
2,150 \\
2,520 \\
1,310 \\
3,200 \\
3,220\end{array}$ & $\begin{array}{r}2,590 \\
2,620 \\
2,820 \\
2,780 \\
2,820 \\
2,820 \\
18 \\
2,830\end{array}$ & $\begin{array}{l}25 \\
26 \\
27 \\
28 \\
29 \\
30 \\
31\end{array}$ & $\begin{array}{r}447 \\
3,180 \\
3,190 \\
3,200 \\
3,200 \\
3,190\end{array}$ & $\begin{array}{r}2,400 \\
2,420 \\
2,390 \\
2,410 \\
2,400 \\
15 \\
2,410\end{array}$ \\
\hline $\begin{array}{l}\text { Mear } \\
\text { Mear } \\
\text { Run }\end{array}$ & $\begin{array}{l}\text { onthly } \\
\text { onthly } \\
f \text {, in }\end{array}$ & hes ( & & ond & 6 & & $: \dot{0}$ & $\begin{array}{lll}\cdot & \cdot & \bullet \\
\cdot & \cdot & .\end{array}$ & : : & $\begin{array}{r}2,032 \\
2,834 \\
3.02\end{array}$ & $\begin{array}{r}2,198 \\
723 \\
0.80\end{array}$ \\
\hline
\end{tabular}

Mean discharge, in second-feet, for the hour prior to indicated time, 1938

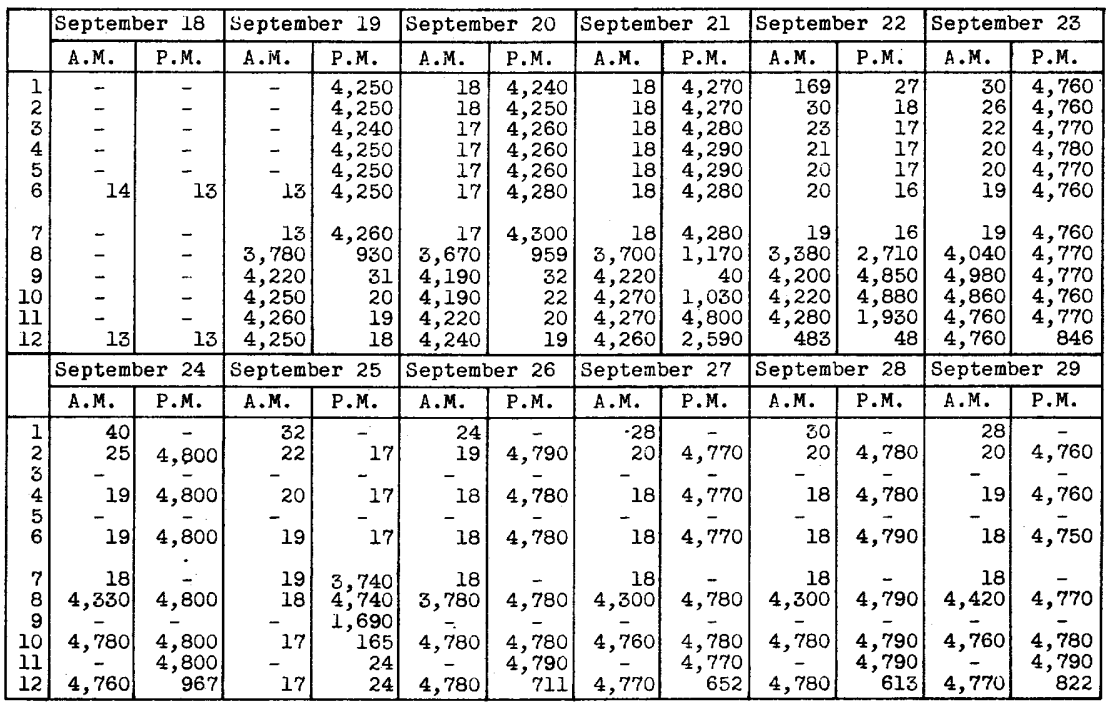


Batten Kill at Arlington, Vt.

Location.- Chain gage on downstream side of bridge, lat. $43^{\circ} 04^{\prime} 40^{\prime \prime}, 10 n g .73^{\circ} 09^{\prime} 30^{\prime \prime}$, at Arlington, Bennington County, 0.9 mile below mouth of Warm Brook. Zero of gage is 597.68 feet ahove mean sea level.

Drainage area.- 152 square miles.

Gage-helght record.- Graph drawn on basis of two gage readings daily, flood marks, and shape of stage graphs of nearby streams.

Stage-discharge relation.- Defined by current-meter measurements below 5,160 secondfeet; extended to peak stage on basis of flood determinations by slope-area method and by flow over dam.

Maxima.- September 1938: Discharge, 8,430 second-feet 9 p.m. Sept. 21 (gage height, 9.08 feet, from flood marks) 1928 to August 1938: Discharge, 11,100 second-feet Mar. 18, 1936 (gage height, 9.87 feet, revised, from floodmarks above bridge converted to equivalent chain-gage height).

Remarks. - Flood run-off not materially affected by artificial or natural storage.

Mean dally discharge, in second-feet, 1938

\begin{tabular}{|c|c|c|c|c|c|c|c|c|c|c|c|}
\hline Day & Sept. & Oct. & Day & Sept. & Oct. & Day & Sept. & 0 ct. & Day & Sept. & Oct. \\
\hline $\begin{array}{l}1 \\
2 \\
3 \\
4 \\
5 \\
6 \\
7 \\
8\end{array}$ & $\begin{array}{l}180 \\
146 \\
119 \\
128 \\
119 \\
112 \\
152 \\
269\end{array}$ & $\begin{array}{l}396 \\
339 \\
303 \\
303 \\
286 \\
253 \\
237 \\
237 \\
\end{array}$ & $\begin{array}{r}9 \\
10 \\
11 \\
12 \\
13 \\
14 \\
15 \\
16\end{array}$ & $\begin{array}{l}156 \\
136 \\
119 \\
119 \\
403 \\
339 \\
575 \\
615 \\
\end{array}$ & $\begin{array}{l}222 \\
207 \\
194 \\
180 \\
180 \\
180 \\
168 \\
180\end{array}$ & $\begin{array}{l}17 \\
18 \\
19 \\
20 \\
21 \\
22 \\
23 \\
24 \\
\end{array}$ & $\begin{array}{r}339 \\
282 \\
488 \\
2,260 \\
4,870 \\
5,300 \\
2,100 \\
1,270 \\
\end{array}$ & $\begin{array}{r}156 \\
156 \\
156 \\
221 \\
435 \\
269 \\
207 \\
368 \\
\end{array}$ & $\begin{array}{l}25 \\
26 \\
27 \\
28 \\
29 \\
30 \\
31\end{array}$ & $\begin{array}{l}906 \\
670 \\
612 \\
641 \\
500 \\
415\end{array}$ & $\begin{array}{l}850 \\
455 \\
376 \\
321 \\
286 \\
237 \\
222\end{array}$ \\
\hline $\begin{array}{l}\text { Mean } \\
\text { Run-c }\end{array}$ & $\begin{array}{l}\text { nthly } \\
\text {, in }\end{array}$ & schar & $\begin{array}{l}11 \\
.\end{array}$ & gecond - & - $\cdot$ & $\dot{0} \cdot \dot{ }$ & $\begin{array}{l}\cdot \\
.\end{array}$ & $\begin{array}{l}\cdot \cdot \cdot \\
\cdot \\
\end{array}$ & $\dot{0}$ & $\begin{array}{r}811 \\
5.96 \\
\end{array}$ & $\begin{array}{r}277 \\
2.10 \\
\end{array}$ \\
\hline
\end{tabular}

Gage helght, in feet, and discharge, in second-feet, at indlcated time, 1938

\begin{tabular}{|c|c|c|c|c|c|c|c|c|c|c|c|c|c|}
\hline \multirow{2}{*}{$\begin{array}{l}\text { 엄 } \\
0 \\
\text { 요 }\end{array}$} & Feet & Sec.ft. & Feet & Sec.ft. & Feet & Sec.ft. & Feet & Sec.ft. & Feet & Sec.ft. & Feet & \multicolumn{2}{|c|}{ Sec.ft. } \\
\hline & \multicolumn{2}{|c|}{ September 18} & \multicolumn{2}{|c|}{ September 19} & \multicolumn{2}{|c|}{ September 20} & \multicolumn{2}{|c|}{ September 21} & \multicolumn{2}{|c|}{ September 22} & \multicolumn{3}{|c|}{ September 23} \\
\hline $\begin{array}{l}1 \\
2 \\
3 \\
4 \\
5 \\
6\end{array}$ & $\begin{array}{l}3.12 \\
3.12 \\
3.11 \\
3.11 \\
3.10 \\
3.10\end{array}$ & $\begin{array}{l}310 \\
310 \\
307 \\
307 \\
303 \\
303\end{array}$ & $\begin{array}{l}3.03 \\
3.08 \\
3.11 \\
3.14 \\
3.18 \\
3.21\end{array}$ & $\begin{array}{l}279 \\
296 \\
307 \\
317 \\
332 \\
343\end{array}$ & $\begin{array}{l}5.25 \\
5.51 \\
5.72 \\
5.84 \\
5.93 \\
6.00\end{array}$ & $\begin{array}{l}1,510 \\
1,730 \\
1,920 \\
2,040 \\
2,130 \\
2,200\end{array}$ & $\begin{array}{l}6.47 \\
6.53 \\
6.60 \\
6.67 \\
6.75 \\
6.83\end{array}$ & $\begin{array}{l}2,770 \\
2,850 \\
2,940 \\
3,040 \\
3,150 \\
3,270\end{array}$ & $\begin{array}{l}8.81 \\
8.70 \\
8.60 \\
8.52 \\
8.40 \\
8.30\end{array}$ & $\begin{array}{l}7,630 \\
7,310 \\
7,030 \\
6,810 \\
6,500 \\
6,250\end{array}$ & \begin{tabular}{|l|}
6.78 \\
6.70 \\
6.60 \\
6.52 \\
6.43 \\
6.33
\end{tabular} & \multicolumn{2}{|c|}{$\begin{array}{l}3,190 \\
3,080 \\
2,940 \\
2,840 \\
2,720 \\
2,590\end{array}$} \\
\hline $\begin{array}{r}7 \\
8 \\
9 \\
10 \\
11 \\
N\end{array}$ & $\begin{array}{l}3.10 \\
3.10 \\
3.10 \\
3.09 \\
3.08 \\
3.05\end{array}$ & $\begin{array}{l}303 \\
303 \\
303 \\
300 \\
296 \\
286\end{array}$ & $\begin{array}{l}3.24 \\
3.28 \\
3.31 \\
3.35 \\
3.38 \\
3.41\end{array}$ & $\begin{array}{l}554 \\
369 \\
380 \\
396 \\
407 \\
419\end{array}$ & $\begin{array}{l}6.03 \\
6.04 \\
6.07 \\
6.08 \\
6.10 \\
6.11\end{array}$ & $\begin{array}{l}2,230 \\
2,240 \\
2,280 \\
2,290 \\
2,310 \\
2,320\end{array}$ & $\begin{array}{l}6.90 \\
6.94 \\
6.99 \\
7.01 \\
7.03 \\
7.11\end{array}$ & $\begin{array}{l}3,380 \\
3,440 \\
3,520 \\
3,560 \\
3,590 \\
3,730\end{array}$ & $\begin{array}{l}8.22 \\
8.15 \\
8.08 \\
8.00 \\
7.93 \\
7.85\end{array}$ & $\begin{array}{l}6,060 \\
5,890 \\
5,720 \\
5,530 \\
5,370 \\
5,180\end{array}$ & & \multicolumn{2}{|c|}{$\begin{array}{r}2,490 \\
2,370 \\
2,260 \\
2,150 \\
2,050 \\
1,950\end{array}$} \\
\hline $\begin{array}{l}1 \\
2 \\
3 \\
4 \\
5 \\
6\end{array}$ & $\begin{array}{l}3.03 \\
3.01 \\
2.98 \\
2.97 \\
2.96 \\
2.95\end{array}$ & $\begin{array}{l}279 \\
272 \\
263 \\
259 \\
256 \\
253\end{array}$ & $\begin{array}{l}3.45 \\
3.48 \\
3.51 \\
3.54 \\
3.60 \\
3.68\end{array}$ & $\begin{array}{l}435 \\
447 \\
460 \\
473 \\
500 \\
536\end{array}$ & $\begin{array}{l}6.12 \\
6.13 \\
6.14 \\
6.15 \\
6.17 \\
6.19\end{array}$ & $\begin{array}{l}2,330 \\
2,350 \\
2,360 \\
2,370 \\
2,390 \\
2,420\end{array}$ & $\begin{array}{l}7.18 \\
7.30 \\
7.44 \\
7.80 \\
8.30 \\
8.70\end{array}$ & $\begin{array}{l}3,850 \\
4,060 \\
4,320 \\
5,070 \\
6,250 \\
7,310\end{array}$ & $\begin{array}{l}7.78 \\
7.70 \\
7.62 \\
7.53 \\
7.45 \\
7.38\end{array}$ & $\begin{array}{l}5,030 \\
4,850 \\
4,680 \\
4,500 \\
4,340 \\
4,200\end{array}$ & $\begin{array}{l}5.65 \\
5.54 \\
5.43 \\
5.37 \\
5.31 \\
5.27\end{array}$ & \multicolumn{2}{|c|}{$\begin{array}{l}1,860 \\
1,760 \\
1,660 \\
1,610 \\
1,560 \\
1,530\end{array}$} \\
\hline $\begin{array}{r}7 \\
8 \\
9 \\
10 \\
11 \\
M\end{array}$ & $\begin{array}{l}2.94 \\
2.94 \\
2.95 \\
2.97 \\
2.98 \\
3.00 \\
\end{array}$ & $\begin{array}{l}250 \\
250 \\
253 \\
259 \\
263 \\
269 \\
\end{array}$ & $\begin{array}{l}3.78 \\
3.92 \\
4.10 \\
4.35 \\
4.64 \\
4.95\end{array}$ & $\begin{array}{r}581 \\
650 \\
740 \\
878 \\
1,050 \\
1,270 \\
\end{array}$ & $\begin{array}{l}6.22 \\
6.25 \\
6.30 \\
6.33 \\
6.38 \\
6.42\end{array}$ & $\begin{array}{l}2,450 \\
2,490 \\
2,550 \\
2,590 \\
2,650 \\
2,710 \\
\end{array}$ & $\begin{array}{l}8.94 \\
9.07 \\
9.08 \\
9.07 \\
9.00 \\
8.91\end{array}$ & $\begin{array}{l}8,010 \\
8,400 \\
8,430 \\
8,400 \\
8,190 \\
7,920\end{array}$ & $\begin{array}{l}7.30 \\
7.20 \\
7.13 \\
7.03 \\
6.95 \\
6.87\end{array}$ & $\begin{array}{l}4,060 \\
3,880 \\
3,760 \\
3,590 \\
3,460 \\
3,330\end{array}$ & $\begin{array}{l}5.23 \\
5.21 \\
5.20 \\
5.19 \\
5.18 \\
5.17\end{array}$ & \multicolumn{2}{|c|}{$\begin{array}{l}1,490 \\
1,480 \\
1,470 \\
1,460 \\
1,450 \\
1,446\end{array}$} \\
\hline & \multicolumn{2}{|c|}{ September 24} & \multicolumn{2}{|c|}{ September 25} & \multicolumn{2}{|c|}{ September 26} & \multicolumn{2}{|c|}{ September 27} & \multicolumn{2}{|c|}{ September 28} & \multicolumn{3}{|c|}{ September 29} \\
\hline $\begin{array}{r}2 \\
4 \\
6 \\
8 \\
10 \\
N\end{array}$ & $\begin{array}{l}5.14 \\
5.11 \\
5.08 \\
5.04 \\
5.00 \\
4.95\end{array}$ & $\begin{array}{l}1,420 \\
1,400 \\
1,370 \\
1,340 \\
1,310 \\
1,270\end{array}$ & $\begin{array}{l}4.62 \\
4.58 \\
4.52 \\
4.47 \\
4.42 \\
4.38\end{array}$ & $\begin{array}{r}1,030 \\
1,010 \\
972 \\
944 \\
916 \\
894\end{array}$ & $\begin{array}{l}4.14 \\
4.10 \\
4.05 \\
4.00 \\
3.98 \\
3.94\end{array}$ & $\begin{array}{l}762 \\
740 \\
715 \\
690 \\
680 \\
660\end{array}$ & $\begin{array}{l}3.79 \\
3.78 \\
3.76 \\
3.75 \\
3.74 \\
3.76\end{array}$ & $\begin{array}{l}586 \\
581 \\
572 \\
568 \\
563 \\
572\end{array}$ & \begin{tabular}{|l|}
4.00 \\
3.99 \\
3.98 \\
3.97 \\
3.94 \\
3.91
\end{tabular} & $\begin{array}{l}690 \\
685 \\
680 \\
675 \\
660 \\
645\end{array}$ & $\begin{array}{l}3.70 \\
3.67 \\
3.64 \\
3.61 \\
3.60 \\
3.58\end{array}$ & & $\begin{array}{l}545 \\
532 \\
518 \\
504 \\
500 \\
491\end{array}$ \\
\hline $\begin{array}{r}2 \\
4 \\
6 \\
8 \\
10 \\
M\end{array}$ & $\begin{array}{l}4.90 \\
4.87 \\
4.82 \\
4.78 \\
4.72 \\
4.68\end{array}$ & $\begin{array}{l}1,230 \\
1,210 \\
1,170 \\
1,150 \\
1,100 \\
1,080\end{array}$ & $\begin{array}{l}4.34 \\
4.30 \\
4.28 \\
4.24 \\
4.20 \\
4.18\end{array}$ & $\begin{array}{l}872 \\
850 \\
839 \\
817 \\
795 \\
784\end{array}$ & $\begin{array}{l}3.90 \\
3.88 \\
3.86 \\
3.84 \\
3.82 \\
3.80\end{array}$ & $\begin{array}{l}640 \\
630 \\
620 \\
610 \\
600 \\
590\end{array}$ & $\begin{array}{l}3.80 \\
3.88 \\
3.95 \\
3.99 \\
4.00 \\
4.01\end{array}$ & $\begin{array}{l}590 \\
630 \\
665 \\
685 \\
690 \\
695\end{array}$ & $\begin{array}{l}3.89 \\
3.87 \\
3.83 \\
3.80 \\
3.77 \\
3.73\end{array}$ & $\begin{array}{l}635 \\
625 \\
605 \\
590 \\
576 \\
558\end{array}$ & $\begin{array}{l}3.58 \\
3.58 \\
3.56 \\
3.54 \\
3.53 \\
3.51\end{array}$ & & $\begin{array}{l}491 \\
491 \\
482 \\
473 \\
468 \\
460\end{array}$ \\
\hline
\end{tabular}


Location. - Water-stage recorder, lat. $43^{\circ} 06^{\prime} 05^{\prime \prime}$, long. $73^{\circ} 25^{\prime} 55^{\prime \prime}$, 1 mile southwest of Battenville, Washington County .

Dralnage area.- 394 square miles.

Gage-he1ght record. - Water-stage recorder graph except for period 11 p.m. Sept. 21 to 10:30 a.m. Sept. 22, record for which was based on three gage observations including that of the peak.

Stage-discharge relation.- Defined by current-meter measurements below 16,000 second-

Maxima.- September 1938: D1scharge, 16,000 second-feet 9 a.m. Sept. 22 (gage height, 14. 82 feet).

October 1922 to August 1938: D1scharge, 21,300 second-feet Nov. 4, 1927 (gage height, 17.7 feet, from floodmarks)

Remarks.- Flood discharge not affected by storage or diversion.

Mean da1ly discharge, in second-feet, 1938

\begin{tabular}{|c|c|c|c|c|c|c|c|c|c|c|c|}
\hline Day & Sept. & Oct. & Day & Sept. & Oct. & Day & Sept. & oct. & Day & Sept. & oct. \\
\hline $\begin{array}{l}1 \\
2 \\
3 \\
4 \\
5 \\
6 \\
7 \\
8 \\
\end{array}$ & $\begin{array}{l}225 \\
258 \\
221 \\
198 \\
202 \\
187 \\
184 \\
345\end{array}$ & $\begin{array}{l}942 \\
839 \\
776 \\
707 \\
662 \\
616 \\
564 \\
519\end{array}$ & $\begin{array}{r}9 \\
10 \\
11 \\
12 \\
13 \\
14 \\
15 \\
16 \\
\end{array}$ & $\begin{array}{l}302 \\
237 \\
191 \\
198 \\
380 \\
578 \\
413 \\
965\end{array}$ & $\begin{array}{l}489 \\
465 \\
443 \\
426 \\
405 \\
389 \\
384 \\
379\end{array}$ & $\begin{array}{l}17 \\
18 \\
19 \\
20 \\
21 \\
22 \\
23 \\
24\end{array}$ & $\begin{array}{r}682 \\
551 \\
636 \\
2,090 \\
4,240 \\
13,400 \\
6,480 \\
3,560\end{array}$ & $\begin{array}{l}363 \\
353 \\
339 \\
348 \\
522 \\
544 \\
421 \\
478\end{array}$ & $\begin{array}{l}25 \\
26 \\
27 \\
28 \\
29 \\
30 \\
31\end{array}$ & $\begin{array}{l}2,500 \\
1,880 \\
1,560 \\
1,510 \\
1,260 \\
1,060\end{array}$ & $\begin{array}{r}1,290 \\
899 \\
720 \\
688 \\
616 \\
551 \\
525\end{array}$ \\
\hline $\begin{array}{l}\text { Mean } \\
\text { Run- }\end{array}$ & $\begin{array}{l}\text { onthly } \\
\text {, in }\end{array}$ & schar & 1 & econd-1 & ot. . & : &.$\dot{*} \cdot \dot{ }$ &.$\quad \cdot$ & $\dot{0}$ & $\begin{array}{r}1,550 \\
4.38\end{array}$ & $\begin{array}{r}570 \\
1.67\end{array}$ \\
\hline
\end{tabular}

Gage height, in feet, and discharge, in second-feet, at indicated time, 1938

\begin{tabular}{|c|c|c|c|c|c|c|c|c|c|c|c|c|}
\hline \multirow{2}{*}{$\begin{array}{r}9 \\
\text { 옥 } \\
\end{array}$} & Feet & Sec.ft. & Feet & Sec.ft. & Feet & Sec.ft. & Feet & Sec.ft. & Feet & Sec.ft. & Fe日t & Sec.ft. \\
\hline & \multicolumn{2}{|c|}{ September 18} & \multicolumn{2}{|c|}{ September 19} & \multicolumn{2}{|c|}{ September 20} & \multicolumn{2}{|c|}{ September 21} & \multicolumn{2}{|c|}{ September 22} & \multicolumn{2}{|c|}{ September 23} \\
\hline $\begin{array}{l}1 \\
2 \\
3 \\
4 \\
5 \\
6\end{array}$ & $\begin{array}{l}3.10 \\
3.08 \\
3.08 \\
3.08 \\
3.07 \\
3.03\end{array}$ & $\begin{array}{l}590 \\
577 \\
577 \\
577 \\
570 \\
544\end{array}$ & $\begin{array}{l}3.04 \\
3.04 \\
3.05 \\
3.13 \\
3.06 \\
3.16\end{array}$ & $\begin{array}{l}551 \\
551 \\
558 \\
610 \\
564 \\
629\end{array}$ & $\begin{array}{l}3.52 \\
3.59 \\
3.64 \\
3.72 \\
3.80 \\
3.93\end{array}$ & $\begin{array}{r}875 \\
928 \\
965 \\
1,030 \\
1,090 \\
1,190\end{array}$ & & $\begin{array}{l}2,980 \\
3,020 \\
3,040 \\
3,100 \\
3,160 \\
3,220\end{array}$ & $\begin{array}{l}10.07 \\
11.97 \\
12.97 \\
13.57 \\
14.00 \\
14.37\end{array}$ & $\begin{array}{r}8,260 \\
11,200 \\
12,800 \\
13,800 \\
14,500 \\
15,200\end{array}$ & $\begin{array}{r}10.87 \\
10.59 \\
10.29 \\
10.07 \\
9.79 \\
9.53\end{array}$ & \\
\hline $\begin{array}{r}7 \\
8 \\
9 \\
10 \\
11 \\
\mathrm{~N}\end{array}$ & $\begin{array}{l}3.00 \\
3.02 \\
3.03 \\
3.05 \\
3.03 \\
3.03\end{array}$ & $\begin{array}{l}525 \\
538 \\
544 \\
558 \\
544 \\
544\end{array}$ & $\begin{array}{l}3.13 \\
3.14 \\
3.11 \\
3.10 \\
3.10 \\
3.10\end{array}$ & $\begin{array}{l}610 \\
616 \\
596 \\
590 \\
590 \\
590\end{array}$ & $\begin{array}{l}4.20 \\
4.50 \\
4.89 \\
5.02 \\
5.25 \\
5.35\end{array}$ & $\begin{array}{l}1,410 \\
1,650 \\
1,970 \\
2,090 \\
2,310 \\
2,410\end{array}$ & $\begin{array}{l}.22 \\
.28 \\
.38 \\
.48 \\
.58 \\
.74\end{array}$ & $\begin{array}{l}3,310 \\
3,380 \\
3,490 \\
3,600 \\
3,710 \\
3,880\end{array}$ & $\begin{array}{l}14.62 \\
14.77 \\
14.82 \\
14.72 \\
14.61 \\
14.52\end{array}$ & $\begin{array}{l}600 \\
900 \\
000 \\
800 \\
600 \\
400\end{array}$ & & $\begin{array}{l}260 \\
030 \\
770 \\
530 \\
340 \\
160\end{array}$ \\
\hline $\begin{array}{l}1 \\
2 \\
3 \\
4 \\
5 \\
6\end{array}$ & $\begin{array}{l}3.03 \\
3.02 \\
3.02 \\
3.02 \\
3.05 \\
3.01\end{array}$ & $\begin{array}{l}544 \\
538 \\
538 \\
538 \\
558 \\
532\end{array}$ & $\begin{array}{l}3.11 \\
3.14 \\
3.17 \\
3.19 \\
3.22 \\
3.25\end{array}$ & $\begin{array}{l}596 \\
616 \\
636 \\
648 \\
668 \\
688\end{array}$ & $\begin{array}{l}5.45 \\
5.49 \\
5.58 \\
5.63 \\
5.68 \\
5.71\end{array}$ & $\begin{array}{l}2,510 \\
2,550 \\
2,640 \\
2,690 \\
2,740 \\
2,770\end{array}$ & $\begin{array}{l}89 \\
00 \\
09 \\
21 \\
45 \\
71\end{array}$ & $\begin{array}{l}4,050 \\
4,180 \\
4,290 \\
4,430 \\
4,720 \\
5,040\end{array}$ & $\begin{array}{l}14.37 \\
14.20 \\
13.97 \\
13.75 \\
13.50 \\
13.19\end{array}$ & $\begin{array}{l}15,200 \\
14,900 \\
14,400 \\
14,100 \\
13,600 \\
13,100\end{array}$ & $\begin{array}{l}8.43 \\
8.31 \\
8.19 \\
8.04 \\
7.93 \\
7.83\end{array}$ & $\begin{array}{l}985 \\
320 \\
670 \\
470 \\
330 \\
200\end{array}$ \\
\hline \multirow[t]{2}{*}{$\begin{array}{r}7 . \\
8 \\
9 \\
10 \\
11 \\
M\end{array}$} & $\begin{array}{l}3.02 \\
3.02 \\
3.02 \\
3.02 \\
3.02 \\
3.03\end{array}$ & $\begin{array}{l}538 \\
538 \\
538 \\
538 \\
538 \\
544 \\
\end{array}$ & $\begin{array}{l}3.28 \\
3.32 \\
3.35 \\
3.38 \\
3.42 \\
3.46\end{array}$ & $\begin{array}{l}707 \\
734 \\
755 \\
776 \\
804 \\
832\end{array}$ & $\begin{array}{l}5.76 \\
5.78 \\
5.82 \\
5.85 \\
5.87 \\
5.89\end{array}$ & $\begin{array}{l}2,820 \\
2,840 \\
2,880 \\
2,910 \\
2,930 \\
2,950\end{array}$ & $\begin{array}{l}94 \\
09 \\
34 \\
70 \\
06 \\
54\end{array}$ & $\begin{array}{l}40 \\
40 \\
60 \\
30 \\
20 \\
00\end{array}$ & $\begin{array}{l}12.89 \\
12.57 \\
12.24 \\
11.96 \\
11.54 \\
11.22\end{array}$ & $\begin{array}{r}12, \\
12, \\
11, \\
11, \\
10, \\
9,\end{array}$ & $\begin{array}{l}7.71 \\
7.63 \\
7.52 \\
7.43 \\
7.34 \\
7.26\end{array}$ & $\begin{array}{l}40 \\
40 \\
300 \\
100 \\
990 \\
190\end{array}$ \\
\hline & \multicolumn{2}{|c|}{ September 24} & \multicolumn{2}{|c|}{ September 25} & \multicolumn{2}{|c|}{ September 26} & \multicolumn{2}{|c|}{ September 27} & \multicolumn{2}{|c|}{ September 28} & \multicolumn{2}{|c|}{ September 29} \\
\hline $\begin{array}{r}2 \\
4 \\
6 \\
8 \\
10 \\
N\end{array}$ & $\begin{array}{l}7.04 \\
6.89 \\
6.74 \\
6.63 \\
6.49 \\
6.37\end{array}$ & $\begin{array}{l}4,230 \\
4,050 \\
3,880 \\
3,760 \\
3,610 \\
3,480\end{array}$ & $\begin{array}{l}5.78 \\
5.73 \\
5.64 \\
5.57 \\
5.51 \\
5.43\end{array}$ & $\begin{array}{l}2,840 \\
2,790 \\
2,700 \\
2,630 \\
2,570 \\
2,490\end{array}$ & $\begin{array}{l}5.00 \\
4.94 \\
4.90 \\
4.85 \\
4.80 \\
4.76\end{array}$ & $\begin{array}{l}2,070 \\
2,020 \\
1,980 \\
1,940 \\
1,890 \\
1,860\end{array}$ & \begin{tabular}{|l|}
4.48 \\
4.46 \\
4.44 \\
4.41 \\
4.39 \\
4.35
\end{tabular} & $\begin{array}{l}1,630 \\
1,620 \\
1,600 \\
1,580 \\
1,560 \\
1,530\end{array}$ & $\begin{array}{l}4.39 \\
4.42 \\
4.43 \\
4.41 \\
4.39 \\
4.36\end{array}$ & $\begin{array}{l}1,560 \\
1,590 \\
1,590 \\
1,580 \\
1,560 \\
1,540\end{array}$ & $\begin{array}{l}4.13 \\
4.10 \\
4.08 \\
4.05 \\
4.03 \\
4.00\end{array}$ & $\begin{array}{l}1,350 \\
1,230 \\
1,310 \\
1,290 \\
1,270 \\
1,250\end{array}$ \\
\hline $\begin{array}{r}2 \\
4 \\
6 \\
8 \\
10 \\
M\end{array}$ & $\begin{array}{l}6.30 \\
6.19 \\
6.10 \\
6.01 \\
5.95 \\
5.87\end{array}$ & $\begin{array}{l}3,400 \\
3,280 \\
3,180 \\
3,080 \\
3,020 \\
2,930\end{array}$ & $\begin{array}{l}5.37 \\
5.31 \\
5.24 \\
5.17 \\
5.11 \\
5.05\end{array}$ & $\begin{array}{l}2,430 \\
2,370 \\
2,300 \\
2,230 \\
2,170 \\
2,120\end{array}$ & $\begin{array}{l}4.73 \\
4.67 \\
4.65 \\
4.60 \\
4.55\end{array}$ & $\begin{array}{l}1,830 \\
1,790 \\
1,770 \\
1,730 \\
1,690 \\
1,680\end{array}$ & $\begin{array}{l}4.34 \\
4.34 \\
4.33 \\
4.32 \\
4.35 \\
4.38\end{array}$ & $\begin{array}{l}1,520 \\
1,520 \\
1,510 \\
1,510 \\
1,530 \\
1,550\end{array}$ & $\begin{array}{l}4.32 \\
4.31 \\
4.26 \\
4.23 \\
4.21 \\
4.17\end{array}$ & $\begin{array}{l}1,510 \\
1,500 \\
1,460 \\
1,430 \\
1,420 \\
1,390\end{array}$ & $\begin{array}{l}3.99 \\
3.94 \\
3.95 \\
3.92 \\
3.90\end{array}$ & $\begin{array}{l}240 \\
200 \\
210 \\
190 \\
170 \\
150\end{array}$ \\
\hline
\end{tabular}


Kayaderosseras Creok near West Milton, N. Y.

Location. - Water-stage recorder, lat. $43^{\circ} 02^{\prime} 25^{n}$, long. $73^{\circ} 54^{\prime} 30^{n}$, 500 feet below mouth of Glowegee Creek, and 1 mile east of West Milton, Saratoga County.

Drainege area.- 90 square miles.

lage-helght record. - Water-stage recorder graph.

Stage-discharge relation.- Defined by current-meter measurements below 2,050 secondfeet; extended logarithmically to peak stage.

Yaxima.- September 1938: Discharge, 1,700 second-feet midnight Sept. 21 (gage helght, 6.56 feet).

July 1927 to August 1938: D1scharge, 3,590 second-feet Mar. 18, 1936 (gage

helght, 10.78 feet, from floodmarks).

Remarks. - Flood discharge not affected by storage or diversion.

Mean dally discharge, in second-feet, 1938

\begin{tabular}{|c|c|c|c|c|c|c|c|c|c|c|c|}
\hline Day & Sopt. & Oct. & Day & Sept. & oct. & Day & Sept. & Oct. & Day & Sept. & 0et. \\
\hline $\begin{array}{l}1 \\
2 \\
3 \\
4 \\
5 \\
6 \\
7 \\
8\end{array}$ & $\begin{array}{l}28 \\
28 \\
22 \\
23 \\
24 \\
22 \\
23 \\
46\end{array}$ & $\begin{array}{l}81 \\
74 \\
69 \\
64 \\
62 \\
57 \\
54 \\
54\end{array}$ & $\begin{array}{l}9 \\
10 \\
11 \\
12 \\
13 \\
14 \\
15 \\
16\end{array}$ & $\begin{array}{r}28 \\
22 \\
22 \\
22 \\
38 \\
35 \\
157 \\
100\end{array}$ & $\begin{array}{l}53 \\
55 \\
50 \\
49 \\
49 \\
49 \\
49 \\
48\end{array}$ & $\begin{array}{l}17 \\
18 \\
19 \\
20 \\
21 \\
22 \\
23 \\
24\end{array}$ & $\begin{array}{r}56 \\
60 \\
65 \\
292 \\
993 \\
1,190 \\
482 \\
278\end{array}$ & $\begin{array}{l}48 \\
46 \\
45 \\
46 \\
60 \\
61 \\
53 \\
69\end{array}$ & $\begin{array}{l}25 \\
26 \\
27 \\
28 \\
29 \\
30 \\
31\end{array}$ & $\begin{array}{r}191 \\
143 \\
124 \\
118 \\
97 \\
85\end{array}$ & $\begin{array}{r}126 \\
88 \\
75 \\
72 \\
66 \\
61 \\
57\end{array}$ \\
\hline $\begin{array}{l}\text { Mean } \\
\text { Run- }\end{array}$ & in & hes. & in & & & . : & $\cdot \dot{0} \cdot$ & . & $\because:$ & $\begin{array}{r}160 \\
1.99\end{array}$ & $\begin{array}{l}61.0 \\
0.78\end{array}$ \\
\hline
\end{tabular}

Gage helght, in feet, and discharge, in second-feet, at indicated time, 1938

\begin{tabular}{|c|c|c|c|c|c|c|c|c|c|c|c|c|}
\hline \multirow{2}{*}{ 官 } & Feet & Sec.ft. & Feet & Sec.ft. & Feet & Sec.ft. & Feet & Sec.ft. & Feet & Sec.ft. & Feet & Sec.ft. \\
\hline & \multicolumn{2}{|c|}{ September 18} & \multicolumn{2}{|c|}{ September 19} & \multicolumn{2}{|c|}{ September 20} & \multicolumn{2}{|c|}{ September 21} & \multicolumn{2}{|c|}{ September 22} & \multicolumn{2}{|c|}{ September 23} \\
\hline $\begin{array}{l}1 \\
2 \\
3 \\
4 \\
5 \\
6\end{array}$ & $\begin{array}{l}1.58 \\
1.59 \\
1.60 \\
1.61 \\
1.62 \\
1.63\end{array}$ & $\begin{array}{l}54 \\
55 \\
56 \\
57 \\
58 \\
60\end{array}$ & $\begin{array}{l}1.62 \\
1.61 \\
1.61 \\
1.60 \\
1.60 \\
1.59\end{array}$ & $\begin{array}{l}58 \\
57 \\
57 \\
56 \\
56 \\
55\end{array}$ & $\begin{array}{l}2.08 \\
2.18 \\
2.29 \\
2.36 \\
2.43 \\
2.50\end{array}$ & $\begin{array}{l}130 \\
150 \\
173 \\
188 \\
204 \\
219\end{array}$ & $\begin{array}{l}3.77 \\
3.82 \\
3.85 \\
3.86 \\
3.85 \\
3.85\end{array}$ & $\begin{array}{l}600 \\
617 \\
628 \\
631 \\
628 \\
628\end{array}$ & $\begin{array}{l}6.47 \\
6.38 \\
6.29 \\
6.23 \\
6.15 \\
6.04\end{array}$ & $\begin{array}{l}1,670 \\
1,630 \\
1,600 \\
1,570 \\
1,540 \\
1,500\end{array}$ & $\begin{array}{l}3.87 \\
3.79 \\
3.74 \\
3.69 \\
3.64 \\
3.60\end{array}$ & $\begin{array}{l}634 \\
606 \\
589 \\
572 \\
554 \\
640\end{array}$ \\
\hline $\begin{array}{r}7 \\
8 \\
9 \\
10 \\
11 \\
N\end{array}$ & $\begin{array}{l}1.64 \\
1.64 \\
1.65 \\
1.65 \\
1.66 \\
1.66\end{array}$ & $\begin{array}{l}61 \\
61 \\
62 \\
62 \\
63 \\
63\end{array}$ & $\begin{array}{l}1.59 \\
1.59 \\
1.59 \\
1.59 \\
1.59 \\
1.59\end{array}$ & $\begin{array}{l}55 \\
55 \\
55 \\
55 \\
55 \\
55\end{array}$ & $\begin{array}{l}2.54 \\
2.58 \\
2.63 \\
2.66 \\
2.69 \\
2.74\end{array}$ & $\begin{array}{l}228 \\
237 \\
249 \\
256 \\
264 \\
276\end{array}$ & $\begin{array}{l}3.84 \\
3.84 \\
3.88 \\
3.95 \\
4.10 \\
4.26\end{array}$ & $\begin{array}{l}624 \\
624 \\
638 \\
662 \\
720 \\
784\end{array}$ & $\begin{array}{l}5.93 \\
5.83 \\
5.70 \\
5.55 \\
5.42 \\
5.25\end{array}$ & $\begin{array}{l}1,450 \\
1,410 \\
1,360 \\
1,300 \\
1,250 \\
1,180\end{array}$ & $\begin{array}{l}3.56 \\
3.53 \\
3.51 \\
3.48 \\
3.45 \\
3.42\end{array}$ & $\begin{array}{l}526 \\
516 \\
509 \\
499 \\
490 \\
480\end{array}$ \\
\hline $\begin{array}{l}1 \\
2 \\
3 \\
4 \\
5 \\
6\end{array}$ & $\begin{array}{l}1.66 \\
1.66 \\
1.66 \\
1.66 \\
1.66 \\
1.66\end{array}$ & $\begin{array}{l}63 \\
63 \\
63 \\
63 \\
63 \\
63\end{array}$ & $\begin{array}{l}1.61 \\
1.62 \\
1.64 \\
1.71 \\
1.74 \\
1.74\end{array}$ & $\begin{array}{l}57 \\
58 \\
61 \\
69 \\
74 \\
74\end{array}$ & $\begin{array}{l}2.78 \\
2.83 \\
2.90 \\
2.91 \\
2.92 \\
2.97\end{array}$ & $\begin{array}{l}287 \\
300 \\
319 \\
322 \\
325 \\
339\end{array}$ & $\begin{array}{l}4.55 \\
4.80 \\
5.00 \\
5.20 \\
5.50 \\
5.80\end{array}$ & $\begin{array}{r}900 \\
1,000 \\
1,080 \\
1,160 \\
1,280 \\
1,400\end{array}$ & $\begin{array}{l}5.12 \\
4.97 \\
4.84 \\
4.70 \\
4.60 \\
4.50\end{array}$ & $\begin{array}{r}1,130 \\
1,070 \\
1,020 \\
960 \\
920 \\
880\end{array}$ & $\begin{array}{l}3.39 \\
3.36 \\
3.32 \\
3.28 \\
3.25 \\
3.22\end{array}$ & $\begin{array}{l}470 \\
460 \\
447 \\
434 \\
424 \\
414\end{array}$ \\
\hline \multirow[t]{2}{*}{$\begin{array}{r}7 \\
8 \\
9 \\
10 \\
11 \\
M\end{array}$} & $\begin{array}{l}1.65 \\
1.65 \\
1.64 \\
1.64 \\
1.63 \\
1.62\end{array}$ & $\begin{array}{l}62 \\
62 \\
61 \\
61 \\
60 \\
58\end{array}$ & $\begin{array}{l}1.74 \\
1.75 \\
1.80 \\
1.84 \\
1.91 \\
1.99\end{array}$ & $\begin{array}{r}74 \\
75 \\
82 \\
88 \\
100 \\
113\end{array}$ & $\begin{array}{l}3.03 \\
3.12 \\
3.27 \\
3.44 \\
3.61 \\
3.69\end{array}$ & $\begin{array}{l}356 \\
383 \\
430 \\
486 \\
544 \\
572\end{array}$ & $\begin{array}{l}6.05 \\
6.30 \\
6.42 \\
6.46 \\
6.51 \\
6.56\end{array}$ & $\begin{array}{l}1,500 \\
1,600 \\
1,650 \\
1,660 \\
1,680 \\
1,700\end{array}$ & $\begin{array}{l}4.41 \\
4.32 \\
4.21 \\
4.12 \\
4.04 \\
3.97\end{array}$ & $\begin{array}{l}844 \\
808 \\
764 \\
728 \\
696 \\
670\end{array}$ & $\begin{array}{l}3.18 \\
3.14 \\
3.10 \\
3.06 \\
3.03 \\
3.00\end{array}$ & $\begin{array}{l}402 \\
389 \\
377 \\
365 \\
356 \\
347\end{array}$ \\
\hline & \multicolumn{2}{|c|}{ September 24} & \multicolumn{2}{|c|}{ September 25} & \multicolumn{2}{|c|}{ September 26} & \multicolumn{2}{|c|}{ September 27 } & \multicolumn{2}{|c|}{ September 28} & \multicolumn{2}{|c|}{ September 29} \\
\hline $\begin{array}{r}2 \\
4 \\
6 \\
8 \\
10 \\
N\end{array}$ & $\begin{array}{l}2.94 \\
2.88 \\
2.83 \\
2.80 \\
2.77 \\
2.74\end{array}$ & $\begin{array}{l}330 \\
314 \\
300 \\
292 \\
284 \\
276\end{array}$ & $\begin{array}{l}2.49 \\
2.46 \\
2.43 \\
2.41 \\
2.39 \\
2.37\end{array}$ & $\begin{array}{l}217 \\
210 \\
204 \\
199 \\
195 \\
190\end{array}$ & $\begin{array}{l}2.21 \\
2.20 \\
2.18 \\
2.16 \\
2.15 \\
2.15\end{array}$ & $\begin{array}{l}156 \\
154 \\
150 \\
146 \\
144 \\
144\end{array}$ & $\begin{array}{l}2.04 \\
2.03 \\
2.02 \\
2.02 \\
2.02 \\
2.02\end{array}$ & $\begin{array}{l}123 \\
121 \\
119 \\
119 \\
119 \\
119\end{array}$ & $\begin{array}{l}2.07 \\
2.06 \\
2.05 \\
2.04 \\
2.03 \\
2.02\end{array}$ & $\begin{array}{l}128 \\
126 \\
124 \\
123 \\
121 \\
119\end{array}$ & $\begin{array}{l}1.92 \\
1.92 \\
1.91 \\
1.91 \\
1.90 \\
1.90\end{array}$ & $\begin{array}{r}101 \\
101 \\
100 \\
100 \\
98 \\
98\end{array}$ \\
\hline $\begin{array}{r}2 \\
4 \\
6 \\
8 \\
10 \\
11\end{array}$ & $\begin{array}{l}2.71 \\
2.68 \\
2.64 \\
2.60 \\
2.56 \\
2.52\end{array}$ & $\begin{array}{l}269 \\
261 \\
252 \\
242 \\
233 \\
224\end{array}$ & $\begin{array}{l}2.35 \\
2.33 \\
2.31 \\
2.28 \\
2.25 \\
2.23\end{array}$ & $\begin{array}{l}186 \\
182 \\
177 \\
171 \\
164 \\
160\end{array}$ & $\begin{array}{l}2.14 \\
2.13 \\
2.12 \\
2.09 \\
2.07 \\
2.05\end{array}$ & $\begin{array}{l}142 \\
140 \\
138 \\
132 \\
128 \\
124\end{array}$ & $\begin{array}{l}2.07 \\
2.10 \\
2.06 \\
2.06 \\
2.06 \\
2.07\end{array}$ & $\begin{array}{l}128 \\
134 \\
126 \\
126 \\
126 \\
128\end{array}$ & $\begin{array}{l}2.00 \\
1.99 \\
1.99 \\
1.99 \\
1.96 \\
1.94\end{array}$ & $\begin{array}{l}115 \\
113 \\
113 \\
113 \\
108 \\
105\end{array}$ & $\begin{array}{l}1.89 \\
1.88 \\
1.87 \\
1.87 \\
1.86 \\
1.85\end{array}$ & $\begin{array}{l}96 \\
95 \\
93 \\
93 \\
92 \\
90\end{array}$ \\
\hline
\end{tabular}

supplemental records.- Sept. 27, 1 p.m., 2.02 ft., 119 sec.-ft. 
Hoosic River at Adams, Mass.

Location.- Water-stage recorder, lat, $42^{\circ} 36^{\prime} 45^{\prime \prime}$, long. $73^{\circ} 07^{\prime} 25^{\prime \prime}$, at Adams, Berksh1re County, just below mouth of Dry Brook and 0.3 mile above Pecks Brook. Zero of gage is 837.01 feet above mean sea level (general adjustment of 1929 ).

Drainage area.- 46.3 square miles.

Gage-height record.- Water-stage recorder graph except for period sept. 1 to noon Sept. 20, when there was no record.

Stage-discharge relation.- Defined by current-meter measurements below 2,680 secondfeet; extended to peak stage on basis of determination of flood flow over dam.

Maxima.- September 1938: Discharge, 5,080 second-feet 5 p.m. Sept. 21 (gage helght, 8.25 feet).

1931 to August 1938: Discharge, 3,670 second-feet Mar. 18, 1936 (gage height, 6.33 feet)

Remarks.- Discharge for period Sept. 1-20 computed by hydrographic comparison with nearby streams. Discharges do not include diversion of about 1.2 million gallons daily for Adams water supply. Flood run-off affected by storage in Hoosic Lake.

Mean daliy discharge, in second-feet, 1938

\begin{tabular}{|c|c|c|c|c|c|c|c|c|c|c|c|}
\hline Day & Sept. & Oct. & Day & Sept. & Oct. & Day & Sept. & Oct. & Day & Sept. & Oet. \\
\hline $\begin{array}{l}1 \\
2 \\
3 \\
4 \\
5 \\
6 \\
7 \\
8\end{array}$ & $\begin{array}{l}35 \\
32 \\
30 \\
33 \\
35 \\
25 \\
55 \\
90\end{array}$ & $\begin{array}{r}137 \\
123 \\
111 \\
102 \\
94 \\
89 \\
84 \\
81\end{array}$ & $\begin{array}{r}9 \\
10 \\
11 \\
12 \\
13 \\
14 \\
15 \\
16\end{array}$ & $\begin{array}{r}45 \\
40 \\
35 \\
40 \\
450 \\
120 \\
240 \\
170\end{array}$ & $\begin{array}{l}80 \\
74 \\
69 \\
68 \\
65 \\
66 \\
64 \\
60\end{array}$ & $\begin{array}{l}17 \\
18 \\
19 \\
20 \\
21 \\
22 \\
23 \\
24\end{array}$ & $\begin{array}{r}95 \\
100 \\
330 \\
900 \\
2,170 \\
1,150 \\
563 \\
420 \\
\end{array}$ & $\begin{array}{r}56 \\
54 \\
54 \\
52 \\
82 \\
59 \\
55 \\
116 \\
\end{array}$ & $\begin{array}{l}25 \\
26 \\
27 \\
28 \\
29 \\
30 \\
31\end{array}$ & $\begin{array}{l}316 \\
255 \\
245 \\
226 \\
179 \\
154\end{array}$ & $\begin{array}{r}127 \\
82 \\
74 \\
68 \\
72 \\
68 \\
62\end{array}$ \\
\hline $\begin{array}{l}\text { Mean } \\
\text { Run-c }\end{array}$ & $\begin{array}{l}\text { nthly } \\
, \text { in } 1\end{array}$ & $\begin{array}{l}\text { schare } \\
\text { hes. }\end{array}$ & , ir & $\begin{array}{c}\text { second- } \\
\text {. } . \text {. }\end{array}$ & et. . & . : & $\begin{array}{lll}\cdot & \cdot & \bullet \\
\bullet & \bullet & \bullet \\
\end{array}$ & 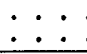 & $\dot{0} \cdot \dot{ }$ & $\begin{array}{r}286 \\
6.90 \\
\end{array}$ & $\begin{array}{r}79 \\
1.97 \\
\end{array}$ \\
\hline
\end{tabular}

Gage helght, in feet, and discharge, in second-feet, at indicated time, 1938

\begin{tabular}{|c|c|c|c|c|c|c|c|c|c|c|c|c|c|}
\hline \multirow{2}{*}{ 皃 } & Feot & Sec.ft. & Feet & Sec.ft. & Feot & Sec.ft. & Feet & Sec.ft. & Feet & Sec.ft. & Feot & Sec & .ft. \\
\hline & \multicolumn{2}{|c|}{ September 18} & \multicolumn{2}{|c|}{ September 19} & \multicolumn{2}{|c|}{ September 20} & \multicolumn{2}{|c|}{ September 21} & \multicolumn{2}{|c|}{ September 22} & \multicolumn{3}{|c|}{ September 23} \\
\hline $\begin{array}{l}1 \\
2 \\
3 \\
4 \\
5 \\
6\end{array}$ & $\begin{array}{l}- \\
- \\
- \\
- \\
-\end{array}$ & $\begin{array}{l}- \\
- \\
- \\
- \\
-\end{array}$ & $\begin{array}{l}- \\
- \\
- \\
-\end{array}$ & $\begin{array}{l}- \\
- \\
- \\
- \\
-\end{array}$ & $\begin{array}{l}- \\
- \\
- \\
- \\
-\end{array}$ & $\begin{array}{l}- \\
- \\
- \\
- \\
- \\
* 887\end{array}$ & $\begin{array}{l}3.41 \\
3.46 \\
3.42 \\
3.40 \\
3.43 \\
3.55\end{array}$ & $\begin{array}{r}936 \\
966 \\
942 \\
930 \\
948 \\
1,020\end{array}$ & $\begin{array}{l}5.17 \\
4.79 \\
4.61 \\
4.43 \\
4.25 \\
4.17\end{array}$ & $\begin{array}{l}2,170 \\
1,870 \\
1,730 \\
1,600 \\
1,480 \\
1,420\end{array}$ & $\begin{array}{l}2.92 \\
2.91 \\
2.81 \\
2.80 \\
2.80 \\
2.81\end{array}$ & & $\begin{array}{l}665 \\
660 \\
610 \\
605 \\
605 \\
610\end{array}$ \\
\hline $\begin{array}{r}7 \\
8 \\
9 \\
10 \\
11 \\
11\end{array}$ & $\begin{array}{l}- \\
- \\
- \\
- \\
-\end{array}$ & $\begin{array}{l}- \\
- \\
- \\
- \\
* 100\end{array}$ & $\begin{array}{l}- \\
- \\
- \\
- \\
-\end{array}$ & $\begin{array}{l}- \\
- \\
- \\
- \\
* * 330\end{array}$ & $\begin{array}{l}- \\
- \\
- \\
- \\
3.43\end{array}$ & $\begin{array}{l}- \\
- \\
- \\
- \\
- \\
948\end{array}$ & $\begin{array}{l}3.74 \\
3.85 \\
3.95 \\
4.03 \\
4.38 \\
4.53\end{array}$ & $\begin{array}{l}1,140 \\
1,210 \\
1,270 \\
1,320 \\
1,570 \\
1,670\end{array}$ & $\begin{array}{l}4.00 \\
3.80 \\
3.76 \\
3.67 \\
3.64 \\
3.59\end{array}$ & $\begin{array}{l}1,300 \\
1,180 \\
1,150 \\
1,090 \\
1,070 \\
1,040\end{array}$ & $\begin{array}{l}2.78 \\
2.75 \\
2.76 \\
2.73 \\
2.73 \\
2.71\end{array}$ & & $\begin{array}{l}596 \\
582 \\
587 \\
574 \\
574 \\
564\end{array}$ \\
\hline $\begin{array}{l}1 \\
2 \\
3 \\
4 \\
5 \\
6\end{array}$ & $\begin{array}{l}- \\
- \\
- \\
-\end{array}$ & $\begin{array}{l}- \\
- \\
- \\
- \\
-\end{array}$ & $\begin{array}{l}- \\
- \\
- \\
- \\
-\end{array}$ & $\begin{array}{l}- \\
- \\
- \\
- \\
-\end{array}$ & $\begin{array}{l}3.36 \\
3.30 \\
3.27 \\
3.25 \\
3.45 \\
3.45\end{array}$ & $\begin{array}{l}906 \\
870 \\
853 \\
842 \\
960 \\
960\end{array}$ & $\begin{array}{l}4.60 \\
4.58 \\
5.00 \\
6.40 \\
8.25 \\
7.80\end{array}$ & $\begin{array}{l}1,720 \\
1,710 \\
2,030 \\
3,240 \\
5,080 \\
4,610\end{array}$ & $\begin{array}{l}3.49 \\
3.41 \\
3.34 \\
3.25 \\
3.23 \\
3.19\end{array}$ & $\begin{array}{l}984 \\
936 \\
894 \\
842 \\
832 \\
810\end{array}$ & $\begin{array}{l}2.64 \\
2.64 \\
2.65 \\
2.64 \\
2.62 \\
2.61\end{array}$ & & $\begin{array}{l}533 \\
533 \\
538 \\
533 \\
524 \\
520\end{array}$ \\
\hline \multirow[t]{2}{*}{$\begin{array}{r}7 \\
8 \\
9 \\
10 \\
11 \\
M\end{array}$} & $\begin{array}{l}- \\
- \\
- \\
- \\
-\end{array}$ & $\begin{array}{l}- \\
- \\
- \\
-\end{array}$ & $\begin{array}{l}- \\
- \\
- \\
-\end{array}$ & $\begin{array}{l}- \\
- \\
- \\
- \\
-\end{array}$ & $\begin{array}{l}3.33 \\
3.32 \\
3.40 \\
3.45 \\
3.44 \\
3.42\end{array}$ & $\begin{array}{l}888 \\
882 \\
930 \\
960 \\
954 \\
942\end{array}$ & $\begin{array}{l}7.50 \\
7.27 \\
6.84 \\
6.40 \\
6.00 \\
5.55\end{array}$ & $\begin{array}{l}4,310 \\
4,080 \\
3,660 \\
3,240 \\
2,870 \\
2,480\end{array}$ & $\begin{array}{l}3.15 \\
3.11 \\
3.05 \\
3.03 \\
2.98 \\
2.95\end{array}$ & $\begin{array}{l}788 \\
766 \\
732 \\
722 \\
695 \\
680\end{array}$ & $\begin{array}{l}2.60 \\
2.58 \\
2.57 \\
2.56 \\
2.54 \\
2.52\end{array}$ & . & $\begin{array}{l}515 \\
507 \\
503 \\
499 \\
491 \\
483\end{array}$ \\
\hline & \multicolumn{2}{|c|}{ September 24} & \multicolumn{2}{|c|}{ September 25} & \multicolumn{2}{|c|}{ September 26} & \multicolumn{2}{|c|}{ September 27} & \multicolumn{2}{|c|}{ September 28} & \multicolumn{3}{|c|}{ September 29} \\
\hline $\begin{array}{r}2 \\
4 \\
6 \\
8 \\
10 \\
N\end{array}$ & $\begin{array}{l}2.49 \\
2.45 \\
2.42 \\
2.40 \\
2.37 \\
2.35\end{array}$ & $\begin{array}{l}471 \\
455 \\
443 \\
435 \\
424 \\
418\end{array}$ & $\begin{array}{l}2.16 \\
2.15 \\
2.14 \\
2.10 \\
2.08 \\
2.06\end{array}$ & $\begin{array}{l}351 \\
348 \\
344 \\
330 \\
324 \\
318\end{array}$ & $\begin{array}{l}1.90 \\
1.89 \\
1.88 \\
1.87 \\
1.85 \\
1.84\end{array}$ & $\begin{array}{l}272 \\
269 \\
267 \\
264 \\
258 \\
256\end{array}$ & $\begin{array}{l}1.74 \\
1.73 \\
1.71 \\
1.71 \\
1.70 \\
1.70\end{array}$ & $\begin{array}{l}230 \\
228 \\
222 \\
222 \\
220 \\
220\end{array}$ & $\begin{array}{l}1.83 \\
1.81 \\
1.80 \\
1.73 \\
1.75 \\
1.74\end{array}$ & $\begin{array}{l}253 \\
248 \\
245 \\
228 \\
232 \\
230\end{array}$ & $\begin{array}{l}1.58 \\
1.57 \\
1.56 \\
1.53 \\
1.52 \\
1.56\end{array}$ & & $\begin{array}{l}191 \\
189 \\
187 \\
180 \\
178 \\
187\end{array}$ \\
\hline $\begin{array}{r}2 \\
4 \\
6 \\
8 \\
10 \\
M\end{array}$ & $\begin{array}{l}2.33 \\
2.30 \\
2.29 \\
2.26 \\
2.22 \\
2.21\end{array}$ & $\begin{array}{l}410 \\
400 \\
396 \\
386 \\
372 \\
368\end{array}$ & $\begin{array}{l}2.00 \\
1.98 \\
1.97 \\
1.96 \\
1.94 \\
1.92\end{array}$ & $\begin{array}{r}300 \\
294 \\
, 292 \\
289 \\
283 \\
278\end{array}$ & $\begin{array}{l}1.83 \\
1.80 \\
1.79 \\
1.78 \\
1.76 \\
1.74\end{array}$ & $\begin{array}{l}253 \\
245 \\
242 \\
240 \\
235 \\
230\end{array}$ & $\begin{array}{l}1.69 \\
1.74 \\
2.13 \\
1.99 \\
1.89 \\
1.84\end{array}$ & $\begin{array}{l}218 \\
230 \\
340 \\
297 \\
269 \\
256\end{array}$ & $\begin{array}{l}1.70 \\
1.67 \\
1.65 \\
1.64 \\
1.62 \\
1.60\end{array}$ & $\begin{array}{l}220 \\
213 \\
208 \\
206 \\
201 \\
196\end{array}$ & $\begin{array}{l}1.50 \\
1.50 \\
1.49 \\
1.48 \\
1.48 \\
1.47\end{array}$ & & $\begin{array}{l}173 \\
173 \\
171 \\
169 \\
169 \\
167\end{array}$ \\
\hline
\end{tabular}

* Mean for 12 hours.

* Mean for the day. 
Hoosic River near Eagle Bridge, N. Y.

Location.- Water-stage recorder, lat. $42^{\circ} 56^{\prime} 10^{n}$, long. $73^{\circ} 22^{\prime} 30^{\prime \prime}$, three-quarters of a mllo below mouth of Walloomsac River and li miles southeast of Eagle Bridge, Rensselaer County.

Drainage area.- 510 square miles.

Gage-helght record.- Water-atage recorder graph.

Stage-discharge relation.- 1938 rating defined by current-meter measurements below 21,400 second-feet; $\theta x$ tended logarithmlcally to peak stage on basis of computations of peak discharge over Schaghticoke and Johnsonville hydroelectric dams. 1927 peak defined by current-meter measurements below 5,230 second-feet; extended logarithmically to peak stage and verifled by 1938 rating.

Maxima.- September 1938: D1 scharge, 35,300 second-feet 2:45 a.m. Sept. 22 (gage height, 17.78 feet).

August 1910 to March 1922, July 1923 to August 1938: Discharge, 29,800 second-feet Nov. 4, 1927 (gage helght, 18.78 feet, former datum and former site a quarter of a mile upstream prior to July 1936).

Remarks.- Flood discharge not affected by storage or diversion. Diurnal fluctuation at medium and low stages caused by operation of power plants.

Mean dally discharge, in second-feet, 1938

\begin{tabular}{|c|c|c|c|c|c|c|c|c|c|c|c|}
\hline Day & Sept. & Oct. & Day & Sept. & Oct. & Day & Sept. & Oct. & Day & Sept. & oct. \\
\hline $\begin{array}{l}1 \\
2 \\
3 \\
4 \\
5 \\
6 \\
7 \\
8\end{array}$ & $\begin{array}{l}287 \\
315 \\
302 \\
260 \\
261 \\
251 \\
272 \\
649\end{array}$ & $\begin{array}{r}1,260 \\
1,120 \\
1,010 \\
926 \\
845 \\
755 \\
715 \\
678\end{array}$ & $\begin{array}{l}99 \\
10 \\
11 \\
12 \\
13 \\
14 \\
15 \\
16\end{array}$ & $\begin{array}{r}414 \\
285 \\
257 \\
303 \\
1,030 \\
852 \\
814 \\
1,130 \\
\end{array}$ & $\begin{array}{l}608 \\
599 \\
559 \\
528 \\
500 \\
472 \\
453 \\
441\end{array}$ & $\begin{array}{l}17 \\
18 \\
19 \\
20 \\
21 \\
22 \\
23 \\
24\end{array}$ & $\begin{array}{r}686 \\
592 \\
922 \\
9,730 \\
16,000 \\
22,700 \\
6,200 \\
3,730\end{array}$ & $\begin{array}{l}429 \\
418 \\
392 \\
443 \\
963 \\
755 \\
543 \\
730 \\
\end{array}$ & $\begin{array}{l}25 \\
26 \\
27 \\
28 \\
29 \\
30 \\
31\end{array}$ & $\begin{array}{l}2,770 \\
2,210 \\
1,920 \\
1,950 \\
1,580 \\
1,380\end{array}$ & $\begin{array}{r}1,850 \\
1,150 \\
926 \\
875 \\
765 \\
705 \\
651\end{array}$ \\
\hline $\begin{array}{l}\text { Mean } \\
\text { Run- }\end{array}$ & nthly & & , 1 & - . . & t.: &.$\dot{ }$ & $\cdot . \dot{ } \cdot \cdot$ & •. & $: \dot{ }$ & $\begin{array}{r}2,668 \\
5.84 \\
\end{array}$ & $\begin{array}{r}744 \\
1.68 \\
\end{array}$ \\
\hline
\end{tabular}

Gage helght, in feet, and discharge, in second-feet, at indicated time, 1938

\begin{tabular}{|c|c|c|c|c|c|c|c|c|c|c|c|c|}
\hline \multirow{2}{*}{ 皇 } & Feet & Sec.ft. & Feot & Sec.ft. & Feet & Sec.ft. & Feet & Sec.ft. & Feet & Sec.ft. & Feet & Sec.ft. \\
\hline & \multicolumn{2}{|c|}{ September 18} & \multicolumn{2}{|c|}{ September 19} & \multicolumn{2}{|c|}{ September 20} & \multicolumn{2}{|c|}{ September 21} & \multicolumn{2}{|c|}{ September 22} & \multicolumn{2}{|c|}{ September 23} \\
\hline $\begin{array}{l}1 \\
2 \\
3 \\
4 \\
5 \\
6\end{array}$ & $\begin{array}{l}4.45 \\
4.45 \\
4.44 \\
4.43 \\
4.41 \\
4.41\end{array}$ & $\begin{array}{l}592 \\
592 \\
585 \\
578 \\
562 \\
562\end{array}$ & $\begin{array}{l}4.41 \\
4.41 \\
4.42 \\
4.44 \\
4.48 \\
4.48\end{array}$ & $\begin{array}{l}562 \\
562 \\
570 \\
585 \\
615 \\
615\end{array}$ & $\begin{array}{l}6.16 \\
6.65 \\
7.28 \\
7.93 \\
8.63 \\
9.22\end{array}$ & $\begin{array}{l}2,580 \\
3,270 \\
4,200 \\
5,280 \\
6,620 \\
7,870\end{array}$ & $\begin{array}{l}10.57 \\
10.52 \\
10.52 \\
10.54 \\
10.58 \\
10.62\end{array}$ & $\begin{array}{l}11,100 \\
11,000 \\
11,000 \\
11,100 \\
11,200 \\
11,300\end{array}$ & $\begin{array}{l}17.46 \\
17.70 \\
17.75 \\
17.68 \\
17.57 \\
17.36\end{array}$ & $\begin{array}{l}34,100 \\
35,000 \\
35,200 \\
34,900 \\
34,500 \\
33,700\end{array}$ & $\begin{array}{r}10.12 \\
9.94 \\
9.75 \\
9.58 \\
9.44 \\
9.29\end{array}$ & $\begin{array}{l}8,970 \\
8,540 \\
8,110 \\
7,740 \\
7,440 \\
7,130\end{array}$ \\
\hline $\begin{array}{r}7 \\
8 \\
9 \\
1.0 \\
1.1 \\
1\end{array}$ & $\begin{array}{l}4.45 \\
4.52 \\
4.46 \\
4.41 \\
4.39 \\
4.44\end{array}$ & $\begin{array}{l}592 \\
646 \\
600 \\
562 \\
548 \\
585\end{array}$ & $\begin{array}{l}4.50 \\
4.52 \\
4.56 \\
4.63 \\
4.63 \\
4.76\end{array}$ & $\begin{array}{l}630 \\
646 \\
678 \\
737 \\
737 \\
860\end{array}$ & $\begin{array}{r}9.71 \\
10.13 \\
10.39 \\
10.56 \\
10.65 \\
10.75\end{array}$ & $\begin{array}{r}8,990 \\
10,000 \\
10,700 \\
11,100 \\
11,300 \\
11,600\end{array}$ & $\begin{array}{l}10.67 \\
10.73 \\
10.82 \\
10.92 \\
11.11 \\
11.44\end{array}$ & $\begin{array}{l}11,400 \\
11,600 \\
11,800 \\
12,100 \\
12,600 \\
13,500\end{array}$ & $\begin{array}{l}17.02 \\
16.07 \\
15.47 \\
14.89 \\
14.40 \\
13.96\end{array}$ & $\begin{array}{l}32,500 \\
29,000 \\
26,800 \\
24,700 \\
23,000 \\
21,400\end{array}$ & $\begin{array}{l}9.19 \\
9.05 \\
8.94 \\
8.84 \\
8.75 \\
8.65\end{array}$ & $\begin{array}{l}6,930 \\
6,650 \\
6,440 \\
6,250 \\
6,080 \\
5,890\end{array}$ \\
\hline $\begin{array}{l}1 \\
2 \\
3 \\
4 \\
5 \\
6\end{array}$ & $\begin{array}{l}4.47 \\
4.45 \\
4.45 \\
4.45 \\
4.46 \\
4.47\end{array}$ & $\begin{array}{l}608 \\
592 \\
592 \\
592 \\
600 \\
608\end{array}$ & $\begin{array}{l}4.89 \\
4.91 \\
4.90 \\
4.89 \\
4.92 \\
4.93\end{array}$ & $\begin{array}{r}999 \\
1,020 \\
1,010 \\
999 \\
1,030 \\
1,040\end{array}$ & $\begin{array}{l}10.88 \\
10.99 \\
11.06 \\
11.08 \\
11.06 \\
11.00\end{array}$ & $\begin{array}{l}12,000 \\
12,300 \\
12,400 \\
12,500 \\
12,400 \\
12,300\end{array}$ & $\begin{array}{l}11.74 \\
12.00 \\
12.31 \\
12.60 \\
13.00 \\
13.39\end{array}$ & $\begin{array}{l}14,400 \\
15,200 \\
16,100 \\
17,000 \\
18,300 \\
19,600\end{array}$ & $\begin{array}{l}13.53 \\
13.15 \\
12.74 \\
12.43 \\
12.13 \\
11.85\end{array}$ & $\begin{array}{l}19,900 \\
18,600 \\
17,100 \\
16,000 \\
15,000 \\
14,100\end{array}$ & $\begin{array}{l}8.55 \\
8.46 \\
8.41 \\
8.30 \\
8.22 \\
8.15\end{array}$ & $\begin{array}{l}5,710 \\
5,550 \\
5,460 \\
5,260 \\
5,120 \\
5,000\end{array}$ \\
\hline \multirow[t]{2}{*}{$\begin{array}{r}7 \\
8 \\
9 \\
2.0 \\
1.1 \\
M\end{array}$} & $\begin{array}{l}4.47 \\
4.46 \\
4.45 \\
4.43 \\
4.42 \\
4.43 \\
\end{array}$ & $\begin{array}{l}608 \\
600 \\
592 \\
578 \\
570 \\
578\end{array}$ & $\begin{array}{l}4.98 \\
5.04 \\
5.14 \\
5.31 \\
5.52 \\
5.77\end{array}$ & $\begin{array}{l}1,100 \\
1,160 \\
1,280 \\
1,480 \\
1,740 \\
2,060\end{array}$ & $\begin{array}{l}10.98 \\
10.92 \\
10.87 \\
10.78 \\
10.73 \\
10.64\end{array}$ & $\begin{array}{l}12,200 \\
12,100 \\
11,900 \\
11,700 \\
11,600 \\
11,300\end{array}$ & $\begin{array}{l}13.70 \\
14.32 \\
14.76 \\
15.26 \\
16.01 \\
17.00\end{array}$ & $\begin{array}{l}20,700 \\
22,800 \\
24,300 \\
26,100 \\
28,800 \\
32,400\end{array}$ & $\begin{array}{l}11.59 \\
11.30 \\
11.07 \\
10.81 \\
10.57 \\
10.34\end{array}$ & $\begin{array}{r}13,200 \\
12,200 \\
11,500 \\
10,700 \\
10,100 \\
9,500\end{array}$ & $\begin{array}{l}8.09 \\
8.03 \\
7.99 \\
7.92 \\
7.86 \\
7.81\end{array}$ & $\begin{array}{l}4,900 \\
4,800 \\
4,730 \\
4,620 \\
4,530 \\
4,450 \\
\end{array}$ \\
\hline & \multicolumn{2}{|c|}{ September 24} & \multicolumn{2}{|c|}{ September 25} & \multicolumn{2}{|c|}{ September 26} & \multicolumn{2}{|c|}{ September 27} & \multicolumn{2}{|c|}{ September 28} & \multicolumn{2}{|c|}{ September 29} \\
\hline $\begin{array}{r}2 \\
4 \\
6 \\
8 \\
10 \\
\text { N }\end{array}$ & $\begin{array}{l}7.72 \\
7.62 \\
7.54 \\
7.45 \\
7.38 \\
7.31\end{array}$ & $\begin{array}{l}4,300 \\
4,150 \\
4,030 \\
3,900 \\
3,790 \\
3,680\end{array}$ & $\begin{array}{l}6.86 \\
6.82 \\
6.77 \\
6.72 \\
6.67 \\
6.62\end{array}$ & $\begin{array}{l}3,060 \\
3,010 \\
2,940 \\
2,880 \\
2,810 \\
2,750\end{array}$ & $\begin{array}{l}6.32 \\
6.28 \\
6.26 \\
6.23 \\
6.20 \\
6.19\end{array}$ & $\begin{array}{l}2,370 \\
2,330 \\
2,300 \\
2,270 \\
2,230 \\
2,220\end{array}$ & $\begin{array}{l}5.97 \\
5.95 \\
5.93 \\
5.92 \\
5.89 \\
5.91\end{array}$ & $\begin{array}{l}1,960 \\
1,940 \\
1,910 \\
1,900 \\
1,870 \\
1,890\end{array}$ & $\begin{array}{l}6.10 \\
6.11 \\
6.09 \\
6.03 \\
5.99 \\
5.98\end{array}$ & $\begin{array}{l}2,110 \\
2,120 \\
2,100 \\
2,030 \\
1,980 \\
1,970\end{array}$ & $\begin{array}{l}5.73 \\
5.69 \\
5.67 \\
5.65 \\
5.63 \\
5.64\end{array}$ & $\begin{array}{l}1,690 \\
1,650 \\
1,630 \\
1,600 \\
1,580 \\
1,590\end{array}$ \\
\hline $\begin{array}{r}2 \\
4 \\
6 \\
8 \\
10 \\
M\end{array}$ & $\begin{array}{l}7.24 \\
7.17 \\
7.12 \\
7.05 \\
6.99 \\
6.93\end{array}$ & $\begin{array}{l}3,590 \\
3,490 \\
3,240 \\
3,320 \\
3,240 \\
3,150\end{array}$ & $\begin{array}{l}6.58 \\
6.53 \\
6.49 \\
6.44 \\
6.39 \\
6.35\end{array}$ & $\begin{array}{l}2,690 \\
2,630 \\
2,580 \\
2,520 \\
2,460 \\
2,410\end{array}$ & $\begin{array}{l}6.15 \\
6.12 \\
6.09 \\
6.05 \\
6.00 \\
5.98\end{array}$ & $\begin{array}{l}2,170 \\
2,130 \\
2,100 \\
2,050 \\
1,990 \\
1,970\end{array}$ & $\begin{array}{l}5.89 \\
5.89 \\
5.93 \\
5.98 \\
6.00 \\
6.08\end{array}$ & $\begin{array}{l}1,870 \\
1,870 \\
1,910 \\
1,970 \\
1,990 \\
2,090\end{array}$ & $\begin{array}{l}5.90 \\
5.87 \\
5.85 \\
5.82 \\
5.78 \\
5.74\end{array}$ & $\begin{array}{l}1,880 \\
1,850 \\
1,820 \\
1,790 \\
1,750 \\
1,700\end{array}$ & $\begin{array}{l}62 \\
59 \\
57 \\
56 \\
52 \\
51 \\
\end{array}$ & $\begin{array}{l}1,570 \\
1,540 \\
1,520 \\
1,510 \\
1,460 \\
1,450\end{array}$ \\
\hline
\end{tabular}

Supplemental records.- Sept. 22, 2:45 a.m., 17.78 ft., 35,300 sec.-ft. 
Locetion.- Water-stage recorder, lat. $42^{\circ} 42^{\prime} 10^{\prime \prime}$, long. $73^{\circ} 05^{\prime} 35^{\prime \prime}$, at North Adams, Berkshire County, $0.4 \mathrm{mile}$ below Hudson Brook (revised) and it miles above mouth Zero of gage 1s 820.46 feet above mean sea level. Prior to Sept. 22 water-stage recorder $100 \mathrm{ft}$. upstream at same datum.

Drajnage area. - 39.0 square miles.

Gage-helght record. - Water-stage recorder graph for period Sept. 1 to 5 p.m. Sept. 20 at temporary site and independent datum during reconstruction of station. No gageheight record for period $5 \mathrm{p.m}$. Sept. 20 to $4 \mathrm{p.m}$. Sept. 22 . Stage graph for period 4 p.m. Sept. 22 to 5 p.m. oct. I based on two or more staff-gage readings daily. Water-stage recorder graph Oct. 1 to 31 .

Stage-discharge relation.- Defined by current-meter measurements below 1,780 secondfeet; extended to peak stage on basis of computation of flood flow over dam. For 1936 defined by current-meter measurements below 5,100 second-feet; extended to peak stage on basis of computation of flood flow over dam.

Maxima.- September 1938: Discharge, 8,950 second-feet 7 p.m. Sept. 21 (gage helght, 12.05 feet, from floodriarks at present site).

1931 to August 1938: Discharge, 6,100 second-feet Mar. 18, 1936 (gage height, 9.25 feet, at former site).

Maximan discharge known, 9,980 second-feet November 1927, determination of peak flow over dam.

Remarks.- Discharge for period $5 \mathrm{p} . \mathrm{m}$. Sept. 20 to $4 \mathrm{p} . \mathrm{m}$. Sept. 22 computed on bas1s of peak flow and records for nearby stations. Flood run-of not materialiy affected by artificial or natural storage.

Meen da1ly discharge, in second-feet, 1938

\begin{tabular}{|c|c|c|c|c|c|c|c|c|c|c|c|}
\hline Day & Sept. & Oet. & Day & Sept. & Oct. & Day & Sept. & Oot. & Dey & Sept. & Oct. \\
\hline $\begin{array}{l}1 \\
2 \\
3 \\
4 \\
5 \\
6 \\
7 \\
8 \\
\end{array}$ & $\begin{array}{l}18 \\
17 \\
15 \\
17 \\
18 \\
14 \\
45 \\
76\end{array}$ & $\begin{array}{l}90 \\
73 \\
66 \\
58 \\
56 \\
55 \\
58 \\
58\end{array}$ & $\begin{array}{r}9 \\
10 \\
11 \\
12 \\
13 \\
14 \\
15 \\
16 \\
\end{array}$ & $\begin{array}{r}28 \\
20 \\
18 \\
21 \\
387 \\
96 \\
206 \\
145 \\
\end{array}$ & $\begin{array}{l}55 \\
55 \\
44 \\
37 \\
29 \\
27 \\
23 \\
23 \\
\end{array}$ & $\begin{array}{l}17 \\
18 \\
19 \\
20 \\
21 \\
22 \\
23 \\
24\end{array}$ & $\begin{array}{r}84 \\
87 \\
277 \\
1,570 \\
3,460 \\
1,220 \\
412 \\
2.42 \\
\end{array}$ & $\begin{array}{r}27 \\
28 \\
27 \\
33 \\
88 \\
47 \\
35 \\
113 \\
\end{array}$ & $\begin{array}{l}25 \\
26 \\
27 \\
28 \\
29 \\
30 \\
31\end{array}$ & $\begin{array}{r}187 \\
154 \\
176 \\
184 \\
140 \\
98\end{array}$ & $\begin{array}{r}163 \\
79 \\
56 \\
44 \\
35 \\
28 \\
25\end{array}$ \\
\hline $\begin{array}{l}\text { Mean } \\
\text { Run- }\end{array}$ & $\begin{array}{l}\text { nthly } \\
\text {, in } 1\end{array}$ & $\begin{array}{l}\text { schare } \\
\text { hes. }\end{array}$ & , in & $\begin{array}{l}\text { econd-f } \\
.\end{array}$ & et. . & $\dot{0}$ & $\begin{array}{l}\cdot . \\
\cdot \\
\end{array}$ & 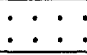 & $\dot{0}$ & $\begin{array}{r}314 \\
8.98 \\
\end{array}$ & $\begin{array}{r}527 \\
1.56 \\
\end{array}$ \\
\hline
\end{tabular}

Gage helght, in feet, and discharge, in second-feet, at indicated time, 1938

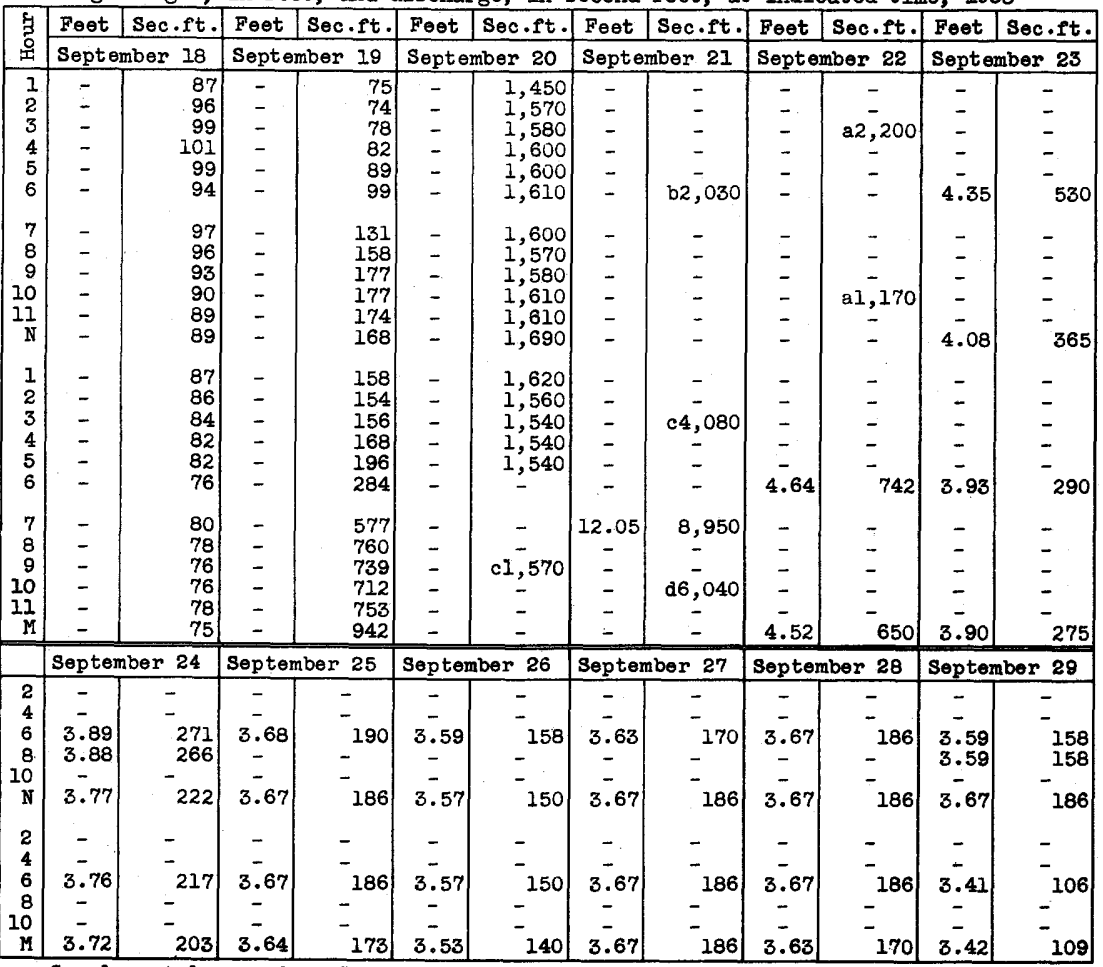

Supplemental records.- Sept. 29, 11 a.m., 3.67 ft., 185 sec.-ft.; 3 p.m., 3.43

ft., 112 sec.-ft.

a Mean for 6-hour period.

b Mean for 12-hour period. 
Walloomsac River near North Bennington, Vt.

Location.- Water-stage recorder, lat. $42^{\circ} 54^{\prime} 45^{n}$, long. $73^{\circ} 15^{\prime} 25^{n}, 0.6$ mile below Paran Creek and 1.4 miles south of North Bennington, Bennington County.

Drainage area.- 111 square miles.

Gage-height record.- Water-stage recorder graph.

Stage-discharge relation.- Defined by current-meter measurements below 2,610 secondfeet; extended to peak stage on basis of determination of flood flow by slope-area and contrected-opening methods and by computation of flow over dam.

Maxima.- September 1938: D1scharge, 8,450 second-feet at 8 p.m. Sept. 21 (gage height, 12.04 feet).

1931 to August 1938: Discharge, 6,600 second-feet Mar. 18, 1936 (gage height, 11.44 feet).

Remarks.- Flood run-off not materially affected by storage.

Mean daily discharge, in second-feet, 1938

\begin{tabular}{|c|c|c|c|c|c|c|c|c|c|c|c|}
\hline Day & Sept. & 0ct. & Day & Sept. & oct. & Day & Sept. & Oct. & Day & Sept. & 0ct. \\
\hline $\begin{array}{l}1 \\
2 \\
3 \\
4 \\
5 \\
6 \\
7 \\
8\end{array}$ & $\begin{array}{r}98 \\
96 \\
78 \\
86 \\
88 \\
77 \\
167 \\
293 \\
\end{array}$ & $\begin{array}{l}276 \\
242 \\
223 \\
206 \\
192 \\
172 \\
165 \\
162\end{array}$ & $\begin{array}{r}9 \\
10 \\
11 \\
12 \\
13 \\
14 \\
15 \\
16\end{array}$ & $\begin{array}{r}130 \\
108 \\
85 \\
93 \\
522 \\
246 \\
380 \\
330 \\
\end{array}$ & $\begin{array}{l}150 \\
146 \\
140 \\
134 \\
125 \\
128 \\
131 \\
120\end{array}$ & $\begin{array}{l}17 \\
18 \\
19 \\
20 \\
21 \\
22 \\
23 \\
24 \\
\end{array}$ & $\begin{array}{r}210 \\
199 \\
439 \\
2,560 \\
4,210 \\
3,050 \\
1,040 \\
674 \\
\end{array}$ & $\begin{array}{l}117 \\
111 \\
111 \\
141 \\
340 \\
212 \\
158 \\
318 \\
\end{array}$ & $\begin{array}{l}25 \\
26 \\
27 \\
28 \\
29 \\
30 \\
31\end{array}$ & $\begin{array}{l}504 \\
414 \\
386 \\
392 \\
316 \\
292\end{array}$ & $\begin{array}{l}530 \\
296 \\
230 \\
216 \\
195 \\
178 \\
168\end{array}$ \\
\hline & & & & & & & $\dot{0}:$ & . . & $\because$ & $\begin{array}{r}585 \\
5.88\end{array}$ & $\begin{array}{r}195 \\
2.03\end{array}$ \\
\hline
\end{tabular}

Gage height, In feet, and discharge, in second-feet, at indicated time, 1938

\begin{tabular}{|c|c|c|c|c|c|c|c|c|c|c|c|c|}
\hline \multirow{2}{*}{ 密 } & Feet & Sec.ft. & Feot & Sec.ft. & Foet & Sec.ft. & Feet & Sec.ft. & Feet & Sec.f.t. & Feet & Sec.ft. \\
\hline & \multicolumn{2}{|c|}{ September 18} & \multicolumn{2}{|c|}{ Sept omber 19} & \multicolumn{2}{|c|}{ September 20} & \multicolumn{2}{|c|}{ September 2I } & \multicolumn{2}{|c|}{ September 22} & \multicolumn{2}{|c|}{ September 23} \\
\hline $\begin{array}{l}1 \\
2 \\
3 \\
4 \\
5 \\
6\end{array}$ & $\begin{array}{l}2.55 \\
2.58 \\
2.60 \\
2.61 \\
2.63 \\
2.60\end{array}$ & $\begin{array}{l}184 \\
194 \\
200 \\
203 \\
210 \\
200\end{array}$ & $\begin{array}{l}2.56 \\
2.56 \\
2.57 \\
2.60 \\
2.67 \\
2.74\end{array}$ & $\begin{array}{l}187 \\
187 \\
190 \\
200 \\
224 \\
249\end{array}$ & $\begin{array}{l}4.65 \\
5.24 \\
6.05 \\
7.10 \\
7.45 \\
7.43\end{array}$ & $\begin{array}{l}1,240 \\
1,630 \\
2,190 \\
2,980 \\
3,260 \\
3,240\end{array}$ & $\begin{array}{l}5.99 \\
6.02 \\
6.02 \\
6.02 \\
6.04 \\
6.04\end{array}$ & & \begin{tabular}{r|}
10.05 \\
9.60 \\
9.20 \\
8.80 \\
8.40 \\
8.02 \\
\end{tabular} & & & \\
\hline $\begin{array}{r}7 \\
8 \\
9 \\
10 \\
11 . \\
N\end{array}$ & $\begin{array}{l}2.6 \\
2.6 \\
2.6 \\
2.6 \\
2.6 \\
2.6\end{array}$ & & $\begin{array}{l}2.76 \\
2.93 \\
3.12 \\
3.13 \\
3.16 \\
3.09\end{array}$ & $\begin{array}{l}257 \\
326 \\
410 \\
415 \\
429 \\
396\end{array}$ & $\begin{array}{l}7.25 \\
7.19 \\
7.09 \\
7.15 \\
7.22 \\
7.16\end{array}$ & $\begin{array}{l}3,100 \\
3,050 \\
2,970 \\
3,120 \\
3,080 \\
3,030\end{array}$ & $\begin{array}{l}6.04 \\
6.12 \\
6.30 \\
6.53 \\
6.89 \\
7.45\end{array}$ & & & & & $\begin{array}{l}1,04 \\
1,09\end{array}$ \\
\hline $\begin{array}{l}1 \\
2 \\
3 \\
4 \\
5 \\
6\end{array}$ & $\begin{array}{l}2.61 \\
2.61 \\
2.60 \\
2.60 \\
2.59 \\
2.59\end{array}$ & $\begin{array}{l}203 \\
203 \\
200 \\
200 \\
197 \\
197\end{array}$ & $\begin{array}{l}3.11 \\
3.11 \\
3.12 \\
3.13 \\
3.24 \\
3.30\end{array}$ & $\begin{array}{l}406 \\
406 \\
410 \\
415 \\
466 \\
494\end{array}$ & $\begin{array}{l}7.00 \\
6.85 \\
6.70 \\
6.60 \\
6.47 \\
6.37\end{array}$ & $\begin{array}{l}2,900 \\
2,790 \\
2,680 \\
2,600 \\
2,500 \\
2,430\end{array}$ & $\begin{array}{r}8.03 \\
8.52 \\
8.63 \\
8.68 \\
9.10 \\
10.32\end{array}$ & & & & & \\
\hline \multirow[t]{2}{*}{$\begin{array}{r}r \\
8 \\
9 \\
20 \\
13 \\
M\end{array}$} & $\begin{array}{l}2.59 \\
2.58 \\
2.57 \\
2.57 \\
2.56 \\
2.56 \\
\end{array}$ & $\begin{array}{l}197 \\
194 \\
190 \\
190 \\
187 \\
187 \\
\end{array}$ & $\begin{array}{l}3.50 \\
3.74 \\
3.92 \\
3.98 \\
4.10 \\
4.29\end{array}$ & $\begin{array}{r}590 \\
711 \\
807 \\
841 \\
910 \\
1,020\end{array}$ & $\begin{array}{l}6.25 \\
6.16 \\
6.07 \\
6.00 \\
5.95\end{array}$ & $\begin{array}{l}2,340 \\
2,260 \\
2,200 \\
2,150 \\
2,160 \\
2,120\end{array}$ & $\begin{array}{l}11.53 \\
12.04 \\
11.62 \\
11.52 \\
11.12 \\
10.56\end{array}$ & $\begin{array}{l}7,840 \\
8,450 \\
7,940 \\
7,820 \\
7,340 \\
6,720\end{array}$ & & & & 796 \\
\hline & \multicolumn{2}{|c|}{ September 24} & \multicolumn{2}{|c|}{ September 25} & \multicolumn{2}{|c|}{ September 26} & \multicolumn{2}{|c|}{ September 27} & \multicolumn{2}{|c|}{ September 28} & \multicolumn{2}{|c|}{ September 29} \\
\hline $\begin{array}{r}2 \\
4 \\
6 \\
83 \\
10 \\
N\end{array}$ & $\begin{array}{l}3.72 \\
3.68 \\
3.63 \\
3.60 \\
3.57 \\
3.54\end{array}$ & $\begin{array}{l}772 \\
749 \\
722 \\
705 \\
688 \\
672\end{array}$ & $\begin{array}{l}3.32 \\
3.31 \\
3.28 \\
3.26 \\
3.25 \\
3.22\end{array}$ & $\begin{array}{l}551 \\
546 \\
530 \\
520 \\
515\end{array}$ & & $\begin{array}{l}450 \\
440 \\
435 \\
435 \\
430 \\
420\end{array}$ & $\begin{array}{l}2.95 \\
2.93 \\
2.92 \\
2.93 \\
2.95 \\
2.91\end{array}$ & $\begin{array}{l}368 \\
358 \\
354\end{array}$ & & & & 33 \\
\hline $\begin{array}{r}2 \\
4 \\
6 \\
8 \\
10 \\
M\end{array}$ & $\begin{array}{l}3.52 \\
3.47 \\
3.44 \\
3.42 \\
3.37 \\
3.35\end{array}$ & $\begin{array}{l}661 \\
634 \\
617 \\
606 \\
578 \\
568\end{array}$ & $\begin{array}{l}3.20 \\
3.18 \\
3.17 \\
3.16 \\
3.15 \\
3.12\end{array}$ & $\begin{array}{l}490 \\
480 \\
475 \\
470 \\
465 \\
450\end{array}$ & $\begin{array}{l}3.0 \\
3 . \\
2.8 \\
2.8 \\
2.8\end{array}$ & $\begin{array}{l}420 \\
395 \\
368 \\
386 \\
381 \\
376\end{array}$ & $\begin{array}{l}2.92 \\
2.98 \\
3.02 \\
3.10 \\
3.16 \\
3.1\end{array}$ & $\begin{array}{l}440 \\
470 \\
465\end{array}$ & & $\begin{array}{l}38 \\
37 \\
34\end{array}$ & $\begin{array}{l}2.84 \\
2.88 \\
2.79 \\
2.82 \\
2.80 \\
2.78\end{array}$ & 29 \\
\hline
\end{tabular}

$2270070-40-17$ 
Black River Canal (flowing south) near Boonville, N. Y.

Location:- Two water-stage recorders and concrete controls, lat. $43^{\circ} 27^{\prime} 20^{\prime \prime}, 10 n g$. $75^{\circ} 19^{\prime} 25^{\prime \prime}-\mathrm{No}$. 1 on main canal at Lock 69 and No. 2 on Lansingkill spiliway, 100 feet downstream from head gates in summit level of canal and 600 feet upstream from Lock 70--2 miles south of Boonville, Oneida County.

Gage-he1ght record.- Water-stage recorder graph.

Stage-discharge relation.- Defined by current-meter measurements.

Remarks.- Discharge is the combined flow at gages 1 and 2 and gives the total diversion from Black River Basin through Forestport feeder and Black River Canal into Mohawk River Basin above Delta Reservoir.

Mean dally discharge, in second-feet, 1938

\begin{tabular}{|c|c|c|c|c|c|c|c|c|c|c|c|}
\hline Dey & Sept. & Oct. & Day & Sept. & oct. & Day & Sept. & oct. & Day & Sept. & Oct. \\
\hline $\begin{array}{l}1 \\
2 \\
3 \\
4 \\
5 \\
6 \\
7 \\
8 \\
\end{array}$ & $\begin{array}{l}41 \\
40 \\
44 \\
45 \\
45 \\
44 \\
48 \\
53\end{array}$ & \begin{tabular}{r|}
59 \\
58 \\
55 \\
49 \\
43 \\
43 \\
44 \\
44 \\
\end{tabular} & $\begin{array}{r}9 \\
10 \\
11 \\
12 \\
13 \\
14 \\
15 \\
16\end{array}$ & $\begin{array}{l}49 \\
47 \\
47 \\
46 \\
58 \\
59 \\
58 \\
62 \\
\end{array}$ & $\begin{array}{l}37 \\
27 \\
27 \\
27 \\
27 \\
28 \\
30 \\
33 \\
\end{array}$ & $\begin{array}{l}17 \\
18 \\
19 \\
20 \\
21 \\
22 \\
23 \\
24\end{array}$ & $\begin{array}{l}59 \\
55 \\
54 \\
55 \\
77 \\
64 \\
31 \\
19 \\
\end{array}$ & $\begin{array}{l}32 \\
30 \\
31 \\
30 \\
32 \\
32 \\
31 \\
33\end{array}$ & $\begin{array}{l}25 \\
26 \\
27 \\
28 \\
29 \\
30 \\
31\end{array}$ & $\begin{array}{l}38 \\
61 \\
64 \\
68 \\
64 \\
61\end{array}$ & $\begin{array}{l}42 \\
41 \\
36 \\
34 \\
33 \\
33 \\
32\end{array}$ \\
\hline $\begin{array}{l}\text { Mean } \\
\text { Run- }\end{array}$ & $\begin{array}{l}\text { nthly } \\
\text {, In } 1\end{array}$ & $\begin{array}{l}\text { scharg } \\
\text { hes. }\end{array}$ & , in & $\begin{array}{l}e \operatorname{cond}-\mathrm{f} \\
\text {. }\end{array}$ & et. . & . & 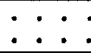 & 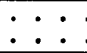 &.$:$ & $\begin{array}{l}51.9 \\
-\end{array}$ & $\begin{array}{l}36.5 \\
-\end{array}$ \\
\hline
\end{tabular}

Delta Reservolr at Delta Dam, near Rome, N. $Y$.

Location.- Staff gage, lat. $43^{\circ} 16^{\prime} 25^{\prime \prime}$, Iong. $75^{\circ} 25^{\prime} 50^{\prime \prime}$, at Delta Dam, 5 miles north of Rome, Oneida County. Crest of apilimay at elevation 550.0 feet (Barge Canal datum). Drainage area.- 145 square miles; affected by diversions into basin. Gage-helght record.- Nean of readings to tenths at $8 \mathrm{a} . \mathrm{m}$. and 4 p.m.

Remarks.- Usable storage capacity 2,800,000,000 cubic feet. Records of storage furnished by New York State Department of Public Works. Monthly gain or loss in storage adjusted for diversion from Black River Basin through Black River Canal. For information on diversion from Black River Basin into Hohavk River Basin above Delta Reservolr see record of Black River Canal (flowing south) near Boonvilie, N. Y.

Gage nelght, in feet, and contents, in millions of cublc feet, 1938

\begin{tabular}{|c|c|c|c|c|c|c|c|c|c|c|}
\hline \multirow[b]{2}{*}{ Day } & \multicolumn{2}{|c|}{ September } & \multicolumn{2}{|r|}{ October } & \multirow[b]{2}{*}{ Day } & \multicolumn{2}{|c|}{ September } & \multicolumn{3}{|c|}{ October } \\
\hline & Feet & $\begin{array}{l}\text { Millions of } \\
\text { cubic feet }\end{array}$ & Feet & $\begin{array}{l}\text { M1llions of } \\
\text { cubic feet }\end{array}$ & & Feet & $\begin{array}{l}\text { Millions of } \\
\text { cubic feet }\end{array}$ & Feet & & $\begin{array}{l}111 \text { ons of } \\
\text { ubic feet }\end{array}$ \\
\hline $\begin{array}{l}1 \\
2 \\
3 \\
4 \\
5\end{array}$ & $\begin{array}{l}536.7 \\
536.55 \\
536.4 \\
536.25 \\
536.05\end{array}$ & $\begin{array}{l}1,466 \\
1,454 \\
1,442 \\
1,430 \\
1,414\end{array}$ & $\begin{array}{l}541 \cdot 95 \\
541 \cdot 75 \\
541.55 \\
541.25 \\
540.95\end{array}$ & $\begin{array}{l}1,935 \\
1,915 \\
1,895 \\
1,865 \\
1,836\end{array}$ & $\begin{array}{l}16 \\
17 \\
18 \\
19 \\
20\end{array}$ & $\begin{array}{l}536.5 \\
536.5 \\
536.5 \\
536.5 \\
536.5\end{array}$ & $\begin{array}{l}1,450 \\
1,450 \\
1,450 \\
1,450 \\
1,450\end{array}$ & $\begin{array}{l}537 \cdot 35 \\
536.95 \\
536.55 \\
536.2 \\
535.85\end{array}$ & & $\begin{array}{l}1,518 \\
1,486 \\
1,454 \\
1,426 \\
1,398\end{array}$ \\
\hline $\begin{array}{r}6 \\
7 \\
8 \\
9 \\
10\end{array}$ & $\begin{array}{l}535.9 \\
535.8 \\
535.8 \\
535.75 \\
535.6\end{array}$ & $\begin{array}{l}1,402 \\
1,394 \\
1,394 \\
1,390 \\
1,378\end{array}$ & $\begin{array}{l}540.65 \\
540.35 \\
540.05 \\
539.75 \\
539.45\end{array}$ & $\begin{array}{l}1,808 \\
1,782 \\
1,754 \\
1,728 \\
1,700\end{array}$ & $\begin{array}{l}21 \\
22 \\
23 \\
24 \\
25\end{array}$ & $\begin{array}{l}536.75 \\
540.1 \\
541 \cdot 5 \\
542 \cdot 15 \\
542.4\end{array}$ & $\begin{array}{l}1,470 \\
1,759 \\
1,890 \\
1,955 \\
1,980\end{array}$ & $\begin{array}{l}535.55 \\
535.25 \\
534.95 \\
534.65 \\
534.35\end{array}$ & & $\begin{array}{l}1,374 \\
1,350 \\
1,326 \\
1,302 \\
1,278\end{array}$ \\
\hline $\begin{array}{l}11 \\
12 \\
13 \\
14 \\
15\end{array}$ & $\begin{array}{l}535.5 \\
535.4 \\
535.55 \\
535.6 \\
536.15\end{array}$ & $\begin{array}{l}1,370 \\
1,362 \\
1,374 \\
1,378 \\
1,422\end{array}$ & $\begin{array}{l}539.15 \\
538.75 \\
538.45 \\
538.1 \\
537.75\end{array}$ & $\begin{array}{l}1,674 \\
1,638 \\
1,610 \\
1,579 \\
1,550\end{array}$ & $\begin{array}{l}26 \\
27 \\
28 \\
29 \\
30 \\
31\end{array}$ & $\begin{array}{l}542 \cdot 5 \\
542 \cdot 4 \\
542 \cdot 5 \\
542 \cdot 4 \\
542 \cdot 25\end{array}$ & $\begin{array}{l}1,990 \\
1,980 \\
1,990 \\
1,980 \\
1,965\end{array}$ & $\begin{array}{l}534.2 \\
533.95 \\
533.65 \\
533.35 \\
532.95 \\
532.55\end{array}$ & & $\begin{array}{l}1,266 \\
1,246 \\
1,226 \\
1,204 \\
1,176 \\
1,148\end{array}$ \\
\hline & & & & & & & & Septembe & & October \\
\hline $\begin{array}{l}\text { Gain } \\
\text { Gain }\end{array}$ & $\begin{array}{l}\text { or loss } \\
\text { or loss }\end{array}$ & $\begin{array}{l}\text { in storage } \\
\text { in storage }\end{array}$ & $\begin{array}{l}\text { in ed } \\
\text { in ed }\end{array}$ & $\begin{array}{l}\text { ivalent mean } \\
\text { ivalent mean }\end{array}$ & $\begin{array}{l}\text { sec } \\
\text { sec }\end{array}$ & $\begin{array}{l}\text { d-feet } \\
\text { d-feet }\end{array}$ & $\left\{\begin{array}{l}\text { observed) } \\
\text { adjusted }\end{array}\right.$ & $\begin{array}{r}+18 \\
+13\end{array}$ & & af $\begin{array}{r}-305 \\
-341\end{array}$ \\
\hline
\end{tabular}

Computed from contents corresponding to gage height interpolated for midnight of last day of month. 
Mohawk River below Delta Dam, near Rome, N. Y.

Location.- Water-stage recorder, lat. $43^{\circ} 15^{\prime} 5^{\prime \prime}$, long. $75^{\circ} 26^{\prime} 10^{\prime \prime}$, at Spring Brook fish hatchery, 1 mile below Delta Dam and 4 miles north of Rome, Oneida County. Prior to January 1937 staff gage located about 200 feet downstream. Zero of both gages is 474.00 feet above mean sea level (Barge Canal datum).

Drainage area.- 150 square miles (revised); 145 square miles affected by storage in Delta Reservoir.

Gage-height record.- Water-stage recorder graph.

Stage-discharge relation.- Defined by current-meter measurements below 2,790 secondfeet; extended logarithmically to peak stage.

Maxima.- September 1938: Discharge, 464 second-feet 10:30 a.m. Sept. 26 (gage height, 2.73 feet).

October 1927 to August 1938: D1scharge, 4,060 second-feet July 9, 1935 (gage height, 8.1 feet, from floodmarks) from rating defined by current-meter measurements below 2,210 second-feet and extended logarithmically to peak stage. Reports of the Stage Engineer and Surveyor record a maximum discharge of 4,210 second-feet Mar. 9 , 1921 .

Remarks.- For information on storage and diversion into the basin see record for Delta Reservolr near Rome, N. Y., and for Black River Canal (flowing south) near Boonville, N. Y. Mean monthly discharge adjusted for storage and diversion into the basin.

Mean daily discharge, in second-feet, 1938

\begin{tabular}{|c|c|c|c|c|c|c|c|c|c|c|c|}
\hline Day & Sept. & Oct. & Day & Sept. & Oct. & Day & Sept. & Oct. & Day & Sept. & Oct. \\
\hline $\begin{array}{l}1 \\
2 \\
3 \\
4 \\
5 \\
6 \\
7 \\
8\end{array}$ & $\begin{array}{l}215 \\
215 \\
215 \\
215 \\
215 \\
215 \\
217 \\
217\end{array}$ & $\begin{array}{l}446 \\
443 \\
443 \\
443 \\
442 \\
446 \\
446 \\
446\end{array}$ & $\begin{array}{r}9 \\
10 \\
11 \\
12 \\
13 \\
14 \\
15 \\
16\end{array}$ & $\begin{array}{l}224 \\
227 \\
227 \\
227 \\
230 \\
232 \\
242 \\
233\end{array}$ & $\begin{array}{l}443 \\
440 \\
440 \\
448 \\
464 \\
464 \\
460 \\
460\end{array}$ & $\begin{array}{l}17 \\
18 \\
19 \\
20 \\
21 \\
22 \\
23 \\
24\end{array}$ & $\begin{array}{l}237 \\
234 \\
232 \\
237 \\
256 \\
125 \\
170 \\
149\end{array}$ & $\begin{array}{l}460 \\
456 \\
431 \\
433 \\
433 \\
433 \\
433 \\
433\end{array}$ & $\begin{array}{l}25 \\
26 \\
27 \\
28 \\
29 \\
30 \\
31\end{array}$ & $\begin{array}{l}140 \\
342 \\
277 \\
328 \\
446 \\
446\end{array}$ & $\begin{array}{l}433 \\
423 \\
420 \\
420 \\
417 \\
417 \\
414\end{array}$ \\
\hline $\begin{array}{l}\text { Mean } \\
\text { Mean } \\
\text { Run- }\end{array}$ & $\begin{array}{l}\text { nonthly } \\
\text { nonthly } \\
\text { if, in }\end{array}$ & $\begin{array}{l}\text { ischar } \\
\text { ischar } \\
\text { ehes }\end{array}$ & $\begin{array}{l}\text { ir } \\
\text { ir } \\
\text { fust }\end{array}$ & econd- & & . & 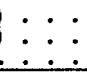 & 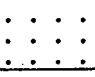 & 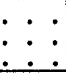 & $\begin{array}{r}240 \\
372 \\
2.77 \\
\end{array}$ & $\begin{array}{r}440 \\
99 \\
0.76 \\
\end{array}$ \\
\hline
\end{tabular}

Gage helgnt, in feet, and discharge, In second-feet, at indicated time, 1938

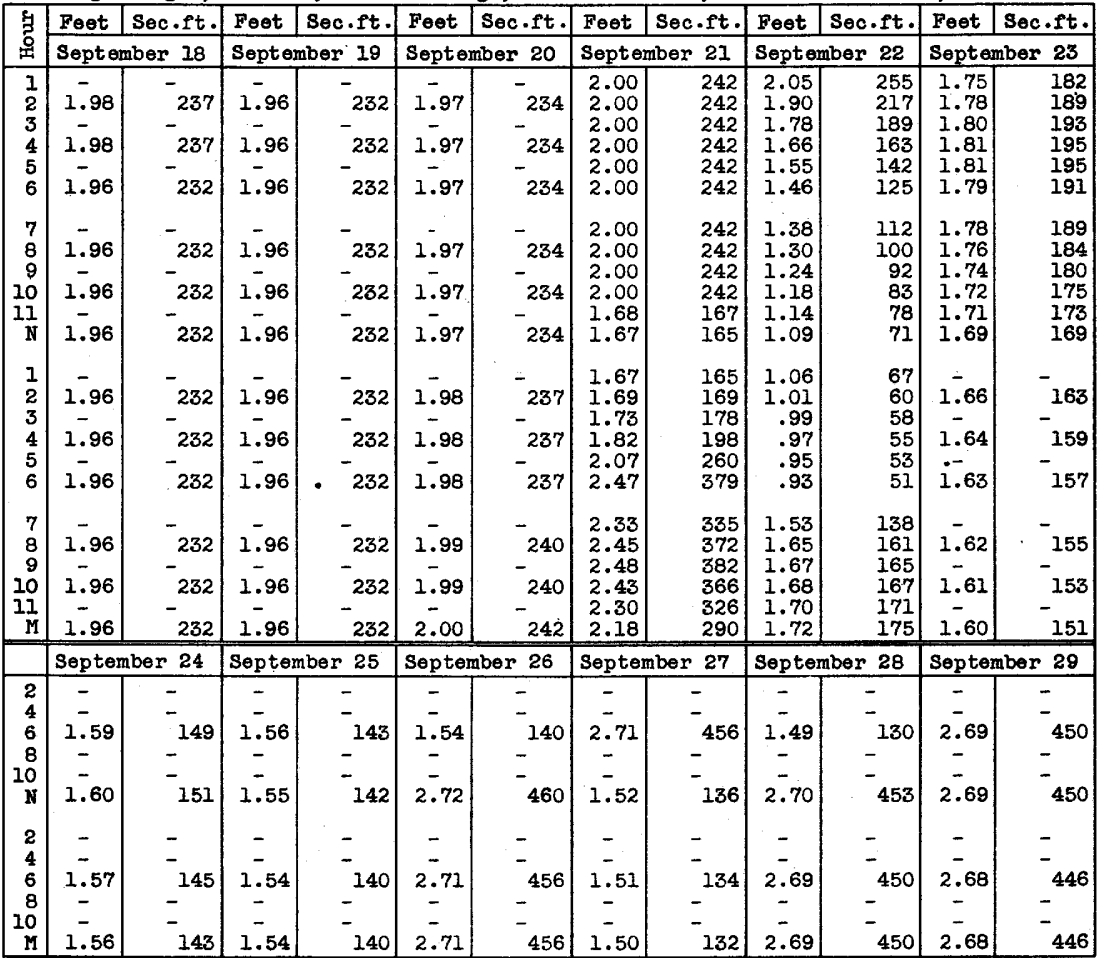

Supplemental records.- Sept. 26, 8:30 a.m., 1.54 ft., 140 sec.-ft.; 9:15 a.m., 2.72 ft., 460 sec.-ft.; $10: 30$ a.m., 2.73 ft., 464 sec.-ft. Sept. 27, 10:15 a.m. $2.72 \mathrm{ft.}, 460 \mathrm{sec} .-\mathrm{ft}$. Sept. $28,8: 50$ a.m., $1.49 \mathrm{ft.}, 130$ sec.-ft.; 9:50 a.m., 2.70 ft., 453 sec. $-f t$. 
Mohawk River near Little Falls, N. Y.

Location.- Water-stage recorder, lat. $43^{\circ} 00^{\prime} 50^{n}$, long. $74^{\circ} 46^{\prime} 40^{\prime \prime}$, 1 , 800 feet below Rocky Rift Dam, 2 miles above mouth of East Canada Creek, and $4 \frac{1}{2}$ miles southeast of Little Falls, Herkimer County. Zero of gage is at elevation 310.0 feet, Barge Canal datum.

Drainage area.- 1,348 square miles; 518 square miles affected by storage in Delta and Hinckley Reservoirs.

Gage-height record. - Water-stage recorder graph.

Stage-discharge relation.- Defined by current-meter measurements below 13,600 feet; extended logarithmically to peak stage.

Maxima.- September 1938: Discharge, 22,700 second-feet (diversion not included $12 \approx 45$ a.m. Sept. 22 (gage helght, 17.01 feet).

October 1927 to August 1938: D1scharge, 23,200 second-feet (diversion not included) Mar. 18, 1936 (gage height, 17.24 feet).

Remarks.- Mean daily discharges include diversion of water into Barge Canal at Rocky Rift Dam. Discharges at indicated time do not include this diversion. For information on diversions into the basin and on storage see records for Delta Reservoir at Delta Dam, near Rome, N. Y., Hinckley Reservoir at Hinckley, N. Y., and Black River Canal (flowing south) near Boonville, N. Y.

Mean daily diversion, in second-feet, at Rocky Rift Dam, September 1938

\begin{tabular}{|r|r|r|r|r|r|r|r|r|r|r|r|}
\hline 18 & 19 & \multicolumn{1}{|c|}{20} & \multicolumn{1}{|c|}{21} & \multicolumn{1}{|c|}{22} & \multicolumn{1}{c|}{23} & \multicolumn{1}{c|}{24} & 25 & 26 & 27 & 28 & 29 \\
\hline 65 & 58 & 99 & 59 & 25 & 25 & 25 & 33 & 29 & 43 & 76 & 121 \\
\hline
\end{tabular}

Mean da1ly discharge, in second-feet, 1938

\begin{tabular}{|c|c|c|c|c|c|c|c|c|c|c|c|}
\hline Day & Sept. & 0 ct. & Day & Sept. & Oct. & Day & Sept. & Oct. & Day & Sept. & Oct. \\
\hline $\begin{array}{l}1 \\
2 \\
3 \\
4 \\
5 \\
6 \\
7 \\
8\end{array}$ & $\begin{array}{l}728 \\
730 \\
691 \\
772 \\
730 \\
676 \\
830 \\
990\end{array}$ & $\begin{array}{l}2,260 \\
1,850 \\
1,750 \\
1,810 \\
1,790 \\
1,760 \\
1,690 \\
1,650\end{array}$ & $\begin{array}{r}9 \\
10 \\
11 \\
12 \\
13 \\
14 \\
15 \\
16\end{array}$ & $\begin{array}{r}910 \\
790 \\
850 \\
834 \\
1,080 \\
1,080 \\
1,730 \\
1,630\end{array}$ & $\begin{array}{l}1,630 \\
1,570 \\
1,600 \\
1,620 \\
1,630 \\
1,580 \\
1,550 \\
1,600\end{array}$ & $\begin{array}{l}17 \\
18 \\
19 \\
20 \\
21 \\
22 \\
23 \\
24\end{array}$ & $\begin{array}{r}1,210 \\
1,240 \\
1,160 \\
1,920 \\
8,960 \\
16,100 \\
10,900 \\
9,870\end{array}$ & $\begin{array}{l}1,460 \\
1,540 \\
1,510 \\
1,530 \\
1,650 \\
1,660 \\
1,640 \\
1,640\end{array}$ & $\begin{array}{l}25 \\
26 \\
27 \\
28 \\
29 \\
30 \\
31\end{array}$ & $\begin{array}{l}5,540 \\
4,020 \\
2,980 \\
2,790 \\
2,150 \\
2,190\end{array}$ & $\begin{array}{l}1,890 \\
1,800 \\
1,750 \\
1,630 \\
1,610 \\
1,560 \\
1,480\end{array}$ \\
\hline $\begin{array}{l}\text { Mean } \\
\text { Run- }\end{array}$ & $\begin{array}{l}\text { nthly } \\
, \text { in }\end{array}$ & schan & , 11 & $\begin{array}{l}\text { econd } \\
. \quad \cdot \text {. }\end{array}$ & t. & . & $\begin{array}{l}\cdot \cdot \\
.\end{array}$ & . $\cdot \dot{\cdot}$ & - & $\begin{array}{r}2,869 \\
2.38\end{array}$ & $\begin{array}{r}1,667 \\
1.43\end{array}$ \\
\hline
\end{tabular}

Gage helght, in feet, and discharge, in second-feet, at Indicated time, 1938

\begin{tabular}{|c|c|c|c|c|c|c|c|c|c|c|c|c|}
\hline \multirow{2}{*}{$\begin{array}{l}5 \\
3 \\
0\end{array}$} & Feet & Sec.ft. & Feet & Sec.ft. & Feet & Sec.ft. & Feet & Sec.ft. & Feet & Sec.ft. & Feot & Sec.ft. \\
\hline & \multicolumn{2}{|c|}{ September 18} & \multicolumn{2}{|c|}{ September 19} & \multicolumn{2}{|c|}{ September 20} & \multicolumn{2}{|c|}{ September 21} & \multicolumn{2}{|c|}{ September 22} & \multicolumn{2}{|c|}{ September 23} \\
\hline $\begin{array}{l}1 \\
2 \\
3 \\
4 \\
5 \\
6\end{array}$ & $\begin{array}{l}5.57 \\
5.54 \\
5.61 \\
5.76 \\
5.68 \\
5.75\end{array}$ & $\begin{array}{l}1,100 \\
1,080 \\
1,130 \\
1,240 \\
1,180 \\
1,230\end{array}$ & $\begin{array}{l}5.30 \\
5.29 \\
5.30 \\
5.4 C \\
5.45 \\
5.48\end{array}$ & $\begin{array}{r}930 \\
924 \\
930 \\
990 \\
1,020 \\
1,040\end{array}$ & $\begin{array}{l}5.69 \\
5.71 \\
5.90 \\
5.90 \\
5.88 \\
5.89\end{array}$ & $\begin{array}{l}1,180 \\
1,200 \\
1,360 \\
1,360 \\
1,340 \\
1,350\end{array}$ & $\begin{array}{l}7.97 \\
8.03 \\
7.94 \\
8.02 \\
8.06 \\
8.07\end{array}$ & $\begin{array}{l}3,900 \\
4,000 \\
3,860 \\
3,980 \\
4,040 \\
4,050\end{array}$ & $\begin{array}{l}17.00 \\
16.91 \\
16.75 \\
16.54 \\
16.26 \\
16.02\end{array}$ & $\begin{array}{l}22,690 \\
22,500 \\
22,100 \\
21,600 \\
21,000 \\
20,400\end{array}$ & $\begin{array}{l}11.11 \\
11.04 \\
11.00 \\
11.01 \\
11.11 \\
11.22\end{array}$ & $\begin{array}{r}9,770 \\
9,620 \\
9,540 \\
9,560 \\
9,770 \\
10,000\end{array}$ \\
\hline $\begin{array}{r}7 \\
8 \\
9 \\
10 \\
11 \\
N\end{array}$ & $\begin{array}{l}5.73 \\
5.83 \\
5.90 \\
5.94 \\
5.89 \\
5.83\end{array}$ & $\begin{array}{l}1,210 \\
1,300 \\
1,360 \\
1,400 \\
1,350 \\
1,300\end{array}$ & $\begin{array}{l}5.53 \\
5.72 \\
5.67 \\
5.63 \\
5.62 \\
5.74\end{array}$ & $\begin{array}{l}1,070 \\
1,210 \\
1,170 \\
1,140 \\
1,130 \\
1,220\end{array}$ & $\begin{array}{l}5.90 \\
5.93 \\
5.99 \\
6.13 \\
6.07 \\
6.20\end{array}$ & $\begin{array}{l}1,360 \\
1,390 \\
1,450 \\
1,590 \\
1,530 \\
1,660\end{array}$ & $\begin{array}{l}8.54 \\
8.21 \\
8.11 \\
8.12 \\
7.99 \\
8.17\end{array}$ & $\begin{array}{l}4,800 \\
4,270 \\
4,120 \\
4,130 \\
3,940 \\
4,200\end{array}$ & $\begin{array}{l}15.74 \\
15.40 \\
15.00 \\
14.45 \\
13.98 \\
13.54\end{array}$ & $\begin{array}{l}19,800 \\
19,000 \\
18,100 \\
16,900 \\
15,900 \\
14,900\end{array}$ & $\begin{array}{l}11.26 \\
11.34 \\
11.48 \\
11.59 \\
11.63 \\
11.74\end{array}$ & $\begin{array}{l}10,100 \\
10,300 \\
10,500 \\
10,800 \\
10,900 \\
11,100\end{array}$ \\
\hline $\begin{array}{l}1 \\
2 \\
3 \\
4 \\
5 \\
6\end{array}$ & $\begin{array}{l}5.73 \\
5.77 \\
5.90 \\
5.80 \\
5.65 \\
5.60\end{array}$ & $\begin{array}{l}1,210 \\
1,250 \\
1,360 \\
1,270 \\
1,160 \\
1,120\end{array}$ & $\begin{array}{l}5.70 \\
5.63 \\
5.74 \\
5.63 \\
5.70 \\
5.78\end{array}$ & $\begin{array}{l}1,190 \\
1,140 \\
1,220 \\
1,140 \\
1,190 \\
1,250\end{array}$ & $\begin{array}{l}6.14 \\
6.24 \\
6.32 \\
6.31 \\
6.55 \\
6.50\end{array}$ & $\begin{array}{l}1,600 \\
1,700 \\
1,790 \\
1,780 \\
2,040 \\
1,990\end{array}$ & $\begin{array}{r}8.32 \\
8.67 \\
9.54 \\
10.09 \\
11.38 \\
13.59\end{array}$ & $\begin{array}{r}4,440 \\
5,020 \\
6,590 \\
7,660 \\
10,200 \\
15,000\end{array}$ & $\begin{array}{l}13.19 \\
12.92 \\
12.69 \\
12.53 \\
12.38 \\
12.21\end{array}$ & $\begin{array}{l}14,200 \\
13,600 \\
13,100 \\
12,800 \\
12,400 \\
12,100\end{array}$ & $\begin{array}{l}11.90 \\
12.01 \\
12.08 \\
12.13 \\
12.14 \\
12.11\end{array}$ & $\begin{array}{l}11,400 \\
11,700 \\
11,800 \\
11,900 \\
11,900 \\
11,900\end{array}$ \\
\hline \multirow[t]{2}{*}{$\begin{array}{r}7 \\
8 \\
9 \\
10 \\
11 \\
M\end{array}$} & $\begin{array}{l}5.67 \\
5.59 \\
5.50 \\
5.40 \\
5.30 \\
5.32\end{array}$ & $\begin{array}{r}1,170 \\
1,110 \\
1,050 \\
990 \\
930 \\
940\end{array}$ & $\begin{array}{l}5.60 \\
5.59 \\
5.60 \\
5.64 \\
5.70 \\
5.70\end{array}$ & $\begin{array}{l}1,120 \\
1,110 \\
1,120 \\
1,150 \\
1,190 \\
1,190\end{array}$ & $\begin{array}{l}6.62 \\
6.90 \\
7.13 \\
7.30 \\
7.62 \\
7.90\end{array}$ & $\begin{array}{l}2,120 \\
2,460 \\
2,750 \\
2,970 \\
3,410 \\
3,800\end{array}$ & $\begin{array}{l}14.61 \\
15.39 \\
16.21 \\
16.68 \\
16.86 \\
16.96\end{array}$ & $\begin{array}{l}17,300 \\
19,000 \\
20,900 \\
22,000 \\
22,400 \\
22,600\end{array}$ & $\begin{array}{l}12.03 \\
11.87 \\
11.68 \\
11.48 \\
11.33 \\
11.20\end{array}$ & $\begin{array}{r}11,700 \\
11,400 \\
11,000 \\
10,500 \\
10,200 \\
9,960\end{array}$ & $\begin{array}{l}12.05 \\
12.02 \\
12.00 \\
11.98 \\
11.95 \\
11.93\end{array}$ & $\begin{array}{l}11,700 \\
11,700 \\
11,600 \\
11,600 \\
11,500 \\
11,500\end{array}$ \\
\hline & \multicolumn{2}{|c|}{ September 24} & \multicolumn{2}{|c|}{ September 25} & \multicolumn{2}{|c|}{ September 26} & \multicolumn{2}{|c|}{ September 27} & \multicolumn{2}{|c|}{ September 28} & \multicolumn{2}{|c|}{ September 29} \\
\hline $\begin{array}{r}2 \\
4 \\
6 \\
8 \\
10 \\
N\end{array}$ & $\begin{array}{l}11.86 \\
11.81 \\
11.74 \\
11.60 \\
11.37 \\
11.25\end{array}$ & $\begin{array}{l}11,300 \\
11,200 \\
11,100 \\
10,800 \\
10,300 \\
10,100\end{array}$ & $\begin{array}{l}9.93 \\
9.77 \\
9.64 \\
9.46 \\
8.48 \\
7.31\end{array}$ & $\begin{array}{l}7,340 \\
7,020 \\
6,780 \\
6,430 \\
4,700 \\
2,980\end{array}$ & $\begin{array}{l}8.41 \\
8.34 \\
8.27 \\
8.18 \\
8.11 \\
8.04\end{array}$ & \begin{tabular}{|l|}
4,590 \\
4,470 \\
4,360 \\
4,220 \\
4,120 \\
4,010
\end{tabular} & $\begin{array}{l}7.52 \\
7.47 \\
7.47 \\
7.31 \\
7.32 \\
7.22 \\
\end{array}$ & $\begin{array}{l}3,270 \\
3,200 \\
3,200 \\
2,980 \\
3,000 \\
2,870\end{array}$ & $\begin{array}{l}7.08 \\
7.15 \\
7.33 \\
7.30 \\
7.51 \\
7.49\end{array}$ & $\begin{array}{l}2,680 \\
2,780 \\
3,010 \\
2,970 \\
3,250 \\
3,230\end{array}$ & $\begin{array}{l}6.44 \\
6.57 \\
6.80 \\
6.83 \\
6.62 \\
6.59\end{array}$ & $\begin{array}{r}1,920 \\
2,070 \\
2,340 \\
2,380 \\
2,120 \\
2,090\end{array}$ \\
\hline $\begin{array}{r}2 \\
4 \\
6 \\
8 \\
10 \\
11\end{array}$ & $\begin{array}{l}11.06 \\
10.98 \\
10.71 \\
10.36 \\
10.20 \\
10.07\end{array}$ & $\begin{array}{l}9,670 \\
9,500 \\
8,930 \\
8,200 \\
7,880 \\
7,620\end{array}$ & $\begin{array}{l}8.93 \\
8.74 \\
8.73 \\
8.62 \\
8.52 \\
8.43\end{array}$ & $\begin{array}{l}5,460 \\
5,140 \\
5,120 \\
4,930 \\
4,760 \\
4,620\end{array}$ & $\begin{array}{l}7.93 \\
7.85 \\
7.79 \\
7.68 \\
7.61 \\
7.65\end{array}$ & $\begin{array}{l}3,840 \\
3,730 \\
3,650 \\
3,490 \\
3,390\end{array}$ & $\begin{array}{l}7.24 \\
7.15 \\
7.02 \\
7.11 \\
7.20 \\
7.19\end{array}$ & $\begin{array}{l}2,890 \\
2,780 \\
2,610 \\
2,720 \\
2,840 \\
2,830\end{array}$ & $\begin{array}{l}7.25 \\
6.91 \\
6.89 \\
6.93 \\
6.69 \\
6.50\end{array}$ & $\begin{array}{l}2,900 \\
2,470 \\
2,450 \\
2,500 \\
2,210 \\
1,990\end{array}$ & $\begin{array}{l}6.59 \\
6.40 \\
6.29 \\
6.43 \\
6.52 \\
6.48\end{array}$ & $\begin{array}{l}2,090 \\
1,880 \\
1,760 \\
1,910 \\
2,010 \\
1,970\end{array}$ \\
\hline
\end{tabular}

Supplemental records.- jept. $21,6: 45 \mathrm{a.m.,} 8.77 \mathrm{ft.}, 5,190 \mathrm{sec.-ft.} \mathrm{Sept.} 22$,

$12: 45$ a.m., 17.01 ft., 22,700 sec.-ft. Sept. 25, 9:30 a.m., 9.23 ft., 6,000 sec.-

ft.; 11 a.m., $6.18 \mathrm{ft} ., 1,640$ sec.-ft.; $1: 40$ p.m., $9.08 \mathrm{ft} ., 5,730$ sec.-ft. Sept. 27,

$6: 30$ a.m., 7.02 ft., 2,610 sec.-ft. 
Location. - Water-stage recorder, lat. $42^{\circ} 47^{\prime} 05^{\prime \prime}$, long. $73^{\circ} 42^{\prime} 25^{n}$, at School Street plant of New York Power \& Light Corporation in Cohoes, Albany County.

Drainage area.- 3,456 square miles; 832 square miles affected by storage in schoharie, Delta, and Hinckley Reservoirs.

Gage-height record.- Water-stage recorder graph.

Stage-discharge relation.- Defined by current-meter measurements below 43,800 secondfeet; extended logarithmically to peak stage of March 1936.

Maxima.- September 1938: Discharge, 102,000 second-feet 9:15 p.m. Sept. 22 (gage height, 20.61 feet).

December 1917 to August 1938: Discharge, 130,000 second-feet Mar. 19, 1936 (gage helght, 22.57 feet).

Remarks.- Daily and monthly discharges not adjusted for diversion or storage. For information on storage and diversions see records for Delta Reservoir at Delta Dam near Rome, N. Y.; Hinckley Reservoir at Hinckley, N. Y.; Schoharie Reservo1r at Gilboa Dam, at Gilboa, N. Y., and Black River Canal (flowing south) near Boonville, N. Y.

Mean dally discharge, in second-feet, 1938

\begin{tabular}{|c|r|r||r|r|r||r|r|r|r|r|r|}
\hline Day & Sept. & 0ct. & Day & Sept. & 0ct. & Day & Sept. & 0ct. & Day & Sept. & Oct. \\
\hline 1 & 1,060 & 3,540 & 9 & 1,460 & 2,010 & 17 & 3,020 & 2,500 & 25 & 16,300 & 4,070 \\
2 & 1,030 & 2,590 & 10 & 723 & 2,560 & 18 & 2,300 & 2,330 & 26 & 8,760 & 3,380 \\
3 & 734 & 3,070 & 11 & 344 & 2,330 & 19 & 1,970 & 2,200 & 27 & 7,900 & 3,410 \\
4 & 242 & 2,380 & 12 & 1,250 & 2,300 & 20 & 4,530 & 2,330 & 28 & 5,940 & 3,360 \\
5 & 64 & 2,800 & 13 & 1,490 & 2,710 & 21 & 24,700 & 2,200 & 29 & 5,880 & 2,960 \\
6 & 829 & 2,800 & 14 & 1,460 & 2,770 & 22 & 89,800 & 1,920 & 30 & 3,910 & 1,940 \\
7 & 874 & 2,800 & 15 & 3,320 & 2,090 & 23 & 59,100 & 1,890 & 31 & & 2,330 \\
8 & 1,120 & 2,700 & 16 & 3,330 & 897 & 24 & 26,900 & 2,820 & & & \\
\hline
\end{tabular}

Gage helght, in feet, and discharge, in second-feet, at indicated time, 1938

\begin{tabular}{|c|c|c|c|c|c|c|c|c|c|c|c|c|}
\hline \multirow{2}{*}{$\begin{array}{l}9 \\
\text { ? } \\
\text { 足 }\end{array}$} & Feet & Sec.ft. & Feet & Sec.ft. & Feet & Sec.ft. & Feet & Sec.ft. & Feet & Sec.ft. & Feet & Sec.ft \\
\hline & \multicolumn{2}{|c|}{ September 18} & \multicolumn{2}{|c|}{ September 19} & \multicolumn{2}{|c|}{ September 20} & \multicolumn{2}{|c|}{ September 21} & \multicolumn{2}{|c|}{ September 22} & \multicolumn{2}{|c|}{ September 23} \\
\hline $\begin{array}{l}1 \\
2 \\
3 \\
4 \\
5 \\
6\end{array}$ & $\begin{array}{l}9.90 \\
9.89 \\
9.92 \\
9.77 \\
9.57 \\
9.53\end{array}$ & $\begin{array}{l}- \\
- \\
- \\
- \\
-\end{array}$ & $\begin{array}{l}4.41 \\
4.38 \\
4.43 \\
4.43 \\
4.42 \\
9.04\end{array}$ & $\begin{array}{l}- \\
- \\
- \\
- \\
- \\
-\end{array}$ & $\begin{array}{l}9.93 \\
9.83 \\
9.47 \\
9.60 \\
9.89 \\
9.83\end{array}$ & & \begin{tabular}{|l|}
10.68 \\
10.74 \\
11.33 \\
11.60 \\
12.30 \\
12.47
\end{tabular} & $\begin{array}{r}5,420 \\
5,630 \\
7,990 \\
9,240 \\
12,900 \\
13,900\end{array}$ & $\begin{array}{l}18.13 \\
18.47 \\
18.67 \\
18.86 \\
19.06 \\
19.17\end{array}$ & $\begin{array}{l}68,200 \\
72,600 \\
75,200 \\
77,700 \\
80,300 \\
81,700\end{array}$ & \begin{tabular}{|l|}
20.26 \\
20.08 \\
19.90 \\
19.64 \\
19.38 \\
19.12
\end{tabular} & $\begin{array}{l}96,800 \\
94,300 \\
91,800 \\
88,200 \\
84,500 \\
81,100\end{array}$ \\
\hline $\begin{array}{r}7 \\
8 \\
9 \\
10 \\
11 \\
\text { N }\end{array}$ & $\begin{array}{l}9.53 \\
9.53 \\
9.53 \\
9.53 \\
9.53 \\
9.53\end{array}$ & $\begin{array}{c}- \\
- \\
- \\
- \\
* 2,300\end{array}$ & $\begin{array}{l}9.5 \\
9.8 \\
9.8 \\
9.8 \\
9.7 \\
9.1\end{array}$ & $\begin{array}{c}- \\
- \\
- \\
- \\
- \\
* 1,970\end{array}$ & $\begin{array}{r}9.90 \\
9.94 \\
9.97 \\
10.00 \\
9.95 \\
10.00\end{array}$ & $\begin{array}{l}3,160 \\
3,260 \\
3,340 \\
3,410 \\
3,280 \\
3,410\end{array}$ & $\left|\begin{array}{l}12.82 \\
13.15 \\
13.35 \\
13.54 \\
13.67 \\
13.75\end{array}\right|$ & $\begin{array}{l}16,000 \\
18,000 \\
19,200 \\
20,500 \\
21,400 \\
22,000\end{array}$ & $\begin{array}{l}19.28 \\
19.45 \\
19.57 \\
19.68 \\
19.83 \\
19.91\end{array}$ & $\begin{array}{l}83,100 \\
85,500 \\
87,200 \\
88,700 \\
90,800 \\
91,900\end{array}$ & & $\begin{array}{l}76,900 \\
72,600 \\
68,600 \\
64,200 \\
59,400 \\
55,700\end{array}$ \\
\hline $\begin{array}{l}1 \\
2 \\
3 \\
4\end{array}$ & $\begin{array}{l}9.89 \\
9.82 \\
9.53 \\
9.53 \\
9.50 \\
9.84\end{array}$ & $\begin{array}{l}- \\
- \\
- \\
- \\
-\end{array}$ & $\begin{array}{l}9.14 \\
9.07 \\
9.09 \\
9.15 \\
9.87 \\
9.89\end{array}$ & $\begin{array}{l}- \\
- \\
- \\
- \\
-\end{array}$ & $\begin{array}{l}10.00 \\
10.40 \\
10.50 \\
10.60 \\
10.66 \\
10.90\end{array}$ & $\begin{array}{l}3,410 \\
4,510 \\
4,820 \\
5,150 \\
5,350 \\
6,210\end{array}$ & $\mid \begin{array}{l}13.86 \\
13.93 \\
13.98 \\
14.06 \\
14.15 \\
14.80\end{array}$ & $\begin{array}{l}22,700 \\
23,200 \\
23,600 \\
24,100 \\
24,800 \\
30,100\end{array}$ & $\left|\begin{array}{l}20.09 \\
20.20 \\
20.35 \\
20.38 \\
20.49 \\
20.48\end{array}\right|$ & $\begin{array}{r}94,500 \\
96,000 \\
98,100 \\
98,500 \\
100,000 \\
99,900\end{array}$ & & $\begin{array}{l}50,500 \\
45,700 \\
42,400 \\
39,800 \\
37,600 \\
36,100\end{array}$ \\
\hline \multirow[t]{2}{*}{$\begin{array}{r}7 \\
8 \\
9 \\
10 \\
11 \\
M \\
\end{array}$} & $\begin{array}{l}9.52 \\
9.13 \\
9.13 \\
5.82 \\
4.60 \\
4.40 \\
\end{array}$ & $\begin{array}{l}- \\
- \\
- \\
- \\
- \\
\end{array}$ & $\begin{array}{r}9.89 \\
9.98 \\
10.03 \\
9.98 \\
9.90 \\
9.94\end{array}$ & $\begin{array}{l}- \\
- \\
- \\
- \\
-\end{array}$ & $\begin{array}{l}1.04 \\
1.54 \\
.54 \\
.38 \\
.76\end{array}$ & $\begin{array}{l}6,760 \\
8,950 \\
8,950 \\
8,210 \\
5,700 \\
5,290\end{array}$ & $\begin{array}{l}15.40 \\
16.00 \\
16.55 \\
16.85 \\
17.45 \\
17.90 \\
\end{array}$ & $\begin{array}{l}35,600 \\
41,800 \\
48,100 \\
51,700 \\
59,400 \\
65,200\end{array}$ & & $\begin{array}{r}101,000 \\
101,000 \\
101,000 \\
101,000 \\
99,500 \\
98,400\end{array}$ & $\begin{array}{l}15.31 \\
15.18 \\
15.10 \\
15.06 \\
15.01 \\
14.97\end{array}$ & $\begin{array}{l}34,700 \\
33,500 \\
32,800 \\
32,400 \\
32,000 \\
31,600 \\
\end{array}$ \\
\hline & \multicolumn{2}{|c|}{ Soptember 24} & \multicolumn{2}{|c|}{ September 25} & \multicolumn{2}{|c|}{ September 26} & \multicolumn{2}{|c|}{ September 27} & \multicolumn{2}{|c|}{ September 28} & \multicolumn{2}{|c|}{ September 29} \\
\hline $\begin{array}{r}2 \\
4 \\
6 \\
8 \\
10 \\
N\end{array}$ & $\begin{array}{l}14.93 \\
14.91 \\
14.87 \\
14.81 \\
14.68 \\
14.40\end{array}$ & $\begin{array}{l}31,300 \\
31,100 \\
30,700 \\
30,200 \\
29,000 \\
26,800\end{array}$ & $\begin{array}{l}13.70 \\
13.62 \\
13.47 \\
12.87 \\
12.50 \\
12.70\end{array}$ & $\begin{array}{l}21,600 \\
21,000 \\
20,000 \\
16,300 \\
14,100 \\
15,300\end{array}$ & $\begin{array}{l}11.71 \\
11.60 \\
11.51 \\
11.41 \\
11.30 \\
11.23\end{array}$ & & & & & $\begin{array}{l}7,000 \\
6,760 \\
6,680 \\
6,370 \\
6,210 \\
6,250\end{array}$ & & \\
\hline $\begin{array}{r}2 \\
4 \\
6 \\
8 \\
10 \\
M \\
\end{array}$ & $\begin{array}{l}14.26 \\
14.11 \\
13.93 \\
13.75 \\
13.69 \\
13.71\end{array}$ & $\begin{array}{l}25,700 \\
24,500 \\
23,300 \\
22,000 \\
21,500 \\
21,700\end{array}$ & $\begin{array}{l}12.64 \\
12.60 \\
12.62 \\
12.52 \\
12.17 \\
11.91 \\
\end{array}$ & $\begin{array}{l}14,900 \\
14,700 \\
14,800 \\
14,200 \\
12,200 \\
10,800\end{array}$ & \begin{tabular}{|l|}
11.40 \\
11.49 \\
11.50 \\
11.54 \\
11.54 \\
11.43 \\
\end{tabular} & $\begin{array}{l}8,300 \\
8,710 \\
8,760 \\
8,950 \\
8,950 \\
8,440\end{array}$ & $\begin{array}{l}11.21 \\
11.30 \\
11.32 \\
11.30 \\
11.30 \\
11.22\end{array}$ & $\begin{array}{l}7,460 \\
7,860 \\
7,950 \\
7,860 \\
7,860 \\
7,510\end{array}$ & & & $\begin{array}{l}10.67 \\
10.93 \\
10.76 \\
10.60 \\
10.47 \\
10.19\end{array}$ & \\
\hline
\end{tabular}

Supplemental records. - Sept. 18, $12: 30$ p.m., $9.53 \mathrm{ft} . ; 2: 10$ p.m., $9.53 \mathrm{ft} . ; 3: 25$ p.m., 9.83 ft.; 6:50 p.m., 9.84 ft. Sept. 19, 5:30 a.m., 4.42 ft.; 4:40 p.m., 9.15 ft. Sept. 22, 9:15 p.m., 20.61 ft., 102,000 sec.-ft.

* Mean for the day. 
Location. - Staff gage, lat. $43^{\circ} 18^{\prime} 25^{\prime \prime}$, long. $75^{\circ} 06^{\prime} 25^{n}$, at Hinckley Dam at Hinckley, One1da County, about 3 miles east of Prospect. Crest of spillway at elevation 1,225 feet (Barge Canal datum).

Drainage area.- 373 square miles.

Gage-helght record. - Gage read to tenths at $8 \mathrm{a.m}$. da11

Remarks.- Usable storage capacity, $3,320,000,000$ cublc feet. Records furnished by New York State Department of Public Works.

Gage height, in feet, and contents, in millions of cublc feet, 1938

\begin{tabular}{|c|c|c|c|c|c|c|c|c|c|}
\hline \multirow[b]{2}{*}{ Day } & \multicolumn{2}{|c|}{ September } & \multicolumn{2}{|c|}{ October } & \multirow[b]{2}{*}{ Day } & \multicolumn{2}{|c|}{ September } & \multicolumn{2}{|c|}{ October } \\
\hline & Feet & $\begin{array}{l}\text { Millions of } \\
\text { cubtc feet }\end{array}$ & Feet & $\begin{array}{l}\text { Millions of } \\
\text { cubic feet }\end{array}$ & & Feet & $\begin{array}{l}\text { Millions of } \\
\text { cubic feet }\end{array}$ & Feet & $\begin{array}{l}\text { Millions of } \\
\text { cubic feet }\end{array}$ \\
\hline $\begin{array}{l}1 \\
2 \\
3 \\
4 \\
5\end{array}$ & $\begin{array}{l}1,211 \cdot 7 \\
1,211 \cdot 5 \\
1,211 \cdot 2 \\
1,210.9 \\
1,210.7\end{array}$ & $\begin{array}{l}1,970 \\
1,953 \\
1,927 \\
1,902 \\
1,886\end{array}$ & $\begin{array}{l}1,225.3 \\
1,225.0 \\
1,224.8 \\
1,224.4 \\
1,224.1\end{array}$ & \begin{tabular}{|l|}
3,359 \\
3,320 \\
3,296 \\
3,248 \\
3,212 \\
\end{tabular} & $\begin{array}{l}16 \\
17 \\
18 \\
19 \\
20\end{array}$ & $\begin{array}{l}1,211.4 \\
1,212.3 \\
1,212.7 \\
1,213.0 \\
1,213.1\end{array}$ & $\begin{array}{l}1,944 \\
2,023 \\
2,058 \\
2,084 \\
2,093\end{array}$ & $\begin{array}{l}1,219.1 \\
1,218.6 \\
1,218.0 \\
1,217: 4 \\
1,216.8\end{array}$ & $\begin{array}{r}2,660 \\
2,610 \\
2,550 \\
2,490 \\
2,430\end{array}$ \\
\hline \begin{tabular}{r|}
6 \\
7 \\
8 \\
9 \\
10
\end{tabular} & $\begin{array}{l}1,210.4 \\
1,210.0 \\
1,209.8 \\
1,210.0 \\
1,209.8\end{array}$ & $\begin{array}{l}1,862 \\
1,830 \\
1,814 \\
1,830 \\
1,814\end{array}$ & $\begin{array}{l}1,223.7 \\
1,223.3 \\
1,223.0 \\
1,222.6 \\
1,222.0\end{array}$ & $\begin{array}{l}3,165 \\
3,119 \\
3,085 \\
3,039 \\
2,970\end{array}$ & $\begin{array}{l}21 \\
22 \\
23 \\
24 \\
25\end{array}$ & $\begin{array}{l}1,21.4 \cdot 3 \\
1,220.8 \\
1,226.8 \\
1,227.3 \\
1,226.7\end{array}$ & $\begin{array}{l}2,199 \\
2,838 \\
3,558 \\
3,625 \\
3,544\end{array}$ & $\begin{array}{l}1,216.3 \\
1,215.8 \\
1,215.3 \\
1,214.7 \\
1,215.0\end{array}$ & $\begin{array}{l}2,380 \\
2,332 \\
2,287 \\
2,234 \\
2,260\end{array}$ \\
\hline $\begin{array}{l}11 \\
12 \\
13 \\
14 \\
15\end{array}$ & $\begin{array}{l}1,209.5 \\
1,209.2 \\
1,209.1 \\
1,209.9 \\
1,210.3\end{array}$ & $\begin{array}{l}1,790 \\
1,766 \\
1,758 \\
1,822 \\
1,854\end{array}$ & $\begin{array}{l}1,221.5 \\
1,221.0 \\
1,220.5 \\
1,220.1 \\
1,219.5\end{array}$ & $\begin{array}{l}2,915 \\
2,860 \\
2,805 \\
2,761 \\
2,700\end{array}$ & $\begin{array}{l}26 \\
27 \\
28 \\
29 \\
30 \\
31\end{array}$ & $\begin{array}{l}1,226 \cdot 2 \\
1,226.0 \\
1,225 \cdot 9 \\
1,225 \cdot 8 \\
1,225 \cdot 5\end{array}$ & $\begin{array}{l}3,477 \\
3,450 \\
3,437 \\
3,424 \\
3,385\end{array}$ & $\begin{array}{l}1,215.5 \\
1,215.8 \\
1,215.7 \\
1,215.3 \\
1,215.1 \\
1,214.8\end{array}$ & $\begin{array}{l}2,305 \\
2,332 \\
2,323 \\
2,287 \\
2,269 \\
2,242 \\
\end{array}$ \\
\hline \multicolumn{10}{|r|}{ October } \\
\hline Gai & in or & in $\mathrm{s}$ & & & & & & +541 & -432 \\
\hline
\end{tabular}

a Computed from contents corresponding to gage height interpolated for midnight of last day of month. 
West Canada Creek at Hinckley, N. Y.

Location. - Water-stage recorder, lat. $43^{\circ} 18^{\prime 2} 20^{n}$, long. $75^{\circ} 07^{\prime} 10^{n}$, 1 mile below Hinckley Dam, at Hinckley, Onelda County, $13 / 4$ miles east of Prospect.

Drafnage area.- 375 square miles; 373 square miles affected by storage in Hinckley Reservolr.

Gage-he1ght record.- Water-stage recorder graph.

Stage-discharge relation.- Defined by current-meter measurements below 6,430 secondfeet.

Maxtma.- September 1938: Discharge, 5,190 second-feet 10:30 to 11:30 p.m. Sept. 23 (gage helght, 6.92 feet).

June 1919 to August 1938: Discharge, 10,800 second-feet Apr. 12, 1922 (gage he1ght, 8.93 feet).

Remarks.- For information on storage see record for Hinckley Reservoir at Hinckley. Mean monthly discharge adjusted for storage. Small diversion made from Hinckley Reservolr for Utica water supply.

Mean dafly discharge, In second-feet, 1938

\begin{tabular}{|c|c|c|c|c|c|c|c|c|c|c|c|}
\hline Day & Sept. & Oct. & Day & Sept. & Oct. & Day & Sept. & Oct. & Day & Sept. & Oet. \\
\hline $\begin{array}{l}1 \\
2 \\
3 \\
4 \\
5 \\
6 \\
7 \\
8\end{array}$ & $\begin{array}{l}400 \\
422 \\
428 \\
422 \\
416 \\
422 \\
438 \\
438\end{array}$ & $\begin{array}{l}920 \\
848 \\
893 \\
911 \\
911 \\
902 \\
902 \\
902\end{array}$ & $\begin{array}{l}9 \\
10 \\
11 \\
12 \\
13 \\
14 \\
15 \\
16\end{array}$ & $\begin{array}{l}444 \\
468 \\
488 \\
488 \\
488 \\
494 \\
500 \\
500\end{array}$ & $\begin{array}{l}902 \\
902 \\
902 \\
893 \\
893 \\
884 \\
884 \\
875\end{array}$ & $\begin{array}{l}17 \\
18 \\
19 \\
20 \\
21 \\
22 \\
23 \\
24\end{array}$ & $\begin{array}{r}507 \\
514 \\
514 \\
520 \\
574 \\
764 \\
4,200 \\
4,480\end{array}$ & $\begin{array}{r}866 \\
857 \\
857 \\
875 \\
893 \\
893 \\
893 \\
884\end{array}$ & $\begin{array}{l}25 \\
26 \\
27 \\
28 \\
29 \\
30 \\
31\end{array}$ & $\begin{array}{l}2,810 \\
1,770 \\
1,240 \\
1,110 \\
1,050 \\
1,080\end{array}$ & $\begin{array}{l}884 \\
884 \\
884 \\
884 \\
884 \\
884 \\
884\end{array}$ \\
\hline $\begin{array}{l}\text { Mean } \\
\text { Mean } \\
\text { Run-c }\end{array}$ & $\begin{array}{l}\text { oonthiy } \\
\text { uonthly } \\
f \text {, in }\end{array}$ & $\begin{array}{l}\text { scharg } \\
\text { Lscharg } \\
\text { hes (e }\end{array}$ & , ir & econd-1 & $\begin{array}{l}\text { ot lobs } \\
\text { ot } \text { lad }\end{array}$ & $\begin{array}{c}\text { erved) } \\
\text { asted) } \\
\cdot . .\end{array}$ & 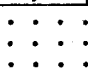 & 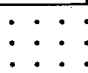 & $\dot{0}:$ & $\begin{array}{r}946 \\
1,487 \\
4.43\end{array}$ & $\begin{array}{r}888 \\
456 \\
1.41\end{array}$ \\
\hline
\end{tabular}

Gage helght, In feet, and discharge, in second-feet, at indicated time, 1938

\begin{tabular}{|c|c|c|c|c|c|c|c|c|c|c|c|c|}
\hline \multirow{2}{*}{$\begin{array}{l}8 \\
0 \\
0 \\
0\end{array}$} & Feet & Sec.et. & Feet & Sec.ft. & Feet & Sec.ft. & Feet & sec.ft. & Feet & Sec.ft. & Feet & Sec.ft. \\
\hline & \multicolumn{2}{|c|}{ September 18} & \multicolumn{2}{|c|}{ September 19} & \multicolumn{2}{|c|}{ September 20} & \multicolumn{2}{|c|}{ September 21} & \multicolumn{2}{|c|}{ September 22} & \multicolumn{2}{|c|}{ September 23} \\
\hline $\begin{array}{l}1 \\
2 \\
3 \\
4 \\
5 \\
6\end{array}$ & $\begin{array}{l}- \\
- \\
- \\
- \\
3.99\end{array}$ & $\begin{array}{l}- \\
- \\
- \\
- \\
514\end{array}$ & $\begin{array}{l}- \\
- \\
- \\
- \\
- \\
3.99\end{array}$ & $\begin{array}{l}- \\
- \\
- \\
- \\
514\end{array}$ & $\begin{array}{c}- \\
3.99 \\
- \\
3.99 \\
- \\
3.99\end{array}$ & $\begin{array}{r}-514 \\
-514 \\
-514\end{array}$ & $\begin{array}{c}\overline{4.00} \\
\overline{4} \\
\overline{4.00} \\
\overline{4.00}\end{array}$ & $\begin{array}{r}-520 \\
-520 \\
-520\end{array}$ & $\begin{array}{l}4.15 \\
4.14 \\
4.14 \\
4.14 \\
4.14 \\
4.14\end{array}$ & $\begin{array}{l}628 \\
620 \\
620 \\
620 \\
620 \\
620\end{array}$ & $\begin{array}{l}5.32 \\
5.54 \\
5.75 \\
5.93 \\
6.09 \\
6.21\end{array}$ & $\begin{array}{l}1,970 \\
2,310 \\
2,670 \\
3,010 \\
3,340 \\
3,590\end{array}$ \\
\hline $\begin{array}{r}7 \\
8 \\
9 \\
10 \\
11 \\
N\end{array}$ & $\begin{array}{l}- \\
- \\
- \\
\overline{3.99}\end{array}$ & $\begin{array}{l}- \\
- \\
- \\
- \\
514\end{array}$ & $\begin{array}{l}- \\
- \\
- \\
- \\
3.99\end{array}$ & $\begin{array}{l}- \\
- \\
- \\
- \\
514\end{array}$ & $\begin{array}{c}\overline{3.99} \\
\overline{3.99} \\
\overline{3.99}\end{array}$ & $\begin{array}{r}-514 \\
-514 \\
-514 \\
514\end{array}$ & $\begin{array}{c}- \\
4.01 \\
\overline{4} \\
4.01 \\
\overline{4.02}\end{array}$ & $\begin{array}{r}- \\
527 \\
- \\
527 \\
- \\
534\end{array}$ & $\begin{array}{l}4.15 \\
4.15 \\
4.15 \\
4.25 \\
4.25 \\
4.25\end{array}$ & $\begin{array}{l}628 \\
628 \\
628 \\
705 \\
705 \\
705\end{array}$ & $\begin{array}{l}6.34 \\
6.45 \\
6.56 \\
6.33 \\
6.44 \\
6.54\end{array}$ & $\begin{array}{l}3,880 \\
4,120 \\
4,360 \\
3,860 \\
4,100 \\
4,320\end{array}$ \\
\hline $\begin{array}{l}1 \\
2 \\
3 \\
4 \\
5 \\
6\end{array}$ & $\begin{array}{l}- \\
- \\
- \\
- \\
- \\
3.99\end{array}$ & $\begin{array}{l}- \\
- \\
- \\
- \\
514\end{array}$ & $\begin{array}{l}- \\
- \\
- \\
\bar{z} \\
3.99\end{array}$ & $\begin{array}{l}- \\
- \\
- \\
- \\
514\end{array}$ & $\begin{array}{l}- \\
4.00 \\
- \\
4.00 \\
- \\
4.00\end{array}$ & $\begin{array}{l}-520 \\
- \\
-520 \\
-520\end{array}$ & $\begin{array}{l}\overline{-} \\
\overline{-} \\
\overline{4.12} \\
\overline{-} \\
4.15\end{array}$ & $\begin{array}{r}-590 \\
-\quad 605 \\
-628\end{array}$ & $\begin{array}{l}4.25 \\
4.26 \\
4.26 \\
4.27 \\
4.27 \\
4.27\end{array}$ & $\begin{array}{l}705 \\
713 \\
713 \\
721 \\
721 \\
721\end{array}$ & $\begin{array}{l}6.60 \\
6.70 \\
6.74 \\
6.80 \\
6.83 \\
6.86\end{array}$ & $\begin{array}{l}4,450 \\
4,680 \\
4,770 \\
4,910 \\
4,980 \\
5,050\end{array}$ \\
\hline \multirow[t]{2}{*}{$\begin{array}{r}7 \\
8 \\
9 \\
10 \\
11 \\
11\end{array}$} & $\begin{array}{l}- \\
- \\
- \\
- \\
3.99\end{array}$ & $\begin{array}{l}- \\
- \\
- \\
- \\
514 \\
\end{array}$ & $\begin{array}{l}- \\
- \\
- \\
\overline{3} \\
\end{array}$ & $\begin{array}{l}- \\
- \\
- \\
- \\
514\end{array}$ & $\begin{array}{l}- \\
4.00 \\
- \\
4.00 \\
\overline{4.00}\end{array}$ & $\begin{array}{r}-520 \\
-\quad 520 \\
-520 \\
\end{array}$ & $\begin{array}{c}- \\
4.16 \\
- \\
4.15 \\
\overline{4.15} \\
\end{array}$ & $\begin{array}{r}-635 \\
-628 \\
-628 \\
\end{array}$ & $\begin{array}{l}4.28 \\
4.28 \\
4.37 \\
4.58 \\
4.84 \\
5.10 \\
\end{array}$ & $\begin{array}{r}729 \\
729 \\
804 \\
1,000 \\
1,300 \\
1,650\end{array}$ & $\begin{array}{l}6.88 \\
6.90 \\
6.91 \\
6.92 \\
6.92 \\
6.92 \\
\end{array}$ & $\begin{array}{l}5,090 \\
5,140 \\
5,160 \\
5,190 \\
5,190 \\
5,190\end{array}$ \\
\hline & \multicolumn{2}{|c|}{ September 24} & \multicolumn{2}{|c|}{ September 25} & \multicolumn{2}{|c|}{ September 26} & \multicolumn{2}{|c|}{ September 27} & \multicolumn{2}{|c|}{ September 28} & \multicolumn{2}{|c|}{ September 29} \\
\hline $\begin{array}{r}2 \\
4 \\
6 \\
8 \\
10 \\
1\end{array}$ & $\begin{array}{l}6.90 \\
6.88 \\
6.83 \\
6.78 \\
6.70 \\
6.64\end{array}$ & $\begin{array}{l}5,140 \\
5,090 \\
4,980 \\
4,860 \\
4,680 \\
4,540\end{array}$ & $\begin{array}{l}6.13 \\
6.07 \\
6.02 \\
5.95 \\
5.88 \\
5.81\end{array}$ & $\begin{array}{l}3,420 \\
3,300 \\
3,190 \\
3,050 \\
2,910 \\
2,780\end{array}$ & $\begin{array}{l}5.41 \\
5.36 \\
5.32 \\
5.26 \\
5.21 \\
5.16\end{array}$ & $\begin{array}{l}2,110 \\
2,030 \\
1,970 \\
1,880 \\
1,800 \\
1,730\end{array}$ & $\begin{array}{c}- \\
\overline{4.84} \\
- \\
\overline{4.79}\end{array}$ & $\begin{array}{c}- \\
- \\
1,300 \\
- \\
\overline{1}, 240\end{array}$ & $\begin{array}{l}- \\
- \\
4.70 \\
- \\
\overline{4} .69\end{array}$ & $\begin{array}{l}- \\
\overline{1,130} \\
- \\
\overline{1,120}\end{array}$ & $\begin{array}{c}- \\
\overline{4.58} \\
- \\
\overline{4.53}\end{array}$ & $\begin{array}{l}- \\
\overline{1,000} \\
- \\
- \\
950\end{array}$ \\
\hline $\begin{array}{r}2 \\
4 \\
6 \\
8 \\
10 \\
1\end{array}$ & $\begin{array}{l}6.57 \\
6.52 \\
6.43 \\
6.36 \\
6.28 \\
6.22\end{array}$ & $\begin{array}{l}4,380 \\
4,270 \\
4,080 \\
3,920 \\
3,750 \\
3,610\end{array}$ & $\begin{array}{l}5.76 \\
5.69 \\
5.64 \\
5.58 \\
5.53 \\
5.48\end{array}$ & $\begin{array}{l}2,690 \\
2,560 \\
2,480 \\
2,380 \\
2,300 \\
2,220\end{array}$ & $\begin{array}{l}5.12 \\
5.08 \\
5.05 \\
5.02 \\
4.98 \\
4.95\end{array}$ & $\begin{array}{l}1,680 \\
1,620 \\
1,580 \\
1,540 \\
1,480 \\
1,440\end{array}$ & $\begin{array}{c}- \\
- \\
4.73 \\
- \\
- \\
4.70\end{array}$ & $\begin{array}{l}- \\
- \\
1,170 \\
- \\
- \\
1,130\end{array}$ & $\begin{array}{c}- \\
- \\
4.66 \\
- \\
- \\
4.62\end{array}$ & $\begin{array}{l}- \\
\overline{1}, 090 \\
- \\
- \\
1,040\end{array}$ & $\begin{array}{c}4.76 \\
- \\
4.69 \\
- \\
- \\
4.61\end{array}$ & $\begin{array}{c}1,200 \\
- \\
1,120 \\
- \\
1,030\end{array}$ \\
\hline
\end{tabular}

Supplemental records.- Sept. $29,1: 00$ p.m., 4.53 ft., 950 sec.-ft. 
West Canada Creek at Kast Bridge, N. Y.

Location.- Water-stage recorder, lat. $43^{\circ} 04^{\prime} 15^{\prime \prime}$, long. $74^{\circ} 59^{\prime} 25^{\prime \prime}$, 600 feet below highway bridge at Kast Bridge, Herkimer County, and 4 miles above mouth at Herkimer.

Drainage area.- 556 square miles; 373 square miles affected by storage in Hinckley Reservoir.

Gage-height record.- Water-stage recorder graph.

Stage-discharge relation.- Defined by current-meter measurements below 9,000 secondfeet; extended logarithmically to peak stage.

Maxima.- September 1938: Discharge, 12,700 second-feet 7:45 p.m. Sept. 21 (gage height, 6.29 feet).

October 1920 to August 1938: Discharge, 16,500 second-feet June 21, 1922

(gage height, 7.3 feet).

May 1905 to December 1909, January 1912 to December 1913: Discharge, 23,300 second-feet Mar. 26, 1913 (records of New York State Engineer and Surveyor).

Remarks.- For information on storage see record for Hinckley Reservoir at Hinckley, N. Y. Diurnal fluctuation at low and medium stages caused by power-plant operations. No diversion through Ninemile feeder.

Mean daily discharge, in second-feet, 1938

\begin{tabular}{|c|c|c|c|c|c|c|c|c|c|c|c|}
\hline Day & Sept. & Oct. & Day & Sept. & 0 ct. & Day & Sept. & $0 \mathrm{ct}$. & Day & Sept. & Oet. \\
\hline $\begin{array}{l}1 \\
2 \\
3 \\
4 \\
5 \\
6 \\
7 \\
8\end{array}$ & $\begin{array}{l}399 \\
416 \\
433 \\
438 \\
422 \\
424 \\
516 \\
526\end{array}$ & $\begin{array}{r}1,250 \\
1,020 \\
1,050 \\
1,130 \\
992 \\
1,040 \\
1,030 \\
1,030\end{array}$ & $\begin{array}{r}9 \\
10 \\
11 \\
12 \\
13 \\
14 \\
15 \\
16\end{array}$ & $\begin{array}{r}471 \\
470 \\
506 \\
524 \\
758 \\
612 \\
1,060 \\
706\end{array}$ & $\begin{array}{r}1,030 \\
1,020 \\
998 \\
1,000 \\
980 \\
982 \\
982 \\
959\end{array}$ & $\begin{array}{l}17 \\
18 \\
19 \\
20 \\
21 \\
22 \\
23 \\
24\end{array}$ & $\begin{array}{r}624 \\
655 \\
630 \\
974 \\
4,480 \\
3,700 \\
4,240 \\
5,340\end{array}$ & $\begin{array}{r}993 \\
930 \\
960 \\
966 \\
1,020 \\
992 \\
1,010 \\
1,090\end{array}$ & $\begin{array}{l}25 \\
26 \\
27 \\
28 \\
29 \\
30 \\
31\end{array}$ & $\begin{array}{l}3,670 \\
2,420 \\
1,700 \\
1,500 \\
1,320 \\
1,340\end{array}$ & $\begin{array}{r}1,210 \\
1,110 \\
1,020 \\
1,020 \\
996 \\
990 \\
980\end{array}$ \\
\hline \multicolumn{6}{|c|}{$\begin{array}{l}\text { Mean monthly discharge, } \\
\text { Run-off, in inches. }\end{array}$} & $\dot{\cdot} \cdot \dot{ }$ & $\cdot \cdot \cdot$ & 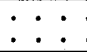 & - $\cdot$ & $\begin{array}{r}1,376 \\
2.76\end{array}$ & $\begin{array}{r}1,025 \\
2.12\end{array}$ \\
\hline
\end{tabular}

Gage helght, in feet, and discharge, in second-feet, at indicated time, 1938

\begin{tabular}{|c|c|c|c|c|c|c|c|c|c|c|c|c|}
\hline \multirow{2}{*}{$\begin{array}{l} \\
3 \\
0 \\
\end{array}$} & Fe日t & Sec.ft. & Feet & Sec.ft. & Feet & Sec.ft. & Feet & Sec.ft. & Feet & Sec.ft. & Feet & Sec.ft. \\
\hline & \multicolumn{2}{|c|}{ September 18} & \multicolumn{2}{|c|}{ September 19} & \multicolumn{2}{|c|}{ September 20} & \multicolumn{2}{|c|}{ September 21} & \multicolumn{2}{|c|}{ September 22} & \multicolumn{2}{|c|}{ September 23} \\
\hline $\begin{array}{l}1 \\
2 \\
3 \\
4 \\
5 \\
6\end{array}$ & $\begin{array}{l}2.00 \\
2.01 \\
2.23 \\
2.37 \\
2.37 \\
2.30\end{array}$ & $\begin{array}{r}613 \\
624 \\
884 \\
1,070 \\
1,070 \\
975\end{array}$ & $\begin{array}{l}1.88 \\
1.89 \\
2.09 \\
2.28 \\
2.24 \\
2.17\end{array}$ & $\begin{array}{l}499 \\
508 \\
712 \\
949 \\
897 \\
808\end{array}$ & $\begin{array}{l}2.13 \\
2.12 \\
2.06 \\
2.03 \\
2.07 \\
2.25\end{array}$ & $\begin{array}{l}760 \\
747 \\
679 \\
646 \\
690 \\
910\end{array}$ & $\begin{array}{l}2.72 \\
2.64 \\
2.57 \\
2.60 \\
2.73 \\
2.74\end{array}$ & $\begin{array}{l}1,580 \\
1,460 \\
1,360 \\
1,400 \\
1,600 \\
1,610\end{array}$ & $\begin{array}{l}5.05 \\
4.80 \\
4.60 \\
4.46 \\
4.29 \\
4.17\end{array}$ & $\begin{array}{l}7,380 \\
6,510 \\
5,860 \\
5,430 \\
4,930 \\
4,600\end{array}$ & & $\begin{array}{l}1,780 \\
1,980 \\
2,550 \\
2,490 \\
2,430 \\
2,860\end{array}$ \\
\hline $\begin{array}{r}7 \\
8 \\
9 \\
10 \\
11 \\
N\end{array}$ & $\begin{array}{l}2.21 \\
2.14 \\
2.10 \\
2.08 \\
2.08 \\
2.07\end{array}$ & $\begin{array}{l}858 \\
772 \\
723 \\
701 \\
701 \\
690\end{array}$ & $\begin{array}{l}2.12 \\
2.09 \\
2.07 \\
2.02 \\
1.98 \\
1.94\end{array}$ & $\begin{array}{l}747 \\
712 \\
690 \\
635 \\
594 \\
555\end{array}$ & $\begin{array}{l}2.36 \\
2.31 \\
2.23 \\
2.17 \\
2.14 \\
2.13\end{array}$ & $\begin{array}{r}1,060 \\
988 \\
884 \\
808 \\
772 \\
760\end{array}$ & $\begin{array}{l}2.69 \\
2.68 \\
2.69 \\
2.70 \\
2.70 \\
2.72\end{array}$ & $\begin{array}{l}1,540 \\
1,520 \\
1,540 \\
1,550 \\
1,550 \\
1,580\end{array}$ & $\begin{array}{l}4.08 \\
3.98 \\
3.87 \\
3.76 \\
3.67 \\
3.55\end{array}$ & $\begin{array}{l}4,360 \\
4,100 \\
3,830 \\
3,560 \\
3,350 \\
3,080\end{array}$ & $\begin{array}{l}3.70 \\
3.75 \\
3.80 \\
4.10 \\
4.22 \\
4.30\end{array}$ & $\begin{array}{l}3,420 \\
3,540 \\
3,660 \\
4,410 \\
4,740 \\
4,960\end{array}$ \\
\hline $\begin{array}{l}1 \\
2 \\
3 \\
4 \\
5 \\
6\end{array}$ & $\begin{array}{l}2.05 \\
2.03 \\
1.97 \\
1.88 \\
1.81 \\
1.77\end{array}$ & $\begin{array}{l}668 \\
646 \\
584 \\
499 \\
440 \\
409\end{array}$ & $\begin{array}{l}1.90 \\
1.88 \\
1.87 \\
1.87 \\
1.87 \\
1.95\end{array}$ & $\begin{array}{l}516 \\
499 \\
490 \\
490 \\
490 \\
564\end{array}$ & $\begin{array}{l}2.12 \\
2.15 \\
2.20 \\
2.25 \\
2.32 \\
2.46\end{array}$ & $\begin{array}{r}747 \\
784 \\
845 \\
910 \\
1,000 \\
1,190\end{array}$ & $\begin{array}{l}2.82 \\
3.00 \\
3.30 \\
3.72 \\
4.68 \\
5.75\end{array}$ & $\begin{array}{r}1,740 \\
2,040 \\
2,610 \\
3,570 \\
6,400 \\
10,400\end{array}$ & $\begin{array}{l}3.47 \\
3.45 \\
3.40 \\
3.29 \\
3.30 \\
3.22\end{array}$ & $\begin{array}{l}2,910 \\
2,860 \\
2,760 \\
2,530 \\
2,550 \\
2,390\end{array}$ & $\begin{array}{l}4.37 \\
4.42 \\
4.39 \\
4.35 \\
4.37 \\
4.40\end{array}$ & $\begin{array}{l}5,160 \\
5,310 \\
5,220 \\
5,100 \\
5,160 \\
5,250\end{array}$ \\
\hline \multirow[t]{2}{*}{$\begin{array}{r}7 \\
8 \\
9 \\
10 \\
11 \\
1 \\
\end{array}$} & $\begin{array}{l}1.76 \\
1.82 \\
1.84 \\
1.88 \\
1.90 \\
1.90\end{array}$ & $\begin{array}{l}402 \\
448 \\
465 \\
499 \\
516 \\
516\end{array}$ & $\begin{array}{l}2.05 \\
2.08 \\
2.05 \\
2.01 \\
2.01 \\
2.11\end{array}$ & $\begin{array}{l}668 \\
701 \\
668 \\
624 \\
624 \\
735\end{array}$ & $\begin{array}{l}2.54 \\
2.59 \\
2.60 \\
2.65 \\
2.73 \\
2.76\end{array}$ & $\begin{array}{l}1,310 \\
1,380 \\
1,400 \\
1,480 \\
1,600 \\
1,650\end{array}$ & $\begin{array}{l}6.24 \\
6.27 \\
6.18 \\
5.93 \\
5.63 \\
5.35\end{array}$ & $\begin{array}{r}12,400 \\
12,600 \\
12,200 \\
11,000 \\
9,700 \\
8,540\end{array}$ & $\begin{array}{l}3.20 \\
3.11 \\
3.01 \\
2.95 \\
3.00 \\
2.96\end{array}$ & $\begin{array}{l}2,350 \\
2,180 \\
2,000 \\
1,900 \\
1,980 \\
1,910\end{array}$ & $\begin{array}{l}4.44 \\
4.47 \\
4.51 \\
4.52 \\
4.55 \\
4.56\end{array}$ & $\begin{array}{l}370 \\
460 \\
580 \\
610 \\
700 \\
740\end{array}$ \\
\hline & \multicolumn{2}{|c|}{ September 24} & \multicolumn{2}{|c|}{ September 25} & \multicolumn{2}{|c|}{ September 26} & \multicolumn{2}{|c|}{ September 27} & \multicolumn{2}{|c|}{ September 28} & \multicolumn{2}{|c|}{ September 29} \\
\hline $\begin{array}{r}2 \\
4 \\
6 \\
8 \\
10 \\
N\end{array}$ & $\begin{array}{l}4.57 \\
4.57 \\
4.56 \\
4.54 \\
4.52 \\
4.46\end{array}$ & $\begin{array}{l}5,770 \\
5,770 \\
5,740 \\
5,670 \\
5,610 \\
5,430\end{array}$ & $\begin{array}{l}4.08 \\
4.02 \\
3.94 \\
3.90 \\
3.84 \\
3.79\end{array}$ & $\begin{array}{l}4,360 \\
4,200 \\
4,000 \\
3,900 \\
3,760 \\
3,640\end{array}$ & $\begin{array}{l}3.43 \\
3.38 \\
3.31 \\
3.34 \\
3.27 \\
3.22\end{array}$ & $\begin{array}{l}2,820 \\
2,720 \\
2,570 \\
2,630 \\
2,490 \\
2,390\end{array}$ & $\begin{array}{l}3.02 \\
3.03 \\
2.97 \\
2.84 \\
2.75 \\
2.60\end{array}$ & $\begin{array}{l}2,020 \\
2,030 \\
1,930 \\
1,710 \\
1,580 \\
1,350\end{array}$ & $\begin{array}{l}3.03 \\
2.91 \\
2.76 \\
2.74 \\
2.65 \\
2.31\end{array}$ & $\begin{array}{r}2,030 \\
1,830 \\
1,590 \\
1,560 \\
1,420 \\
963\end{array}$ & $\begin{array}{l}2.95 \\
2.81 \\
2.63 \\
2.53 \\
2.52 \\
2.35\end{array}$ & $\begin{array}{l}1,900 \\
1,670 \\
1,400 \\
1,250 \\
1,240 \\
1,020\end{array}$ \\
\hline $\begin{array}{r}2 \\
4 \\
6 \\
8 \\
10 \\
M\end{array}$ & $\begin{array}{l}4.43 \\
4.37 \\
4.32 \\
4.25 \\
4.19 \\
4.13\end{array}$ & $\begin{array}{l}5,340 \\
5,160 \\
5,020 \\
4,820 \\
4,650 \\
4,490\end{array}$ & $\begin{array}{l}3.74 \\
3.69 \\
3.60 \\
3.55 \\
3.52 \\
3.53\end{array}$ & $\begin{array}{l}3,520 \\
3,400 \\
3,190 \\
3,080 \\
3,010 \\
3,040\end{array}$ & $\begin{array}{l}3.18 \\
3.13 \\
3.09 \\
3.05 \\
3.05 \\
2.98\end{array}$ & $\begin{array}{l}2,310 \\
2,220 \\
2,140 \\
2,070 \\
2,070 \\
1,950\end{array}$ & $\begin{array}{l}2.82 \\
2.82 \\
2.76 \\
2.91 \\
2.73 \\
2.71\end{array}$ & $\begin{array}{l}1,680 \\
1,680 \\
1,590 \\
1,830 \\
1,540 \\
1,520\end{array}$ & $\begin{array}{l}2.61 \\
2.71 \\
2.71 \\
2.59 \\
2.64 \\
2.63\end{array}$ & $\begin{array}{l}1,360 \\
1,520 \\
1,520 \\
1,340 \\
1,410 \\
1,400\end{array}$ & $\begin{array}{l}2.31 \\
2.50 \\
2.60 \\
2.56 \\
2.40 \\
2.62\end{array}$ & $\begin{array}{r}963 \\
1,210 \\
1,350 \\
1,290 \\
1,200 \\
1,380\end{array}$ \\
\hline
\end{tabular}

Supplemental records.- Sept. $21,7: 45$ p.m., 6.29 ft., 12,700 sec.-ft. Sept. 28 , 1:00 a.m., $2.18 \mathrm{ft.,} 808 \mathrm{sec} . \mathrm{ft}$. Sept. 29, 1:25 p.m., $2.19 \mathrm{ft} ., 819 \mathrm{sec} . \mathrm{ft}$. 
Location.- Water-stage recorder, lat. $43^{\circ} 06^{\prime} 05^{\prime \prime}$, Iong. $74^{\circ} 46^{\prime} 15^{\prime \prime}$, at Dolgeville, Herkimer County, 100 feet below lower highway bridge and 1 mile below Spruce Creek. Zero of gage is 750.00 feet above mean sea level (general adjustment of 1912).

Drainage area.- 261 squaré miles.

Gage-height record.- Water-stage recorder graph.

Stage-discharge relation.- For 1938 defined by current-meter measurements below 5,020 second-feet; extended logarithmically to peak stage. For 1936 defined by currentmeter measurements below 3,600 second-feet; extended to peak stage on basis of determinations of peak flow during March 1936 at Inghams and Beardslee hydroelectric plants of the New York Power \& Light Corporation.

Maxima.- September 1938: D1scharge, 9,920 second-feet 12:45 a.m. Sept. 22 (gage height, 11.09 feet).

September 1927 to August 1938: Discharge, 13,100 second-feet Mar. 18, 1936

(gage height, 11.81 feet).

September 1898 to 1926: Discharge, 14,500 second-feet Mar, 26, 1913. Comparable records of New York State Engineer' and Surveyor at High Falls, 1 mile downstream.

Remarks.- Discharge affected by $441,000,000$ cubic feet of storage capacity in Canada Lakes. City of Little Falls diverts about 5 second-feet for water supply. Diurnal fluctuation caused by power-plant operation.

Mean daily discharge, in second-feet, 1938

\begin{tabular}{|c|c|c|c|c|c|c|c|c|c|c|c|}
\hline Day & Sept. & oct. & Day & Sept. & Oct. & Day & Sept. & Oct. & Day & Sept. & Oet. \\
\hline $\begin{array}{l}1 \\
2 \\
3 \\
4 \\
5 \\
6 \\
7 \\
8\end{array}$ & $\begin{array}{r}165 \\
170 \\
118 \\
111 \\
96 \\
133 \\
211 \\
281 \\
\end{array}$ & $\begin{array}{l}361 \\
302 \\
257 \\
268 \\
258 \\
258 \\
251 \\
214\end{array}$ & $\begin{array}{r}9 \\
10 \\
11 \\
12 \\
13 \\
14 \\
15 \\
16\end{array}$ & $\begin{array}{r}178 \\
103 \\
109 \\
148 \\
431 \\
397 \\
1,280 \\
1,070 \\
\end{array}$ & $\begin{array}{l}207 \\
256 \\
234 \\
228 \\
234 \\
238 \\
263 \\
203 \\
\end{array}$ & $\begin{array}{l}17 \\
18 \\
19 \\
20 \\
21 \\
22 \\
23 \\
24\end{array}$ & $\begin{array}{r}643 \\
570 \\
557 \\
1,440 \\
5,290 \\
7,450 \\
4,010 \\
2,100\end{array}$ & $\begin{array}{l}226 \\
285 \\
286 \\
303 \\
327 \\
284 \\
225 \\
567\end{array}$ & $\begin{array}{l}25 \\
26 \\
27 \\
28 \\
29 \\
30 \\
31\end{array}$ & $\begin{array}{r}1,060 \\
744 \\
585 \\
528 \\
449 \\
406\end{array}$ & $\begin{array}{r}1,040 \\
815 \\
644 \\
522 \\
455 \\
335 \\
366\end{array}$ \\
\hline $\begin{array}{l}\text { Mean } \\
\text { Run- }\end{array}$ & $\begin{array}{l}\text { nthly } \\
\text {, in }\end{array}$ & scher & 1 & econd- & ot. : & $:$ : & 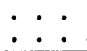 &.$\dot{*}$ & . & $\begin{array}{r}1,028 \\
4.40\end{array}$ & $\begin{array}{r}346 \\
1.53\end{array}$ \\
\hline
\end{tabular}

Gage height, in feet, and discharge, in second-feet, at indicated time, 1938

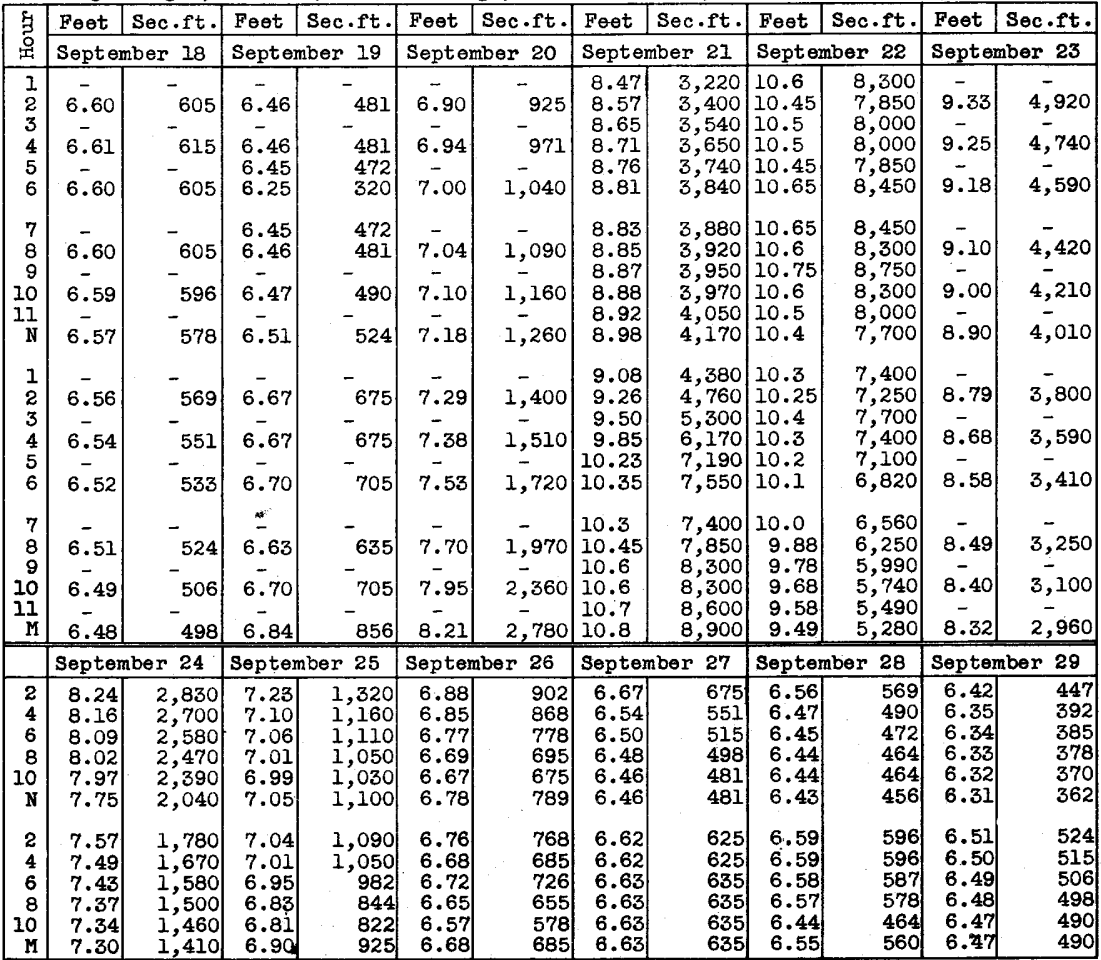

Supplemental records.- Sept. 21 ; $6: 30$ p.m., 10.15 ft., 6,960 sec.-ft.; 11:45 p.m., $11.08 \mathrm{ft.}, 9,880$ sec.-ft. Sept. $22,12: 45$ a.m., 11.09 ft., 9,920 sec.-ft. 
Location.- Water-stage recorder, lat. $42^{\circ} 19^{\prime} 25^{n}$, long. $74^{\circ} 26^{\prime} 05^{n}$, a quarter of a mile belon highway bridge in Prattsvilie, Greene County. Zero of gage is $1,130.01$ feet above mean sea level (general adjustment of 1912 ).

Drainage area. - 236 square n.lles.

Gage-helght record.- Water-stage recorder graph, recorded peak stage adjusted on basis of levels to floodmarks outside of gage well.

Stage-discharge relation.- Defined by current-meter measurements below 4,540 secondfeet; extended logarithmically to Nov. 1926 peak stage on basis of slope-area study by engineers of New York C1ty Board of Water Supply.

Maxima.- September 1938: Discharge, 45,000 second-feet 9 p.m. Sept. 2l (gage he1ght,

15. 60 feet, from floodmarks outside of gage shelter).

November 1902 to August 1938: Discharge, 42,300 second-feet Nov. 16, 1926

(gage height, 19.5 feet, former site and datum) from records of New York City Board of Water Supply.

Remarks. - Flood run-off not affected by storage or diversion.

Mean daily discharge, in second-feet, 1938

\begin{tabular}{|c|c|c|c|c|c|c|c|c|c|c|c|}
\hline Day & Sept. & oct. & Day & Sept. & Oct. & Day & Sept. & oct. & Day & Sept. & Oct. \\
\hline $\begin{array}{l}1 \\
2 \\
3 \\
4 \\
5 \\
6 \\
7 \\
8\end{array}$ & $\begin{array}{l}48 \\
50 \\
44 \\
45 \\
43 \\
38 \\
37 \\
42\end{array}$ & $\begin{array}{l}308 \\
270 \\
240 \\
218 \\
198 \\
181 \\
164 \\
152\end{array}$ & $\begin{array}{r}9 \\
10 \\
11 \\
12 \\
13 \\
14 \\
15 \\
16\end{array}$ & $\begin{array}{l}38 \\
34 \\
32 \\
31 \\
47 \\
48 \\
49 \\
51\end{array}$ & $\begin{array}{l}144 \\
135 \\
127 \\
121 \\
115 \\
109 \\
105 \\
123\end{array}$ & $\begin{array}{l}17 \\
18 \\
19 \\
20 \\
21 \\
22 \\
23 \\
24\end{array}$ & $\begin{array}{r}49 \\
50 \\
74 \\
936 \\
10,500 \\
7,990 \\
2,180 \\
1,380\end{array}$ & $\begin{array}{r}106 \\
96 \\
93 \\
167 \\
240 \\
189 \\
140 \\
165\end{array}$ & $\begin{array}{l}25 \\
26 \\
27 \\
28 \\
29 \\
30 \\
31\end{array}$ & $\begin{array}{l}955 \\
707 \\
569 \\
491 \\
411 \\
355\end{array}$ & $\begin{array}{l}373 \\
261 \\
225 \\
204 \\
219 \\
262 \\
225\end{array}$ \\
\hline $\begin{array}{l}\text { Mean } \\
\text { Run-c }\end{array}$ & $\begin{array}{l}\text { nthly } \\
, \text { in }\end{array}$ & achar & , ir & - . & et. . & . : & $\begin{array}{l}. \\
.\end{array}$ & $\cdot . \cdot$ & . $\cdot$ & $\begin{array}{r}911 \\
4.31\end{array}$ & $\begin{array}{r}183 \\
0.89\end{array}$ \\
\hline
\end{tabular}

Gage helght, in feet, and discharge, in second-feet, at indicated time, 1938

\begin{tabular}{|c|c|c|c|c|c|c|c|c|c|c|c|c|}
\hline \multirow{2}{*}{$\begin{array}{l}5 \\
3 \\
0 \\
3\end{array}$} & Feet & Sec.ft. & Feet & Sec.ft. & Feet & Sec.ft. & Feet & Sec.ft. & Feet & Sec.ft. & Feet & Sec.ft. \\
\hline & \multicolumn{2}{|c|}{ September 18} & \multicolumn{2}{|c|}{ September 19} & \multicolumn{2}{|c|}{ September 20} & \multicolumn{2}{|c|}{ September 21} & \multicolumn{2}{|c|}{ September 22} & \multicolumn{2}{|c|}{ September 23} \\
\hline $\begin{array}{l}1 \\
2 \\
3 \\
4 \\
5 \\
6\end{array}$ & $\begin{array}{l}- \\
- \\
- \\
1.41 \\
- \\
-\end{array}$ & $\begin{array}{l}- \\
- \\
- \\
-\end{array}$ & $\begin{array}{c}- \\
1.43 \\
- \\
1.44 \\
- \\
1.44\end{array}$ & $\begin{array}{r}-53 \\
-55 \\
-55\end{array}$ & $\begin{array}{l}1.91 \\
1.96 \\
2.06 \\
2.18 \\
2.36 \\
2.52\end{array}$ & $\begin{array}{l}178 \\
196 \\
231 \\
277 \\
360 \\
447\end{array}$ & $\begin{array}{l}3.74 \\
3.87 \\
4.01 \\
4.13 \\
4.22 \\
4.29\end{array}$ & $\begin{array}{l}1,500 \\
1,650 \\
1,810 \\
1,960 \\
2,080 \\
2,170\end{array}$ & $\begin{array}{r}11.10 \\
10.25 \\
9.50 \\
9.00 \\
8.50 \\
8.05\end{array}$ & $\begin{array}{l}23,200 \\
19,200 \\
15,800 \\
13,800 \\
12,000 \\
10,600\end{array}$ & $\begin{array}{c}- \\
4.82 \\
- \\
4.75 \\
- \\
4.70\end{array}$ & $\begin{array}{c}2,670 \\
2,540 \\
- \\
2,460\end{array}$ \\
\hline $\begin{array}{r}7 \\
8 \\
9 \\
10 \\
11 \\
11\end{array}$ & $\begin{array}{l}-\overline{41} \\
- \\
- \\
\overline{1.41}\end{array}$ & $\begin{array}{l}-50 \\
- \\
- \\
-50\end{array}$ & $\begin{array}{c}- \\
1.45 \\
\overline{1.45} \\
- \\
1.46\end{array}$ & $\begin{array}{r}-56 \\
-\quad 56 \\
-\quad 58\end{array}$ & $\begin{array}{l}2.86 \\
3.16 \\
3.31 \\
3.38 \\
3.42 \\
3.43\end{array}$ & $\begin{array}{r}698 \\
941 \\
1,070 \\
1,130 \\
1,170 \\
1,180\end{array}$ & $\begin{array}{l}4.30 \\
4.30 \\
4.30 \\
4.32 \\
4.38 \\
4.51\end{array}$ & $\begin{array}{l}2,180 \\
2,180 \\
2,180 \\
2,210 \\
2,290 \\
2,480\end{array}$ & $\begin{array}{l}7.65 \\
7.05 \\
6.75 \\
6.56 \\
6.42 \\
6.25\end{array}$ & $\begin{array}{l}9,350 \\
7,550 \\
6,730 \\
6,240 \\
\mathbf{5}, 920 \\
\mathbf{5}, \mathbf{5 5 0}\end{array}$ & $\begin{array}{c}- \\
4.65 \\
\overline{4.61} \\
\overline{4.55}\end{array}$ & $\begin{array}{c}- \\
2,380 \\
- \\
2,310 \\
\overline{2,210}\end{array}$ \\
\hline $\begin{array}{l}1 \\
2 \\
3 \\
4 \\
5 \\
6\end{array}$ & $\begin{array}{l}- \\
\overline{-} \\
\overline{1.41} \\
-\end{array}$ & $\begin{array}{l}- \\
- \\
- \\
- \\
-\end{array}$ & $\begin{array}{c}- \\
1.47 \\
- \\
1.49 \\
- \\
1.52\end{array}$ & $\begin{array}{r}-60 \\
-\quad 63 \\
-\quad 69\end{array}$ & $\begin{array}{l}3.45 \\
3.48 \\
8.52 \\
3.54 \\
3.53 \\
3.52\end{array}$ & $\begin{array}{l}1,200 \\
1,230 \\
1,270 \\
1,290 \\
1,280 \\
1,270\end{array}$ & $\begin{array}{r}4.75 \\
5.11 \\
6.05 \\
7.00 \\
8.65 \\
10.25\end{array}$ & $\begin{array}{r}2,840 \\
3,420 \\
5,110 \\
7,400 \\
12,600 \\
19,200\end{array}$ & $\begin{array}{l}6.03 \\
5.87 \\
5.75 \\
5.63 \\
5.50 \\
5.38\end{array}$ & $\begin{array}{l}5,070 \\
4,720 \\
4,460 \\
4,220 \\
3,960 \\
3,720\end{array}$ & $\begin{array}{c}\overline{4.46} \\
\overline{4.40} \\
\overline{4.33}\end{array}$ & $\begin{array}{l}- \\
2,070 \\
- \\
1,970 \\
- \\
1,860\end{array}$ \\
\hline \multirow[t]{2}{*}{$\begin{array}{r}7 \\
8 \\
9 \\
10 \\
11 \\
M\end{array}$} & $\begin{array}{l}\overline{1.42} \\
- \\
- \\
\overline{1.42}\end{array}$ & $\begin{array}{l}- \\
- \\
- \\
- \\
-51\end{array}$ & $\begin{array}{c}- \\
1.66 \\
- \\
1.78 \\
- \\
1.88\end{array}$ & $\begin{array}{r}-100 \\
- \\
134 \\
-168\end{array}$ & $\begin{array}{l}3.50 \\
3.49 \\
3.49 \\
3.52 \\
3.56 \\
3.63\end{array}$ & $\begin{array}{l}1,250 \\
1,240 \\
1,240 \\
1,270 \\
1,310 \\
1,380\end{array}$ & $\begin{array}{l}11.75 \\
13.00 \\
15.60 \\
14.00 \\
13.00 \\
12.05\end{array}$ & $\begin{array}{l}26,300 \\
32,300 \\
45,000 \\
37,200 \\
32,300 \\
27,700\end{array}$ & $\begin{array}{l}5.29 \\
5.22 \\
5.14 \\
5.07 \\
5.00 \\
4.93\end{array}$ & $\begin{array}{l}3,540 \\
3,400 \\
3,250 \\
3,120 \\
2,990 \\
2,860\end{array}$ & $\begin{array}{c}\overline{4} \\
\overline{.} \\
\overline{4.23} \\
\overline{4.19}\end{array}$ & $\begin{array}{c}- \\
1,790 \\
- \\
1,720 \\
\overline{1,660}\end{array}$ \\
\hline & \multicolumn{2}{|c|}{ September 24} & \multicolumn{2}{|c|}{ September 25} & \multicolumn{2}{|c|}{ September 26} & \multicolumn{2}{|c|}{ September 27} & \multicolumn{2}{|c|}{ September 28} & \multicolumn{2}{|c|}{ September 29} \\
\hline $\begin{array}{r}2 \\
4 \\
6 \\
8 \\
10 \\
N\end{array}$ & $\begin{array}{l}4.15 \\
4.11 \\
4.07 \\
4.04 \\
4.01 \\
3.98\end{array}$ & $\begin{array}{l}1,600 \\
1,540 \\
1,490 \\
1,450 \\
1,410 \\
1,370\end{array}$ & $\begin{array}{l}- \\
3.72 \\
- \\
3.67 \\
- \\
3.63\end{array}$ & $\begin{array}{c}- \\
1,060 \\
- \\
1,010 \\
-963\end{array}$ & $\begin{array}{c}- \\
3.43 \\
- \\
3.39 \\
- \\
3.36\end{array}$ & $\begin{array}{r}-767 \\
-732 \\
-708\end{array}$ & $\begin{array}{c}- \\
3.21 \\
- \\
3.18 \\
- \\
3.16\end{array}$ & $\begin{array}{c}-597 \\
- \\
577 \\
-565\end{array}$ & $\begin{array}{c}- \\
3.08 \\
- \\
3.06 \\
- \\
3.04\end{array}$ & $\begin{array}{c}-516 \\
-504 \\
- \\
493\end{array}$ & $\begin{array}{c}- \\
2.93 \\
- \\
2.90 \\
- \\
2.89\end{array}$ & $\begin{array}{r}-434 \\
- \\
418 \\
-413\end{array}$ \\
\hline $\begin{array}{r}2 \\
4 \\
6 \\
8 \\
10 \\
M\end{array}$ & $\begin{array}{l}3.94 \\
3.90 \\
3.87 \\
3.84 \\
3.81 \\
3.78\end{array}$ & $\begin{array}{l}1,320 \\
1,270 \\
1,230 \\
1,200 \\
1,160 \\
1,130\end{array}$ & $\begin{array}{c}- \\
3.57 \\
- \\
3.51 \\
- \\
3.47\end{array}$ & $\begin{array}{c}- \\
- \\
- \\
8400 \\
- \\
803\end{array}$ & $\begin{array}{c}- \\
3.32 \\
- \\
3.27 \\
- \\
3.24\end{array}$ & $\begin{array}{r}-676 \\
-6 \\
-639 \\
-618\end{array}$ & $\begin{array}{c}- \\
3.14 \\
- \\
3.13 \\
- \\
3.11\end{array}$ & $\begin{array}{r}- \\
552 \\
-546 \\
-533 \\
533\end{array}$ & $\begin{array}{l}- \\
3.01 \\
- \\
2.98 \\
- \\
2.95\end{array}$ & $\begin{array}{r}-476 \\
- \\
460 \\
-444\end{array}$ & $\begin{array}{c}- \\
2.87 \\
- \\
2.84 \\
- \\
2.82\end{array}$ & $\begin{array}{l}-404 \\
- \\
389 \\
- \\
380\end{array}$ \\
\hline
\end{tabular}


Location.- Lat. $42^{\circ} 23^{\prime} 30^{\prime \prime}$, long. $74^{\circ} 2^{\prime} 05^{\prime \prime}$, at Gilboa Dam, 6 miles south of North Blenheim, Schoharie County. Spillway crest at elevation 1,130 feet above mean sea level (levels of New York City Board of Water Supply).

Drainage area.- 314 square miles.

Gage-height record.- One reading daily at 8 a.m. prior to Sept. 22 and at 9 a.m. oct. 1-31; water-stage recorder graph $8 \mathrm{a} \cdot \mathrm{m}$. Sept. 21 to $9 \mathrm{a} . \mathrm{m}$. Oct. 1. Add 1,100 feet to heights given in table for elevations above mean sea level.

Maxima.- September 1938: Elevation, 1,134.31 feet 10:40 p.m. Sept. 21 (contents, $2,842,000,000$ cubic feet). July 1927 to August 1938: Elevation, 1,134.38 feet Mar. 18, 1936 (contents, 2,846,000,000 cub1c feet)

Remarks.- Total capacity, 2,881,000,000 cubic feet. Total available storage at elevation 1,130 feet (crest of spillway) is $2,618,000,000$ cubic feet. Total flow, except for periods of spiling, is diverted through Shandaken Tunnel into Esopus Creek above Ashoken Reservoir for New York C1ty water supply. Records collected by New York City Department of Water Supply, Gas, and Electricity and furnished by that organization and New York City Board of Water Supply.

Height, in feet, and contents, in millions of cubic feet, $1938 \mathrm{a} /$

\begin{tabular}{|c|c|c|c|c|c|c|c|c|c|}
\hline \multirow[b]{2}{*}{ Day } & \multicolumn{2}{|c|}{ September } & \multicolumn{2}{|r|}{ October } & \multirow[b]{2}{*}{ Day } & \multicolumn{2}{|c|}{ September } & \multicolumn{2}{|r|}{ October } \\
\hline & Feet & $\begin{array}{l}\text { Millions of } \\
\text { cubic feet }\end{array}$ & Feet & $\begin{array}{l}\text { Millions of } \\
\text { cubic feet }\end{array}$ & & Feet & $\begin{array}{l}\text { Millions of } \\
\text { cubic feet }\end{array}$ & Feet & $\begin{array}{l}\text { Millions of } \\
\text { cubic feet }\end{array}$ \\
\hline $\begin{array}{l}1 \\
2 \\
3 \\
4 \\
5\end{array}$ & \begin{tabular}{|l|}
25.17 \\
25.28 \\
25.38 \\
25.49 \\
25.58
\end{tabular} & $\begin{array}{l}2,386 \\
2,391 \\
2,396 \\
2,401 \\
2,406\end{array}$ & $\begin{array}{l}29.92 \\
29.43 \\
28.87 \\
28.25 \\
27.61\end{array}$ & $\begin{array}{r}2,614 \\
2,590 \\
2,564 \\
2,534 \\
2,503\end{array}$ & $\begin{array}{l}16 \\
17 \\
18 \\
19 \\
20\end{array}$ & $\begin{array}{l}15.26 \\
13.46 \\
11.66 \\
09.84 \\
09.50\end{array}$ & $\begin{array}{l}1,949 \\
1,875 \\
1,801 \\
1,727 \\
1,714\end{array}$ & $\left|\begin{array}{l}22.04 \\
22.31 \\
22.52 \\
22.71 \\
22.93\end{array}\right|$ & $\begin{array}{l}2,244 \\
2,256 \\
2,266 \\
2,274 \\
2,284\end{array}$ \\
\hline $\begin{array}{r}6 \\
7 \\
8 \\
9 \\
10\end{array}$ & $\left|\begin{array}{l}25.65 \\
25.72 \\
25.84 \\
25.92 \\
25.44\end{array}\right|$ & $\begin{array}{l}2,409 \\
2,412 \\
2,418 \\
2,422 \\
2,399\end{array}$ & $\begin{array}{l}26.92 \\
26.21 \\
25.46 \\
24.70 \\
23.92\end{array}$ & $\begin{array}{l}2,470 \\
2,436 \\
2,400 \\
2,364 \\
2,329\end{array}$ & $\begin{array}{l}21 \\
22 \\
23 \\
24 \\
25\end{array}$ & $\begin{array}{l}13.59 \\
31.85 \\
30.91 \\
30.82 \\
30.87\end{array}$ & $\begin{array}{l}1,880 \\
2,714 \\
2,665 \\
2,661 \\
2,663\end{array}$ & $\left|\begin{array}{l}21.69 \\
20.42 \\
18.95 \\
17.36 \\
17.61\end{array}\right|$ & $\begin{array}{l}2,228 \\
2,171 \\
2,107 \\
2,039 \\
2,049\end{array}$ \\
\hline $\begin{array}{l}11 \\
12 \\
13 \\
14 \\
15\end{array}$ & $\begin{array}{l}23.98 \\
22.20 \\
20.47 \\
18.75 \\
16.99\end{array}$ & $\begin{array}{l}2,332 \\
2,251 \\
2,173 \\
2,098 \\
2,023\end{array}$ & $\begin{array}{l}23.11 \\
22.30 \\
21.47 \\
21.56 \\
21.80\end{array}$ & $\begin{array}{l}2,293 \\
2,256 \\
2,218 \\
2,222 \\
2,233\end{array}$ & $\begin{array}{l}26 \\
27 \\
28 \\
29 \\
30 \\
31\end{array}$ & $\begin{array}{l}30.80 \\
30.88 \\
30.63 \\
30.46 \\
30.33\end{array}$ & $\begin{array}{l}2,660 \\
2,664 \\
2,651 \\
2,642 \\
2,635\end{array}$ & $\begin{array}{l}18.45 \\
19.03 \\
19.53 \\
20.00 \\
20.62 \\
21.20\end{array}$ & $\begin{array}{l}2,085 \\
2,110 \\
2,132 \\
2,152 \\
2,180 \\
2,206\end{array}$ \\
\hline & & & & & & & & Septer & October \\
\hline 19 & & - & & & & & & + & $\begin{array}{r}-157 \\
-58.6 \\
\end{array}$ \\
\hline
\end{tabular}

a/ At 8 a.m. Sept. 1-24;9 a.m. Sept. 25 to 0ct. 31 .

b/ Computed from contents corresponding to observed height on morning of last day of month. 
Location. - Water-stage recorder, lat. $42^{\circ} 23^{\prime} 30^{\prime \prime}$, long. $74^{\circ} 2^{\prime} 7^{\prime} 05^{\prime \prime}$, at Gilboa Dam, 6 miles south of North Blenheim, Schoharie County.

Drainage area.- 314 square miles.

Gage-helght record.- Water-stage recorder graph.

Maxima.-September 1938: Discharge, 31,300 second-feet 10:40 p.m. Sept. 21 (gage

he1ght, $1,134.31$ feet).

July 1927 to August 1938: Discharge, 32,000 second-feet Mar. 18, 1936 (gage helght, $1,134.38$ feet).

Remarks.- Total discharge is the flow passing Gilboa Dam and the flow diverted through

Shandaken Tunnel into Esopus Creek above Ashokan Reservoir for New York C1ty water

supply. Mean monthly discharge ad justed for storgge in Schoharie Reservoir and diversion through Shandaken Tunnel into Esopus Creek. For information on storage see record for. Schoharle Reservoir at Gliboa Dam, at Gilboa, N. Y. Records collected by New York City Department of Water Supply, Gas, and Electricity and furnished by that organization and New York C1ty Board of Water Supply.

Mean daily discharge, in second-feet, 1938

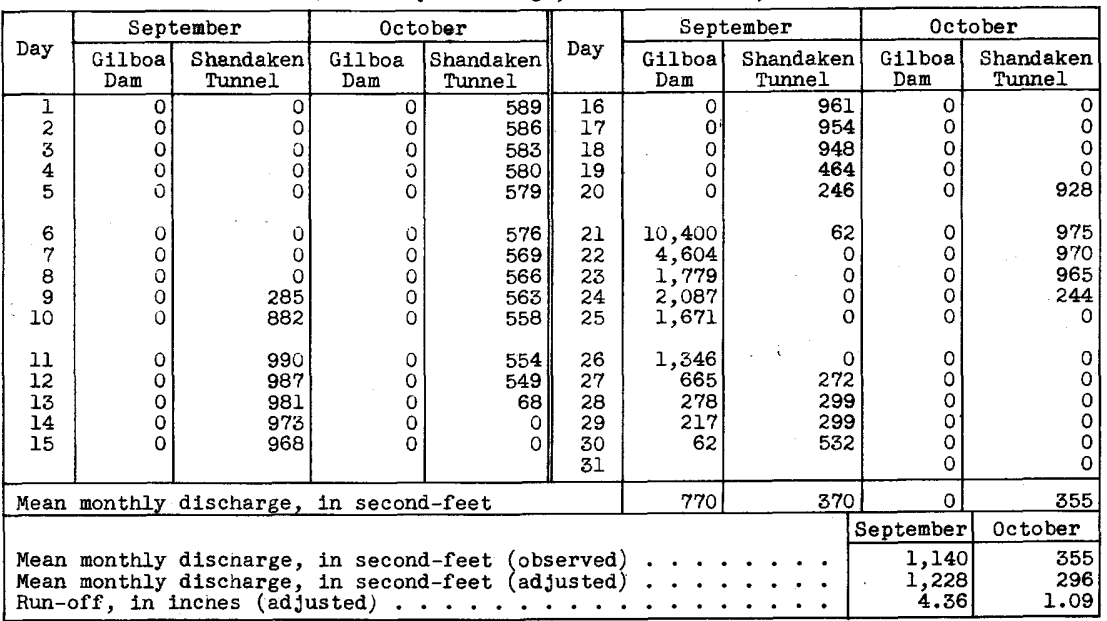


Location. - Water-stage recorder, lat. $42^{\circ} 36^{\prime} 00^{\prime \prime}$, long. $74^{\circ} 20^{\prime} 15^{\prime \prime}, 150$ feet below highway bridge in Middleburg, Schoharle County. Prior to Sept. 24, 1938, wire-weight and staff gage located at highway bridge and at same datum.

Drainage area.- 532 square miles. 314 square miles affected by storage and diversior at Schoharie Reservolr.

Gage-helght record.- Graph based on twice dally gage readings, floodmarks, and eng1neers readings Sept. 18 to noon Sept. 24. Water-stage recorder graph noon Sept. 24 to 0ct. 31 .

Stage-discharge relation.- Defined by current-meter measurements below 13,950 secondfeot; extended logarithmically to peak stage on basis of slope-area determination of peak flow during March 1936 flood and comparison with flood discharge for stations on adjacent streams.

Maxima.- September 1938: Discharge, 40,600 second-feet 2 a.m. Sept. 22 (gage helght, 15.6 feet, from floodmark in gage-house well). July 1927 to August 1938: D1scharge, 47, 800 second-feet Mar. 18, 1936 (gage holght, 16.8 feet, from floodmarks).

August 1906 to June 1927: Discharge, 31,600 second-feet Feb. 20, 1909 (records of New York State Engineer and Surveyor).

Remarks. - Flood discharge affected by storage in and diversion from Schoharie Reservoir. No diversion from Schoharle Reservolr Sept. 22-26. For information on storage and diversions, see records for Schoharie Reservolr at Gilbog Dam, at Gilboa, N. Y. and Schoharle Creek at Gllboa Dam, at Gllboa, N. Y. Mean monthly discharge adjusted for storage in and diversions from Schoharie Reservoir.

Mean daily discharge, in second-feet, 1938

\begin{tabular}{|c|r|r||r|r|r||r|r|r||r|r|r|}
\hline Day & Sept. & 0ct. & Day & Sept. & 0ct. & Day & \multicolumn{1}{|c|}{ Sept. } & 0ct. & Day & Sept. & 0ct. \\
\hline 1 & 25 & 308 & 9 & 21 & 113 & 17 & 46 & 68 & 25 & 2,300 & 105 \\
2 & 23 & 230 & 10 & 22 & 105 & 18 & 44 & 62 & 26 & 1,540 & 100 \\
3 & 22 & 200 & 11 & 19 & 98 & 19 & 46 & 61 & 27 & 1,200 & 83 \\
4 & 23 & 178 & 12 & 17 & 90 & 20 & 243 & 61 & 28 & 920 & 79 \\
5 & 19 & 159 & 13 & 23 & 88 & 21 & 6,630 & 100 & 29 & 632 & 74 \\
6 & 17 & 147 & 14 & 42 & 83 & 22 & 19,300 & 110 & 30 & 465 & 77 \\
7 & 19 & 132 & 15 & 42 & 79 & 23 & 6,130 & 83 & 31 & & 70 \\
8 & 19 & 121 & 16 & 60 & 74 & 24 & 3,380 & 77 & & & \\
\hline
\end{tabular}

Gage helght, in feet, and discharge, in second-feet, at indicated time, 1938

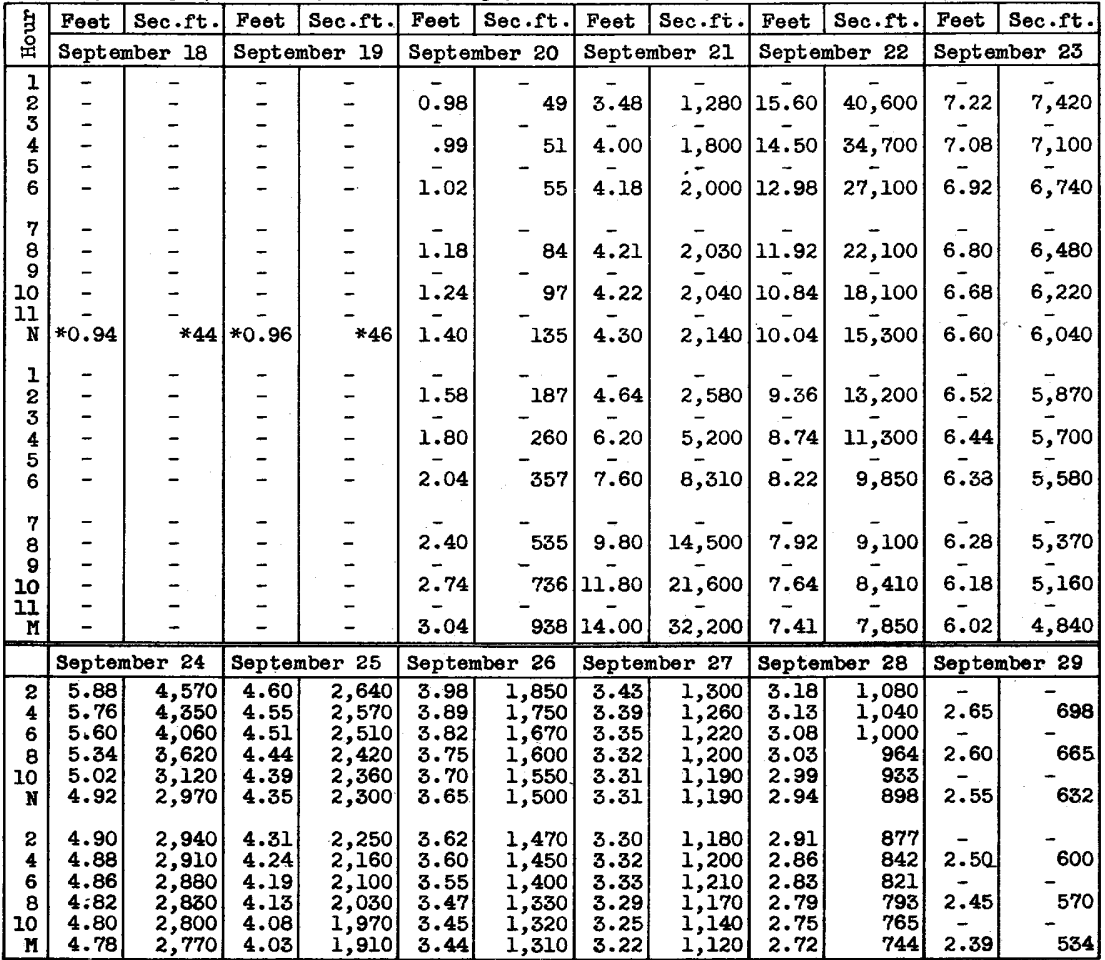

* Mean for the day. 
Location. - Water-stage recorder, lat. $42^{\circ} 44^{\prime} 00^{n}$, long. $73^{\circ} 38^{\prime} 00^{n}, 500$ feet below bridge on Troy-Eagle Milis road, lis miles west of Eagle Mills, and 3 miles east of Troy, Rensselaer County.

Drainage area. - 89 square miles.

Gage-helght record. - Water-stage recorder graph until 1:40 p.m. Sept. 21 when recorder was removed to prevent submergence. Stage graph based on intermittent observations of stage by engineers at reference point 100 feet landward 1:40 p.m. Sept. 21 to

10:15 a.m. Sept. 28; on twice dally observations of stage at reference point at gage Sept. 28 to 0ct. 12; and on twice daily inclined-staff gage readings at new site 60 feet downstream at same datum Oct. 12-31.

Stage-discharge relation. - For 1938 defined by current-meter messurements belor 7,210 second-feet extended logarithmically to peak stage on basis of computations of peak flow over Congress Street and Wilson Dams in Troy and by slope-area determination of peak flow just above gage. For 1927 defined by current-meter measurements below 1,830 second-feet; extended logarithmically to peak stage.

Maxima.- September 1938: D1scharge, 11,900 second-feet 12:30 a.m. Sept. 22 (gage holght, i2.1 feet, from floodmarks in gage house).

Juig 1923 to August 1938: Discharge, 7,030 second-feet Nov, 4, 1927 (gage height, 8.4 feet, from floodmarks at present site and datum).

Remarks. - Flood discharge not affected by storage or diversion.

\begin{tabular}{|c|c|c|c|c|c|c|c|c|c|c|c|}
\hline Day & Sept. & oct. & Day & Sept. & oct. & Day & Sept. & oct. & Day & Sept. & Oct. \\
\hline $\begin{array}{l}1 \\
2 \\
3 \\
4 \\
5 \\
6 \\
7 \\
8\end{array}$ & $\begin{array}{l}32 \\
36 \\
20 \\
20 \\
17 \\
16 \\
21 \\
53\end{array}$ & $\begin{array}{r}128 \\
110 \\
90 \\
74 \\
69 \\
64 \\
58 \\
52\end{array}$ & $\begin{array}{r}9 \\
10 \\
11 \\
12 \\
13 \\
14 \\
15 \\
16\end{array}$ & $\begin{array}{r}38 \\
24 \\
17 \\
29 \\
139 \\
120 \\
128 \\
136\end{array}$ & $\begin{array}{l}51 \\
44 \\
41 \\
40 \\
40 \\
36 \\
34 \\
33\end{array}$ & $\begin{array}{l}17 \\
18 \\
19 \\
20 \\
21 \\
22 \\
23 \\
24\end{array}$ & $\begin{array}{r}79 \\
70 \\
278 \\
1,520 \\
4,780 \\
6,540 \\
1,740 \\
924\end{array}$ & $\begin{array}{r}40 \\
45 \\
45 \\
51 \\
115 \\
88 \\
67 \\
92\end{array}$ & $\begin{array}{l}25 \\
26 \\
27 \\
28 \\
29 \\
30 \\
31\end{array}$ & $\begin{array}{l}611 \\
430 \\
332 \\
324 \\
247 \\
180\end{array}$ & $\begin{array}{r}293 \\
158 \\
123 \\
128 \\
106 \\
97 \\
97\end{array}$ \\
\hline $\begin{array}{l}\text { Mean } \\
\text { Run- }\end{array}$ & $\begin{array}{l}\text { onthiy } \\
\text { f, in }\end{array}$ & $\begin{array}{l}\text { Ascharg } \\
\text { ches. }\end{array}$ & , 1 & second- & et. . & : : & $\begin{array}{l}\cdot \\
.\end{array}$ & 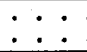 & . & $\begin{array}{r}630 \\
7.90\end{array}$ & $\begin{array}{l}80.9 \\
1.05\end{array}$ \\
\hline
\end{tabular}

Gage height, in feet, and discharge, in second-feet, at indicated time, 1938

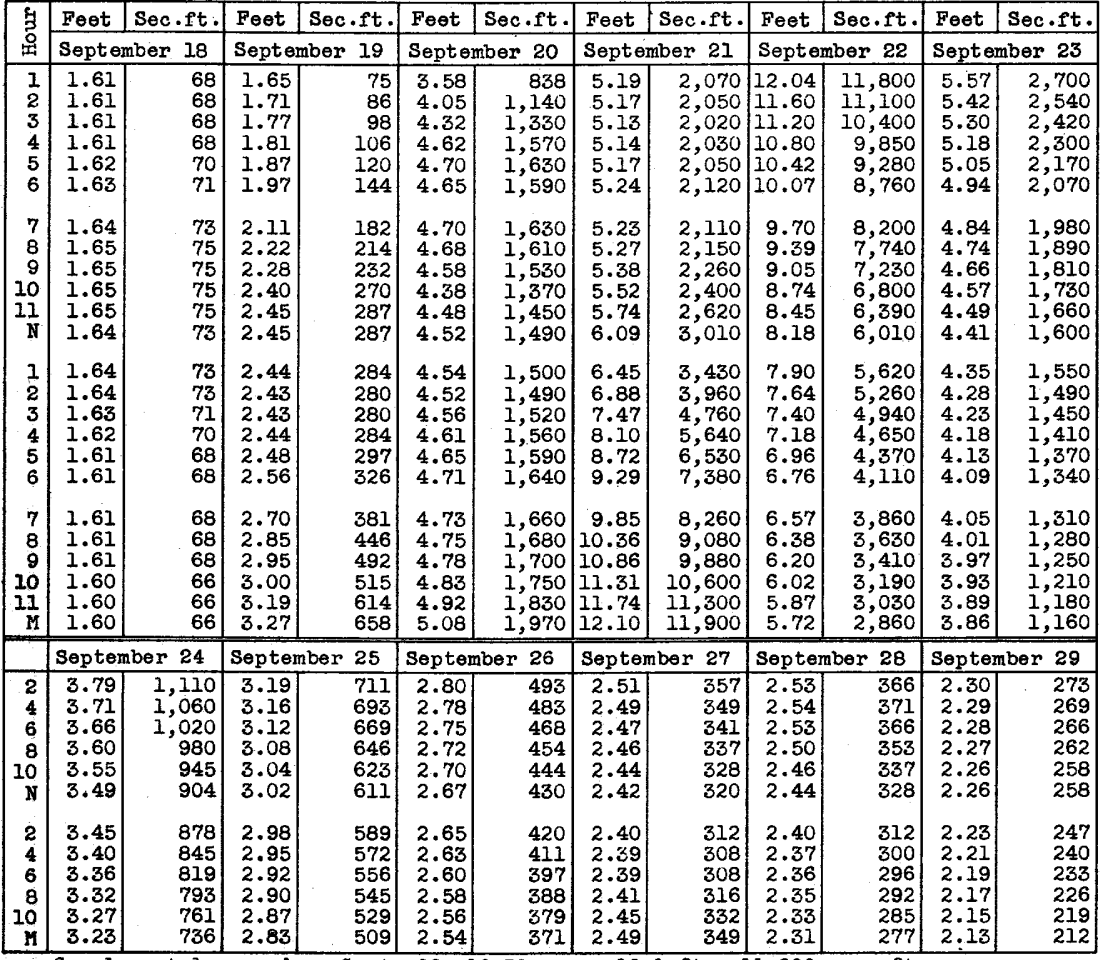

Supplemental records.- Sept. $22,12: 30 \mathrm{a.m.,} 12.1 \mathrm{ft.}, 11,900 \mathrm{sec.-ft.}$ 
Location.- Water-stage recorder, lat. $42^{\circ} 19^{\prime} 50^{\prime \prime}$, long. $73^{\circ} 44^{\prime} 40^{\prime \prime}$; at highway bridge in Rossman, Columbia County, I mile above confluence with Claverack Creek.

Drainage area.- 329 square miles.

Gage-height record.- Water-stage recorder graph until 10:15 p.m. Sept. 2l, when recorder stopped because of submergence. New recorder installed 10:25 a.m. Sept. 25 and water-stage recorder graph thereafter. Stage graph for period of missing record based on intermittent gage readings, floodmarks, and comparison with stage graphs of nearby streams.

Stage-discharge relation.- Defined by current-meter measurements below 9,440 secondfeet and by discharge measurement of 11,000 second-feet by float method; extended logarithmically to peak stage on basis of determination of peak flow on Mar. 13 and 19, 1936, over dam at Stuyvesant Falls hydroelectr1c plant 2 miles upstream and on Sept. 22, 1938, over dam at Midvale Paper Co. 1,000 feet upstream and by slope-area method at the gage.

Maxima.- September 1938: Discharge, 27,800 second-feet 2:30 a.m. Sept. 22 (gage he1ght, 18.4 feet, from floodmarks).

July 1928 to August 1938: D1scharge, 12,900 second-feet Mar. 12, 1936 (gage he1ght, 10.25 feet).

March 1906 to May 1914: Discharge, 11,000 second-feet Jan. 22, 1910 (gage height, 9.04 feet, present datum, from discharge measurement by float method).

Remarks.- Flood discharge not affected by storage or diversion. Diurnal fluctuation at low and medium stages caused by power operations.

Mean dally discharge, in second-feet, 1938

\begin{tabular}{|c|c|c|c|c|c|c|c|c|c|c|c|}
\hline Day & Sept. & oet. & Day & Sept. & Oct. & Day & Sept. & oct. & Day & Sept. & Oct. \\
\hline $\begin{array}{l}1 \\
2 \\
3 \\
4 \\
5 \\
6 \\
7 \\
8\end{array}$ & $\begin{array}{l}168 \\
174 \\
138 \\
109 \\
104 \\
151 \\
151 \\
170\end{array}$ & $\begin{array}{l}616 \\
534 \\
498 \\
456 \\
422 \\
390 \\
349 \\
320\end{array}$ & $\begin{array}{l}9 \\
10 \\
11 \\
12 \\
13 \\
14 \\
15 \\
16\end{array}$ & $\begin{array}{r}220 \\
88 \\
99 \\
162 \\
262 \\
493 \\
308 \\
573\end{array}$ & $\begin{array}{l}302 \\
276 \\
263 \\
246 \\
231 \\
215 \\
208 \\
201\end{array}$ & $\begin{array}{l}17 \\
18 \\
19 \\
20 \\
21 \\
22 \\
23 \\
24\end{array}$ & $\begin{array}{r}390 \\
336 \\
383 \\
5,230 \\
10,000 \\
15,800 \\
5,870 \\
3,070\end{array}$ & $\begin{array}{l}197 \\
197 \\
164 \\
193 \\
400 \\
395 \\
280 \\
322\end{array}$ & $\begin{array}{l}25 \\
26 \\
27 \\
28 \\
29 \\
30 \\
31\end{array}$ & $\begin{array}{r}2,040 \\
1,500 \\
1,170 \\
1,190 \\
905 \\
770\end{array}$ & $\begin{array}{l}821 \\
680 \\
546 \\
510 \\
486 \\
468 \\
422\end{array}$ \\
\hline $\begin{array}{l}\text { Mean } \\
\text { Run- }\end{array}$ & $\begin{array}{l}\text { nthly } \\
\text {, in } 1\end{array}$ & hes. & ? 1 & - . & t. & $: \dot{ }$ & $\begin{array}{l}. \\
.\end{array}$ & $\begin{array}{lll}\cdot & \bullet \\
. & \bullet & \bullet\end{array}$ & $\dot{.}$ & $\begin{array}{r}1,734 \\
5.88\end{array}$ & $\begin{array}{r}374 \\
1.31 \\
\end{array}$ \\
\hline
\end{tabular}

Gage helght, in feet, and discharge, in second-feet, at indicated time, 1938

\begin{tabular}{|c|c|c|c|c|c|c|c|c|c|c|c|c|}
\hline \multirow{2}{*}{$\begin{array}{l}9 \\
0 \\
0\end{array}$} & Peet & Sec.ft. & Feet & Sec.ft. & Feet & Sec.ft. & Feet & Sec.ft. & Feet & Sec.ft. & Feet & Sec ft. \\
\hline & \multicolumn{2}{|c|}{ September 18} & \multicolumn{2}{|c|}{ September 19} & \multicolumn{2}{|c|}{ September 20} & \multicolumn{2}{|c|}{ September 21} & \multicolumn{2}{|c|}{ September 22} & \multicolumn{2}{|c|}{ September 23} \\
\hline $\begin{array}{l}1 \\
2 \\
3 \\
4 \\
5 \\
6\end{array}$ & $\begin{array}{l}1.68 \\
1.67 \\
1.66 \\
1.52 \\
1.46 \\
1.45\end{array}$ & $\begin{array}{l}335 \\
330 \\
325 \\
263 \\
238 \\
234\end{array}$ & $\begin{array}{l}1.46 \\
1.25 \\
1.20 \\
1.18 \\
1.17 \\
1.17\end{array}$ & $\begin{array}{l}238 \\
163 \\
147 \\
141 \\
139 \\
139\end{array}$ & $\begin{array}{l}2.22 \\
2.42 \\
2.92 \\
3.74 \\
4.11 \\
4.78\end{array}$ & $\begin{array}{r}648 \\
785 \\
1,200 \\
2,020 \\
2,450 \\
3,340\end{array}$ & $\begin{array}{l}7.43 \\
7.41 \\
7.38 \\
7.35 \\
7.35 \\
7.35\end{array}$ & $\begin{array}{l}7,950 \\
7,910 \\
7,850 \\
7,800 \\
7,800 \\
7,800\end{array}$ & $\begin{array}{l}16.60 \\
18.20 \\
18.36 \\
17.97 \\
15.58 \\
14.07\end{array}$ & $\begin{array}{l}25,100 \\
27,500 \\
27,700 \\
27,200 \\
23,400 \\
20,800\end{array}$ & $\begin{array}{l}7.60 \\
7.47 \\
7.31 \\
7.18 \\
7.04 \\
6.92\end{array}$ & $\begin{array}{l}8,280 \\
8,020 \\
7,720 \\
7,470 \\
7,210 \\
6,980\end{array}$ \\
\hline $\begin{array}{r}7 \\
8 \\
9 \\
10 \\
11 \\
11\end{array}$ & $\begin{array}{l}1.56 \\
1.57 \\
1.67 \\
1.76 \\
1.76 \\
1.76\end{array}$ & $\begin{array}{l}280 \\
284 \\
330 \\
375 \\
375 \\
375\end{array}$ & $\begin{array}{l}1.59 \\
1.66 \\
1.62 \\
2.01 \\
2.05 \\
2.00\end{array}$ & $\begin{array}{l}293 \\
325 \\
306 \\
516 \\
540 \\
510\end{array}$ & $\begin{array}{l}4.93 \\
5.30 \\
5.67 \\
5.96 \\
6.25 \\
6.45\end{array}$ & $\begin{array}{l}3,550 \\
4,100 \\
4,700 \\
5,200 \\
5,720 \\
6,080\end{array}$ & $\begin{array}{l}7.35 \\
7.35 \\
7.40 \\
7.45 \\
7.49 \\
7.55\end{array}$ & $\begin{array}{l}7,800 \\
7,800 \\
7,890 \\
7,980 \\
8,060 \\
8,180\end{array}$ & $\begin{array}{l}12.93 \\
12.16 \\
11.54 \\
11.03 \\
10.61 \\
10.21\end{array}$ & $\begin{array}{l}18,800 \\
17,300 \\
16,100 \\
15,100 \\
14,300 \\
13,500\end{array}$ & $\begin{array}{l}6.80 \\
6.68 \\
6.56 \\
6.44 \\
6.34 \\
6.22\end{array}$ & $\begin{array}{l}6,750 \\
6,520 \\
6,290 \\
6,070 \\
5,880 \\
5,670\end{array}$ \\
\hline $\begin{array}{l}1 \\
2 \\
3 \\
4 \\
5 \\
6\end{array}$ & $\begin{array}{l}1.76 \\
1.76 \\
1.76 \\
1.76 \\
1.76 \\
1.76\end{array}$ & $\begin{array}{l}375 \\
375 \\
375 \\
375 \\
375 \\
375\end{array}$ & $\begin{array}{l}2.05 \\
2.06 \\
2.07 \\
2.08 \\
2.07 \\
2.01\end{array}$ & $\begin{array}{l}540 \\
546 \\
552 \\
558 \\
552 \\
516\end{array}$ & $\begin{array}{l}6.63 \\
6.78 \\
6.90 \\
7.05 \\
7.20 \\
7.28\end{array}$ & $\begin{array}{l}6,430 \\
6,710 \\
6,940 \\
7,220 \\
7,510 \\
7,660\end{array}$ & $\begin{array}{l}7.64 \\
7.72 \\
7.84 \\
8.10 \\
8.45 \\
8.85\end{array}$ & $\begin{array}{r}8,360 \\
8,520 \\
8,760 \\
9,280 \\
9,980 \\
10,800\end{array}$ & $\begin{array}{l}9.89 \\
9.60 \\
9.33 \\
9.10 \\
8.88 \\
8.69\end{array}$ & $\begin{array}{l}12,900 \\
12,300 \\
11,700 \\
11,300 \\
10,800 \\
10,500\end{array}$ & $\begin{array}{l}6.11 \\
6.01 \\
5.91 \\
5.83 \\
5.73 \\
5.65\end{array}$ & $\begin{array}{l}5,470 \\
5,290 \\
5,110 \\
4,970 \\
4,800 \\
4,660\end{array}$ \\
\hline \multirow[t]{2}{*}{$\begin{array}{r}7 \\
8 \\
9 \\
10 \\
11 \\
11\end{array}$} & $\begin{array}{l}1.76 \\
1.76 \\
1.76 \\
1.76 \\
1.74 \\
1.60\end{array}$ & $\begin{array}{l}375 \\
375 \\
375 \\
375 \\
364 \\
297\end{array}$ & $\begin{array}{l}1.91 \\
1.84 \\
1.85 \\
1.84 \\
1.99 \\
2.23\end{array}$ & $\begin{array}{l}456 \\
417 \\
422 \\
417 \\
504 \\
654\end{array}$ & $\begin{array}{l}7.35 \\
7.35 \\
7.37 \\
7.37 \\
7.37 \\
7.42\end{array}$ & $\begin{array}{l}7,800 \\
7,800 \\
7,830 \\
7,830 \\
7,830 \\
7,930 \\
\end{array}$ & $\begin{array}{r}9.37 \\
10.25 \\
11.02 \\
11.92 \\
12.84 \\
14.26\end{array}$ & $\begin{array}{l}11,800 \\
13,600 \\
15,100 \\
16,800 \\
18,600 \\
21,200\end{array}$ & $\begin{array}{l}8.50 \\
8.35 \\
8.20 \\
8.04 \\
7.89 \\
7.74\end{array}$ & $\begin{array}{r}10,100 \\
9,780 \\
9,480 \\
9,160 \\
8,860 \\
8,560\end{array}$ & $\begin{array}{l}5.57 \\
5.49 \\
5.40 \\
5.33 \\
5.26 \\
5.19 \\
\end{array}$ & $\begin{array}{l}4,530 \\
4,400 \\
4,260 \\
4,150 \\
4,040 \\
3,940\end{array}$ \\
\hline & \multicolumn{2}{|c|}{ September 24} & \multicolumn{2}{|c|}{ Sepțember 25} & \multicolumn{2}{|c|}{ September 26} & \multicolumn{2}{|c|}{ September 27 } & \multicolumn{2}{|c|}{ September 28} & \multicolumn{2}{|c|}{ September 29} \\
\hline $\begin{array}{r}2 \\
4 \\
6 \\
8 \\
10 \\
11\end{array}$ & $\begin{array}{l}5.06 \\
4.94 \\
4.83 \\
4.73 \\
4.63 \\
4.54\end{array}$ & $\begin{array}{l}3,740 \\
3,570 \\
3,410 \\
3,270 \\
3,130 \\
3,010\end{array}$ & $\begin{array}{l}4.03 \\
3.97 \\
3.91 \\
3.86 \\
3.81 \\
3.74\end{array}$ & $\begin{array}{l}2,360 \\
2,280 \\
2,210 \\
2,160 \\
2,100 \\
2,020\end{array}$ & $\begin{array}{l}3.42 \\
3.37 \\
3.33 \\
3.29 \\
3.27 \\
3.24\end{array}$ & $\begin{array}{l}1,680 \\
1,630 \\
1,590 \\
1,550 \\
1,530 \\
1,500\end{array}$ & $\begin{array}{l}2.99 \\
2.96 \\
2.94 \\
2.92 \\
2.90 \\
2.88\end{array}$ & $\begin{array}{l}1,260 \\
1,230 \\
1,220 \\
1,200 \\
1,180 \\
1,160\end{array}$ & $\begin{array}{l}2.90 \\
2.97 \\
3.03 \\
3.03 \\
3.01 \\
2.97\end{array}$ & $\begin{array}{l}1,180 \\
1,240 \\
1,300 \\
1,300 \\
1,280 \\
1,240\end{array}$ & $\begin{array}{l}2.68 \\
2.66 \\
2.63 \\
2.62 \\
2.60 \\
2.60\end{array}$ & $\begin{array}{r}984 \\
968 \\
944 \\
936 \\
920 \\
920\end{array}$ \\
\hline $\begin{array}{r}2 \\
4 \\
6 \\
8 \\
10 \\
11\end{array}$ & $\begin{array}{l}4.46 \\
4.38 \\
4.31 \\
4.22 \\
4.16 \\
4.08\end{array}$ & $\begin{array}{l}2,900 \\
2,790 \\
2,700 \\
2,590 \\
2,510 \\
2,420\end{array}$ & $\begin{array}{l}3.68 \\
3.64 \\
3.61 \\
3.56 \\
3.52 \\
3.46\end{array}$ & $\begin{array}{l}1,960 \\
1,910 \\
1,880 \\
1,830 \\
1,780 \\
1,730\end{array}$ & $\begin{array}{l}3.20 \\
3.16 \\
3.13 \\
3.09 \\
3.05 \\
3.02\end{array}$ & $\begin{array}{l}1,460 \\
1,420 \\
1,390 \\
1,350 \\
1,320 \\
1,290\end{array}$ & $\begin{array}{l}2.87 \\
2.83 \\
2.82 \\
2.80 \\
2.81 \\
2.87\end{array}$ & $\begin{array}{l}1,150 \\
1,120 \\
1,110 \\
1,090 \\
1,100 \\
1,150\end{array}$ & $\begin{array}{l}2.92 \\
2.87 \\
2.82 \\
2.77 \\
2.72 \\
2.70\end{array}$ & $\begin{array}{l}1,200 \\
1,150 \\
1,110 \\
1,060 \\
1,020 \\
1,000\end{array}$ & $\begin{array}{l}2.57 \\
2.54 \\
2.52 \\
2.50 \\
2.49 \\
2.48\end{array}$ & $\begin{array}{l}898 \\
875 \\
860 \\
845 \\
838 \\
830\end{array}$ \\
\hline
\end{tabular}

Supplemental records.- Sept. 19, 11:30 a.m., 1.84 ft., 417 sec.-ft. Sept. 22, $2: 30$ e.m., 18.4 ft., 27,800 sec. - ft. 
Location.- Water-stage recorder, lat. $42^{\circ} 24^{\prime} 20^{n}$, long. $74^{\circ} 09^{\prime} 05^{n}$, just below highway bridge in southermmost part of Oak H1ll, Greene county. Drainage area. - 98 square miles.

Gage-helght record. - Water-stage recorder graph.

Stage-discharge relation:- Defined by current-meter measurements below 1,450 secondfeet; extended on basis of slope-area determination of peak flow of. March 1936 .

Maxima.- September 1938: Discharge, 7,900 second-feet 6:45 p.m. Sept. 21 (gage helght, 12.08 feet).

March 1929 to August 1938: Discharge, 8,880 second-feet March 18, 1936 (gage height, 12.83 feet, from floodmark in shelter).

April 1910 to Febmary 1929: Discharge, 12,300 second-feet Nov. 9, 1913 (from

records of New York C1ty Board of Water Supply).

Remarks.- Flood run-off not affected by storage or diversion.

Mean dally discharge, in second-feet, 1938

\begin{tabular}{|r|r|r||r|r|r|r|r|r||r|r|r|}
\hline Day & Sept. & Oct. & Day & Sept. & Oct. & Day & Sept. & Oct. & Day & Sept. & Oct. \\
\hline 1 & 5.8 & 81 & 9 & 4.0 & 31 & 17 & 12 & 18 & 25 & 296 & 56 \\
2 & 7.2 & 70 & 10 & 4.0 & 28 & 18 & 12 & 17 & 26 & 210 & 55 \\
3 & 6.2 & 59 & 11 & 3.6 & 26 & 19 & 14 & 16 & 27 & 163 \\
4 & 5.8 & 52 & 12 & 3.7 & 25 & 20 & 150 & 17 & 28 & 141 & 39 \\
5 & 4.9 & 46 & 13 & 5.3 & 24 & 21 & 3,150 & 45 & 29 & 112 & 31 \\
6 & 4.2 & 42 & 14 & 9.5 & 21 & 22 & 1,980 & 48 & 30 & 95 & 26 \\
7 & 4.7 & 37 & 15 & 10 & 21 & 23 & 800 & 40 & 31 & 26 \\
8 & 4.9 & 34 & 16 & 15 & 20 & 24 & 450 & 42 & \\
\hline
\end{tabular}

Gage height, In feet, and discharge, in second-feet, at indicated time, 1938

\begin{tabular}{|c|c|c|c|c|c|c|c|c|c|c|c|c|}
\hline \multirow{2}{*}{ 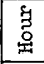 } & Feet & sec.ft. & Feet & Sec.ft. & Feet & Sec.ft. & Feet & Sec.ft. & Feet & Sec.ft. & Feet & Sec.ft. \\
\hline & \multicolumn{2}{|c|}{ September 18} & \multicolumn{2}{|c|}{ September 19} & \multicolumn{2}{|c|}{ September 20} & \multicolumn{2}{|c|}{ September 21} & \multicolumn{2}{|c|}{ September 22} & \multicolumn{2}{|c|}{ September 23} \\
\hline $\begin{array}{l}1 \\
2 \\
3 \\
4 \\
5 \\
6\end{array}$ & $\begin{array}{l}- \\
1.76 \\
- \\
1.74 \\
- \\
1.75\end{array}$ & $\begin{array}{r}-12 \\
-\quad 11 . \\
-\quad 12\end{array}$ & $\begin{array}{l}1.77 \\
- \\
1.77 \\
- \\
1.76\end{array}$ & $\begin{array}{r}-13 \\
-\quad 13 \\
-\begin{array}{r}12 \\
12\end{array}\end{array}$ & $\begin{array}{l}2.02 \\
2.04 \\
2.15 \\
2.23 \\
2.34 \\
2.45\end{array}$ & $\begin{array}{l}28 \\
30 \\
38 \\
45 \\
55 \\
66\end{array}$ & $\begin{array}{l}4.46 \\
4.58 \\
4.52 \\
4.45 \\
4.40 \\
4.38\end{array}$ & $\begin{array}{l}638 \\
704 \\
671 \\
632 \\
605 \\
595\end{array}$ & $\begin{array}{l}8.43 \\
8.14 \\
7.81 \\
7.56 \\
7.31 \\
7.15\end{array}$ & $\begin{array}{l}3,730 \\
3,440 \\
3,130 \\
2,900 \\
2,680 \\
2,540\end{array}$ & $\begin{array}{c}- \\
5.06 \\
- \\
4.99 \\
- \\
5.02\end{array}$ & $\begin{array}{r}-936 \\
-\quad 894 \\
-\quad 912\end{array}$ \\
\hline $\begin{array}{r}7 \\
8 \\
9 \\
10 \\
11 \\
\text { N }\end{array}$ & $\begin{array}{l}- \\
1.75 \\
- \\
1.75 \\
- \\
1.74\end{array}$ & $\begin{array}{r}-12 \\
-\quad 12 \\
-\quad 11\end{array}$ & $\begin{array}{l}- \\
1.76 \\
- \\
1.76 \\
- \\
1.76\end{array}$ & $\begin{array}{r}-12 \\
-\quad 12 \\
-\begin{array}{r}12 \\
12\end{array}\end{array}$ & $\begin{array}{l}2.57 \\
2.69 \\
2.77 \\
2.87 \\
2.99 \\
3.12\end{array}$ & $\begin{array}{r}80 \\
95 \\
105 \\
119 \\
137 \\
162\end{array}$ & $\begin{array}{l}4.46 \\
4.60 \\
4.69 \\
4.72 \\
5.01 \\
5.61\end{array}$ & $\begin{array}{r}638 \\
715 \\
764 \\
781 \\
946 \\
1,330\end{array}$ & $\begin{array}{l}6.98 \\
5.81 \\
6.67 \\
6.54 \\
6.39 \\
6.28\end{array}$ & $\begin{array}{l}2,380 \\
2,230 \\
2,100 \\
1,990 \\
1,860 \\
1,770\end{array}$ & $\begin{array}{c}- \\
5.04 \\
- \\
4.96 \\
- \\
4.88\end{array}$ & $\begin{array}{r}-924 \\
- \\
876 \\
-829\end{array}$ \\
\hline $\begin{array}{l}1 \\
2 \\
3 \\
4 \\
5 \\
6\end{array}$ & $\begin{array}{c}- \\
1.74 \\
- \\
1.74 \\
- \\
1.74\end{array}$ & 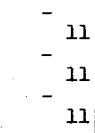 & $\begin{array}{c}- \\
1.77 \\
- \\
1.81 \\
- \\
1.84\end{array}$ & 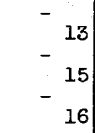 & $\begin{array}{l}3.20 \\
3.23 \\
3.23 \\
3.23 \\
3.23 \\
3.23\end{array}$ & $\begin{array}{l}179 \\
186 \\
186 \\
186 \\
186 \\
186\end{array}$ & $\begin{array}{r}6.90 \\
8.30 \\
9.90 \\
10.66 \\
11.55 \\
11.87\end{array}$ & $\begin{array}{l}2,310 \\
3,600 \\
5,290 \\
6,190 \\
7,260 \\
7,640\end{array}$ & $\begin{array}{l}6.12 \\
6.00 \\
5.87 \\
5.77 \\
5.66 \\
5.58\end{array}$ & $\begin{array}{l}1,650 \\
1,550 \\
1,460 \\
1,390 \\
1,310 \\
1,260\end{array}$ & $\begin{array}{c}- \\
4.78 \\
- \\
4.69 \\
\overline{4.61}\end{array}$ & $\begin{array}{r}-774 \\
-725 \\
-785 \\
685\end{array}$ \\
\hline \multirow[t]{2}{*}{$\begin{array}{r}7 \\
8 \\
9 \\
10 \\
11 \\
\\
\end{array}$} & $\begin{array}{c}- \\
1.75 \\
- \\
1.75 \\
- \\
1.77\end{array}$ & $\begin{array}{r}-12 \\
-\quad 12 \\
-\quad 13\end{array}$ & $\begin{array}{c}- \\
1.85 \\
- \\
1.87 \\
\overline{1.98}\end{array}$ & $\begin{array}{r}-17 \\
-\quad 18 \\
-\quad 26\end{array}$ & $\begin{array}{l}3.27 \\
3.32 \\
3.41 \\
3.58 \\
3.91 \\
4.17\end{array}$ & $\begin{array}{l}195 \\
207 \\
230 \\
277 \\
386 \\
492\end{array}$ & $\begin{array}{r}12.00 \\
11.47 \\
10.72 \\
10.23 \\
9.41 \\
8.91\end{array}$ & $\begin{array}{l}7,800 \\
7,160 \\
6,260 \\
5,680 \\
4,750 \\
4,210\end{array}$ & $\begin{array}{l}5.50 \\
5.43 \\
5.35 \\
5.28 \\
5.21 \\
5.16\end{array}$ & $\begin{array}{r}1,200 \\
1,160 \\
1,110 \\
1,070 \\
1,030 \\
996\end{array}$ & $\begin{array}{c}- \\
4.54 \\
- \\
4.47 \\
- \\
4.39\end{array}$ & $\begin{array}{r}-650 \\
-\quad 615 \\
-\quad 576\end{array}$ \\
\hline & \multicolumn{2}{|c|}{ September 24} & \multicolumn{2}{|c|}{ September 25} & \multicolumn{2}{|c|}{ September 26} & \multicolumn{2}{|c|}{ September 27} & \multicolumn{2}{|c|}{ September 28} & \multicolumn{2}{|c|}{ September 29} \\
\hline $\begin{array}{r}2 \\
4 \\
6 \\
8 \\
10 \\
N\end{array}$ & $\begin{array}{l}4.34 \\
4.29 \\
4.23 \\
4.19 \\
4.15 \\
4.09\end{array}$ & $\begin{array}{l}553 \\
530 \\
504 \\
486 \\
470 \\
446\end{array}$ & $\begin{array}{c}- \\
3.81 \\
- \\
3.74 \\
- \\
3.69\end{array}$ & $\begin{array}{c}-340 \\
- \\
316 \\
- \\
299\end{array}$ & $\begin{array}{c}- \\
3.47 \\
- \\
3.43 \\
- \\
3.39\end{array}$ & $\begin{array}{r}-233 \\
- \\
221 \\
- \\
210\end{array}$ & $\begin{array}{c}\bar{z} \\
3.23 \\
- \\
3.22 \\
- \\
3.21\end{array}$ & $\begin{array}{r}-170 \\
-168 \\
-\quad 165\end{array}$ & $\begin{array}{c}- \\
3.17 \\
- \\
3.14 \\
- \\
3.12\end{array}$ & $\begin{array}{r}-156 \\
- \\
-150 \\
-145\end{array}$ & $\begin{array}{c}- \\
2.99 \\
- \\
2.97 \\
- \\
2.95\end{array}$ & $\begin{array}{r}-119 \\
- \\
116 \\
-112\end{array}$ \\
\hline $\begin{array}{r}2 \\
4 \\
6 \\
8 \\
10 \\
M\end{array}$ & $\begin{array}{l}4.04 \\
4.01 \\
3.96 \\
3.93 \\
3.90 \\
3.87\end{array}$ & $\begin{array}{l}426 \\
414 \\
395 \\
383 \\
372 \\
361\end{array}$ & $\begin{array}{c}- \\
3.60 \\
- \\
3.53 \\
- \\
3.50\end{array}$ & $\begin{array}{r}- \\
270 \\
-250 \\
-241\end{array}$ & $\begin{array}{c}- \\
3.34 \\
- \\
3.29 \\
- \\
3.26\end{array}$ & $\begin{array}{r}-197 \\
- \\
185 \\
-177\end{array}$ & $\begin{array}{c}- \\
3.18 \\
- \\
3.17 \\
- \\
3.18\end{array}$ & $\begin{array}{r}-159 \\
- \\
156 \\
-159\end{array}$ & $\begin{array}{c}\overline{3.08} \\
- \\
3.03 \\
\overline{3.01}\end{array}$ & $\begin{array}{r}-137 \\
- \\
127 \\
- \\
123\end{array}$ & $\begin{array}{c}- \\
2.93 \\
- \\
2.91 \\
2.89\end{array}$ & $\begin{array}{r}-108 \\
-105 \\
-101\end{array}$ \\
\hline
\end{tabular}


Location. - Water-stage recorder, lat. $42^{\circ} 00^{\prime} 45^{\prime \prime}$, long. $74^{\circ} 16^{\prime} 10^{\prime \prime}$, at highwaj bridge at Coldbrook, Ulster County, $1 \frac{1}{2}$ miles above Ashokan Reservoir.

Drainage area. - 192 square miles.

Gage-helght record. - Water-stage recorder graph.

Stage-discharge relation.- Defined by current-meter measurements below 7,100 secondfeet; extended logarithmically to peak stage on basis of determination of peak flow of flood of August 1933 by float method.

Maxima.- September 1938: Discharge, 19,900 second-feet 8 p.m. Sept. 21 (gage height, 13.97 feet).

January 1914 to August 1938: Discharge, 55,000 second-feet Aug. 24, 1933 (gage height, 20.40 feet).

Remarks. - Water diverted through Shandaken Tunnel from Schoharie Creek enters Esopus Creek about $6 \mathrm{miles}$ above this station. Mean monthly discharge adjusted for diversion into the basin. No diversion Sept. 22-26. For information on diversion see record for Schoharle Creek at Gilboa Dam, at Gilboa, N. Y.

Mean daily discharge, in second-feet, 1938

\begin{tabular}{|c|c|c|c|c|c|c|c|c|c|c|c|}
\hline Day & Sept. & oct. & Day & Sept. & Oct. & Day & Sept. & Oct. & Day & Sept. & Oet. \\
\hline $\begin{array}{l}1 \\
2 \\
3 \\
4 \\
5 \\
6 \\
7 \\
8\end{array}$ & $\begin{array}{r}108 \\
94 \\
88 \\
88 \\
81 \\
76 \\
78 \\
86\end{array}$ & $\begin{array}{l}912 \\
882 \\
858 \\
837 \\
816 \\
802 \\
781 \\
767\end{array}$ & $\begin{array}{r}9 \\
10 \\
11 \\
12 \\
13 \\
14 \\
15 \\
16\end{array}$ & $\begin{array}{r}191 \\
541 \\
1,100 \\
1,110 \\
1,140 \\
1,120 \\
1,150 \\
1,120\end{array}$ & \begin{tabular}{l|}
756 \\
746 \\
736 \\
725 \\
576 \\
132 \\
113 \\
108
\end{tabular} & $\begin{array}{l}17 \\
18 \\
19 \\
20 \\
21 \\
22 \\
23 \\
24\end{array}$ & $\begin{array}{l}1,120 \\
1,120 \\
1,150 \\
1,470 \\
6,450 \\
4,660 \\
1,820 \\
1,190\end{array}$ & $\begin{array}{r}104 \\
101 \\
96 \\
541 \\
1,100 \\
1,080 \\
1,080 \\
1,080\end{array}$ & $\begin{array}{l}25 \\
26 \\
27 \\
28 \\
29 \\
30 \\
31\end{array}$ & $\begin{array}{l}860 \\
655 \\
630 \\
792 \\
709 \\
762\end{array}$ & $\begin{array}{l}314 \\
230 \\
202 \\
180 \\
198 \\
196 \\
187\end{array}$ \\
\hline $\begin{array}{l}\text { Mean } \\
\text { Mean } \\
\text { Run- }\end{array}$ & $\begin{array}{l}\text { monthly } \\
\text { monthly } \\
\text { ff, in } 1\end{array}$ & $\begin{array}{l}\text { Ischar } \\
\text { ischar } \\
\text { ches }\end{array}$ & , ir & $\begin{array}{l}\text { second-1 } \\
\text { second-1 } \\
\text { d) . . }\end{array}$ & 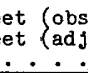 & $\begin{array}{l}\text { rved) } \\
\text { isted) } \\
.\end{array}$ & 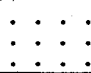 & $\dot{\bullet} \cdot \dot{\bullet}$ & $\dot{0}$ & $\begin{array}{r}1,052 \\
682 \\
3.96\end{array}$ & $\begin{array}{r}556 \\
201 \\
1.21\end{array}$ \\
\hline
\end{tabular}

Gage height, in feet, and discharge, In second-feet, at indicated time, 1938

\begin{tabular}{|c|c|c|c|c|c|c|c|c|c|c|c|c|}
\hline \multirow{2}{*}{ 年 } & Feet & Sec.ft. & Feet & Sec.ft. & Feet & Sec.ft. & Feet & Sec.ft. & Feet & Sec.ft. & Feet & Sec.ft: \\
\hline & \multicolumn{2}{|c|}{ September 18} & \multicolumn{2}{|c|}{ September 19} & \multicolumn{2}{|c|}{ September 20} & \multicolumn{2}{|c|}{ September 21} & \multicolumn{2}{|c|}{ September 22} & \multicolumn{2}{|c|}{ September 23} \\
\hline $\begin{array}{l}1 \\
2 \\
3 \\
4 \\
5 \\
6\end{array}$ & $\begin{array}{l}- \\
- \\
- \\
- \\
- \\
5.69\end{array}$ & $\begin{array}{l}- \\
- \\
- \\
- \\
- \\
1,120\end{array}$ & $\begin{array}{l}5.70 \\
5.74 \\
5.75 \\
5.75 \\
5.75 \\
5.81\end{array}$ & $\begin{array}{l}1,130 \\
1,170 \\
1,180 \\
1,180 \\
1,180 \\
1,230\end{array}$ & $\begin{array}{l}5.40 \\
5.80 \\
5.92 \\
5.95 \\
6.00 \\
6.22\end{array}$ & $\begin{array}{r}890 \\
1,220 \\
1,330 \\
1,360 \\
1,400 \\
1,620\end{array}$ & $\begin{array}{l}6.57 \\
6.59 \\
6.62 \\
6.65 \\
6.72 \\
6.78\end{array}$ & $\begin{array}{l}2,010 \\
2,040 \\
2,070 \\
2,110 \\
2,200 \\
2,270\end{array}$ & $\begin{array}{r}10.40 \\
9.90 \\
9.60 \\
9.36 \\
9.10 \\
8.90\end{array}$ & $\begin{array}{l}9,020 \\
7,800 \\
7,140 \\
6,640 \\
6,120 \\
5,720\end{array}$ & $\begin{array}{l}6.92 \\
6.90 \\
6.88 \\
6.88 \\
6.86 \\
6.84\end{array}$ & $\begin{array}{l}2,160 \\
2,140 \\
2,120 \\
2,120 \\
2,100 \\
2,070\end{array}$ \\
\hline $\begin{array}{r}7 \\
8 \\
9 \\
10 \\
11 \\
N\end{array}$ & $\begin{array}{l}- \\
- \\
- \\
- \\
- \\
5.68\end{array}$ & $\begin{array}{l}- \\
- \\
- \\
- \\
- \\
1,110\end{array}$ & $\begin{array}{l}5.81 \\
5.80 \\
5.79 \\
5.79 \\
5.78 \\
5.77\end{array}$ & $\begin{array}{l}1,230 \\
1,220 \\
1,210 \\
1,210 \\
1,200 \\
1,190\end{array}$ & $\begin{array}{l}6.26 \\
6.18 \\
6.11 \\
6.08 \\
6.05 \\
6.03\end{array}$ & $\begin{array}{l}1,670 \\
1,580 \\
1,510 \\
1,480 \\
1,450 \\
1,430\end{array}$ & $\begin{array}{l}6.86 \\
6.92 \\
7.03 \\
7.13 \\
7.30 \\
7.50\end{array}$ & $\begin{array}{l}2,380 \\
2,460 \\
2,600 \\
2,740 \\
2,990 \\
3,290\end{array}$ & $\begin{array}{l}8.75 \\
8.60 \\
8.39 \\
8.26 \\
8.13 \\
8.01\end{array}$ & $\begin{array}{l}5,440 \\
5,170 \\
4,790 \\
4,560 \\
4,320 \\
4,110\end{array}$ & $\begin{array}{l}6.80 \\
6.76 \\
6.72 \\
6.68 \\
6.62 \\
6.59\end{array}$ & $\begin{array}{l}2,030 \\
1,990 \\
1,950 \\
1,910 \\
1,850 \\
1,820\end{array}$ \\
\hline $\begin{array}{l}1 \\
2 \\
3 \\
4 \\
5 \\
6\end{array}$ & $\begin{array}{l}- \\
- \\
- \\
- \\
- \\
5.68\end{array}$ & $\begin{array}{l}- \\
- \\
- \\
- \\
1,110\end{array}$ & $\begin{array}{l}5.77 \\
5.77 \\
5.81 \\
5.83 \\
5.84 \\
5.84\end{array}$ & $\begin{array}{l}1,190 \\
1,190 \\
1,230 \\
1,250 \\
1,260 \\
1,260\end{array}$ & $\begin{array}{l}6.02 \\
6.01 \\
6.01 \\
6.00 \\
6.00 \\
6.00\end{array}$ & $\begin{array}{l}1,420 \\
1,410 \\
1,410 \\
1,400 \\
1,400 \\
1,400\end{array}$ & $\begin{array}{r}7.62 \\
7.90 \\
8.20 \\
8.90 \\
9.82 \\
11.50\end{array}$ & $\begin{array}{r}3,480 \\
3,930 \\
4,450 \\
5,720 \\
7,620 \\
12,000\end{array}$ & $\begin{array}{l}7.89 \\
7.79 \\
7.68 \\
7.59 \\
7.48 \\
7.40\end{array}$ & $\begin{array}{l}3,910 \\
3,750 \\
3,580 \\
3,430 \\
3,260 \\
3,140\end{array}$ & $\begin{array}{l}6.55 \\
6.52 \\
6.48 \\
6.44 \\
6.41 \\
6.40\end{array}$ & $\begin{array}{l}1,780 \\
1,750 \\
1,710 \\
1,670 \\
1,640 \\
1,630\end{array}$ \\
\hline $\begin{array}{r}7 \\
8 \\
9 \\
10 \\
11 \\
M\end{array}$ & $\begin{array}{l}- \\
- \\
- \\
- \\
- \\
5.68\end{array}$ & $\begin{array}{l}- \\
- \\
- \\
- \\
- \\
1,110\end{array}$ & $\begin{array}{l}5.77 \\
5.75 \\
5.65 \\
5.27 \\
5.20 \\
5.17\end{array}$ & $\begin{array}{r}1,190 \\
1,180 \\
1,090 \\
794 \\
745 \\
726\end{array}$ & $\begin{array}{l}6.01 \\
6.02 \\
6.30 \\
6.42 \\
6.54 \\
6.57\end{array}$ & $\begin{array}{l}1,410 \\
1,420 \\
1,710 \\
1,840 \\
1,980 \\
2,010\end{array}$ & $\begin{array}{l}13.80 \\
13.97 \\
13.05 \\
12.50 \\
11.50 \\
10.90\end{array}$ & $\begin{array}{l}19,300 \\
19,900 \\
16,700 \\
14,900 \\
12,000 \\
10,300\end{array}$ & $\begin{array}{l}7.32 \\
7.25 \\
7.18 \\
7.10 \\
7.03 \\
6.97\end{array}$ & $\begin{array}{l}3,020 \\
2,920 \\
2,810 \\
2,700 \\
2,600 \\
2,520\end{array}$ & $\begin{array}{l}6.35 \\
6.31 \\
6.28 \\
6.26 \\
6.22 \\
6.20\end{array}$ & $\begin{array}{l}1,580 \\
1,540 \\
1,510 \\
1,490 \\
1,460 \\
1,440\end{array}$ \\
\hline & \multicolumn{2}{|c|}{ September 24} & \multicolumn{2}{|c|}{ September 25} & \multicolumn{2}{|c|}{ September 26} & \multicolumn{2}{|c|}{ September 27} & \multicolumn{2}{|c|}{ September 28} & \multicolumn{2}{|c|}{ September 29} \\
\hline $\begin{array}{r}2 \\
4 \\
6 \\
8 \\
10 \\
N\end{array}$ & $\begin{array}{l}6.13 \\
6.08 \\
6.04 \\
6.00 \\
5.95 \\
5.91\end{array}$ & $\begin{array}{l}1,380 \\
1,330 \\
1,300 \\
1,260 \\
1,220 \\
1,190\end{array}$ & $\begin{array}{c}- \\
5.56 \\
- \\
5.50 \\
- \\
5.44\end{array}$ & $\begin{array}{c}-942 \\
- \\
900 \\
-858\end{array}$ & $\begin{array}{c}- \\
5.22 \\
- \\
5.18 \\
- \\
5.14\end{array}$ & $\begin{array}{r}-704 \\
-\quad 676 \\
-648\end{array}$ & $\begin{array}{l}5.01 \\
5.00 \\
4.98 \\
4.98 \\
4.98 \\
4.98\end{array}$ & $\begin{array}{l}557 \\
550 \\
538 \\
538 \\
538 \\
538\end{array}$ & $\begin{array}{c}- \\
5.38 \\
- \\
5.36 \\
- \\
5.34\end{array}$ & $\begin{array}{r}- \\
816 \\
- \\
802 \\
-788\end{array}$ & $\begin{array}{c}- \\
5.25 \\
- \\
5.24 \\
- \\
5.23\end{array}$ & $\begin{array}{r}-725 \\
-718 \\
-711 \\
771\end{array}$ \\
\hline $\begin{array}{r}2 \\
4 \\
6 \\
8 \\
10 \\
M\end{array}$ & $\begin{array}{l}5.85 \\
5.77 \\
5.74 \\
5.70 \\
5.66 \\
5.63\end{array}$ & $\begin{array}{r}1,140 \\
1,090 \\
1,070 \\
1,040 \\
1,010 \\
991\end{array}$ & $\begin{array}{c}- \\
5.38 \\
- \\
5.31 \\
- \\
5.26\end{array}$ & $\begin{array}{c}- \\
-816 \\
-767 \\
-732\end{array}$ & $\begin{array}{l}5.09 \\
- \\
5.04 \\
- \\
5.02\end{array}$ & $\begin{array}{r}-613 \\
- \\
578 \\
-564\end{array}$ & $\begin{array}{l}4.97 \\
4.93 \\
5.38 \\
5.40 \\
5.40 \\
5.40\end{array}$ & $\begin{array}{l}532 \\
508 \\
816 \\
830 \\
830 \\
830\end{array}$ & $\begin{array}{c}- \\
5.31 \\
- \\
5.28 \\
- \\
5.26\end{array}$ & $\begin{array}{r}-767 \\
-746 \\
-746 \\
-732\end{array}$ & $\begin{array}{c}5.22 \\
- \\
5.19 \\
--17\end{array}$ & $\begin{array}{l}-704 \\
- \\
683 \\
-669\end{array}$ \\
\hline
\end{tabular}


Location.- Staff gage, 1at. $41^{\circ} 57^{1} 00^{\prime \prime}$, long. $74^{\circ} 12^{\prime} 30^{\prime \prime}$, at gatehouse and dividing weir, 10 miles west of Kingston, Ulster County. Gage readings are elevations above mean sea level (levels of New York City Board of Water Supply).

Drainage area.- 257 square miles.

Gage-helght record. - Gage read dally at 8 a.m. prior to Sept. 24 and at 9 a.m. thereafter. During period Sept. 20-26, additional readings made at 3 p.m. Sept. 20-24 and at 4 p.m. Sept. 25,26 .

Kemarks.- Reservolr is comprised of two basins. East Basin has available storage of $11,010,000,000$ cuble feet at crest of flashboards, elevation 589.00 feet (crest of spillway at elevation 587.00 feet). West Besin has avallable storage of $6,449,000,000$ cubic feet at crest of flashboards, elevation 592.00 feet (crest of waste weir at elevation 590.00 feet). The combined avallable storage capac1ty 1 s $17,459,000,000$ cuble feet. Total flow, except during perlods of spililing, is diverted through the Catskill Aqueduct for New York City water supply. Records collected by New York City Department of Water Supply, Gas, and Electriolty and furnished by that organization and New York City Board of Water Supply.

East Basin

Elevation in feet, and contents, in millions of cubic feet, 1938 a

\begin{tabular}{|c|c|c|c|c|c|c|c|c|c|}
\hline \multirow[b]{2}{*}{ Day } & \multicolumn{2}{|c|}{ September } & \multicolumn{2}{|c|}{ october } & \multirow[b]{2}{*}{ Day } & \multicolumn{2}{|c|}{ September } & \multicolumn{2}{|c|}{ October } \\
\hline & Feet & $\begin{array}{l}\text { Millions of } \\
\text { cubic feet }\end{array}$ & Feet & $\begin{array}{l}\text { Millions of } \\
\text { cubic feet }\end{array}$ & & Feet & $\begin{array}{l}\text { Millions of } \\
\text { cubic feet }\end{array}$ & Feet & $\begin{array}{l}\text { M1lilons of } \\
\text { cubic feet }\end{array}$ \\
\hline $\begin{array}{l}1 \\
2 \\
3 \\
4 \\
5\end{array}$ & $\begin{array}{l}586.07 \\
585.99 \\
585.89 \\
585.77 \\
585.64\end{array}$ & $\begin{array}{l}10,550 \\
10,540 \\
10,510 \\
10,490 \\
10,460\end{array}$ & $\begin{array}{l}587.69 \\
587.65 \\
587.60 \\
587.56 \\
587.53\end{array}$ & $\begin{array}{l}10,920 \\
10,910 \\
10,900 \\
10,890 \\
10,880\end{array}$ & $\begin{array}{l}16 \\
17 \\
18 \\
19 \\
20\end{array}$ & $\begin{array}{l}583.04 \\
582.82 \\
582.68 \\
582.55 \\
582.91\end{array}$ & $\begin{array}{l}9,891 \\
9,844 \\
9,814 \\
9,786 \\
9,863\end{array}$ & $\begin{array}{l}586.83 \\
586.70 \\
586.54 \\
586.40 \\
586.25\end{array}$ & $\begin{array}{l}10,720 \\
10,700 \\
10,660 \\
10,630 \\
10,590\end{array}$ \\
\hline $\begin{array}{r}6 \\
7 \\
8 \\
9 \\
10\end{array}$ & $\begin{array}{l}585.50 \\
585.33 \\
585.07 \\
584.77 \\
584.48\end{array}$ & $\begin{array}{l}10,430 \\
10,390 \\
10,330 \\
10,260 \\
10,200\end{array}$ & $\begin{array}{l}587.47 \\
587.43 \\
587.40 \\
587.33 \\
587.29\end{array}$ & $\begin{array}{l}10,870 \\
10,860 \\
10,850 \\
10,840 \\
10,830\end{array}$ & $\begin{array}{l}21 \\
22 \\
23 \\
24 \\
25\end{array}$ & $\begin{array}{l}583.54 \\
586.50 \\
588.10 \\
588.36 \\
588.25\end{array}$ & $\begin{array}{l}10,000 \\
10,650 \\
11,010 \\
11,070 \\
11,040\end{array}$ & $\begin{array}{l}586.18 \\
586.05 \\
585.91 \\
585.82 \\
585.79\end{array}$ & $\begin{array}{l}10,580 \\
10,550 \\
10,520 \\
10,500 \\
10,490\end{array}$ \\
\hline $\begin{array}{l}11 \\
12 \\
13 \\
14 \\
15\end{array}$ & $\begin{array}{l}584.20 \\
583.93 \\
583.69 \\
583.46 \\
583.27\end{array}$ & $\begin{array}{r}10,140 \\
10,080 \\
10,030 \\
9,982 \\
9,941\end{array}$ & $\begin{array}{l}587.23 \\
587.17 \\
587.09 \\
587.03 \\
586.94\end{array}$ & $\begin{array}{l}10,810 \\
10,800 \\
10,780 \\
10,770 \\
10,750\end{array}$ & $\begin{array}{l}26 \\
27 \\
28 \\
29 \\
30 \\
31\end{array}$ & $\begin{array}{l}588.14 \\
588.00 \\
587.93 \\
587.86 \\
587.75\end{array}$ & $\begin{array}{l}11,020 \\
10,990 \\
10,970 \\
10,960 \\
10,930\end{array}$ & $\begin{array}{l}585.68 \\
585.56 \\
585.46 \\
585.33 \\
585.18 \\
585.04\end{array}$ & $\begin{array}{l}10,470 \\
10,440 \\
10,420 \\
10,390 \\
10,360 \\
10,320\end{array}$ \\
\hline & & & & & & & & Septembe & October \\
\hline $\begin{array}{l}\text { Gain } \\
\text { Gain }\end{array}$ & $\begin{array}{l}\text { or loss } \\
\text { or los }\end{array}$ & $\begin{array}{l}\text { in storage } \\
\text { in storage }\end{array}$ & $\begin{array}{l}\text { in mi } \\
\text { in } \mathrm{eg}\end{array}$ & $\begin{array}{l}\text { lions of cu } \\
\text { ivalent mea }\end{array}$ & & $u-1000$ & 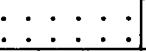 & $\begin{array}{r}+3 \\
+14 \\
\end{array}$ & $\begin{array}{r}-630 \\
-235 \\
\end{array}$ \\
\hline
\end{tabular}

Supplemental records.- Sept. 20, 3 p.m., 583.09 ft., 9,902 mil. cu. ft. Sept.

21, 3 p.m., 583.89 ft., $10,080 \mathrm{mil}$. cu. ft. Sept. 22, 3 p.m., 587.20 ft., $10,810 \mathrm{mil}$

cu. ft. Sépt. 23,3 p.m., $588.26 \mathrm{ft} ., 11,040 \mathrm{mil}$. cu. ft. Sépt. $24,3 \mathrm{p.m} ., 588.34$

ft., 11,060 mil. cu. ft. Sept. 25, 4 p.m., 588.21 ft., $11,030 \mathrm{mil}$. cu. ft. Sept. 26 , 4 p.m., 588.09 ft., $11,010 \mathrm{mil}$. cu. ft.

a) At 8 a.m. Sept. $1-24 ; 9$ a.m. Sept. 25 to Oct. 31.

West Basin

Elevation in feet, and contents, in millions of cubic feet, 1938 a/

\begin{tabular}{|c|c|c|c|c|c|c|c|c|c|c|}
\hline \multirow[b]{2}{*}{ Day } & \multicolumn{2}{|c|}{ September } & \multicolumn{2}{|c|}{ October } & \multirow[b]{2}{*}{ Day } & \multicolumn{2}{|c|}{ September } & \multicolumn{3}{|c|}{ October } \\
\hline & Feet & $\begin{array}{l}\text { Millions of } \\
\text { cubic feet }\end{array}$ & Feet & $\begin{array}{l}\text { Millions of } \\
\text { cubic feet }\end{array}$ & & Feet & $\begin{array}{l}\text { Millions of } \\
\text { cubic feet }\end{array}$ & Feet & $\mathrm{M1}$ & $\begin{array}{l}\text { llions of } \\
\text { ubic feet }\end{array}$ \\
\hline $\begin{array}{l}1 \\
2 \\
3 \\
4 \\
5\end{array}$ & $\begin{array}{l}589.34 \\
588.93 \\
588.51 \\
588.15 \\
587.81\end{array}$ & $\begin{array}{r}6,219 \\
6,165 \\
6,109 \\
6,061 \\
6,016\end{array}$ & $\begin{array}{l}591 \cdot 18 \\
591 \cdot 19 \\
591 \cdot 18 \\
591 \cdot 15 \\
591 \cdot 14\end{array}$ & \begin{tabular}{|l}
6,474 \\
6,476 \\
6,474 \\
6,470 \\
6,469
\end{tabular} & $\begin{array}{l}16^{\circ} \\
17 \\
18 \\
19 \\
20\end{array}$ & $\begin{array}{l}589.80 \\
590.20 \\
590.60 \\
591.04 \\
591.47\end{array}$ & \begin{tabular}{|}
6,281 \\
6,336 \\
6,392 \\
6,454 \\
6,515
\end{tabular} & $\begin{array}{l}590.30 \\
590.01 \\
589.75 \\
589.52 \\
589.27\end{array}$ & & $\begin{array}{r}6,350 \\
6,309 \\
6,274 \\
6,243 \\
6,210\end{array}$ \\
\hline $\begin{array}{r}6 \\
7 \\
8 \\
9 \\
10\end{array}$ & $\begin{array}{l}587.44 \\
587.11 \\
587.07 \\
586.98 \\
586.99\end{array}$ & $\begin{array}{l}5,966 \\
5,922 \\
5,917 \\
5,905 \\
5,906\end{array}$ & $\begin{array}{l}591 \cdot 15 \\
591 \cdot 14 \\
591 \cdot 12 \\
591 \cdot 11 \\
591 \cdot 09\end{array}$ & $\begin{array}{l}6,470 \\
6,469 \\
6,466 \\
6,464 \\
6,461\end{array}$ & $\begin{array}{l}21 \\
22 \\
23 \\
24 \\
25\end{array}$ & $\begin{array}{l}591.52 \\
592 \cdot 58 \\
591.75 \\
591.48 \\
591.30\end{array}$ & $\begin{array}{l}6,522 \\
6,675 \\
6,555 \\
6,517 \\
6,491\end{array}$ & $\begin{array}{l}589.55 \\
589.92 \\
590.24 \\
590.54 \\
590.76\end{array}$ & & $\begin{array}{l}6,247 \\
6,297 \\
6,341 \\
6,384 \\
6,415\end{array}$ \\
\hline $\begin{array}{l}11 \\
12 \\
13 \\
14 \\
15\end{array}$ & $\begin{array}{l}587.29 \\
587.80 \\
588.31 \\
588.79 \\
589.33\end{array}$ & $\begin{array}{l}5,946 \\
6,014 \\
6,082 \\
6,146 \\
6,218\end{array}$ & $\begin{array}{l}591.07 \\
591.07 \\
591.06 \\
590.89 \\
590.59\end{array}$ & $\begin{array}{l}6,459 \\
6,459 \\
6,457 \\
6,433 \\
6,391\end{array}$ & $\begin{array}{l}26 \\
27 \\
28 \\
29 \\
30 \\
31\end{array}$ & $\begin{array}{l}591 \cdot 19 \\
591 \cdot 12 \\
591 \cdot 12 \\
591 \cdot 13 \\
591 \cdot 13\end{array}$ & $\begin{array}{l}6,476 \\
6,466 \\
6,466 \\
6,467 \\
6,467\end{array}$ & $\begin{array}{l}590.50 \\
590.23 \\
589.96 \\
589.78 \\
589.56 \\
589.33\end{array}$ & & $\begin{array}{l}6,378 \\
6,340 \\
6,302 \\
6,278 \\
6,249 \\
6,218\end{array}$ \\
\hline & & & & & & & & Septembe & & October \\
\hline $\begin{array}{l}\text { Gain } \\
\text { Gain }\end{array}$ & $\begin{array}{l}\text { or loss } \\
\text { or loss }\end{array}$ & $\begin{array}{l}\text { In storage, } \\
\text { in storage, }\end{array}$ & , in $\mathrm{m} 1$ & $\begin{array}{l}\text { lions of cu } \\
\text { ivalent mea }\end{array}$ & $c \mathrm{fe}$ & & $\cdot \cdot \cdot \cdot \cdot$ & $\begin{array}{r}+25 \\
+98\end{array}$ & & $\begin{array}{l}-288 \\
-108\end{array}$ \\
\hline
\end{tabular}

Supplemental records.- Sept. 20,3 p.m., 591.48 ft., 6,517 m1l. cu. ft. Sept.

21,3 p.m., 591.75 ft., 6,555 mil. cu. ft. Sept. 22, 3 p.m., 592.21 ft., 6,623 mil.

cu. ft. Sept. 23,3 p.m., 591.65 ft., 6,541 mil. eu. It. Sept. 24,3 p.m., 591.44

ft., 6,51l mil. cu. ft. Sept. 25, 4 p.m., 591.28 ft., 6,488 m1l. cu. ft. Sept. 26 ,

4 p.m. 591.11 ft., $6,464 \mathrm{mil}$. cu. $\mathrm{ft}$.

at A a.m. Sept. 1-24; 9 a.m. Sept. 25 to oct. 31 . 
Esopus Creek at outlet of Ashokan Reservo1r, near Kingston, N. $\mathrm{Y}$.

Location.- Lat. $41^{\circ} 57^{\prime} 00^{n}$, long. $74^{\circ} 12^{\prime} 30^{\prime \prime}$, at gatehouse and spillway, 10 miles west of Kingston, Bister County.

Drainage area.- 257 square miles.

Gage-helght record. - Reservolr elevations observed twice dally and used in determination of rlow over spillways.

Remarks. - Discharge is the flow, measured by venturi meter, through Catskill Aqueduct for New York City water supply and flow over spiliway of East Basin. No flow over waste weir of West Basin during flood period. Mean monthly discharge adjusted for storage in Ashokan Reservolr and for diversion into basin through Shandaken Tunnel from Schoharie Reservo1r. For information on storage and diversion into basin see record for Ashoken Reservoir near Kingston, N. Y., and for Schoharle Reservolr at G11boa, N. Y. Records collected by New York City Department of Water Supply, Gas, and Blectricity and furnished by that organization and New York City Board of Water Supply.

Mean daily discharge, in second-feet, 1938

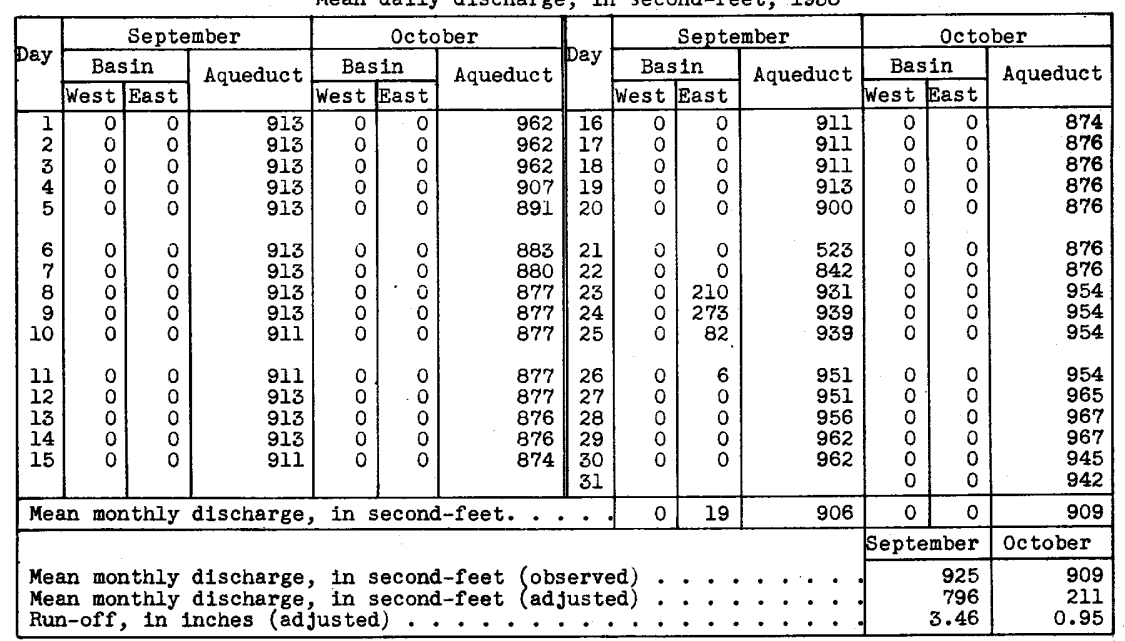


Rondout Creek near Lowes Corners, N. Y.

Location.- Chain gage, lat. $41^{\circ} 51^{\prime} 55^{\prime \prime}$, long. $74^{\circ} 29^{\prime} 10^{n}$, at highway bridge $1.1 \mathrm{miles}$ above Lowes Corners, Sullivan County, and about $23 / 4$ miles above mouth of Chestnut Creek. Subsequent to Oct. 3, water-stage recorder, lat. $41^{\circ} 51^{\prime} 50^{\prime \prime}, 10 n g .74^{\circ} 29^{\prime} 55^{\prime \prime}$, three-quarters of a mile downstream.

Drainage area.- 38.5 square miles; 39.4 square miles subsequent to $0 \mathrm{ct.} 3$.

Gage-helght record.- Graph based on twice daily chain-gage readings Sept. 1 to 0ct. 3 ; water-stage recorder graph oct. 4-3l at site downstream.

Stage-discharge relation.- Defined by current-meter measurements below 2,030 secondfeet; extended logarithmically to peak stage.

Maxima.- September 1938: Discharge, 3,060 second-feet about 6 p.m. Sept. 21 (gage

helght, 5.8 feet, from graph based on gage readings )

February 1937 to August 1938: Discharge, 7,600 second-feet about 8 a.m. July 22,1938 (gage height, 8.2 feet).

Remarks.- Flood mun-off not affected by artificial storage or diversion.

Mean daily discharge, in second-feet, 1938

\begin{tabular}{|c|c|c|c|c|c|c|c|c|c|c|c|}
\hline Day & Sept. & Oct. & Day & Sept. & Oct. & Day & Sept. & Oct. & Day & Sept. & Oct. \\
\hline $\begin{array}{l}1 \\
2 \\
3 \\
4 \\
5 \\
6 \\
7 \\
8\end{array}$ & $\begin{array}{l}43 \\
37 \\
33 \\
34 \\
28 \\
26 \\
40 \\
39\end{array}$ & $\begin{array}{l}76 \\
68 \\
66 \\
60 \\
55 \\
53 \\
51 \\
49\end{array}$ & $\begin{array}{r}9 \\
10 \\
11 \\
12 \\
13 \\
14 \\
15 \\
16\end{array}$ & $\begin{array}{l}29 \\
24 \\
21 \\
24 \\
34 \\
27 \\
76 \\
39\end{array}$ & $\begin{array}{l}47 \\
45 \\
42 \\
41 \\
39 \\
38 \\
37 \\
37\end{array}$ & $\begin{array}{l}17 \\
18 \\
19 \\
20 \\
21 \\
22 \\
23 \\
24\end{array}$ & $\begin{array}{r}28 \\
35 \\
98 \\
388 \\
1,210 \\
648 \\
410 \\
239\end{array}$ & $\begin{array}{l}36 \\
35 \\
34 \\
35 \\
54 \\
38 \\
34 \\
79\end{array}$ & $\begin{array}{l}25 \\
26 \\
27 \\
28 \\
29 \\
30 \\
31\end{array}$ & $\begin{array}{r}187 \\
156 \\
129 \\
116 \\
94 \\
85\end{array}$ & $\begin{array}{l}68 \\
45 \\
42 \\
39 \\
46 \\
44 \\
42\end{array}$ \\
\hline $\begin{array}{l}\text { Mean } \\
\text { Run- }\end{array}$ & $\begin{array}{l}\text { nthy } \\
, \ln 1\end{array}$ & $10 \mathrm{~s}$ & : In & . . & t. . & . : & $\cdot \dot{0} \cdot$ & $\dot{1} \cdot \dot{\bullet}$ & $\therefore$ & $\begin{array}{r}146 \\
4.23\end{array}$ & $\begin{array}{l}47.6 \\
1.40\end{array}$ \\
\hline
\end{tabular}


Rondout Creek near Lackawack, N. Y.

Location. - Water-stage recorder, lat. $41^{\circ} 46^{\prime} 25^{\prime \prime}$, long. $74^{\circ} 23^{\prime} 35^{\prime \prime}$, half a mile below highway bridge knom as Wilburs Bridge and $23 / 4$ miles southeast of Lackawack, Ulster County.

Drainage area.- 100 square miles.

Gage-he1ght record:- Water-stage recorder graph.

Stage-discharge relation. - Defined by current-meter measurements below 10,260 secondfeet; extended logarithmicaliy to peak stage and verified by slope-area determination of peak flow of July 1938 flood.

Maxima.- September 1938: Discharge, 5,930 second-feet 7:45 p.m. Sept. 21 (gage helght, 7.80 feet).

February 1906 to August 1938: Discharge, 26,700 second-feet Aug. 26, 1928

by slope-area determination (from records of New York City Board of Water Supply).

Remarks.- Flood run-off not affected by storage or diversion.

Mean daily discharge, in second-feet, 1938

\begin{tabular}{|c|r|r||r|r|r||r|r|r|r|r|r|}
\hline Day & Sept. & \multicolumn{1}{|c|}{ 0ct. } & Day & \multicolumn{1}{c|}{ Sept. } & 0ct. & Day & Sept. & Oct. & Day & Sept. & 0ct. \\
\hline 1 & 95 & 248 & 9 & 92 & 120 & 17 & 92 & 88 & 25 & 597 & 196 \\
2 & 96 & 210 & 10 & 78 & 117 & 18 & 81 & 84 & 26 & 512 & 138 \\
3 & 86 & 186 & 11 & 72 & 110 & 19 & 112 & 81 & 27 & 435 & 130 \\
4 & 78 & 168 & 12 & 69 & 107 & 20 & 965 & 81 & 28 & 399 & 126 \\
5 & 77 & 152 & 13 & 70 & 101 & 21 & 2,450 & 129 & 29 & 326 & 131 \\
6 & 72 & 143 & 14 & 78 & 96 & 22 & 1,860 & 130 & 30 & 282 & 130 \\
7 & 80 & 134 & 15 & 124 & 96 & 23 & 982 & 110 & 31 & & 126 \\
8 & 102 & 124 & 16 & 130 & 96 & 24 & 759 & 201 & & & \\
\hline
\end{tabular}

Gage helght, in feet, and discharge, in second-feet, at indicated time, 1938

\begin{tabular}{|c|c|c|c|c|c|c|c|c|c|c|c|c|}
\hline \multirow[t]{2}{*}{8} & Feet & Sec.ft. & Feet & Sec.ft. & Feot & Sec.ft. & Feet & Sec.ft. & Feet & Secift. & Feet & Sec.ft. \\
\hline & \multicolumn{2}{|c|}{ September 18} & \multicolumn{2}{|c|}{ September 19} & \multicolumn{2}{|c|}{ September 20} & \multicolumn{2}{|c|}{ September 21} & \multicolumn{2}{|c|}{ September 22} & \multicolumn{2}{|c|}{ September 23} \\
\hline & 1.32 & 81 & - & - & 2.07 & 365 & 3.46 & 1,260 & 5.53 & 3,140 & 3.22 & 1,080 \\
\hline & - & & 1.32 & 81 & & 965 & & & & & & \\
\hline & - & - & - & & & & & & & & & \\
\hline & - & - & 1.32 & 81 & & & & & & & & 1,00 \\
\hline & - & & - & - & & & & & & & & \\
\hline & 1.32 & 81 & 1.33 & 84 & & 70 & & 1,220 & & & & \\
\hline & - & - & - & - & & & & 1,160 & & & & \\
\hline & - & - & 1.34 & & & & & & & & & \\
\hline & - & - & - & - & & & & & & & & \\
\hline & - & - & 1.37 & 94 & & & & & & & & \\
\hline & - & & & & & & & & & & & \\
\hline & 1.32 & 81 & 1.39 & 98 & & 1,1 & & 1,1 & & & & 1,0 \\
\hline & - & - & - & - & & 1,120 & & 1,1 & 3.90 & & & 1,0 \\
\hline & - & - & 1.42 & 107 & & & & & & & & 7 \\
\hline & - & - & - & & 5 & 1,030 & & & 5 & & & \\
\hline & - & - & 1.45 & 116 & 6 & 965 & & & 3. & & & \\
\hline & - & & & & & & & & & & & \\
\hline & 1.32 & 81 & 1.50 & 130 & 2. & 864 & & & 3.56 & & & 9. \\
\hline & _- & - & - & - & 2.8 & 822 & & 5,7 & 3. & & & \\
\hline & - & - & 1.55 & 146 & 2. & 787 & & & & & & \\
\hline & - & - & & & 2. & 760 & & & & & & \\
\hline & - & - & 1.65 & 180 & 2 . & 767 & & & & & & \\
\hline & - & 1 & & & & 850 & & & & & & \\
\hline & 1.32 & 81 & 1.83 & 251 & & 1,070 & & 3,580 & & 1,120 & & \\
\hline & \multicolumn{2}{|c|}{ September 24} & \multicolumn{2}{|c|}{ September 25} & \multicolumn{2}{|c|}{ September 26} & \multicolumn{2}{|c|}{ September 27} & \multicolumn{2}{|c|}{ September 28} & \multicolumn{2}{|c|}{ September 29} \\
\hline & 2.89 & 843 & - & - & & - & & - & & - & & \\
\hline & & & 2.56 & 65 & 2.38 & 52 & & & 2. & & & \\
\hline & & & - & & & & & & & - & & \\
\hline & 2 & 801 & 2.52 & 611 & 2.36 & 523 & 2.20 & & 2.15 & & 2.00 & \\
\hline & & 780 & - & - & $03=1$ & - & - & - & & - & - & \\
\hline & & 760 & 2.48 & 589 & 2.35 & 51 & 2.18 & & 2.12 & & & \\
\hline & 2.75 & 748 & - & - & - & - & - & - & - & - & - & - \\
\hline & & 72 & 2.46 & & 2.33 & & 2.16 & & 2.10 & & 1.97 & \\
\hline & & 7. & 2 & - & - & - & - & & $0^{-}$ & - & - & 3 \\
\hline & $\begin{array}{l}2.64 \\
2.61\end{array}$ & $\begin{array}{l}6 \\
6\end{array}$ & 2.4 & & & & 2.1 & & $\begin{array}{l}2.07 \\
-\end{array}$ & & 1.9 & \\
\hline & 2.60 & 655 & 2.40 & 545 & 2.25 & 462 & 2.22 & 446 & 2.04 & 350 & 1.94 & 301 \\
\hline
\end{tabular}

Supplemental records.- Sept. $21,7: 45$ p.m., $7.80 \mathrm{ft} ., 5,930$ sec.-ft. 
Location. - Water-stage recorder, lat. $41^{\circ} 50^{\prime} 35^{\prime \prime}$, long. $74^{\circ} 05^{\prime} 10^{\prime \prime}$, 150 feet above highway bridge in Rosendale, Jlster County. Zero of gage is 42.81 feet above mean sea level (general adjustment of 1912 ).

Drainage area.- 386 square miles.

Gage-helght record. - Water-stage recorder graph.

Stage-discharge relation.- Defined by current-meter measurements below 14, 800 secondfeet; extended logarithmically to peak stage.

Maxima. - September 1938: Discharge, 18,100 second-feet 12:15 a.m. Sept. 22 (gage holght, 15.38 feet).

July 1901 to November 1903, January 1906 to January 1919, August 1926 to

August 1938: Discharge, 27,300 second-feet Aug. 27, 1928 (gage height, 21.9 feet). Remarks. - Flood run-off not affected by storage or diversion.

Mean daily discharge, in second-feet, 1938

\begin{tabular}{|c|c|c|c|c|c|c|c|c|c|c|c|}
\hline Day & Sept. & 0ct. & Day & Sept. & Oct. & Day & Sept. & Oct. & Day & Sept. & Oct. \\
\hline $\begin{array}{l}1 \\
2 \\
3 \\
4 \\
5 \\
6 \\
7 \\
8\end{array}$ & $\begin{array}{l}218 \\
234 \\
196 \\
178 \\
174 \\
172 \\
156 \\
238\end{array}$ & $\begin{array}{l}538 \\
460 \\
454 \\
448 \\
404 \\
384 \\
358 \\
333\end{array}$ & $\begin{array}{r}9 \\
10 \\
11 \\
12 \\
13 \\
14 \\
15 \\
16\end{array}$ & $\begin{array}{l}214 \\
168 \\
156 \\
154 \\
156 \\
180 \\
270 \\
380\end{array}$ & $\begin{array}{l}301 \\
308 \\
322 \\
299 \\
276 \\
267 \\
235 \\
235\end{array}$ & $\begin{array}{l}17 \\
18 \\
19 \\
20 \\
21 \\
22 \\
23 \\
24\end{array}$ & $\begin{array}{r}236 \\
204 \\
530 \\
4,950 \\
8,700 \\
11,200 \\
3,700 \\
2,260\end{array}$ & $\begin{array}{l}226 \\
235 \\
235 \\
250 \\
547 \\
437 \\
326 \\
507\end{array}$ & $\begin{array}{l}25 \\
26 \\
27 \\
28 \\
29 \\
30 \\
31\end{array}$ & $\begin{array}{r}1,460 \\
1,120 \\
920 \\
875 \\
718 \\
622\end{array}$ & $\begin{array}{r}1,190 \\
677 \\
560 \\
446 \\
524 \\
580 \\
482\end{array}$ \\
\hline $\begin{array}{l}\text { Mean } \\
\text { Run-c }\end{array}$ & $\begin{array}{l}\text { nthly } \\
e, \text { in } 1\end{array}$ & $\begin{array}{l}\text { scharg } \\
\text { hes. }\end{array}$ & $\begin{array}{l}\text { in } \\
.\end{array}$ & rong & et . & & $\begin{array}{l}\cdot \\
.\end{array}$ & . : : & & $\begin{array}{r}1,358 \\
3.52\end{array}$ & $\begin{array}{r}414 \\
1.23\end{array}$ \\
\hline
\end{tabular}

Gage helght, in feet, and discharge, in second-feet, at indicated time, 1938

\begin{tabular}{|c|c|c|c|c|c|c|c|c|c|c|c|c|}
\hline \multirow{2}{*}{$\begin{array}{l}\text { \& } \\
\text { ○ } \\
\text { 足 }\end{array}$} & Feet & Sec.ft. & Feet & Sec.ft. & Feet & Sec.ft. & Feet & Sec.ft. & Feet & Sec.ft. & Feet & Sec.ft. \\
\hline & \multicolumn{2}{|c|}{ September 18} & \multicolumn{2}{|c|}{ September 19} & \multicolumn{2}{|c|}{ September 20} & \multicolumn{2}{|c|}{ September 21} & \multicolumn{2}{|c|}{ September 22} & \multicolumn{2}{|c|}{ September 23} \\
\hline $\begin{array}{l}1 \\
2 \\
3 \\
4 \\
5 \\
6\end{array}$ & $\begin{array}{c}\overline{2 .} \\
- \\
2.41 \\
\overline{2.41} \\
2.41\end{array}$ & $\begin{array}{r}-244 \\
- \\
244 \\
-244\end{array}$ & $\begin{array}{c}- \\
2.41 \\
- \\
2.41 \\
\overline{2.41}\end{array}$ & $\begin{array}{r}-244 \\
- \\
244 \\
- \\
244\end{array}$ & $\begin{array}{l}5.17 \\
5.54 \\
6.05 \\
6.58 \\
7.07 \\
7.53\end{array}$ & $\begin{array}{l}2,300 \\
2,660 \\
3,170 \\
3,740 \\
4,290 \\
4,840\end{array}$ & $\begin{array}{l}7.18 \\
7.22 \\
7.26 \\
7.34 \\
7.48 \\
7.67\end{array}$ & $\begin{array}{l}4,430 \\
4,470 \\
4,520 \\
4,620 \\
4,790 \\
5,030\end{array}$ & $\begin{array}{l}15.34 \\
15.22 \\
15.07 \\
14.88 \\
14.62 \\
14.31\end{array}$ & $\begin{array}{l}18,000 \\
17,700 \\
17,400 \\
17,100 \\
16,500 \\
16,000\end{array}$ & $\begin{array}{l}7.43 \\
7.29 \\
7.16 \\
7.04 \\
6.93 \\
6.83\end{array}$ & $\begin{array}{l}4,730 \\
4,560 \\
4,400 \\
4,260 \\
4,130 \\
4,010\end{array}$ \\
\hline $\begin{array}{r}7 \\
8 \\
9 \\
10 \\
11 \\
N\end{array}$ & $\begin{array}{l}- \\
2.41 \\
2.35 \\
2.18 \\
2.13 \\
2.12\end{array}$ & $\begin{array}{l}- \\
244 \\
217 \\
153 \\
137 \\
134\end{array}$ & $\begin{array}{c}- \\
2.50 \\
2.72 \\
2.65 \\
- \\
2.63\end{array}$ & $\begin{array}{r}- \\
290 \\
413 \\
372 \\
- \\
361\end{array}$ & $\begin{array}{l}7.94 \\
8.36 \\
8.63 \\
8.73 \\
8.73 \\
8.66\end{array}$ & $\begin{array}{l}5,380 \\
5,960 \\
6,360 \\
6,500 \\
6,500 \\
6,400\end{array}$ & $\begin{array}{l}7.87 \\
8.02 \\
8.11 \\
8.17 \\
8.23 \\
8.35\end{array}$ & $\begin{array}{l}5,290 \\
5,490 \\
5,610 \\
5,700 \\
5,780 \\
5,950\end{array}$ & $\begin{array}{l}13.89 \\
13.40 \\
12.85 \\
12.25 \\
11.67 \\
11.03\end{array}$ & $\begin{array}{l}15,200 \\
14,300 \\
13,300 \\
12,300 \\
11,300 \\
10,200\end{array}$ & $\begin{array}{l}6.75 \\
6.68 \\
6.62 \\
6.57 \\
6.52 \\
6.48\end{array}$ & $\begin{array}{l}3,920 \\
3,850 \\
3,780 \\
3,730 \\
3,670 \\
3,630\end{array}$ \\
\hline $\begin{array}{l}1 \\
2 \\
3 \\
4 \\
5 \\
6\end{array}$ & $\begin{array}{l}- \\
2.12 \\
2.12 \\
2.19 \\
2.25 \\
2.30\end{array}$ & $\begin{array}{l}- \\
134 \\
134 \\
156 \\
177 \\
195\end{array}$ & $\begin{array}{l}- \\
2.64 \\
2.76 \\
2.92 \\
- \\
2.94\end{array}$ & $\begin{array}{r}- \\
367 \\
436 \\
532 \\
- \\
544\end{array}$ & $\begin{array}{l}8.58 \\
8.47 \\
8.34 \\
8.17 \\
7.97 \\
7.78\end{array}$ & $\begin{array}{l}6,280 \\
6,120 \\
5,940 \\
5,700 \\
5,420 \\
5,170\end{array}$ & $\begin{array}{r}8.52 \\
8.80 \\
9.58 \\
10.74 \\
11.68 \\
12.60\end{array}$ & $\begin{array}{r}6,190 \\
6,610 \\
7,840 \\
9,720 \\
11,300 \\
12,900\end{array}$ & $\begin{array}{r}10.66 \\
10.20 \\
9.81 \\
9.46 \\
9.15 \\
8.86\end{array}$ & $\begin{array}{l}9,580 \\
8,830 \\
8,210 \\
7,650 \\
7,750 \\
6,700\end{array}$ & $\begin{array}{l}6.44 \\
6.41 \\
6.38 \\
6.35 \\
6.30 \\
6.25\end{array}$ & $\begin{array}{l}3,580 \\
3,550 \\
3,520 \\
3,480 \\
3,430 \\
3,380\end{array}$ \\
\hline $\begin{array}{r}7 \\
8 \\
9 \\
10 \\
11 \\
M\end{array}$ & $\begin{array}{l}- \\
2.32 \\
2.40 \\
2.39 \\
2.39 \\
2.40\end{array}$ & $\begin{array}{l}- \\
204 \\
239 \\
235 \\
235 \\
239\end{array}$ & $\begin{array}{l}3.19 \\
3.39 \\
3.65 \\
3.90 \\
4.26 \\
4.67\end{array}$ & $\begin{array}{r}698 \\
833 \\
1,020 \\
1,200 \\
1,490 \\
1,840\end{array}$ & $\begin{array}{l}7.56 \\
7.37 \\
7.22 \\
7.12 \\
7.09 \\
7.13\end{array}$ & $\begin{array}{l}4,890 \\
4,650 \\
4,470 \\
4,350 \\
4,320 \\
4,370\end{array}$ & $\begin{array}{l}13.37 \\
14.12 \\
14.72 \\
15.12 \\
15.32 \\
15.37\end{array}$ & $\begin{array}{l}14,300 \\
15,600 \\
16,700 \\
17,500 \\
17,900 \\
18,000\end{array}$ & $\begin{array}{l}8.59 \\
8.36 \\
8.14 \\
7.94 \\
7.76 \\
7.58\end{array}$ & $\begin{array}{l}6,300 \\
5,960 \\
5,660 \\
5,380 \\
5,150 \\
4,910\end{array}$ & $\begin{array}{l}6.18 \\
6.11 \\
6.04 \\
5.98 \\
5.90 \\
5.81\end{array}$ & $\begin{array}{l}3,300 \\
3,230 \\
3,160 \\
3,100 \\
3,020 \\
2,930\end{array}$ \\
\hline & \multicolumn{2}{|c|}{ September 24} & \multicolumn{2}{|c|}{ September 25} & \multicolumn{2}{|c|}{ September 26} & \multicolumn{2}{|c|}{ September 27} & \multicolumn{2}{|c|}{ September 28} & \multicolumn{2}{|c|}{ September 29} \\
\hline $\begin{array}{r}2 \\
4 \\
6 \\
8 \\
10 \\
N\end{array}$ & $\begin{array}{l}5.65 \\
5.52 \\
5.41 \\
5.32 \\
5.25 \\
5.17\end{array}$ & $\begin{array}{l}2,770 \\
2,640 \\
2,530 \\
2,440 \\
2,380 \\
2,300\end{array}$ & $\begin{array}{l}4.45 \\
4.38 \\
4.33 \\
4.28 \\
4.23 \\
4.20\end{array}$ & $\begin{array}{l}1,650 \\
1,590 \\
1,550 \\
1,510 \\
1,470 \\
1,440\end{array}$ & $\begin{array}{l}4.01 \\
3.96 \\
3.89 \\
3.83 \\
3.79 \\
3.77\end{array}$ & $\begin{array}{l}1,290 \\
1,250 \\
1,190 \\
1,150 \\
1,120 \\
1,100\end{array}$ & $\begin{array}{l}3.60 \\
3.55 \\
3.51 \\
3.49 \\
3.49 \\
3.49\end{array}$ & $\begin{array}{l}980 \\
945 \\
917 \\
903 \\
903 \\
903\end{array}$ & $\begin{array}{c}- \\
3.51 \\
- \\
3.49 \\
\overline{3.46}\end{array}$ & $\begin{array}{c}-917 \\
- \\
903 \\
- \\
882\end{array}$ & $\begin{array}{c}- \\
3.29 \\
\overline{3.22} \\
\overline{3.19}\end{array}$ & $\begin{array}{r}-764 \\
-718 \\
-798\end{array}$ \\
\hline $\begin{array}{r}2 \\
4 \\
6 \\
8 \\
10 \\
M\end{array}$ & $\begin{array}{l}5.08 \\
4.92 \\
4.76 \\
4.66 \\
4.58 \\
4.52\end{array}$ & $\begin{array}{l}2,220 \\
2,070 \\
1,920 \\
1,830 \\
1,760 \\
1,710\end{array}$ & $\begin{array}{l}4.16 \\
4.12 \\
4.12 \\
4.12 \\
4.08 \\
4.05\end{array}$ & $\begin{array}{l}1,410 \\
1,380 \\
1,380 \\
1,380 \\
1,340 \\
1,320\end{array}$ & $\begin{array}{l}3.75 \\
3.73 \\
3.71 \\
3.68 \\
3.65 \\
3.63\end{array}$ & $\begin{array}{l}1,090 \\
1,070 \\
1,060 \\
1,040 \\
1,020 \\
1,000\end{array}$ & $\begin{array}{l}3.48 \\
3.48 \\
3.49 \\
3.50 \\
3.50 \\
3.51\end{array}$ & $\begin{array}{l}896 \\
896 \\
903 \\
910 \\
910 \\
917\end{array}$ & $\begin{array}{c}- \\
3.41 \\
- \\
3.40 \\
- \\
3.35\end{array}$ & $\begin{array}{c}- \\
-847 \\
-840 \\
-805\end{array}$ & $\begin{array}{c}- \\
3.17 \\
- \\
3.20 \\
- \\
3.14\end{array}$ & $\begin{array}{r}-686 \\
- \\
-705 \\
-666\end{array}$ \\
\hline
\end{tabular}


Chestnut Creek above Red Brook, at Grahamsville, N. Y.

Location.- Staff gage, lat. $41^{\circ} 50^{\prime} 45^{\prime \prime}$, long. $74^{\circ} 32^{\prime} 50^{n}$, about 300 feet above steel highway bridge at Grahams ville, Sullivan County, and a quarter of a mile above mouth of Red Brook.

Drainage area.- 12.2 square miles.

Gage-helght record.- Oraph based on twice dally ataff gage readings.

Stege-discharge relation.- Defined by current-meter measurements below 523 second-feet;

extended logarithmicaliy to peak stage on basis of determination of flood flow through bridge opening on July $22,1938$.

Maxima. - September 1938: Discharge, 965 second-feet about 5 p.m. Sept. 21 (gage he1ght, 3.8 feet, from graph based on gage readings).

May 1937 to August 1938: Discharge, 2,600 second-feet about 8 a.m. July 22,

1938 (gage height, 5.8 feet, observed at time of flood).

Remarks.- Flood mun-off not affected by artificlal storage or diversion.

Mean daily discharge, in second-feet, 1938

\begin{tabular}{|c|c|c|c|c|c|c|c|c|c|c|c|}
\hline Day & Sept. & Oct. & Day & Sept. & Oct. & Day & Sept. & oct. & Day & Sept. & Oct. \\
\hline $\begin{array}{l}1 \\
2 \\
3 \\
4 \\
5 \\
6 \\
7 \\
8 \\
\end{array}$ & $\begin{array}{l}16 \\
14 \\
14 \\
16 \\
13 \\
13 \\
18 \\
15\end{array}$ & $\begin{array}{l}14 \\
14 \\
13 \\
12 \\
12 \\
12 \\
12 \\
10\end{array}$ & $\begin{array}{r}9 \\
10 \\
11 \\
12 \\
13 \\
14 \\
15 \\
16\end{array}$ & $\begin{array}{l}14 \\
13 \\
13 \\
13 \\
17 \\
16 \\
25 \\
14\end{array}$ & $\begin{array}{l}10 \\
10 \\
10 \\
10 \\
9.5 \\
9.5 \\
9.5 \\
9.5\end{array}$ & $\begin{array}{l}17 \\
18 \\
19 \\
20 \\
21 \\
22 \\
23 \\
24\end{array}$ & $\begin{array}{r}12 \\
13 \\
26 \\
109 \\
320 \\
113 \\
68 \\
35\end{array}$ & $\begin{array}{c}9.5 \\
9.5 \\
9.5 \\
10 \\
10 \\
9.5 \\
10 \\
22\end{array}$ & $\begin{array}{l}25 \\
26 \\
27 \\
28 \\
29 \\
30 \\
31\end{array}$ & $\begin{array}{l}27 \\
21 \\
24 \\
20 \\
17 \\
15\end{array}$ & $\begin{array}{l}20 \\
17 \\
15 \\
14 \\
14 \\
14 \\
14\end{array}$ \\
\hline $\begin{array}{l}\text { Mean } \\
\text { Run- }\end{array}$ & , in & $\begin{array}{l}\text { chare } \\
\text { is. }\end{array}$ & 1) & $\begin{array}{l}\text { econd-f } \\
.\end{array}$ & et. . & & $\cdot \dot{*} \cdot \dot{ }$ & $\cdot \dot{0} \cdot \dot{ }$ & : & $\begin{array}{l}35.5 \\
3.25\end{array}$ & $\begin{array}{l}12.1 \\
1.14\end{array}$ \\
\hline
\end{tabular}


Location. - Wire-weight gage, lat. $41^{\circ} 15^{\prime} 35^{\prime \prime}$, long. $74^{\circ} 32^{\prime} 55^{\prime \prime}$, at the highway bridge on the Quarryilie-Milton road about 2 miles south of the New York-New Jersey State line and $3 \mathrm{miles}$ south of Unionville, Orange County.

Drainage area.- 144 square miles.

Gage-height record.- Graph based on twice dally wire welght gage readings.

Stage-discharge relation. - Defined by current-meter measurements.

Maxima.- September 1938: Discharge, 3,120 second-feet 10 to 12 p.m. Sept. 22 (gage height, 11.20 feet, from readings during discharge measurement).

September 1937 to August 1938: Discharge, 1,680 second-feet Jan. 26, 1938

(gage helght, 10.06 feet, from readings during discharge measurement).

Remarks. - No regulation or diversion. Natural storage in small lakes and swampy areas.

Mean daily discharge, in second-feet, 1938

\begin{tabular}{|c|c|c|c|c|c|c|c|c|c|c|c|}
\hline Day & Sept. & Oct. & Day & Sept. & oct. & Day & Sept. & Oct. & Day & Sept. & Oct. \\
\hline $\begin{array}{l}1 \\
2 \\
3 \\
4 \\
5 \\
6 \\
7 \\
8\end{array}$ & $\begin{array}{l}52 \\
61 \\
46 \\
41 \\
52 \\
40 \\
37 \\
35 \\
\end{array}$ & $\begin{array}{l}517 \\
393 \\
283 \\
214 \\
175 \\
162 \\
175 \\
188\end{array}$ & $\begin{array}{r}9 \\
10 \\
11 \\
12 \\
13 \\
14 \\
15 \\
16\end{array}$ & $\begin{array}{r}34 \\
33 \\
32 \\
31 \\
33 \\
42 \\
69 \\
104 \\
\end{array}$ & $\begin{array}{l}175 \\
149 \\
137 \\
125 \\
114 \\
109 \\
104 \\
104\end{array}$ & $\begin{array}{l}17 \\
18 \\
19 \\
20 \\
21 \\
22 \\
23 \\
24\end{array}$ & $\begin{array}{r}84 \\
74 \\
94 \\
467 \\
951 \\
2,500 \\
2,970 \\
2,400 \\
\end{array}$ & $\begin{array}{l}104 \\
100 \\
100 \\
100 \\
199 \\
268 \\
240 \\
227\end{array}$ & $\begin{array}{l}25 \\
26 \\
27 \\
28 \\
29 \\
30 \\
31\end{array}$ & $\begin{array}{r}1,850 \\
1,430 \\
1,140 \\
926 \\
752 \\
640\end{array}$ & $\begin{array}{l}348 \\
353 \\
283 \\
240 \\
214 \\
188 \\
168\end{array}$ \\
\hline $\begin{array}{l}\text { Mean } \\
\text { Run- }\end{array}$ & $\begin{array}{l}\text { onthly } \\
\text {, in }\end{array}$ & $\begin{array}{l}\text { scharg } \\
\text { hes. }\end{array}$ & $\because$ & $\begin{array}{l}\text { econd-1 } \\
.\end{array}$ & et. & $\dot{.} \cdot \dot{ }$ & 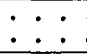 & $\begin{array}{ccc}\cdot & \cdot & \\
. & \cdot & \\
\end{array}$ & . $\dot{ }$ & $\begin{array}{r}567 \\
4.40 \\
\end{array}$ & $\begin{array}{r}202 \\
1.61 \\
\end{array}$ \\
\hline
\end{tabular}

Gage helght, in feet, and discharge, in second-feet, at indicated time, 1938

\begin{tabular}{|c|c|c|c|c|c|c|c|c|c|c|c|c|}
\hline \multirow{2}{*}{$\begin{array}{l}4 \\
3 \\
0 \\
\text { : }\end{array}$} & Feet & Sec.ft. & Feet & Sec.ft. & Feet & Sec.ft. & Feet & Sec.ft. & Feet & Sec.ft. & Feet & Sec.ft. \\
\hline & \multicolumn{2}{|c|}{ September 18} & \multicolumn{2}{|c|}{ September 19} & \multicolumn{2}{|c|}{ September 20} & \multicolumn{2}{|c|}{ September 21} & \multicolumn{2}{|c|}{ September 22} & \multicolumn{2}{|c|}{ Sept ember 23} \\
\hline $\begin{array}{l}1 \\
2 \\
3 \\
4 \\
5 \\
6\end{array}$ & $\begin{array}{c}- \\
- \\
- \\
- \\
- \\
5.15\end{array}$ & $\begin{array}{l}- \\
- \\
- \\
- \\
-74\end{array}$ & $\begin{array}{l}- \\
- \\
- \\
- \\
- \\
5.17\end{array}$ & $\begin{array}{l}- \\
- \\
- \\
- \\
-\end{array}$ & $\begin{array}{l}6.60 \\
6.94 \\
7.15 \\
7.28 \\
7.39 \\
7.48\end{array}$ & $\begin{array}{l}254 \\
306 \\
344 \\
369 \\
391 \\
411\end{array}$ & $\begin{array}{l}8.33 \\
8.39 \\
8.43 \\
8.49 \\
8.53 \\
8.59\end{array}$ & $\begin{array}{l}650 \\
672 \\
686 \\
706 \\
722 \\
746\end{array}$ & $\begin{array}{r}9.98 \\
10.06 \\
10.13 \\
10.21 \\
10.30 \\
10.39\end{array}$ & $\begin{array}{l}1,600 \\
1,670 \\
1,740 \\
1,820 \\
1,910 \\
2,010\end{array}$ & $\begin{array}{l}11.19 \\
11.19 \\
11.18 \\
11.17 \\
11.16 \\
11.15\end{array}$ & $\begin{array}{l}3,100 \\
3,100 \\
3,090 \\
3,070 \\
3,050 \\
3,040\end{array}$ \\
\hline $\begin{array}{r}7 \\
8 \\
9 \\
10 \\
11\end{array}$ & $\begin{array}{l}- \\
- \\
- \\
- \\
-\end{array}$ & $\begin{array}{l}- \\
\overline{-} \\
\overline{-} \\
\overline{-}\end{array}$ & $\begin{array}{l}- \\
- \\
- \\
- \\
- \\
5.26\end{array}$ & $\begin{array}{l}- \\
- \\
- \\
- \\
- \\
\end{array}$ & $\begin{array}{l}7.53 \\
7.58 \\
7.62 \\
7.66 \\
7.69 \\
7.73\end{array}$ & $\begin{array}{l}422 \\
434 \\
444 \\
453 \\
461 \\
471\end{array}$ & $\begin{array}{l}8.63 \\
8.70 \\
8.75 \\
8.80 \\
8.85 \\
8.90\end{array}$ & $\begin{array}{l}762 \\
790 \\
812 \\
835 \\
858 \\
880\end{array}$ & $\begin{array}{l}10.46 \\
10.54 \\
10.62 \\
10.70 \\
10.78 \\
10.85\end{array}$ & $\begin{array}{l}2,090 \\
2,180 \\
2,270 \\
2,370 \\
2,470 \\
2,570\end{array}$ & $\begin{array}{l}11.15 \\
11.14 \\
11.13 \\
11.12 \\
11.11 \\
11.11\end{array}$ & $\begin{array}{l}3,040 \\
3,020 \\
3,000 \\
2,980 \\
2,970 \\
2,970\end{array}$ \\
\hline $\begin{array}{l}1 \\
2 \\
3 \\
4 \\
5 \\
6\end{array}$ & $\begin{array}{l}- \\
\overline{-} \\
- \\
-\end{array}$ & $\begin{array}{l}- \\
- \\
- \\
- \\
-\end{array}$ & $\begin{array}{c}- \\
- \\
- \\
- \\
- \\
5.39\end{array}$ & $\begin{array}{l}- \\
- \\
- \\
- \\
- \\
\end{array} 98$ & $\begin{array}{l}7.78 \\
7.82 \\
7.86 \\
7.90 \\
7.95 \\
8.00\end{array}$ & $\begin{array}{l}484 \\
495 \\
506 \\
517 \\
531 \\
545\end{array}$ & $\begin{array}{l}8.96 \\
9.02 \\
9.10 \\
9.18 \\
9.27 \\
9.35\end{array}$ & $\begin{array}{r}910 \\
940 \\
980 \\
1,030 \\
1,080 \\
1,130\end{array}$ & $\begin{array}{l}10.92 \\
11.00 \\
11.05 \\
11.10 \\
11.14 \\
11.17\end{array}$ & $\begin{array}{l}2,670 \\
2,790 \\
2,870 \\
2,950 \\
3,020 \\
3,070\end{array}$ & $\begin{array}{l}11.11 \\
11.10 \\
11.10 \\
11.09 \\
11.09 \\
11.08\end{array}$ & $\begin{array}{l}2,970 \\
2,950 \\
2,950 \\
2,930 \\
2,930 \\
2,920\end{array}$ \\
\hline \multirow[t]{2}{*}{$\begin{array}{r}7 \\
8 \\
9 \\
10 \\
11 \\
M \\
\end{array}$} & $\begin{array}{c}5.11 \\
- \\
- \\
- \\
- \\
-\end{array}$ & $\begin{array}{l} \\
- \\
- \\
- \\
- \\
-\end{array}$ & $\begin{array}{c}- \\
5.50 \\
- \\
5.72 \\
- \\
6.23\end{array}$ & $\begin{array}{c}- \\
- \\
-109 \\
-136 \\
201\end{array}$ & $\begin{array}{l}8.06 \\
8.10 \\
8.16 \\
8.20 \\
8.25 \\
8.29\end{array}$ & $\begin{array}{l}563 \\
575 \\
593 \\
605 \\
622 \\
636\end{array}$ & $\begin{array}{l}9.45 \\
9.52 \\
9.61 \\
9.70 \\
9.77 \\
9.86\end{array}$ & $\begin{array}{l}1,200 \\
1,240 \\
1,310 \\
1,370 \\
1,430 \\
1,500\end{array}$ & $\begin{array}{l}11.17 \\
11.18 \\
11.19 \\
11.20 \\
11.20 \\
11.20\end{array}$ & $\begin{array}{l}3,070 \\
3,090 \\
3,100 \\
3,120 \\
3,120 \\
3,120\end{array}$ & $\begin{array}{l}11.06 \\
11.04 \\
11.03 \\
11.02 \\
11.00 \\
10.98\end{array}$ & $\begin{array}{l}2,890 \\
2,850 \\
2,840 \\
2,820 \\
2,790 \\
2,760\end{array}$ \\
\hline & \multicolumn{2}{|c|}{ September 24} & \multicolumn{2}{|c|}{ September 25} & \multicolumn{2}{|c|}{ September 26} & \multicolumn{2}{|c|}{ September 27} & \multicolumn{2}{|c|}{ September 28} & \multicolumn{2}{|c|}{ September 29} \\
\hline $\begin{array}{r}2 \\
4 \\
6 \\
8 \\
10 \\
N\end{array}$ & $\begin{array}{l}10.93 \\
10.88 \\
10.83 \\
10.79 \\
10.76 \\
10.72\end{array}$ & $\begin{array}{l}2,680 \\
2,610 \\
2,540 \\
2,490 \\
2,450 \\
2,400\end{array}$ & $\begin{array}{l}10.43 \\
10.39 \\
10.34 \\
10.30 \\
10.27 \\
10.23\end{array}$ & $\begin{array}{l}2,050 \\
2,010 \\
1,950 \\
1,910 \\
1,880 \\
1,840\end{array}$ & $\begin{array}{l}9.96 \\
9.91 \\
9.86 \\
9.82 \\
9.79 \\
9.77\end{array}$ & $\begin{array}{l}1,580 \\
1,540 \\
1,500 \\
1,470 \\
1,440 \\
1,430\end{array}$ & $\begin{array}{c}-\overline{9.49} \\
- \\
9.42 \\
- \\
9.37\end{array}$ & $\begin{array}{c}- \\
1,220 \\
- \\
1,170 \\
- \\
1,140\end{array}$ & $\begin{array}{c}- \\
9.10 \\
{ }^{\top} \\
- \\
8.02 \\
8.99\end{array}$ & $\begin{array}{c}-980 \\
- \\
940 \\
-925\end{array}$ & $\begin{array}{c}- \\
8.70 \\
- \\
8.60 \\
- \\
8.56\end{array}$ & $\begin{array}{r}-790 \\
-750 \\
-734\end{array}$ \\
\hline $\begin{array}{r}2 \\
4 \\
6 \\
8 \\
10 \\
M\end{array}$ & $\begin{array}{l}10.67 \\
10.64 \\
10.61 \\
10.57 \\
10.51 \\
10.48\end{array}$ & $\begin{array}{l}2,330 \\
2,300 \\
2,260 \\
2,210 \\
2,140 \\
2,110\end{array}$ & $\begin{array}{l}10.20 \\
10.17 \\
10.13 \\
10.10 \\
10.06 \\
10.00\end{array}$ & $\begin{array}{l}1,810 \\
1,780 \\
1,740 \\
1,710 \\
1,670 \\
1,620\end{array}$ & $\begin{array}{l}9.74 \\
9.71 \\
9.67 \\
9.64 \\
9.60 \\
9.58\end{array}$ & $\begin{array}{l}1,400 \\
1,380 \\
1,350 \\
1,330 \\
1,300 \\
1,290\end{array}$ & $\begin{array}{c}- \\
9.30 \\
- \\
9.25 \\
- \\
9.18\end{array}$ & $\begin{array}{c}- \\
1,100 \\
\overline{1,070} \\
\overline{1,030}\end{array}$ & $\begin{array}{c}- \\
8.94 \\
- \\
8.90 \\
- \\
8.80\end{array}$ & $\begin{array}{r}- \\
-900 \\
-880 \\
-835\end{array}$ & $\begin{array}{c}- \\
8.56 \\
- \\
8.56 \\
- \\
8.50\end{array}$ & $\begin{array}{r}-734 \\
-734 \\
-734 \\
710\end{array}$ \\
\hline
\end{tabular}




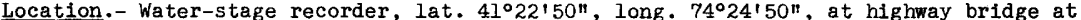
Pellets Island Mountain, Orange County, $4 \frac{1}{2}$ miles south of Middletown. Zero of gage is 357.41 feet above mean sea level (general adjustment of 1912).

Drainage area.- 385 square miles.

Gage-height record.- Water-stage recorder graph.

Stage-discharge relation.- For 1938 defined by current-meter measurements below 4,300 second-feet; extended logarithmically to peak stage on basis of discharge record and two discharge measurements at Phillipsburg, N. Y. For 1936 defined by current-meter measurements below 8,970 second-feet; extended logarithmically to peak stage on basis of comparison with discharge record at Phillipsburg, $N$. $Y$.

Maxima.- September 1938: Discharge, 6,210 second-feet 7:45 a.m. Sept. 23 (gage height, 15.58 feet)

December 1919 to August 1938: Discharge, 12,400 second-feet Mar. 14, 1936

(gage height, 20.0 feet, present site and datum).

Maximum gage height, Mar. 16, 1920, 25.7 feet, chain gage at present site and datum.

Remarks.- No known diversions but natural storage in large swampy areas and small lakes above Pellets Island Mountain.

Mean dafly discharge, in second-feet, 1938

\begin{tabular}{|c|c|c|c|c|c|c|c|c|c|c|c|}
\hline Day & Sept. & oct. & Day & Sept. & oct. & Day & Sept. & oct. & Day & Sept. & Oet. \\
\hline $\begin{array}{l}1 \\
2 \\
3 \\
4 \\
5 \\
6 \\
7 \\
8\end{array}$ & $\begin{array}{r}124 \\
143 \\
131 \\
117 \\
114 \\
108 \\
95 \\
94\end{array}$ & $\begin{array}{l}932 \\
788 \\
641 \\
529 \\
454 \\
413 \\
427 \\
427\end{array}$ & $\begin{array}{r}9 \\
10 \\
11 \\
12 \\
13 \\
14 \\
15 \\
16\end{array}$ & $\begin{array}{r}89 \\
83 \\
77 \\
76 \\
82 \\
90 \\
127 \\
215\end{array}$ & $\begin{array}{l}393 \\
368 \\
342 \\
303 \\
311 \\
326 \\
324 \\
313\end{array}$ & $\begin{array}{l}17 \\
18 \\
19 \\
20 \\
21 \\
22 \\
23 \\
24\end{array}$ & $\begin{array}{r}202 \\
166 \\
233 \\
2,090 \\
3,840 \\
5,930 \\
6,110 \\
5,340\end{array}$ & $\begin{array}{l}303 \\
292 \\
287 \\
287 \\
563 \\
641 \\
578 \\
582\end{array}$ & $\begin{array}{l}25 \\
26 \\
27 \\
28 \\
29 \\
30 \\
31\end{array}$ & $\begin{array}{l}3,960 \\
2,870 \\
2,200 \\
1,760 \\
1,370 \\
1,100\end{array}$ & $\begin{array}{l}890 \\
755 \\
635 \\
582 \\
543 \\
497 \\
436\end{array}$ \\
\hline $\begin{array}{l}\text { Mean } \\
\text { Run- }\end{array}$ & in & & 1 & . • & & & $\cdot \cdot \cdot \dot{ }$ & . : & . $\cdot$ & $\begin{array}{r}1,298 \\
3.76\end{array}$ & $\begin{array}{r}489 \\
1.46 \\
\end{array}$ \\
\hline
\end{tabular}

Gage height, in feet, and discharge, in second-feet, at indicated time, 1938

\begin{tabular}{|c|c|c|c|c|c|c|c|c|c|c|c|c|}
\hline \multirow{2}{*}{$\begin{array}{l}8 \\
7 \\
0 \\
\end{array}$} & Feet & Sec.ft. & Feet & Sec.ft. & Feet & Sec.ft. & Feet & Sec.ft. & Feet & Sec.ft. & Feet & Sec.ft. \\
\hline & \multicolumn{2}{|c|}{ Sept ember 18} & \multicolumn{2}{|c|}{ September 19} & \multicolumn{2}{|c|}{ September 20} & \multicolumn{2}{|c|}{ September 21} & \multicolumn{2}{|c|}{ September 22} & \multicolumn{2}{|c|}{ September 23} \\
\hline $\begin{array}{l}1 \\
2 \\
3 \\
4 \\
5 \\
6\end{array}$ & $\begin{array}{c}- \\
3.56 \\
- \\
3.54 \\
- \\
3.52\end{array}$ & $\begin{array}{r}-176 \\
- \\
174 \\
-171\end{array}$ & $\begin{array}{l}3.45 \\
3.45 \\
3.45 \\
3.45 \\
3.45 \\
3.45\end{array}$ & $\begin{array}{l}161 \\
161 \\
161 \\
161 \\
161 \\
161\end{array}$ & $\begin{array}{l}5.95 \\
6.42 \\
6.88 \\
7.42 \\
7.95 \\
8.48\end{array}$ & $\begin{array}{r}688 \\
826 \\
982 \\
1,198 \\
1,410 \\
1,670\end{array}$ & $\begin{array}{l}10.68 \\
10.74 \\
10.77 \\
10.81 \\
10.85 \\
10.90\end{array}$ & $\begin{array}{l}2,840 \\
2,870 \\
2,890 \\
2,920 \\
2,940 \\
2,970\end{array}$ & \begin{tabular}{|l|}
14.47 \\
14.53 \\
14.61 \\
14.73 \\
14.79 \\
14.89
\end{tabular} & $\begin{array}{l}5,380 \\
5,420 \\
5,480 \\
5,560 \\
5,600 \\
5,670\end{array}$ & $\begin{array}{l}15.57 \\
15.57 \\
15.57 \\
15.57 \\
15.56 \\
15.56\end{array}$ & $\begin{array}{l}6,210 \\
6,210 \\
6,210 \\
6,210 \\
6,200 \\
6,200\end{array}$ \\
\hline $\begin{array}{r}7 \\
8 \\
9 \\
10 \\
11 \\
\mathrm{~N}\end{array}$ & $\begin{array}{c}- \\
3.50 \\
- \\
3.48 \\
- \\
3.47\end{array}$ & $\begin{array}{r}- \\
-168 \\
-165 \\
- \\
164\end{array}$ & $\begin{array}{l}3.45 \\
3.46 \\
3.47 \\
3.48 \\
3.50 \\
3.57\end{array}$ & $\begin{array}{l}161 \\
162 \\
164 \\
165 \\
168 \\
178\end{array}$ & $\begin{array}{r}8.90 \\
9.22 \\
9.45 \\
9.69 \\
9.93 \\
10.03\end{array}$ & $\begin{array}{l}1,880 \\
2,040 \\
2,160 \\
2,280 \\
2,400 \\
2,450\end{array}$ & $\begin{array}{l}10.94 \\
10.97 \\
11.01 \\
11.10 \\
11.23 \\
11.38\end{array}$ & $\begin{array}{l}2,990 \\
3,010 \\
3,040 \\
3,090 \\
3,170 \\
3,260\end{array}$ & $\begin{array}{l}14.93 \\
15.11 \\
15.19 \\
15.27 \\
15.34 \\
15.39\end{array}$ & $\begin{array}{l}5,700 \\
5,840 \\
5,900 \\
5,970 \\
6,020 \\
6,060\end{array}$ & $\begin{array}{l}15.56 \\
15.55 \\
15.54 \\
15.52 \\
15.51 \\
15.50\end{array}$ & $\begin{array}{l}6,200 \\
6,190 \\
6,180 \\
6,170 \\
6,160 \\
6,150\end{array}$ \\
\hline $\begin{array}{l}1 \\
2 \\
3 \\
4 \\
5 \\
6\end{array}$ & $\begin{array}{c}- \\
3.47 \\
- \\
3.46 \\
- \\
3.45\end{array}$ & $\begin{array}{r}- \\
-164 \\
-162 \\
- \\
161\end{array}$ & $\begin{array}{l}3.65 \\
3.72 \\
3.79 \\
3.87 \\
3.96 \\
4.08\end{array}$ & $\begin{array}{l}190 \\
200 \\
210 \\
223 \\
238 \\
259\end{array}$ & $\begin{array}{l}10.08 \\
10.12 \\
10.17 \\
10.20 \\
10.24 \\
10.26\end{array}$ & $\begin{array}{l}2,480 \\
2,500 \\
2,530 \\
2,550 \\
2,570 \\
2,590\end{array}$ & $\begin{array}{l}11.64 \\
12.10 \\
12.80 \\
13.40 \\
13.78 \\
14.01\end{array}$ & $\begin{array}{l}410 \\
720 \\
210 \\
630 \\
900 \\
060\end{array}$ & $\begin{array}{l}.43 \\
.48 \\
52 \\
53 \\
.54 \\
.54\end{array}$ & $\begin{array}{l}090 \\
130 \\
170 \\
170 \\
180 \\
180\end{array}$ & $\begin{array}{l}.49 \\
.47 \\
.44 \\
.41 \\
.38 \\
.35\end{array}$ & $\begin{array}{l}6,140 \\
6,130 \\
6,100 \\
6,080 \\
6,050 \\
6,030\end{array}$ \\
\hline \multirow[t]{2}{*}{$\begin{array}{r}7 \\
8 \\
9 \\
10 \\
11 \\
1 \\
\end{array}$} & $\begin{array}{c}\overline{3.45} \\
- \\
3.45 \\
- \\
3.45\end{array}$ & $\begin{array}{r}- \\
- \\
-161 \\
-\quad 161 \\
161\end{array}$ & $\begin{array}{l}4.22 \\
4.43 \\
4.64 \\
4.93 \\
5.22 \\
5.58\end{array}$ & $\begin{array}{l}285 \\
326 \\
369 \\
434 \\
505 \\
595\end{array}$ & $\begin{array}{l}10.29 \\
10.33 \\
10.37 \\
10.42 \\
10.50 \\
10.59\end{array}$ & $\begin{array}{l}2,600 \\
2,630 \\
2,650 \\
2,680 \\
2,730 \\
2,780\end{array}$ & $\begin{array}{l}14.17 \\
14.24 \\
14.27 \\
14.30 \\
14.34 \\
14.40\end{array}$ & $\begin{array}{l}5,170 \\
5,220 \\
5,240 \\
5,260 \\
5,290 \\
5,330\end{array}$ & & $\begin{array}{l}6,190 \\
6,190 \\
6,190 \\
6,200 \\
6,200 \\
6,200\end{array}$ & $\begin{array}{l}15.31 \\
15.28 \\
15.24 \\
15.20 \\
15.16 \\
15.12\end{array}$ & $\begin{array}{l}6,000 \\
5,970 \\
5,940 \\
5,910 \\
5,880 \\
5,850\end{array}$ \\
\hline & \multicolumn{2}{|c|}{ September 24} & \multicolumn{2}{|c|}{ September 25} & \multicolumn{2}{|c|}{ September 26} & \multicolumn{2}{|c|}{ September 27} & \multicolumn{2}{|c|}{ September 28} & \multicolumn{2}{|c|}{ September 29} \\
\hline $\begin{array}{r}2 \\
4 \\
6 \\
8 \\
10 \\
N\end{array}$ & $\begin{array}{l}15.00 \\
14.91 \\
14.80 \\
14.69 \\
14.58 \\
14.47\end{array}$ & $\begin{array}{l}5,750 \\
5,690 \\
5,610 \\
5,530 \\
5,460 \\
5,380\end{array}$ & $\begin{array}{l}13.29 \\
13.09 \\
12.92 \\
12.78 \\
12.60 \\
12.43\end{array}$ & $\begin{array}{l}4,550 \\
4,410 \\
4,290 \\
4,200 \\
4,070 \\
3,950\end{array}$ & $\begin{array}{l}11.34 \\
11.21 \\
11.08 \\
1.0 .96 \\
10.84 \\
10.72\end{array}$ & $\begin{array}{l}3,230 \\
3,160 \\
3,080 \\
3,010 \\
2,930 \\
2,860\end{array}$ & $\begin{array}{l}9.99 \\
9.91 \\
9.81 \\
9.70 \\
9.60 \\
9.50\end{array}$ & $\begin{array}{l}2,420 \\
2,380 \\
2,340 \\
2,280 \\
2,230 \\
2,180\end{array}$ & & $\begin{array}{l}1,950 \\
1,920 \\
1,880 \\
1,840 \\
1,800 \\
1,770\end{array}$ & $\begin{array}{l}8.07 \\
8.01 \\
7.92 \\
7.83 \\
7.77 \\
7.71\end{array}$ & $\begin{array}{l}1,510 \\
1,480 \\
1,450 \\
1,410 \\
1,390 \\
1,360\end{array}$ \\
\hline $\begin{array}{r}2 \\
4 \\
6 \\
8 \\
10 \\
M\end{array}$ & $\begin{array}{l}14.36 \\
15.21 \\
14.03 \\
13.88 \\
13.70 \\
13.45\end{array}$ & $\begin{array}{l}5,300 \\
5,200 \\
5,070 \\
4,970 \\
4,840 \\
4,660\end{array}$ & $\begin{array}{l}12.27 \\
12.09 \\
11.93 \\
11.78 \\
11.62 \\
11.48\end{array}$ & $\begin{array}{l}3,840 \\
3,710 \\
3,600 \\
3,500 \\
3,400 \\
3,320\end{array}$ & $\begin{array}{l}10.60 \\
10.48 \\
10.36 \\
10.25 \\
10.14 \\
10.06\end{array}$ & $\begin{array}{l}2,790 \\
2,720 \\
2,650 \\
2,580 \\
2,510 \\
2,470\end{array}$ & $\begin{array}{l}9.42 \\
9.33 \\
9.28 \\
9.22 \\
9.17 \\
9.12\end{array}$ & $\begin{array}{l}2,140 \\
2,100 \\
2,070 \\
2,040 \\
2,020 \\
1,990\end{array}$ & $\begin{array}{l}8.59 \\
8.51 \\
8.42 \\
8.32 \\
8.25 \\
8.15\end{array}$ & $\begin{array}{l}1,720 \\
1,600 \\
1,650 \\
1,610 \\
1,580 \\
1,540\end{array}$ & $\begin{array}{l}7.64 \\
7.58 \\
7.51 \\
7.43 \\
7.38 \\
7.31\end{array}$ & $\begin{array}{l}1,340 \\
1,310 \\
1,280 \\
1,250 \\
1,230 \\
1,210\end{array}$ \\
\hline
\end{tabular}

Supplemental records.- Sept. $23,7: 45$ a.m., $15.58 \mathrm{ft} ., 6,210$ sec.-ft. 
Wallkill River near Phillipsburg, N. Y.

Location.- Water-stage recorder, lat. $41^{\circ} 26^{\prime} 00^{\prime \prime}$, long. $74^{\circ} 22^{\prime} 20^{\prime \prime}$, a quarter of a mile upstream from abandoned electric railway bridge and mouth of Masonic Creek, and about one mile southwest of Phillipsburg, Orange County. Zero of gage is 352.61 feet above mean sea level (general adjustment of 1912).

Drainage area.- 432 square miles.

Gage-he1ght record.- Water-stage recorder graph.

Stage-discharge relation:- Defined by current-meter measurements below 6,550 secondfeet; extended logarithmically to peak stage.

Maxima.- September 1938: Discharge, 7,090 second-feet 10:40 p.m. Sept. 21 (gage height, 9.67 feet)

October 1936 to August 1938: Discharge, 5,180 second-feet 11 p.m. July 23, 1938 (gage helght, 7.88 feet).

January 1936 to August 1938: Maximum gage he1ght, Mar. 13, 1936, 11.63 feet, present site and datum, from graph based on staff-gage readings.

Remarks. - No known diversions but natural storage in large swampy areas and lakes above Pellets Island Mountain, N. Y.

Mean dally discharge, in second-feet, 1938

\begin{tabular}{|c|c|c|c|c|c|c|c|c|c|c|c|}
\hline Day & Sept. & Oct. & Day & Sept. & Oct. & Day & Sept. & oct. & Day & Sept. & Oct. \\
\hline $\begin{array}{l}1 \\
2 \\
3 \\
4 \\
5 \\
6 \\
7 \\
8\end{array}$ & $\begin{array}{l}149 \\
157 \\
149 \\
133 \\
126 \\
126 \\
116 \\
113\end{array}$ & $\begin{array}{r}1,070 \\
904 \\
740 \\
610 \\
520 \\
466 \\
479 \\
484\end{array}$ & $\begin{array}{r}9 \\
10 \\
11 \\
12 \\
13 \\
14 \\
15 \\
16\end{array}$ & $\begin{array}{r}106 \\
101 \\
99 \\
95 \\
101 \\
99 \\
145 \\
205\end{array}$ & $\begin{array}{l}438 \\
407 \\
381 \\
338 \\
334 \\
352 \\
349 \\
338\end{array}$ & $\begin{array}{l}17 \\
18 \\
19 \\
20 \\
21 \\
22 \\
23 \\
24\end{array}$ & $\begin{array}{r}211 \\
183 \\
271 \\
2,410 \\
4,610 \\
6,700 \\
6,370 \\
5,600\end{array}$ & $\begin{array}{l}327 \\
313 \\
310 \\
314 \\
638 \\
720 \\
646 \\
682\end{array}$ & $\begin{array}{l}25 \\
26 \\
27 \\
28 \\
29 \\
30 \\
31\end{array}$ & $\begin{array}{l}4,220 \\
3,000 \\
2,310 \\
1,890 \\
1,510 \\
1,250\end{array}$ & $\begin{array}{r}1,050 \\
869 \\
715 \\
646 \\
614 \\
560 \\
492\end{array}$ \\
\hline $\begin{array}{l}\text { Mean } \\
\text { Run- }\end{array}$ & $\begin{array}{l}\text { onthly } \\
e, \text { in }\end{array}$ & $\begin{array}{l}\text { schars } \\
\text { hes. }\end{array}$ & ? 1 & .. & - & $\therefore$ & $\cdot$. & . . & $\dot{\bullet}$ & $\begin{array}{r}1,418 \\
3.66\end{array}$ & $\begin{array}{r}552 \\
1.48\end{array}$ \\
\hline
\end{tabular}

Gage height, In feet, and discharge, in second-feet, at indlcated time, 1938

\begin{tabular}{|c|c|c|c|c|c|c|c|c|c|c|c|c|}
\hline \multirow{2}{*}{$\begin{array}{r}5 \\
3 \\
\text { 通 } \\
\end{array}$} & Feot & Sec.ft. & Feet & Sec.ft. & Feet & Sec.ft. & Feet. & Sec.ft. & Feet & Sec.ft. & Feot & Sec.ft. \\
\hline & \multicolumn{2}{|c|}{ September 18} & \multicolumn{2}{|c|}{ September 19} & \multicolumn{2}{|c|}{ September 20} & \multicolumn{2}{|c|}{ September 21} & \multicolumn{2}{|c|}{ September 22} & \multicolumn{2}{|c|}{ September 23} \\
\hline $\begin{array}{l}1 \\
2 \\
3 \\
4 \\
5 \\
6\end{array}$ & $\begin{array}{c}\overline{-} \\
\overline{1.33} \\
\overline{1.31} \\
\overline{1.29}\end{array}$ & $\begin{array}{r}-198 \\
- \\
192 \\
-186\end{array}$ & $\begin{array}{l}1.26 \\
1.26 \\
1.26 \\
1.26 \\
1.26 \\
1.26\end{array}$ & $\begin{array}{l}177 \\
177 \\
177 \\
177 \\
177 \\
177\end{array}$ & $\begin{array}{l}2.83 \\
3.09 \\
3.36 \\
3.64 \\
3.91 \\
4.24\end{array}$ & $\begin{array}{r}816 \\
960 \\
1,120 \\
1,310 \\
1,500 \\
1,730\end{array}$ & $\begin{array}{l}5.86 \\
5.89 \\
5.93 \\
5.95 \\
5.99 \\
6.01\end{array}$ & $\begin{array}{l}3,160 \\
3,190 \\
3,230 \\
3,250 \\
3,290 \\
3,310\end{array}$ & $\begin{array}{l}9.59 \\
9.52 \\
9.47 \\
9.40 \\
9.36 \\
9.36\end{array}$ & $\begin{array}{l}7,000 \\
6,920 \\
6,870 \\
6,790 \\
6,750 \\
6,750\end{array}$ & $\begin{array}{c}9.18 \\
- \\
9.16 \\
- \\
9.12\end{array}$ & $\begin{array}{c}6,550 \\
- \\
6,530 \\
- \\
6,480\end{array}$ \\
\hline $\begin{array}{r}7 \\
8 \\
9 \\
10 \\
11 \\
11\end{array}$ & $\begin{array}{c}- \\
1.28 \\
- \\
1.27 \\
- \\
1.27\end{array}$ & $\begin{array}{r}-183 \\
- \\
-180 \\
-180\end{array}$ & $\begin{array}{l}1.26 \\
1.26 \\
1.27 \\
1.27 \\
1.28 \\
1.29\end{array}$ & $\begin{array}{l}177 \\
177 \\
180 \\
180 \\
183 \\
186\end{array}$ & $\begin{array}{l}4.59 \\
4.88 \\
5.12 \\
5.33 \\
5.48 \\
5.58\end{array}$ & $\begin{array}{l}2,010 \\
2,260 \\
2,480 \\
2,670 \\
2,800 \\
2,890\end{array}$ & $\begin{array}{l}6.03 \\
6.01 \\
6.06 \\
6.13 \\
6.23 \\
6.35\end{array}$ & $\begin{array}{l}3,330 \\
3,310 \\
3,360 \\
3,430 \\
3,530 \\
3,650\end{array}$ & $\begin{array}{l}9.31 \\
9.29 \\
9.27 \\
9.27 \\
9.28 \\
9.29\end{array}$ & $\begin{array}{l}6,690 \\
6,670 \\
6,650 \\
6,650 \\
6,660 \\
6,670\end{array}$ & $\begin{array}{l}9.10 \\
\overline{-} \\
9.06 \\
- \\
9.04\end{array}$ & $\begin{array}{c}6,460 \\
- \\
6,420 \\
6,390\end{array}$ \\
\hline $\begin{array}{l}1 \\
2 \\
3 \\
4 \\
5 \\
6\end{array}$ & $\begin{array}{c}\overline{1.27} \\
- \\
1.27 \\
\overline{1.26}\end{array}$ & $\begin{array}{r}-180 \\
- \\
180 \\
- \\
177\end{array}$ & $\begin{array}{l}1.33 \\
1.41 \\
1.48 \\
1.63 \\
1.76 \\
1.84\end{array}$ & $\begin{array}{l}198 \\
223 \\
246 \\
296 \\
342 \\
370\end{array}$ & $\begin{array}{l}5.67 \\
5.71 \\
5.75 \\
5.75 \\
5.74 \\
5.73\end{array}$ & $\begin{array}{l}2,970 \\
3,010 \\
3,050 \\
3,050 \\
3,040 \\
3,030\end{array}$ & $\begin{array}{l}6.56 \\
6.94 \\
7.63 \\
8.22 \\
8.68 \\
9.02\end{array}$ & $\begin{array}{l}3,860 \\
4,240 \\
4,930 \\
5,520 \\
6,000 \\
6,370\end{array}$ & $\begin{array}{l}9.28 \\
9.28 \\
9.27 \\
9.27 \\
9.27 \\
9.26\end{array}$ & $\begin{array}{l}6,660 \\
6,660 \\
6,650 \\
6,650 \\
6,650 \\
6,640\end{array}$ & $\begin{array}{c}\overline{9.00} \\
\overline{8.96} \\
\overline{8.92}\end{array}$ & $\begin{array}{c}6,350 \\
\overline{6,310} \\
\overline{6,260}\end{array}$ \\
\hline \multirow[t]{2}{*}{$\begin{array}{r}7 \\
8 \\
9 \\
10 \\
11 \\
M \\
\end{array}$} & $\begin{array}{c}- \\
1.26 \\
- \\
1.26 \\
- \\
1.26\end{array}$ & $\begin{array}{r}-177 \\
-\quad 177 \\
-\quad \\
177 \\
\end{array}$ & $\begin{array}{l}1.89 \\
1.91 \\
1.94 \\
2.08 \\
2.30 \\
2.52 \\
\end{array}$ & $\begin{array}{l}388 \\
396 \\
407 \\
462 \\
560 \\
660\end{array}$ & $\begin{array}{l}5.73 \\
5.72 \\
5.72 \\
5.73 \\
5.77 \\
5.80\end{array}$ & $\begin{array}{l}3,030 \\
3,020 \\
3,020 \\
3,030 \\
3,070 \\
3,100\end{array}$ & $\begin{array}{l}9.28 \\
9.45 \\
9.58 \\
9.63 \\
9.63 \\
9.61\end{array}$ & $\begin{array}{l}6,660 \\
6,840 \\
6,990 \\
7,040 \\
7,040 \\
7,020\end{array}$ & $\begin{array}{l}9.25 \\
9.24 \\
9.23 \\
9.22 \\
9.20 \\
9.19\end{array}$ & $\begin{array}{l}6,620 \\
6,610 \\
6,600 \\
6,590 \\
6,570 \\
6,560\end{array}$ & $\begin{array}{c}8.87 \\
- \\
8.82 \\
- \\
8.75\end{array}$ & $\begin{array}{c}6,210 \\
- \\
6,150 \\
- \\
6,080\end{array}$ \\
\hline & \multicolumn{2}{|c|}{ September 24} & \multicolumn{2}{|c|}{ September 25} & \multicolumn{2}{|c|}{ September 26} & \multicolumn{2}{|c|}{ September 27} & \multicolumn{2}{|c|}{ September 28} & \multicolumn{2}{|c|}{ September 29} \\
\hline $\begin{array}{r}2 \\
4 \\
6 \\
8 \\
10 \\
N\end{array}$ & $\begin{array}{l}8.70 \\
8.62 \\
8.55 \\
8.47 \\
8.39 \\
8.31\end{array}$ & $\begin{array}{l}6,020 \\
5,930 \\
5,860 \\
5,770 \\
5,690 \\
5,610\end{array}$ & $\begin{array}{l}7.55 \\
7.43 \\
7.28 \\
7.16 \\
7.03 \\
6.91\end{array}$ & $\begin{array}{l}4,850 \\
4,730 \\
4,580 \\
4,460 \\
4,330 \\
4,210\end{array}$ & $\begin{array}{l}6.09 \\
6.01 \\
5.93 \\
5.82 \\
5.74 \\
5.68\end{array}$ & $\begin{array}{l}3,390 \\
3,310 \\
3,230 \\
3,120 \\
3,040 \\
2,980\end{array}$ & \begin{tabular}{|l|}
5.19 \\
5.13 \\
5.08 \\
5.03 \\
4.96 \\
4.91
\end{tabular} & $\begin{array}{l}2,540 \\
2,490 \\
2,440 \\
2,400 \\
2,330 \\
2,290\end{array}$ & $\begin{array}{l}4.63 \\
4.60 \\
4.56 \\
4.52 \\
4.48 \\
4.44\end{array}$ & $\begin{array}{l}2,040 \\
2,020 \\
1,990 \\
1,960 \\
1,920 \\
1,890\end{array}$ & $\begin{array}{l}4.13 \\
4.07 \\
4.03 \\
3.99 \\
3.95 \\
3.92\end{array}$ & $\begin{array}{l}1,650 \\
1,610 \\
1,580 \\
1,550 \\
1,520 \\
1,500\end{array}$ \\
\hline $\begin{array}{r}2 \\
4 \\
6 \\
8 \\
10 \\
11\end{array}$ & $\begin{array}{l}8.23 \\
8.15 \\
8.05 \\
7.93 \\
7.81 \\
7.69\end{array}$ & $\begin{array}{l}5,530 \\
5,450 \\
5,350 \\
5,230 \\
5,110 \\
4,990\end{array}$ & $\begin{array}{l}6.78 \\
6.67 \\
6.54 \\
6.43 \\
6.31 \\
6.21\end{array}$ & $\begin{array}{l}4,080 \\
3,970 \\
3,840 \\
3,730 \\
3,610 \\
3,510\end{array}$ & $\begin{array}{l}5.60 \\
5.54 \\
5.46 \\
5.38 \\
5.32 \\
5.25\end{array}$ & $\begin{array}{l}2,910 \\
2,860 \\
2,780 \\
2,710 \\
2,660 \\
2,600\end{array}$ & $\begin{array}{l}4.86 \\
4.82 \\
4.78 \\
4.74 \\
4.70 \\
4.66\end{array}$ & $\begin{array}{l}2,240 \\
2,210 \\
2,170 \\
2,140 \\
2,100 \\
2,070\end{array}$ & $\begin{array}{l}4.40 \\
4.36 \\
4.30 \\
4.26 \\
4.21 \\
4.16\end{array}$ & $\begin{array}{l}1,860 \\
1,830 \\
1,780 \\
1,750 \\
1,710 \\
1,670\end{array}$ & $\begin{array}{l}3.89 \\
3.85 \\
3.82 \\
3.79 \\
3.76 \\
3.72\end{array}$ & $\begin{array}{l}1,480 \\
1,460 \\
1,430 \\
1,410 \\
1,390 \\
1,360\end{array}$ \\
\hline
\end{tabular}

Supplemental records.- Sept. 2l, 10:40 p.m., $9.67 \mathrm{ft.,} 7,090$ sec.-ft. 
Wallkill River at Gardiner, N. Y.

Locat1on. - Water-stage recorder, lat. $41^{\circ} 41^{\prime} 10^{\prime \prime}$, long. $74^{\circ} 09^{\prime} 55^{\prime \prime}$, at highway bridge 500 feet below mouth of Shawangunk Kill and three-quarters of a mile northwest of Gardiner, Ulster County. Zero of gage is 185.70 feet above mean sea level (general adjustment of 1912).

Drainage area.- 711 square miles.

Gage-helght record.- Water-stage recorder graph.

Stage-discharge relation.- Defined by current-meter measurements below 11,200 secondfeet; extended logarithmically to peak stage.

Maxima.- September 1938: Discharge, 17,500.second-feet 1:15 a.m. Sept. 22 (gage he1ght, 14.92 feet).

September 1924 to August 1938: Maximum discharge, 18,000 second-feet Mar. 12, 1936 (gage helght, 15.16 feet); maximum gage he1ght, 16.42 feet Mar. 12, 1936 (1ce Jam).

Remarks.- Large diurnal fluctuations during low and medium stages caused by power-plant operations. Natural storage occurs in swampy areas and small lakes above Pellets Island Mountain, and artificial and natural storage in lakes and ponds in the intervening area.

Mean dally discharge, in second-feet, 1938

\begin{tabular}{|c|c|c|c|c|c|c|c|c|c|c|c|}
\hline Day & Sept. & Oct. & Day & Sept. & oct. & Day & Sept. & oct. & Day & Sept. & Oct. \\
\hline $\begin{array}{l}1 \\
2 \\
3 \\
4 \\
5 \\
6 \\
7 \\
8\end{array}$ & $\begin{array}{l}248 \\
251 \\
228 \\
219 \\
196 \\
184 \\
186 \\
223\end{array}$ & $\begin{array}{r}1,610 \\
1,360 \\
1,120 \\
902 \\
777 \\
700 \\
663 \\
678\end{array}$ & $\begin{array}{r}9 \\
10 \\
11 \\
12 \\
13 \\
14 \\
15 \\
16\end{array}$ & $\begin{array}{l}202 \\
171 \\
155 \\
176 \\
209 \\
233 \\
263 \\
251\end{array}$ & $\begin{array}{l}670 \\
613 \\
579 \\
545 \\
512 \\
514 \\
524 \\
518\end{array}$ & $\begin{array}{l}17 \\
18 \\
19 \\
20 \\
21 \\
22 \\
23 \\
24\end{array}$ & $\begin{array}{r}314 \\
320 \\
784 \\
8,170 \\
11,800 \\
14,700 \\
9,960 \\
8,200\end{array}$ & $\begin{array}{r}518 \\
497 \\
518 \\
470 \\
1,300 \\
1,200 \\
991 \\
1,180\end{array}$ & $\begin{array}{l}25 \\
26 \\
27 \\
28 \\
29 \\
30 \\
31\end{array}$ & $\begin{array}{l}6,620 \\
4,900 \\
3,620 \\
2,930 \\
2,330 \\
1,880\end{array}$ & $\begin{array}{r}2,140 \\
1,520 \\
1,170 \\
982 \\
955 \\
928 \\
825\end{array}$ \\
\hline $\begin{array}{l}\text { Mean } \\
\text { Run- }\end{array}$ & onthly & schar & 1 & $\begin{array}{l}\cos d- \\
.\end{array}$ & et. : & : & $\cdot$. & 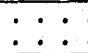 & $\dot{.}$ & $\begin{array}{r}2,664 \\
4.18\end{array}$ & $\begin{array}{r}886 \\
1.44\end{array}$ \\
\hline
\end{tabular}

Gage helght, in feet, and discharge, in second-feet, at indicated time, 1938

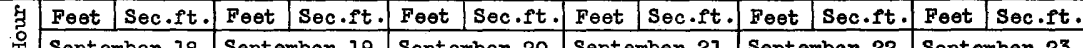

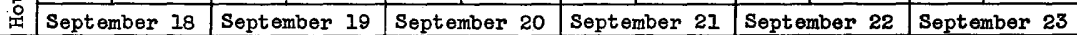

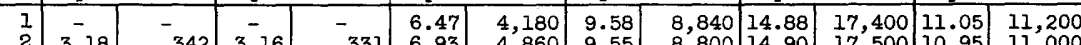

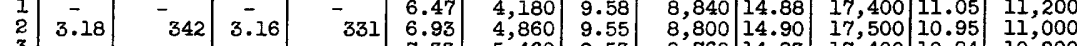

9
10
11
$N$

$$
\begin{array}{|r}
1 \\
2 \\
3 \\
4 \\
5 \\
6 \\
7 \\
8 \\
9 \\
10 \\
11 \\
M \\
\hline \\
\hline 2 \\
4 \\
6 \\
8 \\
10 \\
N \\
2 \\
4 \\
6 \\
8 \\
10 \\
M
\end{array}
$$

\begin{tabular}{|c|c|c|c|c|c|c|c|c|c|c|c|c|}
\hline $\begin{array}{r}10 \\
11 \\
M\end{array}$ & $\begin{array}{c}3.14 \\
- \\
3.15\end{array}$ & $\begin{array}{r}321 \\
-\quad 326 \\
\end{array}$ & $\begin{array}{l}5.09 \\
5.55 \\
6.01 \\
\end{array}$ & $\begin{array}{l}2,230 \\
2,860 \\
3,500 \\
\end{array}$ & $\begin{array}{l}9.37 \\
9.45 \\
9.53\end{array}$ & $\begin{array}{l}8,520 \\
8,640 \\
8,760 \\
\end{array}$ & $\begin{array}{l}14.58 \\
14.76 \\
14.71 \\
\end{array}$ & $\begin{array}{l}16,900 \\
17,200 \\
17,200\end{array}$ & $\begin{array}{l}11.35 \\
11.25 \\
11.15\end{array}$ & $\begin{array}{l}11,700 \\
11,500 \\
11,300\end{array}$ & $\begin{array}{l}9.74 \\
9.71 \\
9.66\end{array}$ & $\begin{array}{l}9,080 \\
9,040 \\
8,960 \\
\end{array}$ \\
\hline & \multicolumn{2}{|c|}{ September 24} & \multicolumn{2}{|c|}{ September 25} & \multicolumn{2}{|c|}{ September 26} & \multicolumn{2}{|c|}{ September 27} & \multicolumn{2}{|c|}{ September 28} & \multicolumn{2}{|c|}{ September 29} \\
\hline $\begin{array}{r}2 \\
4 \\
6 \\
8 \\
10 \\
N\end{array}$ & $\begin{array}{l}9.56 \\
9.48 \\
9.40 \\
9.32 \\
9.25 \\
9.17\end{array}$ & $\begin{array}{l}8,810 \\
8,690 \\
8,570 \\
8,450 \\
8,340 \\
8,220\end{array}$ & $\begin{array}{l}8.55 \\
8.47 \\
8.38 \\
8.30 \\
8.20 \\
8.11\end{array}$ & $\begin{array}{l}7,300 \\
7,180 \\
7,040 \\
6,920 \\
6,770 \\
6,640\end{array}$ & $\begin{array}{l}7.42 \\
7.32 \\
7.22 \\
7.13 \\
7.04 \\
6.95\end{array}$ & $\begin{array}{l}5,600 \\
5,450 \\
5,300 \\
5,160 \\
5,030 \\
4,900\end{array}$ & $\begin{array}{l}6.37 \\
6.31 \\
6.24 \\
6.18 \\
6.13 \\
6.07\end{array}$ & $\begin{array}{l}4,020 \\
3,940 \\
3,830 \\
3,740 \\
3,670 \\
3,590\end{array}$ & $\begin{array}{l}5.77 \\
5.74 \\
5.70 \\
5.66 \\
5.63 \\
5.61\end{array}$ & $\begin{array}{l}3,170 \\
3,130 \\
3,070 \\
3,010 \\
2,970 \\
2,940\end{array}$ & $\begin{array}{l}35 \\
31 \\
27 \\
23 \\
19 \\
16\end{array}$ & \\
\hline $\begin{array}{r}2 \\
4 \\
6 \\
8 \\
10 \\
M\end{array}$ & $\begin{array}{l}9.08 \\
8.98 \\
8.90 \\
8.81 \\
8.73 \\
8.64\end{array}$ & $\begin{array}{l}8,090 \\
7,940 \\
7,820 \\
7,680 \\
7,560 \\
7,430\end{array}$ & $\begin{array}{l}8.01 \\
7.92 \\
7.82 \\
7.73 \\
7.64 \\
7.52\end{array}$ & $\begin{array}{l}6,480 \\
6,350 \\
6,200 \\
6,060 \\
5,930 \\
5,750\end{array}$ & $\begin{array}{l}6.85 \\
6.76 \\
6.68 \\
6.59 \\
6.52 \\
6.44\end{array}$ & $\begin{array}{l}4,740 \\
4,610 \\
4,490 \\
4,360 \\
4,250 \\
4,130\end{array}$ & $\begin{array}{l}6.01 \\
5.96 \\
5.94 \\
5.88 \\
5.84 \\
5.81\end{array}$ & $\begin{array}{l}3,500 \\
3,430 \\
3,410 \\
3,320 \\
3,270 \\
3,220\end{array}$ & $\begin{array}{l}5.57 \\
5.54 \\
5.50 \\
5.46 \\
5.42 \\
5.39\end{array}$ & $\begin{array}{l}390 \\
350 \\
790 \\
730 \\
380 \\
540\end{array}$ & $\begin{array}{l}5 . \\
5 . \\
5 . \\
5 . \\
4 .\end{array}$ & $\begin{array}{l}70 \\
10 \\
80 \\
40 \\
00 \\
60\end{array}$ \\
\hline
\end{tabular}

Supplemental records.- Sept. $21,11: 30$ p.m., $14.88 \mathrm{ft.,} 17,400$ sec.-ft. Sept. 22, 1: 15 a.m., 14.92 ft., 17,500 sec. $-f t$. 
Location.- Water-stage recorder, lat. $41^{\circ} 16^{1} 30^{\prime \prime}$, long. $74^{\circ} 28^{\prime} 20^{\prime \prime}$, at Newport, Orange County, about 2.3 miles south of Pine Island and 4 miles above mouth. Drainage area.- 98.0 square miles.

Gage-height record.- Water-stage recorder graph.

Stage-discharge relation.- For September 1938 defined by current-meter measurements below 2,030 second-feet; extended logarithmically to peak stage. For January 1938 defined by current-meter measurements below 937 second-feet; extended logarithmically to peak stage.

Maxima.- September 1938: Discharge, 2,070 second-feet 8:30 to 10 p.m. Sept. 22 (gage height, 7.80 feet)

September 1937 to August 1938: Discharge, 1,150 second-feet Jan. 26, 1938 (gage height, 6.71 feet).

Remarks.- No known regulation or diversion; netural storage in swampy areas. Stagedischarge relation affected by backwater from weeds and aquatic vegetation.

Mean daily discharge, in second-feet, 1938

\begin{tabular}{|c|c|c|c|c|c|c|c|c|c|c|c|}
\hline Day & Sept. & oct. & Day & Sept. & Oct. & Day & Sept: & Oct. & Day & Sept. & Oct. \\
\hline $\begin{array}{l}1 \\
2 \\
3 \\
4 \\
5 \\
6 \\
7 \\
8\end{array}$ & $\begin{array}{l}39 \\
39 \\
35 \\
34 \\
33 \\
30 \\
28 \\
30\end{array}$ & $\begin{array}{l}242 \\
197 \\
162 \\
135 \\
117 \\
107 \\
116 \\
110\end{array}$ & $\begin{array}{r}9 \\
10 \\
11 \\
12 \\
13 \\
14 \\
15 \\
16\end{array}$ & $\begin{array}{l}28 \\
27 \\
26 \\
25 \\
26 \\
27 \\
32 \\
38\end{array}$ & $\begin{array}{r}100 \\
108 \\
92 \\
81 \\
116 \\
130 \\
130 \\
127 \\
\end{array}$ & $\begin{array}{l}17 \\
18 \\
19 \\
20 \\
21 \\
22 \\
23 \\
24\end{array}$ & $\begin{array}{r}32 \\
32 \\
43 \\
203 \\
504 \\
1,710 \\
1,830 \\
1,330\end{array}$ & $\begin{array}{l}122 \\
118 \\
112 \\
112 \\
165 \\
190 \\
173 \\
156\end{array}$ & $\begin{array}{l}25 \\
26 \\
27 \\
28 \\
29 \\
30 \\
31\end{array}$ & $\begin{array}{r}1,020 \\
802 \\
625 \\
484 \\
380 \\
302\end{array}$ & $\begin{array}{l}173 \\
168 \\
147 \\
138 \\
128 \\
121 \\
109\end{array}$ \\
\hline $\begin{array}{l}\text { Mean } \\
\text { Run- }\end{array}$ & $\begin{array}{l}\text { nthy } \\
\text {, in }\end{array}$ & $\begin{array}{l}\text { schare } \\
\text { hes. }\end{array}$ & , in & $\begin{array}{l}\text { econd-f } \\
\text { - . . . }\end{array}$ & t. . & & $\therefore \quad . \quad$ & $\begin{array}{l}\cdot \cdot \cdot \\
\cdot \quad \cdot \\
\end{array}$ & $\dot{0} \cdot \dot{ }$ & $\begin{array}{r}326 \\
3.72\end{array}$ & $\begin{array}{r}136 \\
1.60\end{array}$ \\
\hline
\end{tabular}

Gage height, in feet, and discharge, in second-feet, at indicated time, 1938

\begin{tabular}{|c|c|c|c|c|c|c|c|c|c|c|c|c|c|c|c|}
\hline \multirow{2}{*}{$\begin{array}{l}4 \\
7 \\
0 \\
\text { 平 }\end{array}$} & Feet & Sec.ft. & Feet & Sec.ft. & Feot & \multicolumn{2}{|c|}{ Sec.ft. } & Feet & \multicolumn{2}{|c|}{ Sec.ft. } & Feet & Sec.ft. & Feet & \multicolumn{2}{|c|}{ Sec.ft. } \\
\hline & \multicolumn{2}{|c|}{ September 18} & \multicolumn{2}{|c|}{ September 19} & \multicolumn{3}{|c|}{ September 20} & \multicolumn{3}{|c|}{ September 21} & \multicolumn{2}{|c|}{ September 22} & \multicolumn{3}{|c|}{ September 23} \\
\hline $\begin{array}{l}1 \\
2 \\
3 \\
4 \\
5 \\
6\end{array}$ & $\begin{array}{c}- \\
1.68 \\
- \\
1.68 \\
- \\
1.69\end{array}$ & $\begin{array}{r}-31 \\
-\quad 31 \\
-\quad 32\end{array}$ & $\begin{array}{l}1.72 \\
1.72 \\
1.72 \\
1.72 \\
1.72 \\
1.73\end{array}$ & $\begin{array}{l}33 \\
33 \\
33 \\
33 \\
33 \\
33\end{array}$ & $\begin{array}{l}2.90 \\
3.09 \\
3.27 \\
3.42 \\
3.56 \\
3.67\end{array}$ & & $\begin{array}{l}103 \\
119 \\
135 \\
150 \\
164 \\
176\end{array}$ & $\begin{array}{l}4.44 \\
4.48 \\
4.52 \\
4.56 \\
4.61 \\
4.65\end{array}$ & & $\begin{array}{l}291 \\
299 \\
306 \\
313 \\
322 \\
330\end{array}$ & $\begin{array}{l}6.64 \\
6.75 \\
6.89 \\
7.02 \\
7.14 \\
7.25\end{array}$ & $\begin{array}{r}985 \\
1,040 \\
1,120 \\
1,220 \\
1,320 \\
1,420\end{array}$ & $\begin{array}{l}7.79 \\
7.78 \\
7.77 \\
7.76 \\
7.75 \\
7.74\end{array}$ & & $\begin{array}{l}050 \\
040 \\
030 \\
020 \\
010 \\
980\end{array}$ \\
\hline $\begin{array}{r}7 \\
8 \\
9 \\
10 \\
11 \\
1\end{array}$ & $\begin{array}{c}1.69 \\
- \\
1.70 \\
1.70\end{array}$ & $\begin{array}{r}-32 \\
-\quad 32 \\
-\quad 32\end{array}$ & $\begin{array}{l}1.73 \\
1.73 \\
1.74 \\
1.75 \\
1.75 \\
1.79\end{array}$ & $\begin{array}{l}33 \\
33 \\
34 \\
34 \\
34 \\
36\end{array}$ & $\begin{array}{l}3.75 \\
3.80 \\
3.84 \\
3.88 \\
3.91 \\
3.94\end{array}$ & & $\begin{array}{l}186 \\
192 \\
198 \\
203 \\
207 \\
212\end{array}$ & $\begin{array}{l}4.69 \\
4.74 \\
4.79 \\
4.85 \\
4.90 \\
4.96\end{array}$ & & $\begin{array}{l}338 \\
348 \\
358 \\
371 \\
382 \\
395\end{array}$ & $\begin{array}{l}7.35 \\
7.43 \\
7.50 \\
7.56 \\
7.60 \\
7.65\end{array}$ & $\begin{array}{l}1,520 \\
1,610 \\
1,690 \\
1,760 \\
1,810 \\
1,880\end{array}$ & $\begin{array}{l}7.73 \\
7.71 \\
7.70 \\
7.68 \\
7.66 \\
7.64\end{array}$ & & $\begin{array}{l}970 \\
940 \\
930 \\
900 \\
870 \\
850\end{array}$ \\
\hline $\begin{array}{l}1 \\
2 \\
3 \\
4 \\
5 \\
6\end{array}$ & $\begin{array}{c}- \\
1.70 \\
- \\
1.70 \\
- \\
1.70\end{array}$ & $\begin{array}{r}-32 \\
-\quad 32 \\
-\quad 32\end{array}$ & $\begin{array}{l}1.84 \\
1.89 \\
1.94 \\
1.99 \\
2.03 \\
2.08\end{array}$ & $\begin{array}{l}38 \\
40 \\
42 \\
44 \\
46 \\
48\end{array}$ & $\begin{array}{l}3.97 \\
4.00 \\
4.02 \\
4.05 \\
4.07 \\
4.11\end{array}$ & & $\begin{array}{l}216 \\
220 \\
223 \\
227 \\
230 \\
236\end{array}$ & $\begin{array}{l}5.09 \\
5.26 \\
5.48 \\
5.63 \\
5.79 \\
5.96\end{array}$ & & $\begin{array}{l}426 \\
471 \\
534 \\
580 \\
631 \\
692\end{array}$ & $\begin{array}{l}7.69 \\
7.71 \\
7.74 \\
7.76 \\
7.77 \\
7.78\end{array}$ & $\begin{array}{l}1,930 \\
1,950 \\
1,990 \\
2,020 \\
2,030 \\
2,040\end{array}$ & $\begin{array}{l}7.62 \\
7.60 \\
7.57 \\
7.55 \\
7.53 \\
7.51\end{array}$ & & $\begin{array}{l}820 \\
800 \\
760 \\
740 \\
710 \\
690\end{array}$ \\
\hline \multirow[t]{2}{*}{$\begin{array}{r}7 \\
8 \\
9 \\
10 \\
11 \\
M\end{array}$} & $\begin{array}{c}- \\
1.70 \\
- \\
1.70 \\
- \\
1.72\end{array}$ & $\begin{array}{r}-32 \\
-\quad 32 \\
-\quad 33 \\
\end{array}$ & $\begin{array}{l}2.13 \\
2.18 \\
2.25 \\
2.40 \\
2.54 \\
2.72\end{array}$ & $\begin{array}{l}50 \\
53 \\
57 \\
66 \\
76 \\
89\end{array}$ & $\begin{array}{l}4.15 \\
4.19 \\
4.24 \\
4.30 \\
4.35 \\
4.39\end{array}$ & & $\begin{array}{l}242 \\
248 \\
256 \\
266 \\
275 \\
282 \\
\end{array}$ & $\begin{array}{l}6.08 \\
6.20 \\
6.29 \\
6.38 \\
6.46 \\
6.54\end{array}$ & & $\begin{array}{l}737 \\
785 \\
821 \\
861 \\
897 \\
935\end{array}$ & $\begin{array}{l}7.79 \\
7.79 \\
7.80 \\
7.80 \\
7.79 \\
7.79\end{array}$ & $\begin{array}{l}2,060 \\
2,060 \\
2,070 \\
2,070 \\
2,060 \\
2,060\end{array}$ & $\begin{array}{l}7.49 \\
7.47 \\
7.45 \\
7.43 \\
7.41 \\
7.39 \\
\end{array}$ & & $\begin{array}{l}660 \\
640 \\
620 \\
600 \\
570 \\
550 \\
\end{array}$ \\
\hline & \multicolumn{2}{|c|}{ September 24} & \multicolumn{2}{|c|}{ September 25} & \multicolumn{2}{|c|}{ September } & 26 & \multicolumn{2}{|c|}{ September } & 27 & \multicolumn{2}{|c|}{ September 28} & \multicolumn{3}{|c|}{ September 29} \\
\hline $\begin{array}{r}2 \\
4 \\
6 \\
8 \\
10 \\
N\end{array}$ & $\begin{array}{l}7.35 \\
7.31 \\
7.27 \\
7.24 \\
7.20 \\
7.15\end{array}$ & $\begin{array}{l}1,510 \\
1,470 \\
1,430 \\
1,400 \\
1,370 \\
1,330\end{array}$ & $\begin{array}{l}6.89 \\
6.86 \\
6.82 \\
6.78 \\
6.74 \\
6.70\end{array}$ & $\begin{array}{l}1,130 \\
1,110 \\
1,080 \\
1,060 \\
1,040 \\
1,020\end{array}$ & $\begin{array}{l}6.42 \\
6.38 \\
6.34 \\
6.30 \\
6.27 \\
6.23\end{array}$ & & $\begin{array}{l}882 \\
866 \\
850 \\
834 \\
822 \\
806\end{array}$ & $\begin{array}{l}5.94 \\
5.90 \\
5.86 \\
5.82 \\
5.78 \\
5.74\end{array}$ & & $\begin{array}{l}693 \\
679 \\
665 \\
651 \\
637 \\
624\end{array}$ & $\begin{array}{l}5.46 \\
5.42 \\
5.38 \\
5.33 \\
5.30 \\
5.26\end{array}$ & $\begin{array}{l}536 \\
525 \\
514 \\
501 \\
493 \\
483\end{array}$ & $\begin{array}{l}5.00 \\
4.97 \\
4.94 \\
4.90 \\
4.86 \\
4.83\end{array}$ & & $\begin{array}{l}416 \\
410 \\
403 \\
394 \\
385 \\
379\end{array}$ \\
\hline $\begin{array}{r}2 \\
4 \\
6 \\
8 \\
10 \\
M\end{array}$ & $\begin{array}{l}7.10 \\
7.07 \\
7.04 \\
7.00 \\
6.96 \\
6.93\end{array}$ & $\begin{array}{l}1,280 \\
1,260 \\
1,230 \\
1,200 \\
1,180 \\
1,160\end{array}$ & $\begin{array}{l}6.65 \\
6.61 \\
6.57 \\
6.53 \\
6.49 \\
6.46\end{array}$ & $\begin{array}{l}990 \\
971 \\
953 \\
935 \\
917 \\
904\end{array}$ & $\begin{array}{l}6.18 \\
6.14 \\
6.10 \\
6.06 \\
6.02 \\
5.98\end{array}$ & & $\begin{array}{l}782 \\
767 \\
752 \\
738 \\
724 \\
710\end{array}$ & $\begin{array}{l}5.70 \\
5.66 \\
5.62 \\
5.58 \\
5.54 \\
5.50\end{array}$ & & $\begin{array}{l}609 \\
597 \\
585 \\
573 \\
562 \\
550\end{array}$ & $\begin{array}{l}5.23 \\
5.18 \\
5.15 \\
5.11 \\
5.07 \\
5.03\end{array}$ & $\begin{array}{l}475 \\
462 \\
455 \\
445 \\
436 \\
426\end{array}$ & $\begin{array}{l}4.79 \\
4.76 \\
4.73 \\
4.70 \\
4.67 \\
4.64\end{array}$ & & $\begin{array}{l}370 \\
364 \\
358 \\
352 \\
346 \\
340\end{array}$ \\
\hline
\end{tabular}

Supplemental records.- Sept. $22,8: 30$ p.m., 7.80 ft., 2,070 sec.-ft. 
Quaker Creek at Florida, N. Y.

Location.- Staff gage, lat. $41^{\circ} 20^{\prime} 20^{n}$, long. $74^{\circ} 21^{\prime} 45^{n}$, about one-quarter of a m1le north of rallroad station at Florlda, Orange County, and about 5 miles southwest of Goshen.

Drainage area.- 9.74 square miles.

Gage-helght record. - Graph based on two or more da1ly readings of inclined-staff gage. Stage-discharge relation.- Defined by current-meter measurements below 209 second-feet; extended logarithmically to peak stage.

Maxima.- September 1938: Discharge observed, 650 second-feet 5 p.m. Sept. 21 (gage heIght, 6.00 feet).

September 1937 to August 1938: Discharge observed, 387 second-feet Jan. 25, 1938 (gage helght, 4.75 feet).

Remarks.- Regulation from swimming pool one-eighth mile upstream during sumner months. No diversion.

Mean dally discharge, in second-feet, 1938

\begin{tabular}{|c|c|c|c|c|c|c|c|c|c|c|c|}
\hline Day & Sept. & oct. & Day & Sept. & Oct. & Day & Sept. & Oct. & Day & Sept. & Oct. \\
\hline $\begin{array}{l}1 \\
2 \\
3 \\
4 \\
5 \\
6 \\
7 \\
8\end{array}$ & $\begin{array}{r}1.1 \\
1.0 \\
1.0 \\
.9 \\
.8 \\
.7 \\
1.2 \\
1.1\end{array}$ & $\begin{array}{c}18 \\
14 \\
10 \\
8.4 \\
6.7 \\
10 \\
10 \\
8.4\end{array}$ & $\begin{array}{r}9 \\
10 \\
11 \\
12 \\
13 \\
14 \\
15 \\
16\end{array}$ & $\begin{array}{r}0.9 \\
.7 \\
.7 \\
.8 \\
1.2 \\
1.0 \\
2.4 \\
1.2\end{array}$ & $\begin{array}{l}6.7 \\
6.0 \\
5.7 \\
5.2 \\
4.4 \\
4.4 \\
4.2 \\
3.9\end{array}$ & $\begin{array}{l}17 \\
18 \\
19 \\
20 \\
21 \\
22 \\
23 \\
24\end{array}$ & $\begin{array}{c}0.9 \\
1.8 \\
5.6 \\
112 \\
303 \\
230 \\
108 \\
72\end{array}$ & $\begin{array}{c}3.6 \\
3.4 \\
7.2 \\
14 \\
7.7 \\
4.9 \\
3.9 \\
16\end{array}$ & $\begin{array}{l}25 \\
26 \\
27 \\
28 \\
29 \\
30 \\
31\end{array}$ & $\begin{array}{l}51 \\
40 \\
33 \\
31 \\
25 \\
22\end{array}$ & $\begin{array}{c}15 \\
7.7 \\
7.7 \\
11 \\
7.7 \\
6.7 \\
6.0\end{array}$ \\
\hline $\begin{array}{l}\text { Mean } \\
\text { Run- }\end{array}$ & $\begin{array}{l}\text { nthly } \\
\text {, In } 1\end{array}$ & & , Ir & . & 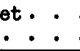 & $\dot{ } \cdot \dot{ }$ & $\begin{array}{lll}\cdot & \cdot & \bullet \\
. & \bullet & \bullet\end{array}$ & $\begin{array}{l}\cdot \\
.\end{array}$ & $\dot{0} \cdot \dot{ }$ & $\begin{array}{l}35.1 \\
4.02\end{array}$ & $\begin{array}{l}8.02 \\
0.92 \\
\end{array}$ \\
\hline
\end{tabular}

Gage height, in feet, and discharge, in second-feet, at indicated time, 1938

\begin{tabular}{|c|c|c|c|c|c|c|c|c|c|c|c|c|}
\hline \multirow{2}{*}{$\begin{array}{l} \\
9 \\
0 \\
\text { 至 } \\
\end{array}$} & Feet & Sec.ft. & Feet & Sec.ft. & Feet & Sec.ft. & Feet & sec.ft. & Feet & sec.ft. & Feet & sec.ft. \\
\hline & \multicolumn{2}{|c|}{ Sept omber 18} & \multicolumn{2}{|c|}{ September 19} & \multicolumn{2}{|c|}{ September 20} & \multicolumn{2}{|c|}{ September 21} & \multicolumn{2}{|c|}{ September 22} & \multicolumn{2}{|c|}{ September 23} \\
\hline 1 & - & - & - & - & - & - & - & & - & - & - & \\
\hline 2 & 0.82 & 1.5 & 0.85 & 2.0 & 1.97 & 50 & 2.57 & 94 & 4.56 & 353 & 3.04 & 139 \\
\hline 3 & - & & - & & - & - & - & & - & - & - & - \\
\hline $\begin{array}{l}4 \\
5\end{array}$ & .83 & 1.6 & .85 & 2.0 & 2.37 & 78 & 2.64 & 101 & 4.27 & 305 & 2.98 & 133 \\
\hline 6 & .83 & 1.6 & .86 & 2.1 & 2.90 & 125 & 2.72 & 108 & 4.06 & 273 & 2.92 & 127 \\
\hline 7 & - & - & & - & - & - & - & - & $=$ & - & - & - \\
\hline 8 & .83 & 1.6 & .87 & 2.2 & 2.33 & 173 & 2.84 & 119 & 3.89 & 248 & 2.86 & 121 \\
\hline 9 & - & & & & - & & - & & - & & - & \\
\hline 10 & .83 & 1.6 & .88 & 2.4 & 3.43 & 185 & 3.01 & 136 & 3.72 & 224 & 2.79 & 114 \\
\hline 11 & -8 & & -8 & & -3 & & - & & 36 & & -70 & - \\
\hline $\mathbb{N}$ & .84 & 1.8 & .89 & 2.6 & 3.30 & 169 & 3.30 & 169 & 3.60 & 207 & 2.70 & 106 \\
\hline 1 & & - & - & & - & & - & & - & & - & \\
\hline 2 & .84 & 1.8 & .91 & 2.9 & 2.97 & 132 & 4.22 & 297 & 3.50 & 194 & 2.62 & 99 \\
\hline 3 & - & & - & & $i^{200}$ & & 5 & & - & & - & \\
\hline 4 & .85 & 2.0 & .96 & 3.7 & 2.70 & 106 & 5.92 & 630 & 3.41 & 182 & 2.56 & 93 \\
\hline $\begin{array}{l}5 \\
6\end{array}$ & .85 & -2.0 & 1.00 & -4.4 & 2.50 & -88 & $\begin{array}{l}6.00 \\
5.99\end{array}$ & $\begin{array}{l}650 \\
648\end{array}$ & $\overline{3.32}$ & -171 & 2.50 & -88 \\
\hline \multirow{6}{*}{$\begin{array}{r}7 \\
8 \\
9 \\
10 \\
21 \\
M\end{array}$} & - & & - & & - & & - & - & - & - & - & -86 \\
\hline & .85 & 2.0 & 1.15 & 8.8 & 2.47 & 86 & 5.73 & 582 & 3.25 & 163 & 2.47 & 86 \\
\hline & - & - & - & & 2. & -87 & 5 & - & - & - & - & $-{ }_{83}$ \\
\hline & & - & $\begin{array}{c}1.07 \\
-\end{array}$ & $\begin{array}{l}10 \\
-\end{array}$ & $\begin{array}{l}2.49 \\
-\end{array}$ & & $\begin{array}{c}0.00 \\
-\end{array}$ & & 0.10 & -100 & $\begin{array}{c}2.44 \\
-\end{array}$ & $-\quad 00$ \\
\hline & .85 & 2.0 & 1.63 & 30 & 2.52 & 90 & 4.90 & 415 & 3.10 & 146 & 2.41 & 81 \\
\hline & \multicolumn{2}{|c|}{ September 24} & \multicolumn{2}{|c|}{ September 25} & \multicolumn{2}{|c|}{ September 26} & \multicolumn{2}{|c|}{ September 27} & \multicolumn{2}{|c|}{ September 28} & \multicolumn{2}{|c|}{ September 29} \\
\hline 2 & 2.40 & 80 & - & & - & & - & - & - & - & - & - \\
\hline 4 & 2.39 & 79 & 2.09 & 57 & 1.85 & 43 & 1.70 & 34 & 1.70 & 34 & 1.56 & \\
\hline $\begin{array}{l}6 \\
8\end{array}$ & $\begin{array}{l}2.37 \\
2.35\end{array}$ & $\begin{array}{l}78 \\
76\end{array}$ & 2.04 & ${ }^{-} 54$ & 1.83 & ${ }^{-} 42$ & 1.70 & -34 & 1.69 & -34 & 1.54 & ${ }^{-} 26$ \\
\hline 10 & 2.32 & 74 & - & & - & & - & & - & & & - \\
\hline $\mathbf{N}$ & 2.30 & 72 & 2.00 & 52 & 1.80 & 40 & 1.68 & 33 & 1.66 & 32 & 1.52 & 25 \\
\hline 2 & 2.27 & 70 & - & & - & & - & & - & & - & - \\
\hline 4 & 2.24 & 68 & 1.93 & 48 & 1.77 & 38 & 1.66 & 32 & 1.61 & 30 & 1.50 & 24 \\
\hline $\begin{array}{l}6 \\
8\end{array}$ & $\begin{array}{l}2.20 \\
2.18\end{array}$ & $\begin{array}{l}65 \\
64\end{array}$ & $\overline{1.89}$ & $-{ }_{45}$ & 1.74 & ${ }^{-} 36$ & $\overline{-} .65$ & -32 & $\overline{1.59}$ & -28 & 1.50 & -24 \\
\hline 10 & & 62 & - & - & - & & - & & - & & - & - \\
\hline M & & 60 & 1.87 & 44 & 1.71 & 35 & 1.67 & 32 & 1.58 & 28 & 1.48 & 23 \\
\hline
\end{tabular}


Location. - Water-stage recorder, 18t. $41^{\circ} 39^{\prime} 05^{\prime \prime}$, long. $73^{\circ} 52^{\prime} 20^{\prime \prime}$, $4 \frac{1}{2}$ miles northeast of Wappinger Falls, Dutchess County.

Drainage area.- 182 square miles.

Gage-height record.- Water-stage recorder graph except for periods 5 to 9 p.m. Sept. 20 , when pen did not function, and from 11 p.m. Sept. 21 to 2 p.m. Sept. 23, when water flooded and stopped recorder. Stage graph for periods of missing record drawn on basis of determination of peak stage by levels, time of peak stage by observer, two gage readings, and two stage determinations made at bridge 300 feet upstream and transferred by slope comparison to gage.

Stage-discharge relation.- For 1938 defined by current-meter measurements below 2,850 second-feet; extended to peak stage on basis of determinations of flood flow over Wappinger Falls dam and through contracted opening at bridge 300 feet upstream; verified by comparison with flood records of Tenmile River near Gaylordsville, Conn. For 1936 defined by current-meter measurements below 2,850 second-feet; extended logarithmically to peak stage.

Maxima.- September 1938: Discharge, 15,900 second-feet 2 a.m. Sept. 22 (gage height, 18.02 feet, from floodmarks).

August 1928 to August 1938: D1scharge, 6,880 second-feet Mar. 12, 1936 (gage height, 12.13 feet) from rating extended logarithmically above 2,850 second-feet.

Remarks.- Flood mun-off not materially affected by storage.

Mean dally discharge, in second-feet, 1938

\begin{tabular}{|c|c|c|c|c|c|c|c|c|c|c|c|}
\hline Dey & Sept. & Oct. & Day & Sept. & Oct. & Day & Sept. & Oct. & Day & Sept. & Oct. \\
\hline $\begin{array}{l}1 \\
2 \\
3 \\
4 \\
5 \\
6 \\
7 \\
8\end{array}$ & $\begin{array}{r}132 \\
130 \\
111 \\
106 \\
106 \\
92 \\
92 \\
113\end{array}$ & $\begin{array}{l}500 \\
428 \\
385 \\
348 \\
325 \\
300 \\
279 \\
256\end{array}$ & $\begin{array}{r}9 \\
10 \\
11 \\
12 \\
13 \\
14 \\
15 \\
16\end{array}$ & $\begin{array}{r}99 \\
88 \\
81 \\
78 \\
81 \\
92 \\
128 \\
194\end{array}$ & $\begin{array}{l}240 \\
224 \\
206 \\
192 \\
181 \\
175 \\
170 \\
160\end{array}$ & $\begin{array}{l}17 \\
18 \\
19 \\
20 \\
21 \\
22 \\
23 \\
24\end{array}$ & $\begin{array}{r}136 \\
114 \\
192 \\
1,460 \\
4,130 \\
7,810 \\
3,380 \\
2,200\end{array}$ & $\begin{array}{l}151 \\
144 \\
139 \\
142 \\
260 \\
233 \\
186 \\
181\end{array}$ & $\begin{array}{l}25 \\
26 \\
27 \\
28 \\
29 \\
30 \\
31\end{array}$ & $\begin{array}{r}1,500 \\
1,110 \\
918 \\
788 \\
670 \\
580\end{array}$ & $\begin{array}{l}240 \\
203 \\
175 \\
163 \\
165 \\
158 \\
144\end{array}$ \\
\hline $\begin{array}{l}\text { Mean } \\
\text { Run- }\end{array}$ & $\begin{array}{l}\text { nthly } \\
\text {, in }\end{array}$ & $\begin{array}{l}\text { schar } \\
\text { hes. }\end{array}$ & , 1 . & $\begin{array}{c}\text { second- } \\
.\end{array}$ & . & . : & $\begin{array}{lll} & \bullet & \bullet \\
\bullet & \bullet & .\end{array}$ & $\begin{array}{lll}. & . & . \\
. & . & \end{array}$ & . : & $\begin{array}{r}890 \\
5.46\end{array}$ & $\begin{array}{r}228 \\
1.44\end{array}$ \\
\hline
\end{tabular}

Gage height, in feet, and discharge, in second-feet, at indicated time, 1938

\begin{tabular}{|c|c|c|c|c|c|c|c|c|c|c|c|c|}
\hline \multirow{2}{*}{$\begin{array}{l}9 \\
3 \\
\text { 出 }\end{array}$} & Feet & Sec.ft. & Feet & Sec.ft. & Feot & Sec.ft. & Feet & Sec.ft, & Feet & Sec.ft. & Feet & Sec.ft \\
\hline & \multicolumn{2}{|c|}{ September 18} & \multicolumn{2}{|c|}{ September 19} & \multicolumn{2}{|c|}{ September 20} & \multicolumn{2}{|c|}{ September 21} & \multicolumn{2}{|c|}{ September 22} & \multicolumn{2}{|c|}{ September 23} \\
\hline $\begin{array}{l}1 \\
2 \\
3 \\
4 \\
5 \\
6\end{array}$ & $\begin{array}{l}3.42 \\
3.42 \\
3.41 \\
3.40 \\
3.40 \\
3.40\end{array}$ & $\begin{array}{l}120 \\
120 \\
118 \\
116 \\
116 \\
116\end{array}$ & $\begin{array}{l}3.38 \\
3.38 \\
3.39 \\
3.38 \\
3.39 \\
3.39\end{array}$ & $\begin{array}{l}113 \\
113 \\
114 \\
113 \\
114 \\
114\end{array}$ & $\begin{array}{l}4.93 \\
5.15 \\
5.30 \\
5.41 \\
5.50 \\
5.60\end{array}$ & $\begin{array}{r}696 \\
820 \\
910 \\
976 \\
1,030 \\
1,090\end{array}$ & $\begin{array}{l}7.01 \\
7.03 \\
7.05 \\
7.09 \\
7.15 \\
7.21\end{array}$ & $\begin{array}{l}2,130 \\
2,140 \\
2,160 \\
2,190 \\
2,240 \\
2,290\end{array}$ & & $\begin{array}{l}13,000 \\
15,900 \\
15,900 \\
13,900 \\
12,100 \\
10,600\end{array}$ & & $\begin{array}{l}4,100 \\
4,030 \\
3,930 \\
3,850 \\
3,790 \\
3,720\end{array}$ \\
\hline $\begin{array}{r}7 \\
8 \\
9 \\
10 \\
11 \\
N\end{array}$ & $\begin{array}{l}3.40 \\
3.39 \\
3.39 \\
3.39 \\
3.38 \\
3.38\end{array}$ & $\begin{array}{l}116 \\
114 \\
114 \\
114 \\
113 \\
113\end{array}$ & $\begin{array}{l}3.3 \\
3.3 \\
3.4 \\
3.4 \\
3.4 \\
3.4\end{array}$ & $\begin{array}{l}114 \\
114 \\
116 \\
116 \\
116 \\
122\end{array}$ & $\begin{array}{l}5.66 \\
5.75 \\
5.86 \\
5.97 \\
6.06 \\
6.13\end{array}$ & $\begin{array}{l}1,130 \\
1,180 \\
1,260 \\
1,340 \\
1,400 \\
1,450\end{array}$ & $\begin{array}{l}7.29 \\
7.38 \\
7.50 \\
7.61 \\
7.76 \\
7.96\end{array}$ & $\begin{array}{l}2,350 \\
2,420 \\
2,520 \\
2,610 \\
2,730 \\
2,890\end{array}$ & $\begin{array}{l}13.70 \\
12.90 \\
12.22 \\
11.80 \\
11.38 \\
11.08\end{array}$ & $\begin{array}{l}9,340 \\
8,250 \\
7,360 \\
6,860 \\
6,360 \\
6,010\end{array}$ & $\begin{array}{l}8.80 \\
8.74 \\
8.67 \\
8.60 \\
8.55 \\
8.48\end{array}$ & $\begin{array}{l}3,650 \\
3,600 \\
3,530 \\
3,470 \\
3,420 \\
3,360\end{array}$ \\
\hline $\begin{array}{l}1 \\
2 \\
3 \\
4 \\
5 \\
6\end{array}$ & $\begin{array}{l}3.38 \\
3.38 \\
3.37 \\
3.37 \\
3.37 \\
3.38\end{array}$ & $\begin{array}{l}113 \\
113 \\
111 \\
111 \\
111 \\
113\end{array}$ & $\begin{array}{l}3.45 \\
3.58 \\
3.61 \\
3.64 \\
3.75 \\
3.92\end{array}$ & $\begin{array}{l}126 \\
154 \\
162 \\
169 \\
200 \\
252\end{array}$ & $\begin{array}{l}6.2 \\
6.3 \\
6.4 \\
6.5 \\
6.6 \\
6.7\end{array}$ & $\begin{array}{l}1,520 \\
1,590 \\
1,660 \\
1,740 \\
1,800 \\
1,880\end{array}$ & $\begin{array}{r}8.13 \\
8.40 \\
8.69 \\
9.01 \\
9.58 \\
10.45\end{array}$ & $\begin{array}{l}3,050 \\
3,290 \\
3,550 \\
3,840 \\
4,410 \\
5,320\end{array}$ & $\begin{array}{l}10.84 \\
10.66 \\
10.49 \\
10.35 \\
10.20 \\
10.06\end{array}$ & $\begin{array}{l}5,740 \\
5,550 \\
5,360 \\
5,200 \\
5,040 \\
4,890\end{array}$ & $\begin{array}{l}8.41 \\
8.35 \\
8.30 \\
8.24 \\
8.17 \\
8.11\end{array}$ & $\begin{array}{l}3,300 \\
3,240 \\
3,200 \\
3,150 \\
3,080 \\
3,030\end{array}$ \\
\hline $\begin{array}{r}7 \\
8 \\
9 \\
20 \\
11 \\
11 \\
\end{array}$ & $\begin{array}{l}3.38 \\
3.38 \\
3.38 \\
3.38 \\
3.38 \\
3.39 \\
\end{array}$ & $\begin{array}{l}113 \\
113 \\
113 \\
113 \\
113 \\
114 \\
\end{array}$ & $\begin{array}{l}4.02 \\
4.10 \\
4.21 \\
4.33 \\
4.50 \\
4.70 \\
\end{array}$ & $\begin{array}{l}285 \\
313 \\
355 \\
404 \\
479 \\
575 \\
\end{array}$ & $\begin{array}{l}6.77 \\
6.84 \\
6.90 \\
6.94 \\
6.97 \\
7.00 \\
\end{array}$ & $\begin{array}{l}1,940 \\
1,990 \\
2,040 \\
2,070 \\
2,100 \\
2,120\end{array}$ & $\begin{array}{l}11.35 \\
12.06 \\
12.74 \\
13.43 \\
14.10 \\
14.75 \\
\end{array}$ & $\begin{array}{r}6,320 \\
7,170 \\
8,040 \\
8,960 \\
9,900 \\
10,900 \\
\end{array}$ & $\begin{array}{l}9.92 \\
9.80 \\
9.67 \\
9.56 \\
9.45 \\
9.35 \\
\end{array}$ & $\begin{array}{l}4,750 \\
4,630 \\
4,500 \\
4,390 \\
4,280 \\
4,180 \\
\end{array}$ & $\begin{array}{l}8.04 \\
7.99 \\
7.91 \\
7.86 \\
7.80 \\
7.73 \\
\end{array}$ & $\begin{array}{l}2,970 \\
2,920 \\
2,850 \\
2,810 \\
2,760 \\
2,700 \\
\end{array}$ \\
\hline & \multicolumn{2}{|c|}{ September 24} & \multicolumn{2}{|c|}{ September 25} & \multicolumn{2}{|c|}{ September 26} & \multicolumn{2}{|c|}{ September 27} & \multicolumn{2}{|c|}{ September 28} & \multicolumn{2}{|c|}{ September 29} \\
\hline $\begin{array}{r}2 \\
4 \\
6 \\
8 \\
10 \\
N\end{array}$ & $\begin{array}{l}7.61 \\
7.48 \\
7.36 \\
7.27 \\
7.17 \\
7.06\end{array}$ & $\begin{array}{l}2,610 \\
2,500 \\
2,410 \\
2,340 \\
2,260 \\
2,170\end{array}$ & $\begin{array}{l}6.50 \\
6.42 \\
6.35 \\
6.26 \\
6.20 \\
6.14\end{array}$ & $\begin{array}{l}1,740 \\
1,680 \\
1,640 \\
1,570 \\
1,530 \\
1,490\end{array}$ & $\begin{array}{l}5.75 \\
5.72 \\
5.68 \\
5.66 \\
5.63 \\
5.61\end{array}$ & $\begin{array}{l}1,220 \\
1,190 \\
1,170 \\
1,150 \\
1,130 \\
1,120\end{array}$ & $\begin{array}{l}5.40 \\
5.36 \\
5.34 \\
5.32 \\
5.29 \\
5.27\end{array}$ & $\begin{array}{l}990 \\
966 \\
954 \\
942 \\
924 \\
912\end{array}$ & $\begin{array}{l}5.16 \\
5.13 \\
5.12 \\
5.10 \\
5.08 \\
5.06\end{array}$ & $\begin{array}{l}846 \\
828 \\
822 \\
810 \\
799 \\
788\end{array}$ & & 711 \\
\hline $\begin{array}{r}2 \\
4 \\
6 \\
8 \\
10 \\
M\end{array}$ & $\begin{array}{l}7.00 \\
6.89 \\
6.81 \\
6.73 \\
6.65 \\
6.57\end{array}$ & $\begin{array}{l}2,120 \\
2,030 \\
1,970 \\
1,900 \\
1,840 \\
1,790\end{array}$ & $\begin{array}{l}6.09 \\
6.03 \\
5.97 \\
5.91 \\
5.85 \\
5.79\end{array}$ & $\begin{array}{l}1,450 \\
1,410 \\
1,370 \\
1,330 \\
1,280 \\
1,240\end{array}$ & $\begin{array}{l}5 . \\
5 . \\
5 \\
5 . \\
5 .\end{array}$ & $\begin{array}{l}1,090 \\
1,070 \\
1,060 \\
1,040 \\
1,020 \\
1,010\end{array}$ & $\begin{array}{l}5.24 \\
5.23 \\
5.22 \\
5.21 \\
5.19 \\
5.18\end{array}$ & $\begin{array}{l}894 \\
888 \\
882 \\
876 \\
864 \\
858\end{array}$ & $\begin{array}{l}03 \\
01 \\
00 \\
97 \\
95 \\
93\end{array}$ & $\begin{array}{l}772 \\
760 \\
755 \\
738 \\
728 \\
716\end{array}$ & $\begin{array}{l}82 \\
80 \\
80 \\
78 \\
76 \\
75\end{array}$ & $\begin{array}{l}63 \\
62\end{array}$ \\
\hline
\end{tabular}


New Croton Reservo1r at New Croton Dam, near Croton, N. Y.

Location. - Staff gage, lat. $41^{\circ} 13^{\prime} 40^{\prime \prime}$, Iong. $73^{\circ} 51^{\prime} 25^{\prime \prime}$, at New Croton Dam, $13 / 4 \mathrm{mlles}$ northeast of Croton, Testchester County. Crest of spillway is at elevation 201.06 feet above mean sea level (202.00 feet, Croton datum).

Drainage erea.- 377 square miles.

Gage-height record. - Gage read at 7 a.m. Sept. 1-24, and at 8 a.m. sept. 25 to 0ct. 31. Gage holghts are elevations referred to Croton dátum.

Remarks.- New Croton Reservolr is the lowest reservolr in the Croton River system of reservolrs, which consists of 10 other storage reservolrs and 6 controlled lakes having a combined atorage capac1ty of about 13,782,000,000 cuble feet. The storage capac1ty of New Croton Reservo1r is about 3,758,000,000 cubic feet. The contents of Muscoot Reservolr, a continuation of New Croton Reservoir after its dam is submerged at elevation 200.0 feet, 18 not included in the contents given in the tables below. For informetion on storage and diversion in the Crotion River Basin see record for Croton River reservolrs above New Croton Dam, near Croton, $N$. Y. Records furnished by New York C1ty Department of Water Supply, Gas, and Electricity.

Elevation, in feet, and contents, in millions of cublc feet, 1938 a/

\begin{tabular}{|c|c|c|c|c|c|c|c|c|c|}
\hline \multirow{2}{*}{ Day } & \multicolumn{2}{|c|}{ September } & \multicolumn{2}{|c|}{ October } & \multirow[b]{2}{*}{ Day } & \multicolumn{2}{|c|}{ September } & \multicolumn{2}{|c|}{ October } \\
\hline & Feet & $\begin{array}{l}\text { Mililons of } \\
\text { cubic feet }\end{array}$ & Feet & $\begin{array}{l}\text { Millions of } \\
\text { cublc feet }\end{array}$ & & Feet & $\begin{array}{l}\text { Millions of } \\
\text { cubic feet }\end{array}$ & Feet & $\begin{array}{l}\text { Millions of } \\
\text { cubic feet }\end{array}$ \\
\hline $\begin{array}{l}1 \\
2 \\
3 \\
4 \\
5\end{array}$ & $\begin{array}{l}201.08 \\
201.01 \\
200.94 \\
200.83 \\
200.71\end{array}$ & $\begin{array}{l}3,666 \\
3,658 \\
3,652 \\
3,641 \\
3,629\end{array}$ & $\begin{array}{l}202.55 \\
202.43 \\
202.37 \\
202.32 \\
202.27\end{array}$ & $\begin{array}{l}3,812 \\
3,800 \\
3,794 \\
3,789 \\
3,784\end{array}$ & $\begin{array}{l}16 \\
17 \\
18 \\
19 \\
20\end{array}$ & $\begin{array}{l}198.33 \\
198.10 \\
197.88 \\
197.80 \\
198.55\end{array}$ & $\begin{array}{l}3,399 \\
3,376 \\
3,355 \\
3,348 \\
3,420\end{array}$ & $\begin{array}{l}202.07 \\
202.07 \\
202.06 \\
202.04 \\
202.03\end{array}$ & $\begin{array}{l}3,765 \\
3,765 \\
3,764 \\
3,762 \\
3,761\end{array}$ \\
\hline $\begin{array}{r}6 \\
7 \\
8 \\
9 \\
10\end{array}$ & $\begin{array}{l}200.59 \\
200.41 \\
200.25 \\
200.03 \\
199.76\end{array}$ & $\begin{array}{l}3,617 \\
3,608 \\
3,583 \\
3,561 \\
3,536\end{array}$ & $\begin{array}{l}202 \cdot 22 \\
202 \cdot 20 \\
202 \cdot 17 \\
202 \cdot 15 \\
202 \cdot 13\end{array}$ & $\begin{array}{l}3,780 \\
3,778 \\
3,775 \\
3,773 \\
3,771\end{array}$ & $\begin{array}{l}21 \\
22 \\
23 \\
24 \\
25\end{array}$ & $\begin{array}{l}199.87 \\
204 \cdot 1.8 \\
204.00 \\
203 \cdot 54 \\
203 \cdot 20\end{array}$ & $\begin{array}{l}3,546 \\
3,976 \\
3,958 \\
3,911 \\
3,877\end{array}$ & $\begin{array}{l}202 \cdot 19 \\
202 \cdot 19 \\
202 \cdot 14 \\
202 \cdot 15 \\
202.19\end{array}$ & $\begin{array}{l}3,777 \\
3,777 \\
3,772 \\
3,773 \\
3,777\end{array}$ \\
\hline $\begin{array}{l}11 \\
12 \\
13 \\
14 \\
15\end{array}$ & $\begin{array}{l}199.48 \\
199.19 \\
198.94 \\
198.75 \\
198.51\end{array}$ & $\begin{array}{l}3,509 \\
3,481 \\
3,457 \\
3,439 \\
3,416\end{array}$ & $\begin{array}{l}202.12 \\
202.09 \\
202.08 \\
202.08 \\
202.07\end{array}$ & $\begin{array}{l}3,770 \\
3,767 \\
3,766 \\
3,766 \\
3,765\end{array}$ & $\begin{array}{l}26 \\
27 \\
28 \\
29 \\
30 \\
31\end{array}$ & $\begin{array}{l}202.97 \\
202.82 \\
202.82 \\
202.72 \\
202.63\end{array}$ & $\begin{array}{l}3,854 \\
3,839 \\
3,839 \\
3,829 \\
3,820\end{array}$ & $\begin{array}{l}202.15 \\
202.10 \\
202.08 \\
202.05 \\
202.04 \\
202.03\end{array}$ & $\begin{array}{l}3,773 \\
3,768 \\
3,766 \\
3,763 \\
3,762 \\
3,761\end{array}$ \\
\hline
\end{tabular}

a/ At 8 a.m. Sept. 1-24; 9 a.m. Sept. 25 to Oct. 31 .

Elevation in feet, and contents, in millions of cubic feet, at indicated time, 1938

\begin{tabular}{|c|c|c|c|c|c|c|c|c|}
\hline \multirow[t]{2}{*}{ Hour } & Feet & $\begin{array}{l}\text { Millions of } \\
\text { cublc feet }\end{array}$ & Feet & $\begin{array}{l}\text { Millions of } \\
\text { cublc feet }\end{array}$ & Feet & $\begin{array}{l}\text { Millions of } \\
\text { cublc feet }\end{array}$ & Feet & $\begin{array}{l}\text { Millions of } \\
\text { cubic feet }\end{array}$ \\
\hline & \multicolumn{2}{|c|}{ September 18} & \multicolumn{2}{|c|}{ September 19} & \multicolumn{2}{|c|}{ September 20} & \multicolumn{2}{|c|}{ September 21} \\
\hline $\begin{array}{l}3 \\
7 \\
1\end{array}$ & $\begin{array}{l}197.92 \\
197.88 \\
197.84\end{array}$ & $\begin{array}{l}3,359 \\
3,355 \\
3,350\end{array}$ & $\begin{array}{l}197.79 \\
197.80 \\
197.81\end{array}$ & $\begin{array}{l}3,347 \\
3,348 \\
3,349\end{array}$ & $\begin{array}{l}198.34 \\
198.55 \\
198.72\end{array}$ & $\begin{array}{l}3,400 \\
3,420 \\
3,436\end{array}$ & $\begin{array}{l}199.50 \\
199.87 \\
200.45\end{array}$ & $\begin{array}{l}3,511 \\
3,546 \\
3,603\end{array}$ \\
\hline \multirow[t]{2}{*}{$\begin{array}{l}3 \\
7 \\
1 \\
1\end{array}$} & $\begin{array}{l}197.81 \\
197.79 \\
197.78 \\
\end{array}$ & $\begin{array}{l}3,349 \\
3,317 \\
3,346\end{array}$ & $\begin{array}{l}197.82 \\
198.07 \\
198.20\end{array}$ & $\begin{array}{l}3,350 \\
3,373 \\
3,386\end{array}$ & $\begin{array}{l}198.87 \\
199.08 \\
199.30\end{array}$ & $\begin{array}{l}3,450 \\
3,470 \\
3,492\end{array}$ & $\begin{array}{l}201.50 \\
202.74 \\
203.63\end{array}$ & $\begin{array}{l}3,708 \\
3,831 \\
3,920\end{array}$ \\
\hline & \multicolumn{2}{|c|}{ September 22} & \multicolumn{2}{|c|}{ September 23} & \multicolumn{2}{|c|}{ September 24} & \multicolumn{2}{|c|}{ September 25} \\
\hline $\begin{array}{ll}3 & \mathrm{a} \cdot \mathrm{m} . \\
4 & \\
7 & \\
8 & \\
1 & \\
12 & \\
3 & \mathrm{p} \cdot \mathrm{m} . \\
4 & \\
7 & \\
8 & \\
11 & \\
12 & \\
\end{array}$ & $\begin{array}{c}204.04 \\
\overline{\overline{4}} .18 \\
\overline{-} \\
204.23 \\
- \\
204.22 \\
\overline{-} \\
20 \overline{4} .18 \\
20 \overline{4} .14 \\
-\end{array}$ & $\begin{array}{r}3,962 \\
-3,976 \\
-3,981 \\
-3,980 \\
-3,976 \\
-3,972 \\
-\end{array}$ & $\begin{array}{c}204.06 \\
\overline{4} .00 \\
-\overline{3} .92 \\
20 \\
203.85 \\
20 \overline{3} .78 \\
\overline{-} .69 \\
20 \overline{-}\end{array}$ & $\begin{array}{r}3,964 \\
-3,958 \\
-3,950 \\
-3,943 \\
-3,935 \\
-3,926 \\
-\end{array}$ & $\begin{array}{c}203.62 \\
- \\
20 \overline{3} .54 \\
\overline{-} .48 \\
203.48 \\
- \\
203.42 \\
\overline{-} .37 \\
203.37 \\
20 \overline{3} .30 \\
-\end{array}$ & $\begin{array}{r}3,919 \\
-3,911 \\
-3,905 \\
-3,899 \\
-3,894 \\
-3,886 \\
-3\end{array}$ & $\begin{array}{c}20 \overline{3} .25 \\
\overline{\overline{3}} .20 \\
20 \overline{3} .16 \\
20 \overline{3} .11 \\
20 \overline{3} .07 \\
\overline{-} .03\end{array}$ & $\begin{array}{r}-3,882 \\
-3,877 \\
-3,873 \\
-3,868 \\
-3,864 \\
-3,860\end{array}$ \\
\hline $\begin{array}{ll}3 & \text { p.m. } \\
4 & \\
7 \\
8 \\
11 \\
12\end{array}$ & \multicolumn{2}{|c|}{ September 26} & \multicolumn{2}{|c|}{ September 27} & \multicolumn{2}{|c|}{ September 28} & \multicolumn{2}{|c|}{ September 29} \\
\hline $\begin{array}{l}4 \\
8 \\
2\end{array}$ & $\begin{array}{l}203.00 \\
202.97 \\
202.94\end{array}$ & $\begin{array}{l}3,857 \\
3,854 \\
3,851\end{array}$ & $\begin{array}{l}202.85 \\
202.82 \\
202.81\end{array}$ & $\begin{array}{l}3,842 \\
3,839 \\
3,838\end{array}$ & $\begin{array}{l}202.82 \\
202.82 \\
202.79\end{array}$ & $\begin{array}{l}3,839 \\
3.839 \\
3,836\end{array}$ & $\begin{array}{l}202 \cdot 73 \\
202.72 \\
202 \cdot 70\end{array}$ & $\begin{array}{l}3,830 \\
3,829 \\
3,827\end{array}$ \\
\hline $\begin{array}{l}4 \\
8 \\
12\end{array}$ & $\begin{array}{l}202.91 \\
202.89 \\
202.87\end{array}$ & $\begin{array}{l}3,848 \\
3,846 \\
3,844\end{array}$ & $\begin{array}{l}202.80 \\
202.82 \\
202.82\end{array}$ & $\begin{array}{l}3,837 \\
3,839 \\
3,839\end{array}$ & $\begin{array}{l}202.77 \\
202.76 \\
202.74\end{array}$ & $\begin{array}{l}3,834 \\
3,833 \\
3,831\end{array}$ & $\begin{array}{l}202.69 \\
202.67 \\
202.66\end{array}$ & $\begin{array}{l}3,826 \\
3,824 \\
3,823\end{array}$ \\
\hline
\end{tabular}


Location.- The flow of the Croton River and its tributaries is controlled and regulated for the New York City water supply by about 13,782,000,000 cubic feet of storage in 11 reservolrs and 6 controlled lakes. The storage reservolrs are Boyd's Corners, West Branch, Middle Branch, East Branch, Croton Falls (main), Croton Falls (diversion), Titicus, Amawalk, Cross River, Muscoot, Croton, and New Croton. The controlled lakes are Mahopoc, Kirk, Gleneida, Gilead and Barrett's Lakes and White Ponds.

Drainage area.- 377 square miles above New Croton Dam near Croton, N. Y., the lowest regulating dam on the Croton River.

Diversions.- Mean daily diversion, in second-feet, is the net diversion from the basin from storage reservolis at Boyd's Corners, West Branch, Middle Branch, East Branch, Croton Falls (main), Croton Falls (diversion), Titicus, Amawalk and Cross River. Mean daily diversions are for 24 hours beginning at 7 a.m. of indicated day, Sept. 1-23; for 25 hours, Sept. 24; and for 24 hours beginning at 8 a.m. of indicated day, Sept. 25 to oct. 31 .

Storage.- Daily gain or loss in storage, in equivalent mean second-feet, is the net change in contents in the 12 storage reservoirs and 6 controlled lakes for 24 hours beglnning at $7 \mathrm{a} \cdot \mathrm{m}$. of indicated day, Sept. 1-23; for 25 hours, Sept. 24; and for 24 hours beginning at 8 a.m. of indicated day, Sept. 25 to 0ct. 31 .

Remarks.- Records furnished by New York City Department of Water Supply, Gas, and Electricity.

Mean daily diversion, in second-feet, and gain or loss in storage, in equivalent mean second-feet, 1938

\begin{tabular}{|c|c|c|c|c|c|c|c|c|c|}
\hline \multirow{2}{*}{ Day } & \multicolumn{2}{|c|}{ September } & \multicolumn{2}{|c|}{ October } & \multirow{2}{*}{ Day } & \multicolumn{2}{|c|}{ September } & \multicolumn{2}{|c|}{ October } \\
\hline & Diversion & Storage & Diversion & Storage & & Diversion & Storage & Diversion & Storage \\
\hline $\begin{array}{l}1 \\
2 \\
3 \\
4 \\
5\end{array}$ & $\begin{array}{l}487 \\
468 \\
469 \\
490 \\
496\end{array}$ & $\begin{array}{l}-278 \\
-388 \\
-396 \\
-391 \\
-394\end{array}$ & \begin{tabular}{|l|}
296 \\
305 \\
293 \\
331 \\
457
\end{tabular} & $\begin{array}{l}-365 \\
-246 \\
-203 \\
-176 \\
-192\end{array}$ & $\begin{array}{l}16 \\
17 \\
18 \\
19 \\
20\end{array}$ & \begin{tabular}{|l|}
500 \\
499 \\
475 \\
447 \\
414 \\
\end{tabular} & $\begin{array}{r}-308 \\
-169 \\
166 \\
2,597 \\
3,934\end{array}$ & \begin{tabular}{|}
430 \\
440 \\
469 \\
478 \\
478
\end{tabular} & $\begin{array}{r}-170 \\
-206 \\
-224 \\
-224 \\
647\end{array}$ \\
\hline $\begin{array}{r}6 \\
7 \\
8 \\
9 \\
10\end{array}$ & $\begin{array}{l}496 \\
496 \\
485 \\
475 \\
484\end{array}$ & $\begin{array}{l}-314 \\
-305 \\
-330 \\
-387 \\
-506\end{array}$ & $\begin{array}{l}458 \\
459 \\
442 \\
447 \\
465\end{array}$ & $\begin{array}{l}-149 \\
-127 \\
-161 \\
-152 \\
-141\end{array}$ & $\begin{array}{l}21 \\
22 \\
23 \\
24 \\
25\end{array}$ & $\begin{array}{l}309 \\
389 \\
311 \\
317 \\
312\end{array}$ & $\begin{array}{r}12,314 \\
-1,550 \\
-2,093 \\
-1,157 \\
-941\end{array}$ & $\begin{array}{l}478 \\
466 \\
403 \\
325 \\
356\end{array}$ & $\begin{array}{r}101 \\
-80 \\
-8 \\
469 \\
51\end{array}$ \\
\hline $\begin{array}{l}11 \\
12 \\
13 \\
14 \\
15\end{array}$ & $\begin{array}{l}495 \\
514 \\
499 \\
517 \\
497\end{array}$ & $\begin{array}{r}-458 \\
-288 \\
-158 \\
-237 \\
-71\end{array}$ & $\begin{array}{l}479 \\
470 \\
449 \\
449 \\
437\end{array}$ & $\begin{array}{l}-226 \\
-170 \\
-167 \\
-200 \\
-189\end{array}$ & $\begin{array}{l}26 \\
27 \\
28 \\
29 \\
30 \\
31\end{array}$ & $\begin{array}{l}325 \\
312 \\
305 \\
305 \\
289\end{array}$ & $\begin{array}{l}-678 \\
-271 \\
-606 \\
-534 \\
-390\end{array}$ & $\begin{array}{l}393 \\
317 \\
332 \\
332 \\
334 \\
346\end{array}$ & $\begin{array}{r}77 \\
84 \\
97 \\
97 \\
17 \\
-22\end{array}$ \\
\hline \multicolumn{3}{|c|}{ Mean } & conond fos & . . & - & 429 & +180 & 407 & -70 \\
\hline
\end{tabular}


Location.- Lat. $41^{\circ} 13^{\prime} 40^{n}$, long. $73^{\circ} 51^{\prime} 25^{n}$, at New Croton Dam, $13 / 4$ miles northeast of Croton, Westchester County.

Drainage area.- 377 square miles.

Gage-height record.- Elevation of New Croton Reservolr observed at 4-hour intervals. For informetion on elevation of New Croton Reservoir see record for New Croton Reservoir at Hew Croton Dam, near Croton, N. Y.

Stage-discharge relation.- Discharge is waste over top of permanent steel flashboards on spillway at elevation 202.00 feet (Croton datum), computed by rating table from observed elevations of New Croton Reservoir.

Maxima.- September 1938: Discharge, 10,240 second-feet 11 a.m. Sept. 22 (gage helght, 204.23 feet, from observation of elevation and estimate of time by engineers of New York City Department of Water Supply, Gas, and Blectricityj.

Remarks.- Mean daily discharges are for 24 hours beginning at 7 a.m. of ind cated day, Sept. 1-23; for 25 hours, Sept. 24; and for 24 hours beginning at 8 a.m. of indicated day, jept. 25 to 0ct. 31. Mean monthly discharge adjusted for diversion and storage in the Croton River system of reservoirs. For information on diversions and storage see records for New Croton Reservoir at New Croton Dam, near Croton, N. $Y$, and for Croton River Reservoirs above New Croton Dam, near Croton, N. Y. Records furnished by New York City Department of Water Supply, Gas, and Blectricity.

Mean dally discharge, in second-feet, 1938

\begin{tabular}{|c|c|c|c|c|c|c|c|c|c|c|c|}
\hline Day & Sept. & oct. & Day & Sept. & oct. & Day & Sept. & oct. & Day & Sept. & oct. \\
\hline $\begin{array}{l}1 \\
2 \\
3 \\
4 \\
5 \\
6 \\
7 \\
8\end{array}$ & $\begin{array}{l}0 \\
0 \\
0 \\
0 \\
0 \\
0 \\
0 \\
0\end{array}$ & $\begin{array}{r}1,033 \\
716 \\
538 \\
429 \\
289 \\
223 \\
195 \\
149\end{array}$ & $\begin{array}{l}9 \\
10 \\
11 \\
12 \\
13 \\
14 \\
15 \\
16\end{array}$ & $\begin{array}{l}0 \\
0 \\
0 \\
0 \\
0 \\
0 \\
0 \\
0\end{array}$ & $\begin{array}{r}122 \\
99 \\
74 \\
62 \\
51 \\
50 \\
42 \\
42\end{array}$ & $\begin{array}{l}17 \\
18 \\
19 \\
20 \\
21 \\
22 \\
23 \\
24\end{array}$ & $\begin{array}{r}0 \\
0 \\
0 \\
0 \\
3,716 \\
9,726 \\
7,289 \\
5,114\end{array}$ & $\begin{array}{r}42 \\
29 \\
12 \\
82 \\
213 \\
152 \\
108 \\
186\end{array}$ & $\begin{array}{l}25 \\
26 \\
27 \\
28 \\
29 \\
30 \\
31\end{array}$ & $\begin{array}{l}3,441 \\
2,596 \\
2,263 \\
2,039 \\
1,703 \\
1,343\end{array}$ & $\begin{array}{r}173 \\
90 \\
63 \\
39 \\
22 \\
19 \\
11\end{array}$ \\
\hline $\begin{array}{l}\text { Mean } \\
\text { Mean } \\
\text { Run- }\end{array}$ & $\begin{array}{l}\text { montnly } \\
\text { monthly } \\
\text { ff, in }\end{array}$ & $\begin{array}{l}\text { scnere } \\
\text { schar: } \\
\text { hes. }\end{array}$ & , in & $\begin{array}{l}\text { second- } \\
\text { second- } \\
.\end{array}$ & $\begin{array}{l}e t \\
e t \\
.\end{array}$ & $\begin{array}{l}\text { erved } \\
\text { isted } \\
\text {. }\end{array}$ & 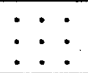 & 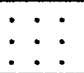 & $\dot{:} \dot{\bullet}$ & $\begin{array}{r}1,308 \\
1,917 \\
5.68\end{array}$ & $\begin{array}{r}173 \\
510 \\
1.56\end{array}$ \\
\hline
\end{tabular}

Discharge, in second-feet, at Indicated time, September 1938

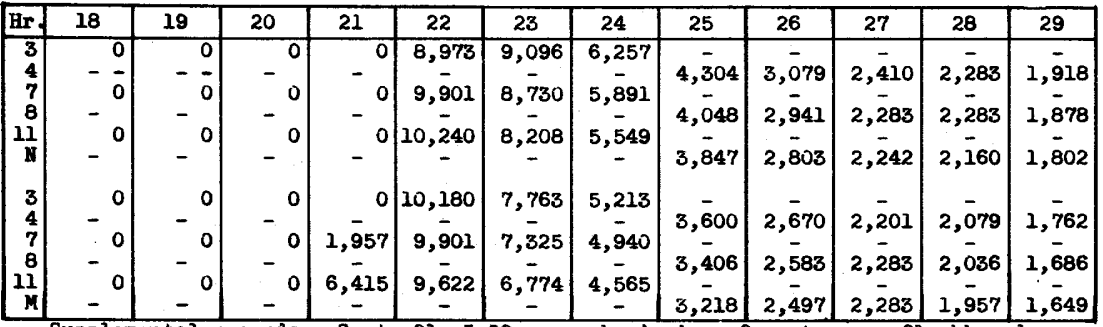

Supplemental records.- Sept. $21,5: 50 \mathrm{p.m} \cdot$, beginning of waste over flashboards. $2279070-40-10$ 
Croton River at Quaker Bridge, near Croton, N. Y.

Location.- Water-stage recorder, lat. 41\%12'40n, long. $73^{\circ} 52^{\prime} 10^{\prime \prime}$, 25 feet below Quaker Bridge, 600 feet below mouth of Bird Brook, and 1 mile east of Croton, Westchester County.

Drainage area.- 379 square miles; 377 square miles affected by storage and diversion in the Croton River system of reservoirs and controlled lakes.

Gage-height record.- Water-stage recorder graph except for period 9:30 p.m. Sept. 21 to $5: 30$ p.m. Sept. 27, when discharge was computed on basis of spillway discharge at New Croton Dam.

Stage-discharge relation.- Sept. Il to 0ct. 31 affected below gage height 2.87 feet by backwater from pipe on control. Defined by current-meter measurements below. 3,310 second-feet; extended logarithmically to peak stage on basis of discharge at New Croton Dam.

Maxima.- September 1938: Discharge, 8,410 second-feet noon. Sept. 22 (gage height, 13.34 feet).

July 1933 to August 1938: Discharge, 4,530 second-feet Mar. 19, 1936 (gage height, 10.30 feet)

Remarks.- Flow regulated at New Croton Dam, where diversion is made for New York City water supply. Diurnal fluctuations caused by pumping for Croton water supply from wells downstream from New Croton Dam. Mean monthiy discharge adjusted for storage and diversion in the entire Croton River system of reservoirs. For information on storage and diversions see records for Croton River Reservoirs above New Croton Dam, near Croton, $\mathrm{N}$. $\mathrm{Y}$.

Mean dally discharge, in second-feet, 1938

\begin{tabular}{|c|c|c|c|c|c|c|c|c|c|c|c|}
\hline Day & Sept. & oct. & Day & Sept. & Oct. & Day & Sept. & Oct. & Day & Sept. & Oct. \\
\hline $\begin{array}{l}1 \\
2 \\
3 \\
4 \\
5 \\
6 \\
7 \\
8\end{array}$ & $\begin{array}{l}4.40 \\
3.77 \\
3.46 \\
3.20 \\
3.03 \\
2.86 \\
2.93 \\
2.73\end{array}$ & $\begin{array}{r}1,040 \\
786 \\
652 \\
553 \\
429 \\
346 \\
320 \\
255\end{array}$ & $\begin{array}{r}9 \\
10 \\
11 \\
12 \\
13 \\
14 \\
15 \\
16\end{array}$ & $\begin{array}{l}2.46 \\
2.49 \\
2.40 \\
2.30 \\
2.7 \\
2.35 \\
2.6 \\
2.5\end{array}$ & $\begin{array}{l}221 \\
187 \\
150 \\
122 \\
110 \\
112 \\
110 \\
104\end{array}$ & $\begin{array}{l}17 \\
18 \\
19 \\
20 \\
21 \\
22 \\
23 \\
24\end{array}$ & $\begin{array}{r}2.3 \\
2.4 \\
6.4 \\
11.2 \\
1,030 \\
7,980 \\
6,690 \\
4,620\end{array}$ & $\begin{array}{r}98 \\
86 \\
58 \\
62 \\
310 \\
260 \\
197 \\
259\end{array}$ & $\begin{array}{l}25 \\
26 \\
27 \\
28 \\
29 \\
30 \\
31\end{array}$ & $\begin{array}{l}3,300 \\
2,430 \\
1,980 \\
1,870 \\
1,570 \\
1,300\end{array}$ & $\begin{array}{r}279 \\
201 \\
150 \\
165 \\
108 \\
98 \\
82\end{array}$ \\
\hline $\begin{array}{l}\text { Mean } \\
\text { Mean } \\
\text { Run- }\end{array}$ & $\begin{array}{l}\text { monthly } \\
\text { monthly } \\
\text { ff, in }\end{array}$ & $\begin{array}{l}\text { Ischarg } \\
\text { ischarg } \\
\text { ches }\end{array}$ & , i & $\begin{array}{l}\text { second-f } \\
\text { second-f } \\
\text { d). . . }\end{array}$ & $\left\{\begin{array}{l}o b \\
a d\end{array}\right.$ & $\begin{array}{l}\text { erved } \\
\text { usted } \\
. \quad . \quad .\end{array}$ & $\dot{0}$ & 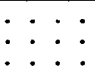 & 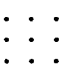 & $\begin{array}{r}1,090 \\
1,699 \\
5.00\end{array}$ & $\begin{array}{r}255 \\
592 \\
1.80\end{array}$ \\
\hline
\end{tabular}

Gage helght, In feet, and discharge, In second-feet; at indicated time, 1938

\begin{tabular}{|c|c|c|c|c|c|c|c|c|c|c|c|c|}
\hline \multirow{2}{*}{$\begin{array}{l}9 \\
3 \\
9 \\
\end{array}$} & Feet & Sec.ft. & Feet & Sec.ft. & Feet & Sec.ft. & Feet & Sec.ft. & Feet & Sec.ft. & Feet & Sec.ft. \\
\hline & \multicolumn{2}{|c|}{ September 18} & \multicolumn{2}{|c|}{ September 19} & \multicolumn{2}{|c|}{ September 20} & \multicolumn{2}{|c|}{ September 21} & \multicolumn{2}{|c|}{ September 22} & \multicolumn{2}{|c|}{ September 23} \\
\hline $\begin{array}{l}1 \\
2 \\
3 \\
4 \\
5 \\
6\end{array}$ & $\begin{array}{r}0.57 \\
.58 \\
.58 \\
.58 \\
.58 \\
.59\end{array}$ & $\begin{array}{l}2.50 \\
2.59 \\
2.59 \\
2.59 \\
2.59 \\
2.68\end{array}$ & $\begin{array}{r}0.66 \\
.66 \\
.66 \\
.77 \\
.89 \\
.88\end{array}$ & $\begin{array}{l}3.35 \\
3.35 \\
3.35 \\
4.45 \\
5.77 \\
5.65\end{array}$ & $\begin{array}{l}1.11 \\
1.11 \\
1.08 \\
1.10 \\
1.23 \\
1.22\end{array}$ & $\begin{array}{c}8.57 \\
8.57 \\
8.15 \\
8.43 \\
10.4 \\
10.2\end{array}$ & $\begin{array}{l}1.44 \\
1.40 \\
1.39 \\
1.41 \\
1.53 \\
1.57\end{array}$ & $\begin{array}{l}16.0 \\
14.8 \\
14.5 \\
15.1 \\
18.7 \\
20.2\end{array}$ & $\begin{array}{l}12.02 \\
12.37 \\
12.64 \\
12.81 \\
12.94 \\
13.04\end{array}$ & $\begin{array}{l}6,580 \\
7,030 \\
7,400 \\
7,630 \\
7,820 \\
7,960\end{array}$ & $\begin{array}{l}12.89 \\
12.80 \\
12.71 \\
12.65 \\
12.60 \\
12.54\end{array}$ & $\begin{array}{l}7,750 \\
7,620 \\
7,490 \\
7,410 \\
7,340 \\
7,260\end{array}$ \\
\hline $\begin{array}{r}7 \\
8 \\
9 \\
10 \\
11 \\
N\end{array}$ & $\begin{array}{l}.59 \\
.59 \\
.59 \\
.59 \\
.59 \\
.59\end{array}$ & $\begin{array}{l}2.68 \\
2.68 \\
2.68 \\
2.68 \\
2.68 \\
2.68\end{array}$ & $\begin{array}{l}.86 \\
.84 \\
.80 \\
.77 \\
.74 \\
.71\end{array}$ & $\begin{array}{l}5.43 \\
5.21 \\
4.77 \\
4.45 \\
4.15 \\
3.85\end{array}$ & $\begin{array}{l}1.20 \\
1.60 \\
1.50 \\
1.42 \\
1.35 \\
1.27\end{array}$ & $\begin{array}{l}9.85 \\
21.4 \\
17.8 \\
15.4 \\
13.3 \\
11.3\end{array}$ & $\begin{array}{l}1.63 \\
1.62 \\
1.78 \\
2.02 \\
2.16 \\
2.12\end{array}$ & $\begin{array}{l}22.6 \\
22.2 \\
29.0 \\
43.6 \\
56 \\
52\end{array}$ & $\begin{array}{l}13.16 \\
13.24 \\
13.29 \\
13.32 \\
13.34 \\
13.34\end{array}$ & $\begin{array}{l}8,140 \\
8,260 \\
8,340 \\
8,380 \\
8,410 \\
8,410\end{array}$ & $\begin{array}{l}12.48 \\
12.40 \\
12.32 \\
12.24 \\
12.16 \\
12.09\end{array}$ & $\begin{array}{l}7,170 \\
7,070 \\
6,970 \\
6,860 \\
6,760 \\
6,670\end{array}$ \\
\hline $\begin{array}{l}1 \\
2 \\
3 \\
4 \\
5 \\
6\end{array}$ & $\begin{array}{l}.58 \\
.57 \\
.56 \\
.54 \\
.53 \\
.53\end{array}$ & $\begin{array}{l}2.59 \\
2.50 \\
2.42 \\
2.26 \\
2.18 \\
2.18\end{array}$ & $\begin{array}{r}.72 \\
.83 \\
1.31 \\
1.41 \\
1.31 \\
1.21\end{array}$ & $\begin{array}{r}3.95 \\
5.10 \\
12.3 \\
15.1 \\
12.3 \\
10.0\end{array}$ & $\begin{array}{l}1.18 \\
1.14 \\
1.17 \\
1.19 \\
1.16 \\
1.14\end{array}$ & $\begin{array}{l}9.55 \\
8.99 \\
9.41 \\
9.70 \\
9.27 \\
8.99\end{array}$ & $\begin{array}{l}2.37 \\
2.70 \\
2.94 \\
2.87 \\
2.63 \\
5.15\end{array}$ & $\begin{array}{r}80 \\
135 \\
189 \\
173 \\
122 \\
960\end{array}$ & $\begin{array}{l}13.34 \\
13.33 \\
13.31 \\
13.27 \\
13.23 \\
13.20\end{array}$ & $\begin{array}{l}8,410 \\
8,400 \\
8,350 \\
8,300 \\
8,240 \\
8,200\end{array}$ & $\begin{array}{l}12.01 \\
11.95 \\
11.88 \\
11.80 \\
11.74 \\
11.67\end{array}$ & $\begin{array}{l}6,560 \\
6,490 \\
6,410 \\
6,310 \\
6,240 \\
6,150\end{array}$ \\
\hline \multirow[t]{2}{*}{$\begin{array}{r}7 \\
8 \\
9 \\
10 \\
11 \\
M \\
\end{array}$} & $\begin{array}{l}.52 \\
.52 \\
.52 \\
.54 \\
.57 \\
.62 \\
\end{array}$ & $\begin{array}{l}2.11 \\
2.11 \\
2.11 \\
2.26 \\
2.50 \\
2.95 \\
\end{array}$ & $\begin{array}{l}1.13 \\
1.06 \\
1.03 \\
1.01 \\
0.99 \\
1.08 \\
\end{array}$ & $\begin{array}{l}8.85 \\
7.89 \\
7.50 \\
7.24 \\
6.98 \\
8.15 \\
\end{array}$ & $\begin{array}{l}1.23 \\
1.25 \\
1.26 \\
1.32 \\
1.44 \\
1.45 \\
\end{array}$ & $\begin{array}{l}10.4 \\
10.8 \\
11.1 \\
12.5 \\
16.0 \\
16.3 \\
\end{array}$ & $\begin{array}{r}7.00 \\
8.38 \\
10.03 \\
10.55 \\
10.96 \\
11.62 \\
\end{array}$ & $\begin{array}{l}2,020 \\
2,990 \\
4,400 \\
4,920 \\
5,350 \\
6,090 \\
\end{array}$ & $\begin{array}{l}13.16 \\
13.12 \\
13.09 \\
13.06 \\
13.02 \\
12.97 \\
\end{array}$ & $\begin{array}{l}8,140 \\
8,080 \\
8,040 \\
7,990 \\
7,930 \\
7,860 \\
\end{array}$ & $\begin{array}{l}11.59 \\
11.51 \\
11.42 \\
11.32 \\
11.22 \\
11.14\end{array}$ & $\begin{array}{l}6,060 \\
5,960 \\
5,850 \\
5,740 \\
5,630 \\
5,540 \\
\end{array}$ \\
\hline & \multicolumn{2}{|c|}{ September 24} & \multicolumn{2}{|c|}{ September 25} & \multicolumn{2}{|c|}{ September 26} & \multicolumn{2}{|c|}{ September 27} & \multicolumn{2}{|c|}{ September 28} & \multicolumn{2}{|c|}{ September 29} \\
\hline $\begin{array}{r}2 \\
4 \\
6 \\
8 \\
10 \\
N\end{array}$ & $\begin{array}{l}10.98 \\
10.83 \\
10.67 \\
10.48 \\
10.32 \\
10.18\end{array}$ & $\begin{array}{l}5,370 \\
5,200 \\
5,040 \\
4,850 \\
4,690 \\
4,550\end{array}$ & $\begin{array}{l}9.35 \\
9.22 \\
9.09 \\
8.96 \\
8.86 \\
8.76\end{array}$ & $\begin{array}{l}3,780 \\
3,670 \\
3,560 \\
3,460 \\
3,380 \\
3,300\end{array}$ & $\begin{array}{l}7.97 \\
7.90 \\
7.82 \\
7.74 \\
7.66 \\
7.57\end{array}$ & $\begin{array}{l}2,700 \\
2,650 \\
2,590 \\
2,540 \\
2,480 \\
2,420\end{array}$ & $\begin{array}{l}7.14 \\
7.09 \\
7.01 \\
6.92 \\
6.90 \\
6.87\end{array}$ & $\begin{array}{l}2,120 \\
2,080 \\
2,030 \\
1,970 \\
1,960 \\
1,940\end{array}$ & $\begin{array}{l}6.95 \\
6.94 \\
6.90 \\
6.88 \\
6.79 \\
6.72\end{array}$ & $\begin{array}{l}1,990 \\
1,980 \\
1,960 \\
1,950 \\
1,890 \\
1,850\end{array}$ & $\begin{array}{l}6.46 \\
6.40 \\
6.38 \\
6.36 \\
6.29 \\
6.25\end{array}$ & $\begin{array}{l}1,700 \\
1,660 \\
1,650 \\
1,640 \\
1,590 \\
1,570\end{array}$ \\
\hline $\begin{array}{r}2 \\
4 \\
6 \\
8 \\
10 \\
M \\
\end{array}$ & $\begin{array}{r}10.06 \\
9.94 \\
9.81 \\
9.68 \\
9.57 \\
9.46 \\
\end{array}$ & $\begin{array}{l}4,430 \\
4,320 \\
4,200 \\
4,080 \\
3,980 \\
3,880\end{array}$ & $\begin{array}{l}8.64 \\
8.50 \\
8.40 \\
8.30 \\
8.19 \\
8.07\end{array}$ & $\begin{array}{l}3,200 \\
3,090 \\
3,010 \\
2,930 \\
2,850 \\
2,770\end{array}$ & $\begin{array}{l}7.49 \\
7.41 \\
7.36 \\
7.30 \\
7.24 \\
7.20\end{array}$ & $\begin{array}{l}2,360 \\
2,310 \\
2,270 \\
2,230 \\
2,190\end{array}$ & $\begin{array}{l}6.83 \\
6.80 \\
6.73 \\
6.90 \\
6.92 \\
6.94\end{array}$ & $\begin{array}{l}1,920 \\
1,900 \\
1,860 \\
1,960 \\
1,970 \\
1,980\end{array}$ & $\begin{array}{l}6.68 \\
6.64 \\
6.61 \\
6.58 \\
6.52 \\
6.49\end{array}$ & $\begin{array}{l}1,830 \\
1,800 \\
1,790 \\
1,770 \\
1,730 \\
1,710\end{array}$ & $\begin{array}{l}6.21 \\
6.16 \\
6.11 \\
6.09 \\
6.04 \\
6.04\end{array}$ & $\begin{array}{l}1,550 \\
1,520 \\
1,490 \\
1,470 \\
1,440 \\
1,440 \\
\end{array}$ \\
\hline
\end{tabular}


Oradell Reservolr at Oradell, N. J.

Location.- Water-stage recorder, lat. $40^{\circ} 57^{1} 24^{n}$, long. $74^{\circ} 01^{\prime 43 \pi}$, at Oradell Dam, Oradell, Bergen County. Gage heights are elevations above mean sea level (general adjustment of 1929)

Drainage area.- 113 square miles.

Gage-height record.- Water-stage recorder graph. Gage heights are given at 8 a.m. in table.

Remarks.- Storage capacity, 381,000,000 cubic feet. Records furnished by Hackensack Water Co.

Gage helght, in feet, and contents, in millions of cubic feet, at 8 a.m., 1938

\begin{tabular}{|c|c|c|c|c|c|c|c|c|c|}
\hline \multirow[b]{2}{*}{ Day } & \multicolumn{2}{|c|}{ September } & \multicolumn{2}{|c|}{ October } & \multirow[b]{2}{*}{ Day } & \multicolumn{2}{|c|}{ September } & \multicolumn{2}{|c|}{ October } \\
\hline & Feet & $\begin{array}{l}\text { Millions of } \\
\text { cub1c feet }\end{array}$ & Feet & $\begin{array}{l}\text { Millions of } \\
\text { cubic feet }\end{array}$ & & Feet & $\begin{array}{l}\text { Millions of } \\
\text { cublc feet }\end{array}$ & Feet & $\begin{array}{l}\text { Millions of } \\
\text { cublc feet }\end{array}$ \\
\hline $\begin{array}{l}1 \\
2 \\
3 \\
4 \\
5\end{array}$ & $\begin{array}{l}22.74 \\
22.73 \\
22.71 \\
22.70 \\
22.68\end{array}$ & $\begin{array}{l}383 \\
383 \\
382 \\
382 \\
382\end{array}$ & $\begin{array}{l}22.19 \\
22.25 \\
22.26 \\
22.25 \\
22.24\end{array}$ & $\begin{array}{l}367 \\
369 \\
369 \\
369 \\
369\end{array}$ & $\begin{array}{l}16 \\
17 \\
18 \\
19 \\
20\end{array}$ & $\begin{array}{l}22.69 \\
22.68 \\
22.67 \\
22.71 \\
22.58\end{array}$ & $\begin{array}{l}382 \\
382 \\
381 \\
382 \\
379\end{array}$ & $\begin{array}{l}22.28 \\
22.24 \\
22.21 \\
22.26 \\
22.33\end{array}$ & $\begin{array}{r}370 \\
369 \\
368 \\
369 \\
371\end{array}$ \\
\hline $\begin{array}{r}6 \\
7 \\
8 \\
9 \\
10\end{array}$ & $\begin{array}{l}22.66 \\
22.66 \\
22.65 \\
22.63 \\
22.59\end{array}$ & $\begin{array}{l}381 \\
381 \\
381 \\
380 \\
379\end{array}$ & $\begin{array}{l}22.19 \\
21.96 \\
22.02 \\
22.11 \\
22.20\end{array}$ & $\begin{array}{l}367 \\
361 \\
363 \\
365 \\
368\end{array}$ & $\begin{array}{l}21 \\
22 \\
23 \\
24 \\
25\end{array}$ & $\begin{array}{l}21.83 \\
21.80 \\
21.75 \\
21.50 \\
21.48\end{array}$ & $\begin{array}{l}357 \\
357 \\
355 \\
348 \\
348\end{array}$ & $\begin{array}{l}22.43 \\
22.54 \\
22.59 \\
22.60 \\
21.81\end{array}$ & $\begin{array}{l}374 \\
378 \\
379 \\
379 \\
357\end{array}$ \\
\hline $\begin{array}{l}11 \\
12 \\
13 \\
14 \\
15\end{array}$ & $\begin{array}{l}22.58 \\
22.54 \\
22.51 \\
22.54 \\
22.58\end{array}$ & $\begin{array}{l}379 \\
378 \\
377 \\
378 \\
379\end{array}$ & $\begin{array}{l}22.29 \\
22.30 \\
22.32 \\
22.32 \\
22.30\end{array}$ & $\begin{array}{l}370 \\
371 \\
371 \\
371 \\
371\end{array}$ & $\begin{array}{l}26 \\
27 \\
28 \\
29 \\
30 \\
31\end{array}$ & $\begin{array}{l}21.49 \\
22.02 \\
22.05 \\
22.04 \\
22.08\end{array}$ & $\begin{array}{l}348 \\
365 \\
363 \\
368 \\
364\end{array}$ & $\begin{array}{l}21.67 \\
21.79 \\
21.85 \\
21.87 \\
21.85 \\
21.77\end{array}$ & $\begin{array}{l}\mathbf{3 5 3} \\
\mathbf{3 5 6} \\
\mathbf{3 5 8} \\
\mathbf{3 5 8} \\
\mathbf{3 5 6} \\
\mathbf{3 5 6}\end{array}$ \\
\hline & & & & & & & & Bepte & $\begin{array}{r}\text { October } \\
-5.25\end{array}$ \\
\hline
\end{tabular}


Location.- Water-stage recorder, lat. $40^{\circ} 56^{\prime} 52^{n}$, long. $74^{\circ} 01^{\prime 3} 34^{n}$, at pumping plant of Hackensack Water Co., New Mifford, Bergen County, $3 \frac{1}{2}$ miles below mouth of Dwars K111. Zero of gage is 6.25 feet above mean sea level (general adjustment of 1929 ). Drainage area.- 113 square miles, materially affected by diversions and by storage in Woodcliff Lake and oradell Reservoir.

Gage-height record.- Water-stage recorder graph.

Stage-discharge relation.- Defined by current-meter measurements. Affected by sheet pling in channel to waste gates sept. 16-27.

Mexima.- September 1938: Discharge, 2,190 second-feet 6 p.m. Sept. 21 (gage height, 4.72 feet).

1921 to August 1938: Discharge, 2,800 second-feet Mar. 12 and 13, 1936 (gage height, 5.08 feet).

Remarks:- Run-off affected by storage and diversions. Mean monthly discharge adjusted for diversions and for storage in woodcliff take and Oradell Reservolr. Mean monthly diversions at West Nyack, N. Y.: September, 1.1 second-feet; 0ctober, 1.0 second-foot. Mean monthly diversions at New Milford: September, 52.1 second-feet; October, 51.7 second-feet. For information on storage see records for 0radell Reservoir at oradell, N. J., and Woodcliff Lake at Hillsdale, N. J. Records of diversions and storage and part of equipment furnished by Hackensack Water Co.

Mean de1ly discharge, in second-feet, 1938

\begin{tabular}{|c|c|c|c|c|c|c|c|c|c|c|c|}
\hline Day & Sept. & Det. & Day & Sept. & Oct. & Day & Sept. & Oct. & Day & Sept. & Oct. \\
\hline $\begin{array}{l}1 \\
2 \\
3 \\
4 \\
5 \\
6 \\
7 \\
8\end{array}$ & \begin{tabular}{r}
\multicolumn{1}{c}{28} \\
23 \\
15.9 \\
12.7 \\
10.5 \\
4.3 \\
4.6 \\
13.0
\end{tabular} & $\begin{array}{r}78 \\
78 \\
78 \\
74 \\
74 \\
127 \\
143 \\
54\end{array}$ & $\begin{array}{r}9 \\
10 \\
11 \\
12 \\
13 \\
14 \\
15 \\
16\end{array}$ & $\begin{array}{r}5.6 \\
1.7 \\
2.2 \\
2.1 \\
.3 \\
0.7 \\
14.6\end{array}$ & $\begin{array}{l}33 \\
34 \\
48 \\
55 \\
56 \\
56 \\
56 \\
55\end{array}$ & $\begin{array}{l}17 \\
18 \\
19 \\
20 \\
21 \\
22 \\
23 \\
24\end{array}$ & $\begin{array}{r}12.9 \\
10.2 \\
151 \\
609 \\
1,650 \\
2,000 \\
1,260 \\
781\end{array}$ & $\begin{array}{r}55 \\
37 \\
25 \\
25 \\
111 \\
78 \\
78 \\
336\end{array}$ & $\begin{array}{l}25 \\
26 \\
27 \\
28 \\
29 \\
30 \\
31\end{array}$ & $\begin{array}{r}515 \\
232 \\
199 \\
195 \\
158 \\
74\end{array}$ & $\begin{array}{r}263 \\
94 \\
48 \\
81 \\
91 \\
116 \\
116\end{array}$ \\
\hline $\begin{array}{l}\text { Mean } \\
\text { Mean } \\
\text { Run- }\end{array}$ & $\begin{array}{l}\text { monthly } \\
\text { monthly } \\
\text { ff, in }\end{array}$ & $\begin{array}{l}\text { ischar } \\
\text { schar } \\
\text { ehes } 1\end{array}$ & in & second- & et ob & rve & $\begin{array}{lll}\cdot & \bullet & \bullet \\
\bullet & \bullet & \bullet \\
\bullet & \bullet & \bullet \\
\end{array}$ & 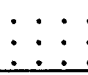 & $\dot{0} \cdot \dot{ }$ & $\begin{array}{r}266 \\
314 \\
3.10 \\
\end{array}$ & $\begin{array}{r}85.6 \\
132 \\
1.35 \\
\end{array}$ \\
\hline
\end{tabular}

Gage nelght, in feet, and discharge, In second-feet, at indicated time, 1958

\begin{tabular}{|c|c|c|c|c|c|c|c|c|c|c|c|c|}
\hline \multirow{2}{*}{ 㝵 } & Feot & Sec.ft. & Feet & Sec.ft. & Feet & Sec.ft. & Feet & sec.ft. & Fevt & Sec.ft. & Peet & Sec.ft. \\
\hline & \multicolumn{2}{|c|}{ September 18} & \multicolumn{2}{|c|}{ September 19} & \multicolumn{2}{|c|}{ September 20} & \multicolumn{2}{|c|}{ September 21} & \multicolumn{2}{|c|}{ September 22} & \multicolumn{2}{|c|}{ September 28} \\
\hline $\begin{array}{l}1 \\
2 \\
3 \\
4 \\
5 \\
6\end{array}$ & $\begin{array}{l}1.11 \\
1.14 \\
1.15 \\
1.15 \\
1.15 \\
1.15\end{array}$ & $\begin{array}{r}9.8 \\
13.2 \\
14.4 \\
14.4 \\
14.4 \\
14.4\end{array}$ & $\begin{array}{l}1.15 \\
1.18 \\
1.21 \\
1.22 \\
1.22 \\
1.22\end{array}$ & $\begin{array}{l}14.4 \\
18.5 \\
24 \\
24 \\
24 \\
24\end{array}$ & $\begin{array}{l}2.12 \\
2.12 \\
2.12 \\
2.13 \\
2.13 \\
2.12\end{array}$ & $\begin{array}{l}378 \\
378 \\
378 \\
384 \\
384 \\
378\end{array}$ & $\begin{array}{l}3.28 \\
3.28 \\
3.28 \\
3.29 \\
3.28 \\
3.27\end{array}$ & $\begin{array}{l}1,150 \\
1,150 \\
1,150 \\
1,160 \\
1,150 \\
1,140\end{array}$ & $\begin{array}{l}4.58 \\
4.57 \\
4.57 \\
4.57 \\
4.56 \\
4.56\end{array}$ & $\begin{array}{l}2,100 \\
2,090 \\
2,090 \\
2,090 \\
2,090 \\
2,090\end{array}$ & $\begin{array}{l}3.66 \\
3.66 \\
3.66 \\
3.66 \\
3.53 \\
3.52\end{array}$ & $\begin{array}{l}1,430 \\
1,430 \\
1,430 \\
1,430 \\
1,340 \\
1,330\end{array}$ \\
\hline $\begin{array}{r}7 \\
8 \\
9 \\
10 \\
11 \\
11\end{array}$ & $\begin{array}{l}1.1 .5 \\
1.14 \\
1.12 \\
1.10 \\
1.07 \\
1.05\end{array}$ & $\begin{array}{r}14.4 \\
13.2 \\
10.9 \\
8.8 \\
5.8 \\
4.0\end{array}$ & $\begin{array}{l}1.19 \\
1.18 \\
1.18 \\
1.18 \\
1.19 \\
1.23\end{array}$ & $\begin{array}{l}20 \\
18.5 \\
18.5 \\
18.5 \\
20 \\
26\end{array}$ & $\begin{array}{l}2.13 \\
2.13 \\
2.65 \\
2.66 \\
2.66 \\
2.66\end{array}$ & $\begin{array}{l}384 \\
384 \\
698 \\
706 \\
706 \\
706\end{array}$ & $\begin{array}{l}3.26 \\
3.26 \\
3.60 \\
3.77 \\
3.90 \\
4.05\end{array}$ & $\begin{array}{l}1,140 \\
1,140 \\
1,390 \\
1,520 \\
1,610 \\
1,720\end{array}$ & $\begin{array}{l}4 . \\
4 . \\
4 . \\
4 . \\
4 . \\
4 .\end{array}$ & $\begin{array}{l}2,080 \\
2,080 \\
2,090 \\
2,090 \\
2,100 \\
2,100\end{array}$ & $\begin{array}{l}3.51 \\
3.52 \\
3.52 \\
3.52 \\
3.52 \\
3.51\end{array}$ & $\begin{array}{l}1,320 \\
1,330 \\
1,330 \\
1,330 \\
1,330 \\
1,320\end{array}$ \\
\hline $\begin{array}{l}1 \\
2 \\
3 \\
4 \\
5 \\
6\end{array}$ & $\begin{array}{l}1.03 \\
1.02 \\
1.05 \\
1.05 \\
1.09 \\
1.12\end{array}$ & $\begin{array}{r}2.4 \\
1.6 \\
4.0 \\
4.0 \\
7.7 \\
10.9\end{array}$ & $\begin{array}{l}1.26 \\
1.31 \\
1.38 \\
2.10 \\
2.17 \\
2.17\end{array}$ & $\begin{array}{r}32 \\
42 \\
60 \\
367 \\
405 \\
405\end{array}$ & $\begin{array}{l}2.66 \\
2.66 \\
2.67 \\
2.67 \\
2.67 \\
2.67\end{array}$ & $\begin{array}{l}706 \\
706 \\
713 \\
713 \\
713 \\
713\end{array}$ & $\begin{array}{l}4.07 \\
4.11 \\
4.52 \\
4.61 \\
4.66 \\
4.72\end{array}$ & $\begin{array}{l}1,730 \\
1,760 \\
2,060 \\
2,120 \\
2,150 \\
2,190\end{array}$ & $\begin{array}{l}4.55 \\
4.54 \\
4.54 \\
4.54 \\
4.54 \\
4.53\end{array}$ & $\begin{array}{l}2,080 \\
2,070 \\
2,070 \\
2,070 \\
2,070 \\
2,070\end{array}$ & $\begin{array}{l}3.51 \\
3.51 \\
3.50 \\
3.33 \\
3.33 \\
3.33\end{array}$ & $\begin{array}{l}1,320 \\
1,320 \\
1,310 \\
1,190 \\
1,190 \\
1,190\end{array}$ \\
\hline \multirow[t]{2}{*}{$\begin{array}{r}7 \\
8 \\
9 \\
10 \\
11 \\
11\end{array}$} & $\begin{array}{l}1.12 \\
1.18 \\
1.13 \\
1.14 \\
1.14 \\
1.14\end{array}$ & $\begin{array}{l}10.9 \\
12.0 \\
12.0 \\
13.2 \\
13.2 \\
13.2\end{array}$ & $\begin{array}{l}2.15 \\
2.13 \\
2.12 \\
2.12 \\
2.12 \\
2.12\end{array}$ & $\begin{array}{l}394 \\
384 \\
378 \\
378 \\
378 \\
378\end{array}$ & $\begin{array}{l}2.68 \\
2.67 \\
2.69 \\
2.68 \\
3.10 \\
3.28\end{array}$ & $\begin{array}{r}719 \\
713 \\
725 \\
719 \\
1,010 \\
1,150\end{array}$ & & $\begin{array}{l}2,180 \\
2,170 \\
2,170 \\
2,130 \\
2,110 \\
2,100\end{array}$ & $\begin{array}{l}53 \\
13 \\
10 \\
75 \\
67 \\
66\end{array}$ & $\begin{array}{l}2,070 \\
1,780 \\
1,750 \\
1,490 \\
1,440 \\
1,450\end{array}$ & $\begin{array}{l}3.33 \\
3.15 \\
3.12 \\
3.08 \\
3.06 \\
3.07\end{array}$ & $\begin{array}{r}1,190 \\
1,060 \\
1,080 \\
999 \\
985 \\
992\end{array}$ \\
\hline & \multicolumn{2}{|c|}{ September 24} & \multicolumn{2}{|c|}{ September 25} & \multicolumn{2}{|c|}{ September 26} & \multicolumn{2}{|c|}{ September 27} & \multicolumn{2}{|c|}{ September 28} & \multicolumn{2}{|c|}{ September 29} \\
\hline $\begin{array}{r}2 \\
4 \\
6 \\
8 \\
10 \\
11\end{array}$ & $\begin{array}{l}2.85 \\
2.84 \\
2.84 \\
2.84 \\
2.83 \\
2.83\end{array}$ & $\begin{array}{l}836 \\
829 \\
829 \\
829 \\
822 \\
822\end{array}$ & $\begin{array}{l}2.64 \\
2.64 \\
2.42 \\
2.41 \\
2.27 \\
2.27\end{array}$ & $\begin{array}{l}692 \\
692 \\
551 \\
545 \\
461 \\
461\end{array}$ & $\begin{array}{l}2.28 \\
2.28 \\
2.11 \\
1.65 \\
1.58 \\
1.59\end{array}$ & $\begin{array}{l}468 \\
468 \\
372 \\
157 \\
130 \\
134\end{array}$ & $\begin{array}{l}1.62 \\
1.62 \\
1.61 \\
1.60 \\
1.60 \\
1.60\end{array}$ & $\begin{array}{l}145 \\
145 \\
141 \\
137 \\
137 \\
137\end{array}$ & $\begin{array}{l}1.64 \\
1.70 \\
1.65 \\
1.65 \\
1.65 \\
1.65\end{array}$ & $\begin{array}{l}274 \\
204 \\
181 \\
181 \\
181 \\
181\end{array}$ & $\begin{array}{l}1.66 \\
1.67 \\
1.66 \\
1.64 \\
1.65 \\
1.65\end{array}$ & $\begin{array}{l}186 \\
190 \\
186 \\
176 \\
181 \\
181\end{array}$ \\
\hline $\begin{array}{r}2 \\
4 \\
6 \\
8 \\
10 \\
11\end{array}$ & $\begin{array}{l}2.83 \\
2.63 \\
2.63 \\
2.64 \\
2.64 \\
2.64\end{array}$ & $\begin{array}{l}822 \\
686 \\
686 \\
692 \\
692 \\
692\end{array}$ & $\begin{array}{l}2.27 \\
2.27 \\
2.27 \\
2.27 \\
2.28 \\
2.28\end{array}$ & $\begin{array}{l}461 \\
461 \\
461 \\
461 \\
468 \\
468\end{array}$ & $\begin{array}{l}1.60 \\
1.60 \\
1.60 \\
1.60 \\
1.61 \\
1.62\end{array}$ & $\begin{array}{l}137 \\
137 \\
137 \\
137 \\
141 \\
145\end{array}$ & $\begin{array}{l}1.82 \\
1.88 \\
1.88 \\
1.88 \\
1.84\end{array}$ & $\begin{array}{l}263 \\
269 \\
269 \\
269 \\
274 \\
274\end{array}$ & $\begin{array}{l}1.66 \\
1.66 \\
1.66 \\
1.66 \\
1.66 \\
1.66\end{array}$ & $\begin{array}{l}186 \\
186 \\
186 \\
186 \\
186 \\
186\end{array}$ & $\begin{array}{l}1.65 \\
1.55 \\
1.55 \\
1.55 \\
1.40 \\
1.39\end{array}$ & $\begin{array}{r}181 \\
187 \\
137 \\
137 \\
78\end{array}$ \\
\hline
\end{tabular}


Woodcliff Lake at H1llsdale, N. J.

Location.- Lat. $41^{\circ} 00^{\prime} 42^{n}$, long. $74^{\circ} 02^{\prime} 55^{\prime \prime}$, at Woodcliff Lake Dam, Hillsdale, Bergen County. Gage heights are elevations above mean sea level (general adjustment of 1929).

Drainage area.- 20.2 square miles.

Gage-height record.- Gage read twice daily to hundredths. Gage heights at 8 a.m. are given in table.

Remarks.- Storage capacity, 112,000,000 cubic feet. Records furnished by Hackensack Water Co.

liage height, in feet, and contents, in millions of cubic feet, at 8 a.m., 1938

\begin{tabular}{|c|c|c|c|c|c|c|c|c|c|c|}
\hline \multirow[b]{2}{*}{ Day } & \multicolumn{2}{|c|}{ September } & \multicolumn{2}{|r|}{ October } & \multirow[b]{2}{*}{ Day } & \multicolumn{2}{|c|}{ September } & \multicolumn{3}{|c|}{ October } \\
\hline & Feet & $\begin{array}{l}\text { Millions of } \\
\text { cubic feet }\end{array}$ & Feet & $\begin{array}{l}\text { Millions of } \\
\text { cubic feet }\end{array}$ & & Feet & $\begin{array}{l}\text { Millions of } \\
\text { cubic feet }\end{array}$ & Feet & & $\begin{array}{l}\text { I11ons of } \\
\text { ubic feet }\end{array}$ \\
\hline $\begin{array}{l}1 \\
2 \\
3 \\
4 \\
5\end{array}$ & $\begin{array}{l}94.53 \\
94.53 \\
94.53 \\
94.43 \\
94.43\end{array}$ & $\begin{array}{l}113 \\
113 \\
113 \\
112 \\
112\end{array}$ & $\begin{array}{l}94.63 \\
94.63 \\
94.63 \\
94.63 \\
94.63\end{array}$ & $\begin{array}{l}114 \\
114 \\
114 \\
114 \\
114\end{array}$ & $\begin{array}{l}16 \\
17 \\
18 \\
19 \\
20\end{array}$ & $\begin{array}{l}94.53 \\
94.43 \\
94.43 \\
94.53 \\
95.13\end{array}$ & $\begin{array}{l}113 \\
112 \\
112 \\
113 \\
117\end{array}$ & $\left|\begin{array}{l}94.53 \\
94.53 \\
94.53 \\
94.53 \\
94.53\end{array}\right|$ & & $\begin{array}{l}113 \\
113 \\
113 \\
113 \\
113\end{array}$ \\
\hline $\begin{array}{r}6 \\
7 \\
8 \\
9 \\
10\end{array}$ & $\begin{array}{l}94.43 \\
94.43 \\
94.43 \\
94.43 \\
94.43\end{array}$ & $\begin{array}{l}112 \\
112 \\
112 \\
112 \\
112\end{array}$ & $\begin{array}{l}94.53 \\
94.63 \\
94.63 \\
94.63 \\
94.53\end{array}$ & $\begin{array}{l}113 \\
114 \\
114 \\
114 \\
113\end{array}$ & $\begin{array}{l}21 \\
22 \\
23 \\
24 \\
25\end{array}$ & $\begin{array}{l}95.33 \\
96.03 \\
95.03 \\
94.83 \\
94.73\end{array}$ & $\begin{array}{l}119 \\
124 \\
117 \\
115 \\
114\end{array}$ & $\left|\begin{array}{l}94.63 \\
94.63 \\
94.63 \\
94.53 \\
94.53\end{array}\right|$ & & $\begin{array}{l}114 \\
114 \\
114 \\
113 \\
113\end{array}$ \\
\hline $\begin{array}{l}11 \\
12 \\
13 \\
14 \\
15\end{array}$ & $\begin{array}{l}94.43 \\
94.43 \\
94.43 \\
94.43 \\
94.53\end{array}$ & $\begin{array}{l}112 \\
112 \\
112 \\
112 \\
113\end{array}$ & $\begin{array}{l}94.53 \\
94.53 \\
94.53 \\
94.53 \\
94.53\end{array}$ & $\begin{array}{l}113 \\
113 \\
113 \\
113 \\
113\end{array}$ & $\begin{array}{l}26 \\
27 \\
28 \\
29 \\
30 \\
31\end{array}$ & $\begin{array}{l}94.63 \\
94.63 \\
94.63 \\
94.63 \\
94.63\end{array}$ & $\begin{array}{l}114 \\
114 \\
114 \\
114 \\
114\end{array}$ & $\mid \begin{array}{l}94.53 \\
94.53 \\
94.53 \\
94.53 \\
94.53 \\
94.53\end{array}$ & & $\begin{array}{l}113 \\
113 \\
113 \\
113 \\
113 \\
113\end{array}$ \\
\hline 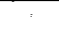 & & & & & & & , & Septem & er & October \\
\hline $\begin{array}{l}\text { Gain } \\
\text { Gain }\end{array}$ & $\begin{array}{l}\text { or } 10 \\
\text { or } 10\end{array}$ & $\begin{array}{l}s \text { in storage } \\
s \text { in storage }\end{array}$ & $\begin{array}{l}\text { in } \mathrm{m} \\
\text { in } \mathrm{e}\end{array}$ & uivalent mea & & & 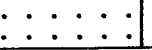 & & $\begin{array}{l}+1 \\
39\end{array}$ & $\begin{array}{r}-1 \\
-.37 \\
\end{array}$ \\
\hline
\end{tabular}


Pascack Brook at Westwood, N. J.

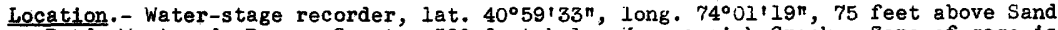
Road, Westwood, Bergen County, 500 feet below iusquapsink Creek. Zero of gage is 28.62 feet above mean sea level (general adjustment of 1929).

Dralnage area.- 29.6 square miles; 20.2 square miles affected by storage in woodcliff Lake.

Gage-helght record.- Water-stage recorder graph.

Stage-discharge relation.- Defined by current-meter measurements below 500 second-feet; extended to peak stage by study of run-off of nearby streams.

Maxtma.- September 1938: Discharge, 1,120 second-feet 2 a.m. Sept. 22 (gage he1ght, 5.37 feet). 5.53 feet).

1934 to August 1938: Discharge, 1,190 second-feet Mar. 12, 1936 (gage neight,

Remarks.- Mean nonthly discharge adjusted for storage in Woodcliff Lake. For information on storage see records for Woodcliff Lake at Hillsdale, iv. J. Recorder operated and storage data furnished by Hackensack Water Co.

Mean dally discharge, in second-feet, 1938

\begin{tabular}{|c|c|c|c|c|c|c|c|c|c|c|c|}
\hline Day & Sept. & Oct. & Day & Sept. & Oct. & Day & Sept. & Oct. & Day & Sept. & Oct. \\
\hline $\begin{array}{l}1 \\
2 \\
3 \\
4 \\
5 \\
6 \\
7 \\
8\end{array}$ & $\begin{array}{l}28 \\
18.8 \\
20 \\
15.8 \\
15.2 \\
19.4 \\
15.2 \\
20\end{array}$ & $\begin{array}{l}39 \\
38 \\
36 \\
35 \\
32 \\
32 \\
48 \\
42\end{array}$ & $\begin{array}{l}9 \\
10 \\
11 \\
12 \\
13 \\
14 \\
15 \\
16\end{array}$ & $\begin{array}{l}14.6 \\
11.4 \\
14.1 \\
11.9 \\
17.0 \\
14.6 \\
27 \\
18.2\end{array}$ & $\begin{array}{l}35 \\
28 \\
30 \\
31 \\
30 \\
23 \\
29 \\
24\end{array}$ & $\begin{array}{l}17 \\
18 \\
19 \\
20 \\
21 \\
22 \\
23 \\
24\end{array}$ & $\begin{array}{l}15.8 \\
19.4 \\
49 \\
195 \\
562 \\
808 \\
232 \\
102\end{array}$ & $\begin{array}{l}30 \\
25 \\
30 \\
30 \\
58 \\
49 \\
36 \\
32\end{array}$ & $\begin{array}{l}25 \\
26 \\
27 \\
28 \\
29 \\
30 \\
31\end{array}$ & $\begin{array}{l}67 \\
54 \\
49 \\
47 \\
43 \\
41\end{array}$ & $\begin{array}{l}46 \\
39 \\
34 \\
31 \\
35 \\
35 \\
25\end{array}$ \\
\hline $\begin{array}{l}\text { Mean } \\
\text { Mean } \\
\text { Run- }\end{array}$ & $\begin{array}{l}\text { aonthly } \\
\text { oonthly } \\
\text {, in i }\end{array}$ & $\begin{array}{l}\text { ischar } \\
\text { ischar } \\
\text { ches }\end{array}$ & , in & $\begin{array}{l}\text { second-f } \\
\text { second-1 }\end{array}$ & $\begin{array}{l}\text { et } \\
\text { et }\end{array}$ & $\begin{array}{l}\text { rved) } \\
\text { sted) } \\
. \quad .\end{array}$ & $\begin{array}{l}\cdot \cdot \cdot \\
\cdot \cdot \cdot \\
\cdot \cdot\end{array}$ & 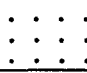 & $: \dot{ }$ & $\begin{array}{l}85.5 \\
85.8 \\
3.24 \\
\end{array}$ & $\begin{array}{l}34.4 \\
34.7 \\
1.35 \\
\end{array}$ \\
\hline
\end{tabular}

Gage helght, in feet, and discharge, in second-feet, at indicated time, 1938

\begin{tabular}{|c|c|c|c|c|c|c|c|c|c|c|c|c|}
\hline \multirow{2}{*}{ 尔 } & Feet & sec.ft. & Feet & Sec.ft. & Feet & sec.ft. & Feet & Sec.ft. & Feet & Sec.ft. & Feet & Sec.ft. \\
\hline & \multicolumn{2}{|c|}{ September 18} & \multicolumn{2}{|c|}{ September 19} & \multicolumn{2}{|c|}{ September 20} & \multicolumn{2}{|c|}{ September 21} & \multicolumn{2}{|c|}{ September 22} & \multicolumn{2}{|c|}{ September 23} \\
\hline $\begin{array}{l}1 \\
2 \\
3 \\
4 \\
5 \\
6\end{array}$ & $\begin{array}{l}1.61 \\
1.61 \\
1.61 \\
1.61 \\
1.60 \\
1.60\end{array}$ & $\begin{array}{l}22 \\
22 \\
22 \\
22 \\
21 \\
21\end{array}$ & $\begin{array}{l}1.56 \\
1.63 \\
1.65 \\
1.72 \\
1.71 \\
1.67\end{array}$ & $\begin{array}{l}18.8 \\
24 \\
25 \\
32 \\
31 \\
27\end{array}$ & $\begin{array}{l}2.28 \\
2.31 \\
2.36 \\
2.44 \\
2.49 \\
2.57\end{array}$ & $\begin{array}{l}709 \\
114 \\
123 \\
139 \\
150 \\
167\end{array}$ & $\begin{array}{l}3.00 \\
3.01 \\
3.04 \\
3.08 \\
3.11 \\
3.13\end{array}$ & $\begin{array}{l}272 \\
275 \\
283 \\
294 \\
302 \\
307\end{array}$ & $\begin{array}{l}5.34 \\
5.37 \\
5.34 \\
5.31 \\
5.26 \\
5.18\end{array}$ & $\begin{array}{l}1,110 \\
1,120 \\
1,110 \\
1,100 \\
1,070 \\
1,040\end{array}$ & $\begin{array}{l}3.40 \\
3.31 \\
3.24 \\
3.15 \\
3.08 \\
3.01\end{array}$ & $\begin{array}{l}386 \\
359 \\
339 \\
313 \\
294 \\
275\end{array}$ \\
\hline $\begin{array}{r}7 \\
8 \\
9 \\
10 \\
11 \\
N\end{array}$ & $\begin{array}{l}1.59 \\
1.58 \\
1.58 \\
1.57 \\
1.56 \\
1.56\end{array}$ & $\begin{array}{l}21 \\
20 \\
20 \\
19.4 \\
18.8 \\
18.8\end{array}$ & $\begin{array}{l}1.65 \\
1.63 \\
1.62 \\
1.62 \\
1.61 \\
1.62\end{array}$ & $\begin{array}{l}25 \\
24 \\
23 \\
23 \\
22 \\
23\end{array}$ & $\begin{array}{l}2.64 \\
2.68 \\
2.69 \\
2.71 \\
2.72 \\
2.74\end{array}$ & $\begin{array}{l}183 \\
192 \\
195 \\
199 \\
202 \\
207\end{array}$ & $\begin{array}{l}3.16 \\
3.24 \\
3.27 \\
3.39 \\
3.50 \\
3.67\end{array}$ & $\begin{array}{l}316 \\
339 \\
347 \\
383 \\
417 \\
470\end{array}$ & $\begin{array}{l}5.11 \\
5.00 \\
4.90 \\
4.81 \\
4.72 \\
4.65\end{array}$ & $\begin{array}{r}1,010 \\
970 \\
930 \\
893 \\
857 \\
829\end{array}$ & $\begin{array}{l}2.98 \\
2.95 \\
2.93 \\
2.88 \\
2.82 \\
2.77\end{array}$ & $\begin{array}{l}267 \\
259 \\
254 \\
241 \\
226 \\
214\end{array}$ \\
\hline $\begin{array}{l}1 \\
2 \\
3 \\
4 \\
5 \\
6\end{array}$ & $\begin{array}{l}1.55 \\
1.55 \\
1.54 \\
1.54 \\
1.54 \\
1.53\end{array}$ & $\begin{array}{l}18.2 \\
18.2 \\
17.6 \\
17.6 \\
17.6 \\
17.0\end{array}$ & $\begin{array}{l}1.73 \\
2.03 \\
2.09 \\
2.07 \\
2.04 \\
2.03\end{array}$ & $\begin{array}{l}33 \\
68 \\
78 \\
74 \\
70 \\
68\end{array}$ & $\begin{array}{l}2.75 \\
2.76 \\
2.76 \\
2.77 \\
2.77 \\
2.80\end{array}$ & $\begin{array}{l}209 \\
211 \\
211 \\
214 \\
214 \\
221\end{array}$ & $\begin{array}{l}3.81 \\
4.02 \\
4.18 \\
4.31 \\
4.42 \\
4.55\end{array}$ & $\begin{array}{l}516 \\
589 \\
648 \\
697 \\
739 \\
790\end{array}$ & $\begin{array}{l}4.55 \\
4.44 \\
4.34 \\
4.24 \\
4.14 \\
4.03\end{array}$ & $\begin{array}{l}790 \\
747 \\
708 \\
670 \\
633 \\
593\end{array}$ & $\begin{array}{l}2.73 \\
2.69 \\
2.65 \\
2.62 \\
2.59 \\
2.56\end{array}$ & $\begin{array}{l}204 \\
195 \\
186 \\
179 \\
172 \\
165\end{array}$ \\
\hline \multirow[t]{2}{*}{$\begin{array}{r}7 \\
8 \\
9 \\
10 \\
11 \\
M\end{array}$} & $\begin{array}{l}1.53 \\
1.53 \\
1.53 \\
1.53 \\
1.53 \\
1.54\end{array}$ & $\begin{array}{l}17.0 \\
17.0 \\
17.0 \\
17.0 \\
17.0 \\
17.6\end{array}$ & $\begin{array}{l}2.06 \\
2.09 \\
2.12 \\
2.17 \\
2.22 \\
2.27\end{array}$ & $\begin{array}{r}73 \\
78 \\
82 \\
90 \\
98 \\
107 \\
\end{array}$ & $\begin{array}{l}2.80 \\
2.85 \\
2.90 \\
2.95 \\
2.98 \\
2.99 \\
\end{array}$ & $\begin{array}{l}221 \\
234 \\
246 \\
259 \\
267 \\
269\end{array}$ & $\begin{array}{l}4.68 \\
4.88 \\
5.03 \\
5.17 \\
5.23 \\
5.30 \\
\end{array}$ & $\begin{array}{r}841 \\
922 \\
982 \\
1,040 \\
1,060 \\
1,090 \\
\end{array}$ & $\begin{array}{l}3.91 \\
3.80 \\
3.77 \\
3.69 \\
3.57 \\
3.48\end{array}$ & $\begin{array}{l}550 \\
513 \\
503 \\
477 \\
439 \\
411 \\
\end{array}$ & $\begin{array}{l}2.53 \\
2.51 \\
2.49 \\
2.46 \\
2.44 \\
2.42 \\
\end{array}$ & $\begin{array}{l}159 \\
154 \\
150 \\
144 \\
139 \\
135 \\
\end{array}$ \\
\hline & \multicolumn{2}{|c|}{ September 24} & \multicolumn{2}{|c|}{ September 25} & \multicolumn{2}{|c|}{ September 26} & \multicolumn{2}{|c|}{ September 27} & \multicolumn{2}{|c|}{ September 28} & \multicolumn{2}{|c|}{ September 29} \\
\hline $\begin{array}{r}2 \\
4 \\
6 \\
8 \\
10 \\
10\end{array}$ & $\begin{array}{l}2.39 \\
2.35 \\
2.32 \\
2.29 \\
2.26 \\
2.24\end{array}$ & $\begin{array}{l}129 \\
122 \\
116 \\
110 \\
105 \\
102\end{array}$ & $\begin{array}{l}2.08 \\
2.07 \\
2.06 \\
2.04 \\
2.03 \\
2.02\end{array}$ & $\begin{array}{l}76 \\
74 \\
73 \\
70 \\
68 \\
67\end{array}$ & $\begin{array}{l}1.95 \\
1.95 \\
1.94 \\
1.94 \\
1.93 \\
1.93\end{array}$ & $\begin{array}{l}58 \\
58 \\
56 \\
56 \\
55 \\
55\end{array}$ & $\begin{array}{l}1.88 \\
1.88 \\
1.88 \\
1.88 \\
1.87 \\
1.87\end{array}$ & $\begin{array}{l}49 \\
49 \\
49 \\
49 \\
48 \\
48\end{array}$ & $\begin{array}{l}1.87 \\
1.87 \\
1.87 \\
1.87 \\
1.87 \\
1.86\end{array}$ & $\begin{array}{l}48 \\
48 \\
48 \\
48 \\
48 \\
47\end{array}$ & $\begin{array}{l}1.84 \\
1.84 \\
1.84 \\
1.83 \\
1.83 \\
1.83\end{array}$ & $\begin{array}{l}44 \\
44 \\
44 \\
43 \\
43 \\
43\end{array}$ \\
\hline $\begin{array}{r}2 \\
4 \\
6 \\
8 \\
10 \\
M\end{array}$ & $\begin{array}{l}2.20 \\
2.18 \\
2.15 \\
2.13 \\
2.12 \\
2.10\end{array}$ & $\begin{array}{l}95 \\
92 \\
87 \\
84 \\
82 \\
79\end{array}$ & $\begin{array}{l}2.00 \\
1.99 \\
1.98 \\
1.97 \\
1.97 \\
1.96\end{array}$ & $\begin{array}{l}64 \\
63 \\
61 \\
60 \\
60 \\
59\end{array}$ & $\begin{array}{l}1.92 \\
1.91 \\
1.90 \\
1.89 \\
1.89 \\
1.89\end{array}$ & $\begin{array}{l}54 \\
52 \\
51 \\
50 \\
50 \\
50\end{array}$ & $\begin{array}{l}1.87 \\
1.87 \\
1.87 \\
1.87 \\
1.87 \\
1.87\end{array}$ & $\begin{array}{l}48 \\
48 \\
48 \\
48 \\
48 \\
48\end{array}$ & $\begin{array}{l}1.86 \\
1.85 \\
1.85 \\
1.84 \\
1.84 \\
1.84\end{array}$ & $\begin{array}{l}47 \\
46 \\
46 \\
44 \\
44 \\
44\end{array}$ & $\begin{array}{l}1.83 \\
1.82 \\
1.82 \\
1.82 \\
1.81 \\
1.81\end{array}$ & $\begin{array}{l}43 \\
42 \\
42 \\
42 \\
41 \\
41\end{array}$ \\
\hline
\end{tabular}


Passa1c River near Mililington, N. J.

Locat1on.- Water-stage recorder, lat. $40^{\circ} 40^{\prime} 48^{\prime \prime}$, Iong. $74^{\circ} 31^{\prime} 40^{\prime \prime}$, at Dav1s Bridge, 1 mile upstream from Millington, Somerset County, and $1 \frac{1}{2}$ miles below mouth of Black Brook. Zero of gage is 215.60 feet above mean sea level (New Jersey Geological Survey benchmark).

Drainage area.- 55.4 square miles; about one-quarter of the area is swamp land, which is overflowed at medlum and high stages.

Gage-helght record. - Water-stage recorder graph.

Stage-discharge relation.- Defined by current-meter measurements below 600 second-feet. Laxima.- September 1938: Discharge, 1,040 second-feet 4-10 a.m. Sept. 22 (gage he1ght, 8.11 leet).

1903-6, 1921 to August 1938 : Discharge, 2,000 second-feet Mar. 8, 1904 (gage helght, 7.50 feet, former $\mathrm{s} 1 \mathrm{te}$ and datum).

Mean dally discharge, in second-feet, 1938

\begin{tabular}{|c|c|c|c|c|c|c|c|c|c|c|c|}
\hline Day & Sept. & Oct. & Day & Sept. & Oct. & Day & Sept. & Oct. & Day & Sept. & oct. \\
\hline $\begin{array}{l}1 \\
2 \\
3 \\
4 \\
5 \\
6 \\
7 \\
8\end{array}$ & $\begin{array}{l}27 \\
27 \\
20 \\
18.8 \\
17.0 \\
16.4 \\
15.8 \\
15.8\end{array}$ & $\begin{array}{l}75 \\
60 \\
52 \\
45 \\
41 \\
41 \\
59 \\
63\end{array}$ & $\begin{array}{r}9 \\
10 \\
11 \\
12 \\
13 \\
14 \\
15 \\
16\end{array}$ & $\begin{array}{l}15.2 \\
14.1 \\
13.6 \\
13.6 \\
14.6 \\
14.6 \\
15.2 \\
17.0\end{array}$ & $\begin{array}{l}53 \\
46 \\
41 \\
39 \\
38 \\
35 \\
34 \\
33\end{array}$ & $\begin{array}{l}17 \\
18 \\
19 \\
20 \\
21 \\
22 \\
23 \\
24\end{array}$ & $\begin{array}{c}15.2 \\
15.2 \\
34 \\
200 \\
624 \\
1,000 \\
895 \\
753\end{array}$ & $\begin{array}{l}31 \\
29 \\
27 \\
29 \\
48 \\
56 \\
45 \\
39\end{array}$ & $\begin{array}{l}25 \\
26 \\
27 \\
28 \\
29 \\
30 \\
31\end{array}$ & $\begin{array}{r}569 \\
402 \\
268 \\
183 \\
125 \\
94\end{array}$ & $\begin{array}{l}52 \\
56 \\
47 \\
56 \\
70 \\
76 \\
68\end{array}$ \\
\hline $\begin{array}{l}\text { Mean } \\
\text { Run- }\end{array}$ & inthy & aho & , ix & anond & - & $:$ : & $: \cdot: \cdot$ & $: \dot{0}$ & $: \dot{ }$ & $\begin{array}{r}182 \\
3.67\end{array}$ & $\begin{array}{l}47.9 \\
1.00\end{array}$ \\
\hline
\end{tabular}

Gege helght, in feet, and discharge, in second-feet, at indicated time, 1938

\begin{tabular}{|c|c|c|c|c|c|c|c|c|c|c|c|c|c|c|c|}
\hline \multirow{2}{*}{$\begin{array}{l} \\
0 \\
0 \\
0\end{array}$} & Feet & Sec.ft. & Feet & Sec.ft. & Feet & Sec & . ft. & Feet & Sec. & . ft. & Feet & Sec.ft. & Feet & Sec. & . ft. \\
\hline & \multicolumn{2}{|c|}{ September 18} & \multicolumn{2}{|c|}{ September 19} & \multicolumn{3}{|c|}{ September 20} & \multicolumn{3}{|c|}{ September 21} & \multicolumn{2}{|c|}{ September 22} & \multicolumn{3}{|c|}{ September 23} \\
\hline $\begin{array}{l}1 \\
2 \\
3 \\
4 \\
5 \\
6\end{array}$ & $\begin{array}{l}3.99 \\
3.99 \\
3.99 \\
3.99 \\
4.00 \\
4.00\end{array}$ & $\begin{array}{l}14.1 \\
14.1 \\
14.1 \\
14.1 \\
14.6 \\
14.6\end{array}$ & $\begin{array}{l}4.01 \\
4.01 \\
4.02 \\
4.02 \\
4.02 \\
4.03\end{array}$ & $\begin{array}{l}15.2 \\
15.2 \\
15.8 \\
15.8 \\
15.8 \\
16.4\end{array}$ & $\begin{array}{l}4.60 \\
4.70 \\
4.83 \\
4.97 \\
5.00 \\
5.01\end{array}$ & & $\begin{array}{r}78 \\
94 \\
116 \\
142 \\
147 \\
149\end{array}$ & $\begin{array}{l}5.98 \\
6.01 \\
6.04 \\
6.07 \\
6.09 \\
6.12\end{array}$ & & $\begin{array}{l}344 \\
352 \\
359 \\
367 \\
372 \\
380\end{array}$ & $\begin{array}{l}8.03 \\
8.06 \\
8.08 \\
8.10 \\
8.10 \\
8.11\end{array}$ & $\begin{array}{l}1,010 \\
1,020 \\
1,030 \\
1,040 \\
1,040 \\
1,040\end{array}$ & $\begin{array}{l}7.86 \\
7.85 \\
7.84 \\
7.83 \\
7.82 \\
7.80\end{array}$ & & $\begin{array}{l}953 \\
949 \\
945 \\
942 \\
938 \\
931\end{array}$ \\
\hline $\begin{array}{r}7 \\
8 \\
9 \\
10 \\
17 \\
N\end{array}$ & $\begin{array}{l}4.00 \\
4.00 \\
4.00 \\
4.00 \\
4.00 \\
4.00\end{array}$ & $\begin{array}{l}14.6 \\
14.6 \\
14.6 \\
14.6 \\
14.6 \\
14.6\end{array}$ & $\begin{array}{l}4.03 \\
4.04 \\
4.04 \\
4.05 \\
4.25 \\
4.29\end{array}$ & $\begin{array}{l}16.4 \\
17.0 \\
17.0 \\
17.6 \\
34 \\
37\end{array}$ & $\begin{array}{l}5.02 \\
5.03 \\
5.06 \\
5.08 \\
5.13 \\
5.19\end{array}$ & & $\begin{array}{l}151 \\
152 \\
158 \\
161 \\
170 \\
181\end{array}$ & $\begin{array}{l}6.20 \\
6.28 \\
6.38 \\
6.55 \\
6.85 \\
7.05\end{array}$ & & $\begin{array}{l}402 \\
424 \\
454 \\
506 \\
602 \\
668\end{array}$ & $\begin{array}{l}8.11 \\
8.11 \\
8.10 \\
8.10 \\
8.08 \\
8.05\end{array}$ & $\begin{array}{l}1,040 \\
1,040 \\
1,040 \\
1,040 \\
1,030 \\
1,020\end{array}$ & $\begin{array}{l}7.79 \\
7.78 \\
7.76 \\
7.75 \\
7.74 \\
7.72\end{array}$ & & $\begin{array}{l}927 \\
924 \\
917 \\
913 \\
909 \\
902\end{array}$ \\
\hline $\begin{array}{l}1 \\
2 \\
3 \\
4 \\
5 \\
6\end{array}$ & $\begin{array}{l}4.00 \\
4.00 \\
4.00 \\
4.00 \\
4.00 \\
4.00\end{array}$ & $\begin{array}{l}14.6 \\
14.6 \\
14.6 \\
14.6 \\
14.6 \\
14.6\end{array}$ & $\begin{array}{l}4.32 \\
4.33 \\
4.34 \\
4.36 \\
4.37 \\
4.38\end{array}$ & $\begin{array}{l}40 \\
41 \\
42 \\
45 \\
46 \\
47\end{array}$ & $\begin{array}{l}5.25 \\
5.30 \\
5.37 \\
5.45 \\
5.55 \\
5.65\end{array}$ & & $\begin{array}{l}192 \\
201 \\
214 \\
228 \\
248 \\
268\end{array}$ & $\begin{array}{l}7.20 \\
7.30 \\
7.31 \\
7.28 \\
7.28 \\
7.33\end{array}$ & & $\begin{array}{l}719 \\
753 \\
756 \\
746 \\
746 \\
764\end{array}$ & $\begin{array}{l}8.04 \\
8.02 \\
8.00 \\
7.99 \\
7.98 \\
7.96\end{array}$ & $\begin{array}{r}1,020 \\
1,010 \\
1,000 \\
997 \\
993 \\
987\end{array}$ & $\begin{array}{l}7.71 \\
7.69 \\
7.68 \\
7.66 \\
7.64 \\
7.63\end{array}$ & & $\begin{array}{l}899 \\
891 \\
888 \\
881 \\
873 \\
870\end{array}$ \\
\hline \multirow[t]{2}{*}{$\begin{array}{r}7 \\
8 \\
9 \\
10 \\
11 \\
M\end{array}$} & $\begin{array}{l}4.00 \\
4.01 \\
4.01 \\
4.01 \\
4.01 \\
4.01\end{array}$ & $\begin{array}{l}14.6 \\
15.2 \\
15.2 \\
15.2 \\
15.2 \\
15.2\end{array}$ & $\begin{array}{l}4.40 \\
4.44 \\
4.48 \\
4.51 \\
4.53 \\
4.57\end{array}$ & $\begin{array}{l}49 \\
55 \\
60 \\
64 \\
68 \\
74\end{array}$ & $\begin{array}{l}5.75 \\
5.83 \\
5.87 \\
5.90 \\
5.93 \\
5.95\end{array}$ & & $\begin{array}{l}290 \\
308 \\
317 \\
324 \\
332 \\
336\end{array}$ & $\begin{array}{l}7.45 \\
7.58 \\
7.70 \\
7.80 \\
7.90 \\
8.00\end{array}$ & & $\begin{array}{r}806 \\
852 \\
895 \\
931 \\
967 \\
, 000\end{array}$ & $\begin{array}{l}7.95 \\
7.94 \\
7.92 \\
7.91 \\
7.89 \\
7.88\end{array}$ & $\begin{array}{l}984 \\
980 \\
974 \\
970 \\
963 \\
960\end{array}$ & $\begin{array}{l}7.61 \\
7.59 \\
7.57 \\
7.55 \\
7.53 \\
7.51\end{array}$ & & $\begin{array}{l}863 \\
855 \\
848 \\
841 \\
854 \\
827\end{array}$ \\
\hline & \multicolumn{2}{|c|}{ September 24} & \multicolumn{2}{|c|}{ September 25} & \multicolumn{2}{|c|}{ September } & 26 & \multicolumn{2}{|c|}{ September } & 27 & \multicolumn{2}{|c|}{ September 28} & \multicolumn{3}{|c|}{ September 29} \\
\hline $\begin{array}{r}2 \\
4 \\
6 \\
8 \\
10 \\
N\end{array}$ & $\begin{array}{l}7.48 \\
7.45 \\
7.42 \\
7.39 \\
7.35 \\
7.30\end{array}$ & $\begin{array}{l}816 \\
806 \\
795 \\
784 \\
770 \\
753\end{array}$ & $\begin{array}{l}7.00 \\
6.95 \\
6.90 \\
6.85 \\
6.80 \\
6.75\end{array}$ & $\begin{array}{l}651 \\
634 \\
618 \\
602 \\
585 \\
569\end{array}$ & $\begin{array}{l}6.42 \\
6.37 \\
6.32 \\
6.27 \\
6.23 \\
6.18\end{array}$ & & $\begin{array}{l}466 \\
451 \\
436 \\
422 \\
410 \\
397\end{array}$ & $\begin{array}{l}5.86 \\
5.82 \\
5.78 \\
5.73 \\
5.69 \\
5.65\end{array}$ & & $\begin{array}{l}315 \\
306 \\
297 \\
286 \\
277 \\
268\end{array}$ & $\begin{array}{l}5.37 \\
5.33 \\
5.30 \\
5.26 \\
5.23 \\
5.20\end{array}$ & $\begin{array}{l}214 \\
206 \\
201 \\
194 \\
188 \\
183\end{array}$ & $\begin{array}{l}4.99 \\
4.97 \\
4.95 \\
4.93 \\
4.90 \\
4.88\end{array}$ & & $\begin{array}{l}145 \\
142 \\
138 \\
134 \\
129 \\
125\end{array}$ \\
\hline $\begin{array}{r}2 \\
4 \\
6 \\
8 \\
10 \\
M\end{array}$ & $\begin{array}{l}7.27 \\
7.23 \\
7.19 \\
7.15 \\
7.10 \\
7.05\end{array}$ & $\begin{array}{l}743 \\
729 \\
716 \\
702 \\
685 \\
668\end{array}$ & $\begin{array}{l}6.70 \\
6.65 \\
6.61 \\
6.56 \\
6.51 \\
6.46\end{array}$ & $\begin{array}{l}553 \\
537 \\
524 \\
509 \\
493 \\
478\end{array}$ & $\begin{array}{l}6.13 \\
6.08 \\
6.03 \\
5.98 \\
5.94 \\
5.90\end{array}$ & & $\begin{array}{l}383 \\
370 \\
357 \\
344 \\
334 \\
324\end{array}$ & $\begin{array}{l}5.60 \\
5.56 \\
5.52 \\
5.48 \\
5.45 \\
5.41\end{array}$ & & $\begin{array}{l}258 \\
250 \\
242 \\
234 \\
228 \\
221\end{array}$ & $\begin{array}{l}5.16 \\
5.13 \\
5.10 \\
5.07 \\
5.05 \\
5.02\end{array}$ & $\begin{array}{l}176 \\
170 \\
165 \\
160 \\
156 \\
151\end{array}$ & $\begin{array}{l}4.86 \\
4.84 \\
4.82 \\
4.80 \\
4.79 \\
4.78\end{array}$ & & $\begin{array}{l}122 \\
118 \\
115 \\
111 \\
109 \\
108\end{array}$ \\
\hline
\end{tabular}


Location.- Water-s tage recorder, lat. $40^{\circ} 43^{\prime} 31^{\prime \prime}$, long. $74^{\circ} 23^{\prime} 23^{\prime \prime}$, 100 feet below Stanley Avonue Bridge, Chatham, Morris County, 3 miles upstream from Canoe Brook. Zero of gage is 193.00 feet above mean sea level (New Jersey Geological Survey benchmark).

Drainage area.- 100 square miles; materialiy affected by natural storage in swampy areas at high stages.

Gage-helght record. - Water-stage recorder graph.

Stage-discharge relation. - Defined by current-meter measurements belon 900 second-feet. Maxima.- September 1938: Discharge, 1,910 second-feet 6 p.m. Sept. 21 (gage helght, 6.86 feet). 6.51 feet).

1937 to August 1938: Discharge, 1,840 second-feet July 23, 1938 (gage helght,

Remarks.- Discharge for periods Sept. 1-19 and 0ct. 3-6 based on twice daily readings of temporary staff gage; the gage heights show in table for these periods are from recorder graph and were affected by backwater caused by construction of concrete control at station.

Mean daily discharge, in second-feet, 1938

\begin{tabular}{|c|c|c|c|c|c|c|c|c|c|c|c|}
\hline Day & Sept. & Oct. & Day & Sept. & Oct. & Day & Sept. & Oct. & Day & Sept. & Oct. \\
\hline $\begin{array}{l}1 \\
2 \\
3 \\
4 \\
5 \\
6 \\
7 \\
8\end{array}$ & $\begin{array}{l}27 \\
32 \\
29 \\
26 \\
23 \\
20 \\
19 \\
17\end{array}$ & $\begin{array}{r}111 \\
89 \\
74 \\
61 \\
55 \\
56 \\
80 \\
89\end{array}$ & $\begin{array}{r}9 \\
10 \\
11 \\
12 \\
13 \\
14 \\
15 \\
16\end{array}$ & $\begin{array}{l}19 \\
19 \\
19 \\
17 \\
18 \\
18 \\
20 \\
19\end{array}$ & $\begin{array}{l}78 \\
53 \\
37 \\
45 \\
48 \\
49 \\
47 \\
45\end{array}$ & $\begin{array}{l}17 \\
18 \\
19 \\
20 \\
21 \\
22 \\
23 \\
24\end{array}$ & $\begin{array}{r}19 \\
19 \\
110 \\
518 \\
1,190 \\
1,410 \\
1,490 \\
1,370\end{array}$ & $\begin{array}{l}42 \\
40 \\
38 \\
38 \\
53 \\
65 \\
61 \\
57\end{array}$ & $\begin{array}{l}25 \\
26 \\
27 \\
28 \\
29 \\
30 \\
31\end{array}$ & $\begin{array}{r}1,180 \\
994 \\
784 \\
576 \\
337 \\
160\end{array}$ & $\begin{array}{l}71 \\
75 \\
72 \\
87 \\
90 \\
92 \\
85\end{array}$ \\
\hline $\begin{array}{l}\text { Mean } \\
\text { Run- }\end{array}$ & $\begin{array}{l}\text { onthly } \\
f \text {, in } 1\end{array}$ & $\begin{array}{l}\text { schar } \\
\text { hes. }\end{array}$ & , In & $\begin{array}{c}\text { second-f } \\
\text {. }\end{array}$ & et. & : : & 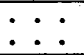 & 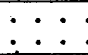 & . & $\begin{array}{r}350 \\
3.90 \\
\end{array}$ & $\begin{array}{r}64.0 \\
.74\end{array}$ \\
\hline
\end{tabular}

Gage height, in feet, and discharge, in second-feet, at indicated time, 1938

\begin{tabular}{|c|c|c|c|c|c|c|c|c|c|c|c|c|}
\hline \multirow{2}{*}{ 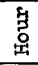 } & Feet & Sec.ft. & Feet & Sec.ft. & Feet & Sec.ft. & Feet & sec.ft. & Feet & sec.ft. & Feet & Sec.ft. \\
\hline & \multicolumn{2}{|c|}{ September 18} & \multicolumn{2}{|c|}{ September 19} & \multicolumn{2}{|c|}{ September 20} & \multicolumn{2}{|c|}{ September 21} & \multicolumn{2}{|c|}{ September 22} & \multicolumn{2}{|c|}{ September 23} \\
\hline $\begin{array}{l}1 \\
2 \\
3 \\
4 \\
5 \\
6\end{array}$ & $\begin{array}{l}3.65 \\
3.65 \\
3.64 \\
3.64 \\
3.64 \\
3.64\end{array}$ & $\begin{array}{l}- \\
- \\
- \\
- \\
- \\
-\end{array}$ & $\begin{array}{l}3.64 \\
3.64 \\
3.64 \\
3.64 \\
3.64 \\
3.65\end{array}$ & $\begin{array}{l}- \\
- \\
- \\
- \\
- \\
-\end{array}$ & $\begin{array}{l}4.32 \\
4.36 \\
4.46 \\
4.56 \\
4.78 \\
5.03\end{array}$ & $\begin{array}{l}231 \\
246 \\
285 \\
328 \\
434 \\
576\end{array}$ & $\begin{array}{l}5.17 \\
5.17 \\
5.17 \\
5.21 \\
5.23 \\
5.24\end{array}$ & $\begin{array}{l}664 \\
664 \\
664 \\
690 \\
703 \\
709\end{array}$ & $\begin{array}{l}6.24 \\
6.19 \\
6.17 \\
6.14 \\
6.13 \\
6.13\end{array}$ & $\begin{array}{l}1,440 \\
1,400 \\
1,390 \\
1,360 \\
1,350 \\
1,350\end{array}$ & $\begin{array}{l}6.31 \\
6.32 \\
6.32 \\
6.32 \\
6.32 \\
6.33\end{array}$ & $\begin{array}{l}1,500 \\
1,500 \\
1,500 \\
1,500 \\
1,500 \\
1,510\end{array}$ \\
\hline $\begin{array}{r}7 \\
8 \\
9 \\
10 \\
11 \\
\mathrm{~N}\end{array}$ & $\begin{array}{l}3.63 \\
3.63 \\
3.63 \\
3.62 \\
3.62 \\
3.62\end{array}$ & $\begin{array}{l}- \\
- \\
* 19 \\
- \\
-\end{array}$ & $\begin{array}{l}3.65 \\
3.66 \\
3.67 \\
3.67 \\
3.67 \\
3.80\end{array}$ & $\begin{array}{l}- \\
- \\
- \\
{ }^{*} 22 \\
-\end{array}$ & $\begin{array}{l}5.02 \\
5.09 \\
5.10 \\
5.10 \\
5.09 \\
5.07\end{array}$ & $\begin{array}{l}570 \\
613 \\
619 \\
619 \\
613 \\
601\end{array}$ & $\begin{array}{l}5.25 \\
5.28 \\
5.34 \\
5.39 \\
5.44 \\
5.72\end{array}$ & $\begin{array}{r}716 \\
736 \\
777 \\
811 \\
846 \\
1,040\end{array}$ & $\begin{array}{l}6.12 \\
6.12 \\
6.13 \\
6.15 \\
6.16 \\
6.17\end{array}$ & $\begin{array}{l}1,350 \\
1,350 \\
1,350 \\
1,370 \\
1,380 \\
1,390\end{array}$ & $\begin{array}{l}6.33 \\
6.33 \\
6.33 \\
6.33 \\
6.33 \\
6.32\end{array}$ & $\begin{array}{l}1,510 \\
1,510 \\
1,510 \\
1,510 \\
1,510 \\
1,500\end{array}$ \\
\hline $\begin{array}{l}1 \\
2 \\
3 \\
4 \\
5 \\
6\end{array}$ & $\begin{array}{l}3.62 \\
3.62 \\
3.62 \\
3.61 \\
3.61 \\
3.61\end{array}$ & $\begin{array}{l}- \\
- \\
- \\
\\
\\
-\end{array}$ & $\begin{array}{l}4.37 \\
4.30 \\
4.29 \\
4.35 \\
4.32 \\
4.24\end{array}$ & $\begin{array}{l}- \\
- \\
-199 \\
- \\
-\end{array}$ & $\begin{array}{l}5.05 \\
5.03 \\
5.02 \\
5.00 \\
4.99 \\
4.98\end{array}$ & $\begin{array}{l}588 \\
576 \\
570 \\
558 \\
552 \\
546\end{array}$ & $\begin{array}{l}6.02 \\
6.42 \\
6.51 \\
6.64 \\
6.82 \\
6.86\end{array}$ & $\begin{array}{l}1,270 \\
1,580 \\
1,650 \\
1,750 \\
1,880 \\
1,910\end{array}$ & $\begin{array}{l}6.19 \\
6.21 \\
6.22 \\
6.23 \\
6.24 \\
6.26\end{array}$ & $\begin{array}{l}1,400 \\
1,420 \\
1,430 \\
1,430 \\
1,440 \\
1,460\end{array}$ & $\begin{array}{l}6.32 \\
6.31 \\
6.31 \\
6.30 \\
6.30 \\
6.29\end{array}$ & $\begin{array}{l}1,500 \\
1,500 \\
1,500 \\
1,490 \\
1,490 \\
1,480\end{array}$ \\
\hline \multirow[t]{2}{*}{$\begin{array}{r}7 \\
8 \\
9 \\
10 \\
11 \\
11\end{array}$} & $\begin{array}{l}3.61 \\
3.61 \\
3.62 \\
3.62 \\
3.62 \\
3.63\end{array}$ & $\begin{array}{l}- \\
- \\
- \\
- \\
-\end{array}$ & $\begin{array}{l}4.22 \\
4.20 \\
4.19 \\
4.20 \\
4.27 \\
4.32\end{array}$ & $\begin{array}{l}- \\
- \\
- \\
-\end{array}$ & $\begin{array}{l}4.99 \\
5.06 \\
5.13 \\
5.16 \\
5.17 \\
5.17\end{array}$ & $\begin{array}{l}552 \\
595 \\
638 \\
657 \\
664 \\
664\end{array}$ & $\begin{array}{l}6.82 \\
6.76 \\
6.62 \\
6.49 \\
6.38 \\
6.30\end{array}$ & $\begin{array}{l}1,880 \\
1,840 \\
1,740 \\
1,630 \\
1,550 \\
1,490\end{array}$ & $\begin{array}{l}6.27 \\
6.28 \\
6.29 \\
6.30 \\
6.31 \\
6.31\end{array}$ & $\begin{array}{l}1,470 \\
1,470 \\
1,480 \\
1,490 \\
1,500 \\
1,500\end{array}$ & $\begin{array}{l}6.29 \\
6.28 \\
6.28 \\
6.27 \\
6.26 \\
6.25\end{array}$ & $\begin{array}{l}1,480 \\
1,470 \\
1,470 \\
1,470 \\
1,460 \\
1,450\end{array}$ \\
\hline & \multicolumn{2}{|c|}{ September 24} & \multicolumn{2}{|c|}{ September 25} & \multicolumn{2}{|c|}{ September 26} & \multicolumn{2}{|c|}{ September 27} & \multicolumn{2}{|c|}{ September 2B } & \multicolumn{2}{|c|}{ September 29} \\
\hline $\begin{array}{r}2 \\
4 \\
6 \\
8 \\
10 \\
N\end{array}$ & $\begin{array}{l}6.24 \\
6.22 \\
6.21 \\
6.19 \\
6.18 \\
6.16\end{array}$ & $\begin{array}{l}1,440 \\
1,430 \\
1,420 \\
1,400 \\
1,390 \\
1,380\end{array}$ & $\begin{array}{l}6.02 \\
6.01 \\
5.98 \\
5.96 \\
5.94 \\
5.92\end{array}$ & $\begin{array}{l}1,270 \\
1,260 \\
1,240 \\
1,220 \\
1,210 \\
1,190\end{array}$ & $\begin{array}{l}5.77 \\
5.74 \\
5.72 \\
5.69 \\
5.67 \\
5.64\end{array}$ & $\begin{array}{r}1,080 \\
1,060 \\
1,040 \\
1,020 \\
1,010 \\
986\end{array}$ & $\begin{array}{l}5.48 \\
5.45 \\
5.42 \\
5.40 \\
5.37 \\
5.34\end{array}$ & $\begin{array}{l}873 \\
852 \\
832 \\
818 \\
797 \\
777\end{array}$ & $\begin{array}{l}5.17 \\
5.14 \\
5.12 \\
5.09 \\
5.07 \\
5.04\end{array}$ & $\begin{array}{l}664 \\
645 \\
632 \\
613 \\
601 \\
582\end{array}$ & $\begin{array}{l}4.82 \\
4.78 \\
4.73 \\
4.68 \\
4.63 \\
4.58\end{array}$ & $\begin{array}{l}455 \\
434 \\
408 \\
384 \\
360 \\
337\end{array}$ \\
\hline $\begin{array}{r}2 \\
4 \\
6 \\
8 \\
10 \\
M\end{array}$ & $\begin{array}{l}6.14 \\
6.12 \\
6.10 \\
6.08 \\
6.06 \\
6.04\end{array}$ & $\begin{array}{l}1,360 \\
1,350 \\
1,330 \\
1,310 \\
1,300 \\
1,280\end{array}$ & $\begin{array}{l}5.90 \\
5.88 \\
5.86 \\
5.83 \\
5.81 \\
5.79\end{array}$ & $\begin{array}{l}1,180 \\
1,160 \\
1,150 \\
1,120 \\
1,110 \\
1,090\end{array}$ & $\begin{array}{l}5.62 \\
5.60 \\
5.58 \\
5.55 \\
5.53 \\
5.50\end{array}$ & $\begin{array}{l}972 \\
957 \\
943 \\
922 \\
908 \\
887\end{array}$ & $\begin{array}{l}5.32 \\
5.29 \\
5.27 \\
5.25 \\
5.22 \\
5.20\end{array}$ & $\begin{array}{l}763 \\
742 \\
729 \\
716 \\
696 \\
683\end{array}$ & $\begin{array}{l}5.01 \\
4.99 \\
4.96 \\
4.93 \\
4.90 \\
4.86\end{array}$ & $\begin{array}{l}564 \\
552 \\
535 \\
517 \\
500 \\
478\end{array}$ & $\begin{array}{l}53 \\
48 \\
43 \\
37 \\
33 \\
28\end{array}$ & $\begin{array}{l}314 \\
293 \\
273 \\
250 \\
235 \\
217\end{array}$ \\
\hline
\end{tabular}

* On basis of temporary gage readings at times indicated. 
Passaic River above dam at Little Falls, N. J.

Location.- Lat. $40^{\circ} 53^{\prime} 0^{\prime \prime}$, long. $74^{\circ} 14^{\prime} 03^{n}$, above Beattie Dam at Little Falls, Passa1c County. Gage readings are elevations above mean sea level (New Jersey Geological Survey benchmark)

Drainage area.- 761 square miles.

Gage-height record.- Gage read daily at 8 a.m., 4 p.m., and midnight.

Maxima.- 1938: Gage height observed, 161.90 feet at 4 p.m. and 12 p.m. Sept. 23. Maximum stage known, 168.30 feet 2 to 8 p.m. 0ct. $10,1903$.

Remarks. - The center section of the dam is 160 feet long with crest at elevation 157.18 feet; the north wing is 64 feet long with crest at elevation 157.81 feet; and the south wing, which is parallel to the channel, is 61 feet long with crest at elevation 157.56 feet. Gage-height record furnished by Passaic Valley water Commission.

Mean gage height, in feet, 1938

\begin{tabular}{|c|c|c|c|c|c|c|c|c|c|c|c|}
\hline Day & Sept. & Oct. & Day & Sept. & oct. & Day & Sept. & oct. & Day & Sept. & oct. \\
\hline $\begin{array}{l}1 \\
2 \\
3 \\
4 \\
5 \\
6 \\
7 \\
8\end{array}$ & $\begin{array}{l}157.12 \\
157.06 \\
157.05 \\
157.01 \\
156.99 \\
157.07 \\
156.96 \\
157.62\end{array}$ & $\begin{array}{l}158.50 \\
158.32 \\
157.99 \\
157.71 \\
157.35 \\
157.33 \\
157.40 \\
157.32\end{array}$ & $\begin{array}{r}9 \\
10 \\
11 \\
12 \\
13 \\
14 \\
15 \\
16\end{array}$ & $\begin{array}{l}157.01 \\
156.99 \\
157.07 \\
157.13 \\
157.03 \\
157.05 \\
157.12 \\
157.12\end{array}$ & $\begin{array}{l}157.27 \\
157.26 \\
157.31 \\
157.18 \\
157.07 \\
157.11 \\
157.05 \\
156.96\end{array}$ & $\begin{array}{l}17 \\
18 \\
19 \\
20 \\
21 \\
22 \\
23 \\
24\end{array}$ & $\begin{array}{l}157.07 \\
157.09 \\
157.27 \\
158.32 \\
159.47 \\
160.82 \\
161.72 \\
161.68\end{array}$ & $\begin{array}{l}157.12 \\
157.06 \\
157.01 \\
157.05 \\
157.35 \\
157.45 \\
157.25 \\
157.22\end{array}$ & $\begin{array}{l}25 \\
26 \\
27 \\
28 \\
29 \\
30 \\
31\end{array}$ & $\begin{array}{l}161.13 \\
160.43 \\
159.86 \\
159.40 \\
159.02 \\
158.70\end{array}$ & $\begin{array}{l}157.63 \\
157.42 \\
157.28 \\
157.28 \\
157.21 \\
157.06 \\
157.14\end{array}$ \\
\hline
\end{tabular}

Gage height, in feet, at indicated time, September 1938

\begin{tabular}{|c|c|c|c|c|c|c|c|c|c|c|c|c|}
\hline Hr. & 18 & 19 & 20 & 21 & 22 & 23 & 24 & 25 & 26 & 27 & 28 & 29 \\
\hline $\begin{array}{l}8 \\
4 \\
M\end{array}$ & $\begin{array}{l}157.10 \\
157.10 \\
157.15\end{array}$ & $\begin{array}{l}157.10 \\
157.25 \\
157.80\end{array}$ & $\begin{array}{l}158.00 \\
158.50 \\
159.10\end{array}$ & $\begin{array}{l}159.15 \\
159.60 \\
160.20\end{array}$ & $\begin{array}{l}160.60 \\
161.15 \\
161.20\end{array}$ & $\begin{array}{l}161.70 \\
161.90 \\
161.90\end{array}$ & $\begin{array}{l}161.70 \\
161.65 \\
161.50\end{array}$ & $\begin{array}{l}161.25 \\
161.00 \\
160.80\end{array}$ & $\begin{array}{l}160.50 \\
160.40 \\
160.00\end{array}$ & $\begin{array}{l}159.90 \\
159.80 \\
159.80\end{array}$ & $\begin{array}{l}159.40 \\
159.30 \\
159.20\end{array}$ & $\begin{array}{l}159.00 \\
159.00 \\
158.90\end{array}$ \\
\hline
\end{tabular}

Passaic River below dam at Little Falls, N. J.

Location. - Lat. $40^{\circ} 52^{\prime} 5^{\prime n}$, long. $74^{\circ} 13^{\prime} 40^{\prime \prime}, 2,000$ feet below Beattie Dam, at tailrace of filter plant, Little Falls, Passalc County. Gage readings are elevations above mean sea level (New Jersey Geological Survey benchmark).

Gage-helght record.- Gage read daily at 8 a.m., 4 p.m., and mianight.

Maximum.- 1938: Gage height observed, 129.60 feet at 4 p.m. and 12 p.m. Sept. 23.

Remarks. - Record furnished by Passaic Valley Water Commission.

Mean gage height, in feet, 1938

\begin{tabular}{|c|c|c|c|c|c|c|c|c|c|c|c|}
\hline Day & Sept. & Oct. & Day & Sept. & oct. & Day & Sept. & oct. & Day & Sept. & Oct. \\
\hline $\begin{array}{l}1 \\
2 \\
3 \\
4 \\
5 \\
6 \\
7 \\
8\end{array}$ & $\begin{array}{l}121.28 \\
121.22 \\
121.22 \\
121.23 \\
121.12 \\
121.15 \\
121.02 \\
121.07\end{array}$ & $\begin{array}{l}124.48 \\
124.02 \\
123.62 \\
123.24 \\
122.94 \\
122.60 \\
122.55 \\
122.60\end{array}$ & $\begin{array}{l}9 \\
10 \\
11 \\
12 \\
13 \\
14 \\
15 \\
16\end{array}$ & $\begin{array}{l}121.07 \\
121.07 \\
121.15 \\
121.28 \\
121.19 \\
121.16 \\
121.17 \\
121.15\end{array}$ & $\begin{array}{l}122.46 \\
122.34 \\
122.22 \\
122.15 \\
122.00 \\
121.85 \\
121.80 \\
121.77\end{array}$ & $\begin{array}{l}17 \\
18 \\
19 \\
20 \\
21 \\
22 \\
23 \\
24\end{array}$ & $\begin{array}{l}121.09 \\
121.16 \\
121.84 \\
124.10 \\
125.86 \\
127.73 \\
129.31 \\
129.20\end{array}$ & $\begin{array}{l}121.72 \\
121.68 \\
121.67 \\
121.69 \\
121.84 \\
122.22 \\
122.30 \\
122.05\end{array}$ & $\begin{array}{l}25 \\
26 \\
27 \\
28 \\
29 \\
30 \\
31\end{array}$ & $\begin{array}{l}128.17 \\
127.12 \\
126.34 \\
125.65 \\
125.15 \\
124.77\end{array}$ & $\begin{array}{l}122.48 \\
122.36 \\
122.22 \\
122.34 \\
122.40 \\
122.36 \\
122.21\end{array}$ \\
\hline
\end{tabular}

Gage height, in feet, at indicated tire, September 1938

\begin{tabular}{|c|c|c|c|c|c|c|c|c|c|c|c|c|}
\hline $\mathrm{Hr}$. & 18 & 19 & 20 & 21 & 22 & 23 & 24 & 25 & 26 & 27 & $28-$ & 29 \\
\hline $\begin{array}{l}8 \\
4 \\
M\end{array}$ & $\begin{array}{l}121 \cdot 10 \\
121 \cdot 25 \\
121 \cdot 25\end{array}$ & $\begin{array}{l}121.15 \\
122.00 \\
123.50\end{array}$ & $\begin{array}{l}123.50 \\
124.40 \\
125.30\end{array}$ & $\begin{array}{l}125.30 \\
126.20 \\
126.85\end{array}$ & $\begin{array}{l}127.50 \\
128.15 \\
128.25\end{array}$ & $\begin{array}{l}129.40 \\
129.60 \\
129.60\end{array}$ & $\begin{array}{l}129.40 \\
129.00 \\
128.80\end{array}$ & $\begin{array}{l}128.40 \\
127.90 \\
127.60\end{array}$ & $\begin{array}{l}127.25 \\
127.00 \\
126.65\end{array}$ & $\begin{array}{l}126.40 \\
126.20 \\
126.20\end{array}$ & $\begin{array}{l}125.70 \\
125.50 \\
125.30\end{array}$ & $\begin{array}{l}125.20 \\
125.10 \\
125.00\end{array}$ \\
\hline
\end{tabular}




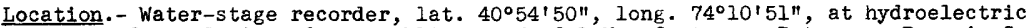
plant of the Society for Establishing Useful Manufactures, Paterson, Passaic County. Gage heights are elevations above mean sea level (New Jersey Geological Survey benchmark).

Drainage area.- 785 square miles; materlally affected by diversions, by storage in large swamp areas, and by storage in large reservoirs for water supply.

Gage-neight record.- Water-stage recorder graph. Add 100.00 feet to gage heights published in this report to convert to observed gage heights or to mean sea level. Stage-discharge relation.- Defined by current-meter measurements. Affected by break in flashboards Sept. 21 to 0ct. 6.

Maxima.- September 1938: Discharge, 9,350 second-feet 7 to 12 p.m. Sept. 23 (gage height, 19.22 feet).

898 to August 1938: Maximum mean dally discharge, 28,000 second-feet oct, 10,1903

Remarks.- Tables of daily and hourly discharges give total flow over spillway and tinrough power plant and raceway, representing total flow just above Great Falls. Mean monthly discharge adjusted'for diversions and for storage in Boonton, Wanaque, and Pequannock River reservoirs and in Greenwood Lake. Mean monthly diversions were: September, 267 second-feet; october, 277 second-feet. For information on storage see records for Boonton Reservolr at Boonton, N. J., Wanaque Reservoir at Wanaque, N. J., Oak Ridge Reservoir at Oak Ridge, N. J., Canistear Reservoir near Stockholm, N. J., Clinton Reservolr near Newfoundland, N. J., Echo Lake Reservoir near Charlotteburg, N. J., and Greenwood Lake at The Glens, N. J.

Mean dally discharge, in second-feet, 1938

\begin{tabular}{|c|c|c|c|c|c|c|c|c|c|c|c|}
\hline Day & Sept. & oet. & Day & Sept. & Oct. & Day & Sept. & Oct. & Day & Sept. & Oct. \\
\hline $\begin{array}{l}1 \\
2 \\
3 \\
4 \\
5 \\
6 \\
7 \\
8\end{array}$ & $\begin{array}{l}236 \\
279 \\
236 \\
247 \\
202 \\
207 \\
149 \\
205\end{array}$ & $\begin{array}{r}2,180 \\
1,860 \\
1,610 \\
1,320 \\
1,050 \\
866 \\
964 \\
943\end{array}$ & $\begin{array}{l}9 \\
10 \\
11 \\
12 \\
13 \\
14 \\
15 \\
16\end{array}$ & $\begin{array}{l}197 \\
158 \\
248 \\
389 \\
332 \\
204 \\
244 \\
214 \\
\end{array}$ & $\begin{array}{l}884 \\
779 \\
713 \\
603 \\
560 \\
517 \\
451 \\
464\end{array}$ & $\begin{array}{l}17 \\
18 \\
19 \\
20 \\
21 \\
22 \\
23 \\
24\end{array}$ & $\begin{array}{r}214 \\
219 \\
469 \\
1,920 \\
4,590 \\
7,020 \\
9,140 \\
8,810\end{array}$ & $\begin{array}{l}412 \\
450 \\
421 \\
409 \\
564 \\
802 \\
745 \\
700\end{array}$ & $\begin{array}{l}25 \\
26 \\
27 \\
28 \\
29 \\
30 \\
31\end{array}$ & $\begin{array}{l}7,210 \\
5,480 \\
4,300 \\
3,480 \\
2,940 \\
2,510\end{array}$ & $\begin{array}{l}867 \\
934 \\
823 \\
788 \\
813 \\
771 \\
640\end{array}$ \\
\hline $\begin{array}{l}\text { Mean } \\
\text { Mean } \\
\text { Run-c }\end{array}$ & $\begin{array}{l}\text { nonthiy } \\
\text { nonthly } \\
\text { ef, in }\end{array}$ & $\begin{array}{l}\text { schar } \\
\text { schar } \\
\text { hes ( }\end{array}$ & , in & $\begin{array}{l}\text { econd- } \\
\text { econd- }\end{array}$ & $\begin{array}{l}\text { et } \\
\text { et }\end{array}$ ab & as te & 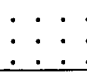 & 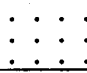 & $\dot{*} \dot{ }$ & $\begin{array}{r}2,068 \\
2,442 \\
3.47 \\
\end{array}$ & $\begin{array}{r}836 \\
1,019 \\
1.50 \\
\end{array}$ \\
\hline
\end{tabular}

Gage helght, in feet, and discherge, In second-feet, at indicated time, 1938

\begin{tabular}{|c|c|c|c|c|c|c|c|c|c|c|c|c|}
\hline \multirow{2}{*}{$\begin{array}{l}4 \\
0 \\
0 \\
\text { 워 } \\
\end{array}$} & Feet & Sec.ft. & Feet & Sec.ft. & Feet & Sec.ft. & Feet & Sec.ft. & Feet & Sec.ft. & Feet & Sec.ft. \\
\hline & \multicolumn{2}{|c|}{ September 18} & \multicolumn{2}{|c|}{ September 19} & \multicolumn{2}{|c|}{ September 20} & \multicolumn{2}{|c|}{ September 21} & \multicolumn{2}{|c|}{ September 22} & \multicolumn{2}{|c|}{ September 23} \\
\hline $\begin{array}{l}1 \\
2 \\
3 \\
4 \\
5 \\
6\end{array}$ & $\begin{array}{l}15.46 \\
15.43 \\
15.39 \\
15.38 \\
15.37 \\
15.37\end{array}$ & $\begin{array}{l}260 \\
260 \\
260 \\
217 \\
217 \\
217\end{array}$ & $\begin{array}{l}15.45 \\
15.47 \\
15.47 \\
15.47 \\
15.46 \\
15.44\end{array}$ & $\begin{array}{l}217 \\
238 \\
238 \\
265 \\
265 \\
272\end{array}$ & $\begin{array}{l}15.25 \\
15.26 \\
15.30 \\
15.32 \\
15.38 \\
15.58\end{array}$ & $\begin{array}{r}834 \\
952 \\
1,050 \\
1,050 \\
1,300 \\
1,330\end{array}$ & $\begin{array}{l}16.92 \\
16.92 \\
16.92 \\
16.93 \\
16.97 \\
17.01\end{array}$ & $\begin{array}{l}3,090 \\
3,090 \\
3,090 \\
3,110 \\
3,190 \\
3,270\end{array}$ & $\begin{array}{l}18.04 \\
18.07 \\
18.10 \\
18.14 \\
18.17 \\
18.21\end{array}$ & $\begin{array}{l}5,720 \\
5,810 \\
5,890 \\
5,990 \\
6,080 \\
6,180\end{array}$ & & $\begin{array}{l}8,720 \\
8,820 \\
8,930 \\
8,990 \\
9,100 \\
9,130\end{array}$ \\
\hline $\begin{array}{r}7 \\
8 \\
9 \\
10 \\
11 \\
\text { N }\end{array}$ & $\begin{array}{l}15.38 \\
15.41 \\
15.44 \\
15.45 \\
15.43 \\
15.38\end{array}$ & $\begin{array}{l}181 \\
181 \\
181 \\
181 \\
238 \\
285\end{array}$ & $\begin{array}{l}15.42 \\
15.38 \\
15.37 \\
15.39 \\
15.41 \\
15.33\end{array}$ & $\begin{array}{l}272 \\
249 \\
249 \\
191 \\
191 \\
191\end{array}$ & $\begin{array}{l}15.82 \\
15.96 \\
16.05 \\
16.11 \\
16.15 \\
16.19\end{array}$ & $\begin{array}{l}1,500 \\
1,630 \\
1,720 \\
1,780 \\
1,840 \\
1,870\end{array}$ & $\begin{array}{l}17.07 \\
17.10 \\
17.14 \\
17.18 \\
17.22 \\
17.30\end{array}$ & $\begin{array}{l}3,400 \\
3,460 \\
3,540 \\
3,630 \\
3,710 \\
3,890\end{array}$ & $\begin{array}{l}18.25 \\
18.31 \\
18.44 \\
18.50 \\
18.45 \\
18.48\end{array}$ & $\begin{array}{l}6,310 \\
6,480 \\
6,540 \\
6,720 \\
6,880 \\
7,010\end{array}$ & $\begin{array}{l}19 \\
19 \\
19 \\
19 \\
19 \\
19\end{array}$ & $\begin{array}{l}9,200 \\
9,190 \\
9,200 \\
9,190 \\
9,190 \\
9,220\end{array}$ \\
\hline $\begin{array}{l}1 \\
2 \\
3 \\
4 \\
5 \\
6\end{array}$ & $\begin{array}{l}15.37 \\
15.37 \\
15.37 \\
15.37 \\
15.38 \\
15.39\end{array}$ & $\begin{array}{l}285 \\
238 \\
217 \\
217 \\
217 \\
217\end{array}$ & $\begin{array}{l}15.38 \\
15.58 \\
15.48 \\
15.37 \\
15.12 \\
15.00\end{array}$ & $\begin{array}{r}393 \\
261 \\
394 \\
907 \\
1,070 \\
1,060\end{array}$ & $\begin{array}{l}16.24 \\
16.33 \\
16.41 \\
16.47 \\
16.55 \\
16.60\end{array}$ & $\begin{array}{l}1,930 \\
2,050 \\
2,160 \\
2,260 \\
2,380 \\
2,450\end{array}$ & $\begin{array}{l}17.41 \\
17.67 \\
17.95 \\
18.16 \\
18.30 \\
18.40\end{array}$ & $\begin{array}{l}4,140 \\
4,780 \\
5,520 \\
6,100 \\
6,480 \\
6,760\end{array}$ & $\begin{array}{l}18.51 \\
18.56 \\
18.61 \\
18.66 \\
18.70 \\
18.76\end{array}$ & $\begin{array}{l}7,100 \\
7,240 \\
7,390 \\
7,550 \\
7,670 \\
7,850\end{array}$ & $\begin{array}{l}19.18 \\
19.19 \\
19.20 \\
19.20 \\
19.21 \\
19.21\end{array}$ & $\begin{array}{l}9,210 \\
9,250 \\
9,280 \\
9,280 \\
9,320 \\
9,330\end{array}$ \\
\hline \multirow[t]{2}{*}{$\begin{array}{r}7 \\
8 \\
9 \\
10 \\
11 \\
M\end{array}$} & $\begin{array}{l}39 \\
40 \\
41 \\
41 \\
43 \\
44\end{array}$ & $\begin{array}{l}217 \\
217 \\
217 \\
217 \\
217 \\
217\end{array}$ & $\begin{array}{l}14 \\
14 \\
14 \\
15 \\
15 \\
15\end{array}$ & $\begin{array}{l}884 \\
850 \\
789 \\
627 \\
713 \\
840\end{array}$ & $\begin{array}{l}16.66 \\
16.71 \\
16.76 \\
16.81 \\
16.87 \\
16.91\end{array}$ & $\begin{array}{l}2,550 \\
2,640 \\
2,730 \\
2,830 \\
2,950 \\
3,020\end{array}$ & $\begin{array}{l}18.40 \\
18.33 \\
18.20 \\
18.10 \\
18.05 \\
18.04\end{array}$ & $\begin{array}{l}6,730 \\
6,530 \\
6,150 \\
5,870 \\
5,750 \\
5,720\end{array}$ & $\begin{array}{l}81 \\
85 \\
90 \\
93 \\
98 \\
01\end{array}$ & $\begin{array}{l}010 \\
140 \\
300 \\
400 \\
550 \\
650\end{array}$ & $\begin{array}{l}19.22 \\
19.22 \\
19.22 \\
19.22 \\
19.22 \\
19.22\end{array}$ & $\begin{array}{l}350 \\
350 \\
350 \\
350 \\
350 \\
350\end{array}$ \\
\hline & \multicolumn{2}{|c|}{ September 24} & \multicolumn{2}{|c|}{ September 25} & \multicolumn{2}{|c|}{ September 26} & \multicolumn{2}{|c|}{ September 27} & \multicolumn{2}{|c|}{ September 28} & \multicolumn{2}{|c|}{ September 29} \\
\hline $\begin{array}{l}2 \\
4 \\
6 \\
8\end{array}$ & $\begin{array}{l}19.20 \\
19.18 \\
19.16 \\
19.14 \\
19.09 \\
19.04\end{array}$ & $\begin{array}{l}9,280 \\
9,200 \\
9,140 \\
9,090 \\
8,920 \\
8,740\end{array}$ & $\begin{array}{l}18.79 \\
18.73 \\
18.69 \\
18.64 \\
18.60 \\
18.55\end{array}$ & $\begin{array}{l}7,930 \\
7,740 \\
7,620 \\
7,470 \\
7,350 \\
7,190\end{array}$ & $\begin{array}{l}18.17 \\
18.12 \\
18.07 \\
18.09 \\
18.00 \\
17.95\end{array}$ & $\begin{array}{l}6,080 \\
5,950 \\
5,820 \\
5,870 \\
5,650 \\
5,520\end{array}$ & $\begin{array}{l}17.62 \\
17.59 \\
17.55 \\
17.51 \\
17.47 \\
17.43\end{array}$ & & $\begin{array}{l}17.22 \\
17.19 \\
17.16 \\
17.13 \\
17.10 \\
17.07\end{array}$ & $\begin{array}{l}3,760 \\
3,700 \\
3,640 \\
3,570 \\
3,510 \\
3,450\end{array}$ & & $\begin{array}{l}3,140 \\
3,100 \\
3,060 \\
3,000 \\
2,960 \\
2,900\end{array}$ \\
\hline $\begin{array}{r}2 \\
4 \\
6 \\
8 \\
10 \\
11\end{array}$ & $\begin{array}{l}19.01 \\
18.99 \\
18.96 \\
18.93 \\
18.88 \\
18.83\end{array}$ & $\begin{array}{l}8,640 \\
8,580 \\
8,470 \\
8,380 \\
8,220\end{array}$ & $\begin{array}{l}18.50 \\
18.44 \\
18.39 \\
18.33 \\
18.28 \\
18.22\end{array}$ & $\begin{array}{l}7,030 \\
6,850 \\
6,700 \\
6,530 \\
6,390 \\
6,220\end{array}$ & $\begin{array}{l}18.02 \\
17.87 \\
17.81 \\
17.76 \\
17.71 \\
17.67\end{array}$ & $\begin{array}{l}5,380 \\
5,320 \\
5,160 \\
5,030 \\
4,900 \\
4,780\end{array}$ & $\begin{array}{l}17.41 \\
17.38 \\
17.36 \\
17.33 \\
17.29 \\
17.25\end{array}$ & $\begin{array}{l}4,200 \\
4,130 \\
4,090 \\
4,020 \\
3,930 \\
3,840\end{array}$ & & $\begin{array}{l}3,430 \\
3,400 \\
3,360 \\
3,300 \\
3,260 \\
3,200\end{array}$ & $\begin{array}{l}16.78 \\
16.78 \\
16.77 \\
16.75\end{array}$ & $\begin{array}{l}2,860 \\
2,860 \\
2,850 \\
2,810 \\
2,760 \\
2,720\end{array}$ \\
\hline
\end{tabular}


Passaic River at Dundee Dam, Clifton, N. J.

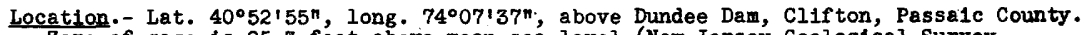
Zero of gage is 25.3 feet above mean sea level (New Jersey Geological Survey benchmerks).

Gage-helght record.- Gage read to inches daily at $6: 30$ a.m., 1 p.m., and 6:30 p.m.

Maxima.- 1938: Gage helght observed, 3.50 feet 1 p.m., 6:30 p.m. Sépt. 23; 6:30 a.m., 1 p.m., and $6: 3 \mathrm{C}$ p.m. Sept. 24 .

haximum stage known, 7.62 feet oct. $10,1903$.

Remarks. - Elevation of crest of dam is zero gage height. Flashboards (16 inches high) placed on dam on September 1 and were partiy broken on September 2l. Records furnished by The Dundee Water Power \& Land Co.

Mean da1ly gage height, in feet, 1938

\begin{tabular}{|c|c|c|c|c|c|c|c|c|c|c|c|}
\hline Day & Sept. & oct. & Day & Sept. & oct. & Day & Sept. & oct. & Day & Sept. & oct. \\
\hline $\begin{array}{l}1 \\
2 \\
3 \\
4 \\
5 \\
6 \\
7 \\
8\end{array}$ & $\begin{array}{l}0.57 \\
1.53 \\
1.58 \\
1.53 \\
1.50 \\
1.57 \\
1.52 \\
1.60\end{array}$ & $\begin{array}{l}1.83 \\
1.70 \\
1.58 \\
1.44 \\
1.33 \\
1.23 \\
1.24 \\
1.25\end{array}$ & $\begin{array}{l}9 \\
10 \\
11 \\
12 \\
13 \\
14 \\
15 \\
16\end{array}$ & $\begin{array}{l}1.58 \\
1.58 \\
1.59 \\
1.66 \\
1.66 \\
1.59 \\
1.58 \\
1.58\end{array}$ & $\begin{array}{r}1.24 \\
1.12 \\
1.11 \\
1.08 \\
1.01 \\
1.00 \\
1.00 \\
.99\end{array}$ & $\begin{array}{l}17 \\
18 \\
19 \\
20 \\
21 \\
22 \\
23 \\
24\end{array}$ & $\begin{array}{r}1.58 \\
1.59 \\
1.87 \\
2.36 \\
2.83 \\
3.00 \\
3.43 \\
3.49\end{array}$ & $\begin{array}{r}0.92 \\
.92 \\
.92 \\
.92 \\
1.01 \\
1.16 \\
1.16 \\
1.09\end{array}$ & $\begin{array}{l}25 \\
26 \\
27 \\
28 \\
29 \\
30 \\
31\end{array}$ & $\begin{array}{l}3.19 \\
2.78 \\
2.51 \\
2.18 \\
2.17 \\
1.94\end{array}$ & $\begin{array}{l}1.17 \\
1.24 \\
1.24 \\
1.17 \\
1.09 \\
1.16 \\
1.17\end{array}$ \\
\hline
\end{tabular}

Gage height, in feet, at indicated time, September 1938

\begin{tabular}{|c|c|c|c|c|c|c|c|c|c|c|c|c|}
\hline Hour & 18 & 19 & 20 & 21 & 22 & 23 & 24 & 25 & 26 & 27 & 28 & 29 \\
\hline $\begin{array}{l}6: 30 \text { a.m. } \\
\text { l:00 p.m. } \\
\text { 6:30 p.m. }\end{array}$ & $\begin{array}{l}1.58 \\
1.58 \\
1.58\end{array}$ & $\begin{array}{l}1.67 \\
1.92 \\
2.00\end{array}$ & $\begin{array}{l}2.25 \\
2.42 \\
2.42\end{array}$ & $\begin{array}{l}2.75 \\
2.92 \\
2.92\end{array}$ & $\begin{array}{l}2.83 \\
2.92 \\
3.17\end{array}$ & $\begin{array}{l}3.33 \\
3.50 \\
3.50\end{array}$ & $\begin{array}{l}3.50 \\
3.50 \\
3.50\end{array}$ & $\begin{array}{l}3.33 \\
3.17 \\
3.08\end{array}$ & $\begin{array}{l}2.83 \\
2.75 \\
2.75\end{array}$ & $\begin{array}{l}2.50 \\
2.50 \\
2.50\end{array}$ & $\begin{array}{l}2.33 \\
2.08 \\
2.00\end{array}$ & $\begin{array}{l}2.33 \\
2.25 \\
2.00\end{array}$ \\
\hline
\end{tabular}


Rockaway River at Dover, N. J.

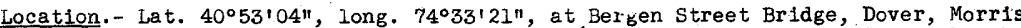

County. Zero of gage is at mean sea level (New Jersey Geological Survey benchmark). Gage-height record.- One gage reading daily at $11 \mathrm{a} . \mathrm{m}$.

Maxima.- September 1938: Gage height observed, 556.7 feet 11 a.m. Sept. 22 . Stage of 559.5 feet reached on Mar. 12, 1936.

Remarks. - Record furnished by Department of streets and Public Improvements, Bureau of Water, Jersey City.

Gage height, in feet, 1938

\begin{tabular}{|c|c|c||r|r|r||r|r|r||r|r|r|}
\hline Day & Sept. & \multicolumn{1}{|c|}{ Oct. } & Day & Sept. & \multicolumn{1}{|c|}{ Oct. } & Day & \multicolumn{1}{|c|}{ Sept. } & 0ct. & Day & Sept. & 0ct. \\
\hline 1 & 554.2 & 554.5 & 9 & 554.1 & 554.4 & 17 & 554.1 & 554.3 & 25 & 555.7 & 554.5 \\
2 & 554.2 & 554.5 & 10 & 554.1 & 554.4 & 18 & 554.1 & 554.2 & 26 & 555.3 & 554.5 \\
3 & 554.2 & 554.4 & 11 & 554.1 & 554.4 & 19 & 554.2 & 554.2 & 27 & 555.1 & 554.5 \\
4 & 554.2 & 554.4 & 12 & 554.1 & 554.3 & 20 & 555.2 & 554.2 & 28 & 554.9 & 554.4 \\
5 & 554.2 & 554.4 & 13 & 554.1 & 554.3 & 21 & 555.5 & 554.4 & 29 & 554.7 & 554.3 \\
6 & 554.1 & 554.5 & 14 & 554.1 & 554.3 & 22 & 556.7 & 554.4 & 30 & 554.6 & 554.3 \\
7 & 554.1 & 554.5 & 15 & 554.1 & 554.3 & 23 & $* 556.9$ & 554.4 & 31 & & 554.3 \\
8 & 554.1 & 554.5 & 16 & 554.1 & 554.3 & 24 & 556.3 & 554.4 & & & \\
\hline
\end{tabular}

* Probably in error. 
Rockaway River above reservoir at Boonton, N. J.

Location. - Water-stage recorder, lat. $40^{\circ} 54^{\prime} 06^{\prime \prime}$, long. $74^{\circ} 24^{\prime} 40^{\prime \prime}$, at Morr1s Street, Boonton, Morris Counity. Zero of gage is 364.47 feet above mean sea level (New Jersey Geological Survey benchmark).

Drainage area.- 116 square miles.

Gage-height record. - Water-stage recorder graph.

Stage-discharge relation.- Defined by current-meter measurements.

Maxima.- September 1938: Discharge, 2,220 second-feet 9:15 to 10 a.m. Sept. 22 (gage height, 5.55 feet).

1937 to August 1938: Discharge 2,120 second-feet July 24, 1958 (gage height, 5.43 feet).

Remarks.- Mean monthly discharge and run-off, in inches, adjusted for diversion through trunk sewer. Mean monthly diversions were: September, 4.8 second-feet; October, 4.4 second-feet. Water-stage recorder operated by Department of Streets and Public Improvements, Bureau of Water, Jersey City.

Mean daily discharge, in second-feet, 1938

\begin{tabular}{|c|c|c|c|c|c|c|c|c|c|c|c|}
\hline Day & Sept. & oct. & Day & Sept. & Oct. & Day & Sept. & oct. & Day & Sept. & oct. \\
\hline $\begin{array}{l}1 \\
2 \\
3 \\
4 \\
5 \\
6 \\
7 \\
8 \\
\end{array}$ & $\begin{array}{l}96 \\
85 \\
73 \\
69 \\
64 \\
57 \\
57 \\
57\end{array}$ & $\begin{array}{l}212 \\
180 \\
164 \\
151 \\
151 \\
170 \\
248 \\
204\end{array}$ & $\begin{array}{r}9 \\
10 \\
11 \\
12 \\
13 \\
14 \\
15 \\
16\end{array}$ & $\begin{array}{l}54 \\
49 \\
50 \\
52 \\
53 \\
47 \\
64 \\
65\end{array}$ & $\begin{array}{l}170 \\
151 \\
145 \\
131 \\
125 \\
122 \\
120 \\
115\end{array}$ & $\begin{array}{l}17 \\
18 \\
19 \\
20 \\
21 \\
22 \\
23 \\
24\end{array}$ & $\begin{array}{r}60 \\
67 \\
174 \\
723 \\
1,200 \\
2,020 \\
1,470 \\
1,090\end{array}$ & $\begin{array}{l}112 \\
110 \\
108 \\
112 \\
221 \\
195 \\
164 \\
170\end{array}$ & $\begin{array}{l}25 \\
26 \\
27 \\
28 \\
29 \\
30 \\
31\end{array}$ & $\begin{array}{l}765 \\
540 \\
437 \\
361 \\
305 \\
253\end{array}$ & $\begin{array}{l}253 \\
208 \\
173 \\
157 \\
151 \\
142 \\
134\end{array}$ \\
\hline $\begin{array}{l}\text { Mean } \\
\text { Mean } \\
\text { Run- }\end{array}$ & $\begin{array}{l}\text { thly } \\
\text { thly } \\
\text { in }\end{array}$ & the & & cond-f & $\left.\begin{array}{l}t \\
t\end{array}\right\}$ & as ted) & $: \dot{*}:$ & $\because \because:$ & $\therefore$ & $\begin{array}{r}349 \\
353 \\
3.39 \\
\end{array}$ & $\begin{array}{r}160 \\
165 \\
1.64 \\
\end{array}$ \\
\hline
\end{tabular}

Gage helght, in feet, and discharge, in second-feet, at indicated time, 1938

\begin{tabular}{|c|c|c|c|c|c|c|c|c|c|c|c|c|}
\hline \multirow{2}{*}{ 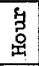 } & Feot & Sec.ft. & Feet & Sec.ft. & Feet & Sec.ft. & Feet & Sec.ft. & Feet & Sec.ft. & Feet & Sec.ft. \\
\hline & \multicolumn{2}{|c|}{ September 18} & \multicolumn{2}{|c|}{ September 19} & \multicolumn{2}{|c|}{ September 20} & \multicolumn{2}{|c|}{ September 21} & \multicolumn{2}{|c|}{ September 22} & \multicolumn{2}{|c|}{ September 23} \\
\hline $\begin{array}{l}1 \\
2 \\
3 \\
4 \\
5 \\
6\end{array}$ & $\begin{array}{l}2.12 \\
2.13 \\
2.13 \\
2.13 \\
2.13 \\
2.13\end{array}$ & $\begin{array}{l}64 \\
65 \\
65 \\
65 \\
65 \\
65\end{array}$ & $\begin{array}{l}2.17 \\
2.18 \\
2.18 \\
2.18 \\
2.18 \\
2.18\end{array}$ & $\begin{array}{l}73 \\
74 \\
74 \\
74 \\
74 \\
74\end{array}$ & $\begin{array}{l}3.07 \\
3.10 \\
3.15 \\
3.20 \\
3.26 \\
3.36\end{array}$ & \begin{tabular}{|}
415 \\
431 \\
459 \\
487 \\
522 \\
583
\end{tabular} & $\begin{array}{l}3.93 \\
3.92 \\
3.91 \\
3.92 \\
3.95 \\
3.99\end{array}$ & $\begin{array}{r}967 \\
959 \\
952 \\
959 \\
982 \\
1,010\end{array}$ & $\begin{array}{l}5.18 \\
5.28 \\
5.36 \\
5.42 \\
5.47 \\
5.51\end{array}$ & $\begin{array}{l}1,920 \\
2,000 \\
2,070 \\
2,120 \\
2,160 \\
2,190\end{array}$ & $\begin{array}{l}4.89 \\
4.85 \\
4.82 \\
4.78 \\
4.75 \\
4.72\end{array}$ & $\begin{array}{r}1,690 \\
1,660 \\
1,640 \\
1,610 \\
1,580 \\
1,560\end{array}$ \\
\hline $\begin{array}{r}7 \\
8 \\
9 \\
10 \\
11 \\
\text { N }\end{array}$ & $\begin{array}{l}2.13 \\
2.13 \\
2.13 \\
2.13 \\
2.13 \\
2.13\end{array}$ & $\begin{array}{l}65 \\
65 \\
65 \\
65 \\
65 \\
65\end{array}$ & $\begin{array}{l}2.18 \\
2.18 \\
2.18 \\
2.18 \\
2.19 \\
2.19\end{array}$ & $\begin{array}{l}74 \\
74 \\
74 \\
74 \\
76 \\
76\end{array}$ & $\begin{array}{l}3.40 \\
3.45 \\
3.50 \\
3.55 \\
3.60 \\
3.65\end{array}$ & $\begin{array}{l}608 \\
640 \\
672 \\
705 \\
738 \\
772\end{array}$ & $\begin{array}{l}4.00 \\
4.04 \\
4.04 \\
4.07 \\
4.09 \\
4.13\end{array}$ & $\begin{array}{l}1,020 \\
1,050 \\
1,050 \\
1,070 \\
1,080 \\
1,110\end{array}$ & $\begin{array}{l}5.53 \\
5.49 \\
5.48 \\
5.55 \\
5.51 \\
5.48\end{array}$ & $\begin{array}{l}2,200 \\
2,170 \\
2,160 \\
2,220 \\
2,190 \\
2,160\end{array}$ & $\begin{array}{l}4.69 \\
4.67 \\
4.65 \\
4.63 \\
4.61 \\
4.59\end{array}$ & $\begin{array}{l}1,540 \\
1,530 \\
1,510 \\
1,490 \\
1,480 \\
1,460\end{array}$ \\
\hline $\begin{array}{l}1 \\
2 \\
3 \\
4 \\
5 \\
6\end{array}$ & $\begin{array}{l}2.13 \\
2.13 \\
2.13 \\
2.13 \\
2.13 \\
2.14\end{array}$ & $\begin{array}{l}65 \\
65 \\
65 \\
65 \\
65 \\
67\end{array}$ & $\begin{array}{l}2.52 \\
2.63 \\
2.68 \\
2.73 \\
2.76 \\
2.80\end{array}$ & $\begin{array}{l}160 \\
199 \\
221 \\
244 \\
258 \\
276\end{array}$ & $\begin{array}{l}3.67 \\
3.68 \\
3.73 \\
3.76 \\
3.82 \\
3.83\end{array}$ & $\begin{array}{l}785 \\
792 \\
826 \\
846 \\
888 \\
895\end{array}$ & $\begin{array}{l}4.16 \\
4.24 \\
4.36 \\
4.43 \\
4.42 \\
4.45\end{array}$ & $\begin{array}{l}1,130 \\
1,190 \\
1,280 \\
1,330 \\
1,330 \\
1,350\end{array}$ & $\begin{array}{l}5.38 \\
5.33 \\
5.27 \\
5.26 \\
5.22 \\
5.17\end{array}$ & $\begin{array}{l}2,080 \\
2,040 \\
2,000 \\
1,990 \\
1,960 \\
1,920\end{array}$ & $\begin{array}{l}4.57 \\
4.55 \\
4.53 \\
4.51 \\
4.50 \\
4.48\end{array}$ & $\begin{array}{l}1,450 \\
1,430 \\
1,410 \\
1,400 \\
1,390 \\
1,370\end{array}$ \\
\hline $\begin{array}{r}7 \\
8 \\
9 \\
10 \\
11 \\
M\end{array}$ & $\begin{array}{l}2.14 \\
2.15 \\
2.15 \\
2.15 \\
2.15 \\
2.16\end{array}$ & $\begin{array}{l}67 \\
69 \\
69 \\
69 \\
69 \\
71\end{array}$ & $\begin{array}{l}2.85 \\
2.90 \\
2.93 \\
2.99 \\
3.01 \\
3.05 \\
\end{array}$ & $\begin{array}{l}300 \\
325 \\
341 \\
372 \\
382 \\
404\end{array}$ & $\begin{array}{l}3.87 \\
3.88 \\
3.91 \\
3.91 \\
3.92 \\
3.92 \\
\end{array}$ & $\begin{array}{l}923 \\
930 \\
952 \\
952 \\
959 \\
959 \\
\end{array}$ & $\begin{array}{l}4.50 \\
4.65 \\
4.80 \\
4.89 \\
5.01 \\
5.11\end{array}$ & $\begin{array}{l}1,390 \\
1,510 \\
1,620 \\
1,690 \\
1,790 \\
1,870\end{array}$ & $\begin{array}{l}5.14 \\
5.10 \\
5.06 \\
5.01 \\
4.97 \\
4.93 \\
\end{array}$ & $\begin{array}{l}1,890 \\
1,860 \\
1,830 \\
1,790 \\
1,760 \\
1,720\end{array}$ & $\begin{array}{l}4.46 \\
4.43 \\
4.41 \\
4.39 \\
4.37 \\
4.35\end{array}$ & $\begin{array}{l}1,360 \\
1,330 \\
1,320 \\
1,300 \\
1,290 \\
1,280 \\
\end{array}$ \\
\hline & \multicolumn{2}{|c|}{ September 24} & \multicolumn{2}{|c|}{ September 25} & \multicolumn{2}{|c|}{ September 26} & \multicolumn{2}{|c|}{ September 27} & \multicolumn{2}{|c|}{ September 28} & \multicolumn{2}{|c|}{ September 29} \\
\hline $\begin{array}{r}2 \\
4 \\
6 \\
8 \\
10 \\
N\end{array}$ & $\begin{array}{l}4.30 \\
4.26 \\
4.22 \\
4.21 \\
4.17 \\
4.12\end{array}$ & $\begin{array}{l}1,240 \\
1,210 \\
1,180 \\
1,170 \\
1,140 \\
1,100\end{array}$ & $\begin{array}{l}3.83 \\
3.80 \\
3.76 \\
3.72 \\
3.67 \\
3.63\end{array}$ & \begin{tabular}{|l|}
895 \\
874 \\
846 \\
819 \\
785 \\
758
\end{tabular} & $\begin{array}{l}3.41 \\
3.38 \\
3.35 \\
3.33 \\
3.30 \\
3.28\end{array}$ & $\begin{array}{r}614 \\
596 \\
577 \\
565 \\
546 \\
534\end{array}$ & $\begin{array}{l}3.16 \\
3.15 \\
3.13 \\
3.12 \\
3.11 \\
3.10\end{array}$ & \begin{tabular}{|l|}
465 \\
459 \\
448 \\
442 \\
437 \\
431
\end{tabular} & $\begin{array}{l}3.07 \\
3.05 \\
3.03 \\
2.97 \\
2.93 \\
2.93\end{array}$ & \begin{tabular}{|l|}
415 \\
404 \\
393 \\
361 \\
341 \\
341
\end{tabular} & $\begin{array}{l}2.91 \\
2.90 \\
2.89 \\
2.88 \\
2.87 \\
2.86\end{array}$ & $\begin{array}{l}330 \\
325 \\
320 \\
315 \\
310 \\
305\end{array}$ \\
\hline $\begin{array}{r}2 \\
4 \\
6 \\
8 \\
10 \\
M\end{array}$ & $\begin{array}{l}4.08 \\
4.04 \\
3.99 \\
3.95 \\
3.91 \\
3.87\end{array}$ & $\begin{array}{r}1,080 \\
1,050 \\
1,010 \\
982 \\
952 \\
923\end{array}$ & $\begin{array}{l}3.59 \\
3.55 \\
3.52 \\
3.49 \\
3.46 \\
3.43\end{array}$ & $\begin{array}{l}731 \\
705 \\
685 \\
666 \\
646 \\
627\end{array}$ & $\begin{array}{l}3.26 \\
3.23 \\
3.22 \\
3.20 \\
3.19 \\
3.18\end{array}$ & $\begin{array}{l}522 \\
505 \\
499 \\
487 \\
481 \\
476\end{array}$ & $\begin{array}{l}3.10 \\
3.09 \\
3.10 \\
3.09 \\
3.08 \\
3.08\end{array}$ & $\begin{array}{l}431 \\
426 \\
431 \\
426 \\
420 \\
420\end{array}$ & $\begin{array}{l}2.94 \\
2.94 \\
2.94 \\
2.93 \\
2.92 \\
2.92\end{array}$ & $\begin{array}{l}346 \\
346 \\
346 \\
341 \\
335 \\
335\end{array}$ & $\begin{array}{l}2.85 \\
2.84 \\
2.83 \\
2.82 \\
2.81 \\
2.80\end{array}$ & $\begin{array}{l}300 \\
296 \\
291 \\
286 \\
281 \\
276\end{array}$ \\
\hline
\end{tabular}

Supplemental records.- Sept. $21,4: 30$ p.m., $4.46 \mathrm{ft} ., 1,360$ sec. $-\mathrm{ft}$. Sept. 22 , $9: 15 \mathrm{~g}$.m., $5.55 \mathrm{ft.}, 2,220 \mathrm{sec} . \mathrm{ft}$. 
Location.- Lat. $40^{\circ} 53^{\prime} 3^{\prime \prime}$, Long. $74^{\circ} 23^{\prime} 5^{\prime \prime}$, at Boonton Reservoir dam, Boonton, Morris County. Zero of gage is 305.25 feet above mean sea level (New Jersey Geological Survey benchmark).

Drainage area.- 119 square miles.

Gage-helght record.- One gage reading daily, usually about 8 a.m.

Remarks.- Usable storage capacity $870,000,000$ cubic feet. Elevation of crest of dam

is zero gage helght. Records furnished by Department of Streets and Public Improve-

ments, Bureau of Water, Jersey City.

Gage height, in feet, and contents, in millions of cubic feet, 1938

\begin{tabular}{|c|c|c|c|c|c|c|c|c|c|c|}
\hline \multirow[b]{2}{*}{ Day } & \multicolumn{2}{|c|}{ September } & \multicolumn{2}{|c|}{ October } & \multirow[b]{2}{*}{ Day } & \multicolumn{2}{|c|}{ September } & \multicolumn{3}{|c|}{ October } \\
\hline & Fevt & $\begin{array}{l}\text { Millions of } \\
\text { cubic feet }\end{array}$ & Feet & $\begin{array}{l}\text { Millions of } \\
\text { cubic feet }\end{array}$ & & Feet & $\begin{array}{l}\text { Millions of } \\
\text { cubic feet }\end{array}$ & Feet & \multicolumn{2}{|c|}{$\begin{array}{l}\text { Millions of } \\
\text { cubic feet }\end{array}$} \\
\hline $\begin{array}{l}1 \\
2 \\
3 \\
4 \\
5\end{array}$ & $\begin{array}{l}1.39 \\
1.38 \\
1.36 \\
1.33 \\
1.29\end{array}$ & $\begin{array}{r}1,067 \\
1,067 \\
1,066 \\
1,065 \\
1,063\end{array}$ & $\begin{array}{l}2.02 \\
1.98 \\
1.95 \\
1.93 \\
1.92\end{array}$ & $\begin{array}{r}1,089 \\
1,087 \\
1,086 \\
1,086 \\
1,085\end{array}$ & $\begin{array}{l}16 \\
17 \\
18 \\
19 \\
20\end{array}$ & $\begin{array}{r}-0.69 \\
-.77 \\
-.84 \\
-.86 \\
-.01\end{array}$ & $\begin{array}{r}995 \\
992 \\
989 \\
989 \\
1,018\end{array}$ & $\begin{array}{l}1.85 \\
1.85 \\
1.85 \\
1.86 \\
1.83\end{array}$ & & $\begin{array}{l}1,083 \\
1,083 \\
1,083 \\
1,083 \\
1,082\end{array}$ \\
\hline $\begin{array}{r}6 \\
7 \\
8 \\
9 \\
10\end{array}$ & $\begin{array}{r}1.26 \\
1.17 \\
1.09 \\
.97 \\
.86\end{array}$ & $\begin{array}{l}1,062 \\
1,059 \\
1,057 \\
1,052 \\
1,049\end{array}$ & $\begin{array}{l}1.90 \\
2.01 \\
2.01 \\
1.96 \\
1.92\end{array}$ & $\begin{array}{l}1,085 \\
1,088 \\
1,088 \\
1,087 \\
1,085\end{array}$ & $\begin{array}{l}21 \\
22 \\
23 \\
24 \\
25\end{array}$ & $\begin{array}{l}1.90 \\
3.01 \\
2.86 \\
2.59 \\
2.39\end{array}$ & $\begin{array}{l}1,085 \\
1,123 \\
1,118 \\
1,109 \\
1,102\end{array}$ & $\begin{array}{l}1.92 \\
1.99 \\
1.96 \\
1.96 \\
2.00\end{array}$ & & $\begin{array}{l}1,085 \\
1,088 \\
1,087 \\
1,087 \\
1,088\end{array}$ \\
\hline $\begin{array}{l}11 \\
12 \\
13 \\
14 \\
15\end{array}$ & $\begin{array}{r}.30 \\
-.32 \\
-.47 \\
-.53 \\
-.64\end{array}$ & $\begin{array}{r}1,029 \\
1,008 \\
1,002 \\
1,000 \\
996\end{array}$ & $\begin{array}{l}1.91 \\
1.91 \\
1.90 \\
1.88 \\
1.87\end{array}$ & $\begin{array}{l}1,085 \\
1,085 \\
1,085 \\
1,084 \\
1,084\end{array}$ & $\begin{array}{l}26 \\
27 \\
28 \\
29 \\
30 \\
31\end{array}$ & $\begin{array}{l}2.23 \\
2.22 \\
2.19 \\
2.15 \\
2.07\end{array}$ & $\begin{array}{l}1,096 \\
1,096 \\
1,095 \\
1,093 \\
1,091\end{array}$ & $\begin{array}{l}2.01 \\
1.98 \\
1.96 \\
1.95 \\
1.93 \\
1.92\end{array}$ & & $\begin{array}{l}1,088 \\
1,087 \\
1,087 \\
1,086 \\
1,086 \\
1,085\end{array}$ \\
\hline & & & & & & & & eptem & & October \\
\hline $\begin{array}{l}\text { Gain } \\
\text { Gain }\end{array}$ & $\begin{array}{l}\text { or } 10 \\
\text { or } 10\end{array}$ & $\begin{array}{l}\text { in storage, } \\
\text { in storage, }\end{array}$ & in $\mathrm{m}$ & $\begin{array}{l}\text { lions of } \\
\text { ivalent mes }\end{array}$ & & & $\div: \cdot \dot{0}$ & & & $\begin{array}{r}-5 \\
-1.9\end{array}$ \\
\hline
\end{tabular}


Rockaway River below reservoir at boonton, N. J.

(formerly Rockaway River at Boonton, N. J.)

Location.- Water-stage recorder, lat. $40^{\circ} 53^{\prime} 47^{\prime \prime}$, long. $74^{\circ} 23^{\prime} 36^{n}$, 1,500 feet below dam of Boonton Reservoir, Boonton, Morris County. Zero of gage is 195.68 feet above mean sea level (New Jersey Geological Survey benchmark).

Drainage area.- 119 square miles; affected by storage and diversion.

Gage-helght record. - Water-stage recorder graph.

Stage-discharge relation.- Defined by current-meter measurements below 1,300 secondfeet; extended to peak stage on basis of discharge over Boonton Reservolr dam obtained by weir formula.

Naxima. - September 1938: Discharge, Including effluent from sewage disposal plant, 1,870 second-feet 1 to 2 p.m. Sept. 22 (gage helght, 6.06 feet). 8.03 feet)

1906 to August 1938: Discharge, 3,770 second-feet Mar. 12, 1936 (gage helght,

Kaximum observed daily discharge, 7,560 second-feet 0ct. 10, 1903, at site a quarter of a mile below present gage.

Remarks.- Tables of dally and hourly discharges indicate total flow over dam, through waste gate, and from sewage disposal plant. Mean monthly discharge and run-off, in inches, adjusted for diversion and effect of storage in Boonton Reservolr. Mean monthly diversions were: September, 78.7 second-feet; october, 78.8 second-feet. For information on storage see record for Boonton Reservoir at Boonton, N. J. Waterstage recorder owned and operated by Department of Streets and Public Improvements, Bureau of Water, Jersey City.

Mean dally discharge, in second-feet, 1938

\begin{tabular}{|c|r|r||r|r|r||r|r|r||r|r|r|}
\hline Day & Sept. & 0ct. & Day & Sept. & Oct. & Day & Sept. & Oct. & Day & Sept. & Oct. \\
\hline 1 & 5.3 & 152 & 9 & 5.0 & 92 & 17 & 4.4 & 32 & 25 & 717 & 148 \\
2 & 4.6 & 116 & 10 & 126 & 67 & 18 & 4.5 & 30 & 26 & 445 & 140 \\
3 & 4.6 & 90 & 11 & 224 & 64 & 19 & 7.5 & 30 & 27 &. & 351 \\
106 \\
4
\end{tabular}

Gage helght, in feet, and discharge, in second-feet, at indicated time, 1938

\begin{tabular}{|c|c|c|c|c|c|c|c|c|c|c|c|c|}
\hline \multirow{2}{*}{$\begin{array}{l}4 \\
3 \\
0 \\
0\end{array}$} & Feet & Sec.ft. & Feet & Sec.ft. & Feet & Sec.ft. & Feet & Sec.ft. & Feet & Sec.ft. & Feet & Sec.ft. \\
\hline & \multicolumn{2}{|c|}{ September 18} & \multicolumn{2}{|c|}{ September 19} & \multicolumn{2}{|c|}{ September 20} & \multicolumn{2}{|c|}{ September 21} & \multicolumn{2}{|c|}{ Sept ember 22} & \multicolumn{2}{|c|}{ Sept ember 23} \\
\hline $\begin{array}{l}1 \\
2 \\
3 \\
4 \\
5 \\
6\end{array}$ & $\begin{array}{l}1.21 \\
1.21 \\
1.21 \\
1.21 \\
1.21 \\
1.21\end{array}$ & $\begin{array}{l}4.4 \\
4.4 \\
4.4 \\
4.4 \\
4.4 \\
4.4\end{array}$ & $\begin{array}{l}1.24 \\
1.25 \\
1.25 \\
1.25 \\
1.25 \\
1.25\end{array}$ & $\begin{array}{l}4.5 \\
4.6 \\
4.6 \\
4.6 \\
4.6 \\
4.6\end{array}$ & $\begin{array}{l}1.55 \\
1.52 \\
1.52 \\
1.60 \\
1.55 \\
1.70\end{array}$ & $\begin{array}{l}13.3 \\
12.2 \\
12.2 \\
15.3 \\
13.3 \\
20\end{array}$ & $\begin{array}{l}1.61 \\
1.57 \\
1.54 \\
1.53 \\
1.53 \\
1.60\end{array}$ & $\begin{array}{l}17.3 \\
15.7 \\
14.5 \\
14.1 \\
14.1 \\
16.9\end{array}$ & $\begin{array}{l}5.14 \\
5.24 \\
5.34 \\
5.45 \\
5.55 \\
5.64\end{array}$ & $\begin{array}{l}1,290 \\
1,350 \\
1,410 \\
1,480 \\
1,540 \\
1,600\end{array}$ & $\begin{array}{l}5.74 \\
5.70 \\
5.65 \\
5.61 \\
5.57 \\
5.52\end{array}$ & $\begin{array}{l}1,660 \\
1,640 \\
1,610 \\
1,580 \\
1,550 \\
1,520\end{array}$ \\
\hline $\begin{array}{r}7 \\
8 \\
9 \\
10 \\
11 \\
\mathrm{~N}\end{array}$ & $\begin{array}{l}1.21 \\
1.22 \\
1.22 \\
1.22 \\
1.22 \\
1.22\end{array}$ & $\begin{array}{l}4.4 \\
4.5 \\
4.5 \\
4.5 \\
4.5 \\
4.5\end{array}$ & $\begin{array}{l}1.25 \\
1.25 \\
1.25 \\
1.25 \\
1.25 \\
1.25\end{array}$ & $\begin{array}{l}4.6 \\
4.6 \\
4.6 \\
4.6 \\
4.6 \\
4.6\end{array}$ & $\begin{array}{l}1.98 \\
1.80 \\
1.68 \\
1.62 \\
1.56 \\
1.52\end{array}$ & $\begin{array}{l}42 \\
27 \\
19.2 \\
16.2 \\
13.7 \\
12.2\end{array}$ & $\begin{array}{l}1.68 \\
2.16 \\
2.54 \\
2.86 \\
3.01 \\
3.20\end{array}$ & $\begin{array}{r}21 \\
66 \\
142 \\
232 \\
276 \\
340\end{array}$ & $\begin{array}{l}5.71 \\
5.84 \\
5.92 \\
5.96 \\
6.01 \\
6.05\end{array}$ & $\begin{array}{l}1,650 \\
1,730 \\
1,780 \\
1,810 \\
1,840 \\
1,870\end{array}$ & $\begin{array}{l}5.49 \\
5.44 \\
5.40 \\
5.35 \\
5.30 \\
5.28\end{array}$ & $\begin{array}{l}1,500 \\
1,470 \\
1,450 \\
1,420 \\
1,390 \\
1,380\end{array}$ \\
\hline $\begin{array}{l}1 \\
2 \\
3 \\
4 \\
5 \\
6\end{array}$ & $\begin{array}{l}1.22 \\
1.22 \\
1.22 \\
1.22 \\
1.22 \\
1.22\end{array}$ & $\begin{array}{l}4.5 \\
4.5 \\
4.5 \\
4.5 \\
4.5 \\
4.5\end{array}$ & $\begin{array}{l}1.25 \\
1.93 \\
1.72 \\
1.55 \\
1.44 \\
1.39\end{array}$ & $\begin{array}{c}4.6 \\
37 \\
20 \\
12.0 \\
8.2 \\
6.9\end{array}$ & $\begin{array}{l}1.51 \\
1.51 \\
1.49 \\
1.47 \\
1.46 \\
1.46\end{array}$ & $\begin{array}{l}11.8 \\
11.8 \\
11.1 \\
10.4 \\
10.1 \\
10.1\end{array}$ & $\begin{array}{l}3.62 \\
4.16 \\
4.52 \\
4.92 \\
4.81 \\
4.82\end{array}$ & $\begin{array}{r}516 \\
772 \\
958 \\
1,170 \\
1,110 \\
1,120\end{array}$ & $\begin{array}{l}6.06 \\
6.06 \\
6.05 \\
6.04 \\
6.01 \\
5.98\end{array}$ & $\begin{array}{l}1,870 \\
1,870 \\
1,870 \\
1,860 \\
1,840 \\
1,820\end{array}$ & $\begin{array}{l}5.26 \\
5.23 \\
5.17 \\
5.13 \\
5.11 \\
5.09\end{array}$ & $\begin{array}{l}1,370 \\
1,350 \\
1,310 \\
1,290 \\
1,280 \\
1,270\end{array}$ \\
\hline \multirow[t]{2}{*}{$\begin{array}{r}7 \\
8 \\
9 \\
10 \\
11 \\
M\end{array}$} & $\begin{array}{l}1.22 \\
1.23 \\
1.23 \\
1.23 \\
1.24 \\
1.24\end{array}$ & $\begin{array}{l}4.5 \\
4.6 \\
4.6 \\
4.6 \\
4.7 \\
4.7\end{array}$ & $\begin{array}{l}1.36 \\
1.35 \\
1.34 \\
1.33 \\
1.63 \\
1.54\end{array}$ & $\begin{array}{r}6.3 \\
6.1 \\
5.9 \\
5.7 \\
15.3 \\
11.6\end{array}$ & $\begin{array}{l}1.46 \\
1.51 \\
1.55 \\
1.63 \\
1.64 \\
1.66\end{array}$ & $\begin{array}{l}10.1 \\
11.8 \\
13.3 \\
16.6 \\
17.1 \\
18.1\end{array}$ & $\begin{array}{l}4.80 \\
4.82 \\
4.89 \\
4.95 \\
4.97 \\
5.05\end{array}$ & $\begin{array}{l}1,110 \\
1,120 \\
1,150 \\
1,190 \\
1,200 \\
1,250\end{array}$ & $\begin{array}{l}5.94 \\
5.91 \\
5.89 \\
5.85 \\
5.81 \\
5.77\end{array}$ & $\begin{array}{l}1,790 \\
1,780 \\
1,760 \\
1,730 \\
1,710 \\
1,680\end{array}$ & $\begin{array}{l}5.07 \\
5.06 \\
5.02 \\
5.00 \\
4.98 \\
4.96\end{array}$ & $\begin{array}{l}1,250 \\
1,250 \\
1,230 \\
1,220 \\
1,210 \\
1,200\end{array}$ \\
\hline & \multicolumn{2}{|c|}{ September 24} & \multicolumn{2}{|c|}{ September 25} & \multicolumn{2}{|c|}{ September 26} & \multicolumn{2}{|c|}{ September 27} & \multicolumn{2}{|c|}{ September 28} & \multicolumn{2}{|c|}{ September 29} \\
\hline $\begin{array}{r}2 \\
4 \\
6 \\
8 \\
10 \\
N\end{array}$ & $\begin{array}{l}4.92 \\
4.86 \\
4.81 \\
4.76 \\
4.74 \\
4.64\end{array}$ & $\begin{array}{l}1,170 \\
1,140 \\
1,110 \\
1,090 \\
1,070 \\
1,020\end{array}$ & $\begin{array}{l}4.26 \\
4.21 \\
4.18 \\
4.15 \\
4.10 \\
4.06\end{array}$ & $\begin{array}{l}823 \\
797 \\
782 \\
767 \\
742 \\
722\end{array}$ & $\begin{array}{l}3.75 \\
3.71 \\
3.66 \\
3.63 \\
3.60 \\
3.57\end{array}$ & \begin{tabular}{|l|}
574 \\
556 \\
533 \\
520 \\
506 \\
493
\end{tabular} & $\begin{array}{l}3.27 \\
3.26 \\
3.26 \\
3.24 \\
3.24 \\
3.22\end{array}$ & $\begin{array}{l}367 \\
363 \\
363 \\
355 \\
355 \\
348\end{array}$ & $\begin{array}{l}3.17 \\
3.16 \\
3.15 \\
3.12 \\
3.10 \\
3.08\end{array}$ & \begin{tabular}{|l|}
330 \\
326 \\
322 \\
312 \\
305 \\
299
\end{tabular} & $\begin{array}{l}2.97 \\
2.95 \\
2.94 \\
2.92 \\
2.92 \\
2.90\end{array}$ & \begin{tabular}{|l}
263 \\
257 \\
254 \\
248 \\
248 \\
242
\end{tabular} \\
\hline $\begin{array}{r}2 \\
4 \\
6 \\
8 \\
10 . \\
1\end{array}$ & $\begin{array}{l}4.60 \\
4.52 \\
4.43 \\
4.40 \\
4.34 \\
4.30\end{array}$ & $\begin{array}{r}1,000 \\
958 \\
911 \\
895 \\
864 \\
843\end{array}$ & $\begin{array}{l}4.02 \\
3.97 \\
3.92 \\
3.88 \\
3.83 \\
3.79\end{array}$ & $\begin{array}{l}703 \\
679 \\
655 \\
636 \\
612 \\
593\end{array}$ & $\begin{array}{l}3.17 \\
3.21 \\
3.24 \\
3.27 \\
3.28 \\
3.28\end{array}$ & $\begin{array}{l}430 \\
344 \\
355 \\
367 \\
370 \\
370\end{array}$ & $\begin{array}{l}3.21 \\
3.20 \\
3.22 \\
3.20 \\
3.19 \\
3.19\end{array}$ & $\begin{array}{l}344 \\
340 \\
348 \\
340 \\
336 \\
336\end{array}$ & $\begin{array}{l}3.06 \\
3.04 \\
3.02 \\
3.01 \\
3.00 \\
2.98\end{array}$ & $\begin{array}{l}292 \\
286 \\
279 \\
276 \\
273 \\
267\end{array}$ & $\begin{array}{l}2.89 \\
2.87 \\
2.85 \\
2.84 \\
2.83 \\
2.83\end{array}$ & $\begin{array}{l}239 \\
233 \\
227 \\
225 \\
222 \\
219\end{array}$ \\
\hline
\end{tabular}

Supplemental records.- Sept. $20,6: 30$ a.m., 2.00 ft., 44 sec.-ft. Sept. 21,

4:40 p.m., 4.91 ft., 1,170 sec.-ft.; 5:15 p.m., 4.91 ft., 1,170 sec.-ft. Sept. 27, $10: 30$ a.m., 3.25 ft., 359 sec.-ft.; $4: 30$ p.m., 3.24 ft., 355 sec.-ft. 


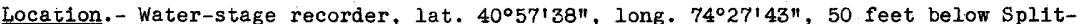
rock Pond, 2 miles northeast of Hibernia, Morris County, and $3 \frac{1}{2}$ miles above mouth of Hibernia Brook.

Drainage area.- 5.50 square miles; affected by storage in Splitrock Pond.

Gage-height record.- Water-stage recorder graph.

Stage-discharge relation.- Based on Francis formula for sharp-crested weir; verifled by current-meter measurements below 40 second-feet.

Maxima.- September 1938: Discharge, 75 second-feet 11 a.m. Sept. 22 to 2 a.m. Sept. 23 (gage height, 2.12 feet).

1925 to August 1938: Discharge, 126 second-feet Mar. 12, 1936 (gage helght estimated, 2.70 feet).

Remarks.- Discharge regulated by operation of gates in Splitrock Pond dam. Water-stage recorder owned and operated by Department of Streets and Public Improvements, Bureau of Water, Jersey City, N. J.

Mean dally discharge, in second-feet, 1938

\begin{tabular}{|c|c|c|c|c|c|c|c|c|c|c|c|}
\hline Day & Sept. & oct. & Day & Sept. & Oct. & Day & Sept. & Oct. & Day & Sept. & Oct. \\
\hline $\begin{array}{l}1 \\
2 \\
3 \\
4 \\
5 \\
6 \\
7 \\
8\end{array}$ & $\begin{array}{l}2.2 \\
2.2 \\
1.81 \\
1.40 \\
1.25 \\
1.03 \\
.89 \\
.70\end{array}$ & $\begin{array}{r}15.2 \\
12.7 \\
10.2 \\
8.7 \\
7.4 \\
7.0 \\
7.5 \\
7.1\end{array}$ & $\begin{array}{r}9 \\
10 \\
11 \\
12 \\
13 \\
14 \\
15 \\
16\end{array}$ & $\begin{array}{r}0.52 \\
.36 \\
.27 \\
.27 \\
.27 \\
.27 \\
.27 \\
.32\end{array}$ & $\begin{array}{l}6.6 \\
6.1 \\
5.7 \\
5.5 \\
5.6 \\
5.5 \\
4.6 \\
4.0\end{array}$ & $\begin{array}{l}17 \\
18 \\
19 \\
20 \\
21 \\
22 \\
23 \\
24\end{array}$ & $\begin{array}{l}0.36 \\
.36 \\
1.52 \\
12.9 \\
33 \\
68 \\
70 \\
54\end{array}$ & $\begin{array}{l}3.6 \\
3.3 \\
3.1 \\
3.3 \\
4.5 \\
4.8 \\
4.9 \\
5.7\end{array}$ & $\begin{array}{l}25 \\
26 \\
27 \\
28 \\
29 \\
30 \\
31\end{array}$ & $\begin{array}{l}45 \\
39 \\
32 \\
27 \\
23 \\
19.0\end{array}$ & $\begin{array}{l}7.0 \\
7.3 \\
7.3 \\
6.2 \\
5.6 \\
5.6 \\
5.6\end{array}$ \\
\hline $\begin{array}{l}\text { Mean } \\
\text { Run- }\end{array}$ & onthly & $\begin{array}{l}\text { schare } \\
\text { hes. }\end{array}$ & Ir & $\begin{array}{l}\text { econd- } \\
\text {. }\end{array}$ & et. : & & $\begin{array}{l}\cdot \cdot \dot{ } \\
.\end{array}$ & . $\cdot$ : & • & $\begin{array}{l}14.6 \\
-\end{array}$ & $\begin{array}{l}6.36 \\
-\end{array}$ \\
\hline
\end{tabular}

Gage height, in feet, and discharge, in second-feet, at indicated time, 1938

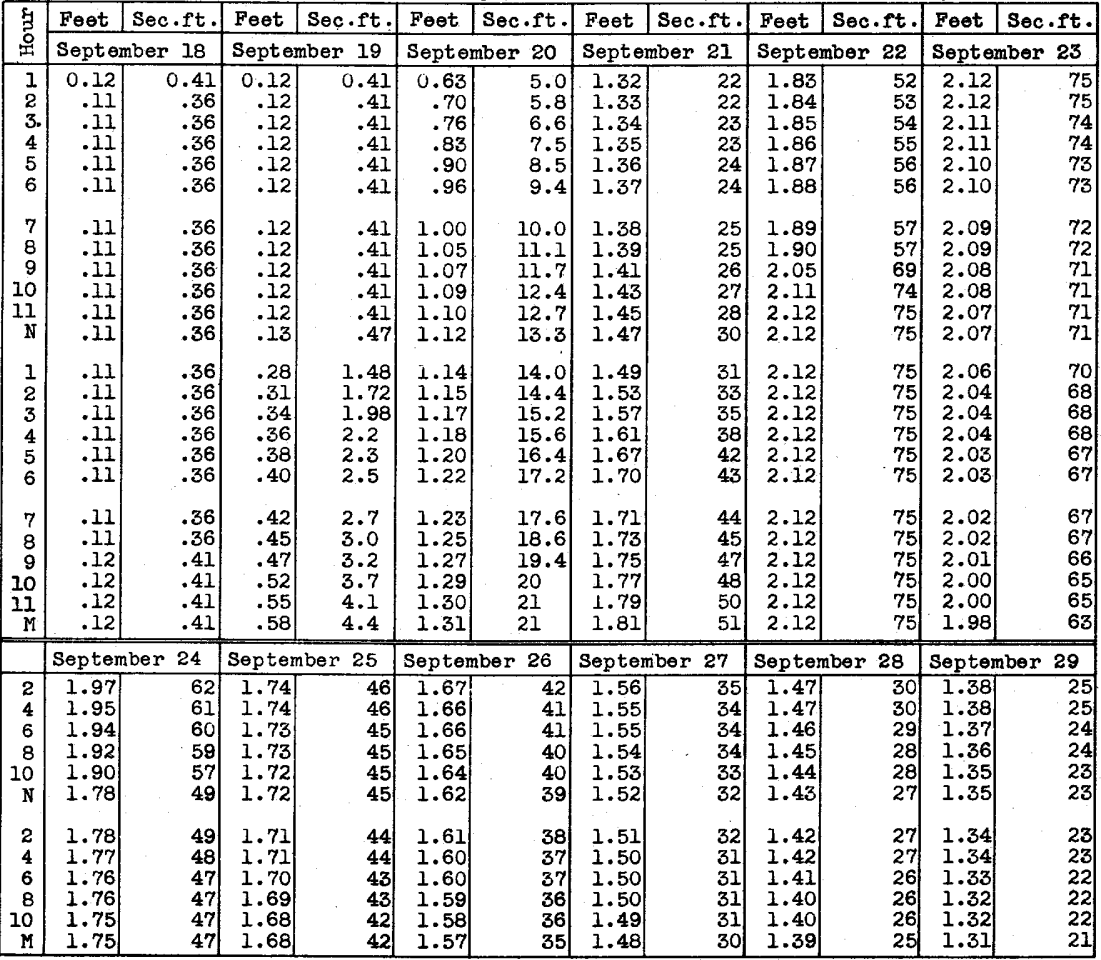


Location:- Water-stage recorder, lat. $40^{\circ} 48^{\prime} 21^{\prime \prime}$, long. $74^{\circ} 27^{\prime} 22^{\prime \prime}$, at Morristown sewagedisposal plant, three-quarters of a mile below Morristown, Morris County, and 9

miles above mouth of the river. Zero of gage is 260.01 feet above mean sea leve] (New Jersey Geological Survey benchmark).

Drainage area.- 29.4 square miles; not materially affected by artificial storage. Gage-height record.- Water-stage recorder graph.

Stage-discharge relation.- Defined by current-meter measurements below 300 second-feet; extended to peak stage on basis of determinations of flood flow over dam and by slope-area method.

Maxima:- September 1938: Discharge, 1,170 second-feet 4 a.m. Sept. 22 (gage height, 5.62 feet).

1921-August 1938: Discharge, about 1,500 second-feet Aug, 26, 1928, and Mar. 12, 1936; maximum gage height, 7.30 feet Aug. 26, 1928.

Mean delly discharge, in second-feet, 1938

\begin{tabular}{|c|c|c|c|c|c|c|c|c|c|c|c|}
\hline Day & Sept. & Oct. & Day & Sept. & Oct. & Day & Sept. & oct. & Day & Sept. & oct. \\
\hline $\begin{array}{l}1 \\
2 \\
3 \\
4 \\
5 \\
6 \\
7 \\
8 \\
\end{array}$ & $\begin{array}{l}34 \\
23 \\
23 \\
22 \\
21 \\
20 \\
21 \\
21\end{array}$ & $\begin{array}{l}41 \\
36 \\
36 \\
38 \\
36 \\
44 \\
57 \\
39 \\
\end{array}$ & $\begin{array}{r}9 \\
10 \\
11 \\
12 \\
13 \\
14 \\
15 \\
16 \\
\end{array}$ & $\begin{array}{l}20 \\
18.7 \\
19.3 \\
19.3 \\
22 \\
20 \\
24 \\
21\end{array}$ & $\begin{array}{l}35 \\
33 \\
32 \\
31 \\
30 \\
30 \\
30 \\
30\end{array}$ & $\begin{array}{l}17 \\
18 \\
19 \\
20 \\
21 \\
22 \\
23 \\
24\end{array}$ & $\begin{array}{c}18.7 \\
23 \\
96 \\
287 \\
489 \\
676 \\
129 \\
80\end{array}$ & $\begin{array}{l}28 \\
28 \\
28 \\
32 \\
57 \\
34 \\
31 \\
42\end{array}$ & $\begin{array}{l}25 \\
26 \\
27 \\
28 \\
29 \\
30 \\
31\end{array}$ & $\begin{array}{l}61 \\
54 \\
50 \\
48 \\
44 \\
43\end{array}$ & $\begin{array}{l}46 \\
34 \\
41 \\
41 \\
35 \\
31 \\
28\end{array}$ \\
\hline $\begin{array}{l}\text { Mean } \\
\text { Run- }\end{array}$ & $\begin{array}{l}\text { nthly } \\
, \text { in } 1\end{array}$ & $\begin{array}{l}\text { schar } \\
\text { hes. }\end{array}$ & Ir & $\begin{array}{c}\text { econd- } \\
.\end{array}$ & b. & . : & . : & . : & : & $\begin{array}{l}81.6 \\
3.10\end{array}$ & $\begin{array}{l}35.9 \\
1.41\end{array}$ \\
\hline
\end{tabular}

Gage height, in feet, and discharge, in second-feet, at indicated time, 1938

\begin{tabular}{|c|c|c|c|c|c|c|c|c|c|c|c|c|c|}
\hline \multirow{2}{*}{$\begin{array}{r}5 \\
7 \\
0 \\
\end{array}$} & Feet & Sec.ft. & Feet & Sec.ft. & Feet & Sec.ft. & Feet & Sec.ft. & Feet & Sec.ft. & Feet & Sec & ft. \\
\hline & \multicolumn{2}{|c|}{ September 18} & \multicolumn{2}{|c|}{ September 19} & \multicolumn{2}{|c|}{ September 20} & \multicolumn{2}{|c|}{ September 21} & \multicolumn{2}{|c|}{ September 22} & \multicolumn{3}{|c|}{ September 23} \\
\hline $\begin{array}{l}1 \\
2 \\
3 \\
4 \\
5 \\
6\end{array}$ & $\begin{array}{l}1.95 \\
1.95 \\
1.95 \\
1.96 \\
1.96 \\
1.96\end{array}$ & $\begin{array}{l}22 \\
22 \\
22 \\
23 \\
23 \\
23\end{array}$ & $\begin{array}{l}1.97 \\
1.97 \\
1.97 \\
1.97 \\
1.98 \\
1.98\end{array}$ & $\begin{array}{l}23 \\
23 \\
23 \\
23 \\
24 \\
24\end{array}$ & $\begin{array}{l}3.01 \\
3.05 \\
3.02 \\
3.00 \\
3.17 \\
3.07\end{array}$ & \begin{tabular}{|l|}
213 \\
222 \\
216 \\
211 \\
251 \\
227
\end{tabular} & $\begin{array}{l}3.24 \\
3.18 \\
3.15 \\
3.13 \\
3.12 \\
3.13\end{array}$ & $\begin{array}{l}268 \\
253 \\
246 \\
241 \\
239 \\
241\end{array}$ & $\begin{array}{l}5.51 \\
5.56 \\
5.60 \\
5.62 \\
5.56 \\
5.46\end{array}$ & $\begin{array}{l}1,120 \\
1,140 \\
1,160 \\
1,170 \\
1,140 \\
1,090\end{array}$ & $\begin{array}{l}2.94 \\
2.89 \\
2.83 \\
2.79 \\
2.76 \\
2.73\end{array}$ & & $\begin{array}{l}196 \\
183 \\
168 \\
157 \\
149 \\
141\end{array}$ \\
\hline $\begin{array}{r}7 \\
8 \\
9 \\
10 \\
11 \\
N\end{array}$ & $\begin{array}{l}1.96 \\
1.96 \\
1.96 \\
1.96 \\
1.95 \\
1.95\end{array}$ & $\begin{array}{l}23 \\
23 \\
23 \\
23 \\
22 \\
22\end{array}$ & $\begin{array}{l}1.98 \\
1.97 \\
1.97 \\
1.97 \\
1.98 \\
2.00\end{array}$ & $\begin{array}{l}24 \\
23 \\
23 \\
23 \\
24 \\
26\end{array}$ & $\begin{array}{l}3.38 \\
3.69 \\
3.47 \\
3.41 \\
3.42 \\
3.42\end{array}$ & $\begin{array}{l}304 \\
393 \\
329 \\
312 \\
315 \\
315\end{array}$ & $\begin{array}{l}3.15 \\
3.15 \\
3.13 \\
3.12 \\
3.20 \\
3.30\end{array}$ & $\begin{array}{l}246 \\
246 \\
241 \\
239 \\
258 \\
283\end{array}$ & $\begin{array}{l}5.33 \\
5.12 \\
4.86 \\
4.65 \\
4.56 \\
4.45\end{array}$ & $\begin{array}{r}1,030 \\
938 \\
825 \\
739 \\
703 \\
660\end{array}$ & $\begin{array}{l}2.71 \\
2.68 \\
2.67 \\
2.67 \\
2.66 \\
2.65\end{array}$ & & $\begin{array}{l}136 \\
128 \\
126 \\
126 \\
123 \\
121\end{array}$ \\
\hline $\begin{array}{l}1 \\
2 \\
3 \\
4 \\
5 \\
6\end{array}$ & $\begin{array}{l}1.95 \\
1.95 \\
1.95 \\
1.95 \\
1.96 \\
1.96\end{array}$ & $\begin{array}{l}22 \\
22 \\
22 \\
22 \\
23 \\
23\end{array}$ & $\begin{array}{l}2.00 \\
2.01 \\
2.78 \\
3.50 \\
2.91 \\
3.00\end{array}$ & $\begin{array}{r}26 \\
27 \\
155 \\
337 \\
188 \\
211\end{array}$ & $\begin{array}{l}3.41 \\
3.40 \\
3.40 \\
3.40 \\
3.41 \\
3.39\end{array}$ & $\begin{array}{l}312 \\
309 \\
309 \\
309 \\
312 \\
306\end{array}$ & $\begin{array}{l}3.30 \\
3.39 \\
3.72 \\
4.50 \\
4.95 \\
4.96\end{array}$ & $\begin{array}{l}283 \\
306 \\
402 \\
679 \\
864 \\
868\end{array}$ & $\begin{array}{l}4.31 \\
4.12 \\
3.93 \\
3.74 \\
3.61 \\
3.47\end{array}$ & $\begin{array}{l}606 \\
536 \\
470 \\
408 \\
369 \\
329\end{array}$ & $\begin{array}{l}2.65 \\
2.65 \\
2.64 \\
2.63 \\
2.61 \\
2.59\end{array}$ & & $\begin{array}{l}121 \\
121 \\
119 \\
116 \\
111 \\
107\end{array}$ \\
\hline \multirow[t]{2}{*}{$\begin{array}{r}7 \\
8 \\
9 \\
10 \\
11 \\
M \\
\end{array}$} & $\begin{array}{l}1.96 \\
1.96 \\
1.96 \\
1.96 \\
1.96 \\
1.96\end{array}$ & $\begin{array}{l}23 \\
23 \\
23 \\
23 \\
23 \\
23 \\
\end{array}$ & $\begin{array}{l}3.01 \\
2.97 \\
2.93 \\
2.92 \\
2.91 \\
3.15\end{array}$ & $\begin{array}{l}213 \\
204 \\
194 \\
191 \\
188 \\
246\end{array}$ & $\begin{array}{l}3.39 \\
3.38 \\
3.37 \\
3.36 \\
3.35 \\
3.29\end{array}$ & $\begin{array}{l}306 \\
304 \\
301 \\
299 \\
296 \\
280\end{array}$ & $\begin{array}{l}5.00 \\
4.96 \\
5.06 \\
5.22 \\
5.29 \\
5.38\end{array}$ & $\begin{array}{r}885 \\
868 \\
911 \\
983 \\
1,020 \\
1,050 \\
\end{array}$ & $\begin{array}{l}3.35 \\
3.26 \\
3.17 \\
3.10 \\
3.05 \\
3.00\end{array}$ & $\begin{array}{l}296 \\
273 \\
251 \\
234 \\
222 \\
211\end{array}$ & $\begin{array}{l}2.57 \\
2.55 \\
2.54 \\
2.53 \\
2.52 \\
2.51\end{array}$ & & $\begin{array}{r}103 \\
99 \\
97 \\
95 \\
93 \\
91 \\
\end{array}$ \\
\hline & \multicolumn{2}{|c|}{ September 24 : } & \multicolumn{2}{|c|}{ September 25} & \multicolumn{2}{|c|}{ September 26} & \multicolumn{2}{|c|}{ September 27} & \multicolumn{2}{|c|}{ September 28} & \multicolumn{3}{|c|}{ September 29} \\
\hline $\begin{array}{r}2 \\
4 \\
6 \\
8 \\
10 \\
N\end{array}$ & $\begin{array}{l}2.50 \\
2.49 \\
2.48 \\
2.47 \\
2.46 \\
2.46\end{array}$ & $\begin{array}{l}89 \\
87 \\
86 \\
84 \\
82 \\
82\end{array}$ & $\begin{array}{l}2.36 \\
2.35 \\
2.34 \\
2.33 \\
2.33 \\
2.33\end{array}$ & $\begin{array}{l}66 \\
65 \\
63 \\
62 \\
62 \\
62\end{array}$ & $\begin{array}{l}2.28 \\
2.26 \\
2.26 \\
2.26 \\
2.27 \\
2.27\end{array}$ & \begin{tabular}{|l|}
55 \\
53 \\
53 \\
53 \\
54 \\
54
\end{tabular} & $\begin{array}{l}2.25 \\
2.24 \\
2.24 \\
2.24 \\
2.24 \\
2.24\end{array}$ & $\begin{array}{l}52 \\
50 \\
50 \\
50 \\
50 \\
50\end{array}$ & $\begin{array}{l}2.24 \\
2.23 \\
2.23 \\
2.22 \\
2.22 \\
2.22\end{array}$ & \begin{tabular}{|l|}
50 \\
49 \\
49 \\
48 \\
48 \\
48
\end{tabular} & $\begin{array}{l}2.20 \\
2.19 \\
2.19 \\
2.19 \\
2.19 \\
2.19\end{array}$ & & $\begin{array}{l}46 \\
44 \\
44 \\
44 \\
44 \\
44\end{array}$ \\
\hline $\begin{array}{r}2 \\
4 \\
6 \\
8 \\
10 \\
11\end{array}$ & $\begin{array}{l}2.45 \\
2.45 \\
2.44 \\
2.42 \\
2.41 \\
2.38\end{array}$ & $\begin{array}{l}80 \\
80 \\
79 \\
75 \\
74 \\
69\end{array}$ & $\begin{array}{l}2.32 \\
2.32 \\
2.32 \\
2.31 \\
2.30 \\
2.29\end{array}$ & $\begin{array}{l}61 \\
61 \\
61 \\
59 \\
58 \\
57\end{array}$ & $\begin{array}{l}2.27 \\
2.28 \\
2.28 \\
2.27 \\
2.26 \\
2.25\end{array}$ & $\begin{array}{l}54 \\
55 \\
55 \\
54 \\
53 \\
52\end{array}$ & $\begin{array}{l}2.24 \\
2.24 \\
2.24 \\
2.24 \\
2.25 \\
2.25\end{array}$ & $\begin{array}{l}50 \\
50 \\
50 \\
50 \\
52 \\
52\end{array}$ & $\begin{array}{l}2.22 \\
2.22 \\
2.22 \\
2.22 \\
2.21 \\
2.20\end{array}$ & $\begin{array}{l}48 \\
48 \\
48 \\
48 \\
47 \\
46\end{array}$ & $\begin{array}{l}2.19 \\
2.20 \\
2.20 \\
2.20 \\
2.20 \\
2.19\end{array}$ & & $\begin{array}{l}44 \\
46 \\
46 \\
46 \\
46 \\
44\end{array}$ \\
\hline
\end{tabular}

Supplemental records.- Sept. $21,5: 30$ p.m., 4.78 ft., 792 sec.-ft.

227007 O $10-20$ 
Location.- Water-stage recorder, lat. $41^{\circ} 05^{\prime} 51^{\prime \prime}$, long. $74^{\circ} 09^{\prime} 43^{\prime \prime}$, 150 feet below State Highway 2, three-quarters of a mile below Mahwah River, and 1 mile west of Mahwah, Bergen County. Zero of gage is 254.19 feet above mean sea level (New Jersey Geological Survey benchmark).

Draingge area.- 118 square miles; not materially affected by artificlal storage.

Gage-height record. - Water-stage recorder graph except for periods 10 a.m. Sept. 7 to noon Sept. 19, 10 a.m. Sept. 21 to 11 a.m. Sept. 28, and 9 p.m. Oct. 1 to 5 p.m. Oct. 3 .

Stage-discharge relation.- Defined by current-meter measurements below 1,200 secondfeet; extended to peak stage on basis of study of determination of peak flows over 3 nearby dams and study of yleld of Ramapo River at Pompton Lakes.

Maxima.- September 1938: D1scharge estimated, 5,500 second-feet on Sept. 22. 1903-6, 1922 to August 1938: Discharge, about 12,400 second-feet 0ct. 9, 1903 (gage helght, 9.8 feet, former datum).

Remarks.- Discharge for periods of missing record computed on basis of record at Pompton Lakes.

Mean dally discharge, in second-feet, 1938

\begin{tabular}{|c|c|c|c|c|c|c|c|c|c|c|c|}
\hline Day & Sept. & oct. & Day & Sept. & $0 \mathrm{ct}$. & Day & Sept. & Oct. & Day & Sept. & oct. \\
\hline $\begin{array}{l}1 \\
2 \\
3 \\
4 \\
5 \\
6 \\
7 \\
8\end{array}$ & $\begin{array}{r}62 \\
52 \\
42 \\
41 \\
45 \\
44 \\
* 45 \\
* 43\end{array}$ & $\begin{array}{r}161 \\
* 140 \\
* 130 \\
117 \\
108 \\
103 \\
140 \\
113\end{array}$ & $\begin{array}{r}9 \\
10 \\
11 \\
12 \\
13 \\
14 \\
15 \\
16\end{array}$ & $\begin{array}{l}* 38 \\
* 42 \\
* 38 \\
* 35 \\
* 40 \\
* 45 \\
* 45 \\
* 45\end{array}$ & $\begin{array}{r}102 \\
98 \\
87 \\
81 \\
74 \\
76 \\
65 \\
58\end{array}$ & $\begin{array}{l}17 \\
18 \\
19 \\
20 \\
21 \\
22 \\
23 \\
24\end{array}$ & $\begin{array}{r}* 45 \\
* 45 \\
* 140 \\
664 \\
* 2,200 \\
* 4,200 \\
* 1,880 \\
* 960\end{array}$ & $\begin{array}{r}69 \\
68 \\
58 \\
56 \\
192 \\
152 \\
109 \\
110 \\
\end{array}$ & $\begin{array}{l}25 \\
26 \\
27 \\
28 \\
29 \\
30 \\
31\end{array}$ & $\begin{array}{r}* 550 \\
* 400 \\
* 280 \\
* 250 \\
222 \\
190\end{array}$ & $\begin{array}{r}174 \\
133 \\
113 \\
106 \\
105 \\
101 \\
87\end{array}$ \\
\hline $\begin{array}{l}\text { Mean } \\
\text { Run- }\end{array}$ & $\begin{array}{l}\text { lonthly } \\
f \text {, in } 1\end{array}$ & $\begin{array}{l}\text { Lcharg } \\
\text { shes. }\end{array}$ & ir & $\begin{array}{l}\text { second- } \\
\text {. }\end{array}$ & et. : & : & . : & 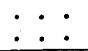 & : & $\begin{array}{r}424 \\
4.00\end{array}$ & $\begin{array}{r}106 \\
1.04\end{array}$ \\
\hline
\end{tabular}

Gege height, in feet, and discherge, in second-feet, at indicated time, 1938

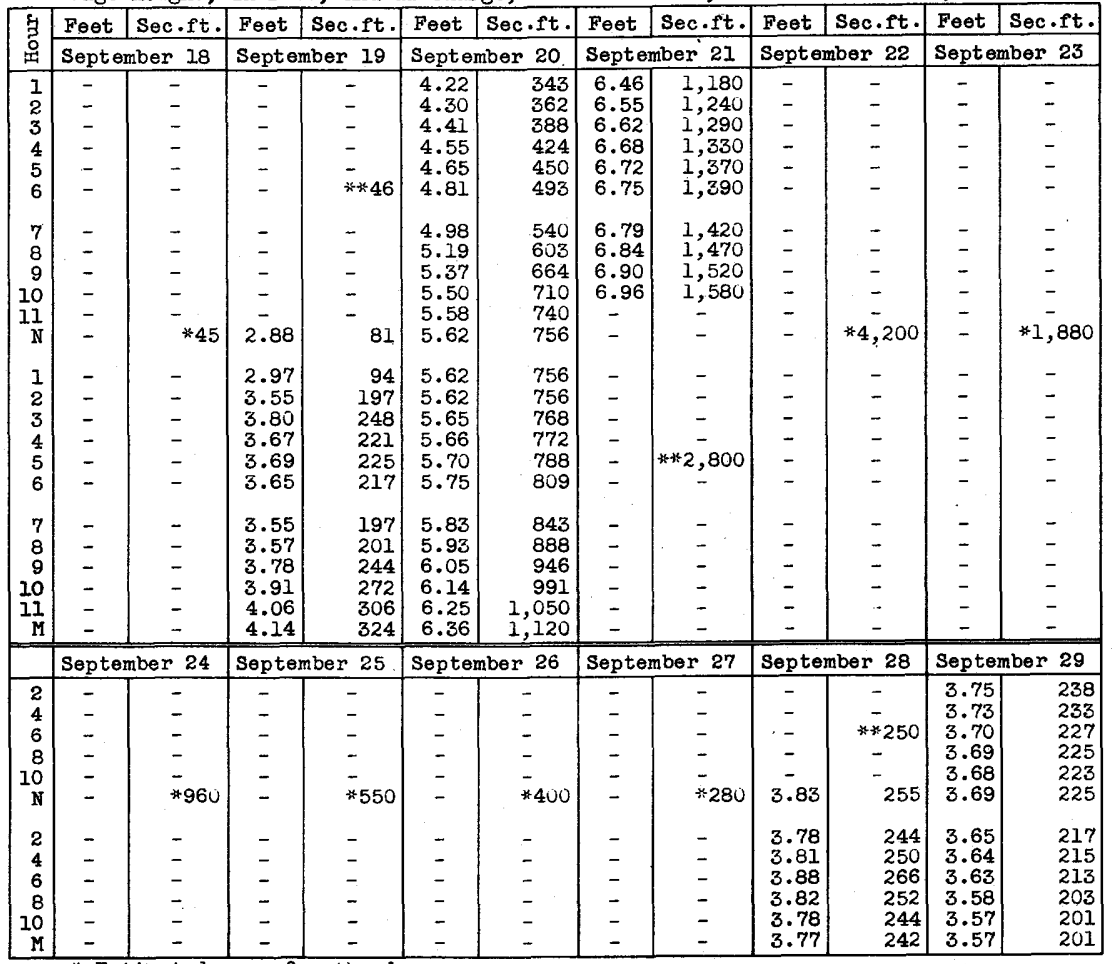

* Estimated mean for the day.

** Estimated mean for the period. 
Location. - Water-stage recorder, lat. $40^{\circ} 59^{\prime} 20^{\prime \prime}$, long. $74^{\circ} 16^{\prime} 48^{\prime \prime}$, at hydroelectric plant in Pompton Lakes, Passaic County, $1 \frac{1}{2}$ miles above mouth of the river. Zero of gage is 200.93 feet above mean sea level (New Jersey Geological Survey benchmark).

Drainage area.- 160 square miles; not materlaliy affected by artificial storage.

Gagethelght record.- Vater-stage recorder graph of head on spillway dam.

Stage-discharge relation.- Defined by current-meter measurements below 1,600 second-feet; extended to peak stage by determination of flow by weir formula based on the currentmeter measurements.

Maxima.- September 1938: Discharge, about 6,620 second-feet 6 to 7:30 a.m. Sept. 22 (gage height, 3.13 feet).

1921 to August 1938: D1scharge, about 12,300 second-feet Mar. 12, 1936 (gage height, 3.56 feet).

Remarks.- Discharge is total flow over apillway and through power house (waste gate in dam not open during this period).

Mean daily discharge, in second-feet, 1938

\begin{tabular}{|c|c|c|c|c|c|c|c|c|c|c|c|}
\hline Day & Sept. & Oct. & Day & Sept. & oct. & Day & Sept. & oct. & Day & Sept. & Oct. \\
\hline $\begin{array}{l}1 \\
2 \\
3 \\
4 \\
5 \\
6 \\
7 \\
8\end{array}$ & $\begin{array}{l}90 \\
81 \\
63 \\
63 \\
69 \\
63 \\
69 \\
63\end{array}$ & $\begin{array}{l}256 \\
218 \\
199 \\
180 \\
170 \\
170 \\
199 \\
180\end{array}$ & $\begin{array}{r}9 \\
10 \\
11 \\
12 \\
13 \\
14 \\
15 \\
16\end{array}$ & $\begin{array}{l}58 \\
63 \\
58 \\
53 \\
63 \\
69 \\
69 \\
69\end{array}$ & $\begin{array}{l}161 \\
152 \\
144 \\
136 \\
128 \\
121 \\
121 \\
113\end{array}$ & $\begin{array}{l}17 \\
18 \\
19 \\
20 \\
21 \\
22 \\
23 \\
24\end{array}$ & $\begin{array}{r}69 \\
69 \\
167 \\
816 \\
2,210 \\
5,680 \\
2,840 \\
1,410\end{array}$ & $\begin{array}{l}113 \\
113 \\
113 \\
106 \\
218 \\
237 \\
180 \\
180\end{array}$ & $\begin{array}{l}25 \\
26 \\
27 \\
28 \\
29 \\
30 \\
31\end{array}$ & $\begin{array}{l}828 \\
584 \\
440 \\
378 \\
333 \\
289\end{array}$ & $\begin{array}{l}218 \\
208 \\
180 \\
161 \\
161 \\
161 \\
136\end{array}$ \\
\hline $\begin{array}{l}\text { Mean } \\
\text { Run- }\end{array}$ & $\begin{array}{l}\text { nthly } \\
\text {, in }\end{array}$ & $\begin{array}{l}\text { schar } \\
\text { hes. }\end{array}$ & , 1 . & .. & $\dot{.}$ &. : & : : & $: \dot{0}$ &.$:$ & $\begin{array}{r}573 \\
3.99\end{array}$ & $\begin{array}{r}166 \\
1.20\end{array}$ \\
\hline
\end{tabular}

Gage helght, In feet, and discharge, in second-feet, at Indicated time, 1938

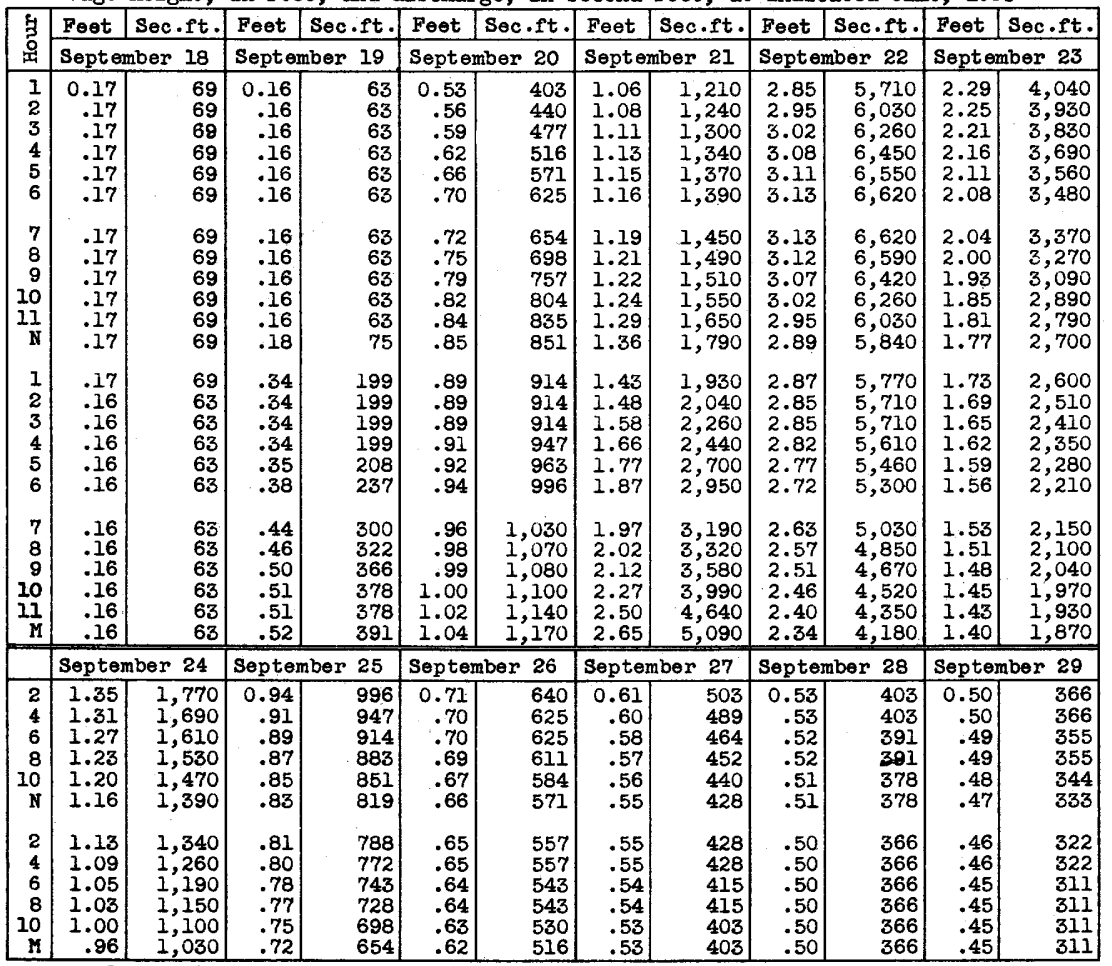

Supplemental records.- Sept. 22, 7:30 a.m., 3.13 ft., 6,620 sec.-ft. 
Location.- Water-stage recorder, lat. $41^{\circ} 09^{1} 36^{\prime \prime}$, long. $74^{\circ} 20^{\prime} 03^{\prime \prime}$, in gatehous $\theta$ above dam at The Glens, Passalc County. Zero of gage is 608.86 feet above mean sea level (New Jersey Geologlcal Survey benchmark).

Drainage area.- 27.1 square miles.

Gage-helght record.- Water-stage recorder graph except for period Sept. 1-5, 18, and 19 , records for which were based on study of recorder graph of river below dam. Gage helghts given are for midnight.

Remarks.- Storage capacity above sill of blow-off gate (gage height, -4.00 feet) $1 \mathrm{~s}$ $919,000,000$ cubic feet. Contents shown in table is contents above gage height -0.8 foot. Qage-he1ght record furnished by Morris Canal \& Banking Co.

Gage helght, in feet, and contents, in millions of cubic feet, 1938

\begin{tabular}{|c|c|c|c|c|c|c|c|c|c|c|}
\hline \multirow[b]{2}{*}{ Day } & \multicolumn{2}{|c|}{ September } & \multicolumn{2}{|c|}{ October } & \multirow[b]{2}{*}{ Day } & \multicolumn{2}{|c|}{ September } & \multicolumn{3}{|c|}{ october } \\
\hline & Feet & $\begin{array}{l}\text { Millions of } \\
\text { cubic feet }\end{array}$ & Feet & $\begin{array}{l}\text { Millions of } \\
\text { cubic feet }\end{array}$ & & Feet & $\begin{array}{l}\text { Millions of } \\
\text { cubic feet }\end{array}$ & Feet & & $\begin{array}{l}\text { llions of } \\
\text { ubic feet }\end{array}$ \\
\hline $\begin{array}{l}1 \\
2 \\
3 \\
4 \\
5\end{array}$ & $\begin{array}{r}* 9.97 \\
* 9.96 \\
* 9.94 \\
* 9.92 \\
* 9.90\end{array}$ & $\begin{array}{l}768 \\
767 \\
765 \\
763 \\
762\end{array}$ & $\begin{array}{r}10.04 \\
9.87 \\
9.82 \\
9.80 \\
9.80\end{array}$ & \begin{tabular}{|l}
773 \\
759 \\
755 \\
754 \\
754
\end{tabular} & $\begin{array}{l}16 \\
17 \\
18 \\
19 \\
20\end{array}$ & $\begin{array}{r}9.83 \\
9.82 \\
* 9.82 \\
* 10.05 \\
10.35\end{array}$ & $\begin{array}{r}756 \\
755 \\
755 \\
774 \\
799\end{array}$ & $\begin{array}{l}9.77 \\
9.79 \\
9.78 \\
9.77 \\
9.89\end{array}$ & & $\begin{array}{l}751 \\
753 \\
752 \\
751 \\
761\end{array}$ \\
\hline $\begin{array}{r}6 \\
7 \\
8 \\
9 \\
10\end{array}$ & $\begin{array}{l}9.89 \\
9.87 \\
9.85 \\
9.81 \\
9.82\end{array}$ & $\begin{array}{l}761 \\
759 \\
758 \\
754 \\
755\end{array}$ & $\begin{array}{l}9.82 \\
9.79 \\
9.79 \\
9.77 \\
9.76\end{array}$ & $\begin{array}{l}755 \\
753 \\
753 \\
751 \\
750\end{array}$ & $\begin{array}{l}21 \\
22 \\
23 \\
24 \\
25\end{array}$ & $\begin{array}{l}11.46 \\
11 \cdot 44 \\
11.11 \\
10.82 \\
10.67\end{array}$ & $\begin{array}{l}892 \\
890 \\
862 \\
838 \\
825\end{array}$ & $\begin{array}{r}9.89 \\
9.89 \\
9.89 \\
9.99 \\
10.00\end{array}$ & & $\begin{array}{l}761 \\
761 \\
761 \\
769 \\
770\end{array}$ \\
\hline $\begin{array}{l}11 \\
12 \\
13 \\
14 \\
15\end{array}$ & $\begin{array}{l}9.81 \\
9.79 \\
9.82 \\
9.80 \\
9.84\end{array}$ & $\begin{array}{l}754 \\
753 \\
755 \\
754 \\
757\end{array}$ & $\begin{array}{l}9.77 \\
9.77 \\
9.77 \\
9.77 \\
9.77\end{array}$ & $\begin{array}{l}751 \\
751 \\
751 \\
751 \\
751\end{array}$ & $\begin{array}{l}26 \\
27 \\
28 \\
29 \\
30 \\
31\end{array}$ & $\begin{array}{l}10.52 \\
10.40 \\
10.36 \\
10.31 \\
10.22\end{array}$ & $\begin{array}{l}813 \\
803 \\
800 \\
796 \\
788\end{array}$ & $\begin{array}{l}9.97 \\
9.96 \\
9.94 \\
9.93 \\
9.92 \\
9.90\end{array}$ & & $\begin{array}{l}768 \\
767 \\
765 \\
764 \\
763 \\
762\end{array}$ \\
\hline & & & & & & & & Septembe & & October \\
\hline $\begin{array}{l}\text { Gain } \\
\text { Gain }\end{array}$ & $\begin{array}{l}\text { or loss } \\
\text { or loss }\end{array}$ & $\begin{array}{l}\text { in storage, } \\
\text { in storage, }\end{array}$ & $\begin{array}{l}\text { in } \mathrm{mi} \\
\text { in } \mathrm{eq}\end{array}$ & $\begin{array}{l}\text { Lions of cul } \\
\text { divalent mear }\end{array}$ & $\begin{array}{r}\text { ic } f \\
\text { sec }\end{array}$ & d-fieet & 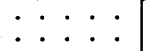 & $\begin{array}{r}+2 \\
+7 .\end{array}$ & & $\begin{array}{r}-26 \\
-9.71\end{array}$ \\
\hline
\end{tabular}

* Estimated. 
Wanaque River at Monks, N. J.

Location.- Water-stage recorder, lat. $41^{\circ} 07^{1} 14^{\prime \prime}$, long. $74^{\circ} 17^{\prime} 41^{\prime \prime}$, just above Wanaque Reservolr, in Monks, Passaic County. Zero of gage is 303.17 feet above mean sea level (New Jersey Geological Survey benchmark).

Drainage area.- 40.4 square miles; affected by storage in Greenwood Lake.

Gage-height record,- Water-stage recorder graph except for period 4 p.m. Sept. 21 to 3 p.m. Sept. 22 .

Stage-discharge relation.- For spillway defined by current-meter measurements below 800 second-feet; extended to peak flow by logarithmic plotting.

Maxima.- September 1938: Discharge estimated, 1,260 second-feet midnight Sept. 21. 1935 to August 1938: Discharge, about 1,920 second-feet Mar. 12, 1936 (gage helght estimated, 3.15 feet).

Remarks.- Discharges shown in tables are total of flow over weir, through ports in we1r, and down fish ladder. Discharge for period of missing gage heights, Sept. 21 , 22, computed on basis of record at outlet of Greenwood Lake. Mean monthly discharge adjusted for storage in Greenwood Lake. For information on storage see record for Greenwood Lake at The Glens, N. J. Water-stage recorder owned and operated by North Jersey District Water Supply Commission.

Mean dally discharge, in second-feet, 1938

\begin{tabular}{|c|c|c|c|c|c|c|c|c|c|c|c|}
\hline Day & Sept. & Oct. & Day & Sept. & Oct. & Day & Sept. & Oct. & Day & Sept. & Oct. \\
\hline $\begin{array}{l}1 \\
2 \\
3 \\
4 \\
5 \\
6 \\
7 \\
8\end{array}$ & $\begin{array}{l}13.9 \\
13.2 \\
11.7 \\
13.2 \\
12.4 \\
11.7 \\
11.7 \\
11.7\end{array}$ & $\begin{array}{r}218 \\
184 \\
95 \\
22 \\
21 \\
32 \\
48 \\
30\end{array}$ & $\begin{array}{r}9 \\
10 \\
11 \\
12 \\
13 \\
14 \\
15 \\
16\end{array}$ & $\begin{array}{l}11.0 \\
11.0 \\
11.0 \\
11.0 \\
11.0 \\
11.0 \\
12.4 \\
10.4\end{array}$ & $\begin{array}{l}30 \\
24 \\
17.1 \\
16.3 \\
16.3 \\
16.3 \\
16.3 \\
15.5\end{array}$ & $\begin{array}{l}17 \\
18 \\
19 \\
20 \\
21 \\
22 \\
23 \\
24\end{array}$ & $\begin{array}{r}9.7 \\
9.7 \\
30 \\
144 \\
560 \\
1,030 \\
688 \\
436\end{array}$ & $\begin{array}{l}15.5 \\
15.5 \\
15.5 \\
17.4 \\
37 \\
22 \\
18.8 \\
27\end{array}$ & $\begin{array}{l}25 \\
26 \\
27 \\
28 \\
29 \\
30 \\
31\end{array}$ & $\begin{array}{l}300 \\
214 \\
164 \\
128 \\
102 \\
122\end{array}$ & $\begin{array}{l}37 \\
46 \\
26 \\
30 \\
57 \\
55 \\
37\end{array}$ \\
\hline $\begin{array}{l}\text { Mean } \\
\text { Mean } \\
\text { Run- }\end{array}$ & $\begin{array}{l}\text { monthly } \\
\text { monthly } \\
\text { ff, in }\end{array}$ & $\begin{array}{l}\text { ischar } \\
\text { Ischar } \\
\text { ches ( }\end{array}$ & , 1 & $\begin{array}{l}\text { second- } \\
\text { second- } \\
\text { d) . }\end{array}$ & 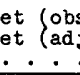 & $\begin{array}{l}\text { erve } \\
\text { aste }\end{array}$ & 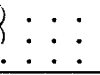 & 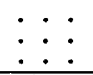 & $\dot{0}: \dot{ }$ & $\begin{array}{r}138 \\
145 \\
4.00 \\
\end{array}$ & $\begin{array}{l}40.6 \\
30.7 \\
0.88 \\
\end{array}$ \\
\hline
\end{tabular}

Gage height, in feet, and discharge, in second-feet, at indicated time, 1938

\begin{tabular}{|c|c|c|c|c|c|c|c|c|c|c|c|c|c|}
\hline \multirow{2}{*}{ 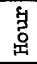 } & Feet & Sec.ft. & Feet & Sec.ft. & Feet & Sec.ft. & Feet & Sec.ft. & Feet & Sec.ft. & Feet & Sec & . ft. \\
\hline & \multicolumn{2}{|c|}{ September 18} & \multicolumn{2}{|c|}{ September 19} & \multicolumn{2}{|c|}{ September 20} & \multicolumn{2}{|c|}{ September 21} & \multicolumn{2}{|c|}{ September 22} & \multicolumn{3}{|c|}{ September 23} \\
\hline $\begin{array}{l}1 \\
2 \\
3 \\
4 \\
5 \\
6\end{array}$ & $\begin{array}{r}0.21 \\
.21 \\
.21 \\
.21 \\
.21 \\
.21\end{array}$ & $\begin{array}{l}9.7 \\
9.7 \\
9.7 \\
9.7 \\
9.7 \\
9.7\end{array}$ & $\begin{array}{r}0.21 \\
.21 \\
.21 \\
.22 \\
.22 \\
.22\end{array}$ & $\begin{array}{r}9.7 \\
9.7 \\
9.7 \\
10.4 \\
10.4 \\
10.4\end{array}$ & $\begin{array}{r}0.64 \\
.66 \\
.72 \\
.77 \\
.81 \\
.90\end{array}$ & $\begin{array}{r}70 \\
74 \\
91 \\
105 \\
117 \\
149\end{array}$ & $\begin{array}{l}0.99 \\
1.01 \\
1.02 \\
1.02 \\
1.04 \\
1.06\end{array}$ & $\begin{array}{l}184 \\
192 \\
196 \\
196 \\
205 \\
214\end{array}$ & $\begin{array}{l}- \\
- \\
- \\
- \\
-\end{array}$ & $\begin{array}{l}1,250 \\
1,220 \\
1,200 \\
1,180 \\
1,160 \\
1,140\end{array}$ & $\begin{array}{l}2.04 \\
2.02 \\
2.00 \\
1.98 \\
1.96 \\
1.94\end{array}$ & & $\begin{array}{l}848 \\
832 \\
814 \\
798 \\
782 \\
766\end{array}$ \\
\hline $\begin{array}{r}7 \\
8 \\
9 \\
10 \\
11 \\
1\end{array}$ & $\begin{array}{l}.21 \\
.21 \\
.21 \\
.21 \\
.21 \\
.21\end{array}$ & $\begin{array}{l}9.7 \\
9.7 \\
9.7 \\
9.7 \\
9.7 \\
9.7\end{array}$ & $\begin{array}{l}.22 \\
.22 \\
.23 \\
.23 \\
.23 \\
.23\end{array}$ & $\begin{array}{l}10.4 \\
10.4 \\
11.0 \\
11.0 \\
11.0 \\
11.0\end{array}$ & $\begin{array}{r}1.00 \\
1.00 \\
1.03 \\
1.04 \\
1.02 \\
.98\end{array}$ & $\begin{array}{l}188 \\
188 \\
201 \\
205 \\
196 \\
180\end{array}$ & $\begin{array}{l}1.08 \\
1.10 \\
1.13 \\
1.16 \\
1.18 \\
1.21\end{array}$ & $\begin{array}{l}223 \\
231 \\
246 \\
260 \\
270 \\
284\end{array}$ & $\begin{array}{l}- \\
- \\
- \\
- \\
-\end{array}$ & $\begin{array}{r}1,100 \\
1,080 \\
1,070 \\
1,050 \\
1,020 \\
990\end{array}$ & $\begin{array}{l}1.93 \\
1.91 \\
1.89 \\
1.87 \\
1.85 \\
1.83\end{array}$ & & $\begin{array}{l}758 \\
742 \\
726 \\
710 \\
694 \\
680\end{array}$ \\
\hline $\begin{array}{l}1 \\
2 \\
3 \\
4 \\
5 \\
6\end{array}$ & $\begin{array}{l}.21 \\
.21 \\
.21 \\
.21 \\
.21 \\
.21\end{array}$ & $\begin{array}{l}9.7 \\
9.7 \\
9.7 \\
9.7 \\
9.7 \\
9.7\end{array}$ & $\begin{array}{l}.26 \\
.47 \\
.54 \\
.54 \\
.56 \\
.60\end{array}$ & $\begin{array}{l}13.2 \\
37 \\
49 \\
49 \\
53 \\
61\end{array}$ & $\begin{array}{l}.94 \\
.91 \\
.89 \\
.87 \\
.86 \\
.85\end{array}$ & $\begin{array}{l}164 \\
153 \\
146 \\
138 \\
134 \\
131\end{array}$ & $\begin{array}{l}1.30 \\
1.48 \\
1.74 \\
- \\
- \\
-\end{array}$ & $\begin{array}{r}331 \\
436 \\
612 \\
770 \\
900 \\
1,010\end{array}$ & $\begin{array}{c}- \\
- \\
- \\
2.14 \\
2.13 \\
2.11\end{array}$ & $\begin{array}{l}980 \\
960 \\
950 \\
934 \\
926 \\
908\end{array}$ & $\begin{array}{l}1.81 \\
1.80 \\
1.78 \\
1.76 \\
1.74 \\
1.72\end{array}$ & $\therefore$ & $\begin{array}{l}664 \\
656 \\
642 \\
628 \\
612 \\
598\end{array}$ \\
\hline \multirow[t]{2}{*}{$\begin{array}{r}7 \\
8 \\
9 \\
10 \\
11 \\
M\end{array}$} & $\begin{array}{l}.21 \\
.21 \\
.21 \\
.21 \\
.21 \\
.21\end{array}$ & $\begin{array}{l}9.7 \\
9.7 \\
9.7 \\
9.7 \\
9.7 \\
9.7\end{array}$ & $\begin{array}{l}.60 \\
.59 \\
.58 \\
.58 \\
.58 \\
.62\end{array}$ & $\begin{array}{l}61 \\
59 \\
57 \\
57 \\
57 \\
65\end{array}$ & $\begin{array}{l}.85 \\
.85 \\
.86 \\
.89 \\
.92 \\
.95\end{array}$ & $\begin{array}{l}131 \\
131 \\
134 \\
146 \\
157 \\
168\end{array}$ & $\begin{array}{l}- \\
- \\
- \\
- \\
-\end{array}$ & $\begin{array}{l}1,100 \\
1,180 \\
1,210 \\
1,240 \\
1,250 \\
1,260\end{array}$ & $\begin{array}{l}2.10 \\
2.10 \\
2.10 \\
2.10 \\
2.08 \\
2.06\end{array}$ & $\begin{array}{l}900 \\
900 \\
900 \\
900 \\
882 \\
866\end{array}$ & $\begin{array}{l}1.70 \\
1.69 \\
1.68 \\
1.67 \\
1.66 \\
1.64\end{array}$ & & $\begin{array}{l}583 \\
576 \\
570 \\
562 \\
555 \\
542\end{array}$ \\
\hline & \multicolumn{2}{|c|}{ September 24} & \multicolumn{2}{|c|}{ September 25} & \multicolumn{2}{|c|}{ September 26} & \multicolumn{2}{|c|}{ September 27} & \multicolumn{2}{|c|}{ September 28} & \multicolumn{3}{|c|}{ September 29} \\
\hline $\begin{array}{r}2 \\
4 \\
6 \\
8 \\
10 \\
N\end{array}$ & $\begin{array}{l}1.60 \\
1.57 \\
1.55 \\
1.52 \\
1.49 \\
1.47\end{array}$ & $\begin{array}{l}514 \\
494 \\
482 \\
462 \\
442 \\
430\end{array}$ & $\begin{array}{l}1.33 \\
1.31 \\
1.29 \\
1.26 \\
1.25 \\
1.23\end{array}$ & $\begin{array}{l}347 \\
337 \\
326 \\
310 \\
305 \\
294\end{array}$ & $\begin{array}{l}1.12 \\
1.11 \\
1.09 \\
1.08 \\
1.07 \\
1.06\end{array}$ & $\begin{array}{l}241 \\
236 \\
227 \\
223 \\
218 \\
214\end{array}$ & $\begin{array}{r}0.98 \\
.97 \\
.96 \\
.95 \\
.94 \\
.92\end{array}$ & $\begin{array}{l}180 \\
176 \\
172 \\
168 \\
164 \\
157\end{array}$ & $\begin{array}{r}0.90 \\
.87 \\
.87 \\
.86 \\
.85 \\
.84\end{array}$ & $\begin{array}{l}149 \\
138 \\
138 \\
134 \\
131 \\
128\end{array}$ & $\begin{array}{r}0.79 \\
.79 \\
.78 \\
.77 \\
.77 \\
.76\end{array}$ & & $\begin{array}{l}110 \\
110 \\
107 \\
105 \\
105 \\
102\end{array}$ \\
\hline $\begin{array}{r}2 \\
4 \\
6 \\
8 \\
10 \\
11\end{array}$ & $\begin{array}{l}1.45 \\
1.44 \\
1.43 \\
1.41 \\
1.39 \\
1.36\end{array}$ & $\begin{array}{l}418 \\
412 \\
406 \\
394 \\
382 \\
365\end{array}$ & $\begin{array}{l}1.21 \\
1.20 \\
1.18 \\
1.17 \\
1.15 \\
1.14\end{array}$ & $\begin{array}{l}284 \\
279 \\
270 \\
264 \\
255 \\
250\end{array}$ & $\begin{array}{r}1.04 \\
1.03 \\
1.02 \\
1.01 \\
1.00 \\
.99\end{array}$ & $\begin{array}{l}205 \\
201 \\
196 \\
192 \\
188 \\
184\end{array}$ & $\begin{array}{l}.92 \\
.92 \\
.91 \\
.91 \\
.91 \\
.91\end{array}$ & $\begin{array}{l}157 \\
157 \\
153 \\
153 \\
153 \\
153\end{array}$ & $\begin{array}{l}.82 \\
.81 \\
.81 \\
.80 \\
.80 \\
.79\end{array}$ & $\begin{array}{l}121 \\
117 \\
117 \\
114 \\
114 \\
110\end{array}$ & $\begin{array}{l}.76 \\
.76 \\
.75 \\
.74 \\
.73 \\
.73\end{array}$ & & $\begin{array}{r}102 \\
102 \\
99 \\
96 \\
93 \\
93\end{array}$ \\
\hline
\end{tabular}


Wanaque Reservoir at Wanaque, N. J.

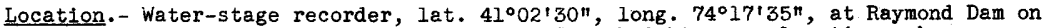
Wanaque River, Wanaque, Passaic County. Gage helghts are elevations above mean sea level (New Jersey Geological Survey benchmark).

Drainage area.- 90.4 square miles (not including portion of Post Brook area diverted into reservo1r).

Gage-height record. - Water-stage recorder graph for rage heights above 300.00 feet; gage read to hundredths dally at $8 \mathrm{a.m}$. for lower gage heights. Gage heights at $8 \mathrm{a} . \mathrm{m}$. are given in table.

Remarks. - Usable storage capacity, 3,476,000,000 cubic feet. Crest of spillway at gage helght 300.00 feet. Records furnished by North Jersey District Water Supply Commission.

Gage height, in feet, and contents, in millions of cubic feet, at 8 a.m., 1938

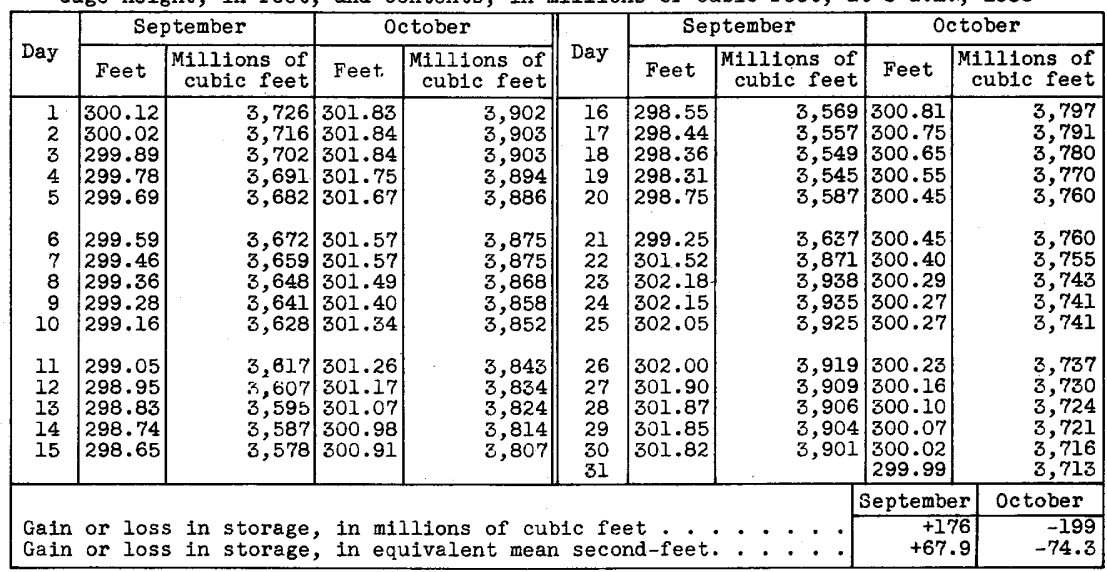


Location.- Water-stage recorder, lat. $41^{\circ} 02^{\prime} 33^{\prime \prime}$, long. $74^{\circ} 17^{\prime} 36^{\prime \prime}$, above weir which is 50 feet above highway bridge in Wanaque, Passaic County. Zero of gage is 210.00 feet above mean sea level (New Jersey Geological Survey benchmark).

Drainage area.- 90.4 square miles (not including Post Brook); affected by storage in Greenwood Lake and Wanaque Reservoir.

Gage-height record. - Water-stage recorder graph.

Stage-discharge relation.- Defined by current-meter measurements below 1,700 secondfeet.

Maxima.- September 1938: Discharge, 912 second-feet 12:40 p.m. Sept. 23 (gage heignt, 4.03 feet).

1903-5, 1912-15, 1919 to August 1938: Gage height, 8.35 feet (former site and datum), from high-water marks, June 22 or 23,1919 (discharge, uncertain); maximum daily discharge, 3,630 second-feet Apr. 7, i924.

Remarks.- Mean monthly discharge adjusted for diversions from Post Brook into Wanaque Reservoir, diversions from Wanaque Reservoir, and storage in Wanaque Reservoir and Greenwood Lake. For information on diversions and storage see records for Wanaque Reservoir at Wanaque, N. J., and Greenwood Lake at The Glens, N. J. Mean monthly diverstons from Post Brook into Wanaque Reservoir were: September, 4.6 second-feet; october, 0.4 second-foot. Mean monthly diversions from Wanaque Reservolr were:

September, 113 second-feet; October, 111 second-feet. Basic data furnished by North Jersey District Water Supply Commission.

Mean dally discharge, in second-feet, 1938

\begin{tabular}{|c|c|c|c|c|c|c|c|c|c|c|c|}
\hline Day & Sept. & Oct. & Day & Sept. & Oct. & Day & Sept. & $0 \mathrm{ct}$. & Day & Sept. & Oct. \\
\hline $\begin{array}{l}1 \\
2 \\
3 \\
4 \\
5 \\
6 \\
7 \\
8 \\
\end{array}$ & $\begin{array}{l}17.5 \\
16.9 \\
16.9 \\
16.9 \\
16.9 \\
16.9 \\
17.5 \\
17.5\end{array}$ & $\begin{array}{r}118 \\
117 \\
100 \\
52 \\
38 \\
44 \\
44 \\
35\end{array}$ & $\begin{array}{r}9 \\
10 \\
11 \\
12 \\
13 \\
14 \\
15 \\
16 \\
\end{array}$ & $\begin{array}{l}16.9 \\
17.5 \\
17.5 \\
17.5 \\
17.5 \\
17.5 \\
17.5 \\
16.9\end{array}$ & $\begin{array}{l}37 \\
34 \\
32 \\
31 \\
30 \\
29 \\
27 \\
26\end{array}$ & $\begin{array}{l}17 \\
18 \\
19 \\
20 \\
21 \\
22 \\
23 \\
24\end{array}$ & $\begin{array}{l}16.9 \\
16.9 \\
19.6 \\
19.6 \\
23 \\
146 \\
841 \\
778\end{array}$ & $\begin{array}{l}25 \\
24 \\
24 \\
24 \\
24 \\
23 \\
23 \\
23\end{array}$ & $\begin{array}{l}25 \\
26 \\
27 \\
28 \\
29 \\
30 \\
31\end{array}$ & $\begin{array}{l}476 \\
300 \\
208 \\
146 \\
115 \\
116\end{array}$ & $\begin{array}{l}23 \\
23 \\
24 \\
24 \\
24 \\
24 \\
23\end{array}$ \\
\hline $\begin{array}{l}\text { Mean } \\
\text { Mean } \\
\text { Run- }\end{array}$ & $\begin{array}{l}\text { monthly } \\
\text { monthly } \\
\text { ff, in }\end{array}$ & $\begin{array}{l}\text { ischar } \\
\text { ischar } \\
\text { ches }\end{array}$ & $\begin{array}{l}1 \\
1 \\
\text { jus }\end{array}$ & $\begin{array}{l}\text { econd- } \\
\text { econd- } \\
\text { i) }\end{array}$ & $\begin{array}{l}\text { et }\left\{\begin{array}{l}o b \\
\text { et } \\
\text { ad }\end{array}\right. \\
\text {. }\end{array}$ & erve & $: \dot{0}:$ & 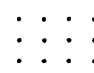 & $\dot{:}: \dot{ }$ & $\begin{array}{r}117 \\
301 \\
3.72\end{array}$ & $\begin{array}{r}37.1 \\
63.8 \\
.81\end{array}$ \\
\hline
\end{tabular}

Gage helght, in feet, and discharge, in second-feet, at indicated time, 1938

\begin{tabular}{|c|c|c|c|c|c|c|c|c|c|c|c|c|c|}
\hline \multirow{2}{*}{ 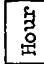 } & Feet & Sec.ft. & Feet & Sec.ft. & Feot & Sec.ft. & Feet & Sec.ft. & Feet & Sec.ft. & Feet & Sec. & .ft. \\
\hline & \multicolumn{2}{|c|}{ September 18} & \multicolumn{2}{|c|}{ September 19} & \multicolumn{2}{|c|}{ September 20} & \multicolumn{2}{|c|}{ September 21} & \multicolumn{2}{|c|}{ September 22} & \multicolumn{3}{|c|}{ September 23} \\
\hline $\begin{array}{l}1 \\
2 \\
3 \\
4 \\
5 \\
6\end{array}$ & $\begin{array}{l}1.28 \\
1.28 \\
1.28 \\
1.28 \\
1.28 \\
1.28\end{array}$ & $\begin{array}{l}16.9 \\
16.9 \\
16.9 \\
16.9 \\
16.9 \\
16.9\end{array}$ & $\begin{array}{l}1.28 \\
1.28 \\
1.28 \\
1.28 \\
1.28 \\
1.28\end{array}$ & $\begin{array}{l}16.9 \\
16.9 \\
16.9 \\
16.9 \\
16.9 \\
16.9\end{array}$ & $\begin{array}{l}1.32 \\
1.31 \\
1.32 \\
1.32 \\
1.33 \\
1.42\end{array}$ & $\begin{array}{l}19.6 \\
18.8 \\
19.6 \\
19.6 \\
20 \\
27\end{array}$ & $\begin{array}{l}1.31 \\
1.30 \\
1.30 \\
1.31 \\
1.31 \\
1.31\end{array}$ & $\begin{array}{l}18.8 \\
18.2 \\
18.2 \\
18.8 \\
18.8 \\
18.8\end{array}$ & $\begin{array}{l}1.32 \\
1.33 \\
1.34 \\
1.36 \\
1.37 \\
1.38\end{array}$ & $\begin{array}{l}19.6 \\
20 \\
21 \\
22 \\
23 \\
24\end{array}$ & $\begin{array}{l}3.34 \\
3.44 \\
3.53 \\
3.61 \\
3.68 \\
3.75\end{array}$ & & $\begin{array}{l}630 \\
687 \\
732 \\
764 \\
788 \\
812\end{array}$ \\
\hline $\begin{array}{r}7 \\
8 \\
9 \\
10 \\
11 \\
\text { N }\end{array}$ & $\begin{array}{l}1.28 \\
1.28 \\
1.28 \\
1.28 \\
1.28 \\
1.28\end{array}$ & $\begin{array}{l}16.9 \\
16.9 \\
16.9 \\
16.9 \\
16.9 \\
16.9\end{array}$ & $\begin{array}{l}1.28 \\
1.28 \\
1.28 \\
1.28 \\
1.28 \\
1.28\end{array}$ & $\begin{array}{l}16.9 \\
16.9 \\
16.9 \\
16.9 \\
16.9 \\
16.9\end{array}$ & $\begin{array}{l}1.35 \\
1.32 \\
1.31 \\
1.31 \\
1.30 \\
1.30\end{array}$ & $\begin{array}{l}22 \\
19.6 \\
18.8 \\
18.8 \\
18.2 \\
18.2\end{array}$ & $\begin{array}{l}1.31 \\
1.31 \\
1.31 \\
1.31 \\
1.31 \\
1.31\end{array}$ & $\begin{array}{l}18.8 \\
18.8 \\
18.8 \\
18.8 \\
18.8 \\
18.8\end{array}$ & $\begin{array}{l}1.39 \\
1.54 \\
1.54 \\
1.54 \\
1.55 \\
1.59\end{array}$ & $\begin{array}{l}24 \\
36 \\
36 \\
36 \\
37 \\
40\end{array}$ & $\begin{array}{l}3.80 \\
3.84 \\
3.88 \\
3.92 \\
3.94 \\
3.98\end{array}$ & & $\begin{array}{l}830 \\
844 \\
858 \\
872 \\
879 \\
893\end{array}$ \\
\hline $\begin{array}{l}1 \\
2 \\
3 \\
4 \\
5 \\
6\end{array}$ & $\begin{array}{l}1.28 \\
1.28 \\
1.28 \\
1.28 \\
1.28 \\
1.28\end{array}$ & $\begin{array}{l}16.9 \\
16.9 \\
16.9 \\
16.9 \\
16.9 \\
16.9\end{array}$ & $\begin{array}{l}1.42 \\
1.50 \\
1.33 \\
1.31 \\
1.30 \\
1.30\end{array}$ & $\begin{array}{l}27 \\
33 \\
20 \\
18.8 \\
18.2 \\
18.2\end{array}$ & $\begin{array}{l}1.30 \\
1.30 \\
1.30 \\
1.30 \\
1.30 \\
1.30\end{array}$ & $\begin{array}{l}18.2 \\
18.2 \\
18.2 \\
18.2 \\
18.2 \\
18.2\end{array}$ & $\begin{array}{l}1.47 \\
1.52 \\
1.62 \\
1.49 \\
1.51 \\
1.44\end{array}$ & $\begin{array}{l}31 \\
35 \\
43 \\
32 \\
34 \\
28\end{array}$ & $\begin{array}{l}1.77 \\
2.02 \\
2.19 \\
2.33 \\
2.44 \\
2.56\end{array}$ & $\begin{array}{r}57 \\
86 \\
122 \\
162 \\
201 \\
246\end{array}$ & $\begin{array}{l}4.01 \\
4.00 \\
4.01 \\
4.02 \\
3.98 \\
3.94\end{array}$ & & $\begin{array}{l}904 \\
900 \\
904 \\
908 \\
893 \\
879\end{array}$ \\
\hline \multirow[t]{2}{*}{$\begin{array}{r}7 \\
8 \\
9 \\
10 \\
11 \\
M\end{array}$} & $\begin{array}{l}1.28 \\
1.28 \\
1.28 \\
1.28 \\
1.28 \\
1.28\end{array}$ & $\begin{array}{l}16.9 \\
16.9 \\
16.9 \\
16.9 \\
16.9 \\
16.9\end{array}$ & $\begin{array}{l}1.30 \\
1.30 \\
1.30 \\
1.42 \\
1.37 \\
1.34\end{array}$ & $\begin{array}{l}18.2 \\
18.2 \\
18.2 \\
27 \\
23 \\
21\end{array}$ & $\begin{array}{l}1.30 \\
1.32 \\
1.33 \\
1.32 \\
1.32 \\
1.31\end{array}$ & $\begin{array}{l}18.2 \\
19.6 \\
20 \\
19.6 \\
19.6 \\
18.8\end{array}$ & $\begin{array}{l}1.36 \\
1.33 \\
1.32 \\
1.31 \\
1.31 \\
1.31\end{array}$ & $\begin{array}{l}22 \\
20 \\
19.6 \\
18.8 \\
18.8 \\
18.8\end{array}$ & $\begin{array}{l}2.69 \\
2.80 \\
2.91 \\
3.02 \\
3.13 \\
3.23\end{array}$ & $\begin{array}{l}300 \\
348 \\
400 \\
455 \\
513 \\
568\end{array}$ & $\begin{array}{l}3.91 \\
3.91 \\
3.90 \\
3.89 \\
3.88 \\
3.87\end{array}$ & & $\begin{array}{l}868 \\
868 \\
865 \\
862 \\
858 \\
854\end{array}$ \\
\hline & \multicolumn{2}{|c|}{ September 24} & \multicolumn{2}{|c|}{ September 25} & \multicolumn{2}{|c|}{ September 26} & \multicolumn{2}{|c|}{ September 27} & \multicolumn{2}{|c|}{ September 28} & \multicolumn{3}{|c|}{ September 29} \\
\hline $\begin{array}{r}2 \\
4 \\
6 \\
8 \\
10 \\
N\end{array}$ & $\begin{array}{l}3.83 \\
3.81 \\
3.77 \\
3.71 \\
3.66 \\
3.59\end{array}$ & $\begin{array}{l}840 \\
834 \\
820 \\
798 \\
781 \\
756\end{array}$ & $\begin{array}{l}3.28 \\
3.19 \\
3.14 \\
3.11 \\
3.10 \\
3.05\end{array}$ & $\begin{array}{l}596 \\
546 \\
519 \\
502 \\
497 \\
471\end{array}$ & $\begin{array}{l}2.84 \\
2.81 \\
2.80 \\
2.76 \\
2.71 \\
2.67\end{array}$ & $\begin{array}{l}367 \\
353 \\
348 \\
330 \\
308 \\
291\end{array}$ & $\begin{array}{l}2.53 \\
2.51 \\
2.50 \\
2.48 \\
2.44 \\
2.43\end{array}$ & $\begin{array}{l}235 \\
227 \\
223 \\
216 \\
201 \\
197\end{array}$ & $\begin{array}{l}2.35 \\
2.35 \\
2.35 \\
2.32 \\
2.30 \\
2.27\end{array}$ & $\begin{array}{l}169 \\
169 \\
169 \\
159 \\
152 \\
144\end{array}$ & $\begin{array}{l}2.20 \\
2.20 \\
2.20 \\
2.18 \\
2.17 \\
2.17\end{array}$ & & $\begin{array}{l}124 \\
124 \\
124 \\
119 \\
117 \\
117\end{array}$ \\
\hline $\begin{array}{r}2 \\
4 \\
6 \\
8 \\
10 \\
\mathrm{M}\end{array}$ & $\begin{array}{l}3.54 \\
3.55 \\
3.55 \\
3.50 \\
3.38 \\
3.32\end{array}$ & $\begin{array}{l}736 \\
740 \\
740 \\
720 \\
653 \\
619\end{array}$ & $\begin{array}{l}3.00 \\
2.96 \\
2.94 \\
2.92 \\
2.89 \\
2.87\end{array}$ & $\begin{array}{l}445 \\
425 \\
415 \\
405 \\
390 \\
381\end{array}$ & $\begin{array}{l}2.63 \\
2.60 \\
2.59 \\
2.57 \\
2.56 \\
2.54\end{array}$ & $\begin{array}{l}275 \\
262 \\
258 \\
250 \\
246 \\
239\end{array}$ & $\begin{array}{l}2.41 \\
2.41 \\
2.42 \\
2.44 \\
2.44 \\
2.42\end{array}$ & $\begin{array}{l}190 \\
190 \\
193 \\
201 \\
201 \\
193\end{array}$ & $\begin{array}{l}2.25 \\
2.23 \\
2.23 \\
2.23 \\
2.22 \\
2.21\end{array}$ & $\begin{array}{l}138 \\
132 \\
132 \\
132 \\
130 \\
127\end{array}$ & $\begin{array}{l}2.15 \\
2.14 \\
2.13 \\
2.13 \\
2.13 \\
2.14\end{array}$ & & $\begin{array}{l}112 \\
110 \\
108 \\
108 \\
108 \\
110\end{array}$ \\
\hline
\end{tabular}

Supplemental records.- Sept. 19, 1:20 p.m., 1.62 ft., 43 sec.-ft.; 10:30 p.m., 1.46 ft., 30 sec. $-\mathrm{ft}$ sept. 21, l:30 p.m., l.44 ft., 28 sec.-ft. Sept. 23, 12340 p.m., 4.03 ft., 912 sec.-ft. Sept. 24,5 p.m., 3.68 ft., 788 sec.-ft.; 7 p.m., 3.64 ft., 774 sec.-ft. 
Oak Ridge Reservoir at Oak Ridge, N. J.

Location.- Lat. $41^{\circ} 02^{\prime} 20^{\prime \prime}$, Iong 74\%30'05", at 0ak Ridge Dam on Pequannock River, I mile southwest of Oak Ridge, Passaic County. Gage heights are elevations above mean sea level (New Jersey Geological Survey benchmark).

Drainage area. - 33.7 square miles.

Gage-height record.- Gage read daily at $6 \mathrm{a} \cdot \mathrm{m}$, and $6 \mathrm{p.m}$. Gage heights at 6 a.m. are given in table.

Remarks.- Usable storage capacity, 532,000,000 cubic feet. Record furnished by Department of Public Affairs, Division of Water, Newark, N. J.

Gage height, in feet, and contents, in millions of cubic feet, at 6 a.m., 1938

\begin{tabular}{|c|c|c|c|c|c|c|c|c|c|}
\hline \multirow[b]{2}{*}{ Day } & \multicolumn{2}{|c|}{ September } & \multicolumn{2}{|c|}{ October } & \multirow[b]{2}{*}{ Day } & \multicolumn{2}{|c|}{ September } & \multicolumn{2}{|c|}{ October } \\
\hline & Feet & $\begin{array}{l}\text { Millions of } \\
\text { cubic feet }\end{array}$ & Feet & $\begin{array}{l}\text { Millions of } \\
\text { cubic feet }\end{array}$ & & Fieet & $\begin{array}{l}\text { Millions of } \\
\text { cubic feet }\end{array}$ & Feet & $\begin{array}{l}\text { Millions of } \\
\text { cubic feet }\end{array}$ \\
\hline $\begin{array}{l}1 \\
2 \\
3 \\
4 \\
5\end{array}$ & $\begin{array}{l}845.44 \\
845.53 \\
845.55 \\
845.56 \\
845.57\end{array}$ & \begin{tabular}{|l}
510 \\
512 \\
512 \\
512 \\
513
\end{tabular} & $\begin{array}{l}846.12 \\
846.10 \\
846.08 \\
846.07 \\
846.06\end{array}$ & \begin{tabular}{|l|}
523 \\
523 \\
522 \\
522 \\
522
\end{tabular} & $\begin{array}{l}16 \\
17 \\
18 \\
19 \\
20\end{array}$ & $\begin{array}{l}845.42 \\
845.40 \\
845.41 \\
845.42 \\
845.98\end{array}$ & \begin{tabular}{|}
510 \\
509 \\
509 \\
510 \\
520
\end{tabular} & $\left|\begin{array}{l}845.83 \\
845.79 \\
845.75 \\
845.70 \\
845.65\end{array}\right|$ & $\begin{array}{l}517 \\
517 \\
516 \\
515 \\
514\end{array}$ \\
\hline $\begin{array}{r}6 \\
7 \\
8 \\
9 \\
10\end{array}$ & $\begin{array}{l}845.58 \\
845.59 \\
845.60 \\
845.60 \\
845.59\end{array}$ & $\begin{array}{l}513 \\
513 \\
513 \\
513 \\
513\end{array}$ & $\begin{array}{l}846.04 \\
846.08 \\
846.07 \\
846.06 \\
846.04\end{array}$ & $\begin{array}{l}521 \\
522 \\
522 \\
522 \\
521\end{array}$ & $\begin{array}{l}21 \\
22 \\
23 \\
24 \\
25\end{array}$ & $\begin{array}{l}846.36 \\
846.89 \\
846.54 \\
846.36 \\
846.27\end{array}$ & $\begin{array}{l}528 \\
538 \\
531 \\
528 \\
526\end{array}$ & $\mid \begin{array}{l}845.78 \\
845.98 \\
846.03 \\
846.03 \\
846.12\end{array}$ & $\begin{array}{l}517 \\
520 \\
521 \\
521 \\
523\end{array}$ \\
\hline $\begin{array}{l}11 \\
12 \\
13 \\
14 \\
15\end{array}$ & $\begin{array}{l}845.54 \\
845.49 \\
845.45 \\
845.41 \\
845.36\end{array}$ & $\begin{array}{l}512 \\
511 \\
510 \\
510 \\
509\end{array}$ & $\begin{array}{l}846.02 \\
845.99 \\
845.95 \\
845.91 \\
845.87\end{array}$ & $\begin{array}{l}521 \\
520 \\
520 \\
519 \\
518\end{array}$ & $\begin{array}{l}26 \\
27 \\
28 \\
29 \\
30 \\
31\end{array}$ & $\begin{array}{l}846.21 \\
846.18 \\
846.16 \\
846.15 \\
846.14\end{array}$ & $\begin{array}{l}525 \\
524 \\
524 \\
524 \\
523\end{array}$ & $\mid \begin{array}{l}846.09 \\
846.11 \\
846.10 \\
846.04 \\
846.02 \\
846.02\end{array}$ & $\begin{array}{l}522 \\
523 \\
523 \\
521 \\
521 \\
521\end{array}$ \\
\hline & & & & & & & & September & October \\
\hline $\begin{array}{l}\text { Gain } \\
\text { Gain }\end{array}$ & $\begin{array}{l}\text { or loss } \\
\text { or loss }\end{array}$ & $\begin{array}{l}\text { s in storage, } \\
s \text { in storage, }\end{array}$ & $\begin{array}{l}\text {, in mil } \\
\text { in equ }\end{array}$ & $\begin{array}{l}\text { llions of cut } \\
\text { divalent mean }\end{array}$ & c $f$ & t-i eet. & $\cdot: \cdot \cdot \cdot \cdot$ & $\begin{array}{r}+13 \\
+5.0\end{array}$ & $\begin{array}{r}-2 \\
-.75 \\
\end{array}$ \\
\hline
\end{tabular}

Canistear Reservoir near Stockholm, N. J.

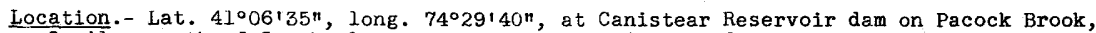
2 miles north of Stockholm, Sussex County. Add 1,000 feet to heights given in table to obtain gage heights and elevations above mean sea level (New Jersey Geological Survey benchmark).

Drainage area.- 5.59 square miles.

Gage-height record. - One gage reading daily at noon.

Remarks.- Usable storage capacity, 322,000,000 cubic feet. Record furnished by Department of Public Affairs, Division of Water, Newark, N. J.

Height, in feet, and contents, in miliions of cubic feet, at noon, 1938

\begin{tabular}{|c|c|c|c|c|c|c|c|c|c|c|c|}
\hline \multirow{2}{*}{ Day } & \multicolumn{2}{|c|}{ September } & \multicolumn{2}{|c|}{ October } & \multirow[b]{2}{*}{ Day } & \multicolumn{3}{|c|}{ September } & \multicolumn{3}{|c|}{ October } \\
\hline & Feet & $\begin{array}{l}\text { Millions of } \\
\text { cubic feet }\end{array}$ & Feet & $\begin{array}{l}\text { Millions of } \\
\text { cubic feet }\end{array}$ & & Feet & \multicolumn{2}{|c|}{$\begin{array}{l}\text { Millions of } \\
\text { cubic feet }\end{array}$} & Feet & \multicolumn{2}{|c|}{$\begin{array}{l}\text { Millions of } \\
\text { cubic feet }\end{array}$} \\
\hline $\begin{array}{l}1 \\
2 \\
3 \\
4 \\
5\end{array}$ & $\begin{array}{l}86.09 \\
86.08 \\
86.08 \\
86.08 \\
86.08\end{array}$ & $\begin{array}{l}323 \\
323 \\
323 \\
323 \\
323\end{array}$ & $\begin{array}{l}86.17 \\
86.16 \\
86.16 \\
86.15 \\
86.15\end{array}$ & \begin{tabular}{|l}
324 \\
324 \\
324 \\
324 \\
324
\end{tabular} & $\begin{array}{l}16 \\
17 \\
18 \\
19 \\
20\end{array}$ & $\begin{array}{l}86.03 \\
86.03 \\
86.08 \\
86.08 \\
86.35\end{array}$ & & $\begin{array}{l}322 \\
322 \\
323 \\
323 \\
327\end{array}$ & $\begin{array}{l}86.12 \\
86.12 \\
86.12 \\
86.12 \\
86.11\end{array}$ & & $\begin{array}{l}324 \\
324 \\
324 \\
324 \\
323\end{array}$ \\
\hline $\begin{array}{r}6 \\
7 \\
8 \\
9 \\
10\end{array}$ & $\begin{array}{l}86.08 \\
86.07 \\
86.07 \\
86.07 \\
86.06\end{array}$ & $\begin{array}{l}323 \\
323 \\
323 \\
323 \\
323\end{array}$ & $\begin{array}{l}86.15 \\
86.13 \\
86.13 \\
86.13 \\
86.13\end{array}$ & $\begin{array}{l}324 \\
324 \\
324 \\
324 \\
324\end{array}$ & $\begin{array}{l}21 \\
22 \\
23 \\
24 \\
25\end{array}$ & $\begin{array}{l}86.32 \\
86.50 \\
86.33 \\
86.23 \\
86.24\end{array}$ & & $\begin{array}{l}326 \\
329 \\
326 \\
325 \\
325\end{array}$ & $\begin{array}{l}86.14 \\
86.14 \\
86.14 \\
86.15 \\
86.20\end{array}$ & & $\begin{array}{l}324 \\
324 \\
324 \\
324 \\
325\end{array}$ \\
\hline $\begin{array}{l}11 \\
12 \\
13 \\
14 \\
15\end{array}$ & $\begin{array}{l}86.05 \\
86.04 \\
86.03 \\
86.02 \\
86.00\end{array}$ & $\begin{array}{l}322 \\
322 \\
322 \\
322 \\
322\end{array}$ & $\begin{array}{l}86.13 \\
86.13 \\
86.12 \\
86.12 \\
86.12\end{array}$ & $\begin{array}{l}324 \\
324 \\
324 \\
324 \\
324\end{array}$ & $\begin{array}{l}26 \\
27 \\
28 \\
29 \\
30 \\
31\end{array}$ & $\begin{array}{l}86.20 \\
86.19 \\
86.19 \\
86.18 \\
86.18\end{array}$ & & $\begin{array}{l}325 \\
325 \\
325 \\
324 \\
324\end{array}$ & $\begin{array}{l}86.19 \\
86.18 \\
86.18 \\
86.18 \\
86.18 \\
86.17\end{array}$ & & $\begin{array}{l}325 \\
324 \\
324 \\
324 \\
324 \\
324\end{array}$ \\
\hline & & & & & & & & & eptembe & & October \\
\hline $\begin{array}{l}\text { Gain } \\
\text { Gain }\end{array}$ & $\begin{array}{l}\text { or loss } \\
\text { or loss }\end{array}$ & $\begin{array}{l}\text { in storage, } \\
\text { in storage, }\end{array}$ & in $\mathrm{mi}$ & $\begin{array}{l}\text { llions of cub } \\
\text { divalent mean }\end{array}$ & $\begin{array}{l}\text { ic } f e \\
\text { seco }\end{array}$ & t-feet. & : : : & & & & $\begin{array}{l}0 \\
0\end{array}$ \\
\hline
\end{tabular}


Clinton Reservoir near Newfoundland, N. J.

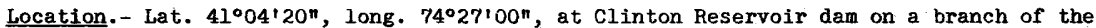
Pequannock River, 2 miles north of Newfoundland, Passaic County. Gage heights are elevations above mean sea level (New Jersey Geological Survey benchmark).

Drainage erea.- 10.5 square miles.

Cage-height record.- One gage reading daily at $9 \mathrm{a} . \mathrm{m}$.

Remarks.- Usable storage capacity, 470,000,000 cubic feet. Record furnished by Department of Public Affairs, Division of Water, Newark, N. J.

Gage height, in feet, and contents, in millions of cubic feet, at 9 a.m., 1938

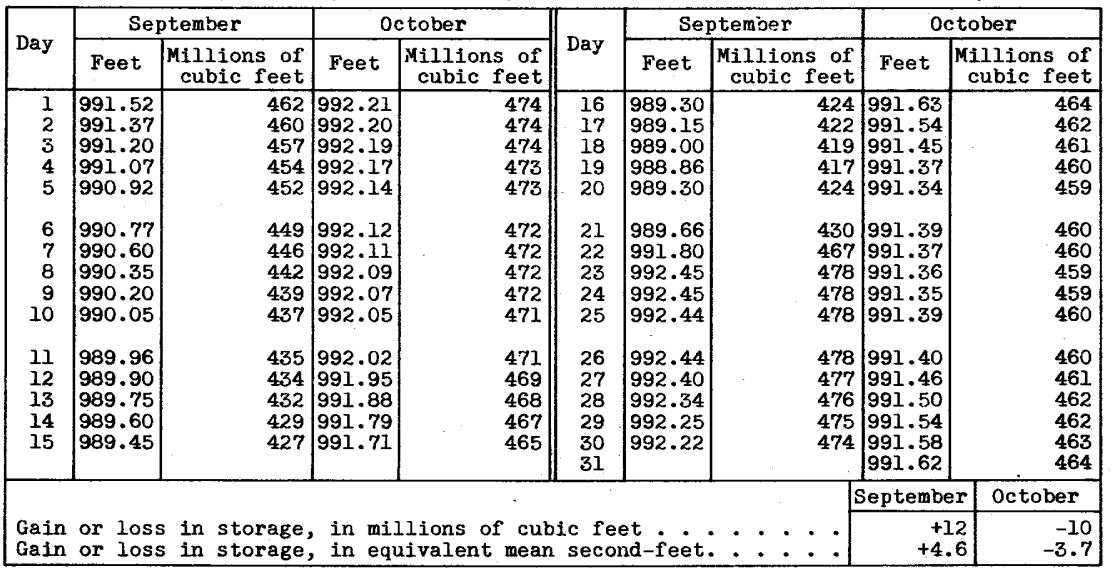

Echo Lake Reservoir near Charlotteburg, N. J.

Location.- Lat. $41^{\circ} 02^{\prime} 55^{n}$, long. $74^{\circ} 24^{\prime} 25^{\prime \prime}$, on branch of Pequannock River, lit miles northeast of Charlotteburg, Passaic County. Gage heights are elevations above mean sea level (New Jersey Geological Survey benchmark).

Drainage area.- 2.51 square miles.

Gage-helght record.- One gage reading daily at noon.

Remarks.- Usable storage capacity, 225,000,000 cubic feet. Records furnished by Department of Public Affairs, Division of Water, Newark, N. J.

Gage height, in feet, and contents, in millions of cubic feet, at noon, 1938

\begin{tabular}{|c|c|c|c|c|c|c|c|c|c|}
\hline \multirow[b]{2}{*}{ Day } & \multicolumn{2}{|c|}{ September } & \multicolumn{2}{|c|}{ October } & \multirow[b]{2}{*}{ Day } & \multicolumn{2}{|c|}{ September } & \multicolumn{2}{|c|}{ October } \\
\hline & Feet & $\begin{array}{l}\text { Millions of } \\
\text { cubic feet }\end{array}$ & Feet & $\begin{array}{l}\text { Millions of } \\
\text { cubic feet }\end{array}$ & & Feet & $\begin{array}{l}\text { Millions of } \\
\text { cubic feet }\end{array}$ & Feet & $\begin{array}{l}\text { Millions of } \\
\text { cubic feet }\end{array}$ \\
\hline $\begin{array}{l}1 \\
2 \\
3 \\
4 \\
5\end{array}$ & $\begin{array}{l}890.12 \\
890.03 \\
889.95 \\
889.86 \\
889.79\end{array}$ & $\begin{array}{l}178 \\
177 \\
176 \\
175 \\
174\end{array}$ & \begin{tabular}{|l|}
892.78 \\
892.80 \\
892.81 \\
892.82 \\
892.83
\end{tabular} & $\begin{array}{l}209 \\
209 \\
209 \\
209 \\
209\end{array}$ & $\begin{array}{l}16 \\
17 \\
18 \\
19 \\
20\end{array}$ & $\begin{array}{l}889.16 \\
889.15 \\
889.17 \\
889.20 \\
889.80\end{array}$ & $\begin{array}{l}167 \\
167 \\
167 \\
168 \\
174\end{array}$ & $\begin{array}{l}892.85 \\
892.85 \\
892.63 \\
892.52 \\
892.41\end{array}$ & \begin{tabular}{|l}
210 \\
210 \\
207 \\
206 \\
204
\end{tabular} \\
\hline $\begin{array}{r}6 \\
7 \\
8 \\
9 \\
10\end{array}$ & $\begin{array}{l}889.71 \\
889.63 \\
889.56 \\
889.49 \\
889.42\end{array}$ & $\begin{array}{l}173 \\
172 \\
171 \\
170 \\
170\end{array}$ & $\begin{array}{l}892.84 \\
892.96 \\
892.98 \\
893.00 \\
893.01\end{array}$ & $\begin{array}{l}210 \\
211 \\
211 \\
212 \\
212\end{array}$ & $\begin{array}{l}21 \\
22 \\
23 \\
24 \\
25\end{array}$ & $\begin{array}{l}890.26 \\
890.90 \\
891.27 \\
891.49 \\
891.60\end{array}$ & $\begin{array}{l}179 \\
187 \\
191 \\
194 \\
195\end{array}$ & $\begin{array}{l}892.49 \\
892.40 \\
892.32 \\
892.30 \\
892.41\end{array}$ & $\begin{array}{l}205 \\
204 \\
203 \\
203 \\
204\end{array}$ \\
\hline $\begin{array}{l}11 \\
12 \\
13 \\
14 \\
15\end{array}$ & $\begin{array}{l}889.36 \\
889.30 \\
889.26 \\
889.22 \\
889.19\end{array}$ & $\begin{array}{l}169 \\
169 \\
168 \\
168 \\
167\end{array}$ & $\begin{array}{l}893.00 \\
892.99 \\
892.99 \\
892.99 \\
892.97\end{array}$ & $\begin{array}{l}212 \\
212 \\
212 \\
212 \\
211\end{array}$ & $\begin{array}{l}26 \\
27 \\
28 \\
29 \\
30 \\
31\end{array}$ & $\mid \begin{array}{l}891.68 \\
892.70 \\
892.71 \\
892.73 \\
892.75\end{array}$ & $\begin{array}{l}196 \\
208 \\
208 \\
208 \\
208\end{array}$ & $\mid \begin{array}{l}892.40 \\
892.31 \\
892.28 \\
892.21 \\
892.17 \\
892.13\end{array}$ & $\begin{array}{l}204 \\
203 \\
203 \\
202 \\
202 \\
201\end{array}$ \\
\hline & & & & & & & & Septembe & October \\
\hline & & & & & & & $\div:$ & $\begin{array}{r}+3 \\
+12\end{array}$ & $\begin{array}{r}-8 \\
-3.0\end{array}$ \\
\hline
\end{tabular}


Location.- Lat. $41^{\circ} 01^{\prime} 0^{\prime \prime}$, Iong. $74^{\circ} 23^{\prime} 47^{\prime \prime}$, at lacopin intake dam of Newark waterworks, 3 miles above Butier, Morris County. Zero of gage is 583.74 feet above mean sea level (New Jersey Geological Survey benchmark).

Drainage area.- 63.7 square miles; materially affected by artificial storage.

Gage-helght record.- Two gage readings dally. Elevation of crest of dam is zero gage neight.

Stage-discharge relation.- Based on determinations of flow over 40-foot sharp-crested weir.

Maxima.- September 1938: Discharge observed, 1,300 second-feet at 6 a.m. Sept. 22 (gage height, 1.40 feet).

1892 to August 1938: Discharge observed, about 6,100 second-feet 0ct. 10 , 1903 (gage height, 3.85 feet)

Remarks. - Tables of daily and hourly discharges give flow over intake dam only. Mean monthly discharge and run-off, in inches, are adjusted for storage and diversion. For information on storage see records for Oak Ridge Reservoir at Oak Ridge, N. J.; Canistear Reservoir near Stockholm, N. J.; Clinton Reservoir near Newfoundland, N. J.; and Echo Lake Reservoir near Charlotteburg, N. J. Mean monthly diversions: September, 52.2 second-feet; October, 63.9 second-feet. Records furnished by Department of Public Affairs, Division of Water, Newark, N. J.

Mean daily discharge, in second-feet, 1938

\begin{tabular}{|c|c|c|c|c|c|c|c|c|c|c|c|}
\hline Day & Sept. & oct. & Day & Sept. & oct. & Day & Sept. & oct. & Day & Sept. & Oct. \\
\hline $\begin{array}{l}1 \\
2 \\
3 \\
4 \\
5 \\
6 \\
7 \\
8\end{array}$ & $\begin{array}{l}0 \\
0 \\
0 \\
0 \\
0 \\
0 \\
0 \\
0\end{array}$ & $\begin{array}{l}38 \\
28 \\
16.7 \\
25 \\
25 \\
22 \\
35 \\
49\end{array}$ & $\begin{array}{l}9 \\
10 \\
11 \\
12 \\
13 \\
14 \\
15 \\
16\end{array}$ & $\begin{array}{l}0 \\
0 \\
0 \\
0 \\
0 \\
0 \\
0 \\
0\end{array}$ & $\begin{array}{r}49 \\
38 \\
28 \\
13.8 \\
11.1 \\
16.7 \\
10.4 \\
9.6\end{array}$ & $\begin{array}{l}17 \\
18 \\
19 \\
20 \\
21 \\
22 \\
23 \\
24\end{array}$ & $\begin{array}{r}0 \\
0 \\
0 \\
225 \\
783 \\
1,160 \\
781 \\
489\end{array}$ & $\begin{array}{l}11.1 \\
11.1 \\
11.1 \\
19.3 \\
38 \\
38 \\
28 \\
61\end{array}$ & $\begin{array}{l}25 \\
26 \\
27 \\
28 \\
29 \\
30 \\
31\end{array}$ & $\begin{array}{r}297 \\
200 \\
139 \\
99 \\
73 \\
49\end{array}$ & $\begin{array}{l}95 \\
46 \\
42 \\
46 \\
33 \\
28 \\
17.0\end{array}$ \\
\hline $\begin{array}{l}\text { Mean } \\
\text { Mean } \\
\text { Run- }\end{array}$ & $\begin{array}{l}\text { monthly } \\
\text { monthiy } \\
\text { ff, in }\end{array}$ & $\begin{array}{l}\text { schar } \\
\text { schar } \\
\text { hes }\end{array}$ & $\begin{array}{l}\text { in } \\
\text {, in } \\
\text { just }\end{array}$ & $\begin{array}{l}\text { econd- } \\
\text { econd- } \\
\text { i) }\end{array}$ & et $\left\{\begin{array}{l}\text { obs } \\
\mathrm{ad}\end{array}\right.$ & $\begin{array}{l}\text { rved) } \\
\text { isted) } \\
. \quad . \quad\end{array}$ & $\begin{array}{lll} & . & . \\
. & . & . \\
. & \bullet & .\end{array}$ & $\dot{0}: \dot{ }$ & $\dot{0}: \dot{ }$ & $\begin{array}{r}143 \\
217 \\
3.80 \\
\end{array}$ & $\begin{array}{l}30.3 \\
86.8 \\
1.57\end{array}$ \\
\hline
\end{tabular}

Gage helght, in feet, and discharge, in second-feet, at indicated time, 1938

\begin{tabular}{|c|c|c|c|c|c|c|c|c|c|c|c|c|}
\hline & Feet & Sec.ft. & Feet & sec.ft. & Feet & Sec.ft. & Feet & ec.ft. & Feet & sec.ft. & Feet & Sec.ft. \\
\hline & \multicolumn{2}{|c|}{ September 18} & \multicolumn{2}{|c|}{ September 19} & \multicolumn{2}{|c|}{ September 20} & \multicolumn{2}{|c|}{ September 21} & \multicolumn{2}{|c|}{ September 22} & \multicolumn{2}{|c|}{ September 23} \\
\hline \multirow[t]{2}{*}{$\begin{array}{l}6 \\
6 \\
\end{array}$} & $\begin{array}{r}-1.20 \\
-.80 \\
\end{array}$ & $\begin{array}{l}0 \\
0 \\
\end{array}$ & $\begin{array}{r}-0.50 \\
.15 \\
\end{array}$ & $\begin{array}{r}0 \\
49 \\
\end{array}$ & $\begin{array}{r}0.55 \\
.55 \\
\end{array}$ & $\begin{array}{l}312 \\
312\end{array}$ & $\begin{array}{l}0.70 \\
1.35\end{array}$ & $\begin{array}{r}447 \\
1,230\end{array}$ & $\begin{array}{l}1.40 \\
1.30\end{array}$ & $\begin{array}{l}1,300 \\
1,160\end{array}$ & $\begin{array}{l}1.05 \\
1.10\end{array}$ & $\begin{array}{l}832 \\
895\end{array}$ \\
\hline & Septe & ember 24 & Sept & ember 25 & Septe & ember 26 & Septe & ber 27 & Septe & ber 28 & Septe & ember 29 \\
\hline $\begin{array}{l}6 \\
6\end{array}$ & $\begin{array}{l}.75 \\
.65 \\
\end{array}$ & $\begin{array}{l}497 \\
401 \\
\end{array}$ & $\begin{array}{l}.55 \\
.50 \\
\end{array}$ & $\begin{array}{l}312 \\
270\end{array}$ & $\begin{array}{l}.45 \\
.35\end{array}$ & $\begin{array}{l}231 \\
160\end{array}$ & $\begin{array}{l}.35 \\
.30\end{array}$ & $\begin{array}{l}160 \\
128\end{array}$ & $\begin{array}{l}.25 \\
.25\end{array}$ & $\begin{array}{l}99 \\
99\end{array}$ & $\begin{array}{l}.20 \\
.20\end{array}$ & $\begin{array}{l}73 \\
73\end{array}$ \\
\hline
\end{tabular}


Saddle River at Lodi, N. J.

Location.- Water-stage recorder, lat. $40^{\circ} 53^{\prime} 24^{\prime \prime}$, long. $74^{\circ} 04^{\prime} 50^{\prime \prime}$, at highway bridge 1 mile above Lodi, Bergen County, and $23 / 4$ miles above mouth. Zero of gage is 22.46 feet above mean sea level (general adjustment of 1929).

Drainage area.- 54.6 square miles.

Gage-height record.- Water-s tage recorder graph.

Stage-discharge relation.- Defined by current-meter measurements below 700 second-feet; extended to peak stage on basis of study of peak discharge of Pascack Brook.

Maxima.- September 1938: Discharge, about 2,150 second-feet 11 a.m. Sept. 22 (gage helight, 6.21 feet).

1923 to August 1938: Discharge, about 2,200 second-feet Mar. 12, 1936 (gage height, 6.27 feet).

Mean dally discharge, in second-feet, 2938

\begin{tabular}{|c|r|r||r|r|r|r|r|r|r|r|r|}
\hline Day & Sept. & Oct. & Day & Sept. & 0ct. & Day & Sept. & 0ct. & Day & Sept. & Oct. \\
\hline 1 & 52 & 85 & 9 & 61 & 78 & 17 & 61 & 56 & 25 & 138 & 102 \\
2 & 48 & 78 & 10 & 67 & 73 & 18 & 65 & 54 & 26 & 109 & 88 \\
3 & 38 & 76 & 11 & 54 & 67 & 19 & 116 & 56 & 27 & 100 & 74 \\
4 & 36 & 79 & 12 & 46 & 63 & 20 & 286 & 61 & 28 & 95 & 71 \\
5 & 33 & 74 & 13 & 65 & 59 & 21 & 772 & 12 & 29 & 91 & 74 \\
6 & 38 & 71 & 14 & 59 & 59 & 22 & 1,720 & 108 & 30 & 87 & 84 \\
7 & 49 & 108 & 15 & 94 & 59 & 23 & 705 & 80 & 31 & & 71 \\
8 & 57 & 92 & 16 & 91 & 57 & 24 & 262 & 76 & & & \\
\hline
\end{tabular}

Gage helght, in feet, and discharge, in second-feet, at indicated time, 1938

\begin{tabular}{|c|c|c|c|c|c|c|c|c|c|c|c|c|}
\hline \multirow{2}{*}{$\begin{array}{l}4 \\
3 \\
0 \\
\end{array}$} & Feet & Sec.ft. & Feet & Sec.ft. & Feet & Sec.ft. & Feet & Sec.ft. & Feet & Sec.ft. & Feet & Sec.ft. \\
\hline & \multicolumn{2}{|c|}{ September 18} & \multicolumn{2}{|c|}{ September 19} & \multicolumn{2}{|c|}{ September 20} & \multicolumn{2}{|c|}{ September 21} & \multicolumn{2}{|c|}{ September 22} & \multicolumn{2}{|c|}{ September 23} \\
\hline 1 & 1.96 & 65 & 1.99 & 71 & 2.77 & 208 & 3.50 & 444 & 5.00 & 1,210 & 4.90 & 1,150 \\
\hline$\frac{1}{2}$ & & 65 & & 73 & & & & & & & & 1,100 \\
\hline 3 & & 67 & & 76 & & 221 & & 501 & & & & 1,040 \\
\hline 4 & 99 & 71 & 6 & 96 & 2.8 & 227 & & 522 & & & & 982 \\
\hline 5 & & 74 & & 88 & 7. & 235 & & 539 & & & & 931 \\
\hline 6 & 2.0 & 74 & 2.06 & 82 & 2.9 & 243 & & 556 & 5.77 & 1,770 & & 882 \\
\hline 7 & 1.98 & 69 & 05 & 80 & 92 & 249 & 3.79 & 565 & 5.90 & 1,870 & & 834 \\
\hline 8 & 1.96 & 65 & & 82 & & 255 & & 578 & & & & 793 \\
\hline 9 & 1.94 & 61 & & 84 & & 260 & & 600 & & & & 747 \\
\hline 10 & 1.94 & 61 & 0 & 88 & & 266 & & 632 & & & & 708 \\
\hline II & 1.94 & 61 & & 91 & & 275 & & 655 & & 150 & 02 & 670 \\
\hline $\mathrm{N}$ & 1.94 & 61 & & 96 & & 278 & & 694 & 6.20 & 2,1 & & 651 \\
\hline 1 & 1.94 & 61 & 22 & 104 & & 281 & 4.2 & 782 & 6.17 & 2,110 & & 632 \\
\hline 2 & & 59 & & & & 291 & & 844 & & & & 600 \\
\hline 3 & 1.93 & 59 & & 122 & & 297 & & 887 & & & & 569 \\
\hline 4 & 1.93 & 59 & & 13 & & 303 & & 920 & & & & 543 \\
\hline 5 & 1.93 & 59 & 2.4 & 140 & 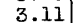 & 306 & & 959 & 5. & & & 518 \\
\hline 6 & 1.93 & 59 & & 147 & & 323 & & 1,000 & 5.70 & & 3.62 & 492 \\
\hline \multirow{7}{*}{$\begin{array}{r}7 \\
8 \\
9 \\
10 \\
11 \\
M \\
\end{array}$} & & 61 & & & & 333 & & & & & & 468 \\
\hline & 1.97 & 67 & 2 & 168 & & 353 & & 080 & & & & 448 \\
\hline & 1.98 & 69 & & 17 & & 374 & & 1,110 & & & & 433 \\
\hline & 1.98 & 69 & 2.66 & 182 & 5 & 388 & 4.8 & 1,140 & & & & 414 \\
\hline & 1.98 & 69 & 2 . & 19 & & 399 & & 1,160 & & & & 395 \\
\hline & 1.98 & 69 & & 201 & & 417 & & & & & & 381 \\
\hline & \multicolumn{2}{|c|}{ September 24} & \multicolumn{2}{|c|}{ September 25} & \multicolumn{2}{|c|}{ September 26} & \multicolumn{2}{|c|}{ September 27} & \multicolumn{2}{|c|}{ September 28} & \multicolumn{2}{|c|}{ September 29} \\
\hline 2 & 3.25 & 353 & 2.58 & 164 & 2.32 & 116 & 2.22 & 104 & 2.17 & 98 & & 95 \\
\hline 4 & & & & 158 & & 114 & & 10 & & & & 94 \\
\hline 6 & & 310 & & 15 & & 112 & & 103 & & 9 & & 92 \\
\hline 8 & 3.06 & 291 & 2. & 143 & & 110 & & 100 & & 95 & & 91 \\
\hline 10 & 3.00 & & & & & 109 & & 99 & & 95 & & 90 \\
\hline $\mathrm{N}$ & 2.94 & 255 & & 136 & 2.25 & 108 & & 99 & & 95 & & \\
\hline 2 & 2.89 & 240 & & 133 & & 106 & & 98 & & 95 & & 90 \\
\hline 4 & & & & & & 10 & & 98 & & & & 90 \\
\hline 6 & 2. & 21 & & 12 & & 106 & & 98 & & 9 & 2.11 & 90 \\
\hline 8 & & 19 & & 122 & & 105 & & 9 & & & 2.1 & 88 \\
\hline 10 & & 18 & 2. & 120 & 2 & 105 & 2 . & 98 & & 95 & 2.10 & 88 \\
\hline$M$ & & 173 & 2.33 & 117 & 2.23 & 105 & 2.17 & 98 & 2.15 & 95 & 2.11 & 90 \\
\hline
\end{tabular}

Supplemental records.- Sept. 20, 6:30 a.m., 2.95 ft., 258 sec.-ft.; 8:15 p.m., $3.20 \mathrm{ft.}, 336 \mathrm{sec} . \mathrm{ft}$. 
Location.- Water-stage recorder, lat. $40^{\circ} 40^{\prime} 03^{\prime \prime}$, long. $74^{\circ} 13^{\prime} 09^{\prime \prime}$, just above westfield Avenue Bridge, Elizabeth, Union County, and $2 \frac{1}{2}$ : miles above mouth.

Drainage area.- 18.0 square miles; (revised); affected by diversions for municipal use. Gage-helght record.- Water-stage recorder graph.

Stage-discharge relation.- Defined by current-meter measurements below 190 second-feet; extended to peak stage on basis of determination of flood flow by contracted-opening method.

Maxima.- September 1938: Discharge, about 2,020 second-feet 5:15 p.m. Sept. 21 (gage height, 9.25 feet). 1921 to August 1938: Discharge, about 2,720 second-feet July 23, 1938 (gage height, 13.05 feet, from floodmark).

Remarks.- Mean monthly discharge and run-off, in inches, adjusted for diversion. Mean monthly diversions were: September, 4.5 second-feet; October, 4.9 second-feet.

Mean delly discharge, in second-feөt, 1938

\begin{tabular}{|c|c|c|c|c|c|c|c|c|c|c|c|}
\hline Day & Sept. & Oct. & Day & Sept. & Oct. & Day & Sept. & Oct. & Day & Sept. & Oct. \\
\hline $\begin{array}{l}1 \\
2 \\
3 \\
4 \\
5 \\
6 \\
7 \\
8\end{array}$ & $\begin{array}{r}30 \\
7.6 \\
6.5 \\
6.1 \\
6.1 \\
10.5 \\
6.3 \\
6.3\end{array}$ & $\begin{array}{r}11.3 \\
9.6 \\
9.3 \\
9.3 \\
9.0 \\
44 \\
16.6 \\
9.6\end{array}$ & $\begin{array}{r}9 \\
10 \\
11 \\
12 \\
13 \\
14 \\
15 \\
16\end{array}$ & $\begin{array}{r}6.1 \\
6.0 \\
5.4 \\
5.4 \\
11.9 \\
6.1 \\
15.5 \\
8.2\end{array}$ & $\begin{array}{l}8.5 \\
7.9 \\
8.5 \\
8.2 \\
8.2 \\
8.2 \\
7.6 \\
6.5\end{array}$ & $\begin{array}{l}17 \\
18 \\
19 \\
20 \\
21 \\
22 \\
23 \\
24\end{array}$ & $\begin{array}{l}6.9 \\
12.5 \\
140 \\
230 \\
751 \\
84 \\
16.2 \\
33\end{array}$ & $\begin{array}{c}6.5 \\
7.3 \\
7.3 \\
23 \\
26 \\
8.2 \\
7.1 \\
23\end{array}$ & $\begin{array}{l}25 \\
26 \\
27 \\
28 \\
29 \\
30 \\
31\end{array}$ & $\begin{array}{l}26 \\
23 \\
36 \\
20 \\
15.7 \\
14.4\end{array}$ & $\begin{array}{r}10.2 \\
7.9 \\
18.0 \\
16.0 \\
10.7 \\
7.1 \\
6.8\end{array}$ \\
\hline $\begin{array}{l}\text { Mean } \\
\text { Mean } \\
\text { Run-0 }\end{array}$ & $\begin{array}{l}\text { monthly } \\
\text { monthly } \\
\text { if, in i }\end{array}$ & $\begin{array}{l}\text { Ischar } \\
\text { ischare } \\
\text { ches }\end{array}$ & , 1 & econd- & 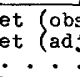 & $\begin{array}{l}\text { erved } \\
\text { asted } \\
. \quad\end{array}$ & 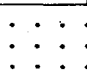 & 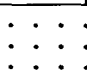 & 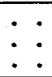 & $\begin{array}{l}51.8 \\
56.8 \\
3.49\end{array}$ & $\begin{array}{l}11.9 \\
16.8 \\
1.08\end{array}$ \\
\hline
\end{tabular}

Gage height, in feet, and discharge, in second-feet, at indlcated time, 1938

\begin{tabular}{|c|c|c|c|c|c|c|c|c|c|c|c|c|}
\hline \multirow{2}{*}{$\begin{array}{l}9 \\
9 \\
0 \\
\text { 足 }\end{array}$} & Feet & Sec.ft. & Feet & Sec.ft. & Feot & Sec.ft. & Feet & Sec.ft. & Feet & Sec.ft. & Feet & Sec.ft \\
\hline & \multicolumn{2}{|c|}{ September 18} & \multicolumn{2}{|c|}{ September 19} & \multicolumn{2}{|c|}{ September 20} & \multicolumn{2}{|c|}{ September 21} & \multicolumn{2}{|c|}{ September 22} & \multicolumn{2}{|c|}{ September 23} \\
\hline $\begin{array}{l}1 \\
2 \\
3 \\
4 \\
5 \\
6\end{array}$ & $\begin{array}{l}2.77 \\
2.75 \\
2.74 \\
2.73 \\
2.72 \\
2.72\end{array}$ & $\begin{array}{l}8.5 \\
7.9 \\
7.6 \\
7.3 \\
7.1 \\
7.1\end{array}$ & $\begin{array}{l}3.34 \\
3.26 \\
3.52 \\
3.41 \\
3.60 \\
3.50\end{array}$ & $\begin{array}{r}38 \\
32 \\
53 \\
44 \\
61 \\
51\end{array}$ & $\begin{array}{l}4.18 \\
4.19 \\
4.20 \\
4.21 \\
4.26 \\
4.60\end{array}$ & $\begin{array}{l}140 \\
141 \\
143 \\
145 \\
154 \\
225\end{array}$ & $\begin{array}{l}5.04 \\
4.70 \\
4.31 \\
4.34 \\
4.73 \\
4.92\end{array}$ & $\begin{array}{l}344 \\
249 \\
163 \\
169 \\
257 \\
309\end{array}$ & $\begin{array}{l}5.06 \\
4.70 \\
4.35 \\
4.17 \\
4.07 \\
3.99\end{array}$ & $\begin{array}{l}351 \\
249 \\
171 \\
138 \\
122 \\
110\end{array}$ & $\begin{array}{l}2.69 \\
2.68 \\
2.67 \\
2.66 \\
2.95 \\
3.28\end{array}$ & $\begin{array}{r}6.3 \\
6.1 \\
6.0 \\
5.8 \\
14.8 \\
34\end{array}$ \\
\hline $\begin{array}{r}7 \\
8 \\
9 \\
10 \\
11 \\
N\end{array}$ & $\begin{array}{l}2.72 \\
2.71 \\
2.70 \\
2.69 \\
2.68 \\
2.68\end{array}$ & $\begin{array}{l}7.1 \\
6.8 \\
6.5 \\
6.3 \\
6.1 \\
6.1\end{array}$ & $\begin{array}{l}3.47 \\
3.32 \\
3.20 \\
3.20 \\
3.17 \\
3.25\end{array}$ & $\begin{array}{l}49 \\
37 \\
28 \\
28 \\
26 \\
32\end{array}$ & $\begin{array}{l}5.16 \\
5.58 \\
5.29 \\
5.15 \\
4.80 \\
4.24\end{array}$ & $\begin{array}{l}383 \\
528 \\
427 \\
380 \\
275 \\
150\end{array}$ & $\begin{array}{l}4.89 \\
4.84 \\
4.99 \\
5.16 \\
5.24 \\
5.41\end{array}$ & $\begin{array}{l}300 \\
286 \\
329 \\
383 \\
41.0 \\
468\end{array}$ & $\begin{array}{l}3.92 \\
3.87 \\
3.83 \\
3.80 \\
3.76 \\
3.73\end{array}$ & $\begin{array}{r}100 \\
93 \\
88 \\
84 \\
79 \\
76\end{array}$ & $\begin{array}{l}3.36 \\
3.38 \\
3.40 \\
3.40 \\
3.41 \\
3.42\end{array}$ & $\begin{array}{l}40 \\
41 \\
43 \\
43 \\
44 \\
45\end{array}$ \\
\hline $\begin{array}{l}1 \\
2 \\
3 \\
4 \\
5 \\
6\end{array}$ & $\begin{array}{l}2.69 \\
2.77 \\
2.78 \\
2.78 \\
2.84 \\
2.87\end{array}$ & $\begin{array}{r}6.3 \\
8.5 \\
8.7 \\
8.7 \\
10.7 \\
11.7\end{array}$ & $\begin{array}{l}4.20 \\
5.04 \\
5.59 \\
5.40 \\
5.01 \\
4.92\end{array}$ & $\begin{array}{l}143 \\
344 \\
532 \\
465 \\
335 \\
309\end{array}$ & $\begin{array}{l}3.88 \\
3.69 \\
3.61 \\
3.68 \\
4.20 \\
4.70\end{array}$ & $\begin{array}{r}94 \\
71 \\
62 \\
70 \\
143 \\
249\end{array}$ & $\begin{array}{l}5.80 \\
6.90 \\
7.17 \\
8.10 \\
9.18 \\
9.00\end{array}$ & $\begin{array}{r}615 \\
1,130 \\
1,280 \\
1,690 \\
2,010 \\
1,960\end{array}$ & $\begin{array}{l}3.55 \\
3.00 \\
2.88 \\
2.84 \\
2.81 \\
2.80\end{array}$ & $\begin{array}{r}56 \\
17.0 \\
12.0 \\
10.7 \\
9.6 \\
9.3\end{array}$ & $\begin{array}{l}3.42 \\
3.42 \\
3.41 \\
3.39 \\
3.36 \\
3.35\end{array}$ & $\begin{array}{l}45 \\
45 \\
44 \\
42 \\
40 \\
39\end{array}$ \\
\hline \multirow[t]{2}{*}{$\begin{array}{r}7 \\
8 \\
9 \\
10 \\
11 \\
11\end{array}$} & $\begin{array}{l}2.87 \\
2.87 \\
3.14 \\
3.20 \\
3.56 \\
3.48\end{array}$ & $\begin{array}{l}11.7 \\
11.7 \\
24 \\
28 \\
57 \\
49\end{array}$ & $\begin{array}{l}4.75 \\
4.30 \\
3.92 \\
3.76 \\
4.12 \\
4.16\end{array}$ & $\begin{array}{r}262 \\
161 \\
100 \\
79 \\
129 \\
136\end{array}$ & $\begin{array}{l}4.78 \\
4.64 \\
4.83 \\
5.08 \\
5.17 \\
5.18\end{array}$ & $\begin{array}{l}270 \\
235 \\
283 \\
357 \\
386 \\
389\end{array}$ & $\begin{array}{l}8.26 \\
7.38 \\
6.79 \\
6.10 \\
5.53 \\
5.31\end{array}$ & $\begin{array}{r}1,740 \\
1,390 \\
1,030 \\
745 \\
510 \\
434\end{array}$ & $\begin{array}{l}2.78 \\
2.76 \\
2.75 \\
2.73 \\
2.71 \\
2.70\end{array}$ & $\begin{array}{l}8.7 \\
8.2 \\
7.9 \\
7.7 \\
6.8 \\
6.5\end{array}$ & $\begin{array}{l}3.34 \\
3.34 \\
3.33 \\
3.33 \\
3.32 \\
3.32\end{array}$ & $\begin{array}{l}38 \\
38 \\
37 \\
37 \\
37 \\
37\end{array}$ \\
\hline & \multicolumn{2}{|c|}{ September 24} & \multicolumn{2}{|c|}{ September 25} & \multicolumn{2}{|c|}{ September 26} & \multicolumn{2}{|c|}{ September 27} & \multicolumn{2}{|c|}{ September 28} & \multicolumn{2}{|c|}{ September 29} \\
\hline $\begin{array}{r}2 \\
4 \\
6 \\
8 \\
10 \\
N\end{array}$ & $\begin{array}{l}3.30 \\
3.30 \\
3.29 \\
3.28 \\
3.27 \\
3.27\end{array}$ & $\begin{array}{l}35 \\
35 \\
34 \\
34 \\
33 \\
33\end{array}$ & $\begin{array}{l}3.19 \\
3.19 \\
3.18 \\
3.18 \\
3.17 \\
3.16\end{array}$ & $\begin{array}{l}27 \\
27 \\
27 \\
27 \\
26 \\
26\end{array}$ & $\begin{array}{l}3.12 \\
3.12 \\
3.11 \\
3.11 \\
3.11 \\
3.11\end{array}$ & $\begin{array}{l}23 \\
23 \\
23 \\
23 \\
23 \\
23\end{array}$ & $\begin{array}{l}3.10 \\
3.09 \\
3.08 \\
3.07 \\
3.07 \\
3.07\end{array}$ & $\begin{array}{l}22 \\
22 \\
21 \\
20 \\
20 \\
20\end{array}$ & $\begin{array}{l}3.19 \\
3.10 \\
3.07 \\
3.05 \\
3.04 \\
3.04\end{array}$ & $\begin{array}{l}27 \\
22 \\
20 \\
19.5 \\
19.0 \\
19.0\end{array}$ & $\begin{array}{l}3.00 \\
2.98 \\
2.97 \\
2.97 \\
2.95 \\
2.95\end{array}$ & $\begin{array}{l}17.0 \\
16.1 \\
15.7 \\
15.7 \\
14.8 \\
14.8\end{array}$ \\
\hline $\begin{array}{r}2 \\
4 \\
6 \\
8 \\
10 \\
M\end{array}$ & $\begin{array}{l}3.26 \\
3.25 \\
3.24 \\
3.24 \\
3.20 \\
3.19\end{array}$ & $\begin{array}{l}32 \\
32 \\
31 \\
31 \\
28 \\
27\end{array}$ & $\begin{array}{l}3.15 \\
3.15 \\
3.14 \\
3.14 \\
3.13 \\
3.13\end{array}$ & $\begin{array}{l}25 \\
25 \\
24 \\
24 \\
24 \\
24\end{array}$ & $\begin{array}{l}3.11 \\
3.11 \\
3.11 \\
3.11 \\
3.11 \\
3.10\end{array}$ & $\begin{array}{l}23 \\
23 \\
23 \\
23 \\
23 \\
22\end{array}$ & $\begin{array}{l}3.07 \\
3.07 \\
3.07 \\
4.44 \\
3.76 \\
3.36\end{array}$ & $\begin{array}{r}20 \\
20 \\
20 \\
189 \\
79 \\
40\end{array}$ & $\begin{array}{l}3.02 \\
3.02 \\
3.02 \\
3.02 \\
3.01 \\
3.00\end{array}$ & $\begin{array}{l}18.0 \\
18.0 \\
18.0 \\
18.0 \\
17.5 \\
17.0\end{array}$ & $\begin{array}{l}2.95 \\
2.95 \\
2.95 \\
2.95 \\
2.95 \\
2.95\end{array}$ & $\begin{array}{l}14.8 \\
14.8 \\
14.8 \\
14.8 \\
14.8 \\
14.8\end{array}$ \\
\hline
\end{tabular}

Supplemental records.- Sept. 22, 3:30 a.m., 4.24 ft., 150 sec.-ft. Sept. 21, $5: 15$ p.m., $9.25 \mathrm{ft.}, 2,020 \mathrm{sec} .-\mathrm{ft}$. 
Location.- Water-stage recorder, lat. $40^{\circ} 41^{\prime} 11^{\prime \prime}$, long. $74^{\circ} 18^{\prime} 44^{\prime \prime}$, 50 feet below state Route 29, just below Pope Brook, and $1 \frac{1}{2}$ miles south of Springfield, Union County. Zero of gage is 64.47 feet above mean sea level (New Jersey Geological Survey benchmark).

Drainage area.- 25.5 square miles; affected by diversions for municipal use.

Gage-helght record.- Water-stage recorder graph except for period 3 a.m. Sept. 27 to 3 p.m. Oct. 7 .

Stage-discharge relation.- Defined by current-meter measurements below 900 second-feet; extended to peak stage by logarithmic plotting.

Maxima.- September 1938: Discharge, about 1,590 second-feet 7:30 p.m. Sept. 21 (gage height, 6.70 feet).

July to August 1938: Discharge, about 1,940 second-feet 1:15 p.m. July 23, 1938 (gage height, 7.41 feet)

Remarks.- Discharge for period of missing gage-height record computed on basis of record at Rahway. Mean monthly discharge and run-off, in inches, adjusted for diversions, Mean monthly diversions were: September, 13.9 second-feet; 0ctober, 13.3 second-feet.

Mean dally alscharge, in second-feet, 1938

\begin{tabular}{|c|c|c|c|c|c|c|c|c|c|c|c|}
\hline Day & Sept. & oot. & Day & Sept. & Oot. & Day & Sept. & Oet. & Day & Sept. & Oet. \\
\hline $\begin{array}{l}1 \\
2 \\
3 \\
4 \\
5 \\
6 \\
7 \\
8\end{array}$ & $\begin{array}{r}18.4 \\
7.3 \\
7.3 \\
7.3 \\
7.3 \\
6.9 \\
6.2 \\
6.5\end{array}$ & $\begin{array}{l}* 13 \\
* 12 \\
* 11 \\
* 10 \\
* 10 \\
* 38 \\
* 15 \\
10.5\end{array}$ & $\begin{array}{l}9 \\
10 \\
11 \\
12 \\
13 \\
14 \\
15 \\
16\end{array}$ & $\begin{array}{l}5.9 \\
5.6 \\
6.2 \\
6.5 \\
7.8 \\
6.2 \\
6.5 \\
6.2\end{array}$ & $\begin{array}{r}10.0 \\
8.6 \\
8.2 \\
8.6 \\
8.6 \\
8.6 \\
8.6 \\
8.2\end{array}$ & $\begin{array}{l}17 \\
18 \\
19 \\
20 \\
21 \\
22 \\
23 \\
24\end{array}$ & $\begin{array}{r}5.9 \\
7.8 \\
82 \\
168 \\
731 \\
530 \\
68 \\
31\end{array}$ & $\begin{array}{r}8.2 \\
7.8 \\
7.8 \\
8.6 \\
26 \\
9.1 \\
8.2 \\
16.4\end{array}$ & $\begin{array}{l}25 \\
26 \\
27 \\
28 \\
29 \\
30 \\
31\end{array}$ & $\begin{array}{c}21 \\
17.0 \\
* 15 \\
* 20 \\
* 15 \\
* 13\end{array}$ & $\begin{array}{r}11.1 \\
8.6 \\
10.4 \\
15.0 \\
10.0 \\
8.6 \\
8.2\end{array}$ \\
\hline $\begin{array}{l}\text { Mean } \\
\text { Mean } \\
\text { Run- }\end{array}$ & $\begin{array}{l}\text { onthly } \\
\text { onthly } \\
f, \text { in } 1\end{array}$ & $\begin{array}{l}\text { schar } \\
\text { schar } \\
\text { hes }\end{array}$ & ir & econd-f & $\begin{array}{ll}\text { at } & \text { obs } \\
\text { ot } & \text { lads }\end{array}$ & $\begin{array}{c}\text { orved) } \\
\text { isted) } \\
\text {. }\end{array}$ & $\begin{array}{lll}\cdot & \bullet & \bullet \\
. & \bullet & \bullet \\
. & \bullet & \cdot\end{array}$ & 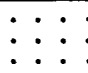 & $: \dot{:}$ & $\begin{array}{l}61.4 \\
75.3 \\
3.29\end{array}$ & $\begin{array}{l}11.4 \\
24.6 \\
1.11\end{array}$ \\
\hline
\end{tabular}

Gage helght, in feet, and discharge, in second-feet, at indicated time, 1958

\begin{tabular}{|c|c|c|c|c|c|c|c|c|c|c|c|c|}
\hline \multirow{2}{*}{$\begin{array}{l}3 \\
0 \\
0\end{array}$} & Feot & Sec.ft. & Feet & Sec.ft. & Feet & Sec.ft. & Feet & sec.ft. & Feet & Sec.ft. & Foet & seo.ft. \\
\hline & \multicolumn{2}{|c|}{ September 18} & \multicolumn{2}{|c|}{ September 19} & \multicolumn{2}{|c|}{ September 20} & \multicolumn{2}{|c|}{ September 21} & \multicolumn{2}{|c|}{ September 22} & \multicolumn{2}{|c|}{ September 23} \\
\hline $\begin{array}{l}1 \\
2 \\
3 \\
4 \\
5 \\
6\end{array}$ & $\begin{array}{l}1.45 \\
1.45 \\
1.44 \\
1.44 \\
1.44 \\
1.44\end{array}$ & \begin{tabular}{|l|}
7.3 \\
7.3 \\
6.9 \\
6.9 \\
6.9 \\
6.9
\end{tabular} & $\begin{array}{l}1.58 \\
1.61 \\
1.61 \\
1.61 \\
1.65 \\
1.72\end{array}$ & $\begin{array}{l}14.7 \\
17.0 \\
17.0 \\
17.0 \\
20 \\
27\end{array}$ & \begin{tabular}{|l|}
2.20 \\
2.24 \\
2.24 \\
2.31 \\
2.48 \\
2.53
\end{tabular} & $\begin{array}{l}108 \\
119 \\
119 \\
138 \\
186 \\
201\end{array}$ & $\begin{array}{l}2.67 \\
2.62 \\
2.55 \\
2.50 \\
2.51 \\
2.59\end{array}$ & $\begin{array}{l}241 \\
227 \\
206 \\
192 \\
195 \\
218\end{array}$ & $\begin{array}{l}5.83 \\
5.60 \\
5.36 \\
5.14 \\
4.90 \\
4.65\end{array}$ & $\begin{array}{r}1,220 \\
1,140 \\
1,040 \\
968 \\
885 \\
802\end{array}$ & $\begin{array}{l}2.22 \\
2.19 \\
2.16 \\
2.14 \\
2.12 \\
2.10\end{array}$ & $\begin{array}{r}113 \\
106 \\
98 \\
94 \\
89 \\
84\end{array}$ \\
\hline $\begin{array}{r}7 \\
8 \\
9 \\
10 \\
11 \\
11\end{array}$ & $\begin{array}{l}1.44 \\
1.44 \\
1.43 \\
1.44 \\
1.45 \\
1.46\end{array}$ & $\begin{array}{l}6.9 \\
6.9 \\
6.5 \\
6.9 \\
7.3 \\
7.8\end{array}$ & $\begin{array}{l}1.75 \\
1.75 \\
1.73 \\
1.71 \\
1.69 \\
1.69\end{array}$ & $\begin{array}{l}30 \\
30 \\
28 \\
26 \\
24 \\
24\end{array}$ & $\begin{array}{l}2.61 \\
2.71 \\
2.71 \\
2.64 \\
2.54 \\
2.44\end{array}$ & $\begin{array}{l}224 \\
253 \\
253 \\
233 \\
204 \\
175\end{array}$ & $\begin{array}{l}2.64 \\
2.70 \\
2.80 \\
2.94 \\
3.10 \\
3.33\end{array}$ & $\begin{array}{l}233 \\
250 \\
279 \\
320 \\
365 \\
429\end{array}$ & $\begin{array}{l}4.40 \\
4.15 \\
3.92 \\
3.70 \\
3.50 \\
3.30\end{array}$ & $\begin{array}{l}723 \\
648 \\
584 \\
524 \\
473 \\
421\end{array}$ & $\begin{array}{l}2.08 \\
2.06 \\
2.05 \\
2.03 \\
2.01 \\
1.99\end{array}$ & $\begin{array}{l}80 \\
76 \\
74 \\
71 \\
67 \\
63\end{array}$ \\
\hline $\begin{array}{l}1 \\
2 \\
3 \\
4 \\
5 \\
6\end{array}$ & $\begin{array}{l}1.46 \\
1.46 \\
1.45 \\
1.45 \\
1.46 \\
1.47\end{array}$ & $\begin{array}{l}7.8 \\
7.8 \\
7.3 \\
7.3 \\
7.8 \\
8.2\end{array}$ & $\begin{array}{l}1.75 \\
2.10 \\
2.61 \\
2.71 \\
2.66 \\
2.55\end{array}$ & $\begin{array}{r}30 \\
84 \\
224 \\
253 \\
238 \\
206\end{array}$ & $\begin{array}{l}2.36 \\
2.27 \\
2.23 \\
2.26 \\
2.27 \\
2.28\end{array}$ & $\begin{array}{l}152 \\
127 \\
116 \\
124 \\
127 \\
130\end{array}$ & $\begin{array}{l}3.58 \\
4.12 \\
4.95 \\
5.70 \\
6.28 \\
6.57\end{array}$ & $\begin{array}{r}493 \\
640 \\
902 \\
1,170 \\
1,400 \\
1,530\end{array}$ & $\begin{array}{l}3.15 \\
3.01 \\
2.88 \\
2.77 \\
2.67 \\
2.58\end{array}$ & $\begin{array}{l}379 \\
340 \\
302 \\
270 \\
241 \\
215\end{array}$ & $\begin{array}{l}1.97 \\
1.96 \\
1.94 \\
1.93 \\
1.91 \\
1.90\end{array}$ & $\begin{array}{l}60 \\
59 \\
55 \\
54 \\
51 \\
49\end{array}$ \\
\hline \multirow[t]{2}{*}{$\begin{array}{r}7 \\
8 \\
9 \\
20 \\
11 \\
11\end{array}$} & $\begin{array}{l}1.48 \\
1.49 \\
1.49 \\
1.49 \\
1.50 \\
1.54\end{array}$ & $\begin{array}{r}8.6 \\
9.1 \\
9.1 \\
9.1 \\
9.5 \\
11.8\end{array}$ & $\begin{array}{l}2.45 \\
2.34 \\
2.23 \\
2.15 \\
2.11 \\
2.10\end{array}$ & $\begin{array}{r}178 \\
146 \\
116 \\
96 \\
86 \\
84\end{array}$ & $\begin{array}{l}2.32 \\
2.35 \\
2.41 \\
2.56 \\
2.65 \\
2.67\end{array}$ & $\begin{array}{l}141 \\
149 \\
166 \\
209 \\
236 \\
241\end{array}$ & $\begin{array}{l}6.69 \\
6.68 \\
6.58 \\
6.45 \\
6.27 \\
6.07\end{array}$ & $\begin{array}{l}1,580 \\
1,580 \\
1,530 \\
1,480 \\
1,400 \\
1,320\end{array}$ & $\begin{array}{l}2.51 \\
2.45 \\
2.38 \\
2.33 \\
2.30 \\
2.26\end{array}$ & $\begin{array}{l}195 \\
178 \\
157 \\
143 \\
135 \\
124\end{array}$ & $\begin{array}{l}1.89 \\
1.88 \\
1.87 \\
1.86 \\
1.85 \\
1.84\end{array}$ & $\begin{array}{l}48 \\
46 \\
45 \\
44 \\
42 \\
41\end{array}$ \\
\hline & \multicolumn{2}{|c|}{ September 24} & \multicolumn{2}{|c|}{ September 25} & \multicolumn{2}{|c|}{ September 26} & \multicolumn{2}{|c|}{ September 27} & \multicolumn{2}{|c|}{ September 28} & \multicolumn{2}{|c|}{ September 29} \\
\hline $\begin{array}{r}2 \\
4 \\
6 \\
8 \\
10 \\
14\end{array}$ & $\begin{array}{l}1.83 \\
1.81 \\
1.80 \\
1.80 \\
1.78 \\
1.77\end{array}$ & $\begin{array}{l}40 \\
37 \\
36 \\
36 \\
33 \\
32\end{array}$ & $\begin{array}{l}1.68 \\
1.67 \\
1.67 \\
1.67 \\
1.67 \\
1.66\end{array}$ & $\begin{array}{l}23 \\
22 \\
22 \\
22 \\
22 \\
21\end{array}$ & $\begin{array}{l}1.62 \\
1.62 \\
1.62 \\
1.61 \\
1.62 \\
1.62\end{array}$ & $\begin{array}{l}17.9 \\
17.9 \\
17.9 \\
17.0 \\
17.9 \\
17.9\end{array}$ & $\begin{array}{c}1.58 \\
- \\
- \\
- \\
-\end{array}$ & $\begin{array}{l}14.7 \\
- \\
- \\
- \\
\\
\end{array}$ & $\begin{array}{l}- \\
- \\
- \\
- \\
- \\
-\end{array}$ & $\begin{array}{l}- \\
- \\
- \\
- \\
\\
\end{array}$ & $\begin{array}{l}- \\
- \\
- \\
- \\
- \\
-\end{array}$ & $\begin{array}{l}- \\
\overline{-} \\
- \\
\bar{*} \\
* 15\end{array}$ \\
\hline $\begin{array}{r}2 \\
4 \\
6 \\
8 \\
10 \\
11\end{array}$ & $\begin{array}{l}1.75 \\
1.75 \\
1.75 \\
1.71 \\
1.69 \\
1.68\end{array}$ & $\begin{array}{l}30 \\
30 \\
28 \\
26 \\
24 \\
23\end{array}$ & $\begin{array}{l}1.65 \\
1.64 \\
1.64 \\
1.64 \\
1.63 \\
1.62\end{array}$ & $\begin{array}{l}20 \\
19.6 \\
19.6 \\
19.6 \\
18.7 \\
17.9\end{array}$ & $\begin{array}{l}1.61 \\
1.62 \\
1.61 \\
1.59 \\
1.58 \\
1.58\end{array}$ & $\begin{array}{l}17.0 \\
17.9 \\
17.0 \\
15.4 \\
14.7 \\
14.7\end{array}$ & $\begin{array}{l}- \\
- \\
- \\
-\end{array}$ & $\begin{array}{l}- \\
- \\
- \\
-\end{array}$ & $\begin{array}{l}- \\
- \\
- \\
-\end{array}$ & $\begin{array}{l}- \\
\overline{-} \\
\overline{-} \\
-\end{array}$ & $\begin{array}{l}- \\
\overline{-} \\
\overline{-} \\
\overline{-}\end{array}$ & $\begin{array}{l}- \\
\overline{-} \\
\overline{-}\end{array}$ \\
\hline
\end{tabular}

Supplemental records.- Sept. $21,7: 30$ p.m., $6.70 \mathrm{ft} ., 1,590$ sec.-ft.

* Estimated mean for the dey. 
Rahway River at Rahway, N. J.

Location. - Water-stage recorder, lat. 40037105", long. $74^{\circ} 17^{\prime} 00^{\prime \prime}$, 100 feet above St. George Avenue Bridge, Rahway, Union County, 1 mile above mouth 01 Robinsons Branch of Rahway River. Zero of gage is 8.63 feet above mean sea level (New Jersey Geological Survey benchmark).

Drainage area.- 40.9 square miles; affected by diversions for municipal use.

Gage-height record. - Water-stage recorder graph except for periods Sept. 1 to 7 a.m. Sept. 20 and Sept. 27.

Stage-discharge relation.- Defined by current-meter measurements below 500 second-feet; extended to peak stage by logarithmic plotting and study of laboratory rating of control having similar cross section.

Maxima.- September 1938: Discharge, 1,780 second-feet 6-7 a.m. Sept. 22 (gage height, 4.94 feet).

1908-15, 1921 to August 1938: Discharge, 3,140 second-feet July 24, 1938 (gage height, 6.35 feet).

Remarks.- For periods of missing gage-height record, discharge computed on basis of recorded range of stage and record near springfield. Mean monthly discharge and run-off, in inches, adjusted for diversions. Mean monthly diversions were: September, 19.2 second-feet; October, 18.3 second-feet.

Mean dally discharge, in second-feet, 1938

\begin{tabular}{|c|c|c||c|c|c||r|r|r|r|r|r|}
\hline Day & Sept. & 0ct. & Day & Sopt. & 0ct. & Day & Sept. & 0ct. & Day & Sept. & 0ct. \\
\hline 1 & $* 30$ & 23 & 9 & $* 10$ & 21 & 17 & $* 10$ & 14.5 & 25 & 60 & 30 \\
2 & $* 15$ & 22 & 10 & $* 10$ & 19.2 & 18 & $* 15$ & 19.2 & 26 & 33 & 20 \\
3 & $* 14$ & 19.2 & 11 & $* 11$ & 17.1 & 19 & $* 130$ & 15.2 & 27 & 26 & 19.5 \\
4 & $* 13$ & 19.2 & 12 & $* 12$ & 18.1 & 20 & $* 260$ & 15.2 & 28 & 40 & 33 \\
5 & $* 13$ & 19.2 & 13 & $* 13$ & 19.2 & 21 & 897 & 35 & 29 & 28 & 26 \\
6 & $* 13$ & 21 & 14 & $* 12$ & 19.2 & 22 & 1,380 & 24 & 30 & 24 & 19.7 \\
7 & $* 12$ & 50 & 15 & $* 11$ & 16.1 & 23 & 340 & 18.1 & 31 & & 18.1 \\
8 & $* 11$ & 27 & 16 & $* 10$ & 16.1 & 24 & 89 & 18.1 & & & \\
\hline
\end{tabular}

Gage height, in feet, and discharge, in second-feet, at indicated time, 1938

\begin{tabular}{|c|c|c|c|c|c|c|c|c|c|c|c|c|c|}
\hline \multirow{2}{*}{$\begin{array}{l}\text { 多 } \\
\text { 总 } \\
\end{array}$} & Feot & Sec.ft. & Feet & Sec.ft. & Feot & Sec.ft. & Feet & Sec.ft. & Feet & Sec.ft. & Feet & Sec. & . ft. \\
\hline & \multicolumn{2}{|c|}{ September 18} & \multicolumn{2}{|c|}{ September 19} & \multicolumn{2}{|c|}{ September 20} & \multicolumn{2}{|c|}{ September 21} & \multicolumn{2}{|c|}{ September 22} & \multicolumn{3}{|c|}{ September 23} \\
\hline $\begin{array}{l}1 \\
2 \\
3 \\
4 \\
5 \\
6\end{array}$ & & \multirow{4}{*}{$* 15$} & & \multirow{4}{*}{ *130 } & & $* 190$ & $\begin{array}{l}2.74 \\
2.68 \\
2.63 \\
2.62 \\
2.62 \\
2.68\end{array}$ & $\begin{array}{l}377 \\
352 \\
331 \\
327 \\
327 \\
352\end{array}$ & $\begin{array}{l}4.56 \\
4.66 \\
4.77 \\
4.84 \\
4.90 \\
4.94\end{array}$ & $\begin{array}{l}1,470 \\
1,550 \\
1,640 \\
1,690 \\
1,740 \\
1,780\end{array}$ & $\begin{array}{l}3.40 \\
3.31 \\
3.22 \\
3.13 \\
3.04 \\
2.97\end{array}$ & & $\begin{array}{l}703 \\
654 \\
606 \\
559 \\
515 \\
481\end{array}$ \\
\hline $\begin{array}{r}7 \\
8 \\
9 \\
10 \\
11 \\
\text { N }\end{array}$ & & & & & $\begin{array}{l}2.41 \\
2.48 \\
2.63 \\
2.54 \\
2.48\end{array}$ & $\begin{array}{l}247 \\
273 \\
331 \\
296 \\
273\end{array}$ & $\begin{array}{l}2.74 \\
2.84 \\
2.94 \\
3.06 \\
3.20 \\
3.34\end{array}$ & $\begin{array}{l}377 \\
421 \\
467 \\
524 \\
595 \\
670\end{array}$ & $\begin{array}{l}4.94 \\
4.92 \\
4.88 \\
4.80 \\
4.74 \\
4.64\end{array}$ & $\begin{array}{l}1,780 \\
1,760 \\
1,720 \\
1,660 \\
1,610 \\
1,530\end{array}$ & $\begin{array}{l}2.89 \\
2.80 \\
2.72 \\
2.66 \\
2.60 \\
2.54\end{array}$ & & $\begin{array}{l}444 \\
403 \\
369 \\
344 \\
319 \\
296\end{array}$ \\
\hline $\begin{array}{l}1 \\
2 \\
3 \\
4 \\
5 \\
6\end{array}$ & & & & & $\begin{array}{l}2.45 \\
2.43 \\
2.43 \\
2.44 \\
2.48 \\
2.52\end{array}$ & $\begin{array}{l}262 \\
254 \\
254 \\
258 \\
273 \\
288\end{array}$ & $\begin{array}{l}3.54 \\
3.91 \\
4.28 \\
4.60 \\
4.81 \\
4.84\end{array}$ & $\begin{array}{r}782 \\
1,010 \\
1,270 \\
1,500 \\
1,670 \\
1,690\end{array}$ & $\begin{array}{l}4.57 \\
4.47 \\
4.37 \\
4.27 \\
4.17 \\
4.07\end{array}$ & $\begin{array}{l}1,480 \\
1,410 \\
1,330 \\
1,260 \\
1,190 \\
1,120\end{array}$ & $\begin{array}{l}2.48 \\
2.42 \\
2.37 \\
2.31 \\
2.26 \\
2.21\end{array}$ & & $\begin{array}{l}273 \\
250 \\
232 \\
212 \\
195 \\
179\end{array}$ \\
\hline $\begin{array}{r}7 \\
8 \\
9 \\
10 \\
11 \\
\frac{11}{1}\end{array}$ & & & & & $\begin{array}{l}2.55 \\
2.56 \\
2.60 \\
2.63 \\
2.71 \\
2.75\end{array}$ & $\begin{array}{l}300 \\
303 \\
319 \\
331 \\
364 \\
382\end{array}$ & $\begin{array}{l}4.80 \\
4.74 \\
4.64 \\
4.54 \\
4.48 \\
4.50\end{array}$ & $\begin{array}{l}1,660 \\
1,610 \\
1,530 \\
1,460 \\
1,410 \\
1,430\end{array}$ & $\begin{array}{l}3.96 \\
3.86 \\
3.76 \\
3.66 \\
3.57 \\
3.48\end{array}$ & $\begin{array}{r}1,040 \\
976 \\
914 \\
853 \\
800 \\
748\end{array}$ & $\begin{array}{l}2.16 \\
2.12 \\
2.09 \\
2.06 \\
2.03 \\
2.00\end{array}$ & & $\begin{array}{l}164 \\
153 \\
144 \\
137 \\
129 \\
121\end{array}$ \\
\hline & \multicolumn{2}{|c|}{ September 24} & \multicolumn{2}{|c|}{ September 25} & \multicolumn{2}{|c|}{ September 26} & \multicolumn{2}{|c|}{ September 27 } & \multicolumn{2}{|c|}{ September 28} & \multicolumn{3}{|c|}{ September 29} \\
\hline $\begin{array}{r}2 \\
4 \\
6 \\
8 \\
10 \\
\mathbb{N}\end{array}$ & $\begin{array}{l}1.95 \\
1.92 \\
1.89 \\
1.86 \\
1.84 \\
1.84\end{array}$ & \begin{tabular}{|r|}
110 \\
103 \\
96 \\
90 \\
85 \\
85
\end{tabular} & $\begin{array}{l}1.78 \\
1.77 \\
1.75 \\
1.72 \\
1.71 \\
1.71\end{array}$ & $\begin{array}{l}73 \\
71 \\
68 \\
62 \\
60 \\
60\end{array}$ & $\begin{array}{l}1.65 \\
1.62 \\
1.61 \\
1.59 \\
1.60 \\
1.56\end{array}$ & $\begin{array}{l}50 \\
44 \\
43 \\
40 \\
41 \\
35\end{array}$ & & $\# 26$ & $\begin{array}{l}* 1.49 \\
1.53 \\
1.60 \\
1.66 \\
1.67 \\
1.66\end{array}$ & $\begin{array}{r}* 26 \\
31 \\
41 \\
51 \\
53 \\
51\end{array}$ & $\begin{array}{l}1.55 \\
1.54 \\
1.52 \\
1.51 \\
1.51 \\
1.50\end{array}$ & & $\begin{array}{l}34 \\
33 \\
30 \\
28 \\
28 \\
27\end{array}$ \\
\hline $\begin{array}{r}2 \\
4 \\
6 \\
8 \\
10 \\
M\end{array}$ & $\begin{array}{l}1.83 \\
1.83 \\
1.83 \\
1.82 \\
1.81 \\
1.79\end{array}$ & $\begin{array}{l}83 \\
83 \\
83 \\
81 \\
79 \\
75\end{array}$ & $\begin{array}{l}1.69 \\
1.68 \\
1.68 \\
1.67 \\
1.66 \\
1.65\end{array}$ & $\begin{array}{l}56 \\
55 \\
55 \\
53 \\
51 \\
50\end{array}$ & $\begin{array}{l}1.54 \\
1.45 \\
1.44 \\
1.43 \\
1.42 \\
1.41\end{array}$ & $\begin{array}{l}33 \\
21 \\
20 \\
19.2 \\
18.1 \\
17.1\end{array}$ & & & $\begin{array}{l}1.64 \\
1.60 \\
1.59 \\
1.57 \\
1.56 \\
1.55\end{array}$ & $\begin{array}{l}48 \\
41 \\
40 \\
37 \\
35\end{array}$ & $\begin{array}{l}1.50 \\
1.49 \\
1.49 \\
1.49 \\
1.48 \\
1.48\end{array}$ & & $\begin{array}{l}27 \\
26 \\
26 \\
26 \\
25 \\
25\end{array}$ \\
\hline
\end{tabular}

Supplemental records.- Sept. 26,9 a.m., $1.57 \mathrm{ft.}, 37$ sec. $-\mathrm{ft.;} 9: 30$ a.m., 1.64

ft., 48 sec.-ft.; l:30 p.m., l.70 ft., 58 sec.-ft.

* Estimated mean for the period. 
South Branch of Raritan River near High Bridge, N. J.

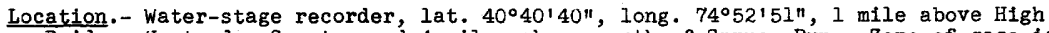
Bridge, Hunterdon County, and 4 miles above mouth of Spruce Run. Zero of gage is 282.10 feet above mean sea level (New Jersey Geological Survey benchmark).

Drainage area.- 65.3 square miles; not affected by storage.

Gage-he1ght record.- Water-stage recorder graph.

Stage-discharge relation.- Defined by current-meter measurements below 1 , 600 secondfeet; extended to peak stage by logarithmic plotting.

Maxima.- September 1938: Discharge, 2,650 second-feet 11 p.m. Sept. 21 (gage height, 10.17 feet)

1919 to August 1938: Discharge, about 3,600 second-feet Feb. 2, 1922 (gage height, 10.97 feet).

Mean daily discharge, in second-feet, 1938

\begin{tabular}{|c|r|r||r|r|r||r|r|r||r|r|r|}
\hline Day & Sept. & 0ct. & Day & Sept. & Oct. & Day & Sept. & Oct. & Day & Sept. & Oct. \\
\hline 1 & 91 & 115 & 9 & 48 & 93 & 17 & 50 & 76 & 25 & 178 & 174 \\
2 & 65 & 108 & 10 & 48 & 91 & 18 & 52 & 74 & 26 & 154 \\
3 & 62 & 102 & 11 & 50 & 87 & 19 & 80 & 72 & 27 & 146 \\
4 & 58 & 100 & 12 & 45 & 84 & 20 & 553 & 76 & 28 & 139 \\
5 & 55 & 95 & 13 & 50 & 82 & 21 & 1,130 & 147 & 29 & 129 \\
6 & 51 & 106 & 14 & 50 & 80 & 22 & 983 & 96 & 30 & 121 \\
7 & 50 & 150 & 15 & 56 & 79 & 23 & 299 & 82 & 31 & 86 \\
8 & 51 & 108 & 16 & 56 & 77 & 24 & 221 & 137 & 80 \\
\end{tabular}

Gage height, in feet, and discharge, in second-feet, at indicated time, 1938

\begin{tabular}{|c|c|c|c|c|c|c|c|c|c|c|c|c|c|}
\hline \multirow{2}{*}{ 월 } & Feet & Sec.ft. & Feet & Sec.ft. & Feet & Sec.ft. & Feet & Sec.ft. & Feet & Sec.ft. & Peet & Sec & .ft. \\
\hline & \multicolumn{2}{|c|}{ September 18} & \multicolumn{2}{|c|}{ September 19} & \multicolumn{2}{|c|}{ Sept ember 20} & \multicolumn{2}{|c|}{ September 21} & \multicolumn{2}{|c|}{ September 22} & \multicolumn{3}{|c|}{ September 23} \\
\hline $\begin{array}{l}1 \\
2 \\
3 \\
4 \\
5 \\
6\end{array}$ & $\begin{array}{l}5.97 \\
5.97 \\
5.97 \\
5.97 \\
5.97 \\
5.98\end{array}$ & $\begin{array}{l}48 \\
48 \\
48 \\
48 \\
48 \\
50\end{array}$ & $\begin{array}{l}6.05 \\
5.98 \\
5.91 \\
5.87 \\
5.97 \\
6.01\end{array}$ & $\begin{array}{l}59 \\
50 \\
41 \\
37 \\
48 \\
53\end{array}$ & $\begin{array}{l}7.08 \\
7.20 \\
7.30 \\
7.45 \\
7.67 \\
7.80\end{array}$ & $\begin{array}{l}299 \\
343 \\
383 \\
448 \\
551 \\
617\end{array}$ & $\begin{array}{l}7.52 \\
7.52 \\
7.57 \\
7.63 \\
7.65 \\
7.64\end{array}$ & $\begin{array}{l}479 \\
479 \\
503 \\
532 \\
542 \\
537\end{array}$ & $\begin{array}{r}10.02 \\
9.87 \\
9.65 \\
9.45 \\
9.22 \\
9.01\end{array}$ & $\begin{array}{l}2,470 \\
2,310 \\
2,060 \\
1,860 \\
1,630 \\
1,440\end{array}$ & $\begin{array}{l}7.23 \\
7.21 \\
7.19 \\
7.17 \\
7.16 \\
7.14\end{array}$ & & $\begin{array}{l}355 \\
347 \\
339 \\
332 \\
328 \\
321\end{array}$ \\
\hline $\begin{array}{r}7 \\
8 \\
9 \\
10 \\
11 \\
N\end{array}$ & $\begin{array}{l}5.99 \\
5.99 \\
5.99 \\
5.99 \\
5.99 \\
5.99\end{array}$ & $\begin{array}{l}51 \\
51 \\
51 \\
51 \\
51 \\
51\end{array}$ & $\begin{array}{l}6.01 \\
6.02 \\
6.03 \\
6.04 \\
6.08 \\
6.10\end{array}$ & $\begin{array}{l}53 \\
55 \\
56 \\
58 \\
63 \\
66\end{array}$ & $\begin{array}{l}7.90 \\
7.98 \\
8.00 \\
8.04 \\
8.06 \\
8.07\end{array}$ & $\begin{array}{l}670 \\
714 \\
725 \\
748 \\
759 \\
765\end{array}$ & $\begin{array}{l}7.59 \\
7.56 \\
7.55 \\
7.57 \\
7.67 \\
7.92\end{array}$ & $\begin{array}{l}512 \\
498 \\
494 \\
503 \\
551 \\
681\end{array}$ & $\begin{array}{l}8.81 \\
8.58 \\
8.35 \\
8.71 \\
7.92 \\
7.78\end{array}$ & $\begin{array}{r}1,270 \\
1,090 \\
931 \\
788 \\
681 \\
607\end{array}$ & $\begin{array}{l}7.14 \\
7.13 \\
7.12 \\
7.11 \\
7.09 \\
7.09\end{array}$ & & $\begin{array}{l}321 \\
317 \\
313 \\
310 \\
303 \\
303\end{array}$ \\
\hline $\begin{array}{l}1 \\
2 \\
3 \\
4 \\
5 \\
6\end{array}$ & $\begin{array}{l}5.99 \\
5.99 \\
5.99 \\
5.99 \\
6.00 \\
6.00\end{array}$ & $\begin{array}{l}51 \\
51 \\
51 \\
51 \\
52 \\
52\end{array}$ & $\begin{array}{l}6.12 \\
6.11 \\
6.11 \\
6.22 \\
6.21 \\
6.24\end{array}$ & $\begin{array}{l}69 \\
68 \\
68 \\
86 \\
84 \\
89\end{array}$ & $\begin{array}{l}8.05 \\
8.00 \\
7.92 \\
7.79 \\
7.63 \\
7.54\end{array}$ & $\begin{array}{l}754 \\
725 \\
681 \\
612 \\
532 \\
489\end{array}$ & $\begin{array}{l}8.20 \\
8.54 \\
8.91 \\
9.26 \\
9.29 \\
9.31\end{array}$ & $\begin{array}{r}840 \\
1,060 \\
1,350 \\
1,670 \\
1,700 \\
1,720\end{array}$ & $\begin{array}{l}7.68 \\
7.63 \\
7.58 \\
7.54 \\
7.49 \\
7.44\end{array}$ & $\begin{array}{l}556 \\
532 \\
508 \\
489 \\
466 \\
443\end{array}$ & $\begin{array}{l}7.09 \\
7.08 \\
7.08 \\
7.07 \\
7.05 \\
7.04\end{array}$ & & $\begin{array}{l}303 \\
299 \\
299 \\
296 \\
289 \\
286\end{array}$ \\
\hline \multirow[t]{2}{*}{$\begin{array}{r}7 \\
8 \\
9 \\
10 \\
17 \\
M\end{array}$} & $\begin{array}{l}6.00 \\
6.00 \\
6.00 \\
6.15 \\
6.13 \\
6.08\end{array}$ & $\begin{array}{l}52 \\
52 \\
52 \\
74 \\
71 \\
63\end{array}$ & $\begin{array}{l}6.34 \\
6.30 \\
6.40 \\
6.56 \\
6.73 \\
6.90\end{array}$ & $\begin{array}{l}108 \\
100 \\
119 \\
152 \\
193 \\
241\end{array}$ & $\begin{array}{l}7.42 \\
7.36 \\
7.38 \\
7.42 \\
7.52 \\
7.53\end{array}$ & $\begin{array}{l}434 \\
408 \\
417 \\
434 \\
479 \\
484\end{array}$ & $\begin{array}{r}9.39 \\
9.55 \\
9.85 \\
10.10 \\
10.17 \\
10.13\end{array}$ & $\begin{array}{l}1,800 \\
1,960 \\
2,280 \\
2,570 \\
2,650 \\
2,610\end{array}$ & $\begin{array}{l}7.42 \\
7.38 \\
7.34 \\
7.30 \\
7.27 \\
7.25\end{array}$ & $\begin{array}{l}434 \\
417 \\
400 \\
383 \\
371 \\
363\end{array}$ & $\begin{array}{l}6.99 \\
6.99 \\
6.97 \\
6.95 \\
6.94 \\
6.93\end{array}$ & & $\begin{array}{l}269 \\
269 \\
263 \\
256 \\
253 \\
250\end{array}$ \\
\hline & \multicolumn{2}{|c|}{ September 24} & \multicolumn{2}{|c|}{ September 25} & \multicolumn{2}{|c|}{ Septomber 26} & \multicolumn{2}{|c|}{ September 27} & \multicolumn{2}{|c|}{ September 28} & \multicolumn{3}{|c|}{ September 29} \\
\hline $\begin{array}{r}2 \\
4 \\
6 \\
8 \\
10 \\
\end{array}$ & $\begin{array}{l}6.91 \\
6.89 \\
6.88 \\
6.86 \\
6.85 \\
6.84\end{array}$ & $\begin{array}{l}244 \\
238 \\
235 \\
229 \\
226 \\
224\end{array}$ & $\begin{array}{l}6.71 \\
6.70 \\
6.69 \\
6.68 \\
6.68 \\
6.67\end{array}$ & $\begin{array}{l}188 \\
185 \\
183 \\
180 \\
180 \\
178\end{array}$ & $\begin{array}{l}6.60 \\
6.59 \\
6.59 \\
6.59 \\
6.60 \\
6.57\end{array}$ & $\begin{array}{l}161 \\
159 \\
159 \\
159 \\
161 \\
154\end{array}$ & $\begin{array}{l}6.53 \\
6.53 \\
6.53 \\
6.53 \\
6.53 \\
6.53\end{array}$ & \begin{tabular}{|l|}
146 \\
146 \\
146 \\
146 \\
146 \\
146
\end{tabular} & $\begin{array}{l}6.51 \\
6.51 \\
6.51 \\
6.51 \\
6.53 \\
6.52\end{array}$ & \begin{tabular}{|l|}
141 \\
141 \\
141 \\
141 \\
146 \\
143
\end{tabular} & $\begin{array}{l}6.45 \\
6.45 \\
6.45 \\
6.45 \\
6.46 \\
6.45\end{array}$ & & $\begin{array}{l}129 \\
129 \\
129 \\
129 \\
131 \\
129\end{array}$ \\
\hline $\begin{array}{r}2 \\
4 \\
6 \\
8 \\
10 \\
11\end{array}$ & $\begin{array}{l}6.81 \\
6.80 \\
6.77 \\
6.75 \\
6.74 \\
6.72\end{array}$ & $\begin{array}{l}215 \\
212 \\
204 \\
198 \\
196 \\
190\end{array}$ & $\begin{array}{l}6.66 \\
6.65 \\
6.64 \\
6.63 \\
6.61 \\
6.60\end{array}$ & $\begin{array}{l}175 \\
173 \\
171 \\
168 \\
163 \\
161\end{array}$ & $\begin{array}{l}6.57 \\
6.58 \\
6.55 \\
6.55 \\
6.55 \\
6.54\end{array}$ & $\begin{array}{l}154 \\
157 \\
150 \\
150 \\
150 \\
148\end{array}$ & $\begin{array}{l}6.53 \\
6.52 \\
6.55 \\
6.52 \\
6.52 \\
6.52\end{array}$ & $\begin{array}{l}146 \\
143 \\
150 \\
143 \\
143 \\
143\end{array}$ & $\begin{array}{l}6.48 \\
6.49 \\
6.50 \\
6.46 \\
6.46 \\
6.46\end{array}$ & $\begin{array}{l}135 \\
137 \\
139 \\
131 \\
131 \\
131\end{array}$ & $\begin{array}{l}6.45 \\
6.45 \\
6.44 \\
6.42 \\
6.42 \\
6.42\end{array}$ & & $\begin{array}{l}129 \\
129 \\
127 \\
123 \\
123 \\
123\end{array}$ \\
\hline
\end{tabular}


Location.- Water-stage recorder, lat. $40^{\circ} 34^{\prime} 21^{\prime \prime}$, Iong. $74^{\circ} 52^{\prime}$ lon $^{\prime}$, at highway bridge near Stanton railroad station, Reading Township, Hunterdon County, and half a mile above mouth of Prescott Brook. Zero of gage is 125.01 feet above nean sea level (general adjustment of 1929 )

Drainage area.- 147 square miles; not materially affected by artificial storage.

Gage-height record. - Water-stage recorder graph except for period 6 to 11 p.m. Sept. 19, when gage heights were based on study of stage graphs at stations on the North

Stage-discharge relation.- Defined by current-meter measurements below 1,200 secondfeet; extended to peak stage on basis of average discharge deteruined by slope-area method and computation of flow over dams.

Maxima.- September 1938: Discharge, 8,130 second-feet 7:30 p.m. Sept. 21 (gage height, 10.72 feet) $1903-6,1919$ to August 1938 : Discharge, about 8,280 second-feet (revised)
July 9, 1935 (gage height, 10.80 feet).

Mean daily discharge, in second-feet, 1938

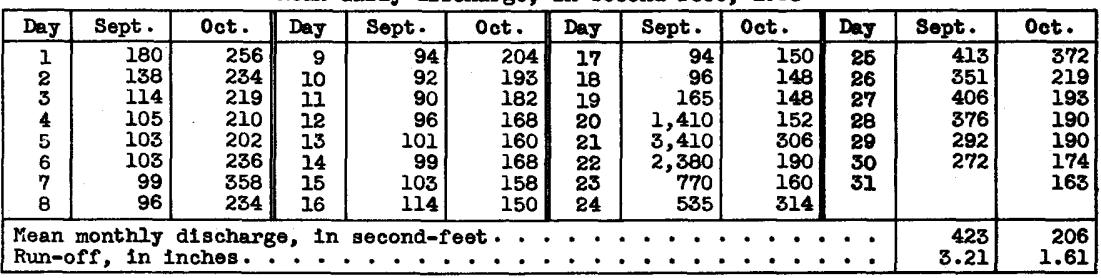

Gage height, in feet, and discharge, in second-feet, at indicated time, 1938

\begin{tabular}{|c|c|c|c|c|c|c|c|c|c|c|c|c|c|}
\hline \multirow{2}{*}{ 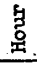 } & Feet & Sec.ft. & Feet & Sec.ft. & Feot & Sec.ft. & Feet & Sec.ft. & Feet & Sec.ft. & Feet & \multicolumn{2}{|c|}{ Sec.ft. } \\
\hline & \multicolumn{2}{|c|}{ September 18} & \multicolumn{2}{|c|}{ September 19} & \multicolumn{2}{|c|}{ September 20} & \multicolumn{2}{|c|}{ September 21} & \multicolumn{2}{|c|}{ September 22} & \multicolumn{3}{|c|}{ September 23} \\
\hline $\begin{array}{l}1 \\
2 \\
3 \\
4 \\
5 \\
6\end{array}$ & $\begin{array}{l}2.42 \\
2.43 \\
2.43 \\
2.43 \\
2.43 \\
2.43\end{array}$ & $\begin{array}{l}90 \\
92 \\
92 \\
92 \\
92 \\
92\end{array}$ & $\begin{array}{l}2.49 \\
2.50 \\
2.50 \\
2.51 \\
2.55 \\
2.57\end{array}$ & $\begin{array}{l}105 \\
107 \\
107 \\
109 \\
118 \\
123\end{array}$ & $\begin{array}{l}3.37 \\
3.70 \\
4.40 \\
4.95 \\
5.45 \\
5.75\end{array}$ & $\begin{array}{r}371 \\
520 \\
929 \\
1,300 \\
1,660 \\
1,880\end{array}$ & $\begin{array}{l}5.89 \\
6.06 \\
6.08 \\
5.87 \\
5.45 \\
5.10\end{array}$ & $\begin{array}{l}1,980 \\
2,110 \\
2,120 \\
1,970 \\
1,660 \\
1,410\end{array}$ & $\begin{array}{l}8.67 \\
8.28 \\
8.08 \\
8.01 \\
7.98 \\
7.86\end{array}$ & $\begin{array}{l}4,810 \\
4,300 \\
4,060 \\
3,970 \\
3,940 \\
3,790\end{array}$ & $\begin{array}{l}4.38 \\
4.34 \\
4.31 \\
4.28 \\
4.26 \\
4.24\end{array}$ & & $\begin{array}{l}916 \\
890 \\
870 \\
851 \\
839 \\
826\end{array}$ \\
\hline $\begin{array}{r}7 \\
8 \\
9 \\
10 \\
11 \\
N\end{array}$ & $\begin{array}{l}2.43 \\
2.43 \\
2.43 \\
2.43 \\
2.44 \\
2.46\end{array}$ & $\begin{array}{l}92 \\
92 \\
92 \\
92 \\
94 \\
99\end{array}$ & $\begin{array}{l}2.57 \\
2.57 \\
2.56 \\
2.54 \\
2.52 \\
2.59\end{array}$ & $\begin{array}{l}123 \\
123 \\
121 \\
116 \\
112 \\
128\end{array}$ & $\begin{array}{l}6.00 \\
6.13 \\
6.14 \\
6.04 \\
5.85 \\
5.58\end{array}$ & $\begin{array}{l}2,060 \\
2,160 \\
2,170 \\
2,090 \\
1,950 \\
1,750\end{array}$ & $\begin{array}{l}4.89 \\
4.80 \\
4.76 \\
4.75 \\
4.85 \\
5.17\end{array}$ & $\begin{array}{l}1,260 \\
1,200 \\
1,170 \\
1,160 \\
1,240 \\
1,460\end{array}$ & $\begin{array}{l}7.66 \\
7.37 \\
7.00 \\
6.60 \\
6.27 \\
5.95\end{array}$ & $\begin{array}{l}3,570 \\
3,260 \\
2,890 \\
2,540 \\
2,280 \\
2,020\end{array}$ & $\begin{array}{l}4.21 \\
4.19 \\
4.17 \\
4.15 \\
4.14 \\
4.12\end{array}$ & & $\begin{array}{l}807 \\
795 \\
783 \\
770 \\
764 \\
752\end{array}$ \\
\hline $\begin{array}{l}1 \\
2 \\
3 \\
4 \\
5 \\
6\end{array}$ & $\begin{array}{l}2.47 \\
2.47 \\
2.47 \\
2.46 \\
2.45 \\
2.46\end{array}$ & $\begin{array}{r}101 \\
101 \\
101 \\
99 \\
96 \\
99\end{array}$ & $\begin{array}{r}2.63 \\
2.64 \\
2.66 \\
2.67 \\
2.75 \\
* 3.05\end{array}$ & $\begin{array}{l}138 \\
140 \\
145 \\
148 \\
168 \\
256\end{array}$ & $\begin{array}{l}5.35 \\
5.20 \\
5.09 \\
5.01 \\
4.92 \\
4.84\end{array}$ & $\begin{array}{l}1,580 \\
1,480 \\
1,400 \\
1,350 \\
1,280 \\
1,230\end{array}$ & $\begin{array}{l}5.78 \\
6.75 \\
7.62 \\
8.26 \\
8.90 \\
9.89\end{array}$ & $\begin{array}{l}1,900 \\
2,660 \\
3,520 \\
4,280 \\
5,130 \\
6,630\end{array}$ & $\begin{array}{l}5.64 \\
5.35 \\
5.12 \\
4.95 \\
4.83 \\
4.74\end{array}$ & $\begin{array}{l}1,790 \\
1,580 \\
1,420 \\
1,300 \\
1,220 \\
1,160\end{array}$ & $\begin{array}{l}4.11 \\
4.10 \\
4.08 \\
4.07 \\
4.05 \\
4.03\end{array}$ & & $\begin{array}{l}746 \\
740 \\
728 \\
722 \\
710 \\
699\end{array}$ \\
\hline \multirow[t]{2}{*}{$\begin{array}{r}7 \\
8 \\
9 \\
10 \\
11 \\
11\end{array}$} & $\begin{array}{l}2.47 \\
2.47 \\
2.47 \\
2.48 \\
2.48 \\
2.49\end{array}$ & $\begin{array}{l}101 \\
101 \\
101 \\
103 \\
103 \\
105\end{array}$ & $\begin{array}{r}* 3.30 \\
* 3.28 \\
* 3.11 \\
* 2.98 \\
* 2.97 \\
3.11\end{array}$ & $\begin{array}{l}343 \\
336 \\
275 \\
234 \\
231 \\
275\end{array}$ & $\begin{array}{l}4.75 \\
4.67 \\
4.66 \\
4.76 \\
5.04 \\
5.55\end{array}$ & $\begin{array}{l}1,160 \\
1,110 \\
1,100 \\
1,170 \\
1,370 \\
1,720\end{array}$ & $\begin{array}{r}10.62 \\
10.71 \\
10.46 \\
10.02 \\
9.55 \\
9.09\end{array}$ & $\begin{array}{l}7,940 \\
8,110 \\
7,650 \\
6,860 \\
6,080 \\
5,400\end{array}$ & $\begin{array}{l}4.65 \\
4.60 \\
4.55 \\
4.49 \\
4.45 \\
4.41\end{array}$ & $\begin{array}{r}1,100 \\
1,060 \\
1,030 \\
989 \\
962 \\
936\end{array}$ & $\begin{array}{l}4.01 \\
3.99 \\
3.97 \\
3.95 \\
3.93 \\
3.90\end{array}$ & & $\begin{array}{l}687 \\
675 \\
664 \\
653 \\
642 \\
625\end{array}$ \\
\hline & \multicolumn{2}{|c|}{ September 24} & \multicolumn{2}{|c|}{ September 25} & \multicolumn{2}{|c|}{ September 26} & \multicolumn{2}{|c|}{ September 27} & \multicolumn{2}{|c|}{ September 28} & \multicolumn{3}{|c|}{ September 29} \\
\hline $\begin{array}{r}2 \\
4 \\
6 \\
8 \\
10 \\
11\end{array}$ & $\begin{array}{l}3.86 \\
3.83 \\
3.80 \\
3.78 \\
3.76 \\
3.74\end{array}$ & $\begin{array}{l}603 \\
587 \\
571 \\
561 \\
551 \\
540\end{array}$ & $\begin{array}{l}3.55 \\
3.53 \\
3.51 \\
3.50 \\
3.48 \\
3.47\end{array}$ & $\begin{array}{l}449 \\
440 \\
431 \\
426 \\
417 \\
413\end{array}$ & $\begin{array}{l}3.36 \\
3.35 \\
3.34 \\
3.33 \\
3.32 \\
3.32\end{array}$ & $\begin{array}{l}367 \\
363 \\
359 \\
355 \\
351 \\
351\end{array}$ & $\begin{array}{r}* 3.26 \\
3.25 \\
3.24 \\
3.23 \\
3.23 \\
3.23\end{array}$ & $\begin{array}{l}328 \\
324 \\
321 \\
317 \\
317 \\
317\end{array}$ & $\begin{array}{l}3.64 \\
3.49 \\
3.41 \\
3.36 \\
3.33 \\
3.33\end{array}$ & $\begin{array}{l}491 \\
422 \\
387 \\
367 \\
355 \\
355\end{array}$ & $\begin{array}{l}3.20 \\
3.19 \\
3.18 \\
3.17 \\
3.17 \\
3.17\end{array}$ & & $\begin{array}{l}306 \\
303 \\
299 \\
296 \\
296 \\
296\end{array}$ \\
\hline $\begin{array}{r}2 \\
4 \\
6 \\
8 \\
10 \\
11\end{array}$ & $\begin{array}{l}3.71 \\
3.69 \\
3.65 \\
3.61 \\
3.59 \\
3.56\end{array}$ & $\begin{array}{l}525 \\
515 \\
496 \\
477 \\
467 \\
454\end{array}$ & $\begin{array}{l}3.46 \\
3.44 \\
3.42 \\
3.40 \\
3.38 \\
3.37\end{array}$ & $\begin{array}{l}409 \\
400 \\
392 \\
383 \\
375 \\
371\end{array}$ & $\begin{array}{l}3.32 \\
3.31 \\
3.30 \\
3.28 \\
3.27 \\
3.26\end{array}$ & $\begin{array}{l}351 \\
347 \\
343 \\
336 \\
332 \\
328\end{array}$ & $\begin{array}{l}3.23 \\
3.23 \\
3.48 \\
4.32 \\
3.91 \\
3.90\end{array}$ & $\begin{array}{l}317 \\
317 \\
417 \\
877 \\
631 \\
625\end{array}$ & $\begin{array}{l}3.37 \\
3.30 \\
3.27 \\
3.23 \\
3.22 \\
3.21\end{array}$ & $\begin{array}{l}371 \\
343 \\
332 \\
317 \\
313 \\
310\end{array}$ & $\begin{array}{l}3.17 \\
3.15 \\
3.15 \\
3.14 \\
3.12 \\
3.12\end{array}$ & & $\begin{array}{l}296 \\
289 \\
289 \\
286 \\
279 \\
279\end{array}$ \\
\hline
\end{tabular}

Supplementel recorde.- Sopt. $21,7: 30$ p.m., 10.72 ft., 8,130 vec.-ft. 
Location.- Water-stage recorder, lat. $40^{\circ} 33^{\prime} 18^{\prime \prime}$, long. $74^{\circ} 35^{\prime} 02^{\prime \prime}$, at highway bridge, Manvilie, Somerset County, and $1 \frac{2}{4}$ miles above mouth of Millstone River. Zero of gage is 20.61 feet above mean sea level (general adjustment of 1929).

Drainage area. - 490 square miles.

Gage-he1ght record. - Water-stage recorder graph except for period 10 p.m. Sept. 21 to 3 p.m. Sept. 24, record for which was based on floodmark, hourly gage heights at pump house of Johns-Manville Co. $10 \mathrm{p.m}$. Sept. 21 to noon Sept. 22, and comparison with readings of a gage at Somerville.

Stage-discharge relätion.- Defined by current-meter measurements below 14,000 secondfeet; extended to peal stage on basis of determination of flood flow by slope-area method.

Maxima.- September 1938: Discharge, 36,100 second-feet about 2 a.m. Sept. 22 (gage neight, 20.42 feet, from floodmark). 1903-7, 1921 to August 1938: D1scharge, 26,000 second-feet July 23, 1938 (gage helght, 17.75 feet).

Remarkg.- Discharge for Sept. 21 to 24 based on gage-helght graph obtained as explained above and verified by comparison with sum of discharges of South Branch of Raritan River at Stanton, North Branch of Raritan River at Milltown, and Neshanic River at Reaville.

Mean daily discharge, in second-feet, 1938

\begin{tabular}{|c|r|r||r|r|r||r|r|r|r|r|r|}
\hline Day & Sept. & \multicolumn{1}{|c|}{ 0ct. } & Day & \multicolumn{1}{|c|}{ Sept. } & 0ct. & Day & Sept. & 0ct. & Day & Sopt. & 0ct. \\
\hline 1 & 223 & 681 & 9 & 149 & 537 & 17 & 165 & 352 & 25 & 1,380 & 1,060 \\
2 & 263 & 597 & 10 & 142 & 489 & 18 & 149 & 329 & 26 & 1,080 & 597 \\
3 & 203 & 537 & 17 & 142 & 452 & 19 & 688 & 329 & 27 & 1,080 & 498 \\
4 & 188 & 498 & 12 & 153 & 434 & 20 & 6,060 & 336 & 28 & 1,870 & 471 \\
5 & 179 & 462 & 13 & 153 & 400 & 21 & 12,100 & 607 & 29 & 860 & 537 \\
6 & 149 & 489 & 14 & 161 & 400 & 22 & 21,600 & 517 & 30 & 735 & 489 \\
7 & 157 & 968 & 15 & 153 & 400 & 23 & 3,760 & 384 & 31 & & 434 \\
8 & 161 & 660 & 16 & 170 & 376 & 24 & 2,200 & 416 & & & \\
\hline
\end{tabular}

Gage height, in feet, and discharge, in second-feet, at indicated time, 1938

\begin{tabular}{|c|c|c|c|c|c|c|c|c|c|c|c|c|}
\hline & pet & Sec.ft. & Feet & Sec.ft. & Feet & Sec.ft. & Feet & Sec.ft. & Feet & Sec.ft. & Feet & Sec.ft \\
\hline & \multicolumn{2}{|c|}{ September 18} & \multicolumn{2}{|c|}{ September 19} & \multicolumn{2}{|c|}{ September 20} & \multicolumn{2}{|c|}{ September 21} & \multicolumn{2}{|c|}{ September 22} & \multicolumn{2}{|c|}{ September 23} \\
\hline & $\begin{array}{l}4.04 \\
4.02 \\
4.01 \\
4.00 \\
4.00 \\
4.00\end{array}$ & $\begin{array}{l}146 \\
138 \\
134 \\
130 \\
130 \\
130\end{array}$ & $\begin{array}{l}7.0 \\
4.0 \\
4.0 \\
4.0\end{array}$ & & $\begin{array}{l}6.07 \\
5.89 \\
5.90 \\
6.37 \\
7.15 \\
8.00\end{array}$ & & \begin{tabular}{|r|}
8.81 \\
9.33 \\
9.80 \\
10.08 \\
10.26 \\
10.40
\end{tabular} & & & & & \\
\hline & $\begin{array}{l}4.00 \\
4.02 \\
4.05 \\
4.06 \\
4.07 \\
4.07\end{array}$ & $\begin{array}{l}130 \\
138 \\
149 \\
153 \\
157 \\
157\end{array}$ & & $\begin{array}{l}157 \\
165 \\
179 \\
188 \\
193 \\
207\end{array}$ & $\begin{array}{r}8.90 \\
9.55 \\
9.94 \\
10.21 \\
10.47 \\
10.75\end{array}$ & $\begin{array}{l}5, \\
6, \\
7, \\
7, \\
8, \\
8,\end{array}$ & & $\begin{array}{l}80 \\
90 \\
80 \\
60 \\
70 \\
60\end{array}$ & & & & \\
\hline & & $\begin{array}{l}157 \\
157 \\
157 \\
157 \\
157 \\
157\end{array}$ & & $\begin{array}{l}218 \\
235 \\
309 \\
316 \\
336 \\
352\end{array}$ & $\begin{array}{l}10.98 \\
11.13 \\
11.21 \\
11.14 \\
10.90 \\
10.42\end{array}$ & $\begin{array}{l}8, \\
9, \\
9, \\
9, \\
8, \\
7,\end{array}$ & & $\begin{array}{r}7, \\
8, \\
9, \\
10, \\
13, \\
16,\end{array}$ & & & $\begin{array}{l}6.85 \\
6.8 \\
6.7 \\
6.65 \\
6.6 \\
6.55\end{array}$ & \\
\hline & $\begin{array}{l}4.07 \\
4.08 \\
4.09 \\
4.10 \\
4.10 \\
4.09\end{array}$ & $\begin{array}{l}157 \\
161 \\
165 \\
170 \\
170 \\
165\end{array}$ & $\begin{array}{l}4.62 \\
5.50 \\
6.30 \\
6.57 \\
6.51 \\
6.31\end{array}$ & $\begin{array}{r}537 \\
1,640 \\
2,780 \\
3,080 \\
3,020 \\
2,790\end{array}$ & $\begin{array}{l}9.80 \\
9.18 \\
8.68 \\
8.32 \\
8.20 \\
8.36\end{array}$ & $\begin{array}{l}30 \\
70 \\
30 \\
60 \\
10 \\
10\end{array}$ & & & & $\begin{array}{r}9,030 \\
8,160 \\
7,330 \\
6,530\end{array}$ & $\begin{array}{l}6.5 \\
6.4 \\
6.4 \\
6.3 \\
6.3 \\
6.25\end{array}$ & $\begin{array}{l}3,000 \\
3,000 \\
2,890 \\
2,890 \\
2,830\end{array}$ \\
\hline & \multicolumn{2}{|c|}{ September 24} & \multicolumn{2}{|c|}{ September 25} & \multicolumn{2}{|c|}{ September 26} & \multicolumn{2}{|c|}{ September 27} & \multicolumn{2}{|c|}{ September 28} & \multicolumn{2}{|c|}{ September 29} \\
\hline & \begin{tabular}{|l|}
6.15 \\
6.1 \\
6.0 \\
5.9 \\
5.85 \\
5.8 \\
\end{tabular} & $\begin{array}{r}2,710 \\
2,650 \\
2,520 \\
2,370 \\
2,300\end{array}$ & & $\begin{array}{l}1,560 \\
1,510 \\
1,470 \\
1,440 \\
1,410 \\
1,370\end{array}$ & & $\begin{array}{l}1,160 \\
1,140 \\
1,110 \\
1,110 \\
1,100 \\
1,070\end{array}$ & & \begin{tabular}{|l|}
968 \\
943 \\
943 \\
931 \\
919 \\
956
\end{tabular} & & & $\begin{array}{l}4.89 \\
4.86 \\
4.85 \\
4.84 \\
4.84 \\
4.82\end{array}$ & 849 \\
\hline & $\begin{array}{l}5.7 \\
5.64 \\
5.57 \\
5.53 \\
5.46 \\
5.40\end{array}$ & $\begin{array}{l}2,070 \\
1,980 \\
1,880 \\
1,820 \\
1,710 \\
1,620\end{array}$ & & $\begin{array}{l}1,000 \\
1,300 \\
1,270 \\
1,240 \\
1,210 \\
1,190\end{array}$ & & $\begin{array}{l}1, \\
1, \\
1,\end{array}$ & & $\begin{array}{r}931 \\
1,160 \\
3,680\end{array}$ & & & $\begin{array}{l}4.82 \\
4.81 \\
4.79 \\
4.78 \\
4.78 \\
4.76\end{array}$ & $\begin{array}{l}814 \\
803 \\
803 \\
780\end{array}$ \\
\hline
\end{tabular}

Supplemental records.- jept. 20, 3:20 p.m., $11.24 \mathrm{ft.,} 9,370$ sec.-ft. Sept. 28, $1: 30 \mathrm{a} . \mathrm{m} ., 7.82 \mathrm{ft}:, 4,220 \mathrm{sec} .-\mathrm{ft}$.

$2269070-10-21$ 
Location. - Water-stage recorder, lat. $40^{\circ} 28^{\prime} 18^{\prime \prime}$, long. $74^{\circ} 49^{\prime} 42^{\prime \prime}$, at highway bridge half a mile southwest of Reaville, Hunterdon' County.

Drainage area.- 25.7 square miles.

Gage-helght record. - Water-stage recorder graph.

Stage-discharge relation.- Defined by current-meter measurements below 1,700 secondfeet; extended to peak stage by logarithmic plotting.

Max1ma.- September 1938: Discharge, about 4,300 second-feet 4:30 p.m. Sept. 21 (gage helght, 10.74 feet).

i930 to August 1938: Discharge, about 4,370 second-feet Aug. 23, 1933 (gage

he1ght, 10.80 feet).

Mean dally discharge, in second-feet, 1938

\begin{tabular}{|c|c|c|c|c|c|c|c|c|c|c|c|}
\hline Day & Sept. & Oct. & Day & Sept. & Oct. & Day & Sept. & Oct. & Day & Sept. & Oet. \\
\hline $\begin{array}{l}1 \\
2 \\
3 \\
4 \\
5 \\
6 \\
7 \\
8\end{array}$ & $\begin{array}{l}5.0 \\
3.4 \\
3.0 \\
2.7 \\
2.4 \\
2.3 \\
2.3 \\
2.6\end{array}$ & $\begin{array}{l}27 \\
20 \\
16.7 \\
14.4 \\
12.8 \\
32 \\
41 \\
23\end{array}$ & $\begin{array}{r}9 \\
10 \\
11 \\
12 \\
13 \\
14 \\
15 \\
16\end{array}$ & $\begin{array}{l}2.3 \\
2.1 \\
2.1 \\
2.1 \\
2.1 \\
2.4 \\
2.4 \\
2.3\end{array}$ & $\begin{array}{r}18.5 \\
16.7 \\
14.4 \\
13.3 \\
12.3 \\
11.4 \\
10.5 \\
9.7\end{array}$ & $\begin{array}{l}17 \\
18 \\
19 \\
20 \\
21 \\
22 \\
23 \\
24\end{array}$ & \begin{tabular}{|c|}
2.1 \\
2.3 \\
154 \\
727 \\
1,480 \\
174 \\
76 \\
48
\end{tabular} & $\begin{array}{r}8.9 \\
8.2 \\
7.5 \\
8.2 \\
16.2 \\
9.3 \\
8.2 \\
40\end{array}$ & $\begin{array}{l}25 \\
26 \\
27 \\
28 \\
29 \\
30 \\
31\end{array}$ & $\begin{array}{r}33 \\
26 \\
315 \\
78 \\
43 \\
33\end{array}$ & $\begin{array}{l}30 \\
18.5 \\
16.7 \\
23 \\
34 \\
25 \\
22\end{array}$ \\
\hline $\begin{array}{l}\text { Mean } \\
\text { Run- }\end{array}$ & $\begin{array}{l}\text { nthly } \\
\text {, In }\end{array}$ & $\begin{array}{l}\text { schar } \\
\text { hes. }\end{array}$ & : Ir & $\begin{array}{l}\operatorname{second}=f \\
.\end{array}$ & $\begin{array}{l}\text { et. . } \\
.\end{array}$ & $\dot{.}$ & 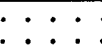 & $\begin{array}{lll} & \cdot & . \\
. & . & .\end{array}$ & $: \dot{ }$ & $\begin{array}{r}108 \\
4.69\end{array}$ & $\begin{array}{r}18.4 \\
.83\end{array}$ \\
\hline
\end{tabular}

Gage height, in feet, and discharge, in second-feet, at indlcated time, 1938

\begin{tabular}{|c|c|c|c|c|c|c|c|c|c|c|c|c|c|}
\hline \multirow{2}{*}{$\begin{array}{l}\text { ga } \\
\text { 号 }\end{array}$} & Feet & Sec.ft. & Feet & Sec.ft. & Feot & Sec.ft. & Feet & sec.ft. & Feet & Sec.ft. & Feet & \multicolumn{2}{|c|}{ Sec.ft: } \\
\hline & \multicolumn{2}{|c|}{ September 18} & \multicolumn{2}{|c|}{ September 19} & \multicolumn{2}{|c|}{ September 20} & \multicolumn{2}{|c|}{ September 21} & \multicolumn{2}{|c|}{ September 22} & \multicolumn{3}{|c|}{ September 23} \\
\hline $\begin{array}{l}1 \\
2 \\
3 \\
4 \\
5 \\
6\end{array}$ & $\begin{array}{l}2.31 \\
2.31 \\
2.31 \\
2.31 \\
2.31 \\
2.31\end{array}$ & $\begin{array}{l}2.1 \\
2.1 \\
2.1 \\
2.1 \\
2.1 \\
2.1\end{array}$ & $\begin{array}{l}2.33 \\
2.33 \\
2.33 \\
2.33 \\
2.33 \\
2.33\end{array}$ & $\begin{array}{l}2.4 \\
2.4 \\
2.4 \\
2.4 \\
2.4 \\
2.4\end{array}$ & $\begin{array}{l}5.23 \\
6.12 \\
6.40 \\
6.73 \\
6.80 \\
6.88\end{array}$ & $\begin{array}{r}724 \\
1,110 \\
1,250 \\
1,420 \\
1,460 \\
1,500\end{array}$ & $\begin{array}{l}5.38 \\
4.84 \\
4.47 \\
4.27 \\
4.13 \\
4.05\end{array}$ & $\begin{array}{l}786 \\
568 \\
418 \\
336 \\
283 \\
255\end{array}$ & $\begin{array}{l}4.32 \\
4.21 \\
4.13 \\
4.06 \\
3.99 \\
3.93\end{array}$ & $\begin{array}{l}356 \\
313 \\
283 \\
258 \\
235 \\
216\end{array}$ & $\begin{array}{l}3.41 \\
3.40 \\
3.40 \\
3.39 \\
3.39 \\
3.38\end{array}$ & & $\begin{array}{l}92 \\
90 \\
90 \\
88 \\
88 \\
87\end{array}$ \\
\hline $\begin{array}{r}7 \\
8 \\
9 \\
10 \\
11 \\
N\end{array}$ & $\begin{array}{l}2.32 \\
2.32 \\
2.32 \\
2.32 \\
2.32 \\
2.32\end{array}$ & $\begin{array}{l}2.3 \\
2.3 \\
2.3 \\
2.3 \\
2.3 \\
2.3\end{array}$ & $\begin{array}{l}2.33 \\
2.34 \\
2.34 \\
2.34 \\
2.36 \\
2.54\end{array}$ & $\begin{array}{l}2.4 \\
2.6 \\
2.6 \\
2.6 \\
3.0 \\
7.8\end{array}$ & $\begin{array}{l}6.92 \\
6.17 \\
5.60 \\
4.90 \\
4.40 \\
4.15\end{array}$ & $\begin{array}{r}1,520 \\
1,140 \\
880 \\
592 \\
389 \\
290\end{array}$ & $\begin{array}{l}4.00 \\
3.98 \\
4.08 \\
4.50 \\
5.90 \\
7.52\end{array}$ & $\begin{array}{r}238 \\
232 \\
265 \\
431 \\
1,020 \\
1,870\end{array}$ & $\begin{array}{l}3.88 \\
3.84 \\
3.80 \\
3.77 \\
3.73 \\
3.70\end{array}$ & $\begin{array}{l}201 \\
190 \\
178 \\
170 \\
160 \\
152\end{array}$ & $\begin{array}{l}3.38 \\
3.37 \\
3.36 \\
3.35 \\
3.34 \\
3.32\end{array}$ & & $\begin{array}{l}87 \\
85 \\
84 \\
82 \\
80 \\
77\end{array}$ \\
\hline $\begin{array}{l}1 \\
2 \\
3 \\
4 \\
5 \\
6\end{array}$ & $\begin{array}{l}2.32 \\
2.32 \\
2.32 \\
2.32 \\
2.33 \\
2.33\end{array}$ & $\begin{array}{l}2.3 \\
2.3 \\
2.3 \\
2.3 \\
2.4 \\
2.4\end{array}$ & $\begin{array}{l}3.62 \\
5.14 \\
5.52 \\
5.06 \\
4.47 \\
3.98\end{array}$ & $\begin{array}{l}134 \\
688 \\
846 \\
656 \\
418 \\
232\end{array}$ & $\begin{array}{l}3.97 \\
3.82 \\
3.73 \\
3.64 \\
3.58 \\
3.54\end{array}$ & $\begin{array}{l}229 \\
184 \\
160 \\
138 \\
125 \\
116\end{array}$ & $\begin{array}{r}8.52 \\
9.12 \\
10.08 \\
10.62 \\
10.64 \\
9.90\end{array}$ & $\begin{array}{l}2,520 \\
2,960 \\
3,710 \\
4,190 \\
4,210 \\
3,570\end{array}$ & $\begin{array}{l}3.66 \\
3.63 \\
3.60 \\
3.57 \\
3.54 \\
3.51\end{array}$ & $\begin{array}{l}143 \\
136 \\
129 \\
123 \\
116 \\
110\end{array}$ & $\begin{array}{l}3.31 \\
3.30 \\
3.27 \\
3.26 \\
3.24 \\
3.22\end{array}$ & & $\begin{array}{l}76 \\
74 \\
70 \\
68 \\
66 \\
63\end{array}$ \\
\hline \multirow[t]{2}{*}{$\begin{array}{r}7 \\
8 \\
9 \\
10 \\
11 \\
M \\
\end{array}$} & $\begin{array}{l}2.33 \\
2.33 \\
2.33 \\
2.33 \\
2.33 \\
2.33\end{array}$ & $\begin{array}{l}2.4 \\
2.4 \\
2.4 \\
2.4 \\
2.4 \\
2.4\end{array}$ & $\begin{array}{l}3.65 \\
3.48 \\
3.38 \\
3.40 \\
3.90 \\
4.60\end{array}$ & $\begin{array}{r}140 \\
104 \\
87 \\
90 \\
207 \\
472 \\
\end{array}$ & $\begin{array}{l}3.68 \\
4.16 \\
5.78 \\
6.62 \\
6.60 \\
6.00\end{array}$ & $\begin{array}{r}147 \\
294 \\
961 \\
1,360 \\
1,350 \\
1,060\end{array}$ & $\begin{array}{l}8.94 \\
8.06 \\
6.05 \\
5.03 \\
4.67 \\
4.46\end{array}$ & $\begin{array}{r}2,820 \\
2,210 \\
1,080 \\
644 \\
500 \\
414 \\
\end{array}$ & $\begin{array}{l}3.49 \\
3.47 \\
3.46 \\
3.44 \\
3.43 \\
3.42\end{array}$ & $\begin{array}{r}106 \\
103 \\
101 \\
97 \\
95 \\
94 \\
\end{array}$ & $\begin{array}{l}3.21 \\
3.20 \\
3.19 \\
3.18 \\
3.17 \\
3.17\end{array}$ & & $\begin{array}{l}61 \\
60 \\
59 \\
58 \\
56 \\
56 \\
\end{array}$ \\
\hline & \multicolumn{2}{|c|}{ September 24} & \multicolumn{2}{|c|}{ September 25} & \multicolumn{2}{|c|}{ September 26} & \multicolumn{2}{|c|}{ September 27} & \multicolumn{2}{|c|}{ September 28} & \multicolumn{3}{|c|}{ September 29} \\
\hline $\begin{array}{r}2 \\
4 \\
6 \\
8 \\
10 \\
N\end{array}$ & $\begin{array}{l}3.16 \\
3.15 \\
3.14 \\
3.14 \\
3.13 \\
3.12\end{array}$ & $\begin{array}{l}55 \\
54 \\
53 \\
53 \\
52 \\
50\end{array}$ & $\begin{array}{l}2.99 \\
2.99 \\
2.98 \\
2.98 \\
2.97 \\
2.96\end{array}$ & $\begin{array}{l}37 \\
37 \\
36 \\
36 \\
35 \\
34\end{array}$ & $\begin{array}{l}2.88 \\
2.88 \\
2.88 \\
2.88 \\
2.88 \\
2.88\end{array}$ & $\begin{array}{l}27 \\
27 \\
27 \\
27 \\
27 \\
27\end{array}$ & $\begin{array}{l}2.82 \\
2.82 \\
2.82 \\
2.82 \\
2.82 \\
2.82\end{array}$ & $\begin{array}{l}23 \\
23 \\
23 \\
23 \\
23 \\
23\end{array}$ & $\begin{array}{l}3.63 \\
3.48 \\
3.39 \\
3.33 \\
3.29 \\
3.26\end{array}$ & $\begin{array}{r}136 \\
104 \\
88 \\
79 \\
73 \\
68\end{array}$ & $\begin{array}{l}3.09 \\
3.09 \\
3.08 \\
3.07 \\
3.06 \\
3.05\end{array}$ & & $\begin{array}{l}47 \\
47 \\
46 \\
45 \\
44 \\
43\end{array}$ \\
\hline $\begin{array}{r}2 \\
4 \\
6 \\
8 \\
10 \\
M\end{array}$ & $\begin{array}{l}3.10 \\
3.08 \\
3.05 \\
3.02 \\
3.01 \\
3.00\end{array}$ & $\begin{array}{l}48 \\
46 \\
43 \\
40 \\
39 \\
38\end{array}$ & $\begin{array}{l}2.94 \\
2.92 \\
2.91 \\
2.90 \\
2.89 \\
2.88\end{array}$ & $\begin{array}{l}33 \\
31 \\
30 \\
29 \\
28 \\
27\end{array}$ & $\begin{array}{l}2.87 \\
2.86 \\
2.84 \\
2.82 \\
2.82 \\
2.82\end{array}$ & $\begin{array}{l}27 \\
26 \\
24 \\
23 \\
23 \\
23\end{array}$ & $\begin{array}{l}2.81 \\
2.81 \\
3.84 \\
7.60 \\
6.40 \\
4.05\end{array}$ & $\begin{array}{r}22 \\
22 \\
190 \\
1,920 \\
1,250 \\
255\end{array}$ & $\begin{array}{l}3.21 \\
3.17 \\
3.14 \\
3.12 \\
3.11 \\
3.10\end{array}$ & $\begin{array}{l}61 \\
56 \\
53 \\
50 \\
49 \\
48\end{array}$ & $\begin{array}{l}3.04 \\
3.02 \\
3.01 \\
3.00 \\
2.99 \\
2.99\end{array}$ & & $\begin{array}{l}42 \\
40 \\
39 \\
38 \\
37 \\
37\end{array}$ \\
\hline
\end{tabular}

Supplemental records.- Sept. 19, 9:45 p.m., 3.35 ft., 82 sec.-ft. Sept. 20, 4:40 a.m., 6.82 ft., 1,470 sec.-ft.; $6: 40$ a.m., 6.98 ft., 1,550 sec.-ft.; 10:30 p.m., $6.70 \mathrm{ft} ., 1,400$ sec.-ft. Sept. $21,4: 30$ p.m., 10.74 ft., 4,300 sec.-ft.; 8:30 p.m., $7.66 \mathrm{ft} ., 1,960$ sec. $-\mathrm{ft}$. 
North Branch of Raritan River near Far Hills, N. J.

Location.- Water-stage recorder, lat. $40^{\circ} 42^{\prime} 2^{\prime \prime}$, long. $74^{\circ} 38^{\prime} 20^{\prime \prime}$, at Ravine Lake dam 2 miles north of Far Hills, Somerset County, and 2 miles above mouth of Peapack Brook. Zero of gage is 224.49 feet above mean sea level (New Jersey Geological Survey benchmark).

Drainage area.- 26.2 square miles; not materially affected by storage.

Gage-he1ght record. - Water-stage recorder graph.

Stage-discharge relation.- Defined by current-meter measurements below 500 secondfeet; extended to peak stage by weir formula based on current-meter measurements.

Maxima.- September 1938: Discharge, 2,700 second-feet $8 \mathrm{p.m.} \mathrm{Sept.} 21$ (gage height, 5.31 feet).

1922 to August 1938: Discharge, about 2,630 second-feet Sept. 30, 1934 (gage height, 5.24 feet)

Stage of 7.6 feet, from authentic floodmark, reached on July 23, 1919 (d1scharge, about 7,000 second-feet).

Mean dally discharge, in second-feet, 1938

\begin{tabular}{|c|r|r||r|r|r||r|r|r||r|r|r|}
\hline Day & Sept. & 0ct. & Day & Sept. & 0ct. & Day & Sept. & 0ct. & Day & Sept. & Oct. \\
\hline 1 & 34 & 65 & 9 & 24 & 44 & 17 & 22 & 37 & 25 & 122 & 62 \\
2 & 30 & 55 & 10 & 24 & 40 & 18 & 23 & 35 & 26 & 105 & 42 \\
3 & 27 & 49 & 11 & 23 & 38 & 19 & 96 & 34 & 27 & 92 & 37 \\
4 & 27 & 46 & 12 & 22 & 38 & 20 & 310 & 37 & 28 & 88 & 38 \\
5 & 26 & 46 & 13 & 24 & 37 & 21 & 793 & 72 & 29 & 79 & 37 \\
6 & 23 & 55 & 14 & 24 & 37 & 22 & 316 & 40 & 30 & 68 & 34 \\
7 & 24 & 80 & 15 & 24 & 37 & 23 & 151 & 34 & 31 & & 32 \\
8 & 24 & 49 & 16 & 24 & 37 & 24 & 136 & 58 & & \\
\hline
\end{tabular}

Gage helght, in feet, and discharge, in second-feet, at indicated time, 1938

\begin{tabular}{|c|c|c|c|c|c|c|c|c|c|c|c|c|}
\hline \multirow{2}{*}{$\begin{array}{l}9 \\
0 \\
0\end{array}$} & Feet & Sec.ft. & Feot & Sec.ft. & Feot & Sec.ft. & Feet & Sec.ft. & Feet & Sec.ft. & Feet & Sec.ft. \\
\hline & \multicolumn{2}{|c|}{ September 18} & \multicolumn{2}{|c|}{ September 19} & \multicolumn{2}{|c|}{ September 20} & \multicolumn{2}{|c|}{ September 21} & \multicolumn{2}{|c|}{ September 22} & \multicolumn{2}{|c|}{ September 23} \\
\hline $\begin{array}{l}1 \\
2 \\
3 \\
4 \\
5 \\
6\end{array}$ & $\begin{array}{l}2.11 \\
2.11 \\
2.11 \\
2.12 \\
2.12 \\
2.12\end{array}$ & $\begin{array}{l}22 \\
22 \\
22 \\
23 \\
23 \\
23\end{array}$ & $\begin{array}{l}2.13 \\
2.13 \\
2.13 \\
2.13 \\
2.13 \\
2.13\end{array}$ & $\begin{array}{l}24 \\
24 \\
24 \\
24 \\
24 \\
24\end{array}$ & $\begin{array}{l}2.71 \\
2.81 \\
2.89 \\
2.98 \\
3.13 \\
3.22\end{array}$ & \begin{tabular}{|l|}
228 \\
284 \\
332 \\
389 \\
491 \\
556
\end{tabular} & $\begin{array}{l}2.65 \\
2.72 \\
2.75 \\
2.75 \\
2.74 \\
2.71\end{array}$ & $\begin{array}{l}196 \\
233 \\
250 \\
250 \\
244 \\
228\end{array}$ & & $\begin{array}{l}661 \\
556 \\
491 \\
443 \\
409 \\
389\end{array}$ & & \begin{tabular}{|l}
160 \\
160 \\
160 \\
160 \\
160 \\
160
\end{tabular} \\
\hline $\begin{array}{r}7 \\
8 \\
9 \\
10 \\
11 \\
\text { N }\end{array}$ & $\begin{array}{l}2.12 \\
2.12 \\
2.12 \\
2.12 \\
2.12 \\
2.12\end{array}$ & $\begin{array}{l}23 \\
23 \\
23 \\
23 \\
23 \\
23\end{array}$ & $\begin{array}{l}13 \\
13 \\
13 \\
13 \\
13\end{array}$ & $\begin{array}{l}24 \\
24 \\
24 \\
24 \\
24 \\
24\end{array}$ & $\begin{array}{l}3.22 \\
3.23 \\
3.21 \\
3.13 \\
3.04 \\
2.95\end{array}$ & $\begin{array}{l}556 \\
563 \\
548 \\
491 \\
429 \\
370\end{array}$ & $\begin{array}{l}.68 \\
.65 \\
.64 \\
.63 \\
.63 \\
.66\end{array}$ & $\begin{array}{l}212 \\
196 \\
191 \\
186 \\
186 \\
201\end{array}$ & & $\begin{array}{l}370 \\
351 \\
338 \\
326 \\
308 \\
272\end{array}$ & & $\begin{array}{l}160 \\
160 \\
160 \\
160 \\
156 \\
151\end{array}$ \\
\hline $\begin{array}{l}1 \\
2 \\
3 \\
4 \\
5 \\
6\end{array}$ & $\begin{array}{l}2.12 \\
2.12 \\
2.12 \\
2.12 \\
2.12 \\
2.12\end{array}$ & $\begin{array}{l}23 \\
23 \\
23 \\
23 \\
23 \\
23\end{array}$ & $\begin{array}{l}2.17 \\
2.28 \\
2.48 \\
2.72 \\
2.77 \\
2.77\end{array}$ & $\begin{array}{r}27 \\
42 \\
113 \\
233 \\
261 \\
261\end{array}$ & $\begin{array}{l}2.87 \\
2.80 \\
2.73 \\
2.67 \\
2.61 \\
2.57\end{array}$ & $\begin{array}{l}320 \\
278 \\
239 \\
206 \\
175 \\
156\end{array}$ & $\begin{array}{l}2.74 \\
2.93 \\
3.25 \\
3.66 \\
4.18 \\
4.74\end{array}$ & $\begin{array}{r}244 \\
357 \\
578 \\
911 \\
1,400 \\
2,020\end{array}$ & $\begin{array}{l}2.73 \\
2.70 \\
2.68 \\
2.66 \\
2.65 \\
2.64\end{array}$ & $\begin{array}{l}239 \\
222 \\
212 \\
201 \\
196 \\
191\end{array}$ & & $\begin{array}{l}151 \\
146 \\
146 \\
146 \\
146 \\
146\end{array}$ \\
\hline \multirow[t]{2}{*}{\begin{tabular}{r|}
7 \\
8 \\
9 \\
10 \\
11 \\
$M$ \\
\end{tabular}} & $\begin{array}{l}2.13 \\
2.13 \\
2.13 \\
2.13 \\
2.13 \\
2.13\end{array}$ & $\begin{array}{l}24 \\
24 \\
24 \\
24 \\
24 \\
24\end{array}$ & & $\begin{array}{l}244 \\
222 \\
201 \\
191 \\
180 \\
180\end{array}$ & $\begin{array}{l}2.54 \\
2.53 \\
2.52 \\
2.52 \\
2.52 \\
2.58\end{array}$ & $\begin{array}{l}141 \\
136 \\
132 \\
132 \\
132 \\
160\end{array}$ & $\begin{array}{l}5.21 \\
5.31 \\
4.95 \\
4.40 \\
3.98 \\
3.62\end{array}$ & $\begin{array}{r}2,580 \\
2,700 \\
2,270 \\
1,640 \\
1,200 \\
875\end{array}$ & & $\begin{array}{l}186 \\
180 \\
175 \\
170 \\
165 \\
165\end{array}$ & & $\begin{array}{l}146 \\
146 \\
146 \\
146 \\
146 \\
146\end{array}$ \\
\hline & \multicolumn{2}{|c|}{ September 24} & \multicolumn{2}{|c|}{ September 25} & \multicolumn{2}{|c|}{ September 26} & \multicolumn{2}{|c|}{ September 27} & \multicolumn{2}{|c|}{ September 28} & \multicolumn{2}{|c|}{ September 29} \\
\hline $\begin{array}{r}2 \\
4 \\
6 \\
8 \\
10 \\
N\end{array}$ & $\begin{array}{l}2.55 \\
2.54 \\
2.54 \\
2.54 \\
2.53 \\
2.53\end{array}$ & & & $\begin{array}{l}127 \\
127 \\
122 \\
122 \\
122 \\
122\end{array}$ & & $\begin{array}{l}113 \\
113 \\
109 \\
109 \\
109 \\
109\end{array}$ & & $\begin{array}{l}92 \\
92 \\
92 \\
92 \\
92 \\
92\end{array}$ & & $\begin{array}{l}92 \\
92 \\
92 \\
92 \\
88 \\
83\end{array}$ & & $\begin{array}{l}83 \\
83 \\
83 \\
79 \\
79 \\
75\end{array}$ \\
\hline $\begin{array}{r}2 \\
4 \\
6 \\
8 \\
10 \\
M\end{array}$ & $\begin{array}{l}2.53 \\
2.52 \\
2.51 \\
2.51 \\
2.51 \\
2.51\end{array}$ & $\begin{array}{l}136 \\
132 \\
127 \\
127 \\
127 \\
127\end{array}$ & & $\begin{array}{l}122 \\
122 \\
118 \\
118 \\
113 \\
113\end{array}$ & $\begin{array}{l}2.46 \\
2.46 \\
2.46 \\
2.45 \\
2.44 \\
2.44\end{array}$ & $\begin{array}{r}105 \\
105 \\
105 \\
100 \\
96 \\
96\end{array}$ & $\begin{array}{l}2.43 \\
2.43 \\
2.43 \\
2.43 \\
2.43 \\
2.43\end{array}$ & $\begin{array}{l}92 \\
92 \\
92 \\
92 \\
92 \\
92\end{array}$ & $\begin{array}{l}2.41 \\
2.41 \\
2.41 \\
2.41 \\
2.41 \\
2.41\end{array}$ & $\begin{array}{l}83 \\
83 \\
83 \\
83 \\
83 \\
83\end{array}$ & & $\begin{array}{l}75 \\
75 \\
75 \\
75 \\
75 \\
75\end{array}$ \\
\hline
\end{tabular}




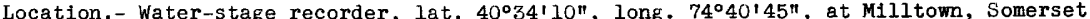
County, $1 \frac{1}{2}$ miles upstream from junction of North and South Branches of Raritan River. Zero of gage is 50.43 feet above mean sea level (general adjustment of 1929 ).

Drainage area.- 190 square miles; not materially affected by storage.

Gage-height record.- Water-stage recorder graph.

Stage-discharge relation.- Defined by current-meter measurements below 2,100 secondfeet; extended to peak stage on basis of determinations of flood flow by slope-area method.

Maxíma.- September 1938: Discharge, 16,500 second-feet 8:40 p.m. Sept. 21 (gage height, 12.16 feet).

1923 to August 1938: Discnarge, 14,400 second-feet Jan. 3, 1936 (gage height, 11.35 feet, from floodmark).

Mean daily discharge, in secondefeet, 1938

\begin{tabular}{|c|c|c|c|c|c|c|c|c|c|c|c|}
\hline Day & Sept. & Oct. & Day & Sept. & Oct. & Day & Sept. & Oct. & Day & Sept. & Oct. \\
\hline $\begin{array}{l}1 \\
2 \\
3 \\
4 \\
5 \\
6 \\
7 \\
8\end{array}$ & $\begin{array}{r}137 \\
119 \\
106 \\
106 \\
99 \\
93 \\
88 \\
96\end{array}$ & $\begin{array}{l}244 \\
216 \\
206 \\
195 \\
185 \\
206 \\
328 \\
211\end{array}$ & $\begin{array}{r}9 \\
10 \\
11 \\
12 \\
13 \\
14 \\
15 \\
16\end{array}$ & $\begin{array}{l}85 \\
85 \\
82 \\
85 \\
88 \\
91 \\
93 \\
96\end{array}$ & $\begin{array}{l}195 \\
185 \\
175 \\
171 \\
167 \\
167 \\
162 \\
158\end{array}$ & $\begin{array}{l}17 \\
18 \\
19 \\
20 \\
21 \\
22 \\
23 \\
24\end{array}$ & $\begin{array}{r}85 \\
91 \\
516 \\
3,130 \\
7,040 \\
3,340 \\
977 \\
722\end{array}$ & $\begin{array}{l}154 \\
154 \\
150 \\
154 \\
272 \\
185 \\
162 \\
265\end{array}$ & $\begin{array}{l}25 \\
26 \\
27 \\
28 \\
29 \\
30 \\
31\end{array}$ & $\begin{array}{l}535 \\
428 \\
372 \\
342 \\
286 \\
262\end{array}$ & $\begin{array}{l}346 \\
216 \\
195 \\
195 \\
200 \\
180 \\
171\end{array}$ \\
\hline $\begin{array}{l}\text { Miean } \\
\text { Run- }\end{array}$ & thly & & & & - . & $: \dot{ }$ & . $\cdot \dot{\text { : }}$ & . : & $\dot{.}$ & $\begin{array}{r}656 \\
3.85 \\
\end{array}$ & $\begin{array}{r}199 \\
1.21 \\
\end{array}$ \\
\hline
\end{tabular}

Gage height, in feet, and discharge, in second-feet, at indicated time, 1938

\begin{tabular}{|c|c|c|c|c|c|c|c|c|c|c|c|c|c|}
\hline \multirow{2}{*}{$\begin{array}{r}9 \\
3 \\
0 \\
19 \\
\end{array}$} & Feet & $\mathrm{Sec}$ &.$f t$. & Feet & Sec.ft. & Feet & Sec.ft. & Feet & Sec.ft. & Feet & Sec.ft. & Feet & Sec.ft. \\
\hline & \multicolumn{3}{|c|}{ September 18} & \multicolumn{2}{|c|}{ September 19} & \multicolumn{2}{|c|}{ September 20} & \multicolumn{2}{|c|}{ September 21} & \multicolumn{2}{|c|}{ September 22} & \multicolumn{2}{|c|}{ September 23} \\
\hline $\begin{array}{l}1 \\
2 \\
3 \\
4 \\
5 \\
6\end{array}$ & $\begin{array}{l}2.76 \\
2.75 \\
2.74 \\
2.74 \\
2.74 \\
2.75\end{array}$ & & $\begin{array}{l}88 \\
85 \\
82 \\
82 \\
82 \\
85\end{array}$ & $\begin{array}{l}2.79 \\
2.79 \\
2.79 \\
2.79 \\
2.79 \\
2.79\end{array}$ & $\begin{array}{l}96 \\
96 \\
96 \\
96 \\
96 \\
96\end{array}$ & $\begin{array}{l}4.55 \\
5.20 \\
6.00 \\
6.57 \\
7.00 \\
7.31\end{array}$ & $\begin{array}{l}1,780 \\
2,560 \\
3,200 \\
3,670 \\
4,170 \\
4,680\end{array}$ & $\begin{array}{l}6.05 \\
6.12 \\
5.93 \\
5.57 \\
5.15 \\
4.83\end{array}$ & $\begin{array}{l}3,240 \\
3,280 \\
3,160 \\
2,910 \\
2,500 \\
2,140\end{array}$ & $\begin{array}{r}10.57 \\
9.98 \\
9.32 \\
8.60 \\
7.60 \\
6.45\end{array}$ & $\begin{array}{r}12,100 \\
10,400 \\
8,820 \\
7,190 \\
5,190 \\
3,560\end{array}$ & $\begin{array}{l}4.01 \\
4.00 \\
3.99 \\
3.98 \\
3.97 \\
3.96\end{array}$ & $\begin{array}{l}1,090 \\
1,080 \\
1,070 \\
1,060 \\
1,050 \\
1,030\end{array}$ \\
\hline $\begin{array}{r}7 \\
8 \\
9 \\
10 \\
11 \\
\mathrm{~N}\end{array}$ & $\begin{array}{l}2.77 \\
2.77 \\
2.78 \\
2.78 \\
2.78 \\
2.78\end{array}$ & & $\begin{array}{l}91 \\
91 \\
93 \\
93 \\
93 \\
93\end{array}$ & $\begin{array}{l}2.79 \\
2.79 \\
2.80 \\
2.80 \\
2.80 \\
2.82\end{array}$ & $\begin{array}{r}96 \\
96 \\
99 \\
99 \\
99 \\
106\end{array}$ & $\begin{array}{l}7.53 \\
7.70 \\
7.84 \\
7.92 \\
7.86 \\
7.45\end{array}$ & $\begin{array}{l}5,060 \\
5,380 \\
5,650 \\
5,800 \\
5,680 \\
4,920\end{array}$ & $\begin{array}{l}4.65 \\
4.58 \\
4.58 \\
4.66 \\
5.10 \\
5.95\end{array}$ & $\begin{array}{l}1,900 \\
1,810 \\
1,810 \\
1,920 \\
2,450 \\
3,170\end{array}$ & $\begin{array}{l}5.55 \\
5.00 \\
4.70 \\
4.56 \\
4.47 \\
4.41\end{array}$ & $\begin{array}{l}2,890 \\
2,340 \\
1,970 \\
1,790 \\
1,670 \\
1,590\end{array}$ & $\begin{array}{l}3.95 \\
3.95 \\
3.95 \\
3.94 \\
3.93 \\
3.92\end{array}$ & $\begin{array}{r}1,020 \\
1,020 \\
1,020 \\
1,010 \\
1,000 \\
989\end{array}$ \\
\hline $\begin{array}{l}1 \\
2 \\
3 \\
4 \\
5 \\
6\end{array}$ & $\begin{array}{l}2.78 \\
2.78 \\
2.78 \\
2.78 \\
2.78 \\
2.78\end{array}$ & & $\begin{array}{l}93 \\
93 \\
93 \\
93 \\
93 \\
93\end{array}$ & $\begin{array}{l}2.92 \\
2.99 \\
3.11 \\
3.50 \\
4.35 \\
4.53\end{array}$ & $\begin{array}{r}141 \\
171 \\
232 \\
535 \\
1,520 \\
1,750\end{array}$ & $\begin{array}{l}6.30 \\
5.10 \\
4.59 \\
4.37 \\
4.22 \\
4.10\end{array}$ & $\begin{array}{l}3,420 \\
2,450 \\
1,830 \\
1,540 \\
1,360 \\
1,200\end{array}$ & $\begin{array}{r}7.10 \\
7.95 \\
8.55 \\
9.45 \\
10.40 \\
11.14\end{array}$ & $\begin{array}{r}4,330 \\
5,860 \\
7,080 \\
9,130 \\
11,600 \\
13,700\end{array}$ & $\begin{array}{l}4.37 \\
4.34 \\
4.29 \\
4.24 \\
4.20 \\
4.17\end{array}$ & $\begin{array}{l}1,540 \\
1,510 \\
1,450 \\
1,380 \\
1,330 \\
1,290\end{array}$ & $\begin{array}{l}3.92 \\
3.91 \\
3.89 \\
3.88 \\
3.87 \\
3.85\end{array}$ & $\begin{array}{l}989 \\
977 \\
955 \\
943 \\
932 \\
910\end{array}$ \\
\hline $\begin{array}{r}7 \\
8 \\
9 \\
10 \\
11 \\
11\end{array}$ & $\begin{array}{l}2.78 \\
2.78 \\
2.78 \\
2.78 \\
2.78 \\
2.78\end{array}$ & & $\begin{array}{l}93 \\
93 \\
93 \\
93 \\
93 \\
93\end{array}$ & $\begin{array}{l}4.43 \\
4.25 \\
4.10 \\
4.00 \\
3.94 \\
4.05\end{array}$ & $\begin{array}{l}1,620 \\
1,400 \\
1,200 \\
1,080 \\
1,010 \\
1,140\end{array}$ & $\begin{array}{l}4.03 \\
4.06 \\
4.28 \\
4.70 \\
5.27 \\
5.78\end{array}$ & $\begin{array}{l}1,120 \\
1,150 \\
1,430 \\
1,970 \\
2,630 \\
3,070\end{array}$ & $\begin{array}{l}11.70 \\
12.05 \\
12.08 \\
11.85 \\
11.50 \\
11.08\end{array}$ & $\begin{array}{l}15,300 \\
16,200 \\
16,300 \\
15,600 \\
14,700 \\
13,500\end{array}$ & $\begin{array}{l}4.13 \\
4.11 \\
4.08 \\
4.06 \\
4.04 \\
4.02\end{array}$ & $\begin{array}{l}1,240 \\
1,210 \\
1,180 \\
1,150 \\
1,130 \\
1,100\end{array}$ & $\begin{array}{l}3.84 \\
3.82 \\
3.80 \\
3.79 \\
3.78 \\
3.77\end{array}$ & $\begin{array}{l}898 \\
876 \\
853 \\
842 \\
831 \\
820\end{array}$ \\
\hline & \multicolumn{3}{|c|}{ September 24} & \multicolumn{2}{|c|}{ September 25} & \multicolumn{2}{|c|}{ September 26} & \multicolumn{2}{|c|}{ September 27} & \multicolumn{2}{|c|}{ September 28} & \multicolumn{2}{|c|}{ September 29} \\
\hline $\begin{array}{r}2 \\
4 \\
6 \\
8 \\
10 \\
N\end{array}$ & $\begin{array}{l}3.75 \\
3.74 \\
3.73 \\
3.72 \\
3.71 \\
3.70\end{array}$ & & $\begin{array}{l}798 \\
787 \\
776 \\
765 \\
754 \\
743\end{array}$ & $\begin{array}{l}3.56 \\
3.55 \\
3.54 \\
3.53 \\
3.52 \\
3.51\end{array}$ & $\begin{array}{l}596 \\
586 \\
576 \\
566 \\
555 \\
\mathbf{5 4 5}\end{array}$ & $\begin{array}{l}3.42 \\
3.42 \\
3.41 \\
3.41 \\
3.40 \\
3.40\end{array}$ & \begin{tabular}{|l}
456 \\
456 \\
446 \\
446 \\
436 \\
436
\end{tabular} & $\begin{array}{l}3.33 \\
3.33 \\
3.32 \\
3.32 \\
3.32 \\
3.32\end{array}$ & $\begin{array}{l}380 \\
380 \\
372 \\
372 \\
372 \\
372\end{array}$ & $\begin{array}{l}3.33 \\
3.33 \\
3.32 \\
3.30 \\
3.29 \\
3.28\end{array}$ & $\begin{array}{l}380 \\
380 \\
372 \\
356 \\
349 \\
342\end{array}$ & $\begin{array}{l}3.22 \\
3.21 \\
3.21 \\
3.21 \\
3.21 \\
3.20\end{array}$ & $\begin{array}{l}300 \\
293 \\
293 \\
293 \\
293 \\
286\end{array}$ \\
\hline $\begin{array}{r}2 \\
4 \\
6 \\
8 \\
10 \\
M\end{array}$ & $\begin{array}{l}3.68 \\
3.67 \\
3.65 \\
3.62 \\
3.59 \\
3.57\end{array}$ & & $\begin{array}{l}722 \\
711 \\
690 \\
658 \\
627 \\
606\end{array}$ & $\begin{array}{l}3.50 \\
3.48 \\
3.47 \\
3.46 \\
3.44 \\
3.43\end{array}$ & $\begin{array}{l}535 \\
515 \\
505 \\
495 \\
476 \\
466\end{array}$ & $\begin{array}{l}3.39 \\
3.38 \\
3.37 \\
3.36 \\
3.35 \\
3.34\end{array}$ & $\begin{array}{l}428 \\
420 \\
412 \\
404 \\
396 \\
388\end{array}$ & $\begin{array}{l}3.32 \\
3.32 \\
3.32 \\
3.32 \\
3.32 \\
3.33\end{array}$ & $\begin{array}{l}372 \\
372 \\
372 \\
372 \\
372 \\
380\end{array}$ & $\begin{array}{l}3.27 \\
3.26 \\
3.25 \\
3.24 \\
3.23 \\
3.22\end{array}$ & $\begin{array}{l}335 \\
328 \\
321 \\
314 \\
307 \\
300\end{array}$ & $\begin{array}{l}3.20 \\
3.20 \\
3.20 \\
3.19 \\
3.18 \\
3.17\end{array}$ & $\begin{array}{l}286 \\
286 \\
286 \\
280 \\
274 \\
268\end{array}$ \\
\hline
\end{tabular}

Supplemental records.- Sept. 21, 8:40 p.⿴., 12.16 ft., 16,500 sec.-ft. 
Location.- Water-stage recorder, lat. $40^{\circ} 43^{\prime} 39^{\prime \prime}$, long. $74^{\circ} 43^{\prime} 50^{\prime \prime}$, 1 mile above highway bridge at Pottersville; Somerset County, and' 8 miles above mouth of Rockaway Creek. Zero of gage is 284.14 feet above mean sea level (New Jersey Geological Survey benchmark).

Drainage area.- 32.8 square miles; slightly affected by storage in swampy area above station.

Gage-neight record.- Water-stage recorder graph. Record missing 0ct. 4-10.

Stage-discharge relation.- Defined by current-meter measurements below 200 second-feet; extended to peak stage on basis of laboratory rating of control having similar cross section.

Maxima.- September 1938: Discharge, about 760 second-feet 4:40 p.m. Sept. 21 (gage neight, 3.97 feet).

1921 to August 1938: Discharge, about 1,600 second-feet Nov. 17, 1927 (gage height, 4.75 feet)

Remarks.- Discharge for period of missing gage-neight record, 0ct. 4-10, computed on basis of record of North Branch of Raritan River near Far Hilis.

Mean daily discharge, in second-feet, 1938

\begin{tabular}{|c|c|c|c|c|c|c|c|c|c|c|c|}
\hline Day & Sept. & oct. & Day & Sept. & Oct. & Day & Sept. & Oct. & Day & Sept. & Oct. \\
\hline $\begin{array}{l}1 \\
2 \\
3 \\
4 \\
5 \\
6 \\
7 \\
8\end{array}$ & $\begin{array}{l}32 \\
27 \\
26 \\
25 \\
22 \\
20 \\
19.6 \\
19.6\end{array}$ & $\begin{array}{r}64 \\
60 \\
59 \\
* 58 \\
* 56 \\
* 60 \\
* 75 \\
* 65\end{array}$ & $\begin{array}{r}9 \\
10 \\
11 \\
12 \\
13 \\
14 \\
15 \\
16\end{array}$ & $\begin{array}{l}18.8 \\
18.8 \\
18.0 \\
17.3 \\
18.8 \\
18.8 \\
19.6 \\
19.6\end{array}$ & $\begin{array}{r}* 60 \\
* 55 \\
54 \\
54 \\
52 \\
49 \\
48 \\
45\end{array}$ & $\begin{array}{l}17 \\
18 \\
19 \\
20 \\
21 \\
22 \\
23 \\
24\end{array}$ & $\begin{array}{l}19.6 \\
20 \\
62 \\
185 \\
323 \\
302 \\
263 \\
227 .\end{array}$ & $\begin{array}{l}43 \\
42 \\
42 \\
47 \\
62 \\
52 \\
49 \\
72\end{array}$ & $\begin{array}{l}25 \\
26 \\
27 \\
28 \\
29 \\
30 \\
31\end{array}$ & $\begin{array}{r}183 \\
144 \\
116 \\
96 \\
79 \\
72\end{array}$ & $\begin{array}{l}79 \\
68 \\
66 \\
66 \\
64 \\
59 \\
54\end{array}$ \\
\hline $\begin{array}{l}\text { Mean } \\
\text { Run } \rightarrow c\end{array}$ & $\begin{array}{l}\text { nthly } \\
\text { In }\end{array}$ & $\begin{array}{l}\text { schar } \\
\text { hes. }\end{array}$ & , Ir & $\begin{array}{c}\text { econd- } \\
. \cdot \text {. }\end{array}$ & et. . & . & . : : & . : & $: \dot{ }$ & $\begin{array}{l}81.1 \\
2.76\end{array}$ & $\begin{array}{l}57.4 \\
2.02 \\
\end{array}$ \\
\hline
\end{tabular}

Gage helght, in feet, and discharge, in second-feet, at indicated time, 1938

\begin{tabular}{|c|c|c|c|c|c|c|c|c|c|c|c|c|c|}
\hline \multirow{2}{*}{$\begin{array}{l}9 \\
\text { ? } \\
\text { : }\end{array}$} & Feet & Sec.ft. & Feet & Sec.ft. & Feet & Sec.ft. & Feet & sec.ft. & Feet & Sec.ft. & Feet & \multicolumn{2}{|c|}{ Sec.ft. } \\
\hline & \multicolumn{2}{|c|}{ September 18} & \multicolumn{2}{|c|}{ September 19} & \multicolumn{2}{|c|}{ September 20} & \multicolumn{2}{|c|}{ September 21} & \multicolumn{2}{|c|}{ September 22} & \multicolumn{3}{|c|}{ September 23} \\
\hline $\begin{array}{l}1 \\
2 \\
3 \\
4 \\
5 \\
6\end{array}$ & $\begin{array}{l}1.66 \\
1.66 \\
1.66 \\
1.66 \\
1.66 \\
1.66\end{array}$ & $\begin{array}{l}19.6 \\
19.6 \\
19.6 \\
19.6 \\
19.6 \\
19.6\end{array}$ & $\begin{array}{l}1.68 \\
1.69 \\
1.69 \\
1.69 \\
1.69 \\
1.69\end{array}$ & $\begin{array}{l}21 \\
22 \\
22 \\
22 \\
22 \\
22\end{array}$ & $\begin{array}{l}2.53 \\
2.78 \\
2.77 \\
2.73 \\
2.80 \\
2.71\end{array}$ & \begin{tabular}{|l}
183 \\
254 \\
251 \\
239 \\
260 \\
233
\end{tabular} & $\begin{array}{l}2.57 \\
2.51 \\
2.47 \\
2.45 \\
2.43 \\
2.43\end{array}$ & $\begin{array}{l}194 \\
178 \\
167 \\
162 \\
157 \\
157\end{array}$ & $\begin{array}{l}3.09 \\
3.07 \\
3.04 \\
3.02 \\
3.01 \\
2.99\end{array}$ & $\begin{array}{l}358 \\
351 \\
340 \\
333 \\
330 \\
323\end{array}$ & $\begin{array}{l}2.84 \\
2.84 \\
2.84 \\
2.84 \\
2.84 \\
2.84\end{array}$ & & $\begin{array}{l}273 \\
273 \\
273 \\
273 \\
273 \\
273\end{array}$ \\
\hline $\begin{array}{r}7 \\
8 \\
9 \\
10 \\
11 \\
N\end{array}$ & $\begin{array}{l}1.66 \\
1.66 \\
1.66 \\
1.66 \\
1.66 \\
1.66\end{array}$ & $\begin{array}{l}19.6 \\
19.6 \\
19.6 \\
19.6 \\
19.6 \\
19.6\end{array}$ & $\begin{array}{l}1.69 \\
1.69 \\
1.69 \\
1.70 \\
1.76 \\
2.07\end{array}$ & $\begin{array}{l}22 \\
22 \\
22 \\
23 \\
29 \\
75\end{array}$ & $\begin{array}{l}2.59 \\
2.51 \\
2.46 \\
2.43 \\
2.42 \\
2.41\end{array}$ & $\begin{array}{l}199 \\
178 \\
165 \\
157 \\
154 \\
152\end{array}$ & $\begin{array}{l}2.43 \\
2.43 \\
2.44 \\
2.50 \\
2.61 \\
2.87\end{array}$ & $\begin{array}{l}157 \\
157 \\
159 \\
175 \\
205 \\
282\end{array}$ & $\begin{array}{l}2.97 \\
2.96 \\
2.94 \\
2.93 \\
2.92 \\
2.91\end{array}$ & $\begin{array}{l}316 \\
312 \\
306 \\
302 \\
299 \\
295\end{array}$ & $\begin{array}{l}2.83 \\
2.83 \\
2.83 \\
2.82 \\
2.82 \\
2.82\end{array}$ & & $\begin{array}{l}270 \\
270 \\
270 \\
266 \\
266 \\
266\end{array}$ \\
\hline $\begin{array}{l}1 \\
2 \\
3 \\
4 \\
5 \\
6\end{array}$ & $\begin{array}{l}1.66 \\
1.66 \\
1.67 \\
1.67 \\
1.67 \\
1.67\end{array}$ & $\begin{array}{l}19.6 \\
19.6 \\
20 \\
20 \\
20 \\
20\end{array}$ & $\begin{array}{l}2.33 \\
2.25 \\
2.18 \\
2.13 \\
2.08 \\
2.05\end{array}$ & $\begin{array}{r}132 \\
114 \\
98 \\
87 \\
77 \\
72\end{array}$ & $\begin{array}{l}2.41 \\
2.40 \\
2.40 \\
2.37 \\
2.36 \\
2.36\end{array}$ & $\begin{array}{l}152 \\
149 \\
149 \\
142 \\
139 \\
139\end{array}$ & $\begin{array}{l}3.04 \\
3.32 \\
3.61 \\
3.91 \\
3.92 \\
3.59\end{array}$ & $\begin{array}{l}340 \\
448 \\
577 \\
727 \\
733 \\
567\end{array}$ & $\begin{array}{l}2.90 \\
2.89 \\
2.88 \\
2.88 \\
2.87 \\
2.86\end{array}$ & $\begin{array}{l}292 \\
289 \\
286 \\
286 \\
282 \\
279\end{array}$ & $\begin{array}{l}2.81 \\
2.80 \\
2.80 \\
2.80 \\
2.79 \\
2.79\end{array}$ & & $\begin{array}{l}263 \\
260 \\
260 \\
260 \\
257 \\
257\end{array}$ \\
\hline \multirow[t]{2}{*}{$\begin{array}{r}7 \\
8 \\
9 \\
10 \\
11 \\
\mathbf{M}\end{array}$} & $\begin{array}{l}1.67 \\
1.67 \\
1.67 \\
1.67 \\
1.68 \\
1.68\end{array}$ & $\begin{array}{l}20 \\
20 \\
20 \\
20 \\
21 \\
21\end{array}$ & $\begin{array}{l}2.03 \\
2.02 \\
2.09 \\
2.27 \\
2.42 \\
2.49\end{array}$ & $\begin{array}{r}68 \\
66 \\
79 \\
118 \\
154 \\
172\end{array}$ & $\begin{array}{l}2.37 \\
2.42 \\
2.52 \\
2.59 \\
2.65 \\
2.63\end{array}$ & $\begin{array}{l}142 \\
154 \\
180 \\
199 \\
216 \\
210\end{array}$ & $\begin{array}{l}3.35 \\
3.20 \\
3.14 \\
3.11 \\
3.11 \\
3.10\end{array}$ & $\begin{array}{l}461 \\
400 \\
377 \\
366 \\
366 \\
362\end{array}$ & $\begin{array}{l}2.86 \\
2.85 \\
2.85 \\
2.85 \\
2.85 \\
2.85\end{array}$ & $\begin{array}{l}279 \\
276 \\
276 \\
276 \\
276 \\
276\end{array}$ & $\begin{array}{l}2.78 \\
2.78 \\
2.78 \\
2.77 \\
2.77 \\
2.77\end{array}$ & & $\begin{array}{l}254 \\
254 \\
254 \\
251 \\
251 \\
251\end{array}$ \\
\hline & \multicolumn{2}{|c|}{ September 24} & \multicolumn{2}{|c|}{ September 25} & \multicolumn{2}{|c|}{ September 26} & \multicolumn{2}{|c|}{ September 27} & \multicolumn{2}{|c|}{ September 28} & \multicolumn{3}{|c|}{ September 29} \\
\hline $\begin{array}{r}2 \\
4 \\
6 \\
8 \\
10 \\
N\end{array}$ & $\begin{array}{l}2.76 \\
2.74 \\
2.73 \\
2.72 \\
2.71 \\
2.70\end{array}$ & $\begin{array}{l}248 \\
242 \\
239 \\
236 \\
233 \\
230\end{array}$ & $\begin{array}{l}2.60 \\
2.59 \\
2.57 \\
2.56 \\
2.55 \\
2.53\end{array}$ & $\begin{array}{l}202 \\
199 \\
194 \\
191 \\
188 \\
183\end{array}$ & $\begin{array}{l}2.44 \\
2.42 \\
2.41 \\
2.40 \\
2.39 \\
2.38\end{array}$ & $\begin{array}{l}159 \\
154 \\
152 \\
149 \\
147 \\
144\end{array}$ & $\begin{array}{l}2.31 \\
2.30 \\
2.29 \\
2.28 \\
2.27 \\
2.26\end{array}$ & $\begin{array}{l}127 \\
125 \\
123 \\
120 \\
118 \\
116\end{array}$ & $\begin{array}{l}2.20 \\
2.20 \\
2.19 \\
2.18 \\
2.17 \\
2.16\end{array}$ & \begin{tabular}{|r|}
102 \\
102 \\
100 \\
98 \\
96 \\
94
\end{tabular} & $\begin{array}{l}2.12 \\
2.11 \\
2.11 \\
2.10 \\
2.10 \\
2.09\end{array}$ & & $\begin{array}{l}85 \\
83 \\
83 \\
81 \\
81 \\
79\end{array}$ \\
\hline $\begin{array}{r}2 \\
4 \\
6 \\
8 \\
10 \\
M\end{array}$ & $\begin{array}{l}2.68 \\
2.67 \\
2.65 \\
2.64 \\
2.62 \\
2.61\end{array}$ & $\begin{array}{l}224 \\
222 \\
216 \\
213 \\
208 \\
205\end{array}$ & $\begin{array}{l}2.51 \\
2.50 \\
2.48 \\
2.47 \\
2.46 \\
2.45\end{array}$ & $\begin{array}{l}178 \\
175 \\
170 \\
167 \\
165 \\
162\end{array}$ & $\begin{array}{l}2.36 \\
2.35 \\
2.34 \\
2.33 \\
2.32 \\
2.31\end{array}$ & $\begin{array}{l}139 \\
137 \\
135 \\
132 \\
130 \\
127\end{array}$ & $\begin{array}{l}2.25 \\
2.24 \\
2.23 \\
2.23 \\
2.22 \\
2.21\end{array}$ & $\begin{array}{l}114 \\
111 \\
109 \\
109 \\
107 \\
104\end{array}$ & $\begin{array}{l}2.16 \\
2.15 \\
2.14 \\
2.13 \\
2.13 \\
2.12\end{array}$ & $\begin{array}{l}94 \\
92 \\
89 \\
87 \\
87 \\
85\end{array}$ & $\begin{array}{l}2.09 \\
2.08 \\
2.08 \\
2.07 \\
2.07 \\
2.06\end{array}$ & & $\begin{array}{l}79 \\
77 \\
77 \\
75 \\
75 \\
73\end{array}$ \\
\hline
\end{tabular}

Supplemental records.- Sept. 20, 2:30 a.m., $2.82 \mathrm{ft.,2} 266 \mathrm{sec} . \mathrm{ft}$. Sept. 2l,

4:40 p.m., 3.97 ft., 760 sec. $-\mathrm{ft}$.

* Estimated. 
Lake Carnegie at Princeton, N. J.

Location.- Lat. $40^{\circ} 22^{\prime}$ I0 $^{\prime \prime}$, long. 74\%37'20", at Kingston Dam on Millstone River, 2 miles northeast of Princeton, Mercer County.

Drainage area.- 159 square miles.

Gage-height record.- One gage reading daily at about 8 a.m.

Remarks.- Only contents above crest of spillway are given in table. Elevation of crest of lower spillway is zero gage helght. Records furnished by Princeton University.

Gage height, in feet, and contents, in millions of cubic feet, 1938

\begin{tabular}{|c|c|c|c|c|c|c|c|c|c|c|}
\hline \multirow{2}{*}{ Day } & \multicolumn{2}{|c|}{ September } & \multicolumn{2}{|c|}{ October } & \multirow{2}{*}{ Day } & \multicolumn{2}{|c|}{ September } & \multicolumn{3}{|c|}{ October } \\
\hline & Feet & $\begin{array}{l}\text { Millions of } \\
\text { cubic feet }\end{array}$ & Feet & $\begin{array}{l}\text { Millions of } \\
\text { cubic feet }\end{array}$ & & Feet & $\begin{array}{l}\text { Millions of } \\
\text { cubic feet }\end{array}$ & Feet & \multicolumn{2}{|c|}{$\begin{array}{l}\text { Mililions of } \\
\text { cubic feet }\end{array}$} \\
\hline $\begin{array}{l}1 \\
2 \\
3 \\
4 \\
5\end{array}$ & $\begin{array}{l}0.26 \\
.24 \\
.24 \\
.24 \\
.24\end{array}$ & $\begin{array}{r}2.73 \\
2.52 \\
2.52 \\
2.52 \\
2.52\end{array}$ & $\begin{array}{r}0.50 \\
.46 \\
.44 \\
.44 \\
.42\end{array}$ & $\begin{array}{l}5.24 \\
4.82 \\
4.61 \\
4.61 \\
4.40\end{array}$ & $\begin{array}{l}16 \\
17 \\
18 \\
19 \\
20\end{array}$ & $\begin{array}{r}0.26 \\
.26 \\
.34 \\
.34 \\
1.12\end{array}$ & $\begin{array}{r}2.73 \\
2.73 \\
3.56 \\
3.56 \\
11.74\end{array}$ & $\begin{array}{l}0.36 \\
.36 \\
.38 \\
.36 \\
.36\end{array}$ & & $\begin{array}{l}3.78 \\
3.78 \\
3.98 \\
3.78 \\
3.78\end{array}$ \\
\hline $\begin{array}{r}6 \\
7 \\
8 \\
9 \\
10\end{array}$ & $\begin{array}{l}.24 \\
.24 \\
.24 \\
.24 \\
.24\end{array}$ & $\begin{array}{l}2.52 \\
2.52 \\
2.52 \\
2.52 \\
2.52\end{array}$ & $\begin{array}{l}.40 \\
.54 \\
.54 \\
.52 \\
.50\end{array}$ & $\begin{array}{l}4.19 \\
5.66 \\
5.66 \\
5.45 \\
5.24\end{array}$ & $\begin{array}{l}21 \\
22 \\
23 \\
24 \\
25\end{array}$ & $\begin{array}{r}1.30 \\
3.21 \\
1.50 \\
.94 \\
.70\end{array}$ & $\begin{array}{r}13.63 \\
33.66 \\
15.73 \\
9.86 \\
7.34\end{array}$ & $\begin{array}{l}.38 \\
.40 \\
.38 \\
.38 \\
.44\end{array}$ & & $\begin{array}{l}3.98 \\
4.19 \\
3.98 \\
3.98 \\
4.61\end{array}$ \\
\hline $\begin{array}{l}11 \\
12 \\
13 \\
14 \\
15\end{array}$ & $\begin{array}{l}.22 \\
.22 \\
.24 \\
.24 \\
.26\end{array}$ & $\begin{array}{l}2.31 \\
2.31 \\
2.52 \\
2.52 \\
2.73\end{array}$ & $\begin{array}{l}.46 \\
.42 \\
.42 \\
.38 \\
.36\end{array}$ & $\begin{array}{l}4.82 \\
4.40 \\
4.40 \\
3.98 \\
3.78\end{array}$ & $\begin{array}{l}26 \\
27 \\
28 \\
29 \\
30 \\
31\end{array}$ & $\begin{array}{l}.60 \\
.82 \\
.76 \\
.68 \\
.50\end{array}$ & $\begin{array}{l}6.29 \\
8.60 \\
7.97 \\
7.16 \\
5.24\end{array}$ & $\begin{array}{l}.44 \\
.44 \\
.44 \\
.48 \\
.50 \\
.52\end{array}$ & & $\begin{array}{l}4.61 \\
4.61 \\
4.61 \\
5.03 \\
5.24 \\
5.45\end{array}$ \\
\hline & & & & & & & & Septem & & October \\
\hline $\begin{array}{l}\text { Gain } \\
\text { Gain }\end{array}$ & $\begin{array}{l}\text { or los } \\
\text { or los }\end{array}$ & $\begin{array}{l}s \text { in storage } \\
s \text { in storage }\end{array}$ & in $\mathrm{m}$ & $\begin{array}{l}\text { llions of cu } \\
\text { uivalent mea }\end{array}$ & sec & -feet & $: \cdot: \cdot \dot{ }$ & $\begin{array}{r}+2 \\
+\end{array}$ & & $\begin{array}{r}+0.21 \\
+.08\end{array}$ \\
\hline
\end{tabular}


Millstone River near Kingston, N. J.

Location.- Water-stage recorder, lat. $40^{\circ} 23^{\prime} 05^{\prime \prime}$, long. $74^{\circ} 37^{\prime 2} 29^{\prime \prime}$, at Princeton sewage disposal plant, I mile domnstream from Heathcots Brook, Kingston, Middlesex County. Zero of gage is 38.00 feet above mean sea level (New Jersey Geological Survey benchmark).

Drainage area.- 171 square miles; affected by storage in Lake Carnegle and by water diverted into basin from Deleware River in Delaware \& Raritan Canal.

Gage-ho1ght record.- Water-stage recorder graph except for period 3 p.m. Sept. 21 to 10 p.m. Sept. 22 and 7 p.m. Sept. 25 to 11 a.m. Sept. 28 .

Stage-discharge relation.- Defined by current-meter measurements below 2,100 secondfeet; extended to peak stage on basis of study of run-off of Millstone River at Blackwells Mills, N. J.

Maxima.- September 1938: Discharge, 9,820 second-feet about 10 p.m. Sept. 21 (gage helght, 14.12 feet, from floodmark).

1933 to August 1938: D1scharge, 8,600 second-feet July 23, 1938 (gage height, 13.37 feet, from floodmark).

Remarks.- Discharge for periods of missing gage-height record, 3 p.m. Sept. 21 to 10 p.m. Sept. 22 and 7 p.m. Sept. 25 to 11 a.m. Sept. 28 , computed on basis of floodmark and record at Blackwelis Mills. For information on storage see record for Lake Carnegie at Princeton, N. J.

Mean dally discharge, in second-feet, 1938

\begin{tabular}{|c|r|r||r|r|r||r|r|r|r|r|r|}
\hline Day & Sept. & 0ct. & Day & Sept. & Oct. & Day & Sept. & 0ct. & Day & Sept. & 0ct. \\
\hline 1 & 114 & 255 & 9 & 80 & 263 & 17 & 103 & 148 & 25 & 542 & 220 \\
2 & 107 & 222 & 10 & 85 & 233 & 18 & 118 & 165 & 26 & 400 & 224 \\
3 & 100 & 196 & 11 & 72 & 193 & 19 & 350 & 159 & 27 & 450 & 198 \\
4 & 80 & 174 & 12 & 88 & 163 & 20 & 1,560 & 148 & 28 & 680 & 191 \\
5 & 96 & 159 & 13 & 98 & 149 & 21 & 5,000 & 187 & 29 & 330 & 259 \\
6 & 85 & 182 & 14 & 92 & 144 & 22 & 6,800 & 198 & 30 & 278 & 294 \\
7 & 98 & 278 & 15 & 96 & 142 & 23 & 2,510 & 178 & 31 & & 286 \\
8 & 85 & 278 & 16 & 97 & 136 & 24 & 947 & 189 & & & \\
\hline
\end{tabular}

Gage helght, in feet, and discharge, in second-feet, at indicated time, 1938

\begin{tabular}{|c|c|c|c|c|c|c|c|c|c|c|c|c|}
\hline \multirow{2}{*}{ 象 } & Feot & Soc.ft. & Feet & Sec.ft. & Feet & Sec.ft. & Feet & Sec.ft. & Feet & Sec.ft. & Feet & sec.ft. \\
\hline & \multicolumn{2}{|c|}{ September 18} & \multicolumn{2}{|c|}{ September 19} & \multicolumn{2}{|c|}{ September 20} & \multicolumn{2}{|c|}{ September 21} & \multicolumn{2}{|c|}{ September 22} & \multicolumn{2}{|c|}{ September 23} \\
\hline $\begin{array}{l}1 \\
2 \\
3 \\
4 \\
5 \\
6\end{array}$ & $\begin{array}{l}1.73 \\
1.75 \\
1.77 \\
1.79 \\
1.81 \\
1.82\end{array}$ & \begin{tabular}{|r|}
90 \\
93 \\
96 \\
99 \\
101 \\
103 \\
\end{tabular} & $\begin{array}{l}2.05 \\
2.05 \\
2.04 \\
2.03 \\
2.02 \\
2.02\end{array}$ & & $\begin{array}{l}4.07 \\
4.25 \\
4.42 \\
4.75 \\
5.58 \\
6.25\end{array}$ & \begin{tabular}{|r|}
548 \\
600 \\
655 \\
768 \\
1,100 \\
1,420 \\
\end{tabular} & & & $\begin{array}{l}- \\
\overline{-} \\
\overline{-} \\
\overline{-}\end{array}$ & & & \\
\hline $\begin{array}{r}7 \\
8 \\
9 \\
10\end{array}$ & $\begin{array}{l}1.83 \\
1.84 \\
1.85 \\
1.86 \\
1.90 \\
1.95\end{array}$ & $\begin{array}{l}104 \\
106 \\
107 \\
108 \\
114 \\
122\end{array}$ & $\begin{array}{l}2.02 \\
2.02 \\
2.01 \\
2.05 \\
2.11 \\
2.67\end{array}$ & & $\begin{array}{l}6.80 \\
7.13 \\
7.32 \\
7.37 \\
7.34 \\
7.29\end{array}$ & $\begin{array}{l}1,720 \\
1,920 \\
2,040 \\
2,070 \\
2,050 \\
2,020\end{array}$ & $\begin{array}{l}7.88 \\
7.95 \\
8.01 \\
8.10 \\
8.24 \\
8.48\end{array}$ & $\begin{array}{l}2,4 \\
2, \\
2, \\
2, \\
2, \\
2,8\end{array}$ & $\begin{array}{l}- \\
- \\
- \\
-\end{array}$ & & & \\
\hline $\begin{array}{l}7 \\
2 \\
3 \\
4 \\
5 \\
6\end{array}$ & $\begin{array}{l}1.98 \\
2.00 \\
2.02 \\
2.04 \\
2.04 \\
2.03\end{array}$ & $\begin{array}{l}127 \\
130 \\
133 \\
136 \\
136 \\
135\end{array}$ & $\begin{array}{l}3.90 \\
4.52 \\
4.80 \\
4.84 \\
4.72 \\
4.53\end{array}$ & & $\begin{array}{l}7.23 \\
7.17 \\
7.10 \\
7.00 \\
6.85 \\
6.73\end{array}$ & $\begin{array}{l}1,990 \\
1,950 \\
1,900 \\
1,840 \\
1,750 \\
1,680\end{array}$ & $\begin{array}{c}9.00 \\
10.00 \\
- \\
- \\
- \\
-\end{array}$ & & $\begin{array}{l}- \\
- \\
- \\
- \\
-\end{array}$ & & & \\
\hline \multirow[t]{2}{*}{$\begin{array}{r}7 \\
8 \\
9 \\
10 \\
11 \\
\frac{11}{1}\end{array}$} & $\begin{array}{l}2.03 \\
2.05 \\
2.06 \\
2.06 \\
2.06 \\
2.06\end{array}$ & $\begin{array}{l}135 \\
138 \\
140 \\
140 \\
140 \\
140 \\
\end{array}$ & $\begin{array}{l}4.28 \\
4.04 \\
3.89 \\
3.82 \\
3.89 \\
3.98 \\
\end{array}$ & $\begin{array}{l}610 \\
539 \\
498 \\
480 \\
498 \\
523\end{array}$ & $\begin{array}{l}6.66 \\
6.65 \\
6.71 \\
6.82 \\
6.97 \\
7.12 \\
\end{array}$ & $\begin{array}{l}1,650 \\
1,640 \\
1,680 \\
1,730 \\
1,820 \\
1,910\end{array}$ & $\begin{array}{c}- \\
- \\
- \\
14.12 \\
- \\
-\end{array}$ & & $\begin{array}{c}- \\
- \\
10.22 \\
10.05 \\
9.88\end{array}$ & & & \\
\hline & \multicolumn{2}{|c|}{ September 24} & \multicolumn{2}{|c|}{ September 25} & \multicolumn{2}{|c|}{ September 26} & \multicolumn{2}{|c|}{ September 27} & \multicolumn{2}{|c|}{ September 28} & \multicolumn{2}{|c|}{ Septiomber 29} \\
\hline $\begin{array}{r}2 \\
4 \\
6 \\
8 \\
10 \\
1\end{array}$ & $\begin{array}{l}6.09 \\
5.88 \\
5.70 \\
5.55 \\
5.41 \\
5.20\end{array}$ & $\begin{array}{r}1,340 \\
1,240 \\
1,160 \\
1,090 \\
1,020 \\
940\end{array}$ & \begin{tabular}{l|}
4.38 \\
4.26 \\
4.20 \\
4.10 \\
4.06 \\
3.97
\end{tabular} & & $\begin{array}{l}- \\
\pm \\
\pm \\
- \\
-\end{array}$ & \begin{tabular}{|l|}
450 \\
440 \\
430 \\
420 \\
410 \\
400
\end{tabular} & $\begin{array}{l}- \\
- \\
- \\
-\end{array}$ & \begin{tabular}{|l|}
340 \\
340 \\
330 \\
320 \\
320 \\
310
\end{tabular} & $\begin{array}{c}- \\
\overline{-} \\
- \\
\overline{4.25}\end{array}$ & $\begin{array}{r}1,100 \\
1,000 \\
900 \\
\end{array}$ & & \\
\hline $\begin{array}{r}2 \\
4 \\
6 \\
8 \\
10 \\
\mathrm{M}\end{array}$ & & $\begin{array}{l}87 \\
81 \\
75 \\
68 \\
70 \\
67\end{array}$ & $\begin{array}{c}3.95 \\
3.88 \\
3.85 \\
-\end{array}$ & $\begin{array}{l}470 \\
470 \\
460\end{array}$ & $\begin{array}{l}\bar{z} \\
\bar{z} \\
\bar{z}\end{array}$ & $\begin{array}{l}39 \\
38 \\
37 \\
36\end{array}$ & $\begin{array}{l}\bar{z} \\
\bar{z}\end{array}$ & $\begin{array}{r}310 \\
310 \\
320 \\
700 \\
1,100 \\
1,150\end{array}$ & & $\begin{array}{l}54 \\
48 \\
44 \\
41 \\
39 \\
38\end{array}$ & $\begin{array}{l}3.07 \\
3.07 \\
3.06 \\
3.04 \\
3.03 \\
3.00\end{array}$ & $\begin{array}{l}310 \\
314 \\
310\end{array}$ \\
\hline
\end{tabular}


Millstone River at Blackwells Mills, N. J.

Location.- Water-stage recorder, lat. $40^{\circ} 28^{\prime} 30^{\prime \prime}$, long. $74^{\circ} 34^{\prime} 34^{n}$, at highway bridge in Blackwells Mills, Somerset County, a quarter of a mile below mouth of Middlebrush Brook. Zero of gage is 26.97 feet above mean sea level (general ad justment of 1929 ). Drainage area.- 258 square miles; affected by water diverted from Delaware River in Delaware \&aritan Canal.

Gage-height record.- Water-stage recorder graph except for period 7 p.m. Sept. 21 to $10 \bar{a} \cdot \mathrm{m}$. Sept. 22 , record for which was based on floodmark and shape of avallable water-stage recorder graph.

Stage-discharge relation.- Defined by current-meter measurements below 4,000 secondfeet; extended to peak stage on basis of average discharge obtalned by slope-area determinations of flood flow.

Maxima.- September 1938: Discharge, about 18,300 second-feet about midnight Sept. 21 (gage height, 15.29 feet, from floodmark). 1921 to August 1938: Discharge, about 12,400 second-feet July 23, 1938 (gage height, 13.22 feet, from floodmark).

Remarks.- Delaware \& Raritan Canal parallels river for some distance; canal loses water to river by leakage, seepage, and flow over splllways. Daily discharge also affected by storage in Lake Carnegle. For information on storage see record for Lake Carnegle at Princeton, N. J.

Mean daily discharge, in second-feet, 1938

\begin{tabular}{|c|c|c|c|c|c|c|c|c|c|c|c|}
\hline Day & Sept. & oct. & Day & Sept. & Oct. & Day & Sept. & $0 \mathrm{ct}$. & Day & Sept. & Oct. \\
\hline $\begin{array}{l}1 \\
2 \\
3 \\
4 \\
5 \\
6 \\
7 \\
8\end{array}$ & $\begin{array}{l}145 \\
138 \\
135 \\
112 \\
112 \\
125 \\
119 \\
112\end{array}$ & $\begin{array}{l}399 \\
337 \\
302 \\
273 \\
263 \\
308 \\
554 \\
457\end{array}$ & $\begin{array}{r}9 \\
10 \\
11 \\
12 \\
13 \\
14 \\
15 \\
16\end{array}$ & $\begin{array}{l}112 \\
112 \\
109 \\
103 \\
125 \\
116 \\
122 \\
122\end{array}$ & $\begin{array}{l}399 \\
362 \\
322 \\
273 \\
249 \\
240 \\
235 \\
226\end{array}$ & $\begin{array}{l}17 \\
18 \\
19 \\
20 \\
21 \\
22 \\
23 \\
24\end{array}$ & $\begin{array}{r}125 \\
135 \\
594 \\
2,260 \\
7,860 \\
13,500 \\
5,130 \\
2,160\end{array}$ & $\begin{array}{l}235 \\
240 \\
235 \\
217 \\
268 \\
249 \\
213 \\
213\end{array}$ & $\begin{array}{l}25 \\
26 \\
27 \\
28 \\
29 \\
30 \\
31\end{array}$ & $\begin{array}{r}917 \\
614 \\
622 \\
1,450 \\
554 \\
457\end{array}$ & $\begin{array}{l}268 \\
258 \\
231 \\
217 \\
363 \\
399 \\
362\end{array}$ \\
\hline $\begin{array}{l}\text { Mean } \\
\text { Run-c }\end{array}$ & nthly & $\begin{array}{l}\text { schare } \\
\text { hes. }\end{array}$ & , 1 & second-1 & et. : &.$\dot{ }$ & $\begin{array}{l}\cdot \cdot \dot{ } \\
\cdot \cdot\end{array}$ & $\dot{*} \cdot \dot{ } \cdot$ & $: \dot{ }$ & $\begin{array}{l}1,277 \\
-\end{array}$ & $\begin{array}{c}296 \\
---\end{array}$ \\
\hline
\end{tabular}

Gage height, in feet, and discharge, in second-feet, at indicated time, 1938

\begin{tabular}{|c|c|c|c|c|c|c|c|c|c|c|c|c|}
\hline \multirow{2}{*}{$\begin{array}{r}5 \\
7 \\
0 \\
\text { 오 }\end{array}$} & Feet & Sec.ft. & Feet & Sec.ft. & Feet & Sec.ft. & Feet & Sec.ft. & Feet & Sec.ft. & Feet & Sec.ft. \\
\hline & \multicolumn{2}{|c|}{ September 18} & \multicolumn{2}{|c|}{ September 19} & \multicolumn{2}{|c|}{ September 20} & \multicolumn{2}{|c|}{ September 21} & \multicolumn{2}{|c|}{ September 22} & \multicolumn{2}{|c|}{ September 23} \\
\hline $\begin{array}{l}1 \\
2 \\
3 \\
4 \\
5 \\
6\end{array}$ & $\begin{array}{l}1.79 \\
1.79 \\
1.78 \\
1.77 \\
1.76 \\
1.76\end{array}$ & $\begin{array}{l}135 \\
135 \\
132 \\
128 \\
125 \\
125\end{array}$ & $\begin{array}{l}1.86 \\
1.86 \\
1.87 \\
1.87 \\
1.87 \\
1.87\end{array}$ & \begin{tabular}{|l}
160 \\
160 \\
164 \\
164 \\
164 \\
164
\end{tabular} & $\begin{array}{l}3.29 \\
3.25 \\
3.28 \\
3.47 \\
4.35 \\
5.38\end{array}$ & $\begin{array}{r}954 \\
942 \\
959 \\
1,060 \\
1,450 \\
1,890\end{array}$ & $\begin{array}{l}7.43 \\
7.55 \\
7.68 \\
7.76 \\
7.84 \\
7.89\end{array}$ & $\begin{array}{l}3,260 \\
3,360 \\
3,480 \\
3,560 \\
3,640 \\
3,690\end{array}$ & $\begin{array}{l}15.28 \\
15.26 \\
15.21 \\
15.15 \\
15.06 \\
14.96\end{array}$ & $\begin{array}{l}18,200 \\
18,200 \\
18,000 \\
17,800 \\
17,600 \\
17,300\end{array}$ & $\begin{array}{r}10.83 \\
10.65 \\
10.43 \\
10.30 \\
10.14 \\
9.95\end{array}$ & $\begin{array}{l}7,590 \\
7,280 \\
6,920 \\
6,710 \\
6,470 \\
6,200\end{array}$ \\
\hline $\begin{array}{r}7 \\
8 \\
9 \\
10 \\
11 \\
N\end{array}$ & $\begin{array}{l}1.75 \\
1.75 \\
1.75 \\
1.75 \\
1.75 \\
1.77\end{array}$ & $\begin{array}{l}122 \\
122 \\
122 \\
122 \\
122 \\
128\end{array}$ & $\begin{array}{l}1.87 \\
1.87 \\
1.87 \\
1.87 \\
1.87 \\
1.99\end{array}$ & $\begin{array}{l}164 \\
164 \\
164 \\
164 \\
164 \\
213\end{array}$ & $\begin{array}{l}5.90 \\
6.14 \\
6.28 \\
6.38 \\
6.48 \\
6.54\end{array}$ & $\begin{array}{l}2,150 \\
2,280 \\
2,370 \\
2,430 \\
2,500 \\
2,540\end{array}$ & $\begin{array}{l}7.93 \\
7.97 \\
8.01 \\
8.09 \\
8.23 \\
8.50\end{array}$ & $\begin{array}{l}3,730 \\
3,770 \\
3,810 \\
3,890 \\
4,030 \\
4,320\end{array}$ & $\begin{array}{l}14.78 \\
14.51 \\
14.26 \\
14.04 \\
13.80 \\
13.55\end{array}$ & $\begin{array}{l}16,700 \\
15,900 \\
15,200 \\
14,500 \\
13,900 \\
13,200\end{array}$ & $\begin{array}{l}9.80 \\
9.63 \\
9.48 \\
9.32 \\
9.18 \\
9.02\end{array}$ & $\begin{array}{l}5,990 \\
5,750 \\
5,540 \\
5,330 \\
5,140 \\
4,940\end{array}$ \\
\hline $\begin{array}{l}1 \\
2 \\
3 \\
4 \\
5 \\
6\end{array}$ & $\begin{array}{l}1.77 \\
1.78 \\
1.78 \\
1.79 \\
1.80 \\
1.81\end{array}$ & $\begin{array}{l}128 \\
132 \\
132 \\
135 \\
138 \\
142\end{array}$ & $\begin{array}{l}2.41 \\
2.95 \\
3.38 \\
3.63 \\
3.75 \\
3.84\end{array}$ & $\begin{array}{r}421 \\
765 \\
1,010 \\
1,140 \\
1,200 \\
1,250\end{array}$ & $\begin{array}{l}6.60 \\
6.66 \\
6.72 \\
6.75 \\
6.78 \\
6.82\end{array}$ & $\begin{array}{l}2,580 \\
2,620 \\
2,670 \\
2,690 \\
2,710 \\
2,750\end{array}$ & $\begin{array}{r}8.65 \\
8.97 \\
9.80 \\
10.80 \\
11.92 \\
13.15\end{array}$ & $\begin{array}{r}4,480 \\
4,870 \\
5,990 \\
7,540 \\
9,640 \\
12,300\end{array}$ & $\begin{array}{l}13.33 \\
13.11 \\
12.88 \\
12.65 \\
12.44 \\
12.22\end{array}$ & $\begin{array}{l}12,700 \\
12,200 \\
11,700 \\
11,100 \\
10,700 \\
10,200\end{array}$ & $\begin{array}{l}8.86 \\
8.71 \\
8.56 \\
8.42 \\
8.27 \\
8.14\end{array}$ & $\begin{array}{l}4,730 \\
4,550 \\
4,390 \\
4,230 \\
4,070 \\
3,940\end{array}$ \\
\hline \multirow[t]{2}{*}{$\begin{array}{r}7 \\
8 \\
9 \\
10 \\
11 \\
M \\
\end{array}$} & $\begin{array}{l}1.82 \\
1.83 \\
1.84 \\
1.85 \\
1.86 \\
1.86 \\
\end{array}$ & $\begin{array}{l}145 \\
149 \\
153 \\
156 \\
160 \\
160\end{array}$ & $\begin{array}{l}3.90 \\
3.87 \\
3.77 \\
3.64 \\
3.51 \\
3.39 \\
\end{array}$ & $\begin{array}{l}1,270 \\
1,260 \\
1,220 \\
1,150 \\
1,080 \\
1,020\end{array}$ & $\begin{array}{l}6.87 \\
6.93 \\
7.02 \\
7.11 \\
7.20 \\
7.31\end{array}$ & $\begin{array}{l}2,790 \\
2,830 \\
2,910 \\
2,980 \\
3,050 \\
3,150\end{array}$ & $\begin{array}{l}14.25 \\
14.90 \\
15.10 \\
15.22 \\
15.28 \\
15.29\end{array}$ & $\begin{array}{l}15,200 \\
17,100 \\
17,700 \\
18,100 \\
18,200 \\
18,300\end{array}$ & $\begin{array}{l}12.00 \\
11.80 \\
11.60 \\
11.40 \\
11.20 \\
11.01\end{array}$ & $\begin{array}{l}9,800 \\
9,400 \\
9,000 \\
8,620 \\
8,260 \\
7,920\end{array}$ & $\begin{array}{l}8.00 \\
7.87 \\
7.73 \\
7.60 \\
7.46 \\
7.34\end{array}$ & $\begin{array}{l}3,800 \\
3,670 \\
3,530 \\
3,410 \\
3,280 \\
3,180\end{array}$ \\
\hline & \multicolumn{2}{|c|}{ September 24} & \multicolumn{2}{|c|}{ September 25} & \multicolumn{2}{|c|}{ September 26} & \multicolumn{2}{|c|}{ September 27} & \multicolumn{2}{|c|}{ September 28} & \multicolumn{2}{|c|}{ September 29} \\
\hline $\begin{array}{r}2 \\
4 \\
6 \\
8 \\
10 \\
\mathrm{~N}\end{array}$ & $\begin{array}{l}7.09 \\
6.86 \\
6.64 \\
6.40 \\
6.16 \\
5.89\end{array}$ & $\begin{array}{l}2,960 \\
2,780 \\
2,610 \\
2,440 \\
2,300 \\
2,140\end{array}$ & $\begin{array}{l}3.67 \\
3.52 \\
3.39 \\
3.28 \\
3.20 \\
3.13\end{array}$ & $\begin{array}{r}1,160 \\
1,090 \\
1,020 \\
959 \\
915 \\
873\end{array}$ & $\begin{array}{l}2.84 \\
2.81 \\
2.78 \\
2.75 \\
2.73 \\
2.72\end{array}$ & $\begin{array}{l}696 \\
676 \\
656 \\
635 \\
621 \\
614\end{array}$ & $\begin{array}{l}2.57 \\
2.55 \\
2.53 \\
2.52 \\
2.50 \\
2.49\end{array}$ & \begin{tabular}{|l|}
517 \\
505 \\
493 \\
487 \\
475 \\
469
\end{tabular} & $\begin{array}{l}5.38 \\
5.40 \\
5.27 \\
5.08 \\
4.83 \\
4.56\end{array}$ & $\begin{array}{l}1,890 \\
1,900 \\
1,840 \\
1,740 \\
1,640 \\
1,530\end{array}$ & \begin{tabular}{|l|}
2.79 \\
2.74 \\
2.71 \\
2.67 \\
2.64 \\
2.61
\end{tabular} & $\begin{array}{l}663 \\
628 \\
607 \\
580 \\
561 \\
542\end{array}$ \\
\hline $\begin{array}{r}2 \\
4 \\
6 \\
8 \\
10 \\
M\end{array}$ & $\begin{array}{l}5.59 \\
5.25 \\
4.85 \\
4.48 \\
4.15 \\
3.88\end{array}$ & $\begin{array}{l}2,000 \\
1,820 \\
1,650 \\
1,500 \\
1,370 \\
1,260\end{array}$ & $\begin{array}{l}3.06 \\
3.00 \\
2.96 \\
2.93 \\
2.90 \\
2.87 \\
\end{array}$ & $\begin{array}{l}831 \\
795 \\
771 \\
753 \\
735 \\
716\end{array}$ & $\begin{array}{l}2.71 \\
2.68 \\
2.67 \\
2.64 \\
2.60 \\
2.57\end{array}$ & $\begin{array}{l}607 \\
587 \\
580 \\
561 \\
535 \\
517\end{array}$ & $\begin{array}{l}2.49 \\
2.48 \\
2.45 \\
2.70 \\
4.30 \\
5.13\end{array}$ & $\begin{array}{r}469 \\
463 \\
445 \\
600 \\
1,430 \\
1,760 \\
\end{array}$ & $\begin{array}{l}4.24 \\
3.88 \\
3.51 \\
3.21 \\
3.00 \\
2.87\end{array}$ & $\begin{array}{r}1,410 \\
1,260 \\
1,080 \\
920 \\
795 \\
716 \\
\end{array}$ & $\begin{array}{l}2.58 \\
2.56 \\
2.55 \\
2.54 \\
2.53 \\
2.52 \\
\end{array}$ & $\begin{array}{l}523 \\
511 \\
505 \\
499 \\
493 \\
487 \\
\end{array}$ \\
\hline
\end{tabular}


Location.- Water-stage reeorder, lat. 40 $36^{\prime} 50^{\prime \prime}$, long. $74^{\circ} 25^{\prime} 5^{\prime \prime}$, just below Sycamore

Avenue, Plainfield, Union County, and 1 mile upstream from Stony Brook. Drainage area.- 9.75 square miles.

Gage-height record.- Water-stage recorder graph.

Stage-discharge relation.- Defined by current-meter measurements below 200 second-feet; extended to peak stage by averaging discharges obtained in 2 reaches by contractedopening determinations of flood flow.

Maxima.- September 1938: Discharge, 1,740 second-feet 3:40 p.m. Sept. 21 (gage height, 4.89 feet).

May to August 1938: D1scharge, 2,890 second-feet July 23, 1938 (gage height,

5.82 feet)

Remarks.- Record started May 12, 1938.

Mean daily discharge, in second-feet, 1938

\begin{tabular}{|c|c|c|c|c|c|c|c|c|c|c|c|}
\hline Dey & Sept. & 0 ct. & Day & Sept. & Oct. & Day & Sept. & Oct. & Day & Sept. & oct. \\
\hline $\begin{array}{l}1 \\
2 \\
3 \\
4 \\
5 \\
6 \\
7 \\
8\end{array}$ & $\begin{array}{l}3.5 \\
2.2 \\
2.0 \\
2.0 \\
2.0 \\
1.8 \\
2.0 \\
1.7\end{array}$ & $\begin{array}{l}6.2 \\
3.3 \\
3.2 \\
4.2 \\
4.2 \\
7.7 \\
8.2 \\
4.2\end{array}$ & $\begin{array}{r}9 \\
10 \\
11 \\
12 \\
13 \\
14 \\
15 \\
16\end{array}$ & $\begin{array}{l}1.7 \\
1.7 \\
1.5 \\
1.4 \\
1.7 \\
1.7 \\
2.9 \\
2.4\end{array}$ & $\begin{array}{l}3.6 \\
3.2 \\
3.4 \\
3.4 \\
3.4 \\
3.2 \\
3.2 \\
3.2\end{array}$ & $\begin{array}{l}17 \\
18 \\
19 \\
20 \\
21 \\
22 \\
23 \\
24\end{array}$ & $\begin{array}{c}2.9 \\
2.9 \\
44 \\
104 \\
498 \\
81 \\
26 \\
16.4\end{array}$ & $\begin{array}{l}3.2 \\
2.9 \\
2.6 \\
4.2 \\
5.9 \\
4.5 \\
3.4 \\
4.8\end{array}$ & $\begin{array}{l}25 \\
26 \\
27 \\
28 \\
29 \\
30 \\
31\end{array}$ & $\begin{array}{r}14.0 \\
10.1 \\
7.4 \\
7.2 \\
6.0 \\
4.8\end{array}$ & $\begin{array}{l}5.5 \\
4.2 \\
4.2 \\
8.3 \\
5.5 \\
4.5 \\
3.9\end{array}$ \\
\hline $\begin{array}{l}\text { Mean } \\
\text { Run- }\end{array}$ & $\begin{array}{l}\text { nthly } \\
, \text { in }\end{array}$ & & & & - & & $\begin{array}{lll} & \bullet & \bullet \\
\bullet & \bullet & \bullet\end{array}$ & $\begin{array}{ll}\cdot & \cdot \\
. & \cdot\end{array}$ & . & $\begin{array}{l}28.6 \\
3.27\end{array}$ & $\begin{array}{l}4.37 \\
0.52\end{array}$ \\
\hline
\end{tabular}

Gage height, in feet, and discharge, in second-feet, at indlcated time, 1938

\begin{tabular}{|c|c|c|c|c|c|c|c|c|c|c|c|c|}
\hline \multirow{2}{*}{ 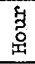 } & Feet & Sec.ft. & Feet & Sec.ft. & Feet & Sec.ft. & Feet & Sec.ft. & Feet & Sec.ft. & Feet & Sec.ft. \\
\hline & \multicolumn{2}{|c|}{ September 18} & \multicolumn{2}{|c|}{ Sept ember 19} & \multicolumn{2}{|c|}{ September 20} & \multicolumn{2}{|c|}{ September 21} & \multicolumn{2}{|c|}{ September 22} & \multicolumn{2}{|c|}{ September 23} \\
\hline $\begin{array}{l}1 \\
2 \\
3 \\
4 \\
5 \\
6\end{array}$ & $\begin{array}{r}0.83 \\
.83 \\
.83 \\
.82 \\
.82 \\
.82\end{array}$ & $\begin{array}{l}2.6 \\
2.6 \\
2.6 \\
2.4 \\
2.4 \\
2.4\end{array}$ & $\begin{array}{r}0.84 \\
1.04 \\
.94 \\
.88 \\
.86 \\
.94\end{array}$ & $\begin{array}{l}2.9 \\
9.5 \\
5.8 \\
3.9 \\
3.4 \\
5.8\end{array}$ & $\begin{array}{l}1.32 \\
1.79 \\
1.52 \\
1.87 \\
1.90 \\
2.02\end{array}$ & $\begin{array}{r}28 \\
102 \\
54 \\
119 \\
126 \\
155\end{array}$ & $\begin{array}{l}1.98 \\
1.87 \\
1.83 \\
1.81 \\
1.80 \\
1.82\end{array}$ & $\begin{array}{l}145 \\
119 \\
111 \\
106 \\
104 \\
108\end{array}$ & $\begin{array}{l}2.12 \\
2.04 \\
1.98 \\
1.90 \\
1.85 \\
1.80\end{array}$ & $\begin{array}{l}180 \\
160 \\
145 \\
126 \\
115 \\
104\end{array}$ & $\begin{array}{l}1.37 \\
1.36 \\
1.35 \\
1.35 \\
1.34 \\
1.33\end{array}$ & $\begin{array}{l}34 \\
33 \\
32 \\
32 \\
31 \\
29\end{array}$ \\
\hline $\begin{array}{r}7 \\
8 \\
9 \\
10 \\
11 \\
\mathbf{N}\end{array}$ & $\begin{array}{l}.82 \\
.81 \\
.81 \\
.81 \\
.80 \\
.94\end{array}$ & $\begin{array}{l}2.4 \\
2.2 \\
2.2 \\
2.2 \\
2.0 \\
5.8\end{array}$ & $\begin{array}{r}.90 \\
.88 \\
.88 \\
.87 \\
.87 \\
2.00\end{array}$ & $\begin{array}{r}4.5 \\
3.9 \\
3.9 \\
3.6 \\
3.6 \\
150\end{array}$ & $\begin{array}{l}2.36 \\
2.40 \\
2.22 \\
2.00 \\
1.80 \\
1.66\end{array}$ & $\begin{array}{r}249 \\
261 \\
208 \\
150 \\
104 \\
76\end{array}$ & $\begin{array}{l}1.89 \\
1.98 \\
2.07 \\
2.31 \\
2.32 \\
2.71\end{array}$ & $\begin{array}{l}124 \\
145 \\
168 \\
234 \\
237 \\
366\end{array}$ & $\begin{array}{l}1.76 \\
1.72 \\
1.68 \\
1.65 \\
1.63 \\
1.60\end{array}$ & $\begin{array}{l}96 \\
88 \\
79 \\
74 \\
70 \\
66\end{array}$ & $\begin{array}{l}1.33 \\
1.32 \\
1.32 \\
1.31 \\
1.30 \\
1.30\end{array}$ & $\begin{array}{l}29 \\
28 \\
28 \\
27 \\
26 \\
26\end{array}$ \\
\hline $\begin{array}{l}1 \\
2 \\
3 \\
4 \\
5 \\
6\end{array}$ & $\begin{array}{l}.92 \\
.86 \\
.83 \\
.82 \\
.82 \\
.81\end{array}$ & $\begin{array}{l}5.2 \\
3.4 \\
2.6 \\
2.4 \\
2.4 \\
2.2\end{array}$ & $\begin{array}{l}1.81 \\
1.94 \\
1.93 \\
1.70 \\
1.65 \\
1.56\end{array}$ & $\begin{array}{r}106 \\
136 \\
133 \\
84 \\
74 \\
59\end{array}$ & $\begin{array}{l}1.56 \\
1.52 \\
1.45 \\
1.42 \\
1.43 \\
1.51\end{array}$ & $\begin{array}{l}59 \\
54 \\
44 \\
40 \\
41 \\
52\end{array}$ & $\begin{array}{l}3.20 \\
3.70 \\
4.10 \\
4.59 \\
4.69 \\
4.57\end{array}$ & $\begin{array}{r}564 \\
818 \\
1,070 \\
1,450 \\
1,540 \\
1,440\end{array}$ & $\begin{array}{l}1.58 \\
1.55 \\
1.58 \\
1.51 \\
1.48 \\
1.47\end{array}$ & $\begin{array}{l}62 \\
58 \\
55 \\
52 \\
48 \\
47\end{array}$ & $\begin{array}{l}1.29 \\
1.28 \\
1.27 \\
1.26 \\
1.26 \\
1.24\end{array}$ & $\begin{array}{l}25 \\
25 \\
24 \\
23 \\
23 \\
21\end{array}$ \\
\hline \multirow[t]{2}{*}{$\begin{array}{r}7 \\
8 \\
9 \\
10 \\
11 \\
\\
\end{array}$} & $\begin{array}{l}.81 \\
.82 \\
.90 \\
.88 \\
.86 \\
.85\end{array}$ & $\begin{array}{l}2.2 \\
2.4 \\
4.5 \\
3.9 \\
3.4 \\
3.2\end{array}$ & $\begin{array}{l}1.47 \\
1.40 \\
1.36 \\
1.36 \\
1.49 \\
1.33\end{array}$ & $\begin{array}{l}47 \\
38 \\
33 \\
33 \\
49 \\
29\end{array}$ & $\begin{array}{l}1.52 \\
1.68 \\
1.75 \\
1.91 \\
2.02 \\
2.03\end{array}$ & $\begin{array}{r}54 \\
79 \\
94 \\
128 \\
155 \\
158 \\
\end{array}$ & $\begin{array}{l}4.20 \\
3.50 \\
2.88 \\
2.52 \\
2.33 \\
2.21\end{array}$ & $\begin{array}{r}1,140 \\
709 \\
430 \\
300 \\
240 \\
205\end{array}$ & $\begin{array}{l}1.45 \\
1.43 \\
1.42 \\
1.40 \\
1.39 \\
1.38\end{array}$ & $\begin{array}{l}44 \\
41 \\
40 \\
38 \\
37 \\
35\end{array}$ & $\begin{array}{l}1.24 \\
1.23 \\
1.22 \\
1.22 \\
1.22 \\
1.21\end{array}$ & $\begin{array}{l}21 \\
21 \\
19.8 \\
19.8 \\
19.8 \\
19.0\end{array}$ \\
\hline & \multicolumn{2}{|c|}{ September 24} & \multicolumn{2}{|c|}{ September 25} & \multicolumn{2}{|c|}{ September 26} & \multicolumn{2}{|c|}{ September 27} & \multicolumn{2}{|c|}{ September 28} & \multicolumn{2}{|c|}{ September 29} \\
\hline $\begin{array}{r}2 \\
4 \\
6 \\
8 \\
10 \\
\mathrm{~N}\end{array}$ & $\begin{array}{l}1.20 \\
1.19 \\
1.19 \\
1.18 \\
1.18 \\
1.17\end{array}$ & $\begin{array}{l}18.3 \\
17.7 \\
17.7 \\
17.1 \\
17.1 \\
16.4\end{array}$ & $\begin{array}{l}1.14 \\
1.14 \\
1.14 \\
1.14 \\
1.13 \\
1.13\end{array}$ & $\begin{array}{l}14.6 \\
14.6 \\
14.6 \\
14.6 \\
14.0 \\
14.0\end{array}$ & $\begin{array}{l}1.12 \\
1.11 \\
1.11 \\
1.10 \\
1.10 \\
1.09\end{array}$ & $\begin{array}{l}13.5 \\
12.9 \\
12.9 \\
12.4 \\
12.4 \\
11.8\end{array}$ & $\begin{array}{r}0.94 \\
.94 \\
.94 \\
.94 \\
.94 \\
.94\end{array}$ & $\begin{array}{l}5.8 \\
5.8 \\
5.8 \\
5.8 \\
5.8 \\
5.8\end{array}$ & $\begin{array}{r}1.00 \\
.99 \\
.99 \\
.98 \\
.98 \\
.98\end{array}$ & $\begin{array}{l}7.9 \\
7.5 \\
7.5 \\
7.2 \\
7.2 \\
7.2\end{array}$ & $\begin{array}{l}0.98 \\
.98 \\
.98 \\
.98 \\
.98 \\
.95\end{array}$ & $\begin{array}{l}7.2 \\
7.2 \\
7.2 \\
7.2 \\
7.2 \\
6.2\end{array}$ \\
\hline $\begin{array}{r}2 \\
4 \\
6 \\
8 \\
10 \\
M\end{array}$ & $\begin{array}{l}1.17 \\
1.17 \\
1.15 \\
1.15 \\
1.15 \\
1.15\end{array}$ & $\begin{array}{l}16.4 \\
16.4 \\
15.2 \\
15.2 \\
15.2 \\
15.2\end{array}$ & $\begin{array}{l}1.13 \\
1.13 \\
1.12 \\
1.12 \\
1.12 \\
1.12\end{array}$ & $\begin{array}{l}14.0 \\
14.0 \\
13.5 \\
13.5 \\
13.5 \\
13.5\end{array}$ & $\begin{array}{r}1.02 \\
.98 \\
.96 \\
.95 \\
.95 \\
.95\end{array}$ & $\begin{array}{l}8.7 \\
7.2 \\
6.6 \\
6.2 \\
6.2 \\
6.2\end{array}$ & $\begin{array}{r}.94 \\
.94 \\
1.12 \\
1.08 \\
1.03 \\
1.00\end{array}$ & $\begin{array}{r}5.8 \\
5.8 \\
13.5 \\
11.3 \\
9.1 \\
7.9\end{array}$ & $\begin{array}{l}.98 \\
.98 \\
.98 \\
.98 \\
.98 \\
.98\end{array}$ & $\begin{array}{l}7.2 \\
7.2 \\
7.2 \\
7.2 \\
7.2 \\
7.2\end{array}$ & $\begin{array}{l}.93 \\
.92 \\
.91 \\
.90 \\
.90 \\
.90\end{array}$ & $\begin{array}{l}5.5 \\
5.2 \\
4.8 \\
4.5 \\
4.5 \\
4.5\end{array}$ \\
\hline
\end{tabular}

Supplemental records.- Sept. 19, 11:55 a.m., $2.14 \mathrm{ft} ., 186 \mathrm{sec} .-\mathrm{ft} . ; 12: 05 \mathrm{p.m}$; sec.-ft. 7:30 a.m., $2.43 \mathrm{ft}$., 271 sec.-ft.; 4:20 'p.m., 1.49 ft., 49 sec.-ft. Sept. 21 , 8:40 a.m.' $1.97 \mathrm{ft.}, 143$ sec.ft.; $10: 30$ a.m., $2.23 \mathrm{ft} ., 211$ sec.-ft.; $3: 40$ p.m., 4.89 ft., 1,740 sec. $-\mathrm{ft}$. 
Location.- Water-stage recorder, lat. $40^{\circ} 27^{\prime} 00^{\prime \prime}$, Iong. $74^{\circ} 27^{\prime} 05^{\prime \prime}$, on Lawrence Brook. at Farrington Dem, half a mile southwest of Militow, Middlesex County.

Draingge area.- 34.4 square miles.

cage-helght record. - Water-stage recorder graph.

Remarks.- Usable torage capacity is $87,600,000$ cubic feet. Crest of notch in dam at

gage helght 24.00 feet. Blor-off gate open after 8:15 a.m. Sept. 12. For additional information on tage see record of gage helghts for Lawrence Brook at Farrington Dam, N. J.

Gage helght, in.feet, and contents, in millions of cubic feet, $1938 \underline{\mathrm{a}}$

\begin{tabular}{|c|c|c|c|c|c|c|c|c|c|}
\hline \multirow[b]{2}{*}{ Day } & \multicolumn{2}{|c|}{ September } & \multicolumn{2}{|c|}{ October } & \multirow[b]{2}{*}{ Day } & \multicolumn{2}{|c|}{ September } & \multicolumn{2}{|c|}{ October } \\
\hline & Feet & $\begin{array}{l}\text { Millions of } \\
\text { cubic feet }\end{array}$ & Feet & $\begin{array}{l}\text { Millions of } \\
\text { cubic feet }\end{array}$ & & Feet & $\begin{array}{l}\text { Millions of } \\
\text { cubic feet }\end{array}$ & Feet & $\begin{array}{l}\text { Millions of } \\
\text { cublc feet }\end{array}$ \\
\hline $\begin{array}{l}1 \\
2 \\
3 \\
4 \\
5\end{array}$ & $\begin{array}{l}24.51 \\
24.50 \\
24.49 \\
24.48 \\
24.48\end{array}$ & $\begin{array}{r}92.4 \\
92.2 \\
92.1 \\
92.1 \\
92.1\end{array}$ & $\begin{array}{l}22.06 \\
21.76 \\
21.55 \\
21.46 \\
21.49\end{array}$ & \begin{tabular}{|l|}
70.2 \\
67.8 \\
66.0 \\
65.4 \\
65.5 \\
\end{tabular} & $\begin{array}{l}16 \\
17 \\
18 \\
19 \\
20\end{array}$ & $\begin{array}{l}24.16 \\
24.14 \\
24.15 \\
24.74 \\
25.01\end{array}$ & $\begin{array}{r}89.0 \\
88.9 \\
89.0 \\
94.5 \\
97.1\end{array}$ & $\begin{array}{l}21.66 \\
21.72 \\
21.81 \\
21.82 \\
21.85\end{array}$ & $\begin{array}{r}67.0 \\
67.4 \\
68.2 \\
68.2 \\
68.4\end{array}$ \\
\hline $\begin{array}{r}6 \\
7 \\
8 \\
9 \\
10\end{array}$ & $\begin{array}{l}24.48 \\
24.46 \\
24.44 \\
24.45 \\
24.45\end{array}$ & $\begin{array}{l}92.1 \\
91.8 \\
91.8 \\
91.7 \\
91.7\end{array}$ & $\begin{array}{l}21.47 \\
21.68 \\
22.11 \\
22.26 \\
22.23\end{array}$ & $\begin{array}{l}65.4 \\
67.1 \\
70.6 \\
71.8 \\
71.5\end{array}$ & $\begin{array}{l}21 \\
22 \\
23 \\
24 \\
25\end{array}$ & $\begin{array}{l}25.95 \\
24.88 \\
24.74 \\
24.66 \\
24.61\end{array}$ & $\begin{array}{r}107.1 \\
95.8 \\
94.5 \\
93.7 \\
93.3\end{array}$ & $\begin{array}{l}21.80 \\
21.58 \\
21.40 \\
21.40 \\
21.48\end{array}$ & $\begin{array}{l}68.0 \\
66.3 \\
64.8 \\
64.8 \\
65.5\end{array}$ \\
\hline $\begin{array}{l}11 \\
12 \\
13 \\
14 \\
15\end{array}$ & $\begin{array}{l}24.45 \\
24.38 \\
24.30 \\
24.23 \\
24.21\end{array}$ & $\begin{array}{l}91.7 \\
91.2 \\
90.4 \\
89.7 \\
89.6\end{array}$ & $\begin{array}{l}21.98 \\
21.72 \\
21.57 \\
21.60 \\
21.64\end{array}$ & $\begin{array}{l}69.5 \\
67.4 \\
66.2 \\
66.4 \\
66.7\end{array}$ & $\begin{array}{l}26 \\
27 \\
28 \\
29 \\
30 \\
31\end{array}$ & $\begin{array}{l}24.50 \\
24.41 \\
24.06 \\
23.33 \\
22.57\end{array}$ & $\begin{array}{l}92.2 \\
91.4 \\
88.1 \\
81.3 \\
74.2\end{array}$ & $\begin{array}{l}21.76 \\
22.02 \\
22.16 \\
22.64 \\
22.59 \\
22.34\end{array}$ & $\begin{array}{l}67.8 \\
69.8 \\
71.0 \\
74.9 \\
74.3 \\
72.3\end{array}$ \\
\hline \multirow[b]{2}{*}{$\begin{array}{l}\text { Gain } \\
\text { Gain }\end{array}$} & & & & & & & & September & October \\
\hline & $\begin{array}{l}\text { or los: } \\
\text { or los: }\end{array}$ & $\begin{array}{l}\text { s in storage, } \\
s \text { in storage, }\end{array}$ & $\begin{array}{l}\text { in } \mathrm{mi} \\
\text { in eqi }\end{array}$ & $\begin{array}{l}\text { Ilions of cu } \\
\text { ufvalent mea }\end{array}$ & & & $\therefore: \therefore$ & $\begin{array}{l}-17.9 \\
-6.9\end{array}$ & $\begin{array}{l}-1.9 \\
-0.7\end{array}$ \\
\hline
\end{tabular}

a/ At 12 p.m. of day Indicated. 
Location. - Water-stage recorder, lat. $40^{\circ} 27^{100^{n}}$, long. $74^{\circ} 27^{\prime} 05^{n}$, at Farrington Dam, half mile southwest of Militown, Middlesex County, and 5 miles above mouth.

Drainage area.- 34.4 square miles; effected by artiflcial storage.

Gago-he1ght record. - Water-s tage recorder graph.

Stsge-discharge relation. - For flow over spillwey defined by current-meter measurements below 500 second-feet; extended to peak stage on basis of determination of flow by weir formula. Discharge through waste gates defined by current-meter measurements.

Maxima. - September 1938: Discharge, about 2,660 second-feet 8 p.m. Sept. 21 (gage heIght, 26.18 foot).

1927 to August 1938: D1scharge, about 1,900 second-feet July 6, 1928 (gage helght, 25.84 feot).

Remarks.- Dally, hourly, and peak discharges are the sum of discharge over sp1llway and through blow-off gates. Blow-off gates open after 8:15 a.m. Sept. 2l. Mean monthly discharge and run-off, in inches, adjusted for storage in reservolr. For Information on storage see record for Reservolr on Lawrence Brook at Farrington Dam, N. J. Water-stage recorder operated by emplojee of clty of New Brunswick.

Mean dally discharge, in second-feet, 1938

\begin{tabular}{|c|r|r||r|r|r||r|r|r||r|r|r|}
\hline Day & Sept. & Oct. & Day & Sept. & Oct. & Day & Sept. & oct. & Day & Sept. & Oct. \\
\hline 1 & 19.4 & 97 & 9 & 9.0 & 39 & 17 & 12.7 & 22 & 25 & 87 & 52 \\
2 & 17.1 & 64 & 10 & 9.0 & 51 & 18 & 12.7 & 22 & 26 & 59 & 52 \\
3 & 15.0 & 49 & 11 & 9.0 & 66 & 19 & 45 & 22 & 27 & 36 & 53 \\
4 & 13.1 & 35 & 12 & 15.9 & 64 & 20 & 401 & 22 & 28 & 107 & 55 \\
5 & 13.1 & 35 & 13 & 17.5 & 45 & 21 & 1,280 & 40 & 29 & 150 & 58 \\
6 & 13.1 & 35 & 14 & 15.4 & 21 & 22 & 822 & 52 & 30 & 143 & 62 \\
7 & 10.0 & 35 & 15 & 14.1 & 21 & 23 & 233 & 52 & 31 & & 59 \\
8 & 10.0 & 36 & 16 & 13.8 & 21 & 24 & 130 & 52 & & & \\
\hline
\end{tabular}

Gage height, in feet, and discharge, in second-feet, at Indicated time, 1938

\begin{tabular}{|c|c|c|c|c|c|c|c|c|c|c|c|c|}
\hline 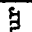 & Feot & Sec.ft. & Feet & Seo.ft. & Feet & Sec.ft. & Feet & Sec.ft. & Beet & Sec.ft. & Feet & Sec.ft \\
\hline & Septem & aber 18 & Septen & nber 19 & Septe & ber 20 & Septer & aber 21 & Septer & ber 22 & Septer & eer 23 \\
\hline & $\begin{array}{l}24.14 \\
24.14 \\
24.14 \\
24.14 \\
24.14 \\
24.14\end{array}$ & $\begin{array}{l}12.7 \\
12.7 \\
12.7 \\
12.7 \\
12.7 \\
12.7\end{array}$ & $\begin{array}{l}24.15 \\
24.15 \\
24.16 \\
24.16 \\
24.16 \\
24.16\end{array}$ & $\begin{array}{l}12.9 \\
12.9 \\
13.0 \\
13.0 \\
13.0 \\
13.0\end{array}$ & $\begin{array}{l}24.74 \\
24.76 \\
24.77 \\
24.78 \\
24.80 \\
24.88\end{array}$ & $\begin{array}{l}173 \\
193 \\
203 \\
213 \\
233 \\
322\end{array}$ & $\begin{array}{l}25.02 \\
25.02 \\
25.03 \\
25.05 \\
25.08 \\
25.09\end{array}$ & $\begin{array}{l}494 \\
494 \\
509 \\
534 \\
574 \\
589\end{array}$ & $\begin{array}{l}25.85 \\
25.74 \\
25.64 \\
25.56 \\
25.48 \\
25.42\end{array}$ & $\begin{array}{l}1,940 \\
1,700 \\
1,500 \\
1,350 \\
1,200 \\
1,100\end{array}$ & & $\begin{array}{l}310 \\
310 \\
299 \\
287 \\
276 \\
266\end{array}$ \\
\hline & $\begin{array}{l}24.14 \\
24.14 \\
24.14 \\
24.14 \\
24.14 \\
24.14\end{array}$ & $\begin{array}{l}12.7 \\
12.7 \\
12.7 \\
12.7 \\
12.7 \\
12.7\end{array}$ & $\begin{array}{l}24.17 \\
24.17 \\
24.17 \\
24.17 \\
24.17 \\
24.19\end{array}$ & $\begin{array}{l}13.3 \\
13.3 \\
13.3 \\
13.3 \\
13.3 \\
13.8\end{array}$ & $\begin{array}{l}24.92 \\
24.95 \\
24.97 \\
24.98 \\
25.00 \\
25.01\end{array}$ & $\begin{array}{l}369 \\
405 \\
430 \\
443 \\
468 \\
481\end{array}$ & $\begin{array}{l}25.1 \\
25.1 \\
25.1 \\
25.1 \\
25.1 \\
25.1\end{array}$ & $\begin{array}{l}604 \\
604 \\
604 \\
619 \\
659 \\
720\end{array}$ & $\begin{array}{l}25.31 \\
25.27 \\
25.23 \\
25.19 \\
25.16\end{array}$ & $\begin{array}{r}1,000 \\
920 \\
855 \\
795 \\
735 \\
689\end{array}$ & $\begin{array}{l}24 . \\
24 . \\
24 . \\
24 . \\
24 .\end{array}$ & $\begin{array}{l}254 \\
244 \\
244 \\
233 \\
223 \\
213\end{array}$ \\
\hline & $\begin{array}{l}24.14 \\
24.14 \\
24.14 \\
24.14 \\
24.14 \\
24.14\end{array}$ & $\begin{array}{l}12.7 \\
12.7 \\
12.7 \\
12.7 \\
12.7 \\
12.7\end{array}$ & $\begin{array}{l}24.32 \\
24.44 \\
24.50 \\
24.54 \\
24.58 \\
24.60\end{array}$ & $\begin{array}{l}16.8 \\
21 \\
30 \\
42 \\
59 \\
69\end{array}$ & $\begin{array}{l}25.03 \\
25.03 \\
25.04 \\
25.02 \\
25.02 \\
25.00\end{array}$ & $\begin{array}{l}509 \\
509 \\
519 \\
494 \\
494 \\
468\end{array}$ & $\begin{array}{l}25.26 \\
25.40 \\
25.62 \\
25.77 \\
25.90 \\
26.02\end{array}$ & $\begin{array}{r}840 \\
1,060 \\
1,460 \\
1,760 \\
2,040 \\
2,300\end{array}$ & $\begin{array}{l}25.11 \\
25.06 \\
25.03 \\
25.01 \\
24.98 \\
24.96\end{array}$ & $\begin{array}{l}619 \\
549 \\
509 \\
481 \\
443 \\
418\end{array}$ & & $\begin{array}{l}213 \\
203 \\
203 \\
203 \\
193 \\
193\end{array}$ \\
\hline & $\begin{array}{l}24.14 \\
24.14 \\
24.14 \\
24.15 \\
24.15 \\
24.15\end{array}$ & $\begin{array}{l}12.7 \\
12.7 \\
12.7 \\
12.9 \\
12.9 \\
12.9\end{array}$ & $\begin{array}{l}24.63 \\
24.66 \\
24.68 \\
24.71 \\
24.74 \\
24.74\end{array}$ & $\begin{array}{r}87 \\
107 \\
122 \\
147 \\
173 \\
173 \\
\end{array}$ & $\begin{array}{l}24.99 \\
24.98 \\
24.99 \\
25.00 \\
25.01 \\
25.01\end{array}$ & $\begin{array}{l}455 \\
443 \\
455 \\
468 \\
481 \\
481 \\
\end{array}$ & $\begin{array}{l}26.13 \\
26.18 \\
26.17 \\
26.12 \\
26.04 \\
25.95\end{array}$ & $\begin{array}{l}2,550 \\
2,660 \\
2,640 \\
2,530 \\
2,350 \\
2,150\end{array}$ & $\begin{array}{l}24.94 \\
24.92 \\
24.91 \\
24.90 \\
24.88\end{array}$ & $\begin{array}{l}405 \\
393 \\
369 \\
357 \\
345 \\
322 \\
\end{array}$ & & $\begin{array}{l}193 \\
183 \\
173 \\
173 \\
173 \\
173 \\
\end{array}$ \\
\hline & Septe: & 24 & Septer & er 25 & Septe & or 26 & Septer & ber 27 & Septe & er 28 & Septem & ber 29 \\
\hline & $\begin{array}{l}24.73 \\
24.72 \\
24.71 \\
24.71 \\
24.70 \\
24.70\end{array}$ & $\begin{array}{l}164 \\
155 \\
147 \\
147 \\
138 \\
138\end{array}$ & $\begin{array}{l}24.65 \\
24.65 \\
24.64 \\
24.64 \\
24.63 \\
24.63\end{array}$ & $\begin{array}{r}100 \\
100 \\
93 \\
93 \\
87 \\
87\end{array}$ & $\begin{array}{l}24.61 \\
24.61 \\
24.60 \\
24.60 \\
24.60 \\
24.59\end{array}$ & $\begin{array}{l}75 \\
75 \\
69 \\
69 \\
69 \\
64\end{array}$ & & $\begin{array}{l}41 \\
40 \\
37 \\
36 \\
36 \\
35\end{array}$ & & $\begin{array}{r}36 \\
36 \\
36 \\
36 \\
164 \\
162\end{array}$ & & $\begin{array}{l}152 \\
152 \\
151 \\
151 \\
150 \\
150\end{array}$ \\
\hline & $\begin{array}{l}24.69 \\
24.68 \\
24.67 \\
24.66 \\
24.66 \\
24.66\end{array}$ & $\begin{array}{l}130 \\
122 \\
115 \\
107 \\
107 \\
107\end{array}$ & $\begin{array}{l}24 \\
24 \\
24 \\
24 \\
24\end{array}$ & $\begin{array}{l}87 \\
81 \\
81 \\
81 \\
75 \\
75\end{array}$ & $\begin{array}{l}24.59 \\
24.57 \\
24.55 \\
24.53 \\
24.51 \\
24.50\end{array}$ & $\begin{array}{l}64 \\
70 \\
61 \\
53 \\
47 \\
45\end{array}$ & & $\begin{array}{l}35 \\
35 \\
35 \\
35 \\
35 \\
35\end{array}$ & & $\begin{array}{l}160 \\
159 \\
157 \\
156 \\
154 \\
154\end{array}$ & & $\begin{array}{l}149 \\
149 \\
148 \\
148 \\
147 \\
147\end{array}$ \\
\hline
\end{tabular}


Tinton Falls Reservoir near Red Bank, N. J.

Locat1on. - Water-stage recorder, lat. $40^{\circ} 19^{\prime} 03^{\prime \prime}$, long. $74^{\circ} 06^{\prime} 57^{\prime \prime}$, on Swimming River above dam of Consolidated Water Co., 3 miles above mouth of river at Red Bank, Monmouth County.

Drainaze area.- 48.5 square miles.

Gage-height record. - Water-stage recorder graph.

Remarks.-Contents above zero gage helght given in table. For additional information on stage see record for Swimming River near Red Bank, N. J.

Gage height, in feet, and contents, in millions of cubic feet, 1938 a/

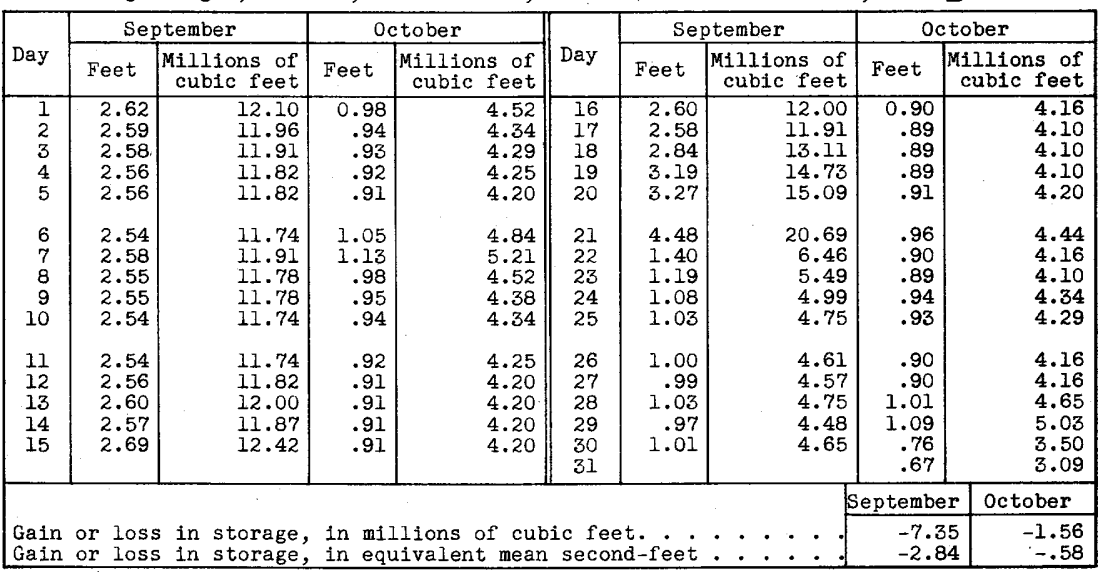

a/ At midnight of indicated day. 
Location:- Water-stage recorder, lat. $40^{\circ} 19^{\prime} 03^{n}$, long. $74^{\circ} 06^{\prime} 57^{n}$, above dam of Monmouth Consolidated Water Co., $3 \mathrm{miles}$ above mouth of river at Red Bank, Monmouth County.

Drainage area.- 48.5 square miles; affected by storage.

Gage-height record. - Water-stage recorder graph.

Stage-discharge relation. - Defined by current-meter measurements below 500 second-feet; extended to peak stago on basis of determination of flow by weir formula. Discharge through blow-off gates defined by current-meter measurements.

Maxima.- September 1938: Discharge, 7,370 second-feet 7:30 p.m. Sept. 21 (gage helght, 6.96 feet).

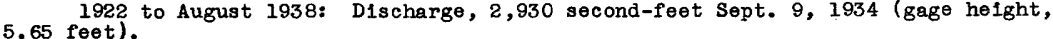
Remarks. - Hourly and dally discharges indlcate sum of discharge over sp1llway, through blow-off gates, and divergion to pumping station. Blow-off gate open subsequent to noon on oct. 29. Part of the crest of dam falled about 6 p.m. on Sept. 21. Mean monthly discharge and run-off, in inches, adjusted for storage in Tinton Falls Reservolr. For information on storage see record of Tinton Falls Reservoir near Red Bank, N. J. Water-stage recorder inspected and record of diversion furnished by Monmouth Consolidated Water Co.

Mean daily discharge, in second-feet, 1938

\begin{tabular}{|c|c|c|c|c|c|c|c|c|c|c|c|}
\hline Day & Sept. & Oct. & Day & Sept. & Oct. & Day & Sept. & Oct. & Day & Sept. & Oct. \\
\hline $\begin{array}{l}1 \\
2 \\
3 \\
4 \\
5 \\
6 \\
7 \\
8\end{array}$ & $\begin{array}{l}57 \\
57 \\
52 \\
50 \\
4 i \\
45 \\
46 \\
46\end{array}$ & $\begin{array}{l}151 \\
126 \\
119 \\
114 \\
110 \\
126 \\
249 \\
159\end{array}$ & $\begin{array}{r}9 \\
10 \\
11 \\
12 \\
13 \\
14 \\
15 \\
16\end{array}$ & $\begin{array}{l}41 \\
43 \\
41 \\
44 \\
49 \\
52 \\
56 \\
69\end{array}$ & $\begin{array}{l}130 \\
122 \\
118 \\
110 \\
110 \\
110 \\
110 \\
105\end{array}$ & $\begin{array}{l}17 \\
18 \\
19 \\
20 \\
21 \\
22 \\
23 \\
24\end{array}$ & $\begin{array}{r}51 \\
64 \\
245 \\
364 \\
2,380 \\
1,050 \\
259 \\
201\end{array}$ & $\begin{array}{l}106 \\
102 \\
103 \\
103 \\
122 \\
113 \\
102 \\
109\end{array}$ & $\begin{array}{l}25 \\
26 \\
27 \\
28 \\
29 \\
30 \\
31\end{array}$ & $\begin{array}{l}165 \\
151 \\
139 \\
156 \\
138 \\
143\end{array}$ & $\begin{array}{r}126 \\
110 \\
106 \\
125 \\
185 \\
158 \\
88\end{array}$ \\
\hline $\begin{array}{l}\text { Mean } \\
\text { Mean } \\
\text { Run- }\end{array}$ & $\begin{array}{l}\text { monthly } \\
\text { monthly } \\
\text { ff, in }\end{array}$ & hes ( & ir & econd- & $60 h$ & . . . & 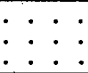 & 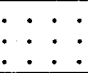 & 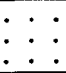 & $\begin{array}{r}210 \\
207 \\
4.76 \\
\end{array}$ & $\begin{array}{r}123 \\
123 \\
2.93\end{array}$ \\
\hline
\end{tabular}

Gage helght, in feet, and discharge, in second-feet, at indicated time, 1938

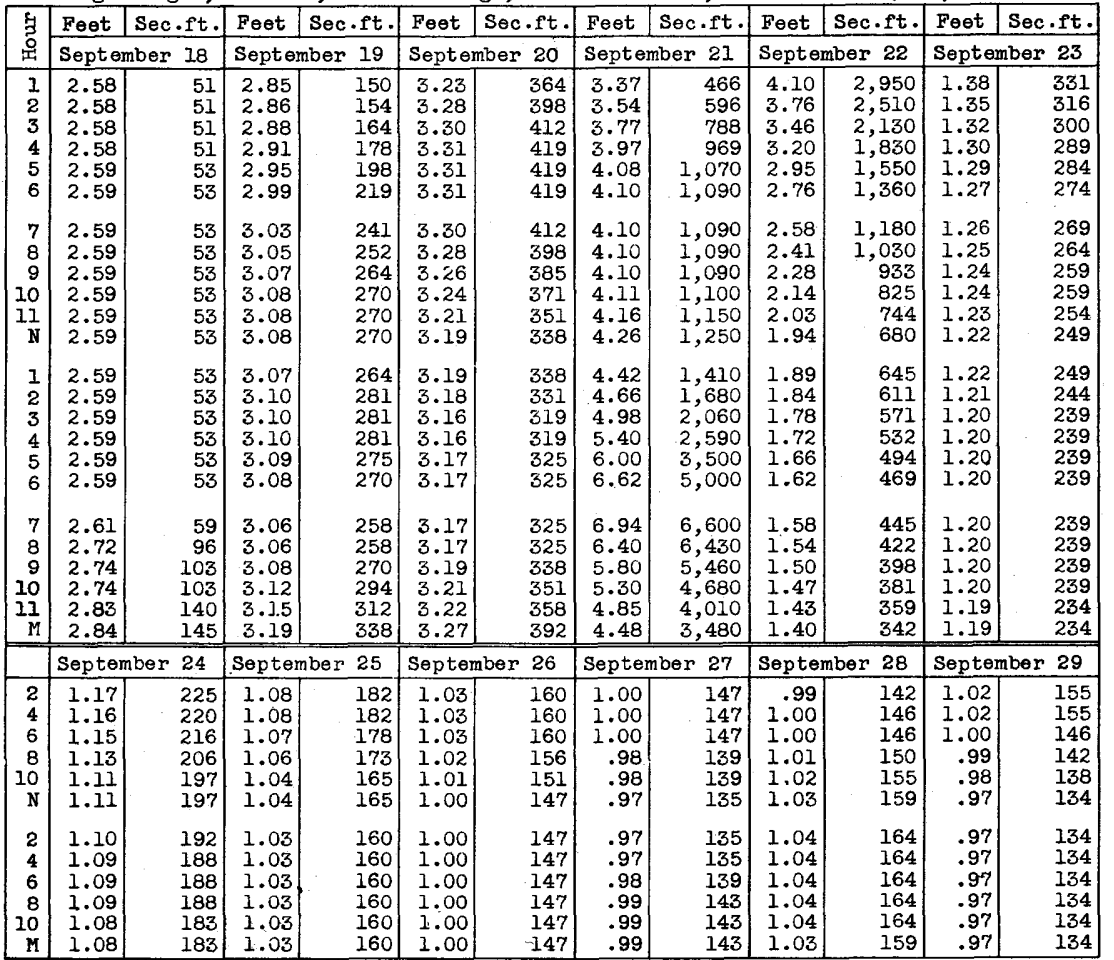

Supplemental records.- Sept. 21 , 7:30 p.m., $6.96 \mathrm{ft.,} 7,370$ sec.-ft. 
Manasquan RIver at Squankum, N. J.

Location.- Water-8tage recorder, lat, $40^{\circ} 09^{\prime} 47^{\prime \prime}$, long. $74^{\circ} 09^{\prime} 21^{\prime \prime}$, at FarmingdaleLakewood highway bridge in Squankum, Monmouth County, half a mile below mouth of Marshbog Brook.

Drainage erea.- 43.4 square miles; not affected by artificial storage.

fage-helght record. - Water-stage recorder graph except 1 p.m. Sept. 21 to 5 p.m. Sept. 30, when there is no record.

Stage-discharge relation.- Defined by current-meter measurements below 720 second-feet; extended to peak stage on basis of determination of flood flow by contracted-opening method.

Maxima. - September 1938: Discharge, 2,940 second-feet Sept. 21 (gage he1ght, 12.45 foot, from floodmark .

1931 to August 1938: Discharge, 1,550 second-feet June 28, 1938 (gage he1ght, 10.09 feet).

Remarks.- Discharge for perlod of missing gage helghts, 1 p.m. Sept. 21 to 5 p.m., Sept. 30 , computed on basis of floodmark and records of swimming River near Red Bank, N. J., and other nearby stresms.

Mean delly discharge, in second-feet, 1938

\begin{tabular}{|c|c|c|c|c|c|c|c|c|c|c|c|}
\hline Day & Sept. & Oet. & Day & Sept. & Oct. & Day & Sept. & oct. & Day & Sept. & Oct. \\
\hline $\begin{array}{l}1 \\
2 \\
3 \\
4 \\
5 \\
6 \\
7 \\
8\end{array}$ & $\begin{array}{l}48 \\
44 \\
42 \\
40 \\
38 \\
36 \\
35 \\
36\end{array}$ & $\begin{array}{r}112 \\
93 \\
84 \\
79 \\
75 \\
85 \\
151 \\
104\end{array}$ & $\begin{array}{r}9 \\
10 \\
11 \\
12 \\
13 \\
14 \\
15 \\
16\end{array}$ & $\begin{array}{l}35 \\
34 \\
34 \\
34 \\
38 \\
38 \\
38 \\
37\end{array}$ & $\begin{array}{l}87 \\
80 \\
74 \\
70 \\
68 \\
67 \\
66 \\
66\end{array}$ & $\begin{array}{l}17 \\
18 \\
19 \\
20 \\
21 \\
22 \\
23 \\
24\end{array}$ & $\begin{array}{r}37 \\
73 \\
206 \\
323 \\
1,650 \\
1,300 \\
300 \\
190\end{array}$ & $\begin{array}{l}66 \\
66 \\
66 \\
66 \\
85 \\
80 \\
80 \\
80\end{array}$ & $\begin{array}{l}25 \\
26 \\
27 \\
28 \\
29 \\
30 \\
31\end{array}$ & $\begin{array}{l}150 \\
130 \\
130 \\
160 \\
130 \\
114\end{array}$ & $\begin{array}{r}90 \\
90 \\
85 \\
100 \\
150 \\
130 \\
100\end{array}$ \\
\hline $\begin{array}{l}\text { Mean } \\
\text { Run-c }\end{array}$ & $\begin{array}{l}\text { onthly } \\
f, \text { in } 1\end{array}$ & $\begin{array}{l}\text { schare } \\
\text { hes. }\end{array}$ & in & - . . & et. : & $\dot{.}$ & $\therefore \quad$. & 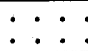 & $\dot{0}$ & $\begin{array}{r}183 \\
4.71\end{array}$ & $\begin{array}{l}86.9 \\
2.31\end{array}$ \\
\hline
\end{tabular}

Gage helght, in feet, and discharge, in second-feet, at indicated time, 1938

\begin{tabular}{|c|c|c|c|c|c|c|c|c|c|c|c|c|}
\hline \multirow{2}{*}{ 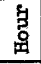 } & Feet & sec.ft. & Feet & Sec.ft. & Feot & Sec.ft. & Feet & Sec.ft. & Feet & Sec.ft. & Feot & Sec.ft. \\
\hline & \multicolumn{2}{|c|}{ September 18} & \multicolumn{2}{|c|}{ September 19} & \multicolumn{2}{|c|}{ September 20} & \multicolumn{2}{|c|}{ Sept ember 21} & \multicolumn{2}{|c|}{ September 22} & \multicolumn{2}{|c|}{ September 23} \\
\hline $\begin{array}{l}1 \\
2 \\
3 \\
4 \\
5 \\
6\end{array}$ & $\begin{array}{l}1.66 \\
1.66 \\
1.66 \\
1.66 \\
1.66 \\
1.66\end{array}$ & $\begin{array}{l}39 \\
39 \\
39 \\
39 \\
39 \\
39\end{array}$ & $\begin{array}{l}4.28 \\
4.23 \\
4.16 \\
4.10 \\
4.01 \\
3.91\end{array}$ & $\begin{array}{l}231 \\
227 \\
220 \\
215 \\
207 \\
198\end{array}$ & $\begin{array}{l}4.75 \\
4.66 \\
4.55 \\
4.42 \\
4.35 \\
4.30\end{array}$ & $\begin{array}{l}274 \\
266 \\
256 \\
244 \\
238 \\
233\end{array}$ & $\begin{array}{l}7.62 \\
7.72 \\
7.81 \\
7.94 \\
8.04 \\
8.15\end{array}$ & \begin{tabular}{|l|}
659 \\
682 \\
704 \\
736 \\
763 \\
793
\end{tabular} & $\begin{array}{l}- \\
- \\
- \\
- \\
-\end{array}$ & $\begin{array}{l}- \\
- \\
- \\
\overline{-} \\
-\end{array}$ & $\begin{array}{l}- \\
- \\
- \\
- \\
-\end{array}$ & $\begin{array}{l}\overline{-} \\
\overline{-} \\
\overline{-} \\
\overline{-}\end{array}$ \\
\hline $\begin{array}{r}7 \\
8 \\
9 \\
10 \\
11 \\
11\end{array}$ & $\begin{array}{l}1.66 \\
1.66 \\
1.66 \\
1.67 \\
1.67 \\
1.67\end{array}$ & $\begin{array}{l}39 \\
39 \\
39 \\
40 \\
40 \\
40\end{array}$ & $\begin{array}{l}3.80 \\
3.65 \\
3.50 \\
3.36 \\
3.26 \\
3.22\end{array}$ & $\begin{array}{l}188 \\
175 \\
163 \\
152 \\
144 \\
141\end{array}$ & $\begin{array}{l}4.26 \\
4.24 \\
4.22 \\
4.20 \\
4.17 \\
4.21\end{array}$ & $\begin{array}{l}229 \\
228 \\
226 \\
224 \\
221 \\
225\end{array}$ & $\begin{array}{r}8.31 \\
8.47 \\
8.80 \\
9.10 \\
9.60 \\
10.08\end{array}$ & $\begin{array}{r}839 \\
889 \\
1,000 \\
1,110 \\
1,320 \\
1,540\end{array}$ & $\begin{array}{l}- \\
- \\
- \\
- \\
-\end{array}$ & $\begin{array}{c}- \\
- \\
- \\
- \\
- \\
* 1,300\end{array}$ & $\begin{array}{l}- \\
- \\
- \\
- \\
-\end{array}$ & $\begin{array}{l}- \\
- \\
- \\
- \\
* 300\end{array}$ \\
\hline $\begin{array}{l}1 \\
2 \\
3 \\
4 \\
5 \\
6\end{array}$ & $\begin{array}{l}1.67 \\
1.67 \\
1.68 \\
1.75 \\
1.94 \\
2.40\end{array}$ & $\begin{array}{l}40 \\
40 \\
41 \\
48 \\
66 \\
94\end{array}$ & $\begin{array}{l}3.34 \\
3.67 \\
4.00 \\
4.20 \\
4.28 \\
4.29\end{array}$ & $\begin{array}{l}150 \\
177 \\
206 \\
224 \\
231 \\
232\end{array}$ & $\begin{array}{l}4.33 \\
4.54 \\
4.81 \\
5.17 \\
5.57 \\
6.00\end{array}$ & $\begin{array}{l}236 \\
255 \\
280 \\
313 \\
350 \\
398\end{array}$ & $\begin{array}{c}10.34 \\
- \\
- \\
- \\
- \\
-\end{array}$ & $\begin{array}{l}1,660 \\
- \\
- \\
- \\
-\end{array}$ & $\begin{array}{l}- \\
- \\
- \\
- \\
-\end{array}$ & $\begin{array}{l}- \\
- \\
- \\
- \\
-\end{array}$ & $\begin{array}{l}- \\
- \\
- \\
- \\
-\end{array}$ & $\begin{array}{l}- \\
- \\
- \\
-\end{array}$ \\
\hline \multirow[t]{2}{*}{$\begin{array}{r}7 \\
8 \\
9 \\
10 \\
11 \\
11\end{array}$} & $\begin{array}{l}2.92 \\
3.22 \\
3.44 \\
3.78 \\
4.14 \\
4.27\end{array}$ & $\begin{array}{l}121 \\
141 \\
158 \\
186 \\
219 \\
230\end{array}$ & $\begin{array}{l}4.31 \\
4.38 \\
4.48 \\
4.59 \\
4.68 \\
4.74\end{array}$ & $\begin{array}{l}234 \\
240 \\
249 \\
260 \\
268 \\
274\end{array}$ & $\begin{array}{l}6.36 \\
6.66 \\
6.91 \\
7.16 \\
7.38 \\
7.51\end{array}$ & $\begin{array}{l}443 \\
483 \\
522 \\
565 \\
607 \\
634\end{array}$ & $\begin{array}{l}- \\
- \\
= \\
- \\
-\end{array}$ & $\begin{array}{c}* 2,500 \\
- \\
- \\
- \\
-\end{array}$ & $\begin{array}{l}- \\
- \\
- \\
- \\
-\end{array}$ & $\begin{array}{l}- \\
- \\
- \\
- \\
-\end{array}$ & $\begin{array}{l}- \\
- \\
- \\
- \\
-\end{array}$ & $\begin{array}{l}- \\
- \\
- \\
- \\
-\end{array}$ \\
\hline & \multicolumn{2}{|c|}{ September 24} & \multicolumn{2}{|c|}{ September 25} & \multicolumn{2}{|c|}{ September 26} & \multicolumn{2}{|c|}{ September 27} & \multicolumn{2}{|c|}{ September 28} & \multicolumn{2}{|c|}{ September 29} \\
\hline $\begin{array}{r}2 \\
4 \\
6 \\
8 \\
10 \\
N\end{array}$ & $\begin{array}{l}- \\
- \\
- \\
- \\
-\end{array}$ & $\begin{array}{l}- \\
- \\
- \\
- \\
* 190\end{array}$ & $\begin{array}{l}- \\
- \\
- \\
- \\
-\end{array}$ & $\begin{array}{l}- \\
- \\
- \\
- \\
* 150\end{array}$ & $\begin{array}{l}- \\
- \\
- \\
-\end{array}$ & $\begin{array}{l}- \\
- \\
- \\
- \\
- \\
* 130\end{array}$ & $\begin{array}{l}- \\
- \\
- \\
-\end{array}$ & $\begin{array}{l}- \\
- \\
- \\
- \\
\bar{*} \\
* 130\end{array}$ & $\begin{array}{l}- \\
- \\
- \\
-\end{array}$ & $\begin{array}{l}- \\
- \\
- \\
- \\
* 160\end{array}$ & $\begin{array}{l}- \\
- \\
- \\
-\end{array}$ & $\begin{array}{l}- \\
- \\
- \\
- \\
* 130\end{array}$ \\
\hline $\begin{array}{r}2 \\
4 \\
6 \\
8 \\
10 \\
1\end{array}$ & $\begin{array}{l}- \\
- \\
- \\
-\end{array}$ & $\begin{array}{l}- \\
- \\
- \\
-\end{array}$ & $\begin{array}{l}- \\
\text { - } \\
\text { - } \\
\text { - }\end{array}$ & $\begin{array}{l}- \\
- \\
- \\
-\end{array}$ & $\begin{array}{l}- \\
- \\
- \\
-\end{array}$ & $\begin{array}{l}- \\
- \\
- \\
-\end{array}$ & $\begin{array}{l}- \\
\overline{-} \\
\overline{-} \\
\overline{-}\end{array}$ & $\begin{array}{l}- \\
- \\
- \\
-\end{array}$ & $\begin{array}{l}- \\
\overline{-} \\
\overline{-} \\
-\end{array}$ & $\begin{array}{l}- \\
- \\
- \\
-\end{array}$ & $\begin{array}{l}- \\
- \\
- \\
-\end{array}$ & $\begin{array}{l}- \\
- \\
- \\
-\end{array}$ \\
\hline
\end{tabular}

* Mean for the day. 
Toms River near Toms River, N. J.

Location.- Water-stage recorder, lat. $39^{\circ} 59^{\prime} 10^{\mathrm{n}}$, long. $74^{\circ} 13^{\prime} 29^{\prime \prime}$, 1 mile below mouth of Union Branch and 2 miles northwest of viliage of Toms River, Ocean County.

Dralnage area.- 124 square miles.

Gage-helght record.- Water-stage recorder graph except for period 4 p.m. Sept. 22 to 9 a.m. Sept. 24, when graph was based on floodmark and shape of recorder graph before and after the period.

Stgge-d1scharge relation.- Defined by current-meter measurements below 650 second-feet; extended to peak stage by logarithic plotting.

Maxima.- September 1938: Discharge, 1,540 second-feet 7 to 10 a.r. Sept. 23 (gage

helght, 12.50 feet, from floodmark)

1928 to August 1938: D1scharge, 1,240 second-feet June 29, 1938 (gage he1ght, 11.1 feet, from floodmark).

Mean dally discharge, In second-feet, 1938

\begin{tabular}{|c|c|c|c|c|c|c|c|c|c|c|c|}
\hline Day & Sept. & Oot. & Day & Sept. & Oct. & Day & Sept. & Oct. & Day & Sept. & Oct. \\
\hline $\begin{array}{l}1 \\
2 \\
3 \\
4 \\
5 \\
6 \\
7 \\
8\end{array}$ & $\begin{array}{l}162 \\
174 \\
174 \\
166 \\
160 \\
153 \\
149 \\
149\end{array}$ & $\begin{array}{l}328 \\
307 \\
307 \\
287 \\
276 \\
270 \\
287 \\
297 \\
\end{array}$ & $\begin{array}{r}9 \\
10 \\
11 \\
12 \\
13 \\
14 \\
15 \\
16\end{array}$ & $\begin{array}{l}149 \\
146 \\
146 \\
144 \\
146 \\
149 \\
149 \\
146\end{array}$ & $\begin{array}{l}307 \\
297 \\
287 \\
270 \\
253 \\
247 \\
235 \\
241\end{array}$ & $\begin{array}{l}17 \\
18 \\
19 \\
20 \\
21 \\
22 \\
23 \\
24\end{array}$ & $\begin{array}{r}147 \\
156 \\
216 \\
282 \\
511 \\
1,080 \\
1,500 \\
1,120\end{array}$ & $\begin{array}{l}235 \\
222 \\
216 \\
216 \\
216 \\
222 \\
229 \\
235\end{array}$ & $\begin{array}{l}25 \\
26 \\
27 \\
28 \\
29 \\
30 \\
31\end{array}$ & $\begin{array}{l}736 \\
542 \\
444 \\
389 \\
351 \\
328\end{array}$ & $\begin{array}{l}253 \\
247 \\
247 \\
265 \\
287 \\
307 \\
328\end{array}$ \\
\hline $\begin{array}{l}\text { Mean } \\
\text { Run- }\end{array}$ & $\begin{array}{l}\text { onthly } \\
c, \text { in } 1\end{array}$ & hes. & , 1 & - & et. & . $\dot{ }$ & ... & $\begin{array}{ll}\cdot & \bullet \\
. & \bullet\end{array}$ & . $\dot{ }$ & $\begin{array}{r}342 \\
3.08 \\
\end{array}$ & $\begin{array}{r}265 \\
2.47 \\
\end{array}$ \\
\hline
\end{tabular}

Gege height, In feet, and discharge, In second-feet, at indicated time, 1938

\begin{tabular}{|c|c|c|c|c|c|c|c|c|c|c|c|c|c|}
\hline \multirow{2}{*}{$\begin{array}{l}4 \\
3 \\
0 \\
\end{array}$} & Feot & Sec.ft. & Feet & Sec.ft. & Feet & Sec.ft. & Feet & Sec & . ft. & Feet & Sec.ft. & Feet & Sec.ft. \\
\hline & \multicolumn{2}{|c|}{ September 18} & \multicolumn{2}{|c|}{ September 18} & \multicolumn{2}{|c|}{ September 20} & \multicolumn{3}{|c|}{ September 21} & \multicolumn{2}{|c|}{ September 22} & \multicolumn{2}{|c|}{ Sept ember 23} \\
\hline $\begin{array}{l}1 \\
2 \\
3 \\
4 \\
5 \\
6\end{array}$ & $\begin{array}{l}3.83 \\
3.83 \\
3.83 \\
3.83 \\
3.83 \\
3.84\end{array}$ & $\begin{array}{l}149 \\
149 \\
149 \\
149 \\
149 \\
150\end{array}$ & $\begin{array}{l}4.25 \\
4.26 \\
4.27 \\
4.28 \\
4.28 \\
4.29\end{array}$ & $\begin{array}{l}198 \\
199 \\
200 \\
202 \\
202 \\
203\end{array}$ & $\begin{array}{l}4.68 \\
4.70 \\
4.72 \\
4.73 \\
4.74 \\
4.75\end{array}$ & $\begin{array}{l}251 \\
253 \\
255 \\
257 \\
258 \\
259\end{array}$ & $\begin{array}{l}5.63 \\
5.67 \\
5.72 \\
5.79 \\
5.86 \\
5.94\end{array}$ & & $\begin{array}{l}355 \\
359 \\
366 \\
375 \\
384 \\
394\end{array}$ & $\begin{array}{l}8.47 \\
8.59 \\
8.72 \\
8.83 \\
8.96 \\
9.10\end{array}$ & $\begin{array}{l}766 \\
785 \\
806 \\
824 \\
845 \\
868\end{array}$ & $\begin{array}{l}12.27 \\
12.34 \\
12.39 \\
12.43 \\
12.46 \\
12.48\end{array}$ & $\begin{array}{l}1,490 \\
1,510 \\
1,520 \\
1,530 \\
1,530 \\
1,540\end{array}$ \\
\hline $\begin{array}{r}7 \\
8 \\
9 \\
10 \\
11 \\
N\end{array}$ & $\begin{array}{l}3.84 \\
3.84 \\
3.84 \\
3.84 \\
3.85 \\
3.85\end{array}$ & $\begin{array}{l}150 \\
150 \\
150 \\
150 \\
152 \\
152\end{array}$ & $\begin{array}{l}4.31 \\
4.33 \\
4.34 \\
4.36 \\
4.37 \\
4.38\end{array}$ & $\begin{array}{l}205 \\
208 \\
209 \\
211 \\
212 \\
214\end{array}$ & $\begin{array}{l}4.78 \\
4.80 \\
4.82 \\
4.85 \\
4.87 \\
4.89\end{array}$ & $\begin{array}{l}263 \\
265 \\
267 \\
270 \\
273 \\
275\end{array}$ & $\begin{array}{l}5.99 \\
6.07 \\
6.14 \\
6.21 \\
6.30 \\
6.42\end{array}$ & & $\begin{array}{l}401 \\
412 \\
422 \\
431 \\
444 \\
461\end{array}$ & $\begin{array}{r}9.25 \\
9.39 \\
9.54 \\
9.73 \\
9.90 \\
10.10\end{array}$ & $\begin{array}{r}894 \\
917 \\
943 \\
976 \\
1,010 \\
1,040\end{array}$ & $\begin{array}{l}12.50 \\
12.50 \\
12.50 \\
12.50 \\
12.49 \\
12.47\end{array}$ & $\begin{array}{l}1,540 \\
1,540 \\
1,540 \\
1,540 \\
1,540 \\
1,530\end{array}$ \\
\hline $\begin{array}{l}1 \\
2 \\
3 \\
4 \\
5 \\
6\end{array}$ & $\begin{array}{l}3.85 \\
3.85 \\
3.86 \\
3.87 \\
3.87 \\
3.87\end{array}$ & $\begin{array}{l}152 \\
152 \\
153 \\
154 \\
154 \\
154\end{array}$ & $\begin{array}{l}4.39 \\
4.41 \\
4.45 \\
4.48 \\
4.52 \\
4.56\end{array}$ & $\begin{array}{l}215 \\
217 \\
222 \\
226 \\
231 \\
236\end{array}$ & $\begin{array}{l}4.91 \\
4.95 \\
4.97 \\
4.98 \\
5.07 \\
5.16\end{array}$ & $\begin{array}{l}277 \\
282 \\
284 \\
285 \\
294 \\
303\end{array}$ & $\begin{array}{l}6.80 \\
7.06 \\
7.35 \\
7.50 \\
7.63 \\
7.74\end{array}$ & & $\begin{array}{l}514 \\
551 \\
594 \\
617 \\
636 \\
653\end{array}$ & $\begin{array}{l}10.30 \\
10.52 \\
10.72 \\
10.90 \\
11.12 \\
11.33\end{array}$ & $\begin{array}{l}1,080 \\
1,120 \\
1,160 \\
1,200 \\
1,240 \\
1,290\end{array}$ & $\begin{array}{l}12.44 \\
12.40 \\
12.37 \\
12.32 \\
12.26 \\
12.19\end{array}$ & $\begin{array}{l}1,530 \\
1,520 \\
1,510 \\
1,500 \\
1,490 \\
1,470\end{array}$ \\
\hline \multirow[t]{2}{*}{$\begin{array}{r}7 \\
8 \\
9 \\
10 \\
11 \\
M \\
\end{array}$} & $\begin{array}{l}3.88 \\
3.94 \\
4.02 \\
4.10 \\
4.18 \\
4.22 \\
\end{array}$ & $\begin{array}{l}155 \\
161 \\
170 \\
180 \\
190 \\
194\end{array}$ & $\begin{array}{l}4.59 \\
4.61 \\
4.63 \\
4.64 \\
4.66 \\
4.67\end{array}$ & $\begin{array}{l}240 \\
242 \\
245 \\
246 \\
248 \\
249 \\
\end{array}$ & $\begin{array}{l}5.25 \\
5.32 \\
5.40 \\
5.47 \\
5.54 \\
5.59\end{array}$ & $\begin{array}{l}312 \\
319 \\
328 \\
336 \\
344 \\
350\end{array}$ & $\begin{array}{l}7.84 \\
7.93 \\
8.05 \\
8.15 \\
8.25 \\
8.35\end{array}$ & & $\begin{array}{l}668 \\
682 \\
700 \\
715 \\
731 \\
747 \\
\end{array}$ & $\begin{array}{l}11.58 \\
11.75 \\
11.90 \\
12.02 \\
12.12 \\
12.20\end{array}$ & $\begin{array}{l}1,340 \\
1,370 \\
1,410 \\
1,430 \\
1,450 \\
1,470\end{array}$ & $\begin{array}{l}12.11 \\
12.04 \\
11.96 \\
11.88 \\
11.80 \\
11.70\end{array}$ & $\begin{array}{l}1,450 \\
1,440 \\
1,420 \\
1,400 \\
1,380 \\
1,360\end{array}$ \\
\hline & \multicolumn{2}{|c|}{ September 24} & \multicolumn{2}{|c|}{ September 25} & \multicolumn{2}{|c|}{ September 26} & \multicolumn{3}{|c|}{ September 27} & \multicolumn{2}{|c|}{ September 28} & \multicolumn{2}{|c|}{ September 29} \\
\hline $\begin{array}{r}2 \\
4 \\
6 \\
8 \\
10 \\
N\end{array}$ & $\begin{array}{l}11.50 \\
11.30 \\
11.08 \\
10.88 \\
10.65 \\
10.49\end{array}$ & $\begin{array}{l}1,320 \\
1,280 \\
1,240 \\
1,200 \\
1,150 \\
1,120\end{array}$ & $\begin{array}{l}9.09 \\
8.90 \\
8.73 \\
8.58 \\
8.42 \\
8.28\end{array}$ & $\begin{array}{l}866 \\
835 \\
808 \\
784 \\
758 \\
736\end{array}$ & $\begin{array}{l}7.42 \\
7.33 \\
7.24 \\
7.17 \\
7.09 \\
7.01\end{array}$ & $\begin{array}{l}605 \\
592 \\
578 \\
568 \\
556 \\
544\end{array}$ & $\begin{array}{l}6.56 \\
6.50 \\
6.44 \\
6.39 \\
6.33 \\
6.27\end{array}$ & & $\begin{array}{l}480 \\
472 \\
464 \\
457 \\
448 \\
440\end{array}$ & $\begin{array}{l}5.92 \\
5.89 \\
5.85 \\
5.87 \\
5.94 \\
5.95\end{array}$ & $\begin{array}{l}392 \\
388 \\
382 \\
385 \\
394 \\
396\end{array}$ & $\begin{array}{l}5.76 \\
5.69 \\
5.62 \\
5.57 \\
5.52 \\
5.49\end{array}$ & $\begin{array}{l}371 \\
362 \\
353 \\
347 \\
341 \\
338\end{array}$ \\
\hline $\begin{array}{r}2 \\
4 \\
6 \\
8 \\
10 \\
14\end{array}$ & $\begin{array}{r}10.30 \\
10.10 \\
9.88 \\
9.69 \\
9.48 \\
9.28\end{array}$ & $\begin{array}{r}1,080 \\
1,040 \\
1,010 \\
969 \\
933 \\
899\end{array}$ & $\begin{array}{l}8.14 \\
7.98 \\
7.84 \\
7.72 \\
7.61 \\
7.51\end{array}$ & $\begin{array}{l}713 \\
689 \\
668 \\
650 \\
634 \\
618\end{array}$ & $\begin{array}{l}6.94 \\
6.87 \\
6.80 \\
6.73 \\
6.67 \\
6.62\end{array}$ & $\begin{array}{l}534 \\
524 \\
514 \\
504 \\
496 \\
489\end{array}$ & $\begin{array}{l}6.22 \\
6.16 \\
6.11 \\
6.06 \\
6.01 \\
5.96\end{array}$ & & $\begin{array}{l}433 \\
424 \\
417 \\
410 \\
403 \\
397\end{array}$ & $\begin{array}{l}5.91 \\
5.85 \\
5.86 \\
5.90 \\
5.89 \\
5.83\end{array}$ & $\begin{array}{l}390 \\
382 \\
384 \\
389 \\
388 \\
380\end{array}$ & $\begin{array}{l}5.46 \\
5.43 \\
5.44 \\
5.47 \\
5.50 \\
5.49\end{array}$ & $\begin{array}{l}335 \\
331 \\
332 \\
336 \\
339 \\
338\end{array}$ \\
\hline
\end{tabular}


Great Egg River at Folsom, N. J.

Location.- Water-stage recorder, lat. $39^{\circ} 35^{\prime} 42^{\prime \prime}$, Iong. $74^{\circ} 51^{\prime} 05^{\prime \prime}$, at highway bridge 1 mile south of Folsom, Atlantic County, and 2 iniles above Pennypot Stream.

Drainage area.- 56.3 square miles.

Gage-height record. - Water-stage recorder graph.

Stage-discharge relation.- Defined by current-meter measurements below 600 second-feet.

Maxima.- September 1938: Discharge, 718 second-feet 6 a.m. to 1 p.m. Sept. 23 (gage height, 6.59 feet).

6.18 feet).

to August 1938: Discharge, 599 second-feet Sept. 8, 1935 (gage height,

Mean daily discharge, in second-feet, 1938

\begin{tabular}{|c|c|c|c|c|c|c|c|c|c|c|c|}
\hline Day & Sept. & oct. & Day & Sept. & Oct. & Day & Sept. & Oct. & Day & Sept. & oct. \\
\hline $\begin{array}{l}1 \\
2 \\
3 \\
4 \\
5 \\
6 \\
7 \\
8\end{array}$ & $\begin{array}{l}60 \\
69 \\
69 \\
74 \\
77 \\
70 \\
64 \\
60 \\
\end{array}$ & $\begin{array}{l}276 \\
318 \\
296 \\
239 \\
196 \\
167 \\
148 \\
139 \\
\end{array}$ & $\begin{array}{r}9 \\
10 \\
11 \\
12 \\
13 \\
14 \\
15 \\
16\end{array}$ & $\begin{array}{l}57 \\
56 \\
54 \\
53 \\
53 \\
53 \\
53 \\
53 \\
\end{array}$ & $\begin{array}{l}141 \\
141 \\
138 \\
130 \\
117 \\
108 \\
101 \\
101\end{array}$ & $\begin{array}{l}17 \\
18 \\
19 \\
20 \\
21 \\
22 \\
23 \\
24 \\
\end{array}$ & $\begin{array}{r}53 \\
56 \\
68 \\
129 \\
406 \\
651 \\
707 \\
624 \\
\end{array}$ & $\begin{array}{l}108 \\
117 \\
121 \\
117 \\
112 \\
106 \\
104 \\
108 \\
\end{array}$ & $\begin{array}{l}25 \\
26 \\
27 \\
28 \\
29 \\
30 \\
31\end{array}$ & $\begin{array}{l}465 \\
318 \\
233 \\
192 \\
169 \\
180\end{array}$ & $\begin{array}{l}114 \\
119 \\
125 \\
130 \\
141 \\
150 \\
154\end{array}$ \\
\hline $\begin{array}{l}\text { Mean } \\
\text { Run-c }\end{array}$ & $\begin{array}{l}\text { lonthly } \\
f \text {, in }\end{array}$ & hes. & Ir & - . & et. . & $\cdot \dot{ }$ & $\begin{array}{l}\cdot \cdot \dot{ } \\
\cdot\end{array}$ & $\begin{array}{l}: \quad \cdot \\
\cdot \quad \cdot \\
\end{array}$ & $: \dot{ }$ & $\begin{array}{r}174 \\
3.45 \\
\end{array}$ & $\begin{array}{r}148 \\
3.03 \\
\end{array}$ \\
\hline
\end{tabular}

Gage helght, in feet, and discharge, in second-feet, at indlcated time, 1938

\begin{tabular}{|c|c|c|c|c|c|c|c|c|c|c|c|c|c|c|c|c|}
\hline \multirow{2}{*}{$\begin{array}{l}9 \\
0 \\
0 \\
0\end{array}$} & Feet & Sec.ft. & Feet & \multicolumn{2}{|c|}{ Sec.ft. } & Feet & Sec.ft. & Feet & \multicolumn{2}{|c|}{ Sec.ft. } & Feet & \multicolumn{2}{|c|}{ Sec.ft. } & Feet & \multicolumn{2}{|c|}{ Sec.ft. } \\
\hline & \multicolumn{2}{|c|}{ September 18} & \multicolumn{3}{|c|}{ September 19} & \multicolumn{2}{|c|}{ September 20} & \multicolumn{3}{|c|}{ September $2 I$} & \multicolumn{3}{|c|}{ September 22} & \multicolumn{3}{|c|}{ September 23} \\
\hline $\begin{array}{l}1 \\
2 \\
3 \\
4 \\
5 \\
6\end{array}$ & $\begin{array}{l}3.67 \\
3.67 \\
3.68 \\
3.68 \\
3.68 \\
3.68\end{array}$ & $\begin{array}{l}53 \\
53 \\
54 \\
54 \\
54 \\
54\end{array}$ & $\begin{array}{l}3.71 \\
3.71 \\
3.71 \\
3.71 \\
3.71 \\
3.71\end{array}$ & & $\begin{array}{l}58 \\
58 \\
58 \\
58 \\
58 \\
58\end{array}$ & $\begin{array}{l}3.90 \\
3.91 \\
3.92 \\
3.95 \\
3.96 \\
3.97\end{array}$ & $\begin{array}{r}88 \\
90 \\
92 \\
97 \\
99 \\
101\end{array}$ & $\begin{array}{l}4.61 \\
4.69 \\
4.78 \\
4.85 \\
4.92 \\
5.00\end{array}$ & & $\begin{array}{l}222 \\
239 \\
259 \\
274 \\
289 \\
307\end{array}$ & $\begin{array}{l}6.06 \\
6.09 \\
6.12 \\
6.15 \\
6.19 \\
6.21\end{array}$ & & $\begin{array}{l}572 \\
580 \\
588 \\
596 \\
607 \\
613\end{array}$ & $\begin{array}{l}6.55 \\
6.56 \\
6.57 \\
6.57 \\
6.58 \\
6.59\end{array}$ & & $\begin{array}{l}707 \\
710 \\
713 \\
713 \\
715 \\
718\end{array}$ \\
\hline $\begin{array}{r}7 \\
8 \\
9 \\
10 \\
11 \\
\text { N }\end{array}$ & $\begin{array}{l}3.69 \\
3.69 \\
3.69 \\
3.69 \\
3.69 \\
3.69\end{array}$ & $\begin{array}{l}56 \\
56 \\
56 \\
56 \\
56 \\
56\end{array}$ & $\begin{array}{l}3.71 \\
3.71 \\
3.71 \\
3.72 \\
3.72 \\
3.74\end{array}$ & & $\begin{array}{l}58 \\
58 \\
58 \\
60 \\
60 \\
63\end{array}$ & $\begin{array}{l}3.99 \\
4.00 \\
4.02 \\
4.03 \\
4.05 \\
4.06\end{array}$ & $\begin{array}{l}104 \\
106 \\
110 \\
112 \\
116 \\
117\end{array}$ & $\begin{array}{l}5.07 \\
5.16 \\
5.23 \\
5.29 \\
5.38 \\
5.48\end{array}$ & & $\begin{array}{l}323 \\
344 \\
361 \\
376 \\
397 \\
422\end{array}$ & $\begin{array}{l}6.24 \\
6.26 \\
6.28 \\
6.31 \\
6.34 \\
6.35\end{array}$ & & $\begin{array}{l}621 \\
626 \\
632 \\
640 \\
648 \\
651\end{array}$ & $\begin{array}{l}6.59 \\
6.59 \\
6.59 \\
6.59 \\
6.59 \\
6.59\end{array}$ & & $\begin{array}{l}718 \\
718 \\
718 \\
718 \\
718 \\
718\end{array}$ \\
\hline $\begin{array}{l}1 \\
2 \\
3 \\
4 \\
5 \\
6\end{array}$ & $\begin{array}{l}3.69 \\
3.69 \\
3.70 \\
3.70 \\
3.70 \\
3.70\end{array}$ & $\begin{array}{l}56 \\
56 \\
57 \\
57 \\
57 \\
57\end{array}$ & $\begin{array}{l}3.76 \\
3.78 \\
3.80 \\
3.80 \\
3.81 \\
3.82\end{array}$ & . & $\begin{array}{l}66 \\
69 \\
72 \\
72 \\
74 \\
75\end{array}$ & $\begin{array}{l}4.08 \\
4.10 \\
4.12 \\
4.14 \\
4.18 \\
4.24\end{array}$ & $\begin{array}{l}121 \\
125 \\
129 \\
132 \\
139 \\
150\end{array}$ & $\begin{array}{l}5.57 \\
5.64 \\
5.68 \\
5.71 \\
5.75 \\
5.79\end{array}$ & & $\begin{array}{l}444 \\
462 \\
473 \\
481 \\
491 \\
501\end{array}$ & $\begin{array}{l}6.37 \\
6.39 \\
6.42 \\
6.44 \\
6.46 \\
6.48\end{array}$ & & $\begin{array}{l}657 \\
662 \\
671 \\
676 \\
682 \\
687\end{array}$ & $\begin{array}{l}6.59 \\
6.58 \\
6.58 \\
6.58 \\
6.57 \\
6.57\end{array}$ & & $\begin{array}{l}718 \\
715 \\
715 \\
715 \\
713 \\
713\end{array}$ \\
\hline \multirow[t]{2}{*}{$\begin{array}{r}7 \\
8 \\
9 \\
10 \\
11 \\
11 \\
\end{array}$} & $\begin{array}{l}3.70 \\
3.70 \\
3.70 \\
3.70 \\
3.70 \\
3.70\end{array}$ & $\begin{array}{l}57 \\
57 \\
57 \\
57 \\
57 \\
57 \\
\end{array}$ & $\begin{array}{l}3.83 \\
3.84 \\
3.84 \\
3.86 \\
3.87 \\
3.87 \\
\end{array}$ & & $\begin{array}{l}77 \\
78 \\
78 \\
82 \\
83 \\
83 \\
\end{array}$ & $\begin{array}{l}4.29 \\
4.36 \\
4.41 \\
4.46 \\
4.50 \\
4.55\end{array}$ & $\begin{array}{l}159 \\
172 \\
182 \\
192 \\
200 \\
210 \\
\end{array}$ & $\begin{array}{l}5.83 \\
5.88 \\
5.92 \\
5.95 \\
5.99 \\
6.03 \\
\end{array}$ & & $\begin{array}{l}512 \\
525 \\
535 \\
543 \\
553 \\
564\end{array}$ & $\begin{array}{l}6.49 \\
6.50 \\
6.52 \\
6.53 \\
6.54 \\
6.55 \\
\end{array}$ & & $\begin{array}{l}690 \\
693 \\
699 \\
701 \\
704 \\
707 \\
\end{array}$ & $\begin{array}{l}6.56 \\
6.55 \\
6.55 \\
6.54 \\
6.53 \\
6.52 \\
\end{array}$ & & $\begin{array}{l}710 \\
707 \\
707 \\
704 \\
701 \\
699 \\
\end{array}$ \\
\hline & \multicolumn{2}{|c|}{ September 24} & \multicolumn{3}{|c|}{ September 2} & \multicolumn{2}{|c|}{ September 2} & \multicolumn{3}{|c|}{ September 27} & \multicolumn{3}{|c|}{ September 28} & \multicolumn{3}{|c|}{ September 29} \\
\hline $\begin{array}{r}2 \\
4 \\
6 \\
8 \\
10 \\
\mathrm{~N}\end{array}$ & $\begin{array}{l}6.49 \\
6.46 \\
6.42 \\
6.38 \\
6.34 \\
6.29\end{array}$ & $\begin{array}{l}690 \\
682 \\
671 \\
659 \\
648 \\
634\end{array}$ & $\begin{array}{l}5.90 \\
5.85 \\
5.80 \\
5.75 \\
5.70 \\
5.64\end{array}$ & & $\begin{array}{l}530 \\
517 \\
504 \\
491 \\
478 \\
462\end{array}$ & $\begin{array}{l}5.29 \\
5.24 \\
5.20 \\
5.15 \\
5.11 \\
5.07\end{array}$ & $\begin{array}{l}376 \\
364 \\
354 \\
342 \\
332 \\
323\end{array}$ & $\begin{array}{l}4.80 \\
4.77 \\
4.74 \\
4.70 \\
4.67 \\
4.65\end{array}$ & & $\begin{array}{l}263 \\
256 \\
250 \\
241 \\
235 \\
230\end{array}$ & $\begin{array}{l}4.52 \\
4.50 \\
4.49 \\
4.47 \\
4.47 \\
4.45\end{array}$ & & $\begin{array}{l}204 \\
200 \\
198 \\
194 \\
194 \\
190\end{array}$ & \begin{tabular}{|l|}
4.38 \\
4.37 \\
4.36 \\
4.35 \\
4.34 \\
4.34
\end{tabular} & & $\begin{array}{l}176 \\
174 \\
172 \\
170 \\
169 \\
169\end{array}$ \\
\hline $\begin{array}{r}2 \\
4 \\
6 \\
8 \\
10 \\
1\end{array}$ & $\begin{array}{l}6.23 \\
6.18 \\
6.13 \\
6.08 \\
6.02 \\
5.96\end{array}$ & $\begin{array}{l}618 \\
605 \\
591 \\
578 \\
561 \\
546\end{array}$ & $\begin{array}{l}5.58 \\
5.53 \\
5.49 \\
5.44 \\
5.39 \\
5.34\end{array}$ & & $\begin{array}{l}447 \\
434 \\
424 \\
412 \\
400 \\
388\end{array}$ & $\begin{array}{l}5.03 \\
4.99 \\
4.95 \\
4.91 \\
4.88 \\
4.84\end{array}$ & $\begin{array}{l}314 \\
305 \\
296 \\
287 \\
281 \\
272\end{array}$ & $\begin{array}{l}4.62 \\
4.59 \\
4.57 \\
4.58 \\
4.56 \\
4.53\end{array}$ & & $\begin{array}{l}224 \\
218 \\
214 \\
216 \\
212 \\
206\end{array}$ & $\begin{array}{l}4.44 \\
4.43 \\
4.42 \\
4.41 \\
4.39 \\
4.38\end{array}$ & & $\begin{array}{l}188 \\
186 \\
184 \\
182 \\
178 \\
176\end{array}$ & $\begin{array}{l}4.33 \\
4.32 \\
4.33 \\
4.33 \\
4.32 \\
4.32\end{array}$ & & $\begin{array}{l}167 \\
165 \\
167 \\
167 \\
165 \\
165\end{array}$ \\
\hline
\end{tabular}


Location.- Water-stage recorder, lat. $42^{\circ} 08^{\prime} 40^{\prime \prime}$, long. $74^{\circ} 39^{\prime} 15^{\prime \prime}$, at bridge at southwest end of Margaretvilie, Delaware County, and $13 / 4$ miles below mouth of Bush Kill.

Dralnage area.- 163 square miles.

Gage-height record. - Water-stage recorder graph.

Stage-discharge relation.- Defined by current-meter measurements below 4,840 secondfeet; extended logarithmically to peak stage on basis of area-mean velocity study.

Maxima.- September 1938: Discharge, 13,200 second-feet 8:15 p.m. Sept. 21 (gage

height, 11.74 feet).

February 1937 to August 1938: Discharge, 6,000 second-feet May 15, 1937 (gage height, 7.6 feet).

Remarks.- Flood run-off not affected by storage or diversion.

Mean dally discharge, in second-feet, 1938

\begin{tabular}{|c|c|c|c|c|c|c|c|c|c|c|c|}
\hline Day & Sept. & Oct. & Day & Sept. & Oct. & Day & Sept. & oct. & Day & Sept. & Oct. \\
\hline $\begin{array}{l}1 \\
2 \\
3 \\
4 \\
5 \\
6 \\
7 \\
8 \\
\end{array}$ & $\begin{array}{l}91 \\
80 \\
74 \\
78 \\
74 \\
79 \\
88 \\
91 \\
\end{array}$ & $\begin{array}{r}302 \\
253 \\
224 \\
201 \\
183 \\
171 \\
154 \\
146 \\
\end{array}$ & $\begin{array}{r}9 \\
10 \\
11 \\
12 \\
13 \\
14 \\
15 \\
16\end{array}$ & $\begin{array}{r}68 \\
62 \\
57 \\
56 \\
136 \\
96 \\
120 \\
118 \\
\end{array}$ & $\begin{array}{r}137 \\
128 \\
120 \\
122 \\
118 \\
100 \\
90 \\
88 \\
\end{array}$ & $\begin{array}{l}17 \\
18 \\
19 \\
20 \\
21 \\
22 \\
23 \\
24\end{array}$ & $\begin{array}{r}85 \\
108 \\
108 \\
870 \\
5,100 \\
5,500 \\
2,460 \\
1,420 \\
\end{array}$ & $\begin{array}{r}85 \\
81 \\
79 \\
84 \\
169 \\
114 \\
94 \\
133 \\
\end{array}$ & $\begin{array}{l}25 \\
26 \\
27 \\
28 \\
29 \\
30 \\
31\end{array}$ & $\begin{array}{l}970 \\
716 \\
600 \\
500 \\
402 \\
340\end{array}$ & $\begin{array}{l}188 \\
139 \\
124 \\
118 \\
128 \\
124 \\
118\end{array}$ \\
\hline $\begin{array}{l}\text { Mean } \\
\text { Run- }\end{array}$ & $\begin{array}{l}\text { onthly } \\
f, \text { in } 1\end{array}$ & $\begin{array}{l}\text { scharg } \\
\text { hes. }\end{array}$ & 1r & $\begin{array}{l}\text { econd }-\mathrm{f} \\
.\end{array}$ & 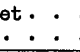 & : $:$ & . : . & $\cdot \dot{0} \cdot$ & $\dot{0}$ & $\begin{array}{r}685 \\
4.69 \\
\end{array}$ & $\begin{array}{r}139 \\
0.98 \\
\end{array}$ \\
\hline
\end{tabular}

Gage height, in feet, and discharge, in second-feet, at indicated time, 1938

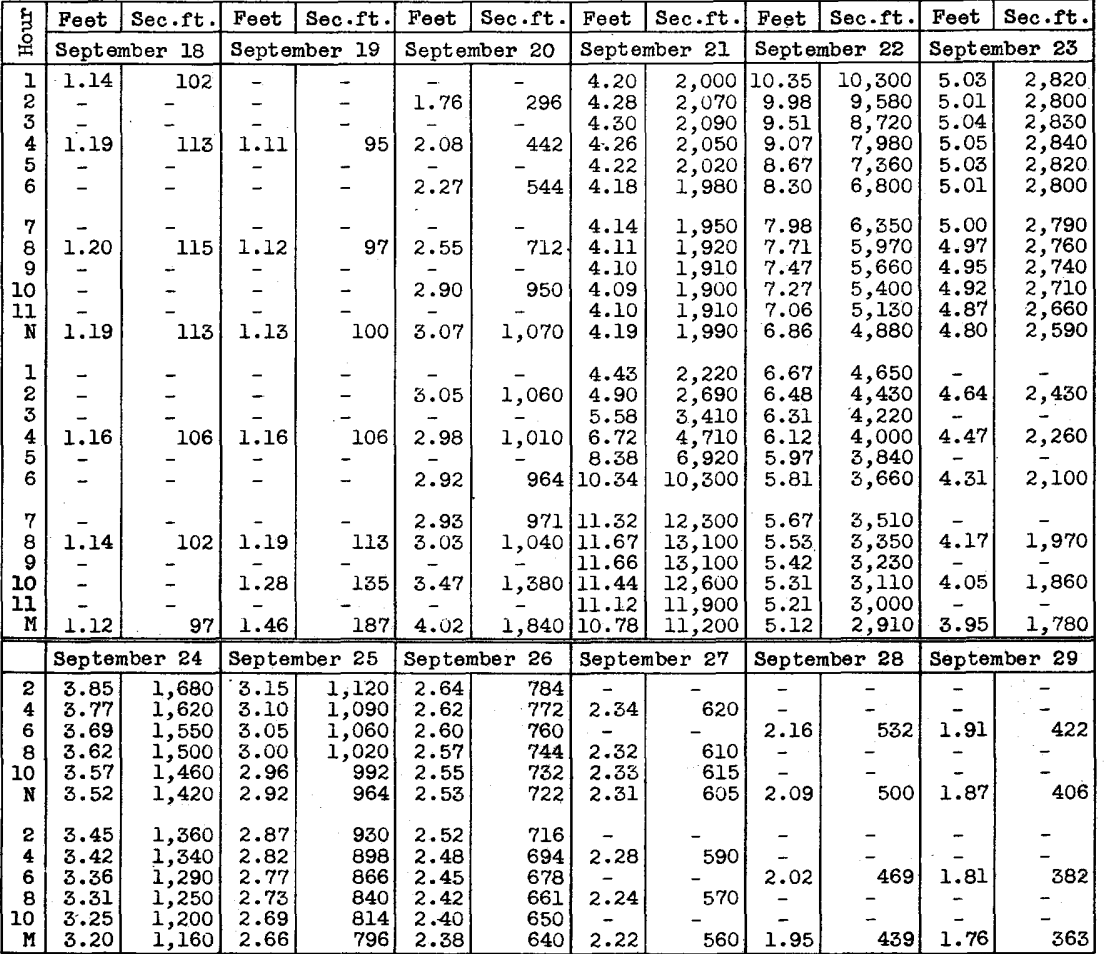

Supplemental records.- Sept. $21,8: 15$ p.m., 11.74 ft., 13,200 sec.-ft.

$2279 ; \%$ O $-40-22$ 
East Branch of Delaware River at Harvard, N. Y.

Location.- Water-stage recorder, lat. $42^{\circ} 01^{\prime} 15^{n}$, long. $75^{\circ} 07^{\prime} 05^{\prime \prime}$, at highway bridge at Harvard, Deleware County, about 400 feet above Baxter Brook. Zero of gage is $1,007.96$ feet above mean sea level (general adjustment of 1912).

Drainage area.- 443 square miles.

Gege-he1ght record.- Water-stage recorder graph.

Stage-discharge relation. - Defined by current-meter measurements below 9,300 secondfeet; extended logarithmically to peak stage on basis of slope-area determination of the peak flow of the March 1936 flood.

Maxima.- September 1938: D1scharge, 31,400 second-feet 6:10 a.m. Sept. 22 (gage height, 16.93 feet).

October 1934 to August 1938: Discharge, 26,200 second-feet Mar. 18,1936

Remarks.- Flood run-off not affected by storage or diversion.

Mean dally discharge, in second-feet, 1938

\begin{tabular}{|c|c|c|c|c|c|c|c|c|c|c|c|}
\hline Day & Sept. & Oet. & Day & Sept. & Oet: & Day & Sept. & oct. & Day & Sept. & Oct. \\
\hline $\begin{array}{l}1 \\
2 \\
3 \\
4 \\
5 \\
6 \\
7 \\
8\end{array}$ & $\begin{array}{l}226 \\
223 \\
187 \\
173 \\
167 \\
153 \\
172 \\
274 \\
\end{array}$ & $\begin{array}{l}806 \\
720 \\
615 \\
560 \\
506 \\
463 \\
425 \\
389 \\
\end{array}$ & $\begin{array}{r}9 \\
10 \\
11 \\
12 \\
13 \\
14 \\
15 \\
16\end{array}$ & $\begin{array}{l}210 \\
156 \\
133 \\
123 \\
206 \\
340 \\
285 \\
395\end{array}$ & $\begin{array}{l}362 \\
336 \\
315 \\
297 \\
284 \\
267 \\
245 \\
230\end{array}$ & $\begin{array}{l}17 \\
18 \\
19 \\
20 \\
21 \\
22 \\
23 \\
24\end{array}$ & $\begin{array}{r}300 \\
305 \\
333 \\
1,520 \\
8,900 \\
20,400 \\
6,800 \\
3,950 \\
\end{array}$ & $\begin{array}{l}217 \\
208 \\
199 \\
208 \\
359 \\
367 \\
274 \\
336\end{array}$ & $\begin{array}{l}25 \\
26 \\
27 \\
28 \\
29 \\
30 \\
31\end{array}$ & $\begin{array}{r}2,750 \\
2,020 \\
1,620 \\
1,340 \\
1,100 \\
930\end{array}$ & $\begin{array}{l}560 \\
484 \\
425 \\
397 \\
401 \\
413 \\
381\end{array}$ \\
\hline $\begin{array}{l}\text { Mean } \\
\text { Run-c }\end{array}$ & $\begin{array}{l}\text { onthly } \\
f, \ln 1\end{array}$ & scharg & ?, In & $\begin{array}{l}\text { econd-1 } \\
.\end{array}$ & et. . & . & 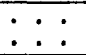 & $\begin{array}{ll}\cdot & \cdot \\
. & .\end{array}$ & $\dot{1}$. & $\begin{array}{r}1,856 \\
4.68\end{array}$ & $\begin{array}{r}389 \\
1.01\end{array}$ \\
\hline
\end{tabular}

Gage helght, In feet, and discharge, in second-feet, at indicated time, 1938

\begin{tabular}{|c|c|c|c|c|c|c|c|c|c|c|c|c|}
\hline \multirow{2}{*}{$\begin{array}{l}5 \\
0 \\
0 \\
\end{array}$} & Feet & Sec.ft. & Feet & Sec.ft. & Feet & Sec.ft. & Feet & Sec.ft. & Feet & Sec.ft. & Feet & Sec.ft. \\
\hline & \multicolumn{2}{|c|}{ September 18} & \multicolumn{2}{|c|}{ September 19} & \multicolumn{2}{|c|}{ September 20} & \multicolumn{2}{|c|}{ September 21} & \multicolumn{2}{|c|}{ Sept ember 22} & \multicolumn{2}{|c|}{ September 23} \\
\hline $\begin{array}{l}1 \\
2 \\
3 \\
4 \\
5 \\
6\end{array}$ & $\begin{array}{c}- \\
3.09 \\
- \\
3.10 \\
- \\
3.11\end{array}$ & $\begin{array}{r}-274 \\
- \\
-277 \\
-280\end{array}$ & $\begin{array}{c}- \\
3.27 \\
- \\
3.27 \\
- \\
3.25\end{array}$ & $\begin{array}{r}- \\
-336 \\
-336 \\
-\quad 329\end{array}$ & $\begin{array}{l}3.35 \\
3.39 \\
3.44 \\
3.50 \\
3.58 \\
3.70\end{array}$ & \begin{tabular}{|l|}
366 \\
381 \\
401 \\
425 \\
459 \\
510
\end{tabular} & $\begin{array}{r}7.57 \\
7.82 \\
8.11 \\
8.37 \\
8.63 \\
8.86\end{array}$ & $\begin{array}{l}3,660 \\
3,970 \\
4,350 \\
4,740 \\
5,140 \\
5,510\end{array}$ & $\begin{array}{l}15.34 \\
15.82 \\
16.17 \\
16.54 \\
16.82 \\
16.93\end{array}$ & $\begin{array}{l}24,500 \\
26,400 \\
27,800 \\
29,500 \\
30,900 \\
31,400\end{array}$ & $\begin{array}{r}10.51 \\
10.36 \\
10.22 \\
10.11 \\
10.02 \\
9.94\end{array}$ & $\begin{array}{l}8,720 \\
8,390 \\
8,080 \\
7,840 \\
7,640 \\
7,480\end{array}$ \\
\hline $\begin{array}{r}7 \\
8 \\
9 \\
10 \\
11 \\
N\end{array}$ & $\begin{array}{c}- \\
\overline{3.13} \\
\overline{3.15} \\
\overline{3.17}\end{array}$ & $\begin{array}{r}- \\
- \\
- \\
287 \\
- \\
301\end{array}$ & $\begin{array}{c}\overline{3.24} \\
- \\
3.23 \\
- \\
3.21\end{array}$ & $\begin{array}{r}-325 \\
-\quad 322 \\
-\quad 315\end{array}$ & $\begin{array}{l}3.83 \\
3.98 \\
4.17 \\
4.45 \\
4.82 \\
5.16\end{array}$ & $\begin{array}{r}568 \\
640 \\
735 \\
882 \\
1,090 \\
1,320\end{array}$ & $\begin{array}{l}8.98 \\
9.04 \\
9.05 \\
9.06 \\
9.08 \\
9.15\end{array}$ & $\begin{array}{l}5,720 \\
5,820 \\
5,840 \\
5,850 \\
5,890 \\
6,000\end{array}$ & $\begin{array}{l}16.83 \\
16.55 \\
16.08 \\
15.53 \\
14.98 \\
14.45\end{array}$ & $\begin{array}{l}31,000 \\
29,600 \\
27,400 \\
25,200 \\
23,000 \\
20,900\end{array}$ & $\begin{array}{l}9.85 \\
9.79 \\
9.73 \\
9.69 \\
9.65 \\
9.59\end{array}$ & $\begin{array}{l}7,300 \\
7,180 \\
7,070 \\
6,990 \\
6,920 \\
6,800\end{array}$ \\
\hline $\begin{array}{l}1 \\
2 \\
3 \\
4 \\
5 \\
6\end{array}$ & $\begin{array}{c}\overline{3.20} \\
\overline{3.24} \\
\overline{3.27}\end{array}$ & $\begin{array}{r}- \\
-311 \\
-325 \\
-336\end{array}$ & $\begin{array}{c}- \\
3.20 \\
- \\
3.24 \\
- \\
3.25\end{array}$ & $\begin{array}{r}- \\
-311 \\
-325 \\
-329\end{array}$ & $\begin{array}{l}5.50 \\
5.83 \\
6.10 \\
6.29 \\
6.43 \\
6.55\end{array}$ & $\begin{array}{l}1,590 \\
1,850 \\
2,090 \\
2,260 \\
2,400 \\
2,520\end{array}$ & $\begin{array}{r}9.28 \\
9.53 \\
9.94 \\
10.46 \\
11.07 \\
11.79\end{array}$ & $\begin{array}{r}6,230 \\
6,690 \\
7,480 \\
8,610 \\
10,000 \\
11,900\end{array}$ & $\begin{array}{l}13.95 \\
13.53 \\
13.13 \\
12.77 \\
12.45 \\
12.13\end{array}$ & $\begin{array}{l}18,900 \\
17,400 \\
16,000 \\
14,900 \\
13,800 \\
12,900\end{array}$ & $\begin{array}{l}9.52 \\
9.45 \\
9.37 \\
9.34 \\
9.20 \\
9.11\end{array}$ & $\begin{array}{l}6,670 \\
6,540 \\
6,400 \\
6,340 \\
6,090 \\
5,940\end{array}$ \\
\hline \multirow[t]{2}{*}{$\begin{array}{r}7 \\
8 \\
9 \\
10 \\
11 \\
1\end{array}$} & $\begin{array}{c}- \\
\overline{3.28} \\
- \\
3.28 \\
\overline{3.28}\end{array}$ & $\begin{array}{l}- \\
- \\
- \\
340 \\
- \\
340\end{array}$ & $\begin{array}{c}- \\
3.29 \\
- \\
3.30 \\
- \\
3.34\end{array}$ & $\begin{array}{l}- \\
343 \\
- \\
347 \\
- \\
362\end{array}$ & $\begin{array}{l}6.63 \\
6.73 \\
6.83 \\
6.97 \\
7.13 \\
7.32\end{array}$ & $\begin{array}{l}2,600 \\
2,700 \\
2,810 \\
2,970 \\
3,140 \\
3,360\end{array}$ & $\begin{array}{l}12.48 \\
13.05 \\
13.56 \\
13.98 \\
14.40 \\
14.88\end{array}$ & $\begin{array}{l}13,900 \\
15,800 \\
17,500 \\
19,100 \\
20,700 \\
22,600\end{array}$ & $\begin{array}{l}11.87 \\
11.60 \\
11.35 \\
11.10 \\
10.90 \\
10.70\end{array}$ & $\begin{array}{r}12,200 \\
11,400 \\
10,800 \\
10,100 \\
9,640 \\
9,160\end{array}$ & $\begin{array}{l}9.02 \\
8.93 \\
8.84 \\
8.75 \\
8.65 \\
8.55\end{array}$ & $\begin{array}{l}5,780 \\
5,630 \\
5,480 \\
5,330 \\
5,170 \\
5,010\end{array}$ \\
\hline & \multicolumn{2}{|c|}{ September 24} & \multicolumn{2}{|c|}{ September 25} & \multicolumn{2}{|c|}{ September 26} & \multicolumn{2}{|c|}{ September 27} & \multicolumn{2}{|c|}{ September 28} & \multicolumn{2}{|c|}{ September 29} \\
\hline $\begin{array}{r}2 \\
4 \\
6 \\
8 \\
10 \\
N\end{array}$ & $\begin{array}{l}8.38 \\
8.22 \\
8.08 \\
7.95 \\
7.84 \\
7.73\end{array}$ & $\begin{array}{l}4,750 \\
4,510 \\
4,310 \\
4,140 \\
3,990 \\
3,860\end{array}$ & $\begin{array}{l}7.10 \\
7.03 \\
6.96 \\
6.88 \\
6.82 \\
6.75\end{array}$ & $\begin{array}{l}3,110 \\
3,030 \\
2,960 \\
2,870 \\
2,800 \\
2,720\end{array}$ & $\begin{array}{l}6.30 \\
6.23 \\
6.18 \\
6.12 \\
6.06 \\
6.01\end{array}$ & $\begin{array}{l}2,270 \\
2,210 \\
2,160 \\
2,110 \\
2,050 \\
2,010\end{array}$ & \begin{tabular}{|l|}
5.68 \\
5.63 \\
5.60 \\
5.57 \\
5.53 \\
5.50
\end{tabular} & $\begin{array}{l}1,730 \\
1,690 \\
1,670 \\
1,650 \\
1,610 \\
1,590\end{array}$ & \begin{tabular}{c|}
- \\
5.32 \\
- \\
5.26 \\
- \\
5.20
\end{tabular} & $\begin{array}{l}1,450 \\
1,400 \\
- \\
1,350\end{array}$ & $\begin{array}{c}-\overline{-} \\
4.92 \\
- \\
4.87 \\
- \\
4.81\end{array}$ & $\begin{array}{c}1,150 \\
- \\
1,120 \\
- \\
1,090\end{array}$ \\
\hline $\begin{array}{r}2 \\
4 \\
6 \\
8 \\
10 \\
\mathrm{M}\end{array}$ & $\begin{array}{l}7.63 \\
7.54 \\
7.44 \\
7.35 \\
7.26 \\
7.19\end{array}$ & $\begin{array}{l}3,740 \\
3,630 \\
3,510 \\
3,400 \\
3,290 \\
3,210\end{array}$ & $\begin{array}{l}6.69 \\
6.63 \\
6.57 \\
6.50 \\
6.43 \\
6.36\end{array}$ & $\begin{array}{l}2,660 \\
2,600 \\
2,540 \\
2,470 \\
2,400 \\
2,330\end{array}$ & $\begin{array}{l}5.97 \\
5.92 \\
5.88 \\
5.83 \\
5.78 \\
5.73\end{array}$ & $\begin{array}{l}1,970 \\
1,930 \\
1,890 \\
1,850 \\
1,810 \\
1,770\end{array}$ & $\begin{array}{l}5.49 \\
5.47 \\
5.45 \\
5.43 \\
5.42 \\
5.40\end{array}$ & $\begin{array}{l}1,580 \\
1,570 \\
1,550 \\
1,530 \\
1,530 \\
1,510\end{array}$ & $\begin{array}{c}- \\
5.12 \\
- \\
5.06 \\
- \\
4.99\end{array}$ & $\begin{array}{c}- \\
1,290 \\
- \\
1,250 \\
- \\
1,200\end{array}$ & $\begin{array}{c}-\overline{4} \\
-76 \\
4.72 \\
- \\
4.63\end{array}$ & $\begin{array}{c}1,060 \\
- \\
1,030 \\
-982\end{array}$ \\
\hline
\end{tabular}

Supplemental records.- Sept. 22, 6:10 \&.m., 16.93 ft., 31,400 sec.-ft. 
East Branch of Delaware River at Fishs Eddy, N. Y.

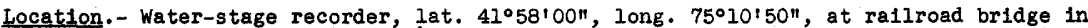
Fishs Eddy, Delaware County, 4t miles below mouth of Beaver Kill. Zero of gage is 950.80 feet above mean sea level (general adjustment of 1912).

Drainare area.- 783 square miles.

Gage-he1ght record.- Water-stage recorder graph.

Stage-discharge relation.- Defined by current-meter measurements below 21,400 secondfeet; extended to peak stage on bas1s of area-mean veloc1ty study and logarithmic plotting.

Maxima.- September 1938: Discharge, 41,000 second-feet 12:45 a.m. Sept. 22 (gage helght, 18.21 feet).

November 1912 to August 1938: D1scharge, 53,300 second-feet Aug. 24, 1933

(gage height, 20.60 feet).

Maximum discharge known, about 70,000 second-feet (from present.rating extended logarithmically to peak stage) 0ct.9, 1903 (gage height, 23.6 feet, present site and

datum, from information by local residents).

Remarks.- Flood run-off not affected by storage or diversion.

Mean daily discharge, in second-feet, 1938

\begin{tabular}{|c|c|c|c|c|c|c|c|c|c|c|c|}
\hline Day & Sept. & oet. & Day & Sept. & oct. & Day & Sept. & Oct. & Day & Sept. & Oct. \\
\hline $\begin{array}{l}1 \\
2 \\
3 \\
4 \\
5 \\
6 \\
7 \\
8\end{array}$ & $\begin{array}{l}473 \\
468 \\
416 \\
387 \\
387 \\
368 \\
397 \\
590\end{array}$ & $\begin{array}{r}1,590 \\
1,370 \\
1,210 \\
1,090 \\
973 \\
893 \\
810 \\
740\end{array}$ & $\begin{array}{r}9 \\
10 \\
11 \\
12 \\
13 \\
14 \\
15 \\
16\end{array}$ & $\begin{array}{l}468 \\
373 \\
332 \\
320 \\
395 \\
572 \\
536 \\
662\end{array}$ & $\begin{array}{l}712 \\
664 \\
605 \\
581 \\
551 \\
528 \\
487 \\
448\end{array}$ & $\begin{array}{l}17 \\
18 \\
19 \\
20 \\
21 \\
22 \\
23 \\
24\end{array}$ & $\begin{array}{r}548 \\
566 \\
620 \\
2,950 \\
17,600 \\
29,500 \\
11,400 \\
7,000\end{array}$ & $\begin{array}{l}420 \\
410 \\
399 \\
415 \\
626 \\
657 \\
516 \\
613\end{array}$ & $\begin{array}{l}25 \\
26 \\
27 \\
28 \\
29 \\
30 \\
31\end{array}$ & $\begin{array}{l}4,900 \\
3,650 \\
3,000 \\
2,650 \\
2,160 \\
1,840\end{array}$ & $\begin{array}{r}1,170 \\
965 \\
832 \\
761 \\
740 \\
740 \\
670\end{array}$ \\
\hline $\begin{array}{l}\text { Mean } \\
\text { Run-c }\end{array}$ & $\begin{array}{l}\text { nthly } \\
\text {, in }\end{array}$ & schar & 1n & $\begin{array}{c}\text { secona } \\
. \\
\end{array}$ & et. & & $: \dot{0}$ & $\because \quad \cdot$ & $:$ : & $\begin{array}{r}3,184 \\
4.54\end{array}$ & $\begin{array}{r}748 \\
1.11\end{array}$ \\
\hline
\end{tabular}

Gage helght, in feet, and discharge, in second-feet, at indicated time, 1938

\begin{tabular}{|c|c|c|c|c|c|c|c|c|c|c|c|c|}
\hline \multirow{2}{*}{ 里 } & Feet & Sec.ft. & Feet & Sec.ft. & Feet & Sec.ft. & Feet & Sec.ft. & Feet & Soc.ft. & Feet & Sec.ft \\
\hline & \multicolumn{2}{|c|}{ September 18} & \multicolumn{2}{|c|}{ September 19} & \multicolumn{2}{|c|}{ September 20} & \multicolumn{2}{|c|}{ September 21} & \multicolumn{2}{|c|}{ September 22} & \multicolumn{2}{|c|}{ September 23} \\
\hline $\begin{array}{l}1 \\
2 \\
3 \\
4 \\
5 \\
6\end{array}$ & $\begin{array}{c}- \\
- \\
- \\
2.80 \\
- \\
-\end{array}$ & $\begin{array}{l}- \\
- \\
- \\
- \\
-\end{array}$ & $\begin{array}{c}- \\
- \\
\bar{z} \\
\overline{-} \\
-\end{array}$ & $\begin{array}{l}- \\
- \\
-610 \\
- \\
-\end{array}$ & $\begin{array}{c}- \\
3.18 \\
- \\
3.31 \\
- \\
3.57\end{array}$ & $\begin{array}{r}- \\
-776 \\
-867 \\
- \\
1,070\end{array}$ & $\begin{array}{l}8.1 \\
8.6 \\
9.2 \\
9.5 \\
9.7 \\
9.8\end{array}$ & $\begin{array}{r}7,240 \\
8,300 \\
9,520 \\
10,400 \\
11,000 \\
11,300\end{array}$ & & $\begin{array}{l}41,000 \\
40,500 \\
39,900 \\
39,500 \\
39,500 \\
39,700\end{array}$ & $\begin{array}{l}11.09 \\
10.90 \\
10.72 \\
10.60 \\
10.49 \\
10.39\end{array}$ & $\frac{1}{1}$ \\
\hline $\begin{array}{r}7 \\
8 \\
9 \\
10 \\
11 \\
\text { N }\end{array}$ & $\begin{array}{c}- \\
2.81 \\
- \\
- \\
- \\
2.86\end{array}$ & $\begin{array}{l}- \\
- \\
- \\
- \\
566\end{array}$ & $\begin{array}{c}- \\
2.91 \\
- \\
- \\
\overline{2.90}\end{array}$ & $\begin{array}{l}- \\
-596 \\
- \\
- \\
590\end{array}$ & $\begin{array}{c}- \\
3.93 \\
- \\
4.55 \\
- \\
5.20\end{array}$ & $\begin{array}{c}\overline{1,380} \\
\overline{1,980} \\
\overline{2,670}\end{array}$ & $\begin{array}{r}10 \\
10 \\
10 \\
9 \\
9 \\
10\end{array}$ & $\begin{array}{l}11, \\
11 \\
11, \\
11, \\
11 \\
11,\end{array}$ & & & & \\
\hline $\begin{array}{l}1 \\
2 \\
3 \\
4 \\
5 \\
6\end{array}$ & $\begin{array}{c}- \\
- \\
- \\
2.90 \\
- \\
-\end{array}$ & $\begin{array}{l}- \\
- \\
- \\
- \\
-\end{array}$ & $\begin{array}{c}- \\
- \\
- \\
2.93 \\
- \\
-\end{array}$ & $\begin{array}{l}- \\
- \\
- \\
-610 \\
-\end{array}$ & $\begin{array}{c}- \\
5.92 \\
- \\
6.37 \\
- \\
6.69\end{array}$ & $\begin{array}{c}- \\
3,560 \\
- \\
4,200 \\
4,700\end{array}$ & $\begin{array}{l}10 \\
10 \\
10 \\
11 \\
12 \\
14\end{array}$ & $\begin{array}{l}11 \\
12 \\
14 \\
16 \\
20 \\
24\end{array}$ & & $\begin{array}{l}00 \\
00 \\
300 \\
00 \\
00 \\
00\end{array}$ & & $\begin{array}{l}11 \\
11 \\
10 \\
10 \\
10\end{array}$ \\
\hline \multirow[t]{2}{*}{$\begin{array}{r}7 \\
8 \\
9 \\
10 \\
11 \\
M\end{array}$} & $\begin{array}{c}- \\
2.92 \\
- \\
- \\
- \\
2.93\end{array}$ & $\begin{array}{l}-603 \\
- \\
- \\
-610\end{array}$ & $\begin{array}{c}- \\
3.00 \\
- \\
- \\
3.10\end{array}$ & $\begin{array}{l}- \\
-655 \\
- \\
- \\
720\end{array}$ & $\begin{array}{c}-\overline{6.91} \\
\overline{7.22} \\
\overline{7.70}\end{array}$ & $\begin{array}{c}\overline{5,070} \\
\overline{5,620} \\
\overline{6,480}\end{array}$ & & $\begin{array}{l}28,400 \\
32,500 \\
35,700 \\
38,300 \\
40,000 \\
41,000\end{array}$ & & & & \\
\hline & \multicolumn{2}{|c|}{ September 24} & \multicolumn{2}{|c|}{ September 25} & \multicolumn{2}{|c|}{ September 26} & \multicolumn{2}{|c|}{ September 27} & \multicolumn{2}{|c|}{ September 28} & \multicolumn{2}{|c|}{ September 29} \\
\hline $\begin{array}{r}2 \\
4 \\
6 \\
8 \\
10 \\
N\end{array}$ & $\begin{array}{l}8.60 \\
8.40 \\
8.24 \\
8.10 \\
7.96 \\
7.82\end{array}$ & $\begin{array}{l}8,400 \\
8,010 \\
7,710 \\
7,440 \\
7,180 \\
6,930\end{array}$ & $\begin{array}{l}7.04 \\
6.94 \\
6.86 \\
6.78 \\
6.69 \\
6.60\end{array}$ & $\begin{array}{l}5,570 \\
5,400 \\
5,280 \\
5,150 \\
5,000 \\
4,860\end{array}$ & \begin{tabular}{|l|}
6.04 \\
5.99 \\
5.92 \\
5.87 \\
5.81 \\
5.76
\end{tabular} & & & & $\begin{array}{c}- \\
5.13 \\
- \\
5.04 \\
- \\
4.97\end{array}$ & $\begin{array}{c}2,820 \\
- \\
2,710 \\
- \\
2,620\end{array}$ & \begin{tabular}{|c|}
- \\
4.67 \\
- \\
4.60 \\
- \\
4.55
\end{tabular} & 2,14 \\
\hline $\begin{array}{r}2 \\
4 \\
6 \\
8 \\
10 \\
11\end{array}$ & $\begin{array}{l}7.70 \\
7.59 \\
7.47 \\
7.37 \\
7.26 \\
7.16\end{array}$ & $\begin{array}{l}6,710 \\
6,510 \\
6,300 \\
6,130 \\
5,940 \\
5,770 \\
\end{array}$ & $\begin{array}{l}6.51 \\
6.42 \\
6.35 \\
6.27 \\
6.20 \\
6.11\end{array}$ & $\begin{array}{l}4,720 \\
4,590 \\
4,480 \\
4,360 \\
4,260\end{array}$ & $\begin{array}{l}5.71 \\
5.67 \\
5.62 \\
5.57 \\
5.51 \\
5.47\end{array}$ & $\begin{array}{l}3,570 \\
3,520 \\
3,450 \\
3,380 \\
3,300\end{array}$ & & & $\begin{array}{c}- \\
4.90 \\
- \\
4.81 \\
- \\
4.74\end{array}$ & $\begin{array}{c}- \\
2,540 \\
- \\
2,430 \\
- \\
2,350\end{array}$ & $\begin{array}{c}- \\
4.49 \\
- \\
4.43 \\
4.39\end{array}$ & $\begin{array}{l}\overrightarrow{2,08} \\
\overrightarrow{2,02} \\
\overline{1,98}\end{array}$ \\
\hline
\end{tabular}

Supplemental records.- Sept. $22,12: 45 \mathrm{a.m.,} 18.21 \mathrm{ft} ., 41,000$ sec.-ft. 
Location.- Water-stage recorder, lat. $41^{\circ} 22^{\prime} 20^{\prime \prime}$, long. $74^{\circ} 41^{\prime} 50^{\prime \prime}$, near highway bridge at Port Jervis, Orange County, $1 \frac{1}{2}$ miles above mouth of Neversink River. Zero of gage is 415.35 feet above mean sea level (general adjustment of 1929).

Drainage area.- 3,076 square miles; 369 square miles affected by storage in Lake wallenpaupack and Toronto and Swinging Bridge Reservoirs.

Gage-height record.- Water-stage recorder graph.

Stage-discharge relation.- For 1938 defined by current-meter measurements below 44,500 second-feet; extended to peak stage on basis of slope-area determination and area-mean velocity study. For 1936 defined by current-meter measurements below 32,300 secondfeet; extended logarithmically to peak stage.

Maxima.- September 1938: Discharge, 101,000 second-feet noon Sept. 22 (gage height, 14.95 feet)

October 1904 to August 1938: Discharge, 108,000 second-feet Mar. 18, 1936 gage height, 17.55 feet).

Maximum known discharge, about 155,000 second-feet 0ct. 10, 11, 1903 (gage height, 23.3 feet); maximum known stage, 25.5 feet Mar. 8, 1904 (ice gorge).

Remarks.- Large diurnal fluctuation at medium and low stages due to operation of power plants on tributary streams. Mean monthly discharge adjusted for storage in Toronto Reservoir at Toronto Dam, N. Y.; Swinging Bridge Reservoir at Swinging Bridge Dam,

N. Y.; and Wallenpaupack Reservoir at Wilsonville, Pa.

Mean da1ly discharge, in second-feet, 1938

\begin{tabular}{|c|c|c|c|c|c|c|c|c|c|c|c|}
\hline Day & Sept. & Oct. & Day & Sept. & Oct. & Day & Sept. & Oct. & Day & Sept. & oct. \\
\hline $\begin{array}{l}1 \\
2 \\
3 \\
4 \\
5 \\
6 \\
7 \\
8\end{array}$ & $\begin{array}{l}2,950 \\
2,850 \\
2,220 \\
1,700 \\
1,640 \\
1,800 \\
2,650 \\
2,800\end{array}$ & $\begin{array}{l}5,700 \\
4,860 \\
4,680 \\
4,280 \\
3,760 \\
3,840 \\
3,890 \\
3,000\end{array}$ & $\begin{array}{r}9 \\
10 \\
11 \\
12 \\
13 \\
14 \\
15 \\
16\end{array}$ & $\begin{array}{l}2,800 \\
2,850 \\
2,040 \\
1,980 \\
2,480 \\
2,500 \\
3,300 \\
3,650\end{array}$ & $\begin{array}{l}2,770 \\
2,720 \\
2,750 \\
2,480 \\
2,580 \\
3,220 \\
2,950 \\
2,400\end{array}$ & $\begin{array}{l}17 \\
18 \\
19 \\
20 \\
21 \\
22 \\
23 \\
24\end{array}$ & $\begin{array}{r}3,800 \\
3,000 \\
3,500 \\
5,400 \\
24,000 \\
89,000 \\
49,000 \\
26,500\end{array}$ & $\begin{array}{l}2,110 \\
2,660 \\
2,760 \\
2,850 \\
3,000 \\
2,830 \\
2,520 \\
2,340\end{array}$ & $\begin{array}{l}25 \\
26 \\
27 \\
28 \\
29 \\
30 \\
31\end{array}$ & $\begin{array}{r}17,400 \\
13,000 \\
10,400 \\
8,800 \\
7,600 \\
6,600\end{array}$ & $\begin{array}{l}3,820 \\
4,360 \\
3,520 \\
3,720 \\
3,340 \\
2,710 \\
2,760\end{array}$ \\
\hline $\begin{array}{l}\text { Mean } \\
\text { Run- } \\
\text { Mean } \\
\text { Run- }\end{array}$ & $\begin{array}{l}\text { onthly } \\
\text { f, in } \\
\text { onthly } \\
\text { f, in }\end{array}$ & $\begin{array}{l}\text { hes ( } \\
\text { schar } \\
\text { hes ( }\end{array}$ & i & . $\cdot$ & & & $\begin{array}{l}\cdot \dot{*} \\
\dot{*} \cdot \dot{ } \\
\dot{*}\end{array}$ & 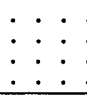 & $: \dot{:}$ & $\begin{array}{r}10,270 \\
3.73 \\
9,994 \\
3.63\end{array}$ & $\begin{array}{r}3,264 \\
1.22 \\
2,649 \\
0.99\end{array}$ \\
\hline
\end{tabular}

Gage height, in feet, and discharge, in second-feet, at indicated time, 1938

\begin{tabular}{|c|c|c|c|c|c|c|c|c|c|c|c|c|}
\hline \multirow{2}{*}{$\begin{array}{l}4 \\
3 \\
0 \\
0 \\
\end{array}$} & Feet & Sec.ft. & Feet & Sec.ft. & Feet & Sec.ft. & Feet & Sec.ft. & Feet & Sec.ft. & Feet & Sec.ft. \\
\hline & \multicolumn{2}{|c|}{ September 18} & \multicolumn{2}{|c|}{ September 19} & \multicolumn{2}{|c|}{ September 20} & \multicolumn{2}{|c|}{ September 21} & \multicolumn{2}{|c|}{ September 22} & \multicolumn{2}{|c|}{ September 23} \\
\hline $\begin{array}{l}1 \\
2 \\
3 \\
4 \\
5 \\
6\end{array}$ & $\begin{array}{l}3.10 \\
2.99 \\
2.91 \\
2.86 \\
2.88 \\
3.10\end{array}$ & $\begin{array}{l}3,580 \\
3,300 \\
3,100 \\
2,970 \\
3,020 \\
3,580\end{array}$ & $\begin{array}{l}2.78 \\
2.73 \\
2.68 \\
2.63 \\
2.61 \\
2.88\end{array}$ & $\begin{array}{l}2,790 \\
2,680 \\
2,570 \\
2,460 \\
2,410 \\
3,020\end{array}$ & $\begin{array}{l}3.57 \\
3.53 \\
3.57 \\
3.61 \\
3.66 \\
3.67\end{array}$ & $\begin{array}{l}4,970 \\
4,860 \\
4,980 \\
5,110 \\
5,280 \\
5,320\end{array}$ & $\begin{array}{l}4.49 \\
4.69 \\
4.90 \\
4.94 \\
4.90 \\
4.97\end{array}$ & $\begin{array}{r}8,420 \\
9,260 \\
10,200 \\
10,400 \\
10,200 \\
10,500\end{array}$ & $\begin{array}{l}12.26 \\
12.64 \\
12.96 \\
13.28 \\
13.60 \\
13.97\end{array}$ & $\begin{array}{l}66,700 \\
71,200 \\
75,000 \\
78,900 \\
83,100 \\
87,900\end{array}$ & $\begin{array}{l}12.88 \\
12.58 \\
12.28 \\
12.00 \\
11.70 \\
11.44\end{array}$ & $\begin{array}{l}74,100 \\
70,500 \\
66,900 \\
63,800 \\
60,500 \\
57,600\end{array}$ \\
\hline $\begin{array}{r}7 \\
8 \\
9 \\
10 \\
11 \\
N\end{array}$ & $\begin{array}{l}3.18 \\
3.10 \\
2.99 \\
2.90 \\
2.83 \\
2.79\end{array}$ & $\begin{array}{l}3,800 \\
3,580 \\
3,300 \\
3,070 \\
2,900 \\
2,810\end{array}$ & $\begin{array}{l}3.04 \\
3.01 \\
3.04 \\
3.09 \\
3.04 \\
3.00\end{array}$ & $\begin{array}{l}3,420 \\
3,350 \\
3,420 \\
3,530 \\
3,420 \\
3,320\end{array}$ & $\begin{array}{l}3.61 \\
3.53 \\
3.45 \\
3.38 \\
3.33 \\
3.31\end{array}$ & $\begin{array}{l}5,110 \\
4,860 \\
4,600 \\
4,380 \\
4,230 \\
4,170\end{array}$ & $\begin{array}{l}5.23 \\
5.72 \\
6.30 \\
6.69 \\
6.90 \\
7.02\end{array}$ & $\begin{array}{l}11,700 \\
14,100 \\
17,000 \\
19,200 \\
20,500 \\
21,200\end{array}$ & $\begin{array}{l}14.24 \\
14.50 \\
14.68 \\
14.80 \\
14.90 \\
14.95\end{array}$ & $\begin{array}{r}91,400 \\
95,000 \\
97,500 \\
99,200 \\
101,000 \\
101,000\end{array}$ & $\begin{array}{l}11.18 \\
10.98 \\
10.72 \\
10.50 \\
10.30 \\
10.18\end{array}$ & $\begin{array}{l}54,900 \\
52,900 \\
50,300 \\
48,100 \\
46,300 \\
45,200\end{array}$ \\
\hline $\begin{array}{l}1 \\
2 \\
3 \\
4 \\
5 \\
6\end{array}$ & $\begin{array}{l}2.76 \\
2.72 \\
2.70 \\
2.67 \\
2.64 \\
2.62\end{array}$ & $\begin{array}{l}2,740 \\
2,650 \\
2,610 \\
2,540 \\
2,480 \\
2,430\end{array}$ & $\begin{array}{l}2.97 \\
2.92 \\
2.91 \\
2.91 \\
2.91 \\
3.08\end{array}$ & $\begin{array}{l}3,240 \\
3,120 \\
3,100 \\
3,100 \\
3,100 \\
3,530\end{array}$ & $\begin{array}{l}3.30 \\
3.29 \\
3.33 \\
3.38 \\
3.70 \\
4.01\end{array}$ & $\begin{array}{l}4,140 \\
4,110 \\
4,230 \\
4,380 \\
5,420 \\
6,540\end{array}$ & $\begin{array}{l}7.23 \\
7.50 \\
7.70 \\
7.96 \\
8.22 \\
8.66\end{array}$ & $\begin{array}{l}22,500 \\
24,100 \\
25,500 \\
27,300 \\
29,100 \\
32,400\end{array}$ & $\begin{array}{l}14.89 \\
14.78 \\
14.68 \\
14.51 \\
14.40 \\
14.32\end{array}$ & $\begin{array}{r}100,000 \\
98,900 \\
97,500 \\
95,100 \\
93,600 \\
92,500\end{array}$ & $\begin{array}{r}10.11 \\
10.00 \\
9.88 \\
9.71 \\
9.50 \\
9.38\end{array}$ & $\begin{array}{l}44,600 \\
43,600 \\
42,500 \\
41,000 \\
39,100 \\
38,100\end{array}$ \\
\hline \multirow[t]{2}{*}{$\begin{array}{r}7 \\
8 \\
9 \\
10 \\
1.1 \\
M\end{array}$} & $\begin{array}{l}2.63 \\
2.68 \\
2.78 \\
2.83 \\
2.85 \\
2.80\end{array}$ & $\begin{array}{l}2,460 \\
2,570 \\
2,790 \\
2,900 \\
2,950 \\
2,830\end{array}$ & $\begin{array}{l}3.40 \\
3.53 \\
3.58 \\
3.61 \\
3.60 \\
3.59\end{array}$ & $\begin{array}{l}4,440 \\
4,860 \\
5,020 \\
5,110 \\
5,080 \\
5,050\end{array}$ & $\begin{array}{l}4.11 \\
4.16 \\
4.26 \\
4.33 \\
4.40 \\
4.43\end{array}$ & $\begin{array}{l}6,920 \\
7,110 \\
7,500 \\
7,780 \\
8,060 \\
8,180\end{array}$ & $\begin{array}{r}9.10 \\
9.50 \\
9.96 \\
10.56 \\
11.10 \\
11.78\end{array}$ & $\begin{array}{l}35,900 \\
39,100 \\
43,200 \\
48,700 \\
54,100 \\
61,400\end{array}$ & $\begin{array}{l}14.18 \\
14.06 \\
13.86 \\
13.66 \\
13.45 \\
13.17\end{array}$ & $\begin{array}{l}90,600 \\
89,100 \\
86,500 \\
83,900 \\
81,200 \\
77,500\end{array}$ & $\begin{array}{l}9.27 \\
9.18 \\
9.10 \\
9.00 \\
8.92 \\
8.90\end{array}$ & $\begin{array}{l}37,300 \\
36,500 \\
35,900 \\
35,100 \\
34,500 \\
34,300\end{array}$ \\
\hline & \multicolumn{2}{|c|}{ September 24} & \multicolumn{2}{|c|}{ September 25} & \multicolumn{2}{|c|}{ September 26} & \multicolumn{2}{|c|}{ September 27} & \multicolumn{2}{|c|}{ September 28} & \multicolumn{2}{|c|}{ September $29^{\circ}$} \\
\hline $\begin{array}{r}2 \\
4 \\
6 \\
8 \\
10 \\
10 \\
\text { N }\end{array}$ & $\begin{array}{l}8.70 \\
8.50 \\
8.33 \\
8.16 \\
7.97 \\
7.80\end{array}$ & $\begin{array}{l}32,700 \\
31,100 \\
29,900 \\
28,700 \\
27,400 \\
26,200\end{array}$ & $\begin{array}{l}7.00 \\
6.72 \\
6.60 \\
6.50 \\
6.40 \\
6.31\end{array}$ & $\begin{array}{l}21,100 \\
19,400 \\
18,700 \\
18,100 \\
17,500 \\
17,000\end{array}$ & $\begin{array}{l}5.80 \\
5.64 \\
5.57 \\
5.52 \\
5.49 \\
5.42\end{array}$ & $\begin{array}{l}14,500 \\
13,700 \\
13,400 \\
13,100 \\
13,000 \\
12,600\end{array}$ & $\begin{array}{l}5.21 \\
5.13 \\
4.94 \\
4.88 \\
4.89 \\
4.86\end{array}$ & $\begin{array}{l}11,600 \\
11,200 \\
10,400 \\
10,100 \\
10,100 \\
10,000\end{array}$ & $\begin{array}{l}4.80 \\
4.73 \\
4.55 \\
4.50 \\
4.54 \\
4.53\end{array}$ & $\begin{array}{l}9,740 \\
9,430 \\
8,670 \\
8,460 \\
8,630 \\
8,590\end{array}$ & $\begin{array}{l}4.35 \\
4.51 \\
4.31 \\
4.20 \\
4.25 \\
4.23\end{array}$ & $\begin{array}{l}7,860 \\
8,500 \\
7,700 \\
7,260 \\
7,460 \\
7,380\end{array}$ \\
\hline $\begin{array}{r}2 \\
4 \\
6 \\
8 \\
10 \\
M\end{array}$ & $\begin{array}{l}7.65 \\
7.50 \\
7.36 \\
7.21 \\
7.09 \\
6.98\end{array}$ & $\begin{array}{l}25,200 \\
24,100 \\
23,300 \\
22,400 \\
21,600 \\
21,000\end{array}$ & $\begin{array}{l}6.22 \\
6.13 \\
6.02 \\
5.97 \\
5.90 \\
5.80\end{array}$ & $\begin{array}{l}16,600 \\
16,200 \\
15,600 \\
15,400 \\
15,000 \\
14,500\end{array}$ & $\begin{array}{l}5.37 \\
5.41 \\
5.54 \\
5.41 \\
5.40 \\
5.16\end{array}$ & $\begin{array}{l}12,400 \\
12,600 \\
13,200 \\
12,600 \\
12,500 \\
11,400\end{array}$ & $\begin{array}{l}4.81 \\
4.90 \\
5.09 \\
4.92 \\
4.72 \\
4.67\end{array}$ & $\begin{array}{r}9,780 \\
10,200 \\
11,100 \\
10,300 \\
9,390 \\
9,170\end{array}$ & $\begin{array}{l}4.51 \\
4.52 \\
4.63 \\
4.60 \\
4.49 \\
4.39\end{array}$ & $\begin{array}{l}8,500 \\
8,540 \\
9,010 \\
8,880 \\
8,420 \\
8,020\end{array}$ & $\begin{array}{l}4.21 \\
4.20 \\
4.38 \\
4.33 \\
4.20 \\
4.08\end{array}$ & $\begin{array}{l}7,300 \\
7,260 \\
7,980 \\
7,780 \\
7,260 \\
6,800\end{array}$ \\
\hline
\end{tabular}


Delaware River at Belvidere, N. J.

Location.- Water-stage recorder, lat. $40^{\circ} 49^{\prime} 36^{\prime \prime}$, long. $75^{\circ} 05^{\prime} 02^{n}$, at Belvidere, Warren County, fust below mouth of Pequest River. zero of gage is 226.43 feet (revisad) above mean sea level (general adjustment of 1929).

Drainage area.- 4,542 square miles; 369 square miles affected by storage in Lake Wallenpaupack and Toronto and Swinging Bridge Reservolrs.

Gage-helght record.. Water-stage recorder graph.

Stage-discharge relation.- Defined by current-meter messurements below 170,000 secondfeet.

Maxima.- September 1938: Discharge, 116,000 second-feet 9 to 11 p.m. Sept. 22 (gage helght, 19.27 feet). 1922 to August 1938: Discharge, 179,000 second-feet Mar. 19, 1936 (gage helght, 25.0 feet).

Maximum discharge known, 220,000 second-feet Oct. 10, 1903 (gage height, 28,6 feet, from floodmarks).

Remarks.- Mean monthly discharge and run-off, in inches, adjusted for storage in Lake Wallenpaupack and in Toronto and Swinging Bridge Reservoirs.

Mean dally discharge, in second-feet, 1938

\begin{tabular}{|c|c|c|c|c|c|c|c|c|c|c|c|}
\hline Day & Sept. & Oct. & Day & Sept. & Oct. & Day & Sept. & Oct. & Day & Sept. & Oct. \\
\hline $\begin{array}{l}1 \\
2 \\
3 \\
4 \\
5 \\
6 \\
7 \\
8 \\
\end{array}$ & $\begin{array}{l}4,190 \\
4,060 \\
3,820 \\
3,140 \\
2,630 \\
2,440 \\
2,730 \\
3,470\end{array}$ & $\begin{array}{l}9,220 \\
7,910 \\
7,030 \\
6,860 \\
6,210 \\
5,900 \\
6,700 \\
5,740\end{array}$ & $\begin{array}{r}9 \\
10 \\
11 \\
12 \\
13 \\
14 \\
15 \\
16\end{array}$ & $\begin{array}{l}3,580 \\
3,580 \\
3,470 \\
2,730 \\
2,830 \\
3,140 \\
3,580 \\
4,580\end{array}$ & $\begin{array}{l}5,000 \\
4,720 \\
4,450 \\
4,450 \\
4,060 \\
4,320 \\
4,580 \\
4,190\end{array}$ & $\begin{array}{l}17 \\
18 \\
19 \\
20 \\
21 \\
22 \\
23 \\
24\end{array}$ & $\begin{array}{r}4,720 \\
4,580 \\
4,190 \\
8,380 \\
21,500 \\
89,800 \\
87,000 \\
44,200\end{array}$ & $\begin{array}{l}3,700 \\
3,470 \\
3,940 \\
4,190 \\
5,290 \\
5,290 \\
4,450 \\
4,450\end{array}$ & $\begin{array}{l}25 \\
26 \\
27 \\
28 \\
29 \\
30 \\
31\end{array}$ & $\begin{array}{l}28,400 \\
20,100 \\
16,100 \\
13,700 \\
11,500 \\
10,200\end{array}$ & $\begin{array}{l}5,900 \\
7,030 \\
6,530 \\
5,900 \\
5,900 \\
5,140 \\
4,720\end{array}$ \\
\hline \multicolumn{7}{|c|}{$\begin{array}{l}\text { Mean monthly discharge, in second-feet } \\
\text { Mean monthly discharge, in second-feet } \\
\text { Run-off, in inches (adjusted)... }\end{array}$} & $: \dot{0}$ & $: \dot{0}:$ & $\dot{\bullet}$ & $\begin{array}{r}13,940 \\
13,670 \\
3.36 \\
\end{array}$ & $\begin{array}{r}5,395 \\
4,779 \\
1.21 \\
\end{array}$ \\
\hline
\end{tabular}

Gage helght, in feet, and discharge, in second-feet, at indicated time, 1938

\begin{tabular}{|c|c|c|c|c|c|c|c|c|c|c|c|c|}
\hline \multirow{2}{*}{$\begin{array}{l}9 \\
\text { 夏 } \\
\end{array}$} & Feet & Sec.ft. & Feet & Sec.ft. & Fe日t & Sec.ft. & Feet & Sec.ft. & Beet & Sec.ft. & Feet & Sec.ft \\
\hline & \multicolumn{2}{|c|}{ September 18} & \multicolumn{2}{|c|}{ September 19} & \multicolumn{2}{|c|}{ September 20} & \multicolumn{2}{|c|}{ September 21} & \multicolumn{2}{|c|}{ September 22} & \multicolumn{2}{|c|}{ September 23} \\
\hline $\begin{array}{l}1 \\
2 \\
3 \\
4 \\
5 \\
6\end{array}$ & $\begin{array}{l}4.62 \\
4.60 \\
4.58 \\
4.55 \\
4.52 \\
4.50\end{array}$ & $\begin{array}{l}4,780 \\
4,720 \\
4,670 \\
4,580 \\
4,500 \\
4,450\end{array}$ & $\begin{array}{l}4.45 \\
4.46 \\
4.44 \\
4.42 \\
4.40 \\
4.37\end{array}$ & $\begin{array}{l}4,320 \\
4,350 \\
4,290 \\
4,240 \\
4,190 \\
4,120\end{array}$ & $\begin{array}{l}4.80 \\
4.90 \\
4.98 \\
5.05 \\
5.12 \\
5.18\end{array}$ & $\begin{array}{l}5,290 \\
5,590 \\
5,840 \\
6,060 \\
6,270 \\
6,470\end{array}$ & $\begin{array}{l}6.66 \\
6.66 \\
6.67 \\
6.73 \\
6.83 \\
6.98\end{array}$ & $\begin{array}{l}12,100 \\
12,100 \\
12,200 \\
12,400 \\
12,900 \\
13,600\end{array}$ & $\begin{array}{l}12.66 \\
13.00 \\
13.30 \\
13.64 \\
14.10 \\
14.58\end{array}$ & $\begin{array}{l}50,400 \\
53,500 \\
56,200 \\
59,300 \\
63,400 \\
68,000\end{array}$ & $\begin{array}{l}19.10 \\
19.00 \\
18.85 \\
18.70 \\
18.55 \\
18.32\end{array}$ & $\begin{array}{l}114,000 \\
112,000 \\
110,000 \\
109,000 \\
108,000 \\
105,000\end{array}$ \\
\hline $\begin{array}{r}7 \\
8 \\
9 \\
10 \\
11 \\
\mathrm{~N}\end{array}$ & $\begin{array}{l}4.48 \\
4.46 \\
4.44 \\
4.43 \\
4.44 \\
4.50\end{array}$ & $\begin{array}{l}4,400 \\
4,350 \\
4,290 \\
4,270 \\
4,290 \\
4,450\end{array}$ & $\begin{array}{l}4.35 \\
4.32 \\
4.30 \\
4.29 \\
4.29 \\
4.30\end{array}$ & $\begin{array}{l}4,060 \\
3,990 \\
3,940 \\
3,920 \\
3,920 \\
3,940\end{array}$ & $\begin{array}{l}5.24 \\
5.30 \\
5.39 \\
5.50 \\
5.63 \\
5.77\end{array}$ & $\begin{array}{l}6,660 \\
6,860 \\
7,170 \\
7,550 \\
8,020 \\
8,530\end{array}$ & $\begin{array}{l}7.15 \\
7.32 \\
7.46 \\
7.60 \\
7.70 \\
7.80\end{array}$ & $\begin{array}{l}14,400 \\
15,200 \\
15,900 \\
16,600 \\
17,100 \\
17,600\end{array}$ & $\begin{array}{l}15.05 \\
15.57 \\
16.07 \\
16.52 \\
17.00 \\
17.35\end{array}$ & $\begin{array}{l}72,500 \\
77,700 \\
82,700 \\
87,200 \\
92,000 \\
95,500\end{array}$ & $\begin{array}{l}18.12 \\
17.85 \\
17.60 \\
17.30 \\
17.00 \\
16.65\end{array}$ & $\begin{array}{r}103,00 \\
100,00 \\
98,00 \\
95,00 \\
92,00 \\
88,50\end{array}$ \\
\hline $\begin{array}{l}1 \\
2 \\
3 \\
4 \\
5 \\
6\end{array}$ & $\begin{array}{l}4.56 \\
4.62 \\
4.65 \\
4.66 \\
4.65 \\
4.61\end{array}$ & $\begin{array}{l}4,610 \\
4,780 \\
4,860 \\
4,890 \\
4,860 \\
4,750\end{array}$ & $\begin{array}{l}4.31 \\
4.33 \\
4.35 \\
4.38 \\
4.43 \\
4.48\end{array}$ & $\begin{array}{l}3,960 \\
4,020 \\
4,060 \\
4,140 \\
4,270 \\
4,400\end{array}$ & $\begin{array}{l}5.88 \\
5.96 \\
6.03 \\
6.10 \\
6.17 \\
6.23\end{array}$ & $\begin{array}{r}8,940 \\
9,250 \\
9,530 \\
9,800 \\
10,100 \\
10,300\end{array}$ & $\begin{array}{l}7.92 \\
8.12 \\
8.35 \\
8.70 \\
8.95 \\
9.34\end{array}$ & $\begin{array}{l}18,200 \\
19,200 \\
20,400 \\
22,400 \\
23,900 \\
26,200\end{array}$ & $\begin{array}{l}17.72 \\
18.05 \\
18.30 \\
18.60 \\
18.80 \\
19.00\end{array}$ & $\begin{array}{r}99,200 \\
102,000 \\
105,000 \\
108,000 \\
110,000 \\
112,000\end{array}$ & $\begin{array}{l}.32 \\
.00 \\
.65 \\
.30 \\
.00 \\
.65\end{array}$ & $\begin{array}{l}78,50 \\
75,00 \\
72,00 \\
68,60\end{array}$ \\
\hline \multirow[t]{2}{*}{$\begin{array}{r}7 \\
8 \\
9 \\
10 \\
11 \\
M\end{array}$} & $\begin{array}{l}4.57 \\
4.52 \\
4.48 \\
4.45 \\
4.45 \\
4.45 \\
\end{array}$ & $\begin{array}{l}4,640 \\
4,500 \\
4,400 \\
4,320 \\
4,320 \\
4,320\end{array}$ & $\begin{array}{l}4.50 \\
4.52 \\
4.57 \\
4.60 \\
4.63 \\
4.70\end{array}$ & $\begin{array}{l}4,450 \\
4,500 \\
4,640 \\
4,720 \\
4,800 \\
5,000\end{array}$ & $\begin{array}{l}6.30 \\
6.36 \\
6.42 \\
6.50 \\
6.57 \\
6.62\end{array}$ & $\begin{array}{l}10,600 \\
10,800 \\
11,100 \\
11,500 \\
11,800 \\
12,000\end{array}$ & $\begin{array}{r}9.82 \\
10.40 \\
11.00 \\
11.45 \\
11.91 \\
12.33\end{array}$ & $\begin{array}{l}29,100 \\
33,100 \\
37,300 \\
40,600 \\
44,300 \\
47,600\end{array}$ & $\begin{array}{l}19.10 \\
19.20 \\
19.25 \\
19.27 \\
19.25 \\
19.20\end{array}$ & $\begin{array}{l}114,000 \\
115,000 \\
116,000 \\
116,000 \\
116,000 \\
115,000\end{array}$ & $\begin{array}{l}14.40 \\
14.12 \\
13.90 \\
13.70 \\
13.53 \\
13.35\end{array}$ & $\begin{array}{l}66,30 \\
63,60 \\
61,60 \\
59,80 \\
58,30 \\
56,60\end{array}$ \\
\hline & \multicolumn{2}{|c|}{ September 24} & \multicolumn{2}{|c|}{ September 25} & \multicolumn{2}{|c|}{ September 26} & \multicolumn{2}{|c|}{ September 27} & \multicolumn{2}{|c|}{ September 28} & \multicolumn{2}{|c|}{ September 29} \\
\hline $\begin{array}{r}2 \\
4 \\
6 \\
8 \\
10 \\
N\end{array}$ & $\begin{array}{l}13.02 \\
12.70 \\
12.42 \\
12.20 \\
12.00 \\
11.80\end{array}$ & $\begin{array}{l}53,700 \\
50,800 \\
48,400 \\
46,600 \\
45,000 \\
43,400\end{array}$ & $\begin{array}{r}10.40 \\
10.22 \\
10.05 \\
9.90 \\
9.78 \\
9.65\end{array}$ & $\begin{array}{l}33,100 \\
31,800 \\
30,600 \\
29,600 \\
28,900 \\
28,100\end{array}$ & & $\begin{array}{l}22,800 \\
22,200 \\
21,500 \\
21,000 \\
20,400 \\
20,000\end{array}$ & & $\begin{array}{l}17,400 \\
17,400 \\
17,400 \\
17,200 \\
16,800 \\
16,400\end{array}$ & & $\begin{array}{l}14,200 \\
14,200 \\
14,500 \\
14,400 \\
14,000 \\
13,600\end{array}$ & & $\begin{array}{l}12,200 \\
12,200 \\
12,200\end{array}$ \\
\hline $\begin{array}{r}2 \\
4 \\
6 \\
8 \\
10 \\
M\end{array}$ & $\begin{array}{l}11.64 \\
11.35 \\
11.13 \\
11.00 \\
10.78 \\
10.60\end{array}$ & $\begin{array}{l}42,100 \\
39,800 \\
38,200 \\
37,300 \\
35,800 \\
34,500\end{array}$ & $\begin{array}{l}9.55 \\
9.40 \\
9.27 \\
9.10 \\
8.98 \\
8.88\end{array}$ & $\begin{array}{l}500 \\
600 \\
800 \\
800 \\
100 \\
500\end{array}$ & $\begin{array}{l}8 . \\
8 . \\
8 . \\
7 . \\
7 . \\
7 .\end{array}$ & $\begin{array}{l}600 \\
100 \\
600 \\
200 \\
900 \\
600\end{array}$ & $\begin{array}{l}7 . \\
7 . \\
7 . \\
7 . \\
7 .\end{array}$ & $\begin{array}{l}000 \\
700 \\
200 \\
800 \\
500 \\
200\end{array}$ & $\begin{array}{l}6 . \\
6 . \\
6 . \\
6 . \\
6 . \\
6 .\end{array}$ & $\begin{array}{l}13,400 \\
13,200 \\
12,900 \\
12,700 \\
12,400 \\
12,300\end{array}$ & $\begin{array}{l}52 \\
50 \\
47 \\
40 \\
35 \\
31\end{array}$ & $\begin{array}{l}11,6 \\
11,5 \\
11,4 \\
11,0 \\
10,8 \\
10,6\end{array}$ \\
\hline
\end{tabular}


Delaware River at Rlegelsville, N. J.

Location. - Water-stage recorder, lat. $40^{\circ} 35^{\prime} 36^{\prime \prime}$, long. $75^{\circ} 11^{\prime} 17^{\prime \prime}$, at suspension bridge, kiegelsville, Warren County, 600 feet above mouth of Musconetcong River, flow of which is included in records. Zero of gage is 125.12 feet (revised) above mean sea level (general ad justment of 1929 ).

Dralnage area.- 6,344 square miles (including drainage area of Musconetcong River); 395 square miles effected by storage in Lake Wallenpaupack, Toronto and Swinging Bridge Reservolra, and Lake Hopatcong.

Gage-he1ght record. - Water-stage recorder graph.

Stage-discharge relation.- Defined by current-meter measurements below 27,000 secondfeet; extended to peak stage by averaging discharges obtained from slope-area determination and from a rating curve based on shape of former rating curve, which was defined by current-meter measurements below 95,000 second-feet.

Haxima.- September 1838: Discharge, 123,000 second-feet 11 p.m. Sept. 22 to 2 a.m. Sept. 23 (gage height, 23.00 feet).

1906 to August í938: Discharge, 210,000 second-feet Mar. 19, 1936 (gage height, 32.45 feet).

Maximum discharge known, about 275,000 second-feet oct. 10, 1903 (gage height, 35.9 feet, from floodmarks).

Remarks.- Mean monthly discharge and run-off, in inches, adjusted for storage in Lake Wallenpaupack, Toronto and Swing1ng Bridge Reservolrs, and Lake Hopatcong and for diversion in Delaware Division Canal.

Mean dafly discharge, in second-feet, 1938

\begin{tabular}{|c|c|c|c|c|c|c|c|c|c|c|c|}
\hline Day & Sept. & Oet. & Day & Sept. & oct. & Day & Sept. & oct. & Day & sept. & Oct. \\
\hline $\begin{array}{l}1 \\
2 \\
3 \\
4 \\
5 \\
6 \\
7 \\
8\end{array}$ & $\begin{array}{l}6,230 \\
6,080 \\
5,460 \\
5,010 \\
4,290 \\
4,020 \\
3,880 \\
4,860\end{array}$ & $\begin{array}{r}12,800 \\
11,300 \\
9,850 \\
9,500 \\
8,810 \\
8,470 \\
9,850 \\
9,150\end{array}$ & $\begin{array}{r}9 \\
10 \\
11 \\
12 \\
13 \\
14 \\
15 \\
16\end{array}$ & $\begin{array}{l}5,010 \\
5,010 \\
5,010 \\
4,430 \\
4,020 \\
4,720 \\
5,160 \\
6,700\end{array}$ & $\begin{array}{l}7,650 \\
7,170 \\
6,850 \\
6,700 \\
6,380 \\
6,230 \\
6,850 \\
6,540\end{array}$ & $\begin{array}{l}17 \\
18 \\
19 \\
20 \\
21 \\
22 \\
23 \\
24\end{array}$ & $\begin{array}{r}6,380 \\
6,380 \\
6,540 \\
12,400 \\
30,300 \\
91,900 \\
103,000 \\
56,200 \\
\end{array}$ & $\begin{array}{l}5,920 \\
5,460 \\
5,920 \\
6,230 \\
7,810 \\
7,810 \\
7,170 \\
7,010\end{array}$ & $\begin{array}{l}25 \\
26 \\
27 \\
28 \\
29 \\
30 \\
31\end{array}$ & $\begin{array}{l}37,900 \\
27,700 \\
22,300 \\
19,000 \\
16,000 \\
14,000\end{array}$ & $\begin{array}{l}8,810 \\
9,850 \\
9,500 \\
8,470 \\
8,470 \\
7,980 \\
7,330\end{array}$ \\
\hline $\begin{array}{l}\text { Mean } \\
\text { Mean } \\
\text { Run- }\end{array}$ & $\begin{array}{l}\text { nthly } \\
\text { nthly } \\
\text { in } 1\end{array}$ & ches & 1 & econd- & t lobs & $\begin{array}{l}\text { rved } \\
\text { isted }\end{array}$ & : $: \dot{0}$ & 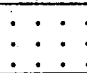 & $: \dot{:}$ & $\begin{array}{r}17,660 \\
17,460 \\
3.07\end{array}$ & $\begin{array}{r}7,995 \\
7,407 \\
1.35\end{array}$ \\
\hline
\end{tabular}

Gage helght, In feet, and discharge, in second-feet, at indicated time, 1938

\begin{tabular}{|c|c|c|c|c|c|c|c|c|c|c|c|c|}
\hline \multirow{2}{*}{ 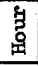 } & Feet & sec.ft. & Feet & Sec.ft. & Feet & Sec.ft. & Feet. & Sec.ft. & - Feet & Sec:ft. & Feet. & Sec.ft: \\
\hline & \multicolumn{2}{|c|}{ September 18} & \multicolumn{2}{|c|}{ September 19} & \multicolumn{2}{|c|}{ September 20} & \multicolumn{2}{|c|}{ September 21} & \multicolumn{2}{|c|}{ September 22} & \multicolumn{2}{|c|}{ September 23} \\
\hline $\begin{array}{l}1 \\
2 \\
3 \\
4 \\
5 \\
6\end{array}$ & $\begin{array}{l}4.11 \\
4.09 \\
4.06 \\
4.03 \\
4.01 \\
3.99\end{array}$ & $\begin{array}{l}6,880 \\
6,820 \\
6,730 \\
6,630 \\
6,570 \\
6,510\end{array}$ & $\begin{array}{l}3.97 \\
3.94 \\
3.92 \\
3.88 \\
3.85 \\
3.84\end{array}$ & $\begin{array}{l}6,450 \\
6,350 \\
6,290 \\
6,170 \\
6,080 \\
6,040\end{array}$ & $\begin{array}{l}4.34 \\
4.41 \\
4.49 \\
4.58 \\
4.67 \\
4.82\end{array}$ & $\begin{array}{l}7,620 \\
7,840 \\
8,110 \\
8,400 \\
8,710 \\
9,220\end{array}$ & $\begin{array}{l}7.58 \\
7.72 \\
7.86 \\
7.94 \\
7.98 \\
7.99\end{array}$ & $\begin{array}{l}20,400 \\
21,000 \\
21,700 \\
22,100 \\
22,200 \\
22,300\end{array}$ & $\begin{array}{l}14.18 \\
14.64 \\
15.12 \\
15.50 \\
15.90 \\
16.24\end{array}$ & $\begin{array}{l}56,700 \\
59,700 \\
62,900 \\
65,500 \\
68,300 \\
70,700\end{array}$ & $\begin{array}{l}23.00 \\
22.95 \\
22.85 \\
22.75 \\
22.60 \\
22.45\end{array}$ & $\begin{array}{l}123,000 \\
123,000 \\
122,000 \\
122,000 \\
120,000 \\
118,000\end{array}$ \\
\hline $\begin{array}{r}7 \\
8 \\
9 \\
10 \\
11 \\
N\end{array}$ & $\begin{array}{l}3.97 \\
3.94 \\
3.91 \\
3.89 \\
3.87 \\
3.86\end{array}$ & $\begin{array}{l}6,450 \\
6,350 \\
6,260 \\
6,200 \\
6,140 \\
6,110\end{array}$ & $\begin{array}{l}3.83 \\
3.83 \\
3.83 \\
3.83 \\
3.86 \\
3.85\end{array}$ & $\begin{array}{l}6,010 \\
6,010 \\
6,010 \\
6,010 \\
6,110 \\
6,080\end{array}$ & $\begin{array}{l}4.98 \\
5.10 \\
5.23 \\
5.41 \\
5.52 \\
5.58\end{array}$ & $\begin{array}{r}9,780 \\
10,200 \\
10,700 \\
11,300 \\
11,800 \\
11,900\end{array}$ & $\begin{array}{l}7.99 \\
8.01 \\
8.04 \\
8.17 \\
8.34 \\
8.59\end{array}$ & $\begin{array}{l}22,300 \\
22,400 \\
22,500 \\
23,200 \\
23,900 \\
25,200\end{array}$ & $\begin{array}{l}16.70 \\
17.20 \\
17.72 \\
18.28 \\
18.86 \\
19.35\end{array}$ & $\begin{array}{l}73,900 \\
77,500 \\
81,300 \\
85,500 \\
89,900 \\
93,700\end{array}$ & $\begin{array}{l}22.25 \\
22.05 \\
21.82 \\
21.60 \\
21.30 \\
21.00\end{array}$ & $\begin{array}{l}118,000 \\
116,000 \\
113,000 \\
112,000 \\
109,000 \\
107,000\end{array}$ \\
\hline $\begin{array}{l}1 \\
2 \\
3 \\
4 \\
5 \\
6\end{array}$ & $\begin{array}{l}3.85 \\
3.83 \\
3.82 \\
3.81 \\
3.81 \\
3.83\end{array}$ & $\begin{array}{l}6,080 \\
6,010 \\
5,980 \\
5,950 \\
5,950 \\
6,010\end{array}$ & $\begin{array}{l}3.87 \\
3.89 \\
3.91 \\
3.98 \\
4.04 \\
4.11\end{array}$ & $\begin{array}{l}6,140 \\
6,200 \\
6,260 \\
6,480 \\
6,660 \\
6,880\end{array}$ & $\begin{array}{l}5.64 \\
5.74 \\
5.86 \\
6.00 \\
6.18 \\
6.36\end{array}$ & $\begin{array}{l}12,200 \\
12,600 \\
13,000 \\
13,600 \\
14,300 \\
15,000\end{array}$ & $\begin{array}{r}8.87 \\
9.23 \\
9.73 \\
10.25 \\
10.66 \\
11.00\end{array}$ & $\begin{array}{l}26,600 \\
28,400 \\
30,900 \\
33,600 \\
35,900 \\
37,700\end{array}$ & $\begin{array}{l}19.88 \\
20.34 \\
20.76 \\
21.20 \\
21.56 \\
21.90\end{array}$ & $\begin{array}{r}97,800 \\
101,000 \\
105,000 \\
108,000 \\
112,000 \\
114,000\end{array}$ & $\begin{array}{l}20.62 \\
20.25 \\
19.85 \\
19.40 \\
19.00 \\
18.60\end{array}$ & $\begin{array}{r}104,000 \\
100,000 \\
97,600 \\
94,100 \\
91,000 \\
87,900\end{array}$ \\
\hline \multirow[t]{2}{*}{$\begin{array}{r}7 \\
8 \\
9 \\
10 \\
11 \\
M\end{array}$} & $\begin{array}{l}3.86 \\
3.90 \\
3.94 \\
3.97 \\
3.99 \\
3.97\end{array}$ & $\begin{array}{l}6,110 \\
6,230 \\
6,350 \\
6,450 \\
6,510 \\
6,450\end{array}$ & $\begin{array}{l}4.16 \\
4.18 \\
4.19 \\
4.23 \\
4.26 \\
4.29\end{array}$ & $\begin{array}{l}7,040 \\
7,110 \\
7,140 \\
7,270 \\
7,360 \\
7,460\end{array}$ & $\begin{array}{l}6.52 \\
6.71 \\
6.94 \\
7.15 \\
7.31 \\
7.44\end{array}$ & $\begin{array}{l}15,700 \\
16,400 \\
17,500 \\
18,400 \\
19,000 \\
19,700\end{array}$ & $\begin{array}{l}11.28 \\
11.70 \\
12.10 \\
12.58 \\
13.04 \\
13.60\end{array}$ & $\begin{array}{l}300 \\
600 \\
900 \\
800 \\
500 \\
000\end{array}$ & $\begin{array}{l}22.20 \\
22.42 \\
22.64 \\
22.80 \\
22.92 \\
22.98\end{array}$ & $\begin{array}{l}117,000 \\
118,000 \\
120,000 \\
122,000 \\
123,000 \\
123,000\end{array}$ & $\begin{array}{l}18.20 \\
17.80 \\
17.40 \\
17.00 \\
16.70 \\
16.40\end{array}$ & $\begin{array}{l}84,900 \\
81,900 \\
79,000 \\
76,100 \\
73,900 \\
71,800\end{array}$ \\
\hline & \multicolumn{2}{|c|}{ September 24} & \multicolumn{2}{|c|}{ September 25} & \multicolumn{2}{|c|}{ September 26.} & \multicolumn{2}{|c|}{ September 27} & \multicolumn{2}{|c|}{ September 28} & \multicolumn{2}{|c|}{ September 29} \\
\hline $\begin{array}{r}2 \\
4 \\
6 \\
8 \\
10 \\
N\end{array}$ & $\begin{array}{l}15.90 \\
15.42 \\
15.00 \\
14.60 \\
14.22 \\
13.90\end{array}$ & $\begin{array}{l}68,300 \\
64,900 \\
62,100 \\
59,500 \\
56,900 \\
54,900\end{array}$ & $\begin{array}{l}12.00 \\
11.80 \\
11.60 \\
11.40 \\
11.20 \\
11.00\end{array}$ & $\begin{array}{l}43,300 \\
42,200 \\
41,000 \\
39,900 \\
38,800 \\
37,700\end{array}$ & $\begin{array}{l}9.81 \\
9.65 \\
9.50 \\
9.35 \\
9.20 \\
9.10\end{array}$ & $\begin{array}{l}31,400 \\
30,400 \\
29,700 \\
29,700 \\
28,200 \\
27,700\end{array}$ & $\begin{array}{l}8.31 \\
8.23 \\
8.16 \\
8.12 \\
8.10 \\
8.07\end{array}$ & $\begin{array}{l}23,800 \\
23,400 \\
23,100 \\
22,900 \\
22,800 \\
22,600\end{array}$ & $\begin{array}{l}7.46 \\
7.40 \\
7.38 \\
7.38 \\
7.39 \\
7.39\end{array}$ & & $\begin{array}{l}6.81 \\
6.75 \\
6.71 \\
6.68 \\
6.68 \\
6.68\end{array}$ & $\begin{array}{l}16,900 \\
16,600 \\
16,400 \\
16,300 \\
16,300 \\
16,300\end{array}$ \\
\hline $\begin{array}{r}2 \\
4 \\
6 \\
8 \\
10 \\
M\end{array}$ & $\begin{array}{l}13.64 \\
13.35 \\
13.05 \\
12.80 \\
12.50 \\
12.22\end{array}$ & $\begin{array}{l}53,200 \\
51,400 \\
49,600 \\
48,100 \\
46,300 \\
44,600\end{array}$ & $\begin{array}{l}10.90 \\
10.75 \\
10.55 \\
10.35 \\
10.15 \\
10.00\end{array}$ & $\begin{array}{l}37,200 \\
36,400 \\
35,200 \\
34,200 \\
33,100 \\
32,300\end{array}$ & $\begin{array}{l}9.00 \\
8.89 \\
8.78 \\
8.65 \\
8.52 \\
8.42\end{array}$ & $\begin{array}{l}27,200 \\
26,600 \\
26,100 \\
25,400 \\
24,800 \\
24,300\end{array}$ & $\begin{array}{l}7.98 \\
7.89 \\
7.95 \\
7.77 \\
7.64 \\
7.53\end{array}$ & $\begin{array}{l}22,200 \\
21,800 \\
22,100 \\
21,200 \\
20,700 \\
20,200\end{array}$ & $\begin{array}{l}7.32 \\
7.21 \\
7.12 \\
7.07 \\
7.00 \\
6.90\end{array}$ & $\begin{array}{l}19,100 \\
18,600 \\
18,300 \\
18,000 \\
17,700 \\
17,300\end{array}$ & $\begin{array}{l}6.65 \\
6.60 \\
6.52 \\
6.46 \\
6.42 \\
6.35\end{array}$ & $\begin{array}{l}16, \\
16, \\
15, \\
15, \\
15, \\
15,\end{array}$ \\
\hline
\end{tabular}


Delaware R1ver at Trenton, N. J.

Location. - Water-stage recorder, lat. $40^{\circ} 13^{\prime} 18^{\prime \prime}$, long. $74^{\circ} 46^{\prime} 38^{\prime \prime}, 200$ feet above Calhoun Stroet Bridge, Trention, Mercer County, half a mile above mouth of Assunplnk Creok. zero of gage is 7.77 feet above mean sea lovel (general ad justment of 1929).

Drainage area.- 6,796 square m1les; 395 square miles affected by storage in Lake Wallenpaupack, Toronto and Swinging Bridge Reservolrs, and Lake Hopatoong.

Gage-helpht rooord. - Water-stage recorder graph.

stege-dircherge relation.- Defined by current-meter messurements below 225,000 secondreet

Kaxima. - September 1938: D1scharge, 125,000 second-feet 6 to 7 a.m. Sept. 23 (gage holght, 11.45 feet). ig13 to Augugt 1938: D1scharge, 227,000 second-feet Mar. 19, 1936 (gage holght, 16.66 foot).

Maxlmum stage known, 22.8 foet, from floodmark, caused by 100 jam Mar. 8, 1904.

Remark. - Mean monthly discharge and run-off, in inches, adjusted for diversion in Delarare and Rar1tan Canel and for storage In Lake Wallenpaupack, Toronto and SwingIng Bridge Reservolrs, and Lake Hopatcong.

Mean deliy discharge, in second-feet, 1938

\begin{tabular}{|c|c|c|c|c|c|c|c|c|c|c|c|}
\hline Day & Sept. & Oct. & Day & Sept. & Oct. & Day & Sept. & oct. & Day & Sept. & Oot. \\
\hline $\begin{array}{l}1 \\
2 \\
3 \\
4 \\
5 \\
6 \\
7 \\
8 \\
\end{array}$ & $\begin{array}{l}5,860 \\
6,060 \\
6,060 \\
5,260 \\
4,710 \\
4,180 \\
4,010 \\
4,180\end{array}$ & $\begin{array}{r}13,500 \\
12,200 \\
11,000 \\
10,100 \\
9,770 \\
9,150 \\
10,100 \\
10,400\end{array}$ & $\begin{array}{r}9 \\
10 \\
11 \\
12 \\
13 \\
14 \\
15 \\
16\end{array}$ & $\begin{array}{l}4,890 \\
4,890 \\
4,890 \\
4,710 \\
4,180 \\
4,180 \\
4,710 \\
5,860\end{array}$ & $\begin{array}{l}8,280 \\
7,470 \\
7,220 \\
6,970 \\
6,740 \\
6,280 \\
6,740 \\
6,740\end{array}$ & $\begin{array}{l}17 \\
18 \\
19 \\
20 \\
21 \\
22 \\
23 \\
24\end{array}$ & $\begin{array}{r}6,500 \\
6,280 \\
6,740 \\
12,900 \\
42,000 \\
82,200 \\
114,000 \\
63,500 \\
\end{array}$ & $\begin{array}{l}6,280 \\
5,650 \\
5,650 \\
6,060 \\
6,970 \\
8,280 \\
7,740 \\
6,970\end{array}$ & $\begin{array}{l}25 \\
26 \\
27 \\
28 \\
29 \\
30 \\
31\end{array}$ & $\begin{array}{l}41,900 \\
30,500 \\
23,900 \\
20,800 \\
17,500 \\
15,200\end{array}$ & $\begin{array}{r}9,150 \\
10,400 \\
10,400 \\
9,460 \\
9,150 \\
8,860 \\
7,740\end{array}$ \\
\hline $\begin{array}{l}\text { Mean } \\
\text { Mean } \\
\text { Run- }\end{array}$ & & & & cond -1 & et (obs & & $\therefore:$ & $: \vdots$ & & $\begin{array}{r}18,750 \\
18,580 \\
3.05\end{array}$ & $\begin{array}{r}8,433 \\
7,845 \\
1.33\end{array}$ \\
\hline
\end{tabular}

Gage height, in feet, and discharge, in second-feet, at indicated time, 1938

\begin{tabular}{|c|c|c|c|c|c|c|c|c|c|c|c|c|}
\hline \multirow{2}{*}{$\begin{array}{l}8 \\
\text { 올 } \\
\end{array}$} & Feet & Sec.ft. & Feet & Sec.ft. & oet & Sec.ft. & Feet & Sec.ft. & Beot & Sec.ft & Feet & Sec.ft. \\
\hline & \multicolumn{2}{|c|}{ September 18} & \multicolumn{2}{|c|}{ September 18} & \multicolumn{2}{|c|}{ September 20} & \multicolumn{2}{|c|}{ September 21 } & \multicolumn{2}{|c|}{ September 22} & \multicolumn{2}{|c|}{ September 23} \\
\hline $\begin{array}{l}1 \\
2 \\
3 \\
4 \\
5 \\
6\end{array}$ & $\begin{array}{l}1.20 \\
1.19 \\
1.18 \\
1.17 \\
1.17 \\
1.19\end{array}$ & & $\begin{array}{l}1.20 \\
1.19 \\
1.19 \\
1.20\end{array}$ & & 1.43 & & & & & & & \\
\hline $\begin{array}{l}7 \\
8 \\
9\end{array}$ & $\begin{array}{l}1.22 \\
1.26 \\
1.29 \\
1.32 \\
1.35 \\
1.36\end{array}$ & & $\begin{array}{l}1.22 \\
1.24 \\
1.26 \\
1.27 \\
1.45\end{array}$ & & $\begin{array}{l}0 \\
5 \\
5 \\
0\end{array}$ & & & & & & & \\
\hline $\begin{array}{l}1 \\
2 \\
3 \\
4 \\
5 \\
6\end{array}$ & $\begin{array}{l}1.36 \\
1.35 \\
1.35 \\
1.34 \\
1.32 \\
1.31\end{array}$ & & $\begin{array}{l}1.39 \\
1.39 \\
1.42 \\
1.49 \\
1.54 \\
1.53\end{array}$ & & $\begin{array}{l}47 \\
45 \\
45 \\
45 \\
46\end{array}$ & & & & & & & \\
\hline \multirow[t]{2}{*}{$\begin{array}{r}7 \\
8 \\
9 \\
10 \\
17 \\
M \\
\end{array}$} & $\begin{array}{l}1.30 \\
1.29 \\
1.27 \\
1.25 \\
1.24 \\
1.22\end{array}$ & & $\begin{array}{l}1.44 \\
1.41 \\
1.39 \\
1.38\end{array}$ & & $\begin{array}{l}8 \\
5 \\
2 \\
4 \\
0\end{array}$ & & & & $\begin{array}{l}10.11 \\
10.29 \\
10.43 \\
10.64 \\
10.80 \\
10.95\end{array}$ & & $\begin{array}{r}10.07 \\
9.88 \\
9.70 \\
9.45 \\
9.21 \\
9.01\end{array}$ & \\
\hline & \multicolumn{2}{|c|}{ September 24} & \multicolumn{2}{|c|}{ Septembor 25} & \multicolumn{2}{|c|}{ September 26} & \multicolumn{2}{|c|}{ September 27} & \multicolumn{2}{|c|}{ September 28} & \multicolumn{2}{|c|}{ September 29} \\
\hline $\begin{array}{r}2 \\
4 \\
6 \\
8 \\
10 \\
\mathrm{~N}\end{array}$ & $\begin{array}{l}8.67 \\
8.35 \\
8.04 \\
7.75 \\
7.50 \\
7.38\end{array}$ & & & & & & & & $\begin{array}{l}3.74 \\
3.64\end{array}$ & & & \\
\hline $\begin{array}{r}2 \\
4 \\
6 \\
8 \\
10 \\
M\end{array}$ & & & $\begin{array}{l}5.2 \\
5.2 \\
5.3 \\
5.8\end{array}$ & & $\begin{array}{l}4 . \\
4 . \\
4 . \\
4 . \\
4 .\end{array}$ & & & & & & & \\
\hline
\end{tabular}


Mill Brook at Arena, N. Y.

Location.- Lat. $42^{\circ} 06^{\prime} 30^{\prime \prime}$, long. $74^{\circ} 43^{\prime} 55^{\prime \prime}, 0.2$ mile above steel highway bridge, 0.6 mile southeast of Arena, Delaware County, and about 1 mile above confluence with East Branch of Delaware River.

Drainage area.- 25.0 square miles.

Gage-he1ght record.- Graph based on twice-daily readings of staff-gage and floodmarks. Stage-discharge relation.- For 1938 defined by curreit-meter measurements below 957 second-feet; extended to peak stage on basis of area-mean velocity study. For 1937 defined by current-meter measurements below 269 second-feet; extended logarithmically to peak stage.

Maxima.- September 1938: Discharge, 4,500 second-feet at about 7 p.m. Sept. 21 (gage helght, 7.6 feet, from floodmarks).

February 1937 to August 1938: Discharge, 1,550 second-feet oct. 23, 1937

(gage height, 5.0 feet, from graph based on twice-dally readings of staff-gage). Remarks.- Flood run-off not affected by storage or diversion.

Mean daily discharge, in second-feet, 1938

\begin{tabular}{|c|c|c|c|c|c|c|c|c|c|c|c|}
\hline Dey & Sept. & oct. & Day & Sept. & oct. & Day & Sept. & oct. & Day & Sept. & Oct. \\
\hline $\begin{array}{l}1 \\
2 \\
3 \\
4 \\
5 \\
6 \\
7 \\
8\end{array}$ & $\begin{array}{l}17 \\
14 \\
12 \\
12 \\
11 \\
11 \\
10 \\
14\end{array}$ & $\begin{array}{l}41 \\
35 \\
31 \\
30 \\
28 \\
26 \\
25 \\
24\end{array}$ & $\begin{array}{r}9 \\
10 \\
11 \\
12 \\
13 \\
14 \\
15 \\
16\end{array}$ & $\begin{array}{l}11 \\
11 \\
10 \\
9.6 \\
17 \\
12 \\
21 \\
18\end{array}$ & \begin{tabular}{l|}
22 \\
21 \\
20 \\
20 \\
18 \\
17 \\
16 \\
16
\end{tabular} & $\begin{array}{l}17 \\
18 \\
19 \\
20 \\
21 \\
22 \\
23 \\
24\end{array}$ & $\begin{array}{r}14 \\
16 \\
23 \\
150 \\
1,540 \\
624 \\
283 \\
164\end{array}$ & $\begin{array}{l}14 \\
13 \\
14 \\
27 \\
22 \\
19 \\
22 \\
30\end{array}$ & $\begin{array}{l}25 \\
26 \\
27 \\
28 \\
29 \\
30 \\
31\end{array}$ & $\begin{array}{r}118 \\
85 \\
82 \\
64 \\
55 \\
47\end{array}$ & $\begin{array}{l}31 \\
33 \\
33 \\
35 \\
33 \\
30 \\
29\end{array}$ \\
\hline $\begin{array}{l}\text { Mean } \\
\text { Run- }\end{array}$ & nthly & $\begin{array}{l}\text { scharg } \\
\text { hes. }\end{array}$ & , Ir & econd- & et. & $: \dot{ }$ & : : : & $\therefore:$ & $: \dot{ }$ & $\begin{array}{r}116 \\
5.18\end{array}$ & $\begin{array}{l}25.0 \\
1.15\end{array}$ \\
\hline
\end{tabular}


Location.- Water-stage recorder, lat. $42^{\circ} 07^{\prime} 15^{\prime \prime}$, long. $74^{\circ} 49^{\prime} 10^{\prime \prime}$, 500 feet above highway bridge, $2 \frac{1}{4}$ miles northeast of Shavertown, Delaware County, and $2 \frac{1}{4}$ miles above confluence with East Branch of Delaware River.

Drainage area.- 33.0 square miles.

Gage-height record.- Water-stage recorder graph.

Stage-discharge relation.- For 1938 defined by current-meter measurements below 594 second-feet; extended logarithmically to peak stage, verified by run-off comparison with other streams in Delaware River Basin. For 1937 defined by current-meter measurements below 217 second-feet; extended logarithmically to peak stage. Concrete control subsequent to November 1937.

Maxima.- September 1938: Discharge, 4,250 second-feet 6 p.m. Sept. 21 (gage height, 7.12 feet).

February 1937 to August 1938: Discharge, 1,800 second-feet 0ct. 23, 1937 (gage height, 4.07 feet, present site and datum but prior to concrete control).

Remarks.- Flood run-off not affected by storage or diversion.

Mean daily discharge, in second-feet, 1938

\begin{tabular}{|c|r|r||r|r|r||r|r|r|r|r|r|}
\hline Day & Sept. & 0ct. & Day & Sept. & 0ct. & Day & Sept. & oct. & Day & Sept. & 0ct. \\
\hline 1 & 16 & 47 & 9 & 9.5 & 20 & 17 & 22 & 13 & 25 & 170 & 29 \\
2 & 10 & 40 & 10 & 6.7 & 20 & 18 & 28 & 12 & 26 & 128 & 22 \\
3 & 8.8 & 35 & 11 & 6.0 & 18 & 19 & 27 & 12 & 27 & 100 & 21 \\
4 & 8.8 & 33 & 12 & 5.7 & 17 & 20 & 260 & 17 & 28 & 82 & 20 \\
5 & 7.4 & 29 & 13 & 43 & 16 & 21 & 1,620 & 36 & 29 & 65 & 21 \\
6 & 5.7 & 27 & 14 & 18 & 16 & 22 & 1,060 & 20 & 30 & 53 & 21 \\
7 & 13 & 26 & 15 & 34 & 15 & 23 & 465 & 16 & 31 & & 20 \\
8 & 16 & 23 & 16 & 29 & 14 & 24 & 250 & 24 & & & \\
\hline
\end{tabular}

Gage helght, in feet, and discharge, in second-feet, at indicated time, 1938

\begin{tabular}{|c|c|c|c|c|c|c|c|c|c|c|c|c|}
\hline \multirow{2}{*}{$\begin{array}{l}9 \\
\text { 覀 } \\
\end{array}$} & Feet & Sec.ft. & Feet & Sec.ft. & Feet & Sec.ft. & Feet & Sec.ft. & Feet & Sec.ft. & Feet & Sec.ft. \\
\hline & \multicolumn{2}{|c|}{ September 18} & \multicolumn{2}{|c|}{ September 19} & \multicolumn{2}{|c|}{ September 20} & \multicolumn{2}{|c|}{ September 21} & \multicolumn{2}{|c|}{ September 22} & \multicolumn{2}{|c|}{ September 23} \\
\hline 1 & - & - & - & - & 2.50 & 60 & 4.10 & 706 & 5.46 & 2,070 & 3.62 & 516 \\
\hline 2 & 2.31 & 32 & 2.22 & 23 & & 66 & & 640 & & 1,860 & & 522 \\
\hline 3 & - & & & & & 73 & & 566 & & 1,720 & & 549 \\
\hline 4 & 2.31 & 32 & 2.22 & 23 & & 85 & & 520 & & 1,540 & & 590 \\
\hline 5 & & & & & & 110 & & 509 & & & & 620 \\
\hline 6 & 2.30 & 31 & 2.22 & 23 & 2. & 159 & 3.7 & 515 & 4. & 1,340 & 3.80 & 620 \\
\hline 7 & - & - & - & - & 3.13 & 222 & 3.81 & 526 & 4.66 & 1,260 & 3.76 & 596 \\
\hline 8 & 2.28 & 29 & 2.22 & 23 & & 257 & & 526 & & 1,150 & & 566 \\
\hline 9 & & & & & & 280 & & 526 & & 1,080 & & 538 \\
\hline 10 & 2.27 & 28 & 2.22 & 23 & & 284 & 3.83 & 537 & & 1,030 & 3. & 510 \\
\hline 11 & - & & & & & 276 & 3.5 & 621 & 4. & 984 & 3. & 488 \\
\hline $\mathrm{N}$ & 2.26 & 27 & 2.21 & 22 & 3.23 & 257 & 4.23 & 798 & & 932 & 3.53 & 466 \\
\hline 1 & - & - & - & - & 3.19 & 242 & 4.58 & 1,080 & 4.19 & 883 & 3.50 & 450 \\
\hline 2 & 2.25 & 26 & 2.21 & 22 & & 228 & & 1,210 & & 841 & & 428 \\
\hline 3 & & - & & & & 222 & 5.18 & 1,660 & & 792 & & 412 \\
\hline 4 & 2.24 & 25 & 2.21 & 22 & 3.1 & 225 & 5.85 & 2,420 & 3.96 & 722 & 3.40 & 395 \\
\hline 5 & - & & - & & & 236 & 6.58 & 3,390 & & 715 & 3.38 & 384 \\
\hline 6 & 2.23 & 24 & 2.26 & 27 & 3.2 & 261 & 7.12 & 4,250 & & 674 & 3.35 & 368 \\
\hline \multirow{7}{*}{$\begin{array}{r}7 \\
8 \\
9 \\
10 \\
11 \\
M\end{array}$} & _ & - & - & - & 3.33 & 296 & 6.80 & 3,750 & 3.84 & 644 & 3.33 & 356 \\
\hline & 2.23 & 24 & 2.29 & 30 & 3.45 & 347 & 6.60 & 3,460 & 3.81 & 626 & & 346 \\
\hline & - & & - & & 3.62 & 426 & 6.40 & 3,190 & 3. & 608 & 3.29 & 335 \\
\hline & 2.23 & 24 & 2.40 & 44 & 3.90 & 578 & 6.30 & 3,060 & & 566 & & 330 \\
\hline & - & - & - & & 4.0 & 673 & 5.97 & 2,640 & & 549 & & 320 \\
\hline & 2.22 & 23 & 2.47 & 55 & 4.10 & 706 & 75 & & & 532 & 3.25 & 315 \\
\hline & \multicolumn{2}{|c|}{ September 24} & \multicolumn{2}{|c|}{ September 25} & \multicolumn{2}{|c|}{ September 26} & \multicolumn{2}{|c|}{ September 27} & \multicolumn{2}{|c|}{ September 28} & \multicolumn{2}{|c|}{ September 29} \\
\hline 2 & 3.22 & 300 & - & - & - & - & - & - & - & - & -1 & - \\
\hline 4 & & & 2.96 & 191 & 2.79 & 136 & & - & & & & - \\
\hline 6 & 17 & $2^{\prime} 76$ & - & - & - & - & 2.67 & 105 & 2.59 & 86 & 2.51 & $6 s$ \\
\hline 8 & 15 & 268 & 2.92 & 177 & 2.78 & 134 & - & - & - & $\begin{array}{ll}- & \text { r }\end{array}$ & - & - \\
\hline 10 & & 25 & & & & & - & - & - & & - & - \\
\hline $\mathrm{N}$ & 3 & 250 & 2.90 & $I 74$ & 2.76 & 128 & 2.65 & 100 & 2.57 & 82 & 2.49 & 65 \\
\hline 2 & 3.09 & 241 & - & - & - & - & - & - & - & - & - & - \\
\hline 4 & .07 & 23 & 2.87 & 161 & 2.73 & 120 & - & - & - & & - & - \\
\hline 6 & .05 & 225 & - & & - & & 2.64 & 98 & 2.54 & & 2.47 & 62 \\
\hline 8 & .03 & 217 & 2.83 & 148 & 2.71 & 115 & - & - & - & & - & - \\
\hline 10 & 3.01 & 209 & - & & - & & - & - & - & & - & - \\
\hline M & 2.99 & 202 & 2.82 & 145 & 2.69 & 110 & 2.61 & 90 & 2.52 & 71 & 2.45 & \\
\hline
\end{tabular}

Supplemental records.- Sept. 20, 9:30 a.m., $3.31 \mathrm{ft.}, 288 \mathrm{sec} . \mathrm{ft}$. Sept. 21, 12:30 a.m., 4.12 ft., 720 sec. $-\mathrm{ft}$. 
Terry Clove K1ll near Pepacton, $\mathrm{N}$. $\mathrm{Y}$.

Location.- Lat. $42^{\circ} 07^{\prime} 4^{\prime \prime}$, long. $74^{\circ} 53^{\prime} 55^{n}$, at timber farm bridge, 3t miles north of Pepacton, Sulilvan County, and it miles above confluence with Fall Clove K1ll. Dreingge area.- 14.1 square miles.

Gage-helght record.- Graph based on twice-delly readings of staff-gage and floodmark. Stege-discharge relat1on.- Defined by current-meter measurements below 335 second-

feet; extended to peak stage on basis of area-mean velocity study and logarithmic plotting.

Maxima.- September 1938: Discharge, 1,700 second-feet about 8 p.m. Sept. 21 (gage

height, 6.2 feet, from floodmark).

February 1937 to August 1938: D1scharge, 850 second-feet Jan. 25, 1938

(gage helght, 4.7 feet, from graph based on twice-dally readings of staff-gage). Remarks.- Flood run-off not affected by storage or diversion.

Mean dally discharge, in second-feet, 1938

\begin{tabular}{|c|c|c|c|c|c|c|c|c|c|c|c|}
\hline Day & Sept. & Oct. & Day & Sept. & Oct. & Day & Sept. & Oot. & Day & Sept. & Oot. \\
\hline $\begin{array}{l}1 \\
2 \\
3 \\
4 \\
5 \\
6 \\
7 \\
8\end{array}$ & $\begin{array}{c}6.6 \\
4.7 \\
4.2 \\
3.6 \\
3.5 \\
3.5 \\
10 \\
8.8\end{array}$ & $\begin{array}{l}16 \\
14 \\
11 \\
10 \\
9.4 \\
9.0 \\
8.1 \\
7.4\end{array}$ & $\begin{array}{r}9 \\
10 \\
11 \\
12 \\
13 \\
14 \\
15 \\
16\end{array}$ & $\begin{array}{c}4.8 \\
3.8 \\
3.5 \\
3.8 \\
22 \\
8.4 \\
21 \\
15\end{array}$ & $\begin{array}{l}7.2 \\
6.9 \\
6.2 \\
6.0 \\
5.8 \\
5.5 \\
5.2 \\
5.1\end{array}$ & $\begin{array}{l}17 \\
18 \\
19 \\
20 \\
21 \\
22 \\
23 \\
24\end{array}$ & $\begin{array}{r}12 \\
14 \\
20 \\
126 \\
603 \\
464 \\
226 \\
128\end{array}$ & $\begin{array}{c}4.9 \\
4.7 \\
4.7 \\
6.3 \\
12 \\
7.2 \\
5.5 \\
22\end{array}$ & $\begin{array}{l}25 \\
26 \\
27 \\
28 \\
29 \\
30 \\
31\end{array}$ & $\begin{array}{l}75 \\
52 \\
44 \\
33 \\
26 \\
21\end{array}$ & $\begin{array}{l}19 \\
12 \\
11 \\
11 \\
12 \\
11 \\
9.9\end{array}$ \\
\hline $\begin{array}{l}\text { Mean } \\
\text { Run- }\end{array}$ & nthy & $\begin{array}{l}\text { char } \\
\text { aes. }\end{array}$ & 1 & $\begin{array}{c}\text { second } \\
.\end{array}$ & et. : &.$\dot{ }$ & $\begin{array}{l}\cdot \cdot \cdot \\
\cdot . \\
\end{array}$ & $\begin{array}{ll} & \cdot \\
. & \cdot \\
\end{array}$ & $\begin{array}{l}\cdot . \\
. \\
.\end{array}$ & $\begin{array}{l}65.7 \\
5.20\end{array}$ & $\begin{array}{r}9.23 \\
.76 \\
\end{array}$ \\
\hline
\end{tabular}


Location. - Water-stage recorder, lat. $41^{\circ} 57^{\prime} 45^{\mathrm{n}}$, long. $74^{\circ} 52^{\prime} 00^{\prime}$, 100 feet below highway bridge at Craigie Clair, Sullivan County, $43 / 4$ miles above confluence with Willowemoc Creek. Zero of gage is $1,399.69$ feet above mean sea level (general adjustment of 1912).

Drainage area.- 82 square miles.

Gage-helght record.- Water-stage recorder graph.

Stage-discharge relation.- Defined by current-meter measurements below 2,680 secondfeet; extended logarithmically to peak stage.

Max1ma.- September 1938: D1scharge, 8,360 second-feet 8 p.m. Sept. 21 (gage he1ght, 9.72 feet).

May 1937 to August 1938: Discharge, 9,530 second-feet Aug. 11, 1938 (gage height, 10.11 feet).

Remarks.- Flood run-off not affected by storage or diversion.

Mean dally discharge, in second-feet, 1938

\begin{tabular}{|c|r|r||r|r|r||r|r|r||r|r|r|}
\hline Day & Sept. & Oct. & Day & Sept. & 0ct. & Day & Sept. & 0ct. & Day & Sept. & 0ct. \\
\hline 1 & 73 & 161 & 9 & 54 & 86 & 17 & 56 & 60 & 25 & 432 & 138 \\
2 & 69 & 139 & 10 & 49 & 81 & 18 & 61 & 59 & 26 & 332 & 100 \\
3 & 63 & 125 & 11 & 47 & 78 & 19 & 73 & 57 & 27 & 293 & 90 \\
4 & 61 & 117 & 12 & 46 & 73 & 20 & 630 & 59 & 28 & 253 & 86 \\
5 & 57 & 106 & 13 & 67 & 69 & 21 & 3,400 & 86 & 29 & 208 & 88 \\
6 & 53 & 99 & 14 & 59 & 66 & 22 & 2,080 & 70 & 30 & 180 & 84 \\
7 & 62 & 95 & 15 & 66 & 64 & 23 & 980 & 63 & 31 & & 81 \\
8 & 78 & 88 & 16 & 64 & 63 & 24 & 610 & 86 & & & \\
\hline
\end{tabular}

Gage helght, in feet, and discharge, in second-feet, at indicated time, 1938

\begin{tabular}{|c|c|c|c|c|c|c|c|c|c|c|c|c|}
\hline \multirow[t]{2}{*}{ 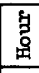 } & eet & Sec.ft. & Feet & Sec.ft. & Feet & Sec.ft. & Feet & sec.ft. & Feot & Sec.ft. & Foet & Sec.ft. \\
\hline & \multicolumn{2}{|c|}{ September 18} & \multicolumn{2}{|c|}{ September 19} & \multicolumn{2}{|c|}{ September 20} & \multicolumn{2}{|c|}{ September 21} & \multicolumn{2}{|c|}{ September 22} & \multicolumn{2}{|c|}{ September 23} \\
\hline & $\begin{array}{l}- \\
- \\
- \\
\overline{3.07}\end{array}$ & $\begin{array}{l}- \\
- \\
- \\
- \\
-63\end{array}$ & $\begin{array}{c}- \\
\overline{-} \\
3.04 \\
-\end{array}$ & $\begin{array}{l}- \\
- \\
- \\
- \\
-\end{array}$ & $\begin{array}{c}\overline{-} \\
3.61 \\
\overline{3.81} \\
\overline{4.20}\end{array}$ & $\begin{array}{r}233 \\
-\quad 386\end{array}$ & & $\begin{array}{l}1,700 \\
1,600 \\
1,500 \\
1,430 \\
1,360 \\
1,330\end{array}$ & $\begin{array}{l}7.98 \\
7.66 \\
7.40 \\
7.18 \\
7.01 \\
6.84\end{array}$ & & $\begin{array}{c}- \\
.5 .41 \\
- \\
5.49 \\
- \\
5.51\end{array}$ & $\begin{array}{l}\overline{1,10} \\
\overline{1,15} \\
\overline{1,1}\end{array}$ \\
\hline & $\begin{array}{l}\bar{z} \\
\bar{z} \\
\bar{z} \\
3.07\end{array}$ & $\begin{array}{l}- \\
\bar{z} \\
\bar{z} \\
\\
\end{array}$ & $\begin{array}{c}\overline{5} \\
- \\
\overline{-} \\
\overline{3.04}\end{array}$ & $\begin{array}{l}-59 \\
- \\
- \\
- \\
59\end{array}$ & $\begin{array}{l}-\overline{4.55} \\
\overline{4.72} \\
\overline{4.79}\end{array}$ & $\begin{array}{l}- \\
558 \\
-651 \\
-6 \\
690\end{array}$ & $\begin{array}{l}5.69 \\
5.66 \\
5.62 \\
5.61 \\
5.70 \\
5.94\end{array}$ & $\begin{array}{l}1,3 \\
1,2 \\
1,2 \\
1,2 \\
1,3 \\
1,5\end{array}$ & $\begin{array}{l}6 . \\
6 .\end{array}$ & & $\begin{array}{c}- \\
5.45 \\
- \\
5.38 \\
- \\
5.28\end{array}$ & $\begin{array}{l}\overline{1,1} \\
- \\
1,08 \\
\overline{1,0}\end{array}$ \\
\hline & $\begin{array}{l}\overline{-} \\
- \\
\bar{z} \\
3.05\end{array}$ & $\begin{array}{l}- \\
\bar{z} \\
\bar{z} \\
- \\
\end{array}$ & $\begin{array}{c}- \\
\overline{-} \\
3.11 \\
\overline{-}\end{array}$ & $\begin{array}{l}\bar{z} \\
\overline{-} \\
-\end{array}$ & $\begin{array}{l}\overline{4.75} \\
\overline{4.69} \\
\overline{-} \\
4.72\end{array}$ & $\begin{array}{r}634 \\
-651\end{array}$ & $\begin{array}{l}6.28 \\
6.65 \\
7.26 \\
8.00 \\
8.67 \\
9.23\end{array}$ & $\begin{array}{l}1,890 \\
2,310 \\
3,100 \\
4,300 \\
5,610 \\
6,980\end{array}$ & $\begin{array}{l}5.95 \\
5.88 \\
5.81 \\
5.76\end{array}$ & $\begin{array}{l}1, \\
1, \\
1, \\
1, \\
1, \\
1,\end{array}$ & $\begin{array}{c}\overline{5.20} \\
\overline{5.12} \\
\overline{5.05}\end{array}$ & - \\
\hline & $\begin{array}{c}\overline{-} \\
\overline{-} \\
\overline{3.04}\end{array}$ & $\begin{array}{l}- \\
- \\
\overline{-} \\
\\
\end{array}$ & $\begin{array}{c}- \\
3.26 \\
\overline{-} \\
\overline{3.45}\end{array}$ & $\begin{array}{l}-94 \\
- \\
- \\
- \\
132\end{array}$ & $\begin{array}{c}- \\
4.81 \\
- \\
5.61 \\
- \\
6.10\end{array}$ & $\begin{array}{l}- \\
1,250 \\
- \\
1,700\end{array}$ & $\begin{array}{l}9.58 \\
9.72 \\
9.57 \\
9.19 \\
8.76 \\
8.34\end{array}$ & $\begin{array}{l}7,940 \\
8,360 \\
7,910 \\
6,880 \\
5,810 \\
4,940\end{array}$ & $\begin{array}{l}5.70 \\
5.64 \\
5.59 \\
5.54 \\
5.48 \\
5.44\end{array}$ & & $\begin{array}{l}- \\
4.99 \\
- \\
4.94 \\
- \\
4.89\end{array}$ & $\begin{array}{r}-809 \\
-\quad 779 \\
-749 \\
-749\end{array}$ \\
\hline & \multicolumn{2}{|c|}{ September 24} & \multicolumn{2}{|c|}{ September 25} & \multicolumn{2}{|c|}{ September 26} & \multicolumn{2}{|c|}{ September 27} & \multicolumn{2}{|c|}{ September 28} & \multicolumn{2}{|c|}{ September 29} \\
\hline & $\begin{array}{l}-\overline{4.79} \\
\overline{4.72} \\
\overline{4.64}\end{array}$ & $\begin{array}{l}-65 \\
-60\end{array}$ & $\begin{array}{l}- \\
4.39 \\
- \\
4.35 \\
- \\
4.31\end{array}$ & ${ }^{4}$ & $\begin{array}{c}- \\
\overline{4} \\
4.12 \\
\dot{-} \\
4.07\end{array}$ & - & $\begin{array}{c}- \\
- \\
3.98 \\
- \\
\overline{3.98}\end{array}$ & $\begin{array}{l}- \\
- \\
297 \\
- \\
297\end{array}$ & $\begin{array}{c}- \\
- \\
3.90 \\
- \\
\overline{3.86}\end{array}$ & $\begin{array}{l}- \\
- \\
253\end{array}$ & $\begin{array}{c}- \\
- \\
3.76 \\
- \\
- \\
3.72\end{array}$ & $\begin{array}{l}- \\
- \\
- \\
- \\
208\end{array}$ \\
\hline & $\begin{array}{l}4.50 \\
- \\
4.44\end{array}$ & $\begin{array}{r}-530 \\
-500\end{array}$ & $\begin{array}{c}- \\
4.26 \\
\overline{4.21} \\
\overline{4.17}\end{array}$ & $\begin{array}{l}- \\
-392 \\
-374\end{array}$ & $\begin{array}{c}- \\
4.02 \\
\overline{-} \\
\overline{3.98}\end{array}$ & $\begin{array}{l}- \\
- \\
312\end{array}$ & $\begin{array}{c}- \\
- \\
3.98 \\
- \\
3.94\end{array}$ & $\begin{array}{l}- \\
- \\
297 \\
- \\
282\end{array}$ & $\begin{array}{c}- \\
\overline{3.82} \\
- \\
\overline{3.79}\end{array}$ & $\begin{array}{l}- \\
240 \\
- \\
230\end{array}$ & $\begin{array}{c}\overline{-} \\
\overline{3.69} \\
\overline{3} \\
\overline{3.67}\end{array}$ & $\overline{-}_{194}$ \\
\hline
\end{tabular}


Location. - Water-stage recorder, lat. $41^{\circ} 56^{\prime} 50^{n}$, long. $74^{\circ} 58^{\prime} 45^{\prime \prime}$, about 125 feet below highway bridge in Cooks Falls, Delaware County, $5 \frac{1}{2}$ miles below mouth of willowemoc Creek.

Drainage area.- 241 square miles.

Gage-height record.- Water-stage recorder graph.

Stage-discharge relation. - For 1938 defined by current-meter measurements below 9,440 second-feet; extended to peak stage on basis of slope-area determination of peak $f l o w$ of March $1936 \mathrm{flood}$. For 1933 defined by current-meter measurements below 2 , 700 second-feet; extended to peak stage on basis of slope-area determination of peak flow of March $1936 \mathrm{flood}$.

Maxima.- September 1938: Discharge, 15,300 second-feet 9:15 p.m. Sept. 21 (gage height, 13.67 feet)

July i913 to August 1938: Discharge, 19,000 second-feet Aug. 24, 1933 (gage height, 17.8 feet, former site, same datum, from floodmarks).

Remarks.- Flood run-off not affected by storage or diversion.

Mean daily discharge, in second-feet, 1938

\begin{tabular}{|c|c|c|c|c|c|c|c|c|c|c|c|}
\hline Day & Sept. & oct. & Day & Sept. & oct. & Day & Sept. & oct. & Day & Sept. & Oct. \\
\hline $\begin{array}{l}7 \\
2 \\
3 \\
4 \\
5 \\
6 \\
7 \\
8\end{array}$ & $\begin{array}{l}212 \\
191 \\
175 \\
173 \\
171 \\
153 \\
174 \\
275\end{array}$ & $\begin{array}{l}494 \\
431 \\
394 \\
358 \\
326 \\
300 \\
277 \\
257\end{array}$ & $\begin{array}{r}9 \\
10 \\
11 \\
12 \\
13 \\
14 \\
15 \\
16\end{array}$ & $\begin{array}{l}182 \\
158 \\
147 \\
142 \\
184 \\
186 \\
210 \\
226\end{array}$ & $\begin{array}{l}246 \\
234 \\
224 \\
212 \\
214 \\
199 \\
189 \\
179\end{array}$ & $\begin{array}{l}17 \\
18 \\
19 \\
20 \\
21 \\
22 \\
23 \\
24\end{array}$ & $\begin{array}{r}182 \\
208 \\
232 \\
1,780 \\
7,600 \\
5,800 \\
2,800 \\
1,800\end{array}$ & $\begin{array}{l}175 \\
168 \\
160 \\
168 \\
250 \\
210 \\
177 \\
225\end{array}$ & $\begin{array}{l}25 \\
26 \\
27 \\
28 \\
29 \\
30 \\
31\end{array}$ & $\begin{array}{r}1,260 \\
960 \\
850 \\
760 \\
640 \\
560\end{array}$ & $\begin{array}{l}454 \\
306 \\
257 \\
234 \\
231 \\
226 \\
217\end{array}$ \\
\hline $\begin{array}{l}\text { Mean } \\
\text { Run- }\end{array}$ & $\begin{array}{l}\text { onthly } \\
{[, \text { in } 1}\end{array}$ & aes. & , ir & & $\dot{.}$ & $\dot{0} \cdot \dot{ }$ & . : & . $\cdot \dot{\cdot}$ & . : & $\begin{array}{r}946 \\
4.38 \\
\end{array}$ & $\begin{array}{r}258 \\
1.23\end{array}$ \\
\hline
\end{tabular}

Gage height, in feet, and discharge, in second-feet, at indicated time, 1938

\begin{tabular}{|c|c|c|c|c|c|c|c|c|c|c|c|c|}
\hline \multirow{2}{*}{$\begin{array}{l}\text { 多 } \\
\text { 号 }\end{array}$} & Feet & Sec.ft. & Feet & Sec.ft. & Feet & Sec.ft. & Feet & Sec.ft. & Feet & Sec.ft. & Feet & Sec.ft. \\
\hline & \multicolumn{2}{|c|}{ September 18} & \multicolumn{2}{|c|}{ September 19} & \multicolumn{2}{|c|}{ September 20} & \multicolumn{2}{|c|}{ September 21} & \multicolumn{2}{|c|}{ September 22} & \multicolumn{2}{|c|}{ September 23} \\
\hline $\begin{array}{l}1 \\
2 \\
3 \\
4 \\
5 \\
6\end{array}$ & $\begin{array}{c}- \\
- \\
- \\
2.00 \\
- \\
-\end{array}$ & $\begin{array}{l}- \\
- \\
- \\
- \\
-\end{array}$ & $\begin{array}{c}2.00 \\
- \\
1.99 \\
\overline{2.00}\end{array}$ & $\begin{array}{c}-199 \\
-197 \\
-199 \\
199\end{array}$ & $\begin{array}{l}2.83 \\
2.96 \\
3.12 \\
3.41 \\
3.70 \\
3.94\end{array}$ & \begin{tabular}{|l|}
462 \\
514 \\
579 \\
710 \\
850 \\
984
\end{tabular} & $\begin{array}{l}7.89 \\
8.02 \\
7.98 \\
7.85 \\
7.68 \\
7.51\end{array}$ & $\begin{array}{l}4,860 \\
5,040 \\
4,980 \\
4,800 \\
4,560 \\
4,340\end{array}$ & $\begin{array}{r}11.72 \\
11.12 \\
10.59 \\
10.13 \\
9.73 \\
9.39\end{array}$ & $\begin{array}{r}11,400 \\
10,300 \\
9,280 \\
8,450 \\
7,730 \\
7,140\end{array}$ & $\begin{array}{c}- \\
6.40 \\
- \\
6.38 \\
- \\
6.48\end{array}$ & $\begin{array}{c}- \\
3,000 \\
- \\
2,980 \\
- \\
3,090\end{array}$ \\
\hline $\begin{array}{r}7 \\
8 \\
9 \\
10 \\
11 \\
N\end{array}$ & $\begin{array}{c}- \\
2.08 \\
- \\
- \\
- \\
2.07\end{array}$ & $\begin{array}{l}- \\
- \\
- \\
- \\
214\end{array}$ & $\begin{array}{c}- \\
2.00 \\
- \\
2.01 \\
- \\
2.01\end{array}$ & $\begin{array}{c}- \\
- \\
209 \\
- \\
201\end{array}$ & $\begin{array}{l}4.22 \\
4.61 \\
5.00 \\
5.30 \\
5.52 \\
5.59\end{array}$ & $\begin{array}{l}1,150 \\
1,420 \\
1,710 \\
1,950 \\
2,150 \\
2,210\end{array}$ & $\begin{array}{l}7.37 \\
7.23 \\
7.13 \\
7.08 \\
7.08 \\
7.19\end{array}$ & $\begin{array}{l}4,160 \\
3,980 \\
3,850 \\
3,790 \\
3,790 \\
3,930\end{array}$ & $\begin{array}{l}9.09 \\
8.82 \\
8.59 \\
8.38 \\
8.19 \\
8.01\end{array}$ & $\begin{array}{l}6,630 \\
6,210 \\
5,860 \\
5,550 \\
5,280 \\
5,020\end{array}$ & $\begin{array}{c}- \\
6.52 \\
- \\
6.46 \\
- \\
6.37\end{array}$ & $\begin{array}{l}\overline{3,130} \\
\overline{3,070} \\
\overline{2,970}\end{array}$ \\
\hline $\begin{array}{l}1 \\
2 \\
3 \\
4 \\
5 \\
6\end{array}$ & $\begin{array}{c}- \\
- \\
\overline{2.06} \\
- \\
-\end{array}$ & $\begin{array}{l}- \\
- \\
- \\
- \\
-\end{array}$ & $\begin{array}{c}- \\
2.05 \\
- \\
2.12 \\
- \\
2.21\end{array}$ & $\begin{array}{c}- \\
- \\
210 \\
- \\
249\end{array}$ & $\begin{array}{l}5.62 \\
5.62 \\
5.59 \\
5.52 \\
5.50 \\
5.47\end{array}$ & $\begin{array}{l}2,240 \\
2,240 \\
2,210 \\
2,150 \\
2,130 \\
2,100\end{array}$ & $\begin{array}{r}7.51 \\
8.18 \\
9.23 \\
10.43 \\
11.42 \\
12.22\end{array}$ & $\begin{array}{r}4,340 \\
5,260 \\
6,870 \\
8,990 \\
10,900 \\
12,400\end{array}$ & $\begin{array}{l}7.85 \\
7.70 \\
7.55 \\
7.41 \\
7.27 \\
7.14\end{array}$ & $\begin{array}{l}4,800 \\
4,590 \\
4,400 \\
4,210 \\
4,030 \\
3,860\end{array}$ & $\begin{array}{c}- \\
6.21 \\
- \\
6.05 \\
- \\
5.92\end{array}$ & $\begin{array}{l}2,800 \\
- \\
2,640 \\
- \\
2,510\end{array}$ \\
\hline \multirow[t]{2}{*}{$\begin{array}{r}7 \\
8 \\
9 \\
10 \\
11 \\
M\end{array}$} & $\begin{array}{c}- \\
2.04 \\
- \\
- \\
- \\
2.01\end{array}$ & $\begin{array}{l}- \\
- \\
- \\
- \\
201\end{array}$ & $\begin{array}{c}- \\
2.33 \\
- \\
2.50 \\
- \\
2.72\end{array}$ & $\begin{array}{c}- \\
-284 \\
340 \\
- \\
420\end{array}$ & $\begin{array}{l}5.48 \\
5.54 \\
5.74 \\
6.13 \\
6.78 \\
7.48\end{array}$ & $\begin{array}{l}2,110 \\
2,170 \\
2,350 \\
2,720 \\
3,430 \\
4,300\end{array}$ & $\begin{array}{l}12.92 \\
13.42 \\
13.65 \\
13.58 \\
13.17 \\
12.45\end{array}$ & $\begin{array}{l}13,800 \\
14,800 \\
15,300 \\
15,200 \\
14,300 \\
12,900\end{array}$ & $\begin{array}{l}7.03 \\
6.91 \\
6.81 \\
6.71 \\
6.62 \\
6.53\end{array}$ & $\begin{array}{l}3,730 \\
3,580 \\
3,460 \\
3,340 \\
3,240 \\
3,140\end{array}$ & $\begin{array}{c}5.77 \\
- \\
5.65 \\
- \\
5.55\end{array}$ & $\begin{array}{c}- \\
2,370 \\
- \\
2,260 \\
- \\
2,180\end{array}$ \\
\hline & \multicolumn{2}{|c|}{ September 24} & \multicolumn{2}{|c|}{ September 25} & \multicolumn{2}{|c|}{ September 26} & \multicolumn{2}{|c|}{ September 27} & \multicolumn{2}{|c|}{ September 28} & \multicolumn{2}{|c|}{ September 29} \\
\hline $\begin{array}{r}2 \\
4 \\
6 \\
8 \\
10 \\
N\end{array}$ & $\begin{array}{l}5.47 \\
5.38 \\
5.30 \\
5.23 \\
5.16 \\
5.10\end{array}$ & $\begin{array}{l}2,100 \\
2,020 \\
1,950 \\
1,890 \\
1,840 \\
1,790\end{array}$ & $\begin{array}{c}- \\
4.57 \\
- \\
4.46 \\
- \\
4.36\end{array}$ & $\begin{array}{c}1,390 \\
- \\
1,310 \\
- \\
1,240\end{array}$ & $\begin{array}{c}- \\
4.02 \\
- \\
3.95 \\
- \\
3.90\end{array}$ & $\begin{array}{c}- \\
1,030 \\
- \\
990 \\
-960\end{array}$ & $\begin{array}{c}- \\
3.66 \\
- \\
3.67 \\
- \\
3.67\end{array}$ & $\begin{array}{c}- \\
-830 \\
- \\
835 \\
- \\
835\end{array}$ & $\begin{array}{c}- \\
3.62 \\
- \\
3.56 \\
- \\
3.51\end{array}$ & $\begin{array}{c}-810 \\
- \\
780 \\
-755\end{array}$ & $\begin{array}{c}- \\
\overline{3} \\
- \\
- \\
\overline{3} \\
.26\end{array}$ & $\begin{array}{l}- \\
- \\
-660 \\
- \\
642\end{array}$ \\
\hline $\begin{array}{r}2 \\
4 \\
6 \\
8 \\
10 \\
M\end{array}$ & $\begin{array}{l}5.03 \\
4.99 \\
4.92 \\
4.84 \\
4.77 \\
4.69\end{array}$ & $\begin{array}{l}1,730 \\
1,700 \\
1,650 \\
1,580 \\
1,530 \\
1,470\end{array}$ & $\begin{array}{c}- \\
4.26 \\
- \\
4.17 \\
\overline{4} \\
4.08\end{array}$ & $\begin{array}{c}- \\
1,180 \\
- \\
1,120 \\
- \\
1,070\end{array}$ & $\begin{array}{c}- \\
3.85 \\
- \\
3.76 \\
- \\
3.70\end{array}$ & $\begin{array}{r}-930 \\
- \\
880 \\
-850\end{array}$ & $\begin{array}{c}- \\
3.74 \\
- \\
3.76 \\
- \\
3.70\end{array}$ & $\begin{array}{c}- \\
-870 \\
-880 \\
- \\
850\end{array}$ & $\begin{array}{c}- \\
3.46 \\
- \\
3.40 \\
- \\
3.35\end{array}$ & $\begin{array}{r}-732 \\
-705 \\
-782\end{array}$ & $\begin{array}{c}- \\
\overline{3.19} \\
- \\
\overline{3.15}\end{array}$ & $\begin{array}{l}- \\
-610 \\
- \\
- \\
592\end{array}$ \\
\hline
\end{tabular}

Supplemental records.- Sept. 21, 9:15 p.m., 13.67 ft., 15,300 sec.-ft. 
W1llowemoc Greek near Iivingston Manor, N. Y.

Location.- Water-stage recorder, lat. $41^{\circ} 54^{\prime} 15^{\prime \prime}$, long. $74^{\circ} 48^{\prime} 50^{\prime \prime}$, three-quarters of a mile above highway bridge in Livingston Manor, Sulilvan County, and lis miles above confluence with Iittle Besver Kill.

Drainage area.- 63 square miles.

Gage-helght record. - Water-stage recorder graph.

Stage-discharge relation.- Defined by current-meter measurements below 3 , 220 secondfeet and a measurement of 5,730 second-feet obtained by using standard cross section at cable with velocity determined by timing of floating drift.

Maxima.- September 1938: Discharge, 3,730 second-feet at 6 p.m. Sept. 21 (gage height,

August 1937 to August 1938: Discharge, 6,200 second-feet Aug. 11, 1938 (gage height, 7.87 feet).

Remarks:- Flood run-off not materlally affected by storage or diversion.

Mean da1Iy discharge, in second-fe日t, 1938

\begin{tabular}{|c|c|c|c|c|c|c|c|c|c|c|c|}
\hline Day & Sept. & Oct. & Day & Sept. & oct. & Day & Sept. & Oct. & Day & Sept. & Oet. \\
\hline $\begin{array}{l}1 \\
2 \\
3 \\
4 \\
5 \\
6 \\
7 \\
8 \\
\end{array}$ & $\begin{array}{l}60 \\
51 \\
45 \\
46 \\
44 \\
39 \\
53 \\
86\end{array}$ & $\begin{array}{r}115 \\
104 \\
98 \\
89 \\
83 \\
76 \\
70 \\
66 \\
\end{array}$ & $\begin{array}{r}9 \\
10 \\
11 \\
12 \\
13 \\
14 \\
15 \\
16\end{array}$ & $\begin{array}{l}50 \\
42 \\
36 \\
35 \\
52 \\
45 \\
62 \\
62\end{array}$ & $\begin{array}{l}64 \\
60 \\
59 \\
64 \\
74 \\
59 \\
51 \\
46\end{array}$ & $\begin{array}{l}17 \\
18 \\
19 \\
20 \\
21 \\
22 \\
23 \\
24\end{array}$ & $\begin{array}{r}48 \\
62 \\
90 \\
570 \\
1,980 \\
1,300 \\
620 \\
390 \\
\end{array}$ & $\begin{array}{l}45 \\
44 \\
44 \\
46 \\
74 \\
55 \\
46 \\
89 \\
\end{array}$ & $\begin{array}{l}25 \\
26 \\
27 \\
28 \\
29 \\
30 \\
31\end{array}$ & $\begin{array}{l}263 \\
206 \\
181 \\
162 \\
142 \\
127\end{array}$ & $\begin{array}{r}137 \\
89 \\
72 \\
64 \\
62 \\
60 \\
55\end{array}$ \\
\hline \multicolumn{4}{|c|}{$\begin{array}{l}\text { Mean monthly discharge, } \\
\text { Run-off, in inches. }\end{array}$} & $\begin{array}{l}\text { second-f } \\
\cdot \cdot \cdot \cdot\end{array}$ & et. $\cdot$ & $\dot{.}$ & 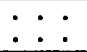 & $\dot{*} \cdot \dot{ }$ & $\dot{0}$ & $\begin{array}{r}232 \\
4.11 \\
\end{array}$ & $\begin{array}{l}69.7 \\
1.28\end{array}$ \\
\hline
\end{tabular}

Gage helght, in feet, and discharge, In second-feet, at indicated time, 1938

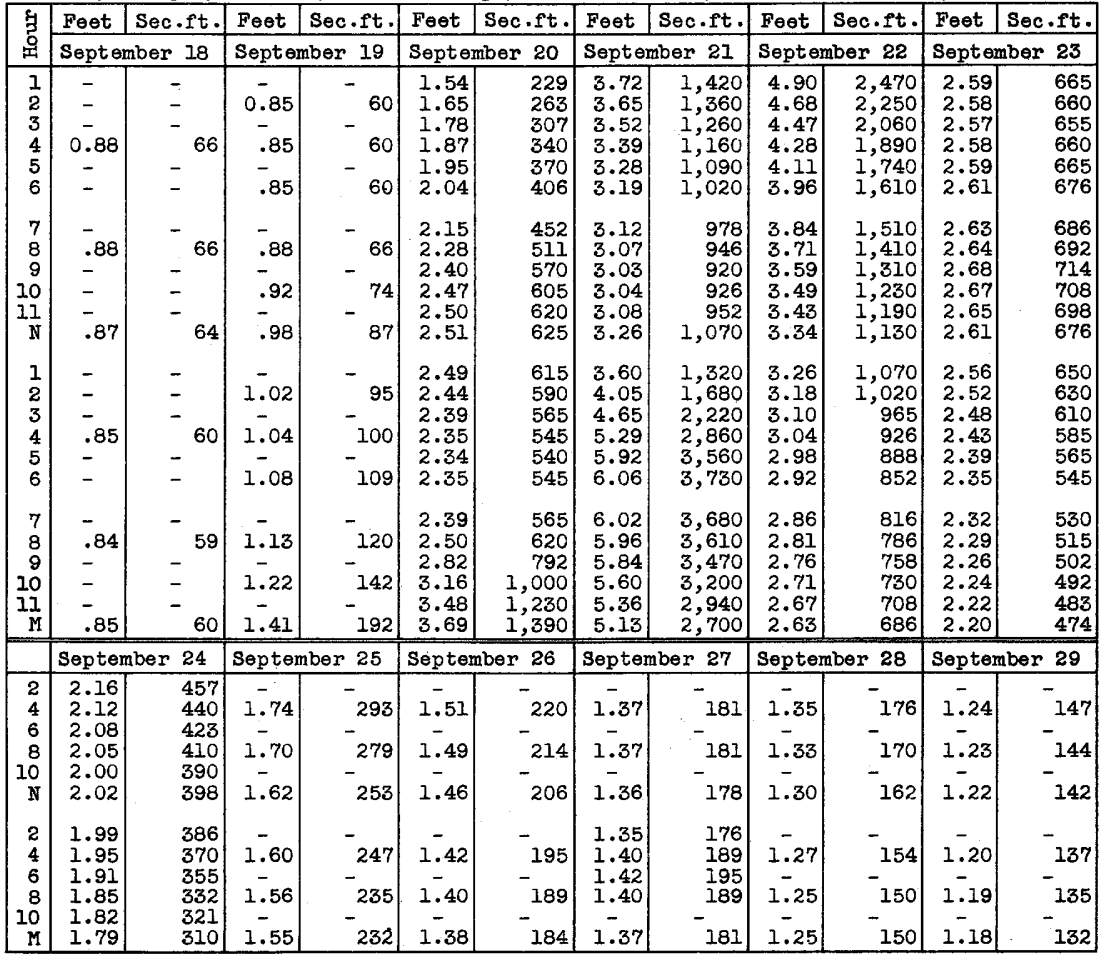

Supplemental records.- Sept. 24, 1l:30 a.m., 1.98 ft., 382 sec.-ft. 
Location. - Lat. $41^{\circ} 52^{\prime 2} 20^{\prime \prime}$, long. $74^{\circ} 47155^{n}, 2 \frac{1}{2}$ miles southeast of Livingston Manor, Sullivan County, and 3 miles above Cattail Brook. Zero of gage is $1,496.89$ feet above mean sea level (general adjustment of 19i2).

Drainage area.- 19.8 square miles.

Gage-helght record.- From graph based on twice-dally gage readings and comparison with Willowemoc Creek water-stage recorder graph.

Stage-discharge relation. - For 1938 defined by current-meter measurements below 1, 130 second-feet; extended logarithmically to peak stage. For 1928 defined by currentmeter measurements below 462 second-feet; extended logarithmically to peak stage. Maxima.- September 1938: Discharge observed, 2,070 second-feet 5:30 p.m. Sept. 22 (gage helght, 7.0 feet).

July 1924 to August 1938: D1scharge, 2,500 second-feet Aug. 26, 1928 (gage height, 8.7 feet, from floodmarks).

Remarks.- Flood run-off not materialiy affected by artificial storage or diversion.

Mean daily discharge, in second-feet, 1938

\begin{tabular}{|c|c|r||r|r|r||r|r|r||r|r|r|}
\hline Dey & Sept. & 0ct. & Day & Sept. & 0ct. & Day & Sept. & 0ct. & Day & Sept. & Oct. \\
\hline 1 & 14 & 27 & 9 & 9.9 & 14 & 17 & 13 & 9.4 & 25 & 85 & 39 \\
2 & 10 & 24 & 10 & 9.4 & 15 & 18 & 18 & 8.9 & 26 & 62 & 22 \\
3 & 9.9 & 20 & 11 & 7.9 & 14 & 19 & 40 & 9.4 & 27 & 53 & 17 \\
4 & 9.9 & 19 & 12 & 7.9 & 13 & 20 & 280 & 9.9 & 28 & 44 & 14 \\
5 & 8.9 & 19 & 13 & 12 & 13 & 21 & 925 & 20 & 29 & 39 & 14 \\
6 & 8.4 & 16 & 14 & 10 & 13 & 22 & 446 & 14 & 30 & 33 & 14 \\
7 & 19 & 15 & 15 & 26 & 10 & 23 & 230 & 11 & 31 & & 11 \\
8 & 20 & 14 & 16 & 16 & 9.9 & 24 & 128 & 34 & & & \\
\hline
\end{tabular}


West Branch of Delaware River at Delhi, N. Y.

Location.- Water-stage recorder, lat. $42^{\circ} 16^{\prime} 15^{\prime \prime}$, long. $74^{\circ} 55^{\prime} 10^{\prime \prime}$, about 300 feet below mouth of Steele Brook and about one-quarter of a mile below lower highway bridge in

Delht, Delaware County. Zero of gage 1s 1,345.97 feet above mean sea level (general adjus tment of 1912).

Drainage area.- 142 square miles.

GBge-he1ght record.- Water-stage recorder graph.

Stage-discharge relation.- For September 1938 defined by current-meter measurements below 2,880 second-feet; extended logarithmically to peak stage on basis of area-mean velocity study. For January 1938 defined by current-meter measurements below 1,930 second-feet; extended logarithmically to peak stage.

Maxima.- September 1938: Discharge, 8,940 second-feet 11 p.m. Sept. 21 (gage he1ght, 8.81 feet).

February 1937 to August 1938: Discharge, 4,290 second-feet Jan. 25, 1938 (gage height, 6.82 feet).

Remarks.- Flood mun-off not affected by storage or diversion.

Mean dafly discharge, in second-feet, 1938

\begin{tabular}{|c|r|r|r|r|r||r|r|r|r|r|r|}
\hline Day & Sept. & 0ct. & Day & Sept. & 0ct. & Day & Sept. & Oct. & Day & Sept. & 0ct. \\
\hline 1 & 82 & 260 & 9 & 60 & 112 & 17 & 218 & 68 & 25 & 870 & 174 \\
2 & 65 & 218 & 10 & 53 & 106 & 18 & 144 & 66 & 26 & 653 & 112 \\
3 & 60 & 190 & 11 & 49 & 97 & 19 & 138 & 64 & 27 & 547 & 95 \\
4 & 68 & 168 & 12 & 49 & 92 & 20 & 730 & 70 & 28 & 470 & 86 \\
5 & 60 & 154 & 13 & 168 & 86 & 21 & 3,350 & 139 & 29 & 358 & 85 \\
6 & 55 & 143 & 14 & 94 & 79 & 22 & 4,000 & 96 & 30 & 302 & 82 \\
7 & 60 & 130 & 15 & 194 & 76 & 23 & 2,040 & 79 & 31 & & 79 \\
8 & 71 & 118 & 16 & 174 & 72 & 24 & 1,240 & 141 & & & \\
\hline
\end{tabular}

Gage helght, in feet, and discharge, in second-feet, at indicated time, 1938

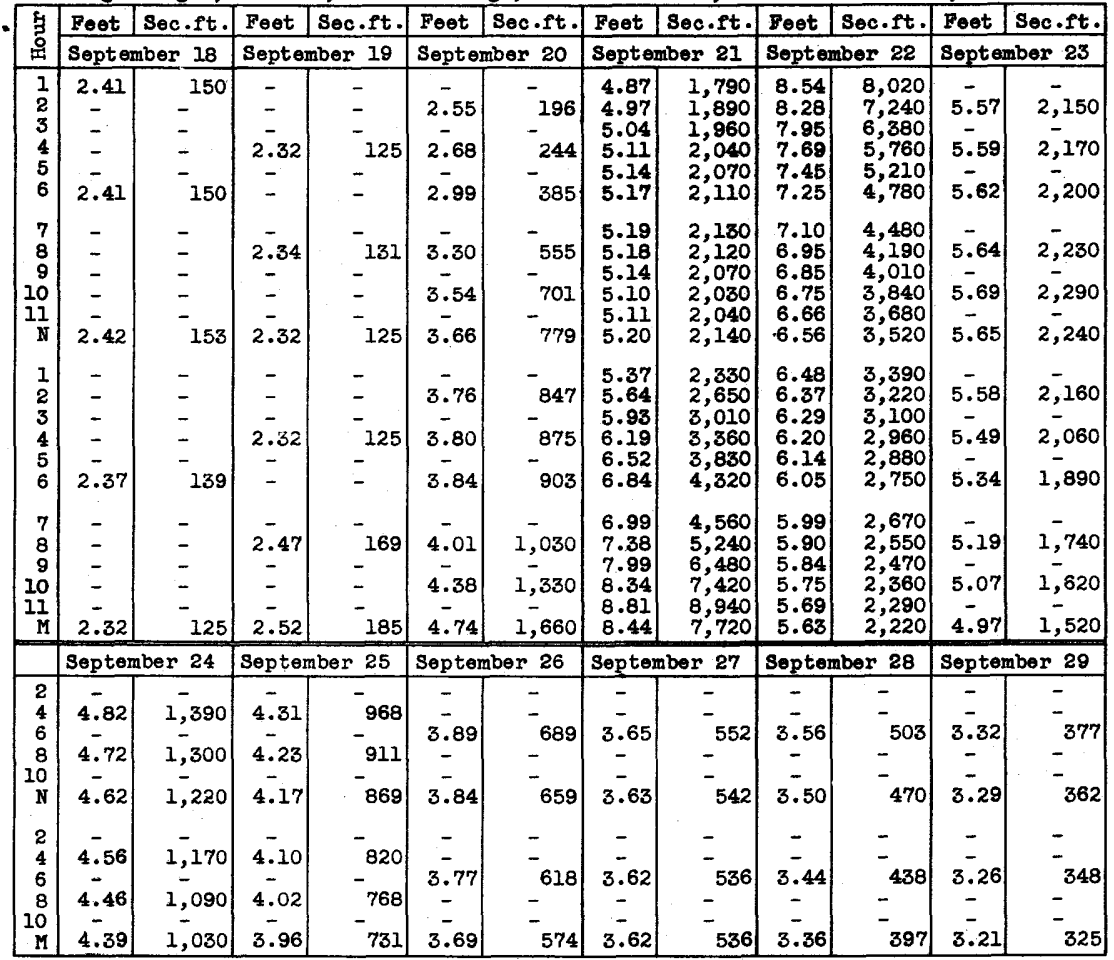


West Branch of Delaware River at Hale Eddy, N. Y.

Location.- Water-stage recorder, lat. $42^{\circ} 00^{\prime} 10^{\mathrm{n}}$, long. $75^{\circ} 23^{\prime} 15^{\mathrm{t}}$, at highway bridge in Fale Eddy, Delaware County, 9 miles above confluence with East Branch of Delaware

River. Zero of gage is 946.34 feet above mean sea level (general adjustment of 1912). Dralnage area.- 593 square miles.

Gage-height record.- Water-stage recorder graph.

Stage-discharge relation.- For 1924 and 1938 defined by current-meter measurements below 22,800 second-feet; extended logarithmically to peak stage.

Maxima.- September 1938: Discharge, 25,600 second-feet 1l:30 a.m. Sept. 22 (gage helght, 15.59 feet).

November 1912 to August 1938: Discharge, 26,500 second-feet Sept. 30, 1924

(gage he1ght, about 15.8 feet, from graph based on gage readings).

Maximum discharge known, about 46,000 second-feet 0ct. 10, ig03 (gage height, 20.3 feet).

Remarks.- Flood run-off not affected by storage or diversion.

Mean dally discharge, in second-feet, 1938

\begin{tabular}{|c|r|r||r|r|r||r|r|r||r|r|r|}
\hline Day & Sept. & 0ct. & Day & Sept. & Oct. & Day & Sept. & Oct. & Day & Sept. & Oct. \\
\hline 1 & 325 & 1,060 & 9 & 305 & 437 & 17 & 880 & 271 & 25 & 3,550 & 1,090 \\
2 & 335 & 922 & 10 & 229 & 411 & 18 & 850 & 251 & 26 & 2,600 & 773 \\
3 & 278 & 787 & 11 & 196 & 382 & 19 & 787 & 244 & 27 & 2,080 & 660 \\
4 & 232 & 691 & 12 & 178 & 358 & 20 & 1,960 & 258 & 28 & 1,760 \\
5 & 235 & 614 & 13 & 330 & 339 & 21 & 9,500 & 376 & 29 & 1,420 & 643 \\
6 & 213 & 565 & 14 & 640 & 313 & 22 & 22,400 & 430 & 30 & 1,200 & 603 \\
7 & 218 & 510 & 15 & 1,100 & 302 & 23 & 10,000 & 339 & 31 & \\
8 & 365 & 472 & 16 & 1,280 & 284 & 24 & 5,500 & 559 & & \\
\hline
\end{tabular}

Gage helght, in feet, and discharge, in second-feet, at indicated time, 1938

\begin{tabular}{|c|c|c|c|c|c|c|c|c|c|c|c|c|}
\hline \multirow{2}{*}{$\begin{array}{l}8 \\
5 \\
0 \\
2\end{array}$} & Feet & Sec.ft. & Feet & Sec.ft. & Feet & Sec.ft. & Feet & Sec.ft. & Feet & Sec.ft. & Feet & Sec.ft. \\
\hline & \multicolumn{2}{|c|}{ September 18} & \multicolumn{2}{|c|}{ September 19} & \multicolumn{2}{|c|}{ September 20} & \multicolumn{2}{|c|}{ September 21} & \multicolumn{2}{|c|}{ September 22} & \multicolumn{2}{|c|}{ September 23} \\
\hline $\begin{array}{l}1 \\
2 \\
3 \\
4 \\
5 \\
6\end{array}$ & $\begin{array}{l}- \\
\overline{-} \\
3.36 \\
- \\
-\end{array}$ & $\begin{array}{l}- \\
- \\
- \\
- \\
-\end{array}$ & $\begin{array}{c}- \\
- \\
\overline{3} \\
- \\
-\end{array}$ & $\begin{array}{l}- \\
- \\
- \\
- \\
-\end{array}$ & $\begin{array}{l}3.40 \\
3.49 \\
3.58 \\
3.67 \\
3.79 \\
3.97\end{array}$ & $\begin{array}{r}870 \\
928 \\
987 \\
1,050 \\
1,130 \\
1,260\end{array}$ & $\begin{array}{l}6.74 \\
6.87 \\
7.01 \\
7.17 \\
7.34 \\
7.50\end{array}$ & $\begin{array}{l}3,950 \\
4,120 \\
4,310 \\
4,540 \\
4,780 \\
5,020\end{array}$ & $\begin{array}{l}15.26 \\
15.42 \\
15.48 \\
15.46 \\
15.48 \\
15.43\end{array}$ & $\begin{array}{l}24,400 \\
25,000 \\
25,200 \\
25,100 \\
25,200 \\
25,000\end{array}$ & $\begin{array}{l}11.48 \\
11.28 \\
11.08 \\
10.95 \\
10.84 \\
10.76\end{array}$ & $\begin{array}{l}13,000 \\
12,500 \\
12,100 \\
11,700 \\
11,500 \\
11,300\end{array}$ \\
\hline $\begin{array}{r}7 \\
8 \\
9 \\
10 \\
11 \\
N\end{array}$ & $\begin{array}{c}- \\
3.37 \\
- \\
- \\
- \\
3.39\end{array}$ & $\begin{array}{l}- \\
-850 \\
- \\
- \\
864\end{array}$ & $\begin{array}{l}- \\
3.29 \\
- \\
- \\
\overline{3.25}\end{array}$ & $\begin{array}{l}-799 \\
- \\
- \\
- \\
775\end{array}$ & $\begin{array}{l}4.11 \\
4.17 \\
4.21 \\
4.28 \\
4.39 \\
4.53\end{array}$ & $\begin{array}{l}1,360 \\
1,400 \\
1,430 \\
1,480 \\
1,570 \\
1,680\end{array}$ & $\begin{array}{l}7.69 \\
7.90 \\
8.06 \\
8.21 \\
8.40 \\
8.62\end{array}$ & $\begin{array}{l}5,310 \\
5,650 \\
5,910 \\
6,170 \\
6,490 \\
6,890\end{array}$ & $\begin{array}{l}15.46 \\
15.48 \\
15.52 \\
15.56 \\
15.56 \\
15.52\end{array}$ & $\begin{array}{l}25,100 \\
25,200 \\
25,300 \\
25,500 \\
25,500 \\
25,300\end{array}$ & $\begin{array}{l}10.68 \\
10.60 \\
10.51 \\
10.41 \\
10.31 \\
10.16\end{array}$ & $\begin{array}{r}11,100 \\
10,900 \\
10,700 \\
10,500 \\
10,300 \\
9,930\end{array}$ \\
\hline $\begin{array}{l}1 \\
2 \\
3 \\
4 \\
5 \\
6\end{array}$ & $\begin{array}{l}- \\
- \\
- \\
3.39 \\
- \\
-\end{array}$ & $\begin{array}{l}- \\
- \\
- \\
- \\
-\end{array}$ & $\begin{array}{l}- \\
- \\
- \\
3.23 \\
- \\
-\end{array}$ & $\begin{array}{l}- \\
- \\
- \\
-763 \\
-\end{array}$ & $\begin{array}{l}4.70 \\
4.88 \\
5.08 \\
5.30 \\
5.51 \\
5.68\end{array}$ & $\begin{array}{l}1,820 \\
1,970 \\
2,150 \\
2,360 \\
2,570 \\
2,740\end{array}$ & $\begin{array}{r}8.87 \\
9.17 \\
9.52 \\
10.07 \\
10.80 \\
11.58\end{array}$ & $\begin{array}{r}7,340 \\
7,900 \\
8,590 \\
9,730 \\
11,400 \\
13,300\end{array}$ & $\begin{array}{l}15.42 \\
15.27 \\
14.98 \\
14.67 \\
14.27 \\
13.86\end{array}$ & $\begin{array}{l}25,000 \\
24,400 \\
23,400 \\
22,300 \\
21,100 \\
19,900\end{array}$ & $\begin{array}{r}10.04 \\
9.92 \\
9.80 \\
9.67 \\
9.53 \\
9.43\end{array}$ & $\begin{array}{l}9, \\
9, \\
9, \\
8, \\
8, \\
8,\end{array}$ \\
\hline \multirow[t]{2}{*}{$\begin{array}{r}7 \\
8 \\
9 \\
10 \\
11 \\
M\end{array}$} & $\begin{array}{l}- \\
3.39 \\
- \\
- \\
3.37\end{array}$ & $\begin{array}{l}- \\
- \\
- \\
- \\
854\end{array}$ & $\begin{array}{c}- \\
3.21 \\
- \\
3.23 \\
- \\
3.34\end{array}$ & $\begin{array}{r}-751 \\
-763 \\
-763 \\
831\end{array}$ & $\begin{array}{l}5.82 \\
5.95 \\
6.09 \\
6.28 \\
6.46 \\
6.60\end{array}$ & $\begin{array}{l}2,880 \\
3,020 \\
3,180 \\
3,390 \\
3,600 \\
3,770\end{array}$ & $\begin{array}{l}12.28 \\
12.90 \\
13.46 \\
14.00 \\
14.51 \\
14.93\end{array}$ & $\begin{array}{l}15,100 \\
17,000 \\
18,700 \\
20,300 \\
21,800 \\
23,300\end{array}$ & $\begin{array}{l}13.44 \\
13.06 \\
12.68 \\
12.34 \\
12.06 \\
11.76\end{array}$ & $\begin{array}{l}18,600 \\
17,500 \\
16,300 \\
15,300 \\
14,500 \\
13,700\end{array}$ & $\begin{array}{l}9.33 \\
9.24 \\
9.16 \\
9.06 \\
8.97 \\
8.86\end{array}$ & $\begin{array}{l}10 \\
40 \\
80 \\
90 \\
20 \\
20\end{array}$ \\
\hline & \multicolumn{2}{|c|}{ September 24} & \multicolumn{2}{|c|}{ September 25} & \multicolumn{2}{|c|}{ September 26} & \multicolumn{2}{|c|}{ September 27} & \multicolumn{2}{|c|}{ September 28} & \multicolumn{2}{|c|}{ September 29} \\
\hline $\begin{array}{r}2 \\
4 \\
6 \\
8 \\
10 \\
N\end{array}$ & $\begin{array}{l}8.68 \\
8.50 \\
8.31 \\
8.10 \\
7.90 \\
7.72\end{array}$ & $\begin{array}{l}6,990 \\
6,670 \\
6,340 \\
5,980 \\
5,650 \\
5,360\end{array}$ & $\begin{array}{l}6.87 \\
6.77 \\
6.68 \\
6.59 \\
6.50 \\
6.41\end{array}$ & $\begin{array}{l}4,120 \\
3,990 \\
3,870 \\
3,760 \\
3,650 \\
3,540\end{array}$ & $\begin{array}{c}- \\
5.78 \\
- \\
5.65 \\
- \\
5.54\end{array}$ & $\begin{array}{c}2,840 \\
- \\
2,710 \\
2,600\end{array}$ & $\begin{array}{c}- \\
5.15 \\
- \\
5.06 \\
- \\
5.00\end{array}$ & $\begin{array}{c}2,220 \\
- \\
2,130 \\
2,080\end{array}$ & $\begin{array}{c}- \\
4.75 \\
- \\
4.67 \\
- \\
4.62\end{array}$ & $\begin{array}{c}- \\
1,860 \\
- \\
1,800 \\
- \\
1,760\end{array}$ & $\begin{array}{c}- \\
4.34 \\
- \\
4.27 \\
- \\
4.20\end{array}$ & $\begin{array}{l}\overline{1,530} \\
\overline{1,480} \\
- \\
1,420\end{array}$ \\
\hline $\begin{array}{r}2 \\
4 \\
6 \\
8 \\
10 \\
M\end{array}$ & $\begin{array}{l}7.58 \\
7.43 \\
7.31 \\
7.20 \\
7.09 \\
6.98\end{array}$ & $\begin{array}{l}5,140 \\
4,920 \\
4,740 \\
4,580 \\
4,430 \\
4,270\end{array}$ & $\begin{array}{l}6.33 \\
6.24 \\
6.16 \\
6.07 \\
6.00 \\
5.92\end{array}$ & $\begin{array}{l}3,450 \\
3,340 \\
3,260 \\
3,160 \\
3,080 \\
2,990\end{array}$ & $\begin{array}{c}- \\
5.44 \\
- \\
5.34 \\
- \\
5.24\end{array}$ & $\begin{array}{c}- \\
2,500 \\
- \\
2,400 \\
- \\
2,300\end{array}$ & $\begin{array}{c}- \\
4.92 \\
- \\
4.86 \\
- \\
4.81\end{array}$ & $\begin{array}{c}- \\
2,010 \\
- \\
1,950 \\
- \\
1,910\end{array}$ & $\begin{array}{c}- \\
4.56 \\
- \\
4.49 \\
- \\
4.41\end{array}$ & $\begin{array}{c}- \\
1,710 \\
- \\
1,650 \\
- \\
1,590\end{array}$ & $\begin{array}{c}- \\
4.15 \\
- \\
4.10 \\
4.05\end{array}$ & $\begin{array}{l}\overline{1,380} \\
\overline{1,350} \\
\overline{1,320}\end{array}$ \\
\hline
\end{tabular}

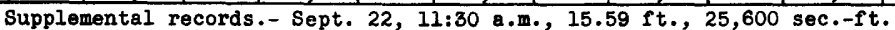


Little Delaware River near Delhi, $N . Y$.

Location. - Lat. $42^{\circ} 15$ ! 10 n, long. $74^{\circ} 54^{\prime} 10^{\prime \prime}, 20$ feet below highway bridge at Peck Hill, $1 \frac{1}{2}$ miles above confluence with West Branch of Delaware River, and 2 miles south of Delhi, Dalaware County.

Drainage area.- 49.8 square miles.

Gage-helght record.- Graph based on two or more dally readings of staff-gage.

Stage-discharge reiation. - For September 1938 defined by current-meter measurement be10w 964 second-feet; extended logarithmically to peak stage. For January 1938 defined by current-meter measurements below 723 second-feet; extended logarithmically to peak stage.

Maxima.- September 1938: D1scharge, 3,280 second-feet 8 p.m. Sept. 2l (gage helght, 8.5 feet, from floodmark on bridge abutment). October 1937 to August 1938: Discharge, 2,180 second-feet Jan. 25, 1938 (gage he1ght, 6.95 feet).

Remarks.- Flood mun-off not affected by storage or diversion.

Mean daily discharge, in second-feet, 1938

\begin{tabular}{|c|c|c|c|c|c|c|c|c|c|c|c|}
\hline Day & Sept. & Oct. & Day & Sept. & Oct. & Day & Sept. & Oct. & Day & Sept. & Oct. \\
\hline $\begin{array}{l}1 \\
2 \\
3 \\
4 \\
5 \\
6 \\
7 \\
8\end{array}$ & $\begin{array}{l}26 \\
20 \\
16 \\
30 \\
18 \\
14 \\
22 \\
33\end{array}$ & $\begin{array}{l}88 \\
73 \\
66 \\
62 \\
55 \\
50 \\
43 \\
39\end{array}$ & $\begin{array}{l}9 \\
10 \\
11 \\
12 \\
13 \\
14 \\
15 \\
16\end{array}$ & $\begin{array}{l}18 \\
14 \\
13 \\
13 \\
64 \\
38 \\
72 \\
52\end{array}$ & $\begin{array}{l}37 \\
33 \\
30 \\
29 \\
25 \\
21 \\
19 \\
18\end{array}$ & $\begin{array}{l}17 \\
18 \\
19 \\
20 \\
21 \\
22 \\
23 \\
24\end{array}$ & $\begin{array}{r}35 \\
45 \\
50 \\
423 \\
1,740 \\
1,470 \\
944 \\
561\end{array}$ & $\begin{array}{l}17 \\
13 \\
11 \\
21 \\
93 \\
44 \\
35 \\
39\end{array}$ & $\begin{array}{l}25 \\
26 \\
27 \\
28 \\
29 \\
30 \\
31\end{array}$ & $\begin{array}{l}385 \\
278 \\
224 \\
184 \\
141 \\
111\end{array}$ & $\begin{array}{l}58 \\
50 \\
41 \\
37 \\
41 \\
35 \\
31\end{array}$ \\
\hline $\begin{array}{l}\text { Mean } \\
\text { Run- }\end{array}$ & $\begin{array}{l}\text { nthly } \\
e, \text { in }\end{array}$ & 8. & ? 1 & . . & $\therefore$ & $\dot{0}$ & $\therefore:$ & 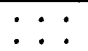 & : & $\begin{array}{r}235 \\
5.27\end{array}$ & $\begin{array}{l}40.5 \\
0.94\end{array}$ \\
\hline
\end{tabular}

$2270070-40-23$ 


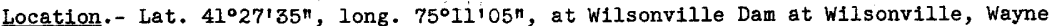
County, lit miles south of Hawley.

Dralnage area.- 228 square miles.

Gage-height record.- Gage read at midnight to half tenths.

Remarks.- Contents given in the table show the usable storage. Records furnished by Pennsylvania Power \& Light Co.

Elevation, in feet, and contents, in acre-feet, 1938

\begin{tabular}{|c|c|c|c|c|c|c|c|c|c|}
\hline \multirow{2}{*}{ Day } & \multicolumn{2}{|c|}{ September } & \multicolumn{2}{|c|}{ October } & \multirow{2}{*}{ Day } & \multicolumn{2}{|c|}{ September } & \multicolumn{2}{|c|}{ October } \\
\hline & Feet & Acre-feet & Feet & Acre-feet & & Feet & Acre-feet & Feet & ficre-feet \\
\hline $\begin{array}{l}1 \\
2 \\
3 \\
4 \\
5\end{array}$ & $\begin{array}{l}1,176.35 \\
1,176.10 \\
1,176.10 \\
1,176.05 \\
1,176.05\end{array}$ & $\begin{array}{l}132,320 \\
130,950 \\
130,950 \\
130,680 \\
130,680\end{array}$ & $\begin{array}{l}1,173: 90 \\
1,173: 95 \\
1,173 \cdot 75 \\
1,173 \cdot 60 \\
1,173 \cdot 55\end{array}$ & $\begin{array}{l}119,070 \\
119,340 \\
118,280 \\
117,480 \\
117,220\end{array}$ & $\begin{array}{l}16 \\
17 \\
18 \\
19 \\
20\end{array}$ & $\begin{array}{l}1,172.80 \\
1,174.80 \\
1,172.10 \\
1,171.75 \\
1,171.85\end{array}$ & $\begin{array}{l}113,260 \\
123,920 \\
109,620 \\
107,820 \\
108,340\end{array}$ & $\begin{array}{l}1,172 \cdot 45 \\
1,172 \cdot 25 \\
1,171 \cdot 90 \\
1,171 \cdot 55 \\
1,171.25\end{array}$ & $\begin{array}{l}111,440 \\
110,400 \\
108,590 \\
106,800 \\
105,280\end{array}$ \\
\hline $\begin{array}{r}6 \\
7 \\
8 \\
9 \\
10\end{array}$ & $\begin{array}{l}1,175.65 \\
1,175.30 \\
1,174.95 \\
1,174.55 \\
1,174.40\end{array}$ & $\begin{array}{l}128,510 \\
126,620 \\
124,730 \\
122,570 \\
121,760\end{array}$ & $\begin{array}{l}1,173 \cdot 25 \\
1,173 \cdot 20 \\
1,173 \cdot 25 \\
1,173.30 \\
1,173.25\end{array}$ & $\begin{array}{l}115,620 \\
115,360 \\
115,620 \\
115,890 \\
115,620\end{array}$ & $\begin{array}{l}21 \\
22 \\
23 \\
24 \\
25\end{array}$ & $\begin{array}{l}1,172.80 \\
1,173.30 \\
1,173.65 \\
1,173.85 \\
1,174.00\end{array}$ & $\begin{array}{l}113,260 \\
115,890 \\
117,740 \\
118,800 \\
119,600\end{array}$ & $\begin{array}{l}1,170.95 \\
1,170.90 \\
1,170.85 \\
1,170.75 \\
1,170.55\end{array}$ & $\begin{array}{l}103,750 \\
103,500 \\
103,250 \\
102,750 \\
101,750\end{array}$ \\
\hline $\begin{array}{l}11 \\
12 \\
13 \\
14 \\
15\end{array}$ & $\begin{array}{l}1 ; 174.40 \\
1 ; 173.85 \\
1 ; 173.50 \\
1 ; 173.15 \\
1,172.85\end{array}$ & $\begin{array}{l}121,760 \\
118,800 \\
116,950 \\
115,100 \\
113,520\end{array}$ & $\begin{array}{l}1,173 \cdot 20 \\
1,173 \cdot 25 \\
1,172 \cdot 90 \\
1,172 \cdot 60 \\
1,172 \cdot 45\end{array}$ & $\begin{array}{l}115,360 \\
115,620 \\
113,780 \\
112,220 \\
111,440\end{array}$ & $\begin{array}{l}26 \\
27 \\
28 \\
29 \\
30 \\
31\end{array}$ & $\begin{array}{l}1,174.10 \\
1,174.05 \\
1,174.05 \\
1,174.00 \\
1,173.85\end{array}$ & $\begin{array}{l}120,140 \\
119,870 \\
119,870 \\
119,600 \\
118,800\end{array}$ & $\begin{array}{l}1,170.55 \\
1,170.30 \\
1,170.00 \\
1,169.95 \\
1,169.95 \\
1,169.95\end{array}$ & $\begin{array}{r}101,750 \\
100,500 \\
99,000 \\
98,750 \\
98,750 \\
98,750\end{array}$ \\
\hline \multirow[b]{2}{*}{ Gain } & & & & & & & & September & october \\
\hline & iss & & & & & & & -274 & -326 \\
\hline
\end{tabular}


Swinging Bridge Reservoir at Swinging Bridge Dam, N. Y.

Location. - Lat. $41^{\circ} 34^{\prime} 20^{n}$, long. $74^{\circ} 47^{\prime} 0^{\prime \prime}$, at Swinging Bridge Dam, on Mongaup River, It mles northwest of Forlersville, Sulilvan County. Crest of flash boards (5.0 feet) at elevation 1,070 feet above mean sea level (U. S. Geologlcal Survey datum). Drainage area. - 118 square miles.

Gage-holght record.- Gage read at 7 a.m., 11 a.m., and 8 p.m. Sept. 1 to 24 , and at 8 8.m., 12 noon, and 9 p.m. Sept. 25 to 0ct. 31 .

Maxima.- September 1938: Elevation observed, 1,051.9 feet 7 a.m. Sept. 1 (contents, $952,000,000$ cubic feet).

January 1930 to August 1938: Elevation, 1,072.4 feet Mar. 18, 1936 (contents, $1,711,000,000$ cub1c feet).

Remarks. - Jasble storage capacity 1,387,000,000 cubic feet. No record of flow of Mongaup River is available. No spliling at Swinging Bridge Dam during September and

October. Records furnished by Rockland Light \& Power Co.

Gage height, in feet, and contents, in millions of cublc feet, at indicated time, 1938

\begin{tabular}{|c|c|c|c|c|c|c|c|c|c|c|}
\hline \multirow{3}{*}{\begin{tabular}{|l|} 
\\
0 \\
0 \\
7 \\
1 \\
8 \\
\end{tabular}} & & & \multirow{2}{*}{\multicolumn{2}{|c|}{\begin{tabular}{|c|c|}
$\begin{array}{c}\text { Gage } \\
\text { height }\end{array}$ & Contents \\
September 2
\end{tabular}}} & \multirow{2}{*}{\multicolumn{2}{|c|}{\begin{tabular}{|c|c|}
$\begin{array}{c}\text { Gage } \\
\text { height }\end{array}$ & Contents \\
September 3 \\
\end{tabular}}} & \multirow{2}{*}{\multicolumn{2}{|c|}{\begin{tabular}{|c|c|}
$\begin{array}{c}\text { Gage } \\
\text { helght }\end{array}$ & Contents \\
September 4
\end{tabular}}} & \multicolumn{2}{|c|}{ 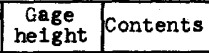 } \\
\hline & \multicolumn{2}{|c|}{ September I } & & & & & & & \multicolumn{2}{|c|}{ September 5} \\
\hline & $\begin{array}{l}1,051 \cdot 9 \\
1,051.7 \\
1,051.1\end{array}$ & $\begin{array}{l}952 \\
946 \\
928\end{array}$ & $\begin{array}{l}1,050.5 \\
1,050.3 \\
1,049.7\end{array}$ & $\begin{array}{l}911 \\
906 \\
889\end{array}$ & $\begin{array}{l}1,049.0 \\
1,048.9 \\
1,048.4\end{array}$ & $\begin{array}{l}869 \\
867 \\
853\end{array}$ & $\begin{array}{l}1, \overline{047} .7 \\
1,047.1\end{array}$ & \begin{tabular}{|c|}
- \\
835 \\
819
\end{tabular} & $\begin{array}{l}1,046.7 \\
1,046.4 \\
1,045.8\end{array}$ & \\
\hline & \multicolumn{2}{|c|}{ September 6} & \multicolumn{2}{|c|}{ September 7} & \multicolumn{2}{|c|}{ September 8} & \multicolumn{2}{|c|}{ September 9} & \multicolumn{2}{|c|}{ September 10} \\
\hline \multirow[t]{2}{*}{$\begin{array}{r}7 \\
8 \\
8 \\
\end{array}$} & \begin{tabular}{|l|}
$1,045.2$ \\
$1,044.9$ \\
$1,044.2$
\end{tabular} & $\begin{array}{l}771 \\
764 \\
747 \\
\end{array}$ & $\begin{array}{l}1,043.8 \\
1,043.5 \\
1,043.0\end{array}$ & $\begin{array}{l}738 \\
731 \\
719 \\
\end{array}$ & $\begin{array}{l}1,042.5 \\
1,042.2 \\
1,041.6\end{array}$ & $\begin{array}{l}708 \\
701 \\
687 \\
\end{array}$ & $\begin{array}{l}1,041.1 \\
1,040.8 \\
1,040.0\end{array}$ & $\begin{array}{l}676 \\
670 \\
652 \\
\end{array}$ & $\begin{array}{l}1,039.6 \\
1,039.3 \\
1,038.9\end{array}$ & \\
\hline & \multicolumn{2}{|c|}{ September II } & \multicolumn{2}{|c|}{ September 12} & \multicolumn{2}{|c|}{ September 13} & \multicolumn{2}{|c|}{$\frac{1}{\text { September } 14}$} & \multicolumn{2}{|c|}{ September 15} \\
\hline \multirow[t]{2}{*}{\begin{tabular}{|l|l|}
7 \\
8 \\
\end{tabular}} & $\begin{array}{l}1, \overline{-} \\
1,038.0 \\
1,037.8\end{array}$ & $\begin{array}{r}-\overline{6} 10 \\
606 \\
\end{array}$ & $\begin{array}{l}1,037.0 \\
1,036.7 \\
1,035.9\end{array}$ & \begin{tabular}{|l|}
590 \\
584 \\
568 \\
\end{tabular} & $\begin{array}{l}1,035.0 \\
1,034.6 \\
1,033.8\end{array}$ & \begin{tabular}{|l|}
551 \\
544 \\
528 \\
\end{tabular} & $\begin{array}{l}1,033.2 \\
1,032.8 \\
1,032.0\end{array}$ & \begin{tabular}{|l|}
517 \\
510 \\
496 \\
\end{tabular} & $\begin{array}{l}1,031.1 \\
1,030.8 \\
1,030.4\end{array}$ & $\begin{array}{l}480 \\
475 \\
468 \\
\end{array}$ \\
\hline & \multicolumn{2}{|c|}{ September 16} & \multicolumn{2}{|c|}{ September 17} & \multicolumn{2}{|c|}{ September 18} & \multicolumn{2}{|c|}{ September 19} & \multicolumn{2}{|c|}{ September 20} \\
\hline \multirow[t]{2}{*}{$\begin{array}{l}7 \\
8 \\
8\end{array}$} & $\begin{array}{l}1,029.8 \\
1,029.4 \\
1,028.6\end{array}$ & $\begin{array}{l}458 \\
451 \\
438 \\
\end{array}$ & $\begin{array}{r}1,027.6 \\
* 1,027.3 \\
1,026.6\end{array}$ & $\begin{array}{l}422 \\
417 \\
406 \\
\end{array}$ & $\begin{array}{l}1, \overline{1} \\
1,025.3 \\
1,024.5\end{array}$ & $\begin{array}{r}-- \\
387 \\
375\end{array}$ & $\begin{array}{l}1,023 \cdot 4 \\
1,023.0 \\
1,022.7\end{array}$ & $\begin{array}{l}360 \\
354 \\
350 \\
\end{array}$ & $\begin{array}{l}1,023.6 \\
1,023.7 \\
1,025.3\end{array}$ & $\begin{array}{l}362 \\
364 \\
387 \\
\end{array}$ \\
\hline & \multicolumn{2}{|c|}{ Soptenber 21} & \multicolumn{2}{|c|}{ September 22} & Septer & inber 23 & Septem & ber 24 & Septe: & ber 25 \\
\hline $\begin{array}{l}7 \\
8 \\
1 \\
1 \\
8 \\
9 \\
\end{array}$ & $\begin{array}{c}1,028.4 \\
\overline{1}, 029.5 \\
- \\
1,034.1 \\
-\end{array}$ & $\begin{array}{c}435 \\
-- \\
453 \\
-- \\
534 \\
- \\
\end{array}$ & $\begin{array}{c}1,043.7 \\
1,045.3 \\
-\overline{7} \\
1,04.7 \\
-\end{array}$ & $\begin{array}{r}-735 \\
--774 \\
-- \\
- \\
-\end{array}$ & $\begin{array}{c}1,049.2 \\
-049.6 \\
1,050.3 \\
-\end{array}$ & $\begin{array}{r}875 \\
--886 \\
-- \\
-- \\
\end{array}$ & $\begin{array}{c}1,051.1 \\
-- \\
1,051.2 \\
1,051.3 \\
-\end{array}$ & $\begin{array}{r}929 \\
--931 \\
--934 \\
- \\
\end{array}$ & $\begin{array}{c}\overline{-} \\
\overline{-} \\
1,051.6 \\
\overline{1}, 051.5 \\
\end{array}$ & $\begin{array}{l}-- \\
-- \\
-- \\
-943 \\
- \\
940\end{array}$ \\
\hline & Septem & ber 26 & Septemb & ber 27 & Septem & ber 28 & Septem & ber 29 & Septe: & ber 30 \\
\hline $\begin{array}{l}8 \\
N \\
9 \\
\end{array}$ & \begin{tabular}{l|}
$1,051.3$ \\
$1,051.2$ \\
$1,051.0$
\end{tabular} & $\begin{array}{l}934 \\
931 \\
926 \\
\end{array}$ & $\begin{array}{l}1,050.7 \\
1,050.6 \\
1,050.2\end{array}$ & $\begin{array}{r}917 \\
914 \\
903 \\
\end{array}$ & $\begin{array}{l}1,049.9 \\
1,049.7 \\
1,049.4\end{array}$ & $\begin{array}{r}894 \\
889 \\
880 \\
\end{array}$ & $\begin{array}{l}1,048.9 \\
1,048.8 \\
1,048.3\end{array}$ & $\begin{array}{l}867 \\
864 \\
851 \\
\end{array}$ & $\begin{array}{l}1,047.8 \\
1,047.6 \\
1,047.1\end{array}$ & $\begin{array}{r}837 \\
832 \\
819 \\
\end{array}$ \\
\hline & Octob & er 1 & Octobe & er 2 & Octob & ber 3 & Octob & eer 4 & Octob & er 5 \\
\hline $\begin{array}{l}8 \\
\mathbf{N} \\
9 \\
\end{array}$ & $\begin{array}{l}1,046.5 \\
1,046.3 \\
1,045.8 \\
\end{array}$ & \begin{tabular}{|r|}
804 \\
799 \\
786 \\
\end{tabular} & $\begin{array}{l}1,045.0 \\
1,044.5 \\
\end{array}$ & \begin{tabular}{|r|}
-- \\
766 \\
754 \\
\end{tabular} & $\begin{array}{l}1,043.8 \\
1,043.6 \\
1,043.1 \\
\end{array}$ & \begin{tabular}{|r|}
738 \\
733 \\
721 \\
\end{tabular} & $\begin{array}{l}0,042.4 \\
042.2 \\
041.7 \\
\end{array}$ & \begin{tabular}{|r|}
705 \\
701 \\
689 \\
\end{tabular} & $\begin{array}{l}1,040.9 \\
1,040.7 \\
1,040.1 \\
\end{array}$ & $\begin{array}{r}672 \\
667 \\
654 \\
\end{array}$ \\
\hline & Octob & eer 6 & Octobe & er 7 & Octob & ber 8 & Octob & er 9 & Octob & oer 10 \\
\hline $\begin{array}{l}8 \\
N \\
9 \\
\end{array}$ & $\begin{array}{l}1,039.4 \\
1,039.1 \\
1,038.5 \\
\end{array}$ & \begin{tabular}{|l|}
639 \\
633 \\
621 \\
\end{tabular} & $\begin{array}{l}1,037.7 \\
1,037.5 \\
1,036.8 \\
\end{array}$ & $\begin{array}{r}604 \\
600 \\
586 \\
\end{array}$ & $\begin{array}{l}1,035.9 \\
1,035.6 \\
1,034.9\end{array}$ & $\begin{array}{r}568 \\
563 \\
549 \\
\end{array}$ & $\begin{array}{l}1,-\overline{-} \\
1,033.8 \\
1,033.1 \\
\end{array}$ & \begin{tabular}{|r|}
- \\
528 \\
516 \\
\end{tabular} & $\begin{array}{l}1,032.1 \\
1,031.8 \\
1,031.0\end{array}$ & $\begin{array}{r}498 \\
492 \\
478 \\
\end{array}$ \\
\hline & octob & erII & Octobe & er 12 & octob & ber 13 & octob & er 14 & octor & er 15 \\
\hline $\begin{array}{l}8 \\
N \\
9 \\
\end{array}$ & $\begin{array}{l}1,030.1 \\
1,029.8 \\
1,028.8\end{array}$ & $\begin{array}{l}463 \\
458 \\
441 \\
\end{array}$ & $\begin{array}{l}1,027.9 \\
1,027.5 \\
1,026.6 \\
\end{array}$ & $\begin{array}{l}427 \\
420 \\
406 \\
\end{array}$ & & $\begin{array}{l}393 \\
385 \\
372 \\
\end{array}$ & $\begin{array}{l}1,023.2 \\
1,022.7 \\
1,021.8\end{array}$ & $\begin{array}{l}357 \\
350 \\
338 \\
\end{array}$ & & $\begin{array}{l}324 \\
318 \\
305 \\
\end{array}$ \\
\hline & Octob & er $\overline{16}$ & Octobe & er 17 & octob & ber 18 & octob & er 19 & Octok & oer 20 \\
\hline $\begin{array}{l}8 \\
N \\
9 \\
\end{array}$ & \begin{tabular}{|l|} 
\\
$1,0 \overline{17} .3$ \\
$1,016.1$
\end{tabular} & \begin{tabular}{|c|}
- \\
284 \\
271 \\
\end{tabular} & $\begin{array}{l}1,014.8 \\
1,014.1 \\
1,012.8\end{array}$ & $\begin{array}{l}258 \\
251 \\
238\end{array}$ & $\begin{array}{l}1,011.3 \\
1,010.8 \\
1,009.7\end{array}$ & $\begin{array}{l}224 \\
220 \\
210 \\
\end{array}$ & $\begin{array}{l}1,008.9 \\
1,008.2 \\
1,006.8\end{array}$ & $\begin{array}{l}203 \\
198 \\
186 \\
\end{array}$ & $\begin{array}{l}1,005.9 \\
1,005.3 \\
1,003.8\end{array}$ & $\begin{array}{l}179 \\
175 \\
164 \\
\end{array}$ \\
\hline & Octob & er $2 I$ & Octobe & er 22 & octob & ber 23 & octob & er 24 & Octol & ser 25 \\
\hline $\begin{array}{l}8 \\
N \\
9 \\
\end{array}$ & $\begin{array}{l}1,003.1 \\
1,002.5 \\
1,001.1\end{array}$ & $\begin{array}{l}159 \\
154 \\
145 \\
\end{array}$ & $\begin{array}{r}1,001.6 \\
1,001.0 \\
999.6 \\
\end{array}$ & $\begin{array}{l}148 \\
144 \\
135\end{array}$ & $\frac{1}{1}, 000.1$ & $\begin{array}{l}-- \\
138 \\
138\end{array}$ & $\begin{array}{r}1,000.5 \\
999.9 \\
999.9 \\
\end{array}$ & $\begin{array}{l}141 \\
137 \\
137 \\
\end{array}$ & $\begin{array}{l}1,001.5 \\
1,001.1 \\
1,001.1\end{array}$ & $\begin{array}{l}148 \\
145 \\
145 \\
\end{array}$ \\
\hline & 0ctob & Der 26 & 0ctobe & er 27 & octob & ber 28 & $\overline{\text { octob }}$ & er 29 & octol & Der 30 \\
\hline $\begin{array}{l}8 \\
N \\
9\end{array}$ & $\begin{array}{l}1,000.8 \\
1,000.3 \\
1,000.7\end{array}$ & $\begin{array}{l}143 \\
140 \\
142\end{array}$ & $\begin{array}{l}1,001.4 \\
1,001.3 \\
1,001.5\end{array}$ & $\begin{array}{l}147 \\
146 \\
148\end{array}$ & & $\begin{array}{l}152 \\
154 \\
148\end{array}$ & $\begin{array}{r}1,001.2 \\
1,000.6 \\
999.6\end{array}$ & $\begin{array}{l}146 \\
142 \\
135\end{array}$ & & $\begin{array}{l}- \\
136 \\
135\end{array}$ \\
\hline & octob & 31 & & & & & & & & \\
\hline $\begin{array}{l}8 \\
N \\
9\end{array}$ & $\begin{array}{r}, 000.1 \\
999.9 \\
999.5 \\
\end{array}$ & $\begin{array}{l}138 \\
137 \\
134\end{array}$ & & & & & & & & \\
\hline
\end{tabular}

\begin{tabular}{|l|l|l|l|}
\hline & Septenber & Oc tober \\
\hline
\end{tabular}

Gain or loss in storage, in equivalent mean second-feet .....

* Interpolated. 
Toronto Reservoir at Toronto Dam, N. Y.

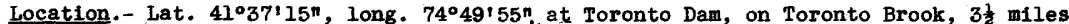
south of White Lake, Sullivan County. 'Crest of flashboards at elevation' 1,220 feet above mean sea level (U. S. Geological survey datum).

Drainage area.- 23.2 square miles.

Gage-height record.- Gage read daily except Sundays at 7 a.m. prior to Sept. 24; at 8 a.m. thereaf ter.

Maxima:- September and October 1938: Elevation, 1,220.5 feet Sept. 30 to Oct. 5 (contents, $1,141,000,000$ cub1c feet).

May 1925 to August 1938: Elevation, 1,221.6 feet July 1, 1928 (contents, $1,180,000,000$ cubic feet).

Remarks.- Usable storage capacity, 1,108,000,000 cubic feet. No record of flow of Toronto Brook is available. Spiliage at Toronto Dam was equivalent to a mean monthly discharge of 7.53 second-feet for September and 26.7 second-feet for $0 c t o b e r$. Records furnished by Rockland Light * Power Co.

Gage height, in feet, and contents, in millions of cubic feet, 1938

\begin{tabular}{|c|c|c|c|c|c|c|c|c|c|}
\hline \multirow{2}{*}{ Day } & \multicolumn{2}{|c|}{ September } & \multicolumn{2}{|c|}{ October } & \multirow[b]{2}{*}{ Day } & \multicolumn{2}{|c|}{ September } & \multicolumn{2}{|c|}{ October } \\
\hline & Feet & $\begin{array}{l}\text { Millions of } \\
\text { cubic feet }\end{array}$ & Feet & $\begin{array}{l}\text { Millions of } \\
\text { cubic feet }\end{array}$ & & Feet & $\begin{array}{l}\text { Millions of } \\
\text { cubic feet }\end{array}$ & Feet & $\begin{array}{l}\text { Millions of } \\
\text { cublc feet }\end{array}$ \\
\hline $\begin{array}{l}1 \\
2 \\
3 \\
4 \\
5\end{array}$ & $\begin{array}{r}1,216.3 \\
1,216.3 \\
1,216.3 \\
- \\
1,216.4\end{array}$ & $\begin{array}{r}999 \\
999 \\
999 \\
-\quad 1,002\end{array}$ & $\begin{array}{l}1,220.5 \\
- \\
1,220.5 \\
1,220.5 \\
1,220.5\end{array}$ & $\begin{array}{r}1,141 \\
- \\
1,141 \\
1,141 \\
1,141\end{array}$ & $\begin{array}{l}16 \\
17 \\
18 \\
19 \\
20\end{array}$ & $\begin{array}{r}1,216.4 \\
1,216.4 \\
- \\
1,216.4 \\
1,216.5\end{array}$ & $\begin{array}{r}1,002 \\
1,002 \\
-1,002 \\
1,005\end{array}$ & $\begin{array}{r}1, \overline{1} \overline{19} .9 \\
1,219.8 \\
\overline{1}, 2 \overline{19} .6\end{array}$ & $\begin{array}{r}1,120 \\
1,116 \\
-1,109\end{array}$ \\
\hline $\begin{array}{r}6 \\
7 \\
8 \\
9 \\
10\end{array}$ & $\begin{array}{l}1,216.4 \\
1,216.4 \\
1,216.4 \\
1,216.4 \\
1,216.4\end{array}$ & $\begin{array}{l}1,002 \\
1,002 \\
1,002 \\
1,002 \\
1,002\end{array}$ & $\begin{array}{c}1,220.4 \\
1,220.4 \\
1,220.4 \\
\overline{1}, 220.4\end{array}$ & $\begin{array}{r}1,137 \\
1,137 \\
1,137 \\
-1,137\end{array}$ & $\begin{array}{l}21 \\
22 \\
23 \\
24 \\
25\end{array}$ & $\begin{array}{c}1,216.9 \\
1,217.9 \\
1,218.9 \\
1,219.5 \\
-\end{array}$ & $\begin{array}{r}1,018 \\
1,051 \\
1,085 \\
1,106\end{array}$ & $\begin{array}{c}1,219.5 \\
- \\
1,219.0 \\
1,219.0 \\
1,218.9\end{array}$ & $\begin{array}{r}1,106 \\
- \\
1,088 \\
1,088 \\
1,085\end{array}$ \\
\hline $\begin{array}{l}11 \\
12 \\
13 \\
14 \\
15\end{array}$ & $\begin{array}{l}1,216.4 \\
1,216.4 \\
1,216.4 \\
1,216.4\end{array}$ & $\begin{array}{r}- \\
1,002 \\
1,002 \\
1,002 \\
1,002\end{array}$ & $\begin{array}{l}1,220.4 \\
1,220.4 \\
1,220.3 \\
1,220.2 \\
1,220.1\end{array}$ & $\begin{array}{l}1,137 \\
1,137 \\
1,134 \\
1,130 \\
1,127\end{array}$ & $\begin{array}{l}26 \\
27 \\
28 \\
29 \\
30 \\
31\end{array}$ & $\begin{array}{l}1,220.1 \\
1,220.3 \\
1,220.4 \\
1,220.4 \\
1,220.5\end{array}$ & $\begin{array}{l}1,127 \\
1,134 \\
1,137 \\
1,137 \\
1,141\end{array}$ & $\begin{array}{r}1,218.9 \\
1,218.9 \\
1,218.8 \\
1,218.7 \\
1,218.3\end{array}$ & $\begin{array}{r}1,085 \\
1,085 \\
1,082 \\
1,078 \\
-1,065\end{array}$ \\
\hline \multirow[b]{2}{*}{ Gai } & & & & & & & & Septembe & October \\
\hline & in or 1 & ss in & & & & & & +14 & -76 \\
\hline
\end{tabular}


Neversink River at Halls Mills, near Curry, N. Y.

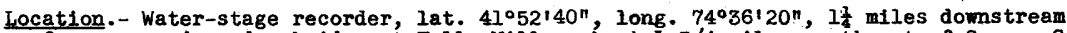
from covered wooden bridge at Halis Mills, about $13 / 4$ miles northwest of Curry, sullivan County.

Drainage area.- 68 square miles.

Gage-height record. - Water-stage recorder graph.

Stage-discharge relation.- For September 1938 defined by current-meter measurements below 5,010 second-feet; extended logarithmically to peak stage on basis of slope-area study and run-off comparison with other stations downstream. For July 1938 defined by current-meter measurements below 1,430 second-feet; extended logarithmically to peak stage on basis of slope-area study and run-off comparison with other stations downstream.

Maxima.- September 1938: Discharge, 10,000 second-feet 7 p.m. Sept. 21 (gage height, 8.70 feet).

October 29, 1937, to August 1938: Discharge, 12,400 second-feet July 22, 1938 (gage height, 10.05 feet).

Maximum discharge known, 13,000 second-feet 0ct. 23, 1937 (gage height, 10.37

feet, from floodmarks in we11).

Remarks. - Flood run-off not affected by storage or diversion.

Mean daily discharge, in second-feet, 1938

\begin{tabular}{|c|c|c|c|c|c|c|c|c|c|c|c|}
\hline Day & Sept. & Oct. & Day & Sept. & 0 ct. & Day & Sept. & Oct. & Day & Sept. & Oct. \\
\hline $\begin{array}{l}1 \\
2 \\
3 \\
4 \\
5 \\
6 \\
7 \\
8\end{array}$ & $\begin{array}{r}105 \\
88 \\
82 \\
85 \\
73 \\
65 \\
94 \\
110\end{array}$ & $\begin{array}{l}168 \\
150 \\
135 \\
128 \\
121 \\
118 \\
104 \\
101\end{array}$ & $\begin{array}{r}9 \\
10 \\
11 \\
12 \\
13 \\
14 \\
15 \\
16\end{array}$ & $\begin{array}{r}71 \\
65 \\
59 \\
57 \\
89 \\
73 \\
134 \\
106\end{array}$ & $\begin{array}{l}98 \\
92 \\
86 \\
79 \\
76 \\
73 \\
70 \\
64\end{array}$ & $\begin{array}{l}17 \\
18 \\
19 \\
20 \\
21 \\
22 \\
23 \\
24\end{array}$ & $\begin{array}{r}76 \\
73 \\
146 \\
840 \\
3,100 \\
1,460 \\
590 \\
385\end{array}$ & $\begin{array}{r}56 \\
56 \\
53 \\
58 \\
131 \\
76 \\
64 \\
198\end{array}$ & $\begin{array}{l}25 \\
26 \\
27 \\
28 \\
29 \\
30 \\
31\end{array}$ & $\begin{array}{l}300 \\
264 \\
246 \\
221 \\
196 \\
184\end{array}$ & $\begin{array}{l}226 \\
154 \\
128 \\
121 \\
121 \\
121 \\
108\end{array}$ \\
\hline $\begin{array}{l}\text { Mean } \\
\text { Run- }\end{array}$ & onthly & $\begin{array}{l}\text { schar } \\
\text { ches. }\end{array}$ & , 1 & .. & et. & . & . : & $\cdot: \dot{ }$ & . & $\begin{array}{r}315 \\
5.17 \\
\end{array}$ & $\begin{array}{r}108 \\
1.83 \\
\end{array}$ \\
\hline
\end{tabular}

Gage height, in feet, and discharge, In second-feet, at indicated time, 1938

\begin{tabular}{|c|c|c|c|c|c|c|c|c|c|c|c|c|}
\hline \multirow{2}{*}{$\begin{array}{l}9 \\
\text { 马् } \\
\text { 号 }\end{array}$} & Feet & Sec.ft. & Feet & Sec.ft. & Feet & Sec.ft. & Feet & Sec.ft. & Feet & Sec.ft. & Feet & Sec.ft. \\
\hline & \multicolumn{2}{|c|}{ September 18} & \multicolumn{2}{|c|}{ September 19} & \multicolumn{2}{|c|}{ September 20} & \multicolumn{2}{|c|}{ September 21} & \multicolumn{2}{|c|}{ Sept omber 22} & \multicolumn{2}{|c|}{ September 23} \\
\hline $\begin{array}{l}1 \\
2 \\
3 \\
4 \\
5 \\
6\end{array}$ & $\begin{array}{c}- \\
- \\
- \\
0.08 \\
- \\
-\end{array}$ & $\begin{array}{l}- \\
- \\
- \\
- \\
-\end{array}$ & $\begin{array}{c}- \\
0.11 \\
- \\
.13 \\
-.15\end{array}$ & $\begin{array}{r}-82 \\
-\quad 88 \\
-\quad 94\end{array}$ & $\begin{array}{l}1.38 \\
1.65 \\
1.83 \\
1.84 \\
1.80 \\
1.79\end{array}$ & $\begin{array}{l}560 \\
717 \\
842 \\
850 \\
820 \\
813\end{array}$ & $\begin{array}{l}2.39 \\
2.40 \\
2.35 \\
2.26 \\
2.17 \\
2.08\end{array}$ & $\begin{array}{l}1,330 \\
1,340 \\
1,290 \\
1,200 \\
1,120 \\
1,040\end{array}$ & $\begin{array}{l}4.12 \\
3.83 \\
3.57 \\
3.36 \\
3.15 \\
2.97\end{array}$ & $\begin{array}{l}3,340 \\
2,980 \\
2,660 \\
2,410 \\
2,160 \\
1,960\end{array}$ & $\begin{array}{l}1.46 \\
1.44 \\
1.44 \\
1.44 \\
1.48 \\
1.54\end{array}$ & $\begin{array}{l}601 \\
589 \\
589 \\
589 \\
613 \\
649\end{array}$ \\
\hline $\begin{array}{r}7 \\
8 \\
9 \\
10 \\
11 \\
N\end{array}$ & $\begin{array}{l}- \\
.08 \\
- \\
- \\
.09\end{array}$ & $\begin{array}{l}-73 \\
-\quad 73 \\
- \\
-76\end{array}$ & $\begin{array}{l}- \\
.16 \\
. \\
.19 \\
.23\end{array}$ & $\begin{array}{r}- \\
96 \\
- \\
105 \\
- \\
117\end{array}$ & $\begin{array}{l}1.84 \\
1.94 \\
2.03 \\
2.09 \\
2.10 \\
2.06\end{array}$ & $\begin{array}{r}850 \\
927 \\
1,000 \\
1,050 \\
1,060 \\
1,030\end{array}$ & $\begin{array}{l}2.04 \\
2.03 \\
2.03 \\
2.03 \\
2.03 \\
2.11\end{array}$ & $\begin{array}{l}1,010 \\
1,000 \\
1,000 \\
1,000 \\
1,000 \\
1,070\end{array}$ & $\begin{array}{l}2.81 \\
2.67 \\
2.54 \\
2.42 \\
2.31 \\
2.22\end{array}$ & $\begin{array}{l}1,780 \\
1,630 \\
1,480 \\
1,360 \\
1,250 \\
1,170\end{array}$ & $\begin{array}{l}1.59 \\
1.62 \\
1.62 \\
1.61 \\
1.57 \\
1.54\end{array}$ & $\begin{array}{l}679 \\
698 \\
698 \\
692 \\
667 \\
649\end{array}$ \\
\hline $\begin{array}{l}1 \\
2 \\
3 \\
4 \\
5 \\
6\end{array}$ & $\begin{array}{l}- \\
- \\
.09 \\
-\end{array}$ & $\begin{array}{l}- \\
- \\
- \\
- \\
-\end{array}$ & $\begin{array}{l}- \\
.30 \\
- \\
.34 \\
.39\end{array}$ & $\begin{array}{c}- \\
-138 \\
-150 \\
-166\end{array}$ & $\begin{array}{l}1.98 \\
1.90 \\
1.81 \\
1.73 \\
1.65 \\
1.59\end{array}$ & $\begin{array}{l}959 \\
895 \\
828 \\
771 \\
717 \\
678\end{array}$ & $\begin{array}{l}2.35 \\
2.84 \\
3.51 \\
4.30 \\
5.90 \\
7.90\end{array}$ & $\begin{array}{l}1,290 \\
1,810 \\
2,590 \\
3,570 \\
5,760 \\
8,720\end{array}$ & $\begin{array}{l}2.1 .2 \\
2.03 \\
1.95 \\
1.88 \\
1.82 \\
1.75\end{array}$ & $\begin{array}{r}1,080 \\
1,000 \\
935 \\
880 \\
835 \\
785\end{array}$ & $\begin{array}{l}1.50 \\
1.46 \\
1.43 \\
1.39 \\
1.36 \\
1.34\end{array}$ & $\begin{array}{l}625 \\
601 \\
583 \\
560 \\
543 \\
532\end{array}$ \\
\hline \multirow[t]{2}{*}{$\begin{array}{r}7 \\
8 \\
9 \\
10 \\
11 \\
11 \\
\end{array}$} & $\begin{array}{l}- \\
.08 \\
- \\
.08\end{array}$ & $\begin{array}{l}-73 \\
-\quad \\
-73 \\
-7 \\
\end{array}$ & $\begin{array}{c}- \\
.49 \\
- \\
.73 \\
- \\
1.09\end{array}$ & $\begin{array}{r}-198 \\
- \\
282 \\
- \\
428\end{array}$ & $\begin{array}{l}1.56 \\
1.58 \\
1.70 \\
1.89 \\
2.11 \\
2.31\end{array}$ & $\begin{array}{r}660 \\
672 \\
750 \\
888 \\
1,070 \\
1,250\end{array}$ & $\begin{array}{l}8.70 \\
7.68 \\
6.36 \\
5.48 \\
4.92 \\
4.51\end{array}$ & $\begin{array}{r}10,000 \\
8,370 \\
6,400 \\
5,170 \\
4,390 \\
3,840\end{array}$ & $\begin{array}{l}1.70 \\
1.65 \\
1.60 \\
1.56 \\
1.52 \\
1.49\end{array}$ & $\begin{array}{l}750 \\
718 \\
685 \\
661 \\
637 \\
619\end{array}$ & $\begin{array}{l}1.31 \\
1.28 \\
1.26 \\
1.24 \\
1.22 \\
1.21\end{array}$ & $\begin{array}{l}516 \\
499 \\
488 \\
477 \\
466 \\
460\end{array}$ \\
\hline & \multicolumn{2}{|c|}{ September $2 \dot{4}$} & \multicolumn{2}{|c|}{ September 25} & \multicolumn{2}{|c|}{ September 26} & \multicolumn{2}{|c|}{ September 27} & \multicolumn{2}{|c|}{ September 28} & \multicolumn{2}{|c|}{ September 29} \\
\hline $\begin{array}{r}2 \\
4 \\
6 \\
8 \\
10 \\
1 \\
\\
2 \\
4 \\
6 \\
8 \\
10 \\
11\end{array}$ & $\begin{array}{c}- \\
1.16 \\
\overline{1.11} \\
\overline{1.07}\end{array}$ & $\begin{array}{r}-483 \\
- \\
406 \\
-385\end{array}$ & $\begin{array}{l}-.95 \\
-.93 \\
.93 \\
.90\end{array}$ & $\begin{array}{c}- \\
325 \\
- \\
315 \\
- \\
300\end{array}$ & $\begin{array}{l}- \\
-84 \\
.84 \\
.82\end{array}$ & $\begin{array}{l}- \\
- \\
273 \\
- \\
264 \\
- \\
-255 \\
- \\
-246\end{array}$ & $\begin{array}{l}- \\
- \\
.77 \\
- \\
.77 \\
- \\
- \\
.77 \\
- \\
-76\end{array}$ & $\begin{array}{l}- \\
- \\
-242 \\
- \\
242 \\
- \\
-242 \\
- \\
-288\end{array}$ & $\begin{array}{l}- \\
- \\
.74 \\
- \\
.72 \\
- \\
- \\
.70 \\
- \\
.68\end{array}$ & $\begin{array}{l}- \\
-229 \\
- \\
- \\
221 \\
- \\
- \\
-212 \\
- \\
204\end{array}$ & $\begin{array}{l}- \\
- \\
.68 \\
- \\
- \\
.66 \\
- \\
-.64 \\
-6 \\
.63\end{array}$ & $\begin{array}{l}- \\
-178 \\
- \\
- \\
184\end{array}$ \\
\hline
\end{tabular}


Locntion. - Water-stage recorder, lat. $41^{\circ} 45^{\prime} 25^{n}$, long. $72^{\circ} 35^{\prime} 5^{n}$, a quarter of a mile below highway bridge in Woodbourne, Sullivan County, and 0.4 mile above small unnamed strean entering from left.

Drainage area. - 113 square miles.

Gape-heleht Fecond:- jept. 1 to 20 , graph based on twice daily readings of staff gage. Water-stage recorder graph Sept. 20 to 0ct. 31 .

Stare-discharge relation.- For sept. 1938 defined by current-meter measurements below 5,510 second-feet; extended logarithmically to peak stage. For July 1938 defined by current-meter measurements below 9,040 second-feet; extended logarithmically to peak stage.

Maxima:- September 1938: Discharge, 8,300 second-feet 10:15 p.m. Sept. 21 (gage helght,

October 1937 to August 1938: Discharge, 12,300 second-feet July 22, 1938 (gage height, 11.2 feet, from floodmarks and graph based on gage readings).

Renarlcs.- Flood mun-off not affeeted by storage or diversion.

Mean daily discharge, in second-feet, 1938

\begin{tabular}{|c|r|r||r|r|r|r|r|r|r|r|r|}
\hline Day & Sept. & 0ct. & Day & Sept. & 0ct. & Day & Sept. & Oct. & Day & Sept. & Oct. \\
\hline 1 & 134 & 207 & 9 & 109 & 129 & 17 & 107 & 98 & 25 & 487 & 320 \\
2 & 115 & 188 & 10 & 103 & 122 & 18 & 107 & 96 & 26 & 372 & 185 \\
3 & 111 & 176 & 11 & 89 & 117 & 19 & 213 & 94 & 27 & 328 & 150 \\
4 & 107 & 164 & 12 & 85 & 115 & 20 & 1,360 & 97 & 28 & 294 & 134 \\
5 & 103 & 155 & 13 & 111 & 110 & 21 & 3,550 & 161 & 29 & 251 & 136 \\
6 & 96 & 147 & 14 & 115 & 110 & 22 & 2,500 & 124 & 30 & 227 \\
7 & 108 & 139 & 15 & 190 & 106 & 23 & 1,120 & 102 & 31 & 134 \\
8 & 168 & 131 & 16 & 153 & 102 & 24 & 710 & 195 & & 122 \\
\hline
\end{tabular}

Gage height, in feet, and discharge, in second-feet, at indicated t1me, 1938

\begin{tabular}{|c|c|c|c|c|c|c|c|c|c|c|c|c|}
\hline \multirow{2}{*}{$\begin{array}{l}4 \\
9 \\
9 \\
\end{array}$} & Peet & Sec.ft. & Foet & Sec.ft. & Feet & Sec.ft. & Feet & Sec.ft. & Feet & Sec.ft. & Feet & Sec.ft. \\
\hline & \multicolumn{2}{|c|}{ September 18} & \multicolumn{2}{|c|}{ September 19} & \multicolumn{2}{|c|}{ September 20} & \multicolumn{2}{|c|}{ September 21} & \multicolumn{2}{|c|}{ September 22} & \multicolumn{2}{|c|}{ September 23} \\
\hline $\begin{array}{l}1 \\
2 \\
3 \\
4 \\
5 \\
6\end{array}$ & $\begin{array}{l}- \\
- \\
- \\
- \\
-\end{array}$ & $\begin{array}{l}- \\
\overline{-} \\
\overline{-} \\
-\end{array}$ & $\begin{array}{c}- \\
2.00 \\
- \\
2.01 \\
- \\
2.04\end{array}$ & $\begin{array}{r}-111 \\
- \\
-113 \\
119\end{array}$ & $\begin{array}{l}3.45 \\
3.69 \\
3.95 \\
4.23 \\
4.29 \\
4.27\end{array}$ & $\begin{array}{r}710 \\
878 \\
1,070 \\
1,280 \\
1,320 \\
1,310\end{array}$ & $\begin{array}{l}5.18 \\
5.16 \\
5.13 \\
5.06 \\
5.00 \\
4.91\end{array}$ & $\begin{array}{l}2,040 \\
2,020 \\
2,000 \\
1,930 \\
1,880 \\
1,810\end{array}$ & $\begin{array}{r}8.22 \\
7.64 \\
7.18 \\
6.78 \\
6.48 \\
6.31\end{array}$ & $\begin{array}{l}5,780 \\
4,920 \\
4,270 \\
3,740 \\
3,380 \\
3,070\end{array}$ & $\begin{array}{l}4.13 \\
4.09 \\
4.07 \\
4.05 \\
4.06 \\
4.07\end{array}$ & $\begin{array}{l}1,200 \\
1,170 \\
1,160 \\
1,140 \\
1,150 \\
1,160\end{array}$ \\
\hline $\begin{array}{r}7 \\
8 \\
9 \\
10 \\
11 \\
11\end{array}$ & $\begin{array}{c}- \\
- \\
- \\
- \\
- \\
* 1.98\end{array}$ & $\begin{array}{l}- \\
- \\
- \\
- \\
* 107\end{array}$ & $\begin{array}{c}2.08 \\
\overline{-} \\
2.14 \\
\overline{2.22}\end{array}$ & $\begin{array}{r}-128 \\
- \\
141 \\
-160\end{array}$ & $\begin{array}{l}4.27 \\
4.35 \\
4.45 \\
4.53 \\
4.56 \\
4.58\end{array}$ & $\begin{array}{l}1,310 \\
1,370 \\
1,440 \\
1,500 \\
1,530 \\
1,540\end{array}$ & $\begin{array}{l}4.83 \\
4.75 \\
4.68 \\
4.64 \\
4.65 \\
4.75\end{array}$ & $\begin{array}{l}1,740 \\
1,680 \\
1,620 \\
1,590 \\
1,600 \\
1,680\end{array}$ & & $\begin{array}{l}2,780 \\
2,590 \\
2,430 \\
2,270 \\
2,150 \\
2,030\end{array}$ & $\begin{array}{l}4.08 \\
4.09 \\
4.12 \\
4.15 \\
4.17 \\
4.16\end{array}$ & $\begin{array}{l}1,170 \\
1,170 \\
1,200 \\
1,220 \\
1,230 \\
1,220\end{array}$ \\
\hline $\begin{array}{l}1 \\
2 \\
3 \\
4 \\
5 \\
6\end{array}$ & $\begin{array}{l}- \\
- \\
- \\
- \\
-\end{array}$ & $\begin{array}{l}- \\
- \\
- \\
- \\
-\end{array}$ & $\begin{array}{c}\overline{2.32} \\
\overline{2.45} \\
\overline{2.60}\end{array}$ & $\begin{array}{c}- \\
186 \\
- \\
224 \\
-273\end{array}$ & $\begin{array}{l}4.59 \\
4.55 \\
4.50 \\
4.42 \\
4.33 \\
4.25\end{array}$ & $\begin{array}{l}1,550 \\
1,520 \\
1,480 \\
1,420 \\
1,350 \\
1,290\end{array}$ & $\begin{array}{l}5.05 \\
5.52 \\
6.15 \\
6.84 \\
7.68 \\
8.18\end{array}$ & $\begin{array}{l}1,920 \\
2,360 \\
3,000 \\
3,810 \\
4,970 \\
5,720\end{array}$ & $\begin{array}{l}5.05 \\
4.95 \\
4.85 \\
4.76 \\
4.68 \\
4.60\end{array}$ & $\begin{array}{l}1,920 \\
1,840 \\
1,760 \\
1,690 \\
1,620 \\
1,560\end{array}$ & $\begin{array}{l}4.14 \\
4.10 \\
4.05 \\
4.00 \\
3.96 \\
3.91\end{array}$ & $\begin{array}{l}1,210 \\
1,180 \\
1,140 \\
1,110 \\
1,080 \\
1,050\end{array}$ \\
\hline \multirow[t]{2}{*}{$\begin{array}{r}7 \\
8 \\
9 \\
10 \\
11 \\
1\end{array}$} & $\begin{array}{l}- \\
\overline{-} \\
\overline{-} \\
-\end{array}$ & $\begin{array}{l}- \\
- \\
- \\
-\end{array}$ & $\begin{array}{c}- \\
2.76 \\
- \\
2.97 \\
- \\
3.25\end{array}$ & $\begin{array}{r}- \\
-334 \\
-428 \\
-580\end{array}$ & $\begin{array}{l}4.21 \\
4.21 \\
4.35 \\
4.66 \\
4.92 \\
5.10\end{array}$ & $\begin{array}{l}1,260 \\
1,260 \\
1,370 \\
1,610 \\
1,820 \\
1,970\end{array}$ & $\begin{array}{l}8.53 \\
9.08 \\
9.52 \\
9.78 \\
9.58 \\
8.88\end{array}$ & $\begin{array}{l}6,250 \\
7,130 \\
7,840 \\
8,290 \\
7,950 \\
6,810\end{array}$ & $\begin{array}{l}4.52 \\
4.45 \\
4.38 \\
4.31 \\
4.25 \\
4.19\end{array}$ & $\begin{array}{l}1,500 \\
1,440 \\
1,390 \\
1,340 \\
1,290 \\
1,250\end{array}$ & $\begin{array}{l}3.86 \\
3.82 \\
3.77 \\
3.73 \\
3.69 \\
3.66\end{array}$ & $\begin{array}{r}1,010 \\
988 \\
956 \\
930 \\
904 \\
884\end{array}$ \\
\hline & \multicolumn{2}{|c|}{ September 24} & \multicolumn{2}{|c|}{ September 25} & \multicolumn{2}{|c|}{ September 26} & \multicolumn{2}{|c|}{ September 27} & \multicolumn{2}{|c|}{ September 28} & \multicolumn{2}{|c|}{ September 29} \\
\hline $\begin{array}{r}2 \\
4 \\
6 \\
8 \\
10 \\
11\end{array}$ & $\begin{array}{l}3.59 \\
3.54 \\
3.49 \\
3.44 \\
3.39 \\
3.35\end{array}$ & $\begin{array}{l}839 \\
809 \\
779 \\
749 \\
720 \\
698\end{array}$ & $\begin{array}{l}3.08 \\
3.05 \\
3.03 \\
3.00 \\
2.98 \\
2.95\end{array}$ & $\begin{array}{l}549 \\
534 \\
523 \\
507 \\
497 \\
482\end{array}$ & $\begin{array}{c}- \\
2.76 \\
- \\
2.73 \\
- \\
2.71\end{array}$ & $\begin{array}{c}- \\
-394 \\
- \\
381 \\
- \\
372\end{array}$ & $\begin{array}{c}- \\
2.61 \\
- \\
2.60 \\
- \\
2.58\end{array}$ & $\begin{array}{c}-332 \\
- \\
328 \\
- \\
320\end{array}$ & $\begin{array}{c}- \\
2.57 \\
- \\
2.54 \\
- \\
2.51\end{array}$ & $\begin{array}{c}-317 \\
- \\
305 \\
- \\
294\end{array}$ & $\begin{array}{c}\overline{2 .} \\
\overline{-} \\
2.41 \\
- \\
2.39\end{array}$ & $\begin{array}{r}-261 \\
- \\
258 \\
- \\
251\end{array}$ \\
\hline $\begin{array}{r}2 \\
4 \\
6 \\
8 \\
10 \\
M\end{array}$ & $\begin{array}{l}3.32 \\
3.28 \\
3.23 \\
3.19 \\
3.15 \\
3.11\end{array}$ & $\begin{array}{l}681 \\
659 \\
632 \\
610 \\
588 \\
566\end{array}$ & $\begin{array}{l}2.93 \\
2.90 \\
2.88 \\
2.85 \\
2.82 \\
2.80\end{array}$ & $\begin{array}{l}472 \\
457 \\
448 \\
434 \\
420 \\
411\end{array}$ & $\begin{array}{c}- \\
2.69 \\
- \\
2.66 \\
- \\
2.63\end{array}$ & $\begin{array}{c}-364 \\
- \\
352 \\
-340\end{array}$ & $\begin{array}{c}- \\
2.57 \\
- \\
2.59 \\
- \\
2.59\end{array}$ & $\begin{array}{c}-317 \\
-324 \\
- \\
324\end{array}$ & $\begin{array}{c}\overline{2 .} \\
\overline{-} \\
2.46 \\
\overline{2.44}\end{array}$ & $\begin{array}{r}- \\
-283 \\
276 \\
-268\end{array}$ & $\begin{array}{c}- \\
2.37 \\
- \\
2.36 \\
- \\
2.34\end{array}$ & $\begin{array}{r}-244 \\
- \\
240 \\
-234\end{array}$ \\
\hline
\end{tabular}

Supplemental records.- Sept. $21,10: 15$ p.m., 9.79 ft., 8,300 sec.-ft.

* Mean for the day. 
Neversink River at Oakland Valley, N. Y.

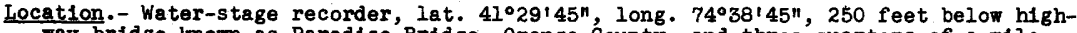
way bridge known as Paradise Bridge, Orange County, and three-quarters of a mile south of Oakland Valley, Sullivan County. Zero of gage is 632.00 feet above mean sea level (general adjustment of 1912).

Drainage area.- 222 square miles.

Gege-height record.- Water-stage recorder graph.

Stage-discharge relation. - For 1938 defined by current-meter measurements below 7,520 second-feet; extended logarithmically to peak stage. For 1933 defined by currentmeter measurements below 4,090 second-feet; extended logarithmically to peak stage.

Maxima.- September 1938: Discharge, 11,100 second-feet 2 a.m. Sept. 22 (gage height, 9.47 feet)

July 1928 to August 1938: Discharge, 20,000 second-feet Aug. 24, 1933 (gage helght, 12.61 feet).

Remarks.- Flood run-off not affected by storage or diversion.

Mean daily discharge, in second-feet, 1938

\begin{tabular}{|c|c|c|c|c|c|c|c|c|c|c|c|}
\hline Day & Sept. & Oct. & Day & Sept. & oct. & Day & Sept. & Oct. & Day & Sept. & Oct. \\
\hline $\begin{array}{l}1 \\
2 \\
3 \\
4 \\
5 \\
6 \\
7 \\
8\end{array}$ & $\begin{array}{l}162 \\
162 \\
143 \\
136 \\
126 \\
117 \\
117 \\
176 \\
\end{array}$ & $\begin{array}{l}409 \\
359 \\
330 \\
297 \\
274 \\
261 \\
252 \\
234 \\
\end{array}$ & $\begin{array}{r}9 \\
10 \\
11 \\
12 \\
13 \\
14 \\
15 \\
16\end{array}$ & $\begin{array}{l}176 \\
136 \\
126 \\
120 \\
126 \\
150 \\
224 \\
261 \\
\end{array}$ & $\begin{array}{l}225 \\
217 \\
205 \\
196 \\
188 \\
180 \\
173 \\
169 \\
\end{array}$ & $\begin{array}{l}17 \\
18 \\
19 \\
20 \\
21 \\
22 \\
23 \\
24 \\
\end{array}$ & $\begin{array}{r}184 \\
169 \\
232 \\
1,460 \\
4,400 \\
5,500 \\
2,080 \\
1,400 \\
\end{array}$ & $\begin{array}{l}162 \\
162 \\
150 \\
165 \\
279 \\
266 \\
192 \\
301 \\
\end{array}$ & $\begin{array}{l}25 \\
26 \\
27 \\
28 \\
29 \\
30 \\
31\end{array}$ & $\begin{array}{l}950 \\
740 \\
615 \\
560 \\
484 \\
439\end{array}$ & $\begin{array}{l}630 \\
426 \\
340 \\
316 \\
311 \\
325 \\
283\end{array}$ \\
\hline $\begin{array}{l}\text { Mean } \\
\text { Run- }\end{array}$ & $\begin{array}{l}\text { nth } \mathrm{y} \\
, \text { in } 1\end{array}$ & schar & In & second-f & t. & . : & $\cdot \quad: \quad$ & $\begin{array}{l}\cdot \cdot \dot{ } \\
\cdot\end{array}$ & $\dot{*}:$ & $\begin{array}{r}722 \\
3.63 \\
\end{array}$ & $\begin{array}{r}267 \\
1.38 \\
\end{array}$ \\
\hline
\end{tabular}

Gage helght, in feet, and discharge, In second-feet, at indicated t1me, 1938

\begin{tabular}{|c|c|c|c|c|c|c|c|c|c|c|c|c|}
\hline \multirow{2}{*}{ 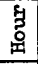 } & Feot & Sec.ft. & Feet & Sec.ett. & Feot & Sec.ft. & Feet & Sec.ft. & Beet & Sec.ft. & Feet & sec.ft. \\
\hline & \multicolumn{2}{|c|}{ Sept ember $18^{\circ}$} & \multicolumn{2}{|c|}{ September 19} & \multicolumn{2}{|c|}{ September 20} & \multicolumn{2}{|c|}{ September 21} & \multicolumn{2}{|c|}{ September 22} & \multicolumn{2}{|c|}{ September 23} \\
\hline $\begin{array}{l}1 \\
2 \\
3 \\
4 \\
5 \\
6\end{array}$ & $\begin{array}{c}- \\
- \\
- \\
\bar{z} \\
2.07\end{array}$ & $\begin{array}{l}- \\
\overline{-} \\
\overline{-} \\
169\end{array}$ & $\begin{array}{c}\overline{2.10} \\
\overline{2.11} \\
\overline{2.11}\end{array}$ & $\begin{array}{c}- \\
-180 \\
-184 \\
- \\
184\end{array}$ & $\begin{array}{c}- \\
2.78 \\
- \\
3.01 \\
- \\
3.34\end{array}$ & $\begin{array}{r}-499 \\
-\quad 621 \\
-\quad 833\end{array}$ & $\begin{array}{l}4.71 \\
4.82 \\
5.05 \\
5.20 \\
5.30 \\
5.33\end{array}$ & $\begin{array}{l}2,080 \\
2,200 \\
2,480 \\
2,670 \\
2,800 \\
2,840\end{array}$ & $\begin{array}{l}9.30 \\
9.47 \\
9.30 \\
8.89 \\
8.31 \\
7.83\end{array}$ & $\begin{array}{r}10,600 \\
11,100 \\
10,600 \\
9,600 \\
8,220 \\
7,170\end{array}$ & $\begin{array}{c}- \\
5.02 \\
- \\
4.91 \\
- \\
4.82\end{array}$ & $\begin{array}{l}2,440 \\
- \\
2,310 \\
2,200\end{array}$ \\
\hline $\begin{array}{r}7 \\
8 \\
9 \\
10 \\
11 \\
11\end{array}$ & $\begin{array}{c}- \\
- \\
- \\
- \\
2.07\end{array}$ & $\begin{array}{l}- \\
- \\
- \\
- \\
169\end{array}$ & $\begin{array}{c}- \\
2.11 \\
- \\
2.11 \\
\overline{2.12}\end{array}$ & $\begin{array}{r}- \\
-184 \\
-184 \\
-188\end{array}$ & $\begin{array}{c}\overline{3.77} \\
\overline{4.01} \\
\overline{4.42}\end{array}$ & $\begin{array}{l}- \\
1,170 \\
\overline{1,380} \\
\overline{1,770}\end{array}$ & $\begin{array}{l}5.31 \\
5.28 \\
5.25 \\
5.22 \\
5.20 \\
5.21\end{array}$ & $\begin{array}{l}2,810 \\
2,770 \\
2,740 \\
2,700 \\
2,670 \\
2,680\end{array}$ & $\begin{array}{l}7.42 \\
7.18 \\
6.95 \\
6.76 \\
6.59 \\
6.45\end{array}$ & $\begin{array}{l}6,340 \\
5,860 \\
5,420 \\
5,080 \\
4,770 \\
4,540\end{array}$ & $\begin{array}{c}- \\
4.75 \\
- \\
4.71 \\
- \\
4.69\end{array}$ & $\begin{array}{l}\overline{2,120} \\
\overline{2,080} \\
2,060\end{array}$ \\
\hline $\begin{array}{r}1 \\
2 \\
3 \\
4 \\
-5 \\
6\end{array}$ & $\begin{array}{c}- \\
- \\
- \\
\overline{2} \\
2.06\end{array}$ & $\begin{array}{l}- \\
- \\
- \\
- \\
165\end{array}$ & $\begin{array}{c}- \\
2.18 \\
- \\
2.22 \\
- \\
2.27\end{array}$ & $\begin{array}{r}-213 \\
- \\
230 \\
-252\end{array}$ & $\begin{array}{c}\overline{4.64} \\
\overline{4.66} \\
\overline{4.65}\end{array}$ & $\begin{array}{c}\overline{2,000} \\
\overline{2,030} \\
\overline{2,020}\end{array}$ & $\begin{array}{l}5.30 \\
5.42 \\
5.74 \\
6.18 \\
6.85 \\
7.50\end{array}$ & $\begin{array}{l}2,800 \\
2,960 \\
3,410 \\
4,090 \\
5,240 \\
6,500\end{array}$ & $\begin{array}{l}6.31 \\
6.17 \\
6.03 \\
5.91 \\
5.79 \\
5.69\end{array}$ & $\begin{array}{l}4,300 \\
4,070 \\
3,850 \\
3,660 \\
3,480 \\
3,340\end{array}$ & $\begin{array}{c}\overline{4} .67 \\
- \\
4.66 \\
\overline{4.60}\end{array}$ & $\begin{array}{c}\overline{2,040} \\
\overline{-}, 030 \\
- \\
1,960\end{array}$ \\
\hline \multirow[t]{2}{*}{$\begin{array}{r}7 \\
8 \\
.9 \\
10 \\
11 \\
11\end{array}$} & $\begin{array}{c}- \\
- \\
- \\
2.06 \\
2.09\end{array}$ & $\begin{array}{l}- \\
- \\
- \\
165 \\
176\end{array}$ & $\begin{array}{c}- \\
2.38 \\
- \\
2.52 \\
- \\
2.68\end{array}$ & $\begin{array}{c}- \\
-302 \\
-369 \\
- \\
449\end{array}$ & $\begin{array}{c}- \\
4.63 \\
- \\
4.63 \\
- \\
4.67\end{array}$ & $\begin{array}{c}1,990 \\
\overline{1,990} \\
- \\
2,040\end{array}$ & $\begin{array}{l}8.06 \\
8.40 \\
8.57 \\
8.63 \\
8.77 \\
9.05\end{array}$ & $\begin{array}{l}7,670 \\
8,420 \\
8,830 \\
8,970 \\
9,310 \\
9,980\end{array}$ & $\begin{array}{l}5.59 \\
5.49 \\
5.39 \\
5.30 \\
5.22 \\
5.15\end{array}$ & $\begin{array}{l}3,200 \\
3,060 \\
2,920 \\
2,800 \\
2,700 \\
2,600\end{array}$ & $\begin{array}{c}- \\
4.52 \\
- \\
4.43 \\
\overline{-} \\
4.35\end{array}$ & $\begin{array}{l}- \\
1,870 \\
1,780 \\
\overline{1,700}\end{array}$ \\
\hline & \multicolumn{2}{|c|}{ September 24} & \multicolumn{2}{|c|}{ September 25} & \multicolumn{2}{|c|}{ September 26} & \multicolumn{2}{|c|}{ September 27} & \multicolumn{2}{|c|}{ September 28} & \multicolumn{2}{|c|}{ September 29} \\
\hline $\begin{array}{r}2 \\
4 \\
6 \\
8 \\
10 \\
18\end{array}$ & $\begin{array}{l}4.29 \\
4.20 \\
4.14 \\
4.08 \\
4.05 \\
4.00\end{array}$ & $\begin{array}{l}1,640 \\
1,550 \\
1,500 \\
1,440 \\
1,420 \\
1,370\end{array}$ & $\begin{array}{l}3.67 \\
3.62 \\
3.57 \\
3.52 \\
3.49 \\
3.47\end{array}$ & $\begin{array}{r}1,090 \\
1,050 \\
1,010 \\
966 \\
942 \\
928\end{array}$ & $\begin{array}{c}- \\
3.29 \\
\overline{3.23} \\
\overline{3.19}\end{array}$ & $\begin{array}{r}-798 \\
-760 \\
-764\end{array}$ & $\begin{array}{c}\overline{-} \\
\overline{3.02} \\
\overline{-} \\
2.98\end{array}$ & $\begin{array}{l}- \\
- \\
-627 \\
- \\
604\end{array}$ & $\begin{array}{c}\overline{-} \\
\overline{2.95} \\
- \\
\overline{-} \\
2.90\end{array}$ & $\begin{array}{l}- \\
- \\
- \\
- \\
588\end{array}$ & $\begin{array}{c}- \\
- \\
2.77 \\
- \\
- \\
2.74\end{array}$ & $\begin{array}{l}- \\
- \\
- \\
- \\
4794\end{array}$ \\
\hline $\begin{array}{r}2 \\
4 \\
6 \\
8 \\
10 \\
4\end{array}$ & $\begin{array}{l}4.02 \\
3.99 \\
3.92 \\
3.86 \\
3.79 \\
3.73\end{array}$ & $\begin{array}{l}1,390 \\
1,360 \\
1,300 \\
1,240 \\
1,180 \\
1,130\end{array}$ & $\begin{array}{l}0.44 \\
3.48 \\
3.47 \\
3.43 \\
3.39 \\
3.35\end{array}$ & $\begin{array}{l}905 \\
935 \\
928 \\
898 \\
868 \\
840\end{array}$ & $\begin{array}{c}- \\
3.15 \\
- \\
3.18 \\
- \\
3.10\end{array}$ & $\begin{array}{c}-708 \\
-694 \\
-675\end{array}$ & $\begin{array}{c}- \\
- \\
2.97 \\
- \\
\overline{2.96}\end{array}$ & $\begin{array}{l}- \\
- \\
-598 \\
- \\
593\end{array}$ & $\begin{array}{c}- \\
\overline{2} \\
2.86 \\
\overline{-} \\
2.81\end{array}$ & $\begin{array}{l}- \\
- \\
540 \\
- \\
514\end{array}$ & $\begin{array}{c}- \\
\overline{-} \\
2.73 \\
- \\
\overline{2.72}\end{array}$ & $\begin{array}{l}- \\
- \\
-474 \\
- \\
469\end{array}$ \\
\hline
\end{tabular}


Neversink River at Godeffroy, N. Y.

Location.- Water-stage recorder, lat. $41^{\circ} 26^{\prime} 30^{\prime \prime}$, long. $74^{\circ} 36^{\prime} 10^{\prime \prime}$, lo feet above county highway bridge, half a mile below Brasher Kill, three-quarters of a mile southeast of Godeffroy, Orange County, and $8 \frac{1}{4}$ miles above confluence with Delaware River.

Drainage area.- 302 square miles.

Gage-height record. - Water-stage recorder graph.

Stage-discharge relation. - For 1938 defined by current-meter measurements below 8,060 second-feet; extended logarithmically to peak stage. For 1913 defined by currentmeter measurements below 1,680 second-feet; extended on basis of area-mean velocity study.

Maxima.- September 1938: Discharge, 13,400 second-feet 3 a.m. Sept. 22 (gage height, 10.00 feet)

August 1937 to August 1938: Discharge, 16,100 second-feet July 22, 1938

(gage helght, 10.73 feet)

August 1909 to April 1914: Discharge, about 12,800 second-feet Mar. 27, 1913

(gage height, 7.3 feet, present datum).

August 1903 to October 1903: Maximum gage height recorded, about 10.5 feet present datum, 0ct. 9, 1903 (discharge not determined).

Remarks.- Discharge at low and medium stages affected by operation by power plant upstream. Flood run-off not affected by artificial storage or diversion.

Mean daily discharge, in second-feet, 1938

\begin{tabular}{|c|c|c|c|c|c|c|c|c|c|c|c|}
\hline Day & Sept. & Oct. & Day & Sept. & Oct. & Day & Sept. & Oct. & Day & Sept. & Oct. \\
\hline $\begin{array}{l}1 \\
2 \\
3 \\
4 \\
5 \\
6 \\
7 \\
8 \\
\end{array}$ & $\begin{array}{l}223 \\
210 \\
198 \\
180 \\
172 \\
166 \\
158 \\
218\end{array}$ & $\begin{array}{l}606 \\
537 \\
488 \\
436 \\
412 \\
382 \\
376 \\
337\end{array}$ & $\begin{array}{r}9 \\
10 \\
11 \\
12 \\
13 \\
14 \\
15 \\
16\end{array}$ & $\begin{array}{l}234 \\
180 \\
168 \\
168 \\
168 \\
194 \\
265 \\
321\end{array}$ & $\begin{array}{l}332 \\
310 \\
290 \\
269 \\
269 \\
265 \\
249 \\
207\end{array}$ & $\begin{array}{l}17 \\
18 \\
19 \\
20 \\
21 \\
22 \\
23 \\
24\end{array}$ & $\begin{array}{r}227 \\
202 \\
300 \\
1,640 \\
4,850 \\
7,100 \\
2,950 \\
2,180 \\
\end{array}$ & $\begin{array}{l}247 \\
222 \\
222 \\
226 \\
355 \\
352 \\
284 \\
400 \\
\end{array}$ & $\begin{array}{l}25 \\
26 \\
27 \\
28 \\
29 \\
30 \\
31\end{array}$ & $\begin{array}{r}1,620 \\
1,290 \\
1,060 \\
906 \\
774 \\
699\end{array}$ & $\begin{array}{l}792 \\
560 \\
465 \\
455 \\
446 \\
464 \\
418\end{array}$ \\
\hline $\begin{array}{l}\text { Mean } \\
\text { Run- }\end{array}$ & $\begin{array}{l}\text { nthly } \\
\text {, in }\end{array}$ & $\begin{array}{l}\text { gchar } \\
\text { hes. }\end{array}$ & , 11 & gend-f & : & . & $\dot{*} \cdot \dot{ }$ & . $\cdot \dot{0}$ & $\dot{0} \cdot$ & $\begin{array}{r}967 \\
3.57 \\
\end{array}$ & $\begin{array}{r}377 \\
1.44 \\
\end{array}$ \\
\hline
\end{tabular}

Gage helght, in feet, and discharge, in second-feet, at indlcated time, 1938

\begin{tabular}{|c|c|c|c|c|c|c|c|c|c|c|c|c|}
\hline \multirow{2}{*}{$\begin{array}{l}4 \\
9 \\
\text { 운 }\end{array}$} & Feet & Sec.ft. & Feet & Sec.ft. & Feet & Sec.ft. & Feet & Sec.ft. & Feet & Sec.ft. & Feet & Sec.ft. \\
\hline & \multicolumn{2}{|c|}{ September 18} & \multicolumn{2}{|c|}{ September 19} & \multicolumn{2}{|c|}{ September 20} & \multicolumn{2}{|c|}{ September 21} & \multicolumn{2}{|c|}{ September 22} & \multicolumn{2}{|c|}{ September 23} \\
\hline $\begin{array}{l}1 \\
2 \\
3 \\
4 \\
5 \\
6\end{array}$ & $\begin{array}{l}- \\
- \\
- \\
3.33 \\
- \\
-\end{array}$ & $\begin{array}{l}- \\
- \\
- \\
- \\
-\end{array}$ & $\begin{array}{c}3.48 \\
3.49 \\
- \\
3.49 \\
3.49 \\
3.47\end{array}$ & $\begin{array}{r}265 \\
269 \\
-\quad \\
269 \\
269 \\
260\end{array}$ & $\begin{array}{l}4.07 \\
4.13 \\
4.20 \\
4.27 \\
4.38 \\
4.53\end{array}$ & $\begin{array}{r}635 \\
683 \\
740 \\
800 \\
897 \\
1,040\end{array}$ & $\begin{array}{l}5.62 \\
5.65 \\
5.75 \\
5.90 \\
6.02 \\
6.09\end{array}$ & $\begin{array}{l}2,320 \\
2,360 \\
2,500 \\
2,720 \\
2,900 \\
3,000\end{array}$ & $\begin{array}{r}9.66 \\
9.91 \\
10.00 \\
9.80 \\
9.39 \\
8.88\end{array}$ & $\begin{array}{r}12,200 \\
13,100 \\
13,400 \\
12,700 \\
11,300 \\
9,680\end{array}$ & $\begin{array}{c}6.29 \\
- \\
6.21 \\
- \\
6.15\end{array}$ & $\begin{array}{c}\overline{3,320} \\
\overline{3,200} \\
\overline{3,100}\end{array}$ \\
\hline $\begin{array}{r}7 \\
8 \\
9 \\
10 \\
11 \\
\text { N }\end{array}$ & $\begin{array}{c}- \\
3.33 \\
- \\
- \\
- \\
3.33\end{array}$ & $\begin{array}{l}-198 \\
- \\
- \\
- \\
198\end{array}$ & $\begin{array}{c}\overline{3.47} \\
\overline{3.48} \\
\overline{3.49}\end{array}$ & $\begin{array}{r}-260 \\
-265 \\
-269\end{array}$ & $\begin{array}{l}4.75 \\
4.71 \\
4.90 \\
5.00 \\
5.11 \\
5.31\end{array}$ & $\begin{array}{l}1,260 \\
1,220 \\
1,430 \\
1,540 \\
1,660 \\
1,900\end{array}$ & $\begin{array}{l}6.10 \\
6.10 \\
6.10 \\
6.07 \\
6.06 \\
6.10\end{array}$ & $\begin{array}{l}3,020 \\
3,020 \\
3,020 \\
2,980 \\
2,960 \\
3,020\end{array}$ & $\begin{array}{l}8.49 \\
8.20 \\
8.00 \\
7.82 \\
7.64 \\
7.52\end{array}$ & $\begin{array}{l}8,510 \\
7,680 \\
7,120 \\
6,650 \\
6,180 \\
5,890\end{array}$ & $\begin{array}{c}- \\
6.09 \\
- \\
6.05 \\
- \\
6.03\end{array}$ & $\begin{array}{c}\overline{3,000} \\
\overline{2,940} \\
\overline{2,920}\end{array}$ \\
\hline $\begin{array}{l}1 \\
2 \\
3 \\
4 \\
5 \\
6\end{array}$ & $\begin{array}{c}3.41 \\
3.42 \\
3.34 \\
3.33 \\
- \\
-\end{array}$ & $\begin{array}{l}232 \\
236 \\
202 \\
198 \\
- \\
-\end{array}$ & $\begin{array}{c}3.43 \\
3.43 \\
- \\
3.44 \\
3.45 \\
3.62\end{array}$ & $\begin{array}{r}241 \\
241 \\
-\quad \\
246 \\
250 \\
337\end{array}$ & $\begin{array}{l}5.45 \\
5.52 \\
5.55 \\
5.55 \\
5.55 \\
5.58\end{array}$ & $\begin{array}{l}2,080 \\
2,180 \\
2,220 \\
2,220 \\
2,220 \\
2,260\end{array}$ & $\begin{array}{l}6.17 \\
6.40 \\
6.55 \\
6.90 \\
7.35 \\
7.96\end{array}$ & $\begin{array}{l}3,130 \\
3,500 \\
3,770 \\
4,460 \\
5,480 \\
7,020\end{array}$ & $\begin{array}{l}7.37 \\
7.21 \\
7.08 \\
6.99 \\
6.90 \\
6.80\end{array}$ & $\begin{array}{l}5,530 \\
5,140 \\
4,860 \\
4,660 \\
4,460 \\
4,260\end{array}$ & $\begin{array}{l}6.00 \\
- \\
6.00 \\
- \\
6.00\end{array}$ & $\begin{array}{c}2,870 \\
- \\
2,870 \\
\overline{2,870}\end{array}$ \\
\hline \multirow[t]{2}{*}{$\begin{array}{r}7 \\
8 \\
9 \\
10 \\
11 \\
M\end{array}$} & $\begin{array}{c}- \\
3.33 \\
- \\
3.33 \\
3.37 \\
3.36\end{array}$ & $\begin{array}{r}- \\
- \\
- \\
198 \\
214 \\
210\end{array}$ & $\begin{array}{l}3.67 \\
3.69 \\
3.72 \\
3.75 \\
3.90 \\
3.99\end{array}$ & $\begin{array}{l}365 \\
376 \\
394 \\
412 \\
508 \\
573\end{array}$ & $\begin{array}{l}5.57 \\
5.56 \\
5.56 \\
5.57 \\
5.58 \\
5.60\end{array}$ & $\begin{array}{l}2,250 \\
2,230 \\
2,230 \\
2,250 \\
2,260 \\
2,290\end{array}$ & $\begin{array}{l}8.44 \\
8.76 \\
9.00 \\
9.13 \\
9.23 \\
9.40 \\
\end{array}$ & $\begin{array}{r}8,360 \\
9,320 \\
10,100 \\
10,500 \\
10,800 \\
11,300\end{array}$ & $\begin{array}{l}6.73 \\
6.64 \\
6.56 \\
6.50 \\
6.44 \\
6.38 \\
\end{array}$ & $\begin{array}{l}4,120 \\
3,940 \\
3,790 \\
3,680 \\
3,570 \\
3,470\end{array}$ & $\begin{array}{c}5.92 \\
- \\
5.85 \\
- \\
5.80\end{array}$ & $\begin{array}{c}- \\
2,750 \\
- \\
2,640 \\
- \\
2,570\end{array}$ \\
\hline & \multicolumn{2}{|c|}{ September 24} & \multicolumn{2}{|c|}{ September 25} & \multicolumn{2}{|c|}{ September 26} & \multicolumn{2}{|c|}{ September 27} & \multicolumn{2}{|c|}{ September 28} & \multicolumn{2}{|c|}{ September 29} \\
\hline $\begin{array}{r}2 \\
4 \\
6 \\
8 \\
10 \\
N\end{array}$ & $\begin{array}{l}5.75 \\
5.67 \\
5.62 \\
5.60 \\
5.46 \\
5.46\end{array}$ & $\begin{array}{l}2,500 \\
2,390 \\
2,320 \\
2,290 \\
2,100 \\
2,100\end{array}$ & $\begin{array}{c}5.18 \\
- \\
5.10 \\
- \\
5.03\end{array}$ & $\begin{array}{c}- \\
1,750 \\
- \\
1,650 \\
- \\
1,570\end{array}$ & $\begin{array}{c}4.86 \\
- \\
4.81 \\
\overline{4.75}\end{array}$ & $\begin{array}{c}- \\
1,390 \\
- \\
1,330 \\
- \\
1,260\end{array}$ & $\begin{array}{c}- \\
4.61 \\
- \\
4.58 \\
- \\
4.54\end{array}$ & $\begin{array}{c}- \\
1,120 \\
- \\
1,090 \\
- \\
1,050\end{array}$ & $\begin{array}{l}\overline{-} \\
\overline{4.45} \\
- \\
\overline{4.40}\end{array}$ & $\begin{array}{l}- \\
- \\
- \\
- \\
915\end{array}$ & $\begin{array}{l}\overline{-} \\
\overline{4.29} \\
- \\
\overline{4} \\
\overline{4} 25\end{array}$ & $\begin{array}{l}- \\
- \\
- \\
- \\
-782\end{array}$ \\
\hline $\begin{array}{r}2 \\
4 \\
6 \\
8 \\
10 \\
M\end{array}$ & $\begin{array}{l}5.53 \\
5.47 \\
5.43 \\
5.37 \\
5.31 \\
5.28\end{array}$ & $\begin{array}{l}2,190 \\
2,110 \\
2,060 \\
1,980 \\
1,900 \\
1,870\end{array}$ & $\begin{array}{l}- \\
4.99 \\
5.01 \\
4.98 \\
- \\
4.91\end{array}$ & $\begin{array}{c}- \\
1,530 \\
1,550 \\
1,520 \\
- \\
1,440\end{array}$ & $\begin{array}{l}\overline{-} \\
\overline{-72} \\
4.69 \\
\overline{4.65}\end{array}$ & $\begin{array}{l}\overline{1,230} \\
\overline{1,200} \\
\overline{1,160}\end{array}$ & $\begin{array}{l}- \\
4.52 \\
- \\
4.50 \\
\overline{4.47}\end{array}$ & $\begin{array}{c}\overline{1,030} \\
\overline{1}, 010 \\
- \\
982\end{array}$ & $\begin{array}{c}- \\
- \\
4.36 \\
- \\
- \\
4.32\end{array}$ & $\begin{array}{l}- \\
- \\
-879 \\
- \\
843\end{array}$ & $\begin{array}{c}- \\
\overline{4} \\
\overline{4} \\
\overline{4.21} \\
4.21\end{array}$ & $\begin{array}{l}- \\
-757 \\
- \\
-748\end{array}$ \\
\hline
\end{tabular}

Supplemental records.- Sept. $18,5: 30$ p.m., 3.46 ft., 255 sec.-ft. Sept. 20 , 7:15 a.m., 4.79 ft., 1,310 sec.-ft.; 7:45 a.m., 4.69 ft., 1,200 sec.-ft. Sept.'21, 9:25 a.m., 5.95 ft., 2,800 sec.-ft.; $1: 50$ p.m., 6.45 ft., 3,590 sec.-ft.; $2: 10$ p.m., $6.36 \mathrm{ft} ., 3,440$ sec. $-\mathrm{ft}$. 
Location.- Water-stage recorder, lat. $42^{\circ} 29^{\prime} 5^{\prime \prime}$, long. $74^{\circ} 58^{\prime} 55^{\prime \prime}$, a quarter of a mile below power plant of Associated Gas \& Electric System, and half a mile north of Colliersville, Otsego County. Zero of gage is $1,110.80$ feet above mean sea level (general adjustment of 1912).

Drainage area.- 351 square miles.

Gage-height record. - Water-stage recorder graph.

Stage-discharge relation.- Defined by current-meter measurements below 5,420 secondfeet; extended logarithmically to peak stage.

Maxima.- September 1938: Discharge, 6,300 second-feet 7:30 p.m. Sept. 22 (gage height, 7.20 (eet).

July 1924 to August 1938: Discharge, 8,740 second-feet Mar. 19, 1936 (gage height, 8.13 feet).

Remarks.- Flow regulated by natural storage in 0tsego Lake and Canadarago Lake and by storage in Goodyear Lake above power plant upstream. Large fluctuations Sept. 18 to 21 and Sept. 25 to 29 due to power-plant operation.

Mean dally discharge, in second-feet, 1938

\begin{tabular}{|c|c|c|c|c|c|c|c|c|c|c|c|}
\hline Day & Sept. & oct. & Day & Sept. & 0 ct. & Day & Sept. & Oct. & Day & Sept. & Oct. \\
\hline $\begin{array}{l}1 \\
2 \\
3 \\
4 \\
5 \\
6 \\
7 \\
8\end{array}$ & $\begin{array}{r}105 \\
57 \\
80 \\
89 \\
71 \\
92 \\
157 \\
195\end{array}$ & $\begin{array}{r}1,090 \\
908 \\
889 \\
676 \\
834 \\
602 \\
487 \\
468\end{array}$ & $\begin{array}{r}9 \\
10 \\
11 \\
12 \\
13 \\
14 \\
15 \\
16\end{array}$ & $\begin{array}{r}142 \\
18 \\
18 \\
18 \\
19 \\
168 \\
142 \\
113\end{array}$ & $\begin{array}{l}364 \\
430 \\
422 \\
295 \\
379 \\
308 \\
240 \\
322\end{array}$ & $\begin{array}{l}17 \\
18 \\
19 \\
20 \\
21 \\
22 \\
23 \\
24\end{array}$ & $\begin{array}{r}160 \\
94 \\
136 \\
388 \\
1,260 \\
4,440 \\
4,790 \\
2,730\end{array}$ & $\begin{array}{l}307 \\
250 \\
241 \\
253 \\
206 \\
259 \\
222 \\
476\end{array}$ & $\begin{array}{l}25 \\
26 \\
27 \\
28 \\
29 \\
30 \\
31\end{array}$ & $\begin{array}{l}1,970 \\
1,630 \\
1,440 \\
1,400 \\
1,350 \\
1,290\end{array}$ & $\begin{array}{l}608 \\
359 \\
326 \\
284 \\
290 \\
226 \\
248\end{array}$ \\
\hline Run & thly & char & , 1 & $\begin{array}{l}\text { lecond- } \\
. \quad \cdot\end{array}$ & өt. & $\dot{0}$ & $\begin{array}{l}\bullet \cdot \\
\cdot\end{array}$ & 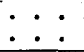 & $:$ & $\begin{array}{r}819 \\
2.60 \\
\end{array}$ & $\begin{array}{r}428 \\
1.41 \\
\end{array}$ \\
\hline
\end{tabular}

Gage helght, in feet, and discharge, in second-feet, at indicated time, 1938

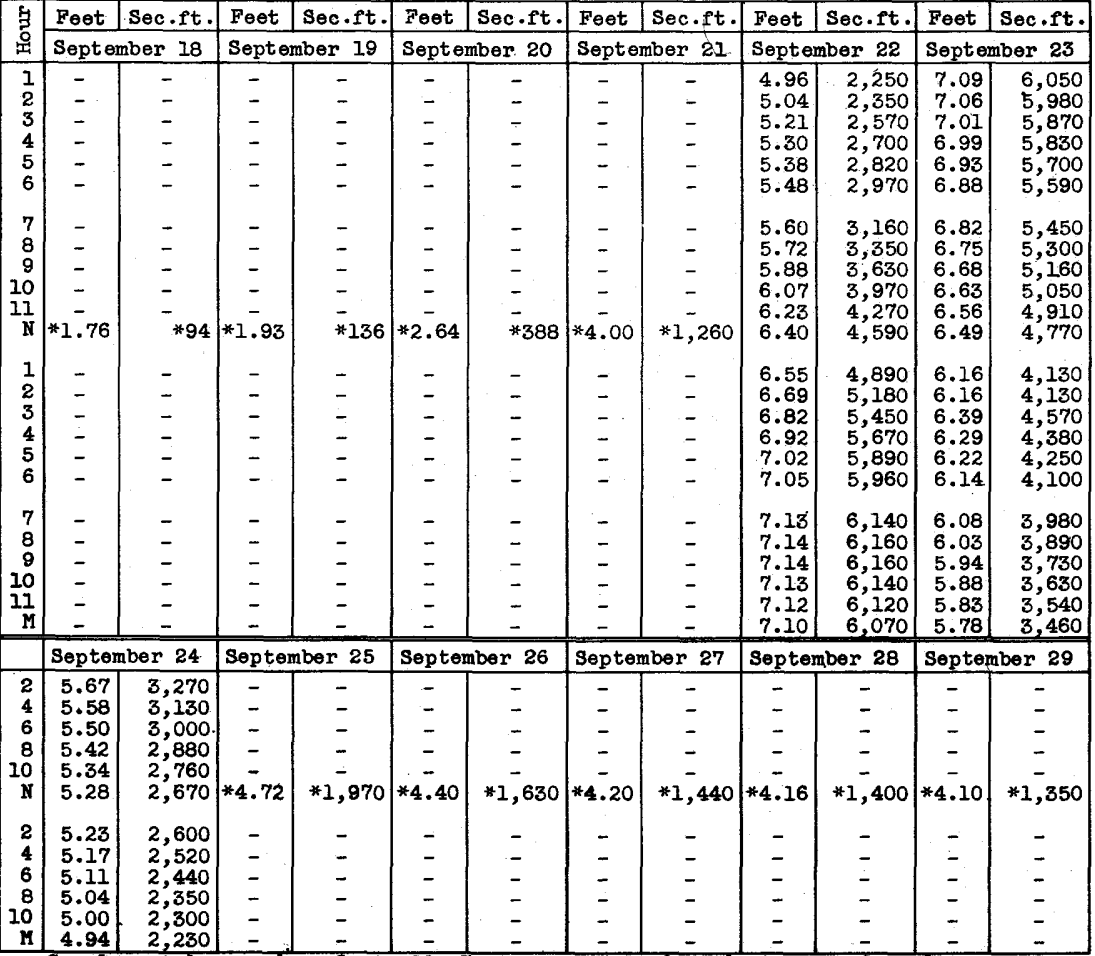

Supplemental records.- Sept. $22,7: 30$ p.m., 7.20 ft., 6,300 sec.-ft. Sept. 23,

$2: 10$ p.m., $6.46 \mathrm{ft} ., 4,710$ sec. $-\mathrm{ft}$.

* Mean for the dáy. 
Oaks Creek at Index, N. Y.

Location. - Water-stage recorder, lat. $42^{\circ} 40^{\prime} 00^{\prime \prime}$, long. $74^{\circ} 5^{\prime} 7^{\prime \prime} 5^{\prime \prime}$, about 200 ft. above highway bridge in Index, Otsego County, half a mile above mouth and three miles southwest of Cooperstown. Zero of present gage is $1,174.50$ feet above mean sea level (general adjustment of 1912). Staff and wire-welght gage at same site but different datum from November 1929 to September 1932.

Drainage area.- 103 square miles.

Gage-helght record. - Water-stage recorder graph except for period 12 p.m. Sept. 21 to 10 a.m. Sept. 22, for which graph was draw based on floodmarks, comparison with graphs of previous floods, and the shape of water-stage recorder graph before and after missing period.

Stage-discharge relation.- For 1938 defined by current-meter measurements below 1,090 second-feet; extended logarithmically to peak stage. For 1932 defined by currentmeter measurements below 331 second-feet; extended logarithmically to peak stage.

Maxima.- September 1938: Discharge, 1,460 second-feet 3:30 a.m. Sept. 22 (gage height, 5.71 feet, from floodmarks).

November 1929 to September 1932: D1scharge observed, 1,060 second-feet Apr. 12, 1932 (gage helght, 5.3 feet, present site and former datum) March 1937 to August 1938: Discharge, 1,300 second-feet Feb. 7, 1938 (gage height, 5.53 feet, present site and datum).

Remarks.- Discharge affected by storage in Canadarago Lake.

Mean dally discharge, in second-feet, 1938

\begin{tabular}{|c|c|c|c|c|c|c|c|c|c|c|c|}
\hline Day & Sept. & Oct. & Day & Sept. & Oct. & Day & Sept. & Oct. & Day & Sept. & Oct. \\
\hline $\begin{array}{l}1 \\
2 \\
3 \\
4 \\
5 \\
6 \\
7 \\
8\end{array}$ & $\begin{array}{l}30 \\
30 \\
29 \\
30 \\
27 \\
26 \\
27 \\
27\end{array}$ & $\begin{array}{l}350 \\
321 \\
300 \\
280 \\
260 \\
244 \\
222 \\
207\end{array}$ & $\begin{array}{r}9 \\
10 \\
11 \\
12 \\
13 \\
14 \\
15 \\
16\end{array}$ & $\begin{array}{l}26 \\
25 \\
25 \\
24 \\
30 \\
28 \\
34 \\
34\end{array}$ & $\begin{array}{l}195 \\
181 \\
167 \\
157 \\
147 \\
137 \\
130 \\
121\end{array}$ & $\begin{array}{l}17 \\
18 \\
19 \\
20 \\
21 \\
22 \\
23 \\
24\end{array}$ & $\begin{array}{r}32 \\
34 \\
34 \\
61 \\
265 \\
860 \\
590 \\
595\end{array}$ & $\begin{array}{r}115 \\
109 \\
105 \\
105 \\
105 \\
98 \\
92 \\
123\end{array}$ & $\begin{array}{l}25 \\
26 \\
27 \\
28 \\
29 \\
30 \\
31\end{array}$ & $\begin{array}{l}554 \\
510 \\
473 \\
446 \\
412 \\
381\end{array}$ & $\begin{array}{r}147 \\
113 \\
103 \\
98 \\
94 \\
91 \\
87\end{array}$ \\
\hline $\begin{array}{l}\text { Mean } \\
\text { Run- }\end{array}$ & nthly & $a a_{n}$ & 1 & & et. . & . & $\dot{0} \cdot \dot{ }$ & .. . & . & $\begin{array}{r}190 \\
2.05\end{array}$ & $\begin{array}{r}161 \\
1.80 \\
\end{array}$ \\
\hline
\end{tabular}

Gage helght, in feet, and discharge, in second-feet, at indicated time, 1938

\begin{tabular}{|c|c|c|c|c|c|c|c|c|c|c|c|c|c|}
\hline \multirow{2}{*}{ 㝵 } & Feet & Sec.ft. & Feet & Sec.ft. & Feet & Sec.ft. & Feet & Sec.ft. & Feet & Sec.ft. & Feet & \multicolumn{2}{|c|}{ Sec.ft. } \\
\hline & \multicolumn{2}{|c|}{ September 18} & \multicolumn{2}{|c|}{ September 19} & \multicolumn{2}{|c|}{ September 20} & \multicolumn{2}{|c|}{ September 21} & \multicolumn{2}{|c|}{ September 22} & \multicolumn{3}{|c|}{ September 23} \\
\hline $\begin{array}{l}1 \\
2 \\
3 \\
4 \\
5 \\
6\end{array}$ & $\begin{array}{l}2.56 \\
2.56 \\
2.56 \\
2.56 \\
2.56 \\
2.56\end{array}$ & $\begin{array}{l}33 \\
33 \\
33 \\
33 \\
33 \\
33\end{array}$ & $\begin{array}{l}2.57 \\
2.57 \\
2.57 \\
2.57 \\
2.57 \\
2.57\end{array}$ & $\begin{array}{l}34 \\
34 \\
34 \\
34 \\
34 \\
34\end{array}$ & $\begin{array}{l}2.65 \\
2.66 \\
2.67 \\
2.67 \\
2.68 \\
2.69\end{array}$ & $\begin{array}{l}40 \\
41 \\
42 \\
42 \\
43 \\
44\end{array}$ & $\begin{array}{l}3.20 \\
3.23 \\
3.26 \\
3.29 \\
3.32 \\
3.35\end{array}$ & $\begin{array}{l}121 \\
128 \\
135 \\
142 \\
149 \\
157\end{array}$ & $\begin{array}{l}5.13 \\
5.41 \\
5.69 \\
5.68 \\
5.56 \\
5.43\end{array}$ & $\begin{array}{r}982 \\
1,200 \\
1,440 \\
1,430 \\
1,330 \\
1,220\end{array}$ & $\begin{array}{l}4.43 \\
4.43 \\
4.43 \\
4.44 \\
4.45 \\
4.46\end{array}$ & & $\begin{array}{l}554 \\
554 \\
554 \\
559 \\
564 \\
570\end{array}$ \\
\hline $\begin{array}{r}7 \\
8 \\
9 \\
10 \\
11 \\
N\end{array}$ & $\begin{array}{l}2.56 \\
2.56 \\
2.56 \\
2.57 \\
2.57 \\
2.57\end{array}$ & $\begin{array}{l}33 \\
33 \\
33 \\
34 \\
34 \\
34\end{array}$ & $\begin{array}{l}2.57 \\
2.57 \\
2.57 \\
2.57 \\
2.57 \\
2.57\end{array}$ & $\begin{array}{l}34 \\
34 \\
34 \\
34 \\
34 \\
34\end{array}$ & $\begin{array}{l}2.70 \\
2.72 \\
2.73 \\
2.75 \\
2.76 \\
2.77\end{array}$ & $\begin{array}{l}45 \\
47 \\
48 \\
50 \\
52 \\
53\end{array}$ & $\begin{array}{l}3.36 \\
3.37 \\
3.38 \\
3.39 \\
3.40 \\
3.43\end{array}$ & $\begin{array}{l}160 \\
162 \\
165 \\
167 \\
170 \\
178\end{array}$ & $\begin{array}{l}5.31 \\
5.18 \\
5.06 \\
4.96 \\
4.88 \\
4.81\end{array}$ & $\begin{array}{r}1,120 \\
1,020 \\
932 \\
864 \\
811 \\
767\end{array}$ & $\begin{array}{l}4.46 \\
4.47 \\
4.47 \\
4.48 \\
4.49 \\
4.49\end{array}$ & & $\begin{array}{l}570 \\
575 \\
575 \\
580 \\
585 \\
585\end{array}$ \\
\hline $\begin{array}{l}1 \\
2 \\
3 \\
4 \\
5 \\
6\end{array}$ & $\begin{array}{l}2.57 \\
2.57 \\
2.57 \\
2.57 \\
2.57 \\
2.57\end{array}$ & $\begin{array}{l}34 \\
34 \\
34 \\
34 \\
34 \\
34\end{array}$ & $\begin{array}{l}2.57 \\
2.57 \\
2.57 \\
2.57 \\
2.60 \\
2.61\end{array}$ & $\begin{array}{l}34 \\
34 \\
34 \\
34 \\
36 \\
37\end{array}$ & $\begin{array}{l}2.78 \\
2.80 \\
2.81 \\
2.83 \\
2.85 \\
2.88\end{array}$ & $\begin{array}{l}54 \\
56 \\
57 \\
60 \\
62 \\
66\end{array}$ & $\begin{array}{l}3.46 \\
3.50 \\
3.55 \\
3.63 \\
3.72 \\
3.86\end{array}$ & $\begin{array}{l}187 \\
198 \\
213 \\
238 \\
267 \\
314\end{array}$ & $\begin{array}{l}4.76 \\
4.70 \\
4.65 \\
4.61 \\
4.57 \\
4.54\end{array}$ & $\begin{array}{l}737 \\
701 \\
672 \\
650 \\
628 \\
612\end{array}$ & $\begin{array}{l}50 \\
52 \\
53 \\
54 \\
55 \\
56\end{array}$ & & $\begin{array}{l}590 \\
601 \\
606 \\
612 \\
617 \\
622\end{array}$ \\
\hline \multirow[t]{2}{*}{$\begin{array}{r}7 \\
8 \\
9 \\
10 \\
11 \\
11\end{array}$} & $\begin{array}{l}2.57 \\
2.57 \\
2.57 \\
2.57 \\
2.57 \\
2.57\end{array}$ & $\begin{array}{l}34 \\
34 \\
34 \\
34 \\
34 \\
34\end{array}$ & $\begin{array}{l}2.61 \\
2.61 \\
2.61 \\
2.62 \\
2.63 \\
2.63\end{array}$ & $\begin{array}{l}37 \\
37 \\
37 \\
38 \\
39 \\
39\end{array}$ & $\begin{array}{l}2.92 \\
2.97 \\
3.02 \\
3.07 \\
3.12 \\
3.16\end{array}$ & $\begin{array}{r}72 \\
80 \\
87 \\
96 \\
105 \\
113\end{array}$ & $\begin{array}{l}4.02 \\
4.17 \\
4.35 \\
4.54 \\
4.76 \\
4.98\end{array}$ & $\begin{array}{l}373 \\
433 \\
515 \\
612 \\
737 \\
877\end{array}$ & $\begin{array}{l}4.52 \\
4.48 \\
4.47 \\
4.45 \\
4.44 \\
4.43\end{array}$ & $\begin{array}{l}601 \\
580 \\
575 \\
564 \\
559 \\
554\end{array}$ & $\begin{array}{l}4.56 \\
4.56 \\
4.56 \\
4.56 \\
4.56 \\
4.55\end{array}$ & & $\begin{array}{l}622 \\
622 \\
622 \\
622 \\
622 \\
617\end{array}$ \\
\hline & \multicolumn{2}{|c|}{ September 24} & \multicolumn{2}{|c|}{ September 25} & \multicolumn{2}{|c|}{ September 26} & \multicolumn{2}{|c|}{ September 27} & \multicolumn{2}{|c|}{ September 28} & \multicolumn{3}{|c|}{ September 29} \\
\hline $\begin{array}{r}2 \\
4 \\
6 \\
8 \\
10 \\
7\end{array}$ & $\begin{array}{l}4.54 \\
4.53 \\
4.52 \\
4.51 \\
4.50 \\
4.50\end{array}$ & $\begin{array}{l}612 \\
606 \\
601 \\
595 \\
590 \\
590\end{array}$ & $\begin{array}{l}4.46 \\
4.45 \\
4.44 \\
4.44 \\
4.43 \\
4.43\end{array}$ & $\begin{array}{l}570 \\
564 \\
559 \\
559 \\
554 \\
554\end{array}$ & $\begin{array}{l}4.38 \\
4.36 \\
4.35 \\
4.34 \\
4.33 \\
4.34\end{array}$ & $\begin{array}{l}529 \\
520 \\
515 \\
510 \\
505 \\
510\end{array}$ & $\begin{array}{l}4.29 \\
4.29 \\
4.28 \\
4.27 \\
4.26 \\
4.25\end{array}$ & $\begin{array}{l}486 \\
486 \\
482 \\
478 \\
473 \\
468\end{array}$ & $\begin{array}{l}4.23 \\
4.22 \\
4.21 \\
4.20 \\
4.19 \\
4.20\end{array}$ & $\begin{array}{l}460 \\
455 \\
450 \\
446 \\
442 \\
446\end{array}$ & & & $\begin{array}{l}429 \\
425 \\
421 \\
417 \\
412 \\
417\end{array}$ \\
\hline $\begin{array}{r}2 \\
4 \\
6 \\
8 \\
10 \\
M\end{array}$ & $\begin{array}{l}4.50 \\
4.50 \\
4.50 \\
4.50 \\
4.49 \\
4.48\end{array}$ & $\begin{array}{l}\mathbf{5 9 0} \\
\mathbf{5 9 0} \\
\mathbf{5 9 0} \\
\mathbf{5 9 0} \\
\mathbf{5 8 5} \\
\mathbf{5 8 0}\end{array}$ & $\begin{array}{l}4.43 \\
4.43 \\
4.42 \\
4.41 \\
4.40 \\
4.39\end{array}$ & $\begin{array}{l}554 \\
554 \\
549 \\
544 \\
539 \\
534\end{array}$ & $\begin{array}{l}4.34 \\
4.34 \\
4.33 \\
4.32 \\
4.31 \\
4.30\end{array}$ & $\begin{array}{l}510 \\
510 \\
505 \\
501 \\
496\end{array}$ & $\begin{array}{l}4.25 \\
4.24 \\
4.24 \\
4.24 \\
4.24\end{array}$ & $\begin{array}{l}468 \\
464 \\
464 \\
464 \\
464\end{array}$ & $\begin{array}{l}4.20 \\
4.19 \\
4.19 \\
4.18 \\
4.17\end{array}$ & $\begin{array}{l}446 \\
442 \\
442 \\
438 \\
433\end{array}$ & $\begin{array}{l}4.13 \\
4.12 \\
4.11 \\
4.10 \\
4.09\end{array}$ & & $\begin{array}{l}417 \\
412 \\
408 \\
404 \\
400\end{array}$ \\
\hline
\end{tabular}

Supplemental records.- Sept. $22,3: 30$ a.m., 5.71 ft., 1,460 sec.-ft. 
Cherry Valley Creek at Westville, N. Y.

Location.- Water-stage recorder, lat. $42^{\circ} 38^{\prime} 00^{\prime \prime}$, long. $74^{\circ} 52^{\prime} 55^{\prime \prime}$, 40 feet below highway bridge in Westvilie, Otsego County, about five miles below mouth of 0'Connell Brook and about four miles above mouth. Wire-weight gage at same site and datum for January 1930 to September 1931 .

Drainage area.- 81.3 square miles, (revised).

Gage-height record. - Water-stage recorder graph except for periods 8 p.m. Sept. 1 to 7 a.m. Sept. 3, 7 a.m. Sept. 15 to 7 p.m. Sept. 17, and 9 p.m. oct. 5 to 8 p.m. 0ct. 6 , for which graph was drawn based on recorded range of stage and shape of waterstage recorder graph before and after missing periods.

Stage-discharge relation.- For 1938 defined by current-meter measurements below 4,370 second-feet; extended logarithmically to peak stage. For 1931 defined by currentmeter measurements below 663 second-feet.

Maxima.- September 1938: Discharge, 4,470 second-feet 9:55 a.m. Sept. 22 (gege helght, 8.65 feet).

January 1930 to September 1931: Discharge observed, 1,780 second-feet April 11,1931 (gage helght, 6.3 feet).

June 1938 to August 1938; Discharge, 120 second-feet Aug. 11, 1938 (gage height, 2.55 feet).

Remarks.- Discharge not affected by storage or diversion.

Mean daily discharge, in second-feet, 1938

\begin{tabular}{|c|c|c|c|c|c|c|c|c|c|c|c|}
\hline Day & Sept. & oct. & Day & Sept. & 0 ct. & Day & Sept. & Oct. & Day & Sept. & Oct. \\
\hline $\begin{array}{l}1 \\
2 \\
3 \\
4 \\
5 \\
6 \\
7 \\
8\end{array}$ & $\begin{array}{l}14 \\
12 \\
12 \\
19 \\
14 \\
12 \\
12 \\
16\end{array}$ & $\begin{array}{r}121 \\
109 \\
90 \\
80 \\
73 \\
66 \\
61 \\
58\end{array}$ & $\begin{array}{r}9 \\
10 \\
11 \\
12 \\
13 \\
14 \\
15 \\
16\end{array}$ & $\begin{array}{l}14 \\
12 \\
11 \\
10 \\
25 \\
30 \\
47 \\
34\end{array}$ & $\begin{array}{l}56 \\
52 \\
48 \\
47 \\
44 \\
41 \\
40 \\
37\end{array}$ & $\begin{array}{l}17 \\
18 \\
19 \\
20 \\
21 \\
22 \\
23 \\
24\end{array}$ & $\begin{array}{r}24 \\
24 \\
28 \\
127 \\
992 \\
3,640 \\
1,530 \\
692\end{array}$ & $\begin{array}{l}34 \\
32 \\
31 \\
38 \\
53 \\
48 \\
39 \\
84\end{array}$ & $\begin{array}{l}25 \\
26 \\
27 \\
28 \\
29 \\
30 \\
31\end{array}$ & $\begin{array}{l}414 \\
289 \\
230 \\
204 \\
163 \\
137\end{array}$ & $\begin{array}{r}175 \\
87 \\
70 \\
63 \\
58 \\
55 \\
53\end{array}$ \\
\hline $\begin{array}{l}\text { Mean } \\
\text { Run- }\end{array}$ & $\begin{array}{l}\text { onthly } \\
e, \text { in }\end{array}$ & schar & ?. 11 & $\begin{array}{c}\text { second- } \\
.\end{array}$ & et. : & . & $\begin{array}{lll}\cdot & \cdot & \bullet \\
& \bullet & -\end{array}$ & $\begin{array}{ll}\cdot & \bullet \\
. & \bullet\end{array}$ & : : & $\begin{array}{r}293 \\
4.02\end{array}$ & $\begin{array}{r}62.7 \\
.771\end{array}$ \\
\hline
\end{tabular}

Gage height, in feet, and discharge, in second-feet, at indlcated time, 1938

\begin{tabular}{|c|c|c|c|c|c|c|c|c|c|c|c|c|}
\hline \multirow{2}{*}{ 荧 } & Feet & Sec.ft. & Feet & Sec.ft. & Feet & Sec.ft. & Feet & sec.ft. & \multicolumn{2}{|r|}{ Sec.ft. } & Feet & Sec.ft. \\
\hline & \multicolumn{2}{|c|}{ September 18} & \multicolumn{2}{|c|}{ September 19} & \multicolumn{2}{|c|}{ September 20} & \multicolumn{2}{|c|}{ September 21} & \multicolumn{2}{|c|}{ September 22} & \multicolumn{2}{|c|}{ Sept amber 23} \\
\hline $\begin{array}{l}1 \\
2 \\
3 \\
4 \\
5 \\
6\end{array}$ & $\begin{array}{l}1.94 \\
1.94 \\
1.94 \\
1.94 \\
1.94 \\
1.94\end{array}$ & $\begin{array}{l}24 \\
24 \\
24 \\
24 \\
24 \\
24\end{array}$ & $\begin{array}{l}1.94 \\
1.94 \\
1.94 \\
1.94 \\
1.94 \\
1.94\end{array}$ & $\begin{array}{l}24 \\
24 \\
24 \\
24 \\
24 \\
24\end{array}$ & $\begin{array}{l}2.14 \\
2.17 \\
2.20 \\
2.22 \\
2.25 \\
2.28\end{array}$ & $\begin{array}{l}50 \\
54 \\
59 \\
62 \\
67 \\
72\end{array}$ & $\begin{array}{l}3.33 \\
3.40 \\
3.48 \\
3.56 \\
3.66 \\
3.72\end{array}$ & $\begin{array}{l}334 \\
359 \\
389 \\
419 \\
460 \\
484\end{array}$ & $\begin{array}{l}7.25 \\
7.51 \\
7.80 \\
8.12 \\
8.32 \\
8.42\end{array}$ & $\begin{array}{l}2,960 \\
3,220 \\
3,520 \\
3,870 \\
4,090 \\
4,200\end{array}$ & $\begin{array}{l}6.66 \\
6.54 \\
6.45 \\
6.35 \\
6.23 \\
6.12\end{array}$ & $\begin{array}{l}2,400 \\
2,300 \\
2,220 \\
2,120 \\
2,020 \\
1,940\end{array}$ \\
\hline $\begin{array}{r}7 \\
8 \\
9 \\
10 \\
11 \\
N\end{array}$ & $\begin{array}{l}1.94 \\
1.94 \\
1.94 \\
1.94 \\
1.94 \\
1.94\end{array}$ & $\begin{array}{l}24 \\
24 \\
24 \\
24 \\
24 \\
24\end{array}$ & $\begin{array}{l}1.94 \\
1.94 \\
1.94 \\
1.94 \\
1.94 \\
1.94\end{array}$ & $\begin{array}{l}24 \\
24 \\
24 \\
24 \\
24 \\
24\end{array}$ & $\begin{array}{l}2.31 \\
2.34 \\
2.37 \\
2.40 \\
2.45 \\
2.49\end{array}$ & $\begin{array}{r}77 \\
82 \\
87 \\
92 \\
101 \\
108\end{array}$ & $\begin{array}{l}3.76 \\
3.88 \\
3.94 \\
4.01 \\
4.11 \\
4.20\end{array}$ & $\begin{array}{l}501 \\
553 \\
580 \\
612 \\
658 \\
700\end{array}$ & $\begin{array}{l}8.48 \\
8.52 \\
8.56 \\
8.58 \\
8.50 \\
8.43\end{array}$ & $\begin{array}{l}4,270 \\
4,310 \\
4,360 \\
4,390 \\
4,290 \\
4,210\end{array}$ & $\begin{array}{l}6.02 \\
5.90 \\
5.78 \\
5.66 \\
5.55 \\
5.44\end{array}$ & $\begin{array}{l}1,860 \\
1,760 \\
1,660 \\
1,570 \\
1,500 \\
1,420\end{array}$ \\
\hline $\begin{array}{l}1 \\
2 \\
3 \\
4 \\
5 \\
6\end{array}$ & $\begin{array}{l}1.94 \\
1.94 \\
1.94 \\
1.94 \\
1.94 \\
1.94\end{array}$ & $\begin{array}{l}24 \\
24 \\
24 \\
24 \\
24 \\
24\end{array}$ & $\begin{array}{l}1.94 \\
1.94 \\
1.94 \\
1.95 \\
1.98 \\
2.00\end{array}$ & $\begin{array}{l}24 \\
24 \\
24 \\
25 \\
29 \\
31\end{array}$ & $\begin{array}{l}2.54 \\
2.58 \\
2.62 \\
2.67 \\
2.72 \\
2.76\end{array}$ & $\begin{array}{l}118 \\
126 \\
134 \\
145 \\
157 \\
166\end{array}$ & $\begin{array}{l}4.30 \\
4.44 \\
4.60 \\
4.86 \\
5.10 \\
5.50\end{array}$ & $\begin{array}{r}748 \\
817 \\
901 \\
1,050 \\
1,190 \\
1,460\end{array}$ & $\begin{array}{l}8.29 \\
8.19 \\
8.09 \\
7.94 \\
7.80 \\
7.65\end{array}$ & $\begin{array}{l}4,060 \\
3,950 \\
3,840 \\
3,670 \\
3,520 \\
3,360\end{array}$ & $\begin{array}{l}5.33 \\
5.23 \\
5.13 \\
5.05 \\
4.97 \\
4.90\end{array}$ & $\begin{array}{l}1,340 \\
1,270 \\
1,210 \\
1,160 \\
1,110 \\
1,070\end{array}$ \\
\hline $\begin{array}{r}7 \\
8 \\
9 \\
10 \\
11 \\
M\end{array}$ & $\begin{array}{l}1.94 \\
1.94 \\
1.94 \\
1.94 \\
1.94 \\
1.94\end{array}$ & $\begin{array}{l}24 \\
24 \\
24 \\
24 \\
24 \\
24\end{array}$ & $\begin{array}{l}2.04 \\
2.05 \\
2.07 \\
2.08 \\
2.10 \\
2.12\end{array}$ & $\begin{array}{l}36 \\
38 \\
40 \\
41 \\
44 \\
47\end{array}$ & $\begin{array}{l}2.81 \\
2.87 \\
2.95 \\
3.06 \\
3.17 \\
3.24\end{array}$ & $\begin{array}{l}179 \\
194 \\
216 \\
248 \\
282 \\
304\end{array}$ & $\begin{array}{l}5.89 \\
6.06 \\
6.26 \\
6.45 \\
6.71 \\
6.95\end{array}$ & $\begin{array}{l}1,750 \\
1,890 \\
2,050 \\
2,220 \\
2,450 \\
2,660\end{array}$ & $\begin{array}{l}7.50 \\
7.35 \\
7.20 \\
7.05 \\
6.91 \\
6.78\end{array}$ & $\begin{array}{l}3,210 \\
3,060 \\
2,910 \\
2,760 \\
2,630 \\
2,510\end{array}$ & $\begin{array}{l}4.85 \\
4.80 \\
4.75 \\
4.71 \\
4.67 \\
4.63\end{array}$ & $\begin{array}{r}1,040 \\
1,020 \\
986 \\
966 \\
944 \\
922\end{array}$ \\
\hline & \multicolumn{2}{|c|}{ September } & \multicolumn{2}{|c|}{ September 25} & \multicolumn{2}{|c|}{ September 26} & \multicolumn{2}{|c|}{ September 27} & \multicolumn{2}{|c|}{ September 28} & \multicolumn{2}{|c|}{ September 29} \\
\hline $\begin{array}{r}2 \\
4 \\
6 \\
8 \\
10 \\
N\end{array}$ & $\begin{array}{l}4.54 \\
4.46 \\
4.40 \\
4.31 \\
4.23 \\
4.15\end{array}$ & $\begin{array}{l}873 \\
832 \\
801 \\
757 \\
718 \\
681\end{array}$ & $\begin{array}{l}3.71 \\
3.66 \\
3.62 \\
3.58 \\
3.54 \\
3.50\end{array}$ & $\begin{array}{l}491 \\
471 \\
455 \\
439 \\
424 \\
409\end{array}$ & $\begin{array}{l}3.26 \\
3.23 \\
3.20 \\
3.17 \\
3.15 \\
3.13\end{array}$ & $\begin{array}{l}326 \\
317 \\
307 \\
298 \\
292 \\
286\end{array}$ & $\begin{array}{l}2.99 \\
2.97 \\
2.95 \\
2.92 \\
2.90 \\
2.90\end{array}$ & $\begin{array}{l}246 \\
241 \\
236 \\
227 \\
222 \\
222\end{array}$ & $\begin{array}{l}2.88 \\
2.88 \\
2.87 \\
2.87 \\
2.86 \\
2.84\end{array}$ & $\begin{array}{l}217 \\
217 \\
214 \\
214 \\
212 \\
207\end{array}$ & $\begin{array}{l}2.71 \\
2.69 \\
2.68 \\
2.67 \\
2.66 \\
2.65\end{array}$ & $\begin{array}{l}176 \\
172 \\
170 \\
167 \\
165 \\
163\end{array}$ \\
\hline $\begin{array}{r}2 \\
4 \\
6 \\
8 \\
10 \\
11\end{array}$ & $\begin{array}{l}4.07 \\
4.00 \\
3.93 \\
3.87 \\
3.81 \\
3.76\end{array}$ & $\begin{array}{l}644 \\
613 \\
583 \\
557 \\
532 \\
512\end{array}$ & $\begin{array}{l}3.46 \\
3.43 \\
3.40 \\
3.36 \\
3.32 \\
3.29\end{array}$ & $\begin{array}{l}395 \\
384 \\
373 \\
359 \\
346 \\
336\end{array}$ & $\begin{array}{l}3.11 \\
3.09 \\
3.07 \\
3.05 \\
3.03 \\
3.01\end{array}$ & $\begin{array}{l}280 \\
274 \\
269 \\
263 \\
257 \\
252\end{array}$ & $\begin{array}{l}2.91 \\
2.91 \\
2.90 \\
2.90 \\
2.89 \\
2.88\end{array}$ & $\begin{array}{l}225 \\
225 \\
222 \\
222 \\
220 \\
217\end{array}$ & $\begin{array}{l}2.82 \\
2.81 \\
2.79 \\
2.77 \\
2.75 \\
2.73\end{array}$ & $\begin{array}{l}202 \\
200 \\
195 \\
190 \\
186 \\
181\end{array}$ & $\begin{array}{l}2.64 \\
2.63 \\
2.62 \\
2.61 \\
2.59 \\
2.58\end{array}$ & $\begin{array}{l}161 \\
159 \\
156 \\
154 \\
150 \\
148\end{array}$ \\
\hline
\end{tabular}

Supplemental records.- Sept, 22, 9:55 a.m., 8.65 ft., 4,470 sec.-ft. 
Charlotte Creek at Davenport Center, N. Y.

Location.- Water-stage recorder, lat. $42^{\circ} 26^{\prime} 30^{\prime \prime}$, long. $74^{\circ} 56^{\prime} 0^{\prime \prime}$, 1,000 feet below covered highway bridge, three-quarters of a mile below Davenport Center, Delaware County, about 200 feet below mouth of Pumpkin Hollow, and about 5 miles above mouth. Drainage area. - 163 square miles.

Gage-height record. - Water-stage recorder graph except for periods 7 a.m. Sept. 3 to noon sept. 5, 1 a.m. Sept. Il to noon Sept. 12, 11:30 p.m. Sept. 17 to 9 a.m. Sept. 20, and 10 p.m. Sept. 21 to 10:30 a.m. Oct. 27. During periods of missing record graph was drawn based on twice daily readings of staff gage Sept. 25 to 0 ct. 22 and Oct. 24, observed range of stage, floodmarks, shape of water-stage recorder graph before and after periods of missing record, comparisons with gage-height records of nearby stations, comparisons with shape of observed stage graphs at this station, and study of precipitation records.

Stage-discharge relation.- Defined by current-meter measurements below 2,240 secondfeet; extended logarithmically to peak stage on basis of slope-area determination of peak flow.

Maxima.- September 1938: Discharge, 14,000 second-feet at about 12:30 a.m. Sept. 22 (gage height, 9.65 feet, from floodmarks).

June to August 1938: Discharge, 553 second-feet at 11 a.m. Aug. 11, 1938

(gage helght, 2.29 feet).

Remarks.- Discharge not affected by storage or diversion.

Mean daily discharge, in second-feet, 1938

\begin{tabular}{|c|c|c|c|c|c|c|c|c|c|c|c|}
\hline Day & Sept. & Oct. & Day & Sept. & Oct. & Day & Sept. & 0 ct. & Day & Sept. & Oct. \\
\hline $\begin{array}{l}1 \\
2 \\
3 \\
4 \\
5 \\
6 \\
7 \\
8\end{array}$ & $\begin{array}{l}33 \\
36 \\
31 \\
28 \\
24 \\
21 \\
21 \\
34 \\
\end{array}$ & $\begin{array}{l}271 \\
236 \\
196 \\
172 \\
155 \\
139 \\
124 \\
119\end{array}$ & $\begin{array}{l}9 \\
10 \\
11 \\
12 \\
13 \\
14 \\
15 \\
16\end{array}$ & $\begin{array}{r}31 \\
25 \\
22 \\
21 \\
93 \\
74 \\
111 \\
122\end{array}$ & $\begin{array}{r}112 \\
101 \\
88 \\
76 \\
70 \\
66 \\
61 \\
57\end{array}$ & $\begin{array}{l}17 \\
18 \\
19 \\
20 \\
21 \\
22 \\
23 \\
24\end{array}$ & $\begin{array}{r}76 \\
82 \\
78 \\
412 \\
3,820 \\
5,600 \\
2,700 \\
1,300\end{array}$ & $\begin{array}{r}52 \\
49 \\
47 \\
50 \\
63 \\
72 \\
68 \\
127\end{array}$ & $\begin{array}{l}25 \\
26 \\
27 \\
28 \\
29 \\
30 \\
31\end{array}$ & $\begin{array}{l}770 \\
568 \\
469 \\
438 \\
377 \\
313\end{array}$ & $\begin{array}{r}122 \\
108 \\
108 \\
99 \\
92 \\
88 \\
84\end{array}$ \\
\hline $\begin{array}{l}\text { Mean } \\
\text { Run-c }\end{array}$ & $\begin{array}{l}n t h y y \\
\text { in }\end{array}$ & scharg & , In & $\begin{array}{c}\theta \operatorname{con} a-1 \\
.\end{array}$ & et. & $\dot{0} \cdot \dot{ }$ & . : : & . : & $:$ : & $\begin{array}{r}591 \\
4.05 \\
\end{array}$ & $\begin{array}{l}106 \\
.75\end{array}$ \\
\hline
\end{tabular}

Gage helght, in and, and discharge, in second-feet, at indicated time, I938

\begin{tabular}{|c|c|c|c|c|c|c|c|c|c|c|c|c|}
\hline \multirow{2}{*}{$\begin{array}{l}5 \\
5 \\
3 \\
\end{array}$} & Feet & Sec.ft. & Peet & Sec.ft. & Feet & Sec.ft. & Feet & Sec.ft. & Feet & Sec.ft. & Feet & Sec.ft. \\
\hline & \multicolumn{2}{|c|}{ September 18} & \multicolumn{2}{|c|}{ September 19} & \multicolumn{2}{|c|}{ September 20} & \multicolumn{2}{|c|}{ September 21} & \multicolumn{2}{|c|}{ September 22} & \multicolumn{2}{|c|}{ September 23} \\
\hline $\begin{array}{l}1 \\
2 \\
3 \\
4 \\
5 \\
6\end{array}$ & $\begin{array}{r}0.84 \\
.84 \\
.86 \\
.87 \\
.88 \\
.89\end{array}$ & $\begin{array}{l}69 \\
69 \\
72 \\
74 \\
76 \\
78\end{array}$ & $\begin{array}{r}0.90 \\
.89 \\
.89 \\
.89 \\
.88 \\
.87\end{array}$ & $\begin{array}{l}80 \\
78 \\
78 \\
78 \\
76 \\
74\end{array}$ & $\begin{array}{l}1.00 \\
1.04 \\
1.09 \\
1.14 \\
1.23 \\
1.29\end{array}$ & $\begin{array}{l}101 \\
110 \\
122 \\
134 \\
157 \\
173\end{array}$ & $\begin{array}{l}3.37 \\
3.56 \\
3.74 \\
3.94 \\
4.04 \\
4.12\end{array}$ & $\begin{array}{l}1,210 \\
1,360 \\
1,510 \\
1,690 \\
1,780 \\
1,860\end{array}$ & $\begin{array}{l}9.51 \\
8.94 \\
8.43 \\
8.00 \\
7.67 \\
7.34\end{array}$ & $\begin{array}{r}13,500 \\
11,500 \\
9,890 \\
8,600 \\
7,680 \\
6,870\end{array}$ & $\begin{array}{l}4.95 \\
4.98 \\
5.01 \\
5.04 \\
5.09 \\
5.12\end{array}$ & $\begin{array}{l}2,780 \\
2,820 \\
2,850 \\
2,890 \\
2,960 \\
3,000\end{array}$ \\
\hline $\begin{array}{r}7 \\
8 \\
9 \\
10 \\
11 \\
\mathrm{~N}\end{array}$ & $\begin{array}{l}.89 \\
.90 \\
.91 \\
.92 \\
.93 \\
.94\end{array}$ & $\begin{array}{l}78 \\
80 \\
82 \\
84 \\
86 \\
88\end{array}$ & $\begin{array}{l}.86 \\
.86 \\
.85 \\
.85 \\
.85 \\
.86\end{array}$ & $\begin{array}{l}72 \\
72 \\
70 \\
70 \\
70 \\
72\end{array}$ & $\begin{array}{l}1.35 \\
1.43 \\
1.52 \\
1.64 \\
1.73 \\
1.88\end{array}$ & $\begin{array}{l}190 \\
214 \\
243 \\
283 \\
315 \\
372\end{array}$ & $\begin{array}{l}4.24 \\
4.37 \\
4.44 \\
4.46 \\
4.48 \\
4.54\end{array}$ & $\begin{array}{l}1,980 \\
2,120 \\
2,190 \\
2,220 \\
2,240 \\
2,300\end{array}$ & $\begin{array}{l}7.10 \\
6.88 \\
6.66 \\
6.45 \\
6.25 \\
6.07\end{array}$ & $\begin{array}{l}6,320 \\
5,860 \\
5,420 \\
5,030 \\
4,680 \\
4,370\end{array}$ & $\begin{array}{l}5.14 \\
5.16 \\
5.18 \\
5.18 \\
5.17 \\
5.13\end{array}$ & $\begin{array}{l}3,020 \\
3,050 \\
3,070 \\
3,070 \\
3,060 \\
3,010\end{array}$ \\
\hline $\begin{array}{l}1 \\
2 \\
3 \\
4 \\
5 \\
6\end{array}$ & $\begin{array}{l}.94 \\
.95 \\
.95 \\
.95 \\
.95 \\
.94\end{array}$ & $\begin{array}{l}88 \\
90 \\
90 \\
90 \\
90 \\
88\end{array}$ & $\begin{array}{l}.86 \\
.86 \\
.87 \\
.87 \\
.88 \\
.89\end{array}$ & $\begin{array}{l}72 \\
72 \\
74 \\
74 \\
76 \\
78\end{array}$ & $\begin{array}{l}2.00 \\
2.16 \\
2.26 \\
2.33 \\
2.39 \\
2.41\end{array}$ & $\begin{array}{l}421 \\
492 \\
539 \\
573 \\
603 \\
613\end{array}$ & $\begin{array}{l}4.65 \\
4.81 \\
5.00 \\
5.29 \\
5.69 \\
6.29\end{array}$ & $\begin{array}{l}2,420 \\
2,610 \\
2,840 \\
3,220 \\
3,780 \\
4,740\end{array}$ & $\begin{array}{l}5.90 \\
5.76 \\
5.62 \\
5.50 \\
5.40 \\
5.30\end{array}$ & $\begin{array}{l}4,100 \\
3,890 \\
3,680 \\
3,510 \\
3,370 \\
3,230\end{array}$ & $\begin{array}{l}5.08 \\
5.00 \\
4.94 \\
4.87 \\
4.79 \\
4.69\end{array}$ & $\begin{array}{l}2,940 \\
2,840 \\
2,770 \\
2,680 \\
2,590 \\
2,470\end{array}$ \\
\hline \multirow[t]{2}{*}{$\begin{array}{r}7 \\
8 \\
9 \\
10 \\
11 \\
11 \\
\end{array}$} & $\begin{array}{l}.94 \\
.93 \\
.92 \\
.92 \\
.91 \\
.90\end{array}$ & $\begin{array}{l}88 \\
86 \\
84 \\
84 \\
82 \\
80\end{array}$ & $\begin{array}{l}.90 \\
.91 \\
.92 \\
.94 \\
.95 \\
.97\end{array}$ & $\begin{array}{l}80 \\
82 \\
84 \\
88 \\
90 \\
95\end{array}$ & $\begin{array}{l}2.44 \\
2.50 \\
2.60 \\
2.74 \\
2.94 \\
3.16\end{array}$ & $\begin{array}{r}629 \\
660 \\
715 \\
794 \\
916 \\
1,060 \\
\end{array}$ & $\begin{array}{l}6.87 \\
7.23 \\
7.64 \\
8.30 \\
9.10 \\
9.62\end{array}$ & $\begin{array}{r}5,840 \\
6,610 \\
7,600 \\
9,500 \\
12,000 \\
13,900\end{array}$ & $\begin{array}{l}5.21 \\
5.12 \\
5.05 \\
5.00 \\
4.96 \\
4.94\end{array}$ & $\begin{array}{l}3,110 \\
3,000 \\
2,900 \\
2,840 \\
2,790 \\
2,770\end{array}$ & $\begin{array}{l}4.60 \\
4.50 \\
4.40 \\
4.31 \\
4.22 \\
4.13\end{array}$ & $\begin{array}{l}2,370 \\
2,260 \\
2,150 \\
2,050 \\
1,960 \\
1,870\end{array}$ \\
\hline & \multicolumn{2}{|c|}{ September 24} & \multicolumn{2}{|c|}{ September 25} & \multicolumn{2}{|c|}{ September 26} & \multicolumn{2}{|c|}{ September 27} & \multicolumn{2}{|c|}{ September 28} & \multicolumn{2}{|c|}{ September 29} \\
\hline $\begin{array}{r}2 \\
4 \\
6 \\
8 \\
10 \\
\mathbf{N}\end{array}$ & $\begin{array}{l}3.98 \\
3.85 \\
3.72 \\
3.60 \\
3.50 \\
3.41\end{array}$ & $\begin{array}{l}1,720 \\
1,600 \\
1,490 \\
1,390 \\
1,310 \\
1,240\end{array}$ & $\begin{array}{l}2.92 \\
2.87 \\
2.82 \\
2.77 \\
2.73 \\
2.70\end{array}$ & $\begin{array}{l}803 \\
872 \\
842 \\
812 \\
788 \\
770\end{array}$ & $\begin{array}{l}2.44 \\
2.41 \\
2.39 \\
2.37 \\
2.34 \\
2.31\end{array}$ & $\begin{array}{l}629 \\
613 \\
603 \\
593 \\
578 \\
563\end{array}$ & $\begin{array}{l}2.15 \\
2.12 \\
2.11 \\
2.11 \\
2.11 \\
2.11\end{array}$ & $\begin{array}{l}487 \\
473 \\
469 \\
469 \\
469 \\
469\end{array}$ & $\begin{array}{l}2.10 \\
2.10 \\
2.10 \\
2.09 \\
2.09 \\
2.06\end{array}$ & $\begin{array}{l}464 \\
464 \\
464 \\
460 \\
460 \\
446\end{array}$ & $\begin{array}{l}1.94 \\
1.93 \\
1.92 \\
1.91 \\
1.90 \\
1.90\end{array}$ & $\begin{array}{l}394 \\
390 \\
386 \\
381 \\
377 \\
377\end{array}$ \\
\hline $\begin{array}{r}2 \\
4 \\
6 \\
8 \\
10 \\
M\end{array}$ & $\begin{array}{l}3.32 \\
3.24 \\
3.18 \\
3.10 \\
3.04 \\
2.98\end{array}$ & $\begin{array}{r}1,170 \\
1,120 \\
1,080 \\
1,020 \\
981 \\
942\end{array}$ & $\begin{array}{l}2.66 \\
2.62 \\
2.59 \\
2.54 \\
2.50 \\
2.47\end{array}$ & $\begin{array}{l}748 \\
726 \\
710 \\
682 \\
660 \\
644\end{array}$ & $\begin{array}{l}2.30 \\
2.28 \\
2.25 \\
2.22 \\
2.20 \\
2.18\end{array}$ & $\begin{array}{l}558 \\
548 \\
584 \\
520 \\
510 \\
501\end{array}$ & $\begin{array}{l}2.11 \\
2.10 \\
2.10 \\
2.10 \\
2.10 \\
2.10\end{array}$ & $\begin{array}{l}469 \\
464 \\
464 \\
464 \\
464 \\
464\end{array}$ & $\begin{array}{l}2.03 \\
2.01 \\
1.99 \\
1.98 \\
1.97 \\
1.95\end{array}$ & $\begin{array}{l}433 \\
424 \\
416 \\
411 \\
407 \\
398\end{array}$ & $\begin{array}{l}1.90 \\
1.89 \\
1.88 \\
1.86 \\
1.84 \\
1.82\end{array}$ & $\begin{array}{l}377 \\
373 \\
369 \\
361 \\
352 \\
344\end{array}$ \\
\hline
\end{tabular}

Supplemental records.- Sept. $22,12: 30 \mathrm{a.m.,} 9.65 \mathrm{ft} ., 14,000$ sec. $-\mathrm{ft}$. 
Richelieu River (Lake Champlain) at Rouses Point, N. Y.

Location.- Water-stage recorder, lat. $44^{\circ} 59^{\prime} 45^{n}$, long. $73^{\circ} 21^{\prime} 40^{n}$, at Rutland Ra1lroad bridge in Rouses Point, Clinton County, I mile south of Fort Miontgomery. Zero of gage is 92.50 feet above mean sea level. Prior to 0ct. 15, 1938, staff gage at same site and datum.

Drainage area.- 8,277 square miles.

Gage-height record.- Prior to Oct. 15, staff gage read dally at 10 a.m. Water-stage recorder graph subsequent to oct. 15. Mean dally gage helghts given for period 0ct. 15-31.

Maxima.- September 1938: Maximum gage helght observed, 4.00 feet Sept. 28. 1871 to August 1938: Maximum gage height observed, 8.80 feet Mar. 30, 1903; observations at S.t. Johns, Quebec, indicate a maximum computed gage height of 8.83 feet during April 1869.

Remarks.- Gage-helght record furnished by Corps of Engineers, U. S. Army .

Gage height, in feet, 1938

\begin{tabular}{|c|r|r||r|r|r||r|r|r||r|r|r|}
\hline Day & \multicolumn{1}{|c|}{ Sept. } & \multicolumn{1}{c|}{ oct. } & Day & Sept. & \multicolumn{1}{c|}{ Oct. } & Day & Sept. & Oct. & Day & Sept. & Oct. \\
\hline 1 & 1.43 & 3.82 & 9 & 1.20 & 3.42 & 17 & 1.42 & 3.01 & 25 & 3.66 & 2.71 \\
2 & 1.46 & 3.80 & 10 & 1.26 & 3.40 & 18 & 1.48 & 2.96 & 26 & 3.95 & 2.94 \\
3 & 1.55 & 3.82 & 11 & 1.34 & 3.50 & 19 & 1.52 & 3.04 & 27 & 3.95 & 2.64 \\
4 & 1.60 & 3.75 & 12 & 1.45 & 3.34 & 20 & 1.57 & 2.85 & 28 & 4.00 & 2.61 \\
5 & 1.32 & 3.80 & 13 & 1.24 & 3.50 & 21 & 1.68 & 2.81 & 29 & 3.80 & 2.60 \\
6 & 1.28 & 3.50 & 14 & 1.40 & 3.30 & 22 & 3.30 & 2.76 & 30 & 3.87 & 2.43 \\
7 & 1.52 & 3.55 & 15 & 1.55 & 3.15 & 23 & 3.35 & 2.90 & 31 & & 2.51 \\
8 & 1.20 & 3.65 & 16 & 1.35 & 3.10 & 24 & 3.55 & 2.80 & & & \\
\hline
\end{tabular}

Lake Champlain at Burlington; Vt.

Location.- Float gage, lat. $44^{\circ} 28^{\prime} 55^{\prime \prime}$, long. $73^{\circ} 13^{\prime} 30^{\prime \prime}$, in pump house of Burlington Water Department, nalf a mile north of railroad station in Burlington, Chittenden County. Zero of gage is about 92.5 feet above mean sea level.

Gage-height record.- lage read dally about 9 a.m.

Maxima.- September 1938: Gage neight observed, 3.90 feet 9 a.m. Sept. 29.

1907 to August 1938: Gage neight observed, 8.65 feet Mar. 27, 28, 1936

Remarks.- Water surface area of Lake Champlain is 440 square miles. Record furnished by Water Department, City of Burlington.

Gage height, in feet, 1938

\begin{tabular}{|c|c|c|c|c|c|c|c|c|c|c|c|}
\hline Day & Sept. & Oct. & Day & Sept. & oct. & Day & Sept. & oct. & Day & Sept. & oct. \\
\hline $\begin{array}{l}1 \\
2 \\
3 \\
4 \\
5 \\
6 \\
7 \\
8\end{array}$ & $\begin{array}{l}1.54 \\
1.48 \\
1.48 \\
1.38 \\
1.41 \\
1.41 \\
1.32 \\
1.34\end{array}$ & $\begin{array}{l}3.89 \\
3.86 \\
3.83 \\
3.78 \\
3.74 \\
3.72 \\
3.66 \\
3.62\end{array}$ & $\begin{array}{r}9 \\
10 \\
11 \\
12 \\
13 . \\
14 \\
15 \\
16\end{array}$ & $\begin{array}{l}1.35 \\
1.32 \\
1.28 \\
1.22 \\
1.30 \\
1.33 \\
1.34 \\
1.40\end{array}$ & $\begin{array}{l}3.54 \\
3.48 \\
3.38 \\
3.38 \\
3.28 \\
3.23 \\
3.21 \\
3.12\end{array}$ & $\begin{array}{l}17 \\
18 \\
19 \\
20 \\
21 \\
22 \\
23 \\
24\end{array}$ & $\begin{array}{r}1.49 \\
1.52 \\
1.52 \\
1.54 \\
1.80 \\
2.50 \\
3.50 \\
3.60\end{array}$ & $\begin{array}{l}3.08 \\
3.05 \\
2.93 \\
2.90 \\
2.90 \\
2.84 \\
2.75 \\
2.68\end{array}$ & $\begin{array}{l}25 \\
26 \\
27 \\
28 \\
29 \\
30 \\
31\end{array}$ & $\begin{array}{l}3.72 \\
3.73 \\
3.74 \\
3.86 \\
3.90 \\
3.89\end{array}$ & $\begin{array}{l}2.75 \\
2.66 \\
2.66 \\
2.67 \\
2.67 \\
2.64 \\
2.68\end{array}$ \\
\hline
\end{tabular}


Saranac River at Saranac, H. Y.

Location. - Water-stage recorder, lat. $44^{\circ} 38^{\prime} 45^{n}$, long. $73^{\circ} 44^{1} 40^{n}$, 500 feet above hlghway bridge at Saranac, Clinton County.

Drafnage area.- 521 square miles.

Gage-height record.- Water-stage recorder graph.

Stage-discharge relation.- For 1938 defined by current-meter measurements below 3,640

second-feet. For 1933 defined by current-meter measurements below 2,870 second-

feet; extended logarithmically to peak stage.

Maxima.- September 1938: Discharge, 3,170 second-feet 12:30 a.m. Sept. 22 (gage helght, 5.27 feet).

September 1930 to August 1938: Maximum discharge, 5,780 second-feet Apr. 17, 1933 (gage height, 7.68 feet); maximum gage height, 12.74 feet Dec, 2,1936 ( $1 \mathrm{ce} J \mathrm{~lm}$ ) Remarks. - Considerabie diurnal fiuctuation caused by operation of power plants. Flow partiy regulated by storage. in Lower Saranac Lake and elsewhere.

Mean dally discharge, in second-feet, 1938

\begin{tabular}{|c|c|c|c|c|c|c|c|c|c|c|c|}
\hline Day & Sept. & Oct. & Day & Sept. & Oct. & Day & Sept. & Oet. & Day & Sept. & Oct. \\
\hline $\begin{array}{l}1 \\
2 \\
3 \\
4 \\
5 \\
6 \\
7 \\
8 \\
\end{array}$ & $\begin{array}{l}563 \\
578 \\
599 \\
436 \\
310 \\
410 \\
426 \\
391 \\
\end{array}$ & $\begin{array}{r}1,220 \\
990 \\
977 \\
926 \\
780 \\
774 \\
679 \\
671 \\
\end{array}$ & $\begin{array}{r}9 \\
10 \\
11 \\
12 \\
13 \\
14 \\
15 \\
16\end{array}$ & $\begin{array}{l}296 \\
282 \\
369 \\
348 \\
466 \\
402 \\
422 \\
406\end{array}$ & $\begin{array}{l}624 \\
672 \\
681 \\
654 \\
651 \\
524 \\
636 \\
530\end{array}$ & $\begin{array}{l}17 \\
18 \\
19 \\
20 \\
21 \\
22 \\
23 \\
24\end{array}$ & $\begin{array}{r}395 \\
450 \\
526 \\
614 \\
1,360 \\
2,280 \\
2,150 \\
2,180\end{array}$ & $\begin{array}{l}650 \\
600 \\
600 \\
500 \\
500 \\
600 \\
420 \\
500\end{array}$ & $\begin{array}{l}25 \\
26 \\
27 \\
28 \\
29 \\
30 \\
31\end{array}$ & $\begin{array}{l}1,850 \\
1,700 \\
1,580 \\
1,510 \\
1,430 \\
1,310\end{array}$ & $\begin{array}{l}700 \\
600 \\
460 \\
420 \\
420 \\
500 \\
550\end{array}$ \\
\hline $\begin{array}{l}\text { Mean } \\
\text { Run-c }\end{array}$ & $\begin{array}{l}\text { onthly } \\
\text {, in }\end{array}$ & es. & 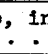 & - & : & & $\cdot \dot{0} \cdot \dot{ }$ & $\begin{array}{l}\cdot \cdot \cdot \\
.\end{array}$ & • & $\begin{array}{r}868 \\
1.86\end{array}$ & $\begin{array}{r}645 \\
1.43 \\
\end{array}$ \\
\hline
\end{tabular}

Gage helght, in feet, and discharge, In second-feet, at indicated time, 1938

\begin{tabular}{|c|c|c|c|c|c|c|c|c|c|c|c|c|}
\hline \multirow{2}{*}{$\begin{array}{l}9 \\
9 \\
0 \\
\text { 出 }\end{array}$} & Feet & Sec.ft. & Feet & Sec.ft. & Feet & Sec.ft. & Feet & Sec.ft. & Feet & Sec.et. & Feet & Sec.ft. \\
\hline & \multicolumn{2}{|c|}{ September 18} & \multicolumn{2}{|c|}{ September 19} & \multicolumn{2}{|c|}{ Sept ember 20} & \multicolumn{2}{|c|}{ September 21} & \multicolumn{2}{|c|}{ September 22} & \multicolumn{2}{|c|}{ September 23} \\
\hline $\begin{array}{l}1 \\
2 \\
3 \\
4 \\
5 \\
6\end{array}$ & $\begin{array}{l}2.91 \\
2.93 \\
2.92 \\
2.83 \\
2.71 \\
2.58\end{array}$ & $\begin{array}{l}718 \\
732 \\
725 \\
658 \\
572 \\
488\end{array}$ & $\begin{array}{l}2.37 \\
2.44 \\
2.49 \\
2.50 \\
2.50 \\
2.48\end{array}$ & $\begin{array}{l}364 \\
404 \\
433 \\
439 \\
439 \\
427\end{array}$ & $\begin{array}{l}2.92 \\
2.87 \\
2.79 \\
2.67 \\
2.57 \\
2.48\end{array}$ & $\begin{array}{l}725 \\
688 \\
628 \\
546 \\
482 \\
427\end{array}$ & $\begin{array}{l}3.22 \\
3.24 \\
3.19 \\
3.12 \\
3.08 \\
3.05\end{array}$ & $\begin{array}{l}962 \\
979 \\
937 \\
881 \\
849 \\
825\end{array}$ & $\begin{array}{l}5.24 \\
5.11 \\
4.95 \\
4.79 \\
4.69 \\
4.64\end{array}$ & $\begin{array}{l}3,140 \\
2,980 \\
2,790 \\
2,600 \\
2,480 \\
2,420\end{array}$ & & $\begin{array}{l}2,000 \\
2,020 \\
2,030 \\
2,020 \\
2,000 \\
1,080\end{array}$ \\
\hline $\begin{array}{r}7 \\
8 \\
9 \\
10 \\
11 \\
N\end{array}$ & $\begin{array}{l}2.50 \\
2.43 \\
2.40 \\
2.37 \\
2.36 \\
2.35\end{array}$ & $\begin{array}{l}439 \\
398 \\
381 \\
364 \\
359 \\
354\end{array}$ & $\begin{array}{l}2.43 \\
2.39 \\
2.38 \\
2.36 \\
2.35 \\
2.40\end{array}$ & $\begin{array}{l}398 \\
376 \\
370 \\
359 \\
354 \\
381\end{array}$ & $\begin{array}{l}2.42 \\
2.37 \\
2.36 \\
2.37 \\
2.40 \\
2.49\end{array}$ & $\begin{array}{l}393 \\
364 \\
359 \\
364 \\
381 \\
433\end{array}$ & $\begin{array}{l}3.05 \\
3.05 \\
3.07 \\
3.11 \\
3.17 \\
3.36\end{array}$ & $\begin{array}{r}825 \\
825 \\
841 \\
873 \\
921 \\
1,080\end{array}$ & $\begin{array}{l}4.59 \\
4.55 \\
4.50 \\
4.46 \\
4.47 \\
4.49\end{array}$ & $\begin{array}{l}2,360 \\
2,310 \\
2,250 \\
2,210 \\
2,220 \\
2,240\end{array}$ & $\begin{array}{l}4.25 \\
4.27 \\
4.30 \\
4.33 \\
4.36 \\
4.40\end{array}$ & $\begin{array}{l}1,980 \\
2,000 \\
2,030 \\
2,060 \\
2,100 \\
2,140\end{array}$ \\
\hline $\begin{array}{l}1 \\
2 \\
3 \\
4 \\
5 \\
6\end{array}$ & $\begin{array}{l}2.36 \\
2.41 \\
2.44 \\
2.44 \\
2.42 \\
2.40\end{array}$ & $\begin{array}{l}359 \\
387 \\
404 \\
404 \\
393 \\
38.2\end{array}$ & $\begin{array}{l}2.62 \\
2.80 \\
2.85 \\
2.87 \\
2.88 \\
2.88\end{array}$ & $\begin{array}{l}513 \\
635 \\
672 \\
688 \\
695 \\
695\end{array}$ & $\begin{array}{l}2.83 \\
2.95 \\
2.99 \\
3.02 \\
3.01 \\
2.99\end{array}$ & $\begin{array}{l}658 \\
748 \\
778 \\
801 \\
793 \\
778\end{array}$ & $\begin{array}{l}3.50 \\
3.56 \\
3.63 \\
3.68 \\
3.70 \\
3.74\end{array}$ & $\begin{array}{l}1,210 \\
1,260 \\
1,330 \\
1,380 \\
1,400 \\
1,440\end{array}$ & $\begin{array}{l}4.46 \\
4.43 \\
4.40 \\
4.35 \\
4.30 \\
4.25\end{array}$ & $\begin{array}{l}2,210 \\
2,170 \\
2,140 \\
2,080 \\
2,030 \\
1,980\end{array}$ & $\begin{array}{l}4.45 \\
4.47 \\
4.49 \\
4.50 \\
4.52 \\
4.55\end{array}$ & $\begin{array}{l}2,200 \\
2,220 \\
2,240 \\
2,250 \\
2,270 \\
2,310\end{array}$ \\
\hline \multirow[t]{2}{*}{$\begin{array}{r}7 \\
8 \\
9 \\
10 \\
11 \\
11\end{array}$} & $\begin{array}{l}2.39 \\
2.38 \\
2.37 \\
2.37 \\
2.37 \\
2.37\end{array}$ & $\begin{array}{l}376 \\
370 \\
364 \\
364 \\
364 \\
364\end{array}$ & $\begin{array}{l}2.88 \\
2.88 \\
2.88 \\
2.87 \\
2.88 \\
2.92\end{array}$ & $\begin{array}{l}695 \\
695 \\
695 \\
688 \\
695 \\
725 \\
\end{array}$ & $\begin{array}{l}2.98 \\
2.94 \\
2.86 \\
2.97 \\
3.08 \\
3.15\end{array}$ & $\begin{array}{l}770 \\
740 \\
680 \\
762 \\
849 \\
905 \\
\end{array}$ & $\begin{array}{l}3.88 \\
4.23 \\
4.75 \\
5.03 \\
5.19 \\
5.26\end{array}$ & $\begin{array}{l}1,580 \\
1,950 \\
2,550 \\
2,890 \\
3,080 \\
3,160\end{array}$ & $\begin{array}{l}4.21 \\
4.20 \\
4.21 \\
4.24 \\
4.25 \\
4.26\end{array}$ & $\begin{array}{l}1,930 \\
1,920 \\
1,930 \\
1,960 \\
1,980 \\
1,990\end{array}$ & $\begin{array}{l}4.57 \\
4.59 \\
4.61 \\
4.62 \\
4.63 \\
4.63\end{array}$ & $\begin{array}{l}2,330 \\
2,360 \\
2,380 \\
2,390 \\
2,410 \\
2,410\end{array}$ \\
\hline & \multicolumn{2}{|c|}{ September 24} & \multicolumn{2}{|c|}{ September 25} & \multicolumn{2}{|c|}{ September 26} & \multicolumn{2}{|c|}{ September 27} & \multicolumn{2}{|c|}{ September 28} & \multicolumn{2}{|c|}{ September 29} \\
\hline $\begin{array}{r}2 \\
4 \\
6 \\
8 \\
10 \\
N\end{array}$ & $\begin{array}{l}4.62 \\
4.60 \\
4.54 \\
4.47 \\
4.41 \\
4.40\end{array}$ & $\begin{array}{l}2,390 \\
2,370 \\
2,300 \\
2,220 \\
2,150 \\
2,140\end{array}$ & $\begin{array}{l}4.34 \\
4.28 \\
4.21 \\
4.14 \\
4.10 \\
4.10\end{array}$ & $\begin{array}{l}2,070 \\
2,010 \\
1,930 \\
1,850 \\
1,810 \\
1,810\end{array}$ & $\begin{array}{l}4.13 \\
4.09 \\
4.02 \\
3.98 \\
3.96 \\
3.97\end{array}$ & $\begin{array}{l}1,840 \\
1,800 \\
1,720 \\
1,680 \\
1,660 \\
1,670\end{array}$ & $\begin{array}{l}3.96 \\
3.87 \\
3.77 \\
3.72 \\
3.72 \\
3.80\end{array}$ & $\begin{array}{l}1,660 \\
1,570 \\
1,470 \\
1,420 \\
1,420 \\
1,500\end{array}$ & $\begin{array}{l}4.02 \\
3.88 \\
3.75 \\
3.68 \\
3.68 \\
3.79\end{array}$ & $\begin{array}{l}1,720 \\
1,580 \\
1,450 \\
1,380 \\
1,380 \\
1,490\end{array}$ & $\begin{array}{l}3.90 \\
3.77 \\
3.67 \\
3.60 \\
3.58 \\
3.70\end{array}$ & $\begin{array}{l}1,600 \\
1,470 \\
1,370 \\
1,300 \\
1,280 \\
1,400\end{array}$ \\
\hline $\begin{array}{r}2 \\
4 \\
6 \\
8 \\
10 \\
M\end{array}$ & $\begin{array}{l}4.39 \\
4.39 \\
4.36 \\
4.33 \\
4.32 \\
4.34\end{array}$ & $\begin{array}{l}2,130 \\
2,130 \\
2,100 \\
2,060 \\
2,050 \\
2,070\end{array}$ & $\begin{array}{l}4.09 \\
4.09 \\
4.09 \\
4.07 \\
4.09 \\
4.12\end{array}$ & $\begin{array}{l}1,800 \\
1,800 \\
1,800 \\
1,780 \\
1,800\end{array}$ & $\begin{array}{l}3.99 \\
4.00 \\
3.99 \\
3.98 \\
3.98 \\
3.99\end{array}$ & $\begin{array}{l}1,690 \\
1,700 \\
1,690 \\
1,680 \\
1,680\end{array}$ & $\begin{array}{l}3.91 \\
3.97 \\
4.01 \\
4.03 \\
4.03 \\
4.05\end{array}$ & $\begin{array}{l}1,610 \\
1,670 \\
1,710 \\
1,730 \\
1,730 \\
1,760\end{array}$ & $\begin{array}{l}3.87 \\
3.90 \\
3.77 \\
3.73 \\
3.84 \\
3.91\end{array}$ & $\begin{array}{l}1,570 \\
1,600 \\
1,470 \\
1,430 \\
1,540 \\
1,610\end{array}$ & $\begin{array}{l}3.78 \\
3.80 \\
3.80 \\
3.76 \\
3.78 \\
3.80\end{array}$ & $\begin{array}{l}80 \\
500 \\
500 \\
60 \\
80 \\
800\end{array}$ \\
\hline
\end{tabular}

Supplemental records.- Sept. $22,12: 30$ a.m., 5.27 ft., 3,170 sec.-ft. 
Location.- Water-stage recorder, lat. $44^{\circ} 18^{\prime} 40^{n}$, long. $73^{\circ} 55^{\prime} 00^{\prime \prime}, 4$ miles northeast of Newman, Essex County, and 4 miles below mouth of Lake Placid outlet.

Dralnage area. - 116 square miles.

Gage-helght record.- Water-stage recorder graph.

Stage-d1scharge reletion.- Defined by current-meter measurement below 3 , 140 secondfeet; extended logarithmically to peak stage.

Max 1ma.- September 1938: D1scharge, 10,800 second-feet 3:45 a.m. Sept. 22 (gage helght, 12.20 feet)

June 1916 to December 1917, July 1919 to August 1938: Discharge, 6,200 secondfeet oct. 6,1932 (gage height, 9.61 feet):

Remarks.- Diurnal fluctuation at low and medium stages caused by operation of power

plants. Some regulation by operation of gates in logging dam. Flood flows affec-

ted by natural storage in Lake Placid and several small ponds.

Mean daily discharge, in second-feet, 1938

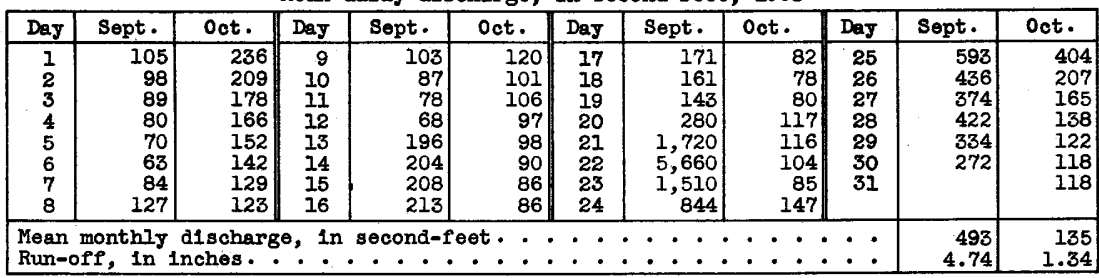

Gage helght, In feet, and discharge, in second-feet, at indicated time, 1938

\begin{tabular}{|c|c|c|c|c|c|c|c|c|c|c|c|c|}
\hline \multirow{2}{*}{ 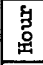 } & Feet & Sec.ft. & Feet & Sec.ft. & Feet & Sec.ft. & Feet & Sec.ft. & Feet & Sec.et. & Feet & Sec.ft. \\
\hline & \multicolumn{2}{|c|}{ September 18} & \multicolumn{2}{|c|}{ September 19} & \multicolumn{2}{|c|}{ September 20} & \multicolumn{2}{|c|}{ September 21} & \multicolumn{2}{|c|}{ September 22} & \multicolumn{2}{|c|}{ September 23} \\
\hline $\begin{array}{l}1 \\
2 \\
3 \\
4 \\
5 \\
6\end{array}$ & $\begin{array}{l}3.21 \\
3.24 \\
3.25 \\
3.25 \\
3.25 \\
3.25\end{array}$ & $\begin{array}{l}187 \\
196 \\
1.98 \\
198 \\
198 \\
198\end{array}$ & $\begin{array}{l}3.24 \\
3.17 \\
3.07 \\
2.97 \\
2.92 \\
2.89\end{array}$ & $\begin{array}{r}196 \\
176 \\
150 \\
125 \\
114 \\
108\end{array}$ & $\begin{array}{l}3.18 \\
3.21 \\
3.22 \\
3.23 \\
3.23 \\
3.15\end{array}$ & $\begin{array}{l}179 \\
187 \\
190 \\
193 \\
193 \\
170\end{array}$ & $\begin{array}{l}4.76 \\
4.85 \\
4.94 \\
5.05 \\
5.16 \\
5.22\end{array}$ & $\begin{array}{r}881 \\
938 \\
998 \\
1,080 \\
1,150 \\
1,190\end{array}$ & $\begin{array}{l}10.26 \\
11.33 \\
12.03 \\
12.16 \\
11.88 \\
11.47\end{array}$ & $\begin{array}{r}7,240 \\
9,160 \\
10,500 \\
10,800 \\
10,200 \\
9,420\end{array}$ & $\begin{array}{l}6.29 \\
6.22 \\
6.14 \\
6.05 \\
5.98 \\
5.92\end{array}$ & $\begin{array}{l}2,070 \\
2,010 \\
1,940 \\
1,860 \\
1,790 \\
1,740\end{array}$ \\
\hline $\begin{array}{r}7 \\
8 \\
9 \\
10 \\
11 \\
\text { N }\end{array}$ & $\begin{array}{l}3.23 \\
3.13 \\
3.03 \\
2.96 \\
2.92 \\
2.90\end{array}$ & $\begin{array}{l}193 \\
165 \\
140 \\
123 \\
114 \\
110\end{array}$ & $\begin{array}{l}2.87 \\
2.86 \\
2.85 \\
2.85 \\
3.01 \\
3.17\end{array}$ & $\begin{array}{l}104 \\
102 \\
100 \\
100 \\
134 \\
176\end{array}$ & $\begin{array}{l}3.05 \\
2.98 \\
2.95 \\
2.94 \\
2.94 \\
2.95\end{array}$ & $\begin{array}{l}144 \\
128 \\
121 \\
119 \\
119 \\
121\end{array}$ & $\begin{array}{l}5.25 \\
5.23 \\
5.21 \\
5.22 \\
5.24 \\
5.27\end{array}$ & $\begin{array}{l}1,220 \\
1,200 \\
1,190 \\
1,190 \\
1,210 \\
1,230\end{array}$ & $\begin{array}{r}10.98 \\
10.53 \\
10.06 \\
9.57 \\
9.12 \\
8.75\end{array}$ & $\begin{array}{l}8,510 \\
7,700 \\
6,910 \\
6,140 \\
5,460 \\
4,930\end{array}$ & $\begin{array}{l}5.85 \\
5.79 \\
5.73 \\
5.68 \\
5.62 \\
5.57\end{array}$ & $\begin{array}{l}1, \\
1, \\
1, \\
1, \\
1, \\
1,\end{array}$ \\
\hline $\begin{array}{l}1 \\
2 \\
3 \\
4 \\
5 \\
6\end{array}$ & $\begin{array}{l}2.89 \\
2.90 \\
3.09 \\
3.14 \\
3.07 \\
2.99\end{array}$ & $\begin{array}{l}108 \\
110 \\
154 \\
168 \\
150 \\
130\end{array}$ & $\begin{array}{l}3.21 \\
3.22 \\
3.22 \\
3.22 \\
3.18 \\
3.08\end{array}$ & $\begin{array}{l}187 \\
190 \\
190 \\
190 \\
179 \\
152\end{array}$ & $\begin{array}{l}3.02 \\
3.30 \\
3.47 \\
3.52 \\
3.66 \\
3.74\end{array}$ & $\begin{array}{l}137 \\
213 \\
269 \\
286 \\
338 \\
371\end{array}$ & $\begin{array}{l}5.35 \\
5.48 \\
5.64 \\
5.81 \\
5.99 \\
6.21\end{array}$ & $\begin{array}{l}1,280 \\
1,380 \\
1,510 \\
1,650 \\
1,800 \\
2,000\end{array}$ & $\begin{array}{l}8.42 \\
8.15 \\
7.90 \\
7.67 \\
7.46 \\
7.27\end{array}$ & $\begin{array}{l}4,480 \\
4,120 \\
3,810 \\
3,530 \\
3,290 \\
3,080\end{array}$ & $\begin{array}{l}5.52 \\
5.47 \\
5.42 \\
5.37 \\
5.33 \\
5.29\end{array}$ & $\begin{array}{l}1, \\
1, \\
1, \\
1, \\
1, \\
1,\end{array}$ \\
\hline \multirow[t]{2}{*}{$\begin{array}{r}7 \\
8 \\
9 \\
10 \\
11 \\
M\end{array}$} & $\begin{array}{l}2.94 \\
3.02 \\
3.17 \\
3.22 \\
3.24 \\
3.24\end{array}$ & $\begin{array}{l}119 \\
137 \\
176 \\
190 \\
196 \\
196\end{array}$ & $\begin{array}{l}3.01 \\
2.96 \\
2.92 \\
2.89 \\
2.87 \\
3.05\end{array}$ & $\begin{array}{l}134 \\
123 \\
114 \\
108 \\
104 \\
144\end{array}$ & $\begin{array}{l}3.81 \\
3.92 \\
4.08 \\
4.27 \\
4.48 \\
4.62\end{array}$ & $\begin{array}{l}400 \\
448 \\
522 \\
615 \\
720 \\
797\end{array}$ & $\begin{array}{l}6.47 \\
6.68 \\
7.13 \\
7.56 \\
8.16 \\
9.06\end{array}$ & $\begin{array}{l}2,240 \\
2,450 \\
2,920 \\
3,400 \\
4,140 \\
5,370\end{array}$ & $\begin{array}{l}7.10 \\
6.94 \\
6.78 \\
6.65 \\
6.50 \\
6.38\end{array}$ & $\begin{array}{l}2,890 \\
2,710 \\
2,550 \\
2,420 \\
2,270 \\
2,150\end{array}$ & $\begin{array}{l}5.25 \\
5.21 \\
5.17 \\
5.13 \\
5.09 \\
5.05\end{array}$ & $\begin{array}{l}1,220 \\
1,190 \\
1,160 \\
1,130 \\
1,100 \\
1,080\end{array}$ \\
\hline & \multicolumn{2}{|c|}{ September 24} & \multicolumn{2}{|c|}{ September 25} & \multicolumn{2}{|c|}{ September 26} & \multicolumn{2}{|c|}{ September 27} & \multicolumn{2}{|c|}{ September 28} & \multicolumn{2}{|c|}{ September 29} \\
\hline $\begin{array}{r}2 \\
4 \\
6 \\
8 \\
10 \\
N\end{array}$ & $\begin{array}{l}4.96 \\
4.89 \\
4.83 \\
4.76 \\
4.71 \\
4.66\end{array}$ & \begin{tabular}{|r|}
1,010 \\
964 \\
924 \\
881 \\
851 \\
821
\end{tabular} & \begin{tabular}{|l|}
4.40 \\
4.36 \\
4.32 \\
4.28 \\
4.25 \\
4.22
\end{tabular} & $\begin{array}{l}680 \\
660 \\
640 \\
620 \\
605 \\
590\end{array}$ & & $\begin{array}{l}489 \\
475 \\
462 \\
452 \\
439 \\
435\end{array}$ & $\begin{array}{l}3.74 \\
3.71 \\
3.69 \\
3.69 \\
3.68 \\
3.70\end{array}$ & $\begin{array}{l}371 \\
359 \\
351 \\
351 \\
347 \\
355\end{array}$ & & \begin{tabular}{|l|}
439 \\
439 \\
439 \\
439 \\
439 \\
435
\end{tabular} & & $\begin{array}{l}367 \\
355 \\
351 \\
343 \\
336\end{array}$ \\
\hline $\begin{array}{r}2 \\
4 \\
6 \\
8 \\
10 \\
M\end{array}$ & $\begin{array}{l}4.62 \\
4.58 \\
4.55 \\
4.52 \\
4.48 \\
4.44\end{array}$ & $\begin{array}{l}797 \\
774 \\
758 \\
741 \\
720 \\
700\end{array}$ & $\begin{array}{l}4.19 \\
4.15 \\
4.12 \\
4.09 \\
4.07 \\
4.04\end{array}$ & $\begin{array}{l}575 \\
556 \\
541 \\
526 \\
517 \\
503\end{array}$ & $\begin{array}{l}3.87 \\
3.85 \\
3.83 \\
3.80 \\
3.78 \\
3.76\end{array}$ & $\begin{array}{l}426 \\
418 \\
409 \\
386 \\
388 \\
380\end{array}$ & $\begin{array}{l}3.70 \\
3.74 \\
3.76 \\
3.80 \\
3.85 \\
3.89\end{array}$ & $\begin{array}{l}355 \\
371 \\
380 \\
396 \\
418 \\
435\end{array}$ & $\begin{array}{l}3.87 \\
3.85 \\
3.81 \\
3.80 \\
3.78\end{array}$ & $\begin{array}{l}426 \\
418 \\
400 \\
396 \\
388 \\
376\end{array}$ & & $\begin{array}{l}324 \\
16 \\
12 \\
109 \\
05\end{array}$ \\
\hline
\end{tabular}

Supplemental records.- Sept. $22,3: 45$ a.m., $12.20 \mathrm{ft} ., 10,800$ sec. $-\mathrm{ft}$. 
Location, - Water-stage recorder, lat. $44^{\circ} 27^{\prime} 05^{\prime \prime}$, long. $73^{\circ} 38^{\prime} 35^{\prime \prime}, 1.3 / 4$ miles below junction of East and West Branches of Ausable River at Ausable Forks, Clinton County. Drainage area.- 448 square miles.

Grge-height record.- Water-stage recorder graph.

Stage-discharge relation.- Defined by current-meter measurements below 9,040 second-

feet; extended logarithmically to peak stage.

Maxima.- September 1938: Discharge, 24,200 second-feet 3:30 a.m. Sept. 22 (gage height,

11.65 feet). Maximum gage height at former site and datum, 12.6 feet, from flood-

marks, 2:45 a.m. Sept. 22 .

September 1924 to August 1938: Maximum discharge, 21,200 second-feet 0ct. 1,

1924 (gage height, 11.15 feet); maximum gage height, 14.0 feet Mar. 27, 1934 (1ce

jam). Maximum gage height at former site and datum, 9.5 feet, from constructed graph, oct. 1, 1924

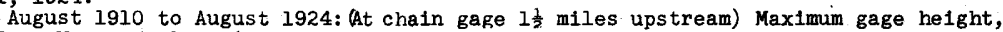
10.2 feet Mar. 27, 1913 (revised discharge not determined).

Remarks.- Flow partly regulated by storage principally in Taylor Pond and Fern Lake.

Diurnal fluctuations caused by operation of power plants upstream. Flood peak also affected by some natural storage in Lake Placid and several small ponds.

Mean dally discharge, in second-feet, 1938

\begin{tabular}{|c|c|c|c|c|c|c|c|c|c|c|c|}
\hline Day & Sept. & oct. & Day & Sept. & oct. & Day & Sept. & Oot. & Day & Sept. & Oct. \\
\hline $\begin{array}{l}1 \\
2 \\
3 \\
4 \\
5 \\
6 \\
7 \\
8\end{array}$ & $\begin{array}{l}236 \\
228 \\
213 \\
194 \\
184 \\
205 \\
214 \\
268\end{array}$ & $\begin{array}{l}533 \\
476 \\
444 \\
408 \\
378 \\
363 \\
335 \\
318\end{array}$ & $\begin{array}{r}9 \\
10 \\
11 \\
12 \\
13 \\
14 \\
15 \\
16\end{array}$ & $\begin{array}{l}252 \\
234 \\
215 \\
181 \\
294 \\
449 \\
432 \\
599\end{array}$ & $\begin{array}{l}308 \\
293 \\
284 \\
273 \\
266 \\
262 \\
262 \\
248\end{array}$ & $\begin{array}{l}17 \\
18 \\
19 \\
20 \\
21 \\
22 \\
23 \\
24\end{array}$ & $\begin{array}{r}465 \\
397 \\
360 \\
592 \\
5,840 \\
14,300 \\
3,790 \\
2,070\end{array}$ & $\begin{array}{l}245 \\
241 \\
230 \\
258 \\
301 \\
322 \\
280 \\
328 \\
\end{array}$ & $\begin{array}{l}25 \\
26 \\
27 \\
28 \\
29 \\
30 \\
31\end{array}$ & $\begin{array}{r}1,360 \\
972 \\
847 \\
920 \\
740 \\
599\end{array}$ & $\begin{array}{l}947 \\
659 \\
480 \\
423 \\
382 \\
360 \\
354\end{array}$ \\
\hline $\begin{array}{l}\text { Mean } \\
\text { Run- }\end{array}$ & $\begin{array}{l}\text { nthly } \\
\text { in }\end{array}$ & 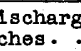 & , 1 & . . . & ot. : & $\dot{0}$ & $\begin{array}{lll}\cdot & \bullet & \bullet \\
. & \bullet & \bullet\end{array}$ & . : & $\dot{0}$ & $\begin{array}{r}1,255 \\
3.12\end{array}$ & $\begin{array}{r}363 \\
0.93\end{array}$ \\
\hline
\end{tabular}

Gage helght, in feet, and discharge, in second-feet, at indicated time, 1938

\begin{tabular}{|c|c|c|c|c|c|c|c|c|c|c|c|c|}
\hline \multirow{2}{*}{ 象 } & Feot & Sec.ft. & Feet & Sec.ft. & Feet & Sec.ft. & Feet & Sec.ft. & Beet & Sec.ft. & Feet & Sec.ft. \\
\hline & \multicolumn{2}{|c|}{ September 18} & \multicolumn{2}{|c|}{ September 19} & \multicolumn{2}{|c|}{ September 20} & \multicolumn{2}{|c|}{ September 21} & \multicolumn{2}{|c|}{ September 22} & \multicolumn{2}{|c|}{ September 23} \\
\hline $\begin{array}{l}1 \\
2 \\
3 \\
4 \\
5 \\
6\end{array}$ & $\begin{array}{l}2.02 \\
2.03 \\
2.03 \\
2.00 \\
1.95 \\
1.93\end{array}$ & $\begin{array}{l}444 \\
449 \\
449 \\
433 \\
408 \\
397\end{array}$ & $\begin{array}{l}1.87 \\
1.85 \\
1.84 \\
1.83 \\
1.83 \\
1.83\end{array}$ & $\begin{array}{l}368 \\
358 \\
354 \\
349 \\
349 \\
349\end{array}$ & $\begin{array}{l}1.97 \\
1.99 \\
1.99 \\
1.98 \\
1.96 \\
1.94\end{array}$ & $\begin{array}{l}418 \\
428 \\
428 \\
423 \\
413 \\
402\end{array}$ & $\begin{array}{l}3.66 \\
3.86 \\
4.09 \\
4.29 \\
4.42 \\
4.56\end{array}$ & $\begin{array}{l}1,880 \\
2,140 \\
2,460 \\
2,740 \\
2,940 \\
3,150\end{array}$ & $\begin{array}{l}10.95 \\
11.34 \\
11.60 \\
11.62 \\
11.38 \\
11.00\end{array}$ & $\begin{array}{l}21,400 \\
23,000 \\
24,000 \\
24,100 \\
23,100 \\
21,600\end{array}$ & $\begin{array}{l}5.81 \\
5.71 \\
5.59 \\
5.47 \\
5.38 \\
5.30\end{array}$ & $\begin{array}{l}5,350 \\
5,150 \\
4,910 \\
4,680 \\
4,510 \\
4,370\end{array}$ \\
\hline $\begin{array}{r}7 \\
8 \\
9 \\
10 \\
11 \\
\text { N }\end{array}$ & $\begin{array}{l}1.91 \\
1.88 \\
1.86 \\
1.91 \\
1.95 \\
1.98\end{array}$ & $\begin{array}{l}387 \\
373 \\
363 \\
387 \\
408 \\
423\end{array}$ & $\begin{array}{l}1.95 \\
1.93 \\
2.14 \\
2.00 \\
1.94 \\
1.92\end{array}$ & $\begin{array}{l}408 \\
397 \\
510 \\
433 \\
402 \\
392\end{array}$ & $\begin{array}{l}1.94 \\
1.94 \\
1.95 \\
1.96 \\
2.03 \\
2.20\end{array}$ & $\begin{array}{l}402 \\
402 \\
408 \\
413 \\
449 \\
545\end{array}$ & $\begin{array}{l}4.64 \\
4.71 \\
4.78 \\
4.85 \\
4.90 \\
4.96\end{array}$ & $\begin{array}{l}3,270 \\
3,390 \\
3,500 \\
3,610 \\
3,690 \\
3,790\end{array}$ & $\begin{array}{r}10.65 \\
10.32 \\
9.92 \\
9.49 \\
9.12 \\
8.68\end{array}$ & $\begin{array}{l}20,200 \\
18,900 \\
17,300 \\
15,600 \\
14,300 \\
12,900\end{array}$ & $\begin{array}{l}5.22 \\
5.13 \\
5.06 \\
4.99 \\
4.93 \\
4.86\end{array}$ & $\begin{array}{l}4,230 \\
4,070 \\
3,950 \\
3,830 \\
3,740 \\
3,630\end{array}$ \\
\hline $\begin{array}{l}1 \\
2 \\
3 \\
4 \\
5 \\
6\end{array}$ & $\begin{array}{l}1.99 \\
1.99 \\
1.99 \\
1.97 \\
1.93 \\
1.91\end{array}$ & $\begin{array}{l}428 \\
428 \\
428 \\
418 \\
397 \\
387\end{array}$ & $\begin{array}{l}1.83 \\
1.86 \\
1.83 \\
1.81 \\
1.67 \\
1.66\end{array}$ & $\begin{array}{l}349 \\
363 \\
349 \\
340 \\
280 \\
276\end{array}$ & $\begin{array}{l}2.20 \\
2.20 \\
2.23 \\
2.27 \\
2.26 \\
2.40\end{array}$ & $\begin{array}{l}545 \\
545 \\
563 \\
587 \\
581 \\
670\end{array}$ & $\begin{array}{l}5.07 \\
5.24 \\
5.51 \\
5.77 \\
6.08 \\
6.45\end{array}$ & $\begin{array}{l}3,970 \\
4,260 \\
4,760 \\
5,270 \\
5,910 \\
6,740\end{array}$ & $\begin{array}{l}8.42 \\
8.07 \\
7.80 \\
7.52 \\
7.27 \\
7.02\end{array}$ & $\begin{array}{r}12,200 \\
11,100 \\
10,300 \\
9,500 \\
8,810 \\
8,140\end{array}$ & $\begin{array}{l}4.81 \\
4.76 \\
4.71 \\
4.65 \\
4.58 \\
4.54\end{array}$ & $\begin{array}{l}3,550 \\
3,470 \\
3,390 \\
3,290 \\
3,180 \\
3,120\end{array}$ \\
\hline $\begin{array}{r}7 \\
8 \\
9 \\
10 \\
11 \\
1\end{array}$ & $\begin{array}{l}1.87 \\
1.84 \\
1.83 \\
1.82 \\
1.81 \\
1.80\end{array}$ & $\begin{array}{l}368 \\
354 \\
349 \\
344 \\
340 \\
335\end{array}$ & $\begin{array}{l}1.71 \\
1.75 \\
1.76 \\
1.77 \\
1.93 \\
1.93\end{array}$ & $\begin{array}{l}296 \\
314 \\
318 \\
322 \\
397 \\
397\end{array}$ & $\begin{array}{l}2.47 \\
2.51 \\
2.64 \\
2.71 \\
3.19 \\
3.44\end{array}$ & $\begin{array}{r}719 \\
748 \\
847 \\
904 \\
1,350 \\
1,620\end{array}$ & $\begin{array}{r}6.85 \\
7.60 \\
8.42 \\
9.18 \\
10.05 \\
10.58\end{array}$ & $\begin{array}{r}7,700 \\
9,720 \\
12,200 \\
14,400 \\
17,800 \\
19,900\end{array}$ & $\begin{array}{l}6.80 \\
6.62 \\
6.42 \\
6.26 \\
6.10 \\
5.96\end{array}$ & $\begin{array}{l}7,580 \\
7,140 \\
6 ; 670 \\
6,300 \\
5,950 \\
5,660\end{array}$ & $\begin{array}{l}4.47 \\
4.43 \\
4.38 \\
4.33 \\
4.28 \\
4.24\end{array}$ & $\begin{array}{l}3,020 \\
2,960 \\
2,880 \\
2,800 \\
2,730 \\
2,670\end{array}$ \\
\hline & \multicolumn{2}{|c|}{ September 24} & \multicolumn{2}{|c|}{ September 25} & \multicolumn{2}{|c|}{ September 26} & \multicolumn{2}{|c|}{ September 27} & \multicolumn{2}{|c|}{ September 28} & \multicolumn{2}{|c|}{ September 29} \\
\hline $\begin{array}{r}2 \\
4 \\
6 \\
8 \\
10 \\
N\end{array}$ & $\begin{array}{l}4.15 \\
4.06 \\
3.99 \\
3.91 \\
3.83 \\
3.77\end{array}$ & $\begin{array}{l}2,540 \\
2,410 \\
2,320 \\
2,200 \\
2,100 \\
2,020\end{array}$ & $\begin{array}{l}3.41 \\
3.36 \\
3.32 \\
3.27 \\
3.23 \\
3.19\end{array}$ & $\begin{array}{l}1,590 \\
1,540 \\
1,490 \\
1,440 \\
1,390 \\
1,350\end{array}$ & $\begin{array}{l}2.93 \\
2.90 \\
2.88 \\
2.84 \\
2.81 \\
2.78\end{array}$ & $\begin{array}{r}1,100 \\
1,070 \\
1,050 \\
1,020 \\
989 \\
963\end{array}$ & $\begin{array}{l}2.62 \\
2.57 \\
2.57 \\
2.57 \\
2.56 \\
2.58\end{array}$ & $\begin{array}{l}831 \\
792 \\
792 \\
792 \\
785 \\
800\end{array}$ & $\begin{array}{l}2.76 \\
2.77 \\
2.78 \\
2.78 \\
2.76 \\
2.75\end{array}$ & $\begin{array}{l}946 \\
954 \\
963 \\
963 \\
946 \\
938\end{array}$ & $\begin{array}{l}2.61 \\
2.58 \\
2.56 \\
2.54 \\
2.52 \\
2.49\end{array}$ & $\begin{array}{l}823 \\
800 \\
785 \\
770 \\
755 \\
733\end{array}$ \\
\hline $\begin{array}{r}2 \\
4 \\
6 \\
8 \\
10 \\
M\end{array}$ & $\begin{array}{l}3.72 \\
3.66 \\
3.60 \\
3.56 \\
3.50 \\
3.46\end{array}$ & $\begin{array}{l}1,960 \\
1,880 \\
1,810 \\
1,760 \\
1,690 \\
1,650\end{array}$ & $\begin{array}{l}3.14 \\
3.11 \\
3.08 \\
3.04 \\
3.00 \\
2.96\end{array}$ & $\begin{array}{l}1,300 \\
1,270 \\
1,240 \\
1,200 \\
1,160\end{array}$ & $\begin{array}{l}2.76 \\
2.74 \\
2.71 \\
2.66 \\
2.66 \\
2.64\end{array}$ & $\begin{array}{l}946 \\
929 \\
904 \\
863 \\
863 \\
847\end{array}$ & $\begin{array}{l}2.64 \\
2.65 \\
2.72 \\
2.72 \\
2.74 \\
2.76\end{array}$ & $\begin{array}{l}847 \\
855 \\
912 \\
912 \\
929 \\
946\end{array}$ & $\begin{array}{l}2.74 \\
2.72 \\
2.70 \\
2.69 \\
2.66\end{array}$ & $\begin{array}{l}929 \\
912 \\
895 \\
887 \\
863 \\
839\end{array}$ & $\begin{array}{l}47 \\
46 \\
44 \\
42 \\
40 \\
38\end{array}$ & $\begin{array}{l}719 \\
712 \\
698 \\
684 \\
670 \\
657\end{array}$ \\
\hline
\end{tabular}

Supplemental records.- Sept. $22,3: 30 \mathrm{a.m.,} 11.65 \mathrm{ft} ., 24,200 \mathrm{sec} .-\mathrm{ft}$. 
Black Brook at Black Brook, N. Y.

Location.- Water-stage recorder, lat. 44\%26'50n, long. $73^{\circ} 44^{\prime} 45^{\prime \prime}$, 100 feet below hydroelectric plant of Associated Gas \& Electric System and three-quarters of a mile south of Black Brook, Clinton County. (Prior to Oct. 24, 1937, staff gage at same site and datum)

Drainge area.- 49.4 square miles.

Gage-helght record. - Water-stage recorder graph.

Stage-discharge relation.- Defined by current-meter measurements below 449 second-feet; extended logarithmicaily to peak stage. Affected by faulty intake for periods noon Sept. 16 to 10 a.m. Sept. 19 and $1 \mathrm{a} . \mathrm{m}$. Sept. 23 to $10 \mathrm{a} . \mathrm{m}$. Sept. 24.

Maxima.- September 1938: Discharge, 694 second-feet 1 p.m. Sept. 22 (gage helght, 5.60 feet)

September 1924 to August 1938: Discharge, 1,050 second-feet Apr. 6, 1937 (gage height, 6.95 feet).

Remarks.- Flows regulated by storage in Taylor Pond and Fern Lake. No regulation during flood period by power plant, which was not operating.

Mean daliy discharge, in second-feet, 1938

\begin{tabular}{|c|c|c|c|c|c|c|c|c|c|c|c|}
\hline Day & Sept. & oct. & Day & Sept. & Oct. & Day & Sept. & Oct. & Day & Sept. & Oct. \\
\hline $\begin{array}{l}1 \\
2 \\
3 \\
4 \\
5 \\
6 \\
7 \\
8\end{array}$ & $\begin{array}{r}8.7 \\
8.1 \\
7.0 \\
6.4 \\
6.4 \\
5.8 \\
7.5 \\
12\end{array}$ & $\begin{array}{l}28 \\
26 \\
23 \\
21 \\
20 \\
19 \\
17 \\
18\end{array}$ & $\begin{array}{r}9 \\
10 \\
11 \\
12 \\
13 \\
14 \\
15 \\
16\end{array}$ & $\begin{array}{l}9.1 \\
7.5 \\
7.2 \\
7.0 \\
17 \\
19 \\
15 \\
13\end{array}$ & $\begin{array}{l}19 \\
17 \\
17 \\
16 \\
16 \\
16 \\
15 \\
15\end{array}$ & $\begin{array}{l}17 \\
18 \\
19 \\
20 \\
21 \\
22 \\
23 \\
24\end{array}$ & $\begin{array}{c}10 \\
9.1 \\
10 \\
20 \\
117 \\
494 \\
213 \\
88\end{array}$ & $\begin{array}{l}15 \\
17 \\
14 \\
15 \\
21 \\
59 \\
54 \\
55\end{array}$ & $\begin{array}{l}25 \\
26 \\
27 \\
28 \\
29 \\
30 \\
31\end{array}$ & $\begin{array}{l}52 \\
36 \\
33 \\
48 \\
42 \\
33\end{array}$ & $\begin{array}{l}61 \\
34 \\
22 \\
43 \\
57 \\
55 \\
54\end{array}$ \\
\hline $\begin{array}{l}\text { Mean } \\
\text { Run }=c\end{array}$ & $\begin{array}{l}\text { nthly } \\
, \text { in } 1\end{array}$ & $\begin{array}{l}\text { scharg } \\
\text { hes. }\end{array}$ & 1n & $\begin{array}{c}\text { econd- } \\
\text { - }\end{array}$ & et. . & . & 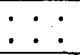 & $\begin{array}{ll}\cdot & \cdot \\
. & . \\
\end{array}$ & . & $\begin{array}{l}45.4 \\
1.03 \\
\end{array}$ & $\begin{array}{r}28.4 \\
.66 \\
\end{array}$ \\
\hline
\end{tabular}

Gage helght, in feet, and discharge, in second-feet, at indicated time, 1938

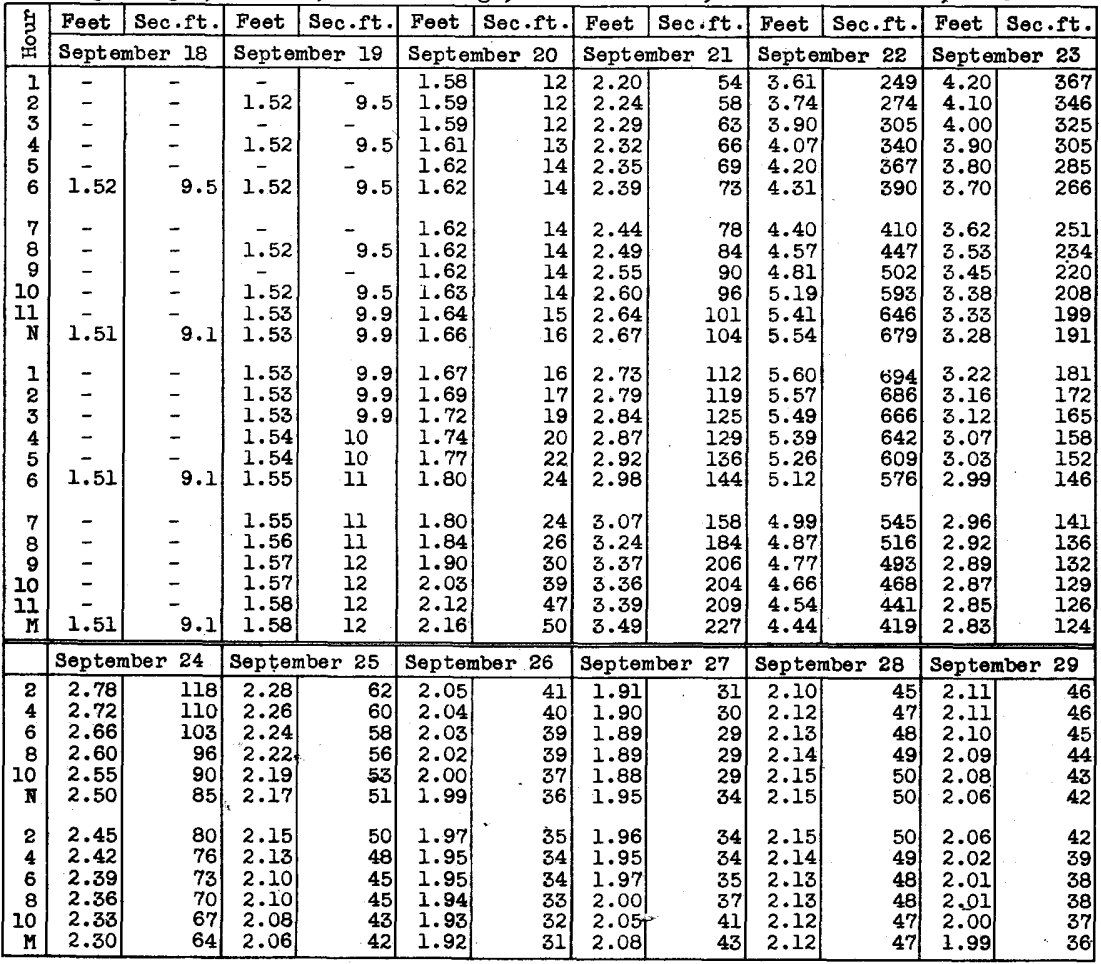

$2279 \% 70-40-24$ 
Location. - Water-stage recorder, lat. $44^{\circ} 26 ! 20^{\prime \prime}$, long. $73^{\circ} 40^{\prime} 55^{\prime \prime}$, on left bank on outside of river bend, 700 feet above Jersey Bridge in village of Ausable Forks, Essex County, and half a mile above junction of East and West Branches of Ausable River. Zero of gage is 545.32 feet above mean sea level and zero of former gage $0.4 \mathrm{mlle}$ downstream is 541.78 feet above mean sea level (general adjustment of 1912).

Drainage area.- 198 square miles.

Gage-he1ght record.- Water-stage recorder graph 0ct. 7-3l. Hook gage read twice da1ly Sept. 24 to Oct. 7. Hook gage read 19 times $3-12$ p.m. Sept. 21,29 times Sept. 22 , and 4 times sept. 23. Twice daily readings of staff gage at former site Sept. 18 to 3 p.m. Sept. 21 converted to equivalent readings at upper gage by gage-helght relationship based on comparative observations.

Stage-discharge relation. - Defined at new site by current-meter measurements below 5,780 second-feet, extended logarithmically to peak stage on basis of area-velocity studies and study of flow in Ausable River near Ausable Forks, $N$. $Y .$, and in adjacent streams. Defined at former site by current-meter measurements below 4,910 second-feet; extended logarithmically to peak stage.

Maxima.- September 1938: Discharge observed, 20,100 second-feet 2:30 a.m. Sept. 22 (gage height, 12.91 feet); gage height at former site and datum, 11.2 feet, from floodmarks.

September 1924 to August 1938: Maximum discharge, 11,000 second-feet 0ct. 1, 1924 (gage height, 7.3 feet, from graph based on twice daily staff gage observations at former site and datum); maximum gage helght, 11.4 feet Mar. 28, 1925, from floodmarks at former site and datum (probably backwater from West Branch of Ausable River).

Remarks.- Discharge Sept. 1-20 based on discharge at former site, which is practically the same. Upper gage not affected by backwater from West Branch of Ausable River.

Mean daliy discharge, in second-feet, 1938

\begin{tabular}{|c|c|c|c|c|c|c|c|c|c|c|c|}
\hline Day & Sept. & Oct. & Day & Sept. & Oct. & Day & Sept. & oct. & Day & Sept. & Oct. \\
\hline $\begin{array}{l}1 \\
2 \\
3 \\
4 \\
5 \\
6 \\
7 \\
8\end{array}$ & $\begin{array}{r}88 \\
94 \\
88 \\
82 \\
76 \\
71 \\
71 \\
110\end{array}$ & $\begin{array}{l}199 \\
184 \\
166 \\
154 \\
150 \\
139 \\
128 \\
128\end{array}$ & $\begin{array}{r}9 \\
10 \\
11 \\
12 \\
13 \\
14 \\
1.5 \\
16\end{array}$ & $\begin{array}{r}88 \\
82 \\
79 \\
76 \\
124 \\
145 \\
173 \\
272\end{array}$ & $\begin{array}{l}124 \\
120 \\
115 \\
113 \\
109 \\
108 \\
104 \\
102\end{array}$ & $\begin{array}{l}17 \\
18 \\
19 \\
20 \\
21 \\
22 \\
23 \\
24\end{array}$ & $\begin{array}{r}220 \\
165 \\
145 \\
330 \\
4,000 \\
7,830 \\
1,530 \\
825\end{array}$ & $\begin{array}{r}99 \\
101 \\
96 \\
106 \\
115 \\
111 \\
104 \\
122\end{array}$ & $\begin{array}{l}25 \\
26 \\
27 \\
28 \\
29 \\
30 \\
31\end{array}$ & $\begin{array}{l}537 \\
379 \\
324 \\
336 \\
259 \\
216\end{array}$ & $\begin{array}{l}505 \\
324 \\
236 \\
188 \\
166 \\
150 \\
137\end{array}$ \\
\hline $\begin{array}{l}\text { Mean } \\
\text { Run- }\end{array}$ & $\begin{array}{l}\text { onthly } \\
f, \text { in } \mathrm{I}\end{array}$ & aho & : 11 & second- & et. & $\dot{0} \cdot \dot{ }$ & : . & . . & $\dot{\bullet} \cdot$ & $\begin{array}{r}627 \\
3.54\end{array}$ & $\begin{array}{r}152 \\
0.89\end{array}$ \\
\hline
\end{tabular}

Gage helght, in feet, and discharge, In second-feet, at indicated time, 1938

\begin{tabular}{|c|c|c|c|c|c|c|c|c|c|c|c|c|c|}
\hline \multirow{2}{*}{\begin{tabular}{|l|l} 
\\
3 \\
通 \\
\end{tabular}} & Feet & Sec.ft. & Feot & Sec.ft. & Feet & Sec & ft. & Feet & Sec.ft. & Feet & Sec.ft. & Feet & Sec.ft. \\
\hline & \multicolumn{2}{|c|}{ September 18} & \multicolumn{2}{|c|}{ September 19} & \multicolumn{3}{|c|}{ Sept ember 20} & \multicolumn{2}{|c|}{ September 21} & \multicolumn{2}{|c|}{ September 22} & \multicolumn{2}{|c|}{ September 23} \\
\hline $\begin{array}{l}1 \\
2 \\
3 \\
4 \\
5 \\
6\end{array}$ & $\begin{array}{l}1.92 \\
1.91 \\
1.90 \\
1.89 \\
1.87 \\
1.84\end{array}$ & $\begin{array}{l}197 \\
194 \\
191 \\
188 \\
184 \\
176\end{array}$ & $\begin{array}{l}1.74 \\
1.74 \\
1.74 \\
1.74 \\
1.73 \\
1.73\end{array}$ & $\begin{array}{l}152 \\
152 \\
152 \\
152 \\
150 \\
150\end{array}$ & $\begin{array}{l}1.78 \\
1.78 \\
1.79 \\
1.80 \\
1.82 \\
1.83\end{array}$ & & $\begin{array}{l}161 \\
161 \\
164 \\
166 \\
171 \\
174\end{array}$ & $\begin{array}{l}3.46 \\
3.60 \\
3.75 \\
3.89 \\
4.02 \\
4.14\end{array}$ & $\begin{array}{r}960 \\
1,070 \\
1,190 \\
1,310 \\
1,430 \\
1,540\end{array}$ & $\begin{array}{r}12.34 \\
12.82 \\
12.78 \\
12.09 \\
10.60 \\
9.48\end{array}$ & $\begin{array}{l}18,600 \\
19,900 \\
19,800 \\
17,900 \\
14,000 \\
11,200\end{array}$ & $\begin{array}{l}4.72 \\
4.65 \\
4.58 \\
4.52 \\
4.46 \\
4.39\end{array}$ & $\begin{array}{l}2,120 \\
2,040 \\
1,970 \\
1,900 \\
1,840 \\
1,770\end{array}$ \\
\hline $\begin{array}{r}7 \\
8 \\
9 \\
10 \\
11 \\
N\end{array}$ & $\begin{array}{l}1.83 \\
1.82 \\
1.80 \\
1.79 \\
1.78 \\
1.76\end{array}$ & $\begin{array}{l}174 \\
171 \\
166 \\
164 \\
161 \\
157\end{array}$ & $\begin{array}{l}1.73 \\
1.73 \\
1.72 \\
1.71 \\
1.70 \\
1.70\end{array}$ & $\begin{array}{l}150 \\
150 \\
148 \\
145 \\
143 \\
143\end{array}$ & $\begin{array}{l}1.85 \\
1.88 \\
1.91 \\
1.95 \\
1.99 \\
2.04\end{array}$ & & $\begin{array}{l}178 \\
186 \\
194 \\
205 \\
216 \\
231\end{array}$ & $\begin{array}{l}4.24 \\
4.36 \\
4.44 \\
4.51 \\
4.59 \\
4.70\end{array}$ & $\begin{array}{l}1,630 \\
1,740 \\
1,820 \\
1,890 \\
1,980 \\
2,100\end{array}$ & $\begin{array}{l}8.68 \\
8.10 \\
7.66 \\
7.28 \\
6.96 \\
6.68\end{array}$ & $\begin{array}{l}9,260 \\
7,970 \\
7,040 \\
6,270 \\
5,620 \\
5,070\end{array}$ & $\begin{array}{l}4.33 \\
4.28 \\
4.23 \\
4.17 \\
4.12 \\
4.07\end{array}$ & $\begin{array}{l}1,710 \\
1,660 \\
1,620 \\
1,560 \\
1,520 \\
1,470\end{array}$ \\
\hline $\begin{array}{l}1 \\
2 \\
3 \\
4 \\
5 \\
6\end{array}$ & $\begin{array}{l}1.75 \\
1.74 \\
1.74 \\
1.74 \\
1.74 \\
1.74\end{array}$ & $\begin{array}{l}154 \\
152 \\
152 \\
152 \\
152 \\
152\end{array}$ & $\begin{array}{l}1.70 \\
1.69 \\
1.68 \\
1.68 \\
1.68 \\
1.68\end{array}$ & $\begin{array}{l}143 \\
141 \\
139 \\
139 \\
139 \\
139\end{array}$ & $\begin{array}{l}2.09 \\
2.15 \\
2.21 \\
2.28 \\
2.36 \\
2.45\end{array}$ & & $\begin{array}{l}247 \\
268 \\
289 \\
315 \\
347 \\
384\end{array}$ & $\begin{array}{l}4.86 \\
5.08 \\
5.35 \\
5.66 \\
6.04 \\
6.48\end{array}$ & $\begin{array}{l}2,290 \\
2,570 \\
2,940 \\
3,380 \\
3,960 \\
4,700\end{array}$ & $\begin{array}{l}6.43 \\
6.20 \\
6.00 \\
5.80 \\
5.64 \\
5.48\end{array}$ & $\begin{array}{l}4,610 \\
4,220 \\
3,900 \\
3,590 \\
3,350 \\
3,120\end{array}$ & $\begin{array}{l}4.03 \\
3.98 \\
3.04 \\
3.90 \\
3.86 \\
3.82\end{array}$ & $\begin{array}{l}1,440 \\
1,390 \\
1,360 \\
1,320 \\
1,280 \\
1,250\end{array}$ \\
\hline \multirow[t]{2}{*}{$\begin{array}{r}7 \\
8 \\
9 \\
10 \\
11 \\
11 \\
\end{array}$} & $\begin{array}{l}1.74 \\
1.74 \\
1.74 \\
1.74 \\
1.74 \\
1.74\end{array}$ & $\begin{array}{l}152 \\
152 \\
152 \\
152 \\
152 \\
152\end{array}$ & $\begin{array}{l}1.69 \\
1.70 \\
1.70 \\
1.72 \\
1.74 \\
1.77\end{array}$ & $\begin{array}{l}141 \\
143 \\
143 \\
148 \\
152 \\
159\end{array}$ & $\begin{array}{l}2.56 \\
2.69 \\
2.83 \\
3.00 \\
3.15 \\
3.31\end{array}$ & & $\begin{array}{l}432 \\
493 \\
564 \\
655 \\
746 \\
851\end{array}$ & $\begin{array}{r}7.04 \\
8.03 \\
8.67 \\
9.59 \\
10.75 \\
11.65\end{array}$ & $\begin{array}{r}5,780 \\
7,820 \\
9,240 \\
11,400 \\
14,400 \\
16,700\end{array}$ & $\begin{array}{l}5.33 \\
5.20 \\
5.08 \\
4.98 \\
4.88 \\
4.80\end{array}$ & $\begin{array}{l}2,910 \\
2,730 \\
2,570 \\
2,440 \\
2,320 \\
2,220\end{array}$ & $\begin{array}{l}3.78 \\
3.75 \\
3.71 \\
3.67 \\
3.64 \\
3.61\end{array}$ & $\begin{array}{l}1,210 \\
1,190 \\
1,160 \\
1,130 \\
1,100 \\
1,080\end{array}$ \\
\hline & \multicolumn{2}{|c|}{ September 24} & \multicolumn{2}{|c|}{ September 25} & \multicolumn{3}{|c|}{ September $\mathbf{2 6}$} & \multicolumn{2}{|c|}{ September 27} & \multicolumn{2}{|c|}{ September 28} & \multicolumn{2}{|c|}{ September 29} \\
\hline $\begin{array}{r}2 \\
4 \\
6 \\
8 \\
10 \\
\text { N }\end{array}$ & $\begin{array}{l}3.53 \\
3.47 \\
3.41 \\
3.35 \\
3.30 \\
3.25\end{array}$ & $\begin{array}{r}1,010 \\
968 \\
922 \\
880 \\
844 \\
810\end{array}$ & $\begin{array}{l}2.95 \\
2.91 \\
2.87 \\
2.83 \\
2.80 \\
2.77\end{array}$ & $\begin{array}{l}628 \\
606 \\
584 \\
564 \\
548 \\
533\end{array}$ & $\begin{array}{l}2.55 \\
2.53 \\
2.49 \\
2.47 \\
2.44 \\
2.42\end{array}$ & & $\begin{array}{l}428 \\
418 \\
401 \\
392 \\
380 \\
371\end{array}$ & $\begin{array}{l}2.30 \\
2.28 \\
2.26 \\
2.26 \\
2.26 \\
2.27\end{array}$ & $\begin{array}{l}323 \\
315 \\
308 \\
308 \\
308 \\
312\end{array}$ & $\begin{array}{l}2.39 \\
2.39 \\
2.39 \\
2.38 \\
2.37 \\
2.35\end{array}$ & $\begin{array}{l}359 \\
359 \\
359 \\
355 \\
351 \\
343\end{array}$ & $\begin{array}{l}2.19 \\
2.18 \\
2.16 \\
2.14 \\
2.13 \\
2.12\end{array}$ & $\begin{array}{l}282 \\
278 \\
271 \\
264 \\
260 \\
257\end{array}$ \\
\hline $\begin{array}{r}2 \\
4 \\
6 \\
8 \\
10 \\
M\end{array}$ & $\begin{array}{l}3.20 \\
3.15 \\
3.11 \\
3.07 \\
3.02 \\
2.98\end{array}$ & $\begin{array}{l}777 \\
746 \\
720 \\
696 \\
667 \\
644\end{array}$ & $\begin{array}{l}2.74 \\
2.71 \\
2.67 \\
2.64 \\
2.62 \\
2.58\end{array}$ & $\begin{array}{l}518 \\
503 \\
484 \\
469 \\
460 \\
441\end{array}$ & $\begin{array}{l}2.41 \\
2.39 \\
2.38 \\
2.37 \\
2.35 \\
2.32\end{array}$ & & $\begin{array}{l}367 \\
359 \\
355 \\
351 \\
343 \\
331\end{array}$ & $\begin{array}{l}2.28 \\
2.30 \\
2.32 \\
2.36 \\
2.37 \\
2.38\end{array}$ & $\begin{array}{l}315 \\
323 \\
331 \\
347 \\
351 \\
355\end{array}$ & $\begin{array}{l}2.33 \\
2.31 \\
2.28 \\
2.25 \\
2.23 \\
2.22\end{array}$ & $\begin{array}{l}335 \\
327 \\
315 \\
304 \\
296 \\
293\end{array}$ & $\begin{array}{l}2.11 \\
2.10 \\
2.09 \\
2.08 \\
2.06 \\
2.03\end{array}$ & $\begin{array}{l}254 \\
250 \\
247 \\
244 \\
238 \\
228\end{array}$ \\
\hline
\end{tabular}




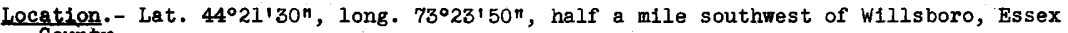
County.

Drainage area.- 275 square miles.

Gage-helght record.- Water-stage recorder graph.

Stage-discharge relation.- Defined by current-meter measurements below 4,590 secondfeet; extended iogarithmically to peak discharge.

Maxima.- September 1938: Discharge, 7,640 second-feet noon Sept. 22 (gage helght, 8.77 feet).

July 1923 to August 1938: Discharge, 11,800 second-feet Oct. 1, 1924 (gage height, 10.85 feet).

Remarks.- Records of gage he1ghts and discharge measurements only avallable August to September 1904 and August to November 1908.

Mean dally discharge, in second-feet, 1938

\begin{tabular}{|c|c|c|c|c|c|c|c|c|c|c|c|}
\hline Day & Sept. & Oct. & Day & Sept. & Oct. & Day & Sept. & Oct. & Day & Sept. & Oct. \\
\hline $\begin{array}{l}1 \\
2 \\
3 \\
4 \\
5 \\
6 \\
7 \\
8\end{array}$ & $\begin{array}{r}107 \\
104 \\
92 \\
78 \\
70 \\
63 \\
68 \\
87\end{array}$ & $\begin{array}{l}235 \\
218 \\
201 \\
193 \\
189 \\
178 \\
166 \\
159\end{array}$ & $\begin{array}{l}9 \\
10 \\
11 \\
12 \\
13 \\
14 \\
15 \\
16\end{array}$ & $\begin{array}{r}85 \\
75 \\
73 \\
70 \\
125 \\
135 \\
145 \\
163\end{array}$ & $\begin{array}{l}155 \\
155 \\
155 \\
152 \\
148 \\
145 \\
141 \\
138\end{array}$ & $\begin{array}{l}17 \\
18 \\
19 \\
20 \\
21 \\
22 \\
23 \\
24\end{array}$ & $\begin{array}{r}138 \\
110 \\
107 \\
247 \\
2,180 \\
\mathbf{5}, 800 \\
1,430 \\
747\end{array}$ & $\begin{array}{l}135 \\
135 \\
131 \\
138 \\
141 \\
141 \\
135 \\
154\end{array}$ & $\begin{array}{l}25 \\
26 \\
27 \\
28 \\
29 \\
30 \\
31\end{array}$ & $\begin{array}{l}550 \\
410 \\
344 \\
334 \\
291 \\
253\end{array}$ & $\begin{array}{l}337 \\
296 \\
231 \\
201 \\
185 \\
178 \\
163\end{array}$ \\
\hline $\begin{array}{l}\text { Mean } \\
\text { Run- }\end{array}$ & $\begin{array}{l}\text { nthly } \\
e, \text { In }\end{array}$ & ahar & , ir & $\begin{array}{c}\text { second- } \\
. .\end{array}$ & $\dot{.}$ & . $\cdot$ & $\begin{array}{l}\cdot \cdot \cdot \\
\cdot\end{array}$ & 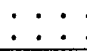 & $\dot{0} \cdot \dot{ }$ & $\begin{array}{r}483 \\
1.96\end{array}$ & $\begin{array}{r}175 \\
0.73\end{array}$ \\
\hline
\end{tabular}

Gage he1ght, in feet, and discharge, in second-feet, at indicated time, 1938

\begin{tabular}{|c|c|c|c|c|c|c|c|c|c|c|c|c|c|}
\hline \multirow{2}{*}{$\begin{array}{l}\mathbf{g} \\
\text { 量 } \\
\end{array}$} & Feet & Sec & .ft. & Feet & Sec.ft. & Foot & Sec.ft. & Feet & Sec.ft. & Feet & sec.ft. & Feet & Sec.ft. \\
\hline & \multicolumn{3}{|c|}{ September 18} & \multicolumn{2}{|c|}{ September 19} & \multicolumn{2}{|c|}{ September 20 . } & \multicolumn{2}{|c|}{ September 21} & \multicolumn{2}{|c|}{ September 22} & \multicolumn{2}{|c|}{ September 23} \\
\hline $\begin{array}{l}1 \\
2 \\
3 \\
4 \\
5 \\
6\end{array}$ & $\begin{array}{l}2.59 \\
2.59 \\
2.58 \\
2.58 \\
2.58 \\
2.57\end{array}$ & & $\begin{array}{l}118 \\
118 \\
115 \\
115 \\
115 \\
112\end{array}$ & $\begin{array}{l}2.54 \\
2.54 \\
2.54 \\
2.54 \\
2.54 \\
2.54\end{array}$ & $\begin{array}{l}104 \\
104 \\
104 \\
104 \\
104 \\
104\end{array}$ & $\begin{array}{l}2.62 \\
2.62 \\
2.62 \\
2.62 \\
2.63 \\
2.65\end{array}$ & $\begin{array}{l}128 \\
128 \\
128 \\
128 \\
131 \\
138\end{array}$ & $\begin{array}{l}3.52 \\
3.56 \\
3.60 \\
3.64 \\
3.69 \\
3.75\end{array}$ & $\begin{array}{l}584 \\
612 \\
640 \\
668 \\
703 \\
748\end{array}$ & $\begin{array}{l}7.56 \\
7.51 \\
7.49 \\
7.50 \\
7.59 \\
7.75\end{array}$ & $\begin{array}{l}5,540 \\
5,460 \\
5,420 \\
5,440 \\
5,580 \\
5,860\end{array}$ & $\begin{array}{l}5.51 \\
5.31 \\
5.17 \\
5.01 \\
4.90 \\
4.80\end{array}$ & $\begin{array}{l}2,540 \\
2,280 \\
2,110 \\
1,920 \\
1,800 \\
1,690\end{array}$ \\
\hline $\begin{array}{r}7 \\
8 \\
9 \\
10 \\
11 \\
11\end{array}$ & $\begin{array}{l}2.57 \\
2.57 \\
2.56 \\
2.56 \\
2.56 \\
2.56\end{array}$ & & $\begin{array}{l}112 \\
112 \\
109 \\
109 \\
109 \\
109\end{array}$ & $\begin{array}{l}2.54 \\
2.54 \\
2.54 \\
2.55 \\
2.55 \\
2.55\end{array}$ & $\begin{array}{l}104 \\
104 \\
104 \\
106 \\
106 \\
106\end{array}$ & $\begin{array}{l}2.66 \\
2.67 \\
2.69 \\
2.71 \\
2.75 \\
2.79\end{array}$ & $\begin{array}{l}141 \\
145 \\
152 \\
159 \\
174 \\
189\end{array}$ & $\begin{array}{l}3.85 \\
4.01 \\
4.21 \\
4.40 \\
4.60 \\
4.80\end{array}$ & $\begin{array}{r}822 \\
948 \\
1,120 \\
1,290 \\
1,490 \\
1,690\end{array}$ & $\begin{array}{l}7.98 \\
8.28 \\
8.44 \\
8.65 \\
8.73 \\
8.77\end{array}$ & $\begin{array}{l}6,250 \\
6,760 \\
7,040 \\
7,420 \\
7,560 \\
7,640\end{array}$ & $\begin{array}{l}4.71 \\
4.63 \\
4.55 \\
4.49 \\
4.43 \\
4.37\end{array}$ & $\begin{array}{l}1,600 \\
1,520 \\
1,440 \\
1,380 \\
1,320 \\
1,260\end{array}$ \\
\hline $\begin{array}{l}1 \\
2 \\
3 \\
4 \\
5 \\
6\end{array}$ & $\begin{array}{l}2.55 \\
2.55 \\
2.55 \\
2.55 \\
2.55 \\
2.55\end{array}$ & & $\begin{array}{l}106 \\
106 \\
106 \\
106 \\
106 \\
106\end{array}$ & $\begin{array}{l}2.55 \\
2.55 \\
2.55 \\
2.55 \\
2.55 \\
2.55\end{array}$ & $\begin{array}{l}106 \\
106 \\
106 \\
106 \\
106 \\
106\end{array}$ & $\begin{array}{l}2.84 \\
2.89 \\
2.95 \\
3.00 \\
3.06 \\
3.13\end{array}$ & $\begin{array}{l}210 \\
231 \\
258 \\
281 \\
311 \\
347\end{array}$ & $\begin{array}{l}4.98 \\
5.17 \\
5.34 \\
5.52 \\
5.72 \\
5.90\end{array}$ & $\begin{array}{l}1,890 \\
2,110 \\
2,320 \\
2,560 \\
2,820 \\
3,060\end{array}$ & $\begin{array}{l}8.65 \\
8.52 \\
8.30 \\
8.05 \\
7.77 \\
7.47\end{array}$ & $\begin{array}{l}7,420 \\
7,190 \\
6,790 \\
6,360 \\
5,890 \\
5,390\end{array}$ & $\begin{array}{l}4.31 \\
4.27 \\
4.24 \\
4.20 \\
4.16 \\
4.13\end{array}$ & $\begin{array}{l}1,210 \\
1,170 \\
1,150 \\
1,110 \\
1,080 \\
1,050\end{array}$ \\
\hline \multirow[t]{2}{*}{$\begin{array}{r}7 \\
8 \\
9 \\
10 \\
11 \\
M\end{array}$} & $\begin{array}{l}2.55 \\
2.55 \\
2.55 \\
2.55 \\
2.55 \\
2.55 \\
\end{array}$ & & $\begin{array}{l}106 \\
106 \\
106 \\
106 \\
106 \\
106\end{array}$ & $\begin{array}{l}2.56 \\
2.56 \\
2.57 \\
2.58 \\
2.60 \\
2.61 \\
\end{array}$ & $\begin{array}{l}109 \\
109 \\
112 \\
115 \\
121 \\
124\end{array}$ & $\begin{array}{l}3.19 \\
3.25 \\
3.30 \\
3.35 \\
3.41 \\
3.47\end{array}$ & $\begin{array}{l}380 \\
414 \\
443 \\
474 \\
512 \\
550 \\
\end{array}$ & $\begin{array}{l}6.17 \\
6.67 \\
7.15 \\
7.40 \\
7.52 \\
7.56\end{array}$ & $\begin{array}{l}3,440 \\
4,160 \\
4,880 \\
5,280 \\
5,470 \\
5,540\end{array}$ & $\begin{array}{l}7.15 \\
6.85 \\
6.53 \\
6.25 \\
5.98 \\
5.72 \\
\end{array}$ & $\begin{array}{l}4,880 \\
4,420 \\
3,940 \\
3,550 \\
3,170 \\
2,820\end{array}$ & $\begin{array}{l}4.10 \\
4.07 \\
4.04 \\
4.01 \\
3.99 \\
3.96\end{array}$ & $\begin{array}{r}1,020 \\
1,000 \\
974 \\
948 \\
932 \\
908 \\
\end{array}$ \\
\hline & \multicolumn{3}{|c|}{ September 24} & \multicolumn{2}{|c|}{ September 25} & \multicolumn{2}{|c|}{ September 26} & \multicolumn{2}{|c|}{ September 27} & \multicolumn{2}{|c|}{ September 28} & \multicolumn{2}{|c|}{ September $2 \theta$} \\
\hline $\begin{array}{r}2 \\
4 \\
6 \\
8 \\
10 \\
N\end{array}$ & $\begin{array}{l}3.92 \\
3.87 \\
3.82 \\
3.79 \\
3.75 \\
3.73\end{array}$ & & $\begin{array}{l}876 \\
838 \\
800 \\
778 \\
748 \\
732\end{array}$ & $\begin{array}{l}3.58 \\
3.55 \\
3.53 \\
3.51 \\
3.49 \\
3.47\end{array}$ & $\begin{array}{l}626 \\
605 \\
591 \\
577 \\
564 \\
550\end{array}$ & $\begin{array}{l}3.32 \\
3.30 \\
3.29 \\
3.27 \\
3.25 \\
3.24\end{array}$ & $\begin{array}{l}455 \\
443 \\
437 \\
426 \\
414 \\
408\end{array}$ & $\begin{array}{l}3.16 \\
3.15 \\
3.15 \\
3.14 \\
3.13 \\
3.12\end{array}$ & $\begin{array}{l}363 \\
358 \\
358 \\
353 \\
347 \\
342\end{array}$ & $\begin{array}{l}3.11 \\
3.11 \\
3.12 \\
3.12 \\
3.13 \\
3.12\end{array}$ & $\begin{array}{l}336 \\
336 \\
342 \\
342 \\
347 \\
342\end{array}$ & $\begin{array}{l}3.05 \\
3.05 \\
3.05 \\
3.04 \\
3.03 \\
3.02\end{array}$ & $\begin{array}{l}306 \\
306 \\
306 \\
301 \\
296 \\
291\end{array}$ \\
\hline $\begin{array}{r}2 \\
4 \\
6 \\
8 \\
10 \\
M\end{array}$ & $\begin{array}{l}3.71 \\
3.69 \\
3.66 \\
3.64 \\
3.61 \\
3.59\end{array}$ & & $\begin{array}{l}718 \\
703 \\
682 \\
668 \\
647 \\
633\end{array}$ & $\begin{array}{l}3.44 \\
3.42 \\
3.40 \\
3.37 \\
3.35 \\
3.33\end{array}$ & $\begin{array}{l}531 \\
518 \\
505 \\
486 \\
474 \\
462\end{array}$ & $\begin{array}{l}3.22 \\
3.21 \\
3.20 \\
3.19 \\
3.18 \\
3.17\end{array}$ & $\begin{array}{l}397 \\
391 \\
385 \\
380 \\
374 \\
369\end{array}$ & $\begin{array}{l}3.11 \\
3.10 \\
3.10 \\
3.10 \\
3.10 \\
3.10\end{array}$ & $\begin{array}{l}336 \\
331 \\
331 \\
331 \\
331 \\
331\end{array}$ & $\begin{array}{l}3.11 \\
3.10 \\
3.10 \\
3.09 \\
3.08 \\
3.07\end{array}$ & $\begin{array}{l}336 \\
331 \\
331 \\
326 \\
321 \\
316\end{array}$ & $\begin{array}{l}3.00 \\
3.00 \\
3.00 \\
2.99 \\
2.98 \\
2.98\end{array}$ & $\begin{array}{l}281 \\
281 \\
281 \\
276 \\
272 \\
272\end{array}$ \\
\hline
\end{tabular}


Lake George at Rogers Rock, N. Y.

Location.- Water-stage recorder, lat. $43^{\circ} 48^{\prime} 10^{\prime \prime}$, long. $73^{\circ} 27^{\prime} 25^{\prime \prime}$, about 500 feet north of Hooper's dock, on south side of Stones Bay, Rogers Rock, Essex County. Zero of gage is 315.93 feet above mean sea level.

Gage-height record.- Water-stage recorder graph. Prior to Nov. 11, 1936, staff gage is at same site and datum.

Maxima.- September 1938: Gage helght, 4.37 feet 1:30 a.m. Sept. 22. July 1913 to August 1938: Gage height, 5.09 feet Apr. 9, 1936

Remarks.- Elevation of lake surface regulated by power operations and flood gates at

Ticonderoga. Mean dally gage heights estimated for period october $29-31$.

Mean daily gage height, in feet, 1938

\begin{tabular}{|c|c|c|c|c|c|c|c|c|c|c|c|}
\hline Day & Sept. & oct. & Day & Sept. & oct. & Day & Sept. & oct. & Day & Sept. & oct. \\
\hline $\begin{array}{l}1 \\
2 \\
3 \\
4 \\
5 \\
6 \\
7 \\
8\end{array}$ & $\begin{array}{l}3.36 \\
3.30 \\
3.30 \\
3.31 \\
3.22 \\
3.20 \\
3.19 \\
3.11\end{array}$ & $\begin{array}{l}4.01 \\
3.96 \\
3.94 \\
3.92 \\
3.88 \\
3.78 \\
3.78 \\
3.77\end{array}$ & $\begin{array}{l}9 \\
10 \\
11 \\
12 \\
13 \\
14 \\
15 \\
16\end{array}$ & $\begin{array}{l}3.10 \\
3.10 \\
3.08 \\
3.10 \\
3.13 \\
3.12 \\
3.21 \\
3.21\end{array}$ & $\begin{array}{l}3.73 \\
3.71 \\
3.72 \\
3.70 \\
3.70 \\
3.69 \\
3.69 \\
3.69\end{array}$ & $\begin{array}{l}17 \\
18 \\
19 \\
20 \\
21 \\
22 \\
23 \\
24\end{array}$ & $\begin{array}{l}3.20 \\
3.19 \\
3.22 \\
3.33 \\
3.58 \\
4.19 \\
4.17 \\
4.19\end{array}$ & $\begin{array}{l}3.65 \\
3.64 \\
3.66 \\
3.63 \\
3.62 \\
3.57 \\
3.60 \\
3.61\end{array}$ & $\begin{array}{l}25 \\
26 \\
27 \\
28 \\
29 \\
30 \\
31\end{array}$ & $\begin{array}{l}4.15 \\
4.17 \\
4.15 \\
4.12 \\
4.05 \\
4.03\end{array}$ & $\begin{array}{l}3.65 \\
3.65 \\
3.58 \\
3.52 \\
3.53 \\
3.52 \\
3.51\end{array}$ \\
\hline
\end{tabular}

Gage hejght, in feet, at ind1cated time, September 1938

\begin{tabular}{|c|c|c|c|c|c|c|c|c|c|c|}
\hline \multirow{2}{*}{ Hour } & \multicolumn{2}{|c|}{ September 19} & \multicolumn{2}{|c|}{ September 20} & \multicolumn{2}{|c|}{ September 21} & \multicolumn{2}{|c|}{ September 22} & \multicolumn{2}{|c|}{ September 23} \\
\hline & A.M. & P.M. & A.M. & P.M. & A.M. & P.M. & A.M. & P.M. & A.M. & P.M. \\
\hline $\begin{array}{l}1 \\
2 \\
3 \\
4 \\
5 \\
6\end{array}$ & $\begin{array}{l}3.19 \\
3.21 \\
3.22 \\
3.20 \\
3.21 \\
3.21\end{array}$ & $\begin{array}{l}3.20 \\
3.21 \\
3.21 \\
3.22 \\
3.22 \\
3.23\end{array}$ & $\begin{array}{l}3.29 \\
3.31 \\
3.28 \\
3.32 \\
3.31 \\
3.31\end{array}$ & $\begin{array}{l}3.33 \\
3.32 \\
3.30 \\
3.32 \\
3.34 \\
3.32\end{array}$ & $\begin{array}{l}3.39 \\
3.36 \\
3.42 \\
3.42 \\
3.45 \\
3.48\end{array}$ & $\begin{array}{l}3.54 \\
3.66 \\
3.58 \\
3.46 \\
3.41 \\
3.42\end{array}$ & $\begin{array}{l}4.21 \\
4.19 \\
4.07 \\
4.22 \\
4.12 \\
4.17\end{array}$ & $\begin{array}{l}4.20 \\
4.18 \\
4.28 \\
4.19 \\
4.21 \\
4.24\end{array}$ & $\begin{array}{l}4.20 \\
4.17 \\
4.18 \\
4.19 \\
4.17 \\
4.18\end{array}$ & $\begin{array}{l}4.15 \\
4.17 \\
4.16 \\
4.16 \\
4.17 \\
4.16\end{array}$ \\
\hline $\begin{array}{r}7 \\
8 \\
9 \\
10 \\
11 \\
12\end{array}$ & $\begin{array}{l}3.20 \\
3.22 \\
3.21 \\
3.20 \\
3.21 \\
3.20\end{array}$ & $\begin{array}{l}3.25 \\
3.28 \\
3.26 \\
3.27 \\
3.30 \\
3.27\end{array}$ & $\begin{array}{l}3.34 \\
3.33 \\
3.32 \\
3.33 \\
3.32 \\
3.32\end{array}$ & $\begin{array}{l}3.36 \\
3.39 \\
3.35 \\
3.39 \\
3.39 \\
3.37\end{array}$ & $\begin{array}{l}3.43 \\
3.46 \\
3.51 \\
3.49 \\
3.52 \\
3.56\end{array}$ & $\begin{array}{l}3.54 \\
4.07 \\
3.99 \\
3.96 \\
4.26 \\
4.02\end{array}$ & $\begin{array}{l}4.24 \\
4.14 \\
4.24 \\
4.24 \\
4.16 \\
4.22\end{array}$ & $\begin{array}{l}4.22 \\
4.22 \\
4.20 \\
4.20 \\
4.18 \\
4.16\end{array}$ & $\begin{array}{l}4.16 \\
4.16 \\
4.17 \\
4.16 \\
4.17 \\
4.16\end{array}$ & $\begin{array}{l}4.19 \\
4.19 \\
4.18 \\
4.21 \\
4.18 \\
4.20\end{array}$ \\
\hline
\end{tabular}

Supplemental records. - Sept. $21,8: 30 \mathrm{pm}, 4.12 \mathrm{ft} ; 9: 30 \mathrm{p.m}, 3.89 \mathrm{ft}$.

Sept. 22, 1:30 a.m., 4.37 ft.; 6:30 a.m., 4.27 ft.; 9:20 a.m., 4:28 ft.; 1:30 p.m., 4.17 ft.; 2:30 p.m., 4:29 ft.; 4:20 p.m., 4.17 ft.; 5:30 p.m., $4.28 \mathrm{ft}$. 
Poultney River below Fair Haven, Vt.

Location.- Water-stage recorder, lat. $43^{\circ} 37^{\prime} 40^{\prime \prime}$, long. $73^{\circ} 18^{\prime} 50^{\prime \prime}$, a third of a mfle below Carver Falls, 1.9 miles above mouth of Hubbardion River, and $3 \frac{1}{4}$ miles northwest of Fair Haven, Rutland County.

Drainage area.- 187 gquare miles.

Gage-he1ght record. - Water-stage recorder graph except for perlods 12 a.m. Sept. 24 to Sept. 29, 0ct. 2,3 , and 29 , records for which were based on shape of stage graphs at nearby stations.

Stage-discharge relation. - Defined by current-meter messurements below 1,190 secondfeet; extended to peak stage on basis of determinations of flood flows over dam.

Maxima:- September 1938: Discharge, 10,300 second-feet 5 a.m. Sept. 22 (gage height, 21.40 feet).

1928 to August 1938: Maximum discharge, 6,190 second-feet Mar. 18, 1936 (gage

he1ght, 16.50 feet); maximum gage helght, 22.90 feet Mar. 12, 1936 (1ce jam).

Remarks. - Flood run-off affected by storage in Lake Bomoseen.

Mean daily discharge, in second-feet, 1938

\begin{tabular}{|c|c|c||c|c|c||c|c|c||c|c|c|}
\hline Day & Sept. & 0ct. & Day & Sept. & 0ct. & Day & Sept. & 0ct. & Day & Sept. & 0ct. \\
\hline 1 & 42 & 411 & 9 & 63 & 188 & 17 & 360 & 148 & 25 & 895 & 279 \\
2 & 39 & 370 & 10 & 60 & 224 & 18 & 282 & 158 & 26 & 660 & 253 \\
3 & 26 & 350 & 11 & 17 & 202 & 19 & 241 & 110 & 27 & 595 & 244 \\
4 & 13 & 349 & 12 & 63 & 189 & 20 & 632 & 180 & 28 & 580 & 226 \\
5 & 29 & 332 & 13 & 231 & 207 & 21 & 1,880 & 168 & 29 & 545 & 206 \\
6 & 51 & 314 & 14 & 270 & 170 & 22 & 6,880 & 156 & 30 & 472 & 165 \\
7 & 50 & 293 & 15 & 308 & 164 & 23 & 2,540 & 95 & 31 & & 154 \\
8 & 72 & 251 & 16 & 620 & 52 & 24 & 1,450 & 173 & & & \\
\hline
\end{tabular}

Gage helght, in feet, and discharge, in second-feet, at indicated time, 1938

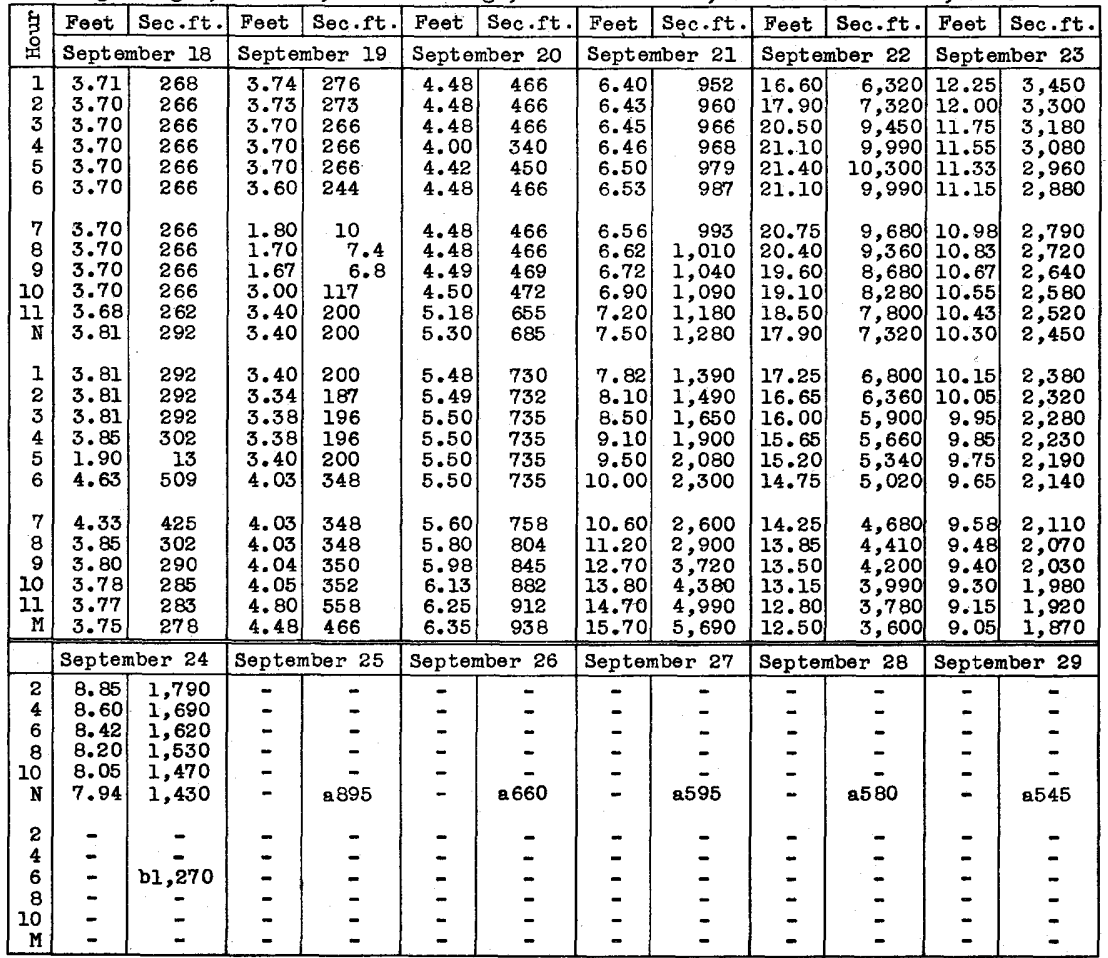

Mean for the day.

b Mean for 12 hours. 
Location.- Water-stage recorder, lat. $43^{\circ} 36^{\prime} 15^{\mathrm{n}}$, long. $73^{\circ} 00^{\prime} 50^{\mathrm{n}}$, at highway bridge in Center Rutland, Rutland County, IOO feet below dam and 1 mile below mouth of East Creek.

Drainage area.- 307 square miles.

Gage-height record.- Water-stage recorder graph.

Stage-discharge relation.- Defined by current-meter measurements below 3,450 second-feet; extended to peak stage on basis of determination of flood flow over dam.

Maxima,- September 1938: Discharge, 13,700 second-feet 1 a.m. Sept. 22 (gage he1ght, 12.45 feet).

1928 to August 1938: Discharge, 8,580 second-feet Mar. 18, 19, 1936 (gage helght, 10.84 feet).

Remarks.- Flood run-off not materlally affected by storage.

Mean dally discharge, in second-feet, 1938

\begin{tabular}{|c|c|c|c|c|c|c|c|c|c|c|c|}
\hline Day & Sept. & oct. & Day & Sept. & Oct. & Day & Sept. & Oct. & Day & Sept. & Oct. \\
\hline $\begin{array}{l}1 \\
2 \\
3 \\
4 \\
5 \\
6 \\
7 \\
8\end{array}$ & $\begin{array}{l}276 \\
256 \\
182 \\
202 \\
173 \\
220 \\
261 \\
376\end{array}$ & $\begin{array}{l}576 \\
540 \\
494 \\
494 \\
436 \\
416 \\
396 \\
388\end{array}$ & $\begin{array}{l}9 \\
10 \\
11 \\
12 \\
13 \\
14 \\
15 \\
16\end{array}$ & $\begin{array}{r}304 \\
204 \\
134 \\
216 \\
1,660 \\
944 \\
1,250 \\
1,410\end{array}$ & $\begin{array}{l}346 \\
334 \\
362 \\
376 \\
374 \\
342 \\
324 \\
330\end{array}$ & $\begin{array}{l}17 \\
18 \\
19 \\
20 \\
21 \\
22 \\
23 \\
24\end{array}$ & $\begin{array}{r}819 \\
756 \\
787 \\
1,910 \\
5,520 \\
10,100 \\
4,790 \\
2,620 \\
\end{array}$ & $\begin{array}{l}297 \\
315 \\
324 \\
316 \\
430 \\
445 \\
404 \\
467\end{array}$ & $\begin{array}{l}25 \\
26 \\
27 \\
28 \\
29 \\
30 \\
31\end{array}$ & $\begin{array}{r}1,650 \\
1,190 \\
966 \\
921 \\
775 \\
668\end{array}$ & $\begin{array}{r}1,090 \\
693 \\
519 \\
476 \\
388 \\
346 \\
337\end{array}$ \\
\hline $\begin{array}{l}\text { Mean } \\
\text { Run- }\end{array}$ & $\begin{array}{l}\text { nthly } \\
\text {, in }\end{array}$ & & & - . & - & $: \dot{0}$ & • : & . $\cdot \dot{0}$ & $\dot{0}$ & $\begin{array}{r}1,385 \\
5.03 \\
\end{array}$ & $\begin{array}{r}431 \\
1.61 \\
\end{array}$ \\
\hline
\end{tabular}

Gage height, in feet, and discharge, in second-feet, at indicated time, 1938

\begin{tabular}{|c|c|c|c|c|c|c|c|c|c|c|c|c|}
\hline \multirow{2}{*}{$\begin{array}{l}\text { 89 } \\
\text { : } \\
\text { : }\end{array}$} & Feet & Sec.ft. & Feet & Sec.ft. & Feet & Sec.ft. & Feet & Sec.ft. & Feet & Sec.ft. & Feet & Sec.ft. \\
\hline & \multicolumn{2}{|c|}{ September 18} & \multicolumn{2}{|c|}{ September 19} & \multicolumn{2}{|c|}{ September 20} & \multicolumn{2}{|c|}{ September 21} & \multicolumn{2}{|c|}{ September 22} & \multicolumn{2}{|c|}{ Septiember 23} \\
\hline $\begin{array}{l}1 \\
2 \\
3 \\
4 \\
5 \\
6\end{array}$ & $\begin{array}{l}2.71 \\
2.63 \\
2.62 \\
2.65 \\
2.67 \\
2.68\end{array}$ & $\begin{array}{l}631 \\
594 \\
589 \\
603 \\
612 \\
617\end{array}$ & $\begin{array}{l}2.87 \\
2.78 \\
2.73 \\
2.72 \\
2.70 \\
2.69\end{array}$ & $\begin{array}{l}707 \\
664 \\
640 \\
635 \\
626 \\
621\end{array}$ & $\begin{array}{l}3.21 \\
3.26 \\
3.39 \\
3.64 \\
3.92 \\
4.17\end{array}$ & $\begin{array}{r}876 \\
906 \\
984 \\
1,140 \\
1,330 \\
1,510\end{array}$ & $\begin{array}{l}5.47 \\
5.52 \\
5.61 \\
5.70 \\
5.76 \\
5.88\end{array}$ & $\begin{array}{l}2,580 \\
2,630 \\
2,710 \\
2,800 \\
2,860 \\
2,980\end{array}$ & $\begin{array}{l}12.45 \\
12.37 \\
12.24 \\
12.24 \\
11.99 \\
11.78\end{array}$ & $\begin{array}{l}13,700 \\
13,600 \\
13,300 \\
13,300 \\
12,800 \\
12,300\end{array}$ & $\begin{array}{l}8.55 \\
8.44 \\
8.32 \\
8.21 \\
8.10 \\
8.00\end{array}$ & $\begin{array}{l}6,330 \\
6,160 \\
5,980 \\
5,820 \\
5,650 \\
5,500\end{array}$ \\
\hline $\begin{array}{r}7 \\
8 \\
9 \\
10 \\
I 1 \\
N\end{array}$ & $\begin{array}{l}2.70 \\
2.72 \\
3.03 \\
3.15 \\
3.21 \\
3.24\end{array}$ & $\begin{array}{l}626 \\
635 \\
785 \\
845 \\
876 \\
894\end{array}$ & $\begin{array}{l}2.72 \\
2.64 \\
2.93 \\
3.02 \\
3.10 \\
3.10\end{array}$ & $\begin{array}{l}635 \\
598 \\
735 \\
780 \\
820 \\
820\end{array}$ & $\begin{array}{l}4.47 \\
4.66 \\
4.69 \\
4.72 \\
4.77 \\
4.84\end{array}$ & $\begin{array}{l}1,740 \\
1,890 \\
1,910 \\
1,940 \\
1,980 \\
2,030\end{array}$ & $\begin{array}{l}6.02 \\
6.09 \\
6.25 \\
6.50 \\
6.74 \\
7.00\end{array}$ & $\begin{array}{l}3,120 \\
3,190 \\
3,360 \\
3,630 \\
3,890 \\
4,200\end{array}$ & $\begin{array}{l}11.62 \\
11.36 \\
11.11 \\
10.87 \\
10.72 \\
10.50\end{array}$ & $\begin{array}{r}12,000 \\
11,500 \\
11,000 \\
10,500 \\
10,200 \\
9,750\end{array}$ & $\begin{array}{l}7.89 \\
7.80 \\
7.70 \\
7.59 \\
7.49 \\
7.40\end{array}$ & $\begin{array}{l}5,350 \\
5,220 \\
5,080 \\
4,940 \\
4,810 \\
4,690\end{array}$ \\
\hline $\begin{array}{l}1 \\
2 \\
3 \\
4 \\
5 \\
6\end{array}$ & $\begin{array}{l}3.25 \\
3.25 \\
3.15 \\
2.96 \\
2.91 \\
2.99\end{array}$ & $\begin{array}{l}900 \\
900 \\
845 \\
750 \\
726 \\
765\end{array}$ & $\begin{array}{l}3.12 \\
3.12 \\
3.14 \\
3.15 \\
3.19 \\
3.23\end{array}$ & $\begin{array}{l}830 \\
820 \\
840 \\
845 \\
865 \\
888\end{array}$ & $\begin{array}{l}4.95 \\
5.02 \\
5.09 \\
5.12 \\
5.15 \\
5.21\end{array}$ & $\begin{array}{l}2,120 \\
2,180 \\
2,240 \\
2,270 \\
2,300 \\
2,350\end{array}$ & $\begin{array}{l}7.22 \\
7.51 \\
7.97 \\
8.41 \\
8.73 \\
9.13\end{array}$ & $\begin{array}{l}4,460 \\
4,830 \\
5,460 \\
6,120 \\
6,620 \\
7,270\end{array}$ & $\begin{array}{r}10.31 \\
10.15 \\
9.97 \\
9.82 \\
9.70 \\
9.55\end{array}$ & $\begin{array}{l}9,390 \\
9,080 \\
8,750 \\
8,480 \\
8,260 \\
7,990\end{array}$ & $\begin{array}{l}7.30 \\
7.22 \\
7.13 \\
7.02 \\
6.94 \\
6.84\end{array}$ & $\begin{array}{l}4,560 \\
4,460 \\
4,360 \\
4,220 \\
4,130 \\
4,010\end{array}$ \\
\hline \multirow[t]{2}{*}{$\begin{array}{r}7 \\
8 \\
9 \\
10 \\
11 \\
M \\
\end{array}$} & $\begin{array}{l}2.93 \\
3.15 \\
3.19 \\
3.19 \\
3.18 \\
3.09\end{array}$ & $\begin{array}{l}736 \\
845 \\
865 \\
865 \\
860 \\
815 \\
\end{array}$ & $\begin{array}{l}3.25 \\
3.27 \\
3.29 \\
3.32 \\
3.38 \\
3.25\end{array}$ & $\begin{array}{l}900 \\
912 \\
924 \\
942 \\
978 \\
900\end{array}$ & $\begin{array}{l}5.23 \\
5.27 \\
5.32 \\
5.41 \\
5.47 \\
5.51\end{array}$ & $\begin{array}{l}2,370 \\
2,400 \\
2,450 \\
2,530 \\
2,580 \\
2,620\end{array}$ & $\begin{array}{r}9.55 \\
9.98 \\
10.72 \\
11.42 \\
12.07 \\
12.37\end{array}$ & $\begin{array}{r}7,990 \\
8,760 \\
10,200 \\
11,600 \\
13,000 \\
13,600\end{array}$ & $\begin{array}{l}9.41 \\
9.22 \\
9.08 \\
8.94 \\
8.80 \\
8.68 \\
\end{array}$ & $\begin{array}{l}7,750 \\
7,420 \\
7,190 \\
6,950 \\
6,730 \\
6,540\end{array}$ & $\begin{array}{l}6.73 \\
6.65 \\
6.59 \\
6.52 \\
6.42 \\
6.32 \\
\end{array}$ & $\begin{array}{l}3,880 \\
3,800 \\
3,730 \\
3,650 \\
3,540 \\
3,430 \\
\end{array}$ \\
\hline & \multicolumn{2}{|c|}{ September 24} & \multicolumn{2}{|c|}{ September 25} & \multicolumn{2}{|c|}{ September 26} & \multicolumn{2}{|c|}{ September 27} & \multicolumn{2}{|c|}{ September 28} & \multicolumn{2}{|c|}{ September 29} \\
\hline $\begin{array}{r}2 \\
4 \\
6 \\
8 \\
10 \\
N\end{array}$ & $\begin{array}{l}6.16 \\
6.00 \\
5.84 \\
5.70 \\
5.58 \\
5.43\end{array}$ & $\begin{array}{l}3,260 \\
3,100 \\
2,940 \\
2,800 \\
2,680 \\
2,550\end{array}$ & $\begin{array}{l}4.72 \\
4.63 \\
4.56 \\
4.48 \\
4.40 \\
4.33\end{array}$ & $\begin{array}{l}1,940 \\
1,860 \\
1,810 \\
1,740 \\
1,680 \\
1,620\end{array}$ & $\begin{array}{l}3.90 \\
3.84 \\
3.80 \\
3.76 \\
3.72 \\
3.71\end{array}$ & $\begin{array}{l}1,320 \\
1,280 \\
1,250 \\
1,220 \\
1,194 \\
1,187\end{array}$ & \begin{tabular}{|l|}
3.48 \\
3.45 \\
3.40 \\
3.38 \\
3.32 \\
3.29 \\
\end{tabular} & $\begin{array}{r}1,040 \\
1,020 \\
990 \\
978 \\
942 \\
924\end{array}$ & $\begin{array}{l}3.40 \\
3.38 \\
3.36 \\
3.34 \\
3.31 \\
3.28\end{array}$ & \begin{tabular}{|l|}
990 \\
978 \\
966 \\
954 \\
936 \\
918
\end{tabular} & $\begin{array}{l}3.12 \\
3.10 \\
3.08 \\
3.05 \\
3.02 \\
2.98\end{array}$ & $\begin{array}{l}830 \\
820 \\
810 \\
795 \\
780 \\
760\end{array}$ \\
\hline $\begin{array}{r}2 \\
4 \\
6 \\
8 \\
10 \\
M\end{array}$ & $\begin{array}{l}5.35 \\
5.27 \\
5.12 \\
4.97 \\
4.88 \\
4.80\end{array}$ & $\begin{array}{l}2,480 \\
2,400 \\
2,270 \\
2,140 \\
2,060 \\
2,000\end{array}$ & $\begin{array}{l}4.28 \\
4.20 \\
4.13 \\
4.08 \\
4.01 \\
3.96\end{array}$ & $\begin{array}{l}1,590 \\
1,530 \\
1,480 \\
1,450 \\
1,400 \\
1,360\end{array}$ & $\begin{array}{l}3.69 \\
3.65 \\
3.62 \\
3.58 \\
3.55 \\
3.51\end{array}$ & $\begin{array}{l}1,170 \\
1,140 \\
1,120 \\
1,100 \\
1,080 \\
1,060\end{array}$ & $\begin{array}{l}3.29 \\
3.25 \\
3.30 \\
3.32 \\
3.37 \\
3.40\end{array}$ & $\begin{array}{l}924 \\
900 \\
930 \\
942 \\
972 \\
990\end{array}$ & $\begin{array}{l}3.25 \\
3.24 \\
3.21 \\
3.19 \\
3.18 \\
3.14\end{array}$ & $\begin{array}{l}900 \\
894 \\
876 \\
865 \\
860 \\
840\end{array}$ & $\begin{array}{l}2.98 \\
2.97 \\
2.94 \\
2.94 \\
2.92 \\
2.89\end{array}$ & $\begin{array}{l}760 \\
755 \\
741 \\
741 \\
731 \\
716\end{array}$ \\
\hline
\end{tabular}


Otter Creek at uiddlebury, vt.

Location. - Water-stage recorder, lat. $44^{\circ} 00^{\prime} 45^{\prime \prime}$, long. $73^{\circ} 10^{\prime} 05^{\prime \prime}$, 150 feet above highwaj bridge at Middlebury, Addison County, $3 \frac{1}{2}$ miles below Middiebury River.

Drainage area. - 628 square íles.

Gage-helght record.- Water-stage recorder graph except for per1od 7 a.m. 0ct. 16 to 10

a.m. 0ct. 20, record for which was based on shape of stage graph at nearby stations. Stage-dischgrge relation.- Defined by current-meter measurements below 8,790 secondfeet; extended logarithmically to maximum flood stage.

Maxima.- September 1938: Discharge, 6,630 second-feet 6 p.m. Sept. 25 (gage helght, 7.55 feet)

1803 to August 1938: Discherge, 13,600 second-feet Nov. 4, 1927 (gage he1ght,

13.3 feet, at site of chain gage-1,800 feet upstream, present datum).

Remarks.- Flood mun-off affected by some artificial and natural storage.

Mean dally discharge, in second-feet, I838

\begin{tabular}{|c|r|r||r|r|r||r|r|r||r|r|r|}
\hline Dey & Sept. & Oct. & Day & Sept. & Oct. & Day. & Sept. & 0ct. & Day & Sept. & 0ct. \\
\hline 1 & 624 & 3,550 & 9 & 787 & 1,010 & 17 & 2,280 & 710 & 25 & 6,540 & 1,190 \\
2 & 604 & 3,210 & 10 & 704 & 874 & 18 & 2,190 & 660 & 26 & 6,410 & 1,460 \\
3 & 582 & 2,940 & 11 & 604 & 815 & 19 & 2,060 & 680 & 27 & 5,820 & 1,230 \\
4 & 553 & 2,670 & 12 & 378 & 787 & 20 & 2,400 & 671 & 28 & 5,170 & 984 \\
5 & 453 & 2,310 & 13 & 1,610 & 774 & 21 & 3,030 & 741 & 29 & 4,500 & 866 \\
6 & 402 & 1,850 & 14 & 2,030 & 774 & 22 & 3,720 & 882 & 30 & 3,960 \\
7 & 566 & 1,460 & 16 & 2,220 & 734 & 23 & 3,670 & 836 & 31 & \\
8 & 815 & 1,160 & 16 & 2,330 & 700 & 24 & 5,310 & 767 & & \\
\hline
\end{tabular}

Gage helght, in feet, and discharge, In second-feet, at indicated time, I938

\begin{tabular}{|c|c|c|c|c|c|c|c|c|c|c|c|c|}
\hline \multirow{2}{*}{ 熺 } & Feet & Sec.ft. & Feet & Sec.ft. & Feet & sec.ft. & Feet & Sec.ft. & Feet & Sec.ft. & Feot & Sec.ft. \\
\hline & \multicolumn{2}{|c|}{ September 18} & \multicolumn{2}{|c|}{ September 19} & \multicolumn{2}{|c|}{ September 20} & \multicolumn{2}{|c|}{ September 21} & \multicolumn{2}{|c|}{ September 22} & \multicolumn{2}{|c|}{ September 23} \\
\hline $\begin{array}{l}1 \\
2 \\
3 \\
4 \\
5 \\
6\end{array}$ & $\begin{array}{l}3.74 \\
3.73 \\
3.73 \\
3.72 \\
3.72 \\
3.71\end{array}$ & $\begin{array}{l}2,260 \\
2,250 \\
2,250 \\
2,240 \\
2,240 \\
2,230\end{array}$ & $\begin{array}{l}3.60 \\
3.60 \\
3.60 \\
3.59 \\
3.58 \\
3.57\end{array}$ & $\begin{array}{l}2,090 \\
2,090 \\
2,090 \\
2,080 \\
2,070 \\
2,050\end{array}$ & $\begin{array}{l}3.70 \\
3.71 \\
3.75 \\
3.77 \\
3.78 \\
3.79\end{array}$ & $\begin{array}{l}2,220 \\
2,230 \\
2,280 \\
2,300 \\
2,310 \\
2,320\end{array}$ & $\begin{array}{l}4.06 \\
4.07 \\
4.08 \\
4.10 \\
4.14 \\
4.17\end{array}$ & $\begin{array}{l}2,610 \\
2,620 \\
2,630 \\
2,650 \\
2,690 \\
2,710\end{array}$ & \begin{tabular}{|l|}
5.30 \\
5.34 \\
5.35 \\
5.36 \\
5.36 \\
5.35
\end{tabular} & $\begin{array}{l}3,810 \\
3,850 \\
3,860 \\
3,880 \\
3,880 \\
3,860\end{array}$ & $\begin{array}{l}5.04 \\
5.04 \\
5.04 \\
5.04 \\
5.04 \\
5.04\end{array}$ & $\begin{array}{l}3,530 \\
3.530 \\
3,530 \\
3,580 \\
3,530 \\
3,530\end{array}$ \\
\hline $\begin{array}{r}7 \\
8 \\
9 \\
10 \\
11 \\
11\end{array}$ & $\begin{array}{l}3.70 \\
3.70 \\
3.70 \\
3.69 \\
8.68 \\
3.68\end{array}$ & $\begin{array}{l}2,220 \\
2,220 \\
2,220 \\
2,210 \\
2,190 \\
2,190\end{array}$ & $\begin{array}{l}3.57 \\
3.57 \\
3.56 \\
3.57 \\
3.57 \\
3.57\end{array}$ & $\begin{array}{l}2,050 \\
2,050 \\
2,040 \\
2,050 \\
2,050 \\
2,050\end{array}$ & $\begin{array}{l}3.80 \\
3.80 \\
3.81 \\
3.82 \\
3.84 \\
3.85\end{array}$ & $\begin{array}{l}2,330 \\
2,330 \\
2,340 \\
2,350 \\
2,370 \\
2,380\end{array}$ & $\begin{array}{l}4.21 \\
4.24 \\
4.27 \\
4.34 \\
4.39 \\
4.42\end{array}$ & $\begin{array}{l}2,750 \\
2,780 \\
2,800 \\
2,860 \\
2,900 \\
2,930\end{array}$ & $\begin{array}{l}5.33 \\
5.31 \\
5.29 \\
5.29 \\
5.29 \\
5.23\end{array}$ & $\begin{array}{l}3,840 \\
3,820 \\
3,800 \\
3,800 \\
3,800 \\
3,730\end{array}$ & $\begin{array}{l}5.04 \\
5.04 \\
5.05 \\
5.07 \\
5.08 \\
5.10\end{array}$ & $\begin{array}{l}530 \\
530 \\
540 \\
560 \\
570 \\
590\end{array}$ \\
\hline $\begin{array}{l}1 \\
2 \\
3 \\
4 \\
5 \\
6\end{array}$ & $\begin{array}{l}3.68 \\
3.67 \\
3.66 \\
3.66 \\
3.65 \\
3.65\end{array}$ & $\begin{array}{l}2,190 \\
2,180 \\
2,170 \\
2,170 \\
2,160 \\
2,160\end{array}$ & $\begin{array}{l}3.56 \\
3.56 \\
3.56 \\
3.55 \\
3.55 \\
3.55\end{array}$ & $\begin{array}{l}2,040 \\
2,040 \\
2,040 \\
2,030 \\
2,080 \\
2,030\end{array}$ & $\begin{array}{l}3.86 \\
3.88 \\
3.91 \\
3.92 \\
3.94 \\
3.96\end{array}$ & $\begin{array}{l}2,400 \\
2,420 \\
2,450 \\
2,460 \\
2,480 \\
2,510\end{array}$ & $\begin{array}{l}4.52 \\
4.54 \\
4.57 \\
4.65 \\
4.75 \\
4.84\end{array}$ & $\begin{array}{l}3,020 \\
3,040 \\
3,060 \\
3,140 \\
3,240 \\
3,330\end{array}$ & $\begin{array}{l}5.20 \\
5.18 \\
5.16 \\
5.15 \\
5.13 \\
5.12\end{array}$ & $\begin{array}{l}3,700 \\
3,680 \\
3,660 \\
3,640 \\
3,620 \\
3,610\end{array}$ & $\begin{array}{l}5.12 \\
5.14 \\
5.16 \\
5.20 \\
5.28 \\
5.26\end{array}$ & $\begin{array}{l}3,610 \\
3,680 \\
3,660 \\
3,700 \\
3,730 \\
3,770\end{array}$ \\
\hline \multirow[t]{2}{*}{$\begin{array}{r}7 \\
8 \\
9 \\
10 \\
11 \\
M\end{array}$} & $\begin{array}{l}3.65 \\
3.64 \\
3.63 \\
3.68 \\
3.62 \\
3.61\end{array}$ & $\begin{array}{l}2,160 \\
2,140 \\
2,130 \\
2,130 \\
2,120 \\
2,100\end{array}$ & $\begin{array}{l}3.56 \\
3.56 \\
3.57 \\
3.58 \\
3.60 \\
3.64\end{array}$ & $\begin{array}{l}2,040 \\
2,040 \\
2,050 \\
2,070 \\
2,090 \\
2,140\end{array}$ & $\begin{array}{l}3.97 \\
3.98 \\
4.00 \\
4.02 \\
4.03 \\
4.04\end{array}$ & $\begin{array}{l}2,520 \\
2,530 \\
2,550 \\
2,570 \\
2,580 \\
2,590\end{array}$ & $\begin{array}{l}4.92 \\
4.98 \\
5.08 \\
5.12 \\
5.17 \\
5.25\end{array}$ & $\begin{array}{l}3,410 \\
3,470 \\
3,570 \\
3,610 \\
3,670 \\
3,760\end{array}$ & $\begin{array}{l}5.10 \\
5.09 \\
5.07 \\
5.06 \\
5.06 \\
5.05\end{array}$ & $\begin{array}{l}3,590 \\
3,580 \\
3,560 \\
3,550 \\
3,550 \\
3,540\end{array}$ & $\begin{array}{l}5.31 \\
5.36 \\
5.42 \\
5.47 \\
5.52 \\
5.61\end{array}$ & $\begin{array}{l}320 \\
380 \\
940 \\
500 \\
550 \\
150\end{array}$ \\
\hline & \multicolumn{2}{|c|}{ September 24} & \multicolumn{2}{|c|}{ September 25} & \multicolumn{2}{|c|}{ September 26} & \multicolumn{2}{|c|}{ September 27} & \multicolumn{2}{|c|}{ September 28} & \multicolumn{2}{|c|}{ September 29} \\
\hline $\begin{array}{r}2 \\
4 \\
6 \\
8 \\
10 \\
1\end{array}$ & $\begin{array}{l}5.76 \\
5.95 \\
6.12 \\
6.32 \\
6.46 \\
6.63\end{array}$ & $\begin{array}{l}4,320 \\
4,550 \\
4,750 \\
4,990 \\
5,160 \\
5,380\end{array}$ & $\begin{array}{l}7.36 \\
7.42 \\
7.46 \\
7.46 \\
7.50 \\
7.53\end{array}$ & $\begin{array}{l}6,360 \\
6,450 \\
6,500 \\
6,500 \\
6,560 \\
6,600\end{array}$ & $\begin{array}{l}7.51 \\
7.49 \\
7.48 \\
7.44 \\
7.42 \\
7.41\end{array}$ & $\begin{array}{l}6,570 \\
6,550 \\
6,530 \\
6,480 \\
6,450 \\
6,430\end{array}$ & $\begin{array}{l}7.16 \\
7.13 \\
7.09 \\
7.05 \\
7.01 \\
6.97\end{array}$ & $\begin{array}{l}6,080 \\
6,040 \\
5,990 \\
5,930 \\
5,870 \\
5,820\end{array}$ & $\begin{array}{l}6.67 \\
6.63 \\
6.59 \\
6.55 \\
6.50 \\
6.46\end{array}$ & $\begin{array}{l}\mathbf{5}, \mathbf{4 3 0} \\
\mathbf{5}, 380 \\
\mathbf{5}, 330 \\
\mathbf{5}, 280 \\
\mathbf{5}, 210 \\
\mathbf{5}, 160\end{array}$ & $\begin{array}{l}6.15 \\
6.11 \\
6.06 \\
6.00 \\
5.94 \\
5.89\end{array}$ & $\begin{array}{l}4,790 \\
4,740 \\
4,680 \\
4,610 \\
4,540 \\
4,480\end{array}$ \\
\hline $\begin{array}{r}2 \\
4 \\
6 \\
8 \\
10 \\
11\end{array}$ & $\begin{array}{l}6.79 \\
6.82 \\
7.00 \\
7.12 \\
7.20 \\
7.29\end{array}$ & $\begin{array}{l}5,590 \\
5,760 \\
5,860 \\
6,030 \\
6,140 \\
6,270\end{array}$ & $\begin{array}{l}7.54 \\
7.54 \\
7.55 \\
7.54 \\
7.54 \\
7.58\end{array}$ & $\begin{array}{l}6,620 \\
6,620 \\
6,630 \\
6,620 \\
6,620 \\
6,600\end{array}$ & $\begin{array}{l}7.39 \\
7.36 \\
7.33 \\
7.30 \\
7.24 \\
7.21\end{array}$ & $\begin{array}{l}6,410 \\
6,360 \\
6,320 \\
6,280 \\
6,200 \\
6,150\end{array}$ & $\begin{array}{l}6.93 \\
6.89 \\
6.83 \\
6.80 \\
6.76 \\
6.71\end{array}$ & $\begin{array}{l}5,770 \\
5,720 \\
5,640 \\
5,600 \\
5,550 \\
5,480\end{array}$ & $\begin{array}{l}6.43 \\
6.38 \\
6.32 \\
6.29 \\
6.24 \\
6.20\end{array}$ & $\begin{array}{l}5,130 \\
5,070 \\
4,990 \\
4,960 \\
4,900 \\
4,850\end{array}$ & $\begin{array}{l}5.84 \\
5.80 \\
5.76 \\
5.72 \\
5.68\end{array}$ & $\begin{array}{l}20 \\
70 \\
20 \\
70 \\
80\end{array}$ \\
\hline
\end{tabular}


Location.- Water-stage recorder, lat. $44^{\circ} 15^{\prime} 25^{\prime \prime}$, long. $72^{\circ} 35^{\prime} 35^{\prime \prime}$, three-eighths of a mile above mouth of Dog River and 1 mile downstream from depot in Montpelier, Washington County. Zero of gage is 499.97 feet above mean sea level.

Drainage area.- 433 square miles.

Gage-helght record.- Water-stage recorder graph.

Stage-discharge relation.- Rating curve defined by current-meter measurements below 6,880 second-feet; extended to peak stage of November 1927 on basis of determination of flood flow by slope-area method.

Maxima.- September 1938: Discharge, 14,000 second-feet 1 a.m. Sept. 22 (gage he1ght, 14.11 feet)

1909 to August 1938: Discharge, 57,000 second-feet Nov. 3, 1927 (gage helght, 27.1 feet)

Remarks.- Flood run-off affected by artificial storage in reservoirs on Mollys Brook (24 square miles), North Branch of Winooski River, and Jail Branch. For information on storage see records for Wrightsville Detention Reservolr on North Branch of Winooski River at Wrightsville, Vt., and for East Barre Detention Reservolr on Jail Branch at East Barre, Vt.

Mean daily discharge, in second-feet, 1938

\begin{tabular}{|c|c|c|c|c|c|c|c|c|c|c|c|}
\hline Day & Sept. & oet. & Day & Sept. & Oct. & Day & Sept. & Oct. & Day & Sept. & Oct. \\
\hline $\begin{array}{l}1 \\
2 \\
3 \\
4 \\
5 \\
6 \\
7 \\
8\end{array}$ & $\begin{array}{l}250 \\
275 \\
192 \\
114 \\
130 \\
168 \\
217 \\
232\end{array}$ & $\begin{array}{l}218 \\
462 \\
388 \\
402 \\
376 \\
338 \\
314 \\
259\end{array}$ & $\begin{array}{l}9 \\
10 \\
11 \\
12 \\
13 \\
14 \\
15 \\
16\end{array}$ & $\begin{array}{l}212 \\
180 \\
111 \\
129 \\
520 \\
433 \\
736 \\
819\end{array}$ & $\begin{array}{l}273 \\
272 \\
309 \\
300 \\
253 \\
250 \\
228 \\
172\end{array}$ & $\begin{array}{l}17 \\
18 \\
19 \\
20 \\
21 \\
22 \\
23 \\
24\end{array}$ & $\begin{array}{r}457 \\
543 \\
463 \\
1,150 \\
4,280 \\
6,040 \\
2,120 \\
1,770\end{array}$ & $\begin{array}{l}222 \\
258 \\
334 \\
248 \\
350 \\
342 \\
208 \\
344\end{array}$ & $\begin{array}{l}25 \\
26 \\
27 \\
28 \\
29 \\
30 \\
31\end{array}$ & $\begin{array}{r}1,580 \\
1,410 \\
1,200 \\
1,120 \\
930 \\
718\end{array}$ & $\begin{array}{l}858 \\
576 \\
430 \\
360 \\
310 \\
244 \\
250\end{array}$ \\
\hline $\begin{array}{l}\text { Mean } \\
\text { Run- }\end{array}$ & $\begin{array}{l}n+h l y \\
, \text { in }\end{array}$ & & 11 & & : & - : & . $\cdot$ : & $\dot{0} \cdot \dot{ }$ & $\dot{0}:$ & $\begin{array}{r}950 \\
2.44\end{array}$ & $\begin{array}{l}327 \\
.87 \\
\end{array}$ \\
\hline
\end{tabular}

Gage helght, In feet, and discharge, in second-feet, at indicated time, 1938

\begin{tabular}{|c|c|c|c|c|c|c|c|c|c|c|c|c|}
\hline \multirow{2}{*}{ 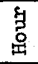 } & Feet & Sec.ft. & Feet & Sec.ft. & Feet & Sec.ft. & Feet & sec.ft. & Feet & Sec.ft. & Feet & Sec.ft \\
\hline & \multicolumn{2}{|c|}{ September 18} & \multicolumn{2}{|c|}{ September 19} & \multicolumn{2}{|c|}{ September 20} & \multicolumn{2}{|c|}{ September 21} & \multicolumn{2}{|c|}{ September 22} & \multicolumn{2}{|c|}{ September 23} \\
\hline $\begin{array}{l}1 \\
2 \\
3 \\
4 \\
5 \\
6\end{array}$ & $\begin{array}{l}4.04 \\
4.06 \\
4.10 \\
4.19 \\
4.21 \\
4.23\end{array}$ & \begin{tabular}{|l}
411 \\
424 \\
450 \\
508 \\
522 \\
536
\end{tabular} & $\begin{array}{l}4.18 \\
4.17 \\
4.15 \\
4.12 \\
4.11 \\
4.10\end{array}$ & $\begin{array}{l}502 \\
496 \\
482 \\
463 \\
456 \\
450\end{array}$ & $\begin{array}{l}4.46 \\
4.51 \\
4.56 \\
4.59 \\
4.60 \\
4.65\end{array}$ & $\begin{array}{l}697 \\
732 \\
767 \\
788 \\
795 \\
830\end{array}$ & $\begin{array}{l}5.98 \\
6.22 \\
6.35 \\
6.40 \\
6.42 \\
6.44\end{array}$ & $\begin{array}{l}1,890 \\
2,120 \\
2,250 \\
2,300 \\
2,320 \\
2,340\end{array}$ & $\begin{array}{l}14.11 \\
14.00 \\
13.45 \\
12.68 \\
11.75 \\
10.92\end{array}$ & $\begin{array}{r}14,000 \\
13,800 \\
12,500 \\
11,000 \\
9,250 \\
7,840\end{array}$ & $\begin{array}{l}6.63 \\
6.58 \\
6.51 \\
6.47 \\
6.42 \\
6.38\end{array}$ & $\begin{array}{l}2,530 \\
2,480 \\
2,410 \\
2,370 \\
2,320 \\
2,280\end{array}$ \\
\hline $\begin{array}{r}7 \\
8 \\
9 \\
10 \\
11 \\
\mathrm{~N}\end{array}$ & $\begin{array}{l}4.26 \\
4.29 \\
4.30 \\
4.31 \\
4.31 \\
4.31\end{array}$ & $\begin{array}{l}557 \\
578 \\
585 \\
592 \\
592 \\
592\end{array}$ & $\begin{array}{l}4.19 \\
4.20 \\
4.20 \\
4.10 \\
4.14 \\
4.05\end{array}$ & $\begin{array}{l}508 \\
515 \\
515 \\
450 \\
476 \\
418\end{array}$ & $\begin{array}{l}4.76 \\
4.79 \\
4.80 \\
4.81 \\
4.85 \\
5.01\end{array}$ & $\begin{array}{r}907 \\
928 \\
935 \\
942 \\
970 \\
1,090\end{array}$ & $\begin{array}{l}6.49 \\
6.51 \\
6.60 \\
6.76 \\
7.00 \\
7.24\end{array}$ & $\begin{array}{l}2,390 \\
2,410 \\
2,500 \\
2,660 \\
2,900 \\
3,140\end{array}$ & $\begin{array}{r}10.21 \\
9.71 \\
9.26 \\
8.81 \\
8.54 \\
8.31\end{array}$ & $\begin{array}{l}6,780 \\
6,090 \\
5,510 \\
4,920 \\
4,600 \\
4,320\end{array}$ & $\begin{array}{l}6.15 \\
6.01 \\
6.22 \\
6.22 \\
6.21 \\
6.16\end{array}$ & $\begin{array}{l}2,050 \\
1,920 \\
2,120 \\
2,120 \\
2,110 \\
2,060\end{array}$ \\
\hline $\begin{array}{l}1 \\
2 \\
3 \\
4 \\
5 \\
6\end{array}$ & $\begin{array}{l}4.30 \\
4.30 \\
4.30 \\
4.30 \\
4.29 \\
4.29\end{array}$ & $\begin{array}{l}585 \\
585 \\
585 \\
585 \\
578 \\
578\end{array}$ & $\begin{array}{l}4.17 \\
4.15 \\
4.11 \\
4.01 \\
3.86 \\
3.70\end{array}$ & $\begin{array}{l}496 \\
482 \\
456 \\
392 \\
310 \\
236\end{array}$ & $\begin{array}{l}5.11 \\
5.22 \\
5.28 \\
5.29 \\
5.35 \\
5.46\end{array}$ & $\begin{array}{l}1,150 \\
1,240 \\
1,280 \\
1,290 \\
1,340 \\
1,430\end{array}$ & $\begin{array}{l}7.42 \\
7.69 \\
8.00 \\
8.38 \\
8.41 \\
8.42\end{array}$ & $\begin{array}{l}3,340 \\
3,640 \\
3,980 \\
4,410 \\
4,440 \\
4,450\end{array}$ & $\begin{array}{l}8.11 \\
7.94 \\
7.87 \\
7.61 \\
7.47 \\
7.28\end{array}$ & $\begin{array}{l}4,100 \\
3,810 \\
3,840 \\
3,550 \\
3,400 \\
3,190\end{array}$ & $\begin{array}{l}6.19 \\
6.14 \\
6.10 \\
6.09 \\
6.04 \\
6.06\end{array}$ & $\begin{array}{l}090 \\
040 \\
000 \\
990 \\
950 \\
960\end{array}$ \\
\hline \multirow[t]{2}{*}{$\begin{array}{r}7 \\
8 \\
9 \\
10 \\
11 \\
M\end{array}$} & $\begin{array}{l}4.28 \\
4.27 \\
4.25 \\
4.23 \\
4.21 \\
4.20\end{array}$ & $\begin{array}{l}571 \\
564 \\
550 \\
536 \\
522 \\
515\end{array}$ & $\begin{array}{l}3.91 \\
4.07 \\
4.19 \\
4.28 \\
4.30 \\
4.38\end{array}$ & $\begin{array}{l}336 \\
430 \\
508 \\
571 \\
585 \\
641\end{array}$ & $\begin{array}{l}5.57 \\
5.68 \\
5.79 \\
5.82 \\
5.83 \\
5.85\end{array}$ & $\begin{array}{l}1,520 \\
1,620 \\
1,710 \\
1,750 \\
1,760 \\
1,770\end{array}$ & $\begin{array}{r}8.64 \\
9.51 \\
11.10 \\
12.49 \\
13.40 \\
13.88\end{array}$ & $\begin{array}{r}4,720 \\
5,830 \\
8,140 \\
10,600 \\
12,400 \\
13,500\end{array}$ & $\begin{array}{l}7.19 \\
7.08 \\
6.98 \\
6.89 \\
6.78 \\
6.71\end{array}$ & $\begin{array}{l}3,090 \\
2,980 \\
2,880 \\
2,790 \\
2,680 \\
2,610\end{array}$ & $\begin{array}{l}6.07 \\
6.06 \\
6.05 \\
6.04 \\
6.03 \\
6.01\end{array}$ & $\begin{array}{l}1,970 \\
1,960 \\
1,960 \\
1,950 \\
1,940 \\
1,920\end{array}$ \\
\hline & \multicolumn{2}{|c|}{ September 24} & \multicolumn{2}{|c|}{ September 25} & \multicolumn{2}{|c|}{ September 26} & \multicolumn{2}{|c|}{ September 27} & \multicolumn{2}{|c|}{ September 28} & \multicolumn{2}{|c|}{ September 29} \\
\hline $\begin{array}{r}2 \\
4 \\
6 \\
8 \\
10 \\
N\end{array}$ & $\begin{array}{l}5.99 \\
5.93 \\
5.89 \\
5.88 \\
5.84 \\
5.80\end{array}$ & $\begin{array}{l}1,900 \\
1,850 \\
1,810 \\
1,800 \\
1,770 \\
1,730\end{array}$ & \begin{tabular}{|l|}
5.74 \\
5.71 \\
5.70 \\
5.69 \\
5.66 \\
5.64
\end{tabular} & $\begin{array}{l}1,680 \\
1,650 \\
1,640 \\
1,630 \\
1,600 \\
1,590\end{array}$ & $\begin{array}{l}5.50 \\
5.50 \\
5.50 \\
5.53 \\
5.49 \\
5.45\end{array}$ & $\begin{array}{l}1,460 \\
1,460 \\
1,460 \\
1,490 \\
1,450 \\
1,420\end{array}$ & $\begin{array}{l}5.30 \\
5.26 \\
5.21 \\
5.21 \\
5.14 \\
5.10\end{array}$ & $\begin{array}{l}1,300 \\
1,270 \\
1,230 \\
1,230 \\
1,170 \\
1,140\end{array}$ & $\begin{array}{l}5.20 \\
5.17 \\
5.10 \\
5.15 \\
5.11 \\
5.13\end{array}$ & $\begin{array}{l}1,220 \\
1,190 \\
1,150 \\
1,180 \\
1,150 \\
1,160\end{array}$ & & $\begin{array}{r}1,020 \\
1,010 \\
984 \\
1,010 \\
970 \\
942\end{array}$ \\
\hline $\begin{array}{r}2 \\
4 \\
6 \\
8 \\
10 \\
M\end{array}$ & $\begin{array}{l}5.81 \\
5.78 \\
5.78 \\
5.79 \\
5.79 \\
5.76\end{array}$ & $\begin{array}{l}1,740 \\
1,710 \\
1,710 \\
1,720 \\
1,720 \\
1,690\end{array}$ & $\begin{array}{l}\mathbf{5 . 6 1} \\
5.60 \\
\mathbf{5 . 5 7} \\
\mathbf{5 . 5 5} \\
\mathbf{5 . 5 8} \\
\mathbf{5 . 5 2}\end{array}$ & $\begin{array}{l}1,560 \\
1,550 \\
1,520 \\
1,500 \\
1,490 \\
1,480\end{array}$ & $\begin{array}{l}5.41 \\
5.39 \\
5.31 \\
5.38 \\
5.40 \\
5.36\end{array}$ & $\begin{array}{l}1,390 \\
1,370 \\
1,310 \\
1,360 \\
1,380\end{array}$ & $\begin{array}{l}5.11 \\
5.08 \\
5.04 \\
5.13 \\
5.20 \\
5.21\end{array}$ & $\begin{array}{l}1,150 \\
1,140 \\
1,110 \\
1,160 \\
1,220 \\
1,230\end{array}$ & $\begin{array}{l}5.00 \\
5.01 \\
4.96 \\
4.89 \\
4.97 \\
4.98\end{array}$ & $\begin{array}{r}1,080 \\
1,090 \\
1,040 \\
1,998 \\
1,050 \\
1,060\end{array}$ & $\begin{array}{l}4.71 \\
4.71 \\
4.60 \\
4.62 \\
4.70 \\
4.72\end{array}$ & $\begin{array}{l}872 \\
914 \\
795 \\
809 \\
865 \\
879\end{array}$ \\
\hline
\end{tabular}


Winoosk1 River near Essex Junction, Vt.

Location.- Water-stage recorder, lat. $44^{\circ} 28^{\prime} 40^{\prime}$, long. $73^{\circ} 08^{\prime} 20^{n}$, half a mile below mouth of Muddy Brook, 2 miles southwest of Essex Junction, Chittenden County. Drainage area.- 1,079 square miles.

Gare-height record. - Water-stage recorder graph.

Stage-discharge relation.- Defined by current-meter measurements below 21,800 secondfeet; extended to peak stage on basis of determinations of flood flow over dam and by siope-area method.

Maximg.- September 1938: Discharge, 34,300 second-feet 1 p.m. Sept. 22 (gage height, 18.72 feet)

1928 to August 1938: D1scharge, 45,300 second-feet Mar. 19, 1936 (gage height, 23.54 feet).

Maximum discharge known, 113,000 second-feet Nov. 4, 1927. (gage he1ght, 50.4

feet, from floodmarks)

Remarks.- Flood run-off from 232 square miles affected by artificial storage in reservolrs on Mollys Brook, Jail Branch, North Branch of Winooski River, and Waterbury River. For information on storage see records for East Barre Detention Reservoir on Jail Branch at East Barre, Vt., for Wrightsville Detention Reservoir on North Branch of Winooski River at Wrightsville, Vt., and for Waterbury Reservoir on Waterbury River near Waterbury, vt.

Mean daily discharge, in second-fe日t, 1938

\begin{tabular}{|c|c|c|c|c|c|c|c|c|c|c|c|}
\hline Day & Sept. & Oct. & Day & Sept. & Oct. & Day & Sept. & oct. & Day & Sept. & Oct. \\
\hline $\begin{array}{l}1 \\
2 \\
3 \\
4 \\
5 \\
6 \\
7 \\
8\end{array}$ & $\begin{array}{l}530 \\
576 \\
557 \\
372 \\
164 \\
492 \\
684 \\
852\end{array}$ & $\begin{array}{r}1,380 \\
1,160 \\
1,150 \\
890 \\
964 \\
911 \\
1,040 \\
759 \\
\end{array}$ & $\begin{array}{r}9 \\
10 \\
11 \\
12 \\
13 \\
14 \\
15 \\
16\end{array}$ & $\begin{array}{r}623 \\
464 \\
450 \\
521 \\
1,190 \\
1,510 \\
1,840 \\
2,670\end{array}$ & $\begin{array}{l}506 \\
760 \\
766 \\
816 \\
810 \\
689 \\
619 \\
408\end{array}$ & $\begin{array}{l}17 \\
18 \\
19 \\
20 \\
21 \\
22 \\
23 \\
24\end{array}$ & $\begin{array}{r}1,650 \\
1,520 \\
1,260 \\
1,410 \\
10,400 \\
29,800 \\
8,750 \\
5,340\end{array}$ & $\begin{array}{l}562 \\
563 \\
611 \\
737 \\
730 \\
794 \\
698 \\
954\end{array}$ & $\begin{array}{l}25 \\
26 \\
27 \\
28 \\
29 \\
30 \\
31\end{array}$ & $\begin{array}{l}4,520 \\
3,830 \\
3,370 \\
3,150 \\
2,600 \\
1,770\end{array}$ & $\begin{array}{r}1,680 \\
1,930 \\
1,420 \\
1,260 \\
857 \\
488 \\
822\end{array}$ \\
\hline $\begin{array}{l}\text { Kean } \\
\text { Run-c }\end{array}$ & in & charo & , in & - . . & • . & $\dot{*} \cdot \dot{ }$ & $\dot{1} \cdot \dot{0}$ & . : & $\dot{0}$ & $\begin{array}{r}3,096 \\
3.20 \\
\end{array}$ & $\begin{array}{r}895 \\
0.96 \\
\end{array}$ \\
\hline
\end{tabular}

Gage helght, In feet, and discharge, in second-feet, at indicated time, 1938

\begin{tabular}{|c|c|c|c|c|c|c|c|c|c|c|c|c|}
\hline \multirow{2}{*}{$\begin{array}{l}4 \\
9 \\
9 \\
0\end{array}$} & Feet & Sec.ft. & Feet & Sec.ft. & Feet & Sec.ft. & Feet & Sec.ft. & Feet & Sec.et. & Feet & Sec.ft: \\
\hline & \multicolumn{2}{|c|}{ September 18} & \multicolumn{2}{|c|}{ September 19} & \multicolumn{2}{|c|}{ September 20} & \multicolumn{2}{|c|}{ Sept ember 21} & \multicolumn{2}{|c|}{ September 22} & \multicolumn{2}{|c|}{ September 23} \\
\hline $\begin{array}{l}1 \\
2 \\
3 \\
4 \\
5 \\
6\end{array}$ & $\begin{array}{l}2.41 \\
2.42 \\
2.42 \\
2.42 \\
2.42 \\
2.42\end{array}$ & $\begin{array}{l}1,500 \\
1,510 \\
1,510 \\
1,510 \\
1,510 \\
1,510\end{array}$ & $\begin{array}{r}2.30 \\
2.30 \\
2.20 \\
1.00 \\
.62 \\
1.25\end{array}$ & $\begin{array}{r}1,370 \\
1,370 \\
1,260 \\
305 \\
181 \\
432\end{array}$ & $\begin{array}{r}2.31 \\
2.30 \\
1.50 \\
.65 \\
.65 \\
.72\end{array}$ & $\begin{array}{r}1,380 \\
1,370 \\
605 \\
190 \\
190 \\
211\end{array}$ & $\begin{array}{l}4.06 \\
4.14 \\
4.22 \\
4.39 \\
4.47 \\
4.62\end{array}$ & $\begin{array}{l}4,240 \\
4,410 \\
4,580 \\
4,950 \\
5,120 \\
5,420\end{array}$ & $\begin{array}{l}14.46 \\
15.08 \\
15.66 \\
16.24 \\
16.72 \\
17.10\end{array}$ & $\begin{array}{l}25,100 \\
26,400 \\
27,600 \\
28,800 \\
29,900 \\
30,700\end{array}$ & $\begin{array}{r}10.64 \\
9.60 \\
8.70 \\
7.85 \\
7.30 \\
7.00\end{array}$ & $\begin{array}{l}17,300 \\
15,200 \\
13,400 \\
11,800 \\
10,800 \\
10,200\end{array}$ \\
\hline $\begin{array}{r}7 \\
8 \\
9 \\
10 \\
11 \\
N\end{array}$ & $\begin{array}{l}2.48 \\
2.48 \\
2.47 \\
2.46 \\
2.45 \\
2.43\end{array}$ & $\begin{array}{l}1,590 \\
1,590 \\
1,570 \\
1,560 \\
1,550 \\
1,530\end{array}$ & $\begin{array}{l}2.20 \\
2.36 \\
2.37 \\
2.37 \\
2.37 \\
2.36\end{array}$ & $\begin{array}{l}1,260 \\
1,440 \\
1,450 \\
1,450 \\
1,450 \\
1,440\end{array}$ & $\begin{array}{l}2.31 \\
2.34 \\
2.25 \\
2.34 \\
2.34 \\
2.22\end{array}$ & $\begin{array}{l}1,380 \\
1,420 \\
1,320 \\
1,420 \\
1,420 \\
1,280\end{array}$ & $\begin{array}{l}4.72 \\
5.03 \\
5.10 \\
5.26 \\
5.50 \\
6.29\end{array}$ & $\begin{array}{l}5,620 \\
6,240 \\
6,380 \\
6,700 \\
7,180 \\
8,760\end{array}$ & $\begin{array}{l}17.46 \\
17.76 \\
18.04 \\
18.30 \\
18.50 \\
18.65\end{array}$ & $\begin{array}{l}31,500 \\
32,200 \\
32,800 \\
33,400 \\
33,800 \\
34,100\end{array}$ & $\begin{array}{l}6.55 \\
6.22 \\
5.98 \\
5.80 \\
5.68 \\
5.57\end{array}$ & $\begin{array}{l}9,280 \\
8,620 \\
8,140 \\
7,780 \\
7,540 \\
7,320\end{array}$ \\
\hline $\begin{array}{l}1 \\
2 \\
3 \\
4 \\
5 \\
6\end{array}$ & $\begin{array}{l}2.42 \\
2.42 \\
2.35 \\
2.34 \\
2.47 \\
2.47\end{array}$ & $\begin{array}{l}1,510 \\
1,510 \\
1,430 \\
1,420 \\
1,570 \\
1,570\end{array}$ & $\begin{array}{l}2.36 \\
2.35 \\
2.34 \\
2.34 \\
2.33 \\
2.33\end{array}$ & $\begin{array}{l}1,440 \\
1,430 \\
1,420 \\
1,420 \\
1,410 \\
1,410\end{array}$ & $\begin{array}{l}2.32 \\
2.34 \\
2.36 \\
2.38 \\
2.40 \\
2.43\end{array}$ & $\begin{array}{l}1,390 \\
1,420 \\
1,440 \\
1,470 \\
1,490 \\
1,530\end{array}$ & $\begin{array}{l}6.52 \\
7.00 \\
7.40 \\
7.80 \\
9.10 \\
9.47\end{array}$ & $\begin{array}{r}9,220 \\
10,200 \\
11,000 \\
11,700 \\
14,200 \\
14,900\end{array}$ & $\begin{array}{l}18.72 \\
18.69 \\
18.52 \\
18.25 \\
17.85 \\
17.30\end{array}$ & $\begin{array}{l}34,300 \\
34,200 \\
33,800 \\
33,200 \\
32,400 \\
31,200\end{array}$ & $\begin{array}{l}5.47 \\
5.37 \\
5.27 \\
5.15 \\
5.03 \\
5.03\end{array}$ & $\begin{array}{l}7,120 \\
6,920 \\
6,720 \\
6,480 \\
6,240 \\
6,240\end{array}$ \\
\hline \multirow[t]{2}{*}{$\begin{array}{r}7 \\
8 \\
9 \\
10 \\
11 \\
11\end{array}$} & $\begin{array}{l}2.46 \\
2.45 \\
2.45 \\
2.44 \\
2.33 \\
2.31\end{array}$ & $\begin{array}{l}1,560 \\
1,550 \\
1,550 \\
1,540 \\
1,410 \\
1,380\end{array}$ & $\begin{array}{l}2.32 \\
2.32 \\
2.32 \\
2.32 \\
2.32 \\
2.32\end{array}$ & $\begin{array}{l}1,390 \\
1,390 \\
1,390 \\
1,390 \\
1,390 \\
1,390\end{array}$ & $\begin{array}{l}2.48 \\
2.53 \\
2.67 \\
3.00 \\
3.33 \\
3.98\end{array}$ & $\begin{array}{l}1,590 \\
1,650 \\
1,830 \\
2,300 \\
2,830 \\
4,070\end{array}$ & $\begin{array}{r}9.97 \\
10.66 \\
11.56 \\
12.49 \\
13.18 \\
13.84\end{array}$ & $\begin{array}{l}15,900 \\
17,300 \\
19,100 \\
21,000 \\
22,400 \\
23,800\end{array}$ & $\begin{array}{l}16.60 \\
15.80 \\
14.85 \\
13.85 \\
12.75 \\
11.68\end{array}$ & $\begin{array}{l}29,600 \\
27,900 \\
25,900 \\
23,800 \\
21,500 \\
19,400\end{array}$ & $\begin{array}{l}5.02 \\
5.01 \\
4.98 \\
4.85 \\
4.87 \\
4.85\end{array}$ & $\begin{array}{l}20 \\
200 \\
40 \\
380 \\
220 \\
380\end{array}$ \\
\hline & \multicolumn{2}{|c|}{ September 24} & \multicolumn{2}{|c|}{ September 25} & \multicolumn{2}{|c|}{ September 26} & \multicolumn{2}{|c|}{ September 27} & \multicolumn{2}{|c|}{ September 28} & \multicolumn{2}{|c|}{ September 29} \\
\hline $\begin{array}{r}2 \\
4 \\
6 \\
8 \\
10 \\
Y\end{array}$ & $\begin{array}{l}4.79 \\
4.74 \\
4.74 \\
4.68 \\
4.60 \\
4.56\end{array}$ & $\begin{array}{l}5,760 \\
5,660 \\
5,660 \\
5,540 \\
5,380 \\
5,300\end{array}$ & $\begin{array}{l}4.35 \\
4.31 \\
4.30 \\
4.32 \\
4.24 \\
4.20\end{array}$ & $\begin{array}{l}4,860 \\
4,780 \\
4,760 \\
4,800 \\
4,630 \\
4,540\end{array}$ & $\begin{array}{l}3.99 \\
3.96 \\
3.93 \\
4.08 \\
3.91 \\
3.85\end{array}$ & $\begin{array}{l}4,090 \\
4,030 \\
3,960 \\
4,280 \\
3,920 \\
3,800\end{array}$ & $\begin{array}{l}3.70 \\
3.69 \\
3.68 \\
3.81 \\
3.68 \\
3.65\end{array}$ & $\begin{array}{l}3,500 \\
3,480 \\
3,460 \\
3,720 \\
3,460 \\
3,400\end{array}$ & $\begin{array}{l}3.50 \\
3.51 \\
3.60 \\
3.72 \\
3.62 \\
3.26\end{array}$ & $\begin{array}{l}3,130 \\
3,150 \\
3,310 \\
3,540 \\
3,350 \\
2,710\end{array}$ & $\begin{array}{l}3.38 \\
3.32 \\
3.33 \\
3.58 \\
3.32 \\
3.20\end{array}$ & $\begin{array}{l}2,920 \\
2,810 \\
2,830 \\
3,270 \\
2,810 \\
2,610\end{array}$ \\
\hline $\begin{array}{r}2 \\
4 \\
6 \\
8 \\
10 \\
M\end{array}$ & $\begin{array}{l}4.48 \\
4.48 \\
4.46 \\
4.42 \\
4.40 \\
4.35\end{array}$ & $\begin{array}{l}5,140 \\
5,140 \\
5,100 \\
5,010 \\
4,970 \\
4,860\end{array}$ & $\begin{array}{l}4.13 \\
4.03 \\
4.20 \\
4.08 \\
3.96 \\
4.00\end{array}$ & $\begin{array}{l}4,390 \\
4,170 \\
4,540 \\
4,280 \\
4,030 \\
4,110\end{array}$ & $\begin{array}{l}3.84 \\
3.62 \\
3.81 \\
3.77 \\
3.73 \\
3.69\end{array}$ & $\begin{array}{l}3,780 \\
3,350 \\
3,720 \\
3,640 \\
3,560 \\
3,480\end{array}$ & $\begin{array}{l}3.62 \\
3.57 \\
3.59 \\
3.61 \\
3.42 \\
3.35\end{array}$ & $\begin{array}{l}3,350 \\
3,260 \\
3,290 \\
3,330 \\
2,990 \\
2,860\end{array}$ & $\begin{array}{l}3.62 \\
3.58 \\
3.51 \\
3.52 \\
3.40 \\
3.18\end{array}$ & $\begin{array}{l}3,350 \\
3,270 \\
3,150 \\
3,170 \\
2,950 \\
2,580\end{array}$ & $\begin{array}{l}3.32 \\
3.11 \\
3.04 \\
2.92 \\
2.70 \\
2.66\end{array}$ & $\begin{array}{l}2,810 \\
2,470 \\
2,360 \\
2,180 \\
1,870 \\
1,820\end{array}$ \\
\hline
\end{tabular}


East Barre Detention Reservoir on Jajl Branch at East Barre, Vt.

Location.- Staff gage, lat. $44^{\circ} 10^{\prime}$, long. $72^{\circ} 27^{\prime}$, in East Barre, Washington County, about three-quarters of a mile above gaging station on Ja1l Branch and $3 \frac{1}{2}$ miles above confluence with Stevens Branch. Zero of gage is $1,127.9$ feet above mean sea level.

Drainage area.- 32.2 square miles.

Gage-height record.- Graph based on one or more readings daily.

Remarks.- Capacity of reservo1r, 522,720,000 cubic feet. Capacity curve developed from areas furnished by Corps of Engineers, U. S. Army.

Gain or loss in storage, in millions of cubic feet, 1938

\begin{tabular}{|c|c|c|c|c|c|c|c|c|c|c|c|}
\hline Day & Sept. & oct. & Day & Sept. & oct. & Day & Sept. & oct. & Day & Sept. & Oct. \\
\hline $\begin{array}{l}1 \\
2 \\
3 \\
4 \\
5 \\
6 \\
7 \\
8\end{array}$ & $\begin{array}{r}+0.16 \\
+.06 \\
+.06 \\
+.03 \\
-.26 \\
+.17 \\
+.40 \\
-. .22\end{array}$ & $\begin{array}{r}-0.04 \\
-.16 \\
-.40 \\
-.06 \\
-.09 \\
-.13 \\
-.06 \\
+.06\end{array}$ & $\begin{array}{r}9 \\
10 \\
11 \\
12 \\
13 \\
14 \\
15 \\
16\end{array}$ & $\begin{array}{r}-0.33 \\
-.05 \\
-.04 \\
+.30 \\
+1.56 \\
+1.56 \\
+.87 \\
-2.87\end{array}$ & $\begin{array}{r}+0.10 \\
-.06 \\
+.06 \\
+.03 \\
-.19 \\
.00 \\
.00 \\
-.03\end{array}$ & $\begin{array}{l}17 \\
18 \\
19 \\
20 \\
21 \\
22 \\
23 \\
24\end{array}$ & $\begin{array}{r}-0.24 \\
+.20 \\
-.04 \\
+11.33 \\
+60.33 \\
+5.46 \\
-18.55 \\
-18.11\end{array}$ & $\begin{array}{r}-0.03 \\
-.03 \\
.00 \\
+.22 \\
+.45 \\
-.50 \\
+.64 \\
+1.78\end{array}$ & $\begin{array}{l}25 \\
26 \\
27 \\
28 \\
29 \\
30 \\
31\end{array}$ & $\begin{array}{r}-18.15 \\
-16.42 \\
-3.45 \\
-1.83 \\
-.43 \\
-.14\end{array}$ & $\begin{array}{r}-0.96 \\
-1.08 \\
-.17 \\
-.03 \\
-.06 \\
-.12 \\
-.10\end{array}$ \\
\hline $\begin{array}{l}\text { Gain } \\
\text { Gain }\end{array}$ & $\begin{array}{l}\text { or loss } \\
\text { or loss }\end{array}$ & $\begin{array}{l}\text { In } \\
\text { in }\end{array}$ & $\theta$ & $\begin{array}{l}\text { milli } \\
\text { equiv }\end{array}$ & of $c$ & & & . $\cdot \cdot$ & $\therefore$ & $\begin{array}{l}+1.24 \\
+0.4\end{array}$ & $\begin{array}{l}-0.90 \\
-0.3\end{array}$ \\
\hline
\end{tabular}

Gage height, in feet, and contents, in millions of cubic feet, at indicated time, 1938

\begin{tabular}{|c|c|c|c|c|c|c|c|c|c|c|}
\hline \multirow[t]{2}{*}{ Hour } & $\begin{array}{c}\text { Gage } \\
\text { helght }\end{array}$ & Contents & $\begin{array}{c}\text { Gage } \\
\text { helght }\end{array}$ & Contents & $\begin{array}{c}\text { Gage } \\
\text { helght }\end{array}$ & Contents & $\begin{array}{c}\text { Gage } \\
\text { helght }\end{array}$ & Contents & $\begin{array}{c}\text { Gage } \\
\text { helght }\end{array}$ & Contents \\
\hline & \multicolumn{2}{|c|}{ September 11} & \multicolumn{2}{|c|}{ September 12} & \multicolumn{2}{|c|}{ September 13} & \multicolumn{2}{|c|}{ September 14} & \multicolumn{2}{|c|}{ September 15} \\
\hline $\begin{array}{l}6 \\
N \\
6 \\
M\end{array}$ & $\begin{array}{r}0.60 \\
.60 \\
.55 \\
.52 \\
\end{array}$ & \begin{tabular}{|l|}
6.40 \\
6.40 \\
6.38 \\
6.36 \\
\end{tabular} & $\begin{array}{r}0.50 \\
.50 \\
.55 \\
1.10 \\
\end{array}$ & $\begin{array}{l}6.35 \\
6.35 \\
6.38 \\
6.66 \\
\end{array}$ & $\begin{array}{l}2.50 \\
4.60 \\
5.80 \\
3.30 \\
\end{array}$ & $\begin{array}{r}7.58 \\
9.47 \\
10.91 \\
8.22 \\
\end{array}$ & $\begin{array}{l}3.40 \\
3.90 \\
4.40 \\
4.90 \\
\end{array}$ & $\begin{array}{l}8.31 \\
8.75 \\
9.26 \\
9.78 \\
\end{array}$ & $\begin{array}{l}5.50 \\
5.90 \\
6.05 \\
5.60 \\
\end{array}$ & $\begin{array}{l}10.52 \\
11.03 \\
11.24 \\
10.65 \\
\end{array}$ \\
\hline \multirow[b]{2}{*}{$\begin{array}{l}6 \\
N \\
6 \\
M \\
\end{array}$} & \multicolumn{2}{|c|}{ September 16} & \multicolumn{2}{|c|}{ September 17} & \multicolumn{2}{|c|}{ September 18} & \multicolumn{2}{|c|}{ September 19} & \multicolumn{2}{|c|}{ September 20} \\
\hline & $\begin{array}{l}4.50 \\
3.60 \\
3.10 \\
2.75 \\
\end{array}$ & \begin{tabular}{|l|}
9.36 \\
8.49 \\
8.05 \\
7.78 \\
\end{tabular} & $\begin{array}{l}2.50 \\
2.30 \\
2.30 \\
2.45 \\
\end{array}$ & \begin{tabular}{|l|}
7.58 \\
7.44 \\
7.44 \\
7.54 \\
\end{tabular} & $\begin{array}{l}2.55 \\
2.70 \\
2.80 \\
2.70 \\
\end{array}$ & \begin{tabular}{|l|}
7.62 \\
7.74 \\
7.81 \\
7.74 \\
\end{tabular} & $\begin{array}{l}2.50 \\
2.30 \\
2.25 \\
2.65 \\
\end{array}$ & \begin{tabular}{|l|}
7.58 \\
7.44 \\
7.40 \\
7.70 \\
\end{tabular} & $\begin{array}{r}3.50 \\
4.90 \\
6.70 \\
9.70 \\
\end{array}$ & $\begin{array}{r}8.40 \\
9.78 \\
12.25 \\
19.03 \\
\end{array}$ \\
\hline \multirow[b]{2}{*}{$\begin{array}{l}6 \\
N \\
6 \\
M\end{array}$} & \multicolumn{2}{|c|}{ September 21} & \multicolumn{2}{|c|}{ September 22} & \multicolumn{2}{|c|}{ September 23} & \multicolumn{2}{|c|}{ September - 24} & \multicolumn{2}{|c|}{ September 25} \\
\hline & $\begin{array}{l}13.20 \\
13.40 \\
13.70 \\
17.00 \\
\end{array}$ & \begin{tabular}{|l|}
37.72 \\
39.48 \\
42.12 \\
79.36 \\
\end{tabular} & $\begin{array}{l}18.55 \\
18.40 \\
17.95 \\
17.40 \\
\end{array}$ & $\begin{array}{r}101.02 \\
98.84 \\
92.34 \\
84.82 \\
\end{array}$ & $\begin{array}{l}17.10 \\
16.80 \\
16.40 \\
15.97 \\
\end{array}$ & $\begin{array}{l}80.73 \\
76.82 \\
71.74 \\
66.27 \\
\end{array}$ & $\begin{array}{l}15.65 \\
15.20 \\
14.80 \\
14.33 \\
\end{array}$ & \begin{tabular}{|l|}
62.60 \\
57.38 \\
53.00 \\
48.16 \\
\end{tabular} & $\begin{array}{l}13.90 \\
13.40 \\
12.90 \\
12.15 \\
\end{array}$ & $\begin{array}{l}43.88 \\
39.48 \\
35.26 \\
30.01 \\
\end{array}$ \\
\hline \multirow[b]{2}{*}{$\begin{array}{l}6 \\
N \\
6 \\
M\end{array}$} & \multicolumn{2}{|c|}{ September 26} & \multicolumn{2}{|c|}{ September 27} & \multicolumn{2}{|c|}{ September 28} & \multicolumn{2}{|c|}{ September 29} & \multicolumn{2}{|c|}{ September 30} \\
\hline & $\begin{array}{r}11.50 \\
10.50 \\
9.35 \\
7.46 \\
\end{array}$ & \begin{tabular}{|l|}
26.36 \\
21.84 \\
18.00 \\
13.59 \\
\end{tabular} & $\begin{array}{l}6.00 \\
4.20 \\
3.60 \\
5.20 \\
\end{array}$ & $\begin{array}{r}11.16 \\
9.05 \\
8.49 \\
10.14 \\
\end{array}$ & $\begin{array}{l}4.50 \\
3.90 \\
3.60 \\
3.40 \\
\end{array}$ & \begin{tabular}{|l|}
9.36 \\
8.75 \\
8.49 \\
8.31 \\
\end{tabular} & $\begin{array}{l}3.20 \\
3.00 \\
2.90 \\
2.90 \\
\end{array}$ & $\begin{array}{l}8.14 \\
7.96 \\
7.88 \\
7.88 \\
\end{array}$ & $\begin{array}{l}2.80 \\
2.75 \\
2.75 \\
2.70 \\
\end{array}$ & $\begin{array}{r}7.81 \\
7.78 \\
7.78 \\
7.74 \\
\end{array}$ \\
\hline \multirow[b]{2}{*}{$\begin{array}{l}6 \\
N \\
6 \\
M\end{array}$} & \multicolumn{2}{|c|}{ October 1} & \multicolumn{2}{|c|}{ October 2} & \multicolumn{2}{|c|}{ October 3} & \multicolumn{2}{|c|}{ October 4} & \multicolumn{2}{|c|}{ October 5} \\
\hline & $\begin{array}{l}2.70 \\
2.70 \\
2.70 \\
2.70 \\
\end{array}$ & $\begin{array}{l}7.74 \\
7.74 \\
7.74 \\
7.74 \\
\end{array}$ & $\begin{array}{l}2.70 \\
2.60 \\
2.60 \\
2.50 \\
\end{array}$ & $\begin{array}{r}7.74 \\
7.66 \\
7.66 \\
7.58 \\
\end{array}$ & $\begin{array}{l}2.30 \\
2.10 \\
2.00 \\
1.95 \\
\end{array}$ & $\begin{array}{r}7.44 \\
7.28 \\
7.21 \\
7.18 \\
\end{array}$ & $\begin{array}{l}1.95 \\
1.90 \\
1.90 \\
1.85 \\
\end{array}$ & $\begin{array}{r}7.18 \\
7.15 \\
7.15 \\
7.12 \\
\end{array}$ & $\begin{array}{l}1.85 \\
1.85 \\
1.75 \\
1.70 \\
\end{array}$ & $\begin{array}{l}7.12 \\
7.12 \\
7.06 \\
7.03 \\
\end{array}$ \\
\hline \multirow[b]{2}{*}{$\begin{array}{l}6 \\
N \\
6 \\
M \\
\end{array}$} & \multicolumn{2}{|c|}{ October 6} & \multicolumn{2}{|c|}{ October 7} & \multicolumn{2}{|c|}{ October 8} & \multicolumn{2}{|c|}{ October 9} & \multicolumn{2}{|c|}{ October 10} \\
\hline & $\begin{array}{l}1.60 \\
1.55 \\
1.50 \\
1.50 \\
\end{array}$ & $\begin{array}{r}6.97 \\
6.94 \\
6.90 \\
6.90 \\
\end{array}$ & $\begin{array}{l}1.50 \\
1.45 \\
1.40 \\
1.40 \\
\end{array}$ & $\begin{array}{r}6.90 \\
6.87 \\
6.84 \\
6.84 \\
\end{array}$ & $\begin{array}{l}1.40 \\
1.40 \\
1.40 \\
1.50 \\
\end{array}$ & \begin{tabular}{|l}
6.84 \\
6.84 \\
6.84 \\
6.90 \\
\end{tabular} & $\begin{array}{l}1.55 \\
1.60 \\
1.60 \\
1.65 \\
\end{array}$ & $\begin{array}{r}6.94 \\
6.97 \\
6.97 \\
7.00 \\
\end{array}$ & $\begin{array}{r}1.60 \\
.1 .60 \\
1.55 \\
1.55 \\
\end{array}$ & $\begin{array}{r}6.97 \\
6.97 \\
6.94 \\
6.94 \\
\end{array}$ \\
\hline & octo & ober 11 & oct & ber 12 & oct & ober 13 & octs & ober 14 & Oet & ber 15 \\
\hline $\begin{array}{l}6 \\
N \\
6 \\
M\end{array}$ & $\begin{array}{l}1.50 \\
1.50 \\
1.50 \\
1.65\end{array}$ & $\begin{array}{l}6.90 \\
6.90 \\
6.90 \\
7.00\end{array}$ & $\begin{array}{l}1.75 \\
1.80 \\
1.80 \\
1.70\end{array}$ & $\begin{array}{l}7.06 \\
7.09 \\
7.09 \\
7.03\end{array}$ & $\begin{array}{l}1.60 \\
1.50 \\
1.40 \\
1.40\end{array}$ & $\begin{array}{r}6.97 \\
6.90 \\
6.84 \\
6.84\end{array}$ & $\begin{array}{l}1.40 \\
1.40 \\
1.40 \\
1.40\end{array}$ & $\begin{array}{l}6.84 \\
6.84 \\
6.84 \\
6.84\end{array}$ & $\begin{array}{l}1.40 \\
1.40 \\
1.40 \\
1.40\end{array}$ & $\begin{array}{l}6.84 \\
6.84 \\
6.84 \\
6.84\end{array}$ \\
\hline
\end{tabular}


Ja11 Branch at East Barre, Vt.

Location. - Water-stage recorder, lat. $44^{\circ} 10^{\prime}$, long. $72^{\circ} 27^{\prime}$, in East Barre, Washington county, just below highway bridge, three-quarters of a mile below Fast Barre Detention Reservo1r, and $23 / 4$ miles above confluence with Stevens Branch. Zero of gage is $1,071.59$ feet above mean sea level.

Drainage area. - 33.0 square miles.

Gage-holght record.- Water-stage recorder graph except for perlod 1 p.m. Sept. 6 to 10 a.m. Sopt. 22, record for which was based on relationship with stage in East Barre Detention Reservoir.

Stage-d1scharge relation.- For 1938 defined by current-meter measurements below 391 second-feet. For 1936 defined by current-meter measurements below 131 second-feet; extended to peak stage on basis of determinations of flood flow over dam.

Maxima.- September 1938: Mean dally discharge djusted for storage, 1,080 second-feet Sept. 21 .

1920-1923, 1934 to August 1938: Mean dally discharge adjusted for storage, 1,920 second-feet Mar. 18, 1936.

Maximum discharge knom, il,500 second-feet November 1927.

Remarks. - Mean dally and monthly discharges ad fusted for storage in East Barre Detention Reservo1r (capacity, 522,720,000 cubic feet). For information on storage see record for Bast Barre Detention Reservolr on Jall Branch at East Barre, Vt.

Mean daily discharge, in second-feet, 1938

\begin{tabular}{|r|r|r|r|r||r|r|r|r|r|}
\hline \multirow{2}{*}{ Day } & \multicolumn{2}{|c|}{ September } & \multicolumn{2}{c|}{ Oc tober } & \multicolumn{2}{c|}{ September } & \multicolumn{2}{|c|}{ October } \\
\cline { 2 - 8 } & Observed & Adjusted & Observed & Adjus ted & Day & Observed & Adjus ted & Observed & Adjus ted \\
\hline 1 & 10 & 11.9 & 53 & 53 & 16 & 84 & 51 & 23 & 23 \\
2 & 15 & 14.3 & 50 & 48 & 17 & 47 & 44 & 22 & 22 \\
3 & 9.6 & 10.3 & 40 & 35 & 18 & 53 & 55 & 20 & 20 \\
4 & 15 & 15.3 & 32 & 31 & 19 & 48 & 48 & 19 & 19 \\
5 & 7.6 & 4.6 & 30 & 29 & 20 & 134 & 265 & 22 & 25 \\
6 & 6.6 & 8.6 & 25 & 23 & 21 & 382 & 1,080 & 52 & 57 \\
7 & 25 & 30 & 23 & 22 & 22 & 362 & 425 & 34 & 28 \\
8 & 25 & 22 & 23 & 24 & 23 & 337 & 122 & 26 & 33 \\
9 & 9.6 & 5.8 & 26 & 27 & 24 & 317 & 107 & 71 & 92 \\
10 & 4.5 & 3.9 & 26 & 25 & 25 & 290 & 80 & 124 & 113 \\
11 & 4.2 & 3.7 & 24 & 25 & 26 & 243 & 53 & 50 & 38 \\
12 & 4.5 & 8 & 26 & 26 & 27 & 100 & 60 & 38 & 36 \\
13 & 96 & 114 & 23 & 21 & 28 & 78 & 57 & 33 & 33 \\
14 & 112 & 130 & 23 & 23 & 60 & 55 & 31 & 28 \\
15 & 140 & 150 & 23 & 23 & 30 & 55 & 53 & 25 & 24 \\
\hline
\end{tabular}

Gage height, In feet, and discharge, in second-feet, at indicated time, 1938

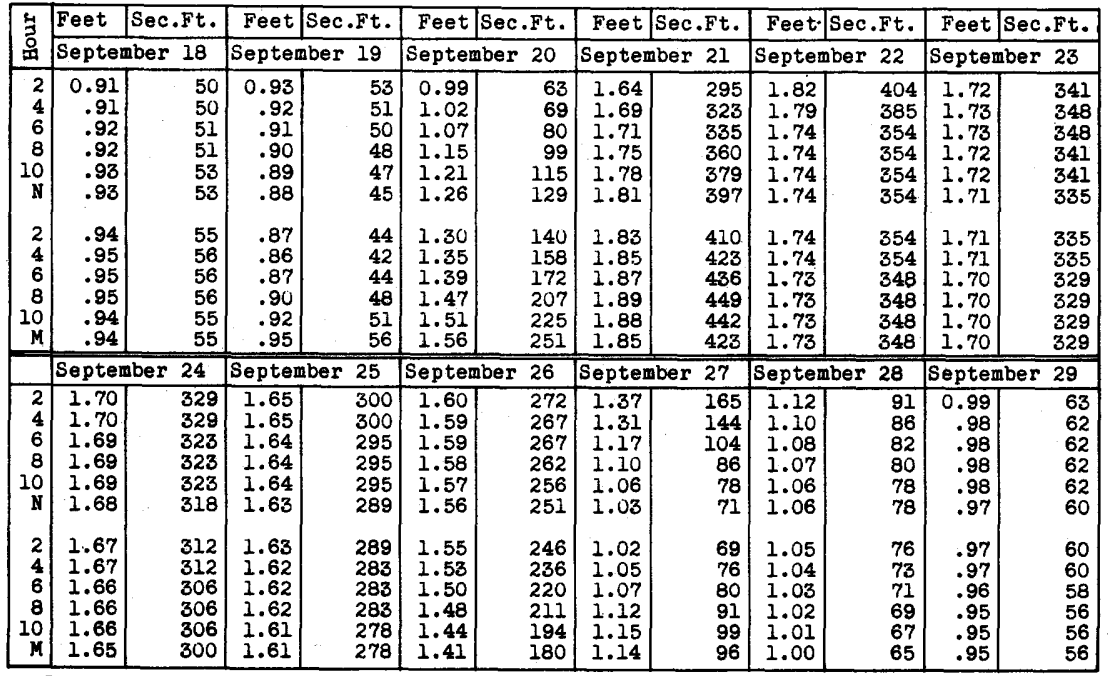

Supplemental records.- Sept. 19,7 p.m., 0.90 ft., 48 sec.-ft. Sept. 21,9 p.m., 1.90 ft., 455 sec.-ft. Sept. 23 , 1 a.m., 1.74 ft., 354 sec.-ft. 
Wrightsville Detention Reservoir on North Branch of Winooski River at Wrightsville, Vt.

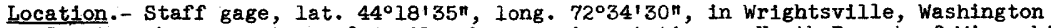
County, three-quarters of a mile above gaging station on North Branch of Winooski River and $4 \frac{1}{t}$ miles above confluence with Winooski River. Zero of gage is 612.75

feet above mean sea level.

Drainage area.- 66.5 square miles.

Gage-helght record. - Graph based on one or more readings dally.

Remarks.- Capacity of reservolr, 893,000,000 cubic feet. Capacity curve developed from areas furnished by Corps of Engineers, U. S. Army.

Gain or loss in storage, in millions of cubic feet, 1938

\begin{tabular}{|c|c|c|c|c|c|c|c|c|c|c|c|}
\hline Day & Sept. & oct. & Day & Sept. & oct. & Day & Sept. & oct. & Day & Sept. & oct, \\
\hline $\begin{array}{l}1 \\
2 \\
3 \\
4 \\
5 \\
6 \\
7 \\
8\end{array}$ & $\begin{array}{r}+1.26 \\
.00 \\
.00 \\
-.34 \\
-.42 \\
-.50 \\
+.75 \\
.00\end{array}$ & $\begin{array}{r}-3.17 \\
-1.38 \\
-.70 \\
-.62 \\
-.53 \\
-.53 \\
-.42 \\
-.41\end{array}$ & $\begin{array}{r}9 \\
10 \\
11 \\
12 \\
13 \\
14 \\
15 \\
16\end{array}$ & $\begin{array}{r}-0.09 \\
-.16 \\
-.25 \\
+.25 \\
+5.35 \\
+2.19 \\
+9.88 \\
-3.72\end{array}$ & $\begin{array}{r}-0.35 \\
+.35 \\
-.35 \\
-.36 \\
-.34 \\
+.433 \\
-.34 \\
-.35\end{array}$ & $\begin{array}{l}17 \\
18 \\
19 \\
20 \\
21 \\
22 \\
23 \\
24\end{array}$ & $\begin{array}{r}-2.82 \\
-5.53 \\
+3.50 \\
+25.92 \\
+157.83 \\
+58.93 \\
-33.33 \\
-38.18\end{array}$ & $\begin{array}{r}-0.15 \\
-.26 \\
.00 \\
+.26 \\
+2.37 \\
.00 \\
-1.87 \\
+6.89\end{array}$ & $\begin{array}{l}25 \\
26 \\
27 \\
28 \\
29 \\
30 \\
31\end{array}$ & $\begin{array}{r}-39.66 \\
-37.69 \\
-34.05 \\
-28.80 \\
-21.36 \\
-9.94\end{array}$ & $\begin{array}{r}+2.94 \\
-.33 \\
-3.55 \\
-2.12 \\
-1.13 \\
-.83 \\
-.83\end{array}$ \\
\hline $\begin{array}{l}\text { Gain } \\
\text { Gain }\end{array}$ & $\begin{array}{l}\text { or loss } \\
\text { or loss }\end{array}$ & $\begin{array}{l}\text { sto } \\
\text { sto }\end{array}$ & e, & $\begin{array}{l}\text { mil11 } \\
\text { equive }\end{array}$ & $\begin{array}{l}\text { of } \mathrm{cl} \\
\text { at mes }\end{array}$ & 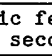 & & $\therefore$ & $\dot{.} \cdot$ & $\begin{array}{r}+9.02 \\
+3\end{array}$ & $\begin{array}{r}-7.48 \\
-3 \\
\end{array}$ \\
\hline
\end{tabular}

Gage helght, In feet, and contents, in millions of cubic feet, at indicated time, 1938

\begin{tabular}{|c|c|c|c|c|c|c|c|c|c|c|}
\hline \multirow[t]{2}{*}{ Hour } & $\begin{array}{c}\text { Gage } \\
\text { helght }\end{array}$ & Contents & $\begin{array}{c}\text { Gage } \\
\text { hetght }\end{array}$ & Contents & $\begin{array}{c}\text { Gage } \\
\text { helght }\end{array}$ & Contents & $\begin{array}{c}\text { Gage } \\
\text { helght }\end{array}$ & Contents & $\begin{array}{c}\text { Gage } \\
\text { helght }\end{array}$ & Contents \\
\hline & \multicolumn{2}{|c|}{ September 11} & \multicolumn{2}{|c|}{ September 12} & \multicolumn{2}{|c|}{ September 13} & \multicolumn{2}{|c|}{ September 14} & \multicolumn{2}{|c|}{ September 15} \\
\hline $\begin{array}{l}6 \\
N \\
6 \\
M\end{array}$ & $\begin{array}{l}1.70 \\
1.70 \\
1.70 \\
1.60\end{array}$ & $\begin{array}{l}12.62 \\
12.62 \\
12.62 \\
12.37\end{array}$ & $\begin{array}{l}1.40 \\
1.40 \\
1.50 \\
1.70\end{array}$ & $\begin{array}{l}11.86 \\
11.86 \\
12.12 \\
12.62\end{array}$ & $\begin{array}{l}2.20 \\
2.40 \\
3.00 \\
3.60\end{array}$ & $\begin{array}{l}13.93 \\
14.49 \\
16.15 \\
17.97\end{array}$ & $\begin{array}{l}4.20 \\
4.60 \\
4.60 \\
4.30\end{array}$ & $\begin{array}{l}19.83 \\
21.14 \\
21.14 \\
20.16 \\
\end{array}$ & $\begin{array}{l}4.40 \\
5.20 \\
6.20 \\
7.10 \\
\end{array}$ & $\begin{array}{l}20.49 \\
23.15 \\
26.69 \\
30.04 \\
\end{array}$ \\
\hline \multirow[b]{2}{*}{$\begin{array}{l}6 \\
\mathbf{N} \\
6 \\
\mathbf{H} \\
\end{array}$} & \multicolumn{2}{|c|}{ September 16} & \multicolumn{2}{|c|}{ September 17} & \multicolumn{2}{|c|}{ September 18} & \multicolumn{2}{|c|}{ September 19} & \multicolumn{2}{|c|}{ September 20} \\
\hline & $\begin{array}{l}7.50 \\
7.30 \\
6.50 \\
6.10\end{array}$ & $\begin{array}{l}31.60 \\
30.82 \\
27.80 \\
26.32\end{array}$ & $\begin{array}{l}5.70 \\
5.60 \\
5.50 \\
5.30\end{array}$ & $\begin{array}{l}24.90 \\
24.55 \\
24.20 \\
23.50\end{array}$ & $\begin{array}{l}4.90 \\
4.00 \\
3.80 \\
3.60 \\
\end{array}$ & $\begin{array}{l}22.12 \\
19.18 \\
18.57 \\
17.97 \\
\end{array}$ & $\begin{array}{l}3.60 \\
3.70 \\
4.00 \\
4.70\end{array}$ & $\begin{array}{l}17.97 \\
18.27 \\
19.18 \\
21.47 \\
\end{array}$ & $\begin{array}{r}5.50 \\
5.90 \\
8.70 \\
11.20 \\
\end{array}$ & $\begin{array}{l}24.20 \\
25.60 \\
36.42 \\
47.39 \\
\end{array}$ \\
\hline \multirow[b]{2}{*}{$\begin{array}{l}6 \\
N \\
6 \\
M\end{array}$} & \multicolumn{2}{|c|}{ September 21} & \multicolumn{2}{|c|}{ September 22} & \multicolumn{2}{|c|}{ September 23} & \multicolumn{2}{|c|}{ September 24} & \multicolumn{2}{|c|}{ September 25} \\
\hline & $\begin{array}{l}14.30 \\
16.80 \\
20.40 \\
31.70\end{array}$ & $\begin{array}{r}62.98 \\
77.92 \\
103.56 \\
205.22\end{array}$ & $\begin{array}{l}36.20 \\
37.00 \\
37.20 \\
37.00\end{array}$ & $\begin{array}{l}254.69 \\
264.15 \\
266.58 \\
264.15\end{array}$ & $\begin{array}{l}36.60 \\
35.80 \\
35.00 \\
34.10\end{array}$ & $\begin{array}{l}259.42 \\
250.03 \\
240.85 \\
230.82\end{array}$ & $\begin{array}{l}33.10 \\
32.20 \\
31.30 \\
30.46\end{array}$ & $\begin{array}{l}219.94 \\
210.41 \\
201.10 \\
192.64\end{array}$ & $\begin{array}{l}29.30 \\
28.30 \\
27.30 \\
26.30\end{array}$ & $\begin{array}{l}181.15 \\
171.54 \\
162.15 \\
152.98\end{array}$ \\
\hline \multirow[b]{2}{*}{$\begin{array}{l}6 \\
N \\
6 \\
M\end{array}$} & \multicolumn{2}{|c|}{ September 26} & \multicolumn{2}{|c|}{ September 27} & \multicolumn{2}{|c|}{ September 28} & \multicolumn{2}{|c|}{ September 29} & \multicolumn{2}{|c|}{ September 30} \\
\hline & $\begin{array}{l}25.20 \\
24.10 \\
23.00 \\
21.90\end{array}$ & $\begin{array}{l}143.13 \\
133.55 \\
124.25 \\
115.29\end{array}$ & $\begin{array}{l}20.80 \\
19.60 \\
18.40 \\
17.30\end{array}$ & $\begin{array}{r}106.62 \\
97.55 \\
88.85 \\
81.24 \\
\end{array}$ & $\begin{array}{l}16.10 \\
14.80 \\
13.60 \\
12.26\end{array}$ & \begin{tabular}{|l}
73.44 \\
65.74 \\
59.23 \\
52.44 \\
\end{tabular} & $\begin{array}{r}11.20 \\
9.80 \\
8.60 \\
7.37\end{array}$ & \begin{tabular}{|l|}
47.39 \\
41.09 \\
36.01 \\
31.08
\end{tabular} & $\begin{array}{l}6.30 \\
5.50 \\
5.00 \\
4.60 \\
\end{array}$ & $\begin{array}{l}27.06 \\
24.20 \\
22.45 \\
21.14 \\
\end{array}$ \\
\hline \multirow[b]{2}{*}{$\begin{array}{l}6 \\
N \\
6 \\
M \\
\end{array}$} & \multicolumn{2}{|c|}{ October 1} & \multicolumn{2}{|c|}{ october 2} & \multicolumn{2}{|c|}{ October 3} & \multicolumn{2}{|c|}{ October 4} & \multicolumn{2}{|c|}{ October 5} \\
\hline & $\begin{array}{l}4.20 \\
4.00 \\
3.80 \\
3.60 \\
\end{array}$ & $\begin{array}{l}19.83 \\
19.18 \\
18.57 \\
17.97 \\
\end{array}$ & $\begin{array}{l}3.40 \\
3.30 \\
3.20 \\
3.15\end{array}$ & $\begin{array}{l}17.36 \\
17.06 \\
16.76 \\
16.59 \\
\end{array}$ & $\begin{array}{l}2.70 \\
2.50 \\
2.70 \\
2.91\end{array}$ & \begin{tabular}{|l|}
15.32 \\
14.76 \\
15.32 \\
15.89 \\
\end{tabular} & $\begin{array}{l}2.50 \\
2.30 \\
2.50 \\
2.68 \\
\end{array}$ & $\begin{array}{l}14.76 \\
14.21 \\
14.76 \\
15.27 \\
\end{array}$ & $\begin{array}{l}2.00 \\
2.00 \\
2.20 \\
2.49 \\
\end{array}$ & $\begin{array}{r}13.38 \\
13.38 \\
13.93 \\
14.74 \\
\end{array}$ \\
\hline \multirow[b]{2}{*}{$\begin{array}{l}6 \\
N \\
6 \\
M \\
\end{array}$} & \multicolumn{2}{|c|}{ october 6} & \multicolumn{2}{|c|}{ october 7} & \multicolumn{2}{|c|}{ october 8} & \multicolumn{2}{|c|}{ October 9} & \multicolumn{2}{|c|}{ October 10} \\
\hline & $\begin{array}{l}2.50 \\
2.50 \\
2.40 \\
2.30 \\
\end{array}$ & $\begin{array}{l}14.76 \\
14.76 \\
14.49 \\
14.21 \\
\end{array}$ & $\begin{array}{l}2.10 \\
2.00 \\
2.00 \\
2.15 \\
\end{array}$ & $\begin{array}{l}13.66 \\
13.38 \\
13.38 \\
13.79 \\
\end{array}$ & $\begin{array}{l}2.00 \\
2.00 \\
2.00 \\
2.00 \\
\end{array}$ & $\begin{array}{l}13.38 \\
13.38 \\
13.38 \\
13.38 \\
\end{array}$ & $\begin{array}{l}2.00 \\
1.90 \\
1.80 \\
1.86 \\
\end{array}$ & $\begin{array}{l}13.38 \\
13.13 \\
12.87 \\
13.03 \\
\end{array}$ & $\begin{array}{l}1.80 \\
1.90 \\
2.00 \\
2.00 \\
\end{array}$ & $\begin{array}{l}12.87 \\
13.13 \\
13.38 \\
13.38 \\
\end{array}$ \\
\hline & Oct & ober 11 & oct & ober 12 & oct & ober 13 & oct & ber 14 & oct & ber 15 \\
\hline $\begin{array}{l}6 \\
\mathbb{N} \\
6 \\
M\end{array}$ & $\begin{array}{l}2.00 \\
2.00 \\
1.80 \\
1.66\end{array}$ & $\begin{array}{l}13.38 \\
13.38 \\
12.87 \\
12.53\end{array}$ & $\begin{array}{l}1.70 \\
1.70 \\
1.80 \\
1.80\end{array}$ & $\begin{array}{l}12.62 \\
12.62 \\
12.87 \\
12.87\end{array}$ & $\begin{array}{l}1.80 \\
1.80 \\
1.60 \\
1.66\end{array}$ & $\begin{array}{l}12.87 \\
12.87 \\
12.37 \\
12.53\end{array}$ & $\begin{array}{l}1.70 \\
1.80 \\
1.80 \\
1.84\end{array}$ & $\begin{array}{l}12.62 \\
12.87 \\
12.87 \\
12.97\end{array}$ & $\begin{array}{l}1.50 \\
1.60 \\
1.70 \\
1.70\end{array}$ & $\begin{array}{l}12.12 \\
12.37 \\
12.62 \\
12.62 \\
\end{array}$ \\
\hline
\end{tabular}


Location.- Water-stage recorder, lat. $44^{\circ} 18^{\prime} 00^{\prime \prime}$, long. $72^{\circ} 34^{\prime} 45^{\prime \prime}$, In Wrightsville, Washington County, three-quarters of a mile below Wrightsville Detention Reservoir and $3 \frac{1}{2}$ miles above confluence with Winooski River. Zero of gage is 550.53 feet above mean sea level.

Drainge area.- 69.2 square miles.

Gage-helght record. - Water-stage recorder graph.

Stage-discharge relation.- Defined by current-meter measurements below 813 secondfeet; extended to peak stage by determination of maximum flow through tunnel.

Max1ma.- September 1938: Mean dally discharge adjusted for storage, 2,340 secondfeet Sept. 21 .

1933 to August 1938: Mean da1ly discharge adjusted for storage, 3,300 second-feet Mar. 18,1936

Maximum discharge known, 17,200 second-feet Nov. 3, 1927.

Remarks. - Mean da1ly and monthly discharges adjusted for storage in Wrightsv11le Detention Reservoir (capacity, 893,000,000 cubic feet). For information on storage see record for Wrightsville Detention Reservolr on North Branch of Winooski RIver at Wrightsville, vt.

\begin{tabular}{|c|c|c|c|c|c|c|c|c|c|}
\hline \multirow{2}{*}{ Day } & \multicolumn{2}{|c|}{ September } & \multicolumn{2}{|c|}{ October } & \multirow[b]{2}{*}{ Day } & \multicolumn{2}{|c|}{ September } & \multicolumn{2}{|c|}{ October } \\
\hline & Observed & Adjusted & observed & Adjusted & & Observed & Adjusted & Observed & Adjusted \\
\hline $\begin{array}{l}1 \\
2 \\
3 \\
4 \\
5\end{array}$ & $\begin{array}{l}25 \\
32 \\
31 \\
28 \\
27\end{array}$ & $\begin{array}{l}40 \\
32 \\
31 \\
24 \\
22\end{array}$ & \begin{tabular}{r|}
102 \\
68 \\
54 \\
48 \\
44
\end{tabular} & $\begin{array}{l}65 \\
52 \\
46 \\
41 \\
38\end{array}$ & $\begin{array}{l}16 \\
17 \\
18 \\
19 \\
20\end{array}$ & $\begin{array}{r}267 \\
169 \\
109 \\
82 \\
209\end{array}$ & $\begin{array}{r}224 \\
136 \\
45 \\
123 \\
509\end{array}$ & $\begin{array}{l}29 \\
27 \\
27 \\
26 \\
26\end{array}$ & $\begin{array}{l}25 \\
25 \\
24 \\
26 \\
29\end{array}$ \\
\hline $\begin{array}{r}6 \\
7 \\
8 \\
9 \\
10\end{array}$ & $\begin{array}{l}26 \\
23 \\
29 \\
27 \\
24\end{array}$ & $\begin{array}{l}20 \\
32 \\
29 \\
26 \\
22\end{array}$ & $\begin{array}{l}40 \\
37 \\
35 \\
34 \\
34\end{array}$ & $\begin{array}{l}34 \\
32 \\
30 \\
30 \\
38\end{array}$ & $\begin{array}{l}21 \\
22 \\
23 \\
24 \\
25\end{array}$ & $\begin{array}{l}511 \\
725 \\
714 \\
682 \\
641\end{array}$ & $\begin{array}{r}2,340 \\
1,410 \\
328 \\
240 \\
182\end{array}$ & $\begin{array}{r}34 \\
43 \\
40 \\
44 \\
152\end{array}$ & $\begin{array}{r}61 \\
43 \\
18 \\
124 \\
186\end{array}$ \\
\hline $\begin{array}{l}11 \\
12 \\
13 \\
14 \\
15\end{array}$ & $\begin{array}{r}22 \\
18 \\
60 \\
106 \\
169\end{array}$ & $\begin{array}{r}19 \\
21 \\
122 \\
131 \\
283\end{array}$ & $\begin{array}{l}36 \\
31 \\
31 \\
29 \\
31\end{array}$ & $\begin{array}{l}32 \\
29 \\
27 \\
34 \\
27\end{array}$ & $\begin{array}{l}26 \\
27 \\
28 \\
29 \\
30 \\
31\end{array}$ & $\begin{array}{l}590 \\
533 \\
458 \\
355 \\
204\end{array}$ & $\begin{array}{r}154 \\
139 \\
125 \\
108 \\
89\end{array}$ & $\begin{array}{r}150 \\
109 \\
81 \\
63 \\
53 \\
47\end{array}$ & $\begin{array}{r}146 \\
68 \\
56 \\
50 \\
43 \\
37\end{array}$ \\
\hline $\begin{array}{l}\text { Hee } \\
\text { Run }\end{array}$ & monthly & $\begin{array}{l}\text { ischarge, } \\
\text { ches. }\end{array}$ & In secon & feet. & $\dot{.}$ & -230 & $\begin{array}{r}233 \\
3.76\end{array}$ & 51.8 & $\begin{array}{l}48.9 \\
0.82\end{array}$ \\
\hline
\end{tabular}

Gage helght, in feet, and discharge, in second-feet, at indicated t1me, 1938

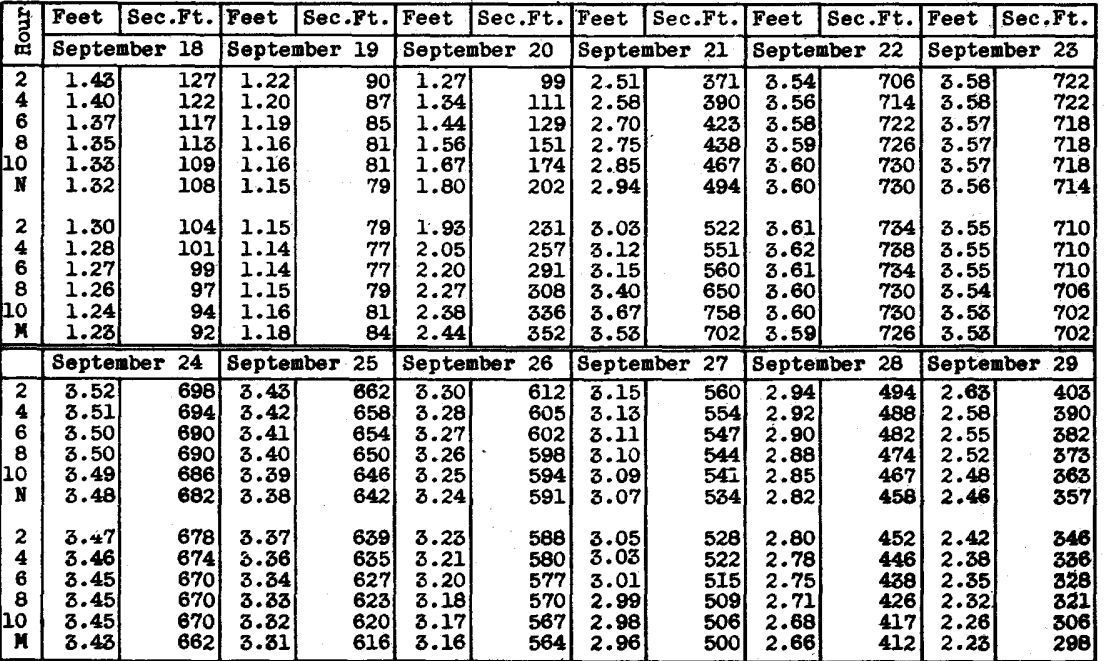

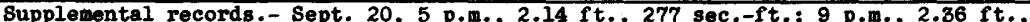

331 sec.-ft. Sept. 21,1 a.m., $2.46 \mathrm{ft}$., 357 sec. $-\mathrm{ft}$.; 5 a.m., $2.61 \mathrm{ft}$, 398 sec. $\mathrm{ft}$.; 7 p.m., 3.20 ft., 577 sec. ft.; 9 p.m., 3.60 ft., 730 sec. ft.; 9:40 p.m., 3.75 ft., 790 sec.-ft.; 11 p.m., 3.57 ft., 718 sec.-ft. 


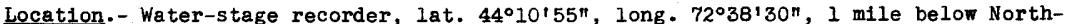
fleld Falls, Washington County, and lt miles below mouth of Cox Branch. Zero of gage is 603.00 feet above mean sea level.

Drainage area.- 76.1 square miles.

Gaze-helght record. - Water-stage recorder graph.

Stage-discharge relation.- Rating curve defined by current-meter measurements below 950 second-feet; extended to peak stage on basis of determinations of flood flow over dam and by slope-area method.

Maxima.- September 1938: Discharge, 9,750 second-feet 10 p.m. Sept. 21 (gage he1ght, 11.53 feet).

1934 to August 1938: D1scharge, 5,700 second-feet 8 p.m. Mar, 18, 1936 (gage height, 8.49 feet).

Remarks.- Flood run-off not materlally affected by storage.

Mean daily discharge, in second-feet, 1938

\begin{tabular}{|c|c|c|c|c|c|c|c|c|c|c|c|}
\hline Day & Sept. & oct. & Day & Sept. & Oct. & Day & Sept. & oct. & Day & Sept. & oct. \\
\hline $\begin{array}{l}1 \\
2 \\
3 \\
4 \\
5 \\
6 \\
7 \\
8\end{array}$ & $\begin{array}{l}29 \\
30 \\
20 \\
30 \\
25 \\
22 \\
27 \\
34\end{array}$ & $\begin{array}{r}114 \\
106 \\
93 \\
89 \\
82 \\
76 \\
71 \\
66\end{array}$ & $\begin{array}{r}9 \\
10 \\
11 \\
12 \\
13 \\
14 \\
15 \\
16\end{array}$ & $\begin{array}{r}29 \\
20 \\
19 \\
25 \\
89 \\
53 \\
161 \\
115\end{array}$ & $\begin{array}{l}64 \\
60 \\
58 \\
57 \\
48 \\
49 \\
49 \\
48\end{array}$ & $\begin{array}{l}17 \\
18 \\
19 \\
20 \\
21 \\
22 \\
23 \\
24\end{array}$ & $\begin{array}{r}71 \\
84 \\
80 \\
347 \\
2,660 \\
1,880 \\
511 \\
340\end{array}$ & $\begin{array}{l}46 \\
43 \\
41 \\
43 \\
60 \\
53 \\
47 \\
76\end{array}$ & $\begin{array}{l}25 \\
26 \\
27 \\
28 \\
29 \\
30 \\
31\end{array}$ & $\begin{array}{l}255 \\
204 \\
187 \\
172 \\
140 \\
123\end{array}$ & $\begin{array}{r}105 \\
72 \\
64 \\
59 \\
57 \\
54 \\
52\end{array}$ \\
\hline $\begin{array}{l}\text { Mean } \\
\text { Run- }\end{array}$ & $\begin{array}{l}\text { nthly } \\
\text {, in }\end{array}$ & hes. & . & & t. & & . $\cdot \dot{\text {. }}$ & - $\cdot$ : & - & $\begin{array}{r}259 \\
3: 79\end{array}$ & $\begin{array}{l}64.6 \\
0.98 \\
\end{array}$ \\
\hline
\end{tabular}

Gage helght, in feet, and discharge, In second-feet, at indicated time, 1938

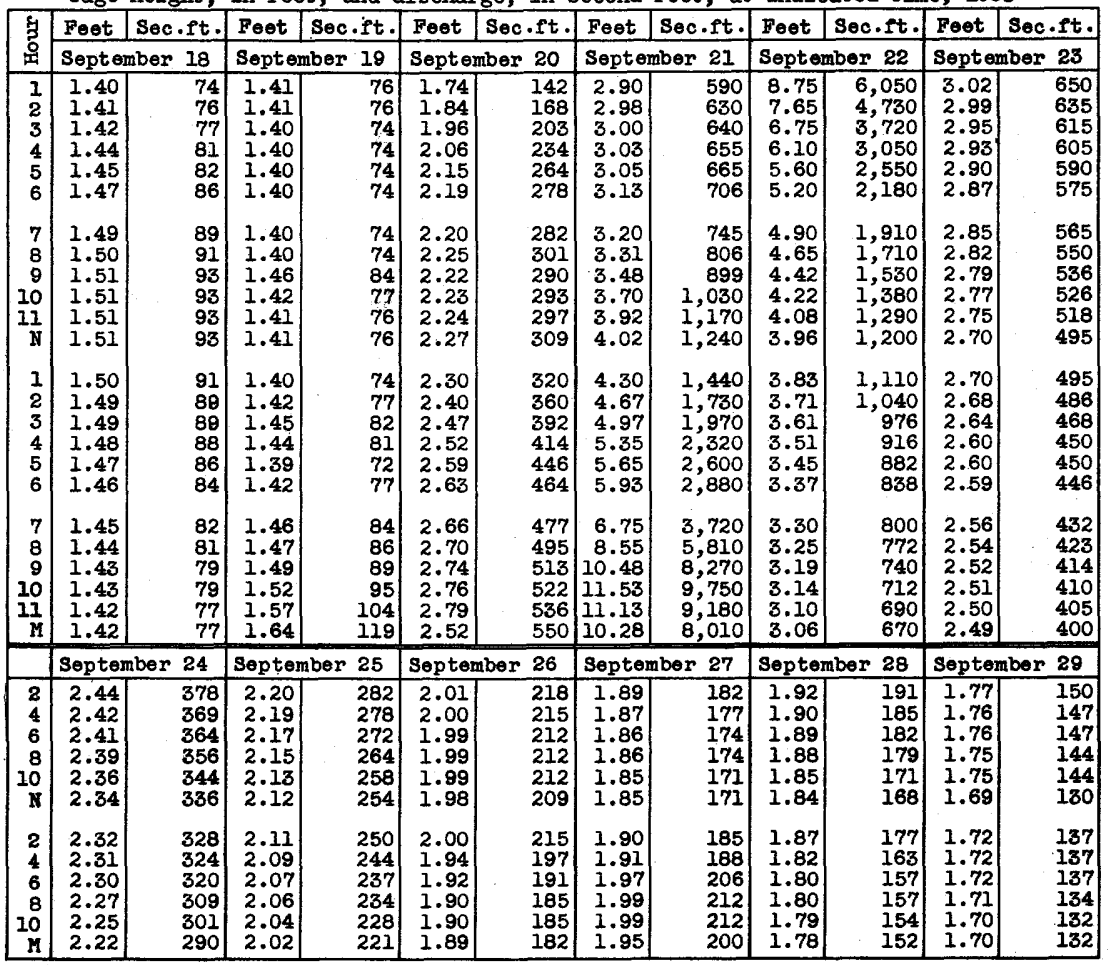


Location.- Water-stage recorder, lat. $44^{\circ} 16^{\prime} 40^{\prime \prime}$, long. $72^{\circ} 44^{\prime} 35^{\prime \prime}$, at highway bridge 2.4 miles below Moretown, Washington County.

Drainage area. - 139 square miles.

Gage-helght record. - Water-stage recorder graph, except for period 2 a.m. Sept. 17 to 10 a.m. Sept. 28 , record for which was based on two or more gage readings daily and on floodmarks.

Stage-discharge relation.- Defined by current-meter measurements below 2,690 secondfeet; extended to peak stage on basis of determinations of flood flows over dam.

Maxima.- September 1938: Discharge, 18,400 second-feet 12:30 a.m. Sept. 22 (gage helght, 16.34 feet).

1928 to August 1938: Maximum discharge, 8,120 second-feөt (revised) Apr. 12, 1934 ,(gage helght, 10.20 feet); maximum gage height, 11.20 fe日t Mar. 17, 1935 ( $1 \mathrm{ce}$ jam). Maximum discharge known, 23,000 second-feet Nov. 3, 1927 (gage he1ght, 19.4
feet, revised, from floodmarks).

Remarks:- Flood mun-off not materially affected by storage.

Mean dally discharge, in second-feet, 1938

\begin{tabular}{|c|r|r|r|r|r||r|r|r|r|r|r|}
\hline Day & Sept. & oct. & Day & Sept. & Oct. & Day & Sept. & Oct. & Day & Sept. & Oct. \\
\hline 1 & 94 & 200 & 9 & 83 & 116 & 17 & 237 & 89 & 25 & 474 & 349 \\
2 & 83 & 190 & 10 & 66 & 110 & 18 & 190 & 77 & 26 & 366 & 202 \\
3 & 65 & 164 & 11 & 57 & 108 & 19 & 267 & 78 & 27 & 305 & 160 \\
4 & 65 & 152 & 12 & 55 & 100 & 20 & 803 & 80 & 28 & 307 & 139 \\
5 & 61 & 140 & 13 & 336 & 93 & 21 & 5,540 & 173 & 29 & 240 & 126 \\
6 & 55 & 135 & 14 & 182 & 89 & 22 & 4,620 & 132 & 30 & 211 & 117 \\
7 & 77 & 125 & 15 & 608 & 90 & 23 & 987 & 100 & 31 & \\
8 & 153 & 120 & 16 & 409 & 82 & 24 & 659 & 165 & & 112 \\
\hline
\end{tabular}

Gage helght; In feet, and discharge, In second-feet, at indicated t1me, 1938

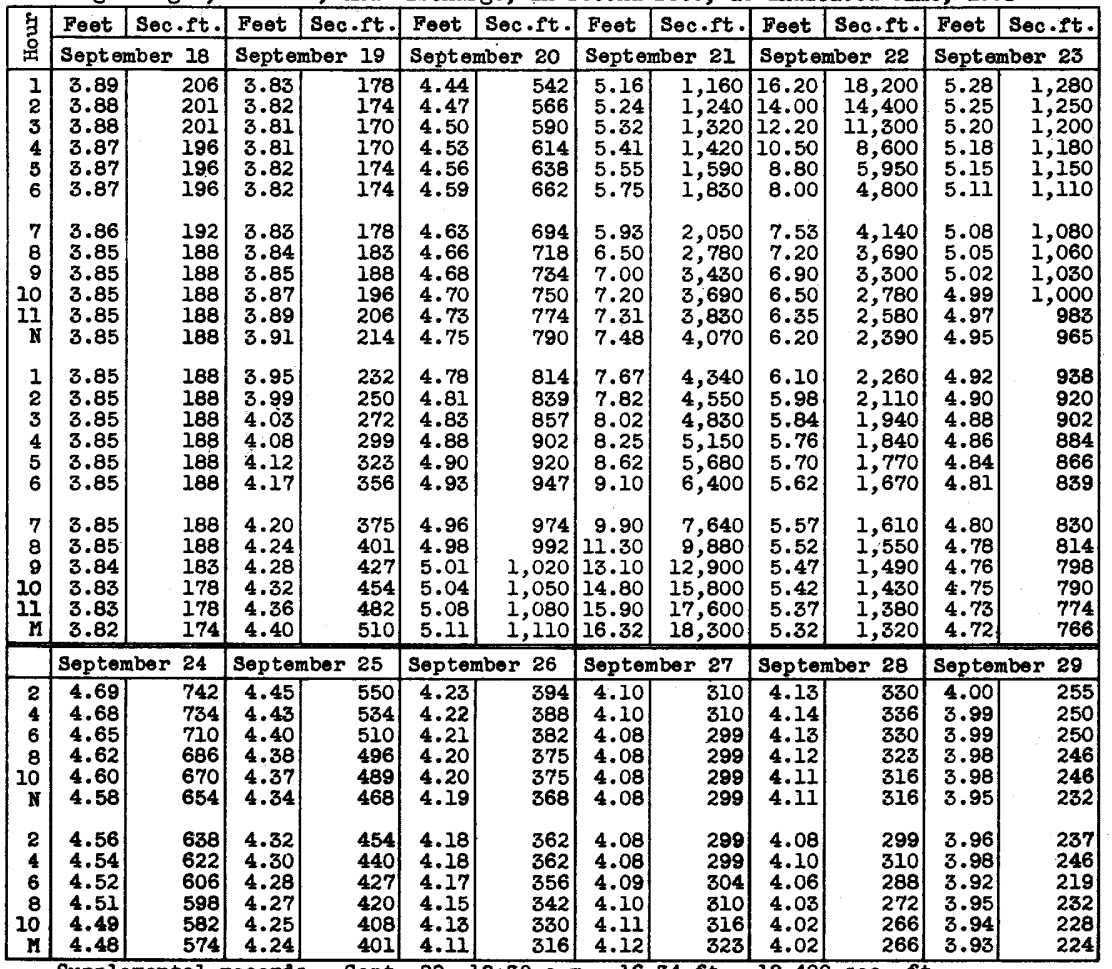

Supplemental records.- Sept. $22,12: 30$ a.m., $16.34 \mathrm{ft}$, , 18,400 sec.-ft. 
Location.- Staff gage, lat. $44^{\circ} 22^{\prime} 55^{n}$, long. $72^{\circ} 46^{\prime} 15^{n}$, about one mile above gaging station on Waterbury River, $22 / 3$ miles above mouth, and $3 \frac{1}{2}$ miles north of Waterbury, Washington county. Gage heights are elevations above mean sea level.

Drainage area.- 109 square miles.

Gage-helght record.- Graph based on several readings dally.

Remarks.- Capac1ty of reservoir, 2,807,440,000 cubic feet. Capacity curve developed

from areas furnished by Corps of Engineers, U. S. Army.

Gain or loss in storage, in millions of cublc feet, 1938

\begin{tabular}{|c|c|c|c|c|c|c|c|c|c|c|c|}
\hline Day & Sept. & oct. & Day & Sept. & Oct. & Day & Sept. & oct. & Day & Sept. & oct. \\
\hline $\begin{array}{l}1 \\
2 \\
3 \\
4 \\
5 \\
6 \\
7 \\
8\end{array}$ & $\begin{array}{r}-0.87 \\
+3.05 \\
+6.79 \\
+3.36 \\
0 \\
-6.23 \\
-10.28 \\
+2.44\end{array}$ & $\begin{array}{r}+6.71 \\
+6.53 \\
-19.25 \\
+1.22 \\
+7.58 \\
-8.50 \\
+.62 \\
+7.18\end{array}$ & $\begin{array}{l}9 \\
10 \\
11 \\
12 \\
13 \\
14 \\
15 \\
16\end{array}$ & $\begin{array}{r}+6.53 \\
-14.11 \\
-12.89 \\
+8.71 \\
+18.73 \\
-17.10 \\
-.86 \\
+17.96\end{array}$ & $\begin{array}{c}0 \\
-2.09 \\
-2.44 \\
-2.05 \\
+5.54 \\
+5.27 \\
-13.55 \\
0\end{array}$ & $\begin{array}{l}17 \\
18 \\
19 \\
20 \\
21 \\
22 \\
23 \\
24\end{array}$ & $\begin{array}{r}-21.54 \\
--5.30 \\
+10.96 \\
+8.87 \\
+277.07 \\
+159.36 \\
-52.93 \\
-65.20\end{array}$ & $\begin{array}{r}+6.53 \\
+4.27 \\
-8.36 \\
+.61 \\
+17.42 \\
+.87 \\
-3.92 \\
+10.02\end{array}$ & $\begin{array}{l}25 \\
26 \\
27 \\
28 \\
29 \\
30 \\
31\end{array}$ & $\begin{array}{r}-71.84 \\
-75.14 \\
-78.49 \\
-70.14 \\
-28.14 \\
-2.09\end{array}$ & $\begin{array}{c}-7.84 \\
+0.87 \\
+5.05 \\
-12.36 \\
+9.05 \\
+3.31 \\
0\end{array}$ \\
\hline $\begin{array}{l}\text { Gain } \\
\text { Gain }\end{array}$ & $\begin{array}{ll}\mathbf{r} & \text { loss } \\
\mathbf{r} & \text { loss }\end{array}$ & $\begin{array}{l}\text { n stor } \\
\text { n stor }\end{array}$ & 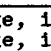 & & & & -feet & $\because \cdots$ & $\because \cdot$ & $\begin{array}{r}-9.32 \\
-4\end{array}$ & $\begin{array}{r}+18.29 \\
+7\end{array}$ \\
\hline
\end{tabular}

Gage height, in feet, and contents, in willions of cubic feet, at indicated time, 1968

\begin{tabular}{|c|c|c|c|c|c|c|c|c|c|c|}
\hline \multirow[t]{2}{*}{ Hour } & $\begin{array}{c}\text { Gage } \\
\text { helght }\end{array}$ & Contents & \begin{tabular}{|c|} 
Gage \\
height
\end{tabular} & Contents & $\begin{array}{c}\text { Gage } \\
\text { helght }\end{array}$ & Contents & $\begin{array}{l}\text { Gage } \\
\text { height }\end{array}$ & Contents & $\begin{array}{c}\text { Gage } \\
\text { height }\end{array}$ & Contents \\
\hline & \multicolumn{2}{|c|}{ September 11} & \multicolumn{2}{|c|}{ September 12} & \multicolumn{2}{|c|}{ September 13} & \multicolumn{2}{|c|}{ September 14} & \multicolumn{2}{|c|}{ September 15} \\
\hline \multirow[t]{2}{*}{$\begin{array}{l}6 \\
1 \\
6 \\
M\end{array}$} & $\begin{array}{l}503.10 \\
502.60 \\
502.30 \\
502.00\end{array}$ & $\begin{array}{l}29.06 \\
27.71 \\
26.92 \\
26.14\end{array}$ & \begin{tabular}{|l|}
501.50 \\
501.90 \\
503.40 \\
505.00
\end{tabular} & $\begin{array}{r}25.05 \\
25.92 \\
29.97 \\
34.85\end{array}$ & $\begin{array}{l}506.40 \\
507.60 \\
508.70 \\
509.80\end{array}$ & $\begin{array}{l}39.73 \\
44.17 \\
48.78 \\
53.58\end{array}$ & $\begin{array}{l}511.00 \\
511.30 \\
509.50 \\
505.47\end{array}$ & $\begin{array}{l}59.24 \\
60.68 \\
52.27 \\
36.48\end{array}$ & $\begin{array}{l}504.45 \\
505.82 \\
505.80 \\
505.22\end{array}$ & $\begin{array}{l}33.17 \\
37.70 \\
37.63 \\
35.62\end{array}$ \\
\hline & \multicolumn{2}{|c|}{ September 16} & \multicolumn{2}{|c|}{ September 17} & \multicolumn{2}{|c|}{ September 18} & \multicolumn{2}{|c|}{ September 19} & \multicolumn{2}{|c|}{ September 20} \\
\hline \multirow[t]{2}{*}{$\begin{array}{l}6 \\
N \\
6 \\
M \\
\end{array}$} & $\begin{array}{l}504.60 \\
506.70 \\
508.45 \\
509.80\end{array}$ & $\begin{array}{l}33.63 \\
40.77 \\
47.70 \\
53.58\end{array}$ & $\begin{array}{l}510.70 \\
509.53 \\
505.41 \\
504.08\end{array}$ & \begin{tabular}{|l|}
57.80 \\
52.40 \\
36.28 \\
32.04 \\
\end{tabular} & $\begin{array}{l}502.96 \\
502.52 \\
502.28 \\
502.23\end{array}$ & $\begin{array}{l}28.65 \\
27.49 \\
26.87 \\
26.74\end{array}$ & \begin{tabular}{|l}
502.15 \\
502.94 \\
504.14 \\
505.82
\end{tabular} & $\begin{array}{l}26.53 \\
28.59 \\
32.22 \\
37.70\end{array}$ & \begin{tabular}{|l|}
507.76 \\
509.39 \\
508.61 \\
508.19
\end{tabular} & $\begin{array}{l}44.80 \\
51.79 \\
48.39 \\
46.57\end{array}$ \\
\hline & \multicolumn{2}{|c|}{ September 21} & \multicolumn{2}{|c|}{ September 22} & \multicolumn{2}{|c|}{ September 23} & \multicolumn{2}{|c|}{ September 24} & \multicolumn{2}{|c|}{ September 25} \\
\hline $\begin{array}{l}6 \\
1 \\
6 \\
M \\
\end{array}$ & \begin{tabular}{|l|}
508.38 \\
515.30 \\
524.44 \\
538.53
\end{tabular} & $\begin{array}{r}47.39 \\
82.85 \\
157.54 \\
323.64\end{array}$ & $\begin{array}{l}546.98 \\
549.12 \\
549.43 \\
548.97\end{array}$ & $\begin{array}{l}448.36 \\
485.61 \\
491.01 \\
483.00\end{array}$ & $\begin{array}{l}548.38 \\
547.56 \\
546.68 \\
545.78\end{array}$ & $\begin{array}{l}471.84 \\
458.42 \\
443.79 \\
430.07\end{array}$ & $\begin{array}{l}544.77 \\
543.70 \\
542.59 \\
541.46\end{array}$ & $\begin{array}{l}414.67 \\
398.36 \\
381.61 \\
364.87\end{array}$ & $\begin{array}{l}540.18 \\
538.88 \\
537.52 \\
536.29\end{array}$ & $\begin{array}{l}346.63 \\
328.51 \\
309.56 \\
293.03\end{array}$ \\
\hline \multirow[b]{2}{*}{$\begin{array}{l}6 \\
H \\
6 \\
H\end{array}$} & \multicolumn{2}{|c|}{ September 26} & \multicolumn{2}{|c|}{ September 27} & \multicolumn{2}{|c|}{ September 28} & \multicolumn{2}{|c|}{ September 29} & \multicolumn{2}{|c|}{ September 30} \\
\hline & $\begin{array}{l}535.00 \\
533.50 \\
531.90 \\
530.20\end{array}$ & $\begin{array}{l}276.17 \\
257.00 \\
237.53 \\
217.89 \\
\end{array}$ & \begin{tabular}{|l|}
528.20 \\
526.20 \\
524.30 \\
522.50
\end{tabular} & $\begin{array}{l}195.24 \\
174.93 \\
156.20 \\
139.40 \\
\end{array}$ & $\begin{array}{l}520.00 \\
517.70 \\
515.40 \\
513.00\end{array}$ & \begin{tabular}{r|}
117.61 \\
99.27 \\
83.46 \\
69.26 \\
\end{tabular} & $\begin{array}{l}506.50 \\
504.40 \\
506.90 \\
506.80\end{array}$ & $\begin{array}{l}40.08 \\
33.02 \\
41.47 \\
41.12 \\
\end{array}$ & $\begin{array}{l}502.70 \\
501.70 \\
508.20 \\
506.20\end{array}$ & $\begin{array}{l}27.97 \\
25.49 \\
29.36 \\
39.08 \\
\end{array}$ \\
\hline & \multicolumn{2}{|c|}{ October 1} & \multicolumn{2}{|c|}{ October 2} & \multicolumn{2}{|c|}{ October 3} & \multicolumn{2}{|c|}{ October 4} & \multicolumn{2}{|c|}{ October 5} \\
\hline $\begin{array}{l}6 \\
M \\
6 \\
M\end{array}$ & $\begin{array}{l}505.30 \\
506.00 \\
507.00 \\
508.00\end{array}$ & \begin{tabular}{|l|}
35.89 \\
38.33 \\
41.82 \\
45.74 \\
\end{tabular} & $\begin{array}{l}508.70 \\
509.20 \\
509.30 \\
509.50\end{array}$ & \begin{tabular}{|l|}
48.78 \\
50.96 \\
51.40 \\
52.27
\end{tabular} & $\begin{array}{l}510.90 \\
511.40 \\
508.40 \\
504.40\end{array}$ & $\begin{array}{l}58.76 \\
61.16 \\
47.48 \\
33.02\end{array}$ & $\begin{array}{l}502.50 \\
503.10 \\
503.90 \\
504.80\end{array}$ & $\begin{array}{l}27.44 \\
29.06 \\
31.50 \\
34.24\end{array}$ & \begin{tabular}{|l}
505.90 \\
506.50 \\
506.80 \\
507.00
\end{tabular} & $\begin{array}{l}37.98 \\
40.08 \\
41.12 \\
41.82\end{array}$ \\
\hline & \multicolumn{2}{|c|}{ October 6} & \multicolumn{2}{|c|}{ October 7} & \multicolumn{2}{|c|}{ October 8} & \multicolumn{2}{|c|}{ 0ctober 9} & \multicolumn{2}{|c|}{ October 10} \\
\hline $\begin{array}{l}6 \\
4 \\
6 \\
M\end{array}$ & $\begin{array}{l}508.40 \\
508.90 \\
507.80 \\
504.50\end{array}$ & $\begin{array}{l}47.48 \\
49.66 \\
44.96 \\
33.32 \\
\end{array}$ & $\begin{array}{l}502.60 \\
503.10 \\
503.90 \\
504.70\end{array}$ & \begin{tabular}{|l|}
27.71 \\
29.06 \\
31.50 \\
33.94 \\
\end{tabular} & \begin{tabular}{|l}
505.60 \\
506.10 \\
506.50 \\
506.80.
\end{tabular} & $\begin{array}{l}36.94 \\
38.68 \\
40.08 \\
41.12 \\
\end{array}$ & $\begin{array}{l}508.00 \\
508.50 \\
508.70 \\
506.80\end{array}$ & $\begin{array}{l}45.74 \\
47.92 \\
48.78 \\
41.12 \\
\end{array}$ & $\begin{array}{l}505.00 \\
505.20 \\
505.70 \\
506.20\end{array}$ & $\begin{array}{l}34.85 \\
35.55 \\
37.29 \\
39.03\end{array}$ \\
\hline & oct & ober II & Oeto & ober 12 & oct & ber 18 & oct & ber 14 & Octc & ber 15 \\
\hline $\begin{array}{l}6 \\
6 \\
6 \\
4\end{array}$ & $\begin{array}{l}507.00 \\
507.60 \\
507.80 \\
505.50\end{array}$ & $\begin{array}{l}41.82 \\
44.17 \\
44.96 \\
36.59\end{array}$ & \begin{tabular}{|l|}
503.10 \\
503.10 \\
504.10 \\
504.90
\end{tabular} & $\begin{array}{l}29.06 \\
29.06 \\
32.10 \\
34.54\end{array}$ & \begin{tabular}{|l|}
505.30 \\
505.70 \\
506.10 \\
506.50
\end{tabular} & $\begin{array}{l}35.89 \\
37.29 \\
38.68 \\
40.08\end{array}$ & $\begin{array}{l}507.30 \\
507.90 \\
507.20 \\
507.90\end{array}$ & $\begin{array}{l}43.00 \\
45.35 \\
42.60 \\
45.35\end{array}$ & $\begin{array}{l}509.10 \\
509.10 \\
506.80 \\
504.00\end{array}$ & $\begin{array}{l}50.53 \\
50.58 \\
41.12 \\
31.80\end{array}$ \\
\hline
\end{tabular}


Waterbury River near Waterbury, Vt.

Location. - Water-stage recorder and concrete control, lat, $44^{\circ} 22^{\prime} 10^{\prime \prime}, 10 n g .72^{\circ} 46^{\prime} 10^{\prime \prime}$, $12 / 3$ miles above moutin and $2 \frac{i}{2}$ miles north of Waterbury, Washington County. Drainage area.- 111 square miles.

Gage-height record.- Water-stage recorder graph.

stage-discharge relation.- Defined by current-meter measurements below 4 , 100 secondfeet; extended logarithmically to peak stage.

Maxima.- September 1938: Discharge, 1,190 second-feet 5 p.m. Sept. 22 to 1 a.m. Sept. 23 (gage height, 8.94 feet).

1935 to August 1938: Discharge, 6,520 second-feet Mar. 18, 1936 (gage height, 19.38 feet).

Remarks.- Mean daily and monthly discharges adjusted for storage in Waterbury Reser-

volr (capacity 2,807,440,000 cubic feet). For information on storage see record

for Waterbury Reservoir on Waterbury River near Waterbury, Vt.

Mean dally discharge, in second-feet, 1938

\begin{tabular}{|c|c|c|c|c|c|c|c|c|c|}
\hline \multirow[b]{2}{*}{ pay } & \multicolumn{2}{|c|}{ September } & \multicolumn{2}{|c|}{ October } & \multirow[b]{2}{*}{ Day } & \multicolumn{2}{|c|}{ September } & \multicolumn{2}{|c|}{ october } \\
\hline & Observed & Ad Justed & Observed & Adjus ted & & Observed & Ad justed & Observed & Adjusted \\
\hline $\begin{array}{l}1 \\
2 \\
3 \\
4 \\
5\end{array}$ & $\begin{array}{c}88 \\
78 \\
1.0 \\
39 \\
48\end{array}$ & $\begin{array}{r}78 \\
113 \\
80 \\
78 \\
48\end{array}$ & $\begin{array}{c}2.6 \\
2.0 \\
303 \\
65 \\
1.7\end{array}$ & $\begin{array}{l}81 \\
78 \\
80 \\
79 \\
90\end{array}$ & $\begin{array}{l}16 \\
17 \\
18 \\
19 \\
20\end{array}$ & $\begin{array}{r}139 \\
345 \\
155 \\
54 \\
360\end{array}$ & $\begin{array}{r}347 \\
96 \\
94 \\
181 \\
463\end{array}$ & $\begin{array}{c}59 \\
1.4 \\
1.3 \\
151 \\
81\end{array}$ & $\begin{array}{l}59 \\
77 \\
50 \\
54 \\
88\end{array}$ \\
\hline $\begin{array}{r}6 \\
7 \\
8 \\
9 \\
10\end{array}$ & $\begin{array}{c}103 \\
180 \\
85 \\
1.1 \\
207\end{array}$ & $\begin{array}{r}31 \\
61 \\
113 \\
76 \\
44\end{array}$ & $\begin{array}{c}183 \\
81 \\
1.6 \\
81 \\
101\end{array}$ & $\begin{array}{l}85 \\
88 \\
85 \\
81 \\
77\end{array}$ & $\begin{array}{l}21 \\
22 \\
23 \\
24 \\
25\end{array}$ & $\begin{array}{r}694 \\
437 \\
1,180 \\
1,140 \\
1,100\end{array}$ & $\begin{array}{r}3,900 \\
2,280 \\
567 \\
385 \\
269\end{array}$ & $\begin{array}{l}2.9 \\
132 \\
169 \\
177 \\
400\end{array}$ & $\begin{array}{l}205 \\
142 \\
124 \\
293 \\
309\end{array}$ \\
\hline $\begin{array}{l}11 \\
12 \\
13 \\
14 \\
15\end{array}$ & $\begin{array}{r}178 \\
25 \\
148 \\
472 \\
471\end{array}$ & $\begin{array}{r}29 \\
126 \\
365 \\
274 \\
461\end{array}$ & $\begin{array}{c}103 \\
96 \\
1.6 \\
1.4 \\
232\end{array}$ & $\begin{array}{l}75 \\
72 \\
66 \\
62 \\
75\end{array}$ & $\begin{array}{l}26 \\
27 \\
28 \\
29 \\
30 \\
31\end{array}$ & $\begin{array}{r}1,060 \\
1,000 \\
924 \\
420 \\
111\end{array}$ & $\begin{array}{r}190 \\
92 \\
112 \\
94 \\
87\end{array}$ & $\begin{array}{c}236 \\
100 \\
267 \\
2.6 \\
66 \\
103\end{array}$ & $\begin{array}{l}246 \\
158 \\
124 \\
108 \\
104 \\
103\end{array}$ \\
\hline $\begin{array}{l}\text { Me } \\
\text { Ru }\end{array}$ & $\begin{array}{l}\text { an monthly } \\
n \text {-off, in }\end{array}$ & $\begin{array}{l}\text { discharge } \\
\text { nches. }\end{array}$ & $\begin{array}{l}\text { in secon } \\
\text { - }\end{array}$ & feet: : & & $\begin{array}{r}375 \\
-\quad-3\end{array}$ & $\begin{array}{r}371 \\
3.73\end{array}$ & $\begin{array}{l}103 \\
-\end{array}$ & $\begin{array}{r}110 \\
1.14\end{array}$ \\
\hline
\end{tabular}

Gage height, in feet, and discharge, in second-feet, at indicated time, 1938

\begin{tabular}{|c|c|c|c|c|c|c|c|c|c|c|c|c|}
\hline & Feet & Sec.Ft. & Feet & Sec.Ft. & Feet & Sec.Ft. & Feet & Sec.Ft. & Feet & Sec.Ft. & Feet & Sec.Ft. \\
\hline & \multicolumn{2}{|c|}{ September 18} & \multicolumn{2}{|c|}{ September 19} & \multicolumn{2}{|c|}{ September 20} & \multicolumn{2}{|c|}{ September 21} & \multicolumn{2}{|c|}{ September 22} & \multicolumn{2}{|c|}{ September 23} \\
\hline $\begin{array}{r}2 \\
4 \\
6 \\
8 \\
10 \\
\mathrm{~N}\end{array}$ & $\begin{array}{l}6.79 \\
6.68 \\
6.60 \\
6.54 \\
6.49 \\
6.45\end{array}$ & $\begin{array}{l}213 \\
189 \\
172 \\
160 \\
150 \\
142\end{array}$ & $\begin{array}{l}6.31 \\
6.30 \\
6.31 \\
6.31 \\
6.25 \\
5.10\end{array}$ & $\begin{array}{c}118 \\
116 \\
118 \\
118 \\
108 \\
7.5\end{array}$ & $\begin{array}{l}4.99 \\
4.98 \\
4.97 \\
4.97 \\
4.99 \\
5.04\end{array}$ & $\begin{array}{l}4.5 \\
4.3 \\
4.1 \\
4.1 \\
4.5 \\
5.8\end{array}$ & $\begin{array}{l}8.15 \\
8.15 \\
8.20 \\
8.24 \\
8.25 \\
8.46\end{array}$ & $\begin{array}{l}745 \\
745 \\
770 \\
792 \\
798 \\
913\end{array}$ & $\begin{array}{l}5.62 \\
5.50 \\
5.43 \\
5.36 \\
5.32 \\
5.28\end{array}$ & $\begin{array}{l}36 \\
27 \\
23 \\
19 \\
17 \\
15\end{array}$ & & $\begin{array}{l}1,190 \\
1,190 \\
1,190 \\
1,180 \\
1,180 \\
1,180\end{array}$ \\
\hline \multirow[t]{2}{*}{$\begin{array}{r}2 \\
4 \\
6 \\
8 \\
10 \\
M \\
\end{array}$} & $\begin{array}{l}6.43 \\
6.40 \\
6.37 \\
6.35 \\
6.34 \\
6.33\end{array}$ & $\begin{array}{l}139 \\
133 \\
128 \\
124 \\
123 \\
121\end{array}$ & $\begin{array}{l}5.00 \\
4.94 \\
4.92 \\
4.92 \\
4.95 \\
4.99\end{array}$ & $\begin{array}{l}4.7 \\
3.5 \\
3.1 \\
3.1 \\
3.7 \\
4.5\end{array}$ & $\begin{array}{l}8.16 \\
8.15 \\
8.15 \\
8.15 \\
8.15 \\
8.15\end{array}$ & $\begin{array}{l}750 \\
745 \\
745 \\
745 \\
745 \\
745\end{array}$ & $\begin{array}{l}8.56 \\
8.57 \\
8.67 \\
6.78 \\
6.20 \\
5.81\end{array}$ & $\begin{array}{r}968 \\
974 \\
1,030 \\
211 \\
101 \\
53\end{array}$ & $\begin{array}{l}5.24 \\
8.93 \\
8.94 \\
8.94 \\
8.94 \\
8.94\end{array}$ & $\begin{array}{r}13 \\
1,190 \\
1,190 \\
1,190 \\
1,190 \\
1,190\end{array}$ & $\begin{array}{l}90 \\
90 \\
90 \\
89 \\
89 \\
88\end{array}$ & $\begin{array}{l}1,170 \\
1,170 \\
1,170 \\
1,160 \\
1,160 \\
1,160\end{array}$ \\
\hline & \multicolumn{2}{|c|}{ September 24} & \multicolumn{2}{|c|}{ September 25} & \multicolumn{2}{|c|}{ September 26} & \multicolumn{2}{|c|}{ September 27} & \multicolumn{2}{|c|}{ September 28} & \multicolumn{2}{|c|}{ September 29} \\
\hline $\begin{array}{r}2 \\
4 \\
6 \\
8 \\
10 \\
\mathrm{~N}\end{array}$ & $\begin{array}{l}8.88 \\
8.87 \\
8.86 \\
8.86 \\
8.85 \\
8.85\end{array}$ & $\begin{array}{l}1,160 \\
1,150 \\
1,150 \\
1,150 \\
1,140 \\
1,140\end{array}$ & $\begin{array}{l}8.82 \\
8.81 \\
8.80 \\
8.80 \\
8.80 \\
8.79\end{array}$ & $\begin{array}{l}1,120 \\
1,120 \\
1,110 \\
1,110 \\
1,110 \\
1,100\end{array}$ & $\begin{array}{l}8.75 \\
8.75 \\
8.74 \\
8.73 \\
8.73 \\
8.72\end{array}$ & $\begin{array}{l}1,080 \\
1,080 \\
1,070 \\
1,070 \\
1,070 \\
1,060\end{array}$ & $\begin{array}{l}8.66 \\
8.65 \\
8.65 \\
8.64 \\
8.63 \\
8.62\end{array}$ & $\begin{array}{l}1,030 \\
1,020 \\
1,020 \\
1,010 \\
1,010 \\
1,000\end{array}$ & $\begin{array}{l}8.55 \\
8.54 \\
8.53 \\
8.51 \\
8.50 \\
8.48\end{array}$ & $\begin{array}{l}962 \\
957 \\
952 \\
940 \\
935 \\
924\end{array}$ & & $\begin{array}{l}852 \\
836 \\
695 \\
507 \\
393 \\
314\end{array}$ \\
\hline $\begin{array}{r}2 \\
4 \\
6 \\
8 \\
10 \\
M\end{array}$ & $\begin{array}{l}8.85 \\
8.85 \\
8.84 \\
8.84 \\
8.83 \\
8.82\end{array}$ & $\begin{array}{l}1,140 \\
1,140 \\
1,130 \\
1,130 \\
1,130\end{array}$ & $\begin{array}{l}8.78 \\
8.78 \\
8.77 \\
8.77 \\
8.76 \\
8.75\end{array}$ & $\begin{array}{l}1,100 \\
1,100 \\
1,090 \\
1,090 \\
1,090 \\
1,080\end{array}$ & $\begin{array}{l}8.71 \\
8.70 \\
8.70 \\
8.69 \\
8.68 \\
8.67\end{array}$ & $\begin{array}{l}1,060 \\
1,050 \\
1,050 \\
1,040 \\
1,040 \\
1,030\end{array}$ & $\begin{array}{l}8.62 \\
8.60 \\
8.60 \\
8.58 \\
8.57 \\
8.56\end{array}$ & $\begin{array}{r}1,000 \\
990 \\
990 \\
979 \\
974 \\
968\end{array}$ & $\begin{array}{l}8.47 \\
8.45 \\
8.44 \\
8.42 \\
8.40 \\
8.37\end{array}$ & $\begin{array}{l}918 \\
908 \\
902 \\
891 \\
880 \\
864\end{array}$ & $\begin{array}{l}6.92 \\
5.15 \\
6.95 \\
6.82 \\
6.70 \\
6.62\end{array}$ & $\begin{array}{c}246 \\
9.2 \\
254 \\
220 \\
193 \\
176\end{array}$ \\
\hline
\end{tabular}

Supplemental records.- Sept. 19, 9 a.m., $6.32 \mathrm{ft.,} 119$ sec.-ft.; 11 a.m., $5.30 \mathrm{ft}$. , 16 sec.-ft.; 1 p.m., 5.03 ft., 5.5 se6.-ft. Sept. 20, I p.m., 8.15 ft., 745 sec.-ft. Sept. $21,5 \mathrm{a.m}$, 8.16 ft., 750 sec.-ft.; il a.m., 8.41 ft., 886 sec.-ft.; 1 p.m., 8.54 ft., 957' sec.-ft.; 5 p.m., 8.60 ft., 990 sec.-ft.; 7 p.m., 7.23 ft., 340 sec.-ft.; 9 p.m., $6.55 \mathrm{ft.}, 162$ sec.-ft.; 11 p.m., $5.98 \mathrm{ft.,} 72$ sec.-ft. Sept. 22,1 a.m., 5.70 ft., 42 sec.-ft.; 9 a.m., 5.35 ft., 18 sec.-ft.; 3 p.m., 5.22 ft., 12 sec.-ft.

$2279070-40-25$ 
Lamoille R1ver at Johnson, Vt.

Iocation.- Water-stage recorder, lat. $44^{\circ} 37^{\prime} 20^{\prime \prime}$, long. $72^{\circ} 40^{\prime} 50^{\prime \prime}$, at falls $0.9 \mathrm{mlle}$ above original site at bridge in Johnson, Lamollle County, and $11 / 8$ miles above mouth of Gihon River.

Drainage area.- 335 square miles.

Gage-neight record.- Water-stage recorder graph.

Stage-discharge relation.- Rating curve defined by current-meter measurements below 4,460 second-feet; extended to peak stage on basis of determinations of flood flow over dem and by critical-depth method at control.

Maxima.- September 1938: Discharge, 9,120 second-feet 1 a.m. Sept. 22 (gage he1ght, 13.58 feet).

1910-13, 1928 to August 1938: D1scharge, 13,000 second-feet Mar. 18, 1936

(gage helght, 16.48 feet).

Remarks.- Flood mu-off not materially affected by storage.

Mean da1ly discharge, in second-feet, 1938

\begin{tabular}{|c|r|r|r|r|r|r|r|r|r|r|r|}
\hline Dey & Sept. & oct. & Day & Sept. & Oct. & Day & Sept. & Oct. & Day & Sept. & Oct. \\
\hline 1 & 222 & 350 & 9 & 183 & 130 & 17 & 368 & 185 & 25 & 588 & 787 \\
2 & 297 & 79 & 10 & 95 & 200 & 18 & 274 & 170 & 26 & 492 \\
3 & 147 & 103 & 11 & 44 & 173 & 19 & 355 & 175 & 27 & 403 & 399 \\
4 & 104 & 127 & 12 & 205 & 161 & 20 & 521 & 218 & 28 & 368 & 339 \\
5 & 148 & 167 & 13 & 584 & 196 & 21 & 3,910 & 260 & 29 & 289 & 218 \\
6 & 173 & 190 & 14 & 500 & 178 & 22 & 5,180 & 224 & 30 & 268 & 231 \\
7 & 200 & 190 & 15 & 618 & 119 & 23 & 1,370 & 174 & 31 & 287 \\
8 & 184 & 171 & 16 & 721 & 53 & 24 & 833 & 299 & \\
\hline
\end{tabular}

Gage helght, in feet, and discharge, in second-feet, at indicated time, 1938

\begin{tabular}{|c|c|c|c|c|c|c|c|c|c|c|c|c|c|}
\hline \multirow{2}{*}{ 告 } & Feet & Sec.ft. & Feet & \multicolumn{2}{|c|}{ Sec.ft. } & Feet. & Sec.ft. & Feot & sec.ft. & Feet & Sec.et. & Foet & Sec.ft. \\
\hline & \multicolumn{2}{|c|}{ September 18} & \multicolumn{3}{|c|}{ Sept ember 19} & \multicolumn{2}{|c|}{ Sept ember 20} & \multicolumn{2}{|c|}{ September 21} & \multicolumn{2}{|c|}{ September 22} & \multicolumn{2}{|c|}{ September 23.} \\
\hline $\begin{array}{l}1 \\
2 \\
3 \\
4 \\
5 \\
6\end{array}$ & $\begin{array}{l}2.42 \\
2.41 \\
2.40 \\
2.39 \\
2.38 \\
2.37\end{array}$ & $\begin{array}{l}310 \\
305 \\
300 \\
295 \\
290 \\
285\end{array}$ & $\begin{array}{l}2.35 \\
2.35 \\
2.35 \\
2.35 \\
2.36 \\
2.36\end{array}$ & & $\begin{array}{l}276 \\
276 \\
276 \\
276 \\
280 \\
280\end{array}$ & $\begin{array}{l}2.09 \\
2.02 \\
2.05 \\
2.18 \\
2.28 \\
2.35\end{array}$ & $\begin{array}{l}158 \\
130 \\
142 \\
196 \\
242 \\
276\end{array}$ & $\begin{array}{l}4.20 \\
4.50 \\
5.16 \\
5.75 \\
5.81 \\
5.88\end{array}$ & $\begin{array}{l}1,140 \\
1,270 \\
1,600 \\
1,900 \\
1,920 \\
1,960\end{array}$ & $\begin{array}{l}13.58 \\
13.48 \\
13.28 \\
13.00 \\
12.65 \\
12.28\end{array}$ & $\begin{array}{l}9,120 \\
8,990 \\
8,730 \\
8,370 \\
7,920 \\
7,470\end{array}$ & $\begin{array}{l}6.09 \\
5.92 \\
5.78 \\
5.62 \\
5.50 \\
5.39\end{array}$ & $\begin{array}{l}2,070 \\
1,980 \\
1,910 \\
1,830 \\
1,770 \\
1,720\end{array}$ \\
\hline $\begin{array}{r}7 \\
8 \\
9 \\
10 \\
11 \\
\mathrm{~N}\end{array}$ & $\begin{array}{l}2.35 \\
2.33 \\
2.32 \\
2.32 \\
2.32 \\
2.32\end{array}$ & $\begin{array}{l}276 \\
266 \\
261 \\
261 \\
261 \\
261\end{array}$ & $\begin{array}{l}2.36 \\
2.36 \\
2.45 \\
2.74 \\
2.83 \\
2.80\end{array}$ & & $\begin{array}{l}280 \\
280 \\
325 \\
473 \\
522 \\
505\end{array}$ & $\begin{array}{l}2.40 \\
2.45 \\
2.65 \\
2.89 \\
2.95 \\
2.97\end{array}$ & $\begin{array}{l}300 \\
325 \\
426 \\
554 \\
585 \\
595\end{array}$ & $\begin{array}{l}6.08 \\
6.50 \\
7.40 \\
8.20 \\
8.41 \\
8.48\end{array}$ & $\begin{array}{l}2,060 \\
2,300 \\
2,860 \\
3,430 \\
3,590 \\
3,640\end{array}$ & $\begin{array}{r}11.86 \\
11.42 \\
10.95 \\
10.48 \\
10.05 \\
9.64\end{array}$ & $\begin{array}{l}6,960 \\
6,440 \\
5,920 \\
5,420 \\
4,990 \\
4,600\end{array}$ & $\begin{array}{l}5.28 \\
5.18 \\
5.02 \\
4.86 \\
4.75 \\
4.15\end{array}$ & $\begin{array}{l}1,660 \\
1,610 \\
1,530 \\
1,450 \\
1,400 \\
1,100\end{array}$ \\
\hline $\begin{array}{l}1 \\
2 \\
3 \\
4 \\
5 \\
6\end{array}$ & $\begin{array}{l}2.32 \\
2.32 \\
2.32 \\
2.32 \\
2.32 \\
2.32\end{array}$ & $\begin{array}{l}261 \\
261 \\
261 \\
261 \\
261 \\
261\end{array}$ & $\begin{array}{l}2.76 \\
2.70 \\
2.66 \\
2.61 \\
2.59 \\
2.57\end{array}$ & & $\begin{array}{l}484 \\
452 \\
431 \\
405 \\
395 \\
385\end{array}$ & $\begin{array}{l}2.99 \\
3.00 \\
3.01 \\
3.02 \\
3.11 \\
3.21\end{array}$ & $\begin{array}{l}605 \\
610 \\
614 \\
619 \\
660 \\
704\end{array}$ & $\begin{array}{l}8.55 \\
8.78 \\
9.10 \\
9.40 \\
9.64 \\
9.80\end{array}$ & $\begin{array}{l}3,700 \\
3,870 \\
4,130 \\
4,380 \\
4,600 \\
4,750\end{array}$ & $\begin{array}{l}9.25 \\
8.82 \\
8.46 \\
8.14 \\
7.83 \\
7.54\end{array}$ & $\begin{array}{l}4,260 \\
3,910 \\
3,620 \\
3,390 \\
3,160 \\
2,960\end{array}$ & $\begin{array}{l}3.69 \\
3.71 \\
3.91 \\
4.05 \\
4.12 \\
4.15\end{array}$ & $\begin{array}{r}866 \\
875 \\
975 \\
1,040 \\
1,080 \\
1,100\end{array}$ \\
\hline \multirow[t]{2}{*}{$\begin{array}{r}7 \\
8 \\
9 \\
10 \\
11 \\
\mathrm{M}\end{array}$} & $\begin{array}{l}2.32 \\
2.33 \\
2.34 \\
2.35 \\
2.35 \\
2.35\end{array}$ & $\begin{array}{l}261 \\
266 \\
271 \\
276 \\
276 \\
276\end{array}$ & $\begin{array}{l}2.56 \\
2.55 \\
2.54 \\
2.42 \\
2.28 \\
2.19\end{array}$ & & $\begin{array}{l}380 \\
375 \\
370 \\
310 \\
242 \\
201\end{array}$ & $\begin{array}{l}3.35 \\
3.48 \\
3.55 \\
3.48 \\
3.64 \\
3.93\end{array}$ & $\begin{array}{r}768 \\
826 \\
855 \\
826 \\
891 \\
1,010\end{array}$ & $\begin{array}{l}10.14 \\
11.16 \\
12.20 \\
12.91 \\
13.34 \\
13.50\end{array}$ & $\begin{array}{l}5,080 \\
6,160 \\
7,370 \\
8,250 \\
8,810 \\
9,020\end{array}$ & $\begin{array}{l}7.27 \\
7.03 \\
6.80 \\
6.62 \\
6.41 \\
6.25\end{array}$ & $\begin{array}{l}2,780 \\
2,620 \\
2,480 \\
2,370 \\
2,250 \\
2,160\end{array}$ & $\begin{array}{l}4.17 \\
4.17 \\
4.12 \\
4.07 \\
4.00 \\
3.98\end{array}$ & $\begin{array}{l}1,105 \\
1,105 \\
1,080 \\
1,060 \\
1,020 \\
1,010\end{array}$ \\
\hline & \multicolumn{2}{|c|}{ September 24} & \multicolumn{3}{|c|}{ September 25} & \multicolumn{2}{|c|}{ September 26} & \multicolumn{2}{|c|}{ September 27} & \multicolumn{2}{|c|}{ September 28} & \multicolumn{2}{|c|}{ September 29} \\
\hline $\begin{array}{r}2 \\
4 \\
6 \\
8 \\
10 \\
\mathrm{~N}\end{array}$ & $\begin{array}{l}3.90 \\
3.84 \\
3.76 \\
3.69 \\
3.60 \\
3.56\end{array}$ & $\begin{array}{l}970 \\
940 \\
900 \\
866 \\
825 \\
807\end{array}$ & $\begin{array}{l}3.26 \\
3.18 \\
3.14 \\
3.17 \\
3.16 \\
3.12\end{array}$ & & $\begin{array}{l}672 \\
636 \\
618 \\
632 \\
627 \\
609\end{array}$ & $\begin{array}{l}2.87 \\
2.84 \\
2.82 \\
2.81 \\
2.84 \\
3.16\end{array}$ & $\begin{array}{l}496 \\
483 \\
474 \\
470 \\
483 \\
627\end{array}$ & $\begin{array}{l}2.51 \\
2.45 \\
2.52 \\
2.57 \\
2.62 \\
2.71\end{array}$ & $\begin{array}{l}334 \\
308 \\
339 \\
362 \\
384 \\
424\end{array}$ & $\begin{array}{l}2.70 \\
2.67 \\
2.61 \\
2.58 \\
2.47 \\
2.65\end{array}$ & $\begin{array}{l}420 \\
406 \\
380 \\
366 \\
316 \\
398\end{array}$ & $\begin{array}{l}2.39 \\
2.32 \\
2.31 \\
2.31 \\
2.31 \\
2.61\end{array}$ & $\begin{array}{l}280 \\
249 \\
244 \\
244 \\
244 \\
380\end{array}$ \\
\hline $\begin{array}{r}2 \\
4 \\
6 \\
8 \\
10 \\
M\end{array}$ & $\begin{array}{l}3.59 \\
3.54 \\
3.45 \\
3.40 \\
3.37 \\
3.31\end{array}$ & $\begin{array}{l}821 \\
798 \\
758 \\
735 \\
722 \\
695\end{array}$ & $\begin{array}{l}3.09 \\
3.05 \\
2.84 \\
2.86 \\
2.90 \\
2.89\end{array}$ & & $\begin{array}{l}596 \\
578 \\
483 \\
492 \\
510 \\
506\end{array}$ & $\begin{array}{l}3.01 \\
2.92 \\
2.86 \\
2.71 \\
2.69 \\
2.66\end{array}$ & $\begin{array}{l}560 \\
519 \\
492 \\
424 \\
416 \\
402\end{array}$ & $\begin{array}{l}2.72 \\
2.84 \\
2.79 \\
2.77 \\
2.75 \\
2.73\end{array}$ & $\begin{array}{l}429 \\
483 \\
460 \\
452 \\
442 \\
434\end{array}$ & $\begin{array}{l}2.71 \\
2.61 \\
2.54 \\
2.48 \\
2.42 \\
2.41\end{array}$ & $\begin{array}{l}424 \\
380 \\
348 \\
321 \\
294 \\
290\end{array}$ & $\begin{array}{l}2.63 \\
2.59 \\
2.57 \\
2.30 \\
2.23 \\
2.28\end{array}$ & $\begin{array}{l}388 \\
370 \\
362 \\
240 \\
208 \\
231\end{array}$ \\
\hline
\end{tabular}


Lamoille River at East Georgia, Vt.

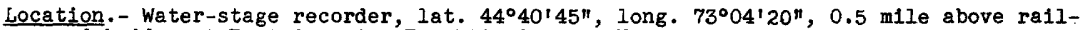
road bridge at East Georgia, Franklin County, Vermont.

Drainage area.- 711 square miles.

Gage-height record.- Water-stage recorder graph.

Stage-discharge relation.- Defined by current-meter measurements below 8,380 secondfeet; extended to peak stage on basis of determinations of flood flows over dams.

Maxima.- September 1938: Discharge, 20,200 second-feet 10 a.m. Sept. 22 (gage height, 11.76 feet).

1929 to August 1938: Discharge, 23,200 second-feet Mar. 19, 1936 (gage helght, 12.52 feet, former site and datum).

Remarks.- Flood mun-off not materially affected by artificial or natural storage.

Mean dasly discharge, in second-feet, 1938

\begin{tabular}{|c|c|c|c|c|c|c|c|c|c|c|c|}
\hline Day & Sept. & Oct. & Day & Sopt. & Oct. & Day & Sept. & oct. & Day & Sept. & Oct. \\
\hline $\begin{array}{l}1 \\
2 \\
3 \\
4 \\
5 \\
6 \\
7 \\
8\end{array}$ & $\begin{array}{l}566 \\
889 \\
675 \\
460 \\
460 \\
443 \\
406 \\
718\end{array}$ & $\begin{array}{l}896 \\
878 \\
628 \\
544 \\
504 \\
634 \\
640 \\
568\end{array}$ & $\begin{array}{r}9 \\
10 \\
11 \\
12 \\
13 \\
14 \\
15 \\
16\end{array}$ & $\begin{array}{r}604 \\
489 \\
348 \\
398 \\
1,760 \\
1,960 \\
844 \\
1,880\end{array}$ & $\begin{array}{l}562 \\
520 \\
556 \\
526 \\
510 \\
489 \\
489 \\
431\end{array}$ & $\begin{array}{l}17 \\
18 \\
19 \\
20 \\
21 \\
22 \\
23 \\
24\end{array}$ & $\begin{array}{r}1,330 \\
968 \\
928 \\
1,340 \\
6,880 \\
17,000 \\
6,920 \\
2,750\end{array}$ & $\begin{array}{l}439 \\
446 \\
474 \\
551 \\
819 \\
868 \\
670 \\
640\end{array}$ & $\begin{array}{l}25 \\
26 \\
27 \\
28 \\
29 \\
30 \\
31\end{array}$ & $\begin{array}{r}1,980 \\
1,520 \\
1,380 \\
1,550 \\
1,170 \\
982\end{array}$ & $\begin{array}{r}1,950 \\
1,670 \\
1,200 \\
918 \\
805 \\
694 \\
646\end{array}$ \\
\hline $\begin{array}{l}\text { Mean } \\
\text { Run- }\end{array}$ & $\begin{array}{l}\text { nthly } \\
\text {, in }\end{array}$ & & & & . & . : & $\cdot \dot{0}$ &.. & $: \dot{ }$ & $\begin{array}{r}1,987 \\
3.11\end{array}$ & $\begin{array}{r}715 \\
1.15\end{array}$ \\
\hline
\end{tabular}

Gage height, in feet, and discharge, In second-reet, at indicated time, 1938

\begin{tabular}{|c|c|c|c|c|c|c|c|c|c|c|c|c|}
\hline \multirow{2}{*}{$\begin{array}{l}9 \\
3 \\
0 \\
\text { 出 } \\
\end{array}$} & Feet & Sec.ft. & Feet & Sec.ft. & Feet & Sec.It. & Feet & Sec.ft. & Feet & Sec.ft. & Feet & Sec.ft. \\
\hline & \multicolumn{2}{|c|}{ September 18} & \multicolumn{2}{|c|}{ September 19} & \multicolumn{2}{|c|}{ September 20} & \multicolumn{2}{|c|}{ September 21} & \multicolumn{2}{|c|}{ September 22} & \multicolumn{2}{|c|}{ September 23} \\
\hline $\begin{array}{l}1 \\
2 \\
3 \\
4 \\
5 \\
6\end{array}$ & $\begin{array}{l}3.96 \\
3.95 \\
3.95 \\
3.93 \\
3.89 \\
3.87\end{array}$ & $\begin{array}{r}1,040 \\
1,030 \\
1,030 \\
1,010 \\
982 \\
966\end{array}$ & $\begin{array}{l}3.75 \\
3.71 \\
3.68 \\
3.68 \\
3.69 \\
3.71\end{array}$ & $\begin{array}{l}875 \\
847 \\
826 \\
826 \\
833 \\
847\end{array}$ & $\begin{array}{l}4.06 \\
4.09 \\
4.09 \\
4.10 \\
4.11 \\
4.11\end{array}$ & $\begin{array}{l}1,120 \\
1,140 \\
1,140 \\
1,150 \\
1,160 \\
1,160\end{array}$ & $\begin{array}{l}5.19 \\
5.29 \\
5.39 \\
5.47 \\
5.55 \\
5.66\end{array}$ & $\begin{array}{l}2,280 \\
2,400 \\
2,530 \\
2,630 \\
2,740 \\
2,880\end{array}$ & $\begin{array}{l}10.76 \\
10.68 \\
10.65 \\
10.68 \\
10.86 \\
11.17\end{array}$ & $\begin{array}{l}15,860 \\
15,690 \\
15,400 \\
15,600 \\
16,300 \\
17,600\end{array}$ & $\begin{array}{l}9.79 \\
9.61 \\
9.43 \\
9.23 \\
9.04 \\
8.84\end{array}$ & $\begin{array}{r}12,200 \\
11,600 \\
11,000 \\
10,400 \\
9,820 \\
9,270\end{array}$ \\
\hline $\begin{array}{r}7 \\
8 \\
9 \\
10 \\
17 \\
N\end{array}$ & $\begin{array}{l}3.87 \\
3.87 \\
3.88 \\
3.88 \\
3.88 \\
3.87\end{array}$ & $\begin{array}{l}966 \\
966 \\
974 \\
974 \\
974 \\
966\end{array}$ & $\begin{array}{l}3.72 \\
3.76 \\
3.82 \\
3.83 \\
3.82 \\
3.82\end{array}$ & $\begin{array}{l}854 \\
882 \\
926 \\
934 \\
926 \\
926\end{array}$ & $\begin{array}{l}4.11 \\
4.14 \\
4.18 \\
4.19 \\
4.18 \\
4.17\end{array}$ & $\begin{array}{l}1, \\
1, \\
1, \\
1, \\
1, \\
1,\end{array}$ & $\begin{array}{l}5.81 \\
6.02 \\
6.23 \\
6.48 \\
6.73 \\
7.11\end{array}$ & $\begin{array}{l}3,080 \\
3,380 \\
3,720 \\
4,120 \\
4,560 \\
5,270\end{array}$ & $\begin{array}{l}11.47 \\
11.67 \\
21.74 \\
11.76 \\
11.71 \\
11.62\end{array}$ & $\begin{array}{l}18,900 \\
19,800 \\
20,100 \\
20,200 \\
20,000 \\
19,600\end{array}$ & $\begin{array}{l}62 \\
41 \\
20 \\
95 \\
74 \\
53\end{array}$ & $\begin{array}{l}570 \\
L 30 \\
330 \\
440 \\
580 \\
120\end{array}$ \\
\hline $\begin{array}{l}1 \\
2 \\
3 \\
4 \\
5 \\
6\end{array}$ & $\begin{array}{l}3.85 \\
3.84 \\
3.84 \\
3.83 \\
3.83 \\
3.83\end{array}$ & $\begin{array}{l}950 \\
942 \\
942 \\
934 \\
934 \\
934\end{array}$ & $\begin{array}{l}3.80 \\
3.75 \\
3.76 \\
3.82 \\
3.86 \\
3.88\end{array}$ & $\begin{array}{l}910 \\
875 \\
882 \\
926 \\
958 \\
974\end{array}$ & $\begin{array}{l}4.17 \\
4.18 \\
4.23 \\
4.27 \\
4.32 \\
4.39\end{array}$ & $\begin{array}{l}1, \\
1, \\
1, \\
1, \\
1, \\
1,\end{array}$ & $\begin{array}{l}7.47 \\
7.91 \\
8.30 \\
8.62 \\
8.88 \\
9.12\end{array}$ & $\begin{array}{r}5, \\
6, \\
7, \\
8, \\
9 \\
10\end{array}$ & $\begin{array}{l}11.52 \\
11.40 \\
11.29 \\
11.13 \\
11.00 \\
10.87\end{array}$ & $\begin{array}{l}100 \\
500 \\
100 \\
100 \\
300 \\
500\end{array}$ & $\begin{array}{l}7.35 \\
7.19 \\
7.03 \\
6.90 \\
6.77 \\
6.65\end{array}$ & $\begin{array}{l}50 \\
50 \\
10 \\
170 \\
40 \\
20\end{array}$ \\
\hline \multirow[t]{2}{*}{$\begin{array}{r}7 \\
8 \\
9 \\
10 \\
11 \\
11\end{array}$} & $\begin{array}{l}3.84 \\
3.86 \\
3.86 \\
3.84 \\
3.82 \\
3.79\end{array}$ & $\begin{array}{l}942 \\
958 \\
958 \\
942 \\
926 \\
903\end{array}$ & $\begin{array}{l}3.89 \\
3.92 \\
3.97 \\
4.01 \\
4.05 \\
4.06\end{array}$ & $\begin{array}{r}982 \\
1,010 \\
1,050 \\
1,080 \\
1,110 \\
1,120\end{array}$ & $\begin{array}{l}4.49 \\
4.60 \\
4.69 \\
4.81 \\
4.94 \\
5.08\end{array}$ & $\begin{array}{l}1, \\
1, \\
1, \\
1, \\
1, \\
2,\end{array}$ & $\begin{array}{r}9.51 \\
10.01 \\
10.20 \\
10.38 \\
10.64 \\
10.78\end{array}$ & $\begin{array}{l}11, \\
12, \\
13, \\
14, \\
15, \\
15,\end{array}$ & $\begin{array}{r}10.71 \\
10.56 \\
10.40 \\
10.23 \\
10.08 \\
9.95\end{array}$ & $\begin{array}{l}15, \\
15, \\
14, \\
13, \\
13, \\
12,\end{array}$ & $\begin{array}{l}6.54 \\
6.43 \\
6.32 \\
6.21 \\
6.11 \\
6.03\end{array}$ & \\
\hline & \multicolumn{2}{|c|}{ September 24} & \multicolumn{2}{|c|}{ Soptember 25} & \multicolumn{2}{|c|}{ September 26} & \multicolumn{2}{|c|}{ September 27} & \multicolumn{2}{|c|}{ September 28} & \multicolumn{2}{|c|}{ September 29} \\
\hline $\begin{array}{r}2 \\
4 \\
6 \\
8 \\
10 \\
1\end{array}$ & $\begin{array}{l}5.89 \\
5.80 \\
5.73 \\
5.68 \\
5.60 \\
5.53\end{array}$ & $\begin{array}{l}3,200 \\
3,070 \\
2,970 \\
2,900 \\
2,800 \\
2,710\end{array}$ & $\begin{array}{l}5.17 \\
5.11 \\
5.07 \\
5.01 \\
4.96 \\
4.93\end{array}$ & $\begin{array}{l}2,250 \\
2,180 \\
2,130 \\
2,060 \\
2,010 \\
1,970\end{array}$ & $\begin{array}{l}4.64 \\
4.59 \\
4.56 \\
4.55 \\
4.52 \\
4.48\end{array}$ & $\begin{array}{l}1,660 \\
1,610 \\
1,580 \\
1,570 \\
1,540 \\
1,500\end{array}$ & $\begin{array}{l}4.37 \\
4.34 \\
4.31 \\
4.31 \\
4.27 \\
4.26\end{array}$ & $\begin{array}{l}1,390 \\
1,370 \\
1,340 \\
1,340 \\
1,300 \\
1,290\end{array}$ & & $\begin{array}{l}1,640 \\
1,670 \\
1,670 \\
1,670 \\
1,630 \\
1,580\end{array}$ & $\begin{array}{l}4.27 \\
4.23 \\
4.21 \\
4.20 \\
4.16 \\
4.09\end{array}$ & $\begin{array}{l}1,300 \\
1,270 \\
1,250 \\
1,240 \\
1,200 \\
1,140\end{array}$ \\
\hline $\begin{array}{r}2 \\
4 \\
6 \\
8 \\
10 \\
1 \\
\end{array}$ & $\begin{array}{l}5.47 \\
5.40 \\
5.35 \\
5.32 \\
5.27 \\
5.22\end{array}$ & $\begin{array}{l}2,630 \\
2,540 \\
2,480 \\
2,440 \\
2,370 \\
2,310\end{array}$ & $\begin{array}{l}4.88 \\
4.84 \\
4.82 \\
4.77 \\
4.73 \\
4.68\end{array}$ & $\begin{array}{l}1,920 \\
1,870 \\
1,850 \\
1,800 \\
1,750 \\
1,700\end{array}$ & $\begin{array}{l}4.45 \\
4.45 \\
4.41 \\
4.41 \\
4.39 \\
4.37\end{array}$ & $\begin{array}{l}1,470 \\
1,470 \\
1,430 \\
1,430 \\
1,410 \\
1,390\end{array}$ & $\begin{array}{l}4.28 \\
4.30 \\
4.32 \\
4.43 \\
4.55\end{array}$ & $\begin{array}{l}1, \\
1, \\
1, \\
1, \\
1,\end{array}$ & $\begin{array}{l}50 \\
46 \\
43 \\
39 \\
35\end{array}$ & $\begin{array}{l}1, \\
1, \\
1, \\
1, \\
1,\end{array}$ & $\begin{array}{l}08 \\
84 \\
01 \\
99 \\
96 \\
93\end{array}$ & $\begin{array}{l}1, \\
1, \\
1, \\
1, \\
1,\end{array}$ \\
\hline
\end{tabular}


Location.- Water-stage recorder, lat. $44^{\circ} 58^{\prime} 20^{\prime \prime}$, long. $72^{\circ} 23^{\prime} 15^{\prime \prime}$, just above Big Falls, $l_{\frac{1}{2}}$ miles below mouth of Jay Branch, and $2 \frac{1}{2}$ miles above North Troy, Troy County. Drainage area.- 131 square miles.

Gage-height record.- Water-stage recorder graph.

Stage-discharge relation.- Defined by current-meter measurements below 1,650 secondfeet; extended to peak stage on basis of determinations of flood flows over dam.

Maxima.- September 1938: Discharge, 2,540 second-feet $10 \mathrm{a} . \mathrm{m}$. Sept. 22 (gage height, 7.72 feet)

1931 to August 1938: Discharge, 5,140 second-feet Oct. 7, 1932 (gage height, 12.26 feet).

Remarks.- Flood run-off not materially affected by storage.

Mean daily discharge, in second-feet, 1938

\begin{tabular}{|c|c|c|c|c|c|c|c|c|c|c|c|}
\hline Day & Sept. & oct. & Day & Sept. & oct. & Day & Sept. & Oct. & Day & Sept. & oct. \\
\hline $\begin{array}{l}7 \\
2 \\
3 \\
4 \\
5 \\
6 \\
7 \\
8\end{array}$ & \begin{tabular}{r|}
194 \\
169 \\
96 \\
77 \\
72 \\
57 \\
64 \\
98
\end{tabular} & \begin{tabular}{r|}
113 \\
108 \\
104 \\
98 \\
90 \\
108 \\
104 \\
92
\end{tabular} & $\begin{array}{r}9 \\
10 \\
11 \\
12 \\
13 \\
14 \\
15 \\
16\end{array}$ & $\begin{array}{r}76 \\
56 \\
46 \\
60 \\
302 \\
235 \\
316 \\
344\end{array}$ & $\begin{array}{l}74 \\
90 \\
74 \\
76 \\
67 \\
72 \\
62 \\
55\end{array}$ & $\begin{array}{l}17 \\
18 \\
19 \\
20 \\
21 \\
22 \\
23 \\
24\end{array}$ & $\begin{array}{r}202 \\
158 \\
149 \\
210 \\
1,260 \\
2,000 \\
517 \\
301\end{array}$ & $\begin{array}{r}76 \\
62 \\
67 \\
132 \\
184 \\
151 \\
104 \\
148\end{array}$ & $\begin{array}{l}25 \\
26 \\
27 \\
28 \\
29 \\
30 \\
31\end{array}$ & $\begin{array}{l}230 \\
172 \\
175 \\
240 \\
159 \\
126\end{array}$ & $\begin{array}{l}478 \\
242 \\
169 \\
134 \\
117 \\
104 \\
101\end{array}$ \\
\hline $\begin{array}{l}\text { Mean } \\
\text { Run- }\end{array}$ & $\begin{array}{l}\text { nthly } \\
\text {, in }\end{array}$ & & in &. & et. : &.$\dot{ }$ & $\dot{1} \cdot \dot{1}$ & $\begin{array}{lll}\cdot & . & . \\
. & . & \cdot\end{array}$ & . : & $\begin{array}{r}272 \\
2.32 \\
\end{array}$ & $\begin{array}{r}118 \\
1.04\end{array}$ \\
\hline
\end{tabular}

Gage height, in feet, and discharge, in second-feet, at indicated time, 1938

\begin{tabular}{|c|c|c|c|c|c|c|c|c|c|c|c|c|c|}
\hline \multirow{2}{*}{$\begin{array}{l}9 \\
9 \\
0 \\
\text { 出 }\end{array}$} & Feet & Sec.It. & Feet & Sec.ft. & Feet & Sec.ft. & Fe日t & Sec.ft. & Feet & Sec.ft. & Feet & \multicolumn{2}{|c|}{ Sec.ft. } \\
\hline & \multicolumn{2}{|c|}{ September 18} & \multicolumn{2}{|c|}{ September 19} & \multicolumn{2}{|c|}{ September 20} & \multicolumn{2}{|c|}{ September 21} & \multicolumn{2}{|c|}{ September 22} & \multicolumn{3}{|c|}{ September 23} \\
\hline $\begin{array}{l}1 \\
2 \\
3 \\
4 \\
5 \\
6\end{array}$ & $\begin{array}{l}2.29 \\
2.28 \\
2.28 \\
2.28 \\
2.28 \\
2.28\end{array}$ & $\begin{array}{l}162 \\
160 \\
160 \\
160 \\
160 \\
160\end{array}$ & $\begin{array}{l}2.21 \\
2.20 \\
2.20 \\
2.19 \\
2.18 \\
2.18\end{array}$ & $\begin{array}{l}145 \\
143 \\
143 \\
141 \\
139 \\
139\end{array}$ & $\begin{array}{r}2.22 \\
2.24 \\
2.26 \\
2.27 \\
2.28 \\
2.28\end{array}$ & $\begin{array}{l}147 \\
151 \\
156 \\
158 \\
160 \\
160\end{array}$ & $\begin{array}{l}3.28 \\
3.43 \\
3.58 \\
3.76 \\
3.95 \\
4.13\end{array}$ & $\begin{array}{l}445 \\
500 \\
556 \\
625 \\
700 \\
772\end{array}$ & $\begin{array}{l}7.35 \\
7.31 \\
7.32 \\
7.33 \\
7.38 \\
7.42\end{array}$ & $\begin{array}{l}2,340 \\
2,320 \\
2,320 \\
2,330 \\
2,350 \\
2,370\end{array}$ & $\begin{array}{l}4.13 \\
4.02 \\
3.92 \\
3.85 \\
3.78 \\
3.70\end{array}$ & & $\begin{array}{l}772 \\
728 \\
688 \\
660 \\
633 \\
602\end{array}$ \\
\hline $\begin{array}{r}7 \\
8 \\
9 \\
10 \\
11 \\
N\end{array}$ & $\begin{array}{l}2.28 \\
2.28 \\
2.28 \\
2.28 \\
2.28 \\
2.28\end{array}$ & $\begin{array}{l}160 \\
160 \\
160 \\
160 \\
160 \\
160\end{array}$ & $\begin{array}{l}2.18 \\
2.19 \\
2.24 \\
2.25 \\
2.25 \\
2.24\end{array}$ & $\begin{array}{l}139 \\
141 \\
151 \\
154 \\
154 \\
151\end{array}$ & $\begin{array}{l}2.29 \\
2.31 \\
2.37 \\
2.38 \\
2.38 \\
2.38\end{array}$ & $\begin{array}{l}162 \\
166 \\
180 \\
182 \\
182 \\
182\end{array}$ & $\begin{array}{l}4.32 \\
4.48 \\
4.57 \\
4.70 \\
4.90 \\
5.10\end{array}$ & $\begin{array}{r}848 \\
912 \\
952 \\
1,010 \\
1,100 \\
1,190\end{array}$ & $\begin{array}{l}7.50 \\
7.60 \\
7.68 \\
7.72 \\
7.65 \\
7.55\end{array}$ & $\begin{array}{l}2,420 \\
2,480 \\
2,520 \\
2,540 \\
2,510 \\
2,450\end{array}$ & $\begin{array}{l}3.64 \\
3.62 \\
3.58 \\
3.50 \\
3.44 \\
3.40\end{array}$ & & $\begin{array}{l}579 \\
571 \\
556 \\
526 \\
504 \\
489\end{array}$ \\
\hline $\begin{array}{l}1 \\
2 \\
3 \\
4 \\
5 \\
6\end{array}$ & $\begin{array}{l}2.28 \\
2.28 \\
2.28 \\
2.28 \\
2.28 \\
2.27\end{array}$ & $\begin{array}{l}160 \\
160 \\
160 \\
160 \\
160 \\
158\end{array}$ & $\begin{array}{l}2.23 \\
2.22 \\
2.24 \\
2.27 \\
2.28 \\
2.28\end{array}$ & $\begin{array}{l}149 \\
147 \\
151 \\
158 \\
160 \\
160\end{array}$ & $\begin{array}{l}2.39 \\
2.40 \\
2.47 \\
2.51 \\
2.56 \\
2.61\end{array}$ & $\begin{array}{l}185 \\
187 \\
204 \\
214 \\
227 \\
240\end{array}$ & $\begin{array}{l}5.29 \\
5.46 \\
5.63 \\
5.92 \\
5.97 \\
5.99\end{array}$ & $\begin{array}{l}1,280 \\
1,370 \\
1,460 \\
1,600 \\
1,620 \\
1,640\end{array}$ & $\begin{array}{l}7.40 \\
7.15 \\
6.90 \\
6.60 \\
6.23 \\
5.86\end{array}$ & $\begin{array}{l}2,360 \\
2,230 \\
2,090 \\
1,940 \\
1,760 \\
1,570\end{array}$ & $\begin{array}{l}3.36 \\
3.32 \\
3.30 \\
3.26 \\
3.22 \\
3.17\end{array}$ & & $\begin{array}{l}474 \\
459 \\
452 \\
438 \\
424 \\
406\end{array}$ \\
\hline \multirow[t]{2}{*}{$\begin{array}{r}7 \\
8 \\
9 \\
10 \\
11 \\
M \\
\end{array}$} & $\begin{array}{l}2.26 \\
2.25 \\
2.24 \\
2.23 \\
2.22 \\
2.21\end{array}$ & $\begin{array}{l}156 \\
154 \\
151 \\
149 \\
147 \\
145\end{array}$ & $\begin{array}{l}2.25 \\
2.24 \\
2.25 \\
2.26 \\
2.23 \\
2.21\end{array}$ & $\begin{array}{l}154 \\
151 \\
154 \\
156 \\
149 \\
145\end{array}$ & $\begin{array}{l}2.68 \\
2.77 \\
2.87 \\
2.95 \\
2.99 \\
3.12\end{array}$ & $\begin{array}{l}258 \\
282 \\
311 \\
335 \\
347 \\
389\end{array}$ & $\begin{array}{l}6.07 \\
6.22 \\
6.72 \\
7.47 \\
7.64 \\
7.45\end{array}$ & $\begin{array}{l}1,680 \\
1,750 \\
2,000 \\
2,400 \\
2,500 \\
2,390\end{array}$ & $\begin{array}{l}5.50 \\
5.15 \\
4.87 \\
4.61 \\
4.41 \\
4.26\end{array}$ & $\begin{array}{r}1,390 \\
1,220 \\
1,090 \\
970 \\
884 \\
824\end{array}$ & $\begin{array}{l}3.10 \\
3.09 \\
3.10 \\
3.07 \\
3.02 \\
3.00\end{array}$ & & $\begin{array}{l}382 \\
379 \\
382 \\
372 \\
356 \\
350\end{array}$ \\
\hline & \multicolumn{2}{|c|}{ September 24} & \multicolumn{2}{|c|}{ September 25} & \multicolumn{2}{|c|}{ September 26} & \multicolumn{2}{|c|}{ September 27} & \multicolumn{2}{|c|}{ September 28} & \multicolumn{3}{|c|}{ September 29} \\
\hline $\begin{array}{r}2 \\
4 \\
6 \\
8 \\
10 \\
N\end{array}$ & $\begin{array}{l}2.97 \\
2.92 \\
2.89 \\
2.87 \\
2.87 \\
2.81\end{array}$ & $\begin{array}{l}341 \\
326 \\
317 \\
311 \\
311 \\
293\end{array}$ & $\begin{array}{l}2.69 \\
2.67 \\
2.65 \\
2.62 \\
2.60 \\
2.58\end{array}$ & $\begin{array}{l}260 \\
255 \\
250 \\
242 \\
237 \\
232\end{array}$ & $\begin{array}{l}2.41 \\
2.40 \\
2.38 \\
2.37 \\
2.42 \\
2.38\end{array}$ & $\begin{array}{l}190 \\
187 \\
182 \\
180 \\
192 \\
182\end{array}$ & $\begin{array}{l}2.18 \\
2.19 \\
2.19 \\
2.18 \\
2.21 \\
2.24\end{array}$ & $\begin{array}{l}139 \\
141 \\
141 \\
139 \\
145 \\
151\end{array}$ & $\begin{array}{l}2.75 \\
2.80 \\
2.77 \\
2.72 \\
2.74 \\
2.63\end{array}$ & $\begin{array}{l}276 \\
290 \\
282 \\
268 \\
274 \\
245\end{array}$ & $\begin{array}{l}2.37 \\
2.35 \\
2.32 \\
2.30 \\
2.34 \\
2.31\end{array}$ & & $\begin{array}{l}180 \\
176 \\
169 \\
164 \\
173 \\
166\end{array}$ \\
\hline $\begin{array}{r}2 \\
4 \\
6 \\
8 \\
10 \\
M\end{array}$ & $\begin{array}{l}2.76 \\
2.78 \\
2.79 \\
2.77 \\
2.74 \\
2.69\end{array}$ & $\begin{array}{l}279 \\
285 \\
287 \\
282 \\
274 \\
260\end{array}$ & $\begin{array}{l}2.55 \\
2.52 \\
2.50 \\
2.48 \\
2.45 \\
2.43\end{array}$ & $\begin{array}{l}224 \\
217 \\
212 \\
207 \\
200 \\
194\end{array}$ & $\begin{array}{l}2.30 \\
2.30 \\
2.29 \\
2.20 \\
2.25 \\
2.20\end{array}$ & $\begin{array}{l}164 \\
164 \\
162 \\
143 \\
154 \\
143\end{array}$ & $\begin{array}{l}2.25 \\
2.45 \\
2.59 \\
2.58 \\
2.60 \\
2.61\end{array}$ & $\begin{array}{l}154 \\
200 \\
234 \\
232 \\
237 \\
240\end{array}$ & $\begin{array}{l}2.55 \\
2.54 \\
2.51 \\
2.41 \\
2.40 \\
2.38\end{array}$ & $\begin{array}{l}224 \\
222 \\
214 \\
190 \\
187 \\
182\end{array}$ & $\begin{array}{l}2.23 \\
2.21 \\
2.24 \\
2.18 \\
2.20 \\
2.15\end{array}$ & & $\begin{array}{l}149 \\
145 \\
151 \\
139 \\
143 \\
134\end{array}$ \\
\hline
\end{tabular}


Missisquoi River near Richford, Vt.

Location.- Water-stage recorder, lat. $44^{\circ} 57^{\prime} 30^{\prime \prime}$, long. $72^{\circ} 41^{\prime} 55^{\prime \prime}, 12 / 3$ miles above mouth of Trout River, 3 miles south of Richford, Franklin County, and $33 / 4$ miles below mouth of North Branch.

Drainage area.- 479 square miles.

Gage-neight record.- Water-stage recorder graph except for periods Sept. 1 to 1 p.m. Sept. 15 and 11 a.m. Oct. 14 to $4 \mathrm{p} . \mathrm{m}$. Oct. 29, record for which was based on shape of stage graphs at nearby stations.

Stage-discharge relation.- Defined by current-meter measurements below 7,240 secondfeet; extended logarithmically to maximum flood stage.

Maxima.- September 1938: Discharge, 12,200 second-feet 12 p.m. Sept. 21 (gage height, 12.90 feet) 23.1 feet).

1909 to August 1938: Discharge, 45,000 second-feet November 1927 (gage height,

Remarks.- Flood run-off not materially affected by artificial storage or natural pondage.

Mean da1ly discharge, in second-feet, 1938

\begin{tabular}{|c|c|c|c|c|c|c|c|c|c|c|c|}
\hline Day & Sept. & Oct. & Day & Sept. & Oct. & Day & Sept. & $0 \mathrm{ct}$. & Day & Sept. & 0 ct. \\
\hline $\begin{array}{l}1 \\
2 \\
3 \\
4 \\
5 \\
6 \\
7 \\
8\end{array}$ & $\begin{array}{l}700 \\
550 \\
450 \\
350 \\
320 \\
260 \\
300 \\
400\end{array}$ & $\begin{array}{l}540 \\
493 \\
448 \\
403 \\
381 \\
434 \\
416 \\
360\end{array}$ & $\begin{array}{r}9 \\
10 \\
11 \\
12 \\
13 \\
14 \\
15 \\
16\end{array}$ & $\begin{array}{r}330 \\
270 \\
230 \\
300 \\
1,100 \\
850 \\
990 \\
1,330 \\
\end{array}$ & $\begin{array}{l}335 \\
312 \\
308 \\
282 \\
272 \\
251 \\
230 \\
220 \\
\end{array}$ & $\begin{array}{l}17 \\
18 \\
19 \\
20 \\
21 \\
22 \\
23 \\
24\end{array}$ & $\begin{array}{r}955 \\
695 \\
727 \\
926 \\
5,070 \\
7,080 \\
3,810 \\
1,810 \\
\end{array}$ & $\begin{array}{l}230 \\
250 \\
280 \\
450 \\
660 \\
540 \\
400 \\
500\end{array}$ & $\begin{array}{l}25 \\
26 \\
27 \\
28 \\
29 \\
30 \\
31\end{array}$ & $\begin{array}{r}1,260 \\
929 \\
842 \\
922 \\
754 \\
605\end{array}$ & $\begin{array}{r}1,100 \\
850 \\
650 \\
500 \\
450 \\
430 \\
368\end{array}$ \\
\hline $\begin{array}{l}\text { Mean } \\
\text { Run- }\end{array}$ & $\begin{array}{l}\text { onthly } \\
f \text {, in }\end{array}$ & $\begin{array}{l}\text { schar } \\
\text { ches. }\end{array}$ & , ir & $\begin{array}{l}\text { econd- } \\
. \cdot \text {. }\end{array}$ & et. & . & . $\cdot$ : & : & $\dot{.}$ & $\begin{array}{r}1,170 \\
2.72 \\
\end{array}$ & $\begin{array}{r}430 \\
1.04 \\
\end{array}$ \\
\hline
\end{tabular}

Gage height, In feet, and discharge, in secondi-feet, at indicated time, 1938

\begin{tabular}{|c|c|c|c|c|c|c|c|c|c|c|c|c|}
\hline \multirow{2}{*}{ 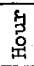 } & Feet & Sec.ft. & Feet & Sec.ft. & Feet & Sec.ft. & Feet & Sec.ft. & Feet & Sec.ft. & Feet & Sec.ft. \\
\hline & \multicolumn{2}{|c|}{ September 18} & \multicolumn{2}{|c|}{ September 19} & \multicolumn{2}{|c|}{ September 20} & \multicolumn{2}{|c|}{ September 21} & \multicolumn{2}{|c|}{ September 22} & \multicolumn{2}{|c|}{ September 23} \\
\hline $\begin{array}{l}1 \\
2 \\
3 \\
4 \\
5 \\
6\end{array}$ & $\begin{array}{l}4.18 \\
4.16 \\
4.14 \\
4.13 \\
4.12 \\
4.11\end{array}$ & $\begin{array}{l}778 \\
766 \\
754 \\
748 \\
742 \\
736\end{array}$ & $\begin{array}{l}3.90 \\
3.90 \\
3.89 \\
3.88 \\
3.88 \\
3.88\end{array}$ & $\begin{array}{l}620 \\
620 \\
615 \\
610 \\
610 \\
610\end{array}$ & $\begin{array}{l}4.21 \\
4.20 \\
4.20 \\
4.20 \\
4.20 \\
4.20\end{array}$ & $\begin{array}{l}796 \\
790 \\
790 \\
790 \\
790 \\
790\end{array}$ & $\begin{array}{l}5.00 \\
5.06 \\
5.15 \\
5.29 \\
5.42 \\
5.60\end{array}$ & $\begin{array}{l}1,370 \\
1,420 \\
1,490 \\
1,600 \\
1,720 \\
1,880\end{array}$ & $\begin{array}{l}12.82 \\
12.61 \\
12.31 \\
12.01 \\
11.68 \\
11.22\end{array}$ & $\begin{array}{r}12,000 \\
11,600 \\
11,100 \\
10,500 \\
9,920 \\
9,120\end{array}$ & $\begin{array}{l}8.29 \\
8.27 \\
8.23 \\
8.20 \\
8.15 \\
8.10\end{array}$ & $\begin{array}{l}4,780 \\
4,750 \\
4,700 \\
4,660 \\
4,600 \\
4,540\end{array}$ \\
\hline $\begin{array}{r}7 \\
8 \\
9 \\
10\end{array}$ & $\begin{array}{l}4.10 \\
4.09 \\
4.08 \\
4.06 \\
4.05 \\
4.03\end{array}$ & $\begin{array}{l}730 \\
724 \\
718 \\
706 \\
700 \\
688\end{array}$ & $\begin{array}{l}3.89 \\
3.89 \\
3.90 \\
3.93 \\
3.97 \\
4.00\end{array}$ & $\begin{array}{l}615 \\
615 \\
620 \\
635 \\
655 \\
670\end{array}$ & $\begin{array}{l}4.20 \\
4.21 \\
4.23 \\
4.24 \\
4.28 \\
4.30\end{array}$ & $\begin{array}{l}790 \\
796 \\
808 \\
814 \\
838 \\
850\end{array}$ & $\begin{array}{l}5.84 \\
6.33 \\
7.03 \\
7.62 \\
8.00 \\
8.30\end{array}$ & $\begin{array}{l}2,100 \\
2,570 \\
3,290 \\
3,960 \\
4,420 \\
4,790\end{array}$ & $\begin{array}{r}10.80 \\
10.32 \\
9.95 \\
9.55 \\
9.24 \\
9.01\end{array}$ & $\begin{array}{l}8,430 \\
7,660 \\
7,080 \\
6,480 \\
6,040 \\
5,710\end{array}$ & $\begin{array}{l}8.02 \\
7.96 \\
7.88 \\
7.79 \\
7.68 \\
7.57\end{array}$ & $\begin{array}{l}4,440 \\
4,370 \\
4,280 \\
4,170 \\
4,040 \\
3,900\end{array}$ \\
\hline $\begin{array}{l}1 \\
2\end{array}$ & $\begin{array}{l}4.01 \\
4.00 \\
4.00 \\
3.99 \\
3.98 \\
3.97\end{array}$ & $\begin{array}{l}676 \\
670 \\
670 \\
665 \\
660 \\
655\end{array}$ & $\begin{array}{l}4.07 \\
4.22 \\
4.33 \\
4.36 \\
4.35 \\
4.34\end{array}$ & $\begin{array}{l}712 \\
802 \\
871 \\
892 \\
885 \\
878\end{array}$ & $\begin{array}{l}4.31 \\
4.35 \\
4.40 \\
4.43 \\
4.49 \\
4.55\end{array}$ & $\begin{array}{r}857 \\
885 \\
920 \\
941 \\
983 \\
1,020\end{array}$ & $\begin{array}{l}8.53 \\
8.90 \\
9.33 \\
9.62 \\
9.69 \\
9.69\end{array}$ & $\begin{array}{l}5,090 \\
5,570 \\
6,160 \\
6,580 \\
6,680 \\
6,680\end{array}$ & $\begin{array}{l}8.88 \\
8.77 \\
8.67 \\
8.59 \\
8.51 \\
8.47\end{array}$ & $\begin{array}{l}5,540 \\
5,400 \\
5,270 \\
5,170 \\
5,060 \\
5,010\end{array}$ & $\begin{array}{l}7.45 \\
7.34 \\
7.22 \\
7.12 \\
7.00 \\
6.90\end{array}$ & $\begin{array}{l}3,760 \\
3,630 \\
3,500 \\
3,390 \\
3,260 \\
3,150\end{array}$ \\
\hline $\begin{array}{l}1 \\
1\end{array}$ & $\begin{array}{l}3.96 \\
3.95 \\
3.94 \\
3.93 \\
3.92 \\
3.90\end{array}$ & $\begin{array}{l}650 \\
645 \\
640 \\
635 \\
630 \\
620\end{array}$ & $\begin{array}{l}4.32 \\
4.30 \\
4.28 \\
4.26 \\
4.24 \\
4.22\end{array}$ & $\begin{array}{l}864 \\
850 \\
838 \\
826 \\
814 \\
802\end{array}$ & $\begin{array}{l}4.63 \\
4.70 \\
4.78 \\
4.82 \\
4.89 \\
4.95\end{array}$ & $\begin{array}{l}1,080 \\
1,130 \\
1,190 \\
1,230 \\
1,280 \\
1,330\end{array}$ & $\begin{array}{r}9.78 \\
10.42 \\
11.60 \\
12.35 \\
12.80 \\
12.90\end{array}$ & $\begin{array}{r}6,820 \\
7,820 \\
9,780 \\
11,200 \\
12,000 \\
12,200\end{array}$ & $\begin{array}{l}8.43 \\
8.40 \\
8.38 \\
8.34 \\
8.32 \\
8.30\end{array}$ & $\begin{array}{l}4,960 \\
4,920 \\
4,890 \\
4,840 \\
4,820 \\
4,790\end{array}$ & $\begin{array}{l}6.79 \\
6.67 \\
6.55 \\
6.45 \\
6.34 \\
6.23\end{array}$ & $\begin{array}{l}3,030 \\
2,910 \\
2,790 \\
2,690 \\
2,580 \\
2,470\end{array}$ \\
\hline & \multicolumn{2}{|c|}{ September 24} & \multicolumn{2}{|c|}{ September 25} & \multicolumn{2}{|c|}{ September 26} & \multicolumn{2}{|c|}{ September 27} & \multicolumn{2}{|c|}{ September 28} & \multicolumn{2}{|c|}{ September 29} \\
\hline $\begin{array}{r}2 \\
4 \\
6 \\
8 \\
10 \\
\mathrm{~N}\end{array}$ & $\begin{array}{l}6.02 \\
5.86 \\
5.70 \\
5.55 \\
5.43 \\
5.37\end{array}$ & $\begin{array}{l}2,260 \\
2,110 \\
1,970 \\
1,840 \\
1,730 \\
1,670\end{array}$ & $\begin{array}{l}5.10 \\
5.03 \\
4.99 \\
4.94 \\
4.90 \\
4.86\end{array}$ & $\begin{array}{l}1,450 \\
1,590 \\
1,360 \\
1,320 \\
1,290 \\
1,260\end{array}$ & $\begin{array}{l}4.59 \\
4.55 \\
4.52 \\
4.48 \\
4.44 \\
4.41\end{array}$ & $\begin{array}{r}1,050 \\
1,020 \\
1,000 \\
976 \\
948 \\
927\end{array}$ & $\begin{array}{l}4.22 \\
4.20 \\
4.18 \\
4.16 \\
4.13 \\
4.14\end{array}$ & $\begin{array}{l}802 \\
790 \\
778 \\
766 \\
748 \\
754\end{array}$ & $\begin{array}{l}4.43 \\
4.42 \\
4.41 \\
4.40 \\
4.40 \\
4.40\end{array}$ & $\begin{array}{l}941 \\
934 \\
927 \\
920 \\
920 \\
920\end{array}$ & $\begin{array}{l}4.29 \\
4.27 \\
4.24 \\
4.20 \\
4.17 \\
4.12\end{array}$ & \begin{tabular}{|l}
844 \\
832 \\
814 \\
790 \\
772 \\
742
\end{tabular} \\
\hline $\begin{array}{r}2 \\
4 \\
6 \\
8 \\
10 \\
M\end{array}$ & $\begin{array}{l}5.35 \\
5.36 \\
5.37 \\
5.31 \\
5.24 \\
5.17\end{array}$ & $\begin{array}{l}1,660 \\
1,660 \\
1,670 \\
1,620 \\
1,560 \\
1,510\end{array}$ & $\begin{array}{l}4.81 \\
4.78 \\
4.73 \\
4.70 \\
4.67 \\
4.62\end{array}$ & $\begin{array}{l}1,220 \\
1,190 \\
1,150 \\
1,130 \\
1,110 \\
1,070\end{array}$ & $\begin{array}{l}4.37 \\
4.33 \\
4.30 \\
4.29 \\
4.26 \\
4.23\end{array}$ & $\begin{array}{l}899 \\
871 \\
850 \\
844 \\
826 \\
808\end{array}$ & $\begin{array}{l}4.20 \\
4.32 \\
4.42 \\
4.50 \\
4.50 \\
4.48\end{array}$ & $\begin{array}{l}790 \\
864 \\
934 \\
990 \\
990 \\
976\end{array}$ & $\begin{array}{l}4.40 \\
4.40 \\
4.40 \\
4.39 \\
4.38 \\
4.33\end{array}$ & $\begin{array}{l}920 \\
920 \\
920 \\
913 \\
906 \\
871\end{array}$ & $\begin{array}{l}4.09 \\
4.07 \\
4.05 \\
4.02 \\
4.00 \\
3.99\end{array}$ & $\begin{array}{l}724 \\
712 \\
700 \\
682 \\
670 \\
665\end{array}$ \\
\hline
\end{tabular}


Lake Memphremagog at Newport, Vt.

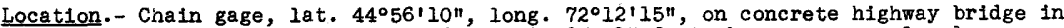
Newport, Orleans County. Zero of gage is 673.15 feet above mean sea level. Gage-helght record.- Gage read daily in the afternoon.

Maxima.- September 1938: Gage height observed, 9.36 feet 5 p.m. Sept. $28,29$.

1931 to August 1938: Gage he1ght observed, 12.92 feet Apr. 20, 1933.

Remarks. - No record on days for which no gage helghts shown. Water surface area of Lake Memphremagog is 38.4 square miles.

Gage height, in feet, 1938

\begin{tabular}{|c|c|c|c|c|c|c|c|c|c|c|c|}
\hline Day & Sept. & Oct. & Day & Sept. & Oct. & Day & Sept. & 0 ct. & Day & Sept. & oct. \\
\hline $\begin{array}{l}1 \\
2 \\
3 \\
4 \\
5 \\
6 \\
7 \\
8\end{array}$ & $\begin{array}{l}\overline{8} .80 \\
\overline{-} \\
\bar{z} \\
\overline{-} \\
=\end{array}$ & $\begin{array}{l}9.38 \\
9.40 \\
9.42 \\
9.40 \\
9.40 \\
9.32 \\
9.33 \\
9.30\end{array}$ & $\begin{array}{r}9 \\
10 \\
11 \\
12 \\
13 \\
14 \\
15 \\
16\end{array}$ & $\begin{array}{l}- \\
- \\
- \\
- \\
- \\
-\end{array}$ & $\begin{array}{l}9.26 \\
9.23 \\
9.20 \\
9.18 \\
9.14 \\
9.10 \\
9.07 \\
9.04\end{array}$ & $\begin{array}{l}17 \\
18 \\
19 \\
20 \\
21 \\
22 \\
23 \\
24\end{array}$ & $\begin{array}{l}- \\
- \\
\overline{8} .62 \\
8.74 \\
8.80 \\
9.04 \\
9.16\end{array}$ & $\begin{array}{l}9.02 \\
9.00 \\
8.98 \\
8.97 \\
8.94 \\
8.91 \\
- \\
8.88\end{array}$ & $\begin{array}{l}25 \\
26 \\
27 \\
28 \\
29 \\
30 \\
31\end{array}$ & $\begin{array}{l}9.22 \\
9.28 \\
9.34 \\
9.36 \\
9.36 \\
9.35\end{array}$ & $\begin{array}{l}8.88 \\
8.86 \\
8.84 \\
8.84 \\
8.83 \\
8.82 \\
8.82\end{array}$ \\
\hline
\end{tabular}


The results of the determinations of maximum flood flows at existing stream-gaging stations and other places on streams in the area covered by this report are summarized and presented in table 10, "Summary of flood discharges." Generally, the time of day in this table is for standard time or has been adjusted to standard time when possible. The map reference number in this table is applicable to plate 11 (in pocket) and will ald in 1dentifying the place where the discharge was determined.

The discharges for the existing stream-gaging stations were determined by methods described in greater detail in the presentation of the record for the respective stations in the section "Stages and discharges at stream-gaging stations." For existing stream-gaging stations the method of determination is designated "Stage-discharge relation," because the determination 1s based on the comprehensive studies of that subject that are conducted at such stations. Where the recorded discharge was not measured at a regular station a brief reference is made to the method of determination. For general information, some discharges are presented for streams in basins adjoining or near those most affected by the floods. At some places information of maximum stages only is avaliable, and that information is presented with an appropriate footnote in order to show the relative magnitudes of the flood of 1938 and previous floods. For other places, pertinent information regarding stages antedating the perlod of record of discharge is shown by a footnote. Although the tabulation is intended to be reasonably complete, the reader is referred to the section "Records of previous floods" in this report and in WaterSupply Papers 798 and 799, which cover the floods of March 1936 in the affected regions, for possible additional references to notable floods not included in the summary table. Explanatory footnotes on other features of the table are also included.

Figure 41 shows the flood discharges, in second-feet per square mile, which are 1isted in table 10, plotted against the corresponding drainage areas. In this connection it should be understood that except for a small number of items as indicated in the table the discharges are given as observed and many are affected by artificial storage, release of water resulting from fallure of dams, or other similar factors, on which avaliable information is presented in the preceding section, "Stages and discharges at stream-gaging stations during the flood period."

The basic data and computations for the determinations of discharge are filed in the district offices of the Geological Survey in the several districts where the floods occurred and may be examined in those offices. 
Table 10.--Sumnary of flood discharses

\begin{tabular}{|c|c|c|c|c|c|c|c|c|c|c|c|}
\hline \multirow{2}{*}{$\begin{array}{l}\text { No. } \\
\text { on } \\
\text { pl. } \\
11\end{array}$} & \multirow[b]{2}{*}{ Stream and place of determination } & \multirow[b]{2}{*}{$\begin{array}{l}\text { Drainage } \\
\text { area } \\
(\text { sq. mi. })\end{array}$} & \multirow[b]{2}{*}{$\begin{array}{l}\text { Period } \\
\text { of } \\
\text { reoord }\end{array}$} & \multicolumn{3}{|c|}{$\begin{array}{l}\text { Maximum disoharge } \\
\text { previously knowm }\end{array}$} & \multicolumn{5}{|c|}{ Maximum disoharge during floods of September 1938} \\
\hline & & & & Date & $\begin{array}{c}\text { Seoond- } \\
\text { foot }\end{array}$ & $\begin{array}{c}\text { seo.-ft. } \\
\text { per } \\
\text { sq. mi. }\end{array}$ & Day & Hour & $\begin{array}{c}\text { Second- } \\
\text { feet }\end{array}$ & $\begin{array}{l}\text { seo, }-\mathrm{ft} . \\
\text { per } \\
\text { sq. mi. }\end{array}$ & Method of determination \\
\hline & Androsooggin Rivor Basin & & & & & & & & & & \\
\hline 1 & Androsoogrin River at Errol Dam, I. H. & 1,095 & $1905-1938$ & May 10, 1929 & 15,300 & 14.0 & 22 & - & 24,450 & 4.1 & Gates in dam. \\
\hline 2 & $\begin{array}{r}\text { Androsooggin River near Gorham, N. H. } \\
\text { Saco River Basin }\end{array}$ & 3,390 & $1929-1938$ & Mar. 22, 1936 & 19,900 & 14.3 & 22 & 6 to 8 p.m. & 10,300 & 7.4 & Stage-disoharge relation. \\
\hline 3 & $\begin{array}{l}\text { Saco River near Conway, N. H. } \\
\qquad \text { Piscataqua River Basin }\end{array}$ & 386 & $\begin{array}{l}1903-1910 \\
1929-1938\end{array}$ & Mar. 19, 1936 & 40,600 & 105 & 21 & $11: 45$ a.m. & 20,800 & 53.9 & Do. \\
\hline 4 & Salmon Falls RAver noar South Lebanon, Jaine & 147 & $1928-1938$ & Kar. 19, 1936 & 5,490 & 37.3 & 20 & 10 p.m. & 403 & 2.7 & Do. \\
\hline 5 & $\begin{array}{l}\text { Lamproy R1ter near Nowmarket, Ne H. } \\
\qquad \text { Morrimack River Bas in }\end{array}$ & 183 & $1934-1938$ & Kar. 20, 1936 & 5,490 & 30.0 & 22 & 12 p.m. & 1,180 & 6.4 & Do. \\
\hline 6 & Bast Branoh of Pemigewasset River near Linooln, N. H. & 104 & $1928-1938$ & Lar. 19, 1936 & 17,000 & 163 & 21 & $9 \mathrm{p} . \mathrm{m}$. & 16,200 & 256 & Do. \\
\hline 7 & Penigomaset River at Livermore Falls, N. H. & 406 & -- & Lar. 19, 1936 & 54,000 & 133 & 21 & -- & 44,900 & 111 & Dam. \\
\hline 8 & Pemigowasset River at Plymouth, N. H. & 622 & $1903-1938$ & Kar. 19, 1936 & 65,400 & 105 & 21 & 9 p.m. & 60,900 & 81.8 & Stage-discharge relation. \\
\hline 9 & Pemigenasset River at Ayers Island, near Bristol, $\mathrm{N}$. $\mathrm{H}$. & 746 & -- & Mar. 19, 2936 & 71,400 & 95.7 & 22 & $5 \mathrm{a} \cdot \mathrm{m}$. & 49,700 & 66.6 & Do. \\
\hline 10 & Pemigewasset River at Eastman Falls, at Franklin, N. B. & 1,000 & -- & - & -- & - & 22 & 4 to 9 a.m. & 54,400 & 54.4 & Do. \\
\hline 11 & Worrimack Rivor at Franklin Junotion, N. H. & 1,507 & $1903-1938$ & Mar. 19, 1936 & 83,000 & 55.1 & 22 & 9 a.m. & 69,200 & 39.3 & Do. \\
\hline 12 & Nerrimack River at Garvins Falls, N. H. & 2,427 & -- & Nar. 20, 1936 & 122,000 & 50.3 & 22 & 11 p.m. & 86,900 & 35.8 & Do. \\
\hline 13 & Norrimack River at Amoskoag Dam, Mnohester, N. H. & 2,854 & $1924-1938$ & Nar. 20, 1936 & 144,000 & 50.5 & 23 & 2 a.m. & 97,600 & 34.2 & Dam. \\
\hline 14 & Yorrimack River at Gorfs Falls, below Manohester, W. B. & 3,092 & -- & Mar. 20, 1936 & 150,000 & 48.5 & 23 & 4 a.m. & 102,500 & 33.2 & Stage-dis charge relation. \\
\hline 15 & Yorrimaok River below Conoord River, Lowoll, Mass. & 4,635 & $1848-1938$ & Mar. 20, 1936 & 173,000 & 37.3 & 23 & 11 to 12 a.m. & 121,100 & 26.1 & Do. \\
\hline 16 & Bekers River near Rumney, N. H. & 143 & $1928-1938$ & Nov. 3, 1927 & 25,900 & 181 & 21 & 3 p.m. & 15,900 & 211 & Do. \\
\hline 17 & $\begin{array}{l}\text { Smith River at Danbury Novelty Co. Dam, lit miles } \\
\text { northeast of kilmrood, X. H. }\end{array}$ & 64.7 & -- & Mar. 19, 1936 & 6,070 & 93.8 & 22 & - & 2,580 & 39.9 & Dem. \\
\hline
\end{tabular}


18 Smith River near Bristol, N. $B$.

19 Winnipesaukee River at Tilton, N. H.

20 Contoooook River near East Jaffroy, N. H.

21 Contoooook River noar Badloy, N. B.

22 Contoooook River at North Village, below Peterboro, r.

23 Contoocook River near Hillsboro. N. B.

24 Contoooook River near West Hopkinton, N. H.

25 Contoocook River at Penacook, N. H.

26 Mubanus it Brook at dam, at Woat Peterboro, H. H.

27 Worth Branch of Contoocook River near Antrim, N. H.

28 North Branoh of Contoooook River at Jaciman Dam, near Hillaboro, B. Bo

29 Warner River at dam, at Bradford, N. E.

30 Blackwater River near Webster, N. H.

31 Sunoook Rtror at North Chichester, N. B.

32 P1scataquog River at Greggs Falls, near Goffstown, N, Ho

33 Clark Brook near Auburn, H. Ho

34 Souhogan River at otis Will Dam, at Greenville, N. H.

35 Souhegan River at Morrimaik, N. H.

36 Stony Brook at dam $\frac{1}{2}$ mille above mouth, at Wilton, N. H.

87 North Yashua R1 ver noar Leominster, Mass.

38 Hashua River at East Pepperell, knss.

39 South Branch of Nashua River at Clinton, Hass.

40 Round Yoadow Pond (Merrimack Pond) at Westminster, Kass

11 Conoord Rfver at Lowell, Mass.

\begin{tabular}{|c|c|c|c|c|c|c|c|c|c|}
\hline 85.8 & 1918-1938 & Mar. 19, 1936 & 8,100 & 94.4 & 22 & $5 \mathrm{a}, \mathrm{m}$. & 5,070 & 59.1 & Stage-discharge relation. \\
\hline 471 & $1937-1938$ & Lay 27, 1937 & 3,120 & 6.6 & 21 & $6: 15$ p.m. & 3,810 & 8.1 & Do. \\
\hline 36.1 & -- & Mar. 18, 1936 & 2,580 & 72.5 & 21 & - & 3,560 & 98.6 & slope area. \\
\hline 36.9 & - & - & -- & -- & 21 & - & 3,390 & 91.9 & Do. \\
\hline 124 & -- & -- & - & -- & 21 & $12 \mathrm{~m}$ & 10,400 & 83.9 & Contraoted opening. \\
\hline 367 & -- & - & - & -- & 21 & - & 22,170 & 60.4 & Dam. \\
\hline 416 & - & Mar, 19, 1936 & 25,200 & 80.6 & 21 & - & 22,300 & 53.6 & Do. \\
\hline 766 & $1928-1938$ & Mar. 20, 1936 & 46,800 & 61.1 & 23 & 3 a.m. & 42,400 & 55.4 & Stage-discharge relation. \\
\hline 45.2 & - & Mar. 19, 1936 & 4,140 & 91.6 & 21 & 12 a.m. & 4,100 & 90.7 & Dam. \\
\hline 54.8 & $1924-1938$ & Mar. 19, 1936 & $b 4,680$ & 85.4 & 22 & 7 a.m. & 3,850 & 70.3 & Stage-disoharge relation. \\
\hline 63.9 & -- & Mar. 20, 1936 & 8,300 & 130 & 22 & - & 3,090 & 48.4 & Dam. \\
\hline 19.7 & -- & Mar. 18, 1936 & 2,370 & 120 & 21 & -- & 1,730 & 87.8 & Do. \\
\hline 129 & $1918-1938$ & Mar. 19, 1936 & b11,000 & 85.3 & 22 & $6 \mathrm{p} . \mathrm{m}$. & 6,880 & 53.3 & Stage-discharge relation. \\
\hline 157 & $1918-1938$ & Mar. 19, 1986 & 12,900 & 82.2 & 21 & 10 a.m. & 2,110 & 13.4 & Do. \\
\hline 201 & -- & -- & -- & -- & 21 & $10: 30$ to $11: 45 \mathrm{p} \cdot \mathrm{mo}$ & 21,900 & 109 & Dam. \\
\hline 27.7 & 1938 & July 30,1938 & 290 & 10.5 & 21 & Noon to $5 \mathrm{p} . \mathrm{m}$. & 218 & 7.9 & Stage-disoharge relation. \\
\hline 29.9 & -- & Mar. 18, 1936 & 6,160 & 206 & 21 & - & 4,970 & 166 & Dam. \\
\hline 171 & $1909-1938$ & Mar. 19, 1936 & 16,900 & 98.8 & 21 & $11: 45$ p.m. & 10,800 & 63.2 & Stage-disoharge relation. \\
\hline 33.2 & $\cdots$ & Mar. 18, 1936 & 5,780 & 174 & 21 & $21: 30$ a.m. & 4,880 & 147 & Dam. \\
\hline 107 & $1935-1938$ & Har. 18, 1936 & 16,300 & 152 & 21 & 3 p.m. & 10,300 & 96.3 & Stage-discharge relation. \\
\hline 433 & $1935-1938$ & Mar. 20, 1936 & 20,900 & 48.3 & 23 & 8 to $10 \mathrm{a.m}$. & 10,200 & 23.6 & Do. \\
\hline 117 & $1896-1938$ & Kar. 18, 1936 & 011,100 & 94.9 & 21 & - & $\mathrm{d4}, 150$ & -- & Do. \\
\hline 4.6 & -- & -- & - & -- & 21 & - & 580 & 126 & Dam. \\
\hline 405 & $1936-1938$ & July 29, 1938 & 3,790 & 9.4 & 24 & 2 p.m. & 3,210 & 7.9 & Stage-discharge relation. \\
\hline
\end{tabular}

o Adjusted for storage.
d Mean daily discharge adjusted for storage. 
Table 10.-_Summary of flood discharges--Continued

\begin{tabular}{|c|c|c|c|c|c|c|c|c|c|c|c|}
\hline \multirow{2}{*}{$\begin{array}{l}\text { Yo. } \\
\text { on } \\
\text { pl. } \\
11\end{array}$} & \multirow[b]{2}{*}{ Strean and plece of determination } & \multirow[b]{2}{*}{$\begin{array}{l}\text { Drainage } \\
\text { area } \\
\text { (sq. mi.) }\end{array}$} & \multirow[b]{2}{*}{$\begin{array}{l}\text { Period } \\
\text { of } \\
\text { reoord }\end{array}$} & \multicolumn{3}{|c|}{$\begin{array}{l}\text { Maximum discharge } \\
\text { previously known }\end{array}$} & \multicolumn{5}{|c|}{ Meximum disoharge during floods of September 1938} \\
\hline & & & & Date & $\begin{array}{c}\text { Second- } \\
\text { feet }\end{array}$ & \begin{tabular}{|c|} 
Sec.-ft. \\
per \\
sq. mi.
\end{tabular} & Day & Hour & $\begin{array}{c}\text { Second- } \\
\text { feet }\end{array}$ & $\begin{array}{c}\text { sec.-rt. } \\
\text { per } \\
\text { sq. mi. }\end{array}$ & Yothod of determination \\
\hline & Worrimeak River Bas in--Continued & & & & & & & & & & \\
\hline $\mathbf{4 2}$ & Sudbury River at Framingham Conter, Mass. & 75.2 & $1875-1938$ & Feb. 14, 1886 & $e 2,050$ & - & 21 & - & $e 1,120$ & - & Stage-discharge relation. \\
\hline 43 & $\begin{array}{l}\text { Lake coohituate Outlet at Cochituate, Mass. } \\
\qquad \text { Ipawioh River Basin }\end{array}$ & 17.4 & $1898-1936$ & Yar. 22, 1936 & e248 & -- & 21 & - & e211 & - & Do. \\
\hline 44 & Ipenioh River at South Middletom, Mass. & 43.4 & 1958 & July 24, 1938 & 603 & 14.0 & 21 & 8 a.m. & 378 & 8.7 & Do. \\
\hline 45 & $\begin{array}{l}\text { Ipowiloh River near Iperiloh, Mass. } \\
\text { Charles River Basin }\end{array}$ & 124 & $1930-1938$ & Mar. 15, 1936 & 2,610 & 21.0 & 22 & 11 to 12 pom. & 1,080 & 8.7 & Do. \\
\hline 46 & Charl es River at Charles River Village, Mass. & 182 & $1936-1938$ & March 1936 & 3,170 & 10.1 & 24 & 1 to 5 p.m. & 881 & 4.8 & Do. \\
\hline 47 & Charles River at Waltham, Wass. & 251 & $1931-1938$ & War. 19, 1936 & 2,540 & 10.2 & 26 & 11 a.m. & P795 & 3.2 & Do. \\
\hline 48 & $\begin{array}{l}\text { Wother Brook at Dodham, Mass. } \\
\text { Taunton R1 vor Basin }\end{array}$ & - & $1931-1938$ & July 29, 1938 & $90 \mathrm{~s}$ & - & 26 & 8 a.m. & 225 & -- & Do. \\
\hline 49 & Taunton River at State Farm, Wass, & 260 & $1929-1938$ & Apr. 14, 1935 & 3,050 & 11.7 & 21 & 8 p.m. & 1,040 & 4.0 & Do. \\
\hline so & $\begin{array}{l}\text { Wading River near Morton, Wass. } \\
\text { Providonoe River Basin }\end{array}$ & 42.4 & 1925-1938 & Har. 12, 13, 1936 & 1,030 & 24.3 & & & 200 & 4.7 & Do. \\
\hline 51 & Blackstone River at Worcester, Mass. & 31.5 & $1923-1938$ & Mar. 18, 1936 & 2,520 & 80.5 & 21 & 4:30 p.m. & 1,280 & 40.9 & Do. \\
\hline 52 & $\begin{array}{l}\text { Blackstone River at Woonsocket, R. I. } \\
\text { Thames River Basin }\end{array}$ & 416 & 1929-1938 & July 24, 1938 & 15,100 & 36.3 & 22 & $12: 30 \mathrm{p} \cdot \mathrm{m}$. & 6,130 & 14.7 & Do. \\
\hline 53 & Square Pond Brook at West Stafford, Conn. & 6.5 & -- & - & - & - & -- & -- & 470 & 72.3 & Dam. \\
\hline 64 & Willimantic River at Eagleville, Conn. & 110 & -- & Mar. 12, 1936 & 7,620 & 69.3 & - & -- & g 22,900 & 117 & Dam. \\
\hline 65 & willimantic River near South Coventry, Conn. & 121 & $1931-1938$ & Mar. 12, 1936 & 7,880 & 65.1 & 21 & 11 a.m. & 15,500 & 128 & Stage-discharge relation. \\
\hline 56 & Willimantio Biver at Willimantio, Conn & 224 & - & Mar. 12, 1936 & 11,200 & 50.0 & 21 & -- & 21,000 & 93.8 & Dam. \\
\hline
\end{tabular}




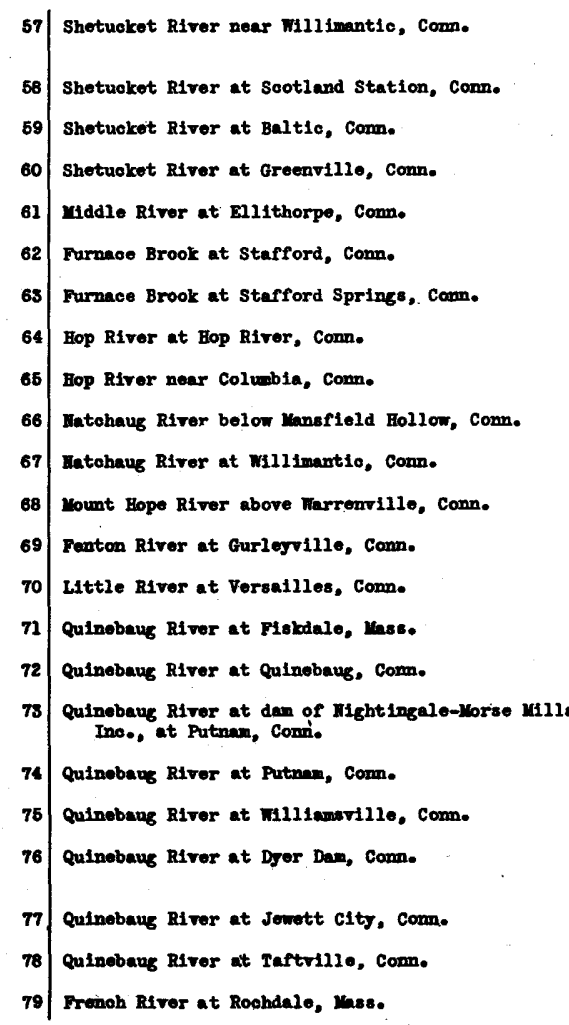


Table 10.- Strmmary of flood discharges--Continued

\begin{tabular}{|c|c|c|c|c|c|c|c|c|c|c|c|}
\hline \multirow{2}{*}{$\begin{array}{l}\text { 80. } \\
\text { on } \\
\text { pl. } \\
\text { I1 }\end{array}$} & \multirow[b]{2}{*}{ Stream and place of determination } & \multirow{2}{*}{$\left|\begin{array}{l}\text { Drainage } \\
\text { area } \\
(\text { sq. mi. })\end{array}\right|$} & \multirow{2}{*}{$\begin{array}{l}\text { Portod } \\
\text { of } \\
\text { rooord }\end{array}$} & \multicolumn{3}{|c|}{$\begin{array}{l}\text { Maximum disoharge } \\
\text { previousiy known }\end{array}$} & \multicolumn{5}{|c|}{ Laximum discharge during floods of September 1938} \\
\hline & & & & Date & $\begin{array}{l}\text { Second- } \\
\text { foet }\end{array}$ & $\mid \begin{array}{c}\text { sec.-ft. } \\
\text { per } \\
\text { sq. mi. }\end{array}$ & Day & Hour & \begin{tabular}{|c|c|}
$\begin{array}{c}\text { Second- } \\
\text { feot }\end{array}$ & $\mathrm{s}$ \\
\end{tabular} & $\left|\begin{array}{c}\text { Sec.-ft. } \\
\text { per } \\
\text { sq. mi. }\end{array}\right|$ & Method of determination \\
\hline & Thames River Basin--Continued & & & & & & & & & & \\
\hline 80 & French River at North Oxford, Mass. & 24.1 & -- & Mar. 18, 1936 & 2,030 & 84.2 & - & - & 985 & 40.9 & Dem. \\
\hline 81 & Fronoh River at Wobster, Mass. & 85.6 & -- & Mar. 19, 1936 & 4,700 & 54.9 & - & -- & 2,700 & 31.5 & Do. \\
\hline 82 & Fronoh River at North Grosvenordale, Conn. & 98.5 & -- & Mar. 19, 1936 & 5,990 & 60.8 & -- & - & 3,190 & 32.4 & Do. \\
\hline 83 & Muddy Brook at Barrisville, Conn. I/ & 36.4 & -- & Nar. 19,1936 & 2.920 & 80.2 & 21 & 7 p.m. & 2,010 & 55.2 & Do. \\
\hline 84 & Five Lile River at Killingly, Conn. & 58.2 & $1937-1938$ & July 24, 1938 & 2,480 & 42.6 & 21 & 11.20 p.m. & 1,060 & 18.2 & Stage-discharge relation. \\
\hline 85 & Five yile River at Danielson, Conn. & 77.6 & -- & Mar. 12, 1936 & 1,990 & 25.6 & -- & -- & $1,420^{\circ}$ & 18.3 & Dam. \\
\hline 86 & Moosup R1ver at Moosup, Conn. & 83.5 & $1932-1938$ & July 24, 1938 & 4,100 & 49.1 & 21 & 7 a.m. & 686 & 8.2 & Stage-disoharge relation. \\
\hline 87 & Pachaug River at Jewett C1ty, Conn. & 59.0 & -- & March 1936 & 1,500 & 25.4 & 21 & -- & 2,240 & 38.0 & Dem. \\
\hline 88 & Yent10 River at Fitohrille, Conn. & 69.1 & $\cdots$ & Mar. 12, 1936 & 5,250 & 76.0 & -- & -- & 9,700 & 140 & Do. \\
\hline 89 & Yunt10 River at Yantic, Conn. & 88.6 & $1930-1938$ & July 24, 1938 & 6,980 & 78.8 & 21 & 8 a.me & 13,500 & 152 & Stage-discharge relation. \\
\hline 90 & $\begin{array}{l}\text { Yantio River at Norwichtown, Conn. } \\
\text { Conneotlout River Besin }\end{array}$ & 96.9 & -- & -- & -- & -- & - & - & 27,000 & 175 & Dam. \\
\hline 91 & $\begin{array}{l}\text { Connoctiout River at First Conneoticut Lake, near } \\
\text { P1ttsburg, H. H. }\end{array}$ & 83.0 & 1917-1938 & Way 27, 1930 & 1,810 & 21.8 & 21 & $8 \mathrm{p} . \mathrm{m}$. & 2,000 & 24.1 & Stage-disoharge relation. \\
\hline 92 & Connectiout River at Xorth Stratford, $\mathrm{x}$, H. & 796 & $1930-1958$ & Nar. 19, 1936 & 28,400 & 35.7 & 22 & $10: 45$ a.m. & 12,800 & 16.1 & Do. \\
\hline 93 & Conneoticut River near Dalton, I. H. & 1,538 & $1927-1938$ & Mar. 20, 1936 & 48,300 & 31.4 & 22 & 7 a.m. & 19,600 & 12.7 & Do. \\
\hline 94 & $\begin{array}{l}\text { Conneotiout River at outlet of Fifteonmile Falls } \\
\text { Reservolr, noar Barnet, Vt. }\end{array}$ & 1,650 & - & Mar. 20, 1936 & 55,000 & 33.3 & 22 & - & 28,000 & 17.0 & Do. \\
\hline 95 & Comnootiout Ríver at YoIndoes Falls, Vt. & 2,200 & - & Mar. 20, 1936 & 68,000 & 30.9 & 22 & - & 33,000 & 15.0 & Do. \\
\hline 96 & Conneotiout River at South Newibury, vt. & 2,825 & $1918-1938$ & War. $19,20,1936$ & 77,800 & 27.5 & 22 & 3 p.m. & 43,700 & 15.5 & Do. \\
\hline 97 & Connoctiout River at White River Junotion, Vt. & 4,068 & $1911-1938$ & Nor. 4, 1927 & 236,000 & 33.4 & 22 & 5 to $6 \mathrm{aom}$ & 82,400 & 20.3 & Do. \\
\hline 98 & Connectiout River at Vernon, $\nabla t$. & 6,240 & - & War. 19, 20, 2938 & 176,000 & 28.2 & 22 & 5 to 9 a.m. & 132,500 & 21.2 & Do. \\
\hline
\end{tabular}


99 Connectiout River at Turners Falls, Mass.

100 Connectiout River at Yontague City, Mass.

101 Connectiout River at Holyoke, Mass.

02 Connecticut River at Springfield, Mass.

103 Connecticut River at Thompsonville, conn.

104 Connectiout River at Hartford, Conn.

05 Iorael River at upper Twin State Gas \& Electrio Co. dam, at Lanoaster, N. B.

106 Johns Rivor at F. P. Spaulding Co. dam, at WhiteField, N. H.

107 Passumpsic Riter at Bay St. hydroeleotrie plant, at St. Johnsbury, Vt.

108 Passumps 10 River at Passumpsio, Vt.

109 Yoose River at St. Johnsbury, Vt.

110 Amozoosuo River at Saranao Glove co. dam at Littieton H. $\mathbf{H}_{0}$

111 Ammonoosuc RIver near Bath, N. Ho

112 Waits River at Bradford Eleotrio Light Co. dam, at Bradford, Vt.

113 White River at Stookbridge, Vt.

114 Whito River near Bothel, Vt.

115 Thite Fiver at Central Vermont Publio Sorvioe dam, below Bothel, $\nabla t$.

116 White River at West Eartford, vt.

117 Iweed River near Stookbridgo, Vt.

118 West Branch of Tweed River noar Pittsfield, vt.

J Pabliened as Little River on pege 319 of Watex-Supply Paper 798.

\begin{tabular}{|c|c|c|}
\hline 7,138 & $1916-1938$ & Mar. 19, 20, 1936 \\
\hline 7,840 & $1904-1938$ & Lar. 19, 1936 \\
\hline 8,284 & $1860-1938$ & Mar. 19, 20, 1936 \\
\hline 9,587 & $1801-1938$ & Mar. $19,20,1936$ \\
\hline 9,637 & $1928-1938$ & Nar. 20, 1936 \\
\hline 10,480 & $1639-1938$ & Jar. 20, 1936 \\
\hline 132 & - & November 1927 \\
\hline 34.6 & -- & March 1936 \\
\hline 371 & - & -- \\
\hline 423 & $1928-1938$ & Har. 18, 1936 \\
\hline 126 & $1928-1938$ & Apr. 30,1929 \\
\hline 233 & - & Hovember 1927 \\
\hline 393 & $1935-1938$ & Mar. 18, 1936 \\
\hline 162 & - & November 1927 \\
\hline 143 & -- & -- \\
\hline 241 & $1931-1938$ & Nar. 18, 1936 \\
\hline 411 & - & Warch 1936 \\
\hline 690 & $1915-1938$ & Nov. 4, 1927 \\
\hline 50.1 & -- & -- \\
\hline 17.0 & -- & -- \\
\hline
\end{tabular}

\begin{tabular}{|c|c|c|c|}
\hline 210,000 & 29.4 & 22 & 8 a.me to 3 \\
\hline 236,000 & 30.1 & 22 & $11: 30 \mathrm{mom}$. \\
\hline 244,000 & 29.5 & $\left|\begin{array}{c}22 \\
\text { to } 23\end{array}\right|$ & $\mid \begin{array}{ll}11 & \text { p.m. } \\
5 & \text { a.m. }\end{array}$ \\
\hline 281,000 & 29.3 & $\left|\begin{array}{c}22 \\
\text { to } 23\end{array}\right|$ & $\begin{array}{l}10 \text { p.m॰ } \\
1 \text { p.m॰ }\end{array}$ \\
\hline 282,000 & 29.3 & $\left|\begin{array}{c}22 \\
\text { to } 23\end{array}\right|$ & $\begin{array}{l}11 \text { p.m. } \\
2 \text { a.m. }\end{array}$ \\
\hline 313,000 & 29.9 & $\left|\begin{array}{c}22 \\
\text { to } 23\end{array}\right|$ & $\begin{array}{lll}12 & \text { p.m. } \\
4 & \text { a.m. }\end{array}$ \\
\hline$k 8,840$ & k71.3 & -- & - \\
\hline 1,540 & 44.5 & -- & - \\
\hline-- & - & 21 & night \\
\hline 16,000 & 37.8 & 22 & $1 \mathrm{a} \cdot \mathrm{m}$. \\
\hline 5,220 & 41.4 & 21 & 3:15 p.m. \\
\hline$k] 6,600$ & k134 & - & - \\
\hline 27,900 & 71.0 & 21 & 6 p.m. \\
\hline 10,500 & 64.8 & 22 & 2 pom. \\
\hline-- & - & 21 & - \\
\hline 16,100 & 66.8 & 22 & 12 p.m. \\
\hline 27,600 & 67.2 & 21 & 10 p.m. \\
\hline 120,000 & 174 & 22 & $3: 30 \mathrm{a} . \mathrm{m}$ \\
\hline-- & -- & 21 & 11 p•m• \\
\hline- & -- & 21 & - \\
\hline
\end{tabular}

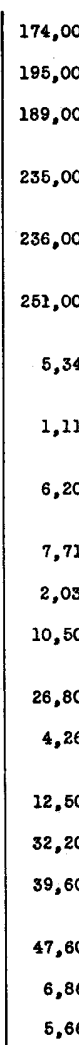

24.4 Stage-discharge relation.

24.9 Do.

22.8 Do.

24.5 Do.

24.5 Do.

Do.

Do.

Do.

Do.

18.2 Stage-discharge relation.

Do.

78.9 Dam.

68.2 Stage-disoharge relation. 26.3 Dam.

87.4 Slope area.

134 Stage-dis oharge relation.

96.4 Dam.

69.0 Stage-discharge relation. 137 Dam.

333 Slope area. 
Table 10.--Sumbiary of flood discharses--Continued

\begin{tabular}{|c|c|c|c|c|c|c|c|c|c|c|c|}
\hline \multirow{2}{*}{$\begin{array}{l}\text { No. } \\
\text { on } \\
\text { n1. } \\
11\end{array}$} & \multirow[b]{2}{*}{ Stream and place of detornination } & \multirow{2}{*}{$\begin{array}{l}\text { Drainage } \\
\text { area } \\
\text { (sq. mi. })\end{array}$} & \multirow{2}{*}{$\begin{array}{l}\text { Period } \\
\text { of } \\
\text { record }\end{array}$} & \multicolumn{3}{|c|}{$\begin{array}{l}\text { Maximum discharge } \\
\text { previously loom }\end{array}$} & \multicolumn{5}{|c|}{ Maximum disoharge during floods of September 1938} \\
\hline & & & & Date & $\begin{array}{c}\text { Second- } \\
\text { feet }\end{array}$ & $\begin{array}{c}\text { Sec.-ft. } \\
\text { per } \\
\text { eq. mi. }\end{array}$ & Day & Hour & $\begin{array}{c}\text { Second- } \\
\text { foet }\end{array}$ & $\begin{array}{c}\text { Sece-ft. } \\
\text { per } \\
\text { sq. mi. }\end{array}$ & Wothod of determination \\
\hline & Connooticut River Basin--Continued & & & & & & & & & & \\
\hline 119 & Stony Brook near Gaysville, Vt. & 24.1 & -- & -- & -- & - & 21 & - & 4,640 & 193 & Contracted opening. \\
\hline 120 & Third Branch of White River above Randolph, vt. & 54.6 & -- & -- & - & - & 21 & - & 9,720 & 178 & slope ares. \\
\hline 121 & $\begin{array}{l}\text { Second Branch of White River at Byde Hial dam, at } \\
\text { East Bethel, Vt. }\end{array}$ & 63.8 & - & March 1936 & 3,030 & 47.5 & 21 & 21 p.m. & 1,590 & 24.9 & Dam. \\
\hline 122 & $\begin{array}{l}\text { First Branch of white River at Ralston co. dam, at } \\
\text { South Royaltion, Vt. }\end{array}$ & 114 & - & March 1936 & 4,990 & 43.8 & -- & - & 2,060 & 28.1 & Do. \\
\hline 123 & Whscoma River at Masooma, H. H. & 153 & $1923-1938$ & Mar. 19, 1936 & 5,840 & 38.2 & 22 & $8 \mathrm{p} . \mathrm{m}$. & 4,400 & 28.8 & Stage-discharge relation. \\
\hline 124 & $\begin{array}{l}\text { Mascoma River at Plent no. 2, Graxite State Gas \& } \\
\text { Electrio Co. dam, at West Lebanon, I. H. }\end{array}$ & 193 & $\cdots$ & March 1936 & 6,600 & 34.2 & 22 & - & 5,240 & 27.2 & Dam. \\
\hline 125 & Ottauqueohee River above Bridgewater, vt. & 99.7 & - & -- & $\cdots$ & - & 21 & - & 18,100 & 182 & slope area. \\
\hline 126 & Ottauquechee River at Trfitsville, vt. & 190 & - & November 1927 & 25,400 & 134 & 21 & - & 24,400 & 128 & Dam. \\
\hline 127 & Ottauquechee River at Deweys Mills, Vt. & 208 & - & November 1927 & 27,200 & 131 & 21 & -- & 23,200 & 112 & Do. \\
\hline 128 & Ottauquechee River at North Fartland, Vt. & 221 & $1930-1938$ & November 1927 & 30,400 & 138 & 21 & $11: 45$ p.m. & 24,400 & 110 & Stage-discharge relation. \\
\hline 129 & Sugar R1vor at Wost Claremont, N. H. & 269 & $1928-1938$ & Kar. 19, 1936 & 14,000 & 52.0 & 21 & $8: 30$ p.m. & 13,100 & 48.7 & Do. \\
\hline 130 & Black Rivar at Slate vill dam, at Perkinsville, vt. & 116 & - & Waroh 1936 & 10,900 & 94.0 & - & - & 13,400 & 116 & Dam. \\
\hline 131 & Black River at North Springfield, Vt. & 158 & $1930-1938$ & Har. 18, 1936 & 14,700 & 93.0 & 22 & $12: 30 \mathrm{a.m}$ & 15,500 & 98.1 & Stage-discharge relation. \\
\hline 132 & $\begin{array}{l}\text { Blaok River at Lorojoy Tool Co. dam, at Springfield, } \\
\text { Vt. }\end{array}$ & 191 & -- & -- & $-\infty$ & -- & 22 & - & 16,800 & 88.0 & Dam. \\
\hline 133 & Great Brook above North Springfield, vt. & 11.3 & -- & Warch 1936 & 1,110 & 98.2 & 21 & 10 p.m. & 2,450 & 217 & Contracted opening. \\
\hline 134 & williams River above Chester, Vt. & 23.5 & - & -- & $\cdots$ & -- & 21 & -- & 8,690 & $\$ 70$ & $\begin{array}{l}\text { Slope area and contreoted } \\
\text { opening. }\end{array}$ \\
\hline 135 & Middle Branch of Williams River above Simonsville, Jt. & 3.4 & - & -- & -- &.-- & 21 & $\begin{array}{l}\text { Between } 5 \text { and } 8 \\
\text { p.m. }\end{array}$ & 3,050 & 897 & slope area. \\
\hline 136 & Middle Branch of Williams River above Chester, vt. & 27.4 & -- & - & -- & $\cdots$ & 21 & - & 12,200 & 445 & Contracted opening. \\
\hline
\end{tabular}




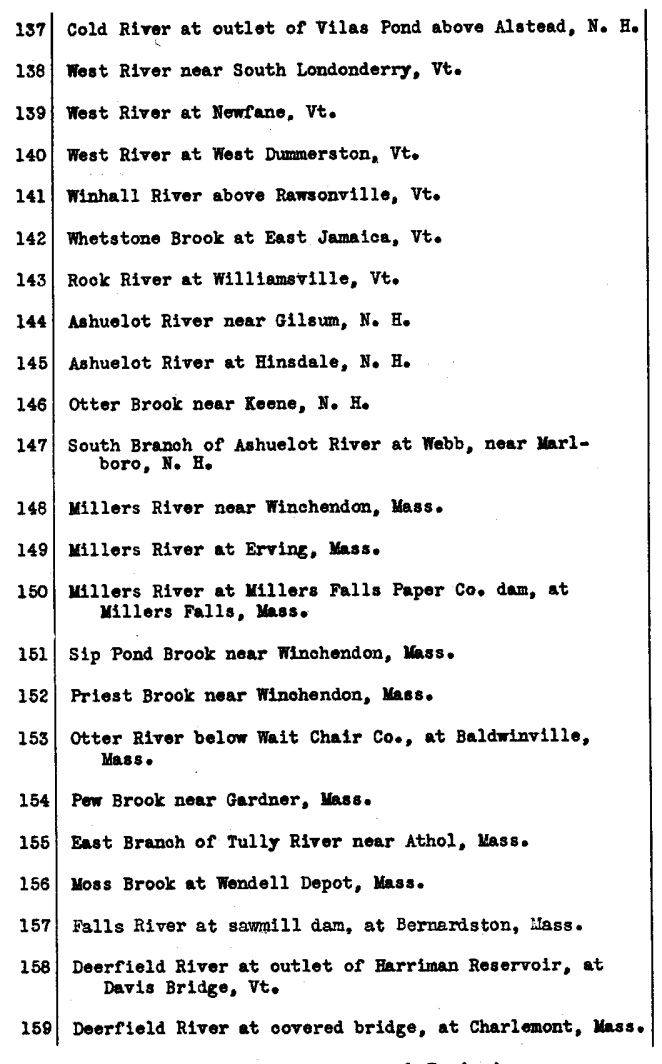

$b$ Revised.

\begin{tabular}{|c|c|c|c|c|c|c|}
\hline 60.3 & - & 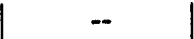 & - & -- & 21 & - \\
\hline 89.5 & - & -- & - & $\cdots$ & 21 & \\
\hline 308 & $1919-1938$ & Nov. 3, 1927 & 45,000 & 146 & 21 & 11 posm. \\
\hline 410 & $\cdots$ & November 1927 & 54,000 & 132 & 21 & $10-11$ p.m \\
\hline 32.0 & -- & -- & -- & - & 21 & $6 \mathrm{p} \cdot \mathrm{m}$. \\
\hline 36.2 & - & - & -- & - & 21 & - \\
\hline 42.6 & -- & -- & -- & - & 21 & . \\
\hline 71.1 & $1922-1938$ & Mar. $18,19,1936$ & 4,400 & 61.9 & 21 & $6 \mathrm{p} \cdot \mathrm{m}$ \\
\hline 420 & $1907-1938$ & Nar. 29, 1920 & 18,000 & 42.9 & 22 & 12 p.m. \\
\hline 41.8 & $1923-1938$ & Whar. 18, 1936 & 3,580 & 85.6 & 21 & 1 p.m. \\
\hline 36.6 & $1920-1938$ & Mar. 18, 1936 & 3,880 & 106 & 21 & $10,15 \mathrm{a} . \mathrm{m}$ \\
\hline 83.8 & $1916-1938$ & Mar. 19, 1936 & 5,530 & 66.0 & 22 & 2 a.mo \\
\hline 370 & $1914-1938$ & Yar. 19, 1936 & 19,700 & 63.2 & 22 & 8 a.m. \\
\hline 386 & -- & March 1936 & 20,100 & 52.1 & 22 & - \\
\hline 19,0 & $1916-1938$ & Mar. 18, 19, 1936 & 1,430 & 75.3 & 21 & 10 a.m. \\
\hline 18.8 & $1916-1938$ & Mar. 18, 1936 & 1,840 & 97.9 & 21 & Hoon. \\
\hline 43.6 & $\cdots$ & March 1936 & 2,880 & 66.1 & 21 & - \\
\hline 8.9 & -- & - & - & -- & 21 & - \\
\hline 49.9 & $1916-1938$ & Mar. 18, 19, 1936 & 3,700 & 74.1 & 21 & 4 p.m. \\
\hline 12.2 & $1916-1938$ & Mar. 19, 1936 & b1, 540 & b126 & 21 & $5 \mathrm{p} \cdot \mathrm{m} \bullet$ \\
\hline 27.3 & $\cdots$ & - & -- & - & 21 & - \\
\hline $\operatorname{ml} 54$ & -- & Nov. 4,1927 & e30,800 & c200 & 21 & - \\
\hline n159 & -- & - & -- & - & 21 & - \\
\hline
\end{tabular}

- Adfusted for B torage.

m Exelusive of drainage area above Somorwet Reservoir.

\begin{tabular}{|c|c|c|}
\hline 5,300 & 87.9 & Dam. \\
\hline 25,200 & 282 & slope area. \\
\hline 52,300 & 170 & Stago-disoharge reletion. \\
\hline 65,000 & 159 & Dam. \\
\hline 10,400 & 325 & slope aree. \\
\hline 15,500 & 428 & Do. \\
\hline 27,200 & 638 & Do. \\
\hline 5,220 & 73.4 & Stage-discharge relation. \\
\hline 16,200 & 38.6 & Do. \\
\hline 6,130 & 147 & Do. \\
\hline 5,960 & 263 & Do. \\
\hline 8,500 & 101 & Do. \\
\hline 29,000 & 78.4 & Do. \\
\hline 32,100 & 83.2 & Dam. \\
\hline 2,630 & 138 & Stage-disoharge relation. \\
\hline 3,000 & 160 & Do. \\
\hline 11,600 & 266 & slope area. \\
\hline 1,280 & 144 & Contracted opening. \\
\hline 5,140 & 103 & Stage-discharge relation. \\
\hline 1,070 & 87.7 & Do. \\
\hline 2,550 & 93.4 & Dam. \\
\hline 044,400 & 0288 & Rate of storage. \\
\hline$n 56,000$ & n352 & Contreoted opening. \\
\hline
\end{tabular}

n Exclusive of drainage area above Harriman Reservoir. 
Table 10.--Sumnery of flood discharges--Cont inued

\begin{tabular}{|c|c|c|c|c|c|c|c|c|c|c|c|}
\hline \multirow{2}{*}{$\begin{array}{l}\text { Ho. } \\
\text { on } \\
\text { N. }_{11} \\
11\end{array}$} & \multirow{2}{*}{ Stream and place of determination } & \multirow[b]{2}{*}{$\left|\begin{array}{l}\text { Drainage } \\
\text { area } \\
\text { (sq. mi.) }\end{array}\right|$} & \multirow[b]{2}{*}{$\begin{array}{l}\text { Period } \\
\text { of } \\
\text { reoord }\end{array}$} & \multicolumn{3}{|c|}{$\begin{array}{l}\text { Waximum disoharge } \\
\text { previously imown }\end{array}$} & \multicolumn{5}{|c|}{ Maximum discharge during floods of September 1938} \\
\hline & & & & Date & $\begin{array}{c}\text { Second- } \\
\text { feet }\end{array}$ & $\mid \begin{array}{c}\text { seo.-ft. } \\
\text { per } \\
\text { sq. mi. }\end{array}$ & Day & Hour & $\begin{array}{c}\text { Seaond- } \\
\text { foet }\end{array}$ & $\begin{array}{c}\text { Soc.-ft. } \\
\text { per } \\
\text { sq. mi. }\end{array}$ & Method of determination \\
\hline & Comneotiout River Besin--Continued & & & & & & & & & & \\
\hline 260 & Doerfield River at Charlemont, Mass. & nl78 & $1913-1938$ & July 8, 1915 & 38,200 & 0115 & 21 & $6: 45$ p.sn. & n56,300 & n316 & Stage-disoharge relation. \\
\hline 161 & $\begin{array}{l}\text { East Branch of Deorfield River at outlet of Somerset } \\
\text { Reservolr, near Somerset, vt. }\end{array}$ & 30.0 & - & Mar. 18, 1936 & 05,200 & 0173 & 21 & -- & 07,500 & c250 & Rate of storage. \\
\hline 162 & Pelham Brook at outlet of Pelham Lake, at Rowe, Wass. & 4.4 & -- & $\infty$ & -- & -- & 21 & $6: 30 \mathrm{p} . \mathrm{me}$ & 1,580 & 359 & Dam. \\
\hline 163 & Cold River above Black Brook, near Charlemont, Mass. & 23.4 & - & -- & - & -- & 21 & - & 24,600 & 624 & Slope area. \\
\hline 264 & Cold River below Blaok Brook, near Charlemont, Mass. & 30.1 & -- & -- & -- & - & 21 & -- & 16,900 & 561 & Do. \\
\hline 166 & Tannery Pond at C.C.C. dem, near Savoy, Mass. & 1.5 & -- & -- & -- & - & 21 & - & 725 & 483 & Dam. \\
\hline 166 & Chiokley R1ver noar West Hamloy, Mass. & 25.1 & - & -- & -- & -- & 21 & - & 17,800 & 709 & Slope area. \\
\hline 167 & $\begin{array}{l}\text { Unoamed tributary of Chiokley River near Wost Hawley, } \\
\text { Yhass. }\end{array}$ & 6.2 & - & - & -- & - & 21 & -- & 3,660 & 590 & Contracted opening. \\
\hline 168 & Will Brook at dem, near Charlemont, Mass. & 11.3 & -- & - & -- & - & 21 & 6 p.m. & 5,460 & 483 & Dam. \\
\hline 169 & Clark Brook near Shelburne Falls, Mass. & 2.9 & - & -- & -- & -- & 21 & $6: 20$ p.m. & 1,600 & 552 & Contracted opening. \\
\hline 170 & East Branch of Horth R1ver at Foundry Village, Mass. & 51.3 & - & Maroh 1936 & 8,640 & 168 & 21 & $6: 45 \mathrm{p} . \mathrm{m}$. & 19,800 & 386 & Dem. \\
\hline 171 & $\begin{array}{l}\text { Wost Branoh of Horth River at Hillman Bridge, near } \\
\text { Ademsvillo, Mass. }\end{array}$ & 19.8 & -- & -- & -- & -- & 21 & $6: 30 \mathrm{p.m}$ & 7,200 & 364 & Contracted opening. \\
\hline 172 & $\begin{array}{l}\text { Groen River at Greonfield Water Supply dam, near Green- } \\
\text { fiold, Yass. }\end{array}$ & 51.8 & - & -- & -- & - & 21 & - & 13,400 & 259 & Dam. \\
\hline 178. & $\begin{array}{l}\text { Olon Brook at Greenfield Water Supply upper dam, noar } \\
\text { Greenfiold, Hass. }\end{array}$ & 5.2 & - & $-\infty$ & -- & - & 21 & - & 1,800 & 346 & Do. \\
\hline 174 & Mill Brook at W.P.A. dem, at Greonfield, Mass. & 11.2 & -- & -- & - & - & 21 & -- & 1,090 & 97.3 & Do. \\
\hline 175 & $\begin{array}{l}\text { Cranberry Pond at out let, in Mount Toby Forest, } \\
\text { near Montague, Lass. }\end{array}$ & 2.4 & - & -- & - & -- & 21 & - & 300 & 125 & Do. \\
\hline 176 & Puffor Pond at Horth Amhorst, Mass. & 16.1 & - & - & - & - & 21 & - & 1,230 & 76.4 & Do. \\
\hline
\end{tabular}




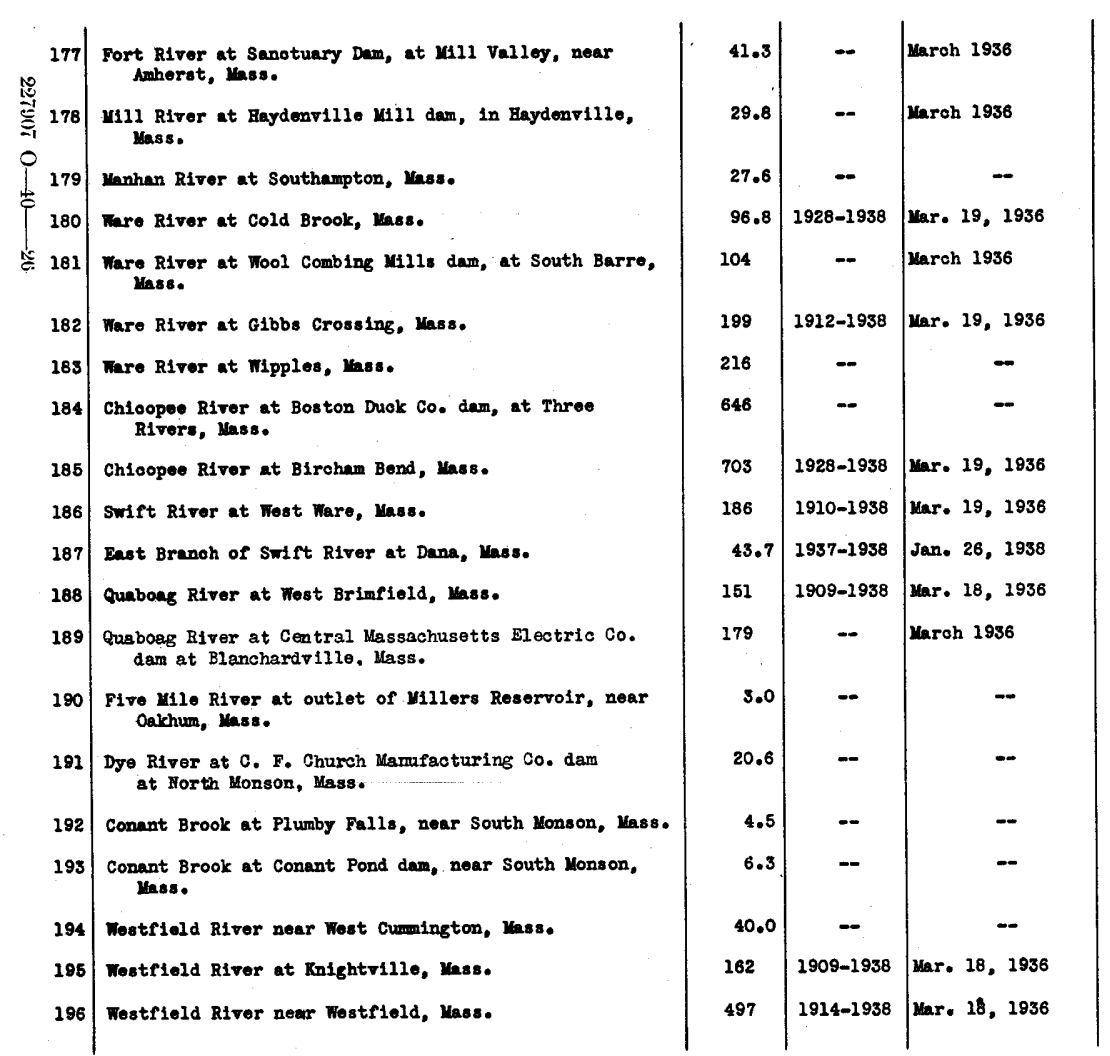

- Adjusted for storage.

\begin{tabular}{|c|c|c|c|c|c|c|}
\hline 2,360 & 57.1 & - & -- & 1,640 & 39.7 & Dam. \\
\hline 4,130 & 139 & 21 & $-\infty$ & 7,330 & 246 & Do. \\
\hline-- & $\cdots$ & 21 & $6: 30$ p.m. & 2,870 & 104 & Do. \\
\hline 5,990 & 61.9 & 21 & $10: 15$ a.m. & 14,000 & 145 & Stage-discharge relation. \\
\hline 6,220 & 59.8 & 21 & -- & 13,800 & 133 & Dam. \\
\hline 11,200 & 56.3 & 21 & $12 \mathrm{~m}$. & 22,700 & 114 & Stage-discharge relation. \\
\hline- & - & - & - & 23,100 & 107 & Slope area. \\
\hline-- & -- & 22 & $2 a \cdot m$ & 40,400 & 62.5 & Dam. \\
\hline 20,400 & 29.0 & 21 & - & 45,200 & 64.3 & Stage-dis charge relation. \\
\hline 7.590 & 40.8 & 22 & 11 a.m. & 5,540 & 29.8 & Do. \\
\hline 900 & 20.6 & 21 & $12: 45$ p•m. & 6,780 & 155 & Do. \\
\hline 3,620 & 24.0 & 21 & 7 p.m• & 8,470 & 56.1 & Do. \\
\hline 4,120 & 23.0 & 21 & $7 \mathrm{p} \cdot \mathrm{m} \bullet$ & 12,800 & 71.5 & Dam. \\
\hline-- & - & -- & - & 259 & 86.3 & Do. \\
\hline- & - & 21 & - & 2,440 & 118 & Do. \\
\hline-- & - & -- & - & 1,560 & 347 & Falls. \\
\hline 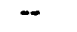 & -- & - & - & 1,230 & 195 & Dam. \\
\hline- & - & 21 & -- & 15,700 & 392 & slope area. \\
\hline 25,700 & 159 & 21 & 9 p.m. & 37,900 & 234 & Stage-discharge relation. \\
\hline 48,200 & 97.0 & $\begin{array}{c}21 \\
022\end{array}$ & $\begin{array}{l}12 \text { p.m. } \\
1 \text { a.m. }\end{array}$ & 55,500 & 112 & Do. \\
\hline
\end{tabular}

o For 332 square miles of drainage area below Somerset Rieservotr. 
Pable 10.- Sumnary of flood discharges-Continued

\begin{tabular}{|c|c|c|c|c|c|c|c|c|c|c|c|}
\hline \multirow{2}{*}{$\begin{array}{l}\text { No. } \\
\text { on } \\
\text { p1. } \\
11\end{array}$} & \multirow[b]{2}{*}{ Stream and place of determination } & \multirow{2}{*}{$\begin{array}{c}\text { Drainage } \\
\text { area } \\
\text { (sq. mi. })\end{array}$} & \multirow[b]{2}{*}{$\begin{array}{l}\text { Perlod } \\
\text { of } \\
\text { record }\end{array}$} & \multicolumn{3}{|c|}{$\begin{array}{l}\text { Yaximum discharge } \\
\text { previously knowa }\end{array}$} & \multicolumn{5}{|c|}{ Maximum discharge during floods of September 1938} \\
\hline & & & & Date & $\begin{array}{c}\text { Seoond- } \\
\text { feot }\end{array}$ & $\mid \begin{array}{c}\text { sec.-ft. } \\
\text { per } \\
\text { sq. mi. }\end{array}$ & Day & Hour & $\begin{array}{c}\text { Second- } \\
\text { feet }\end{array}$ & $\begin{array}{c}\text { Sec.-ft. } \\
\text { per } \\
\text { sq. mit. }\end{array}$ & Method of determination \\
\hline & Conneotiout River Basin--Continued & & & & & & & & & & \\
\hline 197 & $\begin{array}{l}\text { Westrield River at Strathmore Paper Co. dam, at West } \\
\text { Springfield, Kass. }\end{array}$ & 513 & - & Warch 1936 & 49,800 & 97.1 & 22 & -- & 55,000 & 107 & Dam. \\
\hline 198 & Pond Brook at Horwtoh, Yass. & 2.6 & - & -- & -- & -- & 21 & -- & 875 & 337 & Contracted opening. \\
\hline 199 & Middlo Branch of Westrield River at Goss Heights, Mass. & 52.6 & $1910-1938$ & Dar. 18, 1936 & 8,400 & 160 & 21 & 6,30 p.m. & 19,900 & 378 & Stage-discharge relation. \\
\hline 200 & West Branoh of Wostrield River at Huntington, Lass. & 93.7 & $1935-1938$ & Mar. 18, 1936 & 14,400 & 154 & 21 & 7 p.m. & 21,800 & 233 & Do. \\
\hline 201 & $\begin{array}{l}\text { Westfield Little River at outlet of Cobble Mountain } \\
\text { Reservolr, near Wostfield, Mass. }\end{array}$ & 45.8 & $1905-1938$ & Hov. 3, 1927 & 6,100 & 133 & 21 & - & $d 4,760$ & - & Do. \\
\hline 202 & Scantio River at Somersvilie, Conn. & 62.8 & -- & -- & - & -- & 21 & $\begin{array}{l}11: 30 \text { a.m. to } \\
2: 30 \text { p.m. }\end{array}$ & 4.500 & 71.7 & Dam. \\
\hline 203 & Soantic River at Soitico, Conn. & 66.3 & -- & -- & - & -- & 22 & 9:30 to 10 a.m. & 11,000 & 166 & Do. \\
\hline 204 & Soantio River at Broad Brook, Conn. & 98.4 & $1928-1938$ & Mar. 13, 1936 & b1,820 & 18.5 & 21 & $2: 30 \mathrm{p} \bullet \mathrm{m}$ & 7,360 & 74.8 & Stage-discharge relation. \\
\hline 205 & Broad Brook at Brond Brook, Conn. & 14.0 & -- & - & -- & - & -- & - & 900 & 64.3 i & Dam. \\
\hline 206 & Farmington River near Yow Boston, Mass. & 92.0 & $1913-1938$ & Kar. 18, 1936 & 9,080 & 98.7 & 21 & 6 p.m. & p18,500 & 201 & Stage-disoharge relation. \\
\hline 207 & Parmington River at Riverton, Conn. & 216 & 1929-1938 & Mar. 18,1936 & 19,900 & 92.1 & 21 & $6,30 \mathrm{p} \cdot \mathrm{m}$. & 37,100 & 172 & Do. \\
\hline 208 & Farnington River at Collinsville, Conn. & 354 & -- & Kar. 18, 1936 & 21,000 & 59.3 & 21 & 10 p.m. & $q 54,000$ & 153 & Dam. \\
\hline 209 & Farmington River at Tariffville, Conn. & 578 & $1928-1938$ & Mar. 19, 1936 & $\mathrm{~b} 26,900$ & 46.5 & 22 & 3 to 4 p.m. & 29,900 & 51.7 & Stage-discharge relation. \\
\hline 210 & $\begin{array}{l}\text { Farmington River at dam of Hartford Electric Light } \\
\text { Co. at Tariffille, Conn. }\end{array}$ & 578 & -- & Mar. 19, 1936 & 22,000 & 38.1 & 22 & 3 to 4 p.m. & 29,800 & 51.6 & Dam. \\
\hline 211 & Farmington River at Rainbow, Conn. $[$ / & 590 & -- & Lar. 19, 1936 & 26,600 & 45.1 & 22 & 1 p.m. & 25,500 & 43.2 & Do. \\
\hline 212 & Still River at Winsted, Conn. & 42.6 & -- & Kareh 1936 & 3,060 & 71.8 . & 21 & evening & 3,700 & 86.9 & Do. \\
\hline 213 & Burlington Brook near Burlington, Conn. & 4.1 & $1931-1938$ & Lar. 12, 1936 & 503 & 123 & 21 & $6: 30 \mathrm{p} \cdot \mathrm{m}$ & 645 & 157 & Stage-dis charge relation. \\
\hline 214 & South Branoh of Park River at Hartford, Conn. & 40.6 & $1936-1938$ & Jan. 25, 1938 & 2,860 & 70.4 & 21 & $10 \mathrm{p} . \mathrm{me}$ & 3,600 & 88.7 & Do. \\
\hline 215 & Park River at Hartford, Conn. & 74.0 & $1936-1938$ & Jan. 25,1938 & 5,650 & 76.4 & 21 & $3: 15$ p.m. & 5,320 & 71.9 & Do. \\
\hline
\end{tabular}


216 North Branch of Park River at Hartford, conn.

217 Hookanum River at outlet of Shenipsit Lake, at Rookvillo, conn.

218 Hookanum River near East Hartford, Conn.

219 Hockanum Kiver near East Hartford, Conn.

220 Hockanum River near Fast Hartford, Oonn.

221 Tancanhoosen River at Vernon, conn.

222 Roaring Brook near Buckingham, Conn.

223 Cold Brook near East Glastonbury, Corn.

224 Portland Reservoir outlet near Portland, Conn.

225 Great Hill Pond Brook near Portlend, Conn.

226 Hine Brook at Middle Haddam, Conn.

227 Salmon River at tyman Viaduct, Conn.

228 Salmon River near Bast Hampton, Conn.

\section{Quinnipiec River Basin}

229 Quinnipiac River at Fallingford, Conn.

230 2uinnipiac River at Wallingford, Conn.

\section{Housatonio River Basin}

231 Housatonic River at Byron Weston Co. dam, at Dalton, Mass.

232 Housatonic River at Pioneer Mill dam, at Dalton, Mass.

233 Housatonic River at Coltsville, Mass.

234 Housatonio River at Monument Mill dom, at Glendale, vass.

235 Housatonic River near Great Barrington, Mass.

$$
\text { b Revlsed. }
$$

d Hoan daily dischareg ad fas ted for storage.

\begin{tabular}{|c|c|c|c|c|c|c|}
\hline 25.3 & $1936-1938$ & Jan. 25,1938 & 1,640 & 64.8 & 21 & 10 p.m. \\
\hline 16.5 & - & - & - & $\cdots$ & 21 & 5.30 p.m. \\
\hline 74.5 & - & - & -- & -- & 21 & 2 p.m. \\
\hline 74.5 & $\begin{array}{l}1919-1921 \\
1928-1938\end{array}$ & Jan. 25,1938 & 2,140 & 23.7 & 21 & 2 p.m. \\
\hline 75.3 & -- & - & $\cdots$ & -- & 21 & - \\
\hline 21.4 & - & - & - & - & - & - \\
\hline 4.7 & $m$ & - & - & $\cdots$ & - & -- \\
\hline 6.2 & -- & -- & $\cdots$ & - & - & - \\
\hline 3.4 & - & - & - & - & - & 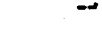 \\
\hline 81.3 & - & -- & -- & - & -- & - \\
\hline 1.6 & - & - & - & $-\infty$ & -- & -- \\
\hline 105 & - & -- & -- & - & 21 & - \\
\hline 105 & $\begin{array}{l}1905-1906 \\
1928-1938\end{array}$ & Mar. 12, 1936 & 6,250 & 59.5 & 21 & 8 a.m. \\
\hline 107 & - & - & - & - & 21 & - \\
\hline 109 & $1930-1938$ & War. 12, 1936 & 68,240 & 29.7 & 21 & 9 p.m. \\
\hline 55.1 & 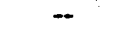 & Har. 18, 1936 & 4,650 & 84.4 & 21 & - \\
\hline 55.5 & - & - & $\cdots$ & - & 21 & -- \\
\hline 57.1 & $1936-1938$ & Lar. 18, 1936 & $b 6,000$ & 105 & 21 & $8: 30$ p.m. \\
\hline 276 & -- & March 1936 & 8,710 & 31.6 & 22 & $\cdots$ \\
\hline 280 & $1913-1938$ & Nar. 19, 1936 & 8,990 & 32.1 & 22 & 2 p.m. \\
\hline
\end{tabular}

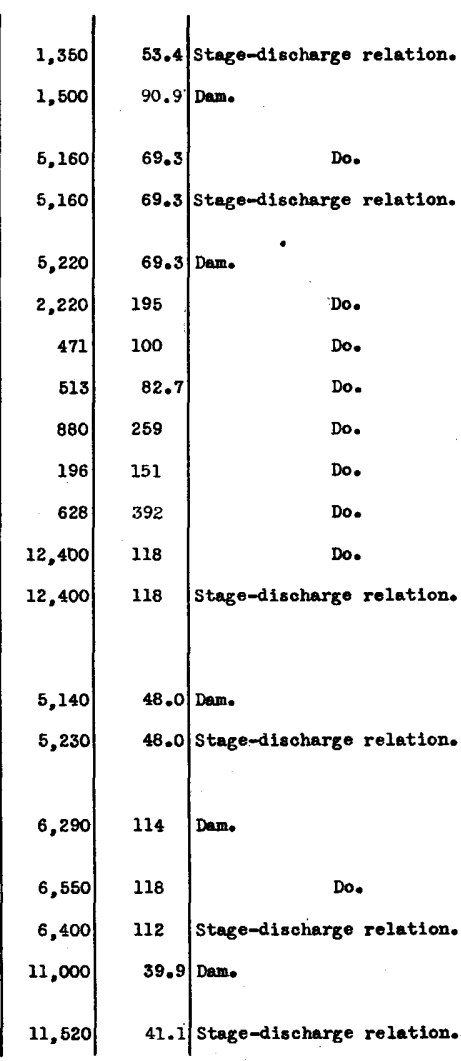


Table 10. - Sumnary of flood discharges--Continued

\begin{tabular}{|c|c|c|c|c|c|c|c|c|c|c|c|}
\hline \multirow{2}{*}{$\begin{array}{l}\text { No. } \\
\text { on } \\
\text { pl } \\
11\end{array}$} & \multirow[b]{2}{*}{ Stream and plaoe of determination } & \multirow{2}{*}{$\begin{array}{c}\text { Drainage } \\
\text { area } \\
\text { (8q. m1. }\end{array}$} & \multirow{2}{*}{$\begin{array}{l}\text { Pertod } \\
\text { of } \\
\text { record }\end{array}$} & \multicolumn{3}{|c|}{$\begin{array}{l}\text { Maximum dis charge } \\
\text { previously known }\end{array}$} & \multicolumn{5}{|c|}{ Maximum discharge during floods of September 1938} \\
\hline & & & & Date & $\begin{array}{c}\text { Seoond- } \\
\text { reet }\end{array}$ & $\begin{array}{c}\text { seo.-ft. } \\
\text { per } \\
\text { sq. mi. mi. }\end{array}$ & Day & Hour & $\begin{array}{c}\text { Second- } \\
\text { feet }\end{array}$ & $\begin{array}{c}\text { sec.-ft. } \\
\text { per } \\
\text { sq. mi. }\end{array}$ & Method of determination \\
\hline & Bousatonio River Basin--Continued & & & & & & & & & & \\
\hline 236 & $\begin{array}{l}\text { Housatonic River at South Berkshire Paver \& Electric } \\
\text { Co. dam at Great Barring ton, ilass. }\end{array}$ & 333 & -- & Mar. 19, 1936 & 9,600 & 28.8 & 22 & -- & 11,700 & 35.1 & Dare. \\
\hline 237 & Housatonfo River at Falls Village, Conn. & 632 & $1912-1958$ & War. 20, 1936 & 14,500 & 22.9 & 23 & 2 to $6 \mathrm{a.m}$ & 19,900 & 31.5 & Stage-discharge relation. \\
\hline 238 & Bousatonic River at Bulls Bridge, Conn. $t$ / & 782 & -- & - & -- & - & 22 & 8 a.m. & 24,000 & 30.7 & Dam. \\
\hline 239 & Housatonic River at Stevenson, Conn. $t$ / & 1,544 & - & Mar. 12, 1936 & 69,400 & 44.9 & 22 & I a.m. & 60,000 & 38.9 & Do. \\
\hline 240 & Housatonio River at Stevenson, Conn. & 1,545 & $1928-1958$ & Mar. 12, 1936 & 69,500 & 45.0 & to 22 & 12 p.me & 59,500 & 38.5 & Stage-disoharge relation. \\
\hline 241 & Housatonio River at Derby, Conn. & 1,581 & -- & Kar. 12, 1936 & 69,600 & 44.0 & to 22 & 12 p.m. & 58,100 & 36.7 & Dam. \\
\hline 242 & Bast Branoh of Housatonic River near Windsor, Mass. & 3.6 & $-\cdot$ & -- & -- & - & 21 & -- & 1,290 & 358 & Contracted opening. \\
\hline 243 & Tementle River near Gaylordsville, Conn. & 204 & $1929-1938$ & Mar. 12, 1936 & 10,200 & 50.0 & 22 & 4 to 5 a.m. & 12,500 & 61.3 & Stage-discharge relation. \\
\hline 244 & St111 River near Lanesville, Conn. & 68.5 & $1931-1938$ & Mar. 12, 1936 & b3,930 & 57.4 & 22 & 8 a.me. & 4,410 & 64.4 & Do. \\
\hline 245 & Shopaug River at Woodville, Conn. $y /$ & 38.0 & $1935-1938$ & Mar. 12, 1936 & 4,070 & 107 & 21 & 7 p.m. & 6,000 & 158 & Dam. \\
\hline 246 & Shopaug River at Roxbury Station, Conn. & 132 & - & March 2936 & $\nabla 8,440$ & 63.9 & 21 & -- & $w 11,800$ & 89.4 & Do. \\
\hline 247 & Shopaug River near Roxbury, Conn. & 133 & $1930-1938$ & Mar. 12, 1936 & 7,000 & 52.6 & 21 & 7 p.m. & 10,500 & 78.9 & Stage-disoharge relation. \\
\hline 248 & Pomperaug River at Southbury, Comn. & 75.3 & $1932-1938$ & Mar. 12, 1936 & $b 5,990$ & 79.5 & 21 & $9 \mathrm{p} \cdot \mathrm{m}$ & 7,420 & 98.5 & Do. \\
\hline 249 & Pomperaug River at South Britain, Conn. & 87.4 & - & march 1936 & 6,720 & 76.8 & - & -- & 7,950 & 91.0 & Dam. \\
\hline 250 & Naugatuok River near Thomaston, Conn. & 73.9 & $1930-1938$ & Jan. 25, 1938 & 6,830 & 95.0 & 21 & $9: 40$ p.m. & 9,970 & 139 & Stage-disoharge relation. \\
\hline 251 & Naugatuok RIver near Naugatuok, conn. & 246 & $\begin{array}{l}1918-1924 \\
1928-1938\end{array}$ & November 1927 & 18,300 & 74.4 & 21 & $10 \mathrm{p} . \mathrm{m}$. & 17,000 & 69.1 & Do. \\
\hline 252 & Leadmine Brook near Thomaston, Conn. & 24.0 & $1930-1938$ & Sept. 17, 1934 & 2,800 & 117 & 21 & $6: 30 \mathrm{pem}$ & 3.050 & 127 & Do. \\
\hline 253 & Branch of Neugatuck Rlver near Thomaston, Conn. $\underline{y}$ & 18.0 & - & Mar. 12,1936 & 2,700 & 150 & 21 & $6 \mathrm{p} \cdot \mathrm{m} \cdot \underline{x}$ & $\times 3,610$ & $\times 201$ & Dam. \\
\hline
\end{tabular}




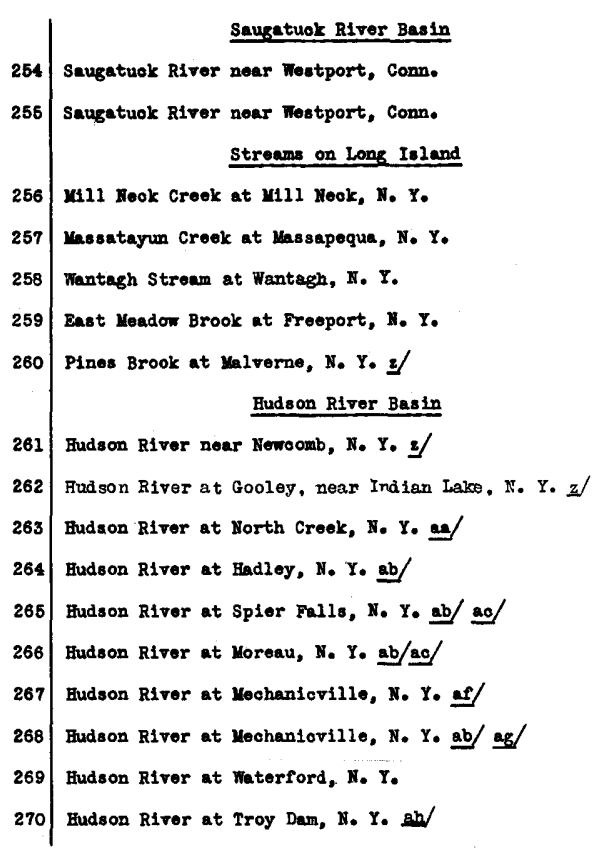

b Rerlsed.

$t$ Reoords furnished by conneotiout Light \& Power co.

u Rocords furnished by Bureau or thy ineering, city of Waterbury, Conn.

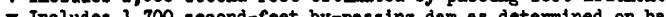

Ther orossrlot been oompleted st the time of peak stage at the dam, thus 1,700 secondfoet of overflow may be as muoh as 10 percent too large.

$\times$ Obsorved $\max i \operatorname{mmm}$

y Approximates offective drainage basin not well defined.

\begin{tabular}{|c|c|c|c|c|c|c|}
\hline-- & - & - & -- & 3,850 & 58.9 & Dam. \\
\hline 5,310 & 68.5 & 21 & 12 pom. & 4,420 & 57.0 & Stage-discharge relation. \\
\hline 49 & 4.9 & 21 & 4:45 p.m. & 86 & 8.6 & Do. \\
\hline 64 & 1.7 & 21 & $3 ; 20$ p.m. & 90 & 2.4 & Do. \\
\hline 55 & 3.2 & 21 & $9: 20$ a.m. & 74 & 4.4 & Do. \\
\hline 92 & 3.0 & 21 & 3 p.m. & 149 & 4.8 & Do. \\
\hline 37 & 3.7 & 21 & 4:50 p.m. & 74 & 7.4 & Do. \\
\hline 6,250 & 32.6 & 22 & 11 p.m. & 4,970 & 25.9 & Do. \\
\hline 13,900 & 33.2 & 22 & 10 a.m. & 9,980 & 23.8 & Do. \\
\hline 27,400 & 34.6 & 22 & 10 a.m. & 16,700 & 21.1 & Do. \\
\hline 41,200 & 24.8 & 22 & 11 a.m. & 23,200 & 13.9 & Do. \\
\hline 89,100 & 32.1 & 22 & 11 a.m. & ad26,600 & 9.6 & Dam and through plant. \\
\hline -- & -- & 22 & 2 p.m. & ae306.4 & -- & -- \\
\hline ae15.8 & - & 22 & 8 a.m. & ne56.0 & -- & - \\
\hline 120,000 & 26.7 & 22 & 3 p.m. & 78,000 & 17.3 & Dam and through plant. \\
\hline-- & -- & 23 & 2 a.m. & a.e29.6 & -- & - \\
\hline- & -- & 22 & 7:30 p.m. & a127.1 & -- & -- \\
\hline
\end{tabular}

2 S1ight rogulation by omall reservoirs.

an Not adjusted for storage in Indian Lake and amall reservoirs. ab Affooted by storago.

ao Rocords furnishod by Now York Power \& Light Corporation.

ad Altitudo 436.8 feot.

af Records furnished by $\mathrm{J}$, S. Weather Buroau.

of Rooords furnished by host Virginia Pulp \& Paper co.

ah Records furnished by oorps of Rng ineers. U. S. Army. 
Table 10.--Summary of flood disoharges-Continued

\begin{tabular}{|c|c|c|c|c|c|c|c|c|c|c|c|}
\hline \multirow{2}{*}{$\begin{array}{l}\text { No. } \\
\text { on } \\
\text { pl. } \\
\text { II }\end{array}$} & \multirow[b]{2}{*}{ Stream and place of determination } & \multirow{2}{*}{$\begin{array}{l}\text { Drainage } \\
\text { area } \\
\text { (sq. m1.) }\end{array}$} & \multirow{2}{*}{$\begin{array}{l}\text { Period } \\
\text { of } \\
\text { record }\end{array}$} & \multicolumn{3}{|c|}{$\begin{array}{l}\text { Maximum disoharge } \\
\text { previously known }\end{array}$} & \multicolumn{5}{|c|}{ Maximum discharge during floods of September 1938} \\
\hline & & & & Date & $\begin{array}{c}\text { Second- } \\
\text { feet }\end{array}$ & $\begin{array}{c}\text { sec.-ft. } \\
\text { per } \\
\text { sq. mi. }\end{array}$ & Day & Hour & $\begin{array}{c}\text { Second- } \\
\text { feet }\end{array}$ & $\begin{array}{c}\text { sec.-ft. } \\
\text { per } \\
\text { sq. mi. }\end{array}$ & Method of determination \\
\hline & Hudson River Basin--Continued & & & & & & & & & & \\
\hline 271 & Hudson River at Albany, N. Y. af/ & 8,304 & $1903-1938$ & $\begin{array}{l}\text { Yar. } 28,1913 \\
\text { Feb. 9, } 1857\end{array}$ & $\begin{array}{l}2022.4 \\
2 \mathrm{e} 22.5\end{array}$ & -- & 22 & $6: 30 \mathrm{p} . \mathrm{m}$. & aj16.5 & - & -- \\
\hline 272 & $\begin{array}{l}\text { Cedar River below Chain Lakes, near Indian Lake, } \\
\text { I. Y. abj }\end{array}$ & 160 & $1930-1938$ & oot. 7, 1932 & 6,050 & 37.8 & 22 & $7 \mathrm{a} \cdot \mathrm{m}$. & 4,800 & 30.0 & Stage-discharge relation. \\
\hline 273 & Indian Lake Reservoir near Indian Lake, $\mathrm{X}_{0} \mathrm{Y}$. & 131 & $1900-1938$ & Mar. 28,2913 & ak38.8 & -- & 30 & $8 \mathrm{a.m.}$ & ak24.1 & -- & -- \\
\hline 274 & Indian Rivor near Indian Lake, N. Y. ab/ & 132 & $\begin{array}{r}1912-1914 \\
1915-1938\end{array}$ & Mar. 28, 1913 & 3,460 & 26.2 & 21 & $8: 30 \mathrm{p}, \mathrm{m}$. & 58 & - & Stage-discharge relation. \\
\hline 275 & The Branoh of Schroon River at Blue Ridge, N. Y. & 65 & -- & $1919-1925$ & ae868.6 & - & 21 & 8 p.me & 20868.0 & -- & - \\
\hline 276 & Schroon River at Riverbank, N. Y. & 527 & $1907-1938$ & Mar. 21, 1936 & 12,100 & 23.0 & 24 & I a.m. & 3,850 & 7.3 & Stage-disoharge relation. \\
\hline 277 & East Branch of Sacandaga River at Griffin, W. Y. & 114 & $1933-1937$ & Mar. 18, 1936 & 8,830 & 77.5 & 21 & $12 \mathrm{p} \cdot \mathrm{m}$ & 6,400 & 56.1 & Do. \\
\hline 278 & Sacandaga River near Hope, N. Y. & 491 & $1911-1938$ & lar. 27, 1913 & 32,000 & 65.2 & 22 & 1 a.m. & 16,200 & 33.0 & Do. \\
\hline 279 & Sacandaga Reservolr at Conkl ingtille, N. Y. & 1,044 & $1930-1938$ & July 11,1935 & 20769.34 & - & 25 & 8 p.m. & ae759.3 & -- & - \\
\hline 280 & Sacandaga River at Conklingrille, H. Yo ab/ & 1,044 & $1932-1938$ & Uay 16,1937 & 7,800 & 7.5 & 23 & 9 a.m. & 5,040 & 4.8 & Stage-discharge relation. \\
\hline 281 & Wost Stony Creek near Northville, H. X. & 88 & $1933-1937$ & Mar. 18,1936 & 8,470 & 96.2 & - & -- & 8,680 & 98.6 & Do. \\
\hline 282 & Glens Falls foeder at Glens Falls, N. $Y_{*}$ & -- & $1927-1938$ & - & -- & - & - & -- & - & -- & -- \\
\hline 283 & Batton Kill at Arlington, vt. & 152 & $1928-1938$ & Kar. 18, 1936 & 11,100 & 73.0 & 21 & $9 \mathrm{p} \cdot \mathrm{m}$. & 8,430 & 55.5 & Stage-discharge relation. \\
\hline 284 & Batten Kill at Battenville, Y. Y. $_{\text {. }}$ & 394 & $1922-1938$ & Nov. 4, 1927 & 21,300 & 54.1 & 22 & 9 a.m. & 16,000 & 40.6 & Do. \\
\hline 285 & Batten K11l at loiddle Falls, N, Y. ao/ & 435 & $1927-1938$ & - & -- & $\cdots$ & 22 & 3 to 5 a.m. & ae101.2 & -- & - \\
\hline 286 & Kayaderosseras Creek near West Milton, $N_{\odot} Y_{0}$ & 90 & $1927-1938$ & Mar. 18,1936 & 3,590 & 39.9 & 21 & 12 p.m. & 1,700 & 18.9 & Stage-discharge relation. \\
\hline 287 & Hoos to River at Hoos io Lake outlet, at Cheshire, Uass. & 15.1 & - & Larch 1936 & 447 & 29.6 & 21 & - & 341 & 22.6 & Dam. \\
\hline 288 & Hoos 10 River at Adams, Kass. & 46.3 & $1931-1938$ & Lar. 18, 1936 & 3,670 & 79.3 & 21 & 5 p.m. & 5,080 & 110 & Stage-disoharge relation. \\
\hline 289 & Hoos 10 River near Eagle Bridge, Y. Y. ab/ & 510 & $\begin{array}{l}1910-1922 \\
1923-1938\end{array}$ & Nov. 4, 1927 & 29,800 & 58.4 & 22 & 2,45 a.m. & aim35,300 & 69.2 & Do. \\
\hline
\end{tabular}


290 Hoosio River at Jolmaonville, II. Y. ab/

291 Hoosio River at Sohaghticoke, H. Y. ab/ao/

292 Worth Branoh of Hoos 10 River near Stamford, Vt.

293 Horth Branoh of Hoosio Rivor at North Adams, Wass.

294 Birch Brook noar Williamstown, llass.

295 Walloomsac Riror noar Horth Bomnington, vt.

296 City Stroam at Sammill dam, at Woodford, Vt.

297 Paran Creek at Vormont Grevure Co, dan, at Horth Bonnington, Vt.

298 Delta Reservoir at Delta Dam, near Rome, $X_{0} Y_{0}$

299 Mohawik River below Delta Dam, near Romo, N. Y. ab/

300 Mohawk River near Little Falls, I. Y. ab/

301 Wohawk Rivor at Iribes Hill, N. Y. af/

302 Mohawk River at General Electric Co. pump house, Sohonootady, H. $Y$. 303 Wohawk River at Great Wostern Gateway, Schenectady,

304 Mohank River at Looomotive Works, Schonectady, Y. $Y$.

305 Mohank River at Rexford Bridge, No $Y_{0}$

306 Mohawk River at Vischer Ferry, N. Y.

307 Wohamk River at Crescent Dam, above Cohoss, M. Y.

308 Mohawk River at New York Power \& Light Corporation dam, near Cohoes, Wo Yo

\begin{tabular}{|c|c|c|}
\hline 604 & 1909-1938 & -- \\
\hline 635 & $1908-1938$ & |Nor. 4, 1927 \\
\hline 8.8 & - & -- \\
\hline 39.0 & $1931-1938$ & Novermber 1927 \\
\hline ap0.3 & -- & -- \\
\hline 111 & $1931-1938$ & Mar. 18, 1936 \\
\hline 2.8 & - & $-\infty$ \\
\hline 15.1 & -- & -- \\
\hline 145 & - & -- \\
\hline 150 & $1927-1938$ & Mar. 9, 1921 \\
\hline 1,348 & $1927-1938$ & Whar. 18, 1936 \\
\hline 3,131 & $1903-1938$ & Mar. 9, 1904 \\
\hline-- & - & - \\
\hline-- & - & - \\
\hline-- & -- & -- \\
\hline 3,375 & - & - \\
\hline 3,385 & - & - \\
\hline 3,453 & - & -- \\
\hline- & - & $\cdots$ \\
\hline
\end{tabular}

ab Affected by storege.

ac Records furnished by Hew York Power \& Light Corporation.

a. Altitude in foet.

af Records furnished by V. S. Weather Bureav.

aj Altitude in feet. Predioted high tide 3:30 p.m.1 low tide at 10:09 p.m.

al Observed gage height in feet.

\begin{tabular}{l|l|l|l}
-- & - & 22 & 6 a.m. \\
40,000 & 63.0 & 22 & 8 a.m. \\
-- & - & 21 & \multicolumn{2}{|c}{-} \\
9,980 & 256 & 21 & 7 p.m. \\
-- & - & -- & \multicolumn{2}{|c}{-} \\
6,600 & 59.5 & 21 & 8 p.m. \\
-- & -- & 21 & \multicolumn{2}{|c}{-} \\
-- & - & 21 & \\
-- & - & 26,28 & \\
4,210 & 28.1 & 26 & 10.30 a.m. \\
23,200 & 17.2 & 22 & $12: 45$ a.m. \\
ar30.0 & -- & 22 & 8 a.m. \\
-- & -- & 22 & 8 p.m. \\
-- & -- & 22 & 4 p.m. \\
-- & -- & 22 & 6 p.m. \\
-- & -- & 22 & 4 to 8 p.m. \\
-- & -- & 22 & 4 p.m. \\
-- & - & 22 & 9 to 10 p.m. \\
-- & - & 22 & 11 p.m. \\
& & &
\end{tabular}

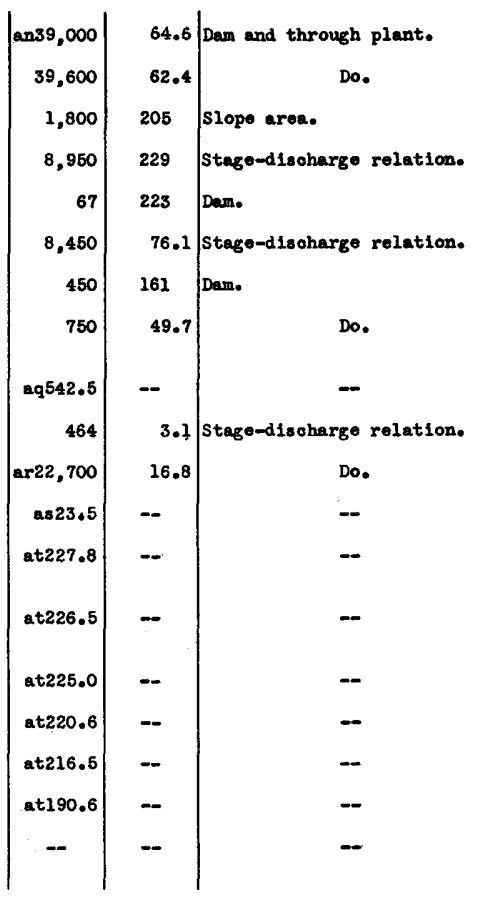

an From basio data furnished by New York Power \& Light Corporation. ap Furnished by U. S. Forest Service, Hopkins Memorial Forest.

aq Altitude in foet (Barge Conal datum); mean of two readings daily.

ar Diversions through Barge Canal not included.

as Gage height in feet; altitude of zero of gage is 255.0 feet.
at Altitude in feet (Barge Canal datum). 
Table 10.--Sumbary of Plood discharges-Contimued

\begin{tabular}{|c|c|c|c|c|c|c|c|c|c|c|c|}
\hline \multirow{2}{*}{$\begin{array}{l}\text { No. } \\
\text { on } \\
\text { p1. } \\
11\end{array}$} & \multirow[b]{2}{*}{ Stream and plaoe of determination } & \multirow{2}{*}{$\left|\begin{array}{l}\text { Drainage } \\
\text { aren } \\
\text { (sq. mi.) }\end{array}\right|$} & \multirow{2}{*}{$\begin{array}{l}\text { Perlod } \\
\text { of } \\
\text { rooord }\end{array}$} & \multicolumn{3}{|c|}{$\begin{array}{l}\text { Maximum dischargo } \\
\text { previously known }\end{array}$} & \multicolumn{5}{|c|}{ Maximum disoharge during floods of September 1938} \\
\hline & & & & Date & $\begin{array}{c}\text { Second- } \\
\text { foot }\end{array}$ & \begin{tabular}{|} 
Seo.-ft. \\
per \\
sq. mi.
\end{tabular} & Day & Bour & $\begin{array}{c}\text { Second- } \\
\text { feet }\end{array}$ & $\begin{array}{c}\text { Seo.-rt. } \\
\text { per } \\
\text { sq. mi. mi. }\end{array}$ & Wothod of dotermination \\
\hline & Budson River Basin--Continued & & & & & & & & & & \\
\hline 309 & Mohawik River at Cohoes, N. Y, ab/ & 3,456 & $1917-1938$ & Lar. 19, 1936 & 130,000 & 37.6 & 22 & 0,15 p.m. & 102,000 & 29.5 & Stage-discharge relation. \\
\hline 310 & Hinokloy Reservoir at Hinokloy Dam, Hinokley, Y. Y. & 373 & -- & -- & $\cdots$ & -- & 24 & -- & aul, 227.3 & -- & -- \\
\hline 311 & Wost Canada Croek at Binokley, H. $Y_{\odot}$ ab/ & $\mathbf{3 7 5}$ & $1919-1938$ & Apr. 12, 1922 & 10,800 & 28.8 & 23 & $\begin{array}{l}\text { 10:30 to } 11,30 \\
p \cdot m \cdot\end{array}$ & 5,190 & 13.8 & stage-discharge relation. \\
\hline \multirow[t]{2}{*}{312} & Wost Canada Croek at Kast Bridge, N. Y. ab/ & - & $\begin{array}{l}1905-1909 \\
1912-1913\end{array}$ & Lar. 26, 1913 & $=\mathbf{2 3}, 300$ & 41.9 & -- & - & -- & - & Do. \\
\hline & & 556 & $1920-1938$ & June 21, 1922 & 16,500 & 29.7 & 21 & $7: 45$ p.m. & 12,7000 & 22.8 & Do. \\
\hline 313 & Hinemile foeder near Hollend Patont, N. Y. & -- & -- & -- & -- & -- & - & - & 0 & - & -- \\
\hline 314 & East Canada Crook at Dolgeville, H. Y. $z$ / & 261 & $1927-1938$ & Lar. 26, 1913 & 14.500 & 55.6 & 22 & 12,45 2.m. & 9,920 & 38.0 & Stage-discharge relation. \\
\hline 315 & East Canada Crook at Inghams, N. Y. ab/ ao/ & 276 & $1912-1938$ & March 1913 & 17,500 & 63.4 & 22 & 2 to 3 a.m. & 12,800 & 46.4 & Dam and through plant. \\
\hline 316 & Bast Canada Creek at Beardslee, N. Y. ab/ac/ & 288 & 1924-1938 & March 1936 & 12,500 & 43.4 & to 21 & $\begin{array}{l}11 \text { p.m. } \\
3 \text { a.me }\end{array}$ & 12,700 & 44.1 & Do. \\
\hline 317 & Spyite Croek at Sprite Creek, H. Y. ab/ao/ & 41 & $1924-1938$ & 1926 & 1,510 & 36.8 & 22 & 9 a.m. & 1,256 & 30.6 & Do. \\
\hline 318 & Caroga Crook at Ephratah, N. Y. ab/ ao/ & 54 & $1911-1938$ & March 1936 & 1,870 & 34.6 & to 21 & $9 \begin{array}{l}9 \\
4 \\
4\end{array}$ & 1,170 & 21.7 & Do. \\
\hline 319 & Sohoharie Croek at Prattsville, N. Y. & 236 & $1902-1938$ & Nov. 16,1926 & 42,300 & 179 & 21 & $8 \mathrm{p} \cdot \mathrm{m}$. & 45,000 & 191 & Stage-disoharge relation. \\
\hline 320 & Sohohario Resarroir at Gilboa Dam at Gilboa, N, Y. & 314 & $1927-1938$ & Mar. 18, 1936 & $a \cdot 1,134,4$ & -- & 21 & $10: 40$ p.m. & $201,134.3$ & -- & - \\
\hline 321 & Sohoharie Creek at Gilboe Dam at Gilboa, N. Y. aw/ & 314 & $1927-1938$ & Mar. 18, 1936 & 32,000 & 102 & 21 & $10: 40$ p.m. & 31,300 & 99.7 & Stage-discharge relation. \\
\hline 322 & Sohohario Croek at Middleburg, N. Y. aw/ & 532 & $1927-1938$ & Kar. 18, 1936 & 47,800 & 89.8 & 22 & 2 a.m. & 40,600 & 76.3 & Do. \\
\hline 323 & Poosten X111 noar Troy, Y. Y. & 84 & - & - & - & - & 22 & $12: 30$ a.m. & 10,500 & 125 & slope area. \\
\hline 324 & Poosten Kill near Troy, X. Y. & 89 & $1923-1938$ & Nov. 4, 1927 & 7,030 & 79.0 & 22 & $12: 30$ a.m. & 11,900 & 134 & Stage-disoharge relation. \\
\hline 325 & Poeston IIll at Barl Wilson Dam at Troy, Y. Y. & 94 & -- & -- & -- & $\cdots$ & 22 & About 1 a.m. & 11,000 & 217 & Dam. \\
\hline 326 & Poesten Xill at Lower Dam at Troy, Y. Y. & 94 & - & -- & - & - & 22 & About 1 a.m. & 12,800 & 136 & Do. \\
\hline
\end{tabular}


327 Kinderhook Creak it Stuyvesant exl18, h. T. Be/

329 Kinderhook Creok at 'Rossman, N. Y.

331 Catskill Crook at Oak 피1, I. Y. 뜨/

332 Bsopus Crook at Coldbrook, H. Y. en/

333 Rondout Creek noar Lowes Corners, Y. Y.

334 Rondout Croek near Lackamack, W. Y.

335 Rondout Creok at Rosendale, M, Y.

336 Chostrut Croek above Red Brook, at Grahamsville, X. Y.

337 mallkill River near Unionville, 1. Y.

338 Wallkill River at Pellets Island Yountain, N. Y.

339 vallkill River near Phillipsburg, N. Y.

340 Wallkill River at Gardinor, N. Y.

341 Wallkill River at Newpaltz, N. Y:

342 Poohuck Creok at Hewport, near Pino Island, N. Y.

343 Quaker Creok at Florida, S. Y.

344 Shamengunk Iill at Pine Bush, N. Y.

346 Wappinger Crook at Rod Oak Bridge, X. Y.

346 mappinger croek near Wappinger Falls, N. Y.

347 Tappinger Creek at dam, at Wappinger Falls, $Y$. Y.

$\approx$ slight regulation by amall reservoirs.

ab Affeoted by storage.

a Records furnishod by Now York Power \& Light Corporation.

au Altitude in feet. in foet (Barge Canal datum).

\begin{tabular}{|c|c|c|}
\hline 325 & - & March 1936 \\
\hline 329 & $\begin{array}{l}1906-1914 \\
1928-1938\end{array}$ & Her. 12, 1936 \\
\hline 98 & 1910-1988 & Nov. 9, 1913 \\
\hline 192 & 1914-1938 & Aug. 24, 1933 \\
\hline 38. & $1937-1938$ & July 22, 1938 \\
\hline 100 & $1906-1938$ & Aug . 26, 1928 \\
\hline 386 & $\begin{array}{l}1901-1903 \\
1906-1919 \\
1926-1938\end{array}$ & Aug. 27, 1928 \\
\hline 12.2 & $1937-1938$ & July 22, 1938 \\
\hline 144 & $1937-1938$ & Jan, 26,1938 \\
\hline 385 & $1919-1938$ & Mar. 14, 1936 \\
\hline 432 & $1936-1938$ & July 23, 1938 \\
\hline 711 & 1924-1938 & Har. 12, 1936 \\
\hline 739 & $1901-1903$ & Har. 3, 1902 \\
\hline 98 & $1937-1938$ & Jan. 26,1938 \\
\hline 9.7 & $1937-1938$ & Jan, 25,1938 \\
\hline 102 & $1924-1932$ & Sept. 1, 1927 \\
\hline 182 & 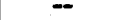 & \\
\hline 182 & $1928-1938$ & Mar. 12, 1936 \\
\hline 194 & - & \\
\hline
\end{tabular}

\begin{tabular}{r|c|l|l|}
15,000 & 46.2 & 22 & 2 a.m. \\
12,900 & 39.2 & 22 & $2: 30$ a.m. \\
12,300 & 126 & 21 & $6: 45$ p.m. \\
55,000 & 286 & 21 & 8 p.m. \\
7,600 & 197 & 21 & 6 p.m. \\
26,700 & 267 & 21 & $7: 45$ p.m. \\
27,300 & 70.7 & 22 & 12,15 a.m. \\
& & & \\
2,600 & 213 & 21 & 5 p.m. \\
1,680 & 11.7 & 22 & 10 to 12 p.m. \\
12,400 & 32.2 & 23 & $7: 45$ a.m. \\
5,180 & 12.0 & 21 & $10: 40$ p.m. \\
18,000 & 25.3 & 22 & 1,15 a.m. \\
24,500 & 33.2 & -- & \\
1,150 & 11.7 & 22 & $8: 30$ to 10 p.m. \\
387 & 39.9 & 21 & 5 p.m. \\
4,310 & 42.3 & -- & \\
-- & -- & -- & - \\
6,880 & 37.8 & 22 & 2 a.m. \\
-- & -- & 22 & $11: 30$ a.m. \\
& &
\end{tabular}

\begin{tabular}{|c|c|c|}
\hline 29,000 & 89.2 & Do.. \\
\hline 27,800 & 84.5 & Stage-dischargè relation. \\
\hline 7,900 & 80.6 & Stage-disoharge relation. \\
\hline 19,900 & 104 & Do. \\
\hline 3,060 & 79.5 & Do. \\
\hline 5,930 & 59.3 & Do. \\
\hline 18,100 & 46.9 & Do. \\
\hline 965 & 79.1 & Do. \\
\hline 3,120 & 21.7 & Do. \\
\hline 6,210 & 16.1 & Do. \\
\hline 7,090 & 16.4 & Do. \\
\hline 17,500 & 24.6 & Do. \\
\hline 19,800 & 26.8 & Do. \\
\hline 2,070 & 21.1 & Do. \\
\hline 650 & 67.0 & Do. \\
\hline 3,760 & 36.9 & Do. \\
\hline 16,000 & 87.9 & Contracted opening. \\
\hline 15,900 & 87.4 & Stage-disoharge relation. \\
\hline 15,700 & 80.9 & Dam, \\
\hline
\end{tabular}

av One-eighth of a mile upstream from present site. aw Arfooted by storage and divorslons. ax Records of New York City Board of Water Supply,
$1910-1928$. 
Table 10.- Sumary of flood discharges--Contimued

\begin{tabular}{|c|c|c|c|c|c|c|c|c|c|c|c|}
\hline \multirow{2}{*}{$\begin{array}{l}\text { No. } \\
\text { on } \\
\text { pl. } \\
11\end{array}$} & \multirow{2}{*}{ Stream and place of dotermination } & \multirow{2}{*}{$\begin{array}{c}\text { Drainage } \\
\text { area } \\
\text { (sq. mi. })\end{array}$} & \multirow{2}{*}{$\begin{array}{l}\text { Perlod } \\
\text { of } \\
\text { reoord }\end{array}$} & \multicolumn{3}{|c|}{$\begin{array}{l}\text { Maximum discharge } \\
\text { previously knom }\end{array}$} & \multicolumn{5}{|c|}{ Maximum discharge during floods of September 1938} \\
\hline & & & & Date & $\begin{array}{l}\text { Second- } \\
\text { foet }\end{array}$ & $\mid \begin{array}{c}\text { Sec.-ft. } \\
\text { per } \\
\text { sg. mi. }\end{array}$ & Day & Bour & $\begin{array}{c}\text { Seoond- } \\
\text { feet }\end{array}$ & $\mid \begin{array}{c}\text { soo.-rt. } \\
\text { per } \\
\text { sq. mi. }\end{array}$ & Nethod of determination \\
\hline & Hudeon River Basin--Continued & & & & & & & & & & \\
\hline 348 & Croton River at Hew Croton Dam, noar Croton, H. Y. an/ & 377 & -- & -- & -- & - & 22 & $11 \mathrm{a.m.}$ & 10,240 & $27 \cdot 2$ & Stage-disoharge relation. \\
\hline 349 & $\begin{array}{l}\text { Croton River below Hew Croton Dam, noar Croton, } H_{0} Y_{4} \\
\text { af }\end{array}$ & 378 & $1933-1938$ & Har. 19, 1936 & 4,570 & 12.1 & - & -- & -- & - & Do. \\
\hline 350 & Croton Rivor at Quaker Bridgo, near Croton, N. Y. au/ & 3779 & $1933-1938$ & war. 19, 1936 & 4,530 & 12.0 & 22 & $12 \mathrm{~m}$. & 8,410 & 22.2 & Do. \\
\hline 351 & $\begin{array}{l}\text { Bird Brook noar Croton, H. Y. } \\
\text { Brokensaok Rivor Basin }\end{array}$ & .36 & $1933-1938$ & Mar. 12, 1936 & 21 & 58.3 & 21 & 4:30 p.m. & 27 & 75.0 & Do. \\
\hline 352 & Hackensaok River at New uliford, M. J. aw/ & 113 & $1921-1938$ & $\ln x \cdot 12,13,1936$ & 2,800 & 24.8 & 21 & 6 p.m. & 2,190 & 19.4 & Do. \\
\hline 363 & $\begin{array}{l}\text { Puscaok Brook at Wostwood, I. J. ab/ } \\
\text { Passa1c River Basin }\end{array}$ & 29.6 & $1934-1938$ & War. 12, 1936 & 1,190 & 40.2 & 22 & 2 a.m. & 1,120 & 37.8 & Do. \\
\hline 354 & Passale River near Milington, N. J. & 55.4 & $\begin{array}{r}1903-1906 \\
1921-1938\end{array}$ & Mar. 8, 1904 & 2,000 & 36.1 & 22 & 4 to $10 \mathrm{a} \cdot \mathrm{m}$. & 1,040 & 18.8 & Do. \\
\hline 365 & Pasaufo River noar Chatham, N. J. & 100 & $\begin{array}{l}1903-1911 \\
1937-1938\end{array}$ & Jan. 9, 1905 & 2,990 & 29.6 & 21 & 6 p.m. & 1,910 & 19.1 & Do. \\
\hline 356 & Passalo River at Paterson, H. J. aw/ & 785 & $1898-1938$ & oct. 10,1903 & 028,000 & 35.7 & 23 & 7 to $12 \mathrm{p} . \mathrm{m}$. & 9,350 & 11.9 & $\begin{array}{l}\text { Stage-disoharge and power } \\
\text { output-d1soharge rela- } \\
\text { tions. }\end{array}$ \\
\hline 367 & Rookamay River above resorroir at Boonton, Y. J. & 116 & $1937-1958$ & July 24, 1938 & 2,120 & 18.3 & 22 & 9:15 to $10 \mathrm{acm}$ & 2,220 & 19.1 & Stage-disoharge relation. \\
\hline 358 & Rookamay River below reservoir at Boonton, H. J. aw/ & 119 & $\begin{array}{l}1903-1904 \\
1906-1938\end{array}$ & 0ot. 10,1903 & 07,560 & 63.5 & 22 & 2 to 2 p.m. & 1,870 & 15.7 & Do. \\
\hline 369 & Beaver Brook at outlet of Splitrook Pond, N. J. ab/ & 5.5 & $1925-1938$ & Mar. 12, 1936 & 126 & 22.9 & to 22 & 31 a.m. & 75 & 13.6 & Do. \\
\hline 360 & Mhippany River at Horristom, H. J. & 29.4 & $1921-1938$ & $\begin{array}{l}\text { Aug. 26, } 1928 \\
\text { Mar. } 12,1936\end{array}$ & 1,500 & 51.0 & 22 & 4 a.m. & 1,170 & 39.8 & Do. \\
\hline 361 & Rampo River noer Mahwah, H. J. & 118 & $\begin{array}{l}1903-1906 \\
1922-1938\end{array}$ & Dot. 5, 1903 & 12,400 & 105 & 22 & -- & 5,500 & 46.6 & Do. \\
\hline 362 & Ramepo River at Pompton Lakes, Y. J. & 160 & $1921-1938$ & Mar. 12, 1936 & 12.300 & 76.9 & 22 & |6 to $7: 30$ a.m. & 6,620 & 41.4 & Do. \\
\hline
\end{tabular}




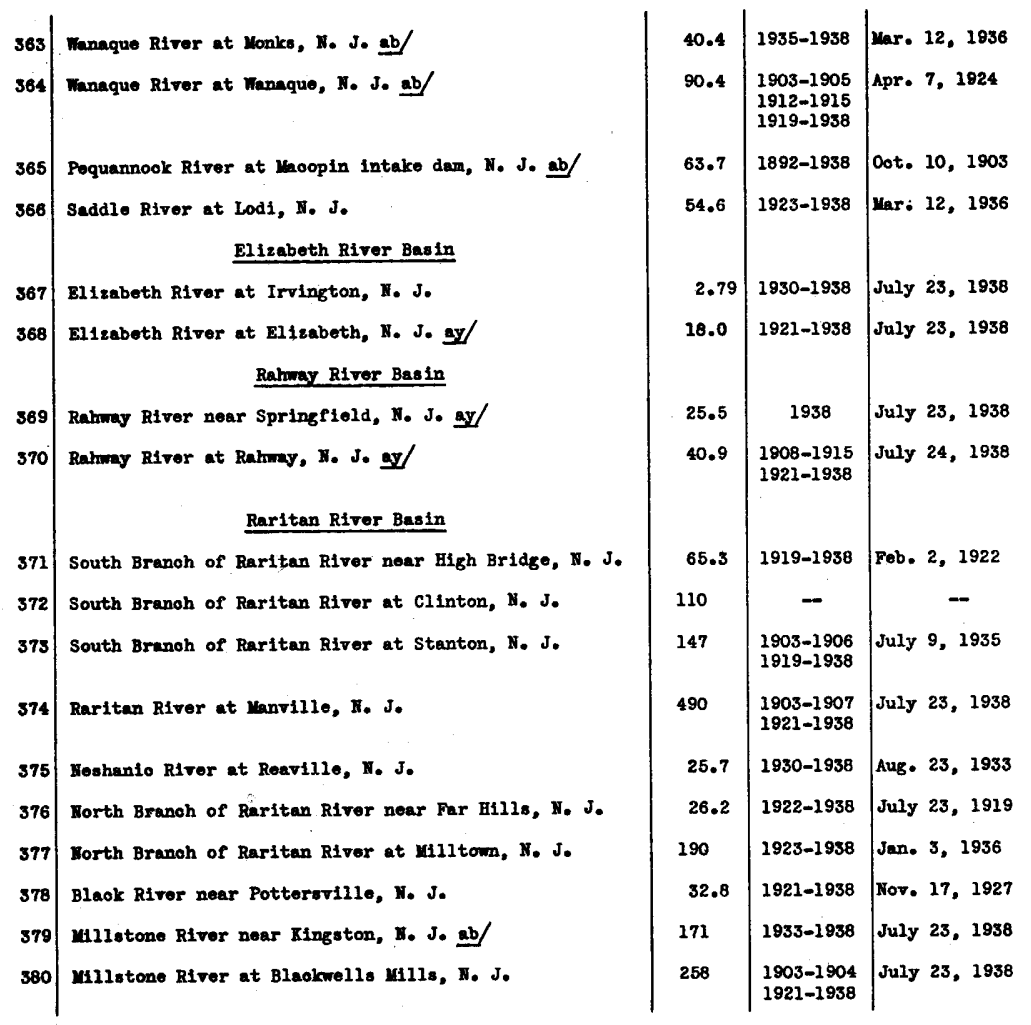

b Revised.

ab Moan daily disoharge.

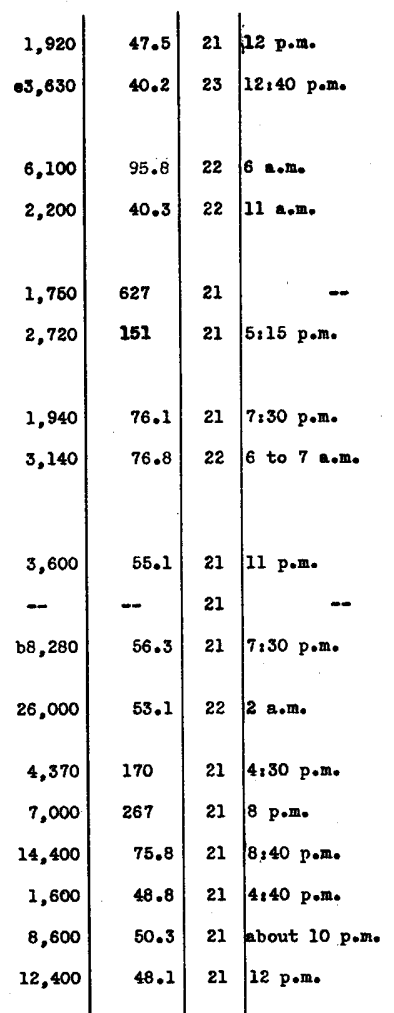

aw Affected by storage and diversions. ay Affected by diversions.

\begin{tabular}{|c|c|c|c|}
\hline 1,260 & 31.2 & Do & b. \\
\hline 812 & 10.1 & Do & •. \\
\hline 1,300 & 20.4 & Do & o. \\
\hline 2,150 & 39.4 & Do & o. \\
\hline 1,150 & 412 & Do & o. \\
\hline 2,020 & 112 & Do & o. \\
\hline 1,690 & 62.4 & Do & o. \\
\hline 1,780 & 43.5 & Do & o. \\
\hline 2,650 & 40.6 & Do & o. \\
\hline 6,110 & 55.5 & Dam. & \\
\hline 8,130 & 55.3 & Stage-disoharg & $g$ relation. \\
\hline 36,100 & 73.7 & Do & 0. \\
\hline 4,300 & 167 & Do & 0. \\
\hline 2,700 & i03 & Do & o. \\
\hline 16,500 & 86.8 & Do & o. \\
\hline 760 & 23.2 & Do & o. \\
\hline 9,820 & 57.4 & Do & 10. \\
\hline 18,300 & 70.9 & Do & 10. \\
\hline
\end{tabular}


Table 10.- Stwmary of flood discharges--Continued

\begin{tabular}{|c|c|c|c|c|c|c|c|c|c|c|c|}
\hline \multirow{2}{*}{$\begin{array}{l}\text { Ho. } \\
\text { on } \\
\text { pl. } \\
11\end{array}$} & \multirow[b]{2}{*}{ Stroam and place of dotermination } & \multirow{2}{*}{$\left|\begin{array}{l}\text { Drainege } \\
\text { aroa } \\
(\text { sq. mi. })\end{array}\right|$} & \multirow{2}{*}{$\begin{array}{l}\text { Poriod } \\
\text { of } \\
\text { reoord }\end{array}$} & \multicolumn{3}{|c|}{$\begin{array}{l}\text { Kaximum disoharge } \\
\text { previously known }\end{array}$} & \multicolumn{5}{|c|}{ Waximum discharge during floods of September 1938} \\
\hline & & & & Date & $\begin{array}{c}\text { Sooond- } \\
\text { foet }\end{array}$ & $\begin{array}{l}\text { seo.-rt. } \\
\text { per } \\
\text { sq. mi. }\end{array}$ & Day & Bour & $\begin{array}{c}\text { Sooond- } \\
\text { foet }\end{array}$ & $\begin{array}{c}\text { Secoft. } \\
\text { per } \\
\text { sq. mi. }\end{array}$ & Method of determination \\
\hline & Rariten River Banin--Continued & & & & & & & & & & \\
\hline 381 & arean Brook at Plainfield, W. J. & 8.75 & 1,938 & July 23, 1938 & 2,890 & 296 & 21 & $3: 40$ p.m. & 1,740 & 178 & Stage-disoharge relation. \\
\hline 382 & Lawrenoe Brook at Farrington Dam, I. J. ab/ & 34.4 & $\begin{array}{l}1922-1926 \\
1927-1938\end{array}$ & July 6, 1928 & 1,900 & 56.2 & 21 & 8 p.m. & 2,660 & 77.3 & Do. \\
\hline 383 & $\begin{array}{l}\text { Doop thun noar Browntom, I. J. } \\
\qquad \text { Coentel Baeins }\end{array}$ & 8.07 & $1952-1938$ & Sopt. 9, 1934 & 917 & 114 & 21 & $6: 15$ p.m. & 1,240 & 154 & Do. \\
\hline 384 & Surimening River near Red Bank, II. J. & $48: 5$ & $1922-1938$ & Sept. 9, '1934 & 2,930 & 60.4 & 21 & $7: 30$ p.m. & $=27,370$ & 152 & Do. \\
\hline 385 & Wanasquan River at Squankum, X. J. & 43.4 & $1931-1938$ & June 28, 1938 & 1,560 & 35.7 & 21 & - & 2,940 & 67.7 & Do. \\
\hline 386 & Tams R17er near Toms R1trer, H. J. & 124 & $1928-2958$ & June 29, 1938 & 1,240 & 10.0 & 23 & 7 to 10 a.m. & 2,540 & 22.4 & Do. \\
\hline 387 & Groat EGG RIvor at Folsom, $\mathrm{Z}_{0}$ J. & 66.3 & $1925-1958$ & Sept. 8, 1935 & 599 & 10.6 & 23 & 6 a.m. to I p.m. & 718 & 12.8 & Do. \\
\hline 388 & $\begin{array}{r}\text { Mnant 100 Crook noar Millville, N. J. } \\
\text { Delavare River Basin }\end{array}$ & 22.3 & $1931-1938$ & Sopt. 7, 1935 & 566 & 25.4 & 22 & 7 a.m. & 413 & 18.5 & Do. \\
\hline 589 & East Branoh of Dolaware Ritor at Murgaretville, B. Y. & 163 & $1937-1938$ & Hay 15,1937 & 6,000 & 36.8 & 21 & $8,15 \mathrm{p} \cdot \mathrm{m}$ & 13,200 & 81.0 & Do. \\
\hline 390 & Bast Branoh of Dolaware River at Harvard, $X_{0} Y_{0}$ & 443 & $1934-1938$ & Mar. 18, 1936 & 26,200 & 59.1 & 22 & $6: 10$ a.m. & 31,400 & 70.9 & Do. \\
\hline $\mathbf{s 9 1}$ & East Branoh of Dolamare River at Flshs Eddy, I. Y. & 783 & $1912-1938$ & $\begin{array}{l}\text { Aug. 24, } 1983 \\
\text { pot. } 9,1903\end{array}$ & $\begin{array}{c}53,300 \\
\text { about } \\
70,000\end{array}$ & $\begin{array}{l}68.1 \\
89.4\end{array}$ & 22 & $12: 45$ a.m. & 41,000 & 52.4 & Do. \\
\hline 392 & East Brenoh of Delamare River at Bnnoook, X. Y. & 838 & $1902-1912$ & oot. 9, 2903 & b.25.2 & -- & 22 & \#orning & bal6.4 & -- & -- \\
\hline 393 & Delamare RAvor at Port Jorvis, Y. Y. & 3,076 & $1904-1938$ & oat. 20, 11, 1903 & about & 50.4 & 22 & $12 \mathrm{~m}$. & $2101, \infty 00$ & 32.8 & Stage-discharge relation. \\
\hline 394 & Delaware RIver at Belridere, H. J. & 4,542 & $1922-1938$ & Oat. 10, 1903 & 220,000 & 48.4 & 22 & 10 p.m. & 2116,000 & 25.5 & Do. \\
\hline 395 & Dolavire River at Rlegelorille, I. J. & 6,344 & $1906-1938$ & oot. 10,1903 & 275,000 & 43.3 & 23 & 1 a.m. & 2123,000 & 19.4 & Do. \\
\hline 396 & Delamare R1vor at Trenton, $\mathrm{X} . \mathrm{J}$. & 6,796 & $1913-1938$ & Mar. 19,1936 & 2227,000 & 33.4 & 23 & 6 to $7 \mathrm{a} . \mathrm{m}$. & $=125,000$ & 18.4 & Do. \\
\hline 387 & Will Brook at Areme, I. I. & 25.0 & $1937-1938$ & oot. 23, 2937 & 1,550 & 62.0 & 22 & About 7 p.m. & 4,500 & 180.0 & Do. \\
\hline
\end{tabular}




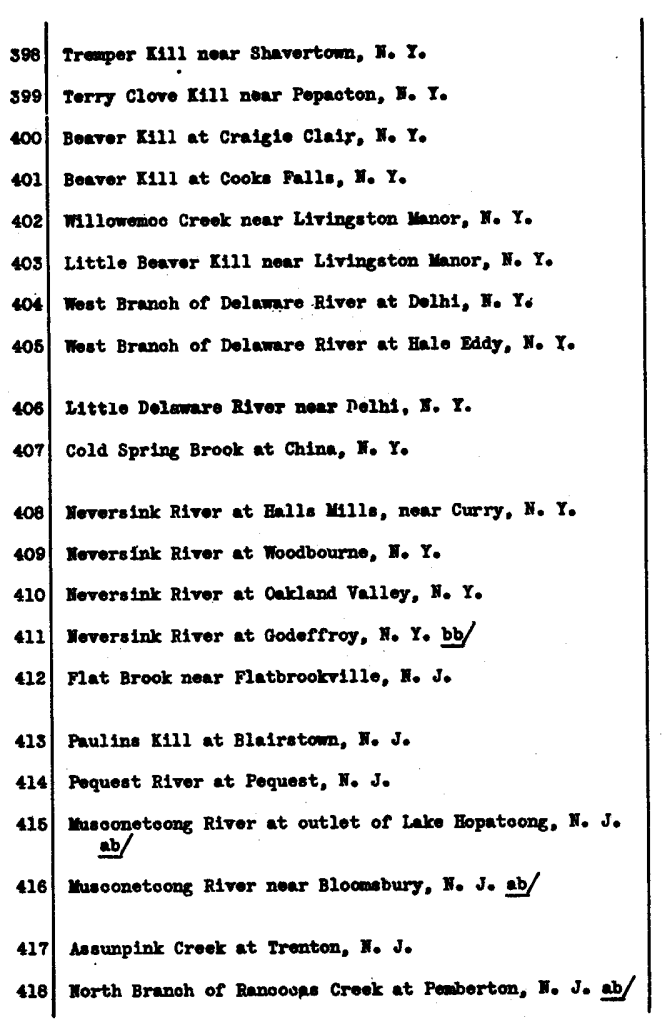

- Yoan dally disohargo.

\begin{tabular}{|c|c|c|}
\hline 35.0 & 1937-1988 & oot. 23, 1937 \\
\hline 14.1 & 1957-1958 & Jan. 25, 1938 \\
\hline 82 & $1937-1938$ & Aug. 11,1958 \\
\hline 241 & 1913-1958 & Aug. 24, 1983 \\
\hline 63 & $1937-1938$ & Aug. 11, 1938 \\
\hline 19.8 & 1924-1938 & Aug. 26, 1928 \\
\hline 142 & 1937-1938 & Jan. 25, 1938 \\
\hline 593 & 1912-1938 & Dot. 10,1903 \\
\hline 49.8 & $1957-1938$ & Jan. 25, 1938 \\
\hline $\begin{array}{r}\text { about } \\
2.0\end{array}$ & $1934-1938$ & 0ot. 30,1935 \\
\hline 68 & 1957-1958 & Cot. 23, 1937 \\
\hline 113 & $1937-1958$ & July 22,1938 \\
\hline 222 & $1928-1958$ & Aug. 24,1933 \\
\hline 302 & $1937-1938$ & July 22, 1938 \\
\hline 65.2 & $1923-1938$ & $\begin{array}{l}\text { Apr. 7, } 1924 \\
\text { Pob. 1i, } 1925\end{array}$ \\
\hline 126 & 1921-1938 & kar. 12, 1956 \\
\hline 108 & 1921-1938 & Mar. 14, 1936 \\
\hline 25.6 & 1928-1938 & Mar. 19, 1936 \\
\hline 143 & $\begin{array}{l}1903-1907 \\
1921-1938\end{array}$ & $\operatorname{cost}_{1903}^{10}$ or 11 . \\
\hline 89.4 & 1923-1938 & Apr. 7, 1924 \\
\hline 111 & $1921-1938$ & oot. 20, 1927 \\
\hline
\end{tabular}

\begin{tabular}{|c|c|c|}
\hline 54.5 & 21 & $6 \mathrm{p} . \mathrm{m}_{\mathrm{s}}$ \\
\hline 60.3 & 21 & B p.m. \\
\hline 116 & 21 & $8 \mathrm{p} . \mathrm{m}$ \\
\hline 78.8 & 21 & 9,15 p.m. \\
\hline 98.4 & 21 & 6 p.m. \\
\hline 126 & 21 & 5,30 p.m. \\
\hline 30.2 & 21 & 11 p.m. \\
\hline 77.6 & 22 & $11: 30 \mathrm{a.m}$ \\
\hline 43.8 & 21 & 8 p.m. \\
\hline 59.5 & 21 & 5.15 p.m. \\
\hline 191 & 21 . & 7 p.m. \\
\hline 109 & 21 & $10: 15$ p.m. \\
\hline 90.1 & 22 & 2 a.m. \\
\hline 53.3 & 22 & 5 a.me \\
\hline 53.3 & 22 & s a.m. \\
\hline 27.6 & 22 & s a.m. \\
\hline 16.8 & 22 & 1 to 2 a.m. \\
\hline 20.9 & 23 & $12 \cdot \mathrm{mo}$ \\
\hline-- & 21 & 10 to $12 \mathrm{p} . \mathrm{m}$. \\
\hline 26.8 & 22 ! & 3 a.m. \\
\hline 11.8 & 22 & 6 to $10 \mathrm{pom}$. \\
\hline
\end{tabular}

be Gage hioight in foot, 3.5 foot over crest of dam. Gage helghts and discharge measurements only are arailablo for 1903, 1909-10, 1913-14.
Do.

Do.

Do.

Do.

Do.

Do.

Do.

Do.

Do.

Do.

Do.

Do.

Do.

Do.

Do.

Do.

Do.

Do.

Do.

Do.

Do. 


\begin{tabular}{|c|c|c|c|c|c|c|c|c|c|c|c|}
\hline \multirow{2}{*}{$\begin{array}{l}\text { No. } \\
\text { on } \\
\text { p1. } \\
11\end{array}$} & \multirow[b]{2}{*}{ Stream and place of determination } & \multirow{2}{*}{$\left|\begin{array}{l}\text { Drainage } \\
\text { area } \\
\text { sq. mi. })\end{array}\right|$} & \multirow{2}{*}{$\begin{array}{l}\text { Period } \\
\text { of } \\
\text { reoord }\end{array}$} & \multicolumn{3}{|c|}{$\begin{array}{l}\text { Maximum discharge } \\
\text { previously knomn. }\end{array}$} & \multicolumn{5}{|c|}{ Maximum discharge during floods of September 1938} \\
\hline & & & & Date & $\begin{array}{c}\text { Second- } \\
\text { feet }\end{array}$ & $\begin{array}{c}\text { sec.-ft. } \\
\text { per } \\
\text { sq. mi. }\end{array}$ & Day & Hour & $\begin{array}{c}\text { Seoond- } \\
\text { feet }\end{array}$ & $\begin{array}{l}\text { Sec.-ft. } \\
\text { per } \\
\text { sq. mi. }\end{array}$ & Method of determination \\
\hline & Susquehanna River Basin & & & & & & & & & & \\
\hline 419 & Susquehanna River at Colllersville Dam, I. Y. & -- & - & - & -- & -- & 22 & $6 \mathrm{p} \cdot \mathrm{m} \bullet$ & be33.5 & -- & - \\
\hline 420 & Susqueharna River at Collierstille, N. Y. & 351 & 1924-1938 & Nar. 19, 1936 & 8,740 & 24.9 & 22 & $7: 30$ p.m. & bd6, 300 & 17.9 & Stage-discharge relation. \\
\hline 421 & Susquehenna River at Oneontr, Y. Y. af / & 680 & $1907-1938$ & Mar. 27, 1913 & bP19.9 & - & 22 & 5 a.m. & bf21.30 & -- & - \\
\hline 422 & Susquehanna River at highway bridge, Otego, N. Y. & -- & -- & - & -- & - & - & -- & bg1,049.0 & - & - \\
\hline 423 & Susquohanna River at bridge, Wells Bridge, N. Y. & - & - & - & -- & - & -- & - & bg $1,043.0$ & -- & - \\
\hline 424 & Susquehanne R1ver at Onadilla, I. Y. & 984 & 1938 & -- & -- & - & 22 & 3,30 p.m. & bh23,700 & 24.1 & Stago-disoharge relation. \\
\hline 425 & Susquehanne Rivor at highnay bridgo, Sidnoy, H. Y. & - & - & - & -- & -- & - & - & bg984.0 & -- & - \\
\hline 426 & $\begin{array}{l}\text { Susquehanno River } 2.3 \text { miles east of Delaware \& Hudson } \\
\text { R. R. bridge, Bainbridge, K. Y. }\end{array}$ & -- & - & - & -- & - & - & - & bg 975.0 & - & -- \\
\hline 427 & Susquehanne River at Bainbridgo, X* Y. af/ & 1,618 & $1907-1908$ & Yar. 18, 1936 & 21.5 & -- & 22 & 7 p.m. & 16.5 & -- & - \\
\hline 428 & Suequehanne River at highmay bridge, at Afton, X. Y. & - & - & -- & -- & -- & - & - & bg964.0 & $\cdots$ & - \\
\hline 428 & $\begin{array}{l}\text { Susquehanne River below highway bridge, at Ninevah, } \\
\text { N. } X_{\text {. }}\end{array}$ & - & - & - & -- & - & - & - & bg 957.5 & -- & - \\
\hline 450 & Susquehanne River at highway bridge, at Windsor, N. $Y_{0}$ & - & -- & - & -- & - & -- & - & bg914.5 & $\cdots$ & - \\
\hline by $/$ & $\begin{array}{l}\text { Susquehanne River at highway bridgo, at Susquehanna, } \\
\text { Pa. }\end{array}$ & -- & $\cdots$ & -- & -- & - & - & - & bg894.5 & - & - \\
\hline 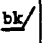 & Susquehenne River at Great Bend, Pa. & - & - & - & -- & - & - & $\cdots$ & bg870.0 & - & - \\
\hline 431 & Susquehama River at Conklin, $Y_{0} Y_{0}$ & 2,240 & $1912-1938$ & Mar. 28, 1936 & 61,600 & 27.5 & 23 & 5 p.m. & $b m 34,100$ & 15.2 & Stage-discharge relation. \\
\hline 432 & Susquehanna River at Binghamton, N. Y. af/ & 2,293 & $1902-1938$ & Mar. 18, 1936 & $\begin{array}{r}b n 22.85 \\
b n 23.5\end{array}$ & -- & 23 & - & bn12.9 & -- & - \\
\hline 433 & Susquehanna River at Vestal, S. $_{\text {. }} \mathrm{Y}_{\text {. }}$ & 3,960 & $\cdot 1937-1938$ & Apr. 8, 1937 & 47,500 & 12.0 & 23 & 7 p.m. & bp47,600 & 12.0 & Stage-discharge relation. \\
\hline 434 & Susquehanna River at highway bridge, at Owego, X. Y. & -- & -- & -- & -- & - & - & - & bg802.5 & - & - \\
\hline 435 & Suaquehanna R1ver near Waverly, K. Y. & 4,780 & $1937-1938$ & oct. 24,1937 & 53,300 & 11.2 & 23 & 9 to 10 a.m. & bq54,900 & 11.5 & Stage-di soharge relation. \\
\hline
\end{tabular}




\begin{tabular}{|c|c|c|c|c|}
\hline 436 & Onke Crook at Indox, $H_{0} Y_{0}, a b /$ & 103 & $\begin{array}{l}1929-1832 \\
1937-1938\end{array}$ & Apr. 12, 1932 \\
\hline 437 & Cherry Valley Creek at Westville, H. Y. & 81.3 & $\underset{1938}{1930-1931}$ & Apr. 11, 1931 \\
\hline 438 & Charlotte Creek at Daveuport Ceater, I. I. & 165 & 1938 & Aug. 11, 1938 \\
\hline 139 & Unadilla River near New Berlin, I. Y. & 196 & 1924-1938 & phar. 18, 1936 \\
\hline 140 & Unadilla Rivor at Rookdalo, No $Y_{\text {. }}$ & 518 & $\begin{array}{l}1929-1933 \\
1937-1938\end{array}$ & $00 t .7,1932$ \\
\hline 41 & Sage Brook noar South Now Berlin, N, Y. & .69 & $1932-1838$ & July 8,1935 \\
\hline 42 & Butternut Creok at Morris, $X_{0}$ Y. & 59.6 & 1938 & - \\
\hline & Chenango River at Shorburne, M. $Y$. & 264 & $1907-1938$ & Mar. 28, 1914 \\
\hline 44 & Chenango RIver noar Groene, $H_{0} Y_{0}$ as/ & - & 1936-1938 & - \\
\hline & Chenango River at Greene, N. Y. $_{\text {. }}$ & 698 & $1937-1938$ & Apr. 7, 1937 \\
\hline & Chenango River near Chenango Forks, 8. Y. & 1,492 & 1912-1938 & July 8,1935 \\
\hline 47 & Chenango River at Binghamton, H. Y. af/ & 1,553 & $\begin{array}{l}1901-1911 \\
1933-1938\end{array}$ & Mar. 18, 1936 \\
\hline & Genegantslot Croek at Smithville Flats, N. Y. & 83.1 & 1938 & - \\
\hline & Tioughnioga River et Cortland, W. Y. & 296 & 1938 & -- \\
\hline & Tioughnioga River at Whitney Point, No Yo af, & - & $1937-1938$ & - \\
\hline & Tloughnioge RItor at Itaska, H. Y. & 735 & 1929-1938 & July 8, 1935 \\
\hline & Shackbam Brook near Fruxton, N. Y. & 3.12 & $1932-1938$ & Mar. 12, 1936 \\
\hline
\end{tabular}

ab Affected by storage.

af Reoords furnished by U. S. Woather Bureau.

be Gage hoight in feot; 3.5 foet over crest of dam.

bd Altitude $1,118.0$ reet.

To Toather Buroau datum.

bf Gage height in reot; zero of gage at altitude 1,065.85 foot, V. S. Noathor Buroau datum.

bg Altitude in feet, Corps of Engineers, U. S. A Inav, datum

bh Altitude 1,008.8 feot, Corps of Englnoers, U. S. Army.

bm Altitude 856.8 foet, corpe of Dngineers, D. S. Arma, datum.

\begin{tabular}{|r|r|r|l}
1,080 & 10.3 & 22 & 3,30 a.m. \\
1,780 & 21.9 & 22 & 0,55 a.m. \\
553 & 3.4 & 22 & 12,30 a.m. \\
6,320 & 32.2 & 25 & 4 a.m. \\
10,400 & 20.1 & 22 & 6,50 p.m. \\
201 & 291 & 21 & 7.40 p.m. \\
-- & - & 22 & 12.30 a.m. \\
be11.2 & -- & 22 & 3 a.m. \\
-- & - & 22 & 7 a.m. \\
6,900 & 11.5 & 22 & 7 a.m. \\
82,800 & 55.5 & 22 & 9 a.m. \\
bu26.74 & -- & 22 & 4 p.m. \\
-- & - & 22 & 2 a.m. \\
-- & - & 23 & 9 a.m. \\
-- & - & 22 & 7 a.m. \\
44,700 & 60.8 & 22 & 10 a.m. \\
153 & 49.0 & 21 & $9: 45$ p.m. \\
& & &
\end{tabular}

\begin{tabular}{|r|}
1,460 \\
4,470 \\
14,000 \\
3,280 \\
6,650 \\
38 \\
1,900 \\
br2, 440 \\
$b 89.00$ \\
bt5, 590 \\
17,500 \\
bu16.75 \\
2,430 \\
2,430 \\
$b v 13.3$ \\
$b w 6,640$ \\
133 \\
\hline
\end{tabular}

\begin{tabular}{l|l}
14.2 & Do. \\
65.0 & Do. \\
85.9 & Do.
\end{tabular}

16.7 Stage-disoharge relation.

12.8 Do.

55.1 Do.

31.9 Do.

9.2 Do.

-

9.3 Stage-disoharge relation.

11.7

Do.

$-$

29.2 Stage-disoharge relation.

8.2 Do.

-

-

11.8 Stage-disoharge relation.

Do.

42.6

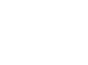

Gago height in foet; zero of gage

bp Altitude 818.3 foet, Corps of Fngineers, U. S. Army, datum. bq Altitude 756.5 feot, Corps of Engineers, U. S. Army, datum.

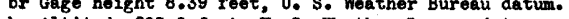

bs Altitude 903.0 reot, 0. S. Weather Bureau datumo

bt Alt1tude 903.6 feet, Corps of Engineers, U. S. Army, àatum. bu Gage height in feot; zero of gage at altitude 817.92 feet, by Aititude 9478 seat das.

Weather Bureau datum. 
Table 10.- - Summary of flood discharges--Continued

\begin{tabular}{|c|c|c|c|c|c|c|c|c|c|c|c|}
\hline \multirow{2}{*}{$\begin{array}{l}\text { 1o. } \\
\text { on } \\
\text { pl. } \\
\text { il }\end{array}$} & \multirow[b]{2}{*}{ Stroam and place of deteraination } & \multirow[b]{2}{*}{$\begin{array}{c}\text { Drainage } \\
\text { area } \\
\text { (sq. mi. })\end{array}$} & \multirow{2}{*}{$\begin{array}{l}\text { Period } \\
\text { of } \\
\text { reoord }\end{array}$} & \multicolumn{3}{|c|}{$\begin{array}{l}\text { Maxłmum discharge } \\
\text { previously known }\end{array}$} & \multicolumn{5}{|c|}{ Waximum discharge during floods of September 1938} \\
\hline & & & & Date & $\begin{array}{c}\text { Second- } \\
\text { feet }\end{array}$ & \begin{tabular}{|} 
Sec, -rt. \\
per \\
sq. mi.
\end{tabular} & Day & Hour & $\begin{array}{c}\text { Second- } \\
\text { feet }\end{array}$ & \begin{tabular}{|} 
sec.-ft. \\
per \\
sg. mi.
\end{tabular} & Method of determination \\
\hline & Susquehanne River Basin--Continued & & & & & & & & & & \\
\hline 453 & Dudley Creok at Lisle, $K_{*} . \chi_{\text {. }}$ & 30.0 & 1938 & July 8,1935 & $b \times 16,200$ & $b x 540$ & 21 & 9 p.m. & 1,730 & $57.7 \mathrm{~s}$ & Stage-discharge relation. \\
\hline 454 & Otsel10 River at Cinoinnatus, N. Y. & 148 & 1938 & - & -- & -- & 22 & 2 a.m. & 2,850 & 19.3 & Do. \\
\hline 455 & Otsel lo River near Upper Lisle, N. Y. & 216 & $1937-1938$ & July 8,1935 & by15,400 & by 71.3 & 228 & a a.m. & 3,750 & 17.4 & Do. \\
\hline 456 & Orrego Croek noar Orrogo, N. Y. & 186 & $1930-1938$ & July 8,1935 & 23,500 & 126 & 22 & 4,30 a.m. & 3,910 & 21.0 & Do. \\
\hline 457 & Orogo Creek below Lower Orego Power Plant. N. Y. & - & - & Har. 19, 1936 & ae811.5 & -- & 23 & 8 to 10 a.m. & ae801.1 & -- & -- \\
\hline by $/$ & $\begin{array}{l}\text { Chemming River at Chemung, W. Y. } \\
\text { Streams tributary to Lake Ontario }\end{array}$ & 2,530 & $1903-1938$ & Mar. 12, 1936 & 92,300 & 36.5 & 24 & i a.m. & $7,170^{\circ}$ & $2.8 \mathrm{~s}$ & Stage-discharge relation. \\
\hline 458 & Oswego River at Look 7, Oowrogo, Y. Y. ab/ & 5,121 & $1933-1938$ & Mar. 28, 1936 & 37,500 & 7.3 & 25 & $7,30 \mathrm{a.m}$ & 9,780 & 1.9 & Do. \\
\hline bef/ & Cayruga Inlet near Ithaca, H. Y. & 36.7 & $1937-1938$ & Aug. 27,1937 & 2,100 & 57.2 & 21 & 10.15 p.m. & 302 & 8.2 & Do. \\
\hline 459 & Fall crook near Ithaok, X. Y. & 124 & $1925-1938$ & July 8, 1935 & 15,500 & 125 & 22 & 4 a.m. & 3,040 & 24.5 & Do. \\
\hline by $/$ & Orasco Lake outlet near Auburn, N. Y. ab/ & 208 & $1912-1938$ & Mar. 19, 1936 & 2,090 & 10.0 & 25 & $10: 20$ a.m. & 333 & 1.6 & Do. \\
\hline 460 & East Branch of Fish Creok at Taberg, N. Y. & 189 & $1923-1938$ & oct. 6, 1932 & 16,500 & 87.3 & 22 & 4,30 a.m. & 4,700 & 24.9 & Do. \\
\hline 461 & Blaok RIver noar Boonville, Y. Y. ab/ & 295 & $1911-1938$ & Mar. 28, 1913 & 10,000 & 33.9 & 22. 1 & 10 p.m. & 6,080 & 20.6 & Do. \\
\hline 462 & Blaok River et Watertown, M. Y. ab/ & 1,876 & $1920-1958$ & Apr. 9, 1928 & 33,900 & 18.1 & 251 & 10 a.m. & 15,600 & 8.3 & Do. \\
\hline 468 & Hoose River at Moose River, M. Y. ab/ & 370 & $1900-1922$ & war. 27, 1913 & 16,500 & 44.6 & $\cdots$ & - & -- & - & Do. \\
\hline 464 & Woose River at MoKeeter, K. Y, ab/ & 365 & $1922-1938$ & June 22, 1922 & 11,000 & 30.1 & 22 & 21,30 a.m. & 9,410 & 25.8 & Do. \\
\hline 465 & Middle Branoh of Yoose River at Old Forge, N. Y. ab/ & 52 & $1911-1938$ & Mar. 23, 1921 & 862 & 16.6 & $\begin{array}{l}25 \\
26\end{array}$ & - & e340 & 6.5 & Do. \\
\hline 466 & Middle Branch of Yoose River near HoKeever, X. Y. ab/ & 148 & $1925-1938$ & Apr. 27, 1926 & 2,100 & 14.2 & 25 & 6 to 10 p.m. & 1,010 & 6.8 & Do. \\
\hline 467 & Independence River at Sperryville, M. Y. & 85 & $1927-1938$ & oct. 6, 1932 & 4,700 & 55.3 & 22 & 9 p.m. & 2,300 & 27.1 & Do. \\
\hline 468 & Stillmator Reservolr near Beaver River, M. Y. & 172 & $1925-1938$ & May 4, 1929 & b279.46 & -- & oat. & 8 a.m. & b272.82 & & -- \\
\hline
\end{tabular}




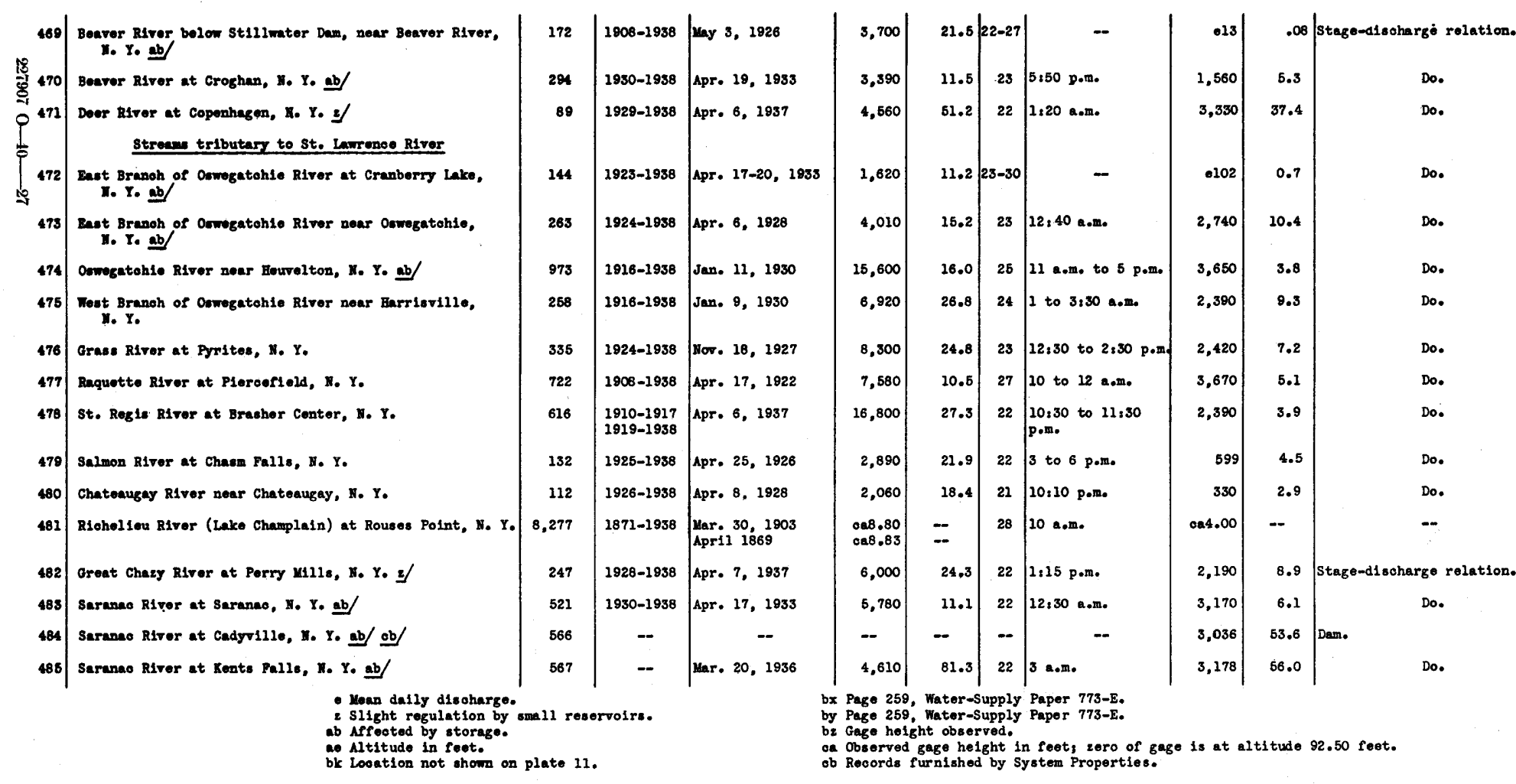


Table 10.-Summary of flood discharges-Continued

\begin{tabular}{|c|c|c|c|c|c|c|c|c|c|c|c|}
\hline \multirow{2}{*}{$\begin{array}{l}\text { No. } \\
\text { on } \\
\text { p1. } \\
\text { II }\end{array}$} & \multirow[b]{2}{*}{ Stream and place of determination } & \multirow{2}{*}{$\begin{array}{l}\text { Drainage } \\
\text { area } \\
\text { (sq. mi.) }\end{array}$} & \multirow{2}{*}{$\begin{array}{l}\text { Period } \\
\text { of } \\
\text { reoord }\end{array}$} & \multicolumn{3}{|c|}{$\begin{array}{l}\text { Maximun dis oharge } \\
\text { previously known }\end{array}$} & \multicolumn{5}{|c|}{ Maximum dis charge during floods of September 1938} \\
\hline & & & & Date. & $\begin{array}{c}\text { Second- } \\
\text { feet }\end{array}$ & \begin{tabular}{|c|} 
seo.-ft. \\
per \\
sq. mi.
\end{tabular} & Day & Hour & $\begin{array}{c}\text { Second- } \\
\text { feet }\end{array}$ & $\begin{array}{c}\text { sec.-ft. } \\
\text { per } \\
\text { sg. mi. }\end{array}$ & Method of determination \\
\hline & Streams tributary to St. Lamrenoe River--Continued & & & & & & & & & & \\
\hline 486 & Chubb River at Lake Placid, $\mathbb{H}_{\bullet} \mathrm{Y}_{\bullet}$ & $\begin{array}{l}\text { about } \\
20\end{array}$ & - & -- & -- & -- & - & -- & 670 & 33.5 & Dam. \\
\hline 487 & West Branch of Ausable River near Nemman, N. Y. & 116 & $\begin{array}{l}1916-1917 \\
1919-1938\end{array}$ & oct. 6,1932 & 6,200 & 63.4 & 22 & $3,45 \mathrm{a.m}$ & 10,800 & 93.1 & Stage-discharge relation. \\
\hline 488 & West Branch of Ausable River at Wilmington Dam, N. Y. & 140 & -- & -- & -- & - & 22 & 4 to 6 . a.m. & 13,000 & 92.9 & Dam. \\
\hline 489 & $\begin{array}{l}\text { West Branch of Ausable River at Rogers Mill, at } \\
\text { Ausable Forks, N. Y. }\end{array}$ & 236 & $\cdots$ & - & -- & -- & 22 & 8.30 a.m. & 10,200 & 43.2 & Do. \\
\hline 490 & Ausable RIver at Ausable Forks, I. Y. & 444 & $1910-1924$ & Mar. 27, 1913 & balo.2 & - & 22 & $2: 45$ a.m. & ba12.6 & -- & -- \\
\hline 491 & Ausable River near Ausable Forks, $\mathrm{Y}, \mathrm{Y}$. & 448 & $1924-1938$ & oct. 1, 1924 & 21,200 & 47.3 & 22 & $3: 30 \mathrm{a.m}$ & 24,200 & $54.0 \mathrm{~s}=$ & Stage-discharge relation. \\
\hline 492 & Aus able River at Ieoseville, X. Y. & 477 & -- & - & - & - & 22 & 6 a.m. & 25,300 & 53.0 & Dam. \\
\hline 493 & Ausable River at Ausable Chasm, H. Yo & 502 & - & - & - & -- & 22 & 7 a.m. & 25,800 & 51.4 & Do. \\
\hline 494 & Blaok Brook at Blaok Brook, W. Y. ab/ & 49.4 & 1924-1938 & Apr. 6, 1937 & 1,050 & 21.3 & 22 & I p.m. & 694 & $14.0 \mathrm{~s}$ & Stage-d1scherge relation. \\
\hline 495 & Bast Branoh of Ausable River at Xeene, X. Y. & $\begin{array}{l}\text { about } \\
90\end{array}$ & -- & -- & -- & -- & 22 & 12 p.m. to 2 a.m. & 12,000 & 133 & Dam. \\
\hline 496 & East Branch of Ausable River at Ausable Forks, N. Y. & 198 & 1938 & -- & -- & - & 22 & $2: 30$ a.m. & 20,100 & 201.5 & Stage-dis charge relation. \\
\hline 497 & East Branoh of Ausable River at Ausable Forks, N. Y. & 198 & $1924-1938$ & oot. 1, 1924 & 11,000 & 55.6 & 22 & $2: 30$ a.m. & 20,100 & 101.5 & of \\
\hline 498 & Bouquet River at Willsboro, N. $Y_{\text {. }}$ & 275 & $1923-1938$ & oot. 1, 1924 & 11,800 & 42.9 & 22 & $12 \mathrm{m.}$ & 7,640 & 27.8 & Stage-discharge relation. \\
\hline 499 & Bouquet Rtiver at Willeboro, N. Y. (Opper dam) & 276 & - & 1913 & ed & -- & -- & -- & 7,640 & 27.7 & Dam. \\
\hline 500 & Bouquet RIver at Willaboro, M. Y. (Lomer dam) & 276 & -- & 1913 & od & -- & -- & -- & 7,640 & 27.7 & Do. \\
\hline 501 & Lake George at Rogera Rook, N. Y. & about & $1913-1938$ & Apr. 9, 1936 & 005.09 & - & 22 & $1: 30$ a.m. & $\cos .37$ & -- & - \\
\hline 502 & Poultney River below Fair Haven, vt. & 187. & $1928-1938$ & War. 18, 1936 & 6,190 & 33.1 & 22 & 5 a.m. & 10,300 & 55.15 & Stage-disoharge relation. \\
\hline 503 & $\begin{array}{l}\text { Castloton River at Vormont Struetural Slate Co. dam, } \\
\text { at Pair Eaven, Vt. }\end{array}$ & 97.8 & - & Maroh 1936 & 2,210 & 22.6 & 22 & $5 \mathrm{a.m}$. & 2,050 & 21.0 & Dam. \\
\hline
\end{tabular}


504 Otter Creek at Center Rutland, vt.

505 Otter Creek at Middlebury, vt.

506 Will River at East Clarendon, $\mathrm{Vt}$.

607 East Creek at Central Vermont Publ ic Service Cor poration dom, 2 miles above Rut lend, $V_{t}$.

508 Kiddlebury River above Ripton, Vt.

509 North Branch of Middlebury River near Ripton, Vt.

510 New Haven River above Lincoln, vt.

511 New Haven River at New Haven Mills, Vt.

512 Baldwin Brook near Bristol, Vt.

613 Lewis Creek above Starksboro, Vt.

514 Winooski River at Montpelier, vt.

515 Winooski River near Essex Junction, vt.

516 Jail Branch at East Barre, vt.

517 North Branch of Winooski River at Wrighteville, Vt.

518 Dog River near lorthfield Falla, vt.

519 Lad River near Horotom, Vt.

520 Naterbury River near Waterbury, $v t$.

521 Huntington River above Hanksville, vt.

522 Huntington River at luntington, $v t$.

523 Lamo1lle Rirer at Johnson, vt.

524 Lamoille River at Fairfex Falls, vt.

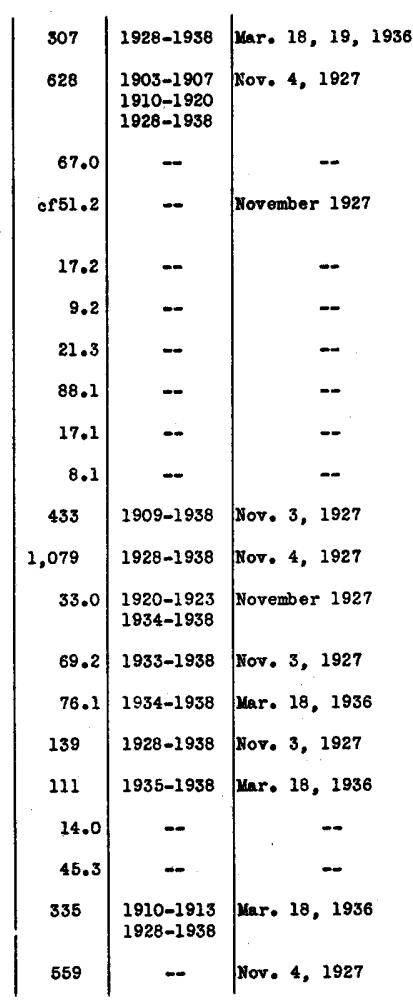

d Moan delly disoharge adjustod for storage.

ab Affeoted by storage:

ba Gago height in feet, from flood marks.

oc From atage-disoharge relation at new site $\frac{2}{4}$ mile upstream.

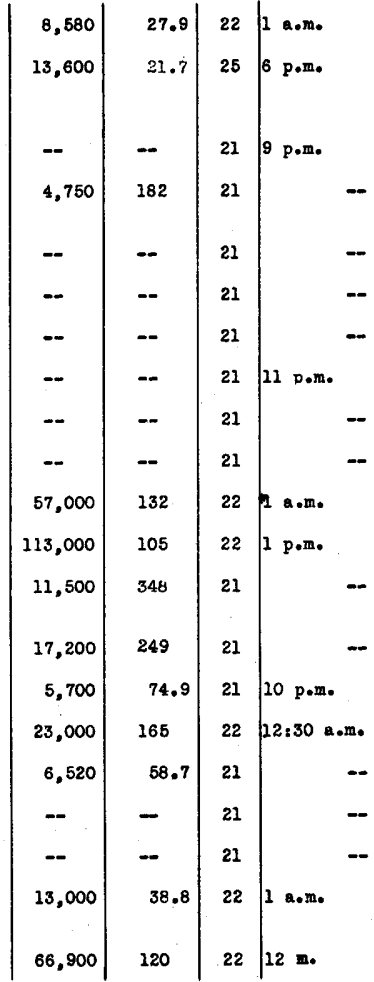

od Greater than September 1938. co Gage helght in foet.

of Net drainage area, 26.1 square miles. 
Table 10.- Grumary of flood disoharges-Cont imied

\begin{tabular}{|c|c|c|c|c|c|c|c|c|c|c|c|}
\hline \multirow{2}{*}{$\begin{array}{l}\text { To. } \\
\text { on } \\
\text { pl. } \\
11\end{array}$} & \multirow[b]{2}{*}{ 8trean and place of dotormination } & \multirow{2}{*}{$\mid \begin{array}{l}\text { Drainage } \\
\text { area } \\
\text { (sog. mi. })\end{array}$} & \multirow{2}{*}{$\begin{array}{l}\text { Pertod } \\
\text { of } \\
\text { reoord }\end{array}$} & \multicolumn{3}{|c|}{$\begin{array}{l}\text { Maximom diecharge } \\
\text { preolous } 1 \mathrm{y} \text { known }\end{array}$} & \multicolumn{5}{|c|}{ Vaximm discharge during floods of September 1838} \\
\hline & & & & Date & $\begin{array}{c}\text { Sooond- } \\
\text { foot }\end{array}$ & $\begin{array}{l}\text { sec.-rt. } \\
\text { por } \\
\text { sq. mi. }\end{array}$ & Day & Hour & $\begin{array}{l}\text { Seoond- } \\
\text { foot }\end{array}$ & $\begin{array}{c}\text { soo.-ft. } \\
\text { por } \\
\text { oq. mi. }\end{array}$ & Wothod of determination \\
\hline & Stroems tributary to St. Leirrenoe River--Continued & & & & & & & & & & \\
\hline 625 & Lanoll1e Riror at East Georgia, vt. & 711 & 1929-1988 & Mar. 19, 1936 & og23, 200 & 32.1 & 22 & 10 a.m. & 20,200 & 28.4 & Stago-disoharge relation. \\
\hline 626 & $\begin{array}{l}\text { Lanolile Rivor at Pablise Eleotrio Co. upper and lower } \\
\text { dame, at Milton, Vt. }\end{array}$ & 726 & - & Mar. 19,1936 & 23,300 & 32.1 & 22 & 2 p.m. & 18,800 & 25.9 & Dams (2). \\
\hline 527 & OShon River at Stearna dem, at Johneon, Vt. & 64.4 & -- & Pharoh 2936 & 2,500 & 38.8 & 22 & 1 a o.m. & 2,260 & 35.1 & Dam. \\
\hline 528 & Misstequol River neer Worth Troy, Vt. & 131 & $2931-1938$ & oot. 7, 1932 & 5,140 & 39.2 & 22 & 10 a.m. & 2,640 & 19.4 & Stage-disoharge relation. \\
\hline 829 & Miesloquol River near Riohford, Vt. & 479 & $1909-1938$ & provenber 1027 & 46,000 & 93.9 & 21 & $12 \mathrm{p} \cdot \mathrm{m}$. & 12,200 . & 25.5 & Do. \\
\hline s30 & $\begin{array}{l}\text { Mesisquol Rivor at Missisquoi co. dam, at Sholdon } \\
\text { springs, Vt. }\end{array}$ & 812 & - & Hovember 1927 & 62,800 & 77.5 & 22 & -- & 21,400 & 26.4 & pam. \\
\hline 631 & Miseisquol Rivor at Smanton dam, at Rggato Fulle, vt. & 828 & - & Waroh 1936 & 23,800 & 28.8 & 22 & 21 a.m. & 21,200 & 25.7 & Do. \\
\hline 582 & $\begin{array}{l}\text { Tomifobla Rivor at Butterfield co. dam, at Rook } \\
\text { Inlend, Queboes }\end{array}$ & 58.0 & -- & Hov ember 1927 & 8,700 & 150 & - & - & 2,630 & 43.6 & Do. \\
\hline
\end{tabular}

og At formor site near milton, Vt., drainage area 723 square miles. 


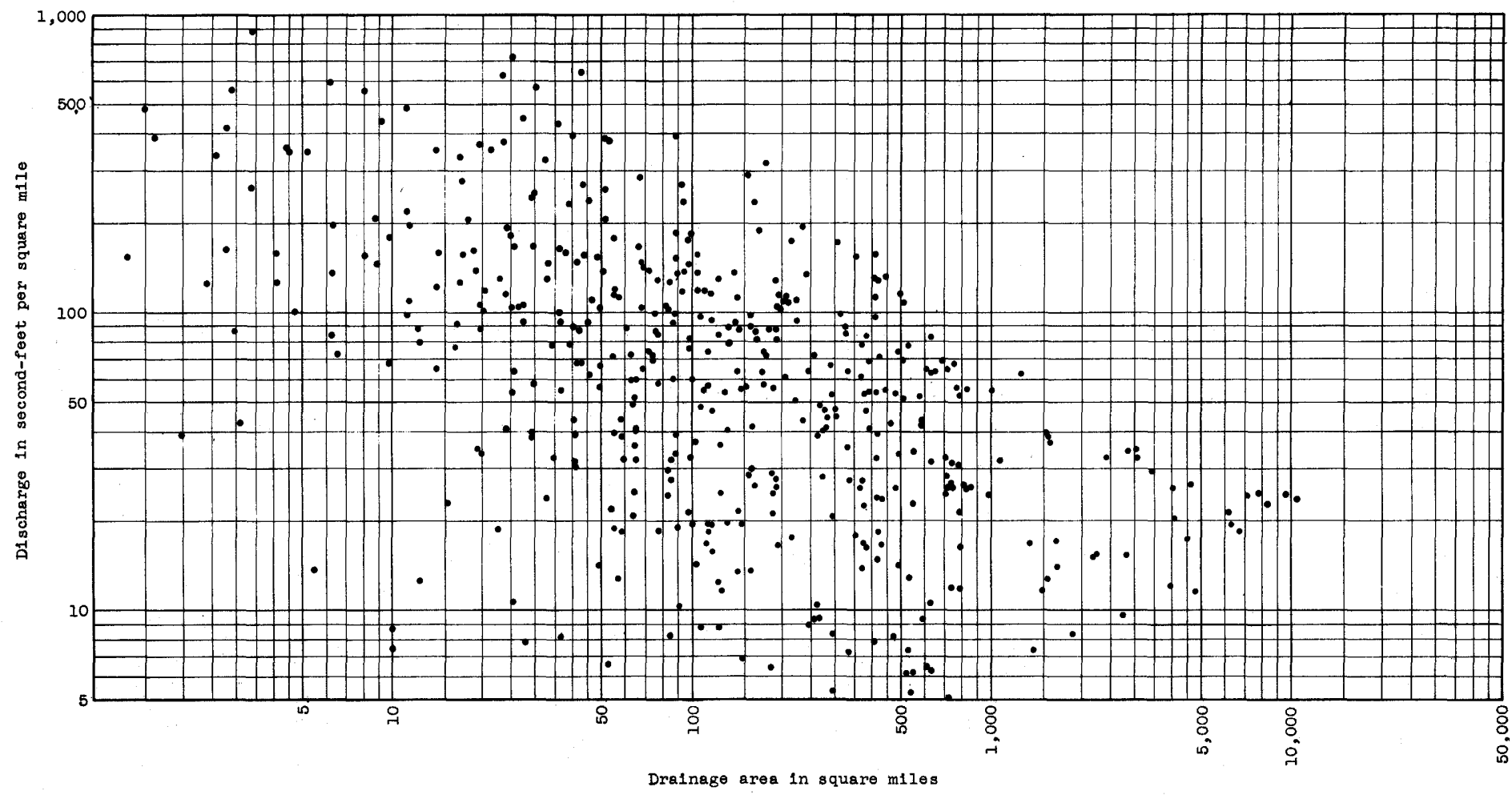

Figure 41.--Chart showing flood discharges, in second-feet per square mile, for numerous drainage areas as given in table 10 . 


\section{Scope and Utility}

Basic information on storage and discussion of the effect of storage on flood mu-off are presented in the section "Stages and discharges at stream-gaging stations during the flood period." Treatment of the subject In this section is limited to a brief discussion of some of the outstandIng examples of storage regulation and to an outline of available storage facilities in some of the river basins.

The development of storage reservolrs has been general throughout the region covered by this report, first in connection with the use of water for industrial purposes, later in connection with municipal water supply and with hydroelectric power systems, and more recently in some basins primarliy for flood control. These storage reservolrs, both natural and artificlal, contributed measurably to the lowering of flood peaks in September 1938 below what they would otherwise have been.

Records of storage operations are included in this report insofar as they are available. Reference is made to the notes on upstream storage under the "remarks" paragraph accompanying each station record. Special efforts have been made to incorporate all records of storage for all of the larger reservolrs. There was, of course, storage in many small reservolrs, lakes, and ponds of which no records are available. These reservoirs probably did not have any appreciable influence individually on flood behavior although collectively they may have had a measurable effect. In basins where such reservoirs are situated, a statement is given in the station descriptions that the flood run-off is not materially affected by storage or that it is affected by unregulated storage in several lakes and ponds. Many lakes and ponds in New England have been controlled in the past for storage for small mill operation or for recreational purposes by building dams across the outlet streams. Some of the dams have no control works and others have gates of varlous kinds, sometimes used and sometimes not used. Under these circumstances it is a question whether the storage may be termed artificial, semiartificial, or natural. Many of the dams are so old that any "artificial" effect is now accepted as "natural" by the riparian owners downstream. However, the effect is not natural in the strictest sense of the term as the lakes and ponds are capable of withholding more water then in their naturel state of perhaps a century or more ago. The fact that there is sometimes considerable storage in such lakes and 
ponds is demonstrated by the discharge record of Hop River at Columbia, Conn., by which it may be shown that there is a decided "mump" on the recession side of the flood hydrograph caused by the breaking of the dam at Holton Lake (Willimantic Reservoir on topographic maps of the Geological Survey).

During great floods these ponds and lakes rapidly $f 111$ up and generally are discharging freely at the highest stages. It seems probable that this storage is not greatiy in excess of the storage that would have accumulated in the natural state of the pond or lake when there were no dams at the outlets. Except during the early stages of a flood it is generally considered that these ponds and lakes have very little "artificial" effect.

\section{Merrimack River Basin}

Records of storage in lakes in the Merrimack River Basin are available only for Lake Winnipesaukee, althoygh appreclable storage exists in several other lakes, notably Newfound, Squam, and Winnisquam Lakes. Although the rainfall was considerably less over the Lake Winnipesaukee Basin than over the basins farther west, the records may be cited as an index to the effect of storage in reducing peak flows at points downstream.

Control works built about 1845 in the outlet of Lake Winnipesaukeo at Lakeport, N. H., permit the use of about 7,000,000,000 cubic feet of the storage by lowering the water surface of the lake 44 inches below the full regulation level.

During the flood of September 1938 storage of water in Lake Winnipesaukee began on September 17 and continued through September 23. DurIng this period 1,257,000,000 eubic feet of water was stored, which is equivalent to 1.49 Inches over the entire basin of 363 square miles above Lakeport, N. H. During the peak days September 21 and 22 water was stored in the lake at an average rate of 5,700 second-feet. Records indicate that had this water been released naturally it would have reached the Pemigewasset River synchronously with the maximum flow of that stream to produce greater mean daily flows at points dowstream. During the 14-day interval September 17-30, the average rate of storage in Lake Winnipesaukee was equivalent to 860 second-feet or 6.7 percent of the mean discharge of the Merrimack River at Franklin Junction, N. H., or 2.3 percent of the discharge at Lowell, Mass., during the same period. 


\section{Connecticut River Basin}

Soon after the beginning of the storm, the rivers began to rise, and as the rivers were deepening and widening in response to the increased demands upon their capacity, the volume of water in the channels: of the streams and over adjacent flood plains was also increasing. With respect to downstream points such volume was effective in reducing peak rates of flow, because at the downstream points the average rate of flow during any interval is less than it might otherwise have been by the average rate of increase in the total upstream storage during the same interval, whether the storage is in the natural channels of flow, over their associated flood plains, or otherwise.

Study has been made of volume of storage in the Connecticut River Besin during the floods of September 1938 with the object of demonstrating its influence on flood behevior. Three evaluations of the rolumes of storage during the flood were made; first, the amount of channel and artificial storage in the entire basin above Hartford, Conn., at 6-hour intervals, second, the storage in the main channel of the Connecticut River at the end of each calendar day, and third, the storage in the principal artificial reservolrs.

The total storage in the Connecticut River Basin has been determined by the comparison of the measured discharge at Hartford, with a derived graph of average inflow into the upstream channel system. These graphs are shown in the upper part of figure 42. The hydrograph of channel inflow has been derived by the following method.

It was considered that the hydrographs of discharge of the small flashy unregulated streams are nearly representative of channel inflow conditions, and the hydrographs of these streams are adjusted, even approximately, for the relatively small volume of storage in thelr channels, a still closer approach to the regimen of inflor may be obtained. Accordingly, the following $s 1 x$ unregulated streams in the Connecticut River Besin were selected as representative of the distribution of the Inflow into the channel system: White River near Bethel, vt., Ottauquechee River at North Hartland, Vt., Otter Brook near Keene, N. H., Black River at North Springfield, Vt., Priest Brook at Winchendon, Mass., and Burlington Brook near Burlington, Conn. The discharge hydrographs of these streams were adjusted for channel storage through the application to the observed hydrograph of discharge-storage curves derived according 


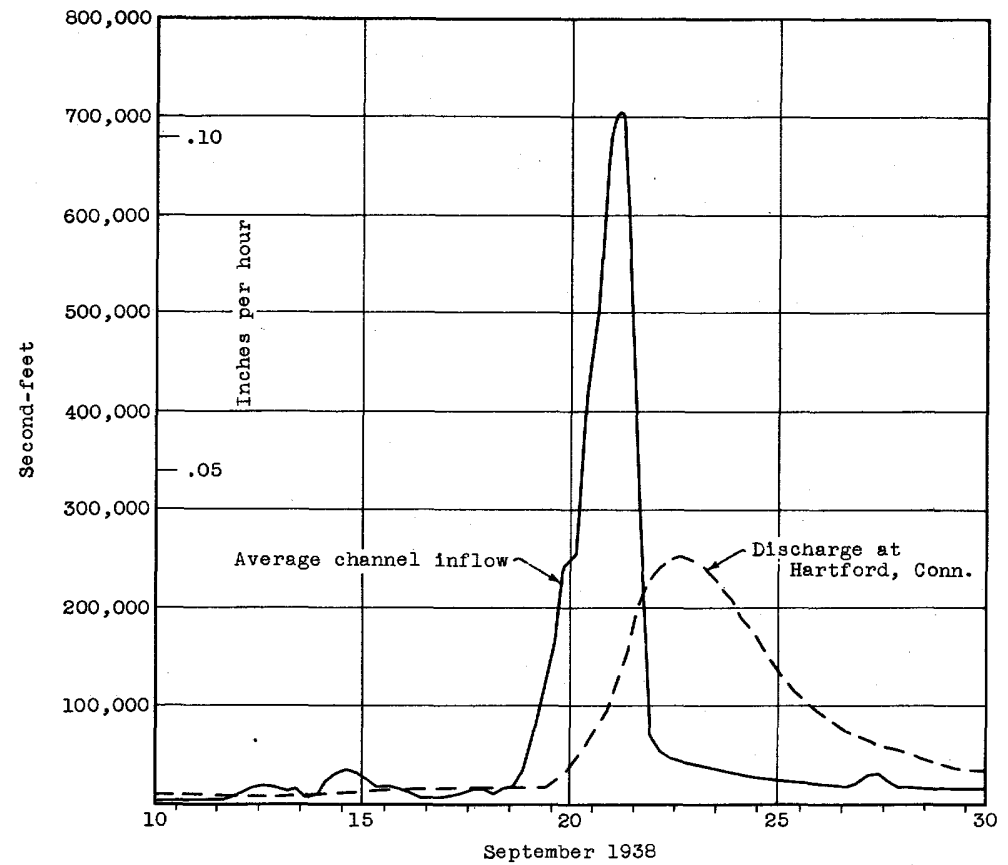

Hydrograph of average inflow into the channels of the Connecticut River Basin, and hydrograph of discharge at Hartford, Conn.

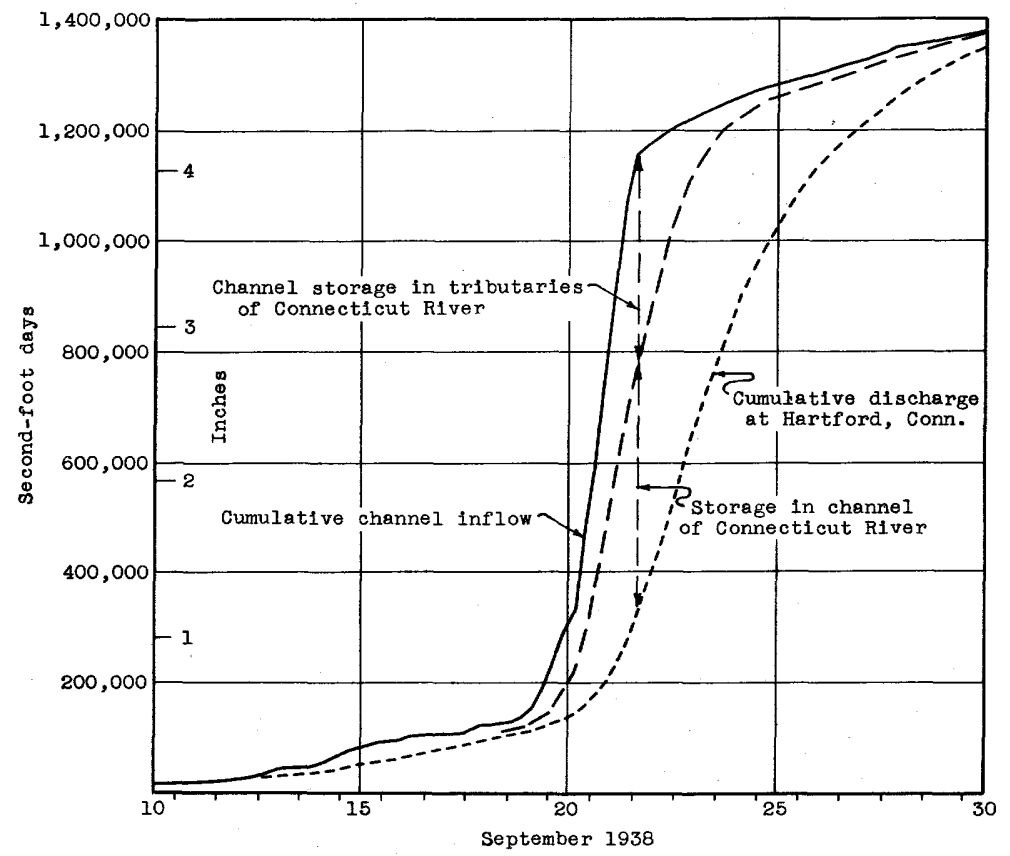

Cumulative inflow into the channels of the Connecticut River Basin and cumulative discharge at Hartford, Conn.; volume of storage in the entire channel system and storage in main channel of the Connecticut River.

F1gure 42.--Channel storage in the Connecticut River Basin. 
to methods described by Horton?/ The hydrographs were then converted to flow in terms of second-feet per square mile and the $\mathrm{six}$ results were averaged, so as to give equal weight to each as a sample of inflow conditions in its region irrespective of the size of its drainage area. The ordinates of the average hydrograph so computed were multiplied by a factor so that the enclosed volume was equivalent to the total volume of flood run-off of the Connecticut River at Hartford, Conn. The resulting hydrograph is shown on figure 42 together with the discharge hydrograph of the Connecticut River at Hartford. The peak inflow shown on the graph 1s about 700,000 second-feet, about 2.75 times as great as the peak outflow at Hartford. This reduction shows the effect of storage, the greater part of which is in the channel system. The peak rate of inflow thus determined is, of course, not the total of all the maximum instaneous inflow rates into the channel whlch may have occurred at somewhat different times and whose average would be much greater, but rather the maximum simultaneous inflow to the channel system.

The lower part of figure 42 presents the cumulative inflow into the upstream channels based on the hydrograph in the upper part of the figure and a graph of cumulative outflow at Hartford. The difference between the two graphs at any given time represents the volume of storage. The maximum storage occurred at about $6 \mathrm{a} . \mathrm{m}$. on September 22 when there was about $71,000,000,000$ cubic feet of storage, equivalent to an average depth of 2.90 inches over the basin, or about 72 percent of the total direct mun-off associated with the storm of september 17-21.

Figure 42 also shows the storage in the main channel of the Connecticut River in relation to the storage in the entire basin. The storage in the main river channel was computed by the use of diagrams derived by study of measured inflow to and the outflow from reaches of the river between the river-measurement stations, with allowance for unmeasured inflow.

The storage at $12 \mathrm{p} . \mathrm{m}$. on September 22 was about $45,000,000,000$ cubic feet, equivalent to 1.85 inches over the basin above Hartford and about 45 percent of the total direct run-off associated with the storm of September 17-21, and 64 percent of the maximum total storage in the entire basin. The Corps of Engineers, United States Army, reported that during the flood of March 1936 there was a total volume of about $74,000,000,000$ cuble feet of storage in the valley of the Connecticut River, which was

7/ Horton, R. E., Natural stream channel storage: Am. Geophys. Union Trans., pt. 2, July 1936, pp. 406-15. 
more than 40 percent of the total flood mun-off. Obviously any studies of flood behavior and the effect of potential reservoir storage mast be based on thorough knomledge of the action of channel storage.

There are 12 reservolrs and pondage in the Connecticut River Basin with a combined capacity of $19,260,000,000$ cubic feet for which records of contents during the floods are available and are included in this report. Although storage in these reservolrs is maintalned by various agencles primarily to provide for the economical use of the stream flow for power or water supply, they also efford flood control to the extent that the flood waters are retarded in their passage domstream. Thus the storage in two reservolis and one pondage above white River Junction, vt., at 12 p.m., September 21, when river stages were near their peak, was $260,000,000$ cubic feet in excess of the storage at $12 \mathrm{p} . \mathrm{m} .$, September 16. At 12 p.m., September 22, four reservolrs between White River Junction and Montague C1ty contained $2,600,000,000$ cubic feet of water and at the same time the five reservolrs between Montague City and Hartford contained $1,300,000,000$ cub1c feet in excess of their storage on September 16. The total detention in artificial reservoirs in the basin between $12 \mathrm{p.m}$. September 16, and 12 p.m. September 22, was 4,150,000,000 cuble feet wh1ch, although equivalent to only 0.17 inch over the basin, contributed messurably to the reduction of flood helghts during the critical perlod. The total detention of such reservoirs between September 16 and 30 was $30,500,000,000$ cublc feet, equivalent to 2,500 second-feet, or 2.7 percent of the average discharge of the Connecticut River at Hartford during the same 14-day period.

\section{Hudson R1ver Basin}

Table 11 shows the reservolrs in the Hudson River Basin in New York for which records of operation are included in this report.

The greatest regulation of the flood water in the Hudson River Basin was provided by the Sacandaga Reservolr above Conklingville, H. Y., which affected the Sacandaga River and the upper Hudson River below the mouth of the Sacandaga River, and the Schoharie Reservoir, which affected Schoharie Creok and the lower Mohawk River. During september 21 and 22 , the 2 days of maximu flow, the Sacandaga Reservoir stored $1,560,000,000$ and 1,710,000,000 cubic feet, respectively. On the same days the schoharie Reservolr stored $1,540,000,000$ and $640,000,000$ cublc feet, respectively. Between September 18 and 29 the average flow of the river below these 
reservolrs was reduced by 4,200 second-feet and 2,900 second-feet respectively. The total average reduction effected by the Sacandaga and Schoharle Reservolrs between September 18 and 29 was 5,000 second-feet, equivalent to 23 percent of the mean flow at Mechanicville. The reduction effected by the four reservoirs in the Mohawk River Basin averaged 4,600 second-feet for the same period, which was 22 percent of the mean flow at Cohoes, N. $Y$.

Table 1l.--Summary of storage, in millions of cubic feet, in reservoirs in the Hudson River Basin

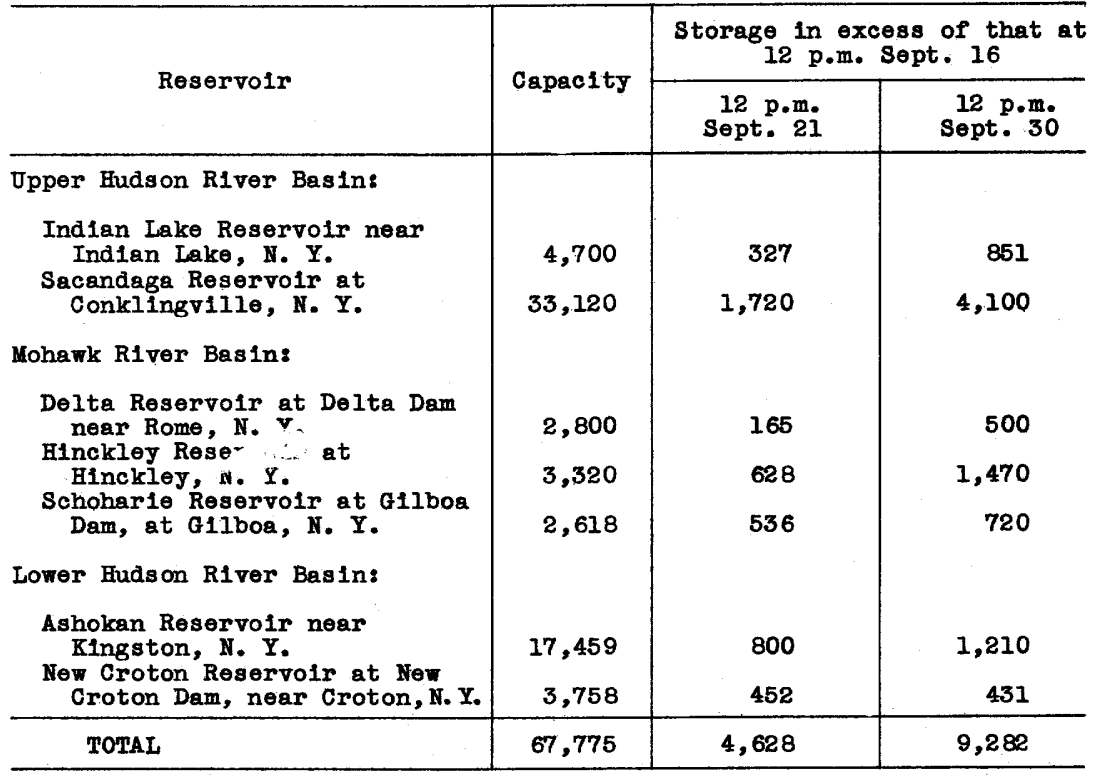

These findings indicate that these reservoirs produced significant lowering of the flood heights and consequent savings in damage to property. They point to a valuable incidental service rendered by these reservolrs, all of which serve other primary functions.

\section{Fastern Hew Jersey basins}

The Passaic River Basin contains appreciable volumes of channel storage over the low-1ying lands between the Watchung Ridges of central New Jersey. No computation has been made of the amount of such natural storage. Artificial storage of $6,814,000,000$ cublc feet has been developed. in this basin in the reservolrs listed in table 12 essentlally for muicipal water supply. Records of operations at these reservolrs are included in this report. 
The total storage in these reservolrs between September 16 and 30 was $568,000,000$ cubic feet, the equivalent of a mean reduction in flow of 470 second-feet or about 11 percent of the mean discharge at Paterson, N. J., during the 14-day period.

Table 12.--summary of storage, in millions of cuble feet, in reservolrs in the Passalc River Basin

\begin{tabular}{|c|c|c|c|}
\hline \multirow{2}{*}{ Reservolr } & \multirow{2}{*}{ Capacity } & \multicolumn{2}{|c|}{$\begin{array}{l}\text { Storage in excess of that at } \\
12 \text { p.m. Sept. } 16\end{array}$} \\
\hline & & $\begin{array}{l}12 \mathrm{p} \cdot \mathrm{m} \\
\text { sept. }\end{array}$ & $\begin{array}{l}12 \mathrm{p} \cdot \mathrm{m} \\
\text { Sept. }\end{array}$ \\
\hline $\begin{array}{l}\text { Boonton Reservolr at } \\
\text { Boonton, N. J. }\end{array}$ & 870 & 118 & 97 \\
\hline $\begin{array}{l}\text { Greenwood Lake at the } \\
\text { Glens, N. J. }\end{array}$ & 919 & 136 & 32 \\
\hline $\begin{array}{l}\text { Wanaque Reservolr at } \\
\text { Wanaque, N. J. }\end{array}$ & 3,476 & 232 & 331 \\
\hline $\begin{array}{l}\text { Oak Ridge Reservoir at } \\
\text { Oak Ridge, N. J. }\end{array}$ & 532 & 27 & 14 \\
\hline $\begin{array}{l}\text { Canistear Reservoir near } \\
\text { Stockholm, N. J. }\end{array}$ & 322 & 5 & 2 \\
\hline $\begin{array}{l}\text { Clinton Reservoir near } \\
\text { Newfoundland, } \mathrm{N} . \mathrm{J} \text {. }\end{array}$ & 470 & 32 & 51 \\
\hline $\begin{array}{l}\text { Echo Lake Reservolr near } \\
\text { Charlotteburg, N. J. }\end{array}$ & 225 & 16 & 41 \\
\hline TOTAL & 6,814 & 566 & 568 \\
\hline
\end{tabular}

The only storage reservoir in the Raritan River Basin was Lake Carnegie at Princeton, N. J., which effected only slight regulation of the lower Millstone River. At peak stage Kingston Dam, which impounds the water in Lake Carnegle, was substantially drowned out, and the lake levels rose and fell with those of the river downstream.

Oradell Reservolr at Oradell, N. J., and Woodcliff Lake at Hillsdale, H. J., In the Hackensack River Basin are both operated for municipal water supply needs. The effect of storage in these reservoirs on flood heights downstream was not appreciable.

\section{St. Lawrence River Basin}

In the Winooski River Basin are three flood-control reservoirs constructed in 1935-1938 by the Corps of Engineers, United States Army. The operation of these reservolrs under flood conditions in March 1936 is described by curran 8 - Based on reservoir records included in this report, It has been computed that during the floods of September 1938 the three

8/ Curran, C. D., Spring floods test Winooski flood-control system: Eng. News-Record, pp. 510-513, Oct: 8, 1936. 
reservolrs reduced the daily rates of flow as indicated in table 13. The manner in which these reservoirs operated during the flood can be illustrated by constructing hydrographs of observed and computed natural flow for each reservolr from data given in the section "Stages and discharges at stream-gaging stations during the flood period."

Table 13.--Summary of storage data for reservolrs in Winoosk1 River Basin

\begin{tabular}{|c|c|c|c|c|c|}
\hline \multirow{3}{*}{ Reservolr } & \multirow{3}{*}{$\begin{array}{l}\text { Capacity } \\
\text { (millions } \\
\text { of cubic } \\
\text { feot) }\end{array}$} & \multirow{2}{*}{\multicolumn{2}{|c|}{$\begin{array}{l}\text { Maximum contents } \\
\text { during flood }\end{array}$}} & \multicolumn{2}{|c|}{ Maximum daily } \\
\hline & & & & \multirow{2}{*}{$\begin{array}{l}\text { Computed } \\
\text { inflow } \\
\text { (second- } \\
\text { feet) }\end{array}$} & \multirow{2}{*}{$\begin{array}{c}\text { Observed } \\
\text { outflow } \\
\text { (second- } \\
\text { feet) }\end{array}$} \\
\hline & & $\begin{array}{c}\text { Millions } \\
\text { of cuble } \\
\text { feet }\end{array}$ & $\begin{array}{l}\text { inches } \\
\text { over } \\
\text { basin }\end{array}$ & & \\
\hline East Barre Detention & 523 & 101 & 1.35 & 1,080 & 382 \\
\hline Vrightsville Detention & 893 & 267 & 1.73 & 2,340 & 725 \\
\hline Waterbury & 2,807 & 491 & 1.94 & 3,901 & 694 \\
\hline
\end{tabular}

\section{RAINFAIL AND RUN-OFF STUDIES}

\section{Methods of analysis}

To a very considerable extent the satisfactory solution of the flood problems in any drainage basin depends on an understanding of the relations between rainfall and run-off in that basin. With the objective of advancing such understanding the significant features of rainfall and run-off during the floods of September 1938 are presented and analyzed in this report. The plan of study was first, to determine the mean areal precipitation over the respective areas tributary to the river-measurement stations within the flood area; second, to determine the flood run-off directIf attributable to such precipitation; and finally, to compare the precipitation with its associated direct run-off.

As explained in the section on meteorologic and hydrologic conditions, the total storm period comprised two distinct storm or rainfall periods. The first or antecedent period included the rains between september 12 and 16, and the second--the major storm period--included the heavy rains of September 17-21. Rainfall subsequent to September 21 has not been considered except to the small extent indicated later in this section. The first step was the preparation of isohyetal maps based on all available records as listed in tables 4 and 5 (pp. 46-61). The amounts of precipitation measured at the respective gages during the first or antecedent perlod have been plotted in their proper locations on 1:1,000,000 scale base maps of the Geological Survey and lines of equal precipitation drawn to conform as closely as practicable to the plotted points. The map thus prepared hes been reduced for publication in figure 2 on page 9 . 
The total precipitation measured and reported during the period September 17-2l was similarly treated. The total amounts listed in tables 4 PGE $F G$ and 5 were appropriately plotted on 1:500,000 scale maps and lines of equal precipitation drawn so as to conform with the plotted points, giving some attention to storm characteristics and influence of altitude as developed by the records. The map has been reduced to $1: 1,000,000$ scale for purposes of detalled study and appears as plate ip pockef. shown on a smaller scale in figure 3 for ready comparison with that for other periods shown in associated figures on the same scale.

The areas between isohyetal Iines on the original base map were measured by planimeter for all the drainage basins above each rivermeasurement station for which flood records were avaliable. The results of the determinations of mean precipitation are shown in table 14 for $4 \mathrm{fach}$ basin during the two selected periods.

The direct run-off associated with each storm perlod as given in page 424

table 14 was computed by the following procedure, which was based on records of discharge at the gaging stations as published in this report. page 427

Figure 43 is a discharge hydrograph of Black River at North Springfield, Vt., that illustrates the typical stream behavior in this region prior to and during the floods. On September 11, most streams were at low stage as at $A$ on this flgure. As a result of the rains of September 12-16 river levels generally rose moderately to two minor peaks $B$ associated with rains of September 13 and 15 respectively. On September 16 when there was no rain and during the light rains of September 17 and 18 the streams receded as shown in figure 43 to point $\mathrm{C}$. During the heavy rains of late September 18 or early September 19, the streams rose steadily and culminated in peak $D$, which on the tributary streams occurred during the afternoon or evening of September 2l. On some of the smaller streams in Connecticut and Massachusetts the peaks occurred durIng the morning of September 21. On the larger streams the peak occurred later in accordance with the characteristics of concentration.

After the abrupt cessation of rainfall later on September 21, the streams receded along the recession curve DEF, with a small rise on September 27 associated with some light rains on that day, which are not analyzed in this study.

As shown in figure 4 (p. 11), light rain fell in central New York September 22-24 after the cessation of the main storm and while the streams in that area were receding. Inasmuch as the direct run-off from these 
rains was not readily separable from that associated with the main storm period, the rainfall of September 22-24 in these areas, mainiy in the Mohawk River Basin, was added to that of the main period.

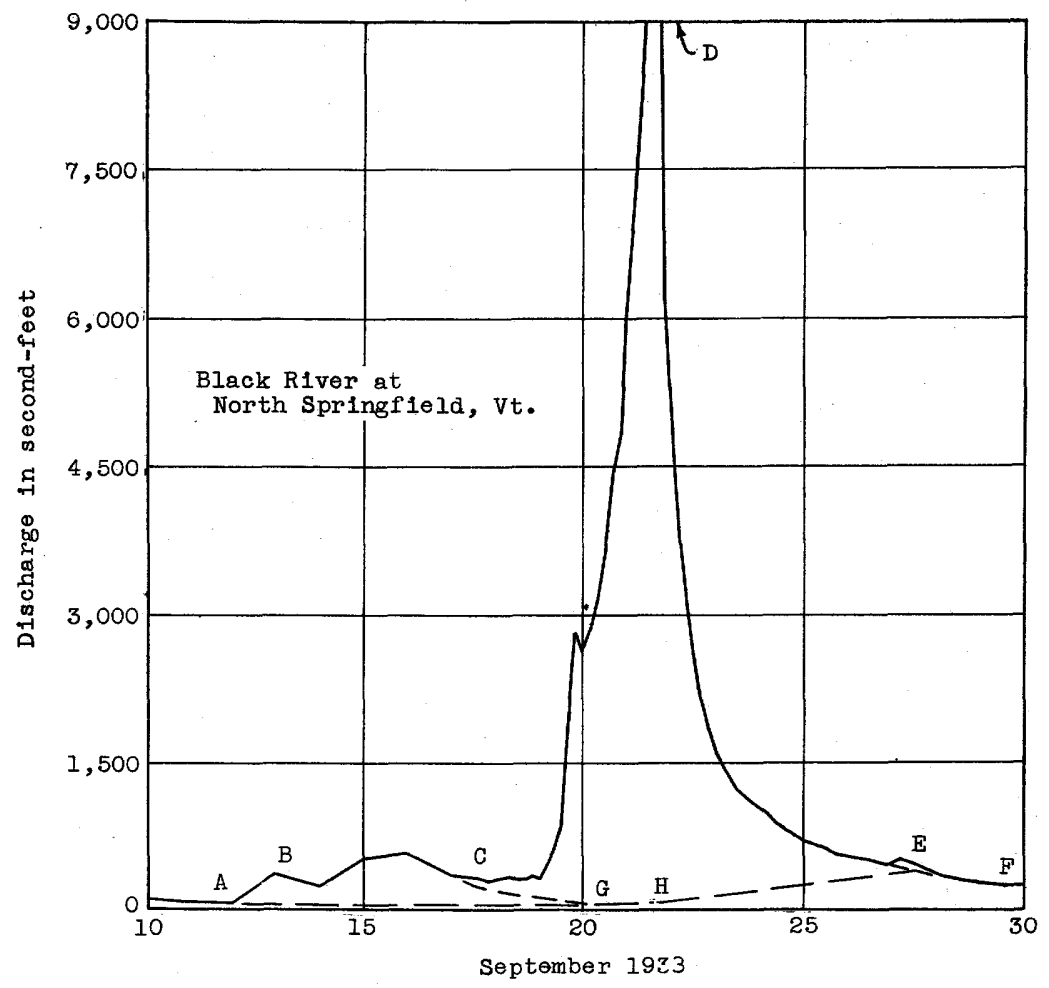

Figure 43.--Method of analyses used in determining the direct run-off associated with the rains of September $12-16$ and $17-21,1938$.

The total area under the hydrograph represents the run-off that reached the stream channels both as surface and as ground water run-off resulting from the storm precipitation, plus the run-off that would have been maintained if there had been no increment of supply after September 11. The increase in stream flow directly attributable to the rains between September 12 and 21 has been estimated by making an approximation of the position of the line AGHE on the graph, the area below which representing ground water flow, and assuming that the area above that line represents the increment in stream flow resulting from the direct runoff associated with the precipitation that occurred after september 11. The area above line AGHE is believed to include essentially all the surface run-off resulting from the storm precipitation and may include some ground water that was discharged into stream channels with a promptness 
approaching that of the surface run-off. This increment has been further analyzed to show, within reasonable limits, the run-off directly attributable to the precipitation during each storm period. This analysis has involved an estimation of the short recession curve GG. It follows that the area $A B C G$ represents the direct run-off resulting from the rains of the antecedent period September 12-16, and the area CDEHC represents the direct run-off resulting from the major storm period september 17-21.

For the computation of direct run-off all discharge records have been adjusted for the effects of artificial storage of those reservoirs or lakes for which records of storage operation are included in this report. Some storage exists for which no records are avallable, and therefore the data given in table 14 may be in error to the extent of such unadjusted storage. The adjustments have been made on a daily basis. For those river-measurement stations that are situated immediately below storage reservoirs the dally discharge has been adjusted for the contemporaneous change in storage; that is, the midnight to midnight gain or loss in storage has been applied algebraically to the measured mean discharge during the intervening calendar day. Where appreciable distance intervened between the place of storage and the river-measurement station, the daily changes in artificial storage were apportioned to the downstream gaging station over a period and in dally amounts estimated to conform to the natural regimen of the stream.

An important characteristic of flood run-off is the degree to which It is concentrated with respect to time. The concentration may be conveniently evaluated in the form of a ratio between discharge during a se- $f$ in lected short interval of time and the discharge during the flood period. The last column of table 14 lists the ratio between the run-off during the maximum 24 hours and the total run-off associated with the rains of September 17-24. The factors that are believed to be of greatest influence upon these concentration ratios are as follows: duration and intensity of storm, direction of storm movement, channel characteristics, and shape and slope of drainage basin. As the characteristics of the September 17-21 storm were fairly uniform over the entire area variations In the concentration ratio between different basins may be largely ascribed to the inherent basin characteristics. Reference to these concentration ratios is made in the discussions of rainfall and run-off relations in the several major basins. 227 พ0T $0-40-28$ 
Fable 14.--Preolpitation and associated ran-off of floods of September 1938

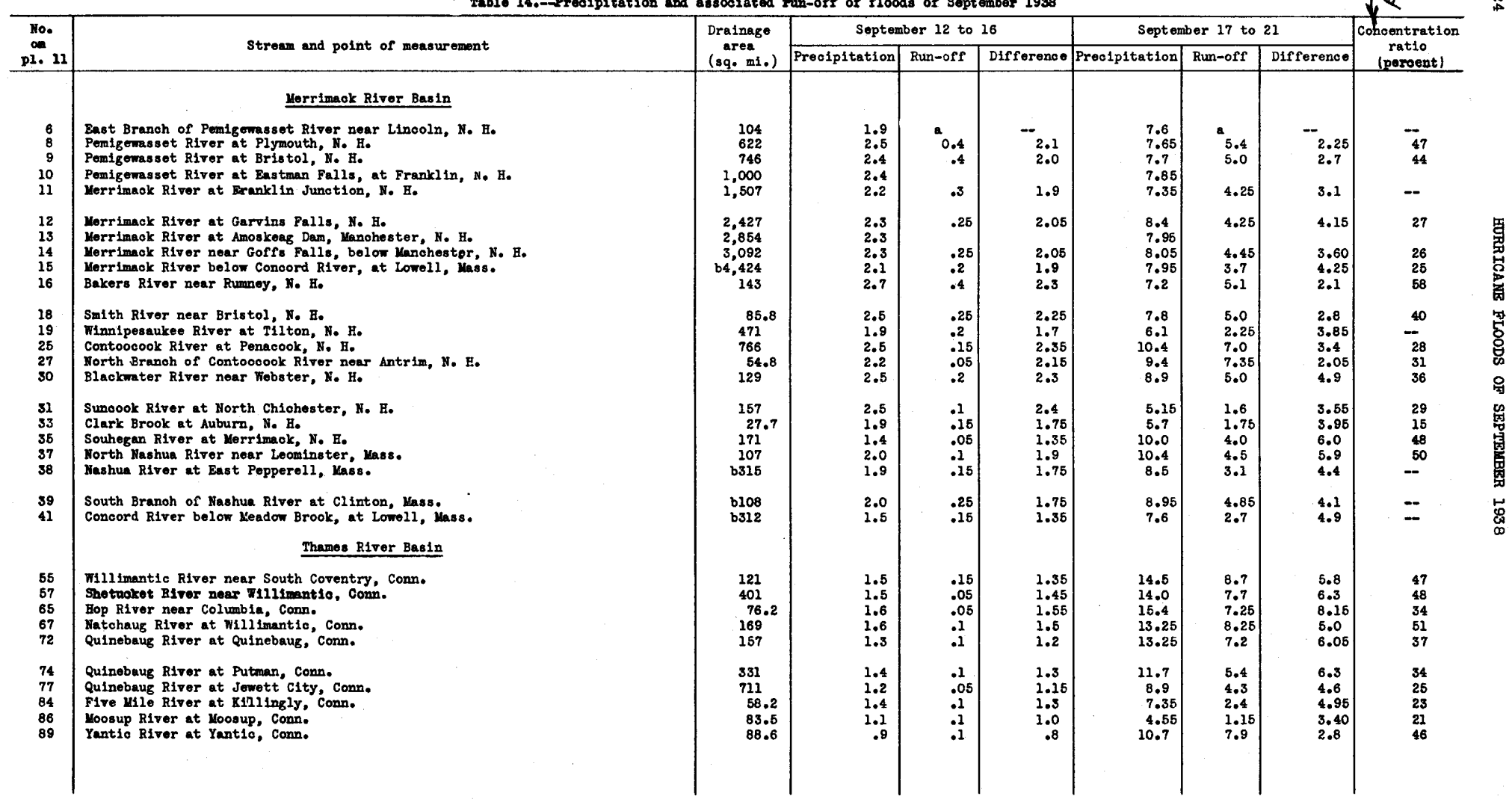


Connooticut River at First Conneoticut Lake, near Pittsburg, N. B. Connecticut River at North Stratford, N, B.

Conneoticut River near Dalton, No H.

connectiout R1ver at outlet of Fifteenmile Falls Reservo1r, near Barnet, Vt. Conneotiout River at Mo Indoes Falls, Vt.

Connecticut River at South Newbury, Vt.

Connecticut River at White River Junotion, Vt.

Connecticut River at Vernon, Vt.

Comnecticut River at Yontegue C1ty, hase.

Connectiout River at Holyoke, Mass.

Connectiout River at Springfield, Kass.

Comnectiout River at Thompsonville, Conn.

Connecticut River at Bartford, Conn.
Passumpsio River at Passumpsic, Vt.

Yoose River at St. Johnsbury, vt.

Amnonoosuc River near Bath, H. Bo

mite River at Piest Bartford, vt.

Mascona Piver at Yasoome,

Ottauqueohoe River at North Hartland, Vt.

Sugar River at Wost Claremont, N. B.

Black River at Worth Springfield, vt.

Wost River at Newfane, Vt,
Ashuelot River near Gilsum, No Ho

Ashuelot River at Hinsdale, $\mathrm{N}$. $\mathrm{B}$

otter Brook near Ileene, No. Eo

at Webb, near Karlboro, Y. $_{\text {. }}$

Miliers Rivor noar minchend on, Hass.

S1p Pond Brook near winchendon, Mass.

Priest Brook near Winchendon, Mass.

Bast Branch of Tully River near Athol, Lass.

Deerfield River at outlet of Harriman Reservoir, at Davis Bridge, vt.

Doerfield River at Charlemont, Mass.

East Branch of Deerfield River at outlet of Somerset Reservoir, near Somerset,

Ware River at Cold Brook, Mass.

Chicopee River at Bircham Bend, wass. 


\begin{tabular}{|c|c|c|c|c|c|c|c|c|c|}
\hline \multirow{2}{*}{\begin{tabular}{c|c|} 
No. \\
on \\
pl. 11
\end{tabular}} & \multirow{2}{*}{ Stroam and point of measurement } & \multirow{2}{*}{$\begin{array}{l}\text { Drainage } \\
\text { (sagea } \\
\text { (si.). }\end{array}$} & \multicolumn{3}{|c|}{ September 12 to 16} & \multicolumn{3}{|c|}{ September 17 to 21} & \multirow{2}{*}{$\begin{array}{c}\text { concentration } \\
\text { ratio } \\
\text { (reroont) }\end{array}$} \\
\hline & & & Precipitation & Run-off & \begin{tabular}{|l|} 
Differenoe \\
\end{tabular} & Precipitation & \begin{tabular}{|l|} 
Run-off \\
\end{tabular} & Differenoe & \\
\hline & Conneotiout R1vor Basin--Continued & & & & & & & & \\
\hline $\begin{array}{l}186 \\
187 \\
188 \\
195 \\
196\end{array}$ & 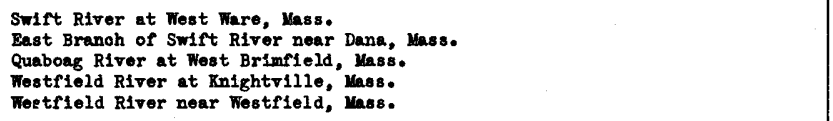 & $\begin{array}{l}186 \\
43.7 \\
151 \\
162 \\
497\end{array}$ & $\begin{array}{l}2.3 \\
1.8 \\
2.0 \\
1.5 \\
1.3\end{array}$ & $\begin{array}{c}0.15 \\
.2 \\
.2 \\
.15 \\
.1\end{array}$ & $\begin{array}{l}2.15 \\
1.6 \\
1.8 \\
1.35 \\
1.2\end{array}$ & \begin{tabular}{c|c|}
11.4 \\
11.6 \\
11.9 \\
9.75 \\
10.05
\end{tabular} & $\begin{array}{l}6.4 \\
8.45 \\
9.25 \\
5.8 \\
5.3\end{array}$ & $\begin{array}{l}5.0 \\
4.45 \\
2.65 \\
3.95 \\
4.75\end{array}$ & $\begin{array}{l}16 \\
52 \\
21 \\
35 \\
50\end{array}$ \\
\hline $\begin{array}{l}199 \\
200\end{array}$ & $\begin{array}{l}\text { Middle Branoh of Westrield River at Cooss Heights, Mass. } \\
\text { West Branoh of Westfield River at Huntington, Mass. }\end{array}$ & $\begin{array}{l}52.6 \\
93.7\end{array}$ & $\begin{array}{l}1.4 \\
1.7\end{array}$ & .1 & $\begin{array}{l}1.3 \\
1.6\end{array}$ & $\begin{array}{l}10.2 \\
10.1\end{array}$ & $\begin{array}{l}5.96 \\
5.9\end{array}$ & $\begin{array}{l}4.25 \\
4.2\end{array}$ & $\begin{array}{l}56 \\
43\end{array}$ \\
\hline 204 & $\begin{array}{l}\text { Westfield Little River at outlet of cobble Mountain Reservoir, near Westrield, } \\
\text { Hass. } \\
\text { Soantio River at Broad Brook, Conn. }\end{array}$ & 45.8 & 1.3 & .05 & 1.25 & 12.65 & $\begin{array}{l}6.8 \\
5.55\end{array}$ & 4.2 & $\ddot{38}$ \\
\hline $\begin{array}{l}207 \\
209 \\
\frac{d}{6}\end{array}$ & 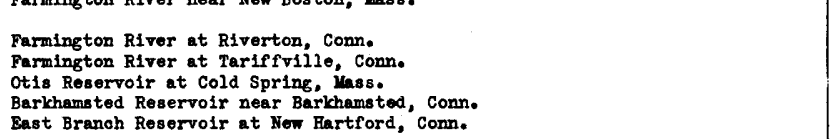 & $\begin{array}{l}216 \\
578 \\
17.2 \\
50.5 \\
61.2\end{array}$ & $\begin{array}{l}1.9 \\
1.7 \\
1.1 \\
1.8 \\
1.0 \\
1.0\end{array}$ & $a^{.15}:{ }_{11}^{.1}$ & $=\begin{array}{l}1.7 \\
1.55 \\
1.0 \\
--\end{array}$ & $\begin{array}{l}11.35 \\
10.85 \\
13.1 \\
12.25 \\
12.15\end{array}$ & $\begin{array}{l}6.5 \\
5.2 \\
6.9 \\
6.9 \\
a\end{array}$ & $=\begin{array}{l}4.85 \\
5.65 \\
--\end{array}$ & $\begin{array}{l}= \\
=\end{array}$ \\
\hline $\begin{array}{l}\frac{\%}{213} \\
214 \\
215 \\
216\end{array}$ & $\begin{array}{l}\text { Nopaug Reservolr near Collinsville, Conn. } \\
\text { Burlington Brook near Burlington, conn. } \\
\text { south Branoh of Park River at Hartford, Conn. } \\
\text { Park River at Hartford, Conn. } \\
\text { North Branch of Park Rivor at Hartford, Conn. }\end{array}$ & $\begin{array}{l}32 \\
4.1 \\
40.6 \\
74.0 \\
25.3\end{array}$ & $\begin{array}{l}.7 \\
.8 \\
.9 \\
.9 \\
.8\end{array}$ & $\begin{array}{c}0 \\
.05 \\
.05 \\
0\end{array}$ & $\begin{array}{cc}-8 \\
.85 \\
.85 \\
.8\end{array}$ & $\begin{array}{l}10.54 \\
10.1 \\
10.75 \\
10.5 \\
10.15\end{array}$ & $\begin{array}{c}a \\
3.15 \\
6.4 \\
5.35 \\
4.15\end{array}$ & $\begin{array}{c}- \\
6.95 \\
4.35 \\
5.15 \\
6.0\end{array}$ & $\begin{array}{l}- \\
-62 \\
48 \\
46 \\
46\end{array}$ \\
\hline $\begin{array}{l}217 \\
219 \\
228 \\
d \\
d\end{array}$ & 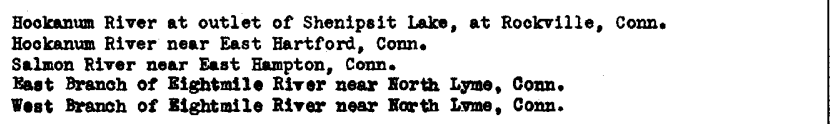 & $\begin{array}{r}16.5 \\
74.5 \\
105 \\
22.0 \\
19.2\end{array}$ & $\begin{array}{r}1.2 \\
1.1 \\
1.0 \\
.8 \\
.9\end{array}$ & $\begin{array}{c}.15 \\
.05 \\
.1 \\
.05\end{array}$ & $\begin{array}{c}-.95 \\
.95 \\
.7 \\
.85\end{array}$ & $\begin{array}{l}14.8 \\
11.7 \\
13.9 \\
11.85 \\
12.15\end{array}$ & $\begin{array}{l}9.9 \\
6.75 \\
6.8 \\
6.75 \\
7.0\end{array}$ & $\begin{array}{l}4.9 \\
7.95 \\
7.1 \\
5.1 \\
5.15\end{array}$ & $\begin{array}{l}- \\
39 \\
44 \\
42 \\
38\end{array}$ \\
\hline & Quimniplac River Basin & & & & & & & & \\
\hline 230 & $\begin{array}{l}\text { Quinnipiac River at Wallingford, Conn. } \\
\text { Housatonio River Basin }\end{array}$ & 109 & 1.7 & .1 & 1.6 & 12.05 & 4.65 & 7.4 & 35 \\
\hline $\begin{array}{l}233 \\
235 \\
237 \\
240 \\
243\end{array}$ & 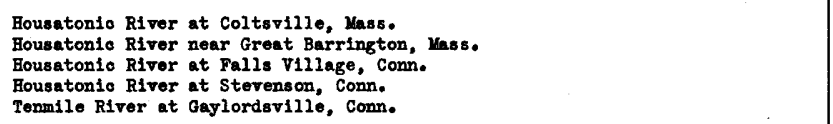 & $\begin{array}{l}57.1 \\
280 \\
632 \\
1,545 \\
204\end{array}$ & $\begin{array}{l}2.0 \\
2.2 \\
2.1 \\
1.7 \\
1.5\end{array}$ & $\begin{array}{l}.3 \\
.25 \\
.2 \\
.1 \\
0.1\end{array}$ & $\begin{array}{l}1.7 \\
1.95 \\
1.9 \\
1.6 \\
1.5\end{array}$ & $\begin{array}{l}8.4 \\
8.4 \\
8.65 \\
9.2 \\
8.45\end{array}$ & $\begin{array}{l}4.6 \\
5.05 \\
4.95 \\
5.25 \\
4.45\end{array}$ & $\begin{array}{l}3.8 \\
3.05 \\
3.7 \\
3.95 \\
4.0\end{array}$ & $\begin{array}{l}51 \\
29 \\
23 \\
23 \\
41\end{array}$ \\
\hline
\end{tabular}




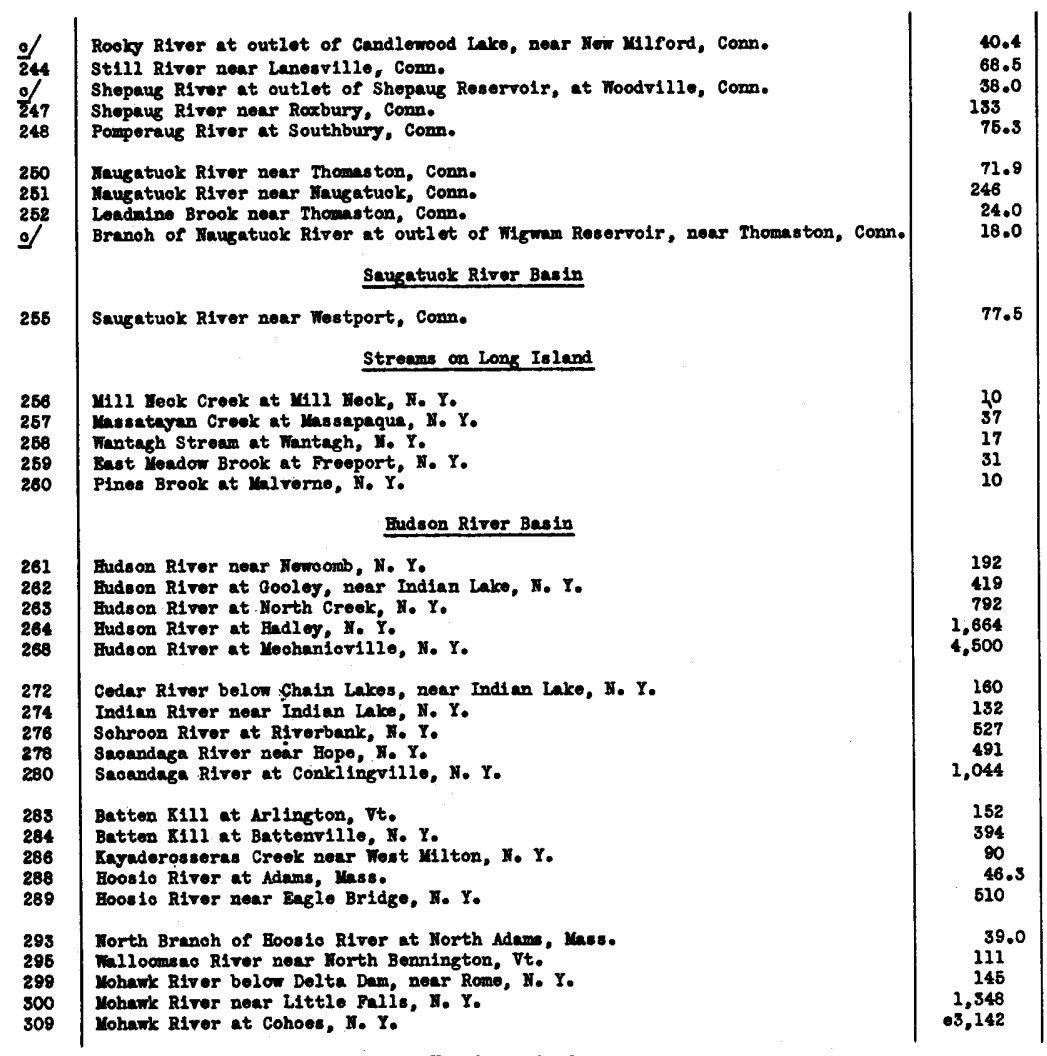

a Xot dotermined.

- Losation not shown on plate 31.

\begin{tabular}{|c|c|c|c|c|}
\hline $\begin{array}{l}1.1 \\
1.1 \\
1.3 \\
1.3 \\
1.5\end{array}$ & $\begin{array}{cc}\cdot & \\
.05 \\
.1 \\
.05 \\
.05\end{array}$ & $\begin{array}{c}--05 \\
1.05 \\
1.2 \\
1.25 \\
1.45\end{array}$ & $\begin{array}{c}9.8 \\
10.5 \\
10.85 \\
10.6 \\
9.6\end{array}$ & $\begin{array}{l}4.95 \\
4.6 \\
7.65 \\
5.7 \\
3.2\end{array}$ \\
\hline $\begin{array}{l}1.0 \\
1.2 \\
.8 \\
1.6\end{array}$ & $\begin{array}{l}0 \\
.05 \\
.05 \\
.05\end{array}$ & $\begin{array}{l}1.0 \\
1.15 \\
.75 \\
1.55\end{array}$ & $\begin{array}{l}10.95 \\
10.3 \\
10.45 \\
10.2\end{array}$ & $\begin{array}{l}5.56 \\
3.85 \\
4.25 \\
6.8\end{array}$ \\
\hline 1.6 & .05 & 1.55 & 20.95 & 4.5 \\
\hline $\begin{array}{l}.8 \\
1.0 \\
1.0 \\
1.0 \\
1.0\end{array}$ & $\begin{array}{l}0 \\
0 \\
0 \\
0 \\
0\end{array}$ & $\begin{array}{l}.8 \\
1.0 \\
1.0 \\
1.0 \\
1.0\end{array}$ & $\begin{array}{l}11.55 \\
10.85 \\
10.65 \\
11.0 \\
10.75\end{array}$ & $\begin{array}{l}.6 \\
.15 \\
.2 \\
.3 \\
.3\end{array}$ \\
\hline $\begin{array}{l}2.2 \\
2.0 \\
1.9 \\
1.8 \\
1.9\end{array}$ & $\begin{array}{l}.6 \\
.35 \\
.3 \\
.2 \\
.15\end{array}$ & $\begin{array}{l}1.6 \\
1.65 \\
1.6 \\
1.6 \\
1.75\end{array}$ & $\begin{array}{l}4.5 \\
4.5 \\
4.75 \\
5.0 \\
5.6\end{array}$ & $\begin{array}{l}3.1 \\
2.85 \\
2.8 \\
2.1 \\
2.4\end{array}$ \\
\hline $\begin{array}{l}1.6 \\
1.8 \\
1.5 \\
1.8 \\
2.0\end{array}$ & $\begin{array}{l}.15 \\
.2 \\
.05 \\
.1 \\
.15\end{array}$ & $\begin{array}{l}1.45 \\
1.6 \\
1.45 \\
1.7 \\
1.85\end{array}$ & $\begin{array}{l}4.6 \\
4.9 \\
5.1 \\
4.95 \\
5.15\end{array}$ & $\begin{array}{l}2.5 \\
2.45 \\
1.85 \\
2.5 \\
2.45\end{array}$ \\
\hline $\begin{array}{l}1.8 \\
1.8 \\
2.0 \\
1.8 \\
2.15\end{array}$ & $\begin{array}{l}.4 \\
.25 \\
.1 \\
.7 \\
.25\end{array}$ & $\begin{array}{l}1.4 \\
1.55 \\
1.9 \\
1.1 \\
1.9\end{array}$ & $\begin{array}{l}6.85 \\
6.55 \\
5.85 \\
7.7 \\
7.0\end{array}$ & $\begin{array}{l}4.1 \\
3.25 \\
1.4 \\
4.35 \\
4.4\end{array}$ \\
\hline $\begin{array}{l}2.3 \\
2.2 \\
1.7 \\
2.2 \\
1.9\end{array}$ & $\begin{array}{l}.8 \\
.45 \\
.4 \\
.25 \\
.2\end{array}$ & $\begin{array}{l}1.5 \\
1.75 \\
1.3 \\
1.96 \\
1.7\end{array}$ & $\begin{array}{r}7.75 \\
7.0 \\
\text { d3.05 } \\
d 4.45 \\
d 5.35\end{array}$ & $\begin{array}{l}6.65 \\
4.0 \\
1.6 \\
2.2 \\
2.7\end{array}$ \\
\hline
\end{tabular}

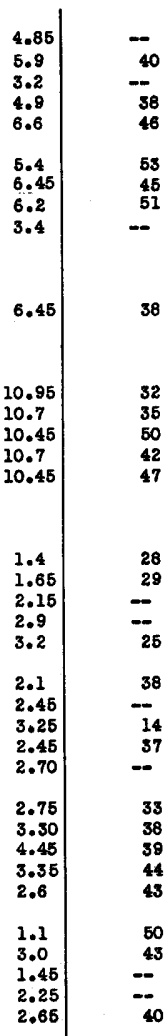

- Does not inolude dralnago area of Schoharte Creok above Gilboa Dam, at Gilboa, N. Y. 
Table 14.--Preolpitation and associated rum-off of floods of September 1938--Continued

\begin{tabular}{|c|c|c|c|c|c|c|c|c|c|}
\hline \multirow{2}{*}{$\begin{array}{l}\text { Yo. } \\
\text { on } \\
\text { p1. 11 }\end{array}$} & \multirow{2}{*}{ Stroam and point of measurement } & \multirow{2}{*}{$\begin{array}{l}\text { Drainage } \\
\text { area } \\
\text { (sq. mi.) }\end{array}$} & \multicolumn{3}{|c|}{ Sept enber 12 to 16} & \multicolumn{3}{|c|}{ September 17 to 21} & \multirow{2}{*}{$\mid \begin{array}{c}\text { Concentration } \\
\text { ratio } \\
\text { (percent) }\end{array}$} \\
\hline & & & Proolpitation & Run-off & Difference & Preolpitation & Run-off & Differenoo & \\
\hline & Budson River Basin--Continued & & & & & & & 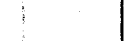 & \\
\hline $\begin{array}{l}311 \\
312 \\
314 \\
319 \\
321\end{array}$ & 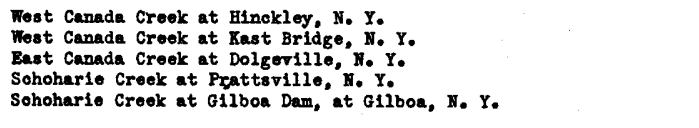 & $\begin{array}{l}375 \\
556 \\
281 \\
236 \\
314\end{array}$ & $\begin{array}{l}2.5 \\
2.5 \\
2.4 \\
1.2 \\
1.2\end{array}$ & $\begin{array}{l}0.55 \\
.5 \\
.5 \\
0 \\
0\end{array}$ & $\begin{array}{l}1.95 \\
2.0 \\
1.9 \\
1.2 \\
1.2\end{array}$ & $\begin{array}{l}\text { d4.9 } \\
d 4.8 \\
d 5.6 \\
d 7.5 \\
d 7.4\end{array}$ & $\begin{array}{l}2.85 \\
2.65 \\
3.1 \\
3.6 \\
3.7\end{array}$ & $\begin{array}{l}2.05 \\
2.15 \\
2.5 \\
3.9 \\
3.7\end{array}$ & $\begin{array}{l}-- \\
-36 \\
69 \\
--\end{array}$ \\
\hline $\begin{array}{l}322 \\
324 \\
329 \\
331 \\
332\end{array}$ & 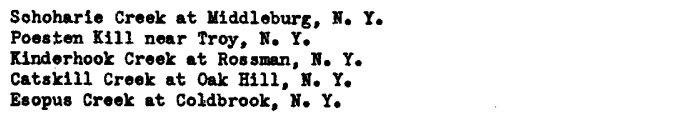 & $\begin{array}{r}2218 \\
89 \\
329 \\
98 \\
192\end{array}$ & $\begin{array}{l}1.2 \\
1.7 \\
1.7 \\
.8 \\
2.1\end{array}$ & $\begin{array}{l}0 \\
.2 \\
0.2 \\
.1\end{array}$ & $\begin{array}{l}1.2 \\
3.5 \\
1.5 \\
.8 \\
1.0\end{array}$ & $\begin{array}{c}d 5.8 \\
7.1 \\
7.5 \\
5.95 \\
6.75\end{array}$ & $\begin{array}{l}3.1 \\
6.7 \\
4.65 \\
2.45 \\
3.15\end{array}$ & \begin{tabular}{l|}
2.7 \\
.4 \\
2.85 \\
3.5 \\
3.6
\end{tabular} & $\begin{array}{r}-- \\
52 \\
41 \\
62 \\
--\end{array}$ \\
\hline $\begin{array}{l}\text { of } \\
333 \\
334 \\
335 \\
336\end{array}$ & 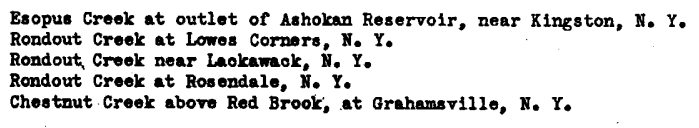 & $\begin{array}{l}257 \\
39.4 \\
100 \\
386 \\
12.2\end{array}$ & $\begin{array}{l}.9 \\
1.0 \\
1.1 \\
1.1 \\
1.2\end{array}$ & $\begin{array}{l}.05 \\
.2 \\
.05 \\
.05 \\
.05\end{array}$ & $\begin{array}{r}.85 \\
.9 \\
1.05 \\
1.05 \\
1.15\end{array}$ & $\begin{array}{l}7.0 \\
6.85 \\
6.4 \\
6.75 \\
5.9\end{array}$ & $\begin{array}{l}3.05 \\
2.85 \\
2.35 \\
2.95 \\
1.8\end{array}$ & $\begin{array}{l}3.95 \\
4.00 \\
4.05 \\
3.8 \\
4.1\end{array}$ & $\begin{array}{l}-- \\
60 \\
45 \\
45 \\
--\end{array}$ \\
\hline $\begin{array}{l}337 \\
338 \\
339 \\
340 \\
342\end{array}$ & 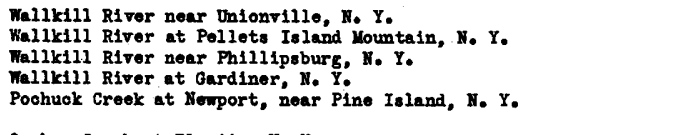 & $\begin{array}{c}144 \\
385 \\
432 \\
711 \\
98.0\end{array}$ & $\begin{array}{l}1.1 \\
1.1 \\
1.1 \\
1.1 \\
1.0\end{array}$ & $\begin{array}{l}.05 \\
.05 \\
.05 \\
.0 \\
0\end{array}$ & $\begin{array}{l}1.05 \\
1.05 \\
1.05 \\
1.1 \\
1.0\end{array}$ & $\begin{array}{l}7.65 \\
8.1 \\
8.05 \\
7.95 \\
8.75\end{array}$ & $\begin{array}{l}4.05 \\
3.45 \\
3.75 \\
3.65 \\
3.25\end{array}$ & $\begin{array}{l}3.6 \\
4.65 \\
4.3 \\
4.3 \\
5.5\end{array}$ & $\begin{array}{l}19 \\
18 \\
18 \\
23 \\
23\end{array}$ \\
\hline $\begin{array}{l}343 \\
346 \\
348 \\
350\end{array}$ & $\begin{array}{l}\text { Quaker Creek at Florida, N. Y. } \\
\text { Wappinger Croek noar Wappingor Falls, N. Y. } \\
\text { Croton River at Now Croton Dam, near Croton, N. Y. } \\
\text { Croton R1ver at Quaker Bridgo, near Croton, N. Y. } \\
\text { Haokenseok River Basin }\end{array}$ & $\begin{array}{l}9.74 \\
182 \\
377 \\
379\end{array}$ & $\begin{array}{l}1.1 \\
1.3 \\
.9 \\
.9\end{array}$ & $\begin{array}{l}0 \\
.05 \\
.1 \\
.15\end{array}$ & $\begin{array}{c}1.1 \\
1.25 \\
.8 \\
.75\end{array}$ & $\begin{array}{l}8.6 \\
7.75 \\
9.8 \\
9.8\end{array}$ & $\begin{array}{l}3.3 \\
3.9 \\
4.8 \\
4.2\end{array}$ & $\begin{array}{l}5.3 \\
3.85 \\
5.0 \\
5.6\end{array}$ & $\begin{array}{l}45 \\
44 \\
--\end{array}$ \\
\hline $\begin{array}{l}\mathbf{3 5 2} \\
\mathbf{3 5 5}\end{array}$ & $\begin{array}{l}\text { Haokenseok River at New Milford, H. J. } \\
\text { Pascaok Brook at Wostwood, H. J. } \\
\qquad \text { Passaio River Basin }\end{array}$ & ${ }_{29.6}^{113}$ & $\begin{array}{l}.7 \\
.7\end{array}$ & $\begin{array}{l}.05 \\
.05\end{array}$ & $\begin{array}{l}.65 \\
.65\end{array}$ & $\begin{array}{l}8.15 \\
7.8\end{array}$ & $\begin{array}{l}2.3 \\
2.35\end{array}$ & $\begin{array}{l}5.85 \\
5.45\end{array}$ & $=$ \\
\hline $\begin{array}{l}354 \\
355 \\
366 \\
357 \\
358\end{array}$ & $\begin{array}{l}\text { Passaic River near yillington, N. J. } \\
\text { Passaio River noar Chatham, N. J. } \\
\text { Passalo River at Paterson, N. J. } \\
\text { Rookaway River above reservoir at Boonton, N. J. } \\
\text { Rookaway River bolow reservolr at Boonton, N. J. }\end{array}$ & $\begin{array}{l}55.4 \\
100 \\
785 \\
116 \\
119\end{array}$ & $\begin{array}{l}.2 \\
.25 \\
.4 \\
.4 \\
.4\end{array}$ & $\begin{array}{l}0 \\
0 \\
0 \\
0\end{array}$ & $\begin{array}{l}.2 \\
.25 \\
.35 \\
.4 \\
.4\end{array}$ & $\begin{array}{l}8.1 \\
8.5 \\
8.1 \\
7.7 \\
7.7\end{array}$ & $\begin{array}{l}3.2 \\
3.5 \\
2.9 \\
2.5 \\
2.45\end{array}$ & \begin{tabular}{l|}
4.9 \\
5.0 \\
5.2 \\
5.2 \\
5.25
\end{tabular} & $\begin{array}{l}21 \\
16 \\
16 \\
25 \\
--\end{array}$ \\
\hline
\end{tabular}




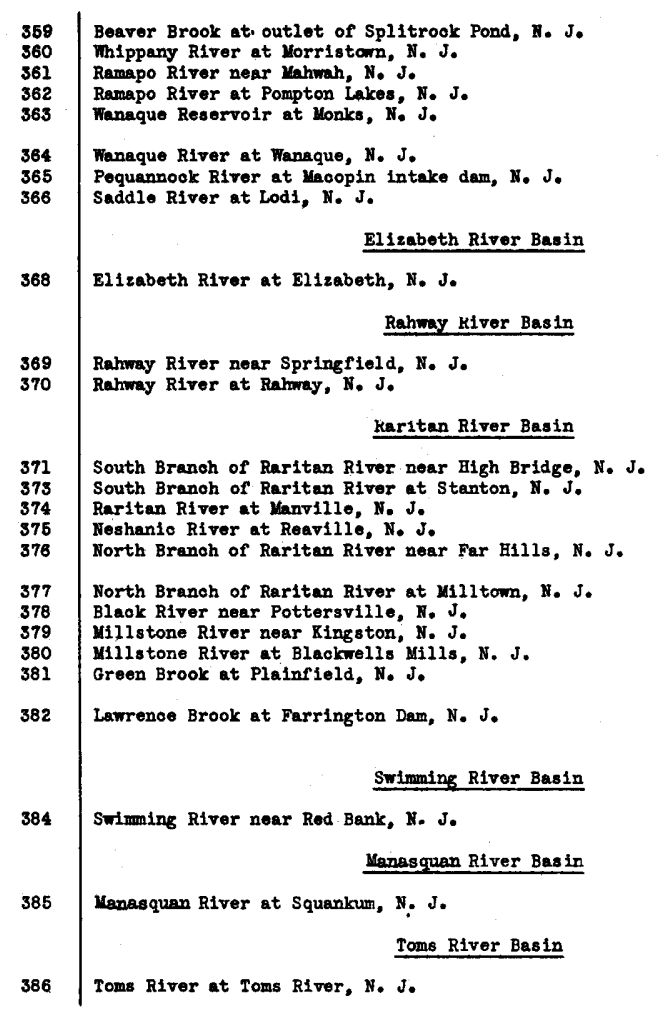

Not determined.

- Location not shown on plate 11. 
2able 14.-Preolpitation and asaool sted ron-oft of noods of September 1938-Continned

\begin{tabular}{|c|c|c|c|c|c|c|c|c|c|}
\hline \multirow{2}{*}{$\begin{array}{c}\text { Yo. } \\
\text { on } \\
\text { pi. } 21\end{array}$} & \multirow{2}{*}{ Stream and point of measurement } & \multirow{2}{*}{$\begin{array}{l}\text { Drainage } \\
\text { area } \\
\text { (sg. mi.) }\end{array}$} & \multicolumn{3}{|c|}{ September 12 to 16} & \multicolumn{3}{|c|}{ September 17 to 21} & \multirow{2}{*}{$\begin{array}{c}\text { Concentration } \\
\text { ratio } \\
\text { (peroent) }\end{array}$} \\
\hline & & & Proolp1tation & Run-off & Difference & Procipitation & Run-off & Difference & \\
\hline $\mathbf{s 8 7}$ & 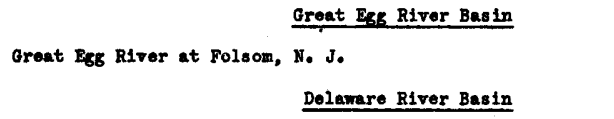 & 56.3 & 0.1 & 0 & 0.1 & 7.6 & 2.2 & 5.4 & 20 \\
\hline $\begin{array}{l}389 \\
390 \\
391 \\
393 \\
397\end{array}$ & $\begin{array}{l}\text { East Branch of Delaware River at Margaretville, N. Y. } \\
\text { East Branoh of Delaware River at Harvard, N. Y. } \\
\text { East Branoh of Delaware River at Fishs Eddy, B. Y. } \\
\text { Delaware R1ver at Port Jervis, N. Y. } \\
\text { Mill Brook at Areng, Y. Y. }\end{array}$ & $\begin{array}{r}163 \\
443 \\
783 \\
3,076 \\
25\end{array}$ & $\begin{array}{l}1.75 \\
1.5 \\
1.4 \\
1.4 \\
1.4\end{array}$ & $\begin{array}{r}.05 \\
.05 \\
.05 \\
.05\end{array}$ & $\begin{array}{r}1.7 \\
1.45 \\
1.35 \\
--3.35\end{array}$ & \begin{tabular}{l|}
6.2 \\
6.2 \\
5.95 \\
5.4 \\
6.8
\end{tabular} & $\begin{array}{l}3.65 \\
3.75 \\
3.7 \\
a^{3.3}\end{array}$ & $\begin{array}{r}2.55 \\
2.35 \\
2.25 \\
-- \\
2.5\end{array}$ & $\begin{array}{l}50 \\
49 \\
43 \\
--\end{array}$ \\
\hline $\begin{array}{l}398 \\
399 \\
400 \\
401 \\
402\end{array}$ & 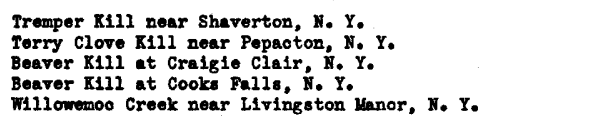 & $\begin{array}{l}33 \\
14.1 \\
82 \\
241 \\
65\end{array}$ & $\begin{array}{l}1.85 \\
1.5 \\
1.5 \\
1.3 \\
1.2\end{array}$ & $\begin{array}{l}.1 \\
.15 \\
0 \\
0 \\
.05\end{array}$ & $\begin{array}{l}1.75 \\
1.35 \\
1.5 \\
1.3 \\
1.15\end{array}$ & $\begin{array}{l}5.9 \\
6.1 \\
6.5 \\
6.1 \\
6.0\end{array}$ & $\begin{array}{l}3.85 \\
4.25 \\
3.35 \\
2.95 \\
2.65\end{array}$ & $\begin{array}{l}2.05 \\
1.85 \\
3.15 \\
3.15 \\
3.35\end{array}$ & $\begin{array}{r}59 \\
-55 \\
48 \\
48\end{array}$ \\
\hline $\begin{array}{l}403 \\
404 \\
405 \\
406 \\
408\end{array}$ & 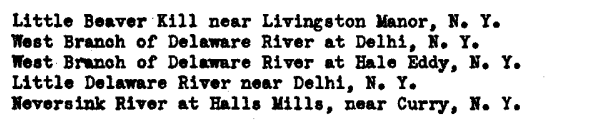 & $\begin{array}{l}19.8 \\
142 \\
593 \\
49.8 \\
68\end{array}$ & $\begin{array}{l}2.05 \\
2.1 \\
2.0 \\
2.0 \\
1.25\end{array}$ & $\begin{array}{l}.05 \\
.15 \\
.25 \\
.15 \\
.1\end{array}$ & $\begin{array}{l}2.0 \\
1.95 \\
1.75 \\
1.85 \\
1.15\end{array}$ & $\begin{array}{l}6.1 \\
5.7 \\
5.15 \\
6.0 \\
6.3\end{array}$ & \begin{tabular}{l|}
3.8 \\
3.0 \\
3.45 \\
4.3 \\
3.4
\end{tabular} & $\begin{array}{l}2.3 \\
2.7 \\
1.7 \\
1.7 \\
2.9\end{array}$ & $\begin{array}{c}-- \\
44 \\
42 \\
-- \\
57\end{array}$ \\
\hline $\begin{array}{l}409 \\
410 \\
411\end{array}$ & 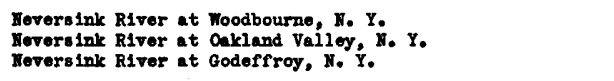 & $\begin{array}{l}113 \\
222 \\
302\end{array}$ & $\begin{array}{l}1.2 \\
1.2 \\
1.2\end{array}$ & $\begin{array}{l}.1 \\
.05 \\
.05\end{array}$ & $\begin{array}{l}1.1 \\
1.15 \\
1.15\end{array}$ & $\begin{array}{l}6.1 \\
5.95 \\
6.1\end{array}$ & $\begin{array}{l}3.05 \\
2.45 \\
2.4\end{array}$ & $\begin{array}{l}3.05 \\
3.5 \\
3.7\end{array}$ & $\begin{array}{l}53 \\
47 \\
44\end{array}$ \\
\hline & Susquehanna River Bas in & & & & & & & & \\
\hline $\begin{array}{l}480 \\
436 \\
457 \\
458\end{array}$ & $\begin{array}{l}\text { Susquehanna River at Collifersville, Y. Y. } \\
\text { Oaks Croek at Index, N. Y. } \\
\text { Chorry Valley Creek at Wostrille, W. Y. } \\
\text { Charlotte Creek at Davenport Center, Y. Y. } \\
\text { Streans tributary to St. Lawrenoe River }\end{array}$ & $\begin{array}{c}351 \\
103 \\
81.3 \\
163\end{array}$ & $\begin{array}{l}1.65 \\
1.65 \\
1.55 \\
1.8\end{array}$ & $\begin{array}{r}.05 \\
.05 \\
.05\end{array}$ & $-\begin{array}{r}1.50 \\
1.50 \\
1.75\end{array}$ & $\begin{array}{l}4.9 \\
5.2 \\
5.2 \\
5.6\end{array}$ & $\begin{array}{c}1.75 \\
3.25 \\
2.65\end{array}$ & 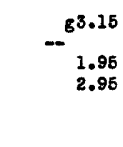 & $\begin{array}{c}31 \\
--50 \\
58\end{array}$ \\
\hline $\begin{array}{l}488 \\
487 \\
491 \\
494 \\
496\end{array}$ & $\begin{array}{l}\text { Saranac River at Saranac, N. Y. } \\
\text { Wost Branoh of Ausable River near Nowman, Y. Y. } \\
\text { Ausable R1ver near Ausable Forks; H. Y. } \\
\text { Black Brook at Black Brook, N. Y. } \\
\text { Bast Branoh of Ausable River at Ausable Forka, N. Y. }\end{array}$ & $\begin{array}{l}621 \\
116 \\
448 \\
49.4 \\
198\end{array}$ & $\begin{array}{l}1.1 \\
1.4 \\
1.4 \\
1.1 \\
1.5\end{array}$ & $\begin{array}{l}.2 \\
.2 \\
.05 \\
.1\end{array}$ & $\begin{array}{l}1.2 \\
1.3 \\
1.05 \\
1.4\end{array}$ & $\begin{array}{l}4.25 \\
5.1 \\
5.0 \\
4.35 \\
5.35\end{array}$ & $\begin{array}{l}1.2 \\
3.2 \\
2.3 \\
.7 \\
2.65\end{array}$ & $\begin{array}{l}3.05 \\
1.9 \\
2.7 \\
3.65 \\
2.7\end{array}$ & $\begin{array}{l}-- \\
57 \\
56 \\
62 \\
68\end{array}$ \\
\hline $\begin{array}{l}498 \\
602\end{array}$ & $\begin{array}{l}\text { Bouquet River at Willeboro, B. Y. } \\
\text { Poultney Rivor at Fair Haven, Vt. }\end{array}$ & $\begin{array}{l}275 \\
187\end{array}$ & $\begin{array}{l}1.5 \\
3.4\end{array}$ & .05 & $\begin{array}{l}1.45 \\
3.05\end{array}$ & $\begin{array}{l}4.9 \\
4.85\end{array}$ & $\begin{array}{l}1.35 \\
2.65\end{array}$ & $\begin{array}{l}3.55 \\
2.2\end{array}$ & $\begin{array}{l}57 \\
52\end{array}$ \\
\hline
\end{tabular}


Otter Creok at Center Rutland, vt.

Nontry iler.

Winoost hifer at Nontpollor, Vt.

Ja1l Branch at zant Barro, Vt.

Yorth Branoh of Winoosed Hivox at Wrighterille, Vt.

Dog River at Morthrield Falls, vt.

and River near lorotom, vt.

haterbury River noar Waterbury, $\nabla t$

Lamollle R1ver at Rant Goorg1a, $v t$.

Miselsquol Rivor noer North Troy, $\nabla t$.
Miselequol River noar Riohford, Vt.

\begin{tabular}{|c|c|c|}
\hline $\begin{array}{r}507 \\
628 \\
453 \\
, 079 \\
\text {, 33 }\end{array}$ & $\begin{array}{l}3.5 \\
3.5 \\
1.9 \\
2.0 \\
2.1\end{array}$ & $\begin{array}{l}.6 \\
.8 \\
.2 \\
.25 \\
.5\end{array}$ \\
\hline $\begin{array}{c}69.2 \\
76.1 \\
139 \\
111 \\
335\end{array}$ & $\begin{array}{l}2.0 \\
1.9 \\
2.1 \\
2.1 \\
1.0\end{array}$ & $\begin{array}{l}.35 \\
.15 \\
.4 \\
.5 \\
.3\end{array}$ \\
\hline $\begin{array}{l}712 \\
131 \\
479\end{array}$ & $\begin{array}{l}1.9 \\
1.8 \\
1.8\end{array}$ & $\begin{array}{l}.35 \\
.44 \\
.35\end{array}$ \\
\hline
\end{tabular}


Fatimates of the ground-water recharge attributable to the rains of September 17-21 were made by the following method. An average groundwater depletion curve has been derived and a relation developed between the rate of ground-water discharge and the assoclated volume of storage. The storage relation has been applied to the estimated base flow at both the beginning (point $G$ on figure 43 ) and the end (point $E$ ) of the period of the ground-water accretion produced by the rains of September 17-21, thereby determining the increase in ground-water storage represented by the $r$ ise in base flow from $\theta$ to $E$. To this increment in storage has been added. the estimated base run-off during the flood period, represented by the area below the line GHE in $f$ Igure 43, the total being approximately equivalent to the ground-water effluent that may be ascribed to meteorologic events of September 17-21. The amount of effluent so computed is not equivalent to the total ground-water recharge, being less by the amount of the recharge that is transpired by vegetation in those areas where the ground-water surface is at or above the root-zone, instead of being discharged into the streams.

The relation of the amount of water retained to the storm rainfall in the several basins, as shown in figures 44 to 55 , indicates a tendency for the retention to increase with the rainfall, thus signifying that under given conditions the retention increases with the amount of the supply arailable for such retention. The ratio of such increases in retention to increases in rainfall intensities may tend to decrease as such rainfall intensities vary from light to heavy. The study of the relation of the rainfall at different stations for a given storm, shows that in general greater depths of rainfall are associated with longer perlods of significant rainfall and with greater intensity rates. Graphical representations of the relations of precipitation with the retention and of precipitation and the duration of significant rainfall are similar in shape and their similarity suggests a basis for comparing the retention in areas of differing rainfall amounts.

In order to relate the retention more closely to the capacity of the ground to absorb rainfall, the values of the retention, as indicated by difference between precipitation and mun-off given in table 14, may be divided by the duration in hours of significant rainfall in a manner similar to that followed in Water-Supply Paper 838 (pp. 492-3), s1gnificant rainfall being defined as rain that falls ot a rate approximately equal to or greater than one-half the maximim rate of absorption or the infiltration capacity. Discussion and definitions of these latter 
concepts have been given by Houk $9 /$ and more recently by Horton 10/. The quotient so obtained in this report has been termed the infiltration index. As explained in Water-Supply Paper 838 the intensity of rainfall that may be considered significant with respect to run-off depends in large part on the infiltration or absorptive capacity of the ground. The term "capacity" as used in this report refers to its general sense as the power to receive, contain, or absorb and not to any specific limiting rate of retention.

For a constant rate of absorption, the duration of significant rainfall during a storm has been found in earlier studies $11 /$ to vary geographically and with the total rainfall. Studies based on data given in table 15 indicate that the geographical variation could safely be neglected during the September 1938 storm and that an acceptable graphical relation could be derived between the total rainfall during september 17-21 and the duration in hours of rainfall at rates corresponding to selected intensities of significant rainfall. These selected intensities were converted Into terms of the infiltration index by a formula given by Langbein $\frac{12 / \text {. As }}{}$ the infiltration index by definftion equals the quotient found by dividing the retention by the duration in hours of significant rainfall the above graphical relation of precipitation, duration of significant rainfall, and selected values of the infiltration index could readily be transformed Into a relation between the precipitation, the retention, and the infilK page 437 tration index. Figure 44 shows a diagram that expresses this relation during the September 1938 storm. Total precipitation is given as ordinate and the retention as abscissas with the infiltration indices corresponding to the several values of precipitation and retention represented by a family of curves designated $0.06,0.10,0.14,0.20$, and 0.26 inch per hour. This graph has been used in computing values of the infiltration index as determined by the values of precipitation and retention for each basin listed in table 14. Page $42 \not$

Although analagous with the infiltration capacity as used by Horton $13 /$ in a study of the 1927 flood in New England, it is not implied that the infiltration index as derived above corresponds to any limiting rate of absorption. It is used rather as a statistical measure of the absorptive

9/ Houk, I. E., Rainfall and run-off in the Miaml Valley: Tech. Repts., Miami Conservancy District, pt. 8, pp. 81-82, 1921 .

$10 /$ Horton, R. E., Surface run-off phenomena, pt. 1 , analysis of the hydrograph: Pub. 101, Horton Hydrological Laboratory, Voorheesville, N. Y. 11 Floods of Ohio and Mississippi Rivers, January-February 1937: U. s. Geol. Survey Water-Supply Paper 838, pp. 492-523, 1938.

12 Langbein, W. B., Some channel storage studies and their application to the determination of infiltration: Am. Geophys. Union Trans., 1938 , pt. 1 , pp. 435-447.

13 Horton, R. E., Determination of infiltration capacity for large drainage basins: Am. Geophys. Union Trans. 1937, pp. 371-385. 
Table 15.-- Rate and duration of preofpitation September 17-21, based on hourly reoord

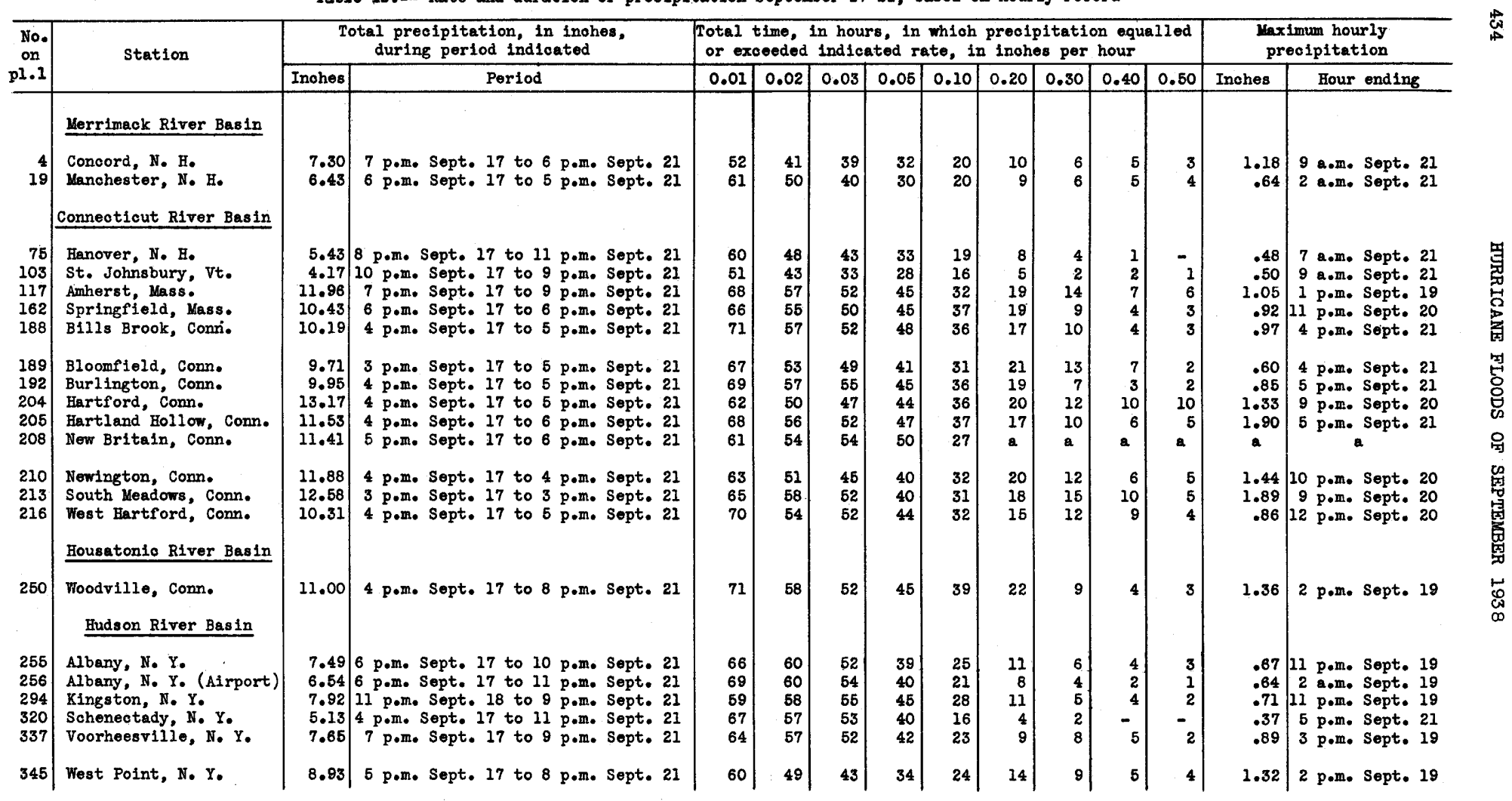


348 Palisades Park $Y$. 349 Southfield, N. Y. 351 Bowling Green, N. J. 352 Brook Valley, N. J.

362 Freehold, N. Jo

373 Mahwah, N. J.

374 Millington, $\mathrm{N}$. J

376 Morristown, N. J.

377 Morristown, N. J. Res

387 Rockaway, N. J.

390 Woodeliff Lake, H. J. Delaware River Basin

398 China, N. Y.

407 Harvard, N. Y.

415 Oakland Valley, N. Y.

438 Trenton No. 1 , N. J.

Susquehanna River Basin

443 Binghamton, N. Y.

58 Hunts Corners, N. $Y$

464 North Edmeston, N. Y.

469 Richford, N. Y

471 Smithvilie Flats, N. Y.

472 Smyrna, N. Y.

479 Worcester, N. Y.

\section{St. Lawrence Basin}

481 Burlington, vt.

490 Northfield, Vt.

492 Waterbury, vt.

505 Canton, N. Y.
$8.94 \mid 5$ p.m. Sept. 17 to 10 p.m. Sept. 21 9.40 3 p.m. Sept. 17 to 8 p.m. Sept. 21 8.224 p.m. Sept. 17 to 9 p.m. Sept. 21 8.543 p.m. Sept. 17 to 7 p.m. Sept. 21 7.531 p.m. Sept. 17 to 5 p.m. Sept. 21

8.063 p.m. Sept. 17 to 10 p.m. Sept. 21 $8.368 \mathrm{p} . \mathrm{m}$. Sept. 17 to $10 \mathrm{p.m}$. Sept. 21 6.173 p.m. Sept. 17 to 4 p.m. Sept. 21 7.154 p.me Sept. 17 to 8 p.m. Sept. 21 7.10 4 p.m. Sept. 17 to 7 p.m. Sept. 21

7.695 p.m. Sept. 17 to 7 p.m. Sept. 21

3.8612 a.m. Sept. 17 to 12 p.m. Sept. 21 4.91 3 p.m. Sept. 17 to 11 p.m. Sept. 21 5.93 1 p.m. Sept. 17 to 9 pom. Sept. 21 8.121 p.m. Sept. 17 to 5 p.m. Sept. 21

3.2011 a.m. Sept. 17 to 11 p.m. Sept. 21 2.2912 a.m. Sept. 17 to 11 p.m. Sept. 21 3.641 p.m. Sept. 17 to 2 a.m. Sept. 22 \begin{tabular}{l|rl}
2.95 & 12 a.m. Sept. 17 to 11 p.m. Sept. 21 \\
2.85 & 2 p.m. Sept. 17 to 12 p.m. Sept. 21
\end{tabular} 2.9712 a.m. Sept. 17 to 12 p.m. Sept. 21 5.674 p.m. Sept. 17 to 9 p.m. Sept. 21

To 6 pom. Sept. 17 to 12 pom. Sept. 21 4.596 p.m. Sept. 17 to $10 \mathrm{pom}$. Sept. 21 4.28 p.m. Sept. 17 to 10 p.m. Sept. 21 2.76 Il p.m. Sept. 19 to 5 a.m. Sept. 22 2.19 11 a.m. Sept. 17 to 11 p.m. Sept. 21
.83 p.m. Sept. 21

1.302 p.m. Sept. 19

.71 3 p.m. Sept. 21

.807 a.m. Sept. 20

.861 p.m. Sept. 21

1.502 p.m. Sept. 19

1.052 p.m. Sept. 19

$1.00 \quad 2$ p.m. Sept. 19

3 pom. Sept. 21

100 pame septo 21

1.001 p.m. Sept. 19

.753 p.m. Sept. 19

745 p.m. Sept. 21

.324 p.m. Sept. 21

.483 p.m. Sept. 21

1.3312 a.mo sept 19

24 . 3 p.m. Sept. 21

.243 p.m. Sept. 21

$.18 \quad 4$ p.m. Sept. 21

.28 5 p.m. Sept. 21

.23 $7-9$ p.m. Sept. 21

.27

p.m. Sept. 19

\begin{tabular}{r|rrr}
.18 & $4-6$ & p.m. Sept. 21 \\
.60 & 6 & p.m. Sept. 21
\end{tabular}

.517 p.m. Sept. 21

.517 p.m. Sept. 21

.58 T.m. Sept. 21

-45 8 g.m. Sept. 21

\begin{tabular}{l|ll}
.48 & 7 & pom. Sept. 21 \\
.19 & 7 & p.m. Sept. 21
\end{tabular}

a Not determined. 
Table 15.-- Rate and duration of preolpitation September 17-21, based on hourly reoord--Continued

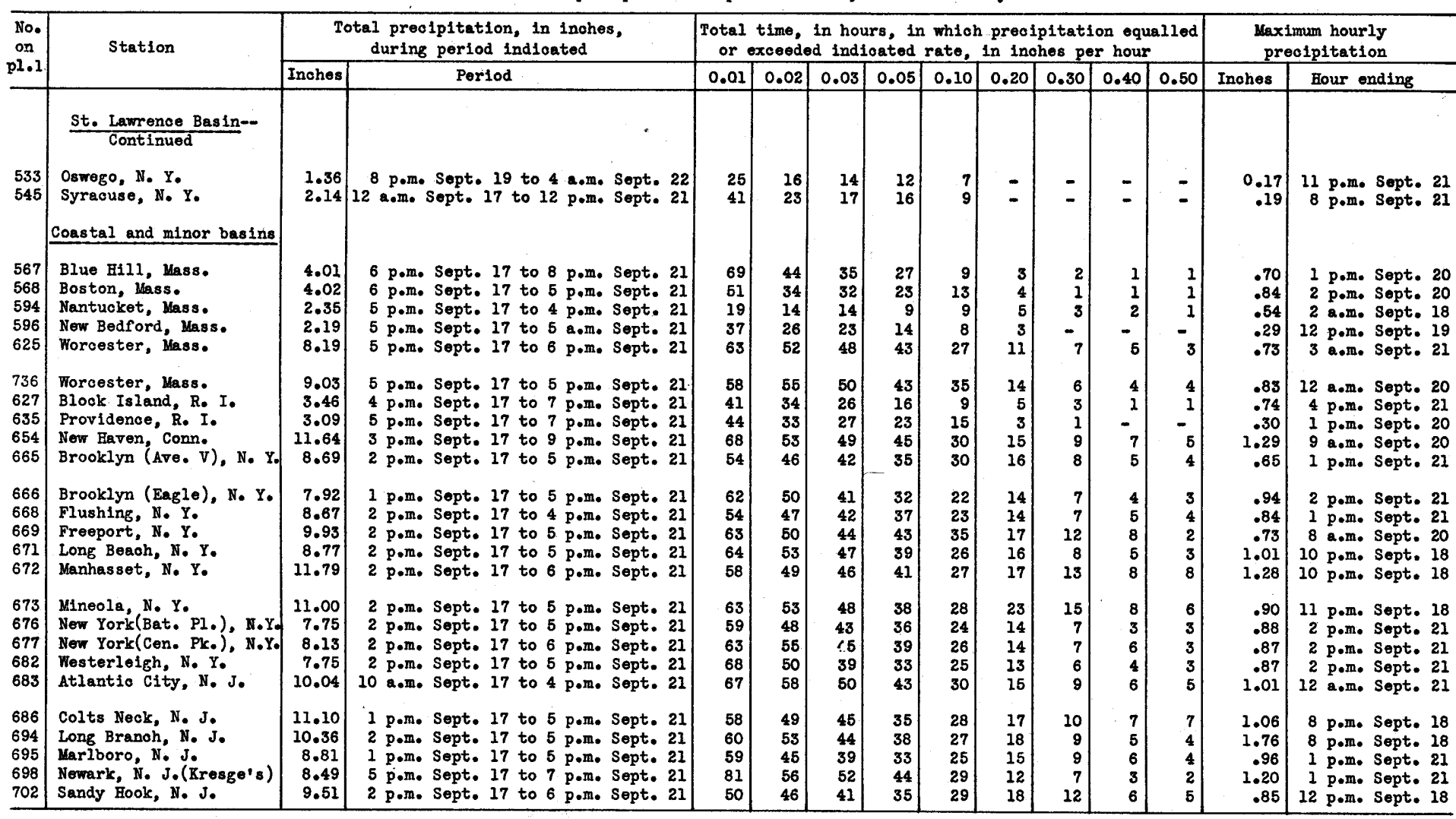


capacity that is more nearly independent of the amount of rainfall, and thus suitable as a basis for comparison and discussion. In those areas where the retention is large in proportion to the rainfall the value of the infiltration index becomes uncertain because small variations in the retention produce disproportionate changes in the infiltration index. .

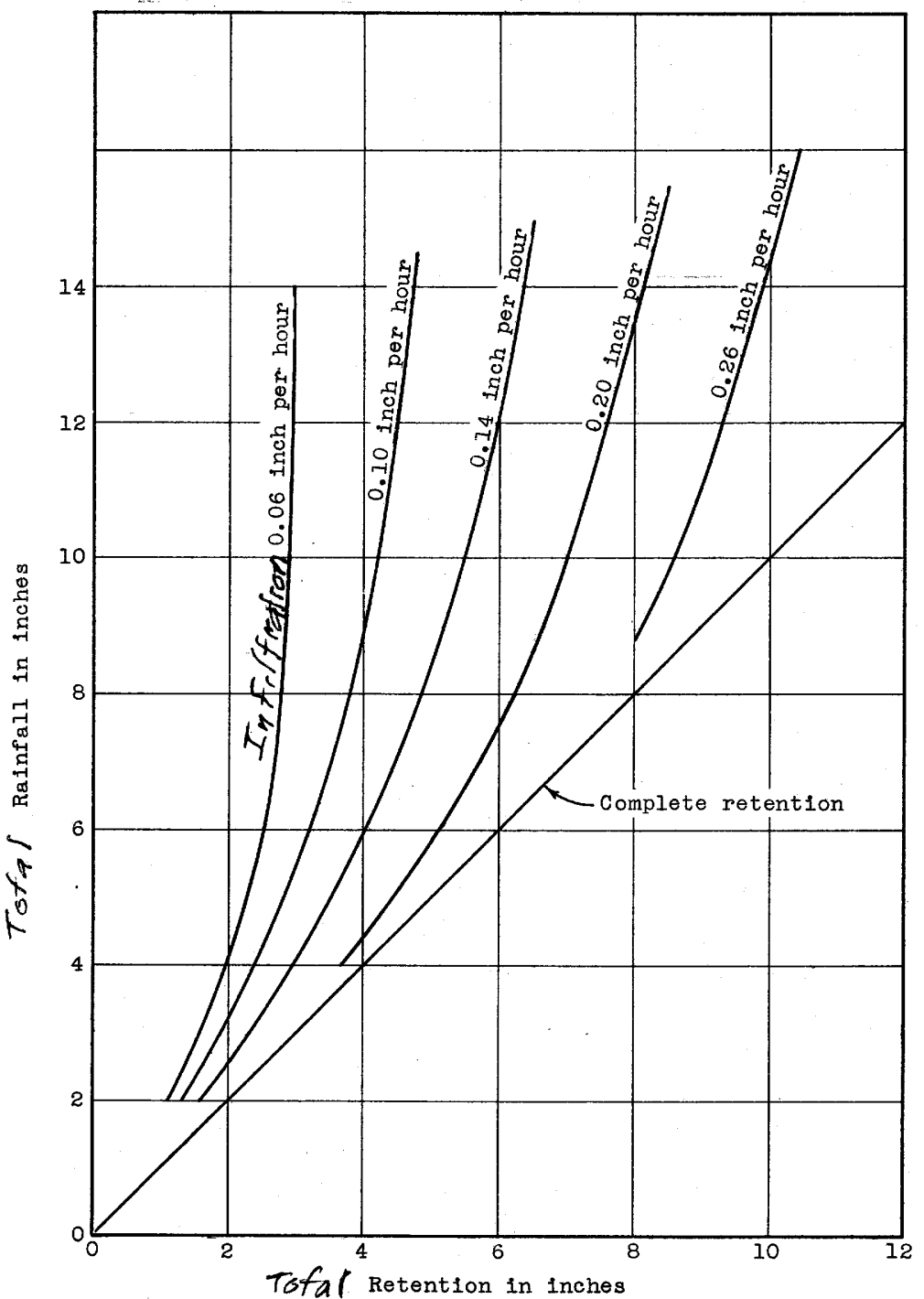

Figure 44.--Chart showing relation of total precipitation and retention, Sept. 17-21, 1938, to indicated infiltration indices.

These disproportionate changes are a result of the sharp curvature of the higher portion of the infiltration index-retention relation. For this reason all computed figures of the infiltration index in excess of 0.26 
inch per hour were designated "over 0.26 inch per hour", no attempt being made toward further refinement.

Engineers and hydrologists readily realize the approximations that have been necessary with respect to the many 1tems presented in the rainfall and run-off studies. Wide departures from the average may be indicative of elther corresponding varlations in the meteorologic and hydrologic conditions or errors in base data. Users are cautioned to apply the results to specific flood problems only after a thorough understanding of the nature of the basic data and of the methods of derivation.

\section{Discussion of results}

The data compiled in table 14 afford a basis for appraisal of the effects of rainfall and other hydrologic factors on the flood mun-off.

In the first three columns of table 14 are listed the river-measurement stations where records were available for the entire flood period and the corresponding dralnage areas. The next three columns list in inches the mean areal precipitation september 12-16, the resulting direct run-off, and the difference between these factors. The next three columns in the table 11st similar data for the mafor storm period of september 17-21. The last column shows the degree to which the run-off was concentrated with respect to time. Detalled discussion of these rainfall and run-off characteristics is given later in this section for each of the separate basins. This discussion is limited to generalized conclusions based on the accumulated evidence.

The objectives of this study of the relation of rainfall and run-off are three: first, the appraisal of the absorptive or retentive capacity of the ground and vegetation; second, the appraisal of storage and the est1mation of the utility of the stream channels for accommodating and discharging flood waters; and third, the utilization of the results of the analyses, so far as practicable, in checking the accuracy and adequacy of the basic data published in the report. Detalled studies of channel conveyance and storage are beyond the scope of this report; the discussion herein is general and is Iimited to the major basins, attention being directed mainly to the retention of water on an areal basis.

Under given rainfall conditions the factors that determine the amount of retention are: (a) the initial abstrection of the rainfall, equivalent to the volume of water intercepted by vegetation, required to wet the ground, and to f1ll surface depressions, (b) the absorption or infiltration in the ground, equivalent to the water absorbed by the ground through the 
continuing process of infiltration during the storm, and (c) evaporation and transpiration losses.

The difference between rainfall and the associated direct run-off as listed in table 14 represents total retention of the storm rainfali as closely as may be determined from the avallable data. During the first storm perlod, September 12-16, under relatively light rainfall, which generally ranged between 1 and 2 inches but reached as high as 4 inches in local areas in Vermont, there was very little direct run-off and the retention is largely accounted for by initial abstraction and possible increments in soll molsture in areas of 1 inch or more of rain. Little If any of the water represented by the retention reached the ground-water table as most ground-water levels showed no rise during this period and there is little evidence of an increase in ground-water flow in the streams (see pl. 20). Page 543

This period prior to the major storm was of significance in the development of the floods to the extent that the rainfall increased soll molsture and molstened ground surfaces, thereby occupying some of the retentive capacity that would otherwise have been available for the rain of the maj, $r$ storm. It is belleved, however, that during the short rainless interval between september 15 and 17, evaporation and transpiration disposed of some of the retained water and to that extent restored the retentive capacity.

The extraordinary storm of september 17-21 (se日 pl. i) i) brought rainfall that exceeded 17 inches in some areas in central connecticut and Massachusetts and in the central storm area resulted in volumes of flood run-off of 9 to 10 inches. In the northesstern United States the run-off from single storms not associated with snow has very rarely exceeded these amounts.

The total retention during the major storm period varied materially, being influenced by factors which, although they cannot be exactly delineated, probably relate to the total amount of precipitation (the source of supply available for retention), the local soll and vegetal conditions, and temperature. The maximum retention of 10 inches occurred on Long Island, where there was heavy precipitation over areas of very favorable absorptive conditions. It is believed that dissimilarities in the character of the rainfall were not sufficient to have produced material variations in the retention. Comparison of the rate and duration of hourly rainfall at recording rain gages listed in table 15 indicates appreciable uniformity at locations with equal total rainfall. $22 \pi 00 \overline{\mathrm{T}} \mathrm{O} \longrightarrow 40-20$ 
In the discussions by basins, the retention of rainfall has been studied in relation to the total rainfall and as explained in the preceding section converted into terms of an infiltration index, in order to obtain a convenient measure of the average absorptive rate of the soll that is as nearly independent as possible of the amount of rainfall. For several of the basins a bihourly inventory of the retention has been made with appropriate discussion. These detalled studies seem to indicate (1) that during the periods of most intense rainfall, water was apparently being absorbed at rates considerably in excess of the average rates, (2) that after the beginning of active run-off, nearly all rates of rainfall were productive of rum-off, and (3) that mun-off fluctuated in response to the variation in rainfall intensities.

Figure $45, x^{a}$ map of the region, gives the generalized values of the infiltration index in inches per hour in the areas covered by the data listed in table 14. This map shows that the infiltration index ranged from 0.06 inch per hour in central Vermont and New Hampshire to 0.26 inch and more per hour in Long Island, N. $Y$. The values of infiltration index as shown on figure 45 have the following distribution according to area.

Table 16.--Areal variation. of infiltration index

\begin{tabular}{c|c}
\hline \multicolumn{1}{c|}{ Infiltration index } & $\begin{array}{c}\text { Area } \\
\text { (square m1les) }\end{array}$ \\
\hline Over 0.26 inch per hour & 160 \\
Between .20 and .26 inch per hour & 240 \\
Between .14 and .20 inch per hour & 6,600 \\
Between .10 and .14 inch per hour & 9,700 \\
Between .06 and .10 inch per hour & 19,700 \\
Between .02 and .06 inch per hour & 3,800 \\
\hline Total area & 40,200 \\
\hline
\end{tabular}

A tendency is disclosed for the infiltration index to increase in a downstream direction and for a predominance of higher values along the coastal plain. The high infiltration Index shown in the upper Hudson River Basin and areas in New York tributary to Lake Champlain may be due in part to the large amount of surface storage ava1lable in swamps and lakes rather than to ordinary ground retention. A brief study of the infiltration index in relation to the mean land slope as computed by the Geological Survey from its topographic maps discloses a tendency for the infiltration Index to increase with decrease in the mean land slope. Although the slope of the land itself might influence the retentive capacity of the 


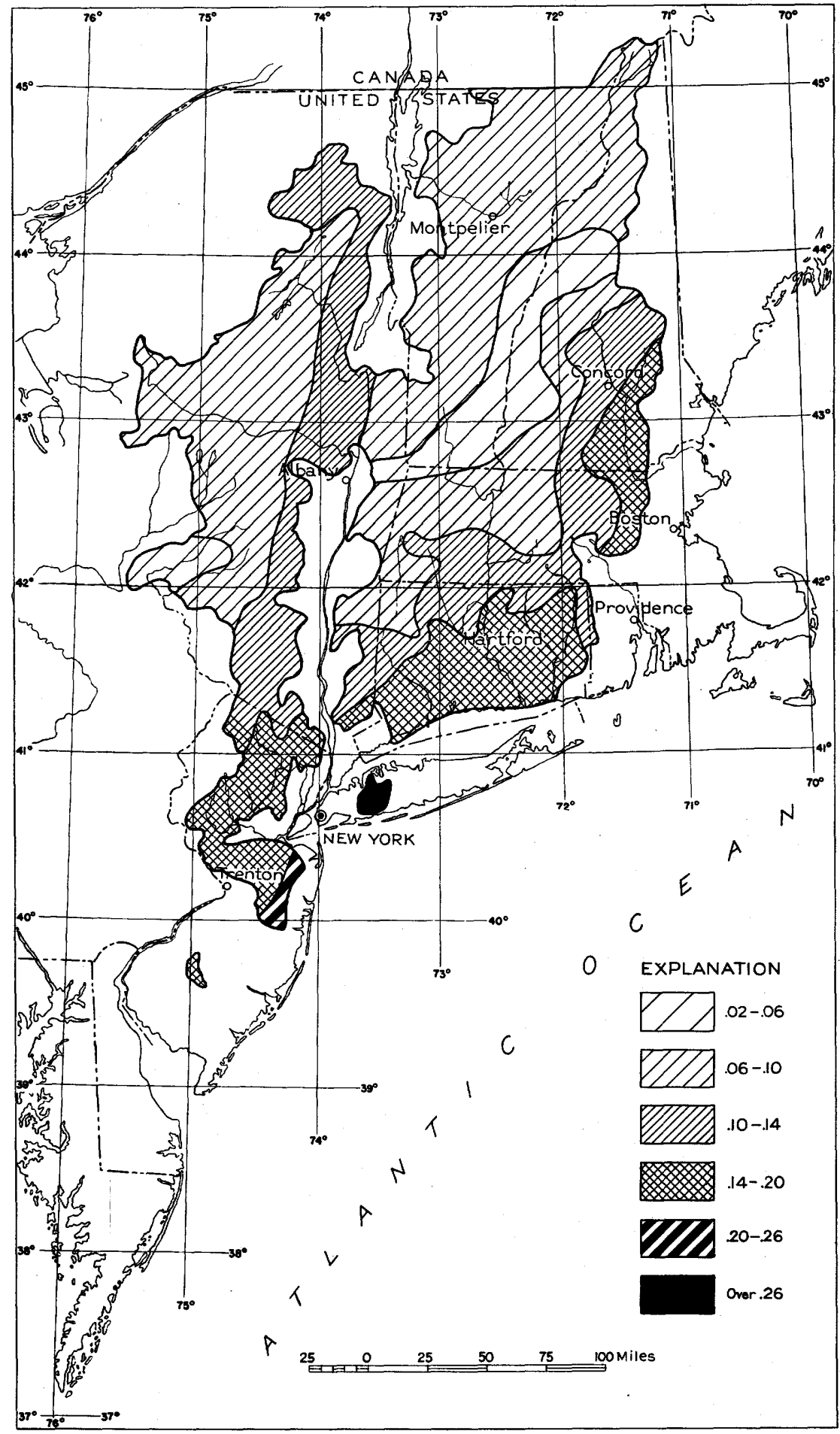

F1gure 45.--Lap showing generalized values of infiltration index, in inches per hour, Septembor 17-21, 1938. 
ground, this tendency mag be due to other factors related to slope, such as depth of soll cover. No study has been made of soll type or cover.

The data shown on figure 45 correspond to a general average of 0.10 inch per hour. The data are based on basin averages and are merely intended to show generallzed tendencies and not to indicate actual infiltration rates at particular points on the map.

\section{Merrimack River Basin}

The storm of September 17-21 crossed the Merrimack River Basin as show on plate 1 in a course that extended from the Contoocook River in the southwestern part, where the precipitation reached 15 inches, northward over the central basin to the northern watershed line, where the precipitation was about 8 inches. The precipltation decreased east and west of this central path. Measurable precipitation fell during a perlod of about 56 hours. Ifttle information is ava1lable, however, concerning precipitation intensities. The maximum rates in inches per hour recorded at automatic rain gages in the bas in were as follows: at Manchester, N. H., 0.64 inch; at Concord, N. H., 1.18 inches; and at Lowell, Mass., 0.57 inch. The maximum rainfall recorded in a 1 -day period was 6.85 Inches at Webster, N. H., on September 21. The observer at W11ton, N. H., measured 6.12 inches during the 24-hour pertod ending at $5 \mathrm{p} . \mathrm{m}$. on September 21. A total storm rainfall of 15 inches was recorded at Peterboro, N. H., (situated in the path of maximum precipitation), by Mr. Charles L. Whittle, who also reported very intense rainfall during the evening of September 20.

The antecedent rains of September 12-16 were fairly uniform, averaging 2.1 inches over the besin. The resultant 1 ise in stream flow was small, the direct run-off averaging about 0.2 lnch, left 1.9 inches in the basin which, partially utilizing the absorptive capacity of the basin, had a significant effect on the rainfall and run-off relations during the major storm period.

The volume of direct run-off resulting from the rains of september 17-21 listed in table 14 runged between 1.6 inches and 7.35 inches for different drainage arvas and averaged 3.7 inches over the basin above Lowe11, Mass. The volume of run-off was generaliy a function of the total rainfall. The direct run-off has been adjusted for all known art1flcial storage for which records were available, and of which the princ1pal amount was in Lake Winnipesaukee. The average precipitation over the Merrimack Basin above Lowell, Mass., was 7.95 inches, thus Indicating an 
average retention of 4.25 inches. As shown in table 14 the retention in the smaller basins ranged from 2.05 to 6.0 inches and no significant geographical trend can be observed. The varlations of the retention in the basin with respect to rainfall are shown on figure 46. The scattered plotting may be ascribed to differences in the retentive capacities of the several basins and to errors or deficiencies in base data, particularly with respect to the determination of the mean precipitation over

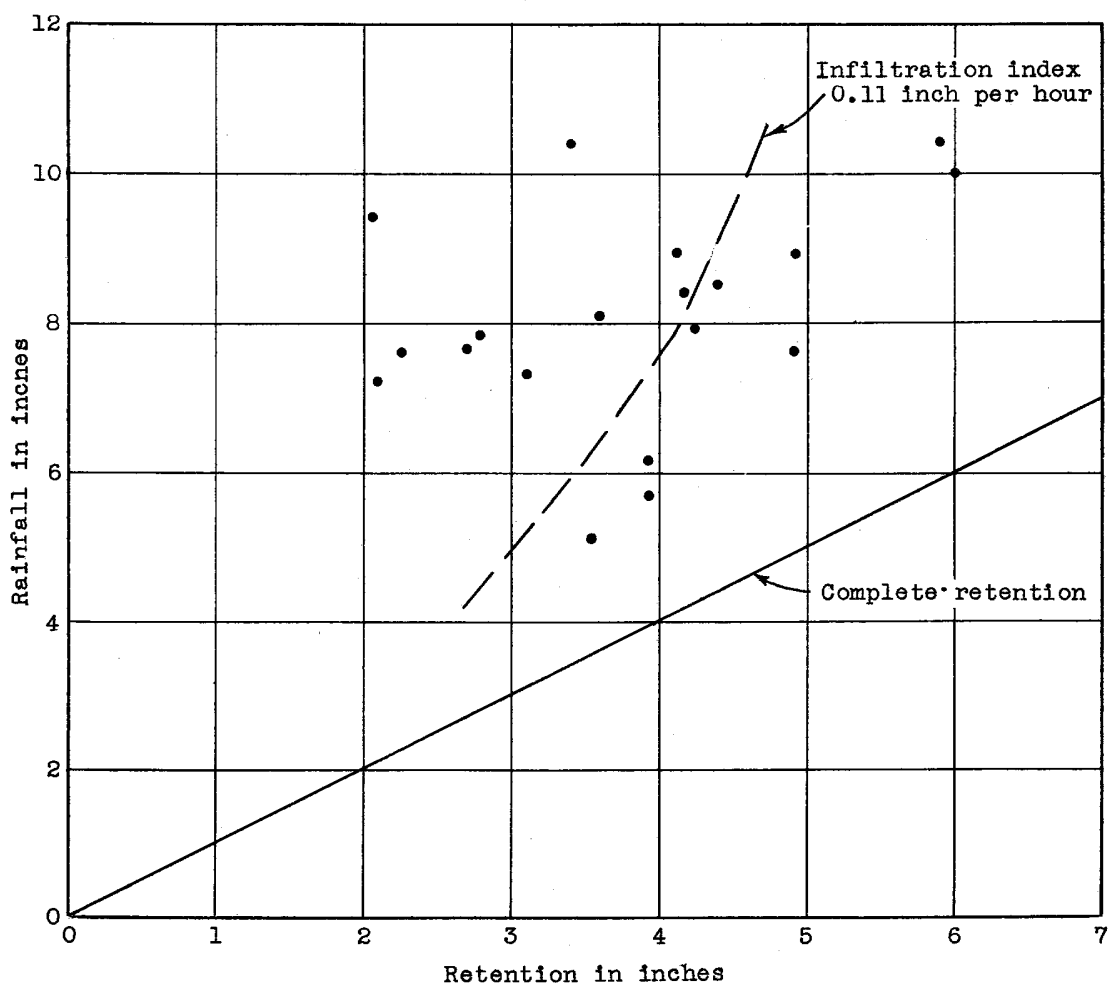

Figure 46.--Relation of total rainfall September 17-21, 1938, to difference between total rainfall and direct run-off, Merrimack River Basin.

the smaller drainage basins in the mountalnous headwater areas. Based on figure 44, flgure 46 shows a line representing an infiltration index of 0.11 inch per hour. In general the retention in drainage areas in the headwater areas and along the western part of the Merrimack Basin from the Contoocook River northward plot to the left of this index line, indicating relatively less absorptive capacity for those areas, the lowest values of the corresponding indices being about 0.05 inch per hour. Also, in general, the retention in the lower basins plot to the right, thus indicating relatively greater absorptive capacity, the maximum value being about 0.15 inch per hour. 
Based on an analysis of the hydrographs of eight basins as described in the section "Methods of analysis", there was an accretion to ground water from the rains of the major storm period of 0.58 to 1.7 inches, which on the average amounts to about 35 percent of the total retention. This accretion represents that portion of the retention that appeared as ground-water offluent during and subsequent to the flood.

During the storm of March 1936, there was an average rainfall during 12 deys of 8.2 inches in the Merrimack River Basin above Lowell, Mass.14/ Antecedent snow cover contained an equivalent of 4 inches of water, thus making the total supply of water 12.2 inches, of whlch about 11.5 inches appeared as direct run-off, leaving a retention of 0.7 inch. Although as discussed in Water-Supply Paper 798, rainfall observations in the westerm parts of the Merrimack River Basin were inadequate for very accurate deductions, the low retention indicated during that storm and flood probably signifies the prevalence of very unfavorable absorptive conditions.

In contrast, there was during less than 24 hours on September 16-17, 1932 , an average rainfall of 5.2 inches over 3,930 square miles of contributing area above Lawrence, Mass., of which only 0.35 inch appeared as direct run-off, indicating a retention of about 4.85 inches 15 . During the same storm there was an average rainfall of about 6.7 inches over the basin of the Suncook River above North Chichester, N. H., with assoclated run-off of 0.7 inch and a residual of 6.0 inches. This storm followed a dry period and apparently the conditions for absorption and other abstractions were extraordinarily favorable.

In November 1927 there was an average rainfall of 4.95 inches over the basin above Lawrence, Mass., of which 2.0 inches appeared as direct run-off. The retention of 2.95 inches is comparable with those of the storm and flood of September 1938.

The degree to which the direct run-off associated with the storm of September 17-21, 1938, was concentrated with respect to time, as measured by the ratio between the direct run-off during the maximum 24 hours and the total direct run-off ranged between 15 and 58 percent. For the main stem of the Pemigewasset-Merrimack Rivers, these ratios are shown in table 14 to decrease in a downstream direction, indicative of the increased effect of channel storage. Comparisons of these ratios are also

14/ Floods of March 1936, pt. 1, New England Rivers: U. S. Geol. Surve Tater-Supply Paper 798, pp. 350-351, 1937.

15 Kinnison, H. B., in White, G. V., The great storm of sept. 16 and 17, 1932: New England Water Works Assoc. Jour. vol. 47, no. 2, p. $181,1933$. 
Indicative of the relative storage effects of the tributary streams. The lowest ratio of 15 percent was obtained on Clark Brook at Auburn, N. H. This stream drains a relatively flat basin that contains several small natural ponds and swamps and has a main channel slope of about 22 feet per mile. The Bakers River near Rumney, N. H., which has the highest ratio, 58 percent, is in the upper mountainous region and has a mean slope in 1ts tributary streams of 326 feet per mile and a mean slope in its main channel of 55 feet per mile.

\section{Thames River Basin}

The storm of September 17-21 was noted for the steep precipitation gradient along 1ts easterly front as shown on plate 1. This front covered the Thames River Basin where it was most clearly defined. Near the mouth of the Thames River the precipitation apparently increased in a westward direction from 4 to 11 inches in the short distance of $5 \mathrm{miles}$. Northward or upstream from the mouth the steepness of this gradient decreased, although the front continued to be sharply defined. Thus in this basin the storm precipitation at the southeasterly divide was only about 3.5 inches, but at the southwesterly divide it reached 16 inches.

The antecedent ralns of September 12-16 were light, averaging only about 1.4 inches over the basin, of which only about 0.1 inch appeared as direct run-off, thus leaving a retention that averaged 1.3 inches. This amount was probably disposed of by evaporation, transpiration, and absorption, and was insufficlent to exercise material effect on the rainfall and run-off relations during the mejor storm that followed. Inspection of the stream-flow records discloses that significant run-off did not begin until late on September 18, or until September 19 in some places, after 1 to 2 inches of rain had fallen. This large amount of the initial abstraction seems to indicate that soll and vegetal conditions prevalling immediately prior to the major storm were quite favorable for the retention of water.

The direct run-off that followed the initiation of the active runoff ranged between 1.15 inches and 8.7 inches (table 14), the smaller amount being in the southeastern part of the basin and the higher amount in the northwestern part of the basin near the area of maximum precipitation. The maximum run-off of 8.7 Inches approaches closely the heretofore measured upper limit of direct run-off for a single flood rise in the northeastern part of the country without snow melt. 
The difference between precipitation and direct run-off ranged from 2.8 to 8.15 inches, the magnitude corresponding generally to the depth of rainfall as shown in figure 47. The minimum retention of 2.8 inches for the basin of the Yant1c River at Yant1c, Conn., was computed for a

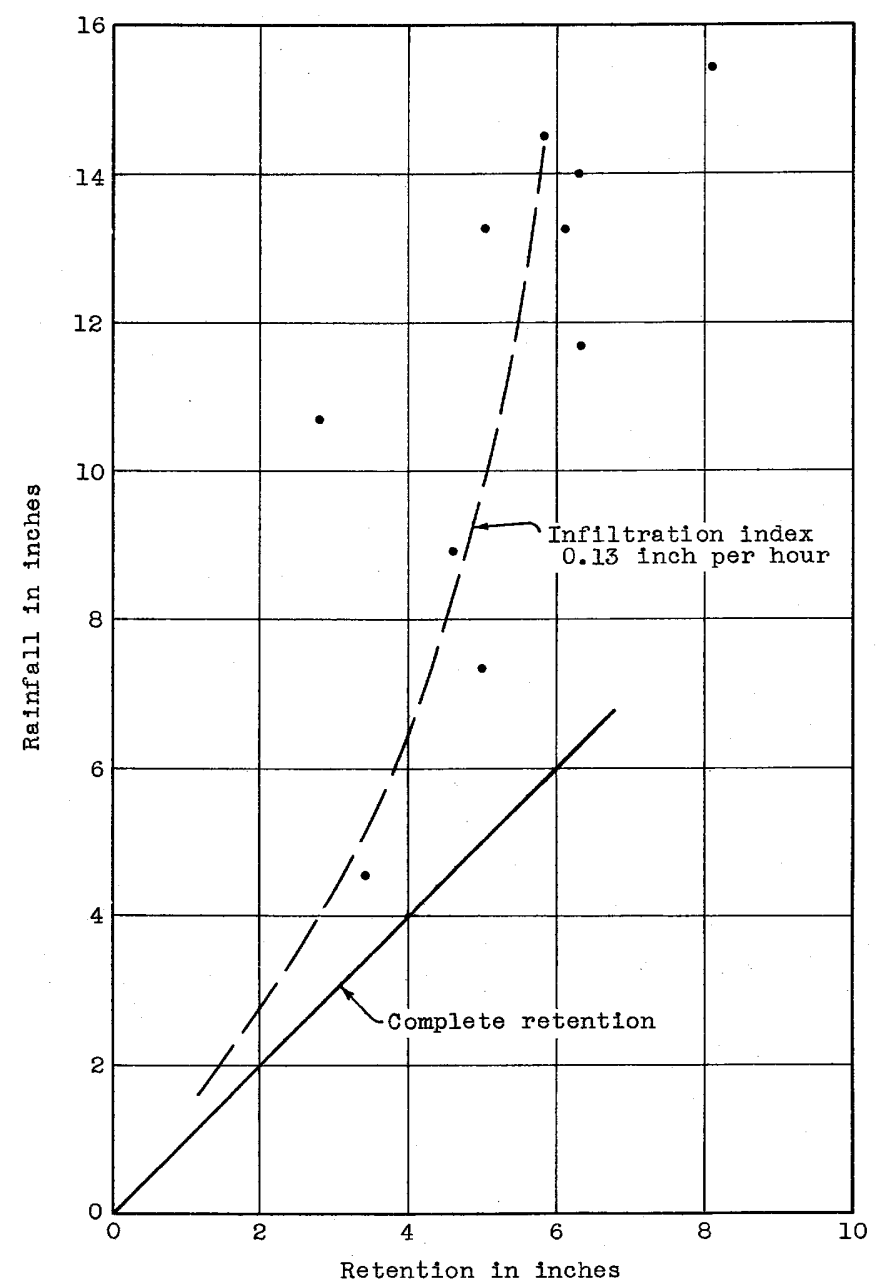

Figure 47.--Relation of total rainfall September 17-21, 1938, to difference between total rainfall and direct run-off, Thames River Basin.

region of Intense rainfall along the storm front where the gradient was perticulariy steep. It is, therefore, likely that the indicated precipitation for this basin is inaccurate. The observed precipitation of 9.96 inches at Colchester, just west of the basin, on which record the position of the isohyetal lines in the Yantic River Basin has been mainly based, may not have been given appropriate weight in the determination of the 
precipitation over the besin. Disregarding this value, the remaining points on figure 47 seem to be satisfactorily consistent. Figure 47 shows a plot of the retention in relation to the precipitation. Based on the method explained in the section on "Methods of analysis" a line representing an infiltration index of 0.13 inch per hour is also shown in figure 47. The plotted points group close to the indicated infiltration index of 0.13 inch per hour. Variations of the points probably relate to the differences in soll and vegetal condtions as well as to inadequacies in base data. Figure 45, showing the geographical variation of the infiltration index, indicates that the Thames River Basin is situated in a region of more than average retentive capacity. There were only eight records of precipitation in the basin, none of which were from automatic recorders, an insufficient number for defining satisfactorily the variations of precipitation during outstanding storm periods.

The relatively high absorption in the area resulted in proportionately large contributions to the ground water. Based on analysis of hydrographs as previously explained, it is estimated that the portion of the ground-water accretions that later appeared as stream flow ranged between 1 and 3 inches and averaged about 40 percent of the residual.

In the outstanding storm of september 16 and 17, 1932, which centered just east of the Thames River Basin, there was an average precipitation of about 7 inches in the Quinebaug River Basin above Jewett City, Conn. The associated direct run-off following this storm was about 0.7 inch, leaving a difference of 6.3 inches. During the storm of November 2-4, 1927, there was a rainfall of about 5.9 inches over the same basin followed by direct run-off of 1.7 inches. The indicated retention of 4.2 inches is comparable with that of the storm of September 1938. Between March 9 and 22, 1936, there was a rainfall of 8.1 inches over the Quinebaug River Basin above Jewett City, Conn., and 2.6 inches of water on the ground in the form of snow. The resultant direct run-off was 9.4 inches from the total supply of 10.7 inches, indicating a retention of only 1.3 inches. Although the total supply, and therefore the retention, may have been greater than reported, this flood, due mainly to the season and the presence of frost in the ground, occurred under highly unfavorable conditions for absorption and retention. The soil and vegetation in the storm of September 1932, on the other hand, were apparently in a very absorptive and retentive condition. 
The base flow or rate of outflow from the ground-water reservolr durIng nonwinter periods may be used as an index of the receptive capacity of the soll on the assumption that there is a significant relation between such base flow, the state of the ground-water reservoir, and soll-molsture conditions. Thus prior to the 1932 storm, the base flow of the Quinebaug River at Jewett City was about 300 second-feet; prior to the $1927 \mathrm{storm}$; 850 second-feet; and prior to the $1938 \mathrm{storm}, 640$ second-feet. The magnitudes of these base flows are in inverse order from those of the retention found for the respective storms.

The degree to which direct run-off was concentrated with respect to time as measured by the ratio between the direct run-off during the maximum 24 hours and the total direct run-off associated with the storm of September 17-21, 1938, ranged between 21 and 51 percent, as shown in table 14. Under uniform storm conditions, this ratio may be presumed to be definitive of the topographic characteristics of the basin. On this basis, the following streams appeared to be relatively sluggish: Hop River, Five Mile River, and Moosup River. The remaining basins do not appear to be markedly different from the other basins of the region if allowance is made for the normal variation of the concentration ratio with the size of the drainage area.

\section{Connecticut River Basin}

The eastern divide of the Connecticut River Basin In Massachusetts and connecticut was in the approximate center of the area of heaviest precipitation. In fact, the maximum precipitation at any station in the entire storm area for the period September 17-21 was recorded at two points in the easterly part of this basin, namely, 17.07 inches at Camp Buck near Portland, Conn., and 17.03 Inches at Barre, Mass. This high rainfall resulted in equally outstanding volumes of run-off, which in some basins in the central storm area reached nearly 10 inches, so markIng a new high record for run-off during a single flood rise in the northeastern Jnited States in which melting snow was not involved.

The major storm perlod was preceded by an average precipitation of 2.2 Inches over the basin during september 12-16, generally ranging between limits of 1 and 3 inches, as shown in figure 2. As discussed in the section on "Meteorologic and hydrologic conditions", this precipitation fell mainly during two general rains and served to raise stream levels moderately as shown in figure 43 and to some degreo utilized the 
absorptive capacity of the soll. Table 14 indicates that the direct runoff areraged about 0.3 inch and the volume retained in the basin up to September 16 averaged nearly 2 inches. The greater part of this retention is accounted for by vegetal interception, ground wetting, depression storage, so11-moisture accretion, and evaporation. As shown in figure 43 it is estimated that relatively little rainfall reached the ground-water table during the antecedent storm period.

The major storm periof began with the rains of the afternoon of September 17 and ended befjore sidight of the 2lst. Figure 49 shows the general distribution of ainfall and run-off at Burlington, Conn., in the lower Connecticut River Basin with respect to time during this storm period. The rain of september 17 was separated from the succeeding rains and produced inappreciable run-off. Between the afternoon of September 18 and the end of the storm there was almost continual rain (an average of about 57 hours of measurable rainfall) generally increasing in intensity from the beginning to the end of the storm perlod, although there was considerable variation in this respect. Thus, the greatest hourly rainfall occurred at $9 \mathrm{p.m}$. on September 20 at Hartford, Conn., whereas the greatest hourly rainfall at Burlington, Conn., only 15 miles west of Hartford, occurred at 5 p.m., September 2l. The maximum hourly rates of precipitation recorded in the storm area occurred in the Connecticut River Basin and were as follows: 1.90 inches at Hartland Hollow, Conn., and 1.89 Inches at South Meadows, Conn. No hourly records of precipitation are available in the area of maximum total precipltation but at Barre, Mass., 11.83 inches of rain was recorded during the 24 hours ending at 8 a.m., September 21, indicating an average rate of about 0.5 inch per hour. It is estimated that about 8 inches of rain fell at Barre between 5 and 11 p.m., September 21. Although rain was nearly continual during the last 24-hour period of the storm, the hourly rates were probably greatly in excess of the indicated average. At nearby recording gages the ratio between the maximum hourly precipitation and the average hourly precipitation during the maximum 24 hours was about 5 to 1 , and accordingly, the indicated maximum hourly precipitation at Barre may have been as high as $2 \frac{1}{2}$ inches per hour.

The total storm precipitation, as shown in table 14, ranged from 2.8 inches over the basin above Pittsburg, N. H., to 14.8 inches over the Hockamum River Basin above Rockville, Conn. The average precipitation over the basin above Hartford, Conn., was 7.55 inches, based on 153 records within the basin as well as those adjacent thereto. 
Direct run-off averaged 4.05 inches over the Connecticut River Basin above Hartford, Conn., and reached a maximum of 9.9 inches in the Hockanum River Basin above the outlet of Shenipsit Lake at Rockville, Conn., with two other basins, namely, Priest Brook above Winchendon, Mass., and Quaboag River above West Brimfield, having run-off in excess of 9 inches. (See pls. 12, 13, and 14.) As shown in table 14, seven basins draining 513 square miles had 8 inches or more of direct run-off. The data on direct run-off listed in table 14 are based on stream-flow records adjusted for storage in all upstream reservoirs where records of daily changes in volume were avaliable. In addition to known storage there are numerous small regulated ponds and reservolrs for which records of changes in storage are not avallable. The effects of known artificlal storage on the flood run-off in the lower Connecticut River were not appreciable although the tendency was to reduce the flood peak.

The difference between total precipitation and total direct mu-off averaged 3.5 inches over the basin above Hartford, Conn., and ranged between 7.95 inches in the Hockanum River Basin in Connecticut and an indicated 0.65 inch in the Otter Brook Basin above Keene, N. H. Although these two extremes are very likely indicative of local conditions inherent in the respective basins it is possible that some error due to inadequate base data may be involved. Both of the last two basins were 10cated near places where the precipitation gradient was steep, making the accurate determination of mean areal precipitation for such small areas very difficult. Figure 48 shows the relation between the mean areal precipitation and the total retention and indicates substantial scattering of the plotted points. This scattering results from differences in soil and vegetal conditions in the several basins and to deficiencies in base data particularly with respect to areal precipitation in small areas near the storm centers. Based on the duration of significant rainfall as previously defined, there are shown on figure 48 two lines, one representing an infiltration Index of 0.07 inch per hour and the other an index of 0.10 inch per hour. Most of the computed values of the retention for upper basins in Vermont and New Hampshire plot close to or toward the left of the index of 0.07 inch, indlcating average rates of absorption of 0.07 inch per hour or less. Most of the basins in Connecticut plot toward the right of the figure indicating rates of 0.10 inch per hour or greater. The data in table 14 and shown in figure 48 indicate a seemingly significant downstream increase in the retention, particularly with respect to the areas tributary to gaging stations on the main river; in 
figure 45 the mean infiltration index shows a similar tendency to increase. It may be further noted that the basins with drainage areas in excess of 500 square miles tend to plot close to or between the two index lines. It may be assumed that the indicated mean precipitation

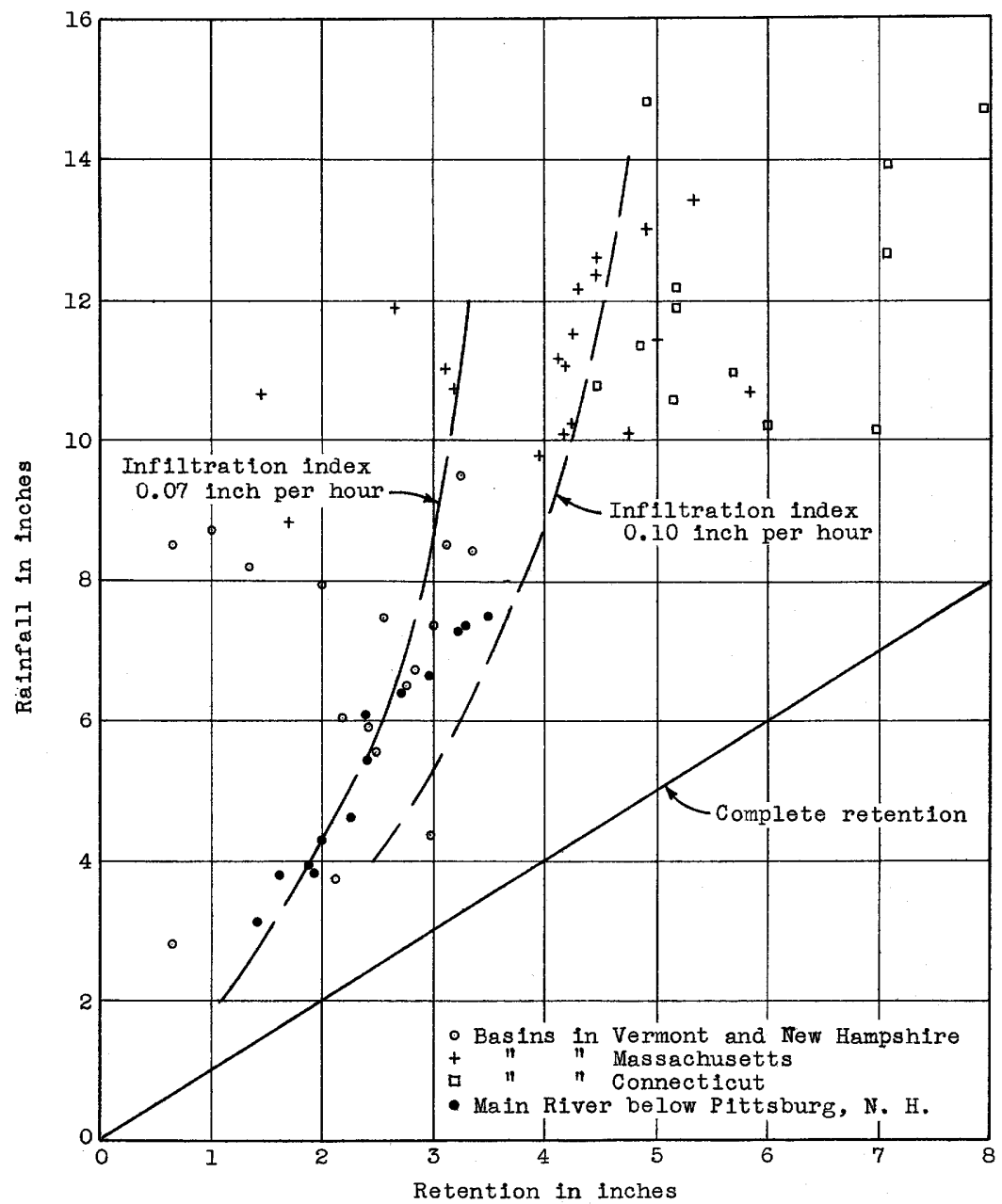

Figure 48.--Relation of total rainfall September 17-21, 1938 , to difference between total rainfall and direct mun-off, Connecticut River Basin.

for the larger basins is less subject to error than that for the smaller drainage basins and furthermore that integration of the effects of variable so11 and vegetal conditions on the larger drainage areas, comprising the Connecticut Basin, would tend to produce uniformity in the values of the infiltration index. It has been shown that an average of about 2 inches was held back in the basin from the rains of September 12-16. Ground-water 
accretion during September 17-21 as computed by the method explained previously, ranged between 0.5 and 2.5 inches, which amounts to about one-third of the retention.

As discussed in Water-Supply Paper 798, the total retention in the Connecticut River Basin above Thompsonville, Conn., during the storm of March 1936 was about 1.6 inches over the basin from 6.4 inches of rain and 6.3 inches of water in the form of snow. This retention may represent the lower limits of basin retention during very unfavorable conditions with respect to soll absorption and evaporation. On the other hand, in the storm of September 16-17, 1932, in a different season and following a long dry period there was an average of about 2.4 inches of precipitation, of which only 0.13 inch ran off, indicative of relatively high absorption and evaporation. During the storm of November 2-5, 1927, there was an average of 5.75 inches of rainfall followed by 2.95 inches of run-off, leaving a retention of 2.8 inches. The latter is closely comparable with the retention indicated for equal rainfall during the storm period of September 1938.

The results of a more detailed analysis of rainfall and run-off from the rain of September 18-21 for Burlington Brook above Burlington, Conn., a small basin in the lower Connecticut River Basin, is presented in figure 49. The upper part of the figure shows the hourly rainfall in inches per hour at Burlington, Conn., and the continuous graph of stream flow in second-feet at the Burlington Brook weir nearby. The rains of September 17 produced no rise in the flow. Beginning with the afternoon of September 18, the rainfell at Burlington, Conn., Increased in intensity unt1I 1t ended at 5 p.m:, September 21. The graph of stream flow shows a like increase, reaching a peak immediately after the intense rain that marked the termination of the storm. Inspection of the graph also shows that as the storm progressed, the stream flow became increasingly greater in proportion to the rainfall, indicating a decreased rate of retention. The discharge following the peak was largely composed of channel storage and ground-water effluent.

There was no appreciable increase in stream flow until near midnight of September 18, after a total rain of about 0.75 inch, which represents the depth of inftial abstraction from rain for this flood period. The amount is shown graphically in the lower part of figure 49. The figure also shows the cumulative rainfall and its computed segregation and disposal. First there is the initial abstraction just mentioned. As the rain increased in amount and intensity, direct run-off into stream channels 


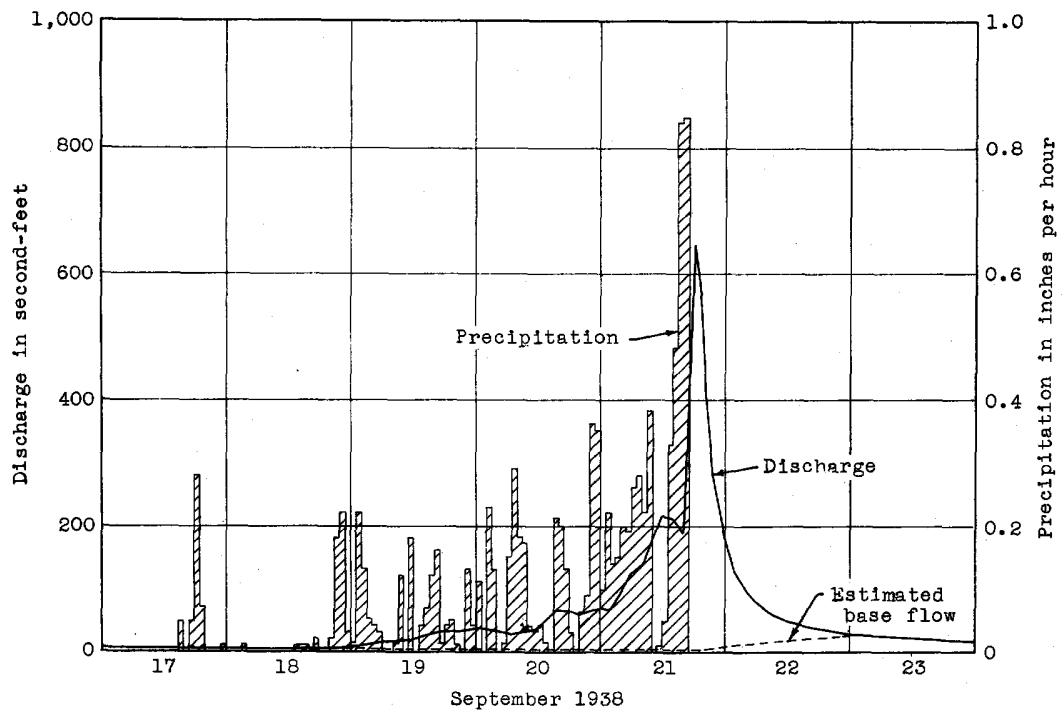

Hydrograph of discharge and graph of hourly precipitation at Burlington, Conn., Sept. 17-23, 1938.

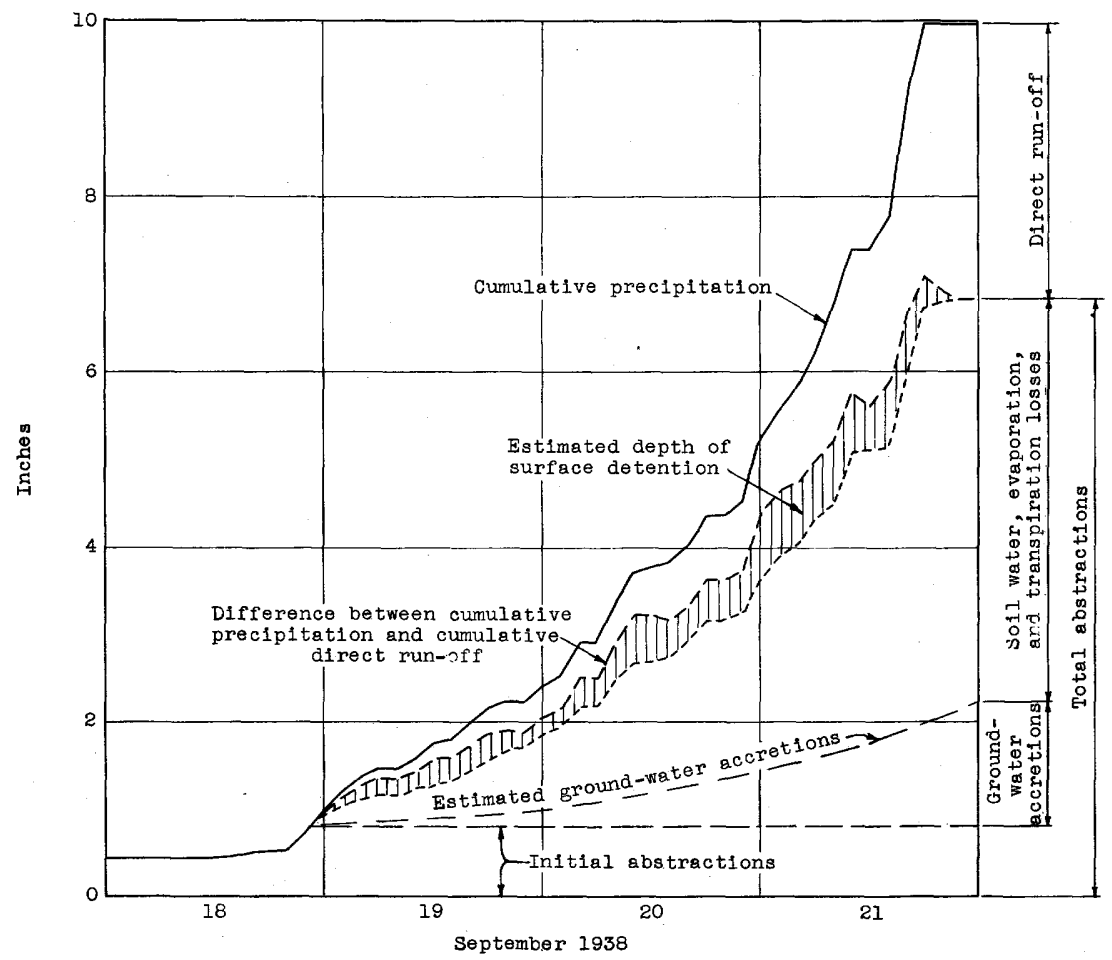

Graphs of cumulative precipitation, difference between precipitation and direct run-off, and estimated ground-water accretion, Sept. 18-21, 1938 .

Figure 49.--Analyses of rainfall and rin-off in basin of Burlington Brook near Burlington, Conn. 
became appreciable and continued to increase in amount and rate as determined by the rain and the absorption by the ground. Accumulative direct run-off, adjusted for channel storage, has been computed at 2-hour Intervals and deducted from the cumulative rainfall at like intervals. The accumulative difference so obtained is shown on figure 49. The total precipitation was 9.95 inches, the total direct mun-off 3.05 inches, and the retention 6.9 inches. Of this retention, initial abstraction accounted for 0.75 inch, leaving 6.15 inches predominantly for the groundwater and so11-water accretions and evaporation. Based on the assumption that the stream flow after September 22 was derived from ground-water storage as shown in the upper part of figure 49, it has been computed by the methods previously explained that the total ground-water accretion was 1.6 inches, leaving 4.25 inches for soll-water accretions and $10 s s e s$ by evaporation and transpiration. The total accretion to ground-water storage was distributed with respect to time during the storm period in figure 49 in proportion to the difference between rainfall and direct run-off as Indicative of the supply avallable for such accretion. DurIng a storm there may be a certain depth of water in transit toward stream channels. Although this water is effective in producing run-off, it is at the same time being absorbed by the ground and receiving contribution from the continuing rainfal1. This depth of water which has been termed surface detention but which perhaps can also be appropriately defined as water in transit to stream channels, was estimated essentially by methods

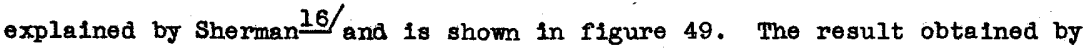
deducting this quantity from the difference between cumulative rainfall and cumlative direct run-off is also shown.

Thus, at any time, figure 49 shows an inventory of the total depth of rainfali, its segregation into initial abstraction, the estimated accretion to ground water, soll moisture, and evaporation, the surface detention (marking the indefinite boundary between the abstraction and runoff), and ultimately the remainder of the precipitation avallable, for direct run-off.

From figure 49 may be computed the infiltration rates that correspond to the slope of the line represented by the difference between precipitation and direct run-off minus the estimated depth of surface detention. The maximum rate of infiltration was about 0.43 inch per hour and was

16/ Sherman, L. K., Determination of infiltration rates from run-off: Am. Geophys. Union Trans., 1938, pp. 430 et seq. 


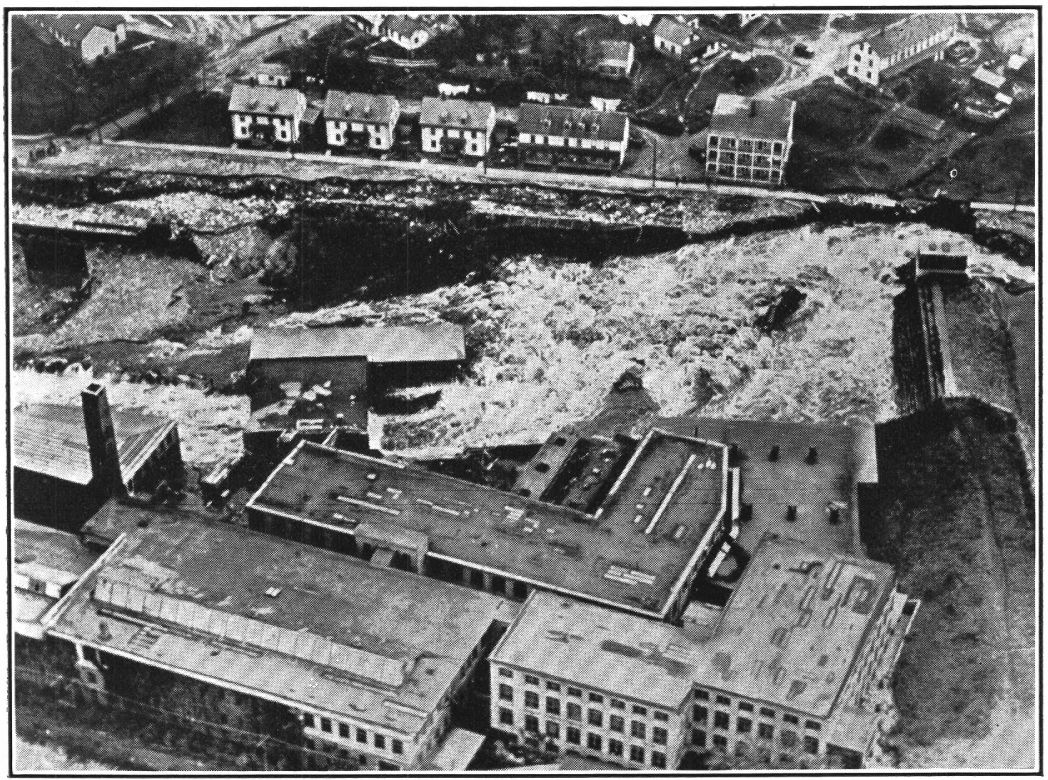

A. SCENE ON QUINEBAUG RIVER AT SOUTHBRIDGE, MASS.

Water passing around end of dam and destroying a street.

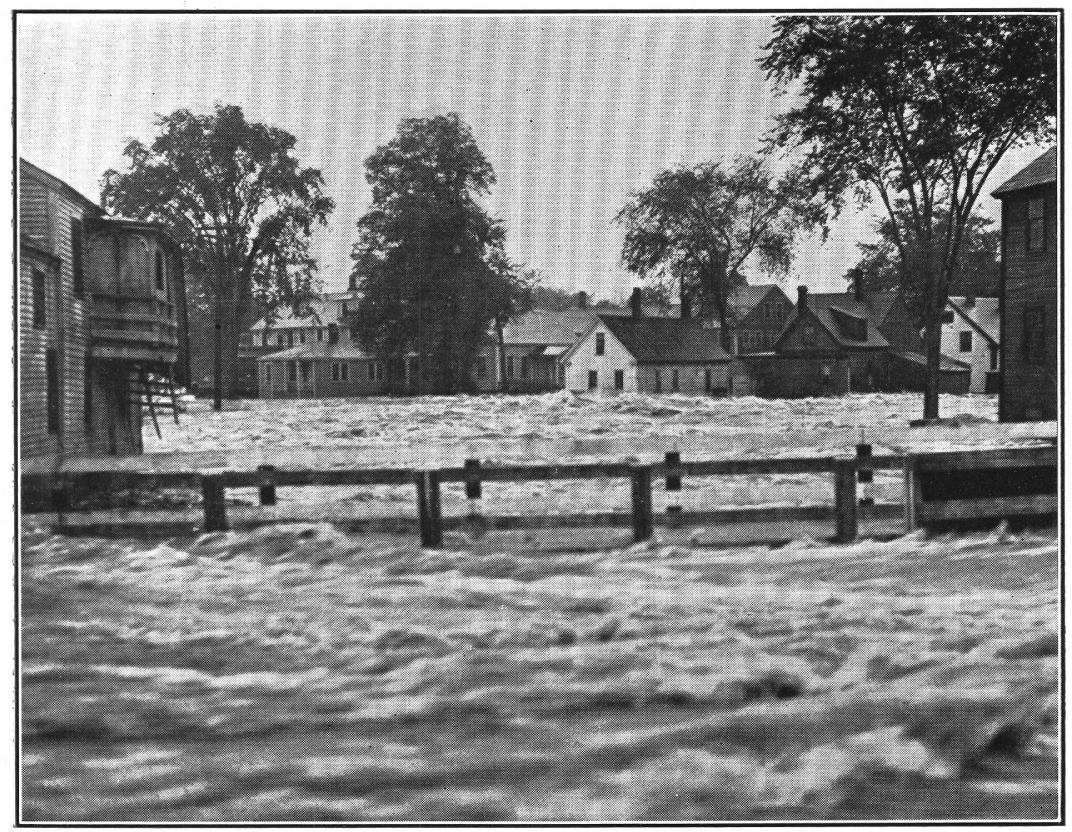

B. SCENE ON MILLERS RIVER AT WINCHENDON, MASS.

Courtesy of International News Photo. 


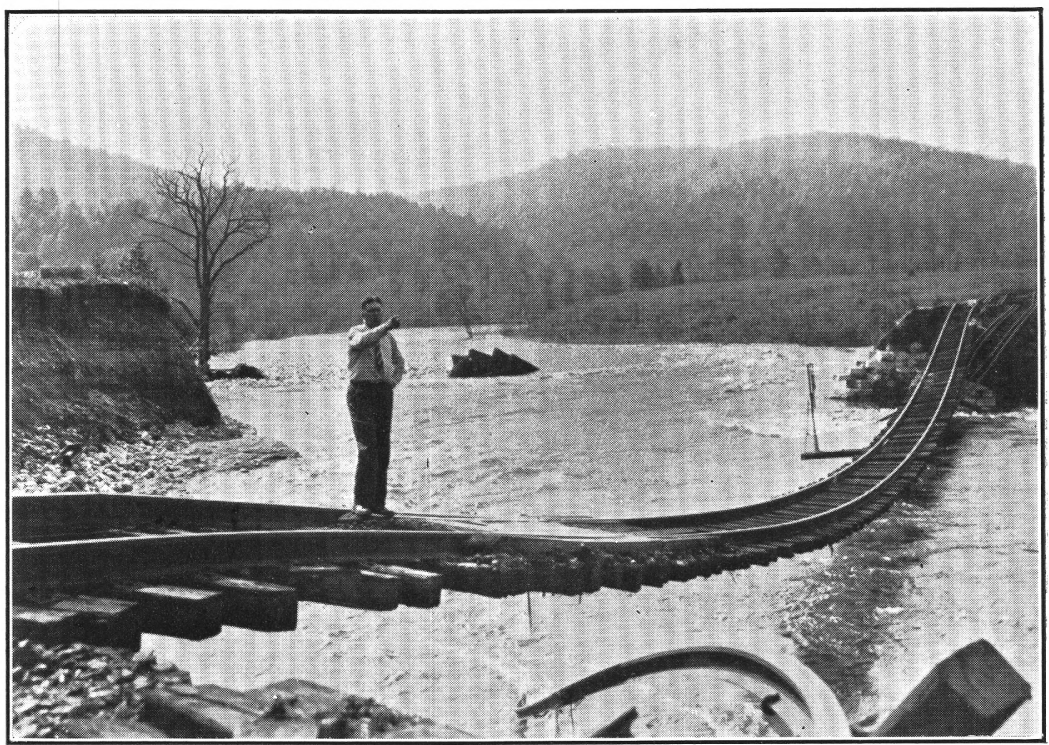

A. APPROACH TO BOSTON \& MAINE RAILROAD BRIDGE DESTROYED BY FLOOD AT WENDELL, MASS.

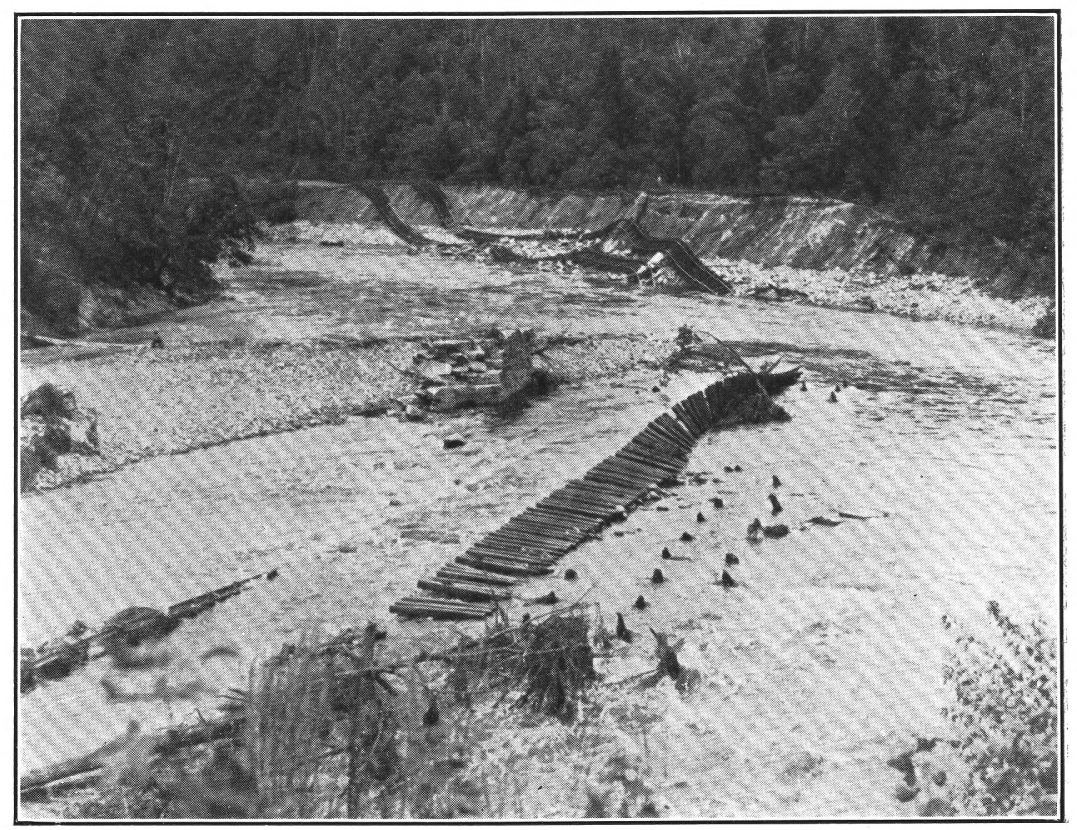

B. VIEW ON BOSTON \& MAINE RAILROAD AT MILLERS FALLS, MASS. WASH-OUTS ON MILLERS RIVER. 


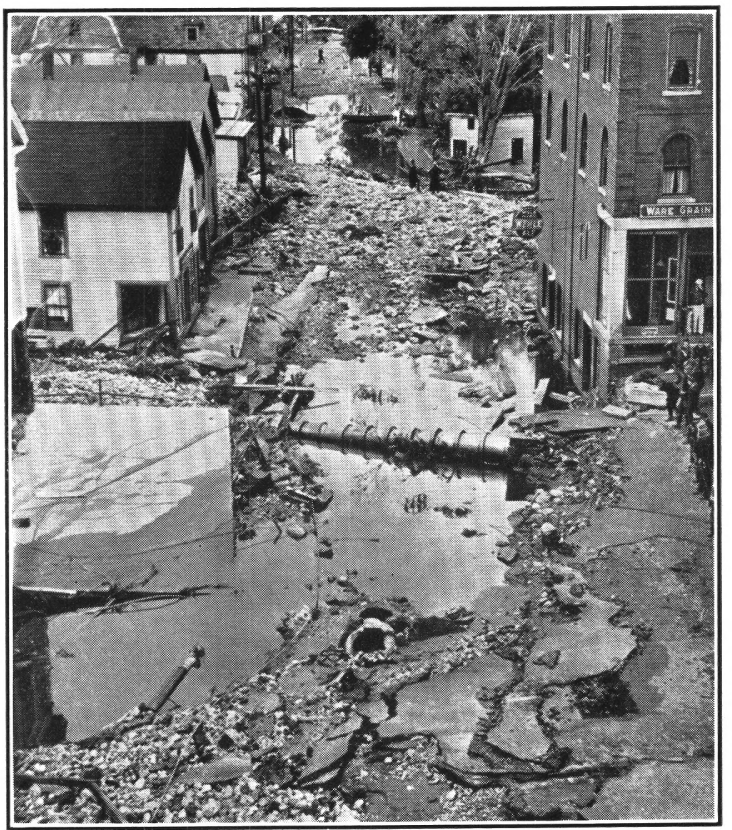

A. CITY STREETS IN WARE, MASS., DESTROYED BY FLOOD OF WARE RIVER

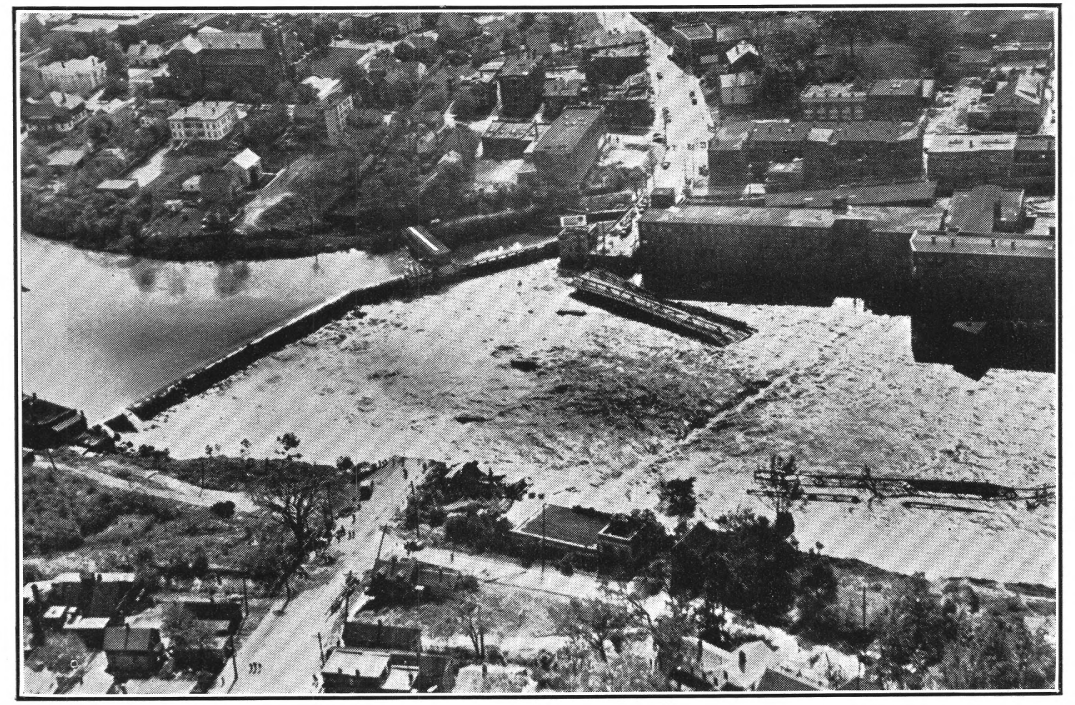

B. CHICOPEE RIVER AT CHICOPEE FALLS, MASS. 


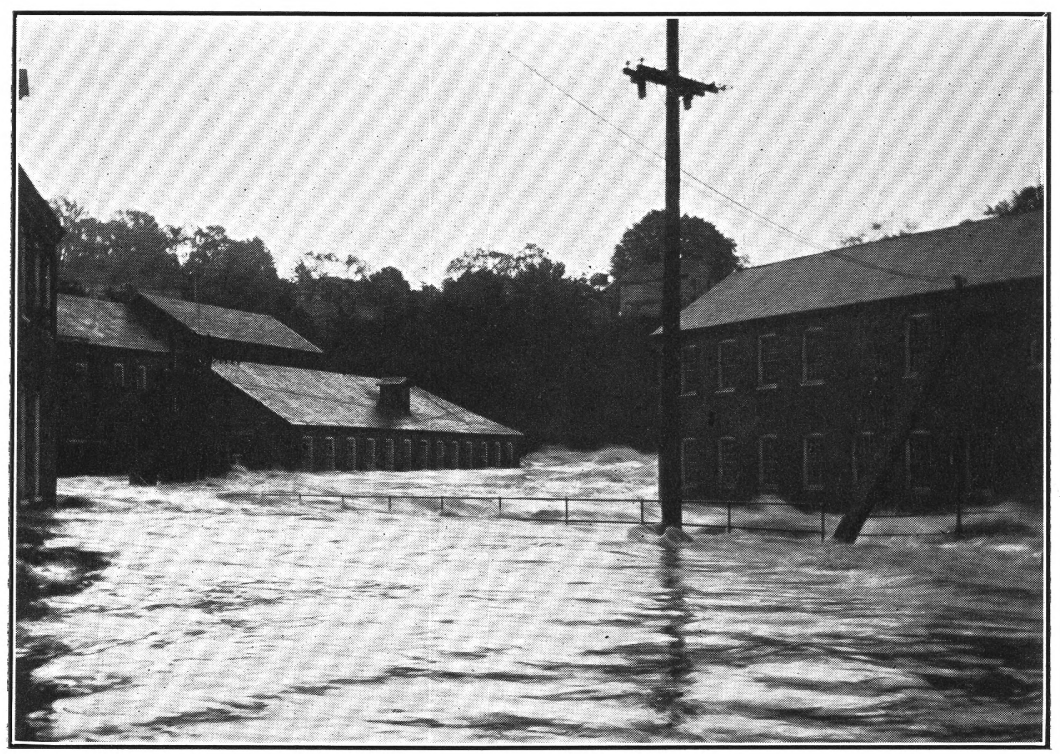

A. WAPPINGER CREEK AT WAPPINGER FALLS, N. Y., AT HEIGHT OF FLOOD. Photograph by George Pettit.

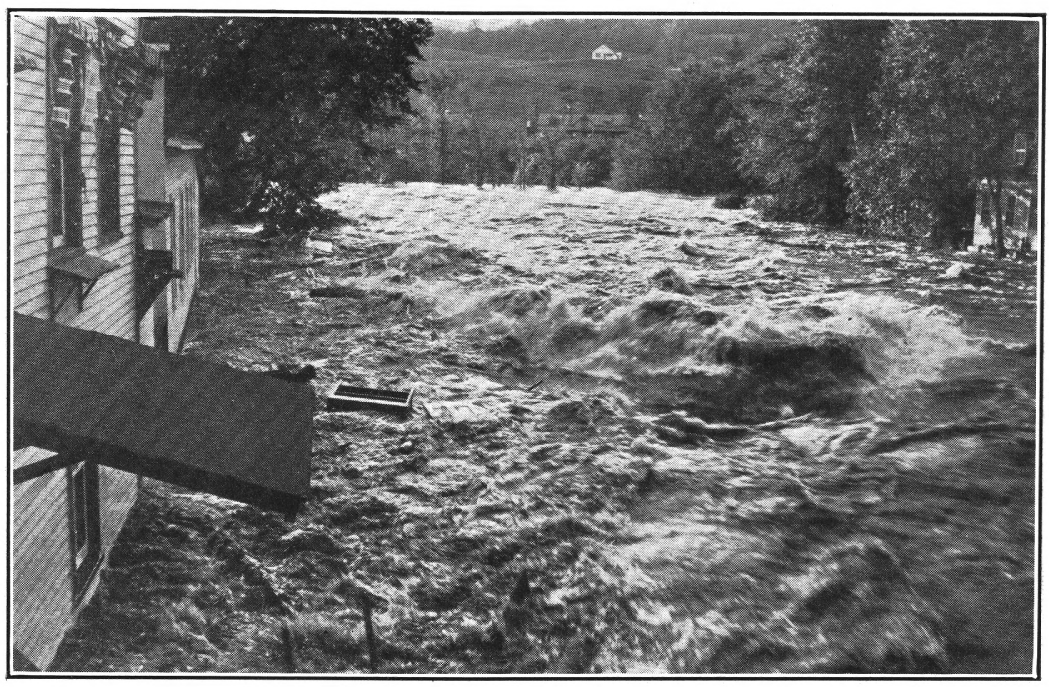

B. WEST BRANCH OF AUSABLE RIVER AT AUSABLE FORKS, N. Y. 
closely assoclated with the period of maximum rainfall intensity. The average rate was 0.20 inch per hour, from data given in table 14 and $\mathrm{flg}-$ ure 44. The decrease in the ability of the basin to absorb water as the storm continued is indicated by the increasing ratio between direct runoff and rainfall as follows: 19 percent on September 18, 26 percent on September 19, 27 on September 20, and 38 on September 21.

\section{Housatonic River Bas in}

The rainfall during the antecedent period September 12-16 was comparatively light, averaging about 1.7 inches over the basin, and the resulting direct run-off ranged from zero to 0.35 inch. Basins with less than 1.5 inches of precipitation had 1 inch or less of direct run-off, indicating about 1.4 inches as the amount of initial detention required to start active run-off under the existing conditions. The average detention of about 1.5 inches probably only partly utilized the absorptive capacity of the basin.

Two continuous records of precipitation in the Housationic River Basin are avallable, one at Woodville, Conn., and the other at Waterbury, Conn., (a fragmentary record at Candlewood Lake has been excluded).17/ The Woodville gage recorded 11.0 inches of rainfall during 71 hours between 4 p.m. September 17, and 8 p.m., September 21, and the Waterbury. gage recorded 9.10 inches of rainfall during 59 hours in nearly the same interval. The maximum hourly rate of precipitation registered during the storm at Woodville was 1.36 inches for the hour ending at 2 p.m., September 19. The maximum 24-hour precipitation recorded in the basin was 5.42 inches at Salisbury, Conn., for the 24 hours ending at 5 p.m., September 21 , as compared with a total storm rainfall of 8.9 inches, thus indicating that more than 60 percent of the rain fell during the last 24 hours of the storm.

Based on 29 records in the basin and adjoining areas, the precipitation during September 17-21 ranged from 7 to nearly 12 inches. The associated direct run-off as shown in table 14 ranged from 3.2 to 7.65 inches, generally varying with the rainfall. The difference between the total storm precipitation and the total direct run-off ranged between 3.05 and 6.6 inches and represents the depth of water disposed of by vegetal interception, surface storage, absorption, and evaporation. Figure 50

17/ The automatic record at Waterbury, Conn., was received too late to permit its inclusion in this report although the daily record of rainfall is published as no. 248 in table 4 .

$2279070-40-30$ 
shows the retention for the several basins listed in table 14 in relation to the storm rainfall. Estimates made by methods described in a previous section indicate that the average accretion to ground water was about 1.6 inches or about one-third of the total retention.

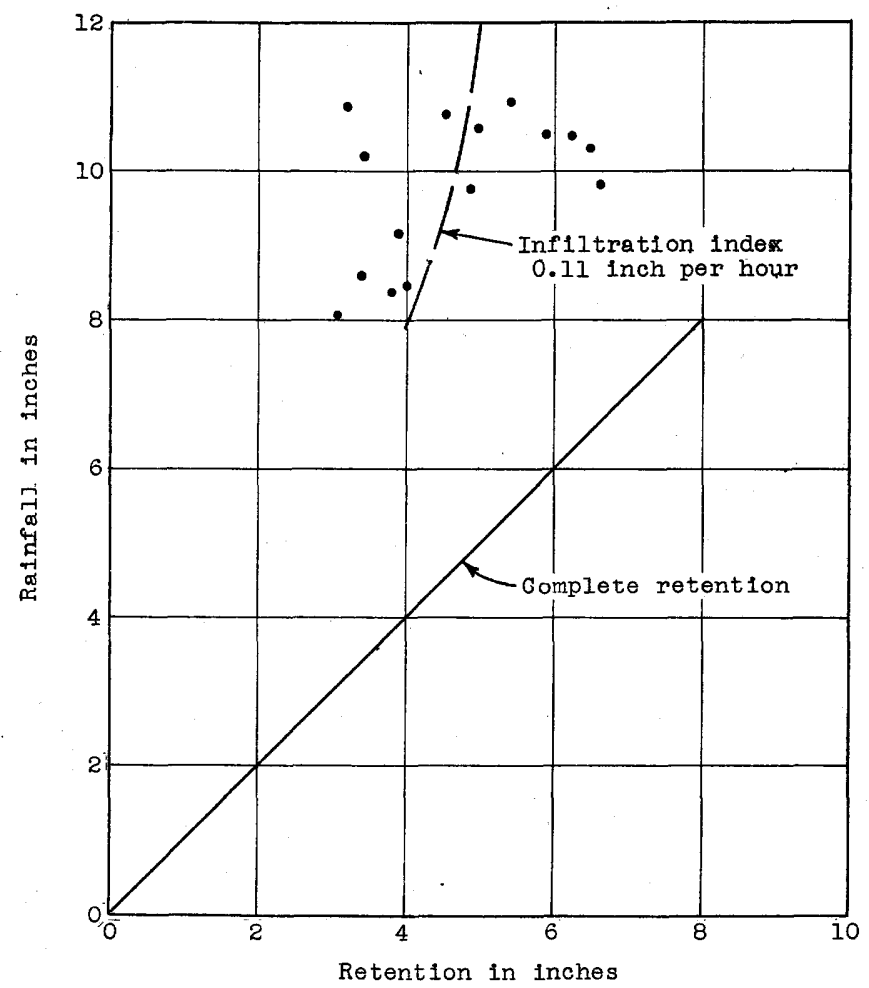

Figure 50.--Relation of total rainfall September 17-21, 1938, to difference between total rainfall and direct run-off, Housatonic River Basin.

Based on the number of hours of significant rainfall, as defined in the section on "Method of analysis", a line representing an infiltration index of 0.11 inch per hour is shown in figure 50. There is some scattering of the plotted points with respect to the index line which may be ascribed to variations in retentive capacity of the various basins, difference in storm characteristics, and deficiencies in base data. Figure 45 shows that the infiltration index increases in a downstream direction in a manner similar to those of adjoining basins.

In the storm of March 9-22, 1936, there was an average rainfall of 5.45 inches over the Housatonic River Basin above Stevenson, Conn., upon an antecedent snow cover with a water content of about 4.0 inches. The average direct run-off was 8.4 inches, leaving a retention of 1.05 inches, 
from the total supply of 9.45 inches. The small retention reflects the effects of frost and other adverse factors in restricting infiltration.

The storm of September 1932 was of negligible intensity in this basin. During the storm of November 1927, however, there was about 6.15 inches of precipitation in the Housatonic River Basin above Falls Village, Conn., of which 3.05 inches appeared as direct run-off, leaving a retention of 3.1 Inches, an, amount comparable with that of the storm of september 1938.

The ratio between the direct run-off during the maximum 24 hours and the total direct run-off ranged between 29 and 53 percent. Study of this percentage in relation to arainage area indicates that most of the drainage basins are consistent with respect to concentration characteristics. The results for the Naugatuck River Basin indicate that it is more flashy.

\section{Streams on Long Island}

Western Long Island recelved about 11 inches of rainfall, but in contrast with other regions on the mainland, there were no severe freshets in the streams. Inspection of table 14 reveals that the direct run-off from the 1-inch rainfall of September 12-16 was negligible and that the 11 Inches of rainfall on september 17-21 resulted in but 0.2 to 0.6 inch of direct run-off, leaving a retention of about 10.6 inches.

The surface of Long Island is composed of unconsolidated materials of glacial origin, and rock is not to be found except at the extreme western edge or at great depths, generally beneath sea level. The low relief and high porosity of the thick, unconsolidated deposits combine to provide very high absorptive and retentive capacities and rapid passage of Infiltrated water to the ground-water table. Consequentiy in an inventory of the water resources of Long Island the ground-water storage is an Item of great Importance.

The average retention following the rains of September 17-21, which nearly equalled the rainfall, may be segregated as follows: (a) Initial losses, such as vegetal interception; (b) soll-water accretion; (c) evaporation and transpiration losses; and (d) addition to the ground-water storage from which it reaches stream channels, discharges directly to the ocean or is pumped for domestic or industrial uses.

Although no definite quantitative segregation of the residual can be made, if it is assumed that the first three items above are similar to those in the Thames River Basin or in the Lower Connecticut River Basin (soil molsture capacities of the two regions may differ somewhat), where 
under like rainfall they averaged about 3.9 inches, then of the retention of 10.6 inches remaining after the rains of September 17-21, it is est1mated that about 6.7 inches or about 63 percent of the retention was available for ground-water run-off or pumpage. Based on an interpretation of ground-water levels and an estimation of the specific yield of the material in the zone of ground-water fluctuation, as discussed in the section "Ground-water recharge on Long Island", it was estimated that the recharge in the area south of the glacial moraine was 7.2 inches.

Largely as a result of the high rates of infiltration that are characteristic of this region and of the flat channel slopes bordered by marshy ground, peak rates of surface flow were 10w, the maximum being 8.6 secondfeet per square mile ( 0.013 inch per hour) compared with rates of rainfall in the area which reached a maximum of 1.28 inches per hour at Manhasset, N. Y., during the hour ending at $10 \mathrm{p.m.,} \mathrm{September} \mathrm{18.} \mathrm{At} \mathrm{Setauket} \mathrm{the}$ Weather Bureau observer reported 1.64 inches of rain in 75 minutes on the morning of September 20, equivalent to 1.31 inches per hour.

Hourly records of rainfall on Long Island indicate irregular rainfall distribution with respect to time. Table 6 shows that the maximum rate occurred on September 21 at Brooklyn, in Flushing, N. Y., on September 20 at Freeport, and on September 18 at Long Beach, Manhasset, and Mineola, N. Y. Inspection of the dally amounts at the several gages on Long Island likewise does not disclose any great measure of similarity of distribution with respect to time. This condition makes any hourly correlation of rainfall and run-off in this area more difficult than might be presumed from the relatively large number of recording gages available. It may also indicate that generalizations with respect to rainfall characteristics without adequate continuous records may load to error.

Figure 51 shows a hydrograph of stream flow of Pines Brook at Malverne, N. Y., together with a graph of hourly precipitation at Mineola, N. Y. The hydrograph may be seen to conform rather closely with the rainfall distribution, the two principal peaks following, respectively, the two periods of intensive rainfall. The hydrograph of direct run-off for this drainage area of 10 square miles, which is superimposed upon a proportionately large discharge from ground water, shows the effects of modification by stream channel and swamp storage, of which there are considerable amounts. Stream flow became greater in proportion to the rainfall as the storm continued. 
In the low pervious areas of Long Island there is great difficulty In sharply tracing the basin divides, particularly with respect to the division of ground water, inasmuch as the phreatic and topographic divides are not necessarily coincident. Consequently the mean depths in Inches of direct run-off given in table 14 may be in error from this source, but by amounts of relatively small magnitude. Any determination of ground-water run-off, in inches, may, however, be subject to material error.

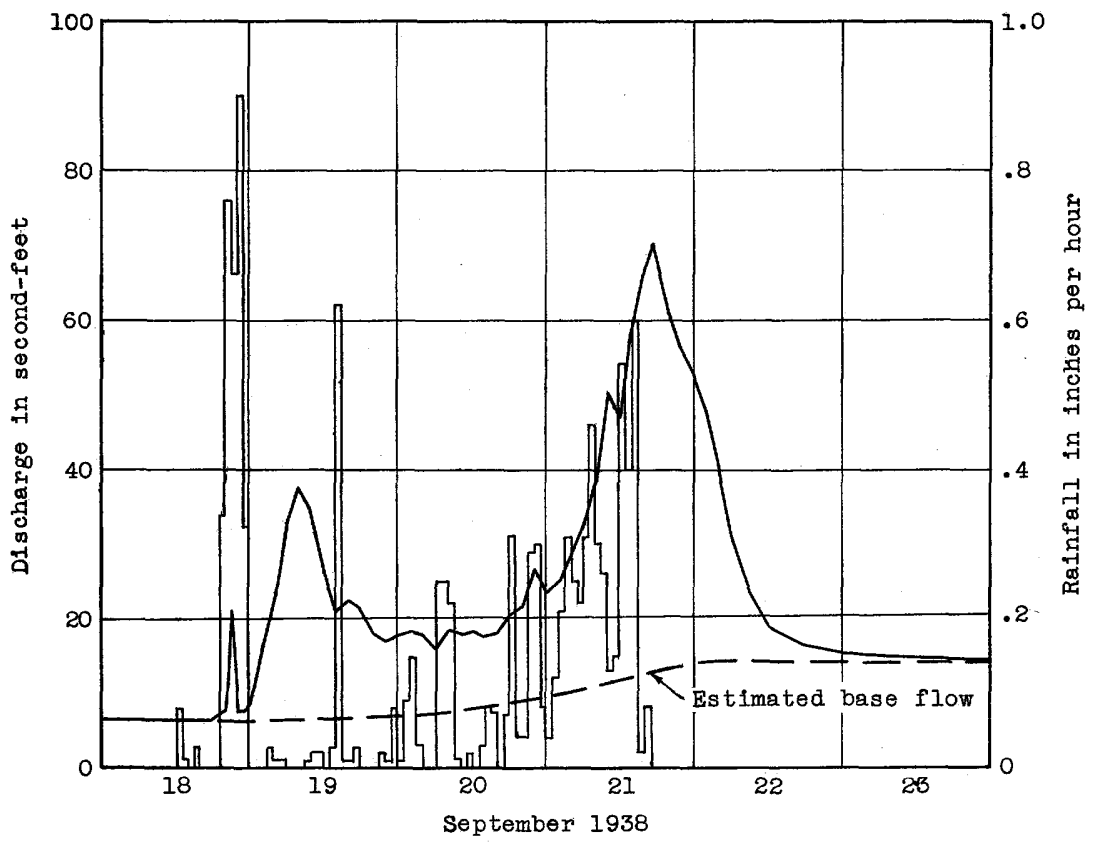

Flgure 51.--Hydrograph of aischarge, Pines Brook at Malverne, N. Y., and graph of hourly rainfall at Mineola, $N$. Y.

The average of the differences between rainfall and direct run-off as listed in table 14 is about 10.6 inches, which corresponds with an infiltration index of more than 0.26 inch per hour and greatly in excess of the index of infiltration obtained for areas on the mainland during this storm, which generally averaged between 0.08 and 0.12 inch per hour.

\section{Hudson River Basin}

The Hudson River Basin, although west of the central storm area, received fairly sizeable amounts of precipitation during September 17-21, ranging from more than 9 inches in the lower basin and in the upper Hoosic River Basin to less than 3 inches in the upper Mohawk River Basin. In 
general, the rainfall decreased from the southern and eastern portions toward the north and west. An example of the flood conditions in the eastern part of the basin on Wappinger Creok is shown in plate 15, A.

Rainfall began during the late afternoon of September 17 and continued wh about 65 hours of measurable rainfall until nearly mianight of September 21. The maximum precipitation during any one hour, 1.32 inches, was recorded during the hour ending at 2 p.m., September 19, at West Point, N. Y., where a total storm rainfall of 8.93 inches was recorded. Although most of the recording gages indicated that the maximum hourly rate occurred on september 19, the major portion of the rain fell on september 21. Thus the greatest dally amount recorded in the basin was 6.00 inches at Bedford H111s, N. Y. (In the lower basin), for the 24-hour period ending at 5 p.m., September 21 , as compared with the total storm rainfall at Bedford Hills of 9.83 inches. The storm of September 17-21 was preceded by an average of 1.9 Inches of rain during the perlod September 12-16, distributed somewhat irregularly as shown in figure 2. There were moderate rises in stream flow following the storm. There was practically no direct mun-off in areas of 1 inch or less or rain, but the direct mun-off was as much as 0.8 inch in the upper Hoosic River Basin, where there was more than 2 inches of rainfall. The retention from the first storm was generally proportional to the rainfall and averaged about 1.7 inches. It tended to relleve surface dryness and undoubtedly had a signiflcant effect on the rainfall and run-off relations during the major storm that followed.

Run-off associated with the storm of September 17-21 as shown in table 14 ranged from 1.5 to 6.7 inches and left a retention that averaged about $3 \frac{1}{8}$ inches. The retention, being limited by the supply, was generally greater in those areas where precipitation was heaviest. It was also Influenced by other factors, principally rainfall rates and soll and vegetal conditions. Flgure 52 has been prepared in order to study the variation of the residual with respect to the total rainfall. Based on procedure explained in the section on "Method of analysis", Iines of equal infiltration index have been drawn on figure 52. These Iines show that most points 110 within the 0.08 and 0.13 inch per hour indices and that there was a tendency for the average rates of infiltration to increase with the amount of rainfall. The geographical distribution of the infiltration index shown in figure 45 indicates a general tendency towards greater infiltration in the lower basins. An infiltration index of 0.10 to 0.14 
Inch is indicated for parts of the upper Hudson River Basin. This relatively high retentive capacity in this region may be due in large part to the surface storage available in swamps rather than to ordinary ground retention.

The Portion of the difference between rainfall and run-off that resulted in accretion to ground water has been estimated to average about 1 inch or about 33 percent of the total retention.

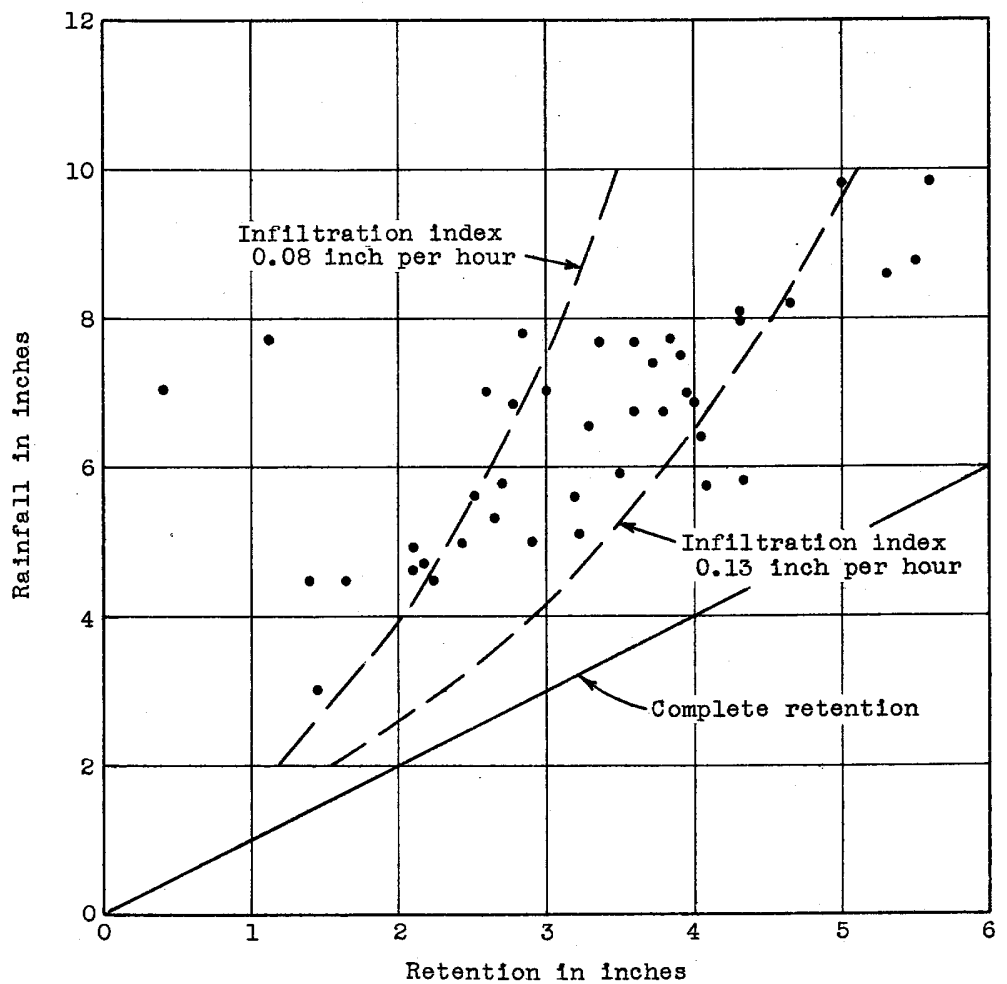

Figure 52.--Relation of total rainfall September 17-21, 1938, to difference between total rainfall and drect run-off, Hudson River Besin.

With an average rain of about 4.8 inches, March 9-22, 1936, falling upon a snow cover having an average water content of about 4.4 inches, there was a total direct min-off of 7.7 inches from the Hudson River Basin above Albany, leaving an average residual of about 1.5 inch. As reported In Water-Supply Paper 799, this small retention, associated with a 13-day storm period, largely reflects the restrictive influence of frost and other adverse factors on infiltration. It is believed the conditions at the time approached the most unfavorable that may be expected in this area in respect to basin retention. 
Concentration of the run-off with respect to time as indicated by the ratio of direct mun-off during the maximum 24-hour period and the total direct run-off for the flood ranged between 18 and 69 percent. Study of the relation between the concentration ratio and the size of the drainage area Indicates that the Schoharle Creek at Prattsville, N. Y., is a stream of more than normal flashiness, whereas the run-off of the upper Wallkill River Basin, owing to the effects of large volumes of storage over wide flood plains, 1s characteristically sluggish. It is of interest to note that the concentration ratio of Wallkill River at Phillipsburg is only 18 percent, whereas, downstream at Gardiner, N. Y., the ratio increases to 23 percent, reflecting the effect of the prompt discharge of inflow from the 279 square miles of intervening dreinage.

\section{Eastern New Jersey basins}

During the storm of September 17-21, eastern New Jersey as shown on plate 1 recelved 7 to nearly 12 inches of rainfall in 50 to 81 hours. The maximum rainfall in an hour, 1.76 inches, was recorded on the sea coast at Long Branch, N. J., during the hour ending at 8 p.m., September 18. The automatic gage at Mahwah, N. J., recorded 1.50 inches during an Isolated shower at 2 p.m., September 19. Nine recording gages reported rainfall in 1 hour in excess of 1 inch. There was, however, much divergence in the time during which the maximum intensity of precipitation occurred. In common with other areas the greater part of the rain fell during the 24 hours ending on the evening of September 21, as evidenced by the maximum 24-hour amount (6.35 inches out of the total of 10.29 inches) recorded at Lakewood, N. J., during the 24 hours ending at 5 p.m., September 21 .

In general, the rivers in the area began to rise about noon on September 19 in response to comparatively heavy rains following light separate rainfalls on September 17-18. There was nearly continual rainfall of measurable amounts between noon on September 19 and the evening of the 2lst. All the larger streams rose steadily to a single peak, which was reached late on September 21 or early on September 22. Some of the smaller streams had two or more well defined rises in response to the variations in the rainfall form. However, in all rivers, the final peak of September 21 was the greatest. Peak rates of run-off are given in table 10. The maximum for Green Brook at Plainfield, N. J., was 178 second-feet per square mile, corresponding to nearly 0.28 inch per hour. Indicative of the degree to which the run-off was concentrated in respect 
to time, table 14 lists the ratio between the direct run-off during the maximum 24 hours and the total direct run-off, for all unregulated streams. Study of this ratio with respect to size of the drainage area indicates that the streams in the Raritan River Basin are generally more directly responsive to the rainfall than are those in the Passaic River Besin. The relatively sluggish character of the Passaic River is mainly due to the large volume of storage over the lowlands lying between the Watchung Ridges in central New Jersey. Thus the discharge hydrograph of the Neshanic River In the upper Raritan River Basin, which has the greatest concentration ratio ( 61 percent), falthfully displays the variations in rainfall intensity shown in figure 53. The lowest concentration ratio was that of the Passaic River at Chatham (15 percent), whose basin is affected by large flood-plain storage described above. The basins in the southern part of the State as exemplified by the Great Egg River above Folsom, which has a concentration ratio of 20 percent, are sluggish, owing to low rellef and flat channel slopes.

Table 14 lists the rainfall and mun-off over the several basins in eastern New Jersey during the periods September 12-16 and 17-21. Rainfal1 during the first period was generally less than 1 inch and produced inappreclable run-off. The storm of September 17-21, with 5 to 11 inches of rain, resulted in direct run-off that ranged between 1.6 and 4.5 inches, as determined by the rainfall and other factors peculiar to each basin. The difference between rainfall and direct run-off ranged from 4.45 inches for the Wanaque River Basin in northern New Jersey to 8.5 inches for the Toms River Basin in southern New Jersey.

As determined by the infiltration index computed by methods previously explained, the Infiltration capacity in the Passaic and Hackensack River Basins ranged between 0.13 and 0.17 inch, with an average of 0.15 inch per hour. In the Raritan River Basin, the index ranged between 0.14 and 0.20 inch with an average of 0.16 inch per hour. In the southern part of the State, the Toms River and Great Egg River Basins had infiltration indices of 0.26 and 0.17 Inch per hour respectively. As shown in figure 45 there is a tendency for the retentive capacity to increase from the northem to the southern part of the state and toward the coast.

Based on continuous records of stream flow and records of rainfall at Millington, N. J., and Trenton, N. J., flgure 53 has been prepared to show a detalled analysis of the rainfall and run-off of the Neshanic River Basin above Reaville, N. J. The upper part of figure 53 presents a hydrograph of stream flow in second-feet and 2-hour rainfall in inches per hour. 


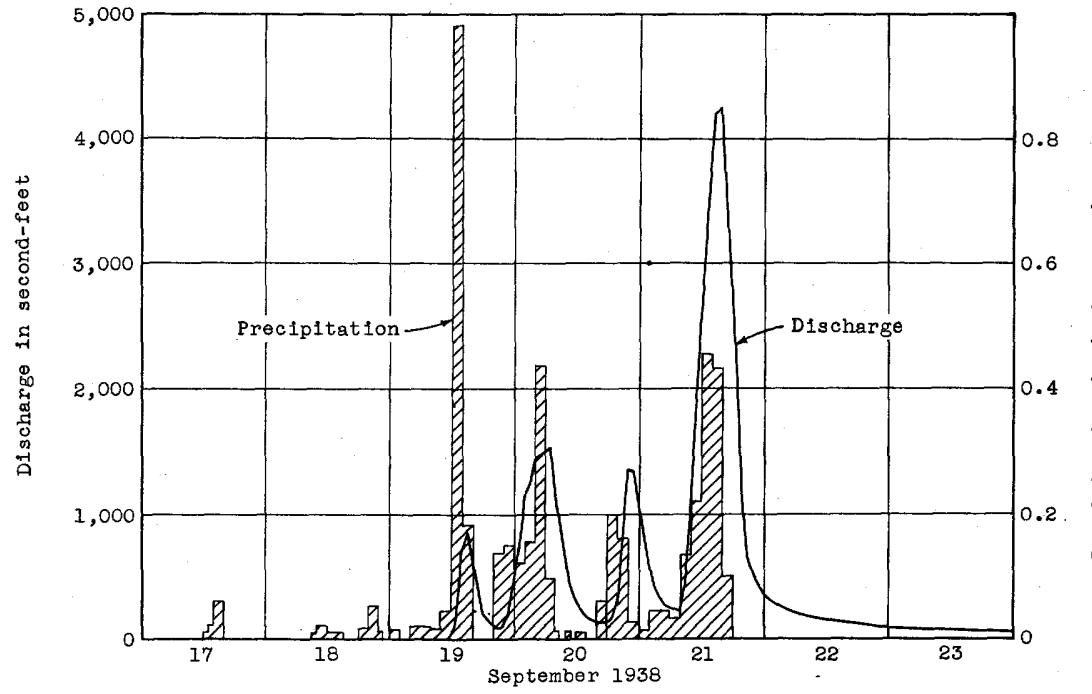

Hydrograph of discharge and graph of precipitation, September 17-23, 1938 .

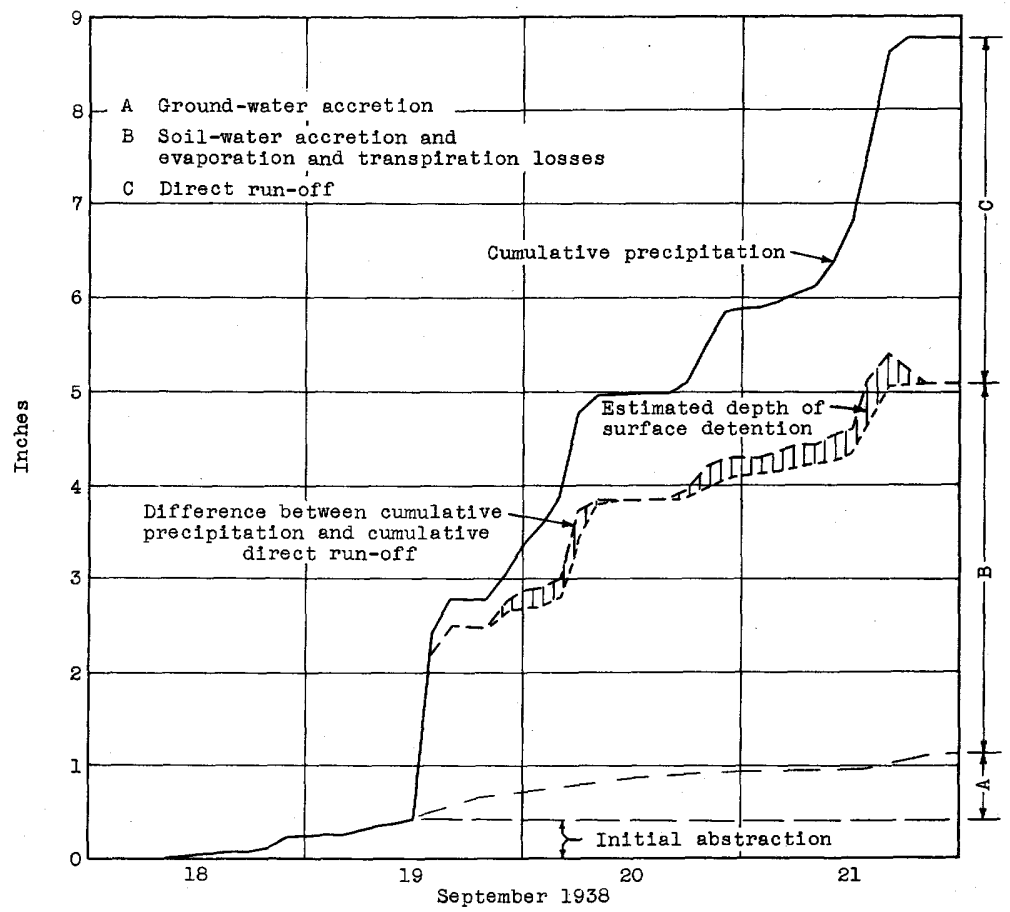

Graphs of cumulative preclpitation, direct run-off, and estimated infiltration, September 18-21, 1938 .

Figure 53.--Analyses of rainfall and run-off in basin of Neshanic River at Reaville, N. J. 
The responsiveness of the stream flow of this basin to the rainfall variation has already been mentioned. The stream-flow graph shows that the mun-off increased in proportion to the rainfall as the storm continued.

The lower part of flgure 53 shows a graph of cumulative rainfall (total, 8.65 inches) and 1ts computed segregation. First are the initial abstractions, which amounted to about 0.4 inch. It may be noted that the 0.5 inch of rainfall on September $12-16$ produced no appreciable run-off. It is quite likely that the apparently and relatively low value of the initial losses may be in error as a result of the early beginning of the direct rum-off due to the intense rainfall about noon of september 19, which probably quickly completed the remalning abstractions. The total direct run-off following the satisfaction of the initial demands was 3.7 Inches, leaving a total retention of 5 inches, of which 0.4 inch was accounted for by the initial abstractions. Of the remaining 4.6 inches, an estimated 0.8 inch was added to the ground water, from which 1t was discharged into stream channels either during or subsequent to the storm, leaving 3.8 inches for soli-water accretion and losses by evaporation and transpiration. The rate of accumulation of these component parts of the retention, or difference between precipitation and direct run-off is shown on the lower part of figure 53. The cumulative direct run-off has been adjusted for channel storage and subtracted for contemporaneous intervals from the cumulative rainfall graph to obtain a cumulative graph of the difference. During a storm, water in a basin both on the surface and in many places immediately beneath it is in transit towards the stream channels. This water in transit, which is being simultaneously diminished by percolation and increased by the continuing rainfall, has been termed surface detention and is shown on figure 53. Surface detention marks the indefinite zone that exists during a storm between direct run-off and retention. The estimated ground-water accretion has been distributed with respect to time approximately in proportion to the difference between rainfall and run-off minus the estimated depth of surface detention, as indicative of the source of supply for such accretion. 
The decrease in the rate at which the basin absorbed water through the storm period is indicated by the increasing ratio between the direct run-off and the rainfall as follows:

\begin{tabular}{cc}
$\begin{array}{c}\text { Ratio } \\
\text { (percent) }\end{array}$ & \multicolumn{1}{c}{$\begin{array}{c}\text { Time } \\
\text { (September) }\end{array}$} \\
11 & 18th, midnight -19 th, 8 p.m. \\
38 & 19 th, 8 p.m. -20 th, 4 p.m. \\
59 & 20 th, 4 p.m. - 2lst, 8 a.m. \\
71 & $21 s t, 8$ a.m. - 2lst, 6 p.m.
\end{tabular}

\section{Delaware River Basin}

The precipitation over the Delaware River Basin during the antecedent storm period September 12-16 ranged from 1.2 to 2.0 Inches and was neariy all retained in the basin or evaporated, the direct run-off from the first storm averaging less than 0.1 inch. As in other basins, the general effect of the antecedent atorm was to lower the retention capacity during the main storm period and thus to increase the resulting flood run-off.

The central path of the storm of September 17-21 was east of the Delaware River Basin and consequently there was a tendency for the precipitation in the basin to increase from west to east. On an areal basis the precipitation ranged from about 5.15 to 6.8 inches over the tributary drainage areas. Most of the rain fell on September 21, al though there was a total of 65 hours of significant rainfa11. A maximum intensity of 0.74 inch per hour was recorded at China, N. Y., in the West Branch of the Delaware River Basin during the hour ending at $5 \mathrm{p.m.,}$ September 2l. The flood run-off was marked by a single peak, the maximum stage occurring generaliy during the afternoon or evening of september 21. The total direct mun-off ranged from 2.4 to 4.3 inches, and 43 to 59 percent ran off during a 24-hour period ending during the afternoon of september 22 .

The besin differences between rainfall and direct run-off ranged from 1.7 to 3.7 Inches and averaged about 2.65 inches. Using the described method of analysis, the infiltration index was computed to be about 0.075 inch per hour. Figure 45 showing the geographical distribution of the infiltration index in the region studied indicates that the retention capacity in the upper Delaware River Basin in New York is lower than the average found elsewhere. The average accretion to ground water, recovered as stream flow, is estimated to have been about 1 inch or 40 percent of the a verage residual. 


\section{St. Lamrence R1ver Basin}

Although not in the center of the storm area, some of the streams in northern New York and Vermont tributary to the St. Lawrence River exper1enced extraordinary floods, as shown on plate 15, B, facing page 454. As show on plate 1 the greatest precipltation in this area was about 7 inches in the upper Otter Creek Basin. Other Basins did not recelve nearly so much, as for example, the Missisquol River Basin above North Troy, Vt., where the period rainfall was only 2.5 inches. Preclpitation during the antecedent perlod September 12-16 ranged from 1 inch in New York to more than 4 inches in the Otter Creek Basin in Vermont, where the greatest amount during this storm was recorded. Direct run-off, however, was small, ranging from about 0.05 to 0.9 inch and tending toward the lowest amounts in areas where the preaipitation ranged from 1 to 1.5 inches and reaching the greatest amounts in the Otter Creok Basin, where the precipitation areraged 3.5 inches. The net retention resulting from the antecedent storm ranged from $I$ to 2.9 inches. It is unlikely that there were large contributions to ground water. Inspection of run-off amounts shom in table 14 in relation to rainfall indicates that about 1 inch of rain was required to produce a sensible increase in run-off.

September 16 was generally clear and rainfall on september 17 and 18 was nogligible. In rermont the main storm was confined to the period between 4 a.m., September 19, and mianlght, September 21. Table 6 shows that all atations in the ares tributary to the St. Lawrence River recorded their maximum precipltation rate on September 21 towards the end of the scorm period.

The direct run-off assoclated with the rain of September 17-21, as shom in table 14, ranged from 0.7 inch in the Black Brook Basin in New York to more than 3 inches in three basins in Ner York and Vermont. The retention, or the difference between the total precipltation and the total difect run-off ranged between 1.15 and 3.65 inches The retention affords a messure of the quantity of water absorbed by the ground, intercepted ana transpired by vegetation, or evaporated.

Figure 54 shows a plot of the differences between storm rainfall and direct run-off in relation to corresponding rainfall. The scattering shown may be ascribed to varlations in the retentive capecity of respective reas and to differences in rainfall characteristics as well as to possible deflciencies in the base data. Based on the information shom on figure 44, a line representing an infiltration index of 0.08 inch per 
hour has been drawn on figure 54. The lowest value of the retention, 1.15 inches for the North Branch of the Winoosk1 River above Wrightsville, Vt., with 3.9 inches of precipitation, corresponds to an average infiltration Index during the storm of 0.05 inch per hour; and the greatest value of the retention, 3.65 inches for Black Brook above Black Brook, N. Y., with 4.35 inches of precipitation, corresponds to an average infiltration index of 0.18 inch per hour. In general, as shown by figure 45,

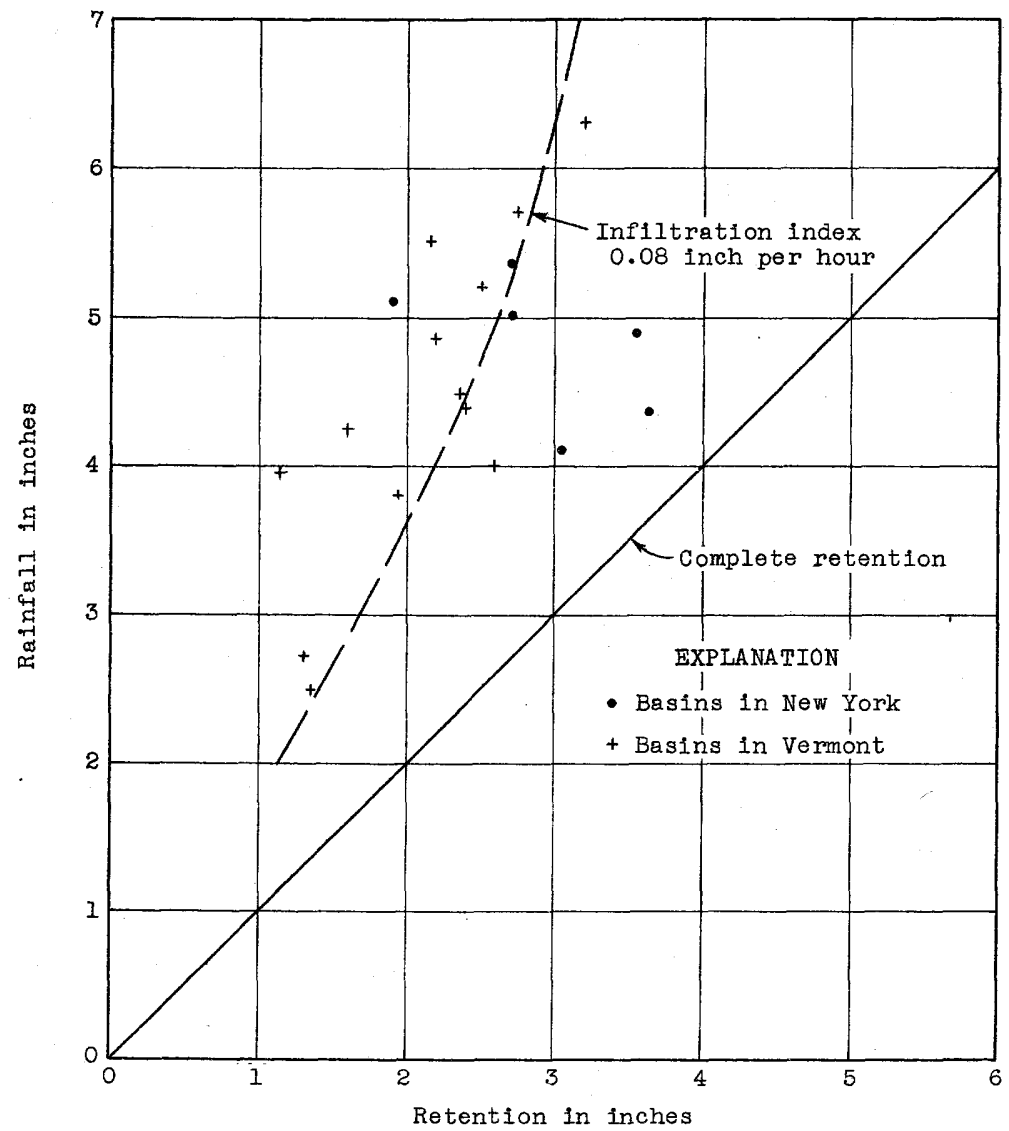

Figure 54.--Relation of total rainfall September 17-21, 1938, to difference between total rainfall and direct run-off, St. Lawrence River Basin.

higher retention capacities were found in the basins in New York. This condition may be due in pert to the difference between the basins in New York and Vermont in respect to soll characteristics and swamp and lake storage.

Figure 55 shows the results of a detalled analysis of the rainfall and run-off of the Dog River above Northfield Falls, Vt. The upper part of the figure shows the hourly rainfall at Northfield, Vt., and hydrograph 


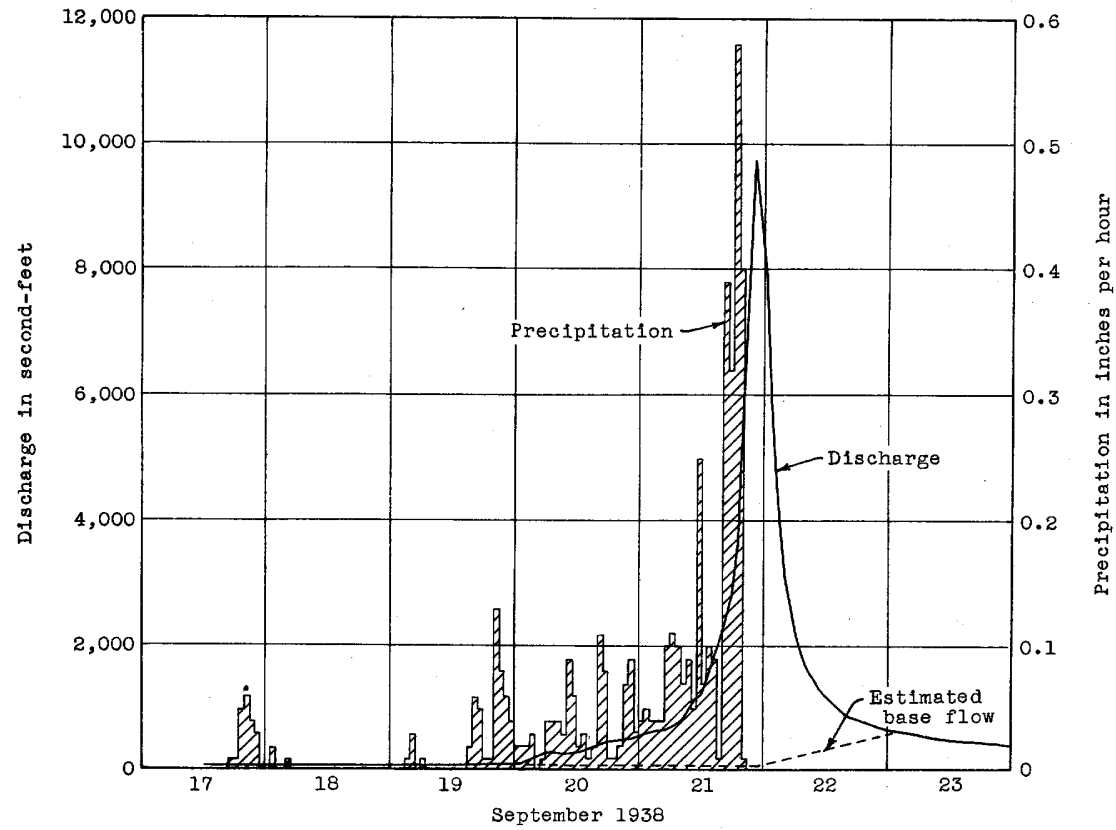

Hydrograph of discharge and graph of hourly precipitation at Northfield, Vt., September 17-23, 1938.

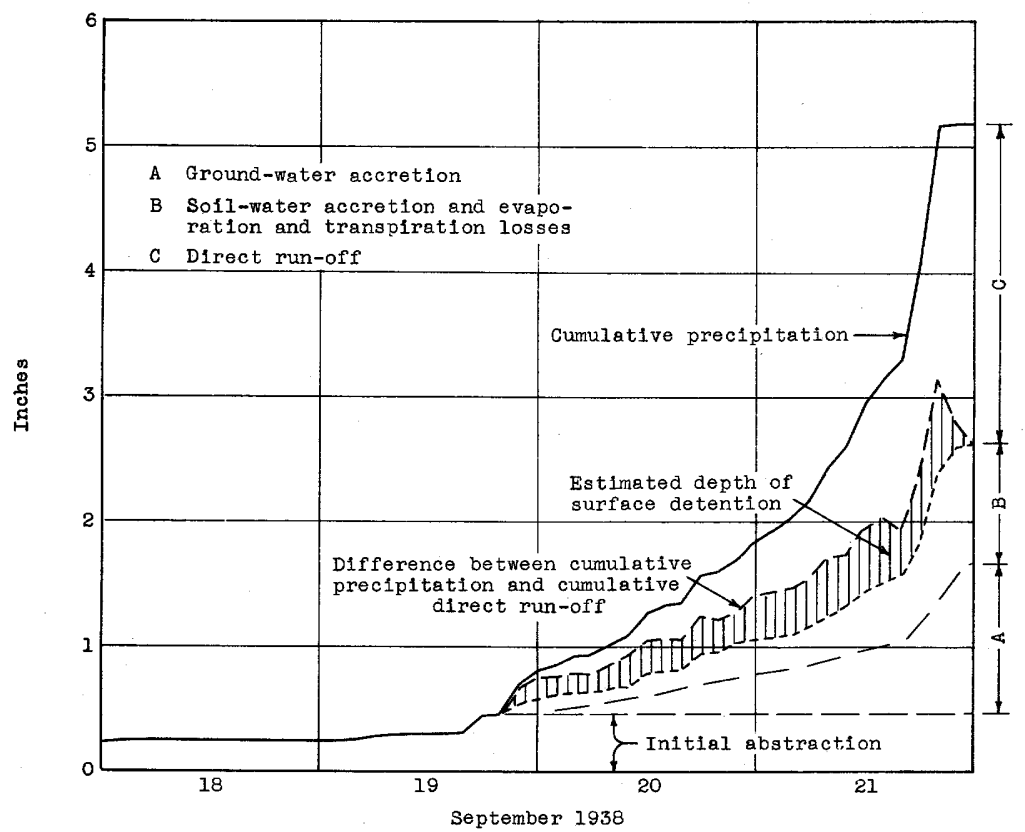

Graphs of cumulative precipitation, direct run-off, and eatimated infiltration, September 18-21, 1938 .

Figure 55.--Analyses of rainfall and run-off in basin of Dog River at Northfield Falls, Vt. 
of discharge at Northfield Falls, Vt., for the period September 17-23. There was no material rise in stream flow until nearly midnight on september 19, and from that time the stream flow continuously increased unt1l the peak was reached on September 21. The stream flow appears to have become increasingly greater in proportion to the rainfall as the storm continued. The peaks of both the rainfall and run-off intensities came together at the close of the storm. The highest rainfall intensities occurred at the end of the storm, when the absorptive capacity of the ground was least, thus contributing further to the intensity of the flood run-off.

The lower part of figure 55 shows the cumulative ralnfall and the segregation thereof. By 8 p.m., September 19, vegetal interception, surface wetting, and depression storage had caused an Initial abstraction of about 0.5 inch, after which there was direct surface run-off into the stream channels. The rainfall was totaled at 2 -hour intervals, from which the cumulative direct run-off (adjusted for channel storage) was subtracted at corresponding intervals, the difference at any time representing total ground and soll-water accretion, surface detention, and evaporation and transpiration. During the progress of the storm there was an indefinite accumalation of water in temporary storage, which was effective in producing direct run-off and at the same time, was being diminished by absorption and increased by the continuing rains. The amount of this water in transit to stream channels, termed the surface detention, was computed essentially by the methods explained by Sherman 18/ and subtracted from the difference between rainfall and run-off, as shown on the lower part of figure 55. The surface detention delimits the indefinite zone that exists between the direct run-off and the retention during a storm. Immediately after the cessation of rainfall the surface detention, as shown on figure 55, decreases to zero through absorption and surface drainage. On the assumption that after september $22, a 11$ flow at this station, as shown on the upper part of figure 55, was from ground water, it is estimated that the ground-water accretion was about 1.2 Inches ( 45 percent of the total residusl), leaving 1.05 inches of the 2.25 inches of the net residual ( 0.5 had already been abstracted by the initial losses) to represent soll-water accretion and losses by evaporation and transpiration. The total ground-water accretion during the storm has been distributed in proportion to the difference between

18/ Sherman, L. K., Determination of infiltration rates from surface run-off: Am. Geophys. Union Trans., 1938, p. 430. 
cumulative rainfali and cumulative direct run-off minus initial abstractions, as indicative of the source of supply for such accretion.

The maximum rate of mean areal rainfall over the basin of the Dog River above Northfield Falls, Vt., was about 0.6 inch per hour and the maximum rate of direct run-off into stream channels was 0.19 inch per hour. The maximum rate of infiltration as indicated by the slope of the line represented by the difference between rainfall and direct run-off minus the estimated depth of the surface detention was 0.30 inch per hour. This value should be compared with the average rate of absorption of 0.08 inch per hour determined by referring to figure 44 , with a retention of 2.6 inches and a total rainfall of 5.2 inches.

The rate of absorption decreased materially during the storm period as indicated by the decreased ratio between direct run-off and rainfall into stream channels as follows: On September 17 and 18 the ratio was virtually zero; on September 19, 20 percent; September 20, 42 percent; and on September 21, 60 percent.

The only two records of run-off available in this region for the storm of Hovember 2-5, 1927, were those of Green River at Garfield, Vt., and Dog River at Northrield, Vt. The total storm precipitation over these basins as listed in table 17 averaged 8.2 inches and the associated direct run-off averaged 4.75 inches, indicating an average retention of 3.45 Inches, which is comparable with the difference between rainfall and runoff in this region during september 1938. The Green River gaging station was not in operation in September 1938. From March 9-22, 1936, the total rain ranged from 3.5 to 5.5 inches over the st. Lawrence River Basin in Vermont, falling on 3 to 8 inches of water in the form of snow. The resultant direct mun-off ranged from 8.5 to 11 inches, leaving an average retention of only about 1.75 inches, a value very much less than resulted from the hydrologic conditions that prevallod efther in September 1938 or November 1927, which Indicates the effeots of frost and other restrictive factors upon absorption.

The ratios between the direct run-off during the maximum day and the total direct run-off, as listed in table 14, ranged between 12 and 68 percent, being penerally inversely related to the sizes of the drainage areas. These ratios indicate that the Ausable River Basin in Ner York is comparatively responsive to rainfall rates and that the Otter Creek Basin in Vermont is very sluggish, particularly the reach betwon Center. Rutland and Middlebury. The center of mass of direct run-off passed Center Rutland 1.8 days after the center of mass of rainfall, whereas 40.9 miles downstream at Middlebury the lag was 7.0 days. 


\section{Rainfall and run-off of storm of November 1927}

The storm and flood of November 1927 was one of the greatest on record in parts of New England19/. A comparison of this storm with other major storms is given in table 8. In common with the storm of September 17-2l, 1938, the storm of November $2-4,1927$, was preceded by considerable antecedent precipitation, and the absorptive capacity of the ground (as shown by fig. 9) may have been falrly comparable during the two storm periods. The amount of storm rainfall during the storm of November 1927 was materially less than during the storm of September 1938, averaging 8.9 Inches over 1,000 square piles in comparison with 14.8 inches over 1,000 square miles during the later storm. The duration of significant rainfall in. 1927 was likewise much less than that in 1938. Table 17 shows for several basins within the storm area in which the run-off was not materially affected by the artificial storage, the precipitation for the period November 2-5, 1927, the direct run-off, and the difference between the rainfall and the run-off, all expressed in depth in inches over the drainage area. In the discussions of rainfall and run-off relations during the storm and floods of September 1938 it was indlcated that the total precipitation and assoclated retention for the 1927 and 1938 storms were of comparable magnitude. In other words, in both storms for the same total precipitation about the same amount of water was retained in the basins. On the basis that the total retention divided by the number of hours of significant rainfall gives a measure of the rate of absorption, such rate must have been greater during the storm of 1927 than during that of 1938 , as the retention was the same but the duration of rainfall was much less.

Based on the duration of rainfall at rates equal to or greater than 0.09 inch per hour it has been computed that the retention 1isted in table 17 correspond to an average infiltration index of about 0.18 inch per hour. Ten areas had infiltration indices in excess of 0.2 inch per hour, 13 between 0.1 and 0.2 , and 5 less than 0.1 .

The storm and rainfall and run-off relations are also described by Horton $20 /$.

19/ Kinnison, H. B., New England flood of November 1927: U. S. Geol. Survey Water-Supply Paper 636, pp. 45-100, 1930.

20/ Horton, R. E., Infiltration capacity for large drainage basins: Am. Geophys. Union Trans., 1937, pp. 371-385. 


\begin{tabular}{|c|c|c|c|c|}
\hline Stream and place & $\begin{array}{c}\text { Drainage } \\
\text { area } \\
\text { (square } \\
\text { miles) }\end{array}$ & $\begin{array}{c}\text { Rain- } \\
\text { fall } \\
\text { (1nches) }\end{array}$ & $\begin{array}{l}\text { Direct } \\
\text { mun-off } \\
\text { (Inches) }\end{array}$ & $\begin{array}{c}\text { Differ- } \\
\text { ence } \\
\text { (inches) }\end{array}$ \\
\hline Pemigewasset River at Plymouth, N. H. & 622 & 5.5 & 4.8 & 0.7 \\
\hline Smith River near Bristol, N. H. & 78.5 & 6.0 & 3.05 & 2.95 \\
\hline Nubanusit Brook near Peterboro, $N$. H. & 48.1 & 4.6 & 2.05 & 2.55 \\
\hline $\begin{array}{l}\text { North Branch of Contoocook River near } \\
\text { Antrim, N. H. }\end{array}$ & 54.8 & 4.9 & 3.15 & 1.75 \\
\hline Blackwater River near Contoocook, N. H. & 131 & 5.6 & 2.4 & 3.2 \\
\hline Souhegan RIver at Werrimack, N. H. & 171 & 4.45 & 2.05 & 2.4 \\
\hline Quinebaug River at Jewett City, Conn. & a.711 & 5.7 & 1.8 & 3.9 \\
\hline Ashuelot River near Gilsum, N. H. & 71.1 & 4.85 & 3.35 & 1.5 \\
\hline Ashuelot River at Hinsdale, N. H. & 420 & 4.8 & 2.25 & 2.55 \\
\hline Otter Brook near Keene, N. H. & 41.8 & 4.7 & 3.0 & 1.7 \\
\hline $\begin{array}{l}\text { South Branch of Ashuelot River at Webb, near } \\
\text { Marlboro, N. B. }\end{array}$ & 36.6 & 4.8 & 3.2 & 1.6 \\
\hline Mlllers River near Winchendon, Mass. & 83.8 & 5.0 & 1.4 & 3.6 \\
\hline Millers River at Erving, Mass. & 370 & 5.0 & 2.2 & 2.8 \\
\hline Stp Pond Brook near Winchendon, Mass. & 19.0 & 5.0 & 1.75 & 3.25 \\
\hline Priest Brook near Finchendon, Hass. & 18.8 & 5.0 & 4.0 & 1.0 \\
\hline East Branch of Tully River near Athol, Mass. & 49.9 & 5.1 & 2.9 & 2.2 \\
\hline Moss Brook at Wendell Depot, Mass. & 12.2 & 5.0 & 1.65 & 3.35 \\
\hline Ware River at Gibbs Crossing, Mass. & 199 & 4.6 & 1.65 & 2.95 \\
\hline Swift River at West Ware, Mass. & 186 & 4.9 & 1.7 & 3.2 \\
\hline Westfield River at Knightsvillo, Mass. & 162 & 6.5 & 3.65 & 2.85 \\
\hline Westfield River near Westfleld, Mass. & 497 & 6.6 & 3.8 & 2.8 \\
\hline $\begin{array}{l}\text { Middle Branch of Weatfleld River at Goss } \\
\text { Helghts, Mass. }\end{array}$ & 52.6 & 6.7 & 3.45 & 3.25 \\
\hline Housatonic River near Oreat Barrington, Mass. & 280 & 5.95 & 3.85 & 2.1 \\
\hline Housatonic River at Falls V1liage, Conn. & 632 & 6.15 & 3.05 & 3.1 \\
\hline Batten K1ll at Battenville, N. Y. & 394 & 5.8 & 3.7 & 2.1 \\
\hline Hoosic River near Eagle Bridge, $N . Y$. & 510 & 6.75 & 3.65 & 3.1 \\
\hline Poesten K111 near Troy, N. Y. & 89 & 5.15 & 4.55 & .6 \\
\hline Green River at Garfield, Vt. & 18 & 7.9 & 4.6 & 3.3 \\
\hline Dog R1ver at Northrield, Vt. & 52 & 8.5 & 4.9 & 3.6 \\
\hline
\end{tabular}

a Revised. 
Table 18.--Mean areal rainfall and associated direct run-off, September 16-17, 1932

\begin{tabular}{|c|c|c|c|c|}
\hline Stream and place & $\begin{array}{c}\text { Drainage } \\
\text { area } \\
\text { (square } \\
\text { miles) }\end{array}$ & $\begin{array}{l}\text { RaIn- } \\
\text { fall } \\
\text { (Inches) }\end{array}$ & $\begin{array}{l}\text { Direct } \\
\text { mun-off } \\
\text { (Inches) }\end{array}$ & $\begin{array}{c}\text { Differ- } \\
\text { ence } \\
\text { (inches) }\end{array}$ \\
\hline P1scataquis RIver near Foxcroft, Maine & 286 & 7.2 & 2.5 & 4.7 \\
\hline Pleasant River near M110, Maine & 322 & 8.1 & 3.9 & 4.2 \\
\hline Aust In Stream at Blngham, Haine & 92 & 6.5 & 3.4 & 3.1 \\
\hline Carrabasset River near Horth Anson, Maine & 351 & 5.5 & 2.45 & 3.05 \\
\hline Sandy River near Mercer, Maine & a514 & 6.0 & 1.45 & 4.55 \\
\hline $\begin{array}{l}\text { Little Androscoggin River near South Paris, } \\
\text { Ma ine }\end{array}$ & 76.2 & 6.6 & 1.65 & 4.95 \\
\hline Saco RIver near Conway, H. H. & $\mathbf{a 3 8 6}$ & 6.2 & 1.4 & 4.8 \\
\hline $\begin{array}{l}\text { Bast Branch of Pemigewasset River near } \\
\text { Lincoln, } \mathrm{H} \text {. H. }\end{array}$ & 104 & 4.6 & 1.4 & 3.2 \\
\hline Pemigerasset River at Plymouth, N. H. & 622 & 4.0 & .7 & 3.3 \\
\hline Merrimack River at Lawrence, Lass. & $b 3,930$ & 5.2 & .35 & 4.85 \\
\hline Bakers River near Rumey, $\mathrm{H}$. H. & 143 & 2.9 & .3 & 2.6 \\
\hline Smith River near Bristol, H. H. & c 83.6 & 3.2 & .25 & 2.95 \\
\hline Contoocook RIver at Penacook, H. H. & 2766 & 3.5 & .1 & 3.4 \\
\hline Suncook River at Horth Chichester, N. H. & 157 & 6.7 & .7 & 6.0 \\
\hline Souhegan River at Herrimack, H. H. & 171 & 5.0 & .3 & 4.7 \\
\hline Wading River near Horton, Hass. & 42.4 & 5.0 & .2 & 4.8 \\
\hline Quinebaup RIver at Putnam, Conn. & a331 & 4.9 & .45 & 4.45 \\
\hline Quinebaug River at Jewett City, Conn. & 2711 & 6.4 & .7 & 5.7 \\
\hline Willimant1c River near South Coventry, Conn. & 121 & 3.5 & .4 & 3.1 \\
\hline Shetucket River at South Windham, Conn. & 406 & 3.5 & .35 & 3.15 \\
\hline Vatchaug River at Willimantic, Corm. & 169 & 4.0 & .4 & 3.6 \\
\hline Yant1c River at Yant1c, Conn. & 88.6 & 3.9 & .3 & 3.6 \\
\hline Passumpsic River at Passumpsic, Vt. & 423 & 2.0 & .3 & 1.7 \\
\hline Moose River at St. Johnabury, vt. & al26 & 2.3 & .3 & 2.0 \\
\hline Salwon River near kast Hampton, Conn. & 105 & 3.15 & .35 & 2.8 \\
\hline
\end{tabular}

a Revised.

b Contributing area only.

c Revised in 1931. After Hov. 25, 1933, drainage a rea 85.8 square mlles. 


\section{Reinfall and mun-off of storm of September 1932}

White $21 /$ describes the storm of September 16-17, 1932, as surpassing all preceding storms in New England since that occurring October 3-4, 1869, and points out that 1t followed an extended drought period with the result that flood run-off was so small as to be of little consequence. A.11 the basic rainfall data are contained in the paper by White and the meteorology of the storm is described by Brooks 22/.

During a period of about 18 hours between $6 \mathrm{a.m}$. and midnight, September 16, more than 8 inches of rain fell over an area exceeding 1,500 square miles centering near Westerly, R. I., where a maximum of 12.13 inches in 19: hours was recorded. A maximum hourly rate of 1.34 inches was recorded at Pawtucket, R. I. During the severe drought that preceded this storm the ground water and soil molsture had become seriously depleted, as shown by figure 23 on page 44, resulting in a high absorptive capacity. Table 18 shows the rainfall, direct run-off, and retention in inches over the area for basins in which there was no material storage and situated within the general storm area but not necessarily within the area of greatest precipitation. The outstanding feature is the relatively small amoumt of direct mun-off following the storm and the large retention, or difference between rainfall and run-off.

It would appear that the rates of absorption indicated by the differences between rainfall and run-off for the storm of September 1932 approached the maximum that could be expected during a major storm period, in contrast to the rates during the storm and flood of Maroh 1936, which are indicative of minimum values.

\section{FLOOD CRESTS}

During or Immediately after the floods of September 1938 various agencies of the Federal and State govermments, together with public service companies and individuals, began the work of locating and marking crest stages reached by the rivers in the flood areas. Field parties examined important streams to obtain comprehensive and systematic information from existing flood marks. The Corps of Engineers, United States Army, the Connecticut State Water Commission (Ground-water Project), and in New Jersey the Riparian Survey of the Works Progress Administration and Union

21/ White, G. V., The great storm of September 16 and 17, 1932: New England Water Works Assoc. Jour., vol. 42, no. 2 , pp. 164-183, 1933 . 22/ Brooks, C. F., Rain storm of september 16-17, 1932, in New England: Am. Meteorol. Soc. Bull., January 1933, pp. 26-27. 
County Park Commission contributed in a notable way in these activities. Except as otherwise noted, the flood marks were referred to the mean sea level datum of the United States Coast and Geodetic Survey. Their relative positions were ldentifled by distances along the rivers.

Table 19 presents records of flood crest stages for the major river systems in the region covered by this report. These records are of special interest in presenting a limiting factor with respect to future developments along the rivers and in furnishing basic information as to velocity of transmission of flood crests, valley or flood-channel storage, the effects of natural or artificial channel constrictions, and other aspects of river behavior. The table shows the observation points by reference to local features and river distances, date and time of crest (where known), and altitude of crest at avallable observation points, generally sufficient in number for satisfactory definition of the profile of the flood crest along the river. Where observations were more plentiful than needed for adequate definition of a flood profile, selection for publication has been limited to those that are essential for that purpose. Some of the observations that were close together have been combined and the mean recorded as of one polnt. Certain observations that were obviously unreliable or that were impracticable of reference to mean sea level are not included. In the Merrimack River Basin the crest stages have generally been taken from profiles prepared by the Corps of Engineers, Onited States Army, on the basis of their surveys and investigations.

The times of crest at river-measurement stations and at certain other points, such as power dams, are in general well established, but at many other points this information is approximate. It has been found that the crests of floods within the building limits of cities and towns and at other places more or less distant from a river may, for various reasons, be materially different from those along the main river channel and seemingIy inconsistent if consideration is not given to the effect of the slope. Consequently such inconsistencles may appear to exist between local information and the records as herein published. Flood crests on opposite banks of a stream may differ materially because of the effects of bends and obstructions in the channel.

In the table, "upstream" signifies that the observation was made at the upstream side of a bridge or other structure; "downstream" signifies that the observation was made at the downstream side of the stmucture. 
Table 19.--Flood crest stages

\begin{tabular}{c|c|}
\hline \multicolumn{2}{|c|}{ Table 19.--Flood crest stages } \\
\hline Stream and location
\end{tabular}

\section{Merrimack River Basin}

Pemigewasset River:

Livermore Falls, N. H., dam, headwater

Livermore Falls, N. H., dam, tallwater

Livermore Falls, N. H.', bridge below dam

Livermore Falls, N. H., 0.08 mile below bridge

Livermore Falls, N. H., 0.1 mile below bridge

Livermore Falls, N. H., 0.4 mile below bridge

Bakers River, mouth of

Plymouth, N. H., U. S. Geological Survey gage, right bank

Plymouth, N. H., 0.35 mile below U. S. Geological Survey gage

Glove Hollow Brook, 0.55 mile above mouth of

Glove Hollow Brook, mouth of

Plymouth and Ashland, N. H., bridge on Highway 3 between

Boston \& Maine R.R. bridge

Squam River, 0.1 mile above mouth of

Squam River, 1.35 miles below mouth of

Woodman and Fogg Brooks, 1.15 miles below mouth of

Harpers Brook, mouth of

Bagoon Brook, 0.2 mile below mouth of

New Hampton, N. H., 0.1 mile below bridge

Bristol, N. H., dam, headwater

Bristol, N. H., dam, tailwater

Bristol, N. H.', 0.1 mile below dam

Bristol, N. H., 0.2 mile below dam

Bristol, N. H., 0.1 mile above bridge

Bristol, N. H., just above bridge

Newfound River, mouth of

Newfound River, 0.7 mile below mouth of

Blake Brook, 0.15 mile above mouth of

Smith River, 0.6 mile above mouth

Smith R1ver, 0.1 mile above mouth of

Dyer Brook, 0.2 mile above mouth of

prescott Brook, 0.1 mile above mouth of

Prescott Brook, 0.6 mile below mouth of

Heedle Shop Brook, 0.75 mile above mouth of

Knox Brook, mouth of, bridge

Knox Brook, 0.15 mile below mouth of

Bennett Brook, 0.2 mile below mouth of

Weeks Brook, 1.05 miles above mouth of

Weeks Brook, 0.15 mile above mouth of

Salmon Brook, 0.25 mile below mouth of

Salmon Brook, 1.15 miles below mouth of

Franklin, N. H., 0.85 mile above dam at Eastman Falls

Franklin Fails, N. H., dam at Eastman Fells, headwater

Franklin Falls, N. H., dam at Eastman Falls, tailmater

Franklin, N. H., 0.2 mile below mouth of Chance Pond Brook

Confluence of Pemigewasset and Winnipesaukee Rivers, 0.1 mile above

\section{Merrlmack River:}

Confluence of Pemigewasset and Winnipesaukee Rivers, 0.1 mile below

Franklin Junction, N. H., U. S. Geological Survey gage, left bank

Franklin Junction, N. H., Boston \& Malne R.R. bridge, ups tream

Frankil Junction, N. H., Boston \& Maine R.R. bridge, domstream

Punch Brook, mouth of

Cross Brook, 0.25 mile below mouth of

Stirmp Iron Brook, mouth of

Glines Brook, mouth of

Bryant Brook, mouth of

Tannery Brook, 0.1 mile above mouth of

Boscawen, N. H., highway bridge, upstream

Boscamen, N. H., highway bridge, downstream

Periacook, H. H., bridge 0.1 mile above south mouth of Contoocook River

Penacook, N. H., south mouth of Contoocook River

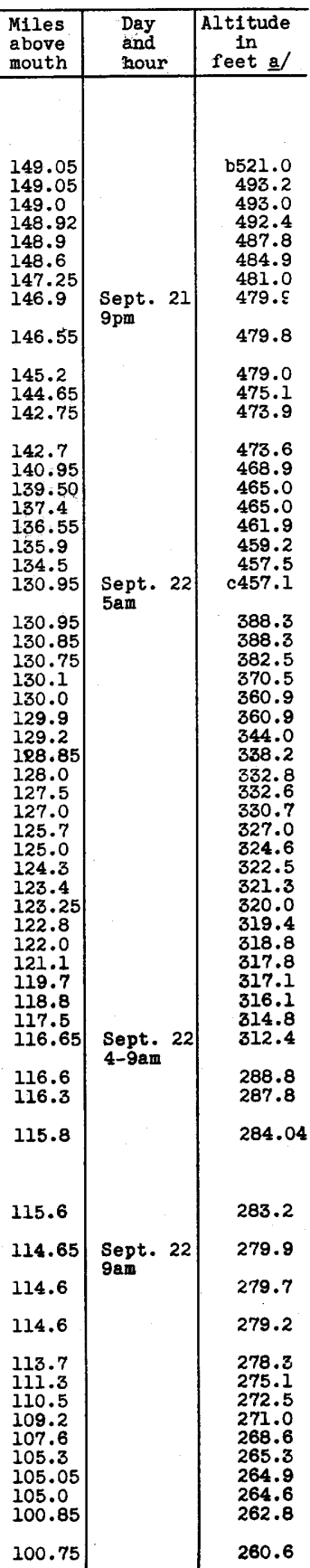

a From profiles prepared by Corps of Englneers, U. S. Army, on basis of their surveys and investigations.

b Alt1tude of crest of dam, 511.0 feet, with fleshboards, 514.0 feet.

c Altitude of crest of dam, 445.3 feet, with flashboards, 452.3 feet. 
Table 19.--Plood crest stages--Contimued

\begin{tabular}{|c|}
\hline Stream and location \\
\hline Merrimack River Basin--Continued
\end{tabular}

Merrimack River--Continued.

Burnham Brook, 0.2 mile below mouth of

Sewalls Falls, N. H., highway bridge 0.9 mile above dam, upstream

Sewalls Falis, N. H., highway bridge 0.9 mile above dam, downstream

Sewalls Falls, N. H., dam, headwater

Sewalls Falls, N. H., dam, tailmater

Beaver Meadow Brook, 0.05 mile above mouth of

Rattlesnake Brook, 0.7 mile above mouth of

East Concord, N. H., highway bridge

East Concord, N. H., 0.35 mile below highway bridge

East Concord, N. H., 1.35 miles below highwey bridge

Con'cord, N. H., highway bridge upstream

Concord, N. H., highway bridge, downstream

Concord, N. H., 0.6 mile below highway bridge

Concord, N. H., bridge on U. S. Highway 3

Boston \& Maine R.R. bridge, 1.1 miles above

Boston \& Maine R.R. bridge

Garvins Falls, N. H., dam, headwater

Garvins Falls, N. H., 0.05 mile below dam, tallwater

Soucook River, mouth of

Soucook River, 0.7 mile below mouth of

Suncook River, mouth of

Hooksett, N. H., dam, headwater

Hooksett, N. H., dam, tailwater

Hooksett, N. H., 0.3 mile below dam

Hooksett, N. H.', Boston \& Malne R.R. bridge

Peters Brook, 0.8 mile above mouth of

Peters Brook, 0.2 mile below mouth of

Messer Brook, 0.05 mile above mouth of

Manchester, N. H., 0.9 mile above Amoskeag Dam

Manchester, N. H., Amoskeag Dam, headwater

Manchester, N. H., 0.1 mile below Amoskeag Dam

Manchester, N. H., 0.3 mile belor Amoskeag Dam

Manchester, N. H., 0.4 mile below Amoskeag Dam

Manchester, N. H., McGregor highway bridge, upstream

Manchester, N. H., 0.25 mile below McGregor highway bridge

Manchester, N. H., 0.25 mile below McGregor highway bridge

ianchester, N. H., Granite Street highway bridge, upstream

Manchester, N. H., Granite Street highway bridge, downstream

Manchester, N. H., 0.45 mile below Granite street highway bridge

Manchester, N. H., Boston \& Maine R.R. bridge, upstream

Manchester, N. H., Boston \& Maine R.R. bridge, downstream

Piscataquog River, mouth of

Piscataquog River, mouth of

Manchester, N. H., Queen City Avenue highway bridge, upstream

Hanchester, N. H., Queen City Avenue highway bridge, downstream

Manchester, H. H., 0.1 mile below Queen city Avenue big wray bridge

Baker Brook, 0.1 mile above mouth of

Baker Brook, 0.25 mile below mouth of

Bowman Brook, mouth of

Bowmen Brook, 0.95 mile below mouth of

Boston \& Maine R.R. bridge

Cohas Brook, mouth of

Stebbins Brook, 0.2 mile above mouth of

Stebbins Brook, 1.15 miles below mouth of

Sawatl1 Brook, 0.3 wile above mouth of

Merrtwack, H. H., mouth of Souhegan River

Merrimack, N. H., 1.0 mile belor mouth of Souhegan River

iesenkeag Brook, 0.7 mile below mouth of

Hashie River, 0.2 mile above mouth of

Nasha, H. H., Boston \& Malne R.R. bridge, upstream

Nastua, H. H., Boston \& Malne R.R. bridge, dowstream

Massachusetts-Her Hampshine State 1ine, 1.25 miles above

Massachasetts-Nev Rampshire state Iine, 0.2 mile above

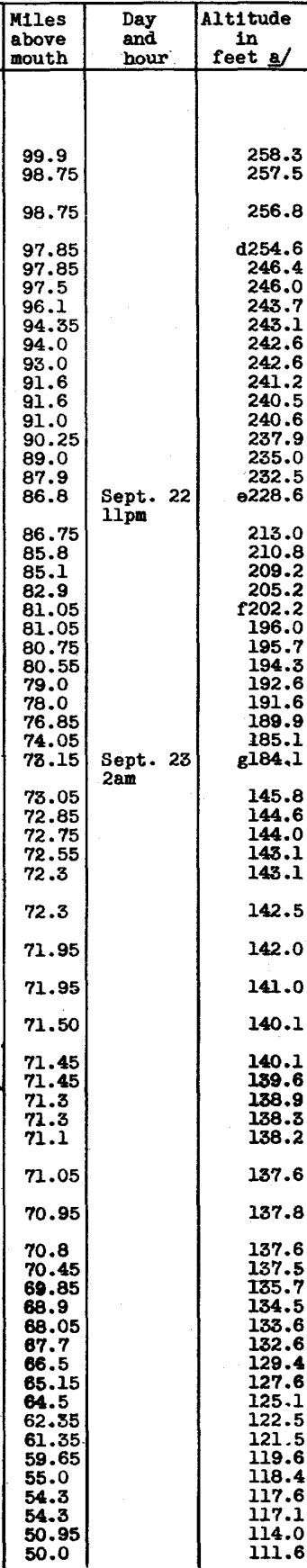

a Fron profiles prepared by Corps of Englneers, U. S. Aray, on basis of their aurveys and investigations.

d Altitude of erest of dam, 240.9 feet.

- Altitude of crest of dam, 216.8 feet, with flashboands 218.8 feet.

$f$ Altitude of crest of dam, 187.0 feet.

$B$ Altitudes of crest of dem, 178.0 feet and 171.0 feet. 
Pable 19.--Flood crest stages--Continued

\begin{tabular}{|c|c|}
\hline Stream and location & Stion \\
\hline
\end{tabular}

\section{Merrimack River Basin--Continued}

Merrimack River--Continued.

Tyngsborough, Mass., highway bridge

Lawrence Brook, 0.1'mile below mouth of

Scarlet Brook, mouth of

North Chelmsford, Mass., 0.6 mile below mouth of Stony Brook

Lowell, Mass., $0.8 \mathrm{mile}$ above Pawtucket Dam

Lowell, Mass., Pawtucket Dam, headwater

Lowell, Mass., 0.05 mile below Pawtucket Dam

Lowell, Mass., 0.2 mile below Pawtucket Dam

Lowell, Mass., Moody Street Bridge, upstream

Lowell, Mass., $0.15 \mathrm{mlle}$ below Moody Street Bridge

Lowe1l, Mass., mouth of Beaver Brook

Lowell, Mass., Alken Street Bridge

Lowell, Mass., Boott Mill gage

Lowell, Mass., 0.05 mile below Centralville bridge

Lowell, Mass:; U. S: Geological Survey gage

Lowell, Mass.; 0.15 mile below U. S. Geological Survey gage

Richardson Brook, 0.2 mile above mouth of

Trull Brook, 0.6 mile below mouth of

Fish Brook, 0.25 mile above mouth of

Bartletts Brook, mouth of

Lawrence, Mass., Essex Co. dam, headwater

Lawrence, Mass., Boston \& Maine R.R. bridge, $0.5 \mathrm{mile}$ below Essex Co, dam

Shawsheen River, 0.3 mile below mouth of

Hawkes Brook, 0.45 mile above mouth of

Hawkes Brook, mouth of

Creek Brook, mouth of

Haverhill, Mass., County highway bridge

Haverhill, Mass., Boston \& Maine R.R. bridge

Haverhill, Mass., highway bridge

Groveland highway bridge

Neal Pond Brook, 0.55 mile below mouth of

Rocks Village, Mass., $0.2 \mathrm{mile}$ above highway bridge

Cobblers Brook, Mass., 0.1 mile below mouth of

Artichoke River, 0.2 mile above mouth of

Pow Wow River, 0.7 mile above mouth of

Pow Wow River, mouth of

Amesbury, Mass., Deer Island chain bridge

Newfound River:

Newfound Lake, outlet of

Public Service Co. of New Hampshire dam, headwater

Public Service Co. of New Hampshire dam, tailwater

Highray bridge, 0.05 mile above

Highway bridge

Public Service Co. of New Hampshire dam, 0.25 mile above

Public Service Co. of New Hampshire dam, headwater

Public Service Co. of New Hampshire dam, tailwater

Concrete highray bridge

Dam (old)

Highway bridge, 0.1 mile above

Dodge Davis Mfg. Co. dam, headwater

Dodge Davis Mfg. Co. dam, tailwater

Dan

Bristol, N. H., 0.05 mile below highway bridge

Bristol, N. H., highway bridge

Bristol, N. H. highway bridge on road to H1ll, upstream

Bristol, N. H., Cawley Dam, headwater

Bristol, N. H., Cawley Dam, tallwater

Bristol, N. H., Public Service Co. of New Hamphire dam, headwater

Bristol, N. H., Public Service Co. of New Hampshire dam, tallwater

Bristol, N. H., Depot Street highway bridge

Bristol, M. H., Confluence of Pemigewasset and Newfound RIvers

Contoocook River:

East Jaffrey, N. H., U. S. Highway 202 bridge Just above mouth of Contoocook Lake

East Jaffrey, N. H., $0.8 \mathrm{mile}$ below highway bridge

East Jaffrey, N. B., dam 0.5 mile above Tyler Brook Bridge, headwater

\begin{tabular}{|c|c|c|}
\hline $\begin{array}{l}\text { M1les } \\
\text { above } \\
\text { mouth }\end{array}$ & $\begin{array}{l}\text { Day } \\
\text { and } \\
\text { hour }\end{array}$ & $\begin{array}{l}\text { Altitude } \\
\text { in } \\
\text { feet } a /\end{array}$ \\
\hline $\begin{array}{l}47.35 \\
46.55 \\
44.05 \\
42.55\end{array}$ & & $\begin{array}{l}107.7 \\
106.8 \\
102.7 \\
100.1\end{array}$ \\
\hline $\begin{array}{l}41.35 \\
40.55 \\
40.5 \\
40.35 \\
40.15 \\
40.0 \\
39.8 \\
39.6 \\
38.95 \\
38.8 \\
38.55 \\
38.4\end{array}$ & . & $\begin{array}{r}98.7 \\
\text { h97.4 } \\
91.1 \\
89.9 \\
84.2 \\
76.5 \\
72.4 \\
71.3 \\
68.5 \\
67.8 \\
65.8 \\
65.3\end{array}$ \\
\hline $\begin{array}{l}36.55 \\
35.35 \\
33.3 \\
31.9 \\
29.0 \\
28.5\end{array}$ & & $\begin{array}{r}60.5 \\
58.8 \\
52.5 \\
52.5 \\
j 49.0 \\
39.2\end{array}$ \\
\hline $\begin{array}{l}27.15 \\
23.3 \\
22.85 \\
21.85 \\
19.15 \\
19.1 \\
18.5 \\
15.7 \\
14.0 \\
12.0 \\
10.0 \\
8.0 \\
7.1 \\
6.4 \\
5.15\end{array}$ & & $\begin{array}{r}36.2 \\
30.1 \\
28.3 \\
28.1 \\
22.2 \\
22.0 \\
18.6 \\
18.0 \\
17.5 \\
16.6 \\
14.0 \\
13.0 \\
11.6 \\
10.8 \\
8.9\end{array}$ \\
\hline$\cdot$ & & . \\
\hline $\begin{array}{l}3.1 \\
3.0 \\
3.0 \\
2.7 \\
2.65 \\
2.25 \\
2.0 \\
2.0 \\
1.95 \\
1.75 \\
1.6 \\
1.45 \\
1.45 \\
1.25 \\
.95 \\
.45 \\
.2 \\
.2 \\
.2 \\
.1\end{array}$ & & $\begin{array}{r}590.5 \\
590.0 \\
587.5 \\
577.0 \\
572.0 \\
554.0 \\
553.5 \\
539.0 \\
538.0 \\
499.0 \\
489.5 \\
488.5 \\
485.0 \\
464.0 \\
457.0 \\
454.5 \\
454.5 \\
\mathbf{k 4 5 2 . 5} \\
\mathbf{4 3 9 . 0} \\
\mathbf{4 2 5 . 0}\end{array}$ \\
\hline $0^{.1}$ & & $\begin{array}{l}420.0 \\
407.0 \\
361.0\end{array}$ \\
\hline 67.4 & & $\mathrm{ml}, 013.7$ \\
\hline $\begin{array}{l}66.6 \\
66.25\end{array}$ & & $\begin{array}{r}1,003.7 \\
\text { n992.0 }\end{array}$ \\
\hline
\end{tabular}

a From profiles prepared by Corps of Engineers, U. S. Army, on basis of their surveys and investigations.

h Altitude of crest of dam, 87.2 feet.

$j$ Altitude of crest of dam, 39.2 feet.

r Altitude of crest of dam, 446.6 feet.

in Altitude of crest of dam, 1,008.25 feet.

$n$ Altitude of crest of dam, 983.75 feet.

$2279070-40-31$ 
Table 19.--Flood crest stages-Continued

\section{Stream and location
Merrimack River Basin--Continued
Contoocook River--Continued.
East Jaffrey, N. H., 0.5 mile above Tyler Brook
Bridge, tailwater}

East Jaffrey, N. H., highway bridge 0.05 mile below dam, upstream

East Jaffrey, N. H., highway bridge $0.05 \mathrm{mile}$ below dam, downstream

Tyler Brook Dam, headwater

Tyler Brook Dam, tallwater

Tyler Brook Bridge

Cheshire Pond Bridge and Dam, headwater

East Jaffrey, N. H., Boston \& Maine R.R. bridge, 0.If mile below Cheshire Pond Bridge

East Jaffrey, N. H., Boston \& Malne R.R. bridge, U.35 mile below Cheshire Pond Bridge

East Jaffrey, N. H., Boston \& Malne R.R. bridge, 0.75 mile below Cheshire Pond Bridge

East Jaffrey, N. H., Boston \& Maine R.R. bridge, 1.25 miles below Cheshire Pond Bridge

East Jaffrey, N. H., Boston \& Maine R.R. bridge, 1.6

miles below Cheshire Pond Bridge bridge (destroyed),
Jaffrey-Peterboro town line, wooden bridge 0.3 mile above

Drury, N. H., 0.25 mile above mouth of Meadow Brook

Drury, N. H., highway bridge

Peterboro, N. H., highway bridge 0.7 mile below mouth of Meadow Brook

Peterboro, N. H., 0.1 mile above highway bridge and dam (déstroyed)

Peterboro, N. H., highway bridge and dam (destroyed)

Peterboro, N. H., 0.35 mile above highway bridge

Peterboro, N. H., highway bridge

Peterboro, N. H., 0.2 mile above bridge

Peterboro, N. H., bridge 0.35 mile above mouth

Peterboro, N. H., Transcript Dam and bridge

Peterboro, N. H., Boston \& Maine R.R. bridge

Peterboro, N. H., 0.1 mile below Boston \& Maine R.R. bridge

Peterboro, N. H., $0.35 \mathrm{mile}$ below Boston \& Maine R.R. bridge

North Village, N. H., 0.25 mile above dam at

North Village, N. H., dam, headwater

North Village, N. H., dam, tallwater

Ferguson Brook, bridge 0.2 mile above mouth of, upstream

Ferguson Brook, bridge 0.2 mile above mouth of, downstream

Elmwood, N. H., Boston \& Maine R.R. bridge

Powder Mili Dam, headwater

Powder Mill Dam, tailwater

Bennington, N. H., Monadnock Power Dam, headwater

Bennington, N. H., highway bridge, 0.1 mile below Monadnock Power Dam, upstream

Bennington, N. H., highway bridge, 0.1 mile below Monadnock Fower Dam, downstream

Bennington, N. H., 0.05 mile above Plerce power dam

Bennington, N. H., Plerce power dam, tallwater

Bennington, N. H., 0.1 mile below Plerce power dam

Bennington, N. H., 0.05 mile above Monadnock Paper Co. dam

Bennington, N. H., just below Boston \& Maine R.R. bridge, 0.05 mile below dam

Bennington, N. H., 0.15 mile below Monadnock Paper Co. dam

Bennington, N. H., 0.4 mile below Monadnock Paper Co. den

Great Brook, highway bridge just below mouth of, upstream

Great Brook, highway bridge Just below mouth of, downstream

Cochran Brook, highway bridge 0.1 mile below mouth of, upstream

\begin{tabular}{|l|l|l}
\hline $\begin{array}{l}\text { Miles } \\
\text { above } \\
\text { mouth }\end{array}$ & $\begin{array}{l}\text { Day } \\
\text { and } \\
\text { hour }\end{array}$ & $\begin{array}{c}\text { Altitude } \\
\text { in } \\
\text { feet a/ }\end{array}$ \\
\hline & &
\end{tabular}

988.0

66.25

986.0

66.2

984.0

66.2

65.75

65.75

65.7

64.9
64.9

64.75

64.55

64.15

981.6

977.0

973.0
$q 962.2$

955.5

949.0

946.5

63.65

940.5

63.3

928.8

\subsection{5}

61.25

60.9

60.3

59.8

59.7

59.65

59.3

58.45

58.25

57.75

57.6

57.5

57.25

978.5

890.5

794.0

786.6

773.9

$\mathbf{r} 769.2$

749.0

744.0

735.0

730.6

727.8

s726.0

722.0

719.4

717.0

56.3

56.05

56.05

51.35

714.0

t708.6

704.1

695.0

51.35

48.25

46.75

46.75

45.95

45.85

45.85

693.0

685.3

u682.6

677.9

v674.8

662.5

660.0

45.8

46.75

45.65

45.5

656.6

656.6
พ653.8

637.0

$\times 636.7$

45.4

632.2

45.3

612.0

44.05

610.6

42.75

610.1

42.75

40.30

609.0

605.5

a From profiles prepared by Corps of Engineers, U. S. Army, on basis of their surveys and investigations.

$p$ Altitude of crest of dam, 974.67 feet.

q Altitude of crest of dam, 957.92 feet, with flashboards 958.57 feet.

$r$ Altitude of crest of dam, 763.29 feet.

$s$ Altitude of crest of dam, 714.9 feet, w1th flashboards, 715.9 feet.

$t$ Altitude of crest of dam, 702.6 feet.

$u$ Altitude of crest of dam, 675.4 feet, with Plashboards, 677.0 feet.

$\checkmark$ Altitude of crest of dam, 665.8 reet, with riashboards, 667.8 feot.

- Altitude of crest of dan, 651.4 feet.

$x$ Altitude of crest of dam, 627.6 feet, with flashboards, 629.6 feet. 
Table 19.--Flood crest stages--Continued

\begin{tabular}{|c|c|c|c|}
\hline Stream and location & $\begin{array}{l}\text { Miles } \\
\text { above } \\
\text { mouth }\end{array}$ & $\begin{array}{l}\text { Day } \\
\text { and } \\
\text { hour }\end{array}$ & $\begin{array}{c}\text { Altitude } \\
\text { In } \\
\text { feet a/ }\end{array}$ \\
\hline 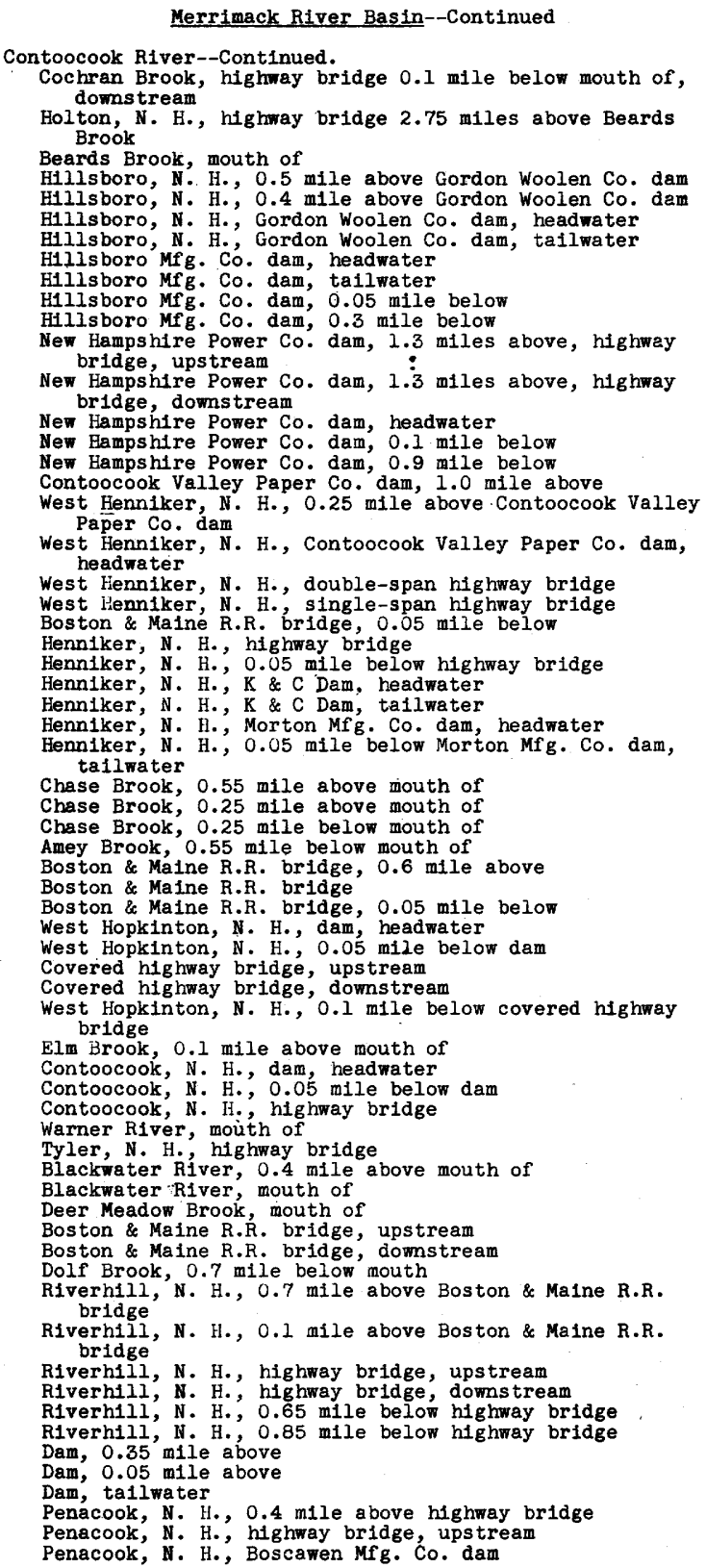 & 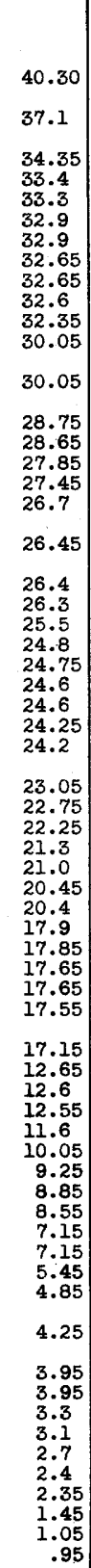 & & $\begin{array}{r}\text { as560.8 } \\
542.4 \\
490.5 \\
476.0 \\
442.0 \\
\text { ab439.1 } \\
434.8 \\
431.1 \\
429.0 \\
427.1 \\
420.5 \\
\text { ac418.5 } \\
410.6 \\
410.0 \\
405.3 \\
404.3 \\
400.4 \\
400.2 \\
400.2 \\
399.8 \\
399.0 \\
397.0 \\
384.3 \\
378.5 \\
378.3 \\
376.2 \\
376.0 \\
373.6 \\
369.8 \\
369.0 \\
368.2 \\
368.2 \\
368.7 \\
367.5 \\
367.0 \\
366.5 \\
365.0 \\
364.5 \\
362.0 \\
359.7 \\
4\end{array}$ \\
\hline
\end{tabular}

a From profiles prepared by Corps of Engineers, U. S. Artiy, on basis of their surveys and investigations.

$y$ Altitude of crest of dam, 582.2 feet, with flashboards, 584.2 feet.

$z$ Altitude of crest of dam, 568.6 feet:

aa Altitude of crest of dam, 549.0 feet, with flashboards 551.0 feet.

$a b$ Altitude of crest of dam, 427.7 feet.

ac Altitude of crest of dam, 409.4 feet. 
Table 19.--Flood crest stages--Continued

\begin{tabular}{|l|l}
\hline Stream and location & \\
\hline
\end{tabular}

Merrimack River Basin--Continued

Contoocook River-Continued.

Penacook, N. H., 0.1 mile below Boscawen Mfg. Co. dam Penarook, N. H., U. S. Geolog1cal Survey gage, right bank

Penacook, N. H., 0.1 mile above steel highway bridge

Penacook, N. H., dam

Penacook, N. H., Harris-Emory Co. dam

Penacook, N. H., mouth of Contoocook River

Blackwater River:

Burbank Mill Dam, tailwater

Swetts Mills, N. H., highway bridge, upstream

Swetts Mills, N. H., highway bridge, downstream

Swetts Milis, N. H., highway bridge, 0.05 mile downstream

Swetts Mills Bridge, 0.8 mile downstream

Dingit Corner, N. F., highway bridge above, upstream

Dingit Corner, highway bridge above, downstream

Dingit Corner, N. H., 0.2 mile below highway bridge above

Dingit Corner, N. H., 0.8 mile below highway bridge above

Dingit Corner, N. H., 0.9 mile below highway bridge above

Snyders Mill, N. H., highway bridge (destroyed), upstream

Snyders Mill, N. H., highway hridge (destroyed), downstream

Snyders Mill, N. H., 0.05 mile below highway bridge

Highway bridge, upstream

Highway bridge, downstrean

Confluence of Blackwater and Contoocook Rivers

Souhegan River:

Ward Pond, 0.15 mile below outlet of

Watatic Pond, 0.05 mile below inlet of

Watatic Pond, 0.25 mile below outlet of

Watatic Pond, 0.60 mile below outlet of

Dam, 0.5 mile above

Dam, 0.43 mile above

Dam, 0.40 mile above

Dam, 0.28 mile above

Dam; headwater

Dam, 0.02 mile below

Dam 0.10 mile below

Wooden bridge, 0.35 mile above Massachusetts-New Hampshire State line, upstream

Wooden bridge, downstream

Gibson's Four Corners, 100 feet below bridge near,

Wooden bridge, 50 feet downstream

"Waterloom Damn, 180 feet above

"Waterloom Dam", 200 feet below

High Bridge, N.'H., 200 feet above bridge

High Bridge, N. H., 200 feet above stone dam

High Bridge, N. H., dam, tailwater

High Bridge, N. H.; 75 feet below stone dam

High Bridge, N. H., 75 feet below Greenville Road Bridge

Furnace Brook, 0.1 mila above mouth of

Greenville, N. H., 0.6 mile upstrean from dam above Main Street

Greenville, N. H., 200 feet upstream from dam above Main Street

Greenville, N. H., below dam, 200 feet above Main Street bridge

Greenvilie, N. H., 80 feet below Main street bridge

Greenville, N. H., 100 feet downstream from dam below Kain Street

Greenville, H. H., 150 feet above Otis Dam

Greenville, N. H., 200 feet below 0tis Dam

Greenville, N. H., Taft Dam, headwater

Greenville, N. H., 0.15 mile below Taft Dam

Concrete bridge and dam, 150 feet upstream

Concrete bridge and dam, 100 feet domstream

Boston \& Maine R.R. bridge, 500 feet above

Boston \& Maine R.R. briage, 100 feet below

"High Falls Dam", 100 feet above

"High Falls Damn', 100 feet below

Stone anch bridge on Highway 31

Stone arch bridge on' Highway $31,0.3$ mile below

Stone arch bridge on Highway 31 , 0.6 mile below

Stone arch bridge on Highway 31 , 1 mile below

Blood Brook, 0.7 mile above mouth of

\begin{tabular}{|c|c|c|}
\hline $\begin{array}{l}\text { Miles } \\
\text { above } \\
\text { mouth }\end{array}$ & $\begin{array}{l}\text { Day } \\
\text { and } \\
\text { hour }\end{array}$ & $\begin{array}{c}\text { Altitude } \\
\text { in } \\
\text { feet a/ }\end{array}$ \\
\hline $\begin{array}{l}0.85 \\
.7 \\
\\
.55 \\
.45 \\
.2 \\
0\end{array}$ & $\begin{array}{l}\text { Sept. } 23 \\
\text { 3am }\end{array}$ & $\begin{array}{l}296.0 \\
293.1 \\
282.0 \\
277.8 \\
264.0 \\
262.8\end{array}$ \\
\hline $\begin{array}{l}9.4 \\
8.6 \\
8.6 \\
8.55 \\
7.8 \\
6.6 \\
6.6 \\
6.4\end{array}$ & & $\begin{array}{l}532.7 \\
532.7 \\
509.0 \\
492.5 \\
459.0 \\
450.8 \\
449.0 \\
442.7\end{array}$ \\
\hline 5.8 & & 442.0 \\
\hline 5.7 & & 434.8 \\
\hline 4.65 & & 377.0 \\
\hline 4.65 & & 374.0 \\
\hline $\begin{array}{l}4.6 \\
1.35 \\
1.35 \\
0\end{array}$ & & $\begin{array}{l}373.5 \\
368.5 \\
367.0 \\
366.1\end{array}$ \\
\hline $\begin{array}{l}33.30 \\
33.15 \\
32.80 \\
32.45 \\
31.95 \\
31.88 \\
31.85 \\
31.73 \\
31.45 \\
31.43 \\
31.35 \\
30.55\end{array}$ & & $\begin{array}{r}1,094.0 \\
1,093.0 \\
1,092.0 \\
1,061.5 \\
1,045.0 \\
1,041.5 \\
1,036.0 \\
1,030.5 \\
1,027.1 \\
1,021.0 \\
1,013.0 \\
987.8\end{array}$ \\
\hline $\begin{array}{l}30.55 \\
28.70 \\
27.0 \\
26.9 \\
26.8 \\
26.35 \\
26.3 \\
26.25 \\
26.25 \\
26.25 \\
25.9 \\
25.1\end{array}$ & & $\begin{array}{l}987.8 \\
934.0 \\
932.0 \\
931.0 \\
914.5 \\
893.5 \\
885.8 \\
874.5 \\
866.0 \\
861.2 \\
843.0 \\
834.0\end{array}$ \\
\hline 24.55 & & 829.5 \\
\hline 24.5 & & 815.5 \\
\hline $\begin{array}{l}24.45 \\
24.4\end{array}$ & & $\begin{array}{l}808.5 \\
797.0\end{array}$ \\
\hline $\begin{array}{l}24.4 \\
24.35 \\
24.3 \\
24.15 \\
23.65 \\
23.6 \\
23.35 \\
23.25 \\
23.05 \\
23.05 \\
22.0 \\
21.7 \\
21.4 \\
21.0 \\
19.85\end{array}$ & & $\begin{array}{l}793.0 \\
774.5 \\
757.2 \\
745.9 \\
735.0 \\
729.2 \\
727.5 \\
726.5 \\
725.1 \\
705.8 \\
611.0 \\
588.0 \\
571.5 \\
544.2 \\
499.5\end{array}$ \\
\hline
\end{tabular}

a From profiles prepared by Corps of Engineers, U. S. Army, on basis of their surveys and investigations. 
Table 19.--Flood crest stqges--Continued

Stream and location

\section{Merrimack River Basin--Continued}

Souhegan River--Continued.

Blood Brook, 0.6 mile above mouth of

Wooden bridge, 80 feet above

Wooden bridge, 140 feet below

Concrete arch bridge on Highway 3I, 200 feet above

Concrete arch bridge on Highway 31,80 feet below

wilton, N. H., 0.3 mile above mouth of Stony Brook

Wilton, N. H., 150 feet below Abbott Dam

Wilton, N. H., 150 feet above concrete arch bridge

Wilton, N. H., 100 feet above lower Boston \& Mrine

R.R. bridge

Wilton, N. H., 50 feet below lower Boston \& Maine R.R. bridge

Wilton, N. H., 75 feet above Abbott Machine Co. dam

Wilton, N. H., 150 feet below Abbott Machine Co. dam

Wilton, N. H., 50 feet above Pine Valley Mill dam

Wilton, N. H., 200 feet below Pine Valley Mill dam

Boston \& Maine R.R. bridge, 0.05 mile above

Stone arch highway bridge, 30 feet above

Stone arch highway bridge, 0.1 mile below

Highway bridge, 20 feet above

HIghway bridge, 180 feet below

Purgatory Brook, 0.1 mile above mouth of

Tucker Brook, 0.1 mile above mouth of

Milford, N. H., stone arch highway bridge, 0.1 mile below mouth of Great Brook

Milford, N. H., 40 feet above Goldsmith Linen Mill dam

Milford, N. H., 250 feet below Goldsmith Linen Mill dam

Milford, N. H., 120 feet above suspension foot bridge

Milford, N. H., 150 feet below Milford Light Co. dam

Highway bridge

Highway bridge, 0.05 mile above

Highway bridge, 200 feet below

Fields Bridge

Fields Bridge, 0.5 mile below

Fields Bridge, 0.8 mile below

Fields Bridge, 1.2 miles below

Turkey Hill Bridge, 1.35 miles above

Turkey Hill. Bridge

Turkey Hill Bridge, 125 feet below

Turkey Hill Bridge, 0.75 mile below

U. S. Geologlcal Survey gage, 1.25 miles above confluence with Merrimack River

Merrimack, N. H., highway bridge, 0.85 mile above

Merrimack, N. H., highway bridge, 0.4 mile above

Merrimack, N. H., 200 feet above dam, $0.4 \mathrm{mlle}$ above confluence with Herrimack River

Merrimack, N, H*, 150 feet below highway bridge

Merrimack, N. H., 150 feet above Boston \& Maine R.R. bridge

Confluence of Souhogan and Merrimack RIvers

North Nashua River:

Fitchburg, Mass., Daniels Street Bridge, $0.25 \mathrm{mile}$ above

Fitchburg, Mass., Daniels Street Bridge, 0.2 mile above

Fitchburg, Mass., Daniels Street Bridge, 360 feet above

Fitchburg, Mass., Daniels Street Bridge, 50 feet below

Fitchburg, Mass., Kimball street Bridge and dam, 50 feet above

F1tchburg, Mass., Kimball Street Bridge and dam, 400 feet below

Fitchburg, Mass., theldon Street Bridge (destroyed), $0.10 \mathrm{mile}$ above

Fitchburg, Mass., Sheldon Street Bridge (destroyed), 100 feet above

Fitchburg, Mass., sheldon Street Bridge (destroyed), 50 feet below

Fitchburg, Mass., Sheldon Street Bridge (destroyed), 0.15 mile below

Fitchburg, Mass., Sheldon street Bridge (destroyed), 0.15 mile below

Fitchburg, Mass., River Street Bridge, 0.10 mile above

Fitchburg, Mass., River street Bridge, 110 feet below

Fitchburg, Mass., Circle Street Bridge, 60 feet below

Fitchburg, Mass., Rollstone Street Bridge, 40 feet above

F1tchburg, Mass., Rollstone Street Bridge, $0.15 \mathrm{mile}$ below

F1tchburg, Mass., Rollstone Street Bridge, 0.20 mile below

\begin{tabular}{|l|l|c}
$\begin{array}{c}\text { Miles } \\
\text { above } \\
\text { mouth }\end{array}$ & $\begin{array}{l}\text { Day } \\
\text { and } \\
\text { hour }\end{array}$ & $\begin{array}{c}\text { Altitude } \\
\text { in } \\
\text { feet }\end{array}$ \\
\hline & & \\
& &
\end{tabular}

17.0

16.9

16.75

16.6

a488.5

2454.5

2447.5

a 419.8

a416.5

a362.5

2358.0

a347.9

a346.8

16.6

a342.5

16.45

16.4

16.0

15.95

15.55

15.4

15.3

14.85

14.8

13.35

12.75

11.25

11.2

11.15

11.1

8.70

7.25

7.2
5.65

5.15

4.85

4.45

3.85

2.5

2.5

1.75

1.25

a340.8

a 331.5

a328.9

a316.8

a302. 5

a 300.6

a294. 5

a278.5

a274.5

a253. 5

a247.2

a246. I

2244. 8

a.237. 8

a237. 5

a230.5

a219.5

a216.0

a.215.1

a214.0

a210.5

2202. 5

al89.2

al 86.5

al85.2

al84.2

a) 81.1

al 73.4

1.20

.75

.4

.3

2151.0

al31.0

al24.0

a] 24.2

a) 24.5

al23.8

0

15.75

15.7

15.55

15.5

15.45

15.35

15.25

15.15

15.15

15.00

15.00

14.90

14.80

14.7

14.55

14.40

14.35

ad497. 5

ad497. 1

ad496. 5

ad489.9

ad489. 4

$\operatorname{ad} 480.9$

$\operatorname{ad} 480.1$

ad479.5

$\operatorname{ad} 473.0$

ad472.1

ad469.6

$\operatorname{ad} 469.4$

ad464. 6

ad 459.0

ad456.2

ad 449.8

$\operatorname{ad} 450.3$

a From profiles prepared by Corps of Englneers, U. S. Army, on basis of their surveys and investigations.

ad From surveys and investigations by Corps of Engineers, U. S. Army. 
Table 19.--Flood erest stages--Continued

Stream and location

Merrimack River Basin--Continued

North Nashua River--Continued.

Fitchburg, Mass., Rolistone street Bridge, $0.25 \mathrm{mile}$ below, average both banks

Fitchburg, Mass., Rollstone Street Bridge, 0.35 mile below

Fitchburg, Mass., Water Street Bridge, 0.35 mile above

Fitchburg, Mass., Water Street Bridge, 0.25 mile above

F1tchburg, Mass., Water Street Bridge, 0.25 mile above

Fitchburg, Mass., Water Street Bridge, 0.10 mile above

Fitchburg, Mass., Water Street Bridge, 0.15 mile below

Fitchburg, Mass., Fifth Street Bridge, 0.20 mile above

Fitchburg, Mass., Fifth Street Bridge, 30 feet above

Fitchburg, Mass., Fifth Street Bridge, 0.15 mile below

Fitchburg, Mass., Fifth Street Bridge, 0.20 mile below

Fitchburg, Mass., Fifth Street Bridge, 0.25 mile below

Fitchburg, Mass., Fifth Street Bridge, 0.25 mile below

Fitchburg, Mass., Fifth Street Bridge, 0.35 mile below

Fitchburg, Mass., Fifth Street Bridge, 0.50 mile below

Fitchburg, Mass., Fifth Street Bridge, $0.50 \mathrm{mile}$ below

Fitchburg, Mass., Fifth Street Bridge, 0.75 mile below

Fitchburg, Mass., Falulah Street Bridge, 0.60 mile above

Fitchburg, Mass., Falulah Street Bridge, $0.35 \mathrm{mile}$ above

Fitchburg, Mass., Falulah Street Bridge, 0.20 mile above

Fitchburg, Mass., Falulah Street Bridge, 0.10 mile above

Fitchburg, Mass., Falulah Street Bridge, 25 feet above

Fitchburg, Mass., Falulah street Bridge, loo feet below

Fitchburg, Mass., Falulah street Bridge, 0.25 mile below

Leominster, Mass., U. S. Geological Survey gage, just

above Worcester Conselidated Street Raflway dam,

headwater, right bank

Leominster, Mass., Ponikin Mill dam, tailwater

Leominster, Mass., Ponikin Mill Bridge, downstream

Nashua R1ver:

Lancaster, Mass., Boston \& Maine R.R. bridge, downstream

Harvard, Mass., highway bridge at Still River station, upstream

Harvard, Mass., highway bridge at St1l1 River Station, dowmstream

Ayer, Mass., 300 feet below Engineers Bridge

Ayer, Mass., abandoned street-railway bridge, upstream

Ayer, Mass., Ayer Ice Co. dam, headwater

Ayer, Mass., Ayer Ice Co. dam, tallwater

Ayer, Mass., Boston \& Maine R.R. bridge

Ayer, Mass.', Boston \& Maine R.R. bridge, just below mouth' of 'Squannacook River, upstream'

Ayer, Mass., Boston \& Maine R.R. bridge, just below mouth of Squannacook River, downstream

Ayer, Mass., highway bridge 1:05 miles below mouth of Squannacook River, upstream

Ayer, Mass., highway bridge 1.05 miles below mouth of Squannacook River, downs tream

Grotion, Mass., highway bridge 0.3 mile above mouth of Robinson Brook

East Pepperell, Mass., Nashua River Paper Co. dam, headwater

East Peppere11, Mass., Nashua R1ver Paper Co. dam, tallwater

East Pepperell, Mass., U. S. Geological Survey gage, 0.1 mile below dam, right bank

East Pepperell, Mass., 0.15 mile below Nashua River Paper Co. dam

Runnels Falis Dam, headwater

Runnels Falls Dam, tallwater

Mine Falls Dam, headwater

Mine Falls Dam, tallwater

Dam, 0.1 mile below Mine Falls Dam

Dam, 0.9 mile below Mine Falls Dam

Nashua, N. H., Jackson Mills dam, headwater

Nashua, N. H., 0.15 mile below Boston \& Maine R.R. bridge

Nashua, N. H., Confluence of Nashua River and Merr1mack River

Concord River:

Confluence of Assabet and Sudbury Rivers

Concord, Mass., old North Bridge, upstream

Concord, Mass., Monument Street bridge, downstream

Carlisle Road bridge on Highway 2,75 feet upstream

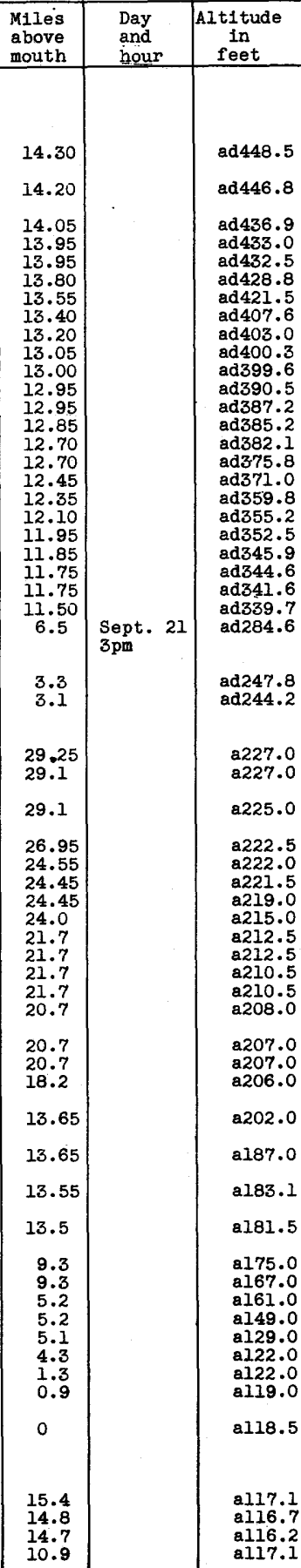

a From profiles prepared by Corps of Engineers, U. S. Army, on basis of their surveys and investigations.

ad From surveys and investigations by Corps of Engineers, U. S. Army. 
Table 19.--Flood crest stages--Continued

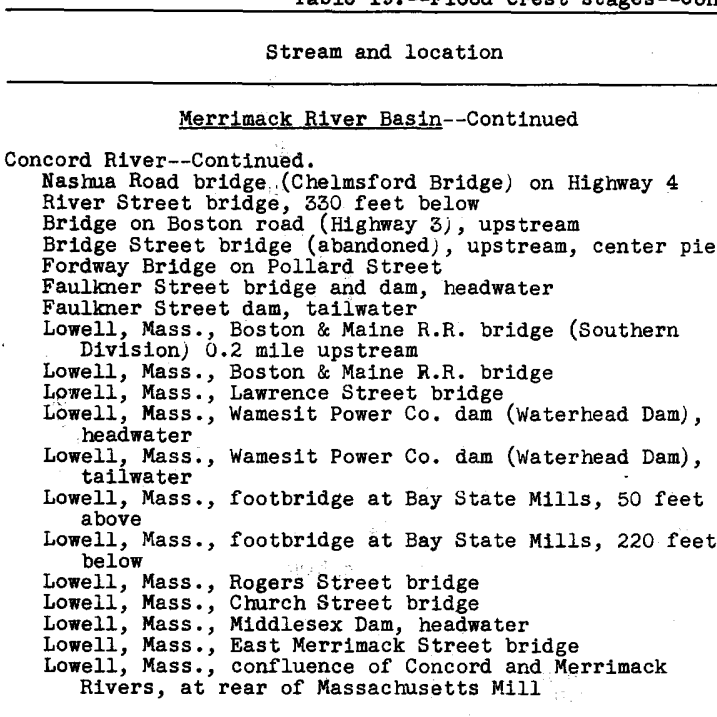

Sudbury River:

Southville, Mass., highway bridge, 0.7 mile above Highway 85 bridge

Cordaville dam, 0.15 mile above Highway 85 bridge, headwater

Cordavilie dam, 100 feet below, tailwater

Cordaville dam, 225 feet below

Highway bridge (abandoned) $0.05 \mathrm{mile}$ above Highway 85 bridge, upstream

Cordaville, Mass., Highway 85 bridge, 100 feet above

old mill dam, 0.8 mile below Highway 85 bridge

Boston \& Albany R.R. bridge, 0.95 mile below Highway 85 bridge, 275 feet above

Boston \& Albany R.R. bridge, upstream

Hopkinton Road bridge, 1.35 miles below Highway 85 bridge, upstream

Pleasant Street bridge, upstream

Dam, 0.1 mile below pleasant street bridge

Ashland, Mass., Lombard Governor Co. dam off Myrtle Street (2 spillways), headwater

Ashland, Mass., Lombard' Governor Co. dam off Myrtle street ( 2 spillways), tailwater

Ashland, Mass., Concord street bridge 0.25 mile below Lombard Governor Co. dam, upstream

Ashland, Mass., westerly bridge on Highway 135 , upstream

Ashland, Mass., easterly bridge on Highway 135 , ups tream

Above dam between Metropolitan water-supply basins Nos. 2 and 1

Dam at outlet of Metropolitan water-supply basin No. 1, just above Winter street, headwater

Dam at outlet of Metropolitan water-supply basin.No. 1, just above Winter street, tallwater

Framingham Center, Mass., Union Avenue bridge, upstream

Framingham Center, Mass., Highway 9 bridge

Framingham, Mass., Gordon Bridge, $0.45 \mathrm{mile}$ below Highway 9 bridge, 100 feet belor

Framingham, Mass., Francis Street bridge, 1.7 miles below Highway 9 bridge, upstream

Framingham, Mass., Francis Street bridge, 1.7 miles below Highway 9 bridge, 50 feet below

Saxonville, Mass., dam at outlet of Sudbury Pond, Just above Central street bridge

Saxonville, Mass., Central Street bridge, downstream

Saxonville, Mass., Concord Street bridge, upstream

Stone bridge, 2.1 miles below Concord Street bridge, 50 feet above

Highray 20 bridge, downstream

Stone Road bridge, Wayland Inn, upstream

Concord-Lincoln town line, Highway 117 bridge (Lees Bridge)

Route 2 bridge, upstream

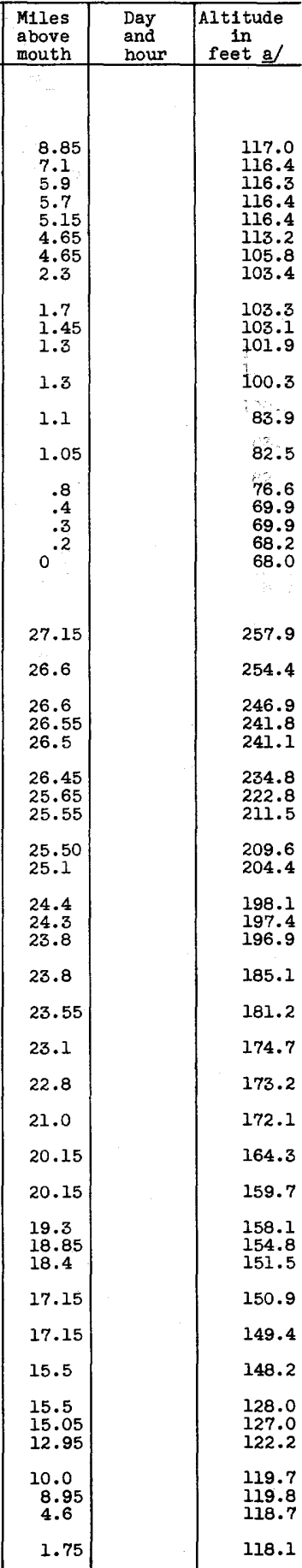

a From profiles prepared by Corps of Engineers, U. S. Army, on basis of their surveys and investigations. 
Table 19.--Flood crest stages--Continued

\begin{tabular}{l} 
Stream and location \\
Merrimack River Basin--Continued \\
\hline Sudbury River--Continued. \\
Concord, Mass., Highway. 62 bridge (Main Street bridge) \\
50 feet above \\
Concord, Mass., Highway 2 A bridge (Elm Street bridge) \\
200 feet below \\
Concord, Mass., Nashawtuc Road bridge, 50 feet upstream \\
Concord, Mass., Nashawtuc Road bridge, 250 feet below \\
Confluence of Sudbury and Assabet Rivers
\end{tabular}

\section{Thames River Basin}

WIllimantic and Shetucket Rivers:

Stafford Springs, Conn., at Rhode Island Worsted Co. dam on Square Pond Brook

Stafford Springs, Conn., 700 feet below Rhode Island Worsted Co. dam on Square Pond Brook

Stafford Springs, Conn., 1,330 feet below Stafford Worsted Co. dam on Square Pond Brook

Stafford Springs, Conn., 1,420 feet below stafford Worsted Co. dam on Square Pond Brook

Stafford Springs, Conn., inside New London Northern R.R. station, 1,850 feet below Stafford Worsted Co. dam on Square Pond Brook

Stafford Springs, Conn., cornerstone of churc' 1,850 feet below Stafford Worsted Co. dam on Square Pond Brook

Stafford Springs, Conn., 250 feet below T. F. Mullen Co. dam

Stafford Springs, Conn., 750 feet below T. F. Mullen Co, dam

West Willington, Conn., 6.4 miles above McCollum Dam, left bank

West Willington, Conn., 6.4 miles above McCollum Dam, left bank

West Willington, Conn., 6.4 miles above McCollum Dam, left bank

Mansfleld Depot, Conn., at McCollum Dam, left bank

Eagleville, Conn., at Eagleville Mills Co. dam, right bank

Eagleville, Conn., 125 feet below Eagleville Mill Co. dam, left bank

South Coventry, Conn., inside New London Northern R.R. Station 1.7 miles below Eagleville Mill Co. dam, right bank

Wililmantic, Conn., at highway bridge 2.0 miles above American Thread Co. building at Windham Road bridge right bank

Willimantic, Conn., at American Thread Co. building just below Windham Road bridge, left bank

Baltic, Conn., 600 feet below Baltic Mills dam

Baltic, Conn., 900 feet below Baltic Milis dam, right bank

Baltic, Conn., 1,200 feet below Baltic Mills dam, right bank

Baltic Conn., 0.7 mile below Baltic Mills dam, right bank

Baltic, Conn., 0.9 mile below Baltic Mills dam, right bank

Baltic, Conn., 1.0 mile below Baltic M1lls dam, right bank

occum, Conn., 400 feet below City of Norwich dam, right bank

occum, Conn., 0.5 mile below City of Norwich dam, right bank

Taftville, Conn., just above highway bridge, $0.05 \mathrm{mile}$ above mouth of Quinebaug River, right bank

Norwich, Conn., 600 feet below Greenville dam $0.4 \mathrm{mile}$ above Eighth street highway bridge, right bank

Norwlch, Conn., 960 feet below Greenville dam, right bank

Norwich, Conn., 960 feet below Greenville dam, right

bank
Norwich, Conn., 2.0 mile below Greenville dam, right bank.

Norwich, Conn., 0.3 nille above Main Street bridge, right bank

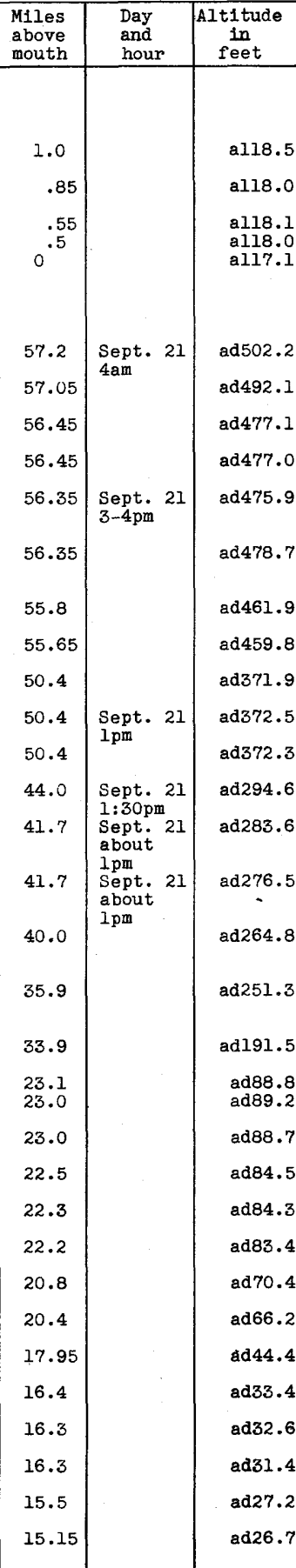

a From profiles prepared by Corps of Engineers, U. S. Army, on basis of their surveys and investigations.

ad From surveys and Investigations by Corps of Engineers, U. S. Army. 
Table 19.--Flood ceest stages--Continued

Stream and location
Themes River Basin--Continued
.
Willimantic and Shetucket Rivers--Continued.
Norwich, Conn., 0.1 mile above Main Street bridge,
left bank
Norwich, Conn., 300 feet above Main Street bridge,
right bank
Norwich, Conn., 60 feet above Main Street bridge
Norwich, Conn., l40 feet below Main Street bridge
Norwich, Conn., New York, New Haven \& Hartford R.R.
depot O.I mile below Main Street bridge
Norwich, Conn., Franklin Square
Norwich, Conn., cormer of Franklin Street and Bath
Street
Norwich, Conn., in shop on City Landing
Norwich, Conn., in theater on City Landing
Norwich, Conn., on building on City Landing
Norwich, Conn., intersection of Broadway and Main
Street
Norwich, Conn., on store \#42 Market Street
Norwich, Conn., on market \#56 Market Street
Norwich, Conn., at New York, New Haven \& Hartford R.R.
freight station
Still and Natchaug Rivers:

Mansfield, Conn., at Gity of Willimantic dam

Mansfield, Conn., 40 feet below City of Willimantic dam

willimantic, Conn., building just above highway bridge below railroad bridge, right bank

Willimantic, Conn., house \#79 Main Street just above highway briage 0.2 mile above confluence of Natchaug and Willimantic Rivers, right bank

W1llimantic, Conn., house \#55 Main Street, just above highway bridge, right bank

Willimantic, Conn., over highway bridge

Willimantic, Conn., house at highway bridge, left bank

willimantic, Conn., building at highway bridge, left bank

Willimantic, conn., just below highway bridge, left bank

Willimantic, Conn., just south of highway, left bank

Quinebaug River:

Southbridge, Mass., at Ames Worsted Co. dam, left bank (right abutment destroyed 6:30am Sept. 21)

Southbridge, Mass., 650 f'eet below Ames Worsted Co. dam, left bank

Southbridge, Mass., 1,300 feet below Ames Worsted Co. dam, left bank

Southbridge, Mass., 1,600 feet below Ames Worsted Co. dam, left bank

Southbridge, Mass., at Russell Harrington Cutlery Co. dam

Southbridge, Mass., 2,600 feet above American 0ptical Co. dam, right bank

Southbridge, Mass., 2,100 feet above American optical Co. dam, right bank

Southbridge, Mass., 1,200 feet above American 0ptical Co. dam, right bank

Southbridge, Mass., 1,150 feet above American 0ptical Co. dam, right bank

Southbridge, Mass., at American optical Co. dam, right bank

Southbridge, Mass., 530 feet below American Optical Co. dam, right bank

Sandersdale, Mass., highway bridge, upstream, left bank

West Dudley, Mass., 300 feet above West Dudley Paper Co. dam (dam failed)

West Dudley, Mass., at West Dudley Paper Co. dam (dam fatled)

Dudley, Mass., at Intervale Mills dam (dam failed Sept. 2l, ilam), left bank

Dudley, Mass., 120 feet below Intervale Mills dam (dam failed), left bank

Dudley, Mass., 300 feet below Intervale M1lls dam (dam failed), right bank

Quinnebaug, Conn., Just above highway bridge $0.5 \mathrm{mile}$ below Intervale Mills dam

Fabyan, Conn., 180 feet below Fabyan Woolen Co. dam, left bank

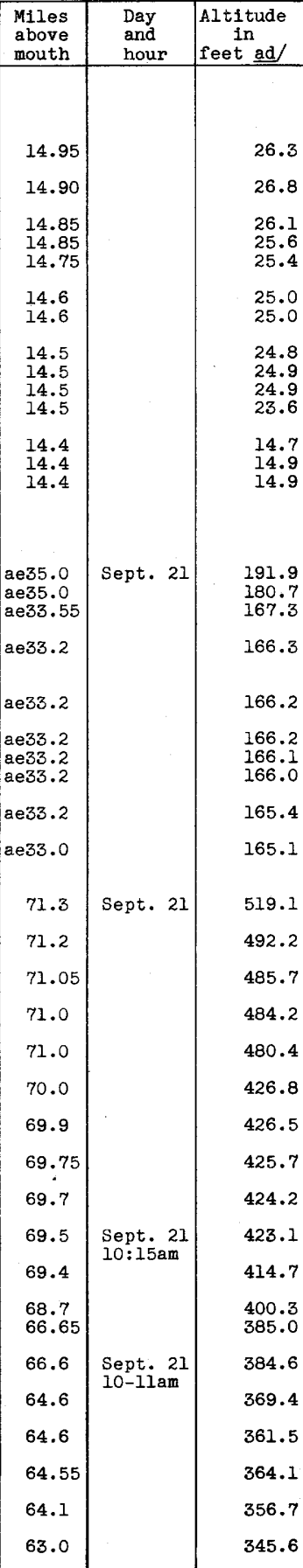

ad From surveys and Investigations by Corps of Engineers, U. S. Army .

ae Measured along middle of river valley.

$22 \pi 9070-40-32$ 
Table 19,--Flood crest stages--Continued

\begin{tabular}{|l|l|}
\hline Stream and location & Stion \\
\hline
\end{tabular}

Thames River Basin--Continued

Quinebaug River--Continued.

Putnam, Conn., 90 feet above Nightingale-Morse Mills Inc. dam

Putnam, Conn., 250 feet below N1ghtingale-Morse Mills Inc. dam

Putnam, Conn., just below Providence Street highway bridge, left bank

Putnam, Conn., just below Providence Street highway bridge, left bank

Putnam, Conn., 1,800 feet above Pütnam Woolen Co. dam, left bank

Putnam, Conn., 1,600 feet above Putnam Woolen Co. dam, left bank

Putnam, Conn., 1,550 feet above Putnam Woolen Co. dam, left bank

Putnam, Conn., 1,240 feet above Putnam Woolen Co. dam, left bank

Putnam, Conn., 1,190 feet above Putnam Woolen Co. dam; left bank

Putnam, Conn., 1,100 feet above Putnam Woolen Co. dam, right bank

Putnain, Conn., 900 feet above Putnam Woolen Co. dam, left bank

Putnam, Conn., 850 feet above Putnam Woolen Co. dam, left bank

Putnam, Conn., 10 feet above Putnam Woolen Co. dam, right bank

Putnam, Conn., 600 feet below Putnam woolen Co. dam, right bank

Putnam, Conn., 600 feet below Putnam Woolen Co. dam, left bank

Putnam, Conn., 1,400 feet below Putnam Woolen Co. dam, left bank

Putnam, Conn., 1,750 feet below Putnam Woolen Co. dam, left bank

Putnam, Conn., 400 feet above U. S. Geological Survey gage, left' bank

Putnam, Conn., 0.25 mile below U. S. Geological Survey gage, left bank

Putnam, Conn., 0.45 mile below U. S. Geological Survey gage, right bank

Goodyear, Conn., 100 feet above Goodyear Cotton Mills Inc. dam

Goodyear, Conn., 0.3 mile below Goodyear Cotton Mills Inc. dam

Danielson, Conn., 260 feet above Wauregan-Quinebaug Mills Inc. dam, right bank

Danielson, Conn., just above Wauregan-Quinebaug Mills Inc. dam, right bank

Danielson, Conn., at Wauregan-Quinebaug Mills Inc. dam

Danielson, Conn., at Dyer Dam of Connecticut Light \& Power Co., heádwater (dam broke during night of Sept. 23, 1938

Danielson, Conn., 40 feet below Dyer Dam of Connecticut Light \& Power Co., tailwater

Packersville, Conn., highway bridge 1.8 miles below Mill Brook, downstream, right bank

Jewett City, Conn., 150 feet above Aspinook Dam, left bank

Jewett City, Conn., Just above highway bridge $0.7 \mathrm{mile}$ below Aspinook Dam, left bank

Yantic River:

Bozrahville, Conn., 900 feet below Bozrah Electric Co. dam

Franklin, Conn., Just above highway bridge 0.05 mile above Franklin-Norwichtown line, right bank

Norwlchtown, Conn., $0.6 \mathrm{mile}$ below alen Woolen Mills Paper Co.

\section{Connecticut River Basin}

Connecticut River:

Holyoke, Mass., Holyoke Dam, headwater

Holyoke, Mass., 400 feet above No. 2 Wasteway, Holyoke Water Power Co.

Holyoke, Mass., 280 feet above No. 2 Wasteway, Holyoke Water Power Co.

Holyoke, Mass., 200 feet above No. 2 Wasteway, Holyoke Water Power Co.

Holyoke, Mass., 200 feet above No. 2 Wasteway, Holyoke Watér Power Co.

\begin{tabular}{l|l|l}
$\begin{array}{l}\text { Miles } \\
\text { above } \\
\text { mouth }\end{array}$ & $\begin{array}{l}\text { Day } \\
\text { and } \\
\text { hour }\end{array}$ & $\begin{array}{c}\text { Altitude } \\
\text { In } \\
\text { feet ad/ }\end{array}$ \\
\hline & &
\end{tabular}

54.8

54.8

54.8

54.8

54.75

54.7

54.7

54.65

54.65

54.6

54.55

54.55

54.4

54.3

54.3

54.15

54.05

54.0

53.65

53.45

47.4

47.1

Sept. 21

$3 \mathrm{pm}$

42.4

42.4

42.4

40.6

40.6

28.5

25.4

24.7

Sept.

9-10pm

24.0

19.1

16.6

81.85
81.8
81.75
81.75
81.75
297.8

280.3

266.5

267.1

264.0

264.5

264.1

262.4

262.9

262.9

262.6

262.5

262.3

238.4

236.8

238.2

236.6

236.5

234.7

233.7

212.3

204.7

196.1

196.0

197.1

170.6

159.8

103.4

102.2

87.6

204.5

114.3

83.3

112.3

74.9

74.3

$74: 5$

74.0

ad From surveys and Investigations by Corps of Engineers, U. S. Army . 
Table 19.--Flood crest stages--Continued

Stream and location
Connecticut River Basin--Continued
Connecticut River--Continued.

Holyoke, Mass., 150 feet above No. 2 Wasteway, Holyoke Water Power Co.

Holyoke, Mass., 100 feet above No. 2 Wasteway, Holyoke Water Power Co.

Holyoke, Mass., 50 feet above No. 2 Wasteway, Holyoke Water Power Co.

Holyoke, Mass., No. 2 Wasteway, Holyoke Water Power Co. Holyoke, Mass., Morart Bullding

Holyoke, Mass., Corps of Engineers, U. S. Army, gage above South Hadley Falis Bridge

Holyoke, Mass., Corps of Engi.jeers, U. S. Army, gage below South' Hadley Falls Bridge' (set during flood)

Holyoke, Mass., Valley Paper Co,

holyoke, Mass., Crocker Division, American Writing Paper Co.

Holyoke, Mass., Albion Division, American Writing Paper Co.

Holyoke, Mass., North Side of Albion Division, American Writing Paper Co.

Holyoke, Mass., between Albion and Mount Tom Division American Writing Paper Co.

Holyoke, Mass., Mount Tom Division, American Writing Paper Co.

Holyoke, Mass., between Mount Tom and Nonotuck Div1Sions, American Writing Paper Co.

Holyoke, Mass., Nonotuck Division, American Writing Paper Co.

Holyoke, Mass., rear of Nonotuck Division, American Writing Paper Co.

Holyoke, Mass., J. C. Gill Division, American Writing Paper Co.

Holyoke, Mass., No. I wasteway, Holyoke Water Power Co.

Holyoke, Mass., near Hampden Giazed Paper Co.

Holyoke, Mass., Corps of Engineers, U. S. Army, gage (set during flood)

Holyoke, Mass., Corps of Engineers, U. S. Army, gage (set during $\mathrm{f} \perp$ ood)

.Holyoke, Mass., Corps of Engineers, U. S. Army, gage (set during flood)

Holyoke, Mass., No. 4 wasteway, Holyoke Water Power Co.

Holyoke, Mass., gage No. 48 Chemical Paper Co.

Holyoke, Mass., Corps of Engineers, U.S. Army, gage (set during flood)

Chilcopee, Mass., mouth of Chicopee River

Chicopee, Mass., Chicopee bridge

Chicopee, Mass., $0.5 \mathrm{mile}$ below Chicopee bridge

Chicopee, Mass., 0.85 mile below Chicopee bridge

Chicopee, Mass., 1.20 miles below Chicopee bridge

Springfield, Mass., 4,300 feet above North End bridge

Springfield, Mass., 3,350 feet above North End bridge

springfield, Mass., 2,000 feet above North End bridge

springfield, Mass., 1,000 feet above North End bridge

Springfield, Mass., 100 feet below North End bridge

Springfield, Mass., 800 feet below North End bridge

springfield, Mass., 1,850 feet below North End bridgo

springfield, Mass., 3,400 feet below North End bridge

Springfield, Mass., 4,300 feet below North End bridge

Springfield, Mass., Boston \& Albany R.R. bridge

springfield, Mass., Memorial Highway bridge

Springfield, Mass., upper mouth of Westfleld River

springfield, Mass., 4,300 feet below Memorial Highway bridge

Springfield, Mass., 5,150 feet below Memorial H1ghway bridge

Springfleld, Mass., 700 feet above South End bridge

Westfleld River, lower mouth of

Springfield, Mass., South End bridge

Springfield, Mass., 0.8 mile below South End bridge

Springfleld, Mass., 1.8 miles below South End bridge

Springfield, Mass., 3.0 miles below South End bridge

springfield, Mass., 4.15 miles below South End bridge

Thompsonvilie, Conn., 1.3 miles above bridge at

Thompsonville, Conn., 0.6 mile above bridge at

Thompsonville, Conn., bridge at

Enfield Dam, 2,100 feet above

Enfleld Dam, 1,600 feet above

Enfield Dam, 1,300 feet above

Enfield Dam, 900 feet above

Enfield Dam, U. S. Geological Survey gage above

Enfield Dam, 300 feet below

Enfleld Dam, 500 feet below

\begin{tabular}{|c|c|c|}
\hline $\begin{array}{l}\text { Miles } \\
\text { above } \\
\text { mouth }\end{array}$ & $\begin{array}{l}\text { Day } \\
\text { and. } \\
\text { hour }\end{array}$ & $\begin{array}{l}\text { Altitude } \\
\text { In } \\
\text { feet ad }\end{array}$ \\
\hline 81.75 & & 74.6 \\
\hline 81.7 & & 74.4 \\
\hline 81.7 & & 75.1 \\
\hline $\begin{array}{l}81.7 \\
81.6 \\
81.6\end{array}$ & & $\begin{array}{l}74.9 \\
74.8 \\
74.5\end{array}$ \\
\hline 81.5 & & 74.0 \\
\hline $\begin{array}{l}81.5 \\
81.4\end{array}$ & & $\begin{array}{l}74.3 \\
73.7\end{array}$ \\
\hline 81.3 & & 73.2 \\
\hline 81.3 & & 73.4 \\
\hline 81.2 & & 73.7 \\
\hline 81.1 & & 72.6 \\
\hline 81.1 & & 72.9 \\
\hline 81.1 & & $72: 4$ \\
\hline 81.1 & & 72.3 \\
\hline 81.0 & & 72.2 \\
\hline $\begin{array}{l}80.6 \\
80.2 \\
80.0\end{array}$ & & $\begin{array}{l}71.6 \\
70.7 \\
70.7\end{array}$ \\
\hline 80.0 & & 70.4 \\
\hline 79.8 & & 70.1 \\
\hline $\begin{array}{l}79.8 \\
79.5 \\
79.1\end{array}$ & & $\begin{array}{l}70.2 \\
70.1 \\
69.6\end{array}$ \\
\hline $\begin{array}{l}75.75 \\
75.45 \\
74.95 \\
74.6 \\
74.25 \\
73.6 \\
73.4 \\
73.1 \\
72.9 \\
72.75 \\
72.65 \\
72.4 \\
72.1 \\
71.9 \\
71.85 \\
71.65 \\
71.05 \\
70.8\end{array}$ & & $\begin{array}{l}66.4 \\
66.1 \\
65.8 \\
65.7 \\
65.1 \\
64.9 \\
64.4 \\
64.4 \\
64.2 \\
64.0 \\
63.7 \\
63.6 \\
63.6 \\
63.5 \\
62.8 \\
62.8\end{array}$ \\
\hline 70.7 & & 62.6 \\
\hline $\begin{array}{l}70.5 \\
70.45 \\
70.35 \\
69.55 \\
68.55 \\
67.35 \\
66.20 \\
65.7 \\
65.0 \\
64.40 \\
63.95 \\
63.85 \\
63.8 \\
63.7 \\
63.55 \\
63.5 \\
63.45\end{array}$ & & $\begin{array}{l}62.1 \\
62.0 \\
60.8 \\
60.4 \\
59.5 \\
59.2 \\
58.3 \\
57.0 \\
56.0 \\
55.6 \\
55.2 \\
54.2 \\
52.7 \\
52.9 \\
49.4 \\
49.3\end{array}$ \\
\hline
\end{tabular}

ad From surveys and investigations by Corps of Engineers, U. S. Army. 
Table 19.--Flood crest stages--Continued

(a) Miles

\begin{tabular}{c|c} 
Stream and location & \\
\hline Connecticut River Basin--Continued &
\end{tabular}

Connecticut River--Continued.

Enfleld, Conn., left bank

East Windsor, Conn., left bank

East Windsor, Conn., left bank

Windsor Locks, Conn., right bank

Windsor Locks, Conn., right bank

Windsor Locks, Conn., right bank

East Windsor, Conn., left bank

Windsor Locks, Conn., right bank

East Windsor, Conn., left bank

East Windsor, Conn., left bank

Windsor Locks, Conn., gage, right bank

Windsor, Conn., raliroad overpass at Broad st. south of

Farmington River, right bank

Windsor, Conn., gage, right bank

Windsor, Conn., right bank

Windsor, Conn., gage, right bank

South windsor, Conn., left bank

Windsor, Conn., right bank

Windsor, Conn., right bank

South Windsor, Conn., left bank

Windsor. (Wilson), Conn., gage, right bank

Windsor (Wilson), Conn., right bank

Windsor (Wilson), Conn., gage, right bank

Windsor (Wilson), Conn., right bank

Hartford-Windsor town line, Windsor Avenue at Meadow Brook, right bank

East Hartford, Conn., gage, left bank

Hartford, Conn., right bank

Hartford, Conn., New York, New Haven \& Hartford R.R. bridge

Hartford, Conn., right bank

Hartford, Conn., right bank

Hartford, Conn., right bank

Hartford, Conn., right bank

hartford, Conn., Memorial Bridge

Hartford, Conn., right bank

Hartford, Conn.', right bank

East Hartford, Conn., left bank

Hartford, Conn., right bank

Hartford, Conn., Park River gage, right bank

East Hartford, Conn., gage, left bank

Hartford, Conn., right bank

East Hartford, Conn., left bank

East Hartford, Conn., left bank

East Hartford, Conn., sidewalk bridge over Willow Brook, left bank

East Hartford, Conn., left bank

Hartford-Wethersfield line, South Meadow pumping station, right bank

East Hartford, Conn., left bank

Wethersfield, Conn., right bank

Wethersfleld, Conn., right bank

Wethersfleld, Conn., right bank

Wethersfleld, Conn., right bank

Glastonbury, Conn., left bank

Wethersfield, Conn., center of, right bank

Glastonbury, Conn., left bank

Glastonbury, Conn., left bank

Glastonbury, Conn.' left bank

Glastonbury, Conn., left bank

Glas tonbury, Conn., left bank

Glastonbury, Conn., left bank

Wethersfield, Conn., right bank

We thersfield, Conn., right bank

Wethersfield, Conn., right bank

Wethersfield-Rocky Hill town line, right bank

Rocky Hill, Conn., right bank

Glastonbury, Conn., left bank

Glastonbury, Conn., left bank

Glastonbury, Conn., left bank

Rocky H111, Conn., right bank

Rocky Hili, Conn., gage, right bank

Rocky Hil, Conn., right bank

Rocky Hill, Conn., right bank

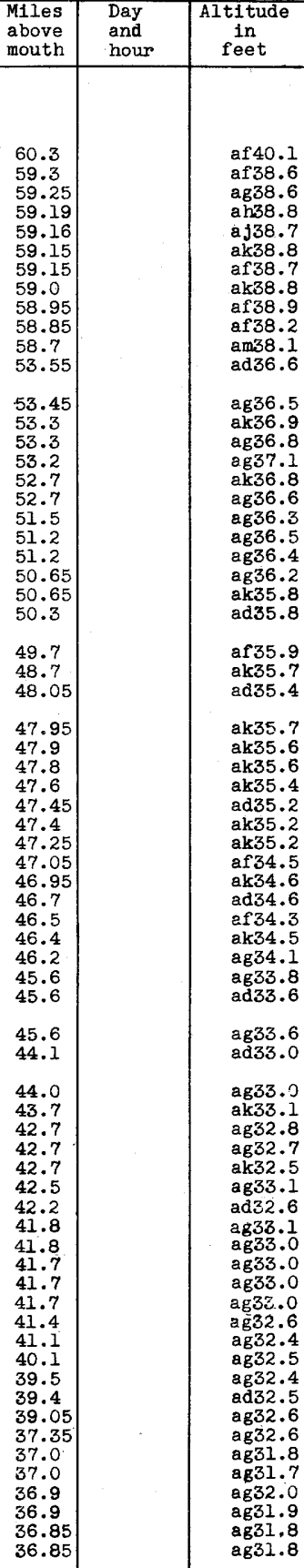

ad From surveys and investigations by Corps of Engineers, U. S. Army.

af-From surveys and investigations by Works Progress Administration.

ag From surveys and investigations by Connecticut State Water Commission (Ground Whter Project)

ah From surveys and investigations by the Horton Co.

af From surveys and investigations by Middletown Department of Public Works.

ak From surveys and investigations by Hartford City Engineer.

an From surveys and investigations by Connecticut Light \& Power Co. 
Table 19.--Flood crest stages--Continued

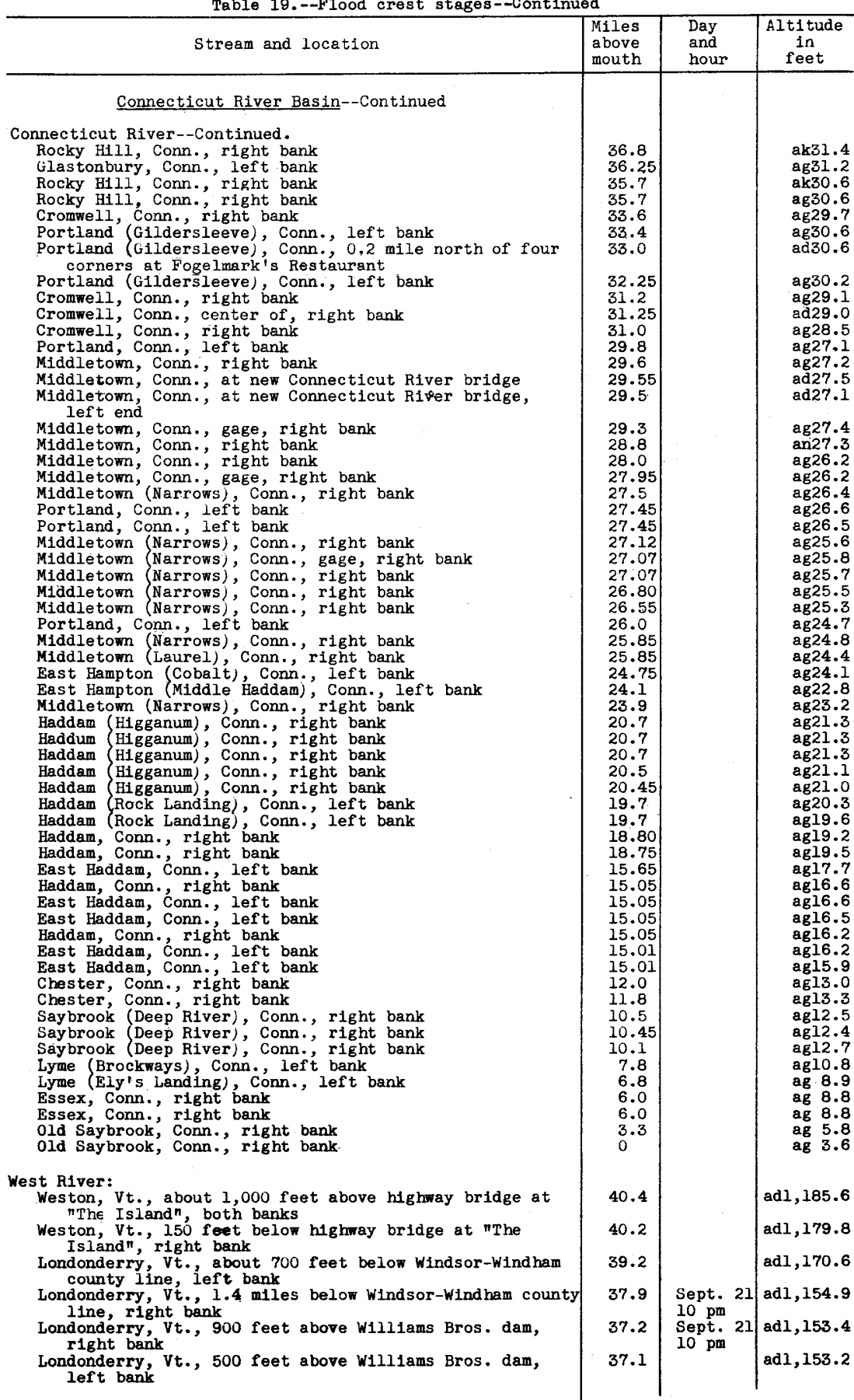

ad From surveys and investigations by Corps of Engineers, U. S. Army.

ag From surveys and investigations by Connecticut State Water Commission (Ground water Project)

ak From surveys and investigations by Hartford City Engineer.

an From surveys and investigations by Montgomery Co. 
Table 19.--Flood crest stages--Continued

Stream and location
Connecticut River Basin--Continued
$\begin{gathered}\text { West R1ver--Continued. } \\ \text { Londonderry, Vt., } 300 \text { feet above Williams Bros. dam, } \\ \text { left bank }\end{gathered}$

Londonderry, Vt., 100 feet above W1lliams Bros. dam, right bank

Londonderry, Vt., 600 feet below Williams Bros. dam, right bank

Londonderry, vt., 1,000 feet below Willlams Bros. dam, right bank

Londonderry, Vt., 1,400 feet below Will1ams Bros. dam, right bank

Londonderry, vt., 1,600 feet below Williams Bros. dam, right bank

Londonderry, Vt., 1,900 feet below Williams Bros. dam, right bank

Iondonderry, Vt., about 2,000 feet below Williams Bros. dam, right bank

South Londonderry, Vt., 300 feet above Londonderry Co. dam, right bank

South Londonderry, Vt., 15 feet above the Londonderry Co. dam, left bank

South, Londonderry, Vt., 150 feet below Londonderry Co. dam, left bank

South Londonderry, Vt., about 550 feet below Londonderry Co. dam, left bank

South Londonderry, Vt., 100 feet above Hewlett dam, left bank

South Londonderry, Vt,, 1.9 miles above junction of Winhall River and West River, left bank

South Londonderry, Vt., about 600 feet above Junction of Winhall River and West River, left bank

Jamalca, Vt., at highway bridge over West River

East Jamaica, Vt., 0.3 mile below junction of Turkey Mountain Brook and West River, left bank

West Townshend, Vt., 1.6 miles below junction of Turkey Mountain Brook and West River, left bank

West Townshend, Vt., 2.0 miles below junction of Turkey Mountain Brook and West River, left bank

Townshend, Vt., 2.1 miles below junction of Turkey Mountain Brook and West River, left bank

Townshend, Vt., 1.0 mile above junction of Fair Brook and West River, left bank

Townshend, Vt., 90 feet above highway bridge below Junction of Falr Brook and West River, left bank

Townshend, Vt., about 150 feet below highway bridge, left bank

Townshend, Vt., 0.3 mile above junction of Mill Brook and West River at. Harmonyvilie, left bank

Townshend, Vt., 0.7 mile below junction of Mill Brook and West River and about 500 feet above highway tridge, left bank

Townshend, $\bar{v} t$., about 250 feet below highway bridge, right bank

Newfane, Vt., about 600 feet above railroad bridge, right bank

Newfane, Vt., 350 feet below rallroad bridge, right bank

Newfane, Vt., 300 feet above highway bridge at U. S. Geological Survey gaging station, right bank

Newfane, Vt., l.1 miles above Junction of Williamsville Branch and main brarich of West River, right bank

Newfane, Vt., about 200 feet above junction of Williamsville Branch and main branch of West River, right bank

Dummerston, Vt, , about 300 feet below junction of W1lliamsville Branch and main branch of West River, right bank

Dummerston, Vt., 10 feet above the Twin State Gas \& Electric Co. dam, right bank

Dummerston, Vt., 100 feet below Twin state Gas \& Electric Co. dam, right bank

Dummerston, Vt., about 550 feet below Twin State Gas \& Electric Co.' dam, right bank

Dummerston, Vt., about 300 feet above covered highway bridge above West Dummerston, Vt., right bank

Dummerston, Vt., about 250 feet below covered highway bridge above West Dummerston, Vt., right bank

Dummerston, Vt., about 80 feet above rallroad bridge at West Dummerston, Vt., right bank

Dummerston, Vt., about 300 ' feet below railroad bridge at West Dummerston, Vt., right bank

Dummerston, Vt., 250 feet above highway bridge below West Dummerston, vt., right bank

\section{Miles}

above

mouth

\begin{tabular}{|c|c|}
\hline $\begin{array}{l}\text { Day } \\
\text { and } \\
\text { hour }\end{array}$ & $\mid \begin{array}{c}\text { Altitude } \\
\text { In } \\
\text { feet ad }\end{array}$ \\
\hline
\end{tabular}

(

37.

37.0 \begin{tabular}{l|l|l} 
lopm & Sept. 21 & $1,152.4$
\end{tabular}

36.9 Sept. 21 $1,136.6$

\begin{tabular}{l|l|l}
36.8 & $10 \mathrm{pm}$ & $1,135.8$
\end{tabular}

36.7

36.7

36.6

Sept. 21

$10 \mathrm{pm}$

$1,135.8$

$1,135.7$

$1,135.6$

36.6 Sept. 21

$10 \mathrm{pm}$

33.9

$10 \mathrm{pm}$

33.8 Sept. 21

, 135.6

$1,049.9$

$1,049.0$

33.8

10:30pm

33.7 Sept. 21

$1,044.6$

$1,041.1$

33.2 Sept. 2]

32.8

9-10pm

$1,032.1$

$1,004.2$

31.0

24.

21.8

Sept.

$10 \mathrm{pm}$

20.5 Sept. 21

20.1 $10 \mathrm{pm}$

20.0

19.2

17.9

17.9

15.9

14.9

Sept. 21 7-8pm

14.7

13.8

13.6

12.3

Sept. 21

9.2

8.1

8.0

7.0

7.0

6.9

6.1

6.0

5.5

5.4

4.7

950.6

672.5

548.5

518.6

506.4

502.6

486.0

469.1

465.8

438.4

428.0

427.2

424.6

420.5

410.3

382.2

361.6

359.3

353.9

332.1

329.4

316.5

312.4

302.6

300.3

290.9

ad From surveys and investigations by Corps of Engineers, U. S. Army. 
Table 19.--Flood crest stages--Continued

Stream and location

West River--Continued.

Dummerston, Vt., about 150 feet below highway bridge beIow West Dummerston, Vt., right bank

Dummerston, Vt., about 600 feet below highway bridge below West Dummerston, Vt., right bank

Dummerston, Vt., right bank

Brattleboro, Vt., right bank

Brattleboro, Vt., right bank

Brattleboro, Vt., right bank

Brattleboro, Vt., right bank

Brattleboro, Vt., confluence with Connecticut River

Orcutt Brook:

Landgrove, vt., about, 75 feet above North Landgrove highway bridge, right bank

Londonderry, vt., 200 feet above highway bridge, left bank

Londonderry, vt., 400 feet below highway bridge, right bank

Londonderry, Vt., 100 feet above highway bridge over Orcutt Brook near mouth, left bank

Londonderry, Vt., 300 feet below highway bridge and about 400 feet above mouth of orcutt Brook, left bank Junction of Orcutt Brook and West River 0.3 mile below Williams Bros. dam

Ashuelot River:

Marlow, N. H., 250 feet below Watson \& Williams Manufacturing Co. dam, left bank

Marlow, N. H., 0.3 mile below mouth of Abbott Brook, left bank

Marlow, N. H., 0.9 mile below mouth of Abbott Brook, left bank

Marlow, N. H., 100 feet above private bridge, left bank

Marlow, N. H., 100 feet above ruins of old dam. left bank

Gilsum, N. H., 200 feet above private bridge 0.3 mile above mouth of Trout Brook, left bank

Gilsum, N. H., 300 feet below private bridge, left bank

G1lsum, N. H., 0.45 mile below mouth of Trout Brook, left bank

Gilsum, N. H., Just above mouth of Heminway Brook, left bank

Gilsum, N. H., 100 feet below highway bridge on Route 10 , right bank

Gilsum, N. H., 0.25 mile above U. S. Geological Survey gage, left bank

G1lsum, N. H., U. S. Geological Survey gage

Gilsum, N. H., 0.6 mile below U. S. Geological Survey gage, right bank

Gilsum, N. H., 0.8 mile below U. S. Geologlcal Survey gage, r1ght bank

Gilsum, N. H., 0.95 mile below U. S. Geological survey gage, right bank

Gilsum, N. H., 200 feet above mouth of Dart Brook, right . bank

G1lsum, N. H., 300 feet below mouth of Dart Brook, right bank

Surry, N. H., 400 feet below mouth of Cannon Brook, right bank

Surry, N. H., 400 feet above mouth of Thompson Brook, right banis

Surry, N. H., 0.7 mile below mouth of Thompson Brook, right bank

Goose Pond Brook, highway bridge, 2.95 miles above, left bank

Goose Pond Brook, 50 feet above highway bridge 0.25 mile below, left bank

Goose Pond Brook, 200 feet below highray bridge 0.25 mile below, left bank

Keene, H. H., 0.9 mile above highray bridge on Route 9 , left bank

Keene, H. H., 0.6 mile above highway bridge on Route $\theta$, left bank'

Keene, N. H., 0.15 mile above highway bridge on Route 9 , left bank

Keene, N. H., Faulkner \& Colony Manufacturing Co. dam

Keene, N. H., 400 feet below Faulkner \& Colony Manufacturing Co. dam

Keene, N. H., Boston \& Maine R.R. bridge, west of station, right bank

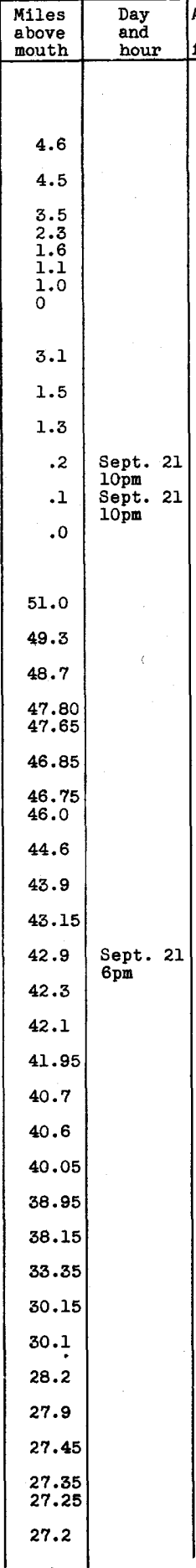

289.5

286.0

265.4

248.6

238.2

233.4

232.0

$1,377.0$

$1,208.6$

$1,199.9$

$1,138.5$

$1,135.6$

$1,157.6$

$1,153.9$

$1,134.0$

$1,093.3$

$1,079.5$

$1,026.0$

$1,022.4$

$1,008.7$

909.4

862.2

808.0

786.7

741.9

726.3

722.9

673.3

671.5

650.7

603.2

566.4

493.9

486.1

485.5

477.0

477.7

477.7

477.8

475.8

474.4

ad From surveys and investigations by Corps of Engineers, U. S. Army. 
Table 19.--Flood crest stages--Continued

\begin{tabular}{|l|l|}
\hline Stream and location & \\
\hline
\end{tabular}

Connecticut River Basin--Continued

Ashuelot River--Continued.

Keene, N. H., 0.15 mile below railroad bridge, left bank

Keene, N. H., just above highway bridge between Route 9 and Route 10 , left bank

Keene, N. H., highway bridge 0.9 mile above mouth of otter Brook, downstream, left bank

Keene, N. H., Boston \& Maine R.R. bridge, south of station

Keene, N. H., 0.55 mile above mouth of otter Brook, left bank

Keene, N. H., 0.40 mile above mouth of 0tter Brook, left bank

Keene, N. H., 0.3 mile above mouth of otter Brook, left bank

Keene, N. H., 0.15 mile above mouth of 0tter Brook, right bank

Swanzey, N. H., 0.3 mile above mouth of Ash Swamp Brook, left bank

Swanzey, N. H., $0.05 \mathrm{mile}$ below mouth of Ash Swamp Brook, right bank

Swanzey, N. H., 0.4 mile below mouth of Ash Swamp Brook, right bank

Swanzey, N. H., just above mouth of Wilson Pond Brook

West Swanzey, N. H., 0.3 mile above M. A. Dickinson dam, left bank

West Swanzey, N. H., 150 feet above M. A. Dickinson dam, just below highway bridge, left bank

West Swanzey, N. H., ils feet below M. A. Dickinson dam, left bank

West. Swanzey, N. H., 0.2 mile below M. A. Dickinson dam, right bank

Westport, N. H., highray bridge, upstream, left bank

Winchester, N. H., highway bridge 0.1 mile below mouth of Forest Lake'Brook, right bank

Winchester, N. H., 0.25 mile below highway bridge, right bank

Winchester, N. H., 0.65 mile below highway bridge, right bank

Winchester, N. H., 0.85 mile below highway bridge, right benk

Winchester, N. H., 1.2 miles below highway bridge, + right bank

Winchester, N. H., 1.3 miles below highway bridge, left bank

Winchester, N. H., 1.4 miles below highway bridge, left bank

Winchester, N. H., 0.45 mile above highway bridge, left bank.

Winchester, N. H., 0.3 mile above highway bridge, left bank

Winchester, N. H., 0.05 mile above highway bridge, right bank

Winchester, N. H., highway bridge, upstream, left bank

Winchester, N. H., 0.1 mile below highway bridge

Winchester, N. H., private bridge

Winchester, N. H., highway bridge, right bank

Winchester, N. H., 0.1 mile below highway bridge, left bank

Winchester, N. H., 0.3 mile above Snow Brook, left bank

Winchester, N. H., 0.05 mile below Snow Brook, left bank

Winchester, N. H. 0.65 mile below Snow Brook, left bank

Ashuelot, N. H., Boston \& Maine R.R. bridge 0.9 mile below Snow Brook, upstream, left bank

Ashuelot, N. H., 0.25 mile belov Boston \& Maine R.R. bridge, ieft' bank

Asmelot, N. H., 0.5 mile below Boston \& Maine R.R. bridge, right bank

Ashuelot, $N$. H., 0.15 mile above covered highway bridge, left bank

Ashuelot, N. H., covered highway bridge, upstream, left bank

Ashuelot, N. H., 0.05 mile below covered highway bridge, right bank

Ashuelot, N. H., 0.15 mile below covered highway bridge

Ashuelot, N. H., covered highway bridge 0.1 ulle above Public Service Co. of New Hampshire dam

Asbrelot Paper Co. dain, headwater, left bank

Asbuelot Paper Co. dam, private bridge 750 feet below, right bank

Hinsdale, N. H., The Canal Co. dam, headwater, right bank

\begin{tabular}{l|l|l}
$\begin{array}{l}\text { Miles } \\
\text { above } \\
\text { mouth }\end{array}$ & $\begin{array}{l}\text { Day } \\
\text { and } \\
\text { hour }\end{array}$ & $\begin{array}{c}\text { Altitude } \\
\text { in } \\
\text { feet ad/ }\end{array}$ \\
\hline & &
\end{tabular}

471.4

26.9

474.7

26.8

475.3

26.6

474.2

26.45

26.3

473.3

472.2

26.

475.0

26.05

24.8

473.3

468.4

24.45

24.1

23.8

18.6

18.3

472.8

474.2

469.4

468.1

464.5

18.3

18.1

14.9

10.6

10.35

9.95

9.75

9.4

9.3

9.2

9.05

8.9

8.65

8. 6

8. 5

8.35

8.0

7.9

7.5

462.2

463.4

457.8

450.0

444.5

449.4

446.4

450.0

445.2

446.4

446.7

444.4

447.6

447.7

447.0

446.1

445.0

444.7

444.6

445.3

444.6

446.5

439.1

438.2

433.0

432.2

430.0

422.2

396.1

345.2

325.2

264.5

ad From surveys and Investigations by Corps of Engineers, U. S. Aray. 
Table 19.--Flood orest stages--Cont1med

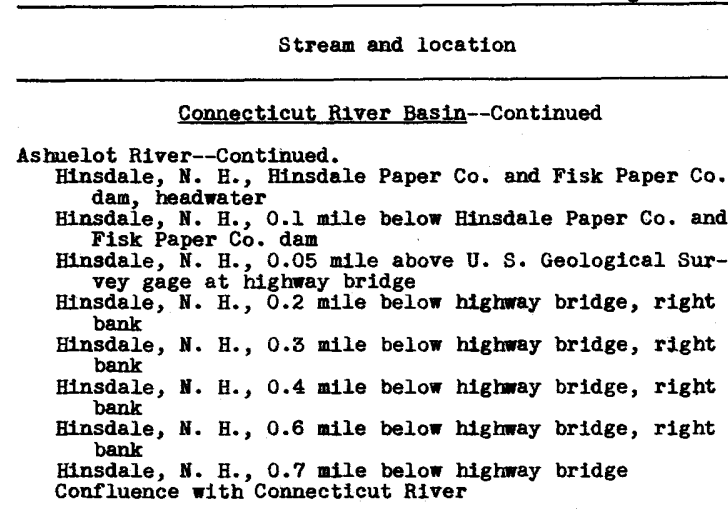

Otter Brook:

East Suliivan, H. H., steel highway bridge in center of village

Bast Sullivan, N. H., 0.1 mile below steel highray bridge in center of village, right bank

East Sullivan, N. H., 100 feet above new concrete highway bridge, right bank

East Sullivan, W. H., new concrete highway bridge, downstream

East Sullivan, N. H., Route $9,0.4$ mile below new concrete highway bridge, right bank

Roxbury, H. H., 50 feet above Hubbard Brook

Roxbury, N. H., steel highray bridge, upstream, left bank

Keene, M. H., Route 9 besow Roxbury-Keene town line, right bank

Keene, N. H., highway bridge at town line, right bank

Keene, N. H., below U. S. Geological Survey gage, left bank

Roxbury, N. H., highway bridge, upstream, left bank

Roxbury, N. H., 0.35 mile above Boston \& Maine R.R. bridge, left bank

Roxbury, N. H., Boston \& Malne R.R. bridge, upstream, left bank

Rorbury, H. H., 0.1 mile below highway bridge, left bank

Roxbury, H. H., just above Roaring Brook, left bank

South Keene, H. H., 0.75 mile below Roaring Brook, left bank

South Keene, H. H., 50 feet downstream from function Fith Minnewawa Brook, left bank

South Keene, N. H., 0.05 mile below Minnewawa Brook, left bank

South Keene, N. H., Keene Chair Co., below ruins of dam

South Keene, H. H., 100 feet above new masonry highway bridge, left bank

South Keene, W. H., 0.05 mile below new masonry highway bridge, left bank

Keene, M. H., Boston \& Maine R.R. masonry arch bridge, upstream, right bank

Keene, N. H., 0.1 mile above concrete highway bridge, right bank

Keeno, N. H., concrete highway bridge, upstream, vight bank

Keene, N. B., between Beaver Brook and Otter Brook, highway bridge, right bank

Confluence with As huelot River

Minnewawa Brook:

Marlboro, N. H., between highway bridge and small dam upstream from Robbins Brook, left bank

Marlboro, N. H., 50 feet above highway bridge near ruins of old dam

Marlboro, N. H., Monadnock Blanket Co. dam, right abutment

Marlboro, $\mathbf{H}$. H., below highway bridge and 350 feet downstream f'rom Monadnock Blanket Co. dam

Marlboro, H. H., at dem, left benk

Marlboro, U. H., 300 feet belon dam, left bank

Marlboro, $\mathbf{N}$. H.' 75 reet above Marlboro Box Co. dam

Marlboro, H. H., 750 feet-below Marlboro Box Co.dam, right bank

Maslboro, $N$. H., at hlghray bridge near road fork

Marlboro, N. H., Knowlton St. bridge, upstream, right bank

\section{Miles}

above

mouth

\begin{tabular}{l|l}
$\begin{array}{l}\text { Day } \\
\text { and } \\
\text { hour }\end{array}$ & $\begin{array}{c}\text { Altitude } \\
\text { In } \\
\text { feet ad/ }\end{array}$ \\
\hline &
\end{tabular}

1.5

233.2

217.8

1.4

216.5

1.3 Sept. 22

213.7

1.05

$12 \mathrm{pm}$

.95

217.0

221.5

210.8

204.1

$0^{.5}$

.65

9.55

$995 \cdot 5$

993.9

997.2

993.2

954.9

896.6

840.7

786.6

746.4

727.1

673.8

650.4

634.7

623.8

621.0

580.4

564.6

560.1

535.3

527.8

518.2

511.7

473.9

475.0

471.3

.15

0

2.6

2.35

2.2

2.15

2.05

2.0

1.9

1.75

1.5

1.3
754.6

738.0

727.6

714.9

704.8

693.8

690.1

677.9

666.4

648.7

ad Fron surveys and Investigations by Corps of Engineers, U. S. Army. 
Table 19.--Flood crest stages--Cont1nued

Stream and location
Connegticut River Basin--Continued
Minnewawa Brook--Continued.
Keene, N. H., Just below Keene-Marlboro town line,
left bank
Keene, N. H., 0.5 mile above junction with otter Brook,
left bank
Keene, N. H., 0.1 mile above junction with otter Brook
Confluence with Otter Brook

Beaver Brook:

Keene, $\mathbf{N}$. H., above concrete highway bridge on Route 10, right' bank

Keene, N. 帛., below concrete highway bridge on Route 9 , left bank

Keene, H. H., at Kafelt Manufacturing Co. plant below Junction of Routes 9 and 10

Keene, N. H., below ruins of old dam, right bank

Keene, N. H., above George St. bridge, left bank

Keene, N. H., off Greenwood Court above cemetery, right bank

Keene, N. H., Beaver Street bridge, below

Keene, N. H., Spring Street bridge

Keene, N. H., Roxbury Street bridge, below

Keene, N. H., near concrete bridge at lower end of Ra1lroad street

Keene, N. H., 500 feet above Water Street bridge, left bank

Keene, N. H., Water Street bridge, upstream, right bank

Keene, N. H., Boston \& Maine R.R. bridge, upstream

Keene, N. H., Kings bury Manufacturing Co., right bank

Keene, N. H.', first house on Dartmouth Street, left bank

Keene, N. H., No. 475 Main Street

Confluence with otter Brook

Soutn Branch of Ashuelot River:

East Swanzey, N. H., highway bridge, left bank, downstream

East Swanzey, N. H., about 0.35 mile below highway bridge, left bank

East Swanzey, N. H., covered highway bridge, upstream, left bank

Swanzey Center, N. H., near The Wee Store, left bank

Swanzey, N. H., 0.3 mile above bridge on road to Spraguevilie, right bank

swanzey, N. H., highway bridge, downstream, right bank

Swanzey, N. H., 0.3 mile below highway bridge

Swanzey, N. H., highway bridge, downstream, right bank

Confluence with Ashuelot River

Millers River:

Ashburmham, Mass., Naukeg dam site 5.2 miles above Whitney Pond, Winchendon, Mass., upstream

Ashburnham, Mass., Naukeg dam site 5.2 miles above Whitney Pond, Winchendon, Mass., downstream

Ashburnham, Mass., concrete bridge 5.0 miles above Whitney Pond, WInchendon, Mass., Corps of Engineers, U. S. Army, gaging station

Ashburnham, Mass., broken mill dam 3.6 miles above Whitney Pond, Winchendon, Mass., 200 feet downstream, left bank

Winchendon, Mass., Cheshire R.R. bridge 3.3 miles above Whitney Pond, upstream, left bank

Winchendon, Mass., Route 12, highway bridge 3.2 miles above Whitney Pond, 50 feet upstream, right bank

Winchendon, Mass., Route 12 , highway bridge 3.2 miles above wht tney Pond, downstream at pool below rapids

Winchendon, Mass., Route 12, highway bridge 2.1 miles above Whitney Pond

Winchendon, Mass., 50 feet below Boston \& Maine R.R. bridge 2.0 miles above Whitney Pond

Winchendon, Mass., near Boston \& Maine R.R. bridge 1.1 miles above Whitney Pond

Winchendon, Mass., 75 feet above Boston \& Maine R.R. bridge 0.6 miles above Whitnev Pond, at stone wall, left bank

Winchendon, Mass., Winchendon water works station 0.5 mile above Whitney Pond

Winchendon, Mass., Whitney Pond above Glen Allen Street bridge

Winchendon, Mass., Whitney Pond Dam of Winchendon Electric \& Power Co. at Boston \& Maine R.R. bridge

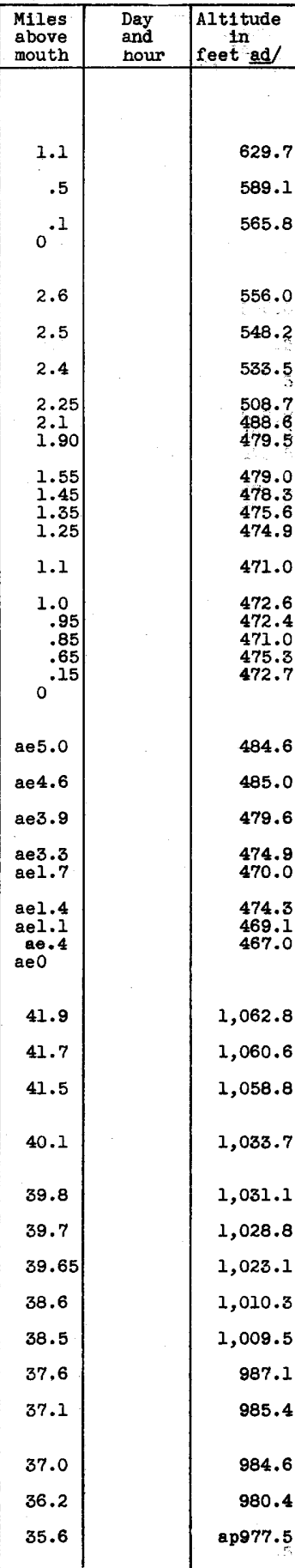

ad From surveys and Investigations by Corps of Engineers, U. S. Army. Measured along middle of river valley.

ap Altitude of crest of dam, 966.20 feet, with flashboards 973.10 feet. 
Table 19.--Flood crest stages--Continued

\begin{tabular}{|l|l|}
\hline Stream and Iocation & \\
\hline
\end{tabular}

Connecticut River Basin--Continued

Miliers River--Continued.

Winchendon, Mass., Whitney Pond Dam of Winchendon Electric \& Power Co., tailwater

Winchendon, Mass., Baxter Whitney Manufacturing Co. 400 feet below' Whitney Pond Dam, right bank

Winchendon, Mass., railroad bridge 400 feet below Baxter Whitney' Manufacturing Co. plant

Winchendon, Mass., house at 11 Beech St.

Winchendon, Mass., Mason and Parker Dam, 200 feet above High Street Bridge, left bank

Winchendon, Mass., 200 feet below Mason and Parker Co. dam, left bank'

Winchendon, Mass., storehouse of Mason and Parker Manufacturing Co., right bank

WInchendon, Mass., 100 feet above Mason and Parker lower dam, right bank

Winchendon, Mass., 100 feet below Mason and Parker lower dam, right bank

WInchendon, Mass., 200 feet above Winchendon Electric \& Power Co. dam (was hed out in 1936)

Winchendon, Mass., 150 feet below Winchendon Electric \& Power Co. dam (washed out in 1936)

Waterville, Mass., 100 feet above George M. Whitney bridge

Watervilie, Mass., 125 feet below George M. Whitney bridge

Waterville, Mass., 200 feet above New England Woodenware Co. dam No. 2

Waterville, Mass., highway bridge 200 feet below New England Woodenware Co. dam No. 2, right bank

Waterville, Mass., 100 feet above New England Woodenware Co. dam No. 1 , right bank

Waterville, Mass., 150 feet below New England Woodenware Co. dam No. 1 , right bank

waterville, Mass., old mill site off River St., Maple tree near retaining wall

Sip Pond Brook, 300 feet above bridge at. U. S. Geological Survey gage $0.35 \mathrm{mile}$ below mouth of

S1p Pond Brook, U. S. Geological Survey gage 0.35 mile below mouth of

S1p Pond Brook, 200 feet below bridge at U. S. Geological survey gage $0.35 \mathrm{mile}$ below mouth of, left bank

Priest Brook, just below highway bridge 2.1 miles above mouth of, right bank

Priest Brook, 300 feet above old bridge site 0.7 mile above mouth of

Hev Boston Road, wooden bridge, downstream, left bank

Royalston-Winchendon town line, 25 feet east of, right bank

South Royalston, Mass., 500 feet above Birch Hill dam site

South Royalston, Mass., B1rch H1ll dam site, right bank South Royalston, Mass., 300 feet below Birch Hill dam site, right bank

South Royalston, Mass., R1verside Cemetery, 500 feet above Main St. bridge

South Royalston, Mass., 250 feet above Main St. bridge, left bank

South Royalston, Mass., Main Street bridge

South Royalston. Mass. 400 feet above American Woolen Co. dam, right bank

South Royalston, Mass., American Woolen Co. dam above King Street bridge, right bank

South Royalston, Mass., 100 feet below King Street bridge, left bank

South Royalston, Mass., 500 feet below King street bridge, right bank

Athol-Phililpston town line, 150 feet above Boston \& Malne R.R. bridge, left bank

Athol-Phillipston town line, 125 feet below Boston \& Maine R.R. bridge, left bank

Buckman Brook, 0.7 mile above, right bank

Buckman Brook, 0.25 mile below, 200 feet above Boston \& Maine R.R. bridge, left bank

Buckman Brook, 0.25 mlie below, 100 feet below Bostan \& Maine R.R. bridge, left bank

\begin{tabular}{|l|l|l}
\hline $\begin{array}{l}\text { Miles } \\
\text { above } \\
\text { mouth }\end{array}$ & $\begin{array}{l}\text { Day } \\
\text { and } \\
\text { hour }\end{array}$ & $\begin{array}{c}\text { Altitude } \\
\text { in } \\
\text { feet ad/ }\end{array}$ \\
\hline & &
\end{tabular}

961.3

960.4

35.5

35.4

958.7

35.25

35.2

35.1

958.4

ag 955.0

951.9

35.1

944.1

34.9

34.8

34.6

34.5

34.45

34.4

34.2

34.2

34.1

34.1

33.9

32.45

32.4

32.35

31.4

30.0

29.5

27.6

26.4

26.3

26.25

26.1

26.0

25.9

25.8

25.7

25.6

25.5

25.0

25.0

24.3

23.4

23.4

$\operatorname{ar} 944.4$

937.2

924.0

920.1

918.0

911.7

as 908.5

903.4

894.8

889.6

873.2

849.1

848.2

847.7

843.8

840.0

838.7

831.2

829.6

at 829.8

828.6

829.0

828.7

826.4

821.5

a่u820.1

811.4

806.6

777.4

771.0

750.6

707.7

706.5

ad From surveys and Investigations by Corps of Engineers, U. S. Army. aq Altitude of crest of dam 948.2 feet, with flashboards 953.5 feet. ar Altitude of crest of dam 936.6 feet, with flashboards 938.3 feet. as Alt1tude of crest of dam 899.7 feet.

at Altitude of crest of dam 816.8 feet, w1th flashboards 817.2 feet.

au Alt1tude of crest of dam 812.4 feet, with flashboards 813.9 feet. 


Stream and location
Connecticut River Basin--Continued
M1llers River--Continued.
Athol, Mass., 200 feet above Athol Manufacturing Co.
dam, right bank
Athol, Mass., 200 feet below Athol Manufacturing Co.
dam, near power house, right bank

Athol, Mass. power house, right bank 100 feet above highway bridge on Chestmut Hill Road' 1.1 miles above mouth of Tuliy River

Athol, Mass., 100 feet above highway bridge on Chestnut Hili Road' 1.1 miles above mouth of Tully River, right bank

Athol, Mass., small dam and canal at Union Tw1st Drill Co., left bank

Athol, Mass., 100 feet below small dam at Union Twist Drill Co., right bank

Athol, Mass., Union Twist Drill bullding, 70 feet above canal outlet, left bank

Athol, Mass., 0.8 mile above mouth of Tully River, Boston \& Maine R.R. overpass

Athol, Mass., L. C. Starrett Tool Co. dam 0.7 mile above mouth of Tully River, headwater

Athol, Mass., Town Hall 0.65 mile above mouth of Tully River

Athol, Mass., Fuller's Garage on Marble Street 0.6 mile above mouth of Tully River

Athol, Mass., Exchange street bridge 0.5 mile above mouth of Tully RIver

Athol, Mass., 700 feet below Exchange street bridge 0.4 mile above mouth of Tully River, left bank

Athol, Mass., mouth of Tully River

Athol, Mass., 200 feet above Main Street bridge 0.4 mile below mouth of Tully River

Athol, Mass., Main Street bridge 0.4 mile below mouth of Pully River

Athol, Mass., Route 2, 100 feet below Main Street bridge 0.4 mile below mouth of Tully River

Boston Haine R.R. bridge, upstream, right bank

Athol, Mass., Route 202 highmay bridge

Orange, Mass., house 2.6 iniles above South Main Street bridge

Orange, Mass., Bogin-Hopert Bullding Just below mouth of Shingle' Swamp Brook, right bank

Orange, Mass., barn above South Main Street bridge, right bank

Orange, Mass., New Home Sewing Machine Co. dam at South Main Street

Orange, Mass., Ner Home Sewing Machine Co. Mill Building fence near railroad underpass

Orange, Mass., 200 feet below Real Silk Mill

Orange, Mass., concrete bullding above Minute Tapioca Co. loading platform

Orange, Mass., 300 feet above Boston \& Malne R.R. bridge, right bank

Orange, Mass., half way between Boston \& Maine R.R. bridges, right bank

West Orange, Mass., below Boston \& Maine R.R. bridge, right bank

West Orange, Mass., 350 feet above Hultshtre Bridge, left bank

West Orange, Mass., Boston \& Maine R.R. overpass at Hultshire Bridge at Orcutt Brook, right bank

Wendell Depot, Mass., 100 feet above Boston \& Maine R.R. bridge

Wendell Depot, Mass., 100 feet below Boston MaIne R.R. bridge, right bank

Wendell Depot, Mass., concrete highway bridge on Wendell Road, upstream

Wendell Depot, Mass., concrete highway bridge on Wendel1 Road, doms tream

Wendell Depot, Mass., 200 feet below Boston \& Malne R.R. bridge at Wendell Dam

Erving, Mass., Erving Paper Co. dam (breached), at covered bridge, headwater

Erving, Mass., 800 feet below Erving Paper Co. dam (breached)
Miles

above

mouth

\begin{tabular}{l|l}
20.1 & av578.3
\end{tabular}

20.0

566.7

19.9

19.9

19.9

19.9

19.7

19.6

19.5

19.45

19.4

19.3

19.2

18.8

18.4

18.4

18.4

17.4

16.6

15.8

14.7

13.3

13.2

13.1

12.9

12.8

12.6

12.2

11.9

11.3

11.2

10.45

10.4

10.2

10.2

10.1

8.8

B. 65
564.0

566.0

am562.6

560.9

553.4

553.3

$\operatorname{ax} 554.0$

530.9

529.4

528.5

527.6

527.4

527.2

527.2

525.9

524.9

524.4

522.2

520.2

519.7

ay 519.3

516.2

515.0

514.8

514.4

511.9

507.6

506.5

505.9

499.6

498.4

498.4

491.8

$\operatorname{az} 483.7$

ba476.2

468.2

ad From surveys and Investigations by Corps of Engineers, $U$. S. Ariay. av Altitude of crest of dam 569.1 feet, with flashboards 571.3 feet.

aw Alt1tude of crest of dan 553.2 feet.

ax Altitude of crest of dan 542.25 feet.

ay Alt1tude of crest of dam 501.3 . feet.

az Altitude of crest of dam 488.2 feet.

be Altitude of crest of dan 466.8 feet. 
Table 19,-Flood crest stages-Continued

Stream and location

M1llers River--Continued.

Erving, Mass., 100 feet above United Shoe Machine Co. dam 0.2 mile above U. S. Geological Survey gage

Erving, Mass., Fred W. Melrs Shoe Factory 0.1 mile above U. S'. Geological Survey gage

Erving, Mass., U. S. Geologlcal Survey gage, rlght bank

Wickett Brook, 2.5 miles above, Boston \& Maine R.R. bridge, right bank, upstream (bridge destroyed)

Wickett Brook, 2.5 miles above, 150 feet below Boston \& Maine R.R. bridge (bridge destroyed)

Wickett Brook, 2.5 miles above, 200 feet below Boston \& Maine R.R. bridge, right bank (bridge destroyed)

Farley, Mass., Athol Gas \& Electric Co. dam, headwater Farley, Mass., Athol Gas \& Electric Co. dam,

Miliers Falls, Mass., Millers Falis Paper Co. upper dam, headwater, right bank

Millers Falls, Mass, 150 feet above Millers Falls Paper Co. iower dam, right bank

Millers Falls, Mass., above Mlllers Falls Paper Co. dam and highway bridge, left bank

Millers Falls, Mass., under Boston \& Maine R.R. trestle, left bank

Millers Falls, Mass., 150 feet above Millers Falls Tool Co. dam and highway bridge

Millers Falls, Mass., 500 feet below Millers Falls Tool Co. dam, right bank

Millers Falis, Mass., 1,800 feet below highway bridge and dam at Millers Falls Tool Co., right bank

Millers Falis, Mass., 0.1 mile above highway bridge just south of French King highway bridge, right bank

Millers Falls, Mass., upstream side of highway bridge just south of French King highway bridge

Confluence with Connecticut River

Priest Brook:

Priest Brook near Winchendon, Mass., U. S. Geological Survey gage

Winchendon, Mass., near church at New Boston, Mass.

Winchendon, Mass., stone wall above highway bridge at otter River State Forest, left bank

Winchendon, Mass., 150 feet below highway bridge at otter River State Forest, left bank

Confluence with Millers River

\section{Otter River:}

Gardner, Mass., Route 2, above highway near Gardner Brick Co., right bank

Gardiner, Mass., Route 2, below highway near Gardner Brick Co., left bank

Gardner, Mas's., concrete highway bridge, retaining wal1, right bank.

Templeton, Mass, 100 feet above Boston \& Malne R.R. bridge, left bank

Teapleton, Mass., 150 feet below Boston Maine R.R. bridge above Otter River Yarn Co. dam, left bank

Templeton, Mass., 200 feet above breached 0tter River Yarn Co. dam

Templeton, Mass., southwest comer of concrete bridge below breachod Otter RIver Yarn Co. dam

Templeton, Mass, dike at wrecked power house at Hanlet Milis Co., right bank

Templeton, Mass, at highway bridge 150 feet below Bamlet Mills Co. dan, right bank

otter River, Templeton, Mass., near highway bridge on Route 64 and 0.1 mile above Otter River Board Co. dam

Otter River, Templeton, Mass., Otter River Board Co. dam

otter River, Templeton, Mass., Otter River Board Co. mill buliding at highway bridge 200 feet below dam, left bank

otter River, Templeton, Mass, 100 feet below highway bridge at Otter River mills (bridge washed out), right bank

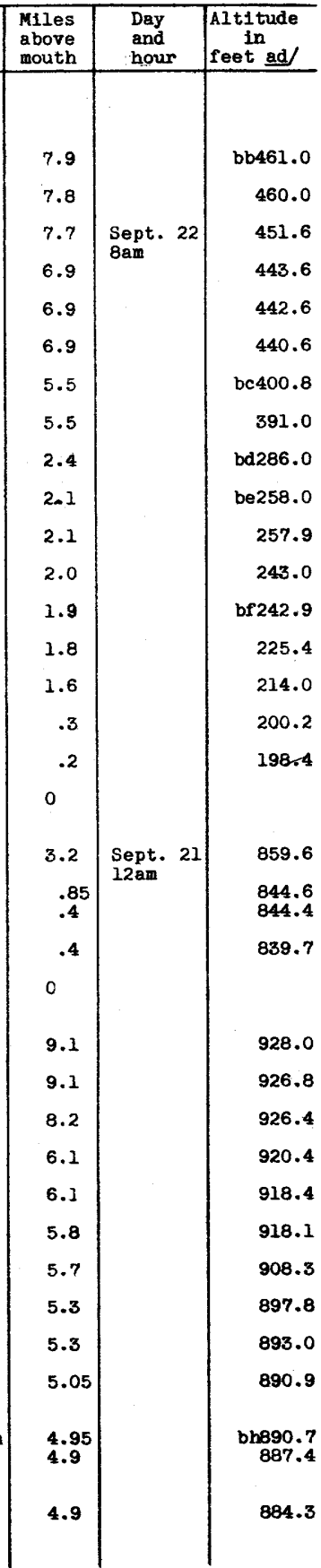

ad From surveys and investigations by Corps of Engineers, U. S. Army.

b b Altitude of crest of dam 452.0 feet.

bc Altitude of crest of dan 390.5 feet.

bd Altitude of crest of dam 271.7 feet, with flashboards 274.2 feet.

be Altitude of crest of dam 243.6 feet.

bf Altitude of crest of dan 229.8 feet.

bh Altitude of crest of dam 879.2 feet. 
Table 19.--Flood crest stages--Continued

$\frac{\text { Stream and location }}{\text { Connecticut River Basin--Continued }}$

otter River--Continued.

Otter River, Templeton, Mass., Boston \& Maine R.R. bridge, upstream, right bank

otter River, Templeton, Mass., Boston \& Maine R.R. bridge, downstream, right bank

Baldwinvilie, Mass., gate at B., H. \& F. Furniture Co. dam (destroyed)

Baldwinville, Mass., Adams Paper Co. storage plant

Baldwinville, Mass., first bullding north of Boston \& Maine R.R. trestie, right bank

Baldwinvilie, Mass., barn behind fire station

Baldwinville, Mass., Waite Chair Co. dam (washed out)

Baldwinville, Mass., 450 feet below Walte Chair Co. dam, right bank

Baldwinville, Mass., Kenney Manufacturing Co. factory at dam (washed out)

Baldwinvilie, Mass., 300 feet below Kenney Manufacturing Co.

Winchendon, Mass., Boston \& Maine R.R. bridge, downstream, left bank

Confluence with Millers River

East Branch of Tully River:

Royalston, Mass., highway bridge at U. S. Geological Survey gage, upstream, left bank

Royalston, Mass., U. S. Geological Survey gage at highway bridge, downstream, right bank

Royalston, Mass., Tully dam site, right bank

Athol, Mass., 100 feet above Packard Pond diversion dam

Athol, Mass., 100 feet above Fryville dam, left bank

Athol, Mass., 100 feet above highway bridge at Fryville sewmil1

Athol, Mass., abutment old highway bridge at Pinedale (bridge out), left bank

Athol, Mass., 150 feet above concrete highway bridge at Pinedale, right bank

Confluence with Tully River

Deerfield River:

Somerset, Vt., highway bridge, left bank

Somerset, Vt., 0.2 mile below Rake Branch, right bank

Searsburg, Vt., 0.2 mile below Windham-Bennington County line, right bank

Searsburg, Vt., 0.5 mile above mouth of East Branch of Deerfield River, right bank

Searsburg, Vt., abandoned bridge 0.1 mile above mouth of East Branch of Deerfield River, right bank

Searsburg, Vt., at mouth of East Branch of Deerfield RIver, 0.9 mile above Searsburg Dam, right bank

Searsburg, Vt., 0.4 mile below mouth of East Branch of Deerfield River, right bank

Searsburg, Vt., headwater on Searsburg Dam, $0.9 \mathrm{mile}$ below mouth of East Branch of Deerfield River, left bank

Searsburg, Vt., 175 feet downstream from spillway of Searsburg Dam

Searsburg, Vt., 0.9 mile below Searsburg Dam, right bank

Searsburg, Vt., concrete highway bridge, left bank

Searsburg, Vt., 2.3 miles above mouth of North Branch of Deerfield River

Searsburg, Vt., 1.4 miles above mouth of North Branch of Deerfield River

W1lmington, Vt., highway bridge 0.9 mile above mouth of North Branch of Deerfleld River, right bank

Wilmington, Vt., at mouth of North Branch of Deerfield River, right' bank

Whitingham, vt., intake of Harriman Dam 0.6 mile below Davis Bridge

Whitingham, vt., 1.2 miles below Harriman Dam, left bank

Readsboro, Vt., 1.8 miles below Harriman Dam, left bank

Readsboro, Vt., 2.0 miles below Harriman Dam, left bank

\section{Miles}

\begin{tabular}{l|l|l}
$\begin{array}{l}\text { Miles } \\
\text { above } \\
\text { mouth }\end{array}$ & $\begin{array}{l}\text { Day } \\
\text { and } \\
\text { hour }\end{array}$ & $\begin{array}{c}\text { Altitude } \\
\text { in } \\
\text { feet ad/ }\end{array}$ \\
\hline & & \\
\end{tabular}

4.7

4.7

883.3

874.0

3.5

3.4

3.2

3.2

3.1

3.0

2.8

2.75

.3

0

2.7

2.

Sept. 21

639.8

869.2

861.7

861.3

860.9

bj850.9

842.7

838.3

838.2

837.9

2.6

4 pin

2.1

1.8

1.6

.65

.2

0

66.4

sept. $2 Z$

$1,909.6$

65.1

1 am

Sept. 22

$1,866.6$

64.1 Sept. 22

$1,848.2$

62.9

1 am 22

1 an

62.5 Sept. 22

$1,802.1$

$1,782.2$

\begin{tabular}{ll|l}
62.4 & Sept. 22 & 1,770.2
\end{tabular}

$62.1 \mid$\begin{tabular}{ll|l}
1 am & Sept. 22 & $1,766.5$
\end{tabular}

61.5 Sept. 22 bkl, 765.8

61

61.

1 am 22

$1,737.1$

60.1 Sept. 22

$1,672.0$

59.95

1 an

1 am

$1,632.2$

59.3 Sept. 22

$1,590.4$

58.4 Sept. $22 \quad 1,531.9$

57.9 Sept. 22

$1,519.0$

57.0 Sept. $22 \quad 1,498.2$

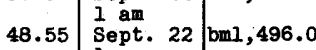

47.45 \begin{tabular}{l|l} 
Sept. 22 & $1,270.7$
\end{tabular}

46.65 Sept. $22 \quad 1,252.5$

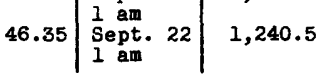

ad From surveys and investigations by Corps of Engineers, U. S. Army.

bf Altitude of crest of dam about 848 feet.

bk Altitude of crest of spiliway 1,754 feet.

bm Altitude of crest of spillway $1,491.9$ feet. 
Table 19.--Flood crest stages--Continued

Stream and location

Deerfield River--Continued.

Readsboro, Vt., 2.3 miles below Harriman Dam, left bank

Readsboro, Vt:, about 50 feet below Heartwellville Branch of Deerfield River

Readsboro, Vt:, highway bridge, right bank

Readsboro, Vt:, 1.8 miles above Vermont-Massachusetts State line, left bank

Readsboro, Vt., tailrace of Harriman hydroelectric station 1.0 mile above Vermont-Massachusetts State line, left bank

Rowe, Mass., penstock intake at Sherman Dam, $0.7 \mathrm{mille}$ below Vermont-Massachusetts State line

Rowe, Mass., just below Sherman Dam at New England Power Co. automatic power:station, 0.7 mile below Vermont-Massachusetts State line

Rowe, Mass., at Monroe Bridge, dam Just above highway bridge, 1.4 miles below Vermont-Massachusetts State line, left bank

Rowe, Mass., 0.7 mile above mouth of Dunbar Brook, left bank

Rowe, Mass., 300 feet below mouth of Dunbar Brook, left bank

Rowe, Mass., at New England Power Co. station no. 5, $0.8 \mathrm{mile}$ above mouth of Smith Brook, left bank

Rowe, Mass., 0.4 mile above mouth of Smith Brook, left bank

Rowe, Mass., at mouth of Smith Brook, left bank

Monroe, Mass., at mouth of Fife Brook, right bank

Hoosac Tunnel, Mass., 0.4 mile below mouth of Fife Brook, left bank

Hoosac Tunnel, Mass., west pier of B. \& M. R.R. bridge, about 0.6 mile west of Hoosac Tunnel Station, right bank

Hoosac Tunnel, Mass., south abutment of highway bridge at Hoosac Tunnel Station, right bank

Hoosac Tunnel, Mass., 0.3 inile below highway bridge at Hoosac Tunnel Station, left bank

Hoosac Tunnel, Mass., 1.1 miles below highway bridge at Hoosac Tunnel Station, left bank

Hoosac Tunnel, Mass., 2.2 miles above mouth of Pelham Brook, left bank

Zoar, Mass., 1.6 miles above mouth of Pelham Brook, left bank

Zoar, Mass., 1.6 miles above mouth of Pelham Brook, right bank

Zoar, Mass., Just upstream from highway bridge opposite Negus Mountain, 1:0 mile above mouth of Pelham Brook, left bank

Zoar, Mass., 0.5 mile above mouth of Pelham Brook, left bank Zoar, Mass., 0.5 mile below mouth of Pelham Brook,

Charlemont, Mass, at mouth of Cold River, right bank

Charlemont, Mass., Just downstream from west end of B.\& M. R.R. bridge, 0.1 mile below mouth of Cold River, left bank

Charlemont, Mass., north end of highway bridge, $0.6 \mathrm{mile}$ above mouth of' Chickley River, left bank, upstream

Charlemont, Mass., at mouth of Chickley River, left bank

Charlemont, Mass., 0.5 mile below mouth of Chickley River, left bank

Charlemont, Mass., 0.5 mile below junction of Chickley River, left bank

Charlemont, Mass., at Charlemont station, 1.1 miles below mouth of Chickley River, right bank

Charlemont, Mass., at mouth of Mill Brook, right bank

Charlemont, Mass., 0.7 mile below mouth of M111 Brook, right bank

Charlemont, Mass., 90 feet upstream from U. S. Geolog1cal Survey gaging station, 1.1 miles below mouth of M11] Brook, left bank

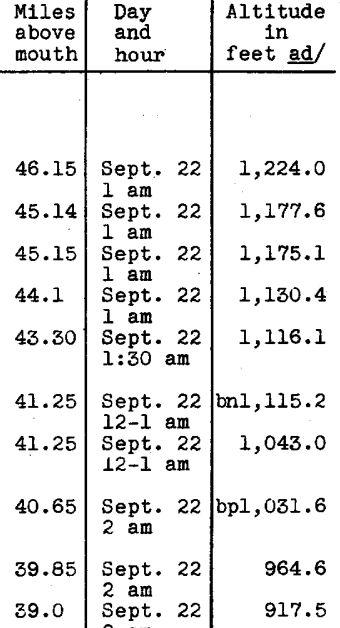

2 am

37.3 Sept. 22

2. am

36.8 Sept. 22

2 am

36.4 Sept. 27

6-12 pm

35.9 Sept. 21

6-12 pm

35.5 Sept. 21

34.4 Sept. 21

6 pim

34.1 Sept. 21

5:30-6pm

33.8 Sept. $2 \overline{1}$

5:30-6pm

33.0 Sept. 21

$5: 30-6 \mathrm{pm}$

32.3 Sept. 21

$6 \mathrm{pm}$

31.6 Sept. 21

$6 \mathrm{pm}$

31.6 Sept. 21

$6 \mathrm{pm}$

31.0 Sept. 21

$5: 30 \mathrm{pm}$

30.6 Sept. 21

6 pm

29.6 Sept. 21

$6: 30 \mathrm{pm}$

28.8 Sept. 21

$7 \mathrm{pm}$

28.7 Sept. 21

7 pis

27.6 Sept. 21

$7 \mathrm{pm}$

27.05 Sept. 21

$7 \mathrm{pm}$

26.5 Sept. 21

7:30 pm

26.5 Sept. 21

7:30 pm

25.9 Sept. 21

$7: 30 \mathrm{pan}$

25.5 Sept. 21

7:30 pm

24.8 Sept. 21

24.4 Sept. 21

789.6

782.3

771.6

762.2

739.6

715.7

711.2

695.5

677.7

668.3

666.0

644.0

627.6

625.3

612.5

603.2

575.1

563.8

558.4

558.2

554.1

550.3

542.4

537.8

ad From surveys and Investigations by Corps of Engineers, U. S. Army.

bn Altitude of crest of spillway $1,103.7$ feet.

bp Altitude of crest of dam $1,022.9$ feet. 
Table 19.--Flood crest stages--Continued

Stream and location

\section{Connecticut River Basin--Continued}

\section{Deerfleld River--Continued.}

Charlemont, Mass., U. S. Geological Survey gage, left bank

Charlenont, Mass., 0.4 mile below U. S. Geological Survey gaging station, left bank

Charlemont, Mass., 1.4 miles above mouth of Avery Brook, left bank

Charlemont, Mass., 0.4 mile above mouth of Avery Brook, left bank

Charlemont, Mass., 300 feet below mouth of Avery Brook, left bank

Charlemont, Mass., 0.6 mile below mouth of Avery Brook, left bank

Charlemont, Mass., 1.2 iniles below mouth of Avery Brook, left bank

Charlemont, Mass., 1.5 miles above Scotts Bridge, above New England Power Co. dam no. 4, left bank

Charlemont, Mass., 0.7 mile above Scotts Bridge, above New England Power Co. dam no. 4, left bank

Buckland, Mass., near tunnel intake of New England Power Co. dam no. 4, 0:8 mile above mouth of North River

Shelburne, Mass., 600 feet below mouth of North River, left bank

Buckland, Mass., 0.6 mile below mouth of North River, right bank

Buckland, Mass., 0.5 mile upstream from shelburne Falls highway bridge, right bank

Buckland, Mass., 30 feet above New England Power Co. dam no. 3 , right bank

Buckland, Mass., just above New England Power Co. dam no. 3 , right bank

Buckland, Mass., 0.5 mile below New England Power Co. dam no. 3 , right bank

Buckland, Mass., about 90 feet above Gardner Falls Dam, right bank

Conway, Mass., abaut 700 feet below Gardner Falls Dam, right bank

Bucklend, Mass., 0.5 mile below Gardner Falls Dam, right bank

Conway, Mass., 0.7 mile above New England Power Co. dam no. 2 , right bank

Conway, Mass., west wing wall, New England Power Co. dam no. 2, right bank

Conway, Mass., Just below New England Power Co. dam no. 2, right bank

Conway, Mass., 0.9 mile below New England Power Co. dam no. 2, right bank

Conway, Mass., 0.6 mile above B. \& M. R.R. bridge above Bardwell Ferry, right bank

Shelburne, Mass., east pier B. \& M. R.R. bridge above Bardweil Ferry, Iejt bank

Shelburne, Mass., Bardwell Ferry highway bridge, left bank

Deerfleld, Mass., 0.6 mile above mouth of South River, left bank

Deerfield, Mass., 0.2 mile above mouth of South River, left bank

Deerfield, Mass., 0.6 mile below mouth of South River, left bank

Deerfield, Mass., 1.0 mile below mouth of South River, left bank

Deerfield, Mass., West Deerfleld highway bridge above Mill Village, right bank

Deerfield, Mass., 0.6 mile below West Deerfleld highway bridge, left bank

Deerfleld, Mass:, below Mill Village, left bank

West Deerfield, Mass, left bank

West DeerfIeld, Mass., left bank

Deerfield, Mass., left bank

Greenfleld, Mass., approach to highway bridge at Cheapside, left bank

Deerfield, Mass., B. \& M. R.R. bridge at Cheapside, right bank, downstream

Deerfield, Mass., about 100 feet upstream from B. \& M. R.R. bridge below Cheapside, right bank

\begin{tabular}{|c|c|c|}
\hline $\begin{array}{l}\text { Miles } \\
\text { above } \\
\text { mouth }\end{array}$ & $\begin{array}{l}\text { Day } \\
\text { and } \\
\text { hour }\end{array}$ & $\begin{array}{l}\text { Altitude } \\
\text { in } \\
\text { feet ad/ }\end{array}$ \\
\hline 24.0 & $\begin{array}{l}\text { Sept. } 21 \\
6: 45 \text { pm } \\
\text { Sept. } 21\end{array}$ & 527.2 \\
\hline $\begin{array}{l}23.3 \\
22.3\end{array}$ & $\begin{array}{l}\text { Sept. } 21 \\
6: 45 \text { pm } \\
\text { Sept. } 21\end{array}$ & $\begin{array}{l}524.8 \\
515.0\end{array}$ \\
\hline 21.9 & $\begin{array}{l}\text { Sept. } 21 \\
6: 50 \mathrm{pm}\end{array}$ & 506.2 \\
\hline $\begin{array}{l}21.3 \\
20.7\end{array}$ & $\begin{array}{ll}\text { Sept. } & 21 \\
7 \text { pm } & \\
\text { Sept. } & 21\end{array}$ & $\begin{array}{r}495.6 \\
495.3\end{array}$ \\
\hline 20.3 & $\begin{array}{l}\text { Sept. } 21 \\
7: 55 \mathrm{pm}\end{array}$ & 489.2 \\
\hline 19.4 & $\begin{array}{l}\text { Sept. } \\
8 \mathrm{pm}\end{array}$ & 484.6 \\
\hline 18.6 & $\begin{array}{l}\text { Sept. } 21 \\
8 \mathrm{pm}\end{array}$ & bq 479.4 \\
\hline 17.7 & $\begin{array}{l}\text { Sept. } 21 \\
8 \text { pm }\end{array}$ & 436.9 \\
\hline 17.2 & $\begin{array}{l}\text { Sept. } 21 \\
8: 10 \mathrm{pm}\end{array}$ & 431.8 \\
\hline 16.7 & Sept. 21 & 425.5 \\
\hline 16.1 & Sept. 21 & Br411.5 \\
\hline 16.1 & Sept. 21 & 411.1 \\
\hline $\begin{array}{l}15.6 \\
14.95\end{array}$ & $\begin{array}{ll}\text { Sept. } & 21 \\
9 \mathrm{pm} & \\
\text { Sept. } & 21\end{array}$ & $\begin{array}{r}353.4 \\
\text { bs } 348.3\end{array}$ \\
\hline $\begin{array}{l}14.8 \\
14.4\end{array}$ & $\begin{array}{ll}\text { Sept. } & 21 \\
9 \text { pm } & \\
\text { Sept. } & 21\end{array}$ & $\begin{array}{l}316.8 \\
311.7\end{array}$ \\
\hline 13.6 & Sept. 21 & 301.9 \\
\hline 12.9 & $\begin{array}{l}\text { Sept, } 21 \\
9: 20 \mathrm{pm}\end{array}$ & bt301.9 \\
\hline $\begin{array}{l}12.9 \\
12.0\end{array}$ & $\begin{array}{l}\text { Sept, } 21 \\
9: 20 \text { pm }\end{array}$ & $\begin{array}{l}254.3 \\
232.6\end{array}$ \\
\hline 11.4 & & 220.9 \\
\hline 10.8 & $\begin{array}{l}\text { Sept. } 21 \\
9: 15 \mathrm{pm}\end{array}$ & 214.6 \\
\hline $\begin{array}{r}10.3 \\
9.6\end{array}$ & $\begin{array}{l}\text { Sept. } 21 \\
9: 15 \mathrm{pm}\end{array}$ & $\begin{array}{l}212.7 \\
189.3\end{array}$ \\
\hline 9.2 & & 187.1 \\
\hline 8.4 & & 180.0 \\
\hline 8.0 & & 178.5 \\
\hline $\begin{array}{l}7.3 \\
6.7\end{array}$ & $\begin{array}{l}\text { Sept. } 21 \\
10 \mathrm{pm}\end{array}$ & $\begin{array}{l}161.6 \\
151.6\end{array}$ \\
\hline $\begin{array}{l}5.8 \\
5.0 \\
4.1 \\
3.2 \\
1.2\end{array}$ & & $\begin{array}{l}149.7 \\
148.8 \\
148.4 \\
145.9 \\
145.9\end{array}$ \\
\hline 1.1 & & 145.9 \\
\hline .5 & & 145.5 \\
\hline
\end{tabular}

ad From surveys and investigations by Corps of Engineers, U. S. Arny.

bq Altitude of crest of dam 465.9 feet.

br Altitude of crest of dam 396.7 feet.

bs Altitude of crest of dam 332.2 feet.

bt Altitude of crest of dam 284.6 feet. 
Table 19.--Flood crest stages--Continued

Stream and location

Connecticut River Basin--Continued

Deerfield River--Continued.

Greenfield, Mass., at confluence of Deerfield River and Connecticut River, left bank

East Branch of North River:

Colrain, Mass., about 100 feet below Vermont-Massachusetts State line, left bank

Colrain, Mass., 0.5 mile below Vermont-Massachusetts State line, left bank

Colrain, Mass., 1.2 miles below Vermont-Massachusetts State line, right bank

Colrain, Mass., 1.8 miles below Vermont-Massachusetts itate line, right bank

Colrain, Mass., 2.6 miles below Vermont-Massachusetts State line, left bank

Colrain, Mass., highway bridge, right bank

Colrain, Mass, right bank

Colrain, Mass., juit above highway bridge, $0.15 \mathrm{mile}$ above Colrain Center, left bank

Colrain, Mass., 1.5 miles above junction of West and East Branches of North River, left bank

Colrain, Mass., 600 feet above dam of Kendall Mfg. Co. plant no. 2, left bank

Colrain, Mass., 500 feet below dam of Kendall Mis. Co. plant no. 2 , left bank

Colrain, Mass., 0.4 mile above junction of West and East Branches of North River, left bank

North River:

Colrain, Mass., above Kendall dam no. 1 in Griswoldvilie

Colrain, Mass., highway bridge, downstream side, 0.1 mile below Kendall dam no. I, left bank

Colrain, Mass., 0.6 mile below Kendall dam no. 1 , left bank

Colrain, Mass., right bank

Colrain, Mass., right bank

Colrain, Mass., about 25 feet above Shattuckville highway bridge, right bank

Colrain, Mass., highway bridge, upstream side, left bank

Colrain, Mass., about 600 feet below highway bridge, lef't bank

Shelburne, Mass., highway bridge, upstream side, left bank, about 80 feet upstream from mouth of river

Green River:

Greenfield, Mass, at mouth of Workman Brook, right bank Greenfield, Mass., pumping station dam, upstream side, left bank

Greenfleld, Mass., at mouth of Glen Brook, right bank

Greenfleld, Mass., 50 feet below mouth of Punch Brook, right bank

Greenfleld, Mass., about 400 feet below mouth of Allen Brook, right bank

Greenfleld, Mass., left bank

Greenfield, Mass., about 180 feet above highway bridge, right bank

Greenfield, Mass., highway bridge, upstream side, left bank

Greenfield, Mess.

Greenfield, Mass., power house of Western Massachusẹtts Electric Co. at Mill st. Dam

Greenfield, Mass., brass tag on wall of Greenfleld Tap \& Die Corporation plant no. 1

Greenfleld, Mass., Burke's filling station on Deerfleld st., left bank

Confluence of Green River and Deerfield River

Ware and Chtcopee Rivers:

Cold Brook, Mass., Ware River intake dam, headwater

Dennyville, Mass., highway bridge 300 feet below Barre Wool Combing Co. dam.

Barre Plains, Mass., highway bridge in center of

Wheelwright Mills dam, San-Nap-Pak Mfg. Co. pump room, tallwater

old Furnace, Mass., highway bridge

Gilbertville, Masi., Gilbert Manufacturing Co. dam, head water

\begin{tabular}{|c|c|c|}
\hline $\begin{array}{l}\text { Miles } \\
\text { above } \\
\text { mouth }\end{array}$ & $\begin{array}{l}\text { Day } \\
\text { and } \\
\text { hour }\end{array}$ & $\begin{array}{l}\text { Altitude } \\
\text { in } \\
\text { feet ad/ }\end{array}$ \\
\hline 0.0 & $\begin{array}{l}\text { Sept. } 21 \\
10 \mathrm{pm}\end{array}$ & 144.8 \\
\hline bu9. 8 & $\begin{array}{l}\text { Sept. } 21 \\
7 \mathrm{pm}\end{array}$ & 751.2 \\
\hline bu9.3 & Sept. 21 & 731.6 \\
\hline bu8.6 & $\begin{array}{l}\text { Sept. } 21 \\
7 \text { pm }\end{array}$ & 698.4 \\
\hline bu8. 0 & $\begin{array}{l}\text { Sept. } 21 \\
7 \text { pm }\end{array}$ & 681.7 \\
\hline bu 7.2 & $\begin{array}{l}\text { Sept. } 2 l \\
7 \text { pm }\end{array}$ & 643.3 \\
\hline bu 6.5 & $\begin{array}{l}\text { Sept. } 21 \\
7 \text { pm }\end{array}$ & 629.5 \\
\hline $\begin{array}{l}\text { bus. } 8 \\
\text { bu } 5.2\end{array}$ & $\begin{array}{l}\text { Sept. } 21 \\
\text { Sept. } 21 \\
7: 45 \mathrm{pm}\end{array}$ & $\begin{array}{l}609.2 \\
602.6\end{array}$ \\
\hline bu 4.8 & $\begin{array}{l}\text { Sept. } 21 \\
7: 45 \mathrm{pm}\end{array}$ & 600.1 \\
\hline bu 4.2 & $\begin{array}{l}\text { Sept. } 21 \\
8 \text { pm }\end{array}$ & 584.8 \\
\hline bu 4.0 & $\begin{array}{l}\text { Sept. } 21 \\
8 \mathrm{pm}\end{array}$ & 551.0 \\
\hline bus. 7 & $\begin{array}{l}\text { Sept. } 21 \\
8 \mathrm{pm}\end{array}$ & 533.9 \\
\hline 3.0 & $\begin{array}{l}\text { Sept. } 21 \\
7 \text { pm }\end{array}$ & 521.7 \\
\hline 2.9 & $\begin{array}{l}\text { Sept. } 21 \\
7 \mathrm{pm}\end{array}$ & 518.9 \\
\hline 2.4 & $\begin{array}{l}\text { Sept. } 21 \\
8 \text { pm }\end{array}$ & 504.1 \\
\hline $\begin{array}{l}1.9 \\
1.5 \\
1.4\end{array}$ & $\begin{array}{l}\text { Sept. } 21 \\
\text { Sept. } 21 \\
\text { Sept. } 21 \\
8: 10 \text { pm }\end{array}$ & $\begin{array}{l}489.3 \\
476.3 \\
468.9\end{array}$ \\
\hline .8 & $\begin{array}{l}\text { Sept. } 21 \\
8: 40 \mathrm{pm}\end{array}$ & 461.1 \\
\hline .6 & $\begin{array}{l}\text { Sept. } 21 \\
8: 40 \mathrm{pm}\end{array}$ & 453.0 \\
\hline .0 & $\begin{array}{l}\text { Sept. } 21 \\
8: 40 \text { pm }\end{array}$ & 439.8 \\
\hline $\begin{array}{l}6.7 \\
6.1\end{array}$ & $\begin{array}{l}\text { Sept. } 21 \\
\text { Sept. } 21\end{array}$ & $\begin{array}{l}266.1 \\
251.1\end{array}$ \\
\hline $\begin{array}{l}5.0 \\
4.1\end{array}$ & $\begin{array}{l}\text { Sept. } 21 \\
\text { Sept. } 21\end{array}$ & $\begin{array}{l}194.5 \\
183.3\end{array}$ \\
\hline 3.3 & Sept. 21 & 165.4 \\
\hline $\begin{array}{l}2.5 \\
1.9\end{array}$ & $\begin{array}{l}\text { Sept. } 21 \\
\text { Sept. } 21\end{array}$ & $\begin{array}{l}163.5 \\
159.4\end{array}$ \\
\hline 1.6 & Sept. 21 & 159.1 \\
\hline 1.1 & $\begin{array}{ll} & \\
\text { Sept. } & 21 \\
11: 30 & \mathrm{pm}\end{array}$ & 155.6 \\
\hline 1.0 & $\begin{array}{ll}\text { Sept. } & 21 \\
11: 30 \mathrm{pm}\end{array}$ & $150: 4$ \\
\hline .5 & $\begin{array}{ll}\text { Sept. } & 21 \\
11: 30 & \mathrm{pm}\end{array}$ & 146.5 \\
\hline $\begin{array}{l}.4 \\
.0\end{array}$ & $\begin{array}{l}\text { Sept. } 21 \\
9: 20 \mathrm{pm}\end{array}$ & 146.3 \\
\hline $\begin{array}{l}44.6 \\
42.6\end{array}$ & & 590.1 \\
\hline $\begin{array}{l}41.9 \\
39.7\end{array}$ & & $\begin{array}{l}589.8 \\
578.7\end{array}$ \\
\hline $\begin{array}{l}37.6 \\
33.1\end{array}$ & & $\begin{array}{l}569.2 \\
548.8\end{array}$ \\
\hline
\end{tabular}

ad From surveys and investigations by Corps of Engineers, U. S. Army.

bu Miles above mouth of North River.

$2479070-40-33$ 
Table 19.--Flood crest atages--Continued

\begin{tabular}{|c|c|c|c|c|}
\hline$\cdot$ & Stream and location & $\begin{array}{l}\text { M1les } \\
\text { above } \\
\text { mouth }\end{array}$ & $\begin{array}{l}\text { Day } \\
\text { and } \\
\text { hour }\end{array}$ & $\begin{array}{l}\text { Altitude } \\
\text { in } \\
\text { feet ad }\end{array}$ \\
\hline & icut River Basin--Con & & & \\
\hline
\end{tabular}

Ware and Chicopee Rivers--Continued.

Gilbertville, Mass., old wooden bridge 1,500 feet below George Gilbert dam

Ware, Mass., Highway 9 bridge below 0 tis Co. dam

ware, Mass., South Street bridge, upstream

Ware, Mass., South Street bridge, downstream

Muddy Brook, mouth of

Muddy Brook, Highwey 32 bridge 1.55 miles below mouth of

U. S. Ceolog1cal Survey gage

Gibbs Crossing, highway bridge

Wipples, Mass., highway bridge

Thorndyke, Mas's., Church Street Bridge

Thorndyke, Mass., Main Street Bridge, upstream

Thorndyke, Mass., upper concrete highway bridge

Three Rivers, Mass., Bridge Street Bridge (Chicopee River)

Three Rivers, Mass., Otis Co. power plant dam about 0.5 mile west of center of, headwater

Three Rivers, Mass., Otis Co. power plant dam about 0.5 mile west of center of, tailwater

Red Bridge, Mass., Ludlow Manufacturing Co. dam, headwater

Red Bridge, Mass., Ludlow Manufacturing Co. dam, tailwater

Red Bridge, Mass., highway bridge 0.11 mile below Ludlow Manufacturing Co. dam

Red Bridge, Mass., highway bridge 0.11 mile below Ludlow Manufacturing Co. dam

North Wilbraham, Mass., Route $20,0.9$ mile upstream from Collins Manufacturing Co. dam

North Wilbraham, Mass., dam above Miller Street Bridge near Collins station, headwater

North Wilbraham, Mass., 400 feet below dam near Collins station, tailwater

Ludlow, Mass., I mile east of, Boston \& Albany R.R. bridge

Indian Orchard, Mass., 200 feet above Ludlow Manufacturing Co. dam, right bank, headwater

Ludlow, Mass., 275 feet above Ludlow Manufacturing Co. dam, left bank, headwater

Ludlow, Mass., below bridge and 675 feet below Ludlow Manufacturing Co. dam, left bank

Indian Orchard, Mass., 0.2 mile below Ludlow Manufacturing Co. dam, right bank

Indian Orchard, Mass., $0.5 \mathrm{mile}$ above Hodges dam, right bank

Indian Orchard, Mass:, United Electric Light Co, dam

Indian Orchard, Mass., 600 feet below Hodges Carpet co. dam, right bank

Indian Orchard, Mass., United Electric Light Co. power plant, 0.2 mile below Hodges dam

Bircham Bend, Mass., 3,000 feet above United Electric Light Co. dam

Bircham Bend, Mass., 900 feet above United Electric Light Co. dam

Chicopee Falls, Mass., Chicopee Manufacturing Co. dam Just above Bridge Street

Chicopee, Mass., 175 feet above Dwight Manufacturing Co. dam, headwater

Ch1copee, Mass., 200 feet below Dwight Manufacturing Co. dam, tailwater

Chicopee, Mass., confluence of Chicopee and Connecticut Rivers

Swift River:

Between Belchertown and Ware, Mass., Route 9, highway bridge 0.5 mile below Quabbin Dam

West Ware, Mass., U. S. Geological Survey gage

Bondsville, Mass., Otis Co. upper dam, headwater

Bondsvilie, Mass., Depot Street Bridge

Bondsville, Mass., Otis Co. lower dam, headwater

Bondsville, Mass., Otis Co. lower dam, tailwater

Confluence of Swift and Ware Rivers near Three Rivers, Mass.

Quaboag River:

Quaboag Pond, outlet of

Brookfleld, Mass., above road bridge, two-story frame dwelling, left bank

Brookfield, Mass., Brookfield Grain Co., scale house

32.6

28.95

28.2

28.2

27.8

26.25

25.35

25.0

21.0

19.7

19.1

18.9

17.1

16.4

16.4

14.3

14.3

14.2

14.2

12.5

11.55

11.45

9.5

8.40

8.40

8.2

8.15

7.6

7.45

6.95

6.85

5.8

5.4

2.7

$1.0 \mathrm{t}$

1.0

0

7.5

7.25

3.5

3.0

2.8

2.8
0

22.9

21.7

21.7
529.8

452.4

418.0

415.2

412.5

411.9

398.0

bv391. 4

375.0

363.6

343.1

342.3

bv319.7

311.2

288.0

282.7

246.7

244.6

242.8

233.8

230.5

227.2

219.7

214.8

214.0

180.6

176.7

168.2

169.8

145.7

143.1

135.2

135.2

bv 116.5

bv 85.4

78.0

384.3

378.9

368.4

345.0

345.0

333.1

607.0

609.1

ad From surveys and investigations by Corps of Engineers, U. S. Army. bv Average of several observations. 


\begin{tabular}{|c|c|}
\hline Stream and location & \\
\hline
\end{tabular}

Connecticut River Basin--Continued

Quaboag River--Continued.

West Brookfield, Mass., Varnum Yeast Co., road bridge Warren, Mass., Route 19, Warren Cleaners and Dyers store, downstream, left bank

Warren. Mass., Main Street Bridge

Warren, Mass., Boston \& Albany R.R. bridge above Fannie Jane Mill

Warren, Mass., Fannie Jane Mill dam, tailwater

West Warren, Mass., 0.8 mile above, dam, headwater

West Warren, Mass., 0.8 mile above, below bridge

West Warren, Mass., $0.4 \mathrm{mile}$ above, dam, headwater

West Warren, Mass., 0.4 mile above, dam, tailwater

West Warren, Mass., W. E. Wright Co.

West Warren, Mass., Boston \& Albany R.R. bridge, upstream and downstream

West Warren, Mass., Crossman Dam, headwater

West Warren, Mass., bridge below. Crossman Dam

West Warren, Mass., bridge below Crossman Dam

West Brimfield, Mass., U. S. Geological Survey gage at highway bridge

West Brimfleld, Mass., 2.7 miles above Cooley's Crossing, wooden bridge abutments

West Brimfield, Mass., 1.5 miles above Cooley's Crossing, one family house, left bank

Palmer, Mass., Central Massachusetts Light \& Power Co. dam, headwater

Palmer, Mass., Route 32 , concrete bridge 1.3 miles above, upstream

Palmer, Mass., Route 32 , concrete bridge 1.3 miles above, downstream

Palmer, Mass., Gulf Oil Co., Water Street

Palmer, Mass., Route 20, highway bridge 1.1 miles below

Palmer, Mass., Route 20, Boston \& Albany R.R. underpass 1.2 miles below

Three Rivers, Mass., Burleigh Bridge, 1.4 miles above

Confluence of Guaboag and Ware Rivers

Sevenmile River:

Between Spencer and East Brookfield, Mass., bridge, upstream

Between Spencer and East Brookfield, Mis:s., bridge, downstream

Confluence of Sevenmile and Fivemile Rivers 2.6 miles above Quaboag River at outlet of Quaboag Pond

Fivemile River:

East Brookfield, Mass., Route 9, frame dwelling above bridge at Furnace Pond, left bank

East Brookfield, Mass., Maclan Hat Factory, freight entrance

East Brookfield, Mass., Boston \& Albany R.R. bridge, 0.2 mile below

Confluence of Fivemile and Sevenmile Rivers 2.6 miles above Quaboag River at outlet of quaboag Pond

Wostfield River:

West Cummington, Mass., 0.2 mile below mouth of Westfield Brook, pight bank

West Cummington, Mass., 1.05 miles below mouth of Westfield Brook, right bank

West Cummington, Mass., 2.1 miles below mouth of Westfleld Brook

M1li Brook, 1.2 miles above mouth of, just below highway bridge, right bank

Mill Brook, 0.5 mile above mouth of, right bank

Mill Brook, mouth of, left bank

Mill Brook, 0.55 mile below mouth of, right bank

Cumington Center, Mass., highway bridge west of, $1.0 \mathrm{mile}$ below mouth of Mill Brook

Cummington Center, Mass., 0.05 mile below mouth of Meadow Brook, right bank

Cumington, Mass., 0.8 mile below mouth of Meadow Brook, left bank

Cumington, Mass., 1.5 miles above mouth of Swift River, left bank

Swift River, $0.6 \mathrm{mile}$ above mouth of, left bank

Swift River, 0.05 mile below mouth of, right bank

\begin{tabular}{|c|c|c|}
\hline $\begin{array}{l}\text { Miles } \\
\text { above } \\
\text { mouth }\end{array}$ & $\begin{array}{l}\text { Day } \\
\text { and } \\
\text { hour }\end{array}$ & $\begin{array}{l}\text { Alt1tude } \\
\text { In } \\
\text { feet ad/ }\end{array}$ \\
\hline $\begin{array}{l}18.7 \\
17.9\end{array}$ & & $\begin{array}{l}609.4 \\
598.7\end{array}$ \\
\hline $\begin{array}{l}15.4 \\
15.4\end{array}$ & & $\begin{array}{l}597.9 \\
585.6\end{array}$ \\
\hline $\begin{array}{l}14.6 \\
13.7 \\
13.6 \\
13.4 \\
13.3 \\
13.0 \\
12.6\end{array}$ & . & $\begin{array}{l}583.1 \\
568.4 \\
561.2 \\
556.0 \\
548.3 \\
528.4 \\
521.6\end{array}$ \\
\hline $\begin{array}{r}12.4 \\
12.3 \\
12.3 \\
9.0\end{array}$ & & $\begin{array}{l}505.1 \\
497.2 \\
496.5 \\
399.2\end{array}$ \\
\hline 8.9 & & 387.7 \\
\hline 8.0 & & 373.8 \\
\hline 5.05 & & 345.2 \\
\hline 4.5 & & 325.1 \\
\hline 4.5 & & 323.9 \\
\hline $\begin{array}{l}3.3 \\
2.2\end{array}$ & . & $\begin{array}{r}\text { bv322.8 } \\
320.4\end{array}$ \\
\hline 2.1 & & 317.1 \\
\hline$\frac{1.4}{0}$ & & $\begin{array}{r}319.2 \\
\text { bv319.9 }\end{array}$ \\
\hline 2.8 & & 639.2 \\
\hline 2.8 & & 636.7 \\
\hline 0 & & \\
\hline .5 & & 623.5 \\
\hline .45 & $\because$ & 617.9 \\
\hline $0^{.3}$ & . & 614.0 \\
\hline $\begin{array}{c}49.5 \\
48.65\end{array}$ & $\begin{array}{l}\text { Sept: } 21 \\
4: 30\end{array}$ & $\begin{array}{l}1,192.8 \\
1,144.0\end{array}$ \\
\hline 47.6 & & $1,102.5$ \\
\hline 46.9 & $\begin{array}{l}\text { Sept. } 21 \\
4: 50 \mathrm{pm}\end{array}$ & $1,075.9$ \\
\hline 46.2 & $\begin{array}{l}\text { Sept. } 21 \\
5 \mathrm{pm}\end{array}$ & $1,048.0$ \\
\hline $\begin{array}{l}45.7 \\
45.15 \\
44.7\end{array}$ & & $\begin{array}{l}1,038.7 \\
1,024.7 \\
1,004.0\end{array}$ \\
\hline 44.25 & & 993.1 \\
\hline 43.5 & $\begin{array}{l}\text { Sept. } 21 \\
5 \mathrm{pm}\end{array}$ & 985.2 \\
\hline $\begin{array}{l}43.2 \\
42.3 \\
41.65\end{array}$ & - -- & $\begin{array}{l}958.8 \\
942.9 \\
922.0\end{array}$ \\
\hline
\end{tabular}

ad From surveys and Investigations by Corps of Engineers, U. S. Army.

bv Average of several observations. 
Table 19,--Flood crest stages--Continued

$\frac{\text { Stream and location }}{\text { Connecticut River Besin - Continued }}$

Westfleld River--Continued.

Swift River, 0.5 mile below mouth of, left bank

Swift River, 0.9 mile below mouth of, left bank

Swift River, 1.3 miles below mouth of, right bank

Swift River, 1.6 miles below mouth of, left bank.

Swift River, 2.0 miles below mouth of, right bank

Chesterfleld, Mass., $1.0 \mathrm{mile}$ above mouth of West Branch of Westfield River, right bank

Chesterfleld, Mass., $0.55 \mathrm{mlle}$ above mouth of West Branch of Westfield River, left bank

chesterfield, Mass., highway bridge 0.25 mile above mouth of West Branch of Westfield River

Chesterfield, Mass., 0.35 mile below mouth of west Branch of Westfield River, right bank

chesterfleld, Mass., $0.9 \mathrm{mile}$ below mouth of West Branch of Westfield River, right bank

Chesterfield, Mass., 1.7 miles below mouth of West Branch of Westfield River, right bank

Chesterfield, Mass., 2.1 miles below mouth of west Branch of Westfield River, right bank

chesterfield, Mass., 2.4 miles below mouth of West Branch of Westfield River, left bank

Chesterfield, Mass:, 2.8 miles below mouth of West Branch of Westfield River, left bank

Chesterfield, Mass., 3.2 miles below mouth of West Branch of Westfield RIver, north end of 1sland

Huntington, Mass., 1.9 miles above mouth of East Branch of Westfield River, left bank

Huntington, Mass., 1.1 miles above mouth of East Branch of Westfield River, right bank

Huntington, Mass., Taylor Bridge, 0.05 mile above mouth of East Branch of Westfield River

Huntington, Mass., 0.4 mile below mouth of East Branch of Westifleld River, right bank

Huntington, Mass., 1.2 miles below mouth of East Branch of Westfield River, right bank

Huntington, Mass., 1.0 mile above mouth of Westfleld Iittle River, right bank

Huntington, Mass., 0.3 mile above mouth of Westfleld Little River, right bank

Huntington, Mass., 1.1 miles above U. S. Geological Survey gage, right bank

Huntington, Mass., U. S. Geological Survey gage 0.6 mile above mouth of Pond Brook

Huntington, Mass., 0.05 mile below U. S. Ceological Survey gage

Huntington, Mass., 0.3 mile below U. S. Geological Survey gage

Huntington, Mass., 1.1 miles below U. S. Geological Survey gage

Middle Branch of Westfield River, $0.15 \mathrm{mlle}$ above mouth of

Middle Branch of Westfield River, $0.7 \mathrm{mile}$ below mouth, left bank, just above Norwich Bridge

West Branch of Westfleld River, dam, 0.8 mile above mouth of

West Branch of Westfield River, 0.3 mile above mouth of, Livingston Fiber Board Co., Inc., bullding

West Branch of Westfleld River, mouth of, left bank

West Branch of Westfield River, 0.1 mile below mouth of, right bank

Russeil, Mass., Chapin-Gould Paper Co. dam, headwater

Russell, Mass., 0.4 mile below Chapin-Gould Peper Co. dam, left bank

Russeli, Mass., 0.9 mile below Chapin-Gould Paper Co. dam, left bank

Russeli, Mass., 1.6 miles below Chapin-Gould Paper Co. dam, left bank

Russeli, Mass., 0.4 mile above hlghway bridge above Westfield River Paper Co. dam, left bank

Russell, Mass., highway bridge above Westfleld RIver Paper Co. dam, left bank

Russell, Mass., 0.8 mile below highway bridge above Westfield paper Co. dam, left bank

Russell, Mass., l.3 mile: above Strathmore paper Co. dam, left bank

Russeli, Mass., 0.7 mile above Strathmore Paper Co. dam, left bank

\begin{tabular}{|c|c|c}
\hline $\begin{array}{c}\text { Miles } \\
\text { above } \\
\text { mouth }\end{array}$ & $\begin{array}{c}\text { Day } \\
\text { and } \\
\text { hour }\end{array}$ & $\begin{array}{c}\text { Alt1tude } \\
\text { in } \\
\text { feet gd/ }\end{array}$ \\
\hline & & \\
& & \\
41.2 & & 908.4 \\
40.8 & & 896.0 \\
40.4 & & 877.5 \\
40.1 & & 856.5 \\
39.7 & & 825.8 \\
38.9 & & 793.1
\end{tabular}

774.9

38.45

767.3

38.15

37.55

738.7

$37: 0$

701.2

36.2

35.8

670.2

654.0

35.5

35.1

34.7

34.1

33.3

32.25

31.8

31.0

30.5

29.8

28.9

Sept. 2

27.8

$9 \mathrm{pm}$

Sept.

27.75 Sept. 21

27.5

$10 \mathrm{pm}$

639.0

628.6

622.9

608.7

591.7

575.5

562.2

551.3

536.1

525.6

517.1

501.4

500.4

479.4

26.7

463.4

25.65

406.6

24.8

400.2

24.1

386.1

23.6

365.8

23.3

359.9

355.6

22.3

bw345.8

21.9

317.4

21.4

304.6

20.7

295.1

20.3

19.9

283.8

19.1

bx283.5

259.3

18.5

251.5

17.9

238.6

ad From surveys and investigations by Corps of Engineers, U. S. Army.

bw Alt1tude of crest of dam 329.6 feet.

bx Alt1tude of crest of dam 267.9 feet. 
Table-19.--Flood crest stages--Continued

\begin{tabular}{|c|c|}
\hline Stream and location & \\
\hline
\end{tabular}

Connecticut River Basin--Continued

Westfield River--Continued.

Russell, Mass., Strathmore Paper Co. dam, headwate

Russell, Mass., 0.5 mile below Strathmore Paper Co. dam, left bank

Russeli, Mass., 1.0 mile below Strathmore Paper Co. dam, left bank

Russell, Mass., 1.6 miles below Strathmore Paper Co. dam, left bank

Westfield, Mass., 0.95 mile above mouth of Moose Meadow Brook, left bank

Westfield, Mass., 0.3 mile above mouth of Moose Meadow Brook, left bank

Westfield, Mass., 0.15 mile below mouth of Moose Meadow Brook, left bank

Westfield, Mass., 0.95 mile below mouth of Moose Meadow Brook, left bank

Westfleld, Mass., railroad bridge 2.1 miles above mouth of Powder Mili Brook

Westfield, Mass., 2.0 miles above mouth of Powder Mill Brook

Westfield, Mass., 1.8 miles above mouth of Powder Mill Brook

Westfield, Mass., 3.5 miles above mouth of Powder Mill Brook

Westfield, Mass., 0.3 mile above mouth of Powder Mill Brook

Westfield, Mass., 0.6 mile below mouth of Powder Mill Brook

Westfield, Mass., U. S. Geological Survey gage 0.8 mile above mouth of Blacis Brook

West Springfield, Mass., 0.2 mile below mouth of Black Brook, left bank

West Springfield, Mass., 1.2 miles below mouth of Black Brook, left bank

West Springfield, Mass., 0.1 mile below mouth of Black Brook, left bank

Confluence of Westfield and Connecticut Rivers.

Middle Branch of Westfield River:

Worthington, Mass., highway bridge 0.05 mile below mouth of 'Fidler' Brook

Worthington, Mass., $0.5 \mathrm{mile}$ below mouth of Fidler Brook

Worthington, Mass., 0.2 mile above mouth of Turtle Brook

Worthington, Mass., 0.4 mile kelow mouth of Turtle Brook

Worthington, Mass., 1.0 mile below mouth of Turtle Brook

Worthington, Mass., 0.6 mile above mouth of Den Stream

Worthington, Mass., 0.05 mile below mouth of Den Stream

Worthington, Mass., 0.2 mile below Shewster dam, right bank

Chester, Mass., 0.6 mile above A. E. Day dam, right bank

Chester, Mass., A. E. Day dam, tailwater

Chester, Mass., 0.4 mile below A. E. Day dam

Chester, Mass., 1.1 miles below A. E. Day dam, right bank

Chester, Mass., 1.05 miles above mouth of Kinney Brook

Chester, Mass., 0.7 mile above mouth of Kinney Brook, right bank

Chester, Mass., 0.3 mile above mouth of Kinney Brook, right bank

Chester, Mass., 0.2 mile below mouth of Kinney Brook

Chester, Mass., 1.1 miles above dam, right bank

Huntington, Mass., 0.6 mile above dam

huntington, Mass., Just above dam, left bank

Huntington, Mass., 0.15 mile below dam, right bank

Huntington, Mass., 1.5 miles above U. S. Geological Survey gage, right bank

Huntington, Mass., 0.6 mile above U. S. Geological Survey gage, right bank

\begin{tabular}{|c|c|c|}
\hline $\begin{array}{l}\text { Miles } \\
\text { above } \\
\text { mouth }\end{array}$ & $\begin{array}{l}\text { Day } \\
\text { and } \\
\text { hour }\end{array}$ & $\begin{array}{c}\text { Altitude } \\
\text { in } \\
\text { feet ad/ }\end{array}$ \\
\hline $\begin{array}{l}17.2 \\
16.7\end{array}$ & & $\begin{array}{r}\text { by } 241.5 \\
195.1\end{array}$ \\
\hline 16.2 & & 186.6 \\
\hline 15.6 & & 176.2 \\
\hline 14.9 & & 167.4 \\
\hline 14.25 & & 163.6 \\
\hline 13.8 & & 159.5 \\
\hline 13.0 & & 153.6 \\
\hline 11.5 & & 146.3 \\
\hline 11.4 & & 139.6 \\
\hline 11.2 & & 138.4 \\
\hline 10.9 & & 137.3 \\
\hline 9.7 & & 133.5 \\
\hline 8.8 & & 130.7 \\
\hline 7.8 & $\begin{array}{l}\text { Sept. } 21 \\
12 \mathrm{pm} \text { to } \\
\text { Sept. } 22 \\
1 \mathrm{am}\end{array}$ & 127.6 \\
\hline 6.8 & & 124.8 \\
\hline 5.8 & & 120.1 \\
\hline 4.45 & & 102.7 \\
\hline 0 & & \\
\hline 1.2 .55 & & $1,047.2$ \\
\hline 12.1 & & $1,008.6$ \\
\hline 11.5 & & 966.4 \\
\hline 10.9 & & 911.9 \\
\hline 10.3 & & 884.9 \\
\hline $\begin{array}{l}9.6 \\
8.95 \\
8.5\end{array}$ & & $\begin{array}{r}852.8 \\
812.7 \\
\mathrm{bz} 785.0\end{array}$ \\
\hline 7.7 & & 748.9 \\
\hline $\begin{array}{l}7.1 \\
6.7 \\
6.0\end{array}$ & & $\begin{array}{r}\text { ca } 717.7 \\
705.5 \\
667.8\end{array}$ \\
\hline $\begin{array}{l}5.35 \\
5.0\end{array}$ & & $\begin{array}{l}638.4 \\
627.9\end{array}$ \\
\hline 4.6 & & 598.5 \\
\hline $\begin{array}{l}4.1 \\
3.8 \\
3.3 \\
2.7\end{array}$ & $\begin{array}{l}\text { Sept. } 21 \\
6: 30 \mathrm{pm}\end{array}$ & $\begin{array}{r}575.9 \\
549.7 \\
525.9 \\
\text { cb504.5 }\end{array}$ \\
\hline $\begin{array}{l}2.55 \\
1.9\end{array}$ & & $\begin{array}{l}491.9 \\
469.3\end{array}$ \\
\hline 1.0 & & 436.9 \\
\hline
\end{tabular}

ad From surveys and investigations by Corps of Engineers, U. S. Army.

by Altitude of crest of dam 229.1 feet.

bz Altitude of crest of dam 800.6 feet.

ca Altitude of crest of dam 711.2 feet.

$\mathrm{cb}$ Altitude of crest of dam 494.3 feet. 
Table 19.--Flood crest stages--Continued

Stream and location

Middle Branch of Westfield River--Continued.

Huntington, Mass., U. S. Geologlcal Survey gage 0.4 mile above confluence with Westfield River

Confluence with Westfleld River

West Branch of Westfield River:

Becket, Mass., just above Boston \& Albany R.R. bridge Becket, Mass., just above Boston \& Albany R.R. bridge 1.2 miles above Center Pond Brook, right bank

Becket, Mass., opposite centerline of Boston \& Albany R.R. bridge 0.8 mile above Center Pond Brook, left bank

Becket, Mass., mouth of Center Pond Brook

Becket, Mass., Just above Boston \& Albany R.R. bridge 0.45 mile above Coles Brook, left bank

Becket, Mass., Boston \& Albany; R.R. bridge 0.15 mile below Coles Brook, left bank

Bancroft, Mass., just above Balkby-Dutton Co, dam 0.6 mile below Coles Brook, left bank

Bancroft, Mass., highray bridge

Bancroft, Mass., just below Boston \& Albany R.R. bridge 0.4 mile below Factory Brook, left bank

Bancroft, Mass., 0.1 mile above Boston \& Albany R.R. bridge 1.8 miles below Factory Brook

Bancroft, Mass., Just below Boston \& Albany R.R. bridge 3.2 miles above mouth of Walker Brook, left bank

Chester, Mass., Just above Boston \& Albany R.R. bridge 2.8 miles above mouth of Walker Brook

Chester, Mass., at Boston \& Albany R.R. bridge 2.1 miles above mouth of Walker Brook

Chester, Mass., on highway bridge abutment 1.7 miles above mouth of Walker Brook, left bank

Chester, Mass., 1.3 miles above mouth of Walker Brook, right bank

Chester, Mass., Hamilton Carbon Co., 0.6 miles above mouth of Walker Brook

Chester, Mass., Main Street bridge

Chester, Mess., 0.15 mile below mouth of Walker Brook

Chester, Mass., 0.7 mile below mouth of Walker Brook, right bank

Chester, Mass., 1.1 miles above mouth of Sanderson Brook

Chester, Mass., highway bridge $0.8 \mathrm{mi} l \theta$ above mouth of Sanderson Brook

Chester, Mass., Boston \& Albany R.R. bridge at mouth of Sandérson Brook

Chester, Mass., Just above highway bridge 1.0 mile below mouth of Sanderson Brook

Chester, Mass.. 2.1 miles above U. S. Geological Survey gage

Chester, Mass., 1.3 miles above U. S. Geological Survey gage

Funtington, Mass., Huntington pumping plant, $0.65 \mathrm{mile}$ above U. S. Geological Survey gage

Huntington, Mass., U. S. Geological Survey gage 0.35 mile below mouth of Roaring Brook, left bank

Euntington, Mass, $0.7 \mathrm{mlle}$ below U. S. Geological Survey gage

Hutington, Mass., new highway bridge, upstream

Confluence with Westfleld River

Farmington River:

Colebrook, Conn., Route 8 at State IIne

Colebrook, Conn., Route 8, 300 feet north of inn

Colebrook, Conn., Route $8,0.5$ mile below bridge

Colebrook, Conn., Route 8 at bridge

Colebrook, Conn., Route $8,0.1$ mile below bridge

Colebrook, Conn., Route $8,0.4$ mile below bridge

Barkhamsted (R1verton), Conn., Grocock House

Barkhamsted, Conn., Route 20 one-eighth mile north of Riverton

Barkhemsted, Conn., Route 20, Riverton

Barkhamsted, Conn., Pleasant Valley

New Hartford, Conn., New Hartford fire house

New Hartford, Conn., New Hartford garage

New Hartford, Conn., Route 44 at Wickett Road

New Hartford, Conn., Route 44, Pine Meadow Center

New Hartford, Conn., Route 44, Satan's Kingdom Grill

Canton (Collinsvilie), Conn., Barnes House

Canton (Collinsville), Conn., C. H. D. garage

Canton (Collinsville), Conn., Smith House

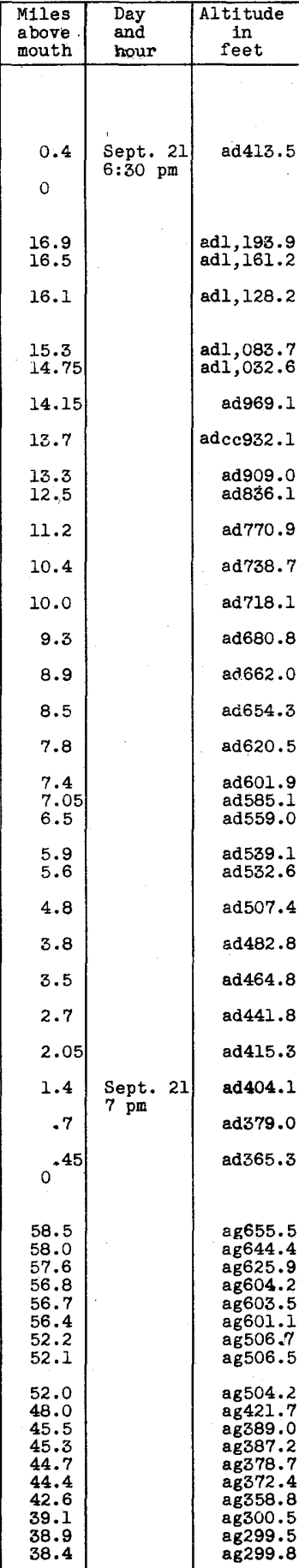

ad From surveys and investigations by Corps of Engineers, U. S. Army.

ag From surveys and investigations by Connecticut State Water Commission (Ground Water Project).

cc Altitude of crest of dam 926.3 feet. 
Table 19.--Flood crest stages--Continued

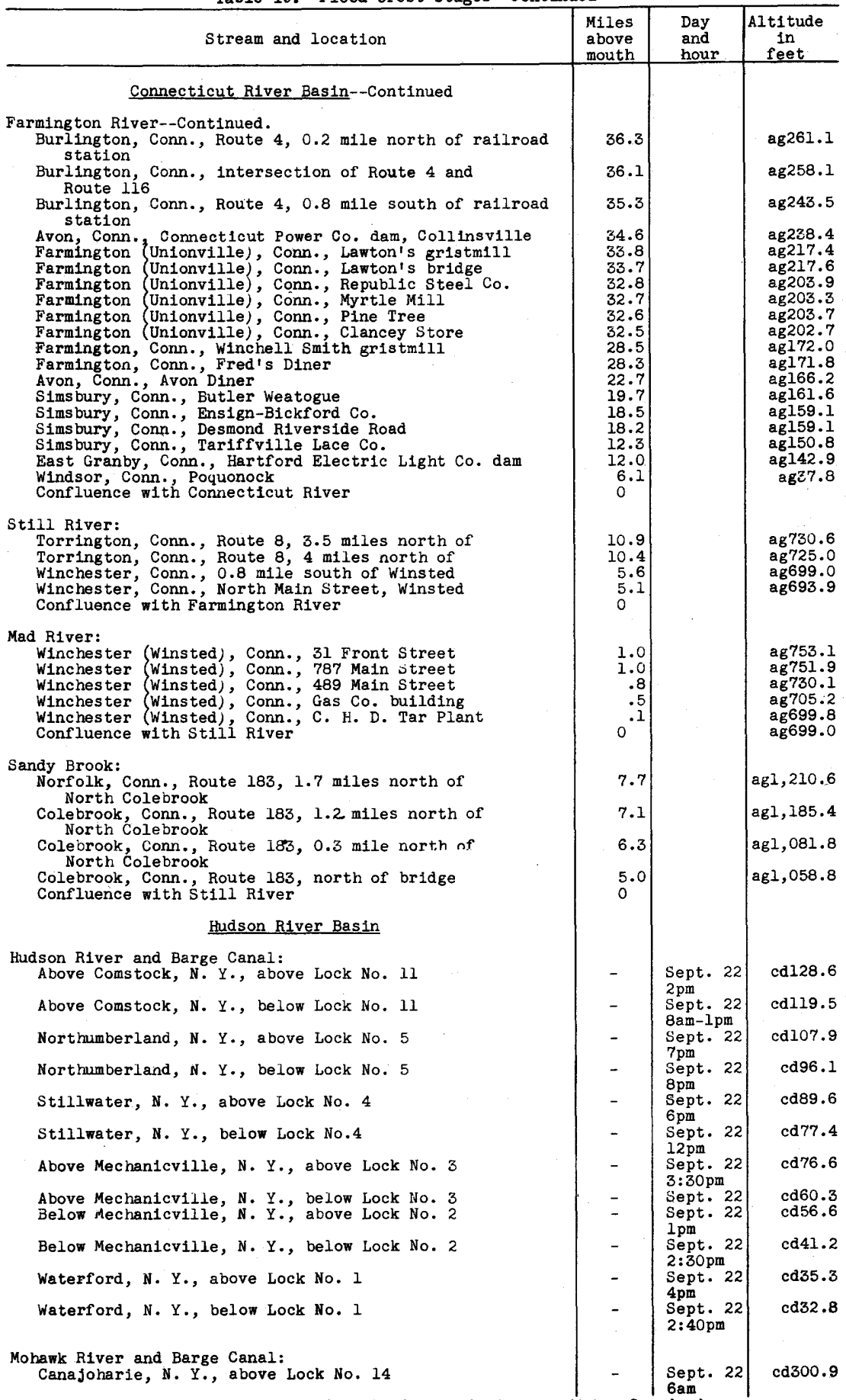

ag From surveys and investigations by Connecticut State Water Commission (Ground Water Project).

cd Barge Canal datum. Records furnished by New York State Department of Public Works. 
Table 19,-Flood crest stages--Cont1nued

\begin{tabular}{|l|l}
\hline Stream and location & Mation \\
\hline
\end{tabular}

Hudson River Basin--Continued

Mohawk River and Barge Canal--Continued: Canajoharie, N. Y., below Lock No. 14

Above Fonda, N. Y., above Lock No. 13

Above Fonda, N. Y., below Lock No. 13

Above Amsterdam, N. Y., above Lock No. 12

Above Amsterdam, N. Y., below Lock No. 12

Amsterdam, N. Y., above Lock No. 11

Amsterdam, N. Y., below Lock No. 11

Above Schenectady, N. Y., above Lock No. 9

Schenectady, N. Y., above Lock No. 8

Schenectady, N. Y., General Electric Co. pump house

Schenectady, N. Y., Great Western Gateway

Schenectady, N. Y., Locomotive Works

Rexford, N. Y., bridge

Vischer Ferry, N. Y., above Lock ifo. 7

Crescent Dam, iv. Y., above Lock No. 6

\section{Hackensack River Basin}

Hackensack River:

Oradell, N. J., above Oradell Dam

New Milford, N. J,, U. S. Geological Survey gaying station above dam of Hackensack Water Co.

Pascack Brook:

Hillsdale, N. J., above Woodcliff lake Dam

Westwood, N. J., U. S. Geological survey gaging station 75 feet above Sand Road Bridge, below mouth of Musquapsink Creek

\section{Passaic River Basin}

Passaic River:

Basking Ridge, N. J., 2 miles north of Van Doren's Mill, Staté Highwáy 32 bridge, upstream

Basking Ridge, N. J., $1 \frac{1}{2}$ miles northeast of osborne Mill Bridge, upstream

Millington, N. J., I mile northwest of Davis Bridge, upstream

Millington, H. J., U. S. Geological Survey gaging station 150 feet below Davis Bridge

Millington, N. J., Haas Road Bridge, upstream

Millington, N. J., Springfield Avenue Bridge, upstrean

Stirling, N. J., three-quarters of a mile east of Plainfield Avenue Bridge, downstream

Gillette, N. J., Mountain Avenue Bridge, upstream

Gillette, N. J., Delaware, Lackawanna w Western R.R. bridge, upstream

Berkeley Heights, N. J., highway bridge, upstream

New Providence, N. J., near, Central Avenue Bridge, upstream

New Providence, N. J., Passaic Avenue Bridge, upstream

Chatham, N. J., upstream from, Mount Vernon Avenue Bridge, downstream

Chatham, N. J., U. S. Geological survey gaging station 100 feet below Stanley Avenue Bridge

Chatham, N. J., Watchung Avenue Bridge, upstream

Chatham, N. J., River Road (Chatham Road Bridge), upstream

Chatham, N. J., Morris Turnpike bridge (Days Bridge), upstream

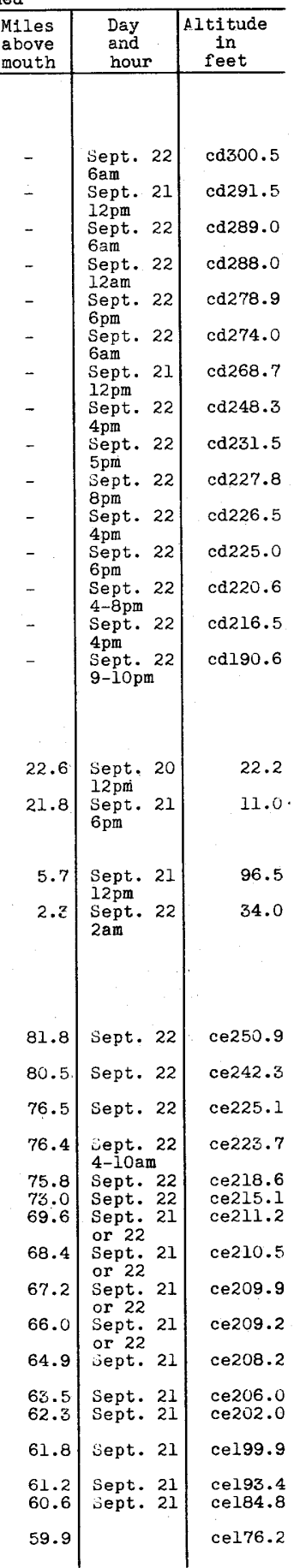

cà Barge Canal datum. Records furnished by New York State Department of Public Works.

ce New Jersey Geological survey mean sea level datum. 
Table 19.--Flood crest stages--Continued

Stream and location
Passaic River Basin--Continued
Passaic River--Continued.
Chatham, N. J., near, Lower Chatham Bridge, upstream
Florham Park, N. J., Columbia Bridge, upstream
Hanover, N. J., State Highway lo bridge (Cook Bridge),
upstream
Hanover Neck, N. J., near Swinefield Bridge, upstream
Pine Brook, N. J., State Highway 6 bridge, upstream
Pine Brook, N. J., l.i. miles northwest of Horseneck
Bridge, upstream
Little Falls, N. J., above Beattie Dam

Little Falis, N. J., at tailrace of filter plant

Paterson, N. J., U. S. Geological Survey gaging station just above spruce Street Bridge

Clifton, N. J., above Dundee Dam

Rockaway River:

Berkshire Valley, N. J., 2 miles north of County Highway 69 bridge, downstream

Berkshire Valley, N. J., County Highway 32 bridge, downstream

Wharton, N. J., $1 \frac{i}{2}$ miles west of Delaware, Lackawanna \& Western R.R. bridge

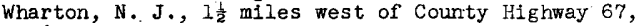
downstream

Wharton, N. J., bridge on road to Spicertown, just below Washington Pond, downstream

Dover, N. J., Rutgers Street. Bridge, downstream

Dover, N. J., Sussex street Bridge, downstream

Dover, N. J., Morris Street Bridge, downstream

Dover, N. J., Essex street Bridge, downstream

Dover, N. J., Bergen Street Bridge, downstream

Dover, N. J., Union Street Bridge, downstream

Dover, N. J., Mercer Street Bridge, downstream

Dover, N. J., East Blackwell Street Bridge; downstream

Rockaway, N. J., Dickerson Road Bridge, upstream

Rockaway, N. J., State Highway 6 bridge, upstream

Rockaway, N. J., Beach Street Bridge, upstream

Denville, N. J., I mile northwest of' Savage Road Bridge, upstream

Denville, N. J., north of, U.2 mile above mouth of Den Brook, Diamond Spring Road Bridge, upstream

Denville, N. J., mouth of Den Brook, State Highway 6 pridge

Denville, N. J., 0.6 mile below mouth of Den Brook, Pocono Road Bridge, upstream

Mountain Lakes, N. J., 1 mile west of, just above mouth of Cedar Lake outlet, sewer crossing, upstream

Mountain Lakes, N. J., li miles west of, 0.6 mile below mouth of Cedar Lake outlet, Cook Lane Bridge, upstream

Powerville, N. J., upper bridge, upstream

Powerville, N. J., above dam of Powerville Lake

Powerville, N. J., lower bridge, upstream

Boonton, N'. J., Pond Bridge, Main Street, upstream

Boonton, N. J., dam at Main Street

Boonton, N. J., U. S. Geological Survey gaging station Just below Morris Avenue

Boonton, N. J., Monroe Avenue Bridge, upstream

Boonton, N. J., high bridge over Boonton Reservoir

Boonton Reservoir at Boonton, N. J.

Boonton, N. J., U. S. Geological Survey gaging station $1,50 u$ feet below Boonton Reservoir

Boonton, N. J., Vreeland Avenue, above dam

Boonton, N. J., Vreeland Avenue, old concrete bridge, upstream

Lake Hiawatha, N. J., northwest of, 2 miles downstream from Boonton Reservoir, highway bridge, upstream

Lake Hiawatha, N. J., above dam

Pine Brook, W. J., l $\frac{1}{3}$ miles west of Vail Road Bridge, upstream

Pine Brook, N. J., State Highway 6, girder bridge, upstream

ce New Jersey Geological Survey mean sea level datum. cf At time of reading. Puak stage may have been hisher. New Jersey Geological
Survey mean sea level datum.

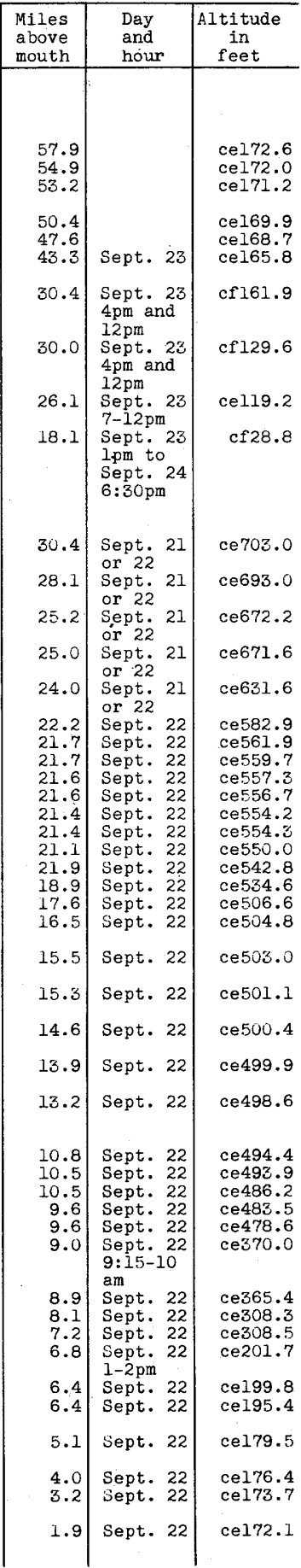


Table 19.--Flood creat stages--Continued

Stream and location
Passalc River Basin--Continued
Whippany River:

Morristown, N. J., U. S. Geological Survey gaging station at sewage disposal plant, 300 feet below MonroeMorris Plains Road

Whippany, N. J., I mile above, Upper Eden Mill Dam

Whippany, N. J., Thomas Street Bridge, downstream Whippany, N. J., Morristown Road Bridge, downstream

Whippany, N. J., 1 mile east of, State Highway 10 bridge, downstream

Hanover Neck, N. J., near Edwards Road Bridge (north channel), downstream

Pompton River:

Pompton Plains, N. J., above Canal Feeder Dam

Ramapo River:

Pompton Lakes, N. J., U. S. Geological Survey gaging station above dam at Pompton Lakes

Wanaque River:

The Glens, N. J., at U.S. Geolog1cal. Survey gaging station on Greenwood Lake

Greenwood Lake, N. J., U. S. Geological Survey gaging station $600^{\circ}$ feet downstream from Greenwood Lake

Wanaque, N. J., Wanaque Reservolr at Raymond Dam

Wanaque, N. J., U. S. Geological jurvey gaging station 50 feet above highway bridge

Cupsaw Brook:

Wanaque, N. J., 5 miles north of U. S. Geological Survey gaging station just above Wanaque Reservoir

Pequannock River:

Oak Ridge, N. J., Oak Ridge Reservoir

Butler, N. J., 3 miles above U. S. Geological Survey gaging station at Macopin intake dam

Pacock Brook:

Stockholm, N. J., Canistear Reservoir near

Clinton Reservoir Branch of Pequannock River:

Newfoundland, N. J., Clinton Reservoir near

Saddle River:

Lodi, N. J., U. S. Geological survey gaging station just above Outwater Lane

\section{Ellzabeth Rlver Basin}

Elizabeth River:

Irvington, N. J., U. S. Geological Survey gaging station Just below Valley Street

Hillside, N. J., at Mill Road Bridge, upstream

Hillside, N. J., Union Avenue Bridge, upstream

Union, N. J., State Highway 29 Bridge, upstream

Union, N. J., above Salem Road, above dam

Union, N. J., Salem Road Bridge, upstream

Unton, N. J., Lehtgh Valley R.R. bridge, upstream

Elizabeth, N. J., Irvington Avenue Bridge, downstream

Ellzabeth, N. J., U. S. Geological Survey gaging station above Westfield Avenue, above dam

West Branch of blizabeth River:

Union, N. J., Chestnut Street Bridge, upstream

Unton, N. J., Morris Avenue Bridge, east, downstream

Union, N. J., Sayre Road Bridge, upstream

\section{Rahway Rlver Basin}

West Branch of Rahway River:

Springfield, N.J., Springfield Avenue, downstream

Rahway River:

Springfield, N. J., Rahway Valley R.R. bridge upstream

ce New Jersey Geological Survey mean sea level datum. cf At time of reading. Peak stage may have been higher. New Jersey Geological
Survey mean sea level datum.

cg Arbitrary datum. 
Table 19.--Flood crest stages--Continued

\begin{tabular}{|c|c|}
\hline Stream and location & \\
\hline
\end{tabular}

Rahway River Basin--Continued

Rahway River--Continued.

Springfieid, N. J., Milltown Road Bridge, downstream Springfield, N. J., U. S. Geological Survey gaging station 50 feet below State Highway 29

Cranford, N. J., Kenilworth Boulevard Bridge, downstream

Cranford, N. J., Springfield Avenue, north bridge, upstream

Cranford, N. J., Eastman Street, south bridge, downstream

Cranford, N: J., above Hansel Dam

Cranford, N. J., Union Avenue Bridge, upstream

Cranford, N. J., North Avenue Bridge, upstream

Cranford, N. J., South Avenue Bridge, upstream

Cranford, N. J., above Droescher Dam

Cranford, N. J., High Street Bridge, upstream

Cranford, N. J., Lehigh Valley R.R. bridge, downstream

Clark Township, N. J., below Sperry Dam

Clark Township, N. J., above Bloodgood Dam

Clark Township, N. J., below Bloodgood Dam

Clark Township, N. J., above Jackson Dam

Clark Township, N. J., below Jackson Dam

Rahway, N. J., north end of waterworks

Rahway, N. J., U. S. Geological Survey gaging station 100 feet above st. George Avenue

Rahway, N. J., Whittier Street Bridge, east, upstream

Rahway, N. J., Grand Street Bridge, upstream

Robinson Branch of Rahway River:

Westfield, N. J., Raritan Road Bridge, upstream

Clark Township, N. J., above dam above Madison Hill Road

Clark Township, N. J., Madison Hill Road, upstream

Rahway, N. J., Maple Averue Bridge, upstream

Rahway, N. J., Jefferson Avenue Bridge, upstream

Rahway, N. J., Central Avenue Bridge, upstream

Rahway, N. J., St. George Avenue Bridge, upstream

Rahway, N. J., Hamilton Street Bridge, upstream

\section{Raritan River Basin}

South Branch of Raritan River:

Crestmoore, N. J., lower highway bridge

Califon, N. J., highway bridge

Hoffmans, N. J'., highway bridge, upstream

Readingsburgh, N. J., Stone Mill Bridge, upstream

High Bridge $\mathbb{N}$. J., 1 mile north of U. S. Geological Survey gaging station

High Bridge, N.J., 0.3 mile north of, above steel plant dam

High Bridge, N. J., ratlroad bridge in steel plant, upstream

High Bridge, N. J., Central Rallroad of New Jersey arch bridge, upstream

High Bridge, N. J., first highway bridge below Central Rellroad of New Jersey, upstream

High Bridge, N. J., I mile south of, highway bridge, upstream

Clinton, N. J., half a mile north of, State Highway 30 bridge, upstream

Clinton, N. J., 0.2 mile above Spruce Run, highway bridge, upstream

Clinton, N. J., State Highway 28 bridge, downstream Landsdowne, N.'J., one-quarter of a mile northeast of, Clinton-Hamden road bridge, upstream

Hamden, N. J., Hamden-Clinton road bridge, upstream

Hamden, N. J., Lehigh Valley R.R. bridge, downstream

Hamden, $N$. J., second highway bridge below rallroad bridge

Sunnyside, N. J., upper highway bridge, upstream

Sunnyside, N. J., highway bridge, upstream

Stanton, N. J., U. S. Geological Survey gaging station just below highway bridge near stanton raliroad station

Flemington Junction, N. J., 1 mile north of, State Highway 30 bridge, upstream

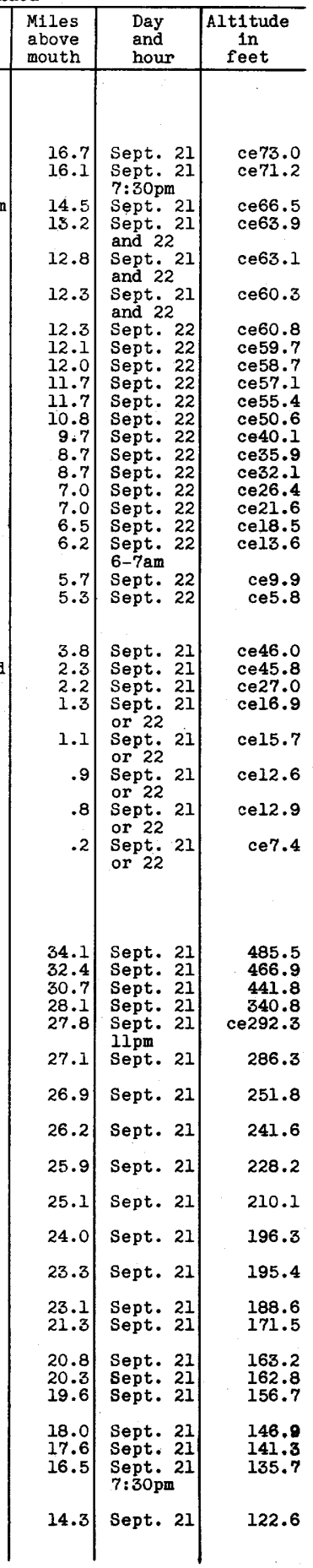

ce New Jersey Geological Survey mean sea level datum. 
Table 19.--Flood crest stages--Continued

Stream and location

Raritan River Basin--Continued

South Branch of Raritan River--Continued.

Flemington Junction, N. J., half a mile northeast of Darts Mills, U. S. Highway 122 bridge, downstream

Flemington Junction, N. J., Lehigh Valley R.R. bridge, downstream

Flemington, N. J., 2 miles northeast of Central Railroad of New Jersey bridge

Flemington, N. J., 2 miles east of Rockafellows Mills highway bridge, upstream

Three Bridges, N. J., highway bridge, downstream

Woodfern, N. J., highway bridge

Neshanic station, N. J., highway bridge

South Branch, N. J., highway bridge

Raritan River:

Somervilie, N. J., just above state Highway 31 bridge

Manville, N. J., U. S. Geological Survey gaging station just below Manville-Finderne highway bridge

Manville, N. J., Just above mouth of Millstone RIver

Bound Brook, N.'J., 1 mile west of Calco Chemical Co. plant

Bound Brook, N. J., Main Street opposite bridge to South Bound Brook

Fieldville, N. J., above dam

Neshanic River:

Reaville, N. J., half a mile southwest of U. S. Geological Survey gaging station at highway bridge to Muirhead

Walnut Brook:

Flemington, N. J., $1 \frac{1}{4}$ miles northwest of U. S. Geological Survey gaging station

North Branch of Raritan River:

Far lilils, N. J., 2 miles north of U. S. Geological Survey gaging station above Ravine Dam

Far Hills, N. J., $1 \frac{1}{2}$ miles south of State Highway 31 bridge

Burnt Mill, N. J., highway bridge, just below mouth of Lamington River

North Branch, N. J., State Highway 28 bridge

Milltown, N. J., U. S. Geological Survey gaging station 400 feet above State Highway 29

south Branch, N. J., three-quarters of a mile north of Old York Hoad Bridge

Black River (head of Lamington River):

Pottersvilie, N. J., I mile above U. S. Geological Survey gaging station

Pottersville, N. J., highway bridge

Lamington River:

Vliettown, N. J., upper highway bridge

vliettown, N. J., lower highway bridge

Lamington, N. J., highway bridge

Chambers Brook:

Pluckemin, N. J., half a mile south of state Highway 31 bridge

Peters Brook:

Somervilie, N. J., State Highway 29 bridge

Somerville, N. J., Grove street bridge

Millstone River:

Princeton, N. J., near, above Kingston Dam of Lake Carnegie

Princeton, N. J., near, Delow Kingston Dam of Lake Carnegie

Kingston, N. J., State Highway 27 bridge

Kingston, N. J., near U. S. Geological Survey gaging station 1 mile downstream from Heathcots Brook

Rocky hill, N. J., highway bridge

Griggstown, N. J., highway bridge

Blackwells Mills, N. J., U. S. Geological survey gaging station just below highway bridge

Milistone, N. J., highway bridge

ce New Jersey Geological Survey mean sea level datum.

cg Arbitrary datum.

\begin{tabular}{|c|c|c|}
\hline $\begin{array}{l}\text { Miles } \\
\text { above } \\
\text { mouth }\end{array}$ & $\begin{array}{l}\text { Day } \\
\text { and } \\
\text { hour }\end{array}$ & $\begin{array}{c}\text { Altitude } \\
\text { in } \\
\text { feet }\end{array}$ \\
\hline 12.9 & Sept. 21 & 112.5 \\
\hline 12.3 & Sept. 21 & 107.5 \\
\hline 21.7 . & Sept. 21 & 102.2 \\
\hline 11.2 & Sept. 2l & 99.8 \\
\hline $\begin{array}{r}10.0 \\
7.7 \\
5.3 \\
.8\end{array}$ & $\begin{array}{ll}\text { Sept. } 2 I \\
\text { Sept. } 2 I \\
\text { Sept. } 2 I \\
\text { Sept. 2I }\end{array}$ & $\begin{array}{l}93.6 \\
84.1 \\
70.5 \\
66.6\end{array}$ \\
\hline 26.1 & $\begin{array}{l}\text { Sept. } 22 \\
\text { lam }\end{array}$ & 44.3 \\
\hline 23.2 & Sept. 22 & 41.0 \\
\hline $\begin{array}{l}21.5 \\
20.5\end{array}$ & $\begin{array}{l}\text { Sept. } 22 \\
\text { Sept. } 22\end{array}$ & $\begin{array}{l}37.5 \\
34.4\end{array}$ \\
\hline 19.3 & Sept. 22 & 30.5 \\
\hline 17.7 & Sept. 22 & 25.2 \\
\hline 6.4 & $\begin{array}{l}\text { Sept. } 21 \\
4: 30 \mathrm{pm}\end{array}$ & $\operatorname{cg} 10.7$ \\
\hline 3.1 & $\begin{array}{l}\text { Sept. } 2 l \\
2 \mathrm{pm}\end{array}$ & $\mathrm{cg} 2.8$ \\
\hline 15.0 & $\begin{array}{l}\text { Sept. } 21 \\
8 \mathrm{pm}\end{array}$ & ce 229.8 \\
\hline 10.1 & Sept. 21 & 111.5 \\
\hline 6.7 & Sept. 21 & 85.5 \\
\hline $\begin{array}{r}3.7 \\
1.4 \\
.1\end{array}$ & $\begin{array}{l}\text { Sept. } 21 \\
\text { Sept. 21 } \\
\text { 8:40pm } \\
\text { Sept. } 21\end{array}$ & $\begin{array}{l}72.1 \\
62.6 \\
58.4\end{array}$ \\
\hline 11.4 & $\begin{array}{l}\text { Sept. } 21 \\
4: 40 \text { pm } \\
\text { Sept. } 21\end{array}$ & $\begin{array}{l}\text { ce288.1 } \\
\text { ce } 215.4\end{array}$ \\
\hline $\begin{array}{l}8.2 \\
7.7 \\
6.7\end{array}$ & $\begin{array}{l}\text { Sept. } 21 \\
\text { Sept. } 21 \\
\text { Sept. } 21\end{array}$ & $\begin{array}{l}160.4 \\
148.0 \\
128.1\end{array}$ \\
\hline 2.7 & Sept. 21 & 167.9 \\
\hline $\begin{array}{r}2.1 \\
.1\end{array}$ & $\begin{array}{ll}\text { Sept. } 21 \\
\text { Sept. } 21\end{array}$ & $\begin{array}{l}60.0 \\
44.3\end{array}$ \\
\hline 16.2 & Sept. 21 & 56.1 \\
\hline $1 \in .2$ & Sept. 21 & 55.4 \\
\hline $\begin{array}{l}16.0 \\
15.1\end{array}$ & $\begin{array}{ll}\text { Sept. } 21 \\
\text { Sept. } 21\end{array}$ & $\begin{array}{r}53.4 \\
c e 52.1\end{array}$ \\
\hline $\begin{array}{r}14.1 \\
9.9 \\
6.2\end{array}$ & $\begin{array}{l}\text { Sept. } 21 \\
\text { Sept. } 21 \\
\text { Sept. } 27\end{array}$ & $\begin{array}{l}47.4 \\
45.5 \\
42.3\end{array}$ \\
\hline 4.2 & $\begin{array}{l}\text { Sept } \\
\text { or } 22\end{array}$ & 41.0 \\
\hline
\end{tabular}


Table 19.--Flood crest stages--Continued

$\frac{\text { Stream and location }}{\text { Raritan River Basin--Continued }}$

Millstone River--Continued.

Weston, N. J., highway bridge

Green Brook:

Scotch Plains, N. J., Union Avenue Bridge, upstream

Scotch Plains, N. J., Mountain Avenue Bridge, downstream

Plainfleld, N. J., Terrill Road Bridge, downstream

Plainfield, N. J., Raymond Avenue Bridge, upstream

Plainfield, N. J., Farragut Road Bridge, upstream

Plainfield, N. J., Norwood Avenue Bridge, upstream

Plainfleld, N. J., U. S. Geological Survey gaging station 20 feet below Sycamore Avenue

Plainfleld, N. J., Geraud Avenue Bridge, upstream

Plainfield, N. J., West End Avenue Bridge, upstream

Ambrose Brook:

East Bound Brook, N. J., Union and Raritan Avenues

Lawrence Brook:

Milltown, N. J., half a mile southwest of, U. S. Geological Survey gaging station above Farrington Dam

Deep Run:

Browntown, N. J., $13 / 4$ miles south of, U. S. Geological Survey gaging station Spring Valley road bridge

Tennent Brook:

Browntown, N. J., $1 \frac{1}{4}$ miles northwest of, U. S. Geological Survey gaging station

Matawan Creek:

Matawan, N. J., U. S. Geological Survey gaging station above Lefferts Lake dam

\section{Coastal basin}

Swimming River:

Red Bank, N. J., U. S. Geological Survey gaging station above dam of Monmouth Consolidated Water Co. near

Manasquan River:

Squankum, N. J., U. S. Ceological Survey gaging station just above Farmingdale-Lakewood road bridge

Toms River:

Toms River, N. J., $2 \frac{i}{2}$ miles northwest of, U. S. Geologica Survey gaging station 1 mile below mouth of Union Branch

Cedar Creek:

Lanoka Harbor, N. J., U. S. Geological Survey gaging sta tion at highway bridge

East Branch of Wading River:

Harrisville, N. J., U. S. Geological Survey gaging station just below highway bridge

\section{Great Egg River:}

Folsom, N. J., 1 mile south of, U. S. Geological Survey gaging station highway bridge

Maurice River:

Norma, N. J., U. S. Geological Survey gaging station at Almond Road bridge

Manantico Creek:

Millville, N. J., 4 miles northeast of, U. S. Geological Survey gaging station Millville-Milmay road bridge

\section{Delaware River Basin}

\section{Delaware River:}

Milford, $\mathrm{Pa} ., \mathrm{U}$. S. Geological Survey gaging station, highway bridge, upstream

Belvidere, N. J., U. S. Geological Survey gaging station just below mouth of Pequest River

Easton, Pa., U. S. Geological Survey gaging station, highway bridge, upstream

Riegelsville, N. J., U. S. Geological Survey gaging station Just above suspension bridge

\section{Milest}

above

\begin{tabular}{l|l|c} 
mouth & $\begin{array}{l}\text { Day } \\
\text { and } \\
\text { hour }\end{array}$ & $\begin{array}{c}\text { Altitud } \\
\text { in } \\
\text { feet }\end{array}$ \\
\hline & &
\end{tabular}


Table 19.--Flood crest stages--Continued

Stream and location

\begin{tabular}{|c|c|c}
$\begin{array}{c}\text { Miles } \\
\text { above } \\
\text { mouth }\end{array}$ & $\begin{array}{c}\text { Day } \\
\text { and } \\
\text { hour }\end{array}$ & $\begin{array}{c}\text { Altitude } \\
\text { in } \\
\text { feet }\end{array}$ \\
\hline 100.6 & $\begin{array}{l}\text { Sept. 23 } \\
6-7 a m\end{array}$ \\
9.8 & $\begin{array}{l}\text { Sept. 22 } \\
\text { 3am } \\
\text { Sept. 22 } \\
\text { 3am }\end{array}$ & 354.8 \\
$\mathrm{cg} 7.6$
\end{tabular}

Pequest River:

Quaker Church, N. J., highway bridge

Quaker Church, N. J., half a mile south of highway bridge

Long Bridge, N. J., Lehigh \& Hudson R.R. bridge above highway

Long Bridge, N. J., Lehigh \& Hudson R.R. bridge below highway

Great Meadows, N. J., Long Bridge road bridge

Great Meadows, N. J., State highway bridge

Great Meadows, N. J., half a mile southwest of Lehigh \& Hudson R.R. bridge

Towmsbury, N. J., highway bridge

Townsbury, N. J., 1 mile southwest of Lehigh \& Hudson R.R. bridge

Pequest, N.J., highway bridge

Pequest, N. J., U.S. Geological Survey gaging station 100 feet above Lehigh \& Hudson R.R. bridge

Buttzvilie, N.J., Lehigh \& Hudson R.R. bridge

Buttzville, N. J., steel-truss highway bridge

Bridgeville, N. J., plank highway bridge

Bridgeville, N. J., stone arch highway bridge

Belvidere, N. J., I mile northeast of highway bridge

Belvidere, N. J., at ribbon mill, downstream from Hardwick Street

Belvidere, N. J., Pennsylvania R.R. bridge

Beaver Brook:

Belvidere, N. J., U. S. Geological Survey gaging station 2 miles east of, 2,000 feet above mouth

Belvidere, N. J., 2 miles east of, State Highway 6 bridge

Musconetcong River:

Landing, N. J., Lake Hopatcong, Just above dam

Landing, N. J., U. S. Geological Survey gaging station 300 feet downs iream from Lake Hopatcong

Hackettstown, N. J., 3 miles above U. S. Geological Survey gaging station just above dam at Saxton Falls

Hackettstown, N.J., 3 miles above U. S. Geological survey gaging station 500 feet above Delaware, Lackawanna \&estern R.R. bridge

Bloomsbury, N. J.; l li miles above U. S. Geological Survey gaging station just above highway bridge

Assunpink Creek:

Trenton, N. J., U. S. Geologlcal Survey gaging station at Chambers street Bridge

$23.7\left|\begin{array}{l}\text { Sept. } 23 \\ 11: 40 \mathrm{am} \\ 23.0 \\ \text { jept. 23 } \\ 11: 30 \mathrm{am} \\ \text { Sept. 23 } \\ 11: 15 \mathrm{~mm}\end{array}\right|$

cf 534.7

cf 532.5

cf 528.1

21.5 Sept. 22

cf 529.3

15.0 Sept. 24 cf 516.9

13.3 Sept. $24^{10: 45 \mathrm{am}}$ cf 514.0

10.7 Sept. 24 $\quad$ of 506.6

$10.4 \mid \begin{aligned} & 1: 55 \mathrm{pm} \\ & \text { Sept. 24 }\end{aligned} \quad$ cf 488.4

$8.9 \begin{aligned} & 10: 10 \mathrm{am} \\ & \text { Sept. } 24\end{aligned} \quad$ cf 438.4

2:15pm

7.6 Sept. 24 cf 406.3

7.1 Sept. 22 $\begin{aligned} & \text { 9:40am } \\ & \text { Se } 402.6\end{aligned}$

5.8 Sept. $24 \quad$ cf 383.7

$5.5 \begin{aligned} & \text { 9:10am } \\ & \text { Sept. 22 }\end{aligned} \quad$ cf 372.8

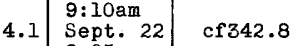

3.9 Sept. 22 cf334.6

1.5 Sept. 22 cf280.9

9: $15 \mathrm{am}$

.4 Sept. 22 $\quad$ cf 257.6

.1 Sept. 22 cf249.5

$4\left|\begin{array}{l}9 a m \\ \text { Sept. } 22\end{array}\right| \operatorname{ce} 307.2$

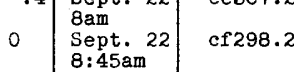

42.4 Sept. 23

42.3 Sept. 23

33.1 Sept. 22

5-7am

32.7 Sept. 22 ce609.5

$9.4 \mid$\begin{tabular}{l|l}
6 am \\
Sept. 21
\end{tabular}$\quad 280.0$

$1.5\left|\begin{array}{l}10-12 \mathrm{pm} \\ \text { Sept. 22 } \\ 2: 45 \mathrm{am} \\ \text { and } 3: 30 \\ \text { am }\end{array}\right|$

$\operatorname{ce} 35.5$

ce924.5

ce907.3

ce 633.9

ce New Jersey Geological Survey mean sea level datum.

cf At time of reading. Peak stage may have been higher. New Jersey Geological Survey mean sea level datum.

cg Arbitrary datum. 
Table 19.--Flood crest stages--Continued

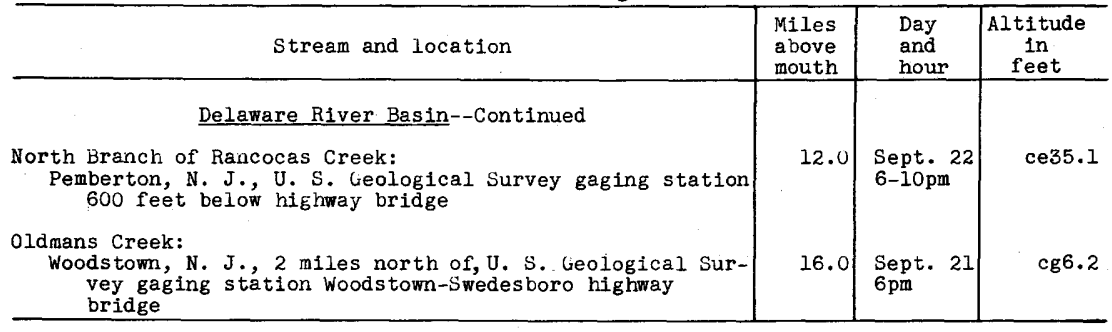

ce New Jersey Geological Survey mean sea level datum. cg Arbitrary datum. 


\section{OCEAN STORM WAVE IN COASTAL AREAS}

Climaxing the events of the storm and the resulting floods, the violent West Indian hurricane that swept in from the Atlant1c Ocean on the afternoon of September 21 added appallingly to the general flood havoc. Over the storm area the hurricane force of the winds alone was sufficlent to wreck innumerable structures of all types. The beautiful trees in cities, towns, villages, along the highways, and in the parks and forests were uprooted and broken to an unbellevable extent. Along the shores of Long Island and the southern coast of New England, a great wave rolled in from the ocean, augmenting the devastation of the hurricane and in many places leaving hardly a vestige of human occupation. Along several miles of beach frontage the destruction in the short space of a few hours was so complete that there was a near reversion to pristine appearance. This great surge of water was forced into the many bays and tidal estuaries and raised them to record-breaking levels, this being particularly true in the eastern sector of the storm area where the great wave was cpproxirnately symchronized with normal high tide. Thus many of the larger towns and cities on the bays and estuaries, some of them a considerable distance from the sea, were engulfed by the highest water of record with a consequent heavy loss of life and property. Perhaps not as awe-inspiring, but no less serious and disastrous, was the like effect of this great storm wave in each of the many smaller, low-lying villages and hamlets so closely spaced along the entire coast line from Cape Cod to Sandy Hook and around Long Island. Although very difficult to appraise, estimates of the destruction of property along the coasts as a result of the hurricane and storm wave reach as high as $\$ 80,000,000$. Loss of life was serlous enough, mounting to the hundreds, but the toll would have been many times greater if the storm had struck only a few weeks earlier, during the height of the summer shore vacation season.

The history of storms in New England (see "Records of previous floods and storms.") demonstrates that the West Indian hurricanes must be placed in the "to-be-expected" class of catastrophe and that there is an established possibility that one may occur in any year. If this be true, then a thorough recording and dissemination of information as to the destructive effects and areal extent of the hurricane winds and great storm waves is warranted as a basis of development of ways and means for protection of human iffe and property. An interesting and valuable part of such information with particular respect to the present or future location and protection of shore and water-front property is a record of storm-wave 


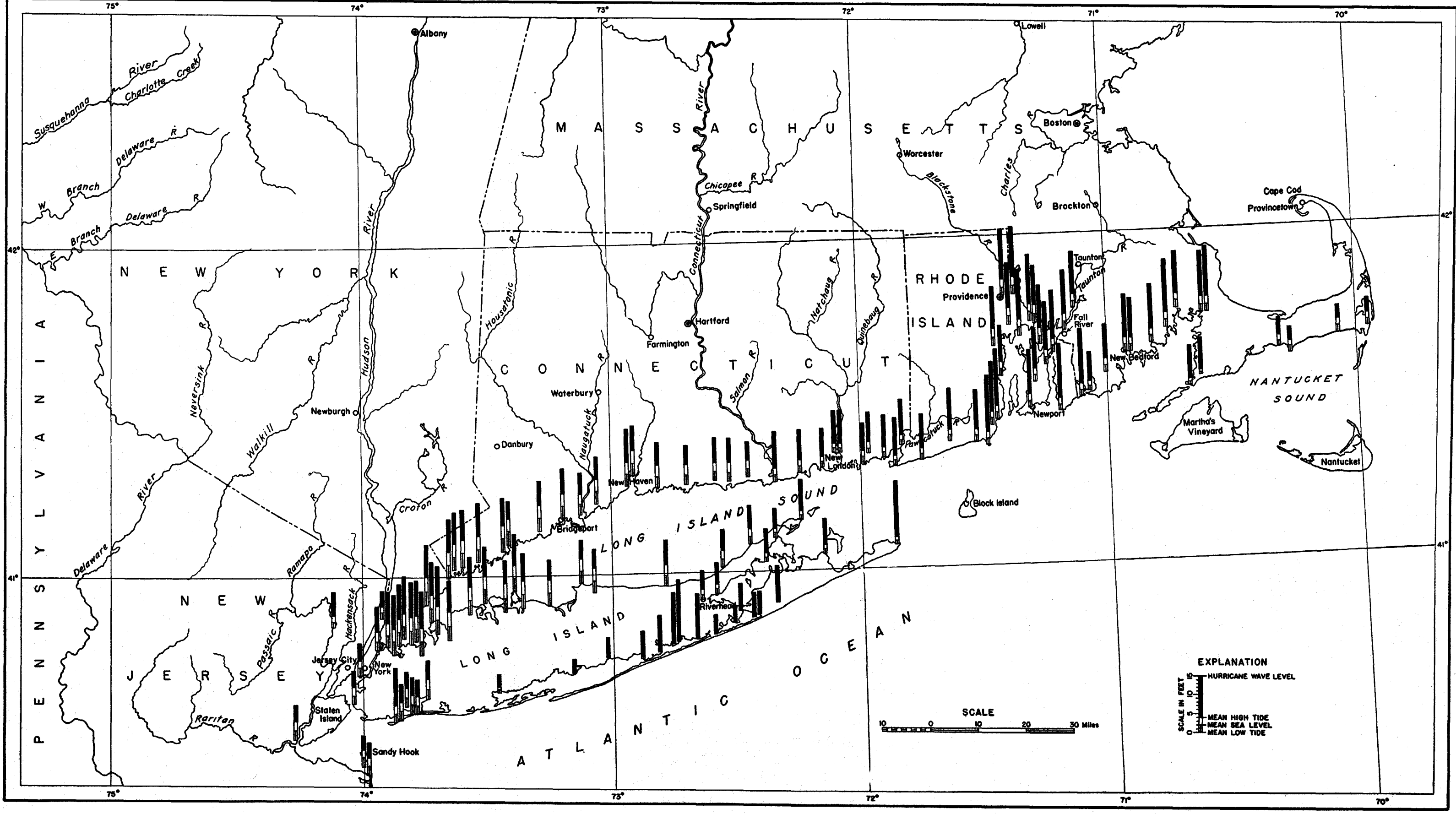

MAP SHOWING HEIGHT OF OCEAN-STORM WAVE FROM CAPE COD, MASS., TO SANDY HOOK, N. J. 



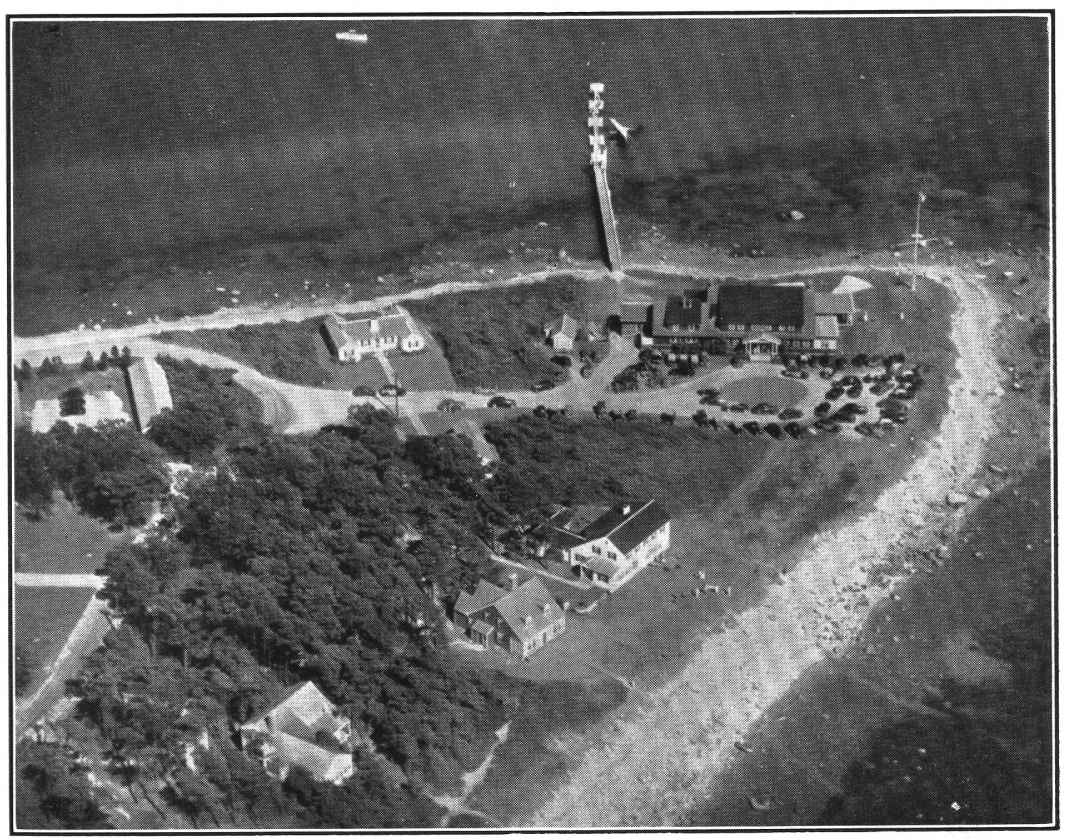

A.

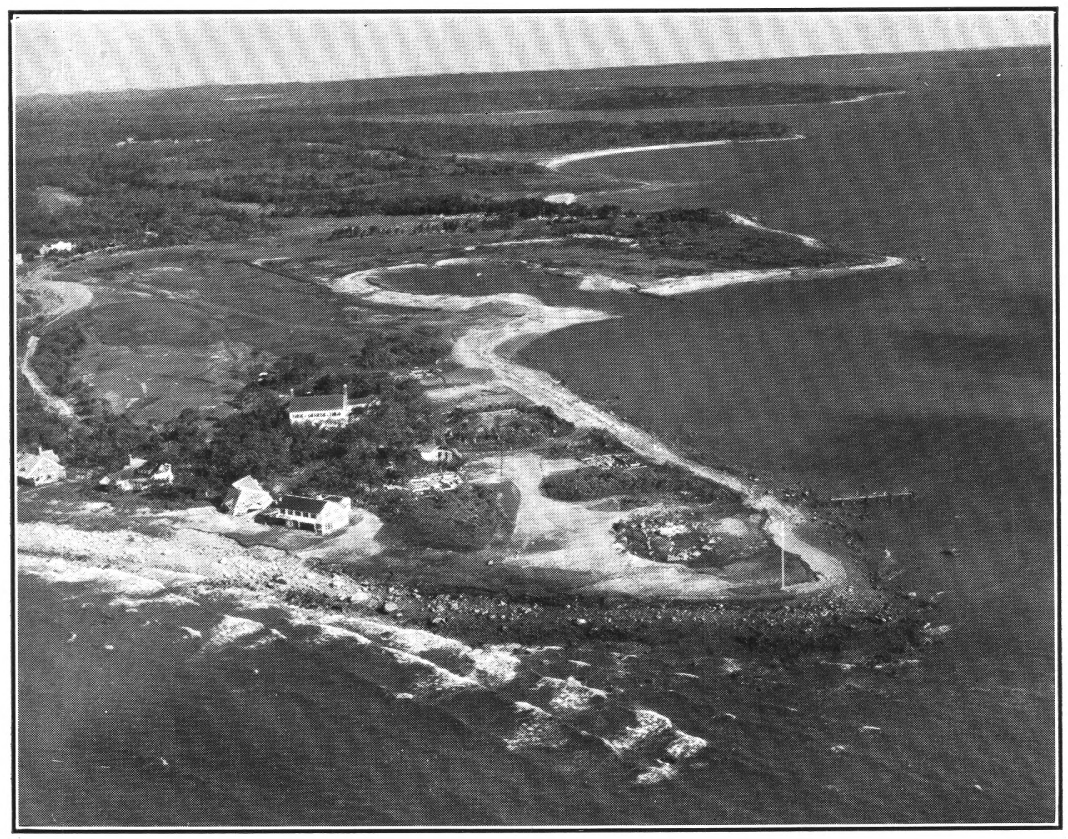

$B$.

BEVERLY YACHT CLUB AT MARIAN, MASS., BEFORE AND AFTER THE HURRICANE. Courtesy of Pictures, Inc. 


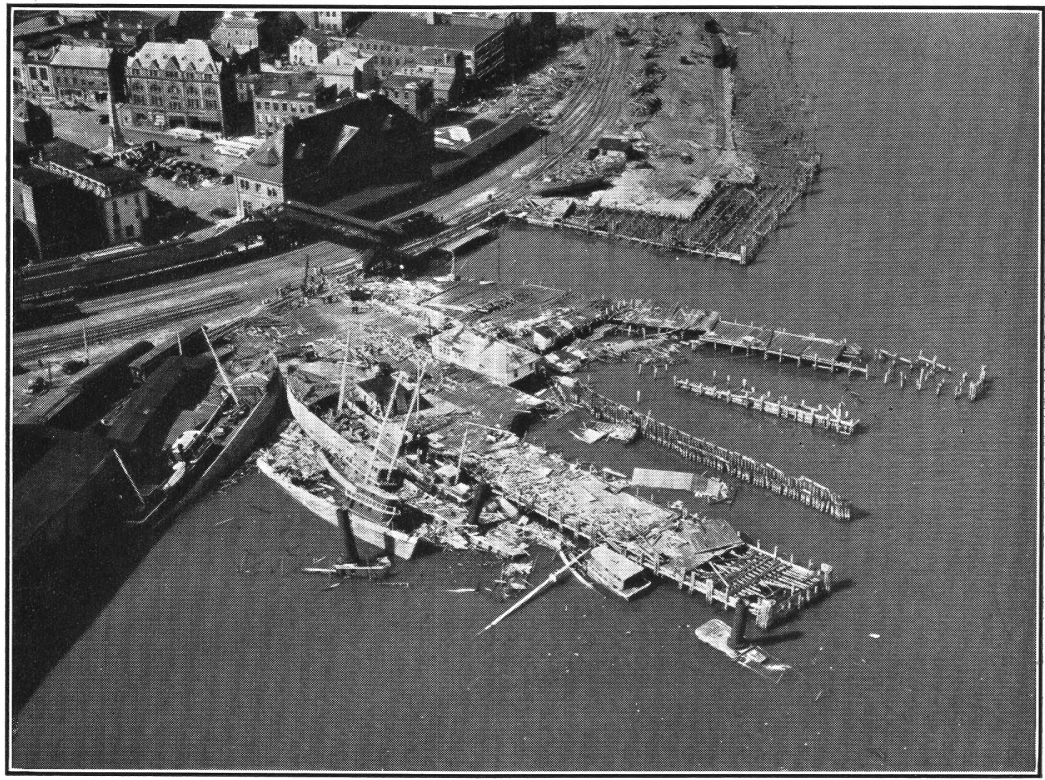

A. PIERS AND BOATS AT NEW LONDON.

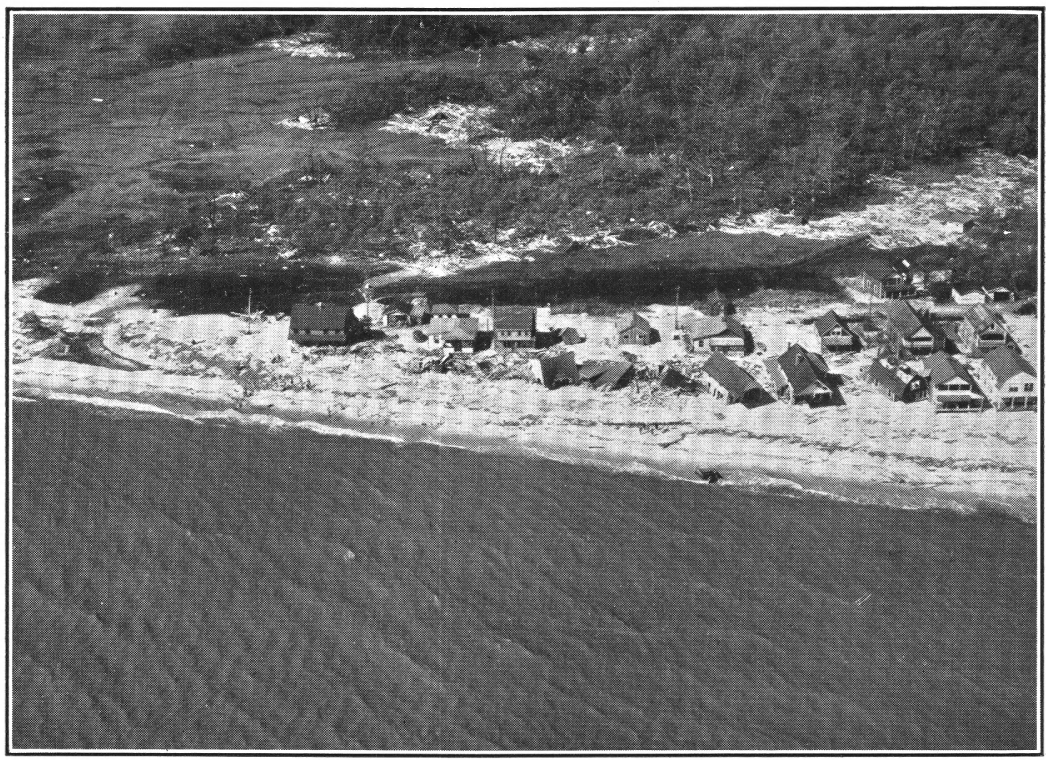

B. SUMMER HOMES AND COTTAGES AT HAWKS NEST.

DAMAGE BY STORM WAVE ON CONNECTICUT COAST.

Photographs by 118th Photo Section, Air Corps, Connecticut National Guard. 


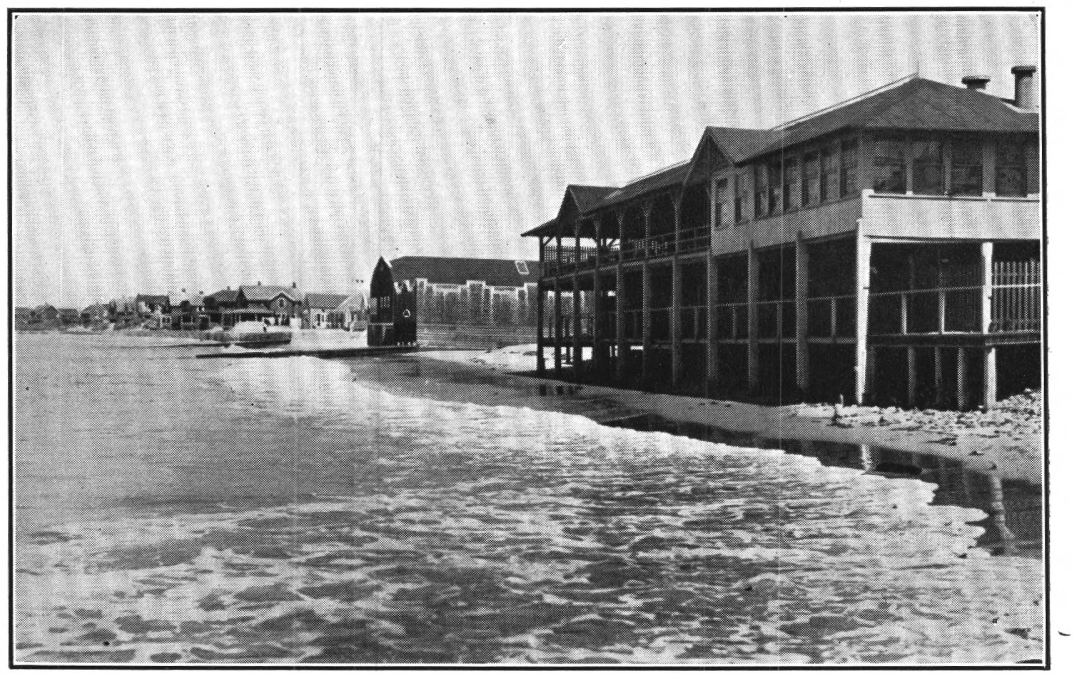

$A$.

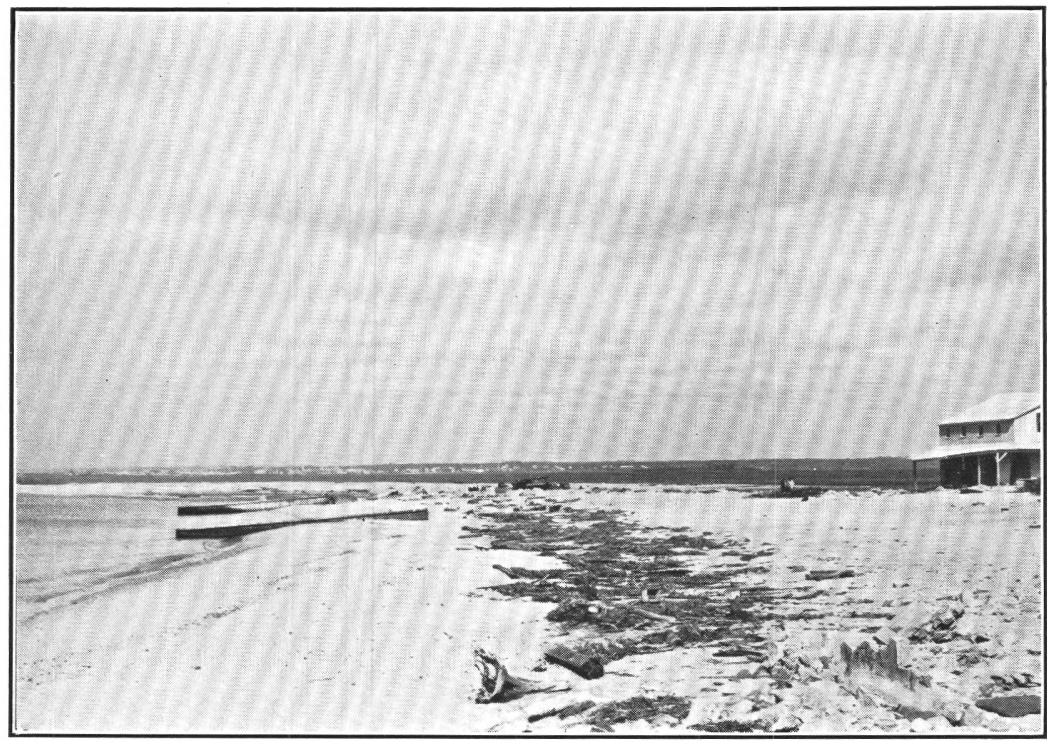

$B$.

WATER FRONT AT WATCH HILL, WESTERLY, R. I., BEFORE AND AFTER THE HURRICANE. Courtesy of Lewis R. Green. 
heights along the coastal reaches. Recognizing the need for information on this destructive phase of the hurricane of september 1938, some State and Federal agencies were able to gather considerable factual data. The United States Coast and Geodetic Survey as part of its regular duties maintains tidal stations at several points along the coast. The Corps of Engineers, United States Army, at its Providence, R. I., and New York, N. Y., offices, assembled considerable data on the storm-wave heights, as did also the Massachusetts Department of Public Works at Boston. The Connecticut State Water Commission (Ground-water Project) at Hartford observed and recorded the wave helght in the lower Connecticut River, but these records are not used because of the masking effect of rising flood discharges in the river itself. The staff of the Geological survey office at Hartford, Conn., established the wave helght at some additional points on the Connecticut shore. Many interested individuals and agencies within and without the government services evinced a keen interest in the collection and compilation of a record of the storm-wave heights along the coast.

The Providence office of the Corps of Engineers made avallable a compllation of the records of storm-wave heights along the southerm New England coast, and the New York office furnished similar data for the New York and Long Island areas. Through the courtesy and cooperation of the district engineers at these offices these compilations are presented in table 20 on the pages immediately following. This table includes the helght records collected by the Massachusetts Department of Public Works. The Coast and Geodetic Survey supplied maximum heights as determined at the several regular tidal stations in the area, which also appear in table 20 .

Plate 16 is a graphical picturization of the tabular data and should ald in visualizing the relative heights of the storm wave at various points along the coast lines and in the bays and estuaries. (See also pls. 17, 18, and 19.) The bases of the columns are located on the map as closely as possible to the sites where the field observations of storm-wave height were made and represent mean low water level. The vertical scale of the columns is indicated in the explanation of the map. The first horizontal Iine above the base represents mean sea level at the place of observation, the second horizontal line represents mean high water level, and the top of the column represents the poak of the storm wave of September 21. At some locations, averages were taken of several observations of storm-wave height made in the vicinity, as listed in table 20. The coast and Geodetic Survey also furnished hourly tidal heights for September 21 and 22 , for $22790160-40-34$ 
Table 20.--Storm wave elevations, in feet

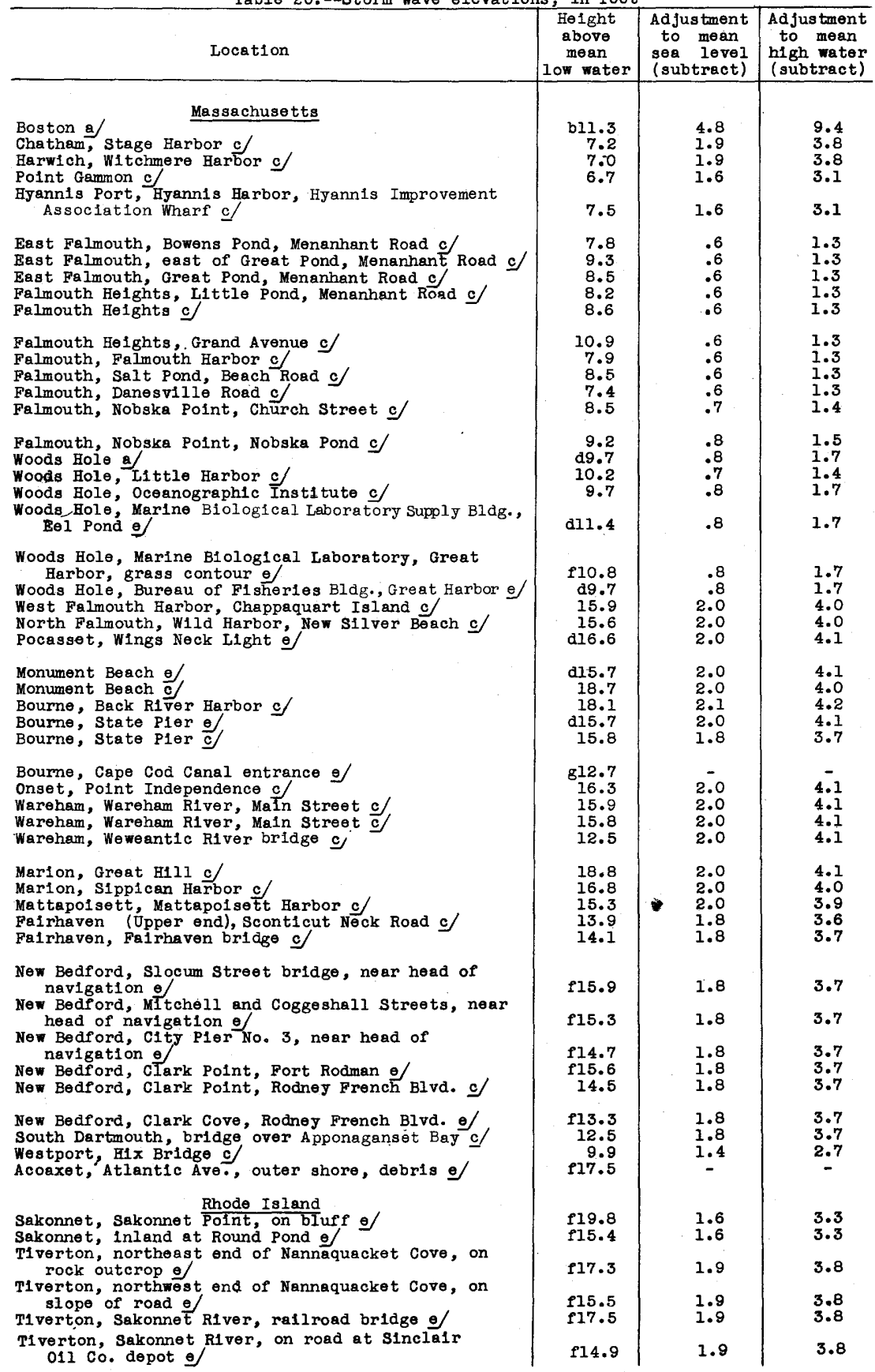

a Furnished by U. S. Coast and Geodetic Survey.

b At 8:36 p.m.; nomal high t1de 9:00 p.m.; measured in st1lling well.

c Furnished by Massachusetts Department of Publ1c Works.

d Measured in stilling well or similar enclosure.

e Furni shed by Corps of Engineers, U. S. Army, Providence, R. I.

$f$ Measured in the open; subject to wave action.

g Elevation above mean sea level. 
Table 20.--Storm wave elevations, in feet--Continued

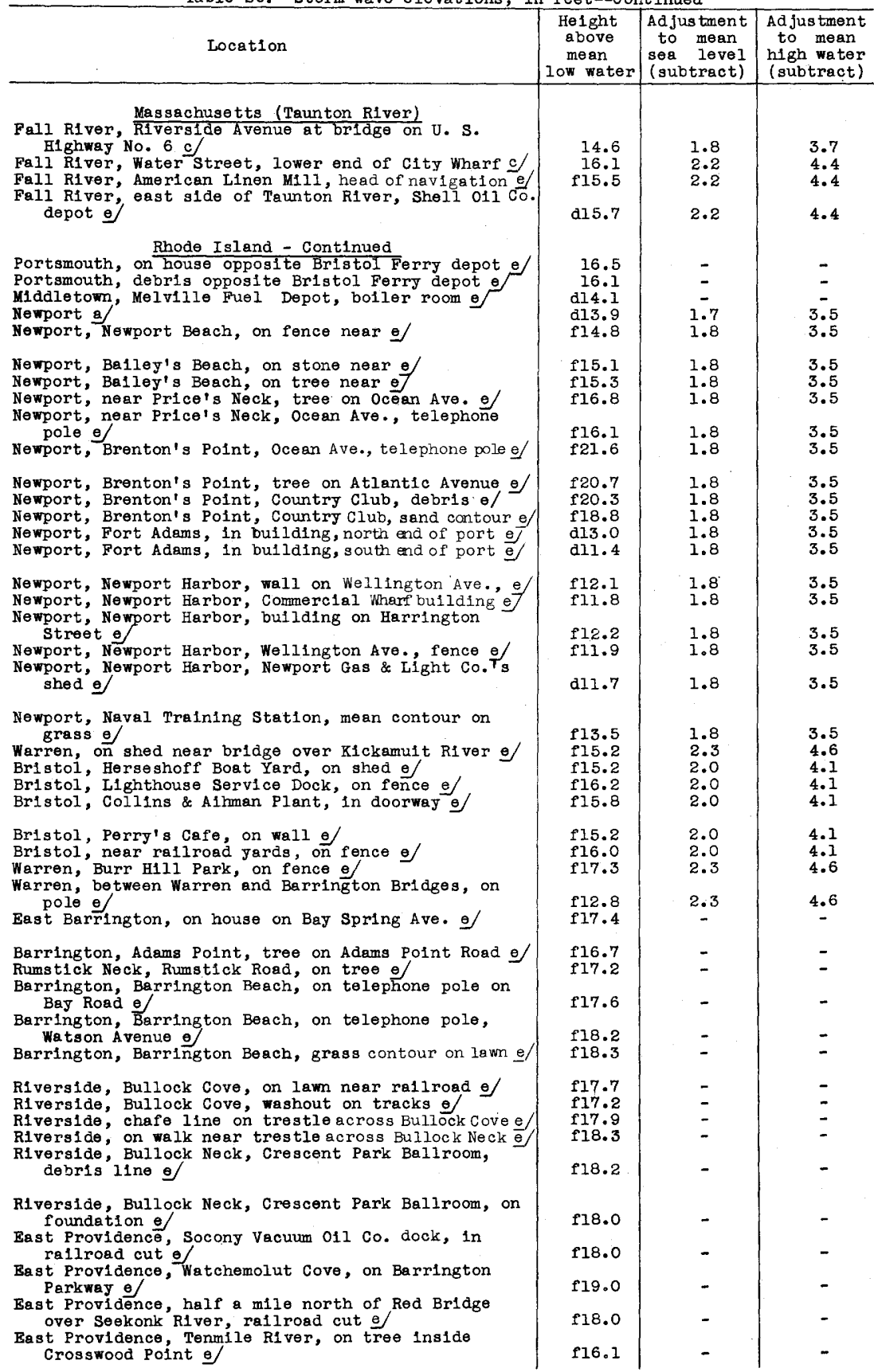

a Furnished by U. S. Coast and Geodetic Survey.

c Furnished by Massachusetts Department of Public Works.

d Messured in stilling well or similar enclosuré.

- Furnished by Corps of Engineers, U. S. Army, Providence, R. I.

$f$ Measured in the open; subject to wave action. 
Table 20.--Storm wave elevations, in feet--Cont inued

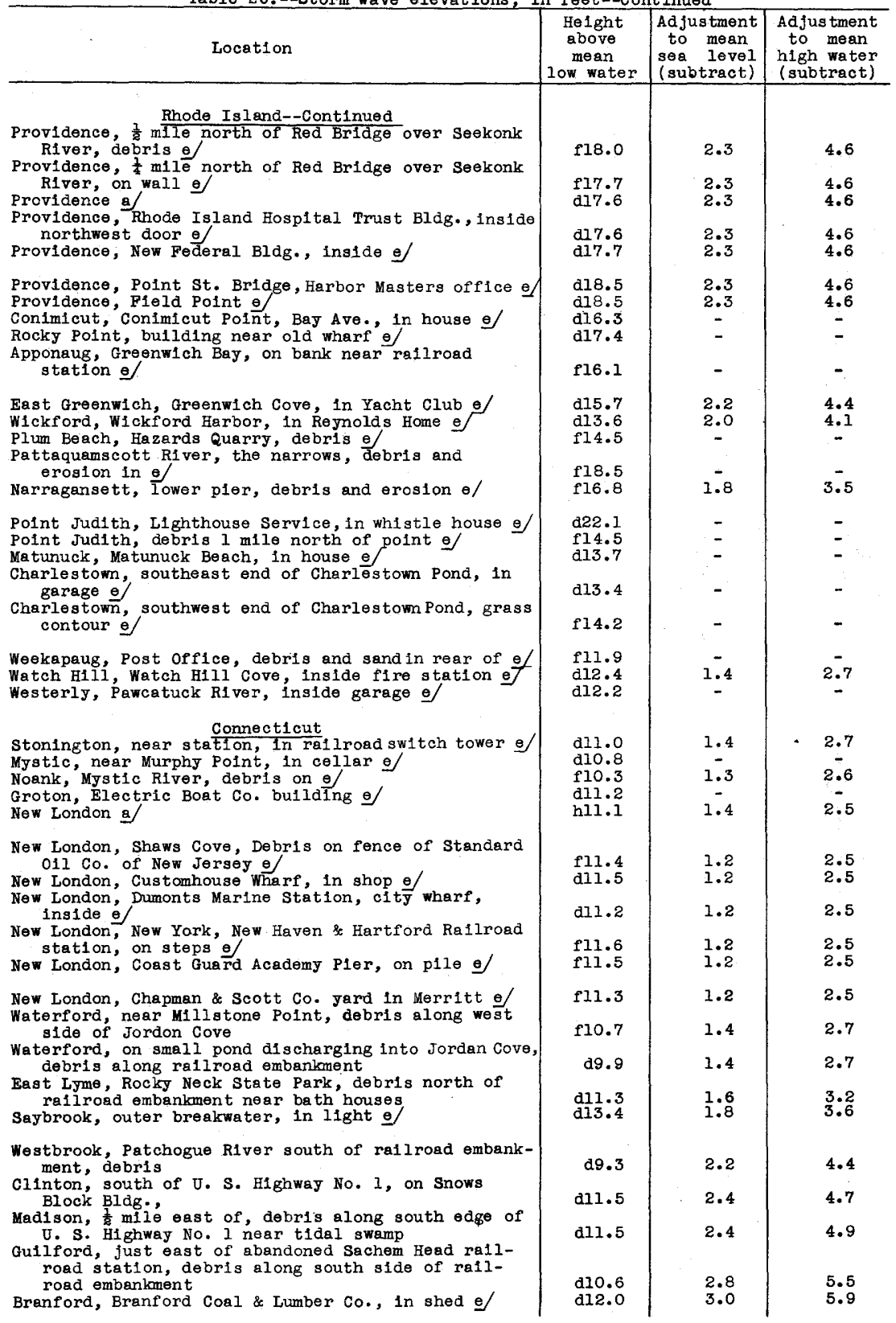

a Furnished by U. S. Coast and Geodetic Survey.

d Messured in stiling well or similar enclosure.

- Furnished by Corps of Engineers, U. S. Army, Providence, R. I.

$f$ Measured in the open; subject to wave action.

$h$ At 4:45 p.m. Normal high tide 7:11 p.m. Measured in stilling well. 
Table 20.--Storm wave elevations, in feet--Continued

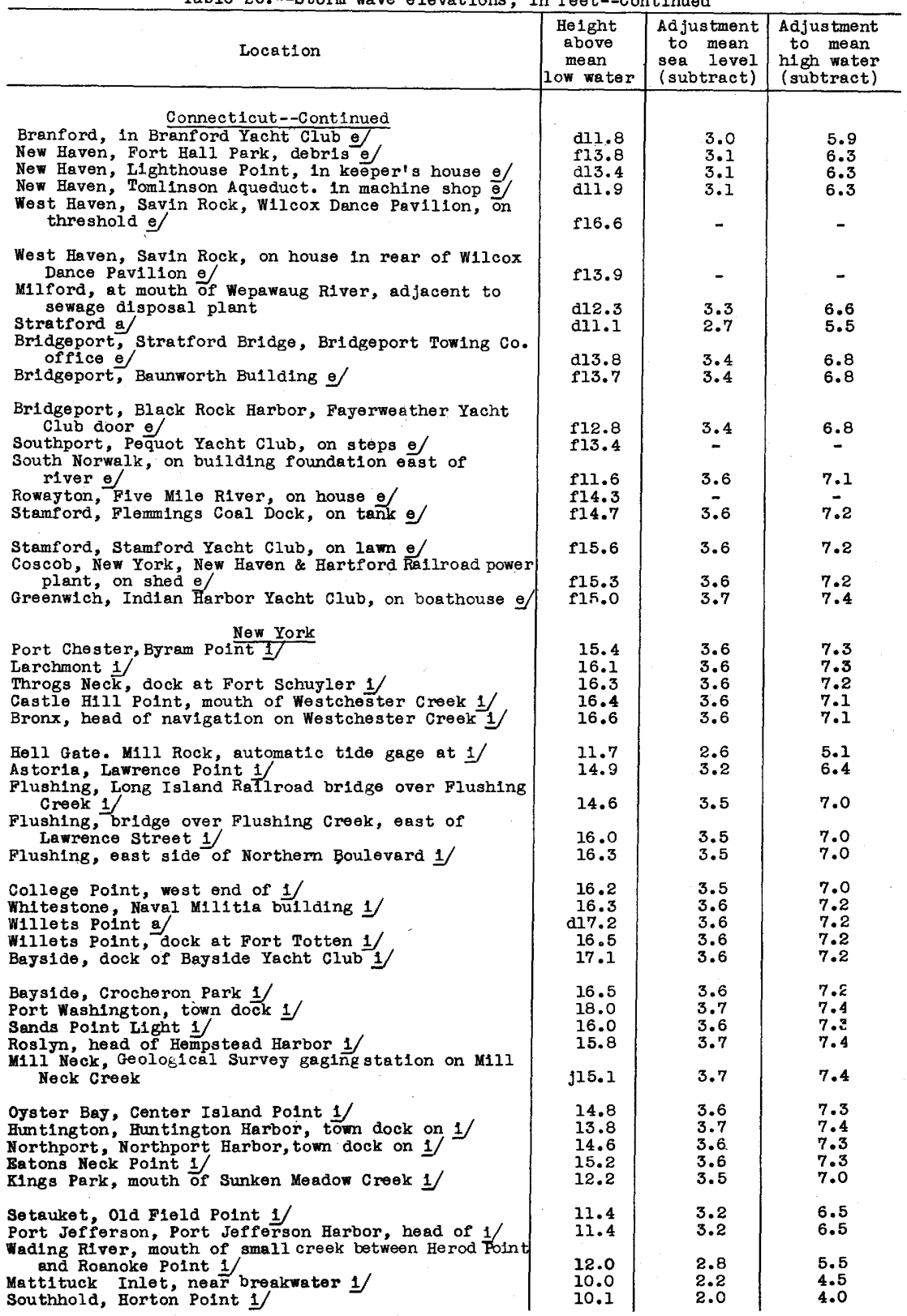

a Furnished by U. S. Coast and Geodetic Survey.

d Neasured in stililing well or similar enclosure.

- Furnished by Corps of Engineers, U. S. Army, Providence, R. I.

$f$ Measured in the open; aubject to wave action.

1 Furnished by Corps of Ingineers, U. S. Army, New York, N. Y.

f At 8 p.m. (normal high tide about $9: 35$ p.m.) messured in stilling well. 
Table 20.--Storm wave elevations, in feet--Continued

\begin{tabular}{|c|c|c|c|}
\hline Location & $\begin{array}{c}\text { Helght } \\
\text { above } \\
\text { mean } \\
\text { low water }\end{array}$ & $\begin{array}{l}\text { Adjustment } \\
\text { to mean } \\
\text { sea level } \\
\text { (subtract) }\end{array}$ & $\begin{array}{l}\text { Adjus tment } \\
\text { to mean } \\
\text { high water } \\
\text { (subtract) }\end{array}$ \\
\hline $\begin{array}{l}\text { Orient, Orient Po New York--Continued } \\
\text { Greenport, Greenport Harbor } 1 / \\
\text { Great Hog Neck, Cedar Beach Point 1// } \\
\text { South Jamesport } 1 / \\
\text { Riverhead } 1 /\end{array}$ & $\begin{array}{r}10.7 \\
7.6 \\
8.6 \\
8.2 \\
7.6\end{array}$ & $\begin{array}{l}1.2 \\
1.2 \\
1.2 \\
1.4 \\
1.4\end{array}$ & $\begin{array}{l}2.5 \\
2.4 \\
2.3 \\
2.7 \\
2.7\end{array}$ \\
\hline $\begin{array}{l}\text { Hog Creek Point, east of Three Mile Harbor } 1 / \\
\text { Montauk Point, drift line } 1 / \\
\text { Mecox Bay, west of Southhampton } 1 / \\
\text { Southhampton, head of Heady Creek } 1 / \\
\text { Southhampton, Shinnecock Indian Reservation, south } \\
\text { shore of } 1 \text {. }\end{array}$ & $\begin{array}{r}9.3 \\
16.7 \\
9.6 \\
5.8 \\
6.3\end{array}$ & $\begin{array}{l}1.2 \\
1.0 \\
\mathrm{kO} 0 \\
\mathrm{kO}\end{array}$ & $\begin{array}{l}2.4 \\
2.0 \\
k 0 \\
k 0 \\
k 0\end{array}$ \\
\hline $\begin{array}{l}\text { Hampton Bays, south end of Shinnecock Canal near } \\
\text { Canoe Place } 1 / \\
\text { Hampton Bays, Ponquogue Point bridge } 1 / \\
\text { Quogue Canal, westerly end } 1 / \text { Jant (Main St.) bridge on } \\
\text { West Hampton Beach, Potunk Point } \\
\text { Quantuck Canal } 1 / \text {. } \\
\text { East Moriches, head of Hart Cove } 1 /\end{array}$ & $\begin{array}{r}7.2 \\
4.2 \\
5.3 \\
11.9 \\
15.7\end{array}$ & $\begin{array}{l}\text { ko } \\
\text { kO } \\
\text { kO } \\
\text { kO } \\
\text { kO }\end{array}$ & $\begin{array}{l}k 0 \\
k 0 \\
k 0 \\
k 0 \\
\text { kO }\end{array}$ \\
\hline $\begin{array}{l}\text { East Moriches, outer end of Hart Cove } 1 / \\
\text { Mast1c Beach, Forge Point } 1 / \\
\text { Mast1c Beach, Smith Point } 1 / \\
\text { Patchogue, north end of breakwater } 1 / \\
\text { Nicholl Point, Heckscher State Park 1/ }\end{array}$ & $\begin{array}{r}13.5 \\
9.8 \\
7.6 \\
5.2 \\
3.9\end{array}$ & $\begin{array}{r}\mathrm{kO} \\
\mathrm{kO} \\
.4 \\
.4 \\
.3\end{array}$ & $\begin{array}{r}\text { ko } \\
\text { k0 } \\
.7 \\
.7 \\
.6\end{array}$ \\
\hline $\begin{array}{l}\text { B1ltmore Shores, South Oyster Bay, south shore of } 1 / \\
\text { Rockaway Beach, at Beach 80th st. } 1 / \\
\text { Rockaway Beach, Ostend Baths } 1 / \text { Guard Station } 1 / \\
\text { Rockaway Beach, Rils Park Coast Guard } \\
\text { Rockaway Beach at Beach Channel Drive and Cross Bay } \\
\text { Blvd. 1/ }\end{array}$ & $\begin{array}{r}4.9 \\
9.0 \\
9 \cdot 5 \\
14.3 \\
9.6\end{array}$ & $\begin{array}{l}2.7 \\
2.3 \\
2.3 \\
2.6\end{array}$ & $\begin{array}{l}1.4 \\
4.6 \\
4.6 \\
4.6 \\
5.1\end{array}$ \\
\hline $\begin{array}{l}\text { Broad Channel, west End, loth st. } 1 / \\
\text { Head of Jamalca Bay, Hook Creek canal } 1 / \\
\text { Fort Hamilton, autometic tide gage on government } \\
\text { dock } 1 / \\
\text { Spuyten Duyvil, automatic tide gage on Harlem River, } \\
\text { at } N \text {. Y. Central R.R. bridge } 1 \text {. } \\
\text { Battery Park, automatic tide gage on ferry slip west } \\
\text { of } 1 \text {. }\end{array}$ & $\begin{array}{r}9.4 \\
10.2 \\
8.8 \\
7.2 \\
8.6\end{array}$ & $\begin{array}{l}2.6 \\
2.7 \\
2.4 \\
1.8 \\
2.2\end{array}$ & $\begin{array}{l}5.1 \\
5.4 \\
4.7 \\
3.6 \\
4.4\end{array}$ \\
\hline Battery Park a/ & $\mathrm{m} 8.7$ & 2.3 & 4.4 \\
\hline $\begin{array}{l}\text { Passaic, Gregory Avenue Bridge on Passalc River } 1 / \\
\text { Perth Amboy, automatic tide gage } 1 / \\
\text { Atlantic Highlands, mouth of Shrewsbury R1ver 1/ } \\
\text { Sandy Hook, qutomatic tide gage at government dock } 1 / \\
\text { Sandy Hook a/ }\end{array}$ & $\begin{array}{r}9.4 \\
9.2 \\
8.7 \\
8.2 \\
\text { n7.7 }\end{array}$ & $\begin{array}{l}1 \cdot 6 \\
2 \cdot 6 \\
2 \cdot 4 \\
2 \cdot 3 \\
2 \cdot 3\end{array}$ & $\begin{array}{l}3 \cdot 3 \\
5 \cdot 2 \\
4 \cdot 7 \\
4 \cdot 6 \\
4 \cdot 6\end{array}$ \\
\hline
\end{tabular}

a Furnished by U. S. Coast and Geodetic Survey.

1 Furnished by Corps of Engineers, U. S. Army, New York, N. Y.

k Normal tidal variation slight, if any, prior to hurricane.

m At $4: 30 \mathrm{p} . \mathrm{m}$. Normal high tide $6: 20 \mathrm{p} . \mathrm{m}$. Measured in stiling well.

$n$ At 4 p.m. Normal high tide at $5: 38$ p.m. Measured in stilling well. 
stations at Sandy Hook, N. J., New York, N. Y., and Boston, Mass., which are presented in table 21 together with a partial record registered at the river-measurement station of the Geological Survey on Mill Neck Creek at Kill Neck, N. Y., near 1ts point of discharge into Long Island Sound.

Táble 2l.--Heights of storm wave above mean low water, in feet, at indicated time, September $21,22,1938.8$

\begin{tabular}{|c|c|c|c|c|c|c|c|}
\hline \multirow{3}{*}{ Hour } & \multirow{2}{*}{\multicolumn{2}{|c|}{$\frac{\begin{array}{c}\text { Sandy Hook, } \\
\text { N. J. }\end{array}}{\text { September }}$}} & \multirow{2}{*}{\multicolumn{2}{|c|}{$\begin{array}{c}\text { The Battery, } \\
\text { N. Y. } \\
\text { September }\end{array}$}} & \multirow{2}{*}{\multicolumn{2}{|c|}{$\frac{\begin{array}{c}\text { Boston, } \\
\text { Mass. }\end{array}}{\text { September }}$}} & \multirow{3}{*}{$\begin{array}{l}\text { Mill Neck, } \\
\text { N. Y. } \\
\frac{\text { September }}{21}\end{array}$} \\
\hline & & & & & & & \\
\hline & 21 & 22 & 21 & 22 & 21 & 22 & \\
\hline $\begin{array}{ll}1 & a \cdot m \\
2 & \\
3 & \\
4 & \\
5 & \\
6 & \end{array}$ & $\begin{array}{l}1.3 \\
2.8 \\
3.9 \\
5.1 \\
5.6 \\
5.3\end{array}$ & $\begin{array}{r}-1.6 \\
-1.2 \\
-.1 \\
1.9 \\
5.0 \\
5.7\end{array}$ & $\begin{array}{l}0.9 \\
2.4 \\
3.7 \\
4.8 \\
5.2 \\
5.3\end{array}$ & $\begin{array}{r}-0.7 \\
-\quad .6 \\
-.4 \\
2.1 \\
4.4 \\
5.6\end{array}$ & $\begin{array}{r}1.0 \\
-\quad .6 \\
-\quad .1 \\
1.6 \\
3.8 \\
6.3\end{array}$ & $\begin{array}{r}2.8 \\
-.1 \\
-1.6 \\
-.4 \\
.8 \\
3.0\end{array}$ & $\begin{array}{l}- \\
\overline{-} \\
- \\
-\end{array}$ \\
\hline $\begin{array}{r}7 \\
8 \\
9 \\
10 \\
11 \\
12 \mathrm{m.} .\end{array}$ & $\begin{array}{l}4.4 \\
3.4 \\
2.5 \\
1.6 \\
1.0 \\
1.0\end{array}$ & $\begin{array}{l}5.2 \\
3.8 \\
2.5 \\
1.1 \\
. .3\end{array}$ & $\begin{array}{r}4.8 \\
4.0 \\
2.9 \\
2.0 \\
1.2 \\
.5\end{array}$ & $\begin{array}{r}5.6 \\
4.7 \\
3.6 \\
2.0 \\
1.1 \\
.3\end{array}$ & $\begin{array}{r}8.7 \\
10.3 \\
10.5 \\
9.2 \\
7.2 \\
5.1\end{array}$ & $\begin{array}{r}6.2 \\
9.2 \\
10.6 \\
10.6 \\
9.2 \\
7.1\end{array}$ & $\begin{array}{l}\overline{-} \\
\bar{z} \\
\bar{z}\end{array}$ \\
\hline $\begin{array}{ll}1 & p \cdot m . \\
2 & \\
3 & \\
4 & \\
5 & \\
6 & \end{array}$ & $\begin{array}{l}1.8 \\
3.5 \\
5.9 \\
7.8 \\
5.1 \\
3.0\end{array}$ & $\begin{array}{r}-.1 \\
.4 \\
1.8 \\
3.3 \\
4.8 \\
5.7\end{array}$ & $\begin{array}{l}.6 \\
1.8 \\
4.4 \\
8.1 \\
6.7 \\
3.8\end{array}$ & $\begin{array}{l}0 \\
0 \\
1.0 \\
3.0 \\
4.5 \\
5.4\end{array}$ & $\begin{array}{r}2.6 \\
.7 \\
.6 \\
3.0 \\
5.3 \\
7.0\end{array}$ & $\begin{array}{r}4.4 \\
1.4 \\
-\quad .8 \\
-1.2 \\
.5 \\
2.7\end{array}$ & $\begin{array}{l}\overline{-} \\
\overline{-} \\
-\end{array}$ \\
\hline $\begin{array}{r}7 \\
8 \\
9 \\
10 \\
11 \\
12\end{array}$ & $\begin{array}{r}.8 \\
.3 \\
2.5 \\
2.6 \\
.8 \\
-1.2\end{array}$ & $\begin{array}{l}5.8 \\
4.7 \\
3.2 \\
1.9 \\
. .8\end{array}$ & $\begin{array}{r}3.3 \\
2.4 \\
2.3 \\
4.0 \\
1.6 \\
-\quad .1\end{array}$ & $\begin{array}{r}5.7 \\
5.4 \\
4.4 \\
3.0 \\
1.7 \\
.7\end{array}$ & $\begin{array}{r}8.8 \\
10.6 \\
11.0 \\
10.0 \\
8.2 \\
6.1\end{array}$ & $\begin{array}{r}5.6 \\
8.3 \\
10.4 \\
11.0 \\
10.0 \\
8.0\end{array}$ & $\begin{array}{l}11.6 \\
15.1 \\
13.2 \\
12.4 \\
12.1 \\
12.0\end{array}$ \\
\hline
\end{tabular}

a Data furnished by U. S. Coast and Geodetic Survey except that for the U. S. Geological Survey gaging station on Mill Neck Creek.

With respect to the helght of the storm wave at stations of the Coast and Geodetic Survey, the director of that Survey states as follows: $23 /$

The extreme height of water in the hurricane of September 21 at the Boston tide station, the most easterly station considered, was 1.9 feet above mean high water. This is only slightly above normal and has been exceeded frequently in the past. At Sandy Hook, most westerly of the tidal stations in the area, the tide reported on September 21 was 3.1 feet above mean high water. This is considerably above normal but is not the highest of record. At Battery Place, New York, N. Y., it was 4.3 feet. At all intemediate stations the observed heights were the greatest of which the coast and Geodetic Survey has record. These measurements were: at Willets Polnt, 10 feet above mean high water; at Stratford, 5.6 feet; at New London, 8.6 feet; at Newport, 10.4 feet; at Woods Hole, 8 feet; and at Providence, 13 feet above mean high water.

The following discussion of the storm wave and assoclated tidal events is based largely on data and information furnished by the coast and Geodetic Survey and by the Corps of Engineers, United States Army, whose cooperation is hereby acknowledged.

23/ Colbert, I. 0., The Coast and Geodetic Survey in relation to our beaches: Shore and Beach, vol. 7, no. 2, pp. 54-56, April 1939. 
The time at which the storm wave reached its maximum height is not definitely known except at the five places indicated in table 20 . Col. C. I. Ha1l, of the Corps of Engineers, United States Army, estimated that the storm wave reached the southern Long Island coast at 2:30 p.m., preceding the predicted high tide by about 3 hours. At the places indicated in the table the maximum stage was reached before the time of normal high water, and the storm wave was superimposed upon the rising tide. At Boston, where the storm wave was not exceptional, the time of high water was advanced by about half an hour. At other places the storm wave crest was reached $1 \frac{1}{2}$ to $2 \frac{1}{2}$ hours before the time of normal high water. Doubtless the fact that the storm wave occurred before the normal tide reached Its peak caused the resultant heights to be slightly lower than they might otherwise have been although the timing was far from favorable. Moreover, comparison of the predicted high tide for the afternoon of september 21 with the mean high tide level of record at the Coast and Geodetic Survey tide stations listed in table 20 gives an approximate measure of the rise attributable to the prevailing astronomical conditions, which was about 1 foot.

The upper part of figure 56 shows a graph of water levels observed at The Battery, New York, N. Y., together with a graph of the predicted undisturbed tide as derived from data fumished by the Coast and Geodetic Survey.

Beginning soon after low water at about noon September 21, the water level rose rapidiy to a peak of 8.7 feet above mean low water at 4:30 p.m., followed by equally rapid recession to a trough below the normal undiaturbed tidal level from 8 to 9 p.m. The harbor level again rose to a second but lower peak at $10 \mathrm{p} . \mathrm{m}$., followed by a return to nearly normal tidal regimen on September 22. The records of water level at Sandy Hook, N. J., and in an observation well of the Geological Survey at Rockaway Beach, N. Y., shows similar behavior. These oscillations are portrayed on the graph of the difference between the observed and the predicted water levels at New York shown in the lower part of figure 56 . A graph of the barometric lowering, in feet of water, is also shown together with notations of the hourly wind direction at New York.

The departures of the height of the sea from normal tidal regimen shown in figure 56 are probably attributable to three factors, namely, variations in the local barometric pressure gradients produced by the hurricane, the tractive force of the hurricane winds, and the complex effects of shore-line configuration. During the first 14 hours of 


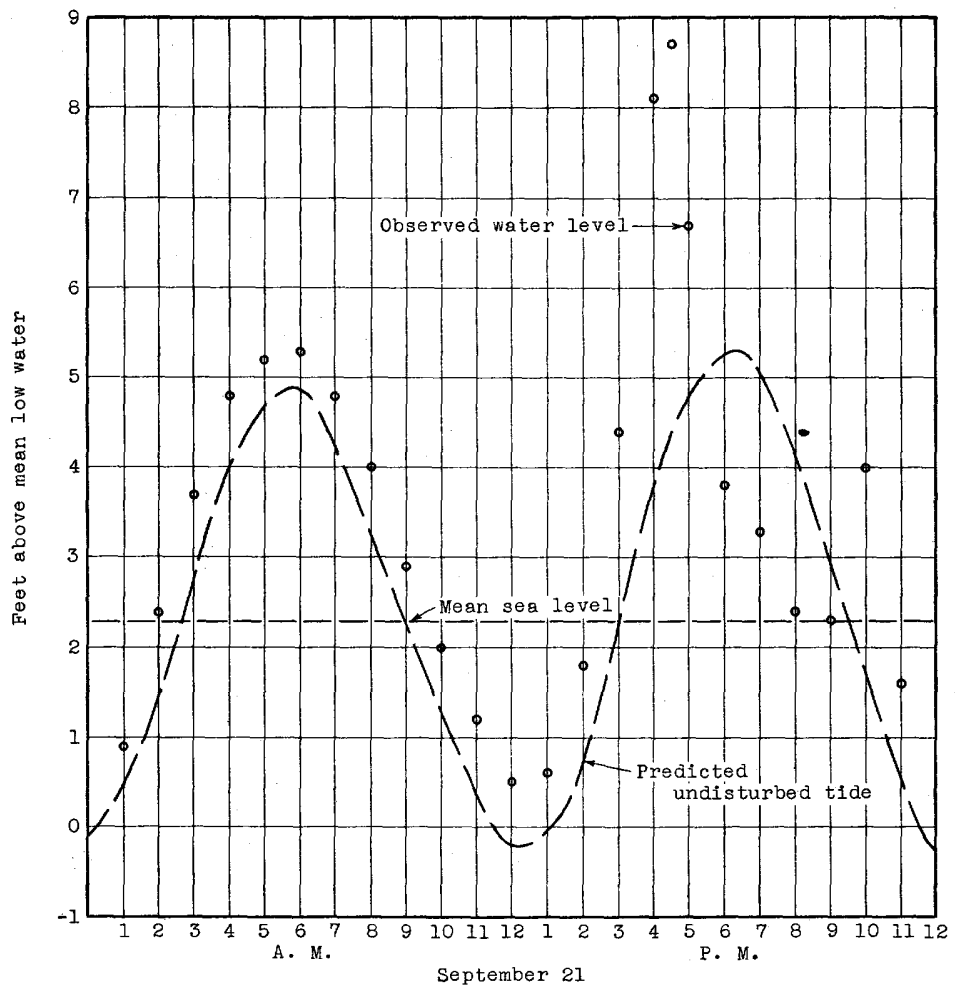

Graph of observed and predicted water levels at The Battery, New York, N. Y.

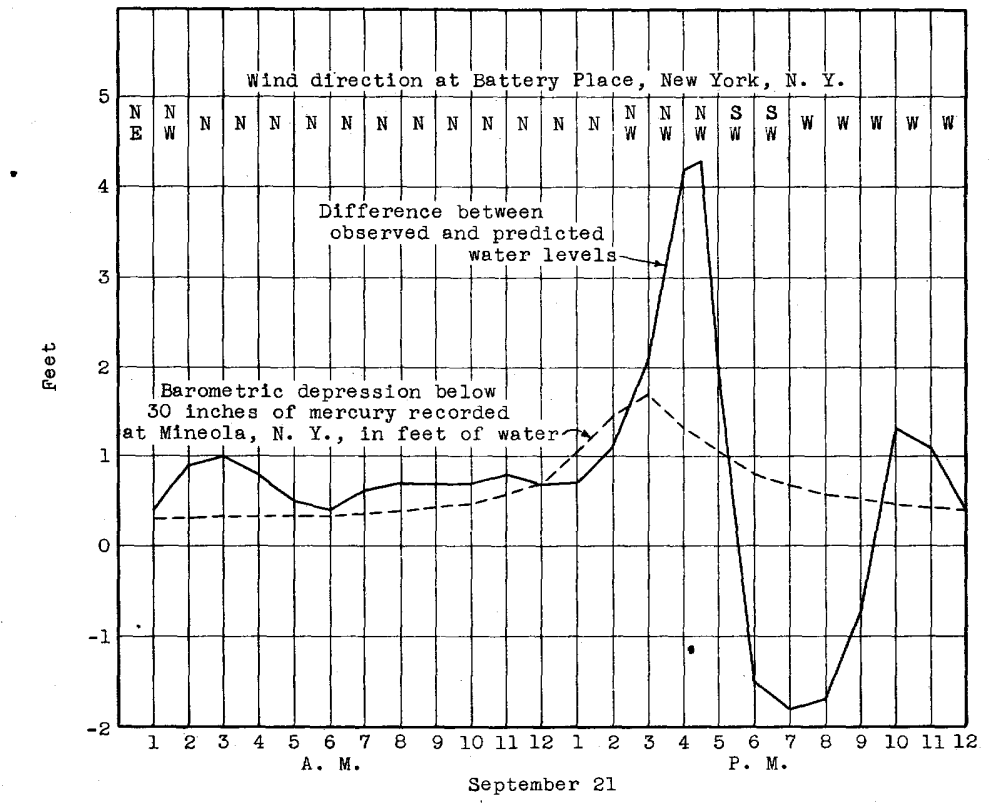

Graph of departures of observed from predicted water levels; barometric depression; and hourly wind direction.

Figure 56.--Study of water levels at The Battery, New York, N. Y., September 21, 1938. 
September 21 the observed water levels were above the normal by an amount approximately equivalent to the reduction of the barometric pressure below 30 inches of mercury. After 2 p.m. water levels rose to a stage greatly above that attributable to barometric effects. The maximum depression at New York was reached at 2:43 p.m., but the peak stage did not occur unt11 4:30 p.m. It is probable that the storm-wave peak at New York was the effect of the hurricane winds upon the water in the open sea to the east, where the storm wave reached its peak nearly simultaneously with the passage of the hurricane. The peak at Sandy Hook, N. J., and at New York Harbor, respectively, occurred about $1 \frac{2}{2}$ and 2 hours later than the estimated time of storm-wave crest on the southern Long Island coast. In contrast, high tide at these places generally occurs, respectively, only about 15 and 45 minutes after high tide on the southern Long Island coast. These observations suggest that the storm wave in New York harbor was a reflection of the wave that the hurricane had built on the Long Island shore. The recession and subsequent rise shown in figure 56, that followed the storm-wave peak at New York probably resulted from osc1llations set up by the release of the water piled up on the southern Long Island shore. The occurrence of the second peak at $10 \mathrm{p} . \mathrm{m}$. In New York harbor was further complicated by the particular configuration of that harbor and by the inflow of water into the harbor through East River from the westerly end of Long Island Sound, where it had crested at about $8 \mathrm{p.m}$.

The actual mean water level at The Battery averaged 0.65 foot above the average level of the predicted undisturbed tidal regimen on September 21. On the same day the barometer at Mineola, N. Y., averaged 0.64 foot of water below a mean of 30 inches of mercury, which is close to the september normal atmospheric pressure at sea level in this locality, indicating that the effective rise in the harbor on September 21 was nearly equivalent to the net barometric effect.

A major part of the storm wave impinged on the southern New England coast at about 4:45 p.m. as observed at New London, Conn. The force of the wave was abated by escaping westward through Long Island Sound, where it reached the Geological Survey gaging station on Mill Neck Creak at Mill Neck, N. Y., at $8 \mathrm{p.m}$. As the wave was constricted in passing through the narrowing Long Island Sotnd towards the East River, it reached increasing heights, so that at Willets Point, N. Y., the Coast and Geodetic Survey reported a wave crest 10 feet above mean high water. The constrictive effects of Narragansett Bay and Providence River aided in producing a wave crest 13 feet above mean high tide at Providence, R. I. 
The coastal aspects of the september 1938 hurricane are further described by Col. C. L. Hal124/, of the Corps of Engineers, United States Army *

\section{GROUND-WATER RECHARGE ON LONG ISIAND}

By R. M. Legget te

\section{Introduction}

The hurricane storm of September 1938 was a major factor in producing an exceptionally high water table in the region that it affected. For example, on most parts of Long Island, N. Y., for which records are ava1lable, the ground-water levels after the storm were about as high as they had been at any time during the preceding 25 years, although during all that period the region has been subjected to pumping at an average rate of more than $100,000,000$ gallons a day. Only in the severely over-pumped area in the Borough of Brooklyn was the recharge insufficient to offset the progressive decline that had occurred.

The records of ground-water levels collected in the western part of Long Island, N. Y., are the most adequate in the region affected by the hurricane. Since about 1932 the Geological Survey, in cooperation with the New York State Water Power and Control Commission and with Nassau and Suffolk Counties, has been carrying on an investigation of the ground-water conditions on Long Island. A part of this investigation has consisted of regular periodic measurements of ground-water levels, chiefly on the western helf of the Island. These records form the basis for the analysis here given of the ground-water recharge that took place as a result of the September hurricane storm.

Much of Long Island consists of a gently southward sloping glacial outwash plain, the surface of which is sandy and of relatively high permeability. This plain is bordered on the north by a glaciel terminal moraine that extends approximately paraliel to the long axis of the Island. The area north of the terminal moraine is considerably smaller than the area south of 1t. North of the terminal moraine the surface of the Island is composed chiefly of glacial till. In the area north of the outwash plain the water table is more than 100 feet below the surface

24/ Hall, C. I., The 1938 hurricane and its effect on Long Island beach-protection structures: Civil Eng., vol. 9, no. 3, pp. 169-172, March, 1939. 
in some places, and perched water-table conditions commonly occur above the main water table. This produces much more complicated and irregular ground-water conditions than those that occur in the southern parts of the Island. For this reason, and because most of the water table observation wells are located in the southerm half of the Island, this chapter deals only with that part of the Island lying south of the terminal moraine.

The water table underlying the outwash plain slopes southward and lies from a few feet to about 40 feet below the land surface. Recharge of these shallow water-bearing beds takes place by rainfall penetration through the permeable sand and gravel. As pointed out in another part of this section, only a small part of the rain that falls on the Island is disposed of as storm run-off. Underlying these relatively shallow water-bearing beds, there is in most places a considerable thickmess of fine sand and clay of Cretaceous age beneath which an artesian aquifer is commonly encountered. This aquifer, known as the Lloyd sand, furnishes the water supply for many communities on Long Island. The Lloyd sand is not exposed at the surface and recharge to it presumably takes place by movement of water from the overlying formations in areas where there is no clay immediately above the aquifer.

\section{Rainfall and fluctuations in ground-water levels}

During the latter parts of June and July 1938 as well as during the following September, there were rains on many parts of Long Island that resulted in a rise of the water table. The recharge from the June and July storms produced antecedent conditions that together with the September storm resulted in the abnormaly high water table. For this reason and for the purpose of comparison, data is presented for each of the three storms.

Table 22 gives the daily precipitation during each of three storms at four stations on Long Island.

During 1938, water-level observations were being made in many wells on Long Island that end in the shallow water-bearing material in which water-table conditions exist. The location of the wells for which data are here given is shown in figure 57. Water-level observations were made in each of these wells once a week. The water-level measurements from 


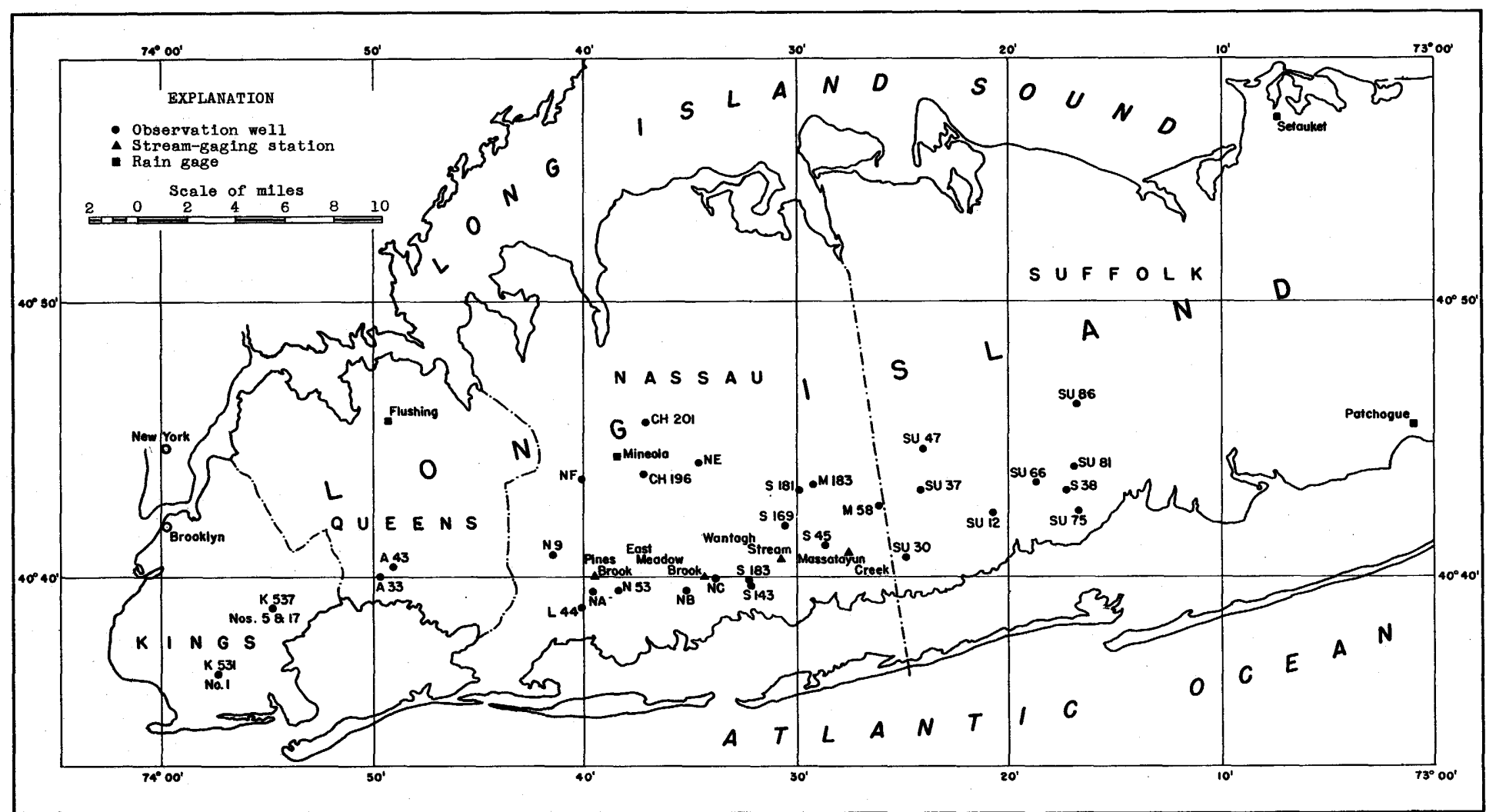

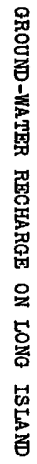

Figure 57.--Index map of the western part of Long Island showing location of observation wells, stream-gaging stations, and raln gages. 
about May 28 to November 4 are given in table 23, in which the we11s are listed in the same order in which they later appear in table 24 on page 538. Other measurements in these wells are published annually in Geological Survey Water-Supply Papers entitled "Water levels and artesian pressure in observation wells in the United States". $25 /$.

Table 22.--Daily precipitation, in inches, during three storms in 1938 at four stations on western Long Island.

\begin{tabular}{|c|c|c|c|c|c|}
\hline \multirow{2}{*}{$\begin{array}{l}\text { Date } \\
1938\end{array}$} & \multicolumn{4}{|c|}{ Station } & \multirow{2}{*}{$\begin{array}{c}\text { Average of } \\
\text { four } \\
\text { stations } \\
\end{array}$} \\
\hline & Patchogue & Setauket & Mineola & Flushing & \\
\hline $\begin{array}{r}\text { June } 26 \\
27 \\
28\end{array}$ & $\begin{array}{l}0 \\
2.07 \\
2.46\end{array}$ & $\begin{array}{l}0.21 \\
1.81 \\
2.34\end{array}$ & $\begin{array}{l}0.69 \\
1.65 \\
1.31\end{array}$ & $\begin{array}{l}0.73 \\
0.82 \\
1.27\end{array}$ & $\begin{array}{l}0.41 \\
1.59 \\
1.85\end{array}$ \\
\hline Total for 3 days & 4.53 & 4.36 & 3.65 & 2.82 & 3.84 \\
\hline $\begin{array}{r}\text { July } 18 \\
19 \\
20 \\
21 \\
22 \\
23 \\
24 \\
\end{array}$ & $\begin{array}{r}1.07 \\
.06 \\
2.85 \\
.25 \\
.40 \\
.53 \\
1.14\end{array}$ & $\begin{array}{l}0.68 \\
0 \\
1.75 \\
1.16 \\
.56 \\
.06 \\
.97\end{array}$ & $\begin{array}{r}0.34 \\
.14 \\
3.17 \\
.84 \\
.33 \\
1.69 \\
.92\end{array}$ & $\begin{array}{r}0.07 \\
.19 \\
.90 \\
.70 \\
.23 \\
2.40 \\
.33\end{array}$ & $\begin{array}{r}0.54 \\
.10 \\
2.17 \\
.74 \\
.38 \\
1.17 \\
.84\end{array}$ \\
\hline Total for 7 days & 6.30 & 5.18 & 7.43 & 4.82 & 5.93 \\
\hline $\begin{array}{r}17 \\
18 \\
19 \\
20 \\
21\end{array}$ & $\begin{array}{r}0.88 \\
.52 \\
2.00 \\
3.69 \\
4.22\end{array}$ & $\begin{array}{r}0.48 \\
.55 \\
1.65 \\
3.98 \\
4.25\end{array}$ & $\begin{array}{l}0.14 \\
3.10 \\
1.02 \\
2.34 \\
4.40\end{array}$ & $\begin{array}{r}0.18 \\
1.58 \\
.76 \\
1.88 \\
4.27\end{array}$ & $\begin{array}{l}0.42 \\
1.44 \\
1.36 \\
2.97 \\
4.29\end{array}$ \\
\hline Total for 5 days & 11.31 & 10.91 & 11.00 & 8.67 & 10.47 \\
\hline
\end{tabular}

Figure 58 shows the relation between precipitation and average groundwater levels on Long Island since 1932. Most of the observation wells used in determining average ground-water level are in Nassau County, the remainder being in Queens and western Suffolk Counties. Records of groundwater levels in a few observation wells are avallable as far back as 1903 , although there are several breaks in the record. There are not sufficient data for most of these earlier years to provide a basis for determining average water levels. However, the data for 1913 and 1914 are adequate for this purpose. The highest average water level in 1913 was essentially the same as the average water level on September 30, 1938. The general upward trend of the water levels during the first 4 months of 1939 (se日 fig. 58) was in part the result of abnormal precipitation during this period and in part because of the favorable conditions for recharge in 
Table 23.- Water levels in observation wells on Long Island, N. Y., in feet, with reference to mean sea level, 1938

We11 N-9

\begin{tabular}{|c|c|c|c|c|c|c|c|}
\hline Date & & $\begin{array}{l}\text { Water } \\
\text { level }\end{array}$ & Date & & $\begin{array}{l}\text { Water } \\
\text { level }\end{array}$ & Date & $\begin{array}{l}\text { Water } \\
\text { level }\end{array}$ \\
\hline $\begin{array}{l}\text { May } \\
\text { June }\end{array}$ & $\begin{array}{r}28 \\
4 \\
11 \\
18 \\
25 \\
2 \\
9 \\
16\end{array}$ & $\begin{array}{l}21.93 \\
21.86 \\
21.84 \\
22.10 \\
21.98 \\
22.31 \\
22.20 \\
22.18\end{array}$ & $\begin{array}{l}\text { July } \\
\text { Aug. } \\
\text { Sept. }\end{array}$ & $\begin{array}{r}23 \\
29 \\
5 \\
12 \\
19 \\
26 \\
2 \\
9\end{array}$ & $\begin{array}{l}22.51 \\
22.77 \\
22.57 \\
22.57 \\
22.34 \\
22.18 \\
22.10 \\
21.99\end{array}$ & $\begin{array}{lr}\text { Sept. } & 16 \\
& 23 \\
30 \\
\text { oct. } \\
\\
\\
14 \\
\\
\text { Nov. } \quad 4\end{array}$ & $\begin{array}{l}22.05 \\
23.62 \\
23.21 \\
22.96 \\
22.74 \\
22.64 \\
22.49 \\
22.37\end{array}$ \\
\hline
\end{tabular}

Test well SU-66

\begin{tabular}{|c|c|c|c|c|c|c|c|}
\hline $\begin{array}{l}\text { May } \\
\text { June }\end{array}$ & $\begin{array}{r}28 \\
4 \\
11 \\
17 \\
24 \\
1 \\
8 \\
15\end{array}$ & $\begin{array}{l}21.71 \\
21.61 \\
21.59 \\
21.59 \\
21.59 \\
22.48 \\
22.25 \\
22.11\end{array}$ & $\begin{array}{l}\text { July } \\
\text { Aug. } \\
\text { Sept. }\end{array}$ & $\begin{array}{r}22 \\
29 \\
5 \\
12 \\
19 \\
26 \\
2 \\
9\end{array}$ & $\begin{array}{l}22.45 \\
22.82 \\
22.57 \\
22.52 \\
22.26 \\
22.08 \\
21.98 \\
21.85\end{array}$ & $\begin{array}{l}\text { Sept. } \\
\text { Oct. } \\
\text { Nov. }\end{array}$ & $\begin{array}{l}21.77 \\
23.30 \\
23.06 \\
22.69 \\
22.48 \\
22.32 \\
22.20 \\
22.07\end{array}$ \\
\hline
\end{tabular}

Test well sU-30

\begin{tabular}{|c|c|c|c|c|c|c|c|}
\hline $\begin{array}{l}\text { Mey } \\
\text { June }\end{array}$ & $\begin{array}{r}28 \\
4 \\
11 \\
17 \\
24 \\
1 \\
8 \\
15\end{array}$ & $\begin{array}{l}10.80 \\
10.74 \\
10.73 \\
10.72 \\
10.66 \\
11.15 \\
10.99 \\
10.90\end{array}$ & $\begin{array}{l}\text { July } \\
\text { Aug. } \\
\text { Sept. }\end{array}$ & $\begin{array}{r}22 \\
29 \\
5 \\
12 \\
19 \\
26 \\
2 \\
9\end{array}$ & $\begin{array}{l}11.14 \\
11.25 \\
11.09 \\
11.08 \\
10.92 \\
10.82 \\
10.75 \\
10.67\end{array}$ & $\begin{array}{ll}\text { Sept. } & 1 \\
& \\
\text { Oct. } & \\
& 2 \\
\text { Nov. }\end{array}$ & $\begin{array}{l}10.66 \\
11.47 \\
11.29 \\
11.23 \\
11.03 \\
10.99 \\
10.96 \\
10.91\end{array}$ \\
\hline
\end{tabular}

Test well SU-75

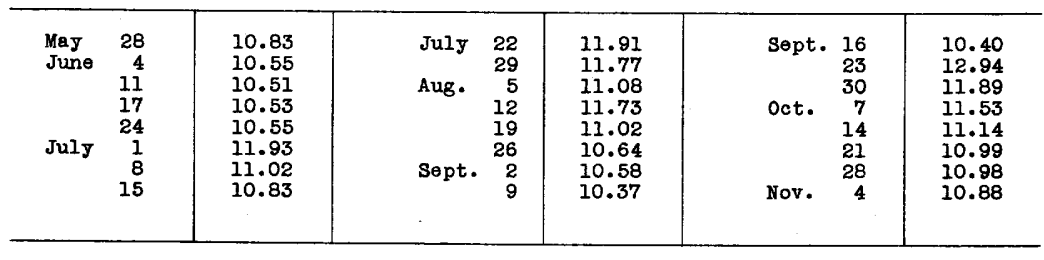

Test well su-12

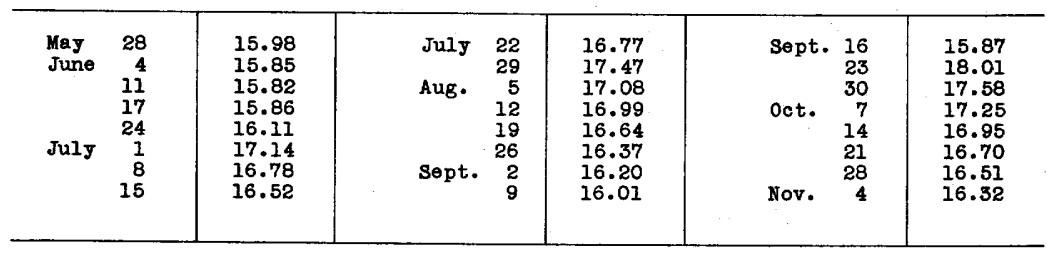

Test well S-169

\begin{tabular}{|c|c|c|c|c|c|c|c|}
\hline $\begin{array}{l}\text { May } \\
\text { June }\end{array}$ & $\begin{array}{r}28 \\
4 \\
11 \\
17 \\
24 \\
1 \\
8 \\
15\end{array}$ & $\begin{array}{l}34.60 \\
34.38 \\
34.37 \\
34.46 \\
34.55 \\
35.10 \\
\mathbf{3 4 . 9 1} \\
\mathbf{3 4 . 9 2}\end{array}$ & $\begin{array}{l}\text { July } \\
\text { Aug. } \\
\text { Sept. }\end{array}$ & $\begin{array}{r}22 \\
29 \\
5 \\
12 \\
19 \\
26 \\
2 \\
9\end{array}$ & $\begin{array}{l}35.27 \\
35.54 \\
35.34 \\
35.42 \\
35.15 \\
34.97 \\
34.87 \\
34.74\end{array}$ & $\begin{array}{l}\text { Sept. } \\
\text { Oct. } \\
\text { Nov. }\end{array}$ & $\begin{array}{l}34.74 \\
36.00 \\
35.78 \\
35.59 \\
35.41 \\
35.36 \\
35.24 \\
35.12\end{array}$ \\
\hline
\end{tabular}


Table 23.- Water levels in observation wells on Long Island, N. Y., in feet, with reference to mean sea level, 1938--Continued

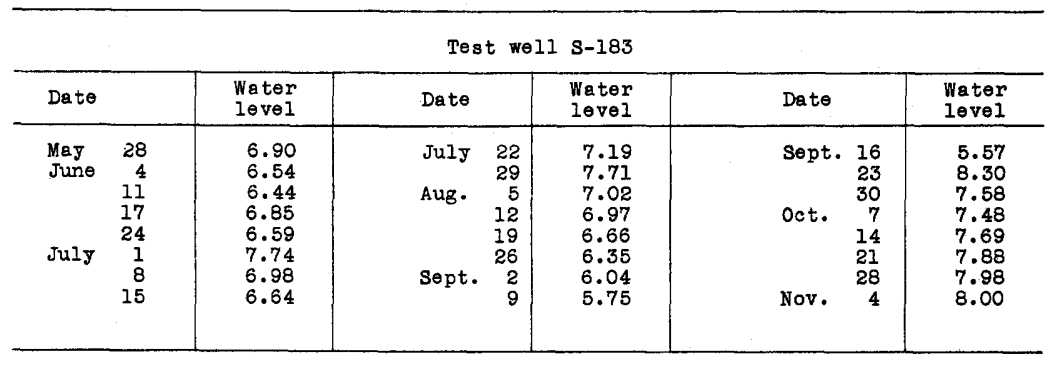

Test well s-143

\begin{tabular}{|c|c|c|c|c|c|c|}
\hline $\begin{array}{l}\text { May } \\
\text { June }\end{array}$ & $\begin{array}{r}28 \\
4 \\
11 \\
17 \\
24 \\
1 \\
8 \\
15\end{array}$ & $\begin{array}{l}6.16 \\
5.90 \\
5.75 \\
6.28 \\
6.01 \\
7.16 \\
6.36 \\
6.03\end{array}$ & $\begin{array}{l}\text { July } \\
\text { Aug. } \\
\text { Sept. }\end{array}$ & $\begin{array}{l}6.62 \\
7.08 \\
6.38 \\
6.34 \\
5.94 \\
5.67 \\
5.44 \\
5.18\end{array}$ & $\begin{array}{l}\text { Sept. } \\
\text { oct. } \\
\text { Nov. }\end{array}$ & $\begin{array}{l}5.05 \\
7.81 \\
6.86 \\
6.67 \\
6.67 \\
6.81 \\
6.91 \\
6.91\end{array}$ \\
\hline
\end{tabular}

Test we11 NE

\begin{tabular}{|c|c|c|c|c|c|c|c|}
\hline $\begin{array}{l}\text { May } \\
\text { June }\end{array}$ & $\begin{array}{r}28 \\
4 \\
11 \\
17 \\
24 \\
1 \\
8 \\
15\end{array}$ & $\begin{array}{l}66.90 \\
66.82 \\
66.75 \\
66.72 \\
66.65 \\
66.86 \\
66.80 \\
66.82\end{array}$ & $\begin{array}{l}\text { July } \\
\text { Aug. } \\
\text { Sept. }\end{array}$ & $\begin{array}{r}22 \\
29 \\
5 \\
12 \\
19 \\
26 \\
2 \\
9\end{array}$ & $\begin{array}{l}67.45 \\
68.26 \\
68.48 \\
68.66 \\
68.49 \\
68.36 \\
68.24 \\
68.12\end{array}$ & $\begin{array}{l}\text { Sept. } \\
\text { Oct. } \\
\text { Nov. }\end{array}$ & $\begin{array}{l}68.09 \\
69.97 \\
70.11 \\
69.99 \\
69.86 \\
69.77 \\
69.60 \\
69.43\end{array}$ \\
\hline
\end{tabular}

Test well NC

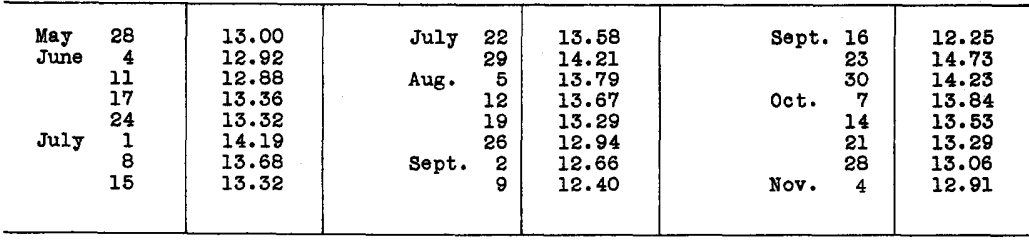

Test well M-58

\begin{tabular}{|c|c|c|c|c|c|c|c|}
\hline $\begin{array}{l}\text { May } \\
\text { June }\end{array}$ & $\begin{array}{r}28 \\
4 \\
11 \\
17 \\
24 \\
1 \\
8 \\
15\end{array}$ & $\begin{array}{l}37.12 \\
37.09 \\
37.06 \\
36.97 \\
37.14 \\
38.34 \\
38.05 \\
37.82\end{array}$ & $\begin{array}{l}\text { July } \\
\text { Aug. } \\
\text { Sept. }\end{array}$ & $\begin{array}{r}22 \\
29 \\
5 \\
12 \\
19 \\
26 \\
2 \\
9\end{array}$ & $\begin{array}{l}38.14 \\
38.99 \\
38.56 \\
38.35 \\
38.12 \\
37.90 \\
37.73 \\
37.54\end{array}$ & $\begin{array}{ll}\text { Sept. } & 1 \\
\text { Oct. } & \\
& \\
\text { Nov. }\end{array}$ & $\begin{array}{l}37.39 \\
39.39 \\
38.88 \\
38.50 \\
38.27 \\
38.10 \\
37.94 \\
37.80\end{array}$ \\
\hline
\end{tabular}

Well s-38

\begin{tabular}{|c|c|c|c|c|c|c|c|}
\hline $\begin{array}{l}\text { May } \\
\text { June }\end{array}$ & $\begin{array}{r}28 \\
4 \\
11 \\
17 \\
24 \\
1 \\
8 \\
15\end{array}$ & $\begin{array}{l}21.97 \\
21.80 \\
21.70 \\
21.69 \\
21.80 \\
23.30 \\
23.07 \\
22.81\end{array}$ & $\begin{array}{l}\text { July } \\
\text { Aug. } \\
\text { Sept. }\end{array}$ & $\begin{array}{r}22 \\
29 \\
5 \\
12 \\
19 \\
26 \\
2 \\
9\end{array}$ & $\begin{array}{l}22.81 \\
23.99 \\
23.60 \\
23.43 \\
23.29 \\
23.04 \\
22.79 \\
22.52\end{array}$ & $\begin{array}{l}\text { Sept. } \\
\text { oct. } \\
\text { Nov. }\end{array}$ & $\begin{array}{l}22.28 \\
24.56 \\
24.05 \\
23.75 \\
23.55 \\
23.37 \\
23.17 \\
22.95\end{array}$ \\
\hline
\end{tabular}


Table 23.- Water levels in observation wells on Long Island, N. Y., In feet, with reference to mean ses level, 1938--Continued

Test well SU-81

\begin{tabular}{|c|c|c|c|c|c|c|c|}
\hline Date & & $\begin{array}{l}\text { Weter } \\
\text { level }\end{array}$ & Date & & $\begin{array}{l}\text { Water } \\
\text { level }\end{array}$ & Dete & $\begin{array}{l}\text { Water } \\
\text { level }\end{array}$ \\
\hline $\begin{array}{l}\text { May } \\
\text { June } \\
\text { July }\end{array}$ & $\begin{array}{r}28 \\
4 \\
11 \\
17 \\
24 \\
1 \\
8 \\
15\end{array}$ & $\begin{array}{l}28.10 \\
28.08 \\
28.00 \\
27.99 \\
28.11 \\
29.26 \\
29.58 \\
29.39\end{array}$ & $\begin{array}{l}\text { July } \\
\text { Aug. } \\
\text { Sept. }\end{array}$ & $\begin{array}{r}22 \\
29 \\
5 \\
12 \\
19 \\
26 \\
2 \\
9\end{array}$ & $\begin{array}{l}29.25 \\
30.50 \\
30.39 \\
30.24 \\
30.08 \\
29.92 \\
29.73 \\
29.51\end{array}$ & $\begin{array}{lr}\text { Sept. } & 16 \\
& 23 \\
& 30 \\
\text { oct. } & 7 \\
& 14 \\
& 21 \\
& 28 \\
\text { Nov. } \quad 4\end{array}$ & $\begin{array}{l}29.31 \\
30.71 \\
31.18 \\
30.88 \\
30.70 \\
30.54 \\
30.35 \\
30.11\end{array}$ \\
\hline
\end{tabular}

WeIl N-53

\begin{tabular}{|c|c|c|c|c|c|c|c|}
\hline $\begin{array}{l}\text { May } \\
\text { June } \\
\text { July }\end{array}$ & $\begin{array}{r}28 \\
4 \\
11 \\
17 \\
24 \\
1 \\
8 \\
15\end{array}$ & $\begin{array}{l}13.97 \\
13.86 \\
13.83 \\
14.06 \\
14.15 \\
14.32 \\
14.42 \\
14.39\end{array}$ & $\begin{array}{l}\text { July } \\
\text { Aug. } \\
\text { Sept. }\end{array}$ & $\begin{array}{r}22 \\
29 \\
5 \\
12 \\
19 \\
26 \\
2 \\
9\end{array}$ & $\begin{array}{l}14.59 \\
15.21 \\
15.24 \\
15.23 \\
14.97 \\
14.81 \\
14.64 \\
14.46\end{array}$ & $\begin{array}{l}\text { Sept. } \\
\text { oct. } \\
\text { Nov. }\end{array}$ & $\begin{array}{l}14.38 \\
15.80 \\
15.94 \\
15.66 \\
15.50 \\
15.34 \\
15.18 \\
14.98\end{array}$ \\
\hline
\end{tabular}

Test well s-45

\begin{tabular}{|c|c|c|c|c|c|c|c|}
\hline $\begin{array}{l}\text { May } \\
\text { June }\end{array}$ & $\begin{array}{r}28 \\
4 \\
11 \\
17 \\
24 \\
1 \\
8 \\
15\end{array}$ & $\begin{array}{l}20.79 \\
20.71 \\
20.64 \\
20.53 \\
20.53 \\
21.75 \\
21.59 \\
21.27\end{array}$ & $\begin{array}{l}\text { July } \\
\text { Aug. } \\
\text { Sept. }\end{array}$ & $\begin{array}{r}22 \\
29 \\
5 \\
12 \\
19 \\
26 \\
2 \\
9\end{array}$ & $\begin{array}{l}21.22 \\
22.51 \\
22.06 \\
21.74 \\
21.43 \\
21.09 \\
20.75 \\
20.45\end{array}$ & $\begin{array}{l}\text { Sept. } \\
\text { Oct. } \\
\text { Nov. }\end{array}$ & $\begin{array}{l}20.20 \\
21.12 \\
21.51 \\
21.22 \\
21.07 \\
20.97 \\
20.87 \\
20.78\end{array}$ \\
\hline
\end{tabular}

Test well NB

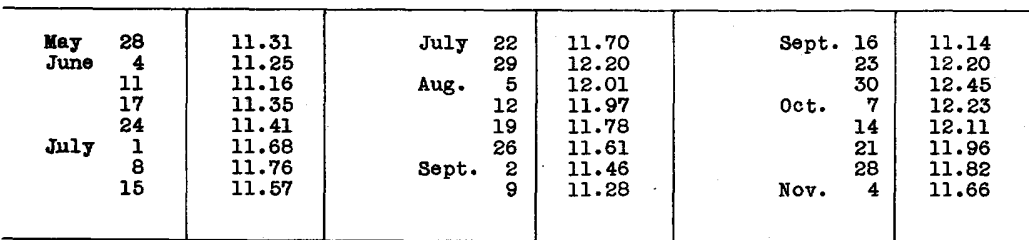

Pest well NA

\begin{tabular}{|c|c|c|c|c|c|c|c|}
\hline $\begin{array}{l}\text { May } \\
\text { June }\end{array}$ & $\begin{array}{r}28 \\
4 \\
11 \\
17 \\
24 \\
1 \\
8 \\
15\end{array}$ & $\begin{array}{l}7.53 \\
7.58 \\
7.49 \\
7.88 \\
7.87 \\
8.12 \\
7.86 \\
7.81\end{array}$ & $\begin{array}{l}\text { July } \\
\text { Aug. } \\
\text { Sept. }\end{array}$ & $\begin{array}{r}22 \\
29 \\
5 \\
12 \\
19 \\
26 \\
2 \\
9\end{array}$ & $\begin{array}{l}8.24 \\
8.97 \\
8.62 \\
8.70 \\
8.39 \\
8.17 \\
8.06 \\
7.91\end{array}$ & $\begin{array}{ll}\text { Sept. } & \frac{1}{2} \\
& 3 \\
\text { oct. } & 1 \\
& 2 \\
\text { Nov. } & 2\end{array}$ & $\begin{array}{l}7.86 \\
9.77 \\
9.45 \\
9.21 \\
9.00 \\
8.85 \\
8.72 \\
8.58\end{array}$ \\
\hline
\end{tabular}

Test well SU-37

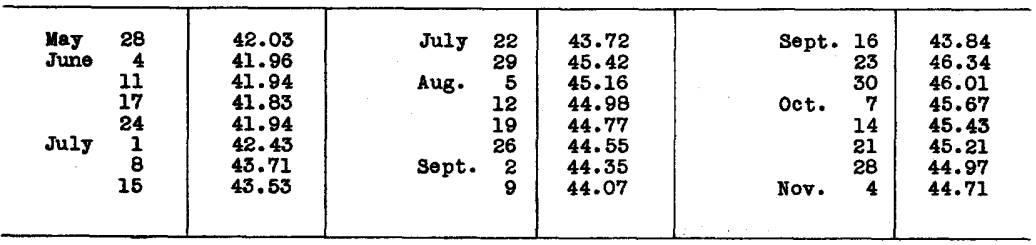


Table 23.- Water levels in observation wells on Long Island, N. Y., in feet, with reference to mean sea level, 1938--Continued

Test wel1 s-181

\begin{tabular}{|c|c|c|c|c|c|c|c|}
\hline Date & & $\begin{array}{l}\text { Water } \\
\text { level }\end{array}$ & Date & & $\begin{array}{l}\text { Water } \\
\text { level }\end{array}$ & Date & $\begin{array}{l}\text { Water } \\
\text { level }\end{array}$ \\
\hline $\begin{array}{l}\text { May } \\
\text { June }\end{array}$ & $\begin{array}{r}28 \\
4 \\
11 \\
17 \\
24 \\
1 \\
8 \\
15\end{array}$ & $\begin{array}{l}50.03 \\
49.96 \\
49.89 \\
49.85 \\
49.81 \\
49.99 \\
50.09 \\
50.19\end{array}$ & $\begin{array}{l}\text { July } \\
\text { Aug. } \\
\text { Sept. }\end{array}$ & $\begin{array}{r}22 \\
29 \\
5 \\
12 \\
19 \\
26 \\
2 \\
9\end{array}$ & $\begin{array}{l}50.32 \\
51.11 \\
51.39 \\
51.63 \\
51.60 \\
51.52 \\
51.42 \\
51.31\end{array}$ & $\begin{array}{l}\text { Sept. } \\
\text { oct. } \\
\text { Nov. }\end{array}$ & $\begin{array}{l}51.46 \\
52.22 \\
52.41 \\
52.50 \\
52.47 \\
52.40 \\
52.26 \\
52.10\end{array}$ \\
\hline
\end{tabular}

Test well $\mathrm{L}-44$

\begin{tabular}{|c|c|c|c|c|c|c|c|}
\hline $\begin{array}{l}\text { May } \\
\text { June }\end{array}$ & $\begin{array}{r}28 \\
4 \\
11 \\
17 \\
24 \\
1 \\
8 \\
15\end{array}$ & $\begin{array}{l}7.33 \\
7.21 \\
7.13 \\
7.50 \\
7.57 \\
7.86 \\
7.83 \\
7.63\end{array}$ & $\begin{array}{l}\text { July } \\
\text { Aug. } \\
\text { Sept. }\end{array}$ & $\begin{array}{r}22 \\
29 \\
5 \\
12 \\
19 \\
26 \\
2 \\
9\end{array}$ & $\begin{array}{l}7.98 \\
9.16 \\
8.80 \\
8.70 \\
8.34 \\
8.01 \\
7.70 \\
7.42\end{array}$ & $\begin{array}{ll}\text { Sept. } & \frac{1}{2} \\
& 3 \\
\text { Oct. } & 1 \\
& 2 \\
& 2 \\
\text { Nov. }\end{array}$ & $\begin{array}{l}7.26 \\
9.88 \\
9.82 \\
9.43 \\
9.13 \\
8.88 \\
8.62 \\
8.39\end{array}$ \\
\hline
\end{tabular}

Test well A-33

\begin{tabular}{|c|c|c|c|c|c|c|c|c|}
\hline $\begin{array}{l}\text { May } \\
\text { June }\end{array}$ & $\begin{array}{r}28 \\
4 \\
11 \\
18 \\
25 \\
2 \\
9 \\
16\end{array}$ & $\begin{array}{l}1.75 \\
1.76 \\
1.79 \\
1.89 \\
1.91 \\
2.49 \\
2.06 \\
1.99\end{array}$ & $\begin{array}{l}\text { July } \\
\text { Aug. } \\
\text { Sept. }\end{array}$ & $\begin{array}{r}23 \\
29 \\
5 \\
12 \\
19 \\
26 \\
2 \\
9\end{array}$ & $\begin{array}{l}2.12 \\
2.72 \\
2.32 \\
2.51 \\
2.07 \\
2.20 \\
1.86 \\
1.94\end{array}$ & $\begin{array}{l}\text { Sept. } \\
\text { Oct. } \\
\text { Nov. }\end{array}$ & $\begin{array}{r}16 \\
23 \\
30 \\
7 \\
14 \\
21 \\
28 \\
4\end{array}$ & $\begin{array}{l}1.82 \\
4.04 \\
3.27 \\
3.16 \\
2.83 \\
2.77 \\
2.60 \\
2.35\end{array}$ \\
\hline
\end{tabular}

We11 K-535 No. I

\begin{tabular}{|c|c|c|c|c|c|c|}
\hline $\begin{array}{l}\text { May } \\
\text { June }\end{array}$ & $\begin{array}{r}28 \\
4 \\
11 \\
18 \\
25 \\
2 \\
9 \\
16\end{array}$ & $\begin{array}{l}1.52 \\
1.56 \\
1.55 \\
1.56 \\
1.54 \\
1.70 \\
1.75 \\
1.77\end{array}$ & $\begin{array}{ll}\text { July } & 2 \\
& 2 \\
\text { Aug. } & 1 \\
& \frac{1}{2} \\
\text { Sept. }\end{array}$ & $\begin{array}{l}1.85 \\
2.26 \\
2.34 \\
2.36 \\
2.34 \\
2.28 \\
2.21 \\
2.14\end{array}$ & $\begin{array}{l}\text { Sept. } \\
\text { oct. } \\
\text { Nov. }\end{array}$ & $\begin{array}{l}2.10 \\
2.64 \\
2.81 \\
2.73 \\
2.67 \\
2.59 \\
2.51 \\
2.45\end{array}$ \\
\hline
\end{tabular}

Test well CH-196

\begin{tabular}{|c|c|c|c|c|c|c|c|c|}
\hline $\begin{array}{l}\text { May } \\
\text { June }\end{array}$ & $\begin{array}{r}28 \\
4 \\
11 \\
17 \\
24 \\
1 \\
9 \\
15\end{array}$ & $\begin{array}{l}60.74 \\
60.71 \\
60.66 \\
60.63 \\
60.60 \\
60.59 \\
60.71 \\
60.69\end{array}$ & $\begin{array}{l}\text { July } \\
\text { Aug. } \\
\text { Sept. }\end{array}$ & $\begin{array}{r}22 \\
29 \\
5 \\
12 \\
19 \\
26 \\
2 \\
9\end{array}$ & $\begin{array}{l}61.57 \\
62.82 \\
62.88 \\
63.07 \\
62.92 \\
62.71 \\
62.49 \\
62.28\end{array}$ & $\begin{array}{l}\text { Sept. } \\
\text { oct. } \\
\text { Nov. }\end{array}$ & $\begin{array}{r}16 \\
23 \\
30 \\
7 \\
14 \\
21 \\
28 \\
4\end{array}$ & $\begin{array}{l}62.12 \\
64.02 \\
64.51 \\
64.46 \\
64.31 \\
64.16 \\
63.98 \\
63.77\end{array}$ \\
\hline
\end{tabular}

Test well M-183

\begin{tabular}{|c|c|c|c|c|c|c|c|}
\hline $\begin{array}{l}\text { May } \\
\text { June }\end{array}$ & $\begin{array}{r}28 \\
4 \\
11 \\
17 \\
24 \\
1 \\
8 \\
15\end{array}$ & $\begin{array}{l}51.61 \\
51.57 \\
51.50 \\
51.44 \\
51.40 \\
51.48 \\
51.67 \\
51.79\end{array}$ & $\begin{array}{l}\text { July } \\
\text { Aug. } \\
\text { Sept. }\end{array}$ & $\begin{array}{r}22 \\
29 \\
5 \\
12 \\
19 \\
26 \\
2 \\
9\end{array}$ & $\begin{array}{l}51.90 \\
52.56 \\
52.93 \\
53.11 \\
53.18 \\
53.13 \\
53.01 \\
52.90\end{array}$ & $\begin{array}{l}\text { Sept. } \\
\text { Oct. } \\
\text { Nov. }\end{array}$ & $\begin{array}{l}52.81 \\
53.31 \\
54.05 \\
54.11 \\
54.06 \\
53.97 \\
53.82 \\
53.68\end{array}$ \\
\hline
\end{tabular}


Table 23.- Water levels in observation wells on Long Island, N. Y, in feet, with reference to mean sea level, 1938--Continued

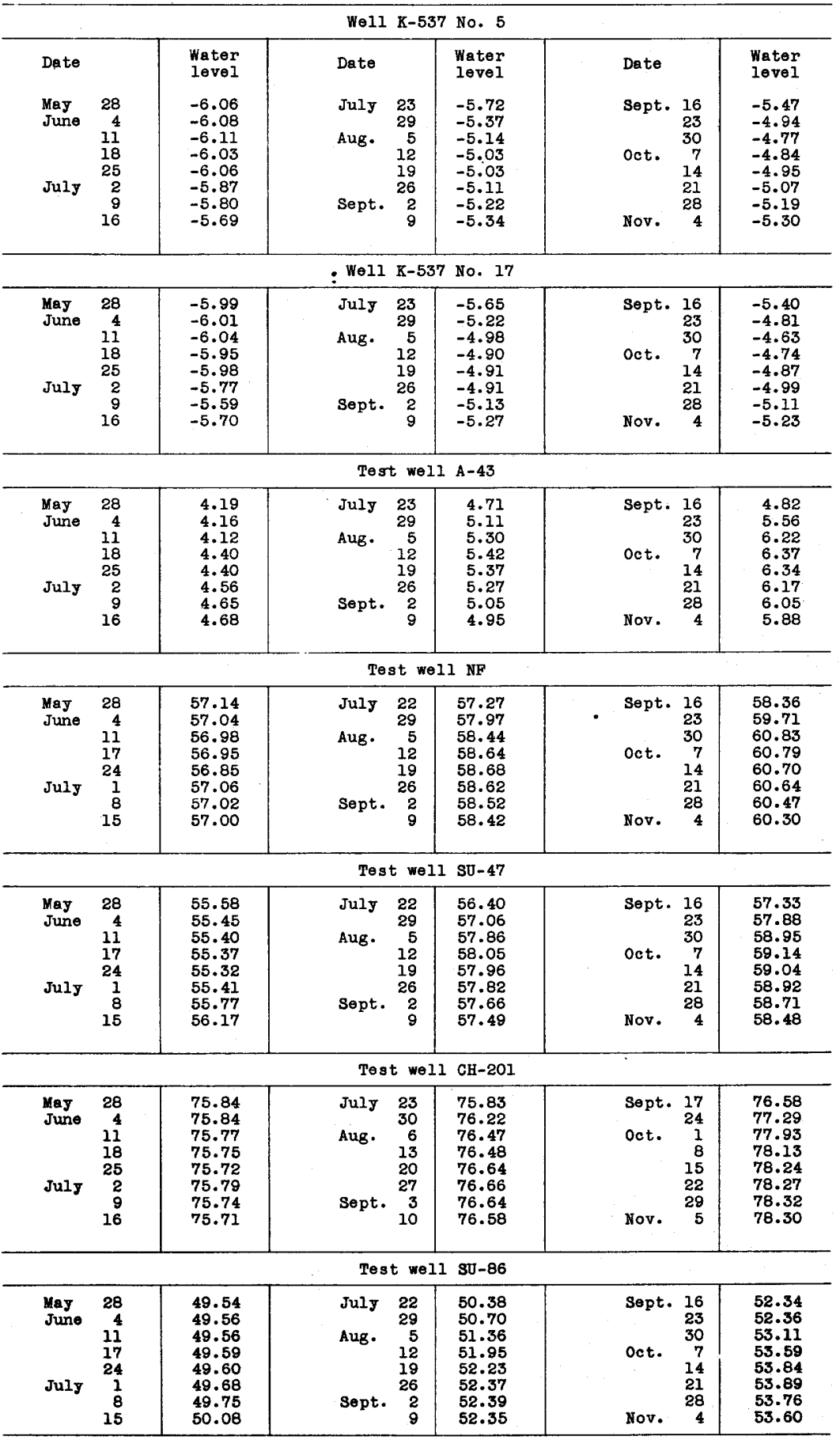


Table 24.- Summary of observation well data and approximate rise of water table

\begin{tabular}{|c|c|c|c|c|c|}
\hline \multirow{2}{*}{ Well No. } & \multirow{2}{*}{$\begin{array}{c}\text { Depth of } \\
\text { well below } \\
\text { measuring } \\
\text { polnt (feot) }\end{array}$} & \multicolumn{2}{|c|}{$\begin{array}{l}\text { Altitude of messuring } \\
\text { point (feet) }\end{array}$} & \multicolumn{2}{|c|}{ Water level Sept. 16,1938} \\
\hline & & $\begin{array}{c}\text { Above mean } \\
\text { sea level }\end{array}$ & $\begin{array}{l}\text { W1 th reference } \\
\text { to land surface }\end{array}$ & $\begin{array}{c}\text { Below measuring } \\
\text { point }\end{array}$ & $\begin{array}{l}\text { With reference to } \\
\text { mean sea level }\end{array}$ \\
\hline$N-9$ & 138 & 24.73 & +1.5 & 2.68 & +22.05 \\
\hline Test SU-66 & 12.3 & 24.67 & +.6 & 2.90 & +21.77 \\
\hline Test SU-30 & 13.6 & 14.86 & +.2 & 4.20 & +10.66 \\
\hline Test sU-75 & 15.4 & 15.85 & +.7 & 5.45 & +10.40 \\
\hline Test sU-12 & 13.7 & 21.69 & +.3 & 5.82 & +15.87 \\
\hline Test S-169 & 17.8 & 40.96 & +.7 & 6.22 & +34.74 \\
\hline Test $\mathrm{s}-183$ & 26.1 & 13.72 & +.9 & 8.15 & +5.57 \\
\hline Test S-143 & 17.7 & 13.44 & +.9 & 8.39 & +5.05 \\
\hline Test NE & 42.8 & 76.49 & +.2 & 8.40 & +68.09 \\
\hline Test NC & 17.1 & 21.12 & +.3 & 8.87 & +12.25 \\
\hline Test M-58 & 21.8 & 48.19 & +1.0 & 10.80 & +37.39 \\
\hline$s-38$ & 200 & 31.68 & -1.2 & 9.40 & +22.28 \\
\hline Test $\mathrm{SU}-81$ & 27.6 & 41.49 & +.6 & 12.18 & +29.31 \\
\hline $\mathrm{N}-53$ & 46.3 & 21.21 & -5 & 6.89 & +14.32 \\
\hline Test S-45 & 22.6 & 32.72 & 0 & 12.52 & +20.20 \\
\hline Test NB & 27.5 & 23.76 & +.1 & 12.62 & +11.14 \\
\hline Test MA & 27.1 & 20.87 & +.2 & 13.01 & +7.86 \\
\hline Test SU-37 & 33.0 & 57.13 & +.3 & 13.29 & +43.84 \\
\hline Test S-181 & 25.4 & 66.41 & +1.3 & 14.95 & +51.46 \\
\hline Test L-44 & 26.4 & 21.87 & +.2 & 14.61 & +7.26 \\
\hline Test A-33 & 27.7 & 17.29 & +1.0 & 15.47 & +1.82 \\
\hline K 535 No. 1 & 83.5 & 9.14 & -9 & 7.04 & +2.10 \\
\hline Test CH-196 & 20.3 & 79.57 & +.4 & 17.45 & +62.12 \\
\hline Test M-183 & 47.9 & 78.37 & +.4 & 25.56 & +52.81 \\
\hline K 537 No. 5 & 154.7 & 8.13 & -13 & 13.60 & -5.47 \\
\hline K 537 พั. 17 & 66.5 & 13.30 & -8 & 18.70 & -5.40 \\
\hline Test $A-43$ & 37.5 & 31.55 & 0 & 26.73 & +4.82 \\
\hline Test NF & 48.8 & 86.74 & +.2 & 28.38 & +58.36 \\
\hline Test $\mathrm{SU}-47$ & 39.9 & 86.38 & \pm .2 & 29.05 & +57.33 \\
\hline Test CH-201 & 43.3 & 112.53 & +.4 & b/ 35.95 & b/ +76.58 \\
\hline Test $\mathrm{sD}-86$ & 48.2 & 90.10 & +.4 & 37.76 & +52.34 \\
\hline Average & & & & & \\
\hline
\end{tabular}

a Estimated.

b On Sept. 17, 1938. 
on Long Island, N. Y., following storms in June, July, and September, 1938

\begin{tabular}{|c|c|c|c|c|c|c|}
\hline \multicolumn{2}{|c|}{ Storm of June $26-28$} & \multicolumn{2}{|c|}{ Storm of July $18-24$} & \multicolumn{2}{|c|}{ Storm of sept. 17-21 } & \multirow[b]{2}{*}{ Well No. } \\
\hline $\begin{array}{l}\text { Net rise of } \\
\text { water level } \\
\text { (feet) }\end{array}$ & $\begin{array}{l}\text { No. of weeks } \\
\text { during which } \\
\text { water level } \\
\text { rose }\end{array}$ & $\begin{array}{l}\text { Net rise of } \\
\text { water level } \\
\text { (feet) }\end{array}$ & $\begin{array}{c}\text { No. of weeks } \\
\text { during which } \\
\text { water level } \\
\text { rose }\end{array}$ & $\begin{array}{l}\text { Net rise of } \\
\text { water level } \\
\text { (feet) }\end{array}$ & $\begin{array}{c}\text { No. of weeks } \\
\text { during which } \\
\text { water level } \\
\text { rose }\end{array}$ & \\
\hline 0.33 & 1 & 0.59 & 2 & 1.57 & 1 & $N-9$ \\
\hline .89 & 1 & .71 & 2 & 1.53 & 1 & Test SU-66 \\
\hline .49 & 1 & .35 & 2 & .81 & 1 & Test SU-30 \\
\hline 1.38 & 1 & 1.08 & 1 & 2.54 & 1 & Test SU-75 \\
\hline 1.03 & 1 & .95 & 2 & 2.14 & 1 & Test $\mathrm{su}-12$ \\
\hline .55 & 1 & .62 & 2 & 1.26 & 1 & Test S-169 \\
\hline 1.15 & 1 & 1.07 & 2 & 2.73 & 1 & Test S-183 \\
\hline 1.15 & 1 & 1.05 & 2 & 2.76 & 1 & Test $\mathrm{S}-143$ \\
\hline .21 & 1 & 1.84 & 4 & 2.02 & 2 & Test NE \\
\hline .87 & 1 & .99 & 2 & 2.48 & 1 & Test NC \\
\hline 1.20 & 1 & 1.17 & 2 & 2.00 & 1 & Test M-58 \\
\hline 1.50 & 1 & 1.18 & 2 & 2.28 & 1 & $s-38$ \\
\hline 1.47 & 2 & 1.25 & 2 & 1.87 & 2 & Test SU-8I \\
\hline .27 & 2 & .85 & 3 & 1.62 & 2 & $\mathrm{~N}-53$ \\
\hline 1.22 & 1 & 1.29 & 2 & 1.31 & 2 & Test $S-45$ \\
\hline .35 & 2 & .63 & 2 & 1.31 & 2 & Test NB \\
\hline .25 & 1 & 1.16 & 2 & 1.91 & 1 & Test NA \\
\hline 1.77 & 2 & 1.89 & 2 & 2.50 & $I$ & Test SU-37 \\
\hline a/.25 & - & 1.44 & 4 & 1.04 & 3 & Test S-18I \\
\hline .29 & 1 & 1.53 & 2 & 2.62 & 1 & Test L-44 \\
\hline .58 & 1 & .73 & 2 & 2.22 & 1 & Test A-33 \\
\hline .20 & - & .59 & 4 & .71 & 2 & K 535 No. 1 \\
\hline .12 & 2 & 2.19 & 3 & 2.39 & 2 & Test CH-196 \\
\hline .50 & - & 1.39 & 5 & 1.30 & 3 & Test $M-183$ \\
\hline .37 & 3 & .69 & 4 & .70 & 2 & K 537 No. 5 \\
\hline .39 & 2 & .80 & 4 & .77 & 2 & K 537 No. 17 \\
\hline .30 & - & .74 & 4 & 1.55 & 3 & Test A-43 \\
\hline .21 & 1 & 1.68 & 5 & 2.47 & 2 & Test NF \\
\hline .85 & - & 1.88 & 4 & 1.81 & 3 & Test SU-47 \\
\hline .07 & 1 & .77 & 4 & 1.74 & 6 & Test CH-201 \\
\hline .60 & - & 2.31 & 7 & 1.55 & 5 & Test SU-86 \\
\hline 0.67 & 1.3 & 1.14 & 2.9 & 1.79 & $1.9^{*}$ & Average \\
\hline
\end{tabular}


the late fall and in the spring. It is apparent that this rise of water level would have started from much lower levels if there had been no recharge during September 1938. Thus the storm of September 1938 was an Important factor in producing the highest ground-rater level that had occurred on Long Island in many years.
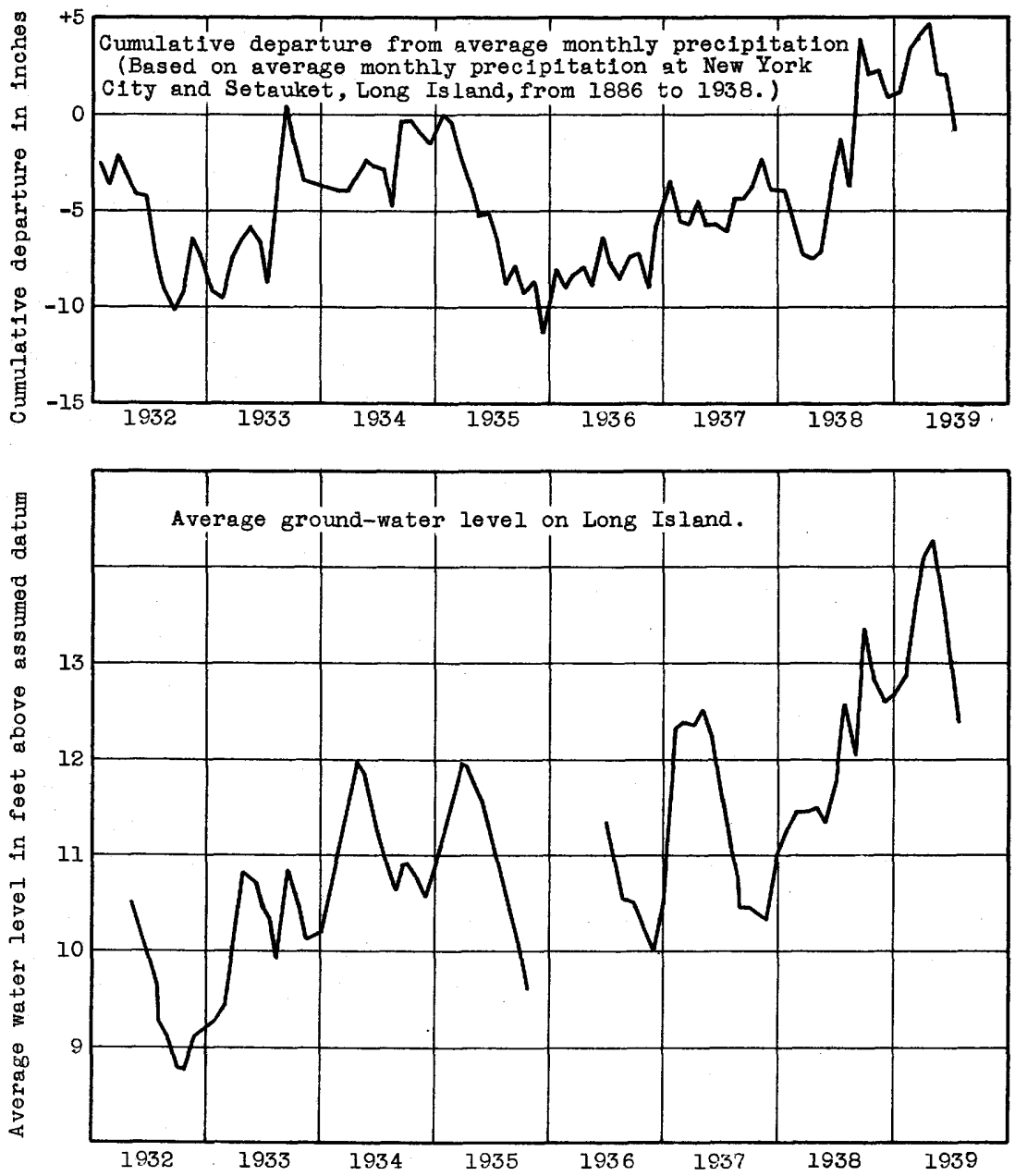

Figure 58.--Graphs showing cumulative departure from average monthly precipitation and average ground-water level on Long Island, N. $Y$.

Plate 20 shows graphs of the water-level fluctuation in a selected group of observation wells together with other related data for 1937 and 1938. It is apparent in plate 20 that the hydrographs for 1938 differ radically from those of 1937. On Long Island, 1937 was more or less a normal year, with reference to both precipitation and water-table fluctuations. (See fig. 58) However, in December 1937 began a period 
of deficient precipitation that continued until about the middle of May 1938. The recharge that took place during this period was, therefore, less than would have occurred if the precipitation had been normal. The records indicate that moderate rains occurring during the growing season on Iong Island do not generally produce ground-water recharge except in areas where the water table is relatively near the land surface. Plate 20 shows that both the June and July storms resulted in ground-water recharge on most parts of Long Island.

Table 24 gives summary data on 31 observation wells and the length of time and amount of rise of water level following each of the three storms here discussed. In table 24 the wells are listed from top to bottom in order of increasing depth of ground-water level below land surface on September 16, 1938. The figures given in the last six columa of table 24 are based on the hydrographs plotted for each individual well, similar to those shown in plate 20.

- The figures given' in the table for approximate net rise of water level after each of the three storms is obviously a minimum because the hydrographs, based on weekly measurements, probably do not indicate the lowest levels reached before each storm, nor the highest levels reached after each storm. For the same reason the figures given for approximate number of weoks during which the water level rose after each storm are doubtless for some wells somewhat smeller and in others somewhat larger than would have been indicated if continuous hydrographs were avallable.

It is apparent from the table that following any one storm, the water table rose for the longest period in those areas where the water table lies farthest below the land surface. In some of the deeper wells recharge was apparently still taking place more than a month after the particular rain. The average period during which the water levels rose was distinctly longer after the July storm than after the June and september storms. This is partly due to the fact that the July storm lasted 7 days whereas the June storm lasted only 3 days and the September storm only 4 or 5 days. It also seems probable that this longer period of recharge after the July storm was in part the result of delayed recharge from the June storm. The hydrographs for some of the wells, part1cularly the deeper wells, do not show distinct separate up-trends for the June and July storms. This indicates that the recharge resulting from the June storm was delayed enough that the water table was atill rising when the recharge resulting from the July storm began. It was, 


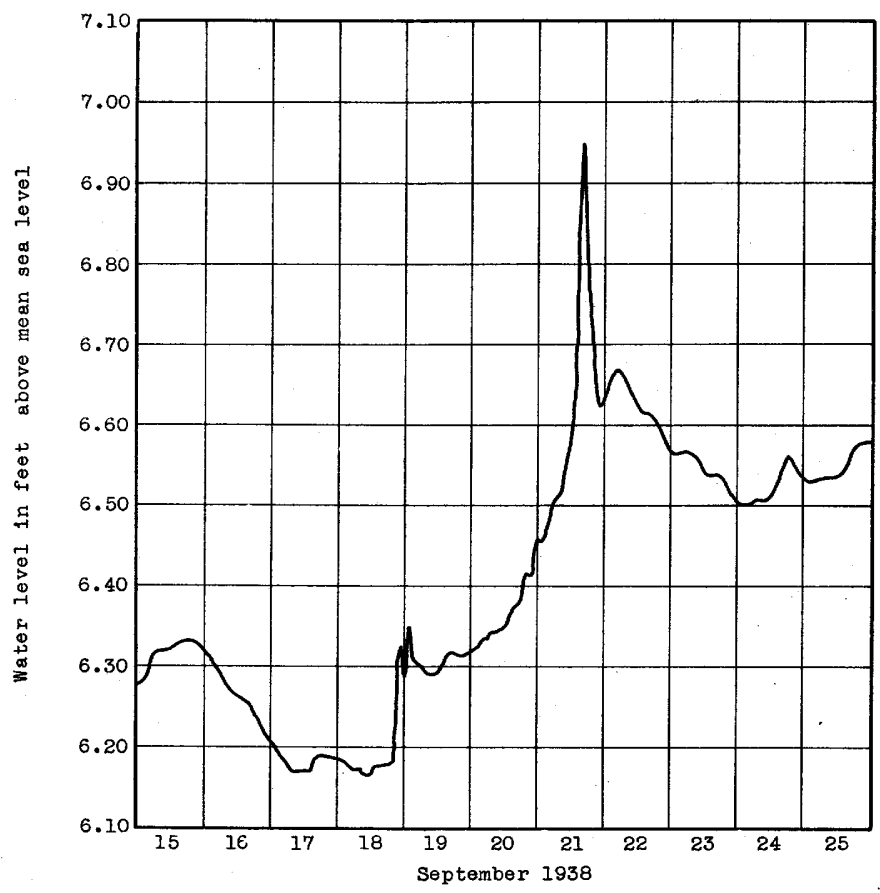

Well Q-273 at Forest H111s, N. Y., 438 feet deep.

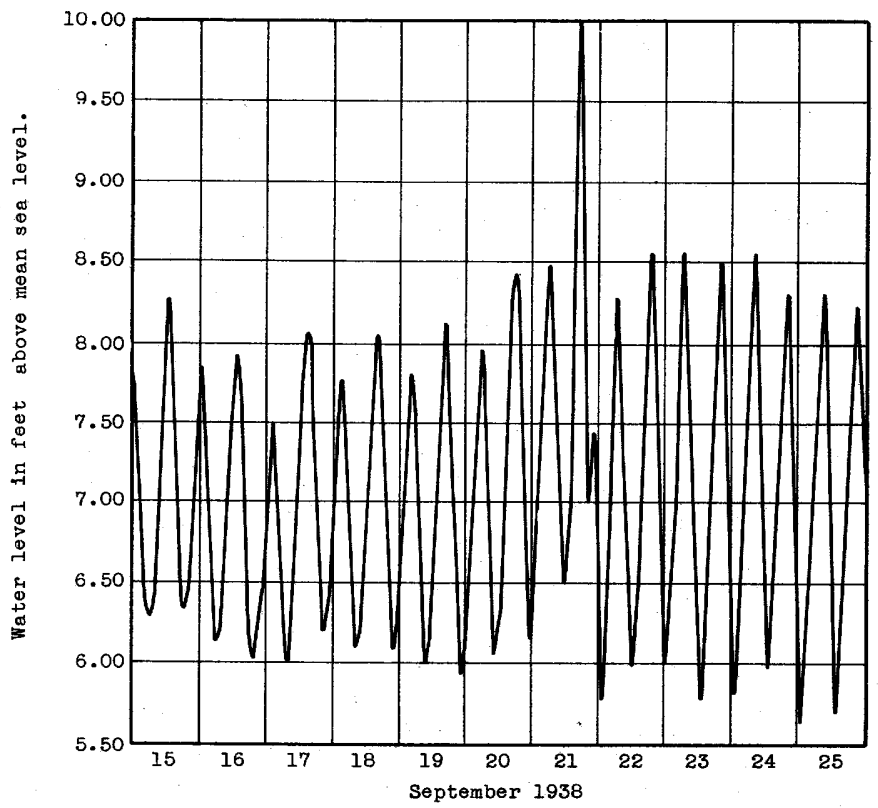

Well Q-543 at Rockaway Park, N. Y., 840 feet deep.

Figure 59.--Graphs showing relation of barometric pressure to water 


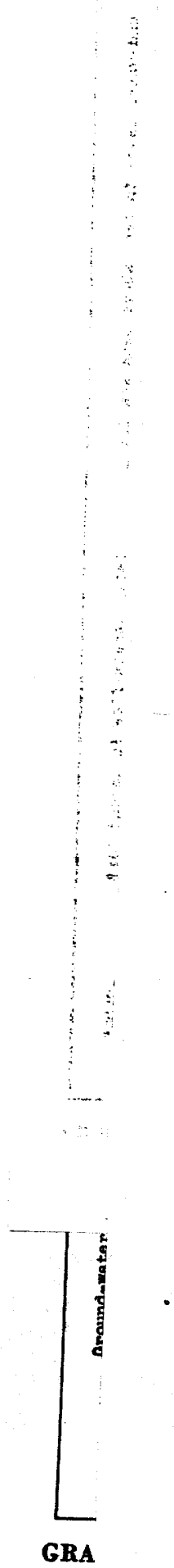





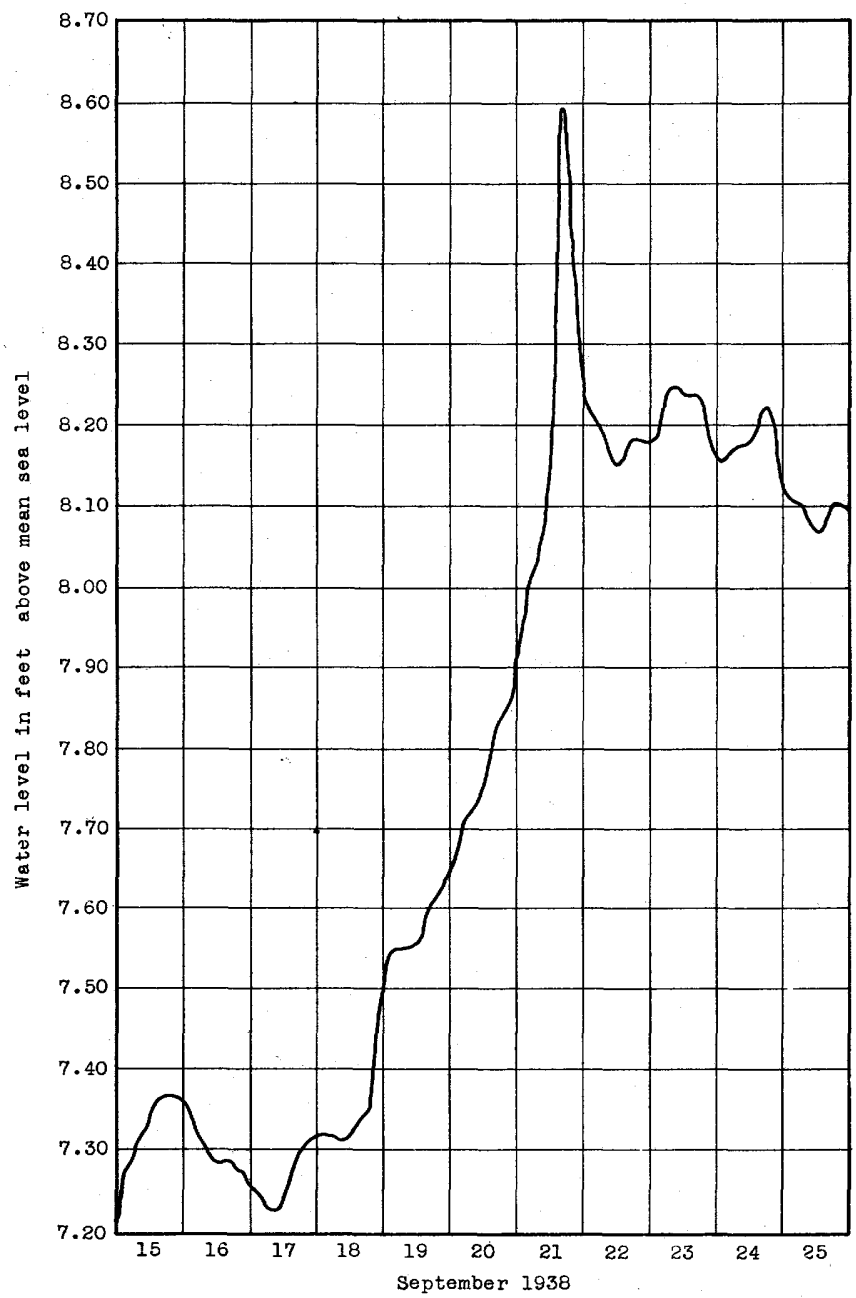

Well $\mathrm{N}-7$ at Valley Stream, N. Y., 911 feet deep.

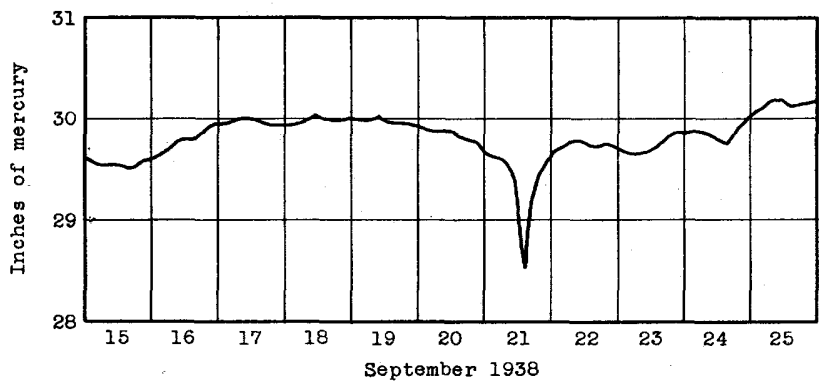

Atmospheric pressure at Jamalca, N. Y. (Altitude, 85 feet above mean sea level.) levels in three artesian wells on Long Island during the hurricane. 
therefore, not possible to determine accurately from some of the hydrographs the amount and duration of the rise of the water table caused by the June storm.

After the June and September storms, the water levels in the wells of the shallower water-table rose slightly more on the average than the water levels in the wells of the deeper water-tabie. After the July storm the conditions were the reverse, probably because the delayed recharge from the June storm was most prominent in the wells of the deeper water-tablo.

It is of interest to note that artesian wells on Iong Island also showed a considerable increase in head during the September hurricane. However, this increase in head was not the result of recharge to the artesian aquifers but rather the result of rapid decrease in atmospheric pressure during the hurricane. Artesian wells near the ocean normally show tidal fluctuations. In these wells, part of the increase in head during the hurricane was the result of the unusually high storm wave in the ocean. Figure 59 shows a graph of the barometer chart at Jamaica, N. Y., and a tracing of three recorder charts from artesian wells on Long Island. It might appear from two of the hydrographs in figure 59 that there was recharge to the artesian aquifer because the water level remained higher after the hurricane than before it. This, however, is not the case, because the hydrographs for these two wells show a simflar uptrend during the fall of each year after the heavy summer pumping from the artesian aquifer has ceased. Figure 60 shows the relation between pumpage and water levels in this artesian aquifer before and after the hurricane. The Long Beach wells are located about 6 miles from well N-7. A study of the records for previous years clearly shows that the major fluctuations of water level in this observation well are the result of changes in rate of withdrawal from the wells at Long Beach. It is apparent from figure 60 that the water level in the observation well began to recover in the first part of September before the hurricane and that if due allowance is made for barometric fluctuations the rate of recovery is about the same before and after the hurricane.

The well at Rockaway Park (see fig. 59) is on a barrier beach and normally shows tidal fluctuations. The highest water level in this well on September 21 occurred about 5:00 p.m., as compared with a high level due to the tide, which normally would have occurred in the well at about 7:00 p.m., indicating an advance of about 2 hours. The maximum ocean level caused by the storm tide was estimated to have been reached at 2830 p.m., as compared with the predicted normal high tide at about 5:00 p.m., 

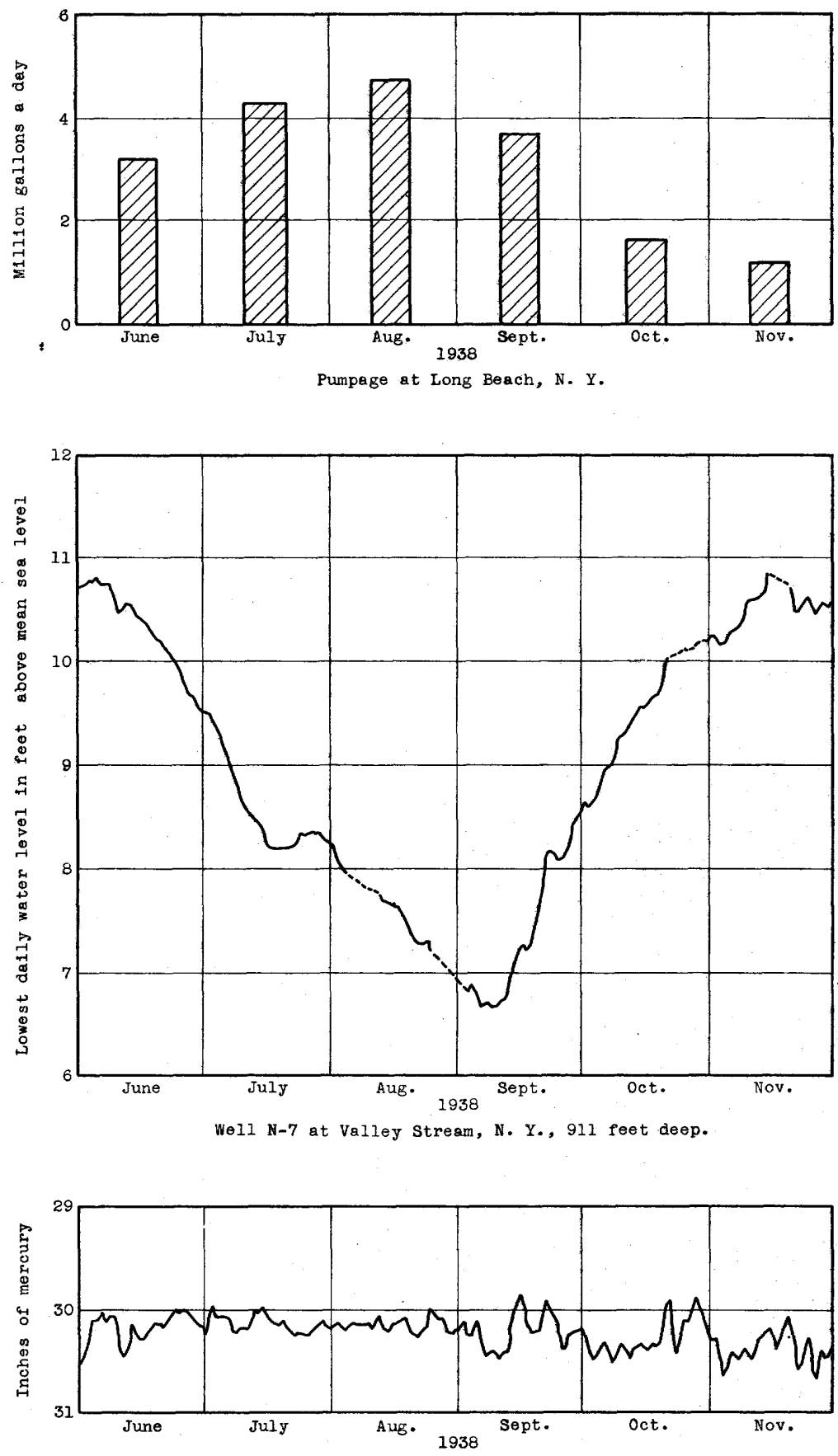

Atmospheric pressure at Jamaica, N. Y. (Based on hishest dalIy barometer.)

F1gure 60.--Graphs showing pumpage from the Lloyd sand at Long Beach, N. Y., water level in $a$ well ending in the Lloyd sand, and atmospheric pressure at Jamaica, N. Y. 
indlcating an advance of about $2 \frac{1}{d}$ hours, comparable with the behavior of the water level in the well. The influences of barometric pressure and local characteristics of tidal occurence may also have been involved. Further discussion of this subject is presented in the section "Ocean storm-wave in coastal areas".

\section{So11-moisture conditions}

As is well known, the soll-molsture conditions that exist at the time of a storm determine in large part the amount of recharge that takes place. Unfortunately no data are available as to the soll-moisture conditions preceding the three storms here discussed. However, table 25 shows the average precipitation on Long Island during each of four weekly periods preceding the three storms.

Table 25.--Aterage precipitation on Long Island during 4 weeks preceding each of the three major rain storms in 1938. a

\begin{tabular}{l|c|c|c|c|c}
\hline \multirow{2}{*}{ Storm } & \multicolumn{5}{|c}{$\begin{array}{c}\text { Precipitation during each of four weekly } \\
\text { periods preceding the particular storm } \\
\text { (1nches) }\end{array}$} \\
\cline { 2 - 6 } & $\begin{array}{c}7 \\
\text { days }\end{array}$ & $\begin{array}{c}8 \text { to } 14 \\
\text { days }\end{array}$ & $\begin{array}{c}15 \text { to 21 } \\
\text { days }\end{array}$ & $\begin{array}{c}22 \text { to 28 } \\
\text { days }\end{array}$ & $\begin{array}{c}\text { Total } \\
28-\text { day } \\
\text { period }\end{array}$ \\
\hline June 26-28 & 0.05 & 1.35 & 0.80 & 0.27 & 2.47 \\
July $18-24$ & .86 & .10 & 3.46 & .46 & 4.88 \\
Sept. $17-21$ & .79 & .06 & .50 & 0 & 1.35 \\
\hline
\end{tabular}

a Figures are averages of precipitation at Patchogue, Setauket, Mineola, and Flushing, N. Y.

In a general way the table indicates the probable soll-moisture conditions preceding each of the three storms. At any one time the soilmolsture conditions depend on the amount of plant growth and amount of precipitation during the preceding period. The relation of these two factors during the first preceding week is probably more largely responsible for the soil-moisture condition at any one time than the conditions during earlier weeks. The periods covered in table 25 are all within the growing season when plant growth was active. As shown in table 25, the first week preceding the June storm had almost no rainfal1, whereas the first week preceding both the July and September storms probably had about normal rainfall. However, the second week preceding the June storm had more than average rainfall, whereas the similar periods preceding the July and September storms had very little rainfall. The 4-week period preceding the September storm was considerably below normal in precipitation. 


\section{Increase in ground-water storage}

On Long Island, the shallow water-bearing beds in which the water table occurs are, in general, relatively uniform. Thus the hydrographs of all of the 31 wells listed in table 24 for both 1937 and 1938 are surprisingly similar in their major form, although there is considerable range in the amplitude of the fluctuations. (See pl, 20.) This fact appears to warrant an attempt to attack quantitatively the recharge problem by using the average rise of ground-water levels after a particular storm.

When water penetrates to the water table only the part of the total pore space that is not already occupled by water is avallable to recelve the recharging water. The specific yield of a material is defined as the ratio of (1) the volume of water it will yield by gravity after being saturated, to (2) its own volume. Within the root zone the moisture content may be further depleted through absorption by the roots of the plants, but below the root zone the specific yield gives an approximate measure of the capacity of the material to store water. Thus, if the specific field of a sand formation is 25 percent, the water table will rise 4 inches for every inch of water added to the zone of saturation of that sand.

In 1903 the physical properties of several natural and graded sands on Long Island were determined by the Burr-Hering-Freemen Commission 26/. Their determinations included porosity and the amount of retained moisture after the samples were saturated and allowed to drain. Their determinations of the amount of retained molsture may be considered to be the specific retention of the samples, that is, the ratio of (1) the volume of water which the material, after being saturated, will retain against the pull of gravity to (2) its own volume. These data provide a basis for obtaining the specific yield because the porosity minus the specific retention is equal to the specific yield. Their method used in determining the amount of retained moisture was to allow tubes of the saturated samples ( 3 inches in diameter by 10 feet long) to drain for 20 days, after which the amount of retained moisture was determined for each quarter foot of the entire length of the 10-foot tubes. In no case did the draining completely stop at the ond of the experiments, and 
the specific yield is therefore somewhat greater than that obtained by subtracting their figures for retained molsture from the porosity. Their experiments were performed on 14 different tubes, the determinations being repeated three or four times in some instances. The materials used In their experiments are belleved to be fairly representative of the material that occurs above the water table in the southern part of Long Island. Their data indicate that the average specific retention is about

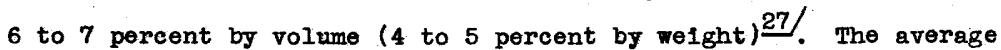
porosity of their samples was about 44 percent, thus indicating a value of about 37 percent for the average speciffe yield. This is a rather high value for specific yleld, and it is possible that a greater number of determinations on a larger number of samples might give a somewhat lower value. For the purpose of this report it has been assumed that one-thira ( $33-1 / 3$ percent) of the total pore space is available to receive recharging water.

Table 26 gives summary data as to the estimated amount of increase in ground-water storage following each of the three storms, assuming a specific yield of $33-1 / 3$ percent. The table indicates that the increase In storage during the period of rising water table was equal to 69 percent of the rain that foll during the September storm.

Table 26.--Summary of data relating to ground-water recharge on Long Island for three storms in 1938

\begin{tabular}{l|c|c|c|c}
\hline Date of storm & $\begin{array}{c}\text { Average of } \\
\text { rainfal1 } \\
\text { at four } \\
\text { stations } \\
\text { (inches) }\end{array}$ & $\begin{array}{c}\text { Average rise } \\
\text { of ground-water } \\
\text { leveI after } \\
\text { storm } \\
\text { (1nches) }\end{array}$ & $\begin{array}{c}\text { Increase in ground- } \\
\text { water sorage during } \\
\text { period of rise, } \\
\text { assuming specific } \\
\text { jield of 33-1/3 } \\
\text { (Inches) }\end{array}$ & $\begin{array}{c}\text { Recharge } \\
\text { divided } \\
\text { by } \\
\text { rainfall } \\
\text { (percent) }\end{array}$ \\
\hline June 26-28 & 3.85 & 8.0 & 2.7 & 70 \\
July 18-24 & 5.95 & 13.7 & 4.6 & 77 \\
Sept. 17-21 & 10.45 & 21.5 & 7.2 & 69 \\
\hline
\end{tabular}

The figures given in the last column of table 26 are based on the measured rise of water level in observation wells at weokly intervals, which is obviousiy somewhat less than the total rise. For example in test well M-58 (see pl. 20) the water level rose 2.00 feet between September 16 and 23. Most of this rise doubtless took place after september 18, the first day on which heavy rains occurred. The highest water level in this well probably occurred a few days before or a few days after september 23, the high point on the hydrograph in plate 20. The highest actual water 
level may have been considerably higher than was measured on September 23. This same feature applies to all the other hydrographs used in computing the average rise of water level, although the difference is probably not large for the deeper water-table wells. In any event, the figures given in the third and fourth columns of table 26 are smaller than the actual average rise of water level that took place after each of the three storms.

It should also be noted that the method utilized above gives the computed increase in ground-water storage after a particular storm. The increase in ground-water storage represents only a part of the total water that reaches the water table. After and during a perlod of recharge the ground-water reservolr is discharging water by ground-water run-off, ground-water underflow directly into the ocean, transpiration, evaporation, and pumpage. Thus, the last column in table 26 represents increase In ground-water storage and not total recharge.

\section{Direct run-off}

During 1938 five stream-gaging stations were being maintained on Long Island by the Geological Survey, in cooperation with the Nassau Oounty Department of Public Works. Four of these stations are on the south shore in the same area discussed in the previous section and one is on the north shore of the Island north of the moraine and outside the area under discussion. The records of the flow of the four south shore streams were studied to determine the amount of direct run-off resulting from the three storms. Figure 61 shows the hydrograph of one of these streams and the precipitation at Mineola, N. Y., for the period of the three storms. A separation of the stream flow of these five streams into direct run-off and ground-water run-off has been made in the general manner described in the section "Rainfall and run-off studies" under "Methods of analysis."

Table 27 indicates the amount of direct run-off resulting from the three storms in each of the four south shore streams. It is apparent that only a very small part of the water that fell during each of these storms was disposed of as direct run-off.

The differences in direct run-off after any one storm for the streams listed in table 27 are doubtless the composite result of numerous factors. The precipitation used in the computation is that recorded at Mineola. The actual precipitation on each of the four drainage areas was probably somewhat different in amount than that recorded at Mineola. The precipitation and direct run-off of each of the streams on Long Island during the storm of September 17-21 is listed in table 14, pages 424-431. The 

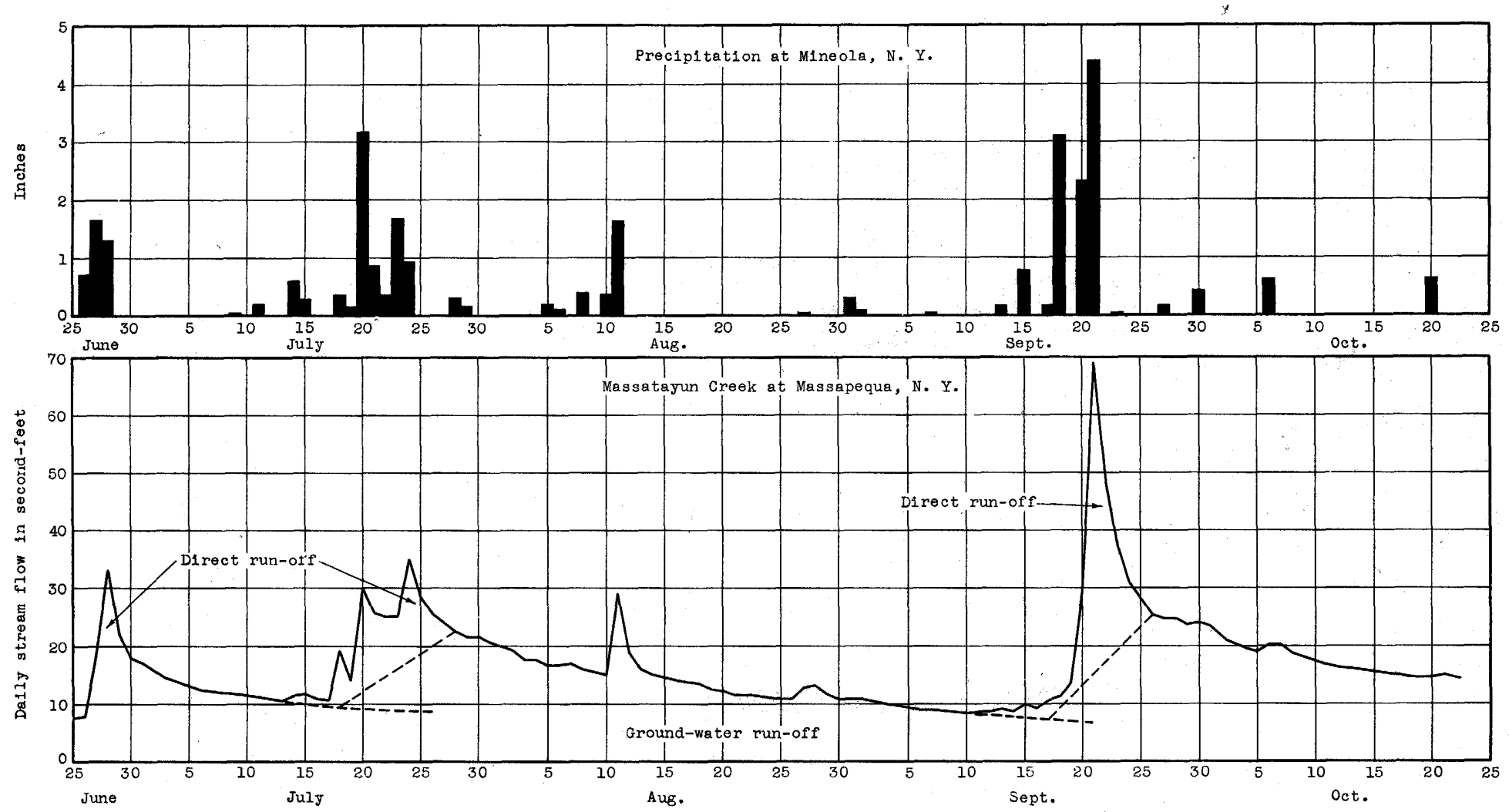

Figure 61.--Graphs showing precipitation at Mineola and stream flow of Massatayun Creek, Long Island, during three storms in 1938. 
gaging station on Pines Brook is located a short distance below a pond, and storage in this pond doubtless affects the run-off characteristics of this stream. Above the gaging station on Wantagh Stream are ponds that at times are regulated. It is therefore believed that the records for Massatayun Creek and East Meadow Brook indicate more nearly the natural run-off characteristics. The direct run-off for East Meadow Brook is larger for each of the three storms than that of Massatayun Creek. This

Table 27.--Rainfall, direct run-off, and retention, in inches, resulting from three storms in 1938 on the south shore of Long Island

\begin{tabular}{|c|c|c|c|c|c|c|c|}
\hline \multirow{2}{*}{ Stream } & \multirow{2}{*}{$\begin{array}{c}\text { Drainage } \\
\text { area } \\
\text { (square } \\
\text { miles) }\end{array}$} & \multicolumn{2}{|c|}{$\begin{array}{c}\text { Storm of June } \\
26-28, \text { rainfal1 } \\
3,65\end{array}$} & \multicolumn{2}{|c|}{$\begin{array}{c}\text { Storm of July } \\
18-24, \text { rainfall } \\
7.45\end{array}$} & \multicolumn{2}{|c|}{$\begin{array}{c}\text { Storm of Sept. } \\
17-21, \text { rainfail } \\
11.00\end{array}$} \\
\hline & & $\begin{array}{l}\text { Run- } \\
\text { off }\end{array}$ & $\begin{array}{l}\text { Reten- } \\
\text { tion }\end{array}$ & $\begin{array}{l}\text { Run- } \\
\text { off }\end{array}$ & $\begin{array}{c}\text { Reten- } \\
\text { tion }\end{array}$ & $\begin{array}{l}\text { Run- } \\
\text { off }\end{array}$ & $\begin{array}{c}\text { Reten- } \\
\text { tion }\end{array}$ \\
\hline $\begin{array}{l}\text { Massatayun } \\
\text { Croek }\end{array}$ & 37 & 0.05 & 3.6 & 0.1 & 7.35 & 0.15 & 10.85 \\
\hline $\begin{array}{l}\text { Eest Meadow } \\
\text { Bronk }\end{array}$ & 31 & .06 & 3.59 & .15 & 7.3 & .3 & 10.7 \\
\hline $\begin{array}{l}\text { Wantagh } \\
\text { Stream }\end{array}$ & 17 & .08 & 3.57 & $\because .2$ & 7.25 & .2 & 10.8 \\
\hline Pines Brook & 10 & .01 & 3.64 & .15 & 7.3 & .3 & 10.7 \\
\hline Average & -- & .05 & 3.6 & .15 & 7.3 & .25 & 10.75 \\
\hline
\end{tabular}

probably results from the fact that in the Bast Meadow Brook area there are numerous construction works for the disposal of storm water as well as a considerable percentage of impervious area, such as pavements, sidewalks, and roofs. The lower parts of the drainage areas of Massatayun Creok and Wantagh Stream are in areas of heavier pumping than those of the other two streams. The rainfall and run-off relation in this area during the hurricane storm of September 1938 are presented in the section "Rainfall and run-off studies" under "Streams on Long Is land."

\section{Summary}

The storms of June, July, and September, 1938, each produced a large amount of ground-water recharge on Long Island. According to the analysis here given, the increase in ground-water storage caused by the September storm was 7.2 inches (69 percent. of the rain that fell during the storm). The stream-flow records indicate that only a small part of the rainfall during these three storms was disposed of by direct run-off, the range for the September storm being 0.15 to 0.3 inches. The remsinder of the rain that fell during the September storm, amounting to approximately $22790 \overline{\mathrm{i}} \mathrm{O}-40-36$ 


\section{6 inches according to the computations, was disposed of in different}

ways. A part of this remainder reached the water table but was discharged during the period of rise as ground-water run-off or ground-water underflow directly to the ocean, or by pumpage from the shallow water-bearing beds, evaporation, and transpiration. Another part did not reach the water table, either having been intercepted by vegetation, remaining as moisture in the soll, or being discharged into the atmosphere by evaporation from the surface or soll or by transpiration of the plants.

\section{Comparison with recharge in Connecticut}

During 1938 periodic water-level measurements were being made in several observation wells in Connecticut by the United States Works Progress Administration under the sponsorship of the Connecticut State Water Commission and under the direction of the United States Geological Survej. These observation wells are located in many different topographic positions and end in a varlety of geologic formations having a wide range of waterbearing characteristics. As might be expected, the amount of $r i s e$ of ground-water level resulting from the recharge of the hurricane storm varied considerably in the observation wells, the range being from a small fraction of a foot to almost 10 feet. On the average, the water level in wells ending in glacial till rose considerably more than that in wells ending in stratified glacial drift. In some of the wells, the high-water level after the hurricane exceeded any previously recorded high-water level, but many of the periods of record are short. The highest recorded water level in several of the wells that were first measured in 1934 occurred, however, at some time other than after the hurricane.

Many of the observation wells in Connecticut end in glacial till or bedrock, both of which have a much lower specific yield than the outwash sand and gravel on the south side of Long Islend.

Although the ground-water levels rose on the average considerably more in Connecticut than on Long Island, the rise represented a much smaller quantity of water, and hence the direct run-off was considerably greater in Connecticut than on Long Island. For the same reason, the amount of ground-water run-off after the period of recharge was considerably smaller in Connecticut than on Long Island.

The water-bearing properties of the stratified drift deposits in Connecticut are similar to those of the outwash sand and gravel on the south shore of Long Island, but on the average the water levels rose more in the stratified-drift wells in Connecticut than in the wells on the southern part of Long Island. 
Records of or references to historical flood information and summaries of data of record floods for streams in the area covered by this report

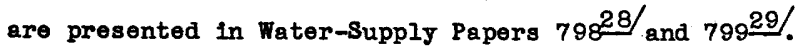

The following notes cover comparisons of the hurricane floods of september 1938 with previous floods for a few streams in Connecticut.

In the outstanding flood of March 1876 in the Thames River Basin, a dam 326 feet long on the Shetucket River at Greenville, Conn., was reported to have had 12 to 14 feet of water passing over it. A dam 401 feet long, about 1,200 feet downstream, had water passing over it to a maximum depth of 11.1 feet on March 12, 1936, and of 14.5 feet on September 21, 1938. Unless the dam in 1876 had an extraordinarily high discharge coefficient, on the basis of these figures it appears that the peak flow of September 1938 was the greater.

During September 1938 stages on the lower part of the Connecticut River did not reach the records of the March 1936 flood because the greater discharge from the lower tributaries was more than offset by smaller flows from the upper headwater streams. On the Connecticut River at Hartford, Conn., the United States Weather Bureau recorded a gage height of 35.42 feet September 23, 1938, which was 2.2 feet lower than that of March 21 , 1936, but 5.6 feet higher than that of May 1, 1854, which was the maximum recorded previous to 1936.

On the upper dam of the Farmington River at Collinsville, Conn., with all flashboards reported out and all wastegates open, a water-stage recorder maintained by the Collins Co. Indicated water passing at a depth of 10.5 feet over the dam on September 21, 1938. As shown in WaterSupply Paper 798, page 457, a maximum depth of 9.0 feet was recorded durIng March 1936. From 1869 to August 1938 the greatest storm rainfall in the Farmington River Basin occurred during October 1869. At that time a maximum depth of only 10 feet was reported on this upper dam and the sp111way was about 4 percent shorter than since 1935. On an interior wall of the Collins Co.'s boller house, about a quarter of a milo downstream from the upper dam at Collinsville, a highwater mark of the flood of september

28/ The floods of March 1936, part 1, New England Rivers: U. S. Geolog 1cal Survey Water-Supply Paper 798, pp. 438-460, 1937.

29/ The floods of March 1936, part 2, Huds on River to susquehanna River region: . S. Geological Survey Water-Supply Paper 799, pp. 359-374, 1937. 
1938 was found to be at an elevation of 286.7 feet and is 2.9 feet higher than the previous noted maximum of December 1878, which is reported as possibly affected by an ice jam.

On the Hockanum River at the outlet of Shenipsit Lake, Rockville, Conn., the dam is reported to have remained unchanged since 1871 with a total splllway length of 48 feet. A maximum stage of 1.6 feet was reported to have occurred in February 1886, 0.6 foot in March 1896, 0.9 foot in March 1936, and 4.23 feet (by levels from floodmarks) on September 21, 1938. The elevation of the lake was unknown prior to the flood of February 1886 and March 1896. Prior to the flood of March 1936 the lake level was 8 feet below the spillway as compared with 3 feet before the September 1938 flood. The lake has a surface area of about I square mile.

Water-Supply Paper 798 on page 458 tabulates maximum depths of water over the dam on the Housatonic River at Derby, Conn. The maximum head noted was 13 feet in October 1869, when the length of spillway was 636 or 637 feet. With a spillway length of 675 feet, a water-stage recorder showed a maximum depth over the dam of 8.4 feet March 1936 and 7.6 feet over the top of about 0.5 foot of flashboards September 1938 .

\section{Previous great storms}

History records that hurricanes and violent storms have visited the North Atlantic coast rather frequently in the past. The first New England hurricane known to the white man occurred in 1635. The following account is taken from Nathaniel Merton's "New England Memorial1", published in 1669 .

This Year, on Saturday, the fifteenth day of August, was such a mighty storm of Wind and Rain, as none now living in these parts, either English or Indian had seen the like, being like unto those Hirricanes or Tuffins that writers mention to be sometimes in the Indies. It began in the morning a little before day, and grew not by degrees, but came with great violence in the beginning, to the great amazement of many; It blew down sundry houses, and uncovered divers others: divers vessels were lost at Sea in $1 \mathrm{t}$, and many more in extream danger. It caused the Sea to Swell in some places to the southward of Plimouth, as that it arose to twenty foot right up and down, and made many of the Indians to climb into Trees for their safety: It threw down all the Corn to the ground, which never rose more; the which through the mercy of God, it being near harvest time, was not lost, though much the worse: and had the wind continued without shifting, in likelihood it would have drowned some part of the country. It blew down many hundred thousands of Trees, turning up the stronger by the roots, and breaking the hlgh Pine Trees and such like in the midst, and the tall young Oaks and Walnut Trees of good bigness, were wound as a Wyth by it; very strange and fearful to behold: It began in the Southeast, and veered sundry wayes, but the greatest force of it at Plimouth, was from the former quarter: It continued not in extremity above five or six hours, ere the violence of it began to abate; the marks of 1 will remain this many years, in those parts where it was sorest: the Moon suffered a great Eclipse two nights after 1 t. 
A storm similar to the hurricane of September 1938 occurred on September 23, 1815. The following account of this "Great blow", as it was called, is given by Tilden $30 /$.

A wonderful hurricane came on this day. The wind the previous night was high. A sensible increase was percelved at $10 \mathrm{a} . \mathrm{m}$. It continued for many hours. Toward night, it became very calm. It began at northeast, and then shifted at its helght to south. Its effects were tremendous. Corn was prostrated, the stoutest trees were eradicated, many chimneys fell, sheds were generally blown over, four barns were blown down in this town, many buildings injured, and immense damage sustalned. The tide at Providence rose twelve feet higher than ever known before, ships drove into the streets, and losses were estimated at $\$ 1,500,000$. The wind extended over New England with nearly equal violence. At New York, the wind was moderate and in a contrary direction. Its ravages did not extend far out at sea. In history, we read of a similar wind in 1635 .

Severe tropical storms of this character are not as rare in northeastern United States as may commonly be supposed. I. R. Tannehilizl/, of the Marine Division of the Weather Bureau in Washington, D. C., described briefly storms that occurred on August 15, 1635; August 19, 1788; September 23, 1815; September 3, 1821; September 8, 1869; October 23-24, 1878; August 24, 1893; August 29, 1893; and September 16, $1903 . \mathrm{Dr}$. Charles F. Brooks 32/, of the Blue Hill Meteorological Observatory, Milton, Mass., cites references to a dozen or more additional storms not contained in Tannehill's list and quotes a frequency of 5 to 10 hurricanes per century in this region with "one that is especially flerce and widespread in each century and a half .

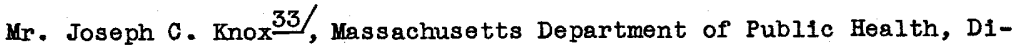
vision of Sanitary Engineering, has also complled records and information relative to previous cyclonic disturbances in New England. Records of historic storms in New England between 1639 and 1891 were taken from Sidney Perley 34 , and from 1888 to 1938 from the files of the United States Weather Bureau at Boston, Mass.

30/ Tilden, History of Medfield, 1650-1886.

3I/ Tannehili, I. R., Hurricane of September 16 to 22, 1938: Monthly Weather Review, U.'S. Weather Bureau, September 1938, vol. 66, no. 9, pp. 286-288.

32/ Brooks, C. F., Hurricanes into New England: Geographical Review, Amer. Geo. Soc. of New York, January 1939, pp. 119-127.

33 Knox, J. C., Cyclonic storms of Sept. 21, 1938.

34/ Perley, Sidney, Historic storms of New England, Salem, Mass., 1891. 

Ackmowledgments

Administration and personnel ...

Ammonoosuc River near Bath, N. H.

Antrim, N. H., North Branch of Contoocook River near

Arena, N. Y., Mill Brook at . .

Axlington, Vt., Batten K1ll at: .

Ashokan Reservolr near Kingston, N. $Y$.

Ashuelot River at Hinsdale, N H.

near Gilsum, N. H.

South Branch of, at Webb, near Marlboro, H. H.

Athol, Mass., East Branch of Tuliy River near.

Auburm, N. B., Clark Brook at : .

Ausable Forks, N. Y., Ausable

River near.........

East Branch of Ausable River at

West Branch of Ausable River at

Ausable River near Ausable Forks, N. Y. * * * *.'. .

Bast Branch of, at Ausable Forks, N. Y. . . .

West Branch of, at Ausable Forks, N. Y. . . . . . pl.15,

near Newman, N. Y. . . . . . . 357

Bakers River near Rumney, N. H.

Barkhamsted Reservolr near Barkhamsted, Conn. , vt., Connecticut River at outlet of Fifteenmile Falls Reservolr near......

Fifteenmile Falls Reservolr near

Bath, N. H., Ammonoosuc River near Batton Kill at Arlington, Vt.

at Battenville, N. Y.

Battenville, N. Y., Batten K111 at .

Beaver Brook at outlet of Splitrock Pond, N. J. * . . . . .

Beaver Kili at Cooks Fails, N. $\dot{Y}$.

at Craigie Clair, N. Y. . . .

Belvidere, N. J., Delaware River at

Benningtion, Vt., flood damage at . pl. $6, \mathrm{~A}$

Bethel, vt., White River near . . . 157

Beverly Yacht Club at Marian, Lass., before and after the hurricane

B1rcham Bend, Mass., Chicope River at $\cdot \dot{*} \cdot \dot{*}^{-} \cdot$

Black Brook at Black Brook, N. Y.

Black River at North Springfield, $\mathrm{Vt}$

near Pottergvilie,

Black Rfver Canal (f́lowing south). near Boonvilie, N. $\mathbf{Y}$. . :

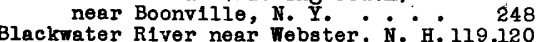

Blackwells Mills, N. J., Millstone River at . . . . . . . .

Boonton, N. J., Boonton Reservoir at

Rockaway River above reservolr at

Rockavay River belor reservoir st

Boonton Reservolr at Boonton, $N$. J.

Boonville, H. Y. Black River

Canal (flowing south) near..

Borden Brook Reservolr in Westfleld Little River Basin near Westfleld, Mass.

Bouquet River at Wilisboro, $\mathrm{H}^{*} \dot{\dot{Y}} \cdot$ Bristol, N. H., Pemigewassét River at . ?. * * * * *

Sulth River near ........

Broad Brook, Conn., Scantic River at

Burlington Brook near Burlington, conn.

Burlington, vi., Lake champlain at :

Canistear Reservolr near Stockholm, N. J. Creok at Oak Hili, N. $\dot{\text { Y. }}$ : Catsk1ll Creok at Oak H111, N. Y. Cedar River below Chain Lakes, near Indian Lake, N. $\mathrm{Y}$.
Charlemont, Mass., Deerfleld River at - - - -

244 Charlotte Creek at Davenport

$5-6$

pl. $5, A$

156

117,118

334
241

264

166

169

174

122

358
360

$1.15, \mathrm{~B}$

358

360

112

195

143

143

156

241
242

242

294

338

337

$6, A$
157

17

181

359

164

315

318

292
291

293

292

248

189

361

105

113

190

198

355

302

262
515

234

Cold Spring, Mass., Ot1s

Coltsville, Mass., Housatonic

Connecticut, ground-water

Cralgle Clair, N. Y., Beaver
Page

177

354

303

286

353

269

nut Creek above Red Brook, at Grahams ville, N. Y. . . .

Chicopee Falls, Mass., Chicopee

River . . . . pl.14,B

Chicopee River at Bircham Bend,

Mass. * * * . . 181

at Chlcopee Falls, Mass. * : pl. 14, B

Clifton, N. J., Passalc River at Dundee Dam * * * * * * 289

Clint on, Mass., South Branch of Nashua River at . . . . . 126

Wachusett Reservoir on South

Branch of Nashua River at. . 126

Clinton Reservolr near Newfoundland, N. J.

303

fleld Little River Basin

near Westfield, Mass. ...

Cochituate, Mass., Lake Cochituate

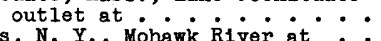

Cohoes, N. Y., Mohawk River at. Reservoir at

Coldbrook, N. Y., Esopus Creek at . $\quad 263$ Colliersville, N. Y., Susquehanna (

Collinsvilie, Conn. Nepaug Reservoir near ... . . . 197 River at ............. 208

Columbia, Conn., Hop River near . . 131

Concord, N. H., flooded areas at pl. 4,A diver below River Meadow Brook, at Lowell, Mass. ingville, N. Y., Sacandaga

Racandaga 239 recharge in .

Connecticut River at First Connec ticut Lake, near Pittsburg,

N. H. . . . . . 140

at Hartford, Conn. : . : . : 153

at Holyoke, Mass. . . . . . . - 150

at Montague City, Mass. . . . 149

at North Stratford, N. H. . . . 141

at outlet of Fifteonmile Falis Reservoir near Barnet, Vt.

at South Newbury, Vt. . . . . 145

at Springfield, Mass. . . . . 151

at Thompsonvilie, Conn. . . . 152

at Turners Falls, Mass.: : : : $14 \varepsilon$

at Vernon, vt. ........ . 147

at White River Junction, vt. . . 146

near Dalton, N. H. . . . . . 142

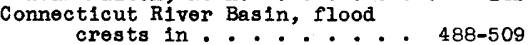
crests in ${ }_{\text {od determinations in } \cdot{ }^{\circ} \cdot 488-509}$

rainfall and run-off in . . 4 448-455

storage in ........ 414-417

Contoocook River at Penacook, N. H. 116

North Branch of, near Antrim, N. H. *

Cooks Falls, N. Y., Beaver Kill at 338

K111 at . . . . . . 337

Croton, N. Y., Croton River near 279,280

Croton River reservolrs near . - 278

New Croton Reservolr at New

Croton Dam, near ..... 277

Croton River at New Crotion Dam, near Croton, N. Y. . . . 279

at Quaker Bridge, near Croton,

N. Y. . . 
Croton River reservoirs above New Croton Dam, near Croton, N. $Y$.

Curry, N. Y., Neversink RIver near.

Dalton, N. H., Connecticut River near buricane at Westeriy; R. I. . . . . . . .

Dana, Mass., East Branch of Swift River near........

Davenport Center, N. $\dot{Y}$., Chariotte Creek at $\cdot \dot{0} \cdot \dot{0} \dot{0} \cdot$

Davis Bridge, Vt., Deerfield River

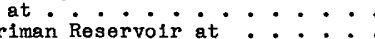

Harriman Reservolr at - $\cdot \dot{\text { Mass }}$.

East Branch of, at outlet of Somerset Reservolr near Somerset, Vt. . . .

at outlet of Harriman Reservoir, at Devis Bridge, vt.....

Delaware River at Belvidere, $\dot{N}^{*} \mathrm{~J}^{*}$ : at Port Jervis, N. Y. . . . . at Riegelsville, N. J. . . . . .

at Trenton, $N$. J.

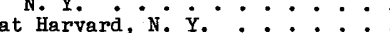
at Margaretvilie, N. $\dot{\mathrm{Y}} \cdot \dot{*}^{*}$ :

West Branch of, at Delhi, N. $\mathrm{Y}$. at Hale Eddy, N. Y. ....

Delaware River Basin, flood crests in . . . . . . . 515-519

flood determinations in . . . pl. 11

rainfall and run-off in ... . . 466

Delhi, N. Y., Little Delaware River near

West Branch of Delaware River at Delta Reservoir at Delta Dam, near Rome, N. $Y$.

Discharge, determination of . .

graphs showing . . . . . 86-103, 411

records of $104-380$

Dog River at Northfieid Falis, it. $\quad 372$

Dolgeville, N. Y., East Canada Creok at : . . . . $\quad 255$

Dover, N. J., Rockaway River at :

Eagle Bridge, N. Y., Hoos1c River

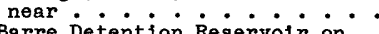

East Barre Detention Reservolr on. Ja11 Branch at East Barre, Vt.

East Barre, Vt., Ja11 Branch at

East Branch Reservolr at New Hartford, Conn.

East Canada Creek at Dolgevilie, $\mathrm{N} . \mathrm{Y}$

East Georgia, vi., Lamoilie River at

East Hampton, Conn., Salmon River

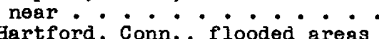

East Hartford, Conn., flooded areas

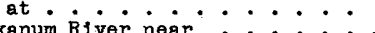

aast Meadow Brook at Freeport, $\dot{N}$.

East Peppere11, Mass., Nashua River at..........

Echo Lake Reservolr near Charlotteburg, N. J. . ...

E1ghtmile River, East Branch of, near North Lyme, Conn.

West Branch of, near North Lyme, Conn.

El1zabeth River at Elizabeth, $\dot{N}^{*} \dot{J}$.

Elizabeth River Basin, flood crests in

flood determinations in $\cdot{ }^{*} \cdot{ }^{*}$

Frving, Mass., Millers River at . 171

Esopus Creek at Coldbrook, N. Y. . . 263

at outlet of Ashokan Reservo1r, near Kingston, $N$. $Y$. .

Essex Junction, Vt., R1ver near.......

Fair Haven, Vt., Poultney River below - ín- - - $\cdot$ River at ?

Far Hills, N. J., North Branch of Raritan River near.....

Farmington River at Rivertion, conn. at Tariffille, Conn.

near New Boston, Mass. : : :
Farrington Dam, N. J., Lawrence Brook at . . . . . . .

reservoir on Lawrence Brook at Fifteenmile Falls Reservoir near Bamet, vt. . . . . . .

First and Second Connecticut Lakes near P1ttsburg, N. H.

Fishs Eddy, N. Y., East Branch of Delaware River at ...... Flood, map showing location of determinations of ...... pl. 11

general features of the.... 34-40 Florlda, Mass., Mohawk Trail along Cold River near - : - pl. 7,A Flor1de, N. Y., Quaker Creek at . . 275 Folsom, N. J., Great Egg River at . 326 Franklin, N. H., Pemigewasset RIver at ......... 106

Franklin Junction, N. H., Merrimack RIver at . - '

Framingham Center, Mass., Sudbury

Freeport, N. Y., East Meadov Brook at...........

Gardiner, N. Y., Wallk1ll River at Garvins Falls, N. H., Merrimack

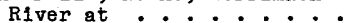

Gaylordsville, Conn., Tenmile River near.

Glbbs Crossing, Masi., Ware River at N. Y., Schoharie creek at:

Gilboa, N. Y., Schoharle Creek at. Schoharie Reservoir at . * - .
Gilsum, N. H., Ashuelot River near Godeffroy, N. Y., Neversink River

Goss Helghts, Mass., Middie Branch: of Westfleld River at... Grahamsville, N. Y., Chestnut Creek at . . . . . .

Great Barrington, Mass., Housetonic River near ........ Great Egg River at Folsom, N. $\dot{J}_{\text {. }}$ : flood crest on ...... 515 Green Brook at Plainfleld, N. J. . 319 Greenwood Lake at The Glens, N. J. Ground-water recharge on Long Island .... . . . . 529-552
368

369

196

255

204

1. $4, \mathrm{~B}$

203
227

303

205

206

306

12

171
263

265

367

363

210

313

192

193

191
Hackensack River at New Milford, N. J. 282

Hackensack River Basin, flood crests in....... 510

flood determinations in: : : : pl. 11

Hedley, N. Y., Hudson R1ver at . . 232

Hale Eddy, N. Y., West Branch of Delaware River at. .

Harriman Reservoir on Deerfield River at Davis Bridge, Vt.

Hartford, Conn., Connecticut River

North Branch of Park River at: : 201

180

258

257
166

350

187

269

209

326

298

Park River at.......... 200

South Branch of Park River at: 199

Harvard, N. Y., East Branch of Delaware River at ......

Hawks Nest, Conn., storm-wave damage at :. . . pl. 18,B

High Bridge, N. J., South Branch of Raritan River near . 309

H111sdale, N. J., Woodcliff Lake at 283 Hinckley, N. Y., Hinckley Reservolr at

252

West Canada Creek at : $\cdot$. : : : 253

Hinsdale, N. H., Ashuelot River at

History of previous floods and storms ........ 553-555

Hockanum River at outlet of Shenlpsit Lake, at Rockville, Conn.

202

near East Hartford, Conn. ... 203

Holyoke, Mess., Connecticut River

Hoos Ic Falis. H. Y., fiood damage at

Hoosic River at Adams, Mags. near Eagle Bridge, H. Y. : : : 245 North Branch of, at North Adams, Mass. 246

Hop River near Columbia, Conn. . . 131 
Page

Hope, N. Y., Sacandaga RIver near Housatonic River at Coltsvilie, Mags.

at Falls viliage, Conn. : : : at Stevenson, Conn. . . 85, $212^{\circ} 210$ near Great Barrington, Hass... pl. 209

Housatonic River Basin, rainfali and run-off in...... 455-457

Hudson RIver at Gooley, near Indian Lake, $\mathrm{K}$. $\mathbf{Y}$. . . . . .

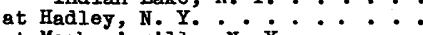
at Mechanfeville, N. Y. . . . . at North Creek, N. Y. . . . . . near Newcomb, N. $Y$.

$455-457$

Hudson River Basin, flood crests in 509-510

flood determinations in . . . pl. 11

rainfall and mun-off in ... 459-462

storage in .......... 417-418

Huntington, Mass; West Branch of Westfield River at....

Hydrologic conditions during flood.

Index, N. Y., Oaks Creek at . . . Indian Lake, N. Y., Cedar River near Hudson River near ........

Indian Lake Reservolr near . . .

Indtan River near . . . . . .

Indian Lake Reservolr near Indian

Indian River near Indian Lake, $\mathrm{N} . \dot{Y}$.

Introduction . . . . . . . . . Ja1l Branch at East Barre, Vt.
Jewett C1ty, Conn., Quinebaug River

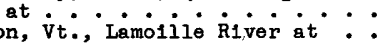

188

41-85

352

234

230

235

236

235

236

369

135

376

Kast Bridge, N. Y., West Canads

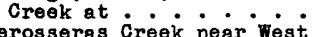

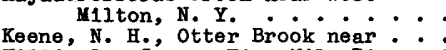
Killingly, Conn., Five Mile River at Kinderhook Creek at Rossman, N. Y. . Kingston, N. J., Millstone River

near
Kingston, Y. $_{\text {near : Ashokan Reservoir }}$ Bsopus Creek near Knightville, Mass., Westfield River

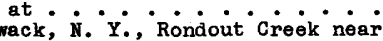
Lackawack, Carnegle at Princeton, N. J. Lake Champlain at Burlington, Vt.

Lake Cochituate outlet at Cochituate, Mass. $\dot{\text { George at Rogers Rock, N. } \dot{\mathrm{Y}} \text {. }}$

Lake George at Rogers Rock, N. Y.

Lake Hallenpaupeck at Wilsonvilie, Pa. Lamolile River at East Georgia, vit. at Johnson, Vt. stili River near Lawrence Brook at Farrington Dam, N. J. Brook near Thomeston, ć. 3 Leadmine Brook near Thomaston,
Leominster, Mass., North Nashua River near? . . . . .

Little Beaver Kili near Livingstón Manor, N. Y. - Mér Deini, N. Y. . . . . .

Little Falls, N. J., Passaic River at Faiı, $\dot{N}_{.} \dot{\mathrm{Y}}$, Mohawk River

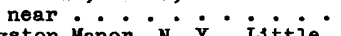

Livingston Hanor, H. Y., Littio Beaver Kili near......

Willowemoc Creek near : : : :

Lod1, N. J., Saddle RIver at : recharge on ". . .

rainfal1, run-off, and water levels on ?

Lowe11, Mass., Concord River at . . 127

Merrimack River at . *. . . . 111

Lowes Corners, N. Y., Rondout

Creek near.

355

128

362
380

344

114

377

215

321

221
230

232

233

231

229

McIndoes Falls, Vt., Connecticut

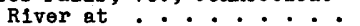

Macopin intake dam, N. J.,

Pequannock River at . . . Mad River near Moretown, vt. . Malverne, N. Y., PInes Brook at. Manantico Creok, flood crest on Manasquan River at Squankum, N. J.

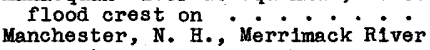
at Manvilie, N. J., Raritan River at. Margaretvilie, i. Y., East Branch of Delaware River at

Marian, Mass., Beverly Yacht ciub before and after the hurri-

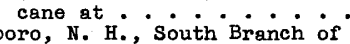
Ashuelot River at Webb, near

Mascoma, N. H., Mascoma River at Mascoma River reservoirs above dassachusetts, flood damage in . pl. hurricane damage in ....: pl. 3 Massapequa, N. Y., Massatayun

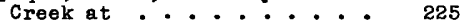
Massatayun Creek at Massapequa, N. Y. : . . . . . . 225

Maurice River, flood crest on Mechanicville, N. Y., Hudson River at .......... 233

Merrimack, N. H., Souhegan River at 123 Merrimack River at Amoskeag Dam, at Manchester, N. H. . . . 109 at Franklin Junction, N. H. . . 107 at Garvins Falls, N. H. . . . 108 below Concord River, at Loweil, Mass. . . . . . . . 111

near Goff Falls, below Manchester, N. H. . .

Merrimack River Basin, flood crests in...... 477-486

lood determinations in ..... pl. 11

.

storage in .........4 413-417 rologic conditions during flood . 41-85

Middleburg, i. Y., Schoharie

Creek at ......... 259

Middlebury, Vt., Otter Creek at . . 365

Mill Brook at Arena, N. Y. * * * 334

Mill Neck Creek at Mili Neck, N. Y. 224

Millers Falls, Mass., Miliers River at ............ 13,B

Millers River at Erving, Mass. . . 171

at Millers Falls, Mass. - . : pl. 13, B

at Wendell, Mass. - . . . : pl. 13,A

at Winchendon, Mass. . . . . pl. 12, B

near Winchendon, Mass. .... 170

Millington, N. J., Passa1c River

Mills tone River at Biackweils

near Kingston $J_{0} \cdot 0.0$

Militown, N. J., North Branch of

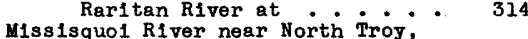

near Richford, vi

Mohawk River at Cohoes, N. Y. : : 251

below Delta Dam, near Rome, N. $Y$. 249

near IIttle Falis, N. Y. . . . . 250

Mohawk Trail along Cold River, at Florida, Mass. ..... pl. $7, \mathrm{~A}$

Monks, N. J., Wanaque River at . . 299

Montague city, Mass., Connecticut River at . : . . .

Montpelier, Vt., Winooski River at

Moretown, Vt., Mad River near : : : $\quad 373$

Morristown, $\mathbb{N}$. J., Whippany River

$$
\text { at . . . . . . . }
$$

Nashue River at East Peppere11, Mass. . . . - . . . 125

South Branch of, at clinton, 
Natchaug River at W1llimant1c, Conn. Naugatuck River, Branch of, at outlet of Wigwam Reservoir near Thomaston, Conn. ...... near Naugatuck, Conn. . . . . near Thomeston, Conn. . - .

Nepaug Reservoir near Collinsville, Conn. . . . . . . . Neshanic River at Reavilio, N. J. Neversink River at Godefiroy, N. Y.
at Halls Mills, near Curry, N. Y. at Oakland Valley, N. Y. . . . at Woodbourne, N. Y.

New Boston, Mass., Farmington River near iesirvir at New croto Dam, near Croton, N. Y.

New Hartford, Conn., East Branch

New Jersey, easterm, rainfeil and mun-off in......4 462-466

storage in.........418-419

New London, Conn, storm wave damage at . . . pl. 18,A

New Milford, Conn., Rocky River near - $\cdot \cdot \cdot \dot{0} \cdot \cdot \dot{0}$

New Milford, N. J., Hackensack Rlver at . * . * * * * Newcomb, N. Y., Hudson River near Newfane, Vt., West River at . . Newfoundland, N. J., Clinton Reservolr near ....

Newman, N. Y., West Branch of Ausable River near ..... Newport, Vt., Lake Memphremagog at North Adams, Mass., North Branch of

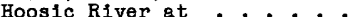

North Bennington, Vt., Walloomsac River near ' * $\dot{\text { H. }}$, Suncook River at .......... .

North Creek, N. Y., Hudson River at

North Hartland, Vt., Ottauquechee River at . E Es Branch of

North Lyme, Conn., East Branch of

West Branch of Elghtmile River

North Nashua River near Leominster,

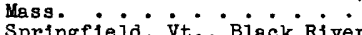
at

North Stratford, i. $\dot{H}^{*}$, Comecticut River at - $\cdot$ : * * -

North Troy, Vt., Missisquoi River

Northfiold Falis, vit., Dog River at

Oak Hill, N. Y., Catskill Creek at . Oak Ridge Reservoir at Oak Ridge, N. J.ile $\dot{y}$, N. $\dot{Y}$. , Neverisink River at .......... oaks Creek at Index, $\mathrm{N}^{\circ} \mathrm{Y}$. : : : : ocean storm wave from Cape cod, Mass., to Sandy Hook,

N. J. . Oradell Reservoir at Oradell, N. J. 281 Ot1s Reservoir at Cold Spring, Mass. ottauquecheo. River at North Hartland, Vt. .......... Otter Brook near Keene, N. H. . . otter Creek at Center Rutland, Vt. at Middlebury, vt. . . . . . .

Park River at Hartford, Conn.

North Branch of, at Hartford, Conn. $\dot{\text { hranch }}$ it Hartford, Conn. - * * * * *

Pascack Brook at Westwood, N. J. . Passaic River above dam at Littlo Falls, N. J. at Dundee Dam, Clifton, N. J. : below dam at Littio Falis, i. J. near Chatham, N. J. . . . . . near M1llington, N. J. . . . Passaic River Basin, flood crests in... 510-512

flood determinations in : : : pl. 11

222
220
219

197

312

347

349

348

196

214

282

229
165

303

357

380

246

247

121

231

161

205

206

124

164

141

378

372

262

302

349

352

281
194

161

161
168
364

364

365

200

201

199

284

287

289

288

287

286
Page

Passumps1c River at Passumpsic, Vt.

191

ts Island Mountain, N. Y.,

Wallkill River at . *.... 271

emigewasset River at Bristoi, N. H. 105

at Franklin, N. H. . - . . - : 106

at Plymouth, 104

Pepaoton, Y. Terry Clove Kill near .................. 336

Pequannock River at Macopin intake dam, N. J. . . 304

Phillipsburg, N. Y., Wilikili River near ........... 272

P1ne Island, N. $\dot{\mathrm{Y}}$., Pochuck Creok near . • . . • • • • • • •

ines Brook at Malveme, N. Y.

Pittsburg, N. H., Connecticut River near ...........

F1rst and Second Connecticut Lakes near ........... 139

Plainfleld, $\dot{N}$. J., Green Brook at . 319

Plymouth, N. H., Pemigewasset River at ............ 104

Pochuck Creek at Newport, near Pine Island, N. Y. ..... 274

Poesten Kill ngar Troy, N. Y. . . . 260

Pomperaug River at Southbury, Conn. - 218

Pompton Lakes, N. J., Ramapo River at 297

Port Jervis, N. Y., Delaware River at 330

Pottersville, N. J., Black River near 315

Poultney River below Falr Haven, Vt. 363

Prattsvilie, N. Y., Schoharie Creek

256

Precipitation, distribution of : $82-83$ general features of - : 45,77-81, pl. 1 isohyetal maps of . 9-12, 14, 15, 19-33 rate and duration of . . . . 434-436 records of .............. 46-76 mun-off associated with. . . 424-431 See also Rainfall and run-off.

Prévious floods and storms . . 553-555 Priest Brook near WInchendon, Mass. - 173 Prínceton, N. J., Lake Carnegie at - 316 Putnam, Conn., Quinebaug River at . : 134 washout on rallroad near . . . pl. 7,B

Quaboar River at West Brimfield, Mass. 184 Quaker Creek at Florida, N. Y. . . . 275 Quinebaug, Conn., Quinebaug River at 133 Quinebaug River at Jewett City, Conn. 135 at Putnam, Conn. . . . . . . 134 at quinebaug, Conn. . . . . . . 133 at Southbridge, Mass. . . . . pl. 12, A Quinnlplac River at Waliingford, Conn. 207

Rahway River at Rahway, N. J. . . 308 near Springfield, N. J. . . . 307 Rahway River Basin, fiood crests in 512-513 flood determinations in.... pl. 11 Rainfall. See Precipitation and Rainfoll and mun-off.

Rainfall and run-off, analysis of $.420,433$ storm of November í27. . . : 472-473 storm of September 1932:.: . . 474-475 studies of results of . . . . . 438-442 in Connecticut River Basin . 448-455

in Delaware River Basin .... 466 in eastern New Jersey Basins : 462-466 in Housatonic RIver Basin. : 455-457 in Hudson River Basin... . 459-462 in Merrimack River Basin . . 442-445 in St. Lawrence River Basin: 467-477 in Streams on Long Island . . 457-459 in Thames River Basin... . 445-448 See also Precipitation.

Ramapo RIver at Pompton Lakes, N. J. 297 near Mahwah, N. J. ....... 296 Raritan River at Manvilie, N. J. : - 311 North Branch of, at Militown, N. J. 314 near Far Hills, N. J. . . * * 313 South Branch of, at Stanton, N. J. 310 Raritan River Basin, flood crests in ........... 513-515

flood determinations in $\cdot$ pl. 11 Reavilie, N. J., Neshanic River at . 312 Red Bank, N. J., Swimming R1ver near 323 Tinton Falls Reservoir near . . . 322 Rhode Island, storm wreckage 
Richelleu River (Lake Champlain) at Rouses Point, N. Y. . Richford, Vt., Missisquol River

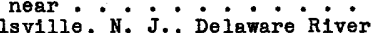
at..$\cdots$

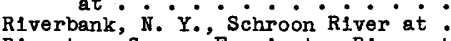
Riverton, Conn., Farmington River at Rockaway River above reservolr at Boonton, N. J. . . . . at Dover, N. J. . . . . . below reservolr at Boonton, $N$. J. Rockville, Conn., Hockanum River at outlet of Shenlpsit Lake at

Rocky River at outlet of Candlewood Lake, near New Milford, Conn.

Rogers Rock, N. Y., Lake George at . Rome, N. Y., Delta Reservoir at Delta Dam, near

Noherk River below Delt

Rondout Creek at Rosendale, N. Y. near Lackawack, $N$. $Y$.

near Lowes Corners, $\dot{N}$. $\dot{Y}$.

Rosendale, N. Y., Rondout Creek at Rossman, N. Y., Kinderhook Creek at

Rouses Polnt, N. Y., Richelleu River (Lake Champla in) at

Roxbury, Conn., Shepaug River near.

Rumney, N. H., Bakers River near.

Run-off, Seo also Rainfall and run $=\mathrm{OT}_{\mathrm{f}}$.

Rutland, Vt., Otter Creek at ....

Sacandaga Reservolr at Conklingville, N. Y. . . . .

Sacandaga River at Conkilingvilie, N. $Y$.

near Hope, i. Y. $: \dot{*}: \vdots \vdots$

Saddle River at Lodi, N. J.

St. Johnsbury, Vt., Moose River at

St. Lawrence River Basin, rainfall and rum-off in..... 467-471

storage in ........ 419-420

Salmon River near East Hampton,

Conn. Sarac-River at Saranac, N. $\dot{Y} \cdot$ :

Saugatuck River near Westport, Conn.

Scantic River at Broad Brook, Conn

Schoharle Creek at Gilboa Dam, at G1lboa, N. Y. $:$ : : : : at Middleburg, N. Y.

Schoharle Reservoir at Gilboa Dam, at Gllboa, N. Y......

Schroon River at Rlverbank, N. Y.

Shavertow, N. Y., Tremper K1ll near

Shepaug River at outlet of Shepaug Reservolr, at Woodville, Conn.

near Roxbury, Conn. . . ...

Shetucket River near Willimantic,

S1p Pond Brook near winchendon, Mass. ........ 17

Smlth River near Bristoi, N. $^{*} \cdot{ }^{*}$ :

Somerset Reservolr on East Branch of Deerfleld River near Somerset, $\mathrm{Vt}$.

Souhegan RIver at Merrimack, $\dot{N}$. H.

South Coventry, Conn., W11limant1c River near. . . . . .

South Newbury, vt., Connecticut River at ........

Southbridge, Mass, Quinebaug

River at ........ pl. 12 ,

Southbury, Conn., Pomperaug River at

Splitrock Pond, N. J., Beaver Brook at outlet of .

Springfield, Mass., Connecticut

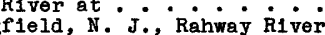

near.
Squankum, N. J., Manasquan River at

Stanton, N. J., South Branch of

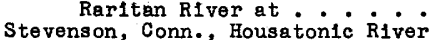
at ...... $85,212, \mathrm{pl} .10$

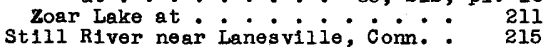

Stockholm, N. J., Canistear

Reservoir near ..... 302

Storage in river channels ... 412-420

Storm wave, damage by ..... pl. 18
Storm wreckage in Rhode Island ... pl. 2

Sudbury River at Framingham

Center, Mass. ...... 128

Sugar River at West Claremont, N. H. 163 Sunapee Lake at Sunapee, N. H. ... 162

Suncook River at North Chichester, N. H. ........... 121

Susquehanna River at Colliersville, N. Y. . . - . -

Swift River at West Ware, Mags.

East Branch of, near Dana, Mass. - 183

Swiming River, flood crest of ... 515

near Red Bank, N. J. . . . : 323

Swinging Bridge Reservolr at

Swinging Bridge Dam, N. Y. . . . 345

Tariffuille, Conn., Farmington River at ........ 193

Tenmile River near Gajlordsvilie, Conn.

Terry Clove Kili near Pepacton,

N. Y. *.... 336

Thames River Basin, fiood crests in $486-488$

flood determinations in ....pl. 11

rainfall and run-off in ... 445-448

The Glens, N. J., Greenwood Lake at

The WeIrs, N. H., Lake WInnipesaukee at ..........

298

Thomaston, Conn., Branch of Naugatuck River near . . . . 222

Leadmine Brook near ...... 221

Naugatuck River near: : : : 219

Thompsonville, Conn., Connecticut River at - * - * -

Tilton, N. H., Winnipesaukee River at Fails Reservoir near Red

Tinton Falls Reservolr near Red

Toms River, flood crest on ....

322

515

near Toms R1 ver, N. J. 325

Toronto Reservolr at Toronto Dam,

Nremper Kili near shavertown, N. ${ }^{\prime}$.

Trenton, N. J., Delaware River at . 333

Troy, N. Y., Poesten Kill near... 260

Tully River, East Branch of, near Athol, Mass. - $\cdot$.

Thurners Falis, Mass., Connecticut

River at ........

Unionville, N. Y., Wallkill River near.........

Vernon, Vt., Connecticut River at . 147

Wachusett Reservoir on South Branch of Nashua River at Clinton, Mass.

Wading R1ver, East Branch of, flood crest on i Dinipiac River at........ $20^{7}$

Wallk1ll River at Gardiner, N. Y. • 273 at Pellets Island Mountain, N. Y. 271 near Phillipsburg, N. Y. ... 272 near Unfonville, N. Y. . : : 270 Walloomsac River near North Bennington, Vt. ...... 247 Wanaque Reservoir at Wanaque, N. J. 300 Wanaque River at Monks, N. J. - . 299 at Wanaque, N. J. : : : : 301 Wantagh Stream at Wantagh, N. Y. : 226 Wappinger Creek at Wappinger Falls, N. Y. ......pl. 15, A near Wapplnger Fails, N. Y. . . 276 Ware River at Cold Brook, Mass. : 179 at Glbbs Crossing, Mass. . : : 180 at Ware, Mass. . 36 , pls. $9,14, \mathrm{~A}$ Waterbury Reservoir on Waterbury R1ver near Waterbury, Vt. . . 374 Waterbury River near Waterbury, vt. 375 Waterville, Mass., scene near pl. 6, B Webster, N. H., Blackwater R1ver near............... 120 Wendell Depot, Mass., Moss Brook at 175 Wendell, Mass:, MiIlers River at . pl. 13, A West Brimfield; Mass., Quaboag RIver at ........ 184

West Canada Creek at Hinckley, N. Y. 253 at Kast Brldge, N. Y. . . . . 254 West Claremont, N. H., Sugar $\dot{R}$ iver at......... 
West Hartford, Vt., White River at West Milton, N. Y., Kayaderosseras 243

West River at Newfane, Vt. . . . . 165

West Springfield, Mass., flood scene at . . . pl. 5, B

West Ware, Mass., Swift River at. . 182

Westerly, R. I., waterfront before

and after the hurricane in . pl. 19

Westfield, Mass., Borden Brook and Cobble Mountain Reservoirs near............ 189

Westfield rittle River near : . 189

Westfleld River near . . . . . 186

Westfield Ifttie River at outlet of Cobble Mountain Reservoir, near Westfield, Mass. ... 189

Westfield River at Knightville, Mass. . . ....... 185

near Westfield, Mass. . . . . 186

Middle Branch of, at Goss Heights, Mass. .........

West Branch of, at Huntington, Mass.......... 188

Westport, Conn., Saugatuck River near . *.*...... . 223

Westville, i. Y., Cherry valley Creek at - $\dot{\text { Cici }} \dot{\mathrm{Br}} \dot{\mathrm{j}} \dot{\mathrm{t}}$ Westwood, N. J., Pascack Brook at White River Junction, Vt.,

Connecticut River at : 'vi.

near Bethel, vt.........
W1llimantic, Conn., Natchaug River at........... 132

Shetucket River near . . . . . 130

W11limantic River near South

Coventry, Conn. Lillowemoc Crek near Livition
W1 Manor, N. Y. ....... 339

W11lsboro, N. Y., Bouquet River at . 361

Wilsonvilie, $\mathrm{Pa}$., Lake Tallenpaupack at'. endon, Mass., Millers River , pl, 12, at * : * : : : : pl. $12, \mathrm{~B}$ Milers River near * . . • • - 170

S1p Pond Brook near . . . . . 172

$\begin{array}{ll}\text { Winnipesaukee River at Tilton, N. H. } & 115 \\ \text { Winooski River at Montpelier, Vt. } & 366\end{array}$ near Essex Junction, Vt. . . . 367 North Branch of, at Wrightsvilie, Vt. ........... 371

Woodbourne, N. Y.; Neversink River at .......... . . 348 Woodcliff Lake at Hilisdalo, N. J. - 283

Woodville, Conn., Shepaug River at outlet of Shepaug Reservoir, 2 Winooski River at .... 371

Wrightsville Detention Reservoir at .......... 370

Yantic River at Yantic, Conn. . . 138

Zoar Lake at Stevenson, Conn. : . 211 
The use of the subjoined mailing label to return this report will be official business, and no postage stamps will be required

\section{UNITED STATES \\ DEPARTMENT OF THE INTERIOR \\ GEOLOGICAL SURVEY \\ OFFICIAL BUSINESS}

This label can be used only for returning official publications. The address must not be changed.

PENALTY FOR PRIVATE USE TO AVOIE PAYMENT OF POSTAGE, $\$ 300$

\section{GEOLOGICAL SURVEY,}



